

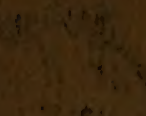

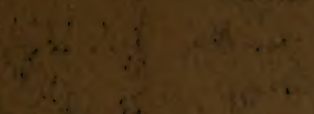

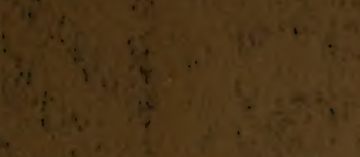

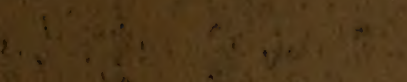

$i, 20,1,2$

in 190

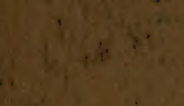

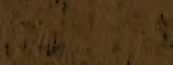

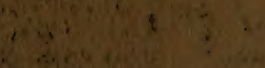

W.tin?

$(4)^{2}$

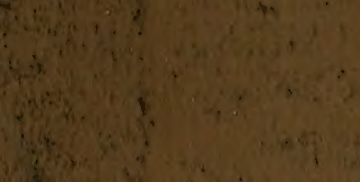

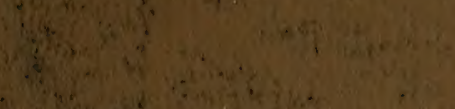

$24+\frac{1}{3}+2 x+2$

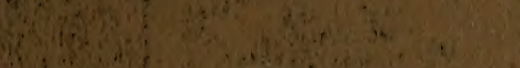

a.

is

$\sin ^{2} x^{2}, x$

dis 25

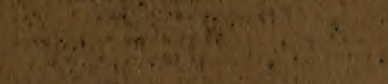

ainiting

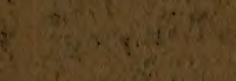

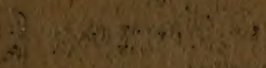

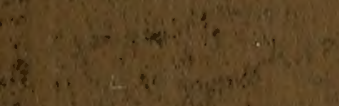

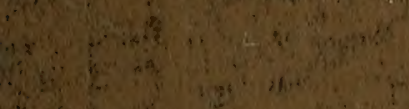

$\left.2 x^{4}\right)^{4}$

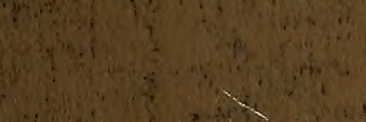

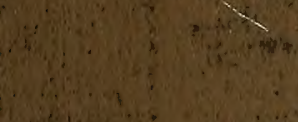

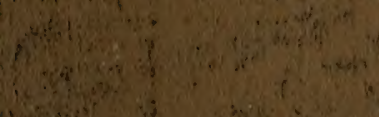

W.

(1)

(i) $?$

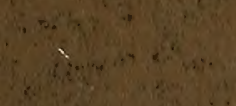

i.

4. $x^{2}+x^{2}$

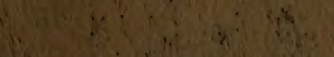

$f(x) y^{2}=x$

$4 \times 16=2 ; 2 x$

14 



$$
\frac{6 a^{1}}{5-}
$$


Sea.5-Shey 6 -Back row Book 7

AH. Eustis

3 Prus ot e / tall 



\section{MANUAL OF GEOLOGY}

TREATING OF THE PRINCIPLES OF THE SCIENCE

WITH SPECIAL REFERENCE TO AMERICAN

GEOLOGICAL HISTORY

BY

JAMES D. DANA

PROFESSOR EMERITUS OF GEOLOGY AND MINERALOGY IN YALE UNIVERSITY: AUTHOR OF A SYSTEM OF MINERALOGY; CORALS AND CORAL ISLANDS; VOLCANOES; REPORTS OF WILKES'S EXPLORING EXPEDITION, ON GEOLOGY, ON ZOÖPHYTES, AND ON CRUSTACEA, ETC.

"Speak to the Earth and it shall teach thee"

ILLUSTRATED BY OVER FIFTEEN HUNDRED AND SEVENTY-FIVE FIGURES IN THE TEXT, AND TWO DOUBLE-PAGE MAPS

FOURTH EDITION

NEW YORK :: CINCINNATI •: CHICAGO

AMERICAN BOOK COMPANY

LONDON : TRÚBNER AND CO. 
COPYRIGHT, 1894,

BT JAMES D. DANA

T. D., P. \& B. Co. -2

NEW YORK 


\section{P R E F A C E.}

Is the preparation of the new edition of this Manual, the work has been wholly rewritten. North American Geological History is still, however, its chief subject. The time divisions in this history, based on the ascertained subdivisions of the formations, were first brought out in my Address before the meeting of the American Association at Providence in 1855 ; and in 1863, the "continuous history" appeared in the first edition of this Manual, written up from the State reports and other geological publications. The idea, long before recognized, that all observations on the rocks, however local, bore directly on the stages in the growth of the Continent derives universal importance from the recognition of North America as the world's type-continent- the only continent that gives, in a full and simple way, the fundamental principles of continental development.

Since 1863, when the first edition of this work was published, investigation, through the geological workers of the United States, Canada, and Mexico, has been extended over nearly all parts of the continent, so that its history admits of being written out with much fullness. The Government Expeditions over the Rocky Mountain region, under F. V. Hayden, ClaRence King, Captain Wheeler and others, and earlier, those especially of the Pacific Railroad Explorations, and the Mexican Boundary Commission, were large contributors to this result; and also, since 1879, the able corps of the United States Geological Survey.

As the rewritten book shows, new principles, new theories, and widely diverse opinions on various subjects are among the later contributions, along with a profusion of new facts relating to all departments of the science.

The Cambrian formation has been traced through a large part of the continent, and the number of its fossils has been increased, chiefly by C. D. WАLсотт, from a few to hundreds. The Appalachian Mountain structure has been shown by Claarence King, Dr. G. M. Dawson, and R. G. McConNELL to have been repeated in the great post-Cretaceous mountain-making of the Rocky Mountain region. The Reptiles, Birds, and Mammals of the Mesozoic and Tertiary have continued coming from the rocks until the species recognized much outnumber those of any other continent. The cañons. and other results of erosion in the west have thrown new light, through their investigators, on the work of the waters. Besides, the science of 
petrology has elucidated much of the obscure in the constitution, relations, and origin of rocks.

Moreover, America, from early in the century, has been receiving instruction through the development and parallel progress of the Science in Europe and other lands.

The first edition of this Manual owed much to the advice of the able paleontologist, F. B. Meek, and also to his skill as a draftsman; and the work still bears prominent evidence of his knowledge, judgment, and scrupulous exactness, traits which give a permanent value to all the results of his too soon ended labors.

In this new edition, the Paleozoic paleontology is largely indebted to Professor C. E. Beecher and Professor H. S. Williams; the Jurassic, of western America, to Professor A. Hyatt; the Cretaceous, to Professor Hyatt, Mr. T. W. Stanton, Mr. R. P. Whitfield, and Professor R. T. Hill; and the Tertiary, as regards the Invertebrates, to Professor G. D. HARRIS. With respect to the Vertebrates of the Jurassic, Cretaceous, and Tertiary, very valuable aid has been received from Professor Marsh, and also in the part on Tertiary Mammals from Professor W. B. Scott. The account of the arrangement and distribution of the Jurassic and Cretaceous rocks of western America was prepared with the assistance of Mr. J. S. DiLler; and that with regard to the marine Tertiary of the country was chiefly written for its place by Professor Harris. I am further indebted to Professor A. E. Verrill for his revision of the pages on the Animal Kingdom.

Moreover, the replies to requests for information have placed me under obligation to almost all the geologists of the Continent, those of Canada as well as the United States, - and especially to Sir William Dawson, Mr. A. R. C. Selfwyn, Dr. G. M. Dawson, Mr. Clarence King, Mr. C. D. Walcott, Professor N. S. Shaler, Professor S. H. Scudder, Mr. Frank Leverett, Professor R. T. Hill, Professor W. Upham, Professor G. F. Wright, Professor J. J. Stevenson, Mr. Wh. H. Dall, Dr. C. A. White, and Professor J. P. Iddings.

Throughout this volume, the dates of papers containing cited facts or views are often stated. If a condensed bibliography, containing in brief form the titles of the most important geological and paleontological works and papers, arranged under the year of publication, were accessible to the student, these dates would be a sufficient means of reference. Without such a Bibliography they may serve as a help in consulting, besides Reports of Geological Surveys, the serial scientific publications. It is best to commence the search with the periodical containing the most geological papers, notes, and book notices, and follow on with the others. The American Journal of Science commenced in 1818; the American Naturalist, in 1868; the American Geologist, in 1888; the Bulletin of the American Geological Society, in 1890; the Journal of Geology, Chicago, in 1893. Then refer to the Proceedings and Memoirs of American Scientific Soci- 
eties or Academies, in the following order: Academy of Natural Sciences of Philadelphia; American Philosophical Society, Philadelphia; Society of Natural History, Boston; American Academy, Boston; Lyceum of Natural History, and later, Academy of Sciences, New York; and so on, not overlooking the Reports of the American Association for the Advancement of Science. The foreign serial works of most importance to the geologist are the Journal of the Geological Society of London; the Geological Magazine, London; Bulletin of the Geological Society of France; "Comptes Rendus" of the Academy of Sciences, Paris; Jahrbuch für Mineralogie, Geologie und Palaeontologie, Stuttgart; Zeitschrift der deutschen geologischen Gesellschaft, Berlin; Jahrbuch der k.-k. geologischen Reichsanstalt, Vienna.

For foreign facts and views I am largely indebted to the able English works of Sir Archibald Geikie, Professor Prestwich, and Professors Etheridge and Seeley, the very full Traité de Géologie of Professor A. de Lapparent, and the Elemente der Geologie of Dr. Credner.

As the volume is necessarily larger than that of the edition of 1880 , partly through more text, but also through a greater profusion of illustrations, - the instructor may find it convenient, in his use of the Historical part, to take up successively its two great subjects, the geological and physical history of the continents, and the history of its life.

JAMES D. DANA.

New Haven, Corn., January, 1895. 


\section{TABLE OF CONTENTS.}

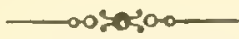

INTRODUCTION.

Relations of the Science of Geology Subdivisions of Geology . . . .

\section{PART I. - Physiographic Geology.}

1. The Earth's General Contour and Surface Subdivisions . . . . 15

2. System in the Reliefs of the Land .

3. System in the Courses of the Earth's Feature Lines.

4. Oceanic and Atmospheric Movements and Temperature . .

5. Geographical Distribution of Plants and Animals . . . . .

PART II. - Structural Geology.

1. Rocks: their Constituents and Kinds

2. Terranes : their Constitution, Characteristics, Positions, and Arrangement

PART III. - Dynamical Geology.

Agencies and General Subdivisions . 117

1. Chemical Work . . . . . 118

2. Life: its Mechanical Work and Rock Contributions . . . . . 140

General Remarks on Rock-making Protective and Other Beneficial Effects . . . . . . 155

Transporting Effects . . . . 156

Destructive Effects . . . . . 157

3. The Atmosphere as a Mechanical Agent . . . . . . . . 158

4. Water as a Mechanical Agent . 166

Fresh Waters : Rivers and Lakes , 171

The Ocean . . . . . . . . 209

Freezing and Frozen Water: Glaciers, Icebergs . . . . . 230
Heat . . . . . . . 253

1. Sources of Heat . . . . . 253

2. Expansion and Contraction . . 259

3. Igneous Action and its Results 265 Volcanoes . . . . . . . 267

Non-volcanic Igneous Eruptions 297

Thermal Waters, Geysers . . 305

4. Metamorphism . . . . . 309

5. Mineral Veins, Lodes, Local Ore Deposits . . . . . 327

6. Hypogeic Work: Earth-shaping, Mountain-making . . . . 345

1. Characteristics of Disturbed Regions and Mountains . . 351

2. Subordinate Effects attending Orographic Movements : Effects from Pressure, Earthquakes . . . . . 369

3. Origin of the Earth's Form and Features: Orogenic Work, Epeirogenic Work . . 376

\section{PART IV. - Historical Geology.}

Subdivisions in Geological History . 397 Review of the System of Life . . . 413

1. Animal Kingdom. . . . . . 414

2. Vegetable Kingdom . . . . . 434

I. ARCH 无AN TIME . . . . 440

1. Subdivisions: Rocks . . . . 445

2. Life . . . . . . . 453

II. PALEOZOIC TIME • • . . 460

I. Cambrian Era . . . . . 462

1. North American . . . . 464

1. Lower Cambrian Period 470

2. Middle Cambrian Period 474

3. Upper Cambrian Period $\mathbf{4 7 6}$ 
2. Foreign . . . . . 480

3. Geographical and Physical Conditions and Progress .

II. Lower Silurian Era

1. North American . . . . 489

2. European . . . . . 517

3. General Observations: Rocks ; Climate ; Biological Progress . . . . .

4. Upturning at the close of the Lower Silurian . . . 526

III. Upper Silurian Era . . . 535

1. North American . . . 535

1. Niagara Period . . 538

2. Onondaga Period . . . 552

3. Lower Helderberg Period 558

2. Foreign . . . . . .

3. General Observations : Geological ; Geographical ; Biological . . . . . 570

IV. Deronian Era . . . . . 575

1. North American . . . 575

1. Oriskany Period . . . 577

2. Corniferous Period . . 579

3. Hamilton Period . . 592

4. Chemung Period . . . 602

2. Foreign . . . . . 622

3. General Observations: Geological; Geographical . .

4. Upturning at the close of the Devonian . . . . 630

V. Carbonic Era . . . . . 631

1. North American . . . . 633

1. Subcarboniferous Period 636

2. Carboniferous Period $\quad 647$

3. Permian Period . . . 660

2. Foreign . . . . . . . 693

3. General Observations: Geological and Geographical ; Meteorological ; Formation of Coal .....

General Observations on Paleozoic Time

Post-Paleozoic, or Appalachian, Revolution . . . . .
Topographic Changes in the Indian

Ocean: Gondwána Land . . . 737

III. MESOZOIC TIME • . . . 738

1. American Triassic and Jurassic Period . . . . . . 739

2. Foreign Triassic and Jurassic . 768

3. General Observations: Continental Comparisons; Climate; Biological Changes; Upturnings and Mountainmaking . . . . . . 791

4. American Cretaceous Period . 812

5. Foreign . . . . . . 856

6. General Observations: Geological ; Geographical ; Biological ; Gondwána Land . . 867

Post-Mesozoic Revolution . . . 874

IV. CENOZOIC TIME . • . 879

I. Tertiary Era . . . . . 879

1. North American . . . 880

2. Foreign . . . . . . 919

3. General Observations: Biological; Orogenic and Epeirogenic ; Climate . 928

II. Quaternary Era . . . . . 940

1. Glacial Period . . . . 943

1. American . . . 943

2. Foreign . . . . 975

3. Cause of Glacial Climate 978

2. Champlain Period . . 981

1. American . . . . . 981

2. Foreign . . . . 995

3. Pleistocene Life . . . 997

4. Recent Period . . . . . 1012

General Observations: Biological; Antarctic Continent; Epeirogenic . . . . 1016

General Observations on Geological

History . . . . . . . . . 1023

714 Geological Time . . . . . 1023

Climate ; the Earth's Development . 1026

Progress in the Earth's Life . . . . 1028 


\section{ABBREVIATIONS.}

Ag. - L. Agassiz.

B. - E. Billings.

Barr. -J. Barrande.

Beyr. - E. Beyrich.

Blum. -J. F. Blumenbach.

Blv. - D. de Blainville.

Br. - H. G. Bronn.

Brngt. - Brongniart.

Brod. - Broderip.

Bu.-L。 von Buch.

Con. - T. A. Conrad.

D. -J. D. Dana.

Dalm. -J. W. Dalman.

Dav. - T. Davidson.

Defr. - Defrance.

Desh. - G. P. Deshayes.

Dawson, Dn. - Sir Wm. Dawson.

D'Orb. - Alcide d'Orbigny.

E. \& H. - Edwards \& Haime. Ehr. - Ch. G. Ehrenberg.

Eich. - E. Eichwald.

Emmr. - H. F. Emmrich.

Fabr. - Fabricius.

Falc. - H. Falconer.

Flem. -J. Fleming.

Fer.-Ferussac.

G. \& H. - Gabb \& Horn.
Gein. - Geinitz.

Gld. - Gould.

Gm. - Gmelin.

Göpp.-H. R. Göppert.

Goldf. - Goldfuss.

H. - J. Hall.

H. \& M. - Hall \& Meek.

Hald. - S. S. Haldeman.

Hising. - W. Hisinger.

Hk. - E. Hitcheock.

Hux. - T. H. Huxley.

Kon.-L. de Koninck.

L. - J. Leidy.

L. \& H. - Lindley \& Hutton.

Lam. - Lamarek.

Linn. - Linnæus.

Lmx. - Lamouroux.

Lsqx., Lx. - L. Lesquereux.

Lyc. - Lycett.

M. - F. B. Meek.

Mant. -G. Mantell.

Mey. - H. von Meyer.

Mh. - O. C. Marsh.

Montf.-Denys de Montfort.

Morr. - Morris.

Mort. - S. G. Morton.

Müll. - Müller.

Murch.-R. I. Murchison.

N. \& P. - Norwood \& Pratten. Woodw. - J. Woodward.
N. \& W. - Newberry \& Worthen.

Newb. - J. S. Newberry.

O. \& N. - Owen \& Norwood.

Ow. - R. Owen (London).

Pack. - A. S. Packard.

Phill. - J. Phillips.

Plien. - T. Plieninger.

Portl. - J. E. Portlock.

R. - F. Römer.

Rém. - A. Rémond.

S. - J. W. Salter.

Saff. -J. M. Safford.

Sc. - S. H. Scudder.

Schafh. - Schafhäntl.

Schlot.-E.F. von Schlotheim.

Schp. - W. P. Schimper.

Sedg. - A. Sedgwick.

Shum. - B. F. Shumard.

Sow. - Sowerby.

St. - Stokes.

Sternb. - K. von Sternberg.

Suck. - Suckow.

Ung. - Unger.

Van.-Vanuxem.

Vern. - E. de Verneuil. 


\section{INTRODUCTION.}

Kingdoms of nature. - ScIENcE, in her survey of the earth, has recognized three kingdoms of nature, - the animal, the vegetable, and the inorganic; or, naming them from the forms characteristic of each, the animal Kingdom, the plant kingdom, and the crystal Kingdom. An individual in either kingdom has its systematic mode of formation or growth.

The plant or animal, (1) endowed with life, (2) commences from a germ, (3) grows by means of imbibed nutriment, and (4) passes through a series of changes and gradual development to the adult state, when (5) it evolves new seeds or germs, and (6) afterward continues on to death and dissolution.

It has, hence, its cycle of growth and reproduction, and cycle follows cycle in indefinite continuance.

The crystal is (1) a lifeless object, and has a simpler history; it (2) begins in a nucleal molecule or particle; (3) it enlarges by external addition or accretion alone; and (4) there is, hence, no proper development, as the crystal is perfect, however minute; (5) it ends in simply existing, and not in reproducing; and, (6) being lifeless, there is no proper death or necessary dissolution.

Such are the individualities in the great kingdoms of nature displayed upon the earth.

But the earth also, according to Geology, has been brought to its present condition through a series of changes or progressive formations, and from a state as utterly featureless as a germ. Moreover, like any plant or animal, it has its special systems of interior and exterior structure, and of interior and exterior conditions, movements, and changes; and, although Infinite Mind has guided all events toward the great end, - a world for mind, - the earth has, under this guidance and appointed law, passed through a regular course of history or growth. Having, therefore, as a sphere, its comprehensive system of growth, it is a unit or individuality, not, indeed, in either of the three kingdoms of nature which have been mentioned, but in a wider, a World KInGDom. Every sphere in space must have had a related system of growth, and all are, in fact, individualities in this Kingdom of Worlds. 
Geology treats of the earth in this grand relation. It is as much removed from Mineralogy as from Botany and Zoölogy. It uses all these departments; for the species under them are the objects which make up the earth and enter into geological history. The science of minerals is more inmediately important to the geologist, because aggregations of minerals constitute rocks, or the plastic material in which the records of the past were made.

The earth, regarded as such an individuality in a world kingdom, has not only its comprehensive system of growth, in which strata have been added to strata, continents and seas defined, mountains reared, and valleys, rivers, and plains formed, all in orderly plan, but also a system of currents in its oceans and atmosphere, - the earth's circulating-system; its equally worldwide system in the distribution of heat, light, moisture, and magnetism, and of plants and animals; its system of secular variations (daily, annual, etc.) in its climate and all meteorological phenomena. In these characteristics the sphere before us is an individual, as much as a dog, or a tree; and, to arrive at any correct views on these subjects, the world must be regarded in this capacity. The distribution of man and nations, and of all productions that pertain to man's welfare, comes in under the same grand relation; for, in helping to carry forward man's progress as a race, the sphere is working out its final purpose. There are, therefore,

Three departments of science, arising out of this individual capacity of the earth.

I. GEoLoGr, which treats of (1) the earth's structure, and (2) its system of development, - the latter including its progress in rocks, lands, seas, mountains, etc.; its progress in all physical conditions, as heat, moisture, etc.; its progress in life, or its vegetable and animal tribes.

II. Physiography, which begins where Geology ends, 一 that is, with the adult or finished earth, - and treats (1) of the earth's final surfacearrangements (as to its features, climates, magnetism, life, ete.); and (2) of its system of physical movements or changes (as atmospheric and oceanic currents, and other secular variations in heat, moisture, magnetism, etc.).

III. The earth with reference to man (including ordinary Geography): (1) the distribution of races or nations, and of all productions or conditions bearing on the welfare of man or nations; and (2) the progressive changes of races and nations.

The first of these departments considers the structure and growth of the earth; the second, its features and world-wide activities in its finished state; the third, the fulfillment of its purpose in man.

Relation of the earth to the universe. - While recognizing the earth as a sphere in a world kingdom, it is also important to observe that it holds a very subordinate position in the system of the heavens. It is one of the smaller satellites of the sun, - its size about $\frac{1}{1200000}$ that of the sun. And the planetary system to which it belongs, although $3,000,000,000$ of miles in radius, is but one among myriads, the nearest star being 7000 times 
farther off than Neptune. Thus it appears that the earth is a very small object in the universe. Hence we naturally conclude that it is a dependent part of the solar system; that, as a satellite of the sun, in conjunction with other planets, it could no more have existed before the sun, or our planetary system before the universe of which it is a part, than the hand before the body which it obediently attends.

Although thus diminutive, the laws of the earth are the laws of the universe. One of the fundamental laws of matter is gravitation; and this we trace not only through our planetary system, but among the fixed stars, and thus know that one law pervades the universe.

The rays of light which come in from the remote limits of space are a visible declaration of unity; for this light depends on molecular vibrations, - that is, the ultimate constitution and mode of action of matter ; and, by the identity of its principles or laws, whatever its source, it proves the essential identity of the molecules of matter.

Meteoric stones are specimens of celestial bodies occasionally reaching us from the hearens. They exemplify the same chemical and crystallographic laws as the rocks of the earth, and have afforded no new element or principle of any kind.

The moon presents to the telescope a surface covered with the craters of volcanoes, having forms that are well illustrated by some of the earth's voleanoes, although of immense size. The principles exemplified on the earth are but repeated in her satellite.

Thus, from gravitation, light, meteorites, and the earth's satellite, we learn that there is oneness of law through space. The elements may differ in different systems, but it is a difference such as exists among known elements, and even if exemplifying new laws, such laws cannot be at variance with those illustrated by nature within reach of terrestrial investigation. The universe, if open throughout to our explorations, would vastly expand our knowledge, and science might have a more beautiful superstructure, but its basement-laws would be the same. A treatise on Celestial Mechanics printed in our printing-offices would serve for the universe.

The earth, therefore, although but an atom in immensity, is immensity itself in its revelations of truth; and science, though gathered from one small sphere, is the deciphered law of all spheres.

It is well to have the mind deeply imbued with this thought, before entering upon the study of the earth. It gives grandeur to science and dignity to man, and will help the geologist to apprehend the loftier characteristics of the last of the geological ages.

Special aim of geology, and method of geological reasoning. - Geology is sometimes defined as the science of the structure of the earth. But the ideas of structure and origin of structure are inseparably connected, and in all geological investigations they go together. Geology had its very beginning and essence in the idea that rocks were made through secondary causes; and its great aim has ever been to study structure in order to com- 
prehend the earth's history. The science, therefore, is a historical science. It finds strata of sandstone, clayey rocks, and limestone, lying above one another in many successions; and, observing them in their order, it assumes, not only that the sandstones were made of sand by some slow process, clayey rocks of clay, and so on, but that the strata were successively formed; that, therefore, they belong to successive periods in the earth's past; that, consequently, the lowest beds in a series were the earliest beds. It hence infers, further, that each rock indicates some facts respecting the condition of the sea or land at the time when it was formed, one condition originating sand deposits, another clay deposits, another lime, - and, if the beds extend over thousands of square miles, that the several conditions prevailed uniformly to at least this same extent. The rocks are thus regarded as records of successive events in the history, - indeed, as actual historical records; and every new fact ascertained by a close study of their structure, be it but the occurrence of a pebble, or a seam of coal, or a bed of ore, or a crack, or any marking whatever, is an addition to the records, to be interpreted by careful study.

Thus every rock marks an epoch in the history; and groups of rocks, periods; and still larger groups, eras or ages; and so the eras which reach through geological time are represented in order by the rocks that extend from the lowest to the uppermost of the series.

If, now, the great beds of rock, instead of lying in even horizontal layers, are much folded up, or lie inclined at various angles, or are broken and dislocated through hundreds or thousands of feet in depth, or are uplifted into mountains, they bear record of still other events in the great history; and should the geologist, by careful study, learn how the great disturbance or uplifting was produced, and succeed in locating its time of occurrence among the epochs registered in the rocks, he would have interpreted the record, and added not only a fact to the history, but also its explanation. The history is, hence, a history of the upturnings of the earth's crust, as well as of its more quiet rock-making.

If, in addition, a fossil shell, or coral, or bone, or leaf, is found in one of the beds, it is a relic of some species that lived when that rock was forming; it belongs to that epoch in the world represented by the particular rock containing it, and tells of the life of that epoch; and, if numbers of such organic remains occur together, they enable us to people the seas or land, to our imagination, with some of the kinds of life that belonged to the ancient epoch.

Moreover, as such fossils are common in a large number of the strata, from the lowest containing signs of life to the top, - that is, from the oldest beds to the most recent, - by studying out the characters of these remains in each, we are enabled to restore to our minds, to some extent, the population of the epochs, as they follow one another in the long series. The strata are thus not simply records of moving seas, sands, clays, and pebbles, and disturbed or uplifted strata, but also of the living beings that have in 
succession occupied the land and waters. The history is a history as complete as can be learned from the fossils of the life of the globe, as well as of its rock-formations; and the life-history, imperfect though it be, is the great topic of Geology: it adds tenfold interest to the other records of the rocks.

These examples are sufficient to explain the basis and general bearing of geological history.

The method of interpreting the records rests upon the simple principle that rocks were made as they are now made, and life lived in olden time as it now lives; and, further, the mind is forced into receiving the conclusions arrived at by its own laws of action. We observe that many of the common rock-strata consist of the same materials that make up the deposits of sand and gravel of sea-beaches or sand-flats, or of the clays or muds of the bottoms of estuaries or the borders of rivers, and that they are arranged in beds like the modern deposits, even have, at times, ripple-marks and other evidences of the action of water or wind; and further remark that these hard rocks differ from the loose sand, clay, or pebbly deposits simply in being consolidated into a rock; and, in other places, discover these sand-deposits in all states of consolidation, from the soft, movable sand, through a half-compacted condition, to the gritty sandstone. By such steps as these, the mind is borne along irresistibly to the conclusion that rocks were slowly made through common-place operations.

These few examples elucidate the mode of reasoning upon which geological deductions are based.

In using the present in order to reveal the past, we assume that the forces in the world are essentially the same through all time; for these forces are based on the very nature of matter, and could not have changed. The ocean has always had its waves, and those waves have ever acted in the same manner. Running water on the land has ever had the same power of wear and transportation and mathematical value to its force. The laws of chemistry, heat, electricity, and mechanics have been the same throughout time. The plan of living structures is fundamentally one, for the whole series belongs to one system, as much almost as the parts of an animal to one body; and the relations of life to light and heat, and to the atmosphere, have ever been the same as now. The laws of the existing world, if perfectly known, are consequently a key to past history.

\section{SUBDIVISIONS OF GEOLOGY.}

(1) Like a plant or animal, the earth has its systematic external form and features, which should be reviewed.

(2) Next, there are the constituents of the structure to be considered: first, their nature; second, their general arrangement.

(3) Next, the successive stages in the formation of the structure, and the concurrent steps in the progress of life, through past time. 
(4) Next, the general plan or laws of progress in the earth and its life.

(5) Finally, there are the active forces and mechanical agencies which were the means of physical progress, - spreading out and consolidating strata, raising mountains, ejecting lavas, wearing out valleys, bearing the material of the heights to the plains and oceans, enlarging the oceans, destroying life, and performing an efficient part in evolving the earth's structure and features.

These topics lead to the following subdivisions of the science:-

I. Physrographic Geologr, - a general survey of the earth's surfacefeatures.

II. Structural Geologr, - a description of the rock-materials in the structure of the globe, - that is, of its kinds of rocks, and of their arrangement or positions.

III. Dynamical Geology, - an account of the agencies or forces that have produced geological changes, and of the laws, methods, and results of their action.

IV. Historical Geologr, - an account of the earth's geological history, or the successive events or steps in the making of the rock-strata, and of the continents, seas, mountains, and valleys, in the progress of the earth's living species, and in all changes that have gone forward in the earth's development.

In the study of the science, a previous knowledge of the methods of change taught in the Dynamical section is desirable in order fully to comprehend Historical geology ; and a knowledge of the actual facts and their succession given in the Historical section is desirable to understand the causes of events and methods of change. There is reason, therefore, for studying Dynamical geology before Historical as well as after it. It is here made to precede. But the last topic under it - that of the formation of mountains - will be best appreciated after the student is familiar with the facts presented in the Historical section. 


\section{PART I.}

\section{PHYSIOGRAPHIC GEOLOGY.}

THE systematic arrangement in the earth's features is an indication of system in the earth's development. The crderly arrangement in the continents and oceans, island chains and mountains, is an outcome of the most fundamental movements in the forming sphere. An appreciation of tne earth's physiognomy is hence the first step toward an investigation of its laws of origin. This subject is therefore an important one to the geologist, although its facts come also within the domain of physical geography. They are the final results in geology, and thence become the arena of the physical geographer.

The following are the divisions in this department:-

I. The earth's general contour and surface subdivisions.

II. System in the reliefs or surface forms of the continental lands.

III. System in the courses of the earth's feature lines.

These topics are followed by a brief review of, -

IV. Oceanic and atmospheric movements and temperature.

V. Geographical distribution of plants and animals.

\section{THE EARTH'S GENERAL CONTOUR AND SURFACE SUBDIVISIONS.}

The subjects under this head are - the earth's form; the distribution of land and water; the true outlines and features of the oceanic depression; the subdivisions, positions, and general features of the land; the height and kinds of surface of the continents.

(1) Spheroidal form. - The form of the earth is spherical, with the poles flattened, the distance from the center to the pole being about $\frac{1}{29} \overline{4}$ shorter than that from the center to the equator. The length of the equatorial radius is 3963 miles, and that of the polar about $13 \frac{1}{3}$ miles less. The form approaches closely that of an ellipsoid of revolution. The mean density is about 5.5 times that of water, which is a little more than twice that of the two most common minerals, calcite $(2 \cdot 72)$ and quartz $(2 \cdot 65)$, and more than two thirds that of pure iron $(7 \cdot 75)$. 
The density of the moon is $3 \cdot 1$, or about that of basalt; of Mercury, $6 \cdot 2$; of Venus and Mars, each, $5 \cdot 2$; of Jupiter, $1 \cdot 3$.

The earth's atmosphere, if considered a part of the sphere, adds several hundred miles to its diameter. Its actual limit is not ascertained; but evidence from meteorites places it at least 200 miles above the earth's surface.

(2) General subdivisions of the earth's surface. - Proportion of land and water. - In the surface of the sphere there are about $73 \%$ of water to $27 \%$ of dry land. The proportion of land north of the equator is nearly three times as great as that south. The zone containing the largest proportion of land is the north temperate, the area equaling that of the water; while it is only one third that of the water in the torrid zone, and hardly one tenth $\left(\frac{2}{21}\right)$ in the south temperate.

Out of the $196,900,000$ of square miles which make up the entire surface of the globe, $144,155,000$ are water and 52,745,000 land. In the northern hemisphere the land covers $38,780,000$ square miles, and the water $59,670,000$; in the southern, the land $13,965,000$ square miles, the water $84,485,000$.

Land in one hemisphere. - If a globe be cut through the center by a plane intersecting the meridian of $175^{\circ} \mathrm{E}$. at the parallel of $40^{\circ} \mathrm{N}$, one of the hemispheres thus made, the northern, will contain nearly all the land of the globe, and the other be almost wholly water. The annexed map represents the two hemispheres.

1.

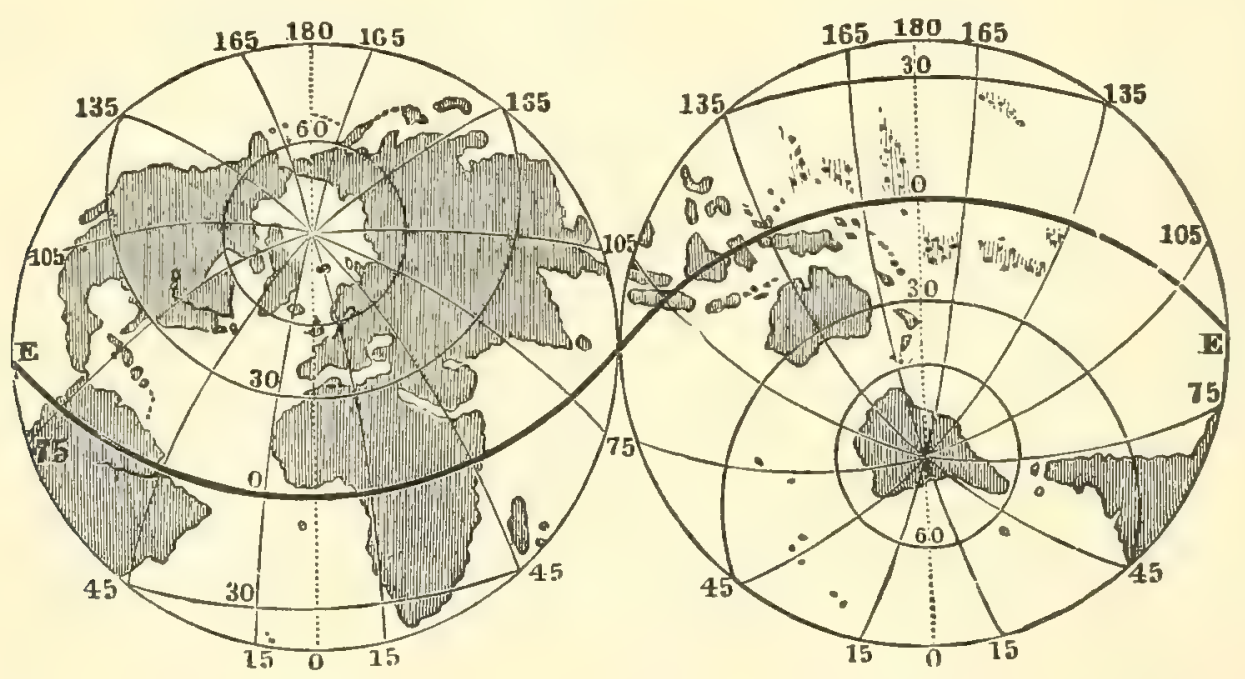

The pole of the land-hemisphere in this map is in the western half of the British Channel; and, if this part, on a common globe, be placed in the zenith, under the brass meridian, the horizon-circle will then mark the line of division between the two hemispheres. Of the $98,450,000$ square miles of surface in each hemisphere, there are about $45,000,000$ of land in the land-hemisphere and only about 7,000,000 in the other. The portions of land in the water-hemisphere are the extremity of South America below 
$25^{\circ}$ S., and Australia, together with the islands of the East Indies, the Pacific, and the Antaretic. London and Paris are situated very near the center of the land-hemisphere.

General arrangement of the oceans and continents. - Oceans and continents are the grander divisions of the earth's surface. But, while the continents are separate areas, the oceans occupy one continuous basin or channel. The waters surround the Antarctic pole and stretch north in three prolongations, - the Atlantic, the Pacific, and the Indian oceans. The land is gathered about the Arctic, and reaches south in two great continental masses, the occidental and oriental, called America and Eurasia; but the latter, through Africa and Australia, has two southern prolongations, making, in all, three, corresponding to the three oceans. Thus the continents and oceans interlock, the former narrowing southward, the latter northward.

This subject is illustrated on the map, page 47. It is a Mercator's chart of the World, which, while it exaggerates the polar regions, has the great advantage of giving correctly all courses, that is, the bearings of places and coasts. The trends of lines ("trend" means merely course or bearing) admit, therefore, of direct comparison upon such a chart. It is important that the globe should be carefully studied in connection with it, in order to correct misapprehensions as to distances in the higher latitudes, and to appreciate the convergences between lines that have the same compass-course. The low lands of the continents on this chart, or those below 800 feet in elevation above the sea, are distinguished from the higher lands and plateaus by a lighter shading. The oceans are crossed by isothermal lines, which are explained beyond.

The Atlantic is the narrow ocean, the mean breadth of the North Atlantic being about 2800 miles. The Pacific is the broad ocean, being 6000 miles across, or more than twice the breadth of the Atlantic. The occident, or America, is the narrow continent, about 2200 miles in average breadth; Eurasia, the broad continent, 6000 miles in average breadth. Each continent has, therefore, as regards size, its representative ocean. The Pacific Ocean, reckoning only to $62^{\circ} \mathrm{S}$., has an area of $62,000,000$ square miles. This is ten millions beyond the area of the continents and islands, and nearly one third of the earth's surface.

(3) Oceanic depression. - $(\alpha)$ Outline. - The oceanic depression is a vast sunken area, varying in depth from 500 feet or less to probably 30,000 feet.

The true outline of the depression is not necessarily the present coastline. About the continents there is often a shallow region which is the submerged border of the continent. On the North American coast, off New Jersey, as shown on the bathymetric map (page 18), this submerged border extends out for 110 miles (and 120 from New York City), with a depth, at this distance, of only 600 feet, its slope outward only one foot in 968. At the 100-fathom line, as shown on the map, the waters suddenly deepen, and here the true oceanic basin begins. This continental border of the ocean (see large bathymetric map following page 20, on which the 100-fathom line is finely dotted) extends northward to Newfoundland and beyond, and DANA's MANUAL -2 
also southward to Cape Hatteras. Off the Carolinas it narrows much; but in the Gulf of Mexico it has its usual width. At times in geological history it has been part of the actual dry border of the continent. This is proved by the existence of a river-channel, that of the Hudson, over its submerged surface, as shown on the accompanying map of the Atlantic border. As here seen, the depth of water over this border is not 50 fathoms ( 300 feet) until within 15 miles of the 100 -fathom line.

2.

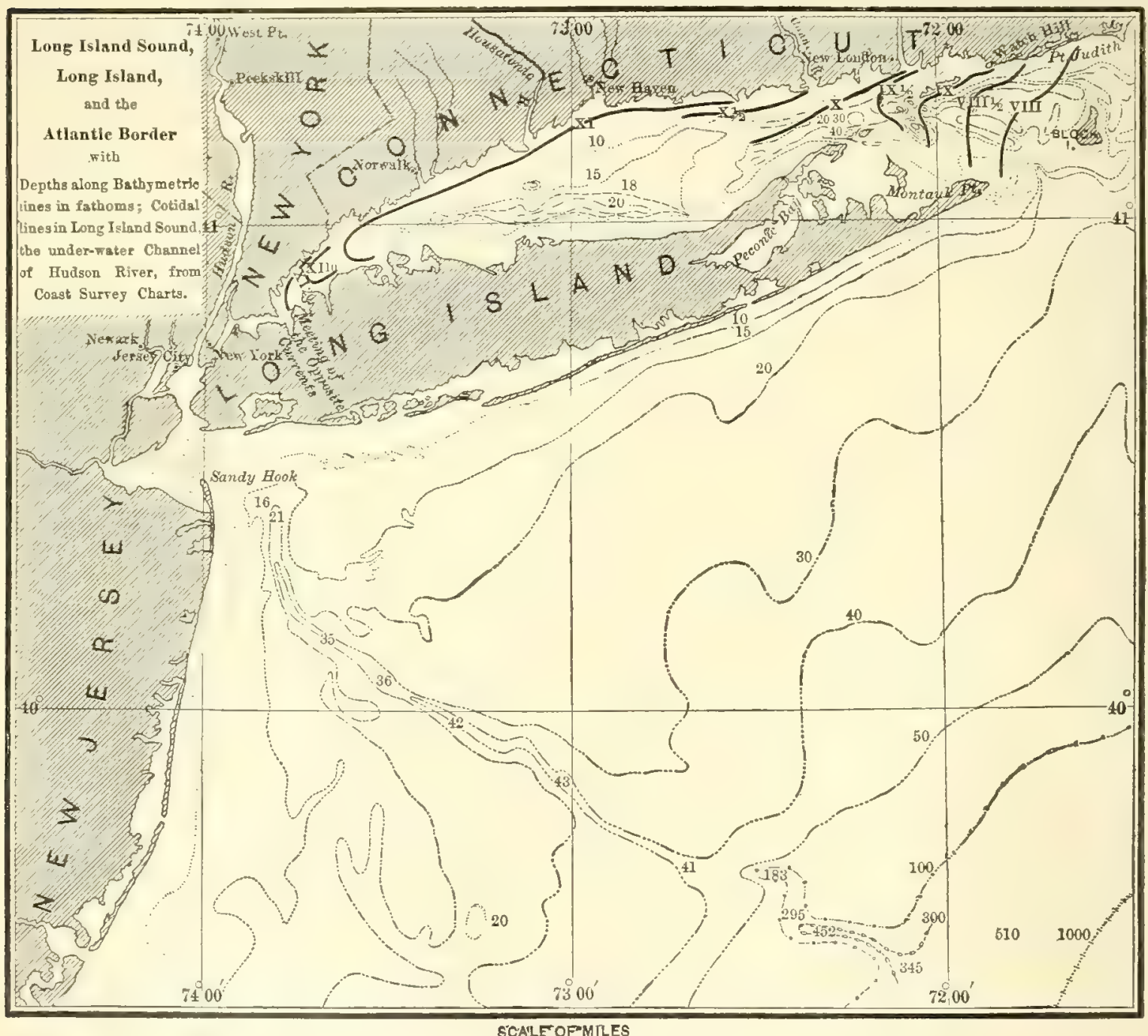

Map of the Atlantic border.

On the Pacific side of both North and South America the submerged continental border is narrow. Off California, the distance to the 100-fathom line is in general only about 10 miles. There is then a sharp descent to 500 or 600 fathoms, and from this a decline of 1600 to 2400 fathoms within 40 or 50 miles. This is in great contrast with the Atlantic border. G. Davidson, of the Coast Survey, reports the existence of several deep submarine channels leading outward from the coast, which are most probably due to streams that flowed along them at some time when the land stood much above its present level. 
Great Britain stands on a broad continental border not over 600 feet deep, and is therefore part of the European continent. A large part of the German Ocean is not over 95 feet deep.

In a similar manner, the East India Islands down to a line by the north of New Guinea and Celebes are a part of Asia, the depth of the seas between seldom exceeding 300 feet, while New Guinea is a part of Australia. In like manner, the Falkland Islands are a part of South America.

These facts with respect to the 100-fathom (600 feet) limit off the American and other coasts are illustrated on the following map.

(b) Depths of the ocean. - The depths of the ocean are given on the following bathymetric map, prepared by the author from the charts of the United States and British Hydrographic Department, and from the soundings of the vessels of the United States Fish Commission. The lines marking equal depths are made heaviest for the greatest depths, as explained on the map. The depths are given in 100 fathoms, 21 meaning 2100 fathoms $(12,600$ feet).

The mean depth of the whole ocean has been estimated at 14,000 feet; that of the North Atlantic, at 15,000; and that of the North Pacific, at 16,000 feet. As exhibited on the map, the western half of the Pacific and Atlantic oceans has greater mean depth than the eastern; for it contains all the 4000 -fathom areas, and the larger part of the 3000 -fathom areas. In the Indian Ocean the eastern side is the deeper.

In the North Atlantic, deep waters and abrupt slopes extend along near the north shores of the West India Islands; and in this line, north of Puerto Rico, occurs the greatest depth of the Atlantic Ocean, 4561 fathoms, or 27,366 feet. The mean slope from the Puerto Rico coast to the bottom is about $1: 14$. A deep trough with abrupt sides extends from this depression westward, north of Haiti or San Domingo; and south of Cuba there are depths between 18,000 and 21,000 feet.

In the Pacific, off the east shore of northern Japan and the Kurile Islands, there is a long 4000 -fathom area, in which the greatest depth found is 4656 fathoms, or 27,936 feet. An isolated depression of 4475 exists south of the largest end of the Ladrone Islands, and others over 4000 fathoms southeast of the Friendly Islands.

In the North Atlantic, between Greenland and Iceland and Norway, the great Scandinavian plateau lies at a depth, in general, of only 1500 to 3000 feet; and along one course the greatest depth does not exceed 3600 feet. Iceland stands upon it and is prolonged in a ridge under water southwestward for 750 miles, and northeastward to the island of Jan Maven. The plateau has to the north of it a large, deep region of 12,000 to 15,000 feet. To the southward it is prolonged southwestward in a relatively shallow area, called the Dolphin shoal, which passes near the middle of the ocean to the parallel of $25^{\circ} \mathrm{N}$. or beyond, with less than 12,000 feet of water over it, and mostly under 9600 feet. Either side, the depths are 15,000 feet or over, and 
to the westward, to a large extent, 17,400 to 21,000 feet. The facts show plainly that if this Doluhin shoal was ever emerged as an Atlantic continent, - the fabled Atlintis of speculation, - it never could have contributed any of its detritus to the American continent. It belongs more to the European side.

Another shallow area occupies the middle of the south Atlantic basin in a north-andsouth direction; and at its north end it is prolonged west-northwestward toward shallow areas farther west. Whether the shallow area about its southern extremity reaches into antarctic seas is not yet ascertained. A large shallow area exists on both sides of Patagonia, with a west-northwest trend (see map). It may be continued in the Pacific to the Paumotus and beyond; if so, it follows the course nearly of the axis of the Pacific Ocean, as the Dolphin shoal does that of the North Atlantic.

The West India sea has three deep areas: that of the Caribbean Sea, 17,000 feet in greatest depth (which has its deepest connection with the Atlantic between Santa Cruz and Puerto Rico, 5400 feet); the Cuban sea, or west Caribbean, separated from the east Caribbean by shallow waters - 600 to 4080 feet (100 to 680 fathoms) - between Honduras and Jamaica, with a maximum depth of more than 20,000 feet; and the Gulf of Mexico, 12,714 feet in maximum depth. The Mediterranean Sea, 2100 miles long, has likewise its three deep-water areas: the eastern or "Levant" sea, about 13,000 feet in greatest depth; the central, between Sardinia and Italy (separated from the eastern by relatively shallow water, not cver 200 fathoms, between western Sicily and Tunis, in Africa), 12,500 feet; and the western, 9500 feet.

The Straits of Gibraltar are mostly about 900 fathoms deep, but only 160 between Cape Spartel and Cape Trafalgar.

The ranges of islands show the chief courses of shallow water in the ocean, and the bathymetric lines drawn about them, the outline of the basement ridges of which the islands are the summits. Some of the isolated islands, especially those of coral-reef origin, have great depths close about them. Bermuda, in the Atlantic, has a depth of nearly 16,000 feet (2650 fathoms) within 25 miles to the eastward, whence the mean submarine slope is $1: 8 \frac{1}{4}$; and a depth of 12,000 feet exists within six miles on one side and $9 \frac{1}{2}$ miles on the opposite - making the mean submarine slopes to this depth very steep, they being $1: 2 \cdot 64$ and 1:4.2. The small Phœnix Islands, in the central Pacific, stand in a large area of 18,000 to 21,000 feet, and have depths of 18,000 to 20,000 feet between them, with similarly steep submarine slopes; in one case a slope to the 12,000 point of $1: 1.5$. At Keeling atoll, in the Paumotu Archipelago, Captain Fitzroy, R. N., found no bottom in 7200 feet at 2200 yards from the breakers - which gives a pitch-off exceeding $1: 0 \cdot 92$.

The island chains of the ocean may seem to indicate that great irregularity prevails elsewhere over the bottom of the ocean. But, while abrupt depressions and elevations do exist, the abyssal slopes are in general very gradual. One remarkable exception is the occurrence in the vicinity of the Canaries of a submarine crater a few miles wide and 1000 feet deep. Such cases are most likely to occur in the vicinity of volcanic islands. Whether the great depths south of the Ladrones and the Friendly Islands are craters or not is undetermined. 



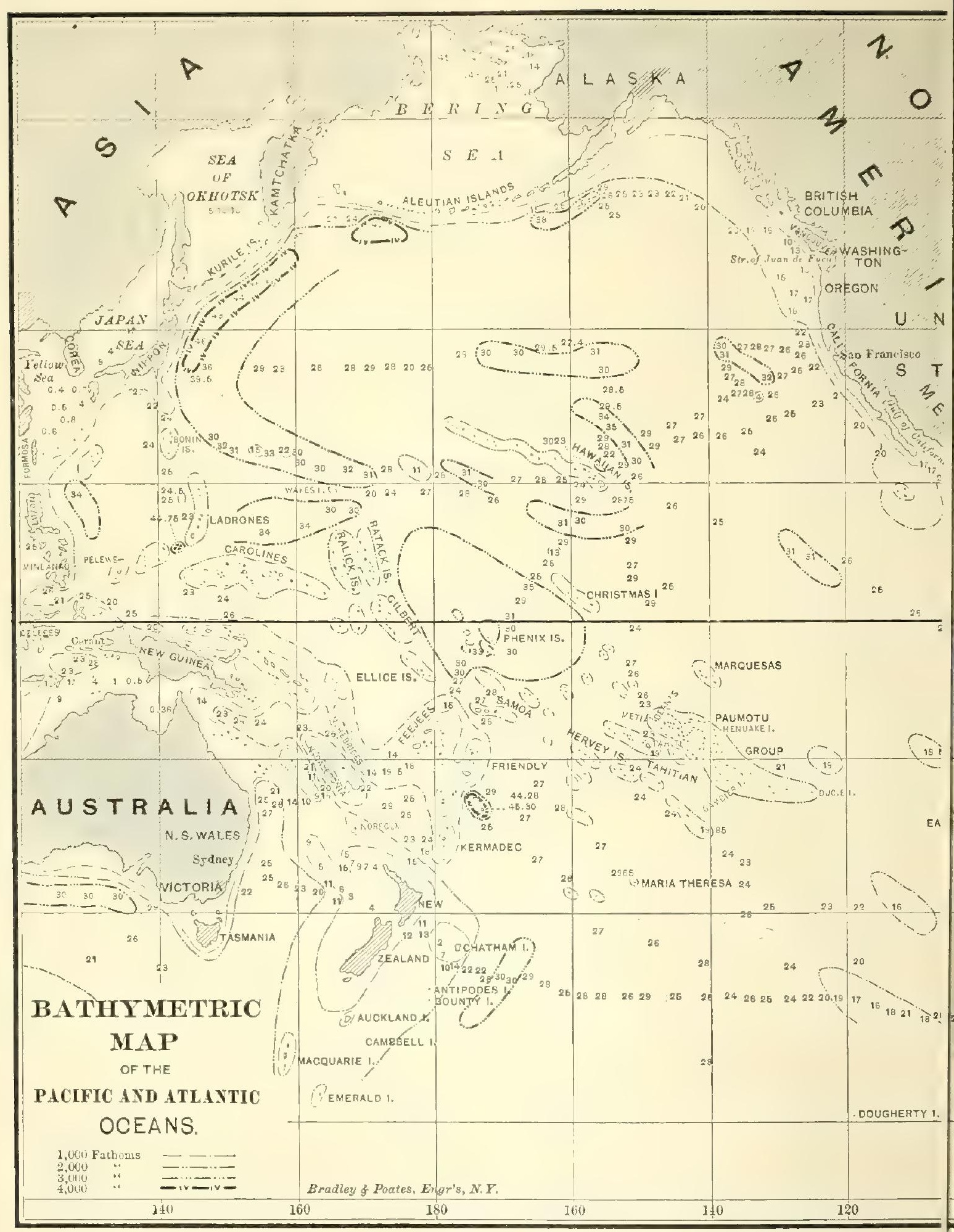




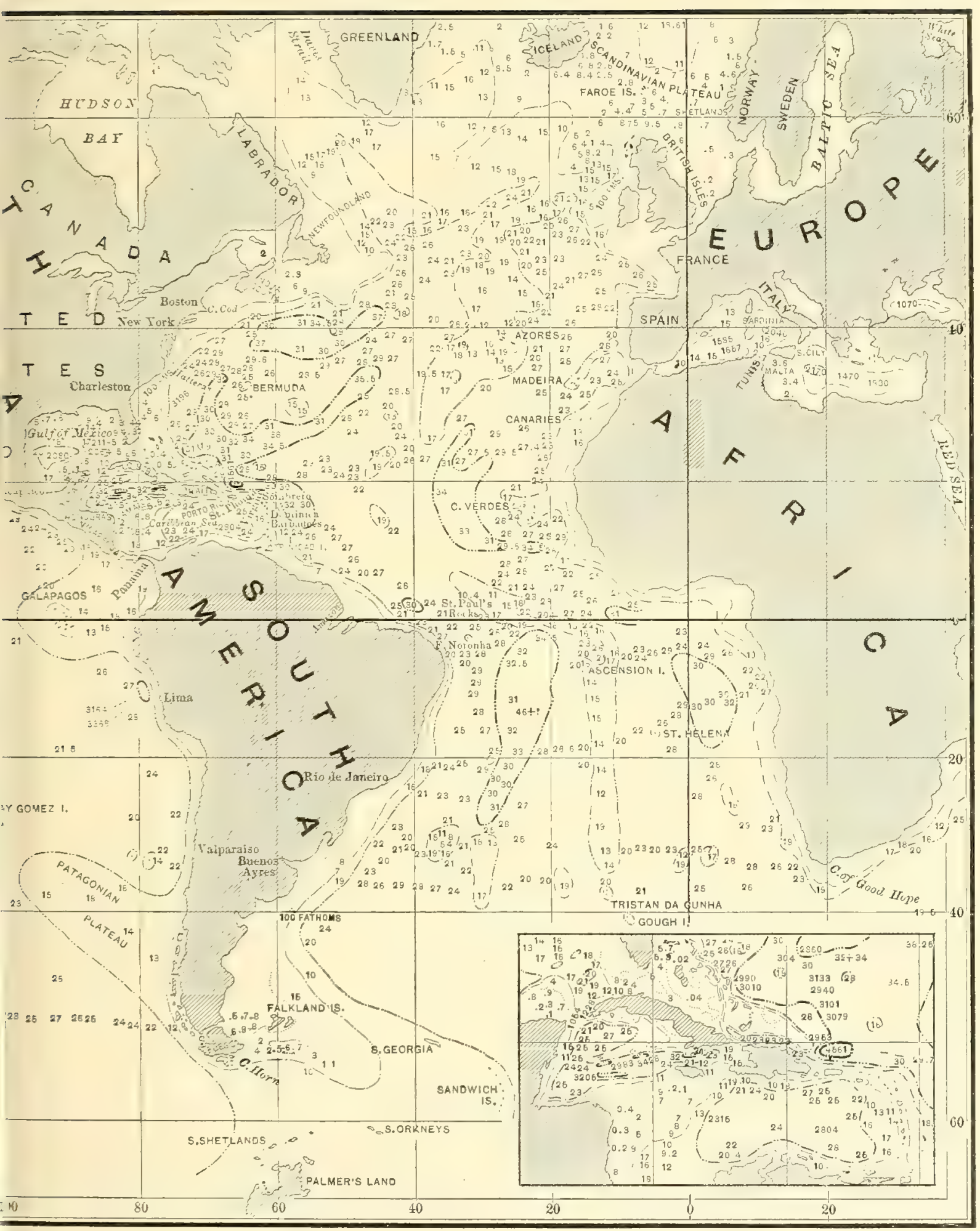


<smiles>[CH]C[Tl]</smiles> 


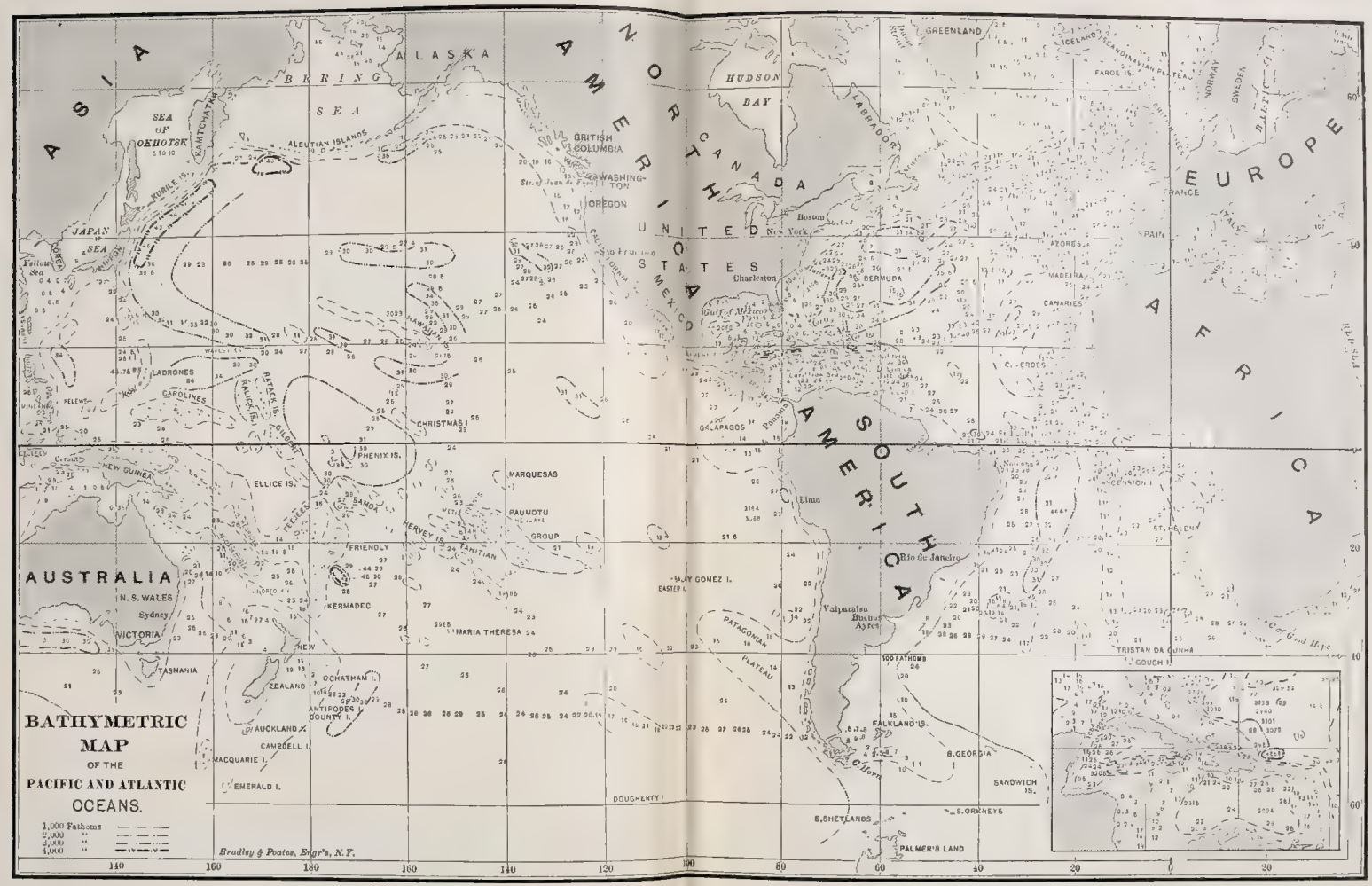



To appreciate the oceanic basins, we must conceive of the earth without water, - the depressed areas, thousands of miles across, sunk 10,000 to perhaps 30,000 feet below the bordering continental regions, and covering four elevenths of the whole surface. The continents, in such a condition, would stand as elevated mountain plateaus encircled by one great uneven, almost featureless, basin. If the earth had been left thus, with but shallow briny lakes about the bottom, there would have been an ascent of five miles or more from the Atlantic basin to the lower part of the continental plateau, and about five miles more to scale the summits of the loftier mountains of the globe. The continents would have been wholly in the regions of the upper cold, all alpine, and the bottoms of the oceanic basin under oppressive heat, with drought and barrenness universal. The uneven surface of the oceanic basin has been leveled off to a plain by filling it with water. The greatest heights of the world have thereby been diminished more than one half, and genial climates substituted for intolerable extremes, rendering nearly all the emerged land habitable, and giving moisture for clouds, rivers, and living species. By the same means distant countries have been bound together by a common highway, into one arena of history.

The calculated mass of the ocean, taking the depth as above given, is $1,320,000,000,000,000,000$ tons.

(4) General view of the land. - (a) Position of the land. - The land of the globe has been stated to lie with its mass to the north, about the Aretic pole, and to narrow as it extends southward into the waters of the southern hemisphere; with the mean southern limit of the continental lands in the parallel of $45^{\circ}$, or just half-way from the equator to the south pole.

South America reaches to $56^{\circ} \mathrm{S}$. (Cape Horn being in $55^{\circ} 58^{\prime}$ ), which is the latitude of Edinburgh or northern Labrador; Africa only to $34^{\circ} 51^{\prime}$ (Cape of Good Hope), nearly the latitude of the southern boundary of Tennessee, and 60 miles nearer the equator than Gibraltar; Tasmania (Van Diemen's Land) to $43 \frac{1}{2}^{\circ}$ S., nearly the latitude of Boston or northern Portugal.

(b) Distribution. - The independent continental areas are three in number: America, one; Europe, Asia, or Eurasia, and Africa, a second; Australia, the third. Through the East India Islands, Australia is approximately connected with Asia, nearly as South America with North America through the West Indies; and, regarding it as thus united, the great masses of land will be but two, - the American, or Occidental, and Europe, Asia, Africa, and Australia, or the Oriental.

But, further, these great masses of land are divided aeross from east to west by seas or archipelagoes. The West Indies (between the parallels of $10^{\circ} \mathrm{N}$. and $30^{\circ} \mathrm{N}$.), the Mediterranean (between $30^{\circ} \mathrm{N}$. and $45^{\circ} \mathrm{N}$.), and the Red Sea, and the East Indies (between $30^{\circ} \mathrm{N}$. and $10^{\circ} \mathrm{S}$.), with the connecting oceans, make a nearly complete band of water around the globe, sub- 
dividing the Occident and Orient into north and south divisions. Cutting across 37 miles at the Isthmus of Darien, where at the lowest pass the greatest height above mean tide level does not exceed $260 \mathrm{feet}$, as has been done at the Isthmus of Suez, where the highest point of the isthmus is only 40 feet above the sea, the girth of water would be unbroken. 'This belt of water, like the continents, is situated mostly in the northern hemisphere, instead of corresponding in its course to any great circle.

America is thus divided into North and South America. The oriental lands have one great area on the north, comprising Europe and Asia combined, often named Eurasia, and, on the south, (1) Africa, separated from Europe by the Mediterranean, and (2) Australia, separated from Asia by the East India seas. Thus the narrow Occident has one southern prolongation, and the wide Orient two. The Orient is thus equivalent to two Occidents in which the northern areas coalesce, - Europe and Africa one, Asia and Australia the other; so that there are really three doublets in the system of continental lands. The Caspian and Aral, which are salt seas, lie in a depression of the continent of great extent, - the Aral being near the level of the ocean, and the Caspian 84 feet below that of the Black Sea.

The continents have several common features entitling them to be viewed as individuals under a common type of structure. They have (1) a like position on the sphere, each lying with its head or broader end to the north, and the tapering extremity to the south. North America, South America, and Africa strongly exhibit this characteristic; Asia somewhat less manifestly, yet decidedly in the great triangles of her southern border, Hindostan and Siam. Australia is seemingly an exception; but there is evidence that this land has been narrowed and shortened by subsidence, and thus has lost New Zealand, its eastern front, and probably a large region to the south. (See large bathymetric map following page 20.)

Another striking fact, showing system in arrangement, is seen (2) in the relative positions of the southern and northern continents. South America and Australia are not to the south of the related northern continent; on the contrary, the center of South America is about $40^{\circ}$ in longitude east of that of North America, or nearly an eighth of the sphere, and Australia $40^{\circ}$ east of that of Asia. Thus there is a zigzag alternation in the positions of the four great masses of land. Further, (3) the curving line of islands in the West Indies from Florida to Trinidad is similar in form to that between Malacea through Sumatra and New Guinea to New Zealand, although much shorter.

These are three of the points in which the continental individualities exhibit the system that exists in the earth's physiognomy.

(c) The islands. - The islands adjoining the continents are properly continental islands. Besides the examples mentioned on page 19, Japan and the ranges of islands of eastern Asia are strictly a part of Asia, for they conform in direction to the Asiatic system of heights, and are united to the 
main by shallow waters. Vancouver Island and others north of it are similarly a part of North America; Chiloe, and the islands south to Cape Horn, a part of South America; and so in other cases. In general they correspond to a broader mountain range more or less submerged.

The oceanic islands are, in general, as has been stated, the summits of submerged oceanic mountain chains. The Atlantic and Indian oceans are mostly free from them. The Pacific contains about 675 islands, with a mean area of only 80,000 square miles. Excluding New Caledonia and some other large islands in its southeastern part, the remaining 600 islands have an area of but 40,000 square miles, or less than that of the state of New York.

(d) Mean elevation of the land. - The mean height of the continents above the sea has been estimated at nearly 1800 feet, and the mean height of them severally is stated as follows: Europe, 975 feet; Asia, 2880; North America, 2000 ; South America, 1750; and Africa, probably about 2000 feet. The material of the Pyrenees spread over Europe would raise the surface only 6 feet; and the Alps, though of four times larger area, only 22 feet.

The following estimates have been made for the mean heights of the United States: for the whole area, Alaska excluded, 2500 feet ; Alabama, 500 ; Arizona, 4100 ; Arkansas, 650 ; California, 2900 ; Colorado, 6800 ; Connecticut, 500 ; Delaware, 60 ; District of Columbia, 150 ; Florida, 100 ; Georgia, 600 ; Idaho, 5000 ; Illinois, 600 ; Indiana, 700 ; Iowa, 1100 ; Kansas, 2000 ; Kentucky, 750 ; Louisiana, 100 ; Maine, 600 ; Maryland, 350 ; Massachusetts, 500 ; Michigan, 900 ; Minnesota, 1200 ; Mississippi, 300 ; Missouri, 800 ; Montana, 3400 ; Nebraska, 2600 ; Nevada, 5500 ; New Hampshire, 1000 ; New Jersey, 250; New Mexico, 5700 ; New York, 900 ; North Carolina, 700 ; North Dakota, 1900 ; Ohio, 850 ; Oklahoma, 1300 ; Oregon, 3300 ; Pennsylvania, 1100 ; Rhode Island, 200 ; South Carolina, 350 ; South Dakota, 2200 ; Tennessee, 900 ; Texas, 1700; Utah, 6100 ; Vermont, 1000 ; Virginia, 950 ; Washington, 1700; West Virginia, 1500; Wisconsin, 1050; Wyoming, 6700. (Gamett.)

The extremes of level in the land, so far as now known, are, 1390 feet below the level of the ocean at the Dead Sea, 1300 feet in the deepest part of the Jordan valley, and 29,002 feet high in Mount Everest of the Himalayas, which have many peaks over 25,000 feet.

In America, Death Valley, on the southeast border of California, descends 480 feet below the sea level. As stated by F. S. Coville, it is 175 miles long and 20 in greatest width, and has the Funeral Mountains, 7000 feet high, on the east, and the Panamints, 11,000 feet, on the west.

(5) Subdivisions of the surface, and character of its reliefs. - The surfaces of continents are conveniently divided into (1) lowlands; (2) plateaus, or elevated table-lands; (3) mountains. The varying levels above the sea make up the reliefs of a continent. The limits between these subdivisions are quite indefinite, and are to be determined from a general survey of a country rather than from any specific definitions.

LowLANDS. - The lowlands include the extended plains or country lying not far above tide level. In general they are less than 1000 feet above the sea; but they are marked off rather by their contrast with higher lands of 
the mountain regions than by any special altitude. The surface is usually undulating, and often hilly. The great interior region of the North American continent, including the Mississippi valley, is an example of an interior plain; also the plains of the Amazon; the pampas of La Plata; the lower lands of Europe and Asia. Frequently the surface rises gradually into the bordering mountain-declivities, as in the case of the Mississippi plains and the Rocky Hountain slope. Broad, low plains between mountain ranges and the seashore are called coastal plains. Along the eastern border of North America from New Jersey southward, the coastal plains are broad and have navigable streams. Next west is a region of more uneven and rocky country with rapid streams - the Piedmont region, which extends to the Appalachian region, or that of the mountains.

A mountain is either a single peak, as Mount Etna, Mount Washington, Mount Blane; or a ridge; or a series of ridges, sometimes grouped in many, more or less parallel, lines.

A mountain range consists of a series of ridges closely related in position, direction, and origin: as in the Appalachian ranges, the Wasatch, the Sierra Nevada. A sierra is, in Spanish, the name of a ridge, or group of ridges, of serrated or irregular outline.

A mountain system consists of two or more mountain ranges, of the same period of origin, belonging to a common region of elevation, and generally either parallel or in consecutive lines, or consecutive curves, with often inferior transverse lines of heights. A mountain chain consists of two or more mountain-systems of different periods of origin, in the same part of a continent. The oldest of the mountain ranges in a chain is called the protaxis - so named from the Greek for first and axis (see the map of the Archæan areas on page 443). The other ranges are usually parallel to the protaxis, and may, or may not, have greater height. The Appalachian Chain extends from Canada to Alabama, and comprises (1) the protaxis, represented by the Highlands of New Jersey and Putnam County, New York, and their continuation northward interruptedly along the eastern half of the Green Mountains into Canada, and southward, as a narrow, interrupted area, through Pennsylvania, and a very broad area through Virginia, to Georgia; (2) the Taconic Range, along the borders of New England and New York to New Jersey and beyond; and (3) the Appalachian Range.

The Rocky Mountains also have a protaxis, with approximately parallel ranges of later formation. This protaxis is the "Front Range" in Colorado, nearly 1000 miles from the Pacific coast, making the Pacific border region in this part very wide. But to the north, in Montana and Wyoming, the protaxis makes a westward bend of 250 miles, and then resumes a northwestward course and continues to the parallel of $52 \frac{1}{2}^{\circ}$, and is represented beyond this in isolated ridges; consequently the Pacific border region of British America is relatively narrow. The line to the north of the United States appears to be represented to the south in the Archæan axis of the Wasatch and some other similar ridges. The very large area of the Pacific 
border, lying between the Wasatch line and the line of the Front Range, is distinctively a Rocky Summit area, and peculiar to the United States portion of the chain. A cordillera is a combination of mountain chains.

The Coast Cordillera within about 150 miles of the coast includes the Sierra Nevada and Cascade ranges and a range in continuation in British Columbia, which constitute together a Sierra Chain, and have heights equal to those of the Rocky Mountain summit, and a Coast Chain 2000 to 4000 feet high in California, which is continued in the Vancouver Range of British America, - 484 feet high in one Vancouver peak, - and, beyond the islands of the coast, in the lofty Fairweather and St. Elias line of heights. On the terms range, system, chain, cordillera, etc., see further, page 389.

Plateaus. - A plateau is an extensive elevated region of flat or hilly surface, sometimes intersected by ranges of mountains. Any extensive range of generally flat country that is over a thousand feet in altitude is called a plateau. It may lie along the course of a mountain chain, or occupy a wide region between distant chains. The high land that forms the southern half of New York is generally 1500 to 2000 feet high, and reaching an elevation of more than 4000 feet in the Catskills, is the northern part of a plateau which southward extends through Pennsylvania to Tennessee, and in the latter region constitutes the Cumberland Table-land. It is an example of a marginal plateau, connected in origin with a mountain range, - that of the Appalachian Mountains, - and constituting its outer margin. The channeling action of runuing water has mostly obliterated the plateau character, and converted the region into a group of peaks, ridges, and valleys. In this way high plateaus have often been sculptured into mountain-like forms. The "high plateaus" of southern Utah, which range in height from 7000 to 9500 feet, are properly a marginal appendage to the Wasatch Range, as their elevation was connected with that attending the making of these mountains.

Other plateaus are intermont plateaus. They occupy the interval between mountain ranges, chains, or cordilleras, and are the highest and largest of plateaus. Between the Rocky and Sierra cordilleras a broad platean extends from Mexico northwestward through British America. It is mostly from 3000 to 5000 feet in altitude, but the Columbia River and the Colorado have each cut a way through the Sierra Chain and reduced the level by denudation. There are many high ridges in the plateau, parallel in course, or nearly so, to the mountain ranges of the sides, and in part of Oregon and of British Columbia ridges occupy the whole breadth; but in general the plateau features are well defined.

The portion of the plateau between the Colorado and Columbia rivers is called the Great Basin. It has the Great Salt Lake and the Wasatch Mountains on the east, and the Sierra Nevada and Cascade Mountains on the west, and in this part it is nearly 500 miles wide. Its surface is mostly 4000 to 5000 feet above tide level; but although so high, it has no outside drainage. Its streams are short, and dry up over arid saline plains or end in saline lakes. Great Salt Lake, in Utah, is one of the se lakes near its eastern 
border, and Mrono Lake in California, at the foot of the lofty Sierra, is another on the western borter. The eastern half of the plateau south of the Colorado River "xtends south into Mexico, and there has similit arid features, with saline lakes and inside drainage.

The platean of 'Tibet is an intermont plateau between the main range of the Himalayas and the Kuen-Lun Mountains. It is about 13,000 feet in altitude, but is orerlooked by mountains having an altitude of 25,000 to 29.000 feet, and has its own ridge of 20,000 feet. It is 1200 miles from east to west, and half this in mean breadth; but its eastern half is much encumbered by ridges.

The plateau of Quito, about 300 miles long, 40 miles wide, and 10,000 feet above tide level, is situated between two parallel cordilleras of the Andes, the eastern of which contains among its snow-capped cones or domes, Cayambe (19,535, and on the equator), Antisana, Cotopaxi (19,613), Sangay ; and the western, including Chimborazo (20,498 feet), Pichincha (15,924 feet), and others. The plateau of Bolivia has an elevation of 12,900 feet, with Lake Titicaca at 12,830 feet, and the city of Potosi at 13,330 feet.

In Europe, Spain is for the most part a plateau about 2250 feet in average elevation; Auvergne, in France, another, of about 1100 feet; Bavaria, another, of 1660 feet. Persia is a plateau varying in elevation between 2000 and 4000 feet, with high ridges in many parts. The Abyssinian plateau, in Africa, has an average elevation of more than 7000 feet; the region of Sahara about 1500 feet, except the southern part, which lies mostly at a greater altitude than 650 feet; that of southern Africa south of the parallel of $10^{\circ} \mathrm{S}$. from 3000 to 4000 feet in mean altitude, and rising into many high summits, with the elevation least to the west.

Mountains. - $(\alpha)$ Slopes of mountains. - The mountain mass. - The slopes of the larger mountains and mountain chains are generally very gradual. Some of the largest volcanoes of the globe, as Etna (Sicily) and Loa (Hawaii), have a slope of only six to eight degrees: such mountains are broad cones, having a base of 40 miles or more. The higher volcanic cones of western America are mostly $25^{\circ}$ to $35^{\circ}$ in angle of slope.

The average eastern slope of the Rocky Mountains seldom exceeds 10 feet a mile, which is about one foot in 500, equal to an angle of only 7 ' On the west the average slope is but little less gradual. The rise on the east continues for 600 miles, and the fall on the other side for 400 to 500 miles; the passes at the summit have a height of 4944 to 10,000 feet; and above them, as well as over different parts of the slopes (especially on the west), there are ridges carrying the altitude above 14,000 feet. The highest part of the range is in Colorado, where the passes are 11,000 to 13,000 feet high; while in latitude $32^{\circ}$ the passes are about 5200 feet; on the Central Pacific Railroad, 6184 feet high; in Canada, 5264 to 7100 feet high; and on the Canadian Pacific (the Kicking Horse Pass) 5300 feet high. The mountain mass, therefore, is not a narrow barrier between the east and west, as might be inferred from the ordinary maps, but a vast yet gentle swell of the surface, having a base 1000 miles in breadth, and the slopes diversified with various mountain ridges, or spreading out in plateaus at different levels. 
In the Sierra Nevada, the western (or gentler) slope is between 100 and 250 feet to the mile, and the eastern, for a larger part of its length, 1000 feet. In the Andes the eastern slope is about 60 feet in a mile, and the western 100 to 150 feet; the passes are at heights from 12,500 to 16,160 feet, and the highest peak - Sorata in Bolivia - 25,290 feet. The slope is much more rapid than in the Rocky Mountains. But there is the same kind of mountain mass variously diversified with ridges and plateaus. The existence of the great mountain mass and its plateaus is directly connected with the existence of the main ridges. But it will be shown in another place that the ridges may have existed long before the mass had its present elevation above the sea.

In the Appalachians the mountain mass is very much smaller, and the component ridges are relatively more distinct and numerous; and still the general features are on the same principle. The greatest height - Mount Mitchell or Black Dome in North Carolina - is 6707 feet.

It is common to err in estimating the angle of a slope. To the eyes of most travelers, a slope of $60^{\circ}$ appears to be as steep as $80^{\circ}$, and one of $30^{\circ}$ to be at least $50^{\circ}$. In a front

3.

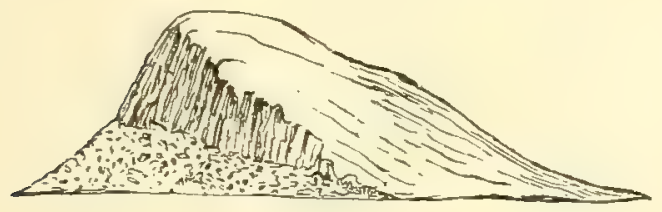
view of a declivity it is not possible to judge rightly. A profile view should always be obtained and carefully observed before registering an opinion.

In Fig. 3 the bluff front facing the left would be ordinarily called a vertical precipice, while its angle of slope is actually about $65^{\circ}$; and the talus of broken stones at its base would seem at first sight to be $60^{\circ}$, when really $40^{\circ}$.

4.

$\mathbf{T}$

B 10

5.

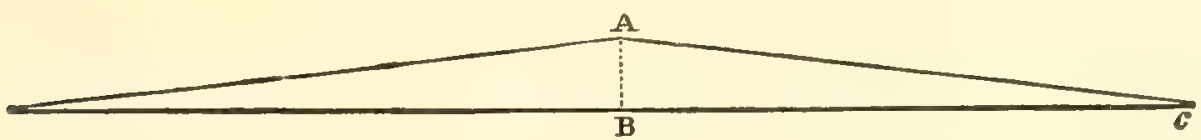

6.

Fig. 4 represents a section of a volcanic mountain $3^{\circ}$ in angle; Fig. 5 , another, of $7^{\circ},-$ the average slope and form of Mount Kea, Hawaii ; Fig. 6, the same slope with the top

7.

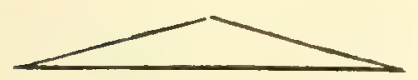

8.

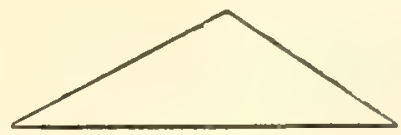

9.

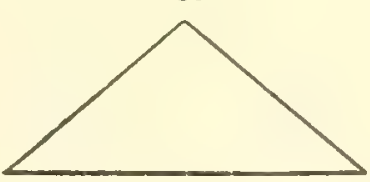

rounded, as in Mount Loa; Fig. 7, a slope of $15^{\circ}$; Fig. 8, Jorullo, in Mexico, which has one side $27^{\circ}$ and the other $34^{\circ}$, as measured by N. S. Manross; Fig. 9, a slope of $40^{\circ}$; - 
the steepest of volcanic comes. The lnfty volcanos of the Andes are not steeper than in Fig. 8, although often represented with angles of $40^{\circ}$ to $50^{\circ}$.

With a clinometer (sec Fig. 89, 1age 100) held between the eye and the mountain, the angle of slope may be approximately measured. When no instrument is at hand, it is easy to estimate with the eye the number of times a vertical, as AB in Fig. 5 , is cuntained in the semi-base, $B C$; ant, this being ascertained, the angle of slope may be easily calculaterl. The ratio $1: 1$ corresponds to the angle $45^{\circ} ; 1: 2$ to $26^{\circ} 34^{\prime} ; 1: 3$ to $18^{\circ} 26^{\prime} ; 1: 4$ to $14^{\circ}$ $2^{\prime} ; 1: 5$ to $11^{\circ} 18^{\prime \prime} ; 1: 6$ to $9^{\circ} 28^{\prime} ; 1: 7$ to $8^{\circ} 8^{\prime} ; 1: 8$ to $7^{\circ} 7_{2}^{\prime \prime} ; 1: 9$ to $6^{\circ} 202_{2}^{\prime \prime} ; 1: 10$ to $5^{\circ} 42^{\prime \prime} ; 1: 12$ to $4^{\circ} 46^{\prime} ; 1: 15$ to $3^{\circ} 49^{\prime} ; 1: 20$ to $2^{\circ} 522^{\prime}$. The inclinations corresponding to these ratios may be easily put into a diagram.

For altitudes over the United States, see Bulletin No. 76, U. S. Geol. Survey, by H. Gannett, 1891.

(b) Ridges. - The ridges of a chain vary along its course. After continuing for a distance, they may gradually become lower and disappear ; and while one is disappearing, another may rise to the right or left; or the mountain, for scores of leagues, may be only a plateau without a high ridge, and then new ranges of elevations may appear. The Rocky Mountains well exemplify this common characteristic, as may be seen on any of the recent maps. The Sierra Nevada dies out where the Cascade Range begins; and each has minor examples of the same principle. The Andes are like the Rocky Mountains; only the parts are pressed into narrower compass, and the crest ranges are hence continuous for longer distances. The Appalachian ridges rise and sink along the course of the chain.

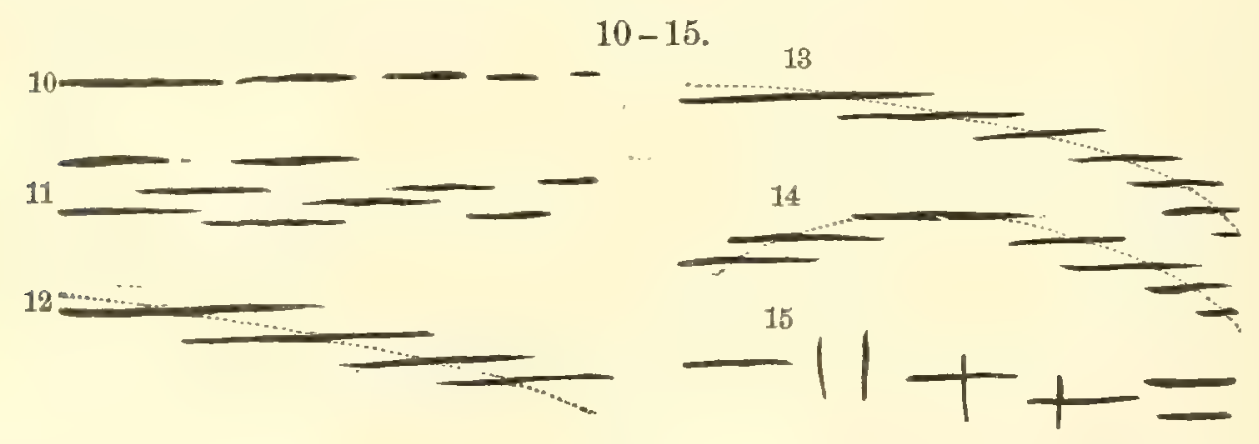

The general idea of this composite structure is shown in Figs. 10 to 15, where each series of lines represents a series of ridges in a composite range. In Fig. 10 the series is simple and straight; in Fig. 11 it is still straight, but complex; in Fig. 12 the parallel parts are so arranged as still to make a nearly straight composite range; while in Figs. 13 and 14 the succession forms a curve; and in Fig. 15 there are transverse ridges in a complex series. In ridges or ranges thus compounded, the component parts may lie distinct, or they may coalesce so as not to be apparent.

RIVER systems. - Plateaus and mountains are the sources of rivers. They pour the waters along many channels into the basin or low country toward which they slope; and the channels, as they continue on, unite into larger channels and trunks which bear the waters to the sea. The basin and its surrounding slopes make up a river system or drainage area. The 
extent of such a region will vary with the position of the mountains and ocean.

Over a continent there are the interior and the border river systems or drainage areas; the former very large and few, the latter many and relatively small.

In North America, having the Rocky Mountains on the west and the Appalachian on the east, the great interior slopes are three: southward, along the Mississippi; eastward, along the St. Lawrence; and northward, along the Mackenzie and other streams.

The tributary streams of the Mississippi rise on the west, among the heights of the Rocky Mountains, the region in and near the Yellowstone Park supplying waters to the Missouri through a number of tributaries including the Yellowstone and the Front Range of Wyoming, Colorado, and New Mexico, giving origin to the Platte, Arkansas, and Canadian rivers; on the north, in the central plateau of the continent, in northern Minnesota, west of Lake Superior, near lat. $47^{\circ}-48^{\circ}$, long. $93^{\circ}-96^{\circ}, 1680$ feet in elevation - a region of lakes which is the source of the Mississippi of the maps; and on the east, in the Appalachians, from western New York to Alabama. There are also other rivers flowing from the west into the Gulf of Mexico; but, in a comprehensive view of the continent, these belong to the same great river system.

The St. Lawrence commences in the head waters of Lake Superior, about the same central plateau, embraces the Great Lakes with their tributaries, and flows finally northeastward, following a northeast slope of the continent. North of Lake Superior and the head waters of the Mississippi, as far as the parallel of $55^{\circ}$, there are other streams, which also flow northeastward, deriving some waters from the Rocky Mountains through the Saskatchewan, and reaching the ocean through Hudson Bay. Winnipeg Lake is here included. These belong with the St. Law rence, the whole together constituting a second continental river system.

The Mackenzie is the central trunk of the northern river system. Starting from near the parallel of $55^{\circ}$, it takes in the slopes of the Rocky Mountains adjoining, and much of the northern portion of the continent. Athabasca, Great Slave, and Great Bear lakes lie in this district.

The border river systems depend for their extent on the height and slope of the mountains, the distance from the coast, and the structure of the mountain region. The Appalachian range, mostly below 5000 feet in height, is 150 to 300 miles from the coast. But the mountains are a succession of overlapping parallel ridges, and the rivers in their higher parts go back and forth between the ridges, thus deriving a more gradual slope, a much greater length, and producing a longer range of watered country. The Rocky Mountains, 10,000 to over 14,000 feet high, are 600 to 1000 miles from the coast. But a second chain of equal height - that of the Sierra and Cascade ranges, with the range of the California peninsula, which is probably a southern continuation of the line - stands as a barrier to the more eastern drainage 
within 150 miles of the coast, and thus infuences the extent of the l'acific border river systems. The western drainage of the Rocky Mountains, rising partly in the Yellowstone Park, and partly just south of it, has its outlet to the ocean through the Colorado and Gulf of California, and along the Columbia River and streams farther north, the Colorado and Columbia reaching salt water at points 1200 miles apart. Thus it is that the "Great Basin" is without drainage. Again, a subordinate range of this chain, that of the Coast Range, 2000 to 4000 feet high, is a barrier, for 800 miles, to most of the drainage waters of the Sierra Nevada and Cascade Mountains; and consequently the Sacramento and Joaquin rivers, and not the ocean, receive all the Sierra waters for 500 miles, and the Willamette, the waters of the Cascade Range for 150 miles.

South America has an arrangement of interior river systems parallel to that of North America; the Amazon flowing eastward, like the St. Lawrence; the La Plata flowing southward, like the Mississippi; the Orinoco and other streams northward, like the Mackenzie. This adds a fourth to the characteristics exhibiting parallelism in structure between two continents, North and South America (page 22). Africa, on the opposite side of the Atlantic, has the arrangement reversed as regards the east and west streams: the great Niger empties into the western ocean, the Atlantic; the Nile is the northward-flowing stream; but the southward-flowing interior waters are divided between the Congo draining to the southwestward and the Zambesi to the southeastward.

The lengths and drainage areas of some of the largest of rivers are as follows: Amazon, length $\left(\mathrm{L}_{*}\right)=3545$ miles, drainage-area $\left(\mathrm{D}_{0}\right)=2,264,000$ square miles ; La Plata, L. $=2400$, D. $=1,250,000 ;$ Mississippi, L. $=2800$ (but from its mouth to the head of the Missouri $4200), D_{.}=1,285,000$; Nile, L. $=3815$, D. $=1,049,000$; Congo, L. $=2900$, D. $=1,540,000$; Yenisei, $\mathrm{L}_{0}=2800, \mathrm{D}_{0}=784,500 ;$ Amur, L. $=2380, \mathrm{D}_{0}=583,000 ;$ Obi-Irtish, L. $=$ 2320, D. $=725,000$; Lena, L。 $=2400$, D. $=594,000$; Yang-tse-Kiang, L。 $=2800$, D. $=$ 548,000 ; Hoang Ho (Yellow River), L. $=2280, D_{0}=537,000$.

The lengths of the valleys, excluding the minor beds, are: the Amazon, 2600 miles; the Mississippi, 1164 ; the Nile, 3100.

\section{SYSTEM IN THE RELIEFS OR SURFACE FORMS OF THE CONTINENTS.}

Law of the system. - The mountains, plateaus, lowlands, and river regions are the elements, in the arrangement of which the system in the surface form of the continents is exhibited. The law at the basis of the system depends on a relation between the continents and their bordering oceans, and is as follows :-

First. The continents have in general elevated mountain borders and a low or basin-like interior.

Second. The highest border faces the larger ocean.

A survey of the continents in succession with reference to this law will exhibit both the unity of system among them and the peculiarities of each, dependent on their different relations to the ocean. 
(1) America. - The two Americas are alike in lying between the Atlantic and the Pacific. North America, in accordance with the law, has on the Pacific side - the side of the great ocean - the Rocky Momntains, on the Atlantic side the low Appalachians, and between the two there is the great plain of the interior. This is seen in the annexed section (Fig. 16) from

16.

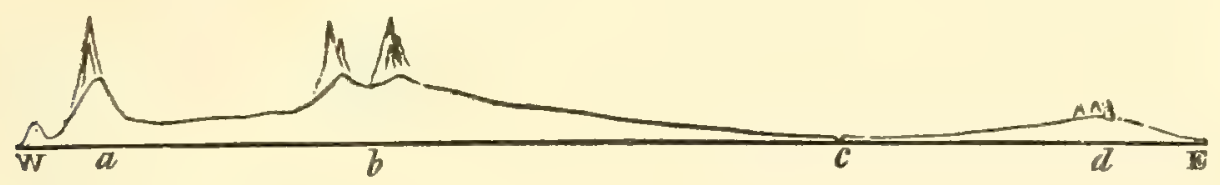

West to east: on the west, the Rocky Mountains, with the double crest, at $b$; the Sierra Range at $a$; between $a$ and $b$ the Great Basin; at $d$ the Appalachians; $c$ the Mississippi; and between $d$ and $b$ a section of the Mississippi river system.

The Appalachians, on the east, reach an extreme height of but 6700 feet, and are in general under 2500 feet.

To the north of North America lies the small Arctic Ocean, much encumbered with land; and without any distinct mountain-chain facing the ocean.

South America, like North America, has its great western range of mountains, and its smaller eastern range (Fig. 17); and the Brazilian line (b) is

17.

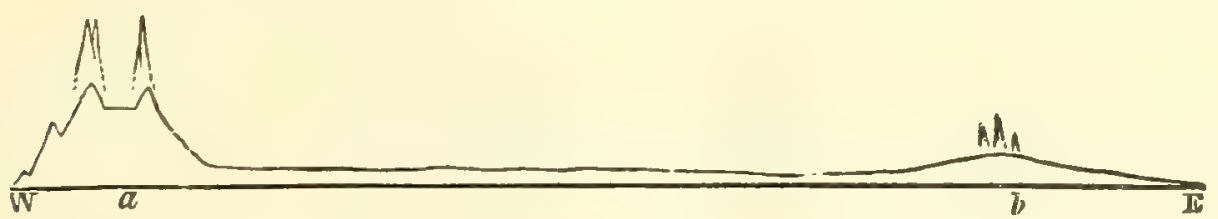

closely parallel to that of the Appalachians. 'The Andes (a) face the very broad South Pacific, and have more than twice the average height of the Rocky Mountains; moreover, they rise more abruptly from the ocean, with narrow shore plains.

Unlike North America, South America has a broad ocean on the north, - the North Atlantic in its longest diameter; and along this northern coast a mountain chain extends through Venezuela and Guiana.

(2) Europe and Asia. - The land covered by Europe and Asia is a single area of land, only partially double in its nature (page 22). Unlike either of the Americas, it lies east-and-west, with an extensive ocean facing Asia on the south; and its great feature lines are in a large degree east-and-west. The small Arctic Ocean is on the north; the larger North Atlantic on the west; the still larger North Pacific on the east; Africa and the broad Indian Ocean, singularly free from islands, are on the south. The boundary is a complex one, and the land between the Atlantic and Pacific is over 6000 miles broad. 
On the sicle of the North Atlantic there are the mountains of Scandinaria and the British Isles, the former having a mean height of 4000 feet and a maximum, in Galdhöpig, of 8400 feet; and farther south, the Alps and other momutinins of eastern Europe, the higher portions covering but small areas. (1n the sicle of the larger Pacific there are loftier mountains in long langes - the Slan-a-lin range of Manchuria, having peaks of 10,000 to 12,000 feet, and the high Khingan range of 15,000 feet, facing China. Off the coast there is still another series of ranges, now partly submerged, viz. those of Japan and other linear groups of islands; these stand in front of the interior chain, very much as the Cascade range and Sierra Nevada of the Pacific border of America are in advance of the summit ridges of the Rocky Mountains, and both are alike in being partly volcanic, with cones of great altitude.

Thus riewing Eurasia across its whole breadth from west to east, there is an interior basin of immense extent, which includes some of the lowest land of the globe. The plains of eastern Europe, north of the Carpathians, comprise three fifths of all Europe, and are situated, with reference to the mountain-border of Europe, like the Mississippi basin with reference to the Appalachians. Farther east there is the low land of the Caspian-Aral basin of western Asia, a million of square miles in area, over a fourth of it lying below the sea level.

Facing the large and open Indian Ocean, and looking southward, stand the Himalayas, - the loftiest of mountains, in which peaks of 20,000 feet and over are very numerous, and few passes are under 16,000 feet, - called the Himalayas as far as Kashmir, and from there, where a new sweep in the curve begins, the Hindu-Kush, - the whole over 2000 miles in length: not so long, it is true, as the Andes, but continued as far as the ocean in front continues. The Kuen-Lun Mountains, to the north of the Himalayas, make another crest to the great chain. Farther north lies the great interior arid plateau, the Desert of Gobi; and then rise other mountain chains, the Thian-Shan to the northwest having peaks of 14,000 to 15,000 feet, the Yablonoi to the northeast, and farther north, the Altai facing Siberia. Beyond these stretches Siberia, an alluvial area, 1000 miles wide.

18.

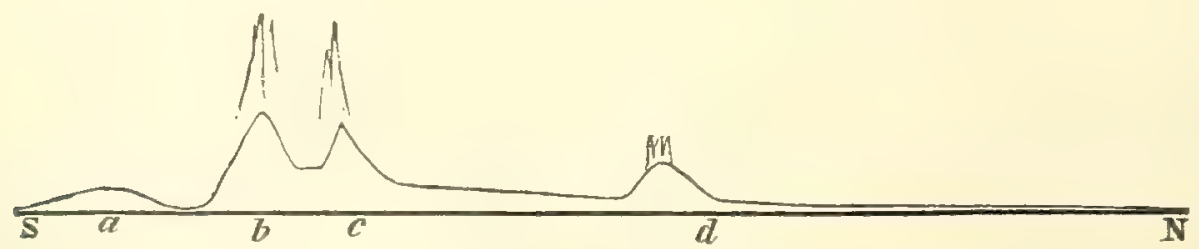

The diagram (Fig. 18) represents the general features of a section from north to south through the Himalayas. At $a$, there is the elevated land of India; between $a$ and $b$, the low river-plain at the base of the Himalayas; at $b$, the Himalayas; $b$ to $c$, Plains of Tibet; $c$, the Kuen-Lun ridge; $c$ to $d$, Plains of Mongolia and Desert of Gobi ; at $d$, the Altai ; $d$ to $N$, the Siberian plains. 
The great desert-plateau of Gobi or Mongolia, 3000 to 4000 feet in elevation, is a great interior basin, and the Altai and associated ranges are the mountains facing the Arctic seas. But the distance to those seas is so great that it is as reasonable to regard the Mongolian area as a plateau between high mountain ranges facing the Indian Ocean, and Arctic Asia, like Arctic America, as without any mountains bordering the small Arctic sea.

The interior drainage system for Asia is without outlet. The waters are shut up within the great basin, the Caspian and Aral being the seas which receive the part of those waters not lost in the plains. The Volga and other streams, from a region of a million of square miles, flow into the Caspian. Lake Baikal, regarded as a Siberian lake, is 30 degrees of latitude, or over 2000 miles, from the Aretic coast.

The Urals, 2000 to 3000 feet in mean altitude, stand as a partial barrier between Asia and Europe, parallel nearly with the mountains of Norway.

Looking over the broad surface of North America and of Eurasia on the map, on page 47 , the fact that the higher lands are on the side of the greater ocean is strikingly illustrated. In each, the dark shaded or more elevated portion is mainly on the Pacific side.

(3) Africa. - Africa has the Atlantic on the west, the broader Indian Ocean on the east, with Europe and the Mediterranean on the north, and the South Atlantic and Southern Ocean on the south. The northern half has the east-and-west position of Asia, and the southern the north-and-south of America; and its reliefs correspond with this structure. The Guinea coast, belonging to the northern half, projects west in front of the south Atlantic, and is faced by the east-and-west Kong range, about 2000 feet high; and opposite, on the Mediterranean, there are the Atlas Mountains, the high plateau of which is about 3000 feet; one peak in the Atlas of Morocco is 13,000 feet high, although the ridges are generally 5000 to 7000 feet.

The larger part of the Abyssinian Plateau is 6000 to 7000 feet in elevation, but it has one summit of 15,000 feet. It extends into the great plateau of southern Africa; and just south of the equator stand Mount Kilima-Njaro, 18,715 feet high, and Mount Kenia, 18,000 feet, and near the meridian of $30^{\circ}$, and $2^{\circ} \mathrm{S}$. , Ruwenzori, 19,000 feet (Stanley). The pass from Zanzibar to Tanganyika is 5700 feet. A height of 6000 to 8000 feet continues south, becoming nearly 9000 feet in the South African Republic. The drainage of the interior is consequently westward, and the Zambesi is the only stream that breaks through and reaches the Indian Ocean. Africa has been well described as a shut-up continent, its coasts being mostly without bays.

19.

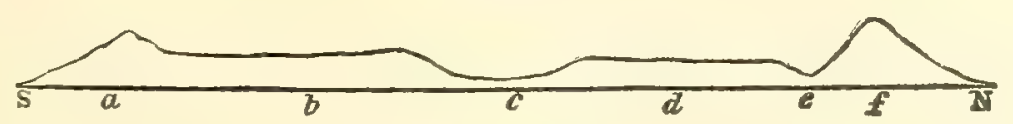

The section Fig. 19 gives a general idea of its features from south to north (the heights necessarily much exaggerated in proportion to the DANA'S MANUAL - 3 
length); $a$, the southern mountains ; $b$, the southern plateau; $c$. Lake Tchad depression; $d$, Sahara plateau; $e$, oases depression; $f$, mountains on the Mediterranean, of which there are two or three parallel ranges.

Africa has, therefore, a basin-like form, but is a double basin; and its highest mountains are on the side of the largest ocean, the Indian. The height of the mountains adjoining the Mediterranean is the only exception to the relation to the oceans.

(4) Australia. - Australia conforms also to the continental model. The highest mountains are on the side of the Pacific, - the larger of its borderoceans. Mountain ranges extend along the whole eastern border from Portland in Victoria to Cape York in the extreme north. The Australian Alps, in New South Wales, facing the southeast shores, have peaks 5000 to 6500 feet in height. The Blue Mountains next to the north are 3000 to 4000 feet high, with some more elevated summits. On the side of the Indian Ocean the heights are 1500 to 2000 feet. The interior is an arid region, the center more than 600 feet above the sea.

The continents thus exemplify the law laid down, and not merely as to high borders around a depressed interior, - a principle stated by many geographers, - but also as to the highest border being on the side of the greatest ocean. ${ }^{1}$

This difference between the interior and the border regions runs paralleI with another of geological nature: the border region in its older rocks, if not the newer, is a region usually of upturned beds, and the interior, for the most part, of nearly horizontal beds. The interior basin has this feature in North America, in South America, and over eastern Europe in the great plains of Turkey and Russia.

It is owing to this law that America and Europe literally stand facing one another, and pouring their waters and the treasures of the soil into a common channel, the Atlantic. America has her loftier mountains, not on the east, as a barrier to intercourse with Europe, but off in the remote west, on the broad Pacific, where they stand open to the moist easterly winds as well as those of the west, to gather rains and snows, and make rivers and alluvial plains for the continent; and the waters of all the great streams, lakes, and seas make their way eastward to the narrow ocean that divides the civilized world. Europe has her slopes, rivers, and great seas opening into the same ocean; and even central Asia has her most natural outlet westward to the Atlantic. Thus, under this simple law, the civilized world is brought within one great country, the center of which is the Atlantic, uniting the land by a convenient ferriage, and the sides the slopes of the Rocky Mountains and Andes on the west, and the remote mountains of Mongolia, India, and Abyssinia on the east. ${ }^{2}$

This subject affords an answer to the inquiry, What is a continent as

1 First announced American Jour. Sci., II., vols. iii. 398, iv. 92, 1847, and zxii. 335, 1856.

2 See Guyot's Easth and Man. 
distinct from an island? It is a body of land so large as to have the typical basin-like form, - that is, independent mountain chains on either side of a low interior. The mountain borders of the continents vary from 500 to 1500 miles in breadth at the base. Hence a continent cannot be less than a thousand miles (twice five hundred) in width.

\section{SYSTEM IN THE COURSES OF THE EARTH'S FEATURE LINES.}

The system in the courses of the earth's outlines is exhibited alike over the oceans and continents, and all parts of the earth are thus drawn together into even a closer relation than appears in the principle already explained.

The principles to which the facts point are as follows: (1) that two great systems of courses or trends prevail over the world, a northwestern and a northeastern, transverse to one another; (2) that the islands of the oceans, the outlines and reliefs of the continents, and the oceanic basins themselves, alike exemplify these systems; (3) that the mean or average directions of the two systems of trends are northwest-by-west and northeast-by-north; (4) that there are wide variations from these courses, but according to principle, and that these variations are often along curving lines ; (5) that, whatever the variations, when the lines of the two systems meet, they meet nearly at right angles or transversely to one another.

(1) Islands of the Pacific Ocean. - The lines or ranges of islands over the ocean are as regular and as long as the mountain ranges of the land. To judge correctly of the seeming irregularities, it is necessary to consider that, in chains like the Rocky Mountains, or Andes, or Appalachians, the ridges vary their course many degrees as they continue on, sometimes sweeping around into some new direction, and then returning again more or less nearly to their former course, and that the peaks of a ridge are very far from being in an exact line even over a short course; -again, that several approximately parallel courses make up a chain.

A. Northwesterly system oF TRENDS. - In the southwestern Pacific the New Hebrides (Fig. 20) show well this linear 20.

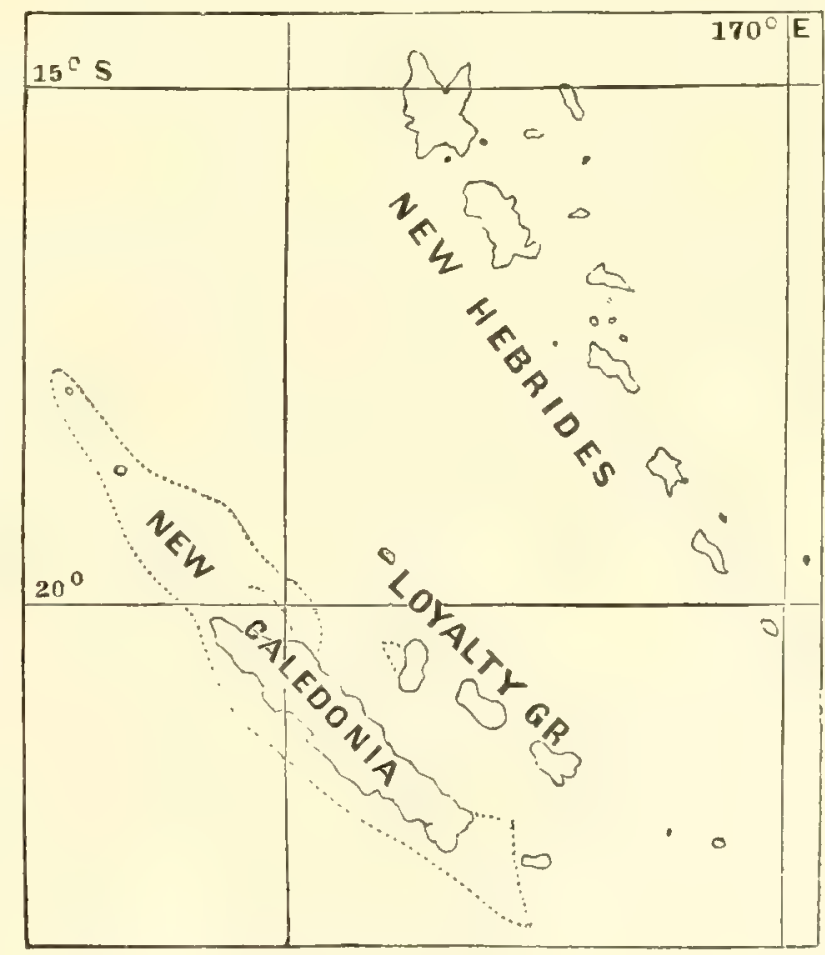
arrangement; and even each island is elongated in the same direction with the group. This direction is nearly northwest $\left(\mathrm{N} .40^{\circ} \mathrm{W}\right.$.), and the length 
of the chain is 500 miles. New Caledonia, more to the sonthwest, has approximately the same course, - about northwest. Between New Hebrides

21.

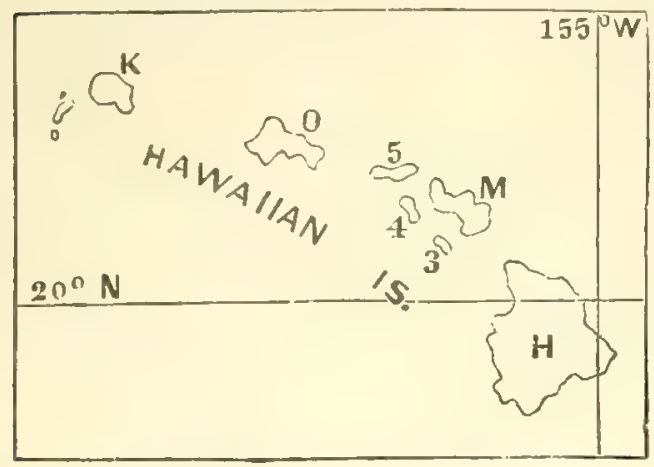

H, Hawaii ; M, Maui ; 3, Kahoolawe ; 4, Lanai ; 5, Molokai ; 0 , Oahu; $\mathbf{K}$, Kauai. and New Caledonia lies another parallel line, the Loyalty Group. The Solomon Islands, farther northwestward, are also a linear group. The chain is mostly a double one, consisting of two parallel ranges; and each islaud is linear, like the group, and with the same trend. The course is northwest-by-west, the length 600 miles.

In the North Pacific, the Hawaiian range has a west-northwest course. The Sandwich or Hawaiian Islands (Fig. 21), from Hawaii to Kauai, make up the southeasterly part of the range, about 400 miles in length. Beyond this, the line extends to $175^{\circ}$ E., making a total length of about 1500 miles, - a distance as great as from New York to the Great Salt Lake in the Rocky Mountains, or from London to Alexandria.

22.

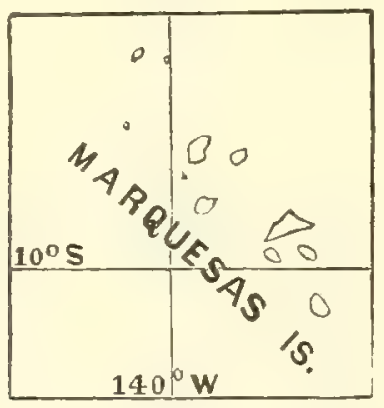

23.

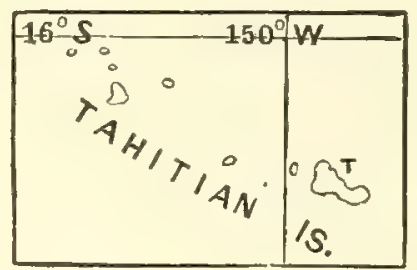

Between these groups lie the islands of mid ocean, all nearly parallel in their courses. Figs. 22, 23 are examples.

The following table gives the courses of the principal chains of the ocean :-

Course.

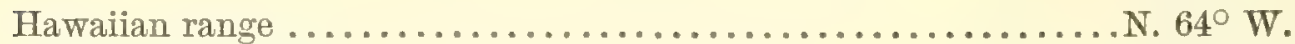

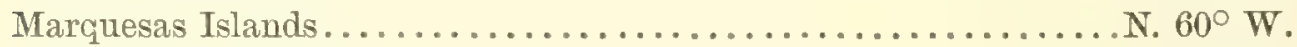

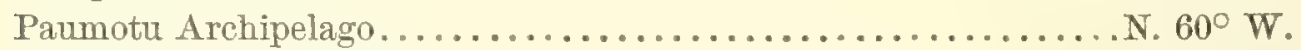

Tahitian or Society Islands............................... $62^{\circ}$ W.

Hervey Islands......................................... $65^{\circ}$ W.

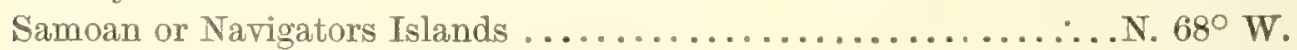

Gilbert, Tarawan, or Kingsmill Islands .................... $34^{\circ} \mathrm{W}$.

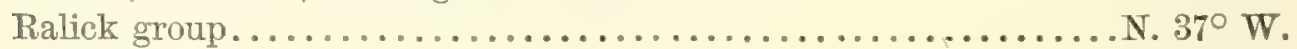

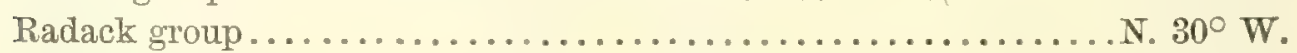

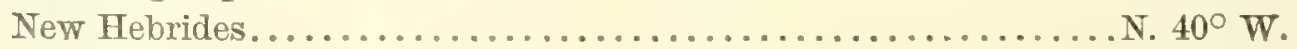

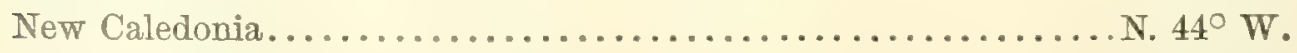

North extremity of New Zealand ........................ $50^{\circ}$ W.

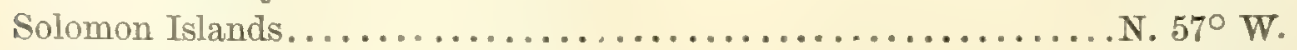

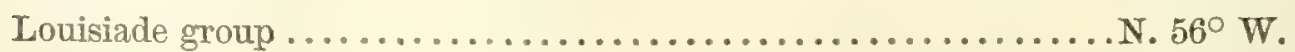

New Ireland ..................................... $65^{\circ}$ W. 
B. Northeasterly system of trends. - The body of New Zealand has a mean N. $40^{\circ} \mathrm{E}$. course. The line is continued to the south, through the Auckland and Macquarie Islands, to $58^{\circ} \mathrm{S}$. To the north, in nearly the same line, near $30^{\circ} \mathrm{S}$, lie the Kermadec Islands, and farther north, near $20^{\circ}$ S., the Tonga or Friendly Islands.

The Ladrones, north of the equator, follow the same general course. It also occurs in many groups of the northwesterly system characterizing subordinate parts of those groups. Thus, the westernmost of the Hawaiian Islands, Niihau, lies in the north-northeast line, and the two lofty peaks of Hawaii have almost the same bearing.

Pacific island chains. - The groups of Pacific islands, with a few exceptions, are not independent lines, but subordinate parts of island chains. There are three great island chains in the ocean which belong to the northwesterly system, - The Hawaiian, the Polynesian, and the Australasian, and, excluding the Ladrones, which pertain to the western Pacific, one belonging to the northeasterly system; viz., the Tongan or New Zealand chain.

Hawaiian chain. - This chain has already been described.

Polynesian chain. - This chain sweeps through the center of the ocean, and has a length of 5500 miles, or nearly one fourth the circumference of the globe. (See Fig. 24.) The Paumotu Archipelago (1), and the Tahitian, Rurutu, and Hervey Islands $(2,3,4)$ are parallel lines in the chain,

24.

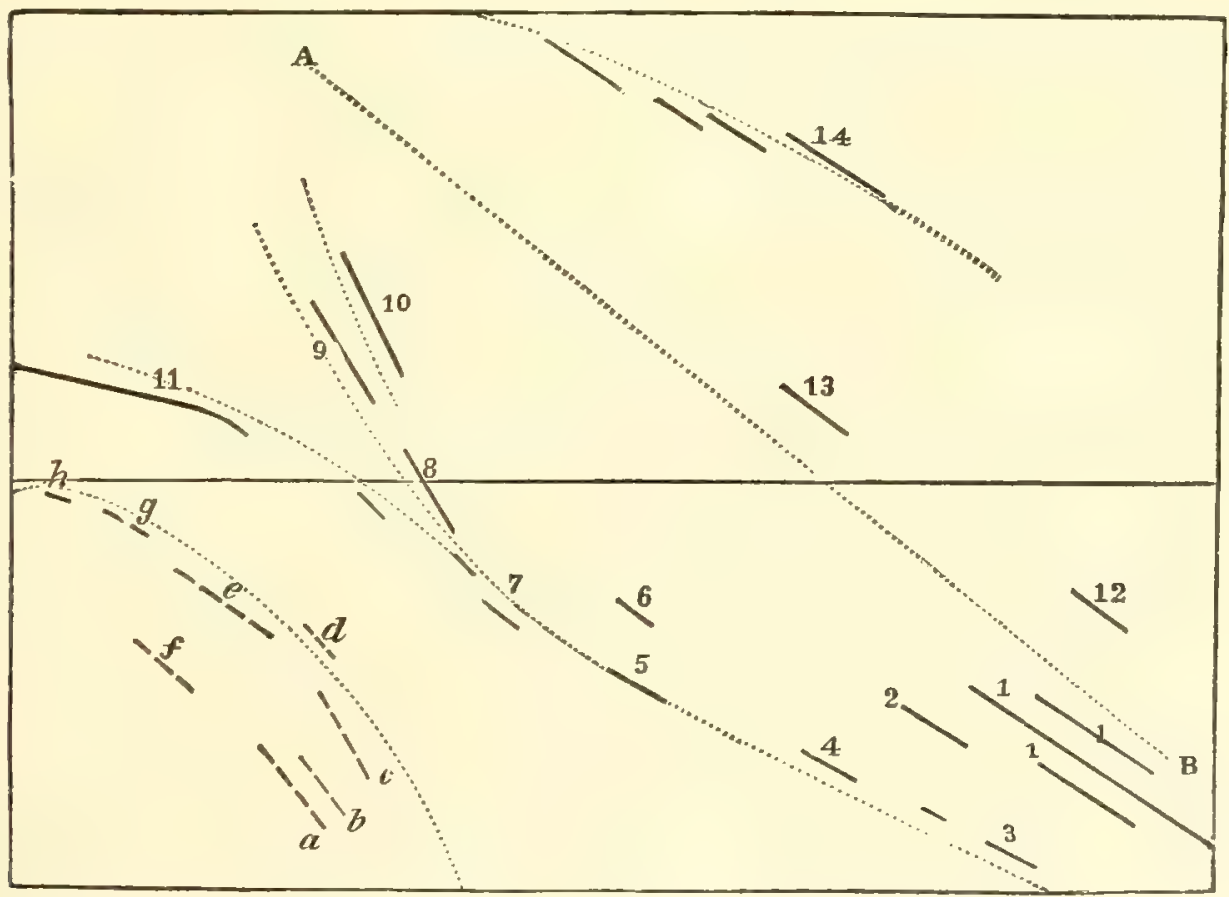

1 to 10, the Polynesian chain: 1, Paumotu group; 2, Tahitian; 3, Rurutu group; 4, Hervey group; 5, Samoan, or Navigators; 6, Vakaafo group; 7, Vaitupu group; 8, Gilbert group; 9, Ralick; 10, Radack; 11, Carolines; 12, Marquesas; 13, Fanning group; 14, Hawailan. a to $h$, part of the Australasian chain: $a$, New Caledonia; $b$, Loyalty group; $c$, New Hebrides; $d$, Santa Cruz group; $e$, Solomon Islands; $f$, Louisiade group; $g$, New Ireland; $h$, Admiralty group. $-D$. 
forming its eastern extremity; westward there are the Samoan (5) and Gilbert (8) groups, and others intermediate; still northwestward there are the Radack and Ralick groups $(9,10)$, and in $20^{\circ} \mathrm{N}$, on the same line, Wakes Island.

(a) The chain, as is seen, consists of a series of parallel ranges, succeeding and overlapping along the general course, in the manner illustrated on page 28 , when speaking of mountains. (b) It varies its course gradually from west-northwest at the eastern extremity to north-northwest at the western. (c) Its mean trend is northwest-by-west (N. $56^{\circ} \mathrm{W}$.), the mean trend of all the groups of the northwesterly system in the ocean. (d) The chain is a curving chain, convex to the southward, and marks the position of a great central elliptical basin of the Pacific having the same northwesterly trend. The Hawaiian is on the opposite side of it, slightly convex to the north.

The Marquesan range (12, Fig. 24) lies in the same line with the Fanning group (13) to the northwest, just north of the equator; and, if a connection exists, another great chain is indicated, - a Marquesan chain.

Australasian chain (Fig. 25), - New Hebrides (K) and New Caledonia (M) belong to the Australasian island chain. The line of New Hebrides is continued northwestward in the Solomon group (I) and New Ireland, though bending a little more to the westward, and terminates in Admiralty land $(G)$, near $145^{\circ}$ E., where it becomes very nearly east-andwest: the length of the range is about 2000 miles. Taking another range in the chain, New Caledonia (M), the course is continued in the Louisiade group $(\mathrm{H})$; then the north side of New Guinea $(\mathrm{E})$, which continues bending gradually till it becomes east-and-west, near $135^{\circ} \mathrm{E}$. In the southeast, belonging to the same general line, there is the foot of the New Zealand boot $(0)$. The coral islands between New Caledonia and Australia appear also to be other lines in the chain.

From New Guinea (E, F), the east-and-west course is taken up by Ceram (D), and again, more to the south, in the Java line of islands (A, B, C) ; and from Java (B) the chain again begins to rise northward, becoming northwest finally in Sumatra (A) and Malacea.

The several ranges make up one grand island chain, with a double curvature, the whole nearly 6000 miles long. In Fig. 25, a line stands for each group, and indicates its course; it shows the composite nature of the chain, and the curving course, in connection with a prevailing conformity to a northwesterly trend.

Blending of the Australasian and Polynesian island chains. - The two chains blend with one another in the region of the Carolines, Fig. 24 (11). This large archipelago properly includes the Ralick and Radack groups Fig. $24(9,10)$. At the Gilbert group, Fig. 24 (8), the Polynesian chain divides into two parts, - the Ralick and Radack ranges. But the main body of the Archipelago, Fig. 24 (11), trends off to the westward, and is a 
third branch, conforming in direction to the Australasian system. ( $a$ to $h$, Fig. 24, are the same as M to G, Fig. 25.)

In other words, the Caroline Archipelago forks at its southeastern extremity, - one portion, the Gilbert, Radack, and Ralick Islands (8, 9, 10 in Fig. 24), conforming to the Polynesian system, while the great body of the Caroline Islands trends off more to the westward (No. 11), parallel with New Ireland and the Admiralty group ( $g, h$ of the same cut), and others of the Australasian system.

25.

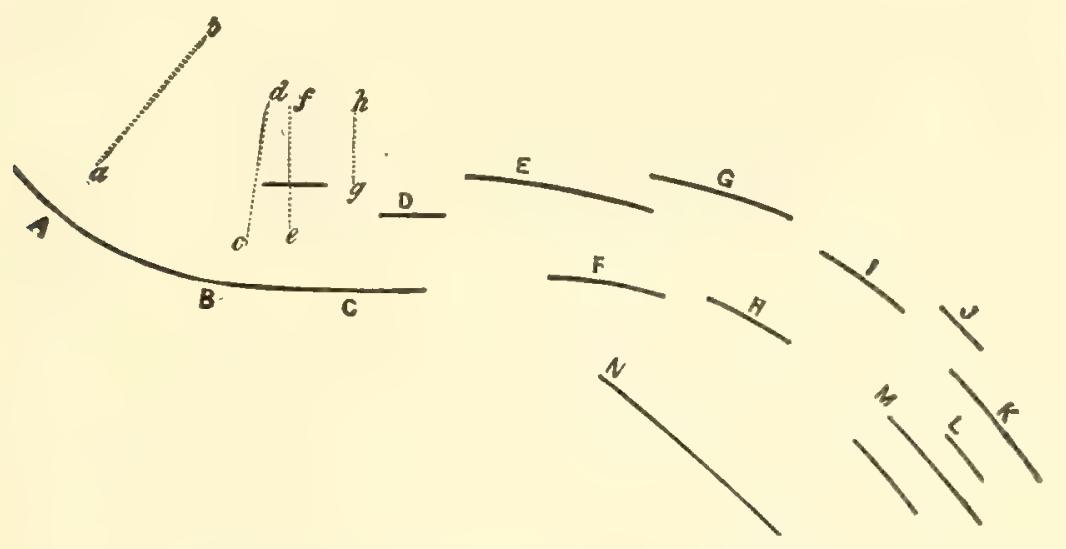

A, B, C, Sumatra and Java line of islands; D, Ceram; E, north coast of New Guinea; F, South New Guinea; G, Admiralty Islands; H, Louisiade group; I, Solomon; J, Santa Cruz group; K, New Hebrides; L, Loyalty group; $\mathrm{M}$, New Caledonia; N, high lande of northeast Australia; $O$, New Zealand; $a b$, northwest shore of Borneo; $c d$, East Borneo; ef, west coast of Celebes; $g h$, west coast of Gilolo. - D.

New Zealand chain. - The ranges in this chain are mentioned on page 37. The whole length, from Macquarie Island, on the south, to Vavau, a volcanic island terminating the Tonga range, on the north, is 2500 miles. To the east of New Zealand lie Chatham Island, Beverly, Campbell, and Emerald, which correspond to another range in the chain.

This transverse chain is at right angles with the Polynesian system at the point where the two meet. Moreover, it is nearly central to the ocean. The central position, great length, and rectangularity to the northwest ranges give great significance to this New Zealand or northeasterly system of the ocean.

(2) Islands of the Pacific and Atlantic Oceans. - The trend of the Pacific Ocean as a whole corresponds with that of its central chain of islands, and very nearly with the mean trend of the whole. It is a vast channel, elongated to the northwest. The range of heights along northeastern Australia (N, Fig. 25) runs northwesterly and passes by the head of the great gulf (Carpentaria) on the north; and the opposite side of the ocean along North America, or its bordering mountain chain, has a similar mean trend. A straight line drawn from northern Japan through the eastern Paumotus to 
Fuegia may be called the axis of the ocean. This axial line is nearly half the circumference of the globe in length, and the transverse diameter of the ocean full one fourth the circumference: so that the facts relating to the Pacific chains must have universal importance.

The North Atluntic Ocean trends to the northeast, - or at right angles, nearly, to the Pacific; this being the course of the coasts, and therefore of the channel. Moreover, it is the course of the central plateau along the bottom of the north Atlantic.

The Asiatic coast of the Pacific has the direction of the northeasterly system. The course is not nearly a straight line, like the corresponding eastern coast of North America, but consists of a series of curves, which series is repeated in the island chains off the coast and in the mountains of the country back. Moreover, the curves meet one another nearly at right angles. The first one, that of the Aleutian Islands, extends as a great festoon between the two continents, America and Asia. The last one, which is 1800 miles long, commences in Formosa, and extends along by Luzon, Palawan, and western Borneo ( $b a$, Fig. 25) to Sumatra, and terminates at right angles with Sumatra; and another furcation of it $(d c)$ passes by eastern Borneo or Celebes, and terminates at right angles with Java and the islands just east. The rectangularity of the intersections is thus preserved; and the curve of the Australasian chain has in this way apparently determined the triangular form of Borneo.

The Aleutian Islands (range No. 1) has a length of 1000 miles. The Kamchatka range (No. 2) commences at right angles with the termination of the Aleutian, and bends around till it strikes Japan at a right angle. The Japan range (No. 3) commences north in Saghalien, and curves around to Corea. The Loochoo range (No. 4) leaves Japan at a right angle, and curves around to Formosa. The Formosa range (No. 5) is explained above. There is apparently a repetition of the Formosa system in the Ladrones near longitude $145^{\circ} \mathrm{E}$.

(3) East and West Indies. - The general courses in the East Indies have been mentioned on pages 38, 39. In the West Indies and Central America there is a repetition of the curves of the East Indies. The course of the range along Central America corresponds to Sumatra and Java; and the line of Florida and the islands to the southeast makes another range in the same system.

(4) The American continents. - In North America, the northwest system is seen in the general course of the Rocky Mountains, the Cascade Range, and Sierra Nevada; in Florida; in the line of lakes, from Lake Superior to the mouth of the Mackenzie; in the southwest coast of Hudson Bay; in the shores of Davis Straits and Baffin Bay; - and with no greater divergencies from a common course than occur in the Pacific. The northeast system is exemplified in the Atlantic coast from Newfoundland to Florida, and, still farther to the northeast, along the coast of Greenland; and to the southwest, along Yucatan, in Central America. The Appalachian Mountains, the river St. Lawrence to Lake Erie, and the northwest shore of Lake Superior, repeat this trend. 
There are curves in the mountain ranges of eastern North America, like those of eastern Asia. The Green Mountains run nearly north-and-south; but the continuation of this line of heights across New Jersey into Pennsylvania curves around gradually to the westward. The Alleghanies, in their course from Pennsylvania to Tennessee and Alabama, have the same curve. There appears also to be an outer curving range bordering the ocean, extending from Newfoundland along Nova Scotia, then becoming submerged, though indicated in the sea-bottom, and continued by southeastern $\mathrm{New}$ England and Long Island.

Between this latter range and that of the Green Mountains lie one or more great basins of ancient geological time, while to the westward of the Green Mountains and Alleghanies was the grand interior basin of the continent. The two were to a great extent distinct in their geological history, being apparently independent in their coal deposits and in some other formations.

In South America, the north coast has the same course as the Hawaiian chain, or pertains to the northwest system; and the coast south of the east cape belongs to the northeast system; and hence the outline of the continent makes a right angle at the cape. The northeast course is very nearly that of eastern North America and New Zealand. The northwest is repeated in the west coast by southern Peru and Bolivia, and the northeast in the coast of northern Peru to Darien: so that this northern part of South America, if the Bolivian line were continued across, would have nearly the form of a parallelogram. South of Bolivia the Andes correspond to the northeast system, although more nearly north-and-south than usual.

(5) Islands of the Atlantic. - The Azores have a west-northwest trend, like the Hawaiian chain, and are partly in three lines, with evidences also of the transverse system. The Canaries, as Von Buch has shown, present two courses at right angles with one another, - a northwest and a northeast.

Again, the line of the southeast coast of South America extends across the ocean, passing along the coast of Europe and the Baltic; and the mountains of Norway and the feature lines of Great Britain are approximately parallel to it.

(6) Asia and Europe. - In Asia, the Sumatra line, taken up by Malacca, turns northward, until it joins the knot of mountains formed by the meeting of the range facing the Pacific and that facing the Indian Ocean. At this point, and partly in continuation of a Chinese range, commence the majestic Himalayas, - at first east-and-west, at right angles with the termination of the Malacea line, then gradually rising to west-northwest. The course is continued northwestward in the Hindu-Kush, extending toward the Caspian, - in the Caucasus, beyond the Caspian, and in the Carpathians, beyond the Black Sea. The northwest course appears also in the Persian Gulf, and the plateaus adjoining, in the Red Sea, the Adriatic and the Apennines. 
Recapitulation. - From this survey of the continents and oceans it follows :-

That, while there are many variations in the courses of the earth's feature-lines, there are two directions of prevalent trends, - the northwesterly and the northeasterly; that the Pacific and Atlantic have thereby their positions and forms, the islands of the oceans their systematic groupings, the continents their triangular and rectangular outlines, and the very physiognomy of the globe an accordance with some comprehensive law.

It has been observed, first by Professor R. Owen, of Indiana (1857), that the outlines of the continents lie in the direction of great circles of the sphere, which great circles are, in general, tangential to the aretic or antarctic circle. By placing the north pole of a globe at the elevation $23^{\circ} 28^{\prime}$ (equal to the distance of the arctic circle from the pole or the tropical from the equator), and revolving the globe eastward, part of these continental outlines, on coming down to the horizon of the globe, will be found to coincide with it; and on revolving it westward, most of the other lines. Other great lines, as part of those of the Pacific, are pointed out as tangents to the tropical circles instead of the arctic. But there are other equally important lines which accord with neither of these two systems, and a diversity of exceptions when we compare the lines over the surfaces of the continents and oceans.

If the views of Mr. Owen are right, the direction of coast lines on the parallel of $66^{\circ} 32^{\prime}$ north or south should be east and west (being tangent to the antarctic circle), and on the equator, about N. $23^{\circ} 28^{\prime} \mathrm{E}$.; and the trend in other places intermediate between these extremes. And in the tropical part of the ocean, great circles tangent to the tropical circles would have the course N. $66^{\circ} 32^{\prime} \mathrm{W}$. crossing the equator, but be E.-W. on the tropical circles; and between the two positions between N. $66^{\circ} 32^{\prime}$ W. and E.-W. The map (see page 47) shows how far these are the actual courses.

\section{OCEANIC AND ATMOSPHERIC MOVEMENTS AND TEMPERATURE.}

The earth has east-west differences, as already pointed out, in the depths of its oceans (page 19). But of greater importance are the east-west or front-and-rear contrasts which are a consequence of its diurnal revolution. Ordinary observation recognizes only the rising and setting of the sun, and day and night, as the chief consequences of the eastward rotation. But these are only the most obvious. The results are manifested universally in the climates of the globe, the winds, the tides, and oceanic currents, in the earth's magnetic currents, in the geological action of waters of the ocean and land, the distribution of plants and animals; and they give to the eastern and western sides of the continents, or the front and rear, differences which are profound in influence both physically and physiologically. The effects are diversified and extreme. They are moderated by the nutation of the earth's axis in its annual revolution, which gives the earth its winters and summers; but they are none the less real and fundamental. Ferrel obtained a mathematical expression for the relation of the rotation to the winds, and announced the fundamental law (1858) that "in whatever direction a body moves on the earth's surface, there is a force, arising from the 
earth's rotation, which tends to deflect it to the right in the northern hemisphere, but to the left in the southern."

To illustrate fully the effects occasioned by the rotation would require volumes. A few only are presented in the following brief account of tides, oceanic currents and temperature, winds and climates.

\section{The Tidal Wave.}

The great tidal wave, due to the attraction of the sun and moon, is a wave-movement in the ocean to its bottom. It goes westward because of the earth's eastward rotation, with consequently the same rate of progress, or 1000 miles an hour at the equator; and 12,000 miles (half the earth's circumference) is the length of a single wave. The Pacific is too narrow to contain over half of the wave-curve; and the Atlantic can contain transversely but a quarter of it. After leaving the Pacific its course is northwesterly in both the Indian Ocean and the Atlantic. The height of the wave can be measured only on islands in the open ocean, since shelving shores and bays increase its elevation and its power as a geological agent. At the prominent American headlands in the north Atlantic, the height of the tide is only one to two feet; being at Cape Hatteras two feet after traversing some miles of coast region under 600 feet in depth, and only one foot at southeastern Nantucket. But the actual height of the tide, according to G. H. Darwin, is only one third of an inch.

The dynamical effects of the tidal wave come up for consideration under the head of The Ocean.

\section{Oceanic Currents and Temperature.}

(1) Oceanic currents. - The general system of oceanic currents is simple. In the tropical portion of the ocean, either side of a narrow equatorial belt, the great movement or current is westward, corresponding with the course of the trade-winds; as if it were a consequence chiefly (as many physicists believe) of the propelling winds. Reaching the continent that lies to the westward, the moving waters are turned poleward. Having passed the parallel of $35^{\circ}$ or $40^{\circ}$, the flow diverges more and more from the continent, and crosses the ocean eastward to its eastern continental border; and there, if there were no great passage-way in the ocean basin opening toward the poiar regions, all would be forced to turn southward toward the region of the trades, there to start anew in the great elliptical circuit.

The north Pacific has the polar regions nearly shut off from it, for Bering Sea is shallow, and Bering Strait has a depth of only 150 feet, so that the circuit is here of the normal kind. But the north Atlantic has a broad open way into the Aretic seas, and the shallow region over which it passes - the Scandinavian plateau - has a depth on it of 1500 to 3000 feet. Consequently, only part of the waters turns southward along the submerged European border - a large part keeping on its course northeastward, along by Great Britain, and northward, by Iceland, into the polar seas. 
The rate of flow of the tropical current is increased somewhat after striking the borders of a continent, because of the diminished depth. As it passes on beyond the parallel of $30^{\circ}$ and $35^{\circ}$, the flow becomes more and more easterly in course, in consequence of loss of motion by friction. In the tropical region, the morement westward indicates a less rapid rate of movement than the earth's surface, in its daily eastward rotation. But beyond $30^{\circ}$ the rate of flow is faster than the rotation there; and hence the result is an eastward movement. As the waters continue on to the Arctic, friction further diminishes the flow, and while part goes on northeastward north of Asia, the rest lags and goes northward and northwestward. From the full polar seas the waters must of necessity escape southward; the lagging part takes a course along the Greenland border and down Baffin Bay, making the Labrador current; and also a submarine course along the western half of the ocean's bottom, while the rest returns along the ocean's bottom, especially along its eastern half, - and thus the Atlantic circuit is completed.

In the accompanying sketch, $\mathrm{WE}$ is the equator with $30^{\circ}$ and $60^{\circ}$ parallels of latitude north and south of it. North, the ellipse represents the

26 .

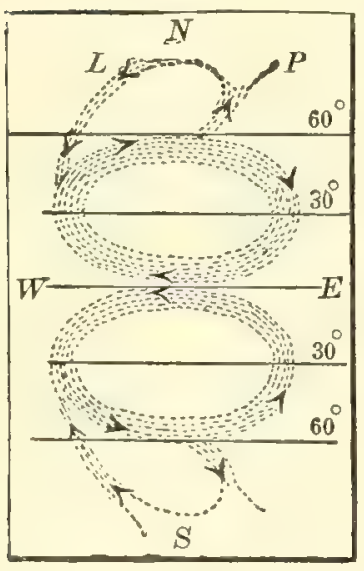
general movement in the north Atlantic; the branch at $\mathrm{P}$, the flow poleward, and the current at $\mathrm{L}$, the returning Labrador current.

The trends of the continental coasts, and their larger bays, gulfs, or seas, and bordering island groups, have much influence on the course and character of the current. Owing to the position of the north coast of South America with reference to the opposite coast of Africa, the circuit-stream of the south Atlantic as it flows westward contributes a considerable branch to the north Atlantic circuit; and because of the outlet among the East India Islands, the eireuits of the north and south Pacific lose part of their waters by their passing off into the Indian Ocean; and still they are plainly distinguishable off Japan, and off Australia, in the currents and their temperature.

The most remarkable example of the effect of gulfs or seas and islands is that afforded by the West India seas and islands. The West India sea faces part of the slowly advancing ocean-stream. It has an area of nearly 2,000,000 square miles. Though rudely fenced in by the Windward Islands, there are spaces over 3000 feet deep between the most of them, and less than twice this at the chief entrance. From the Caribbean Sea the waters, after a circuit, escape partly between the islands northwestward; but part pass the narrow Yucatan channel with an hourly movement of one fourth of a mile, and raise the level of the Gulf of Mexico three feet above its natural level, and, at the same time, act as a hydrostatic reservoir to make of the escaping waters the Gulf Stream, which flows through the Florida straits (according to Commander Bartlett) at a mean rate of three miles an hour, and at a maximum, for 15 miles in the axis of the stream, as high as $5 \frac{1}{4}$ 
miles an hour. Off Charleston the mean hourly flow is three miles; from there to New York it diminishes to $2 \frac{1}{2}$ miles, and off the Banks of Newfoundland it is but $1 \frac{1}{2}$ to two miles. The rate of flow and other characters of the stream are thus largely due to the existence between the American continents of the great Mexican Gulf. The Mediterranean Sea, on the opposite side of the ocean, has no such effects, partly because it is on the wrong side of the ocean for the production of them.

The straits of Florida have a width of about 48 miles off Jupiter Inlet, and a maximum depth of 2634 feet; and 95 billion tons of water pass per hour. The current reaches a zero velocity at a depth of 1800 to 2100 feet. North of the Bahamas the stream passes over the plateau bottom to Charleston with a mean depth of 2400 feet, and width of 75 to 100 miles; and thence to Cape Hatteras, the depth diminishing to 1800 feet. North of Cape Hatteras, the coastward wall is in a depth of about 390 feet; and inside of this wall, as well as to the eastward of the stream and beneath it, flow the cold waters of the Labrador current. Owing to the delay of the waters in the Caribbean Sea and the Mexican Gulf the heat of the tropical waters is much augmented for distribution along their northeastward course.

In the central North Atlantic, between the eastward and westward parts of the circuit, exists a region of calms in both winds and currents, with great areas of floating seaweeds, which is called the Sargasso Sea. The seaweeds shelter a large variety of fishes and inferior living species.

A belt in the equatorial region, just north of the equator, is the course of a counter-current both in the Pacific and Atlantic. Currents are generally made in the ocean by the prevailing winds; and local and temporary currents, often of great geological importance, by the winds of a long-continued storm.

(2) Oceanic temperature. - The currents of the ocean are a means of distributing its heat or cold over the globe, and making cold or warm climates for land and sea. Tropical currents carry tropical heat to the colder regions of the globe; and, conversely, the cold-temperate and polar currents convey cold; but the former mostly as a superficial flow, seldom affecting depths below 3000 feet, while the latter move at all depths from the top to the ocean's bottom. The colder waters are the heavier; but when flowing along a coast region as a lagging current, they move up the shelving bottom to the surface in spite of any warm waters in their way; and whatever shoals they encounter in their course, they spread up and over them, only a little affected in temperature by the waters they displace.

Superficial effects over the ocean. - As a consequence of the elliptical movement pointed out, and illustrated in Fig. 26, the waters of the tropical or warm side in the circuit strike the east borders of the continents; and those of the high latitude, or cold side, the west borders. They therefore tend to widen the areas of warm water on the west side of an ocean, and 
narrow the areas on the east side. The cold or polar latitudes, as has been explained, send a returning current along the continental borders equatorward, which may be stronger on the eastern or western border, according to geographical conditions, and thus these cold waters may moclify the temperature and position of the currents in the warmer latitucles. Thirdly, owing to the effect of the more rapid flow of the current along the borders of the continents, the currents often carry the isothermals poleward, making poleward bends or loops in their courses; and these may be greatly increased in prominence or definition by the polar current along the continental borders.

In Fig. 27, the elliptical line ( $\left.A^{\prime} B^{\prime} A B\right)$ represents the course of the current in an ocean south of the equator (EQ). If now the movement in the circuit were equable,

27.

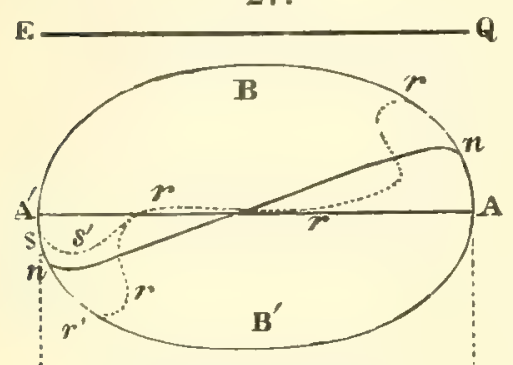

Oceanic Currents, D. '58. an isothermal line, as that of $68^{\circ}$, would extend obliquely across, as $n n$ : it would be thrown south on the west side of the ocean by the warmth of the torrid zone, and north on the east side by the cooling influence derived from its flow in the cold-temperate zone. But if the current, instead of being equable throughout the area, were mainly apparent near the continents (as is actually the fact), the isothermal line should take a long bend near the coasts, as in the line $\mathbf{A}^{\prime} r^{\prime} r$ rrr $\mathrm{A}$, or a shorter bend $\mathbf{A}^{\prime} s s^{\prime}$, according to the nature of the current. This form of the isothermal line of $68^{\circ}$ on the chart indicates the existence of the circuit movement in the ocean, and also some of its characteristics.

For example, the westward tropical flow in the north Atlantic carries its warm waters over the Bermudas, bending northward the isotherm of $68^{\circ}$ (see map, page 47), and also that of $62^{\circ}$; and in the south Atlantic, bending the isotherms of $74^{\circ}$ and $68^{\circ}$ far away from the equator, the latter to latitude $30^{\circ}$; while on the west side of Europe and Africa, as no tropical flow reaches the borders, and only the high-latitude current, the isotherm of $68^{\circ}$ is carried in the north Atlantic to $15^{\circ} \mathrm{N}$., and in the south Atlantic up to $6^{\circ} \mathrm{S}$. Consequently the interval between the isotherms of $68^{\circ}$ in the eastern part of the Atlantic Ocean is only $21^{\circ}$ in width, while it is $64^{\circ}$ in the western.

The isotherms on the following chart (page 47) mark the points which have equal mean temperature for the coldest winter month, and the temperatures are those of a surface layer of the ocean 90 to 180 feet deep. For the northern hemisphere the month of greatest mean cold is January or February, and for the southern, July or August. The chart, while isothermal, differs widely, therefore, from other isothermal charts, and has been named Isocrymal, from the Greek for equal and cold ("Fos, kpvrós). The line of $68^{\circ} \mathrm{F}$., for example, passes through points in which the mean temperature of the surface water in the coldest month of the year is $68^{\circ} \mathrm{F}$.; so with the lines of $62^{\circ}, 56^{\circ}$, etc. All of the chart between the lines of $68^{\circ}$, north and south of the equator, is called the Torrid Zone of the ocean's waters; the region between $68^{\circ}$ and $35^{\circ}$, the Temperate Zone; and that beyond $35^{\circ}$, the Frigid Zone. The line of $68^{\circ}$ is that limiting the coral-reef seas of the globe, 
28.

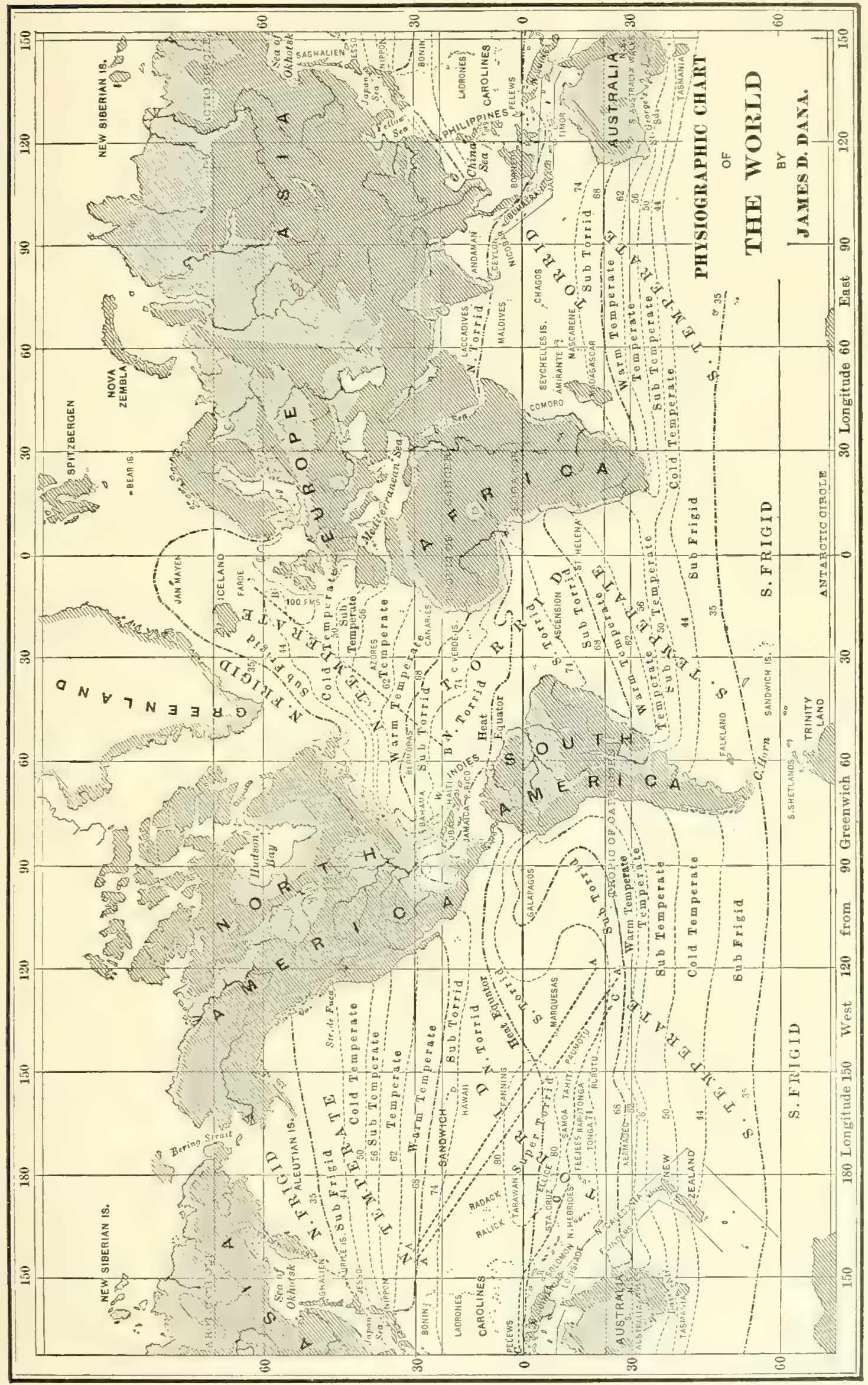


or those in which reef-making corals grow, so that the coral-reef seas and Torrid Zone thus have the same limits.

In the Pacific, the effects are no less striking than in the Atlantic, on the west side of the American continent. Owing to the cold-latitude waters that flow equatorward, the isotherm of $68^{\circ}$ reaches the South American coast at its west cape in latitude $4^{\circ} \mathrm{S}$., and thus a tropical temperature is excluded from nearly the whole of it. In the north Pacific, the cooling effect is much less, becanse of the barrier to the arctic waters at the shallow Bering Strait; the isotherm terminates against the coast at $23^{\circ}$. But on the east border of Asia and Australia, or the west side of the ocean, the width of the area between the north and south isotherms of $68^{\circ}$ is $65^{\circ}$, and the mean width in the central Pacific is about $55^{\circ}$.

The warm Gulf Stream extends its effects over the whole breadth of the north Atlantic, even to Great Britain and Iceland and the polar seas, as is indicated on the map by the long loops in the isotherm of $44^{\circ}$ and $35^{\circ}$. The warm waters extend to Spitzbergen near $82^{\circ} \mathrm{N}$., and to the west side of Nova Zembla, where the absence of ice in summer is its effect; and in favorable times it goes still farther east. Thus the heat of the tropics is made to temper arctic climate. But by the time the waters have reached the polar circle they have lost all tropical heat, and are warm only from contrast with the mean temperature of the northern latitude.

The effects of the polar waters along the east borders of North America are strongly marked, because they there pass alongside of the warm Gulf Stream from the south. The southward course near the continent of the isotherm of $35^{\circ}$ to the sonthern angle of Newfoundland, and the termination of the isotherms of $50^{\circ}, 56^{\circ}$, and $62^{\circ}$ at Cape Hatteras, are a consequence of the Labrador waters. Down to this cape these cold waters cover a cold belt inside of the Gulf Stream; but farther south they are excluded by this stream.

The polar waters are also felt, but to a less extent, on the borders of northwest Europe. The effect is manifest also along the east Asiatic coast, where, as the map shows, the isotherm of $35^{\circ}$ extends down to $45^{\circ} \mathrm{N}$., and that of $68^{\circ}$ even down to $15^{\circ} \mathrm{N}$.

Deep-water effects. - The great currents of the ocean have also deepwater effects. They are, as has been shown, deep-water currents. The Gulf Stream has a depth of 2500 to 1800 feet from the Florida straits to Cape Hatteras, and 1500 to 1000 north of the cape through the ocean; and the effects of the polar currents or movements are of all depths from the surface to the bottom. Between the two systems of movements, that of the tropical and that of the polar waters, the ocean derives its distribution of heat. South of Cape Hatteras, the deeper waters of the Gulf Stream give warmth to the bottom over a belt 50 to 75 miles wide; and north of this cape, the warm belt lies between the 65 -fathom line on the west, where stands the cold wall of the Labrador current, and the 200 -fathom line on the east; giving a temperature of $53^{\circ}$ to $47^{\circ}$ (Verrill) to the bottom, while on 
either side it is $45^{\circ}$ or less. Further, where the Gulf Stream strikes the submarine slopes of the British Islands, it gives the same temperature to the bottom in depths of 60 fathoms or less to 600 or 700 fathoms; and a similar cold wall exists against the polar waters of the Norwegian sea.

But through the breadth of the oceans, owing to the polar movement equatorward, the waters at a depth of 600 fathoms, or 3600 feet, have almost everywhere a temperature near $40^{\circ} \mathrm{F}$., or from $42^{\circ}$ to $39 \frac{1}{2}^{\circ} \mathrm{F}$; and at 500 fathoms, from $42^{\circ}$ to $45^{\circ}$. Further, at 1000 fathoms, the temperature is usually between $36^{\circ}$ and $40^{\circ}$, and $32^{\circ}$ to $36^{\circ}$ at 2000 fathoms and below to the bottom. The deeper part of the north Atlantic has a bottom temperature of $35^{\circ} \mathrm{F}$. (about $34 \cdot 3^{\circ}-35 \cdot 6^{\circ}$ ), while in the south Atlantic it is $31^{\circ}-34^{\circ}$ because the south Atlantic has a more open polar connection (Carpenter). In both the north and the south Atlantic the area of greatest bottom cold is very large in the western half of the ocean and small in the eastern, the ratio being nearly 4 to 1 . In the Pacific, the Challenger Expedition found bottom temperatures of $34^{\circ} 6^{\circ}$ to $35^{\circ} 4^{\circ}$ in both the north and south Pacific, with $40^{\circ} \mathrm{F}$. between 450 and 600 fathoms. In the arctic seas the bottom temperature of $28^{\circ} \mathrm{F}$. has been observed as the extreme.

Adjoining seas, like the Caribbean and the Mexican, have for their minimum temperature the temperature of the bottom waters of the straits connecting them with the ocean, which, in the case of the seas mentioned, is $39 \frac{1}{2}^{\circ} \mathrm{F}$. In the Mediterranean Sea, which has no inflowing cold waters, the temperature below 600 feet is at all depths $54^{\circ}$ to $56^{\circ} \mathrm{F}$. The inflow at the Straits of Gibraltar is of surface Atlantic waters, and, in consequence of the very abundance of evaporation from its surface, the amount of it is more than that of the outflowing, more saline and therefore heavier, Mediterranean waters.

\section{Atmospheric Currents and Temperature. Moist Regions AND Deserts.}

(1) Heat-conditions of the atmosphere. - The amount of heat absorbed by the atmosphere from the sun's rays depends largely on its density or the barometric pressure. It is therefore greater at the sea level, where the pressure has a mean of $29 \cdot 8$ to 30 inches, than at any elevation above it over the land. It is least at the tops of the mountains, and greatest in depressions below tide level, like that of the Dead Sea, 1390 feet below, and the Caspian, 84 feet below. The land surface receives and gives out heat, and is an important source of heat to the air which derives in this way two thirds of its temperature, the rest being due to absorption of the sun's rays. The waters of the ocean also absorb heat, but this takes place slowly; the heat largely becomes latent, and it is also distributed below by convection; hence, under the same exposure, it gives much less heat to the atmosphere than a land surface. Moreover, lands in the colder latitudes and at heights become covered with snow, while the ocean has no ice-covering except near coasts in polar latitudes. 
An increase of density from an addition of carbonic acid would increase proportionally the amount of heat absorbed, the absorptive power of this gas being 90 times that of the atmosphere. The presence of aqueuns vipor also increases the absorptive power.

The winds are a means of distributing heat and moisture, and thus tend to equalize the temperature of the globe. But, at the same time, they make local areas of extreme heat and cold, of extreme precipitation and dryness.

(2) Surface movements of the winds. - For theoretical views and details on this subject, reference should be made to meteorological treatises, the remarks here being confined to a few general facts. They illustrate well the dependence of effects on the east-west characteristics of the earth derived from its rotation.

In general, the courses of the winds are nearly coincident with those of the great oceanic currents, and it is held by many that the winds are the motive power of the currents. In the tropies, the prevailing course of the winds is from the eastward (these winds being called the trades), and in the higher temperate latitudes from the westward. There is a tendency to calms (1) along the equator; (2) in mid ocean between the parallels of $25^{\circ}$ and $35^{\circ}$; and (3) about the poles; but the equatorial area of calms is sometimes in part a region of a counter-current.

The trades strike the east side of the continent, and then, bending away from the equator, curve around to becone the westerly winds. And the reverse is true for the westerly winds; but where they strike the west side of a continent, only part of the wind may be deflected toward the equator and the rest curve around poleward; and when so, the former gradually warms up, since it goes toward warmer regions, and the latter loses heat because going into higher latitudes. These two parts vary in their relative amounts or force according to the trends of the coast-lines or form of the land.

The Indian Ocean makes an exception under the system, because the region there existing to the north of the equator is occupied by a continental mass, Asia, which pushes the circuit to the sonth, the winds that blow there from the eastward corresponding to the trades of the other oceans.

(3) Distribution of moisture. - The capacity of air for moisture - that is, its power of taking up moisture without a loss of transparency - varies with the temperature. When saturated, a loss of heat causes condensation, and thence, mist, clouds, rain. On the contrary, an increase of heat increases capacity for moisture, and the wind, instead of dropping moisture, gathers moisture from the surface it passes over.

In the south Pacific the wind from the west is a cold wind, charged with - moisture derived from the ocean; as it divides on striking South America it becomes in its northern branch desert-making, in its southern, rain-giving. The branch going north passes into regions of increasing warmth, and the vin 1 gathers up the moisture beneath and makes the desert region of 
Atacama, and a dry shore region northward through Peru; while the branch going southward, which encounters increasing cold, makes one of the wetter areas of the globe, Valdivia having an annual rainfall of 115 inches. The same effects of the two branches are produced on the westerm border of North America, the western border of north Africa and Europe; in western south Africa; in western Australia. (See Rainfall map by E. Loomis, Amer. Jour. Sci., III., xxiii., 1882.)

On the contrary, the wind from the east over the tropics is a warm wiml charged with moisture. After striking North and South America it bends away from the equator into cooler latitudes, and makes a great moist region of eastern North America, and of eastern South America, with excessive moisture over large areas; and the position of the higher mountain range of America, far toward the western border, lays open the whole interior to the moisture. The trade winds produce a similar effect on the eastern side of Eurasia and Australia, making the border of China one of the wet regions of the globe, and so also a narrow mountain border for Australia.

Mountains have cold summits, and consequently are great condensers of moisture. They therefore take a prominent part in the above mentioned system of results, and also produce local effects in other regions.

The first high cold land struck by the winds takes a large portion of the moisture out of them and leaves less, or little, for the region beyond. And thus robbed, even the trades may become dry winds. The contrasts are well shown on the opposite slopes of the Hawaiian mountains - the eastern receiving much rain from the trades, the western getting almost none. For the same reason the interior of North America is relatively dry, the amount of precipitation over the Atlantic border being 40 to 50 inches a year, and in the interior 20 to 40 and less. So it is also with the interior of South America as compared with the coast region to the north; and Sahara, begun in northwestern Africa, stretches across the continent. The great Desert of Gobi is thus shut off from sea winds, and winter winds blow from it instead of into it. The higher ridges along the Rocky Mountain summit raise locally the amount of precipitation, but it falls off again over all the western slopes, and continues very small to the Sierra Nevada, averaging less than 10 inches a year over a broad belt from the Great Salt Lake region to the Gulf of California.

It is apparent from the facts which have been presented that the continents have derived many of their individualizing characteristics, their several diversities of surface, climate, and life, from the disposing influence of the earth's rotation. This is strikingly apparent in the existing flora and fauna, briefly described in the following pages; it becomes still more evident after a review of the succession of faunas and floras in the earth's history in which the individual features of each continent are traced back far toward "the beginning."

The great truth is taught by the air and waters, as well as by the lands, that the diversity about us, which seems endless and without order, is an 
exhibition of perfect system under law. If the earth has its barren ice-fields about the poles, and its cleserts no less barren toward the equator, they are not accidents in the making, but results involved in the scheme from its very foundation.

\section{GEOGRAPHICAL DISTRIBUTION OF PLANTS AND ANMMALS.}

The geographical distribution of plants and animals is dependent on both physical and biological conditions.

1. Temperature has universal influence. Species are usually confined within narrow temperature limits. They differ therefore in the different zones from the equator to the poles, some having a range of only a few degrees, and others of half a hemisphere. They differ also with the height on passing from the sea level to the limit of life (the limit of perpetual snow) about the summits of the highest mountains, or even higher, as regards Microbes or Bacteria, the lowest of cryptogamous plants, the only kinds having the range of the world. They also differ as we descend in the ocean.

2. Light is another universal cause. Some species need for successful growth and reproduction the direct rays of the sun; others are confined to shady places, dark places, and very dark places, like caves; some to the surface waters of the ocean, because of the light that penetrates them, and others to dark depths. A lawn will have a rich surface of grass in the sunshine, and become full of weeds under the shade of a tree, because the weeds flourish in the shade, while the grass dwindles and becomes crowded out; and in such a case fertilizers may help only the weeds instead of the grass.

3. Difference in pressure. - This cause also is universal in its action, but very feeble in its effects. The atmospheric pressure near the earth's surface diminishes about one pound per square inch for each 1900 feet of ascent, or, approximately, three pounds for 6000 feet. In the ocean, the pressure increases at the rate of about one pound per square inch for each $2 \cdot 2$ feet of descent, or 2750 pounds for 6000 feet or 1000 fathoms, and 11,000 pounds for 24,000 feet.

But marine species readily become adapted to all pressures, as the outside water penetrates them. Twenty-six fishes are known to have a range of 5400 feet, and some macrural Crustaceans a range of more than 12,000 feet. The Shrimp, Sergestes mollis, for example, ranges from 2238 to 17,694 feet.

But after a sudden change, or when brought to the surface in a dredge, a fish presents "a most disreputable appearance," the swimming bladder protruding from its mouth, the eyes forced from their sockets, and the scales fallen off (A. Agassiz).

4. Differences in moisture and dryness of climate are great sources of limitation in the range of species. Differences in soil have wide influence; for a soil must contain the materials essential to a plant's growth before it will 
grow in it; and what is good for one is bad for another. Rocks favor certain plants; and, in some instances, differences in rocks adapt them to different species of Lichens and Mosses. As the composition of the air, earth, or water varies, the inhabitants differ, what is death to one being life to another.

The general principle that all living species must have food and just the food they need, or die, is one of the foundations for the differences in limitation under all the causes above mentioned. Geological changes that vary these conditions have therefore been a great means of determining distribution, by varying temperatures, climate, and land level; by varying soils and converting deserts into dry land, marshes, or seas by joining lands through change of level, so as to favor or compel migration; or sinking them, to the extermination of species. In addition, as Darwin has shown, the changes brought about in the associations of species, in these ways and through their mutual dependence as to food and all necessities, have been other ceaseless causes of variation in distribution. Those continental lands that are most isolated, like Australia and South America, have, for the reasons mentioned, and others, the largest number of peculiar species, and hence the most homogeneous population.

\section{BRIEF REVIEW OF DISTRIBUTIONAL FACTS OF GEOLOGICAL INTEREST.}

\section{Terrestrial Species.}

1. Plants.

Plants of the land spread to all heights, even above the snow-limit. Among Cryptogams, Ferns and Lycopods flourish in all latitudes from the equator to the polar latitudes; but Tree Ferns, not beyond the parallel of $35^{\circ}$. Under the warm moist climates of tropical and warm-temperate latitudes, Ferns and Lycopods grow in greatest numbers and luxuriance. Palms have their limit in South America in latitude $36^{\circ}$, in North America and Australia in $35^{\circ}$, and in Asia in $34^{\circ}$; in Europe one species, Chamarops humitis, extends as far north as latitude $44^{\circ}$.

The Conifers range through all zones. The Yews, as Salisburia, live in warm-temperate latitudes. But the subdivision of Cycads is confined to tropical and warm-temperate latitudes. They occur in southern Asia, Japan, the East Indies, Madagascar, Australia, southern Africa, and tropical America, including Mexico and the West Indies.

\section{Animals.}

Australian characteristics. - Australia, although near the East India Islands, is remarkable for the absence of all ordinary or placental Mammals except Bats of the genus Pteropus, Rats, and Mice. Instead, it has a large population of Marsupial Mammals, the diversified types of ordinary Mammals being represented under the Marsupial or pouched structure. Wallace, in allusion to the diversity among them, says (Geogr., i. 391): "Some are carnivorous, some herbivorous; some arboreal, some terrestrial; there are insect-eaters, root-gnawers, fruit-eaters, honey-eaters, leaf or grass-feeders. Some are like wolves in habits, others like marmots, weasels, squirrels, flying-squirrels, dormice or jerboas. All are members of one stock, and have no real affinity with the Old-World forms, which they often outwardly resemble." Besides Marsupials, which are sometimes called semi-oviparous, there are the still inferior Monotremes, the Duck-bill and Echidna, both of which are strictly oviparous, although true Mammals inasmuch as they suckle their 
young. The Australian region (which includes also New Guinera, Celebes, and some islands just west) has also numerous Amphibians, more, says Wallace, than any other continent exeept south Ameriea, and but few Reptiles. It is also noted for its number of species of Pigeons, two fifths of all that are known being confined to it; for its Kingfishers, the fauna embracing three fourths of all kinds living ; for Birds of l'aradise, Lyre Birds (the Menurids), its many Parrots, those of the Australia-Malay area comprising 176 species; and muler the (ostrich type, its Cassowaries (genus Casuarius) of 11 species, and Emeus (Dromæus) of 2 species.

New Zealand, which is also a part of the Australian region, has 2 Bats for its only Mammals; the Apteryx, anong its Birds; a single Frog among Amphibians; a dozen Lizards; a Reprile of palieic characteristics, the Hatteria or Sphenodon, which has but 1 species (S. punctatum), the last of an otherwise extinct tribe, the Rhynchocephalidx. It is very poor in Insects, having ouly 11 species of Butterflies, with about 300 Coleopters (Wallace). Besides these, there were, one or two centuries or farther back, the now extinct birds, Dinornis, Palapteryx, and many others of Ostrich-like character. On Chatham Island, 500 miles east of New Zealand, but within what may be called New Zealand seas, there have been found the remains of a flightless bird akin to those of New Zealand.

The Oriental region, including India and eastward to southern Japan, with Sumatra, Java, Borneo, etc. - This tropical region, directly north and northwest of the Australian, is wonderfully different from it. There are no Marsupials or Monotremes; but instead Mammals of other kinds, Man-apes, as the Orang-outang, and Lemurs, Lions, Tigers, Hyenas, Bears, Elephants, Rhinoceroses, Manis among Edentates, and among Reptiles, Crocodile and Gavials.

The African or Ethiopian region, including the part of Africa south of the Atlas Mountains, with Madagascar and the Mascarene Islands. - The Ethiopian region comprises in its fauna the Hippopotamus, Rhinoceros, Camelopard, Elephant, Lion, Hyena, a characteristic type, Hyrax, Horses (Zebras), the Orycteropus and Manis (Ant-eaters) among Edentates; the Hedgehog among Insectivores; Anthropoid Apes, as the Gorilla, besides other Quadrumana (all of which have 32 teeth, like Man), and also many Lemurs; but no Camels, or Bears, or Deer, or Oxen, or species of Sus (Pig). It has among its Birds two species of Ostrich of the genus Struthio.

Madagascar not long since had its Epyornis, related to the Dinornis of New Zealand and the Mascarene Islands, the Dodo (Didus ineptus), and other birds now extinct. Madagascar is noted also for its Lemurs, of which there are 35 species.

The South American or Neotropical region, comprising South America, the West Indies and Central America, and Yexico. - The Neotropical region is remarkable for the number of peculiar families and genera. They embrace Monkeys with prehensile tails, that have a molar tooth more in each jaw than those of Africa; Tapirs; Llamas, Vicuña and Guanaco, of the Camel family; Dicotyles, or Peccary, among Wild Boars; Anteaters, Sloths, and Armadillos among Edentates; Marsupials, in which it is related to the Australian region. Among Birds, there are in America all the Humming Birds of the world, some 400 species in more than 100 genera, having a range from Patagonia to Sitka; Parrots, numbering 141 species; Toucans; the Rhea, of the Ostrich family - a family confined to the three southern continents, Australia, Africa, and South America; among Reptiles, Alligators, Crocodiles, and many Amphibians, being next to Australian in their number and variety; and among Fishes, the Lepidosiren, related to the Dipnoi of Africa and Australia.

Within this region the West India Islands are remarkable, like some of the Hawaiian Islands in the Pacific, for the number of their land-shells, numbering 608 species of Operculates and 737 of Inoperculates. The number of the former in South America is 151 , of the latter 1251 . 
The Nearctic region, or the North American, from Mexico northward, excluding the West India Islands. - Of peculiar types there are among Mammals the Marsupial of the genus Didelphys, successor to genera that extend far back in American geological history; among Reptiles, which, however, are more properly neotropical, the Alligator; among Fishes, the Ganoids, which extend south to Mexico and Cuba; the Humming Birds, (only six) ranging up from South America; and the fresh-water Mollusks, in which this regiou "surpasses all other parts of the globe."

The Patearctic or Eurasian, north of the Atlas Mountains of Africa, and including Persia, the region of the Himalayas and northern Japan. - This great region has its Monkeys of the African genus Macacus at Gibraltar and north Africa, in Tibet and north China; its Camels, ranging from Sahara to Mongolia and Lake Baikal; Horses (Asses); its Bovidæ (Cattle), of which there are more kinds in the old World than in the New; the Hyrax, a genus occurring in Syria as well as in Ethiopia; the Beaver (Castor fiber), near the Castor canadensis of North America.

\section{Aquatic Species.}

Contrary to old ideas, the bottom of the ocean abounds in life through all depths, down to 3000 fathoms, and has its species even to a much greater depth. And along the bottom, from Arctic to Antarctic seas, there is a highway nearly as broad as the ocean, where the temperature is not above $40^{\circ} \mathrm{F}$. or below $28^{\circ} \mathrm{F}$., and by this highway species befitting those depths can migrate the world over.

Limitation in distribution along shores depends much on the kind of bottom, whether rocky, or sandy, or muddy; on the quality of the water, whether pure or impure, or encroached upon by fresh waters from the discharge of rivers. But the two chief sources of limitation, both along shores and throughout the depths, are temperature and amount of light.

The surface distribution of temperature, as illustrated by the temperature chart, has been explained on page 45 . The isothermal line of $68^{\circ}$ is the boundary of the coralreef seas. Within the area, and for the most part between the parallels of $29^{\circ}$ north and south, the reef-making Corals abound. Part of the species require its warmer portions; the hardier extend to its borders. By following the outline of the area it may be seen, where reef Corals can grow, and from what coasts of the Atlantic and Pacific reefs they are excluded by the coolness of waters ; and also why the Bermudas are within the coralreef limit, although situated in latitude $322_{2}^{10} \mathrm{~N}$.

It will also be observed that in the Atlantic Ocean the meeting of the isotherms of $56^{\circ}, 62^{\circ}$, and $68^{\circ}$ at Cape Hatteras signifies that two temperate zones, the temperate and subtemperate, which have great expansion on the European side of the ocean, and even include the whole Mediterranean Sea, with its very abundant life, are wholly excluded from American waters because of the meeting at that point of the Labrador and GulfStream currents (page 46), and thereby of zones of Labrador and Gulf-Stream species. The chart thus explains many strange facts in the distribution of the life along the borders of the ocean.

The second cause of limitation is the amount of light, as explained by Fuchs. It has its effects at 120 to 180 feet, and more marked at 420 to 480 feet. The greatest depth at which gelatine bromide photographic plates were sensible to light in experiments in the Gulf of Nice was 400 meters (1312 feet); 350 meters for eight hours of the day; 300 meters from sunrise to sunset; and in Lake Geneva, the greatest depth 200 meters (Fol and Sarrasin). It is generally held, however, that there can hardly be a total absence of light, even at abyssal depths, since, while many animal species are blind, or have eyes excessively large or excessively small, many others have them of normal size and structure. The phosphorescence of various species among Fishes, Crustaceans, Annelids, Ophiurans, Ascidians, Gorgonias, Antipathes, Medusæ, as well as Infusoria, may be all 
there is of light at abyssal depths; but this is not probable. Murray observes that the eyes of the Fishes are in general unusually large at depths of 480 to 1200 feet; but beyond this depth, small-eyed species as well as large-eyed are common, and many also are blind.

The Littoral zone. - By means of light, rather than temperature, the limits of the Littoral zone are determined. Reef-forming Corals, and therefore coral-made reefs, have their limit in depth at 120 or 150 feet in the equatorial regions, and at 90 to 96 feet near the border of the coral-reef seas; and since the temperature of $68^{\circ} \mathbf{F}$. in the tropics is usually 600 feet below the surface, light is made, by Fuchs, to be the chief cause. A vast variety of species are congregated under like limitation, the coral-reef seas being "the gathering grounds of an extremely rich fauna," says Fuchs, and one so peculiar that the terms coral-fishes, coral-mollusks, and the like, would not be inappropriate; a fauna that embraces "the whole splendor of the animal life" of the Indian and Pacific oceans. Within this Littoral zone belong, moreover, the areas of large Bivalves, such as Oysters, Pearl Oysters, Scallops, which have their maximum development in from 48 to 60 feet, and are not found below 120 feet. $^{1}$

The seaweed areas reach to a depth of 30 fathoms, or about 200 feet. Plants are dependent on light for assimilation, and hence comes this narrow limit for the aquatic part of the vegetable kingdom.

'The Fucoids and strap-like Laminarians, or the brown and olive Seaweeds - related, it is supposed, to the Seaweeds of early time, when no seas were colder than those of the modern temperate zone - live now on most shores from the tropics to the poles, and attain their greatest size in the colder latitudes.

The only deep-water plants thus far observed are Corallines at 900 feet, and small Algæ, found to bore into corals that came up, according to Duncan, from a depth of 6000 feet.

The depths. - Below 420 to 480 feet are the regions of darkness. They are divided locally into two sections, a warm and a frigid, by the Gulf Stream and other tropical currents. The depth to which the warm waters of this stream extend along the borders of the Atlantic basin, and thence across the ocean to Great Britain, are mentioned on page 5. Where these waters wash the sides of the Atlantic basin from Florida northeastward, there is a profusion of life of all marine kinds; and the same is true for the area within the British sea.

The cold belt passes close by the western side of the warm belt off New Jersey and Nantucket. The commingling of the two in a storm is stated by Professor Verrill (1882) to have probably caused the extermination - only temporary, it has proved - of a large food-fish, the Tile-fish, of the genus Lopholatilus, which was caught abundantly by a Fish Commission expedition in 1881 off Nantucket with a trawl at a depth of 420 to 900 feet. During the following winter great numbers of the dead Tile-fish were seen by passing vessels, floating at the surface; and in the dredging of 1882 over the same area not one was obtained; and many other species dredged in 1881 were missing in 1882 . In 1890 the Tile-fish was again found.

The bottom of the ocean through all its depths is constantly receiving contributions of the hard parts of its living species, from the bones of Whales and Sharks to the siliceous shells of Diatoms, and the calcareous of Rhizopods. It is often difficult to determine for the smaller species whether they are denizens of the dark depths or of more superficial waters. Most of the pelagic species that are found abundantly at the surface of the ocean during the dark hours of the night, and may then be easily taken with a hand-net, go to greater depths during the day, showing that they are really part of the fauna of the darkness. Pelagic species, according to Agassiz, are mostly confined to within 1200 feet of the surface.

1 J. Fuchs, Geol. Verhandl. Reichanstalt, No. 4, 1882; Ann. Mag. N. Hist., January, 1883. 
Oceanic species include a large part of Diatoms or silica-secreting microscopic plants. They live near the surface, requiring light like other plants, and are forced to keep near the surface by the bubble of oxygen they give out in assimilation. They abound especially in the southern Atlantic, and great areas over the bottom are covered with a Diatom ooze or soft mud.

The Foraminifers, or calcareous Rhizopods, are solely salt-water species. They in part live near the surface, if not altogether. These abound in many seas, excepting the more frigid, and make by their accumulation at the bottom the Globigerina ooze, even to depths of 174,000 feet. Maury, alluding to the dropping to the ocean's bottom of the Foraminifers, says: "The sea, like the snow-cloud with its flakes, in a calm is always letting fall on its bed, showers of microscopic shells, and all pelagic life adds to the showers."

Radiolarians, or siliceous Rhizopods, occur only in salt water. They are abundant in some localities in the central Pacific, at a depth of 15,000 feet and less. They make a Radiolarian ooze. A Radiolarian deposit on the Barbadoes is supposed to indicate an elevation of the sea-bottom of 1000 to 2000 feet.

Silliceous Sponges occur in the ocean at various depths to 15,000 feet, and from warmer temperatures to $40^{\circ} \mathrm{F}$. The Hexactinellids are most abundant at depths of 80 to 100 fathoms, at which depth the Euplectella (Fig. 29) was obtained near the Philippines, in waters at a temperature of $59^{\circ} \mathrm{F}$, and near Cebu, of $69^{\circ} \mathrm{F}$. For figures of a number of Sponge Spicules see page 432. The Choristid Sponges occur down to 16,200 feet, and the Lithistids to 900 feet. The Sponges with calcareous spicules or skeleton are also widely distributed. Both the calcareous and siliceous also occur in shallow waters, fresh and salt.

The ordinary or the Actinozoan Corals are all marine. Solitary kinds

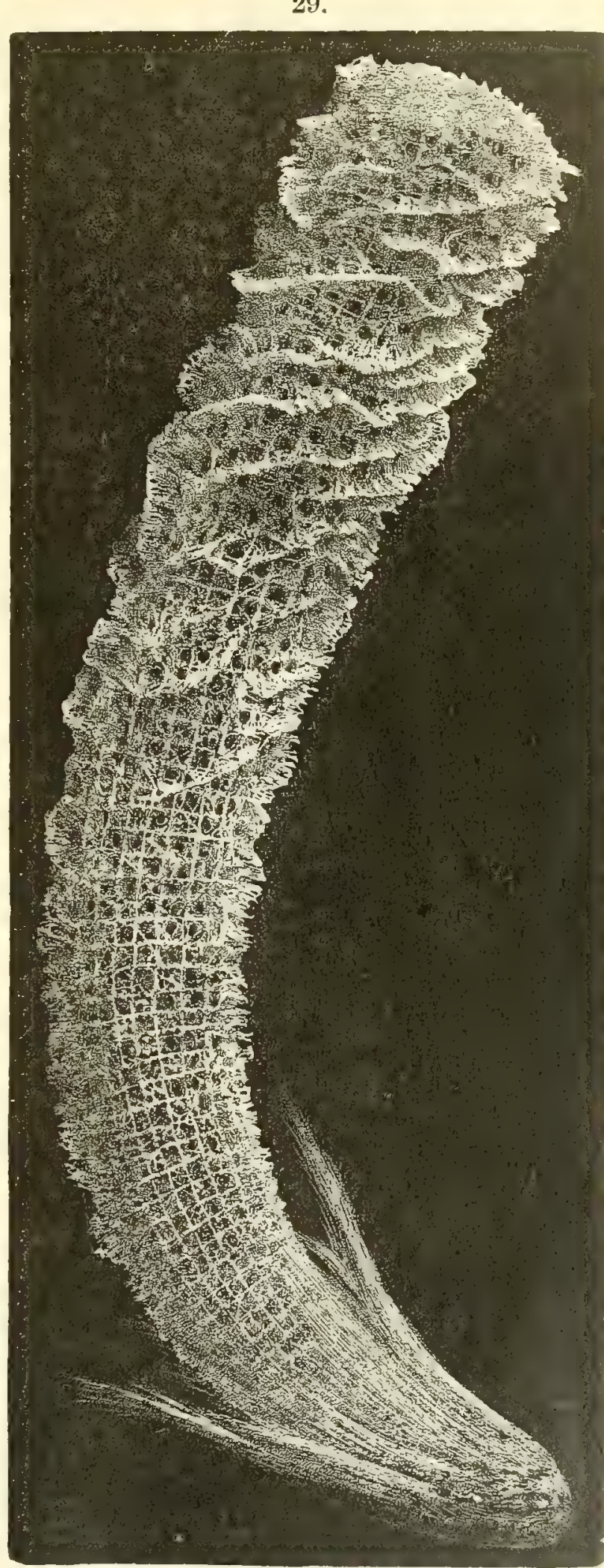

Euplectella speciosa, or Glass Sponge.

extend to great depths, and one species, Bathyactis symmetrica, has a vertical range from 180 to 17,400 feet (Moseley). They are, therefore, species of all temperatures and 
30.

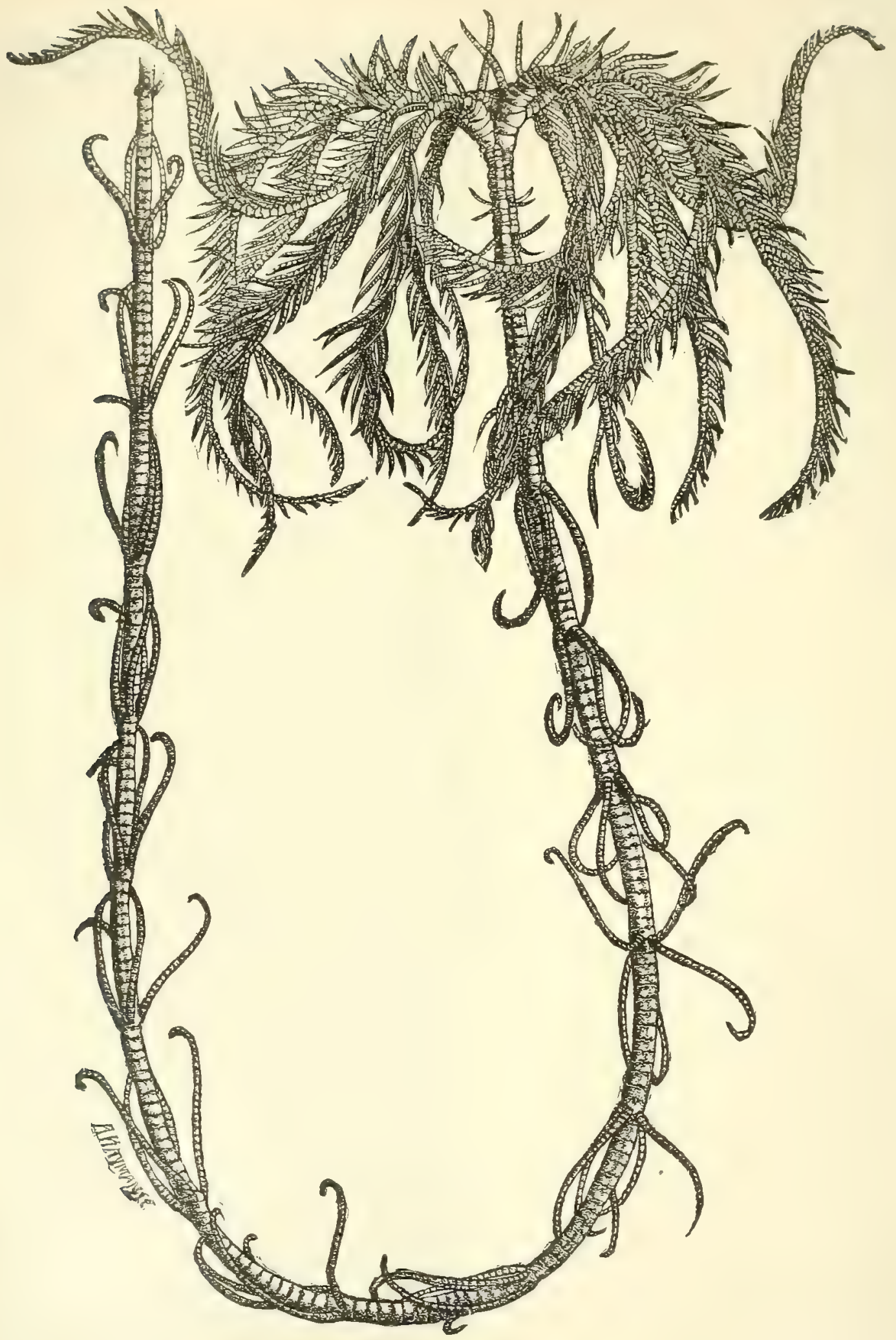

Pentacrinus decorus, of Carpenter. From A. Agassiz. 
degrees of light or darkness. Of reef-making Corals, or those that grow in plantations, an account has already been given.

Echinoderms are solely marine species, and they are found at all depths and temperatures. Crinoids of the genus Pentacrinus (Fig. 30, page 58), and allied to Liassic kinds, with species of Rhizocrinus, Bathycrinus, etc., live at depths above 100 fathoms to below 1000 , many where the temperature is below $40^{\circ} \mathrm{F}$. Sea-urchins (Echinids) of the Cidaris, Diadema, and Ananchytes families, related to Cretaceous types, occur at similar cold depths. A. Agassiz states that the deep-sea fauna of the West Indies includes 5 Jurassic genera of Echinids, 10 Cretaceous, 24 early Tertiary, and 4 of the later Tertiary.

Brachiopods of the Terebratulid type, much like Oölitic and Cretaceous forms, occur at all depths, down to 18,000 feet; and Discina, from the surface to cold depths exceeding 12,000 feet, but the most below 3000 feet; Crania, at 600 to 1200 feet. Lingula occurs in shallow waters. Species of the genera Atretia, Discina, and Waldheimia and others occur beneath the Gulf Stream at depths of 9000 to 9600 feet.

Under Mollusks: Pteropods are pelagic species, and live mostly near the surface. Their shells occur in large numbers in the bottom deposit at depths mostly from 500 to 1500 fathoms in the West Indies and some parts of the Pacific. The form in Fig. 31 of a Mexican Gulf and Atlantic species is much like that of many ancient Pteropods. Deep-sea Gastropods are usually small. The genus Pleurotomaria has only four living species known; and $P$. Adansoniana lives at a depth of 1200 feet. Trigonia is a shallow-water genus. The Nautilus, the last of the Cephalopods having external shells, is restricted to tropical and sub-tropical seas.

Among Worms, the Serpulidæ occur at great depths, species having been obtained by the "Challenger" at depths of nearly 18,000 feet.

Some of the abyssal species of Crustaceans have been shown to range from pole to pole. The large spiny crabs of the genus Lithodesare probably among them. One of the species, L. Agassizii, from a depth of 1000 fathoms underneath the Gulf Stream, is reported by Verrill (1884) as over three feet broad. Many of the deep-sea Crustaceans, according to S. I. Smith, are remarkable for the large size of their eggs. In some of the Eupaguri (Soldier-crabs), the eggs are 8 times the usual size (volume).

The only surviving species of the Trilobite and Eurypterid line are two of the genus Limulus, - one in eastern North America, and the other in the China seas. Crustaceans are found mostly at depths less than 3000 feet; 2 only out of 100 Brachyurans dredged off the United States were from depths greater than 3000 feet; but 30 out of 60 Macrurans were from greater depths, 13 of them from below 6000 feet, and some at depths of 12,000 feet; and one gigantic blind species, Phoberus cacus, is over 2 feet long. One Isopod, Bathynomus giganteus, occurs eleven inches long; in compensation for dark depths it has compound eyes comprising 4000 facets (Milne-Edwards).

Fishes. - The existing Ganoids - Sturgeons included-

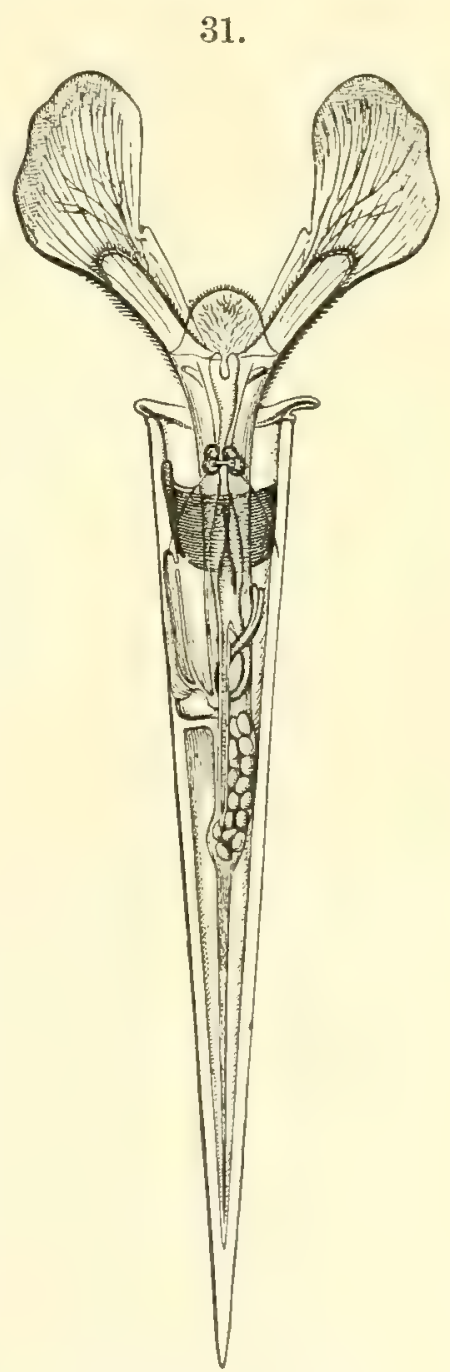

Pteropod, genus Styliola. $\times 5$. A. Agassiz. live only in fresh waters, and are confined to America, Africa, and Australia. North America has 3 species of the genus Lepidosteus, and Africa 2 of Polypterus; and of the related Dipnoi, which are, as the name implies, two-way breathers, they having lungs as well as gills, Queensland, northern Australia, has 2 species of Cera- 
todus, and South Africa has 1 species of Protopterus : in all not a dozen species of a tribe that was once very mrominent. Pelagic fishes occur at all depths to nearly 18,000 feet. The "Albatross" brought up a Cyclothone from a depth of 17,694 feet (Agassiz). The species of the deeper waters are described as having the bones feebly calcareous, being slender and loosely conmected, and some species will take in a fish for food three times as large as themselves. Many kinds are phosphorescent.

Cestraciont Sharks, once very numerous in species, are now but 4 in number, and all are of one genus, Cestracion. These are confined to the coast regions between Japan and Australia or New Zealand. The type has therefore nearly reached extinction.

From the facts reviewed with regard to marine life, it is apparent that the knowledge of depths and temperatures of living species affords little help for conclusions about the habits of ancient species. Many of the tribes that were represented by warm-water species and those of shallow seas, have now species that have become accustomed to great depths and cold temperatures. Modern Brachiopods are no criterion for the ancient; nor modern Crinoids, nor modern Corals.

\section{Hot-water Life.}

In the north point of Owen's Valley, California, according to Dr. H. C. Wood ( $A m$. Jour. Sci., 1868), at $120^{\circ}$ F., and also at $160^{\circ}$ F. (as learned from Mrs. Partz), occur Algæ, some growing to a length exceeding 2 feet. The species is named Nostoc calidarium. At the Hot Springs ("Geysers"), on Pluton Creek, California, Professor William H. Brewer observed Confervæ in waters heated to $140^{\circ}-149^{\circ} \mathrm{F}$., and simpler Algæ where the temperature was $200^{\circ} \mathrm{F}$. At the same place, Dr. James Blake found 2 kinds of Confervæ in a spring of the temperature of $198^{\circ}$, and many Oscillatoriæ and 2 Diatoms, in one of $174^{\circ}$. In the waters of Pluton Creek, of $112^{\circ} \mathrm{F}$, the Algæ formed layers 3 inches thick. Dr. Biake also collected 50 species of Diatoms from a spring in Pueblo Valley, Nevada, the temperature being $163^{\circ} \mathrm{F}$; and they were mostly identical with those of beds of infusorial earth in Utah. At San Bernardino, California, William P. Blake found living Confervæ in water at a temperature of $130^{\circ}$. At Camiguin Island, east of Cebu, Moseley found living Algæ at $1131_{3}^{\circ}$ F. ; and W. T. T. Dyer has reported that Oscillatoriæ have been observed growing at $178^{\circ}$ to $182^{\circ} \mathrm{F}$.

The various hot springs of the several Geyser Basins, in the Yellowstone National Park, contain very various Confervoid forms. The hottest springs, up to $200^{\circ} \mathrm{F}$., contain numerous long, slender, white and yellow vegetable fibers, of undetermined relations, waving in the boiling eddies, and becoming buried in the siliceous deposits over the bottom, where they often form layers several inches thick. The bright green forms appear to be confined to lower temperatures. W. R. Taggart reports that, at the vents on the shores of Lewis's Lake, leafy vegetation is limited to temperatures below $120^{\circ}$ (Hayden's Reports, 1871-2). Dr. Josiah Curtis found, in these hot springs, siliceous skeletons of very numerous Diatoms; but the vegetable matter was wanting in all cases where the temperature exceeded $96^{\circ} \mathrm{F}$. So many different causes might introduce these skeletons to the hotter pools, that their presence has not necessarily any more significance than that of the Grasshoppers and Butterflies which are frequently found in the same pools. - Of animal life, living larves of Helicopsyche were found, by $\mathrm{Mr}$. Taggart, in a spring having the temperature of $108^{\circ}$, into which, however, they might have crawled from the river, which was close by ; so that the eggs were not necessarily laid at the temperature given.

At Baños, on Luzon, Philippine Islands, the author observed feathery Confervæ in waters heated to $160^{\circ} \mathrm{F}$. In springs in the Pass of Chivela, having a temperature of $98^{\circ} \mathrm{F}$., the United States Exploring Expedition of 1872 found Fish; and, according to Mr. James Richardson, Fish occur in springs in Marocco having a temperature of $75^{\circ} \mathrm{F}$.

On the subject of the geographical distribution of animals, the most important works are Wallace's work in 2 volumes under this title, and his Island Life; and on North America, J. A. Allen, 1892, Bulletin American Museum, New York. 


\section{PART II.}

\section{$\rightarrow$. \\ STRUCTURAL GEOLOGY.}

THE earth, separate from its water and air, - that is, the lithosphere, as it is sometimes called, - is made up of rock-material, and the portions, whether masses or beds, which come under geological study, are termed terranes. Structural Geology treats of the mineral constituents of terranes; of the rocks which the minerals form; and of the structure and general arrangement or positions, and other characteristics of terranes. Some terranes, though unconsolidated, in a general way come under the head of rockdeposits; for consolidation is an incident that may or may not take place.

The subdivisions of Structural Geology as here adopted are:-

I. Rocks : their constituents and kinds.

II. Terranes: their constitution, characteristics, positions, and arrangement.

\section{ROCKS: THEIR CONSTITUENTS AND KINDS.}

\section{The Elements, and their Simpler Combinations.}

The number of elements, or substances, not yet shown to be compound, that have been obtained from the earth's rorks and minerals is 70. Of these, oxygen, nitrogen, hydrogen, chlorine, and fluorine, at the ordinary temperature and pressure, are gases. A few facts are here stated respecting the elements of most geological importance.

Oxygen. - Oxygen is the most abundant element. It constitutes 88.89 per cent by weight of water, 21 of the atmosphere, and about 50 of all other material in the earth's structure. It owes its importance in nature to the intensity of its chemical attraction for nearly all the elements. Ordinary combustion of a wood, coal, or gas is due to the combination of its elements with oxygen; and living growth is dependent on the same process.

Combined with (1) hydrogen, oxygen forms water, $\mathrm{H}_{2} \mathrm{O}$; with (2) potassium (called also kalium), potash, $\mathrm{K}_{2} \mathrm{O}$; with (3) sodium (natrium), soda, $\mathrm{Na}_{2} \mathrm{O}$; with (4) lithium, lithia, $\mathrm{Li}_{2} \mathrm{O}$; with (5) calcium, lime, $\mathrm{CaO}$; with (6) magnesium, magnesia, $\mathrm{MgO}$; with (7) iron (ferrum), the two oxides, $\mathrm{FeO}$ and $\mathrm{Fe}_{2} \mathrm{O}_{3}$; with (8) aluminium (the metallic base of clay), alumina, $\mathrm{Al}_{2} \mathrm{O}_{3}$; with (9) 
carbon, carbon dioxide (or carbonic acid), $\mathrm{CO}_{2}$; with (10) silicon (the name from the Latin silex, flint), silica, $\mathrm{SiO}_{2}$.

These and other essentially stable oxides are the chief constituents of rockmaking materials. They are in strong contrast with the compounds that make up organic tissues, or those of plants and minerals. These contain, along with the oxygen present, carbon, hydrogen, nitrogen, and generally a little sulphur and phosphorus, elements that have a strong affinity for oxygen, but they are associated with too little oxygen to satisfy their affinities, and, moreover, all are under a degree of restraint from the living conditions. When these conditions are removed at death, ordinary chemical affinities rule, and oxides are formed out of the elements of the tissues, and of outside as well as inside oxygen - $\mathrm{CO}_{2}, \mathrm{CO}, \mathrm{H}_{2} \mathrm{O}$ being the chief products. If outside oxygen is mainly excluded during the decomposition, hydrocarbon compounds form, or those that constitute mineral coal, oil, gas, and the black or brown carbonaceous material that colors soil and many rocks; but these on burning become mostly $\mathrm{CO}_{2}$ and $\mathrm{H}_{2} \mathrm{O}$.

Carbon. - Carbon is a prime element in living structures, as silicon is in rock-making minerals. In its pure state, crystallized in octahedrons and related forms, it is the diamond, the hardest of minerals. Crystallized in six-sided tables or scales of a dark lead-gray color, it is graphite (or plumbago), one of the softest of minerals; often called "black lead," because it leaves a trace on paper much like, but darker than, that of lead. Substances having like composition, but different in crystallization, as diamond and graphite, are called paramorphs. Charcoal is nearly pure carbon, but contains some hydrogen and oxygen; and the best mineral coal is only 75 to 85 per cent carbon. Carbon combined with oxygen, forming $\mathrm{CO}_{2}$, or carbon dioxide, is given out in the respiration of animals, and is thus contributed to the air, and by aquatic animals to the waters, and is a large result, as before explained, of all decay. At the same time, it is the source of carbon to the growing plant. Carbon dioxide has great geological importance through its combination with lime $(\mathrm{CaO})$, producing calcium carbonate, the formula of which is $\mathrm{CaCO}_{3}$ (or its equivalent $\mathrm{CaO}+\mathrm{CO}_{2}$ ), the material of ordinary limestone.

Silicon. - Silicon combined with oxygen, and thus making silica $\left(\mathrm{SiO}_{2}\right)$, constitutes the two minerals, quartz and opal. Quartz is the most abundant, durable, and indestructible of common minerals. Silica also enters into combination with various oxides, and thus makes silicates.

Of the oxides in these silicates, alumina, $\mathrm{Al}_{2} \mathrm{O}_{3}$, is the hardest, most infusible, and most indestructible. Like silica, it is well fitted for a chief place in the earth's foundations; and next to silica it is the most abundant.

Silica combined with alumina alone, makes only infusible silicates; but if potash, soda, lime, magnesia, or the oxides of iron are present, the minerals in general are fusible, and are, therefore, suited for the material of a melted as well as of a solid globe. 
Sulphur. - The element sulphur has great importance in the mineral kingdom, but more so in connection with the ores of various metals than among ordinary rock materials. Sulphur is a common volcanic product. Sulphur dioxide, or sulphurous acid $\left(\mathrm{SO}_{2}\right)$, is abundant in the vapors of volcanoes; and sulphur trioxide with water $\left(\mathrm{SO}_{3} \mathrm{H}_{2} \mathrm{O}\right)$, the so-called sulphuric acid, enters into combinations with other oxides, making sulphates.

Phosphorus. - Phosphorus forms an acid with oxygen, phosphorus pentoxide $\left(\mathrm{e}_{2} \mathrm{O}_{5}\right)$, which combines with calcium and oxygen and makes calcium phosphate, a chief constituent of bones, of guano, and of the mineral apatite. There are also phosphates of iron, lead, copper, etc.

Nitrogen. - Seventy-nine per cent of the atmosphere is nitrogen, the rest being oxygen. Nitric acid $\left(\mathrm{N}_{2} \mathrm{O}_{5}\right)$ forms nitrates; common saltpeter is a potassium nitrate. Nitrogen is an essential constituent of animal tissues, and of fungoid plants, or those that are not green in color, as the mushroom; and it is present also in the seeds and some other parts of higher plants.

Chlorine, Bromine, Fluorine, Boron. - Chlorine combined with sodium, 60.7 per cent to 29.3 , forms common salt, of which the ocean is the great depository. There are also among ores, chlorides of silver, lead, and copper. Bromides occur in the ocean's water and in some minerals. Fluorine is a constituent of the common mineral, fluor spar or fluorite ( $\mathrm{CaF}_{2}$, and also exists in the minerals, topaz, chondrodite, and a few others. Boron occurs in boracic acid, in borax, which is a sodium borate, and in the mineral silicates, tourmaline, danburite, and datolite.

\section{The Chief Rock-Making Minerals.}

The following brief descriptions of minerals are intended as notes of reference. A sufficient knowledge of the subject for the geologist can be obtained only by á special study of mineralogy.

\section{Silica.}

Quartz. - Hardness 7 (not scratched with the point of a knife-blade). $G=2 \cdot 65$. Infusible and insoluble, but fusible to glass when mixed with soda and heated (quartz sand and soda being constituents of common glass). No cleavage. Often like glass in luster and transparency, but varying to dull and opaque, and from colorless to yellow, red, purple, brown, black, etc. Often in crystals like Figs. 32, 133 , the crystals, six-sided prisms with pyramids at one or both ends; often closely covering the surfaces with the pyramids. Composition: Silicon $46 \cdot 67$, oxygen $53 \cdot 33=100$. Common in massive forms, either glassy or of various dull colors, and of little luster. The stones and sand-grains of the fields and beaches are mostly quartz. This is 32. due to the fact that nearly all other kinds of common stones are softer and get worn down to earth before quartz. Among massive varieties : flint and chert are dull-lustered, with usually a smoky or blackish color, but varying to yellowish, brownish, and other shades.

I In the figures of crystals $O$ indicates the basal plane; $I, I$, the prismatic faces of the fundamental prism; and $R$, a face of the fundamental rhombohedron in rhombohedral forms. 
Opal. - Tnerystallized silica, a little less hard than quartz and of less density $(G=2 \cdot 3)$, and having usually a greasy or waxy luster. Colors, white to milky gray, red, etc.; when showing internal colored reflections it is the gem, opal. Opal is identical with quartz in composition, yet commonly contains some water; it dissolves more readily in heated alkaline waters. Here belongs the material deposited by the hot waters of geysers, making the geyser basins (sometimes called geyserite); also the siliceous secretions of sponges, and the shells of Radiolarians, and of the minute microscopic plants called Diatoms.

T'Ringuite. - Pure silica of the density of opal, but occurring in minute thin glassy hexagonal crystals, in obsidian and some other volcanic rocks.

\section{Alumina.}

Sapphire or Corcndum. - Composition: $\mathrm{Al}_{2} \mathrm{O}_{3}=$ oxygen $46 \cdot 8$, aluminium $53 \cdot 2=100$. The crystals are the hardest of gems next to the diamond; the blue transparent crystals are sapphire, the red crystals, oriental ruby; and the coarser material when ground makes emery.

\section{Silicates of Aluminium and other Basic Elements.}

The Fecdspars. - The feldspars are next in abundance to quartz. Luster nearly like quartz, but often somewhat pearly on smooth faces. $\mathrm{H}=6 \frac{1}{2}-7$, or very nearly as hard as quartz. Specific gravity $2 \cdot 4-2 \cdot 6$. In general white or flesh-colored; rarely greenish or brownish. Crystals stout, never acicular. Differs from quartz in having a perfect cleavage in one direction, yielding under the hammer a smooth lustrous surface, and in another, nearly as perfect a cleavage surface, the two inclined $84^{\circ}$ to $90^{\circ}$ to one another; also in being more or less fusible before the blow-pipe. Composition: Silica and alumina with either potash, soda, or lime, or two or all of these combined. Contains, unless impure, no iron or magnesia.

The group of feldspars includes several species differing in the proportion of silica

34.35 .36 . 35

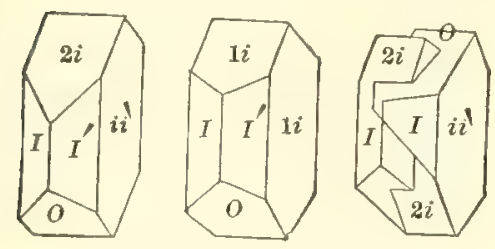

(the acid) to the other ingredients (bases), and in the particular alkali (potash, soda, or lime) predominant, but they graduate to some extent into one another. The kinds are as follows :-

Orthoclase, or potash-feldspar, is the most common. The cleavage surfaces make a right angle with one another, whence the name, signifying cleaving at a right angle; the form is monoclinic. Figs. $34,35,36$, represent crystals of this species, the last a twin crystal; cleavage takes place parallel to the faces $O$ and $i$. Composition: Silica $64 \cdot 7$, alumina $18 \cdot 4$, potash $16 \cdot 9=100$.

The other kinds are triclinic in crystallization, and the cleavages make an oblique angle with one another, of $84^{\circ}-89^{\circ} 44^{\prime}$, and hence they are sometimes called plagioclase, from the Greek plagios, oblique.

Microcline. - Like orthoclase in composition; but the cleavage angle differs $16^{\prime}$ from $90^{\circ}$. The chief distinctions are optical.

Albite. - A soda feldspar, named from the Latin albus, white. When albite and orthoclase occur together, albite is usually the whiter. Composition : Silica $68 \cdot 6$, alumina $19 \cdot 6$, soda $11 \cdot 8=100$. A little more fusible than orthoclase.

Oligoclase. - A soda-lime feldspar. Composition : Silica $61 \cdot 9$, alumina $24 \cdot 1$, lime $5 \cdot 2$, soda $8 \cdot 8=100$. Fuses like albite.

Labradorite. - A lime-soda feldspar. Composition: Silica 52:9, alumina $30 \cdot 3$, lime 12:3, soda $4 \cdot 5=100$. Fuses easily, named from Labrador. Andesite is a species between oligoclase and labradorite in composition, named from the Andes.

Anorthite. - A lime feldspar. Composition: Silica $43 \cdot 1$, alumina $36 \cdot 8$, lime $20 \cdot 1=100$. 
Fuses with much difficulty. The first four of the above species contain over 60 per cent of silica, and hence are called acidic feldspars, while labradorite and anorthite are called basic feldspars.

The following are a few other related silicates containing potash, soda, or lime: -

LEUCITE. - In white to gray trapezohedrons, like those of garnet (Fig. 44, page 66). Occurs in some lavas, as those of Vesuvius. Composition: Silica $55 \cdot 0$, alumina $23 \cdot 5$, potash $21 \cdot 5=100$. Infusible.

NePhelite. - In hexagonal prisms and massive; luster of the massive, greasy, hence the name elcoolite from the Greek elaion, oil. Composition: Silica $44 \cdot 0$, alumina $38 \cdot 2$, soda $15^{\circ} 1$, potash $7 \cdot 7=100$. Fuses easily. Treated with hot hydrochloric acid forms a jelly.

SCAPOLITES. - In square prisms with square pyramidal terminations. Fuses easily. Several species are here included. Wernerite has the composition: Silica $48 \cdot 4$, alumina $28 \cdot 5$, lime $18 \cdot 1$, soda $5 \cdot 0=100$. Meionite is a lime-scapolite.

Sadssurite. - A compact whitish uncrystalline mineral into which crystals of labradorite and anorthite are sometimes changed. Contains soda and has nearly the composition of labradorite. Has a higher specific gravity than the feldspars, $2 \cdot 9-3 \cdot 5$.

37.

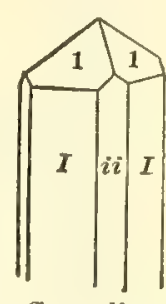

Scapolite.

The Mica Grodp. - The micas are cleavable into thin elastic leaves. Often used, when transparent, in the doors of stoves and lanterns. Occurs colorless to brown, green, reddish, and black; and either in small scales disseminated through rocks - as in granite - or in plates a yard in diameter. Contains silica, alumina, and much potash or soda, like a feldspar, but besides these, in most species, magnesia and iron, which do not exist in any feldspars. Fluorine is sometimes present. Some varieties resemble crystallized talc and chlorite, from which they differ in being elastic. But hydrous micas are generally inelastic, and have also the greasy feel of talc. The more common species of mica are :-

Muscovite (Muscovy glass of early mineralogy). - Light colored to brownish, and usually transparent in thin leaves. One variety afforded silica $46 \cdot 3$, alumina $36 \cdot 8$, iron sesquioxide $4 \cdot 5$, potash $9 \cdot 2$, fluorine $0 \cdot 7$, water $1 \cdot 8=99 \cdot 3$. Three to five per cent of water are often present; and when 4 to 5 per cent, it is called hydromica (or hydrous mica). Sericite and damourite are kinds of hydromica.

Biotite. - Color, usually black, rarely white. One analysis afforded silica 40.0, alumina $17 \cdot 28$, iron sesquioxide $0 \cdot 72$, iron protoxide $4 \cdot 88$, magnesia $23 \cdot 91$, potash $8 \cdot 57$, soda $1 \cdot 47$, water $1 \cdot 37$, fluorine $1 \cdot 57=99 \cdot 77$. Another black mica, lepidomelane, contains 20 to 30 per cent of iron oxides.

Phlogopite. - A brown mica occurring in crystalline limestone in northern New York.

The following are other aluminium silicates often disseminated through crystalline schists or slates :-

38.

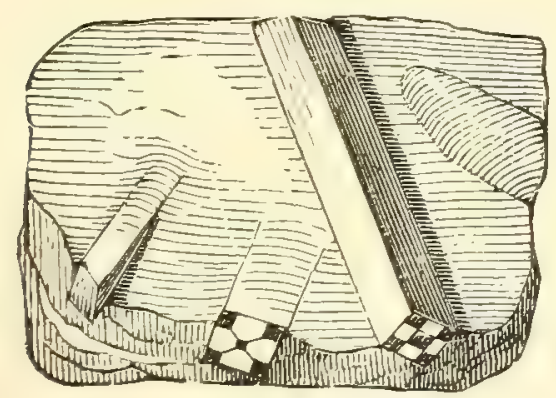

Andalusite, var. Chiastolite.
39.

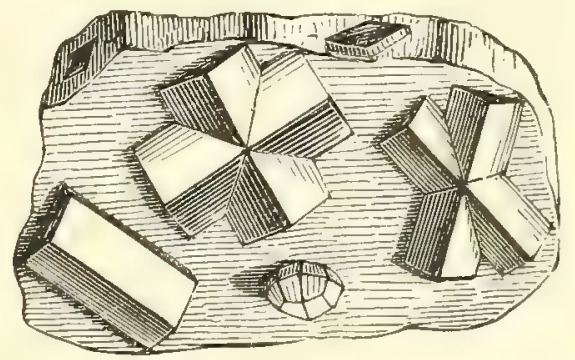

Staurolite.

Andalusite, Cyanite (spelt also Kyanite), Fibrolite, are alike in composition, con. sisting simply of silica 36.9 and alumina $63 \cdot 1=100$. They occur in oblong prisms, often DANA'S MANUAL - 5 
slender. Have $\mathrm{H}=6-7$. Are infusible. Andalusite occurs in gray, stoutish, neariy square, prisms $\left(90^{\circ} 48^{\prime}\right)$ which are often tesselated insile with white (then called chicstolite). Cyanite is commonly in long, bluish, bladed crystals; and fibrolite in rhombic prisms and fibers, having a brilliant diagonal cleavage.

Staurolite. - In rhombic prisms of $129^{\circ} 20^{\prime}$, imbedded in slaty rocks. Lsual colors, brown to black. The crystals are often crossed as in Fig. 39, and hence the name, from the Greek for cross. $\mathrm{H}=7-7 \frac{1}{2}$. Composition: Silica $29 \cdot 3$, alumina $5 \cdot 3 \cdot \overline{5}$, sesquioxide of iron $17 \cdot 2=100$. Infusible.

Tourmaixe. - Usually in three-sided or six-sided black crystals, having the luster within, when black, like that of a black resin; and it has no distinct cleavage, and thus differs from hornblende. Figs. 40, 41 show two of the forms; and Fig. 42, the appear-

40.

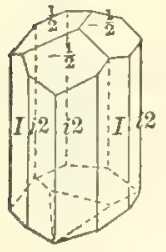

Tourmaline.
41.

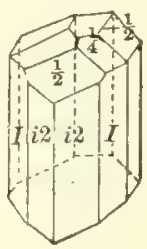

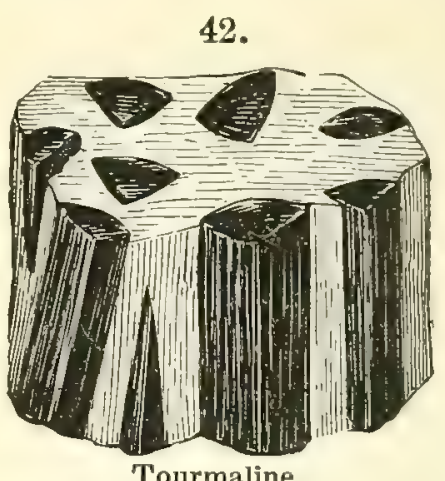

ance of the crystals in the rock, which is often quartz. Besides black, there are also brown, green, red, and white tourmalines. $\mathrm{H}=7-7 \frac{1}{2}$. Constituents: Silica, alumina, magnesia, with fluorine and some boracic acid. Fusible, but fusibility varying much in varieties.

GARNET. - In crystals of the forms in Figs. 43, 44. $H=6 \frac{1}{2}-7 \frac{1}{2}$. Colors usually red to brown and black, rarely green and colorless; sometimes chrome-green. $\mathrm{H}=6-7$. Consists of silica and alumina, with either iron, or lime, or manganese, and varying in its characters according to composition.

43.

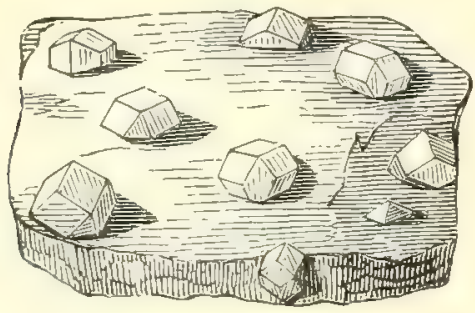

44.

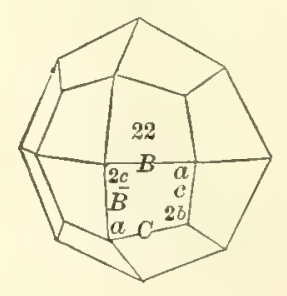

Epidote. - In yellowish green to hair-brown prismatic crystals and masses. A peculiar yellowish green color is most common. It has nearly the composition of an iron garnet. $\mathrm{G}=3 \cdot 25-3 \cdot 5$. Zoisite is a related mineral of ash-gray to whitish color, containing much lime and little or no iron. It has high specific gravity, $G=3 \cdot 1-3 \cdot 4$. Constituents as in

45.

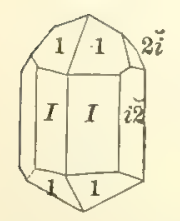

Topaz.

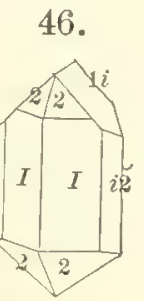

IDOCrase. - In square prisms, of a brown to oil-green color. $\mathrm{H}=6 \frac{1}{2}$. Composition: One kind, silica $37 \cdot 3$, alumina $16 \cdot 1$, iron sesquioxide $3 \cdot 7$, lime $35 \cdot 4$, magnesia $2 \cdot 1$, iron protoxide $2 \cdot 9$, water $2 \cdot 1=99 \cdot 6$. Fusible.

Topaz. - In rhombic prisms of $124^{\circ} 17^{\prime}$, remarkable for cleaving with ease and brilliancy parallel to the base of the prism. Colors, yellowish to white, also brown. Two of the forms of its crystals are shown in Figs. 45, 46. $\mathrm{H}=8$. Consists of silica $16 \cdot 2$, silicon fluoride $28 \cdot 1$, alumina $55 \cdot 7=100$. The amount of fluorine present is a remarkable quality. Infusible. 
Zircon, Berrl, Titanite (Sphene) are other anhydrous silicates. Zircon is a silicate of zirconia; beryl (aquamarine when pale green and transparent), a silicate of alumina and beryllia; titanite or sphene, a silicate of calcium and titanium.

\section{Silicates of Magnesium and Iron or Calcium, with Little or no Alumina and no Water.}

Chrysolite. - Occurs in green glassy grains or crystals in basalt and related rocks, and also paler green in rock masses. Also called olivine, and in France peridot. H $=6-7$. Infusible. Composition of a common variety: Silica 41.4 , magnesia 50.9, iron protoxide $7 \cdot 7=100$. A related mineral, fayalite, contains iron without magnesium, and is fusible. The crystals often occur changed, partly or wholly, to serpentine.

Choxdrodite. - A yellow to brown magnesium silicate, containing fluorine, occurring in crystalline limestones. A kind found in ejected masses of limestone at Vesuvius is called humite.

Hornblende (often called amphibole). - Occurs in prisms of $124^{\circ} 30^{\prime}$ (which is also the cleavage angle). Colors various, from black to green and white. The most common kind in rocks is an irou-bearing variety, in black cleavable grains or in oblong black prisms. Figs. 47, 48, and 49 represent common crystals, and 50 tufts of crystals as they often appear in some rocks. The kind in slender green crystals or fibers is called actinolite - a common form of its crystals is shown in Fig. 49 ; the white (a kind common in erystalline limestones, and containing much lime), tremolite. The mineral

47.

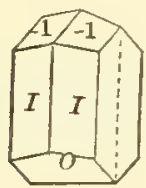

49.

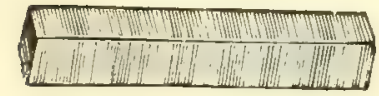

48.

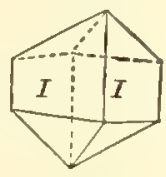

50.

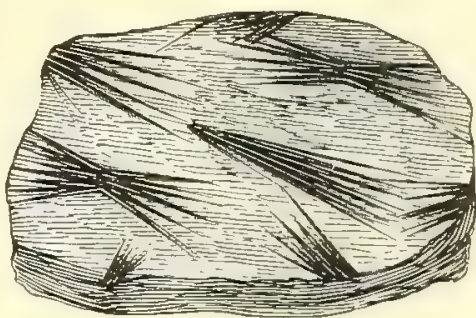

is common in fibrous masses; and, when the fibers are as fine as flax, it is called asbestos. A common black hornblende consists of silica $48 \cdot 8$, alumina $7 \cdot 5$, magnesia $13 \cdot 6$, lime $10 \cdot 2$, iron protoxide $18 \cdot 8$, manganese protoxide, $1 \cdot 1=100$.

Prroxene (including augite). - Like hornblende in chemical composition and in most of its characters; but the crystals, as in the annexed figures, 51, 52, instead of

51.

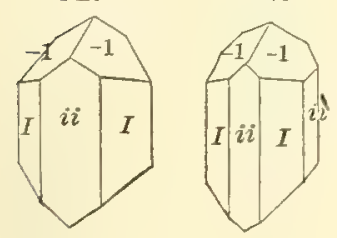
being prisms of $124^{\circ} 30^{\prime}$, are prisms of $87^{\circ} 5^{\prime}$ or nearly (angle $I$ on $I$ ), and are often eight-sided from the truncation of the four edges, as in Fig. 52. Pyroxene and homblende are hence paramorphs, being different in crystallization, but alike in composition. Black and dark green pyroxene in short crystals is called augite; it is an iron-bearing kind, and is common in igneous rocks.

Enstatite. - Near pyroxene in cleavage angle, but prisms orthorhombic. Infusible or nearly so. It is in part a silicate of magnesium. When a silicate of magnesium and iron, it is often called bronzite; and, if containing much iron, hypersthene.

\section{Silicates of Magnesium, etc., with Water.}

TALC. - Very soft, $\mathrm{H}=1$. Crystallizes in flexible folia like mica, but inelastic; also massive-granular (soapstone or steatite); white and very fine-grained (French chalk). Feels very greasy. Consists of silica $62 \cdot 8$, magnesia $33 \cdot 5$, water $3 \cdot 7=100$. Infusible. 
Serpextine. - Oil-green to blackish and yellowish green to greenish white; massive or fibrous; often having the crystalline form of another mineral. II=:3 f feels somewhat greasy. Consists of silica $43 \cdot 48$, magnesia $43 \cdot 48$, water $13 \cdot 04=100$. Hixed with limestone it is verd-antique marble.

The Chlonte Grour. - Like green mica when crystallized, but inelastic; usually granular-massive; of a dark green color, and greasy feel. Silica from 25 to 35 per cent in the different species; the other ingredients are alumina, magnesia, iron, etc., with 12 to 14 per cent of water.

\section{Silicates of Alumina Containing Water.}

Kaolinite. - Pure white clay, derived usually from the decomposition of orthoclase - the silica, alumina, and potash of the orthoclase changing to a compound of silica, alumina, and water, by the loss of potash and gain of water in its place. Consists of silica $46 \cdot 4$, alumina $39 \cdot 7$, water $13 \cdot 9=100$.

Besides the hydrous micas, there are the common species:-

Pinite or Afalmatolite. - A compact mineral, soapy to the touch, often resembling a compact soapstone. Like serpentine and massive pyrophyllite, it is often cut into images in China. Consists of silica, alumina, potash, and water.

Prrophyldite. - A mineral resembling talc in color, cleavage, and soapy feel when crystallized, and like some fine-grained soapstone when massive. Consists of silica, alumina, and water. It differs from tale in containing alumina in place of magnesia.

GLAUCONIte or GreEN EARTh. - The material of the New Jersey marl, or Green sand of the Cretaceous and other rocks. It is a soft, dark or light green silicate of alumina, iron, and potash, with water.

ZEoLITES. - Stilbite, chabazite, analcite, natrolite, prehnite, are some of the zeolites (a word derived from the Greek for to boit, the species fusing easily with intumescence), They are hydrous species, consisting of silica, alumina, lime or soda, and water. Laumontite is another related hydrous silicate. They are common minerals in the cavities of amygdaloid and some other rocks. Pectolite is a hydrous silicate of lime, found in fibrous forms, under similar circumstances.

\section{Carbonates.}

CALCITE (or calcium carbonate), often called carbonate of lime. It is the material of common limestones. $H=3$, it being easily seratehed; and $G=2 \cdot 715$, when pure. Composition: $\mathrm{CaO}_{3} \mathrm{C}=$ Carbonic acid $44 \cdot 0$, lime $56^{\circ} \cdot 0=100$. When dropped in powder into

53.

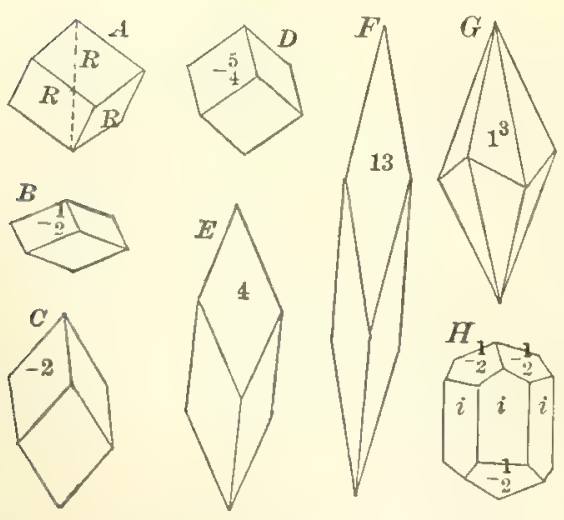

hydrochloric acid diluted with one half water, it effervesces strongly, giving off carbonic acid. The annexed are some of the forms it presents when crystallized. It cleaves alike in three directions, making the angle $105^{\circ} 5^{\prime}$ with one another $(=R$ on $R$ in Fig. $53 \mathrm{~A}$ ); the form, Fig. $53 \mathrm{~A}$, is called a rhombohedron. When crystallized, calcite is often transparent and colorless. But the mineral occurs of various colors from white to black, and the massive kinds from translucent to opaque. All the common marbles are limestones, either of this mineral species or the following, or mixtures of the two.

Dolomite (or calcium-magnesium carbonate). Resembles calcite so closely that the two cannot often be distinguished except by chemical means. It constitutes many limestone strata, both massive and crystalline. When dropped in powder into cold dilute muriatic acid, it effervesces very feebly; but on heating, a brisk effervescence is produced. Cleavage angle 
$106^{\circ} 15^{\prime}$, and this, with crystallized specimens, is an important means of distinction. Composition: Carbonate of lime $54 \cdot 4$, carbonate of magnesia $45 \cdot 6=100$. Formula, $\left(\frac{1}{2} \mathrm{Ca} \frac{1}{2} \mathrm{Mg}\right) \mathrm{O}_{3} \mathrm{C}$.

Siderite (iron carbonate). - A valuable ore of iron, sometimes called steel ore. Crystallizes and cleaves like the preceding, but much heavier. $G=3 \cdot 7-3 \cdot 9$. Color white to gray, but becoming brown on exposure to the air because the iron oxidizes easily and changes to limonite. Cleavage angle $107^{\circ}$. Occurs also massive, gray to brown, with feeble luster. Formula, $\mathrm{FeO}_{3} \mathrm{C}\left(=\mathrm{FeO}+\mathrm{CO}_{2}\right)$.

Aragonite. - Like calcite in composition, but occurring in prismatic form, without the cleavages of calcite. Calcite and aragonite are hence paramorphs. $\mathrm{G}=2 \cdot 9-2 \cdot 94$, which is above that of calcite. Shells, while consisting generally of calcium carbonate, often have a large part of the material in the aragonite state; and hence aragonite is present through most uncrystalline limestones.

\section{Sulphates.}

Grpsum (or hydrous calcium sulphate). - Very soft. $H=1$. One of the few minerals that may be easily impressed with the teeth without producing a grating sensation. Often massive and fine granular. Colors from white to black; the white is common alabaster.

54.

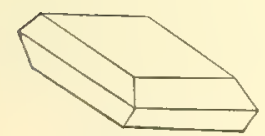

55.

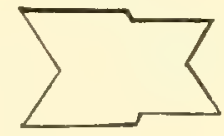

Also occurs in crystals, with pearly luster on a cleavage surface. Figs. 54, 55 give two of the forms of the crystals. It cleaves in broad pearly plates or folia, which look like mica, but are softer, and not elastic. Unlike limestone and other minerals, a little heat reduces it to powder, making the common plaster of

Paris of the shops. It consists of sulphuric acid $46 \cdot 51$, lime $32 \cdot 56$, water $20 \cdot 93=100$. Formula, $\mathrm{CaO}_{4} \mathrm{~S}+2 \mathrm{aq}\left(=\mathrm{CaO} \cdot \mathrm{SO}_{3} 2 \mathrm{aq}\right)$.

Axнy Drite (calcium sulphate, without water). - White and grayish, reddish. $\mathrm{H}=3-3 \frac{1}{2}$. Cleavage affords rectangular blocks or plates. It differs from gypsum also in affording no water when heated.

BARITE (or heavy spar, barium sulphate, also called barytes). - Occurs in tabular crystals, some of the forms of which are given in Fig. 56. It is remarkable for its high specific gravity $(\mathrm{G}=4 \cdot 3-4 \cdot 7)$, whence the name, from the Greek for weight. It contains sulphuric acid $34 \cdot 3$, baryta $65 \cdot 7=100$. Formula, $\mathrm{BaO}_{4} \mathrm{~S}$ $\left(=\mathrm{BaO}+\mathrm{SO}_{3}\right) . \quad$ It is ground up and used for adulterating white lead paint. It is common as a gangue of different ores.

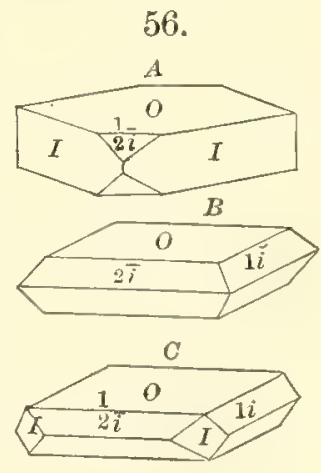

\section{Phosphates, Fluorides.}

Apatite (calcium phosphate). - Occurs in six-sided prisms of a greenish to bluish color, often looking like beryl (and this deceptive appearance led to the name from the Greek, signifying to deceive), but easily distinguished from beryl by its inferior hardness, as it may be scratched with a knife. Composition: Phosphoric acid 40.92, lime 53.80, chlorine $6 \cdot 82=101 \cdot 54$, for a chlorine-bearing variety. Another kind contains fluorine instead of chlorine. Much used for making a fertilizer.

Fldorite (fluor spar, calcium fluoride). - Crystallizes in cubes, octahedrons, and other related forms, which cleave easily in four directions, parallel to the faces of the regular octahedron, the faces of cleavage making angles with one another of $109^{\circ} 28^{\prime}$. Often granular-massive. Easily scratched with a file. Colors, clear purple, yellow, blue, often white, and of other shades. Massive varieties are worked into vases, etc., which have much beauty. When powdered and thrown on a shovel heated nearly to redness, it phosphoresces brightly. Composition : Fluorine $48 \cdot 7$, calcium $51 \cdot 3=100$. 


\section{Sulphides, or Minerals Containing Sulphur.}

Prrite. - Color pale yellow, brass-like, much less yellow than chalcopyrite. Hardness 7, or sufficient to strike fire with steel, whence the name, from the Greek for fire. Occurs often in cubes like Fig. 57. The striæ of the adjoining surfaces, when any are present, are at right angles with one another. Also in other related

57. forms. Frequently very brilliant, but also dull, and sometimes brown from a coating of limonite. Composition: Sulphur $53 \cdot 3$, iron $46 \cdot 7=100$; formula, $\mathrm{FeS}_{2}$. Common in all rocks, in small disseminated crystals; often in veins, and as the gangue of other ores. It is the "gay deceiver" of the mineral world, being often mistaken for silver ores (which are never yellow) and for gold (which is never brittle or hard), or for chalcopyrite or copper pyrites (which is easily scratched, and has an olive-green powder). Often contains gold invisibly disseminated, and is worked for its gold; not good for making iron, but by oxidation converted into vitriol (iron sulphate), and used for this purpose and for making sulphuric acid.

MARCAsite. - Like pyrite in composition $\left(\mathrm{FeS}_{2}\right)$ and hardness, but color paler and crystals prismatic. Pyrite and marcasite are paramorphs.

Prrkhotire, - Iron sulphide, containing sulphur 39.5 , iron $60.5=100$; formula, $\mathrm{Fe}_{7} \mathrm{~S}_{8}$, the atomic ratio being nearly 1 to 1 . Differs from pyrite in having a bronze-yellow color, in being easily scratched $\left(\mathrm{H}=3 \frac{1}{2}\right.$ to $\left.4 \frac{1}{2}\right)$, and in crystallization. Used for the same purposes as pyrite. Often contains nickel, and is then worked for this metal.

Arsenopy Rite. - Silver-white, brittle, $\mathrm{H}=5 \cdot 5-6$, much above that of silver ores. Contains, with iron, arsenic as well as sulphur ; formula, FeAsS. Valuable for its arsenic, and sometimes contains cobalt and gold.

Chalcopyrite (copper pyrites). - Gold-yellow, brittle (in this unlike gold) ; powder olive-green. A valuable ore of copper, consisting of sulphur $34 \cdot 9$, copper $34 \cdot 6$, iron $30 \cdot 5=100$.

GALENA. - Lead sulphide, of light steel-gray color, brittle. Usually breaks into cubes under the hammer, unless fine granular-massive; $H=2 \cdot 5$. The common ore of lead. Contains sulphur $13 \cdot 4$, lead $86 \cdot 6=100$; formula, $\mathrm{PbS}$.

Sphalerite (Blende). - Zine sulphide. Luster not metallic, but resinous, and the powder nearly white. Colors yellow and brown, looking much like resin, also black, rarely white. Composition: Sulphur 33, zine $67=100$; formula, ZnS. A common and valuable ore of zinc.

\section{Oxides.}

Hematite. - Ofton called specular iron ore, because the crystals are brilliant; a steel-gray ore of iron, but also of a deep red color when earthy. Consists of oxygen 30, iron $70=100$; formula, $\mathrm{Fe}_{2} \mathrm{O}_{3}$. Crystals rhombohedral. Powder red, and hence the name (given by the Greeks), from the Greek for blood. H of crystals 6. The red ore is red ocher (common red paint and red chalk), and a hard, massive, impure kind is a variety of clay-ironstone. A valuable but hard iron ore, Menaccanite (Ilmenite, or titanic iron) is a related ore containing much titanium and having a black powder.

MAGNetTE. - Called magnetic iron, because easily taken up with a magnet, unlike other iron ores. Color blackish iron-gray, looking much like hematite, from which it differs in its black powder, and in crystallizing in octahedrons and related forms ; $\mathbf{H}=6$. Composition: Oxygen $27 \cdot 6$, iron $72 \cdot 4=100$; formula, $\mathrm{Fe}_{3} \mathrm{O}_{4}$. Occurs in great beds like the last, and also common in disseminated crystals; often a black iron sand on sea-beaches. A valuable ore of iron. Franklinite is a similar ore (from Sussex Co., N.J.), containing nearly 7 per cent of zinc oxide with nearly 10 of manganese protoxide; valuable for its zinc, as well as its iron. 
Limonite. - A brown, brownish black to ochre-yellow iron ore, consisting of iron in the same state of oxidation as hematite, but combined with water: it is hence equivalent to hematite plus water, $\mathrm{Fe}_{2} \mathrm{O}_{3}+1 \frac{1}{2} \mathrm{H}_{2} \mathrm{O}=$ iron sesquioxide $85 \cdot 6$, water $14 \cdot 4=100$. Contains when pure 59.9 per cent of iron. Its powder is brownish yellow - a distinguishing character. The earthy yellow variety is the common paint, yellow ocher. In the larger deposits this ore is a secondary product; that is, was made from the oxidation of ironbearing minerals in the rocks about the deposits. So named from the Greek for marsh, because a common ore in marshes, marshes being the earth's smaller pockets, catching what iron is decomposed out of the rocks of the surrounding hills and washed in by the waters. The marsh ore is often contaminated with phosphates from organic deposition, and therefore the iron it yields is usually fit only for castings. The larger deposits, not of marsh origin, are commonly pure, or nearly so, from phosphates and sulphur; but they may contain sulphur when the ore has been made from pyrite. When free from sulphur it is a very valuable ore, easily worked. Great beds occur in Salisbury, Conn., Berkshire County., Mass., Amenia and elsewhere in eastern New York, in eastern Pennsylvania, and farther southwest, and in many other states.

Manganite, Psilonelane, Pelagite. - Both hydrous and anhydrous oxides of manganese exist. Manganite is a hydrous sesquioxide, like limonite (under iron); and psilomelane is a massive, impure ore of related character. The color is iron-black and the powder black. Over the sea-bottom concretions of impure hydrous manganese oxide occur, which have been named pelagite. An analysis gave 40 per cent of this oxide to 27 of iron sesquioxide, with 13 per cent of water, 14 of silica, and 40 of alumina. The manganese is supposed to come from the pyroxene of volcanic ashes.

WATER. - Water is hydrogen oxide, $\mathrm{H}_{2} \mathrm{O}=$ Oxygen 88.89, hydrogen $11 \cdot 11=100$. But it is never pure, because of its solvent powers. See beyond, page 118.

\section{Organic Contributions to the Material of Rocks.}

The materials of most rocks are of mineral origin. The rocks have been produced by fusion, or out of the gravel, sand, or clay, made through the wear and decay of preëxisting rocks; and as the constituents drawn upon were mineral, the rocks thus derived are of mineral origin. These are the most common of rocks.

But besides the material from a mineral source, large contributions toward rock-making have come from the organic kingdoms, especially from those divisions of it that produce hard, stony secretions. Shells and corals are examples of these secretions. Animals secreted them for protection, support, or some other purpose; but they were good material for rock-making, and through the geological ages, when the death of animals has set them free, they have been converted into limestones. Plants are the source of coal-beds. Their stems, leaves, tissues, have become gathered in favorable places into beds, like a peat-bed, and after long burial have been converted into coal. Further, some kinds of animal and vegetable life secrete silica, material for siliceous accumulations.

Organic materials may occur not only in deposits that are purely of organic origin, but also mixed with material of mineral origin, that is, with sand, clay, gravel, and the like, in various proportions; and sometimes a few organic relics are all the materials of an organic source that can be distinguished. The organic relics preserved in any rock are called fossils (from 
the Latin for $d u g u p$ ), and a bed of rock containing fossils is described as fossiliferous.

The following are the chief sources of materials of organic origin :-

Calcareous, or the material of limestones. - The most important animal sources are shells of Mollusks, Corals, Crinoids, Foraminifers or the shells of ordinary Rhizopods. The sources under the vegetable kingdom are Corallines of calcareous or semi-calcareous nature, Confervoid and other Algæ, some of which, as the Nullipores, have coral-like forms, while other's are minute and disk-shaped, as the Coccospheres or Coccoliths.

The following are analyses: 1 and 2, Corals, Madrepora palmata and Oculina arbuscula, by S. P. Sharples; 3, shell of a Terebratula, by the same; 4, shell of an oyster :-

1.

Madrepora

Calcium carbonate............. 97:17

Calcium phosphate............. 0.78

Calcium sulphate............. -

Magnesium carbonate........... -

Water and organic matters..... $2 \cdot 81$
2.

Oculina.

$95 \cdot 37$

0.84

$-$

379
3.

Terebratula. Oyster-shell. $98 \cdot 39$

$0 \cdot 61$

-

0.3

$1 \cdot 00 \quad 3 \cdot 9$

In a Millepore (?) Coral Damour found 8.51 per cent of magnesium carbonate in one species, and little in others. Forchhammer obtained 6.36 per cent of magnesium carbonate from the Coral, Isis nobilis, and $2 \cdot 1$ per cent in the precious Coral of the Mediterranean, Corallium nobile. Of the Charce, among plants, Ch. fotida affords $31 \cdot 33$ per cent of ash, $95 \cdot 35$ per cent of which is calcium carbonate.

Siliceous. - The animals that secrete silica are, in the main, (1) the Sponges, and (2) the Radiolarians, a radiate section of the Rhizopods; and the vegetables are chiefly the minute Diatoms and other algoid species.

Sponges usually consist largely of fine horny fibers. Those used for household purposes are an exception, and are selected for this use because free from such fibers, and therefore pliant and strong. The silica, when present, is in spicules, bristling with horny fibers, easily detected with a good pocket lens. In some species they are so abundant as to make a net-work of silica, as in the pure "glass-sponge," free from all horny fiber. See page 57 for a figure of one of the species.

Phosphatic. - The chief sources among animal materials are bones, teeth, epidermis, and other tissues, excrements, and the shells of Lingulce, Discino, Obolus, Pleropods, etc.; the outer integuments or shell of Crustaceans, Insects, etc.; and those of a vegetable source are the stems, leaves, and fruit of plants, especially the edible grains. The phosphoric acid is usually present in combination with lime as calcium phosphate.

Guano comes mostly from islands or coasts that have been for a long time without human residents, and where birds have had undisturbed possession. It is made chiefly of the excrements of birds (sometimes of bats), and owes its value as a fertilizer to its nitrogen and salts of phosphoric acid. But water, from the rains, percolating through it carries down the soluble phosphates into the underlying material, and if this is coral rock or other loose 
calcareous deposit, the solution converts the calcareous rock into calcium phosphate, which goes also by the name of guano. Isolated excrements in rocks are called coprolites.

Analyses of bones: 1, 2, human bones, according to Frerichs; 3, fish (Haddock), according to Duménil ; 4, Shark (Squalus cornubicus), according to Marchand; 5, fossit bear, id. : -

1.

\begin{tabular}{|c|c|c|c|c|}
\hline Calcium phosphate.... . & $50 \cdot 24$ & $59 \cdot 50$ & $55 \cdot 26$ & $32 \cdot 46$ \\
\hline Calcium carbonate.............. & $11 \cdot 70$ & $9 \cdot 46$ & $6 \cdot 16\}$ & \\
\hline Calcium sulphate .............. & - & - & $-\}$ & 4.44 \\
\hline Organic substance $\ldots . . . \ldots \ldots \ldots$ & $38 \cdot 22$ & $30 \cdot 94$ & $37 \cdot 63$ & $58 \cdot 07$ \\
\hline Traces of soda, etc......... & - & - & $1 \cdot 22$ & $3 \cdot 80$ \\
\hline alcium fluoride............... & - & - & - & $1 \cdot 20$ \\
\hline Iagnesium phosphate ............ & - & - & - & $1 \cdot 03$ \\
\hline
\end{tabular}

In No. 4 , a little silica and alumina are included with the fluoride. No. 5 contains also silica $2 \cdot 12$, and oxides of iron and maganese, etc., $3 \cdot 46$.

The enamel of teeth contains 85 to 90 per cent of calcium phosphate, 2 to 5 of calcium carbonate, and 5 to 10 of organic matters. Fish-scales from a Lepidosteus afforded Frémy 40 per cent of organic substance, $51 \cdot 8$ of phosphate of lime, $7 \cdot 6$ of magnesium phosphate, and 4.0 of calcium carbonate. Other fish-scales contained but a trace of the magnesium phosphate and more of organic matters.

T. S. Hunt obtained for the composition of the shell of Lingula ovalis, Calcium phosphate $85 \cdot 79$, calcium carbonate $11 \cdot 75$, magnesium phosphate $2 \cdot 80=100 \cdot 34$. The shells of a fossil Obolus afforded Kupffer the composition nearly of a fluor-apatite (Amer. Jour. Sci., III. vi. 146); and the phosphatic shells are thin, somewhat horny in appearance, and usually become black on fossilization.

The shell of a Lobster (Palinurus) afforded Frémy, calcium carbonate $49 \cdot 0$, calcium phosphate $6 \cdot 7$, organic substance $44 \cdot 3$.

Phosphatic nodules, possibly coprolitic, in the Lower Silurian rocks of Canada (on River Ouelle), afforded T. S. Hunt (see Amer. Jour. Sci., II. xv. and xvii.), in one case, calcium phosphate $40 \cdot 34$, calcium carbonate with fluoride $5 \cdot 14$, magnesium carbonate $9 \cdot 70$, iron peroxide with a little alumina $12 \cdot 62$, sand $25 \cdot 44$, moisture $2 \cdot 13=95 \cdot 37$. In a hollow cylindrical body from the same region, there were 67.53 per cent of phosphate.

Analyses of coprolites. - Nos. 1 and 2 by Gregory and Walker; 3 and 4 by Connell; 5 by Quadrat; 6 by Rochleder (a coprolite from the Permian) :-

\begin{tabular}{|c|c|c|c|c|c|c|}
\hline & $\begin{array}{c}1 . \\
\text { Burdie- } \\
\text { house. }\end{array}$ & $\begin{array}{c}2 . \\
\text { Fife- } \\
\text { shire. }\end{array}$ & $\begin{array}{c}3 . \\
\text { Burdie- } \\
\text { house. }\end{array}$ & $\begin{array}{c}4 . \\
\text { Burdie- } \\
\text { house. }\end{array}$ & $\begin{array}{c}5 . \\
\text { Kosch- } \\
\text { titz. }\end{array}$ & $\begin{array}{c}6 . \\
\text { Oberlan- } \\
\text { genau. }\end{array}$ \\
\hline Calcium phosphate ..... & $9 \cdot 58$ & $63 \cdot 60$ & $85 \cdot 08$ & $83 \cdot 31$ & $50 \cdot 89$ & $15 \cdot 25$ \\
\hline Calcium carbonate ..... & $61 \cdot 00$ & $24 \cdot 25$ & $10 \cdot 78$ & $15 \cdot 11$ & $32 \cdot 22$ & $4 \cdot 57$ \\
\hline Silica ............... & & trace & $0 \cdot 34$ & $0 \cdot 29$ & $0 \cdot 14$ & - \\
\hline Organic material ....... & 4.15 & $3 \cdot 38$ & $3 \cdot 95$ & $1 \cdot 47$ & $7 \cdot 38$ & $74 \cdot 03$ \\
\hline Magnesium carbonate... . & $13 \cdot 57$ & $2 \cdot 89$ & - & - & - & $2 \cdot 75$ \\
\hline Iron sesquioxide........ & $6 \cdot 40$ & trace & - & - & $2 \cdot 08$ & - \\
\hline Alumina .............. & - & - & - & - & $6 \cdot 42$ & 一 \\
\hline 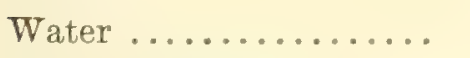 & $5 \cdot 33$ & $3 \cdot 33$ & - & - & - & - \\
\hline Lime of organic part..... & - & - & - & - & - & $1 \cdot 44$ \\
\hline \multirow[t]{2}{*}{ Sodium chloride........ } & - & 一 & - & - & - & $1 \cdot 96$ \\
\hline & $100 \cdot 01$ & $97 \cdot 45$ & $100 \cdot 15$ & $100 \cdot 18$ & $99 \cdot 13$ & $100 \cdot 00$ \\
\hline
\end{tabular}

The ashes of grass, straw, clover, amounting to 5 to 8 per cent of the dried plant, afford usually 5 to 15 per cent of phosphoric acid; and those of the seed in wheat, 
rye, maize, rice. buckwheat (the amount of ash 2 per cent or less) affords 40 to 50 per cent; of leaves of walnut (the ash 7 to 7.72 per cent), 21.1 per cent spring, 4 per cent autumn; of beech (ash 4.8 and 6.75 per cent), 7.8 per cent summer, $4 \cdot 2$ per cent autumn; wood of body of beech (amount of ash in dried 0.65 per cent), 5.3 per cent; of small wood 11.6 per cent, and of brush $12 \cdot 3$ per cent; of pine, fir, larch $(0.3$ per cent of ash), $3 \cdot 6$ to 6 per cent of phosphoric acid.

Carbonaceous. - The carbonaceous material of the rocks has come, as has been stated, from the decomposition of plants and animals, and chiefly the former. Wood contains about 50 per cent of carbon, along with 44 of oxygen and 6 of hydrogen. Peat is woody material altered part way toward coal, and sometimes wholly so in places. Brown coal is coal that has a dark brownish powder. Bituminous coal has a black powder, and burns with a bright flame; anthracite burns with little flame. Each contains some of the oxygen of the original wood, the anthracite the least.

Mineral oil and mineral gas consist of carbon and hydrogen alone, oxygen being wholly absent. They are the source of the flame of bituminous coal; they do not, however, exist in the coal, for when the coal is digested in a solvent of the oil, as benzine, almost no oil is taken up; the oil or gas is produced by the heat from a compound present in the coal. Other carbonaceous substances of similar origin are asphalt, an oxidized hydrocarbon, mineral resins, etc. Moreover, among the mineral resins are one or two which contain sulphur.

Alumina, magnesia, iron, soda, potash, sulphur, etc. - A few of the coalmaking plants, especially the Lycopods, contain much alumina in their ash, and magnesia, iron, potash, soda, exist in many plants. In the decomposition of buried plants, these materials are partly dissolved out and carried away by waters, and partly contributed to rocks. The following are some analyses of the ash of plants:-

Analyses of the ash of Lycopods (1, 2), Ferns (3 to 6), Equiseta (7, 8), Conifer (9), Moss of the genus Sphagnum (10), and an Ilex (11) :-

\begin{tabular}{|c|c|c|c|c|c|c|c|c|c|c|}
\hline & & & & & $\mathrm{Mn}_{3} \mathrm{O}_{4}$ & & & $\mathrm{SO}_{3}$ & $\mathrm{SiO}_{2}$ & \\
\hline 1. Lyc. clavatum . .31·90 & $2 \cdot 68$ & $4 \cdot 13$ & 89 & $6 \cdot 00$ & - & $22 \cdot 20$ & $7 \cdot 30$ & & & \\
\hline ratum . .25̄69 & $1 \cdot 7$ & $7 \cdot 96$ & $6 \cdot 51$ & $2 \cdot 30$ & $2 \cdot 53$ & & $5 \cdot 36$ & & & \\
\hline & & & & & & & $20 \cdot 0$ & & & \\
\hline x.....39.80 & $5 \cdot 31$ & $18 \cdot 74$ & & 0 & & & $2 \cdot 56$ & & & \\
\hline ....23:65 & & & & & 一 & - & & & & \\
\hline & 4 & .5 & 2 & & - & & 15 & & & \\
\hline & & $17 \cdot 2$ & & & - & - & $2 \cdot 79$ & & & \\
\hline .. $8 \cdot 01$ & $0 \cdot 6$ & $8 \cdot 6$ & & & - & - & $1 \cdot 37$ & 2 & & \\
\hline $.12 \cdot 84$ & & $58 \cdot 2$ & & & $t r$ & & $2 \cdot 60$ & & & \\
\hline & & & & & $t r$. & & 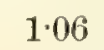 & & $41 \cdot 69$ & \\
\hline . Mex cassine....27·02 & & $10 \cdot 99$ & $16 \cdot 59$ & $0 \cdot 26$ & $1 \cdot 73$ & & $3 \cdot 34$ & $2 \cdot 50$ & $1 \cdot 32$ & \\
\hline
\end{tabular}

Analysis 1 is by Ritthausen; 2, Aderholt; 3, A. Weinhold; 4, Struckmann; 5, 6, 9, Malaguti \& Durocher; 7, 8, E. Wittig ; 10, H. Vohl ; 11, F. P. Venable.

In the analyses that have been made of Lycopods, the amount of ash is $3 \cdot 2$ to 6 per cent in weight of the dried plant; of Ferns, 2.75 to 7.56 per cent; of Equisetum arvense, 
18.71 per cent; of Eq. Telmateia, 26.75 per cent; of Conifers, mostly less than 2 per cent; of Fungi, $3 \cdot 10$ to $9 \cdot 5$ per cent ; of Lichens, $1 \cdot 14$ to 17 per cent (the last in Cladonia), but mostly between $1 \cdot 14$ and $4 \cdot 30$ per cent. In Lycopodium dendroideum, Hawes, in his analyses (p. 362), found $3 \cdot 25$ per cent of ash; in $L$. complanatum, $5 \cdot 47$ per cent, and in Equisetum hyemale, $11 \cdot 82$ per cent.

Lycopodium chamocyparissus afforded Aderholt 51.85 per cent of alumina; or, when without spores, $57 \cdot 36$ per cent; while Ritthausen obtained 39.97 alumina for this species, and 37.87 for L. complanatum. In Lycopods the silica constitutes 10 to 14 per cent of the ash. In the ash of Mosses have been found 8 to $23 \cdot 58$ per cent of potash, 4 to 16 of silica, 1.06 to 6.56 of phosphoric acid, 4.9 to 10.7 of magnesia. Among Ferns, the amount of ash, so far as determined, varies from 5 to 8 per cent.

The ash of Fungi affords 21 to 54 per cent of potash, 0.36 to 11.8 of soda, 1.27 to 8 of magnesia, 15 to 60 of phosphoric acid, and 0 to $\mathbf{1 5 . 4}$ of silica. Among Lichens, the ash of Cladonia rangiferina contains 70.34 per cent of silica; of other species, less, down to 0.9 per cent.

Trapa natans, of bogs, in Europe, affords 13 to 25 per cent of ash ; and 25 per cent of this is oxide of iron $\left(\mathrm{Fe}_{2} \mathrm{O}_{3}\right)$ with a little oxide of manganese. Of the ash of the fruit scales, over 60 per cent is oxide of iron. The Ilex cassine of North Carolina (the leaves of which produced the Black Drink of the Indians) afforded, from leaves collected in May and dried, 5.75 per cent of ash, which is remarkable (No. 11, above) for the amount of potash and magnesia. Another Holly afforded 11.39 of magnesia, and 12.34 of lime.

Ash of bean straw ( 6 to 7 per cent of dried) affords 35 to 45 per cent of potash; of buckwheat straw $(6 \cdot 15$ per cent $), 46 \cdot 6$ of potash ; of oat straw ( $5 \cdot 1$ per cent), 22 per cent of potash.

Soda is a prominent constituent in the ash of Sea-weeds (Fuci), analysis giving 14.39 per cent of ash, and in this, 24 of soda, with 14.5 of potash. Scirpus (bulrush) afforded $8 \cdot 65$ per cent ash, and in it $10 \cdot 3$ per cent of soda with $9 \cdot 7$ of potash ; and Juncus, $6 \cdot 6$ of soda to $36 \cdot 6$ of potash. The ash of beets contains 14.8 per cent of soda; of carrots, $22 \cdot 1$ per cent; but grasses generally 1 to 5 per cent of soda.

The amount of sulphur in the ash of grasses, straws, and woods is usually 1 to $2 \cdot 5$ per cent; in that of Fucus, 18 per cent; in that of common vegetables, 3 to 6 per cent. The amount of chlorine in the ash of grasses is 3 to 5.5 per cent; in that of vegetables, 3 to 11 per cent; in that of Fucus, 10 per cent; in that of Juncus, $14 \cdot 2$ per cent; in that of woods, usually less than 1 per cent. (These percentages are taken from tables in Johnson's How Crops Grow, New York, 1887.)

\section{KINDS OF Rocks.}

(1) General explanations. - Rocks are conveniently divided into two general sections: (1) the Fragmental or Clastic, and (2) the Crystalline.

For the study of even the coarser kinds of rocks, the geological student should have a pocket lens. In investigation, it will generally be necessary to supplement this with a compound polariscope-microscope made especially for the study of rocks; but a thurough study of the elements of petrology is required for the satisfactory use of the latter instrument.

Fragmental Rocks. - The fragmental rocks are those that have been made out of fragments of older rocks. They are also called clastic rocks, from the Greek for to break. All the sand, gravel, stones, earth, mud, and clay of the world is worn or pulverized or decomposed rock. Each grain, however small or large, may hence be spoken of as a fragment of preëxisting rocks. The rocks of an age are mostly made out of the detritus (wornout rocks) of preceding time. 
To appreciate the nature and qualities of fragmental material, the student should go to the hills where sand and gravel are dug; to the sea-beaches where the waves are at their grinding and assorting work, or to the estuaries where mud-flats and sand-flats have been made by their greater action; to the river-valleys, where plunging streams are at their abrading and destroying work, or where quieter streams are bordered by terraces of sand, or gravel, or loam, or clay. All is fragmental material; and all these results of attrition and partial decomposition may be included under the four divisions of (1) sand, (2) gravel (or a mixture of stones and sand), (3) earth or mud (according as it is wet or not), and (4) clay. The last, the material of brick and pottery, is plastic when wet, and feels a little greasy. MIud of the finest kind is usually more or less pure clay.

Fragmental deposits are made up of successive beds or layers; that is, are stratified (using a term from the Latin stratum, a bed). They are also, for the most part, sedimentary beds, the sand and earth deposited by water being its sediment; and hence they are often called sediments. The waters that deposited the sediment and made the stratified accumulations were mostly those of the ocean, or of rivers or lakes; and sea-border, fluvial, and lacustrine formations are illustrations therefore of fragmental deposits.

Crystalline Rocks. - Nearly all substances crystallize on passing to the solid state from a previous state of either fusion, solution, or vapor, and many without fusion if subjected to long-continued heat. The grains of a massive crystalline rock are, in the main, or wholly, imperfect crystals. They are generally angular in form; and when so, it is usually because of the cleavages of the constituent mineral grains. Being crowded together, they very seldom have the external planes of crystals. Granite and crystalline limestone (or ordinary white marble) are examples. In crystalline limestone, all the grains are angular and glisten, owing to the cleavage-surfaces. In granite, those of two of the constituent minerals show sparkling cleavagesurfaces, but the third, quartz, is without cleavage. When the grains are distinctly visible without a glass, the texture is described as macroscopic; if undistinguishable, the texture is microscopic, or aphanitic.

Crystalline rocks are, to a large extent, igneous or eruptive rocks; that is, they have become crystalline masses from a state of fusion, as, for example, lavas and the many kinds of igneous rocks. Others have become crystalline by heat without fusion, with or without attending change in composition; for example, a massive limestone has thus been changed by simply long-continued heat to a crystalline limestone or marble, granitic sandstone to granite or gneiss, and so on. Such rocks are called metcmorphic rocks. Fragmental rocks have been thus metamorphosed on a large scale during times of mountain-making. Metamorphic rocks have sometimes been subjected to a second partial or complete metamorphism, and igneous rocks occur altered in like manner. Crystalline rocks are usually mere mixtures, like the fragmental, as they consist of one, two, or more minerals in various proportions. If of 
more than one, the prominent distinctions are usually based on the two most characteristic; and the others are considered as accessory minerals, and are made to distinguish varieties.

The following are distinctions among crystalline rocks, based on texture and structure :-

1. Granitoid. - Granular-crystalline, like ordinary granite.

2. Micro-granitic. - Like granite, but very fine in grain.

3. Micro-crystalline. - Compact, and so fine in texture as barely to glisten over a surface of fracture.

4. Porphyritic - Having one of the minerals of the rock in distinct crystals (Fig. 58). The original porphyry of geology included a red porphyry (from Egypt), a compact red rock, finely spotted with pale feldspar (orthoclase) crystals; and a green porphyry - the Oriental verd-antique - with rather large crystals of whitish labradorite, from western Greece. The rocks, although alike in being porphyritic, are not of the same species, but are porphyritic varieties of different species, as described beyond.

58.

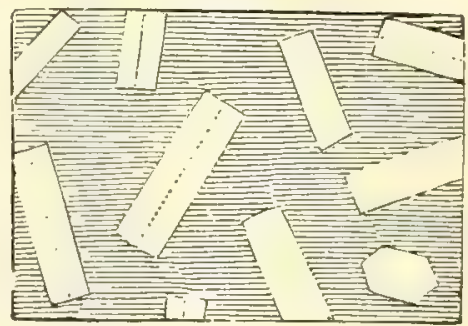

The mineral in crystals in a porphyritic rock may be any feldspar, or it may be augite, leucite, quartz, or some other species; and whatever the mineral, the crystals are called phenocrysts, from the Greek for "visible crystals," a term proposed by J. P. Iddings. 'The kind of mineral is indicated by the terms orthophyric, if orthoclase; labradophyric, if labradorite; augitophyric, if augite; leucitophyric, if leucite; quartzophyric, if quartz; spherophyric, if containing spherical concretions, etc.

5. Foliated. - Having the cleavage-structure of slate, as in extreme cases of foliation; or having an arrangement of the minerals, especially of any foliated mineral like mica, approximately in planes, so that the rock has the appearance of being stratified, and often breaks easily into slates or sheets. The slaty, and all schistose, structure, to the faintest, is here included. The planes of foliation are either pressure-made planes, or correspond to planes of bedding or stratification.

6. Fluidal. - In igneous rocks, having the material of the rock or of portions of it in parallel lines or bands and looking as if due to the flow of the rock while melted.

7. Glassy, glass-bearing. - Melted rocks, when cooled rapidly, often become glass at surface instead of rock; and in some cases all gradations occur in the mass of an igneous rock between glass with microscopic stony points, or microlites, and stone with microscopic glassy particles. Lavas have usually particles in a glassy state among the stony particles, which a microscopic study of the rock will detect. 
8. Vesicular. - Having small cavities in the rock (igneous), made usually by steam, as in many lavas.

9. Scoriaceous. - Having vesicles in so great abundance that they make the chief part of the mass like much furnace slag, as a scoriaceous lava.

10. Amygdaloidal (from amygdalum, an almond). - Having the vesicles (which are often almond-shaped) filled with minerals foreign to the rock, such as quartz, calcite, and the zeolites. Trap, or doleryte, and related basic eruptive rocks are often amygdaloidal.

The following are other terms used in describing either fragmental or crystalline rocks:-

Quartzose. - Consisting of quartz; containing much quartz.

Calcareous. - Consisting of limestone (calcite); containing much calcite.

Ferruginous. - Containing much iron oxide.

Argillaceous (from argilla, clay). — Made of more or less hardened clay or fine mud; containing clayey material.

Pyritiferous. - Containing pyrite.

Granitic. - Made of granite sand, or gravel.

(2) Descriptions of rocks. - The kinds of rocks are described under the heads of -

Limestones, or Calcareous Rocks.

Fragmental Rocks, not Calcareous.

Crystalline Rocks, exclusive of Limestones.

In the names of rocks, the termination ite is here changed to yte, as done in the author's System of Mineralogy (1868), in order to distinguish them from the names of minerals. Granite is excepted.

\section{Limestones, not Crystalline.}

Massive Lmestone. - Compact uncrystalline; color whitish, dull gray, bluish gray, brownish, and black. Texture compact to earthy, sometimes semi-crystalline. Consists essentially of calcite or calcium carbonate (page 68), but is often impure with clay or sand.

Most limestones are of organic origin. A dark or black color is usually owing to some carbonaceous material present, derived from the decomposition of the plants or animals of the waters in which they were formed. When burnt, limestone $\left(\mathrm{CaO}_{3} \mathrm{C}\right)$ becomes quicklime (CaO), through loss of carbonic acid $\left(\mathrm{CO}_{2}\right)$; and, at the same time, all carbonaceous materials are burnt out, and the color, when it is owing solely to these, becomes white. A limestone made of pebbles of limestone is called a limestone conglomerate, as that of the Potomac.

Magnesian Limestone, Dolomyte (page 68). - Calcium-magnesium carbonate. Not distinguishable in color or texture from ordinary limestone. Much of the common limestone of the United States is magnesian. While some of the magnesian limestone is true dolomite (or has the calcium and magnesium in the atomic proportion 1:1), much is a mixture of calcite and dolomite.

In some limestones the fossils are magnesian, while the rock is common limestone. Thus, an orthoceras in the Trenton limestone of Bytown, Canada (which is not magnesian), afforded T.S. Hunt calcium carbonate $56 \cdot 00$, magnesium carbonate $37 \cdot 80$, iron 
carbonate $5 \cdot 95=99 \cdot 75$. The pale yellow veins in the Italian black marble, called "Egyptian marble," are dolomite, according to Hunt.

Hydraulic Limestone. - A limestone containing 20 to 30 per cent of clay, and affording a quicklime, the cement from which will "set" under water. It is often magnesian. An analysis of a kind from Rondout, N. Y., afforded carbonic acid $34 \cdot 20$, lime $25 \cdot 50$, magnesia $12 \cdot 35$, silica $15 \cdot 37$, alumina $9 \cdot 13$, sesquioxide of iron $2 \cdot 25$. In making ordinary mortar, quartz sand is mixed with pure quicklime and water, and the chemical combination is mainly that between the water and lime, together with an absorption subsequently of carbonic acid. Evaporation to dryness is necessary to hardening. With "hydraulic cement," silica and alumina (that of the clay) are disseminated through the lime, and hence these ingredients enter into chemical union with the lime and water, and make a much firmer cement, and one which "sets" under water. Portland cement is made by mixing 70 per cent of chalk with 30 of fine mud from the Thames.

OöLYTE. - Limestone, either magnesian or not, consisting of minute concretionary spherules; looks like the petrified roe of fish, and hence the name, from the Greek $\omega^{\prime} b v$, egg.

Chalk. - A white, earthy limestone, easily leaving a trace on a board. Composition, the same as that of ordinary limestone.

MARL. - A clay containing a large proportion of carbonate of lime - sometimes 40 to 50 per cent. If the marl consists largely of shells or fragments of shells, it is called shell-marl. Marl is used as a fertilizer; and beds of clay or sand that can be so used are often in a popular way called mart.

Shell Limestone, Coral Limestone, - A rock made out of shells or corals.

Travertine. - A massive limestone, formed by. deposition from calcareous waters, and largely through the agency of fresh-water Algæ, as at the Yellowstone Park (W. H. Weed). But part is a deposit from solution. The rock abounds on the river Anio, near Tivoli, and St. Peter's, at Rome, is constructed of it. The name is a corruption of Tiburtine.

\section{Crystalline Limestone.}

Stalagmite, Stalactite, Dripstone. - Depositions from waters trickling through the roofs of limestone caverns form calcareous cones and cylinders pendent from the roofs, which are called stalactites, and incrustations on the floors, which are called stalagmite, and sometimes also dripstone. The waters, filtering down from the overlying soil, contain a little carbonic acid or some organic acid, and are thus enabled to dissolve the limestone, which is deposited again on evaporation. The layers of successive deposition are usually distinct, giving the material a banded appearance.

Grandlar Limestone; Calcyte (statuary marble). - Limestone having a crystalline granular texture, white to gray color, often clouded with other colors from impurities. It is a metamorphic rock. Its impurities are often mica or talc, tremolite, white or gray pyroxene or scapolite; sometimes serpentine, through combination with which it passes into ophiolyte (p. 89); occasionally chondrodite, apatite, corundum.

Varieties. - a. Statuary Marble; pure white and fine grained. b. Ornamental and Architectural Marble; coarse or fine, white, and mottled of various colors, and, when good, free not only from iron in the form of pyrite, but also from iron or manganese in the state of carbonate with the calcium, and also from all accessory minerals, even those not liable to alteration, and especially those of greater hardness than the marble, which would interfere with the polishing. c. Verd-antique, or ophiolyte. d. Micaceous. e. Tremolitic; contains bladed crystallizations of the white variety of hornblende called tremolite. f. Graphitic; contains graphite in iron-gray scales disseminated through it. g. Chtoritic; contains disseminated seales of chlorite. h. Chondroditic; contains disseminated chondrodite in large or small yellow to brown grains.

Dolomyte. - Not distinguishable by the eye from granular limestone. The dolo- 
myte, which is calcitic (a mixture of calcite and dolomite), is apt to crumble from weathering, because the calcite is the most soluble, and becomes removed by filtrating waters.

As the kinds of fragmental materials which the rocks afford over the earth are either sand, gravel, earth, or mud, and clay, the kinds of fragmental rocks are few.

\section{Fragmental Rocks, not Calcareous.}

Conglomerate. - A consolidated gravel-bed, consisting of a mixture of pebbles, or fragments of rocks, and finer material. $a$. If the pebbles are rounded, it is called puddingstone; $b$. if angular, breccia. Conglomerates are named, according to their constituents, siliceous or quartzose, granitic, calcareous.

GriT, GrIT-ROCK. - A hard, gritty rock, consisting of coarse quartz sand and small pebbles; called also millstone grit, because used sometimes for millstones.

Sandstone. - A rock made of sand; a consolidated sand-bed. There are siliceous, granitic, micaceous, feldspathic, calcareous sandstones, according to the character of the material. They are thick-bedded or thin-bedded, according to the thickness of the beds; laminated when divisible into laminæ or slabs; shaly when splitting into thin pieces or sheets like shale or an imperfect slate. There are also compact, friable, argillaceous, gritty, ferruginous, concretionary, massive, flexible, and other kinds. Grindstones are made of an even-grained, rather friable sandstone. Hard, siliceous sandstones, grit, and conglomerate, in regions of metamorphic rocks, are called quartzyte (page 82). The Arkansas Novaculite, or whetstone, is an exceedingly fine-grained sandstone microscopically porous through the loss by infiltrating waters of disseminated calcareous particles (L. S. Griswold).

SAND-Rock. - A rock made of sand of any kind, especially if not siliceous or granitic. A calcareous sand-rock is one made of calcareous sand, as pulverized corals or shells.

Shale. - Consolidated mud or elay; a soft, fragile, slaty, argillaceous rock. Shales are gray to black in color, and sometimes dull greenish, purplish, reddish.

Varieties. - a. Carbonaceous shale; black and impregnated with coaly material, yielding mineral oil or related bituminous matters when heated (Brandschiefer in German). b. Alum shate; impregnated with alum or pyrites, usually a crumbling rock. The alum proceeds from the alteration of pyrite, or an allied iron sulphide, in the rock.

Argillite, or Clay-slate (Phyllyte). - A slaty rock, like shale, but differing in breaking usually into thin and even slates or slabs. Roofing and writing slates are examples. It is sometimes thick-laminated. Moreover, unlike shale, it occurs in regions of metamorphic rocks, and often graduates into hydromica and mica schists. It graduates often into hard, thick-layered sandy beds, which used to be called gray wacke.

TufA. - Consists of comminuted volcanic sand and small fragments of lavas, more or less altered. Usually of a gray, yellowish brown, or brown color, sometimes red. The tufa made from those igneous rocks that contain pyroxene is usually yellowish brown or. brown in color (sometimes red) (often called wacke); and that made from the feldspathic igneous rocks, trachyte, pumice, and the like, is of an ash-gray color, or of other light shades. The finer deposits are often called ash-beds. Since volcanic ashes are often very widely distributed by the winds, they make deposits beyond the limits of the volcano, over the land, or lakes, or the sea-bottom; and sometimes the deposits have great thickness. Pozzuolana is a light-colored tufa, found in Italy, near Rome, and elsewhere, and used for making hydraulic cement. Volcanic sand, or peperino, is sand of volcanic origin, either the "cinders" or "ashes" (comminuted lava) formed by the process of ejection, or lava rocks otherwise comminuted.

ClaY. - Soft, impalpable, more or less plastic material, chiefly aluminous in composition, white, gray, yellow, red to brown and black in color. 
Varieties. - a. Kaolin; purest unctuous clay, white, and when impure, of other colors. The white is used for making porcelain by mixing with pulverized feldspar and quartz, also for giving weight and body to writing-paper. b. Potter's clay; plastic, free from iron, and therefore good for white pottery; mostly unctuous; usually containing some free silica. c. Ferruginous, Brick-clay; containing iron in the state of oxide or carbonate, and consequently burning red, as in making red brick; generally in thin layers, which are alternately good clay and fine sand. d. Containing iron in the state of a silicate, and then failing to turn red on being burnt, as the clay of which the Milwaukee brick are made. e. Alkaline and Vitrifiable; containing 2.5 to 5 per cent of potash or potash and soda, owing to the presence of undecomposed feldspar, and then not refractory enough for pottery or fire-brick. f. Marly; containing some calcium carbonate. g. Carbonaceous, Black, Ampelite; from the presence of lignitic or coaly material. h. Alum-bearing; containing aluminous sulphates, owing to the decomposition of iron sulphides present.

Rork-flour is rock pulverized to extreme fineness, so as often to resemble clay although containing very little of it. Feldspar in this fine state is present in much clay. Some rock-flour consists mainly of pulverized quartz.

Alluvium, Silt, Lass. - Alluvium is the earthy deposit made by running streams or lakes, especially during times of flood. It constitutes the flats adjoining, and is usually in thin layers, varying in fineness or coarseness, being the result of successive depositions. Silt is the same material deposited in bays or harbors, where it forms the muddy bottoms and shores. Loess is an earthy deposit, coarse or fine, following the courses of valleys, like alluvium, but without division into thin layers; fertile ordinarily from the amount of vegetable matter present, and containing also land or fresh-water shells.

Detritus (from the Latin for worn) is a general term applied to earth, sand, alluvium, silt, gravel, because the material is derived, to a great extent, from the wear of rocks through decomposing agencies, mutual attrition in running water, and other methods.

Soit is earthy material, mixed with the results of vegetable and animal decomposition, whence it gets its dark color and also a chief part of its fertility.

Till. - Unstratified or imperfectly stratified deposits of bowlders, gravel, and clay, derived from a continental glacier. Also called bowtder clay. Usually firmly compacted, owing to the presence of clay or rock-flour when not properly consolidated.

Tripolyte (Infusorial Earth). - Resembles clay or chalk, but is a little harsh between the fingers, and scratches glass when rubbed on it. Consists chiefly of siliceous shells of Diatoms. Forms thick deposits, and is often found in swamps beneath the peat (see page 153). Occurs sometimes slaty, as at Bilin, Prussia; and also hard, from consolidation through infiltrating waters. Consists of silica in the opal or soluble state.

\section{Crystaline Rocks.}

The descriptions of crystalline rocks are arranged under the following heads :-

I. Siliceous rocks, or those consisting mainly of Silica.

II. Rocks Having as a CHIEF CONSTITUENT ONE OR MORE OF THE ALKali-Bearing minerals, Feldspar, Mica, Levcite, Nephelite, Sodalite. - In the first three of the following subdivisions, potash-feldspar is present as a distinctive feature; in 4, leucite also contains a potash-bearing mineral; in 5 and 6 a soda-lime or a lime feldspar is characteristic.

1. Potash-Feldspar and Mica Series.

2. Potash-Feldspar and Hornblende or Pyroxene Series.

3. Potash-Feldspar and Nephelite Rocks, Hornblendic or not.

4. Leucite Rocks, Pyroxenic or not.

5. Soda-Iime-Feldspar and Mica Series.

DAYA'S MANUAL -6 
6. Soda-lime-Feldspar Series, with or without Hornblende or Pyroxene, - the feldspar a triclinic species of the series from albite to anorthite.

III. SAlsutrute rocks - Alkali (soda) bearing, but containing saussurite in place of a feldspar.

IV. Without FELDSPAR, OR WiTh VERy LitTLE.

1. Garnet, Epidote, and Tourmaline Rocks.

2. Hornblende, Pyroxene, and Chrysolite Rocks.

V. Hydrous magnesian and aldminous rocks.

\section{Siliceous Rocks.}

Quartzyte, Granclar Quartz. - A siliceous sandstone, usually very firm, occurring in regions of metamorphie rocks. It does not differ essentially from the harder siliceous sandstones of other regions. Conglomerate beds are sometimes included.

Varieties. - a. Massive. b. Schistose. c. Micaceous ("Greisen"). d. Hydromicaceous. e. Feldspathic, and sometimes Porphyritic (then called by some, Arkose). f. Friable. g. Flexible (Itacolumyte). h. Andalusitic. i. Ottrelitic. j. Tourmalinic, containing tourmaline. k. Gneissic, it occasionally graduating into gneiss.

Siliceods State (Phthanyte).- Schistose, flinty, not distinctly granular in texture. Sometimes passes into mica or hydromica schist.

CHERT. - An impure flint or hornstone occurring in beds or nodules in some stratified rocks. It often resembles felsyte, but is infusible. Colors various. Sometimes oölitic. Kinds containing iron oxide graduate into jasper and clay-ironstone.

JASPER Rock. - Dull red, yellow, brown, or green, or of some other dark shade, breaking with a smooth surface like flint. Consists of quartz, with more or less clay and oxide of iron. The red contains the oxide of iron in an anhydrous state, the yellow in a hydrous; on heating the latter, it turns red.

Buhrstone. - A cellular siliceous rock, flinty in texture. Used for millstones. Found mostly in connection with Tertiary rocks, and formed apparently from the action of siliceous solutions removing fossils and so making the cavities. The best is from near Paris, France.

Fioryte (Siliceous Sinter, Pearl Sinter, Geyserite). - Opal-silica, in compact, porous, or concretionary forms, often pearly in luster; made by deposition from hot siliceous waters, as about geysers (geyserite), or through the decomposition of siliceous minerals, especially about the fumaroles of voleanic regions. Geyserite is abundant in Yellowstone Park, about the Iceland geysers, and in the New Zealand geyser region.

\section{Rocks having Alkali-bearing Minerals as Chief Constituents.}

1. The Potash-feldspar and Mica Series.

Granite. - Metamorphic and eruptive. Consists of feldspar, mica, and quartz; has no appearance of layers in the arrangement of the mica or other ingredients. The quartz usually grayish or smoky, glassy, and without any appearance of cleavage. The feldspar commonly whitish or flesh-colored, less glassy than the quartz, and cleavable in two directions; the mica in very cleavable scales.

Metamorphic granite is common in Connecticut and other parts of New England, where it may be often seen graduating into gneiss, or in alternating layers with it.

Varieties. - There are, A, Muscovite-granites; B, Muscovite and Biotite granites; C, Biotite-granites; D, Hydromica granite. The most of the following varieties occur under each except the hornblendic, which is usually a Biotite or Muscovite and Biotite granite. a. Common or ordinary granite. Color, grayish or flesh-colored, according as the feldspar is white or reddish, and dark gray when much black mica is present. Varies in texture from fine and even to coarse; sometimes the mica, feldspar, and quartz 
- especially the two former - in large crystalline masses. b. Porphyritic; has the orthoclase in defined crystals, and may be $(a)$ small-porphyritic, or $(\beta)$ large-porphyritic, and have the base $(\gamma)$ coarse granular, or $(\delta)$ fine, and even subaphanitic. c. Albitic, contains some albite, which is usually white. d. Oligoclase granite (Miarolyte); contains oligoclase. e. Microcline granite; contains the potash triclinic feldspar, microcline. f. Hornblendic; contains black or greenish black hornblende, along with the other constituents of granite. g. Black micaceous granite; consists largely of mica, with defined crystals of feldspar (porphyritic), and but little quartz. h. Chloritic. i. Zirconitic. j. Iolitic. k. Spherophyric or globuliferous; contains concretions which consist of mica, or of feldspar and mica. 1. Gneissoid; a granite in which there are traces of stratification ; graduates into gneiss.

Graxdlyte (Leptynyte). - Metamorphic and eruptive. Like granite, but containing no mica, or only traces.

Tarieties. - a. Common granulyte; white and usually fine granular. b. Fleshcolored; usually coarsely crystalline, granular, and flesh-colored. c. Garnetiferous. d. Hornblendic; containing a little hornblende - a variety that graduates into syenyte. e. Magnetitic; containing disseminated grains of magnetite. f. Graphic; quartzophyric (Pegmatyte), the quartz looking like Persian cuneiform characters over the cleavagesurface of the feldspar; sometimes coarse crystallizations of mica.

Greiss. - Metamorphic ; may be also altered eruptive. Like granite in constituents, but with the mica and other ingredients more or less distinctly in layers, gneiss and granite being closely related rocks. Gneiss breaks most readily in the direction of the mica layers, and thus affords slabs, or is schistose in structure.

Varieties. - Most of them are similar to those under granite. a. Granitoid. b. Strongly schistose and micaceous. c. Muscovite gneiss; not common. d. Muscovitebiotite gneiss. e. Biotite gneiss. f. Albitic. g. Oligoclase-bearing. h. Hornblendic. i. Epidotic. j. Garnetiferous. k. Andalusitic, or containing andalusite in disseminated crystals. 1. Cyanitic; contains cyanite. m. Fibrolitic. n. Quartzose; the quartz largely in excess. o. Quartzytic; consists largely of quartz in grains, and intermediate between quartzyte and gneiss. p. Porphyritic. q. Spherophyric. r. Quartzophyric; containing quartz in defined crystals in a fine-grained base.

Some gneiss is very little schistose, being in thick, heavy beds, granite-like, while other kinds, especially those containing much mica, are thin-bedded, and rery schistose; the latter graduate into mica schist.

Greisen (Hyalomicte). - A micaceous quartz-rock, at Zinnwald, where it sometimes contains tin ore.

Protogine, Protogine Gneiss. - Granite or gneiss-like, but containing some hydromica, or chlorite, or both.

Minette, Ortholyte. - A fine-grained rock consisting of mica and orthoclase without quartz (mica-syenyte). The Vosges, France.

Mica Schist. - Metamorphic. Mica, with usually much quartz, some feldspar. On account of the mica usually thin schistose. Either or both muscovite and biotite present, and the latter (black mica) commonly much the most abundant. Colors silvery to black, according to the mica present. Often crumbles easily, and roadsides sometimes spangled with the scales.

Varieties. - a. Ordinary. b. Gneissoid; between mica schist and gneiss, and containing much feldspar, the two rocks shading into one another. c. Hornblendic. d. Garnetiferous. e. Staurolitic. f. Cyanitic. g. Andalusitic. h. Fibrolitic; containing fibrolite. i. Tourmalinic. j. Ottrelitic. k. Calcareous, limestone occurring in it in occasional beds or masses. 1. Graphitic or Plumbaginous; the graphite being either in scales, or impregnating generally the schist. m. Quartzose; contains much quartz. 11. Quartzytic; a quartzyte with more or less mica, rendering it schistose. o. Specular, or Itabyryte; containing much hematite or specular iron in bright metallic lamellæ or scales. 
Hrdronica Schist or Siate. - Metamorphic. Thin schistose, consisting either chiefly of hydrous mica, or of this mica with more or less quartz; having the surface nearly smooth; feeling greasy to the fingers; pearly to faintly glistening in luster; whitish, grayish, pale greenish in color, and also of darker shades. This rock used to be called talcose slate, but, as first shown by C. Dewey, it contains no talc. It includes parophite schist, damo:trite slate, and sericite slate (glanz-schiefer, sericit-schiefer, and part of the glimmer-schiefer of the Germans).

Varieties. - a. Ordinary; more or less silvery in luster. b. Chloritic; contains chlorite, or is mixed with chlorite slate, and has therefore spots of olive-green color; graduates into chlorite slate. c. Garnetiferous. d. Pyritiferous; contains pyrite in disseminated grains or crystals. e. Magnetitic; contains disseminated magnetite. f. Quartzytic; consists largely of quartzyte, or is a quartzyte rendered schistose and partly pearly by the presence of a hydrous mica. Includes the argillyte or clay-slate which has the composition nearly of a hydrous mica, like that of the White Mountain Notch, where much of it is andalusitic.

Agalmatolyte (Gieseckite, Pinite). - Compact; cut with a knife ; composition that of the hydrous mica, damourite. Derived mostly from the alteration of nephelite. From the Archæan of Lewis County, N.Y. (Dysintrybyte), China, etc.

Paragonite Schist, - Metamorphic. Consists largely of the hydrous soda mica called paragonite; but in other characters resembles hydromica slate.

Felsrte (Euryte, Porphyry, Petrosilex). - Eruptive and metamorphic. Compact orthoclase with often some quartz intimately mixed, flint-like in fracture. Opaque. Colors grayish white to red and brownish red. $G=2 \cdot 56-2 \cdot 7$.

Varieties. - a. Non-porphyritic; of various colors. b. Black; rare. c. Purphyritic Felsyte, or Porphyry, Orthophyric; containing the feldspar in small crystals distributed through the compact base ; color red, and of other shades. d. Quartzophyric; containing quartz in grains; often called Quartz-porphyry. e. Quartzless. f. Spherophyric, the Pyromeride of Corsica.

Porcelanyte or Porcelain Jasper. - Metamorphic. Baked clay, having the fracture of flint, and a gray to red color: it is somewhat fusible before the blowpipe, and thus differs from jasper. Formed by the baking of clay-beds, when they consist largely of feldspar. Such clay-beds are sometimes baked to a distance of thirty or forty rods from a trap dike, and over large surfaces, by burning coal-beds.

Mica-trachyte. - Eruptive. Consisting of orthoclase and black mica, with some orthoclase augite, chrysolite, and glass. Dark grayish green. Mount Catini.

Trachite (Sanidin-trachyte). - Eruptive. Ash-gray, brownish, bluish, rarely reddish. $\mathrm{G}=2 \cdot 6-2 \cdot 7$. Consists mainly of orthoclase, often with disseminated crystals of the glassy tabular variety called sanidin. Named from the Greek for rough, in allusion to the rough surface of fracture. Differs from felsyte in containing some glass, and a rougher surface. Graduates into the following.

Rhyolyte, QuaRtz-TRACHYTe. - Eruptive. Like the preceding in colors, but containing quartz, and sometimes passing into a coarsely crystallized variety called Nevadyte (from Nevada). Common in the Rocky Mountain region and west of it. Pearlyte and Lithoidyte are more or less glassy varieties - between glass and stone; and pitchstone is another similar variety, pitch-like in luster. These graduate into the following.

Obsidian (Volcanic glass). - Eruptive. A true volcanic glass, but more or less microlitic. Colors grayish black, gray, purplish to red, brown. Sometimes orthophyric; often contains spherulites, which are 70-75 per cent silica. Pumice is a scoriaceous variety with linear cells. Constitutes a high bluff in the northwest part of the Yellowstone Park, north of Beaver Lake, which has a top of pumice, and also a large area east of the bluff; cavities in Obsidian bluff often lined with crystals of sanidin, tridymite, quartz, and sometimes of fayalite. 


\section{Potash-feldspar and Hornblende or Pyroxene Series.}

Srente (Syenite of Werner). - Eruptive, metamorphic; granite-like, coarse to fine. Gray to flesh-red and dark gray. Consists of orthoclase, with often microcline and hornblende and little or no quartz; biotite and oligoclase often present. $G=2 \cdot 7-2 \cdot 9$. From Plauen-Grund, Saxony, etc. Nearly all American syenyte is quartz-syenyte.

QUARTZ-SYENYTE (syenite of most early geologists, hornblende-granite, syenite-granite). - Eruptive and metamorphic. Like syenyte, but containing quartz. Silica 70 to 80 per cent. The name syenite is from Syene in Egypt, where a red granite graduating into quartz-syenyte occurs, and is the material used by the ancient Egyptians for the exterior lining of obelisks, etc.

SYENYTE-GNEISs. - Metamorphic, eruptive. Like gneiss in aspect and schistose structure, and also in constitution, except that hornblende replaces mica. Common in Archæan regions, as the New Jersey Highlands, the Adirondacks, etc. Graduates into Hornblendeschist, a schistose rock consisting chiefly of hornblende.

Adgrte-syente. - Eruptive. Like syenyte, but containing, with the orthoclase, pyroxene in place of hornblende. A kind free from quartz occurs at Jackson, N.H.; in southern Norway. Monzonyte is stated to be a variety of augite-syenyte.

Adgite-quartz-syenyte (Augite-granite). - Metamorphic; igneous. Like the preceding, but containing quartz; the augite in part altered to hornblende, and thence in all stages of gradation down to a hornblende-syenyte. The gneissic variety is common in Wisconsin, much more so than the granitoid.

UNAKYTE. - A flesh-colored, granitoid rock consisting of orthoclase, quartz, and epidote. From the Unaka Mountains, Madison County, N.C., and Cooke County, E. Tenn.

\section{Potash-feldspar and Nephelite Rocks, Hornblendic or not.}

ZirCon-sYenyte. - Like syenyte. A crystalline granular rock consisting of orthoclase, microcline, elæolite, little hornblende, crystals of zircon; often also sodalite, ægy rite, eudialyte, etc. From Norway ; Marblehead Peninsula, Mass., containing sodalite.

Foyarte. - Eruptive. Coarse, crystalline granular to aphanitic. Consists of orthoclase, nephelite, hornblende, or ægyrite, with often sodalite, ete. From Mounts Foya and Picota in Portugal, making a dike; on eastern slope of Blue Mountain, New Jersey, between Beemersville and Libertyville.

Miascyte. - Granitoid to schistose. Consists of microcline, elæolite, biotite, with some quartz; often also zircon, monazite, sodalite, cancrinite, etc. From Miask, Ilmen Mountains; Pic Island, Lake Superior; Litchfield, Maine.

Ditroyte. - Coarse to fine-grained. Consists of microcline, nephelite (elæolite), and sodalite. From Ditro, Transylvania.

Phonolyte (Clinkstone). - Eruptive. Compact, more or less slaty in structure. Gray, grayish blue, brownish. Usually clinking under the hammer like metal when struck (and thence the name). $\mathrm{G}=2 \cdot 4-2 \cdot 7$. Consists of glassy orthoclase, with nephelite and some hornblende. In Colorado, Auvergne, Breisgau, Bohemia.

\section{Leucite Rocks, with or without Augite.}

Usually some sanidin (orthoclase) is present, and often also nephelite and labradorite.

Aмphigenxte (Leucitophyre). - Euptive. Contains augite, like doleryte, but leucite (called sometimes amphigene) replaces the feldspar. Often contains chrysolite, nephelite, sanidin, labradorite, brown mica, with sodalite, etc. Dark gray, fine-grained, and more or less cellular to scoriaceous. $G \mathbf{2} \cdot 5-2 \cdot 9$. The leucite is disseminated in grains or in 24-faced crystals. Constitutes the lavas of Vesuvius and some other regions.

Ledcotephryte. - Eruptive. Like the above, and occurring in the same regions, but containing much labradorite. 
Leverryte. - Eruptive. Consists chiefly of leucite, with a very little augite and some biotite. Color, greenish gray. From Point of Rocks, Wyoming.

\section{Soda-lime-feldspar and Mica Rocks.}

Kiersantyte (Mica-dioryte, Mica-porphyryte, Soda-granite). - Granite-like to finegrained. Grayish to brown and grayish black. Consists chiefly of oligoclase and biotite, with usually some homblende, orthoclase, magnetite, apatite. Graduates into dioryte. Occurs granitoid at Stony Point, on the west side of the Hudson River, and near Crugers, nearly opposite; in the Vosges.

\section{Soda-lime-feldspar and Hornblende or Pyroxene Rocks.}

These basic rocks vary in the kind of feldspar present; in texture, from coarse granite-like to aphanitic and scoriaceous, even in the same kind of rock; in composition, through alteration of the pyroxene, in many cases, to hornblende, making them hornblende rocks; and also in the alteration, in many cases, of the pryoxene and chrysolite, when these are present, to serpentine. The dark-colored igneous kinds are conveniently called trap.

Dioryte, QuArTz-Droryte (Greenstone in part). - Metamorphic and eruptive. Typieal dioryte, consisting chiefly of oligoclase and hornblende, with often some orthoclase and biotite. Colors, gray, dark gray, grayish black, green, greenish black, and also red. Chlorite usually present, and sometimes epidote, in green varieties. Often contains disseminated quartz. No glass is present. Varies in texture from granite-like to aphanitic. In the coarse granite-like dioryte of Crugers the crystals of hornblende are sometimes 4 inches long. $\mathrm{G}=2 \cdot 66-3$.

A compact aphanitic kind, of a red color, is the typical red porphyry, or Rosso antico (porphyryte), of Egypt. That of Crugers graduates into kersantyte, by loss of hornblende and increase of biotite. Dioryte Schist is a metamorphic, slaty rock, having the composition essentially of dioryte.

AdGrTe-Dionyte. - Eruptive. Consists of augite and oligoclase with little hornblende. Augite often more or less changed to hornblende, making a hornblende-dioryte or the above-described dioryte. No glass. Colors, dark gray to greenish black and black.

A fine-grained rock between Peekskill and Crugers, on the Hudson, consisting of oligoclase and hypersthene, is essentially a hypersthene-dioryte, although called noryte. The hypersthene is often altered to hornblende, as ascertained by G. H. Williams. Ophyte, a fine-grained greenish black rock of the Pyrenees, related to augite-dioryte in composition.

Labradiorte (Labradorite-dioryte, Metadiabase, Hawes). - Metamorphic and eruptive. Consists of labradorite (or anorthite) and hornblende with some chlorite and magnetite. A fine-grained, grayish green to greenish black and black rock, sometimes porphyritic. No glass present. $\mathrm{G}=2 \cdot 8-3 \cdot 1$. Occurs west of New Haven, Conn., as a part of the metamorphic chloritic hydromica schist of the region, evidently metamorphic. G. W. Hawes obtained in analyses (1876): Silica $48 \cdot 20$, alumina $14 \cdot 12$, iron sesquioxide 2 , iron protoxide 7.41 , manganese protoxide $1 \cdot 24$, lime $11 \cdot 50$, magnesia $8 \cdot 19$, soda $2 \cdot 60$, potash $0 \cdot 23$, titanic acid $1 \cdot 58$, water $2 \cdot 20=99 \cdot 27$. In the Urals.

Andesyte (Hornblende-andesyte). - Eruptive. Consists of oligoclase or andesyte and hornblende, with often some orthoclase and biotite. Dark or light green to gray, sometimes purplish. Has the aspect mostly of trachyte, but varies from granitoid to scoriaceous and glassy, even in the same eruptive mass, at Washoe, as ascertained by Hague and Iddings.

DACYTE (Quartz-andesyte). - Eruptive. Like the above, but contains disseminated quartz, and often much of it. Graduates into the orthoclase rock, quartz-trachyte or 
rhyolyte. From Eureka, Nev., and other parts of the Rocky Mountain region; also from the Andes of Cotopaxi, Chimborazo, etc.

Propylyte is altered andesyte.

Adgite-andesyte. - Eruptive. Like andesyte, but containing augite in place of hornblende, or in part hypersthenic; augite or hypersthene often altered to hornblende, often chrysolitic. Texture, crystalline-granular to aphanitic and fluidal and glassy. Reported from the Great Basin. A chrysolitic variety is one of the rocks that have been called melaphyre.

Hypersthene-andeste. - Eruptive. Like the preceding, but containing hypersthene in place of augite or hornblende. Buffalo Peaks, Col.; Mount Shasta, etc.

Hyperyte (Noryte in part, Hypersthene-gabbro). - Consists chiefly of labradorite or anorthite and hypersthene, with usually some pyroxene, biotite, and magnetite, and sometimes chrysolitic. Occurs west and northwest of Baltimore, $\mathbf{M d}$. ; in the Hartz, Norway, etc.

GabBro. - Eruptive, metamorphic, granitoid. Consisting, like the following, chiefly of labradorite and pyroxene, the latter often a foliaceous (diallagic) variety ; some hornblende often present, also magnetite and ilmenite; sometimes chrysolite, which is often changed to serpentine. Color, dull grayish, flesh-red to brownish and gray. $G=2 \cdot 7-3 \cdot 1$, least when the proportion of pyroxene is small. Quartz-gabbro, containing disseminated quartz, occurs in northeastern Maryland and northern Delaware.

The name gabbro is of Italian origin; but it is used in Italy, as it has long been, for a green serpentine rock. And gabbro-rosso is a red altered variety of the same.

DolerYte (Trap). - Eruptive. Texture varying from granitoid to aphanitic and glassy, scoriaceous and volcanic. Consists of labradorite and pyroxene, the latter sometimes foliaceous. A kind found at Lassens Peak contains much quartz in disseminated grains, and is a quartz-doleryte (Diller). $\quad \mathrm{G}=\mathbf{2} \cdot 8-3 \cdot 1 . \quad$ Color, dark gray to grayish black, greenish black, and brownish to black. Structure frequently columnar, often chrysolitic. Chrysolitic kind sometimes altered to impure serpentine. Ordinary trap often altered to a hydrous, chloritic trap, often also amygdaloidal, with feeble luster and of easy decomposition. Includes three sections: (1) Diabase, containing no glass in the base and no chrysolite. (2) Doleryte, containing glass in the base, but no chrysolite. (3) Basalt, containing usually more or less glass, also chrysolite.

The trap of the Palisades, Connecticut River, and other parts of the Triassic of eastern North America belongs here, and much of that of the copper region of Lake Superior. There is a fine exhibition of columnar trap at Orange, N. J. (Fig. 221, page 262). The name melophyre has sometimes been used for chloritic trap. Diabase-schist is a slaty form of diabase, probably metamorphic.

TACHyLite. - Eruptive. A black basalt-glass, found in connection with basalt lavas.

Camptonyte. - Rock resembling diabase and doleryte. Consisting of hornblende (as an original mineral of the rock) and probably anorthite, the analysis affording only 41 to 44 per cent of silica (Hawes, 1876; Kemp, 1889). From Campton Falls, N.H., and near Whitehall, N.Y.

Eccrite. - Eruptive. A doleryte-like rock, consisting chiefly of anorthite and augite, with sometimes chrysolite. Granitoid to aphanitic, and as a lava. Elfdalen, Norway; Puy de Dome, France; etc.

Corsyte (Orbicular Dioryte). - Eruptive. Consists of anorthite and hornblende, with some quartz and biotite. Contains large concretions consisting of anorthite and hornblende, with some quartz. Corsica; the Shetlands, etc.

Anовтнітүте (Anorthite Rock of Irving). - Eruptive. Crystalline granular. Consists largely of anorthite, or a feldspar near it in composition, and is of a light gray color to white or faintly greenish. North shore of Lake Superior, between Split Rock River and the Great Palisades, and in Carltons Peak, near the mouth of Temperance River.

Nephelinyte (Nepheline-doleryte, Tephryte). - Nephelite and augite, with some 
magnetite. A chrysolitic variety has been called nepheline-busalt. Ash-gray to dark gray. Often contains leucite, haüynite, sanidin, etc. $\Lambda t$ Katzenbückel; Eifel, etc.

Teschenrte. - Consists chiefly of anorthite or labradurite, nephelite, hornblende, and augite. Felsitic in texture. The hornblende sometimes in large black prisms. Dark bluish green. From Teschen, Silesia.

\section{Saussurite Rocks.}

EuPHotide (Gabbro in part). - Grayish white to grayish green or olive green, and very tough. Consists of saussurite, with diallage or smaragdite. $G=2 \cdot 9-3 \cdot 4$. A result of the alteration of a labradorite and pyroxene or other related feldspar-bearing rock, in which the feldspar is changed to the tough aphanitic mineral, saussurite (page 65). Cleavage of the feldspar sometimes retained, and found graduating into this feldspar in some cases. Chrysolite often present; and by its alteration, serpentine is sometimes abundant in connection with it. Occurs near Lake Geneva in Savoy; Mount Genèvre in Dauphiné ; Corsica in the Orezza valley; Isle of Unst, etc.

\section{Rocks without Feldspar.}

\section{Garnet, Epidote, and Tourmaline Rocks.}

GaRnetyte (Garnet Rock). - Metamorphic. Massive, fine-grained. Yellowish or buff to greenish white. Tough. $G=3 \cdot 3-3 \cdot 54$. This rock is the much-used, pale, buffcolored razor stone of Viel Salm, in Belgium, the best of stones for razors. It is a manganesian garnet. It makes layers in a hydromica (sericite) schist. Occurs also as an alumina-lime garnet at St. François and Orford in Canada.

Eclog YTE (Omphacyte). - Metamorphic. Fine-grained, granular. Consists of red garnet in a base of grass-green smaragdite, with occasionally zoisite, actinolite, and mica. Very tough. Also with black or greenish black hornblende and some magnetite.

Erimosrte. - Metamorphic. Compact, and very tough and hard. Pale green to yellowish green. Consists of epidote and quartz. A pale, yellowish variety from the Shickshock Mountains, Gaspé. $\mathrm{H}=7$ and $\mathrm{G}=3-3 \cdot 09$.

Touralayte (Schorl Rock). - Metamorphic. Consists of tourmaline and quartz, with often chlorite and mica. Granular and compact to schistose. Occurs massive in Cornwall, with tin ore; schistose at Eibenstock in Saxony; in Marble Mountains, and Ragged Ridge, Warren County, N. J.

\section{Hornblende, Pyroxene, and Chrysolite Rocks.}

Pyroxenxte. - Eruptive. Consists of black pyroxene. Coarse granular, or fine, sometimes chrysolitic. Cortlandt, N.Y., and Stony Point, on the opposite side of the Hudson.

Picrite. - Eruptive. Consists of chrysolite, with pyroxene or diallage or hypersthene. Blackish green, grayish to brownish red. Often partly changed to serpentine. Graduates into chrysolitic basalt. From the Fichtelgebirge.

Lherzolyte. - Eruptive. Consists of chrysolite, enstatite, whitish pyroxene, chromespinel (picotite), and sometimes garnet. Changed more or less to serpentine. From L. Lherz.

Hornblendye. - Eruptive or metamorphic-eruptive. Consists chiefly of hornblende (which is generally altered augite), with usually chrysolite. Massive or somewhat schistose; coarsely or finely crystalline. Cortlandt and Stony Creek, N.Y.

Hornblende-PICRYte. - Usually or always metamorphic-eruptive. Consists of hornblende (mostly or wholly altered augite) and chrysolite, with magnetite, the chrysolite changed to serpentine; usually more or less pyroxene. Coarse or fine crystalline granular. Greenish black and dark gray. From Anglesey and Carnarvonshire. 
Dunxte, Peridotyte. - Eruptive and metamorphic. Consists almost wholly of chrysolite. Often changed in part or wholly to serpentine. $\mathrm{G}=3.31$. From Mount Dun, New Zealand; Macon County, N.C.

Aмphibolyte. - Metamorphic. Consists chiefly of hornblende, with more or less quartz, and sometimes chlorite. Coarse or fine-grained; hornblende sometimes acicular. Massive or schistose. Graduates often into chlorite schist and mica schist. Actinolyte consists chiefly of green actinolite. Bernardston, Mass., and Vernon, Vt.

Gladcophanite. - Metamorphic. Consists chiefly of the blue soda-bearing hornblende-like mineral glaucophane, with some black mica; sometimes epidotic. From Saxony; Isle of Syra; New Caledonia ; California.

\section{Hydrous Magnesian and Aluminous Rocks.}

Chlorite Schist. - Metamorphic. Schistose. Dark green to grayish green and greenish black. Little greasy to the touch. Consists largely of chlorite, with usually some quartz and feldspar intimately blended. Often contains magnetite in crystals.

Chlorite-argillyte. - Metamorphic. An argillyte-like rock (phyllyte) consisting chiefly of chlorite.

Talcose Schist. - Metamorphic. Schistose. Feels soapy. Consists chiefly of talc. Not common except in local beds, most of the so-called "talcose slate" being hydromica (sericite) schist.

Steatyte (Soapstone). - Metamorphic. Schistose or massive. Consists of talc, often with impurities. Gray to grayish green, white. Easily cut with a knife.

Serpentine. - Metamorphic. Massive. Aphanitic. Easily scratched with a knife. Oil-green, dark green to greenish black; also of pale shades to whitish. Feels a little greasy, especially the powder. This metamorphic rock has been made from various chrysolitic, augitic and hornblendic rocks that were both of eruptive and metamorphic origin.

Ophiolyte (Verd-antique). - Metamorphic. Limestone or marble colored with or containing disseminated serpentine; clouded or spotted with green. West of New Haven, Coun.; Port Henry, Essex County, N.Y.

Pyrophyluxte Schist. - Schistose or massive. Microcrystalline or aphanitic. Feels soapy and looks like a whitish or greenish steatyte, but consists of the hydrous aluminous mineral, pyrophyllite, whose atomic or oxygen ratio is the same as that of the hydrous magnesian mineral, talc. Deep River region, N.C.

\section{TERRANES : THEIR CONSTITUTION, CHARACTERISTICS, POSITIONS, AND ARRANGEMENT.}

More than nine tenths of the rocks of the earth's surface are fragmental in origin. From the time of the first existence of an ocean, the formation of fragmental deposits, through the grinding action of waves and currents, fresh-water streams and winds, aided by the natural decay of the rocks. has gone forward wherever there were rocks exposed to this action. Thus beds of sand, gravel, mud, or clay - that is, fragmental deposits - have been forming, when the conditions favored, through all the geological ages. And those of ancient sea-borders, rivers, valleys, lakes, and plains are like the modern in all respects, even to the frequent ripple-marks over the surface of beds, and the occasional footprints of animals. Whererer igneous ejections have filled the air with volcanic sand or ashes for the winds to drift away, this sand has added to the material of fragmental deposits. Wherever there was nothing for the moving waters to grind up except shells. 
corals, and other calcareous relics of living species, these relics of the seas have been ground up, as now in coral and shell-growing seas, and made into limestones; for limestones are for the most part fragmental rocks.

The metamorphic crystalline rocks, as already stated, are only fragmental rocks metamorphosed or erystallized. The alteration in some mountainmaking epochs has changed fragmental formations thousands of feet in thickness over many thousands of square miles in area. The borders of such areas are usually less altered than the interior portions; and hence in many places the transition may be passed over, in the course of a score or two of miles, from the simply solidified strata of the outskirts and the faintly crystalline slates and limestone, to the thoroughly crystalline mica schist, gneiss, and marble; and sometimes to granite in masses or veins as an extreme effect.

Chemical deposits, or deposits from solution in fresh or salt waters, have added sparingly to the stratified series, and the outflows of igneous rocks from fissures or volcanic rents have made other large additions. Part of such ejections go to make independent conical mountains; but the larger part are in successive sheets interstratified or overlying other formations.

Of these materials, all are of superficial origin excepting the igneous; these are contributions to the surface from the earth's interior.

Besides stratified terranes, there are also vertical or obliquely placed sheets of rock cutting across the former. They are the fillings of opened cracks or fissures made across the terranes, and comprise dikes and veins. They have great geological and economical importance because of the gems and ores which veins and dikes have made accessible to man, and because dikes are the inferior portions of great igneous outflows, and reveal something as to the earth's interior. But they are of small extent compared with the stratified terranes, and will be considered under Dynamical Geology.

Formations. - From the explanations that have been given it is apparent that any group in the series of stratified rocks, whether large or small, may be called a formation, if the parts are related in period or time of origin; as, for example, the Devonian formation, or those of the Devonian era; the Chemung formation, or those of the Chemung period under the Devonian; and so on. The term is also used for a group of rocks of similar constitution; as a calcareous formation, a siliceous formation, etc. The term terrane (from the Latin terra, earth, and the French terrain) has essentially the same signification as formation. Formation is commonly used for stratified terranes.

\section{Stratified Formations.}

\section{Structure and Characteristics.}

The series of stratified formations over the globe has a maximum thickness of about 30 miles. But the existing thickness in any one place is seldom even 10 miles. Since rocks are mostly water-made, and for the larger part originated in oceanic waters of moderate depth, wherever any 
region has remained for ages as permanent dry land, without interior seas, little or no deposits have been made over the surface; and the little has come through the winds or rains or igneous ejections. So, also, where the deep oceans have been located, the deposits have been relatively thin. The earth's coat of stratified material is hence a very irregular and ragged one.

In the description of a formation, the term stratum (from the Latin for bed, stratc in the plural) is used for each section of the formation that consists throughout of approximately the same kind of rock-material. Thus if shale, sandstone, and limestone succeed one another in thick masses, each is an independent stratum. A stratum may consist of an indefinite number of beds, and a bed, of numberless layers. But the distinction of layer and bed is not always obvious.

The series of formations in the earth's structure is divided into series, groups, sub-groups, and stages, according as breaks in the history of higher and lower grade may require. The series are the grander divisions; e.g., the Devonian series, the Carboniferous series. The study of the succession of strata or of beds in the rocks of a region, in order to ascertain their original order and the characteristics of the beds, is a stratical or stratigraphical ${ }^{1}$ investigation. The following are some illustrations:-

Fig. 59 represents a section of the strata as exhibited along Genesee River, at the falls near Rochester. The height of the section is 400 feet. (1) The stratum at bottom is sandstone; next above it (2) lies a hard, gray stratum, which has been called the Gray Band. On this rests (3) a thick stratum of greenish shale, fragile and imperfectly slaty; and (4) a compact limestone. Above this (5) is another greenish shale, much like that below; then (6) another great stratum of limestone; (7) another thicker stratum of

59.

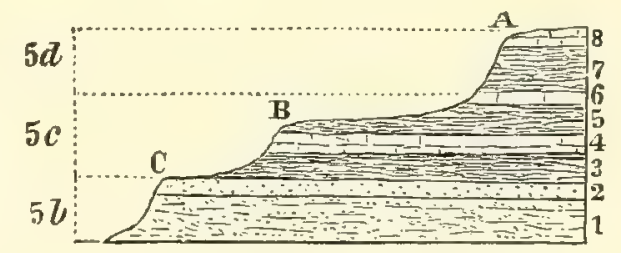
shale; and, finally (8), at the top, is limestone wholly different from those below. The transition from one stratum to another is quite abrupt; and, moreover, each may be traced for a great distance through the adjoining country. It must be here remembered that these transitions in the rocks indicate extended changes in the conditions of the rock-making seas; that when a pure limestone was in progress, the sea was free from currents bringing in mud or sediment; when making shale, the currents carried in fine sediment; when sand, a coarser sediment; so that alternations in depth, limits, and exposure to waves and currents, or not, through the successive periods, were the source of the alternations in the strata.

The succession of strata in stratified rocks is exceedingly various. In other sections, as at Trenton Falls, N.Y., there are only limestones in sight; but, were the rocks in view to a much greater depth, sandstone would be seen. In still other regions, there are alternations of conglomerates and

1 The latter adjective is a mongrel word, half Latin and half Greek; but it has probably been too long used to be displaced. 
shales; or conglomerates with shales and coal-beds; or conglomerates with limestones and sandstones; or shales and sandstones alone.

The thickness of each stratum also varies much, being but a few feet in some cases, and hundreds of feet in others; and the same stratum may change in a few miles from 100 feet to 10 , or disappear altogether, or change from one of shale, or of limestone, to one of sandstone, and so on. In the Coal-formation of Nova Scotia there are 15,000 feet of stratified beds, consisting of a series of strata mainly of sandstones, shales, and conglomerates, with some beds of coal; and in the Coal-formation of Penmsylvania there are 6000 to 7000 feet of a similar character.

In many cases a bed of limestone thins out at short intervals, and is thus in isolated pieces, 100 to 1000 feet, or more, long, called lenticular masses,

60.

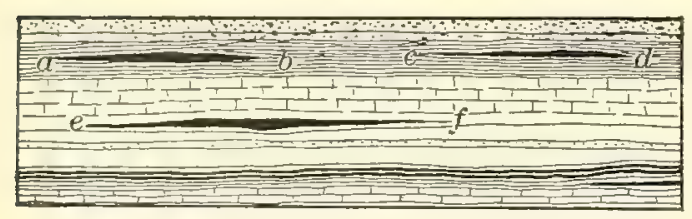
shale or sandstone occupying the interval. This results from the varying conditions in the seas in which the beds were made, some portions being favorable for the animals that make shells and other calcareous materials from which limestones are formed, when the larger part is unfavorable. Such lenticular masses ( $a b, c d$, ef, Fig. 60) may consist of iron-ore, such ores being often deposited locally in marshes or shallow basins, on sea-borders, as well as in interior ponds or shallow lakes.

A seam is a thin layer intercalated between layers and differing from them in composition. Thus, there are seams of coal, of quartz, of iron-ore. Seams become beds, or are so called, when they are of considerable thickness; as, for example, coal-beds. Such seams are sometimes popularly, but wrongly, called veins.

The beds or layers of rock may be (1) massive, that is, of great thickness without division into subordinate layers; or (2) thick-ledded, or (3) thinbedded, or (4) laminated, or (5) shaly. The flagging-stone, much used in Eastern cities of this country, is a good example of a laminated sandstone. Such a variety of sandstone is often called flags.

(6) Straticulate structure is one made up of very thin and even layers, separable or not, as a bed of slate, a bed of clay in a river-ralley, stalagmite, and agate. It is often called a banded structure.

(7) Slaty structure is much like shaly, and frequently a shale is called a slate. But the shale is straticulated parallel to the planes of deposition, and the structure is due more or less to the pressure of the overlying material; while slate (roofing-slate) has much more even layers, with a smoother surface, and has derived the slaty structure from lateral pressure, as explained beyond (page 112).

(8) A cross-bedded structure characterizes a layer when it is obliquely laminated, as in three of the layers in Fig. 61. Such layers generally alternate with horizontally bedded layers. This style of bedding is made by a strong movement of a current over a sandy bottom, as in the move- 
ment of the tidal waters out of an estuary or of a stream over a sand-bed. It has been called current-bedding. 'T'he water, as it moves on, pushes up some of the sand before it, and then keeps depositing the sand over the front slope of the little elevation so made, producing on the slope a series of thin layers pitching at an angle usually of $20^{\circ}$ to $35^{\circ}$ in the direction of the flow. During a time of quiet following, as the ebb of the tide, slower deposition may make a layer that is horizontal in bedding; and thus the cross-bedded layer is often made to alternate with the

61.

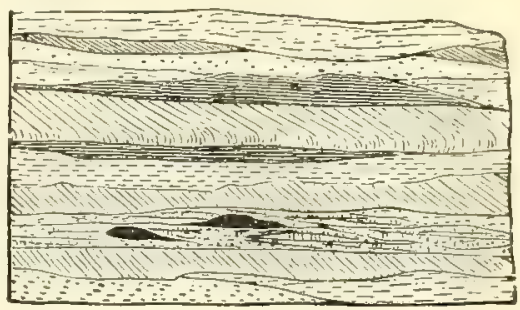
horizontal.

(9) In the flow-and-plunge structure the cross-bedded layer is broken up into curving wave-like parts, as shown in Fig. 62. This effect is produced when there is a wave-like plunging action in the rapidly flowing waters and a large supply of sand or fine gravel for deposition. One of the wave-like

62.

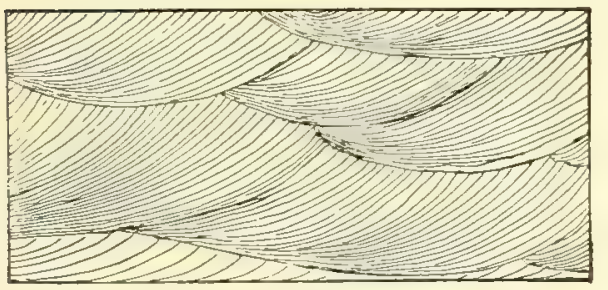
parts in such a layer is usually a yard or more long and six inches to a foot thick; and may be much smaller, as well as very much larger. In one place in the stratified drift near New Haven, Conn., the thickness was six to eight feet. The whole thickness, in all cases, was produced by one fling of the waters.

By studying the structure of layers, we are enabled to determine the conditions under which rock-formations were made; and hence the facts have great interest to the geologist

(10) The beach-structure is another of like interest, indicating a beach origin. The upper part of a beach, above high-tide level, is made by the toss of the waves, and especially in storms; and it is generally irregularly bedded. But the lower part, swept by the tide, has usually an even seaward slope; and the beach deposits over it have therefore a corresponding inclination - usually $5^{\circ}$ to $8^{\circ}$ when the tides are low, but $15^{\circ}$ to $18^{\circ}$ when high. When the sands are coral or shell sands, they become cemented into a calcareous sand-rock, and show well the straticulation.

(11) The wind-drift structure is of very different character. It is made up of straticulate portions, in different positions, oblique to one another, as in Fig. 63. A ridge of sand made by the drifting winds on a coast becomes straticulate parallel to its upper surface, because the deposition by the winds is necessarily over the surface. But if such a ridge has its upper half shaved off obliquely in a heavy storm,

63.

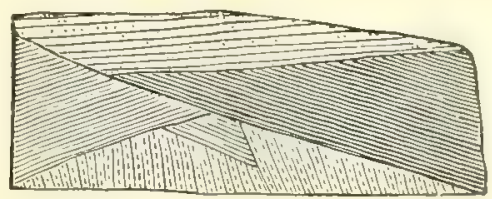
cleposition will afterward go on parallel to the new surface, and hence at an angle with the earlier layers. By repetitions of such events the wind-drift 
structure is produced. It characterizes part of the "Pictured Rocks" of the south shore of Lake Superior (Foster and Whitney's Report, from which the above figure was taken), and shows that the beds were not mide in deep waters, but above the sea level by the drifting winds, like the driftsand ridges of a windward coast.

(12) The mud-crachs made over a drying mud-flat are often preserved in the rocks (Figs. $6 t$ and 65), and prove the mud-flat origin of the bed. Such cracks are necessarily shallow, as they are limited by the depth of the mud. The cracks become filled by the sediment after a return of the waters,

64.

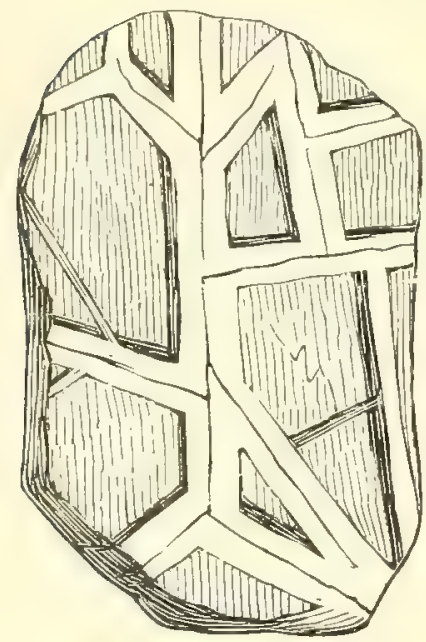

65 .

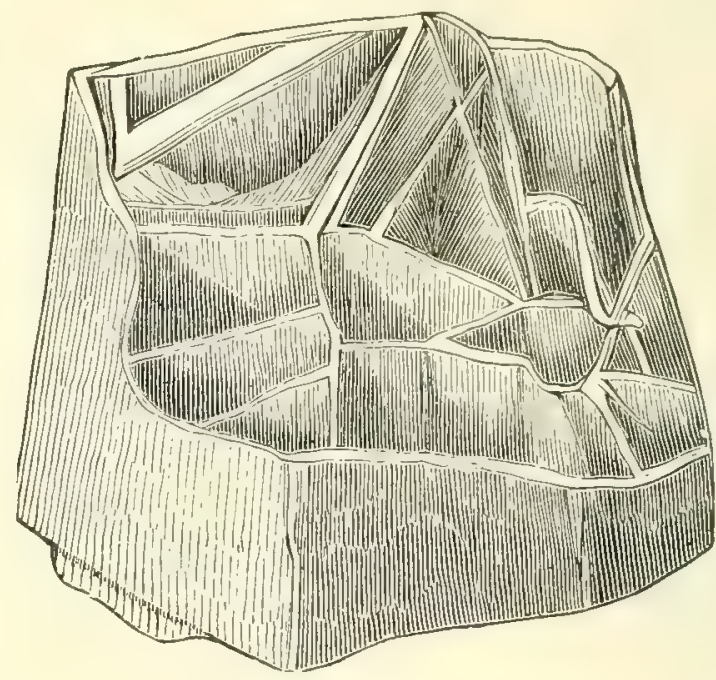

Mud-cracks. D. '49.

and into this filling a cementing solution may pass from above. If the solution is siliceous, the filling becomes harder than the rock either side, so that when worn, the surface is one of prominent intersecting ridgelets, as in the figures. Moreover, these ridges are generally double, the filling having solidified against either wall of the crack until the two sides met at the center, and became more or less perfectly united. Layers having such filledup mud-cracks are very common in stratified rocks.

(13) Ripple-marks (Fig. 66), a series of wavy ridgelets, precisely like the ripples on a sand-beach, are also common in many sandstones, the oldest as well as the latest, and are often indications of sand-flat origin, - like the sand-flats off many seashores or in bays, though not necessarily so, since ripples may form over the bottom as far down as oscillation in the water extends, which may be a hundred yards or more; and they are also formed by the winds over surfaces of loose sand.

(14) Wave-marks are faint outlinings on a bed of sandstone, like the outline left by a wave along the limit where it dies out upon a beach, marking the outline of a very thin deposit of sand. They have the same kind of significance as ripple-marks, but are surer evidence that the beds are of beach origin. 
(15) Rill-marks (Fig. 67) are still clearer evidence of a beach-made deposit; they are the little furrowings made by the rills that flow down a beach as the waters of a wave or tide retreat, and which become apparent especially where a pebble or shell lies, the rising of the water upon the

66.

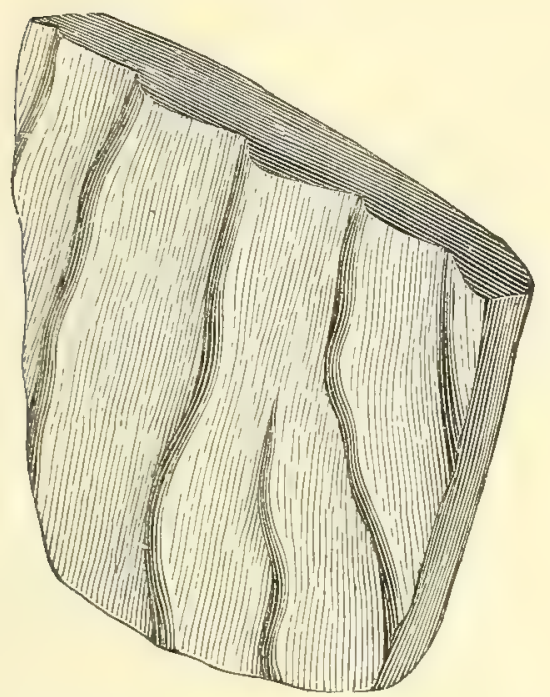

67.

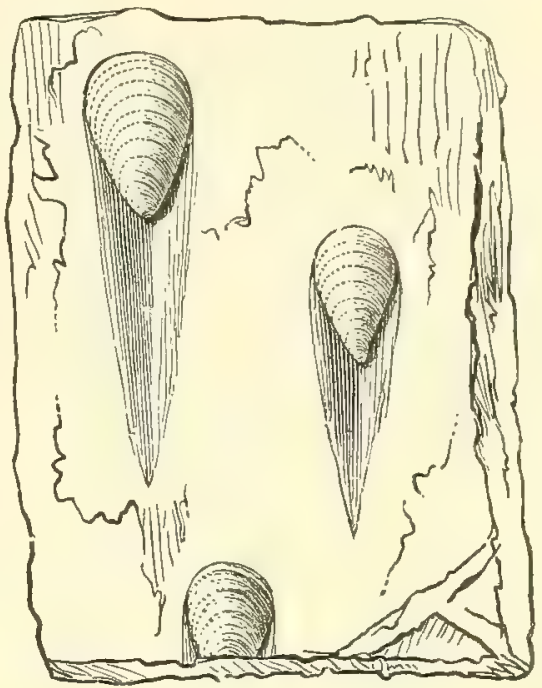

pebble causing a little plunge over it and a slight gullying of the surface for a short distance below. The figure is from a slab of thinly laminated sandstone of the Medina formation, New York, as described and figured by James Hall.

(16) Rain-prints or rain-drop impressions are indications, like mudcracks, of exposure above the water level at low tide, or at least a low stage of the waters, when the bed of rock containing them was yet loose mud or sand. A slab three by eight feet in size, now in the Yale College cabinet (from Greenfield, Mass.), is covered throughout with such impressions; and as the impressions are slightly oblong and oblique, they bear evidence of the direction of the wind at the time of the short brisk shower. The slab is crossed by a line of footprints showing that an animal of long stride (probably a Dinosaur) walked over the mud-flat just before the shower; for there are rain-prints in the tracks. This is an example of the geoglyphics from which the geologist derives facts for geological history. Another lesson, too, comes from the rain-prints, for they show that it rained millions of years since.

(17) Other markings observed at Greenfield, Portland, and other places in the Connecticut valley, are scratches and groovings made apparently by a floating $l o g$, one end or branch of which dragged in the mud.

68.

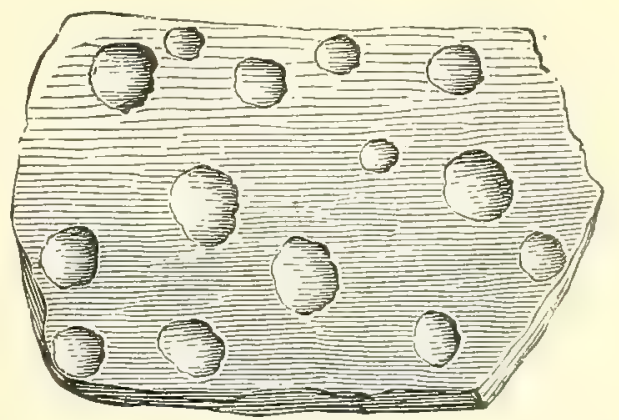

Others found there and elsewhere are the trails of Worms, and tracks of Insects, Crustaceans, Reptiles, and other animals, all of which give instruction in many ways. 
(18) Scratches (striæ) or furows or polished surfuces sometimes cover rocks, which have been produced by abrasion attending movements. They often cover the walls of tissures, and sometimes the surfaces of beds of rock; and in such cases they are called by the miners' term, slickensides. 'They occur also over the rocky surfice of a country as a result of past or recent glacier flows; and such are called simply glacier scratches or striæ. This subject is further explained under Dynamical Geology.

(19) Concentric structure. - In concentric structure there is an aggregation of matter around a center, making, usually, spheres or flattened spheroids, as in Figs. 69-83. The form is usually dependent on growth by deposition from a solution around a center, so that the growth is outward, or centrifugal. In ordinary concretions it is growth by accretion, and it sometimes produces a series of distinct concentric layers. The forms are

69-80.
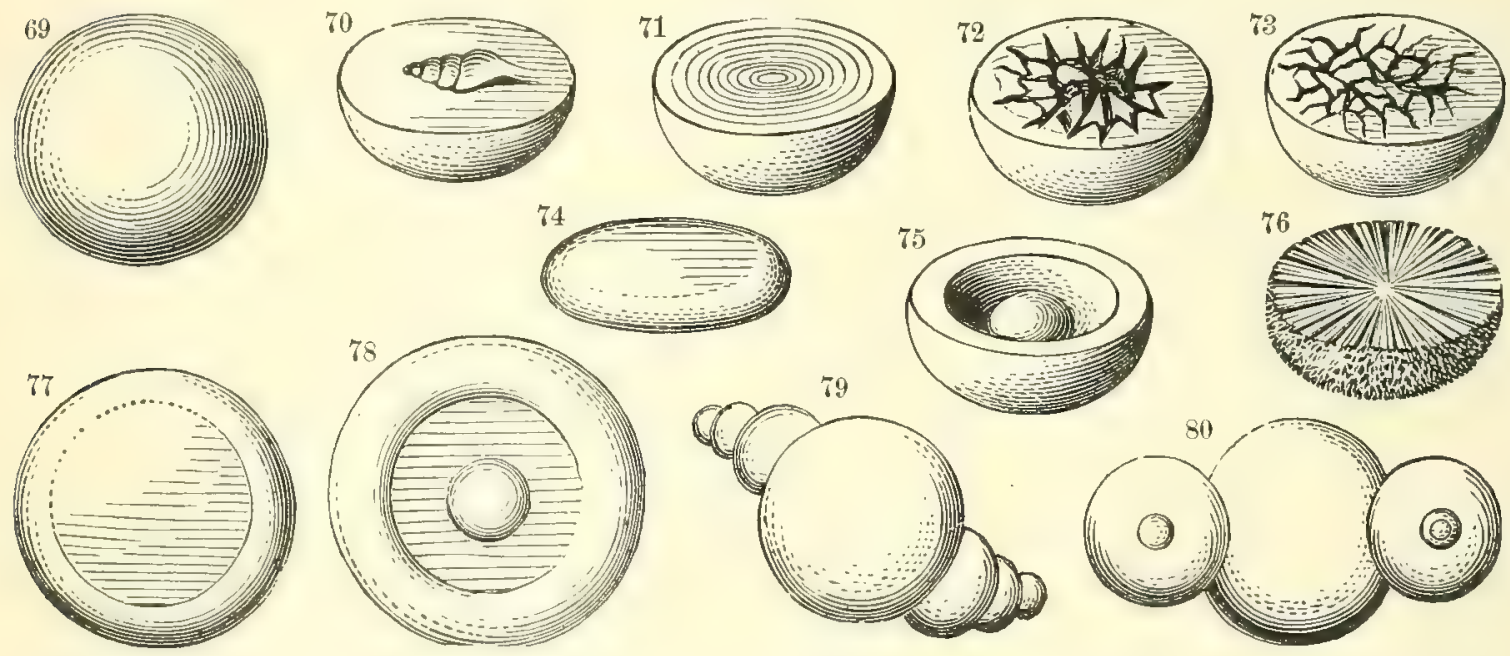

spherical (Fig. 69); more frequently flattened spheroids (Figs. 74, 83); and very frequently aggregations of coneretions that are symmetrical in arrangement (Figs. 79, 80). Concentric layers are shown in Figs. 71 and 81. At the center there may be, as a nucleus, a shell (Fig. 70), or a spider, or insect, or leaf, or merely a grain of sand undistinguishable by the unaided eye. They often form as the first step in the process of consolidation, and make a rock consisting of concretions which may disappear when the consolidation is complete. Some layers may have spherical concretions, and another above and below flattened (Fig. 82), those beds in which filtrating waters spread with equal facility in all directions having spherical, and those of a laminated structure, in which the waters spread laterally most easily, having spheroidal or flattened kinds. They are sometimes hollow rings, or contain a ball within (Figs. 77, 78).

The kind represented in Fig. 81, in which the concretions are about as large as peas, is called pisolite, from the Latin for pea. A similar kind, having the spheres about as large as the roe of fish, but not often with concentric layers, is the rock oölyte. Colyte is now forming on the Florida 
banks, and is common among the old limestones of the world. Calcareous concretions are most common. Those of pyrite, limestone, and quartz are also common; and many other minerals take the concretionary form. Nodules of flint or chert in rocks are often concretions, and frequently have a fossil as a center.

81.

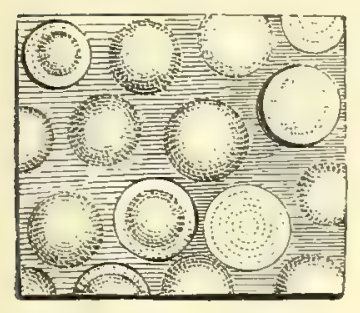

82.

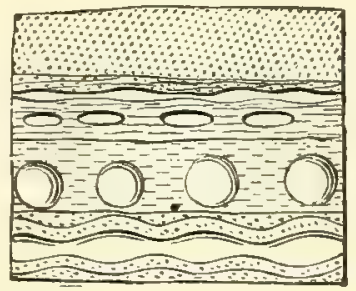

83.

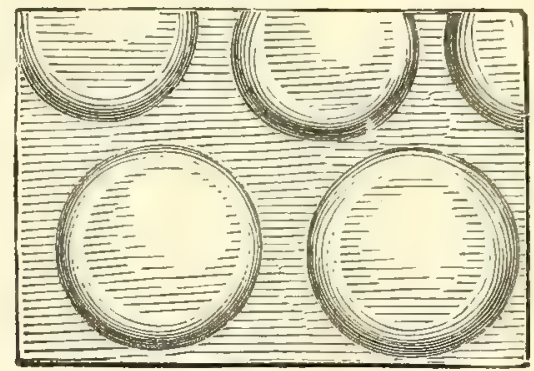

The consolidation of a concretion is sometimes followed by further drying from the outside inward, and in this process the interior often becomes much cracked, as in Figs. 72, 73; and the cracks may be afterward filled with calcite or some other material, and make septaria, the name alluding to the division or septation of the interior. These septaria concretions occur at times in very large flattened forms, even one to three feet in diameter, when they are sometimes popularly called petrified turtles, from the resemblance to the back of a turtle in the divisions; the more beautiful kinds are often sawn into circular slabs and polished for table-tops.

Solidification from fusion often produces concretions in the mass which sometimes consist of more or less distinct concentric layers of different minerals, or, it may be, of a single mineral. Fig. 84 illustrates this structure in a granite-like rock, the "orbicular dioryte" of Corsica. The puddinggranite of Craftsbury, Vt., contains large black, ovoidal concretions, consisting chiefly of black mica.

Concretions are also made by growth radially from a center, but this kind is of inferior geological importance. The process makes attached spheres and hemispheres, radiately fibrous or columnar within. An example - in a reversed position, in order to exhibit the interior structure - is shown in Fig. 76.

Spheres and irregular spheroids or balls in rocks, when hollow within and lined with crystals, are not concretions, but instead geodes; and any eavity so lined, whatever the shape, takes this name. Geodes are often quite large, as in the Keokuk limestone of Iowa and Illinois, where they have been supposed to occupy

84.

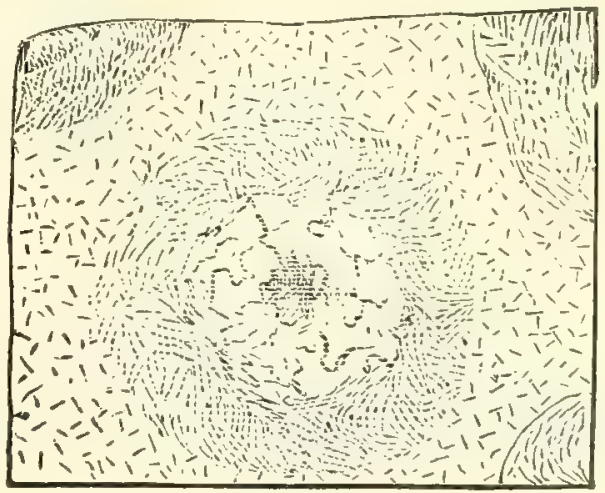
the centers of sponges that were at some time hollowed out by siliceous solutions, like the hollowed corals of Florida, and then lined with crystals 
by deposition from the same or some other mineral solution. Geodes are common in veins of ore, and also occupying the cavities of amygdaloids.

The concentric structure is produced also by consolidution frogressing inward from the exterior - a centripetal process. Sipheroidal masses of sand, often of oblong-spheroidal, as well as other shapes, colored deeply with iron oxide, are often hard outside, and have mere loose sand within; or they have one or more concentric layers of ferruginous color within, or a series of concentric shells of sand, and sometimes also a loose ball, as in Fig. 75 .

A concentric structure is produced also by decomposition along fractureplanes, when these divide a rock into small portions (as explained on page 127), and also by alternate heating and cooling (page 337).

\section{Original Positions of Strata.}

Strata in their original positions are commonly horizontal, or nearly so. The level plains of alluvium and the extensive delta and estuary flats show the tendency in water to make its depositions in nearly horizontal planes. The deposits formed over soundings along seacoasts are other results of sea action; and here the beds vary but little from horizontality. Off the coast of New Jersey, for 80 miles out, the slope of the bottom averages only 1 foot in 700 , - which no eye could distinguish from a perfect level. Over a considerable part of New York and the States west and southwest, and in many other regions of the globe, the strata are actually nearly horizontal at the present time. In the Coal-formation, the strata of which have a thickness, as has been stated, of 5000 to 15,000 feet, there is direct proof that the beds were horizontal when formed; for in many of the layers there are fossil trees or stumps standing in the position of growth, and some-

85.

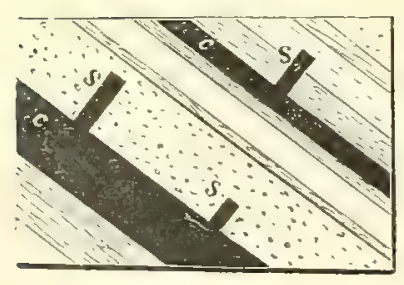
times several of these rising from the same layer. Fig. 85 represents these tilted coal-beds $c$, $c$, with the stumps $s, s, s$. Since these trees must have grown in a vertical position, like all others, and as now they are actually at right angles to the layers, and parallel to one another, they prove that the beds originally were horizontal. The position of shell aceumulations and coral reefs in modern seas shows, further, that all limestone strata must have been nearly or quite horizontal when they were in the process of formation.

Variations from horizontality. - (1) Some variation from horizontality may be produced by the slope of the sea-bottom in certain cases; and in lakes, off the mouths of rivers (Fig. 86), quite a considerable inclination may result from the fact that the succes86. sive layers derived from the inflowing waters take the slope of the bottom on which they fall. 
(2) The depositions of a mountain stream where it abruptly reaches a plain make a broad low cone, stratified parallel to its surface, called an "alluvial cone." See page 194, under Rivers. Such fresh-water accumulations have thus far been found only among recent formations.

(3) The deposits of sand constituting a sea-beach, as stated on page 93, take the slope of the beach, which may vary from $3^{\circ}$ and less to $18^{\circ}$; and they have distinct bedding parallel to the sloping surface.

These cases of an inclined position are relatively of limited extent. They do not affect the truth of the general proposition that the original position of the earth's great stratified rocks is essentially horizontal.

(4) Another example of inclined stratification is affordeg by the volcanic mountains of the globe, whose lava-streams usually have a pitch between $3^{\circ}$ and $20^{\circ}$, but may have a less or a much greater pitch. In the volcanic mountain the stratification is pericentric, more completely so than in the alluvial cone.

\section{Fractured and Displaced Strata.}

Strata, however continuous and horizontal when first formed, are, at the present time, more or less divided up by planes of fracture, and sometimes profoundly so. In general, also, they have lost their original horizontality, and instead the beds have a pitch, small or large, sometimes rising to verticality or even beyond. In many mountain regions the strata are in great flexures, each flexure miles in sweep. Further, fractured and flexed strata have often been displaced along a fracture, either upward or downward, in some cases a few inches, in others miles, the rocks on one side of the plane of fracture being dropped down or shoved up to this extent. In addition, all regions, especially mountain regions, have lost a vast amount of rock through the long-continued wear of flowing waters, which has reduced flexures to ledges and level surfaces, concealing displacements and disguising greatly the original features of a region.

The following are explanations of terms used in describing upturned and displaced rocks : -

An outcrop is a projecting ledge of rock (Fig. 87).
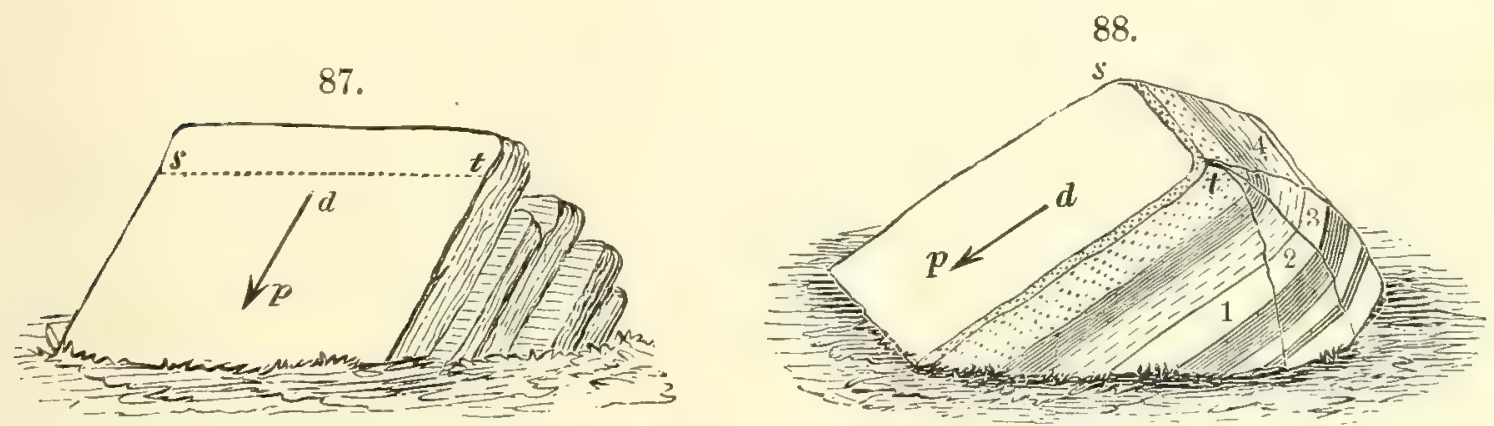

The dip is the angle which the beds make with a horizontal surface; and its direction is down the sloping surface, in the direction in which the angle is greatest - $d p$ in Figs. 87 and 88 . The inclination of a sloping bed or of a wall 
is in the opposite direction from the dip. The strike is the horizontal direction, st (Fig. 87), at right angles to the dip. The direction of strike is ascertained

89.

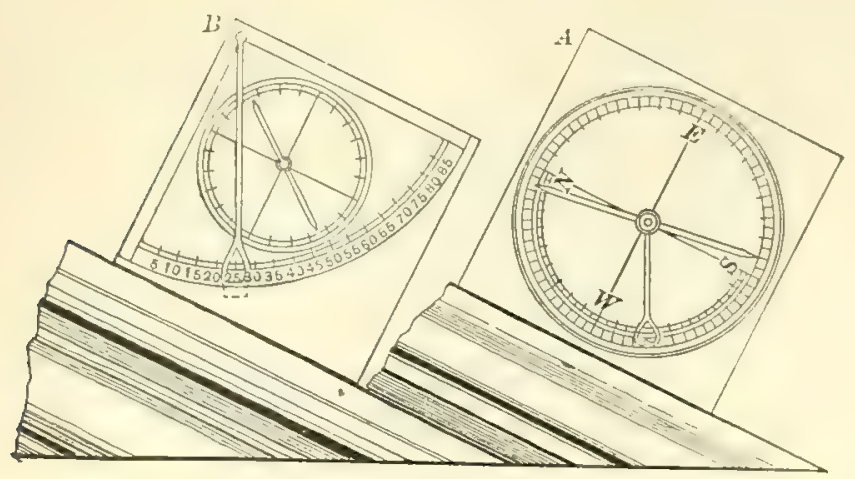

by means of a compass; and the angle of dip by a clinometer.

A clinometer-compass is a compass in which the movement of a plummet measures the angle of dip, the degrees being marked on a graduated are, as shown in Fig. 89. The compass in its best form has a square base, with one side of the square parallel to the N.-S. line, so that the side may be used in place of the line, or the instrument may be applied by one side to the rock, or used in sighting distant slopes.

The edges of outcropping layers give the true dip only when the section affording them has the direction of the dip, as those on the right side of Fig. 87, or those of the side 1 in Fig. 88 ; but those of sides (or sections) 2 and 3 in the latter figure vary in direction from the dip; and those of 4 have no dip, but are horizontal, and have therefore the direction of the strike.

In the best clinometer-compass the square base is about 3 inches in diameter. A clinometer (Fig. 89 B) is easily made out of a block of hard wood, 3 to $3 \frac{1}{2}$ inches square, and half an inch thick. A small compass may be set into the same block, with its N.-S. line parallel to one side of the block, as in the figure, making the instrument serviceable for taking directions of strike or dip, though too small for good compass work.

In making observations, first take the strike, and in recording it refer it to the north point; e.g. N. $20^{\circ} \mathrm{E}$. (if that be the direction), never S. $20^{\circ} \mathrm{W}$.; only the direction of glacial scratches should be referred to the south point. Next note whether the dip is easterly or westerly, and measure the amount; if $50^{\circ}$ easterly, then it is $50^{\circ}$ in the direction S. $70^{\circ}$ E., this course being at right angles to the strike. The entry "strike N. $20^{\circ} \mathrm{E}$., dip $50^{\circ}$ E." includes the whole. To obtain the true strike, the edge of the laminated rock selected for the measurement must be perfectly horizontal; if there is none such in an outcrop, draw a horizontal line on one of the beds. The error from a variation from horizontality increases as the dip decreases, and becomes null only when the dip is vertical.

In taking the strike, the side of the square compass parallel to its N.-S. line should be used; and it is better to apply it to a piece of board laid over the rock than to the rock itself. But it is not necessary to put it on the rock; it is generally best to make the observation standing, with the N.-S. side of the compass between the eye and the outcropping edge. The same method may be used also in taking the dip; and if the observer is in the line of strike, he can thus take the dip even when the ledge is rods distant. The slope also of a mountain on the horizon can be obtained with a clinometer in the same way.

Before making a measurement, it must be ascertained that the outcrop is not that of a bowlder, or of layers displaced by the growing roots of trees; and that the particular locality will give a mean, not a local, result. Perfectly uniform strikes or dips for a distance of a hundred yards are not generally to be expected, - a fact that will trouble the young geologist in his first field observations.

When, among the exposed sections at a place, none is at right angles to the strike, 
the dip may be obtained thus : take the dip and the direction along two of the sections; then, from a point, $\mathrm{A}$, draw two straight lines, $\mathrm{AB}, \mathrm{AC}$, in the, directions of the observed dips, and set off, on each, lengths proportional to the cotangent of its own dip, $\mathrm{A} b, \mathrm{Ac}$; then, a line through $b, c$ will have the direction of the strike, and a perpendicular to it, that of the dip.

In studying a region of rocks it is important that the dip and strike should be obtained at all outcrops, and noted down on a map. For the latter, the best mode is to use a symbol like the letter $\mathbf{T}$, giving the top the direction of the strike and the stem that of the dip; and the different angles of dip may be approximately indicated by variations in

90.

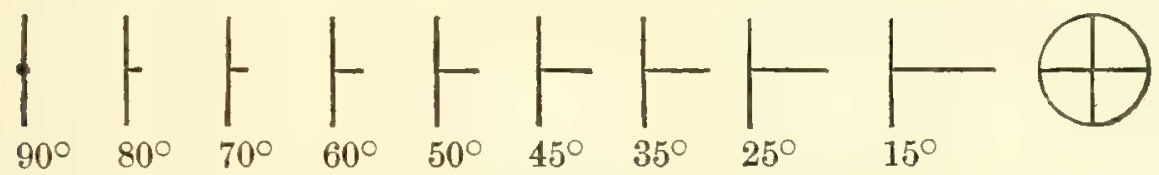

the length of the stem of the $\mathbf{T}$, as in the annexed figure, in which the ratio of the stem to half the top of the $\mathbf{T}$ is for $80^{\circ}=1: 4$; for $70^{\circ}, 1: 3$; for $60^{\circ}, 1: 2$; for $50^{\circ}, 1: 1 \frac{1}{3}$; for $45^{\circ}, 1: 1$; for $35^{\circ}, 1 \frac{1}{4}: 1$; for $25^{\circ}, 1 \frac{1}{2}: 1$; for $15^{\circ}, 2: 1$; and for horizontality, a crossed circle.

Flexures. - Some of the forms of flexures are illustrated in the following figures. Such flexures, while often very small, may be several thousands of feet in height, and many are miles in span. The following are a few of the forms. The slopes either side of the center are seldom equal. In 4, Fig. 91, $A a$ is the axis of the flexure, and in both of those to the right

91.
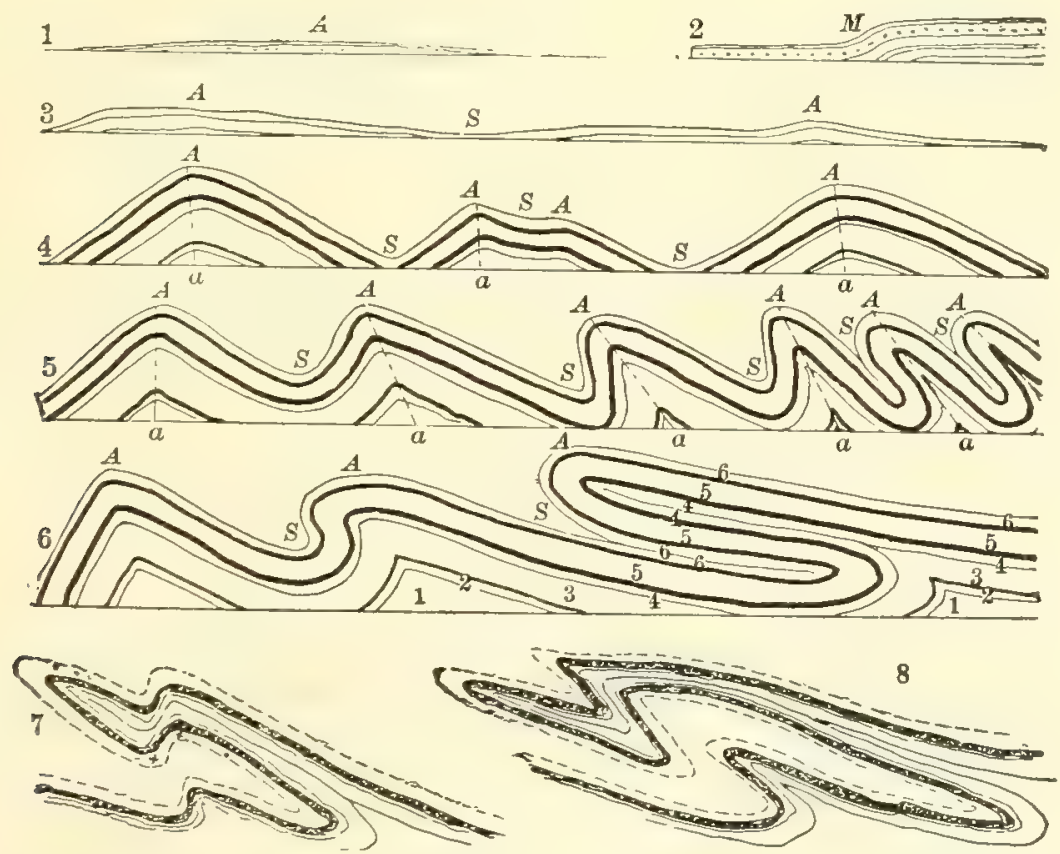

this axis of symmetry is inclined; and in 5 and 6 , still more inclined; while in 7,8 (from the Alps) other complexities are represented. Flexures like those in the right half of 5 and in 6 are called overthrust flexures, the flexing being due to pressure from the right. Supposing the pressure 
to have come from the left, they would be underthrust flexures, - a kind that is exemplified in some sections of the Alps, but is not common like the overthrust.

Flexures are either anticlines or synclines. Upward and downward bends alternate, as the figures show; the upward, lettered $\mathrm{A}$, are anticlines, -

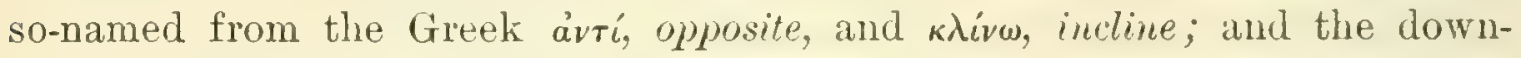
ward, are synclines - from oív, together, and $\kappa \lambda i v \omega$. When strata have been pushed up so as to dip only in one direction, the structure is called mono-

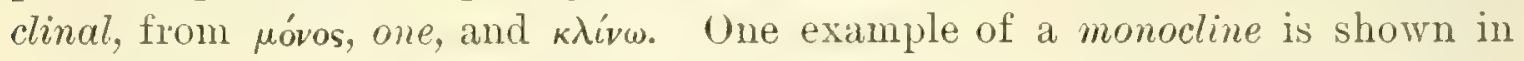
Fig. 91 (2). The beds in Fig. 96, on page 104, have a monoclinal position, but they may be either those of a monocline or of anticlines and synclines, as explained beyond.

As the following figures of actual sections indicate, flexures are not found in nature with their original forms, owing to the wear such regions have always undergone. Fig. 92, by Rogers, represents a section six miles

92.

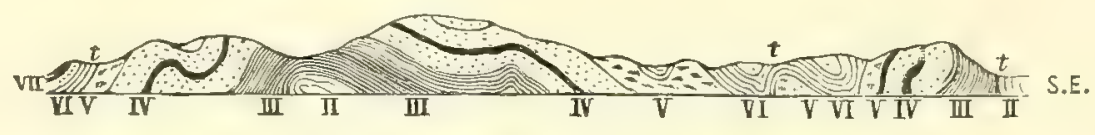

Appalachian section, Virginia. Rogers, '42.

long, from the Appalachians in Virginia. The strata are numbered, so that the flexures of a given stratum may be followed; thus III bends over II, to the left of the middle of the figure, and the right portion descends to come up again in III at the right end of the figure; again, IV, to the left, rises and bends over III and II, though disjoined about the top of the fold by denudation.

Fig. 93 represents a section from the Swiss side of the central Alps. To the right, the strata, 1 to 6 , are so flexed over that the newest stratum 6 is beneath 4, 3, 2, 1, with 1, the oldest, at top. The dotted lines help in tracing out the flexures. Other sections from the Appalachians, the Alps, and other regions, are given under the subject of Mountain-making (pages 355-360).

93.

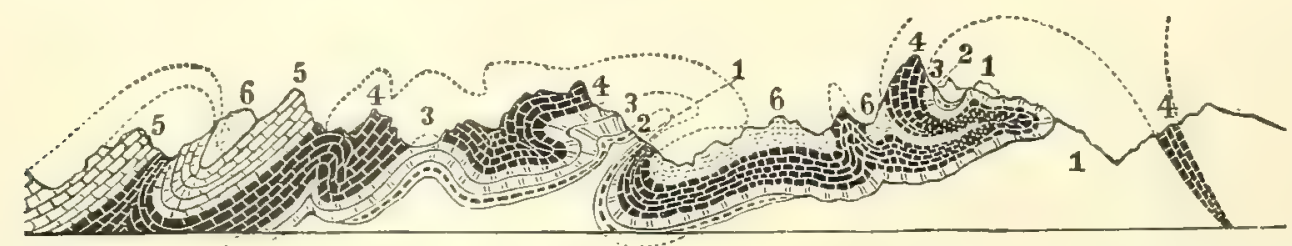

Section east of Lucerne, extending south, $15 \mathrm{~m}$., through Windgälle (4, to the right), a peak 10,455 feet high ; 1, Gneiss; 2, Triassic beds; 3, Lias; 4, Jurassic, above the Lias; 5 , Cretaceous; 6, Eocene Tertiary, including Nummulitic beds. Heim.

Besides the apparent irregularities introduced into a region of flexures by denudation, there are others still greater arising from fractures and faults (displacements). Overthrust flexures very commonly become broken 
and faulted in the direction of the thrust, and the beds become stretched and thinned in the process, as explained beyond.

In Fig. 94, which represents a surface only six feet square, the synclines and anticlines are a few feet only in span; moreover, as is seen, the little anticlines have still smaller anticlines and synclines subordinate to them; so that the 94 . figure represents compound flexures. But these small Hexures at the locality are subordinate to the great flexures of the region, which are thousands of feet in span, so that they are portions of a doubly-compound system of flexures.

Since flexures are greatly disguised, as explained above, so that the kind is seldom indicated in the exterior form, their nature

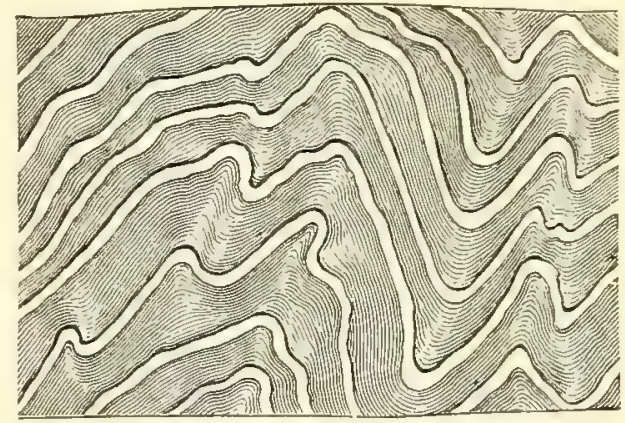
has to be learned from the dip and other characters of the associated beds. A portion of a flexure may be mistaken for a monocline unless the region is well studied.

Fig. 95 represents the rocks with their true dip along 4 parallel sections across a country, the blocked areas being limestone and the others mica schist. They show what may be the actual appearance of a region of folded rocks after it is worn down to a nearly level surface. All that is visible over the region is the upper surface and enough below it to give the true dip; and from these facts and the study of the characters

95.
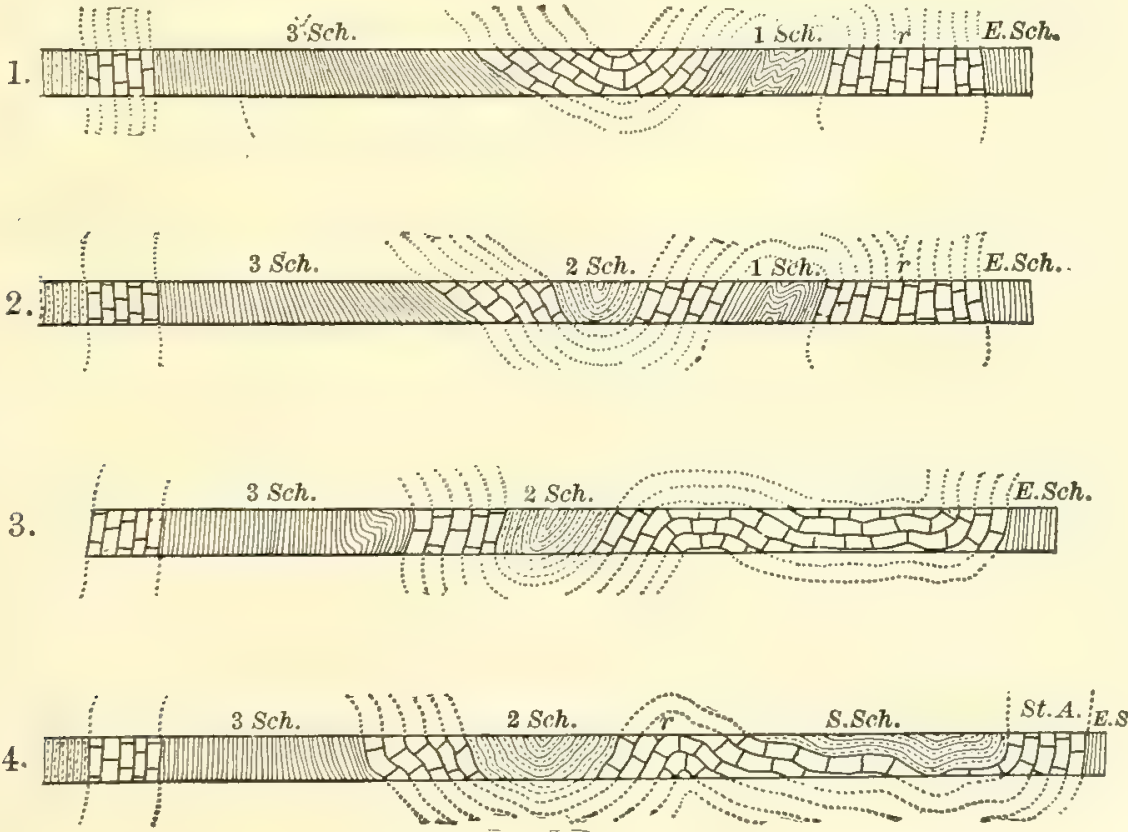

Flexures in limestone and schist, Westchester Co., N.Y. D. '81.

of the beds throughout the region, the kinds of flexures are deduced. The dotted lines show one interpretation of the facts. The synclinal near the middle of section 1 is overlaid by schist in 2, and by still more schist in 3 and 4 ; and changes occur also in the other flexures. But other interpretations are possible. 
Fig. 96 below represents a section of alternating belts of limestone and schist, numbered I to IIIII, to be interpreted.

It may be that each belt, I, II, III, IIII, IIIII, is an independent stratum, alike in dip, with IIIII the highest in the series. This is the simplest explanation. But there may be flexures, and Figs. 97, 98, 99 represent some of the possible methods of interpretation. By comparing each with Fig. 96, the relations may be studied out.

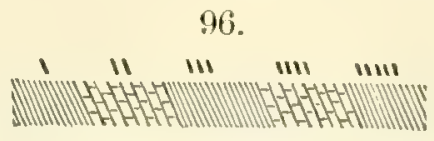

97.
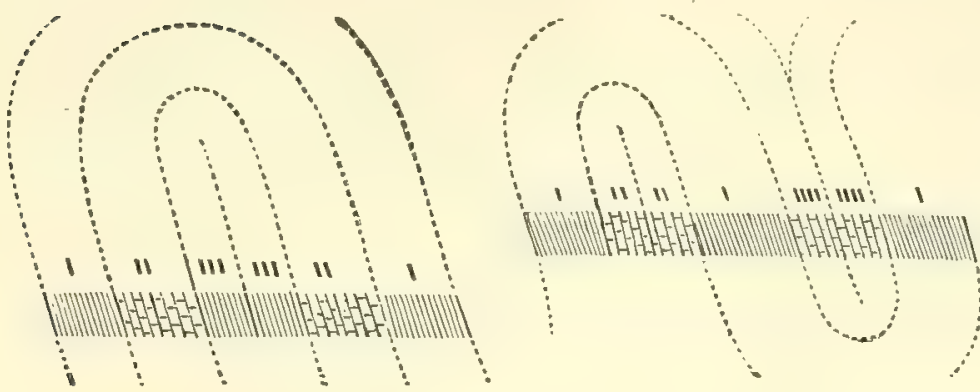

99.

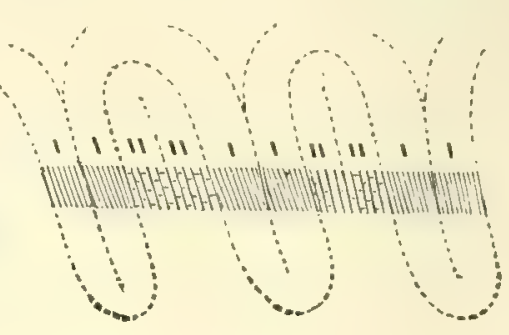

In a region of flexed rocks the same bed, as the illustrations show, may come many times to the surface; and it is therefore easy for the observer to be deceived in such regions as to the number of independent beds. The covering of soil adds greatly to the difficulty, as the following figures illustrate. When the rock in a region of high dips is

100.

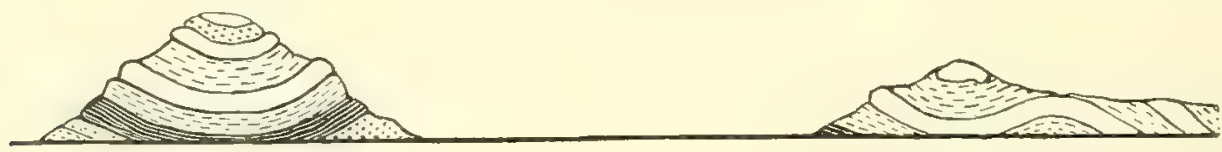

101.

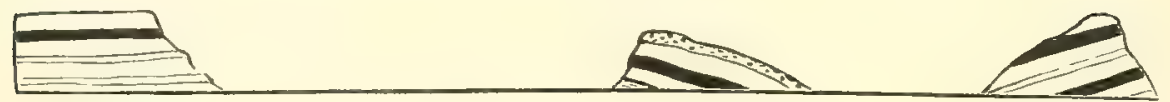

simply a slate or shale, with no associated stratum of permanent horizon, it is almost impossible to decide as to flexures. Such beds bend easily, and may be full of flexures, and yet none may be apparent.

Sometimes an anticlinal flexure has the dips of a synclinal, as in the central part of Fig. 102 A. If worn down to a plane (Fig. $102 \mathrm{~B}$ ), the dips along the center would seem.

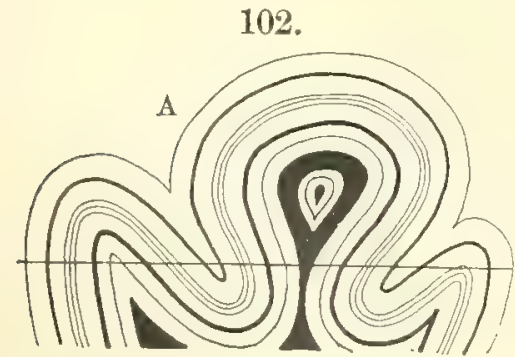

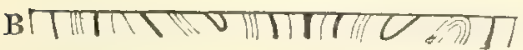
to be good evidence of a syncline. Such fan-shaped folds are common on a small scale in schists, and occasionally they may occur on a scale of mountain magnitude. The facts at Mont Blanc in the Alps are explained on the idea of such a fold.

To reach positive conclusions among the possible explanations, the beds or strata must be carefully compared, and also the sides and middle of the several strata, as to texture and all other differences. Besides, search should be made for outcrops that exhibit the limestone and schist in broad anticlinals or synclinals, as in the

following cases. In Mount Washington and Greylock of the Taconic range on the boundary of western New England, the beds dip at the north end of the mountain mass, nearly 
as in Fig. 103; that is, the dip is alike eastward on the east and west sides of the range, and it is not clear whether the overthrust flexure is anticlinal or synclinal. But toward the other end, the dips of the east side change, through the positions in $\mathrm{C}$ and $\mathrm{B}$ to that in $\mathbf{A}$; and here they are plainly in opposite directions on the two sides, and indicate thus that the mountain is a synclinal flexure, basin-like at one end, and a careened trough at the other.

Flexures have ordinarily, if not always, the ridge-line inclined instead of horizontal. The making of horizontal flexures (that is, those with the ridge line horizontal) would require perfectly equable pressure along a region, and also perfectly equable resistance, neither of which conditions could exist, because of the varying texture in the rocks, if for no other reason, and hence horizontality seldom oceurs.

103.
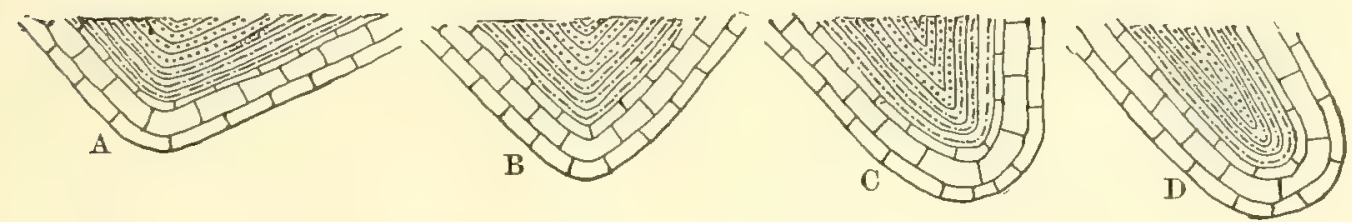

Synclines of Mount Washington, Mass. D. '87.

In a single ordinary flexure, therefore, the strike may vary nearly $180^{\circ}$, and the dip as greatly. For the edge of the horizontal plane (feg in Fig. 104) is a horizontal line; hence it corresponds to the strike for each point it passes over through a circuit of $180^{\circ}$. Supposing the flexure to run north

104.

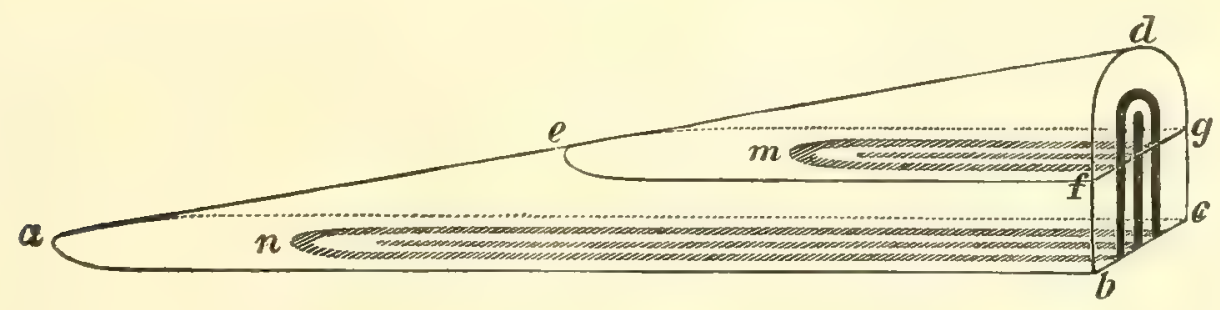

and south, the strike may vary from N.-S. through E.-W. to N.-S. again. Further: since the dip of the outer layer at any point is at right angles to the strike, it is at right angles to the line str. The dip of the beds is least along the axis of the fold.

Folds derive complexity also from torsion in the upturning movement. The following figure of a mountain scene in Colorado (Fig. 105) shows, besides the effects of erosion, those of a twist or torsion in the strata. The light-shaded stratum has opposite dip in the near and distant parts, and of course the strata either side participated in the torsion. The effect is probably far more common than is believed, for only in a region of bare, uncovered rocks is such a condition likely to be appreciated.

Besides the above-mentioned irregularities in a region of flexures, others come from variations in the length of parallel flexures, one flexure lapping 
by another, very much like the folds above the elbow in a woolen coatsleeve. The flexures are those of a warped surface, parallel usually in direction, but mutually involved along their course. Hence there are large variations in dip between the flexures.

105.

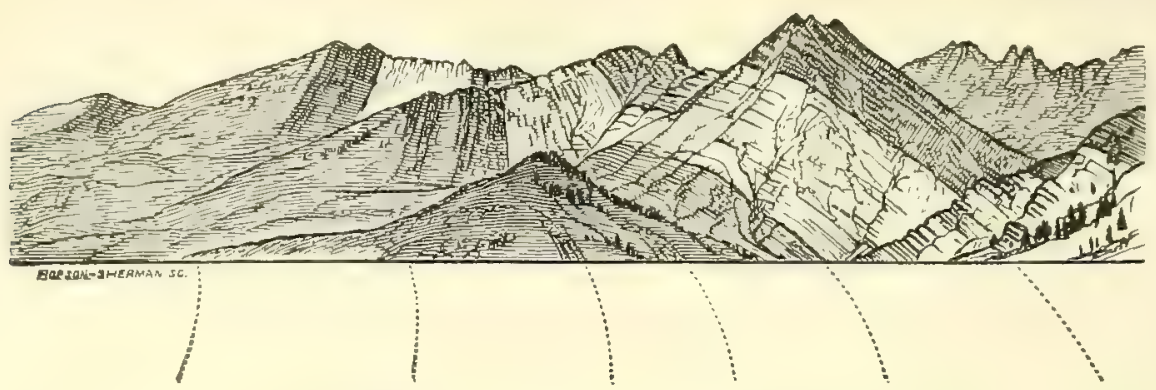

Upturned strata of the west slope of the Elk Mountains, Colorado. The light-shaded stratum, Triassico. Jurassic; that to the right of it, Carboniferous; that to the left, Cretaceous. Holmes, Gardner.

Models of Alexures may be conveniently made out of a large unhewn branch of a tree of coarse-grained wood, having the bark on. A piece of the branch ( 3 or 4 inches or more in diameter) 12 to 18 inches long, cut obliquely from a diametral line at one end at an angle of $20^{\circ}$ or so, will afford two models of a flexure with an inclined axis. By coloring groups of layers in the wood, using for greater simplicity not more than three colors, the appearances of the flexed strata may be studied in horizontal, vertical, and any other sections that may be cut. Such models might be made by pasting together sheets of differently colored paper, or layers of paper-pulp, and so making a cylinder, and then cutting it as above. By pressure the cylinder might be made elliptical, and models might be obtained with unequal dips on the two sides.

Geanticlines, geosynclines. - The flexures in rocks which have been above described and illustrated by figures are flexures of the strata of the earth's exterior, or the supercrust, not of the crust itself. The crust is thick, and it is impossible, were it but 10 miles thick, that it should be bent into so small and abrupt flexures. It has, however, its own great flexures of low angle and of great breadth, both upward and downward. It is proved that the stratified roeks of the Alleghanies were laid down in one such downward bend or trough, a thousand miles long, during the long ages in which it was slowly deepening. There are also evidences that upward bends of similar extent have been made. These flexures of the crust are termed geanticlines and geosynclines, the prefix in these terms being derived from the Greek word for earth. The basin of Lake Superior probably corresponds to a geosyncline, as suggested by T. C. Chamberlin.

Fractures, faults, compression and stretching of rocks. - The fractures intersecting rocks are of all sizes, from those small cracks that result from contraction on drying and cooling, and from gravitational pressure on strata of varying compressibility or of insufficient support, to those, sometimes miles in depth, that are made in the grander movements of the earth's crust. 
Rocks vary greatly in fragility, and break very differently under the same circumstances. Some, as the shales and argillaceous sandstones, yield to pressure by bending or by becoming compressed or stretched; or, like a friable sandstone, become adapted to the pressure as might a bag of corn, by a readjustment of the grains. But the more solid sandstones, having less mobile elements, become divided into blocks, unless the pressure at work is of the extremest slowness; and compact limestone, the most brittle of rocks when pure, breaks into smaller blocks, and sometimes into multitudes of them. The fractures due to stretching or tension are often large in the summit portion of an anticline, and especially when the beds consist of the harder or more brittle rocks. If a stratum of limestone is made up of pure and impure (argillaceous) layers, the former may be broken into columns when the latter are sparingly broken. Only a slight torsion from unequal pressure or support is needed for these results. The scenery of the Rocky Mountain region, and especially of the Colorado Cañon, illustrates finely these various differences in fragility. It is dependent upon the columnar fronts of many of the harder alternating layers for much of its architectural effect.

It has been stated that the flexures in strata are those of a warped sheet. But while the coat-sleeve loses its flexures on straightening it, strata could not be restored to their original condition, because of the great stretching and slipping on one another of the beds in one part, and of the compression in others. Proofs of the stretching and compression are afforded by the deformation of fossils, as illustrated in the chapter on mountain-making. (See page 370.) The smallest of fractures that have geological importance are those of the constituent grains or crystals of a crystalline rock, which are generally so minute as to be detected only by microscopic investigation. They sometimes indicate a flowing of the material, lava-like, before it had cooled, or contraction during cooling, or some progressing change of form through pressure.

Faults are displacements along fractures. When a coal-bed is not continuous across a plane of fracture, but has its continuation at some higher or lower level, a fault exists; and such faults often occasion much trouble to miners. There may be a few inches or less of displacement, or a few feet; but the larger faults of mountain-making regions are sometimes 10,000 to 20,000 feet.

In Figs. 106, 107, $f t$ is the course of a fracture, and $a$ to $b$ the amounit of displacement. In Fig. 106 the part to the right has slipped down against the opposite wall, or there is a downthrow; and this downthrow is in the direction of the dip (or the hade, in miners' language) of the fracture-plane. In Fig. 107, the reverse is the case ; there is an upthrust along this plane. One is an overthrow or downthrust fault, the other an upthrust fault. The angle of dip in the fault-plane is here near $60^{\circ}$; but it may be from $0^{\circ}$ to $90^{\circ}$.

In Fig. 108 a block of the formation has slipped down between two fracture planes; moreover, the resistance or friction has produced a bending of the layers on one side. Reverse the figure, and another condition in faulted 
strata is represented. The surfaces of walls often become scratched or "slickensided" by the movement.

106.

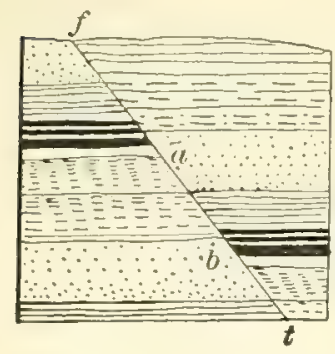

107.

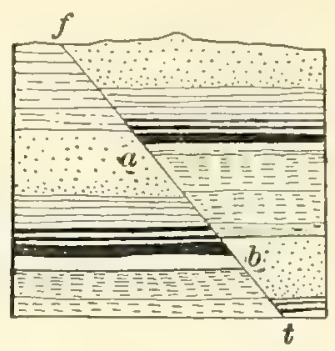

108.

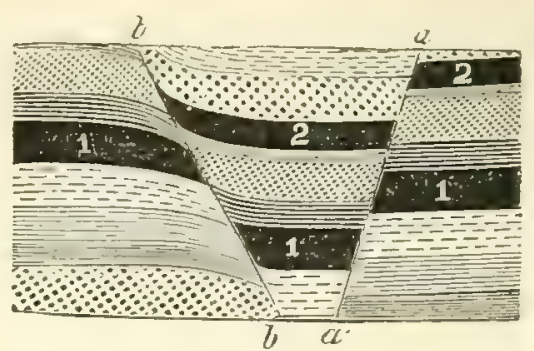

It cannot be affirmed in all cases that the downthrow or upthrust exhibited in the beds was the whole movement, but only that it was the final differential result of whatever up or down movement took place.

Often there are many small faults in a group, as in the annexed figure; and the group may be of the downthrow or upthrust kind, though usually in such cases, of the former. Frequently one or two blocks in the group of a displacement has undergone a reverse movement; but this does not change the general character of the faulting.

109.

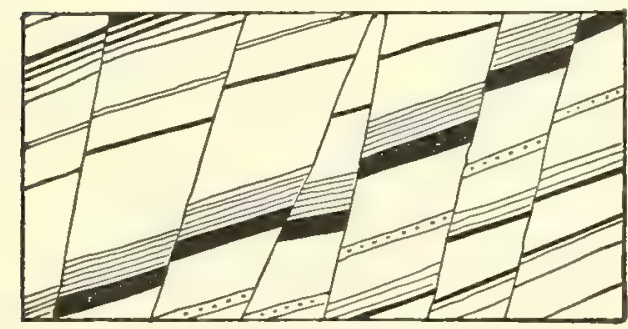

Faulted by beds.
110.

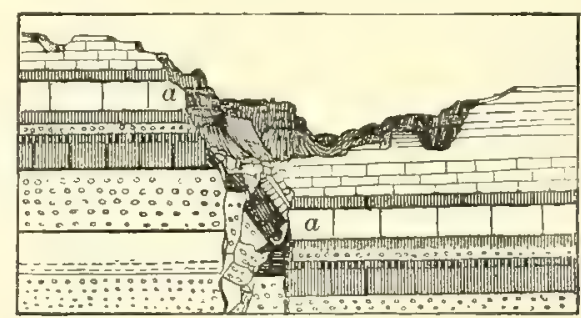

Fault with opened fissure filled with fallen masses. Powell, '75.

Fig. 110 (from Powell) shows a downthrow fault along a vertical fracture; moreover, the fracture is opened so as to become a wide fissure, and the fissure is filled with masses from the inclosing rocks. For other faults in fissures (veins), see pages 328-330.

Downthrow faults are often called normal faults; but only from the fact that they are most common. The smaller faults are usually of this kind, since gravity acts that way. The great faults, thousands of feet in displacement, are often upthrust faults. Those in the Appalachian Mountain region of Pennsylvania and Virginia have the upthrust of the enormous extent above stated, 10,000 to 20,000 feet; and the beds of the eastern side would now have this great height above those on the opposite side were it not that running waters of the sea and land (mostly the latter) had worn all down to a common level. A section of one of these great faults of Virginia, and the worn-off condition of the beds, is shown in Fig. 111. On one side of 
the fault $F$ are coal-beds, on the other, one of the lower limestones of the geological series, which, by upthrust action, has been put on a level with the coal-formation. By the same forced movements, downward displacements or faults are sometimes made, and these have been distinguished

111.

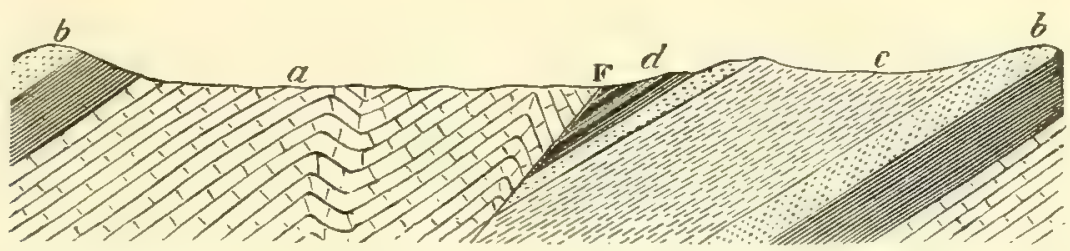

Section of the Paleozoic formations of the Appalachians, in southern Virginia, between Walkers Mountain and the Peak Hills (near Peak Creek Valley) : F, fault; $a$, Lower Silurian limestone; $b$, Upper Silurian; $c$, Devonian; $d$, Subcarboniferous with coal-bedw. Lesley.

from the gravity-made downthrow faults by using the term downthrust fault (E. A. Smith).

The following figures show that after erosion the same surface features may result from a downthrow (Fig. 112) along a vertical fracture and from

112.

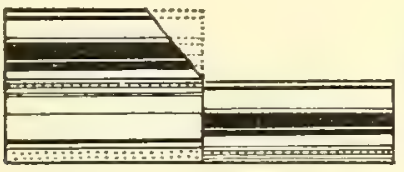

113.

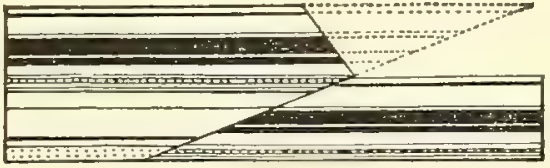

an upthrust (Fig. 113) along an oblique fracture; the dip of the fractureplane is here about $25^{\circ}$.

Not unfrequently a flexure changes, in one direction or the other, into a fault, showing that the force causing the break first produced, as is natural, a bend. Many examples of such flexure-faults have been described by Major Powell, and later by others, from the plateaus of Colorado, where the absence of vegetation and soil affords unusual opportunities for observation on the positions and inside condition of strata. A bend (Fig. 114, from Powell) represents, ideally, the upper layer of a region of a low anticline in the eastern part of the Uinta Mountains. The bend in the part to the right shows that a fracture is begun; and in Fig. 115, which represents

114.

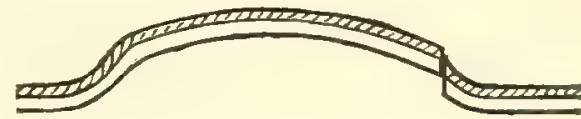

115.

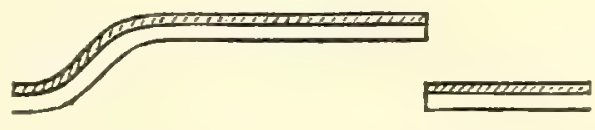

Flexure-fault. Powell, '76. the same line of faulting, the actual displacement amounts to thousands of feet.

A succession of monoclines along faults produces, in the region of the Colorado plateaus, the features shown in Fig. 116, from Powell; and Fig. 117, from the same region, illustrates a section across a large fault having two branches. 
Figs. 118, 119, 120 illustrate a flexure-fracture and fault along the syncline of an overthrust flexure in the Alps, some thousands of feet in span, as figured by Heim. It will be observed that the strata became bent without

116.

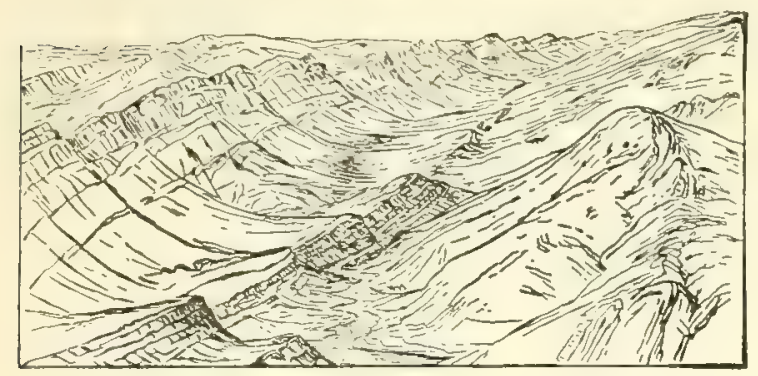

Succession of monoclines; section across a branching fault. Powell, '75.
117.

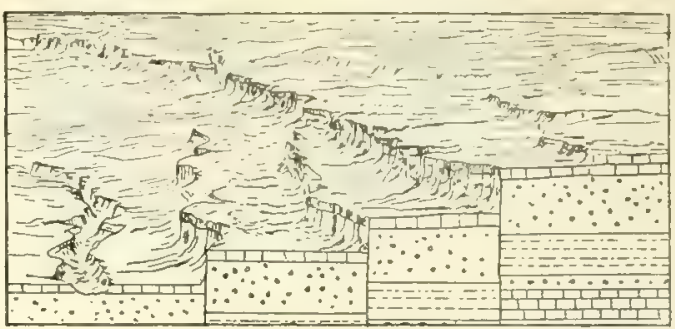

Section across a branching fault. Powell, '75.

breaking till the flexures of Fig. 118 were produced, illustrating thus the important fact that the bending of flexed rocks has in all cases gone forward with extreme slowness. The plane of the flexure from $a$ to $b$, between the

118.

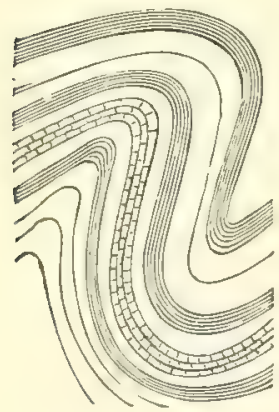

119.

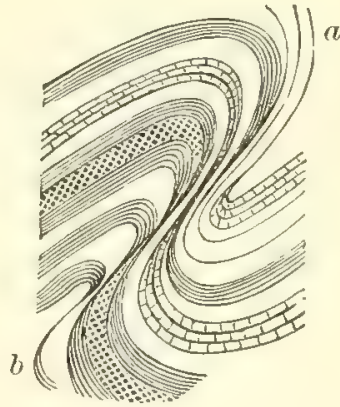

120.

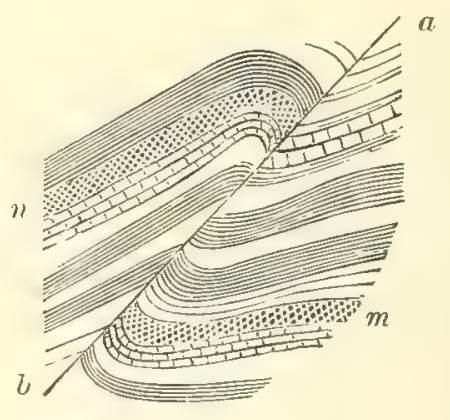

A fold passing into a fault, from the Alps. Heim, '78.

anticline and syncline, is the plane of greatest weakness, and hence the fracture. There is usually much stretching, also, and thinning, of the beds along the fracture. The fault at the bend in Fig. 120 is an upthrust fault, the stratum $m$ to the right being the same with $n$ to the left; and the existing distance between the two is a measure of the extent to which the strata were pushed up the sloping fault-plane. Where the flexures are closely crowded together, the faults may divide up a bed into many parts; and if a bed of iron ore is in the series, its parts may be so far displaced and cut up into so small sections as to make it unprofitable to attempt to follow it.

The great upthrust faults made along fractures many thousands of feet in depth, like those of the Appalachians, have usually taken place along fracture-planes of small dip - between $20^{\circ}$ and $45^{\circ}$. Downthrow or downthrust faults, however great the displacement, may occur along fractureplanes of all slopes to verticality.

The region of the great elevations produced along such faults in the Appalachians has been reduced in general to a level below that of the 
mountain-summits. The faulted region, because a region of fractures, is, in general, the course of a great valley.

Fissures also are faulted in the several ways mentioned, because they are in the terranes, and must share in the displacements. They may be faulted even at the time when they are first made, and faulted at various later periods.

Besides faults of up-and-down displacement, there are also (1) longitudinal faults, and sometimes without much change of level in the beds. Iore common than either vertical or longitudinal faults are (2) the oblique, since resistance and pressure would seldom be so equable as to prevent obliquity. (3) Horizontal displacement of strata also occur, and sometimes of marvelous extent. They are produced by a horizontal or oblique thrust shoving terranes over others. In a case reported from the Scottish Highlands, a mass of the oldest crystalline rocks, many miles in length from north to south, was thrust at least ten miles westward over younger rocks, part of the latter fossiliferous.

(4) Bed-plane faults are still another kind in which the plane of displacement is that between two layers or strata. They are produced by the pushing of one bed or stratum of a series over the surface of that below it. In the Triassic of East Haven, Conn. (on the borders of New Haven), the successive beds of the red granitic sandstone (which dip eastward $15^{\circ}$ to $20^{\circ}$ ) have been shoved over one another upward along the plane of bedding, producing large and general displacements, and great slickensided surfaces; and these surfaces have generally a very thin and hard white coating, apparently due to the ground-up feldspar. In the same region, besides these shoves of layers over one another, there are also ordinary faults with slickensided walls; and in many places the rock is in fragments, and all the fragments, even those no larger than the hand, indicate participation in the movement by the slickensides which cover them.

(5) Pressure has sometimes produced a crushing of the rocks along fractures, either directly or aided by lateral movement, making what has been called in the latter case shear-zones.

(6) In the upturning and flexing there has also been slipping, by the inch and fractions of an inch, along planes of cleavage or bedding, making slip-faults, and producing also small flexings or erumplings of the beds.

Jointed structure, joints. - A jointed structure is a style of fracturing, usually on an extended scale, in which there is a degree of system in the arrangement of the fractures. The divisional planes are termed joints They cut across the stratification, and may have great extent vertically and laterally. The planes of division are often very even, and not enough open to admit the thinnest paper. They may be in one, two, or more directions in the same rock, and extend, with nearly uniform courses, through regions that are many miles in length or breadth. The accompanying sketch represents the falling cliffs of Cayuga Lake, and the fortress-shapes and buttresses arising from the natural joints intersecting the rocks. The wear of the 
waters from time to time tumbles down an outer range, and exposes a new series of structures.

Traversing the surface of a region thus intersected, the joints appear as mere fractures, and are remarkable mainly for their great extent, number,

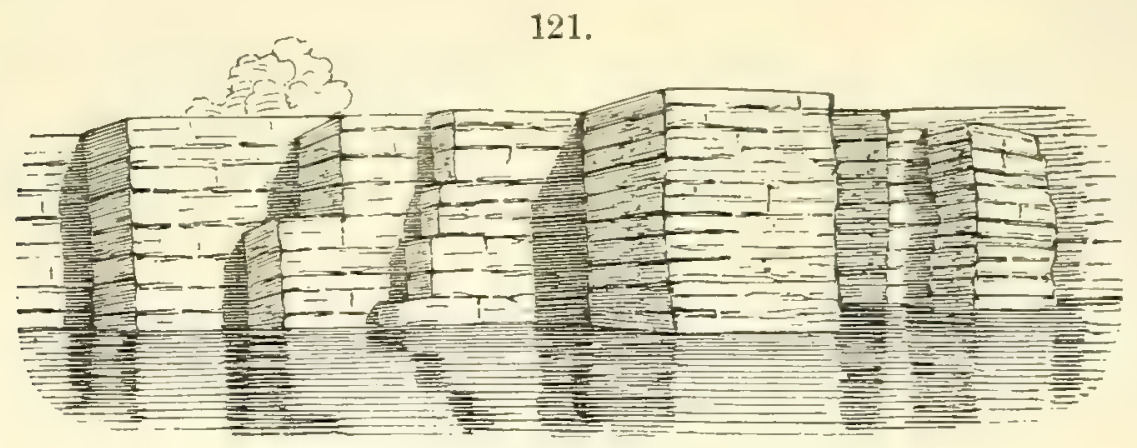

Jointed rocks, Cayuga Lake. Hall, '43.

and uniformity. In case of two systems of joints, - the case most common, - the rock breaks into blocks, which are rectangular or rhomboidal, according as the joints cross at right angles or not. The main system of joints is sometimes parallel to the strike of the uplifts, or else to the range of elevations or mountains in the vicinity, or to some general mountain range of the continent.

In many cases, a rock is so evenly and extensively jointed as to become thereby laminated, and in such a case the joints may be easily mistaken for planes of stratification, especially when the latter have been obliterated. Sometimes there are sudden transitions from the regular stratification to vertical joints, as in Fig. 122. This ease occurs in a section of part of a quartzyte bluff on the railroad near Poughquag, Dutchess County, N.Y. $a, a, a$ are ordinary joints in the stratified rock; $b, b$ is a portion of the rock, which has lost its stratification entirely, and has become jointed vertically; the transition from the stratified to the part $b, b$ is so abrupt that the latter has

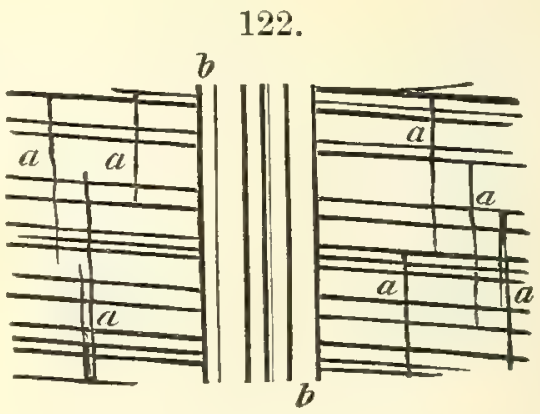

Jointed quartzyte. D. ${ }^{9} 72$. the aspect of an intersecting dike, or of a portion of the laminated sandstone set erect. It occurs in sand-beds, whose grains adjust easily, like shot, to pressure.

Fig. 124 represents a rock with two cleavage-directions; and 125 a quartzose sandstone which has irregular cleavage-lines. These last two cases, together with that represented in Fig. 122, appear to show that the jointed structure and slaty cleavage may have a similar origin.

Slaty and foliated structure. - In the slaty structure, or slaty cleavage, the rock is divided into thin even sheets or laminæ, as in the case of roofingslate or writing-slate. The laminated structure of shales is parallel to the bedding, and is due to the conditions of deposition and the pressure of super- 
incumbent beds; but slates have received their structure from lateral pressure, and it often crosses the bedding, as in Figs. 126, 127. This structure is

123.

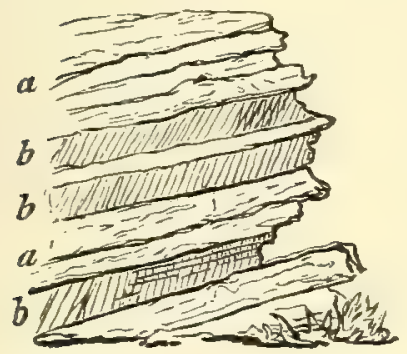

124.

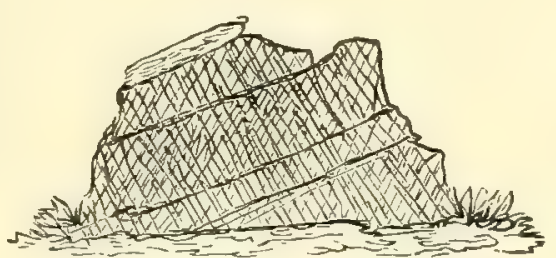

125.

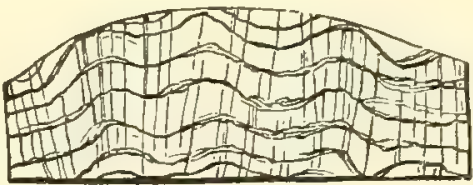

Jointed rocks. De la Beche.

also called the foliated structure. The sections represented in Figs. 126, 127 are from the slate region of Columbia County, N.Y.

Occasionally, the lines of deposition are indicated by a slight flexure in the slate near them, as in Fig. 127. In other cases there is a thin intermediate layer which does not partake of the cleavage. Fig. 123 represents an interstratification of claylayers with limestone, in which the former have the cleavage, but the latter not, though the lime-

126.

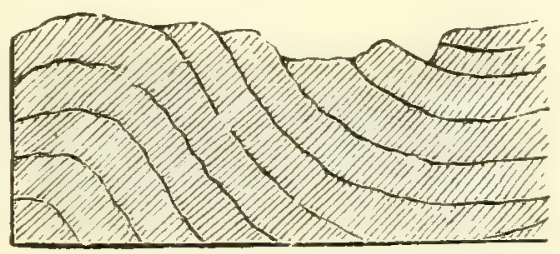

Slaty cleavage, Columbia Co., N.Y. Mather, '43. stone sometimes shows a tendency tò it where argillaceous.

Sedgwick first detected the true lines of bedding, and ascertained that the slaty structure was one that had been superinduced upon the clayey strata by some process since they were first deposited.

The schistose structure of crystalline rocks, or their schistosity, as it is often termed, may be produced by pressure; and hence all schistose structure, and even the fainter parallelism of the planes of a foliated mineral like mica, as in granitoid gneiss, are often termed foliated. The regular fractures producing a jointed or a slaty structure are named diaclases by Daubrée, and fractures accompanied by displacement, paraclases.

\section{Calculating the Thickness of Strata.}

When strata are inclined, as in Fig. 128, the thickness is ascertained by measuring the extent along a horizontal surface, and also the angle of dip, and then calculating the thickness by trigonometry. The thickness of the strata from $a$ to $b$ is $b d$, the line $b d$ being drawn at right angles to the strata. Measuring $a b$ and the dip, which is the angle bad, the angles and hypotenuse of the triangle $a b d$ are given to determine one side $b d$. Or, with the distance ae, the side ce would be found.

But for correct results, the absence of frults must be first ascertained. 
The figure (128) represents a fault at $b g$, so that the strata $1,2,3,4$ to the left are repeated to the right; and hence the whole thickness is $b d$ instead

128.

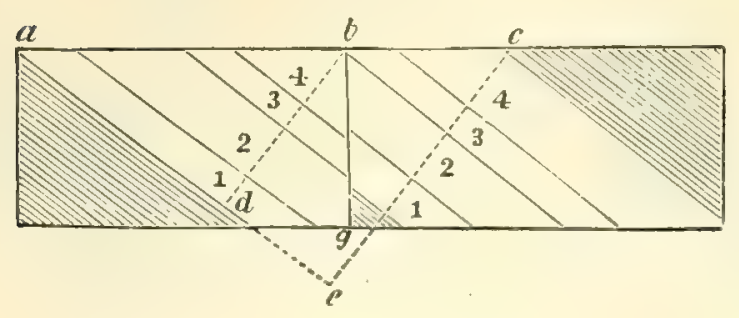
of $c e . a b$ is the width at surface of the strata $1,2,3,4$; but by the fault, $a b$ is increased to $a c$. There may be many such faults, in the course of a few miles; and each one would increase the amount of error, if not guarded against.

So other faults might go on increasing the extent of the surface exposure. This is further illustrated in Fig. 129. Let A be a stratum 10,000 feet thick ( $a$ to $c$ ) and 100,000 feet long ( $a$ to $b$ ). Let it now be faulted, as in Fig. B, and the parts uplifted to a dip of $15^{\circ}$, - taking a common angle for the parts, for the sake of simplicity of illustration. The projecting portions being worn off by the ordinary processes of denudation, it is reduced to Fig. C, $m n$ being the surface exposed to the observer. The first error that might be made from hasty observation would be that there were four distinct outcropping coal layers (calling the black layer thus), instead of one; and the second is the one above explained with regard to calculating the thickness of the whole stratum from the entire length $m n$ in connection with the dip. Very often the beds have been shoved up over one another in the making of a monocline to such an extent that the faults are almost or wholly obliterated. A calculation of the thickness in such a case is impossible.

If the stratum (Fig. 129 A) were in-

129.

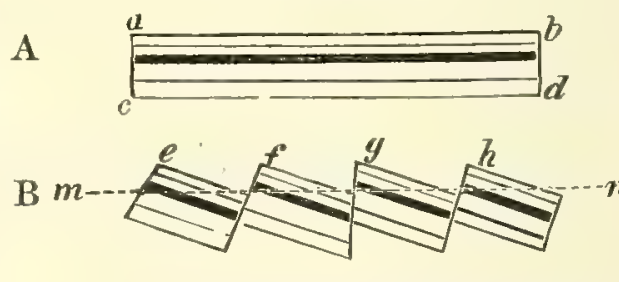

C

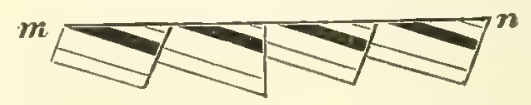

$\mathrm{D}$

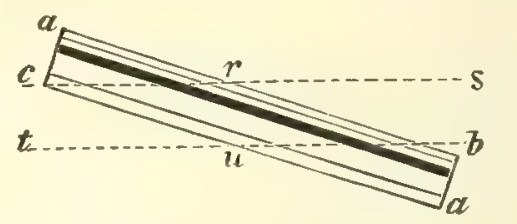

clined $15^{\circ}$ without faulting, it would stand as in $\mathrm{D}$; and if then worn off to a horizontal surface, the widest extent possible would be $c r$, which is less than half what it has with the three faults. A block of the size mentioned would require, in order to make it a monocline of $45^{\circ}$, that one end should be dropped down 70,000 feet, or the other end raised as much, or that this amount of change should be divided between the two ends; and for a monoclinal block having a dip of $60^{\circ}$, the drop-down or upthrust would have to be nearly 87,000 feet, or more than 16 miles. Calculating the thickness from the dip in a region is liable, therefore, to enormous error.

\section{Conformability, Unconformability.}

Successive strata in a region may be conformable to one another or unconformable. In the series of strata made over the earth's erust, the rocks of successive periods and ages have, in large parts of the world, been made 
in regular succession, each stratum conformable in bedding to the preceding. This was true of the 40,000 feet of rock of the Appalachian region (referred to on page 353), out of which the Appalachian Mountains were finally made. This is an example of conformability, as the term is used in geology. Through the long series there is conformity in bedding.

But these conformable strata rest on older rocks that have the bedding upturned and standing at various angles. Between the two there is unconformability in bedding.

Fig. 130 illustrates this subject. The beds $2,3,4 a, 4 b$, are conformable to one another, but unconformable to the flexed rocks numbered 1 . The

130.

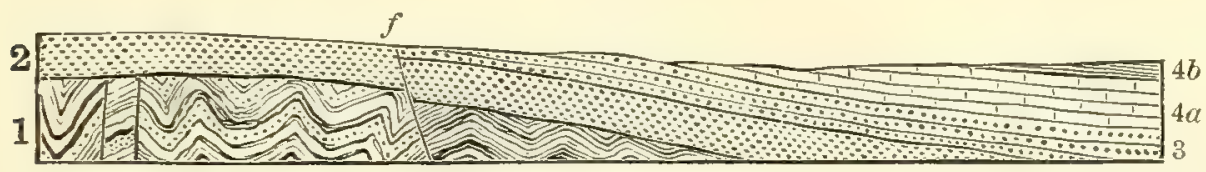

1, Upturned Archæan rocks; 2, 3, 4a, 4b, overlying strata, conformable with one another, but unconformable with the Archæan. Logan.

flexing of the rocks antedated the deposition of No. 2; and knowing the geological age of No. 2, some approximation is made toward a knowledge of the time of flexure. There may be three or four cases of unconformability in the same region. For in each mountain-making epoch, new rocks are upturned, and the succeeding ones are laid down horizontal, as usual, over the upturned. Such unconformabilities belong especially to regions of mountain-making; for there occur the upturned rocks. Only a few miles away from the region of the mountain, the rocks that are unconformable in the latter may rest on one another in regular order, or conformably, as if no disturbance had anywhere taken place.

The preceding figure has a fault-plane at $f$, and there is an unconformity between the beds on each side of it, but not unconformability. The unconformity introduced by faults is easily mistaken for true unconformability. Such unconformity is of frequent occurrence in all formations; while unconformity in bedding indicates an epoch of mountain-making, a thing of rare occurrence in the geological history of a region.

Besides this most important species of uneonformability, that of the first kind, there are also two other kinds: (1) through changed sea-limit or overlap; (2) through surface erosion.

Through overlap. - When, after the deposition of beds, a slight sinking of the region takes place, the next deposits there made may extend beyond the limits of the preceding, and overlap those outside. In such cases, although both deposits are approximately horizontal, there is still a degree of unconformability. Oscillations of the land surface, or of the water level, have gone on through the successive periods, so that unconformity by overlap is of very frequent occurrence, and of minor significance, though always of great geological interest. 
Through an interim of erosion. - Between the time of making two successive horizontal strata there is sometimes an interval of exposure to marine or fluvial erosion, which the worn upper surface of the lower stratum indicates. This, also, is unconformability in geology, and as the interim of erosion may be long, it is of importance. Yet in all periods, as in that of existing time, the deposits made during a period may be extensively worn away in some large regions before the period has closed; partly worn away in many places it is sure to be. An uplift of 600 feet in the present era, putting a coral reef rock this much above the sea, is followed by cavemaking and extensive removals. The amount of erosion is no certain evidence as to the length of time during its progress.

Deposits are sometimes formed in basins or depressions of the surface. Such deposits may, in general, be distinguished by their thinning out toward

131.

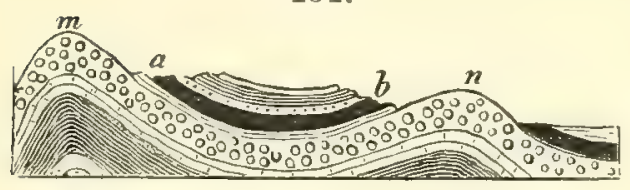
deposit; but they were formed before the folding of the beds, and not after it. clinal valleys are shallow, it is easy, and not uncommon, to mistake beds that are conformable with the strata below for such basin formations. The beds $a b$ (Fig. 131) lie in the synclinal valley $m n$, like a basin the sides of the basin. Yet, when syn-

\section{Unstratified Terranes.}

The unstratified terranes comprise (1) the great unstratified masses of granite and other related crystalline rocks; (2) the various masses of ejected igneous rocks that lie in piles, not having the bedding due to successive flows, and not making part of any stratified series; (3) masses occupying fissures in the earth's crust or supercrust, and having thereby the nature either of dikes or veins.

The facts connected with unstratified terranes are necessarily considered in Part III. on Dynamical Geology, and remarks here are therefore unnecessary. 


\section{PART III.}

\section{DYNAMICAL GEOLOGY.}

Dynamical Geologr, as explained on page 14, treats of the causes of events in the earth's geological progress. These events include: I. Those concerned in the production and modification of the earth's rock structure, and in the development of its form and features. II. The changes in the earth's climates. III. The changes through geological time in the earth's vegetable and animal life. The explanations beyond relate mainly to the first of these classes of subjects. The succession in climates and in vegetable and animal life is considered only historically, under Historical Geology.

The chief of the agencies directly concerned in geological work are the Atmosphere, the Waters, Heat, Chemical Force, and Life, each acting through or under general physical laws.

The atmosphere and the waters, by means of which most rocks have been made, valleys excavated, mountains shaped, and a great amount of chemical work carried on, are the most prominent of the earth's exterior agencies. Life, in its geological work, is another of the exterior agencies. Heat has both an exterior and an interior source, with corresponding effects. As exhibited in igneous ejections and volcanoes it is an interior agent both in source of material and of force; but the distribution of ejected material has taken place in part by means of the exterior agencies, water and air. The agencies that have made continents, oceanic depressions, and mountain ranges are largely interior in the origin of their forees and in their work.

There are three chief sources of energy for these agencies:-

1. The earth's rotation on its axis, and its revolution around THE SUN. (1) The rotation determining the earth's spheroidal shape, the length and alternations of its day, its zones of climate, and the system of movements in physical agencies; (2) the revolution, causing, in case of collision with any foreign body (as a meteorite), a manifestation of force in the production of heat and in violent mechanical effects.

2. THE SUN : which, through its heat, light, and attraction, is the origin of movements in the air, oceans, and rivers; the origin of chemical activity and growth in the kingdoms of life, and of much chemical work in 
inorganic nature; and the chief source of climatal conditions through all time since life began; which, further, in ronjunction with the moon's attraction, is the origin of the energy-distributing tidal wave, and also, incidentally to the tidal movement, of tidal friction, with far-reaching, adverse, and fatal results in the retarding of the earth's rotation.

3. The Earth's interior heat.

Dynamical Geology is discussed beyond under the following heads :-

I. CheMical work, as a means of superficial changes.

II. LIFE, as a geological agent.

III. The Atmosphere, as a mechanical agent.

IV. WATER, as a mechanical agent: under the subordinate heads of Water in general; Fresh waters; Oceanic waters; Glaciers and Icebergs.

V. Нелt : under the heads of Sources of heat and their direct climatal effects; Expansion and contraction; Igneous action; Metamorphism; Veins and ore-deposits.

VI. Hypogeic Work, or earth-shaping, mountain-making, and the attendant phenomena.

\section{CHEMICAL WORK.}

Chemical work is given the first place, because superficial chemical changes have been a prominent cause of the decomposition of rocks, and thereby one of the producers of the earth, clay, and other fragmental materials which are worked into beds by the mechanically acting air and waters. It is also a source of superficial rock formations of different kinds. Chemical changes carried on at temperatures above the ordinary, as those of metamorphism, are not here considered.

The following is the order of subjects: 1, Solution; 2, Oxidation and Deoxidation; 3, Hydration, or the chemical absorption of water ; 4, Carbonic acid $\left(\mathrm{CO}_{2}\right)$ and humus acids as geological agents; 5 , Action of siliceous solutions; 6 , Chemical work of living organisms; 7 , Mechanical work of chemical products; 8 , Concretionary consolidation.

Of this large subject only a brief review of the more prominent facts is possible in this place.

\section{Solution.}

The water descending in rains takes from the atmosphere its elements (in the ratio of about two parts of nitrogen to one of oxygen); carbonic acid; some sulphates and ammonium nitrates, especially about cities where there are coal fires; and three or four parts in 10,000 of sodium chloride or common salt in the vicinity of the ocean; besides atmospheric dust, enough of which is from organic sources to make the waters offensive after standing a few 
days. It gathers other materials as it flows, taking them from the soil and its organic decompositions, and from rocks or minerals, and especially where decompositions are in progress. It finds soda and potash in rocks containing feldspars; lime and magnesia, in limestones and also more or less in many other rocks, fragmental and crystalline; and various other materials in these and other rocks. Among the materials gathered up, the chief are calcium carbonate; salts of iron; magnesium, sodium and potassium carbonate, sulphate or chloride; calcium chloride; humus acids from the soil; and carbonic acid from the soils and other sources; besides, more sparingly, aluminum. sulphates and lithium salts. Besides the gas carbonic acid, the waters often receive and discharge hydrogen sulphide and nitrogen, and sometimes the gases hydrogen and oxygen. The gatherings depend on the kinds of rocks washed by streams, both those of the surface and those of subterranean source. It was long since recognized that, through the gathering action of fresh waters, a lake without outlet might become saline, like the sea.

The desert and semi-desert regions of the world often illustrate through the efflorescences that exist over the surfaces of old lake basins, as well as the salts in the waters of lakes, what solvent work the waters have done. The Great Basin in the west has been studied with reference to this subject by King, Gilbert, Russell, and others. The moisture below comes up by capillary action; and, as evaporation above is almost constant, owing to the excessive dryness and heat $\left(90^{\circ} \mathrm{F}\right.$. the mean over part of it for July), so also the production of the salts is in constant progress. The most abundant are common salt $(\mathrm{NaCl})$, sodium carbonate and sulphate, with often calcium carbonate, and borates.

From one of two samples of the saline deposits from the Lahontan region analyzed by Dr. T. M. Chatard were obtained, as cited by I. C. Russell, $72 \cdot 69$ per cent of sodium carbonate $\left(\mathrm{Na}_{2} \mathrm{O} . \mathrm{CO}_{2}\right), 17 \cdot 49$ of sodium sulphate $\left(\mathrm{Na}_{2} \mathrm{O} . \mathrm{SO}_{3}\right), 4 \cdot 15$ sodium borate $\left(\mathrm{Na}_{2} \mathrm{O} . \mathrm{B}_{4} \mathrm{O}_{6}\right)$, 2.53 sodium chloride $(\mathrm{NaCl}), 1.18$ potassium chloride $(\mathrm{KCl})$, and 1.96 silica. In the other: $9 \cdot 06 \mathrm{Na}_{2} \mathrm{O} . \mathrm{CO}_{2}, 27 \cdot 05 \mathrm{Na}_{2} \mathrm{O} . \mathrm{SO}_{3}, 1.00 \mathrm{Na}_{2} \mathrm{O}_{3} \mathrm{~B}_{4} \mathrm{O}_{6}, 59 \cdot 32 \mathrm{NaCl}, 1.39 \mathrm{KCl}$, and $2 \cdot 18$ $\mathrm{SiO}_{2}$. In deposits of the dried-up Sevier Lake, south of the Great Salt Lake, Dr. O. Low obtained, as reported by G. K. Gilbert, (1) from those of the center of the lake: sodium sulphate $87 \cdot 65$, sodium carbonate $1 \cdot 08$, sodium chloride $2 \cdot 34$, with water $8 \cdot 90=$ $99 \cdot 97$; (2) from the middle or $3 d$ layer of those of the margin, sodium sulphate $83 \cdot 79$, sodium chloride $13 \cdot 84$, magnesium sulphate $1 \cdot 33$, potassium sulphate $0 \cdot 26$, with water $0 \cdot 78=$ 100 ; from a layer overlying the last, (4th layer) sodium sulphate $2 \cdot 71$, sodium chloride $88 \cdot 49$, magnesium sulphate, potassium sulphate $0 \cdot 11$, water $3 \cdot 40=100$. The above are a few of the published analyses. These saline materials were once in solution in lakes of the region that are now dried up.

Salt lakes are in some cases remnants of the ocean that once covered the land. But in the Great Basin, according to Gilbert, the saline ingredients have come from the soil and rocks of the region.

Mineral springs, or sources of water holding mineral ingredients in solution, are hence universally distributed. They include "pure" waters as well as the so-called "mineral waters." The latter contain some mineral salt generally in sufficient quantities to affect the taste; and they are most 
valued when sodium chloride is mostly absent, and when carbonic acid gas is present to give briskness to the waters.

The ocean is the great mineral spring of the world; and Artesian borings over the land very often show, by bringing salt water to the surface, that more or less sea water has generally been left along with the beds. About $3 \frac{1}{2}$ per cent of sea water consists of soluble salts, and of these over $\frac{3}{4}$ is common salt. When sea water along a flat shore becomes temporarily confined so that it can evaporate, the salts are deposited; first gypsum or anhydrite, which goes down, according to Ursiglio, when the Beaumé areometer stands at $16.75^{\circ}$; and then the common salt when it is at $26.25^{\circ}$. While this is depositing, the remaining solution, which is above, holds the magnesium sulphate and chloride, with the calcium chloride, and the iodide and borate, and is called the "mother liquor" or "bittern"; and it is all nearly ready for deposition, the borate being among the latest although not the least soluble. Magnesium sulphate and magnesium-potassium chloride (carnallite) make much the larger part of the final depositions. But a new supply of salt water at this stage may prevent deposition from the bitter magnesium solution; or the latter may be gradually drawn off to mix again with the sea water, or for deposition elsewhere. Common salt dissolves in about three parts of either hot or cold water; magnesium sulphate, in about four parts at $32^{\circ} \mathrm{F}$, but in one third as much water at $212^{\circ} \mathrm{F}$. Sodium sulphate is most soluble in warm water; hence the waters of the Great Salt Lake deposit it if cooled down to $20^{\circ} \mathrm{F}$. (Russell).

The making of salt in large shallow lagoons or "salt-pans" along seacoasts, out of water let in at high tide and then confined for a time, is a common thing under the hot sun of tropical countries. The same process - solar evaporation - is used in many regions of brine springs. On some of the smaller coral islands of the equatorial Pacific, whose lagoons had become very shallow, there are now beds of gypsum - sometimes two feet thick - along with salt in places, that were made from the evaporating waters (Hague), showing that the lagoon basins had passed through a salt-pan condition.

The average composition of ocean water salts, in a hundred parts, has been determined by W. Dittmar to be as follows: chlorine 55.292, bromine $0 \cdot 188$, sulphuric acid $\left(\mathrm{SO}_{3}\right) 6 \cdot 410$, carbonic acid $0 \cdot 152$, lime $1 \cdot 676$, magnesia $6 \cdot 209$, potash $1 \cdot 332$, soda $41 \cdot 234$, less the oxygen in soda and magnesia equivalent to the chlorine and bromine present combined with the sodium and part of the magnesium $12 \cdot 493=100 \cdot 00$; or combining the acids and bases, the salts are: sodium chloride (common salt) $77 \cdot 758$, magnesium chloride $10 \cdot 878$, magnesium sulphate $4 \cdot 737$, calcium sulphate $3 \cdot 600$, potassium sulphate $2 \cdot 465$, magnesium bromide $0 \cdot 217$, calcium carbonate $0 \cdot 345=100 \cdot 00$.

From these results Professor Dittmar calculates for the whole amount of salts in the ocean, as follows, the unit being $1,000,000,000,000$ tons: sodium chloride 35,990 , magnesium chloride 5084 , magnesium sulphate 2192 , calcium sulphate 1666 , potassium sulphate 1141, magnesium bromide 100 , calcium carbonate $160=46,283$; also total bromine $87 \cdot 2$ (Dittmar), total iodine 0.03 (Köttst orfer), total rubidium chloride $25 \cdot 0$ (C. Schmidt).

The lime alone varies appreciably with the depth. As compared with the amount of chlorine and bromine (the latter calculable as chlorine), taking the amount at 100, the lime at surface $(s)$, at medium depth $(m)$, and in the deep sea $(d)$ was found by Dittmar to be $s, 3 \cdot 0175 ; m, 3 \cdot 0300 ; d, 3 \cdot 0308$. The amount of carbonic acid in the waters above what is required for calcium carbonate is large, especially that at great depths; but it is 
not sufficient to convert all the calcium carbonate to bicarbonate. Deep sea water affords more or less free oxygen. (For Dittmar's results, see Rep. Chall. Exp., on ocean water.)

The salinity or proportion of salts varies from dry winds, which tend to concentrate, and from fresh-water streams, which dilute. The area of maximum salinity in the north Atlantic is the Sargasso Sea, a region of calms between $25^{\circ}$ and $35^{\circ} \mathrm{N}$. and $30^{\circ}$ and $20^{\circ} \mathrm{W}$., where the specific gravity is 1.0285 ; while that of minimum is in the region of equatorial rains between $10^{\circ} \mathrm{N}$. and the equator. In the south Pacific there is an area of maximum specific gravity (1.02719) about the Society Islands. In general the salinity decreases downward to 800 or 1000 fathoms, and then increases to the bottom. In the south Atlantic the specific gravity at the bottom is 1.0257 to $1 \cdot 0259$, but in the north Atlantic it is 1.02616 to 1.02632 at 2000 to 4000 fathoms (Buchanan). In the Baltic Sea, the salinity is reduced one half or more by the waters from the rivers, and the maximum specific gravity is only 1.0140. But in the Mediterranean, owing to evaporation and an average rainfall of but 30 inches, the specific gravity is 1.0280 to 1.030 ; and hence the amount of saline matters is about $3 \cdot 9$ per cent to $3 \cdot 6$ for the Atlantic.

The following are analyses of two river waters, and of two mineral springs, from a paper by Professor C. F. Chandler. The Croton River (supplying New York City) is from a region of Archæan rocks; the Mohawk, one of Lower Silurian shales, sandstones, and limestones (underneath); and the two mineral springs arise from the Potsdam sandstone. The amounts of mineral salts are of grains in a U. S. gallon (231 cubic inches $=57,750$ grains); also mean of analyses of Arkansas Hot Springs, by R. N. Brackett (Ark. Geol. Survey), temp. $124^{\circ}$ and $146 \cdot 5 \mathrm{~F}$.

\begin{tabular}{|c|c|c|c|c|c|}
\hline & $\begin{array}{l}\text { Croton River, } \\
\text { N.Y. }\end{array}$ & $\begin{array}{l}\text { Mohnwk, } \\
\text { Utica, N.I }\end{array}$ & $\begin{array}{l}\text { Congress Springs, } \\
\text { Saratoga. }\end{array}$ & $\begin{array}{l}\text { Lithia Well, } \\
\text { Ballston. }\end{array}$ & $\begin{array}{c}\text { Arkansas } \\
\text { Hot Springs. }\end{array}$ \\
\hline Potassium chloride....... & - & $0 \cdot 12$ & $8 \cdot 049$ & $33 \cdot 276$ & - \\
\hline Sodium chloride........ & $0 \cdot 402$ & $0 \cdot 17$ & $400 \cdot 444$ & $750 \cdot 030$ & 027 \\
\hline Sodium bromide........ & - & - & $8 \cdot 559$ & $3 \cdot 643$ & - \\
\hline Sodium iodide.......... & - & - & $0 \cdot 138$ & $0 \cdot 124$ & - \\
\hline Magnesium chloride...... & - & -1 & Na. phosphate $0 \cdot 016$ & $0 \cdot 050$ & - \\
\hline Potassium sulphate....... & $0 \cdot 179$ & - & 0.889 & 0.520 & $0 \cdot 21$ \\
\hline Sodium sulphate........ & $0 \cdot 260$ & 0.57 & Na. Carb. $10 \cdot 775$ & $11 \cdot 928$ & $0 \cdot 45$ \\
\hline Calcium sulphate....... & $0 \cdot 158$ & $1 \cdot 31$ & Li. Carb. $\quad 4 \cdot 761$ & $7 \cdot 750$ & - \\
\hline Magnesium sulphate...... & - & - & Ba. Carb. 0.928 & 3.881 & $\mathrm{Na}_{2} \mathrm{CO}_{3} 0 \cdot 04$ \\
\hline Calcium carbonate...... & $1 \cdot 648$ & $4 \cdot 60$ & $143 \cdot 399$ & $238 \cdot 156$ & $7 \cdot 15$ \\
\hline Magnesium carbonate... & $1 \cdot 100$ & $1 \cdot 71$ & $121 \cdot 757$ & $180 \cdot 602$ & $1 \cdot 13$ \\
\hline Iron carbonate.......... & - & - & $0 \cdot 340$ & 1.581 & $\mathrm{FeSO}_{4} 0.05$ \\
\hline Silica ................ & $0 \cdot 621$ & $0 \cdot 47$ & $0 \cdot 840$ & $0 \cdot 761$ & $2 \cdot 58$ \\
\hline Organic, volatile........ & 0.670 & $1 \cdot 64$ & trace & trace & - \\
\hline Total & $5 \cdot 038$ & $10 \cdot 68^{1}$ & $700 \cdot 895$ & $1233 \cdot 246^{2}$ & $11 \cdot 88$ \\
\hline
\end{tabular}

Pure water has very feeble solvent action on rocks except in the case of gypsum and anhydrite, which yield 1 part to 400 to 500 of cold water. Quartz, feldspar, and other siliceous minerals are essentially unaffected. Only 2 to 10 parts of calcite are taken up by 100,000 parts. Opal, which is silica in the soluble state (like that of Diatoms, Spongespicules, Radiolarians), yields 12 to 15 parts to 100,000 parts of cold water, and much more to warm water.

I The analysis afforded also 0.09 of alumina and iron oxide.

${ }^{2}$ This amount contains also 0.867 strontium bicarbonate and 0.077 alumina; and both the Ballston and Saratoga waters afforded a trace of calcium fluoride and sodium biborate. The carbonates in these waters are reckoned as bicarbonates. The Congress Spring afforded 392.28! cubic inches of carbonic acid to the gallon, and the Ballston, 426 114 . 
Professor A. Corsa sulbjected the rocks mentioned below, after fine pulverization, to the action of pure water at $65^{\circ} \mathrm{F}$. for several days; the weight dissolved was as follows: -

Gneiss, from Ragogna, $0 \cdot 1250$ per cent; porphyritic retinite, from Honte Sieva, 0.0562 ; perlyte, of Monte Sieva, 0.0624 ; phonolyte, of Monte Croci, 0.3260 ; trachyte, of Monte Ortona, $0 \cdot 0871$; granite, of Montorfano (Lago Maggiore), $0 \cdot 0727$; granite, of Baveno (Lago Maggiore), $0 \cdot 0966$.

Professors W. B. and R. E. Rogers found in their experiments (Amer. Jour. Sci., 1848), that under the action of carbonated waters, $0 \cdot 4$ to 1 per cent of the whole weight under digestion dissolved in only 48 hours.

Daubrée exposed orthoclase from Limoges in small fraginents in a vessel containing twice as much water by weight revolving at the rate of 2550 meters per hour. The water in 8 days, after revolutions equivalent to a flow of 460 kilometers, contained 2.52 grams of potash per liter, along with 0.03 of alumina and 0.02 of silica. In salt water (water containing 3 per cent of $\mathrm{NaCl}$ ) there was only a feeble alkaline reaction, incomparably less than with pure water.

Water derives its chemical efficiency through the presence of such impurities as are ready to enter into new combinations. The most common of these foreign materials are carbonic acid $\left(\mathrm{CO}_{2}\right)$, humus acids, and alkaline ingredients. When carbonic acid is present one part of calcite will be taken up by 1000 of water; but in this case the material dissolved is not calcium carbonate, but calcium bicarbonate. Again, the presence of soda or potash gives increased solubility to silica in its soluble or opal state, - the state characterizing organic silica.

The least effect from moisture in rocks is diminished resistance to fracture or cohesion. Part of this is due to the lubricating effect resulting from the wetting of the grains, in consequence of which they slide over one another more easily than when dry. On this principle a grindstone is wet before using it. But in the case of wet rocks there is often, perhaps generally, a solution of a minute portion of some ingredient of the rock which becomes solid again on drying. For this reason, sand rocks, whether calcareous or siliceous, gradually harden at surface from alternate wetting and drying.

The more prominent destructive effects of water, consequent on its solvent powers, are: the easy erosion of beds of gypsum; the rapid removal of beds of salt; and the injury to animal and vegetable life from encroachments of mineral and marine waters, and to marine life by its concentration on evaporation in shallow basins. The constructive effects are: the deposition of salt and gypsum in large beds; and also the local superficial consolidation of rocks alluded to above.

\section{Oxidation AND DeOXidation.}

On account of the very strong attraction between oxygen and nearly all the elements, and also because this gas is always at hand in air and water, it is the most prominent agent in the world's destructive and constructive chemical changes. 
1. Oxidation in inorganic materials. - The effects that have special geological importance are the slow oxidation of iron, manganese, sulphur, and some other elements, which takes place in the mineral constituents of rocks when water and air together have access. Little oxidation takes place under water. The iron of minerals undergoes easy oxidation when it is present in the protoxide state, $\mathrm{FeO}$, or when combined with sulphur. The protoxide state is the unstable state of iron. In oxidizing it combines with one half more oxygen, and becomes the sesquioxide, $\mathrm{Fe}_{2} \mathrm{O}_{3}$. This iron oxide is the mineral hematite having a red powder, if free from combined water; but, if containing water, limonite, which has a yellow or yellow brown color when powdered, if not before (page 71). The latter rust-colored oxide is like that which is produced when the metal iron rusts. But the rust may contain some carbonate besides the iron sesquioxide.

In a similar manner, when a mineral contains manganese protoxide, $\mathrm{MnO}$, the $\mathrm{Mn}$ tends to become $\mathrm{Mn}_{2} \mathrm{O}_{3}$ or $\mathrm{MnO}_{2}$, compounds that have a black powder. Black stains, and black crusts on marble and other rocks, after weathering, usually come from the oxidation of some manganese in the rock.

The oxides $\mathrm{FeO}$ and $\mathrm{MnO}$ are unknown except in combination. But magnetite, $\mathrm{Fe}_{3} \mathrm{O}_{4}$, is common in disseminated grains in many rocks, besides sometimes constituting thick beds; it often oxidizes slowly to the sesquioxide, $\mathrm{Fe}_{2} \mathrm{O}_{3}$, producing hematite or limonite.

Again: the iron sulphides, pyrite and marcasite, each $\mathrm{FeS}_{2}$, oxidize readily, and especially the latter, as shown by Julien; the iron, $\mathrm{Fe}$, becoming $\mathrm{FeO}$, if there is an acid ready to combine with it, but otherwise $\mathrm{Fe}_{2} \mathrm{O}_{3}$; the sulphur, $\mathrm{S}$, becoming $\mathrm{SO}_{3}$, and, with added water, sulphuric acid. This acid, with the $\mathrm{FeO}$ and water, may make the iron sulphate, copperas; but it may combine also with $\mathrm{Fe}_{2} \mathrm{O}_{3}$, and make other sulphates. If there is limestone at hand, the $\mathrm{SO}_{3}$, or sulphuric acid, may combine with the lime and water, and form gypsum, and may thus make beds of gypsum. When pyrite and marcasite are mixed together, the marcasite makes oxidation easy (Julien).

2. Oxidation in organic materials, and other chemical changes. - When life ceases, all organic materials tend to decay; and in this decay, oxidation is the chief process, and oxides the larger part, or all, of the final results.

Wood, when thoroughly dried, consists approximately of carbon (C) $49 \cdot 66$, hydrogen $(\mathrm{H}) 6 \cdot 21$, oxygen $(\mathrm{O}) 43 \cdot 03$, with traces of sulphur $(\mathrm{S})$ and phosphorus (P), nitrogen $(\mathrm{N}) 1 \cdot 10$. Animal fats contain the same elements, and animal tissues the same with much nitrogen.

In dried wood, the $\mathrm{C}, \mathrm{H}, \mathrm{O}$ are atomically in the proportions nearly $\mathrm{C}_{6} \mathrm{H}_{9} \mathrm{O}_{4}$. In decay, the oxygen used may be that of the wood, or of the atmosphere or other substances. The $\mathrm{C}$ may combine with $\mathrm{O}$ and make carbon protoxide, $\mathrm{CO}$, the gas which burns with a blue flame in a furnace; but it generally combines with $2 \mathrm{O}$, making the more stable and incombustible compound $\mathrm{CO}_{2}$, or carbonic dioxide (carbonic acid). The $\mathrm{H}$ may unite with $\mathrm{O}$ and form water, $\mathrm{H}_{2} \mathrm{O}$. But instead of all the $\mathrm{C}$ combining 
with $O$, part, especially when the decomposition goes on under water, or where atmospheric oxygen is excluded, may combine with $\mathrm{H}$ and produce the hydrocarbon $\mathrm{CH}_{4}$ - called marsh-gas, because sometimes bubbling up through marsh waters; it is the gas which burns and makes the flame of a wood fire. Other related hydrocarbons also might form. But the burning of this gas when complete ends in producing $\mathrm{CO}_{2}$ and $\mathrm{H}_{2} \mathrm{O}$. This is the final result when plants decompose in the air, except minor results from the nitrogen (N) and sulphur (S) present, among which are making, with the nitrogen, ammonia, $\mathrm{NH}_{3}$; and, with oxygen, witrous acid $\left(\mathrm{N}_{2} \mathrm{O}_{3}\right)$, and nitric acid $\left(\mathrm{N}_{2} \mathrm{O}_{5}\right)$; and making, with the sulphur, hydrogen sulphide (sulphuretted hydrogen) $\mathrm{H}_{2} \mathrm{~S}$, and with oxygen, sulphurous acid $\left(\mathrm{SO}_{2}\right)$ and sulphuric acid $\left(\mathrm{SO}_{3}\right)$.

In smothered combustion (as in making charcoal by burning wood under a cover of earth), nearly all the $\mathrm{H}$ and $\mathrm{O}$ disappear as $\mathrm{CO}, \mathrm{CO}_{2}$, and $\mathrm{H}_{2} \mathrm{O}$, without a consumption of all the carbon; and this happens when plants decompose under a complete covering of water or earth, because this excludes the air and confines the changes to the elements of the plants; and the more complete the protection, the greater will be the proportion saved of carbon and hydrogen, the combustible elements for the making of coal. With reference to the making of mineral oil or gas, it is to be noted that if the outside air is wholly excluded through overlying fine sediments, they may be produced by the direct decomposition of woody tissues or of animal oils. Thus, if the carbon of the wood $\left(\mathrm{C}_{6} \mathrm{H}_{9} \mathrm{O}_{4}\right.$ nearly $)$ combines with all the oxygen, making thereby $2 \mathrm{CO}_{2}$, it will leave $\mathrm{C}_{4} \mathrm{H}_{9}$, and $2 \mathrm{C}_{4} \mathrm{H}_{9}=\mathrm{C}_{8} \mathrm{H}_{18}$, which is the composition of some mineral oil. So in animal oils, as oleic acid, $\mathrm{C}_{18} \mathrm{H}_{34} \mathrm{O}_{2}$, on separating $\mathrm{CO}_{2}$, there would be left $\mathrm{C}_{17} \mathrm{H}_{34}$, one of the ethylene oils; or from margaric acid, $\mathrm{C}_{17} \mathrm{H}_{34} \mathrm{O}_{2}$, the product would be $\mathrm{C}_{16} \mathrm{H}_{34}$, or a combination of marsh-gas oils. Fossil fishes are often numerous in coaly beds that afford much oil. (D., Min., 1868, p. 726.)

In the change to ordinary bituminous coal the loss in the hydrogen of the wood, proportionally to that of the carbon, is about two fifths, and that of the oxygen about four fifths - about 5.5 per cent of such coal (ash excluded) being hydrogen, and 12 to 15 per cent oxygen, with 80 to 81 per cent carbon.

The carbonaceous products from the decomposition of plants and animals give the black color to soils. In wet soil, other acid products sometimes form, called humus acids, from the Latin humus, soil, or earth.

The returning to the air of the constituents of a plant, by decay, in the form of carbonic acid and water, is restoring what was taken and used in the growth of the plant and balancing the account. The storing of part of the carbon and hydrogen in the rocks in the form of coal and mineral oil and gas was an abstraction of carbonic acid from the air, and commenced a debit account which use in combustion by man is doing only a little in the way of settling. Happily the world is better off for the purification of its atmosphere.

3. Deoxidation, or the abstraction of oxygen fiom a compound by any oxidizing substance at hand. - Most deoxidation in nature is done by organic substances through the process of decay above described. The affinity in the carbon and hydrogen of the plant for oxygen is so strong that it will take it away from iron oxides or salts, and many other kinds. It may take $O$ from $\mathrm{Fe}_{2} \mathrm{O}_{3}$ and reduce it to $\mathrm{FeO}$; so that if there is then an acid at hand for com- 
bination, as carbonic acid, it may take the $\mathrm{FeO}$ and make iron carbonate. Or if the acid is a humus acid, this acid may combine with the FeO, and, as such a compound is soluble, the waters may carry it to the marshes for deposition and re-oxidation.

Since the compounds so made are colorless or nearly so, fragments of a plant in a rock may whiten the rock around them, thus making blotches in red sandstones, or a zone may be bleached around stems and roots. Also, the soaking down of soil waters may make a whitish streak along the top of the less permeable layers.

In like manner iron sulphate or copperas, $\mathrm{FeO} . \mathrm{SO}_{3} .7 \mathrm{aq}$ (which oxidation of $\mathrm{FeS}_{2}$ often produces, as above explained), may be deoxidized and reduced to $\mathrm{FeS}_{2}$; that is, either pyrite or marcasite. Fossil wood may be replaced by pyrite or marcasite as decomposition goes on, and shells may be changed in like manner, as acid waters at hand dissolve and remove the calcareous material.

Calcium sulphate, or gypsum, is, by similar deoxidation, converted into calcium sulphide, CaS; zinc sulphate, into zinc sulphide, $\mathrm{ZnS}$, the mineral, sphalerite; and lead sulphate, into lead sulphide, PbS, which is the common lead ore, galena. After the deoxidation of a sulphate, as gypsum (calcium sulphate), to calcium sulphide, the re-oxidation of the sulphide may take place, and hydrogen sulphide (sulphuretted hydrogen) may result through the agency of the water at hand, thus: Ca takes oxygen from the water, making $\mathrm{CaO}$, or lime (which may combine at once with $\mathrm{CO}_{2}$ to make $\mathrm{CaO} . \mathrm{CO}_{2}$, or calcium carbonate), and the sulphur, $\mathrm{S}$, takes the hydrogen thus set free from the water, making $\mathrm{SH}_{2}$, or hydrogen sulphide (sulphuretted hydrogen); for $\mathrm{CaS}+\mathrm{H}_{2} \mathrm{O}=\mathrm{CaO}+\mathrm{H}_{2} \mathrm{~S}$. This is the ordinary process by which the gas of sulphur springs is made, as for example those of western New York and Virginia.

By the oxidation of the hydrogen of the hydrogen sulphide making $\mathrm{H}_{2} \mathrm{O}$, or water, the sulphur, S, becomes deposited. This is a very prominent source of sulphur; and it accounts for its frequent association with gypsum and limestone.

Further, hydrogen sulphide, $\mathrm{SH}_{2}$ (sulphuretted hydrogen), by action on zinc sulphate, will deoxidize the sulphate and make zinc sulphide; on iron sulphate, it will make an iron sulphide; on lead sulphate, lead sulphide.

But under warm and moist conditions the sulphur may oxidize and make sulphuric acid, $\mathrm{SO}_{3}+$ water; and some sulphuric acid springs in New York have this source. Gypsum may be formed by such waters if limestone is within their reach. Pfaff states that at depths in water under a pressure of 40 atmospheres anhydrite will probably form, and not gypsum. Anhydrite is gypsum minus the water.

It may be added that sulphurous acid, $\mathrm{SO}_{2}$, is formed by the combustion of sulphur (as in volcanoes); and when this gas comes into contact with hydrogen sulphide $\left(\mathrm{SH}_{2}\right)$, the sulphur of both is deposited, the oxygen and hydrogen combining to form water; and this is one source of the sulphur about volcanoes.

With heat, carbon deoxidizes iron oxide and oxides of other metals, producing the pure metal.

\section{Destructive effects. - Since nine tenths of rocks not limestones contain} one or more of the common iron-bearing silicates, pyroxene, hornblende (or other species of the hornblende family), or black mica, and almost all rocks have a sprinkling of pyrite or marcasite, the oxidation process is all-pervading in its destruction. The presence of water and air being necessary, the more porous the rock, the deeper and more rapid the decay. The rocks where the 
destructible mineral is a chief constituent become covered with a rusty crust which is ever encroaching inward; and this crust is slowly reduced to a rusty earth, having parted with all soluble ingredients; or, losing the rusting mineral, it finally falls to earth or sand. A porons granite or gneiss containing black mica may become deeply rusted, and finally reduced to a weak mass of quartz and unaltered feldspar, - good material for a granitic sandstone.

If marcasite or pyrite is present in any rock, there is not only oxidation, but corrosion from the sulphuric acid that may be formed, which attacks any lime present in the minerals of the rock, or any magnesia, or potash, or soda, or alumina, and makes sulphates with each. The aluminum sulphates are alums, but strictly so only when potash, soda, or some other base is also present. Some beds of shale containing iron sulphide are impregnated or interlaminated with alum which has been thereby made, the shale affording the alumina of the alum.

Limestones, even the whitest of marbles, often contain a trace of iron or of manganese in combination, and occasionally masses of the iron carbonate, siderite. The iron carbonate, unless in a massive state, readily oxidizes; and so also does the iron of the limestone on exposure for a few months; and this is a commencement of the change in the whole mass to limonite. The work in progress is illustrated by Fig. 132, representing an

132.

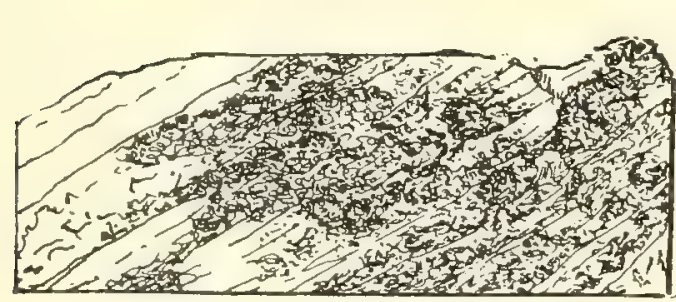

Impure limestone decaying to limonite.
133.

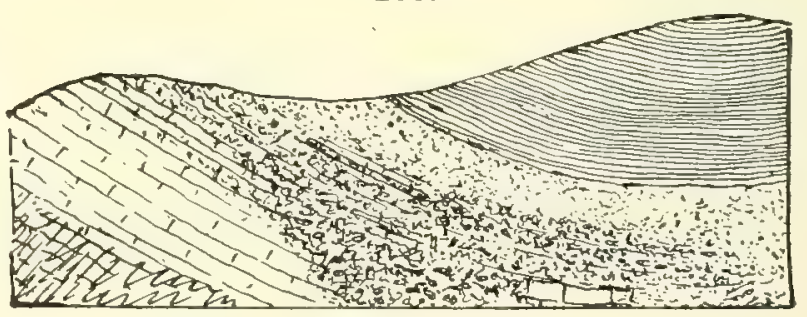

Same, with calciferous schist. D.

impure ferriferous limestone as it appears where the alteration is going on at the Amenia Ore-pit, N.Y., southwest of Salisbury, Conn.; and Fig. 133, the same, with the calciferous schist adjoining also changing. If one per cent of iron is present, a limestone will rust and decay ; if as much manganese is present, it will become covered with black stains. The massive siderite changes slowly over the surface and in rifts.

Limonite - the yellow-brown oxide of iron, or yellow ocher - is the most common result of the oxidation; but hematite, of red-ocher color, is often produced in warm and rather dry climates. Nearly all red, yellow, and brown rocks, sand-beds, or earth-beds, owe their color to iron in one of these two forms.

Oxidation of the iron in pyroxene gives the yellow-brown fronts to trap bluffs - not their gray and black tints, which are due to lichens; and has spread delicate surface shades of red and yellow over sandstones in the Yellowstone Park, and other dry parts of the Rocky Mountains, through the oxidation of the little iron inside. 
This oxidation process, and other methods of decay, go on with greatest rapidity in the fissures of rocks, below a surface of soil, because the descending surface waters keep them almost continuously wet; and it is under such circumstances that a rock which is much fissured or jointed becomes reduced to a pile of great bowlders with rusty earth between, as illustrated in the figure annexed. The balls of rock here represented are very common in decomposing rocks from granites and trap to sandstones. They are simply a result of surface decay along the many planes of fracture (Fig. 134). The decay or oxidation at first produces a thin discoloring of adjoining surfaces, as in the lower part of

134.

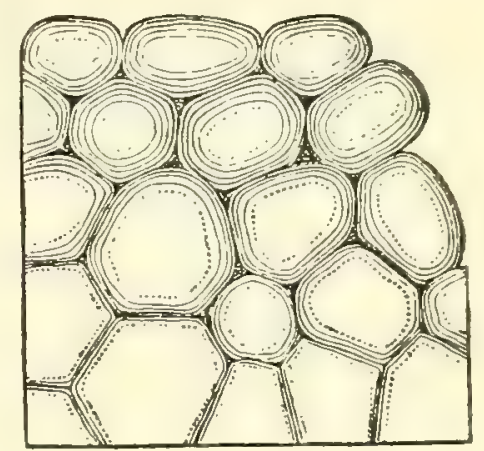
the figure; and this continues, eating off the angles, which are attacked from three directions, until a bluff of solid rock becomes apparently a pile of great bowlders. With the progress of the alteration, the discolored portion becomes banded with yellow and brown; and as it deepens, the outer part of the spheroid sometimes separates in concentric shells, precisely corresponding with the concentrie structure of a concretion. But these concentric shells are due to the decay that is in progress; and apparently to alternations in the work of decay dependent on climate and the capillary action above explained. Rounded stones or bowlders are very often so made. After separation from the pile, and therefore from exposure to almost permanent moisture, the masses may decompose outside with extreme slowness.

5. Constructive effects. - As the process is a means of reducing the hardest rocks to earth and sand, it aids in preparing material for new rock-making, and also in supplying earth and sand for soil and fertility. Without it, and one other associated process mentioned beyond, the earth would have had very scanty geological records and only low-grade life.

This agency has produced, or aided in producing, a large part of the great and valuable iron ore beds of the world's history, from Archæan time onward. The limonite ore beds (often called by miners "hematite" beds) are among the products. They occur of great size and value in West Stockbridge, Mass., Salisbury, Conn., Amenia and elsewhere in New York, in eastern Pennsylvania, western Virginia, and farther south to Alabama, as a result of the oxidation chiefly of a ferriferous limestone, and of any iron carbonate the limestone may contain. In the formation of the iron oxide, carbonic acid is set free, and the weakened calcareous rock is hence readily removed by percolating waters; hence great cavities are made by the process, ready to receive the ore as it is produced. Any slates or schists adjoining are also destroyed by the action.

Iron sulphides have been the source of similar beds, but such ore is likely to contain some sulphur. The Amenia ore bed is a good place for studying the formation of the ore from both a ferriferous limestone and a massive iron carbonate. These ore-beds, although superficial, cannot be 
affirmed to be modern; for they have probably been in progress ever since the land first emerged from the ocean so that air and water could begin the work.

In the destruction of the iron-bearing minerals of surface rocks, the iron oxide combined with a humus acid is often carried into marshes to make "bog iron ores." The ores thus formed have much value, although likely to contain phosphates as impurity, because of the animal and vegetable matters that live and die, or find burial, in swamps.

The consolidation of beds of sand and gravel, or layers of rock, is another of the constructive effects of the iron oxide that is distributed through the material of the beds. In the simplest form of it, the waters, filtering through soil and gravel, take up enough oxide of iron to cement a bed of pebbles lying at a lower level on another layer sufficiently close in texture to hold the water and give the iron a chance to deposit; and this is one way in which what is called hard-pan is sometimes made. The underlying impervious bed is not absolutely necessary to the result, although promoting it. The pebbles wet with the ferruginous waters, when they dry in times of drought, take a deposit of iron; and this process may end in complete consolidation. In other cases the oxide is produced throughout the deposit under the action of infiltrating waters, and slowly becomes a cement as it solidifies.

This mode of consolidation without aid of heat is not the most common nor the most efficient.

The beds of sulphur of the world have been made by the two processes mentioned on page 125 , and chiefly the former.

\section{Hydration, or the Chemical Absorption of Water.}

Many minerals take up water on "weathering." But this usually is an accompaniment of commencing decomposition. An example of simple hydration of geological importance is the change of anhydrite $\left(\mathrm{CaO} \cdot \mathrm{SO}_{3}\right)$ to gypsum $\left(\mathrm{CaO} \cdot \mathrm{SO}_{3} \cdot 2 \mathrm{H}_{2} \mathrm{O}\right)$. As the minerals are very unlike in cleavage, and both occur in large beds, the change is strikingly noticeable.

\section{Carbonic Acid, Humus Acids.}

1. General action. - Carbonic acid $\left(\mathrm{CO}_{2}\right)$ is ever present in the atmosphere, of which it constitutes 3 parts in 10,000 by volume, and in all rain water, river water, and sea water. It is often given off by mineral springs, and occasionally escapes in large volumes from fissures in volcanic regions. In the northeast corner of Yellowstone Park is "Death Gulch," where the gas rises freely from the waters of Cache Creek, to the destruction of bears and other wild animals. Butterflies and other insects, besides skeletons of bears, elk, squirrels, etc., attest to its deadly character (W. H. Weed, 1889). Death's Valley in Asia Minor, and the Dog's Grotto at the Solfatara near Naples, are other localities of escaping carbonic acid. 
Carbonic acid is given out in respiration, and is a product of animal and vegetable decay; and by this means it becomes distributed through the air and waters. The humus acids, among the results of vegetable and animal decay by oxidation, occur in all damp soils in which such decay is going on. The action of these acids has been studied by A. A. Julien. ${ }^{1}$ 'They are effective especially through their affinity for iron protoxide, magnesia, lime, soda, potash, and some other protoxide bases.

a. In water, carbonic acid takes up calcium carbonates from any calcareous material, whether in the state of limestone, or in other conditions, to make calcium bicarbonate for transportation. On evaporation, the bicarbonate again becomes calcium carbonate. The amount taken up is increased by the presence of magnesium or sodium sulphate in the waters (Hunt). The Mammoth Hot Springs contain 0.6254 parts of calcium carbonate in 1000 of water, which is over 4 times as much as pure water saturated with carbonic acid will take up (Russell).

b. It'takes the bases - potash, soda, lime - out of a feldspar, thus destroying the mineral to as great a depth in a rock as the carbonated water and air can penetrate, and reduces it to clay. This is true especially of the potash-feldspars, orthoclase, and microcline. The same work is done by the humus acids. The clay results thus: Orthoclase consists of silica, alumina, and potash. In the change it loses the potash and part of the silica, and becomes silica, alumina, and water. Thus the compound, $\mathrm{K}_{2} \mathrm{O} \cdot \mathrm{Al}_{2} \mathrm{O}_{3} \cdot \mathrm{Si}_{6} \mathrm{O}_{12}$, becomes $\mathrm{H}_{2} \mathrm{O} \cdot \mathrm{Al}_{2} \mathrm{O}_{3} \cdot \mathrm{Si}_{2} \mathrm{O}_{4}$, and 1 of water. Half of the water $\left(\mathrm{H}_{2} \mathrm{O}\right)$ received replaces the potash $\left(\mathrm{K}_{2} \mathrm{O}\right)$ lost.

c. Carbonic acid decomposes other minerals in a similar way, taking out the protoxide bases. It may thus form a soluble iron bicarbonate in waters, which streamlets may convey to marshes. But only a trace of this iron salt can be held in waters under the existing atmospheric pressure. The humus acids also make, with iron, soluble salts, and do, at present, the chief part of such transportation for the making of bog ores. On the evaporation of the solvent waters, the iron in each case is usually deposited as hydrous sesquioxide or limonite.

d. Further: it is supposed that carbonic and humus acids may aid in the oxidation of the protoxide-iron of a mineral by bringing it to the surface of a mass of porous rocks, so as to make the oxidation possible.

2. Destructive effects. - For the reasons stated carbonated water containing humus acids has done a vast amount of eroding work.

(a) Draining out by infiltrating waters. - The lightest work is the draining of any soluble ingredient out of a rock. Calcareous grains are thus drained from a porous calcareous sandstone, or quartzyte, increasing its porosity. So also calcareous fossils are removed from rocks that admit infiltrating waters, leaving the rock cellular. When a crystalline limestone or marble, a porous rock, consists of dolomite, but contains mixed calcite, all the calcite grains are drained out because they are the most soluble, and the rest are left to fall to loose sand, an effect exemplified in many places over Canaan, Conn., and Berkshire County, Mass. If the fossils of a limestone are made of calcite and aragonite (the latter the prismatic calcium carbonate), the aragonite portion is taken away - a fact first reported by Sorby. Shells of the kind referred to are those of the genera Pinna, Mytilus,

1 On the reaction of the humus acids see A. A. Julien, Rep. Amer. Assoc., 1879.

DANA'S MANUAL -9 
Spondylus, Patella, Fusus, Purpura, and Littorina, in which the inner pearly layer is aragonite, and the outer calcite. The shells of most Gastropods and of Cephalopods are aragonite; and Corals, including the Millepores, are mainly so; while shells of Rhizopods, Echinoderms, and Brachiopods consist of calcite.

Further, if the limestone contains iron or manganese combined with the calcite, carbonated water will bring the iron to the surface, or the iron carbonate, or the manganese, for oxidation, weakening and discoloring the rock. The action on feldspar, above mentioned, is a common means of destruction in the case of granites and related rocks.

(b) Process of draining limited. - But it is also to be observed that these effects occur only so far as the rocks are porous. The fossils of compact argillaceous sandstones and shales-common kinds of fossiliferous rocks and some dating from the Cambrian - are seldom drained out or injured at all by infiltrating waters, except when near the surface. The iron and manganese taken out of some crystalline limestones are removed only for a short distance inward; but the process destroys the limestone as it eats in, and is thus enabled to erode farther. Deep below the surface the same rocks are solid and not discolored. All deep-water rocks are moist, but the moisture is ordinarily stationary unless a surface drought reaches downward, or an invasion of heat comes upward from below, when the moisture thus lost may be later replaced. Even beds of salt in subterranean rocks are not dissolved away.

(c) Surface erosion. - Waters containing carbonic acid or humus acids eat away the surface of solid limestone, fluting precipices, widening crevices, excavating caverns. They often leave calcareous fossils projecting slightly above the surface, and develop with great perfection silicified kinds. The length of the caverns thus made in the Carboniferous limestone of Kentucky,

135.

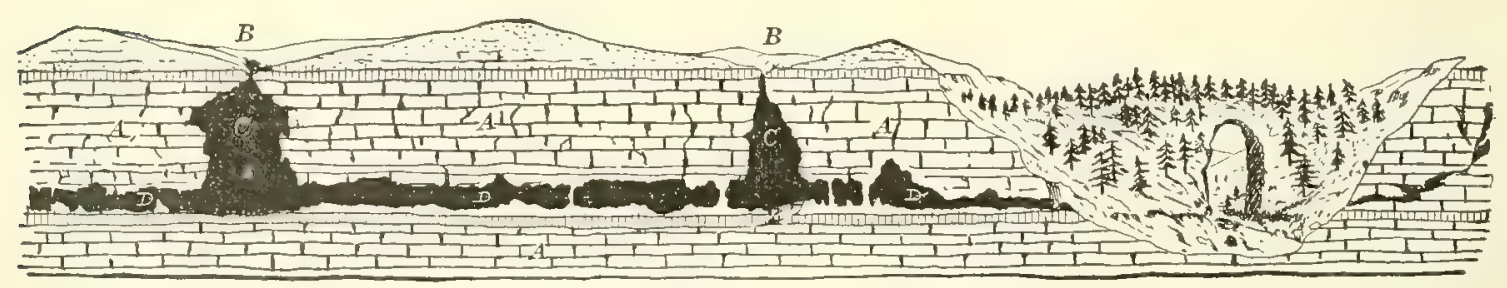

Making of caverns in limestone. Shaler.

a rock 200 to 1000 feet thick, is estimated by N. S. Shaler to amount to 100,000 miles. The work is begun by the descent of waters along joints in the rock, whenever there is a chance for discharge below, by running down or trickling along between layers of the limestone. The process and result are illustrated in the above figure by Shaler. In the movement of the waters, the fissure or joint (B) becomes enlarged to a "sink-hole," and excavation begins between the layers. The end is a great cave, having, it may 
be, its spacious chambers, high water-falls, and free-flowing rivers. The flowing waters sometimes work also by abrasion; but there is usually little loose material to transport for the purpose of abrasion.

In a similar way limestone cliffs have been chiseled into ranges of turrets, and deep recesses and channels made for rivers through limestone strata.

The excavation of the lagoon basins of coral islands has been attributed erroneously to erosion by the carbonic acid of the sea water.

(d) Except for surface erosion, limestone consisting of pure calcite, free from iron sulphides, is a durable rock, whether uncrystalline or crystalline, as in the case of the Carrara marble, of which such marvelous structures as the Milan cathedral have been made. But a magnesian limestone or dolomyte, when crystalline, is often easily destructible, because, as already stated, the porous rock is likely to contain disseminated calcite; and as this is more soluble than dolomyte, percolating waters carry it off, leaving the rest in the state of sand - a bad condition for the marble temple that may be made of it. The presence of the calcite can be detected only by observing whether, at any exposure of a layer in the region of a quarry, it is turning to sand.

Polished limestone marble containing any chert or other hard mineral, if employed in out-door ornamentation or on monuments, is sure to weather rough and become unsightly, and the chert may be made to stand out in ragged points or knobs. Even the vertical movement of the atmosphere over polished marbles will in time take off or dim the polish.

(e) Since carbonic acid attacks feldspar as well as other minerals, this agency, and that of oxidation, leave scarcely any kind of rock safe against destruction. Those are safest that are free from iron sulphides, and especially those that are so fine-grained and compact that water cannot gain access. Hence, the method of testing rocks for porosity by ascertaining how much water they will absorb in 24 hours is excellent. Some slate rocks are very durable becanse of their fine grain and the absence of any soluble minerals. Some granites absorb little water, some very much; and the latter are easily destructible.

3. Constructive effects. - (a) Calcareous deposits. - The most familiar deposits of this kind are the stalactites and stalagmites of caverns, dripstone formations; so-called because made by the calcareous waters dropping from the roofs. "The "Gibraltar rock" is stalagmite. Still more interesting are the travertine or tufa deposits of streams. Leaves, nuts, and stems are often petrified by calcareous waters.

The travertine of 'Tivoli, near Rome, constitutes a large deposit along the Anio, whose waters are there strongly calcareous. Along Gardiners River, in the region of the Yellowstone Park, thick limestone deposits have been made, as is well illustrated and described in the Reports of Hayden's Geological Survey of the Territories. The calcareous waters, in descending the slopes of the hills, have made a series of parapets at different 
levels, inclosing basins, over which the water drips or plunges on its way to the bottom, as illustrated in Fig. 136. Travertine is usually somewhat cellular and concretionary in structure if not in exterior forms, unlike the even-grained material of ordinary limestone.

$1: 30$.

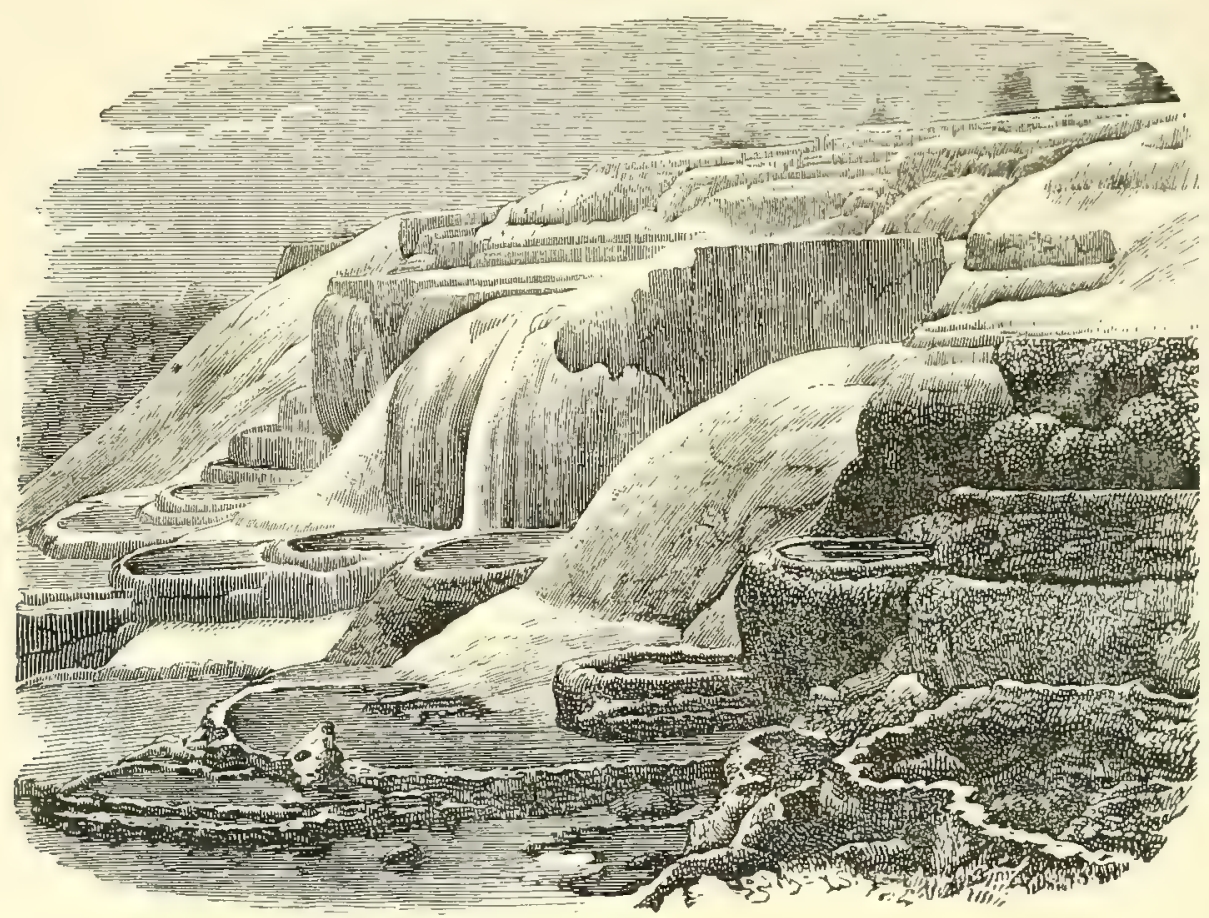

Calcareous formations. Mammoth Hot Springs, Gardiners River. Phot. by Jackson.

About the lakes of the Great Basin calcareous deposits have unusual extent and variety of forms, rising often into groups of rounded columns,

137.

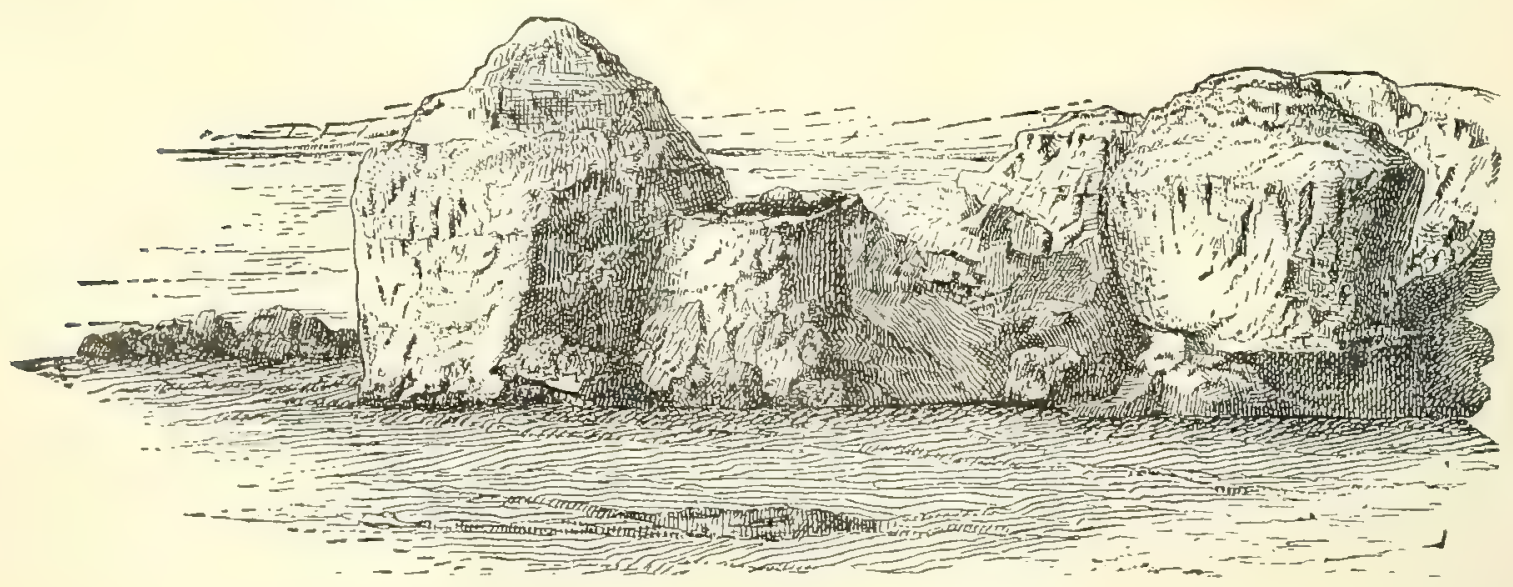

Tufa deposits, Lake Mono. I. C. Russell.

towers, domes, and other shapes. One example, taken from I. C. Russell's Report on Lake Mono (1889), is illustrated in Fig. 137. These deposits are also abundant in other parts of the Basin. 
Some of the travertine deposits of Gardiners River and elsewhere are a result of the growth and secretions of Conferva-like plants, as explained bv W. H. Weed.

In the Lahontan and Mono basins, as described by King and later by Russell, he material has often a crystalline form, the origin of which is yet unexplained : this variety is the thinolite of King. A common form is represented in Fig. 138.

The beautiful translucent limestone of Tecali, Mexico, often

138.

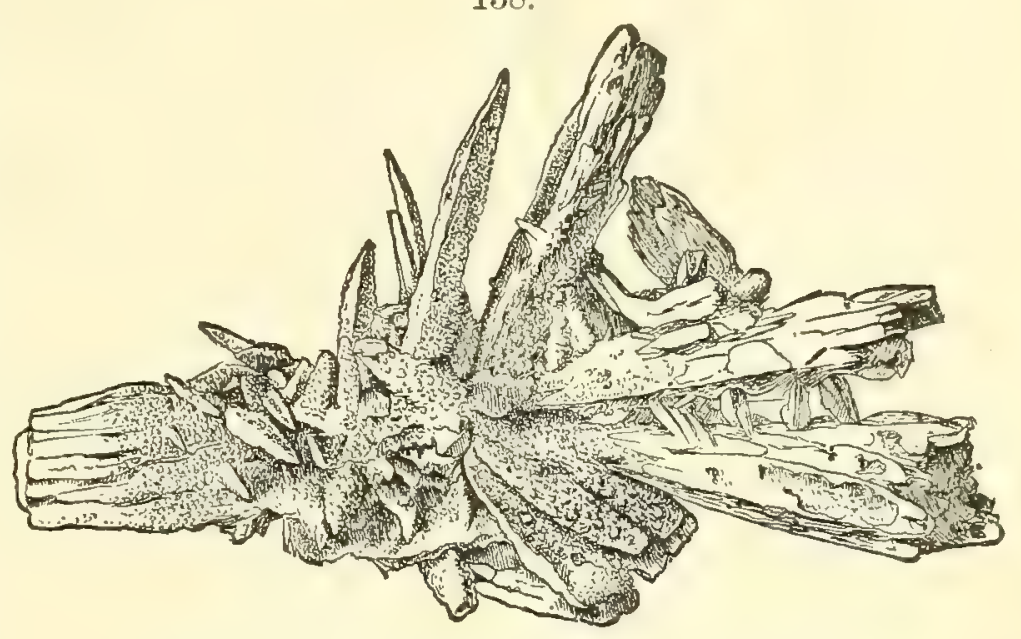

Thinolite: from Lake Mono. I. C. Russell. wrongly called onyx, because banded in colors when polished, is a calcareous deposit failing of the coarse and irregular grain of travertine.

(b) Consolidation. - Of still greater geological range is the cementing work done by calcareous waters. Ordinary sea water, especially where shells and corals abound, consolidates sands made from coral and shell into limestone. The beach sands, drifted sands, and sands over the reefs, when drying from exposure to the air, become cemented in this way. Conglomerates are also made of broken corals, shells, and calcareous or other pebbles, and breccias, in this, as in other ages, out of a talus or any accumulation of limestone blocks.

The under-water calcareous sands, as those about coral reefs, also become cemented by the same means, but into a compact limestone like ordinary limestones, showing usually no sand-like grains in the texture.

(c) Dolomyte-making. - Even dolomyte, $\left(\frac{1}{2} \mathrm{Ca}_{2}^{\frac{1}{2}} \mathrm{Mg}\right) \mathrm{O}_{3} \mathrm{C}$, owes its origin at times - if not always - to the conditions that exist in the history of coral reefs when the magnesia, required to make the calcareous grains magnesian, could have had no source but the ocean. One case of the kind is reported by the author (1849) from the island of Metia, an elevated atoll north of Tahiti (Corals and Coral Islands, page 393). The rock is a compact white limestone. An analysis by B. Silliman proved that it contained 38.07 per cent of magnesium carbonate, the rest being calcium carbonate. The very fine texture of the rock indicates that it was made of the finest of calcareous ooze or mud, such as forms through gentle wave-action in shallow lagoons; and in such lagoons, mainly shut off from the sea, and therefore in a "salt-pan" condition (page 120), the concentrated brines contained the magnesium chloride and sulphate in a state that favored the formation of dolomyte. 
The change, if produced through the magnesium chloride $(\mathrm{MgCl})$, required the removal of $\frac{1}{2} \mathrm{Ca}$ by the chlorine of an equivalent amount of $\mathrm{Mg}$. If this is the true theory of dolomyte-making, then great shallow areas or basins of salt-pan character must have existed in past time over various parts of the continental area and have been a result of the oscillations of the water level. Such magnesian limestones contain few fossils, partly because of the fine trituration, and partly, no doubt, because of the unusually briny condition of the waters. The frequent alternation of calcite and dolomyte strata would indicate alternations between the clear-water and salt-pan conditions. Dolomization, in the case of such beds, has often taken place after partial or complete consolidation; for many dolomytes are exceedingly porous, because of the diminished bulk of the dolomyte - one eighth to one tenth. T. S. Hunt made the porosity of several Canadian Lower Silurian dolomytes, 10 to $13 \frac{1}{2}$ per cent (1866).

Local cases of alteration are well known. Adolf schmidt mentions such at the lead mines of Missouri, which he attributes (following Bischof) to the action of magnesium bicarbonate.

In a memoir on the famous dolomyte region of the Tyrol, Dölter and Hörnes, geologists of Vienna, discuss this subject at length, and reach the following conclusions: (1) Some large limestones, weakly dolomitic, may have been made out of those organic secretions which contain a little magnesia; (2) minor cases of the production of dolomyte are due to the alteration of limestone through the introduction of magnesium carbonate; but (3) the larger part of dolomyte formations, whether more or less rich in magnesia, have been formed from organic calcareous secretions through the action of the magnesium salts of sea water, especially the chloride.

(d) Making of clay and soil. - Pure white clay, or kaolin, used in making porcelain, is sometimes in strata of wide extent; and the common impure river-valley clays, employed in brick-making and coarser pottery, have no less value. One of the largest kaolin beds in New England, at New Marlboro, in Berkshire County, Mass., was probably made by the decomposition of the orthoclase that was disseminated through quartzyte, and its removal by percolating waters to the bed of a streamlet; for in other localities in Berkshire this result is now going on from the same quartzyte. The absence of black mica and other iron-bearing minerals insured its being white.

(e) The blanching of red and rusty rocks by waters containing carbonic acid and organic acids or materials is a common and important effect. Colored clays are drained of their iron oxide and whitened by percolating waters. A deeply rusted block of basalt or granite may thus be made to have a white exterior an inch or more deep.

(f) Again, the impurities of a limestone are sometimes made available for soil, by the continued action of carbonated waters, and the removal thereby of the calcareous part. Shells and corals contain about 0.5 per cent of impurity, consisting chiefly of iron oxide and alumina; and the action of the rains over the hills of coral sand-rock on Bermuda, through centuries past, has left a residuum of red earth which is the soil of the island, as Wyville Thomson suggested. The red ooze or mud over much of the ocean's bottom below 2500 fathoms is due chiefly to the removal, in like manner, of the calcium carbonate of the Globigerinæ and other Rhizopods, in consequence of an excess of carbonic acid in the bottom or abyssal waters. The life of the sea-bottom 
has no accompanying vegetation to use up the carbonic acid of respiration and decomposition, and this gas would therefore become accumulated in its depressions.

\section{Silica: QUartz and Opal Silica.}

Silica in solution does the greater part of its geological work when aided by heat. Still much consolidation has been carried on by cold solutions, especially solutions of alkaline silicates, as potassium and sodium silicates. The former of these silicates is the waterglass of the shops, $\mathrm{K}_{2} \mathrm{O} .4 \mathrm{SiO}_{2}$, much used for making artificial stone and for other purposes.

Waters percolating through beds of volcanic ashes, by decomposing the feldspar present, take up silica and deposit it in the form of quartz and opal, making silicified wood and the finest of opals. In this way petrified forests have been made. In Napa County, California, according to the descriptions of $\mathrm{O}$. C. Marsh, in 1871, one of the prostrate trunks of the silicified forest, exposed to view by the washing away of the tufa and tufaceous sandstone, was 63 feet long, and 7 feet in diameter. In the Yellowstone Park, according to W. H. Holmes, in his paper of 1878, the forest trunks, from one to ten feet in diameter, are at several horizons in a deposit of tufa 5000 feet thick, indicating successive disastrous showers of volcanic ashes, at intervals long enough for the growth of a great forest. In Arizona, near Carrizo, in Apache County, there is a noted locality which affords agatized wood of great beauty, which has been well named Chalcedony Park. In such cases heat from hot springs may often have given aid; but it is probable that the temperature in the Yellowstone region was only that of the descending volcanic ashes and accompanying rainfall. The decomposition of the outside of trap sets silica free, which coats the surface with a whitish pearly layer of opal silica.

Beds of Diatoms and other siliceous organisms are sometimes converted by percolating waters into opal. The siliceous organisms that were originally disseminated in the calcareous materials out of which limestones and chalk were made were the source of the flint and chert, that occur in these rocks. Siliceous sponge-spicules constitute a chief part. This was early proved for flint, and for Lower Devonian and Lower Silurian cherts; but it has been proved to be true, by Dr. G. J. Hinde, for cherts or flints of all geological ages, whatever the size of the beds.

The silicification of wood referred to above is in part due to silica from siliceous organisms.

The amount of silicification of fossils that has taken place in cold rocks makes it probable that more consolidation is due to the process than has been supposed. Cases of the hardening of the exposed surface of a sandstone or quartzyte, making a hard crust, described by M. E. Wadsworth (1883), have an important bearing on the subject. $\mathrm{He}$ speaks of a block of white Potsdam sandstone, in Wisconsin, which was friable on the protected side, but on the side exposed to the prevailing storms was nearly a quartzyte; and a surface freshly exposed by fractures was found, six months later, to be much 
indurated. The St. Peter's sandstone afforded similar facts. In one case the cavities over the exposed surface had a lining of quartz crystals, while the rock a few inches below had the common friable character. The effects were comnected in sonne way with weathering processes. In some cases of the kind the silica math heve come from the decomposing action of percolating acid waters on feldspar grains sparsely disseminated through the rock.

Over the cold bottom of the ocean some silicates have been formed. Among them are masses or concretions of bronzite, a silicate of magnesia and iron related to pyroxene, and small crystalline groups of Phillipsite (Christianite). At depths of 2200 fathoms and over, the pressure on the bottom is 5000 to 12,000 pormds to the square inch; and this may favor the production of silicates, where the siliceous parts of Sponges, Diatoms, or Radiolarians abound, with the results of the decomposition of volcanic dust and pumice. Another silicate of common occurrence, forming in shallow water as well as in deep, is the green-sand called glauconite, a hydrous silicate of iron and potash.

\section{Chemical Work of Living Organisms.}

Respiration in animals, and also in plants, is a means of introducing oxygen from the air to carry on processes of oxidation among the elements in the structure, and the excretion of carbonic acid is one prime result. The growth of green plants, however, depends on a deoxidation process, the carbonic acid of the air being decomposed in the sunlight by the green coloring-matter (chlorophyll) of the plant, its carbon forming the food of the plant and its oxygen being set fiee. Plants of the Fungus division (Mushrooms and the Microbes) are not green (have no chlorophyll), and cannot get their food directly from the carbonic acid in the air. The chemical work of life of most geological importance, apart from the making of coal and related products, is that carried on by the lower plants; and only this is here briefly considered.

Plants, and especially the lower Cryptogams, contribute chemically to geological change through their roots or the fibers with which they come in contact with rocks. The acidity of roots is often very decided, as is manifest from the furrows they make in the surfaces of stones, and especially in limestones. Roots of plants germinated in sand over a slab of marble leave an imprint on the marble. Professor Storer observes that "it is to be noted that this action by chemical corrosion through the roots is incessant and continuous." The lichen Stereocaulon Vesuvianum, which grows on rocks, and among them on Vesuvian lavas, affords one ninth its weight of ash; which from one Vesuvian specimen, according to Roth, contained silica 46.41, alumina $19 \cdot 67, \mathrm{Fe}_{2} \mathrm{O}_{3} 6 \cdot 88$, FeO 4.17, magnesia 5.23, lime 10.53, soda $2 \cdot 02$, potash $4 \cdot 09=99 \cdot 00$. For other analyses, see page 75 .

The microbes, or Bacteria, are at the bottom in much of the world's chemistry. They do not get food from carbon dioxide, but, like true Fungi, find it in other compounds: for example, those consisting of carbon, hydrogen, and oxygen, as sugar, starch; or those containing these elements and nitrogen, ete., as albumen, muscle, or even a mineral sulphate; they taking the part of the compound required for food, and leaving the rest to 
form other products, at the same time usually giving out carbonic acid as a result of the plant's assimilation. The processes of oxidation and deoxidation are carried on by them; and it is a question whether, in the particular cases mentioned on the preceding pages, the changes are not dependent on the presence of microbes. They set sulphur free from sulphates (genus Beggiatoa); make ammonia and nitrates (Micrococcus nitrificans), deoxidize nitrates and other salts; aid plants in taking up nitrogen through the roots; probably aid animals in their digestive processes, besides causing some of their diseases; they are the basis of all processes of fermentation, and are concerned fundamentally in animal putrefaction and vegetable decay. Tyndall proved that flesh would not decay if shut away from Bacteriathe strong affinities of its elements being unable to take a start without help from these minutest of plants. The Bacteria are the smallest of workers and among the largest of producers.

In garden earth which is free from compost, as $\mathrm{T}$. Leone found, the nitrification process converts the nitrous acid into nitrate; while, on adding compost, the nitrate is deoxidized, and ammonia is given out; or in gelatine or other proteid substance and water, the organic substance is rapidly oxidized, attended by denitrification and the production of ammonia. Bacteria liquify muscle and coagulated gelatine, and, according to Brunton and Macfadyen, by producing a peptone-like solvent; and the same kinds produce fermentation in starch and similar non-nitrogenous carbo-hydrogen materials.

This organic source of nitrates explains their occurrence in the earth of caverns, or beneath sheds, and in other covered places; also of the loosening of the sands of sandstones in such places - an agency that may in time cause a vast amount of degradation and removal.

The native nitrate is usually either sodium or calcium nitrate, but sometimes potassium nitrate. The latter, which is salt-peter of the shops, is usually made from the others. In Kentucky caves the calcium nitrate occurs, the caves being in limestone. Sodium nitrate exists in the district of Tarapaca, northern Chile, over a great extent of surface, 3300 feet above the sea, in beds several feet thick, which have a covering of earth and a layer of gypsum, and contain some common salt. Moreover, underneath the bed occur common salt, glauber salt, gypsum, magnesia alum, and large quantities of borates; all of which indicate deposits from hot springs or evaporated sea water. But the source of the nitrate remains unexplained. This Tarapaca region of western South America is much like the Great Basin of North America in position, dryness, and saline deposits.

\section{Mechanical Work of Chemical Products.}

In oxidation and other processes yielding solid products, particles of the new material, when formed among the grains of the surface portion of a rock, or in its rifts, act like growing wedges in loosening and detaching the grains, and opening and extending rifts. The following figure represents a piece of quartzyte from Canaan, Conn., divided up, or septated, by the oxidation process. It looks like breccia, in which limonite is the cement; and specimens from the region were long so considered. But it was produced by the formation and infiltration of limonite. The rifts were thus widened into 
rents; moreover, the iron oxide spread either side, staining the rock, producing the appearance of very wide rifts. Along one rift there is an open

139.

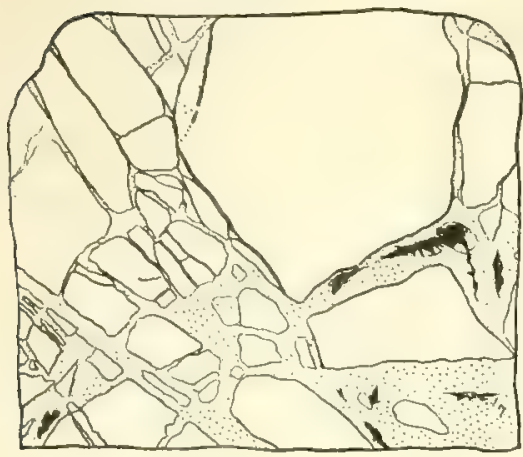

Quartzyte septaria. D. '84. space from the loss of grains, and in it a crust of newly formed quartz crystals. The process often results in pushing the pieces out of place.

Where saline efflorescences - as alums, nitrates, alkaline carbonates, or chlorides - are produced in the pores of a sandstone, the surface grains are successively pried off. Much denudation is thus produced, especially in arid regions. The process often makes a series of excavations along the front of bluffs. The process goes on most actively in covered places and during the heat of the day. A shale often has its laminæ separated by layers of the salt or oxide, and fragments detached.

Displacement by intrusion of crystalline material is a common process. The following figure illustrates a case in which erystals of tourmaline in mica schist are pushed apart at planes of fracture by intruding quartz (the dotted portion) from a siliceous solution. After the first deposit of quartz within the fracture, the additions were made between this deposit and the adjoining part of the crystal, and so the wedging apart went on. A. H. Worthen has described Crinoids, from the Keokuk limestone, as split open and enlarged in this way, and one Barycrinus that was thus made a foot in diameter. The tubular stems are increased four to six diameters in the process. The siliceous solution supplying the quartz of the Keokuk limestone was probably not 140.

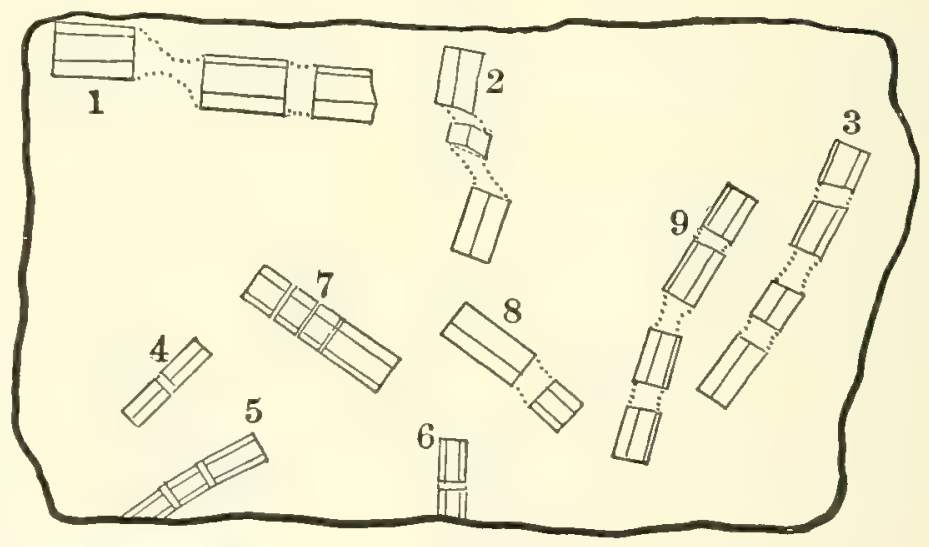

Broken crystals of tourmaline displaced by intruded quartz, Lenox, Mass. D. '85. heated.

The displacements may be great when large masses of a rock undergo change to a kind requiring additional space. In the change of a bed of anhydrite to gypsum the increase of bulk, due to the added water (page 128), is nearly 60 per cent. Dividing the atomic weight of anhydrite, which is 136 , by the specific gravity, $2 \cdot 95$, gives $46 \cdot 1$ for the bulk; and that of gypsum, 172 , by its specific gravity, $2 \cdot 33$, gives the bulk $73 \cdot 8$, making thus the gain in bulk from 46.1 to 73.8 . The change is hence attended by a breaking and displacement of any overlying beds of rock. In the change of calcite to true dolomyte, $\left(\frac{1}{2} \mathrm{Ca} \frac{1}{2} \mathrm{Mg}\right) \mathrm{CO}_{3}$, there is a diminution in bulk of one eighth per cent (or one tenth, if the composition is $\left(\frac{2}{3} \mathrm{Ca} \frac{1}{3} \mathrm{Mg}\right.$ ) $\mathrm{CO}_{3}$ ); which, 
if it takes place in a bed of calcite after its consolidation, would cause fractures, or make the rock porous and thus capable of holding much mineral oil (page 134), as in the Findlay oil region of Ohio.

\section{Concretionary Consolidation.}

The methods of consolidation that have been mentioned in the preceding pages are (1) by calcareous waters; (2) by ferruginous waters; (3) by siliceous solutions. Limestones, and rocks only partly calcareous, have been consolidated almost solely by the first of these methods. The second method is feeble in its results, and occurs in gravel deposits. Rocks that are colored by iron oxide, and appear to have a ferruginous cement, have usually been solidified by the third method.

Consolidation is often commenced or attended with concretionary consolidation, or accretion around centers throughout the mass, as illustrated on page 97. Isolated concretions often form in deposits of earth, clay, or other material, when they contain disseminated calcareous grains (derived from ground shells, or any other source). Percolating waters, aided by the carbonic or humus acids which such waters are likely to contain, dissolve the grains and deposit the material, in a drying time, around grains, or any small object, as a nucleus. In like manner, concretions of limonite and iron carbonate are made, if any ferruginous grains or any decomposable ironbearing mineral is present. Occasionally other materials make disseminated concretions.

The form of the concretion is not owing to any central control of the molecular deposition, but to the regular progress of the superficial accretion, and to the rate of supply of the mineral solution in vertical and horizontal directions, together with the shapes of the nuclei.

The growth of the concentric forms above described is peripheral. There is also centripetal consolidation, or from the exterior inward. It commences outside, owing to outside evaporation and the consequent deposition of the concreting agent. The agent is commonly ferruginous. This process of outside drying is exemplified by the drying away of a spot of milk two inches or so in diameter on a slab of stone (as observed by the author): the evaporation goes on at the outer margin, and makes there the first ring, capillary attraction inside of this ring contributing material toward it; this outer ring completed, another ring begins and forms at the new outer margin of the milk-spot; and so ring after ring forms, until the spot of nilk is reduced to a series of whitish rings. On the same principle, shell after shell may form in a sand-bed penetrated with a ferruginous solution, because drying is gradual from the outside; or there may be a single outer shell, with loose sand inside; or a central ball in the loose sand. The center of the concretion may originally have been a piece of the decomposing ironbearing mineral which afforded the ferruginous solution.

The concentric rings of ferruginous coloration in Fig. 141 had probably 
this mode of origin. The two sets of rings were either side of a crack in the rock, and had together a diameter of about twenty feet.

Fig. 142 represents concentric areolets between mud cracks in an argillaceous shale, made by siliceous waters at the time of the consolidation, when the mud cracks were likewise filled with quartz, a layer of quartz being

142.

141.

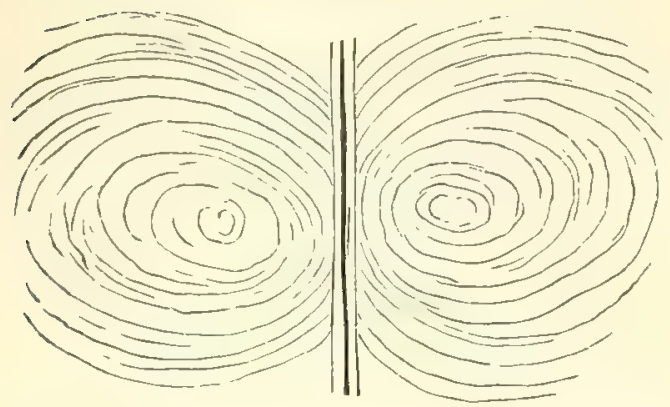

Concentric discoloration, Illewarra, N.S.W. D. '49.

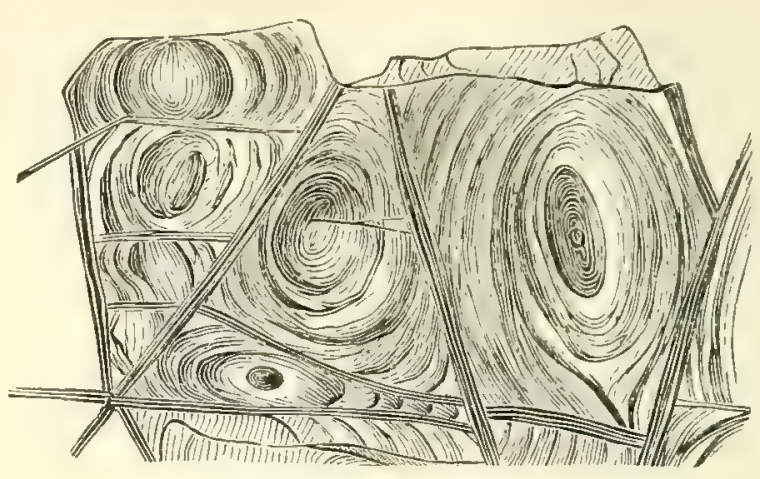

Concentric structure, Australia. D. '49.

deposited against each wall. Whether in this case the concentric consolidation was centrifugal or centripetal is not ascertained. Seashore wear of the rock brought the structure to view.

See further, on Lithophyso, page 337.

\section{LIFE: ITS MECHANICAL WORK AND ROCK CONTRIBUTIONS.}

The making of rocks out of organic contributions, and the protective, transporting, and destructive effects of life, are the subjects here under consideration.

\section{General Remarks on Rock-Making.}

\section{Materials Afforded by Plants and Animals.}

The organic contributions to rock-making are mentioned on page 71 . It appears that

Plants afford -

Calcareous material for rocks: mainly through Nullipores and Coccoliths, and other calcareous Algæ or the lowest of Cryptogams.

Siliceous material: through Diatoms, and some confervoid Algæ; and sparingly through other plants, the ashes of which afford some silica and alumina.

Carbonaceous materials: through plants of all kinds, but especially those that flourish in wet soils and marshes, where means of burial are convenient.

Antmals afford -

Calcareous material: through Rhizopods among Protozoans; Spongiozoans with calcareous spicules, to a very small extent; Actinozoans, or the Corals ; Hydrozoans of the Hydroid section; the lower Echinoderms or the Crinoids and Cystoids, and other Echinoderms sparingly; Molluscoids, as the Brachio- 
pods and Bryozoans; Mollusks of all the divisions; Articulates, or Worms and Arthropods, very sparingly; and sparingly, Fishes among V'ertebrates, and very sparingly, other Vertebrates.

Siliceous material: through Radiolarians among Protozoans; and extensively, Spongiozoans having siliceous spicules or skeleton.

Carbonaceous materials: sparingly through the decomposition of aquatic species and the dissemination of organic matters in bottom muds.

Phosphatic materials: chiefly through excrementitious matters ; sparingly from shells of some of the lower Brachiopods, and of Pteropods; sparingly from tests of Trilobites, Crustaceans, and other Arthropods, and bones of Vertebrates; and animal tissues. For analyses see page 72.

\section{Relations of the Kinds of Life to Rock-making.}

The fitness of species for rock-making depends not only on the amount and character of their stony secretions, but also on their geographical distribution, and this on their relations, as regards growth, to temperature, light, moisture, and the composition and mechanical condition of the air, waters, or soil inhabited; the height over the land, the depth in the water, and all conditions affecting growth and burial.

Marine species of plants and animals are those most likely to become fossils, and so to contribute to rock-formations; and, among terrestrial species, those that live in lakes or marshes, or along their shores or borders. The reasons are two: (1) Because almost all fossiliferous rocks are of marine origin; and (2) because organisms buried under water, or in wet deposits, are preserved from that complete decomposition to which many are liable when exposed on the dry soil, and are also protected from other sources of destruction.

Over the land, the chance of burial is very small. Plants and all animal matter pass off in gases, when exposed in the atmosphere or in dry earth; and bones and shells become slowly removed in solution, when buried in sands through which waters may percolate. Vertebrate animals, as Fishes, Reptiles, etc., which fall to pieces when the animal portion is removed, require speedy burial after death, to escape destruction from this source as well as from animals that would prey upon them.

Among Insects the species that frequent marshy regions, and especially those whose larves live in the water, are the most common fossils, as the Neuropters; while Spiders, and the Insects that live about the flowers of the land, are of rare occurrence. Waders, among Birds, are more likely to become buried and preserved, than those which frequent dry forests. But, whatever their habits, Birds are among the rarest of fossils, because they usually die on the land, are sought for as food by numberless other species, and have slender hollow bones that are easily destroyed. Mastodons have been mired in marshes, and thus have been preserved to the present time; while the thousands that died over the dry plains and hills have left no relics. 
The animals generally of the ocean are little liable to extermination from changes of climate over the land; and hence some marine invertebrate species of the early Tertiary, many of the later, and all of the Quaternary, have continued on until now, while, as regards terrestrial animal life, there were in this interval many successive faunas.

The lowest species of life are the best rock-makers; namely, Corals, Crinoids, Rhizopods, Diatoms, Millepores, Bryozoans, Brachiopods, Mollusks; for the reason that the structures of only the simplest kinds can consist mostly of stone and still perform all their functions. Multiplication of bulk for bulk is more rapid with the minute and simple species than with the higher kinds; for all animals grow principally by the multiplication of cells; and when single cells or minute groups of them, as in the Rhizopods, are independent animals, the increase may still be the same in rate per cubic foot, or even much more rapid, on account of the simplicity of structure.

While, therefore, we may conclude that we have, in known fossils, a fair though incomplete representation of the marine life of the globe, we know very little of its terrestrial life, - enough to assure us of its general course of progress, but not enough for any estimate of the number of living species over the land; or for safe deductions as to lines of succession.

Geology may have within reach of study fossils representing a twentieth of its marine life; but it has not more than a thousandth of its terrestrial life.

Some examples of marine accumulation. - (1) Beds of oysters, along with other living species, exist in the shallow seas, as off the coast of North America, but in waters too deep for disturbance by the waves. Sands or earth encroach upon them through the marine currents, but not to the destruction of the species. Afterward, through some geological change, berls of detritus are washed over them, exterminating the oysters and perhaps other species also. This is one case; and in it the fossils are unbroken. (2) In another place, the relics of the life of the coast, the shells, Corals, Crustaceans, etc., live so near the sea level as to be within reach of the waves, and hence they may be dislodged at times of heavy storms, and may become ground into fragments and sand; or they may be contributed to under-water banks, and some of the shells may be scarcely worn, and therefore good fossils. (3) In another case, the worn fragments, coarse and fine, may be washed up a beach and ground fine or coarse by wave action. (4) Again, the species may live over seashore flats which are so shallow that the triturating waves act gently, and all relics thereby become ground to mud, and not one is left to make a distinguishable fossil. (5) Again, where barriers off a seacoast exclude the salt water with its marine life, not a sea-relic of any kind may be put into the accumulating seashore beds until some change of conditions removes the barrier.

\section{Methods of Fossilization.}

In the simplest kind of fossilization there is merely a burial of the relic in earth or accumulating detritus, where it undergoes no change. Examples 
of this kind are not common. Siliceous Diatoms and flint implements are among them.

In general, there is a change of some kind; usually, either a loss, by decomposition, of the less enduring part of the organic relic, with sometimes the forming of new products in the course of the decomposition, or an alteration, through chemical means, changing the texture of the fossil, or petrifying it, as in the turning of wood into stone.

The change may consist in a fading or blanching of the original colors; in a partial or complete loss of the decomposable animal portion of the bone or shell, a process that leaves shells and bones fragile. It may be a loss of part of the mineral ingredients by solvent waters, as of the phosphates and fluorides of a bone or shell; or a general alteration of the original organism, leaving behind only one or two ingredients of the whole; or a combining of the old elements into new compounds, as when a plant decays and changes to coal or one or more carbohydrogens, a resin to amber, animal matter to adipocere. It may be merely one of crystallization.

The change often consists in the reception of new mineral matter into the pores or cellules of the fossil, as when bones are penetrated by limestone or oxide of iron. Through this method bones may become as firm as when living, though also much heavier.

The change is frequently a true petrifaction, in which there is a substitution of new mineral material for the original; as when a shell, coral, or wood is changed to a siliceous fossil, through a process in which the organism was subjected to the action of waters containing silica in solution. In other cases, the organism becomes changed to calcium carbonate, as in much petrified wood; and in others, to oxide of iron, or to pyrite; and more rarely to fluor spar, barite, or apatite.

The mineral matter first fills the cells of the wood, and then takes the place of each particle as it decomposes and passes away, until finally the original material is all gone. Some fossil logs are carbonized at one end and silicified at the other.

The silica in most siliceous petrifactions has come from siliceous organisms, such as species of Sponges, or shells of Diatoms, from living species of the period that were associated with the fossil in the original deposit.

\section{Examples of the Formation of Strata through the Agency of Life.}

\section{Deposits from Pelagic and Abyssal Life.}

1. Plants. - Ordinary seaweeds, although in general littoral species, float widely over the ocean in some seas, as in the case of the Sargasso Sea of the north Atlantic. Moreover, the shore seaweeds are often drifted off by the currents. But the supply, while of importance as food for the animal species of the sea-bottom, makes no abyssal vegetable deposits. Dredging has brought up no remains of such deposits.

But Diatoms, which becloud the waters of the southern ocean, and there serve for the vegetable food of Whales, make the great deposits of Diatom ooze, as already described, besides giving a sprinkling of siliceous shells over all other parts of the ocean's bottom. These shells, as stated by Murray. are especially noticeable in the deeper Red ooze, because the carbonic acid. which removes calcareous relics, leaves them uninjured. 
2. Animals. - Radiolarians or Rhizopods, having siliceous shells, make Radiolarian ooze in the deeper parts of the ocean. Sponges contribute much silica in the shape of spicules and skeletons to deposits from shallow depths to the lowest. Globigerinæ with other Rhizopods make Globigerina ooze, especially between depths of 1500 and 2900 fathoms, but not in the higher latitudes. Pteropods are a characteristic of other bottom deposits between 500 and 1400 fathoms.

But besides these characteristic species there are also the solitary Corals, the Echinoderms, Mollusks, and various other abyssal species, giving variety to the fossils of the sea-bottom. There are also at the bottom the relics of the great variety of pelagic species which after death escape feeders and sink to the bottom. Murray says that, in the course of the Challenger cruise, over 600 Sharks' teeth (genera Carcharodon, Oxyrhina, and Lamna) and 100 ear-bones of Whales (genera Ziphias, Balcenoptera, Balcena, Orca, and Delphinus), along with 50 fragments of other bones, were obtained in one haul of the dredge in the central Pacific. The locality was, however, not in either of the organic oozes mentioned, but in the "Red ooze"; and the phosphatic nature of bone was its protection from carbonic acid. Along the course of the Gulf Stream and of its abundant life, the bottom deposit is largely earthy or "terrigenous," and sometimes contains stones of considerable size which were distributed by the floating ice of the Glacial period.

The blue and gray muds of the sea-bottom, which are common in the Pacific, are due to the volcanic dust, cinders, and pumice with which it has been sprinkled by the ocean's aerial volcanoes, and to their decomposition; and Phillipsite (page 136) is found chiefly in the areas of the Red ooze.

\section{Deposits from Littoral Species.}

The process of limestone-making by shells and corals is essentially the same in its more important steps, and therefore only the latter is here considered.

CORAL FORMATIONS.

Coral formations are made from the calcareous secretions of coral-making polyps, with large contributions from the shells and other relics of the littoral fauna.

Coral formations, while of one general mode of origin, are of two kinds:-

1. Coral islands. - Isolated coral formations in the open sea.

2. Coral reefs. - Banks of coral, bordering other lands or islands.

The positions of the coral-reef seas and the causes of limitation are explained on pages 46,56 , and illustrated on the chart, page 47 .

The exclusion of corals from certain tropical coasts is owing to different causes:- (1) Cold extratropical oceanic currents, as in the case of western South America (see chart). (2) Muddy or alluvial shores, or the emptying of large rivers; for coral-polyps require clear sea water and generally a solid 
foundation to build upon. (3) The presence of volcanic action, which, through occasional submarine action, destroys the life of a coast. (4) The depth of water on precipitous shores; for the reef-making corals do not grow where the depth exceeds 150 feet.

For the last-mentioned reason, reefs are prevented from commencing to form in the deep ocean. But if by other accumulations, or in any other way, the bottom is brought up to the limiting distance from the surface, Corals may commence the making of reefs.

Coral formations are most abundant in the tropical Pacific, where there are 290 coral islands, besides extensive reefs around other islands. The Paumotu Archipelago, east of Tahiti, contains between 70 and 80 coral islands; the Carolines, including the Radack, Ralick, and Gilbert groups, as many more; and others are distributed over the intermediate region. The Tahitian, Samoan, and Fiji Islands are famous for their reefs; also New Caledonia and the islands to the northwest. There are reefs also about some of the Hawaiian Islands. The Laccadives and Maldives, in the Indian Ocean, are among the largest coral islands in the world. The East Indies, the eastern coast of Africa, the West Indies, and southern Florida abound in reefs; and Bermuda, in latitude $32^{\circ} \mathrm{N}$., is a coral group. Reef-forming Corals are absent from western America, except along the coast of Central America as far north as the Gulf of California, and they are mostly absent from western Africa, on account of the cold extratropical currents that flow toward the equator: for the same reason, there are no reefs on the coast of China. (See the Physiographic Chart.)

\section{Coral Islands.}

1. Forms. - Atolls. - A coral island commonly consists of a narrow rim of reef, surrounding a lagoon, as illustrated in the annexed sketch (Fig. 143).

143.

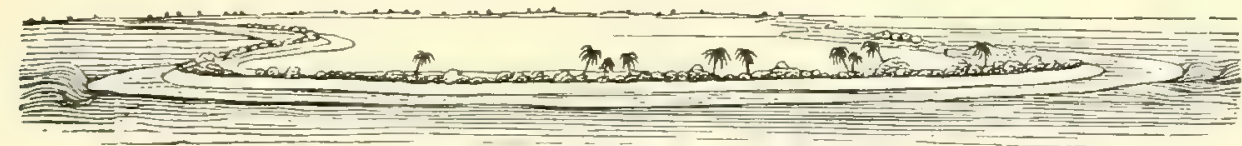

Coral island, or atoll.

Such islands are called atolls, - a name of Maldive origin. Maps of two atolls are given in Figs. 144, 145, showing the rim of coral reef, the saltwater lake or lagoon, and the variations of form. They are never circular.

144.

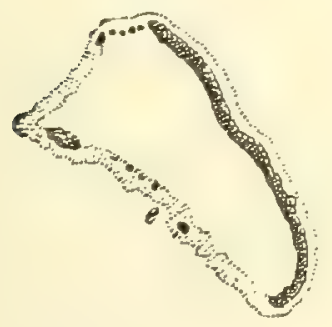

145.

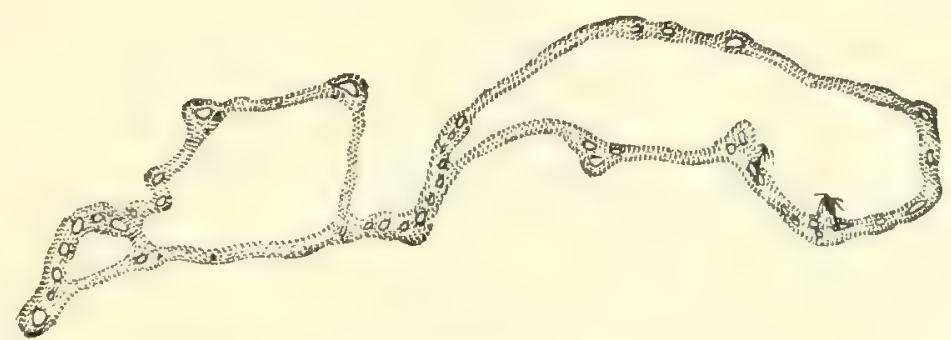

A Touss. - Fig. 144, Apia, one of the Gilbert Islands; 145, Menchikoff, one of the Carolines.

The size varies from a length of fifty miles to two or three; and, when quite small, the lagoon is wanting, or is represented only by a dry depression. 
The reef is usually to a large extent bare coral rock, swept by the waves at high tide. In some reefs the dry land is confined to a few isolated points, as in Fig. 145; in others, one side is wooded continuonsly, or nearly so, while the other is mostly bare, as in Fig. 144. The higher or' wooded side is that to the windward, unless it happens to be under the lee of another island. On the leeward side, channels often open through to the lagoon (e, Fig. 144), which, when deep enough for shipping, make the atoll a harbor; and some of these coral-girt harbors in midocean are large enough to hold all the fleets of the world.

Fig. 146 represents a section of an island, from the ocean (o) to the lagoon $(l)$. On the ocean side, from o to $a$, there is shallow water for some distance out (it may be a quarter or half a mile or more); and, where not too deep (not over 150 feet), the bottom is covered here and there with growing corals. Between $a$ and $b$ there is a platform of coral rock, mostly bare at low tide, but covered at high, having a width usually of about a

146.

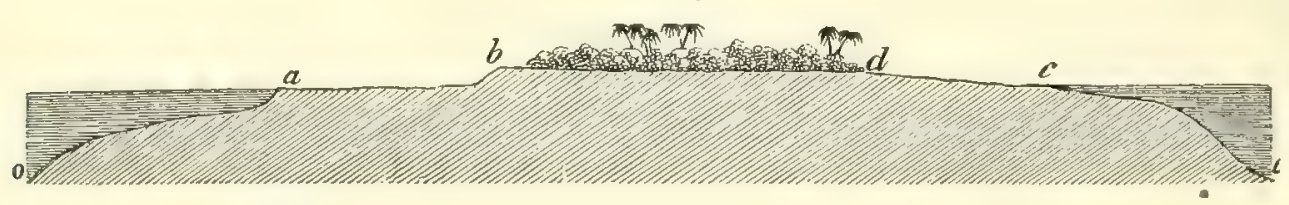

Section of a coral island, from the ocean $(o)$ to the lagoou $(l)$.

hundred yards: there are shallow pools in many parts of it, abounding in living corals and other kinds of tropical life: toward the outer margin, it is quite cavernous; and the holes are frequented by Crabs, Fishes, ete. At $b$ is the white beach, six or eight feet high, made of coral sand or pebbles and worn shells: $b$ to $d$ is the wooded portion of the island. The whole width, from the beach (b) to the lagoon (c), is commonly not over 300 or 400 yards. At $c$ is the beach on the lagoon side, and the commencement of the lagoon. Corals grow over portions of the lagoon, - although, in general, a large part of the bottom, both of the lagoon and of the sea outside, is of coral sand.

Beyond a depth of 150 feet there are no growing corals, except some kinds that enter but sparingly into the structure of reefs.

2. Coral-reef rock. - The rock forming the coral platform and other parts of the solid reef is a white limestone, made out of corals and shells. In some parts it contains imbedded corals; in others, it is as compact as any Silurian limestone and without a fossil of any kind, unless an occasional shell. The compact non-fossiliferous kinds are formed in the lagoons or sheltered channels; the kinds made of broken corals, on the seashore side, in the face of the waves; those made of corals standing as they grew, in sheltered waters, where the sea has free access. Large portions are a coral and shell conglomerate.

3. Coral beach-rock. - The beach-rock is made from the loose coral sands of the shores, which are thrown up by the waves and winds. The sands become 
cemented into a porous calcareous sandstone, or, where pebbly, into a coral pudding-stone. It forms layers, or a laminated bed, along the beach of the lagoon, and also on the seashore side, sloping generally at an angle of five to eight degrees toward the water, but sometimes at a larger angle, this depending on the slope of the beach at the place. The rock is sometimes an oölyte, owing to the coating of the grains with the calcareous cement as solidification goes on. Oölyte is especially common where accumulations of sand make large sand-flats partly emerged at low tide.

4. Formation of the coral reef. - A reef-region is a plantation of living corals, in which various species are growing together in crowded thickets, or in scattered clumps, over fields of coral sand. Besides corals and shells, there are also calcareous plants, called Nullipores, growing over the edge of the reef, in the face of the breakers, as shown by Darwin, and attaining considerable thickness. Even the delicate branching kinds sometimes make thick beds, as observed by Agassiz in the Florida seas. Bryozoans add a little to the material, occasionally making large massive corals. In Paleozoic time, both branching and massive kinds contributed largely to limestone formations.

5. Action of the waves. - The waves, especially in their heavier movements, sweeping over the coral plantations, may be as destructive as winds over forests. They tear up the corals, and, by incessant trituration, reduce the fragments to a great extent to sand; and the debris thus made and ever making is scattered over the bottom, or piled upon the coast by the tide, or swept over the lower parts of the reef into the lagoon, or drifted off by the currents for deposition elsewhere. The corals keep growing; and this sand and the fragments go on accumulating: the consolidation of the material thus accumulated makes the ordinary reef-rock. Thus, by the help of the waves, a solid reef-structure is formed from the sparsely growing corals.

Where the corals are protected from the waves, they grow up bodily to the surface, and make a weak, open structure, instead of the solid reef-rock; or, if it be a closely branching species, so as to be firm, it still wants the compactness of the reef that has been formed amid the waves.

6. History of the emerging atoll. - The growing corals and the accumulating debris reach, at last, low-tide level. The waves continue to pile up on the reef the sand and pebbles and broken masses of coral, - some of the masses even 200 or 300 cubic feet in size, - and a field of rough rocks begins to appear above the waves; and finally a beach is completed. The sands, now mostly above the salt water, are planted by the waves with seeds; trailing shrubs spring up; and afterward, as the soil deepens, palms and other trees rise into forests, and so the finished atoll receives its foliage.

The windward side of such islands is the highest, because here the winds and waves act most powerfully. But where the leeward side of one part of the year is the windward of another, the two may not differ much. The water that is driven by the winds or tides over the reef, into the lagoon, 
tends by its escape to keep one or more passages open, which, when sufficiently deep, make entrances for shipping.

\section{Coral Reefs.}

The coral reefs around other lands or islands rest on the bottom along the shores. 'They are either fringing or barrier reefs, according to their position. Fringing reefs are attached directly to the shore, while barrier reefs, like artificial moles, are separated from the shore by a chanuel of water. The island represented in Fig. 147 has a fringing reef $(f)$, and a barrier reef $(b)$ with an intervening channel. To the right of the middle the reef is wanting, because of the depth of water; and, farther to the right, there is only a fringing reef. Fig. 149 is a map of an island with a fringing reef; and Figs. 150-152, others, with barrier reefs. At two points through the barrier reef, in Fig. 147, there are openings to harbors $(h)$. The channels from harbor to harbor around an island are sometimes deep enough

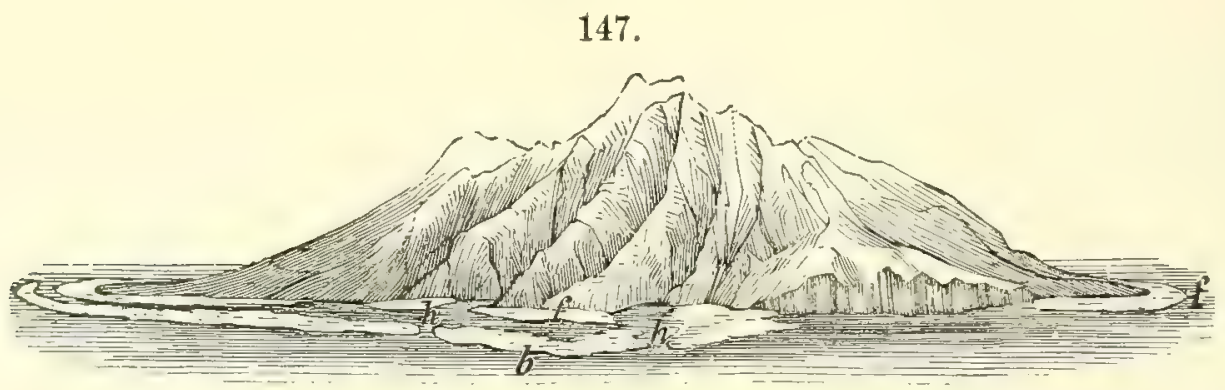

View of a high island with barrier and fringing reefs.

for ship navigation, and occasionally, as off eastern Australia, fifty or sixty miles wide; but they are generally too shallow for boats. The barrier sometimes becomes wooded for long distances, like the reef of an atoll; but commonly the wooded portion, if any exists, is confined to a few islets. Barrier and fringing reefs are formed like atoll reefs; and special explanations are needless.

The reefs adjoining lands have sometimes great width. On the north side of the Fijis, the reef-grounds are five to fifteen miles in width. In New Caledonia, they extend 150 miles north of the island, and 50 south, making a total length of 400 miles. Along northeastern Australia, they stretch on, although with many interruptions, for 1000 miles, and often at a distance, as just stated, of 50 or 60 miles from the coast, with a depth of 300 or 360 feet between. But the reefs, as they appear at the surface, even over the widest reef-grounds, are in patches, seldom over a mile or two broad. The patches of a single reef-ground are, however, connected below by coral rock, which is struck, in sounding, at a depth usually of 10 to 40 or 50 feet.

The transition in the inner channels, from a bottom of coral detritus to one of common mud or earth derived from the hills of the encircled island, is often very abrupt. Streams from the land bring in this mud, and distribute it according to their courses through the channels. 


\section{Origin of the Forms of Reefs, - the Atoll and the Distant Barrier.}

The origin of the atoll form of reefs was first explained by Darwin. According to his theory, each atoll began as a fringing reef, around an ordinary island; and the slow sinking of the island till it disappeared, while the reef continued to grow upward, left the reef at the surface, a ring of coral around a lake.

As reef-forming corals grow only within depths not greater than 150 feet, the bottom on which they began nust have been no deeper than this; and as such a shallow depth is to be found, with rare exceptions, only along the shores of lands or islands, the reef formed would be at first nothing but a fringing reef.

A fringing reef, the first step in coral formations, being begun, slow subsidence would make it a barrier reef.

In the lower part of Fig. 148, a section of a high island, ATPB, is represented. The horizontal line 1 is the level of the sea, $f$ a section of the fringing reef on the left, and $f^{\prime}$ of that on the right. The reef depends for its upward progress on the growth of the coral, and on the waves. The waves act only on the outer margin of a reef, while the dirt and fresh water

148.

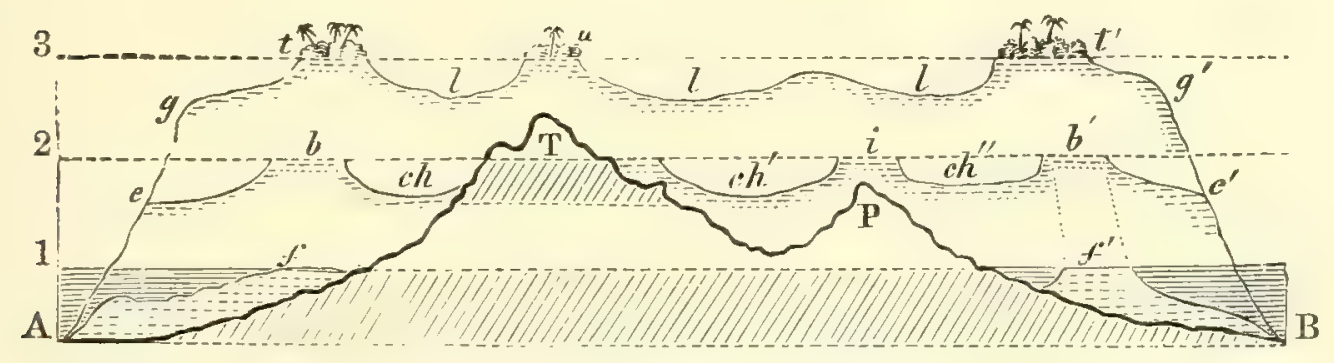

Section of an island bordered by a coral reef, to illustrate the effects of a subsidence.

of the land directly retard the inner part. Hence the outer portion increases most rapidly, and retains itself at the surface, during a slow subsidence that would submerge the inner portion. The first step, therefore, in such a subsidence, is to change a fringing reef into a barrier reef (or one with a channel of water separating it from the shore). Continued subsidence widens and deepens this channel. Then, as the island begins to disappear, the channel becomes a lake, with a few peaks above its surface; and later, a single peak of the old land is all that is left. Finally this peak disappears, and the coral reef comes forth an atoll, with its lagoon complete.

Referring again to the figure: if, in the subsidence, the horizontal line 2 becomes the sea level, the former fringing reef $f$ is then at $b$, a barrier reef, and $f^{\prime}$ is at $b^{\prime}$, and $c h, c h^{\prime}, c h^{\prime \prime}$ are sections of parts of the broad channel or area of water within; over one of the peaks, $\mathrm{P}$, of the sinking island, there is an islet of coral, $i$; when the subsidence has made the horizontal line 3 the sea level, the former land has wliolly disappeared, leaving the barrier 
reef, $t, t^{\prime}$, alone at the surface, around a lagoon, $l l l$, with an islet, $u$, over the peak 'I, which was the last point to disappear.

These steps are well illustrated at the Fijis. The island Goro (Fig. 149) has a tringing reef; Angau (Fig. 150), a barrier; Exploring Isles (Fig. 151), a very distant barrier, with a few islets; Numuku (Fig. 152), a lake with a single rock. The disappearance of this last rock would make the island a true atoll.

Whenever the subsidence ceases, the waves build up the land above the reach of the tides; seeds take root; and the reef becomes covered with foliage.

$149-152$.
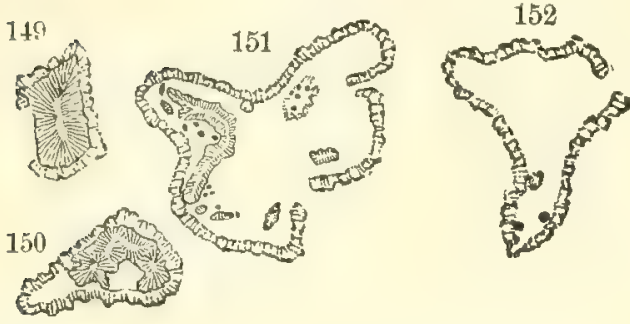

Islands of the Fiji group: Fig. 149, Goro; 150, Angau; 151, Exploring Isles; 152, Numuku.

The lands inside of coral barriers, as illustrated in these figures, very often show, by their narrow broken features and the deep indentations that were once valleys, that they are sunken lands, and thus sustain Darwin's theory.

The atoll Menchikoff (Fig. 145) was evidently formed, as explained by Darwin, about a high island, consisting of two distinct ridges or clusters of summits, like

Maui and Oahu in the Hawaiian group.

If the subsidence be still continued, after the formation of the atoll, the coral island will gradually diminish its diameter, until finally it may be reduced to a mere sand-bank, or become submerged in the depths of the ocean. The occurrence of sunken atolls, like the Maldives, is one of the strong arguments for the theory of subsidence.

Thickness of reefs. - The thickness of a coral formation, supposing Darwin's theory to be the true one, is often very great. From soundings within a short distance of coral islands, it is certain that this thickness is in some cases thousands of feet. The barrier reefs remote from an island stand in deep water, approximately proportional in depth to the distance from the coast-line. Supposing the slope of the bottom at the Gambier Islands to be only five degrees, we find, by a simple calculation, that the reef has a thickness of 1200 feet. In a similar manner, it is found that the thickness must be at least 250 feet at Tahiti, and 2000 or 3000 at the Fijis.

The rate of subsidence required to produce the results described cannot exceed the rate of upward increase of the reef-ground. On page 385 some facts are given illustrating the exceeding slowness of such movements. ${ }^{1}$

As coral debris is distributed, by the waves and currents, according to the same laws that govern the deposition of silt on sea coasts, it does not necessarily follow that the

1 For further information on the subject of Coral reefs and limestones, the reader may refer to the author's work on Corals and Coral Isiands, 400 pp. 8vo., 1891, based on his Exploring Expedition Report on Zoöphytes (740 pp. 4to, and 61 plates in folio, 1846), and to the chapter on Coral Reefs and Islands in his Expedition Report on Geology (750 pp. 4to, with 21 plates in folio, 1849); also to Darwin on the Structure and Distribution of Coral Reefs, 8vo, with maps and illustrations, London, 1842, the last edition, by Professor T. G. Bonney, in 1889. 
existence of a reef in the form of a barrier is evidence of subsidence in that region. On page 224 the existence of sand barriers of similar position is shown to be a common feature of coasts like that of eastern North America. In the cases of the barriers about the islands of the Pacific, however, there is no question on this point. Such barriers do not form about islands so small. Moreover, the great distances of the reefs from the shores, in many cases, and the existence of islands representing all the steps between that with a fringing reef and the true atoll, leave no room for doubt. The remoteness of the Australian barrier from the continent, and the great depth of water in the wide channel, show that this reef is unquestionable proof of a subsidence, - though it is not easy to determine the amount. Along the shores of continents, the question whether a barrier coral reef is evidence of subsidence or not must be decided by the facts connected with each special case.

In opposition to Darwin's theory of subsidence it is held by some writers that the seabottom may have been brought up toward the ocean's surface by deposits of other limesecreting species, as those of the shells of Rhizopods, until they were near enough to become next a plantation of corals, and that, in this way, without any subsidence, atolls became common within the area of the tropical oceans. But the wide oceans are wonderfully free from such banks; and if they were used, the growing reef made over the submerged basement would fail of its deep lagoons. Excavation of lagoon basins has been attributed, by the opposing theorist, to the eroding action of the carbonic acid in sea water, carried by currents over the bank and through depressions that were likely to form about the center of the bank. But many large lagoons have no entrance, and generally there is only a shallow entrance; and currents have no power below the level of the entrance (or exit). J. Murray has proposed the theory that since the fringing reef widens outward by growth and wave-action, this process may be the sole cause of the width of reefs along shores. Against the opposing theories there are the positive facts, that elevated coral reefs and atolls exist, which have a thickness beyond 150 feet. Among the many facts there are the following: Metia, an elevated atoll, north of Tahiti, has a height of 250 feet, which is twice the depth of growing reef corals; Christmas Island, in the Indian Ocean, 1200 feet in height, has an exterior of coral-made terraces to its summit. For a full discussion of this subject reference may be made to the author's work mentioned in the note to the preceding page.

The following are the teachings of the coral reefs:

1. Beds of coral limestone and shell limestone are made (1) by accumulation through growth; 2) by the mechanical action of waves and marine currents; (3) by consolidation taking place as the work goes forward.

2. Limestones of the purest kind on a scale of great magnitude form in the littoral zone within seas not over 150 feet deep. The modern reefs in the midst of the ocean are narrow and have broad channels; but over a continental sea, the same methods would produce solid limestone formations of unsurpassed extent, fossiliferous or unfossiliferous, and also beach sand-rocks, conglomerates, and oölytes; and with the aid of the winds, wind-drift rocks of coral sand.

3. Great limestones are therefore not necessarily, or generally, of deepwater origin.

4. Limestones attain great thickness at the present time by means of a slow subsidence, as they have in all geological time.

5. Further : comparing littoral with abyssal conditions, we learn that the former make stratified deposits containing or consisting of remains of littoral life; the latter make unstratified deposits containing or consisting of 
pelagic life. (See further, page 143.) The stratified limestones and other rocks of North America have no true deep-water characteristics. Wyville Thomson gave this as his general conclusion for all continents.

\section{Deposits made by Continental Species.}

\section{SILICEOUS DEPOSITS.}

Conferva-like Algæ, having columnar, vase-shaped and furze-like forms, grow in the hot geyser waters of the Yellowstone Park, which secrete opalsilica freely throughout the plant, as first reported by W. H. Weed. They cause the deposition of the silica from the waters in a gelatinous form, making the geyserite basins and the wide-spread geyserite deposits. These siliceous plants are described as growing an inch upward in 10 weeks.

Diatoms make beds in shallow ponds over the continents, and thick deposits of them are common beneath the peat of ordinary marshes. Such ponds have only the gentlest of waves; but sufficient to break into pieces most of the infinitesimal shells.

Diatoms are especially abundant in the warm waters of the Yellowstone Park, where the beds made from them cover many square miles in the vicinity of active and extinct hot springs, and vary from three to six feet in depth. Near Monterey, Cal., there is a Diatom bed 50 feet thick. Others occur in Nevada, where, according to Ring, they alternate with beds of tufa; and some are 200 or 300 feet thick. The material of the beds looks like chalk, but it often becomes partially solidified to opal, of a brown, yellowish, or greenish color.

\section{CALCAREOUS DEPOSITS.}

1. The shells of terrestrial and freshwater Mollusks are mostly thin and fragile, especially the Gastropods, breaking easily under the gentlest wave action. Limestones with unbroken shells as fossils are of rare occurrence and small extent, forming only in bodies of water too shallow for windwaves. The more common genera are Sphorium, Limnoca, Physa, Planorbis, Paludina, and Pupa. The deposits over the bottoms of small ponds are usually accumulations of pulverized shells, and have a chalky aspect. The earthy and clayey beds of river valleys ordinarily contain nothing of the shells of the valley except minute grains from their wear, or calcareous concretions made from the grains. The fine earthy loess of large valleys is remarkable for the number of its freshwater shells (Gastropods), its strongly calcareous character, and its calcareous concretions, and bears evidence thus of the sublacustrine and shallow conditions attending its deposition.

2. Loosely textured calcareous rock, called tufa because of its appearance, is formed from the confervoid Algæ of the Yellowstone Park and other regions. It is an aggregation of the algoid growths, some of which resemble somewhat the concretionary forms represented in Fig. 137 on page 132. 
Dr. A. Rothpletz has stated that, according to his observations at Great Salt Lake, Utah, the concretionary grains of oölyte are due to the growth and ealcareous secretion of a minute Alga or water-plant (1893); and that they are formed there within a bluish green alga-mass. He is disposed to account thus for the formation of ordinary oölyte. Oölyte is an abundant product along the low coral-sand shores of southern Florida, and its formation has been attributed to deposition from the sea water around minute grains of the sand, or around some still more minute shell of a Diatom or other microscopic organism.

\section{PHosphatic DEPosits.}

Guano beds are the important deposits of phosphatic material. The origin and constitution of guano are described on page 72. The composition is approximately: organic and volatile matter 40 per cent, phosphoric acid 14 , lime 12 , potash and soda 7 , nitrogen 9 , along with water. The agricultural value is largely owing to the nitrogen. Besides the kinds mentioned, Bat guano is formed in some caves; and in Victoria, southern Australia, it has a depth of 30 feet in the Skipton caves. The prominent localities of guano are: islands on the nearly rainless Peruvian coast, which were worked as early as the sixteenth century; various islands of the equatorial Pacific, between $155^{\circ} \mathrm{W}$. and $277^{\circ} \mathrm{W}$.; Sombrero and neighboring islands in the West Indies, and also large coastal areas in South Carolina and Florida. In the West Indies, and in South Carolina and Florida, where the rains are common, the guano is mostly destitute of nitrogen, it being the impure calcium phosphate made by the filtration of rain-waters through the original guano, carrying the soluble phosphates into underlying calcareous deposits. Fossil shells and bones are among the phosphatized products.

\section{Peat and other Carbonaceous Formations.}

Peat is an accumulation of half-decomposed vegetable matter, in wet or swampy places over the interior of a continent or about its estuaries. In temperate climates, it is due to the growth mainly of spongy Mosses, of the genus Sphagnum, which are very absorbent of water. Beside spreading over

153.

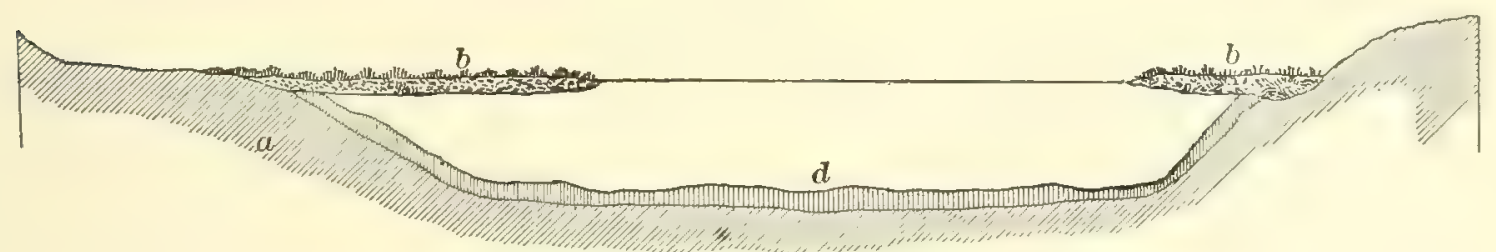

Peat-forming in progress, with a Diatom deposit (d) over the bottom of the pond. Shaler.

the swampy surfaces, they extend out a floating layer from the borders of shallow ponds $(b)$, as illustrated in Fig. 153, from Shaler's Memoir on the Origin and Nature of Soils. The floating layer $(b, b)$ drops portions to the 
bottom from its lower dying surface; for the moss has the property of dying at the extremities of the roots as it grows above. It thus gradually takes possession of the pond, and may form beds of great thickness.

In some limestone regions, the Sphagnous mosses are replaced by species of Hypmum, as in Iowa. The leaves and stems, branches and stumps, of trees and shrubs, growing over the marshy region or in shallow waters, and any other vegetation present, contribute to the accumulating bed. The freshwater shells growing in the waters, and the spicules of any sponges, with the insects, and the carcasses and excrements of animals become included. Earthy material also may be blown over the marsh by the winds, or brought by inflowing streams.

In wet parts of Alpine regions, there are various flowering plants which grow in the form of a close turf, and give rise to beds of peat, like the moss. In Fuegia, although not south of the parallel of $56^{\circ}$, there are large marshes of such Alpine plants, the mean temperature being about $40^{\circ} \mathrm{F}$. On the Chatham Islands, 380 miles east of New Zealand, peat thus formed has a depth of 50 feet.

The dead and wet regetable mass slowly undergoes a change in its lower part, becoming brownish black, loose in texture, and often friable, although commonly penetrated with rootlets. The change is sometimes continued until coal is formed; but unlike good coal it still contains usually 25 to 33 per cent of oxygen.

Peat-beds cover large surfaces of some countries, and occasionally have a thickness of 40 or 50 feet. The rate of growth varies with the amount of vegetation, moisture, and other conditions; a foot in depth may form in five to ten years. One tenth of Ireland is covered by them; and one of the "mosses" of the Shannon is stated to be 50 miles long and two or three broad. A marsh near the mouth of the Loire is described by Blavier as more than 50 leagues in circumference. Over many parts of New England and other portions of North America, there are extensive beds, almost every old marsh having more or less peat below. The amount in Massachusetts alone has been estimated to exceed $120,000,000$ of cords. The Dismal Swamp, 10 miles by 30 in area, situated on the borders of Virginia and North Carolina, is for the most part a region of very deep peat.

Peat-berls sometimes contain standing trees, and entire skeletons of animals that had sunk in the swamp. The peat-waters have an antiseptic power, and consequently tend to prevent complete decay of the vegetable matter of the peat-bed. Flesh is sometimes changed by the burial into adipocere.

Peat is used for fuel, and also as a fertilizer. When prepared for burning, it is cut into large blocks, and dried in the sun. It is sometimes pressed, in order to serve as fuel for steam-engines. Muck is another name for peat, especially for impure kinds, when employed as a manure; any black swamp-earth consisting largely of decomposed vegetable matter is so called.

Beds of marine plants in the rocks of littoral regions are almost unknown. Specimens 
are distributed through the formations, and have been the source of some coaly products; but never abundantly. Tlie trunks of Lessonia, as large as a man's thigh, lie piled in great quantities on the shores of the Falkland Islands. Moreover, the growth of sea-weeds is very rapid. On the coast of Scotland, and below low-tide level, "a surface chiseled smooth in November, was thickly covered in the following May with ribbon kelp 2 feet long, and ordinary kelp 6 feet long." But no peat-like compact beds of marine Fucoids are known. Fucoids contain 74 to 80 per cent of water, some nitrogen, and are very mucilaginous; and hence "when they begin a decay and become disorganized, they melt down into a very small bulk, and seem almost to dissolve away." (Storer.)

The great interest to the geologist in this subject of peat-beds is the essential identity between their method of origin and that of the great accumulations of vegetable debris out of which coal-beds were made. Both were accumulations of leaves and stems of terrestrial (not marine) plants, and occupy, as a general thing, the region where the plants to a large extent grew. The chemical processes of change were also essentially the same. The burial of the ancient beds beneath thick sediments in many successions, as explained on page 712, has made the chief differences.

\section{Protective And other Beneficial Effects.}

The protective effects of life come chiefly from vegetation.

1. Turf protects earthy slopes from the wearing action of rills that would wear a bare surface into gullies; and even hard rocks receive protection in the same way.

2. Tufts of grass and other plants over sand-hills, as on seashores, bind down the moving sands by their long creeping stems or spreading roots.

3. Lines of vegetation along the banks of streams prevent wear during freshets. When the vegetation consists of shrubs or trees, the stems and trunks entangle and detain detritus and floating wood, and serve to increase the height of the margin of the stream.

4. Vegetation on the borders of a pond or bay serves in a similar manner as a protection against the feebler wave-action. In many tropical regions, plants like the mangrove, growing at the water's edge, drop new roots from the branches into the shallow water. These roots act like a thicket of brushwood, to retain the floating leaves, stems, and detritus; and, as the water shallows, other roots are dropped farther out; and thus they keep marching outward, and subserve the double purpose of protecting and making land. The coarse salt-marsh grasses along seashores perform the same kinds of geological work, being very effectual agents in entangling detritus, and in protecting from erosion.

5. Patches of forest-trees, on the declivities in Alpine valleys, serve to turn the course of the descending avalanche, and entangle snows that, but for the presence of the trees, would only add to its extent. Such groves are usually guarded from destruction with great care.

6. Forests retard the melting of snow and ice in spring, and thus lessen the devastations of floods. 
7. Calcareous Algæ, called Nullipores (page 147), serve to protect growing Corals and the margins of coral reefs from wear. Ordinary seaweeds often cover and protect the rocks of a coast nearly to high-tide level; in the higher latitudes the Fucoids (as Macrocystis pyrifer $u$ ) are sometimes 200 to 300 yards long, and the broad green belt off a coast breaks the force of incoming waves so that the rocks are saved from their destructive action.

The common earthworm, as Darwin has shown (1881), transfers a great amount of earth or soil in the pellets it discharges at the surface. He found that the weight so transferred per acre in a year in four cases was $7 \cdot 56,14 \cdot 58$, 16.1 , and 18.12 tons. Lobworms, of seashores, are even greater workers, according to C. Davison, who reports that the amount of sand carried up each year on the shores of Holy Island, Northumberland, was equivalent to 1911 tons per acre (1891). Marmots (Spermatophilus Eversmani), in the Caspian steppes, bring great quantities of earth to the surface. In a few years after their introduction they had brought up 75,000 cubic meters of earth to the square mile. (Muschketoff, 1887.)

\section{Transporting Effects.}

1. Seeds caught in the feathers, hair, or fur of animals, or contained in the mud adhering to their feet, are transported from place to place.

2. Seeds are eaten by animals as food, or in connection with their food, and are dropped in another region undigested. At the Solomon Islands, fruitpigeons carry fruit and seeds in their crops, and have thus planted the land with trees from other islands. (Guppy.)

3. Ova of fish, reptiles, and inferior animals are supposed to be transferred from one region to another by birds and other animals. Authenticated instances of this are wanting.

4. Floating logs and seaweeds carry Mollusks, Crustaceans, Worms, and other species from one region to another, over the broadest oceans, along the courses of marine currents. In tropical countries, islands of shrubbery and trees often float away from estuaries into the sea, bearing with them land, fresh-water shells, and other terrestrial species, which there become mingled with marine shells. A Boa constrictor once floated, on the trunk of a cedar, from Trinidad off South America to the island of St. Vincent - a distance of at least 200 miles. The great floating seaweed areas of the Sargasso Sea in the Atlantic are the dwelling-place of vast numbers of marine species, including Fishes, Mollusks, Crustaceans, Worms, etc.

5. Migrating tribes of men carry, in their grain, or otherwise, the seeds of various weeds, and also, involuntarily, Rats, Mice, Cockroaches, and smaller vermin. The origin of tribes may often be inferred from the species of plants and of domesticated and other animals found to have accompanied them. ${ }^{1}$

1 On this general subject consult Wallace's Island Life. 


\section{Destructive Effects.}

The destructive effects proceed either from living plants or animals, or from the products of decomposition. The latter subject is briefly considered under Chemical Work.

1. The roots which come from the sprouting of a seed in the crevice of a rock, as they increase in size, act like wedges, in tending to press the rock apart; and, when the roots are of large size, masses tons in weight may be

154.

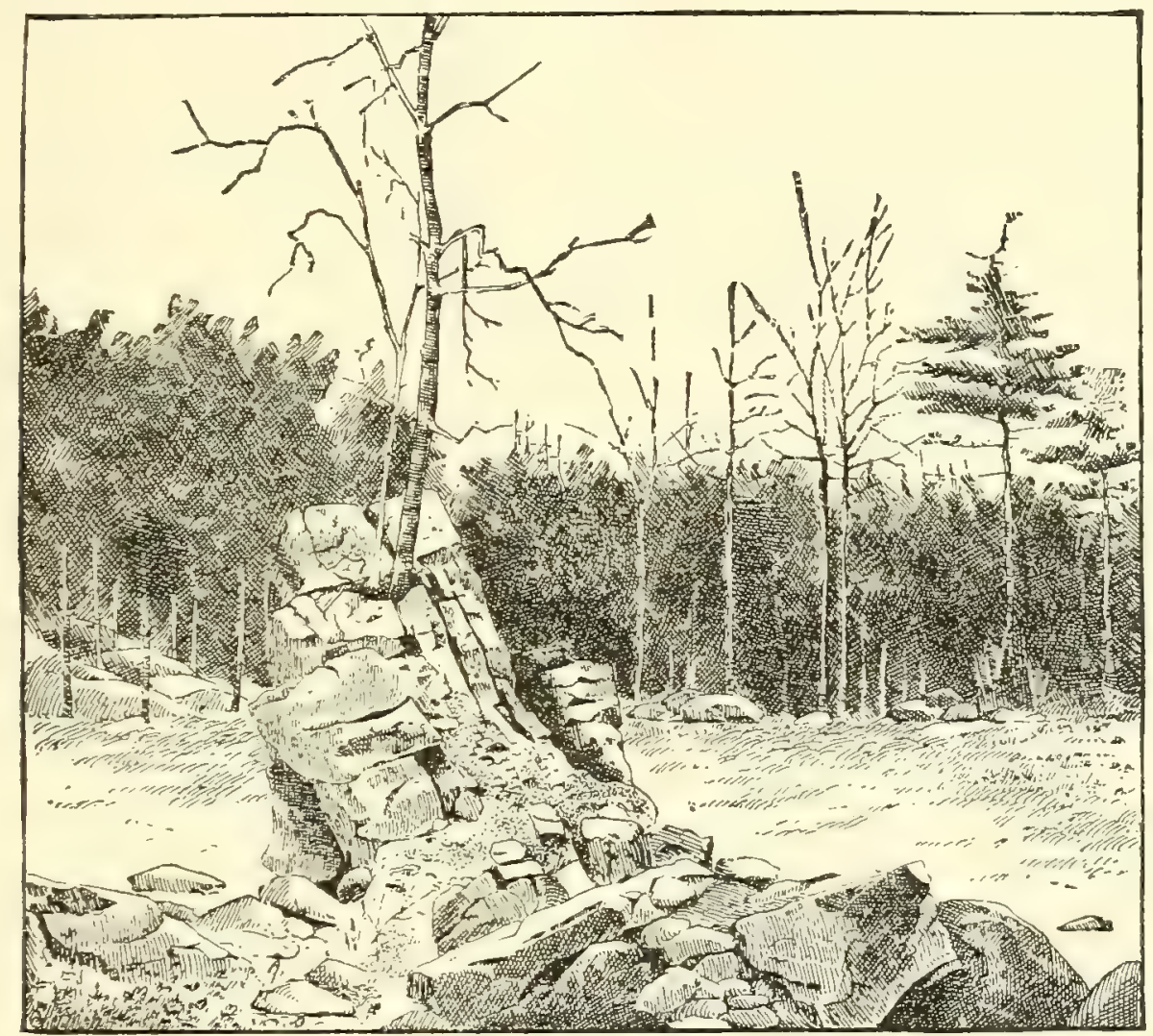

Rocks disrupted by roots of trees, between Gloucester and Rockport, Mass. Shaler, '89.

torn asunder; and if on the edge of a precipice, the detached blocks may be pushed off, to fall to its base. This is one of the most effective causes of the destruction of rocks. Many regions of massive and jointed rocks are thickly covered with huge blocks, looking like transported bowlders, which are the results of this kind of upturning. The Confervæ and other simple plants often commence their wedging work in the smallest of rifts; and yet by constant growth cause great results. Moreover, the opening of rifts and fissures gives access to moisture, and thus contributes further to rock destruction by chemical processes and by frost.

2. Boring animals, like the saxicavous Mollusks, make holes, often as large as the finger, and sometimes larger, in limestone and other rocks, along some seashores. Species of Saxicava, Pholas, Petricola, Lithodomus, Gastrochcena, and eren some Gastropods, Barnacles, Annelids, Echini, and Sponges, 
have this power of boring into stone. Various species also bore into shells or corals. In seven years, Carrara marble, in the sea south of Long Island, became riddled with borings made by a Sponge, the Cliona sulphurea of Verrill. Termites, or White Ants, and many other insects, especially when in the larval state, the Limnoria among Crustaceans, and the Teredo, related to Pholas, among Mollusks, bore into wood; and the last is so destructive to ships, piles, and wharves that it is often called the Shipworm or Pileworm.

3. The tunneling of the earth by small quadrupeds, as the Mole, and by Crustaceans like the Crawfish, sometimes results in the draining of ponds, and the consequent excavation of gullies or gorges by the out-flowing waters. The tunneling of the levees of the Mississippi by Crawfish is one cause of breaks, and thereby of great floods over the country.

4. Animals using Mollusks and Echinoderms as food make great refuseheaps, or beds of broken shells. The animals include Man, as well as other species; and the beds made by Fishes off the coast of Maine, as described by Verrill (who has drawn attention to this mode of making broken shells), are of great extent. They might be taken for beach deposits. The chief enemy of the American Oyster is a Starfish, which spreads its extensile mouth-opening over the young Oyster, and so gets it inside its stomach, and then, as the shell opens, digests the Oyster.

5. Fungi attack dead plants and animals, and rapidly destroy them. They do it by excreting ferments or poisons, which eat into and destroy the tissues. Living plants often suffer from this cause when in an enfeebled state.

6 . The destruction of the vegetation of a region by insect life, and that of animals by one another, are also of great geological importance.

\section{THE ATMOSPHERE AS A MECHANICAL AGENT.}

The weight of 100 cubic inches of dry air, with the barometer at 30 inches, and the thermometer at $60^{\circ} \mathrm{F}$., is 31 grains ; and hence it is but $\frac{1}{815}$ as heavy as water (or $\frac{1}{70}$ at $32^{\circ} \mathrm{F}$.). The weight of a column of the atmosphere a square inch in area of section, when the barometric pressure is 30 inches, and the temperature $32^{\circ} \mathrm{F}$, is $14 \cdot 7$ pounds. On this basis, the total weight of the atmosphere is about $11 \frac{2}{3}$ trillions of pounds (Herschel). In England, an atmosphere of pressure, used as a limit in connection with steam, is 29.905 inches Bar. at $32^{\circ} \mathrm{F}$, or nearly $14 \frac{3}{4}$ pounds to the square inch; in France, it is 760 millimeters, or 29.922 English inches, at the same temperature.

The atmosphere, while rightly called the earth's aerial ocean, is an aerial ocean without a definite upper surface, resting on an ever-disturbing basement. It extends not only to a height of 40 miles, but, with increasing tenuity, to at least 200 miles, - meteorites having become luminous at this height as a consequence of the friction of air. An upper limit is supposed to be determined by the equilibrium between the gravitation of the molecules of the elements constituting it and the expansive force, decreasing upward, that separates the molecules. 
The basement on which it rests - the earth's uneven surface - varies widely in temperature, and this variation passes to extremes in the higher mountains, whatever the zone. The atmosphere's own temperature, even in the tropics, is at the freezing-point at a height of less than four miles. Through these and other conditions the atmosphere has its varying belts of greater and less depth, - that is, of higher and lower barometric pressure, - its areas of high and low pressure moving in great circuits, and, as a consequence, winds, storms, cyclones, tornadoes, in its fruitless effort toward a state of equilibrium. These winds are its chief means of mechanical work.

The Mechanical Work of the Atmosphere. - The atmosphere works mechanically (1) by denudation, or, as it has been termed, defation, with or without abrasion; (2) by transportation; (3) by deposition; and (4) through its pressure. The work and the results are called Eolian, from A'odos, the god of the winds.

The force of the wind, measured by the pressure on a square foot, increases with the square of the velocity. At 5 miles an hour, the pressure is about 2 ounces to the square foot; at 10 miles, which is that of a light breeze, 8 ounces; at 20 miles, a good steady breeze, 2 pounds; at 40 miles, a strong gale, 8 pounds; at 60 miles, 18 pounds; at 100 miles, 50 pounds. The work done is dependent largely on the form of the surface struck. This is well shown in the anemometer made of hemispherical cups: the difference between the pressure on the concave and convex sides being such that the cups move one third as fast as the wind, whereas with flat disks there would be no motion. A velocity of 186 miles an hour (or 170 pounds to the square foot) has been registered by the anemometer.

While the lighter winds, and especially the great currents, like the trades, have a degree of regularity in movement, the storm winds, on which geological work mainly depends, are hurrying bodies of air of inconstant force, breadth, and direction. A single storm includes all the courses of the compass, and all degrees of force, from lulls to extremest violence; and when most constant, these winds are still made up of fitful blasts. Under such conditions, abrasion, transportation, and deposition should be greatly mixed; and this is a striking feature of the results.

\section{Eolian Denudation or Deflation.}

Denudation, or wear by wind-force, is carried on (1) by simple wind-impact and (2) by impact when the air is loaded with sand or other material.

1. By simple impact. - The lighter work of the winds is the taking up of dust from roads, sand-fields, sand-hills, and sea-beaches, to drift away to some other place. The streets of most cities and the roads of the country often afford examples of the work on dry, windy days. It is to be noted, however, that a rather strong wind is required for this light deflation unless moving wheels first stir up the dust. The result is due to the direct impulse 
of the moving air; and so it is when the hurricane tears up trees, prostrates forests, unroofs houses, or moves them from their foundations. These destructive effects are dependent, as already explained, not merely on velocity, but also on the extent, form, and position of the object against which it strikes. The adhesion of the hardened mud along the ruts of a country road may not be overcome by a gale that prostrates forests.

Besides lifting and transporting loose sands, the heavier winds tear off grains from exposed ledges or bluffs of rock, which the action of the sun, or oxidation, or saline efflorescences, or other means have loosened, and thus carry on the work of denudation.

2. By means of the material transported. - But the sand, gravel, or stones borne by the winds give them their chief denuding power. Attention was first called to this wind work by W. P. Blake, who described the granite of the Pass of San Bernardino, Cal., as scratched like rocks of glacier regions, even quartz and tourmaline being finely polished, and the garnets left projecting on pedicels of feldspar, inclined in the direction of the wind; limestone as eroded and channeled as if by dissolving waters. Mr. Blake observed, further, that the scratching and polishing effects were not confined to the Pass, but were visible over all parts of the Colorado desert to the eastward, where hard rocks were exposed; and he dwells on the great importance of this action of the winds as a means of denudation (1855). Later observers have shown that many of the bluffs, needles, and towers of soft sandstone characterizing the scenery in different parts of the Rocky Mountain region have been more or less shaped by this means. Moreover, scratches made by drifted sand, long since noticed on the glass of windows on Cape Cod, have been observed in Maine where it is not arid (G. H. Stone, 1886). In arid parts of India, according to Mr. R. D. Oldham, they differ from those of glaciers in being deepest at the end facing the wind.

Eolian denudation has its best examples in the Egyptian and other true deserts where the annual fall of water is very small. The following fig-

155.

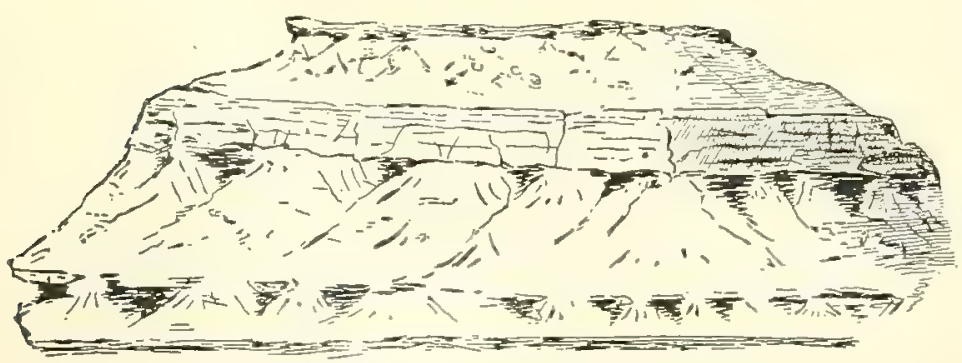

Southwest end of Mokkatam. Walther. ures of Egyptian denudation are from the work of J. Walther (1891), which treats the subject with great fullness and gives many illustrations, after personal observations. The differences in hardness of the layers determines the rate of wear and leads to nearly the same forms that are produced by running water. In Fig. 155 the beds are Eocene limestone and other kinds. In Fig. 156 Cretaceous beds are upturned, and the harder limestone caps each elevation. The deflation leaves silicified fossils (Exogyra and Corals) projecting over the surface, as in Fig. 156. 
Other views in Mr. Walther's book represent deep excavations in nearly vertical bluffs, sometimes in regular alternation with narrow columns - the latter the part which descending solutions of some kind (perhaps calcareous or ferruginous) had hardened; often they are very irregular in form.

A blast of sand propelled by steam is now employed (after Nature's suggestion) in grinding and carving glass, gems, and 156. even granite. Glass covered by lace-work, or by paper having open patterns cut in it, is rapidly worn where its surface is exposed, while the lace or paper, owing to its yielding before the sand, shows scarcely any effect of the blast. Large cornices and

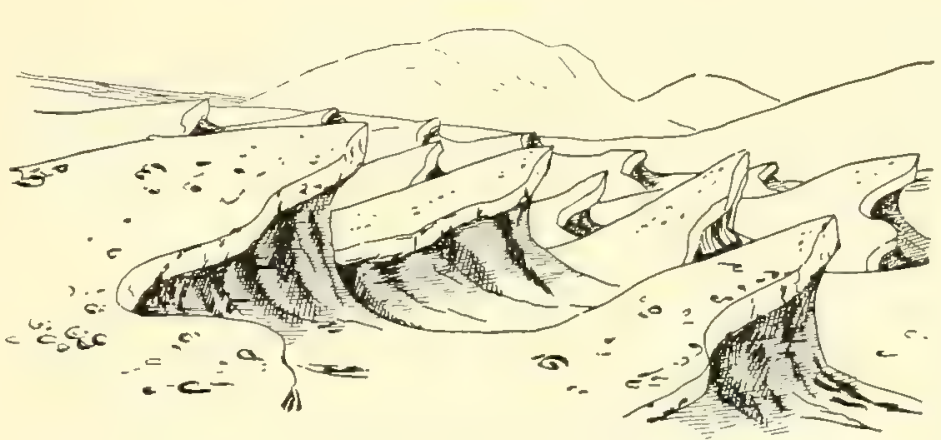

Upturned Cretaceous beds near Abu Roasch. Walther. mouldings of granite are shaped by a blast of steam and sand.

Thoulet, of Paris, has investigated the effects of air-blast abrasion (1887) and found, besides other results, that moist rock abrades most easily, and that the effect is small if the surface struck has a dip of less than $60^{\circ}$.

\section{Transportation and Deposition.}

The deep deposits of earth over ancient monuments in Rome and other old cities is largely a result of eolian transportation. The most extensive drift-sand deposits occur over arid areas where there is little or no vegetation to fasten down the sands, and where nearly all the year through the work is going on. But the best known are those of windward shores where fronted by long beaches. The sands of seabeaches often extend out long distances in the shallow waters. The breakers come in sand-laden, to throw the sand up the beach, and in ordinary weather the beach takes the whole. But storm-winds carry the sands from the breakers and the beach over the low surface beyond and pile it into ridges, often making a series of parallel sanddrifts. The sand keeps moving landward with each season of storms, unless stopped by steep declivities, or by vegetation whose encroachment is favored by moist soil; and sometimes it drifts up the sea-border hills to heights of 100 to 200 feet. The surfaces of drifted sands are often covered with ripple-marks.

The effects are greatest (1) where the sands are fine, and most purely siliceous and therefore incoherent; (2) where the coasts are well open to the winds; (3) in regions exposed to the most violent storms; and (4) especially on projecting points where the work is carried on in succession by the winds of both sides of a rotary storm, and by storms of different directions. Ordinary winds have little effect, and hence on the Pacific coral islands the DANA'S MANUAL - 11 
drift-hills of projecting capes are seldom over 30 feet high; while at the Bermudas and Bahamas, within the belt of Atlantic cyclones whose winds have often a velocity of 60 to 90 miles an hour, the sands cover great surfaces, are sometimes quite coarse, and make ridges 100 to 230 feet in height. The highest drift ridges are on the side which receives the winds of the first half of the cyclone.

On the south side of Long Island, drift-sand ridges extend along for a hundred miles and vary in height from 5 to 40 feet. The coast of New Jersey, down to the Chesapeake, and other coasts farther south, are similarly fronted by sand-hills. Similar hills occur also on the east side of Lake Michigan, where they reach a height of 100 to 200 feet; they are 215 feet high at Grand Haven, and 30 to 93 near New Buffalo. In Norfolk, England, between Hunstanton and Weybourne, they are 50 to 60 feet high.

Such seashore driftings are a means of recovering lands from the sea. The sea first makes the sand-flats or beaches, and the winds do the rest. Lyell observes that, at Yarmouth, England, thousands of acres of land now under cultivation have been thus gained from a former estuary.

The drift-sand also encroaches on fertile lands, forests, and villages. Such regions of encroaching sands are called dunes. On Lake Michigan, as Professor Winchell states, the sands are continually shifting with the winds; at Grand Haven and Sleeping Bear, the forest has become submerged, and "presents the singular spectacle of withered tree-tops projecting a few feet above a waste of sands." The land at this place is extending lakeward, through the wear and contributions of the arenaceous shore rocks. Near Seven-mile Beach, on the New Jersey coast, in 1885, the dune, 40 feet high, had encroached on a dense forest to such an extent that "the tree-tops projected above its sands like the heads of drowning men above the waves." (F. J. H. Merrill, 1890.) By such means, not only bones, shells, tree-trunks, become the fossils of sand-heaps, but, in the existing age, as in Egypt, even monuments, temples, and cities.

1. Characteristics of wind-drift or eolian formations. - The sands of winddrifts, although deposited by blasts of wind, make thin and regular layers over the sand-fields and the surfaces of the rising ridges, producing a straticulate structure about as coarse as that of common alluvial clays, parallel with the successive surfaces of the ridge. But such ridges are liable to be cut off on one side or the other by the most violent of gales; and then deposition from the winds goes on over a new outer surface. By repetitions of such catastrophes, and continued depositions, the quaquaversal dip of the wind-drift structure, represented on page 93 (Fig. 63), is produced. The mode of formation and straticulate structure of sand-drifts is well illustrated in snow-drifts, which are a result of like wind-drift action. As snow drifts readily into heaps and ridges, wherever there is an obstacle however small, so it is with sand. Flat or level surfaces are the exception in such regions.

The drift ridges of coral sand or shell sand readily consolidate, and show well the varying directions of the straticulation, as at the Bermudas, 
Bahamas, Key West and elsewhere on the Florida Banks, and also on Oahu and other Hawaiian Islands.

2. Eolian transportation of volcanic ashes. - The transportation of volcanic ashes usually takes place without drifting, and the bedding, therefore, is commonly horizontal. In 1812, ashes were carried from a volcano on St. Vincent to Barbados, 60 to 70 miles; and in 1835, from the volcano of Coseguina in Guatemala to Jamaica, a distance of 800 miles. In 1883 , the dust from the volcano of Krakatoa, an island just west of Java, was thrown to a height of 50,000 feet, according to Verbeck, and continued to be projected for 36 hours; and it is supposed that the ashes made the circuit of the globe, and were the cause of the sunset glows of the following autumn. The bottom of the Pacific has been found to be very generally covered with volcanic ashes derived from its many volcanoes.

3. Eolian transportation of living species or their relics. - A tornado that becomes what is known as a "water"-spout" over a large river or lake, carrying up at its center great quantities of water, will take up the ova and smaller life of the waters, and transfer them to other places, and may thus contribute new species to distant lakes or rivers. Land Birds and Insects are sometimes drifted far out to sea, and so reach oceanic islands, and sometimes in the case of Birds another continent. Seeds of many kinds go with the winds. A Spider of the ballooning kind, Sarotes venatorius, has probably traveled around the globe, according to H. C. McCook, crossing oceans and continents, and thus has gained a world-wide distribution. A related species is reported by Darwin as suddenly appearing on the rigging of the "Beagle" 60 miles from the land.

Showers of grayish and reddish dust sometimes fall on vessels in the Atlantic off the African coast, and over southern Europe (producing, when they come down with rains, "blood-rains"), the particles of which, as first shown by Ehrenberg, are largely microscopic organisms. The figures on the following page represent the species from a single shower, near Lyons, on October 17, 1846. The whole amount which fell was estimated by Ehrenberg at 720,000 pounds; and of this, one eighth, or 90,000 pounds, consisted of these organisms.

The species figured by Ehrenberg (Passat-Staub und Blut-Regen, 4to, 1847, and Amer. Jour. Sci., II. xi. 372), include 39 species of siliceous Diatoms (Fig. 157, 1-65); 25 of what he calls Phytolitharia (Fig. 157, 66-104), besides 8 Rhizopods. The following are the names of the Diatoms:

Nos. 1, 2, Melosira granulata; 3, M. decussata; 4, M. Marchica; 5-7, M. distans; 8. 9, Coscinodiscus atmosphericus; 10 , Coscinodiscus (?); 11, Trachelomonas levis; 12 , Campyladiscus clypeus; 13-15, Gomphonema gracile; 16, 17, Cocconema cymbiforme; 18, Cymbella maculata; 19, 20, Epithemia longicornis; 21, 22, E. longicornis; 23, E. Argus; 24, E. longicornis; 25, Eunotia grenulata (?); 26, E. Eebrina (?); 27, Himantidium Monodon (?); 28-32, Eunotia amphioxys; 33, 34, Epithemia gibberula; 35, Eunotia zebrina (?); 36, E. zygodon (?) ; 37, Epithemia gibba; 38, Eunotia tridentula; 39, E. (?) lowis; 40, Himantidium arcus; 41, 42, Tabellaria; 43, Odontidium (?), 44, Coccrneïs lineata; 45, C. atmosphrica; 46, Navicula bacillum; 47, N. amphioxys; 
157.

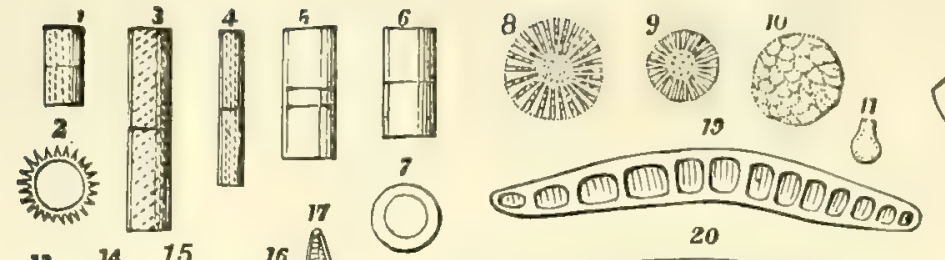

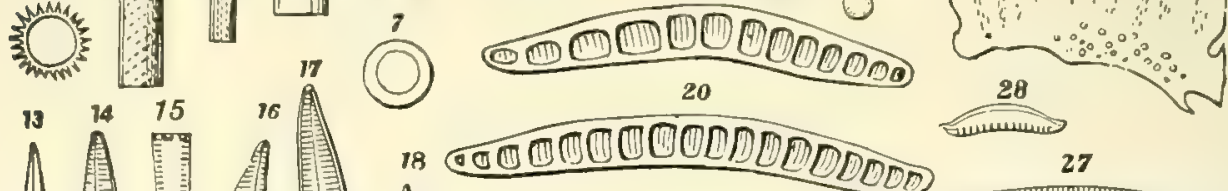
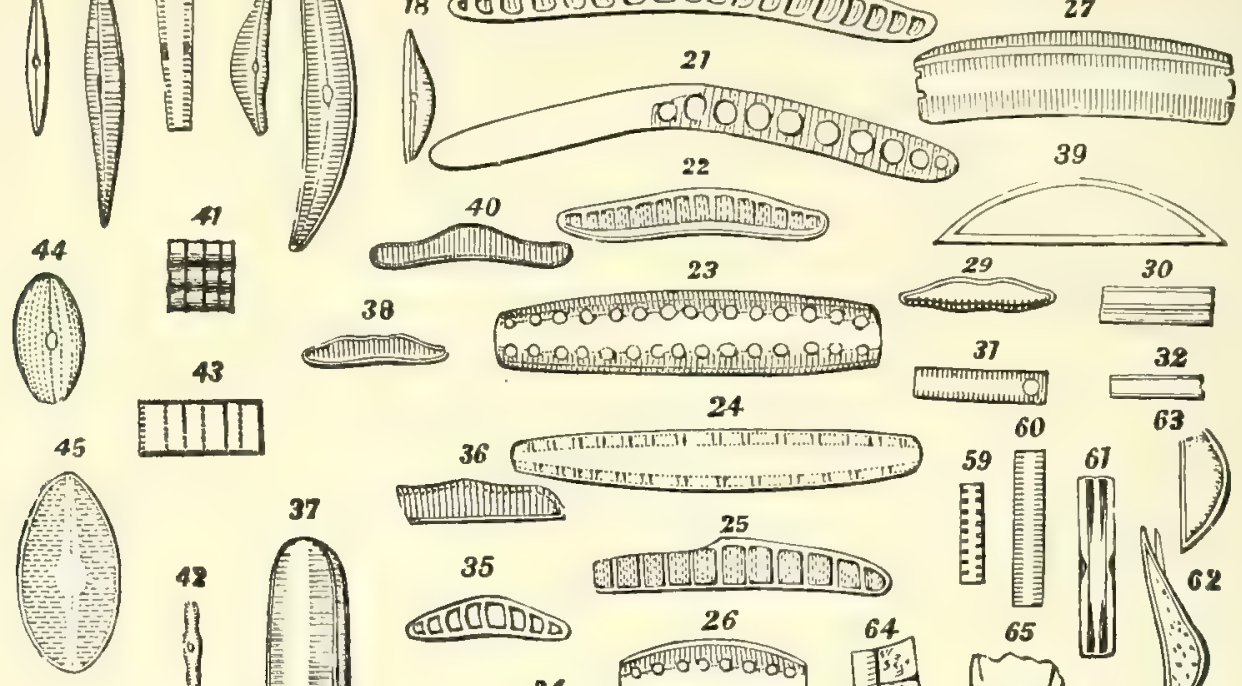

37
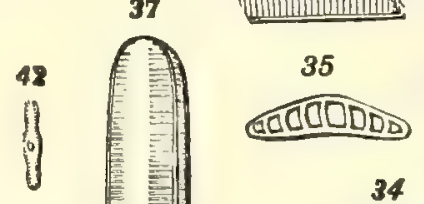

TODD

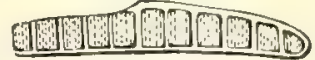
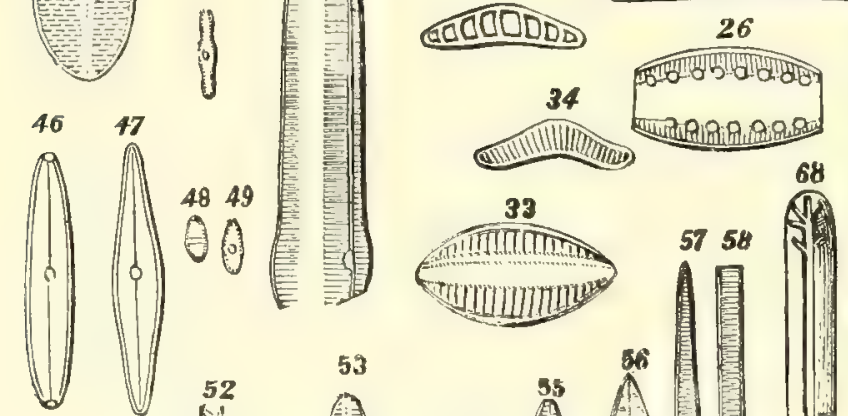

tringringm
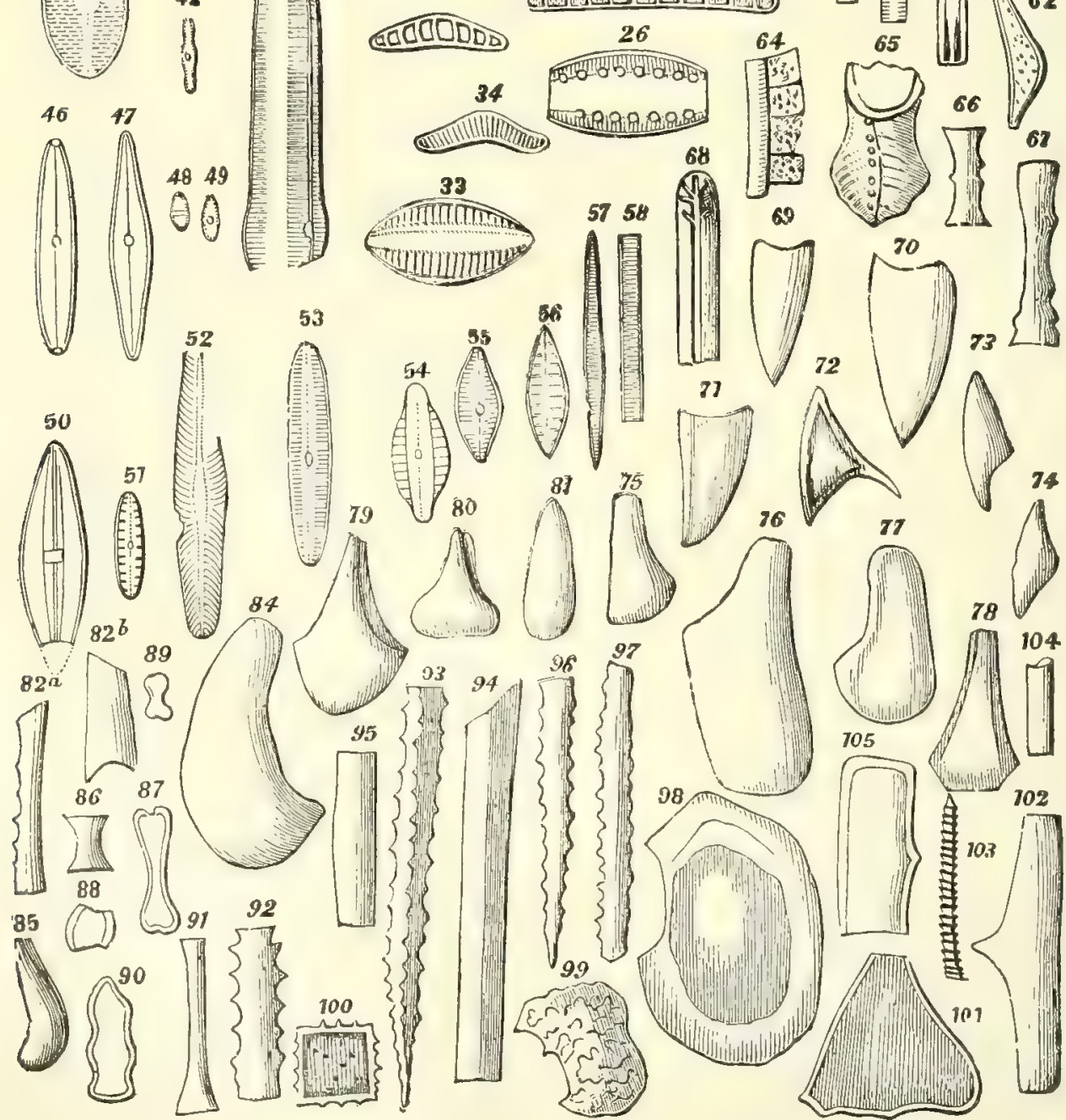

Diatoms and other microscopic organisms of a dust shower. Ehrenberg. 
$48,49, N$. semen; 50, N. serians; 51, Pinnularia borealis; 52, $P$. viridula; 53, $P$. viridis; 54, Mastogloia (?); 55, Pinnularia aqualis (?); 56, Surirella craticula (?); 57, 58, Synedra ulna; 59, Odontidium (?); 60, Fragitaria pinnata (?); 61, Mastogloia (?) ; 62-65, doubtful.

A shower which happened near the Cape Verd Islands, and is described by Darwin, had by his estimate a breadth of more than 1600 miles, - or, according to Tuckey, of 1800 miles, - and reached 800 or 1000 miles from the coast of Africa. These numbers give an area of more than a million square miles.

In 1755, there was a "blood-rain" near Lago Maggiore, in northern Italy, covering about 200 square leagues, which made an earth deposit in some places an inch deep; if averaging two lines in depth, the amount for each square mile would equal 2700 cubic feet. The red color of the "blood-rain" is owing to the presence of some red oxide of iron.

Ehrenberg enumerates a large number of these showers, citing one of the earliest from Homer's Iliad; and among those whose deposits he examined he distinguished over 300 species of organisms. The species, so far as ascertained by him, are not African, and 15 are South American. The zone in which these showers occur covers southern Europe and northern Africa, with the adjoining portion of the Atlantic, and the corresponding latitudes in western and middle Asia.

\section{Angle of Rest of Falling Sand or Gravel.}

The angle of rest in falling sand or gravel varies with the size, density, shape, and smoothness of the grains; and also with the amount of moisture or water present among them, little moisture causing adhesion of grains, much water producing a flowing mud. With no friction, as is essentially the fact in the case of the particles of a liquid, like water, the angle is null; with ordinary dry sand, $30^{\circ}$ to $35^{\circ}$; with ordinary voleanie cinders, $33^{\circ}$ to $40^{\circ}$.

Instructive experiments may be made by inserting vertically a graduated rod at the center of a circular board graduated similarly from its center outward, and then dropping over the board about the rod sand of different kinds, the ratio of height to radius giving the angle. The author obtained in this way for dry angular quartz sand about 0.005 inch in radius, the angle $35^{\circ} 20^{\prime}$ to $36^{\circ} 30^{\prime}$; for iron-sand, of like fineness, $33^{\circ} 10^{\prime}$ to $33^{\circ} 40^{\prime}$; for new (untarnished) shot, No. 10, very fine, $20^{\circ} 12^{\prime}$; same, No. 4 (coarser), $27^{\circ} 50^{\prime}$; same, No. 3 (buck-shot), $29^{\circ} 40^{\prime}$; and with tarnished shot, a higher angle.

When deposition is around a center, or pericentric, the resulting form is approximately conical, varying with irregularities in deposition through the winds and other causes.

\section{Atmospheric Pressure.}

Variations in atmospheric pressure, which may amount to two inches of the barometer in a few hours, or half as many pounds per square inch, are supposed to influence the resistance of the earth's crust to earthquake movements, and to volcanic eruptions. The tide-like movements in large lakes are attributed to other causes. 


\section{WATER AS A MECHANICAL AGENT.}

(1) General sources of activity. - (a) Watel does mechanical work in each of its three states, the liquid, solid, and gaseous state (or that of vapor). Only the first and second states are here considered, the third coming more conveniently under the head of Heat. In the liquid state it constitutes rivers, lakes, oceans; in the solid, snow, ice-crusts, glaciers, and icebergs. Unlike the aerial ocean, it has a defined upper surface; and the basement on which it rests has usually no disturbing influence.

(b) In rivers, water derives its energy from gravitation; it works as it falls, and arrives at its zero of action on reaching the lowest level to which it can fall. It reaches only temporary or approximate zeros in lakes, except when the lakes are like the ocean in having no outlet. Winds make relatively feeble currents and waves in large rivers.

(c) In the ocean, water has three prominent working agencies: (1) the tidal wave; (2) the wind-waves and currents, both the regular winds, like the trades, and the winds of storms, each producing waves and also currents of greater or less depth and velocity; (3) the resupply currents caused by the sun's heat, which in evaporation removes surface waters, and, in the expansion of water, diminishes its density. Gravity acts toward a restoration of the equilibrium that has been disturbed, whether the disturbance be due to the tidal wave, wind-waves, currents, or heat, and in response also to changes in atmospheric pressure.

(d) Lakes of large size, like the ocean, have wind-made currents and waves, and movements due to evaporation, and sometimes appreciable tidal waves and currents. Those of small size are often only still-water incidents in the courses of rivers.

Winds over large rivers may slightly quicken, or retard, the flow. Over great lakes, they may make decided onward movements, which pile the waters, tide-like, on leeward shores, - as sometimes about Duluth at the western end of Lake Superior, - occasioning an under current of escape. But over the ocean they are in all parts a prominent source of currents, and in the tropics, as has been stated, the "trade winds" originate, according to some physicists, the Atlantic and Pacific tropical oceanic currents.

(e) Owing to the earth's eastward rotation, increasing in rate of surface velocity from the pole to the equator as the cosine of the latitude, flowing waters in the northern hemisphere, whether of rivers or the ocean, and whatever their source, are thrown toward the right side as they advance, and in the southern hemisphere toward the left side. The result is seen in the lagging of the Labrador current against the west side of the north Atlantic; in a like effect on the correlate current in the north Pacific; and in the eastward course of the Gulf Stream north of the parallel of $35^{\circ}$. It has also been observed along rivers in many parts of the world where the deposits intersected are earthy, and the pitch of the stream is too small for erosion at bottom. They are marked along the great rivers of Siberia and European 
Russia, on others in southern France, on the streams intersecting the low land of the Atlantic border of the United States (Kerr), and on those of southern Long Island (E. Lewis).

It is shown that in streams the difference between the surface and bottom velocity accounts for this erosion of the right bank, with deposition at the left, thereby making the right steeper and placing the deepest part of the stream near it. The extremely slow transverse motion will be combined with that down stream, so that the actual motion will make a very small angle with the direction of the channel. (A. C. Baines, Am. Jour. Sci., xxviii. 1884.)

(2) Kinds and methods of work. - The kinds of work done by the mechanical action of waters, whether in rivers, lakes, or oceans, are in a comprehensive way (1) Denudation; (2) Transportation; (3) Deposition of the transported material, making usually stratified deposits.

\section{DENUdATION.}

Denudation is going on wherever any rock materials or rocks are within reach of moving waters. It is called erosion or excavation, when the work is the making of valleys, and degradation, when it is the wearing down of hills or mountains. But the term denudation covers both processes. Another style of work under it is that of planation, or the making of flat surfaces by the shearing action of spreading waters, and by deposition up to the surface, or to a common level. The worn material derived from the wear of rocks is called detritus, because made by wear; and also after deposition, sediment, because deposited usually from waters. Sedimentary rocks derive thence their name. Silt, the finest of mud, occurring in the bottom of estuaries and elsewhere, and ooze, soft, sticky mud, are extreme results of the grinding process. The term deposit is a general one for an accumulation made by any natural method.

Denudation depends for its effects on the varieties and conditions of the rocks subjected to it not less than on the powers of the agent, water. It is facilitated not only (1) by softness or fragility of terranes, but also by (2) their subdivision into thin layers; (3) a loose junction of layers; (4) alternation of yielding layers with firmer layers; (5) vertical joints or fractures, and especially multitudes of surface cracks or rifts. (6) Boldness in position is also favorable; for high bluff fronts feel the force of blows of water proportionally to their verticality, and also have gravity to aid in removing loosened material, and to produce rendings where water descends in vertical crevices. (7) Moreover, angular concavities or cavernous openings and projecting points in walls give the waters great advantage. (8) A horizontal position in the bedding of cliffs or walls is especially favorable, because a little removal below undermines, and may cause great downfalls; and, besides, walls and cliffs are thus kept vertical, for the long continuation of the work. (9) Above all, denudation is facilitated by the weakened con- 
dition of rocks, due to decay through chemical methods, and to the superficial riftings and fractures attending chemical changes, organic growths, freezing, and the alternating of cold with heat occasioned by the sun.

The methods of denudation are (1) by water-strokes, or the simple impact of water; (2) by abrasion, which includes (a) wear of rocks by means of the stones and earth carried or thrown against rocky surfaces; and $(b)$ wear of transported stones or grains by their mutual friction or corrasion. By these means much of the shaping of the earth's surface and the trituration of rocks to earth has gone forward. Abrasion becomes a shearing action in planation and terrace-making.

1. Impact of water simply. - In the flow over a smooth surface of rock pure water has no abrading effect. But when thrown in masses, in the form of plunging waves or torrents, into cavities of rocky bluffs or against bold projections, great results may be produced. Blocks of many tons' weight along a shore, if resting on a surface but slightly inclined toward the deeper water, will slip downward with each stroke.

The force of the impact of flowing water is expressed in pounds, by the general equation $\mathrm{P}=0.9702 n s v^{2}$, in which $v$ is the velocity in feet per second, $s$ is the greatest transverse section of the body in square feet, $n$ a coefficient varying with the form of the body, the value being ascertained for any particular form by trials; and 0.9702 is the quotient from dividing the weight of one cubic foot of water ( $62 \frac{1}{2}$ pounds) by $2 g$ (p. 174). Supposing the greatest transverse area to be 1 foot: for a simple plate the value of $n$ is 1.86 ; for a cube, 1.46 ; for a sphere, 0.51 ; for some rounded forms, only $0 \cdot 25$. If the hemispherical end of a cylinder faces the current, the impact is half less than if the flat end were in front. In accordance with the above, the force of impact against a flat plate a foot square, in a current of 5 miles an hour (or $7 \frac{1}{3}$ feet per second), will be nearly 100 pounds; in one of 20 miles an hour (4 times 5 ), 16 times that for 5 miles, and so on. On the other hand, if the surface struck is a hemispherical concavity, the impact would be very much greater than for a flat surface, the value of $n$ being about 2 for a hollow hemisphere with the concavity to the current. The principle is illustrated in the connection between form and resistance, or form and velocity, in a boat.

These results of experiment and mathematical calculation show that while it is not possible to measure the force exerted in the movements of a river, the concavities and deep recesses or channels among the rocks along the sides of a rapid stream afford an opportunity for effective blows.

2. Abrasion; Corrasion. - The transported sand and gravel which is carried by water against the rocks within reach acts like the emery of an emery wheel, yet only under slight pressure. The particles, and especially the pebbles or stones, that are thrown by violent torrents against the surfaces of the solid rock, work more effectively, but less constantly. In a current of given velocity the larger stones earried abrade more rapidly than the smaller. At the same time the transported particles or stones, whether in rivers or on seashores, are wearing one another, and this corrasion tends to reduce the material to that fine impalpable state in which even slow-moving waters will transport them. 
The coarser grains transported by the water suffer the most in cor. rasion, a grain a tenth of an inch thick wearing 10 times as fast as one a hundredth of an inch, and an inch pebble losing more in transportation a few hundred yards than a grain of sand of a thousandth of an inch in drifting for 100 miles (Sorby, 1880). Angular fragments of granite lose more by corrasion than rounded fragments. Ordinary sand-grains become rounded in a similar manner; but those of the finest quartz-flour from glaciers (as that giving the milky tint to the Rhine at Strassburg) remain angular, instead of becoming corraded (Daubrée, 1879).

Shales and soft sandstones yield easily to abrading agents; hard sandstones and quartzytes much less so; basalts, granites, very slowly, unless the wear is promoted by previous decay. Limestones are eroded easily because the material is soft and the waters may dissolve as well as wear away.

Abrasion assorts in proportion to hardness. The softer materials first yield, leaving the harder. When granitic sands, made of quartz, mica, and feldspar, are exposed to beach or river action, the mica first floats off, because in thin scales; next the feldspar is reduced in the corrasion to fine earth and is borne away; and the hard quartz is left in grains. Thus at the same time, out of the same sand are made a bed of quartz sand, for a sandstone, and not far off it may be an argillaceous or mud-like bed, good for forming a shale.

Rivers and beaches are thus ever at work when materials of the right kind are at hand. Where the flood-waters of a river, or the tidal-waters of the ocean, flow widely over shelving shores and bordering flats with little depth, the surface water as it moves onward is like a horizontally cutting blade; and, while admitting of deposition up to its level, it shears off the surface with remarkable evenness, making, by this process of planation, flat shoreplatforms and flood-grounds or terraces, such as occur along many river valleys and sea borders; and the plains are often at heights which make them evidence of ancient water levels.

\section{Transportation and Deposition.}

The rate of denudation depends largely on the velocity of the transporting water. The transporting power increases as the sixth power of the velocity (Hopkins, 1844). With twice the velocity the weight of transportable particles is increased 64 times; or, if the particles are of the same specific gravity, the transportable particles, if the velocity is doubled, may have four times the diameter, or 64 times the weight.

The stones, unless they have the specific gravity of water, are moved mainly along the bottom; and being continuously under the action of gravity, the movement of each, like that of a projected cannon-ball, is in a long curve. It makes a series of leaps, rising from the bottom and returning to it, - the length of the curve varying with the velocity and the specific gravity. The finest of sediment remains long in suspension, giving a cloudiness to waters; and it has been suggested that a partial alteration of the 
feldspar to a hydrous alumina silicate is the cause. This finest of sediment falls on incipient freezing (Brewer, 1883). Very thin particles, like scales of mica, sink slowly, because the rate is that of particles (of the same density) haring a diameter equal to the thickness of the scales. They are hence widely seattered by transporting waters.

Transportation assorts in proportion to size and snecific gravity. - In accordance with the ratio of transportation to velocity, it is found, supposing the material to be alike in specific gravity, that a current of 4 miles an hour will carry along stones $2 \frac{1}{3}$ inches in diameter ; of 2 miles, pebbles of $0 \cdot 6$ inch in diameter; of $\frac{2}{3}$ mile, fine sand about 0.064 inch in diameter; of $\frac{1}{3}$ mile, fine earth or clay, the particles $0 \cdot 016$ inch in diameter. Consequently, materials will be arranged over the bottom by velocity of flow, the coarser dropping first, the finer at greater or less distances beyond, and the finest floating on to other places of deposition.

Again, sands of like size but varying specific gravity will be assorted on the same principle, iron sands $(G=5)$ being left behind where the current is only sufficient to carry on garnet sand and other lighter kinds; and garnet sand $(G=3 \cdot 6)$, where the quartz sand $(G=2 \cdot 6)$ is still kept in movement, so that several sorts of deposits may form by varying rates of flow. If gold dust ( $G=18$ to 20 ) were in the waters, it would drop long before the iron sand. The principle is used in ordinary gold washings.

In drawing inferences as to rate of flow during deposition from the fineness or coarseness of deposits, there is need of caution, because flowing waters do not "scour" at the rates mentioned, unless the materials are quite loose. Very slight compacting at surfaces will hold the sands and earth down. Let any causes stir up the bottom, then the principle works well; and in these modern times steamers up and down rivers, bays, and coasts, often occasion that stirring which favors scour, to the benefit of navigation. Professor Verrill has remarked that the shells broken up by fishes over the ocean's bottom make loose material easy of transportation by the Gulf Stream.

An important exception to this relation between size of particles and hydraulic value, noticed and made the subject of special investigations by E. W. Hilgard, arises from the tendency of the finer kinds of sediment in fresh water, if the water is not absolutely quiet, to agglomerate their particles, when not over $1 \mathrm{~mm}$. in diameter, into larger particles, or to flocculate, as he terms the process, and so take the hydraulic value of coarser sediments. He shows that fine river deposits consist largely of such flocculated particles, and that the fitness of soils for tillage depends largely on the porous condition thus derived.

Some characteristics of water. - (a) A cubic foot of pure water at $62^{\circ} \mathrm{F}$. weighs 436,495 grains, which equals $62 \cdot 355$ pounds, or nearly 1000 ounces avoirdupois $=28,315$ grams. The soluble impurities of ordinary river water are $0 \cdot 000186$ of their weight. (Murray.)

Under a pressure of 1 atmosphere, water boils at $212^{\circ} \mathrm{F} .=100^{\circ} \mathrm{C}$; ; and under 45 atmospheres, at $510 \cdot 6^{\circ} \mathrm{F} .=265 \cdot 9^{\circ} \mathrm{C}$. 
(b) When water freezes, it crystallizes in the hexagonal system: either in slender prisms ; in compact aggregations of prisms, making a mass of ice ; in small 6-rayed stars, as in snow; or in feathery forms, as in the frost over windows and pavements in winter. In the thick crusts made over water in cold seasons, the prismatic structure is vertical except in a thin upper layer : a fact proved by means of polarized light.

(c) The density of water is greatest at $39 \cdot 2^{\circ} \mathrm{F} .=4^{\circ} \mathrm{C}$. From this point, it decreases, or the water expands, as the temperature falls to $32^{\circ} \mathrm{F}$., the freezing-point, and as the temperature rises above $39 \cdot 2^{\circ} \mathrm{F}$. The specific gravity of ice, relatively to water as the unit, is 0.9178 ; and hence 11 volumes of ice make about 10 of water.

(d) The increase of bulk of water when it becomes vapor, which it may at any tem. perature, is, under ordinary pressure, 1700 times; and hence 1 cubic inch of water yields about 1 cubic foot of steam or vapor. The density of vapor at $212^{\circ} \mathrm{F}$, taking air as 1 , is $0 \cdot 6235$.

In the further consideration of the subject of water as a mechanical agent, the natural subdivisions adopted are:-

1. Fresh Waters; including especially Rivers, Lakes, and Subterranean Waters.

2. The OCEAN.

3. Frozen WATER, or Ice, Glaciers, Icebergs.

\section{FRESH WATERS.}

The several topics are the following:-

1. Gathering of water into rivers and lakes.

2. Working-power of rivers.

3. Methods and results of denudation.

4. Transportation and deposition.

5. Special points in fluvial history.

6. Subterranean waters.

\section{Gathering of Water into Rivers and Lakes.}

The fresh waters of the land come from the vapors of the atmosphere, and these chiefly from the ocean, but largely also from the waters and moisture of the land and its regetation.

The conditions favoring the making of large streams are as follows:-

1. Large drainage areas, with high mountains on their borders. - The cold summits of mountains are condensers of moisture, and sometimes perpetual condensers, when the country below is dry; and their elevation gives force to the descending waters. Long slopes and combinations of those of different mountain ridges and ranges make the great rivers. In the Americas the mountain chains of the opposite sides of the continent contribute toward the Mississippi, St. Lawrence, Mackenzie, Amazon, and La Plata; and so it is in the Orient. Short slopes hurry off the waters to the sea and make small drainage areas. 
2. Abundant precipitation. - The annual fall of rain (and snow) over the Mississippi drainage area is, for the eastern, or Appalachian part, 40 to 50 inches; for the much larger west-central part, west of the Mississippi River, 20 to 25 inches; for the western part, among the summits of the Rocky Mountains, 25 to 30 inches. In the vast Amazon drainage area the annual precipitation exceeds 50 inches both on the west and north, and is everywhere over 25 inches.

3. Upward waste, or that by evaporation, small. - Under a hot and dry climate, and in the absence of forests, the waste is great. The western tributaries of the Mississippi lose a large part of the waters received in the mountains while descending the dry, bare eastern slopes. Where the Nile takes its rise, the annual precipitation is over 50 inches, but it is not more than 10 through the lower two thirds of its course. An extravagant example of this waste is shown on the map of western Maui, on page 179, where there are great channels in the mountains and mere threads over the surface to the west where it seldom rains.

4. Downward waste, or that by gravity and soil absorption over the drainage area, small. - Not only loose sands, but also many sandstones are very absorbent; and limestones, although nearly impervious to moisture, are often cavernous, and sometimes swallow up rivers. In western New South Wales the rivers take only $2 \frac{1}{2}$ per cent of the precipitation, owing chiefly, it is stated, to the porosity of the sandstone of the region. Most lavas are porous and somewhat cavernous, but may lose these qualities by infiltration of earth from decomposition. Further, most stratified uncrystalline rocks are loose in bedding, and take off much water along the open spaces between the layers. Granite and other crystalline rocks make the tightest basins; for they absorb little.

Frozen or icy ground is like impervious rock; almost all the water that falls over it goes to the rivers. Moreover, in cold weather evaporation carries off but little. Hence come the sudden rise and height of many spring floods in cold-temperate latitudes.

In very dry and warm climates, where the precipitation is reduced to a few inches a year, rivers fail altogether, or flow only during the short rainy season. Between drying up under the hot sun and soaking away in the sandy soil, they are soon gone, and the lakes along their courses, or receiving their waters, may share their fate.

Other sources of loss in surface waters are (1) the demands of vegetable and animal life; and (2) the chemical combinations attending the decay of rocks in which hydrous minerals, as the hydrous iron oxide and clays, are made.

Of the water precipitated, the rivers may get 45 to 50 per cent over regions of crystalline rocks, as is true of the Connecticut River. In other parts of temperate latitudes the amount is usually a third to two fifths of what falls. But in warm latitudes it may be under one tenth. The mean annual discharge of the Mississippi River is about 25 per cent of the precipitation; it 
averages $19 \frac{1}{2}$ trillions $(19,500,000,000,000)$ of cubic feet, varying from 11 trillions in dry years to 27 trillions in wet years. The Amazon, in the tropics, with a drainage area not twice as large, carries to the sea five times as much water as the Mississippi.

The mean annual discharge of the Missouri River is about $3 \frac{3}{4}$ trillions, or $\frac{15}{100}$ of the amount of the rains over the region. The corresponding amount for the Ohio is 5 trillions, which is $\frac{1}{4}$ the amount of rain. (Humphreys and Abbot.) The Ganges carries down about 4.2 trillions annually, and the Nile $3 \frac{1}{5}$ trillions. The rivers of England and Wales carry to the sea $18 \cdot 3$ inches in depth out of an annual fall of about 32 inches.

\section{WORKING-POWER AND ACtion OF RIVERs.}

1. Energy from height of fall. - It has been stated that in rivers the water works as it falls; so that the amount of work done depends on the rate of fall along its course to its outlet, and the amount of water.

In the mountain stream the slope of the water varies from $90^{\circ}$, or that of a waterfall, downward to one degree and less. But in the large rivers it seldom exceeds 12 inches to a mile, and is sometimes but one third this amount.

The slope of the Mississippi, from Memphis down ( $855 \mathrm{~m}$.$) is 4.82$ inches per mile at low water; from Cairo, at the mouth of the Ohio (1088 m.), 6.94 inches; and above the Missouri, from its source, $11_{1}^{3}$ inches. The Missouri, from its highest source (2908 m.), descends about 6800 feet, or 28 inches a mile; but from Fort Beriton to St. Joseph $\left(2160\right.$ m.), about $11 \frac{1}{2}$ inches; and below St. Joseph to the mouth (484 m.), 91. (From Humphreys and Abbot.) The average slope of the Amazon for 3000 miles from its mouth is less than an inch, the descent in this distance being 210 feet; of the Lower Nile, not 7 inches; of the Lower Ganges, about 4. The Rhone is remarkable for its great slope, it being 80 inches per mile from Geneva to Lyons, and 32 inches below Lyons. The tidal portions of rivers, which have no slope with the rising tide, have a slope and a strong flow with the ebbing tide.

During high floods the course of a river is shortened, because the minor bends are obliterated by the overflow, and where the channel is broad and open, the slope is commonly increased in amount and uniformity. Narrows between rocky bluffs act like a dam, and diminish the pitch above them, often spreading the waters into lakes, while they increase the pitch below. At such narrows floating ice often makes obstructions in the spring, which greatly increase the height of the waters. A dam higher up the stream, that obstructs or holds back the ice during its break-up, may save large areas from the flooding effect of the narrows. Narrows are sometimes created along streams by encroaching human "improvements"; but a narrowing either of a river's natural flood-grounds or its place of discharge may be a source of disaster. The water-power of the flooded river is safely controlled only by keeping the channel and outlet large enough to carry off all the water as it comes. 
2. The amount of work which a body of water, as that of a lake, can theoretically do, on its descent to the level of the sea, is equal to the rroduct of the height of the lake $(h)$ into the weight $\left(W^{\top}\right)$ of the water; and hence $W h$ is an expression in foot-pounds for the energy or working-power potentially present in the lake. The amount of energy in a lake a fourth of a square mile in surface, 10 feet in average depth, and 400 feet above the sea level, is $1,742,400,000,000$ foot-pounds; - a power sufficient, could it be expended without loss, to raise a mass of stone weighing about 87,000 tons to the top of a mountain 10,000 feet high. If now the water were allowed to flow by a continuous slope to the sea level, without loss from evaporation, or from resistance of any kind (such as friction, etc.), its velocity would increase regularly according to the well-known law of falling bodies; and, in this increase of rate, it would be constantly accumulating energy of motion, which would be the exact equivalent of the energy of position it was losing; and when it reached the lower level its velocity would be 160 feet per second (about 109 miles an hour). In the case of falling bodies the relation between the vertical distance fallen through $(h)$ and the acquired velocity (v) is expressed by the formula $v=\sqrt{2 g h}, g$ being the force of gravity, usually taken at $32 \cdot 2$ (it is $32 \cdot 165$ at New York City); or, approximately ( since $2 g=64 \cdot 3$ ), by the formula $v=8 \sqrt{h}$, or $h=\frac{1}{64} v^{2}$. In actual experience the theoretical result cannot be realized. On the contrary, the velocity of a stream does not increase uniformly as it descends, and when it reaches the sea, whatever the elevation at first, its velocity is in most cases nearly zero. This is owing to the fact that its energy, instead of being stored up, is being expended against the various resistances encountered, that is : -

(1) In overcoming friction between $(\alpha)$ the molecules of the water itself; (b) the water and the bed of the stream; $(c)$ the surface of the water and the atmosphere.

(2) In impact, or blows against the rocks or earthy material of the bed and banks of the stream; and in pushing sand or gravel along the bed.

(3) In transporting earth, sand, or stones, held in suspension in the water.

(4) In overcoming the friction between the transported particles and the bed of the stream, and the friction between the particles themselves; and also the loss from eddies made by the character or form of the bed or otherwise.

By these means the energy is so far expended that no accumulation can take place except on portions of a strean where the pitch is uniform and considerable, and the bed is hard and smooth. In a waterfall, accumulation goes on during the descent; but the whole energy of the stream is lost in the stroke of the water at the bottom of the fall, where it is converted into heat, - a fall of 772 feet producing heat enough to raise the temperature of the water $1^{\circ} \mathrm{F}$.

Owing to the rapid increase of velocity in the descending water of a waterfall, the stream in a high fall of small volume becomes divided up, the 
parts running away from one another and finally separating into drops; in which case, owing to the resistance of the air, the velocity, and therefore the energy, is almost wholly dissipated, and the fall becomes a veil of mist, swayed by the winds.

3. Velocity of rivers. - The velocity of rivers varies (1) with their slope strictly the slope of the upper surface; (2) with the volume of water; (3) with the friction of the bottom and sides - which increases with the roughness of its surface, and the shallowness of the stream for a given volume; (4) with the degree of uniformity of the cross-section and uniformity of course, - for abrupt bends and shallowings increase friction. In other words, among rivers a large stream of considerable depth, having a width not a score of times greater than its depth, and a uniform cross-section and course, will be least impeded by friction of the sides and bottom, and will work most effciently. Over a bottom of ordinary kind the velocity is greatest along the line of greatest depth; and in any given section the maximum plane of flow is at or near the surface, at about one tenth of the depth (Humphreys and Abbot), but varying between zero and two tenths. The retardation at surface is attributed by Professor James Thomson to the friction of the bottom and sides; the eddying masses of water are thrown off by this friction, which modify the velocity in all parts of the stream, but most at the surface.

The mean velocity is about four fifths of the greatest velocity; or better, according to Humphreys and Abbot, it is almost uniformly 0.955 of the velocity at mid-lepth. The amount (in cubic feet) of water passing is equal to the product of the mean relocity into the area of the cross-section. When two streams unite without increase of pitch, the velocity is increased because the surface of friction is less than in the two flowing separately.

Humphreys and Abbot, in their Report on the Mississippi River (page 312), give the following formula for calculating the velocity of large rivers. It is applicable strictly to a limited portion of a large river without bends. It is as follows: $v=\left([225 r, s]_{2}^{\frac{1}{3}}-0 \cdot 0388\right)^{2}$, in which $v$ is the velocity sought; $s$, the sine of the slope; and $r$, the mean radius = area of cross-section, $a$, divided by $p+W$, or the length of the wetted perimeter $(p)$ plus the width at surface. In the general formula, the sine of the slope $=s=\frac{l^{\prime}}{l} \cdot l=$ length of a limited portion of the river, $h=h_{1}+h_{l}=$ difference of level of the water-surface at the two extremities of the distance $l$, in which $h_{l}=$ the part of $h$ consumed in overcoming the resistances of the channel supposed to be straight and of nearly uniform cross-section, and $h_{11}=$ the part of $h$ consumed in overcoming the resistances of bends and important irregularities of cross-section. In the equation for large rivers, above quoted, $h_{\|}$is thrown out by the conditions.

When a river expands into a lake, the velocity of flow is diminished because of (1) the greater capacity of the lake for a given amount of length; (2) the decrease in slope; and (3) the increased surface for evaporation. There is little movement in the waters that lie below the level of the outlet.

4. Periadicity in working-power. - Rivers are periodical workers, owing to periodicity in the day, the seasons, and in the longer climatal cycles. 
The changes of the day determine alternations in amount of evaporation, and, with greater effects, alternations in the supply from snow-covered heights. The night suspends part of the supply by the freezing that goes forward; and the day starts the flow again, the effects reaching the plains below some hours after the change in the mountains, so that the night is often the time of greatest flow.

With the alternating seasons, the changes are of great magnitude. All rivers have their annual season of quiet flow, when work is often wholly suspended, extending usually through most of the months of the year; and then, once or twice annually, their periods of floods, when lazy streams become impetuous torrents, and narrow streams mighty rivers, sweeping over the bordering lands for miles, defying human attempts at management.

In mountain regions, and especially those of dry, almost rainless climates, storms, called cloud-bursts, sometimes pass hurriedly and fill the narrow valleys to a depth of 100 feet or more in a few hours, doing quick, short, destructive work over small areas.

The flood season is geologically the working-time of rivers. After their floods have passed, in which all work is of a broad sweeping style, rivers return to quiet action along the bed, and often are divided into several feebly chiseling strands along the channel. Sometimes only the stony bottoms of portions of the channel are left dry; or, as in parts of Australia, there remains merely a string of small, distant muddy pools, in which only Fishes that are doubly equipped with breathing apparatus, like the Ceratodus, could survive.

Rivers that rise in snowy heights, like the Rhine, Rhone, and Danube, have their channels kept well filled in summer, the time of drought, because that is the melting-time of the snows.

The flood season has its effects prolonged in many regions by the great natural reservoirs over the land - the lakes and marshes. These stow away the surplus waters and let them out gradually. Many temporary lakes are made by floods which prolong greatly the period of high water under a condition that is convenient for mill-uses. Man makes reservoirs for the same purpose.

Forest regions also keep the soil beneath them charged with moisture, and, like lakes, help to give rivers constancy of supply and uniformity of flow. And evil often comes when the forests are cut away; for the rain waters then speedily reach the river-channels and may occasion alternate periods of wasteful violence and worthless feebleness. The cutting away of the forests in the French Alps (Dauphiné) has led to uncontrollable erosion, despoiled fields, and impoverishment of the people; and, in America, to annual seasons of dry mill-ponds, an immense sacrifice of available waterpower, and the desertion of many a mill-site.

Where a river has its rainy region confined to the mountains about its source, and flows below through dry plains, the floods travel gradually down the stream, losing by evaporation and soil absorption as they flow on. There is often much hard work done in the mountains, and little below. 
The floods of the Nile commence in southern Abyssinia (where the annual fall of rain is 50 inches or more) in April, and reach Cairo in midsummer, aud exert their beneficial influence over all the flood grounds by the fertile silt deposited, which is estimated to amount annually to 140 millions of tons. The maximum rise is 40 feet, and the area of the region flooded is 2100 square miles.

The distribution of tributaries influences the time and amount of floods. In the Amazon, the tributaries north of the equator are flooded during the rainy season of the northern hemisphere, and those south, during that of the southern. In this way many rivers, by their widespread arms, take advantage of the differences in the seasons or climates of the distant countries whence they get their supplies. The floods of the Amazon convert the larger part of its 500,000 miles of silvas into one great lake; 3000 miles up the river, an elevation above tide of only 210 feet is reached. The Mississippi hardly feels the great floods of the Ohio unless they come when the Rocky Mountain tributaries are also flooded; and these western tributaries are so widely distributed and so large that they may make successive floods, or pour in all together in one vast deluge, giving the Mississippi in some places below the Ohio a breadth of 50 miles. At high water the flood-level is 70 feet above low water at Cincinnati, 51 on the Mississippi at Cairo, and 17 at New Orleans.

The cycles of rainy and dry seasons sometimes seem to correspond with the sun-spot cycle of 11 years; and greater eycles include 4 or 5 of the 11year cycles. No definite conclusions have as yet been formed regarding this point.

5. Causes tending to determine the direction of draining courses. - The chief causes are the following. As regards, -

(a) Slope. - The steepest descent accessible.

(b) Surface-form. - A depression leading downward to concentrate the waters from a large area for work.

(c) Busement rocks. - The belt of least resistance to wear. In the case of upturned strata, whether folded or in monoclines, the belt of weaker rock in the line of strike; or over folded rocks, the course of a region of warped strata between the extremities, overlapping or not, of the folds (page $388)$.

(d) Fractures, faults. - The courses of great fractures and faults, and especially those attending the flexing of rocks in mountain-making, as, for example, those which determined the location of the Great Appalachian valley of eastern Tennessee and its continuation northeastward (page 356).

(e) Meteorological conditions. - The belt or region of greatest precipitation.

\section{Dendodtion.}

1. Work of the rain-drop. - Denudation by simple impact of water commences with the descending rain-drop. The drop makes a shallow impres- 
sion on soft earth or mud by denudation, which is circular or elliptical, according as the wind blows or not. These impressions, if they escape obliteration by succeeding drops and are soon covered by a layer of sediment, become "fossil rain-marks," and many surfaces so marked exist in the older rocks, bearing evidence as to former rains, and also as to the above-water level of the surface rained on. It may have been a mud-flat exposed between high and low tides. When the drops strike a gravel bed, stones in the gravel will protect the material directly beneath, while erosion around may cut away the material, and leave standing slender columns, each capped with a stone, as monumental evidence of the work done.

A miniature specimen of this work was observed by the author in 1887, alongside of the path leading down into Kilauea. It had been produced by

158.

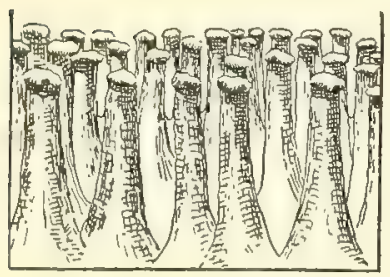

Drop-made columns. D. ' 87 . drops falling from shrubbery, wet with the heavy mist of the night, to a bed of earth, three or four feet below. A portion of the scene is represented, natural size, in Fig. 158.

Columns of 10 to 30 feet are often made out of beds of gravel, glacial drift, and the like. Fig. 159 represents a case near Antelope Park, on a small tributary of the Rio Grande, where a bed of tufa, over 500 feet thick, contains large stones. The waters of the rains descending along the surface of a vertical wall first made, beneath the stones, bas-reliefs of columns, and then the free columns; and, in the end, an area three miles long and half a mile wide was thickly covered with the columns, many 60 to 80 feet high, and some 400 feet (Endlich, 1875).

The power of water-strokes is well illustrated by the effects in gold-washings from a jet under a head of pressure derived from the water in an elevated reservoir, as in California hydraulic mining. The beds of compact auriferous gravel gradually return to their original condition of loose earth and stones, although struck only by a mass of pure water.

At Niagara, the spray made by the waterfall, carried forcibly into an open chamber behind the fall, causes the wear of the shales (James Hall).

2. The excavation of valleys; Denudation.-Erosion, excavation and denudation, or land-sculpture, are parts of one process. The simplest illustrations of the subject are afforded by the great, gently sloping, volcanic mountains, made up chiefly of stratified streams of basaltic lavas. In them, the slopes are

159.

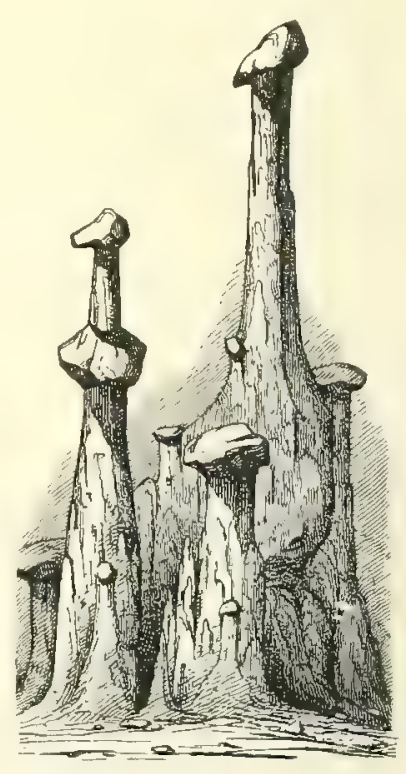

Rain-made columns $\times \cdot 04$. Endlicb, '75. but $5^{\circ}$ to $10^{\circ}$, and conditions determining direction of drainage are in general reduced to two, the first and the last of those mentioned on page 177. The facts here presented are from the author's observations of 1839-1841, published in his Exploring Expedition Report, 1849. 
The earliest stages are well illustrated in the Hawaiian mountains. One of them, Mount Loa, 13,675 feet high (see Figs. 227 and 229), is still active; consequently it is without river valleys or gorges. Another, Mount Kea, 13,805 feet, has many gorges on the wet or windward side, extending upward from the coast, where they are several hundred feet deep; but they go only half-way to the top. The leeward side is yet unchanneled.

The map here introduced is that of the adjoining island of Maui.

160.

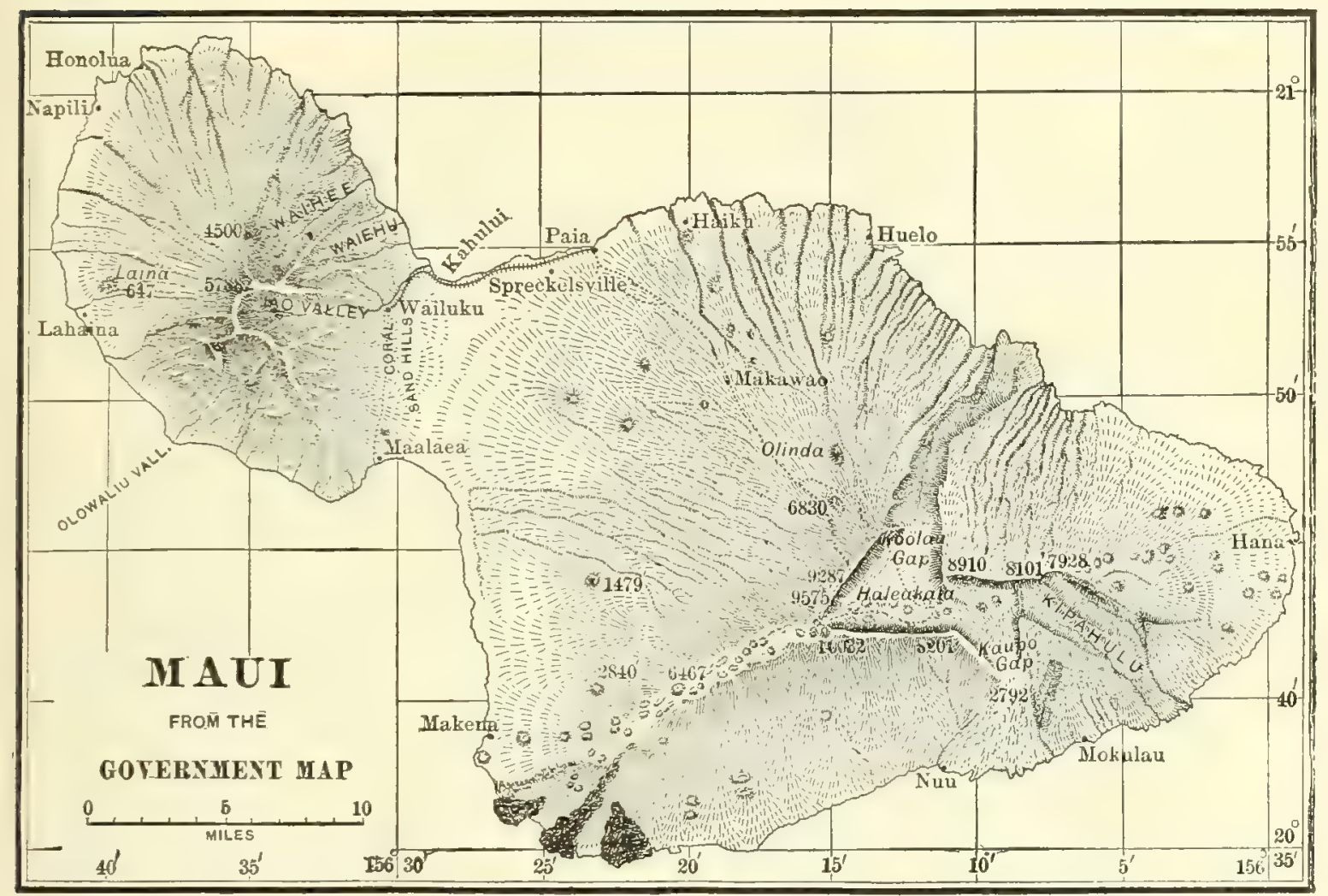

On eastern Maui, the cone, 10,000 feet high, has a somewhat less recent aspect in its rocks than that of Mount Kea. It has chamnels on its windward slopes, some of which reach up to the edge of its great crater; but on the leeward side only narrow trenches that seldom contain water. At the same time, western Maui, nearly 6000 feet, has profound valleys in place of the many small ones, marks of very long exposure to denuding agents; and another island of the group farther west, Oahu (Fig. 257), is like Maui in having a western volcano in ruins, - a few crests and profound valleys in place of even slopes, and an eastern volcano of much more recent aspect, though more gorged than eastern Maui. But it met with a disaster in which over half of its mass sunk beneath the ocean, leaving a precipice for 20 miles facing the northwest or to windward. The nearly vertical surface has consequently a range of alcoves, finely illustrating this style of mountain arehitecture. To the northward the alcoves are lengthened into gorges. Moreover, over eastern Oahu the winds pass the summit of the precipice before the cold heights have deprived them of their moisture, so that the leeward slopes take 
it, and show the fact of this reënforcement of the streams in the depth of the valleys.

Finally, in 'Tahiti, as is shown in the map below, the work of erosion is in a sense completed, in spite of the general covering of vegetation. The few great valleys, which here take the place of the many of the early stages of erosion, extend to the coast; and these valleys, instead of narrowing to the

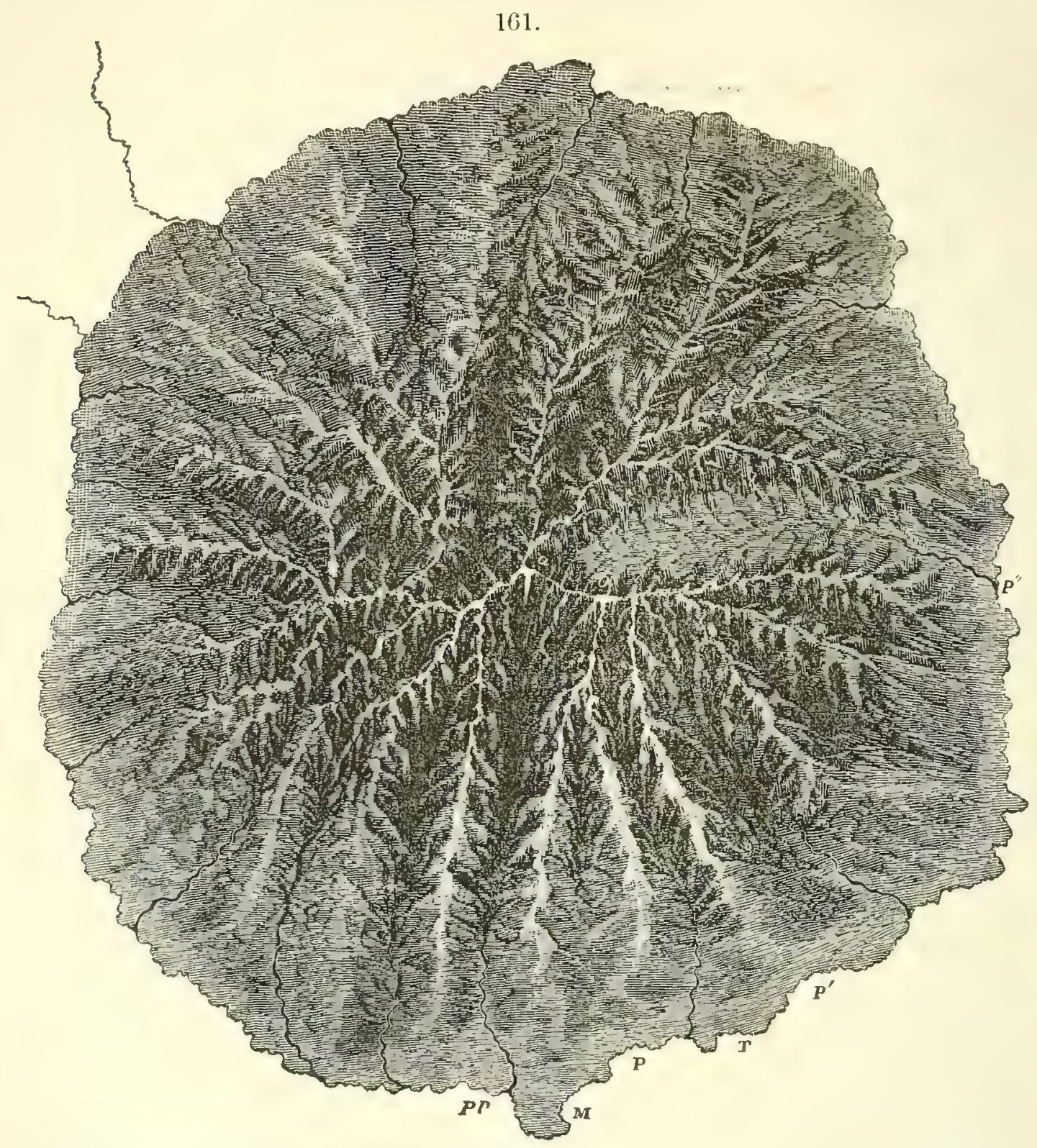

Map of Tahiti, the coral reefs excluded; the lower side is the northern, or that toward the equator: PP, village of Papenoö; M, of Matavai; P, of Papaua; T, of Toanoa; $\mathrm{P}^{\prime}$, of Papieti, the largest; $\mathrm{P}^{\prime \prime}$, of Punavia. The valleys are named from the villages on the coast at their termination. Wilkes' Exploring Expedition Report.

summit, widen out and stop off abruptly under precipices of at least 3000 feet. Some widen at their head into great amphitheaters or circs (the "cirques" of French authors), illustrating well the origin of such amphitheaters.

In the above examples, the rains and mists of the higher and cooler 
parts of the mountains, and especially those of the windward side, are the source of the water. The slopes collect it as it descends into streamlets; these increase toward the foot, where the valley, as Mount Kea shows, first takes shape.

The diagram Fig. 162, although greatly exaggerated in angle of slope, that of the line $\mathrm{AB}$, - will serve to illustrate the steps of progress. In the early stage a valley forms toward the base of the mountain, having its bed

162.

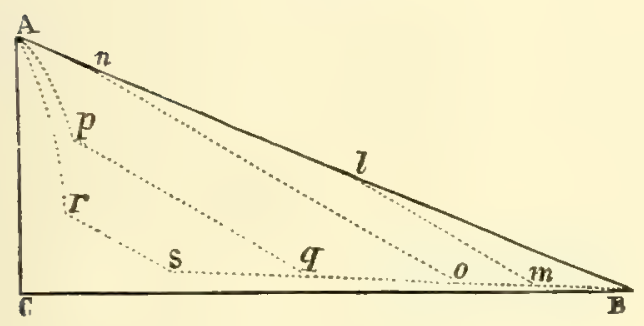

163.

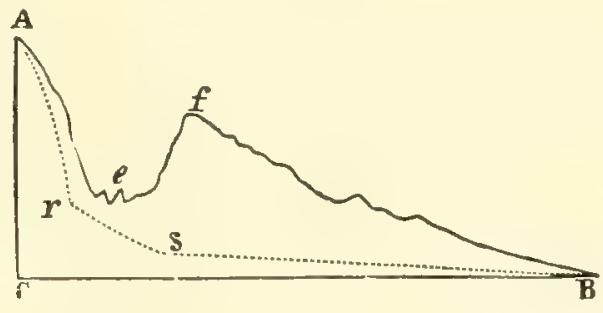

along $l \mathrm{~m}$; and later along no. On reaching $o$, the most of the descent of the declivity is made: the waters from $o$ to $\mathrm{B}$ have, therefore, little eroding power at bottom, and commence to erode laterally during freshets, undermining the cliffs on either side, when the rocks admit of it, thus widening the valley and making a "flood-plain," or "bottom-lands," by deposition of the transported material in consequence of the slackened flow. The river, in this state, consists of its torrent-portion, Ano, and its river-portion, omB. Along the former, a transverse section of the valley is approximately Vshaped, and along the latter nearly $\mathrm{U}$-shaped, or else like a $\mathrm{V}$ flattened at bottom. The river-portion, om $\mathrm{B}$, usually exhibits, even in its incipient stages, its two prominent elements, - a river-channel, occupied at low water, and the alluvial flat, or flood-ground, which is mostly or wholly covered during freshets.

As the waters continue their work of erosion about the summits, where the mists and rains are generally most abundant and often almost perpetual through the year, the next step is the eroding about the summit and the continued deepening of the torrent-channel, making thus a precipice under the summit, or toward the top of the declivity; in this stage, the course of the waters is $\mathrm{A} p q \mathrm{~B}$, and later, $\mathrm{A} r s \mathrm{~B}$. The stream has now (1) a cascadeprortion, and (2) a torrent-portion, besides (3) its river-portion. The precilices of the cascade-portion may be thousands of feet in height; and the waters may descend in many thready lines, to unite below in the torrent. The mountain cone, in such a case, may have its top chiseled into a narrow, crest-like ridge or peak, with many vertical alcoves in the face of the precipice that were made by the falling and leaping streamlets.

The next step in the progressing erosion, as Tahiti illustrates, is the thinning and wearing away of the ridges that intervene between adjoining valleys, in the higher regions where the descending waters are most abundant. It is in this way that two valleys (or perhaps more than two, by the wear of more 
ridges) are combined into an amphitheater or cire. In Fig. 163, ArsB represents the course of the stream, as in Fig. 162; and Aef B the eroded ridge, which has lost at $e$ much of its height.

The ascent of the mountain by following the valleys is in such a case wholly impossible; it can be accomplished only by finding the ridge that has held on to its summit connection with the peak. On Tahiti the ridge by which the author made his ascent to $b$, the peak called Aorai, about 6000 feet in height, narrowed to two or three feet, and for a short distance to a single foot, putting risks into the excursion, since the slope either side fell off for 1000 to 2000 feet at an angle of $60^{\circ}$ to $70^{\circ}$. Between $b$ and $a$ (the highest peak, Orohena) the "divide" was reduced in height more than 1000 feet, and the summit at $b$ was but six feet broad. All the outlines of the original crater had disappeared. The lavas usually lie in beds dipping seaward, but those of the central precipices were without bedding.

From the steps in the work of erosion over such isolated volcanic mountains it becomes evident that further progress would result in narrower, thinner, and if possible steeper ridges; and, even when nearing the end, in sharp crests and ridges, which finally would be likely to disappear through weathering agencies. A flattening of the mountain would come at the very end, and not be a step in the progress toward it.

These explanations show that a river rising in high mountains has (1) its torrent-portion, and (2) its river-portion, along which it is bordered by floodgrounds.

The river-portion consists (1) of an upper section of rapid waters, along which erosion at bottom is continued, and the amount removed exceeds that of deposition; (2) a section of feebler descent and slower flow, where the removal by erosion in floods does not exceed that of subsequent deposition, so that the stream has ceased efficient work. It has reached base-level - as the condition has been termed by J. W. Powell. This base-level section may end below in a decrepit portion, over which deposition along the bed exceeds the amount removed in floods, so that thus a silting up of the channel, and also a corresponding rise of the flood-grounds, go on.

In the small Pacific islands these sections of the river-portion of a stream are short and not always present. But on the western side of Maui there are remarkable examples of a decrepit ending; for, while the valleys in the wet and cool mountains are wide and profound, as the map shows, the stream over the leeward (and hence nearly rainless) plain at the western foot is reduced to a narrow trench, which part of the time is dry.

3. River valleys of the continents. - Over a continent where declivities are long, and the gently sloping plains have large extent, - often hundreds of miles in width, - each of the divisions of the river-portion of a stream, that of rapid-working waters and that of base-level, is often of great length. Moreover, along many streams there are often several base-level portions, made by obstructions; but where this is the case, as Powell remarks, it is evidence of the relatively recent origin of the stream; for the wear of ages tends to 
remove the obstructions and reduce the stream throughout, or far toward its source, to a base-level condition.

In New South Wales, Australia, where a friable Triassic sandstone 2000 to 4000 feet thick is the prevailing rock over large regions, the river-portion of some streams is continued from the coast, between nearly vertical walls of the sandstone, almost to the mountains, and there ends abruptly in the cascade portion of the source. The following figure illustrates the steps of progress: first, the cut of a torrent-channel to $C n^{1}$; and then the retreat of the torrent portion by the continued wear, and the lengthening of a riverportion from $n^{1}$ to $n^{2}$ and so on to $n^{4}, n^{5}, n^{6}$, when the torrent-portion is reduced to a series of waterfalls. Over the wetter interior portion of the

164.

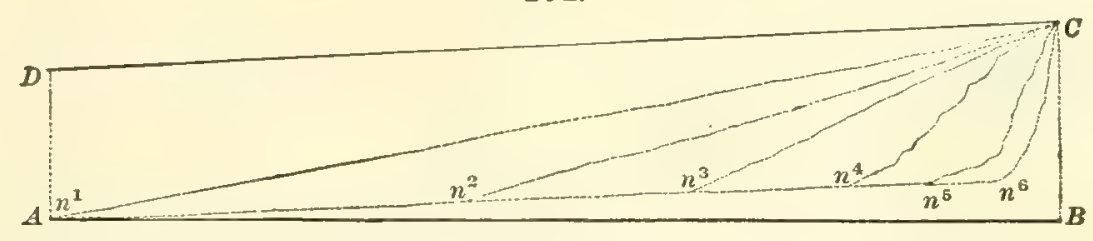

Ideal section illustrating progressing erosion of a stream. D. '49.

country the valleys have often great breadth, and at the head widen into circs, owing to the many streams descending the steep sides; but toward the coast, where the climate is relatively dry, the breadth does not much exceed that of the inclosed stream.

A model of a system of erosion is often admirably worked out in the earthy slopes along a roadside, - the little rill having its cascade-head, then its torrent-channel, and, below, its flat alluvial plain, intersected by the little winding water-channel; some of the ridgelets worn away in their upper parts, until two or more little valleys coalesce; then, at times, the head of the coalesced valleys widened into an amphitheater, and the walls fluted into a series of alcoves and buttresses.

The process of raising the bed and flood-grounds of a river is often promoted by the embankments made along the lower part of their course to prevent extensive flooding, and to increase the depth by scouring. On some Japan rivers, the beds, owing to the silting and the consequent making of artificial embankments, are now 40 feet above the plains over which they flow. In all improvements, it has to be remembered that the amount of water discharged by a flooded Mississippi cannot be lessened by choking it. It must and will have room to flow in, however desirable it may be to rob it for storehouses and dwellings.

The flood-grounds of some large rivers extend scores of miles from the low-water channel. On the Mississippi, abreast of Tennessee, they are in some parts over 50 miles wide; on the Amazon (up which the tides go 400 miles), over 100 miles; and on the Paraguay there are lagoons 300 miles in length.

4. Bends. - Where the pitch of the stream is very small, any obstruction, or inequality of bottom, that throws the flow of maximum velocity to one side 
of the axial line, causes it to strike and erode the bank in front and deepen the water, and to transfer the sand or earth removed by the erosion to the opposite bank of the stream for a sand-flat; and it thus commences a curve in its course, which may become a deep bend; and this bend may continue the action and be the occasion of a succession of such windings. The length of the Mississippi between the mouth of the Ohio and the head of the passes at the Gulf of Mexico is 1080 miles, while the actual distance in a straight line is about 500 miles. Cutting off a bend to shorten the distance along the stream increases at the place the pitch, and thereby the velocity, and gives the waters greater eroding power. The flow, consequently, would deepen the channel. But it is likely also to erode the banks, and may carry away all the farming land the cut was intended to gain or make accessible. During great floods, a stream may cut off one or more of its bends, as has happened in the Mississippi, along which narrow loop-form lakes and dry channels have thus been made.

Many examples are on record of gorges, hundreds of feet deep, cut out of the solid rock by only two or three centuries of work. Lyell mentions the case of the Simeto, in Sicily, which had been dammed up by an eruption of lavas in 1603. In two and a half centuries, it had excavated a channel 50 to several hundred feet deep, and in some parts 40 to 50 feet wide, although the rock is a hard solid basalt. He also describes a gorge made in a deep bed of decomposed rock, three and a half miles west of Milledgeville, Ga., that was at first a mud-crack a yard deep in which the rains found a chance to make a rill, but which in 20 years was 300 yards long, 20 to 180 feet wide, and 55 feet deep; and Liais describes a similar gorge, of twice the length, in Brazil, made in 40 years.

5. Eddies, Pot-holes, Kettle-holes. - Flowing water gathers into its current any still waters alongside, to fill the void behind, which the flow tends to produce, and thus eddies and eddy currents are made. When alongside of a rapid current, any obstruction or shallowing causes there a diminished velocity; eddies become whirls, and the whirling waters bear around stones which abrade the rock beneath — new stones being carried in to replace old ones as they wear out. This kind of boring often goes on with hardly more change of center than in a carpenter's work with his augur, and deep cylindrical holes have been bored into the hardest rocks. Under a waterfall a broad basin may be excavated in like manner. Pot-holes are usually from 1 to 6 feet in diameter, and 2 to 20 feet deep.

Kettle-holes are nearly circular basin-like holes 50 to 150 feet and more in diameter, in stratified or unstratified sands, gravel, or drift. For some reason they have failed to become filled up to the level of the region around. With regard to some, at least, of those in stratified terrace formations (see page 299), the facts appear to indicate that the spots were originally holes of moderate size and depth in the surface beneath; and that in the rush over the spots by the flood waters that deposited the stratified material, the waters kept them free of detritus by the whirl occasioned by the depth. 
6. Waterfalls. - The facts reviewed show that waterfalls are often a consequence of the alternation of hard and soft strata in the course of flowing waters. The hard strata resist downward wear; the soft yield easily. Down the waters go, working with new force from the fall; hence they undermine the hard bed and thereby steepen the descent often to a vertical or even an overhanging front. The columns made by drops (page 178) partly illustrate the principle.

The waterfalls about the head waters of rivers in the mountains have a different origin; for the lofty precipices may be cut out of a single block of rock, as in the case of the central portion of Tahiti. These precipitous walls are a consequence of the prolonged erosion of a region until a larger part of the vertical descent of the stream is made at or near its head.

Waterfalls far down the courses of rivers, like that of Niagara, are looked upon as evidence of the recency of that part of the channel which contains the fall (Powell). But those about the source in the mountains may be, on the contrary, a final result after a long era of erosion; not the ultimate result, for the last end of the work would be the degradation and removal of the crested heights.

7. Features of mountains; Forms made by water-sculpture. - Elevations of all kinds have derived their existing features largely through water-sculpture. Tahiti was originally a lofty mountain, probably twice its present height, with low, nearly even, downward slopes in all directions, and only small unevennesses from the piling here and there of lavas through localized eruptions. It now is a mountain of peaks, crested ridges with lofty precipices, and vertical lines in all the features. But water has no need of a mountain mass to make the grandest of so-called mountains. It will work an elevated plateau, horizontal in surface, into mountain forms, and so make mountains without any upturning or uplifting except that of the plateau.

The chief part of the features produced come from the alternation of hard and soft strata among the stratified rocks; and these are greatly varied by the positions of the strata. The elements of this system of architecture are well illustrated in the figures on page 186 by Lesley, taken from his work on Coal and its Topography (1856), in which the author has given the results of extensive personal observation in the Appalachian region. The harder strata may be hard sandstone or limestone, and the softer, shale or crumbling sandstone. The first figure (165) illustrates the origin of a "table mountain" or "mesa" (Spanish for table), a hard layer making the top, and, by resisting wear, protecting the softer beds directly below it. The other figures illustrate other effects, under the same principle, in rocks having various positions. Figs. 166 to 172 are synclines, and 173 to 176 , anticlines, of different forms, in three of which a valley has the place of the upward bend - a common fact in the Appalachian Mountains.

Nonument Park in Colorado is a region of Tertiary sandstone carved into monumental forms by denuding processes, the winds having given finishing truches. As the view shows, the thin, harder layers in the sandstone make the caps and moldings of the monuments. 
165.

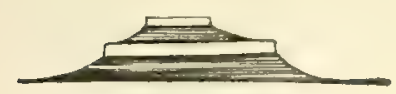

168.

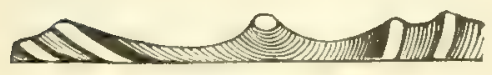

171.

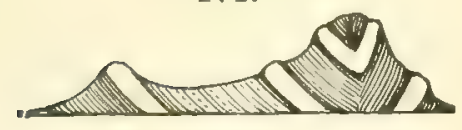

174.

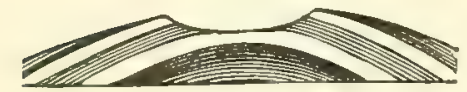

166.

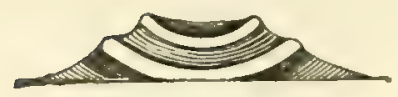

169.

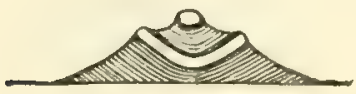

172.

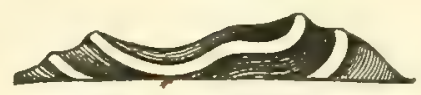

175.
167.

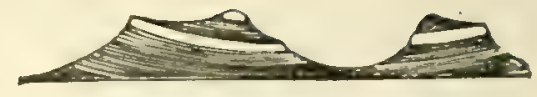

170.

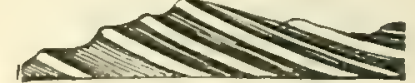

173.

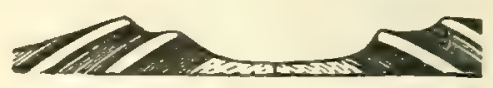

176.

Sections illustrating results of denudation. Lesley.

The Colorado Cañon, along an east and west portion of the river, between the meridians of $111^{\circ}$ and $115^{\circ} \mathrm{W} ., 3000$ to more than 5000 feet in depth, affords grand illustrations of cañon-making by water-sculpture. It was

177.

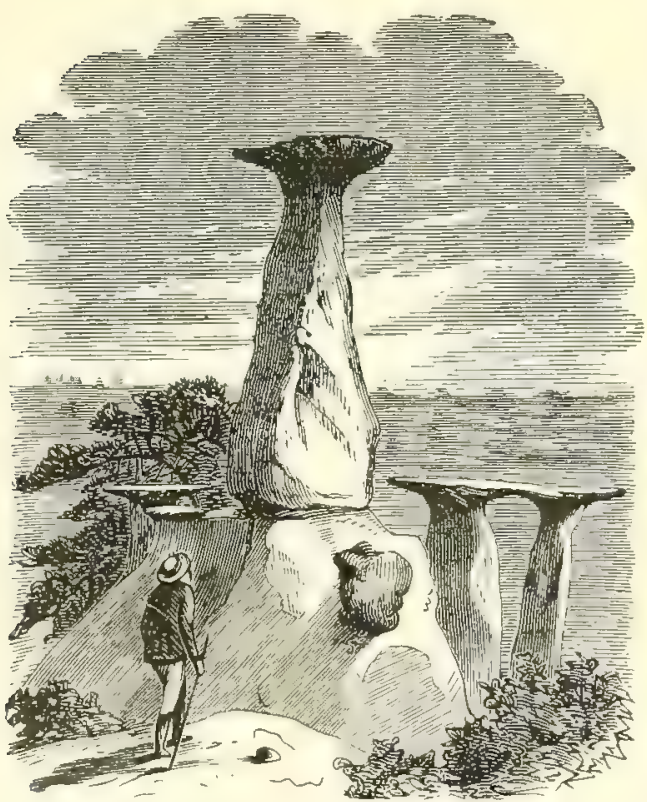

Erosion, Monument Park, Colorado. Hayden. studied at some point, by Newberry in the Ives expedition in $1857-58$, and more fully by Powell in 1869-1872. The rocks are horizontal or nearly so, and their edges make the vertical walls of the cañon. In some parts the cañon is cut out clean from side to side, with barely room between precipitous walls 3000 feet high for the stream, as in the "Marble Cañon," (Fig. 178) - an eastern portion of the stream north of the westward bend. In other parts, a wide region intervening between the lofty walls of rock is sculptured throughout into mountains 3000 to 5500 feet in height, constituting a group of architectural structures of unsurpassed grandeur. Part of one of the views from Captain C. E. Dutton's History of the Grand Cañon (1882) is given on page 188. The principal mass to the left of the center bears the name of Vishnu's Temple, and has a height above its base of 5500 feet. The walls in the distance are the northern walls of the cañon, and the foreground to the right in front is a portion of the opposite or south side. The deeper part of the cañon, at the base of this side, containing the river channel, is not in the view. The peaks of the interior are higher than the Appalachians. As all is bare rock, the view is a remarkably instructive example of simple denudation. 
The effects of alternation in hard and soft layers, distantly spaced or grouped, appear throughout the scene. Besides, there are columnar lines due to vertical joints in the harder beds, or to rill-work down the vertical and sloping surfaces.

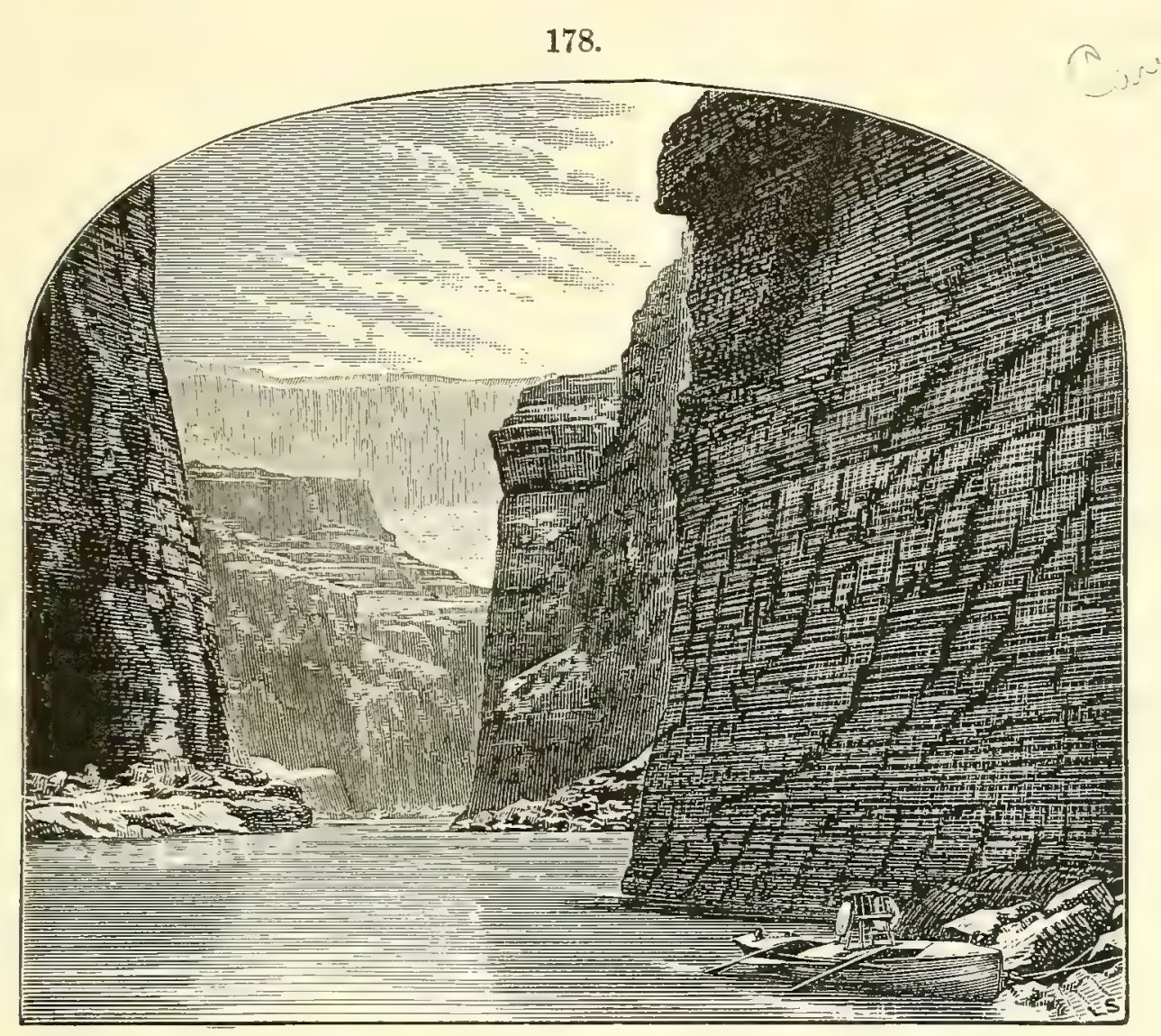

Marble Cañon. From a photograph.

The rock of the level region either side of the cañon, and of the upper part of the walls, is Carboniferous limestone. Below are Paleozoic sandstones and other limestones, descending to the Cambrian; at bottom, in some parts, and for a height of 500 to 1000 feet above, the rocks are granitic.

Many views of the Colorado Cañon also show ranges of flat-topped mountain heights to the north, all of which have similar architectural features in their declivities, yet with peculiarities belonging severally to the rocks of the different periods represented. As described by Dutton, first, in the ascent to the summit, there are the Triassic "Vermilion Cliffs"; above these the white and red Jurassic; then the pale yellow, gray, and brown Cretaceous strata; and at the top great plains, the High Plateaus of Utah, the highest nearly 12,000 feet above sea level, which, unlike the slopes, are covered in some parts with forests. The vegetation at the summit is accounted for, says Dutton, by the fact that the rainfall there is 30 inches a year, while only four to eight inches in the lower country. These mountain plateaus are remnants of formations that once covered the cañon region and extended far away into Arizona. 
The results are the more marvelous in that they are the work of the later part of geological time, commencing after the Tertiary era had begun. They show that to produce a mountain group, with summits thousands of feet above the plain around, it is only necessary that subterranean action should make a plateau of sufficient extent and elevation. Through the rains, the sculpturing will all be done in time. Many of the so-called mountains of Colo-

179.

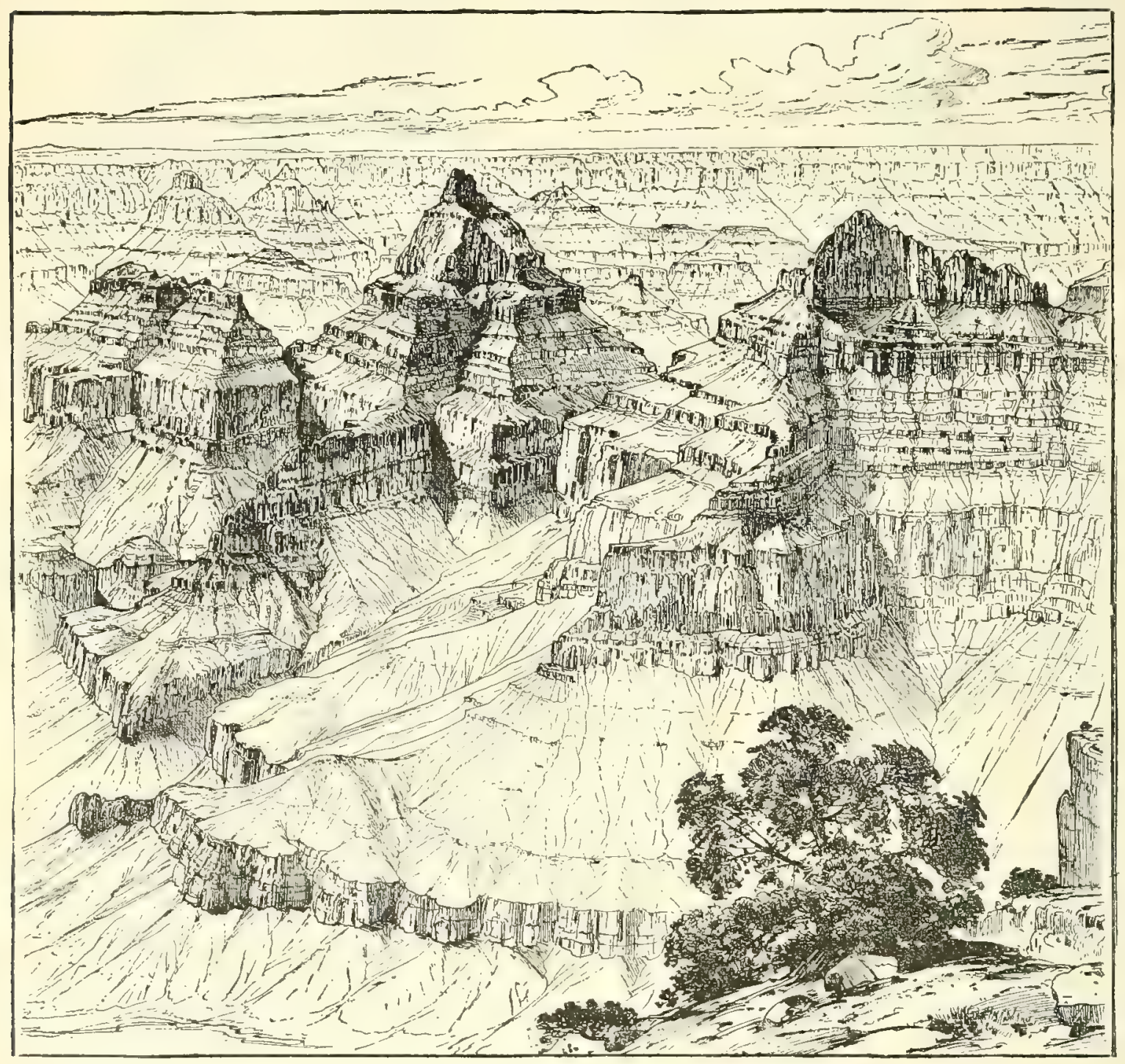

View of peaks and ridges within the Colorado Cañon, south of the Kaibab Plateau. W. H. Holmes.

rado and other parts of the Rocky Mountain region, and some of those in eastern America, as the Catskills in New York, and parts of the Alleghanies, consist of nearly horizontal strata, and are examples - not of mountains made by upturning, but of plateaus carved into models of mountains. Scotch valleys and elevations so modeled gave Hutton the first right ideas on this subject.

The "harder" rocks in the scenes described, it is to be understood, are not granite, gneiss, syenyte, and the like; they are not rocks of any particular kind. Granite may constitute the loftiest and boldest of ridges and moun- 
tain needles; but much of the granite of the world easily crumbles under atmospheric influences, and makes the tamest of scenery. Slates standing on end often bristle slopes with projecting ledges, and rise into lofty needles that defy the elements, like the Matterhorn in the Alps; but other slates are fragile, and wear down into hills of gentle earth-covered slopes.

8. Climatal effects. - Climatal causes also have great effect on the work of rivers. A wet climate produces abundant vegetation, which is more or less a protection from wear; and in tropical regions it covers even precipices with ferns and other foliage. It also oceasions rapid decay by the chemical and other weathering methods. Moreover, it sometimes makes deep, hardworking rivers, torrents that sweep away roughly, degrade rapidly and persistently and leave behind massive peaks, broad mountains, earth-covered slopes ribbed or belted by the more enduring beds, with gently swelling outlines over the lower slopes, and foliage almost everywhere.

A dry climate, on the contrary, as in the Colorado region, and that of Yellowstone Park, makes small streams or streamlets in the mountain valleys, many of which through much of the year are only threads of water, if not wholly dried up. They hence finish off with sharp and delicate outlines. All the variations of the beds in hardness are expressed in series of projecting edges beneath the broader shelves and entablatures. The jointed structure of the thick, durable beds adds much to the diversity of surface, instead of insuring the removal of the beds. The winds also aid with lighter finger.

In such regions, color from foliage may fail. But the dripping waters of the occasional rains, or the oozings through the steep mountain-sides, transfer to the surface the results of oxidations and deoxidations, and paint the walls with various delicate tints.

Even alternations of half-hardened clay-beds and sand-beds, under such conditions, as Colorado scenery illustrates, may be cut into groups of pinnacles, turrets, and columns finished with capitals and bases which will last indefinitely; for whatever the occasional supply of waters to the channels, it ends in reproducing the same features in the soft beds. Appalachian rains, as Powell says in his work on the Colorado Cañon (1875), would soon obliterate much of Colorado scenery. The excavation of the Colorado Cañon has been chiefly due to great floods; but the finishing work carried on within it has been of the gentler kind.

\section{Transportation and Deposition.}

Amount of material transported and deposited by rivers. - The materials transported by running waters are (1) stones, pebbles, sand, and clay or earth; (2) logs and leaves from the forests, and sometimes trees that have heen torn up or dislodged by the current; (3) Mollusks and their dead shells, Worms, Insects, etc., attached to the logs or leaves; (4) occasionally larger 
animals, that have been surprised and drowned by freshets, or bones that have been exhumed by the waters.

The amount of transportation going on over a continent, especially in seasons of floods, is beyond calculation. Streams are everywhere at work, rivers with their large tributaries, and their thousands of little ones spreading among all the hills and to the summit of every mountain; and thus the whole surface of a continent is on the move toward the oceans. The amount transported is a measure of the amount lost by the land, as well as of that gained by the river plains, lakes, and seas. The amount of silt carried to the Mexican Gulf by the Mississippi, according to the Delta Survey under Humphreys and Abbot, is about $\frac{1}{1500}$ the weight of the water, or $\frac{1}{2900}$ its bulk; equivalent for an average year to $812,500,000,000,000$ pounds, or a mass one square mile in area and 241 feet deep.

The following table contains the ratio of sediment to water by weight, as obtained by the Delta Survey, and also the results of other investigations.

\begin{tabular}{|c|c|c|}
\hline & Ratio. & \\
\hline at Carrollton, by De & $1: 1808$ & 12 mos., 1 \\
\hline & $1: 1449$ & s., 1852-1853. \\
\hline us, oy & $1: 1321$ & 9 mos., 1858. \\
\hline ississippi River, at 1 & $1: 1256$ & 2 mos., 1838. \\
\hline at & $1: 1724$ & 1838 \\
\hline ississippi River, at various places, by Prof. Riddell, & $1: 1245$ & 14 days, sur \\
\hline Prof. Riddel & $1: 1155$ & 35 days, summer of \\
\hline by & $1: 17000$ & 1844 \\
\hline hone, at Arles, by Messrs. Gorsse and Subours, & $1: 2000$ & 4 mos., 1808-1809. \\
\hline & $1: 2500$. & \\
\hline & $1: 858$ & at flood-time. \\
\hline
\end{tabular}

For the Danube, the ratio at low water is $1: 33,000$; at flood, $1: 2400$; for the Po, at flood, 1:300 (Lombardini); for the Meuse, at low water, 1:71,420; at flood, 1:2100 (Chandellon); for the Irrawaddy, at low water, 1:5725; at flood, 1:1700 (Login); for the La Plata at Buenos Ayres, $1: 7752$, at which rate it carries seaward about 224,000 tons of sediment each 24 hours, but dropping part of it along the 100 miles before it reaches the sea (Higgin).

The annual discharge of sediment from the Ganges has been estimated at $6,369,000,000$ cubic feet, or $378,100,000$ tons. The Nile brings down annually nearly $150,000,000$ tons. The bulk may be calculated, by taking 1.9 as the specific gravity of the material.

Besides the material held in suspension, the Mississippi pushes along into the Gulf large quantities of earthy matter; and the annual amount thus contributed to the Gulf is estimated to be about $750,000,000$ cubic feet, which would cover a square mile 27 feet deep; and this, added to the 241 feet above mentioned, makes the total 268 feet.

This amount is equivalent to an average of $\frac{1}{4920}$ of a foot annually from the whole drainage area of the river; or, in other words, the area would be lowered by it, on an average, one foot in 4920 years. The Ganges works faster, the amount it transports to the sea being such as would lower its drainage area, on an average, a foot in 1880 years. All the rivers that enter the ocean or the seas over the land, are working in the same way, and with results to the continental surface mostly between these two extremes. 
T. Mellard Reade estimates that the water (about $68,451,000,000$ tons) which annually runs off from the area of England and Wales carries to the sea $8,370,630$ tons of solids in solution, or 1223 parts in every 10,000 of water, consisting of about 0.95 of calcium and magnesium carbonates and sulphates, $0 \cdot 166$ of sodium chloride, and the rest nitrates, sodium carbonate, alkaline sulphates, silica, and iron sesquioxide; and at 15 cubic feet to the ton, the denudations thus occasioned would equal one foot in 12,978 years. Prestwich obtained (1872), in a similar calculation, one foot in 12,000 years for the calcium carbonate carried off by the Thames from the chalk, greensand, and oölitic formations. The total annual denudation for England, from this source alone, is made $143 \cdot 5$ tons per square mile. The Rhine, according to Reade's calculations, removes about $92 \cdot 3$ tons in solution per square mile; the Rhone, 232 tons ; the Danube, $72 \cdot 7$ tons ; the Garonne, 142 tons; the Seine, 97 tons. From these data the conclusion is reached that over the world the average annual amount of rock-material dissolved and carried off by rivers is about 100 tons per square mile, of which about $\frac{1}{2}$ is probably calcium carbonate, $\frac{1}{5}$ calcium sulphate, 7 tons silica, 4 tons each magnesium carbonate and sulphate and sodium chloride, and 6 of alkaline carbonates and sulphates. The annual amount of detritus brought down by the Danube is about $\frac{1}{3000}$ of the water, or three times the amount of solids in solution. Taking the amount of solids removed mechanically at six times that in solution, the total annual amount of denuded material for the globe would be 600 tons per square mile.

While the land loses through erosion, the gain of the oceanic depressions, or of its borders, is exceedingly small. C. G. Forshey, after stating that the Gulf of Mexico has an area of 600,000 square miles, an average depth of 4920 feet, and is about $85,000,000,-$ $000,000,000$ ( 85 quadrillions) of cubic feet in contents; that its whole drainage area is $2,161,890$ square miles, and the amount of fresh water it receives from this area is 37.78 trillions of cubic feet; adds that if empty, it would take its tributary rivers at this rate 2250 years to fill it with water, or the Mississippi alone, 4000 years. Consequently, if all the rivers contribute on an average $\frac{1}{260}$ their bulk of detritus, it would take nearly $6,000,000$ years to grade the depression up to the sea level, or for the Mississippi alone, about $11,000,000$ years. This statement assumes that the bottom does not sink under the load.

The quantity of wood brought down by some American rivers is very great. The well-known natural "raft," obstructing Red River, had a length, in 1854 , of 13 miles, and was increasing at the rate of one and a half to two miles a year, from the annual accessions. The lower end, which was then 53 miles above Shreveport, had been gradually moving up stream, from the decay of the logs, and formerly was at Natchitoches, if not still farther down the stream. Both this stream and others carry great numbers of logs to the delta.

Distribution. - The transported material of rivers is distributed -

(1) Along the channel, forming sand-flats, and mud-flats, and deposits also in the lakes of the drainage area.

(2) Over the flood-grounds, supplying what these may annually lose during floods, and adding, in places, to their height, thus making fluvial or alluvial formations, and, about lakes, lacustrine formations.

(3) About the mouths of tideless rivers, making deltas on the sea border and on lakes.

(4) About the mouths of tidal rivers, making estuary, shore and off-shore deposits. This last subject is deferred to the chapter on the Work of the Ocean. 
(1) General distribution. - The material carried down by a river is only to a very small extent gathered by the main stream from its head sources. 'The upper contributions are nearly all left high up the valley, and only little of the lighter sediment received usually continues far down the main trunk. A river has many contributors along its course, each pouring in coarser or finer sediment from cobble-stones to silt, according to its pitch, velocity, and resources; and what each, in succession, contributes, the trunk stream distributes and deposits about and below the place where received, dropping it near by if it is coarse, carrying it on for awhile if fine. Thus from the successive depositions of the material of the successive tributaries, the trunk stream produces its "fluvial formations." Such a formation may therefore be continuous through the whole length of the river-portion of the stream, but be exceedingly varied in constitution. In addition to all this, the river has often, in its course, steep rocky shallows and deep lake-like portions, if not true lakes; and thereby the waters may have all grades of velocity to the gentlest. These different styles of flow will be continued to some extent through ordinary floods, notwithstanding the generally quickened movement; and this is another source of diversity in the fluvial depositions, since deposition is dependent on rate of flow, and the slow lake-like waters deposit fine material over their flood-grounds as well as along their banks and bottom. No pebbles or stones above a region of sleepy waters could get across to join a pebbly region made below by a tributary; they must be ground up for transportation and then take their chance with other fine sediment.

Depositions are made along broad channels when the flow is not rapid enough throughout the breadth to sweep all the transported material down stream. The chief current (or currents) makes its own deep, often stony, passage-way; but either side the detritus drops because of the slower flow, and raises the bottom more or less, or to the surface, according to the degree of slowness, the eddying currents, and the supply and fineness of detritus. The trend of the shores, pitch of the bottom, and other causes, locate the swifter currents in the channel, and thereby tend to locate the banks or reefs. A stranded log may change the course of the former, and thereby the positions of the latter. The lodging of drift-wood on a sand-bar may serve to increase the accumulation over it, and so change the bar into a wooded island. But high floods rob the bars at the same time that they add to them, or they may sweep them away, even if already an island, to form other bars and islands. They push along the movable detritus of the river's bottom, and also drop more to keep it generally at the old level. Thus all is movement and change along a river's channel, and deposits of all degrees of fineness or coarseness may be of simultaneous origin.

When two rivers unite, one often makes a shoal in the other, by throwing a bar across the channel through the descending detritus of flood-waters. The waters of the upper Mississippi are pushed to the opposite shore by the contributions of a tributary, and a deep, still-water, navigable area is made above the junction, and rapids below it. Further, the tributary, if not in 
flood at the same time, will have its mouth filled with sand-bars by the greater river, and often, also, in spite of its floods. This subject is well illustrated in Reports on the Mississippi and its Tributaries by General G. K. Warren.

Sand-bars; obliquely laminated structure. - A sand-bar, as shown by General Warren, has usually a slight pitch up stream and a steep one at the downstream extremity. The sand is carried on until the crest is reached, when it falls over and stops in the still water below. The stratification will correspond with the surface; and as the sand-bar extends itself down stream by the additions to its extremity, the pitch of the down-stream extremity will determine oblique bedding parallel with it. The pushing of detritus along the bottom of a river must result in similar oblique bedding. But in both cases, oblique deposition will be followed by deposition in horizontal beds when the floods are declining, so that combinations of the two, often of a very irregular character, should exist in such deposits.

(2) Over the flood-grounds. - The flood-grounds or river-flats are under water only in times of floods. As the water rises in the channel, the velocity slowly increases; finally, where too great to be further withstood by the earthy banks, the waters spread laterally to the limits of the flats. They lose in velocity, and drop more or less of the material transported, resting long after the flood ceases for such deposition wherever the surface is low. At the same time, the upper or surface portion of the flood-waters may shear off any accumulations above the general level, left by a former higher flood, or may work with the outer margin to extend the limits of the flood-grounds. The flood-grounds may thus lose from their surface, and, in parts, be cut away to open new channels; but they generally gain as much as they lose or more. Along the sides of the channel they are often built up higher than elsewhere, thus making high banks which may be emerged during an ordinary flood. This raising of the margin takes place because of the deposition from loss of velocity by friction against the banks, and because logs and debris of other kinds are here stranded; the debris serves to impede the velocity still more and thus is buried by the sediment. Further, an emerging bank often catches floating seed and grows shrubbery. These raised banks are most common along the lower, less vigorous portions of a river. They give the flood-plains a slope outward on one or both sides. Along the lower Mississippi the pitch from the river amounts, on an average, to seven feet for the first mile. (H.\& A.) As above explained, the deposits of the flood-grounds may be the finest of silt, or the coarsest of gravel and stones, according to the region and the pitch of the stream. The course of a tributary from a mountain region over the flood-plain of the main stream may throw into and across the earthy or sandy flats of the latter a wide thickening bed of stones or gravel.

A flood-ground is properly the surface of a terrace; and it is the lowest of the terraces where a valley has several. Terraces occur along nearly all DANA'S MANUAL - 13 
river valleys in the northern half of the United States, and in some of the southern half. Fig. 180 represents the terraces in the Connecticut valley, south of Hanover, N.H.

The fluvial beds in these terraces consist of sand, gravel, or clay; and ordinarily the stratification is very distinct. The sand-beds often have the cross-bedded stratification, illustrated on page 93 , and in some places the flow-and-plunge structure.

The height of flood-plains in a valley is determined approximately by the height of the floods. Floods raised to different levels would tend to make plains at different levels, or terraces, in the valleys of a country. If a high Hlood-level had thus made a high flood-plain or terrace, other terraces might

180.

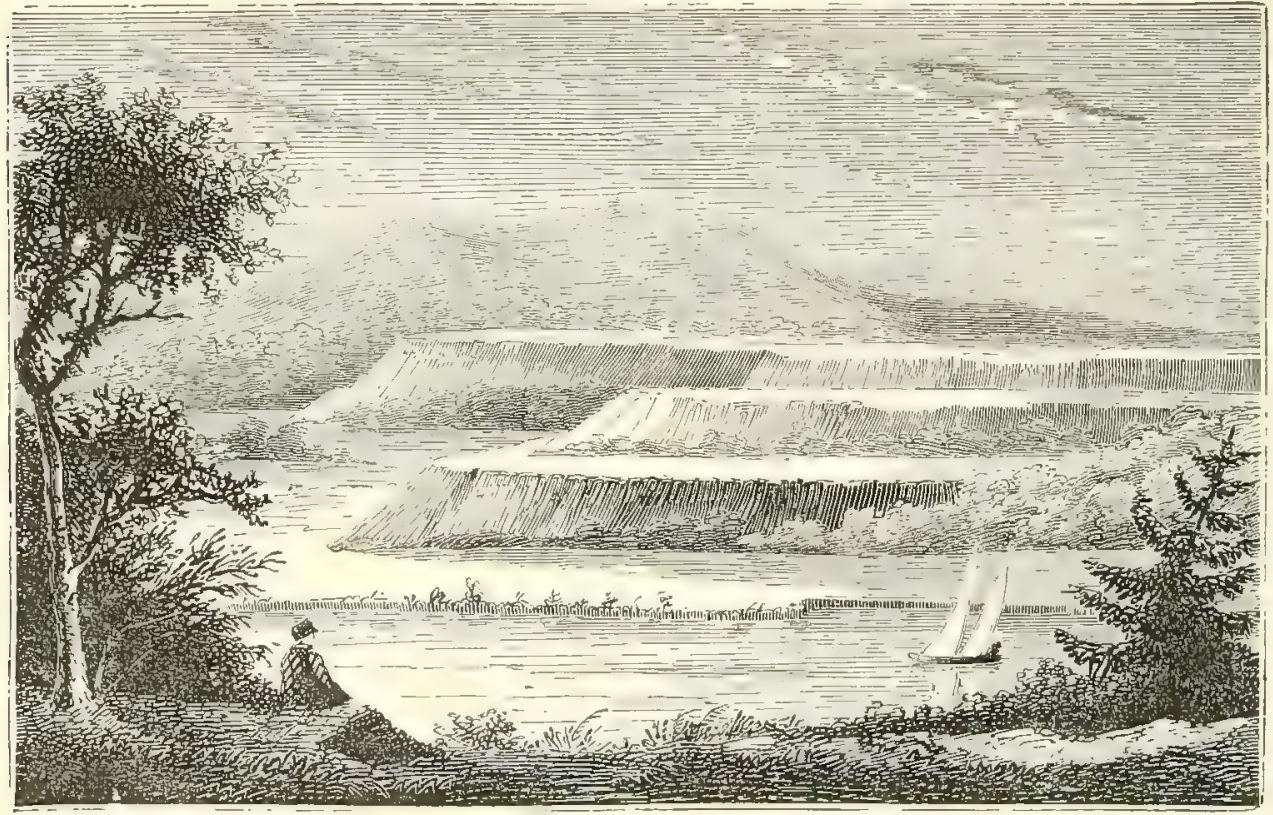

Terraces on the Connecticut River, south of Hanover, N.H. R. Bakewell, '49.

be formed at different levels below this during the decline of the flood, if it were slow and intermittent in progress, by lateral removal of material, or by new depositions. The enormous floods from the melting ice of a glacial era would be subject to just such slowly progressing and intermittent decline, because of the thickness of the ice, and its long continuance about the mountains, and might, therefore, leave the valleys with one or several ranges of terraces.

1. Alluvial cones. - The deposit of a rapid tributary at the base of the ridge it descends, where it meets the broad plain of the valley, piles up and makes a low elevation which is called an alluvial cone. The steeper cones are made by torrents at the base of rapid declivities, and have an angle of $10^{\circ}$ or more, and those of large streams spread away at a very small angle, often $1^{\circ}$ or less, and usually terminate in the main river of the valley, or a lake, with the form approximately of a delta. Figs. 181, 182 represent such cones from the upper Indus Basin, described and figured by F. Drew (1873). 
The torrential stream in its flood-time cuts channels through the cone that later quiet depositions fill up. In Fig. 182 a cone is encroached upon (near $d$ ) by the river. Alluvial cones, of great size and low angle, occur at the base of the mountains in the Great Basin and in some other parts of the Rocky Mountain region, and have been described by Gilbert (1877-1890), Dutton (1880),

181.

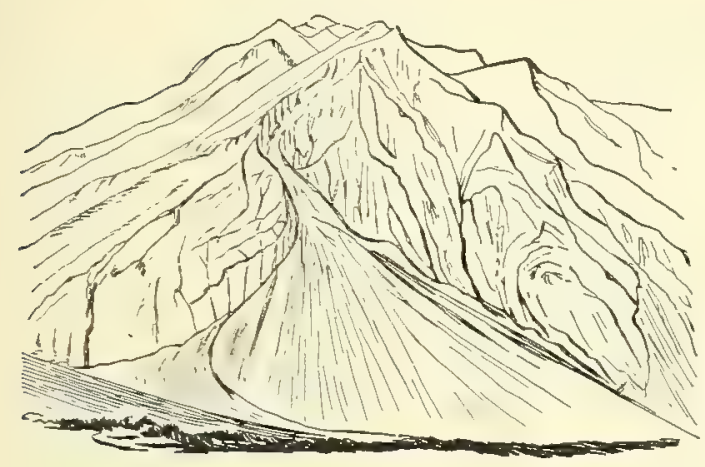

Alluvial cone or fan-talus of upper Indus Basin.
182.

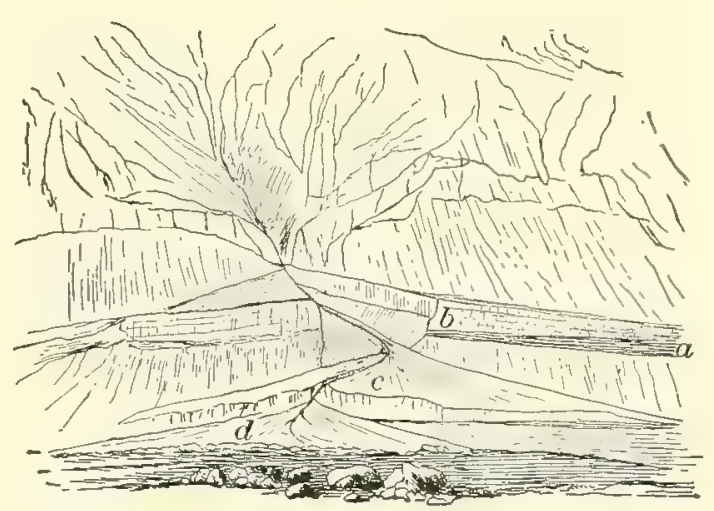

Triple alluvial cone, ibid. Drew.

and I. C. Russell (1885). The gravelly deposits of this kind at the mouth of tributaries in the Connecticut valley and elsewhere were called deltas by E. Hitchcock, and the terraces over the surface either side of the stream, delta-terraces.

2. Loss. - The terrace-like deposits along portions of the valleys of the Rhine, Danube, and Mississippi consist of loamy earth called lœess, which is peculiar in its absence of stratification, and often also in its vertical surfaces of fracture. They have remarkable extent along the Hoang Ho in China. The accompanying sketch, from Richthofen's great work on China (1877), shows its usual landscape features. Erosion reduces portions of its margin to a collection of towers, peaks, and deep and narrow labyrinthine passages; and human contrivance makes dwelling-places by excavation. The thickness is stated to be in some places 2000 to 2500 feet. The material is a brownish yellow earth, containing land-shells and calcareous concretions. It occurs at several different levels along the river, 100 to 250 feet within 175 miles of the sea; next, beyond a region of mountains, 1800 to 3500 feet; after passing another mountain region, 4500 to 5800 feet; and it is stated to extend to the most western sources of the river over 900 miles from the coast. The river at these levels, as in other cases of loss deposition, was probably lakelike. Long-sustained floods of the rivers in the mountains from melting glaciers are one explanation of the source of the material. Eolian drifting of dust from the salt-steppes of Siberia is Baron von Richthofen's theory, which the absence of a wind-drift structure renders improbable.

Deposits occur in the Great Basin resembling the loess in absence of stratification and other characters, which are called adobe by Mr. X. C. Russell, from the name for sunburnt brick, because this material is used for making the brick. It has usually a yellowish color, and is more or less calcareous. It is described as a result of the wash 
and deposition of the ephemeral streams and the thousands of little rills that are occasionally at work over the surface of the dry regions: the annual precipitation is less than 20 inches. The deposits in some places are hundreds of feet in depth. The calcareous portion is attributed to land-shells. It is various in composition, containing 1 to 14 per cent of alumina, 19 to 67 of silica, and 2 to 5 of water, with 3 to 60 per cent of calcium carbonate.

188.

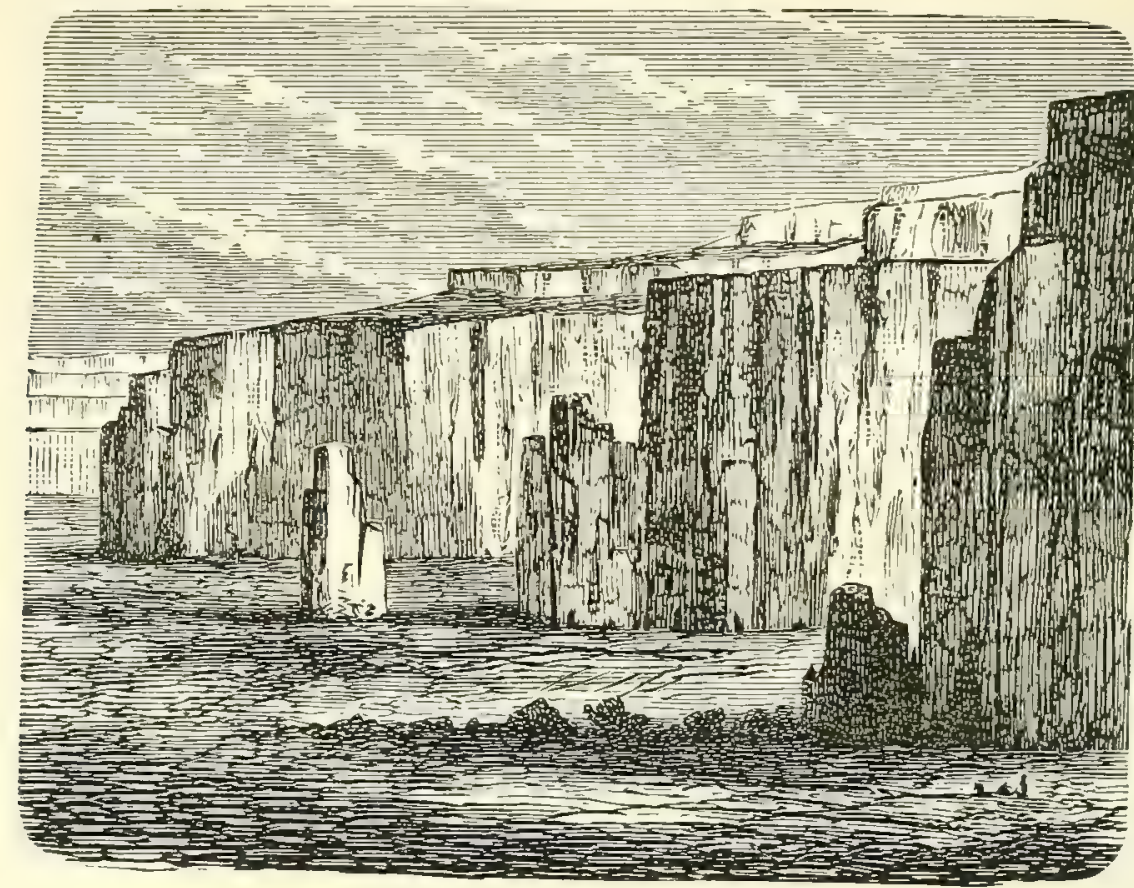

Lœss formation on the Hoang Ho, in the province of Shan-Si, China. Richthofen.

Fine mud-like deposits are formed over the Great Basin in temporary lakes, callea playas, produced by the overflow of rivers, the material of which is related to the preceding. The mud contains more or less of the saline ingredients of the evaporating waters.

(3) Delta-formations. - The larger part of the detritus of a river is carried to the ocean, or lake, into which it empties; and it goes to form more or less extensive flats about the mouth of the stream. Such flats, when large and intersected by a net-work of water-channels, are called deltas; they are rivermade, and reach a large size only where the tides are quite small, or are altogether wanting.

The spread of a river into a delta at its mouth is a consequence of its enfeebled or decrepit state. Deposition is excessive and becomes an obstruction to the flooded river, and consequently, besides keeping open one or two main channels, the waters cut new channels at flood-times, which may partly disappear and become replaced by others in future floods. The surface thereby becomes intersected by many lines of sluggish waters, small and large, which flood-time puts into temporary activity. The deposits have a slight slope seaward, and thus approximate in character to an alluvial cone (Gilbert), although a consequence of the floods of a stream in decrepitude, and not of one in a torrential or vigorous state. Through the flood-deposi- 
tions over the various parts thus carried forward, along with the aid of encroaching vegetation, a large portion of a delta may become emerged. More than two thirds of the Mississippi delta in the ordinary state of the river are above water; and over this part are plantations of rice, sugar, and cotton, and cypress forests. The area of actually productive land within it is $22,920,320$ acres; of reclaimable land, 35,813 square miles. But if the river were unrestrained by levees, the highest floods would fill the alluvial basin and make a sea 600 miles long, 60 miles in mean width, and $12 \frac{1}{2}$ feet in mean depth. (C. G. Forshey, 1873.) The force of the flood-waters of the Mississippi is so great, and the amount of transported detritus so large, that the stream pushes out its long arms into the Gulf, by its method of depositing load after load; and it is still continuing its elongations at the extremities of the passes.

\section{4.}

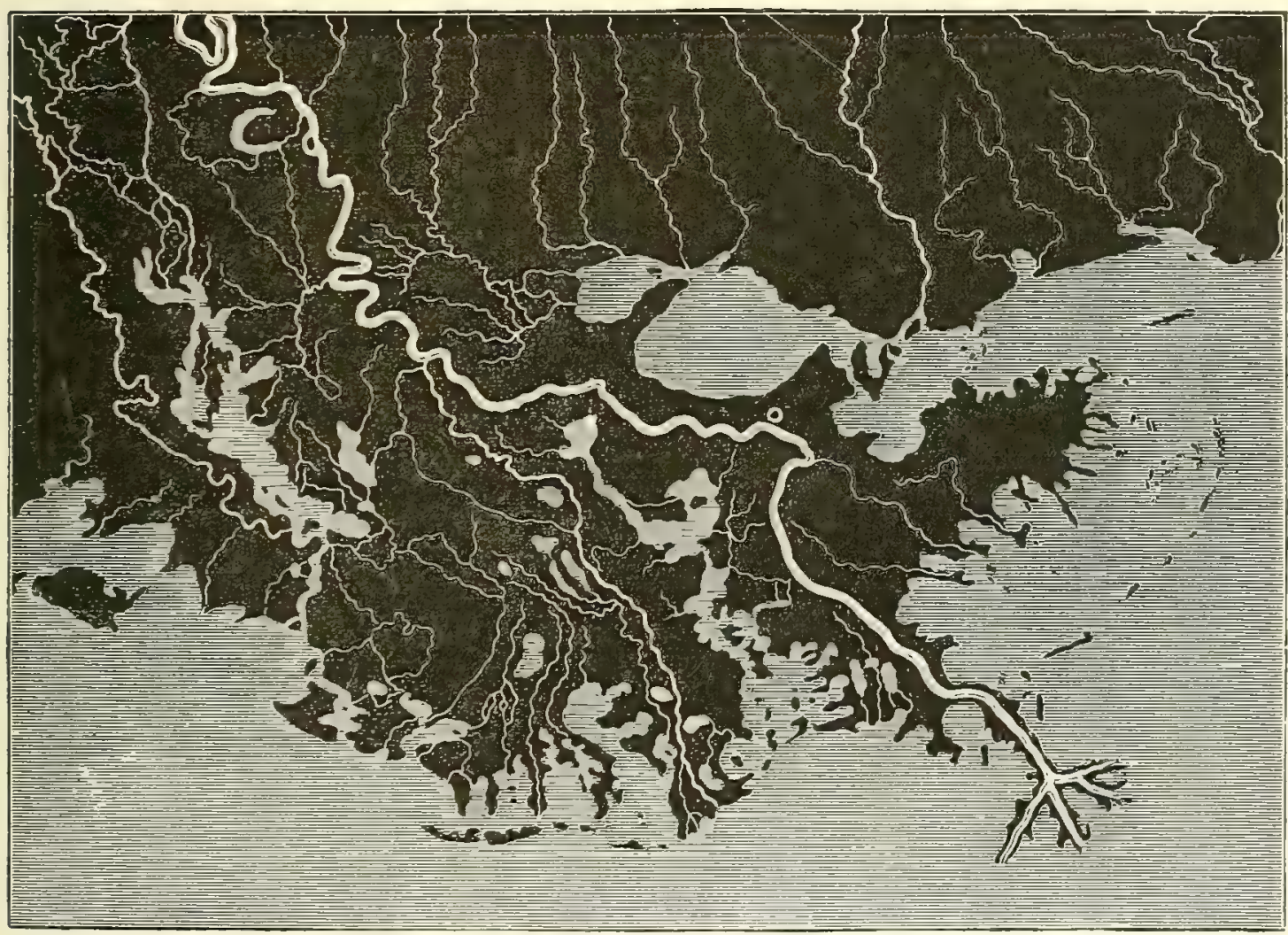

Delta of the Mississippi.

The shallow waters within one to three miles of the main channel at the mouth of the Mississippi River (see map) are dotted with what are called mud-lumps, - convex or low conical elevations, sometimes 100 feet or more in diameter, showing their tops at the surface. They originate in upheavals of the soft but tough bottom. Once formed, they discharge mud from the top, which gives to the material of the low cone the structure of a volcanic cone, the successive layers being, however, of mud, and but a fraction of an inch thick. They finally collapse; and then the cavity of the cone sometimes becomes the site of a pool of salt-water, like the lake in an extinct volcano. They are formed, according to Professor F. W. Hilgard (from whose excellent description in the American Journal of Science, 1871, the facts here given are cited, and who adopts, in the main 
point, the view of Lyell), through the pressure of the surface deposits on a layer of mud which overlies the P'ort IIudson clay, or older alluvium of the river. Some carbo-hydrogen gas is given out, arising from the decomposition of animal or vegetable matters in the mud. The mud-discharges tend to increase the shallowness of the waters and push out the land into the Gulf waters. Mr. Hilgard states, in 1871, that Morgan's mud-lump, in the marsh of Southwest Pass, had been active for 25 years, and during the time the bars had moved gulfward a mile and a half. Ile closes his paper with a remark (vol. i. 435) relating to the distance to which the Southwest Pass must extend in order that there shall be no danger of mud-lumps within the channel. The Eads jetties have since then been made along this pass, in order to give it greater depth. It has secured the depth; but with danger from this source still existing, as Professor Hilgard has observed.

According to Humphreys and Abbot, the outer crest of the bar of the Southwest Pass, the principal one of the Mississippi, advances into the Gulf 338 feet annually, over a width of 11,500 feet; and the erosive power is only about $\frac{1}{10}$ of its depositing power. The depth of the Gulf, where the bar is now formed, being 100 feet, the profile and other dimensions of the river, in connection with the above-mentioned rate of deposit, give for the difference between the cubical contents of yearly deposit and erosion $255,000,000$ cubic feet, or a mass 1 mile square and 9 feet thick: this, therefore, is the volume of earthy matter pushed into the Gulf each year at the Southwest Pass. The quantities of earthy matter pushed along by the several passes being in proportion to their volumes of discharge, the whole amount thus carried yearly to the Gulf is $750,000,000$ cubic feet, or a mass 1 mile square and 27 feet thick. As the cubical contents of the whole mass of the bar of the Southwest Pass are equal to a solid 1 mile square and 490 feet thick, it would require 55 years to form the bar as it now exists, or, in other words, to establish the equilibrium between the advancing rates of erosion and deposit. Hilgard has shown that, about New Orleans, the modern alluvium has a depth of only 31 to 56 feet, there existing below this the alluvial clay, etc., of the Port Hudson group.

The delta of the Hoang Ho (Yellow River) extends along the coast from near Peking, on the north beyond the Pei Ho, to Hung-tse Lake, on the south, where it joins the plains of the Yang-tse-Kiang. The distance is 400 miles; but the mountainous coastprovince of Shan-Tung is to be excluded. From the coast, the delta extends westward for 300 miles. The river is here useless for navigation. The whole delta region would be under water during flood seasons except for drainage by artificial dikes and canals of great length; and these have required constant supervision. At long intervals, the great river has broken loose and swept over the immense area with devastating floods, and ended its mad career with change of channel from the river Pei Ho, or some place near it, on the north, to a southeast route ; or the reverse. In 1820 it occupied a southeast channel, emptying into the Yellow Sea, near latitude $332_{2}^{\circ} \mathrm{N}$. By 1858 this channel was dry; and after some years of uncontrolled waters, it took a new channel into the Gulf of Pe-chi-li, 300 miles north. In the autumn of 1887, a new break occurred near Kai Fung, in Ho-Nan; but the waters instead of resuming the old channel which they left after 1852 took a course south from Kai Fung to the Cha, 70 miles, and then struck off eastsoutheastward to the Hoei Ho and the sea. The Chinese have succeeded in leading off the upper part of the wandering waters into the old channel mentioned above, leaving the more southern part in its new channel. The first of such changes recorded in Chinese annals occurred in 2293 B.C. ; a second, owing to Chinese care, not until 602 B.C. Several have occurred since. The Mississippi has its disastrous floods, but no chance for such changes.

(4) Lakes. - The discharge of lakes, like that of rivers, is (1) evaporational or upward; (2) gravitational or downward; and (3) surficial, ${ }^{1}$ sea-

1 The word superficial is too various in its significations to express the right idea. Surficial is like surface in having for its prefix the French abbreviation sur in place of super. 
ward. They either belong to the continental river systems, and are riversystem lakes, or they are confined or imprisoned lakes.

1. Imprisoned lakes fail of the third method of discharge and are relatively few in number. They lie in basins or depressions that had been made or left in the surface by orographic movements, or had become cut off in some way from a river system, or possibly where the rocks, having little firmness, had been excavated by former glacier action. Some of small size occupy craters of extinct volcanoes. The Caspian Sea, Dead Sea, Great Salt Lake of $\mathrm{C}$ tah, and lakes in the Great Basin, are examples. They are most likely to exist under dry climates, where the supply of water is small and evaporation large; and they may vary from dry beds to lakes in the changing climates of the year. Some imprisoned lakes have had surficial discharge in former eras. A confined river system usually supplies the waters, and carries in what can be gathered from the rocks around by solution and otherwise, as explained on page 118.

2. Lakes connected with river systems occur in all climates and latitudes, and at various heights. They are often situated in lines or clusters over the nearly level summit region of a Continental Interior, where the great rivers are gathering waters and deciding on their courses. They sometimes occupy profound depressions in the earth's crust, like the Great Lakes of North America, or follow the nearly level median line of continental drainage, as the Winnipeg series of British America.

The basins may be a result of geosynclinal movements, like that of Lake Superior; or otherwise of orographic origin, as the intermontane lake basins of many mountain regions; and even a consequence of the feeblest flexures of the earth's crust. They have commonly been made within the area of a river system by damming with transported material. Unusual floods may make barriers by local depositions; more easily, tributaries may throw across a valley dams that have a degree of permanence; still more effectively, ice may carry along gravel and sand and block the deep and narrow channel; or better, in regions of glaciers, more formidable deposits of drift may make obstructions in valleys and give outlines to many lakes over nearly level regions. After a period of elevation when the valleys were excavated to great depths, a period of lower level may have come, in which the transporting waters were in great force and made obstructing deposits, especially when water and gravel were afforded in vast quantities for the purpose by a melting glacier. Lake Geneva, in Switzerland, 45 miles long and 1095 feet deep, the surface 1230 feet above tide-level, is supposed to have been made in the way last mentioned; and even also, Lago Maggiore, of northern Italy, which, although only three miles wide, is 2613 feet deep, with 1920 of this below the sea. Another view attributes the depth of Lake Geneva to a subsidence of the lake bottom since the Glacial period.

Further, a large river in its more aged or decrepit portion may so wall itself in and raise its bed by depositions either side of and along its channel, that every flood makes temporary lakes; and extraordinary floods may 
carry off waters that excavate a course through the alluvium to neighboring depressions and thus make a more permanent lake.

Salton Lake, in the southeastern comer of California, 130 miles long by 40 in greatest. breadth, resulted, in July, 1891, from the overflow of the Colorado River on the west side below Yuma. The alluvial region either side of the river between Yuma and the head of the California Gulf, 50 miles distant, had been gradually built up by river depositions, until a large depression, Coaluila valley, now 300 feet below the sea where deepest, had been separated from the head of the gulf and left as a nearly dry desert basin. 'The flooded waters, pressing westward along the westward course of New River, succeeded in passing the low summit level, and then quickly excavated a way to the depression and filled it. Owing to the hot and extremely dry climate, evaporation will sooner or later make it an empty lake-basin, as it was essentially before. The river at Yuma is about 150 feet above the gulf. Nearly 100 miles north of the Salton Lake is Death Valley, 225 feet. below the sea, also situated in the line of the California Gulf.

W. P. Blake traveled over the desert in 1853 (Geol. Reconn. Cal., 4to, 1858), and describes it as having, in general, a barren, clayey surface, with some saline springs along. the margin and elsewhere. On the rocks of the shore, there was a thick horizontal belt of whitish calcareous tufa about 15 feet (where examined) above the level of the desert, indicating a former water level, and proving that the desert was the dry basin of a former lake. He found that the Indians had a tradition of the existence of a great lake filled with fish; of its slowly drying up, and of a sudden return of the waters, when many were drowned. The recent event is evidently not the only one of the kind in the region.

Other lake-basins have been made by glacier-damming (page 238), and possibly, as above stated, by glacier-excavation. Still others of small size are a result of underminings, especially through removals of clay-beds by pressure; others have come from a damming against the sea by beach-made deposits (page 224), converting inlets into sea-border basins.

The large lakes of the world, after the Caspian, are the Great Lakes of North America, Lake Baikal in Asia, and Lake Victoria in east Central Africa. The map, Fig. 185, gives the positions of the American Great Lakes, and the line of greatest depth, the deepest point in each, and also the limits of the several drainage areas. Lake Superior has an area of 31,200 square miles; Huron, of 23,800 square miles; Michigan, of 22,450 ; Erie, of 9960 ; Ontario, of 7240. The heights of the water above mean sea level are: Lake Superior, $601^{\cdot 8^{\prime}}$; Huron and Michigan, $581 \cdot 3^{\prime}$; Erie, $572 \cdot 9^{\prime}$; Ontario, $246 \cdot 66^{\prime}$. The seetion, Fig. 186, shows their depths, and the extension below the sea level. (Schermerhorn, Amer. Jour. Sci., 1887.) Lake Champlain is $402^{\prime}$ deep, $300^{\prime}$ of it below the sea level.

The heights of some other American lakes are as follows: Winnipeg, $630^{\prime}$; Lake of the Woods, $1640^{\prime}$; Great Salt Lake, 4218'; Y'ellowstone Lake, 7788'; Shoshone Lake, $7870^{\prime}$; Great Bear Lake, 5931'.

The Caspian has an area of 170,000 square miles, a depth of $500^{\prime}$, and descends $90^{\prime}$ below the sea level. Lake Baikal in Siberia (really among the high Altai Mountains. and near. Central Asia) is 397 miles long, 54 miles in maximum width, and has a depth in some parts of over 300 fathoms, nearly $500^{\prime}$ of which is below the sea level. The great African Lake, Victoria, has an area of about 27,000 square miles, and is 3300 feet above the sea level. The Assat Lake lies in a depression east of Abyssinia, $600^{\prime}$ below the level of the Red Sea, and is salt.

Rivers tend to obliterate the lakes along them in two ways : by the deposition of detritus in their still waters and along their borders, and by erosion 
at the outlet where the stream resumes its relatively rapid flow. The final result when reached is the conversion of the bed of a lake into a river channel.

185.

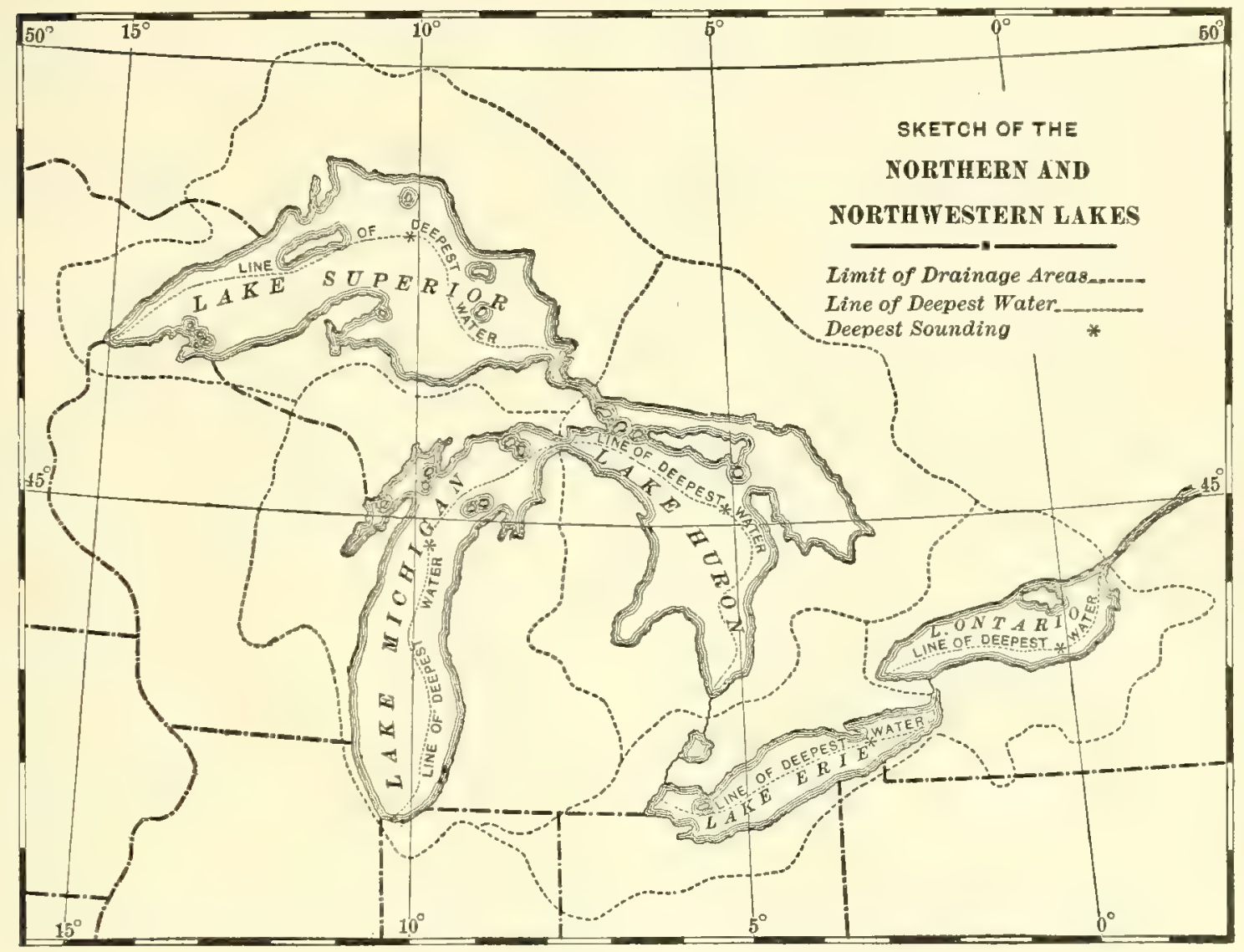

Map of the Great Lakes. L. Y. Sehermerhorn, '87.

The smaller lakes are very feeble workers, and hence, owing to gentle trituration by the little waves, the shores are often muddy. Theoretically

186.

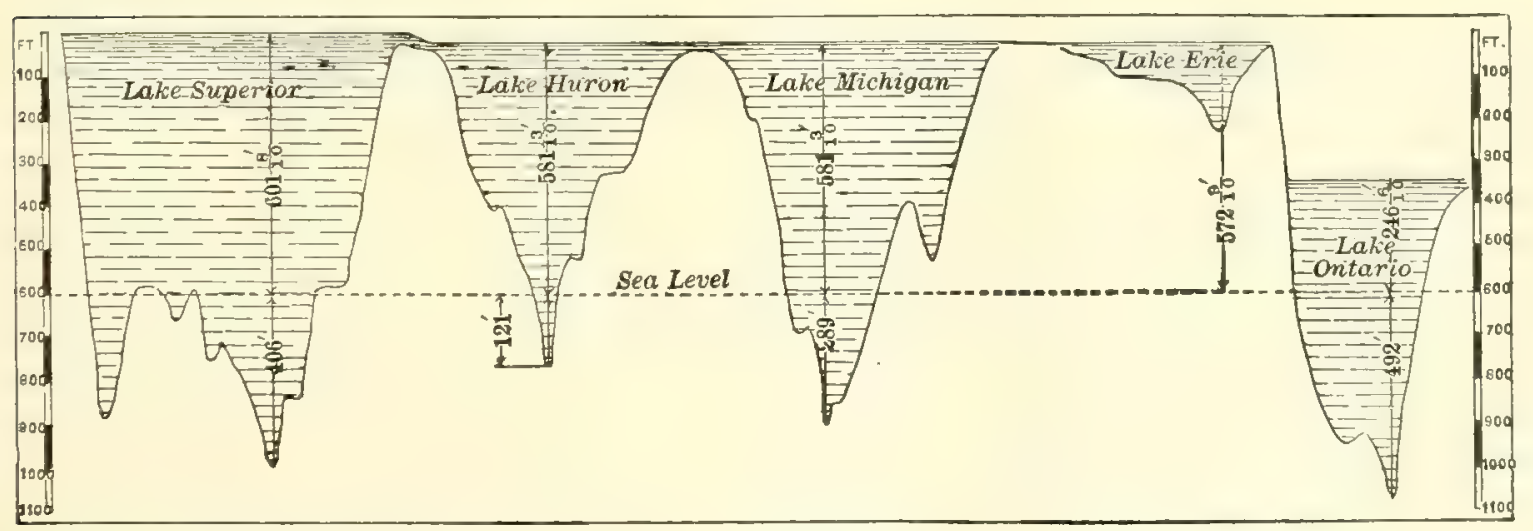

Longitudinal sections of the lakes on the line of deepest water. Schermerhoru, '87.

the waters of the lakes over high plateaus, like those of the head waters of the Mississippi, have great energy; but they usually lie without a chance to 
show it. Occasionally a lake bursts its bounds, and produces in a few hours the derastating effects of the most violent of torrents. But such effects are rare, except where man has interfered.

The large lakes have many of the characteristics of the ocean. The wind, waves, and currents are effective agents of wear and deposition along the shores, and about bays and the mouths of rivers.

The waves work landward on shelving shores, as along the sea border, while a littoral current usually runs parallel, or nearly so, with the coast; and between the two the depositions of sand and making of beaches and sand-bars take place.

The nearly total absence of tides makes marked differences in the effects. The change of level in seashore action with the tidal movements fails. Abrasion sets back the cliffs, but makes a sloping surface at their base.

The tide on Lake Michigan has a range of three inches at spring tides and $1 \frac{1}{2}$ at neap tides. Large oscillations of the surface are produced by storm winds, and lighter ones by floods in the region. On Lake Erie, at Buffalo, the difference between the levels produced by two gales, one from the S. W., and the other off shore, from the N. E., was $15 \frac{1}{2}$ feet (Whittlesey). Small but short tide-like changes of level, called seiches, a few inches in height, observed on Lake Geneva and other Swiss lakes, are attributed by Forel to local variations of atmospherie pressure - an impulse so given producing a long-continued series of oscillations. Larger seiches are supposed to be due to earthquake shocks.

For a thorough discussion of lacustrine methods of work under varying conditions of levels, șee the Memoir of G. K. Gilbert on Lake Bonneville, U. S. G. S., 4to, 1890.

Past geological ages had their fresh-water lakes as well as rivers. But the great lakes and rivers of the world belong to later history, the era of full-grown continents. Yet the lakes of greatest geological interest are not those of the present era, but of that next preceding. Those of North America formed over the emerging land of the Rocky Mountain region had great area, and received abundant debris for lacustrine deposits from a newly made mountain range.

But another condition existed; for the great lake-basins were subsiding areas, so that the deposits continued thickening, as the subsidence made progress, until 5000 to 10,000 feet of beds were laid down, - as the region of modern coral reefs is described, on page 149, as subsiding while the reefs thickened.

These Tertiary lacustrine formations prove their fresh-water origin by containing remains of abundant fresh-water and terrestrial life, from Quadrupeds or Mammals, of many more kinds than now exist in North America, to Snakes and Turtles, Fishes, and Insects and even Butterflies, besides leaves and other relics of the forest. 


\section{Special Points in Fluvial History.}

The history of rivers has been eventful. In the course of the geological past, drainage areas have sometimes changed to areas of marshes, lakes, or ocean; and again back to dry land, with perhaps new limits and slopes. They have experienced changes of level that divided and subdivided them, or forced part of a stream in a new direction for an outlet; that annexed another stream, giving it a new head, and doubling its length, supply of waters, and mean pitch, - as in the case of the Mississippi, which once had the Saskatchewan as its source. They have had portions buried under debris, and have been compelled to make long circuits, and deep cuts, in order to effect a new connection; or have been buried with all their fluvial deposits beneath floods of lavas, - as on the west slope of the Sierra Nevada (Whitney), - and so have made fossil river-channels, some of them to remain buried, others to regain their places wherever the surface conditions favored it. They have had their slopes increased by continental elevation, so that after reaching a state of feebleness, they acquired new energy and were set again to work at the deepening of their channels and the enlarging of their valleys; or they have suffered from subsidences that have slackened the flow over the subsided region and brought on premature old age, or spread a stream into a lazy lake; or by the coming on of a period of enormous precipitation, and of glaciers ending in glacial floods, they have once more been made young and powerful in denudation and transportation over the width of a continent.

Furthermore, streams that originated over a formation covering a country, and derived their courses from its slopes and lines of weakness, have sometimes been forced by the removal, through denudation, of that formation, to chisel down their channels into older underlying beds, and fix upon the latter, as far as possible, their original qualities. An example of a drainage area with such inherited qualities was described, in 1874, by A. R. Marvine (Hayden's Report of 1873), from the slopes east of the Front Range of Colorado. The deposition of Triassic and other strata over the region was followed by its emergence, and the outlining of a system of drainage down the long slopes of the rising continent. But since then the new streams in their upper portion have cut through these strata to the older rocks; and here the work of impressing the courses of the new cañons on these older rocks is going on, mostly irrespective of their slopes and structure-lines. Twelve years earlier, J. Beete Jukes, of the Irish Geological Survey, treating of the mode of formation of some river-valleys in the south of Ireland (Q.J.G. S., 1872), brought out the same general idea that the drainage courses of the present time have often been determined by preëxisting topography.

A course of drainage derived from a formation that once covered the region is called by Powell superimposed drainage. Further, if the course of a river is a consequence of the structure of an upturned region, he terms it consequent drainage; but if derived from conditions prior to the upturning, antecedent. (Exploration Colorado River, 1875.) 
Buried river valleys. - Rivers of the Sierra Nevala, in Tuolumne County, California, that had their channels buried beneath lavas in the later Tertiary, afterward, in a comparatively short time, cut new channels through the thick lava stream and the underlying rocks to depths 1500 to 2000 feet below the old shannels. (Whitney, 1865, 1879.) They hence are strong evidence of increased precipitation, as held by Whitney, and also, according to LeConte $(1879,1886)$, of increased elevation in the mountains; and both conditions characterized the Glacial period which was in progress during part or nearly all of the cutting. Like evidence of elevation exists also in the river channels of southern California beyond the limits of the lava-flood, as observed by LeConte (1886), who thence concludes that the elevation extended along the whole length of the Sierras.

The ultimate result of denudation over a continent is, as usually stated, the transfer of the mountains to the sea, bringing all to a nearly level plain. But the facts from Tahiti, explained on page 182, appear to show that the process would, as a general thing, first thin down the mountains to sharp peaks and ridges; and after this, the continuation of the thinning would ultimate in a general level - given time sufficient. The Adirondacks have stood ever since Archæan time, with the height probably never less than 5000 feet; and yet they are to a large extent in the Tahitian stage. But the streams of extensive drainage areas become to a greater or less extent baseleveled; and through the continued leveling work along them, with that of the minor tributaries, a wide region may be finally reduced approximately to a plain. Such a plain has been termed by W. M. Davis a peneplane, from the Latin for almost and plain; for it may still have ledges of the harder rocks and other irregularities of surface. An elevation of the land, and other causes indicated above, may expose such regions to a new baseleveling.

The fluvial history of a country, it thus appears, may have great complexity, and require a large amount of study and an experienced judgment for its correct elucidation.

\section{Subterranean Waters.}

Water descends from the surface by gravity, filling all open subterranean spaces, and also the pores of the solid rocks. Its lower limit is determined by the earth's interior heat; and the lower limit of outward discharge, by a level not much below that of the ocean's surface. At greater depths, consequently, subterranean water may be that of early ages in geological history, and in part the sea water in which the deposits were made, more or less modified in its saline contents and their amount by long contact with the various rocks. Not only the waters of the rains and rivers thus take a downward way through the porous rocks, between their sloping layers and along all crevices, but also those of lakes, which are sources of permanent supply, and pre-eminently those of the ocean. 
The more solid crystalline rocks imbibe less than 0.2 per cent of water, and hold it so strongly by capillary attraction that when once filled there is little further change, if they are below the influence of surface droughts, and away from that of subterranean heat. But some sandstones are so porous that they give easy passage to the waters from above; and unaltered stratified rocks generally have much open space between the layers.

The amount of water contained in different rocks taken near or at the surface has been found to be as follows : porphyry, 0.012 per cent of the rock-mass; a feldspathic granite, 0.0203 (Durocher, 1853 ); coarse granite, 0.37 per cent; euryte, 0.07 ; milky quartz from a vein, 0.08; flint from the Upper Chalk, at Meudon, 0.12 ; but sandstone (Grès de Fontainebleau, near Meudon), 2.73; a Tertiary limestone (Calcaire grossier), $3 \cdot 11$ (Delesse, 1861). The Calcaire grossier will absorb 18.03 per cent of water; a quartzose Tertiary sandstone, 29.00; the chalk near Issy, 24.10; a Silurian slate, near Angers, $0 \cdot 19$; granite, $0 \cdot 12$ (Delesse, 1861). Chalk will absorb 2 gallons of water per cubic foot (Prestwich); the Old Red Sandstone (Devonian) of Gloucestershire absorbs 11.60 per cent; limestone of the Lower Oölyte, 12.15; Carboniferous limestone of Clifton, England, 0.70 (Wethered, 1882).

The amount of moisture absorbed, after drying at a temperature between $150^{\circ} \mathrm{F}$. and $200^{\circ} \mathrm{F}$., is as follows: for Potsdam sandstone, 3 specimens, $2 \cdot 26$ to $2 \cdot 71$ per cent; 3 others, 6.94-9.35; for Trenton limestone, 0.32 to $1 \cdot 70$, the former for a black variety ; for some dolomytes, 10.0 to 13.55 ; a crystallized dolomyte, of the Calciferous formation, 4 specimens, 1.89 to $2.53 ; 2$ other specimens, 5.90 to 7.22 ; for the Medina argillaceous sandstone, 2 specimens, 8.37 to $10^{\circ} 06$ ('T. S. Hunt, 1865).

A square bar of Triassic building-stone from Runcorn, England, 1.92 inches square and 14.92 high, being half immersed in a can of water, the water rose to the top by capillarity in $2 \frac{1}{4}$ hours, taking in 4 ounces of water; and the same stone made in the form of a siphon, emptied a can of its water. The pore space was nearly $\frac{1}{8}$ of the stone. (M. Reade, 1884.)

1. Flow of underground waters. - In regions of massive or schistose crystalline rocks of close texture, there is no proper flow unless there are vertical fissures; and then the water will descend to the bottom of the fissures, and there remain, or push off laterally if the space admits of it. But if the rocks are uncrystalline stratified kinds, the water flows downward along the surface of the less pervious layer, and soaks more or less through the others. Subterranean waters often come out on the faces of bluffs, and indicate the position of the more impervious layers by a belt of foliage above, kept green by the exuding moisture; or they form springs or streamlets at the base of bluffs; or they feed pools or lakes; or make springs off shores below tide level. In regions of loose sand-beds and gravel-beds they generally find, at a depth of a few yards or scores of yards, a hard layer-hardened by deposits of iron oxide or otherwise (called in popular language hard-pan), which carries along the accumulating waters, and becomes a source of supply to the numerous wells of a village or city; and the same hard layer, if sloping seaward, will afford water by boring, even out in a bay.

In the deep sand deposits of the southern side of Long Island, where the seaward slope of the surface for the 6 miles to low-tide level is $1: 265$ feet, there is a water-plane 
below, which slopes $1: 425$ feet, or $12 \frac{1}{2}$ feet per mile. The discharge of water at sea level is so large, although dependent solely on the rains, that the city of Brooklyn, containing nearly a million inhabitants, has derived from it its supply of water through a series of reservoirs, constructed a little above the sea level. The water-plane is not that of a hard-pan layer. Its position has been determined by well-digging. Out of the 42 ? inches of rain (snow included) which annually falls, nearly 40 per cent becomes absorbed and subterranean. The Brooklyn engineer, Mr. T. Weston, observes that these subterranean waters supply the small streams of the surface with the chief part of their water, and discharge a large amount into the sea; and after a careful survey of a part of this southern slope, east of Brooklyn, 73.64 square miles in area, he reported that the water supply from the surface streams was, on an average, 22 per cent of the precipitation, or $30,000,000$ gallons a day; that 15 per cent additional came out along the shores of the bays ; and that at least 40,000,000 gallons per day might be obtained in reservoirs by proper arrangements. Mr. Weston holds that the water-plane is the upper limit of a water region which extends from this plane downward to and below the sea level, and that there is no hard-pan layer underneath. Friction and capillarity in the sands give it its height.

A coral island but ten feet high and a few hundred yards wide, and consisting of coral rock up to the water level with coral sands above, generally yields, on digging down to the surface of the coral rock, a sufficient supply of water for its inhabitants, and all of it has come from the rains. 'The fresh water, moreover, is sufficient to exclude, by its seaward pressure, all ingress of salt water. If this is true on a coral island, the subterranean waters derived from the rains over larger lands should be very great. Moreover, the salt waters of the ocean do not penetrate far into the basement of a continent. An island may receive sea water to its center at some unascertained depth below the sea level; but not so a continent.

2. Force of flow. - The force of the flow of subterranean waters is due to gravity, like the flow of surface waters. There is everywhere hydrostatic pressure, varying directly with the height of the supply, minus the loss by friction and capillarity. The height may be that of the neighboring hills, or of distant mountains, according to the range of the sloping rock-layers along which the water descends. It may be that of lakes small or large, for these bodies of water have the double duty of supplying above-ground and under-ground streams. While the hydrostatic pressure varies with the height of the water-supply, the extent of the region served by a single source will depend on the area of that source.

Professor Edward Orton, of Columbus, Ohio, has proved that the hydrostatic pressure in the Findlay oil-region, and also in Indiana, where the borings descend to the Trenton limestone, reaching it at various depths to 1000 feet or more below the surface, is determined by the waters of Lake Superior. The level of the lake is 600 feet above tide level; and by adding this height to the number of feet at which the Trenton lies, in any case, below tide level, and calculating the hydrostatic pressure on this basis, he has found that it corresponds closely with the actual gas pressure at each boring. He holds that this hydrostatic pressure determines the gas pressure in other regions; and 
hence that the pressure is rarely, if ever, due, as has been supposed, to the pressure of confined gas. The facts exhibit on a grand scale the influence of a large elevated lake on the conditions of subterranean pressure.

Wherever subterranean water flows between nearly impervious sloping layers, so that it is confined to a given channel, it is like the water in a long inclined tube; and on opening a hole through the overlying material it will rise in a jet, owing to the hydrostatic pressure. The height of the jet so produced is that of the source, diminished by the loss from friction and the resistance of the air ; it may be hundreds of feet.

In the annexed cut (Fig. 187), $a b$ represents a water-supporting layer; $b c$, the boring; and $c d$, the jet of water. Such wells are called Artesian wells, as they were first made in the district of Artois, in France. They are now an important means of securing water for irrigation and other purposes in various parts of the world. By this means abundant water is now obtained even on the seacoast region of New Jersey, from Cretaceous and Tertiary strata, and over various parts of the dry regions of Montana, Colorado, and Nevada, where arid sands have been covered thereby with foliage. But if the rocks are porous throughout, with no impervious layers, boring is of no avail. Borings in regions of metamorphic or crystalline rocks generally prove failures unless a chance bed of decomposed rock extending down from the surface should be reached; for such rocks have been consolidated and crystallized while under heavy pressure. Where slates are vertical, a horizontal boring across the bedding may give a constant stream; but such a source is a small one.

187.

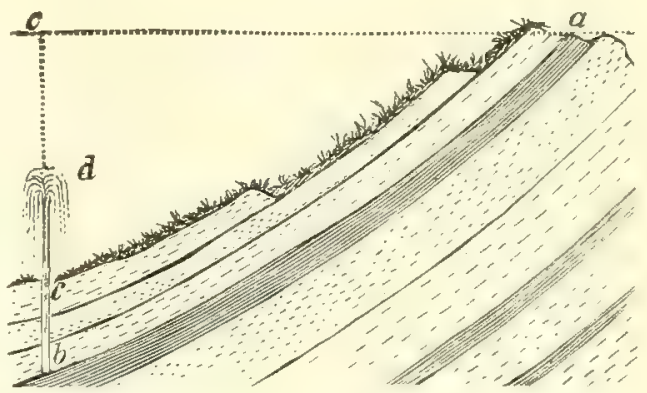

Section illustrating the origin of Artesian wells.

3. Denudation; Transportation. - Subterranean rivers have sometimes large size, especially in limestone regions, where excavation is easy, as explained on page 130, under Chemical Geology. Those of the caverns of Kentucky and Indiana have their cascarles, like ordinary rivers, and may be navigated for long distances. Into such caverns rivers sometimes enter and become "lost rivers;" while from others issue great streams, whose source is unknown. The cave of Adelsberg, 22 miles northeast of Trieste, has its river; and the Jura Mountains send forth streams to daylight full grown. The work of denudation and transportation is like that above ground, although less supplied with materials for transportation and wear.

Subterranean waters do much efficient work in a quiet way by the transportation of sand along the course of streamlets that have their outlet at the base of bluffs. The undermining of centuries in this way may make chambers that lead to the sinking of masses of the land, and determine lines of surface drainage. 
4. Landslides. - Subterranean waters sometimes produce disastrous results by adding their weight to loose or porous deposits and so occasioning landslides.

Landslides are of three kinds :-

(a) The mass of earth on a side-hill, having over its surface, it may be, a growth of forest trees, and, below, beds of gravel and stones, may become so weighted with the waters of a heavy rain, and so loosened below by the same means, as to slide down the slope by gravity.

A slide of this kind occurred, during a dark, stormy night, in August, 1826, in the White Mountains, back of the Willey House. It carried rocks, earth, and trees from the heights to the valley, and left a deluge of stones over the country. The frightened Willey family fled from the house, to their destruction. The house remains, as on an island in the rocky stream.

(b) A clayey layer, overlaid by other horizontal strata, sometimes becomes so softened by water from springs or rains, that the superincumbent mass, by its weight alone, presses it out laterally, provided its escape is possible, and, sinking down, takes its place.

Near Tivoli, on the Hudson River, a subsidence of this kind took place in April, 1862. The land sunk down perpendicularly, leaving a straight wall around the sunken area, 60 or 80 feet in height. An equal area of clay was forced out laterally underneath the shore of the river, forming a point about an eighth of a mile in circuit, projecting into the cove. Part of the surface remained as level as before, with the trees all standing. Three days afterward, the slide extended, partially breaking up the surface of the region which had previously subsided, and making it appear as if an earthquake had passed. The whole area measured 3 or 4 acres.

(c) When the rocks are tilted, and form the slope of a mountain, the softening of a clayey or other layer underneath, in the manner just explained, may lead to a slide of the superincumbent beds down the declivity.

In 1806, a destructive slide of this kind took place on the Rossberg, near Goldau, in Switzerland, which covered a region several square miles in area with masses of conglomerate, and overwhelmed a number of villages. The thick outer stratum of the mountain moved bodily downward, and finally broke up and covered the country with ruins, while other portions were buried in the half-liquid clay which had underlaid it and was the cause of the catastrophe.

Similar subsidences of soil have taken place near Nice, on the Mediterranean. On one occasion, the village of Roccabruna, with its castle, sunk, or rather slid down, without destroying or even disturbing the buildings upon the surface.

Besides $(a)$ the transfer of rocks and earth, landslides also cause $(b)$ a scratching or planing of slopes, by the moving strata and stones; $(c)$ the burial of animal and regetable life; $(d)$ the folding or crumpling of the clayey layer subjected to the pressure, where the effect does not go so far as to produce its extrusion and destruction; while the beds between which it lies are only slightly compacted or are unaltered; and $(e)$ depressions of the surface which may become lake-basins. Fig. 188 is a reduced view of 
a layer thus plicated, from the Quaternary of Booneville, N.Y. Vanuxem illustrates the facts there observed by him, with this and other figures (N. Y. Geological Report), and attributes the plications to lateral pressure while the layer was in a softer state than those contiguous.

In parts of the shores of western Patagonia, where the soil is always wet, the soil-cap is always slipping downward over the basement rock; and it carries along not only its covering of trees and shrubbery, but also a "moraine profonde" of rocks, stones, tree-trunks, peat and mud, denuding the hills, filling valleys, and feeding the ocean. (R. W. Coppinger, 1881.) Areas on the Falklands, called "stone rivers," may have the same origin. (W. Thomson.)

188.

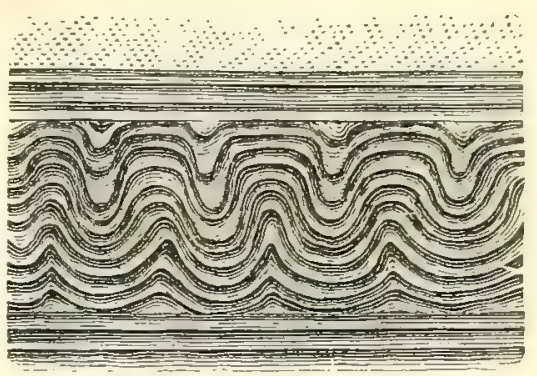

Plicated clayey layer. Vanuxem.

Soil-cap movements and land-slips sometimes dam up valleys and make lakes. But loading with waters is only one of the methods of producing such movements.

Amount of absorbed water within the earth. - The amount of absorbed water in the earth has been increasing from the time of the earth's consolidation. The thickening of the supercrust, by the addition of sedimentary strata, has been attended by a continued addition to the amount. Ejected igneous rocks take in water on cooling. Other sources of augmentation are the making of hydrous iron oxides through oxidation, of clays through the decomposition of feldspar, and of gypsum and other hydrous minerals.

If the thickness of the supercrust over the continental portion of the globe average 10 miles, and the average volume of moisture in the formations, both metamorphic and unaltered, be 2.5 per cent, the whole amount of water absorbed and confined would be $\frac{1}{40}$ of 10 miles, or about 1300 feet in depth, for the area of the continents. The deposits over the oceanic basins have relatively little thickness. Whatever reasonable allowance be made for them, the whole loss to the ocean waters, in depth, from this source, will not exceed 800 feet. The confined water of the rocks, while a feeble agent of change at the ordinary temperature, is one of immense importance when much heat is present.

\section{THE OCEAN AS A MECHANICAL AGENT.}

The working agencies of the ocean of a mechanical kind are, as has been stated, those of (1) the tidal wave; (2) the wind-made waves and currents; and (3) earthquake waves. Besides these agencies, the sun's heat, by varying the temperature and density of the water, affects the ocean's movements.

In mechanical work, the waters of the ocean have an advantage over fresh waters in being of greater specific gravity by $\frac{1}{35}$ to $\frac{1}{40}$. They have also the important quality of depositing sediment more rapidly, because less viscous, owing to the saline condition of the waters. A fine sediment, 
which takes 10 to 14 days to settle in pure water, settles in 14 to 18 hours in a solution of common salt (IV. H. Sidell, 183s). A fine clayey precipitate goes down in a solution of the strength of sea witer in 30 minutes, which in pure water would take as many days (W. H. Brewer, 1883).

Since the chief part of oceanic work requires the presence of rock-nitterial, depth of water is a condition of prime importance. It is only within shallow depths that the waters come extensively into working contact with rocks; only in the shallow belt where water and rocks are together along the emerging line that the greatest amount of force is generated for work. Being at a depth of 500 feet in the ocean is not as complete removal from oceanic forces as being 500 feet above it, but the geological results produced at this and greater depths are relatively small. As explained beyond, there are wide differences between the work of the upper 10 fathoms along shores, and that of the depths from 10 to 100 fathoms; of greater depths along the sides of the oceanic basin when reached by marine currents; and of depths from 100 fathoms to abyssal depths, remote essentially from all currents.

It is therefore obvious that the era in geological history when the ocean carried on the greatest amount of rock-making was that of general continental submergence at shallow depths, with a scattering of emerged rocky ridges or areas. This was the condition of the earth through the Paleozoic eras; and, to a large extent, through Mesozoic time. The condition was in striking contrast with the later and present state, in which the continents have only a narrow margin of shallow water. This fact should be kept in mind when comparing ancient geological events with modern. The time of the greatest amount of ocean work was that of the least amount of river work.

\section{Characteristics of the Working Agencies.}

\section{The Tidal Wave.}

The tidal wave moves as a force wave, and has a mean height, along coasts where least influenced by the land, of less than a foot. The height on the projecting capes of continents is 1 to 2 feet, but along intervening coasts commonly from 4 to 12 feet, and in bays and straits, 15 to 18 feet or more. Along the east coast of North America, sonthern Florida, Cape Hatteras, and Nantucket are the dividing points between a "Southern," "Middle," and "Eastern" Bay (Bache). The height is 1 to $1 \frac{1}{2}$ feet at southern Florida, 2 at Cape Hatteras, and 1 at southeastern Nantucket; but in the Southern Bay at Savannah it is 7 feet; in the Middle Bay, at New York, it is 5 feet; in the Eastern, at Boston, 10 feet.

Up deep bays, when the tide enters between strongly converging coast lines, the wave increases much in height. At the Bay of Fundy, an unusually long wave enters and reaches a height of 40 feet, and even 60 to 70 feet at the highest tides; the advaneing wave is like a moving water-fall of majestic extent, but without foam. At the entrance to the Bristol Channel, 
England, the maximum height is 18 feet, and within it, at the mouth of the Severn, 45 to 50 feet. In Long Island Sound (Fig. 189), which is about 100 miles long, the tide outside, at Block Island, is but 2 feet; but inside, at New London, it is 3 feet; at the mouth of the Connecticut, 4; at New Haven, 6; at Bridgeport, 7; and off Hewlett's Point, near Hell Gate, where it meets the inflowing tide of New York Bay, $7 \frac{1}{2}$ feet. The map shows further, by the cotidal lines over the Sound, that the time of the passage from Block Island to Hewlett's Point is about $4 \frac{1}{2}$ hours; and that, at the fourth hour, it is high tide almost simultaneously along the whole inside coast. The height of the tide is depressed somewhat by high atmospheric pressure, but the amount of depression is not yet precisely ascertained.

189.

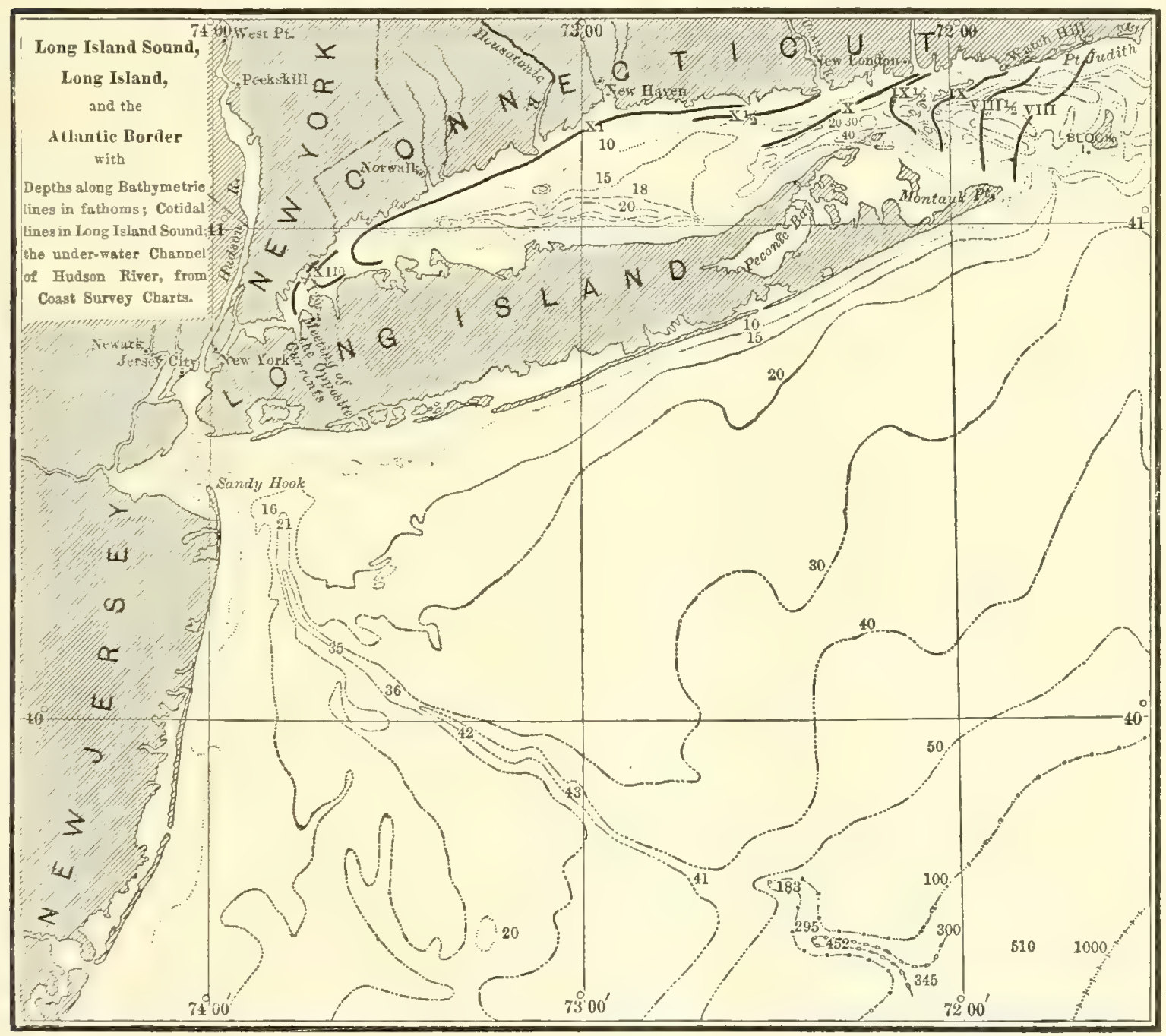

When the tide enters straits by two passages, progress in either direction depends on depth and obstructions, and leads to meeting at different heights. At Batscham, in Tong-king, the waves, coming from the China and India seas, meet bringing opposite but nearly equal changes in the water level, and the result is almost no perceptible tide. The tidal wave of New York Bay meets that of the Sound at varying heights, causing violent currents at Hell Gate; 
and at each ebb, on an average, $448,000,000$ cubic feet pass from the Sound westward.

Again, where the tide up a large river is detained at the head of a gradually contracting estuary by sand-bars with only narrow passages, it sometimes moves up the river all at once in one or a few great waves, producing what is called an eager (or bore); as at the mouth of the Hoogly (one of the mouths of the Ganges), on the T'sien-Tang in China, and on the Amazon. In the 'Tsien-Tang, at the equinoxes, the wave moves as a foaming wall of water, 20 feet or more high and four or five miles broad, and thus it passes HangChau-Fu at a rate of 25 miles an hour, dying out about 80 miles above. The change from ebb to flood tide is almost instantaneous. (Macgowan, 1855.)

At the large northern mouth of the Amazon, the pororoca, as it is there called, passes up the stream in three or four closely following waves, each 15 to 20 feet high. As soon as the previous tide stops running out, the approaching wave is seen as a white line on the eastern horizon; onward it comes with rumbling sounds (imitated in the word pororoca) that grow louder and louder; finally it rushes forward over the top of the long wall, like an endless cataract, in quick pursuit by the other waves; and continues up the river for 70 or 80 miles, or two thirds of the way to Macapa. (J. C. Branner, 1884.)

Rivers with open mouths receive the tidal wave quietly and carry it as far within as high-tide level goes, the movement being communicated to the water of the river, and the salt water following for part of the distance, and ending as an under-current. It extends up the Amazon to Obidos, nearly 500 miles; up the Hudson to Troy, 150 miles, two waves being in the river at once; up the Connecticut to Hartford, 50 miles. Rising above the level of the wells along the coast and the outlets of subterranean streams, it raises their waters, so that such wells also have their tides.

In seas more or less shut in from the ocean and outside of the general course of the tidal wave, the tides are small. In the Mediterranean, for example, the tide is perceived only at the ends of bays, as at Venice in the Adriatic.

In consequence of the tidal movement the sea has its flood-grounds, like rivers; but the floods occur twice a day, with each recurring tide.

At some places in the Pacific, owing to the conjunction of tidal waves, high water occurs uniformly at $12 \mathrm{~h}$, and low at $6 \mathrm{~h}$. This is the case at Tahiti, where the tide has a height of 1 to $1_{2}^{1}$ feet. The author governed himself accordingly in his excursions at low water over the coral reefs.

\section{Winds: Wind-made Waves and Currents.}

As the great currents of the oceans - the Atlantic and others - are attributed by many to the action of the regular winds, these currents may here come under consideration as well as those marle by storm-winds. But the currents made by the storm-winds, that is, the littoral currents and the 
attendant waves, are the efficient agents, because they act directly against and along the coasts, and have great power.

Storm-winds, as stated on page 159, have often a velocity of 60 to 100 miles an hour. They have built up, by drift-sands alone, the east side of the Bermuda reefs to a height exceeding 200 feet, while the regular winds have not raised the side of the coral reef facing them above high-tide level. They have made similar drift-hills on the Bahamas, and over the Florida reefs.

Waves rise in long lines transverse to the course of the winds, but with irregularities in the lines, owing to veerings and other variables in the driving agent. Their height depends on the size of the sea, as well as on the winds, and in shallow water on its depth. But every seventh or eighth wave is often a maximum, it being a combination of two, one overtaking another.

Waves have at times great height. The highest measured by Scoresby stood 43 feet above the intervening trough, or $21 \frac{1}{2}$ feet above the mean water-plane or plane of rest. According to results obtained by the United States Hydrographical Department, the storm-waves of the North Atlantic have a maximum height of 44 to 48 feet, but ordinarily a height of 30 feet, and a length of 500 to 600 feet.

But the depth of the action of waves is moderate. In a wave, each particle of water moves in a circle about its center of rest, - a circle of $21 \frac{1}{2}$ feet radius in a wave of 43 feet. But these circles at a depth of only one wave-length have a radius $\frac{1}{53}$ of that at the surface, and at a depth of two wave-lengths, $\frac{1}{300000}$; so that if, for the 43-foot waves, the wave-length or the distance between the crest of two consecutive waves - is 300 feet, the circle at a depth of one wave-length will have a diameter of $\frac{4}{10}$ of an inch, and at two wave-lengths, $\frac{1}{1200}$ of an inch. Consequently the movement of the heaviest waves in the open ocean is exceedingly slight, if apparent at all, at a depth of 100 fathoms. This depth is the probable limit of the movement of sand by wave-action, but not the limit of the action of currents.

\section{Earthquake Waves.}

In an earthquake, the movement of the earth may be either (1) a simple vibration of a part of the earth's crust, or (2) a vibration with actual elevation or subsidence. If submarine waves are produced, they have a forward impulse, and, in the second case, an actual forward movement or amplitucte equivalent to the amount of change of level; in each case, therefore, they are translation waves. The velocity of propagation varies as the square root of the depth, the number of miles per hour being 12.2 miles in a depth of 10 feet; 38.7 in that of 100 feet; 122.3 in that of 1000 . An earthquake at Concepcion, Chile, set in motion a wave that traversed the ocean to the Society and Navigator Islands, 3000 and 4000 miles distant, and to the Hawaiian Islands, 6000 miles; and on Hawaii it swept up the coast, temporarily deluging the village of Hilo. An earthquake at Arica, and other parts of southern Peru, August 14, 1868, sent a wave across the Pacific, west- 
ward to New Zealand and Australia, northwestward to the Hawaiian Islands, northward to the coast of Oregon; and this was repeated in May, 1877.

\section{The Sun's Heat: a Cause of Varying Temperature and Density.}

Evaporation causes an increase in the proportion of salt in the ocean, or in its salinity, and thereby an increase in density; and this is under certain conditions a potent cause of currents. The Mediterranean sea affords an example. It has been estimated that this sea loses annually 60 per cent of its water by evaporation, and receives, through rivers and precipitation, about 30 per cent; so that there is a deficit of 30 per cent which is supplied by the Atlantic through the straits of Gibraltar. It is consequently inferred that if the connection with the ocean were cut off, the sea would be reduced to a great basin with two intensely salt "Dead Seas," an eastern and a western. (It has been suggested that this may have been its condition during or since the Glacial period.) In consequence of this loss by evaporation, the water is $\frac{1}{12}$ more saline than that of the Atlantic (page 49). On account of this condition the sea has an inward and outward current at Gibraltar; the latter carrying off the denser Mediterranean waters; the former resupplying the loss resulting from both evaporation and the outflow. It has been calculated that the inflowing current is equivalent to a current eight miles wide, 600 feet deep, moving at the rate of 18.3 miles in 24 hours. The currents being reversed with the tides, this is the balance of the inflow over the outflow in the upper current. (Carpenter, 1872; Buchanan, 1883.) On the varying salinity of sea water, see page 121.

\section{Mechanical Effects.}

\section{Tidal Wave and Currents.}

1. The tidal inflow. - Since the tidal wave becomes a translation wave on soundings, it thereby gains theoretically some power of transportation. But on open coasts the inflowing movement at the rate of a few feet only in six hours is too slow for much efficient work. Its feebleness as a geological agent can be best appreciated during a calm day on the seashore when, although the air and waters are seemingly at rest, the tide is nevertheless rising.

The tidal wave in its landward movement follows the deeper parts of the bays and sounds, where friction is least, and with less velocity their coasts. It is therefore weak in sea-border work. This is well shown by the cotidal lines of Long Island Sound on the preceding map as laid down by Schott. These lines reach the coast of the Sound along its western half nearly at the same time. The tide enters the Sound along its bottom, as an "underrun," one and a half hours before the ebb of the surface waters has ceased (E. E. Haskell).

The rising tide affords the wind-made waves a chance twice a day to ply their blows against cliffs and heaches at regularly changing heights, and thus 
promotes abrasion on sea-borders in a way not possible on the shores of lakes. The flow up the coast and the tidal rivers sets back the river waters, gives them increased depth, and floods the tidal flats.

Passing up large bays which gradually narrow inward, the mass of water becomes forced to quicker movement or greater height, or both, to keep time with the advance behind; and in such cases, coasts, against which there is friction, may be worn, and if shallow, some stirring up of the bottom may be produced. And if, further, the waters are held back by obstructing banks until nearly at full tide before they move in, they may rush forward, as in the eager, with greater destruction. When the eager of the Tsien-Tang is approaching Hang-Chau-Fu, the boats along the shore are quickly rowed to the middle of the stream and placed with the bow to the wave; they rise and fall as it passes, - about 20 feet, - and in a few minutes are back at their shore traffic, - facts evincing that the waters are those of a wave, and not of a current. But along shores that obstruct the movement artificial embankments or dykes are often torn up.

The eager or pororoca of the Amazon has the action of an enormous plunging wave. The forest-covered land, as Branner states, is torn up to great depths; forests are uprooted and swept away, the trees left matted and tangled and twisted together upon the shore, or half buried in the sands, "as if they had been so many strings or bits of paper," and the region inland over which the flood has swept is loaded with the debris. Moreover, new islands of large size and new shoals and bars and channels are left behind it. Branner adds that this is the work of the tidal wave, not of a tidal current.

2. The outflow. - By the inflow of the tidal wave a great body of water along a coast is raised some feet above low-tide level, and acquires thereby an amount of energy depending on the height of the tide. 'The energy is expended during the outflow in abrasion, transportation, deposition, overcoming friction, and in other ways; and sometimes it is utilized for impounding a portion of the water at high tide, and making it turn a water-wheel for a mill or a pump. As has been remarked, it may become an important source of heat to man when coal-beds are burnt out.

It is the source of tidal currents. The ebbing waters lie on the bottom of shallow bays and necessarily follow the lowest channels; and they thus become divided into many workers, which may severally abrade or scour the bottom, though generally more or less combined in their work of transportation and deposition. Along the deeper middle portion of Long Island Sound the mean velocity of the outflow is 2.8 feet per second, and of the inflow 3.2 feet (Haskell).

The force of the outflowing waters through bays is augmented where rivers add to the depth, and also by the additions to the waters of a bay by storm-winds.

The denuding or scouring action of the movement, added to that of the inflow, is manifest not only at harbor entrances, but also over the sea-bottom in its shallower parts. In Long Island Sound wherever there is any narrow- 
ing by shoals or islands there is an increase of the depth and velocity, and consequently an increased denuding force. South of Norwalk (long. $73^{\circ} 23^{\prime}$ W.), where the breadth is reduced one half by a projecting point of Long Island, the depth at center is increased from 15 to 32 fathoms. Again, south of Stratford (long. $73^{\circ} 6^{\prime}$ ), there is a shoal, and consequently a deepening to $27 \frac{1}{2}$ fathoms. Again, to the eastward, south of the mouth of the Connecticut River, where the Sound is narrowing toward its obstructed entrance, the depth increases in 5 miles from 12-15 fathoms to $25-29$ fathoms; and then, in 40 miles, nearing the entrance, to 45,50 , and 55 fathoms. The accessions of waters from the rivers give some aid in this deepening. Once outside, the depth of the waters diminishes; but the channel made by the scour may be traced until Block Island is passed; and the loops just south, of 30, 40, 50 fathoms in the bathymetric lines, suggest that it may extend in a wider form nearly to the 100 -fathom line. However this may be, the sea-bottom channel indicated on the map southeastward of New York Bay, while rightly considered the former course of the Hudson River channel during a period of sea-border emergence (D., 1857), probably owes its present depth out to the 40-fathom line, to the combined effects of drifted sands and the scouring action of the ebbing waters (D., 1890).

In the discharge of a river into a salt-water bay, the fresh waters flow over the salt; and in some cases so little commingling takes place that shallow streams, carrying little detritus, leave uninjured the marine life of the bottom.

3. Deposition usually takes place inside of bays or estuaries wherever there is an eddying of the waters or diminished velocity, as well as over tidal flats. There is deposition also at the entrance of the bay, when the tidal waters meet the sea outside, and spread and rapidly lose velocity: and at the ebb, this area of deposition may become prolonged into and up the bay. But part of the inside deposits are scoured away with the next outflow.

Deposition off shore of the detritus made by the grinding of beach sands is only, to a very small degree, a result of tidal action. It is chiefly wave and current work. The making of ripples over sand-flats and shallow seabottoms is partly a result of the gentle tidal inflow or outflow; but it is also the work of wave-and-current movements.

The height of the tide fixes an upper limit to tidal flats and sand-bars in estuaries and bays by the limit it gives to deposition. But the seashore flats along some rocky shores are a result simply of the shearing action of the passing waves.

\section{Wind-made Waves and Currents.}

1. Their power. - The waves that come in from the ocean and break heavily on the beaches and against the cliffs, are wind-made waves; and those of great force are made and propelled by storm-winds. Their progress is landward; and the break at summit takes place when the depth of water below the trough equals about one half the height of the wave. The wave ad- 
vances, and rises in consequence of the diminishing depth. At the breaking, or the collapse, of the wave, the waters are thrown forward, and dash, for the most part, up the shore, while the trough part of the wave flows off as the "undertow," followed down the beach by the returning water of the collapsed wave.

Some features of the movement are well illustrated in Hawaiian surf-riding. The Hawaiian, swimming out with his plank, plunges beneath the first billow and rises beyond it; then dives beneath another, and another, until he has passed one of the great billows. This he mounts, and, if rightly placed on it, rides to the beach with great speed. Should his plank not keep the right angle on the crest of the billow, the surf of the following wave will overtake him; but this he would avoid by diving beneath it and swimming out farther for a fresh start.

The work done by the wave-and-current agency includes abrasion of the most violent kind, as well as the gentlest, and transportation and deposition as extensive as coast lines and shallow sea-borders or seas. It is the agency that preserves to the continents the detritus of the discharging rivers, inasmuch as waves work landward; yet it has aid in this in the fact that sediment drops in salt water in one fifteenth of the time required in fresh. On the borders of the Gulf of Mexico, according to A. Agassiz, river sediments do not extend out beyond the 100 -fathom line, for at this depth there is always the usuál sea-bottom life. Along the Atlantic border there are sediments in deeper water, but this is because icebergs or icefloes have dropped there loads of gravel and sand. This agency also makes impossible the transportation of material from one continental land to another. If the fabled Atlantis were at the surface over the Dolphin shoal (page 19), the waves and currents would work about it and for it, and allow of no contributions to any outside land, and least of all to America - the continent supposed to have needed help.

2. Work of denudation. - The waves bring to bear the violence of a cataract upon whatever is within their reach, - a cataract that girts all the continents and oceanic islands. In stormy seas, they have the force of a Niagara, but with far greater effects; for Niagara falls into a watery abyss, while, in the case of the waves, the rocks are made bare anew for each successive plunge. They work by impact, and with enormous force. They have also great abrading power added to impact, through the load of debris they take up and transport. Stevenson, in his experiments at Skerryvore (west of Scotland), found the average force of the waves for the five summer months to be 611 pounds per square foot, and for the six winter months, 2086 pounds. He mentions that the Bell Rock Lighthouse, 112 feet high, is sometimes buried in spray from ground-swells when there is no wind, and that on November 20, 1827, the spray was thrown to a height of 117 feet, - equivalent to a pressure of nearly three tons per square foot. During a westerly gale in March, 1845, his dynamometer registered a pressure of 6083 pounds per square foot, which gives for the velocity per second, by the formula, $\sqrt{\frac{P g}{64}}$ ( $P$ being 
the pressure in pounds and 64 the weight of a cubic foot of sea water), $\sqrt{\frac{6083 \times 32 \cdot 2}{64}}=55.32$ feet. The hydrostatic pressure due to a ware 20 feet high is over (1280 lbs.) half a ton to the square foot; the rest of the force comes from its velocity. Mr. Stevenson states that on one of the Hebrides a mass of rock of about 42 tons weight was gradually moved in a storm five feet; with each incoming wave it was made to lean landward, and the back run uplifted it with a jerk, leaving it with little water about it.

It is reported that at Unst, one of the Shetlands, walls were overthrown and a door broken open at a height of 196 feet above sea level. Geikie attributes part of the effects of the impact to the compression of the air of cavities by the striking waters, and then its sudden expansion, with tearing effects; and also to the rarefaction of air caused by the sudden withdrawal of the waters after a broad stroke, this leading to displacement of blocks or masses. He mentions the case of a securely fastened door at the Eddystone Lighthouse forced outward by the stroke of the outside surface by a wave; and suggests that the principle may account for stones being started from their places in a solidly built stone wall. The water driven into crevices has great rending force.

The heaviest waves exert little force against rocky cliffs, or the sea-bottom, below a depth of 15 or 20 feet. Their abrading action cannot, therefore, shear off cliffs, or wear away an island in the ocean, to a lower level. This prineiple is recognized in making defense walls of masonry against breakers by planting the wall out where the depth is 15 to 20 feet.

Waves, as they march up a shore, sometimes throw stones to great heights. Geikie cites the report that during northwesterly gales the windows of the Dunnet Head Lighthouse, at the northern extremity of Scotland, 300 feet above high water, are sometimes broken by stones from the enormous breakers.

In view of the force at work it is not surprising that, in regions like Cape Horn, or the coast of Scotland, where storms are common, cliffs should undergo constant degradation, be fronted by lofty castellated and needle-shaped rocks, and that the land should be pierced at times for blow-holes where layers of easy removal, or dikes or veins, face the breakers.

The following figures from a memoir by Professor Shaler illustrate well some of the results. They represent scenes on the coast of Maine, near Mount Desert.

Fig. 190 shows a detached rock on its march seaward; and Fig. 191 a pile of clisplaced masses as it was left at the base of a cliff before an elevation of the coast of 220 feet. All the processes of rock-destruction help in this work of degradation, - the opening of rifts by intruding moisture, or by oxidation, or by change of temperature, or by growing plants and the decay of weak portions of the rocks. Under the incessant beating, every stroke tends to slip out of place masses, however large, that rest on a surface not perfectly horizontal. 
The cliffs of Norfolk and Suffolk, England, afford an example of seashore encroachment that has long been under observation as the country is one of houses and cultivated fields. Lyell states that in 1805, when an inn at Sherringham was built, it was 50 yards from the sea, and it was computed that it would require 70 years for the sea to reach the spot-the mean loss of land having been calculated, from former experience, to be somewhat less than one yard annually. But it was not considered that the slope of the ground was from the sea. Between the years 1824 and 1829, 17 yards were swept away, bringing the waters to the foot of the garden; and in 1829

190.

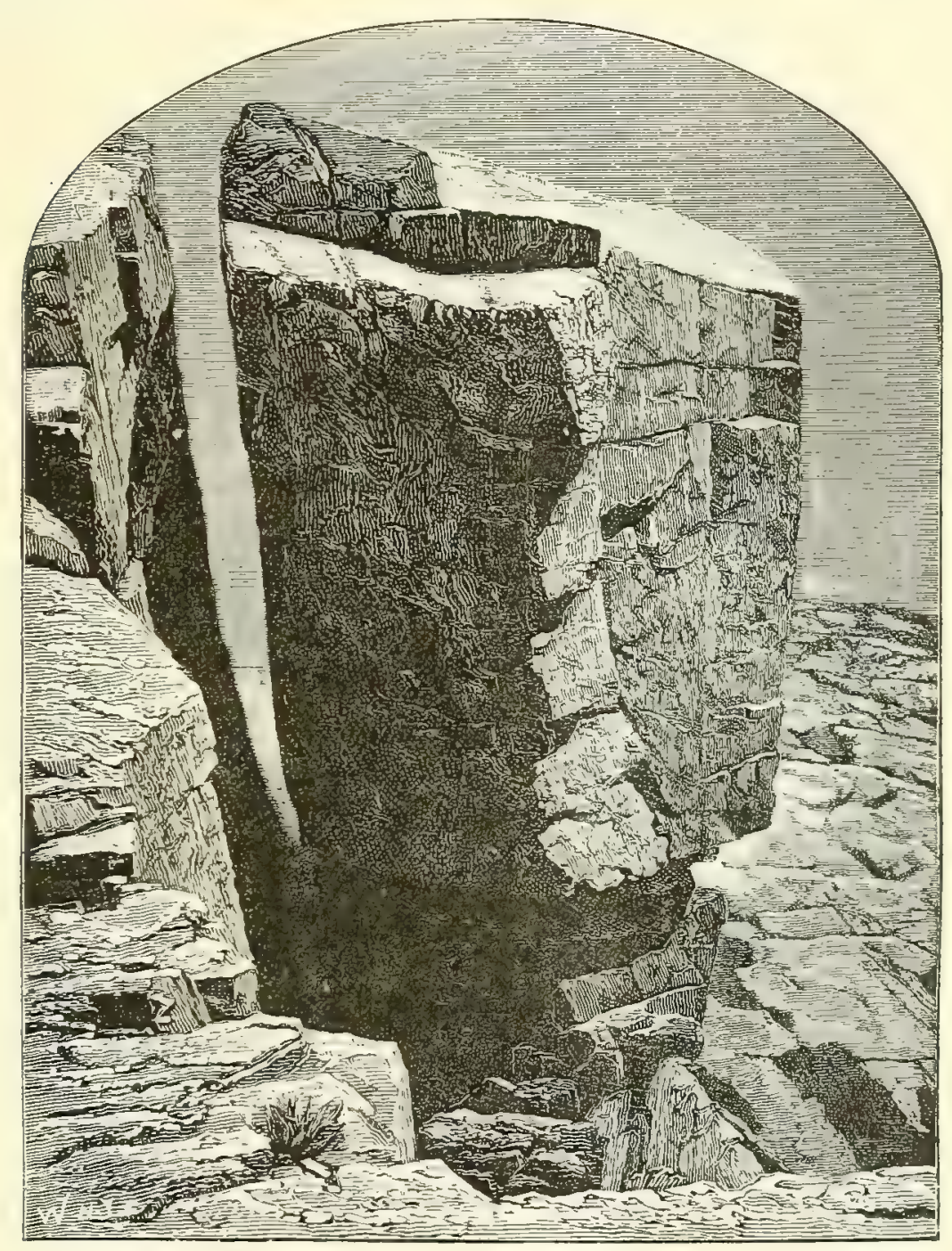

Rock detached by wave-action, Otter Creek, Mount Desert, Me. Shaler, '89.

there was depth enough for a frigate, 20 feet, at a spot where a cliff of 50 feet stood 48 years before. Farther to the south, the ancient villages of Shipden, Wimpwell, and Eccles have disappeared. This encroachment of the sea has been going on from time immemorial.

3. Limit of wave-denudation; Planation. - Besides battering and degrad- 
ing cliffs, wave-action makes shore-platforms, by shearing away the rocks of coasts down to a horizontal surface near low-tide level, and in the process cliffs are undermined and set back. These effects are produced where the rocks are of moderate firmness, - where they are not too hard to yield rather easily to the waves, and not so weak as to be torn up by the gentler attack of low-tide movements. As the tide rises, the earlier waters quietly cover

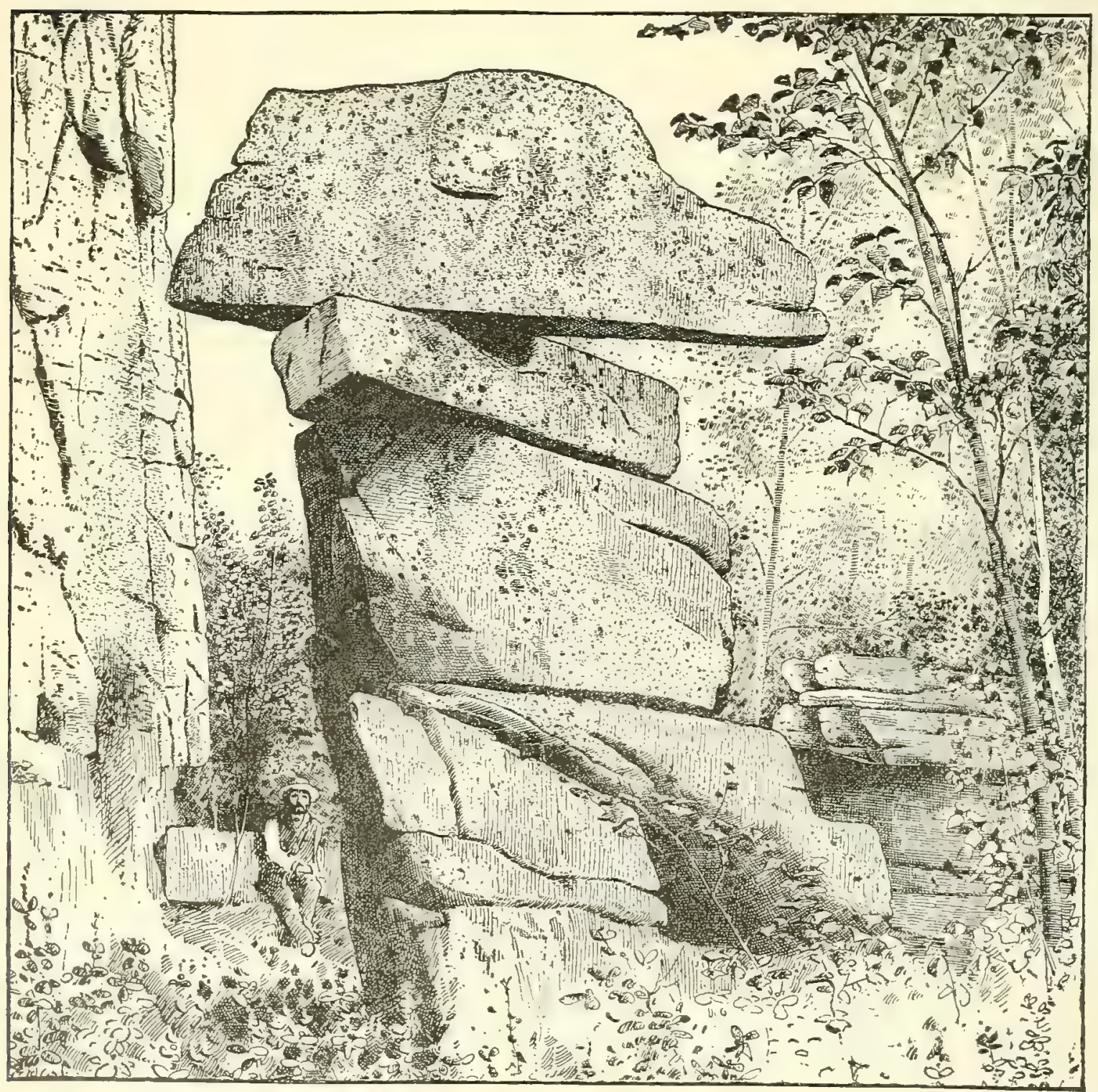

Rocks detached by wave-action, Mount Desert, on an old beach at a height above the sea of 220 feet. Shaler, '89.

the rocks. Then the waves move in; but the rocks below are under protection, and only those of the cliff or wall take the force of the blow. There is hence, in such cases, a level of no wear near low-tide level. The level of greatest wear is that of the stroke of the breaker at or above high tide. 
This feature of wave-action, and the reality of a level of little or no wear above low tide, are well illustrated by facts observed by the author in 1840 on the coasts of Australia and New Zealand. 192. In Fig. 192 (representing the south cape at the en. trance to the harbor of Port Jackson, New South Wales), the horizontal strata making the base of the cliff, cut crosswise by joints, extend out in a platform a hundred yards wide. The tide rises and covers the platform; and the waves, unable to reach its rocks to tear them up, because of the protection thus afforded, drive on to

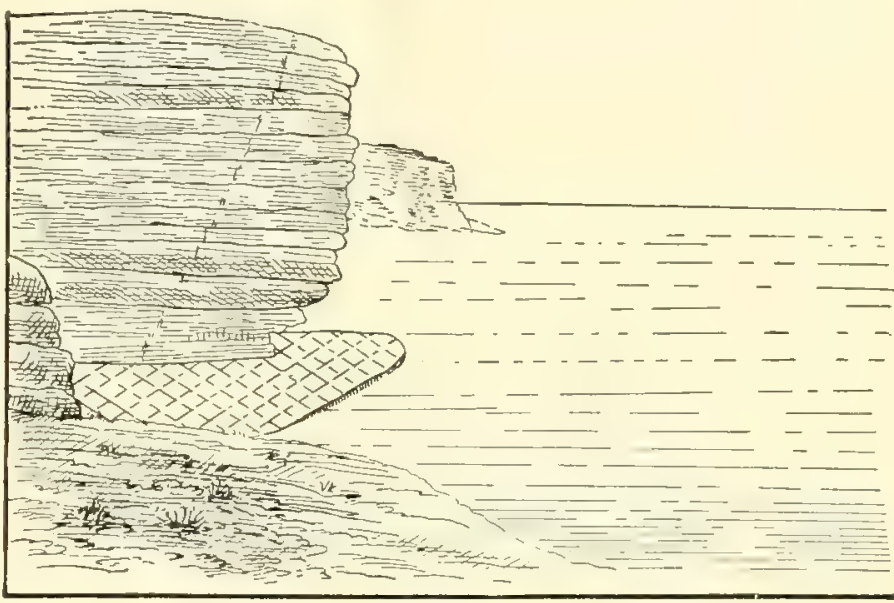

Cliffs at entrance to Port Jackson, New South Wales, Australia. D., Note-book, ' 40 . batter the lower part of the cliff. The strata belong to the Sydney sandstone formation. At the Bay of Islands, New Zealand, there is a similar seashore

193.

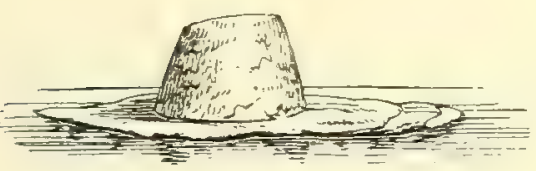

"The Old Hat," New Zealand. D. ' 40. platform, as illustrated in Fig. 193, representing an island in the bay called "The Old Hat." The rock here is a rather firm argillaceous sandstone without bedding. By elevation such shore-platforms become sea-border terraces.

Another region of such shore-platforms is the Island of Anticosti in the Gulf of St. Lawrence. They have a width there of 100 to 150 yards (Verrill). The broad seashore platform of coral islands or atolls has the same origin (page 146). It occurs on both their leeward and windward sides, and varies little in surface from horizontality. Coral-made limestone, like other kinds, is of easy abrasion.

As here shown, there is a limit to wave-abrasion. Under the circumstances stated, it does not cut much below low-tide level. Even an atoll stands its ground and grows in size in spite of the waves of a Pacific. Much less can wave action cut valleys into the land. Its province is to batter down cliffs, wear off headlands, and fill up bays.

The largest blocks that are raised and carried up seashore are those that are forced along by earthquake waves. These waves commence their tearing work at depths that at other times are under the protection of the waters, and the waters, which had retreated from the shore to make the waves, advance to an unwonted height, and make deposits of what they have gathered at varying distances inland, according to their gravity, besides devastating the country they cover. But the depth of their action probably does not exceed 30 feet. A ship afloat is easily moved landward, more easily 
than blocks of rock are torn from submerged strata. The earthquake of 1746 , on the coast of Peru, carried a frigate several miles inland, besides deluging the seaport Callia, and the eity of Lima seven miles distant. The following figures represent masses of coral limestone tur'l off from the margin of an atoll and thrown on the shore-platform. That of Fig. 194, was $10 \times 6 \times 6$ feet in its dimensions, and that of Fig. 195 seven feet high and six

104.

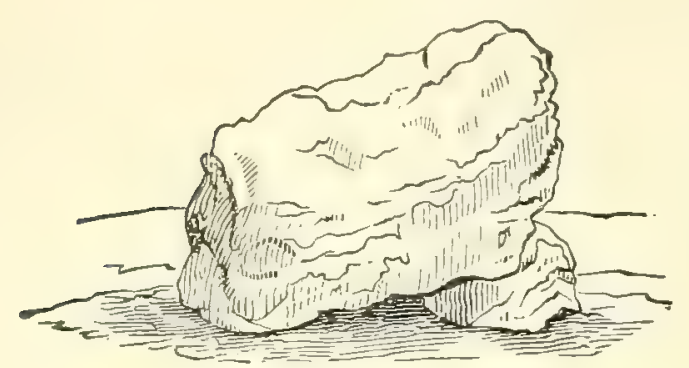

195.

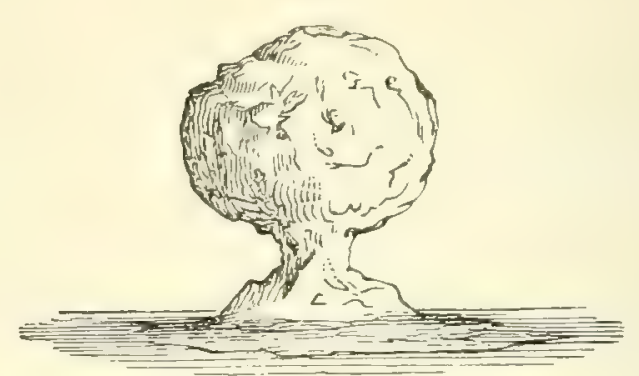

Blocks on the shore-platform of atolls in the Paumotu Archipelago. D. "49.

broad. The latter is attached solidly to the reef-rock, and is half cut through by wave action. Another mass on the shore-platform had a length of 15 feet.

4. Transportation and depostion; the making of beaches. - Waves, as they rise on a shelving coast, take up and bear along detritus of all degrees of coarseness according to the velocity, and throw or wash it up the shore. Grinding work or corrosion is also ever going on. By such means they give the beach its material, and through the return of the waters, by which much of the finer debris is restored to the sea, its angle of slope.

The materials are derived from the wear of cliffs and ledges above the beach; from the loose material of the bottom; from any corals and shells and other organic objects living in the waters; and from the contributions of marine currents as well as those of rivers - whatever is at hand being used. The transported materials may be gathered from depths of 30 feet or more. In regions of high tides and stormy seas, the great, rapidly driven waves, as they move up the coast, may pick up large stones or produce them out of the rocks, and make stony beaches, or they may make a place too rough for a beach. But with lower tides, and away from the rocks, the beaches consist mostly of sand and gravel. Nine tenths of all the beaches between Florida and Cape Cod are sand-made.

The slope of the beaches varies much in angle. It is $15^{\circ}$ to $18^{\circ}$ along the coasts of stormy seas and high tides, $7^{\circ}$ to $10^{\circ}$ along those of lo $\pi^{\circ}$ tides, and $3^{\circ}$ and less in sheltered bays. Deposition by the return-flow waters gives this part of the beach a straticulate structure parallel to the inclined surface (page 93).

Since the waves go up and down the beach twice in each 24 hours, and gradually become stronger in flow and plunge as the tide rises, the beach is made to consist of: (1) The summit ground, of uneven surface. This is the receiving place for the coarser material, including stones, shells, etc., and also 
for long lines of seaweeds, which the wash of the waters carries up the beach and has to leave because the sands of the upper and drier part take most of the waters off by absorption. Here and just below are often found accumulations of magnetic iron sand and garnet sand, which the return-flow was not strong enough to carry back down the beach with the other lighter sands. (See page 170.) (2) The beach-slope, the outer surface of the beach-formation, the stratification being parallel to it. When sand-made, its surface is marked with faint channelings of rills from the return-flow, and more faintly with wave-like outlines of the upward wash. (3) The under-water slope-the continuation of the beach-slope downward beneath the water made by the undertow and perhaps coarser in material than the part above. It is the place for boring Mollusks, Sea-worms, and Crustaceans. Stones and coarse shells that may be dropped by the flinging breakers on the beach-slope are pretty sure to be carried back by the return-flow for another chance of transport, because the plane of rest is underneath them and not through their centers of gravity; and for the same reason the stones of experimenters on beach-action usually go the unexpected way - seaward.

The grinding carried on over the beach reduces the sand to finer sand, and especially the grains of feldspar and of all minerals softer than quartz. The undertow carries these seaward, where the current distributes them over the shallow bottom. In this way deposits of fine earth, clay, or mud are forming near those of coarse sand or gravel. Tidal flats of mud or sand in estuaries, when lying exposed above low water, are likely to receive ripplemarks, foot-prints of passing animals, raindrop prints, mud-cracks, and to secure, when the tide turns, their burial beneath other sands and thus their preservation. Under the tearing action of the heavier seas, the summitground may be put temporarily into the beach-slope, or large portions of a beach may be torn away and reconstructed; and, since the volume of the return-flow would be at the same time augmented, the beach may become temporarily steeper and coarser. Along most windy shores it requires only one of the extraordinary storms that come at long intervals to destroy much of the work of a century.

5. Extension of beaches into points or spits, and barriers. - A beach is, in the long run, essentially permanent in form and structure, unless a coast is undergoing change in level or in other respects. But in regions of frequent storms, the storm-made waves and currents give the sands a set or drift to leeward. When, in this way, the line of a beach reaches in its leeward extension a shallow bay, the drift of sands, still continuing, will build out a point where the current loses velocity against the stiller water of the bay; or, if the water is not too deep, it will extend a barrier of beach-sand across the bay, cutting off an inner shallow portion from the ocean, leaving only a single oblique entrance, which the tides had kept open. By such means the south side of Long Island, and a large part of the Atlantic coast south of New York, has been supplied with its beach-sand barriers, and also, inside of the barriers, with a long range of sounds. 
The map, page 211, affords illustrations of these barriers. Montank Point has its beach, and also its bluffs of sand and coarse gravel. Westward, the beach is continued on in a series of barriers, outside of a series of shallow bays, which extend all the way to Coney Island and New York Bay. The barrier is seldom over 600 yards in width, and is almost wholly bare, yet has stumps at places on the inner side. Moreover, the westward drift of the sands has shallowed the waters south of the western part of Long Island. The zigzags here in the 10 -fathom bathymetric line show the direction of the wave-and-current movement.

Part of the drifted sands of these beaches were supplied from the bluffs to the eastward, but part are the gatherings of the waves from the sea-bottom below the beach and barrier, and a small part are from the feeble streams of southern Long Island.

Along the New Jersey coast and farther south the beaches are usually half a mile to a mile in breadth, and many have an inner forest-covered belt. Sandy Hook -5 miles in length — owes its existence to the drifting of the sands, and an accompanying inside

196.

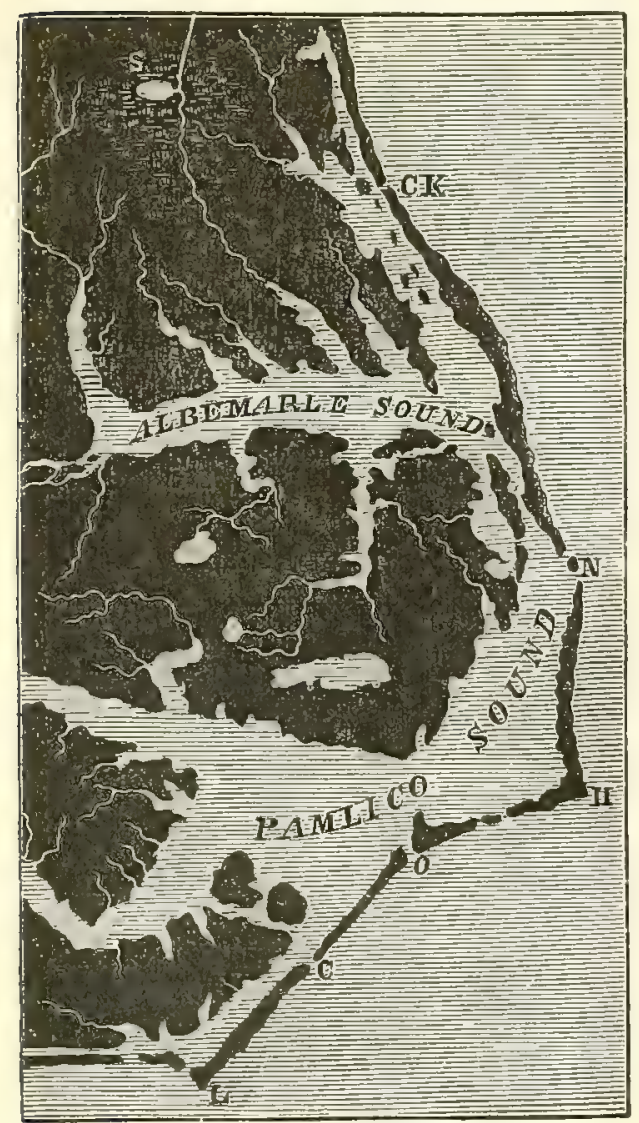

Coast-region of North Carolina; CK, Currituck Inlet (to Currituck Sound); N, New Inlet; $\mathbf{H}$, Cape Hatteras ; $\mathbf{O}$, Ocracock Inlet; C, Cove Inlet; L, Cape Lookout. current, continued through both the ebb and flow of the cide, as long since explained by Bache. The drift of the Atlantic coast is here carried to the very margin of the deepest ship channel out of New York Bay. The hook-like shape of the extremity may be due to drift in the Long Island direction where that of the New Jersey direction is forced to stop.

Fig. 196 is a map of the coast-region either side of Cape Hatteras (H). Along the coast south of New York the rivers carry out a large amount of detritus, which is widely distributed, but the coarser is gathered up by the waves to make the barriers. The position of the cape was probably determined by a cape of rocky ridges which is now submerged. Off the great Middle Bay of the Atlantic coast the storm-winds have their greatest velocity when blowing from the eastward - as they do at the Bermudas; and hence the course of the wave-and-current movement is toward New York Bay, both along southern Long Island westward and from Cape Hatteras northward. South of Cape Hatteras $(\mathrm{H})$ the drifting is, for a similar reason, southwestward.

Examples of remarkable driftings of beach materials along the Atlantic coast are on record. A vessel, the "Sylph," was wrecked in 1814-1815 on the south side of Long Island, and materials from the wreck were drifted westward beyond Fire Island; and 7 years afterward her rudder was found 20 miles west of where she was lost. In another case, coal from the cargo of a vessel wrecked on the south side of Nantucket was carried eastward and then northward, and the keeper of the lighthouse of the north cape, called Great Point, supplied himself from it with fuel for the winter; and brick from another 
vessel pursued the same course. Again, an anchor with 10 fathoms of chain attached, from a brig of 200 tons wrecked on Cape Cod near Truro, was drifted a mile and a half to the north in three weeks. 'These facts are from papers by Lieutenant C. H. Davis (1849, 1851). Such transportation is beyond the power of any currents; it is the work of the dashing, lifting, and propelling waves.

In the following example, the change of position is connected with a change in the seasons. J. D. Hague states that at Baker Island (of coral), in the Pacific $\left(0^{\circ} 15^{\prime} \mathrm{N} ., 176^{\circ} 22^{\prime} \mathrm{W}\right.$. $)$, this fact is well exhibited. In Fig. 197, I, I, I is the southwest point of the island, and $R, R, R$, the outline of the coral-reef platform, mostly a little above low-tide level; its width, $c d, 100$ yards. In the summer season, when the wind is from the southeast, the beach has the outline $s, s, s$; during the winter months, when the wind is northeast, the material is transferred around the point, and has the position $w, w, w$, having a

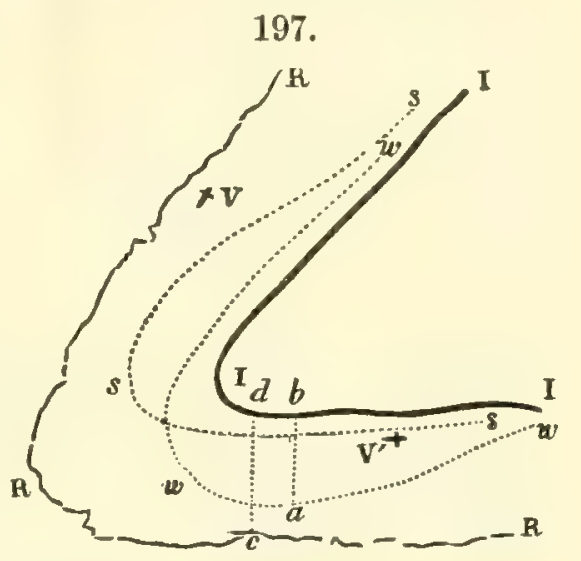
width at $a b$ of 200 feet. A ressel wrecked in summer, and stranded at $\mathrm{V}$, was transferred to $\mathrm{V}^{\prime}$ in the course of the month of November. (J. D. Hague, '62.)

6. Sand-bars at the entrances of harbors or mouths of tidal rivers. - The material of the sand-bars which obstruct the entrances of harbors has two main sources: an inner, and an outer; the former fluvial, the latter the waveand-current driftings of the coast, which contribute so largely to sand-barriers. The positions of the bars depend much on the strength of the river current; but also on the direction, form, and supplies of the wave-anc-current movement produced by the storm-winds. A small stream is often blocked entirely by a sand-bar across its mouths, so that the waters reach the ocean only by percolation through the beach. But large streams make distant sand-reefs or barriers through the aid of the outflow, and keep open channels even in the face of the ocean.

The depth of water over the sand-bars at the mouth of a large river or bay is, in great part, only 3 to 10 feet: a remarkable fact, considering the opposing forces at work - the tidal outflow and inflow, and the plunge of the storm-made waves over the mobile sands. The sands lie along the area of rest between the contesting movements. New York Bay (map, page 211) affords an example. The contributions of river sediment come from the Hudson River and from small New Jersey rivers; and the Hudson is moderate in its supplies, considering its length and size, because it has almost no tributaries for 60 miles, and small ones for 100 miles, owing to the westward dip of the Catskill strata and the barrier of the Palisades in the southern part. The wave-and-current supplies come from the direction of the Long Island and the New Jersey coasts; for New York Bay is exceptional in lying to the leeward of both coasts. Under these circumstances, Sandy Hook, the sand-bars, and the barriers of the Long Island coast adjoining, have been accumulated. The outlining of the bars, and the positions of the three channels through them, are mainly due to the tidal outflow, which DaNa's MANUAL - 15 
includes, besides the tidal waters of the bay and river, the river waters of the Hudson and of the New Jersey streams, with the important addition of the high-tide overflow from Long Island Sound; and the southern channel into the bay is the deepest, apparently because the New Jersey streams empty into the lower bay nearly abreast of this entrance. Large tidal grounds about a harbor are more essential even than a great river for the best conditions of harbor entrances; and any encroachment on the limits in New York Bay is carefully guarded against. The depth over the surface of the bars is mostly between 3 and 10 feet.

198.

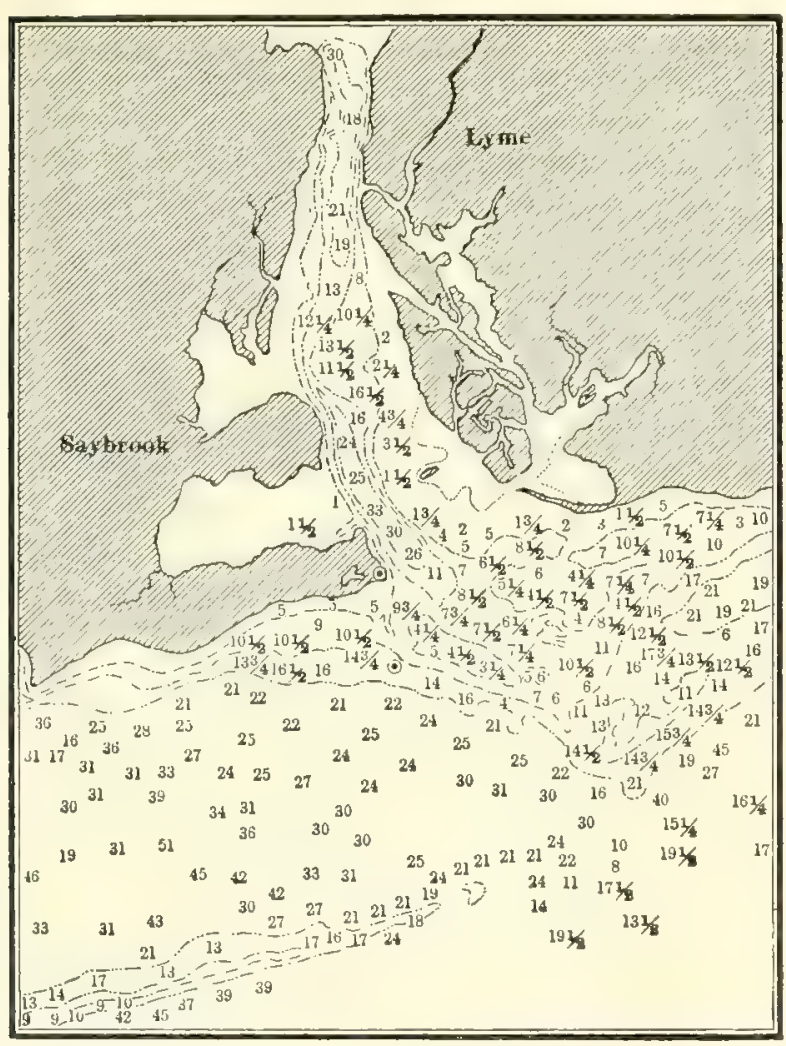

Mouth of Connecticut.
199.

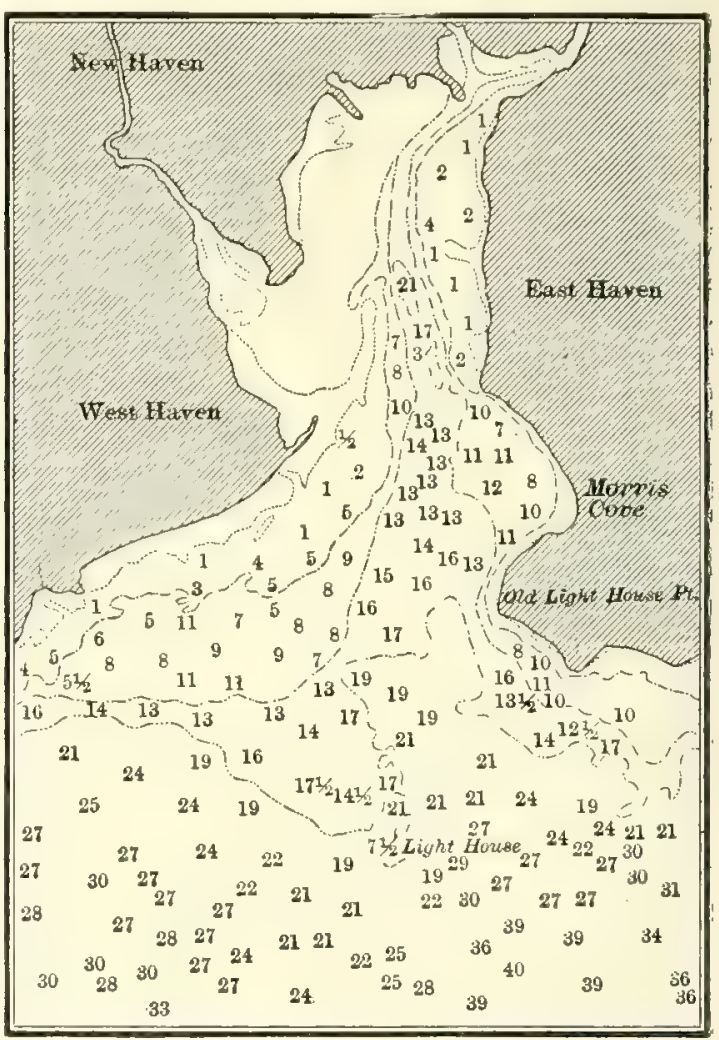

Harbor of New Haven.

Over the bars at the mouth of the Columbia River, Oregon, occurs the same small depth. A vessel ran aground on the outer bar on July 18, 1841, and, after passing a night of calm weather, but of heavy and disastrous tossings as the waves of the Pacific rolled in during the progress of the rising tide, lay quiet at daybreak when the tide was out, fixed in the sands, with a belt of dry sand around her. The next day, she was an abandoned wreck. (D., Notebook, 1841.)

The mouths of the Connecticut and Housatonic rivers, and New Haven Harbor, whose positions are shown on the map on page 211, afford excellent illustrations of this subject. The depths in the figures are in feet; the lines mark depths of $6,12,18$, and 24 feet.

The mouth and sand-bars of the Connecticut River are represented in Fig. 198. The river is the largest of New England, and supplies abundant water and much sediment. 
But the wave-and-current drift, moving westward, finds its mouth open; and the sand-bars there made are so high and large that the greatest depth in the channel at low tide is only 7 feet.

The mouth of the Housatonic River, west of New Haven (a stream 100 miles long) is in a worse plight; for it gapes open directly eastward and faces the drift movement. The greatest depth over the bar at low water is consequently only 3 feet. The tide is 7 feet; but the tidal grounds are small.

The harbor of New Haven (Fig. 199) receives 3 rivers, the longest only 35 miles. But, in contrast with the other cases, there is a prolonged eastern cape of gneissoid granite, and this forces the wave-and-current drift to take a course more to the southward over deeper water. The drift chokes up the mouth of "West River" (the westernmost of the three), but leaves the rest of the harbor mostly unharmed. Although the tidal grounds are not large, the entrance to the harbor has a depth over the bar of 20 feet; and this it owes chiefly to its eastern cape.

Harbor-improvement. - The principle at the basis of improvements of harbors at the mouths of tidal rivers is made plain by the preceding illustrations. It requires that there should exist for each the largest possible 200.

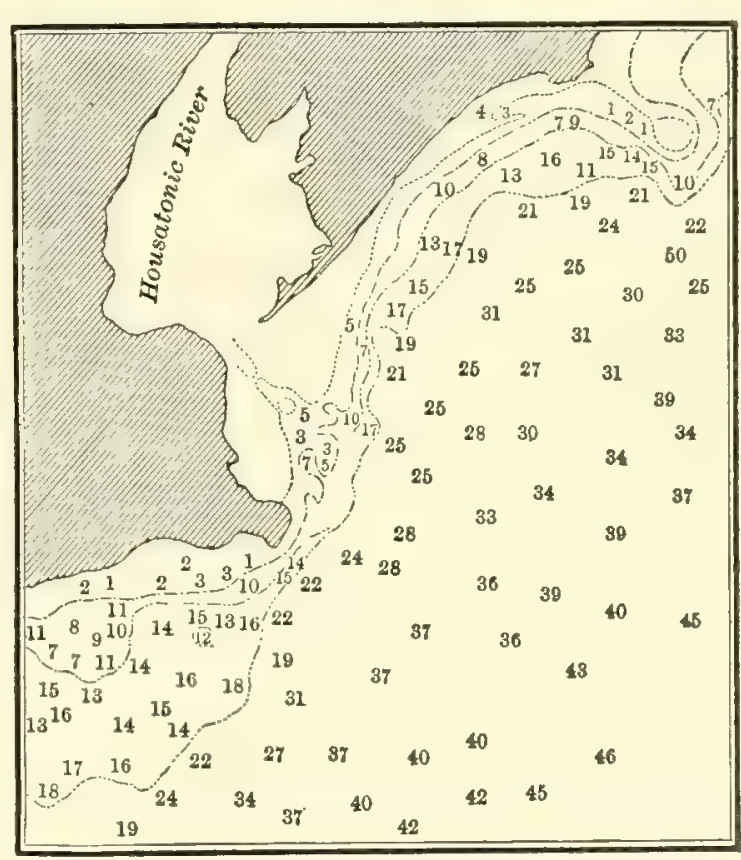

Mouth of the Housatonic. tidal grounds, in order that there may be the largest possible outflow of waters for channel scouring; and where not existing, that they should be obtained by the construction, from the capes either side of the entrance, of a breakwater or levee as far out as the depths will allow; that the breakwater should rise so little above low-tide level that the tide may freely enter over it and fill the bay ; that the windward side of the breakwater should have such a position and extent as will carry the wave-and-current drift far enough out to clear the leeward cape, if possible. A harbor with a large breakwater receives great aid for channel scouring from the waters that are piled in by the storm-winds. These winds sometimes keep driving in water, and making an undercurrent out of the channel, through all states of the tide. As to one or more additional channels to the harbor, the engineer has to decide after examination. In the case of a tideless river, like the Mississippi, the channel may be improved by embankments alongside of it; but not so that of a tidal river.

The harbors made by coral-reef barriers about Pacific islands are in accordance with the best models; and an atoll with a ship entrance to the lagoon is such a harbor isolated in midocean. The outflowing tidal waters keep the channel in good condition.

The formation of sand-bars in Long Island Sound, and the variations in depth, are due mainly to variations in the velocity of the outflowing tide, as partly explained on page 216, the rivers being the chief source of new material. But the position of the deeper channel has come down to a large extent from preceding geological time, and especially from the Glacial and Champlain periods, when depositions were on an enormous scale. In other cases over the coast region the shoais indicate the forms, and partly the positions, 
of former emerged land. Moreover, the eddying of the wave-and-current flow about islands has made long spits as prolongations of their points or capes.

7. Action of the oceanic waters over a submerged continent, and during a progressing submergence or emergence. - Were a slowly progressing submergence of a continent, or of any large part of one, in progress, the waves and marine currents would work over the loose earth, gravel, and alluvium of the surface, thereby changing them into marine deposits; the living species of the land and the fresh waters would be destroyed, and marine life would be introduced; and the general features of the surface would be changed through a wearing off of heights and a flling of preëxisting valleys, and not by the excavation of valleys. It might be supposed, at first thought, that the ocean would wash through the valleys with great excavating force, and make deep gorges over the surface. But from the present action on seacoasts, it is learned that with each foot of submergence, the seabeach would be set a little farther inland, so that the whole would successively pass through the conditions of a seashore. The salt waters, in fact, enter the river-valleys of a coast but a short distance, because they are excluded by the outflowing stream. During a progressing submergence, therefore, the ocean would have no power of excavating narrow valleys, unless they happened to be open at both ends and of great breadth and depth, so as to allow the oceanic currents to sweep through.

In a subsequent emergence, the mountains and ridges would be still further degraded, and the valleys filled by their debris. The laws of seacoast action would again come into play, and the wear of all new headlands and the filling of bays would continue to be the result, so long as the emergence was in progress.

If the continent were to a large extent without mountains, as was the fact in early geological time, the broad flat surface might then lie slightly above or below the tide-level at once, or nearly simultaneously, so that, under a small change of level, the waves might sweep across the whole area and the deposits have a continental extent. Through continental oscillations, causing slight emergences of large areas to alternate with varying submergences, variations in the formations would be produced, differences of depths and differences of currents causing transitions from arenaceous to argillaceous or to pebbly accumulations, or to clear waters fitted for corals and the other life which has contributed to limestone-making.

Evidence of emergence or elevation is to be looked for in the presence of stratified beds containing marine fossils; and when no such evidence exists over a country, the proof is defective, so much so, that facts from elevated, beach-like accumulations or terraces of sand or gravel are not worthy of much consideration, unless on land fronting the seashore. The sea-border animal life readily moves in when a submergence is in progress; for each species has its limits in depth and must move or die, and ova float landward with the waves and currents; hence fossil-bearing, sea-border deposits would 
be sure to form in favorable places. On the emergence, these deposits. remain to mark progress. Beach-like deposits are readily made by rivers. and on lake-shores.

\section{Work in the Ocean's Abyssal Depths.}

The bottom of the ocean, down to about 15,000 feet, has its abundant life, and besides is ever receiving relics in great profusion from the pelagic life of the waters, and thus it may over large portions be making limestones and flint-beds; but it is poor in other geological work. It feels the movement of the tidal wave, and also that of the polar flow toward the equator, each under the ocean's heavy pressure. But these are infinitesimal sources of force, and have, therefore, no sensible, mechanical effects, either in the way of transportation or abrasion. The near convergence of ridges that could bring the waters passing between them into a working condition does not exist.

There are hence no means of producing a stratified or bedded structure in the abyssal deposits, excepting earthquake vibrations, the results of which would be local, and variations, with the passing ages, in the pelagic or abyssal life of the waters, causing variations in the showers of Diatoms or of shells of Rhizopods, or in the growth of Sponges and other species over the bottom. The ride-spread contributions of volcanic ashes from volcanoes, especially the oceanic, drop to the bottom and rest there, undergoing only such chemical changes as may go on at the temperature.

Tidal or current scour is limited to relatively shallow depths or unusual conditions. Mellard Reade mentions cases of probable tidal scour at bottom in channels between islands on the coast of Scotland. But the depths do not exceed 800 feet. He also reports (1885) that, according to Sir James Anderson, the undercurrent out of the Mediterranean near Gibraltar moves the water to its bottom, and that at 500 fathorns the wire of the electric cable was ground like the edge of a razor, so that they had to abandon it and lay a new cable well inshore. This is confirmed by Captain Nares, who reports that he could get no specimen of the bottom probably because of a "perfect swirl at that depth."

The great oceanic currents carry on little transportation and corrosion of detritus, on account of their distance from the land. The Labrador current, with its westward tendency (page 46), acting against the submerged border of the continent, may have produced some results in past time, if not doing so now. But its chief geological work has been the transportation of icebergs, and that has not yet ceased. It has been supposed that the course of the steep outer slope of the submerged Atlantic border has been determined by the oceanic currents; but it is far more probable that the position of the slope has directed the courses of the currents. The Gulf Stream along the Florida Straits and toward Cape Hatteras has a velocity sufficient for abrading action; but the stream does not carry its surface velocity to the bottom, 
even in the Florida Straits. Over a portion of the "Blake plateau," a region southeast of Georgia, between the lines of 100 and 600 fathoms, the bottom is "clean of mud and ooze, and almost so of living species"; and A. Agassiz has hence suggested that abrasion by current action may be going on over it. It is a question for investigation.

The bottom of the Atlantic Ocean, south of Newfoundland and thence southwestward, has received droppings of stones, gravel, and earth from icebergs, and the deposits of the Glacial period extend some distance south of the latitude of Cape Hatteras. They consist of sand, stones, and some large bowlders of granite and other rocks. The "Challenger" expedition dredged up a 500-pound bowlder of syenyte in this region near latitude $41^{\circ} 14^{\prime} \mathrm{W}$., from a depth of 1340 fathoms (Murray, 1885). "The "Albatross," of the United States Fish Commission, obtained granite bowlders of 50 pounds near $71^{\circ}$ $72^{\circ} \mathrm{W}$. and $37^{\circ} 40^{\prime} \mathrm{N}$. (Verrill, 1884). In the Glacial period, even New York Bay, and perhaps Delaware Bay, discharged icebergs for transport by the Labrador current to a melting region on the borders of the Gulf Stream. On the east margin of the Gulf Stream, in 2000 fathoms, the dredge has found, as Verrill states, only the usual Globigerina ooze, and farther south toward the West Indies, the bottom is no less free from continental debris. But the modern era has its new element, which has made exceptions possible over all the ocean.

Owing to the presence of Man in the world, whose life is on the waters as well as the land, the bottom deposits have been found in one case to afford a dredge-load of red bricks. It was brought up from a depth of 1037 fathoms (nearly 10,000 feet) in the Atlantic in latitude $39^{\circ} 3^{\prime}$ and longitude $70^{\circ} 51^{\prime}$; and Professor Verrill, the reporter (1884), remarks that the bricks were probably from the used-up furnace of a returning whaler, and were thrown overboard when nearing home after a whaling voyage.

We are led by the facts to the belief that in the cold, dark, still, abyssal depths, through which transportation is reduced to descent by gravity, ooze, sprinkled with volcanic ashes for concretion-making, is the substitute for sand, gravel, and mud; and where the means of biological progress are simply strife for food and mate and physiological response to living work, there is excessively slow and feeble geological change.

\section{FREEZING AND FROZEN WATER: GLACIERS, ICEBERGS.}

Water performs part of its geological work in the act of freezing, and another part when frozen, in the condition of snow and ice.

\section{WATER FrEezING.}

1. Displacement and fracturing. - Since water on becoming ice, at $32^{\circ} \mathrm{F}$, increases in volume about $\frac{1}{11}$, or lineally about $\frac{1}{35}$, and diminishes in density to 0.92 , whenever freezing takes place in crevices, it opens and deepens them, 
and thus carries on a process of displacement and destruction. It tears to pieces rifted, jointed, and laminated rocks, often separating large masses; and as most rocks absorb moisture at the surface, if not also through the mass, few escape disintegration by this means when exposed to icy weather. Hence rocky bluffs in cold latitudes have usually a talus of broken stone, while, in the tropics, this source of fragments fails. This kind of degradation has produced much of the earth and coarser loose material of the globe.

The divellent effect of freezing in fissures may be increased by an addition to the ice first formed in the fissure through water taken in between the ice and the rock. The same interstitial process often goes on beneath the stones of a pebbly soil, and ends in lifting them out of the ground, to a height of an inch or two, each on its own ice-column. The process serves to bring the stones to the surface, and thus has an assorting effect.

As a body of water 35 feet wide will make a volume of ice a foot thick and 36 feet wide, the freezing of the surface of small ponds brings pressure against the sides, or their rocks, and shoves loose stones up the shore, making a low rampurt. It also causes fractures and ridges over the surface of the ice. Freezing usually begins about the shores, and in its expansion this littoral belt of ice slips over the water, and only the central portion, which becomes frozen later, is thrown into a strain.

2. Downward creeping of soils through freezing. - A displacement or creeping downward of the earth or loose material on inclined surfaces is a common effect of successive freezings and thawings, as well as of changing temperature and other causes. Interesting examples have been described from North Carolina by W. C. Kerr.

201.

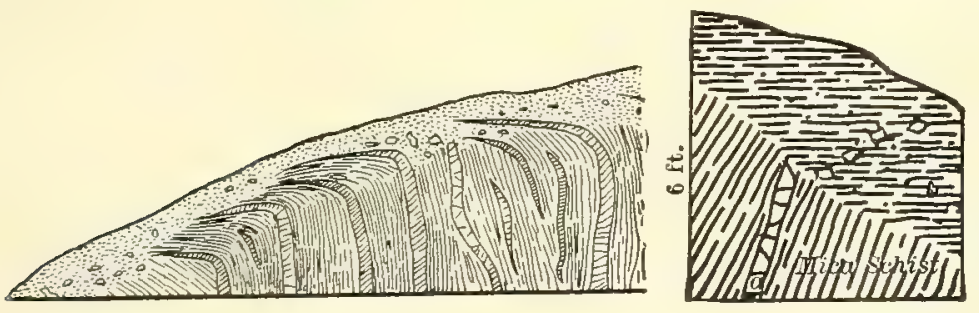

203.

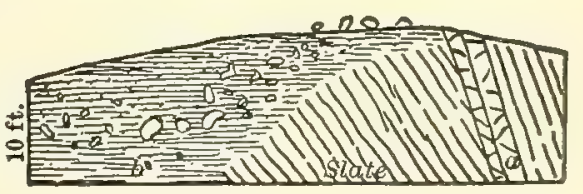

Displacement by the action of frost. Kerr, '81.

Fragments of quartz veins are here represented as traveling down the slope after becoming detached. In the first of the figures, the veins have received a bend downward through the decomposition of the rock, a mica schist, and the slipping movement also includes the soil. According to the experiments of C. Davison (1889), each freezing produces a slight upward movement, normal to the inclined surface, and the thawing, a vertical settling, and thereby a displacement downward. The deeper the freezing in any case, the greater would be the displacement. 


\section{ORDINARY ICE.}

1. Water frozen is rock. It may be rock of nearly pure ice, or a conglomerate or sandstone with a cement of ice. In this state its movements are those of rock-masses, and the effects depend partly on the material cemented.

2. The freezing along shores envelops stones and earth that lie above and below the water's surface or that may fall from adjoining bluffs. With a rise of the water, masses thus loaded may float off with the current, or may be driven up the land by a wind, and make heaps or ridges of stones. These effects occur on the borders of both rivers and lakes, and also along seashores. On the Newfoundland coast the shore-masses of ice, loaded with stones and bowlders, become very thick, and when struck by an ice-pack moving down from the north, are sometimes pushed a hundred yards up a shore; and their blows against the rocky bluffs often do great execution. On the other hand, cables and anchors at times make part of the cemented materials that are carried away from the shore (S. Milne, 1876).

3. Ice formed about stones over the bottoms of streams or lakes is called ground-ice or anchor-ice. It may thicken until the stones are floated, and drift away with the current down stream or up the shores.

Dams are made across rivers at narrows (as at the Delaware Water Gap) by ice-masses, when the ice-layer over streams becomes broken up, occasioning great floods over the regions above.

4. The impervious layer of ice and frozen earth, which sometimes covers many thousands of square miles in cold regions, gives waters derived from precipitation or melting easy flow from the hills to the rivers, absorbing nothing, and usually at a time when evaporation is at a minimum; and thus the greatest of river floods are produced. Further, waters beneath an icy crust, receiving accessions from meltings where rocks outcrop and become heated in the sun, may gather, in consequence of the confinement, into underground streams, and these streams will come to the surface over any spot not frozen, as the cellar of a house, and other places protected from the cold.

5. The ice-layer on a steep slope, enveloping, it may be, much gravel or earth, may slip down as a mass, in a creeping way or abruptly, when the material underneath is much wet, making landslides.

The columnar structure characterizing ice is partly the occasion of its sudden disappearance from lakes in the spring. Totten states (1859), respecting the phenomenon on Lake Champlain, that in the progress toward melting, the ice (one to two feet thick) becomes changed into an aggregation of vertically prismatic crystals, somewhat irregular, which touch only at points and on the edges; and though still appearing to be solid a cane may be shoved through it. In this state, a heavy wind makes the ice of the whole lake vanish in a few hours. The thickness of the disappearing ice may be known from the broken ice left in prismatic fragments fringing the shores. 


\section{Glaciers.}

\section{General Features and Formation of Glaciers.}

1. Nature of glaciers. - Ordinary glaciers are accumulations of ice of sufficient size to flow down from snow-covered elevations. They are ice-streams, 100 to 1000 feet or more in depth, fed by the snows and hoar frost of extensive areas above the limits of perpetual frost. The half-compacted snow of the source is the névé of the Swiss, the firn of the Germans. These fields stretch on from 1000 to 7500 feet below the snow-line, because they are masses of ice so thick that they are not entirely melted during the summer season. Some of them extend down between green hills and blooming banks into open cultivated valleys. The extremities of the glaciers of the Grindelwald and Chamouni valleys lie within a few hundred yards of the gardens and houses of the inhabitants.

Each glacier is the source of a stream made from the melting ice. The sub-glacial stream begins high in the mountains, from the waters that descend through the ice; finally, it gushes forth from its crystal recesses, a full torrent, and hurries along over its stony bed down the valley.

An avalanche is a mass of ice, snow, water, mud, and stones sliding with crashing sounds from some point high up on the side of a mountain; a glacier is ice flowing slowly from a perpetual source. Between the two there are small glacier patches, lodged in steep valleys, called hanging-glaciers that never move far enough to gain a descent.

As in the case of rivers: (1) glaciers depend for formation and size on the amount of precipitation, and on the size of the drainage area; (2) they take possession of all the valleys of a mountain-region and flow down slopes of all angles; (3) the ice-streams of the upper valleys combine, like so many tributaries, to make the large ice-courses or trunk-glaciers; $(4)$ they suffer loss from evaporation.

But unlike rivers : (1) glaciers require for origin a region extending above the limit of perpetual snow; (2) they require for commencement of flow a large accumulation of the material of a stream; (3) the conditions for increase are best when the yearly precipitation is largely snow. Moreover, (4) the drainage areas are always small compared with those of rivers. The Aletsch, the longest glacier of the Alps, and according to Tyndall the grandest, ends in less than 15 miles; and no glacier outside of Greenland and the Antarctic region exceeds 60 miles in length. Further, (5) they often have confluent heads in a snow and ice region, and may have nearly universal confluence over a continent, as in a Glacial era.

The limit of perpetual snow, above which lie the snow-fields of the source, is in general near the line of $32^{\circ} \mathrm{F}$. for the mean temperature of the summer. But it varies with the precipitation; for if this is small, the snows of winter may be mostly melted by the heat even of a cool summer, and the limit may be much above the summer line of $32^{\circ} \mathrm{F}$., while, on the contrary, if very 
large, the snows may be permanent far below the line even if the summers are warm. In accordance with this principle the snow-line in wet southern Chile is 6000 feet lower than it is in corresponding latitudes in North America, and 3000 feet lower than in Europe; and in dry northern Chile, in latitude $33^{\circ} \mathrm{S}$., it is as high as it is 15 degrees farther north (Buchan).

But exceptionally snowy winters followed by a succession of two or more cool summers may make accumulating deposits of snow in some shaded valleys of high mountains that are much below the normal limit of perpetual snow, and produce temporary accumulations of ice that have incipient flow - a fact observed in the White Mountains, N.H.

The height of the line of perpetual snow is $18,500^{\prime}$ in the western Cordillera of the Bolivian Andes near the equator, and $15,920^{\prime}$ in the less dry eastern; $12,980^{\prime}$ on the south side and $16,680^{\prime}$ on the drier north side of the Himalayas ; $12,780^{\prime}$ in the Chilean Andes, near Santiago ; $14,760^{\prime}$ in Mexico ; about $13,000^{\prime}$ in Teneriffe ; $8400^{\prime}$ on the northern and $8800^{\prime}$ on the sunnier southern or Italian slope of the Alps; $5000^{\prime}$ in Norway; $3000^{\prime}$ in Lapland ; $5500^{\prime}$ in Alaska; about $2000^{\prime}$ to $2200^{\prime}$ in Danish Greenland, where the mean annual temperature at the sea level is between $13^{\circ}$ and $33^{\circ} \mathrm{F}$., it being, according to Rink, at Upernavik, in $72^{\circ} 48^{\prime} \mathrm{N}$., $13.3 \mathrm{~F}$; at Jakobshavn, in $69^{\circ} 14^{\prime} \mathrm{N}$., $22.6 \mathrm{~F}$; at Godthaab, in $64^{\circ} 8^{\prime} \mathrm{N} ., 27.8 \mathrm{~F}$; at Lichtenau, in $60^{\circ} 31^{\prime} \mathrm{N}$., $33.2 \mathrm{~F}$; the annual range of monthly means, at Jakobshavn, being $0.3 \mathrm{~F}$. to $45.3 \mathrm{~F}$., and at Godthaab, $11.8 \mathrm{~F}$. to $48.4 \mathrm{~F}$. The temperature of the soil 4 feet under ground at Godthaab varies during the year between 31.5 F. (in March) and 40.1 F. (September).

Lowering the mean temperature of a place, by cooling the summers, lowers the glacierlimit. Great Britain and Fuegia (Tierra del Fuego) are in nearly the same latitude; and yet, in Fuegia, the snow-line is only $3000^{\prime}$ above the sea. If, by any means, the climate of Great Britain could be reduced to that of Fuegia, it would cover the Welsh and Irish mountains with glaciers that would reach the sea, the snow-line being but $1000^{\prime}$ to $2000^{\prime}$ above it; and the same cause would place the snow-line in the Alps at $5000^{\prime}$ to $6000^{\prime}$ above the sea, instead of $8400^{\prime}$. This change of temperature involves a removal of tropical sources of heat, or an increase of aretic sources of cold.

The length of flow of a glacier before it melts away depends mainly, as stated above, on the thickness of the ice-mass, and largely because ice cannot melt without absorbing an amount of heat sufficient to raise the temperature of a like quantity of water $143^{\circ} \mathrm{F}$, the latent heat of water. As a consequence of this, an ice-mass has a thin layer of cold air about it; and if also covered by earth, to shut off the winds that aid evaporation and also to protect it from the sun, the permanence is greatly increased. An ice-house affords a familiar example; and others are the dirt-covered masses of ice only a foot or two thick that linger on the north side of houses at times from winter into April in the middle latitudes of eastern North America.

In the Alps the glaciers extend down 4500 to 5300 feet below the snowline. The snows of the glacier-source in the mountains take the half-compacted condition of the névé for a distance above the snow-line as far as there are seasonal or other alternations in temperature sufficient to produce occasional meltings. Over the snow-fields, the extreme cold of winter is followed by months of less stringent weather, and by meltings that send water down through the mass and make it coarsely granular and more or less 
firm. The accumulations are stratified, because made from a succession of snow-falls. Surfaces exposed during the intervals between the falls become hardened and often sprinkled with dust, and, in some regions, covered with growths of the minute Protococcus. It may be made straticulate also through the drifting of the snow. Gradually the lower part of the névé becomes consolidated into stratified ice. Besides the dust from the winds, the névé may also contain earth and stones from avalanches; but it has no surface accumulations of stones, because those that fall upon the névé sink into it.

$204-208$

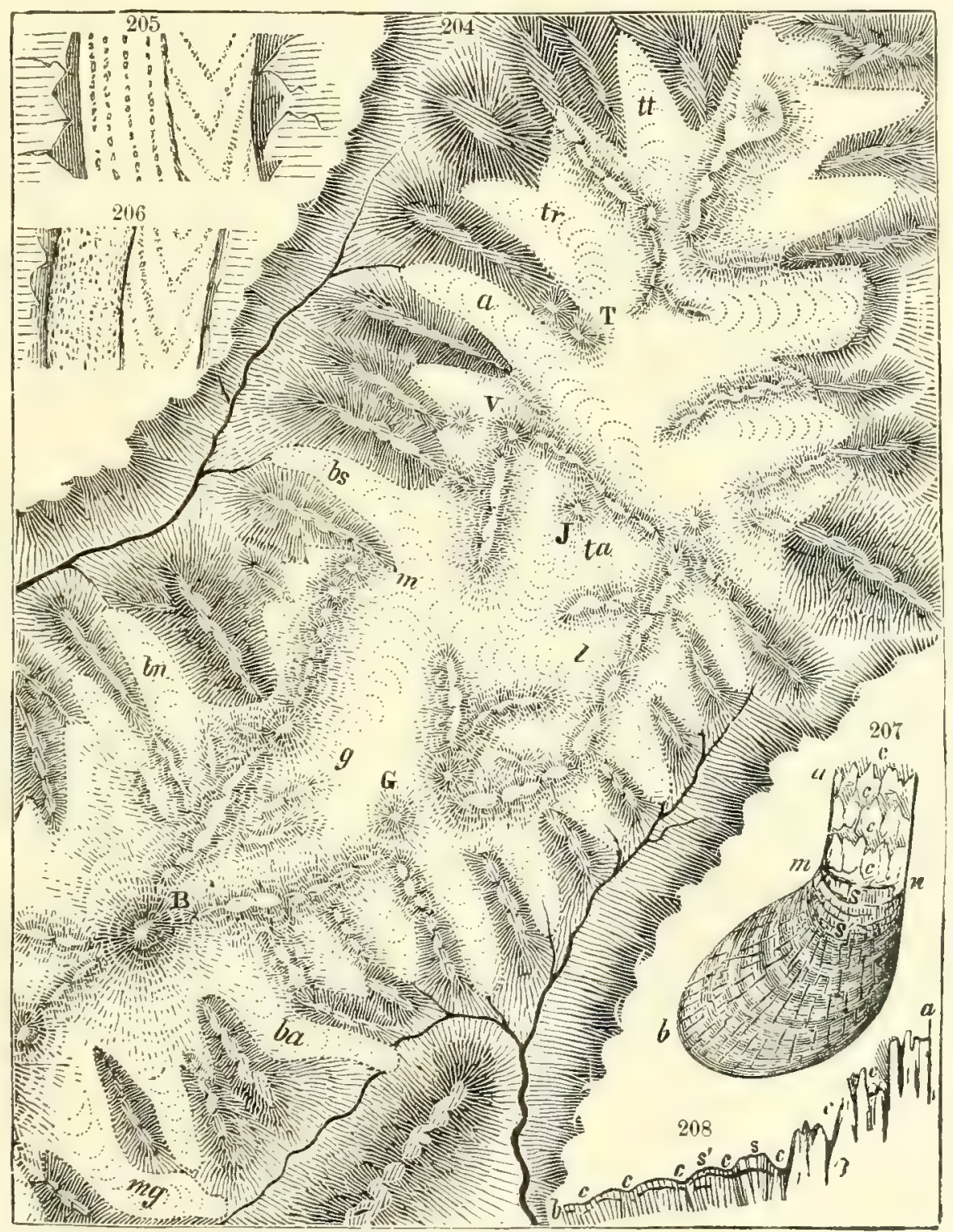

Fig. 204. - Part of the glacier-district of Mont Blanc, the lighter middle portion of the map 16 miles long out of 22 miles, the whole length ; river on the northwest side, the Arve, in the valley of Chamouni, and those on the southeast side, tributaries of the Dora Baltea; B, Mont Blanc; G, Aiguille du Géant; J, the Jardin; T, Aig. du Tour; V, Aig. Verte; $a$, Argentière Glacier; $b a$, Brenva Gl.; $b$, Bossons Gl.; $b s$, Bois GI.; $g$, Géant or Tacul Gl.; $l$, Lechaud Gl.; $m$, Mer de Glace, upper part of the Boir Gl.; $m g$, Miage Gl.; $t a$, Talère G1.; $t r$, Tour Gl.; $t$, Trient Gl.

Fig. 205. - Section of the Mer de Glace, near $m$ of Fig. 204, or opposite Trélaporte; 206, section of same, near bs of Fig. 204, or opposite Montanvert; 207, view of the Rhone Glacier; 208, profile of same, c, $c$, etc., being the transverse crevasses, fading out, and becoming curved after passing the cascade at $m n$. 
Wherever the mass of the névé is sufficient to overcome the resistance to motion, the true glacier begins. The ice is porous, because made of more or less closely united grains. The grains, which are at first small, enlarge as the stream descends, and in the Aletsch glacier some become two to three inches in diameter. (Forel, 1880, 1890.) Moreover, the grains have a crystalline texture, as has been proved by examinations with polarized light.

The porosity of glacier ice is made manifest by pouring on it aniline purple or indigo sulphate; the liquid penetrates it and gives it a marbled appearance. The specific gravity of the iceberg ice off the west-Greenland coast has been found to be only 0.866 , owing to its abundant linear cells (Helland, 1877).

2. Glacier regions. - In further illustration of the general characters of glaciers, reference is first made to the Alps, the best known of glacial regions. The Swiss Alps are divided into northern and southern ranges by the east-and-west part of the valley of the Rhone, and the continuation of the depression westward along the Trient and Chamouni. In the southern range are two glacier regions, the western, of Mont Blanc, and the much

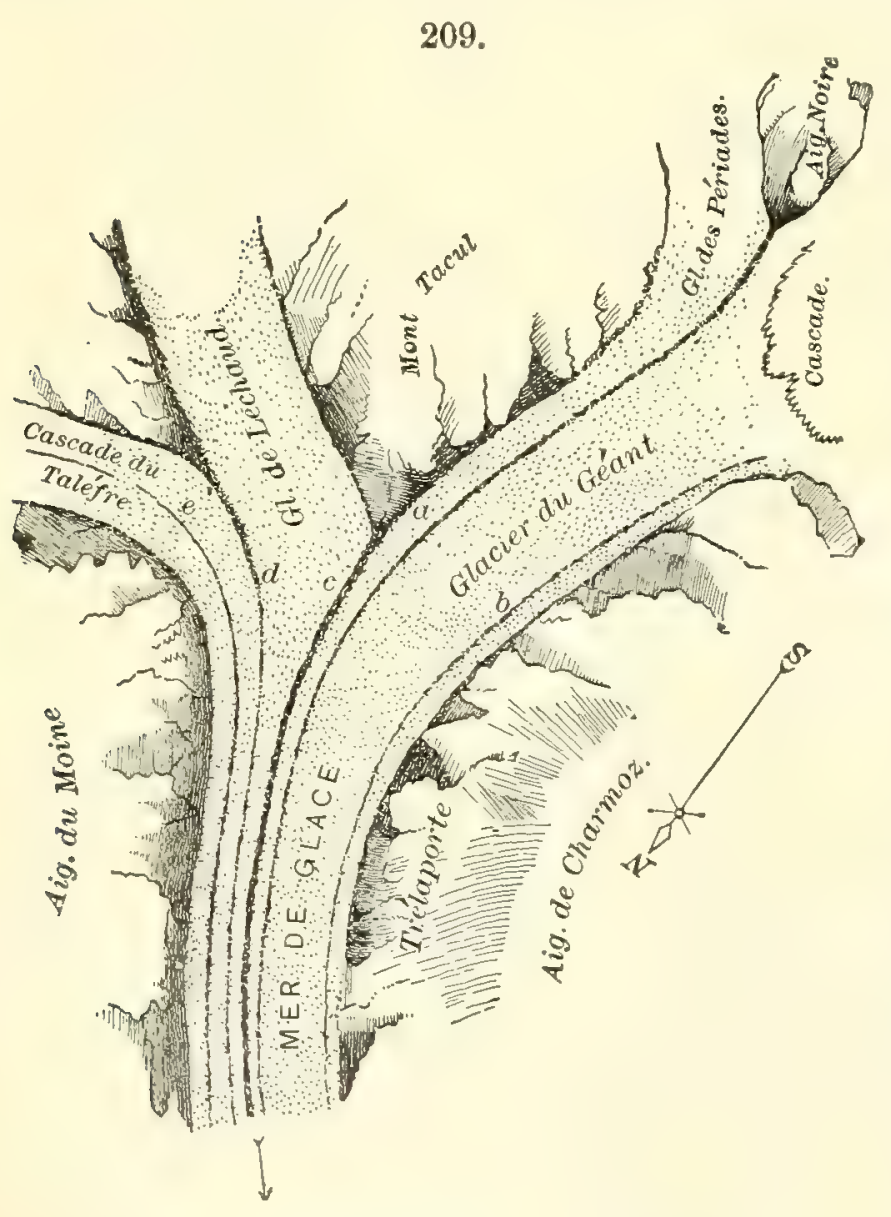

Union of the glaciers. Tyndall. larger eastern, of Monte Rosa, besides some much smaller areas. Mont Blanc has a height of 15,784 feet, and Monte Rosa of 15,163. In the northern range, there is the glacier region of the Bernese Alps (so-named from the Canton of Berne), in which stand the Jungfrau, 13,671 feet high ; Eiger, 13,045 ; Finsteraarhorn, 14,026; and the Aletschhorn, 13,800 feet.

The map on page 235 represents the larger part of the glacier region about Mont Blane, with 30 to 40 of its 50 glaciers. On the northwest side is the valley of Chamouni, or that of the river Arve; on the southwest, Allée Blanche and Val Ferret, in Savoy. The summit of Mont Blane is at B. As just stated, each valley in the ice-covered

area has its glacier. The largest extends from Mont Blanc, northeastward to $g$, where it receives, and for the larger part is, the Glacier du Géant (G being the Col du Géant). At $m$, where it is the Mer de Glace, it receives 
the Lechaud Glacier ( $l$ ), and then becomes the trunk glacier, called the Glacier des Bois $(b s)$. The Lechaud Glacier has its tributaries, one of which is the Glacier du Talèfre $(t \alpha)$, on the border of which is the Jardin $(J)$. This union of tributaries is well shown in Fig. 209 (Tyndall), which is so labeled as not to require special explanation. The glaciers of the steeper and warmer Italian slopes, as the map shows, are relatively short.

The Monte Rosa ice-region has still grander glaciers. It is reached by a road from Visp, on the Rhone, 30 miles long, to Zermatt. Within it stand the Matterhorn or Mont Cervin, 14,780 feet high, the Breithorn, and other peaks, overlooking the Görner Glacier. Fig. 210 is reduced from a plate in Agassiz's great work on glaciers. The Görner Glacier comes in from the left around the Riffelhorn, while on the right a tributary glacier is received from the Matterhorn region.

210.

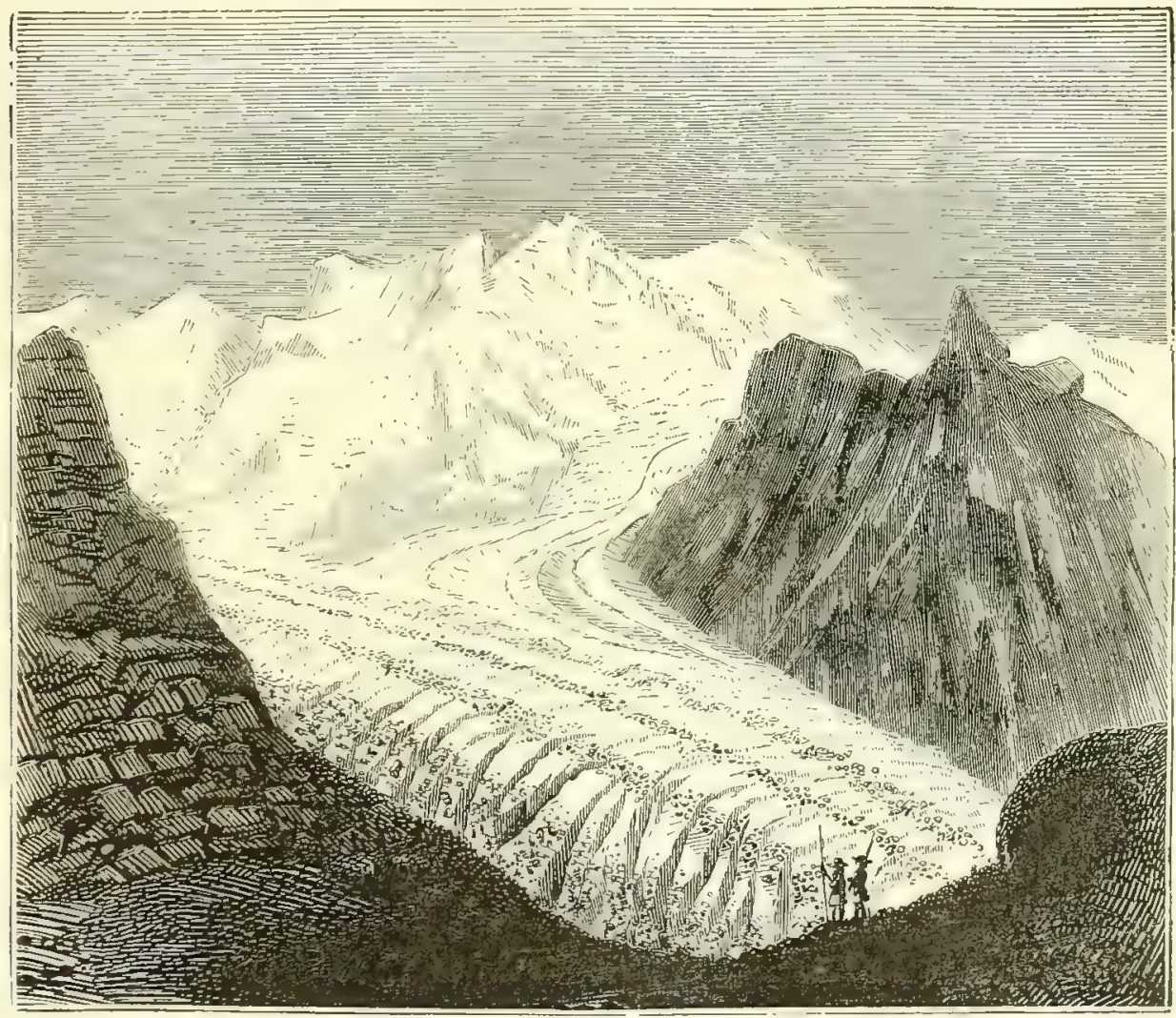

The Görner Glacier, with the Breithorn in the distance. Agassiz.

The glaciers of the Bernese Alps, like those of the Mont Blane and Monte Rosa regions, are largest over the Rhone valley slopes. The long river-like Aletsch and Viesch glaciers have their snow-field sources against the Jungfrau and other north-side peaks, and the former descends to within 4440 feet of the sea level. More to the eastward flow the two great Finsteraar and Lauteraar ice-streams, which unite a few miles from the Grimsel Hospice, to form the Aar Glacier, on which Agassiz made his observations. Sloping northward away from the Rhone valley, there are only 
small glaciers - the Grindelwald and some others. The reason for the difference in length between the glaciers on the Rhone valley slopes and on the slopes outside is therefore chiefly topographical, though temperature shortens the small streams on the Italian side.

3. Glacier Cascades. - The Rhone glacier, east of the river Aar, at the source of the Rhone, is a glacier-cataract (Figs. 207, 208, p. 235), and the Glacier du Géant, of the Mont Blanc region, is another. The descent of the latter is 140 feet; it passes from the plateau of the Col du Géant over a vertical rock-wall of the Tacul.

4. Glacier Lakes. - Against the east side of the Aletsch Glacier lies Lake Merjelen, a glacier-lake. Glacier-ice constitutes the western side or confining barrier of the basin, - which is there 150 feet deep, - and a moraine its bottom. Shiftings in the Aletsch Glacier empty the lake once in one to four or five years, deluging part of the Rhone valley.

The most accessible of the large glaciers of western North America is the grand Muir Glacier, described first by Professor Muir of California (1879), and later by Professor G. F. Wright (1886) and others. It descends to Glacier Bay, at the head of Cross Sound, in latitude $58^{\circ} 50^{\prime}$, and has a width at the sea level on Muir Inlet of about 5000 feet. Several streams are here united over a circ of 30 to 40 miles, the two principal coming from the northwest and north. In this direction is Mount Fairweather, 15,500 feet high, while Mount Crillon is to the south of west, 15,900 feet high.

The glacier had a front on the water in 1886 (Wright) 250 to 408 feet in height; but in 1890, of 250 feet as the maximum, there being evidence, according to H. P. Cushing, of some retreat as well as diminished height since 1886 , the retreat on one side amounting to 3000 feet (1891). On either side of Muir Inlet are mountains under verdure; those on the west reach a height of 2900 feet, while on the east stands Mount Wright, 3150 to 5000 feet. Over the latter are "large areas of flowers in full bloom," "blue-bells, daisies, buttercups, violets, the purple epilobium"; and, "on the north side of a slight elevation, great masses of snow were preserved in the very midst of these brilliant flower-gardens." (Wright's Ice Age.)

Other grand west-American glaciers are those of Mount St. Elias - an elevation over 18,000 feet high. The general features of the great Malaspina Glacier are shown on the accompanying map, from a paper by I. C. Russell. The glacier is named after Malaspina, who explored the coast in 1792. It is a great ice-plateau about 1500 square miles in area, and mostly 1500 feet above the sea level. The Seward Glacier, one of its feeders, is 50 miles long according to Russell, and the Agassiz and Guyot glaciers were given the same length by Schwatka (1886). From the point between the Seward and Agassiz glaciers, a high and broad medial moraine crosses the Malaspina Glacier to the moraine of the border - a large and in part forest-covered region of stones and earth. On the border of the Malaspina Glacier are many lakelets, like Merjelen, which crevasses occasionally discharge; and beneath it are drainage streams. (Russell, 1892.) 
Other glacier regions exist in the Austrian Alps, the Pyrenees, Norway, the Caucasus, Himalayas, New Zealand, the western mountains of South America, and on Greeniand and other lands in polar latitudes north and south.

211.

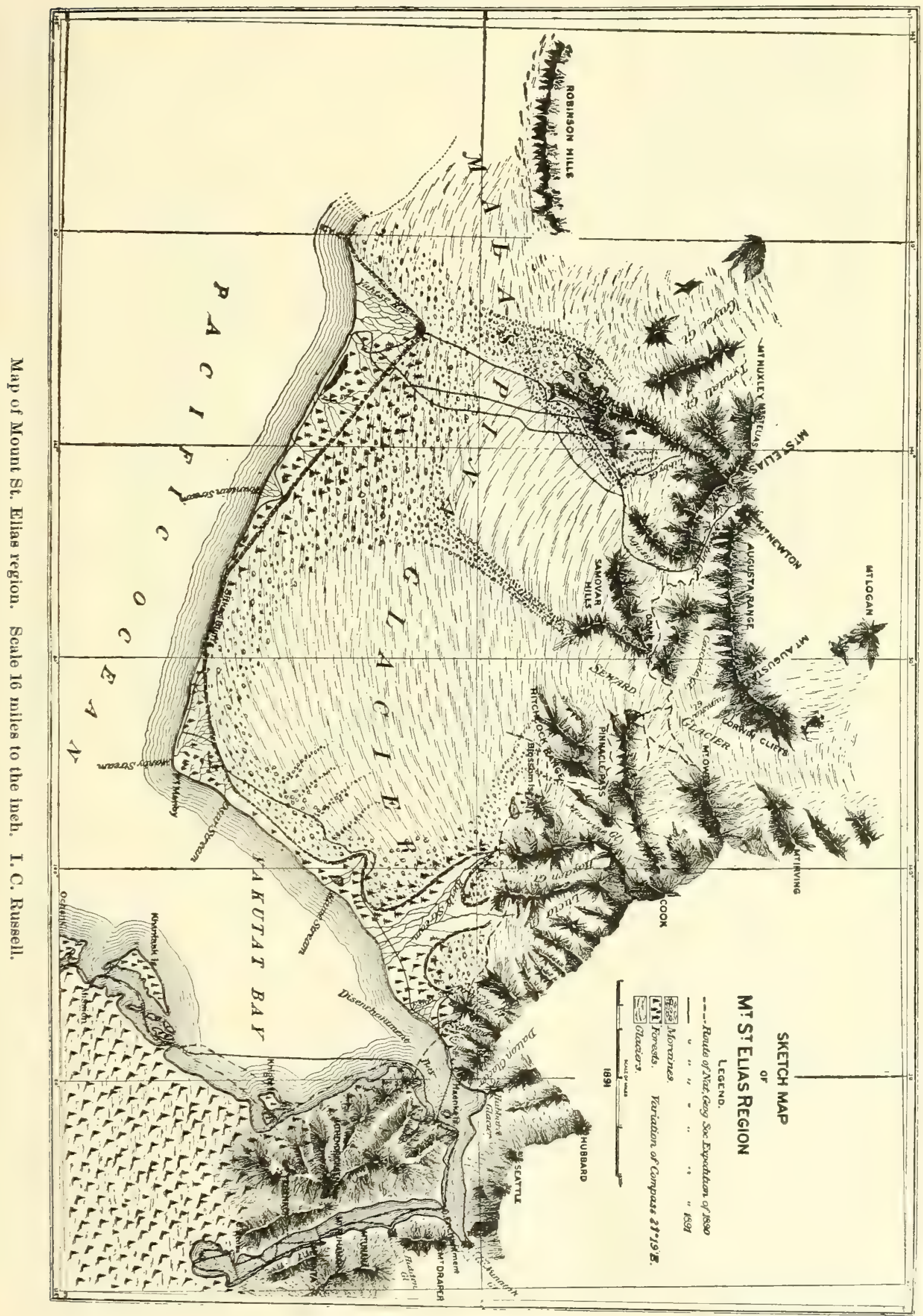


In the Himalayas, on the Bahio Glacier in the Mustakh Range, there are several large lakes spread over the middle of the glacier for 2 miles, some of them 500 yards long and 200 to 300 broad. (Godwin-Austen, 1879.) Colonel Tanner (1891) states that the glaciers of the Sat valley come down to the bottom of the valley, and "forests, fields, orchards, and inhabited houses are scattered about near the ice-heaps."

In South America, the glaciers of Fuegia, first described by Darwin, reach to the sea level. Glaciers occur at intervals northward along the Andes, and even under the equator.

In North America, the most southern glaciers are some of small size about Mount Lyell $\left(13,217^{\prime}\right)$ and Mount Dana $\left(13,227^{\prime}\right)$ in the Sierra Nevada; the length is from half a mile to a mile. (Muir, 1872 ; Le Conte, 1873 ; Russell, in an illustrated paper on the existing United States glaciers, 1885.) There is a small glacier also on Mount Shasta, Cal. (14,511', King, 1870), and others on Mount Jefferson (15,500') and Mount Hood $\left(11,225^{\prime}\right)$ in Oregon; and one of greater size about Mount Tacoma, 14,444' high, in Washington.

Farther north, on the same coast, glaciers are numerous. On the delta of the Stikine River, near latitude $57^{\circ}$, as first described by W. P. Blake (1868), are four glaciers, and one of these terminates in a bluff of ice nearly 2 miles long and $150^{\prime}$ high. Farther north are the Auk and Patterson glaciers, about latitude $58^{\circ}$, the Davidson Glacier, in $59^{\circ}$ $45 '$, and many others. Those about St. Elias are the largest glaciers in the northern hemisphere outside of Greenland and the Prince William Sound Alps.

North of Bering Strait at Kotzebue Sound, lat. $66^{\circ} 15^{\prime}$, the ice-cliffs are the edges of great sheets of ice, which extend far inland and have 2 or 3 feet of soil above, over which there is a luxuriant growth of vegetation. There are no mountains in the vicinity. (Kotzebue, 1818 ; Dall, 1880.)

Along the Rocky Mountains, small glaciers exist in the Wind River Mountains, at the head of the Flathead River in Montana, and north of the Canadian Pacific Railroad in the Selkirk Range, near the cut through the mountains. Near $54^{\circ} \mathrm{N}$. is the northern glacier limit in these mountains.

Greenland, about 700,000 square miles in probable area, has at least five sixths of its surface continuously covered with ice (Peary). The only part bare is a strip along the coast 30 to 60 miles wide on the west, and of less width on the east and north. Its annual precipitation is only 7 to 10 inches.

In the accompanying map of a part of western (Danish) Greenland, by Iieutenant Jensen (Fig. 212), the shaded part, to the left, is the sea (Davis Strait), which extends up into many of the fiords; the white part is the coast fringe, 30 miles or so wide, of bare land with its deep fiords; the black is a portion of the interminable ice-cap of interior Greenland; and the white spots in this part show where rocky peaks, called Nunataks in Greenland, project like islands through the icy surface, those at $J \mathrm{~N}$ to a height over 5000 feet above the sea, and 100 to 500 feet above the ice around. On these Nunataks are growing and flowering plants of the genera Ramunculus, Potentilla, Silene, Saxifraga, Papaver, Luzula, Oxyria, Trisetum, and others. The surface rises inland to 5000 to 10,000 feet, and the ice pushes shoreward. As it descends along the coast, valleys, or fiords, it takes the form of ordinary local glaciers, and such projecting portions are the so-called Greenland glaciers.

The larger glacier on the map, 10 to 12 miles wide, is the Frederikshaab Glacier; the arrows show the directions of movement in the ice. Another glacier occupies the head of the Björne Sund, or fiord. North of latitude $79^{\circ}$ 
20 , the Humboldt Glacier has a breadth on the sea of 45 miles. Over the interior ice there are small lakes and rivers; the latter plunge down crevasses to become underglacial streans. Thus, a large part of the fiords, on the west and east, and also on the north side of Greenland, as shown by Peary, are the courses of glaciers.

212.

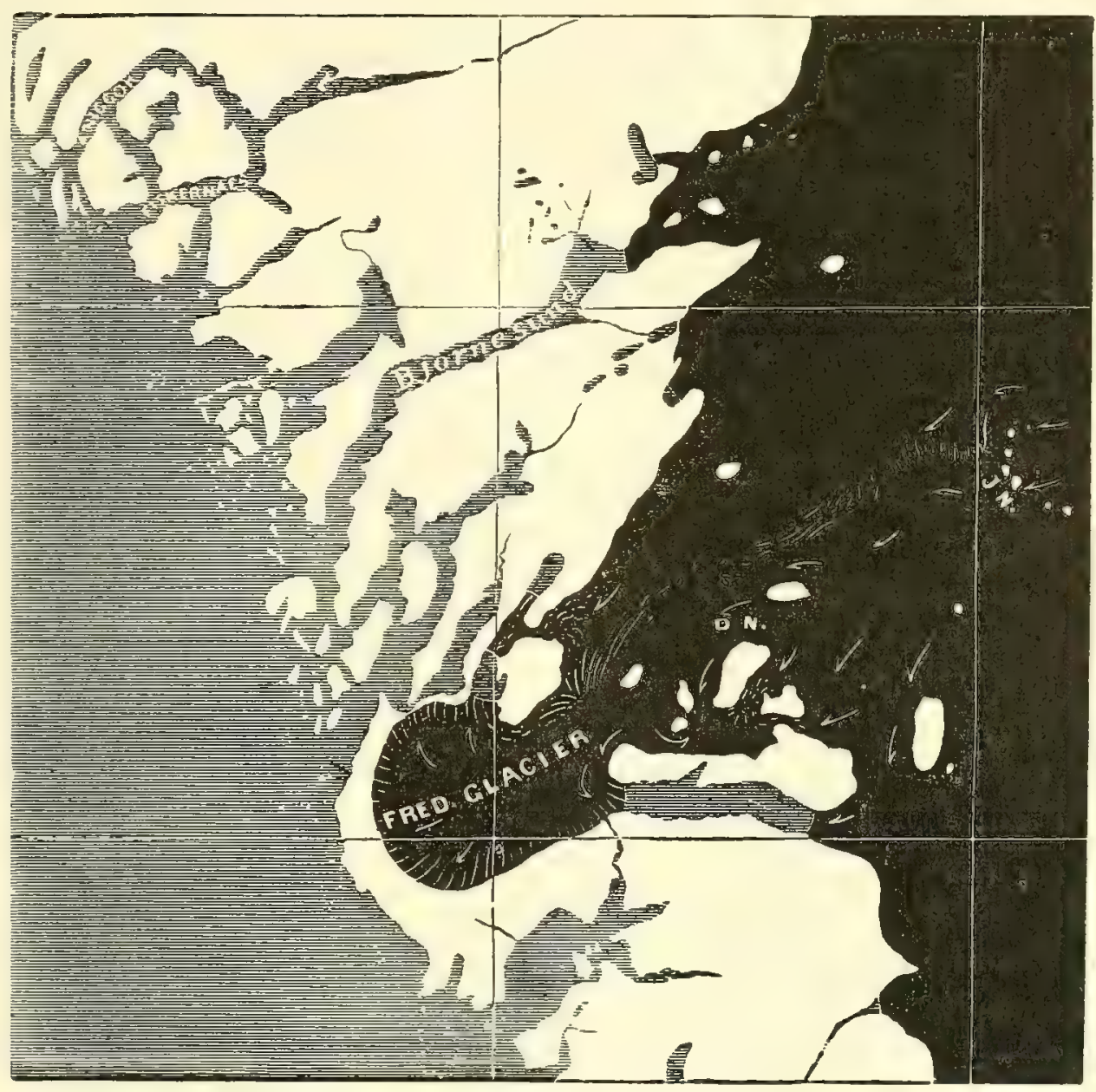

The black part, ice; white, land; shaded, water; J N, Jensen's Nunataks, or rocky peaks; D N, Dala. ger's Nunataks; white lines on the black, crevasses; arrows, glacier-flow. J. A. D. Jensen, '79.

The Greenland ice is in many places covered with a minute Alga, the Protococcus nivalis, and in some places so much of it lies together that it becomes putrescent. There is also much dust - the cryoconite of Nordenskiold - which may be of volcanic origin, and possibly from Hecla. An analysis of it obtained Silica $62 \cdot 25$, alumina $14 \cdot 93$, $\mathrm{Fe}_{2} \mathrm{O}_{3} 0 \cdot 74$, FeO $4 \cdot 64$, MnO $0 \cdot 07$, magnesia $3 \cdot 00$, lime $5 \cdot 09$, soda $4 \cdot 01$, potash $2 \cdot 02$, phosphoric acid $0 \cdot 11$, sodium chloride $0 \cdot 06$, water $3 \cdot 20$, which is near the composition of oligoclase with some hornblende, or pyroxene, and traces of other ingredients. Doctor Rink, the Danish explorer, says that out of the 10 inches of annual precipitation 25 per cent are needed to supply the loss from icebergs, and that the rest makes up the amount lost by evaporation and by the discharge of waters.

In the Antarctic regions, Captain Ross found glaciers in lat. $75^{\circ}-78^{\circ} \mathrm{S}$, near long. $170^{\circ} \mathrm{E}$., and Captain Wilkes (1840) reported the discovery, at intervals between $165^{\circ}$ and $100^{\circ} \mathrm{E}$., along the Antarctic circle, of the outline of a great ice-barrier $150^{\prime}$ to $180^{\prime}$ high. The "Challenger" expedition followed the course of the barrier from $80^{\circ} \mathrm{E}$. on the Antarctic circle to $100^{\circ} \mathrm{E}$., thus carrying Wilkes's line $20^{\circ}$ farther west; and on Heard 
Island (7000' high) in lat. $53^{\circ} 10^{\prime} \mathrm{S}$., long. $73^{\circ} 30^{\prime} \mathrm{E}$., several glaciers were seen which came down to the coast-line, and made eliffs of ice on the shores. On the Now Zealand Alps, whose peaks are $7500^{\prime}$ to $12,350^{\prime}$ in height, there are glaciers, of which the 'Tasman is 18 miles long and 2 wide. The snow-line is at $5000^{\prime}$, and the ice descends on the west side to $600^{\prime}$ above the sea.

The so-called hanging-glaciers occur about steep slopes of many glacier regions, as the peaks of the Mont Blanc region, and between the snow-covered plateau of Norway and the sea. Reconstructed glaciers (glaciers remaines) are made out of the fallen ice of avalanches by regelation. At the Jökuls Fiord is a fine example of it. Geikie, describing it, says the ice slips off in occasional avalanches from the edge of the high snow-field into the defile, and there becomes recemented into a tolerably solid mass, which moves on as a glacier, and continues to the sea level.

\section{The Flow of Glaciers.}

1. Conditions of flow. - In addition to the relations of glaciers to rivers. already mentioned, there are the following:-

As with rivers: (a) Friction impedes flow along the sides and bottom, and consequently the most rapid movement of the glacier is along the middle portion above. This effect is least in large and deep streams, and at a minimum in great continental glaciers.

The more rapid flow of the middle at the surface of the stream is proved by the observation that a straight transverse line marked by poles set up in the ice $(\alpha b)$ becomes a curved line $(c d)$ in consequence of the movement; also by the fact that the transverse crevasses of glaciers become arched in front, as in the Rhone Glacier (Fig. 207), and that transverse dirt bands become

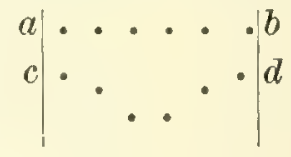
similarly arched (right half of Figs. 205, 206, Forbes, Tyndall), representing the condition in a tributary glacier, the Géant, after union with other tributaries on the left (page 235). Further, the retardation at bottom is proved by the fact that vertical blocks made by transverse crevasses take an up-stream dip, which gradually increases with the flow. (Guyot, 1838.)

(b) At a bend in the stream, the movement is more rapid on the convex side than on the concave; and the medial line of greatest rapidity is nearest the convex side.

(c) When the stream abruptly narrows, the ice above becomes more or less heaped and slower in movement, and then passes the narrows with an increased rate of flow.

(d) On passing small rocky islets, the glacier sometimes bends about the obstacle and envelops it without breaking, as in the case of two islets of rock in the midst of the Brenva Glacier, showing a molecular adjustment in the ice. (Guyot, 1838.)

But, unlike rivers: (e) Winds neither impede nor accelerate the surface movement; and $(f)$, as with other solid substances, the yielding to resistance is commonly attended by fractures called crevasses, and by displacements. 
2. Lamellar or straticulate structure of glacier-ice modified by the flow; the "blue bands," or "veined structure." - The ice of a glacier, as first observed by Guyot (1838), is often vertically laminated parallel to its sides, and sometimes so delicately that the ice appears like a semi-transparent striped marble or agate. The layers are alternations of cellular (or snowy) ice and clear, bluish, solid ice, and an indication of the porosity of a glacier. The melting of the surface sometimes leaves the ledges of the more solid layers projecting. This is well seen either side of the middle portion of the Mer de Glace, and in the Brenva and Aar glaciers. Guyot found the structure in the ice of the summit of the Gries Glacier at a height near 7500 feet. He concluded that the layers were made from the daily driftings, depositions, and hardenings of snow over the névé region; that they were originally horizontal or parallel to the surface of the glacier, as in the bedding and straticulation of a shale; and that the various positions assumed, including parallelism to the sides of the valley, were probably a consequence of the flow, and of the greater velocity at middle. The structure is attributed by Tyndall to the pressure to which the ice is subjected in making its way between the walls of a valley; but regions present it that have had no such pressure.

The view that the movement of glaciers was essentially like that of rivers or "softened wax" was announced by Bordier in 1773; and afterward more fully, with a specific recognition of the idea of plasticity in the ice, and of the influence, on the movement, of friction at bottom and along the sides, by Rendu, in a memoir read before the Academy of Sciences of Savoy, in 1841. Hugi, in 1827, built a hut on the Aar Glacier to determine its rate of motion; and found the movement $330^{\prime}$ in three years, and $2354^{\prime}$ in nine years. Guyot made his early observations in $\mathbf{1 8 3 8}$, and drew up a paper containing his conclusions; but failed to publish it because of his giving the field up to his friend Agassiz. (See Memoir, U. S. Nat. Acad., 1886 ; Am. Jour. Sci., 1886 ; and Smiths. Inst., 1889.) Agassiz commenced in 1841 his grand series of observations on the Aar Glacier, measuring the rate of movement in a section across the glacier ; and, on July 4, 1842, his first results, proving the more rapid flow of the middle portion (his 6 poles in the line across having moved severally $160^{\prime}, 225^{\prime}, 269^{\prime}, 240^{\prime}, 210^{\prime}$, and $120^{\prime}$ ), were published in the Comptes Rendus. His investigations were continued for several years afterward; and in 1847 appeared his first great work, entitled Système Glaciaire. Professor Forbes visited Agassiz at his work on the Aar, in 1841, and in the summer of 1842 undertook an independent investigation on the Mer de Glace, near Chamouni; and in October of 1842 his measurements, confirming those of Agassiz, were published. A year afterward, in 1843, appeared his Travels in the Alps, in which his various careful observations are given in detail, and the theory of glaciers, on the principle that the ice moves like a viscous fluid, is fully elucidated. His later writings on the subject are contained in a volume entitled Occusional Papers on the Theory of Glaciers. Later, Tyndall made a further series of measurements and observations in the Alps, demonstrating the influence of bends in a glacier, and explaining other glacial phenomena. His views are contained in The Glaciers of the Alps, 1860, and The Forms of Water, 1872.

3. Rate of flow. - The rate of descent in the mass of a glacier in the Alps varies from one or two inches a day to over 50 ; it is about half as much in winter as in summer. Ten to twenty inches a day in the warm season is most 
common; twelve inches corresponds to 365 feet a year, or one mile in about $14 \frac{1}{2}$ years.

Forbes found for the maximum in July, at his upper station on the Bois Glacier, $\tilde{5} 2 \cdot 1$ inches a day, and in December 11.5 inches. In the large Muir Glacier, according to G. F. Wright, the average in August, 1886, was 20 feet per day; and according to H. F. Reid, in August, 1890, 10 feet.

The Greenland glaciers are rapid in movement because the outlets from the great interior mass are so narrow. At Disco Bay, the Jakobshavn Glacier moves in summer at middle 65 feet per day, and a fourth of a mile from the side, nearly 50 feet. Helland estimated the daily discharge of ice into the sea, as icebergs, at 432,000,000 cubic feet. Rates of $35 \cdot 70$ and 100 feet per day have been reported. The rate of 99 feet per day was observed in August, 1887, in the fiord east of Upernavik by the Danish Lieutenants, Ryder and Bloch. In glaciers of so great magnitude friction is reduced to a minimum.

In the summer the snow over the ice melts, sending streams and drippings down the crevasses and into all accessible cracks in the ice; as far within as the outside heat penetrates, the many air-cells inside warm up and melt the ice around them, and the dirt grains and all foreign substances absorb and use the heat in like manner. Moreover, the glaciers lose much at surface by evaporation.

4. Intermittent advance. - In glaciers the cycle of advance and retreat is many years in length. The meteorological conditions favoring maximum mass of névé, and thereby maximum rate of flow and elongation, are, as already explained: first, long and wet winters in the névé region, causing an extension of the névé area, which is that of the only permanent annual contributions, and which has great breadth compared with that of the trunk glacier below; second, short and dry summers, especially below the level of the névé. Thus come the largest gain and the smallest loss.

Observation has proved that the cycle of gain and loss is a long one, 20 to 50 years. Forel has reported that in the Alps there have been in this century five half cycles; 1800 probably to 1815 , enlargement; 1815-30, diminution; 1830-45, enlargement; 1845-75, diminution; and that from 1875 to 1890 enlargement was beginning in different glaciers. He observes that the alternating periods correspond to that of a cold and rainy period, and that of a warm and dry, as meteorologically deduced by C. Lang (1886).

5. Capability of flow in an ice-mass. - Yielding to gravity in material so solid as the ice of a glacier, over uneven slopes and along valleys ever-varying in obstacles, is explained on the ground of the following qualities of ice and glaciers. (a) The fragility of ice, in consequence of which it breaks readily and so accommodates itself to obstacles; $(b)$ the dissemination of much water through the mass of the glacier, which increases the fragility and approximates the condition to that of a viscid body; (c) the plasticity of ice, or the quality of molecular adaptation to conditions of pressure; $(d)$ slipping along planes of bedding or straticulation in the ice; $(e)$ sliding of the 
glacier along the under-glacier surface; $(f)$ a local melting of ice, as a consequence of the accumulation of pressure, dininishing thereby resistance and facilitating motion.

(a) Fragility of ice. - Reaching a place of steep descent, great transverse blocks of a glacier drop in succession. Rounding a projecting angle in a valley, the ice is compressed at the side of the short turn, and drawn out on the opposite side, and in the latter great crevasses are opened. Forbes mentions one chasm 500 feet wide extending across the Mer de Glace. Passing narrows, the quickened motion causes irregular cross-fractures often in great numbers. Flowing along a valley the resistance of the sides ( $g g^{\prime}, g g^{\prime}$, Fig. 213), together with the more rapid flow at the center, makes crevasses $\left(c c^{\prime}\right)$ pointing obliquely up stream at angles of about $45^{\circ}$. The direction of the pull tending to produce the fractures (or that of greatest tension) is oblique toward the center down stream. Hopkins has shown that this pull $\left(p p^{\prime}\right)$ is strongest theoretically when it makes an angle of $45^{\circ}$ with the sides of the glacier, and therefore the crevasses are at $45^{\circ}$ with the sides up stream. This angle would be modified by the form of the 213. bottom, and by its pitch.

After being extensively broken up, the glacier, on reaching a broader portion of the valley, of gentler pitch, becomes again solid by a general welding of the pieces. The welding process, called by Faraday regelation, requires only pressure, and takes place whether the surfaces are moist or dry. (Hungerford, 1882.) If a block of ice is supported at its two ends, and a fine wire is passed around it at middle and weighted below, the wire will slowly melt its way through ; but when the cut is completed, the mass will be as solid as at the outset, regelation having gone forward above the wire. The multitudes of fractures made in a glacier on steep slopes hence disappear below where the motion is slow and the ice feels the pressure from above.

(b) Permeating water. - As already explained, the summer's heat produces water over a glacier, and through all its crevasses and smallest crevices, especially during the daytime. At night, when the source of heat is withdrawn, there may be much refreezing; but the days in summer are much longer than the nights. The chief source of the water largely fails in winter, and hence the difference in the summer and winter rates of movement. The melting from local pressure is an addition to the amount of water, and just where needed to meet special resistance. The pressure of one atmosphere lowers the melting-point of water $0.0042^{\circ} \mathrm{F}$.

(c) Plasticity. - Ice may be made by pressure to copy a seal, like wax; or by forcing it through holes to take the form of a cylinder. Kane mentions, in his Arctic Explorations, the case of a table of ice, eight feet thick and 20 or moie wide, supported only at the sides, which, in two months, had the center depressed by gravity five feet. The temperature during the interval was ruany degrees below $32^{\circ} \mathrm{F}$. Guyot concluded, from the flow of the 
glacier around the two rocky islets in the Brenva Glacier (south of Mont Blanc), that the movement was by molecular displacement.

(d) Slipping along planes of bedding or straticulation, or those of the blue bands. - This slipping has been shown to be a fact in several glaciers, by Forel (1889); among them, the Bossons Glacier at Chamouni. In the lower part of a glacier these planes have a dip up stream, and as a consequence the mass of the glacier above, as it flows along, rises by slipping along one or more of the planes of lamellar structure.

Mr. Forel observes that the fact explains the difference of velocity between the upper and lower beds; the little movement at the extremity of a glacier; the reappearance, at the surface, of bodies buried in the interior of the glacier; and the preservation of the thickness of the ice at the lower extremity, notwithstanding the annual loss from melting. The cause must have great influence over the direction of crevasses, and in all adjustments to resistances (1889). Guyot described (1832) the up-stream dip of the stratification at the termination of a glacier, and attributed to it the origin of the caverns.

(e) Sliding along the bottom of the valley. - By the preceding methods, the ice might move by yieldings and adaptations to surfaces, and not necessarily move on the surface beneath so as to abrade it. But the amount of abrasion in glaciated regions shows that these means of yielding and adaptation only help toward an actual flow or sliding of the material along its valley in river-like style.

$(f)$ Movement through the dilatation of freezing in the permeating water of a glacier. - This cause of movement was appealed to by Agassiz, and has been sustained by others. It has taken a new form through Forel, who has suggested that movement may be produced by the freezing of water between the large crystalline grains constituting the glacier. Freezing at night, according to the view, by expanding the mass, would force the glacier forward. The fact that the grains are so much larger in the lower than in the upper part of the glacier is supposed to favor it; but this is far from conclusive. Forel proposes to give the subject further investigation.

With regard to the motion of glaciers, Canon Moseley, after experimenting on the shearing force of pure ice, and making it too great to be overcome by gravity alone, presented a view that glaciers descend as a plate of lead descends a sloping surface, through alternate changes of temperature, the movement from expansion by heat being mainly downward because of gravity, and contraction working the same way. To this theory the obvious objection holds, as has been observed, that glaciers do not undergo the needed change of temperature.

Professor Croll, in his Climate and Time (and in earlier memoirs) accepts Moseley's deduction as to the shearing force of ice, and brings forward a molecular theory to account for the motion of glaciers. He says: "We find that the heat applied to one side of a piece of ice will affect the thermal pile on the opposite side" ; and explains this, not by radiation through the ice, but on the view that the heat applied passes from molecule to molecule through the mass; the transmission of the heat-energy conveyed by $\mathbf{A}$ to B melts B, but crystallizes A, and so it goes on through the ice. Gravitation is the source 
of motion; the expansion of the crystallizing molecule aids it; and the shearing force is lost by the molecular melting. But it seems to be hardly probable that a glacier, hundreds of feet thick, could be thus urged forward. Any crevasse or crack would intercept the molecular transmission; and the cause would hardly have a chance to act in a crevassed glacier like the Mer de Glace. Professor Croll, however, explained the formation of crevasses on the same principle.

Avalanches, like other kinds of landslides, do rapid denuding work over the slopes they descend, ice, water, mud, and stones hurrying on together, each in deluge-like form, with destructive effects. The noted avalanche of the 12th of July, 1892, at St. Gervais, in Switzerland, was more a discharge of water than of ice and mud. The water occupied two great cavities or reservoirs in the ice and was the occasion of the disaster. The cavities had been made by gradual melting.

The movement of glaciers, although so slow, may be illustrated by comparison with that of pitch. Pitch will not only descend all slopes, but will flow over a horizontal surface if the supply of material is kept up; and in case the area is a depression, it will fill the depression, and then flow on beyond it. So it is with the glacier. If there is a deep basin in a glacier valley, the glacier will move on over the ice-filled basin as if it were not there. While the mass of a glacier is flowing in accordance with the surface slope, a lower portion lying in a channel oblique to the course will take, if friction does not prevent, the course of the channel, for the reason that it cannot get out of the channel or valley to flow otherwise. (The principle is easily verified by means of pitch.) Thus in the same part of the glacier an upper portion may have a different course from the lower in spite of the resistance to be overcome.

\section{Denudation, Transportation, and Deposition.}

The weight of the glacier makes it a tool of great power. The pressure for 100 feet of ice in height is about 40 pounds to the square inch, and for 1250 feet, 500 pounds.

A glacier obtains its material for transportation both (1) passively, and (2) aggressively, through its power of denudation.

In a passive way $(\alpha)$ it receives from overhanging bluffs and adjoining ridges a great amount of earth, stones, and rocks, which the frost, waters, and other causes may have loosened; and where the glacier extends down far below regions of vegetation, it may have contributions of vegetable debris and animal relics. (b) The winds contribute dust. (c) Freezing in the colder season or in the advance of a glacier may add gravel and stones that lie along its side or underneath it, a method of acquisition which has its maximum in an avalanche. (d) The materials received may descend opened crevasses, either by falling down, or by being carried in descending waters.

Aggressively, the glacier augments its load $(\alpha)$ by abrasion, carried on by means of the stones with which its sides are armed, or those that may lie between the glacier and the rock against which it moves; it thus occasions 
the undermining of bluffs, and consequently large falls of rock and other debris. (b) It works with greater results through impact or forward thrust of its bottom, sides, and front; for it thus tears off angular stones, slate, and great rocks, from rifted, laminated, and jointed terranes that are alongside or extend up in ledges into the glacier, and takes them into its mass; it also plows into weakly consolidated deposits, such as fragile sandstones, and gathers other supplies, though not able deeply to abrade the harder rocks; and in its movement up the under-glacier slope of a ridge or peak, it bears along stones and other materials from low levels to high. (c) Further, it works by corrosion, in its ever-shifting and crevassing movements, grinding stone against stone or grain against grain, rounding angles and making the finest of earth called rock-flour, which may become clayey by partial decomposition of the feldspar present.

The material gathered by the ice is called moraine material. The larger part in ordinary glaciers lies along or near the borders and constitutes the lateral moraine; that occurring along the bottom, in the glacier and that pushed along by it, is the ground moraine; and the deposit accumulated at the extremity of the glacier, the melting place, is the terminal moraine. The moraine material thus deposited is not stratified; but it has a linear order; for it lies in lines which point upward to the summits from which its materials were gathered. The terminal moraine is a low ridge, belt, or mound of stones and earth transverse to the valley. Agassiz observes (1840) that on the retreat of a glacier, a new moraine may form each year. He also mentions the fact that the stones over the surface of a glacier outside of the lateral moraine gradually move obliquely toward the latter, owing to the greater velocity at the center.

When two glaciers join, the lateral moraines of the two uniting sides become one medial moraine. The number of moraines on a glacier, therefore, can never exceed the number of coalesced glaciers by more than one. An isolated peak rising above a glacier will send off its stones and earth all in a single line or moraine. In the view of the Görner Glacier on page 237, the nearest moraine is that of the Riffelhorn; the second is a union of moraines of the Görnerhorn and Porte Blanche; the third, a union of two moraines from two Monte Rosa glaciers; the fourth, the great moraine of the Breithorn, the summit in the middle of the view. Other moraines may be seen in the distant part of the glacier. Fig. 209 shows the moraines of the Mer de Glace and of the glaciers above it.

The transported masses of rock sometimes have great magnitude. One among those of the Alps contained 200,000 cubic feet. In the lower part of the Glacier of the Aar, after the junction of the great glaciers of the Finsteraar and Lanteraar, the medial moraine is 100 to 250 yards wide and has a height of 100 to 140 feet above the general surface of the ice either side. The wasting of the ice of a glacier by melting often leaves the broader stones perched up on ice-columns (like the perched stones in Figs. 158, 159), the stones having protected the ice beneath it from the sun. 
A remarkable example of the carrying of stones up an under-glacier slope is afforded by the region of the "Nunataks" of Greenland (map, page 241). The dotted belts on the following figure $\left(m^{\prime}, m^{\prime \prime}, m^{\prime \prime \prime}, m^{\text {iv }}\right)$ represent belts of moraine made by this process; and the nunataks $g, h, i, k, l, m$, are emerging peaks of the covered ridges. The moraine $m^{\prime \prime \prime}$ was made by a submerged peak. The stones are not like those from the nunataks. They came up from varying depths in the ice. Some of them are 20 feet across. The stones of the nunatak moraines disappear down crevasses after 200 to 300 yards of sunlit travel, or bury themselves in the ice.

In a similar way, where a glacier crosses marine channels, shells gathered into the ice might be carried along to the tops of the elevations over the land; or possibly, loose sea-border material beneath might be pushed up by the glacier.

The abrasion carried on by the stones in the sides of the glacier planes off, polishes, grooves, and often profoundly channels, the rocks either side or below; and these scorings are evidence of the direction of movement. An example of the grooves or

214.

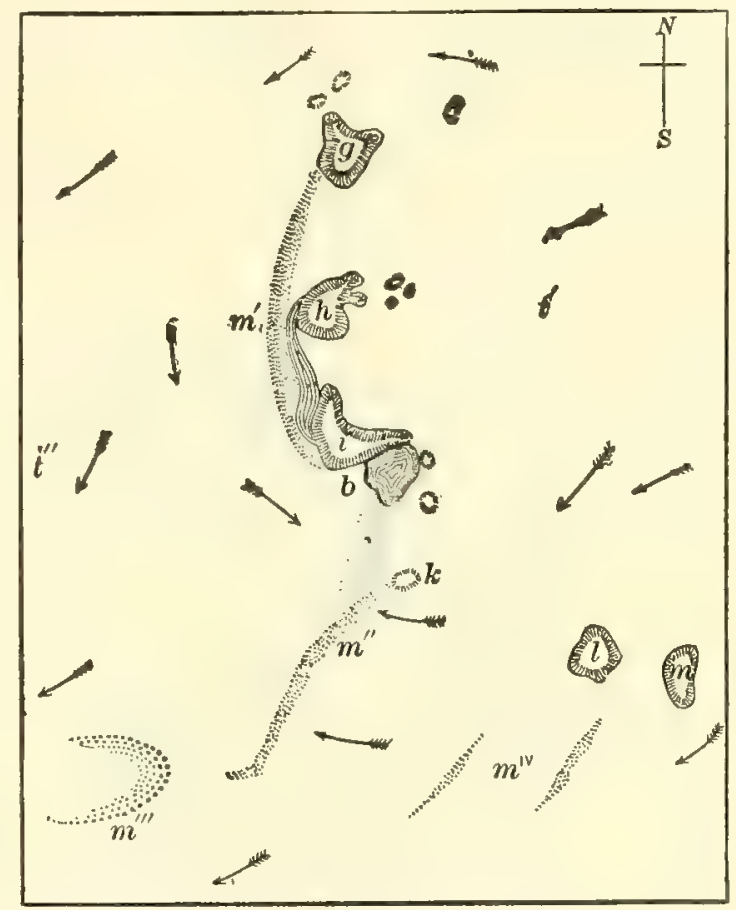

Nunataks, or isolated peaks, $g, h, i, k, l, m$, situated like islands in the Greenland ice. Jensen. scratches is represented in Fig. 215. Crossing lines, which are not unfrequently observed, are produced when glaciers spread widely over a broad region, and, owing to change in the thickness of the ice or some other cause, there is a change of direction in the movement.

215.

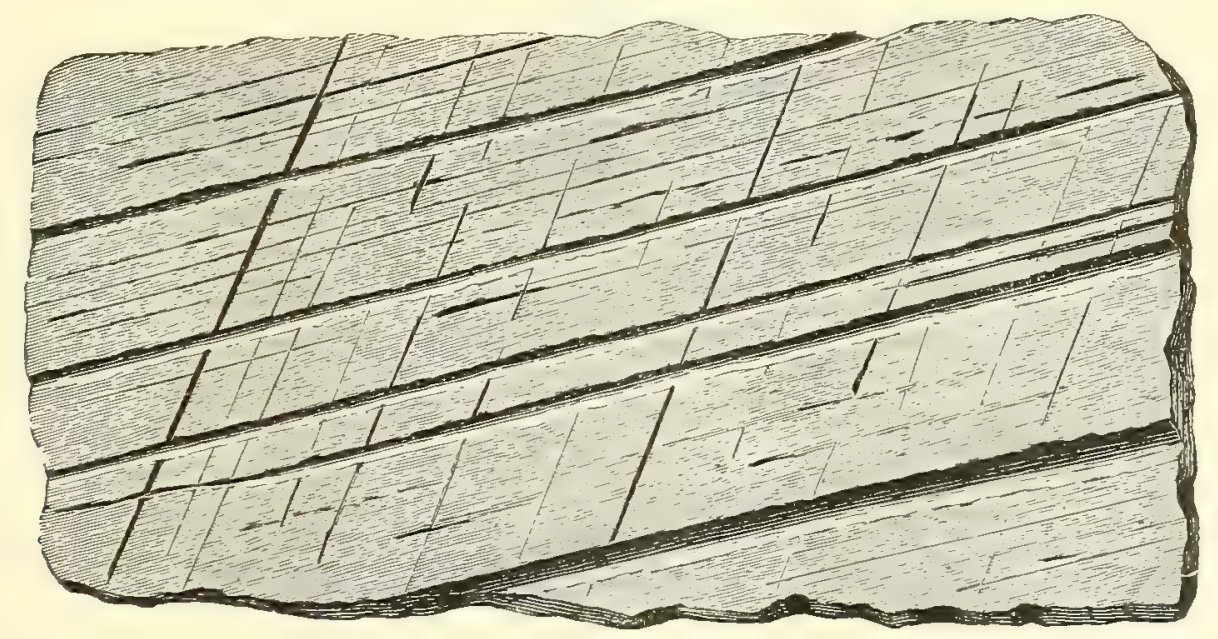

Glacier groovings or scratches.

Moreover, the stones or rock-masses that do this work of abrasion become smoothed and scratched or grooved; and thereby may show their glacier 
origin. Subsequent abrasion by a sub-glacial or glacier-fed stream may, however, remove the scratches from the stones. The ledges underneath, or especially their harder portions, are often made, by glacial abrasion, into rounded, grooved knolls, called sheep-backs (rockes moutonnées) in allusion to their forms. They are a prominent feature of all glacial regions; and those of the Glacial period, when they were formed over a vast extent of country, are sometimes preserved to the present time in great perfection. The view (Fig. 216), from a photograph obtained by the Hayden expedition in 1873 , represents a portion of a great crouching flock of them, extending

216.

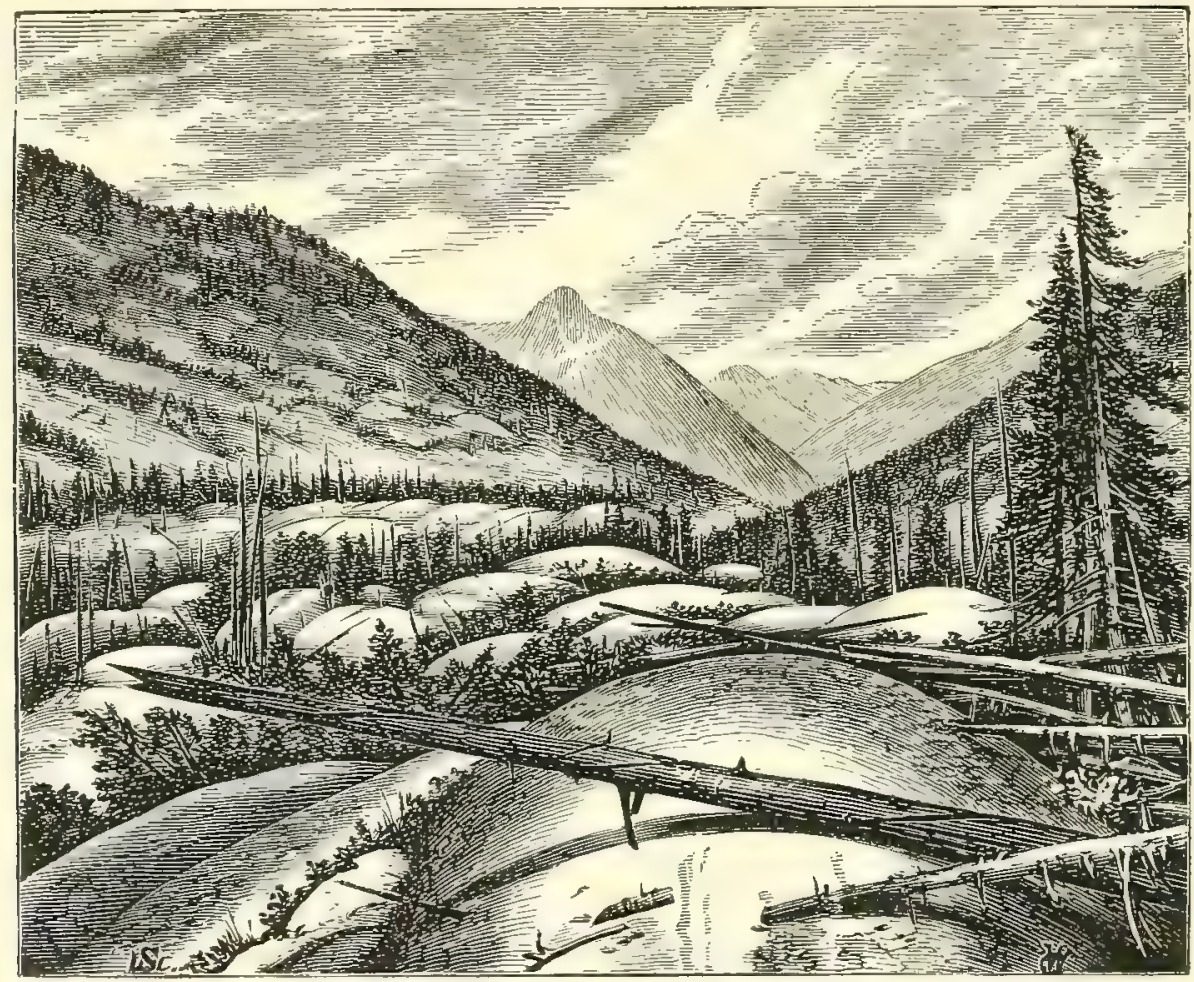

View on Roche-Moutonnée Creek, a tributary of Eagle River, Colorado.

for 2000 feet along a valley leading down from the "Mountain of the Holy Cross," one of the prominent summits, 12,485 feet high, in the mountains of Colorado.

A glacier, too, may have water-falls in crevasses (and sometimes in welllike shafts, formed in erevasses), which not only earry down moraine material, but excavate the rocks underneath. They may thus make broad basins or channels in the rocks as the glacier moves on its way; but without stopping its march for a few centuries the fall cannot bore out a "pot-hole" like the pot-holes of river origin; for these require a stationary tool, they being ordinarily as well-centered as if bored by a revolving bit.

Deposition from the glacier takes place through the melting of the ice, as in the making of the deposit of terminal moraine, above explained. Deposits are also made through crevasses, and the waters of any super-glacier rivers or lakes may add to the contributions. The descending waters carry down 
the rock-flour, which often makes the water discharged by under-glacier streams look milky. The coarser earth within the glacier is added to the bottom deposits, making thereby the unstratified mixture of earth, stones, and clayey rock-flour, which is called bowlder-clay or till.

The retreats of a glacier, during which depositions of a large amount of moraine material take place, afford an opportunity for the growth of plants, and sometimes even forests, over the deserted moraines, and for the spreading out of stratified gravel and earth by the sub-glacial river and other means, so that, whenever the advance takes place, stumps, trunks of trees, and stratified beds become again under the ice and new deposits of bowlderclay are made. The Muir Glacier, according to Wright and others, affords remarkable examples of such intercalations of dismantled forests and gravelbeds, and Russell's account and map of the St. Elias Glacier (page 238) illustrate the process.

\section{Denudation and Transportation by Glacier-made Rivers.}

The greater part of the excavation of valleys carried on in glacier regions is due to the glacier-made rivers. They swell by the summer melting, and become violent, plunging torrents, and thus produce great and rapid work, while the glacier is slowly creeping along, and as they bear the material down stream, it becomes deposited and stratified like other fluvial deposits. Violent effects come from the damming of streams by the snow and ice of Alpine valleys; for in no other way can barriers be thrown so readily across profound valleys. 'The deluges caused by the accumulated waters, when they break loose, are often very destructive. The Alps are full of examples. Again, the valleys are sometimes dammed up by great moraines, making lakes; and such lakes sometimes break through their barriers, and flood the valley below with tearing waters. The lakes of the glacier's surface may add suddenly to the sub-glacial waters, and produce great destruction and widespread stratified deposits.

The amount of rock-flour and coarser sediment discharged daily by the Aar Glacier in August has been estimated to be 280 tons; from the Justedal Glacier, in Norway, in July, about $3 \frac{1}{2}$ times as much; from some Greenland glaciers, varying up to 75 times as much as the Aar.

\section{ICEBERGS.}

A glacier on a seacoast often stretches out its icy foot into the ocean; and, when this part is finally broken off, by the movement of the sea or otherwise, it becomes an iceberg. The break takes place usually in the fiords, where the glaciers extend out into the deep water and are largely submerged. The icebergs carry away the stones and earth which the glacier may have gathered, and transport them often to distant regions, whither they are borne by the polar oceanic currents. Most of those of Greenland, how- 
ever, as Helland states, are clean, but "now and then one is seen with bowlders upon it; and here and there small bergs that are quite covered with stones and gravel" (1877).

Dr. Kane, describing the great pack of icebergs that occupies the center of Baffin Bay, mentions that some were 300 feet high, and large numbers over 200 feet; 280 of the first magnitude (the most of them over 250 feet) were in sight at one time. Taking the specific gravity of iceberg-ice at 0.886 (Helland), one ninth of the mass by weight is out of water. In the Antarctic, the long ice-barrier observed by Captain Wilkes had a height above the sea of 150 to 200 feet; and some of the bergs were 300 feet high.

(1) Icebergs are a means of transporting stones and earth from one region to another; and those of Greenland make their farthest deposits in the Atlantic about the banks of Newfoundland, or between the meridians of of $44^{\circ}$ and $52^{\circ}$ and north of the parallel of $40^{\circ} 30^{\prime}$.

(2) When grounded on rocks, they may scratch the surface; but closely crowded and regular scratches, like those of glaciers, over large areas cannot be made. An iceberg "rocked by the swell of the sea, and sometimes turning over," could not be good at scoring submerged rocks. Moreover, rocks over the sea-bottom where icebergs drop their freight of stones would seldom be uncovered.

The following are important works and memoirs on existing glaciers : -

H. B. De Sa ussure: Voyage dans les Alpes, 4 vols., 1779-1796.

Agassiz: Études sur les Glaciers, 8vo, Neuchatel, 1840. - Système Glaciaire, Nouvelles Études et Expériences sur les Glaciers Actuels, 8vo, with an Atlas of 3 maps and 9 plates, Paris, 1847.

J. De Charpentier: Essai sur les Glaciers et sur le Terrain Erratique du Bassin du Rhone, 8vo, Lausanne, 1841.

J. D. Forbes: Travels in the Alps of Savoy, etc., 8vo, Edinburgh, 1843. - Occasional Papers on the Theory of Glaciers, 8vo, Edinburgh, 1859.

J. Trndall: The Glaciers of the Alps, 8vo, London (and Boston), 1861. - The Forms of Water (in Appleton's International Series), 8vo, New York, 1872.

A. Herm: Handbuch der Gletscherkunde, Stuttgart, 1885.

N. S. Shaler and William M. Davis: Illustrations of the Earth's Surface; Glaciers, a quarto volume containing 196 pages of text, with 25 fine plates mostly from photographs, 1881.

The following relate to existing glaciers of the Pacific Coast of North America :-

Davidson, on the first discovery of glaciers on the Pacific Coast - on Mount Rainier (Tacoma), Mount Baker: Proc. Acad. California, iv. 161, 1871, and Am. Jour. Sc., III., iv. $156,1872$.

Clarence King: "Glaciers of the Pacific Coast" (on Mount Shasta, Mount Hood, Mount Rainier, etc.), Am. Jour. Sc., III., i. 157, 1871, and "Report 40th Parallel," vol. i. $462,1878$.

Johs Muir: "Glaciers in California" (Sierra Nevada), Overland Monthly, December, 1872.

Joseph Le Conte: "Ancient Glaciers of the Sierra Nevada" (with notice of existing), Am. Jour. Sc., III., v. 325, x. 156, xviii. 43, 44.

G. F. Wright: The Ice Age in North America, 1889, 1891. 
I. C. Russell: Existing Glaciers in the United States, 5th Rep. U. S. G. S. ; "Mount St. Elias Glaciers," Nat. Geograph. Mag., iii., 1891, and Amer. Jour. Sc., 1892.

H. P. Cushing: Notes on the Muir Glacier region, American Geologist, viii. 207, 1891.

H. F. Reid: "Studies of Muir Glacier, Alaska," Nat. Geograph. Mag., iv. 19, 1892.

\section{HEAT.}

The sources and effects of heat come here under consideration. The effects are those connected with the making and modifying of the earth's rocks, strata, and life, exclusive of the more comprehensive changes resulting from the earth's gradual refrigeration. They include $(\alpha)$ expansion and contraction; (b) fusion, solidification, and attending igneous phenomena; (c) metamorphism and vein-making, besides chemical compositions, decompositions, and other effects. After some observations on (I.) the Sources of Heat, these subjects are considered under the following heads: (II.) Expansion and Contraction; (III.) Igneous Action and Results; (IV.) Metamorphism; (V.) Veins.

The effects here referred to are mostly due to heat above the ordinary temperature. But some geological changes of the widest influence have been carried forward by simple changes in climate. Hence all sources of change in temperature, however slight, have a geological interest.

\section{SOURCES OF HEAT AND THEIR DIRECT CLIMATAL EFFECTS.}

\section{The Sun as a Source of Heat.}

It has been stated that the heat which the earth receives from the sun's rays gives it a temperature $300^{\circ} \mathrm{F}$. above that which it would have in cold sunless space. The annual amount is constant through all orbital changes, but its distribution through the year varies with these changes.

1. Changes connected with the seasons. - The sun, owing to the obliquity between the earth's equatorial plane (at right angles to the axis of rotation) and the plane of the ecliptic (or that of its orbit) gives more light and heat for about six months, between the vernal and autumnal equinoxes, to the northern hemisphere than to the southern, making thereby a northern summer with a southern winter; and the reverse for the other six months. The difference in the heat received is in the ratio of 5 per cent for the summer interval between the equinoxes to 3 for the winter interval.

Further, the time of the equinoxes, or that of the sun's crossing of the equator, northward and southward, is slowly changing backward in the series of months, and in less than six centuries the vernal equinox, now on Mareh 21 , will be in the month of February; thus the summer months after a while will become those of the winter. The rate of the precession of the equinoxes is about $50 \cdot 1$ seconds a year, or a degree in about $71 \cdot 6$ years, which corresponds nearly to a month in 2158 years, and a complete revolution in 25,868 years. 
2. Changes in the time of the perihelion and aphelion. - The earth is now in aphelion during the northern summer and southern winter. With aphelion in winter, the winters are colder and the summers are warmer than with perihelion in winter. The position of the major axis of the earth's orbit (the extremities of which are the aphelion and perihelion points) is changing, and a complete revolution takes 110,000 years; and since this change is in the opposite direction from that of the precession of the equinoxes, above stated, the cycle of the seasons is shortened from 25,868 years to about 21,000 years ; for, supposing the perihelion and either equinox to coincide, and then the precession to move in its direction and the perihelion in the opposite, at their respective rates, they would again be in conjunction, in consequence of these rates, in 21,000 years. Hence, every 10,500 years, the seasons become reversed, that is, the months of winter become the summer months. Another consequence of this aphelion cycle is, that the winter and summer intervals between the equinoxes vary in relative lengths, the aphelion side being the longer. At the present time the aphelion comes in summer, and the summer interval is therefore seven days longer than the winter interval.

3. Changes in the eccentricity of the earth's orbit. - The earth's elliptical orbit varies slowly in eccentricity, - that is, in the length of its major axis, - making the aphelion distance greater and the perihelion less, but not varying the mean distance or the amount of heat received annually by the earth from the sun. Maxima in the eccentricity occur once in 100,000 to 200,000 years. One maximum was passed, according to calculated results, about 110,000 years since; another (higher), about 210,000 years since; the next anterior (like the latter in height), about 750,000 years; and a maximum of extreme eccentricity, 850,000 years since. (Stockwell, 1868.)

With the sun's mean distance $92,400,000$ miles, the present aphelion distance is about $93,950,000$ miles, and the perihelion, 90,850,000 miles, and the eccentricity, 0.0168. But at the time of extreme maximum eccentricity $(=0.075$ nearly), referred to above, the aphelion distance would be about $99,300,000$ miles, and the perihelion $85,500,000$, making the sun $13 \frac{1}{2}$ millions of miles nearer the earth in summer than in winter.

Owing to the increasing eccentricity there is an increasing difference in the length of the winter interval as compared with the summer interval; and at an extreme maximum it is 33 days longer than the summer interval. As the amount of heat which the earth receives varies inversely as the square of the sun's distance, increasing eccentricity diminishes the amount on the aphelion side and increases it on the other; and if aphelion comes in winter, the winter cold is greatly augmented, besides continuing longer. The summers, on the contrary, would be proportionally hotter, but, in the same proportion, shorter. With aphelion in summer, the winters would be relatively mild and the summers cool. Hersehel first drew attention to this effect of extreme eccentricity (1858), and Croll used,the facts in his Climate and Time (1875) to account for the occurrence of glacial periods in 
the earth's history, though not making it the sole cause of glacial conditions, or holding that such conditions would necessarily ensue. The heat received during the summer and winter intervals being as 5 to 3 , and the winter interval 199 days long in an extreme case, the severe and prolonged cold of the winters might, other things favoring, accumulate more snow than the short summers could melt. This theory makes the Glacial period of the northern hemisphere follow or precede that of the southern by 10,500 years; that is, by half of a revolution of the seasons (21,000 years). Moreover, the condition of maximum eccentricity is so slow in passing that, according to this theory, two or more glacial periods might occur in the course of one maximum.

This subject and Croll's theory have been ably discussed in a volume of 180 pages, entitled The Cause of an Ice-Age, by the Astronomer Royal of Ireland, Sir Robert Ball, 1891. The conclusion is reached that the conditions of a period of maximum eccentricity are fully adequate to cause glacial periods in geological history. See also a notice of the work by G. H. Darwin in Nature for January 28, 1892.

Geology has no evidence in favor of the idea that the latest of Glacial periods occurred in the southern hemisphere 10,500 years after, or before, the northern, and it has probable evidence that the time of the Glacial period was not over 10,000 years since, and therefore not nearly as far back as the maximum of 210,000 years since, or that of 100,000 . Further, it has discovered no satisfactory traces of a second Glacial period, corresponding to the extreme maximum 850,000 years since; for it has good proof that none occurred between the Glacial period and the epoch closing the Cretaceous period, some millions of years since. It is admitted, however, that the calculation of the time to the extreme maximum $(850,000$ years $)$ is not wholly trustworthy.

4. Progressing diminution in the sun's heat. - Since the sun has been radiating heat through all past ages, the earth must receive less heat now than in Archæan time; and the greater heat of the early geological ages may have this as a chief cause.

5. Changes in the condition of the sun's surface. - The changes from maximum to minimum in the spots on the sun's surface have a cycle of about 11 years, the minimum occurring in the year 1 of the century, and the year 1889 being therefore at the minimum. How far this cycle is one of changing temperature to the earth is not known. Other cyclical changes are possible, and are conveniently assumed at times, though not proved.

6. Changes in the position of the earth's axis of rotation. - Mathematical investigations by Lord Kelvin (Sir William Thomson), S. Haughton, G. H. Darwin, and others, have shown this hypothesis to be of no geological value. Darwin has demonstrated that a displacement of the pole of merely $1^{\circ} 46^{\prime}$ would require that a twentieth of the whole earth's surface should be elevated to a height of 10,000 feet, with a corresponding subsidence in another quadrant; and for one of $3^{\circ} 17^{\prime}$, that double the surface should have undergone these great changes. Kelvin concludes from his discussion of the subject that "there is no evidence in geological climate throughout those parts of the world which geological investigation has reached to give any indication of the poles having been anywhere but where they are, at any period of geological time." 
7. Variations in the density of the earth's atmosphere. - The atmosphere absorbs and retains heat, and the amount absorbed increases with its density. In early geological time, the earth's atmesphere contained much more carbonic acid and moisture than now, and hence it would have absorbed more of the sun's rays as they passed through it. It has been shown by Tyndall that the absorptive power of carbonic acid, under ordinary atmospheric pressure, is 90 times greater than that of the atmosphere, and that of moisture 30 to 70 times greater for non-luminous heat. Their presence in the atmosphere would hence have greatly increased its power to absorb and retain about the earth the sun's heat. "They would produce little reduction in the amount of luminous sun-heat received, and would be a formidable obstacle to non-luminous heat escaping by radiation from the earth's surface into the cold of star-space" (Haughton, 1880).

The earth's lower plains are warmer than its elevated regions, because of the greater density of the air. The lowest places should thus have the warmest climate; and accordingly the basin of the Dead Sea, 1308 feet below the sea level, has the heat of the torrid zone.

8. Variations in oceanic currents. - The effect of the Atlantic tropical current on the Aretic and north Atlantic climates has been elucidated by the calculations of Mr. James Croll. His conclusion, based on the amount of water that passes the Florida Strait (nearly agreeing with the latest estimate), and the temperature of the water, is, that the amount of heat conveyed from the equatorial regions northward in the Atlantic by this stream is equivalent to $77,479,650,000,000,000,000$ foot-pounds of energy per day, which is equal to all the heat received by $1,560,935$ square miles at the equator, and more heat than is conveyed by all the aerial currents; and that the stoppage or diversion of the current would diminish to this extent the heat of the Aretic seas and north Atlantic.

It has been supposed that the diversion of the Gulf Stream from the north Atlantic may have taken place through the sinking of the region of the Isthmus of Darien; but there is no sufficient evidence that such a diversion has happened since Mesozoic time. A more reasonable hypothesis is that it may have been accomplished by a raising of the sea-bottom nearly to the surface between Scandinavia, Great Britain, Iceland, and Greenland, where the depth now is mostly less than 100 fathoms and nowhere exceeds 1000 , and along one tract is not over 500 fathoms. The effect of such a north Atlantic barrier would be to confine the Atlantic tropical current to the north Atlantic, and thereby to increase the temperature and amount of evaporation of that ocean. It would reduce the northern part of the stream to the southeast branch, and might diminish its volume; but, in view of the form of the south Atlantic depression and its position with reference to the north Atlantic, the warm stream could not fail to continue its flow.

Again, the Arctic region may formerly have had its climate moderated by receiving the Pacific tropical current, through a submergence about 
Bering Strait - now only 150 feet deep; and if so, this current, upon the opening of the deep passage for discharge northward, would have been augmented in its size and its heating influence.

\section{The Earth's Interior as a Source of Heat.}

Diminution in the heat reaching the surface from the earth's interior. - The proofs of the existence of a source of heat within the earth are the following:-

1. Borings for Artesian wells and shafts in mines have afforded a means of taking the temperature of the earth at different depths. It has thus been found that, after passing the limit of surface action, the heat increases downward, but at a varying rate. The common rate within 4000 feet of the surface is 55 to 60 feet for $1^{\circ} \mathrm{F}$., or the mean $57 \frac{1}{2}$ feet; or in geothermometric language, $57 \frac{1}{2}$ feet corresponds to 1 geothermic degree. At Sperenberg, near Berlin, large variations were obtained in a well 4172 feet deep; but it went down through a stratum of salt, excepting the upper 300 feet; at bottom, the temperature was $118 \cdot 6^{\circ} \mathrm{F}$.

At the Artesian well of Grenelle, Paris, a temperature of $85^{\circ} \mathrm{F}$. was obtained at 2000 feet, equivalent to $1^{\circ} \mathrm{F}$. for every 60 feet. In Westphalia, at Neusalzwerk, in a well 2200 feet deep, the temperature at the bottom was $91^{\circ} \mathrm{F}$, or $1^{\circ} \mathrm{F}$. for 50 feet of descent. At Yakutsk, Siberia, Magnus found a gain of $15^{\circ} \mathrm{F}$. in descending 407 feet, equal to $1^{\circ} \mathrm{F}$. for 27 feet. In Algiers, an increase of $1^{\circ}$ in 42 feet has been observed; and in the Sahara $1^{\circ}$ in 32 feet. In Great Britain the mean is $1^{\circ} \mathrm{F}$. for $51 \frac{1}{2}$ feet.

At Schladenbach, in Prussia, at a depth of 5735 feet, the temperature $134^{\circ} \mathrm{F}$. was obtained; and at Pesth, Hungary, at 3120 feet a boring supplied daily 176,000 gallons of water at $158^{\circ} \mathrm{F}$. The municipality were carrying it down in order to reach $176^{\circ} \mathrm{F}$. $\left(80^{\circ} \mathrm{C}\right.$.) for the brewers.

A boring at Wheeling, W. Va., to a depth of 4500 feet (in 1892), 3700 feet below the sea level, through nearly horizontal rocks, shows a mean rate of increase for the upper half of $1^{\circ} \mathrm{F}$. for 80 feet, and in the lower half of $1^{\circ}$ F. for 60 feet. For great depths the ratio is not an arithmetical one, because of the greater conductivity of the earth below (owing to greater density) and the augmented pressure. But nothing is yet known as to the rate of increase downward, or the number of feet to a geothermic degree.

Doubts with regard to the observations on the increase of heat downward in borings, and in shafts in mines, come from the facts that chemical action, and, prominently, the oxidation of pyrite and other sulphides, is a source of heat; and this has always to be considered in such investigations. Besides, local sources of subterranean heat may exist. At the Comstock lode, in Nevada, the temperature of the mine in some parts, at a depth of 1800 to 2000 feet, is $130^{\circ}$ to $157^{\circ} \mathrm{F}$., and, when mining was there in progress, over 30 tons of ice per day were expended in keeping the air cool enough for the DaNa's MaNUAL - 17 
endurance of the miners. The heat in this case was of local origin, as the region is one of former igneous eruptions.

2. The wide distribution of volcanoes over the globe affords evidence of internal heat. Moreover, the ejection of melted rock through fissures has taken place over all the continents; in Nova Scotia, Canada, New England, New Jersey, and the states south, the region of Lake Superior, the Rocky Mountains, and western America; in Ireland, Scotland, and various parts of Europe; and so over much of the globe. Such facts favor the idea of an internal source of heat. The heat of the earth's interior has reached toward or to the surface for geological work in three ways.

(a) By conduction outward attending the earth's cooling. - The amount thus received at the surface may have been sufficient to modify somewhat the temperature of the oceans, and the earth's climates, during early geological time. At present it is inappreciable; and yet, according to Kelvin, the amount of heat now lost by the earth, as a consequence of cooling, is such as would melt annually a complete covering of ice 0.0085 millimeter thick, to water at $32^{\circ} \mathrm{F}$., or bring 777 cubic miles of ice to the same state.

(b) By fractures of the crust, and the escape of melted rock or hot vapors.

(c) By an accumulation of sedimentary deposits over large regions. - It follows from the conditions of a globe having an internal source of heat, that equal temperatures will exist, as a general thing, at equal depths; in other words, that isothermal planes, or more precisely, isogeothermal, will be parallel to the surface; and that they will even bend upward to correspond with the general curve of the broader mountain regions, and downward beneath the oceanic depressions. Consequently, the isogeothermal planes will rise a thousand feet for every thousand feet in depth of deposits spread out over a wide area; and, as urged by Babbage, solidification, crystallization, and other chemical changes may thus be occasioned in the inferior beds, provided the accumulation reaches a depth adequate to raise upward the requisite amount of heat.

Again, the removal of rock-material from wide areas, as is done in the slow processes of erosion, will tend to produce an equivalent depression of the isogeothermal planes.

\section{Chemical and Physical Changes and Mechanical Action as Sources of Heat.}

Heat is evolved by chemical changes in which there is condensation, as in liquids becoming solids, or gases becoming liquids, and in oxidation, etc. It is often an effect of the natural decomposition of minerals, or vegetable or animal matter. The oxidation of sulphides, and especially of the most common of them, pyrite and marcasite, is a source of heat in many mines, and for many warm springs. In the formation of a pound of water from vapor, heat enough is given out, says Tyndall, to melt five pounds of cast iron.

The heat of lightning has also its effects among geological phenomena. 
Electric currents have long been suspected of various results of other kinds, but little has yet been directly traced to their action, except such as come under the general head of chemical effects.

Under examples of mechanical action, there are the beating of waves on a coast, the falling of water in cascades or rain, the shakings of earthquakes, the sliding of rocks, the motion of the atmosphere in winds, each of which produces heat whenever the action meets with resistance, on the principle that motion corresponds to an amount of heat, or that heat is transformed motion. The heat thus resulting is, however, of little geological importance. But the friction attending uplifting, plicating, shoving along fractures, and crushing of rocks has often been an efficient and wide-reaching source of heat and of geological work. These shovings have flexed strata many thousands of feet in thickness, made displacements along fractures of 10,000 to 20,000 feet, and worked in this way over areas more than 1000 miles long and some hundreds in width. The amount of heat developed has therefore been enormous; but how far available for geological changes would depend in part on the rate at which such work went forward. It has been sufficient, beyond question, for a large amount of consolidations, and for recrystallizations or metamorphism on a large seale, and it has probably been sufficient for much fusion of rocks in the earth's interior wherever the temperature was on the margin of fusion.

Mallet concluded, from his calculations, that 7200 cubic miles of crushed rock would cause heat enough to make all the volcanic mountains of the globe; and that, since the ejections of volcanoes have been going forward through a very long period, the action would require but an infinitesimal amount of annual crushing - not over 0.606 of a cubic mile. (Trans. Roy. Soc., 1872.) But his theory is accepted only in a general way.

\section{EXPANSION AND CONTRACTION.}

1. Amount of expansion. - The amount of expansion of rocks is mostly between 1 and 10 millionths for $1^{\circ} \mathrm{F}$; and one millionth corresponds to 1.2 thousandths of an inch for 100 feet. Colonel Totten, in experiments, made in 1830 to 1833 , on effects of change of temperature, found that an inch of fine-grained granite expands for $1^{\circ} \mathrm{F} ., 0 \cdot 000004825$; an inch of the granular limestone of Sing Sing, N.Y., 0.000005668; of red sandstone, from Portland, Conn., 0.000009632. Adie (Trans. R. Soc., Edinburgh, xiii., and Q. J. G. Soc., 1847) found for the expansion of gray Aberdeen granite for $1^{\circ} \mathrm{F} ., 0 \cdot 00000438$; for white marble of Sicily, 0.00000613. Pfaff found for the expansion between the ordinary temperature and red heat (about $1750^{\circ} \mathrm{F}$.) of granite from the Fichtelgebirge, 0.0168 ; for porphyry from the Tyrol, 0.0127; and for basalt of Auvergne, 0.0120.

2. Effects of changes in temperature due to the sun, or the climate. - (a) The sun is producing somewhere, at all times, alternations of temperature, and thereby change of size and position; and the same effect comes from changes of temperature, whatever the source. The cause is universal in its action. 
With the progress of the sun during a sunny day Bunker Hill Monument, a hollow obelisk, 221 feet high and 30 feet square at base (made of granite blocks), swings to one side and the other, a pendulum suspended from the center of the top describing an irregular ellipse nearly half an inch in its greatest diameter (Horsford). Such a cause, working day after day about rocky peaks and precipices, causing each day some displacement, nust end in degradations of geological importance.

(b) Expansion works with special facility if blocks rest on an inclined surface, even when the inclination is very small. It extends the mass down the slope, - the direction of easiest movement, - and contraction pulls the mass to the expansion line for the same reason; and thus masses slide on till they fall over precipices, or off cliffs into the sea. Even the loose stones or blocks of a talus are kept on a downward move by the same means. The action of frost has already been mentioned (page 231) as another one of the causes of a slipping movement in rocks and soil.

(c) Expansion and contraction also cause grains and thin portions of the exterior of rocks to peel off or crack away from the part below. It hence may open fractures and so give access to air and moisture for other destructive work.

Further: terranes of granite, granitoid gneiss, syenyte, and other massive rocks, as in the domes about the Yosemite in California, are often divided into parallel concentric or horizontal layers a foot to a yard and more thick; and vertical joints at irregular intervals also are made. J. D. Whitney states that the dome-like shapes of the Yosemite summits are thus made; for "the curves are arranged strictly with reference to the surface of the masses" (1865). These effects have been attributed to contraction attending the original cooling; but also to the climatal heat through daily and seasonal cooling.

On some of the Thimble Islands, off the shores of Stony Creek, Conn., the walls of granitoid gneiss facing the water are peeling off in laminæ a third to a half inch thick, without any apparent decomposition, or even a dimming of the luster of the feldspar or mica; and it may be owing to the heat of the day's sun, and the chilling by the waters when the tide is in. In the same region the slipping of great masses of rocks from the islands into the salt water is well exemplified.

Over the rocky surface of countries within the glacial latitudes of the Glacial period, the scratches left by the glacier are generally, when first uncovered, as fresh as when they were made. But, if the surface be open to the sun's heat and light, and to the rains and frosts, for a score of years, far the larger part of the markings disappear; and alternate heating and cooling is an important means of this obliteration.

(d) By drying, the sun's heat produces cracks, the lightest cases of which are mud-cracks (page 94). Such cracks in mud or earth, and therefore in rocks, are shallow, and by this means they may be distinguished from cracks or fissures made by other means.

3. Effects of heat from interior sources. - From Totten's experiments as data, Lyell has calculated that a mass of sandstone a mile thick, raised in 
temperature $200^{\circ} \mathrm{F}$., would have its upper surface elevated 10 feet; and that a portion of the earth's crust 50 miles thick, raised $600^{\circ} \mathrm{F}$. to $800^{\circ} \mathrm{F}$, might become elevated 1000 to 1500 feet. Cooling would tend to reverse the result.

(a) Contraction from cooling in case of fusion generally produces fractures at right angles to the cooling surfaces ; and in this way, "basaltic" columns have been produced. Besides such transverse fractures, there frequently exist longitudinal fractures along the middle or sides of dikes due to transverse contraction; and transverse fractures of columns are very common.

One of the most noted localities of "basaltic columns" is that of the Giant's Causeway on the northern coast of Ireland. The columns (Fig. 217) are divided transversely and have usually the upper surface of each section slightly concave. In the columnar structure the form is often six-sided, but five to nine sides are common, owing to irregularities of texture and cooling.

217.

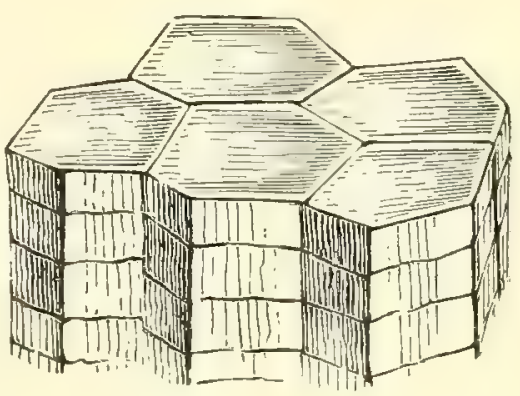

Giant's Causeway.

Fig. 218 represents a scene from the coast of Illawarra, in southeastern Australia, in which there are columns of two outflows, the nearer less per-

218.

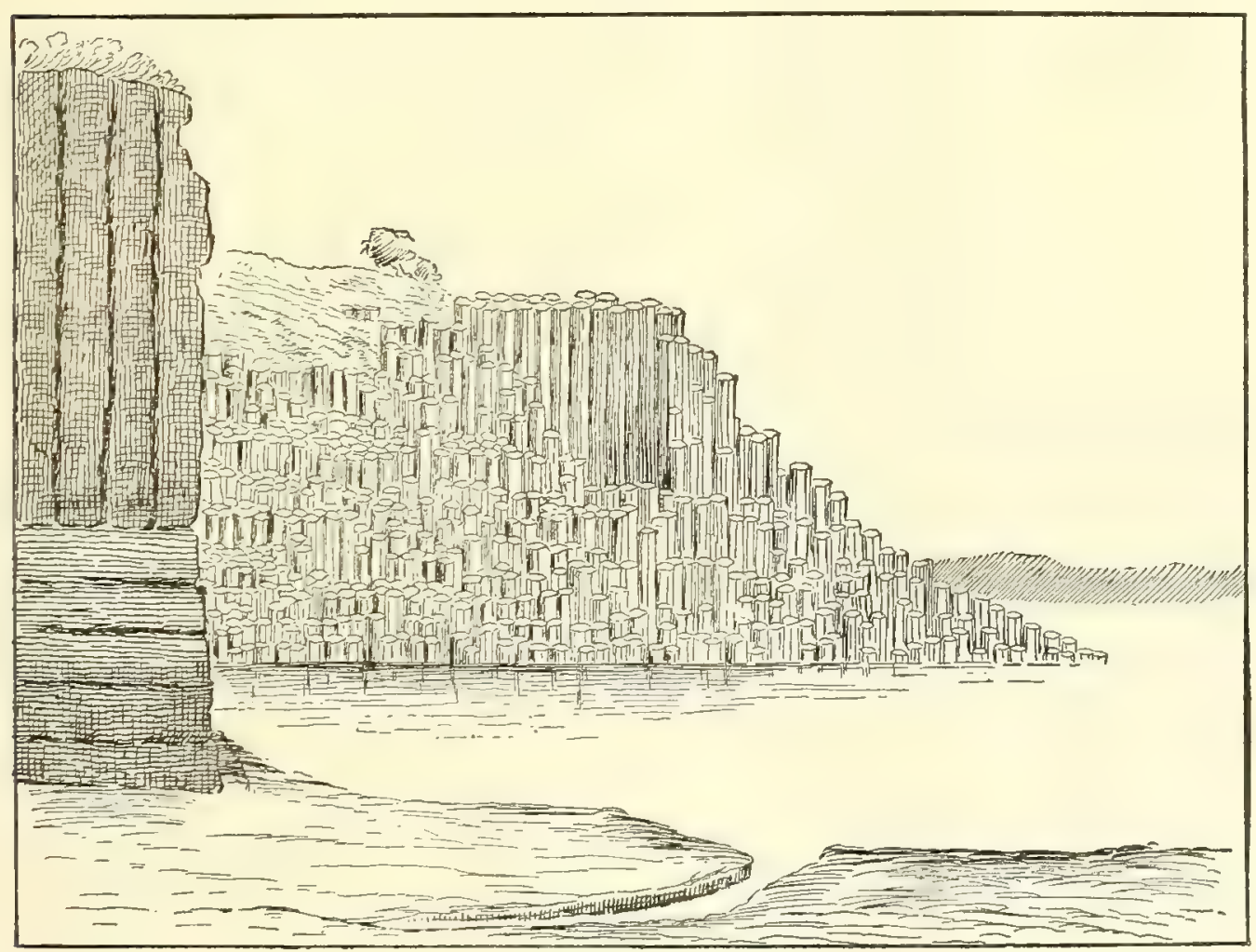

Basaltic columns, at Kiama, on the coast of Illawarra, New Soutb Wales. D., Note-Book, '39.

fect in form resting on horizontal stratified rocks, the other a larger outflow in regular vertical columns five to eight feet in diameter. 
The rertical position shows that the cooling surfaces were (1) the rocks underneath and (2) the air above; and the regularity of position indicates remarkably equable progress through the mass in the cooling. Fig. 219, representing a dike and overflow from the same region, shows the effects of position in cooling surfaces; the dike, with vertical walls having horizontal columns, and the overflow, vertical columns. The rock intersected and overlaid is a conglomerate, and part of the latter is involved in the basalt.

219.

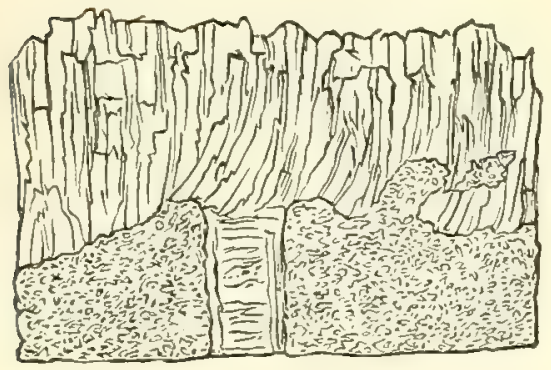

Dike with outflow, Kiama. D.
220.

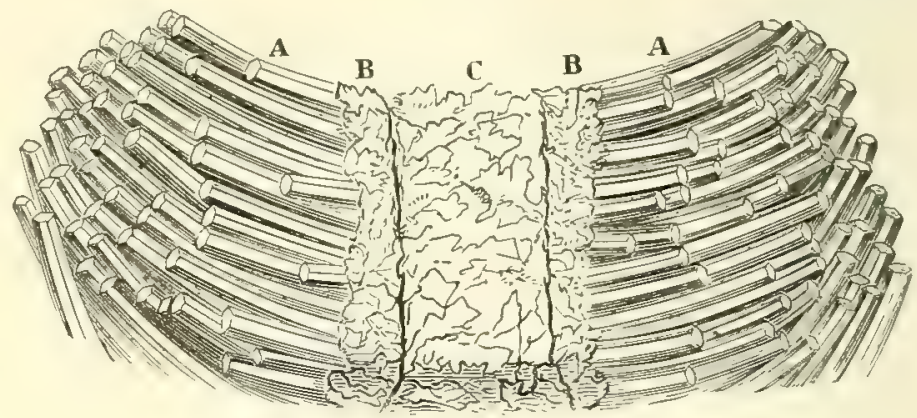

Curved columns, Kiama. D. '49.

The effect of a small ridge (of conglomerate) in making curved columns is shown in Fig. 220. For a short distance the basalt is massive; then the columns - one to four feet in diameter and 30 long - begin abruptly. The low terminal plane of the column is flat; but this plane is nearly horizontal whatever the obliquity of the prism, the variation from it where greatest not exceeding $20^{\circ}$. The stream of basalt was 50 feet thick.

221.

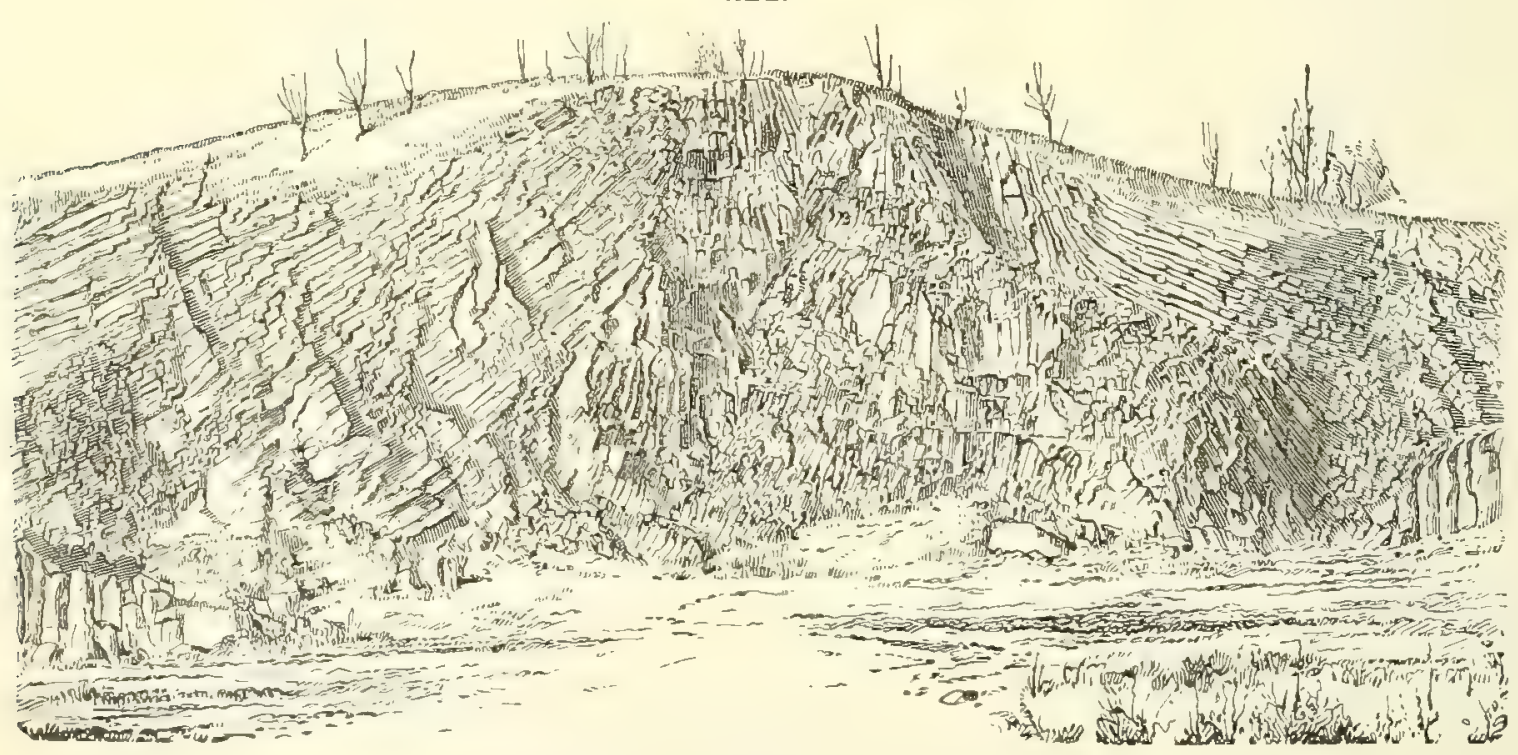

Columnar Basalt, Orange, N.J. Iddings, '86.

The trap of the Triassic of eastern North America is usually more or less columnar; and in some places regularly so. At a quarry in Orange, N.J., west of the city, the columns are in groups which are in some parts 
abruptly diverse in positions and size, as shown above. The diameters vary from four feet to six or eight inches; and some groups are much curved. Iddings refers the abrupt changes to irregular cooling after the surface had crusted over, different rates proceeding from the lower and upper surfaces. To this may be added that the upward flow or thrust of the liquid rock was probably more or less intermittent, as it is a common fact in modern flows about volcanoes.

Basaltic rocks are much more generally columnar than other kinds of igneous rocks. Figs. 222 and 224 show the same structure in phonolyte,

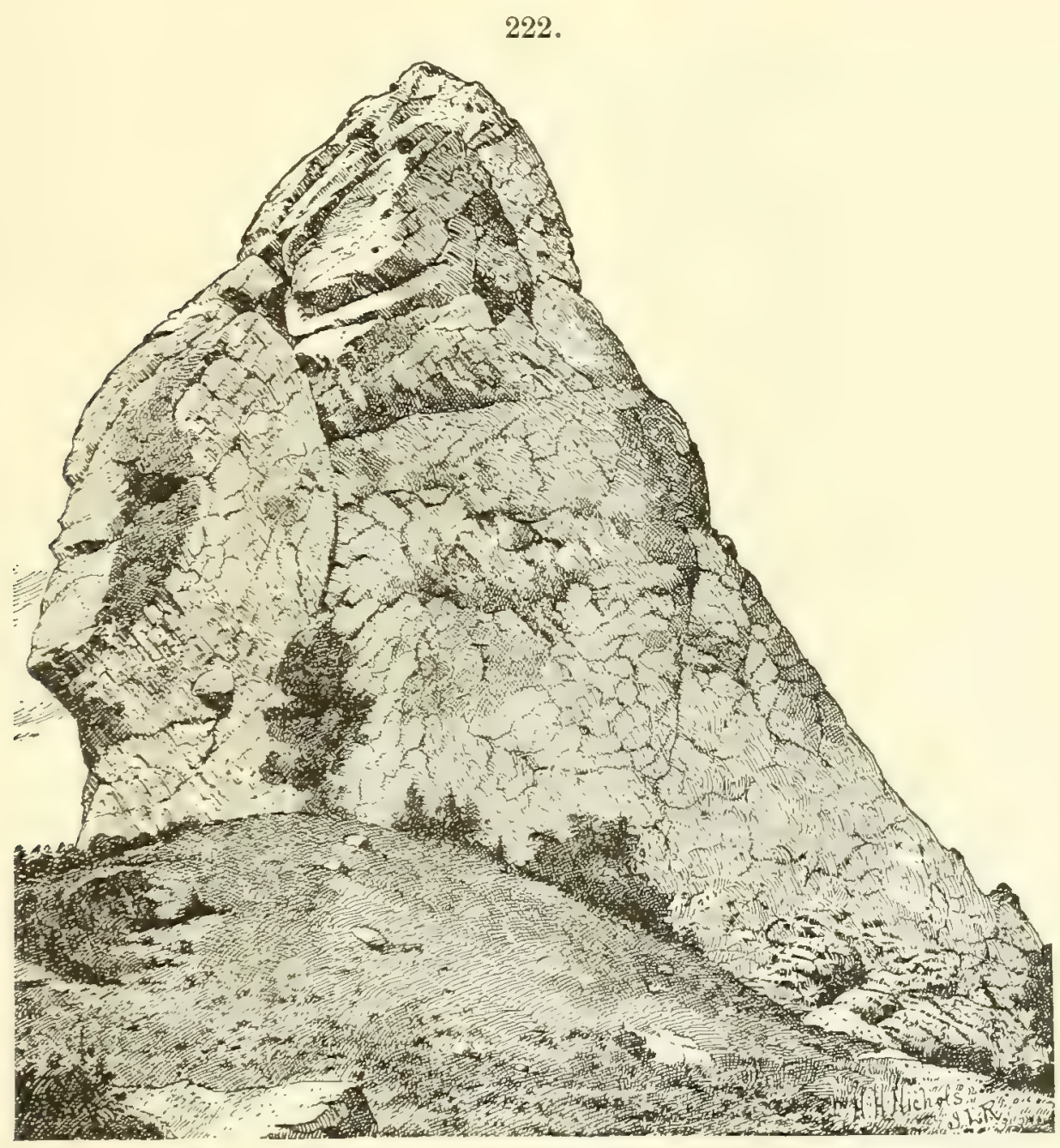

The Phonolyte Peak, 1000 feet high, on Fernando de Noronha. J. C. Branuer, '89.

and in half-stony volcanic glass. The first, representing a peak, 1000 feet high, on the island of Fernando de Noronha, is from a paper by J. C. Branner. The second shows the well-developed columns of "Obsidian Cliff" (a noted locality in the Yellowstone Park). The columns are 50 to 60 feet high; above the columns for 50 feet, or so, the obsidian is massive. (Iddings, 1886.) The cross-lining in the figure represents shading and not the thin laminated structure that characterizes much of the obsidian.

In a cooling layer of fused rock, the smallest number of fractures that 
can be opened about a point on its surface by equable contraction is three, 223. and hence this number is the easiest to make; and since three such lines symmetrically placed make angles with one another of $120^{\circ}$ (Fig. 223), the hexagonal prism, more or less regular, is the most common form of the "basaltic" column.

In the case of large dikes between walls of rock, the set of divisional planes which is nearly or quite vertical is generally more strongly developed than the others, and this occasions a laminated structure in that

224.

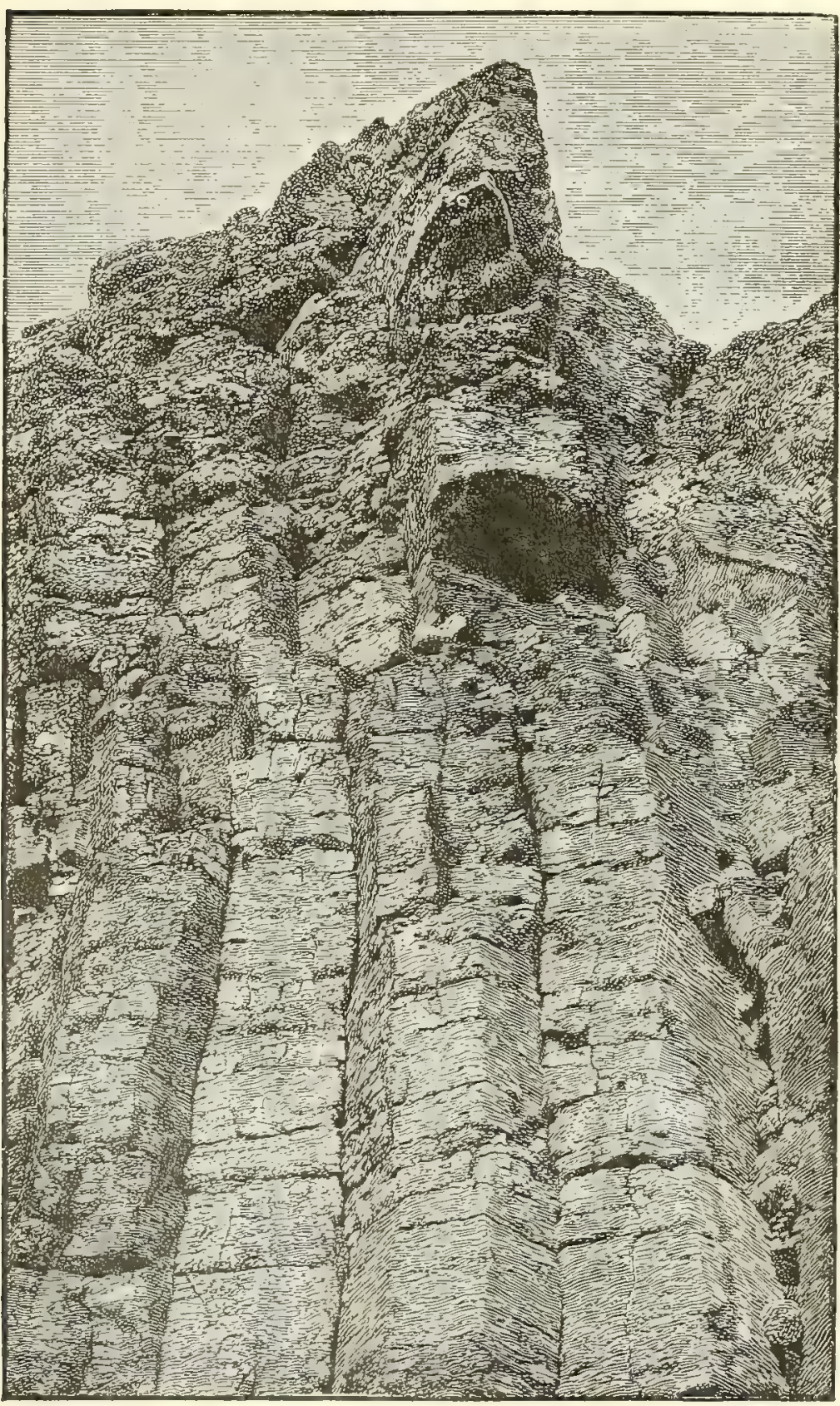

Obsidian columns, Yellowstone Park. Iddings. direction looking like upturned bedding. This structure is common in the trap of the Triassic of the Connecticut valley; and at the same time joints transverse to the apparent lamination also oceur. In many of the nearly vertical fronts, these two courses of joints are predominant.

(b) Contraction from cooling when the heat is short of fusion often produces columnar fractures in finegrained rocks. Sandstones are thus made columnar by contact with melted rocks. Part of the effect is due to drying.

4. Expansion and contraction in the process of solidification and fusion. - Since the glass state of a mineral or rock is a consequence of rapid cooling from fusion, and the stone state is the result of slow cooling, glass will become stone if melted and very slowly cooled. In passing from the liquid to the glass state, in the case of 
plate glass, at the Thames Glass Works, the contraction was 1.59 per cent, 100 parts, by weight, becoming 98.41 (Mallet). In passing from the stone to the glass state, according to Delesse, granite decreases in density 9 to 11 per cent; syenyte, 8 to 9 ; dioryte, 6 to 8 ; doleryte, 5 to 7 ; trachyte, 3 to 5 per cent. Cast iron loses in density on heating, and also on solidifying; trials gave a density of 7.214 when cold, 6.535 before fusion, and 6.883 when liquid (Hannay).

\section{IGNEOUS ACTION AND ITS RESULTS.}

Igneous action has its origin almost exclusively within the earth's heated interior. A few phenomena only are due to exterior agencies. Its chief direct results include: (1) the melting of rocks; (2) the eruption of melted or plastic rock from some subterranean source into or through fissures or spaces opened in the earth's crust, - thus making eruptive rocks; (3) the repeated eruption of melted rock, through long periods, from local vents, thereby making volcanoes; (4) the imbibing by the melted rock, while on its way up, of vapors generated from ingredients encountered in the adjoining rocks, and especially of water-vapor, derived from the moisture of these rocks and from subterranean streams, - producing, in the melted rock, augmented mechanical and chemical powers; (5) the communication of heat and vapors to the adjoining rocks, - producing in these outside rocks chemical and physical changes. Earthquakes, solfataras, fumaroles, hot springs, geysers, and also mineral depositions and emanations in connection with the hot springs and fumaroles, are among the attendant results.

In the following pages the results of exterior agencies are first presented; and then those of interior origin, under the heads of Volcanoes, Non-volcanic Igneous Eruptions, and Geysers.

\section{Action of Exterior Agenctes.}

Lightning, an electric discharge or a combination of them, occasionally leares evidence of its intense heat on rocks and sand-heaps, by the fusion of the constituent minerals into a tube around its pathway, or in patches of glassy beads. The tubes, called fulgurites, have been observed in many places in the sands of dunes, descending to a depth of one to three feet; and one of ten feet is reported. They are one half to two or more inches across, often contorted, taper, and sometimes branch, downward. Tubes two feet long, found near Pensacola, Fla., consisted within of a bright clear glass almost free from grains of quartz (Diller, 1884). A fulgurite from the sand near Waterville, Me., has been described by W. S. Bayley (1872). The fulgurites in rocks occur especially about the summits of mountains. They have been observed in Mexico in the trachytic summit of Toluca (Humboldt); in Little Ararat, Caucasus, in augite-andesyte (Abich); on the top of Mont Blanc and at a dozen other points in the Alys; at many places in the Pyrenees; also in Oregon and Colorado. 
The common effects on the rocks are: the covering of small surface spots, or depressions, with beads of glass, or with sinuous glassy lines sometimes radiating; the production of tubes sometimes half an inch or more in diameter, descending with diminishing size a few inches into the rock, and sometimes dividing downward; the glass being such as the rock, or some of its more fusible ingredients, would afford on fusion. The usual absence of microlites is regarded as an indication of the sudden cooling of the glass.

Specimens from Mount Thielson, Oregon, south of the Columbia, where the rock is hypersthene-basalt, consist, according to Diller, of a coating of patches and beads of glass, and also of tubes $\frac{1}{3}$ to ${ }_{3}^{2}$ inch in diameter, having a brownish glass within, which descend 2 to 3 inches into the rock. On West Peak, east of the Sangre de Cristo Range, Col., tubes glassy within, and surface-depressions with beads of glass, occur in augitedioryte, and in one place a tube appeared to follow the course of a small vein of ore (R. C. Hills, 1890). A fulgurite-glass, occurring in the Alps on Mount Viso, coating furrows made in glaucophane schist, was peculiar in containing microlites (Rutley, 1889).

The disrupting power of lightning is sometimes shown in the fracturing of rocks, and it is supposed that this may have been, in past time, an important agent of rock-destruction. But this theory is opposed by the fact that the strokes producing fulgurites have done very little shattering.

225.

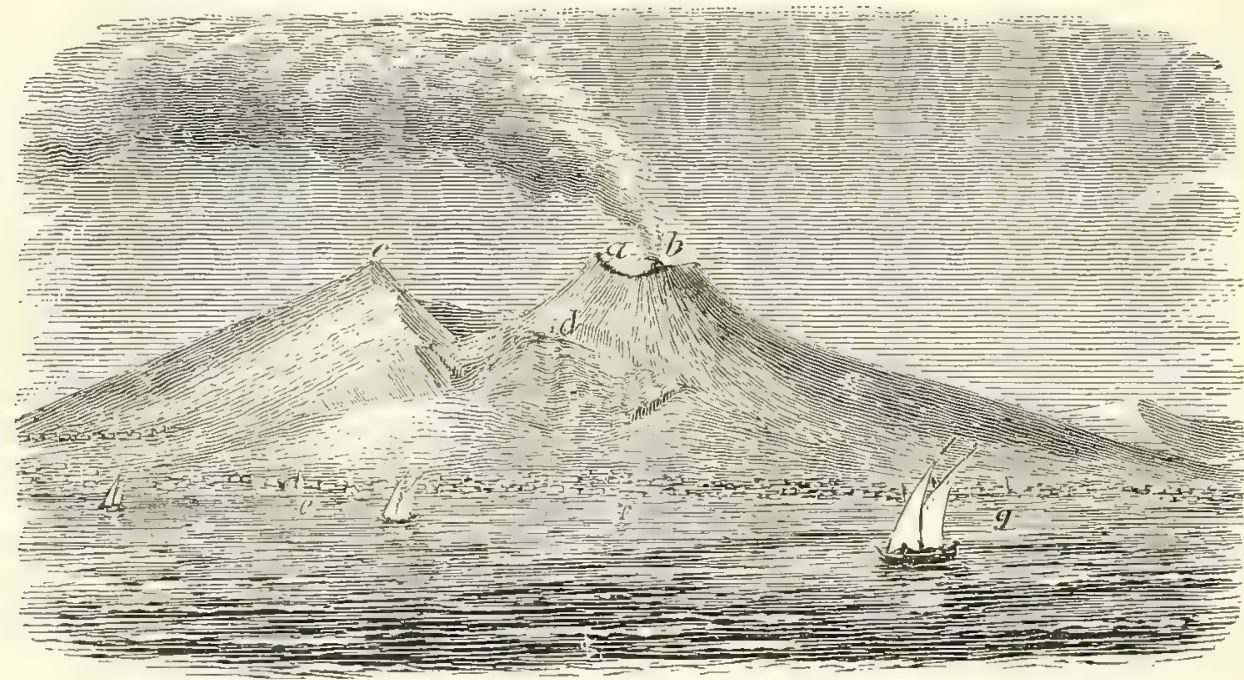

Vesuvius as seen from the harbor of Naples. D. July, '34.

The burning of coal-beds has produced scoria and other igneous results in North Dakota and Montana. But the mode of ignition of the beds is not known. A stroke of lightning is the most probable agent. It is hardly possible that chemical changes ever occasioned it. In the States above mentioned the burning of coal-beds of the Lignitic Tertiary has changed clays to hard and sometimes porcelain-like rocks, usually reddening them, and also to beds of a half-fused cellular or scoriaceous and pumice-like character, looking like the products of a volcano. One of the regions thus burnt over, on the Little Missouri, is 20 to 30 miles broad by 200 miles in length. Others occur in the Yellowstone at the mouth of Powder River and along the latter stream; about the sources of 'Tongue River, within a few miles of the Big Horn Mountains, and on the north fork of the Cheyenne River, as observed by Hayden. Fragments of pumice have been found on the Missouri as far south as Pierre, and the early explorers supposed them to be the products of 
unknown volcanoes, high up in the mountains. The baked rocks, besides giving their red tints to the country, resist erosion, as Mr. Allen states (1874), and so protect the hills from denudation, and become prominent features of the region.

\section{VOLCANOES.}

\section{General Characteristics.}

An active volcano, as ordinarily understood, is a mountain or hill more or less conical in shape, having at or near its top a cavity called a crater; and, within the crater, a vent or source of liquid rock and hot vapors, whence proceed at times ejections of lava in streams, or else in projected fragments. It is fundamentally a vent of vapors and liquid rock, which, by its projectile action has been and is still surrounding itself by an elevation of more or less

226.

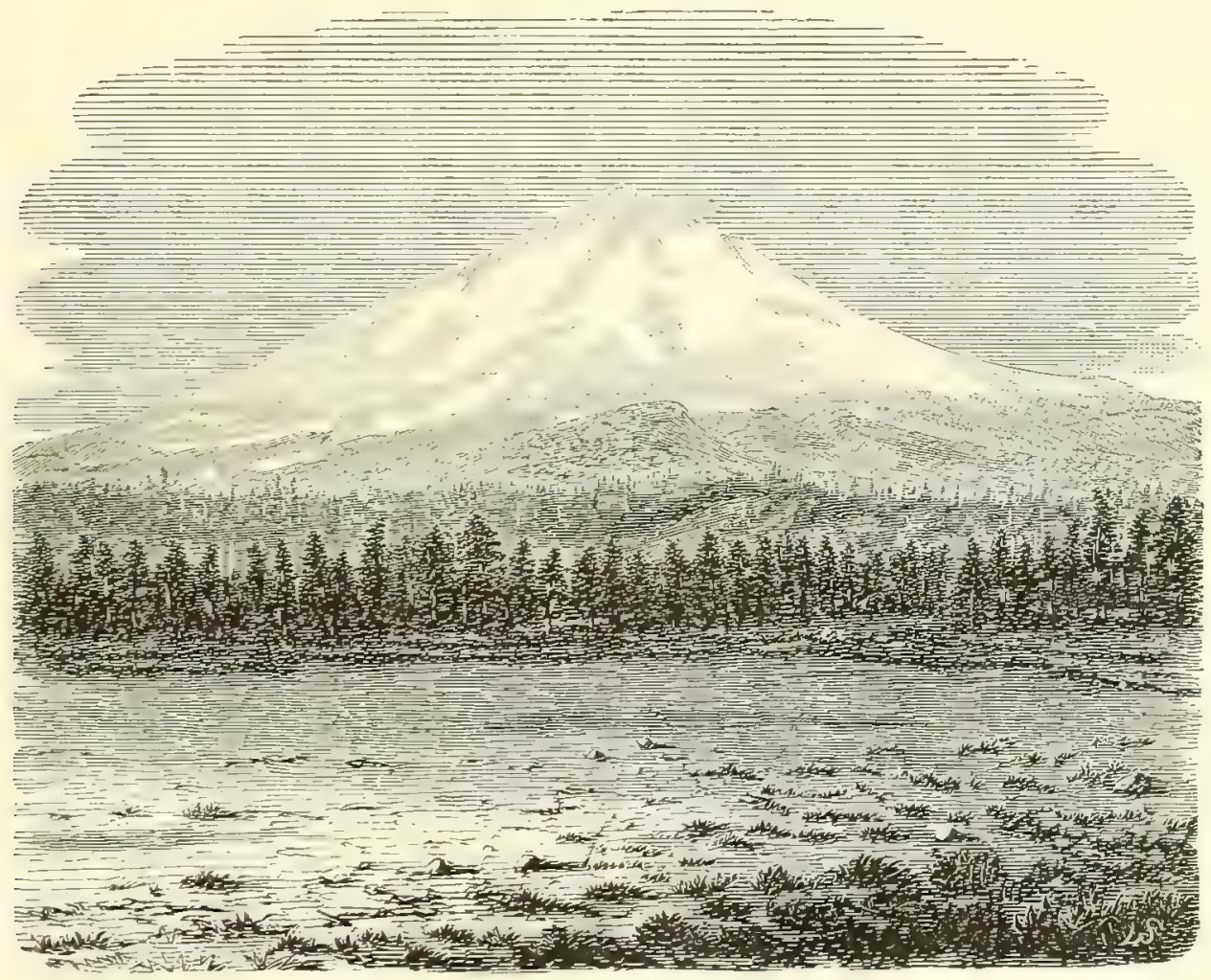

Mount Shasta as seen from the south. Height, 14,401 feet. From a photograph by Watkins.

conical form and pericentric structure. The ejected materials descend around the vent, and by this pericentric work build up the rising volcanic cone. The liquid rock and its cooled streams are the lava of the volcano, and the loftily projected lava-fragments, cooled as they fall, which may be for years the only ejected material, are the cimders (lapilli of the Italians), or volcanic ashes when fine, or volcanic scoria when made up of light cellular pieces.

A view of Vesuvius as it appeared in July, 1834, is given in Figure 225. The main body of the mountain is made of lava streams, with some layers 
of cinders; the large active cone to the right consists outside and at the top of cinders; and the small cone at the very top giving out vapors, of cinders alone. The whole height is nearly 4000 feet.

227.

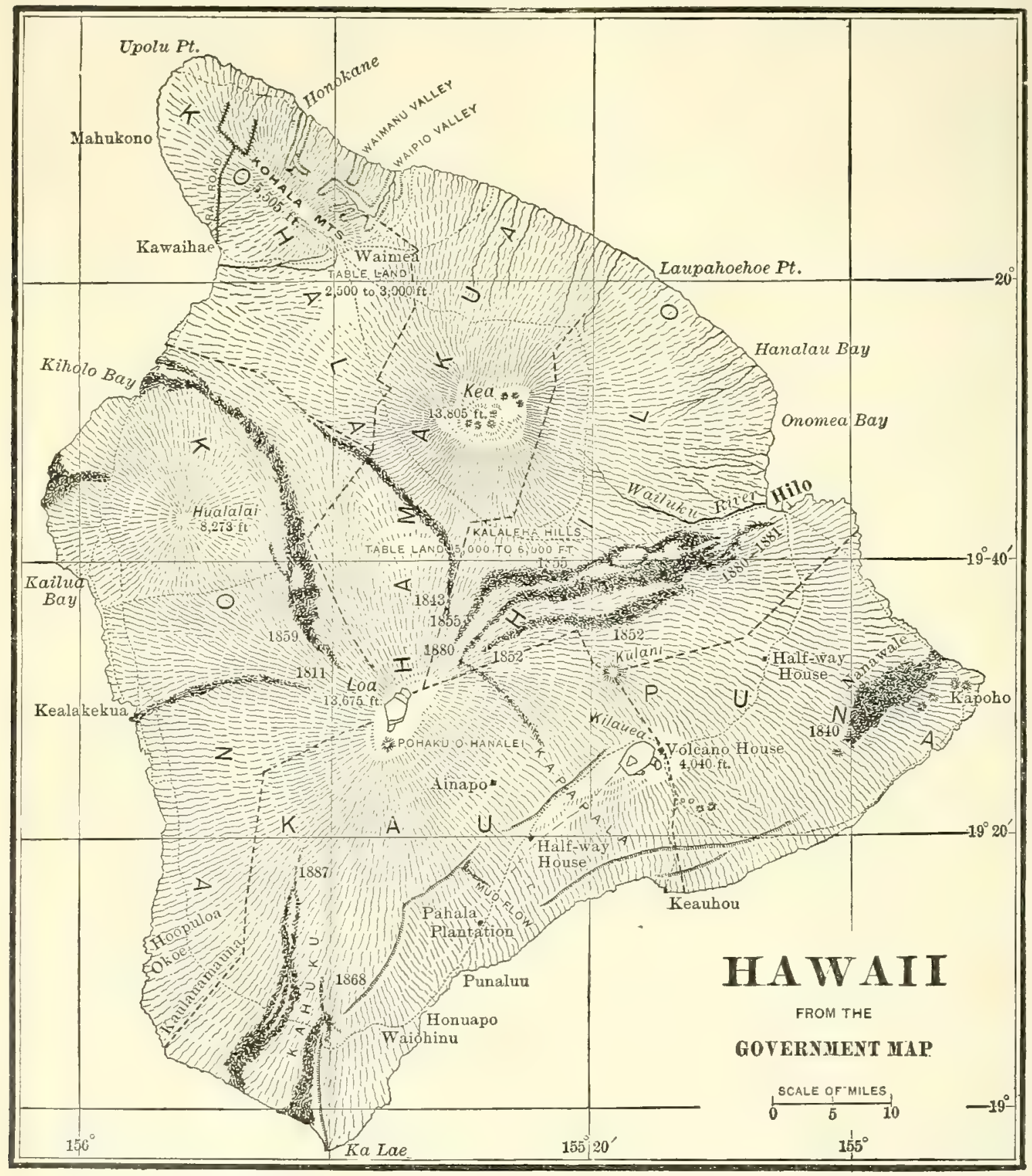

If the projected fragments of lava are thrown only to a small height, as is usual at the volcanoes of Hawaii, they descend without cooling and adhere to the surface on which they fall, where they have the appearance of cooled drops, driblets, or incipient streamlets of lava.

The vapor escaping from the crater, often wrongly called smoke, is chiefly vapor of water, with quantities of other vapors or gases. 
Lava-cones, Cinder-cones, Tufa-cones, Driblet-cones. - An active volcano may have discharges of lavas; or discharges of projected fragments, that is projectile discharges; or discharges, for long periods, of vapors alone.

Outflowing lavas make a lava-cone, which may vary in angle of slope from $3^{\circ}$ to $25^{\circ}$ or more. Mount Shasta (Fig. 226), in northern California, is one of the steeper cones, and those of Hawaii are cones of low angle.

228.

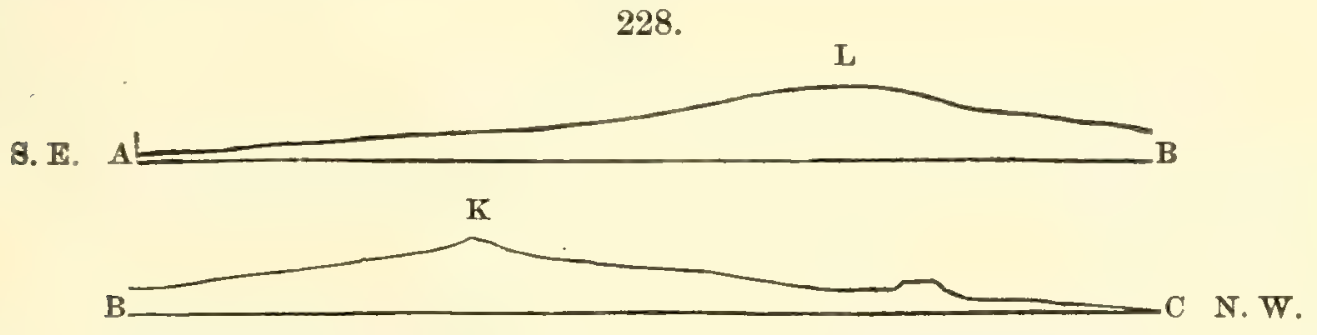

A, B, B, C, profile of Hawaii, as seen from the eastward; L, the dome, Mount Loa; K, Mount Kea.

As shown on the map, Fig. 227, three great cones make up nearly the whole of Hawaii, although the island is 93 miles from north to south and 80 miles broad. These three cones are Mount Kea, now extinct, 13,805 feet high; Mount Hualalai, in eruption in 1801, 8275 feet; and Mount Loa, now in frequent eruption, 13,675 feet. Kilauea, to the east of Mount Loa, is another

229.

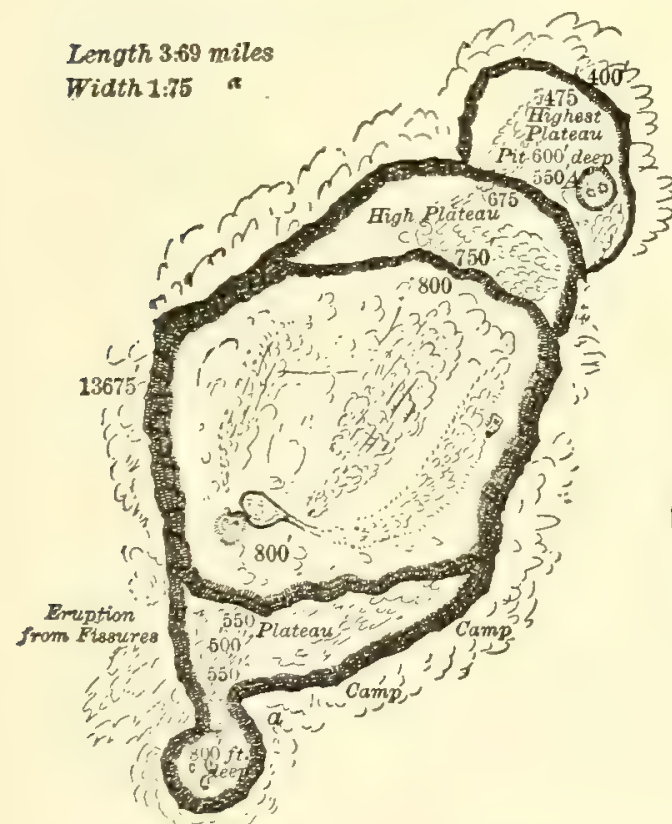

230.

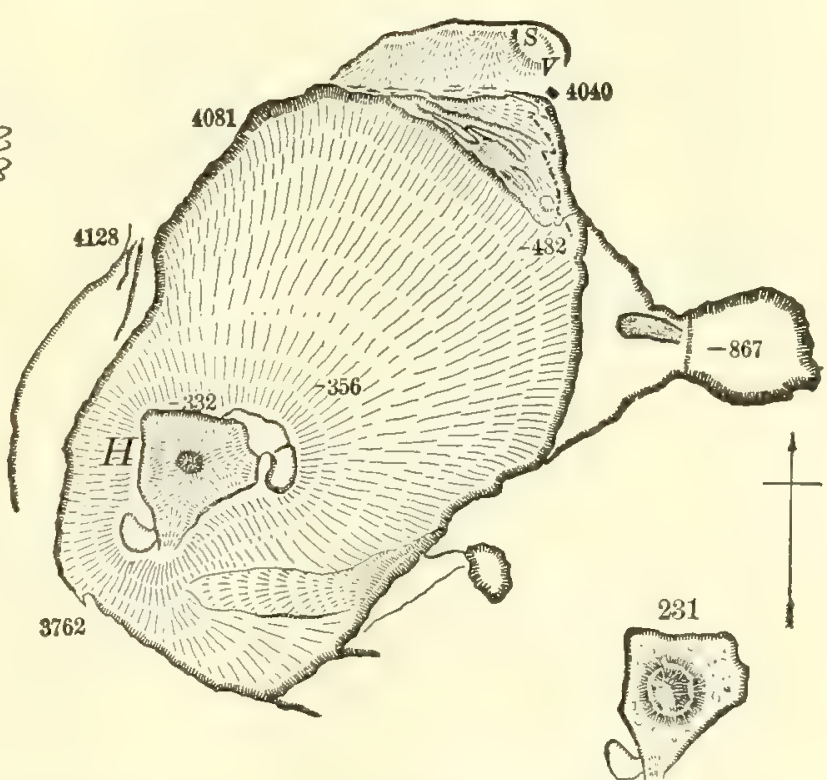

Fig. 229, crater of Mount Loa (J. M. Alezander); Fig. 230, crater of Kilauea (Hawaiian Government Survey) in 1886; V, Volcano House; $H$, the great lake-basin Halemaumau, emptied after an eruption in 1886. Fig. 231, same basin containing a debris-cone 6 months after the eruption. Levels of the floor of Kilauea, in Fig. 230, are measured from the level of the Volcano House, at V.

active volcano, but it makes the eastern flank of Mount Loa, and projects where highest hardly 300 feet above the plain between it and the Mount Loa slopes. The Kohala Range, on the north point, is the half-buried remains of a volcano of unknown extent, which, as its valleys indicate, long since became 
extinct. Fig. 228 represents a nearly north-and-south section of the island through Mount Loa and Mount Kea. The slopes of Mount Loa are $5^{\circ}$ to $8^{\circ}$, except over its broad nearly flat summit; of Mount Kea, $5^{\circ}$ to $10^{\circ}$; and the eastern slopes of Kilauea, only $3^{\circ}$. The map of Hawaii shows also, by the dark-dotted areas, the courses of its great lava-streams since 1840.

Figs. 229 and 230 are maps, on a seale of 9000 feet to the inch, of the crater at the summit of Mount Loa (Fig. 229) and that of Kilauea (Fig. 230), after an eruption in 1886.

Fig. 232 is an excellent view of the crater of Kilauea as it appeared in 1864, taken from the north side. It differs little from that of recent years, except in the low ridge over the bottom toward its left side.

232.

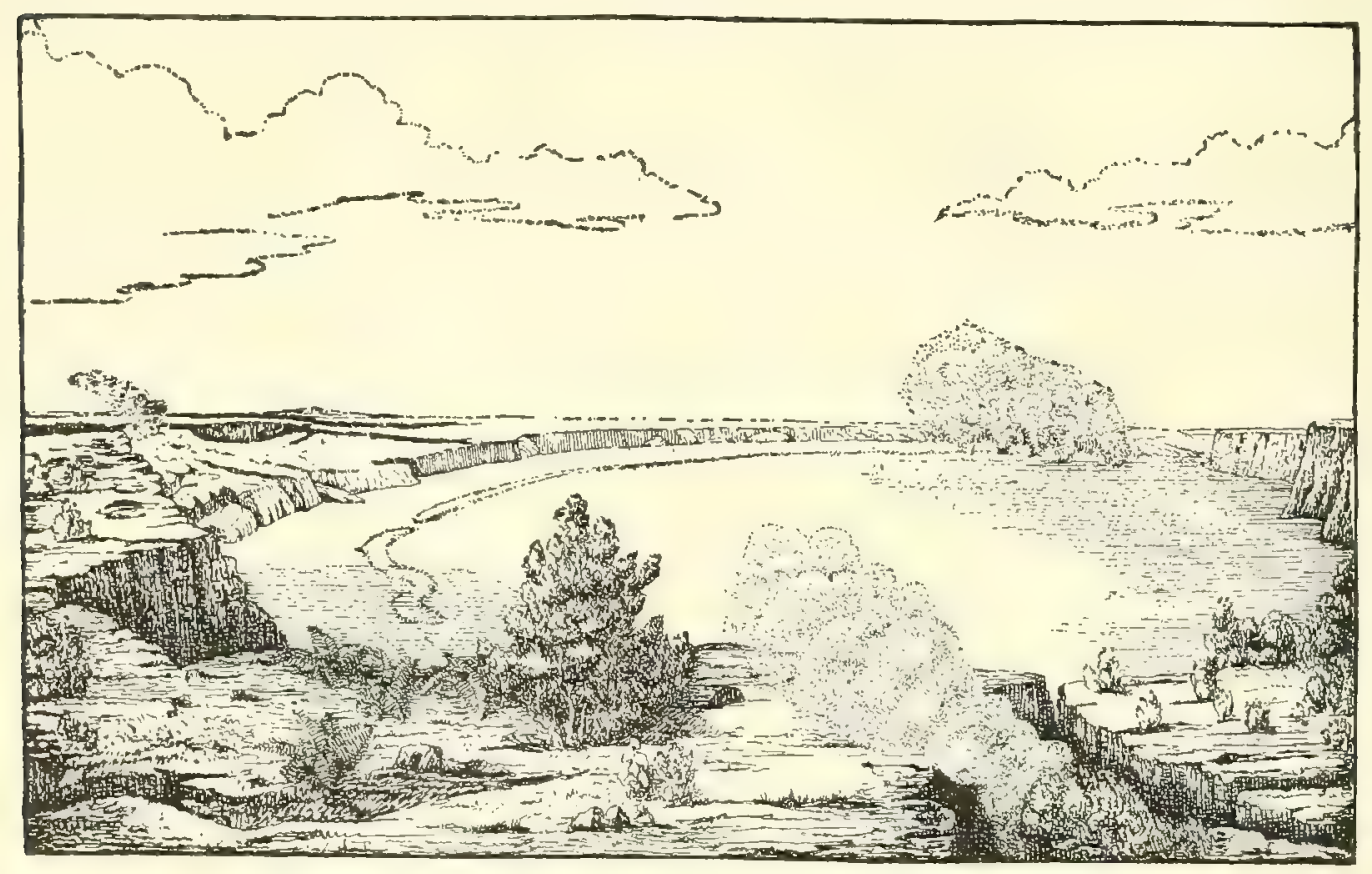

Kilauea, from the north, just west of the Volcano House. Perry.

Maui (Fig. 160), the island just northeast of Hawaii, affords, in its eastern half, another good example of a lava-cone; its height is 10,032 feet, and the crater, called Haleakala, is 2500 feet deep.

Cinders, or the material of high projectile discharges, form cinder-cones (Fig. 233), having slopes commonly of $35^{\circ}$ to $40^{\circ}$, but inade somewhat lower

233.

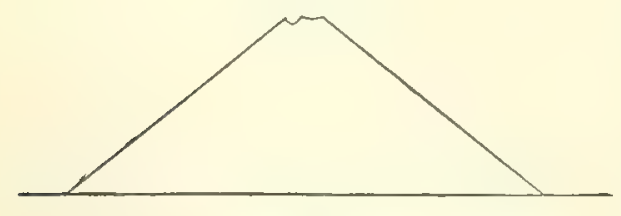

Assumption Island, Northern Ladrones. D. '41. after their formation, through the winds, rains, and surface earth-slipping. They have narrow summits and eraters.

If the cinders are wet by heavy rains, or otherwise, so as to flow like mud, the cone formed has a broad top, a saucer-like crater, and slopes generally of $15^{\circ}$ to $25^{\circ}$, and is a tufa-cone. The sides may spread out below at a very small angle. Figs. 234 and 235 are tufa-cones. They show the 
great breadth of the crater; but the exterior has lost its natural slopes by denudation. In Fig. 235 the cone to the left shows the dip of the layers of tufa inward toward the center of the crater and outward, down the outer slopes. Driblets pile up the fantastic driblet-cone, which has no crater but simply a hole for the projection of lava in small liquid masses, drops, driblets, or worm-like streamlets.

234.

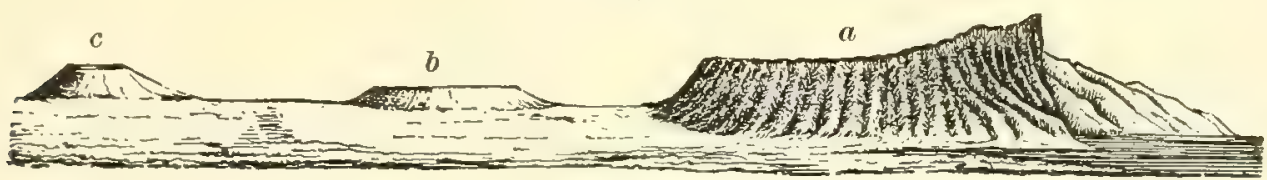

235.

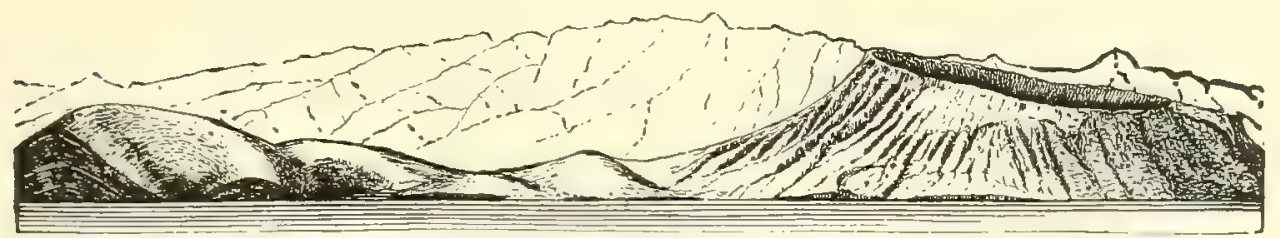

Tufa-cones, Oahn. Fig. 234, $a$, the tufa-cone, Dianond Head, east of Honolulu, the exterior eroded; $b$, $c$, other smaller cones; Fig. 235, Koko Head tufa-cones, east cape of Oahu, the one to the left cut through by the sea, that to the right eroded inside as well as outside. $D$.

Still another kind of cone, occasionally observed in Kilauea, is the debriscone, made at times in Halemaumau after a discharge out of the masses or fragments that fall into the basin from its steep sides. (See Fig. 231.)

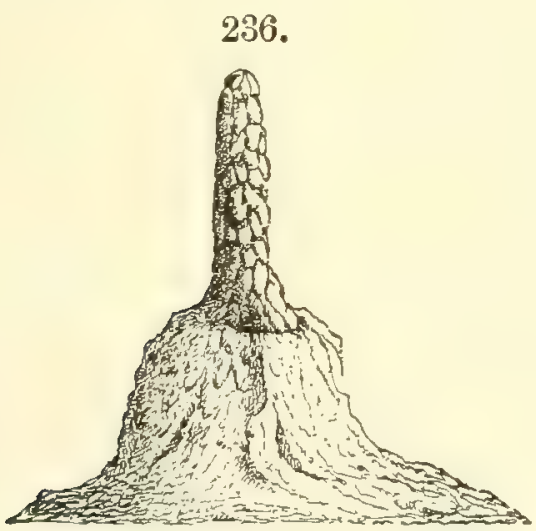

Driblet-cone of Kilauea. D. ' 40.
237.

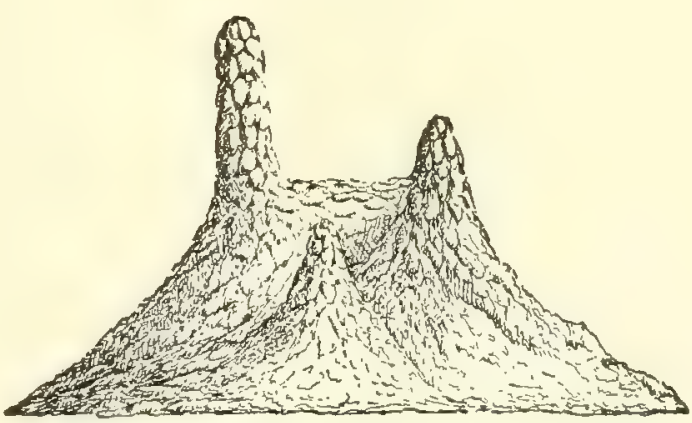

Driblet-cone. Brigham, '64.

At an eruption, the discharged lava: (1) may flow down the mountain in great streams from the crater at the summit; or (2) may escape to the surface through breaks or fissures made by the eruptive forces in the mountain's sides, and thence spread away in streams; or (3) it may flow off through fissures into underground eavities between the old lava streams of the mountain, or it may only fill the opened fissures. Discharges from the crater are probably the prevailing kind at the commencement of a volcano, the lavas then pouring out copiously. But at the present time the outflows are mostly or wholly from fissures, thongh often subterranean. 
The outflow from fissures may take place at any height on the mountain, and also beneath the sea level. If at the latter, the eruptions are submarine; if at the former, surficial, that is, subaerial. The map of Hawaii shows the courses of seven of the great lava streams of the summit eruptions, with their dates. They all commenced some distance from the crater; and the two to the south, those of 1868 and 1887, at points 17 and 12 miles from it, and 12 and 17 from the coast. Only one lava stream from Kilauea is shown, that of 1840, on the eastern point of the island; all its later discharges have been subterranean.

The fissures for the discharge of lavas are often so wide in some places that they pour out the lavas there for weeks, and make cones of lava over each wide place; or if the lava ceases to flow out, there may be projectile discharges for a time and cinder-cones may be made. In either case a line of cones (Fig. 234) may be formed over the fissure. Such cones while in action are true volcanoes in all their characters. They are distinguished as the lateral cones of a volcano or volcanic mountain. The lateral cones of a submarine eruption often stand as islands, or make shoals, off a coast.

Lavas and other igneous rocks. - The kinds of igneous rocks have been described on pages 84 to 89 . There are many of them, but petrology makes distinctions, based on texture and accessory minerals, which have importance, but are not always of fundamental value. These rocks consist ordinarily of a kind of feldspar, or occasionally of some other related alkali-bearing mineral, usually with some additional mineral, as pyroxene, hornblende, chrysolite (olivine), quartz, mica, and a few other species. But hornblende when fused turns to pyroxene; chrysolite may form from fused pyroxene; and mica may be derived at a high temperature from feldspar. Further, all textures from that of glass to granite-like may exist in the igneous sheet or mass of a single ejection - the differences depending on rate of cooling.

The distinctions between granite, granulyte, rhyolyte, and quartz-felsyte, between trachyte and felsyte, between gabbro and doleryte, between chrysolitic gabbro and basalt, between andesyte and dioryte, between dacyte and quartz-dioryte, are differences chiefly in texture - a character of inferior value geologically, although a sufficient reason for their having names in petrology. The minerals pyroxene and hornblende are essentially the same in composition, and they are also mutually convertible under certain heatconditions, as explained beyond, and hence pyroxenic and hornblendic rocks are very closely related; but the distinction, notwithstanding the degree of resemblance, is often of great geological interest.

Igneous rocks are fusible kinds. No lava streams or dikes have been found about volcanoes consisting of the "infusible" minerals quartz, hematite, magnetite. But grains of these minerals are common in the rocks.

Besides, there are often minute grains of native iron in some igneous rocks, especially in the basaltic; and large masses of iron have been found in the basalt of Disco Island, Greenland, and of copper in the related igneous rock of the Lake Superior copper region in Michigan. The copper probably resulted from the reduction, by the heat, of copper ore 
encountered on the way up; and the same may be true of the iron, the reduction in this case having been effected, as J. L. Smith suggested, by the aid of some carbon compound in the ascending liquid basalt. But it may be that the iron was carried up by the liquid rock from the earth's interior.

Some igneous rocks consist chiefly of the "infusible" minerals chrysolite and leucite; but the complete fusion which the capability of flowing indicates is evidence that some part of the constituents of these rocks before ejection were in fusible combinations. By infusible is here meant infusible before the common blowpipe.

The more important volcanic phenomena connected with these rocks depend on the temperature of fusion, those requiring the least heat being the earliest to fuse as the temperature rose, and the longest to continue liquid as it declined, and, therefore, those that have commonly had, when ejected, the temperature of the freest liquidity.

There are three prominent classes of igneous rocks, differing in fusibility. In each class the kinds are nearly alike in chemical constitution, but differ somewhat mineralogically and in state of crystallization. There are intermediate kinds; but still the classes stand out prominently. These three groups are as follows:-

1. Easy fusibility. - The Basaltic Class: These fuse at about $2250^{\circ} \mathrm{F}$. (C. Barus); consist chiefly of pyroxene (or a related species), and of the feldspar, labradorite, whose alkalies are lime and soda; they often carry grains of chrysolite, but very rarely of quartz: as basalt, doleryte, diabase, gabbro, etc. These rocks are basic (pages 65,86 ); but fusibility, not basicity, is the important characteristic as regards volcanic phenomena; for anorthite, the most basic of the feldspars, is one of the most infusible.

2. Medium fusibility (about $2520^{\circ} \mathrm{F}$., Barus). - The Andesrte class: These consist of a mineral of the pyroxene-hornblende group, and, as the feldspar portion, of oligoclase or andesite, whose alkalies are soda and lime; they often carry quartz grains: as andesyte, dacyte, quartz-andesyte, dioryte, and related kinds.

3. Difficult fusibility (about $2700^{\circ} \mathrm{F}$., Barus, for quartz-trachyte or rhyolyte).- The Trachyte class: These consist of potash-feldspar, orthoclase, or of orthoclase with a little oligoclase, or albite; sometimes containing mica, pyroxene, hornblende, quartz: as trachyte, rhyolyte, felsyte, granite, etc. Rhyolyte is quite viscid even at $3100^{\circ} \mathrm{F}$. (Barus).

Lavas, especially the trachytic and andesytic kinds, and including lithoid obsidian, have frequently a thin laminated structure, which is produced, not by a succession in streams, the laminæ being too thin for streams, but by successive action in the supply of lava at the point of outflow; the incipient subdivisions are drawn out as the stream flows into thin sheets or layers (Iddings).

Fouqué and Lévy obtained from fused basalt on cooling after being for 48 hours at white-red fusion, "a temperature above the melting-point of pyroxene and labradorite," "crystals of olivine in a brownish vitreous magma"; but on cooling from cherry-red fusion sustained for 48 hours, numerous microlites of labradorite and pyroxene with magnetite.

Messrs. Ch. and G. Friedel (1890), on heating mica to $500^{\circ} \mathrm{C}$. $\left(900^{\circ}\right.$ F.) with alkaline DaNa's MANUAL - 18 
solutions, obtained crystals of nephelite and orthoclase; and with the addition of silica, obtained leucite.

As early as 1804, Gregory Watt published in the Philosophicul Transartions "Observations on Basalt," in which he gave a detailed account of the melting of 700 pounds of basalt from Rowley-Rag $(G=2 \cdot 743$ ) to glass, and of its becoming, on slow cooling, a gray, crystalline-granular mass (with $\mathrm{G}=2.934-2.949$ ) consisting of spherical concretions, many 2 inches in diameter and having a somewhat radiated structure (which was mostly lost with the slowest cooling); and of the adjoining concretions being often rendered hexagonally prismatic from contact, whence he inferred the concretionary origin of basaltic columns.

\section{Conditions Determining the Forms of Cones.}

1. Dependence on fusibility of the lavas. - Cones of lavas of the basalt class are of gentle slope, and great breadth, owing to the easy flow of the rock. The lavas are glassy only at surface, or when in scoriaceous forms.

The craters also derive their characters from the liquidity. They are broad, with the walls often vertical, meriting the name they have of pitcraters, as is well seen in figures 229-231, on page 269.

But the great cones of western North and South America are mostly examples of the andesyte or trachyte class. The slope seldom exceeds $35^{\circ}$, except where caused by breaks. The steepness, however, may be in part owing to intercalated beds of cinders or tufa. Mount Shasta, represented in Fig. 226, is one of them, - its slopes $28^{\circ}-32^{\circ}$ (Whitney). Chimborazo, 20,498 feet high, has angles of about $25^{\circ}$ in a view looking northeast; Cotopaxi, 19,613 feet high, in a westward view, angles of $27 \frac{1}{2}^{\circ}$ to $30 \frac{1}{2}^{\circ}$, rising near the summit to $37^{\circ}$ (Whymper); and Arequipa, angles of $27 \frac{1}{2}^{\circ}$ to $32^{\circ} 50^{\prime}$.

Trachytes, and other lavas of the third class, take part in cones of the second kind. But as the temperature of free fusion is above $3100^{\circ} \mathrm{F}$, the heat required for complete liquidity is generally wanting, so that at the time of ejection they commonly are already in a pasty state, or that of incipient solidification. The streams are thick, compared with the basaltic. Sometimes the lava swells up into steep and lofty craterless domes, instead of flowing away in streams. The high domes of Auvergne, France, are examples. But when a trachytic lava has the heat of complete fusion, it may flow and make great streams.

The following sketch represents "Gothic Mountain," in Colorado, in which a mountain mass of trachyte rests on a base of Cretaceous rocks, much eroded over its surface. (Hayden Rep., 1873.) In the nearly horizontally stratified base there is an independent dike of the trachyte, which was probably produced contemporaneously with the outflow that made the mountain. The mountain is nearly 2000 feet in height above the Cretaceous base, and 12,465 feet high above the sea level. The rock is without bedding or any evidence of separate lava flows.

Melted beeswax poured out on a flat surface, while heated above the fusing point, would flow off at a very small angle; but if its temperature were below that of fusion, it would be pasty, and the angle of flow would 
increase as the temperature decreased. Copious streams would have the smaller angle, while small streams would give increased pitch, and drops might make a vertical column. The facts with regard to lavas are the same in principle; for basaltic cones, as in those of driblet origin, may have high angles, even $90^{\circ}$.

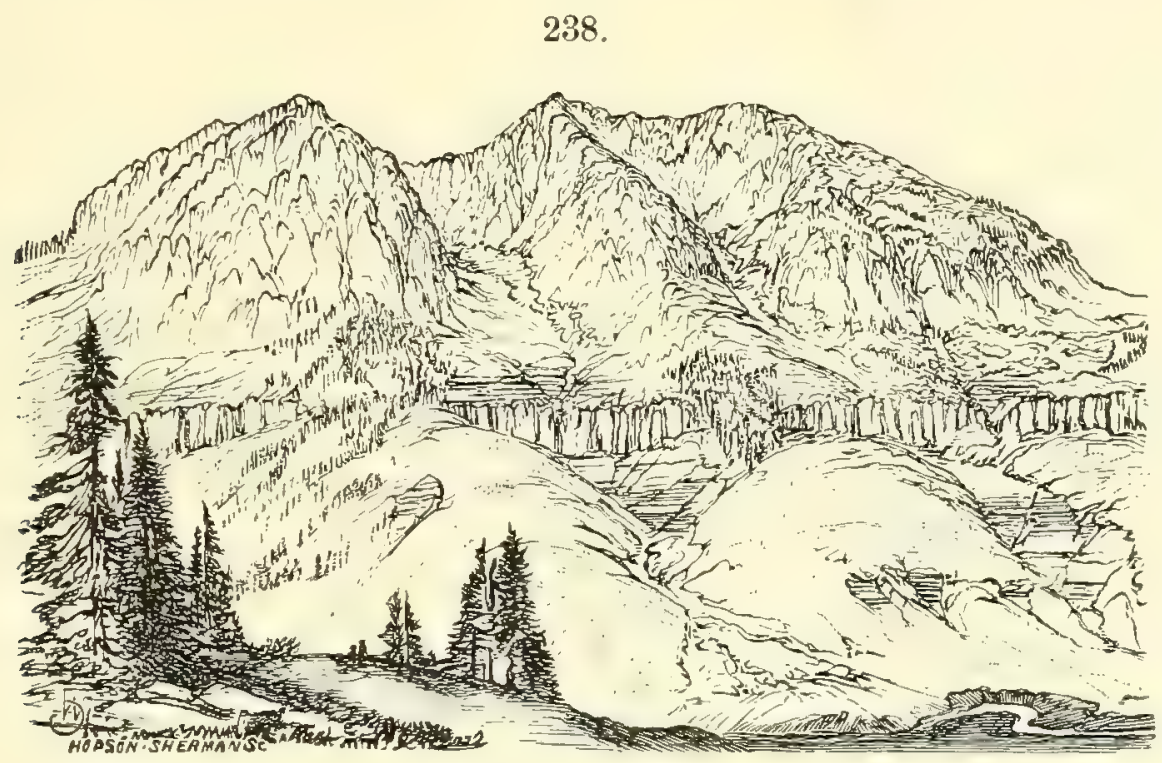

Gothic Mountain, Colorado. A trachytic mass overlying Cretaceous rocks.

If lavas were as liquid as water, cones of sensible slope would be impossible; the most liquid have sufficient viscidity or cohesion to cause some resistance to free movement, and the slope is, in a sense, a measure of this resistance.

2. Dependence of the forms of lava-cones on place and amount of discharge. - Since a cone diminishes in diameter upward, a flow of lava from the summit region, having like width throughout, would cover a much larger part of the circumference in the upper part than in the lower. The part of the cone below would require in fact a great number of ordinary lava streams to make one coat over the surface. The consequence of this condition is that such discharges add to the height and make the cone steeper above, and give it also a concave outline. But if the flows commence for the most part a little below the summit, from an eighth to a sixth of the height, the upper part will be widened and the cone take the form of a low dome, like Mount Loa; or if the streams come from fissures in the lower part of the cone and spread beyond the base, the cone will be flattened below, and the lower part of the profile will be made concave.

Lava-cones often, perhaps generally, derive an oblong or parabolic form of area from their origin over a fissure. The fissure was made by a profound rupture of the earth's crust, and probably the location of the crater was fixed by its intersection with a transverse fissure; but along the larger of the fissures an elongate form is given to the crater. 'The chief focus of action is usually toward one extremity. Over the slopes of the mountain, the belt in the direction of the longer axis is likely to be the region of most frequent eruptions and of long lines of steaming fissures. The craters of both Mount Loa and 
Kilauea are thus elongated and eccentric, and have lines of fissures extending far to the southwest in the direction of the longer axis; moreover, the former has the larger part of its more recent eruptions either to the north-northeast or south-southwest of the crater. The two craters of Maui are also elongated and eccentric. 'The position of the present vent of Vesuvius with reference to the original Mount Somma is eccentric, according to Johnston-Lavis, and perhaps for a like reason.

3. Causes influencing the forms of cinder-and tufa-cones. - Cinder-cones have their forms varied in height, breadth, and slope, on the different sides, by the winds. Moreover, alternations of einder and lava ejections make a cone of steeper slope than lava alone. Summit ejections of cinders may increase the height without adding much to the mass of a mountain. Mount Kea owes its superior height over Mount Loa to a final spurt, when it was becoming extinct, cinder-cones at the top having been then thrown up.

Flowing volcanic mud, from which tufa and tufa-cones are made, necessarily produces broad-topped cones with a saucer-like crater, as explained on page 270; but the winds often carry cinders far away to make horizontal deposits, which sometimes attain great thickness. By making an outline of a section of a cone and drawing lines parallel to the sides, as below, sections representing in a general way the structure of a lava-cone, cinder-cone,

239.

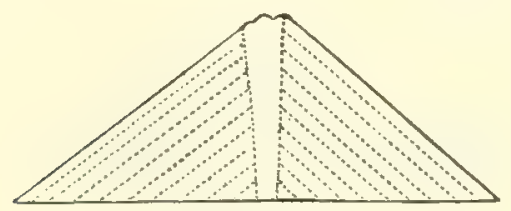

Cinder-cone.
240.

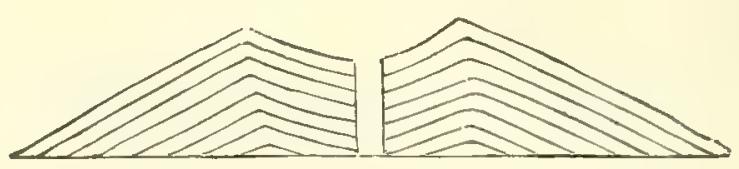

Tufa-cone.

and tufa-cone are easily made. But it is to be noted that such sections are incorrect, since lava streams and cinder deposits are, to a large extent, strips or patches over the surface of the cone and not a series of seamless coats.

4. Relations of glassy lavas to the stony. - Glassy forms of lava (see page 77) occur with each of the three kinds, but make no cones. With basaltic lavas they constitute merely a crust on a lava stream, or the scum of a lava lake; but in a trachytic volcano, the glass, called obsidian, sometimes flows in streams.

"Obsidian Cliff" in the Yellowstone Park is a remarkable example of an obsidian outflow. It has the columnar forms of Fig. 224. The glass is connected with vast eruptions of rhyolyte (quartz-trachyte) at and about Mount Washburn, which have a thickness of thousands of feet, and succeeded to andesyte eruptions (Iddings, Hague). Another locality has been reported by Russell near Mono Lake, in western Nevada. On the trachyte islands, north of Sicily, Lipari (1601 feet high) and Vulcano (1978 feet), the obsidian streams bear evidence of sluggish twisting flow (Judd, 1875). With the glass occurs pumice, and that of Lipari is the pumice of the arts. The northern island of the group, Stromboli ( 3090 feet high), is basaltic in its lavas; the islands intermediate between Stromboli and Lipari have lavas of intermediate kinds. 
5. Sizes of some of the larger craters. - Kilauea has diameters of 14,000 and 9800 feet; the depth in 1840 was about 1000 feet, but now it is less than 450 feet. The crater of Haleakala, east Maui, is 23 miles in circuit and 2500 feet in greatest depth. The crater of the peak of Teneriffe is 8 miles by 6 in area, and has a depth in some parts of 2000 feet. Mauritius has a crater which measures at least 13 miles in its longest diameter. On Java, Papandayang, 7084 feet high, has a crater whose diameters are 15 and 6 miles. The crater of Aso-san, of the island of Kiusiu, Japan, has diameters, according to Milne, of about 10 and 14 miles.

\section{Volcanic Action and its Causes.}

Volcanic action involves the continued supply of liquid lava from depths below the earth's surface to the crater, to keep up heat and action. It comprises (1) work within the crater by means of escaping vapors, by the fusing and contractional effects of heat, and by gravitational pressure; and (2) discharges of lava, either in streams or as cinders.

1. The supplying of lava. - The supply-channel, or conduit, of a volcano must reach down to a region of great heat and fusion. For the liquid column loses heat from contact with the air and cool rocks, and from the expansion of vapors or vaporizable material within the lava. This supply of liquid rock presupposes some upthrusting force. If the level reached by the upthrust lavas is much below the earth's surface, the heat of the melted rock might make hot springs or geysers, or, at a higher level, produce a region of escaping vapors. But,for volcanic action, the ascensive force must be sufficient to restore the lava-column to its mean height in the crater, sooner or later after every eruption; for failure here is the beginning of decline in volcanic activity. When a volcano ceases action entirely, not even vapors escaping, it is said to be extinct; but it may not be so dead that a century later it will not break out anew.

The conduit of lava beneath an active crater probably has nearly the diameter of the crater, judging from facts observed at Kilauea. This would give for the Kilauea conduit a breadth of two to three miles.

2. The escaping vapors. - The work done in a crater is largely owing to the making and escaping of vapors. For if all vaporizable material were absent, the lavas would lie quiet. The liquid lavas in sight in a crater are always in constant activity; and if below but out of sight, there is usually considerable noisy action from escaping steam, and from the movements which the steam occasions.

The vapors of a volcano are 99 per cent vapor of water, as has been ascertained by investigation. For the supply of water the sea is one probable source; the rains, another; and vapors coming up from depths below, with the lavas, a third source. Vapors from the "depths below" are from the subterranean source of the lavas, and this source may be either a perpetual lava-sea of large extent, if such exists, or the rocks of the crust that 
have been melted to produce the supply, since all rocks of the supercrust contain traces of moisture (page 205). But this is not the chief source of the vapor of water.

Among the other materials of the vapors, sulphurous acid $\left(\mathrm{SO}_{2}\right)$ is probably the most abundant. It has the smell of burning sulphur. It is always present, and probably comes from iron sulphides in the melted rocks, since they are often sparingly present in the solid lavas. Hydrogen is sometimes present; it may come from the dissociation of the elements of water $\left(\mathrm{H}_{2} \mathrm{O}\right)$, or from any oxidation in the lava in which the oxygen used is derived from water. Hydrochloric acid $(\mathrm{HCl})$ is one of the gases when sea water gains admission to the hot lavas. Carbonic acid $\left(\mathrm{CO}_{2}\right)$ may be emitted if any limestone $\left(\mathrm{CaO} . \mathrm{CO}_{2}\right)$ exists below in proximity to the melted lavas. Carbonic oxide (CO) has been detected by W. Libbey in spectroscopic observations of the flames, 1, 2, or 3 feet high, that appear about the lava vents of Kilauea. The above, with more or less of atmospheric air, are the chief gases of the melted lavas. There are other vapors given out by solfataras, but these take no part in the eruptive work of the volcano.

The mechanical work of the vapors is due almost wholly to the vapor of water. In view of the relation on Hawaii between times of eruptions and the rainy season, and between length of lava-column above the sea and projectile force, there is strong probability that fresh waters are in many volcanoes the chief agent. Whenever subterranean waters in their descent below the surface approach the hot rocks about the lava-column, they are converted into steam; and the amount of steam generated from even a small continued supply of water would be so large (in view of the fact that at the ordinary pressure one cubic foot of water will yield 1700 cubic feet of steam) that it could not all escape outward through the rocks, but in part would be forced into the rising lavas of the conduit. Moreover, it has been experimentally demonstrated by Daubrée (1879) that, under such circumstances, a molecular absorption of the steam would take place against any pressure outward that might exist within the heated column.

3. Effects of vapors. - (a) Projectile effects. - The escape of vapor and its expansion encounter resistance in consequence of the cohesion of the liquid material, which resistance is proportional to the strength of this cohesion, or is conversely as the degree of liquidity. Water, in boiling, lets very small bubbles of steam through easily; and the elastic force of the steam of the bubble makes low jets, one or two inches in height. But the elastic force of a small bubble of vapor is too feeble to break its way through lava; enlargement, therefore, goes on until the force is sufficient to overbalance the resistance; then comes the break of the liquid lava-shell of the bubble, and the projection of its fragments vertically or nearly so into the air, vertically, because the shell is thinnest at top. The projectile force thus depends largely on the size of the bubble, or, what is equivalent, on the viscidity of the liquid lava, and on the rate of supply of vapors seeking to escape.

On account of the remarkable liquidity of basaltic lavas, the projectile force required to break a way through may be so small as to throw the lava 
to a height of only 8 or 10 yards, as in Kilauea, - a height so small that the projected drops or masses of lava fall back unsolidified, and the jets dance in a lively and brilliant way over the surface of the lava-basin. The scene is a brilliant one, when a lake of lava 500,000 square feet in area is covered throughout with the playing jets, as at Kilauea in 1840.

It is a mark also of such extreme liquidity, that where the escaping vapors throw up the lavas in half-covered places under the rocky sides of a lake, the lavas in the recoil dash out in fiery spray much like the spattering of breaking waves. In the pulling apart of the rising lava-jet dividiug it into drops, the glassy material in fusion is drawn out into hairs, and forms the "Pele's hair" of Kilauea.

In cases, outside of the lava-lakes, where the bubbles are bursting beneath an opening in the bottom of the crater, the vapors and lava driblets escape from the aperture with a rush and a roar, "as if all the steam engines of the world were concentrated in it." (Douglas.) The driblet-cone, thus made, is sometimes called a blowing-cone.

Now and then the regular ebullition is interrupted by larger throws, even to 200 feet. At other times the lake becomes crusted over with a glassy scum, or with a crust of more solid lava, and so remains for a while; and then-at intervals of minutes, or hours, plonger - it breaks anew into activity, attended with a remelting of what had solidifiec and the throwing up of jets as before.

In the Mount Loa crater, situated 13,675 feet above the sea $(10,000$ feet above Kilauea), the jets generally rise 200 feet or more, and instead of the quiet ebullition of Kilauea there is the play of a great fiery fountain. One of the describers states that in 1873 the "fountain of fire," 150 feet broad, played in several united but independent jets to a height of 150 to 300 feet. At one time the jets suddenly became low, and continued thus for a few seconds, then "with a roar like the sound of gathering waters, nearly the whole surface of the lake was lifted up, and its whole radiant mass rose three times in one outburst to a height, as estimated by the surrounding cliffs, of 600 feet. After this the fountain played as before with jets of 300 feet." (I. L. Bird, 1876.) Others report heights of 600 to 800 feet in the playing fountains. These are the conditions in the Mount Loa crater only when eruptions are imminent.

The cause of this high projection of the lavas in fountain-like form in a summit crater can be no other than the escaping vapors; and the difference between such fountains and the gentler ebullition of Kilauea must depend on their amount and rate of supply. Such moisture, if the deep subterranean region of lavas were its source, would be most abundant in the equally large but 10,000 feet lower crater, Kilauea. But if supplied by the fresh waters from the rains over the region, the 10,000 feet of greater altitude are a sufficient reason for the difference.

The idea was put forth by Scrope that the fusion in the lavas of a volcano was aqueoigneous fusion, or a mobility due in part to the water-vapor present. Such vapor must increase the liquidity, but facts show that it is not dependent on it. The white light which the lavas of Kilauea often display in their "ebullition" is evidence of heat sufficient for fusion. Bartoli, on Etna in 1893, found the temperature of a lava stream, at its exit, $1910^{\circ} \mathrm{F}$. 
Vesuvius, with its less liquid lavas, contrasts wonderfully in its way of working with the volcanoes of Hawaii. In the ease of such lavas, the bubbles have to become large before the vapor can break through. Consequently, whenever the break occurs, the accumulated explosive force projects the fragments of the lava-shell, that is, the so-called volcanic ashes, or lapilli, to a height of hundreds or thousands of feet - even 10,000 in some Vesuvian eruptions.

Such high projections are the common fact at most volcanoes. Great viscidity, while leading to the production of large size in the vapor-made bubbles before they are ready for explosion, makes fewer of them form over a given surface of liquid lava; and in times of moderate activity the number may be but half a dozen, or only a single one, at a time, while on a like area, lavas with the Kilauea degree of viscidity would have scores or hundreds. When the author was at Naples, in May, 1834, there was at night an interval of 7 to 8 minutes between the explosions, or the throws (some hundreds of feet in height) of fiery cinders; on the ascent, the following day, the interval was 4 to 5 minutes; and on passing Stromboli, a fortnight later, June 16 , it was 15 to 20 minutes, - the activity being less than usual, explosions every 2 or 3 minutes being common. As Spallanzani, Hofmann, and others have seen the rising bubble within Stromboli, the bursting, and, following this, the rush of vapor and the cinder projections, there is no reason to doubt that at Vesuvius, also, each throw of cinders had the same source. Mr. John Milne states that on his ascent of the Japan volcano, Oshima, in May, 1877, on approaching the top, successive explosions were heard every two seconds with occasional pauses, which explosions he found, on reaching the top, to be due to successive outbursts of steam, each outburst projecting to a height of nearly 6000 feet ashes and lava-fragments that descended vertically, unless wafted by the winds.

When the rains come down in torrents during such an eruption, the projected materials make the flowing mud (called tufa when it is dried and hardened) that buries fields and forests, and has made fossils of cities, of which Herculaneum and Pompeii are examples. Extensive tufa deposits are made by voleanoes of all kinds, but especially by those of the second and third kinds. Some accumulations, apparently from a single series of discharges, without intermediate streams of lava, have a thickness of 1000 feet or more, and cover thousands of square miles.

To the eastward of the Cascade summits, Oregon, Mr. Condon speaks of traveling over an area of tufa for 50 to 60 miles, and states that the volcanic ash was evenly laid over the whole surface, like a covering of snow ; and where attaining its greatest thickness, the sharp features of the older surface ceased to show themselves through it. In many parts of the Rocky Mountain regions, the tufas contain silicified stumps and trunks of large trees (page 135).

(b) Enlarging and vesiculating effects of vapors. - The vapors also enlarge, by their expansion, the bulk of the liquid lava, and may thus increase the height of the lava-column.

They also make the vesicles or air-cells of lavas, producing its vesicular and scoriaceous varieties. These are their noiseless and unseen effects, while they are still inside of the lavas. The vesicular lavas contain relatively 
few vesicles to the bulk of the rock, and the scoriaceous varieties contain many, so many as to make the rock light. Pressure of much overlying lava prevents vesiculation, and this takes place, therefore, near the surface; but it is not ascertained what amount of pressure so limits it.

Ordinary vesicles are usually oblong, rather than spherical, unless the size is quite small; no distinction between those made in volcanoes by different kinds of vapors has been observed. But in some streams of igneous origin (as in the trap of the Connecticut Valley) they sometimes have the form of slender cylinders, 2 or 3 inches long; and such elongated forms imply great expansive action at the moment of vaporization, and therefore point to the vaporization of liquid carbonic acid as the cause.

Oblong vesicles sometimes are pointed at one end, and thus show 241.

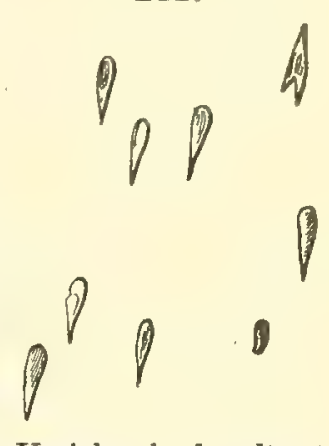
the direction of movement - that of the blunt end; an example from Kiama, New South Wales, is here represented.

The lightest of all kinds of scoria, called "thread-lace scoria," has the thin walls reduced to mere threads, as in the annexed figures of a specimen obtained at Kilauea. Fig. 242 represents a portion of the scoria, magnified 30 times. Figs. 243 and 244 show two forms presented by the more regular of the cells. The form of Fig. 243, which has 12 sides besides the two bases, is the most common. The natural size of the cells is $\frac{1}{30}$ to $\frac{1}{40}$ inch, though

242.

244.
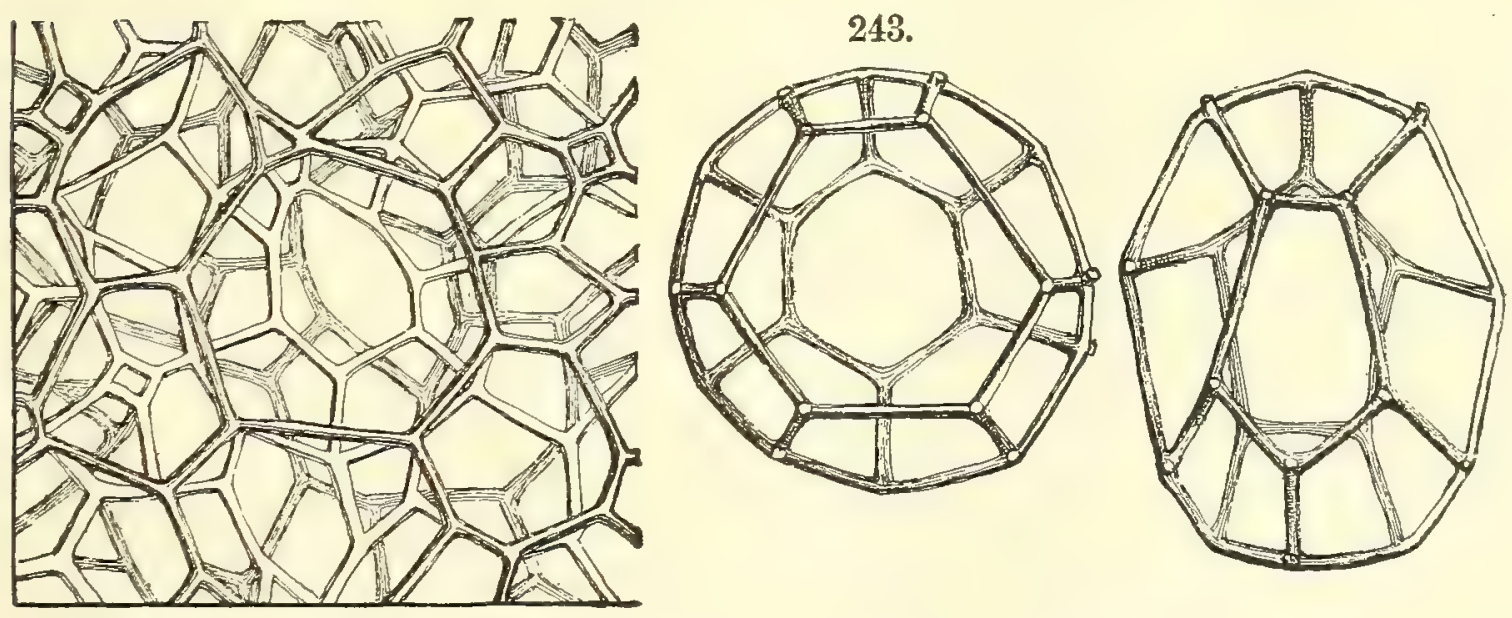

T'hread-lace scoria, from Kilauea. $\times 30 . \quad$ D. '88.

some are much larger. This scoria contains only $1 \cdot 7$ per cent of its bulk in rock-material, and hence a layer of glass one inch thick would make a layer 60 inches thick of the scoria; and 1.2 per cent of moisture in the glass by weight would suffice to produce it.

The light glassy scum of the lava of the Kilauea lava-lakes (like the scum on fermenting molasses) flows off as the top of each outflowing stream, and cools as a separable 
crust 1 or 2 inches thick. Beneath it, the most recent lava is comparatively solid and often columnar in structure. The outside lavas of the mountain which have been ejected through fissures have no such crust, but sometimes a solid glassy exterior of a fourth to half of an inch.

Volcanic glass usually contains moisture enough for making it a light scoria when it is heated to fusion before the blowpipe, as shown by J. W. Judd (1886), and also by Iddings, in the case of the Yellowstone Park obsidian.

(c) Rupturing and other effects from expansive action. - Vapors may also produce fractures in the walls of craters or in the sides of the volcanic mountain by their sudden generation within regions about or beneath the crater, and also by their slow accumulation within confined spaces, and thus may occasion volcanic eruptions. They produce the most violent projectile effects when water in large quantity gains direct access to the lava-conduit; for the conditions are then those that cause the most violent of boiler-explosions, except that they are on a scale as much greater as the volcano is larger than a boiler.

Vapors also bring pressure to bear on surfaces of liquid lava beneath them, and force the lava up fissures to levels hundreds of feet above the bottom of a crater.

The vapors are thus the chief source of power in the volcano. They may work quietly, but they are at the bottom of all violent work.

(d) Vapors of deep-seated origin. - While all the ordinary projectile work of volcanoes may be carried forward by vapors from waters that gain access from the sea, or the fresh waters of the land, it is a question whether vapors from the deep-seated source of volcanic action may not have aided explosively the first opening of the volcano. The lifting action of the ascensive force in Kilauea is so quiet, and its progress so slow, -400 feet at the most in six years, - that we have no favorable answer from this source. Daubrée has experimented on the effects of steam, driven under high pressure along a fracture in blocks of granite, and proved the efficiency of such a course in making a tubular passage through it. The results are published in a volume entitled, Les Regions invisibles du Globe et des Espaces célestes, 1892, and in earlier papers read before the French Academy.

The occurrence of volcanoes in long lines implies dependence as to origin on great fractures, and mutual dependence of the volcanoes along any such line. The lines are often in parallel ranges or series of fissures, and must have opened through the earth's crust to the depths that supplied the melted rock. In some cases the volcanic action along such lines has continued longer at one end of the line, or of che several lines in a series, than at the opposite end, and extinction has been in like manner serial. An example is afforded by the Hawaiian group. The group, now so called, is about 400 miles long and westnorthwest in trend. The islands consist either of a single volcano, or of two or more united. The prominent doublets are Oahu and Maui; and Hawaii is a quintuplet, in two lines. The map of Maui, on page 179, shows plainly by the aged appearance of its erosion over west Maui, that this western of the two volcanoes long since became extinct, while east Maui has the smooth face of youth and may have been active within two or three centuries. There is the same evidence that west Oahu was extinct long before east Oahu, 
as shown on the map, page 292 , and that Kauai, the western island of the group, was one of the earliest, if not the earliest, to become inactive.

But Hawaii, the easternmost, is, on the contrary, the island of most recent activity. Here are the active volcanoes. Further, the northwestern and the northern volcanoes of Hawaii were the first to become extinct. ' The largest and highest volcanic island of the whole group is Hawaii, that on which action has continued the longest. In the Samoa group, south of the equator, the order of extinction was the reverse of that at the Hawaiian, or from east to west - Savaii, at the west end, a broad and lofty cone of lavas recent in aspect, answering geologically to its (dialectic) namesake, Hawaii, of the Hawaiian group.

4. Other methods of work in a volcano. - Besides the action of vapors, there are contractional effects from heat, exhibited in columnar forms, and irregular fracturing; for each lava-stream has cooled down from a temperature above $2000^{\circ} \mathrm{F}$. There are fusing effects; often a remelting of the lavas of a lake that had become solidified; and a fusing also of floating masses in the lakes; and sometimes an extending of the bounds of a lava-lake, or an opening of new lakes.

There are also large bulgings made in a lava-stream, while it is cooling, through the vapors that are generated from moisture underneath it.

There is also hydrostatic and other gravitational pressure arising from the height of the lava-column in a lava-lake, or in the mountain.

5. Eruptions. - (a) Preparation for an eruption. - The crater, as at Vesuvius or Hawaii, after it has been emptied by a great discharge at a time of eruption, often has, at first, a period of apparently extinguished fires, and something like the conditions of an incipient solfatara in the lazy escape of vapors from the fissures and the lining of fissures with sulphur crystals. Next, little outflows of lava take place from apertures or fissures in some part of the bottom on floor of the crater, or driblets of lava or jets of cinders build a small cone about a vent. In the case of basaltic lavas, pools of boiling lava often appear in the crater, which frequently overflow and spread lava-streams over the floor, thus making small eruptions. In the case of the less liquid lavas the ejections at the bottom of the crater are mostly of cinders, and one or more cinder-cones are made thereby over the bottom; but now and then escapes of lava take place through fissures. The process is one that puts new material over the bottom of the crater and raises its level; and it goes on at an increasing rate until the eruption commences. In Kilauea, such overflows from the large lava-lake may have a length of two miles on the floor of the crater.

But this raising of the bottom by overflows and deposits of cinders is accompanied by another action, - the upward thrust of the lavas of the lavacolumn through the ascensive action already mentioned. Owing (1) to this lifting action, and (2) to the ejections, the solid floor of the crater keeps rising; and sometimes, perhaps generally, the larger part of the floor is lifted or shoved up bodily by the lavas from the lava-column that are forced in beneath it. After the eruption of 1840 , the floor of Kilauea was raised bodily between 300 and 400 feet before a new eruption took place. By the 
same methods, the floor in a volcano like Vesuvius may be raised, preparatory for another eruption.

This principle in volcanic science. first made out by C. S. Lyman, is established by facts observed by him on Hawaii. In May, 1840, an eruption emptied the crater of Kilanea, and left it with two thirds of the floor sunken nearly 400 feet below the level which it had just before the eruption. (This was 6 months before the author's first visit to the crater.) Fig. 245 is a transverse section of the crater as it was after the eruption, mo, o $m$ being the opposite walls, and $n p, p^{\prime} n$ ' the sunken central region or "lower pit." Six months later,

245.

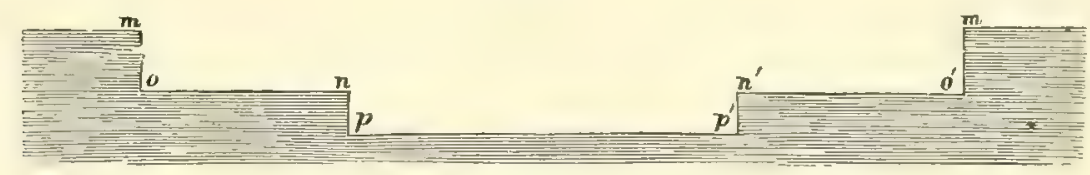

Vertical section of crater of Kilauea in 1840. D. '49.

the walls of the lower pit, which were then 360 feet high, had a talus of broken lava alongside, falls of the rocks being frequent at the time. In 1846, C. S. Lyman found the lower pit of the crater obliterated, and the talus, at the foot of its walls, constituting a ridge 100 to 150 feet high. Its floor had been raised as a whole, with the talus of lava-blocks upon it; and fault-planes made in the sinking of the floor at the eruption in 1840 were those used in the rise. This ridge was gradually buried by the outflow of lavas over the floor, but it still existed in 1864, as shown in the view of Kilauea on page 270, and also in a map of the crater of that date by W. T. Brigham.

At times of approaching eruption, the heat and projectile action of the crater become intense. The heat may be expended, as in Kilauea, in multiplying lava-lakes for ebullition and raising blowing-cones, or, on the other hand, as in Vesuvius, in projecting cinders to enormous heights besides starting some lava-flows.

(b) The eruption. - The eruption begins after the lavas have risen within the crater up to what may be called high-lava mark; and when the pressure from the vapors generated and confined below and from the hydrostatic pressure of the lava-column - chiefly the former - is too great to be withstood by the containing mountain. The mountain consequently breaks; the conduit is rent open on one side or the other, and the lavas run out. If the mountain were too strong to break, as it perhaps is in the earlier part of its history, when it is of little height, the lava would rise to the top of the crater by the methods described, and overflow from the summit on this side or that. But modern eruptions, as has been stated, are usually through fissures.

The discharge of the lavas empties the upper part of the lava-conduit or lowers the level of its upper surface, and undermines the lifted crater-floor ; and the result may be (1) a collapse or down-plunge of the floor within the crater, making again a pit hundreds of feet deep, or 1000 , or 2000 , as the case may be; and (2) sometimes also a down-plunge of the walls of the crater.

Part of the undermining at Vesuvius is due to outflow of lavas, part to discharge of volcanic cinders; but at basaltic Kilauea, it all comes, ordinarily, from the escape of liquid lavas. 
At the eruption of Kilauea in 1840, the first signal to the natives on the coast was not an earthquake, but a "fire in the woods." As a consequence of the action, six miles to the east a fissure opened, and some lavas escaped; in the next seven miles there were other fissures, giving out steam and making small patches of lava. Finally, 10 miles from the sea and 27

246.

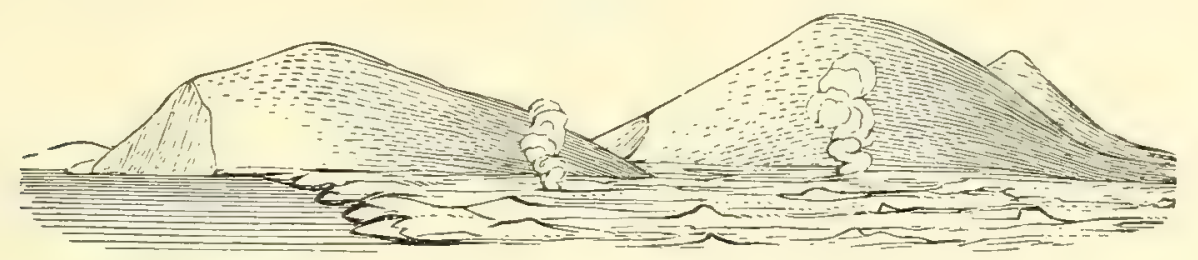

'Three cinder-cones of 1840 , on the seashore south of Nanawale. D. '49.

miles from Kilauea, at a height of 1250 feet above tide level, an outflow began from fissures which continued till it reached the sea, where there was a violent conflict of the hot lavas and water, and three cinder-cones were made, each probably over a separate fissure. The lavas in the crater at the same time sunk, as has been stated, nearly 400 feet in consequence of the outflow.

The following diagram (the height relatively much exaggerated) shows the change in depth of Kilauea (according to the best reports), in several great eruptions, commencing with that of 1823 . In 1823, before the erup-

247.

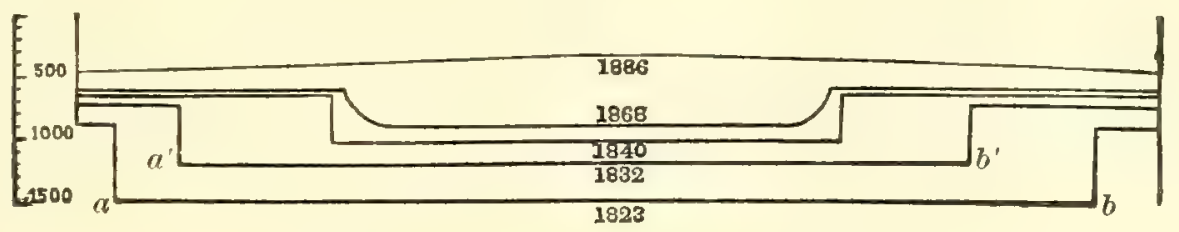

Sections of Kilauea at different periods.

tion, the whole depth of the crater was 800 to 1000 feet; at the eruption, nearly the whole bottom sunk down to the level $a b$, or 600 to 800 feet, making the depth of Kilauea over this deeper, central part about 1500 feet.

In 1832 , the depth before the eruption was 700 feet; after it, the center sunk to $a^{\prime} b^{\prime}$, making the depth 1150 feet; in 1840, the depth of the sinking was between 360 and 400 feet. Six years afterward, the lower pit was obliterated, reducing the depth of Kilauea to only 600 feet. It sunk again at an eruption in 1868. It is now only 480 feet deep where deepest near the northeastern walls, and less than 400 feet at the center.

At the last two of the eruptions, those of 1887 and 1891, the only sinking of the bottom that took place was within the great lake-basin called Halemaumau - half a mile in diameter -in the southwestern part of the crater. The map of the crater, Fig. 230, shows its condition immediately after the eruption of 1886 , with the lake-basin empty to its bottom, 900 feet below the level at the Volcano House, and nearly 600 below the rim of the basin. (Emerson.) The walls of the basin began at once to fall, and in six months the condition was that represented in the adjoining figure 231. The basin contained a debris-cone roade of the fallen blocks, and not at all of ejected material; and the progress afterward 
soon made it evident that it was produced out of the falling blocks by the lifting of the bottom owing to the ascensive action of the lavas beneath, like Lyman's ridge described on page 284. (F. S. Dodge.)

The recent eruptions of Mount Loa, the summit crater, have been vastly more extensive than those of Kilauea. Situated topographically within the same mountain mass, as the following diagram (Fig. 248) shows, the two have yet gone on with their preparations and eruptions simultaneously, but in general independently; the loftier crater unaffected in its lifting and its eruptive forces by the great opening at the lower level. Kilauea has none of the virtues of a safty-valve for Mount Loa, though probably as much of a safety-valve for the mountain as any volcanic vent ever is. The recent eruptions of Mount Loa occurred in the years 1843, 1852, 1855, 1859, 1868, 1880, 1887 ; and excepting the two on the southern slopes, those of 1868 and 1887, the place of outbreak was at heights of 10,500 to 13,000 feet, and the lengths of the streams 20 to 35 miles. At the place of outbreak in several instances, there have been great fountains of lava, 300 to 700 feet in height,

248.

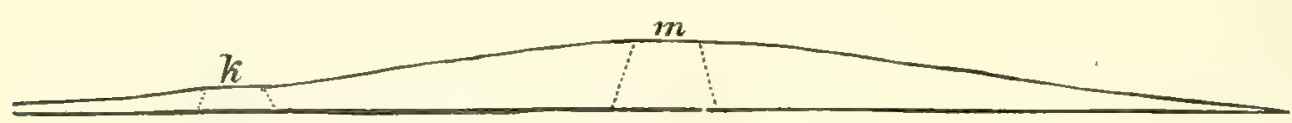

Section of Mount Loa and Kilauea.

that played for a few days, as the stream gushed forth - a consequence either of the projectile force of escaping vapors, or of hydrostatic pressure from the lavas in the Mount Loa lava-column, or from both causes combined. In contrast with Mount Loa, the famous Hecla of Iceland, about 5000 feet in height, has had only five eruptions since 1700 , viz., in $1728,1754,1766$, $1845,1878$.

(c) Earthquakes not an essential feature of volcanic eruptions. - The great eruptions of Mount Loa, excepting those of 1868 and 1887, have been unattended by noticeable earthquakes. The rupturings must have caused vibrations, but they have usually been unperceived at the villages of the island. "A fire on the mountain" has been the first announcement of the outbreak. When the outflow has begun, the liquid lava in the bottom of the summit crater has disappeared, and the crater has lost at the same time its activity.

In 1868 and 1887, however, there were violent earthquakes; but otherwise the circumstances were not different. In 1887, two days intervened between the appearance and fading of the light at the summit and the exit of the lavas, and, in 1868, four days, owing apparently to the distance of the place from the discharging conduit; but when once out the lavas rose into a fountain of 100 to 200 feet, showing that they were under great pressure, and then the shakings ceased. At the eruption of 1868, Kilanea was discharged at the same time as Mount Loa, - Mount Loa forces evidently producing this remarkable result by breaking first the Mount Loa conduit, and then four days later, before the earthquakes ceased, that of Kilauea. In other words, the fracturing of the mountain made by vapors generated by the Mount Loa fires finally extended to the Kilauea conduits. 
The eruptions of Vesuvius are generally heralded by earthquakes. The ejected lavas commonly bear evidence, in the various chlorides among the ingredients deposited by vapors on the lavas, that the waters of the sea had gained access to the fires. The accompanying projection of cinders is often to great heights, and over a wide reach of country. Those of 1779 , according to Sir William Hamilton, were thrown to a height of 10,000 feet.

The sketch of Vesuvius in Fig. 225, page 266, represents its condition a few weeks before an eruption, when the crater was filled to the summit plain there shown, and a cinder-cone on this plain (see sketch) was the most active feature; but there was a sluggish stream of lava in the summit plain, and red heat was visible a foot down in cracks. The eruption, as described by Abich, took place in August, 1834; two streams of lava flowed out, the chief one from the base of the old cone, and it was accompanied by flames, which, according to Abich, were produced by hydrogen; it was half a mile wide, 18 to 30 feet deep, and 9 miles long. It engulfed the village of Caporeco, sparing only 4 houses out of 500. The old cone was laid open by the eruption, and the top plain, that was the floor walked over by the author, had sunk into a deep abyss. (Abich, Vues Illustr. sur le Vésuve et l'Etna, Berlin, 1837.)

6. Lava-streams. - (a) Their general characteristics. - Lava-streams seldom make more than three miles of flow a day, and sometimes take a year for 30 miles. This is true even of the basaltic kinds. They flow rapidly when unobstructed, but often become dammed by coolings, especially at the frequent interruptions. As the stream of basaltic lava moves, it becomes crusted over its exterior surface, and then flows on in the lava-tunnel so made, which, at the end, it may leave empty. Owing to the obstructions, the lavas often break their bounds, and one stream becomes piled over another. The surface of the stream has ropy lines and other marks

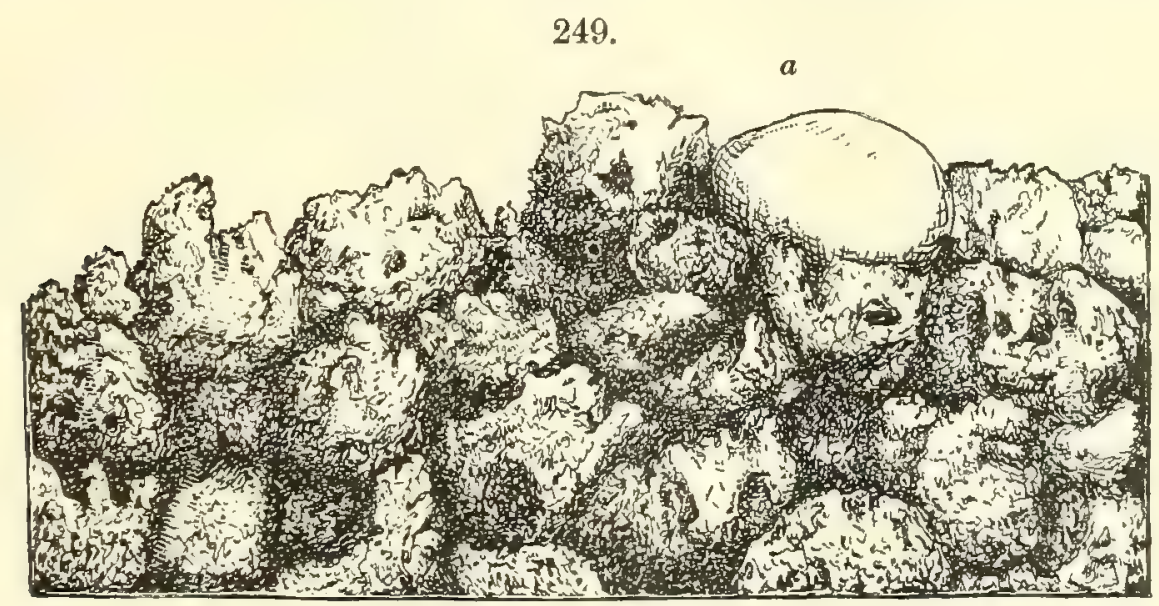

View of the aa lava-stream, with a "bomb," $a, 10$ feet in breadth upon it. D. '87.

made by the flowing movement. This ordinary lava is called by the Hawaiians pahoehoe, alluding to a relatively smooth and shining or satinlike luster. Another kind, the aa, into which the pahoehoe sometimes abruptly changes, shows over its surface no evidence of flow; the stream consists of broken, ragged masses, large and small, bristled all over with points (Fig. 249); and, owing to the masses being piled loosely together, the 
field of aa is usually 20 to 30 feet higher in level than that of pahoehoe. The breaking up is produced while the stream is slowly moving. Some cause, acting beneath, half chills the mass, and the lava, thus rendered brittle, is readily broken during the movement. The only cause of such cooling appears to be the vaporizing of subterranean waters flowed over by the hot lava-stream.

All lavas crust over readily, and then are slow in further consolidation, owing to the rock being a very poor conductor of heat.

The texture depends on rate of cooling, - the most rapid rate producing glass, - glassy crusts in the case of basaltic lavas, and massive glass in trachytic regions. Ordinary cooling ending in an indistinct or fine crystalline texture; and from this, there may be all grades in the same mass or thick stream, up to a true granite-like structure, as shown by Judd (1874), Hague and Iddings (1885), and as indicated by the author in 1849. Judd establishes, through facts from the Western Isles of Scotland, that in a single area a volcanic rock may vary in texture from a glassy lava to a rock of granitoid structure, both among basaltic and feldspathic lavas.

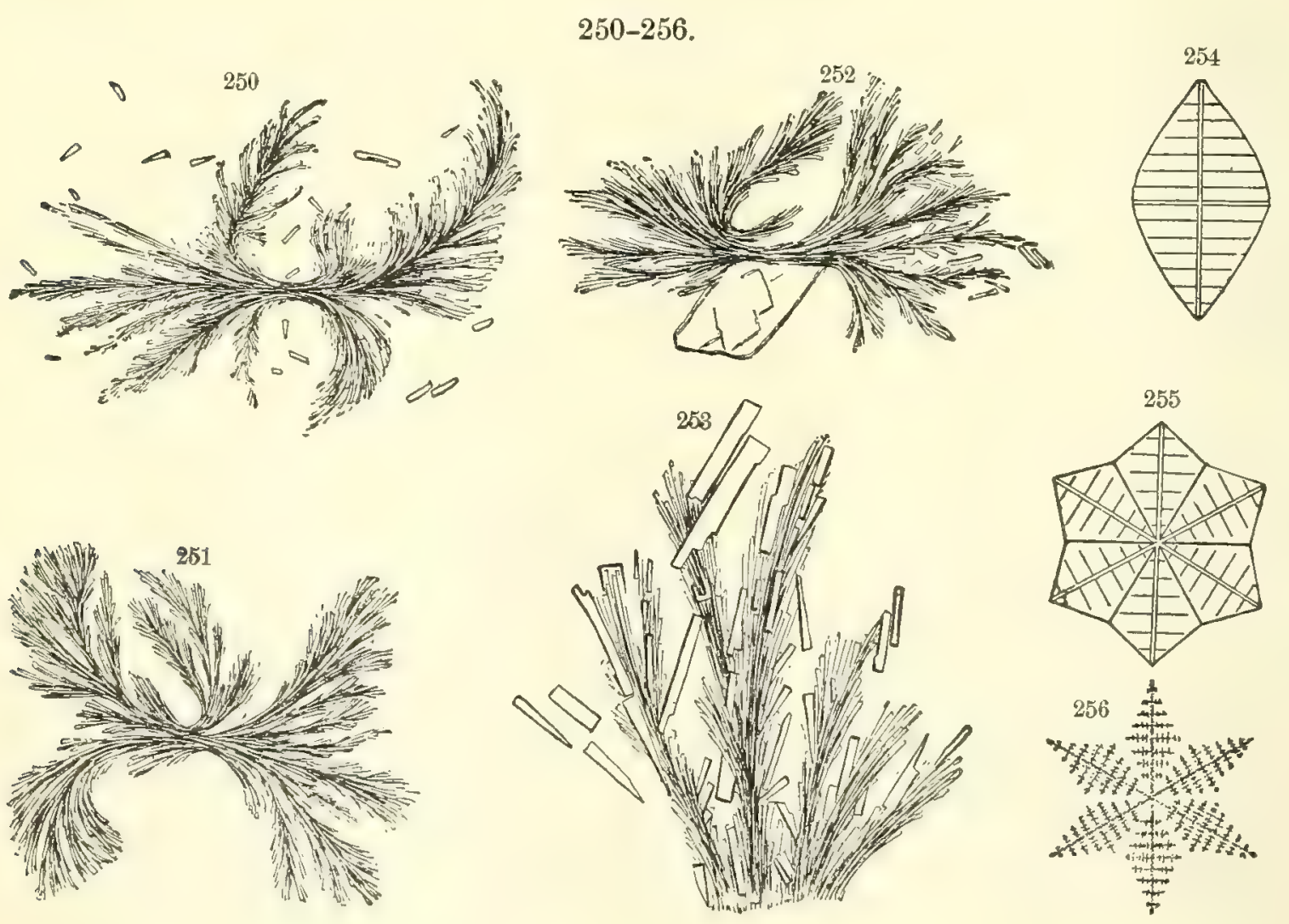

Figs. 250-253, Feathery forms of pyroxene and feldspar; Figs. 254-256, Microlites - all of Mount Loa lavas. E. S. Dana, '88.

Through some method of change, perhaps an alternation of melting and cooling, the fine basalt of Mount Loa and Kilauea often has the pyroxene and feldspar in feathery tufts, like common forms of frost on windows. (Figs. 250-256.) "The feldspar needles lie parallel with the pyroxene 
fibers, as if on erystallizing in these dendritic forms the latter mineral had drawn the feldspar into parallel position with it." Fig. 253 represents the facts well, as the feldspar crystals are larger than usual. Fig. 252 shows one large ordinary erystal of pyroxene below the tuft. Figs. 254-256 represent some of the microlites in the basalt-glass of the region. (E. S.D.,1888.)

In the consolidation of igneous rocks a more decided concretionary structure sometimes results. This is especially true of glassy or semi-glassy kinds, which often contain spherulites, having more or less distinctly a radiately fibrous structure. Spherulites appear to differ little from the radiate concretionary forms common in manufactured glass which has been artificially devitrified. (Rutley, 1890.) Some spherulites are in part separated peripherally from the inclosing glass, as if formed within "lithophyses" or vesicles. (Iddings, 1888.) See page 337, beyond, under Metamorphism. A concretionary form in dioryte is represented on page 97 .

(b) Voleanic bombs. - Volcanic bombs are roundish or ovoid masses of lava, concentric in structure. They sometimes have a center of chrysolite, or of the more scoriaceous lava. They occur on Hawaii in connection with the $a \alpha$, and are of various sizes, from one inch to ten feet or more in diameter. They are produced on Hawaii by the rolling movement of the front of the stream due to friction at bottom. It is possible that the same kind of movement in the ordinary lava-stream may produce them; but on Hawaii they are found only in aa lava-fields; one is shown in Fig. 249 at $a$. Johnston-Lavis gives essentially the same general explanation of the origin of some bombs observed by him about Vesuvius. The bombs of the Eifel region, in many of which chrysolite makes the center, have been supposed to be projected bombs; but in view of the above facts this may be questioned. Projected blocks of ordinary lava are not bombs, but inerely projected blocks.

(c) The opening of subordinate or lateral volcanic cones. - Cones of eruption often form over fissures during the progress of an eruption from the fissure. Each such cone, when it is in progress, has its own lava-conduit, as a branch from the general lava-conduit of the mountain. But it is relatively small, and its liquid lavas consequently may soon become chilled by the cold rocks about it; and hence such lateral or subordinate volcanoes have usually a brief existence. They, however, often work hard during their short life, and even in two or three weeks may make a cone many hundred feet in height.

Such cones occur about the sources of great eruptions; but they are most common near the seashore, where subterranean fresh waters most abound for the supply of moisture, and where the sea is at hand as another source. They may be either cinder-cones or tufa-cones, but are most likely to be the latter if near the seashore. The volcanic origin of such cones can be proved by the pericentric arrangement of the materials constituting them. The sea, with its broad waves and the aiding winds, can make heaps or ridges out of the sands existing or produced on its borders, but it cannot arrange the layers of sand or earth pericentrically into a DANA'S MANUAL - 19 
conical hill. But volcanic cinders or ashes are often carried by the winds to great distances, and when abundant, make extensive deposits with horizontal bedding; and such deposits may, in extreme cases, reach a thickness of hundreds of feet and bury forests.

Where small cones have been mostly removed to their base, they may show a central cone of lava - the lava that in its active state was the source of the ashes, and around it more or less of the ejected ashes or lava. Such places have been called "volcanic necks."

(d) The earlier lava-streams of a great volcano much thicker than the later. - On going up the valleys of Tahiti (Fig. 161), the thickness of the lavastreams was found by the author to increase from 10, 20, and 30 feet along the coast to 500 and 1000 feet, five or six miles in the interior; and in Kauai, of the Hawaiian group, the same general fact proved to be true. These great volcanoes appear to have poured lavas out copiously at their commencement, and to be now in a greatly dwindled condition. In what geological period the Tahitian and Hawaiian volcanoes began to flow is unknown.

(e) The interior of the volcanic mountain before and after extinction. - In times of activity, a great volcanic mountain has within it a column of liquid lavas, the lava-conduit, which may be two, three, or more miles in diameter. During the long period of activity the heat of the column spreads far into the adjacent cooled lavas, occasioning in them a more coarsely crystalline condition than that of the modern lava-stream.

At the extinction of the volcano, if the ascensive force continued to hold the summit of the lava-column to its high position, the enormous liquid mass would have cooled with extreme slowness, and become throughout more or less crystalline. The nearly vertical face of the central peak of Tahiti, 3000 feet or more in height, as seen by the author from a summit near by (page 180 ), was found to be without any trace of layers; it was just such a continuous mass from the top down, as the cooling of a lofty, central lava-mass would have made. And rounded stones of a coarsely crystalline granite rock, found along the bed of the stream six to eight miles up one of the valleys, appeared to be evidence as to the crystalline structure of the central peak, sustaining the principle as to the connection of grade of erystallization with rate of cooling. (D., 1839.)

Extinction is a consequence of a withdrawal of heat, or failure of the ascensive action. But the circumstances attending it may be various. A general collapse or down plunge of the summit at the eruption may leave a crater 2000 feet deep, as in the case of Haleakala in east Maui, or a collapse may fail to take place at the final eruption, through a gradual decline of heat within, and the mountain hence be left without a visible crater, as is true of Mount Kea. E. D. Preston has proved, by gravity determinations with the pendulum, that Haleakala below its crater is solid, the gravity found being $2 \cdot 7$, and that Kea in its upper part, giving $2 \cdot 1$, is hollow. The same evidence has indicated that the volcanic mountains of Ascension Island, St. Helena, and Fujiyama in Japan, are hollow, densities of $1 \cdot 6,1 \cdot 9$, and $2 \cdot 1$ having been found severally for the masses of these mountains; and by the deviation of the plumb-line of only 7 or 8 seconds by Chimborazo, it is believed to be indicated that this mountain also is hollow. Preston obtained for the lower 
part of Mount Kea the extraordinary density of $3 \cdot 7$, for which volcanic science has as yet no explanation.

Haleakala ended its work in throwing up over the bottom of the great crater many cinder-cones $500^{\prime}$ to $900^{\prime}$ high, and Mount Kea gasped out its life in making similar cones, but as summit peaks.

Extinction, besides being due to a downward withdrawal of the conduit lava, may take place in consequence of the cooling of these lavas from the outside, when in contact with the solid rocks. The supply conduit of Kilauea has probably been as large in cross sections as the crater (page 276); and perhaps much larger, this being suggested by an outside range of bluffs on its north and northeast side. It may be as large now ; but the confinement of the recent eruptions to the basin, Halemaumau, in its southwestern part, suggests the possibility that cooling has already reduced it to less than a third of its former size. The reduction may, however, be restricted to the upper portion of the conduit; in which case it may regain its former size at another great eruption. At Vesuvius, the modern active cone is partly surrounded by the walls of a former crater, of far wider extent, called Somma; and the relative sizes of the modern and ancient craters probably indicate the amount of contraction that has taken place in the lava-conduit. Teneriffe and some other large volcanic mountains have extensive amphitheaters marking the limits of the ancient crater, and a cone of relatively small size within it representing the later condition of the fires.

7. Explosive eruptions. - Besides the ordinary eruptions above described, there may be, in all kinds of volcanoes, true explosive eruptions. The projectile action within the crater in such an eruption, instead of ceasing at the commencement of a discharge of the lavas, as described above, becomes at once enormously increased, and projectile discharges of terrific violence are produced, with destructive shakings, violent thunder storms, and copious cinder-ejections over a wide reach of country. The stones thrown out are often of great size. At one such eruption in 1883, that of Krakatoa, an island off western Java, the finer ashes ascended 50,000 feet, and are supposed to have been carried around the world, and to have caused the red sunset-glows of the autumn following. The end came as suddenly as the beginning. The eruption began early one morning, made day into night by its gray and black cinder-ejections, and left the sky clear by the close of the next day. No outflow of lavas took place. Another such eruption occurred in the Tarawera region, New Zealand, in 1886. The eruption was of extreme violence, yet it was ended, and the ashen sky cleared, in six hours. But it destroyed villages and their inhabitants, and deluged with mud-eruptions the beantiful geyser terraces of the region.

Kilauea had such an eruption in 1789 (or about that time). The borders of the crater for one to two miles in breadth, especially to the south and southwest, are covered with the blocks of lava (some of 100 cubie feet), scoria, and ashes of the eruption, and a larger region with the finer material.

For such explosive eruptions water in large volumes must gain sudden access to the interior of a lava-conduit, - that is, to the liquid lavas of the lava-column; for the projectile force of the abruptly generated vapors is enormous, and all is quick work, as in an explosion. The stones ordinarily come up from the throat of the volcano, the region of hot rocks; and this 
origin is sometimes proved by the crystalline structure and minerals of the rocks. It is probable that other islands of the Hawaiian group have suffered from still greater explosions; for, as the accompanying map (Fig. 257) shows, Oahu consists of portions of two mountain-cones. The larger part of the eastern cone - the one of most recent extinction - must have been broken off and sunk. A vertical wall over 20 miles long marks the course of the fracture. Its highest point is over 3000 feet high after long exposure to denudation. Molokai bears evidence of like eatastrophic experience.

The conglomerates made by volcanic ejections contain angular fragments, and never consist chiefly of rounded pebbles or stones.

257.

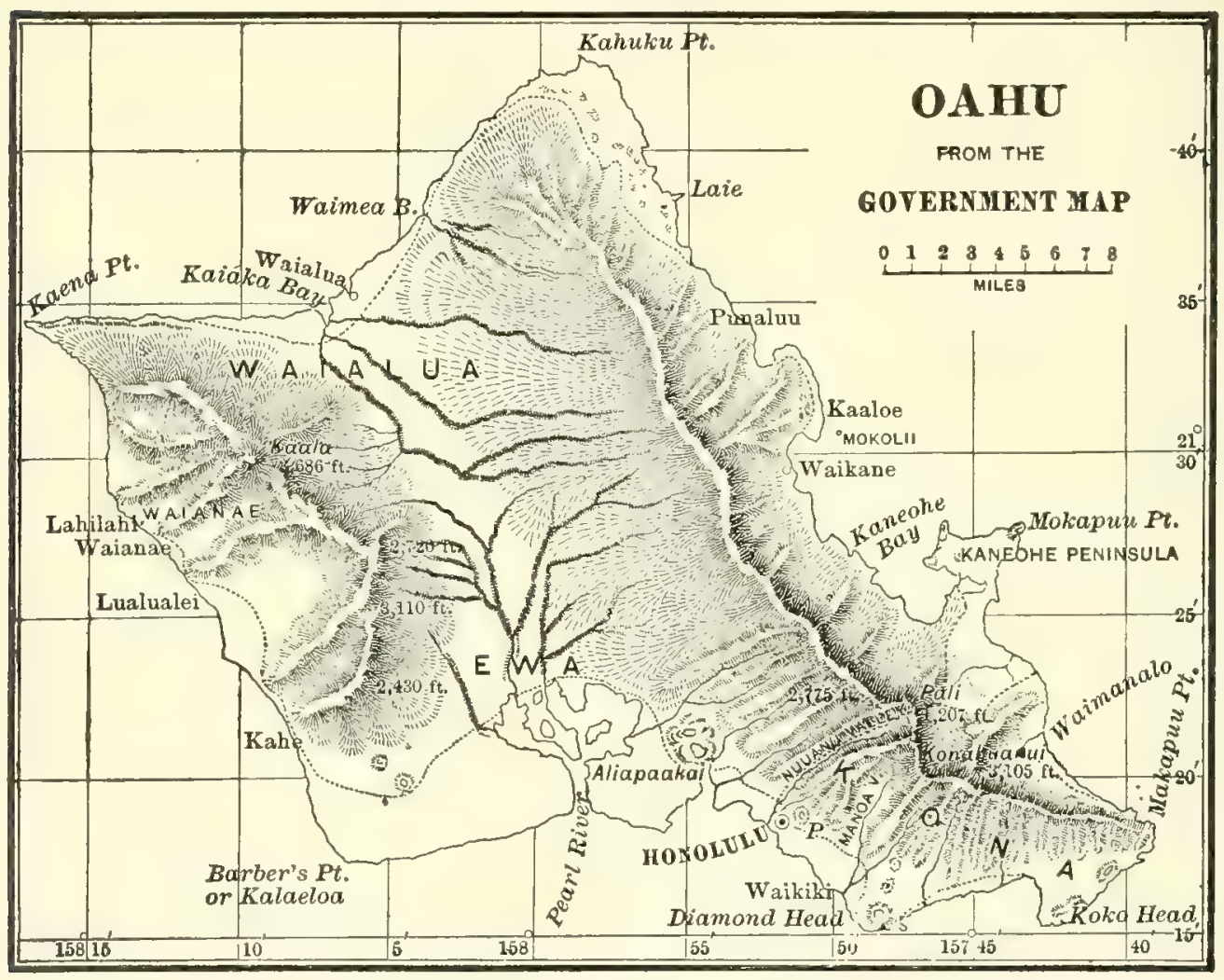

Explosive eruptions of another kind, which might be styled semi-volcanic, are included among described volcanic phenomena. In such eruptions water in large volumes gains sudden access to the heated depths beneath an extinct or nearly extinct volcanic mountain through fractures or movements along planes of weakness, as in other cases; but the heated depths are not hot enough for fused rocks. The consequences are earth-shakings; explosions from the suddenly generated steam; the rending of rocks in the deepseated region of the explosions; projectile action throwing the stones and great rock-masses so made, and the dust from abrasion, into the air and over the adjoining region, attended by vast and violent effusions of steam, making darkness and terrific storms about the mountain; - and not outflows of lava nor the projection of volcanic ashes and scoria from cooled lavas. 
No liquid lavas are in any way directly concerned, and hence the eruptions are only semi-volcanic. Their violence may cease in a few hours.

The eruption at Bandai-san, Japan, in July, 1888, was probably of this kind. The volcano had been extinct for 1000 years. In an hour after it burst out the ash-shower had mostly passed, the pitchy blackness changing so soon to dim twilight; and in 5 hours all was ended. Kikuchi, who describes the eruption, states that no evidence appeared that liquid lavas contributed to the ejected material, or to any of the results.

The blowing off of the summits of volcanoes has been attributed to explosive eruptions. Steam has little expansive power after it escapes into the open air. It expends its energies in work where generated, as in a steam-boiler. Where large open craters exist, the volcanic peaks about it would be little moved by the explosion, except through undermining and a collapse. But if the old mountain had been much denuded, and was essentially solid to its summit, an explosion within it might widely scatter the fragments, besides making great excavations at the center. The stones hurled from Bandai-san are said to have struck the trees, on descending, at an angle of about $30^{\circ}$.

\section{Work of the Spent Vapors and Waste Heat of the Volcano: Fumaroles, Ovens, Solfataras.}

While the chief part of the spent vapors and heat of the volcano go directly from the boiling or discharged lavas into the air, a portion escapes through fissures about a volcano or a volcanic region. They thus make (1) fumaroles (so named from the Latin fumus, smoke), the greater number of which open upward directly into the air, but some into cavernous places in the crater or in lava-streams; (2) solfataras (so named from the Italian solfo, sulphur), which are made up of a combination of steaming fissures, and cover large areas with the results of decomposition and deposit from the escaping gases. Fumaroles are common about the walls of active craters and the courses of lava-streams, and the escaping vapors may have all temperatures from nearly that of the liquid lava to $212^{\circ} \mathrm{F}$. and below. But solfataras are usually more remote from the center of volcanic action, and may occupy regions of long-quiet or essentially extinct craters; and consequently the vapors have a lower temperature.

Vesuvius has its fumaroles; but the solfatara of the region is to the west of Naples, over the extinct volcanic region of the Phlegræan Fields. Kilauea has fumaroles or steaming fissures along its walls and some of large size just west of the Volcano House; and but a few rods northwest of the same house there is a solfatara region. Both fumaroles and solfataras derive accessions to the vapors from descending waters supplied by rains, and some of the fissures afford only odorless steam.

The rocks (solidified lavas), acted upon by the volcanic vapors, consist mostly of silica, alumina, potash, soda, lime, magnesia, and iron oxide; the presence of potash with little or no soda distinguishes those of the third class (p. 273), and the near absence of potash, those of the second and first classes.

The chief vapor or gas coming directly from the lavas is, in all volcanoes, sulphurous acid $\left(\mathrm{SO}_{2}\right)$; and with it may be hydrogen and nitrogen. At Vesuvius, chlorine is given 
out, which becomes hydrochloric acid as it leaves the liquid lava, and is evidence, as has been stated, that sea water aids in the action of that volcano.

Through the sulphurous acid $\left(\mathrm{SO}_{2}\right)$, sulphur and various sulphates are made; e.g., alums by combination of sulphuric acid $\left(\mathrm{SO}_{3}\right)$ with alumina and potash or soda; and

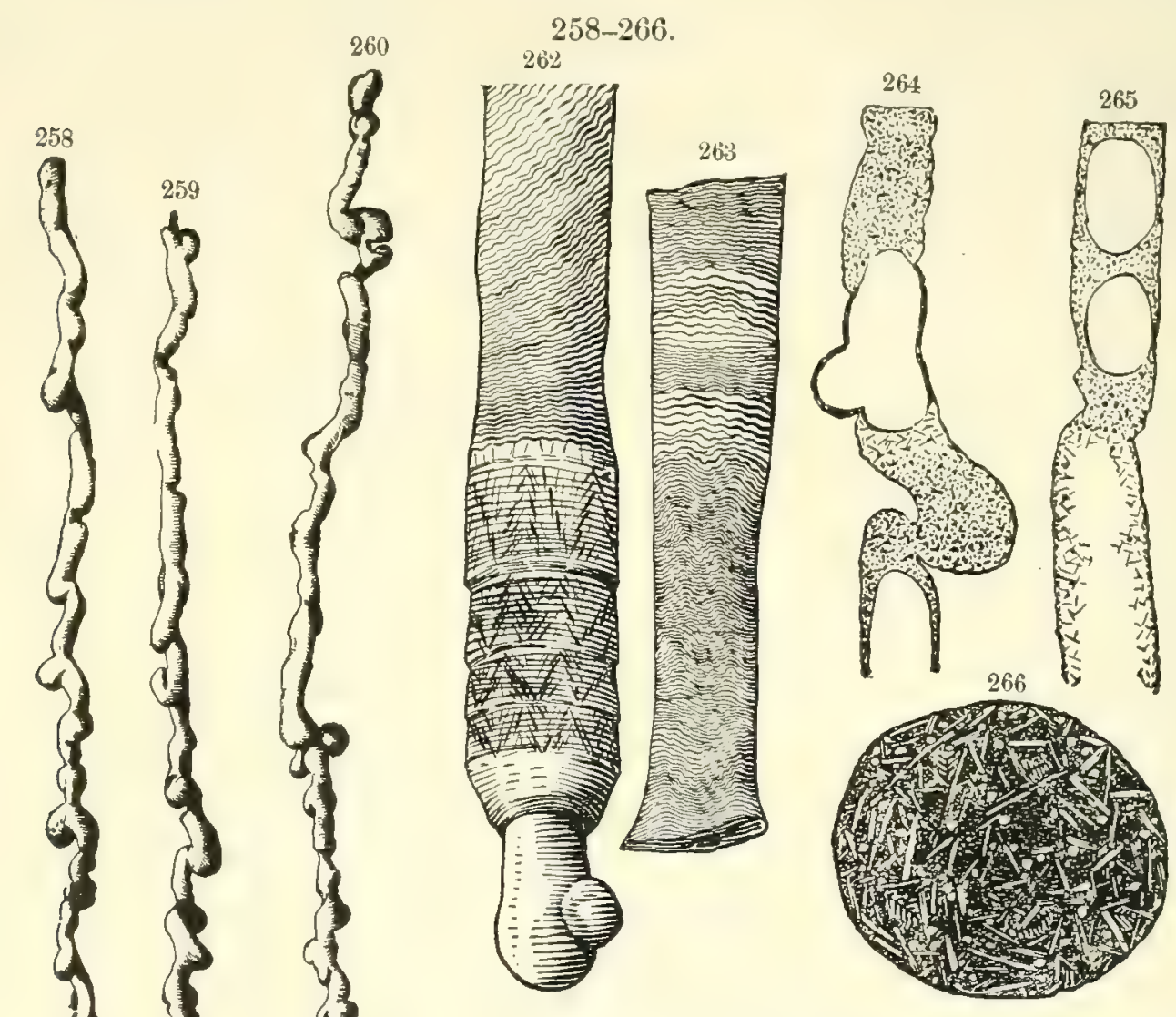

Lava stalactites: Figs. $258-260\left(\frac{1}{3}\right) ; 261$, stalagmite $\left(\frac{1}{3}\right) ; 262$, 263 , portions showing exterior surface $\left(\frac{3}{2}\right) ; 264,265$, sections, showing inside cavities; 266, transverse section (4). E. S. Dana.

gypsum $\left(\mathrm{CaO} \cdot \mathrm{SO}_{3}+2 \mathrm{aq}\right)$ by combination with the lime, as well as Glauber salt or sodium sulphate $\left(\mathrm{Na}_{2} \mathrm{O} . \mathrm{SO}_{3} .10 \mathrm{aq}\right)$ by combination with the soda; and also potassium sulphate $\left(\mathrm{K}_{2} \mathrm{O} . \mathrm{SO}_{3}\right)$ by combination with the potash. Glauber salt and gypsum are common about the fumaroles and in the caverns of the crater and lava-streams of Hawaii, and the aluminum salts or alums with some gypsum, at Vesuvius.

Besides these, numerous chlorides occur in the Vesuvian fumaroles; e.g., common salt or sodium chloride $(\mathrm{NaCl})$, iron chloride $\left(\mathrm{FeCl}_{3}\right)$, and potassium, ammonium, copper, manganese, and other chlorides.

Magnetite $\left(\mathrm{Fe}_{3} \mathrm{O}_{4}\right)$ and hematite $\left(\mathrm{Fe}_{2} \mathrm{O}_{3}\right)$ are also fumarole products. At Vesuvius the crystals of these iron oxides are attributed to the reaction of the steam on the iron chloride. Deville and Fouqué also report hydrogen and hydrocarbon gas as given out at Torre del Greco in 1861. The hydrocarbon gas could well come from organic materials taken in with the sea water. 
The destruction of fissured lavas goes on in connection with the action of steam and other volcanic vapors; and in solfataras the rocks become reduced over large areas, to whitish and yellowish earth, passing to red from the presence of iron oxide. Silica is, to some extent, set free; orthoclase is reduced to kaolin; and nearly all the mimeral species present are decomposed.

On Hawaii, the effects of spent vapors have their climax in the empty tunnels made by a flowing lava-stream (page 287), in which the liquid lavas, as they vacate the tunnels, leave vapors that have at first the extremely high temperature of the lavas. These tunnel-like caves in the lava-stream of 1880-81, near Hilo, are hung in places with slender lava stalactites 10 to 30 inches long (Figs. 258-260, $\frac{1}{3}$ natural size), each having its stalagmite (Fig. 261) below it; and they consist of the same material as the lava (labradorite and augite), in the same rock-like condition, and also have crystals of these minerals, and of magnetite and hematite, in their many cavities. The chrysolite is the only mineral omitted in this remaking of basalt in stalactitic form by the highly heated vapors. (Similar stalactites occur also in Kilauea.) Figs. 262, 263 represent portions of stalactites enlarged, showing the lines of growth (?) over the exterior, and 264, 265, the same with interior eavities; Fig. 266, a section of a stalactite having the usual delicate tabular crystals of labradorite, characterizing basaltic lava, with augite (the clear spots), and the magnetite in dendritic forms. The figures are from the description of Hawaiian rocks by E. S. Dana in the author's work on volcanoes.

\section{Distribution of Volcanoes.}

Volcanoes, now mostly extinct, occur over the border-regions of the continents, - that is, the regions between the oceans and the summit of the border-range of mountains, as between the Pacific and the eastern limit of the summits of the Rocky Mountains; in the continental islands, or those near seacoasts, as on the western border of the Pacific; in oceanic islands, nearly all of which, excepting the coral islands, are throughout volcanic, and the coral islands have probably a volcanic basis. Volcanoes are most numerous along the borders of the larger ocean, the Pacific, - the mainland, or the islands near by, abounding in them on the east, north, and west, and, to some extent, on the south in the Antarctic seas. They are numerous also in the seas separating the northern from the southern continents, namely, the West Indies, between North and South America; the Mediterranean, between Europe and Africa; the Red Sea, between Asia and Africa; the East Indies, between Asia and Australia, - the whole together making a transverse volcanic belt around the globe. Few exist on the borders of the Atlantic, and these few in the West Indies and in the Cameroons Mountains on the coast of the Gulf of Guinea. Over the interior of continents, remote from the regions mentioned, they are almost unknown.

1. Over the Pacific. - The linear arrangement of the islands of the Pacific, explained on page 39 , is the linear arrangement of volcanoes. Active volcanoes occur in the Hawaiian 
group, of the north Pacific; in the west central part of the south Pacific, at Tanna and Ambrym of the New Hebrides, Tofua, Lette and Amargura of the Friendly Islands, and Tinacoro in the Santa Cruz grourp; and in the western north Pacific, among the Ladrones.

2. Borders of the Pacific. - Volcanoes range from Fuegia northward at intervals along the line of the Andes; 32 of them in Chile, - that of Aconcagua, $23,000^{\prime}$ high ; 7 or 8 in Bolivia and southern Peru, - Arequipa, $18,87-$; 19 or 20 about Quito, nearly all over 14,000'; and among them Chimborazo, 20,498'; Antisana, 18,880'; Cotopaxi, 19,660 (by barometer, Dr. Reiss, 19,613' Whymper) ; Pichincha, which has a crater $2500^{\prime}$ deep and $1500^{\prime}$ wide at bottom. Farther north, in Central America, there are 39, about west-southwest in course, and beyond is another line of 7 large cones in Mexico.

In California, from Lassens Peak in the northern extremity of the Sierra Nevada, or rather the southern of the Cascade Range, a grand north and north-northwest line begins, containing cones $10,000^{\prime}$ to $15,000^{\prime}$ in height, consisting, as described in 1833 by Hague and Iddings, of andesyte, dacyte, and basalt lavas, but chiefly of the former. Lassens Peak consists mostly of dacyte (quartz-andesyte), but with some quartz-basalt, as described by Diller, and is $10,437^{\prime}$ high. Mount Shasta, in northern California, has a height of $14,350^{\prime}$; in the view from the westward, there are two summits, the southern the principal one. In Oregon, 75 miles north of Shasta, stands Mount Pitt, a cone $9718^{\prime}$ high ; 150 miles beyond, Mount Jefferson; approaching the Columbia River, Mount Hood, 11,225' ; and north of the river, Mount St. Helens, about 12,000', Mount Adams, 9570', Mount Tacoma (or Rainier), 14,444', and Mount Baker, 10,755', in Washington. Of these, Mount Baker was in action in 1843. At the eastern foot of the Sierra Nevada, near Lake Mono, are cones, and others occur on the plateau region of Oregon, Washington, and beyond.

The summit of the Rocky Mountains has also its volcanic peaks, and among them, in the Yellowstone Park, there is the extinct volcano, Mount Washburn, to the north, $9000^{\prime}$ high, and Mount Sheridan, to the south, 10,200'. 'The rocks and volcanoes of the Park have been described by Hague and Iddings. The Spanish Peaks in southeastern Colorado, according to R. C. Hills, are laccolithic cones, instead of volcanic.

Between North America and Asia there is a festoon of 21 islands with voleanoes, in the Aleutian Islands. Along the Asiatic coast to the East India Islands, there are 15 to 20 in Kamchatka; 13 in the Kuriles; 25 to 30 in the Japan group; 15 to 20 in the Philippines; several along the north coast of New Guinea; and a number in New Zealand. Far south, on Antarctic lands, in $77^{\circ} 46^{\prime}$ S., $176^{\circ} 45^{\prime}$ E., Mount Erebus, $12,400^{\prime}$ high, which, in 1842, when discovered by Captain Ross, sent up dense, lighted vapors and cinders in successive jets, $200^{\prime}$ to $300^{\prime}$ in diameter, to a height above the crater of $1500^{\prime}$ to $2000^{\prime}$; and, standing near it, the extinct Mount Terror, 10,900' high. South of Cape Horn there are the volcanoes of Deception Island, with its hot lake, and Bridgeman's, near $622_{3}^{10} \mathrm{~S}$., in the South Shetlands.

3. In the Indian Ocean.-A few volcanoes exist in Madagascar; also others, on the Isle of Bourbon, Mauritius, and the Comoro Islands, and, to the south, on Kerguelen Land, ete.

4. On the western border of the Indian Ocean. - The lofty peak, Kilima-Njaro, $18,500^{\prime}$, near $3^{\circ} \mathrm{S}$., and $377_{2}^{10} \mathrm{E}$. is volcanic; also Ruwenzori, $12,000^{\prime}$ to $13,000^{\prime}$, in $3^{\circ}$ N.: and $302_{\frac{1}{2}}^{\circ} \mathrm{E}_{*}$; and Mount Gordon-Bennett, just south, $16,000^{\prime}$.

5. Over the seas that divide the northern and southern continents from one another, and the regions in their vicinity. - Volcanoes occur in $(\alpha)$ the West Indies, where 10 islands are volcanic; $(b)$ the Mediterranean and on its borders, as in Sicily and the islands north, Vesuvius, and other parts of Italy ; Spain, Germany, etc., in Europe; the Grecian Archipelago, which contains 5 volcanic islands, - Santorin, Milo, Cimolos, Polenos, and Minyros; in Asia Minor, where are the Catacecaumene and other volcanic regions; and, more to the eastward, toward the Caspian, Mount Ararat, 16,950' high; Little Ararat, $12,800^{\prime}$; Demavend, on the south shore of the Caspian, $21,776^{\prime}$; (c) the Red Sea, along its southern borders, where there are a number of lofty volcanic summits; $(d)$ the East 
Indies, where there are 200 or more volcanoes, of which there are nearly 50 in Java alone (according to Dr. Junghuhn), and 28 out of the 50 now active, nearly as many in Sumatra, 109 in the small islands near Borneo, and a number in the Philippines, etc.

6. On the borders of the South Atlontic. - Only in the Bight of Benin, on the African coast, where a volcano in the Cameroons Mountains is said to be $14,000^{\prime}$ high ; and on the neighboring islands, from Fernando Po to Annabon.

7. On the borders of the North Atlantic. - None on the western north of the West Indies. On the eastern, there are extinct volcanoes in the Auvergne in central France, the Eifel in Prussia, and of past geological ages in Great Britain.

8. In the Atlantic Ocean.--St. Helena, Ascension, Tristan d'Acunha, the Cape Verd, Canaries, Madeira, Azores, Iceland, and Jan Mayen are volcanic. All the islands of the deep part of the ocean (that is, not on the European or American borders) are volcanic.

The number of active volcanic vents in the world is about 300 . Of these, five sixths, or about 250, are within or on the border of the Pacific basin, there being about 148 on the continental islands between New Zealand and Alaska, 45 on the borders of North America (Central America included), 37 in the Andes, and 20 on Pacific oceanic islands. Those within or on the borders of the Atlantic basin are 39 in number: 13 of them in Iceland or near the Arctic circle, 3 in the Canary Islands, 7 in the Mediterranean, 6 in the Lesser Antilles, and 10 in the Atlantic oceanic islands. The Indian Ocean contains but 3, and the Antaretic Ocean only 2, so far as now known.

The proportion of active volcanoes to the total number in volcanic regions varies indefinitely. In the Hawaiian group it is about $1: 5$; in the Japan Islands, where the total number is about 98 , the ratio is $1: 3 \frac{1}{2}$; in the Kurile Islands, out of a total of 49 there are 17 active; in the Marquesas, Tahitian, Samoan, and Fijian groups of the Pacific all are extinct.

\section{Non-Volcanic Igneous Eruptions.}

1. General description. - The ejection of melted rock through fissures, making dikes and outflows, is essentially the same in result whether the ejections are due to distinctively voleanic action or to non-voleanic. The chief difference in method is that the volcano has a localized center, and is pericentric in its work; that is, it has a crater in which projectile work is carried forward at intervals between eruptions, whereas a non-volcanic ejection, when completed, is the end of the outside work until a new and independent fissure is opened. Some reference to a center in the general fracturing may, however, be a fact where there is none for escaping vapors. Commonly, fissures are in long lines, or series of lines, and often, also, in approximately parallel series.

For the origin of large deposits of volcanic ashes or cinders, it is most probable that there has been a center of activity; for such ejections depend on escaping gases, rising and exploding in ebullition style, and for this kind of projectile work and its continuance long enough for thick beds, one or more centers of activity appear to be necessary. The action may be brief, as in an explosive eruption. Stones rounded by wear seldom appear 
among such projectile material, unless water has aided in the deposition. Projectile work throws out angular fragments broken off from the rocks that adjoin the vent. If the vent ascends through non-volcanic rocks, fragments of these rocks may be distributed along with comminuted igneous material, but they could hardly be a predominant part of the mass.

2. Rocks. - The rocks of non-volcanic outflows are the same in kinds with those of volcanic origin. The more scoriaceous lavas are usually absent, but vesicular kinds are common. 'The moisture producing vesiculation, and sometimes a general hydrous condition of the rock, may be either that of the deep-seated igneous source, or that of waters taken in on the way to the surface; for the latter method of receiving moisture, - that by molecular absorption, if a principle in volcanic phenomena (page 278), will be as much so in non-volcanic. Among the ejections of a system of fissures, those that have come up through sedimentary strata may, or may not, be rendered hydrous, while those intersecting impervious metamorphic rocks are generally anhydrous, with no trace of vesiculation. Owing to such subterranean sources of moisture, igneous rocks are sometimes hydrous throughout, and consequently feeble in luster and wanting in durability. In a similar way, the ascending melted rock sometimes gathers in bituminous materials from carbonaceous shales, and puts them into the vesicles.

Igneous rocks are sometimes divided into those of deep-seated origin related in character to granite, syenyte, and the like (called plutonic first by Lyell), and other igneous rocks and lavas. But it is a false distinction; for granite is no more of deep-seated origin than other igneous kinds.

3. The ejections, making dikes and surficial streams. - The ejected rock may fill a fissure, or but partly fill it. On the other hand, it may flow out of a fissure in a stream over the surface of the country, covering the exposed rocks or soil. The part of the flow within the fissure is a dike, whether there is an outflow or not. Fig. 219, on page 262, represents a dike with a surficial stream.

(a) Dikes. - Dikes vary in width from an inch or two to 300 feet or more, and in position from vertical to horizontal, and, as already explained, are usually, unless quite small, transversely columnar. The smallest are branches from a larger; for an inch-thick stream could not flow far between cold rocks. They often have irregularities and interruptions which are due to a faulting of the rocks intersected subsequent to their formation, and others owing to a shifting of the position of the walls of the fissure before it became filled. But, further, there may be, before the filling, a tumbling in of one wall, or the other, of the fissure, especially when the fissure is much inclined and the intersected rock a weak one.

On the following map, two trap dikes, of the region near New Haven, Conn., are represented (inclosed by dotted lines), which are divided into short parts, owing to the caving in of the overhanging wall.

The Pine Rock dike consists of four such parts $(A, B, C C, D)$, and Mill Rock of three (AA,BB, to "Peak" and C). The inclination of the dike of 
Pine Rock is $35^{\circ}$ to $40^{\circ}$ from a vertical, and that of Mill Rock, $22^{\circ}$. East Rock (in which the surface of trap is widened by a short westward outflow) owes its subdivision into short, blunt parts $\left(\mathrm{A}, \mathrm{BB}^{\prime}, \mathrm{CC}^{\prime} \mathrm{C}^{\prime \prime}, \mathrm{DD}\right)$ to the same cause; the dike has a dip of $45^{\circ}$. The weak sandstone walls of these dikes were at least 4000 feet in height, and a downfall of the unsupported wall was a natural result. (D., 1891.) The same cause opened an escape fissure to the north of Mill Rock, at D.

267.

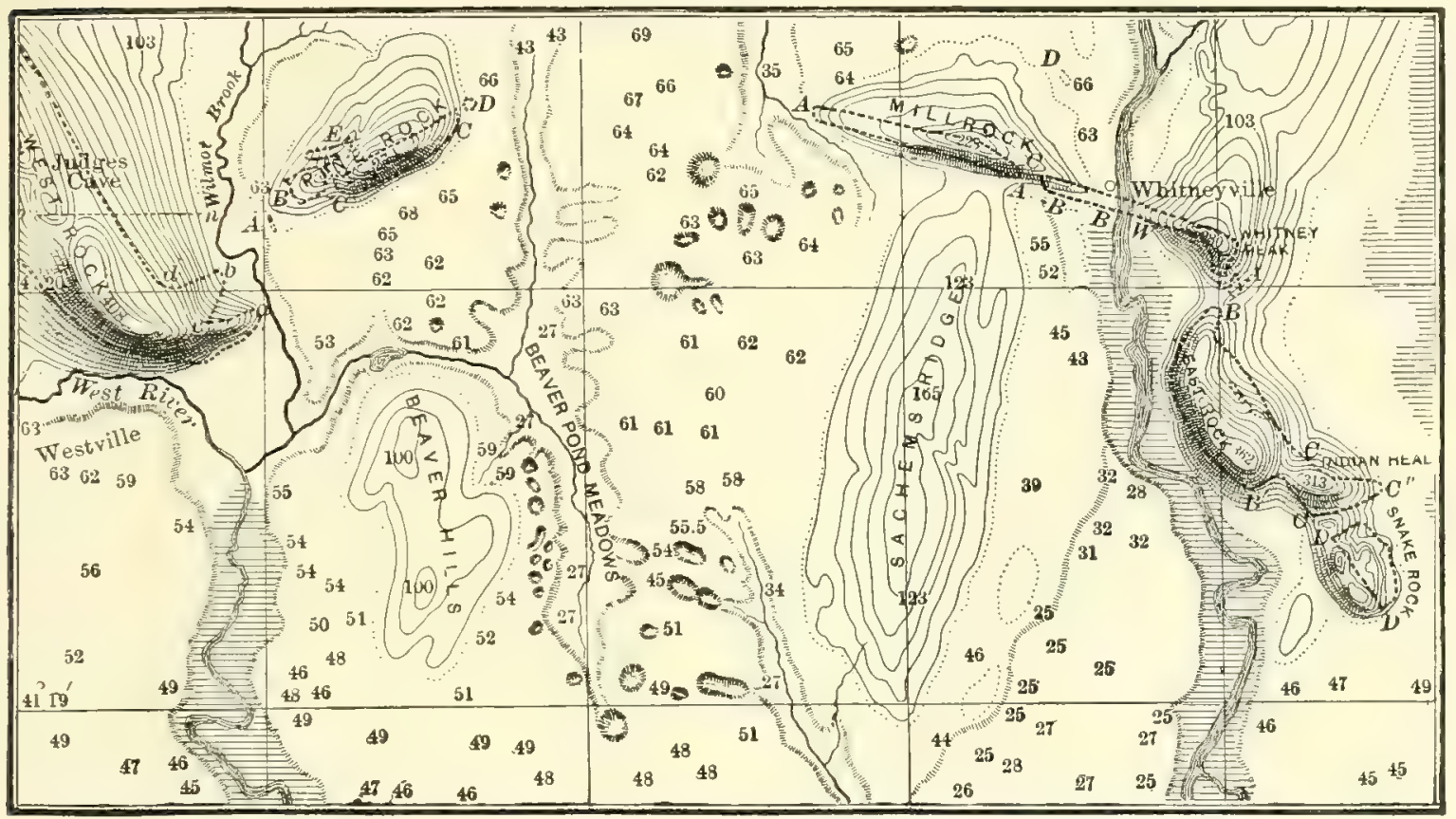

Map of trap dikes, near New Haven, Conn.; figures give heights above sea level. D.

The rock of the outer portion of a dike, besides having the fineness of texture and cracks due to rapid cooling, may be soft from alteration, or may have a stratified appearance parallel to the walls, as in Figs. 268, 269; or parallel fissures occupied by some infiltrating mineral; and occasionally they are vesicular.

(b) Surficial streams. - The most extensive of nearly horizontal igneous outflows - that of the Deccan, India - covers an area of 200,000 square miles, and is of the age of the Cretaceous and early Tertiary periods. It reaches from the seacoast at Bombay to the railway station at Nágpur, 519 miles. It was thickened by successive flows until 6000 feet thick near Bombay, 2500 feet in Cutch, 2000 to 2500 feet at its southern limit; to the northwest in Sind and to the southeast, the thickness is only 100 to 200 feet. (Blanford.)

Western North America, while remarkable for its

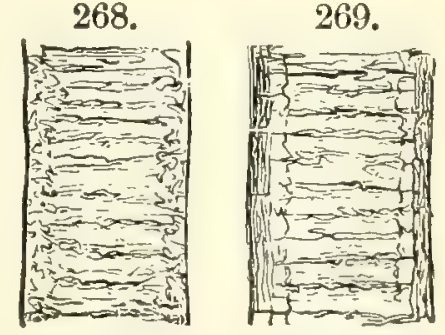

Dikes with the columnar structure along the sides imper. fect. D. great volcanoes, is no less so for its non-volcanic rock-floods; for these cover nearly 100,000 square miles. The largest continuous region stretches from 
the Yellowstone Park down the Snake River region. It spreads north over Oregon and Washington. There are many other areas over the Great Basin, to the south. No cones exist as centers of these floods of lavas, but to the west are lofty volcanoes of the Cascade Range. In the Great Basin the lavas of the areas are commonly rhyolyte.

The two following figures are examples of surficial outflows and of parts of Table Mountain, Cal., which resulted therefrom through denudation. The melted rock flowed over the gravels and river-beds of the country, and thus obliterated the old surface features. Subsequently erosion by waters, cutting through the igneous layers, and then through the easily removable beds beneath, left a flat-topped elevation. 'Such "table mountains," or mesas, are

270.

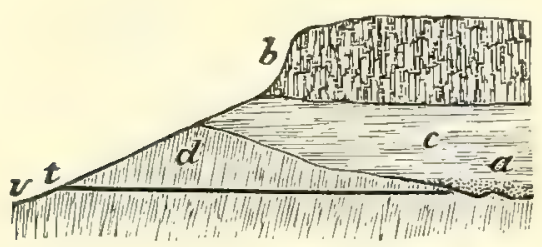

271.

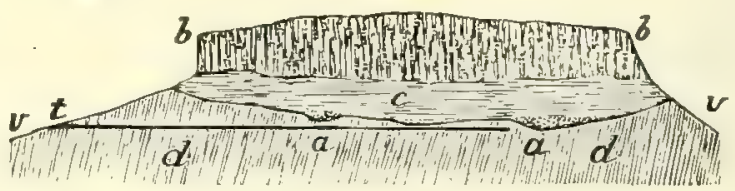

Sections of Table Mountain, Tuolumne County, Cal.: 270, at Maine Boys' tunnel; 271, at Buckeye tunnel. J. D. Whitney.

common in California, Arizona, and some other parts of the Rocky Mountain area. These fissures, as explained by Whitney, show the old, now buried, river valley (cut out of tilted Sierra schists, $d$ ), holding in the river bed (at $\alpha, a$ ) auriferous gravel, and, above, finer fluvial deposits (c), which often are partly volcanic ash, and sometimes contain silicified stumps and logs; and, оver all, the cap of basalt $(b)$; $b v$ is part of the outline of the adjoining modern valley. Tunnels $(t)$ are made through the "rim-rock" of such old valleys to reach the gravel, the gold being collected in these bottom deposits because of its weight.

A stream of melted rock usually hardens more or less the bed of sedimentary rock over which it flows; or it bleaches, blackens, or otherwise changes it. Should it change, in like manner, an overlying bed, this would be evidence that the stream was not surficial but interstitial; that is, an intrusion between two layers. The hardening effects often fail, however, because there was no moisture present; for dry sands cannot be hard baked. Moreover, coarse pebbly beds are consolidated more readily than shales, because they let the steam, that may be generated from moisture, pass through them, when the fine earthy beds do not. Hence the latter may show little or no evidence of the heat. On these changes see further under Metamorphism, page 312.

4. Interstitial outflows. - The intrusion of the melted rock of a fissure between the layers of the stratified formation it intersects may be either a simple gravitational flow; or a forced flow.

(a) The melted rock will naturally flow from a fissure into any opened 
space that may offer a way of escape; and it may thus put layers of its own material into the stratified series.

(b) The lava of a fissure is always forced along by pressure from below; and if the fissure fails to reach the surface, the ascending stream may open a space for itself by lifting the overlying beds, and accumulate in great masses in the chamber so made.

An intercalated mass of igneous rock formed in the latter way is called, by G. K. Gilbert, a laccolite, from the Greek for lake, because it is a lake-like expansion of a stream. (As the termination ite is that used for a mineral or rock, the form laccolith, like that of monolith, is to be preferred.) The thickness depends somewhat on the fusibility of the rock, the more fusible kinds making extended masses or sheets, and the less fusible producing thicker and more bulging forms.

The Henry Mountains in southern Utah are of laccolithic origin, and they are those to which the term was first applied by Gilbert. The following figures are from his memoir (1877). The greatest thickness of the strata bulged upward by the lifting lava, in the manner illustrated in Fig. 272, was about 10,000 feet; and the height of the laccolithic dome in some cases is over 3000 feet. Fig. 273 represents an actual laccolith, called Jukes Butte, completely

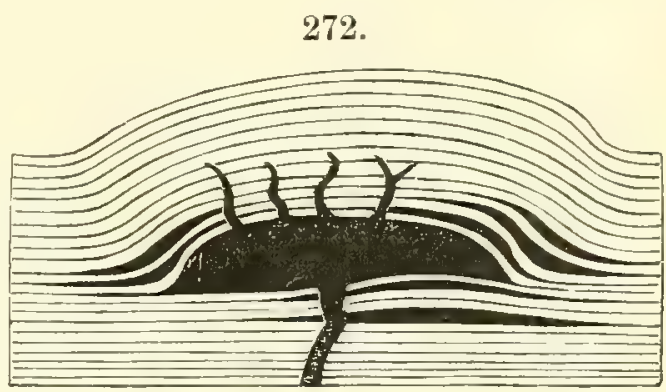

Ideal section of a laccolith. Gilbert. stripped of its inclosing strata and deeply gorged by denudation. The rock is andesyte, a rock less fusible than basalt; and the breadth of the mass is consequently only three to seven times greater than the height.

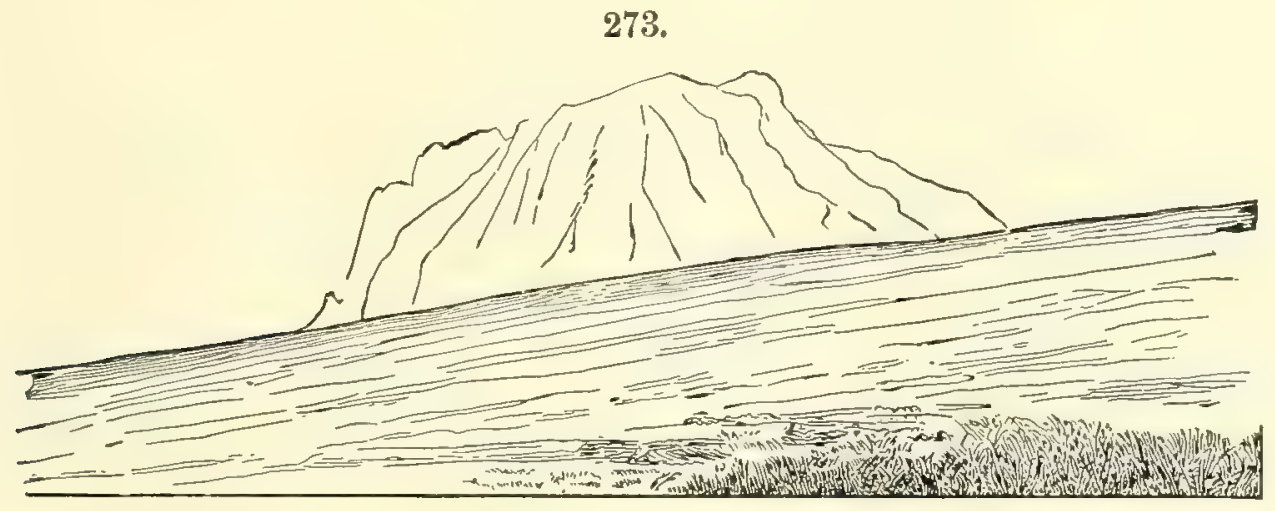

Jukes Butte, a denuded laccolith, as seen from the northwest. Gilbert.

From the laccolith rise dikes of andesyte. The sandstone adjoining is usually more or less altered by the heat to a depth of a foot or more. The chamber occupied by the laceolith was in all cases made along a shaly layer in the formation where the cohesion was least. They occur at different levels in the strata, and the one lowest in geological position is 4500 feet below the level of the highest; the former is between Carboniferous beds, 
and the latter between Cretaceous; and over the Cretaceous lie Tertiary beds.

It follows, from the conditions represented, that the ascensive thrust of the lava was so powerful, that in spite of friction along the passage and the density of the lava, it flowed upward for an unknown number of miles to the laccolith level; and then had energy enough left to lift, in the case of the laccolith lowest in geological level, a mass of beds 10,000 feet or more thick and 2.25 in average specific gravity (equivalent in pressure to 675 atmospheres) to a height of 5000 feet. Some accession to the force, however, may have come from vapors derived from subterranean moisture, or from waters encountered on the way up. As Mr. Gilbert states, the intrusion of the lava

274 .

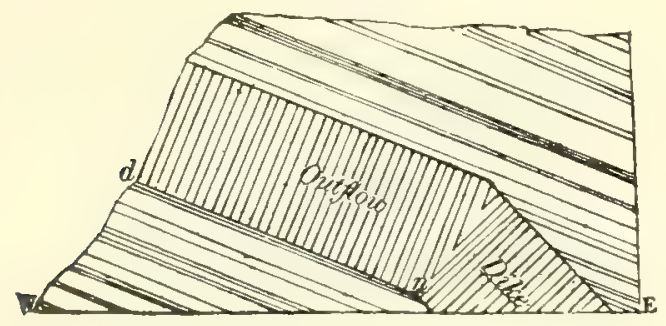

276.

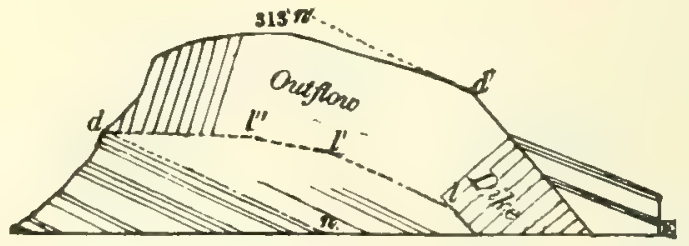

275.

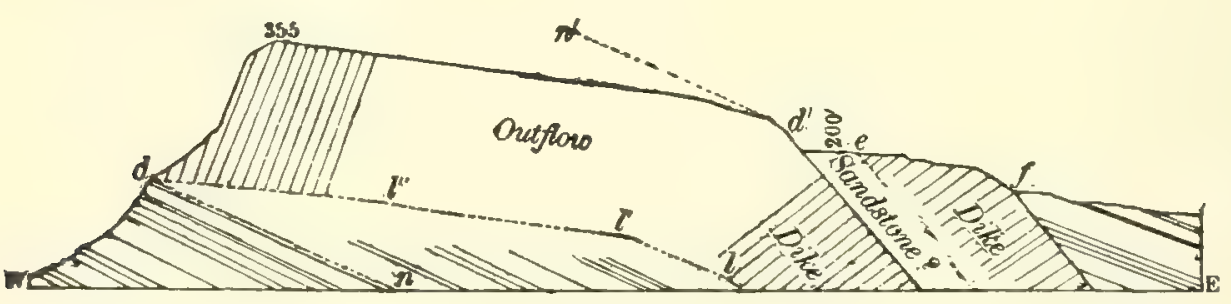

277.

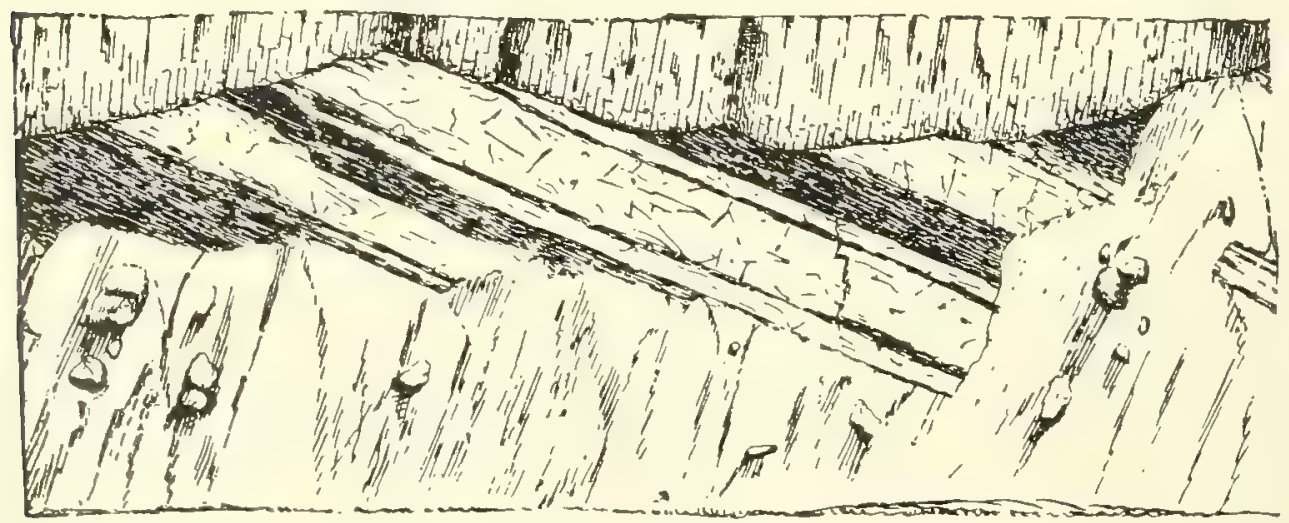

274, Ideal outflow of the main Enst Rock dike; 275 , actual outline of trap in the same, with an eastern supplementary dike; 276, same in a second East Rock summit, called Indian Head; 277, upturned sandstone (with talus covering part of it) underneath the trap of West Rock along a transverse section. D. '91.

laterally into a chamber widened the area of pressure, and thus enabled it, on the principle of the hydraulic press, to accomplish the lift by very slow steps of progress. 
Among the trap-ridges of the Connecticut Valley, East Rock (page 298) is of laccolithic origin. The supply-fissure for East Rock dips eastward at about $45^{\circ}$. The liquid rock on passing up the fissure between the sandstone walls, whose beds also dip eastward, but at an angle of $20^{\circ}$ to $25^{\circ}$, forced a passage westward between the beds of the sandstone, and made a mass of trap 200 to 250 feet or more in thickness, and about 300 yards in breadth. It is known to be laccolithic by the fact that the sheet of trap keeps its thickness quite to its extreme western limit, instead of thinning by gravity, like a surficial flow, and that it has also a rising slope throughout. The section, Fig. 274, represents the intrusion of trap, from an oblique fissure, between layers of sandstone, in laccolithic style; and the removal of the overlying sandstone would give it a general resemblance to a section of East Rock. But in East Rock, and also in West Rock, of the same region (see map, page 299), the trap of the outflow rests on the edge of upturned layers of sandstone, and it has less dip than the sandstone. The condition in East Rock is shown in Fig. 275, and that in a second summit of the East Rock Ridge, in Fig. 276. Fig. 277 represents part of a long exposure of the upturned sandstone in the south front of West Rock - a transverse or eastand-west section of the Rock. Above the sandstone, only the basal portion of the columnar trap is shown in the figure, and below it, a talus of fallen stones and earth. The forced laccolithic flow of the liquid rock under its heavy cover of sandstone must have caused the abrasion of the fragile underlying beds.

In some cases in the Connecticut Valley, portions of the sandstone and trap, at the contact, occur rolled into rounded forms, and make part of an intervening layer between the trap and sandstone. The resistance produced by the weight of sandstone above frequently caused the opening of parallel fissures, for the escape of the lavas; and the rock of these outflows is often amygdaloidal, when the rest is not, owing to the accumulation of subterranean waters produced in consequence of the damming by the descending dike.

\section{Unsolved Questions about Igneous Phenomena.}

1. Origin of the ascensive force. - The ascensive force in the volcano has been attributed to (1) the expansive action of moisture from the deepseated source of the lavas; and (2) the gravitational pressure of the contracting crust of the globe, forcing up the lavas; and some of the very deep depressions in the ocean's bottom near volcanic islands are thought to favor the latter theory. In view of the fact that the central part of a lava column should be the hotter, it is queried whether there is not, owing to the ascending vapors, a more rapid rising along the center, and a consequent descending along the sides of the conduit.

The facts afforded by Kilauea indicate that the upward movement in a lava column, as a consequence of the ascensive force, is very slow - 360 feet in 6 years being the maximum observed (page 280). It appears also to follow from the facts, as stated on page 276 , that the force in the conduit varies with the amount of moisture received from descending subterranean waters. Daubrée, whose experiments on the perforating power 
of vapor on rocks when suddenly developed along an opened crack $(1890,1891)$ are referred to on page 278 , attributes the first opening of the conduit tube of a volcano to such action of vapors.

2. Source of igneous fusion. - It was formerly believed that the earth's liquid interior, or else a liquid layer beneath the crust, or isolated liquid areas in place of a liquid layer, supplied the liquid rock of volcanoes. Now it is generally held that the earth is solid within, but that below a thin exterior there is a temperature just below that of fusion, and that autual fusion results whenever subterranean pressures cause movements and thus develop heat. It is also urged that the removal of surface pressure might cause fusion, since lessening pressure lowers the melting-point. In this process fusion takes place without increase of heat; but in the preceding, there is augmented heat of dynamical origin.

Believing in the earth's igneous fluidity, Bunsen, in 1851, put forth the theory that within the crust the earth contains an acidic layer chiefly of orthoclase and quartz material and with a mean percentage of silica of $76 \cdot 67$; below this a heavier basic layer in which the mean percentage of silica is but 47.48 ; and that igneous rocks are from one or the other of these magmas, or from mixtures of the two. Richthofen in his "Natural System of Volcanic Rocks" (California Acad. Sci., 1868), after a study of the rocks of the Pacific border of the United States, announced as the order of eruption in igneous regions : propylyte (since shown to be andesyte), andesyte, trachyte, rhyolyte (quartz-trachyte), basalt — basalt being the latest — when present with the others.

More recently, Iddings has concluded that the different kinds have arisen from local differentiation of a common magma; that the first that appears in a region is usually one having the mean composition of the series in that region, and that the last is a rock of one or both extremes, that is either rhyolyte (quartz-trachyte), or basalt, or both; also that in each case the portions of the magma that are latest to be extruded are the solvent for the other portions.

A. D. Hague has found, in the Leadville region, the succession in the ejected rocks to be (1) andesyte, (2) dacyte, (3) rhyolyte, (4) basalt; and he regards it as the prevailing order.

This order - which is near that of Richthofen - corresponds to a succession from (1) soda-lime semibasic lavas, to (2) potash-bearing or acidic lavas; to (3) basic lavas: also from (1) those of medium fusibility; to (2) those of difficult fusibility; to (3) those of easy fusibility or which melt at the lowest temperature: also from (1) those of medium specific gravity; to (2) those of least specific gravity; to (3) those of greatest specific gravity. No further physical or chemical explanation for the succession is yet given. If fusibility is the important principle in determining distributions, then basalt should generally be, as the facts make it, the last and the uppermost. Mount Loa shows that specific gravity has little or no importance; for the heaviest chrysolitic basalts occur not only below, but also at the summit, although it is nearly 14,000 feet above the sea level. 


\section{Thermal Waters, Geysers.}

The subject of thermal waters constitutes an important part of Chemical Geology, and is here only briefly treated. Hot springs are (1) common in volcanic regions, and (2) occur also along the courses of non-volcanic eruptions. They are occasionally met with, away from all igneous eruptions, (3) on the lines of faults or the axes of flexures, and sometimes (4) where there are none of these conditions. The heat in the first two cases is generally of volcanic, or deep subterranean, origin; but in the others it may come from the oxidation of sulphides, or from other chemical action.

When the temperature is high, the waters may be either approximately pure, or strong mineral solutions. The waters often hold silica in solution, whose deposition, over the region around, makes irregular accumulations of a coarse opal, or rarely of quartz, and forms low cones or rims about basins. Occasionally, the waters are calcareous, instead of siliceous, and make calcareous basins or cones. The sources of such solutions, and some of the effects resulting from them, are exexplained on pages 131, 135, and beyond.

Geysers. - When a spring or basin of hot water is in nearly constant ebullition, or is alternately boiling and quiet, it is simply a hot spring

278.

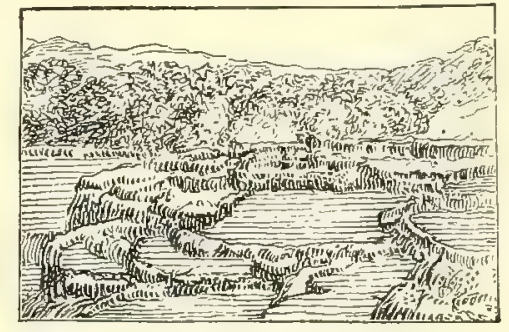

Geyserite Terraces, from the "Pink Terrace" of New Zealand. or basin. But if the water is thrown up at nearly regular intervals, in jets, it is called a geyser. Iceland has long been noted for its geysers, and the theory of geyser action was there first investigated by Bunsen and Des Cloizeaux. It has one great geyser in the vicinity of Hecla, among many hot springs. The geyser sends up a great jet of 100 feet once in about 30 hours, and other smaller ones in the interval. The Icelandic word means a "gusher." New Zealand has its geyser region, about Lake Rotomahana, in the northern island, and had beautiful geyserite terraces until the volcanic eruption of Tarawera in 1886, when mud eruptions buried them.

Far exceeding either of these regions is the geyser area of Yellowstone Park, first described by Messrs. Cook and Folsom in 1870, and by the Hayden expedition in its volumes for 1871, 1872. and 1878, the last containing an extended account by A. C. Peale. The region has since been further studied and described by A. Hague, J. P. Iddings, W. H. Weed, and others. The geysers are situated mainly about the Fire-Hole Fork of the Madison, and near Shoshone Lake at the head of Lake Fork of the Snake. They are exceedingly numerous, and play at all heights up to 200 feet or more; and, besides, there are multitudes of hot springs of various temperatures, the most of them between $160^{\circ}$ and $200^{\circ} \mathrm{F}$., the boiling-point of the region being $198^{\circ}$ to $199^{\circ} \mathrm{F}$. There are also "mud-volcanoes" where steam issues through thick mud or muddy waters, producing, at times, ebullition, and occasionally geyser action. The principal locality at the park is four miles DANA'S MANUAL - 20 
north of Yellowstone Lake, and six from "Crater Hills." Some of the mud pools are simply muddy water; others are like kettles of boiling soap; some like ealdrons of mush or paint, and still others like stiff mortar. They vary in stiffness with the dryness of the season. They have generally a circular pit 10 feet deep, and rise sometimes into a mound several feet above the general level. All together, the number of hot springs and geysers in this region cannot be less than 10,000 . The hot waters are usually siliceous,

279.

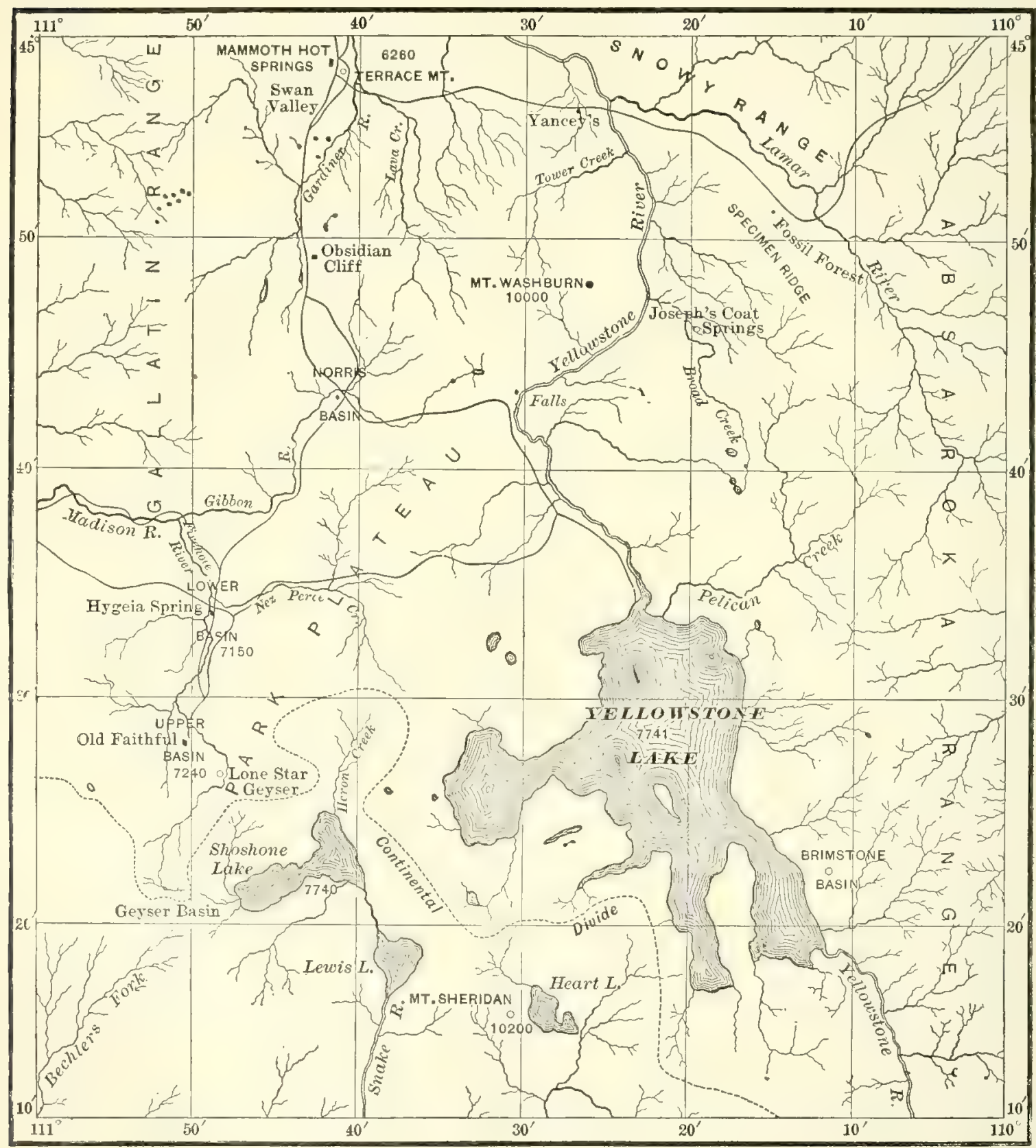

and deposit the silica in the form of a tufaceous or porous opal called geyserite. It makes cones and basins of various shapes, and covers the surface over wide areas. The deposits of the Gardiners River at the Mammoth Hot Springs are calcareous; Fig. 282 represents one of its calcareous cones, the 
"Liberty Cap," 50 feet high and 20 feet in diameter; and Fig. 136, on page 132 , represents calcareous (travertine) terraces on this river.

One of the geysers in the Upper Geyser Basin of the Fire-Hole is shown in action in Fig. 283; the cone (Fig. 281) is but $3 \mathrm{ft}$. high and 5 in diameter, but it throws up a jet beyond $200 \mathrm{ft}$. in height about once a day.

In the eruption of a geyser, the jet is first water, then much steam with the water, and, at last, mostly or wholly steam, the water having been all thrown out; and, when the water partly falls or runs back into the basin, the eruption is sometimes renewed successively, before finally stopping.

280.

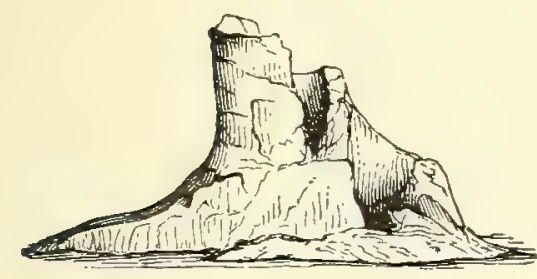

Giant Geyser.
281.

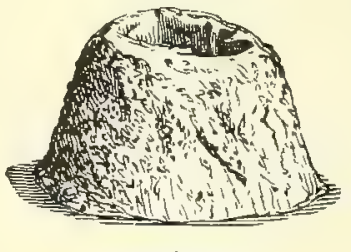

Beehive.

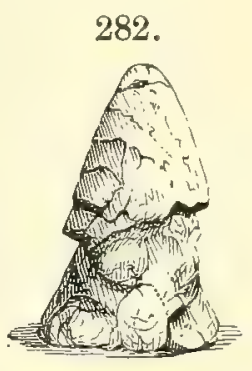

Liberty Cap.

The intermittent action is owing (1) to the access of subterranean waters to hot rocks, producing steam, which seeks exit by conduits upward; (2) to cooler superficial waters descending those conduits to where the steam prevents farther descent, and gradually accumulating until the conduit is filled to the top; (3) to the heating up of these upper waters by the steam from below to near the boiling-point; when (4) the lower portion of these upper waters becomes converted into steam, and the jet of water, or eruption, ensues. This is nearly the explanation given by Bunsen after an examination of the geysers of Iceland. The deposit of silica in the throat of the conduit, after an eruption, tends to diminish its size, and sometimes closes it completely, so that the waters are obliged to open a new vent.

The beauty of the siliceous geyser-cones is often enhanced by the delicate tints of pink, buff, yellow, etc., mingled with white, over their surfaces. Pebbles in the bottom of the small basins formed about the cones are commonly concretions of geyserite, like the rosettes of the bottom and sides. Fig. 280 represents the cone of the "Giant" geyser, in the Upper Geyser Basin of the Fire-Hole; it is about 10 feet high and 24 feet in diameter at base, and has one side partly broken down and bent inward. It throws out, at long intervals, a jet 90 to 200 feet in height. "Old Faithful" is one of the largest of the Madison River geysers; it has a low and broad irregular cone, and throws up its great jet to a height of 150 feet, once in about 65 minutes, the remarkable regularity of its action having suggested the name it bears. The "Giantess," another of the large geysers of the Fire-Hole, throws a still larger body of water to the same height. Another, the "Architectural" geyser, is actually, when in action, a combination of jets of various sizes and angles of inclination, each having some independence in its movements, but all working together, and producing a marvelous effect from the ever-changing views.

Frank H. Bradley observes that, while standing on the mound of "Fountain " geyser, whose pool was overflowing, and watching a steam-jet a hundred yards away, the jets suddenly ceased, and "Fountain" commenced throwing up a jet, 10 feet in diameter, to vary- 
ing heights, from 5 to 40 feet. In 30 minutes, "Fountain" stopped suddenly, and immediately the steam-jet began again; in 20 minutes more, the jet again stopped, and at once a small pool a few yards from "Fountain," which was empty when that was playing, but had become partly filled from its overflow, began to boil and throw up water to a height of 5 or 10 feet, and continued this for half an hour; as it moderated, the steam-jet opened anew, but ceased when the boiling became more violent. The facts, illustrated in other parts of the region, prove a sympathy between different vents.

283.

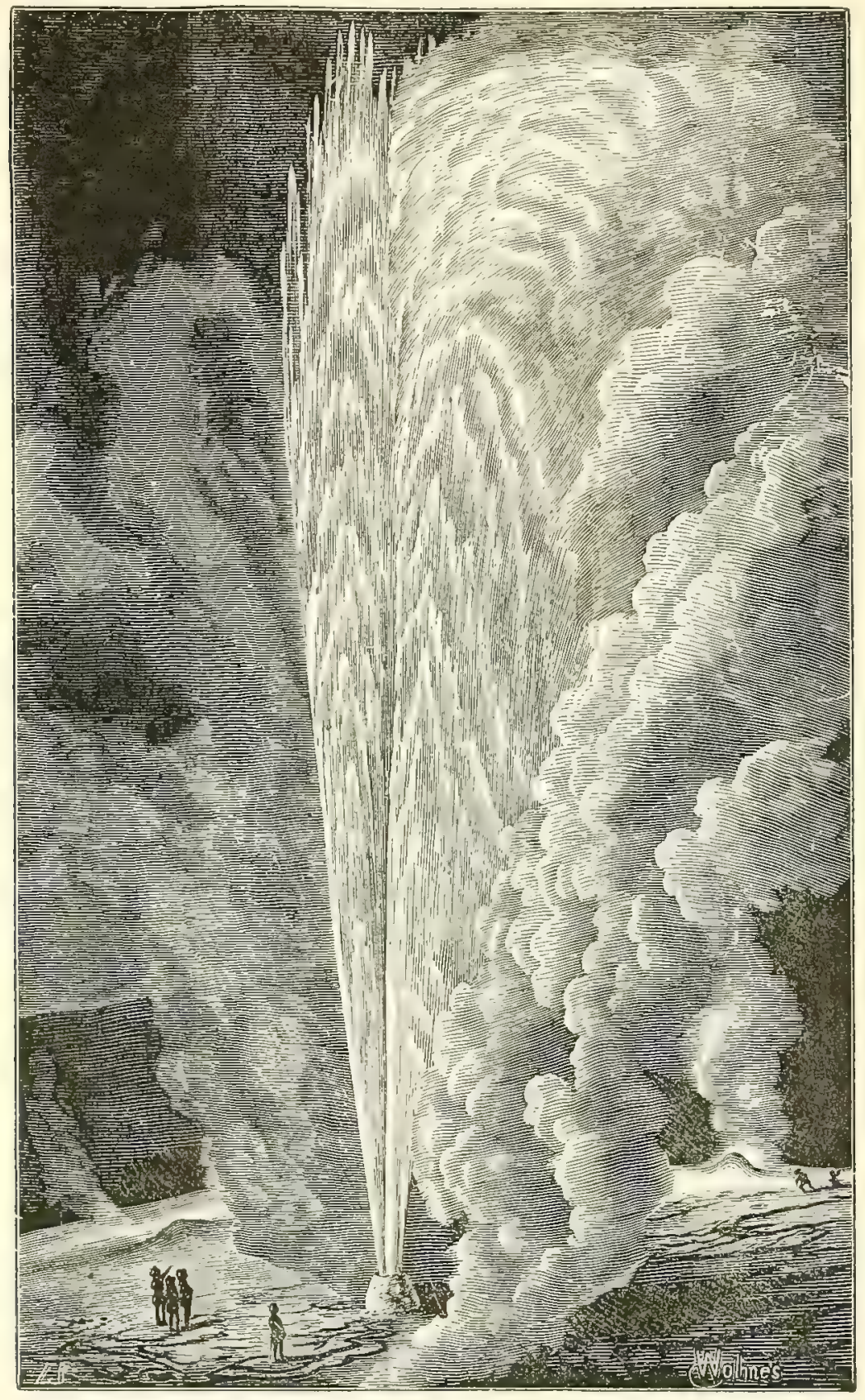

Beehive Geyser in action. Holmes.

On page 152, the agency of plants (Algæ) in the deposition of the silica and calcareous material of the geysers (first observed by W. H. Weed) is described.

There is a small geyser region on Sa ̃ Miguel, one of the Azores, in the north Atlantic. It is situated in the Val de Furnas, where three centuries since there was a volcanic 
eruption. The hot waters are in constant ebullition and have their intermittent jets. Besides escaping steam, there is some carbonic acid given out, and siliceous deposits are made from the hot waters. Geysers occur also on the island of Celebes, in the volcanic region on its northeastern extremity in the district of Manado.

\section{METAMORPHISM.}

Metamorphism signifies change: not merely change in form, as might be inferred from the composition of the word, but also, like the corresponding word metamorphosis, change in nature or constitution. In geology, it is change in texture, crystalline structure, or mineral constitution; as when a common limestone becomes crystallized, and thereby converted into statuary marble, or a sandstone into gneiss or granite, or an augitic rock into a hornblende rock, or a massive rock into a laminated or foliated kind.

The terms metamorphic and metamorphism were proposed by Lyell in the first edition of his Principles of Geology (1831-1833) with reference to altered rocks of both local and regional extent.

In Vol. III. he says, on page 372: "It appears from sections described by Hugi, that some of the secondary beds of limestone and slate, which are overlaid by granite, have been altered into gneiss and mica schist. These altered sedimentary formations are supposed by M. Élie de Beaumont to be of the age of the Lias of England, and others to be even as modern as the Jurassic or Oölytic formations." On page 373 he says: "According to these views, gneiss and mica schist may be nothing more than micaceous and argillaceous sandstones altered by heat, and certainly in their mode of stratification and lamination, they correspond most exactly."

"Granular quartz may have been derived from siliceous sandstone; clay slate may be altered shale, and shale appears to be clay which has been subjected to great pressure." "Granular marble has originated in the form of ordinary marble, having in many instances been replete with shells and corals now obliterated." In the edition of 1842, he speaks of fossiliferous formations, some of them of the age of the Silurian strata, as near Christiania in Norway, others belonging to the Oölytic period, as around Carrara in Italy, which had been converted partially into gneiss and mica schist and statuary marble. Among local changes he mentions the case of the basalt dike in Anglesea, 134 feet wide, cutting through strata of shale and limestone which were altered for 30 feet from the dike, "having the shale in several places converted into hard porcelanous jasper, in the hardest parts of which the fossil shells, principally Productoe, were nearly obliterated"; "and the argillaceous limestone had lost its earthy texture and become granular and crystalline." Through investigation since, such facts, both of regional and local origin, have been greatly multiplied.

The Taconic region, on the borders of New York and New England, affords a good illustration. The rocks are least crystalline in the northern and the western parts of the region, and consequently fossits were to be looked for in those parts. They have been found in Vermont down to 
and beyond the Massachusetts line - Cambrian fossils in the sandstone or quartzyte, and Cambrian and Silurian in the crystalline limestone or marble belt next west; and a few miles farther west they occur going southward in limestones and schists for 150 miles to Poughkeepsie in Dutchess Co., N. Y., and beyond. In the more erystalline parts of the same region to the eastward in Massachusetts, the quartzyte graduates into gneiss and alternates with mica schists, and the slates change to staurolitic mica schists and gneiss. The fossils in the Taconic region were found by A. Wing, Walcott, Dwight, Dale, Wolff, and others.

Again, near Bernardston, Mass., and the region northward along the Connecticut Valley, Crinoids and Brachiopods occur in a crystalline limestone of Devonian age, associated with hydromica schist, gneiss, granite, dioryte, hormblende schist, quartzyte, all of one Devonian series, and of synchronous metamorphism. (E. Hitchcock, B. K. Emerson.)

In the Alps, at the St. Gothard tunnel, crinoidal remains occur in calcareous mica schist (Müller). In the Apuan Alps, Orthocerata exist in limestone between beds of gneiss and mica schist (Meneghini). At Brevig, Norway, a Silurian limestone contains garnets, scapolite, and fossils, and, according to Reusch, mica schist containing Halysites, Favosites, Cyathophyllum, Murchisonia, Calymene, Dalmanites. Schists, in Brittany, afford andalusite crystals and species of Orthis, Spirifer, and Calymene, in one and the same specimen (Boblaye). At Rothau, in the Vosges, in a hornblende rock, corals occur replaced, as stated by Daubrée, without losing their form, by crystals of hornblende, garnet, and axinite, and among the corals the species Calamopora spongites is quite distinct.

The rocks that have become changed into metamorphic rocks are for the most part the fragmental rocks, as sandstones, shales, conglomerates, with the limestones. These, according to their various constitution, have been changed to gneiss, granite, mica schist, and the several other kinds of schist; and the limestones to crystalline limestones; and this change has been the chief method of origin of the schists. In addition, the many crystalline rocks, both the metamorphic and igneous, have undergone, to some extent, related changes.

Under metamorphism might be included the chemical changes in rocks and minerals that take place at the ordinary temperature. But these run down into the common results of decay, and are more conveniently kept separate. They have been described on page 118 and beyond.

\section{Causes of Metamorphism.}

1. Not generally due to infiltrating waters. - The metamorphic changes which rocks have undergone is no evidence of their instability under existing conditions. It has been already shown that the sandstone, shales, and other fragmental rocks are seldom so porous at depths below as to admit the passage of infiltrating waters. It is true also of the crystalline rocks, granite, gneiss, syenyte, and the various igneous rocks, that they are commonly too elose in texture to admit the passage of underground waters. The moisture they hold is stable, and the rocks are stable against changes from 
such a source. In outcrops of an Archæan granite, the feldspar and mica are usually as perfect as when made in Archran time, excepting a thin layer of surface alteration. So in many of the outcrops of trap, the pyroxene and labradorite are still unchanged pyroxene and labradorite; and this, though millions of years have intervened since the outflow; and millions of years of uniformity are sufficient to prove stability. The thin layer of surface alteration indicates the depth of permeation, and to this depth there is alteration, but not metamorphism. Buried in subterranean waters, the conditions would be the same except that even surface alteration would be prevented; for a sandstone that will fall to pieces when exposed to the air will make durable underwater abutments. A trap ledge that decays to a depth of two or three feet, when it is above the tide-level, will remain solid and wholly unaltered below low tide. Pyrite and other iron-bearing minerals oxidize, and help on the decay in the outer layer where it is exposed to the air; but below this they remain unchanged. White marble, although a more porous rock than most others, usually retains its whiteness perfect through the body of the rock, its pyrite and other imbedded minerals losing nothing in their luster or composition.

2. Heat above the ordinary temperature usually necessary. - Lyell attributed metamorphism to the heat of the earth's interior. The rocks bore evidence, in the position of the beds, of upturnings and of great pressure; and those which were left deepest as a consequence of the movements became crystalline or metamorphic. They were hence also called by him Hypogene rocks. Effects from dynamical forces were here recognized, but the heat was statical heat.

This continued to be the theory of geologists until 1868, when Henry Wurtz, of New Jersey, in the Ameivan Journal of Mining, announced the principle that metamorphism was due to heat derived from the friction attending the upturning of the rocks, that is, to heat of dynamical origin. In the editions of this work since that date this theory of regional metamorphism, through heat of a dynamical source, has been adopted. But it has also been recognized that heat of a dynamical source has been more or less supplemented by heat from the earth's interior, that is, by statical heat. At the same time statical heat has been referred to as also the source of local metamorphism. It should be observed here that it is the heat that is dynamic, not the metamorphism; for the metamorphism is the same whatever the source of the heat, whether dynamical or statical, except in some minor points due to pressure, as explained beyond.

3. The presence of moisture. - All rocks are permeated by moisture, and this permeating moisture is sufficient for all metamorphic results. The amount ordinarily present is stated on page 205. If $2 \cdot 67$ per cent, which is less than the average, the amount would correspond to two quarts of water for each cubic foot of rock. At one per cent it would be one pound, and, therefore, one pint of water to 100 pounds or two thirds of a cubic foot of rock; and, since a pint contains 29 cubic inches of water, this amount would 
afford, at the ordinary pressure, nearly 45 cubic feet of steam to the cubic foot of rock. There is no doubt, therefore, about enough moisture.

The distribution of heat through the rocks without the aid of moisture is impossible; for heat travels but a short way into dry rock. A thickness of two or: three feet is sufficient to confine nearly all the heat of the nottest furnace, and will make it safe to walk over liquid lavas. But let the walls of the furnace be wet, and the heat will go through with a rush, for the water becomes steam.

4. Pressure. - Pressure, as already stated, is the chief source of the movements by which a large part of the heat for metamorphism was produced. It has caused (1) a foliated structure in slates and other rocks, and (2) minor changes in the texture of rocks. The first of these subjects is treated under mountain-making; the second, on page 321.

In the following remarks, local metamorphism is first considered, and then regional.

\section{Local Metamorphism.}

Local metamorphism, as above explained, makes changes in rocks in the vicinity of the source of heat, as those of the walls of dikes. The results are often called contact-phenomena, and any minerals formed, contact-minerals.

The results of change along the walls of trap dikes in the Triassic areas of eastern North America comprise minerals in the inclosing rock, in the dike, or partly in both. They include crystallizations of epidote, tourmaline, garnet, chlorite, quartz, hematite, and magnetite, besides various zeolites. Garnets occur in the sandstone within a few yards of the trap, and also in rifts in the trap near its walls, and sometimes the latter are yellow topazolites of great beauty. Many square yards of the surface of a joint in the trap of East Rock, at New Haven, Conn., are thickly covered with garnets and crystals of magnetite. At Rocky Hill, N. J., according to H. D. Rogers (1840), the "baking" effects of a trap dike are distinct for a fourth of a mile from the dike; and, fifty feet off, a thin bed contains "kernels of pure epidote," and cavities that are "studded with crystals of tourmaline;" and at one place the latter crystals are half an inch in diameter. The sandstone, when containing these minerals, has generally lost its usual red color and become grayish-white to greenish, the green color coming sometimes from the chlorite or epidote generated by the heat.

The production of the metamorphic results, and the extent of the region affected, has depended chiefly on the presence of moisture for conveying and utilizing the heat. The sandstone walls of a dike may crumble into small chips, because of the want of moisture there at the time of the eruption, while in other places the rock becomes firmly consolidated. The presence of steam is sometimes indicated by remains of the tubular channels through which it rushed, their walls being bleached and penetrated with chlorite; and chlorite may occur, in some places near by, spangled with minute but perfect crystals of hematite. 
A trap dike intersecting the clayey layers, sandstones, and coal-beds of the island of Nobby, near Neweastle, New South Wales, has baked the clayey layers to a flint-like rock to a distance of 200 yards from the dike, the whole length of the island. (D., 1849.)

In the Spanish Peaks region, southeastern Colorado, the injection of igneous rocks across coal-beds has produced, according to R. C. Hills, a dense natural coke or an impure powdery graphite. The outcrop of coke thus made near Trinidad is probably two miles long; and at other places similar outcrops are four to five miles in length.

A region of igneous eruptions is often also, as a consequent or concurrent fact, a region of steaming fissures and of hot springs, conveying the heated moisture widely through the strata of the region; and in this way probably the sand-beds of the Mesozoic formations of eastern America were generally reddened as well as consolidated.

Baking effects, and sometimes crystallizations, have been occasioned by the burning of coal-beds. (See page 266.)

In the Tyrol, near Monzoni and Predazzo, a Peruvian limestone, in the vicinity of masses of igneous rocks, has been crystallized, and near the contacts occur garnet, idocrase, gehlenite, epidote, spinel, mica, anorthite, magnetite, hematite, and apatite. (Dœlter, 1875.) In the White Mountains, near Crawford's, alongside of granite, an argillitic mica schist is much altered and penetrated with crystals of orthoclase and tourmaline. (Hawes, 1881.)

These examples of alteration illustrate not only local but also regional metamorphism, for the minerals formed are among those that figure extensively in metamorphic rocks. Chlorite, garnet, tourmaline, are among the most common of such minerals; and if these and other species can be made under the rather rapid and coarse conditions afforded by the eruption of an igneous rock, the results of slow-working metamorphism should be much more complete.

It is observed, also, that these minerals are made by selecting and combining the needed elements. The iron of the epidote, chlorite, garnet, tourmaline, must be the iron that gives the red color almost everywhere else to the enclosing rock, or is present in occasional grains of magnetite. The tourmaline crystals seem to show that marine waters (or, perhaps, borate springs, made earlier from the ocean's waters) may supply boracic acid which they require. The hematite erystals $\left(\mathrm{Fe}_{2} \mathrm{O}_{3}\right)$ may be derived from disseminated red hematite coloring the rock, or from the oxidation of grains of magnetite $\left(\mathrm{Fe}_{3} \mathrm{O}_{4}\right)$. The quartz crystals were made out of silica taken from the siliceous minerals (feldspar, etc.) that were decomposed by the steam to furnish material for the new crystallizations; and the heat, as far as it reached through the sand-beds, even if of low degree, in the same way made the siliceous solutions that produced the consolidation of the rocks adjoining.

Special metamorphic power is often attributed to granite in the dike-like condition, and the minerals in the rock adjoining are regarded as contact minerals when the granite 
is actually a vein-formation. Granite eruptions have no more metamorphic power over the adjoining rocks than those of trachyte; for granite in the melted state is identical, essentially, with melted quartz trachyte, and conforms to the same principles as regards cooling. The walls of the dike, or mass, will rapidly chill against the cold inclosing rock, and fail of the coarse crystalline texture of granite; and the dike, or mass, will take the coarse texture only under conditions as to thickness of mass that admit of extreme slowness of cooling. The crystallizing of adjoining rocks to any great distance by ejected granite is as improbable as the same by ejected trachyte. The alleged examples of such change in which the walls retain their coarse crystallization but little altered (when at all), and where the metamorphic schists adjoining are supposed to afford an example of what ejected granite can do, are, probably, either examples of cotemporaneous metamorphism, and the contact minerals some of the products made by the process in the transition region between the terranes or strata; or of metamorphism in overlying beds that were upturned and thrust against the preëxisting range of granite, and which became altered or crystalline as a consequence of the friction.

\section{Regional Metamorphism.}

Regional metamorphism is here considered under the following heads :-

(1) Incipient Metamorphism, that of the lower or incipient stages; (2) Crystallinic, or that in which there is simply change in crystallization; (3) Paramorphic, or that of a change in crystalline form and not in composition, as when pyroxene is changed to hormblende, or aragonite to calcite; (4) Metachemic, in which there is change in chemical constitution (also styled metasomatic, which means change in the body of the rock, a general fact under metamorphism); (5) ENDO-CRYSTALLIC, or effects of pressure in modifying the structure of crystals, or in fracturing them. Finally, after considering the metamorphic effects produced in uncrystalline rocks, those occurring in crystalline rocks are described.

The general effects of metamorphism are the following:-

In the lower or incipient stage it discolors, dries, consolidates. In higher stages it crystallizes the constituents of rocks; it often produces also chemical changes, making new minerals in the mass; and, as a result, obliterates fossils. Under the high temperature, which may attend it, all the methods of mineral chemistry in nature have a chance for work according to the conditions. The heat may reach that of fusion, producing effects that cannot be distinguished from those of fusion from heat of other sources.

The obliteration of fossils comes in an early part of the changes; for shells are seldom a twentieth of an inch thick, while the grains rendered crystalline by the change are seldom so small as this. Large crinoid stems have the best chance among calcareous fossils for preservation. But no calcareous fossils can withstand the chemical action of siliceous solutions at high temperatures; for even strata of limestone are thinned down by it. Trilobites, and other fossils whose tests are phosphatic, resist longer than the calcareous.

The uncrystalline rock-materials that undergo regional metamorphism. - It has been stated that fragmental rocks are the chief kinds. But it is to be 
observed that the small differences among the varieties of these rocks, depending on impurities, or on the composition of the grains, have great influence over the results; and so also has the amount of moisture present in the rocks or in cavities among them. Beds of iron ore, or of coal, or of salt, may be in a sandstone series.

If the fragmental rock consists of quartz grains only, metamorphism can make nothing but a harder sandstone, or quartzyte; while, if it consists of grains of quartz and feldspar, it may be converted by metamorphism into a gneiss, or even a granite; or if there is disseminated clayey material, which contains no alkali, it cannot make a micaceous quartzyte, but may make a kind containing the mineral ottrelite, or andalusite.

These examples illustrate the dependence of the metamorphic products on the chemical composition of the ingredients present, and show that speculations on the origin of the minerals, made without a knowledge of the ordinary impurities, are valueless.

The following are some of the results of metamorphism, arranged under the different heads mentioned :-

\section{Incipient Metamorphism.}

These changes generally involve the loss of some volatile or combustible ingredient.

1. A carbonaceous shale or sandstone, when heated, usually loses some mineral gas or oil, the volatile part of the carbonaceous material; and then "the fixed carbon" that is left may be oxidized and so escape as gas (being burnt out), leaving the rock white (if a limestone, a white marble) unless some other source of color is present. If the carbonaceous material is a bed of coal, the volatile part may escape, and the "fixed carbon" remain as a bed of anthracite. As a consequence of the last process, the coal-bed has become thinner, owing to the loss, and is less pure in proportion to its thickness.

2. The water in the rocks is easily volatilized. But under rock-pressure much may be retained at temperatures above $212^{\circ} \mathrm{F}$. That of clays, 14 per cent of which is chemically combined in pure clay, may, under pressure, be retained and help to make, in low-grade metamorphism, hydrous minerals, as chlorite, serpentine, etc. The water of limonite (the yellow-brown iron oxide, $2 \mathrm{Fe}_{2} \mathrm{O}_{3}+3 \mathrm{H}_{2} \mathrm{O}$ ) is driven off at $212^{\circ}$, reducing it to hematite (the red oxide, $\mathrm{Fe}_{2} \mathrm{O}_{3}$ ) and in this way common sandstones of yellowish, grayish, greenish, brownish, and other colors (generally due to disseminated limonite) become red. Most colored sandstones redden on heating, and in this way many sandstones have been made red. But at a higher temperature under low rock pressure, the red oxide coloring a red sandstone may be converted into steellustered crystals; or become reduced to magnetite $\left(\mathrm{Fe}_{3} \mathrm{O}_{4}\right)$; or combine with silica to make silicates (epidote, chlorite, etc.) and by such means the red color may be discharged. 
3. The carbonic acid of limestones is driven off at a low temperature, as in limekilns. But under heavy rock-pressure the loss does not take place; for limestone may be melted in a strong iron flask without decomposition, as shown by Sir James Hall (1790). Again, when iron carbonate $\left(\mathrm{FeO} . \mathrm{CO}_{2}\right)$ is present in a sandstone, heat may expel the carbonic acid $\left(\mathrm{CO}_{2}\right)$ and leave the iron to oxidize and become the red oxide $\left(\mathrm{Fe}_{2} \mathrm{O}_{3}\right)$. This is a second source of the red color of red sandstones and shales. But under pressure the ore may be crystallized without loss.

4. Consolidation of rocks also goes forward in the feebler stages of metamorphism. Subjection to heavy superincumbent pressure forces the particles into closer contact, and this favors consolidation in clays (W. Spring). The consolidation in the case of ordinary shales, even Silurian, as the Utica shale, is feeble, unless some metamorphic heat has given aid.

\section{Crystallinic Metamorphism.}

Calcyte $\left(\mathrm{CaO} . \mathrm{CO}_{2}\right)$, or dolomyte, magnesian limestone, if pure, becomes under metamorphic action a white crystalline rock, like architectural or statuary marble, in which state, as the naked eye may detect, each grain has the cleavage of crystallized calcite or dolomite. The process is simply that of crystallization. It is a change without fusion. It is a molecular change solely, like the change which takes place in tempering steel from fine to coarse, or the reverse.

Again, under slow metamorphic action, a granitic sandstone, consisting of quartz, feldspar, and mica (the constituents of granite), loses the worn surfaces of the grains and becomes a granite. The sandstone being a massive rock, it is massive still - a true granite, and not gneiss. A sandstone, consisting of feldspar and quartz, without the mica, becomes the granite-like rock called granulyte. Such sandstones make up the Triassic of the Connecticut Valley,

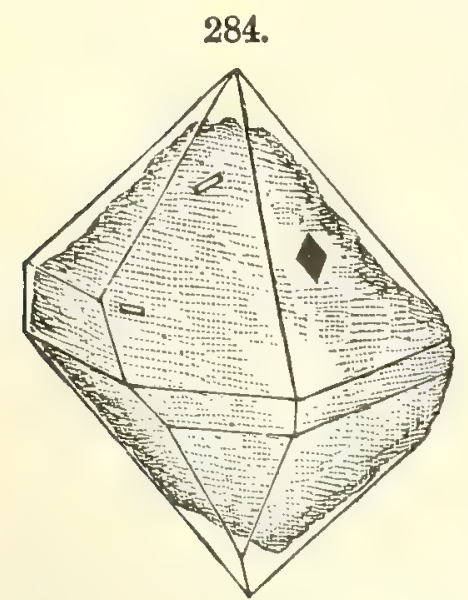

Grain of quartz of Potsdam sandstone, Wisconsin, enlarged into a crystal. A. A. Young, '82. and some portions, well consolidated, look exceedingly like granite, although they have not been subjected to the heat and pressure of the true metamorphic process. The following analysis, by F. W. Taylor, of the Connecticut rock, from Portland, - the common building stone, - shows its granite-like composition (see 10th Census, Vol. 10, Rep. on Building Stones, page 127): silica 69.94, alumina $13 \cdot 55, \mathrm{Fe}_{2} \mathrm{O}_{3} 2 \cdot 48, \mathrm{Mn}_{2} \mathrm{O}_{3} 0 \cdot 70$, lime $3 \cdot 09$, soda $5 \cdot 43$, potash $3 \cdot 30$, moisture $1 \cdot 01=99 \cdot 50$. If the granitic sandstone were thin-bedded it might become gneiss; and a shale might make a mica schist of like composition. Moreover, in the intenser stage of metamorphism a bedded granitic sandstone, instead of being changed to gneiss might become plastic or fused, and so lose all bedding and become granite. Such 
granite is igneous granite, and if it is forced up opened fissures, it is eruptive granite.

Metamorphism in the above cases is simply erystallization, so far as there is any change; for chemical change is not needed for the results mentioned. But in many cases it is even simpler than stated; for in the process the grains of feldspar and quartz may be only enlarged or finished out by surface additions, in a crystalline way, conformubly to their crystallographic axes. In a quartz sandstone, the quartz grains, under the process, are made into quartz crystals (Fig. 284) if there is space for it (Sorby); and they may continue growing until the sandstone becomes a compact mass of quartz rock (or quartzyte) showing its original grains only indistinctly. In a similar way, the feldspar grains present in a rock, and any hornblende or pyroxene grains, may be enlarged or finished out. This process would convert a granitic sandstone into granite, making the rock without the heat of fusion or plasticity. In California Cretaceous sandstones, according to Becker, the feldspar crystals made by metamorphic change occupy the positions of previous groups of grains of feldspar; and the same for pyroxene and hornblende.

A granitic sandstone having its quartz grains changed to quartz erystals, in a process of metamorphism, becomes thus a quartz-porphyry. As quartz crystals are usually formed from siliceous solutions instead of from fusion, the occurrence of such imbedded crystals through the mass of a rock is presumptive evidence against its igneous origin.

\section{Paramorphic Metamorphism.}

When the minerals aragonite and calcite are present together in a limestone (page 69), the first effect of metamorphic action is the conversion of the aragonite into calcite - that is, the making it rhombohedral in cleavage structure, like calcite, its paramorph. Crystallinic metamorphism, also, may go forward simultaneously and make the rock coarsely crystalline. The change of pyroxene crystals to hornblende is a common example of paramorphic change. It has often gone on extensively, changing whole pyroxenic rocks to hornblendic. The inner part of a crystalline grain of pyroxene often has its lines of cleavage crossing at angles of $87^{\circ}$, the angle of pyroxene, when in the outer, the part altered, they are changed to $124 \frac{1}{2}^{\circ}$, the angle of hornblende. The altered pyroxene was named uralite (from the Urals) by G. Rose (1830), and the change is hence called uralitization. Many Archæan crystalline rocks now hornblendic have been proved, by such evidence, to have been originally pyroxenic; and so it is with many other rocks, including some of igneous origin. Even the pyroxene of dikes of doleryte has been found changed to hornblende.

This change in a rock of the basalt type (the doleryte of Land's End, Cornwall) was first observed by Allport (1876); in augite-syenyte of New Hampshire, by S. W. Hawes (1878); in Wisconsin Archæan rocks, by Irving and Van Hise (1883). The mineral hy- 
persthene also occurs altered to hormblende; cyanite to andalusite ; labradorite and anorthite to saussurite. Quartz changes to tridymite, or to biaxial silica, when it is heated to or above $2200^{\circ} \mathrm{F}$., which accounts for the occurrence of tridy mite in volcanic rocks ; and tridymite, or biaxial silica, becomes uniaxial optically at $260^{\circ} \mathrm{F}$.; but further than this it does not change on heating.

Pyroxene, a common volcanic mineral, has long been known as a furnace product, and since 1823 as the result of the fusion of its constituents; but Deville, in 1858, obtained crystals by simply heating to a bright red heat a piece of ferruginous Fontainebleau sandstone with chloride of magnesium; the crystals of pyroxene cemented the quartz grains of the sandstone. Hornblende has never been produced experimentally from fusion; but in 1890 the Russian chemist, Krustchoff, heated together its constituents for three months, at a temperature of only $900^{\circ}$ to $1000^{\circ} \mathrm{F}$, and obtained hornblende in crystals; and along with them were crystals of quartz and of a light-colored pyroxene (diopside). The facts show that the change of pyroxene to hornblende requires only a heating of the rock containing it to $1000^{\circ} \mathrm{F}$. It indicates also that if a pyroxene-bearing rock, on cooling from fusion, rests long at this temperature, it would probably become throughout a hornblende rock, and appear as if so primarily.

Paramorphic metamorphism should be of common occurrence; for paramorphs are essentially identical except in crystallizations (pages $62,67,69$ ).

\section{Metachemic Metamorphism.}

Through the chemical work of metamorphism have been made nearly all the common siliceous minerals among rock constituents, even many kinds that are also of igneous origin: as the feldspars, micas, quartz, minerals of the hornblende and pyroxene group, the chlorites, epidote and the related species, scapolites, garnets, tourmaline, chrysolite, and many others. The older metamorphic and igneous rocks have been the chief sources of the materials. Even in formations not older than the Cretaceous, as described in Becker's account of the rocks of California, the results of metamorphism include orthoclase, albite, oligoclase, labradorite, muscovite, biotite, hornblende, pyroxene, glaucophane, epidote, zoisite, garnet, chlorite, serpentine, talc, and other species.

In these metachemic changes, without aid from outside ingredients, feldspar may be altered to hydromica, or mica (muscovite), under metamorphic action (Van Hise). Each of these minerals contains silica, alumina, and potash, but the mica, a third less of silica; hence a feldspathic or granitic sandstone may be made micaceous, and a feldspathic shale may be converted into a hydromica or mica schist. Hydromica schist is a common rock in the regions of crystalline rocks of eastern North America, and in other such regions over the globe; and feldspathic sediments, derived from the abundant feldspar of these rocks, are their only source. For mica seales float easily in transporting waters and become scattered among other materials instead of being gathered together into beds. A felsyte may change to pinite, as near Boston (Crosby), which mineral is essentially a massive mica.

But if the shale is an argillaceous rock without potash (no undecomposed feldspar being present) it is very likely to contain more or less iron, magnesia, and lime; and then it has the elements required for making a 
chlorite schist or a hornblende schist, and for flling such schists with crystals of the silicates, hornblende, pyroxene, garnet, staurolite, ottrelite; or if free from iron, it has the elements for making andalusite, sillimanite, cyanite (each $\mathrm{Al}_{2} \mathrm{O}_{3} \mathrm{SiO}_{2}$ ), silica and alumina, when no alkali or other bases are free, being ready to form these aluminum silicates.

Increasing remoteness from a region of crystalline rocks favors the making of sediments free from alkali, because the alkali becomes leached out of sediments by the transporting waters. This is illustrated a few miles west of New Haven, Conn., where the mica schist gradually changes to the southward, to a chloritic hornblende schist, - hornblende and chlorite, unlike the mica, containing no potash.

When carbonaceous shales are altered to mica schist, the "fixed carbon" present (page 315) may become crystallized into graphite; for graphitic mica schists are common. It has been suspected that diamonds, another form of carbon, may have been made in the course of the metamorphic changes of carbonaceous shales or sandstones.

Again, if a dolomyte, or magnesian limestone, contains some silica finely disseminated through it as impurity, either in the state of quartz or of organic silica (Diatoms, spicules of Sponges), metamorphic action may, while crystallizing the limestone, fill it with bladed or radiating crystallizations of tremolite (white hornblende) ; for a portion of the dolomite $\left(\frac{1}{2} \mathrm{Ca} \frac{1}{2} \mathrm{MgO} . \mathrm{CO}_{2}\right.$ ) might take the silica $\left(\mathrm{SiO}_{2}\right)$ as a substitute for its carbonic acid $\left(\mathrm{CO}_{2}\right)$, and thus tremolite $\left(\frac{1}{2} \mathrm{Ca} \frac{1}{2} \mathrm{MgO}\right.$. SiO $\left.\mathrm{Si}_{2}\right)$ would result. When the dolomyte contains some iron, as well as the silica, actinolite (green hornblende) may form and in like manner be disseminated through the mass of the rock, instead of tremolite. Under similar circumstances, at a higher temperature, white pyroxene which has the same composition as tremolite, or green pyroxene, which has the composition of actinolite, may be formed in stouter crystallizations.

If clayey impurities are present in the limestone (these consisting of silica and alumina, with or without iron or magnesia), the limestone may become filled with garnets and other silicates. An Eocene limestone, in the Ligurian Apennines, much contorted and in contact with diabase, gabbro, etc., contains crystals of the soda-feldspar albite; and inside of the crystals there are the siliceous tests of Radiolarians (genera Ethmosphæra, Heliosphæra, and others), suggesting that possibly the silica of the albite was of organic origin. (A. Issel, 1890.)

Chrysolite consists of silica $41 \cdot 4$, magnesia $50 \cdot 9$, iron protoxide $7 \cdot 7$. In the rocks it is often found changed to serpentine, which consists, in 100 parts, of silica $43 \cdot 5$, magnesia $43 \cdot 5$, water 13 . The iron protoxide and some magnesia are here rejected and water received; and usually the iron stays about or within the serpentine, as a cloud of black grains or a few black crystals of magnetite. So, also, the magnesian silicates, pyroxene, hornblende, chondrodite, chlorite, and other species, occur changed to serpentine. When such a change happens on a large scale, a chrysolite rock, or pyroxenic rock, or hornblendic rock, etc., becomes, in part or wholly, a serpentine rock. In a similar way, pyroxene, or hornblende, or garnet, may be changed to chlorite, or to epidote, etc., labradorite, or anorthite $(G=2 \cdot 7)$ to saussurite $(G=3-3 \cdot 5)$.

The pure amorphous serpentine often has parallel cracks (apparently due to contraction on drying), which are filled with fibrous serpentine (amianthus, or asbestos); and when the cracks are very thin and numerous, and are filled with calcite or dolomite, the specimens often have the aspect and general structure of the so-called Eozoon of Archæan rocks. 
Again, dikes of trap and other igneous rocks have undergone metachemic alteration through interior heated vapors which ascended with the rock, making the rock hydrous and producing other changes, and by the same means its vesicles have often been filled with secondary minerals made out of the materials of the rock.

Mineral springs are often referred to as a source of outside ingredients. But, for regional work, such springs should have a wide distribution; otherwise the effects would be local. One mineral spring, rich in salts of soda and magnesia, has already been mentioned as the great one of the world the ocean. Nearly all the sedimentary rocks were made in it, or have at some time been submerged in it. Moreover, there is evidence that salt water has an extensive subterranean distribution, in the fact that a large part of the borings for gas and oil, which have been made in recent years, have encountered salt water below depths of 1000 or 2000 feet - depths too great to be made fresh by subterranean drainage. Further, formations of several geological periods contain great beds of rock salt that were beyond doubt of oceanic origin.

Associated with the salt, or in the same series of rocks, there are sometimes deposits of magnesian salts of like oceanic origin; and, more sparingly, of potash salts; and also of boron salts, for the magnesium borate, boracite, occurs in salt mines, and other boron salts exist in hot springs, sometimes in volcanic emanations, - facts that point to a marine source. Moreover, traces of borates have been detected in the ocean's waters. The beds of salt and the briny layers are interstratified, sometimes in many alternations, with shales, sandstones, and limestones; and it is natural, therefore, that the soda and magnesia should be forced to take part in any chemical changes the associated formations might undergo. Metamorphic work may have derived much soda from this source for making soda-lime feldspars, as oligocluse and labradorite; supplies of magnesia for forming hornblende and black mica; smaller supplies of potash for orthoclase-making; and still smaller of boron, yet enough to account for the wide distribution of tourmaline, whose constituents, apart from the boron, differ little from those of garnet, - a mineral that is common in mica and chlorite schists, crystalline limestone, quartzyte, and other rocks.

The wide distribution of alkaline waters over the Great Basin (page 119) suggests another available source of materials, and especially of soda and magnesia. But such regions are a consequence of the absence of drainage, and could exist only in great lands like continents; they, therefore, belong only to the latter end of geological time.

The following are examples of metachemic work in crystalline rocks. Massive talc, called rensselaerite, at Fowler, Dekalb, and other places in northern New York, made from pyroxene, whose cleavage it has ; a pinite, called gieseckite, at Diana, N. Y., and in Greenland, made from crystals of nephelite, the form remaining; pinite also from scapolite, at Franklin, N. J. (algerite) and Arendal, Norway; chlorite in many localities, from garnet (crystals being sometimes chlorite outside only, and sometimes throughout), pyroxene, hornblende, etc.; mica and epidote from scapolite, at Arendal, Norway; and feldspar from scapolite, at Bamle, Norway; epidote from biotite-mica; diaspore, margarite, and other species, from corundum. In a large granitic vein at Branchville, 
Conn., where spodumene crystals occur a yard long, the alteration of the spodumene, a lithia-alumina bisilicate, has produced (as described and explained by G. J. Brush and E. S. Dana, 1878-1880) eucryptite, a different lithia-alumina silicate ; also microcline or potash feldspar, muscovite mica, killinite, which are potash-bearing silicates, free of lithia ; also the soda feldspar, albite, each, excepting killinite, in large crystallizations. Besides, it is evident that the mica and albite were unitedly results of change from the spodumene (the mica, through the eucryptite as a first step), since they occur in minute scales together, making half an inch or more of the outside of the spodumene crystals, the material looking so much like a single simple mineral that it was first (1867) named as such, cymatolite. In addition to these changes, half a dozen phosphates were made out of triphylite (an iron-manganese phosphate), part by combination with the lithia and other bases set free from the alteration of the spodumene; also uranium minerals were made from uraninite.

In mineral veins a still wider range of changes has taken place, through the metallic and other vapors that have ascended the opened fissures and the waters that have descended.

Since most erystalline metamorphic rocks are only recrystallizations of the detritus from such rocks, the feldspar and quartz being earlier feldspar and quartz, and so with many other minerals, and since the ocean's waters have distributed its salts among the formations, it is not necessary to appeal for producing silicates to "springs bringing up mineral waters from below." There is no place in geology for the crenitic hypothesis of Hunt (1884), so named from the Greek for a fountain or spring.

\section{Endo-Crystallic Metamorphism.}

In crystallized limestones, either calcyte or dolomyte, the crystalline grains have commonly a compound twin-structure, which is attributed to the pressure among the grains attending the original crystallization. Another effect of pressure is the breaking and displacement of crystals in rocks.

Professor J. W. Judd and others have drawn especial attention to the changes that have taken place within the crystalline grains of rock through pressure, without aid from rock-movements as a source of heat, endeavoring to distinguish them as far as possible from metamorphic work of other kinds. Like the compound twinning in the grains of crystalline limestone, the lamellar twinning in a triclinic feldspar, including microcline, is referred to stresses attending crystallization.

To the same cause are to be attributed the bronzy luster developed by incipient change in pyroxene and hypersthene, arising from the production interiorly of minute points of mineral material in parallel planes - an effect called by Judd schillerization - and its usual accompaniment, a laminated or diallage-like structure. Of similar origin are changes in orthoclase, giving its crystals an aventurine or iridescent character, or a new direction of cleavage, as in the variety murchisonite, or interlaminations of albite or of some other feldspar, as in perthite. Related changes occur also in other species.

\section{Heat used in Metamorphism.}

The heat for most metamorphic results was probably comparatively low, or between $500^{\circ} \mathrm{F}$. and $1200^{\circ} \mathrm{F}$. It was heat in slow and prolonged action, operating through a period that is long, even according to geological measure. DANA'S MANUAL -21 
A low temperature, acting gradually, during an indefinite age - such as geology proves to have been required for many of the great changes in the earth's history - would produce results that could not be otherwise brought about, even through greater heat.

The lower limit of temperature is sometimes placed much below $300^{\circ} \mathrm{F}$.; and for consolidation it may be rightly so. But there is definite evidence that it generally exceeded this. In the great faults of the Appalachians, 10,000 feet or more in extent, Lower Silurian limestones are brought up to view, containing their fossils, and not metamorphic; and in Nova Scotia the coal formation, though 15,000 feet thick, is not metamorphic at base. Taking the increase of temperature in the earth's crust at $1^{\circ} \mathrm{F}$. for 60 feet of descent, 10,000 feet of depth would give $220^{\circ} \mathrm{F}$. as the temperature of the limestone before the faulting; and $1^{\circ} \mathrm{F}$. per 60 feet of descent must be short of the rate that obtained in the Carboniferous age.

Regional metamorphic rocks are upturned rocks, rocks that have been subjected to the faulting, crushing, and flexing, attending mountain-making. Hence, in accordance with the explanations on page 385, they are rocks which have been subjected to pressure and movement on a vast scale, and thereby to heat made just where it was needed for metamorphic work. Mountain-making movements might be so slow that the heat would become mostly dissipated instead of aceumulating. But the rocks upturned were generally 10,000 to 30,000 feet thick or more, and great pressure and high temperatures should be expected from movements so vast over regions exceeding sometimes a thousand miles in length.

The heat for metamorphism appealed to is heat of a dynamical source, and the conditions are those that will produce its maximum effects.

The movement of rocks along fracture-planes in faulting produces heat; but only occasionally, in connection with the greater upthrust or onthrust faultings, is it sufficient, unless reinforced from accompanying upturnings, for metamorphic action in the walls of the fracture. The changes will seldom, if ever, extend so far as to obliterate the plane of faulting, or to disguise the fact that the heat has a local source along this plane, provided the faulting is not attended with extensive crushing of the adjoining rock. As such a fracturing of the rocks is commonly of the shearing kind, the altered band along the fault-plane is called a shear-zone.

The earth's internal heat has always been a contributor to the heat of the earth's crust, and much more so formerly than now, and would, therefore, have supplemented largely the heat generated by friction. But the alteration of sediments by the heat coming up from the earth's interior alone is proved by many facts to have been inadequate for much more, even during the later Paleozoic, than the solidification of the rocks. Besides. those mentioned above, it may be added that in the South Wales coal-field the Carboniferous limestone, although covered by other rocks to a depth of 10,000 to 12,000 feet, is unaltered. (Geikie.)

The great agent of metamorphic change is heated moisture; and for the 
higher grades of metamorphism, moisture at a temperature that made it superheated steam. In the state of steam it spreads through the rocks with all the chemical energy derived from its high temperature, a destroyer of cohesion, a powerful solvent, and a promoter of decompositions preparatory to recompositions.

The making of deposits of silica in the form of quartz or opal does not require high heat, as already explained (page 135). In addition to the facts there stated, it may be added that geodes of chalcedony and agate, 8 to 10 inches in diameter and of modern origin, come from Florida, that are the remains of hemispherical masses of coral, the exterior still showing the stars of coral, while the interior is a great agate-lined cavity; they were made by the siliceous waters of the region, and it is not certain that the waters were even warm. J. Arthur Phillips found crystallized quartz and chalcedony among the recent deposits of Borax Lake, in Lake County, north of San Francisco, and at Steamboat Springs, in Nevada; and Le Conte and Becker have reported other similar facts. Daubrée detected quartz in the form of chalcedony among the deposits of the hot waters of Plombières. It should be considered, further, that the quartz which makes the flint and chert of the world, and has silicified the fossils of many strata, was dissolved by cold waters; it was mostly in the opal state when dissolved, but was deposited in the state of quartz. Thus the solidification of rocks by means of silica is an easy effect in the presence of hot moisture, and but little heat is necessary.

Many experiments of recent years illustrate the efficiency of superheated steam in confined spaces or under pressure. Mr. J. Jeffrys, in 1840, subjected some feldspathic and other siliceous minerals to a current of steam inside of a kiln made for vitrifying brown stone-ware, and with them a few articles of the stone-ware. At a full red heat, little effect was produced; but above that of fused cast iron, there was rapid erosion, and in ten hours "more than a hundredweight of mineral matter had been carried away in the vapors." Daubrée, having inclosed a little water in a strong glass tube and subjected it to a temperature of $750^{\circ} \mathrm{F}$. $\left(400^{\circ} \mathrm{C}\right.$.) for several weeks, obtained, besides a hydrated silicate allied to the zeolites, quartz in welldefined crystals, and, in another case, perfect crystals of the light-colored variety of pyroxene, called diopside. The glass was completely dissolved and used in making the crystals. A clay, from near Cologne, used in making crucibles, heated in the glass tubes, became charged with scales of a mica or chlorite (the quantity being too small for an analysis). Crystals of the feldspar, orthoclase, occur in the cavities of some igneous rocks in the copper region of Lake Superior as a secondary product, and the accompanying facts make it certain that it was made by means of heated moisture. But experiments in closed tubes containing the ingredients and water have succeeded in making orthoclase and albite, with also tridymite (Hautefeuille, Friedel and Sarrasin), while dry heat has always proved a failure. Experiment has been successful in obtaining, by fusion, the feldspars, oligoclase, labradorite, and anorthite, and also the rocks containing them. 
The lime-soda feldspars, labradorite and oligoclase, and the lime feldspar, anorthite, were obtained in crystals, from the fusion together of their constituents, by Fouqué and Lévy in 1878.

Two days of fusion only were required for labradorite. They have also produced by similar methods the rocks augite-andesyte, doleryte, basalt, and others. The augiteandesyte was made by fusing together 3 parts of oligoclase and 1 of augite, and it contained octahedrons of magnetite formed at the expense of part of the augite. Doleryte was obtained in like manner by substituting labradorite for oligoclase. Such experiments prove that these rocks may be made from the constituents by metamorphic methods, if the heat is sufficient for fusion; and other facts leave scarcely a doubt that they may be formed also at lower metamorphic temperatures.

Hawaiian caves, made by the flowing away of the lava after it was crusted over, and hot with the heat that was left by the lavas, contain long stalactites of basalt, with isolated crystals of the feldspar, pyroxene, and magnetite, in their cavities, as explained on page 295. In this case, there was no decomposition and recomposition, but simply solution, transfer, and recrystallization. The heat was that left by the passing lava; for there was no other possible source; and it was less than that of fusion, for much had been lost by the expansion of the superheated vapor as it escaped. The vapors would have contained sulphur, or sulphurous acid, and perhaps other ingredients, but beyond increasing solvent powers, if this, these aids had nothing to do.

These facts are eminently instructive as to the powers of superheated steam. It can do transfer work, take up labradorite, pyroxene, and magnetite at one place, and transfer and deposit them crystallized in another. The facts above stated also prove that superheated steam, at a high temperature, may produce that plastic state of a rock, which is like fusion in any other way in its ability to obliterate all previous structural features, and which, therefore, could make granite out of materials that otherwise would have the bedding of a gneiss.

At Birmingham, Conn., 10 miles west of New Haven, the porphyritic gneiss of the region comes up, in one place, through the gneiss and mica schist, as a broad and nearly vertical vein, or dike, of porphyritic granite - a rock like the bedded gneiss, except in the absence of bedding, and in its vein-like position. It is plainly a result of the plastic condition of the rock in the vicinity of a fracture. In cases of veins of fine-grained granite, it is always a question to be considered whether it is not the plastic granite of a region of metamorphism rather than vein-made granite, or that of eruption from a deep-seated source. Vein granite is usually coarsely crystalline, and consequently irregular in its grain. If the granite of a narrow dike, or vein, intersecting any rock is crystalline granular to its wall, the evidence is conclusive that the inclosing rock was hot, and it is almost certain that the conditions when it was formed were those of metamorphism.

Further, the pressure which is so enormous in some cases of mountainmaking, increases the solvent power of hot moisture, and promotes the welding of grains by the closeness of the contact.

Variations in degree of heat and amount of moisture. - The metamorphic effects in a region are greatly varied by differences in temperature, and in amount of moisture. The region has necessarily its area of maximum heat, 
and large upturning, and its border of lower heat; for it is surrounded by regions of little or no heat. 'There will be, therefore, gradation in effects in one direction or another.

But it is to be noted that the heat generated in metamorphic regions by the movements does not vary with the variations in dip of the several successive plications, but with the general character of the great range of flexures and their relation to the direction of the chief source of the movements. The cause is regional in its action, not local. The successive flexures may vary from vertical anticlines and synclines to those of very low angle, having nearly horizontal bedding for a mile or more along the axial part of the plications; and yet the gueiss or mica schist of the beds shows no corresponding change in texture. This fact is well illustrated in the Taconic Range, and in the crystalline region along the Housatonic River east of Derby, Conn.

Where the heat is of low grade, the moisture present may partly remain as a constituent of the new rocks; but under intenser conditions, only anhydrous kinds will be made. A penumbra of hydromica and chlorite schists, with coarse mica schists and gneiss making the hotter belt beyond, is, therefore, to be looked for.

Going from New Haven, Conn., 20 miles westward, where the rocks make a single conformable series in anticlines and synclines, there is a regular gradation from chloritic and hydromica schists, with gray slightly crystalline limestone, to mica schists and gneiss, and coarsely porphyritic gneiss; and at 17 miles, the gneiss and mica schist overlie a stratum of coarsely crystallized limestone in a very low and long syncline. In a similar manner, the Taconic metamorphic region on the borders of New England and New York, as already explained, increases in grade of metamorphism, both from north to south and from west to east.

Again, the Bernardston Devonian rocks, of one epoch of metamorphism, mentioned on page 310, bear on this point; and so do the facts from California, that in the altered Cretaceous series the rocks, diabase, dioryte, gabbro occur as results of metamorphism, and that the feldspars, labradorite, and oligoclase, are found even in half-altered sandstone. (Becker, 1888.) It is thus plain that among metamorphic rocks, as well as those of deepseated igneous origin, kind of rock and grade of crystallization are not evidence of differences in geological age.

In some cases the bedding of rocks has been obliterated by metamorphic action, without their reaching the condition of plasticity, in consequence of a tendency to promiscuous crystallization in the grains of the constituent minerals. This is true, for the most part, of rocks consisting of hornblende alone (hornblendyte), hornblende and a feldspar (dioryte, labradioryte), feldspar (felsyte), feldspar and quartz (granulyte or mica-less granite, quartz-felsyte), serpentine, and some others.

A bedded structure may also be obliterated by the soldering together of layers, when the rock is subjected to heavy pressure, and all evidence of it may disappear, unless the layers differ in color or constitution; as has happened in a portion of the marble of Rutland, Vt., and in other cases, 
where a pure limestone is upturned at a high angle, - this position being evidence of its subjection at some time to heavy pressure.

The heat for the changes in granitic veins, like the Branchville, may have been produced by friction from an up or down movement along the vein; and the same is probably true for the bed of iron ore at Brewster, in eastern New York; for veins, and also ore-beds when they are nearly vertical, are planes of weakness. But whether the movement occurred at the epoch of mountain-making at the close of the Lower Silurian, or at some other similar epoch, is unknown.

Relations of metamorphic and igneous rocks. - The earth's interior source of heat has had much to do in geological history with metamorphism as well as with igneous ejections. The depth to the region beneath the earth's surface having a temperature near the fusing point of the rocks has increased with the progress of the geological eras; the amount of metamorphism has correspondingly decreased through the ages.

In early Archæan time the region of fusion was at the surface, and in the later part, before solidification was complete, it was not far below the surface. Great stratified formations had then already been made $-30,000$ feet in thickness at least, and some have said twice this, or more. A temperature close to that of fusion may then have been within this pile of deposits (page 258, paragraph $c$ ), so that but little addition to the heat from subterranean movements would have produced not only ordinary metamorphic effects, but also fusion of portions of the sediments, making granite, gabbro, and other igneous rocks.

Metamorphic work was extensively carried on at the close of the Lower Silurian in eastern North America, and igneous rocks were among the metamorphic results; it was much less extensive at the close of Paleozoic time, and later than this it is not known to have occurred. In western North America, in California, however, the results of heat were large even in the later part of Mesozoic time. We may account for this difference between the two sides of the continent, perhaps, by the fact that the Pacific border had already become a region of extensive volcanic action, - evidence that the depth to great heat was unusually small.

On the contrary, volcanic action has increased through the ages. There is no good reason for believing that there was much volcanic or deep-seated igneous action in Archæan time. The earth had then its granites, its gabbros, its syenytes, and other igneous rocks; but no petrological study can show whether the fusion was among the results of metamorphic action or not.

In this connection it is an instructive fact that in eastern North America, at epochs when there was the greatest amount of friction and crushing, those of the making of the Green Mountains and Appalachians, - no volcanoes were made, and little took piace in the way of eruptions through fissures; the conditions were largely those of the past. But at an epoch in Mesozoic time, when there was almost no Alexing of the rocks, and only low monoclinal uphitts, extensive dolerytic eruptions occurred at intervals for 1000 miles along the Atlantic border. 
The determination of the depth of an igneous source is possible, if at all, only by geological investigation. Petrology can prove a rock to be igneous and eruptive; but it cannot, except in some obvious volcanic cases, prove that it is not, at the same time, metamorphic.

The statement that "massive crystalline rocks are igneous" expresses nothing as to their metamorphism, and especially when it relates to the older crystalline rocks of the globe; and the occurrence of a deposit of hematite or magnetite in gabbro, syenyte, or any related rock, is nothing against the origin of the magnetite as a metamorphic sediment. The igneous granite of metamorphic origin often contains masses and strips of schists, from a few inches to many rods in length, which are pieces broken from the associated schistose formations, in the course of the upturning and metamorphism. Such "inclusions" do not occur in igneous rocks of other modes of origin; the ejections along fractures or vents break off pieces, sometimes 1000 cubic feet in size; but long strips of schist show that the schistose beds were part of the formation that became generally plastic or fused.

The production of metamorphic change by mechanical force without heat has been proved by the experiments of M. Carey Lea on salts of silver ( $\mathrm{Am}$. Jour. Sc., 1893, A. Harker, Geol. Mag., June, 1894). Shearing force, or trituration, produces, without the development of heat, a change which heat will not produce, and more effectively than simple pressure.

\section{MINERAL VEINS, LODES, LOCAL ORE DEPOSITS.}

Veins occur in rocks of all ages and of all kinds. They are the fillings of fissures or of open spaces made in any way - exclusive of those called dikes, which are due to intrusions of melted rock. The materials are usually crystalline; and among the kinds are included a large part of the stony minerals and gems of the world as well as most of its ores, those of iron excepted.

\section{Fissures, Forms of Veins.}

\section{A Brief Review of the Way of Making Fissures.}

Fissures for vein-making have been produced:-

(1) By contraction on drying : examples of which are mud-cracks (for the fillings of mud-cracks are vein-like in formation); the cracks in many limestone coneretions (page 97); the cracks in an argillaceous stratum or in its more argillaceous layers, which are limited to the layer.

(2) By contraction on cooling: either cooling from fusion, as in igneous rocks, or cooling from the heat attending metamorphism.

(3) By subterranean movements: to some extent the lighter movements following underminings and ordinary earthquakes, but preëminently the movements, light and heavy, that have attended mountain-making; movements that flexed strata 10,000 to 30,000 feet or more thick, over regions often hundreds of thousands of miles in area, sometimes raising the rocks to verticality, or shoving up the strata along fractures for miles, besides naking fissures and opened spaces in all parts of the disturbed formations. 
(4) By the disruptive or expansive action of vapors: as of vapors attending volcanic action; resulting not only in fissures, but also in vesicles or cavities in an ejected igneous rock, or along the walls of the dikes.

(5) Corroding vapors or solutions rising in a fissure have sometimes enlarged the fissure in some parts or made open spaces, especially when the rock was a limestone; thus large chambers have been excavated in this yielding rock for the reception of minerals and ores.

(6) Porous strata have taken in vein-material in proportion to their porosity.

(7) Caverns, however made, have become occupied with vein-material.

\section{Forms and Kinds of Fissures.}

Fissures intersect strata vertically or obliquely or make a network. The angle which the plane of a vein makes with the vertical is called the hade of the vein; the hanging wall is the upper wall in an oblique vein, and the opposite is the foot wall.

287.

285.

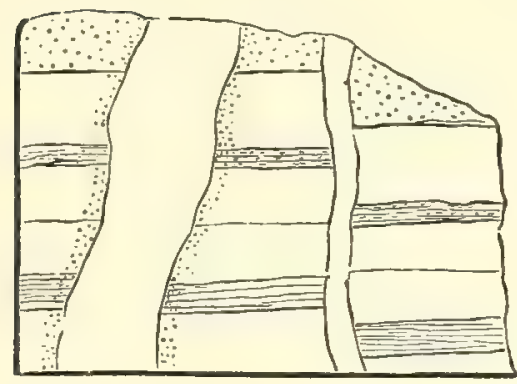

286.

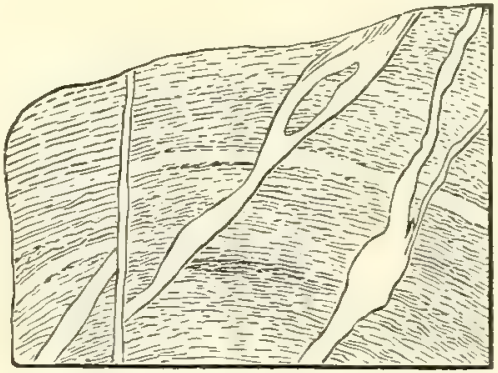

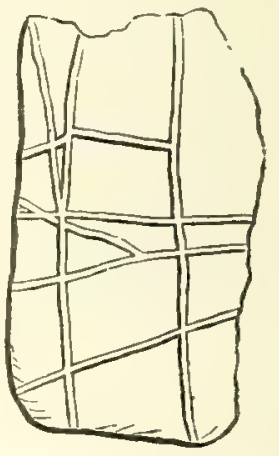

VEINs. - Fig. 235, two simple veins; 286, two veins, one faulted; 287, a network of quartz veins intersecting schist, the slab 5 feet square.

In the case of upturned rocks, veins may either cut across the beds, or occupy spaces between them. Such interstitial veins (Figs. 287, 288, 290) are very common in slaty and schistose rocks, because forces below can more easily open such spaces than make fractures across the beds; for it is fol-

288.

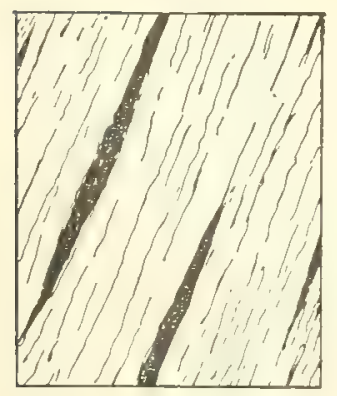

289.

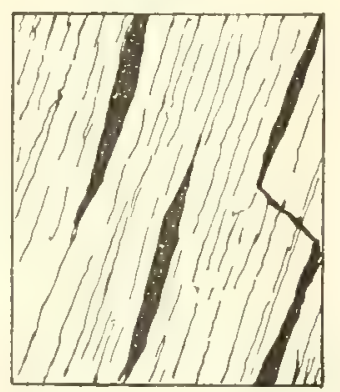

290.

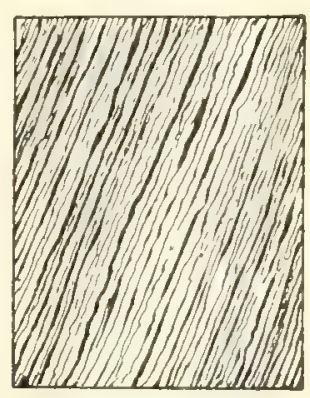

291.

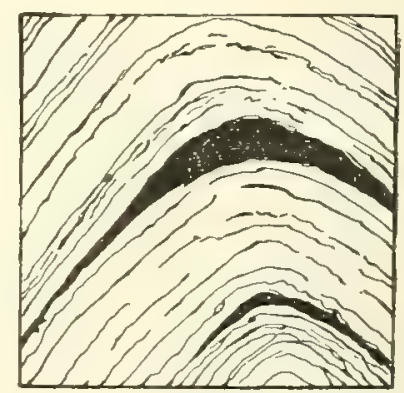

Interstitial veins.

lowing the grain of the rock. Such an opened space may continue for some distance between the bedding, and then cut across to another plane of bedding, and so on, the mean direction being that which the space would have 
followed under the pressure in action, if the rock had had no grain. Or there may have been many spaces opened by tension between the bedding without connections across. Again, the spaces may be simply the thin openings between the laminæ or leaves of a fine-grained schist or slate, of almost paper-like thinness (Fig. 290), like the spaces between the leaves in a folded quire of paper, so that the veins (which are usually of quartz) look like delicate interlaminations of the slate. Moreover, under an oblique warping of the beds by the fissure-making pressure, various irregularities are made in the opened spaces.

The process fills the opened spaces, and makes the shattered rock again solid, even when it is broken to fragments that lie touching at angles instead of being simply fissured. An example (from Cornwall, Eng.) is shown in Fig. 292, in which granite extends in veins into slate. Such cases are common; and not unfrequently, in the 292.

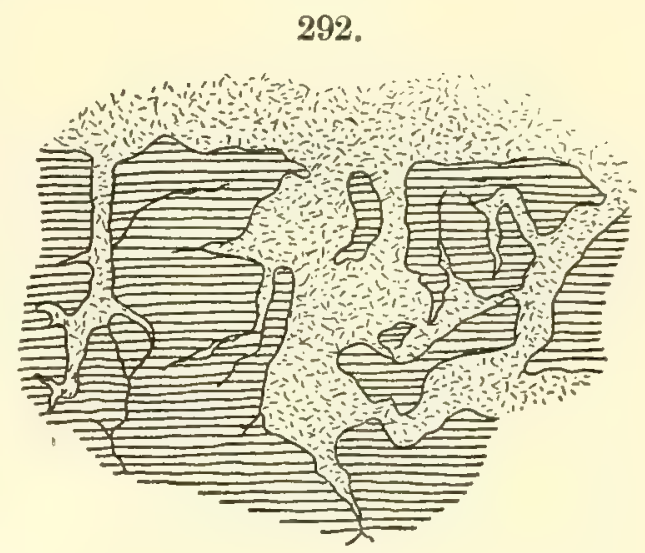

Granite veins in slate. De la Beche. same region slate or schist occurs in masses inside the granite, as in Fig. 495, page 448. The following figures represent three parts of one large granite vein, from gneiss, on the coast south of Valparaiso, where veins are

293.

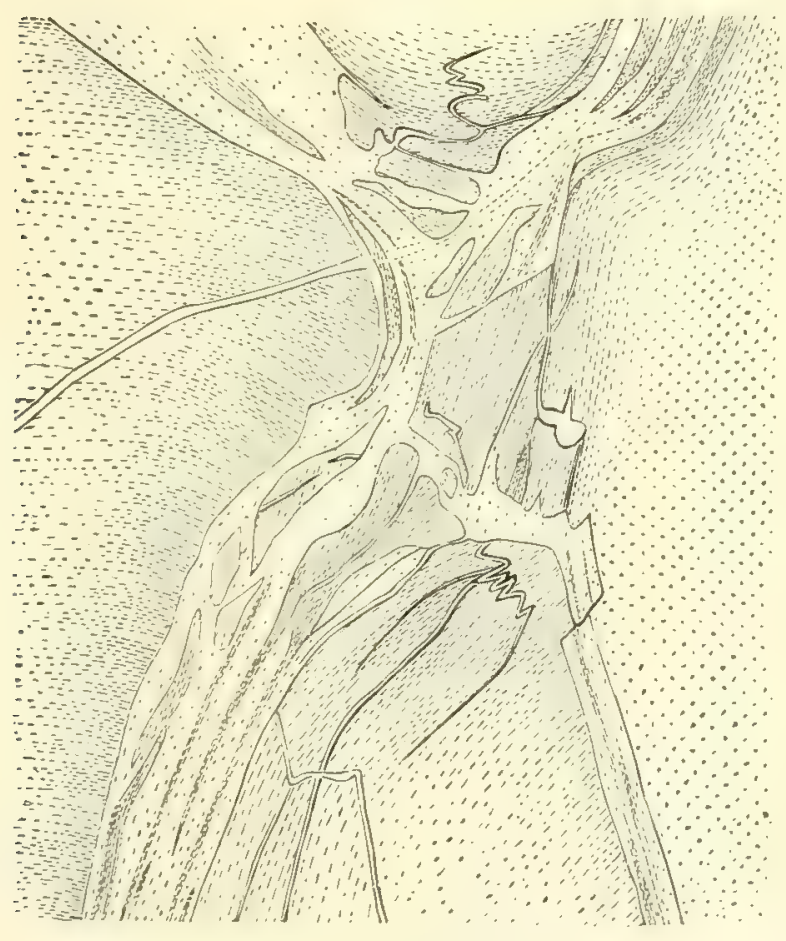

Granite veins, Valparaiso. D., "249.
294.

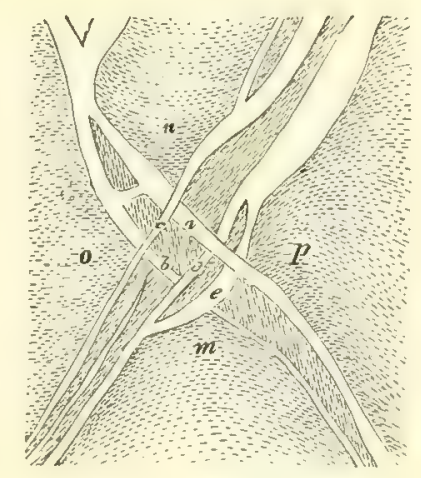

295.

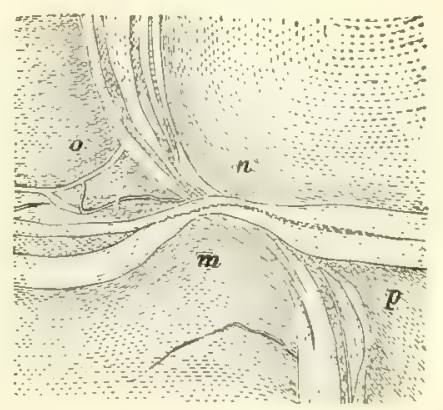

very numerous and of all sizes. The figures show quite accurately the bedding of the micaceous gneiss along the sides of different parts of the 
vein, where the rock in some places becomes a mica schist through the in crease in the amount of mica; the intervals between the sheets of granite are all of mica schist or gneiss.

In the making of fissures, portions of the walls have often fallen into them. A foreign mass in a vein is called by miners a horse; while many masses may make it a brecciated vein.

Veins are often faulted (Fig. 296). The vein $a a^{\prime}$ is faulted by $b b^{\prime}$, and vein 1 is in three parts from other intersecting veins. The faulting shows that the vein $b b^{\prime}$ is of later origin than

$a a^{\prime}$; but not how much later, whether one year or a million. The following figures are from the same region as the large granite veins, Figs. 293-295.

In the pieces of the vein in Fig. 297, the width varies, but this is owing to an oblique shove in connection with 296.

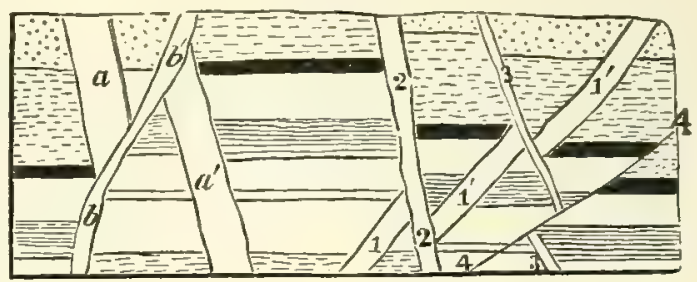
the faulting, and to the fact that the vein-sheet varies in thickness. The parts in Fig. 302 may have connection inside the rock, or they may not. In Fig. 301, two parallel veins, six feet apart, are represented with somewhat similar, but still different, faulting.

Veins, as well as dikes, derive part of their irregularities from lateral displacements after the fracture is made. In Fig. 303, a fissure is reduced

297.

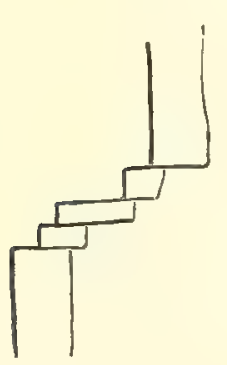

298.

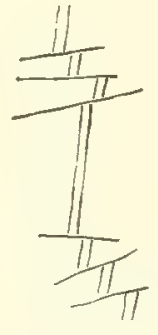

301.

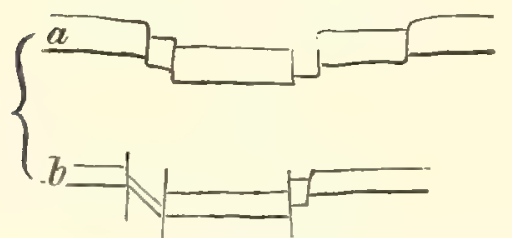

299.
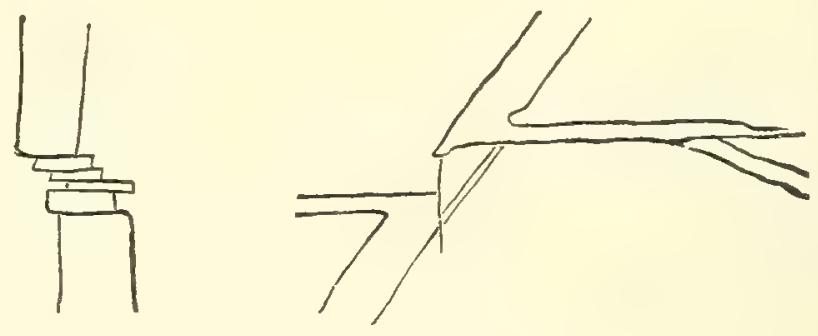

302.

Faulted reins from the vicinity of Valparaiso. D., '49.

to a series of independent open spaces by the downthrow of the side to the left, bringing the sides at intervals into contact. It may be illustrated in a piece of paper by cutting it across in the direction of the line $\alpha$ in Fig. 304 ; then, after opening it a little, and shoving one side first to the right and then to the left, the conditions in $b$ and $c$ will be obtained. The lesson taught is this: that an interruption in a vein, or in a trap ridge, does not prove interruption in the original fracture. 


\section{Mineral Constitution and Structure of Veins.}

1. Constitution. - Quartz is the most common material of veins. This is so because siliceous solutions form at a low temperature, and easily deposit quartz. Others are feldspathic and granitic. Others consist largely of calcite, barite, fluorite; others of hornblende, epidote, pyroxene, etc. Moreover, a large part of the minerals of the world, including most of its gems and ores, occur in veins, and some of them only in veins. The minerals are crystalline in texture, and where there is any open space, or seam, in the course of the vein, crystals of one or more of the minerals line the cavities, making geodes. The most magnificent of crystallizations are found in veins.

303.

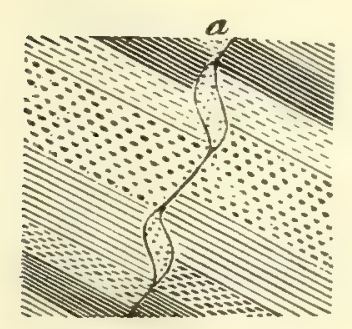

304.

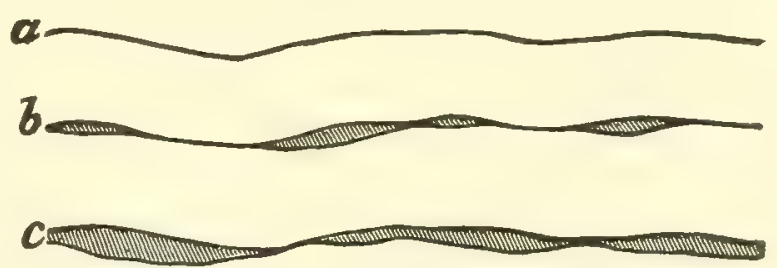

When ores occur along a vein, it is in miners' language a lode. The earthy minerals of the vein are the gangue of the ore, or what goes with it, and also the veinstones; and the rock outside of the vein, the country rock. Quartz, calcite, barite, and fluorite, are the most common kinds of gangue.

Iron sulphide, $\mathrm{FeS}_{2}$, is a very common associate of all kinds of ores, constituting the mineral pyrite or marcasite, generally the former. In a large part of the important ores of veins, the other metals are in combination with sulphur; but in many with arsenic, selenium, tellurium, bismuth, antimony, with or without sulphur; in a few with chlorine, iodine, bromine. Some ores are in the state of carbonates, sulphates, phosphates, arsenates; only two of economical importance are silicates, and two are oxides. The great deposits of oxides of iron are in beds, and not veins.

A few metals occur in the native, or unmineralized, state, essentially pure - as gold, platinum, copper, silver, bismuth, and sparingly so some others. Almost all the gold and platinum of the world is in this condition, and a large part of the copper.

The upper, or exposed, part of a vein is often a region of much decomposition, because (1) ores, being mainly sulphides, often oxidize easily; and (2) water readily percolates downward in many veins, owing to the nearly vertical position and structure of the vein, and the frequent existence of open spaces along the center and sides. Pyrite is often oxidized to red ocher, giving a reddish look to the vein rock; and if it contains gold, it often leaves the scales of gold in the cavities it has deserted. Pyrite also changes to the yellow-brown oxide of iron. Chalcopyrite, or sulphide of copper and 
iron, also on oxidizing gives red or yellow-brown colors to the decomposed material of the rock. Moreover, the percolating waters carry the changes downward, and especially along the sides and center of the vein. The waters descending along the walls of the vein (and any ascending vapors also) often alter the adjoining rock to clay, making along the side walls the selvage of the vein. Further, the waters may carry along earbonic acid, or sulphuric acid (made from oxidized sulphur), and so convert oxidized metals - as of lead or copper - into carbonate and sulphate. In this way phosphates, arsenates, and other salts of the metals, as well as carbonates and sulphates, become mixed with the ores of the vein as secondary products.

2. Structure. - Fissure veins are either simple or banded. Those simple in structure are alike in mineral or minerals from side to side; while the banded have the materials in layers parallel or nearly so to the walls, so that in a cross-section they look banded.

Granitic or feldspathic veins are usually simple. They may have great width, extending sometimes to 100 feet, and may consist of a number of minerals; but the minerals are not ordinarily arranged parallel to the walls. The larger veins sometimes contain feldspar and quartz in crystalline masses that weigh tons, and mica in plates a yard across, and occasionally beryls as large as a flour barrel. A beryl of Grafton, N. H., weighed 2900 pounds. Some spodumene crystals are four feet long. From this extreme magnitude there are gradations to those in which the crystallizations are an inch and less in size. The granite of veins seldom has the moderate fineness and evenness of grain fitting it for architectural purposes; the even-grained kinds are probably always of igneous origin.

305.

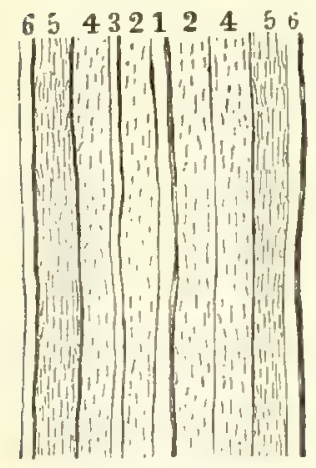

Banded vein, Valparaiso. $D$.
306.

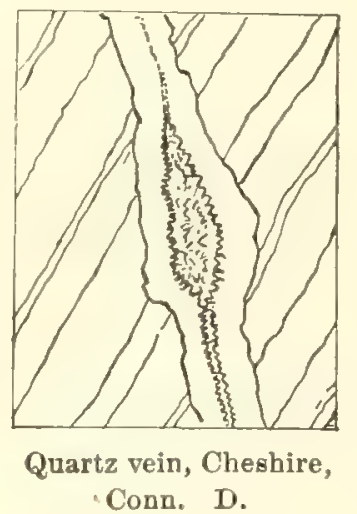

307.

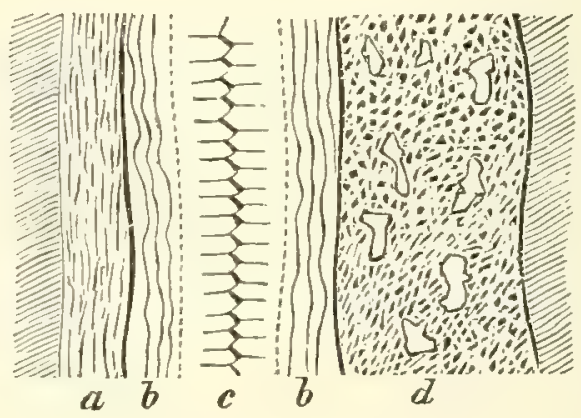

Banded vein, at Godolphin Bridge, Cornwall. De la B.

But granitic veins are sometimes banded, as in Fig. 305, in which 1, 3, and 6 are bands of quartz; 2 and 4, bands having the structure of gneissoid granite, and 5 that of gneiss. Fig. 306 contains a two-banded vein of quartz. It illustrates the usual mode of origin of bands, showing that they are layers made by deposition against the two walls. It is also a vein of copper ore, the ore lying in the wider open portions of the vein.

Figs. 307-309 represent other banded veins, having the bands in two 
or more sets. Fig. 307 appears as if made up of two veins side by side, abcb one, and $d$ another; two bands $b$ are agate bands (uncrystallized quartz), and at $c$ are two bands of crystallized quartz. The two sides of the fissure received simultaneously the deposition of agate, and then, over this, the layer of quartz in crystals. If a band or string of ore had been deposited between the two of quartz, as is common, this would have made it an ore-vein. But in the

308.

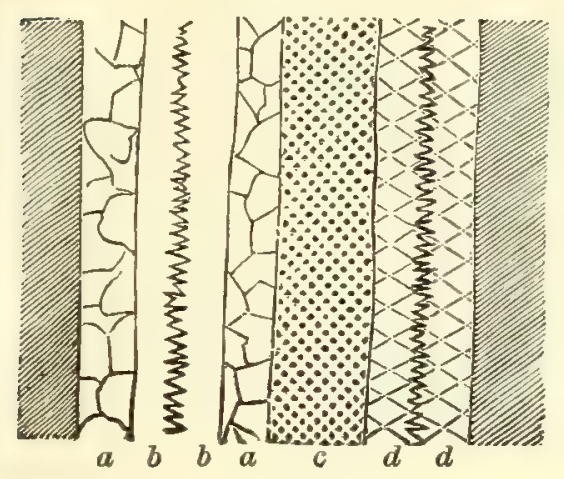

309

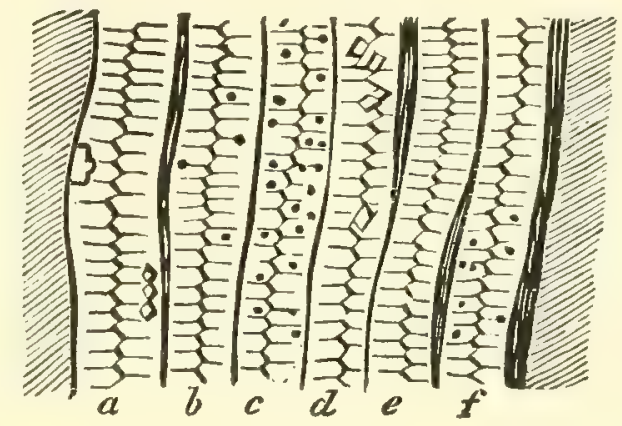

Compound veins from Cornwall. De la B.

figure, the large band $d$ is ore, copper ore; and to make it, the fissure was reopened along the wall to the left, and the ore introduced without any "gangue" material. Fig. 308 represents a triple vein, $a b b a$ one, $c$ a second, and $d d$ the third; and Fig. 309, a sextuple vein, or one that was opened six times for new vein-making. Each of the six parts is called a comb in miners' language. In one great vein, opened at Freiburg, the layer consisted of blende ( $\mathrm{ZnS})$, quartz, fluorite ( $\mathrm{CaF})$, pyrite, galena, barite, calcite, each two or three times repeated, the layers nearly corresponding on either side of the middle seam.

The ore of veins occurs in one or several of the bands; or is gathered along the center; or collected in the broader portions or swellings of a vein, making nests; or distributed through the gangue.

Most quartz veins cutting through crystalline rocks are actually simple, though begun in each case by deposition against the walls. Gold-bearing veins are commonly ordinary quartz veins, but the gold is usually in minute, invisible scales through the quartz, though occasionally in threads of crystals, and "nuggets" or larger masses. In the case of the gold-bearing quartz, crushing, and then either washing or amalgamation, are required to obtain the gold. Gold-bearing quartz veins contain also more or less pyrite in which gold is often present profitably, and also often galena (PbS) and sphalerite or blende $(\mathrm{ZnS})$. A region of chloritic or hydromica schist having interlaminating and intersecting reins of quartz, in which occur some pyrite and galena, is almost always a gold region.

The banded structure of many veins is one of the points in which veins differ from dikes. But they are often like dikes in having contact minerals in the walls of the veins, due to the same process which filled the vein. 


\section{Making of Veins.}

In the making of veins, the material has usually been deposited against the walls; and from the wall layer thus made there has been a thickening to the center. The work is, therefore, centripetal.

The materials have been introduced either (1) from above, or (2) laterally, from the rocks adjoining some part of the fissure, or (3) from below. The filling of superficial cracks is done usually without aid from heat. But in most vein-making, heat has been required.

1. Superficial Vein-making, not requiring Heat. - The shallow cracks of rocks, like those of mud-beds, and any eavities opening upward, may take in calcite, silica, or other ingredients from cold solutions, and make superficial veins. The process is mere deposition, and commonly without heat. In a similar manner cavities and caves have sometimes become filled. Or when a bed is slightly calcareous, permeating waters have taken into solution some of the calcareous portion (ealcite), and if cracks or fissures existed, have filled them with calcite. Siliceous solutions, in like manner, may make veins of quartz. So any solution made by oxidations or other means, may carry material into cracks and produce veins or veinlets.

2. Vein-making requiring Heat. - Vein-making requiring heat is carried on in regions of hot springs in a superficial way. But in general, the process has gone forward in fissures permeating hot rocks, and the work of filling has been dependent on the heat and moisture the rocks afforded. These fissures, in the case of the majority of veins, have not descended to regions of fusion; while in the case of other veins of even greater importance, as regards ore-production, they have reached fusion-depths and have let up melted rock. The veins of the first of these kinds are especially common in Archæan rocks; while those of the second belong mostly to later time.

\section{Superficial Vein-making.}

Superficial vein-making is in progress at hot springs in Nevada, California, and elsewhere. Such springs, making solfatara areas, are usually in regions of former eruptions.

In Nevada, at Steamboat Springs, according to J. Arthur Phillips (1879), fissures are being lined with a siliceous incrustation, while at the same time steam and gases, with boiling water, are escaping; and "they have been subjected to a series of repeated widenings," and become lined, to a thickness of several feet, with silica, which is in bands, amorphous and erystalline alternating, and contains some hematite, pyrite, and chalcopyrite. According to Mr. Laur (1863), the silica of these fissures contains also traces of gold; so that the facts exemplify, as he states, the essential points in the origin of auriferous quartz-veins. This view was presented by B. Silliman and W. P. Blake, in 1864, with reference to the banded quartz-veins (goldbearing) of Bodie Mountain, north of Mono Lake, which are contact veins intersecting porphyry. At Clear or Borax Lake, as observed by Mr. Phillips, 
the siliceous deposits frequently contain pyrite and cinnabar ( $\mathrm{HgS}$ ) and the sulphur bank, which has there been formed through the heated vapors, has been worked as a mercury mine. J. D. Whitney described in 1865 a specimen of gold in cinnabar which was supposed to have come from near "Sulphur Springs," four miles south of Bear Valley, between Clear Lake and Colusa; and Mr. M. Atwood removed doubt as to the source of the specimen by finding in a fissure at the place mentioned (as reported by Mr. Phillips) cinnabar overlaid by a brilliant deposit of metallic gold. Similar facts are reported by Le Conte $(1882,1883)$, from the Clear Lake region and Steamboat Springs. In the former, at "Sulphur Bank," occurs sulphur with cinnabar below (which is now worked), and also pyrite and gelatinous silica.

Le Conte explains the occurrence of cinnabar ( $\mathrm{HgS}$ ) on the ground of its solubility in a hot solution of sodium sulphide $\left(\mathrm{Na}_{2} \mathrm{~S}\right)$, 一 this alkaline sulphide resulting from the action of the sulphur gas on the rocks which contain a soda-lime feldspar, - and its subsequent deposition. (For Le Conte on Vein-making, see Am. Jour. Sc., 1882, 1883.) Becker sustains, by experiments (1887), the view that the metallic sulphides ( $\mathrm{HgS}, \mathrm{FeS}_{2}, \mathrm{ZnS}$, and less easily $\mathrm{Cu}_{2} \mathrm{~S}$ ) are soluble in solutions of alkaline sulphides, and that they pass in vapors to be deposited in the veinlets and fissures of the rocks above. He observes that the Steamboat Springs are now depositing gold; that gold is dissolved by a hot solution of $\mathrm{Na}_{2} \mathrm{~S}$, and that 843 parts of a cold solution of $\mathrm{Na}_{2} \mathrm{~S}$ will dissolve one part of gold. Deposition of the sulphides is occasioned by cooling; by contact with acid waters - these, according to Le Conte, descending from the surface where some of the sulphur in the gases makes sulphuric acid and aluminum sulphate; and also by dilution. Becker published in 1888 a full report on the quicksilver mines of California. The following facts illustrate further mineral transformations. Daubrée found, in the thermal waters at Bourbonne-les-Bains, in the bottom of a part of which, in Roman times, bronze, silver, and gold coins had become buried, the following mineral species, derived from the alteration of the metal of the first two of these kinds of coins through the agency of the mineral waters, their temperature $140^{\circ} \mathrm{F}$ : the copper ores, chalcocite $\left(\mathrm{Cu}_{2} \mathrm{~S}\right)$, chalcopyrite $\left(\mathrm{CuFeS}_{2}\right)$, bornite $\left(\mathrm{Cu}_{3} \mathrm{FeS}_{3}\right)$, tetrahedrite, atacamite, cuprite $\left(\mathrm{Cu}_{2} \mathrm{O}\right)$, chrysocolla, native copper; the lead ores, cerussite $\left(\mathrm{PbO} . \mathrm{CO}_{2}\right)$, anglesite $\left(\mathrm{PbO} . \mathrm{SO}_{3}\right)$, galena $(\mathrm{PbS})$, phosgenite, and pyrite. The bronze was found to consist of copper, tin, and lead, or of copper and zinc, with a trace of iron. The waters afforded, on analysis, chlorides and sulphates of the alkalies $\left(\mathrm{Na}_{2}, \mathrm{~K}_{2}, \mathrm{Ca}, \mathrm{Mg}\right)$, with bromides and carbonates of $\mathrm{Ca}$ and $\mathrm{Fe}$, an alkaline silicate, with traces of arsenic, manganese, iodine, boron, lithium, strontium, cæsium, rubidium, and, in exhalations, some $\mathrm{H}_{2} \mathrm{~S}, \mathrm{~N}$, and $\mathrm{O}$. Similar results were observed by Daubrée at the warm springs of Plombières, Department of the Vosges.

Veins made by heat in the Earth's Crust, without aid from deep-seated Igneous Ejections.

The crustal heat may be that of the earth's crust either during, or not during, an epoch of metamorphism. Under this head are included most of the great and small granite veins of the world, the auriferous (gold-bearing) quartz veins, and all the common veins of metamorphic rocks. They sometimes intersect the foliation, but very often follow it. Their formation was, in general, part of the results of metamorphic heat and conditions; and the movements attending mountain-making, which produced the metamorphic. 
heat, were the source of the larger part of the fissures, and the origin of their great diversity in form and positions. The heat varied, therefore, from $212^{\circ} \mathrm{F}$. and below, to, in extreme cases, the temperature nearly of fusion; and it slowly declined as the epoch of metamorphism closed, thus making the same region to pass through conditions of high-grade heat and low-grade heat, and, therefore, through conditions for different sorts of veins. All the transfer and transformation processes through superheated steam engaged in metamorphism were at work in vein-making with like efficiency - those of low heat for filling fissures with quartz, and those of higher for making feldspathic or coarse granitic veins, and other kinds. Moreover, the heat so derived continued long, and disappeared with extreme slowness; so that the filling of veins was usually slow, and the crystallizations going on had almost indefinite time for growing, and generally became coarse. The gigantic erystals of beryl, mica, and other species mentioned on page 331 were thus made.

With the heat so widely diffused, it was not necessary that the opened spaces for veins should be continuous. An interrupted series of openings in the upturned strata, as well as the spaces between the leaves of slates and the thinner schists, would have become as readily filled by materials supplied from the rocks, as they would if they had been united along continuous fissures.

The hot-vapor solutions, everywhere at work, would have varied their results according to the temperature, the moisture, and the kinds and contents of arjoining rocks. If the fissures penetrated rocks having veins or deposits of ore, or sparsely disseminated ores, the ores would be as readily transferred to the veins as the stony minerals; and the hot vapors, widely distributed, might gather them in from a wide region either side of the fissure, whether at its lowest or highest depths. The vapors, being under great pressure, would find the fissures escape-ways, and the transfer of material would therefore begin as soon as they were opened. Veins of lead ore (galena), copper ores, tin ore, and other kinds are common in the same rocks that elsewhere have their granite veins. Moreover, veins would be likely to contain ores at their intersections with some of the rocks they cross when not at other intersections. As gold occurs commonly in quartz veins, and in those of the feebly crystalline schists, as chlorite schist and hydromica schist, no great amount of heat was required for their formation, and the rocks near by or below must have afforded the gold.

Igneous rocks often have fissures intersecting them (due to contraction on cooling, or to subterranean action) and cavities (amygdaloidal) within them, that were filled, in vein-like style, from materials brought in laterally, and mostly while the rock was slowly cooling, as explained on page 298. The permeating hot moisture takes silica, alumina, soda, and lime from the feldspar of the rock, and makes zeölites (hydrous silicates, related to the feldspar) in the fissures and cavities; and takes silica, lime, magnesia, and iron from the pyroxene to make, with some alumina, the dark green chlorite; and sets free the excess of silica for making quartz crystals. 
The process decomposes the walls of the fissures or cavities to make the filling materials, the walls showing it by their decayed condition. The lateral source may be within an inch or a few inches of the place of deposition; and still it well illustrates much of vein-making. Bitumen or mineral oil may also be taken in from carbonaceous shales, and deposited in the amygdaloidal cavities and fissures; and to its presence J. Lawrence Smith attributed the reduction of the magnetite in igneous rocks to grains of native iron, and even the production of the great masses of native iron brought to the surface by basaltic ejections in Greenland.

The term vesicle, as applied to a vapor-blown eavity in an igneous rock, has been put into Greek form in the word lithophysa (stone-bubble) by Richthofen (1860), and applied especially to peculiar chambered cavities common in obsidian, its variety, lithoidyte, and in rhyolyte. They occur in great perfection, as flattened spheroids, in the region of the Obsidian Cliff, Yellowstone Park (Fig. 279, page 306). The following figures are from

310.

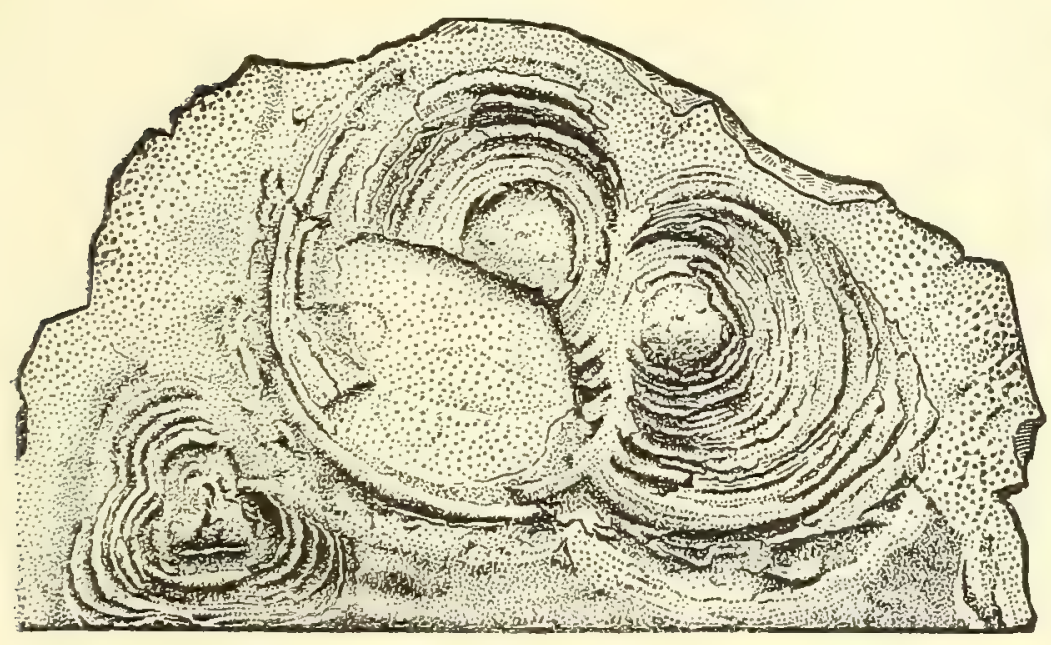

312.

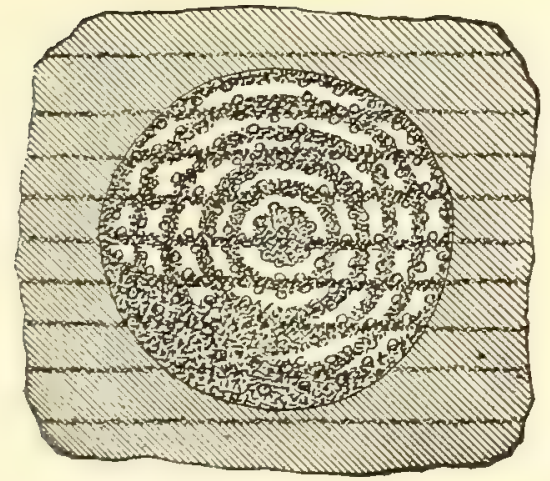

311.

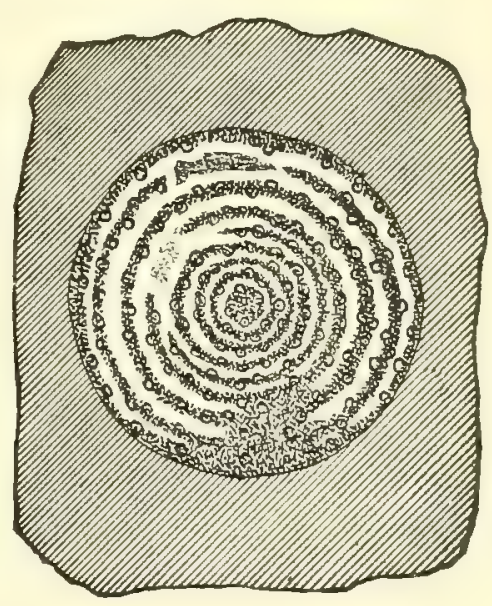

Lithophysæ of the Obsidian Cliff. Iddings.

a memoir by J. P. Iddings (1888). Three of the lithophysæ are shown, of natural size, in Fig. 310, and three others in section in Figs. 311, 312, 313. The rock containing the lithophysæ commonly consists of alternating solid 
and spongy layers as represented in Fig. 313, and the thin harler bands in this lamination or straticulation are persistent throughout the lithophysæ; as the figure shows they were sometimes arched in the making of the cavities, while often, on the other hand, they prevented the cavity from completing a circular form. The concentric partitions are fragile and consist mostly of minute crystals of quartz, feldspar, and tridymite; and sometimes topaz and garnets are in the cavities.

Richthofen regarded the lithophysæ as made by expanding steam, like vesicles in ordinary lava, and the concentric partitions as having been thrown off in the progress of the expansion, and hence the name. Mr. Iddings points out close relation between the lithophysæ and the associated radiate spherulites, and doubts the vesicular mode of origin. 'The following is a possible explanation. If the cavity made by vesiculation became at first filled with an aqueo-igneous or jelly-like solution of the rock, the concentric shells may be a centripetal result, due to progress in cooling and loss of moisture from the outside. The process would first produce a deposition of crystals over the confines or wall of the cavity, and thus deprive the inside solution, adjoining this wall, of part of its mineral material; then, the succession of shells might form inside in a manner analogous to that given for concentric rings on page 130. Johnston Lavis regards lithophysæ as concretions growing radiately outward, and refers the spaces between the concentric shells to the liberation of vapor from moisture contained in the glass, this liberation taking place as the glass becomes changed to feldspar in solidification. Whitman Cross, who adopts the vesiculation theory, found beautiful but minute crystals of topaz and garnets in lithophysæ of the rhyolyte, of Nathrop, Col. $(1884,1886)$. Iddings and S. L. Penfield have described (1885) yellow crystals of fayalite from those of the black obsidian at Yellowstone Park. Utah rhyolyte also has afforded topazes.

\section{Veins made by the aid of deep-seated Igneous Ejections.}

For the formation of veins through the heat of igneous ejections, the earth's crustal heat has been the agent, aided possibly by heat from local crushing and friction. The fissures at great depths may have had the heat required, without addition from mountain-making movements. The general steps of progress - that is, the methods of transfer and formation of mineral material by heated vapors - are the same that have been described.

Fissures descending to regions of fusion are necessarily deep fissures, and for this reason the veins that have been made in connection with them include the richest of ore-bearing veins. The deep fissures let out liquid rock. But they were the means of opening a way for whatever vapors or solutions the melted rock through its heat, supplemented by the earth's crustal heat, might gather from the rocks, or their crevices, along the way up, or from the depths below. The copper veins of the Lake Superior region are an example; and so are also the richest and the chief part of all the silver, lead, and copper veins of western America, from Fuegia on the south, along the western slope of the Andes to Central America, Mexico, Nevada, Arizona, Colorado, Utah, and Wyoming.

The results differ not only according to the kinds of rocks below, but also the kinds along the upper part of the fissure: whether they are (1) of difficult corrosion, or (2) of easy corrosion like limestones. 
1. The upper intersected rocks of difficult corrosion. - These rocks are of any kinds not calcareous: as shales, sandstones, or other related fragmental kinds, or, but much less frequently, crystalline rocks.

The famous copper mines south of Lake Superior are an example. The upper intersected rocks are sandstones, conglomerates, and tufas. The igneous rock is mainly of the basaltic type. The copper is native copper containing generally 3 per cent of silver, and occasionally speckled with silver. It occupies irregular fissures and cavities in the igneous rock, especially its amygdaloidal varieties, and also occurs in the adjoining sandstone. It sometimes constitutes amygdules, has often a gangue of zeolites, or coats crystals of analcite and quartz-crystals, and thus it proves its contemporaneous origin with these materials. One great sheet of copper was 40 feet long, 6 feet wide, and 6 inches thick, and weighed, by estimate, 200 tons. 'The conditions show that the copper came up along with abundant moisture from some deep-seated source. In 1891, the mining at the Calumet and Hecla mine had gone down 4000 feet. It is probable that the deep-seated source was a region of veins in Archæan rocks along the line of the fissure or fissures holding chalcopyrite, the most common of copper ores.

Another example is that of the remarkable Comstock lode, Nevada, along a faulted fissure - now a deserted mining region. The igneous rock at the broad vein is of the basaltic type, and intersects a region of andesyte of Tertiary age. The ore deposit extends along the contact of the igneous rock with those it intersects. The gangue is mainly quartz. The ore is largely silver sulphides with some native silver and native gold, the last nearly half the value of the products. Hot vapors ascend the opening, and during the working it made the cooling of the air with ice necessary in order to reach the lower depths; and finally the heat caused the desertion of the mine. By means of the vapors, the diabase and other adjoining rocks had become deeply decomposed to clay. The total yield up to July, 1880, was over 306 millions of dollars. (King, 1870; Becker, 1882 ; Hague and Iddings, 1885.)

In other related veins, the rocks cut through by the upper part of the fissure vary in porosity and in other ways; and some of the beds become impregnated with ores, while others receive little or none. Such impregnations are occasionally found where no igneous rock by which they could have been produced is in sight. The following sections, illustrating a case

314.

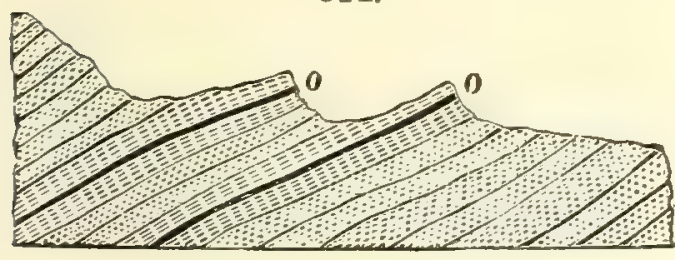

315.

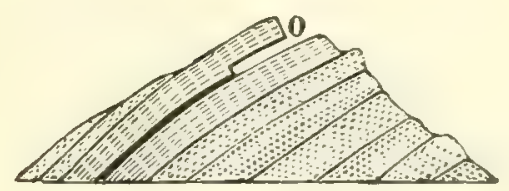

of this kind, are from a report made in 1879, by Rothwell and Crouch, on a district on Virgin River, in Utah, 250 miles south of Salt Lake. The formation containing the ore-beds $(0)$ is probably Cretaceous (see Gilbert's 
Rep., 158, 171, 1875). The ore is chiefly silver chloride or horn-silver. The rocks are sandstone, argillaceous sandstone, and shale. The ore-beds are usually clayey layers or shales, and the ore is most abundant when the clays contain vegetable remains. Eruptive rocks are not far away, and J. E. Clayton, in the same report, urges that hot vapors, derived either from the fissures of eruption, or from other wide-spread fracturings made by the eruptive movements, were the chief source of the distributed ores.

In southern Utah and in Colorado, according to J.S. Newberry, veins exist made of coarse gravel and stones, in which the stones have become coated with argentiferous galena and other ores, including silver chloride, that were received from below. They are worked for the silver. Examples are the Bassick and Bull Domingo mines near Silver Cliff, Col., and the Carbonate mine at Frisco, Utah. The large fissures were opened near the base of the mountains, where they became filled with the pebbles, stones, and bowlders of all kinds there accumulated, and yet received the ascending metallic solutions, and also siliceous solutions, which deposited at the Bassick mine much chalcedony among the stones.

2. The intersected rocks of easy corrosion. - Many of the richest oredeposits of the world occupy cavities in limestone made by the corroding action of solutions or vapors. The cavities were eroded usually along joints or fractures of the limestone. Examples occur in the Leadville region, Colorado; in the Wasateh and Oquirrh mountains, Utah; at the Eureka mine, Nevada; in Lake Valley, New Mexico; in the Los Carlos Mountains, Mexico; and elsewhere. The ores of these mines, as generally of others, are of two classes: (1) the original, and (2) the secondary - mainly the latter. The original ores include galena ( $\mathrm{PbS}$ ), containing some silver and chalcopyrite, with sometimes pyrite and sphalerite $(\mathrm{ZnS})$. Some of the secondary are silver chloride and bromo-chloride, made from the silver of the galena; lead sulphate, carbonate, phosphate (and less commonly vanadate and molybdate), made from the galena; zine silicate, made from sphalerite; and also iron oxide (hematite or limonite), made from pyrite and from iron in the limestone; and manganese oxides, probably from the limestones.

The following figures show the forms, at Leadville, of some of the cavities of ore in the corroded limestone (a blue Carboniferous limestone) underneath a sheet of porphyry, the latter being the igneous rock which carried up with it the ore and heated vapors. They are from the very valuable Report of S. F. Emmons (1886). The porphyry is also usually altered and often penetrated for some distance with ore, and its decomposition has afforded part of the ore for the limestone cavities. Although the ore deposits are usually in a Carboniferous limestone at Leadville, the time of the outflow of the porphyry and of the making of the cavities was not earlier than the Cretaceous period (Emmons). The similar silver-lead mines of all western America are probably likewise Cretaceous (chiefly the Laramie or later Cretaceous), or else Tertiary.

At the famous Eureka Mine, eastern Nevada, where the rocks are all Paleozoic, the eruptions were Tertiary, according to Hague (1892), and mostly late Tertiary; they were partly along old fault-planes of post-Carbonif- 
erous age, and partly through new fissures. The ores occur along the dikes, and also penetrate the limestones; the ejection of the igneous rocks, andesyte and rhyolyte, was accompanied by the upward passage of the ores; and the ores became much changed to secondary kinds by the action of the vapors. The latest eruptions of the region were of basalt.

316.

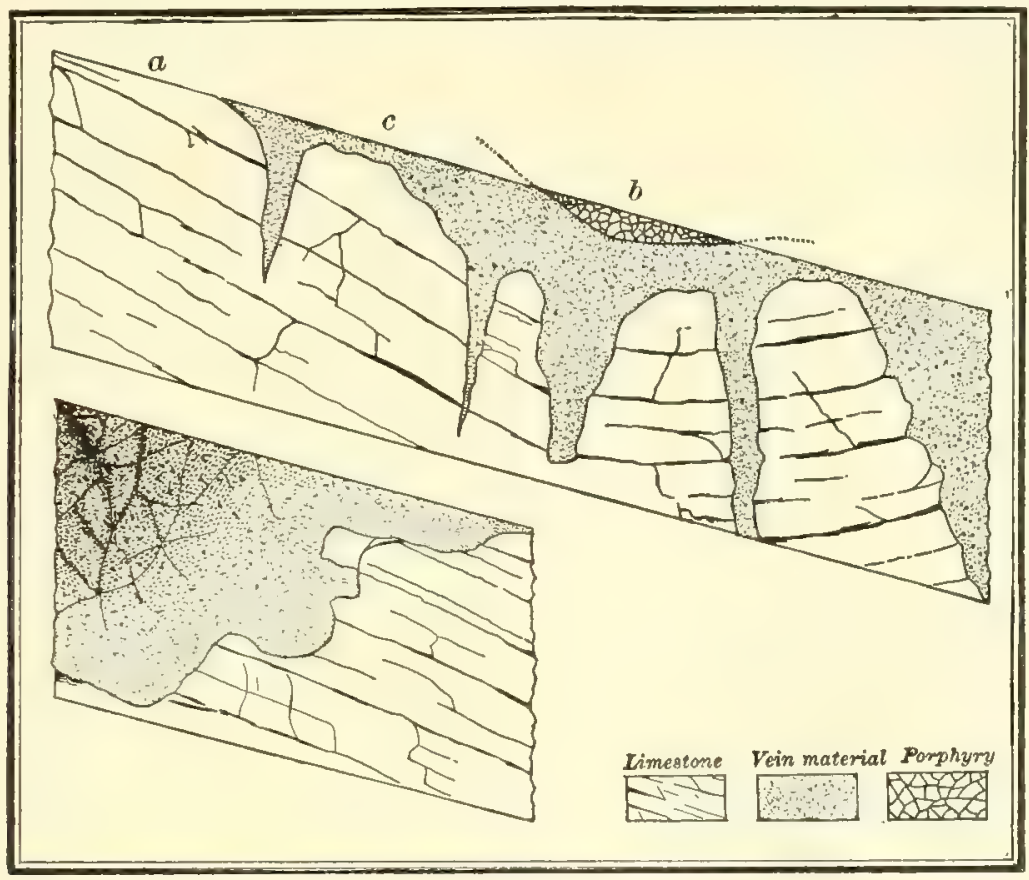

317.
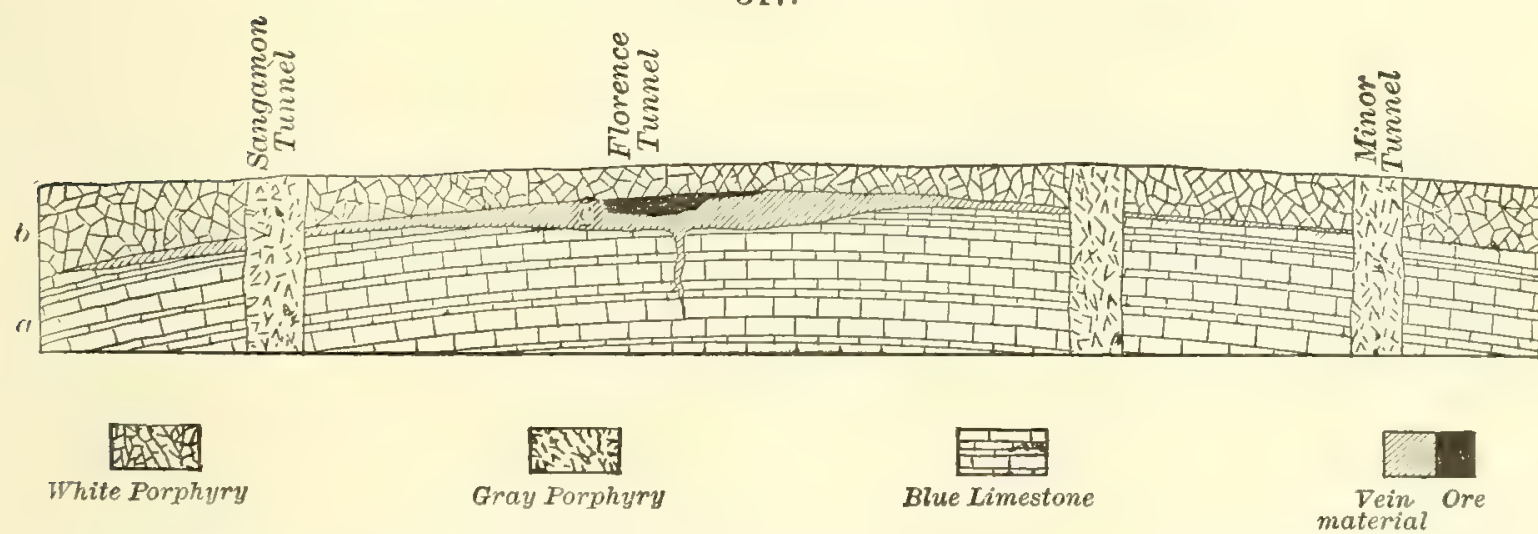

Fig. 316, two Carbonate Hill sections, Leadville, showing cavities of ore in the inclined stratum of limestone. $a$, limestone; $b$, porphyry; $c$, ore. Fig. 317 , section at Printer Boy Hill mine; letters same signification. Emmons.

The abundance of chloride and bromide of silver in these western mines makes it probable that sea water contributed to the ascending vapors, and that salt ( $\mathrm{NaCl}$ ) supplied the chlorine. In the Cretaceous period, the mountain region was mostly submerged. The ores are supposed to have come from the igneous rocks. (Becker, Emmons.) This was probably true to a large extent in some cases, according to the facts afforded by the Keweenaw copper region. The hot lavas carried much of the metallic material to the surface, and as cooling commenced, the ores were condensed in, or gath- 
ered into fissures, and amygdaloidal and other cavities disseminated through the amygdaloidal rock; and under such conditions they have been mined in the Keweenaw copper region to the great depth mentioned.

At Leadville, and other like regions, the liquid lavas were in part the carriers of the ores and vapors to the surface; but the chief part of the concentration of the ores and the corrosion of the limestone may have taken place during the cooling of the lavas. The solid rocks of the globe take in their small percentage of moisture from the waters that become subterranean, and then hold it; a flow of such waters downward through such rocks, and a draining out of their ores, cannot take place, except as complete decomposition is produced; and the small depth to which decomposition extends in most igneous rocks shows that the process is extremely slow. The processes of decomposition and concentration were long kept in progress by the vapors that continued to rise from below after the eruption had ceased. Finally, the infiltration into the vein, or vein-masses, of cold waters from above has carried on further the work of alteration and corrosion, and this work is still in progress.

3. Ore deposits of doubtful origin occurring in limestone. - Great lead deposits occur in Paleozoic limestones of the Mississippi Valley in Wisconsin, northern Illinois, and Iowa, and in Missouri and bordering parts of Kansas and Arkansas. They occupy cavities or caverns in various limestones from the Cambrian to the Subcarboniferous. The mines of Wisconsin and Illinois are in the Galena limestone (or the upper part of the Trenton limestone) of the Lower Silurian; those of southeastern Missouri, in the Third Magnesian limestone, of Cambrian age; those of southwestern Missouri, in the Keokuk limestone of the Subearboniferous period, and to a small extent in the Cambrian; those of central Missouri, chiefly in the Cambrian limestone, but partly in the Subcarboniferous limestone.

The lead ore, galena, is associated with pyrite, marcasite; the zinc ores, calamine (zinc silicate) and smithsonite (zine carbonate); lead carbonate, malachite, barite, and in some places with black cobalt and an ore of nickel.

The ore, in each of the regions mentioned, occurs in cavities or caverns in the different limestones. From the resemblance between the various deposits, it is concluded that the time of origin was the same for all, and not earlier than the Subcarboniferous period, the age of the latest of the limestones.

As first made known in the geological report of Wisconsin by J. G. Percival (1858), the ore-bearing cavities follow the courses of the joints (or system of fractures) in the limestone, and are most extensive along the larger joints, which are sometimes the lines also of faults. This fact has been confirmed by later observations.

In the Transactions of the St. Louis Academy of Science for 1875, A. Schmidt announced the conclusion that the ore-containing cavities in the Missouri limestones were made when the alterations of the galena took place, producing the associated minerals, and principally in the more porous 
part of the limestone stratum where limited above and below by cherty layers; that the rock adjoining was largely converted into dolomite by magnesian solutions, and that this "dolomization" was an early step in the process, and aided in making the cavities; that the ores often occur mixed up with chert or sand that were set loose by the decomposition of the limestone.

There are two theories of origin, one deriving the ore from above, the other from below. The former is favored and the latter opposed by the absence of proof that the bodies of ore extend downward through the limestone vein-like, and that igneous action was concerned. The theory of filling from above encounters the objections that the ores of lead are not soluble, and could not have been carried into the cavities in solution by sea water, and that the gathering of galena from Archæan veins, once in the regions, by abrading and transporting waters, is improbable, and does not account for the presence of the eroding agents which made the cavities.

The other theory, which was suggested by Percival, and is advocated by Jenney (1893), makes the deposits similar in origin to the silver-lead deposits of Leadville and other Rocky Mountain localities. But the objections to it mentioned above exist; and so they do in the case of some Colorado ore deposits, where igneous action below is nevertheless believed to be probable. The making of the ore deposits is generally referred to the close of Paleozoic time, when the Appalachians were made; but Jenney supposes it to have been at the close of the Cretaceous period, simultaneous with that of most Colorado deposits.

In Derbyshire, England, the Subcarboniferous limestones contain similar lead deposits, and along with the ores are Permian fossils, proving that they originated not earlier than the Permian.

The different modes of origin of ore-bearing deposits, above described, are the following. In the deeper veins the earth's interior heat has been accessory to special sources of heat.

A. Heat from Crustal Movements, and not from Igneous Ejections or Hot SPRings.

(1) Regular veins. - Mostly in metamorphic rocks.

(2) Grouped interlaminar veins. - Generally short, as the smaller auriferous quartz veins of gold regions, and some tin, copper and other veins.

\section{B. Heat from Igneods Ejections, Vapors, and Hot Springs.}

(3) Ore impregnating non-calcareous rocks.

(4) Veins or groups of veins intersecting non-calcareous rocks.

(5) The ores in veins intersecting calcareous rocks, and occupying cavities in them made by their corrosion. Often combined in the same region with 3.

Besides these there are, of uncertain origin : -

(6) Cavities supposed to be in part previously made limestone caverns, as those of the Mississippi Valley. 
The principal kinds of ore deposits that have no relation to veins are as follows:-

(1) Beds of iron ore called limonite, including marsh-made ores (page 128), sometimes containing also manganese oxide, cobalt oxide, and some black copper oxide; (2) beds consisting of concretionary masses of clay iron-stone, the ore either hematite, limonite, or siderite, - common in coal regions; (3) beds of hematite and magnetite in metamorphic and other rocks, which often stand vertical and look like veins, whence they are sometimes so called; (4) auriferous gravel deposits along valleys, made by the degradation of schists that are intersected by veins of auriferous quartz.

4. Sediment-filled fissures. - Fissures have sometimes become filled with sand or gravel from the adjoining beds. Near Astoria, Oregon, occur several large sandstone veins of this kind. One of them, half a mile above that place (Fig. 318), is five feet wide, and extends the whole height of the bluff; it has two transverse faults, the upper one eight feet. The filling is granitic sandstone, like that of the inclosing rock. Another, 18 inches wide, is shown in Fig. 319; it is in the same rock two and one half miles above

320.

318.

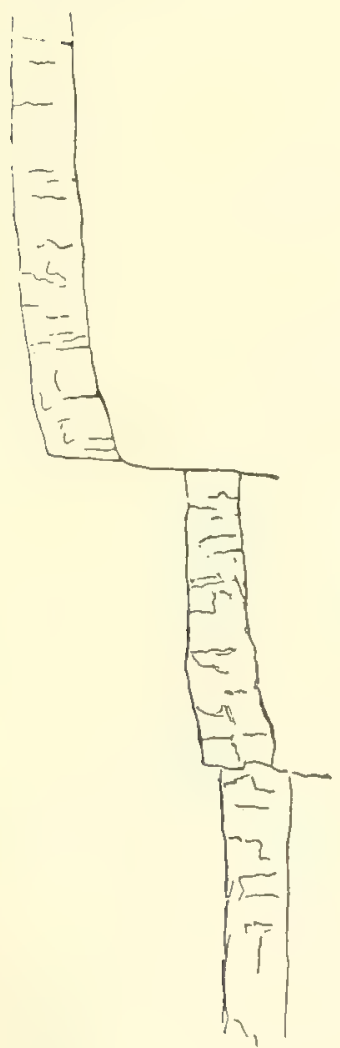

319.

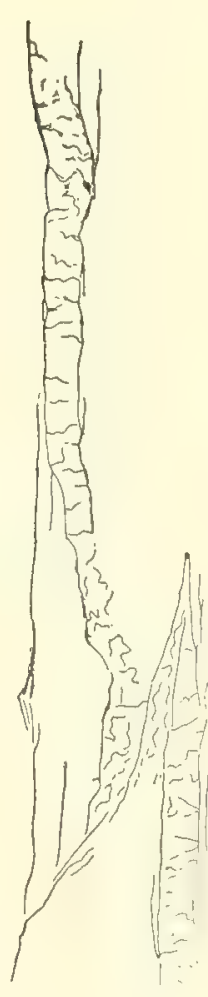

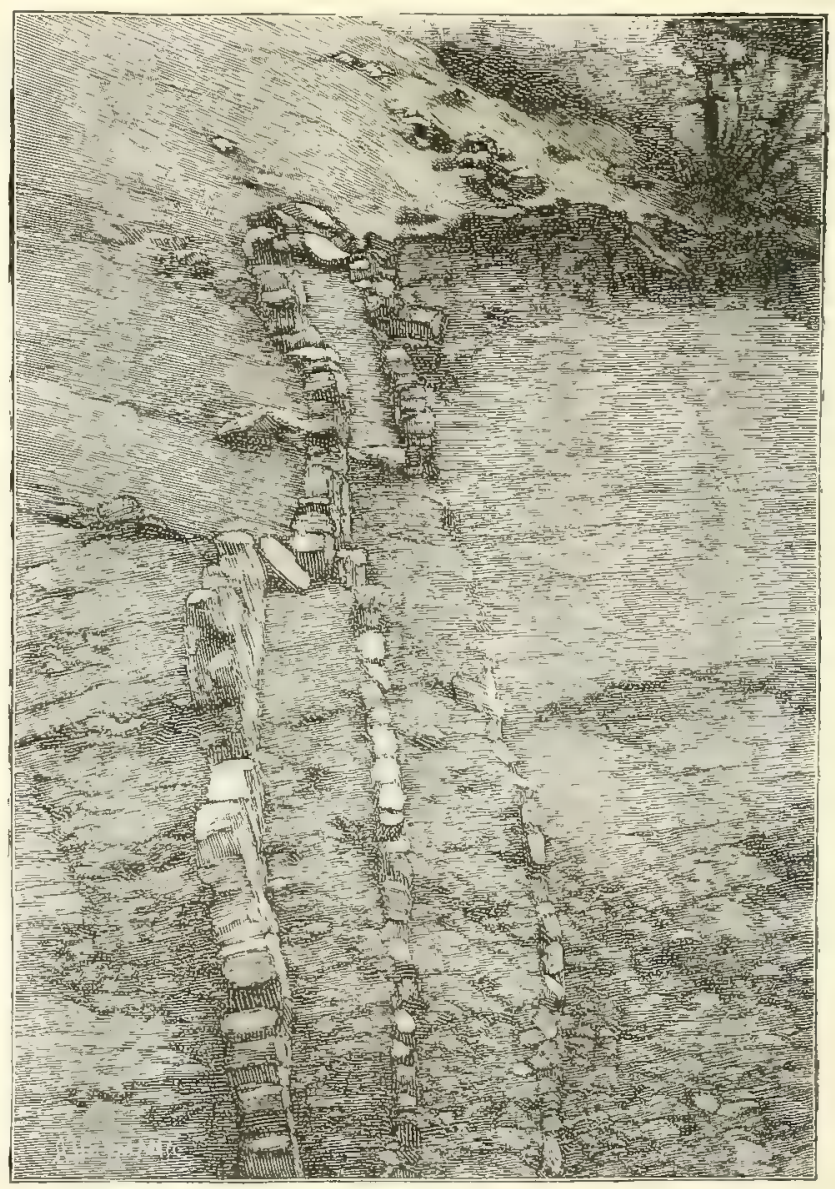

Figs. 318, 319, sandstone veins, near Astoria, Oregon. D., 1849. Fig. 320, sandstone veins, south of Shasta Peak. Diller, 1890 .

Astoria. Fig. 320 represents similar sandstone veins from the coast region in California, south of Mount Shasta, described by J. S. Diller (1890). Diller infers, from his observation, that the fissures were filled from below by upthrust force during the progress of an earthquake. 


\section{EARTH-SHAPING, MOUN'TAIN-MAKING, AND THE ATTENDANT PHENOMENA : HYPOGEIC WORK.}

The preceding chapters on the origin of geological phenomena treat of the agencies by which rocks were made, denuded, crystallized, and filled with veins and ores. The subject of the present chapter is the nature and origin of the changes through which the earth has received its form and features, hypogeic work, of which the orogenic part is the most noticeable. It does not comprise the work of waters in giving mountain-like shapes to plateaus, and thus producing mountains of circumdenudation, or in making, by accumulation, hills of detritus; nor the work of heat in building up volcanic cones, the earth's mountains of igneous accumulation, or in making laccolithic domes or masses (laccoliths) - mountains of subterranean igneous accumulation; for these operations have already been considered; but work that is consequent, whatever its source, on crustal and interior movements in the earth, as expressed in the term HrpogeIc, from the Greek ino, beneath, and $\gamma \hat{\eta}$, the earth. The attendant phenomena comprise fractures of the earth's crust and supercrust, dislocations, flexures, crystallization and alteration of rocks, rock-melting, and other effects.

The facts and explanations here presented are supplemented in the following pages on Historical Geology, and the chapter will be best understood if those pages have already been made familiar.

\section{Actuality of Changes of Level.}

All geological history testifies against the stability of the rocky crust of the globe; and if the earth, as is believed, has cooled from fusion, abundant reason for this unstableness exists; for the effects of the earth's slowly progressing refrigeration reach backward indefinitely, and downward beneath all other agencies of change.

But the evidence of instability, although the fact is so obvious, is beset with doubts as to amount and position, because of possible and actual variations in the base from which measurements are naturally made. This base is the water-line about the land. Hence, we have to consider the sources of variation in sea level.

1. Changes in the level of the sea-bottom. - When water-made strata full of marine fossils are found at a height of 1000 feet above the sea, the evidence of a rise of at least 1000 feet appears to be plain. Yet, a lowering of the sea-bottom might produce the same result; and it may, therefore, be a question whether in such a case part, or all, of the apparent upward change has not been so produced.

So, also, by a reverse movement in the sea-bottom, an apparent subsidence might result. Here there is actual change of level, but it may be thousands of miles away from the land along which the change is made visible. Change so caused will affect all seacoasts alike; and in this fact a criterion exists for judging of its reality. 
2. Changes in the position of the earth's axis. - If a change should take place in the position of the earth's axis, through changes of level in the earth's crust, the coast-lines of the earth would be throughont affected by the new adjustment of the water level. Physicists have very nearly relieved geology of this source of doubt, by the decision that an effective change of this kind is exceedingly improbable (page 255).

3. A change in the level of the land. - By the law of gravitation, elevated lands attract, and thus draw the mobile waters of the ocean toward them to a height dependent on their mass and distance. Consequently the seamargin of all coasts is more or less displaced, and much so, wherever the land mass adjoining rises high above it. It has been calculated that from this cause the sea level at the center of the Eurasian continental mass is about 2900 feet above the sea at its margin (R. S. Woodward); at the center of the Australian mass, about 400 feet (G. G. Stokes, 1849, 1887); of the great plateau of India, 1000 feet, but under the voleanic mountain of Maui, Haleakala, $10^{\circ}$ in mean slope, only 10 feet.

The facts make it evident that the water-line along nearly all coasts, and especially on the west coast of North and South America, must be very largely moved inland by the mountain chains; and that, through geological time, changing levels have always been changing the water-lines. It is to be observed, furthermore, that this inland drawing of the ocean's water diminishes the height of the mountains above the sea. The error is on the side of too little height.

The piling of ice over the land in a glacier epoch has a like effect, but with material having about two fifths the gravity of the ordinary land material. Were the ice of a glacial epoch to be accumulated about the poles, and thus make a polar ice-cap or meniscus thousands of feet high, the ocean level would be changed through all latitudes to the equator. This cause has been thought sufficient to explain apparent subsidences in the hemisphere so eapped.

But since the change of water level from the equator to the pole would follow a geometric ratio, admitting of mathematical calculation, the accordance of the theory with actual facts is easily tested. In eastern America the subsidences closing the Glacial period supposed to be thus accounted for by Croll have no correspondence with the required heights. Moreover, observations have proved that there was no such polar ice-cap in the Glacial period.

4. Abstraction of water from the ocean. - Further, the making of great continental accumulations of ice would lower the level of the ocean and tend to raise the apparent level of the land.

With the above cautionary considerations in view, noting that the observations about ice relate only to glaciated regions, that the error from the attraction of the land is on the side of too little height, and that sea-bottom changes of level affect all coast-lines alike, the following facts may be accepted as proof of changing levels over the earth's surface. 


\section{Examples of Changes of Level in the Land.}

1. Movements, up or down, are now going on along the coast of North America, Scandinavia, Greenland, and elsewhere. Alexander Agassiz states that at Tilibiche, in Peru, there is a coral limestone, 2000 to 3000 feet above the sea level, extending along for 20 miles, in which occur corals modern in aspect; and that the existence, in Lake Titicaca, of eight species of a saltwater genus of Crustaceans, Allorchestes, suggests the presence of the sea over this region, 12,500 feet in height, at no very distant period. There is no proof of corresponding changes over eastern South America.

2. On the coast of Cuba, limestone strata, made in the sea off the shores, are now (according to W. O. Crosby) at different levels up to a height of 1800 feet, and near Havana, over 1200 feet; and on Jamaica (according to Mr. Sawkins), and Haiti (according to W. P. Blake), of 2000 feet.

3. In the early Tertiary, the European and Asiatic seas contained Nummulites, and limestones were made of the multiplying disks. Now, those Eocene Nummulitic beds are at a height of 9000 feet in the Pyrenees, 11,300 feet in the Alps, 16,500 feet in the Himalayas in western Tibet, and a few hundreds only near Paris.

4. In the Cretaceous period, the region of a large part of the Rocky Mountains and of the Atlantic, Gulf, and Pacific borders of the continent were beneath the sea, but mostly near its surface; and the marine life of the sea contributed to the forming of Cretaceous beds. Now, the marine beds, filled with Cretaceous fossils, are at a height of 10,000 to 11,000 feet in the Rocky Mountain region; at a maximum height, on the Pacific border, of only 5000 feet; in Alabama of 700 to 800 feet; and in New Jersey not over 400 ; and in portions of the western mountain regions the beds are in great flexures.

5. In the Appalachian region, from the site of Albany, N.Y., to Alabama, at or near the end of the Carboniferous period, the surface was near the sea level, and the rocks, from the Cambrian to the Carboniferous, lay in a horizontal pile, the upper surface little emerged above sea level. Now, they are in mountain flexures, and heights of several thousand feet occur along the line.

6. All the world's mountains, excepting those of igneous formation, consist of rocks that were made chiefly in the sea; and the highest of them reached their present level during the latest of the geological ages. And while some portions of the earth's surface were raised in later geological time 10,000 to 19,000 feet, other parts underwent little or no recognizable elevation.

7. Formations of all thicknesses to tens of thousands of feet bear evidence of the shallow-water origin of the successive beds; and they thus prove that, while forming, a subsidence of extreme slowness was in progress over the great area; slow enough for the accumulation of the material in the surface waters by living growth if the beds consist of limestone, and by 
water-action, if of sedimentary origin. The shallow-water origin of beds is . so generally true that thick formations in almost all cases are proof that a slow subsidence, equal in amount to the thickness, was going on over the area during the deposition; and also that without such a subsidence the making of thick strata or formations has rarely taken place.

Such evidences of actual change of level are good, and have profound significance. Geology has thus proved that:-

1. Unequal changes have been in progress simultaneously in different parts of the same continent.

2. The changes in level have usually gone forward with extreme slowness - by the few inches or feet a century, though sometimes also by abrupt displacements. The former are termed secular changes, the latter paroxysmal.

Another class of facts is represented by the following from Illinois:-

A section of the coal formation of Illinois, described by Worthen, contains 16 coal-beds, large and small, separated by fragmental beds and limestones containing abundant remains of marine life. The coal-beds indicate eras of emerged land, the marine fossils, intervening eras of submergence, and their number shows that at least sixteen alternations between the two conditions there took place in the Carboniferous period. Facts make it certain that the great Interior Sea of the continent communicated at that time freely with the ocean to the south. The same region thus went up and down, changing the dry land outline and the sea depths; and the changes went on with extreme slowness, for coal-beds, as well as the much thicker marine beds, were slow in accumulation. Facts of similar import are afforded by all the successive formations, from the Cambrian upward, and alike on all the continents. In explanation of such changes it may be questioned whether subsidences over the sea-bottom may not have produced some or all of these oscillations in level. As far as evidence can be obtained, the changes were independent of movements in the ocean; for the coal-beds of Illinois and those of Ohio and Pennsylvania do not show that uniformity of parallelism which this hypothesis requires.

Further: changes of level are now in progress, both of the slow secular kind and of the sudden or paroxysmal. The following sketch represents a case in which a Roman temple has passed through a time of partial submergence below the level of the Mediterranean. The temple is that of Jupiter Serapis at Pozzuoli. It was originally 134 feet long by 115 wide; and the roof was supported by 46 columns, each 42 feet high, and five feet in diameter. Three of the columns are now standing, and they bear evidence of submergence for a considerable time to half their height. The lower twelve feet are smooth; for nine feet above this, they are penetrated by lithodomous or stone-boring shells, remains of which (a species now living in the Mediterranean) were found in the holes. The columns, when submerged, were consequently buried in the mud of the bottom for 12 feet, and were then surrounded by water nine feet deep. The pavement of the temple is now under water. Five feet below 
it, there is a second pavement, proving that these oscillations had gone on before the temple was deserted by the Romans. It has been stated that, for some time previous to 1845 , a slow sinking had been going on, and that since then there has been as gradual a rising.

At the earthquake in 1819, about the delta of the Indus, an area of 2000 square miles became an inland sea; and the fort and village of Sindree sunk till the tops of the houses were just above the water. Five and a half miles from Sindree, parallel with this sunken area, a region 50 miles long and in some parts 10 broad was elevated 10 feet above the delta. The natives call it, with reference to its origin, Ullah Bund, or Mound of God. In 1838, the fort of Sindree was still half buried in the sea; and, during an earthquake in 1845 , the Sindree Lake was turned into a salt marsh.

In 1822, the coast along by Concepcion and Valparaiso, for 1200 miles, was shaken by an earthquake; and it has been estimated that the coast at Valparaiso was raised three or four feet. In February, 1835, another earthquake was felt from Copiapo in Chile, eastward beyond the Andes to Mendoza.

321.

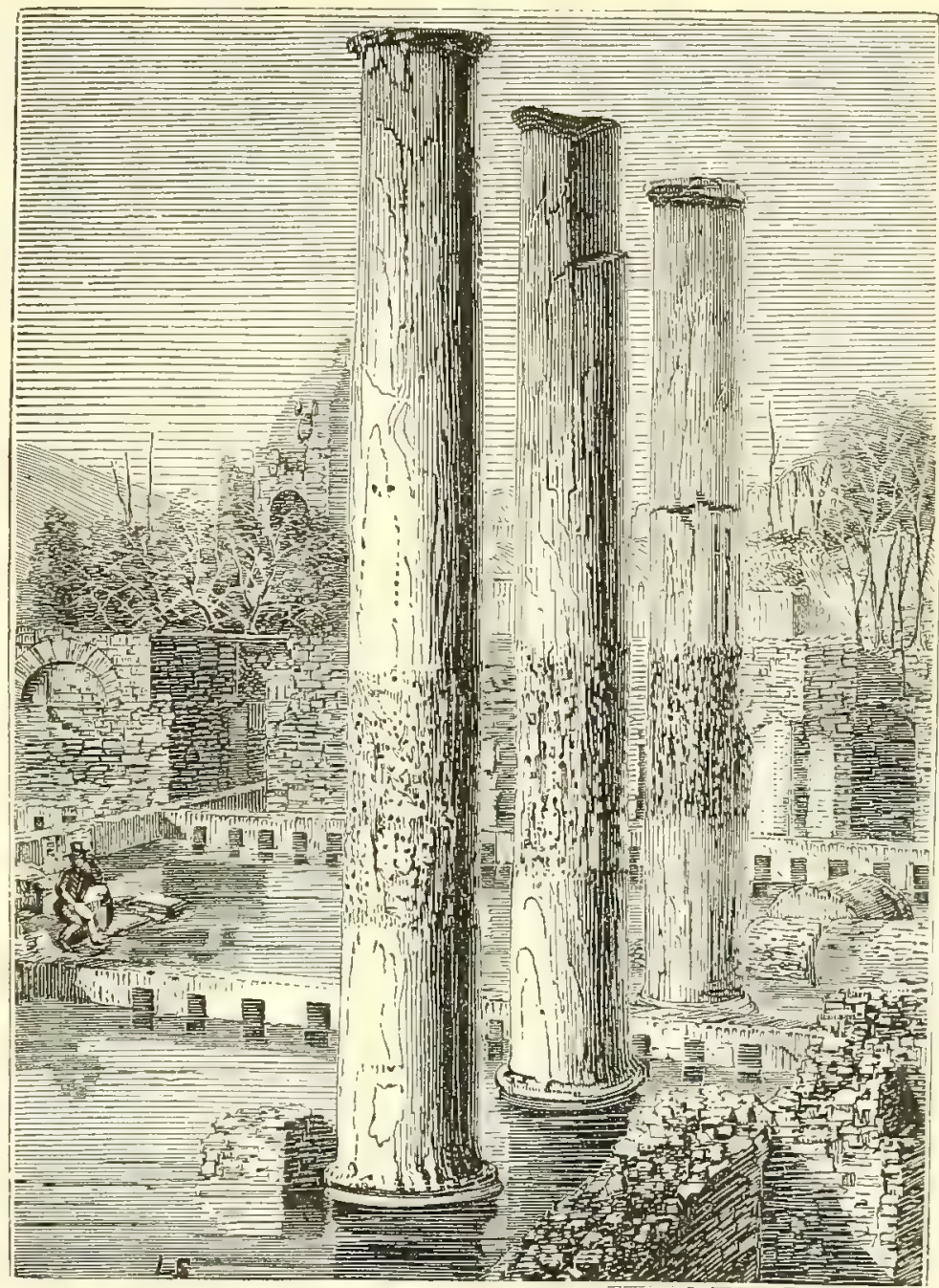

Temple of Jupiter Serapis.

Captain Fitzroy states that there was an elevation of four or five feet at Talcahuano, which was reduced by April to two or three feet. The south side of the island of Santa Maria, near by, was raised eight feet, and the north, ten feet; and beds of dead mussels were found on the rocks, ten feet above high-water mark.

The secular movements which have been observed are confined to the middle and higher temperate latitudes, and may be a continuation of the series which characterized the earlier part of the Quaternary age.

In Greenland a slow subsidence is taking place. For 600 miles from 
Disco Bay, near $69^{\circ} \mathrm{N}$., to the Firth of Igaliko, $60^{\circ} 43^{\prime}$, the coast has been sinking for four centuries past. Old buildings and islands have been submerged; and the inhabitants have had to put down new poles for their boats, the old ones standing, Lyell observes, "as silent witnesses of the change."

On the North American coast, south of Greenland, from Labrador to New Jersey, it is supposed that similar changes are going on. G. H. Cook concludes, from his observations, that a slow subsidence is in progress along the coasts of New Jersey, Long Island, and Martha's Vineyard, and has deduced, from the positions of buried stumps over large areas along the New Jersey coast, a rate of two feet a century. According to A. Gesner the land is rising at St. John, in New Brunswick; sinking at the island of Grand Manan; rising on the coast opposite, at Bathurst; sinking about the head of the Bay of Fundy, where there are regions of stumps submerged 35 feet at high tide, and about Minas Basin, in Nova Scotia, except, perhaps, on the south side.

On page 149 the reasons are given for believing that coral reefs and islands are proof of a slowly progressing subsidence, as first suggested by Darwin. On the physiographic chart, page 47 , the line CCC, extending in an easterly direction from the Pelews, divides coral islands from those not coral. Over the area north of it, to the Hawaiian Islands, all the islands are atolls, excepting the Marquesas and three or four of the Carolines. If, then, the atolls are registers of subsidence, a vast area has partaken in it, - measuring 6000 miles in length (a fourth of the earth's circumference), and 1000 to 2000 in breadth. Just south of the line there are extensive coral reefs; north of it the atolls are large, but they diminish toward the equator, and mostly disappear north of it; and, as the smaller atolls indicate the greater amount of subsidence, and the absence of islands still more, the line AA may be regarded as the axial line of this great Pacific subsidence. The amount of this subsidence may be inferred, from the soundings near some of the islands, to be at least 3000 feet. But as 200 islands have disappeared, and it is probable that some among them were at least as high as the average of existing high islands, the subsidence in some parts cannot be less than 5000 feet. This sinking probably began in the Tertiary era.

During the progress of this subsidence, or since it ceased, there have been many cases of isolated elevation. The following are some examples from the Pacific: Oahu (Hawaiian Islands), 25 feet; Elizabeth Island, Paumotu Archipelago, 80 feet; Metia or Aurora, 250 feet; Atiu, Hervey Group, 12 feet; Mangaia, 300 feet; Rurutu, 150 feet; Eua, Tonga Group, nearly 500 feet; Vavau, 500 feet; Savage Island, 100 feet; Rota and Guam, of the Ladrones, 600 feet. More than 25 others have undergone sone elevation. Off the New Guinea coast, some atolls have been raised to a height of 300 or 400 feet, and a central basin 100 feet deep, with vertical walls around, occupies the place of the old lagoon. 
Thus the earth is still undergoing changes from paroxysmal movements and prolonged oscillations. The changes, while probably more restricted than in the ages of progress, are yet the same in kind.

\section{Characteristics of Disturbed Regions and Mountains.}

\section{General Explanations.}

1. The general range of effects. - A disturbance, in geological usage, is an event in which rocks - formations of wide extent - are moved, and more or less fractured in the process. Over some great areas they have been shoved up or depressed with little variation from horizontality; and over others there have been profound flexures and faults involving thousands of feet of strata throughout regions hundreds of miles wide and thousands long. Explanations and illustrations have already been given of upturned beds, flexures, faults, and flexure-faults (page 99), and of the metamorphism and vein-making, which have attended great mountain-making movements. The object of the present chapter is to present all the various orographic phenomena in their relations as they occur combined in the structure of mountain ranges and systems of ranges, and to explain, so far as is at present possible, the origin of orographic movements and of the resulting structures.

In the first place, some facts in molecular physics of fundamental importance as regards flexures, fractures, and faultings of solids, are here briefly illustrated, and then follow descriptive examples of several mountain-structures, as a prelude to the discussion of the question of origin.

2. The flow of solids. - Solid metal and rock, when under pressure, as first illustrated by Tresca, yield through molecular movement, and may thus become compressed, drawn out, flexed, and otherwise deformed. The yielding is very much like that in a bent bag of shot, through movements in the shot. In the case of metals, ice, and rocks of even texture, the change, if slow enough, may take place without fractures. In the bending of a mass of rock or ice by gravity, molecules of one side push the adjoining, and these others throughout the mass, until the adjustment is complete. Hence the density is nowhere changed. The flow of metals is now utilized extensively in the shaping and punching of cold metal for various purposes in the arts. In experiments at the Stevens Institute, Hoboken, by Mr. David Townsend (Journal of the Franklin Institute for March, 1878), rectangular blocks of iron, accurately planed and measured (being made about 1.75 inches wide and thick, and 2.5 inches long), were punched cold through the center with a punch $\frac{7}{16}$ of an inch in diameter. The core which came out (Fig. 323) was only $\frac{11}{16}$ of an inch (instead of 1.75 inches $=\frac{28}{16}$ ) long; and yet, like the punched block, it was essentially unchanged in density. Mr. Townsend's experiments and measurements show that six tenths of the metal which had filled the hole had moved off lat- 
erally, or in the direction of the width and length of the block; and this lateral movement or flow had bulged the sides much more at bottom than

322.

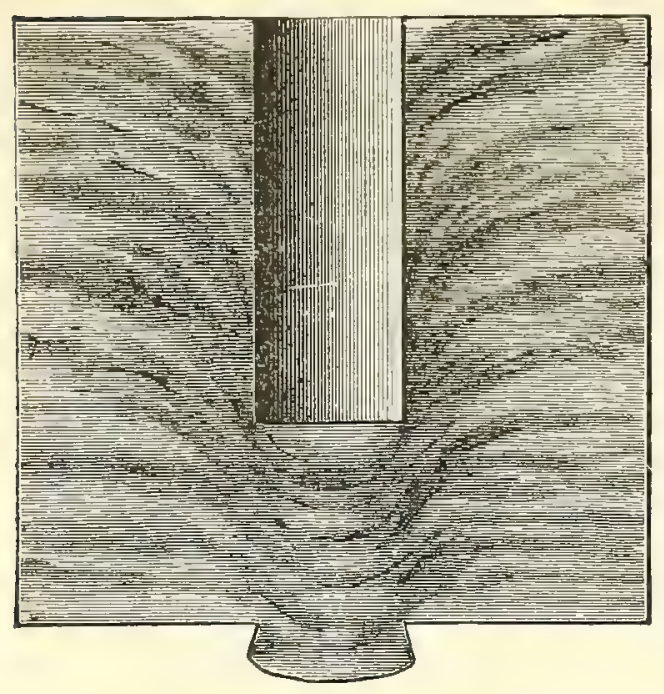

Punch at a depth of $1 \frac{1}{4}$ inches.

323.

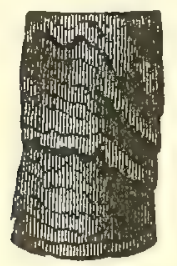

Core out. Townsend. at top, and most about the middle. At bottom the block was increased $\frac{1}{25}$ in width and $\frac{1}{50}$ in length. The block had been made of plates of iron welded together, and these were bent downward as the punch passed in, the lower ones the least; and Fig. 322 shows the appearance of the surface, after polishing and etching with acids, of a section through the middle, when the punch had entered $1 \frac{1}{4}$ inches, and the core projected an eighth of an inch.

Such facts, together with those relating to the heat developed by friction, take the mystery out of the process of flexing rocks.

3 Fractures and displacements under pressure. - The production of fractures through lateral pressure has been experimentally illustrated by Daubrée. In one of his experiments he used an oblong square prism consisting of layers of beeswax, and applied the force at the middle of the two ends after protecting

them by small blocks or plates of the same cross-section. Fig. 324 represents, half the natural size, the prism ready for the experiment. One of the results, after applying the pressure, is shown in Fig. 325 ; and another, after using a stronger pressure, in Fig. 326.

In both, a flexure becomes the course of a fracture, and also of a fault; and in 326 it is shown that the flexure-fault is not at the axis of the flexure, but beyond it, between the anticline and syneline. In Fig. 327 are shown

324.

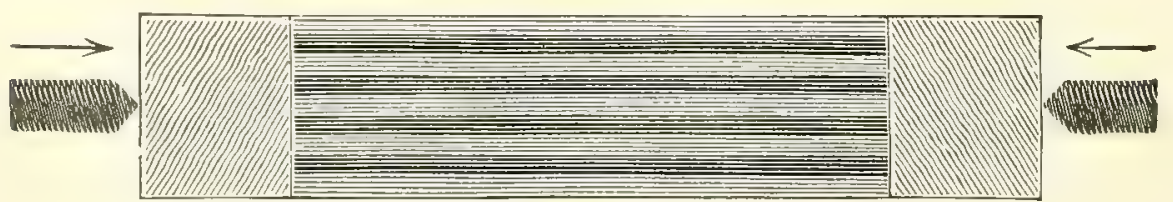

Prism made of layers of wax of different colors. $\left(x_{\frac{1}{2}}\right.$.) Daubrée.

two oblique fractures and faults, obtained in another trial. The fractures have their planes parallel as well as very oblique; and the faults were made by a shove up along the oblique surface. So the greater fractures of mountain regions usually have like obliquity as well as parallelism, and 
sometimes large displacements in the same upthrust way. The direction of dip of the plane of fracture, as the figures show, is, in the case of a synclinal

325.

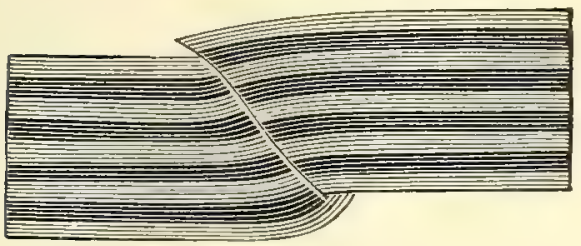

bend, the reverse of that in the anticlinal.

In subjecting to vertical pressure a square block of

326.

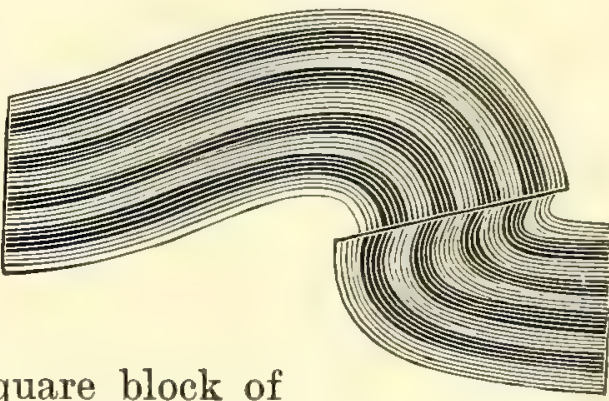
wax, having a breadth of five and a half inches and a height of about a foot, an oblique diagonal fracture was made with some

327.

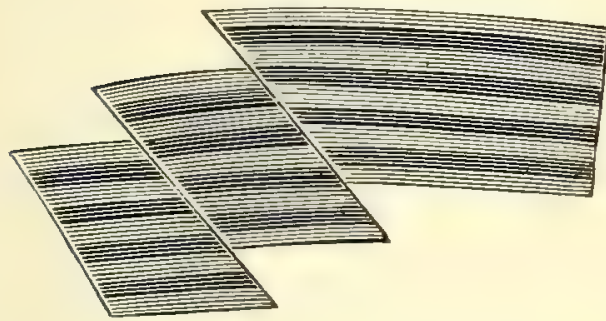
bulging of the sides; and, adjoining the fracture, as a consequence of the molecular movements in the bulging, fine rectangular cracks were produced, like a delicate network.

Cubes of hard rock under vertical pressure usually break off at the angles and edges, leaving two rounded cones with their apexes at the middle; but a tabular block of limestone was reduced by Daubrée to vertical prisms and plates.

\section{Characteristics of Some Typical Mountain Ranges.}

\section{The Appalachian Mountain Range.}

The structure of the Appalachian Mountains was first investigated by Professors W. B. and H. D. Rogers in connection with geological surveys of the States of Virginia and Pennsylvania; and their results (1842) gave many fundamental principles to orographic science.

Fig. 328, A, B, sections of part of the belt in Virginia, by H. D. Campbell, afford a general idea of the system of flexures (1893). Each represents the rocks for a breadth of about 10 miles across the range, in Rockbridge and Bath counties. Between the two sections there is an interval of about eight miles. The numbering of the formations corresponds with that on page 410 ; the limestone areas are blocked, the shales ruled, and the sandstones dotted. Farther to the southeast, in the same line, there are closely crowded overthrust flexures.

In the construction of the mountain range from New York to Alabama (1) the whole Paleozoic series of strata to the floor of crystalline Archæan rocks - in some parts 40,000 feet thick - were involved in the system of flexures; (2) the flexures are generally parallel to the axis of the mountain 
range; (3) the axis is usually nearly straight, but sometimes bends around through a large are; (4) instead of one flexure for the range, or parallel flexures of like length, there is generally a succession along the mountain region, one rising near where another ends, making overlapping series. There is no crumpling of the beds, and no long intervals of horizontal beds alternating with the flexed. Some single flexures are 80 to 100 miles long; and they vary in span from one mile or so to 20 or more. In the finer kinds of rocks flexures occur of a few inches or less, which are like wrinkles on the great rock-sheets.

(5) The flexures have rarely the ridge line horizontal; and, in adjoining flexures it often inclines in opposite directions, this being a mechanical effect in the process of warping.

Further (6), the axial plane of a flexure is seldom vertical, the opposite slopes, in a transverse section, being unlike; hence the flexures are mostly unsymmetrical, even when not overthrust flexures (page 103). Again (7), the flexures have the steeper side generally facing northwest, away from the Atlantic Ocean; at the same time they are by far the most numerous and closepressed, and most generally overthrust, in the eastem part of the range, or the side toward the ocean. The mountains have consequently a front-and-rear structure, the front side facing the ocean.

This flexing of rocks to such depths appears less incredible when it is noted $(a)$ that the strata so treated were generally those of sedimentary formations; $(b)$ that they were, for the most part, only partially consolidated, the limestones excepted; (c) that all the rocks contained much moisture, and had their cohesion diminished thereby; $(d)$ that as the movement proceeded, heat was being generated by friction, which, if low in degree, made siliceous solutions that would diminish friction by the dissolving action, and, if high, produced superheated vapor and a general softening of the flexing masses.

Again (8), great upthrust faults, with displacements 10,000 to 20,000 feet or more, exist in the region of flexed rocks, and especially where the flexures are overthrust and close pressed; and they are sometimes, if not generally, flexure-faults, with the thrust westward along the flank plane of the overthrust flexure. Professors W. B. and H. D. Rogers, in their admirable paper on the Appalachians, observe that "the passage of an inverted fold into a fault is of common occurrence," and that some flexure-faults have, "in southwestern Virginia, a length of about 100 miles." They always occur on the northwest side of the flexure, as in the following figures taken from two of their sections; and they begin, say these authors, with the thinning, or "disappearance of one or more of the groups of softened strata lying immediately to the northwest of the more massive beds." "The dislocation increases as it is followed along, until finally the lower beds (II) of the Lower Silurian are found resting directly on rocks of the Carboniferous series (X, XI)." These two sections are from the same fault, the first near its place of beginning, and the second, where the 
328.
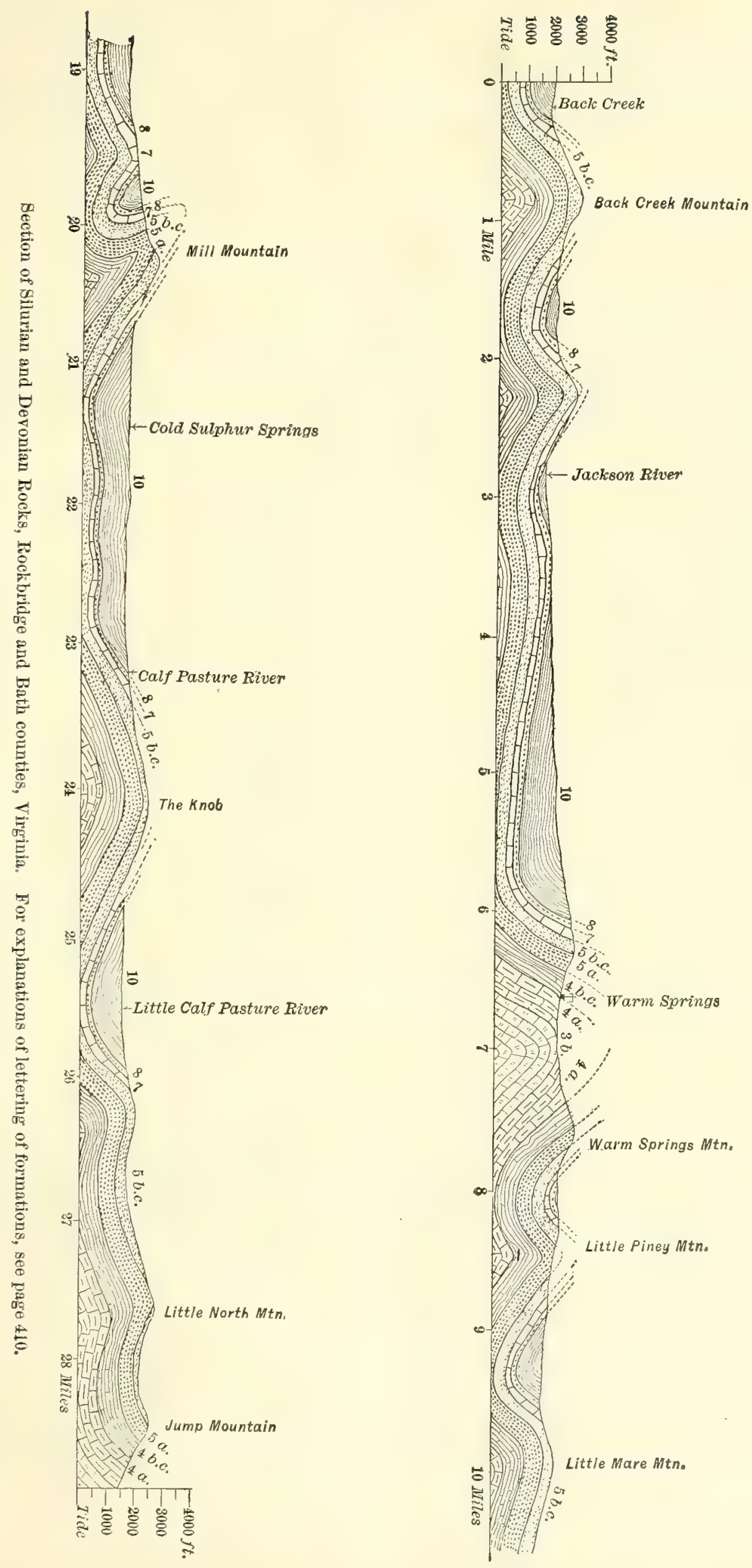
condition is nearly that just stated, the lower beds (II) being in contact with the Devonian (VIII). In the former, III and $V$ (Hutson River and Clinton shales), of the flank of the anticline, are greatly thimned down (as compared with the thickness on the other side of the flexure). To the southwest the strata successively disappear until the condition in Fig. 330

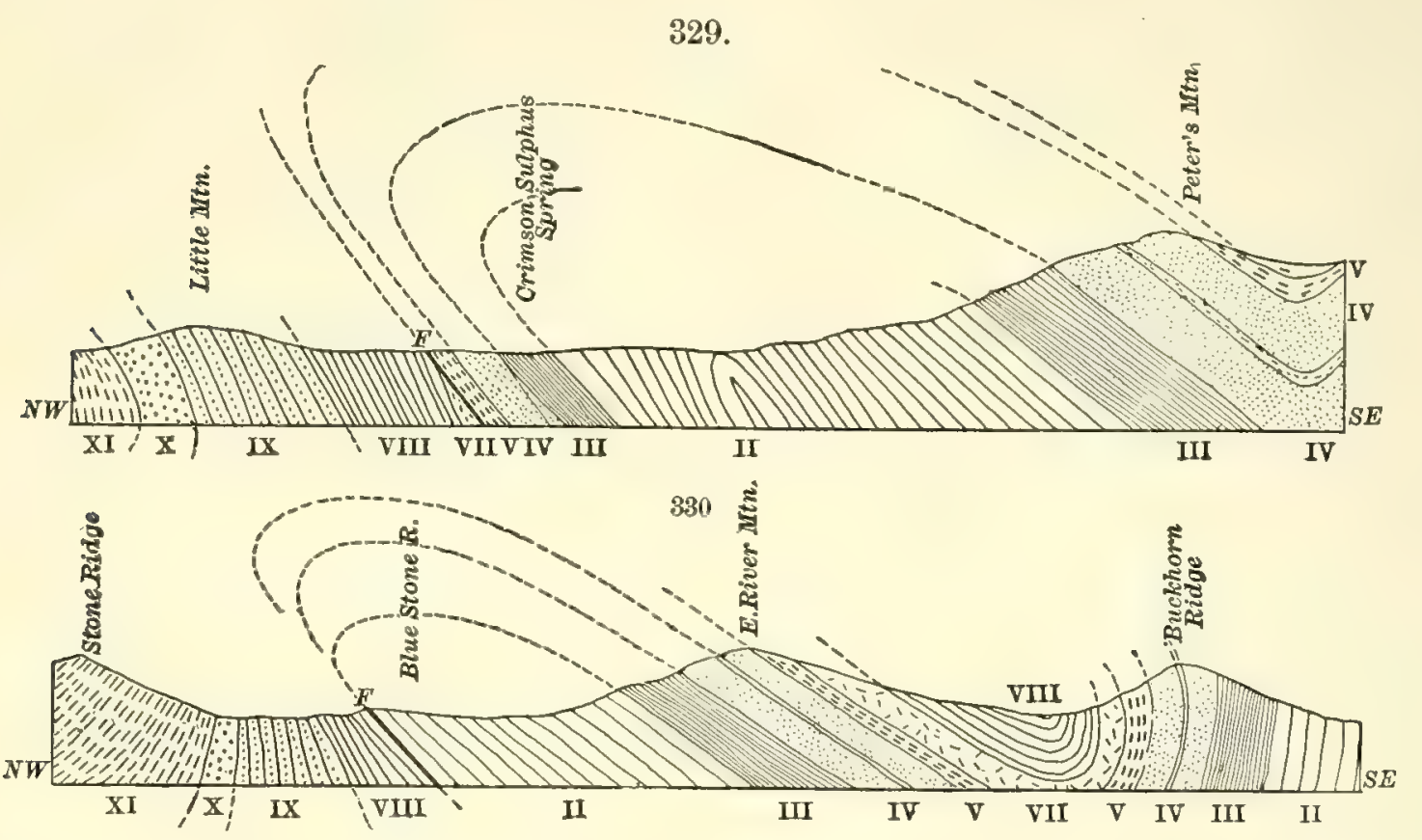

exists; and then that in which II and XI, both great limestones, are in contact. But, as they state, the ingulfed strata may, in some places along the course, be found standing in isolated knobs between the two formations, II and XI. The Professors Rogers observed, as reported by Lesley, that the lines of faults of Virginia are continuous with flexures in Pennsylvania.

Just beyond the cluster of great faults in the Appalachians comes the high plateau, or table-land, characteristic of the northwest border of the Appalachian Range. In East Tennessee it is called the Cumberland Tableland; Fig. 331, by Safford, represents it with the height proportionally

331.

N. W.

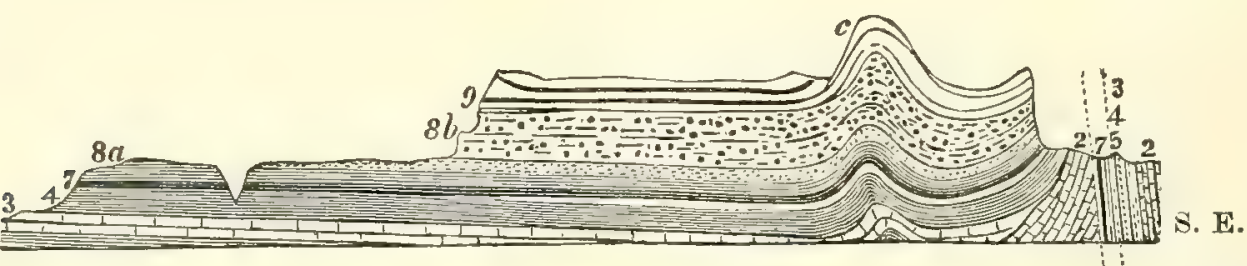

Cumberland Table-land, Tennessee; $c$, Crab Orchard Mountain; 2, Cambrian; 3, 4, Lower Silurian (Calciferous and Trenton); 5, Upper Silurian; 7, Devouian (Black shale); 8, Subcarboniferous; 9, Coal measures. Vertical scale 2000 feet $=1$ inch; horizontal, 12 miles $=1$ inch.

much exaggerated. It is 2000 feet high, and 900 to 1200 above the Great Valley of East Tennessee (the low eastern part in the figure), which is the region of the great flexures and faults reduced to a valley by denudation. 
The width is 40 miles for the higher part, and 25 to 30 for the lower western portion. Farther west is the central basin of Tennessee, a region of Lower Silurian rocks. Tennessee thus owes its grander features, its high eastern table-land, and its transverse plain beyond at a lower level, to movements attending the making of the Appalachian Mountains, and the denudation which ensued.

The Cumberland Table-land is continued northeastward through Virginia and Pennsylvania to southern New York and the Catskills; and in this northern part it is over 4000 feet high, and fronts the Hudson River Valley with precipices of nearly 2000 feet. The Great Valley of East Tennessee becomes, as the Professors Rogers observed, the Shenandoah Valley in Virginia, the Cumberland Valley in Pennsylvania, the Kittatinny of New Jersey, and the Newburg part of the Hudson River Valley in New York.

This prolongation of prominent features, orographic and denudational, gives an individual character to the Appalachian Range. Lesley's colored geological map of Pennsylvania, the first in his geological atlas of counties, illustrates well the interlocking flexures in the rocks as they pass through the state, with the great table-land region on the west and north. The facts are displayed also on his topographical map of the state, a reduced copy of which is introduced on page 730 .

(9) The making of the Appalachian Mountains went forward after the clc se of the Carbonic era, and hence the mountains stand as a fitting timeboundary to Paleozoic history. (10) During all Paleozoic time, the preparatory work of making the rocks was slow in progress. Moreover, the deposition of the 30,000 to 40,000 feet of strata took place within a gradually deepening trough, or geosyncline, the deepening so gradual that the deposition kept pace with it. The great trough had an area as long and wide as that of the future mountain range. The Paleozoic strata in it have consequently a thickness 20,000 to 25,000 feet greater than the same series of strata in Indiana and Illinois - regions outside of the geosyncline. This depth is made certain by the fact that the Carboniferous marshes nowhere lay much above the sea level when the Paleozoic series was completing.

(11) Facts indicate that the trough had some subordinate longitudinal flexures along its bottom; but still, as the diminution westward in the thickness of the beds shows, it was one trough.

The knowledge of the Appalachian facts led Professor James Hall to suggest in 1859 that a similar trough of deposition preceded the upturning in all cases of mountain-making. It was the first statement of this grand principle in orography.

\section{The Post-Triassic or Palisade System of Ranges in Eastern North America.}

The Palisade mountain system comprises eight to ten independent ranges. They occur at intervals over a region 1000 miles long, extending from Nova Scotia and Prince Edward Island on the north, southwestward to the 
northern limit of South Carolina. The runges are from 10 miles in length to about 350 miles; and their general course is closely parallel to that of the Appalachian Mountains, even to its westward bend in Pennsylvania. They overlie Archæan or Cambro-Silurian rocks. The Connecticut River Range is 120 miles long; and the "Palisade Range," extending from southern New York, on the Hudson, into Virginia, is 350 miles long. See, further, the account of the American Triassic under Historical Geology. The rocks are solely Triassic in age. The depth of the rocks of the ranges varies from 3000 to possibly 8000 feet. Facts prove that they were laid down in each case in an independent, gradually deepening geosyncline.

The strata, through the whole 1000 miles, are alike in their essentially fresh-water or brackish-water formation; in the granitoid origin of the sandstones and shales, as well as in their general system of structure.

The dip of the beds is, with rare exceptions, monoclinal, and mostly between $5^{\circ}$ and $25^{\circ}$ in angle. In the Connecticut Valley, it is $5^{\circ}$ to $25^{\circ}$ eastward. In the Palisade belt, about the same westward. In two North Carolina belts, the eastern has eastward dip, and the western, westward. Flexures are local, and of rare occurrence. The only marked one that has been reported is a large syncline in the short Richmond basin.

The rocks are much faulted. But this is not evident in large visible displacements along fractures, but in the striated or scratched surfaces over large areas, which indicate the slipping of bed on bed, and along the surfaces of the numerous small fractures; sometimes all sides of blocks, even when they are no larger than the hand, are striated.

All the Triassic areas have their lines of trap-dikes; and the association of the igneous rocks with the stratified is so intimate and so extended that the two must have had in some way a common history. The ejection of some of the trap, moreover, preceded the later depositions of sandstone. The trap-ridges, which consist of a large trap-mass, generally 200 to 300 feet thick, underlaid, and partly overlaid, by sandstone, have usually a bold palisade-like front (page 804), of which the "Palisades" on the Hudson are an example, and the name Palisade System is, therefore, an appropriate name for the system of ranges.

The facts indicate (1) a general unanimity of movement in a series of geosynclines or troughs that were wholly separated from one another in their rock-making; and (2) a disturbance that resulted almost everywhere in monoclinal uplifts of low angle, and was accompanied in most parts, now and then, or at the close, with fissure-ejections. There is hence a combination in the Palisade System of eight or ten individual mountain ranges. In the nearly total absence of flexures, the ranges differ from the Appalachian Range, while like it in the preparatory geosyncline of deposition and in the occurrence of great faults.

The Sierra Nevada Range is supposed to have been made at the close of the Jurassic, or a period later. 


\section{The Laramide Mountain System, including the Wasatch Range.}

The Laramide system of mountain ranges extends along the summit of the Rocky Mountains far northward into British America, and southward into Mexico. In British America, just north of Montana, the upturned belt lies east of the Archæan protaxis. In the United States it occupies the summit region of the mountains, between the line of the Wasatch Archæan and the Front Range or protaxis. Dr. G. M. Dawson states that, in British America, the belt of upturned rocks along the summit of the Rocky Mountains extends from Montana northwestward, with a small interruption, to the Arctic Ocean, which it reaches west of the Mackenzie delta.

The rocks involved were those of all Paleozoic and Mesozoic time, Cambrian beds making the bottom, and the Laramie, or the uppermost formation of the Cretaceous, the top. The whole thickness of the series in British America, between $50^{\circ}$ and $54^{\circ}$ N., is 34,000 feet (R. G. V. McConnell, 1887), and in the region of the Wasatch, about 31,000 feet (C. King, 1878); as nearly as has been learned this was the final depth of the geosyncline in which the deposits were accumulated.

The facts from British America, as reported by McConnell (1887) and Dawson (1886), are much like those of the Appalachian region.

The following figures, by McConnell, from a point in the range not far from the line of the Canadian Pacific Railway, show the Cretaceous rocks

332
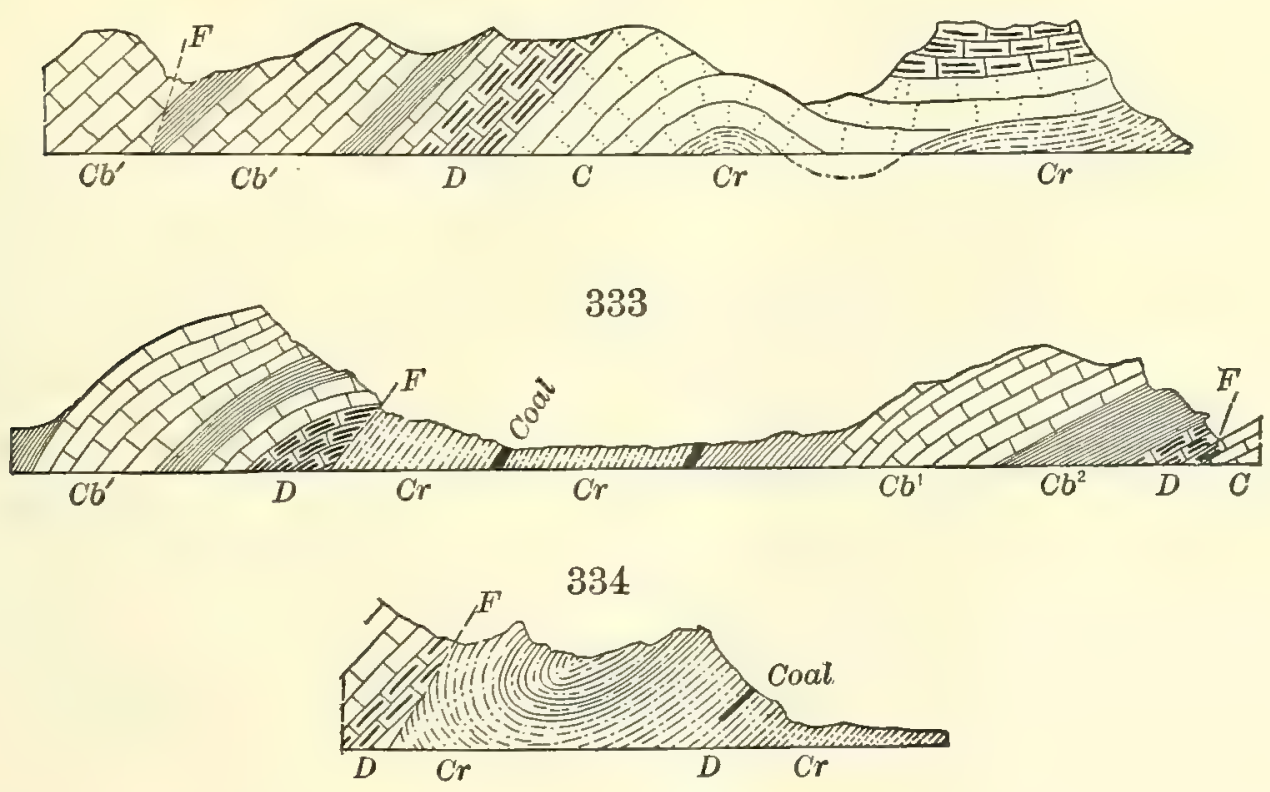

(Cr, Cr) overlaid by the Cambrian (C), or the bottom beds of the Paleozoic, almost horizontally for a width of two miles; and the describer states that the whole width of the overthrust of the Cambrian at this place is, by his estimate, seven miles. These Cambrian beds are overlaid on the west by Deronian beds (D), and by the Carboniferous $\left(\mathrm{Cb}^{\prime}, \mathrm{Cb}^{\prime}\right)$, which have a fault (F) between them. The thrust is away from the ocean, as in the Appa- 
lachian region of east Tennessee; and other flexures in this part of the region are overthrust in the same way. In the western half of the disturbed belt Silurian and Devonian strata occur, and there is one fault in which the thrust is westward. Similar facts and sections are reported by Dawson from the country just south, between the parallels of $51^{\circ}$ and $49^{\circ}$.

335.

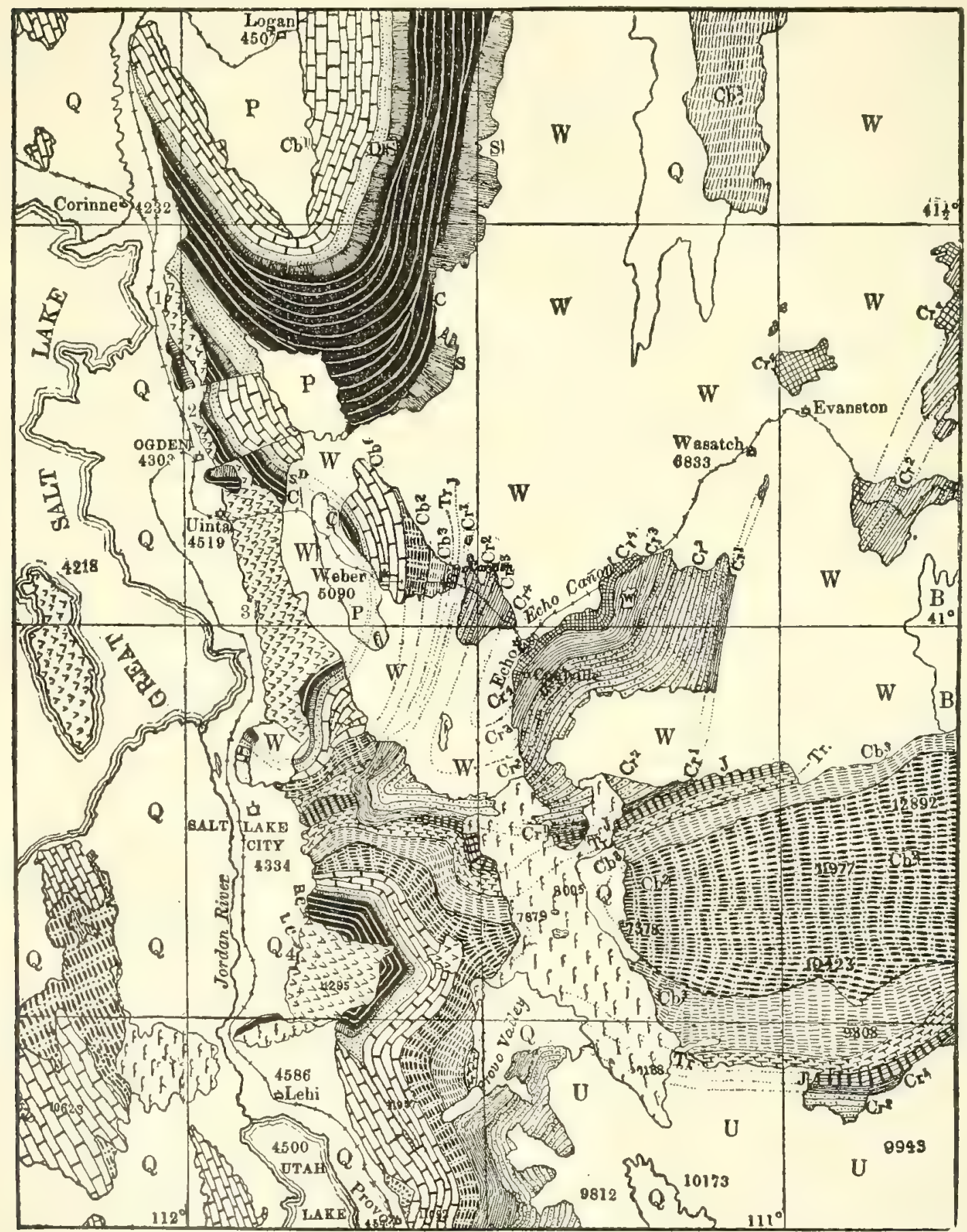

Map of the Wasatch Mountains and adjoining part of Utah. Reduced from the large colored plate of the Atlas of the Fortieth Parallel Survey.

To the south of this region, in western Wyoming, according to A. C. Peale (1877) and O. St. John (1878), there are sections similar to those 
described by McConnell and Dawson. Farther south, in Utah, stands the Wasatch Range of the same Laramide system. The accompanying map of the Wasatch is a reduction of the colored geological map in the Atlas of the Report of the Fortieth Parallel Survey under Clarence King, and the highly instructive facts here presented are from King's volume.

The Wasatch Mountains extend for more than a hundred miles along the east side of the Great Salt Lake Valley. They face west with a bold front, rising abruptly from the plain to a height of 5000 to 6000 feet, which is 10,000 to 12,000 feet above tide level. At the western foot are Ogden, Uinta, Salt Lake City, and Provo. The eastern slopes are more gradual. East of its southern half stretch away the Uinta Mountains for 150 miles, a great east-west plateau, or table-land, feebly anticlinal in structure, and 10,000 to over 13,000 feet high. Only one fourth of its length is within the limits of the map. North of the Uinta Mountains there is the great "Wasatch Eocene basin," lettered W on the map, 5000 to 7000 feet above the sea level, and south of it the "Uinta Eocene basin," nearly 10,000 feet high, lettered $\mathrm{U}$.

One remarkable feature of the Wasatch Range is its backbone of Archæan rocks along its western front, - a mountain range of Archæan origin which stood there, submerged or emerged, through all the rock-making and mountain-making of Paleozoic and Mesozoic time, the prototype and modeller of the later Wasatch Mountains. There are four Archæan areas in sight along the range, indicated on the map by the Nos. 1 to 4 , and by a covering of small v's.

Commencing at the north, Nos. 1 and 2 are short, but No. 3 has a length of 25 miles. Between No. 3 and No. 4, and nearly abreast of the Salt Lake City site, comes the great gap of 15 miles in the Archæan. South of the gap, No. 4 has a height of 11,295 feet, but just to the east of it is Clayton Peak, also Archæan, 11,889 feet.

The rocks of the Wasatch Mountains include those of the long series from the Cambrian to the Upper Cretaceous. The Cambrian areas are lettered $\mathrm{C}$; they are the black areas finely lined with white. The Carboniferous are lettered $\mathrm{Cb}\left(\mathrm{Cb}^{1}, \mathrm{Cb}^{2}, \mathrm{Cb}^{3}\right)$; the Cretaceous, $\mathrm{Cr}\left(\mathrm{Cr}^{1}, \mathrm{Cr}^{2}, \mathrm{Cr}^{3}, \mathrm{Cr}^{4}\right)$; the Silurian, $\mathrm{S}$; the Devonian, D ; the Triassic, $\mathrm{Tr}$; the Jurassic, J. The distinguishing markings of these areas will be learned by means of the lettering.

The flexures of these rocks in the structure of the Wasatch Mountains are not all the usual up-and-down flexures; there is, besides, an in-and-out series between and about the Archæan summits, as well as upon them. They may be traced by following the courses of the black Cambrian areas. Commencing at Ogden, there is first an eastward bend toward Weber, then a westward, back to the summit of the mountains; then, all the formations are gathered into an east-west trough, or syncline, which heads through the Gap, - the strata that lie in the Gap dipping from the north and south toward its center. The head, or western termination, of the bend passed the summit, disastrously to the extremity of the flexure. South of the Great Gap, the Cambrian and the rest of the formations lie around Clayton Peak 
and Archæan No. 4; and then the Subcarboniferous limestone ( $\left.\mathrm{Cb}^{1}\right)$ bends over the summit, saddle-like, with some outcropping Devonian along the middle. It is a complex system of zigzags in the great 30,000 -foot pile of rock formations. From the range of strata involved, and their thickness, it is apparent that the making of the mountain was preceded by an accumulation of strata from the top of the Cretaceous down to the Archæan; and that the strata were slowly formed in a subsiding area, or geosyncline, like the strata of the Appalachians.

The relation of the Wasatch to the Uinta Mountains is learned by following the outcropping belts from near Weber southeastward to Echo, and thence to the Uinta. The whole series of beds, from the Cambrian to the uppermost Cretaceous (the Laramie, $\mathrm{Cr}^{4}$, finely cross-lined), is here included. The dips are eastward $45^{\circ}$ or more to Echo, which has $\mathrm{Cr}^{4}$ either side, where they are $20^{\circ}$, and then northwestward to the top of the Uinta; there is hence a syncline at Echo, and an anticline at the broad Uinta summit, where the dip is $4^{\circ}$ to $5^{\circ}$ north and south ; the rock, $\mathrm{Cb}^{2}$, is the middle Carboniferous.

Over the neck between the Uinta plateau and the Wasatch Range, there is a large area of igneous rock (trachyte) lettered $f$ (the initial of fire, or the Latin focus), apparently a consequence of the enormous amount of warping in the great pile of rocks. Two other smaller trachytic areas exist to the north in the same line. The Wasatch and Uinta regions were, therefore, involved in a common system of profound movements, in which were flexures and warpings, with fractures deep enough to let out melted rock. Moreover, the country east of the Wasatch participated in the warping; for the Cretaceous beds occurring over it have high dips, and are portions of flexures, or of upturned masses, that have become isolated by the large amount of denudation which the country has undergone, the excavations being not now visible only because they became filled by the depositions of the Eocene Tertiary. The Uinta plateau, on the landward side of the Wasatch, has some relation in position to the Cumberland Table-land on the landward side of the Appalachians. The great Uinta mass, 20 by 150 miles in area, is divided by deep fractures into a few blocks which are only slightly displaced, as well illustrated by Powell. Seventy-five miles south of Great Salt Lake, where the Wasatch Mountains proper may be said to end, there commences the series of "high plateaus," which extends southward to the borders of the Colorado Cañon. This plateau region is one of great faults, of few gentle flexures, and of monoclinal uplifts, with intersecting cañons as a result of its denudation. The rocks are the same that make the Wasatch and Uinta Mountains, except that large areas are covered with igneous outflows.

The following cut (Fig. 336), by Powell, represents a portion of the plateau region north of the Colorado Cañon, with its flexures sornetimes passing into faults. The Colorado River flows in Marble Cañon. The heights look small, but the fault at W. K., the West Kaibab fault, is 2000 feet high; at E. K., the East Kaibab, 3000 feet; at T., the Toroweap fault, 700 feet; at 
H., the Hurricane fault, about 1800 feet, becoming 6000 at the Virgen River. And some of the plateaus exceed 11,000 feet in height. The long range of bluffs to the eastward, commeneing above the letter E., is that of the Echo Cliffs; and the upward bend is attributed to a fault of 3000 feet (Dutton).

Ascending the plateaus facing the Grand Cañon region, the Carboniferous rocks are left behind, and a rise made over outcrops of Permian, Triassic, Jurassic, and Cretaceous rocks. At W. K., and to the westward, the faulting is a downthrow of the block next west, while east of it the displacement is a downthrow of the block next east.

These plateaus south of the Wasatch Mountains take the place of the mountains, being results of the same post-Cretaceous disturbance.

Mr. King, in his account of the Wasatch Mountains, recognizes the principle that Archæan forms of surface determined the positions of lines of disturbance or uplift in mountain-making areas of later time, and influenced also the kind and amount of disturbance. He observes that the Archæan ridge which makes the flank and partly the crest of the Wasatch Range was the means of locating there, by mechanical resistance, the great flexures. In other parts of the same region, where there are no Archæan elevations, the disturbance resulted only in "high plateaus." He suggests that the Uinta plateau may have been thus located, although very little Archæan rock is now in sight about it.

To the eastward of Utah, through Colorado, along the Elk Mountains, the San Juan Mountains, and the Park regions farther east, there are other more or less independent ranges of contemporaneous origin, and they are continued interruptedly into the northern part of New Mexico. The narrow upturned belt at the eastern foot of the Front Range of Colorado, described, from the beds near

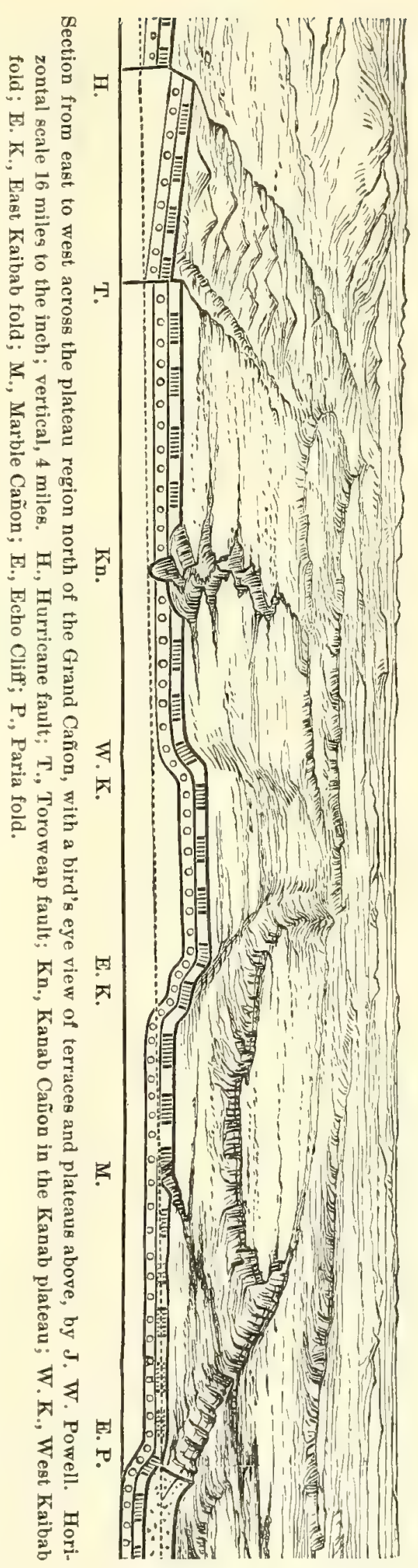


Denver, first by Marvine (1873), is of the Laramide system; and it is continued south through Huerfano County, into New Mexico along by the Raton coal-field (C. S. Hills). Still farther south upturned Cretaceous beds extend along the trans-Pecos region of western Texas, and thence into Mexico. But the limits of the several ranges and their relation to the Laramide system need further study.

The sketch in Fig. 337, from the west slope of the Elk Mountains, in Central Colorado, shows a sigmoid twist in the stratification of the rocks, the highest in the series being the Cretaceous; the warping of the strata is strikingly exhibited. W. H. Holmes has sections of flexures and flexure faults of the Elk Mountains in the Hayden Expedition Report for 1874, two of which are closely like the form obtained by Daubrée in his experiments (Fig. 326, page 351).

337.

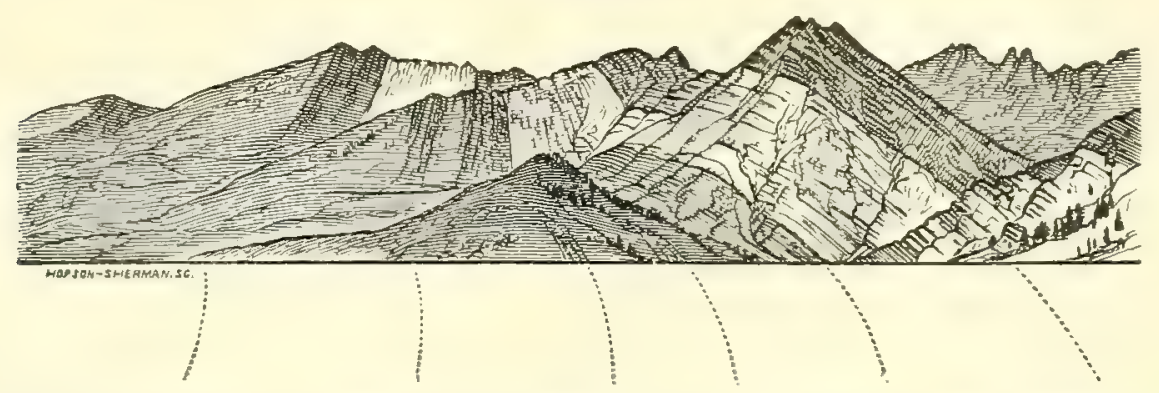

Upturned strata of the west slope of the Elk Mountains, Colorado. The light-sbaded stratum, Jura-Trias; that to the right of it, Carboniferous; that to the left, Cretaceous. Hayden's Report.

Igneous ejections attended the mountain-making in many parts of the upturned region, from Wyoming southward, and some voleanoes may date from this epoch.

\section{Tertiary Orographic Movements along the Pacific Mountain border.}

1. The great geanticline. - At the close of the Cretaceous period the latest beds lay at or near the sea level; and after the making of the Laramide mountain-chain the region was still but little above this level. During the Tertiary era following, especially after the Miocene period, a gradual elevation of the mountain region went forward; and now, as the result, the same Cretaceous strata in some parts of Colorado are 10,000 to 11,000 feet above the sea. From this level the height slowly diminishes to 4000 feet and less near the Arctic coast and to twice this in Mexico.

The region thus placed these thousands of feet above the sea level probably included the whole of the Pacific mountain border, from the line of the Mississippi Valley to the Pacific coast line, and outside of this line for one or more scores of miles. The vast geanticline was made without corresponding flexures of the rocks; there were only minor local bendings, upturnings, and faults. It was a very slow movement upward, continuing probably into the Quaternary. That it made little progress in Eocene time is proved by 
the existence during this period of large freshwater lakes over the summit of the mountain region; for much rise would have made slopes that would have drained the lakes (Hayden). The Wasatch and Uinta Eocene basins of Utah and Wyoming, lettered with W's and $U$ 's on the map (Fig. 335), were two of these lakes. Miocene lake basins, farther to the east, show that even in Miocene time the progress was slow.

Contemporaneously, similar movements were in progress over the other continents : along the Andes, affecting half, at least, of South America; the Pyrenees, Carpathian Alps and a large part of Europe; the Himalayas and much of Asia.

2. The Rocky Mountain geosynclines. - The geanticline, above described, had made little progress when local geosynclines, or subsidences, commenced over the summit region of the mountains. The areas of the fresh-water lakes, referred to above, were the sinking areas; and the sinking went forward, and concurrent deposition of beds, until the troughs contained strata of Eocene Tertiary 8000 to 10,000 feet in thickness - the earlier half in the Wasatch epoch and the later in the Green River. After these Eocene basins ceased to subside, more eastern Miocene and Pliocene geosynclines were formed.

Moreover, an epoch of upturning and plicating took place, both after the laying down of the Wasatch beds and of the Green River beds; and of upturning, in some places, after the close of the Miocene depositions. These were local disturbances apparently quite independent of the great geanticlinal movement, which was also in progress.

Igneous eruptions. - During these Tertiary movements the greatest of igneous ejections occurred over the Rocky Mountain region from its summit westward. It is supposed that a large part of the volcanoes of the world had their birth at the close of the Cretaceous and during the Tertiary era.

3. Faults in the Great Basin and elsewhere. - The Great Basin has many bare ridges, 3000 to 5000 feet above their bases, standing in the great area of lakes and alluvium-like islands in a sea. These ridges trend northward.

There are outcropping crystalline rocks in some of the ridges, but the rocks, according to King, are mostly Paleozoic, except west of the meridian of $117 \frac{1}{2}^{\circ} \mathrm{W}$., within 100 miles of the Sierra Nevada, where Triassic and Jurassic rocks occur. The beds of the ridges are more or less upturned, often in great anticlines or synclines, or elsewhere in simple monoclines; but the island-like isolation of the ridges prevents a study of their stratigraphic relations. King suggested that the more western of the ridges were perhaps part of the Sierra system, which dates from the beginning of the Cretaceous period, or the close of the Lower Cretaceous; and that the more eastern were perhaps post-Carboniferous in epoch of disturbance.

Among the Basin Ranges, according to King, great anticlines characterize the Agui Range, the Promontory, Gosiute, Egan, Peoquop, and Toyabe ranges; the Humboldt Range, although having a nucleal axis of Archæan; the Piñon Range, in which the anti- 
cline is stated to be a magnificent arch of Cambrian, Silurian, and Devonian; the Little Elko, Cortez, Shoshone, Pah-Ute, and other ranges. 'The same flexed condition of the beds is mentioned by I. C. Russell as existing in the ranges of the Oregon part of the Great Basin.

The ranges of the Great Basin have many faults as well as flexures, as described by Gilbert in 1876; and these faults are generally downthrow faults. The following are two of his figures; they illustrate two ridges made up of blocks displaced as described. The dip and the downthrow faults are in opposite directions.

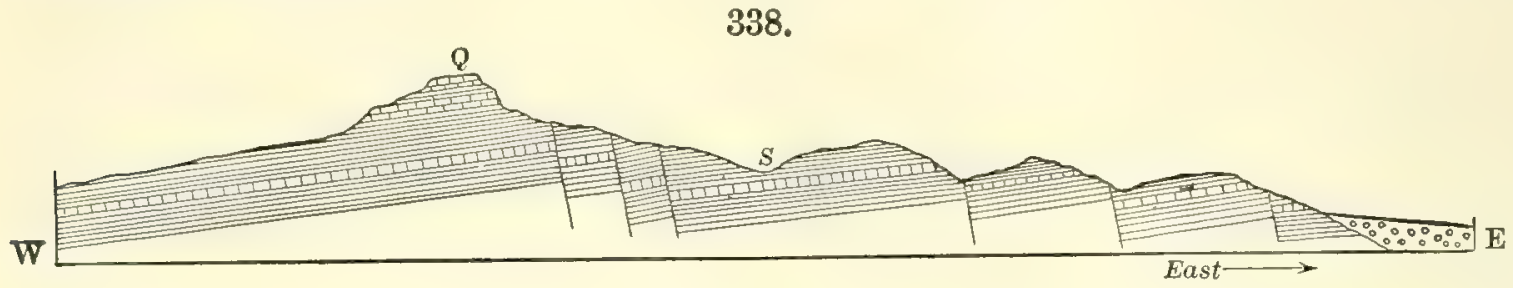

339.

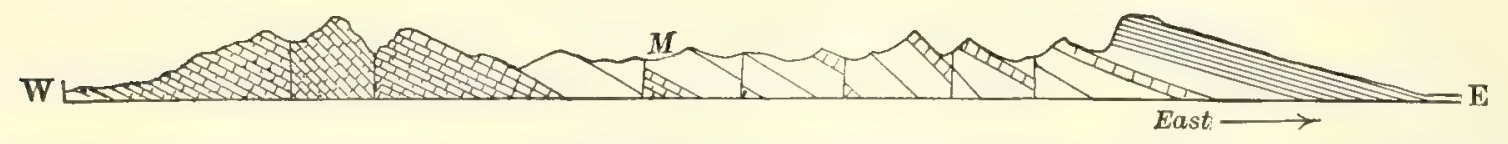

Fig. 338, section of Pahranagat Range at Silver Cañon, southern Nevada, scale $\overline{6} \frac{1}{0 \%}$. Fig. 339, section of Timpahute Range, west of the Pahranagat, scale $\frac{1}{2} \frac{1}{00}$. Gilbert, "76.

Gilbert, in view of the great displacements by nearly vertical and largely downthrow faults, designated the system of mountain-forming movements the "Great Basin System." He shows that the displacements are along old fault planes, and also along new planes of fracture made in the course of the Tertiary era, and later.

Great displacements along old and new fault planes have been shown to have taken place also in the high plateaus of Utah and in the Uinta Mountains, others in the Wasatch, and still others in the Sierra Nevada, which are referred to the Great Basin System. The fact of such movements extending into recent time has been urged by Powell, Gilbert, Russell, Le Conte, Diller, and others.

The ridges of the Great Basin, made thus of upturned and plicated rocks, have been assumed to be each limited by faults, and to have undergone up and down movements, and variously tilting displacements, and thus to have become in effect " monoclinal orographic blocks" in the "Basin System," - each block making by itself a monoclinal mountain, even when not so in its bedding (Russell, 1885). In the ideal sections made to illustrate this hypothesis, the wide intervals of alluvium (that is, of buried and concealed rock) are represented as underlaid each by a block at lower level, or by the subterranean continuance of one sloping ridge to the next; and the actual flexures or lines of bedding have been omitted, and monoclinal lines substituted. They are intended to exhibit the supposed structure. But until the stratigraphy of the ridges of the whole basin shall have been studied and sections of them represented, and the relations of each ridge to those lying on the same northward or northwestward line of strike shall have been thoroughly investigated, general stratigraphic conclusions cannot be safely drawn. 


\section{Foreign Examples of Tertiary Mountain-making.}

1. The Alps. - Among foreign mountain regions those of the Jura Mountains and the Alps - the two combined in system - have been most carefully studied. The former are much like the Appalachians in flexures, as first pointed out by H. D. Rogers. The Alps have far greater complexity. The able work of Heim on mountain-making, based on his study of the Toedi-Windgællen group, gives a full exhibition of the structure in that part of the Alps, and lays down many principles in orography. The section on page 102, showing overturn folds, is reduced from one of Heim's sections. One of the overthrust folds in the region has put the beds upside down over an area of 450 square miles. 50,000 feet of formations of the Jurassic, Cretaceous, Eocene Tertiary and Miocene Tertiary, were upturned at the close of the Miocene period.

Another remarkable section of overturn flexures in the Alps, worked out by Renevier, is represented in Fig. 340. The Dent de Morcles stands between

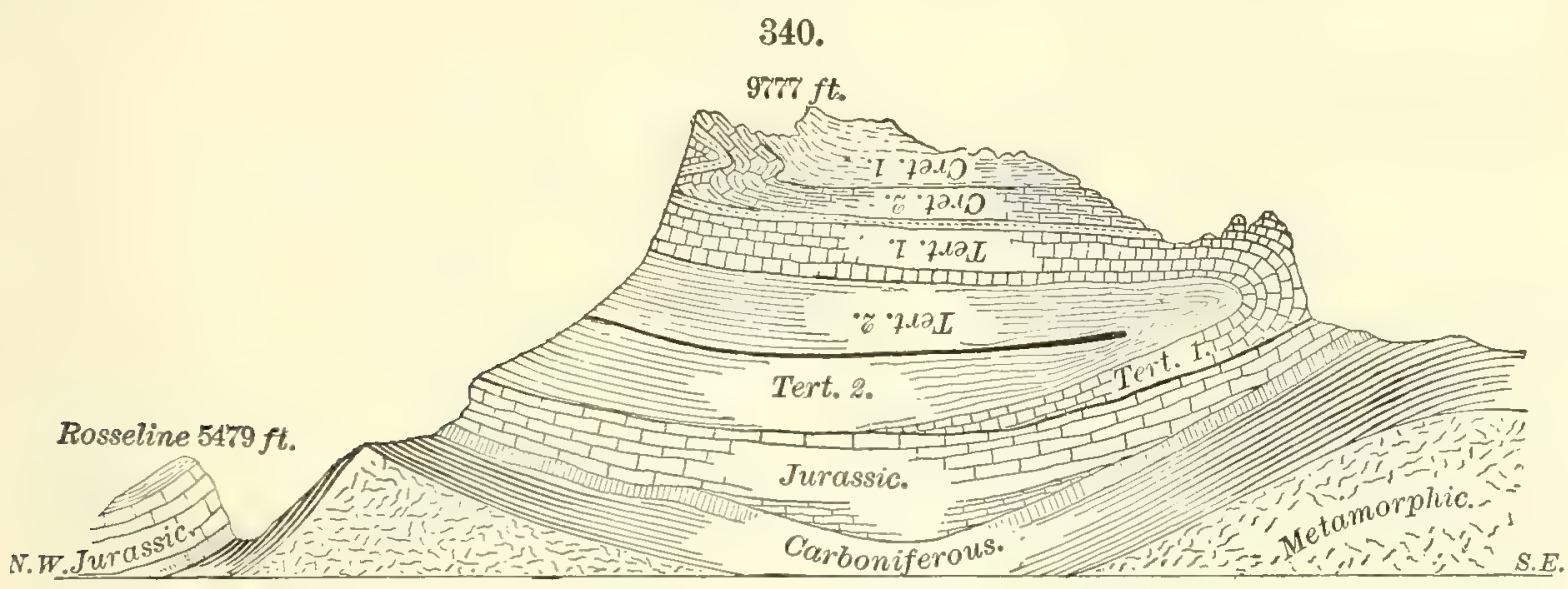

Profile of the Dent de Morcles. Tert. 1, Nummulitic Eocene Tertiary ; Tert. 2, Upper Eocene Tertiary, called the Flysch; Cret. 1, the Neocomian or Lower Cletaceous; Cret. 2, the Urgonian, a higher division of the Lower Cretaceous. Scale, $\frac{1}{5000}$ for height and length. Renevier.

Martigny and Bex on the east side of the Rhone. Cretaceous and Tertiary strata, making the top of the mountain, here lie upside down on Tertiary and older formations. One of the Tertiary formations, the Upper, is folded over on itself. The overturn is indicated in the figure by the lettering. The Cretaceous strata below the plane of the overturn are absent; but above it there are two strata of the Lower Cretaceous. It is probable that Jurassic beds once made the top, and have been removed by denudation.

As stated above, the Jura Mountains, northwest of the Alps, are part of the Alps mountain system. The following section (Fig. 341) illustrates the fact that the flexures are overthrust in a northwest direction, like that in the Dent de Morcles, as if the thrust-force came from the southeastward. This direction is not, like that in the case of the Appalachians, from the ocean, but toward it.

The thickening or the expanding of the beds in the summit of a steep 
flexure, and the thinning, even to removal, of those of the flanks in closepressed overthrust flexures, are two important points well illustrated in Figs. 118 and 119 on page 110, and in Fig. 120, representing the resulting

341.

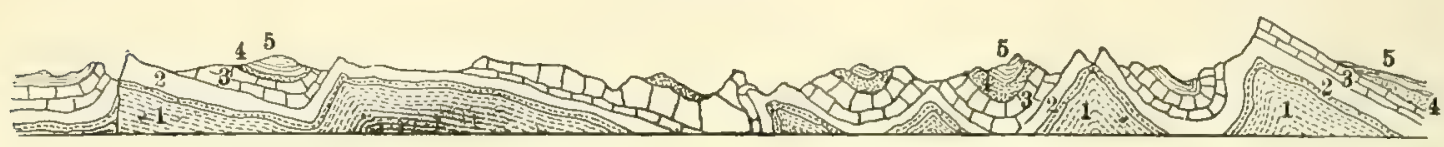

Section of the Jura Mountains, along a line extending northwestward from Geneva through St. Claude to Chaux du Dombiel. 1, Trias; 2, Lower Jurassic; 3, Upper Jurassic ; 4, Cretaceous ; 5, Tertiary. Scale, $\frac{1}{250000 .}$ P. Choffat, in Heim's Mech. Geb.

flexure-fault. Fig. 342 has a still greater displacement along the plane between the anticline and syncline, with a complete separation of the originally continuous beds, as the numbers on them show. This thinning

342.

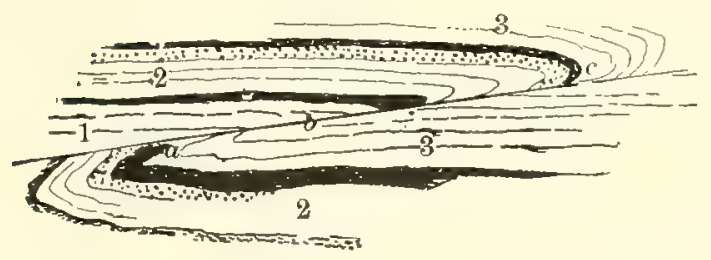

A flexure-fault from the Alps. Heim. and faulting are due to the friction between the overlying and underlying flexures during the overthrust movement. The facts teach that a regular unfaulted overturn flexure, like that represented in the part to the right of Fig. 91 (6), on page 103, is only an ideal form.

The Alps had been the scene of earlier mountain-making after both the Archæan and Carbonic eras. The chain of the Alps includes, therefore, (1) Archæan, (2), post-Carbonic, (3) post-Miocene ranges; and the Juras belong with the last in time. The proof that an upturning took place after the Carboniferous or Permian is shown in Fig. 340; the Jurassic beds (which include, at bottom, the Lias) rest unconformably on the Carboniferous, evincing that a time of upturning had intervened. In the Oriental Alps, the great upturning was post-Cretaceous instead of post-Miocene.

343.

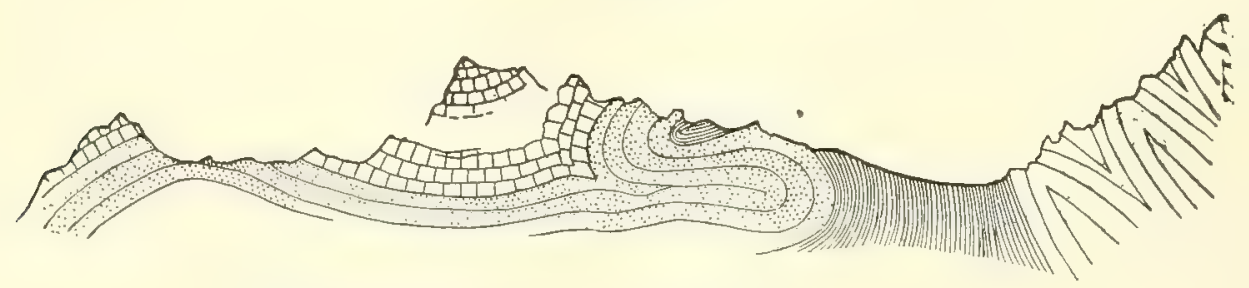

Post-Nummulitic upturning in the Himalayas. La Fouche.

2. Post-Nummulitic upturning in the Himalayan Range. - In the Upper Indus Valley, Middle Tibet, in the district of Zanskar, south of the Indus, Nummulitic limestone (Eocene Tertiary) constitutes the summit of a peak of the Singala, having a height of 19,000 feet. In the section (Fig. 343) the blocked area is the Nummulitic limestone, a blackish fetid rock; the 
folded dotted layers below are quartzytes, and the beds below, shales. (La Fouche, India Survey, 1888.)

3. Aretic upturned rocks. - Flexures as a result of lateral pressure occur in the Aretic regions. On Grinnell Land, from Scoresby Bay to Cape Cresswell, in lat. $82^{\circ} 40^{\prime} \mathrm{N}$., slates, limestone, grits, and quartzytes are in sharp folds, and often vertical, with the strike E.N.E. - Feilden \& De Rance on the results of the Sir George Nares Expedition in 1875-76.

For other examples of orogenic movements see pages 534, 808-812, under Historical Geology.

Conclusion. - Orographic work has been carried forward, in general, by means of flexures, fractures, and slips or faultings along fractures; and the faults have largely been flexure-faults, - that is, have been made in connection with the production of more or less pronounced flexures.

\section{Subordinate Effects attending Orographic Movements.}

Among subordinate orographic effects are first, those incidental to the friction, and the heat thereby produced, namely: (1) part of metamorphism, (2) of vein-making, and (3) of volcanic phenomena - subjects already considered.

Second, those incidental to the pressure: these are (4) variations in the characters of flexures; (5) distortions of beds and of fossils; (6) slaty cleavage or foliation; (7) joints.

Third, (8) earthquakes.

\section{Effects Incidental to the Pressure.}

1. Variations in flexures. - The characteristics of flexures have already been illustrated and explained (page 101). The pressure producing them encounters unequal resistance from inequality of mass in the pile of strata along the axis of the area of disturbance; from unequal consolidation, or firmness, or rigidity, in the beds; and also from friction against the floor of rock beneath. For these reasons flexures of the ordinary kind always have the ridge-line inclined, and are irregularly distributed along an area of disturbance.

The Wasatch Mountains (Fig. 335) illustrate the influence, on the flexures, of the floor of rock underneath the moving strata, and show that a flexure may be made with its axis in the line of the pressure and be thrust forward end foremost.

The minor flexing or wrinkling of beds, not uncommon in the fine slaty rocks and schists, is often occasioned by unequal yielding to pressure in the beds. unequal rigidity, unequal contraction; and it may also come from feeble oscillations in the action of the moving force, and from the action of gravity on the highly upturned or vertical beds.

2. Distortions of beds and their fossils. - The beds subjected to the enormous pressure were more or less yielding. Argillaceous strata are soft DANA'S MANUAL - 24 
and become compressed in the direction of the pressure, and extended at right angles to it; and other earthy beds have suffered more or less in a like way. But strata of quartz sands, not firmly cemented, have accommodated themselves to the pressure in part by rearrangements of the grains; and those of limestone, and hard quartzyte, brittle rocks, mostly by fracturing, displacement, and recementation.

The distortions of fossils vary according to the relation in position between the planes of bedding or cleavage of the rock, and the axial plane at right angles, or nearly so, to the direction of pressure. The inequalities in the pressure and in the varying resistances to motion were a cause of a warping of the beds on a large scale, which had its effects. Hence stretchings, slippings, and contractions of fossils are common in such beds.

Some examples are shown in the following figures from a paper by D. Sharpe (1847, Q. J. G. Soc.), illustrating cases observed by him in a slate rock in Wales. They repre-

344.

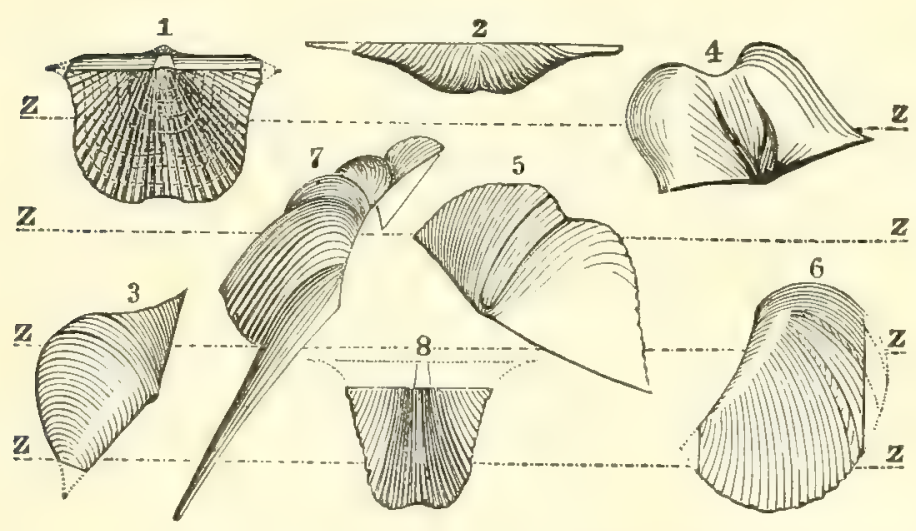
sent two species of shells, the Spirifer disjunctus (Nos. 1 to 4 ) and the Spirifer giganteus (Nos. 5 to 8). No. 1 is the natural form of S. disjunctus; the others are distorted. The lines $z z$ show the lines of cleavage in the slate: 2 lay in the rock inclined $60^{\circ}$ to the planes of cleavage, and is shortened one half ; 3 lay obliquely at an angle of $10^{\circ}$ or $15^{\circ}$, and shortened above the middle and lengthened below it; 4 is a cast, the upper part pressed beneath that shown, while the lower is much drawn out; 5 is like 3 , the angle with the cleavage-plane being less than $5^{\circ}$, and the lower part has lost its plications by the pressure and extension; 6 has a similar angle to the cleavage-plane, but a different position; 7 intersects the cleavage-plane at only $1^{\circ}$, and its lower part is very much elongated. Compression, a sliding of the rock at the cleavageplanes, and more especially a spreading of the rock itself under the pressure, are the causes which have produced these distortions. All fossils are liable to become similarly misshapen under the same conditions.

3. Foliation, slaty structure. - Roofing slates exemplify cleavage-structure, or foliation. They are most common on the outskirts of regions of disturbance. Slaty cleavage often graduates into the foliated structure of hydromica and mica schists. The fact that slaty structure is not coincident with the bedding-planes was explained by Sedgwick in 1835, from observations in Wales. Sorby first pointed out (1849) that the structure was due to the forcing of all flattened and linear particles into parallel planes, approximately perpendicular to the pressure; and that all air-cavities and particles of moisture are flattened likewise. He sustained his conclusions by microscopic examinations, and by subjecting to pressure clay and scales of oxide of iron. Tyndall rendered beeswax, clay, and other substances, laminated 
by simple pressure; and later Daubrée, who experimented with clay and scales of mica, obtained a perfect schistose structure. The rolling and hammering of metals result in a laminated texture, which fracturing or acids may reveal, when not otherwise visible; and several fine examples are figured by Daubrée in his excellent work on Experimental Geology.

Mountain-making was going forward, and the work done was therefore on a large scale, producing at one effort slaty structure over areas of hundreds of square miles, with great uniformity of direction and high angle of pitch. Sedgwick recognized the approximate coincidence of the strike of the slates with the strike of the beds, or rather, as Professor Phillips stated it, with the direction of the main axis of elevation. The uniformity of product and evenness of surface are a consequence of the fineness and evenness of grains of the original argillaceous formation, and the regularity of the long-continued pressure; but partly also of the moderate degree of heat during the action of the pressure.

Further: pressure has been proved to have produced a foliated, and even a schistose, structure in the granite-like rock, of igneous origin, called granulyte, and also in augitic and other igneous rocks.

A slaty formation often contains fossils, and these indicate, to some extent, the degree of compression and distortion which the beds containing them underwent under the pressure. The fossils in Fig. 344 are from a paper on slaty cleavage. This subject has been treated mathematically by Professor Haughton $(1846,1857)$; and more recently by A. Harker (British Association, 1885).

Slaty cleavage, or that characterizing roofing slates, passes gradually into the foliation of hydromica schist and mica schist, and thence into that of gneiss and gneissoid granite, suggesting that the latter may be due in these rocks to pressure. This has been confirmed by experiment and observation. But geological observation is required to settle any doubts that arise, rather than the microscope. In general, the foliation of mica schist and gneiss is not a result of pressure, but, on the contrary, of the original bedding of the formation. The evidence of this often appears in the occurrence of large variations in strike and dip in the planes of foliation, instead of the high angle and evenness characterizing slates; in flexures of the sheets of rock, anticlinal or synclinal; and in alternations of the sheets with those of limestone or other kinds of rock, such alternations in connection with low dips or flexures being good evidence that the sheets are true beds. Only the finer kinds of metamorphic rocks - argillyte and hydromica schist - often lose their bedding by the substitution of the cleavage structure through pressure.

4. Joints. - Joints in rocks (see page 111) have various methods of origin. They are in part due to slow-acting pressure on the outskirts of a region of disturbance. The pressure may act with little or no warping of the beds. That this is often the case is indicated by the general parallelism in the joints. But in other cases warping or torsion is strongly marked, as Daubrée has shown. Daubrée has illustrated the effects of torsion on the courses of joints by subjecting plates of ice to the action. He obtained, as one of his results, with a plate nearly a yard long, the fractures shown on a much reduced scale in Fig. 345 . Fig. 346 shows a portion of one of the plates one fourth of the natural size. (It is from a photograph, and hence 
the reflections from the surfaces of fracture gire a false appearance of ridges along the fractures.) Daubrée draws attention to (1) the approximate parallelism of the lines, and yet their slight divergence; (2) the crossing of one set of lines by another nearly at right angles, anti-parallels, as he calls them; (3) the fact that the lines are in groups; (4) the

345.

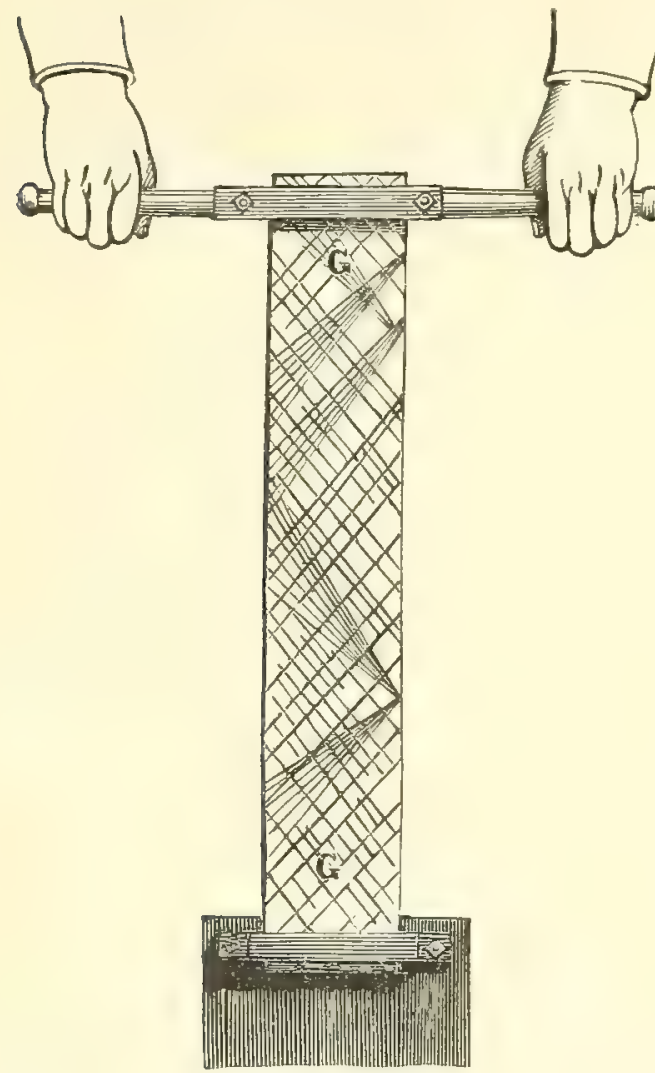

Lines of fracture produced in a plate of ice ( $G G)$ by slight torsion. $\left(x \frac{1}{12} \cdot\right)$ fact that joints may be an instantaneous effect; (5) the very important fact that the force producing the joints did not act at right angles to either set, but at the extremity of a bisectrix to the angle of intersection of the two sets; and (6) the fact that the slower the action of the force and the larger the plates, the nearer the approach to parallelism between the lines in each set. Fractures made by torsion might be left open when those from direct pressure would remain closed. Other instructive figures are given in his work on Experimen-

346.

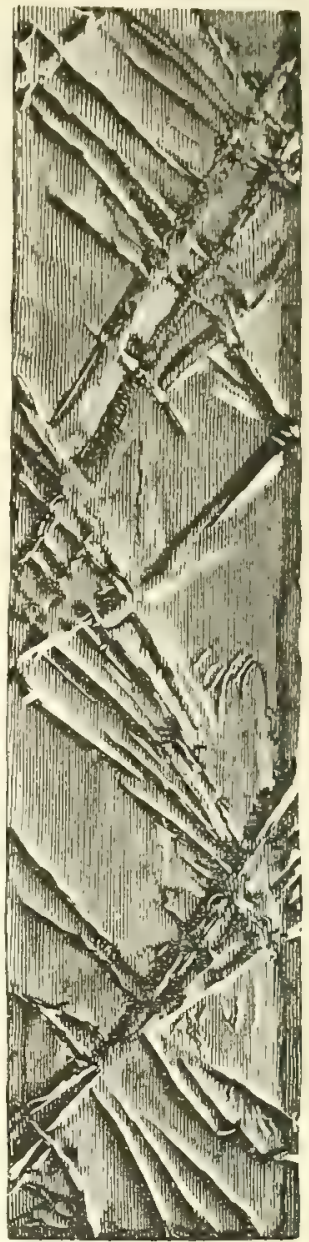

Portion of a plate of ice showing its fractures $\left(\times \frac{1}{4}\right)$. From a photograph.

tal Geology. Joints may also be due to the vibrations of earthquakes (Crosby), and to changes of temperature (pages 260, 264).

\section{Earthquakes.}

An earthquake is a series of vibrations begun in some region of local disturbance in the earth's crust, and propagated upward and outward from this place as a center. Slight tremors may be produced by falls of large rockmasses, where undermining has been carried on. But true earthquakes come, for the most part at least, from one or the other of the following sources of disturbance :-

(1) Vapors suddenly produced, causing ruptures and friction; or, commonly, (2) sudden movements or slips along old or new fractures.

Earthquakes due to the former of these methods are common about volcanoes. At the Hawaiian Islands, shakings that are destructive over the island of Hawaii at the moment of some of the more violent eruptions do 
not often affect the island of Oahu, a depth of 500 fathoms of water, the least depth between the two islands, being sufficient to stop off the vibrations. Milne states that Japan, a country noted for volcanoes, averages, some years, an earthquake a day; and that in two years, in north Japan, 154 out of 387 shook an area of less than 50 miles, and a few of the larger shocks, an area of about 150 miles.

Earthquakes of the second mode of origin may occur in all regions, volcanic or not. They have their origin mostly in the vicinity of mountain regions where old fractures most abound. The vibrations may be begun in a slip of a few inches, or feet, but when there has been a succession of slips, up and up for 10,000 feet and more, as in the faults of the Appalachians, earthquakes of inconceivable violence must have resulted.

Earthquake vibrations have been supposed to be due to wave-like movements in the interior liquid mass of the globe, and Professor A. Perrey of Dijon concluded that the greatest number of earthquakes occurred at the season of the syzygies in each lunar month, synchronous with the tides in the ocean. But if the earth is solid throughout, the facts have another explanation.

The observations of Professor W. H. Niles on the gneiss of a quarry at Monson, Mass., show that even the solid rocks are in some places under a strain; for he states that bendings, sudden fractures, and expansions of the rock often take place; masses, before their ends are detached, become bent upward at middle; and one mass, 354 feet long, 11 wide, and 3 thick, was an inch and a half longer after it was detached than before, showing a strain which was greatest in a direction from north to south - an effect due to compression by the pressure the rocks bad been subjected to, and a consequent expansion in a transverse direction. All are familiar with the crackling sounds oceurring at intervals in a board floor of a house, arising from change of temperature, especially in winter in a room that is heated only during the day; and with the more common sounds of similar character from the jointed metallic pipe of a stove or furnace, given out after a fire is first made, or during its decline. In each case, there is pressure or tension, accumulating for a while from contraction or expansion, which relieves itself, finally, by a movement or slip at some point, though too slight a one to be perceived; and the action and effects are quite analogous to those connected with the lighter kind of earthquakes.

The earthquake of Lisbon, in 1755 , which threw down the greater part of the city, and in six minutes caused the death of 60,000 persons, disturbed an immense area, it being felt at Algiers and Fez as severely as in Spain and Portugal, in the Alps, Great Britain, on the Baltic, and in northern Germany. The effects from sea-waves were of wide extent, but such waves may be propagated across an ocean from the vibrations of a coast region.

An earthquake on the 4 th of January, 1843, reported upon by Professor H. D. Rogers (1843), "was felt from the seacoast of Georgia and South Carolina to and beyond the western frontier military posts, and from the latitude of Natchez to that of Iowa, a distance in each direction of about 800 miles; and there are reasons," Professor Rogers adds, "for believing that its actual extent was much greater. Its course was from N.N.W. to S.S.E., and its rate of progress about 2800 to 3000 feet a second, and equable in rate.

The Charleston (S.C.) earthquake of August 31, 1886, which threw down many buildings in the city, was felt from the Carolina coast, Georgia, and central Florida, northward to southern New England, and across New York to Ontario in Canada, and westward to eastern Louisiana, Arkansas, Missouri, and Iowa, an area 800 miles wide by 1000 miles from north to south. Its course was the reverse of that of 1843 . It was scarcely appreciable in sea disturbance. 
Volcanoes stand on lines of fractures in the opening of which their existence began; and subsequently, through geological time, slips up or down may have occurred along such fractures in the earth's uneasy crust, independent of local action, producing earthquakes, and, perhaps, also initiating eruptions. The Mediterranean area is one of the earth's fire regions, from its eastern to its western limit, and its borders are noted for the relative frequency of earthquakes ; and these earthquakes, in the majority of cases, are independent of action in the volcanoes of the era. This is true also, according to Milne, of the greater earthquakes of Japan.

The New Zealand Tarawera eruption of 1883, which blew out with explosive violence for a day or two, was followed, three days after it had subsided, by an outbreak in White Island, an active volcano in the Bay of Plenty, and, two months later, by a violent eruption on the island of Ninafou in the Tonga group. The three volcanic regions are on the same island line of the ocean, the northeast or New Zealand line, which is one of the most marked in the Pacific. It may be that this succession of disturbances was due to a slight movement from north to south along the old fracture-plane, through the opening of which the range of islands began its existence.

The central region of an earthquake vibration, which may have considerable breadth or length, or have the course of a long fissure, is called the epicentrum. The rock-waves move off from it in all directions, but often most forcibly in one. The waves are: (1) waves of compression, or condensation, in which the vibrations are normal to the origin, or in the direction of the movement of the wave; and (2) waves of distortion, or transverse waves. The sounds of earthquakes are attributed by Milne to preliminary tremors preceding the prineipal shock, which have the more rapid movement required to produce sound.

The amplitude of the wave varies from less than a millimeter to possibly a foot. But destructiveness depends more on rate of vibration than on amplitude. Milne observes that the greater the initial impulse, the greater the speed of propagation; and, as the propagation widens radiately, the velocity of propagation decreases, the period usually becoming larger.

C. Davison (1891) traces several earthquakes of Great Britain to slips along faults. He observes that from the central portions of the slip-area will come, as a rule, the vibrations of largest amplitude and longest period, and from its margin, and especially toward the surface, minute vibrations of a period so short that they may be perceptible only as sound. He thus explains the fact "that the sound-area is not concentric with the disturbed area, and the sound-focus is nearer the surface than the rest of the seismic focus" ; and also, "the fact that, in great earthquakes, the sounds are heard only within a comparatively small area immediately around the epicentrum." Liability to slips, and therefore to earthquakes, diminishes with the progress of time.

Kinds of rocks have great effect on the propagation. Milne obtained in Japan, for velocities of propagation, from 200 feet per second to 630 feet; Mallet obtained, for sand, a rate of 825 feet, and for granite, of 1665 feet; Newcomb and Dutton, in the Charleston earthquake, made out a rate of 17,000 feet per second, without any indications of variation in the speed; H. L. Abbott in his observations on explosions at Hallet's Point in 1876, 
4500 to 20,000 feet per second; and Fouque found the velocity in granite 9200 feet per second.

The position of the epicentrum is ascertained by noting the direction of throw of overturned columns, walls, houses, the converging lines pointing to the region of the surface vertically over the epicentrum. An oblique thrust is most effective in overthrowing objects; and the particular belt-line around the central region along which the waves are most destructive is called the meizoseismic curve, and lines of equal disturbance, isoseismic curves. Such curves are far from circles.

By means of evidence from fractures in walls and overturned objects, R. Mallet inferred the angle of emergence of the wave, and so calculated the depth of the center of disturbance. From 26 observations of the Neapolitan earthquake of 1857 he deduced a depth of $6 \frac{1}{2}$ miles. C. E. Dutton, in his paper on the Charleston earthquake, assumes that the total disturbance is inversely as the square of the distance from the center of disturbance. By noting, in the Charleston earthquake, the circle about the epicentrum at which the total effect diminished most rapidly on going from the epicentrum, he deduced depths of 8 and 12 miles for two distinet centers of disturbance.

The instruments by which the earthquake movements are detected (seismoscopes), measured (seismometers), and recorded (seismographs), are of many kinds. Those which experience in Japan has proved to be most accurate are the so-called Duplex pendulum; the Bracket seismographs of Chaplin, Ewing, Gray, or Milne; and conical pendulums.

The geological effects of earthquakes are small, while those of the causes which produce earthquakes are large. Vibrations loosen rocks and may tumble them down precipices, as they tumble down houses and walls. Occasionally they produce some rotation in the objects moved where the object is not equably attached below. They may fracture the rocks and ground in the region of greatest disturbance. They often oceasion the drying up of springs.

In Calabria, in 1783, fissures were made that were over a mile long, 100 feet wide, and 200 feet deep. In the Charleston earthquake of 1886, and also in that of 1892 at Quetta, in British Baluchistan, described by C. Davison, railway lines were bent; and in the latter ease, on removing the bent rails for repair, the new lines had to be cut $2 \frac{1}{4}$ feet shorter than the old ones, owing to a permanent displacement.

But these rending effects and the uplifts, and other results attending them, are effects rather of the deep-seated cause of the vibration and the fracturing. Besides these effects, earthquakes may destroy life in the sea, by impact, as a blow on the ice of a pond will stun or kill the fish. They may also throw the ocean over the land in waves of 30 to 100 feet, carrying in the animals of the sea, and, in these modern times, man's boats and ships, besides lifting and bearing far inland sea-bottom rocks and sand, and great masses of coral rock on the shores of coral islands (page 222). Further: if a mountain-system of the length of an America were making, like the postCretaceous Laramide System, and a like system cotemporaneously in the other America, sea-borders, continental seas, and land-border's the world over might be mostly stripped of life by earthquake waves. Or, if the mountain systems in progress were of less extent, like the post-Paleozoic, a hemisphere might experience the devastations, and austral land-borders and sea-borders escape. 


\section{Origin of the Earth's Form and Featores.}

This embraces first, the origin of the shape of the earth's mass; second, the origin of continental plateaus and oceanic depressions, and of all movements in the earth's crust through geological time not involving orogenic work; and, third, the origin of the movements producing the upturning of formations and the making of mountains.

The first of these subjects, geogenic work, pertains to astronomy. The movements referred to under the second, by which wide changes of level have occurred without special orogenic results, except displacements along old or new fracture-planes, have been termed by G. K. Gilbert epeirogenic, or continent-making (1890). The work included under the third head is orogenic.

\section{GENERAL CONSIDERATIONS BEARING ON THE EARTH'S FORM.}

1. Solidification of the earth. - The earth solidified from the center outward. This conclusion is established on the evidence that pressure raises the fusing point of rocks. The globe was, therefore, never in a state of complete liquidity. According to Clarence King, experiments made for him by C. Barus with reference to the question as to the earth's rate of cooling (see page 1026), lead collaterally to the conclusion that the depth of the liquid exterior of the globe has at no time exceeded 50 miles.

The study of meteorites has led some astronomers and writers on the constitution of the globe to the opinion, in view of the iron in these bodies, and the fact that their place in the solar system is to a large extent near that of the earth, that the earth's interior consists, for the greater part, of iron. This view is favored, also, by the high percentage (10 to 14) of iron oxide in most igneous rocks; the existence of much native iron in doleryte at Disco Island, Greenland; and the occurrence of the greatest of iron-ore beds of the world in the oldest rocks, the Archæan. Platinum, gold, silver, and copper are heavier metals; but it is remarkable that they are not brought up among the constituents of eruptive rocks, as iron is, but are obtained from the supercrust and its veins : as if these metals, in consequence of being in vaporizable combinations, or those of comparatively little specific gravity, were near the surface of the fused globe, while below these were the iron and whatever, under the conditions, could form alloys with it. If the earth is two thirds iron, or iron to within 500 miles of the surface (without much increase in the density of the iron downward), and the rest were made chiefly of basaltic, or dolerytic, material, it would have about its present specific gravity, $5 \cdot 5$.

The complete solidification of the earth is held to be its present condition by most physicists who have recently discussed the subject. This implies that the crust that was formed over the surface of the liquid stratum by cooling had continued to thicken until the whole was solid. The evidence favoring the earth's essential solidity has been obtained by investigating mathematically the amount of deformation which the sphere, if a liquid mass enveloped in a thin crust, should undergo during its revolution; and also the effect of such tidal movement in the earth's mass on the height of the oceanic tides. Kelvin concludes, on these grounds, that the earth must have an effective rigidity at least as great as that of steel $(1862,1872)$. G. H. Darwin has 
sustained the same conclusion, stating that "if it were true that the earth is a fluid ball coated with a crust, that crust must be of fabulous rigidity to resist the tidal surgings of the subjacent fluid" (1888). At the same time, according to the same authority, the weight of the water of a high flood-tide probably occasions, owing to the elasticity of the crust, "a local elastic yielding along the coast-line of continents"; and "there is reason to believe that such flexure has actually been observed by a delicate form of level on the coast of the Bay of Biscay." Newcomb favors the same conclusion in a paper discussing the cause of the periodic variations of latitude (1893).

O. Fisher, of Cambridge, England, questions the above conclusion from the tides (1892). Basing his mathematical calculations on an investigation by Darwin of the tides upon a yielding earth according to the canal theory, he obtains the result, that the height of the tide for a liquid earth would be only a fifth less than that for a rigid earth, and suggests, as the difference is so small, that the existing tides may have just the height appropriate to a liquid interior. He observes, further, that the heat generated within the earth by the tides in the earth's mass from their commencement-calculated by Darwin to be sufficient "to give a supply of heat, at the present rate of loss, for 3560 millions of years" - would have been only to a small extent expended or wasted, and that, through convection currents, it keeps the liquid layer in fusion, and prevents the crust from growing thicker. Other considerations have led Fisher to make the thickness of the crust about 18 miles. The conclusion of Fisher is objected to by G. F. Becker, on the basis of calculations which lead him to the conclusion that "for a fluid earth the canal theory and the equilibrium theory give the same result, viz.: no relative tide." He adds, that "on any theory of the tides, the existence of semi-diurnal tides indicates an earth presenting great resistance to deformation" (1893).

2. Earth-shaping. - Whether solid to the surface or not, the earth is believed to be so far fluid-like in its mass as to admit of adjustments to gravitational pressure through molecular flow, if not through a liquid layer, and to owe its shape primarily to the principle of gravitational equilibrium, as if liquid. This view of adaptation to gravitational pressure was recognized geologically by Herschel in his Appendix to Babbage's Ninth Bridgewater Treatise (1837), where he attributed changes of level to "changes in the incidence of pressure on the general substratum of liquefied matter which supports the whole," and argued therefrom that the rise in level going on in Scandinavia might be caused by the accumulation of sedimentary deposits over the adjacent ocean bed. The earth's interior liquidity was then generally admitted. In 1888, C. E. Dutton proposed the term isostasy for "the condition of equilibrium to which gravitation tends to reduce a planetary body irrespective of whether it be homogeneous or not," that is, whether solid to the surface or partly liquid beneath it, and whatever its constitution.

The rate of adjustment to changing load would necessarily be very slow in a solid globe, in which it could take place only through molecular flow in 
the mass, while it might be comparatively rapid if a liquid layer existed beneath a thin crust - a flotation crust, as it has been called. Darwin has remarked that through molecular movements the earth's spheroidal forin might change with change of rotation. But what is the minimum limit in a solid globe, to rate of adjustment - that is, to the rate at which resistances from cohesion and other causes can be overcome - no known facts have even approximately indicated. Effects should, in any case, lag behind the cause of change, whether they are those from the deposition or removal of a load.

There are, however, facts that seem to imply a somewhat easy adjustment. Many low coasts over which sediments are borne to the sea border are known to be slowly sinking; as, for example, the coast of New Jersey, where the rate, according to $\mathrm{G}$. H. Cook, is two feet a century. This sinking, and that of other parts of the Atlantic border, is attributed by Cook to gravitation in the sediments. W. J. McGee, in a paper of 1892, has brought together many facts from various coasts, mostly adjoining the mouths of rivers, bearing in the same direction. On the Netherland coast, the rate of sinking, according to Girard, is 0.09 to 0.75 meter per century, and 0.26 meter since 1732. But actual sinking is not a legitimate isostatic effect. The subsidence on such coasts corresponding to the amount of contributed sediments (not exceeding it) is not indicated by the amount of sinking, for the sinking is in excess of it. Other facts are more decisive. A boring on the southeast coast at Atlantic City, 1398 feet deep, extended through beds, as stated by J. C. Smock, which were proved by the fossils to be Miocene; Turritella plebia occurring, according to Heilprin, at 450 feet, and Perna maxillata at 760 feet, of which depth 265 feet are surface gravels and 265 beyond are of doubtful reference. But at Asbury Park and Ocean Grove, farther north, wells afforded the Upper Greensand with Terebratula Harlani and other Upper Cretaceous fossils at a depth severally of only 270 and 280 feet below tide level, and the Lower Greensand at 365 and 382 feet. The facts indicate a very slow rate of subsidence at Asbury Park since the Cretaceous period, and much less slow at Atlantic City, which is 80 miles south of Asbury Park and only 40 from the north cape of Delaware Bay. A boring on the coast of Texas passed through 3070 feet of shore deposits, without reaching, according to the investigations of G. D. Harris, beyond the Miocene. The deposits down to a depth of 458 feet are pronounced Quaternary. Beyond, to the 1511-foot level no Tertiary fossils were found and all of them may still be Quaternary. Between 1511 and 2153 feet, the deposits were Upper Tertiary as shown by fossils; and between 2153 and 2920 feet, Upper Miocene. In the lower 150 feet, clays and sands were found without fossils. Similar facts are reported from the delta of the Ganges and other regions.

'These proofs of rather rapid subsidence along coasts are regarded by many as not inconsistent with the idea of a solid earth. Others have used them as strong evidence of a thin flotation crust over liquid rock.

But a "flotation crust" has its difficulties. The fact that there are high mountains anywhere is one of them. Against this objection it is urged that 
mountains may have great cavities beneath them, through a parting and opening in the crustal terranes underneath, when they were elevated; and it is stated in corroboration that by means of the plumb-line it is proved that the Himalayas have not the density of a solid mass. So also some volcanic peaks have been proved by pendulum experiments to be hollow. If volcanic mountains generally were shells over a cavity that was emptied in making them, the fact that they could stand on a thin crust would be no marvel. But the pendulum experiments of E. D. Preston at the Hawaiian islands have shown that this is not so. He found, in 1892, that Haleakala, on east Maui, 10,000 feet high, has a density of $2 \cdot 7$, or that of the mass of rocks at the surface; and that Mount Kea, on Hawaii, nearly 14,000 feet high, while hollow above, - the density there being only $2 \cdot 1$, — has a density below of 3.7 (page 290). Yet these mountains stand, and, no doubt, under adjusted gravitational pressure; but how so, if on a thin crust, is an unsolved mystery.

Isostasy is earth-shaping in its action, without being mountain-making. It has been in all time conservative of existing conditions of equilibrium. Subsidences made by loads have caused elevations somewhere around the subsided region; but the mean level, according to the principle, must have been retained. Loads over the bed of a Mexican Gulf should cause, in accordance with it, a subsiding, but not a deepening, for the subsidence just equals the load; and on the border of the ocean they should cause a subsiding of the coast region, and not a sinking; for the subsiding could not exceed the filling contributed.

The ice of the Glacial period, which covered a large part of northern North America and Europe to a depth of one or more thousand feet, was a load laid over the surface by moist aërial currents; and to this load has been attributed by Jamieson (1865), Warren Upham, and others, the succeeding subsidence of the same glaciated regions, or that of the Champlain period. (See further, page 1020).

3. Continental plateaus and oceanic depressions. - According to the principle of gravitational equilibrium, the earth's greater unevenness of surface, exhibited in the existence of oceanic depressions and continental plateaus, should be an expression of some difference in the density of the rocks. Perhaps the fact that the prevailing rocks of the oceanic volcanoes are basaltic, and of the continental, andesytic and trachytic, explains how it is that the oceanic crust is made the denser. The difference in the mean densities of the basaltic and andesytic rocks is about one tenth. The depressions, on this view, were made in the earth's cooling.

This origin of the oceanic basins was suggested in 1860 by Archdeacon J. H. Pratt, in his memoir on the Figure of the Earth, where he attributes the existence of continents and these basins to unequal contraction, refers the formation of mountains to lateral pressure, and concludes that "the crust beneath the oceans is of greater density than the average portions of the surface" ; that is, that where the contraction was greatest the density of the rock material below is greatest, and proportionally so. 
Since the mean height of the present continents is about 2000 feet, and the mean depth of the oceans 12,000 feet, and since the continental areas were already outlined and partly emerged, during later Archæan time, this mean depth of the oceanic depressions must also have been then acquired; and only an addition of 1500 to 2000 feet was needed to give the continents their present mean altitude. Of this, more than one half was added in the Tertiary and Quaternary.

\section{OROGENIC WORK, OR THE MAKING OF MOUNTAINS.}

1. In ordinary mountain-making, the rock material to be made into the mountain range has comprised a thick, conformable series of sedimentary strata, resting upon an uneven floor of upturned and usually crystalline rocks which were part of the underlying earth's crust. The Appalachian and Laramide strata were laid down on an Archæan floor; the Palisade beds of the Triassic, from New York southwestward, on one that was partly Archæan and partly consisted of Archæan and Cambro-Silurian terranes combined.

The great facts to be explained in a theory of mountain-making relate (1) to the preparatory geosyncline or trough and its load of strata for the mountain structure; (2) to the mountain-making events; the upturning, flexing, and faulting of the strata, and all other effects of the movements in progress. On any theory of origin, such mountain ranges are synclinoria, as they have been termed by the author, from the Greek for syncline, and öpos, mountain, - they having had their beginning, as first recognized by Hall, in a preparatory geosyncline of accumulation. The geosyncline occupied the area of the future mountain range. It was slowly formed, while the crisis of upturning was relatively short. For the Appalachians the geosyncline, judging from the thickness of the included beds, had a maximum depth of 40,000 feet; for the Laramide Range, north of Montana, 34,000 feet (McConnell) and for the Wasateh portion, 31,000 feet (C. King); for the Alps, at the close of the Miocene, 50,000 feet (Heim); for the Australian Alps, 35,000 feet (Hector); for the Palisade ranges, 3000 to 5000 feet.

The subsidence in the case of the Appalachian Range occupied all of Paleozoic time; of the Wasatch Range and other ranges of the Laramide system, all of Paleozoic and Mesozoic time, - which means many millions of years for each. Again, there is the remarkable fact that the subsidence has not always been continuous, but sometimes alternated with emergences, or ceased for long periods. In the case of the Ouachita Mountains, Arkansas, whose history runs parallel with that of the Appalachians, there was a cessation through the whole of the Upper Silurian and Devonian, for these eras are unrepresented by rocks. Moreover, the area of the geosyncline, as the deposits show, varied, as the ages passed, in width; varied in the position of the belt of maximum subsidence, from one side to the other, or from one part to another; varied in the depth of water in which the deposits 
were made, and in the courses and character of the transporting currents and waves.

Further, the making of the geosyncline must have been attended in each case by a pushing aside of the rock material in the earth's mass existing beneath it, and an upward bulging, or a geanticline, over the region adjoining on one side or the other.

The more prominent theories of mountain-making now current are (1) the Gravitation Theory and (2) the Contraction Theory.

\section{The Gravitation Theory.}

The Gravitation Theory was brought forward in its simplest form by James Hall in 1859. According to it, the making of the preparatory geosyncline, in the case of the Appalachians, was due to the gravitation of the accumulating sediments, in accordance with the principle explained by Herschel, whose views he cites; and the making of the flexures over the region was due to the same cause; that is, to the subsidence and not to heating from below. In the same paper, the general conclusion already referred to is drawn that a geosyncline of accumulation, like that of the Appalachians, is a necessary preliminary in all cases of mountain-making. In 1847, Babbage published the important principle (included in a paper read before the Geological Society of London in 1834) that in deepening accumulations of sediments, heat rises from below into the pile as its depth increases, as explained on page 258 , and that the subterranean heat causes changes of level through the expansion and contraction of the rocks.

T. Mellard Reade, after a study of the expansion of heated rocks of different kinds, adopting the views of Herschel and Babbage, attributes flexures, and other effects attending mountain-making, not merely to the heat from below indicated by the rising isogeothermals, but also to additional heat at intervals from a succession of intrusions of igneous rocks consequent on the conditions. He styles his theory "the origin of mountain ranges by sedimentary loading and cumulative recurrent expansion," - recurrent because of the successive igneous intrusions. He found for the rate of expansion of average rock 2.75 lineal feet per mile for every rise of $100^{\circ} \mathrm{F}$. The igneous intrusions are said to occur generally along the axis or axes of the range in process of construction.

The principle that loading causes subsidence of the crust has been supplemented by $\mathrm{C}$. King (1876) with its apparent complement that unloading by denudation causes elevation, - he holding at the same time that these effects take place in a solid globe. The elevation of the Rocky Mountain area, during Tertiary time, is accordingly attributed by him to the removal, through denudation, of a vast amount of material from the vicinity of the Colorado cañon, and from other parts of the mountains.

With regard to the view of King, and especially this example under it, Le Conte has observed that the weight of the rock material elevated in the rise of the great mountain area to a height of 4000 to 11,000 feet was vastly larger than the amount lost by denuda- 
tion, and adds that the denudation could not have produced any result until the elevation had made some progress. The theory supposes the isostatic condition of the globe; and if this was the condition in Cretaceous time before the elevation began, the elevation never could have taken place without force from some real source.

In accordance with the above, the evaporation of the flooded Great Salt Lake (called Lake Bonneville), which, in the middle of the Quaternary era, had reached a depth of 1000 feet, has been suggested by G. K. Gilbert as the cause of the inequality of height in different parts of the terrace that marks its old coast-line. The change of level indicated is stated to be about 200 feet. The pressure of 1000 feet of water, or that removed by evaporation, is equivalent to 450 pounds to the square inch. The theory implies a molecular transfer (as the waters disappeared in the Middle Quaternary) from the outside region to that beneath the lake. The explanation is put forward by Gilbert with the statement that further investigation is required before the view can be regarded as established.

The difficulty with the Gravitation Theory in its best form is that it does not supply the amount of pressure, and of contraction or expansion, which is required by the facts.

This is true of Reade's theory, even with the recurrent work of igneous intrusions. In the case of the Appalachians the width of the geosyncline from S.E. to N.W. is less than 250 miles. The ratio of maximum depth to width is about 1 to 40, or that of a trough as wide as this printed page and one ninth of an inch deep. The depth of the strata, 40,000 feet, gives for the temperature at the bottom of the geosyncline (supposing the rate of downward increase to be $1^{\circ} \mathrm{F}$. for each 50 feet of descent) $800^{\circ} \mathrm{F}$. Consequently an expansion of 2.75 feet for 250 miles of width and for each $100^{\circ}$ F. amounts to 5500 feet, or a little over a mile. Lesley makes the actual shortening over the breadth of the geosyncline in Pennsylvania, in consequence of the flexures, to be 44 miles, and Claypole 88 miles. The discrepancy is too large to be removed by questioning either estimate. Many of the single folds would use up several times the 5500 feet. So it is in other cases.

In the Laramide Range, of southern British America, a thickness of the rocks in the geosyncline of 34,000 feet, and the width of the trough about 150 miles, give for the temperature of the bottom about $700^{\circ} \mathrm{F}$.; and the expansion, under these conditions, would be only 2900 feet for the whole width. The displacement horizontally of one of the several faults, according to McConnell, is 7 miles, or nearly 13 times the maximum allowed for the range by the theory under consideration. In the Juras, Heim found the contraction by flexures to be 3 miles, or one fourth, for the distance between Lake Geneva and Saint Claude; and in the eastern Jura to be 4 miles in a breadth of 7 miles.

There is the further objection to the theory that in a trough, having the depth only a thirtieth or a fortieth of the breadth, the expansion would act nearly equally in all directions; so that while longitudinal ridges might prevail, transverse should be common instead of uncommon. But the expanding effects from the heat of successive igneous intrusions are to be added, according to the theory, ridges thus succeeding ridges. In the case of the Appalachians, there were no igneous intrusions along the chief part 
of the axis of disturbance, and none in the Laramide Range of British America, and the same is true in a large part of mountain-making. In the Wasatch the igneous effusions were a tinal effect, not an agent of change.

Moreover, the pressure from any igneous intrusions, or their power of compression, is feeble. Plastic rock is little better for pressure than any pasty material; when extruded it is hurried out of the way by the compression of any other agent, or escapes, if it can, by gravity. When it cannot escape, it bulges up the overlying beds and makes laccoliths (page 301), and this is almost its limit of mechanical work. The heat also is wholly inadequate for plicating and faulting rocks in mountain-making style, whether the liquid rock be granitic or of any other constitution; the laws as to heating and cooling are the same for all kinds.

\section{The Contraction Theory.}

1. The source of lateral pressure. - The source of the pressure according to the contraction theory is the contraction of the earth's crust as a consequence of cooling. The theory was suggested by Descartes in his Principia Philosophice in 1644, and by Newton in 1681, and was adopted in geology by James Hall, of Edinburgh, in 1812, and advocated by De La Beche in 1834. The contracting crust derives the lateral pressure from the cooling and solidification that is going on underneath it - the crust being forced to adapt itself to an interior which is becoming smaller by the earth's gradual refrigeration. Mountain-making, according to the theory, is a consequence largely of the earth's shrinkage.

The author's contributions to the subject, including also that of the Origin of Continents and their Features, appeared first in the years 1846, 1847 and 1849, and were continued in 1856 and 1873. The development of the structure of the Appalachians through Virginia and Pennsylvania by the Professors Rogers afforded the first geological demonstration in favor of the contraction theory; and the results they published, although leading the investigators at the time to a theory based on forced movements in the earth's liquid interior, underneath a thin crust, afforded the author illustrations of the views in his early papers.

Since the earth has oceanic basins and continents of diverse dimensions and features, this lateral pressure would work with direct reference to continental lines, and generally have its shoving and relatively resisting sides in epochs of orographic work. If the pressure acted thus unequally from the two opposite directions, it would make inequilateral mountain structures, or those having a front-and-rear character, like the Appalachian Range.

Moreover, the movements would have their limits determined by, or related to, the lengths of continents, or great continental regions, and, in this respect, they accord with the actual characters of mountain chains. The Laramide system, over 4000 miles in length, along the western continental horder of North America, is an example: and perhaps another 4000 miles 
along a line farther west should be added for South America. The agent for such results must be the earth in its entirety.

2. Location of the lateral pressure. - The surface layer of the globe in which the pressure acts has recently been shown to be thin. In the cooling and contraction of the crust, the lower part of the cooled portion, enveloping the uncooled nucleus that had not begun to lose its heat or contract, could not contract without breaking, and, therefore, the cooling would put it into a state of tension, which would result in the opening of fractures. For if a layer undergoing contraction is united to a non-contracting or less-contracting layer, the contraction would necessarily produce tension and fractures. Thus the cooling crust must be made up of an inner portion in a state of tension and an outer in a state of lateral pressure, and the two portions are separated by a level of no strain. The outer is the effective part in orogeny. The lateral pressure within it is greatest at the surface, and diminishes downward. The thickness of the effective layer depends on the length of the time that has elapsed since the solidification of the earth at surface - the time when the strain was initiated. It was estimated by Mellard Reade as only two miles (1886). It has been mathematically discussed first by C. Davison, and afterward by G. H. Darwin and M. P. Rudski, who sustain the contraction theory of mountain-making. Davison made the thickness $(1887,89) 2 \cdot 17$ miles, supposing the elapsed time to be $100,000,000$ years; and Darwin (1887), two miles, for the same elapsed time, adding that "the depth is proportional to the time since consolidation." Darison, in a later "calculation (1894) based on the supposition that the coefficient of dilatation is not constant, as he before had assumed, but increases with the temperature," arrives at the more favorable conclusion that, after $100,000,000$ years, "the depth of the surface of zero-strain would be 7.79 miles." He says further, that "if the material of the earth's interior be such that the conductivity and coefficient of dilatation are greater in it than in the surface rocks, or if initially the temperature increased with the depth, the above figure must be still further increased"; and adds, in conclusion, "that, consequently, calculations as to the alleged insufficiency of the contraction theory to produce mountain-ranges are at present inadmissible." It is therefore safe to assume, in view of the dependence of mountain plications on lateral pressure, that the thickness was fully sufficient for the orographic results; and even in late Archæan time great enough to make Archæan mountains of 8000 to 10,000 feet, such as the Adirondack and Black Mountains must have been before subjected to denudation.

Darwin states at the close of his paper (which follows Davison's in the Philosophical Transactions), after deducing that contraction vanishes at a depth of 2 or 3 miles: "Thus, in $10,000,000$ years, 228,000 square miles of rock will be crumpled on the top of subjacent rocks. The numerical data with which we have to deal are all of them subject to wide limits of uncertainty, but the result just found, although rather small in amount, is such as to appear of the same order of magnitude as the crumpling observed geologically. 
The stretching and probable fracture of the strata at some miles below the surface will have allowed the injection of the lower rocks amongst the upper ones, and the phenomena, which we should expect to find according to Mr. Davison's theory, are eminently in accordance with observation. It therefore appears to me that his view has a strong claim to acceptance."

Further, Mr. Darwin cited, in 1892, the recent calculations of Rudski of Odessa, which showed that if the initial temperature of the sphere be not uniform through the mass, that is, if, as in the case of the earth, the initial temperature increased from the surface to the center, the level of no strain lies deeper than he had made it. As to the actual depth thus indicated he made no statement. (Phil. Mag., Sept., 1892.)

\section{The process of mountain-making according to the Contraction Theory. -} The making of the preparatory geosyncline, with its included series of strata, was slow in its progress. As it included, in the case of the Appalachians, all of Paleozoic time to the close of the Carboniferous, the rate of subsidence - the depth being 40,000 feet - was, if the time was 40,000,000 years, about 1 foot in 1000 years; if $10,000,000$ years, 1 foot in 250 years. The rate, on either supposition as to the elapsed time, was so slow that the subsidence may have been a result of the loading of the area with the sediments. Yet it cannot be asserted that lateral pressure in the crust was not concerned; for if it was the prime cause of movements at the crisis, it could hardly have been dormant through the long preceding ages when the trough was in progress. The subsidence went forward, so far as can be discovered, without much displacement of the beds within them, beyond such as were due to unequal compression by gravitation, drying, and some solidification. The pile of beds had great breadth as compared with its depth, and varied much in thickness, owing to irregularities in the Archæan floor beneath, and to varying rates in the progress of the subsidence. Limestones indicate much slower movement downward than coarse sediments of like thickness; and intercalated beds of coal prove that long periods of slight emergence were among the alternations.

When the mountain-making crisis was at hand, the temperature at the bottom of the deposits was already high from the rise of the geothermals with the increase of thickness. With a thickness of 40,000 feet, and the rate of increase of temperature downward $1^{\circ} \mathrm{F}$. in 50 feet, it would be $800^{\circ} \mathrm{F}$. But the rate was probably as rapid as $1^{\circ} \mathrm{F}$. in 40 feet or less, making the temperature at bottom $1000^{\circ} \mathrm{F}$. or higher. At either temperature the trough would have been greatly weakened below, as first explained by Herschel. In a letter addressed to Lyell, dated February, 1836, and in another to Murchison, dated November, 1836, which are published in the Appendix to Babbage's Ninth Bridgewater Treatise (1837), he presents, besides the view that heat will rise from below into an accumulating series of strata, as had been done by Babbage, the suggestion that "the thicker the deposit, the hotter will its lower portions tend to grow, and if thick enough they may grow redhot, or even melt. In the latter case, their supports, being also melted or softened, may wholly or partially yield under the new circumstances of presDANA'S MANUAL -25 
sure, to which they were originally not adjusted; and the phenomena of earthquakes, volcanic explosions, etc., may arrive." These results are favored by the fact that the deposits were not half consolidated, and, therefore, little able to resist the pressure.

In the consequent collapse from the continued pressure, the included strata would be necessarily shoved up out of place, flexed in anticlines and synclines, and traversed by great oblique fractures, as Daubrée's experiments illustrate, which would become the courses of displacements, all on a scale of magnitude comporting with the thickness of the accumulated formations. The flexures were not flexures of the earth's crust, but of the supererust, or the beds in the geosyncline. The work was slow in progress; for the great flexures in such mountain-making are produced without obliterating or seriously obscuring the stratification.

In the great forced movement, if the pressure on the two sides of the trough was unequal, as was commonly the fact, the beds were shoved from the side of strongest pressure, or thrust, toward the opposite. Consequently the flexures became crowded and steepest on the former side, and the overthrust flexures and upthrust blocks were thrust toward the other side. Hence the resulting mountain range and its flexures are inequilateral. In the ease of the Appalachians, the thrust was strongest on the side toward the ocean. Further: on the side of least pressure, the mountain range often declines into elevated plateaus, with feebly undulating or horizontal stratification, as exemplified, on the landward side of the Appalachians, in the Cumberland plateau and its continuation northward; in the Uinta Mountains and the high plateaus of Utah on the landward side, and to the south, of the Wasatch. In the narrow troughs of deposition of eastern North America, the flexures often fail to indicate inequilateral pressure.

After a mountain-birth there has commonly succeeded a time of relaxed lateral pressure; and then occurred adjustments, largely by gravitation, in the moved masses or faulted blocks making chiefly downthrow displacements, besides producing new fractures and faults. Such displacements have taken place especially in the region of mountain plateaus, where the pressure was least.

Illustrations of the steps in the contraction process of mountain-making have been above derived mostly from the Appalachian Range. They may be found almost equally apposite in most of the mountains of the world, as the examples already given prove. The Taconic Range, on the borders between New England, and New York and Canada, has the same general characteristics as the Appalachian, with the addition of the universal metamorphism of the beds of sandstone, shale, and limestone. Its preparatory geosyncline was on a parallel line with the northern part of the Appalachian; and the two were deepening and taking in deposits together until the close of the Lower Silurian, when the Taconic mountain-making crisis came. The rocks of the range are, therefore, only those of the Cambrian and Lower Silurian. It is probable that this mountain belt extends through 
Virginia southwestward, along a series of Taconic geosynclines that ended in the making of a series of Taconic ranges, on a line east of the Appalachian Range. See further, pages 531, 532 .

4. Geanticlines corresponding to the geosynclines. - It is not always easy to identify the one or more geanticlines that the sinking of a geosyncline may have produced. In the case of the Taconic and Appalachian ranges little doubt exists. When the Taconic Range was completed, already a low geanticline had risen above the continental sea, making two large islands between southern Ohio and Alabama, one over the region of Cincinnati and part of Kentucky, and the other in the same line over Tennessee. The region, often called that of the Cincinnati uplift, was first identified as a Middle Silurian emergence by J. S. Newberry and J. M. Safford. Moreover, an eastern geanticline also showed itself; for the whole Atlantic border from New York southwestward through Virginia and beyond became emerged at the same time, and continued so, with probably increasing height through the Upper Silurian, Devonian, and Carboniferous eras, when the making of the Appalachian Range took place; and also after this, through the Triassic and Jurassic periods until the Middle Cretaceous; for through all this time no beds with marine fossils were formed over this great area.

The contraction theory of mountain-making, as is seen, appeals to an allpervading force that must have been at work from the time the earth first had a solid exterior. Already in later Archæan time it had made Archæan mountain ranges; and it is manifest, from succeeding events, that throughout all time one system of evolution was in progress. Moreover, the theory has the virtue of explaining the facts, which is not true of the gravitation theory. No other adequate explanation has been proposed. If the calculations of physicists do not give a sufficient depth for the results to the "level of no strain," then the calculations may be believed to be in error until some other adequate cause of the great faults and flexures has been brought forward.

5. Relations of mountain ranges to denudation. - Carving, gouging, and leveling through denudation go on very rapidly in elevated regions of even a moderate amount of rain, and have gone on through long ages since the rocks were made, so that the original forms of the anticlines and synclines of mountain ranges have disappeared, generally leaving ridges where synclines once existed.

Yet the geologist may still have little difficulty in tracing out the plications, even if the region over which they extend is now a level plain. The investigator looks for evidence of folds in change of dip. If, on his way westward over a region, he finds eastward dips changed to westward, he has passed the axis of an anticline; and if, going farther, he finds westward dips changed to eastward, he sees proof that he has reached the axis of a syncline. Complexities are added by the great faults, making difficulties which can hardly be surmounted without the aid of fossils.

From the facts presented in the above review of the structure of moun- 
tain ranges, the reasons for the directions of drainage courses over such regions are easily understood. The prevailing courses are longitudinal as regards the range; not because synclinal troughs are longitudinal, for these, in the case of bold Hexures, are not ordinarily the courses of river valleys; but for the more general reason that the flexures and faults in the range are longitudinal. The greater valleys are made along anticlines, because of the profound longitudinal fracturing of their summits, in consequence of the tension produced by the upward bending of the strata. This leaves the intervening synclinal belt as the course of the mountain ridges. Besides, the synclinal strata come under extreme pressure during the flexing process, and may have derived by this means greater durability. If the rocks of the range are crystalline schists and limestone, the limestone yields easily to denudation, and would determine in general the course of the drainage channel. But among uncrystalline rocks, limestone is harder than shale and some sandstone.

It has been stated that in a region of upturned rocks, as that of the Appalachian Range, the flexures are made in series along a few parallel lines, and sometimes in a succession of groups; and consequently that those of different lines often overlap at their extremities. Hence, along these intervening or overlapping portions the strata are irregularly warped and fractured, and thus weakened. Here, consequently, erosion should be easy, and transverse or oblique courses of drainage would result.

Great mountain ranges and systems have been shown to have one or more curves in their courses. The Appalachian Range, for example, changes from its south-by-west course in New York to west-southwest in Pennsylvania, and then leaves this state with a south-southwest course, which to the southward veers again to west-southwest. Here is another cause for transverse lines of drainage; for such a range usually diminishes in height over its more nearly meridional or more latitudinal part. In the Appalachians the lower part is along the latter; and here, as Lesley's map of Pennsylvania shows (page 730), the range is crossed by the Susquehanna.

Finally, along a region of a number of close-pressed folds, having great longitudinal fractures with displacements, a drainage valley may take great width.

If the plications or monoclines over an extended area have small dip, then the broad synclines and the depression between monoclines or lines of displacement may become the courses of streams.

Epeirogenic movements that give a height of many thousands of feet to large continental areas add these thousands to the elevation of the mountain ranges along the region; and hence, besides causing flows of water down the gentle slopes, they produce a vast increase of precipitation and denudation about the summits, and make the streams great rivers. Over the interior of continents such movements may cause undulations or warpings of the surface, which occasionally reverse the flow of rivers, or unite independent river systems into one, or make depressions that become the basins of lakes. 
6. Ranges, Systems, Chains, Cordilleras in North America.-From the explanations given it is apparent that a mountain range includes all the mountain ridges made over the area and border of a single geanticline. The Appalachian is an example 900 miles long; it comprises many ridges, but these are made by denudation. Ranges are the individuals or units in mountain structures.

A mountain system includes all ranges in a region made in different, more or less independent, geosynclines at the same epoch. Besides the birth of the Appalachian Range at the close of the Carbonic era, there was also the birth of an Acadian Range, from Newfoundland through Nova Scotia, and probably to Rhode Island. Here are two simultaneously made ranges on the Atlantic border, and they may be regarded as parts of an Appalachian mountain system. Again, in western Arkansas, the upturned Paleozoic rocks constitute the Ouachita Mountain range, which, as L. S. Griswold has suggested, pertains to the Appalachian Mountain system, the axis of uplift conforming to the southern portion of the latter in Tennessee and Mississippi. As another example, the Wasatch Mountains constitute one of the Laramide ranges. But the mountains to the north of Montana, in British America, described on pages 359-60, were evidently made over another trough in the same line, and correspond to another Laramide range. So there are others, and as many as there were independent or partially independent Laramide troughs along this line in the Rocky Mountains; and all the mountain ranges originating from these troughs make up the Laramide Mountain system of North America, over 4000 miles long.

A mountain chain is a combination of mountain systems, or mountain belts of different epochs. On the Atlantic side, there is, along the Appalachian belt, a combination consisting of the Appalachian system of post-Carboniferous age, the Taconic system of Middle Silurian age, and an Arehæan system; and the Palisade mountain system, of Jurassic age, may be added. Together they constitute the Appalachian Chain.

In the Rocky Mountains, the main Rocky Mountain Chain of British America, which, as has been stated, is continued southward along the Wasatch Range, includes an Archæan system and the Laramide or postCretaceous system. The chain is not continued in sight, south of the Wasatch; but the line is an important geological boundary, it being the western limit of the Cretaceous formation, and the eastern of the Great Basin. The Front Range of Colorado, as it is called, is the course of another Archæan system and also of other Laramide uplifts, and, therefore, of another summit chain, - which may be called the Colorado Chain.

Again, nearer the coast, the mountain belt which includes the Sierra Nevada of California, the Cascade Range of Oregon and Washington, the long Coast Range of British Columbia, as it is called by G. M. Dawson, together with the range to the south, 1000 to nearly 5000 feet high, along the California peninsula, are parts of a Sierra chain, combining ranges or systems of ranges, of Archæan and later time. In like manner there is a 
Coast chain commencing to the south in the Coast ranges of California, and continuing along the islands of British Columbia, and on the sea border beyond to Mount St. Elias.

Finally, the combination of two or more chains makes a Cordillera, as the term is used in South America for the Andes. Accordingly, the Coast and Sierra chains together with the chains of the Rocky Mountain summit constitute the Cordillera of the Rocky Mountains. In South America the term cordillera is used not only for the Andes as a whole but often also for one of its long ridges or ranges or chains. The combined mountain systems of the whole Pacific border of North America were first called a Cordillera by J. D. Whitney.

By the above definitions, range, system, chain, are no longer interchangeable terms, dependent for their use on extent or complexity of mountain regions, but have fixed significations.

Study of a mountain range. - Since an individual mountain range has great magnitude, and commonly great complexity through its long series of involved flexures and faults, and through the excavating work of running waters, investigation requires a long and searching study of the structure as a whole, — that is, as an individual. The geological examination of a single ridge of a range may afford conclusions as to the fact of upturnings, flexures and faults and may obtain evidence as to the force concerned, and perhaps settle the question of the foliation, or bedding, of the schists of the ridge, if any are present. But it can afford no general conclusions as to the range ; and a petrological investigation would accomplish still less. A single section across the range would afford facts, but no general results; for the flexures may vary every few miles, new faults appear and other rocks come out to view. The student should make his sections not merely in one, or a dozen transverse lines, but in as many lines as possible in all directions, studying positions of strata, and noting the changes they undergo from ridge to ridge until the connection of each ridge with every other in the general system of warping has been ascertained. Further, this study should be carried on until the true limits of the mountain individual as far as possible are ascertained. And if the range is more or less metamorphic, the belt of maximum metamorphic change should be studied out, and the fringe of diminishing change, on one or both sides. A ridge of upturned rocks, whether Archæan or of later date, is almost invariably evidence of the existence, in the region, of a mountain range 100 to 1000 miles long, or more; and this should be assumed to be a fact until the contrary is proved.

With the completion of the investigation there will be little further reason for questionings about the fact of pressure and movements as a source of dynamical effects ; and if the beds are metamorphic, none as to the source of the heat that produced the metamorphism. But it remains for petrology to complete the work by investigating the special characteristics of the metamorphic changes, their relations to the positions of the beds, the minerals due to the original metamorphism and the results of later changes, besides other points in the history, for light upon which geology is dependent on its kindred science.

Further, a mountain range being a very large individual, - a length of a thousand miles and breadth of more than a hundred being common, - three such individuals cannot exist on a single area of 50 miles square. When, therefore, indications of three or more periods of upturned rocks are announced, as indicated, by unconformabilities in any limited region of upturned crystalline or uncrystalline rocks, Archæan, or others, it is quite certain that the unconformabilities are in part only unconformities through faults, or overlaps, or erosion, which bave little epochal significance. 
In addition, it should be remembered that the unconformabilities between the upturned rocks of a mountain and those underlying are usually confined to the mountain region. A score or so of miles to one side, the rocks may often be found resting beneath the same strata, perhaps horizontally, with perfect conformability between them. The unconformabilities are on this account none the less important as time-boundaries in geological history.

When, in consecutive epochs of mountain-making, the upturned strata of the later epoch have been thrust up against those of the earlier, by force acting in the two cases from the same direction, the two sets of strata will have more or less nearly the same strike. But their unconformability may possibly still be proved (1) by difference in dip ; (2) by difference in kinds of rocks, when the rocks are studied over a long belt in the line of strike; and (3) by fossils, if the beds are fossiliferous. But when the strata are metamorphic, and fossils are therefore absent, the difficulties are great. Examples occur in western Connecticut and eastern New York, where the metamorphic Taconic rocks come into contact with Archæan. The first and second of the above criteria may still be available, though with great uncertainty; the second may be used especially when the two sets of strata differ in grade of crystallization or metamorphism, or in the presence of some distinctive mineral masses, as of metamorphic beds of iron ore. The belt should, further, be traced along the range of outcrops in order to find, if possible, a region where there is a bend in the strike; for at such a bend the two sets of strata probably would not be found to bend alike; and to make the investigation complete, all possible strikes and dips should be measured and plotted on a large map of the region. Special care is needed in order that unconformity produced by a fault is not mistaken for true unconformability or that in the bedding.

\section{GENERAL RESULTS OF OROGRAPHIC WORK.}

1. Effect of orographic work on the earth's circumference. - Faults and plications are a measure of the shortening of the earth's circumference that has taken place in an orographic crisis. During the ages of preparation, the amount of shortening in the making of the geosyncline has been small; for the slowly accumulating strain reduces widths only by the difference between the shallow arc and its chord. But at the collapse, as already shown, the amount has been a score or more of miles: 74 for the Alps (Heim); 44 for the Appalachians in Pennsylvania; 25 for the Laramide Range in British America (McConnell).

The line of the Appalachian Range is transverse to a zone of the globe having a N.W.-S.E. direction; and the Taconic Range and the Acadian of Nova Scotia and New Brunswick widen this zone northward. The shortening of the earth's circumference for all these ranges was not east-and-west, but in the direction of this zone. In this zone the Archæan nucleus is to the northwest; but to the southeast lies the Atlantic, in its long range between North and South America. In western America, where the mountains made range northwestward instead of northeastward, the shortening was in the direction of a zone N.E.-S.W. in course. It was the same zone of the globe that includes the Alps. The whole amount of shortening on the Atlantic border was probably not over 50 miles along the course of the zone; and on the Pacific border for the Laramide and other systems later than the Archæan, not over 75 miles. 
2. The mountain chains and volcanoes of the continents mostly confined to their borders. - The facts on these points are briefly mentioned on page 32 and beyond. The situation of the chains on the continental borders, so well exhibited in North America, and the position of the greater mountainmass of this continent, greater by 25 times, on the borders of the larger ocean, have manifestly a cause that is in some way connected with the mutual relations of the border region and the oceanic basin adjoining. The author has explained these features $(1847,1873)$ on the view (1) that the lateral pressure at work was lateral thrust chiefly from the oceanic direction against the continental borders (the landward side of the border region being the side of least pressure or greatest resistance); and (2) that since the oceanic area was depressed below the level of the continental, the thrust was in a small degree obliquely upward. If the crust in which the strain exists has only five miles of depth, there is still stronger reason in favor of this explanation, and for accepting it also as accounting for the making of the greater mountain-mass on the side of the widest ocean; for width of ocean, not depth, is the important element. The view explains equally the abundance of border volcanoes.

3. Great mountain uplifts in the later part of geological time and also great igneous ejections. - The fact that the highest and broadest of mountains and the chief part of the mass of the continents were lifted above the ocean mostly after the Cretaceous period is one of the most marvelous in geological history.

After the crust had become stiffened by the thickening, plication, and solidification, and partly the crystallization, of the strata of the supercrust, the chief movement in mountain regions, caused by the ever-continuing lateral pressure, was an upward one, and then mountain chains received through epeirogenic movements their great heights. Under the same circumstances, moreover, igneous ejections and voleanoes reached their maximum at the close of the Cretaceous and during the Tertiary.

In correspondence with the great continental geanticlines of the Tertiary and later time, there should have been oceanic geosynclines, for the material constituting the rising mass could have had no other source than the crustal mass beneath the oceans. On this point there is the great fact of the subsidence over the central Pacific, described on page 349, of which the coral islands are a monumental record. Its area was hardly less than 6000 miles in length, and the breadth, reckoning only from the Hawaiian to the Friendly Islands, over 2500 miles. Such a subsidence fully meets the demands of the Pacific-border geanticline of North America. It suggests, also, that the other great mountain-masses, uplifted during the Tertiary and Quaternary, among them the lofty Andes and the still loftier Himalayas, derived a supply of material by a like method from beneath the oceans. Under this compensating relation, the two great movements become one epeirogenic event, and, therefore, the combined result of one comprehensive cause.

4. North America a type-continent. - Among the continents, North 
America best exhibits typical continental growth, because it stands by itself between the two oceans, free from other lands on the east, south, and west. In this it is greatly in contrast with Europe and Asia. In all its structure it shows that its orographic courses were outlined at its inception, and that its features were gradually developed from age to age, in accordance with the foreshadowed system. The Archæan protaxes have almost the lengths of the adjacent continental borders, and the systems of ranges of later elevation, on the Atlantic and Pacific sides, have parallel courses and like extent. They are not irregularly distributed groups or knots of mountains, but elevated lines in the continental structure, orderly placed according to principles and forces that were already at work in Archæan time.

Rock-making went forward under like comprehensive methods with the mountain-making. When Archæan time closed, North America comprised a great Interior Continental or Mediterranean Sea, partially separated by the protaxes from the continental-border seas on the Atlantic and Pacific; and, besides, there were, in some parts of the borders, parallel troughs or basins between Archæan confines. Through the following ages, these seas were doing their various work in rock-making, bringing first to a finish, and emergence with orographic aid, the eastern half of the continent; and then giving a like degree of progress and emergence to the western half; and, finally, under a comprehensive agency, carrying the whole area, from east to west, to completion.

5. The earth an individual in development. - The system of feature-lines, displayed in the islands of the Pacific, is virtually that of a hemisphere, for nearly half of the equator lies between the ocean's eastern and western limits. It may be rightly taken, therefore, as the system of the globe. All north-and-south lines are subordinate lines in this system. There is no network of pentagonal lines of dislocation (De Beaumont), or of tetrahedral lines (William L. Green, 1857-1887), or of dodecahedral lines, as urged by $\mathrm{R}$. Owen, of Indiana, in his later paper on the earth's features (1888); for the existence of continental regions and oceanic basins implies local differences in the nature of the material over the sphere, when surface cooling began, that made such lines of symmetry impossible. Instead, the actual physiognomy includes long parallel ranges of lines, often bending in great curves, with transverse lines nearly at right angles, and a reference in all to the positions and forms of the continental and oceanic areas. The island chains of the Pacific, 1000 to 5000 miles long, are separated by underwater valleys, reaching in some cases to depths of 28,000 feet, or over 40,000 below the highest island summits. The system of feature-lines of the oceans is exhibited also by the continents, but with irregularities incident to the forms, positions, and consequent resistances of the nucleal land-masses.

System through regular progress is abundantly proved, but the special causes determining the details of the system are not yet all understood. The following are some of the points awaiting explanation:- 
(1) The gathering of the dry land, the continents, the earth's individualities, and arenas of progress, mostly toward the north pole, and of the waters as largely toward the south pole, the great cause of continental differences in the system of progress.

(2) The attitude of the continents on the globe, each mass having the broader extremity to the north and narrowing southward - a fact which Bacon, in his Novum Organum, set forth as a problem for solution.

(3) The zigzag arrangement of the northern and southern continents, South America having its center $40^{\circ}$ east of that of North America, and Australia, as far east of that of Asia.

(4) The separation of the northern and southern continents by a volcanic belt that girts the sphere.

(5) The two systems of courses in the grand feature-lines of the continents and oceans nearly at right angles with one another, the more equatorial and most prevalent varying between $\mathrm{N} .60^{\circ} \mathrm{W}$. and $\mathrm{N}$. $70^{\circ} \mathrm{W}$, but curving to $\mathrm{N}$. $30^{\circ} \mathrm{W}$., and the transverse system with correlate variations.

(6) The existence of a greater mean depth in the western half of the Atlantic and Pacific Oceans than in the eastern half, notwithstanding the fact that the continental border adjoining the west Pacific is a region of high mountains with many voleanoes in the continental islands, and that the border adjoining the west Atlantic has the lower mountains of North America and no volcanoes.

These characteristics of the earth necessarily date from the beginning of solidification; and the first - the existence of a larger part of the continental masses in the northern hemisphere and of the oceanic area in the southernmay have involved the others. For, if the alleged excess of density in the crust beneath the oceans is owing to the prevalence of basaltic rocks, the crust of the oceanic basin would have remained in fusion after that of the continental had generally cooled through an era long enough for a loss of $300^{\circ}$ to $500^{\circ}$ Fahrenheit, - a fact that would have determined differential conditions and consequences at the first cooling of the earth's crust.

The zigzag arrangement of the continents has been attributed to torsion; and the belt of volcanoes that girts the world has been pointed out as the belt of maximum torsion, and the courses of the earth's feature-lines as consequences in part of the pressure or tension attending torsion; and thus an explanation that reaches deeply into the subject of origins has already been presented.

W. L. Green (1875 and 1877), in The Vestiges of a Molten Globe, suggested the idea that the mass of the continental plateaus, occupying the northern hemisphere, caused, during the incipient stage of the first formed crust, a retardation in the rotation of this part of the floating crust, and thereby "a shearing strain . . between the erusts of the northern and southern hemispheres," and hence a yielding to this strain along the earth's great volcanic belt; remarking that thus "South America became separated from its northern half continent, and pushed toward Africa," while Asia, in 
the northern hemisphere, was crowded westward on to Europe and Africa, leaving Australia to the eastward.

Daubrée, in 1880, explained the same characteristics of the sphere by reference to torsion in the crust during its contraction, and referred to the facts as according with his experiments described in his Experimental Geology.

W. Prinz published a paper in the Annuaire de l'Observatoire Royal de Bruxelles for 1891, in which he points out the resemblances between the great continental torsion courses of the earth, and the lines that have been observed on some of the planets. The western outline of North and South America shows well the obliquity of one of the greater torsion courses and movements. On the following diagram, Fig. 347, it is the outline to the left. Parallel with this, as Prinz explains, and about $90^{\circ}$ to the eastward,

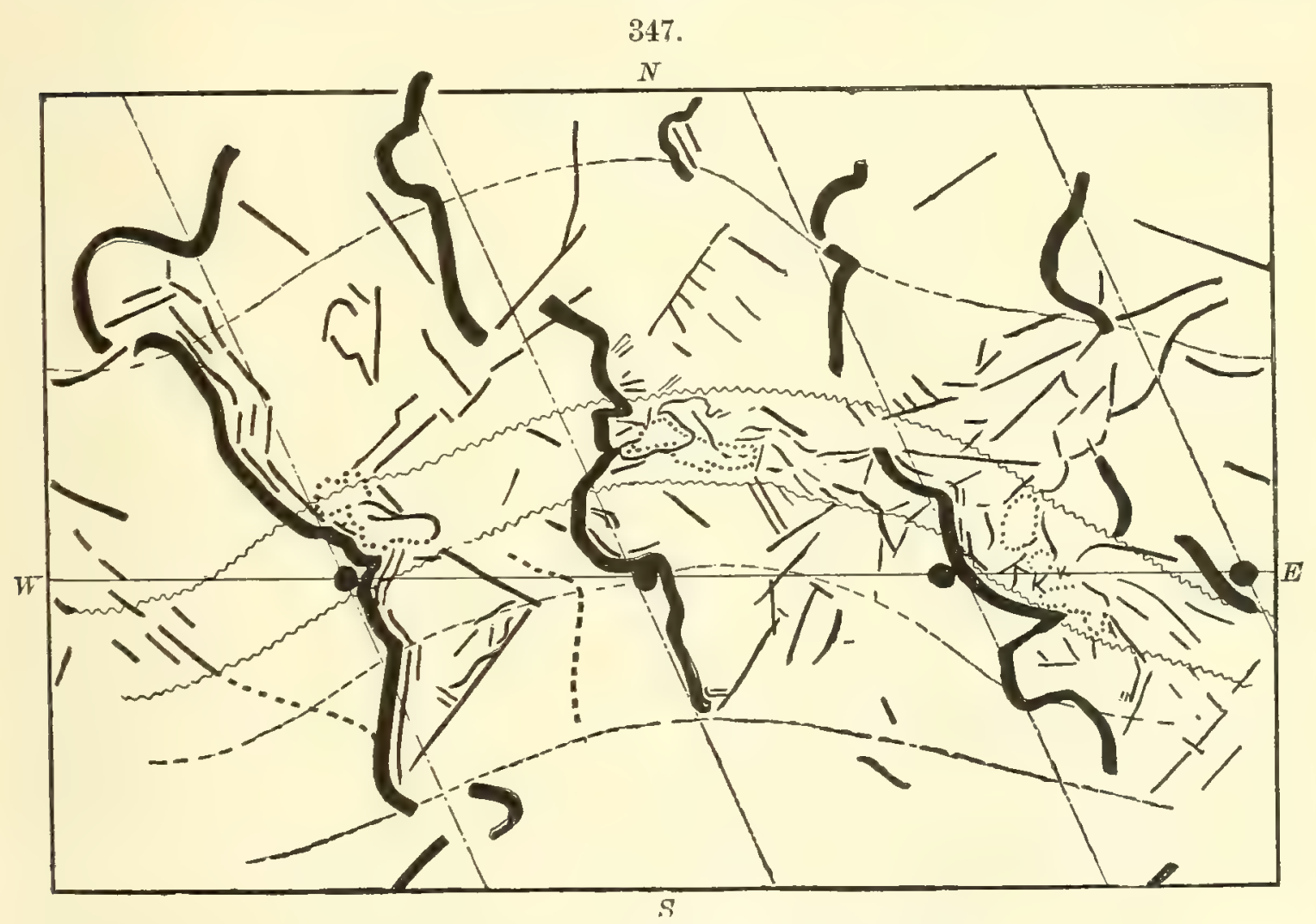

Oblique courses in the earth's grander outlines. Prinz.

there is another, that of the western coast of Africa, continued northwestward to Greenland; and $90^{\circ}$ farther eastward, there is a third, following the course of the western side of Asia, from the Urals and Spitzbergen to western Sumatra and Australia. A fourth is also supposed by him to be indicated in the middle of the Pacific, nearly $90^{\circ}$ more to the eastward, where the great central chain of islands in the ocean bends northward, and crosses the equator in the Marshall Islands. Prinz shows further from published maps that similar oblique lines have been observed on Mars (Fig. 348), and less distinctly on Venus and Jupiter. Finally, he states that M. Duner, by means of the spectroscope, has been able to determine that in the sun the 75 th 
degree of latitude makes a complete revolution in 38.6 days, while the equator revolves in 25.5 days.

The fact of torsion appears thus to be sustained for the other planets as well as for the earth.

348.

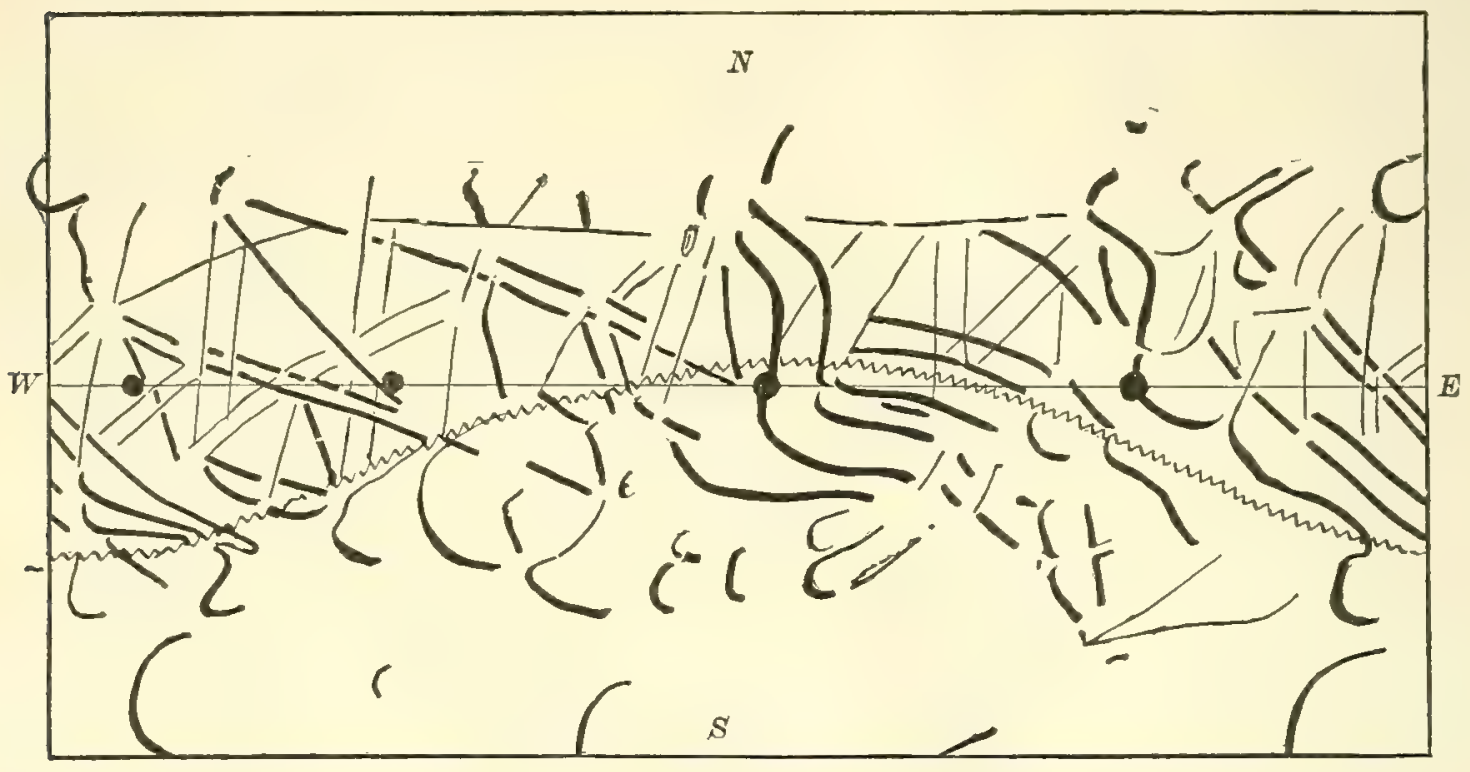

Oblique feature-lines on Mars. Prinz.

Prinz introduces, in closing, the diagram in Fig. 349 to illustrate the general scheme of torsional movements. He implies that such movement may

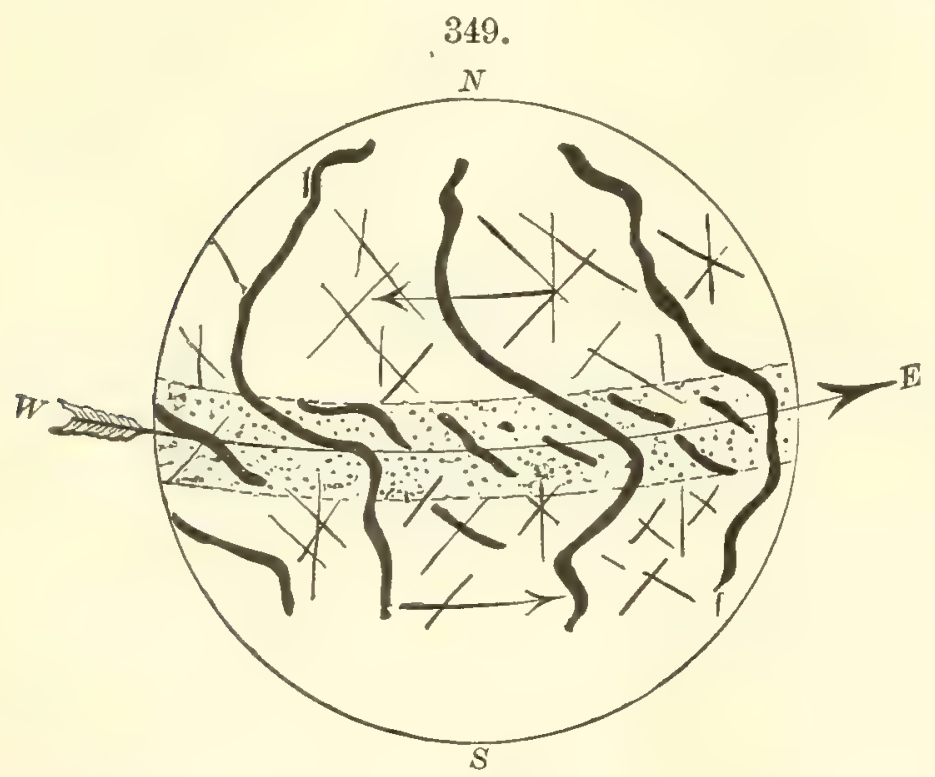
have begun in the incipient stages of surface consolidation, whenever the continental and oceanic areas began to be differentiated, and that in the process a cleavage structure was produced that determined the system of fractures in the earth's surface, and thereby the system in the earth's feature-lines. But he adds that the solution of all the questions that arise demands the profoundest knowledge of celestial mechanics, as well as much experiment, and a complete discussion of the records in the earth's structure.

Historical geology adds greatly to the interest of geomorphic work, by presenting in detail the connection of mountain-making movements with the preparatory stratigraphic events, and also by bringing out to view the bearings of these great topographical changes on the physical conditions of the earth, and their influence on biological distribution and progress. 


\section{PART IV.}

\section{HISTORICAL GEOLOGY.}

\section{SUBDIVISIONS IN GEOLOGICAL HISTORY AND METHODS OF CORRELATION.}

\section{NATURE OF SUBDIVISIONS IN THE HISTORY.}

Is the study of geology, there is often an expectation to find strongly drawn lines between the eras and periods, or the corresponding subdivisions of the rocks; but geological history is like human history in this respect. Time is one in its course, and all progress one in plan.

Some grand strokes there may be, - as in human history there is a beginning in man's creation, and a new starting-point in the advent of Christ. But all attempts to divide the course of progress in man's historical development into periods with bold confines are fruitless. We may trace out the culminant phases of different periods in that progress, and call each culmination the center of a separate period. But the germ of the period was long working onward in preceding time, before it finally came to its full development and stood forth as the characteristic of a new era of progress. It is all one progress, while successive phases stand forth in that progress.

In geological history, the earliest events were simply physical. While the inorganic history was still going on (although finished in its more fundamental ideas), there was, finally, the introduction of life, - a new and great step of progress. That life, beginning with the lower grades of species, was expanded and elevated, through the appearance of new types, until the introduction of Man. In this organic history, there are successive steps of progress, or a series of culminations. As the tribes, in geological order, pass before the mind, the reality of one age after another becomes strongly apparent. The era of Mammals, the era of Reptiles, and the era of Coal-plants come out to view, like mountains in the prospect, although, if the mind should attempt to define precisely where the slopes of the mountain end, as they pass into the plain around, it might be greatly embarrassed.

We note here the following important principles:-

First. The reality of an era in history is marked by the development of some new idea in the system of progress. 
Second. The beginning of the characteristics of an era is to be looked for in the midst of a preceding era; and the marks of the future coming out to view are prophetic of that future.

Third. The end of an era may come, either after the full culmination of the idea or phase, or earlier, at the commencing prominence of a new and grander phase in the history. It may be as ill-defined as the beginning, although its prominent idea may stand out boldly to view. Thus the era of Coal-plants was preceded by the occurrence of related plants far back in the Devonian. The era of Mammals was foreshadowed by the appearance of mammals long before, in the course of the Reptilian era. And the era of Reptiles was prophesied in types that lived in the earlier Carboniferous era. Such is system in all history. Nature has no sympathy with the art which runs up walls to divide off her open fields.

Fourth. Mere length of time, without culminating or characterizing events beyond that of rock-making, is not a criterion of value in the subdividing of geological history.

\section{CORRELATION OF THE RECORDS.}

The chronological order is that demanded, as in any history. The first object is, accordingly, to ascertain which are equivalent strata, or those of the same geological horizon, and where in the chronological succession each stratum belongs.

As even the shorter divisions of geological time have in general been of very long duration, the equivalent or correlate strata of distant regions cannot be known to be precisely synchronous in origin. A long time, measured by thousands of years, may in fact have intervened between the commencement of beds that are most alike in all those points by which age and equivalency are determined.

Huxley, in view of the impossibility of determining true synchronism, proposed to designate by the term homotaxial (from the Greek oros, same, and $\tau \dot{\alpha} \dot{\xi} \iota$, order) those strata, in regions more or less widely separated, that have apparently the same relative position in the geological series.

Difficulties. - The following are some of the difficulties encountered in attempts to ascertain the true chronological succession:-

1. The stratified rocks of the globe include an indefinite number of limestones, sandstones, shales, and conglomerates; and they occur horizontal and displaced; conformable and unconformable; part in America and part in Europe, Asia, and Australia; here and there coming to view, but over wide areas buried beneath soil and forests.

Moreover, even the same bed often changes its character from a sandstone to a shale, or from a shale to a limestone or a conglomerate, or again to a sandstone, within a few miles or scores of miles, and sometimes within a few rods; or, if it retains a uniform composition, it changes its color so as not to be recognized by the mere appearance. In the United States, many a sand- 
stone in New York and Pennsylvania is of cotemporaneous origin with a limestone in the Ohio and Mississippi valleys. Some rocks in eastern New York are not found in the western part of that state, and some in the central and western part not in the eastern.

2. In all periods, sand-beds, mud-beds, clay-beds, pebble-beds, and limestone-beds have been simultaneously in progress over different parts of the globe; and, if a period is known in geology as solely a period of limestone, it is because science has not yet discovered where the beds of sand, mud, or pebbles were being deposited while the limestone was making over its regions. The idea of a perrod of sandstone-making, or of limestone-making, is therefore an absurdity; for sand deposits are local; a short distance off, there may have been, in all times, as now, mud deposits. Still, it is true that, over continental seas, the prevailing depositions have sometimes been of limestone material, and sometimes of mud or sand; yet this has been true for certain great regions in the seas of a continent, rather than for all its seas at once.

3. Again, a stratum of one era may rest upon any stratum in the whole of the series below it, - the Coal-measures on either the Archran, Silurian, or Devonian strata; and the Jurassic, Cretaceous, or Tertiary on any one of the earlier rocks, the intermediate being wanting. The Quaternary in America in some places rests on Archran rocks, in others on Silurian or Devonian, in others on Cretaceous or Tertiary.

4. In addition, denudation and uplifts have thrown confusion among the beds, by disjoining, disarranging, and making complex what once was simple.

Amidst all these sources of difficulty, how is the true order ascertained?

Means of correlation. - The following are the means employed:-

1. Order of superposition. - When strata are little disturbed, vertical sections give the true order in those sections; and so also may outcrops of inclined strata over the surface of a country. In using this method by superposition, several precautions are necessary.

Precaution 1. - Proof should be obtained that the strata have not been folded upon one another, so as to make an upper layer a lower one (see page 104), - a condition to be suspected in regions where the rocks are much tilted.

Precaution 2. - It should be seen that the strata 350. under examination are continuous. A fault in the rocks may deceive; for it makes layers seemingly continuous which are not so. Faults are common in regions of upturned rocks and may occur when the dip is slight. In some cases, beds forming the upper part of a bluff (as $a b$, Fig. 350) have settled down

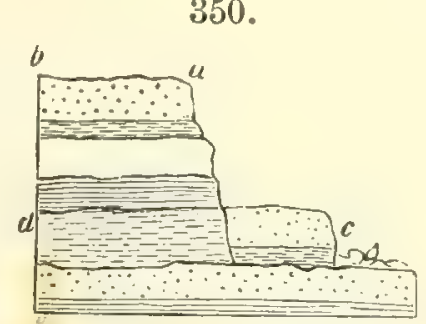
bodily $(c)$ to the bottom, so as to seem to be continuous with the older ones of the bottom (as $c$ with $d$ ). In other cases, caverns in rocks have been filled through openings from above, and the same kind of mistake marle. 
When the continuity can be established, the evidence may sometimes lead to unexpected results. For example, it may be found that a coal-bed, followed for some miles to one side or the other, is continuous with a shale, and both are actually one layer; that a sandstone is one with a limestone a few miles off; that an earthy limestone full of fossils is identical with a layer of white crystalline marble in a neighboring district; or that a fossiliferous shale of one region is the same stratum with the mica schist of another.

Precaution 3. - Note whether the strata overlie one another conformably or not, — that is, conformably as regards bedding.

Precaution 4. - Remember that, where one bed overlies another conformably, it does not follow necessarily that these beds belong to consecutive periods, as has been above explained.

The criterion mentioned, - order of superposition, - unless connected with others, gives no aid in comparing the rocks of distant or disconnected regions. For this purpose, other means must be employed.

2. Color, texture, and mineral composition. - These characteristics may sometimes be used to advantage, but only within limited districts and always with distrust. There were at one time in geology an "old red sandstone" and a "new red sandstone"; and, whenever a red sandstone was found, it was referred at once to one or the other. But it is now well understood that color is of little consequence, even within a small geographical range.

Mineral composition has more value than color, especially when it is not one of the common kinds. But it is usually to be disregarded.

One inference from the mineral constitution of a stratum is safe; that is, that a stratum is more recent than the rock from which its material was derived. Hence, an imbedded fragment of some known rock may afford important evidence with regard to the age of the containing stratum. But the presence of such a fragment does not prove that a long time intervened; the imbedding may have happened in the same period in which the earlier beds of the formation were made. The beds made and consolidated in modern time are often torn up by the waters and put into new beds in some other place. Coral limestones of recent seas are often conglomerates of the recent coral limestone. Limestone breccia is sometimes formed out of the blocks at the foot of a bluff of limestone from which the blocks had fallen.

3. Although mineral composition is ordinarily unsafe, it has value when two or more conformable strata of constant mineral characters accompany one another. Such evidences may prove identity for hundreds of miles. The association of schist, limestone, and quartzyte from central Vermont to Connecticut and beyond, with only small gradational changes in each of the rocks, serves to identify the Taconic series through its wide distribution.

4. Fossils. - The criterion for determining the chronological order of strata dependent on kinds of fossils takes direct hold upon time, and, therefore, is the best; and, moreover, it serves for the correlation of rocks all over the world. The life of the globe has changed with the progress of time. Each 
epoch has had its peculiar species, or peculiar groups of species. Moreover, the succession of life has followed a grand law of progress, involving under a single system a closer and closer approximation in the species, as time moved on, to those which now exist. It follows, therefore, that identity of species of fossils proves approximate identity of age.

Equivalency is sometimes shown in an identity of species; more often in a parallel series of nearly related species; often by an identity or close relation in the genera or families; often also in some prominent peculiarity of the various species under a family or class.

Through a comparison of fossils, it was discovered that the Chalk formation exists on the Atlantic border of the United States, although the region contains no chalk; that the Coal formation of North America and that of Nerrcastle, England, belong in all probability to the same geological age; and so on.

The progress in life has not consisted in change of species alone. The species of a genus often present, in successive periods, some new feature; or the higher groups under an order or class sorne modification, or some new range of genera, so that, even when the species differ, the habit or general characters of the species, or the range of genera or families represented, may serve to determine the era to which a rock belongs, or at least to check off the eras to which it does not belong. 'Thus Spirifer, a genus of mollusks, which has a narrow form in the Silurian, has often a very broad form in the course of the Devonian and the Carboniferous ages. Ganoid fishes, which have vertebrated tails through long ages, have their tails not vertebrated in after time. Trilobites become wholly extinct at a certain epoch in their history. These are examples of a principle availed of in multitudes of cases presenting minor differences.

Much aid is derived also from the canon brought forward by Agassiz in the first volume of his Poissons Fossiles (1833, pages 208-270), and considered at length in one of the chapters in his Natural History of the United States (i. 112, 1857): that, under the various tribes, the geological succession of species often corresponds in some of the more general characteristics with the succession of phases in the development of living representatives of those tribes. In other words, geological succession and modern embryological succession have near parallelisms.

Agassiz says, in his work on Fossil Fishes (vol. i, page 169) : 'J'ai déjà eu plus d'une fois occasion de faire remarquer la grande analogie qu'il y a entre certaines formes embryoniques, qui sont passagères dans le développement des individus, et les caractères constans d'une foule de genres de différentes familles, qui n'ont que peu de représentans dans la création actuelle, ou qui sont complétement éteints." In his work on the Natural History of the United States, on page 112 of the chapter on "the Parallelism between the geological succession of animals and the embryonic growth of their living representatives," Agassiz states the principle as follows: "The phases of development of all living animals correspond to the order of succession of their extinct representatives in past geological time."

DAYA'S MANUAL -26 
In illustration: the vertebrated tails of the ancient Ganoids is one example, since this feature is a characteristic of the young of living Ganoids, and also of some other living fishes. The cartilaginous skeleton of the ancient Ganoids is another embryonic feature. The stem of the ancient Crinoids occurs in the young of the related Comatula. The Mastodon, as regards its teeth, says Agassiz, and in some other points, is embryonic in its relations to the Elephant.

Paleontologists of skill derive a degree of prophetic power through the aid of the canon. The shells of Ammonites have been shown by A. Hyatt to afford an excellent illustration of the principle. Noting that the coiled shell contained within it all the forms it had passed through from the embryo stage to the adult, he proved by his studies of the shells of different genera that the embryological succession corresponded in a general way with the geological succession, and hence that the position in the geological scale of any new species was approximately determinable from its form. It is obvious that through the knowledge thus obtained stratigraphical doubts may often be removed. Moreover, where direct paleontological observation has ascertained in particular cases the steps of progress in the development of organs, as, for example, those of the teeth in Mammals, the facts become a basis for further use in the same direction. But decisions on such grounds have to be made with great reserve; since there were often, throughout paleontological history, retrograde steps in the various tribes of species, and, not unfrequently, in sorne organs when the general progress was upward. Man stands at the head of Mammals, and yet, as regards his teeth, he is below the Monkeys, and related to the earliest Tertiary Mammals.

By the methods which have been above described, great progress has been made in arranging the rocks of the different continents in a chronological series. North America has large blanks in the series which in Europe are filled. In this and other ways the countries of the world are contributing to a general system of life history.

Precautions in the use of fossils for correlation. - Precaution is required for the following reasons :-

1. The difference in species attending difference of conditions in climate, soil, etc. In the same regions, during any era, the species of the land differ from those of the waters; those of fresh water from those of salt; those of the surface or shallow waters from those of deeper; those of warm waters from those of cold, whether at the surface or in the deep ocean where oceanic currents make differences of temperature; those of warm or dry lands from those of cold or wet; those of clear open seas from those of muddy waters or near muddy seashores; those of rocky bottoms from those of muddy; etc. Hence, an ancient rock made in a clear sea, as a limestone, will necessarily contain very different fossils from a rock that was made of mud, although they were formed at the very same time, in the same waters, and within a hundred miles of one another. Even a hundred yards may be all that separates widely different groups of species. Again, a rock made 
in fresh waters will differ in its fossils still more widely from that made synchronously in salt waters; a rock made in shallow waters from one made at great depths; a rock made in the tropics from one made in the temperate zone or the aretic, provided the zones at the time of the making differed as they do now in climate. Hence, a very considerable difference in the fossits of rocks is consistent with their being contemporaneous in origin.

2. As a consequence of the above facts, or the dependence of life on food, temperature, and other physical conditions, migrations in species or faunas will take place whenever there is a marked change in the waters; it may be for a few miles or many. Barrande, first in 1852, pointed to examples of such migrations in his "Colonies," as he styled them; cases of advanced occurrence locally of a fauna that afterwards disappeared, but later became the prevailing fauna of a region, which he explained by migration, implying, as Geikie observes, that "particular species appeared with the conditions favorable to their spread and disappeared when these ceased." The case is the same when the fauna of a bed, which has apparently become extinct, has recurrences in an overlying stratum whenever there is a recurrence of the kind of deposit. In and out the species go with the changing conditions. Hence, as H. S. Williams has said, "the actual order of faunas met with in a vertical section is not necessarily expressive of biological sequence, but only of the sequence of the occupants of that particular area." Such recurrences of species are likely to be met with in all regions where fine shales, coarse shales, argillaceous sandstones, quartzose sandstones, with or without limestones of varying purity, are in alternation.

3. The difference in the time at which species or groups have begun to exist in different regions. The several continents may not have been exactly parallel, in all the steps of progress in the life of the globe. Certain families may have commenced a little earlier in one than in another; or again, one continental sea or region, over a continent, may have received some of its species by migration from another, long after their first appearance. Here is a source of doubt: what may be due, on one side, to special continental idiosyncrasies in condition or history, and, on the other, to migrational distribution, is always to be carefully considered. An example of the doubts and difficulties which may be thus occasioned is afforded by the Cretaceous and Tertiary formations of North America and Europe. Fossil plants of the Rocky Mountain Cretaceous have been pronounced Tertiary by European paleontologists who judged from comparisons with European Tertiary species ; and yet the animal fossils of associated beds made it certain that they were Cretaceous: and the query has thence arisen whether the European plants may not be the successors of emigrants of Cretaceous American species which, through this means, became characteristic in Europe of a post-Cretaceous period, or, whether the differences are not indigenous to the separate continents.

4. The difference in the time at which species or groups of species of different regions have become extinct. In one region, changes may have caused 
species or genera (or higher groups) to disappear, while, in another subjected to the same conditions or causes of catastrophe, the same species, or at least the same genera (or higher groups), may have continued on through another period. Genera or Families may have become extinct sooner on one continent, or part of a continent, than on another; or in one ocean, or part of an ocean, than in another. Again, catastrophes may affect the shallow borders of an ocean, and not reach to a depth of a hundred fathoms.

5. The absence of fossils from a formation, or their extreme fewness, even when the formation is thousands of feet thick, is no evidence as to the paucity of life in the era. The absences may be owing to local conditions; or to the trituration of fossils to the finest of particles which infiltrating waters could wash out; or to the waters of the region having been fresh.

A case in the later Paleozoic is that of the Devonian Catskill Red sandstone 3000 to 4000 feet thick, whose fossils are very few brackish-water or fresh-water species. When formed, the seas of the world contained as large and varied a fauna as in the period of the great Devonian limestones or that of the Subcarboniferous Crinoidal limestones. Such blanks need explanation; for the equivalent fossiliferous can hardly be absent from the whole of a continental area.

6. The inferior value of plants to animals as tests of geological age of equivalency is generally admitted. It appears to be true also that marine fossils are entitled to greater weight than terrestrial or fresh-water species excepting the fossil Vertebrate. But the evidence from Vertebrates is always surest when fortified by that of Invertebrates.

The difficulties are not often sources of final doubt when the conclusions are based on the general range of animal types characterizing an era. Should a Trilobite be hereafter discovered in any Cretaceous rocks of the world, it would lead no one to suspect those rocks to be Paleozoic, because the associated species would be sufficient to settle the question of age.

Among metamorphic rocks, the outcrops of the rock should be followed into the region of feeble metamorphism where traces of fossils may possibly be found. By studying the relations of the associated rocks as to bedding, and proving couformability and continuity, the discovery of a few fossils in one stratum of the series at a single locality may settle the question of age approximately for a whole formation hundreds of miles in length.

\section{SUBDIVISIONS OF GEOLOGICAL TIME.}

General basis of subdivisions. - In view of the principles explained in the preceding pages it follows that -

1. The grander divisions of geological time should be based, in a comprehensive way, on organic progress, independently of events connected with rock-making and disturbances of the crust. Examples of such divisions are those of the four primary divisions, the Archæan, Paleozoic, Mesozoic, and Cenozoic. 
2. Subordinate divisions should recognize the same criterion, but should depend for their limits, as far as practicable, on physical breaks or events registered in the rock-series, and on abrupt transitions in kinds or groups of fossils. Since the latter are dependent on physical changes, they are a convenient criterion when characterizing large areas.

3. When subordinate divisions of the higher grades have been established on any continent, or part of a continent, these divisions should be recognized and adopted as nearly as possible in the study of other regions, and their limits determined if possible by means of the fossils; for only in this way can the history of different regions be brought together into one system. For example: the Permian period, recognized and defined in European geological history, should have its place in American geological history, however intimately the beds and their fossils in America may blend with those of the Carboniferous period. So also the Devonian of Europe should be recognized and have like limits, as nearly as may be, in the Devonian of America. A degree of fixedness in the higher subdivisions and their names is necessary to prevent confusion in the literature of the science and the frustration of its great purpose, - the production of a comprehensive earth-history.

4. Inferior subordinate divisions so far depend on local conditions, that those of different continents, and even of distant parts of the same continent, generally require, in the first study of a region, special designations to avoid assumptions of closer relationships or equivalency than can be made out. The different continents, and often also unlike regions of the same continent. have had their special histories. The periods and epochs of America and Europe are not in general the same in limits, and much less so in rocks. The Devonian subdivisions are different on the two continents; and it is far from certain, also, that the commencement assigned to the Devonian in North America is synchronous with that in Europe. In the Carboniferous, Reptilian, and Mammalian eras the American epochs differ from the European. There is much diversity between the subdivisions in New York and those of the Mississippi valley, and still greater between these and the subdivisions of the Pacific slope and border. Even in Pennsylvania the formations fail of many of the subdivisions that are prominent in New York.

Hence in the study of a new region it is necessary at the outset to make arbitrary subdivisions of its formations, such as may seem most convenient and natural, and give them local names. These names have at first only a note-book value. When the relations of the beds to those recognized in other regions have been ascertained through fossils, the facts begin to take their places in the general geological history of the country; and should the correlation be complete, the local names may give way to those generally accepted elsewhere.

It is of the highest importance to remember that state boundaries are only political limits, and not, ordinarily, at least in America, true geographical or geological limits; and if the subdivisions of one state which have 
already received local names extend into the adjoining, the introduction of new names in the latter is a wrong to the science.

5. In all cases, the characteristics of the species and the beds should be carefully scrutinized, lest abruptness due to local migrations (as those caused by slight changes of depth or currents and kinds of sea-bottom) should be mistaken for abruptness of real importance.

Physical and Organic Breaks. - Prominent among the events influencing the rock-structure and life of a continent is that of mountain-making. The A ppalachian Mountains stand as a grand time-boundary between the Paleozoic æon and the Mesozoic; and cotemporaneous orographic movements make a like limit in European geology. Moreover, it was attended by the most remarkable of organic breaks. The Taconic mountains mark the close of the Lower Silurian, an epoch of abrupt change in North America; and parallel disturbances occurred in Britain and Europe. The Laramide or post-Cretaceous mountain system along the Rocky Mountains is another such boundary for America, separating Mesozoic and Cenozoic time, though not as complete in the attendant organic break as in the physical. But it so happens that no corresponding event occurred at this time in Europe, the orographic movements most nearly synchronous taking place after the commencement of Cenozoic time. Nevertheless, the organic break at the close of the Cretaceous period is even greater for Europe than for America. Such a fact seems to show that there was some other catastrephic event concerned; but its nature is yet to be studied out.

Part of the breaks referred to above were limited in their effects to the hemisphere including America, Europe, northern and middle Asia, and northern Africa. The opposite hemisphere, that of India, Australia, and South Africa, has been more or less independent, although the two were alike in many characteristics; and owing to this, the boundary closing Paleozoic time, so strongly marked in the geological history of Europe and America, cannot be satisfactorily defined in the latter. The coal period is of later date than that of Europe and America, it occurring in the Permian, and the Permian period blends with the Triassic.

Such orographic time-boundaries are registered not only in the rocks that are upturned, but also in unconformabilities between them and the succeeding rocks. It is important to note, however, as already stated, that the unconformability exists only in upturned regions. A short distance away, the succeeding beds will be found lying conformably over the same kinds that are upturned in the mountains; moreover, the organic break there may be less pronounced, and in more distant regions it may fail altogether. The unconformability is, however, none the less important as a time-boundary, for orographic upturnings have been events of great geographical extent after long ages of preparation.

The Subdivisions. - The several grades of subdivisions of geological time are named (1) Eons, (2) Eras, (3) Periods, (4) Epochs; and the corresponding terms applied to the formations are Series, Systems, Groups, 
Stages. For intermediate divisions $s u b$ is prefixed to the name of the division next above. Still lower subdivisions are termed zones, and receive special designations from a characteristic fossil. Subdivisions of zones, corresponding to the vertical distribution of species, have been recently called hemerce, from the Greek for day. In place of any of the above terms, the word time may be used in its usual sense whenever it is thought convenient. It is substituted beyond for the word coon.

I. Archæax Time. - The beginning of Archæan time was without life; but before it closed conditions had been reached that admitted of the existence of protophytic and protozoic life.

II. Paleozoic Time. - Characterized by the more ancient kinds of life, closing with the period of the great Coal formations of Europe and America,

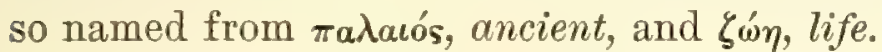

III. Mesozorc Time. - The life of mediæval types or kinds; closes with the period of the Chalk or Cretaceous formation, so named from $\mu$ '́⿴囗⿱一一) middle, and گón.

IV. Cenozorc Time. - The life of more modern types, continuing to the

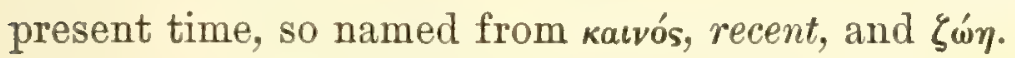

The term Paleozoic was proposed by Sedgwick in 1838, and preferred and adopted by Murchison the same year in place of his own name Protozoic, it "involving no theory." For the terms Mesozoic and Cenozoic, and the upper limit of the Paleozoic, the science is indebted to Professor John Phillips, of Oxford, England. Cenozoic is sometimes written Cainozoic or Kainozoic. But in English, derivatives from the Greek diphthong a become o or e, as in Ethiopia, Eolian, Egypt, Etna, ether, hematite; and $\kappa$ becomes $c$, as in center, circle, calyx, camel, and multitudes of other words. Lyell's names for divisions of the Tertiary, namely, Eocene, Miocene, Pliocene - are examples of both cases, the ce in each being кaı in Greek.

The following table contains some of the subdivisions of inferior grade :

\section{ARCH EAN TIME.}

There are the two divisions, the Azoic and the Archaozoic, but they are not distinguishable in the rocks. The rocks have been divided into -

1. LAURENTIAN.

2. Huronian.

II. PALEOZOIC TIME.

\section{Eopaleozoic Section.}

1. Cambrian, or Cambric, Era.

1. Lower Cambrian, or Georgian Period.

2. Middle Cambrian, or Acadian Period.

3. Upper Cambrian, or Potsdam Period.

2. Lower Silurian, or Lower Siluric, Era.

1. Canadian Period.

2. Trenton Period. 


\section{Neopaleozoic Section.}

1. Upper Silurian, or Upper Siluric, Era.

1. Niagara Period.

2. Onondaga Period.

3. Lower Helderberg Period.

2. Devonian, or Devonic, Era.

1. Oriskany Period.

2. Corniferous Period.

3. Middle Devonian, or Hamilton, Period.

4. Upper Devonian Period.

3. Carbonic Era.
1. Subcarboniferous Period.
2. Carboniferous Period.
3. Permian Period.

\section{MESOZOIC TIME.}

1. Triassic Period.

2. Jurassic Period.

3. Cretaceous, or Cretacic, Period.

\section{CENOZOIC TIME.}

1. Tertiary Era.

2. Quaternary Era.

European geologists, at meetings of the International Congress of Geologists, have decided to make the names of the higher subdivisions of the eras end in $i c$.

In early geologic science, the oldest system of rocks recognized was called the Primary or Primitive system, and it comprised granite, gneiss, mica schist, and all other related crystalline rocks; and the more schistose kinds, like mica schist, chlorite schist, hornblende schist, were made the newer of the series. The terms "Fundamental gneiss," in English, and "Urgneiss," German, are relics of this beginning period.

Under the same geological scheme - that of Werner - the second division was called the Transition rocks. It embraced the semi-crystalline schists, and slates or argillyte, along with hard gritty rocks called gray-wacke, and some limestones which were much upturned and thus were seemingly distinet from the ordinary fossiliferous strata, or the so-called "Secondary" rocks. Their partly semi-crystalline texture and their upturned condition were regarded as evidence of their being older than and separate from "Secondary" rocks; and their imperfectly crystalline or uncrystalline state, that they were younger than the Primary rocks.

The idea that gneiss and mica schist are always "Primary" or Archæan rocks, that grade of crystallization is a safe mark of relative age, was shown to be false by Lyell (Principles, 1830-33), who, with De la Beche (1834), rejected all Wemerian errors. Lyell went so far as to hold - as a table in the third volume of his Principles (1833, p. 387) shows - that crystalline or metamorphic schists may occur in all the formations, from the earliest to the latest. 
The general facts in the progress of life on the globe are illustrated in the annexed diagram:-

351.

ANIMALS.

PLANTS.

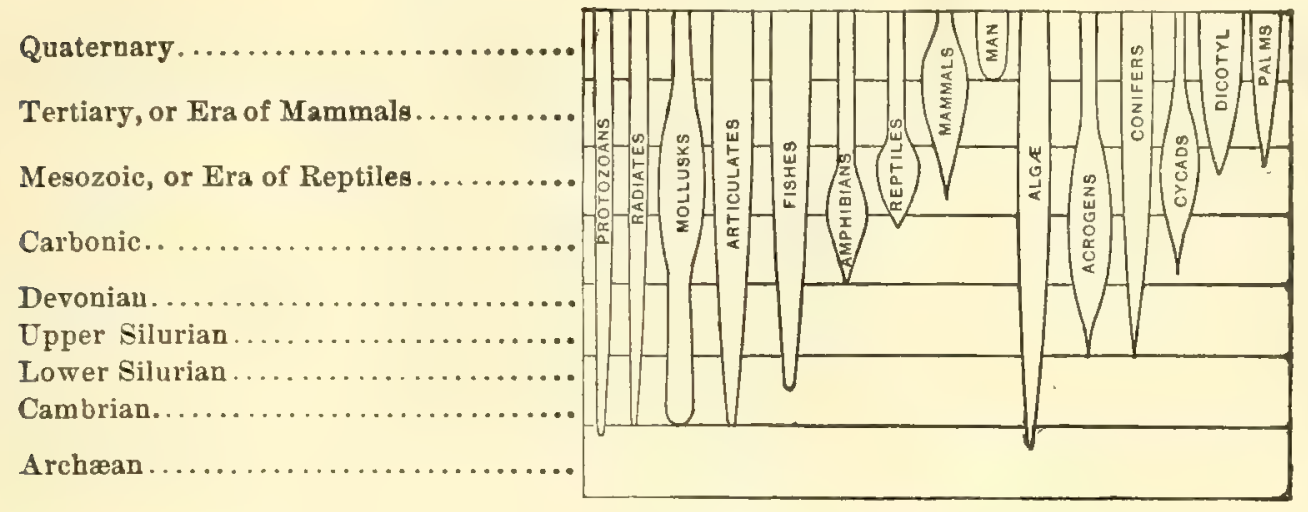

The horizontal bands represent the divisions of time; the vertical correspond to different groups of animals and plants. The lower end of each vertical band marks the point in geological time when, according to present knouledge from fossils, the type it represents began; and the varying width in the same bands indicates the greater or less expansion of the type. The following are the points the diagram illustrates:-

According to present facts from fossils, Radiates began in the Cambrian, and have continued till now, rather increasing throughout the ages.

Mollusks had their beginning in the Cambrian, and continued increasing to the era of Reptiles: they then passed their maximum (as indicated in the figure).

Articulates commenced in the early Cambrian; and, excluding the tribe to which the Trilobite belongs, they continued expanding in numbers and grade to the present time.

Fishes began in the Lower Silurian, were very abundant and of great size in the Devonian, and continued on, becoming further diversified in later periods.

Amphibians began in the Carbonic, and reached their maximum in the early part of the Reptilian era.

Reptiles began in the Permian period of the Carbonic, and had their maximum in the Reptilian era or Mesozoic time.

Mammals began in the Reptilian era, and became the highest of species in the Mammalian era or Cenozoic time.

Sea-weeds (or Algæ) were the earliest plants of the globe, probably preceding animal life. Acrogens and Conifers began in the Upper Silurian and possibly earlier. The Acrogens had their greatest expansion in the era of Coal-plants, in which they occurred with Conifers. Cycads began in the Devonian, and had their greatest expansion in the Reptilian erit. Angiosperms or Dicotyledons began in the closing period of the Reptilian era, and expanded, along with Palms, through the era of Mammals. 
352.

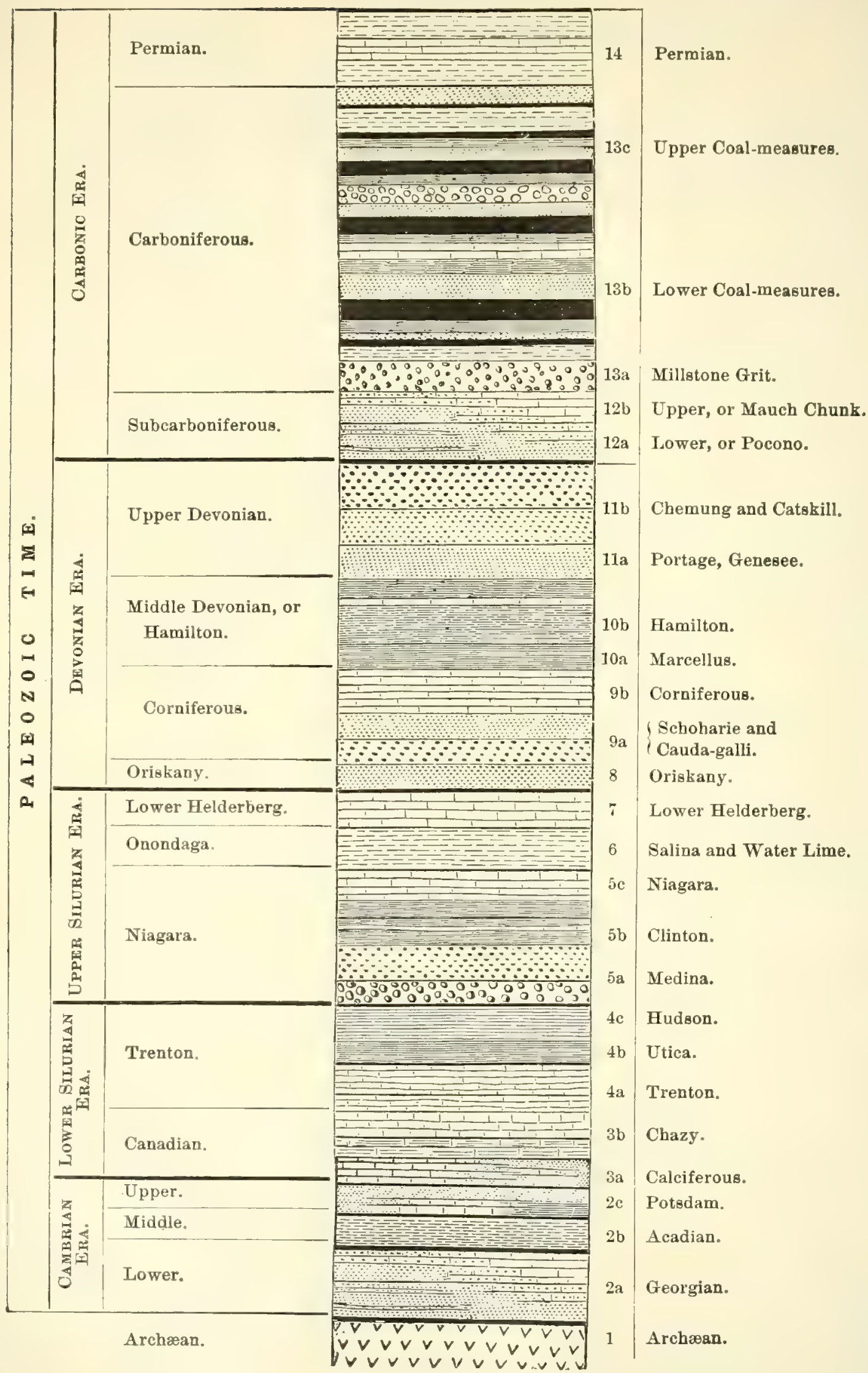


353.

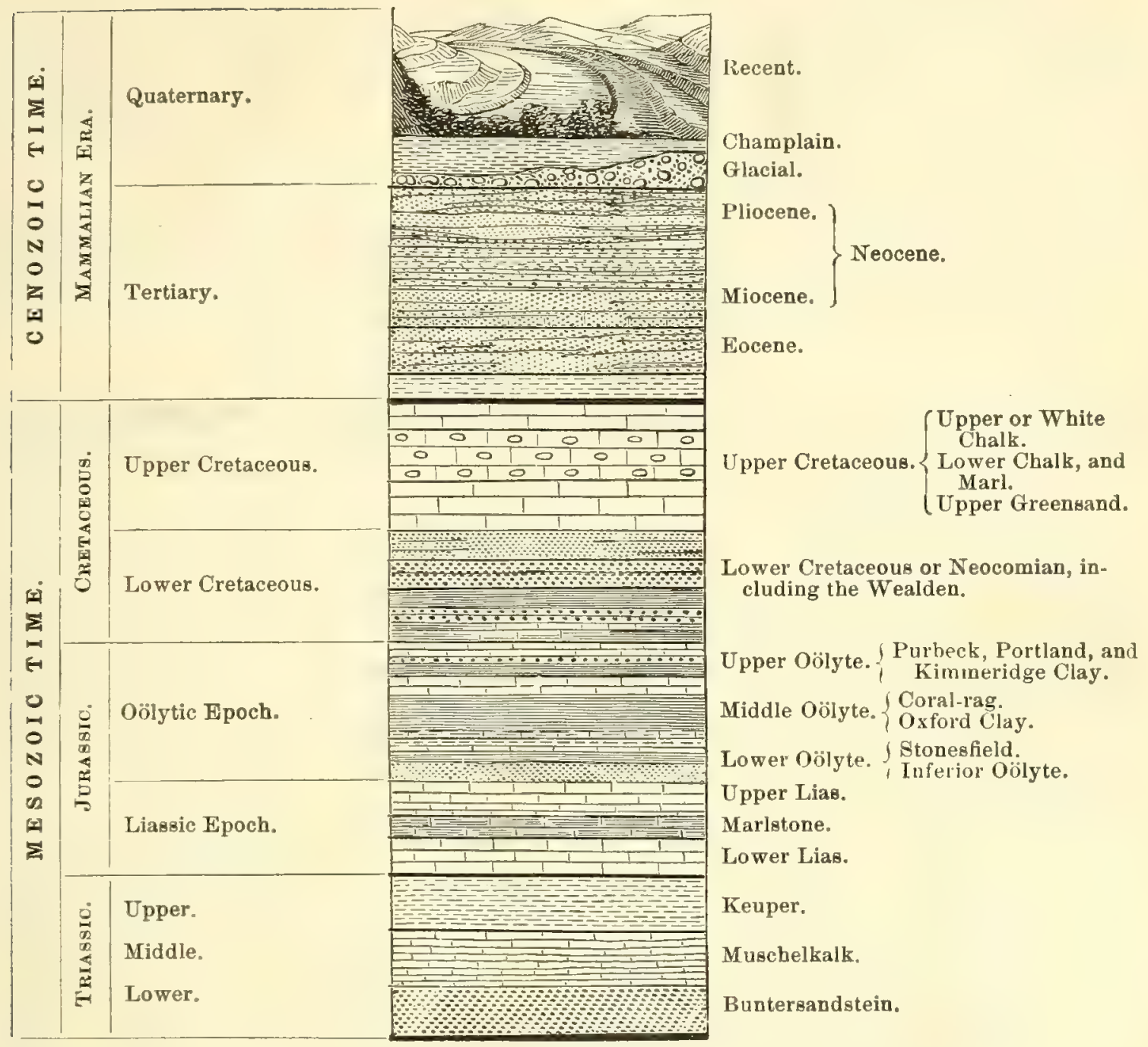

Agassiz, first at Neufchâtel, in 1841, in a Discours sur la Succession et le Développement des Êtres organisés, and later in his Principles of Zoölogy, 1848, distinguished Paleozoic time, as that of the Reign of Fishes ("le Règne des Poissons"); Mesozoic time, as that of the Reign of Reptiles; and Cenozoic time, as that of the Reign of Mammals.

Inferior Subdivisions. - The subdivisions under the eras, - the periods, and epochs, - vary, as has been stated, in different countries. The table (Fig. 352) presents a general view of those of eastern North America, so far as the Paleozoic is concerned, - the Silurian, Devonian, and Carbonic being well represented on the continent. 'The rest of the series (Fig. 353) is partly from European geology, where the system is well represented.

In this Manual, American geology is in general first considered; and afterward such further illustrations are drawn from other continents as are necessary for comprehensive views and generalizations.

The subdivisions, as the table shows, are named, for the most part, from the locality or region where the rocks are well displayed. Owing to conditions explained beyond, the subdivisions of the American Paleozoic series are 
more numerous and more trenchantly distinct in the state of New York than in most other parts of the continent; and, moreover, the rocks of the state were studied in detail and described by the geologists of the New York Survey between the years of 1836 to 1842 , the systematizing period in geological science. For these reasons, but especially the latter, a number of the subdivisions bear the names of New York localities.

The following map of the United States east of the Rocky Mountains exhibits the geographical distribution of the rocks of the several ages; that is, the regions over which they are severally the surface-rocks.

354 .

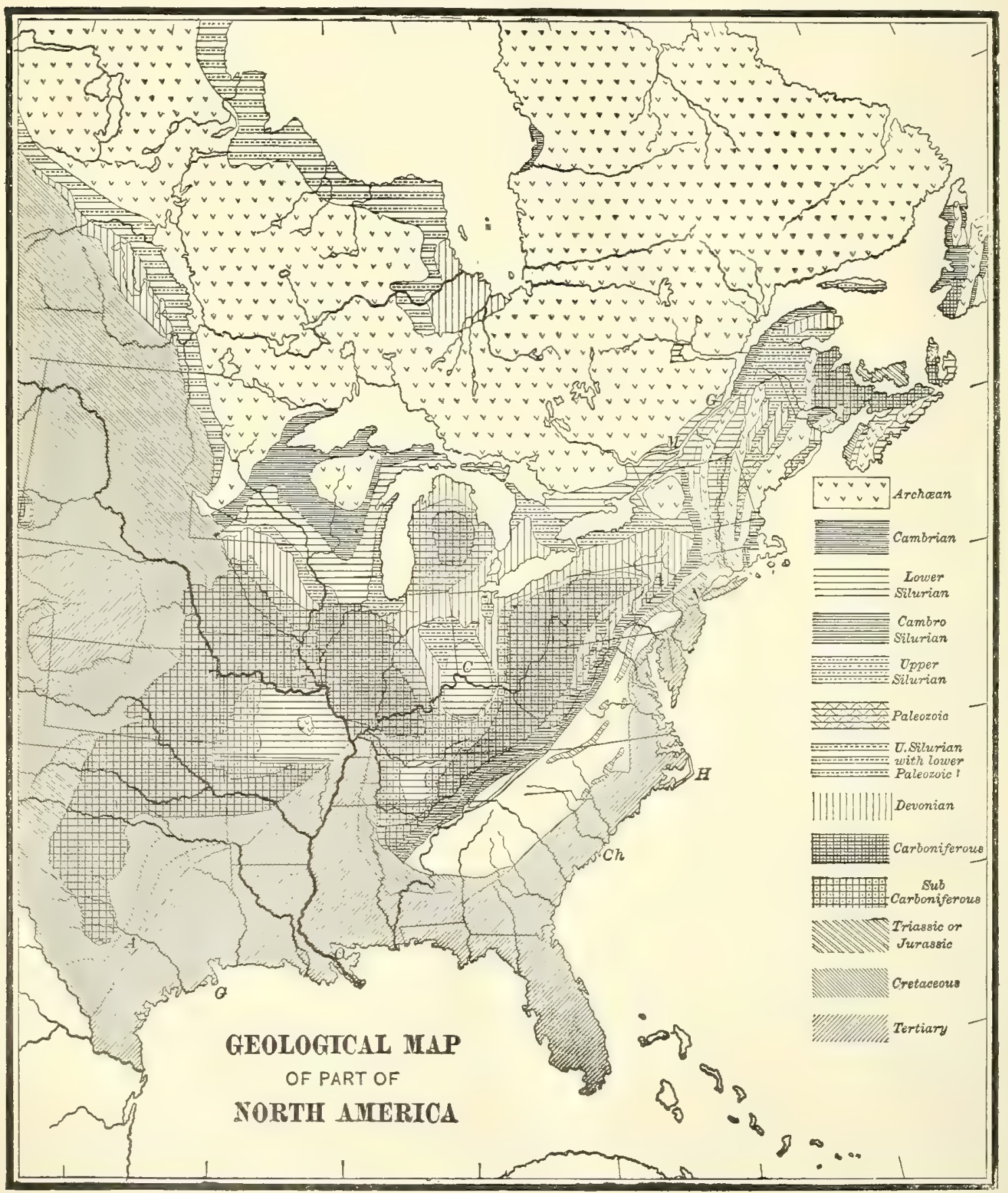


The map is from the geological chart of C. H. Hitcheock, with changes from later publications. The blank area on the eastern border comprises Archæan, Cambrian, and Lower Silurian rocks, not yet having their limits defined.

The progress of the life of the globe is one of the two great subjects that come before the student, in the following part of this Manual, treating of Historical Geologr. By way of introduction to it, a short chapter on its system of structures is here introduced.

\section{BRIEF REVIEW OF THE SYSTEM OF LIFE.}

\section{GENERAL CONSIDERATIONS.}

1. Life. - Some of the distinctions between a living organism and inorganic or mineral substances have been mentioned. Recapitulated, with additions, they are:-

(1) The living being has, as the fundamental element of its structures, visible cells, containing fluids or plastic material.

(2) It enlarges by means of imbibed nutriment, through a process of development; and not by mere accretion or crystallization.

(3) It has the faculty of converting nutriment into the various chemical compounds essential to its constitution, and of continuing this process of assimilation as long as the functions of life continue; and it loses this chemical power when life ceases.

(4) It passes through successive stages in structure, and in chemistry, from the simple germ to a more or less complex adult stage, and finally evolves other germs for the continuance of the species; instead of being equally perfect and equally simple in all its stages, and essentially germless.

There is, therefore, in the living organism, something besides mere physical forces, or the chemistry of dead nature - something that ceases to be when life ceases. There is a vital condition, in which molecules have powers that lead to resulting seed-bearing structures, widely different from those of inorganic nature, and standing on altogether a higher level. There is a power of development, an architectonic power, that not only exalts chemical results, but evolves a diversity of parts and structures, and a heritage of ancestral qualities, of which the laws of material nature give no explanation.

2. Vegetable and Animal life. - The vegetable and animal kingdoms are the mutually dependent sides or parts of one system of life. The following are some of their distinctive characteristics :-

(1) Plants take nutriment into the tissues by absorption; animals have a mouth, and receive food into a sac or stomach. Exceptions to this feature occur in animal life only in the lowest microscopic forms and certain parasitic kinds; and the most of these extemporize a mouth and stomach whenever any particle of food comes in contact with the outer surface, so that even here the food is digested in an interior cavity. Certain insectivo. rous plants "digest" animal material, but the process is not necessary to growth, with small exceptions.

(2) Plants find nutriment in carbonic acid, appropriate the carbon, and set free oxygen, a gas essential to animal life; animals use oxygen in respiration, and set free carbonic acid, a gas essential to vegetable life. (The amount of carbonic acid given out by plants in respiration is too small to need consideration here.)

(3) Plants take inorganic material as food, and turn it into organic; animals take this organic material thus prepared (plants), or other organic materials made from it (animals), finding no nutriment in inorganic matter. 
(4) The Vegetable Kingdom is a provision for the storing away or magazining of force for the Animal Kingdom. 'This force is acquired through the sun's influence or forces acting on the plant, and so promoting growth; mineral matter is thereby carried up to a higher grade of composition, that of starch, gluten, vegetable fiber and other products, and in this there is a concentration or accumulation of force. To this stored force animals go for growth and development; and, moreover, the grade of composition is thus carried yet higher, to muscle and nerve; and this is a magazining of force in a still more concentrated or condensed state.

(5) Plants, of some minute kinds, and the spores of some larger species (some Algæ) have locomotion, or a degree of contractility in certain parts that corresponds to an infinitesimal amount of mechanical power; but the locomotive spores, as they develop, become fixed, like the plants from ordinary seeds, and no increase of mechanical power accompanies vegetable development. In animal development from the germ, on the contrary, there is always an increase of power - an increase, in all, of muscular (mechanical) power, and, in the case of species above the lower grade, of psychical and intellectual power, - until an ant, for example, becomes a one-ant power, a horse a one-horse power. Whence, an animal is a self-propagating piece of enginery, of various power according to the species.

(6) In the plant, the root grows downward (or dark-ward) and the stem upward (or light-ward), and there is thus the up-and-down polarity of growth - the higher developments, those connected with the fruit, taking place above, or in the light. In the animal, there is an antero-posterior polarity of power as well as growth - the head, which is the seat of the chief nervous mass and of the senses, and the locus of the mouth, making the anterior extremity. Consequently, there is in animals a connection between grade and the greater or less dominance and perfection of the head extremity. An animal, as its ordinary movements manifest, is preëminently a go-ahead thing. Even the inferior stationary species, like the Polyp, show it in the superior power that belongs to the mouth extremity.

(7) Plants have no consciousness of self, or of other existences; animals are conscious of an outer world, and even the lowest show it by avoiding obstacles.

From the above diverse characteristics of plants and animals, it follows that, however alike chemically are the germs of the two, they must still be, in their chemical nature, fundamentally different.

\section{ANIMAI KINGDOM.}

The most prominent subdivisions of the Animal Kingdom are :-

\section{Vertebrates; II. Invertebrates.}

These subdivisions are based on the presence in the former alone of a vertebral column, with a bone-sheathed cavity along the dorsal side of the column for the great nervous cord. This vertebral column in the embryo-stage and in many adult fishes is a cartilaginous cord, called the notochord (from the Greek for back and a gut chord of a stringed instrument), situated below and parallel with the spinal cord or nerve; out of it, as development and ossification proceed, the vertebral column is produced. In the sheath of the spinal nervous cord, the dorsal spinous processes of the vertebræ are produced, which more or less inclose the cord. The Invertebrates, besides having no vertebral column within, have the chief nervous cord ventral in position and below the intestinal canal instead of dorsal.

The Vertebrates include, beginning with the highest:-

MaMmats
Birds

REPTILES

Amphibians
Fishes

LEPTOCARDIANS

All other species are Invertebrates. 


\section{VERTEBrates.}

The more prominent characteristics of the six classes of Vertebrates are the following :-

\section{Mammals.}

Species that suckle their young; breathe by means of lungs; have a heart of four cavities. There are three prominent subdivisions: (1) The true Viviparous, as Man, ordinary Quadrupeds, Bats, Whales, Seals. (2) The Semi-oviparous, the young of which are more immature at birth (the birth, therefore, intermediate between the oviparous and viviparous), and which are passed into a pouch where they are suckled until maturity : as the Marsupials, of which the Kangaroo of Australia and the Opossum of North America are examples. (3) The Oviparous, or Monotremes, as the Ornithorhynchus of Australia and Tasmania, and the Echidnæ of Australia, Tasmania, and New Guinea, which produce true eggs. The Ornithorhynchus, or Duckbill, has the bill of the Duck, and lives along streams in holes entered below the level of the water. It has the bones that in Marsupials support the pouch, but not the pouch.

\section{Birds.}

Oviparous; breathing by lungs; heart of four cavities; covered with feathers, and having wings mostly adapted for flying. All existing birds have bills without teeth ; but geological discovery has made known the existence in Mesozoic time of birds with a full set of teeth.

\section{Reptiles.}

Oviparous; breathing by lungs; a heart of three or four cavities ; naked or covered with scales: as Crocodiles, Lizards, Turtles, Snakes.

\section{Amphibians.}

Oviparous; breathing when young by gills, afterward by both gills and Iungs, or by lungs alone; a heart of three cavities ; naked or covered with scales : as Frogs, which lose the tail as well as gills on becoming adults; and Salamanders, the tailed (or lizard-like) Amphibians. The modern species are naked-skinned and often toothless; but many ancient kinds had scales like Reptiles and stout teeth.

\section{Fishes.}

Usually oviparous; heart usually of two cavities; breathing by gills, which take air from the water, and are situated in front of one or more openings in the sides of the throat that let out water which enters by the mouth; skin naked, or covered with scales or bony plates. Locomotion chiefly a process of sculling by means of the posterior or caudal extremity of the body.

Under Fishes there are the following prominent divisions :-

Paxжіснтнуes, or Fishes of ancient type, including the Sharks and Gars, characterized by a heart with the arterial bulb contractile and the intestine having a valve between it and the stomach, both characters showing relations to the Amphibians. The three grand divisions are:-

1. Selachians. - The group includes the Sharks (Fig. 355) and Rays - Fishes having a cartilaginous skeleton; usually several gill openings or slits $(g)$; no gill-cover, and gills attached to the skin by the outer margin instead of being free; embryo with deciduous external gills; no air-bladder; usually no proper scales, but a rough skin (shagreen). The ordinary Sharks have the mouth underneath and separate from the nostrils, with the teeth sharp-edged (Figs. $358,359,360$ ); another group, the Hybodonts, have the teeth of 
similar form to the preceding, but round or blunt-edged (Figs. 361, 362); another, the Cestracionts (Fig. 357), an ancient type, of which only one genus now exists, has a pavement (Fig. 363) of small bony pieces (Figs. 364, 365) in the mouth (for grinding up shellfish, etc.), and a series of smaller teeth at the margin, with the mouth and cavities of the nostrils confluent. Many ancient Sharks, like a few of the modern, had large spines connected with, and usually along the anterior margin of, the fins (Figs. 355, 356). As these fishes have the vertebral column imperfectly ossified when not cartilaginous, the fossils are mostly teeth, spines, fragile vertebræ, and occasionally shagreen.

In the lowest group, the Chimarids, there is a cartilaginous notochord multil licately subdivided, the sheath of which is partly ossified. The species have a few very large teeth, and a single gill-opening, which is covered by a fold in the skin. To this group are referred the Acanthodians, which were formerly supposed to be Ganoids. They have very small rhombic scales, a spine along the front margin of the fins, and are apparently without teeth.

$355-365$.

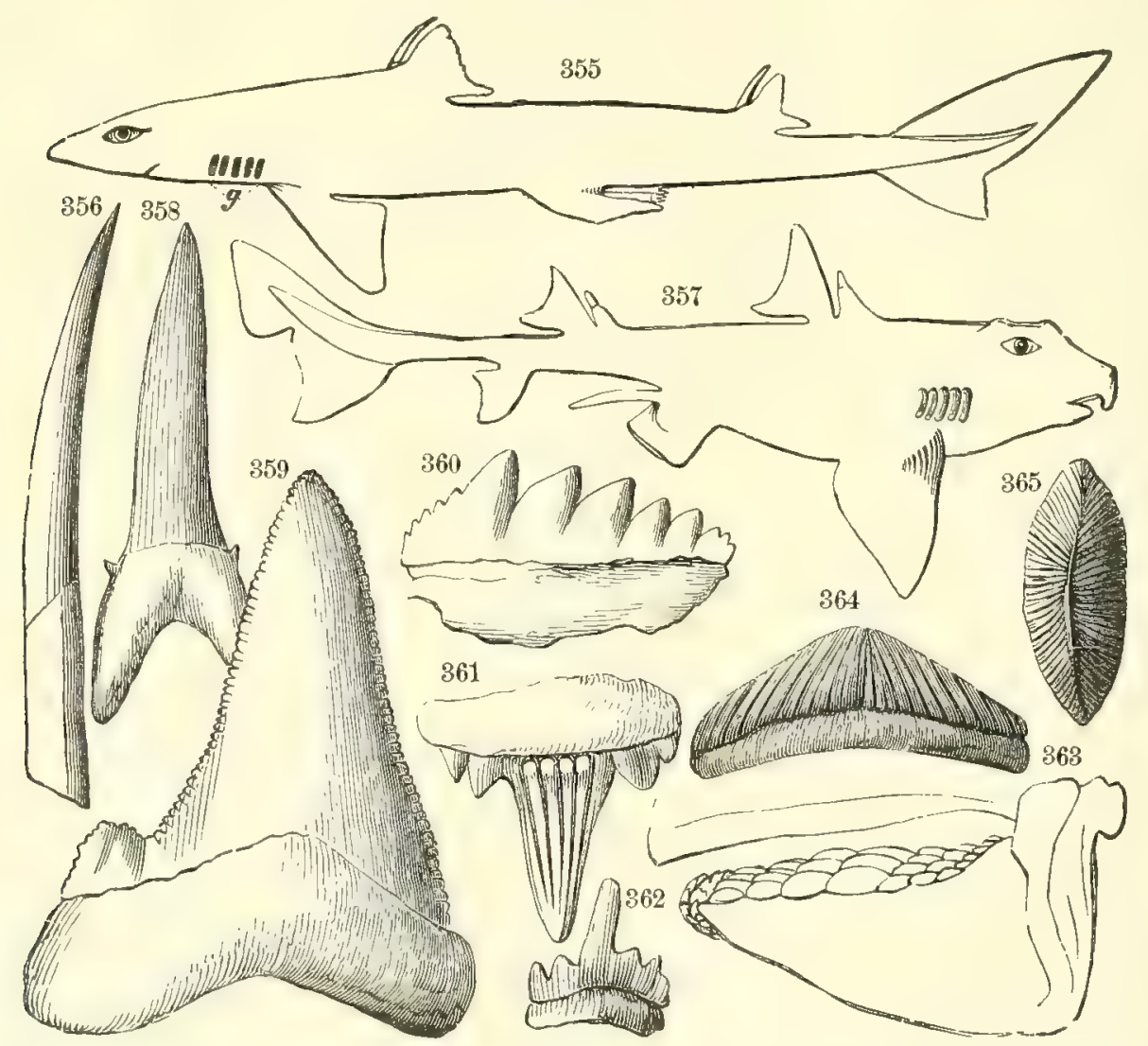

Setachians. - Fig. 355, Spinax Blainvillii $\left(\times \frac{1}{8}\right)$; 356, Spine of anterior dorsal fin, natural size; 357, Cestracion Philippi $\left(\times \frac{1}{6}\right)$; 358, Tooth of Lamna elegans; 359, id. Carcharodon angustidens; 360 , id. Notidawus primigenius; 361, id. Hybodus minor; 362, id. Hyb. plicatilis; 363, Mouth of Cestracion, showing pavement-teeth of lower jaw; 364, Tooth of Acrodus minimus; 365, id. Acrodus nobilis.

2. Ganoids or Gars (Figs. 366 and 375). - The Ganoids have the skeleton cartilaginous in the earlier kinds, but more or less ossified in the later and in the few modern species; one gill-opening; a gill-cover, and gills free; an air-bladder, having a pneumatic duct; embryo sometimes with external gills. Skin covered commonly with thick bony scales, like Reptiles or ancient Amphibians (whence ganoid, from the Greek rávos, shining), or with bony plates, somewhat turtle-like; scales often rhombic and set together like tile (Figs. 366, 375); and interlocked by projecting points (Figs. 367, 368); sometimes cycloid and imbricate. Tails of ancient species vertebrated or heterocercal, like 
the Sharks (Fig. 375), but non-vertebrated or homocercal in many later kinds (Fig. 366), except in the embryonic state. Teeth (Figs. 372, 373) labyrinthine in interior structure (Fig. 374, a cross-section), a feature which is more strongly marked in the teeth of ancient Amphibians (the Labyrinthodonts), which geologically succeeded to the Ganoids.

The Ganoid tribe includes :-

The Placoderms, an aberrant type, having the head and anterior part of the body covered with a shield made up of plates, as represented in figures of Pteraspids, Cephalaspids, Asterolepids, etc., on pages 566, 624. The posterior part of the body has scales, which admit of free movement for sculling locomotion. The pectoral fins are large arms in the Asterolepids, fitted apparently for crawling over muddy surfaces left by the retreating tide.

$360 ;: 974$.

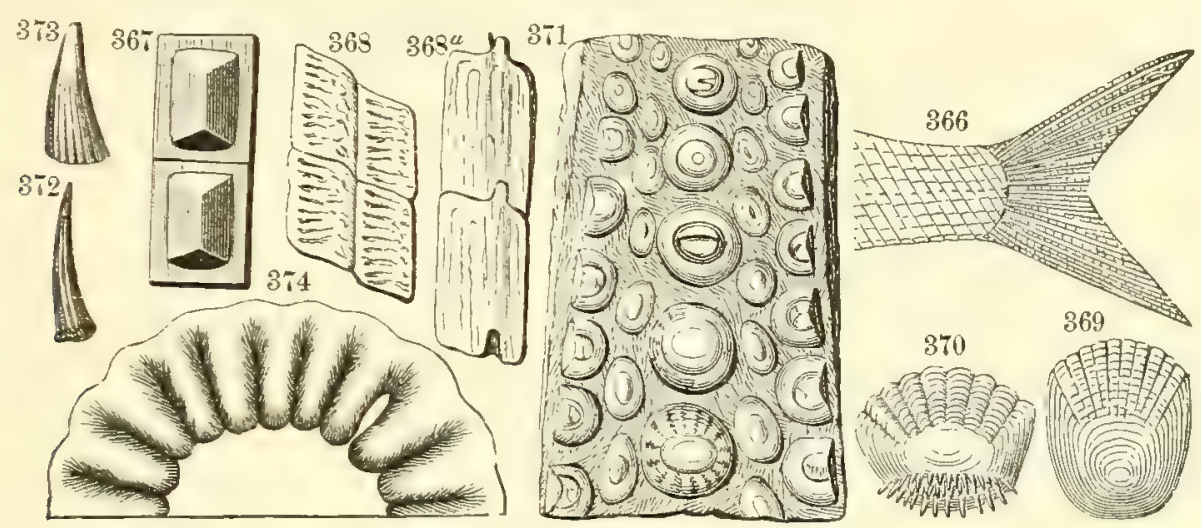

Gavorns (excepting 369, 370). - Fig. 366, Tail of Thrissops ( $\times \frac{1}{2}$ ); 367, Scales of Chirolepis Traillii ( $x$ 12); 368 , id. Palæoniscus lepidurus $(\times 6)$; 368 a, under-view of same; 369 , Scale of a Cycloid; 370 , id. of a Ctenoid; 371, part of pavement-teeth of Gyrodus umbilicus; 372, Tooth of Lepidosteus; 373, id. of a

Cricodus; 374 , Section of tooth of Lepidosteus овseus.

The Crossopterygians, or those haring in the pectoral fin, like many Dipnoi, a thickened finger-like axis, with reference to which the rest of the fin is like a fringe, and thence the name of the group. (Sthenopterygians, referring to the strengthened axis of the fin, would be better.) Holoptychius, Onychodus, Glyptolepis, Rhizodus, Osteolepis, are some of the ancient genera; and Polypterus, of the Upper Nile, is a related genus.

375.

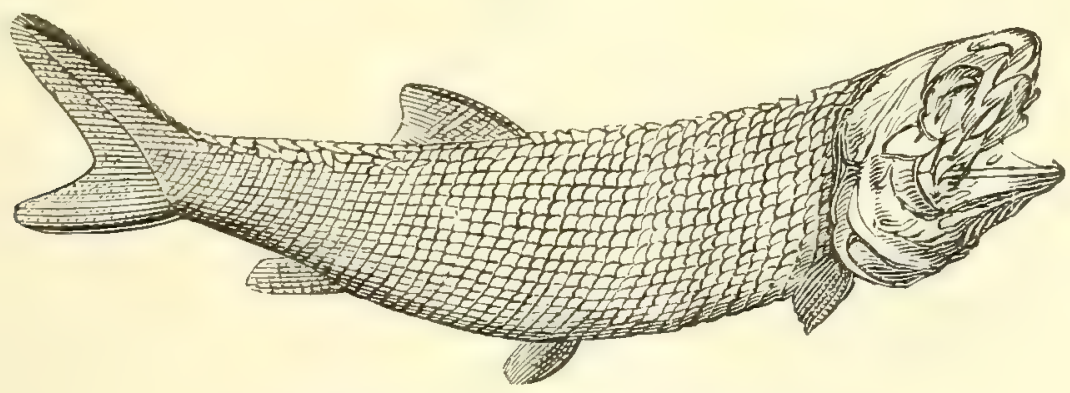

Palæoniscus Freieslebeni $\left(\times \frac{1}{3}\right)$, Permian.

The Palconiscoids, in which the pectoral fins have no thickened axis, besides other peculiarities, as in Palæoniscus (Fig. 375), Chirolepis, Eurynotus, etc.

The Pycnodonts, having the palate paved with blunt rounded molar-like teeth, as in Pycnodus, Gyrodus (Fig. 371), etc.

3. Dipnoans or Lung-fishes. - These fishes, of which the species of Lepidosiren and Ceratrodus are living representatives, lave both gills and lungs, the air-bladder being cellular, so as to have functional value as a lung - a characteristic that enables the DaNa's MaNUaL -27 
living Ceratodus to survive in the muddy pools of dried-up streams in Australia. The pectoral fins are a pair of slender filaments in Lepidosiren; thickened paddle-shaped fins with a jointed axis in Ceratodus, and have a thickened axis in Phaneropleuron and other ancient genera.

TELeosts. - The Teleosts include nearly all of the modern fishes except the Sharks and Rays and the few existing Ganoids. They are closely allied to the Ganoids, through the existing Amia and related forms. They have a bony skeleton, as implied in the name

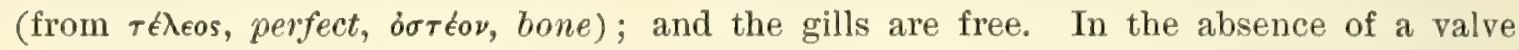
between the intestine and stomach they are unlike the Ganoids and Sharks and inferior to them in type of structure. The body usually has scales, which are either cycloid (Fig. 369), or ctenoid (Fig. 370), the latter term referring to the toothed or spinous margin, and coming from the Greek for comb; but in some kinds there are bony plates.

Crclostomes (Marsipobranchs) or Lampreys, etc., having a simple cartilaginous notochord; no jaws; mouth a circular opening for suction, usually with conical teeth on its inner surface; gills pouch-like; no fins.

\section{Leptocardians.}

Amphioxus (or Branchiostoma): embryonic forms having a simple fibrous notochord in place of a vertebral column; cranium and distinct brain lacking; heart tubular; gill a saccular dilation of the cesophagus; no jaws; the organs of the senses partly wanting. The species are all small.

Relation of Vertebrates to Invertebrates. - The Invertebrates are widely separated in character from the Vertebrates. The nearest group to Fishes among them is that of the Ascidians or Tunicates, formerly referred to the class of Mollusks and regarded as not higher among species than the Oyster, all special organs of locomotion being absent, and little to be seen in an outside view but a bag with two holes for the passage of water - inward at one hole and outward at the other. But the animals are little like Mollusks structurally, and have certain peculiarities in their embryonic development which manifest a relationship to the Vertebrates. In the young stage some of them have a resemblance in form and somewhat in organs to the tadpole of a Frog and the embryo-like fish, Amphioxus. The Ascidians are consequently regarded as related either to a prototype form of Vertebrate, or else to a degenerate form in the Vertebrate series. The relation is briefly presented in a well-illustrated article by Lankester entitled Vertebrata, contained in the 24th volume of the Encyclopadia Britannica.

\section{INVERTEBRATES.}

The old subdivisions of the Invertebrates are: Protozonss; Radites, including Polyps, Hydrozoans, and Echinoderms; Mollusks, including Mollusks, Bryozoans, and Brachiopods; Articulates, including Worms, Crustaceans, and the terrestrial kinds, Myriapods, Arachnids, and Insects. Through embryological study it has been proved that true Protozoans are one-celled in all stages, the embryo cell undergoing no subdivision (that is, segmentation) in the development. In Sponges, on the contrary, while there is much external resemblance to Protozoans, the germ-cell undergoes segmentation as in higher species, and hence there is a nearer relation to Polyps than to the simple Protozoans. It has also been found that Brachiopods are about as nearly related to Worms as to Mollusks; that Echinoderms are more nearly related to Worms than to Polyps and Hydrozoans, notwithstanding the radiate arrangement of the external parts; that Polyps and Hydrozoans (Medusæ) are closely related, and as they have the common character of a single opening to the interior cavity, they now are called Coelenterates, from кoî̀os, hollow, and ${ }^{\prime}{ }^{\prime} \nu T \epsilon \rho \nu$, intestine. 
The Articulates having jointed limbs, including the terrestrial species and Crustaceans, are now generally removed from the Worms, and placed in a separate grand division, called Arthropods (from the Greek a $\rho \theta \rho o v$, joint, and $\pi$ oús, foot). But the typical Worms and the Arthropods are alike in consisting of a series of segments, each normally having its nervous ganglion; and in this fundamental feature, which is more important than their differences, both sections are far removed from Mollusks and Brachiopods, which are nonarticulates, the body and its appendages having no joints. On this account the old division of Articulates still has importance. The relations of Insects are even closer, structurally and embryologically, to Worms, than to Crustaceans, notwithstanding their jointed limbs. This relation of Insects to Worms is shown by the resemblance of the larves to Worms; while Crustaceans, by the same evidence, are proved to be most nearly related to the precursors of Worms.

The grander divisions of Invertebrates are as follows :-

\section{ARTICULATES.}

\section{Arthropons.}

a. The terrestrial or Tracheate species:

1. Insects; 2. Myriapods; 3. Arachnids.

$b$. The aquatic or Branchiate species:

\section{Limuloids; 5. Crustaceans.}

2. Worms.

NON-ARTICUlates. 3. Mollusks; 4. Molluscords (including Brachiopods and Bryozoans). The non-segmented Worms might here make another subdivision.

RADIATES.
5. Echinoderms.
6. Ceelenterates, including Hydrozoans (or Medusæ and Hydroids), and Actinozoans (or Polyps).

7. Sponglozons, or the animals of the Sponges.

8. Protozons, Amoboids, Rhizopods, Radiolarians, Monads, and other Flagellates, etc.

\section{Arthropods.}

The Tracheates have spiracles (breathing-holes), a vascular system for inside aircirculation, and one pair of antennæ, or none; they include Insects, Myriapods, Arachnids.

The Branchiates have gills for the aëration of the circulating fluid, or perform this function through the general surfaces of the body or its foliaceous appendages. The species are Crustaceans, Limuloids, and Pycnogonids.

\section{Insects.}

Having the body in three parts, that is, a distinct head, thorax, and abdomen; and only three pairs of legs: as Hymenopters (Ants, Bees, Wasps); Lepidopters (Butterflies, Moths); Coleopters (Beetles); Dipters (Flies); Neuropters (Dragon-flies, May-flies); Orthopters (Grasshoppers, Locusts, Cockroaches); Hemipters (Cicada, Squash-bug, Aphis); Thysanura (Podura, Lepisma).

\section{Myriapods.}

Having a worm-like form, regularly articulate body, and numerous pairs of legs; part have the body flattened, and one pair of legs to a segment or somite, the Chilopoda. which include the Scolopendra and other Centipeds; and others have the body nearly cylindrical, and two pairs of legs to a segment, the Diploöpoda, which include the Iulids and other Millepeds. 


\section{Arachnids.}

Having the body in two parts, cephalothorax and abdomen (but in the lowest, Mites, only one, - the abdomen and thorax not separate segments): as Spiders, Scorpions, Mites, Ticks.

\section{Limuloids.}

Limuloids are a nearly extinct tribe of species, related more nearly to the Arachnids than to Crustaceans. The only species in American waters is the Limulus polyphemus, or Horse-shoe, common on the coast of southern New England and to the southward. Limuloids differ from Crustaceans in not passing through the Nauplius stage in embryological development ; in having no antennæ corresponding to the first pair in Crustaceans ; and in having the two antennæ of the second pair chelate; that is, terminating in pincers, and used for conveying food to the mouth, - a degenerate service for sense-organs.

A Paleozoic group, under the tribe of Limuloids, includes the Eurypterids - aquatic species having the long, jointed body of a Caligus among Crustaceans, but occasionally several feet in length. For figures, see pages 556,623. They have two antennæ, like the Limulus, or none, and, moreover, the basal joints of part or all of the legs are the animal's jaws. Although aquatic species, they are related to the Scorpions, a division of Spiders. See further, page 513.

\section{Crustaceans.}

The class of Crustaceans is divided into:-

(1) Decapods (so-named from the Greek for ten-footed), as the Crabs, Lobsters, Shrimps, usually having 5 pairs of feet.

(2) Tetradecapods (named from the Greek for fourteen-footed), as the Sow-bugs and Sand-fleas.

(3) Entomostracans, irregular in number of feet, and usually without a regular series of abdominal appendages. $376-385$.
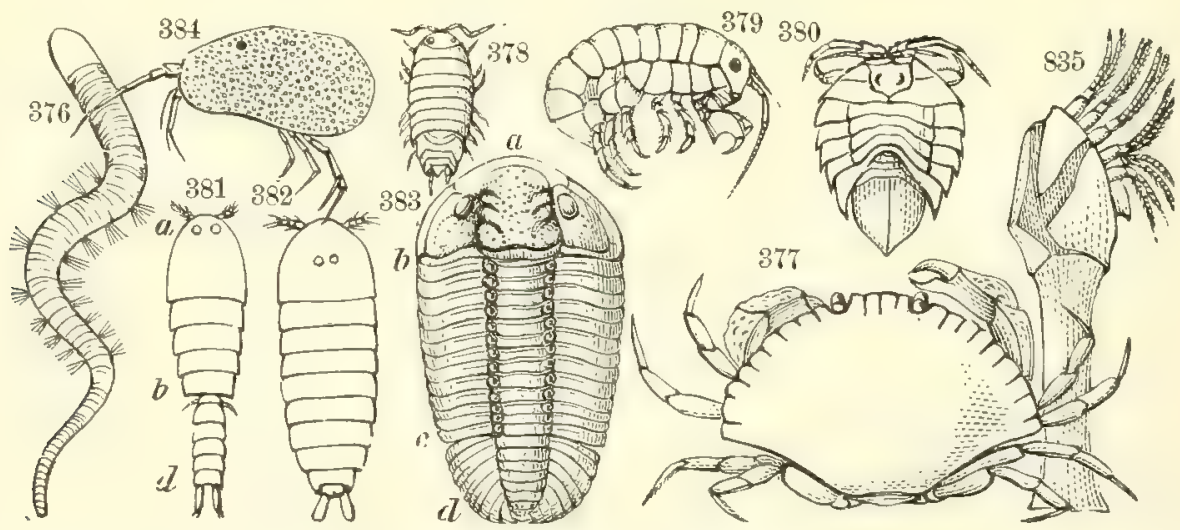

Articulates, - (1) Worms: 376, Arenicola marina, or Lob-worm ( $\left.\times \frac{1}{6}\right)$. (2) Crustaceans:-377, Crab, species of Cancer; 378, an Isopod, species of Porcellio; 379, an Amphipod, species of Orchestia; 380, an Isopod, species of Serolis $\left(\times \frac{1}{2}\right)$; 381, 382, Sapphirina Iris ; 381, female; 382, male $(\times 6)$; 383, Trilobite, Calymene Blumenbachii; 384, Cythere Americana, of the Cypris family $(\times 12)$; 385, Anatifa, of the Cirriped tribe.

In an early stage of development, many young Crustaceans have a 6 -footed freeswimming form, called a Nauplius, 2 of the feet being functionally antennæ and 4 of them legs, the third pair afterward becoming jaws. All Entomostraca pass through this Nauplius stage, and also a few of the higher kinds.

Among the Decapods, Crabs are called Brachyurans, - from the Greek for shorttailed, the abdomen being small and folded up under the body ; the Lobsters and Shrimps, 
Macrurans, - from the Greek for long-tailed, the abdomen being rarely shorter than the rest of the body.

Among the Tetradecapods, Figs. 378, 380 represent species of the tribe of Isopods (a word meaning equal-footed), and Fig. 379 of that of Amphipods (feet of 2 kinds). Fig. 378 is the Sow-bug, common under stones and dead logs in moist places. Fig. 379 is the Sand-flea, abundant among the seaweed thrown up on a coast.

Under Entomostracans, the Cyclops group (Copepods) includes very small species having a shrimp-like, or Caridoid, form, as in Fig. 381. Sometimes the male and female differ much in form : 382 is male, and 381 female of Sapphirina Iris; $a b$ is the cephalothorax, and $b d$ the abdomen. In the Cypris group, the animal is contained in a bivalve shell, as in Fig. 384, and they are hence called Ostracoids.

In the Phyllopod group, the form is either Caridoid, approaching Cyclops, or like Daphnia or Cypris; but the abdominal appendages or legs are usually foliaceous and excessively numerous: the name is from the Greek for lenf-like feet. The Ostracoid Phyllopods are multiplicate species (that is, excessive in number of body segments or limbs) of the tribe of Ostracoids, and the Caridoid kinds often resemble multiplicate species of Copepods.

In the Cirriped or Barnacle group, the animal has usually a hard, calcareous shell, and is permanently attached to some support, as in the Anatifa (Fig. 385) and Barnacle. The animal opens a valve at the top of the shell, and throws out its several pairs of jointed feet looking a little like a curl, and thus takes its food, - whence the name, from the Latin cirrus, a curl, and pes, foot. The Anatifa has a fleshy stem, while the ordinary Barnacle is fixed firmly by the shell to its support. Barnacles are common on the rocks of the seacoast between high and low tide. The young Cirriped or Barnacle is a free-swimming Ostracoid, much like Fig. 384 in form, but, on passing to the adult stage, it drops its bivalve shell, and commences the sedentary life of the species, and the hard, permanent, calcareous shell of the animal is then formed. As with other Crustaceans the animal periodically casts its skin with progress in size, but not the hard calcareous shell about the body. The shell of ordinary Crustaceans is not calcareous, but chitinous, and more or less flexible; the Cirripeds are an exception as regards this outer shell, but not in the integument over the legs and body within this shell. The composition of the chitinous covering of a lobster is given on page 73.

Trilobites are Paleozoic Crustaceans related to the Isopods. They have the general form of an Isopod, the higher division of the Tetradecapods, and were placed near this group, with a query, by the author in 1852. But they are Phyllopod-like or multiplicate species, with the exception of a few of embryonic relations. Like the Isopods, and unlike species of Apus, and most other Entomostracans, they undergo no metamorphosis. Trilobites are represented in Figs. 383, 386, and $387-391$.

In the Trilobite, the shell of the head-portion ( $a b$, Fig. 383) is called the buckler; the tail (or properly, abdominal) shield, when there is one (Fig. 383, d), the pygidium. The buckler $(a b)$ is divided by a longitudinal depression into the cheeks or lateral areas, and the glabella or middle area (Figs. 383, 386). The cheeks are usually divided by a suture extending from the front margin by the inner side of the eye to either the

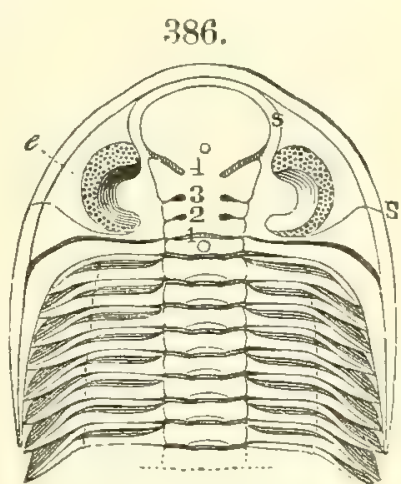

Dalnanites Hausmanni. posterior or the lateral margin of the shell. In Fig. 383 (Calymene Blumenbachii), this suture terminates near the posterior outer angle. The glabella may have a plane surface, or be more or less deeply transversely furrowed (Fig. 383), and usually has only three pairs of furrows. The suture running from the anterior side of the eye forward or outward, and from the posterior side of the eye outward ( $s$ in Fig. 386), is the facial suture; a prominent piece on the under surface of the head, covering the mouth, is called the 
hypostome. The eyes may be very large, as in Dalmanites (Fig. 386), Phacops, and Asaphus (Fig. 689), or small, as in Homalonotus; or not at all projecting, as in Trinucleus (Fig. 692); and may also differ in position in different genera.
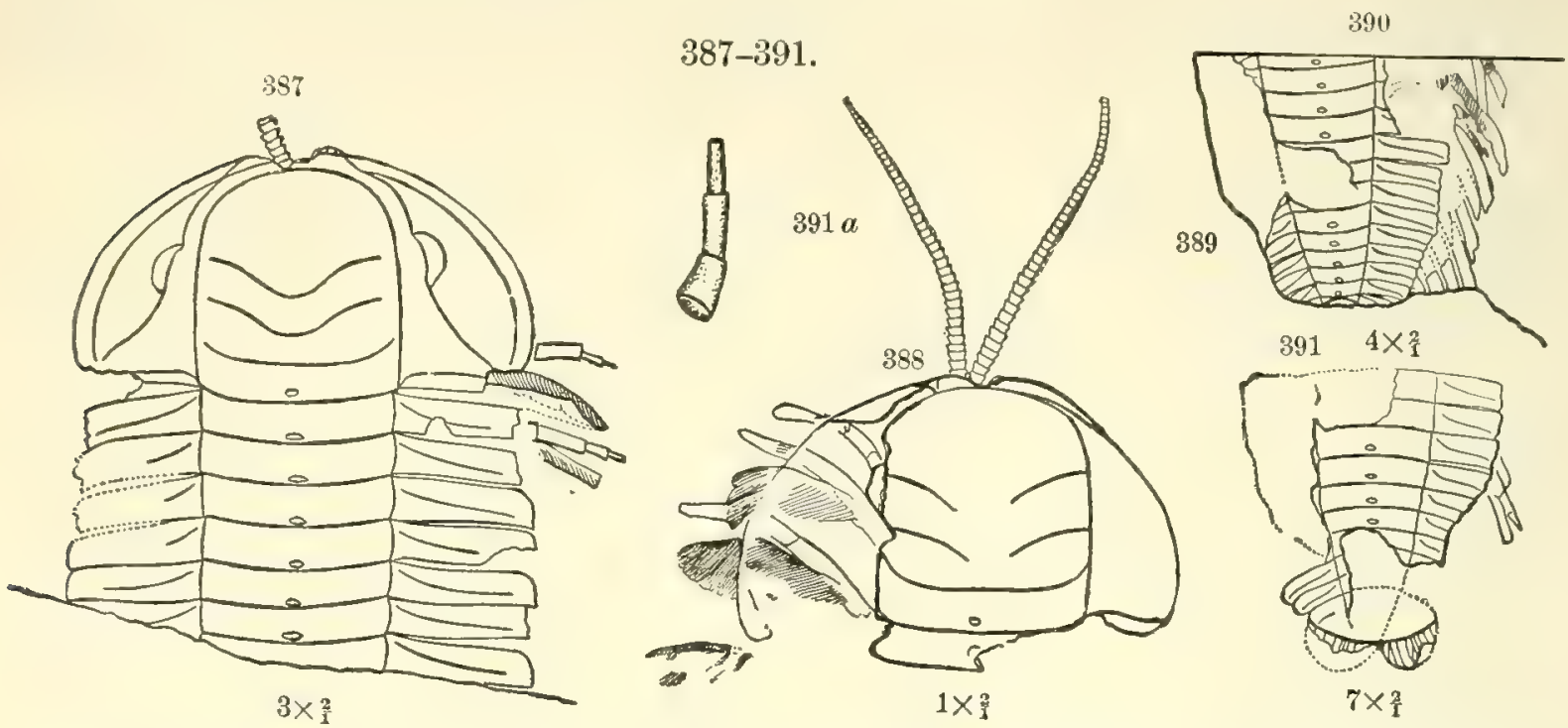

Triarthrus BeCKII. - Figs. 387, 388, specimens with antennæ and portions of cephalic and thoracic appendages $(\times 2)$; 389 , portion of antennæ $(\times 10)$; 390, posterior half, with remains of feet $(\times 2) ; 391 a$, one of the jointed appendages $(\times 6)$; 391 , one of the feet. Matthew.

Specimens of Trilobites are almost always without appendages of any kind. Evidence of pairs of slender limbs extending the whole length of the body were first observed in a specimen of Asaphus platycephatus, by Billings, in 1870; and later, in 1883, in another American species, $\boldsymbol{A}$. megistos, by Mickleborough. New proof was announced by Walcott, in 1876, 1877, and 1881, from slicings of some hundreds of specimens of a species of each of the genera Calymene and Ceraurus; who reached the conclusion that there were four pairs of slender appendages to the head-portion, and a series along the whole under surface to the extremity of the pygidium or abdomen. He also obtained evidence that the thoracic legs had at bases a branch (epipodite), and that they carried also an appendage in the form of slender filaments, some of which were spiral, which he described as probably brancbial. Mr. Walcott also gives figures of what he regards as the fossil ova of the Trilobites.

These results have been in the main confirmed and made more definite from specimens of Triarthrus Beckii, found by W. S. Valiant, and described, in 1893, by W. D. Matthew, some of which are represented in Figs. 387-391, from Matthew's paper. In addition to the existence of legs, the specimens figured show that Trilobites had slender antennæ of the first pair (Figs. 387, 388), consisting of short joints (Fig. 389); and that the slender, bifid, jointed feet were, in part at least, natatory organs, probably, by plumose setre (as is indicated in Fig. 388 and others). The presence of a.second pair of antennæ is probable, but none is indicated. The specimens were from a thin layer in the Utica shale near Rome, Oneida County, New York.

Later investigations of specimens from the same locality, by C. E. Beecher $(1893,1894)$ have ascertained that the abdominal appendages are branchial, as in modern Isopods; he has also made out the precise form and other characters of the thoracic limbs, showing that each consisted of a seven-jointed leg, and a long natatory appendage. (See page 512 for figures.)

The following table exhibits the homologies, as regards segments and their appendages, of different types of Crustaceans. 0 indicates the absence of a segment, and the Roman numerals above, the normal number of the segments in the cephalothorax and abdomen. 
Cephalothorax.

ABdomen.

I II III IV V VI VII VIII IX X XI XII XIII XIV

1. Decapons Pedunc. 2 pairs (Grab). eyes.

of

6 pairs of mouth

5 pairs of feet. organs.

antennæ.

2. Tetradeca- 0 PODS.

3. Crclops

2 pairs
$\begin{gathered}\text { of } \\ \text { antennæ. }\end{gathered}$
2 pairs
of
antennæ.

\section{4 pairs of mouth \\ organs.}

$\begin{array}{ccccc}\begin{array}{c}3 \text { pairs one } \\ \text { of pair }\end{array} & \begin{array}{c}4 \text { pairs of } \\ \text { natatory } \\ \text { mouth feet. }\end{array} & 0 & 0 \\ \text { feet. } & & & \end{array}$

I II III IV V VI

6 pairs of abdominal appendages.

6 pairs of abdominal appendages.

usually no appendages except to last segment.

\section{Worms (Vermes).}

Worm-like in form, consisting of many segments not always distinct, without jointed legs, though often furnished with tubercles, lamellæ, or bristles. Examples: the Earthworm, marine Annelids, Leeches. Among the Annelids or higher Worms, the Arenicola, or Sand-worm family, includes species that burrow in the sands of seashores; Fig. 376 represents the A. marina, or Lob-worm, which is common on European and American shores, and grows to the size of the finger. One species of Eunice has a length of 4 feet. They are supposed to be related to the Scolithus of the Cambrian (Potsdam Sandstone).

Species of Tubicolce, of the Serpula tribe, live in a calcareous or membranous tube, and have a delicate branchial flower, often of great beauty, near the heads. The tubes often penetrate corals, and the branchial flower comes out as a rival of the coral polyps around it.

The Rutifer's are generally made a subdivision of the Worms. They are minute species, having 3 to 6 body segments ; 1 or 2 simple eyes ; a pair of jaws ; disks, situated anteriorly, which are edged with movable cilia in place of limbs. Many have, in appearance, the cephalothorax and jointed abdomen of an Entomostracan, and in this and other ways show a relation to Crustaceans. They are supposed by Lankester to have comprised the precursor species of Annelids, Crustaceans, Limuloids, and other Arthropods ; and others compare the forms of some with the embryos of Mollusks, Molluscoids, and Holothurians, - relations that would make the group the Embryonoid division of the higher Invertebrates. For figures of Rotifers and references see article RotifERs in the Encycl. Brit.

The Helminths, or Intestinal Worms, need no especial remarks in this place, as they have no geological importance.

\section{Mollusks.}

Mollusks consist essentially of a soft, fleshy bag containing the stomach and viscera, without joints or jointed appendages. They were named Mollusks from the Latin mollis, soft. They have on either side a thin fold of the skin of the back, called the mantle or pallium (from the Latin for cloak), which serves to inclose a cavity between it and the body, where are the gills (branchiæ) or aërating organs. The mantle varies from very large to nearly obsolete; and in some (the Pulmonates or land-snails) it is a covering for an internal lung-like organ of respiration. The ventral surface anteriorly has sometimes a firm, fleshy projection which serves as a foot for locomotion, as in the Clam, or for their attachment by horny fibers, as in the Mussel. Again, it is scmetimes spread out flat, making a large, flat foot or ventral surface for locomotion, as in the Gastropods ; or it has the anterior part divided into a pair of wing-like paddles, as in the Pteropods; or into 4 
or 5 pairs of arms furnished with tentacles, suction-disks, or horny claws, as in the Cephalopods.

The subdivisions are as follows:-

1. Cephalopods. Free-swimming; having 4 or 5 or more pairs of arms arranged about the mouth (Fig. 392), so named from $\kappa \in \phi a \lambda \dot{n}$, hered, and nov's, foot. Some, like the Nautilus, have an external chambered shell, and others (Squids) only an internal bone or pen. Rhyncholites, sometimes found as fossils, are the hawkbill-like jaws of the species of Ammonites.

The subdivisions are: the Tetrabranchs, or 4-gilled species (Fig. 401), including the

392.

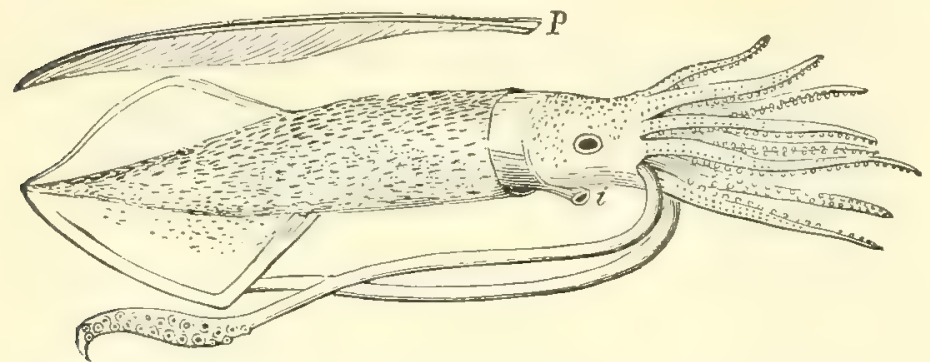

The Calamary or Squid, Loligo vulgaris (length of body, 6 to 12 inches); $i$ the duct by which the ink is thrown out; $p$ the "pen." Nautili and Ammonites, and the Dibranchs, or 2-gilled species, which never have an external chambered shell, and include the large Devil-fishes and the Argonaut, or Octopods; the Cuttlefishes and Squids, or Decapods (Fig. 392). In the latter group, one pair of arms is very long, and there is an internal horny or calcareous bone (sheli) sometimes called the pen (Fig. 392, p) situated in the back. One species of the Newfoundland seas has the body 15 feet long and the long arms about 35 feet. The Sepia, from its ink-bag, affords the brown paint called sepia; and its "pen" is the spongy cuttle-fish bone used to supply lime in bird-cages.

2. Pteropods. - Free-swimming species, having for the purpose of locomotion (Fig. 400 ), a pair of paddle-like plates near the head; shell, when present, often slender, conical, thin, and glassy, but also of other shapes, and rarely spiral (Limacina). Named from

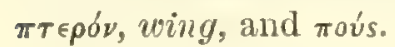

3. Scaphopods. - The foot adapted for burrowing. Shell tubular, conical, or oblong,

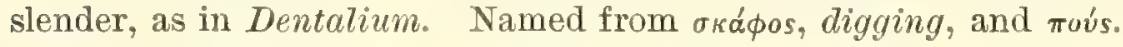

4. Gastropods (Cephalophora).-Head prominent and furnished with eyes and usually tentacles (Fig. 399); the mouth with a rasp-like tongue; the foot, for locomotion, a

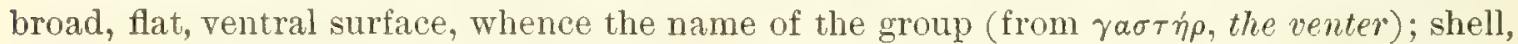
a dorsal secretion, usually spiral, but in Chiton, a jointed symmetrical shield; in some, conical ; sometimes wanting. Includes the Snails (Fig. 399) among land species, and the spiral shells of fresh and salt water, often called Univalves; also species without shells, some of which (Nudibranchs) have the gills in flower-like groupings on the back. The mantle varies much in extent, reaching (at the will of the animal) as far up the outside of a shell as the surface is highly polished. Besides the eyes of the head, several species of Naked Mollusks of the genus Onchidium have eyes over the back; and these eyes, unlike those of other Invertebrates, are like the eyes of Vertebrates in structure, a layer of rods and cones forming the outer layer of the retina, and the general arrangement of the parts being Vertebrate-like (Semper, Animal Life, 1881, page 371).

5. Lamellibranchs (Figs. 396-398). - Include the Clam, Oyster, and other " bivalves." They have no eye in the head portion, and no projecting head (whence called Acephats), and no teeth or denticles in the mouth. The foot in many is a tough, keel-shaped, or flattened muscular projection; but sometimes it is small and spins horny fibers (byssus) for attachment to rocks, and sometimes (as in Oysters, etc.) it is wanting. They have a bivalve shell, the valves situated either side of the body, and articulated together above between the umbones. The valves show, inside, the impressions of one (at 2, Fig. 398) or 
two $(1,2$, Figs. 396, 397), rarely more, adductor muscles, and also an impression of the mantle or pallium, which is concentric with the lower and hinder margin of the shell in integripallial species, and has a sinus posteriorly in sinupallial species. The mantle is large, concealing the body, with the two sides either free at the lower edge, or not con-

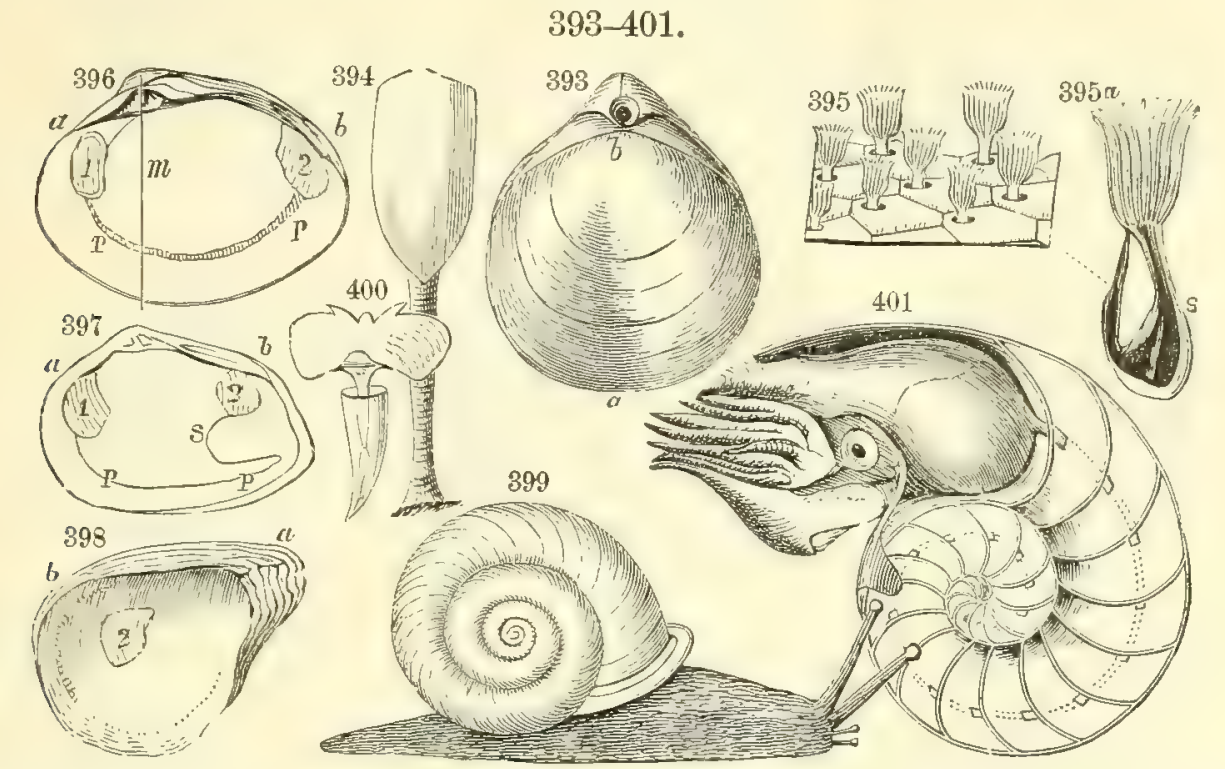

Mollusks, Figs. 393-401. - (1) Brachiopods : 393, Terebratula impressa, of the Oölyte; 394, Lingula on its stem. (2) Bryozoans: 395 ( $\times$ 8), 395 a, genus Eschara. (3) Lamellibranchs: 396, 397, 398, the Oyster. (4) Gastropods: 399, Helix. (5) Pteropods : 400, genus Cleodora. (6) Cephalopods: 401, Nautilus $\left(\times \frac{1}{6}\right)$.

nected (as in the Oyster, etc.), or else grown together into a sac (Venus, Mya); and in the latter case usually having the sac terminate behind in two tubes, as in Mya, Solen, one incurrent, for receiving water, to the gills, and food, and the other excurrent. Imperfect ejes or eye-spots exist in the mantle of some species. Gills are usually lamellar organs (whence the name, Lamellibranchs) situated between the mantle and the body. In a few boring species, the shell includes, or is followed by, a long, calcareous tube, which may be 1 to 2 feet long in Teredo, the timber-borer.

\section{Molluscoids.}

1. Brachiopods. - Brachiopods (Figs. 393, 394, and 402-430) have a bivalve shell, and in this respect are like the Lamellibranchs or ordinary bivalves. But the shell, instead of covering the right and left sides, covers the dorsal and ventral sides. Moreover, it is symmetrical in form, and equal, either side of a vertical line $\alpha b$, Fig. 407. The valves, moreover, are almost always unequal; the larger is the ventral, and the other the dorsal. There is often an aperture at the beak (near b, Fig. 393), that in the young state and often through the adult gives exit to the pedicel, by means of which the animal is fixed to some support. Species having the two valves hinged together are called Artiunlate Brachiopods, and those that are hingeless are the Inarticulate. Some of the genera of the former group are Orthis, Orthisina, Spirifer, Rhynchonella, Strophomena, Pentamerus, Terebratula; and some of those of the latter are Lingula, Lingulella, Obolus, Obolella, Discina, Crania.

Brachiopods have a pallium, but no independent branchial leaflets; and a pair of coiled fringed arms, which in some cases may be extruded, - whence the name Brachiopod, meaning arm-like foot. For the support of these arms, there are often bony processes (Figs. 402, 406, and 409). These calcified arn-supports, when present, are 2 thin lamellæ, attached to the interior of the dorsal valve; they are short and curved in the 
Rhynchonellæ (Fig. 411); are extended toward the front of the shell, and bent back and united, forming a loop, in Terebratula, Magellania, etc. (Figs. 403, 404, and 402); or are extended forward and coiled in variously shaped spiral coils, as in spirifer, Atrypa, etc. (Figs. 405, 408). In many extinct genera (Orthis, Strophomena, etc.) there are no calcified arm-supports. These arms are covered with vibrating cilia, which serve to keep up a current of water over or through the branchial cavity of the animal.

A few of the species are represented in Figs. 402-430:-

$402-421$.
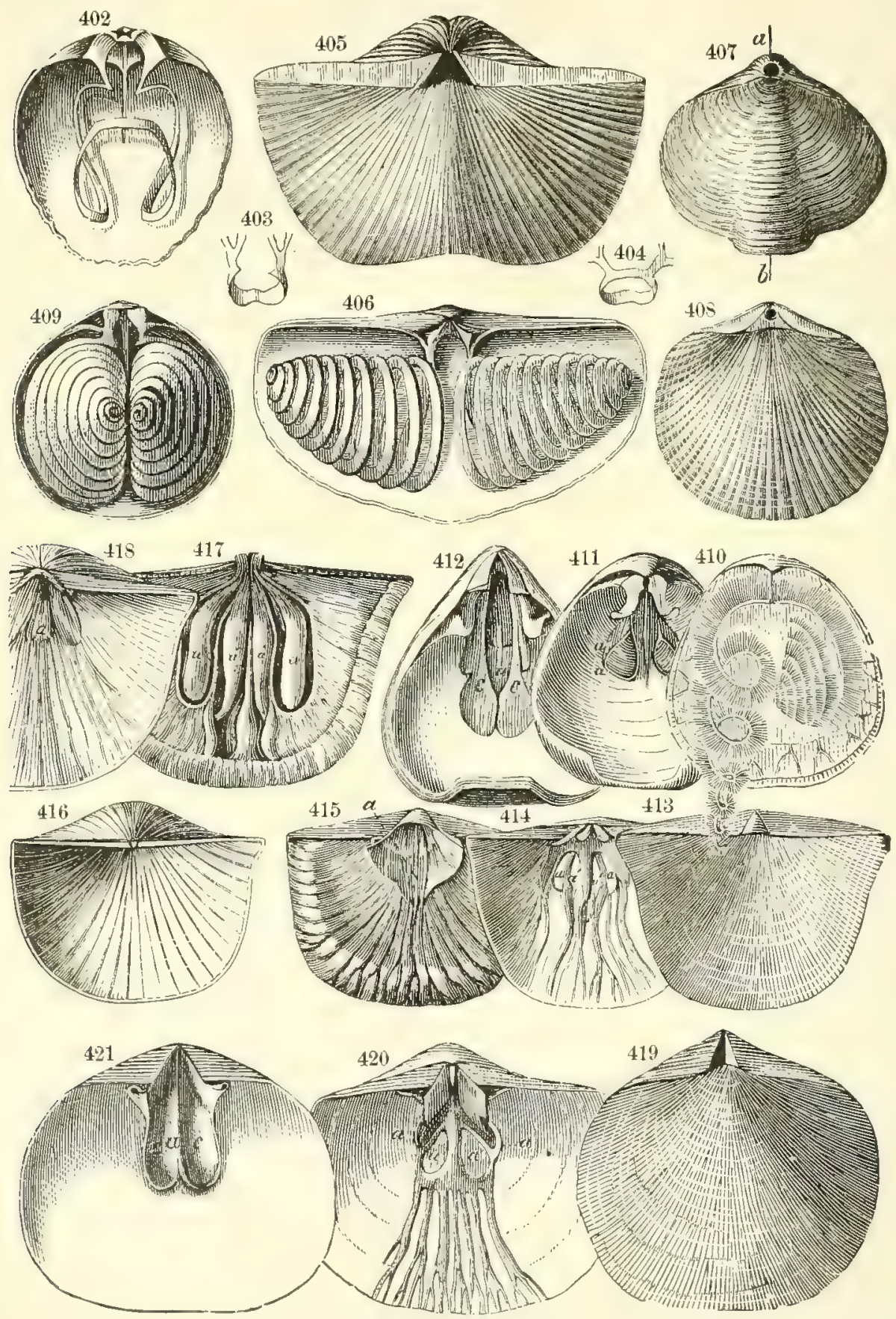

Brachiopods. - Fig. 402, Magellania flavescens; 403, loop of Terebratula vitrea ; 404, id. Terebratulina caputserpentis; 405, Spirifer striatus; 406, same, interior of dorsal valve; 407, Athyris concentrica; 408, 409, Atrypa reticularis, the latter dorsal valve; 410, Rhynchonella psittacea, showing the spiral arms of the animal; 411, id. dorsal valve; 412 , id. ventral; 413, Strophomena planumbona; 414, id. dorbal valve; 415 , id. ventral; 416, Plectambonites transversalis; 417, id. dorsal valve; 418, id. ventral; 419, Orthis striatula; 420 , id. dorsal valve; 421 , id. ventral. 


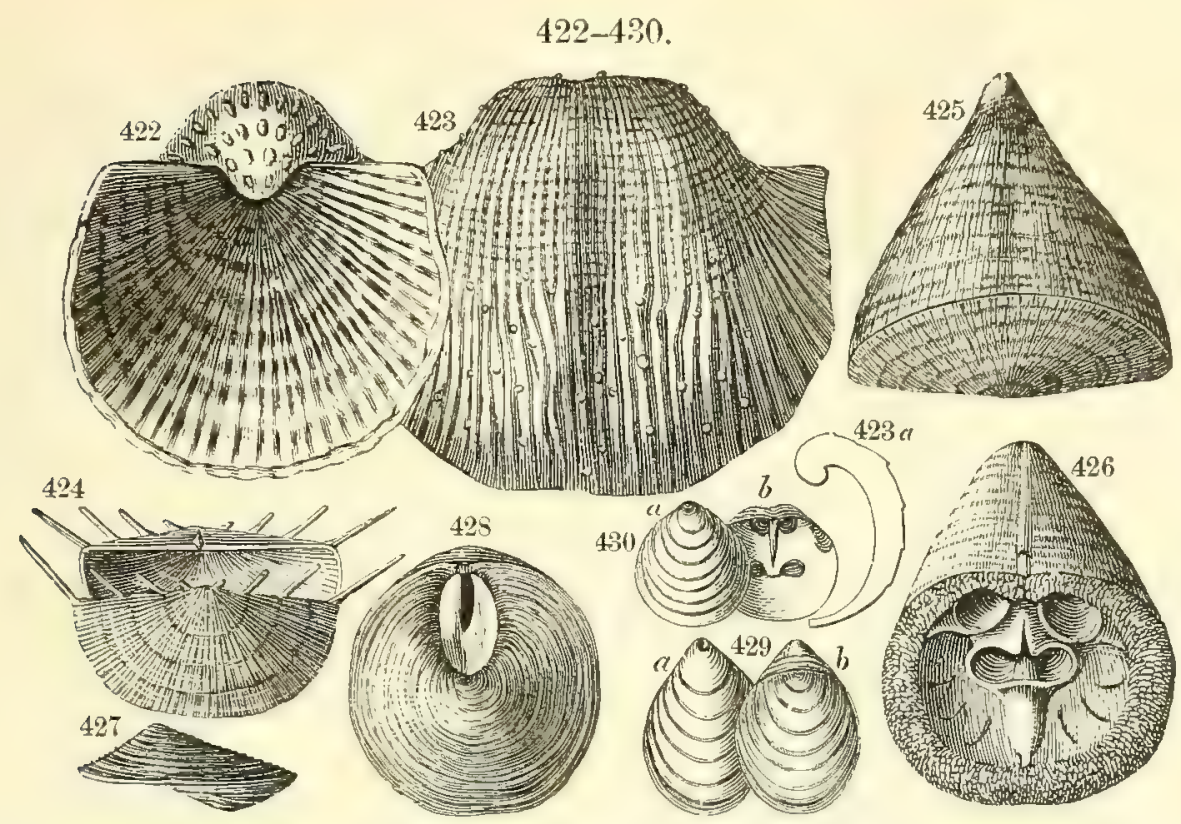

Fig. 422, Productus aculeatus, dorsal view ; 423 , Productus semireticulatus, ventral view ; $423 a$, section of Productus, showing the curvature of the valves; 424 , Chonetes latus, opposite views; 425 , Calceola sandalina (a Coral with lid, resembling a bivalved Brachiopod); 426, Crania antiqua; 427, Discina (Discinisca) lamellosa, side view; 428, id. showing foramen; $429 a, b$, Siphonotreta unguiculata, opposite views; $430 a, b$, Obolus Appollinis.

Brachiopods are among the oldest of fossils. The animals have been shown by Morse to have close relations to the Annelids, though not multiplicate like them, but when adult without distinet segments.

2. Bryozoans (Polyzoans).-Bryozoans, or Moss-animals (so named with reference to the moss-like corals they often form), look like Polyps, owing to the series of slender ciliated organs surrounding the mouth, as represented in Figs. $395,395 \alpha$; 395 is magnified about 8 times; and $395 \alpha$ represents the animal showing its stomach at $s$, and the flexure in the alimentary canal, with its termination alongside of the mouth. The coral consists of minute cells either in branched, reticulated, or incrusting forms. They are often calcareous ; and such were common in the Silurian, and still occur. Eschara, Flustra, Retepora, are names of some of the genera. The Oysters in the market often have their shells encrusted with large groups of the minute cells of Bryozoans.

431.

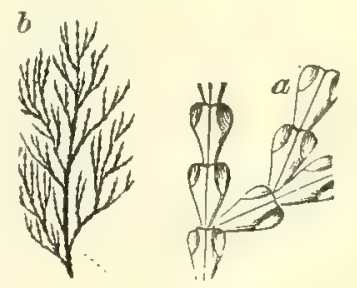

Bryozoan, Gemellaria loricata.

Fig. 431 represents a membranous species (called Gemellaria loricata); $b$ is the mosslike coral, natural size; and $a$ a portion of a branch, enlarged, showing the cells.

\section{Echinoderms.}

Echinoderms, while eminently radiate in the adult stage, in the young have bilateral symmetry; and a few species never get beyond the form of the young. The exterior is more or less calcareous, often furnished with spines. They have distinct nervous and respiratory systems and also a complete digestive system. The name alludes to the spines over the surface in a prominent part of the species, and is from echinus, a hedgehog.

The following are the subdivisions:-

1. Holothurioids (Sea-slugs, Sea-cucumbers). - Having the exterior soft, and throughout extensile or contractile, and the body elongated; mouth at one end surrounded by a wreath of branched tentacles. 
2. Echinoids (Sea-urchins). - Having a thin and firm hollow shell, covered externally with spines (Fig. 441) ; form, spheroidal to disk-shape; the mouth below, at or near the center, as the Echinus. Fig. 441 represents an Echinus partly uncovered of its spines, showing the shell beneath, and 432 another, wholly uncovered. The shell consists of polygonal pieces, in 20 vertical series, arranged in 10 pairs, except in species of the Paleozoic. Five of these 10 pairs are perforated with minute holes, and are called the ambulacral series ( $\alpha$ in Fig. 441 represents one pair); and the other 5, alternating with these, are called the inter-ambulacral $(b)$. The inter-ambulacral areas have the surface covered with tubercles, and the tubercles bear the spines, all which are morable by means of muscles. The ambulacral have few smaller tubercles and spines, or none; but over each pore (or rather each pair of pores) the animal extends out a slender fleshy tentacle or feeler, which has usually a sucker-like termination and is used for clinging or for locomotion. In Fig. 432, the inter-ambulacral areas are broad and the plates large, but the ambulacral are narrow and the plates indistinct. The mouth-opening is situated below, at the center of radiation of the plates. The anal opening in the Regular Echinoids (Fig. 441) is in the opposite or dorsal area or center of radiation. Around the dorsal area there are 5 minute genital openings. In the Irregular Echinoids - constituting a large group - the anal opening is to one side of this dorsal center of radiation, and often on the ventral or under surface of the animal. In Fig. 432, for example, the anal opening is marginal instead of central, while the genital pores are around the dorsal center, as in the Regular Echinoids. To one side of the dorsal center in the Regular Echinoids, there

$432-434$
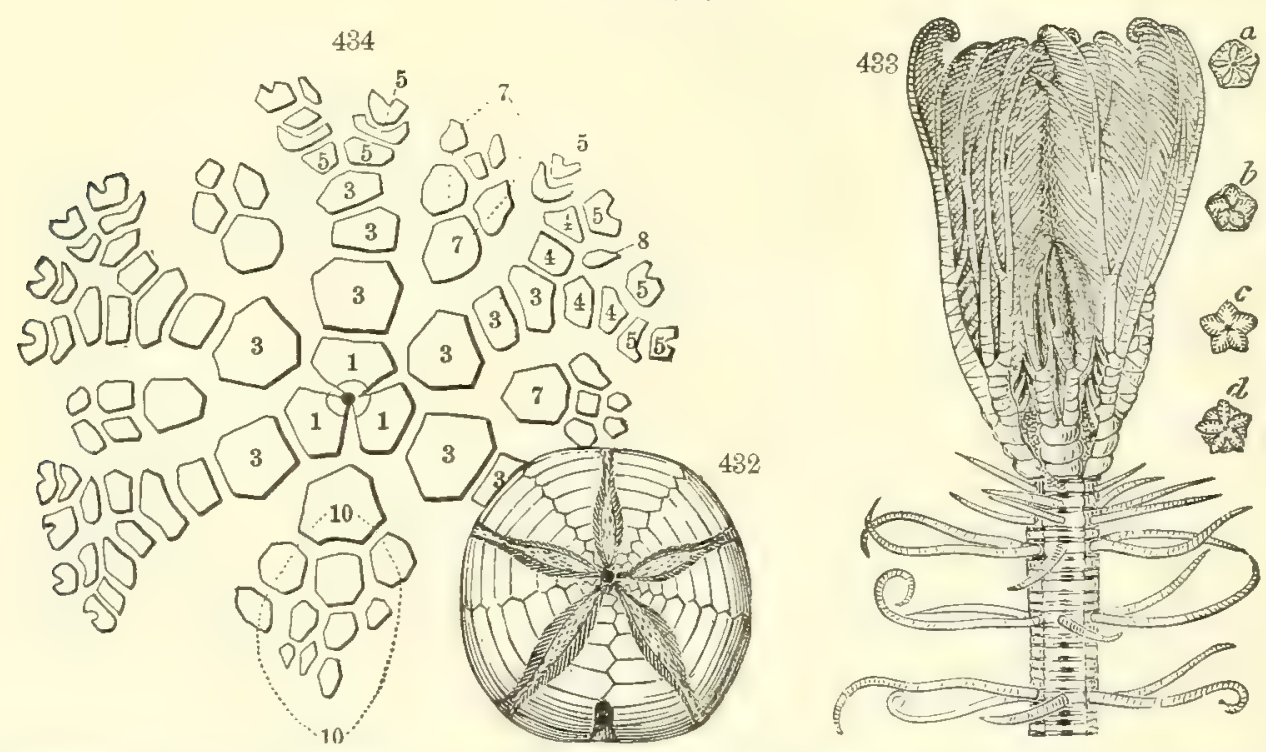

Echinoderus. - Fig. 432, an Echinus without its spines, - the Clypeus Hugi of the Oölyte; 433 , the living Pentacrinus caput-medusæ of the West Indies $\left(\times \frac{1}{2}\right) ; a, b, c, d$, outlines of the stems of different species of Pentacrini; 434, plates composing the body of the Crinoid, Batocrinus longirostris.

is a small porous prominence on the shell, often called the madreporic body, from a degree of resemblance in structure to coral. In some of the Irregular Echinoids, this madreporic body is in the center of dorsal radiation.

The ambulacral areas are sometimes equally perforated throughout their length. But in other cases only a dorsal portion is conspicuously perforated, as in Fig. 432, and, as this portion has in this case some resemblance to the petals of a flower, the ambulacra are then said to be petaloid. A large part of Echinoids have a circle of 5 strong, calcareous jaws in the mouth; in a portion of the Irregular Echinoids there are no jaws.

3. Asterioids (Star-fishes).- - Having the exterior stiffened with articulated calcareous granules or pieces, but still flexible; form star-shaped or polygonal; the viscera extending 
into the arms; mouth below, at center; arms or rays with a groove on the lower side, along which the locomotive suckers protrude through perforated plates; eyes at the tips of the arms. Ex., the Star-fish, Fig. 442.

4. Ophiuroids (Serpent-Stars). - Having a disk-like body with a star-shaped mouth beneath, and long, jointed, flexible arms, which sometimes subdivide by forking, but never bear pinnæ, and have no grooves along the under side, nor eyes at the slender tips. The viscera do not extend into the arms ; the ovarial openings are slit-like, between the bases of the arms; and there is no anal orifice. The disk part is homologous with the whole of an Asterioid.

5. Crinoids (including Comatulids). - Like ordinary star-fishes in having flexible arms or rays; but the calcareous secretions of the rays and body constitute a series of closely fitting solid pieces, and the viscera are confined to the body portion. The rays are

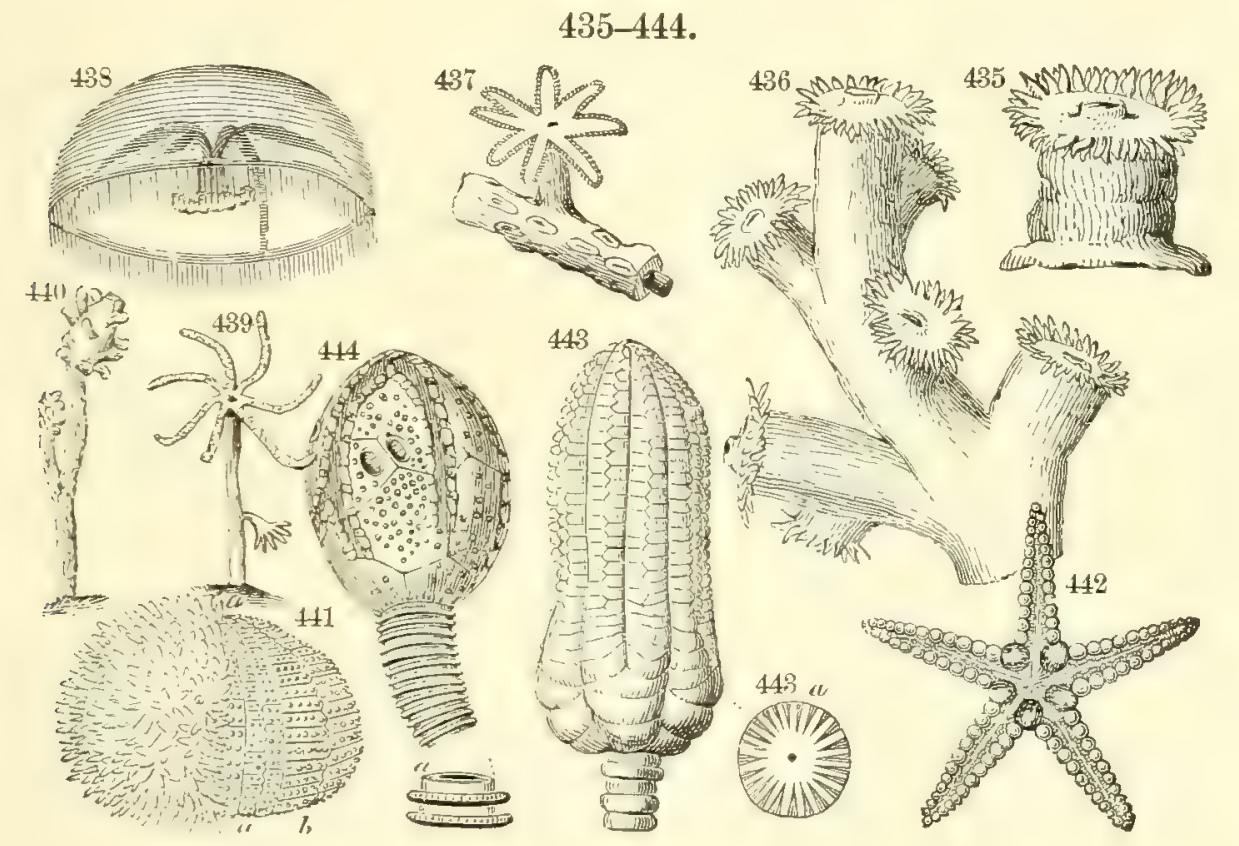

Radiates. -Figs. 435-444. 1. Polyps : Fig. 435, an Actinia; 436, a Coral, Dendrophyllia; 437, a Coral of the genus Gorgonia. 2. Hydrozoans: 438, a Medusa, genus Tiaropsis; 439, Hydra (× 8); 440, Syncoryne. 3. Echinoderms: 441, Echinus, the spines removed from half the surface $\left(\times \frac{1}{3}\right)$; 442 , Star-fisb, Palæaster Niagarensis; 443, Crinoid, Encrinus liliiformis ; 444, Crinoid, of the group of Cystoids, Callocystites Jewetti.

often very much subdivided, and bear pinnæ, in which the generative organs are situated. The species are mostly fossil, and are among the earliest in geological history. A few kinds still live in the ocean mostly below 20 fathoms, some at great depths. There are 3 tribes of Crinoids :-

1. The Brachiates (Encrinites). - Having a radiate structure, and arms proceeding from the margin of the disk; also generally a stem, consisting of calcareous disks, by which, when alive, they are attached to the sea-bottom or some support, so that they stand in the water and spread their rays, like flowers, the mouth being at the center of the flower. Crinoids are represented in Fig. 443, Fig. 433, and Fig. 30 on page 58. The second and third are living species from the West Indies, found at depths below 20 fathoms. The rays open out, when alive, and then the animal has its flower-like aspect. The little pieces that make up the stem, looking like button-molds, are either circular, as in Fig. $443 a$, or 5 sided, as in Figs. $433 a, b, c, d$. Under the Crinidea fall the Comatula (Antedon, etc.), which are free when adult, but have jointed cirri proceeding from the back surface for attachment. 
2. The Blastoids (Pentremites, etc.). - Having a symmetrical ovoidal body, with 5 petal-like ambulacra meeting at the summit, without proper arms, and attached by a stem like that of the Encrinites.

3. The Cystoids (from the Greek for a bladder), Fig. 444. - Arrangement of the plates not often regularly radiate. Arms, when present, proceeding from the center of the summit instead of the margin of a disk; in some, only 2 arms; in others, replaced by radiating ambulacral channels, which are sometimes fringed with pinnules.

In ancient Crinoids, the arms are not generally free down to the base, but there is a union of their lower part, either directly or by means of intermediate plates, into a cupshaped body or calyx (as in Fig. 443, and also Figs. 995, 999, under the Subcarboniferous period, page 640).

In Fig. 434, the plates of one of these cups, in the species Batocrinus longirostris H., are spread out, the bottom plates of the cup being at the center. The plates, it is seen, are in 5 radiating series, corresponding to the 5 rays or arms of the Crinoid, and between are intermediate pieces. The 3 plates numbered 1 are called the basal, as the stem is articulated to the piece composed of them; $3,3,3$ are the radial; 4,4 , supraradial; 5 , brachial, situated at the base of the arms; 7 are immediate plates, called interradial; 8, another intermediate, the inter-supraradial. Sometimes, in other Crinoids, there is another series of plates, at the junction of the plates 1 and 3 , called sub-radial. Finally, the anal opening of a Crinoid is situated toward one side of the disk, it being lateral, as in the Echinoid in Fig. 432 ; and the intermediate group plates numbered 10 are called the anal.

In the Cystoids, the aperture is generally lateral and remote from the top, as in Fig. 444, while the arms often come out from the very summit. The Cystoids are also peculiar in what are called pectinated rhombs (see Fig. 444); that is, rhombic areas crossed by fine bars and openings; the use of them is uncertain, - though they are probably connected with an aquiferous system and respiration.

\section{Cœlenterates.}

The Cœlenterates are distinguished from Echinoderms by the existence of only one opening to the digestive system, the mouth. Moreover, the tentacles and other parts are never normally a multiple of 5 , but either of 4 or 6 ; of 4 in Hydrozoans and 4 or 6 in Polyps.

1. Hydrozoans (Acalephs, Medusæ, Jelly-fishes, Hydroids).-Having the body, in the adult stage, usually nearly transparent or translucent, looking jelly-like; and internally a

445.

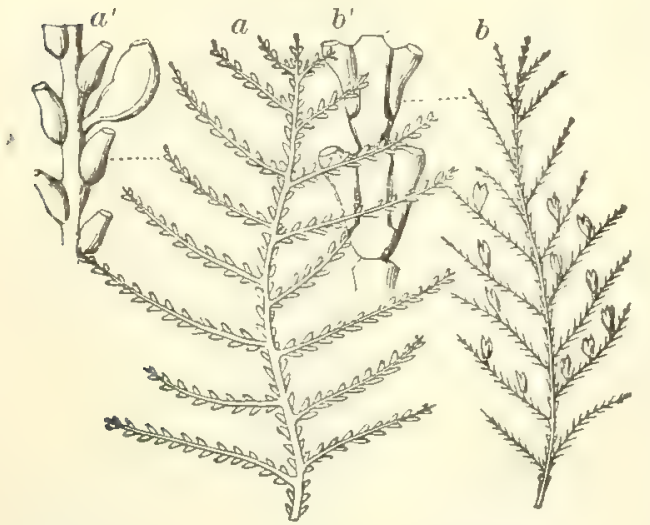

HYDRozoAns. Figs. $a, a^{\prime}$, Sertularia abietina; $\boldsymbol{b}, \boldsymbol{b}^{\prime}$, S. rosacea. stomach-cavity, with radiating branches. Ex., the Medusa, or Jelly-fish (Fig. 438), which generally floats free, when in the adult stage, with the mouth downward. The Hydra and allied species are here included. Most marine Hydroids at times produce sexual buds, which, in many species, break away and become free jelly-fishes.

Many of the Hydroids make corals, and hence are common as fossils. Fig. 439 represents a Hydra enlarged, with a young one budded out from its side. Some species of the group - those of the Sertularia tribe - form delicate chitinous corals, such as are represented in Fig. 445, in which each notch on the little branchlets corresponds to the cup-shaped cell from which an animal protrudes its flower-shaped head. ( $\alpha$ is the Sertularia abietina; $b, S$. rosacea; and $a^{\prime}, b^{\prime}$, portions of branches enlarged.) The interior cavities 
of each animal communicate freely with the tube in the stem; and in this they differ from Bryozoans, whose groups have no tubular axis. The ancient Graptolites (some of which are represented on page 510) are supposed to have been of this nature. Others secrete calcareous corals of large size, and are called Millepores (because the minute cells from which the animals protrude are like pinpunctures in size, and very numerous over the surface of the coral). The Millepores are common in the West Indies and other coral seas. The minute animals of a Millepore have nearly the form represented in Fig. 440, which represents a species of another genus, called Syncoryne.

There are hence stony corals made by Polyps, by Hydrozoans, and by Bryozoans; and others that are made by sea-plants, as explained beyond.

2. Actinozoans, Anthozoans, or Polyps. - Fleshy animals, like a flower in form, having above (Figs. 435, 436) a disk, with a mouth at center, and a margin of tentacles; internally, a radiated arrangement of fleshy muscular plates; and living for the most part attached by the base to some support. Ex., the Actinia, or Sea-Anemone, and the animals of ordinary corals.

There are two groups of coral-making Polyps:-

1. Activolds (Zoantharia) (Figs. 435, 436), which make the ordinary corals. The rays or tentacles of the Polyps are naked, that is, without a fringe of papillæ. In the Madreporaria, the number of tentacles is a multiple of $\mathbf{6}$; in the Cyathophylloids or 'Tetracoralla, a multiple of 4 .

The coral is secreted within the Polyps, and not outside as in the case of shells. It is usually covered with radiate cells, each of which corresponds to a separate Polyp in the group. The calcareous rays or septa are made in the spaces between the fleshy partitions in the interior of the Polyp. The material is calcium carbonate (limestone); and it is taken by the Polyp from the water in which it lives, or from the food it eats.

2. Alcronoids (Alcyonaria) (Fig. 437), or those of the Gorgonia and Alcyonium corals. The rays of the Polyps are 8 in number, and fringed. Fig. 4.37 represents a part of a branch of a Gorgonia (Sea-Fan), with one of the Polyps expanded. The branch consists of a horn-like axis and a fragile crust. The crust is partly calcareous, and consists of the common tissue (cœenenchyma) by which the Polyps are united together; the axis is secreted by the inner surface of the crust. The precious coral used in jewelry comes from the shores of Sicily and some other parts of the Mediterranean, and belongs to this Alcyonoid division. It is related to the Gorgonias, but the axis is red and stony (calcareous) instead of being horny; and this stony axis is the coral so highly esteemed. A few species make calcareous corals much like those of the Actinoids without any separate crust.

\section{Spongiozoans.}

1. The Sponges (Porifera) are mostly complex groups of animals, having internal membranes composed of ciliated cells resembling the collared Flagellate Protozoans. Sorne simple sponges are of one Zoöid only. The groups secrete, excepting in one tribe, - the gelatinous Sponges, or Halisarcoids, - a framework (1) of horny fibers, or (2) of horny fibers set with siliceous spicules; or (3) of siliceous spicules or fibers; or (4) of calcareous spicules or fibers. Of these 4 kinds, the first are the Corneous Sponges of commerce; the second, the Corneo-siticeous, a harsh and more brittle kind; the third, the Siticeous; the fourth, the Calcareous or Calcispongioe.

Some of the forms of the spicules of the corneo-siliceous and siliceous sponge-spicules are shown in Figs. 446-460, by Hinde. All these spicules were found by Hinde in powder filling a single small cavity in flint from Norfolk, England. All are much enlarged.

The Hexactinellid Sponges are siliceous and have the framework made up of spicules with rays crossing at right angles, making it 6-rayed at the crossing; they are mostly from great depths; Tetractinellids are 4-rayeà. But simple forms accompany the more complex. The Sponges occur at all depths in the ocean and are very various in shape. 
The hexactinellid sponge Euplectella (Venus's Flower-Basket), Fig. 29, page 57, which looks as if made of a network of spun glass, comes from a depth of 50 fathoms in the East Indies. The fossil Dictyophyton and Euphontenia are related to Euplectella, as shown by Whitfield. Sponges are mostly marine; but a few, like the Spongilloe, grow in fresh water and contribute siliceous spicules to peat and other swamp deposits. The death and decay of Sponges adds largely to the silica of the sea-bottom.

$446-460$.

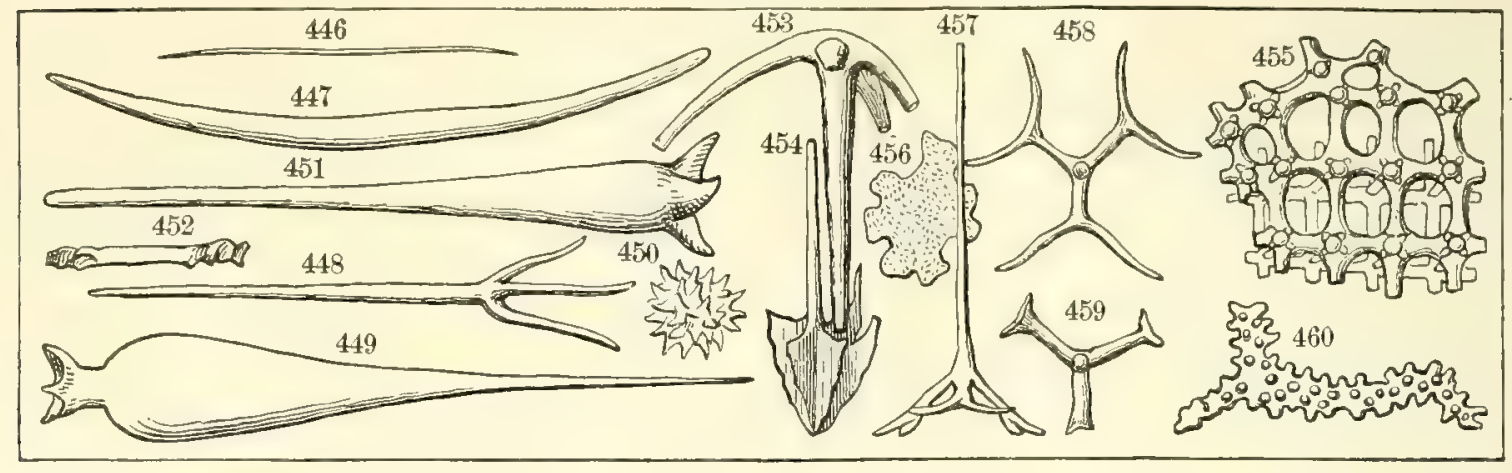

SPONGE-SPICUlES. - Figs. 446-449, Geodia or allied; 450, Globostellate spicule, near Geodia ; 451, Stelletta;452, Carterella; 453, 454, Tetractinellid spicules ; 455, Ventriculites, Hexactinellid ; 456, Ragadinia annulata ; 457, Tisiphonia ; 458, the same?; 459, Racodiscula ; 460, Plinthosella squamosa. Figs. 450, 453, $454(\times 10) ; 456(\times 68)$; others $(\times 34)$. Hinde.

\section{Protozoans.}

Among Protozoans only the Rhizopods and Radiolarians have prominent importance.

1. Rhizopods (Foraminifers). - Species mostly minute, often forming shells; the shells, with few exceptions, not larger than the head of a pin: but the groups sometimes having the shape of disks an inch in diameter, and occasionally of large massive forms. They have usually calcareous shells called Foraminifers (from foramen), and these have contributed largely to the formation of limestone strata. They consist of 1 or more cells ; and the compound kinds present various shapes, as illustrated in Figs. 461-474. The arrangement in a group is usually alternate or spiral. Others make a shell or test by the agglutination of grains of sand or other material.

\section{$461-474$.}
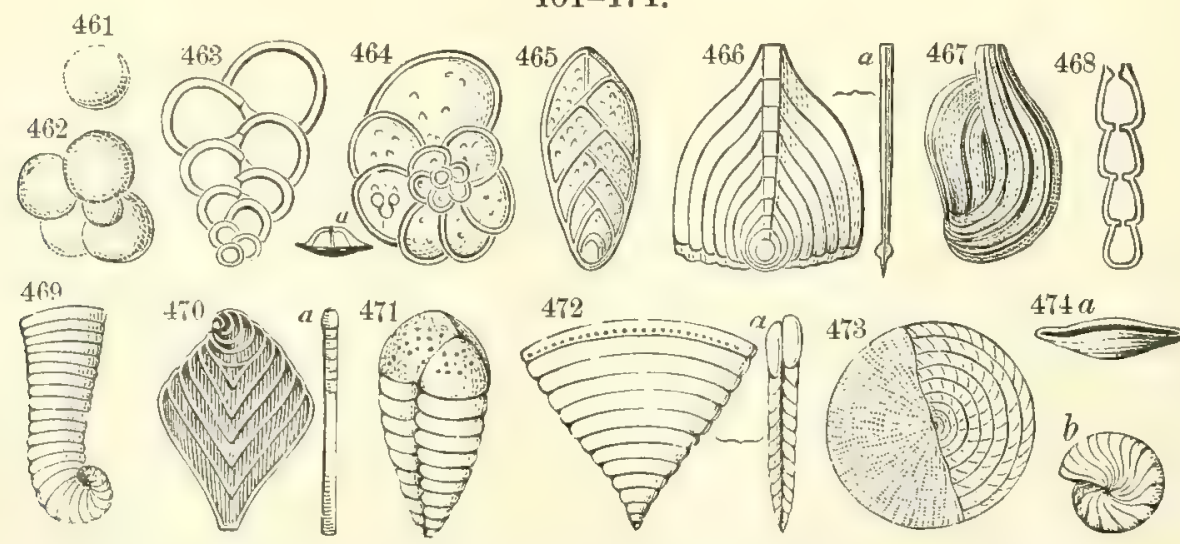

Figs. 461-474-RHIZOPODs, much enlarged (excepting 473, 474). Fig. 461, Orbulina universa ; 462, Globigerina rubra; 463, T'extularia globulosa Ehr.; 464, Rotalia globulosa ; $464 a$, Side-view of Rotalia Boucana ; 465, Grammostomum phyllodes $E h r$; 466, $a$, Frondicularia annularis; 467, Triloculina Josephina; 468, Nodosarja vulgaris; 469, Lituola nautiloides; 470, $\alpha$, Flabellina rngosa; 471, Chrysalidina gradata ; 472, $a$, Cuneolina pavonia : 473 , Nummulites nummularius ; $474 a, b$, Fusulina cylindrica. All but the last two magnified 10 to 20 times. 
Fig. 461 is a 1-celled species; the others are compound, and contain a number of exceedingly minute cells. A few are comparatively large species, and have the shape of a disk or coin, as Fig. 473, a Nummulite, natural size; the figure shows the interior cells of one half : these cells form a coil about the center. Orbitoides is the name of another genus of coin-like species. Fig. $474 \alpha$ is a species of Fusulina, a kind nearly as large as a grain of wheat, related to the Nummulites; $474 b$ is a transverse view of the same. This is one of the ancient forms of Rhizopods, occurring in the rocks of the Coal formation. Rhizopods of the genus Globigerina and other forms have been already mentioned (page 144) as the chief constituents of the calcareous ooze or mud making much of the sea-bottom. Fig. 475 represents an aggregation of Globigerinæ with Diatoms, found at a depth of 880 feet, off Alligator Reef, near the south coast of Florida, as figured by A. Agassiz.

Each Rhizopod cell is occupied by a separate animal or zoöid, though organically connected with the others of the same group or shell. The animal is of the simplest kind, having no mouth or stomach, and no members except slender processes of its own substance, which it extrudes through

475.

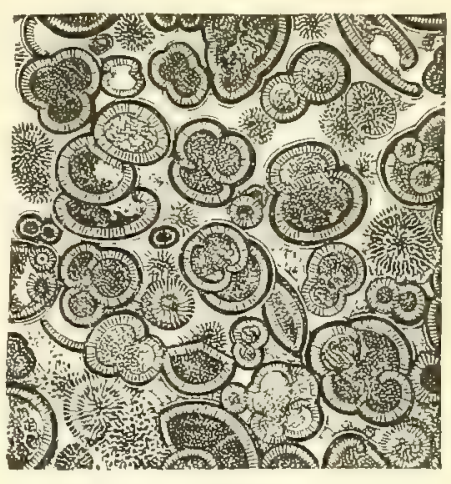

Globigerinx, with Diatoms, from a deposit off Alligator Reef (x 15). A. Agassiz. pores in the shell, if it have any. The name Rhizopods comes from the Greek for rootlike feet, - in allusion to the root-like processes they throw out. Some of the species not secreting shells (as in the genus $A m \infty b a$ ) have been seen to extemporize a mouth and stomach. When a particle of food touches the surface, the part begins to be depressed, and finally the sides of the depression close over the particle, and thus mouth and stomach are made when needed; after digestion is complete, the refuse portion is allowed to escape.

The shells of some Rhizopods do not consist of distinct cells : the aggregate living mass secretes carbonate of lime, without retaining the distinction of the zooids. This is the case, as Carpenter has observed, in the Nummulitelike genus Orbitolites. Some species make large coral-like masses instead of small shells.

2. Radiolarians (Polycystines). - Secrete siliceous shells which are symmetrically radiate or circular. Three species, from the Barbados, are represented in Figs. 476 to 476. $477 . \quad 478$.

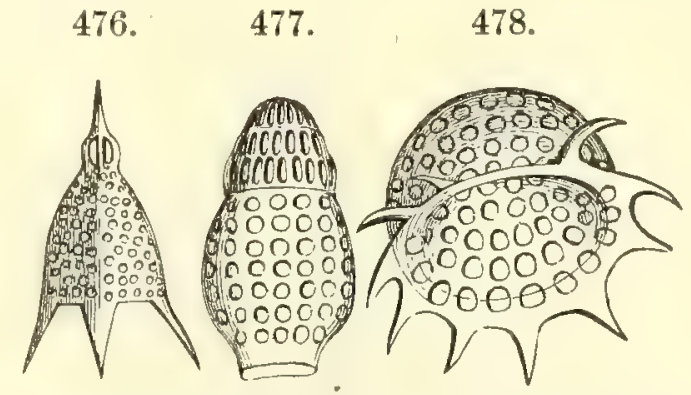

476, Lychnocanium lucerna $(\times 100) ; 477$, Eucyrtidium Mongolfieri $(\times 100) ; 478$, Halicalyptra fimbriata $(\times 75)$. 478. Fig. 476, Lychnocanium Iucerna Ehr.; Fig. 477, Eucyrtidium Mongolfieri Ehr.; Fig. 478, Halicalyptra fimbriata Ehr., the first two magnified 100 diameters, the last about 75. From these deeply concave forms, there are gradations in one direction to disks with concave centers, and to flat disks, both with plain and pointed borders, and in the other direction to elongate, conical, and spindle-shaped forms. Others have the shape of a flattened cross; another is an open diamond, with narrow diagonals and periphery. The disks have a concentric, and not a spiral, structure, and thus are unlike those of Nummulites.

The annexed figure represents a minute spherical species of Radiolarian - a jelly-like globule bristled with spiculeswhich sometimes beclouds the water in the Pacific and East Indian seas (Sphcerowoum orientale D.).

DANA'S MANUAL - 28 


\section{VEGET ABLE KINGDOM.}

A cell with its contents is the fundamental element of a plant, and the simplest and lowest plants are the microscopic unicellular kinds; that is, those made of a single cell, or a few in a series, as the lower Alge and lowest Fungr. From these, the grade in species rises through larger Algæ, and other kinds consisting of cellular tissue, as the FungI, Hepatice, and Mosses, to those which contain also vascular tissue, but subordinately to the cellular - as the Ferns, Equiseta, Lycopods. The kinds thus far mentioned are Cryptogams, or the Flowerless plants.

The remaining plants, or those producing true flowers and seeds, are called Phonogams. They consist of cellular tissue and woody fibers; and also, of vascular tissue in the larger part of the species.

\section{Phanogams.}

Phænogams are divided into two sections, on the basis of the structure of the embryo or seed, and the growth. In the Exogens, the embryo consists of two or more parts called cotyledons. Further, as the name Exogen implies (it signifying growth by the outside), there is, after the first year, with rare exceptions, an annual addition of a layer of woody tissue between the wood and bark. In a section of an exogenous stem more than a year old, the wood has, consequently, rings of growth.

In the Endogens, the seeds consist of a single cotyledon. Besides, there are no rings of growth, and no separable bark; growth goes forward mainly by the pushing out of buds at the extremity of the stem or of its branches. The structure of the wood is said to be endogenous.

\section{Exogens.}

Exogenous species are of two divisions called Gymnosperms and Angiosperms.

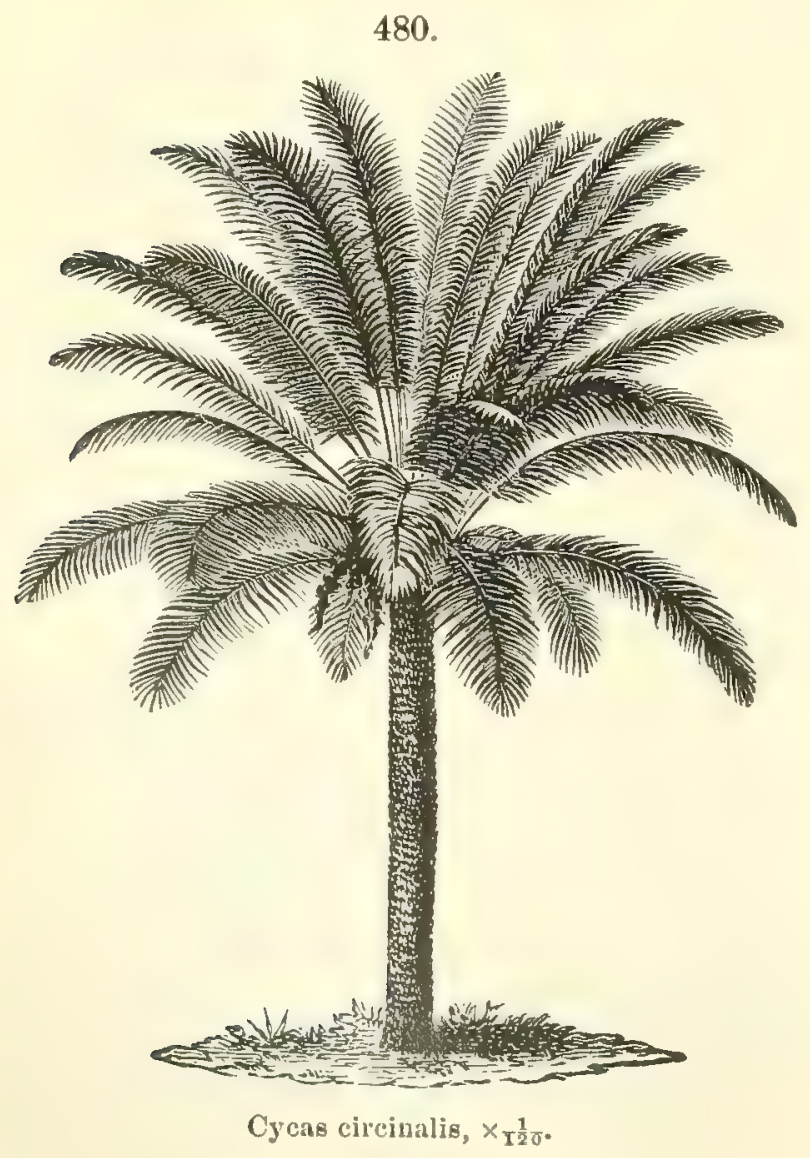

1. Gymnosperms. - In this inferior division of the Exogens, the seeds are naked and there is no stigma. The fruit often consists of a cone made of scales with the seeds beneath the scales. They are called Gymnosperms (from the Greek for naked seed) in allusion to the naked or uncovered state of the seed. The inferiority to other Phænogams is manifested not only in the simple character of the flower, but also in the wood, which contains no vascular tissue, and this inferiority accords with the fact that they preceded geologically other Phænogams. The inferior division, that of Cycads, is now few in species, but formerly included a large part of the common forest trees. The Cycads (with the related Zamiæ) are peculiar in combining the structure and fructification of the Gymnosperm with the habit of a Palm, and the method of uncoiling the leaves as they are developed which belongs to Ferns. The 
wood of the modern tree has a very large pith abounding in starch, surrounded by one or more rings of wood, each the result of several years' growth.

The ordinary "Evergreen" trees, as the Pine, Spruce, Arbor Vitæ, Yew, belong to the second and higher subdivision, the Conifers, so-called because the flowers and fruit ordinarily have the form of cones. In the Pine family the fruit is a cone; but not so in the Yews. The Salisburia, or Ginkgo, a tree witl short and broad, somewhat fanlike leaves, is generally referred to the Yew family, though having some relations to the Cycads.

The woody fiber of the Conifers is marked with circular disks as in Figs. 481, 482 ; fossil woods of the order may thus be distinguished, 481. and genera may often be

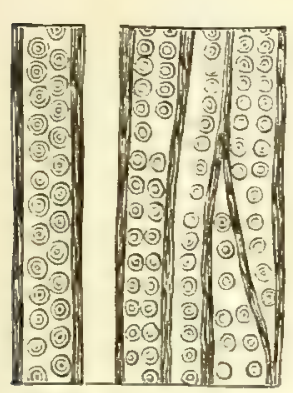

Circular disks on the wrody fibers of Cunifers. rangement.

Another aberrant group, the Gnetacex, includes the genera, Gnetum, Ephedra, and Welwitschia; and the last, of which only one species exists, and that in Africa, approaches the Angiosperms, in its flower, "the staminal flower containing a rudimentary ovule." But it has the

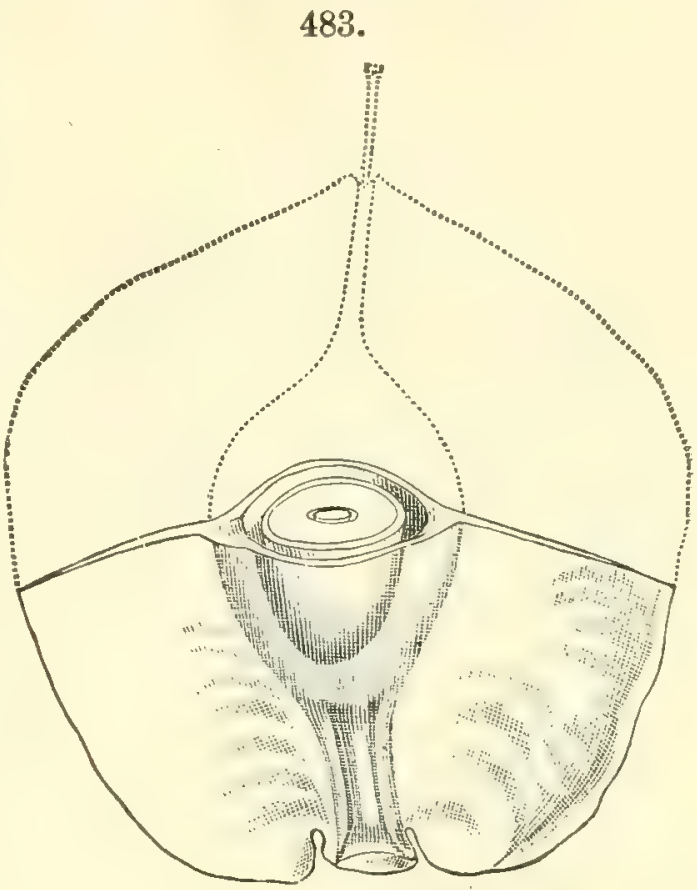

Fig. 483, Welwitschia mirabilis, showing transverse section of fruit, with the outline of the fruit finished in dotted lines.

broad strap-like leaves of the ancient Cordaites, and also, as the Fig. 483 shows, the winged form of fruit characteristic of the Carboniferous Cardiocarpus.

2. Angiosperms. - The higher Exogens, or the Angiosperms, have the seeds covered; the flowers perfect, the wood consisting largely of vascular tissue as well as woody fibers. Examples are the Maple, Elm, Apple, Chestnut, Rose.

\section{Endogens.}

The Endogens are represented by the Palm, Rattan, Smilax, Grasses, Orchids. A section of a woody stem, as that of a Rattan (a species of Calamus) or Smilax, shows the ends of woody fibers and ducts. The leaves are parallel-veined instead of net-veined, and not toothed, and the parts of the flower are commonly in threes.

\section{Cryptogams, or Flowerless Plants.}

\section{The Higher Cryptogams, or Acrogens.}

The Acrogens consist of cellular tissue with more or less of fibro-vascular tissue, and are capable of upward growth, whence the name from ä́spov, top, and $\gamma \in \nu \nu \alpha \omega$, grow.

The lowest species have special interest in the geological history of plants. They are called Rhizocarps (root-fruited) from the position of the fruit at the base of the stem, or at the root. The figures represent, half the natural size, species of three of the very few forms now existing. They show the position of the nuts, and the unlikeness of the species in habit to most Cryptogams. Fig. 486, of Salvinia natans, represents a section of the plant showing only one of the pairs of leaves in the floating plant. 
The other principal divisions of the Acrogens are the following:-

(1) Equiseta, or Horse-tails. - The existing species have hollow-jointed, slender stems ; the leaves arranged in whorls at the nodes; and the cone-like fructification at the ends of the stems. Ancient species grew with stout trunks to a height of 30 feet or more.

(2) Lycopods, or Ground-Pines. - The Lycopods have many leaves, with the habit of

484 .

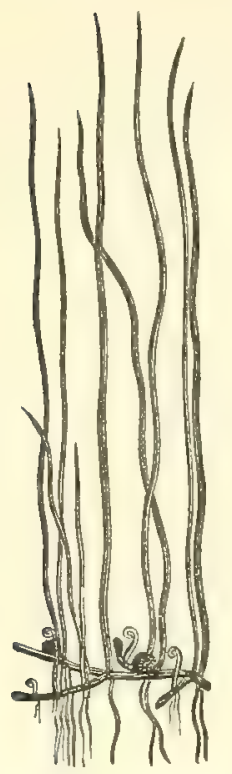

485.

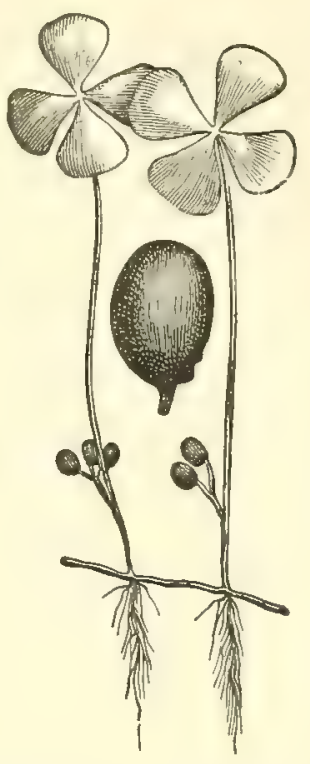

486.

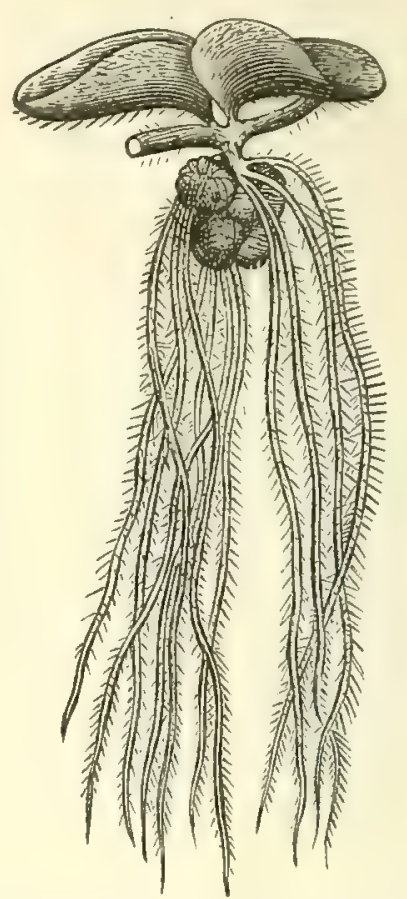

RhizocarPs. - Fig. 484, Pilularia globulifera, with fructification; 485, Marsilea quadrifolia, with an enlarged view of the nut; 486, Salvinia natans, part of plant. All half the natural size, Luersien.

a Spruce or Pine; they are small plants now, but in the Coal era grew up as trees, 30 to 90 feet in height.

(3) Ferns. - Modern Ferns sometimes make trees 20 to 30 feet high.

\section{The Lower Cryptogams.}

The Lower Cryptogams consist of cellular tissue alone. The principal groups are:-

1. Mosses. - Green, terrestrial plants having delicate leaves along the slender stems; limited to a few inches in the height of the living part of stems. Closely related to the Mosses are the Hepatica, or Liverworts.

2. Lichens. - Dry plants, of gray, brown, and black colors, making fronds without leaves, which spread over the surfaces of rocks, the outer bark of trees, etc.

3. Fungi. - Succulent plants, gray to brown in color, and never green; without foliage; grading down to Molds, which consist of strings and groups of cellules, and to Bacteria and other microscopic, free-swimming, unicellular kinds.

4. Algæ, or Seaweeds. - The water-plants are green to brown in color, and contain more or less chlorophyl. They graduate downward from ordinary seaweeds to microscopic, free-swimming, unicellular kinds. Of like grade with the unicellular species are other kinds having the form of threads or groups of threads, each thread consisting of a series of cells. The lowest groups include the species of Protococcus, of which $P$. nivalis is red and gives the red color to the snow or ice in some Alpine regions. The Diatoms 
having siliceous shells are others. A few species are represented in Figs. 487-493. Another group is that of Desmids, which consist of one or a few greenish cells, and secrete little or no silica. They are related to the common Conferva (frog-spittle) of fresh-water pools. Other calcareous kinds take delicate branching forms, as the Corallines; or more stony forms, like those of Corals, but destitute of surface cells, as the Nullipores; or sponge-like or concretion-like forms, as the calcareous Algæe of the Yellowstone Park. Some related to the last-mentioned occurring in warm waters secrete silica. There are also the minute Coccoliths over the ocean's bottom in deep or shallow waters; they are so named from the Greek for seed and stone.

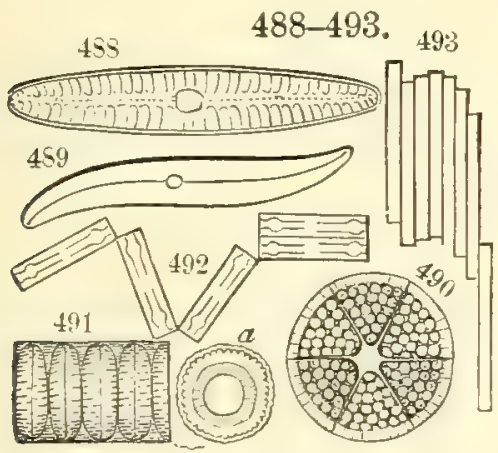

487.

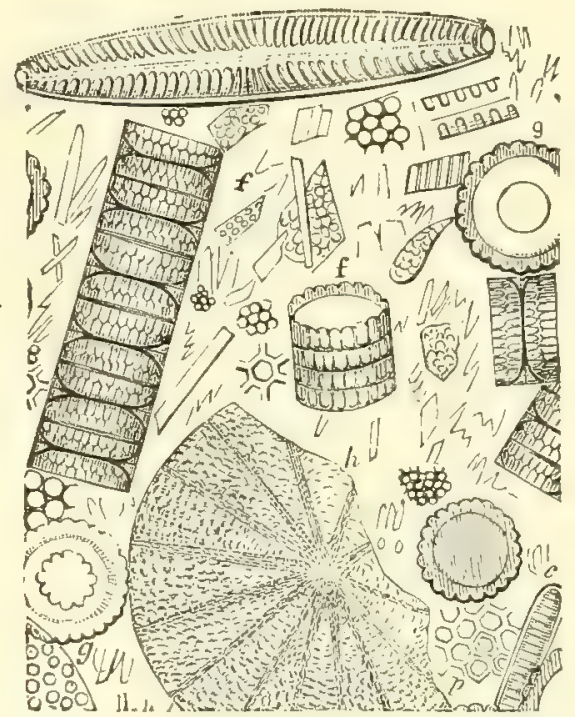

Figs. 487-493, Diatoys highly magnified; 487, A group of fossil Diatoms; 488, Pinmularia peregrina, Richmond, Va.; 489, Pleurosigma angulatum, id.; 490, Actinoptychus senarius, id.; 491, Melosira sulcata, id.; $a$, transverse section of the same; 492, Grammatophora marina, from the salt water at Stonington, Conn.; 493, Bacillaria paradoxa, West Point.

The common leathery seaweeds of the seacoast, or the Fucus division, include the Sargassum of the Atlantic, the air-cavities in which enable it to float.

\section{CEPHALIZATION, A GENERAL PRINCIPLE BEARING ON SYSTEM AND GRADE IN THE ANIMAL KINGDOM.}

Since an animal has, typically, an anterior nervous mass or ganglion determining the position of the head, and antero-posterior conditions in growth, a greater or less subordination to the head in the arrangement of its organs should naturally be looked for. Degree of structural subordination to the head and of concentration headward in body-structure, is referred to under the term Cephalization.

The principle is illustrated in the class of Crustaceans, with special clearness and large distinctive characters, on account of the fewness of the species and their size.

Some preliminary explanations are here first given respecting Worms, and then the facts from the class of Crustaceans.

1. Worms. - An example of á low decephalized condition among Articulates exists in the Tape-worm, Trenia solium, one of the lowest of the so-called Worms. It grows and elongates by the multiplication of segments (by budding), until their number is sumetimes several hundred, the new segments forming successively just behind the head. The head has its very small nervous ganglion, from which slender nerves pass backward; so that in growth and nerves it is an individual. But it has no mouth, and the body no stomach or intestine. Instead of this, each segment is so far complete in its individuality that it takes its independent nutriment, and has its own reproductive system; and if separated from the rest of the series, it has all that is required for propagating the species by ova. Here 
decephalization and a multiplicate or nearly limitless segmentation are extreme. There is $n$ lower extreme, except in that of the compound mass of the sponge or the polyp, where a head fails entirely.

In the higher typical Worms, the Annelids, the many segments of the body have a separate nervous ganglion as an enlargement of the nervous cord, or pair of cords, that passes posteriorly from the cephalic ganglion, giving it a degree of independence. But the head has its mouth, and the body its intestine and reproductive system, so that the structure is one in system of growth and reproduction. Yet the number of body-segments varies greatly, it being not often fixed even for the species of a genus; and all of the segments behind the head participate alike essentially in the work of locomotion. The body structure in Worms is, therefore, multiplicate, and greatly decentralized, and locomotion is of the diffuse kind. Moreover, jointed limbs are wanting.

2. Crustaceans. - Crustaceans contrast strongly with the Worms, high or low. (1) The body consists of a head (which, as in other animals, includes the mouth as well as the organs of the senses), a thorax furnished with limbs, and an abdomen. (2) The number of body-segments, in typical species, is limeted, instead of being multiplicate, it not exceeding $20 ; 6$ of these segments pertain to the abdomen, and 14 to the thorax and head.

On differences in the arrangement and functions of the parts of the structure, exemplifying degrees in cephalization, is based the accepted system of classification in Crustaceans. This system subdivides the typical species into (1) Decapods, or the 10-footed, and (2) Tetradecapods, or the 14-footed; and each of these tribes into two subordinate groups, Brachyurans and Macrurans for the former, and Isopods and Amphipods for the latter.

Decapods and Tetradecapods. - In the Decapods (1) the head includes 9 bodysegments - the 3 anterior bearing the organs of the senses, the eyes, and 2 pairs of antennæ, and the remaining 6 , the jointed mouth organs; and (2) the thorax, comprising the remaining 5 segments of the cephalothorax, bearing 5 pairs of feet. In the Tetradecapods, the head corresponds to only 7 body-segments, and has, therefore, but 4 pairs of mouth organs, while the thorax includes 7 segments and bears 7 pairs of feet. In other words, the anterior 2 pairs of feet of the Tetradecapods are pairs of mouth organs in the Decapods. There is thus a transfer forward of legs to the mouth series on rising from the Tetradecapod tribe to the Decapod. It is a case of concentration headward in the structure, or of higher cephalization. The two tribes also differ in the mean size of the animals, Decapods having, on an average, 100 times the bulk of Tetradecapods.

We pass now to the two subdivisions of the Decapods and Tetradecapods.

Brachyuran and Macruran Decapods. - A Macruran Decapod, as exemplified in a Lobster, Prawn, or Shrimp, has (1) an elongate, loosely compacted body, with the abdomen nearly as long as the cephalothorax, and in some species several times longer; (2) the abdomen is the most powerful organ in locomotion; (3) the thoracic feet are feeble in locomotion; (4) the outer mouth organs are foot-like, free, and long; (5) the antennæ are sometimes a foot or more long.

The Brachyuran, as the common Crab, has, on the contrary, (1) a short body, it being seldom longer than broad; (2) the abdomen in males is very small and narrow, it doing no service in locomotion, but, instead, lying confined in a groove on the under side of the body, so that the animal is almost comprised within the first 14 of the normal 20 segments of the Crustacean; (3) the thoracic feet, or those of the posterior 5 of these 14 segments, are the sole organs of locomotion; besides (4) the mouth organs are small, and closely stowed away together within, or over, a shallow cavity, which is covered by the outer pair, as an operculum; and (5) in harmony with the general compactness of structure, the antennæ are very small, seldom exceeding an inch in length. 
Between the Macrurans and the Brachyurans there is the grand distinction that the former are long extended posteriorly, and urosthenic, as regards locomotion (or strong in the posterior extremity, that is, the abdomen), while the latter have short bodies, gathered in closely and compactly behind the cephalic ganglion, and are podosthenic, thoracic feet being the only locomotive organs. In rising from the Macruran to the Brachyuran there is a forward transfer in the general structure and in the locomotive function, and thus a great rise in degree of cephalization.

Under each of these two types of Decapods a wide range of grade is structurally indicated, illustrating degrees in cephalization.

Isopod and Amphipod Tetradecapods. - The Isopods and Amphipods are brachyuran and macruran Tetradecapods, for the series of Tetradecapods is closely parallel with that of the Brachyurans and Macrurans among Decapods. The Isopods have a compact body, a short abdomen, which is not used in locomotion, with relatively short antennæ, while the Amphipods have a longer body more loosely put together, usually long antennæ, an elongate abdomen, and the abdomen is the chief organ of locomotion - that by which the little animal makes its leaps. Here, again, the lower are the urosthenic and decephalized species, the higher the podosthenic and more cephalized species.

Entomostracans. - Below the Tetradecopods come the Entomostracans. A part of the Entomostracans are multiplicate species, - the Phyllopods; and in this character, both in the Entomostracans of Decapod and of Tetradecapod relations, they show out the ancestral worm, and thereby low-grade cephalization. The structure is eminently primitive and was especially characteristic of early Paleozoic Articulate life.

Besides these there are the simply defective forms among Entomostracans, representative of different stages in embryonic development. Defective forms of similar character occur even among the Macruran Decapods; for some of the inferior shrimp-like species have one or two of the posterior segments of the thorax without legs, or even wanting; and in such species (called Schizopods), the thoracic legs have the form characterizing a young stage in development. But among the Entomostracans, the defective stage appears in more extreme forms. The limbs are partly natatory; the mouth organs are often either pediform or natatory, or of more abnormal forms; and the abdomen has no appendages except ovarian attached to the basal portion and a caudal pair pertaining to the sixth segment.

The preceding remarks on the bearing of the principle of cephalization on system and grade in Crustaceans cannot be true for one branch of the Animal Kingdom without having a wide significance. See, for other examples, Historical Geology, pages 721, 723.

This subject has much interest in connection with the successional lines in the animal life of the globe which geology has brought to light. But the preceding remarks are not to be understood as intimating anything with regard to the origin of species. There was no such reference in the author's first presentation of the views in 1852.1 At that time the idea of evolution by natural causes had scarcely an advocate; for Darwin's work did not appear until 1859. Neither are the facts now to be regarded as adding to the causes of derivation. This much, however, may be learned from them:-

1. Whatever the natural causes or methods concerned in evolution, organic conditions have determined lines, limits, and parallel relations, in accordance with the principle of cephalization.

2. In the evolution of the animal kingdom a "tendency upward" is a necessary consequence of the presence of a cephalic nervous ganglion or brain.

${ }^{I}$ Report on Crustacea of the Wilkes Expl. Exped. around the World, 1618 pp., 4to, with a folio Atlas of 96 plates. In the papers on cephalization published in the American Joumal of Science, eleven to twelve years later, and subsequently a summary in 1876 , the principle of cephalization was illustrated by reference to other classes of animals; but the speculative conclusions added in those papers are not all in accord with the author's present judgment. 


\section{ARCHAAN TIME.}

Sxnonrmy. - Primitivgebirge, Urgebirge, Lehmann, 1756, Werner. Urformation. Urgneissformation. Azoic Rocks, Murchison and De Verneuil, 1845, Russia in the Urals, i. 10. Fundamental Gneiss, Lewisian Gneiss, and later, Laurentian Gneiss, after Logan, Murchison. Mona Series, De La Beche, Geol. Obs., p. xxxii, 1851, for crystalline rocks of Anglesea, etc. Azoique, D'Orbigny, Pal. et Géol., 1851. Azoic System, J. D. Whitney, $R^{\prime \prime}$ p. of Foster and Whitney, Geol. Lake Superior Land District, Part ii., pp. 8-35, 1851, the system comprising rocks north of Lake Superior, others south of the lake, also others in the Adirondacks, etc. Laurentian and Huronian, Logan, 1852, 1854. Azoic (following Whitney, with Logan's subdivisions), first edition of this Geology, 186\%. Archæan, D., Amer. Jour. Sc., viii. 213, 1874, and second edition Geology, 1875. Eozoic, J. W. Dawson, 1875. Crystallophyllian, Belg. Geologists of the Internat. Congr. Geol., 1885.

Archæan time commences geologically with the earth as a solid globe, or one having at least a solid exterior; for only the conditions of such a globe are within reach of geological investigation. By following the lead of ascertained law in physics and chemistry, and the suggestions of astronomy, and also such analogies as are afforded by later geological history, some probable conclusions may be drawn with reference to earlier time. But this is not the place for their discussion, except so far as to state the principal steps of progress. The following is a general view of the natural subdivisions of Archæan time.

I. The Astral æon, as it has been called, or that of the fluid globe having a heavy vaporous envelope containing the future water of the globe or its dissociated elements, and other heavy vapors or gases.

II. The Azoic æon. Without life.

1. The Lithic Era: commencing with the earth a solid globe, or at least solid at the surface; the temperature at the beginning above $2500^{\circ} \mathrm{F}$; the atmosphere still containing all the water of the globe (amounting to 200 atmospheres, according to Mallet, 1880), all the carbonic acid now in limestone and that corresponding to the carbon now in carbonaceous substances and organic substances (probably 50 atmospheres), all the oxygen since shut up in the rocks by oxidation, as well as that of the atmosphere and of organic tissues. The time when lateral pressure for crustal disturbance and orographic work was begun; when "statical metamorphism" or that dependent on heat of a statical source, - the earth's mass and the vapors about it, - began.

2. The OCEANIC ERA : commencing with the waters condensed into an ocean over the earth, or in an oceanic depression, with finally some emerging lands, - the temperature perhaps about $500^{\circ} \mathrm{F}$., if the atmospheric pressure was still 50 atmospheres. The first of tides and the beginning of the retardation of the earth's rotation. Oceanic waves and currents and embryo rivers begin work about 
the emerged and emerging lands; the large excess of carbonic acid and oxygen in the air and water a source of rock-destruction; before the close of the era, the formation of limestones and ironcarbonate by chemical methods, removing carbonic acid from the air and so commencing its purification; the accumulation of sediments without immediate erystallization or metamorphism, and thereby the beginning of the earth's supercrust.

\section{The Archæozoic æon. Life in its lowest forms in existence.}

1. The Era of the First Plants: Algæ, and later of aquatic Fungi (Bacteria), commencing with the mean temperature of the ocean at possibly $150^{\circ} \mathrm{F}$., since plants now live in waters up to and even above $180^{\circ} \mathrm{F}$. Limestones formed from vegetable secretions, and silica deposits from silica secretions; iron-carbonate, and perhaps iron oxides formed through the aid of the carbonic acid of the atmosphere and water; large sedimentary accumulations, where conditions favored, thickening the supercrust.

2. The Era of the First Animal Life: mean temperature at the beginning probably about $115^{\circ} \mathrm{F}$, and at the end $90^{\circ} \mathrm{F}$., or lower; limestones and silica deposits formed from animal secretions; deposits of iron-carbonate and iron-oxides continued; large sedimentary accumulations.

The sedimentary or stratified beds of Archæan time are the oldest and most obscured parts of the geological record. Sooner or later in the Archæozoic era "dynamical metamorphism" began, or metamorphism dependent on heat from a dynamical source, that is, heat generated by movements in the thickening crust, aiding the heat still in the earth's mass, or statical heat. Thereby, during a crisis of upturning, the thick accumulations of sediment became metamorphic or crystalline; but the statical heat was still so great that the temperature was easily made that of fusion, and consequently the fusing of fusible sedimentary beds took place and outflows through openings or fissures of granite, syenyte, dioryte, gabbro, and other like rocks, derived severally from granitic, syenytic, diorytic, and gabbronitic or related sediments; but deep-seated igneous effusions may not have been common, for strains in a thin, rather hot supercrust might extend little below it, and, moreover, igneous ejections from a deep-seated source and through volcanoes reached their maximum in the later part of geological time.

Although these eras are not marked off in the rocks, there are facts enough to prove that they represent, in a general way, the system of progress in Archæan time. Millions of years must have elapsed during the cooling from over $2500^{\circ} \mathrm{F}$. to $500^{\circ} \mathrm{F}$; ; a very long era during that from $500^{\circ} \mathrm{F}$. to $150^{\circ} \mathrm{F}$; and another long era during that from $150^{\circ} \mathrm{F}$. to $115^{\circ} \mathrm{F}$; and still another during that from $115^{\circ} \mathrm{F}$. to $90^{\circ} \mathrm{F}$. Archæan time was long, immensely long. 
The subdivision of Archæan time into Azoic and Archrozoic, here used, is the same as that of the edition of $\mathbf{1 8 7 4}$, except that Archrozoic is substituted for Eozoic. The limiting temperature of Archæozoic time is doubtful for several reasons, and especially because of the uncertainty as to the destructive excess of carbonic acid in the air and waters, and, therefore, as to the possibility of the existence of life.

There is reason to believe that during the progressing consolidation, and long afterward, when the heat was too great for the existence of limestones, the lime now in the limestones of the globe was, to a large extent, combined with silica, making silicates and especially the lime-soda feldspars, labradorite and oligoclase, the soda being that now in the ocean's waters - minerals that may be made artificially by fusing together the ingredients; and, consequently, that rocks of the basalt and dioryte types, which contain these feldspars, were among the most common. Pyroxene was present through the whole era, but hornblende only in the later part; for pyroxene is easily made at the high temperature of fusion, but hornblende only under aqueo-igneous action at the lower temperature of $800^{\circ}$ to $1000^{\circ} \mathrm{F}$. The lime silicates would have used up a large part of what is now free silica or quartz, and hence the igneous rocks would have been, to a great extent, without quartz, and, in this respect, like the most of those that come up from the earth's depth through volcanic eruptions. In fact, most volcanic rocks are portions of the Archæan mass constituting the earth's interior. Such being the prevailing rocks of the crust, the sedimentary beds would have been largely of like constituents.

On the condition of the primeval globe, see further Ebelmen, 1855 ; Bischoff, 1863 ; T. S. Hunt, 1867, 1880. On subdivisions of Archæan time, D., 1892.

\section{NORTH AMERICA.}

\section{DISTRIBUTION OF ARCHEAN AREAS.}

Archæan areas, or those whose surface rocks are of Archæan age, and which indicate, therefore, the probable position of the dry land at the close of Archæan time, have their widest distribution in the more northern portions of the continents of North America, South America, and Europe.

In North America they cover a very large area, situated mostly north of the Great Lakes and the St. Lawrence River, which is approximately $V$-shaped in its southern part, as shown in the accompanying map. The white areas on the map represent the probably emerged land over the great Archæan continental sea. The great northern area has been estimated to contain more than 2,000,000 square miles. From the region of the Great Lakes a broad arm stretches northeastward to Labrador and beyond, and another, 2000 miles long, northwestward to the Arctic shores. Hudson Bay, 800 miles from north to south and 600 in greatest breadth lies between the arms of the V. The eastern arm of this early dry land of North America has a course nearly parallel to the existing eastern coast-line of the continent, and the western as nearly to the mean direction of the western coast-line. The map is on Mercator's projection. The course of the Mississippi River and the outlines of lakes are inserted merely to mark positions. The Archæan area extends south of British America into northern New York, the Adirondack region being a portion of it, and also south of Lake Superior into northern Michigan and Wisconsin. 
Besides the nucleal area of the continent, there are other areas lying in ranges or chains that are approximately parallel to the arms of the nucleal $\mathrm{V}$.

On the Atlantic border, northeastward in general trend. - On the Atlantic border there is the long Appalachian protaxis (page 24), extending interruptedly from Canada south of the St. Lawrence, along the higher land of Ver-

494.

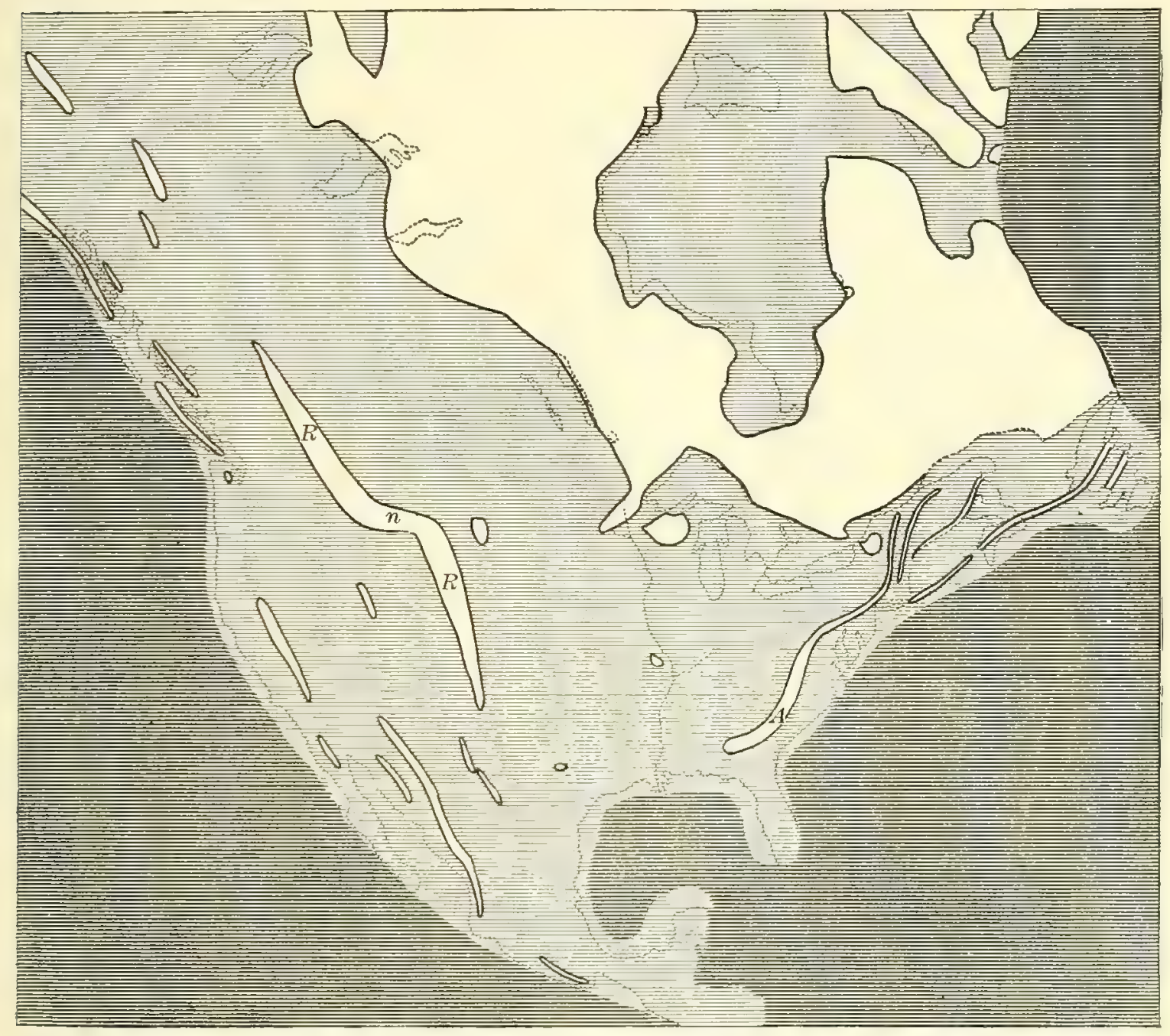

Map of North America at the close of Archæan time, showing approximately the areas of dry land.

mont; eastern Berkshire in Massachusetts; Putnam, Orange, and Rockland counties in New York, and Sussex in New Jersey, making the Highland Range, which crosses the Hudson between Fishkill and Peekskill; constituting some ridges in southeastern Pennsylvania; thence continuing southwestward along the "Piedmont" belt, and through Virginia and North Carolina, constituting in the latter state the Black Mountains; thence into South Carolina and Georgia. It is marked A on the map.

To the northeastward, over New England to Newfoundland, there are other parallel ranges, bounding broad valleys or basins, as follows: (1) To the east of the Connecticut valley, at intervals, from Canada to Connecticut. 
(2) Farther east, from near Chaleur Bay, on the Gulf of St. Lawrence, through New Brunswick, southwest to the coast of Maine (including the Mount Desert rocks) and into eastern Massachusetts. (3) The Acadian Range, along western Newfoundland and central Nova Scotia; then submerged off the coast of Maine and Massachusetts; then over southeastern Massachusetts, and probably along Long Island. (4) A central Newfoundland range, which may have had a submarine extension along Sable Island and the shoals about it, east of Nova Scotia. $(5,6)$ Two other ranges farther east.

The Acadian is the longest of these Archæan ranges; it is the chief eastern belt of the Archæan on the Atlantic border, and is strictly the Acadian protaxis. Its partial submergence is not in doubt; for besides indications of this along the sea-bottom south of Nova Scotia, there is proof of subsidence of several hundred feet in the fiords of Maine and the coast; in the Bay of Fundy, in Massachusetts and Narragansett bays, and in Long Island Sound. The combination of the Acadian and Appalachian protaxes determined the existence of the great "Middle Bay" of the Atlantic Coast (page 210 ), and in the region of their junction lies the bay of New York with the mouth of the Hudson. Thus the foundations were laid in Archæan time.

On the Pacific border, northwestward in general trend. - The chief Archæan ranges on the Pacific border are the following: (1) The Rocky Mountain protaxis, or the "backbone" of the mountains. It extends northward and westward nearly to $53^{\circ} \mathrm{N}$, in the Peace River region, and is represented beyond in isolated areas. It bends eastward 250 miles south of $49^{\circ} \mathrm{N}$., and then extends southward and westward through Colorado into New Mexico. The region of the bend, whence go off eastward and westward several of the large rivers of the continent, is the locality of the Yellowstone Park. Along the west side of the Wasatch Range, near Salt Lake, the Archæan areas appear to be parts of a western spur of the protaxis, nearly in a line with the part of it in British America. To the westward are other nearly parallel Archæan ranges, in the Great Basin; along the Sierra Nevada in California and in the Sierra Madre of western Mexico; and probably in the Coast and Island belts of British America. In addition, isolated areas occur east of the Rocky Mountain chain in the Black Hills of Dakota, the Iron Mountain region of Missouri, and in central Texas. Thus the oldest land areas marked out well the outlines of the continent.

There is a landward bend in Pennsylvania of the Appalachian protaxis, like the landward bend of the Rocky Mountain protaxis, and the two bends are not much south in latitude of the southern end of the nucleal Archæan area of the continent; as if connected in origin with the absence farther south of outcropping Archæan.

Archæan rocks are the prevailing rocks of the portions of Greenland free from its covering of ice, and they make a large part also of Baffin Land, on the opposite side of Baffin Bay. 


\section{SUBDIVISIONS OF THE ARCHEAN TERRANES, AND THE ROCKS.}

Subdivisions. - Two subdivisions have general acceptance:-

I. The Laurentian. - Logan, Rep. Geol. Canada, for 1852-53; named from the Laurentide Mountains.

II. The Huronian Era. - Huronian of Logan and Murray, Rep. Geol. Can., for 1853-4-5, in the special report for 1854; Ésquisse du Géol. du Can., 1855. "Huron Cupriferous Formation" of the north shore of Lake Huron, Rep. Geol. Can., for 1847-8. - Part of Agnotozoic, Irving, 1887, the Keweenaw group of the Agnotozoic being referred beyond to the Paleozoic. Part of Algonkian, Walcott, 1889; a name proposed as a substitute for Agnotozoic, and so accepted by geologists.

The subdivisions were based, according to Logan, on relations of unconformity in bedding between the Huronian and Laurentian terranes. The Huronian areas recognized were situated along the north shore of Lake Huron, and at points on the north and east shores of Lake Superior. Archæan rocks vary from massive crystalline kinds, like granite, syenyte, dioryte, and massive gneisses, to the thinnest of schists; and include, also, limestone, quartzyte, and some uncrystalline sandstone and other fragmental beds, besides large beds of iron ore. The Laurentian division in the vicinity of the lakes was observed to comprise the more massive kinds; and the Huronian, the thinner schists, as mica schist, chlorite schist, with quartzyte. With this distinction in view, the Huronian was made to include also an area south of Lake Superior extending from Marquette, Mich., westward, containing the large beds of iron ore of that region; and this conclusion has since been sustained by evidence proving their unconformability to the Archæan terranes beneath. But most other references of areas to the Huronian that have been made are reasonably questioned, because it is now known, as stated on page 458 , that the distinction based on kinds of rocks is not a safe criterion of geological age. Among metamorphic Paleozoic rocks, massive, thick-bedded and thin-bedded schists are associated in the same formation; and so it is, beyond doubt, in the Huronian, and even in the Laurentian. Still, the thinner schists of the Archæan are to a much larger extent Huronian than Laurentian; and all the uncrystalline Archæan strata are Huronian.

The beds of iron ore have so great thickness in some regions, that the Archæan has been called the Iron Age in the earth's history.

The localities of Huronian described by Logan with special detail in the Canadian Geological Report of 1863 are as follows: (1) to the west of the Mississaga River, north of Lake Huron; (2) to the eastward, in the vicinity of White Fish and Sturgeon rivers; (3) near Lake Temiscaming, 150 miles northeast of the last locality; and a few miles from Michipicnten Island, north of Lake Superior. The iron-bearing rocks south of Lake Superior about Marquette and to the westward are referred to the same period on the colored map in the octavo Atlas accompanying the Report, published in 1863, after investigations by Murray. 
Murray refers to the Huronian also diorytes, slates, quartzytes, and conglomerates, that occur in the peninsula of Avalon, southeastern Newfoundland, and describes, from the upper division, a fossil of uncertain relations which he names Aspidella Terra-novica, and also a worm burrow referred to the genus Avenicalites. The gneisses of the region he calls Laurentian.

The structure and relations of the Huronian along the iron-bearing belt from Marquette to Penokee in Wisconsin (including the Penokee-Gogebic range, and the Menominee iron region) have been studied with care by Irving and Van Hise. Van Hise and Pumpelly have recognized a subdivision of the Huronian north and south of the lakes, on the ground of a stratigraphical break, into Upper and Lower Huronian.

In most cases, kinds of rock have had chief importance in the subdivision of the Archæan. T. S. Hunt proposed the division of the Archæan (commencing below) into Laurentian, Norian, Arvonian (of Hicks), Huronian, Montalban, Taconian. The Montalban includes the White Mountain micaceous gneiss; and the Taconian, the rocks of the Taconic series now known to be of Paleozoic age. C. H. Hitchcock in his Report on the geology of New Hampshire, adopts the subdivisions, beginning below: Laurentian, Montalban (or Atlantic, including granites, gneisses, etc.), Labradorian, and Huronian. A. C. Lawson, from his Canada studies about the Lake of the Woods, Rainy Lake, and elsewhere, has divided the terranes above the Laurentian into the Coutchiching (mica schists and gneisses) and Keewatin (thinner schists with conglomerates and some iron ore), and to the two united he has given the name Ontarian; the term Huronian is not used. A. Winchell arranges the Marquette iron region below the true Huronian in a group called the Marquettian. The Laurentian Gneissic group underneath is made 88,000 feet thick. N. H. Winchell refers the original Huronian beds on the north shore of Lake Superior to the Lower Cambrian; and makes the Archæan of Minnesota to include three divisions : (1) the Laurentian gneiss and related rocks ; (2) the Vermilion schists, partly hornblendic schists (equivalent to the Coutchiching of Lawson); (3) the Keewatin schists, which are iron-bearing. The Animikie beds, consisting of chlorite schist, slates, sandstones, and small beds of iron ore, having in general small dip, have been referred to the Huronian by Logan, Irving, and Van Hise, but to the Cambrian by Selwyn, Winchell, and others ; and Selwyn has announced the discovery in it of markings which, according to G. F. Matthew, are tracks much like the tracks of an animal found in the Middle Cambrian of St. John, New Brunswick. The Mesabi Range with its large beds of iron ore is made Cambrian by Winchell. The Archæan rocks of central Texas are divided by T. B. Comstock (1890) into the Burnetan and Fernandian, corresponding apparently to the Laurentian and Huronian. The latter section is described as containing large beds of magnetite. Overlying beds in which no fossils have been found he calls Eparchæan. M. E. Wadsworth has announced (1892) the following subdivisions of the Archran in northern Michigan: (1) Cascade, (2) Republic, (3) Mesnard, (4) Holyoke, and (5) Negaunee formations ; 2 and 3 corresponding to the Lower Marquette, and 4 and 5 to the Upper.

Van Hise, in 1893, proposed to restrict the term Laurentian to granite-gneisses - a petrological distinction; and gave to a supposed second division of the Archæan, the term Mareniscan, derived from the name of a township in Michigan.

A bibliography of the American Archæan to 1884, with various notes, is contained in the "Azoic System," by Whitney and Wadsworth, pages 331-566 of vol. vii. of the Bull. Mus. Comp. Zoöl., Cambridge, 1886. A full bibliography, coming down to 1892, is published in the Report on the "Archæan and Algonkian," by C. R. Van Hise (1892), constituting Bulletin No. 86 of the U.S. Geol. Survey. The latter work contains brief abstracts of the publications noticed, a full exposition of the views entertained, and the author's own conclusions at length. The distinguishing characteristics of the subdivisions proposed by Hunt, Lawson, and others are given in this Report with much fullness ; and all investigators of Archæan terranes should bave a copy of it at hand. The subject is in an unsettled state, with wide divergences in opinion among investigators. 
Algonkian formation. - The Algonkian formation (Agnotozoic of Irving) is made by its describers to include the Huronian of Logan, north and south of the lakes, and some of the so-called Huronian in other regions. Its rocks (1) comprise the thinner schists, semicrystalline slates, quartzytes, and uncrystalline fragmental and shaly rocks; and (2) they are of pre-Cambrian age. The supplanting of the older name, Huronian, by the newer is not sustained by any rules of nomenclature. It has been given a wider range by including under it the Keweenaw copper-bearing sandstone formation, which lies unconformably on the Huronian, and this change of limit was one reason for the change of name.

T. B. Brooks first recognized the "Keweenawian" as a distinct system of rocks (1876); Irving called it Keweenawan. If Archæan instead of Paleozoic, it marks a Keweenawian period in the long Huronian era. The Keweenaw formation is without fossils, and hence is of uncertain age; but its relations appear to be probably Paleozoic, as explained beyond.

Some of the localities of Algonkian observed by Walcott are the following: (1) the tilted beds of quartzytes and siliceous slates at the base of the Wasatch series, lying conformably beneath the Lower Cambrian; and (2) strata beneath the Cambrian in the Eureka District and elsewhere in Nevada, where there is the same conformability. The beds are described as very thick and as affording no fossils; but the conformability to the Cambrian suggests the query whether the beds are not lowest Cambrian. (3) At the base of the walls in Grand Cañon of the Colorado, lying unconformably beneath Upper Cambrian beds, upturned beds of sandstone, shale, and limestone, named by G. K. Gilbert, the Tonto group. The presence of fossils in some of the Tonto beds (including remains of a Stromatoporid, a Trilobite, and a Hyolithes, and a Discina-like shell) shows that part, at least, of the Tonto group is not Algonkian, and renders it probable that all is Paleozoic. (4) In central Texas, Llano County, beneath Upper Cambrian strata and over the Archæan, a formation which is called the Llano group. (5) Part of the Huronian of southeastern Newfoundland, described by Murray, which Walcott states is unconformable to the overlying Olenellus beds. (6) Below the Potsdam series in the Adirondacks. These are some of the localities of the so-called Algonkian formation.

The facts respecting the Algonkian are reviewed in Van Hise's Report of 1892, mentioned above; also briefly, on some localities, in Walcott's Correlation of the Cambrian, U. S. Geol. Survey, Bulletin No. 81, 1891.

Kinds of rocks. - The more characteristic kinds of Archæan rocks are coarse granites; thick-bedded gneisses, especially hornblendic varieties, syenytes, diorytes, and pyroxenic varieties of these rocks; the granite-like rock of the basalt type, called gabbro; and each of these rocks under gneissic and thin-schistose varieties. Zircon-syenyte is rather common. There are also chrysolite rocks and chrysolitic varieties of some of the above kinds; and with them, serpentine rocks, the serpentine being a result of the alteration of chrysolite or pyroxene and possibly of some other mineral containing magnesia.

Crystalline limestone (usually dolomyte or magnesian limestone) is common in some regions; and it often contains large crystals of apatite (calcium phosphate) and the pale yellow mineral, chondrodite (a fluorinebearing magnesium silicate), supposed to be peculiar to the Archæan, besides many other minerals.

There are also in the Laurentian series, but less abundantly, hornblende schist, mica schist, hydromica (or sericite) schist, chlorite schist, and quartzyte. 
The massive rocks (whether Laurentian or Huronian) are generally igneous; but, most probably, for reasons already stated, metamorphic igneous to a greater extent than deep-seated igneous. The granite and syenyte often contain great masses and long broken strips of schists, or constitute dike-like intrusions. Figures 495,496 of portions of the rocks at Burntside Lake, in northeast Minnesota, are from A. Winchell's Field Studies in the Archuan Rocks of Minnesota. In these examples, granite and mica schist are the two rocks combined. In other figures, syenyte has the place of granite, and the schist is a hornblende schist.

495.

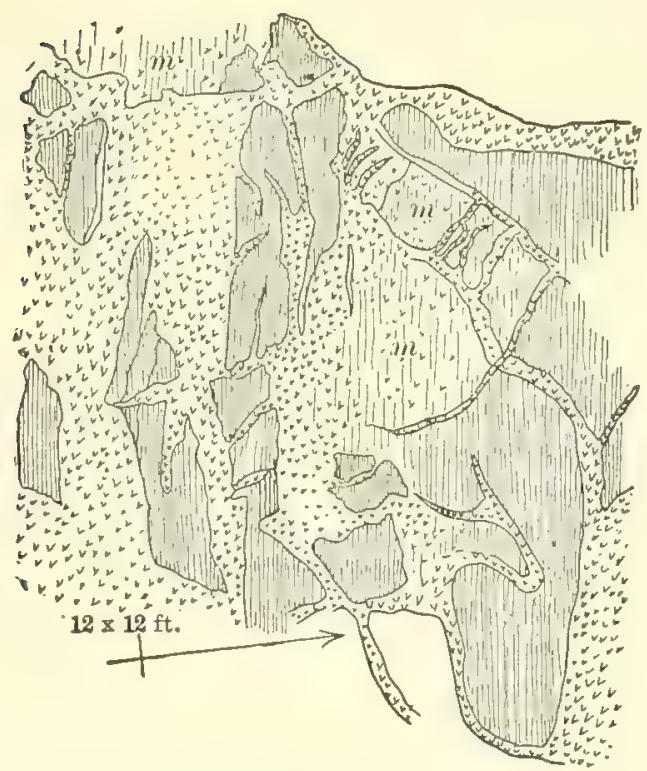

Mica schist (the lined areas) and granite; at $m$ the two intimately mixed. Surface, 12 feet square. A. Winchell, '87.
496.

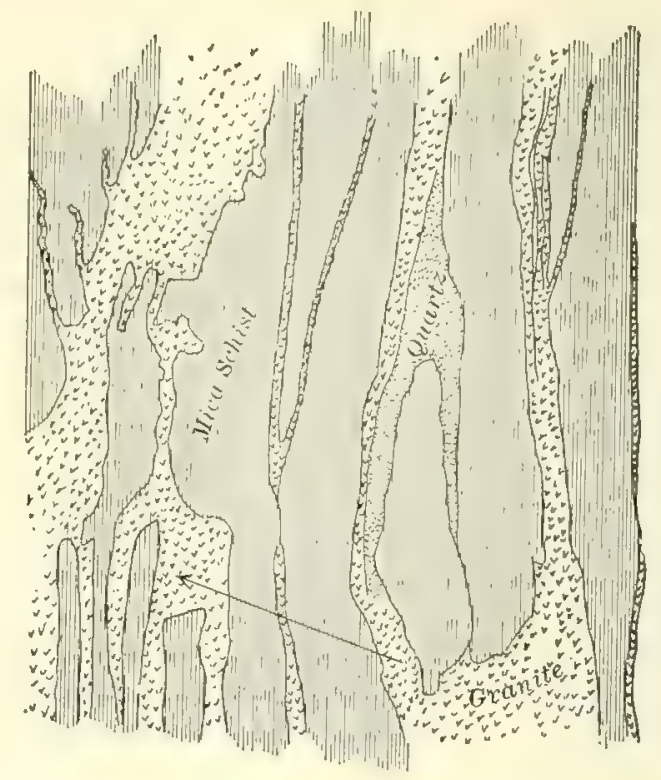

Mica schist and granite. Surface, 12 feet square. A. Winchell, '87.

Often the massive rock contains only isolated blocks; and from this condition there are all gradations to those represented in the figures. The rock fragments are not widely scattered, like those torn from the walls of a fissure by ascending lava, but often are still nearly in their original lines. In cases like those above described, the conclusion seems unavoidable that the extrusion of the melted rock followed closely on a general fracturing of the beds that are now schist, and that this could have happened only at an epoch of metanorphism, during the progress of a great upturning, when some one or more of the strata in a thick series of formations became fused by the excessive heat, and was forced up into fissures or spaces opened in the flexed and fractured unfused strata. The liquid did not make the fractures, but these being made, it flowed in and filled all crevices. In other places, described by Winchell, and especially in the vicinity of Saganaga Lake, the granites and the associated gneiss contain rounded pebbles every rod or two, two to six inches in diameter; and at one locality the pebbles, though not in contact, were "in such abundance as to constitute a 
real conglomerate," giving evidence of "attrition," "fragmental accumulation," and subsequent metamorphism. The rounded stones were four to five inches through, and consisted of crystalline augitic and other rocks.

In the recognized Huronian areas on the north shore of Lake Huron, and in the Penokee-Marquette belt, south of Lake Superior, extending from Wisconsin into northern Michigan, the rocks are quartzyte, siliceous schist, sandstones, conglomerates, micaceous and chloritic slates, chloritic greenstone, dioryte; and in Wisconsin there is a cherty limestone at the base, and carbonaceous as well as graphitic shales above.

A common feature of Archæan rocks, or at least of their veins, is the frequent occurrence of minerals containing rare elements, as niobium, tantalum, lanthanum, thorium, yttrium, zirconium, cæsium, rubidium, and others. The following minerals are common in Archæan rocks, or their veins: nephelite (elæolite), cancrinite, sodalite, spinel, chrysoberyl, danburite, amblygonite, spodumene, petalite, microlite, gadolinite, cryolite, besides others. But garnet, mica, andalusite, cyanite, staurolite, are less common than in later crystalline rocks. Chondrodite is usually, if not always, Archæan.

In the Kent-Cornwall ridge, west of Kent, Conn., and in the high land east of Tyringham, Lee, and Pittsfield, Mass., occur chondroditic limestones, like that of Sussex County, N.J., and at a locality east of South Lee, near the junction of the Archæan rocks with the Cambrian quartzyte, masses of chondrodite occur as large as the fist.

One of the most characteristic features of the Archæan is the occurrence of great beds of valuable iron ore, some of them 100 to 400 feet thick. They are found of great thickness in Canada, northern and southeastern New York, northern New Jersey, and the region south through Virginia to Georgia; in the Penokee-Marquette belt, south of Lake Superior; the Missouri Iron Mountain region; also in Utah, Wyoming, Colorado, New Mexico, and Arizona, and elsewhere.

The ores are usually magnetite, hematite, and titanic iron, of bright, lustrous kinds; and in one region, in Sussex County, N.J., it is a zincmanganese iron ore, called franklinite, mixed with disseminated zinc oxide

497.

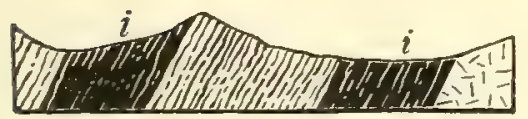

Northern Michigan, Whitney.
498.

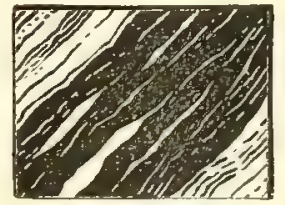

Essex County, N.Y. Emmons.
499.

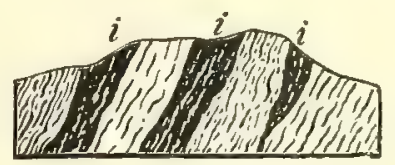

Essex County, N.Y. Emmons.

and zinc silicate. But, besides these kinds, there is also iron carbonate or siderite.

Figs. 497 to 499 show some of the positions of the ore-beds in metamorphic schists, the black beds $i$ being the ore-beds, and the ore magnetite or hematite.

In Fig. 497, the ore-beds (of northern Michigan) are between beds of DANA'S MANUAL - 29 
chlorite schist and dioryte, and have jaspery bands. In 497, 499, from Essex County, N.Y., the associated rock is gneiss, and the ore-bed is interlaminated with quartz. At one Essex County mine, the ore-bed is 150 feet thick; at the Cranberry mine, on the borders of North Carolina and Tennessee, 400 feet. Grains of calcium phosphate (apatite) are often disseminated through the ore.

Iron carbonate is associated with the oxides south of Lake Superior. It occurs only sparingly to the eastward in Michigan, south of Lake Superior, at the Marquette mine, but more abundantly to the westward in Wisconsin. The metamorphism of the beds, correspondingly, is least to the westward. The carbonate is the ore originally laid down, and the hematite and magnetite are results of metamorphic change, in which the carbonic acid was expelled.

In eastern Canada and along the Archæan protaxis, southward through New York, New Jersey, and beyond, the carbonate is wholly absent, the iron ores being magnetite, hematite, or titanic iron. Moreover, the thickness of the ore-beds is far greater and the metamorphism of the region is of higher grade, - thick-bedded, massive, and schistose, crystalline rocks prevailing. Notwithstanding these differences, the eastern iron-bearing series may be Huronian, and unconformable to adjoining Laurentian, but the evidence of this has not been obtained. The same belts have their thick beds of crystalline limestone, often chondroditic, and in this respect rocks of the Appalachian protaxis differ from those of the Lake Superior region. The course of the Appalachian chain was the region in later time of thick sedimentary deposits, great upturnings, intense metamorphism, while, cotemporaneously, little change was in progress over the Mississippi Valley; and it may be that the same kind of difference distinguished the two regions in Archæan time.

\section{STRUCTURE, THICKNESS, AND ORIGIN OF THE ROCKS.}

As is implied in the preceding descriptions, part of the rocks are massive, as granite, syenyte, dioryte, gabbro; and a large part are schistose and distinctly stratified; and into the schistose the massive often graduate. The alternations of ore-beds with schists, quartzyte, limestones, in sections like

500.

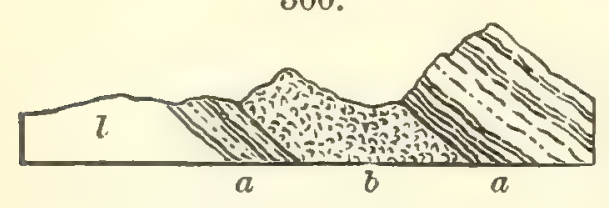

Interstratified limestone, St. Lawrence County, N.Y. Emmons.

those figured above, are evidence of stratification, and, therefore, of the successive formation of the beds, whether now crystalline or not. The quartzytes are old sandstones; the limestones deposited beds of limestone, either of organic or chemical origin; and the schists are fragmental beds in a metamorphic condition. In Fig. 500 a stratum of limestone, $l$, is overlaid by strati of gneiss, $a, a$, and steatyte, $b$. Such sections could be multiplied indefinitely. The following, by Logall, Fig. 501, which is partly ideal, but not untrue, represents white granular or crystalline limestone, $a$, many times folded and interstratified with gneiss and quartz rock, $b$; and the limestone has been traced over the same region (Grenville and the adjacent country, Canada), in the linear and curving bands of a series of great 
flexures. The facts prove that the beds were laid down horizontally over large continental areas, and that denudation in Archæan time, making sediment, was carried on by the ocean along its margins or over partly emerged rocks, and by streams over the land, as it is now. The streams were short in that time of contracted lands, yet well supplied with water

501.

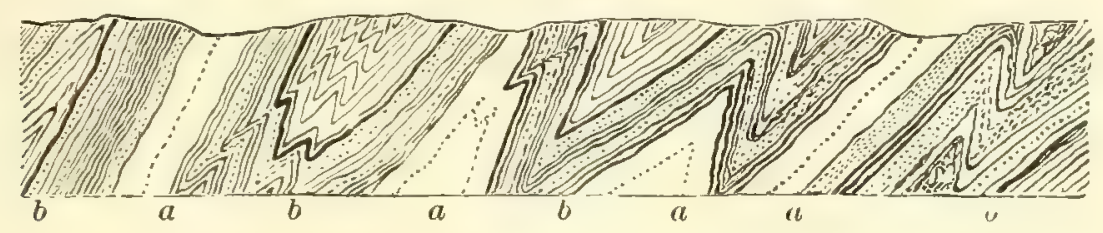

under the hot climate. The thickness of the rocks indicates that the amount of deposition and rock-making was enormous. The waters of the small streams and of the ocean owed much of their efficiency to the carbonic acid they contained, this gas being everywhere in excess. Moreover, under these conditions, the formation of beds of iron ore along the shallow margins of the sea and in the shallow waters of the land would have been necessarily one of the great features of the later part of Archæan time; for the decomposing iron-bearing rocks would have readily yielded their iron to the attacking carbonic acid. Moreover, organic deposits of silica may have accompanied the ore-beds in the basin.

A thickness of $30,000,50,000$, and 80,000 feet has been attributed to the formations piled up in one series or region. If this means 50,000 feet or more in a single geosynclinal area before an upturning, the estimate is to be doubted, for the difficulties of correct measurement of flexed rocks are great. In most cases the facts as to the faults and flexures present cannot be ascertained. A thickness of 50,000 feet of uncrystalline sediments in a geosyncline, during even the later part of Archæan time, militates against all calculations as to the Archæan rate of increase downward in the earth's temperature ; for if the rate were $1^{\circ} \mathrm{F}$. for 10 feet of depth, as Thomson has calculated, the bottom of such a geosyncline would have had a temperature of $5000^{\circ} \mathbf{F}$; or if $1^{\circ} \mathbf{F}$. for 25 feet, it would still have had a temperature sufficient nearly for the fusion of basalt.

\section{ARCHÆAN MOUNTAIN-MAKING。}

The stratified rocks of the Archæan are almost everywhere upturned, and generally at high angles, the dip usually being between $30^{\circ}$ and $90^{\circ}$. Only portions of the Huronian are nearly horizontal. Moreover, as represented in Fig. 501, they are commonly in flexures, from a few yards to miles in span. Such flexures, whenever they occur, are evidence that great upturnings had taken place of the Appalachian kind. The crystallization of the rocks, or their metamorphisrn, was an accompanying result. The rocks of the earliest Paleozoic often lie over them nearly or quite horizontally, as illustrated in the accompanying figure (Fig. 502) from Logan, representing a section from the northern or Canadian side of the Adirondacks. Upon the flexed Archran rocks lie (2) the Potsdam sandstone of the Cambriar, 
and $(3,4 a, 4 b)$ overlying Lower Silurian strata. Such sections of Cambrian strata over the upturned Archæan are proof that the mountain-making in the region preceded the Cambrian era. It is probable that the Adirondacks were made at the close of Archæan time. They were, from the first, great mountains, for the highest of the summits, Mount Marcy, now stands 5000 feet above the Cambrian seashore, or the lowest Cambrian beds, and this is the height remaining after long ages of denudation. For the original height, 8000 feet above the Cambrian tide-level can hardly be too high an estimate.

502.

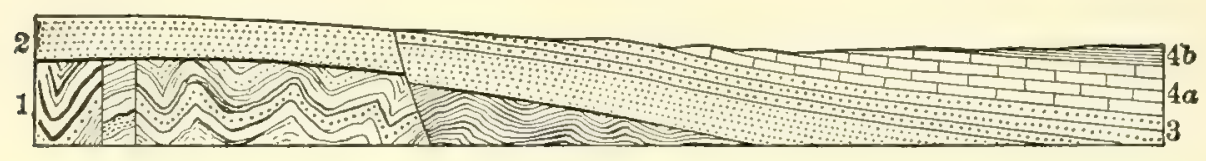

From the south side of the St. Lawrence in Canada, between Cascade Point and St. Louis Rapids: 1, gneiss; 2, overlying Potsdam sandstone; 3, calciferous sand-rock; $4 a$, Trenton limestone; $4 b$, Hudson slates. Logan.

The fusion of beds by the heat in the lower and hotter part of the geosyncline would have made, by the escape of the liquid rock alone, fissures, veins of igneous rock in the metamorphic region, and also inclosures of the broken schists of the upper and less heated part of the mass (page 448). Such igneous eruptions are of the same age as the metamorphism.

How many epochs of upturning occurred in the course of Archæan time is unknown. In the vicinity of lakes Huron and Superior (and probably also farther east) there was one at the close of the Laurentian period.

Over the Archæan area of New Jersey, and of Orange and Putnam counties in New York, there are several long belts of Cambro-Silurian rocks, occupying what were originally valleys of Archæan time, having the northeastward trend of the rocks. They are fossiliferous in New Jersey, and partly metamorphic in Putnam County, N.Y., north of Peekskill. They once spread more widely over the Archæan Highlands, and, perhaps, covered the whole when the Coal-measures were finished, as considered probable by J. P. Lesley. The upturning the beds have undergone took place in spite of resistance to fracture or compression in the underlying Archæan rocks.

\section{SUBSEQUENT ALTERATIONS OF ARCHAEAN ROCKS.}

Archæan rocks have in many places undergone changes in their minerals. They were made at higher temperatures, under greater atmospheric pressures, and with slower rates of cooling, than ordinarily obtain now at the earth's surface; and these changed conditions, and especially those due to heat from orographic movements, have occasioned alterations in some constituents.

Many Archæan rocks that are now hornblendic were originally pyroxenic. Since other pyroxene rocks have remained unchanged, some circumstances must have intervened to commence the alteration; and it may be that it was a heating up of the rocks to $1000^{\circ} \mathbf{F}$., through fracturings, faultings, and crushings attending earth-movements or mountainmaking. Besides the above-mentioned change, chrysolite, pyroxene, hornblende, and 
other minerals have been converted into serpentine; pyroxene into rensselaerite, a variety of tale; nephelite into gieseckite; spinel to hydrotalcite. Another change is that of magnetite to hematite; for the great beds of hematite sometimes contain octahedral crystals now consisting of hematite, which, when formed, were octahedrons of magnetite.

In the ore-beds of the Huronian the layers of ore, jasper, or other materials are often much broken and displaced. The grains of apatite are sometimes more abundant along one side of an ore-bed than the other, or have some reference to the depressions in which the ore lies (Browne, 1889). The dioryte underlying the ore-bed has been altered in many places to a soft clayey material, feeling soapy, resembling the fluccan of a vein. The underlying rock is sometimes that of a dike, but whether consisting of dioryte or diabase, it is, in general, probably, as Hunt held, a rock of sedimentary origin. As dioryte and diabase were very abundant rocks, sediments made from them would have then been common. The broken and otherwise displaced condition of the ore-beds, and the rearrangements of the ore in any depressions that were made, would have been a consequence, under the results of wider disturbance, of the important fact that in the change of the carbonate to hematite or magnetite, there is a reduction in the former of one third in bulk, and in that of limonite to the same ores, a reduction of one half or more, so that large: spaces would have been opened, favoring large displacements.

The subsequent changes, alluded to above, probably occurred at some later epoch of regional disturbance, in the course of which movement was produced along the plane of the ore-bed. Under the action of the heat from friction siliceous and other solutions. would have been formed anew and mineral changes have taken place.

\section{IIFE OF ARCHEAN TIME.}

Although fossils, according to present knowledge, are absent from Archæan rocks, or are of questionable character, the existence during the later part of the Archæan of aquatic life in its simplest forms is rendered almost certain by the fact that the temperature of the waters was favorable to it, and by the occurrence among the stratified rocks of beds of limestone; by the abundance in many limestones, and other rocks, of graphite, which constitutes 20 per cent of some layers in Canada; and the presence in the Huronian of carbonaceous shales or slates containing 40 per cent of carbonaceous materials. The life belonged to that division of Archæan time which is designated, on page 441, the Archæozoic æon; and the Huronian rocks represent the latter part of this æon, if not the whole of it.

Plaxts. - Graphite - crystallized carbon - has been made in many later rocks by the alteration of coal-beds; as at Worcester, in Massachusetts, in Rhode Island, at St. John in New Brunswick, where ferns among the coalplants have been found in the state of graphite, in Ayrshire, Scotland, and in Bavaria. Even anthracite has been observed in the Archæan rocks of Arendal, Norway. Dawson has remarked that it is scarcely an exaggeration to maintain that the quantity of carbon, in the form of graphite, in the Archæan rocks of Canada is equal to that in similar areas of the Carboniferous system. It is reasonable to conclude, therefore, that although graphite may also be produced by heat, that of the Archæan was largely of organic origin, like that of later rocks. The metamorphism of shales containing carbonaceous materials derived from vegetable, if not also animal, tissues, 
has converted the carbon into graphite. The little-altered Huronian beds of Wisconsin still contain much carbonaceous material, as remarked by Brooks and Chamberlin. The former stated, in 1876, that "the considerable amount of carbon distributed through the Huronian indicated much organic life, and leads to the hope that" those imperfect fucoidal impressions reported by Julien, in the second volume of the Report on the Geology of Michigan, may not prove delusive.

The earliest plants were, beyond doubt, Algæ, water species, which grow, like most plants, by taking carbon from carbonic acid; and after these, the microscopic Fungi related to the Bacteria (Microbes), which take their carbon for growth chiefly from organic products; for these minute plants are essential to the process of decay of organic matters and also to the production of many mineral changes, as already explained.

The chert of the limestone in the Penokee belt of Huronian, and the jasper associated with the iron ore of the belt, consist partly of opal-silica, and are probably from silica-secreting Algæ (Irving, Van Hise). It is probable that plants related to those that are now secreting limestone and silica in the hot waters of Yellowstone Park, below temperatures of $185^{\circ}$, were already doing geological work in the making of limestones and silica deposits during the later Archæan. One species of supposed "seaweed" has been named Archoophyton Newberrianum by N. L. Britton. The specimen, from a New Jersey crystalline limestone, consists of graphite arranged in narrow

503.

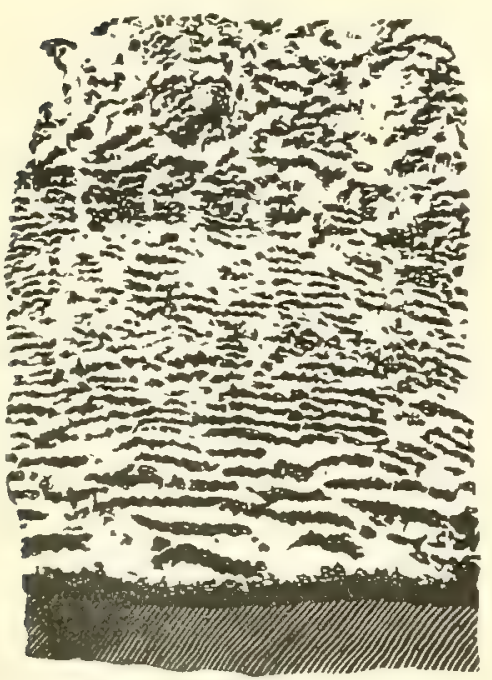

Eozoon Canadense. Dawson. parallel stripes, with a regularity that suggests organic origin; but the arrangement may well be an effect of the pressure attending metamorphism.

AnimALs. - With regard to animal life, the supposed fossil, Eozoon Canadense of Dawson, is regarded by some as proof of the existence of Rhizopods (Foraminifers), while others believe it to be of mineral origin. It occurs in coral-like masses which are sometimes several feet in diameter. Fig. 503 represents, natural size, a section of a specimen from Grenville, Canada. The white bands are the calcareous layers supposed to have been secreted by a layer of the Rhizopods, while the dark bands correspond in position to the layer of Rhizopods, and are made up of mineral material (serpentine generally, sometimes pyroxene, loganite, etc.) that, after the death of the animals, filled the cells. Dilute muriatic acid removes the limestone, and opens the rest to examination.

Localities occur in the third or Grenville stratum of limestone near Grenville, and in the Petite Nation Seignory; also in Burgess (where the calcareous part is dolomite), and at the Grand Calumet, in a limestone whose place in the series is not determined; and at Tudor in Hastings County. Eozoon has also been reported from Archæan rocks in Bavaria 
and named E. Bavaricum; also from Saxony, Bohemia, Hungary, and Pargas in Finland. The specimens of Eozoon were first supposed to be Stromatopora corals (Logan's Rep. Geol. Can., 1863, page 49), and afterward announced as Rhizopod in structure by Dawson ; and this conclusion has since been sustained by W. D. Carpenter and others. But Eozoon specimens have also been examined microscopically by good observers, among them King and Rowney, and Möbius, who have not found the supposed foraminiferal characters. Quite recently, in 1891, the Tudor specimens were examined by J. W. Gregory with this conclusion.

Doubts are excited also by the close resemblance in structure to specimens that are of mineral origin; by the unequal thickness of the calcareous layers and the interstices; and by the fact that serpentine of later formations has afforded similar forms. It is objected to on the ground that this mineral is often minutely interlaminated with fibrous serpentine or some other mineral, showing that the soft amorphous material, as it solidified, sometimes contracted and divided into thin laminæ, leaving spaces between to receive depositions of any kind; in the Eozoon the infiltrating material was usually calcareous.

Notwithstanding the imperfection of the evidence, the existence of Rhizopods and other Protozoans before the close of Archæan time is generally believed.

The calcium phosphate (apatite) of the rocks, which is common in some limestones, is also supposed to be of organic origin, because a constituent of organic tissues and of some shells. Its abundance also in the iron ores favors this view, inasmuch as the beds of ore are believed to be marsh productions. But the phosphate is distributed in grains through many igneous and other crystalline rocks, and the evidence may only prove that it was present in solution in the sea-waters of the era.

Above the grade of Protozoans, the type which is most likely to have existed in the later Archæan is that of Rotifers; for there is good reason for believing, as stated on page 423, that from this group passed off independent successional lines of species to Worms, Limuloids, Crustaceans, and terrestrial Arthropods, and probably also to Bryozoans, Brachiopods, and perhaps other tribes.

\section{ECONOMICAL PRODUCTS.}

The chief economical products of the Archæan terranes are: (1) Gold, platinum, diamond; (2) Iron ores; (3) Copper, and other ores ; (4) Corundum or emery; (5) Graphite; (6) Architectural materials, especially granite and marble; (7) Apatite or calcium phosphate for fertilizing purposes; (8) Feldspar for porcelain-making; (9) Mica for the doors of lanterns, stoves, etc., and various other uses; (10) Zircon and monazite.

The iron ores are among the most valuable. They sometimes contain too much titanium; and occasionally the proportion of disseminated grains of apatite affects their value. This mineral may be distinguished by its greenish or grayish color and by its being soft enough to be scratched by the point of a knife-blade. The American corundum $\left(\mathrm{Al}_{2} \mathrm{O}_{3}\right)$ comes mostly from North Carolina and Georgia. A mass weighing 400 tons was formerly obtained in the rocks of Chester County, Pennsylvania. The mineral is ground up and used for emery, it being the same compound as emery, but in a purer form. 


\section{ARCHÆAN TIME IN OTHER COUNTRIES.}

South America has its northern region of Archrean rocks between the equator and the Orinoco, which would probably have a much larger superficial area but for the great alluvial and Tertiary area of the Amazon and other rivers, which bound it for 150 miles on the north and two to three times this width on the west. Archran ranges also occur in Brazil, and in different parts of the chains of the Andes.

In the continent of Europe the great Archæan region is the Scandinavian, or that covering the most of Sweden, Norway, Lapland, and Finland. The rocks also occupy a large part of the northern half of Scotland and the Outer Hebrides; portions of western Ireland, at Donegal and Galway, and of eastern, in Wicklow; at St. David's, in southwest Wales; in Anglesey, off northwest Wales; in western England, in the Malvern Hills; and probably on the south coast of Devon and Cornwall. They also cover areas in Saxony, Bavaria, and Bohemia; in Brittany, Vosges, and the Central Plateau of France.

Crystalline rocks cover, according to Blanford (1879), very large areas in India. "More than half of Peninsular India is taken up by the eastern gneissic series." They extend, with scarcely an exception, from Cape Comorin to Colgong on the Ganges, 1400 miles. The mean breadth of the area is 350 miles. There are also in the peninsula a northwestern area, the Arvali; and, to the north of the Vindhyan plateau, the Bundelkhand area. But it is not certain that all are Archæan. Besides these, there are also large areas of semi-metamorphic rocks. The main Himalayan range has a gneissic or granitic axis, but the limits are not yet laid down; and in the Zanskar range, its continuation to the northwest, there is a center of gneiss. But the precise relations of these and other gneissic ridges to the later formations has not been ascertained.

The rocks of Scotland, Norway, Sweden, and other Archæan regions are much like those of North America in general constitution, and in the range of the associated minerals; and in Scandinavia there are great iron ore beds. The massive gneisses of the Hebrides and northern Scotland were called the Lewisian group by Murchison (1858), after the island of Lewis in the Outer Hebrides. Like the massive and the thick-bedded or foliated rocks, which contain the iron ore beds of Scandinavia, they have been pronounced on petrological grounds to be of igneous origin. But, for reasons already stated, they are in all probability, wherever igneous, metamorphic-igneous, or the result of fusion attending metamorphic work. The foliation of the gneisses and other rocks represents, in general, on this view, true bedding. The iron ore beds are the best of evidence of metamorphism. The crystalline rocks east of the "Great glen" in Scotland include thin schists and quartzyte with gneiss, and have been called the Grampian group by H. Hicks, and later the Dalradian group by Geikie; it is supposed to be younger than the Lewisian. 
The crystalline rocks of St. Davids, in Wales, have been described by Dr. Hicks as of three periods : (1) the Dimetian; (2) the Arvonian; and (3) the Pebidian. Geikie concluded, after an examination of the region, that the Dimetian rocks are intrusive granite; the Arvonian, "quartz-porphyries" connected with the granite; and that the Pebidian rocks are tufas and diabases belonging to the lowest Cambrian. Dr. Hicks's view that the St. Davids rocks are partly Archæan is favored by the presence in the vicinity of fossiliferous Cambrian. It is now adopted by Geikie.

In the Torridon district, northwestern Scotland, a thick formation of reddish and brownish sandstones, wholly uncrystalline in texture, but upturned to a high angle, lies unconformably both upon Archæan gneisses and underneath strata of Lower or Olenellus Cambrian. The reported thickness is 4000 to 8000 feet. As they are unfossiliferous, it remains doubtful whether the Torridon sandstone, or "Torridonian group," should be referred to the later Archæan, or to the earliest Paleozoic. Murchison referred them to the Cambrian.

\section{OBSERVATIONS ON THE ARCHEAN.}

1. Relations of the North American Archæan areas to the continent. - The position and form of the nucleal Archæan of the continent, and of the parallel ranges on either side, reaching out to the oceans, prove that the continent was not only outlined, but also marked off as regards its grander features in Archæan time. This is established also by the great thickness of metamorphic rocks; for rocks of sedimentary or detrital origin are not made except where there are emerged, or nearly einerged, rocks to be a source of material; and even a slight submergence makes the amount of decay, and of detritus produced, small. Further, the existence of the continents, emerged or at shallow depths, is evidence, as explained on page 380, that the oceanic basin also was defined by the close of the Archæan, and had nearly its present mean depth of 12,000 feet.

The facts thus prove that the scheme of progress, even to minor details, dates from the beginning. In the very inception of the continent, not only was its general topography foreshadowed, but its main mountain chains appear to have been begun, and its great intermediate basins to have been. defined. The evolution of the grand structure lines of the continent was hence early commenced, and the system thus initiated was the system to the end. Tracing out the development of the American continent, from these Archran beginnings, is one of the main purposes of geological history.

2. Correlation of Archæan subdivisions. - Names of Archæan subdivisions are multiplying over the world wherever Archæan rocks are studied. The uncrystalline terranes are safely put at the top of the series in the particular region where they occur; but, as already remarked, they may be the equivalents of crystalline kinds in another more mountainous region. 
With the more crystalline terranes correlation is extremely difficult. This is owing to the absence of fossils; to the uncertain value of the criterion based on kinds of rocks; and to the fact that no subdivision admits of being traced to any great distance, except the kind which depends on unconformity in bedding. Since this kind of unconformity is a consequence of an orographic upturning, and mountain ranges have usually great length, it will theoretically exist for long distances. Subdivisions based on other kinds of unconformity, and on the characters of the rocks, are the most common, and are necessarily of only local value. The study of a region with reference to unconformity in bedding involves a complete investigation of the positions of the planes of bedding, or foliation, wherever the rocks are exposed to view.

The beds of iron ore and the graphite-bearing schists of Wisconsin are proved to belong to the later part of Archæan time - the Huronian; and this is probably true for the associated Archæan beds and schists, whether massive, gneissic, or thin schists, and hence beds of iron ore are a great help in correlation. The beds of limestones may yet be found to give aid in the same direction.

The study of the Archæan rocks has difficulties, but not so great as are implied in the term "Basement Complex," sometimes used for the more crystalline kinds, - an expression that sounds like a wail of despair on the part of those that use it.

3. Source of the material of later fragmental rocks. - The Archæan rocks, and rocks made from them, are the main source of the material of subsequent non-calcareous fragmental rocks. Volcanic eruptions have added a little to the supply; chemical depositions also a little; and the siliceous secretions of the lowest orders of plants and animals have contributed silica to some extent; but all these sources are small compared with those of the Archæan terranes. Even the limestones have derived much of their material from the same source, through the dissolving waters. The areas were well distributed over the continent for supplying, through the help of the ocean, mud, sand, and gravel for the deposits that were in progress as the next era opened - better even than is now apparent, since many once exposed are now covered, especially along the sea-borders, where the later rocks have often great thickness. And their contributions have continued ever since to be used in rock-making, both directly and through the strata which had been made from them.

4. The first of living species. - Science has no explanation of the origin of Life. The living organism, instead of being a product of physical or chemical forces, controls these forces for its higher forms, functions, and purposes. Its introduction was the grandest event in the world's early history.

It is probable that the first species were of the simplest kinds; that the animals were devoid of special organs of sense, and of motion, excepting 
short, hair-like processes; and of nutrition, beyond at the best a cavity for digestion. But the principles inaugurated were those fundamental to all life. Some of them are as follows:-

1. The subordination of chemical and physical forces to the control of living conditions.

2. Germ-development, by which, from a germ-cell, a structure of various functions becomes evolved, and is carried to an adult or germ-producing stage, when new germs are produced for another cycle of development.

3. Death of the adult, a fundamental stage in the cycle, - the institution of life involving the introduction of death.

4. In the case of animal life, dependence on living food for growth - a principle that pervades the animal kingdom from its lowest species to Man.

5. As a consequence of growth and germ-development in animals, the initiation of two diverse moral forces, which later became a power in the world: $(a)$ the affiliating influence, arising out of the relation of parent to progeny; (b) the antagonistic, self-asserting influence, arising from the necessity of food. Each element had reinforcements from other appetites or conditions in animal life. 


\section{PALEOZOIC TIME.}

\section{SUBDIVISIONS.}

The higher subdivisions of Paleozoic time are as follows:-

\section{Eopaleozoic Section.}

\section{Cambrian Era.}

II. Lower Silurian Era.

\section{Neopaleozoic Section.}

\section{Upper Silurian Era. \\ II. Devonian Era. \\ III. Carbonic Era.}

Paleozoic time is naturally divided into two sections at the break between the Lower and Upper Silurian. This boundary line is marked in the history by an epoch of mountain-making in eastern North America and western Europe, and by a somewhat abrupt transition in the animal life of the seas. These sections are here named by using prefixes to the term paleozoic derived from the Greek 'ंw's, dawn, and v'os, new.

The first of these sections, the Eopaleozoic, was characterized by the fact of almost universal seas over the continental area, and of universal marine life, and also by the more specific Paleozoic fact, that marine Invertebrates, or the species of the inferior division of the Animal Kingdom, were displayed under nearly all their grander types before the close of this section of Paleozoic time; and also that the highest division of the Animal Kingdom, Vertebrates, was represented by species of the inferior type of Fishes.

The second of the sections, the Neopaleozoic, was characterized by the gradually increasing extent of dry land over the continental area, and the covering of the emerged surface with land plants, and finally with great forests; and also by the multiplication of terrestrial species of animal life among Invertebrates, and finally among Vertebrates. With the progress of the era, Cryptogams, plants of the lower division of the Vegetable Kingdom, reached their culmination in grade, size, and diversity of kinds; and the superior division of the Vegetable Kingdom, Phænogams, was represented by species of the inferior type of Gymnosperms.

The Eopaleozoic section was, biologically, following Agassiz's method of designation, the time of the Reign of the Invertebrates, and prominently of Trilobites; the Neopaleozoic, in its Upper Silurian and Devonian eras, the time of the Reign of Fishes, and in the Carbonic era, that of the Reign of Amphibians.

The first real progress in correlating the Paleozoic rocks of North America and Europe was made through the labors of the geologists of the survey of the State of New York, and those of Murchison, Sedgwick, De Verneuil, and others abroad. But, in this 
work, American geology owes much to De Verneuil for his "note" of 64 pages in the Bulletin of the Société Géologique de France, iv., 1847, "On the Parallelism of the Paleozoic Formations of North America with those of Europe," which is followed by a list of the species of fossils common to the two continents, and of the rocks in which they occur, with critical remarks respecting each species; and to the paper of D. Sharpe, "On the Fossil Mollusks from the Paleozoic Formations of the United States," contained in the collections of C. Lyell, Q. J. G. Soc., 1848.

\section{AREAS OF GEOLOGICAL PROGRESS.}

Archæan geography, as has been explained, largely determined the areas of later geological progress, and the character of continental geography through all the ages. The prominent points in North American geography, besides the fundamental one of the Archæan nucleus, are the defining of the two great Archæan chains of islands or island ridges, the Appalachian protaxis on the east, the Rocky Mountain protaxis on the west (page 24). By this means a vast Interior Continental Sea was divided off from an Atlantic border region on the east, and a Pacific border region on the west, the former (reckoning to the 100-fathom line, or the steep border of the Atlantic depression) averaging 300 miles in width, but becoming three times this in the latitude of Newfoundland; the latter, 1000 miles in mean width.

Besides this, the shorter Archæan ranges of the Atlantic border region to the north (see the map) divide the surface into a parallel series of broad channels or troughs, all of which open northward into the St. Lawrence valley region.

1. The Champlain and St. Lawrence channel: between the northern part of the protaxis and the Archæan lands; on the west stand the Adirondacks, and on the north the Canada Archæan.

2. The Connecticut valley channel, or trough, along the Connecticut valley, and reaching Long Island Sound at New Haven Bay, Conn.

3. The Maine-Worcester channel: covering Maine and western New Brunswick and extending down to Worcester, Mass.; apparently fading out southward. The fiord of the Thames River, from Norwich to New London, Conn., lies in its course.

4. The Acadian channel: extending from St. Lawrence Bay and western Newfoundland over eastern New Brunswick and much of Nova Scotia, with the Bay of Fundy between, as the remains of this part of the depression; thence southeastward along and off the coast regions of Maine to Massachusetts Bay, and over eastern Massachusetts to Narragansett Bay, on the Atlantic border.

5. The Exploits River channel of central Newfoundland, and two others to the eastward.

The importance of these channels, or troughs, becomes strongly pronounced in the course of Paleozoic history.

Over the Pacific border region the areas are less plainly indicated than 
over the Atlantic, because the western half of the continent is so generally covered with Mesozoic and Cenozoic rocks.

Paleozoic rocks are the prevailing kinds exposed to view over the eastern half of the North American continent, excepting along the borders of the Mexican Gulf and of the Atlantic south of New York. The older formations of the series, as the map on page 412 illustrates, lie near the Archæan area, not far north or south of the northern boundary of the United States; and the newer formations outcrop in succession southward, the Carboniferous covering much of Pennsylvania and other States.

Fig. 504 is an ideal section of the Paleozoic rocks of New York, along a line running southwestward from the Archæan across the state to the coal

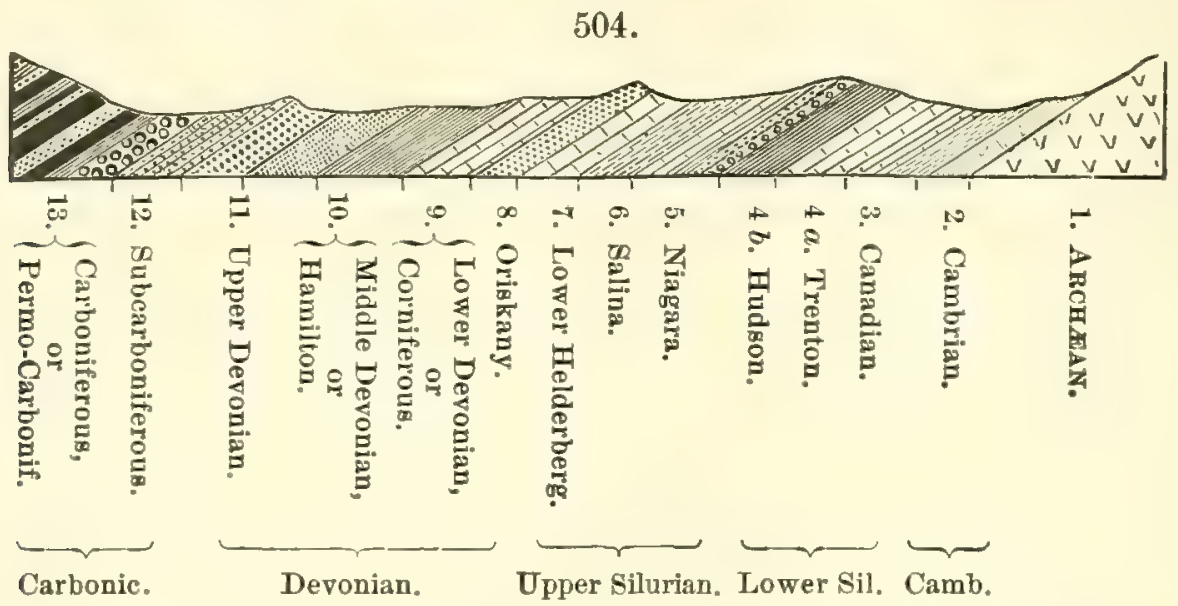

region of Pennsylvania. It shows the relative positions of the successive strata, - bringing out to view the fact that the areas over the region are only the outerops of the successive formations. This is all the section is intended to teach; for the uniformity of dip and its amount are very much exaggerated, and the relative thickness is disregarded. Along the Appalachians the older Paleozoic rocks occur in long belts parallel with the axis of the range, because of the great upturning of the formations that took place at the close of the Carboniferous, when the mountains were made.

\section{EOPALEOZOIC SECTION.}

\section{CAMBRIAN ERA.}

Srw. - Cambrian, Sedgwick, Rep. Brit. Assoc., 1835. Cambrian (Murchison's Lower and Upper Silurian being made higher divisions of the Paleozoic series), Sedgwick, Q. J. G. Soc., 1846, page 130. Cambrian (Murchison's Lower Silurian being included under it), Sedgwick, Q.J.G. Soc., 1852, page 147. Lower part of Lower Silurian, Murchison, Q.J.G. Soc., 1852, page 173; D’Orbigny, Géol., 1851.

Cambrian, Lyell, Elements Geol., 2d ed., 1841 ; 5th ed., 1855; Geikie, Text-book of Geol., 1879, 1885; Lapparent, T'r. de Géol., 1883; Seeley and Etheridge, Man. Geol., 1885 ; Prestwich, Geol., 1886 ; E. Kayser, Lehrb. geol. Form., 1891.

Primordial or lower division of the Silurian System, Stage C, Barrande, Syst. Siturien de Bohême, 1852. Cambrian or Primordial, a subdivision of the Lower Silurian, this Geol., 1874, 1880; C. Vogt, Geol., 2d ed., 1866 ; Credner, Geol., 6th ed., 1887. 
Potsdam Sandstone, New York Geol. Survey, 1842. Primal Sandstone, H. D. and W. B. Rogers. Upper Taconic, fossiliferous slates of Georgia, etc., E. Emmons, 1844, 1846 (not in the Taconic System of 1842).

History of the terms Cambrian and Silurian. - The terms Cambrian and Silurian recognize the united labors of Murchison and Sedgwick in the first careful study, in Great Britain, of the older fossiliferous rocks of Paleozoic time. The two eminent English geologists worked together in some of their earlier investigations. The memoirs of that period, "Communications on Arran and the north of Scotland, including Caithness (1828) and the Moray Firth, others on Gosau and the eastern Alps (1829-1831); and still later, in 1837, a great memoir on the Paleozoic strata of Devonshire and Cornwall, and another on the coeval rocks of Belgium and north Germany, show the labors of these intimate friends combined in the happiest way - the broad generalizations in which the Cambridge professor delighted, well supported by the indefatigable industry of his zealous companion." 1 In 1831, they were both at work" without concert" on the borders of Wales, - Murchison chiefly on the English side and in southern Wales, and Sedgwick beyond the boundary in north Wales. Sedgwick had earlier investigated somewhat similar rocks in the Cumbrian Mountains. By 1834, Murchison had laid down his grand divisions of Ludlow, Wenlock, Caradoc, and Llandeilo, and had referred the first two of them, on the ground of the wide difference in fossils, to the Upper Silurian, and the latter two to the Lower Silurian. In 1835, the terms Cambrian and Silurian appear together in a combined paper presented by the two authors to the first meeting of the British Association. Silurian had been announced by Murchison nearly two months before in the July number of the Philosophical Magazine. In 1838, each put forth more fully his results: Sedgwick, in a paper read before the Geological Society, giving the distribution and character of the rocks, with but little notice of the characteristic fossils; but Murchison, before the close of the year, in a quarto volume of 800 pages copiously illustrated with figures of fossils and geological sections, entitled the "Silurian System." Murchison's work and his names of subdivisions came into immediate use in all countries, and were recognized in all geological treatises.

Gradually it came to light that the Lower Silurian of Murchison comprised rocks and fossils of the age of the Upper Cambrian; and also that the fossils from beds of still lower level differ little in general type from those of the Lower Silurian. Thus geologists, with Murchison's book in hand, were led to use the term Lower Silurian for the fossiliferous Cambrian. No full account of Sedgwick's Cambrian fossils was published before 1852 to $185 \tilde{5}$, and not even lists of species before 1843 .

In 1846 Sedgwick made his first protest against the absorption of the Cambrian by the Lower Silurian of Murchison; and in 1852 the controversy, thus begun, ended in his claiming the whole of the Lower Silurian as Upper 
Cambrian, and in Murchison's expressing his satisfaction that geologists and paleontologists everywhere, in America as well as in Europe, had already adopted, through the use of his publications, his subdivisions and terms. Later, after collections of Cambrian or Primordial fossils had heen much enlarged through new discoveries, the names Cambrian and Lower Silurian became accepted for successive divisions of the Paleozoic series.

The term Cambrian is derived from the old name of Wales, and Silurian from the tribe of Silures, which inhabited southeastern Wales and Monmouth, England.

For a more detailed history of the terms Cambrian and Silurian, see the Am. Jour. Sc., xxxix., 1890 ; also Murchison's Life by A. Geikie, 1875.

\section{AMERICAN.}

\section{SUBDIVISIONS.}

3. Potsdam period, Reports New York Geologists, 1838, 1842. UPPeR Cambrian, Walcott. Later Cambrian.

2. Acadian period, Dawson, Acad. Geol, 1868. Middle Cambrian, or Paradoxides zone, Walcott, 1887. Named Acadian from the locality at St. John, New Brunswick.

1. Georgian period, 1886; Lower Cambrian or Olenellus zone, 1887, C. D. Walcott, Bull. U. S. G. S. Keweenawian, T. B. Brooks, Am. Jour. Sc., xi. 206, 1876; Keweenawan, Chamberlin, 1883; Irving, 1887; Keweenian, A. Winchell, 1886.

\section{ROCKS-RINDS AND DISTRIBUTION.}

General Distribution. - The Cambrian rocks rest upon the upturned Archæan terranes, and usually outcrop along the borders of Archæan areas. In eastern North America they occur, adjoining the Archæan nucleus, on one or both sides of the Appalachian protaxis, from Canada to Alabama, and occupy parts of some, if not all, of the channels or troughs of Archæan confines from the Adirondacks to the eastern limits of Newfoundland. They are in part beach-made and wind-made sandstones, or offshore limestones, or slates or schists that originally were mud beds; and the layers often bear ripple-marks, shrinkage cracks, worm-burrows, and, in some places, tracks of animals.

Similar relations to the Archæan exist at various localities of the Lower Cambriau over the continent, to the far west. They are found about Archæan outcrops in Texas and South Dakota, and along the Rocky Mountain protaxis in British America and the United States, and also farther west in Nevada; and occasionally they are reached, over the Pacific slope, by the cañon cuts of rivers thousands of feet in depth, as in that of the Colorado.

The accompanying sketch of a portion of the "Pictured Rocks" in the Lake Superior sandstone, near Carp River, Michigan, illustrates the usual 
unconformability between the Cambrian beds and the Archæan, exemplifying the fact that the upturned Archæan made the bottom of the Cambrian seas, over which the great sandflats, or other sand depositions, were made. The view also shows that the Cambrian beds had been slightly tilted since their formation.

505.

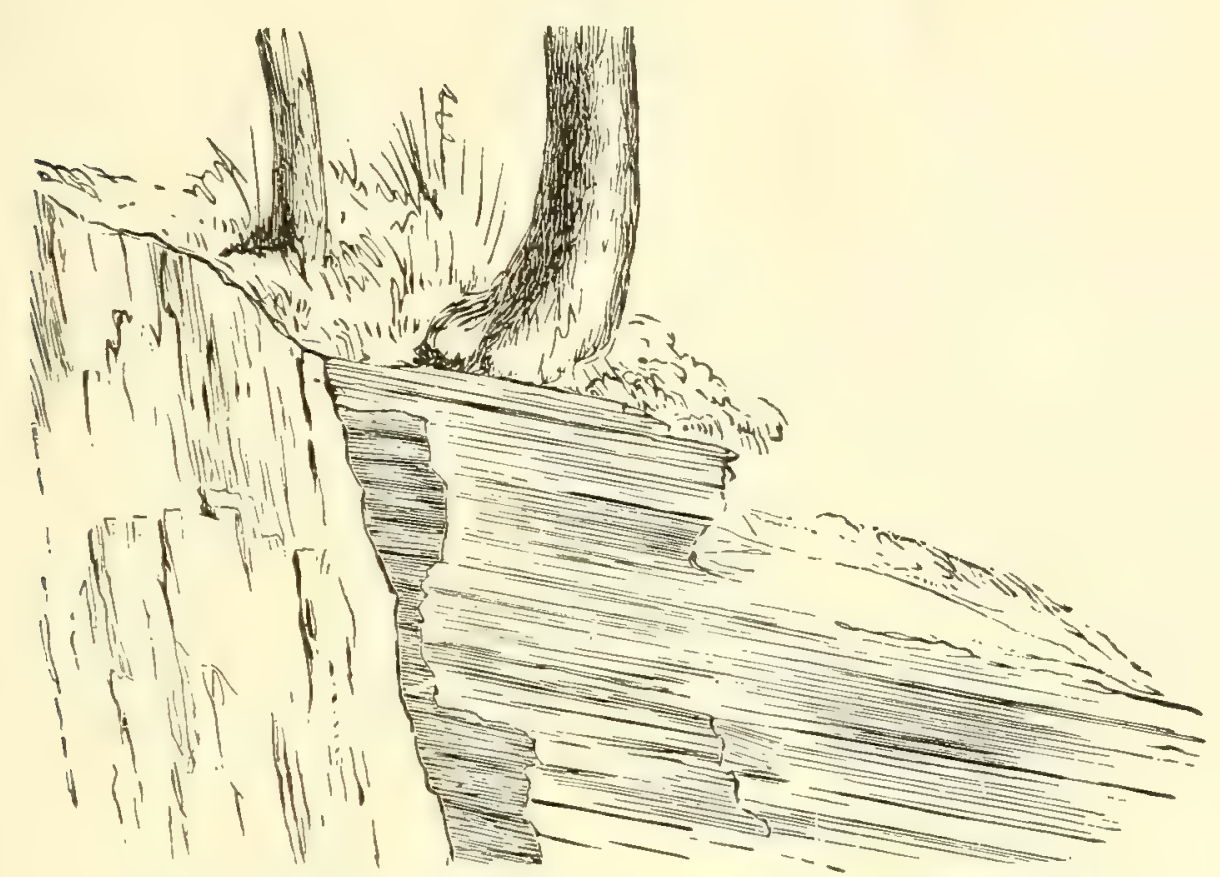

Unconformability at Carp River, Chippewa County, Mich. J. D. Whitney.

The fossiliferous beds in eastern Newfoundland of the Lower Cambrian consist of shales, sandstones, and conglomerates, of shallow water origin, and are hence evidence that the Cambrian continent stretched eastward as far as the existing continent. It probably had the Pacific for its western border; for through the investigations, principally of C. D. Walcott, outcrops have been discovered over the Rocky Mountain border to points within 500 to 400 miles of the Pacific coast; and further investigation is likely to carry the discoveries as far west as Archæan ridges exist.

In the Lower Cambrian region of South Mountain, southeastern Pennsylvania, west of the Susquehanna and in the adjoining part of Maryland, the Cambrian series overlies unconformably, according to the study of the rocks, and the region, by G. H. Williams and C. D. Walcott, beds and dikes of various igneous rocks, as basalts and rhyolytes, and also tufaceous accumulations of the same origin $(1892,1894)$.

The Keweenaw Group, probably Lower Cambrian. - No allusion is made above to the Keweenaw group, because it was a local formation. It occupies a belt of country on the south side of Lake Superior, covering Keweenaw Point, where it is best displayed, and extending from thence westward. It is called the copper-bearing sandstone formation from its characteristic rocks and its noted copper mines. But the feature of greatest geological 
significance is the igneous origin of a large part of the formation. Sheets of basic igneous rocks, partly amygdaloids, with others of felsyte, porphyry, and granite, are interstratified with the sandstones and conglomerates, and the latter are largely made of water-worn detritus of like igneous origin. The beds are wholly unmetamorphic to the bottom, and hence there is nothing in them to prove that the formation is Archæin. At the same time, no fossils have been found to prove it Cambrian. Still, inasmuch as it overlies unconformably the upturned Huronian, it must be of subsequent origin; and as no Cambrian rocks oceur in Wrisconsin older than the Middle Cambrian, it is reasonable to suppose that it may represent the Lower Cambrian. The absence of fossils may be owing to the region's having been under fresh water, or to the igneous action. The copper veins of the Keweenaw region have been discussed on page 341, under the head of Veins.

It is important to note, however, that the igneous effusions which accompanied the deposition of beds below the Lower Cambrian in southeastem Pennsylvania and the adjoining borders of Maryland, are similar, as Williams remarks, to the rocks of the Keweenaw series not only in kinds, but also in the presence of much metallic copper. Walcott and Williams conclude that the eruptions in the two areas were simultaneous and alike pre-Cambrian.

Bearing of the facts connected with the distribution of the Cambrian on questions as to the uptuming preceding the era. - From the facts observed in connection with the distribution of the Cambrian over the Archæan of northern New York and Canada and in Archæan troughs to the eastward, it appears to follow that the mountain ranges in eastern America that were made at the close of the Archæan, and that stand as the time-boundary between the Archæan and Paleozoie, include the Adirondacks, the Appalachian protaxis, and other more eastern ridges; and that these mountains consist, in part, if not largely, of rocks that were laid down as sediments during the long Huronian era, though now crystalline or metamorphic and in part massive crystalline. The disturbances closing Archæan time do not appear to have extended their effects alike over the whole surface of the continent, but to have produced their chief uplifts along the mountain borders; that is, in those regions in which the most extensive mountainmaking occurred in later time. Over the Continental Interior, the Huronian sediments were thinner, the upturnings at the epoch of disturbance less prominent, and the metamorphism feebler, where not wholly wanting.

Walcott has classified the areas of geographic distribution of the surface outcrops of the Cambrian strata as follows (Bull.81, U. S. G. S., page 358) :-

A. Atlantic or Eastern Border Province: $a$, Eastern or Nova Scotia Basin; $b$, Southeastern Newfoundland, Eastern New Brunswick and Massachusetts Basin; $c$, Interior Deposits of Gaspé, Quebec, Maine, New Hampshire, Vermont, Massachusetts.

B. Appalachian or Interior Eastern Border Province.

C. Rocky Mountain or Western Border Province.

D. Interior Continental Province: D 1 , Central Interior, or Upper Mississippi and Missouri ; D2, Eastern Interior, or Adirondack of New York and Canada; $\mathrm{D}^{3}$, Western Interior, or Dakota, Wyoming, etc.; D ${ }^{4}$, Southwestern Interior, or Arizona and Texas. 
Eastern Border Region. - In southeastern Newfoundland, on Manuel's Brook, occur shales, with some limestone, overlying a conglomerate, in all $400^{\prime}$; above occur beds with the Paradoxides fauna, and below it, within $40^{\prime}$ of the conglomerate, species of the Olenellus fauna; the former occurs also at Topsail Head and on Conception Bay (Walcott). In the Acadian trough, Lower Cambrian fossils are reported from the north side of the Straits of Belle Isle, at L'Anso au Loup, and on the opposite coast at Canada Bay, Labrador; Middle Cambrian, as gray and black shales, in New Brunswick, near St. John, with also Upper Cambrian beds; in eastern Massachusetts ; the Lower Cambrian at Nahant, and in Bristol County, near northeastern Rhode Island, and the Middle Cambrian at Braintree, where a thick conglomerate, much flexed, underlies $500^{\prime}$ to $1000^{\prime}$ of slate.

Continental Interior Region (west of the Appalachian protaxis). - Along the Green Mountain region in Vermont and Massachusetts, among the rocks of the Taconic series, a great quartzyte formation, having intercalations of hydromica and mica schist and occasionally ottrelite schist, has been shown by fossils to be in part or wholly Lower Cambrian. The Sillery sandstone of Logan, in Canada, is part of the quartzyte formation. The limestone (white marble), adjoining the quartzyte on the west, has afforded Lower Cambrian fossils to the eastward and northward of Rutland. The continuation of this limestone belt, in Massachusetts, called the Stockbridge limestone, is too highly crystalline for fossils; it may be in part Cambrian. West of the Taconic limestones in central Vermont, Lower Cambrian is represented by the red sandrock of the region. In northeastern Vermont, at Georgia, magnesian limestone, $1000^{\prime}$ thick, is overlaid by a great thickness of shales; at Highgate the same limestone is $1200^{\prime}$ thick.

The reddish, mottled "Winooski limestone," of the Georgia Cambrian, is worked for marble at Swanton.

West of the New England line, Lower Cambrian occurs in Washington County, New York, near Bald Mountain and elsewhere; in the western part of Rensselaer County, at Troy, in shales and limestone and at Schodack Landing; at several places in Dutchess County, at Stissing Mountain, where Middle Cambrian fossils also occur.

West of Lake Champlain, about the Adirondacks, the Potsdam sandstone, chiefly Lpper Cambrian, has a thickness in St. Lawrence County of $60^{\prime}$ to $70^{\prime}$; in St. Lawrence valley, of $300^{\prime}$ to $600^{\prime}$ or more; in Warren and Essex counties, of about $100^{\prime}$. But in Dresden, Washington County, it occupies a depression at a height of $912^{\prime}$ above Lake Champlain. A lower portion of the sandstone, according to Walcott, is Middle Cambrian.

In New Jersey, Sussex County, at Hardistonville, Olenellus occurs in sandstone, and other Cambrian fossils in the Magnesian limestone near Franklin Furnace, and north of Franklin Furnace Pond (C. E. Beecher). Foerste has found the Olenellus fauna in the same region, and also south of Sparta Junction, northeast of Long Pond; and he has traced it southwestward into eastern Pennsylvania; he shows that the quartzyte of the region, instead of being Potsdam Upper Cambrian, is mostly Lower Cambrian as in Vermont (1893).

The Lower Cambrian has been traced by Walcott from New Jersey southwestward acrnss Pennsylvania. In southeastern Pennsylvania, west of the Susquehanna, over parts of York, Adams, Franklin, and Cumberland counties, about South Mountain, east of the river in Lancaster County, and in adjoining parts of Maryland, the Lower Cambrian includes a great thickness of quartzyte with overlying shales or slates and limestone; and besides these rocks there are, in South Mountain, large flows of basaltic and rhyolytic rocks. In Virginia, fossiliferous shales of the Lower and Middle Cambrian occur near Natural Bridge and Balcony Falls.

W. B. Rogers states, in connection with a contribution on the geology of Virginia to Macfarlane's Geological Railway Guide (1879), that the "Potsdam or Primal Group, where complete in Virginia, includes, besides the Potsdam sandstone proper, the ferrife- 
rous shales next above, and the slates, shaly grits, and conglomerates, below, this furmation. It is exposed on the western slope and in the west flanking hills of the Blue Ridge, through much of its length, often, by inversion, dipping to the southeast, in seeming conformity beneath the older rocks of the Blue Ridge, but often, also, resting unconformably upon or against them." These statements are cited from the Reprint of the Annual Reports of 1835-1841, and Other Papers on the Geology of the Virginias, by the late W. B. Rogers, 1884 .

In Tennessee, the Lower Cambrian comprises the "Chilhowee" sandstones of Safford, and beneath these, probably, the Ocoee conglomerates and sandstones. West of Cleveland, in east Tennessee, it includes the lower part of the Knox sandstone of Safford (the Rome sandstone of Hayes, in Georgia), and the thick formation of limestone and shales below ; while the central and upper portions of the Rome sandstone are Middle Cambrian. The same succession occurs near Knoxville. The Lpper Cambrian is probably represented by the lower $2000^{\prime}$ of the Knox dolomyte. The typical New York fauna of the Upper Cambrian has not been recognized along the Appalachians in Pennsylvania, nor to the southwest. Lower Cambrian fossils have been observed in the lower part of the Rome sandstone near Rome, Ga., and in the limestones and shales of the Coosa series, in Coosa valley, Alabama, north and south of Cedar Bluff.

In northwestern Michigan and Wisconsin, south of Lake Superior, the Lake Superior sandstone, on the borders of the lake, rests unconformably on the Keweenaw formation, and is referred to the Cambrian. A broad area of Upper and Middle Cambrian with fossils skirts the Archæan area on the east and south, and consists of crumbling sandstone and arenaceous shale, with, in some places, much green sand (glauconite), and thin beds of limestone; the maximum thickness is $1000^{\prime}$. The quartzyte occurring in isolated hills in the drift-covered region of Wisconsin in Barron County, and at Baraboo in Sauk County (the Baraboo quartzyte), is made Huronian by Chamberlin and Irving, but Lower Cambrian by N. H. Winchell. At St. Croix River, the horizontally bedded Upper Cambrian rests on upturned red beds, which are Middle or Lower Cambrian, and are continuous with the pipestone quartzyte of southwestern Minnesota, where Lingulæ have been found; in this quartzyte, the pipestone bed (Catlinite), used for making pipe bowls by the Indians, is a layer of red argillaceous sandstone about a foot thick; the rock passing south into Iowa is the "Sioux quartzyte" of C. A. White, and extends 10 miles into Dakota to Sioux Falls.

With regard to the fact of unconformability with the Archæan at Carp River, Professor J. D. Whitney states, in a letter to the author of Nov. 7, 1893, that " nothing could be clearer"; that "along the shores of Carp River and throughout the adjacent region, the sandstone strata are recognized as overlying the well-characterized beds of a much older formation which I designated as the 'Azoic Series.' At Carp River the nearly horizontal unaltered sandstone strata abut against and overlie the vertical edges of a well-marked quartzyte." The Lower Magnesian series of Missouri, excepting the First, or Upper, limestone of the series, and the underlying Saccharoidal sandstone, is Cambrian. It consists of alternating strata of dolomyte and sandstone. This Lower Magnesian series of Missouri is the Ozark series of Broadhead.

The Keweenaw beds were described by Foster and Whitney in 1850, 1851, and referred to the age of the Potsdam or Cambrian. The more recent reports are by Irving $(1880,1883$, 1885) and Chamberlin (1883); and, with special reference to copper mining, by M. E. Wadsworth in 1880. The series consists of an upper division, consisting of ordinary sandstone and shales, free from igneous material, made $15,000^{\prime}$ thick by Irving, and a lower division, $25,000^{\prime}$ to $30,000^{\prime}$ thick, made up of detrital and igneous rocks, but chiefly the latter. Chamberlin gives the same aggregate thickness, 45,000 '. The igneous rocks are doleryte (diabase) with porphyritic and amygdaloidal varieties, gabbros, and also acid rocks as felsyte, felsyte-porphyry, and others. (For a full account of the rocks, see Irving, Report U. S. G. S., F., 4to, 1883.) As estimates of the thickness of upturned rocks 
are always more or less doubtful, the above figures can be considered at the best as only approximations. To the great thickness estimated there is the additional source of doubt referred to on page 451, under the Archæan. For if 45,000 ', the temperature in the bottom beds would have been $1800^{\circ} \mathrm{F}$., supposing the increase of temperature downward to have been $1^{\circ} \mathrm{F}$. in 25 feet of descent, or only twice as great as now; and if $35,000^{\prime}$, it would have been $1500^{\circ} \mathrm{F}$, high enough for the complete metamorphism of the lower beds in the series. And yet there is no metamorphism.

The Animikie group, of slates, sandstones, quartzyte, etc., on the north shore of Lake Superior, at the east end of Minnesota, about Grand Portage Bay and beyond, has intercalations of doleryte (diabase), gabbro, and other rocks, much like those of the Keweenaw formation. Supposed tracks or trails of marine animals, mentioned on page 446 , are the only fossils yet found. The Cambrian age of the formation is considered probable by many geologists. The igneous intrusions are regarded as laccolithic by Lawson, and as related in time to those of the Keweenaw formation.

Eastern Rocky Mountain slope. - The Cambrian beds of the Black Hills are red sandstone and with fossiliferous limestone above, pertaining to the Upper Cambrian.

In central Texas, the beds of the Llano formation of Walcott are confined to Llano and Burnet counties; they rest on upturned beds referred to the Algonkian by Walcott (page 447).

Rocky Mountain region and Pacific slope. - Lower Cambrian beds occur in the Rocky Mountains of British America, on the Vermilion and Kicking Horse passes. At Cottonwood Cañon in Ltah, the great section of the Wasatch has at bottom $3000^{\prime}$ of quartzyte, and above this $250^{\prime}$ of hard shales, affording Lower Cambrian fossils, some of them identical with eastern species; then succeed Lower Silurian beds, the Upper Cambrian being absent. Above Ophir City, in Oquirrh Mountain, fossils occur in a limestone over sandstone, the whole $2300^{\prime}$ thick. In Nevada, according to Walcott, in the Eureka district. a section of conformable high-dipping beds $7700^{\prime}$ thick, contains below (1) $1500^{\prime}$ of quartzyte; (2) $3050^{\prime}$ limestone, with Lower Cambrian fossils in the lower $500^{\prime}$; (3) $1600^{\prime}$ shale, and above this $1200^{\prime}$ of limestone, $350^{\prime}$ of shale affording Upper Cambrian fossils at bottom. In the Highland Range, 125 miles south of the last, are $1450^{\prime}$ of limestone and shales overlying $350^{\prime}$ quartzyte which are Lower Cambrian, and above these, $3000^{\prime}$ of massive limestone which are Upper Cambrian.

Other sections occur east of Pioche; at Silver Peak; at the south end of the Timpahute Range. In Arizona, at the Grand Cañon of the Colorado, $3000^{\prime}$ to $5000^{\prime}$ deep, unclerneath horizontal Carboniferous and Subcarboniferous beds, the lower the "Red "Wall Group" of Powell, lie horizontally $700^{\prime}$ to $800^{\prime}$ of shales and sandstones, the Tonto group of Gilbert, made Upper Cambrian; the highly tilted beds beneath are referred by Walcott to the Algonkian. In S. E. California, Inyo Co., Lower Cambrian (Walc., 1894).

For an extended review of the Cambrian of America see Bull.81, U. S. G.S. (1892), by C. D. Walcott, to whom the science is indebted for the discovery of the larger part of the facts.

\section{LIFE.}

The life of the Cambrian, so far as known, was marine. The plants were Algæ (seaweed).

The animals thus far made out from the fossils are all Invertebrates. They include Sponges, Corals, Hydrozoans, Echinoderms, Worms, Brachiopods, Mollusks of the divisions of Lamellibranchs, Pteropods, Gastropods and Cephalopods; and also, among Arthropods, Trilobites and other Crustaceans. All these groups, excepting that of Cephalopods, were represented in the earliest of the three divisions of the era. 


\section{Lower Cambrian.}

1. Protozoans. - No Rhizopor remains have been detected, unless small concretion-like nodules, concentric in structure, occurring crowdedly in is Cimbrian limestone in Nevarla, are of this nature. They may belong to the genus Girvanella (Walcott). See page 501.

2. Sponges, Corals, Graptolites. - Fig. 506 represents one of the Lower Cambrian sponges, Leptomitus Zittelli of Walcott, from Georgia, Vt.

Figs. 507, 508 are of cordls, though supposed, when described, and until investigated microscopically by Hinde, to be Sponges. Fig. 507 represents the Archoeocyathus profundus of Billings, and 508,508 a, views of Spirocyathus

\section{$506-509$.}

506.

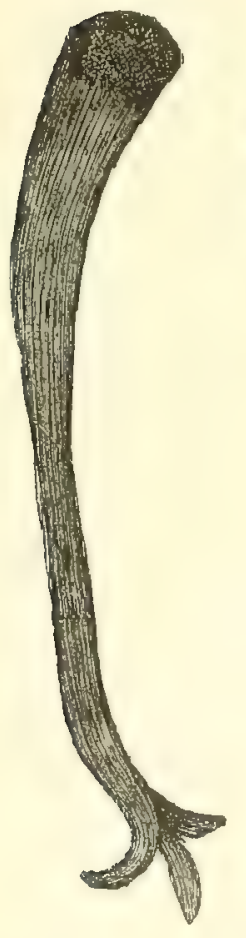

507.

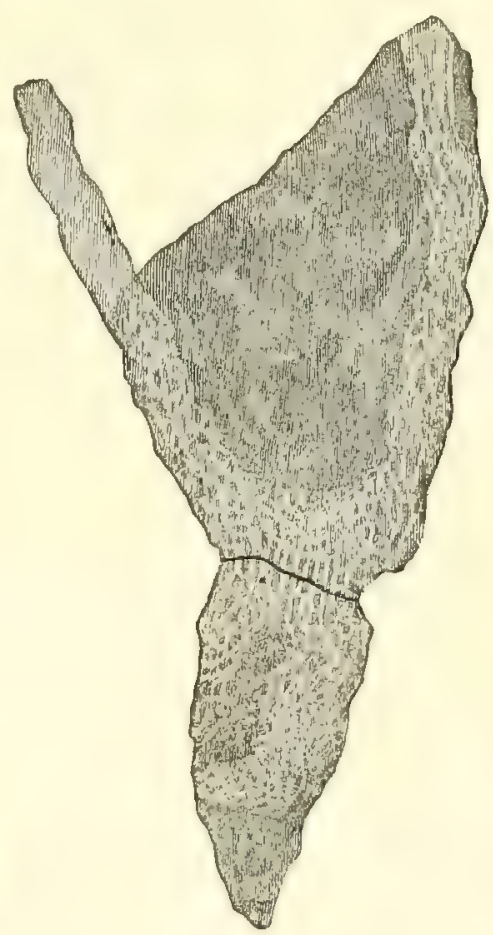

508.

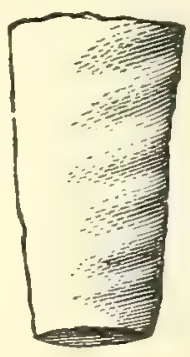

509.

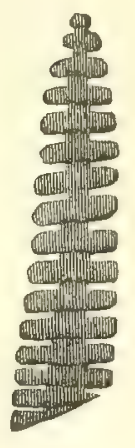

$508 \alpha$.

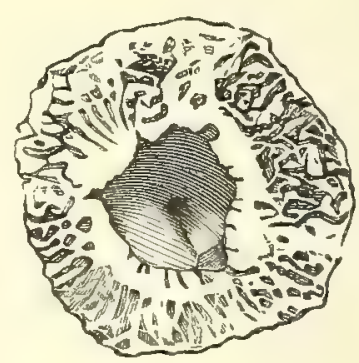

SPONGE. - Fig. 506, Leptomitus Zittelli. - Conals, 507, Archæocyathus profundus; 508, Spirocyathus Atlanticus $\left(\frac{1}{2}\right)$; 508 a, transverse section. - GRaPTolite, 509, Climacograptus (?) Emmonsi. Figs. 506, 509, Walcott ; 507, 508, Billings.

Atlanticus Billings. One of the early Graptolites (so called from the Greek

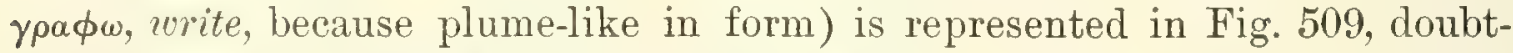
fully placed in the genus Phyllograptus by Walcott, under the name Climacograptus (?) Emmonsi.

3. Echinoderms. - Only fragments of Cystoids, related to Middle Cambrian species, have been observed.

4. Worms. - Tracks and borings of sea-worms or Annelids are not uncommon. Worm-borings, called Scolithus (from the Greek for worm), occur in the Lower Cambrian sandstones and through later periods to the present time: no distinction of species or genera can be made out. 
5. Brachiopods. - The Articulate Brachiopods (or those in which the valves are hinged together), as well as the Inarticulate, were represented, but most abundantly the latter. Figs. 510-513, 515 represent some of the species of the latter division, and Figs. 514, 516-520, some of the former.

\section{$510-520$.}

510.

511.
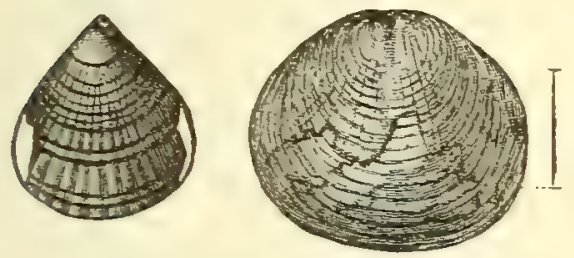

513.

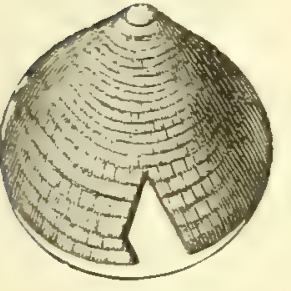

514.

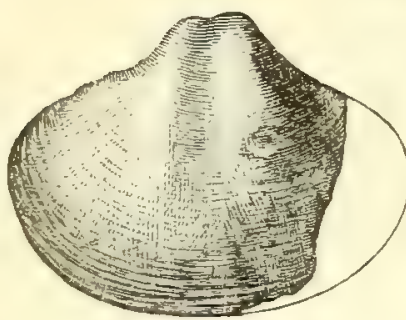

520
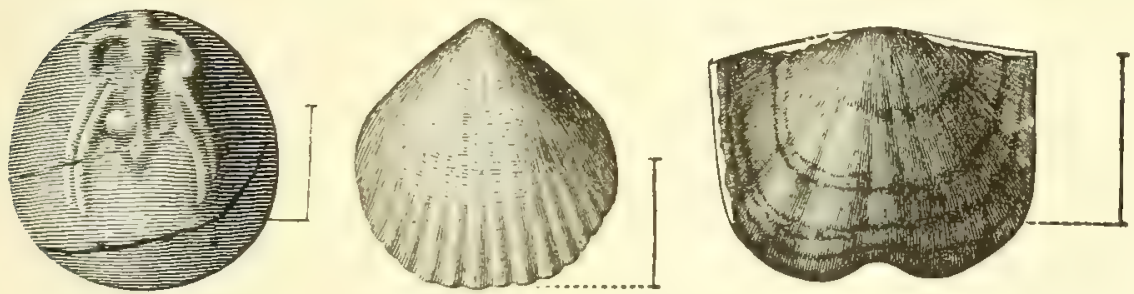

515.

$512 a$.
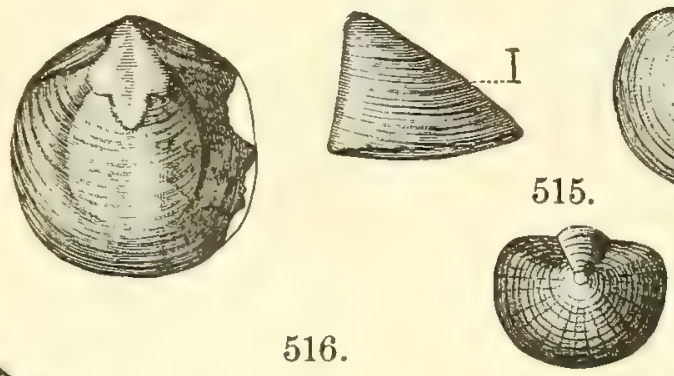

517.
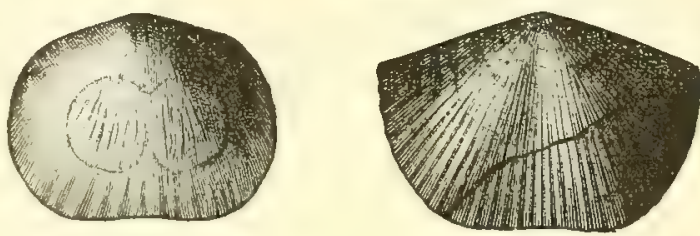

518.

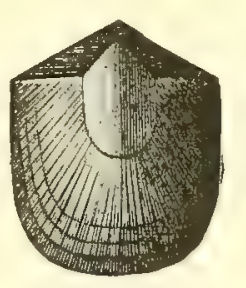

BRAcBIopods. - Fig. 510, Lingulella colata, ventral (2); 511, L. ella, ventral (2); 511 $a$, same, cast of interior of dorsal valve (2); 512, Acrotreta gemma, side view (3); $512 a$, same, upper view, ventral (3); 513 , Obolella crassa, dorsal (2): $513 \alpha$, cast of interior of ventral (2); 514, Kutorgina cingulata, ventral; 515, Iphidea bella: 516, Orthis (?) Highlandensis of Walcott, dorsal shell mostly worn off (1); 517, Orthisina (Billingsella) festinata (1); 518, O. (B.) orientalis, ventral (1) ; 519 , Orthis Salemensis, ventral; 520 , Camarella (?) antiquata, ventral, enlarged. Figs. from Walcott; 010,513 , after Ford; 518 , after Whitfield ; 515 , after Billings.

6. Mollusks. - Figures 521, 522 represent species of Lamellibranchs, each of very small size (here enlarged), and rare fossils; and Figs. 523-525, several Gastropods, cap-like in form, like the modern Patella. The Platyceras primcevum of Walcott (Fig. 526) has a short spiral at the summit, a little like a broad horn, and hence the name, from the Greek; the genus continues to the Carboniferous period, and, according to some anthors, is not generically distinct from the modern genus Capulus. Pleurotomaria Attleborensis is another Gastropod from North Attleborough, Mass.

Other eminently characteristic Mollusks were the Pteropods of the genera Hyolithes and Hyolithellus. They are long, conical, thin shells like Figs. 527, 528. The large end was closed by a shell-like operculum, one of which, of the H.Americanus Walcott, is represented in Fig. $528 \alpha$. The Salterellæ, Figs. 529, 530, are stout shells, probably those of Pteropods. Fig. 529, S. 
pulchella Billings, is common in the red sandrock of Highgate Springs, Vt., and the Winooski marble. Fig. 530 is the same. The very slender species,

$521-526$.

521.

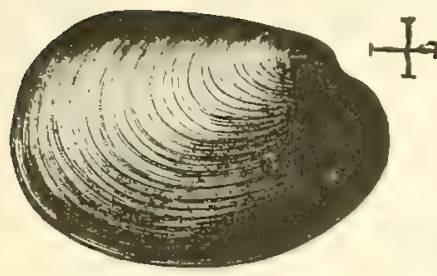

$521 a$.

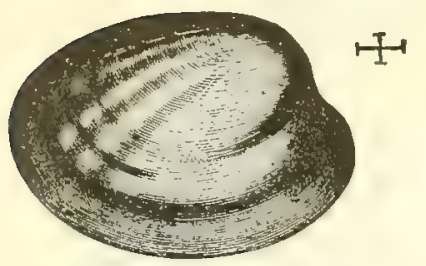

522.

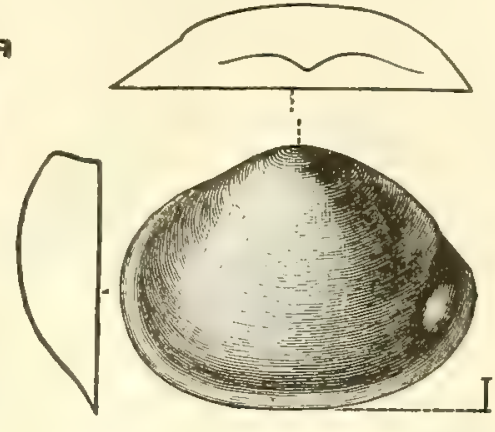

$524 a$.

525.
$523 a$.

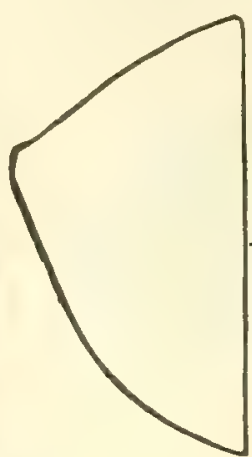

523.

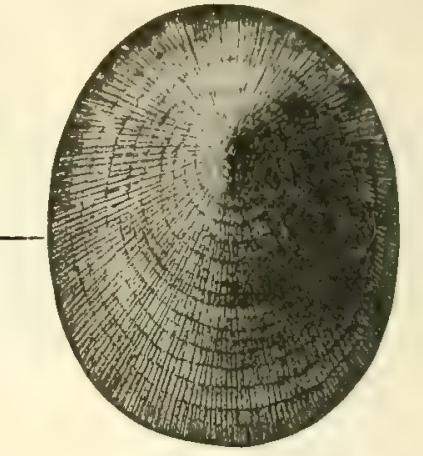

526.

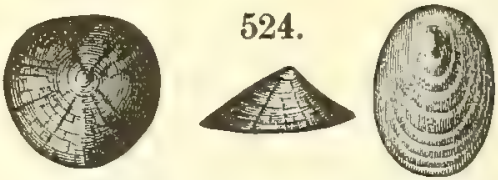

$525 a$.

$525 b$.
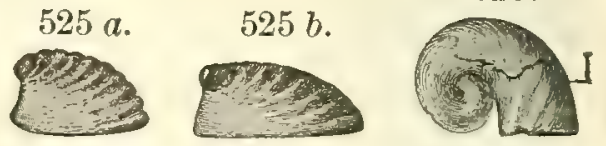

Moldusks, - Lamellibranchs : Fig. 521, Fordilla Troyensis (enlarged); $521 a$, id., cast of interior; 522, Modioloides priscus, very much enlarged. Gastropods : 523 , Scenella reticulata; 523 a, profile as seen in side view showing the height and outline of the conical shell; 524 , Scenella retusa, side view (3); $524 a$, same, upper view ; 525, Stenotheca (?) rugosa, view from above (1); $525 a, 525 b$, same, side views; 526, Platyceras primævum, cast (4). Figures from Walcott; $524,524 a$, after Ford.

Fig. 531, from Troy, is the type of the genus Hyolithellus of Ford. Fig. 532 is the operculum of Hyolithes impar.

\section{7-532.}

527.

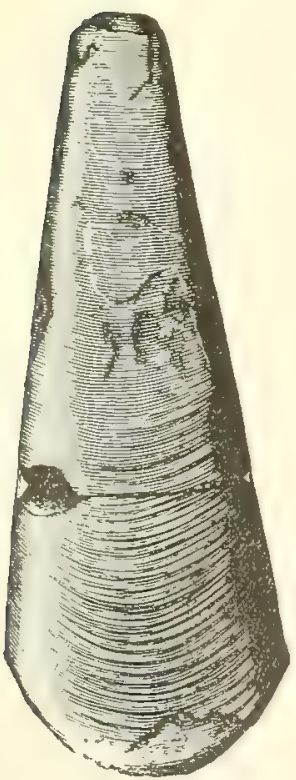

$528 \alpha$.

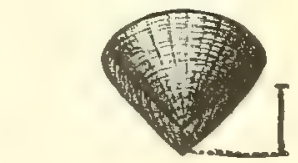

$527 a$.

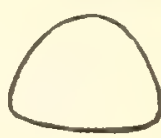

528.

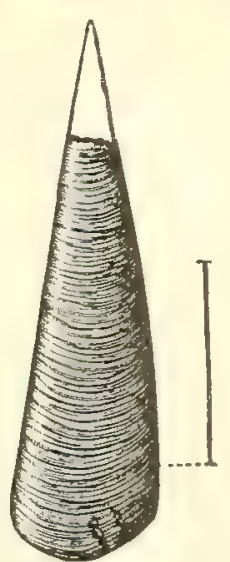

530.

531.

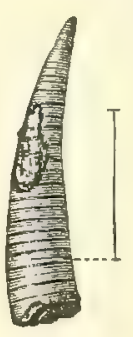

532.
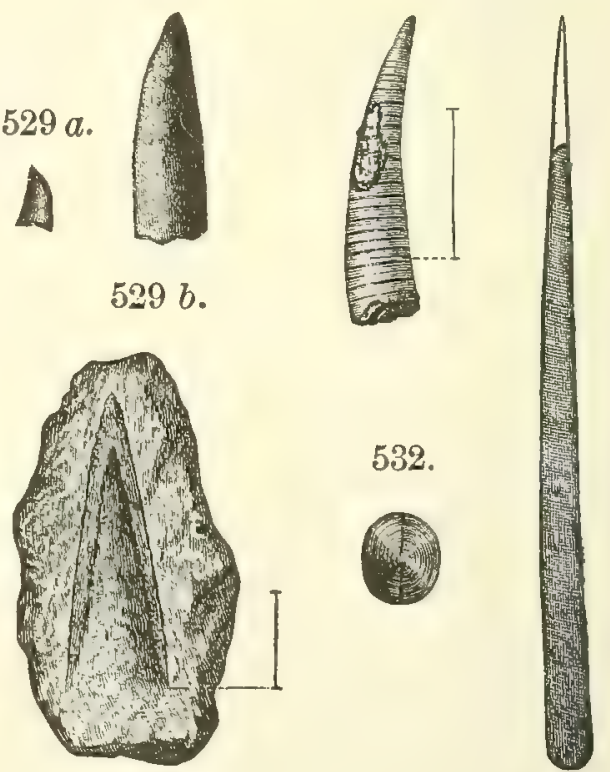

Pteropons.-Fig. 527, Hyolithes princeps (1); 527 , outline of cross-section; 528, H. Americanus (2); $528 a$, operculum of same; 529,530 , Salterella pulchella; $529 b$, cross-section; 531 , Hyolithellus micans (1); 532, the operculum of Hyolithes impar. Walcott. 
7. Crustaceans. - Trilobites, the highest species of the Cambrian seas yet discovered, were of many species and very diverse forms. Figs. 535, 536 represent some of the species of the genus Olenellus; Fig. 535, O. Vermontanus

$533-539$.

535.

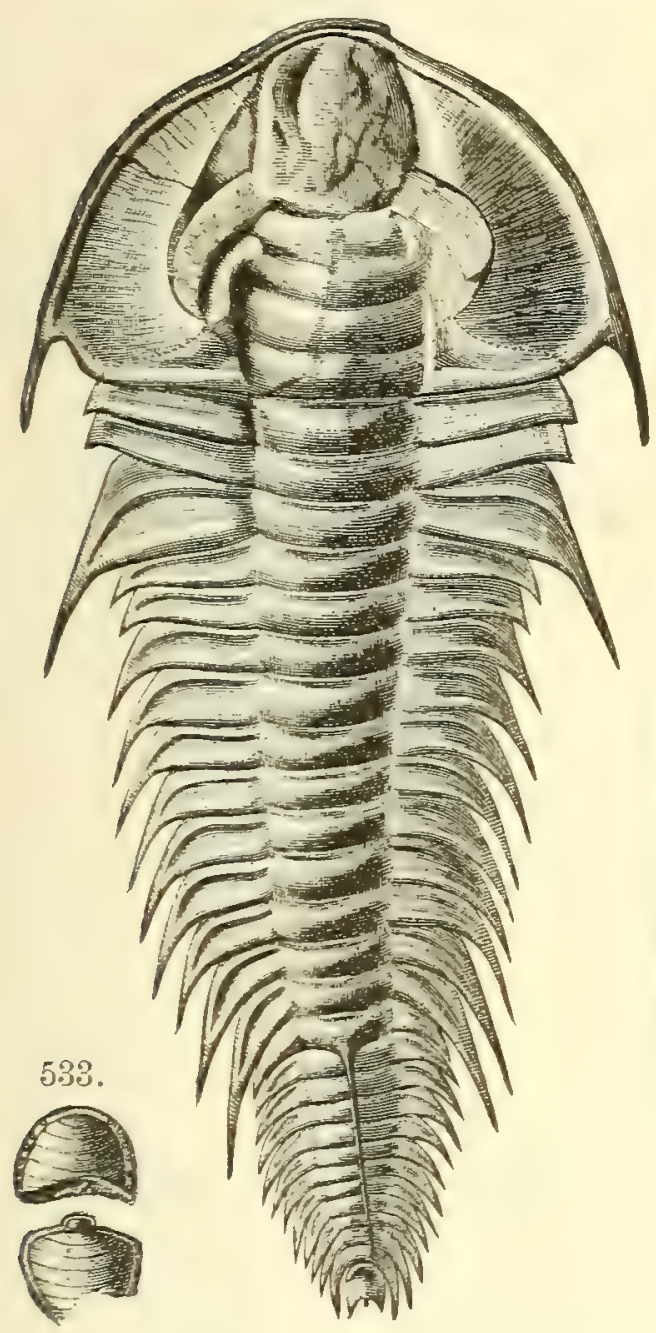

534 .

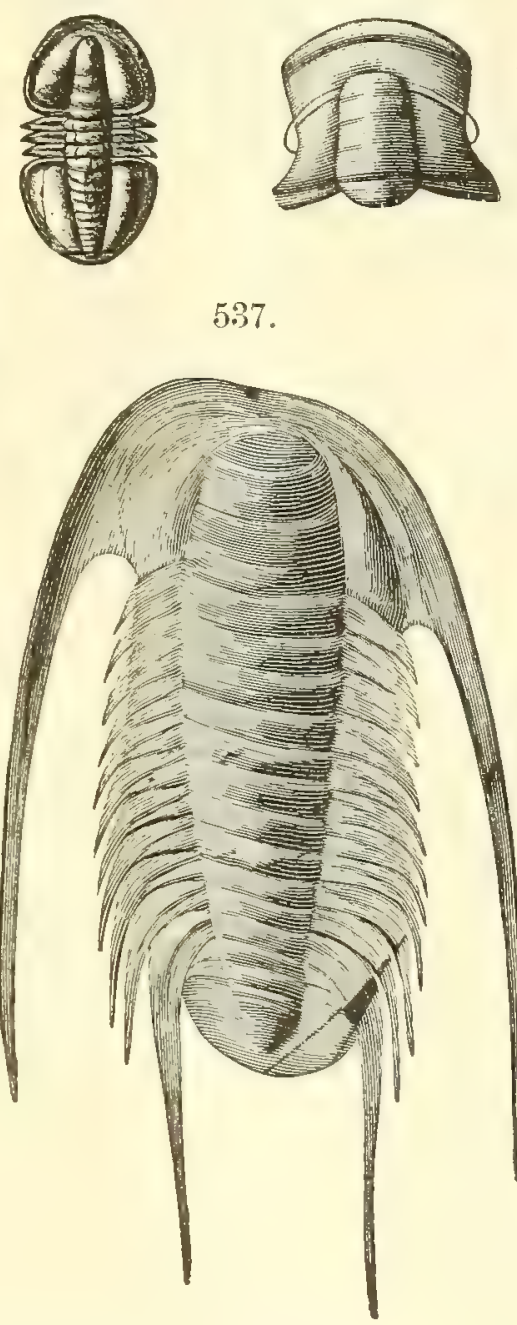

536.

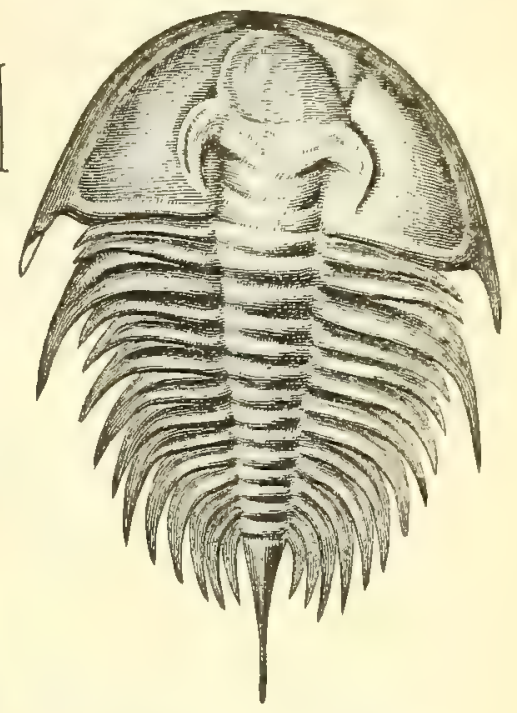

538.

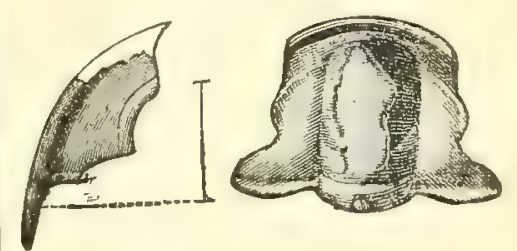

$538 b$.

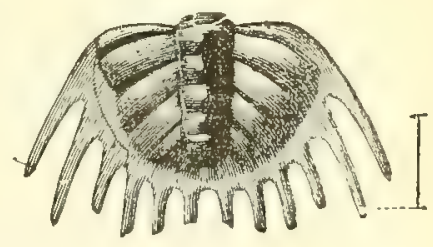

TriLobites. - Fig. 533, Agnostus nobilis, two middle segments absent (1); 534, Microdiscus speciosus (2); 535, Olenellus (Mesonacis) Vermontanus (1); 536, Olenellus Thompsoni (1, $\frac{1}{2}$ max. size); 537, Batby. notus holopyga, distorted (1); 538, Olenoides Fordi, head-shield without the cheek (2); 538 , separated cheek; 538 b, same, pygidium (caudal extremity); 539, Ptychoparia Adamsi. Fige. from Walcott; 533 , after Ford.

Walcott; Fig. 536, O. Thompsoni Hall. These species from Georgia, Vt., are over six inches long; the latter occurs also in western Newfoundland. The Olenellus Gilberti Meek (Fig. 540) is a fine species from Nevada and Utah. Another large species, O. asaphoides of Emmons, is from near Bald Mountain and Troy, Washington County, N.Y. Emmons eited it as characteristic of the "Upper Taconic." The Bathynotus (Fig. 537), remarkable for the long spines of its head-shield, is another Trilobite of large size, from Georgia, Vt. The genera Agnostus and Microdiscus include small species, differing in the former having two segments between the head and caudal shield, and the latter three. 
The other Crustaceans pertain to two still existing tribes of Entomostracans, the Ostracoids and the Phyllopods. Figs. 541 and 542 represent

540.

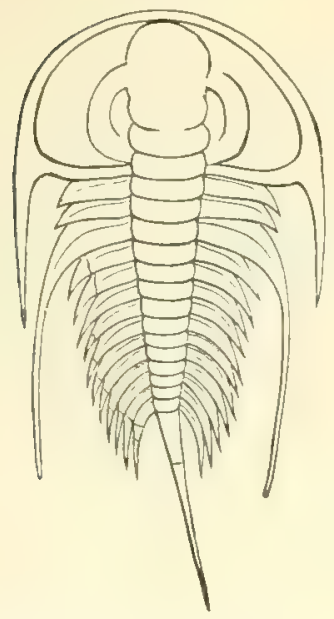

Olenellus Gilberti Meek.
Ostracoids from Washington County, N.Y.; the dot in Fig. 541 shows the position of the eye. Fig. 543 is the Phyllopod, Protocaris Marshi Walcott, from Georgia, Vt. - The shell may owe its flattened form to pressure.

Doubtful tracks. The slender impressions of rounded surface that have been referred to seaweeds (Fucoids) may be those of Worms or Mollusks. Another kind, having a longitudinal impression along the middle, called Cruziana (D'Orbigny) and
$541-543$.

543.

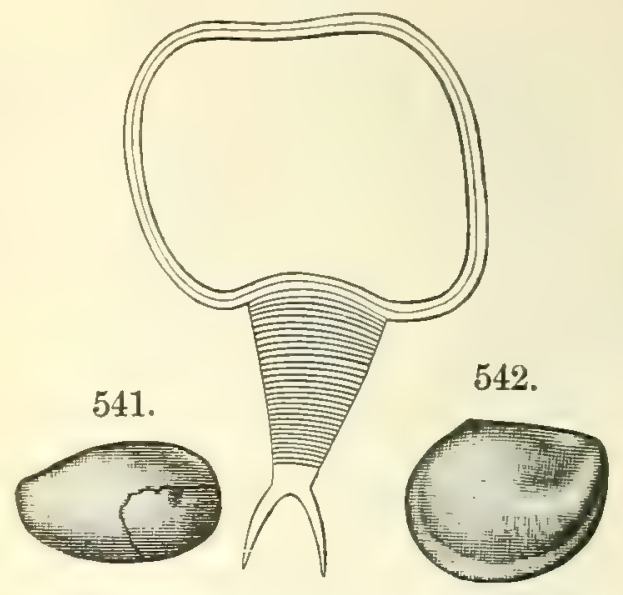

Crustaceans. - Fig. 541, Leperditia dermatoides; 542, Aristozoe rotundata;

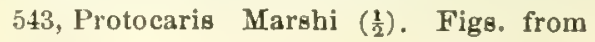
Walcott.

Bilobites (De Kay), are regarded as the tracks of Annelids, Mollusks, or some other Invertebrate. Fine Lower Cambrian examples are figured by Walcott.

\section{Middle Cambrian.}

The range of life in the Middle Cambrian is the same nearly as in the Lower, but the species are mostly different, and in place of the genus Olenellus among Trilobites, Paradoxides has special prominence.

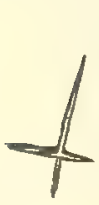
544.
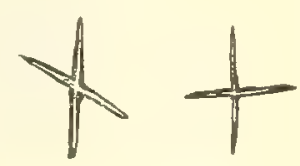

$545 \alpha$.

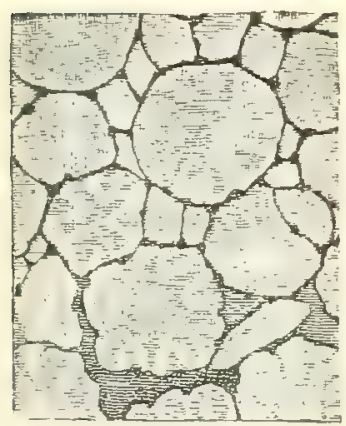

545.

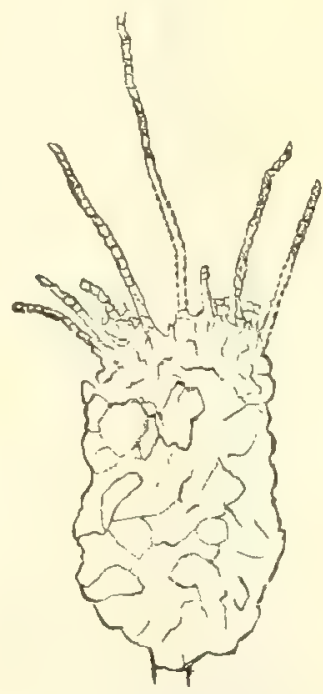

Sponge. - Fig. 5 4 , Spicules; Protospongia fenestrata(?); 545 , Eocystites (?) longidactylus ; $545 a$, plates of portion of body enlarged. Figs, from Walcott.

1. Sponges, Echinoderms. Remains of Sponges occur in Nevada and New Brunswick. The spicules, Fig. 544, are from Nevada and are referred doubtfully to the Protospongia fenestrata of Salter. Some simple forms of Graptolites have been found in New Brunswick.

Cystoids are the prevailing Echinoderms. A Nevada specimen (Fig. 545) has the usual box-like body (whence the name cystoid, from the Greek), with unsymmetrically arranged arms (mutilated in the specimen), and the body-plates of irregular forms

(Fig. $545 a$ ). Plates of Eocystites were first reported from New Brunswick. 
2. Brachiopods. - The following are enlarged figures of some of the forms found in New Brunswick.

3. Mollusks. - Pteropods are still very common (Figs. 527-531): Two supposed Gastropods are from New Brunswick. Fig. 552 represents Stenotheca Acadica, originally supposed to be a Brachiopod of the genus Discina, but now placed among the Gastropods. Fig. 553 is a greatly enlarged view of Harttia. Matthewi Walcott, referred to the Calyptræa family, the cap-like shell having a smaller cap within.

546-549.

546.

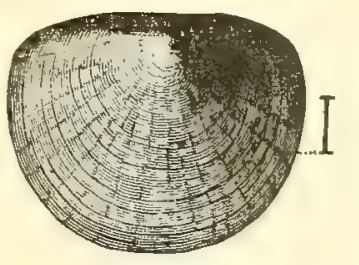

549.

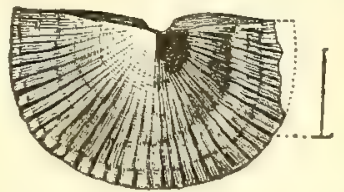

Brachiopods. - Fig. 546, Acrothele Matthewi (2) ; 547, Linnarssonia transversa (8); 548, Lingulella Dawsoni (1); $549,549 \alpha$, Orthis (Protorthis) Billingsi. Figs. 546, 547, 549, from Walcott; 548 , from Hartt.

4. Crustaceans. - Some of the Paradoxides are the largest of Trilobites. P. Harlani (Fig. 556), the first known of American species, from Braintree, near Boston, has a length of 10 inches, and a breadth two-thirds as great, in some specimens; and the spines at the posterior angle of the cheek-piece of

$550-553$.

551.

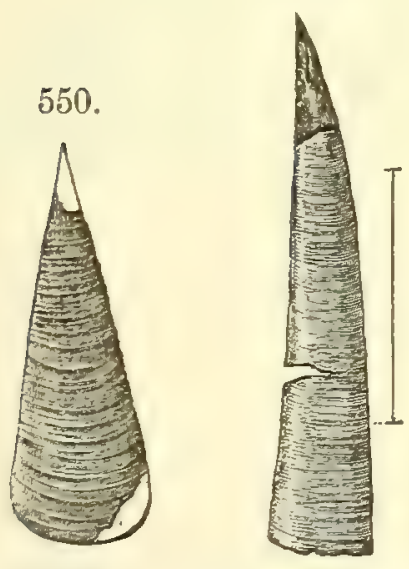

552.

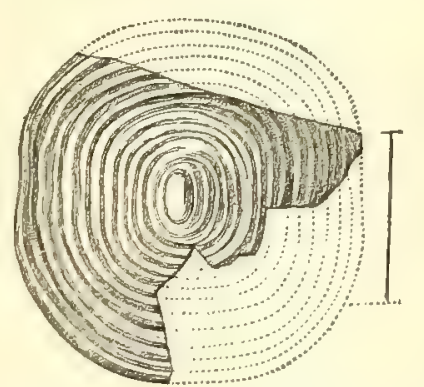

553.

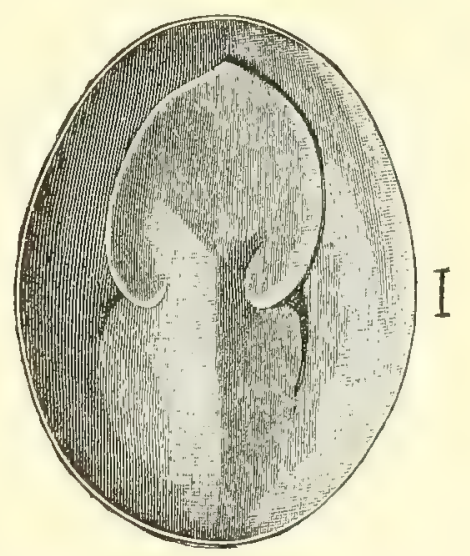

Pteropods and Gastropods. - Fig. 550, Hyolithes Acadicus (1); 551, H. Danianus (1); 552, Stenotheca Acadica (2); 553, Harttia Matthewi (12). Figs. from Walcott.

the head (the piece bounded by a suture passing by the eye) are nearly half as long as the animal. (In Fig. 556 they are shorter than usual.) P. Bennetti Salter, from Newfoundland, was 11 inches long and $9 \frac{1}{2}$ broad; and $P$. Reginu Matthew (Fig. 557) from New Brunswick, 15 inches long and 11 broad. Fig. 554 shows the form of an Agnostus. In Fig. 555 the free segments are absent. 
Fig. 562 represents one of the largest of Ostracoid Crustaceans, - the Leperditia (?) Argenta Walc., from Argenta, Big Cottonwood Cañon, Utah.

554-561.

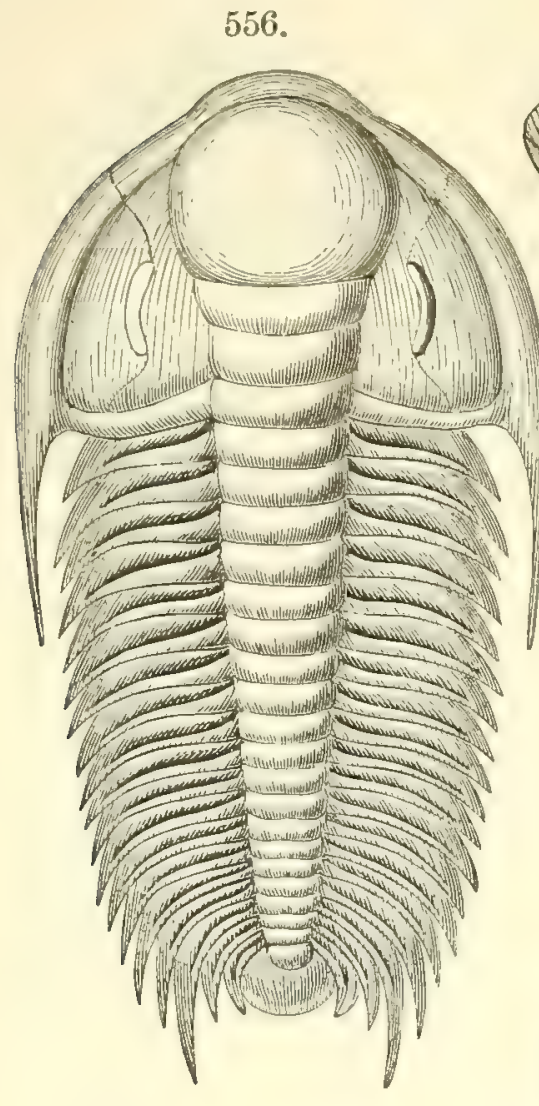

559.
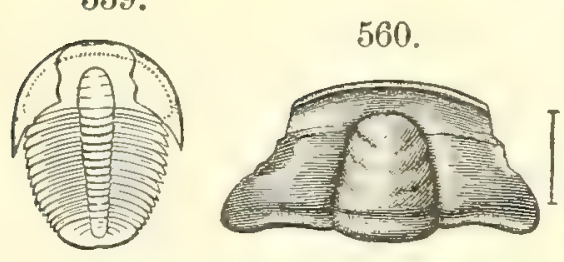

557.

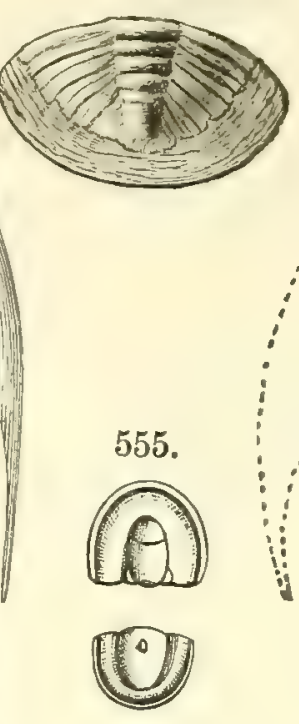

554.

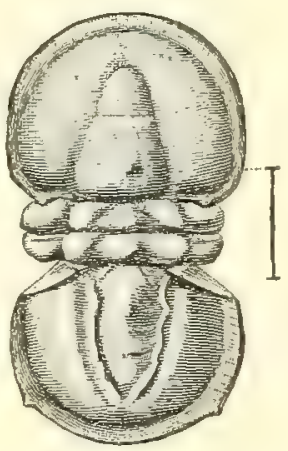

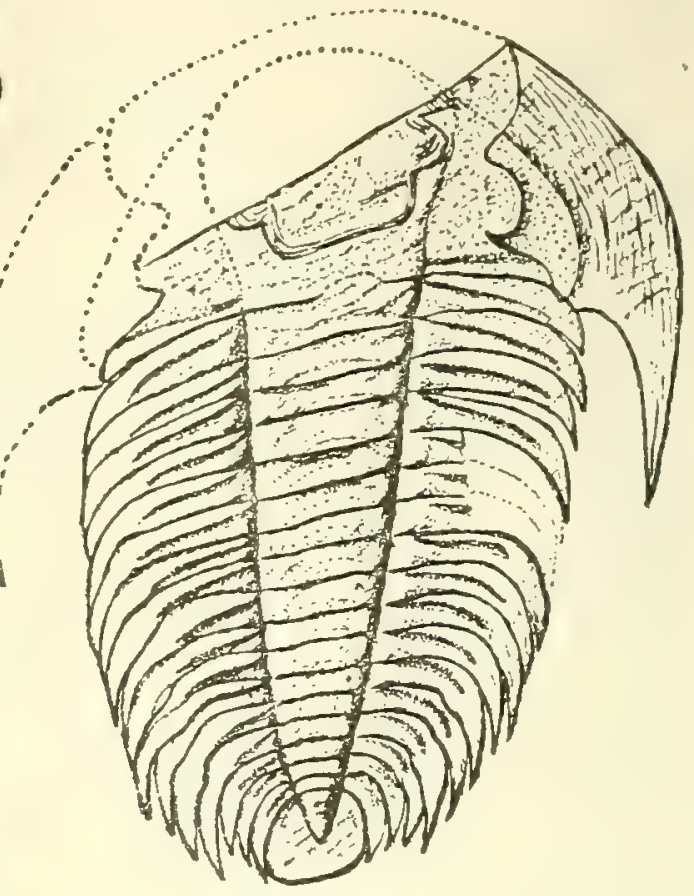

561.

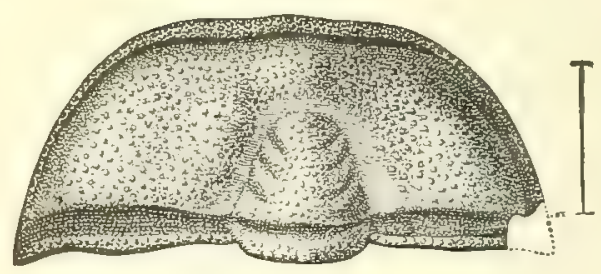

Trilobites. - Fig. 554, Agnostus interstrictus (4); 555, A. Acadicus, head and tail shields; 556, Paradoxides

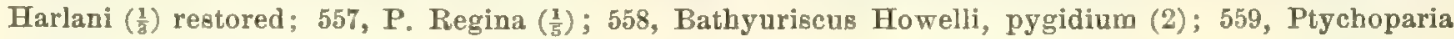
Kingi $\left(\frac{1}{2}\right)$; 560, Pt. formosa, head (2); 561, Pt. Matthewi (2). Fig. 554, 558, 561, from Walcott; 555, 556, Meek; 557, Matthew.

The Caridoid Phyllopods are supposed to be represented by the Anomalocaris Canadensis of Whiteaves, a mutilated specimen of which is shown, natural size, in Fig. 563. It is from the Middle Cambrian shale at Mount Stephens, British Columbia.

\section{Upper Cambrian.}

The typical Upper Cambrian rocks are the Potsdam sandstone of the north and east sides of the Adirondacks and adjoining parts of Canada. Sandstones of the same age occur in South Dakota, Wyoming, Montana, and Colorado; shales and sandstones in Newfoundland, Cape Breton, New Brunswick, and at some localities along the Appalachian province southwest of 
New York. Sandstones and calcareous beds represent the Upper Cambrian in Arizona and Texas, and limestones and shales in Nevada, Idaho, and Montana, and probably in British Columbia.

The chief characteristic of the Fauna, distinguishing it from that of the preceding epoch, is the almost total independence in species, so far as now known; the absence of Paradoxides, and the substitution of Trilobites of the genus Dicellocephalus, of which 30 species have been described; and, further, the multiplication of Gastropods of coiled forms.

1. Rhizopods, Sponges, Graptolites, Cystoids. - The green sand of the beds of Wisconsin is probable evidence of the abundant presence of Rhizopods, since similar grains from later rocks were shown by Ehrenberg to have the form of casts of the interior of Rhizopod shells. Remains of Sponges and of Cystoids, allied to those of the earlier Cambrian, occur in the beds. One of the Graptolites is represented in Fig. 564, and a branch of the same enlarged in Fig. 565 .

2. Worms.-The Scolithus (S.linearis) from the Potsdam 564.

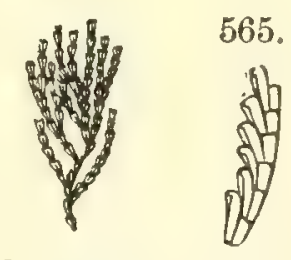

Dendrograptus Hallianus. Prout. sandstone is represented in Fig. 566. The fossil is the filling of the vertical burrow made by the worm in the sand.

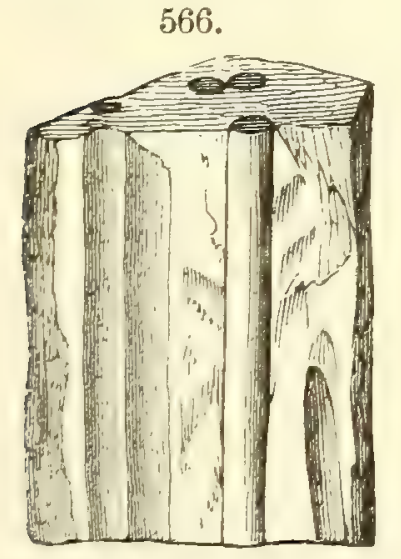

Fig. 566, Scolithus linearis. Hall.
567.

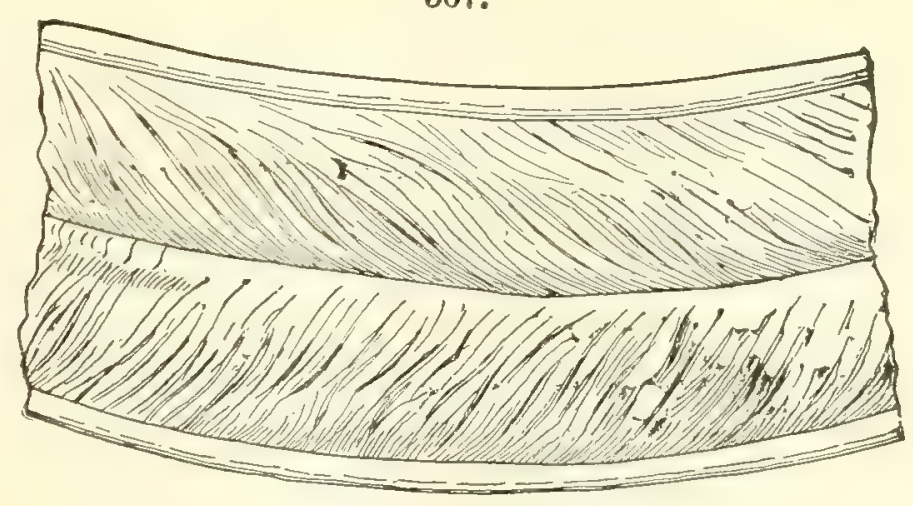

567, Cruziana similis, supposed track of a worm. Billings. 
The peculiar markings, obliquely furrowed from a medial line named Cruziana similis, by Billings, have been supposed to be plants, but are now regarded as the tracks of worms or some other animal (Fig. 567).

3. Brachiopods. - The following are figures of a few species :-

568.

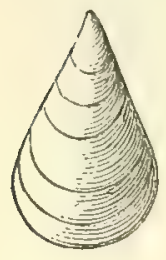

569.

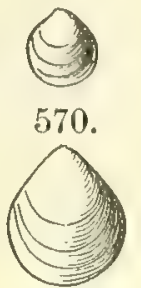

$568-573$.

571.

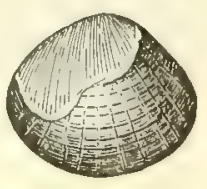

572.

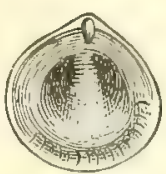

573.

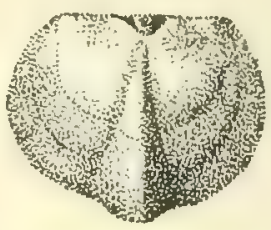

BraChiopods. - Fig. 568, Lingulepis antiqua (1); 569, 570, Lingulella prima (1); 571, 572, Obolella polita (1) ; 573, Triplesia (Camarella ?) primordialis. Fig. 568-570, Hall; 571, 572, Meek; 573, Walcott.

The Lingulids are so abundant in some places that they give the beds a shaly structure.

4. Pteropods. - Fig. 574 is a Hyolithes, from the Big Horn Mountains. Fig. 575 is a peculiar, rather thick, conical shell, doubtfully referred by Walcott to the Pteropods. It is oval below in outline, and has an opercuIum like that of Hyolithes.

5. Gastropods. - The Gastropods here figured (Figs. 578-582) pertain to genera that, like Platyceras of the Lower Cambrian, are characteristic eminently of more or less of later Paleozoic time. Bellerophon has the shell

$574-582$.

574.

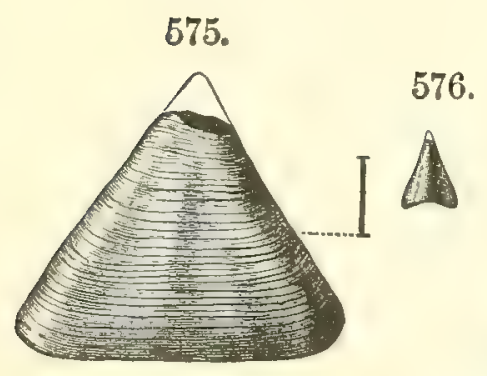

579.

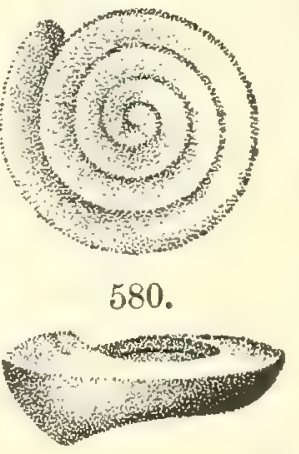

581.

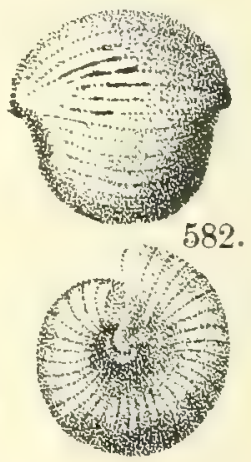

PTERopods. - Fig. 574, Hyolithes gregarius (1); 575, Matheria variabilis, lateral view (3); 576, 577, same, end views of different specimens (1). Gastropods. - Fig. 578, Holopea Sweeti; 579, 580, Ophileta primordialis; 581, 582, Bellerophon antiquatus. Fig. 574, from Meek; 575-577, Walcott; 578-582, Whitfield, Wisconsin G. Rep.

coiled in a plane; it has also (but not shown here) a narrow slit in the lip of the shell at its middle. B. antiquatus Whitf., first described from Wisconsin beds (Fig. 581), occurs also in Eureka, Nev.

6. Trilobites. - Fig. 583 represents, reduced, one of the large species of Dicellocephalus of Owen, from Minnesota, — the real length being six inches. Figs. 585 and $585 a$ are head and pygidium of one of the small species 
from the Potsdam sandstone of Keeseville, N.Y., the total length being a fourth of an inch. The track, $5_{2}^{1}$ inches broad, Fig. 586, from Perth, Canada, described by Logan, has been referved to a large Trilobite, on the view that the limbs of the species were natatory; and on 587 is a similar track, $4 \frac{1}{2}$ inches broad, from New Lisbon, Wis., besides a still smaller kind. The partially natatory character of the limbs has been recently established by Beecher (page 512).

$583-588$.

583.

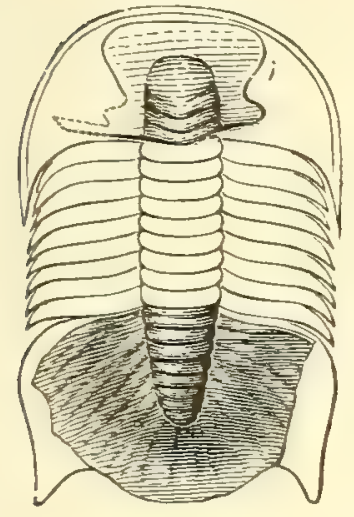

585 .

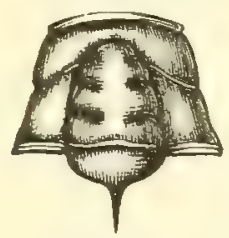

584 .

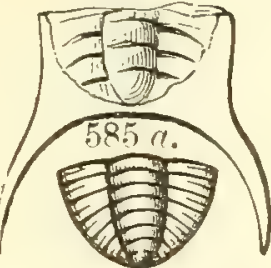

586.

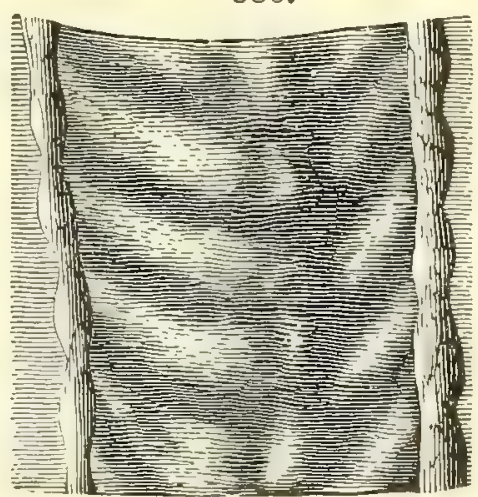

588.

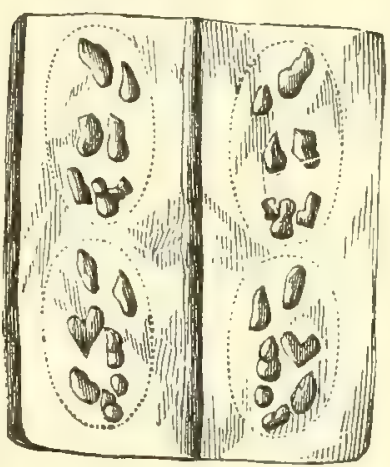

Trilobites. - Fig. 583, Dicellocephalus Minnesotensis $\left(\frac{1}{4}\right) ; 584$, D. Iowensis (1) ; 585, Ptychoparia (Conocoryphe) minuta, head shield (4); $585 a$, same, pygidium (4). Tracks. - Fig. 586, Climactichnites Wilsoni, supposed to be those of a large Trilobite $\left(\frac{2}{7}\right) ; 587$, Climactichnites Youngi (the larger track), with C. Fosteri, the smaller; 588, Protichnites septemnotatus. Fig. 583, 584, from D. D. Owen; 585, 585 a, F. H. Bradley; 586, 588, Logan; 587, Chamberlin.

The tracks, a portion of the series of which is represented in Fig. 588, were described by Owen from specimens found in the Potsdam sandstone of Canada. The breadth of the pairs of tracks was six to seven inches. What made them is not yet known.

Besides the kinds of fossils mentioned above, there are also various markings and impressions that are not fully explained. Among these are impressions 4-sided, 5-sided. and circular in form, from Olenellus beds, which have been referred, first by Nathorst of Swerlen, and later by Walcott and others, to Hydrozoans or Medusæ of large size. Tlic 
5-sided forms among them, and the thickness indicated, make a relation to the Medusæ doubtful. Nathorst states, however, that he has experimented with some species of Medusæ and obtained similar impressions. Moreover, some modern Medusæ have occasionally varieties with five divisions.

A general review of the fossils of the Lower, Middle, and Upper Cambrian will be found in Walcott's papers: Bulletins U.S. Geol. Survey, Nos. 10, 30, and 81, and Tenth Ann. Rep. U. S. Geol. Survey; and details here are therefore unnecessary.

See, also, papers by Billings, Palcozoic Fossils, Canada Survey; J. W. Salter, Q. $J$. G. Soc., Xv., 551, 1859; James Hall, Sixteenth Ann. Report, N. Y. State Cabinet, pp. 119-184, 1863; G. F. Matthew, Royal Soc. Canada Proc. and Trans., vols. i.-v., vii.-ix. ; C. F. Hartt, in Dawson's Acadian Geology; S. W. Ford, Am. Jour. Sc., 3d series, vols. 2, 3, 5, 11, 13, 15, 19, 21, 22 ; Rominger, Phit. Acad. Sc. Proc. 1887, p. 12 ; Whiteaves, Am. Jour. Sc., 3d series, xvi., 224; Whitfield, Geol. Suvey Wis., iv., and Am. Mus. Nat. Hist. Bull., i., p. 139 ; Shaler and Foerste, Bull. Mus. Comp. Zoöl. Camb., xvi., 115, 1888; also Walcott, Am. Jour. Sc., xxxiv., xxxvi., and U.S. Nat. Mus. Proc., vols. xi.-xiii. Besides the above, there are recent studies of the Genera of Cambrian Brachiopods by Hall and Clarke (Pal. N.Y., vol. viii., 1892); a paper on the Classification of the Brachiopods by C. Schuchert (Am. Geologist, March, 1893); and a paper on the Development of Brachiopods by C. E. Beecher (Am. Jour. Sc., xli., 1891). Beecher separates from the genus Kutorgina of Billings (the type of which is $K$. cingulata, an articulate Brachiopod) the species Kutorgina (Obolus) Labradorica of Billings, var. Swantonensis of Walcott (which is inarticulate and undergoes no modification of form during growth), and makes it the type of the new genus Paterina.

The investigation of the Cambrian rocks, in late years, has greatly increased the number of known species. An extended description of the Lower Cambrian fauna is published in the Tenth Ann. Report of the U. S. Geol. Survey, 1890, by Walcott. Matthew has described many species of the Middle Cambrian, and the Upper Cambrian faunas are being studied by Walcott. Over 100 genera and 400 species are already described from the Cambrian of North America. Walcott gives the following table of the number of genera and species of fossils in the Lower Cambrian alone of North America (1890): -

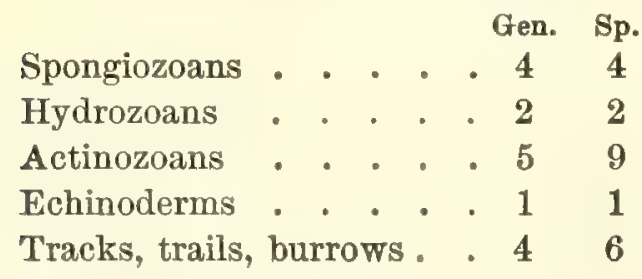

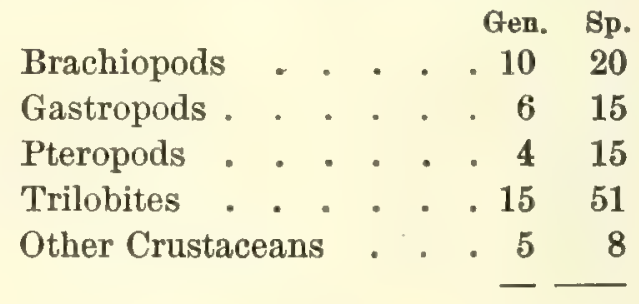

Total . . $56 \quad 131$

Adding species not included above, mostly described by G. F. Matthew, of New Brunswick, the total number of American genera is nearly 70, and of species 170.

\section{FOREIGN.}

The Cambrian rocks of Great Britain outcrop in North and South Wales, and in Shropshire, just east of Wales. The principal regions identified by fossils are the Longmynd, of slate and grits, in Shropshire; the Harlech, and the Bangor and Llanberis toward the Menai Straits, of sandstones, flags, and slates, in North Wales; the St. Davids (ancient Menevia), of sandstones, slates, grits, and conglomerate, in South Wales; and that of the Malvern Hills. In Ireland, Cambrian rocks occur at Brayhead and in Wex- 
ford, County of Wicklow. Other reported regions, partly metamorphic, are those of Charnwood Forest, and the Western Highlands of Scotland.

The lower part of the Cambrian of St. Davids is divided by Dr. Hicks into (1) the Caerfai group, (2) the Solva, and (3) the Menevian. The Lower Cambrian includes (according to Walcott) the first of these groups; it contains Lingulella primceva, L. fermginea, Discina Caerfaiensis, Leperditia Cambrensis, but no Olenellus has been reported. To it, as Lapworth shows, belong also sandstone beds in Shropshire, from which he has described Olenellus Callavei (with which occur species of Kutorgina, Acrothele, etc.). There are there no overlying Paradoxides beds. Here belong also the sandstones, flags, and slates of Bangor and Llanberis, toward the Menai Straits.

The Middle Cambrian or Paradoxides section comprises the Solva and Menevian beds of St. Davids, which have afforded Paradoxides Harknessi, P. Solvensis, P. Davidis, with Protospongia fenestrata and species of Lingulella, Theca or Hyolithes, Discina, Orthis (Orthisina), Stenotheca, Agnostus, Microdiscus, Conocoryphe, Leperditia. The Lower Cambrian and part of the Middle of Sedgwick are here included.

The Upper Cambrian or Olenus division comprises the Lingula flags and Tremadoc slates, which occur along by Maentwrog, Festiniog, and Dolgelly in North Wales, and the Tremadoc beds both in North Wales and at St. Davids.

The genus Olenus here has its largest development. The beds include also Dictyonema, and other Graptolites; species of Lingulella, as $L$. Davisi (Fig. 591), Lingula, Obolella, Kutorgina, Orthis; Hyolithes, Conularia, $589-595$.

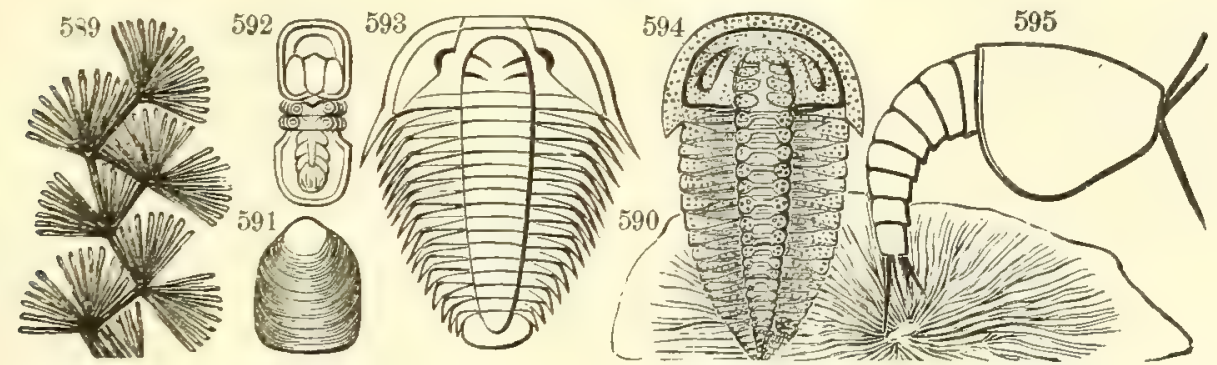

Fig. 589, Oldhamia antiqua; 590, O. radiata; 591, Lingulella Davisi; 592, Agnostus Rex; 593, Olenus micrurus; 594, Sao hirsuta $\left(\frac{1}{2}\right) ; 595$, Hymenocaris vermicauda $\left(\frac{3}{2}\right)$.

Bellerophon (B. Cambrensis); among Trilobites the genera Agnostus, Conocoryphe, Ampyx, Olenus (among the many speeies, Olenus micrurus, Fig. 593), Dicellocephalus, Sphcerophthalmus; also the Crustacean Ostracoids, Leperditia, Primitiu; the Caridoid species, Hymenocaris vermicauda (Fig. 595). In the Tremadoc slates occur several species of Graptolites; Dendrocrinus Cambrensis and Palceaster, among the earliest Echinoderms; Lamellibranchs of the genera Modiolopsis, Palcearca, Ctenodonta, etc.; Pteropods of the genera Theca and Conularia; the earlier of British Cephalopods, of the genera OrthoDANA'S MANUAL - 31 
ceras and Cyrtoceras; among Trilobites, the genera Olenus, Agnostus, Asaphus, Ogygia, Conocoryphe, Cheirurus; and the Caridoid Entomostracans, Ceratiocaris and Lingulocaris.

Oldhamia, from the Bray Head region, Ireland (Figs. 589, 590), has been supposed to be a seaweed, and also Hydrozoan. It is stated by Dr. Kinahan to be only inorganic markings.

In Scandinavia, where the Olenellus zone was first shown to be the true Lower Cambrian by Dr. A. G. Nathorst, the Lower beds oceur at Andrarum in Scania beneath Paradoxides beds. They are also found near Lake Mösen in Norway, and in Esthonia in Russia. They have afforded, besides Olenellus: Kjerulfi, species of Lingulella, Obolus, Discina(?), Hyolithes, Metoptoma, Scenella, and also impressions which, as stated above, page 479, are referred by Nathorst to Medusæ and called Medusites. The Middle Cambrian beds near Kongsberg, Norway, contain Paradoxides Tessini, P. Forchhammeri, Agnostus Kjerulfi, with Protospongia; and in Sweden, the same species of Olenellus with Paradoxides beds at a higher level, and above these Olenus. schists and Dictyonema shales.

The Cambrian beds of Norway are very thin, the beds near Kongsberg being 60 feet thick; in Sweden, the thickness is 2000 feet. The Eophyton sandstone lies beneath the Olenellus beds in Norway and contains the ambiguous Eophyton with Hyolithes levigatus, and worm and other doubtful markings. Nathorst supposes the Eophyton to be the casts of trails of Medusites.

In Bohemia, the region of Barrande's discoveries, - an area about Prague having Archæan rocks around it except on the north and northeast, - the "Primordial zone," his stage C, 300 to 400 yards thick, afforded him the genera of Trilobites, Paradoxides (12 species), Agnostus (5, among them $A$. Rex, Fig. 592), Conocoryphe (4), Ellipsocephalus (2), Hydrocephalus (2), Arionellus (1), Sao (Sao hirsuta, Fig. 594); also five species of Cystoids, with species of Orthis, Orbicula, and five of Hyolithes. From the underlying beds. of stage B (which rest on the Archæan, stage A), consisting of slates, quartzytes, schists, etc., Barrande reported traces of Annelids, Arenicolites. Barrande represents the rocks in a section across from northeast to southwest as lying in a simple synclinal, with an elevation of conformable Upper Silurian strata at the center of the synclinal.

On Sardinia occur Cambrian beds, from which Meneghini described, in 1888, two species of Paradoxides, several of Olenus, and Conocephalites, with others of Anomocare and Asaphus. No species of the Olenellus horizon were reported. J. G. Bornemann described from Sardinia, in 1892, Trilobites of the new genera Olenopsis, Metadoxides, and Giordanella, with Gastropods of the genera Capulus, Bellerophon, and probably Carinaropsis.

In the province of Sian-tung, China, Cambrian fossils were gathered by von Richthofen, and identified by Dames as belonging to the genus Doropyge, and referred to the age of the Quebec group. Walcott refers them to the genus Olenoides, and to the age of the Middle Cambrian. 
In India, the Director of the Survey reports the discovery, by Dr. Warth, of two Trilobites in the Neobolus beds of the Salt Range, and the identification, by Dr. Waagen, of one of them as a species of Conocephalites, and of the other as probably an Olenus; thus indicating the presence of a Cambrian and probably Lower Cambrian fauna.

Species of Conocephalites, Dicellocephalus, Ethmophyllum, and several other Cambrian genera, have been discovered in the rocks of South Australia.

Kayser described, in 1876, a number of Brachiopods and an Olenus from the northern part of the Argentine Republic, thus indicating Upper Cambrian rocks in South America.

\section{GEOGRAPHICAL AND PHYSICAL CONDITIONS AND PROGRESS.}

American. - Cambrian history, as the facts presented show, is the history of a begun and a growing continent; growing not by extension seaward, but by progress in rock-making over its wide surface wherever sufficiently submerged, and in rock destruction over emerged areas as a source of material for the new rocks. The abundance of shells of Pteropods may seem to indicate deep waters, since they now abound in sea-bottom deposits at depths of 100 to 1000 fathoms in the seas of the Mexican Gulf. But these pelagic species live at or near the surface; and if any physical conclusion is to be inferred from their abundance, it is simply that the surface of the water was between $70^{\circ} \mathrm{F}$. and $85^{\circ} \mathrm{F}$.

The gathering of building-material in gradually deepening geosynclines or troughs for future mountain ranges in the neighborhood of the Appalachian and Rocky Mountain protaxes has been stated to have commenced (page 357) with the beginning of Paleozoic time. The Cambrian formations bear testimony to the fact; for they have a great thickness, thousands of feet, over the sites of the Taconic and Appalachian ranges, west, for the most part, of the eastern protaxis, and over that of the future Laramide or postCretaceous Range, partly east and partly west of the western protaxis. Even in the Lower Cambrian a large part of this thickness was attained; while through the interior basin of North America, as far as the facts are known, the Cambrian is thin, and the Lower and Middle Cambrian wanting. Walcott's map, in the U.S.G.S., Tenth Ann. Report, presents the probable condition, and sustains his view of very uniform conditions over the interior, which signifies either emergence of the land or but small submergence, and no subsidence in progress.

In the Lake Superior region, along the southern margin of the Archæan V, between it and the Archæan area of Wisconsin, there was one great exception to uniformity over the interior continental area. But it was apparently confined to the Keweenaw area, where there were extensive igneous eruptions. The igneous rocks of Isle Royale, in Lake Superior, are referred to the same epoch by Whitney. Similar ejections took place also in Michipicoten Island, and at Thunder Bay and other points along the north shore of the lake; but 
their relations to those of Keweenaw are not ascertained. Igneous outflows occurred also in the Cambrian areas of southeastern Pennsylvania (G. H. Williams, 1892).

Foreign. - As in America, Cambrian beds are found along the borders of the Archæan. They occur at various points in the northern part of the Continent of Europe, from England along Sweden, Norway, Lapland, to Esthonia, in Russia, and also about isolated areas in France, Portugal, and Spain; the areas being the outcropping margins of Cambrian deposits. So large a part of the European continent is under Mesozoic or Cenozoic strata that geology cannot claim to know much about the actual distribution of the Cambrian areas.

Epochs of upturning in the course of the Cambrian. - Besides evidence of slow change of level, evidence exists of one or more epochs of disturbance or upturning during the long interval between the Archæan and the close of the Cambrian. The evidence consists of superposition of the horizontal or nearly horizontal beds of the Upper Cambrian on upturned beds of earlier Cambrian in Minnesota, on the St. Croix, in central Texas, and in Arizona in the Grand Cañon of the Colorado. It is not known that any mountains were made at the time in either of the three regions mentioned. In the Eureka district, Nevada, the beds of the Upper and Lower Cambrian are conformable.

Tide and currents the same essentially as now. - The beach material of the early and later Cambrian was fine sands and pebbles, as it is now; for these are the materials of the beach-made rocks, - the Potsdam sandstone and other like deposits. They were as quietly belabored by the waves, as the ripple-marks show; as free from extraordinary current movements, as proved by the usual even regularity of the bedding. A reddish variety of these sand-made rocks, spread out and accumulated on Cambrian beaches or sandflats, is used in American eities as one of the kinds of building-material. The waves and currents were then as quiet in their work about the Adirondack shores as they are now on the New Jersey coast. No evidence exists that the world's tides and currents had greater force than in this modern era of a quiet earth.

Climate in the Cambrian. - The evidence as to climate open to the geologist is that based on the kinds of life represented by fossils in the rocks. The Cambrian fossils thus far studied are from temperate latitudes only. Nothing is gathered from them as to different zones of temperature in the ocean, and nothing that proves the temperature of the waters to have been warmer than that of the existing torrid and warm-temperate zone. We have, therefore, to regard the climate, as well as the tides and waves, to have been such as now characterize the warmer portions of the existing world. There was no frigid zone, and there may have been no excessively torrid zone.

Purity of the air and waters. - The purification of the air and waters through the making of limestone, which commenced in the later part of Archæan time, continued through the Cambrian; for limestones are common rocks in the series, though far from being the only ones. The degree of 
purity attained is unknown; experiments on modern life may possibly lead to some reasonable estinate. This much is certain: that the waters were sufficiently pure for the development of a great diversity, as has been shown, of aquatic life. The types of the early Cambrian are mostly identical with those now represented in existing seas, and although inferior in general as to zrade, they bear no marks of imperfect or stunted growth from unfit or foul surroundings. How the purification was made so complete by the beginning of Paleozoic time has not been expláined.

The following observations have an important bearing on this subject, although falling short of the needed explanation :-

If the carbonic acid in the limestones of the world and other carbonates, and the carbon of the coal and carbonaceous products in the rocks were originally, as is believed, in the air and waters, the amount of these carbonates and carbonaceous products in the formations of the Cambrian and all later periods would afford a basis for estimating approximately the amount of available carbonic acid existing at the beginning of these periods.

For the estimation there are the following data. A cubic foot of pure limestone which is half calcite and half dolomite, and has the normal specific gravity $2 \cdot 75$, weighs $171 \cdot 4$ pounds; and this, allowing for $\frac{1}{12}$ impurity, becomes 157 pounds, and corresponds to 72 pounds of carbonic acid. A cubic foot is equal to an inch-square column 144 feet in height. Since 72 is half of 144 , each foot of the column of such limestone contains half a pound of carbonic acid. Hence a layer of the limestone 1 foot thick would give to the atn osphere, on decomposition, half a pound of carbonic acid for each square inch of surface.

A foot layer of good bituminous coal containing 80 per cent of carbon, $G=1 \cdot 5$, will give to the atmosphere, by oxidation, 1.9 pounds of carbonic acid per square inch of surface.

If the mean thickness of the limestone over the whole earth's surface, that of the oceans included, reckoned on a basis of $\frac{1}{12}$ impurity, is 1000 feet, the contained carbonic acid amounts, according to the above, to 500 pounds per square inch, or 34 atmospheres (of $14 \frac{3}{4}$ pounds), and if the mean thickness of the coal is 1 foot, the carbonic acid it could contribute would be 1.9 pounds per square inch. Adding these amounts to the carbonic acid corresponding to the carbon in the mineral oil and gas and other carbonaceous products of the rocks and organic life, supposing it to be 6 times that of the coal, the total is 513.5 pounds, or 35 atmospheres. The mean thickness of Archran calcium, magnesium, and iron carbonate is not a fourth of that of post-Archæan. Estimating the carbonic acid they contain and that corresponding to the graphite of the rocks at 10 atmospheres, the whole amount becomes 45 atmospheres.

It has been suggested by some writers that the total amount of carbonic acid in the early Archæan was equivalent in pressure to 200 atmospheres. But this would require that the mean thickness of the limestone for Archæan and post-Archæan time should have been nearly 6000 feet.

Part of the limestone of post-Archæan terranes was derived from the wear and solution of Archæan limestones, iron carbonate, etc., and hence all the 35 atmospheres to the square inch were not in the atmosphere at the commencement of the Paleozoic. But if we reduce the 35 atmospheres, on this account, to 25 atmospheres, it is still an enormous amount beyond what ordinary life, even aquatic life, will endure. Reducing the estimated mean thickness for the limestone layer over the globe from 1000 to 500 feet would make the amount less by nearly one half. But with all the reductions that can be explained, the excess is still very large. It has been proved by experiment that an excess also of oxygen diminishes the deleterious influence of carbonic acid on plants; and that if the 
amount of this gas is made equal to that of the oxygen in the present atmosphere, plants will still thrive. How far this principle worked in early times is among the uncertainties.

'The idea has been thrown out by T. Sterry Hunt that carbonic acid has been received by the earth, from time to time, through the fall or near contact of meteorites, since carbon exists sparingly in some of these bodies. But it has not found favor with astronomers.

\section{BIOLOGICAL PROGRESS.}

Display of the system of life in the Cambrian. - The system of life, as exemplified by Lower Cambrian species, was essentially the existing system. Seven of the grander divisions of animal life above the grade of Rhizopods were represented: Sponges, Corals, Echinoderms, Worms, Brachiopods, Mollusks, and Crustaceans. And under Mollusks there were species of Lamellibranchs, Pteropods or related forms, and Gastropods; under Crustaceans, Entomostracans of two sections, - the Ostracoids or Bivalve Crustaceans, and Caridoids or shrimp-shaped species, - and Trilobites. It is true that species are represented only by their hard parts - their shells or skeletons. But the several subdivisions have species living in the existing world, so that the nature of the life and the laws of structure and physiology of the Cambrian species are, with few exceptions, all within man's range of study.

The multiplicate structure a conmon, low-grade feature of the Cambrian fauna. - The multiplicate structure exists among living species. But in the early Paleozoic it was a prevalent feature under all the tribes that admitted of it. The structure is a fundamental one in the Worms of all ages, the body consisting of an indefinite number of body-segments; and, since successional lines of development led off from their precursors to Trilobites and other Crustaceans, it is natural that Cambrian species of these classes should be multiplicate in number of segments. The Protocarids (page 474) are an example among the Crustaceans, as shown by the number of segments in the abdomen; the modern Apus is a representative of the Protocarid structure. The Ostracoids (Fig. 562) have their limbs and segments concealed by the shell; but there is reason to believe that these were multiplicate, and prototypes of the modem Limnadia. The large Trilobites on pages 473, 476 exemplify the feature. Only the small Agnostus family (page 476) fails of it, and these species probably fail because the form represents an embryonic condition.

Other low-grade features of Lower Cambrian species. - The Cystoids are the lowest of Echinoderms, inferior to Crinoids.

Brachiopods are (1) mostly the hingeless or inarticulate species; (2) small in size; and (3), to a great extent, if the number of individuals of the prevailing kinds is considered, species having a chitinous shell: and all these characters are embryonic features. Further, as remarked by Schuchert, no species having spines or loops within the shell are yet known. The special embryonic features of Kutorgina, Obolella, and Paterina have beer well illustrated by Beecher; and, according to this author, the genus Kutorgina is probably the earliest representative of articulate Brachiopods.

The chitinous shells of the Brachiopods, that make up so large a part of the individuals, contain much calcium phosphate, as shown by the analyses 
of T. S. Hunt (page 73), probably indicating, as has been suggested, the presence of much phosphatic material in solution in the seawater.

The Lamellibranchs are the lowest of Mollusks, and the species were very small. The Gastropods were very small, and mostly of the Patella-like symmetrical, non-spiral species; but with these occur species of Platyceras, having a short spire, and some of Pleurotomaria, a Paleozoic genus of coiled species that continue on through later time.

The Crustaceans are either species of the lower division of the class, the Entomostracans, or are Isopod in relations.

Smallness of size is not, however, a universal feature. The Pteropods, among Mollusks, were much larger than the modern species of the tribe. The Trilobites even of the Lower Cambrian comprise species as large as living Crustaceans. The Ostracoids are generally larger than those of recent times.

The most prominent exception to low-grade features in the fauna is that of Trilobites, which have nearly the perfection that belongs to the typical Isopod. Their primitive character is, however, marked in the multiplicate structure of the thorax and its limbs, and in the fact, observed by Beecher, that each of the thoracic legs has a natatory appendage.

Embryonic precursor lines fail.-- The Lower Cambrian species have not the simplicity of structure that would naturally be looked for in the earliest Paleozoic life. They are perfect of their kind and highly specialized structures. No steps from simple kinds leading up to them have been discovered; no line from Protozoans up to Corals, Echinoderms, or Worms, or from either of these groups up to Brachiopods, Mollusks, Trilobites, or other Crustaceans. This appearance of abruptness in the introduction of Cambrian life is one of the striking facts made known by geology. But, as is often urged, this appearance of abruptness is believed to be due to defective records. In some regions there are thick strata in the Cambrian below the lowest fossiliferous beds representing a long lapse of time, besides others in the Archæan, of whose life nothing is yet known. Again, species without shells or stony secretions make no fossils, and can leave no record; and it is for this reason that we know so little of Cambrian Worms, all that remains being the holes or tracks they made.

Further : the Lower Cambrian rocks are often hard slates and grits, and the heat, or heated moisture, or siliceous solutions, that hardened them would have tended to dissolve away calcareous shells. The shells of phosphatic kinds, as the Lingulæ, Discinæ, and the tests of Trilobites, would have suffered least. From this last fact it follows that resistance to solution, not predominance in number, may, in many cases, have determined the relative proportions of the species of fossils. These are sources of uncertainty demanding consideration.

The Olenellus beds have been made the Lower Cambrian. But they are not necessarily the lowest. For if strata should be found containing no Trilobites, but only Worms, the lower types of Brachiopods, Ostracoids among 
Crustaceans, and other inferior species, a place in the Cambrian would properly be made for it, unless the beds were proved to be Huronian by evidence that they had been formed before the epoch of mountain-making which closed Archæan time. Mere divergence to this extent from the Lower Cambrian in life would not be sufficient to require separation from it.

Progress through the appearance and disappearance of species. - This feature in the world's biological progress is well illustrated in Walcott's reports. Of the many species of Trilobites from the Lower Cambrian, very few are known to occur in the Middle Cambrian; and few of those of the Middle, in the Upper. According to the facts thus far gathered, it may seem that events passed with a rush; that exterminations and renewals followed one another at short intervals. But the thickness of the rocks proves that the three divisions of the period were immensely long. There may have been many successive faunas in each. It is quite certain, judging from the teachings of the geological past, that the abrupt breaks are generally, if not always, breaks in the record, not breaks in the succession of species.

The total number of ascertained species from the American Lower Cambrian is stated to be less than 200. The number 200, though large, considering the remoteness of the period, is very small compared with that of the marine invertebrates of existing American seas. There are reasons for its being so small ; for (1) only a small part of the rocks has been examined; (2) hardly a tenth of the deposits made in the Lower Cambrian would have escaped the destroying action of denuding agencies; and (3), in any case, only a small part of any fauna is likely to become fossilized. The number of species known from the Middle Cambrian is much smaller than that from the Lower. This is not evidence of fewer species at one time than another in the fauna of the world. It may be proof that the conditions were unfavorable over the regions geologically studied for the preservation of their remains. These unfavorable conditions may have been due to temporary changes of water level that made densely brackish seas over large parts of the continental surface, or as great fresh-water seas; or to other local circumstances not now discoverable. The absence of Lamellibranchs in the Middle Cambrian, although present in both the Lower and Upper, means the absence of fossils from the rocks, not of species from the faunas.

Progress in Cambrian life after the Lower Cambrian. - This progress is strongly marked. In the Upper Cambrian, Brachiopods are of more genera; Conularia is added to the Pteropods; Gastropods are of normal size, and those with spiral shells are multiplied; and Crustaceans are advanced to the grade of non-multiplicate Hymenocarids; and before the epoch ended there were true Crinoids and Star-fishes in the seas; Trilobites had appeared of the genus Asaphus; Ceratiocarid Crustaceans were in the waters; and besides these, Cephalopods, the higher Mollusks, were represented by species of Orthoceras and Cyrtoceras, the straight form of Orthoceras apparently preceding the curved form of Cyrtoceras. 


\section{LOWER SILURIAN ERA.}

Srmonymy. - Lower Silurian, Murchison, Phil. Mag., vii. 46, 1835 ; Brit. Assoc., v., 1835. Lower Silurian, Upper Cambrian, Sedgwick, but not aware of their identity, Brit. Assoc., V., 1835. Lower Silurian, including the Lingula flags, Murchison, Sit. Syst., 1838 ; Geikie, in 3d edit. of Jukes's Geol., 1872; Dana's Manual of Geol., 1874. Lower Silurian, Lyell, Elements Geol., 2d edit., 1841, and later; Geikie, Text-book Geol.; 1885; Seeley and Etheridge, Man.Geol., 1885; Prestwich, Geol., 1886 ; Credner, Geol., 1887. CambroSilurian, Jukes, Canadian Geological Survey. Fauna D, or Second Fauna, Barrande. Silurienne, Étage Armoricain, Lapparent, Tr. Géol., 1883.

Champlain group, but with the Potsdam sandstone and the Oneida conglomerate included, Hall, Rep. N. Y. G. Surv., 1843 ; same, with the Oneida conglomerate excluded, Mather, Vanuxem, Emmons, Rep. N. Y. G. Surv., 1842, 1843.

Ordovician, Lapworth (from the name of the British tribe, Ordovices), G. Mag., 1879, p. 13. Upper Cambrian, Ordotician, H. B. Woodward, Geol. of Eng. and Wales, 1887.

The counter-claims of Sedgwick and Murchison with reference to the geological formations in which they both had worked, appeared to have been settled by the recognition of a Cambrian system below the Lower Silurian. But the independent characteristics of the Lower and Upper Silurian becoming increasingly evident, it has seemed to demand that the two eras should have independent names. Notwithstanding the great claims of Murchison, the new name of Ordovician, proposed in 1879 by Lapworth, is much used for the Lower Silurian, the one which represents the larger share of Murchison's labors, and thereby the old Murchisonian name of Silurian is left for the Upper division. As this is not the disposal of the question which the law of priority appears to require, the name of Lower Silurian is here retained, awaiting the full expression of geological opinion.

\section{NORTH AMERICAN.}

\section{Subdivisions.}

3. Hudson Epoch: that of the Hudson slate group or Hudson River group, Mather, Ann. Rep. Geol. N.Y., 1840; Hudson River group, Mather, Hall, Vanuxem, Final Rep. Geol. N.Y., 1842, 1843; Lorraine shales, Emmons, Final Rep. N.Y., 1843; Nashville group, of Tennessee, J. M. Safford, Am.

2. Trenton Period.
Jour. Sci., xii., 1851; Cincinnati group, Worthen, Rep. Geol. Ill., i., 1866.

2. Utica Epoch: that of the Utica slate, N.Y. Geol. Rep., 1842, 1843; Black slate, Ann. N.Y. Rep.

1. Trenton Epoch : that of the Trenton, Birdseye, and Black River limestones, Vanuxem, Conrad, Ann. Rep. Geol. N.Y., 1838. 


\section{Chazy Eросн: that of the Chazy limestone, Emmons. Final Rep. Geol. N.Y., 1843. \\ 1. Canadian \\ Period. \\ 1. Calciferous Еросн : that of the Caleiferous sandrock of Amos Eaton, Geol. and Agric. Survey distr. adj. Erie Canal, N.Y., under S. Van Rensselaer, 1824. Part of the Levis, of Logan's Quebec group.}

In the Reports of the first Pennsylvania Geological Survey, Professor H. D. Rogers uses the following terms and numbers: Primal, I., for Cambrian ; A uroral, II., for the Calciferous and Chazy; Matinal, III., for the Trenton. The Taconic series of Emmons, along western New England and eastern New York, corresponds to the Cambrian and Lower Silurian formations combined. The geologists of the New York Geological Survey of 1836 to 1842 were Ebenezer Emmons, W. W. Mather, James Hall, Lardner Vanuxem, and T. A. Conrad, the last acting as paleontologist. After the close of the general survey of the State, Hall was given charge of the paleontology.

\section{ROCKS-KINDS AND DISTRIBUTION.}

The Lower Silurian formations are to a large extent limestone; they are partly calcyte, but more widely dolomyte. Arenaceous and shaly strata are most common in the earlier and later part of the series, that is, in the Calciferous epoch and the Hudson epoch; but in the Interior Continental region the larger part of the rocks of these earliest and latest divisions is calcareous. The Trenton rocks are remarkable for their wide distribution over the continent. Outside of the Archæo-Cambrian areas they extend for the most part from the Atlantic to the Pacific, though covered in general by later rocks. The larger part of the outcrops of the limestones follows the outline of the Archæan areas, separated from them, if at all, only by outcropping belts of Cambrian, showing that the shore line in the Lower Silurian era was not far distant from its Cambrian position.

This is true around the Adirondack area in New York, and from central New York westward to Wisconsin and Minnesota. It is also true along the Appalachian protaxis from Canada and the Green Mountain region to Alabama, on both its east and west sides; also in the Ottawa region, Canada, where there was a large Lower Silurian basin as successor to that of the Cambrian era; also along the St. Lawrence northeastward, along the western arm of the Arehæan $\mathbf{V}$ northwestward, and on some Arctic islands. It was true, also, along portions of the Rocky Mountain protaxis; but here, owing to the thickness of the later formations, the Lower Silurian beds are not commonly at the surface. Some of the deep cañons of the Pacific Border region cut down to them through 1000 to 3000 feet of overlying beds.

In the Continental Interior two isolated areas lie in a line, one over southern Ohio, part of Kentucky, and the border of Indiana; and the other in Tennessee ( $C$, T, on the map, page 536). The region is that of the so-called "Cincinnati uplift," or anticline.

On the borders of western New England and eastern New York, along the Taconic Range and either side of it, the crystalline schists and limestone 
are largely Lower Silurian and Cambrian. They are the Taconic series of Emmons. The Eolian limestone of Vermont, and its continuation, the Stockbridge, of Berkshire, Mass., with the intervening ridges of slates and schists, are of this series, and also, the extension of the lines southward, though interruptedly, into New Jersey and Pennsylvania; and it probably comprises the interrupted series of limestone belts and the associated schists which extend from Canaan, Conn., south through Litchfield County, Conn., and Westchester County, N.Y., to New York or Manhattan Island, and part of this island, the rest being probably Archæan.

\section{Canadian Period.}

1. Calciferous Epoch. - The Calciferous formation, along the borders of the Archæan of northern New York and Canada, consists of a grayish limestone which is often arenaceous and cherty, usually magnesian, and rarely fossiliferous. It then extends southwestward through New Jersey and eastern Pennsylvania. It includes in Missouri the first or upper of the four Lower Magnesian limestones, with the underlying sandstone called the first, or Saccharoidal sandstone. Its equivalent is the "Lower Magnesian" of Iowa and Minnesota.

2. Chazy Epoch. - The Chazy beds in New York consist mostly of limestone. The formation was so named by E. Emmons, after the village Chazy, in Clinton County, N.Y., where the formation has a thickness of 730 feet. The limestone is gray to black in color, and is often recognizable, when in polished slabs of black marble, by the presence of a large fossil shell three inches or more across - the Maclurea magna (Fig. 634). The limestone is mostly dolomyte. It occurs in Canada about the Ottawa basin. On the eastern border of New York and the western of New England it makes part of the Taconic series. The St. Peter's sandstone of the northern part of the Mississippi valley has been referred to the Chazy epoch; but it contains few fossils of any kind, and none are characteristically Chazy.

\section{Trenton Period.}

The Trenton period is represented in New York, in its earlier part, by limestones, and in its later part by shales; and this division in the rocks is the basis of a subdivision of the period into the Trenton and Utica and Hudson epochs. This succession in the rocks implies that a time of clear open seas first existed, in which Trilobites, Gastropods, and Bryozoans abounded, as well as Brachiopods; but that later, through some unexplained topographical change, the waters lost much of their clearness, and bore along so much sediment that mud deposits were made over the bottom, extinguishing life that could not adapt itself to the new conditions, reducing Trilobites to a few species, favoring the multiplication of Lamellibranchs and other Mollusks, and causing many other changes both by migration and modification. The change, moreover, was one of wide extent and influence.

The name Trenton is derived from Trenton Falls, north of Utica, in 
Oneida County, N.I., where the limestone stands in bold bluffs along the wild cañon of IVest Canada Creek, and affords a good place for the study of the rock and its fossils.

1. Trenton Epoch. - In the region of Trenton Falls the linestone is a blackish to dark gray thin-bedded rock, owing its color, like the Utica shale, to carbonaceous or bituminous material. The lower part of the Trenton formation is called the Black River limestone, from Black River; it outcrops to the north of Trenton Falls, and, like the Trenton, it is widely distributed over the country. A stratum, 30 feet or less thick, at the bottom of this limestone in central New York, is the Birdseye limestone - a gray, dovecolored rock, speckled with white crystalline points, that are due in part at least to the presence of a fossil coral and its crystallization into calcite. The Kentucky Chazy limestone contains similar "birdseyes," and has great thickness. The Trenton in Wisconsin, Illinois, and Iowa is a bluish gray to buff-colored rock. Above it lies the "Galena limestone," about 250 feet thick, mostly dolomyte, which is noted for its deposits of lead ore; it corresponds to the later part of the Trenton epoch.

2. Utica and Hudson Epochs. - The shales of the Utica epoch ontcrop along a narrow region in the Mohawk valley, east and west of Utica, the place after which they are named; and those of the later Hudson epoch, along the south side of the Utica shales. They also extend down the Hudson River valley (whence the name) to Fishkill; but part of the shales formerly called Hudson River shales have proved to be Cambrian.

The Hudson shales have their greatest thickness in eastern New York. A boring 15 miles west of Albany passed through 3440 feet of shales, partly the Utica shales, into the Trenton limestone. In central New York, 20 miles west of Oneida Lake, a boring went through 1000 feet of Hudson and Utica shales, and at Utica, through 800 feet of the two. The impure limestone and shales of the region about Cincinnati are of the Hudson epoch. The thickness at Cincinnati is about 750 feet. The lower part of the series contains fossils of the Utica shale of New York, mingled with other species belonging to the Trenton or the Hudson rocks of New York. In Ohiò and Kentucky the Cincinnati beds overlie 600 or 700 feet of limestones and shales which are mainly of the Trenton epoch.

\section{Canadian Period.}

\section{Calciferous Epoch.}

a. Eastern Border region. - In nor thwestern Newfoundland, on the Straits of Belle Isle, Upper Calciferous is stated to include $2061^{\prime}$ of limestone. Below these are the Lower Calciferous of the age of the New York beds (Billings, Logan). The beds continue down the coast of Newfoundland to Bonne Bay and beyond. The Calciferous is $250^{\prime}$ thick at the Mingan Islands, and continues from there to St. Genevieve, on the Lower St. Lawrence.

b. Appalachian and Interior Continental regions. - In some places in New York the layers of the Calciferous are hard and siliceous, and contain geodes of quartz crystals, as at Diamond Rock, Lake George, and at Middleville and elsewhere in Herkimer County, 
ete., where the Archæan has outcrops not far distant (at Little Falls). A cavity is reported to have contained half a bushel of loose, transparent crystals. Fragments and nodules of anthracite coal are sometimes included in the crystals or accompany the crystals in the cavity; the larger nodules are two inches or more long. Besides quartz and calcite, barite, celestite, gypsum, and occasionally blende are found in its cavities.

In Canada, north of New York, the Calciferous beds spread widely over the western part of the Ottawa basin, and in general are nearly pure dolomyte, but with cherty or sandy layers. The fossils are mostly weathered out. Thickness, $50^{\prime}$ to $300^{\prime}$. In Tennessee, the Knox dolomyte, above its lower $2000^{\prime}$ of Upper Cambrian, contains typical Calciferous fossils. In Missouri, the first magnesian limestone, which has been ascertained by fossils to be Calciferous, has a thickness of $50^{\prime}$ to $150^{\prime}$. The Saccharoidal sandstone, $100^{\prime}$ to $133^{\prime}$ thick, is very white, and is used for glass-making.

"Lower magnesian limestone" of Iowa, Minnesota, and Wisconsin, has been found to contain Calciferous fossils in Clayton and Allamaker Counties, according to S. Calvin.

\section{Chazy Epoch.}

At Chazy, according to Brainard and Seely, the Chazy limestone has three divisions: a lower of $310^{\prime}$; a middle of $265^{\prime}$, thick-bedded and abounding in Maclurea; and an upper of 1571, which is very various in character, partly siliceous dolomyte. The middle division contains a 20 -foot bed of pure gray limestone which is often oölitic ; it is 50 feet above the bottom, and is free from the Macturea, - a fact accounted for by the oölitic character, since this structure is produced only in tide-washed calcareous sand-flats or beaches. It makes a handsome marble called "French Gray," while the Maclurea beds make a black or grayish black marble.

The Chazy beds thin out in the valley of the Mohawk, where the Calciferous is often followed directly by the Birdseye.

The Chazy is the Grenville limestone of the Ottawa region; it is largely developed about Montreal. It often contains the shells of Lingulæ in phosphatic concretions; and shells of Pleurotomaria occur as casts of calcium phosphate. 'The beds are $300^{\prime}$ thick at the Mingan Islands. No characteristic Chazy fossils have been reported from the Mississippi valley. The St. Peter's sandstone of Iowa, Minnesota, and the adjoining part of Wisconsin underlies the Trenton, and has been referred to the Chazy. It has been reported as affording a few fossils related to those of the lower part of the Trenton. But in Iowa and Minnesota the name covers limestone beds as well as those of sandstone. The limestones become thicker in the latter State, and constitute the Shakopee limestone, which is the middle member of the sandstone. In Iowa the St. Peter's sandstone includes also the Willow River limestone, and in Wisconsin the New Richmond sandstone. A sandstone has been met with, also, in borings in Indiana, below the Trenton, and over $50^{\prime}$ of magnesian limestone, which is supposed to be the St. Peter's. The thickness is $150^{\prime}$ to $224^{\prime}$; its waters are often saline.

\section{Trenton Period.}

a. Eastern Border region. - The Hudson beds of Anticosti, along its north side, are of limestone, and $959^{\prime}$ thick. Above these are limestone beds of the Upper Silurian, in all about $1400 \%$. The rocks are nearly horizontal. The Trenton occurs in central and western New Brunswick, but on the coast and along the shores of Maine only doubtfully at Foster Island near Machiasport.

b. Appalachian and Interior Continental regions. - The Trenton limestone in central New York extends as a surface rock through Oneida and Lewis counties to Lake Ontario ; then reappears across the lake and stretches westward in a band 30 miles wide to Georgian Bay. It occurs also on the Manitoulin Islands and Drummond's Island, Lake Huron. The thickness at Montreal is $600^{\prime}$, in the Ottawa basin as great, and nearly $1000^{\prime}$ west of 
Lake Ontario. East of the Hudson it occurs over large areas as part of the Taconic series described beyond. In the west-central portion of southern New York it is covered to a depth of $2000^{\prime}$ or more by later formations.

The Utica shale is $15^{\prime}$ to $35^{\prime}$ thick at Glen's Falls, in New York; $250^{\prime}$ in Montgomery County; $300^{\prime}$ in Lewis County.

The Hudson River shales cover the region north of Lake Champlain, in Canada, reaching to Quebec, and northeastward to Montmorency and beyond. They also cover a small area near the center of the Trenton limestone region of the Ottawa basin. "In New York they include shales and sandstones. They are the Lorraine shates of Jefferson County (the Pulaski shales of the New York Annual Reports), containing some thin beds of limestone. The thickness of the shales, in Schoharie County, N.Y., is $700^{\prime}$; in western Canada, $700^{\prime}$; in a boring at Utica, N.Y., 90', below $710^{\prime}$ of Utica shale.

In Pennsylvania the Hudson shales (Matinal of Rogers, or his No. III) border the Trenton areas, and have in general great thickness.

In Ohio the Trenton, in the Cincinnati region, lies beneath $700^{\prime}$ or so of beds of impure thin-bedded limestone and shale of the Hudson (Cincinnati) epoch; and to the north these shales are $500^{\prime}$ to $1000^{\prime}$ thick, and include at base $300^{\prime}$ of Ctica shales. The same beds are continued westward into Indiana, in the eastern part of which State the thickness is about $1650^{\prime}$. Of this, $500^{\prime}$ to $600^{\prime}$ are Trenton and Galena limestone; it is usually of gray to buff and white color, but in the northwestern part of the state, chocolate-brown.

South of the Ohio, in middle Kentucky, the Trenton, which includes the "Blue limestone" of Owen, is well represented by thick-bedded limestone, with some shaly seams; the beds have a small northward dip, toward the Cincinnati region and Lake Erie, along the area of the "Cincinnati anticline."

In the valley of east Tennessee, the Trenton includes the "Blue or Maclurea limestone" of Safford, and is $200^{\prime}$ to $600^{\prime}$ thick; and above this comes the "Nashville shale" of the Hudson epoch, which is partly calcareous (becoming increasingly so to the westward) and is about $2000^{\prime}$ thick. In the Maclurea limestone occurs, as an interpolated bed, the clouded red limestone, affording the famous Tennessee marble; it is about $380^{\prime}$ thick. In middle Tennessee the Trenton and Nashville strata are horizontal, and all is limestone, the later less pure; thickness about $450 \%$ (Safford.)

The Galena or lead-bearing limestone, of Wisconsin and the adjoining States in the West, is $100^{\prime}$ to $200^{\prime}$ thick in northern Illinois and about $250^{\prime}$ thick near Dubuque, Iowa; and the underlying 'Trenton $20^{\prime}$ to 100 '.

In Wisconsin and the adjoining part of Minnesota the Trenton limestone is $300^{\prime}$ to $350^{\prime}$ thick; the lower thinner part represents the Birdseye and Black River limestones of New York. The upper part is the Galena limestone. Although mostly a dolomyte, it is not all so ; in some parts of the lead region only the lower $18^{\prime}$ to $25^{\prime}$, called the Buff limestone, out of a thickness of $100^{\prime}$ or more, is magnesian. The Buff limestone from the southern part of the town of Bristol afforded calcium carbonate 56.07 to magnesium carbonate 35.32. An associated blue limestone afforded 84.02 of the former to 5.33 of the latter; the rock of another bed, 97.92 of the former to 1.00 of the latter. (J. D. Whitney, T. C. Chamberlin.)

In Iowa, at Washington, a boring struck Hudson shales at $700^{\prime}$, the Galena limestone at $800^{\prime}$, the 'Trenton at $1020^{\prime}$, and St. Peter's sandstone at $1100^{\prime}$; and below this, at $1230^{\prime}$, the magnesian limestone.

In Minnesota, the Trenton, as it occurs near Minneapolis, consists of dolomitic limestone, more or less argillaceous, of a buff to a drab color, with intercalated shaly portions and blue shale at base. The thickness in the State is $15^{\prime}$ to $70^{\prime}$. The Trenton in. Missouri, according to Broadhead, has a probable thickness of $400^{\prime}$.

c. In the Rocky Mountain region. - The Calciferous period is represented probably by the Ute limestone in the Wasatch, $1000^{\prime}$ to $2000^{\prime}$ thick; it includes beds in the House 
Range, Utah, and the lower part of the Pogonip limestone, in the White Pine and Eureka districts.

To the Trenton period are referred limestone beds at the Big Cottonwood Cañon, over the Cambrian, part of the Pogonip limestone ; I'rospect Ridge, Fish Creek Mountain, etc., in the Eureka district, Nevada, and later Trenton limestone (Hudson epoch?) in Lone Mountain, with $500^{\prime}$ of quartzyte between the two (Hague, Walcott); beds at Silver City and L'pper Mimbres Mining Camp, New Mexico, referred to Hudson epoch ; in South Park, Arkansas Cañon, ete. (Stevenson, Wheeler Exp., 1876); in British America, graptolitic Utica shales in the Kicking Horse Pass (Can. Rep., 1886).

In the Trenton, near Cañon City, Colorado, occurs the Harding sandstone, in which Walcott discovered, in 1890, the plates of Placoderm Fishes, described on page 510. Walcott gives the following section of the rocks: At the base is a reddish gneiss. This is followed by $22 z^{\prime \prime}$ of reddish arenaceous limestone with thin interbedded layers of chert, carrying fossils of Lpper Cambrian type. Above this limestone lie 51' of pinkish arenaceous limestone, carrying Ophileta, Straparollus, etc., characteristic of the base of the Lower Silurian, or the Calciferous fauna of New York; over this a series of sandstones (Harding sandstone) 101' thick, in which occur, along with an abundant invertebrate fauna, the plates of the Placoderm Fishes. A massive bedded, gray, arenaceous limestone succeeds the sandstone with a thickness of $110^{\prime}$, and this is followed by a thin band of Carboniferous limestone.

d. Arctic region. - Lower Silurian beds have been identified on North Devon, Cornwallis, Griffith, west coast of King William Land, Boothia, in Frobisher Bay, from Hall's collections, on the shores of Kennedy Channel. (For a review of the facts respecting Arctic geology and a geological map, see G. M. Dawson's paper, Can. Rep. for 1886.)

The Taconic system of Emmons. - The Taconic system was first announced by Emmons in 1842, in his $\lambda$. F. Geological Report of that year, and pronounced pre-Potsdam on the general ground of the kinds of rocks and the assumed absence of fossils. In 1844, fossils having become known to him from beds at Bald Mountain, in Washington County, N.Y., that had been included by him within the Taconic, he divided the Taconic series into the Upper Taconic, or that containing fossils, and the Lower Taconic. Later discoveries proved that his Upper Taconic rocks were really the oldest. The rocks of the so-called Lover Taconic were quartzyte, limestone, and schists in several belts, - situated along and near the Taconic range on the western boundary of New England, in Berkshire and eastern New York, and thence extending northward and southward, and also westward to the Hudson River. Although the "Lower Taconic" rocks are metamorphic, and coarsely so in Berkshire, they were afterward found at many points to contain fossils, and are now known to be mainly of Cambrian and Lower Silurian age.

These discoveries were made as follows, and chiefly in the limestone : 1857 to 1861 , Vermont survey, under C. H. Hitchcock and A. D. Hager, Geological Report, 1861; 1871, A. Wing, the fossils of the Chazy from West Rutland, Vt, reported on by E. Billings in $1872 ; 1865$ to 1877 , A. Wing, fossils in central Vermont, of the age of the Calciferous to the Trenton, reported in $1877 ; 1879$, T. N. Dale of the Hudson age, from the slates near Poughkeepsie, N.Y.; 1879 to 1890, W. B. Dwight, fossils from Dutchess County, N.Y., of Cambrian to Trenton and Hudson, and in Canaan, N.Y., 1886 to 1890 ; C. D. Walcott, fossils of Cambrian age in the quartzyte of southern. Vermont, almost down to the Massachusetts line, and in shales or limestone of Washington and Rensselaer counties, N.Y.; also Trenton or Calciferous fossils in the limestone of Bennington, Vt., and in Williamstown, Mass., on the west flank of Greylock, and in Berlin, N.Y., the region of the original Lower Taconic. Further, J. E. Wolff and Foerste have found Cambrian fossils in the limestone of Vermont, near Rutland, and elsewhere.

It has thus been established that the Lower Taconic is a combination of Lower Silurian and Cambrian formations, as already stated. The author's stratigraphical inves- 
tigations in Berkshire, Mass., Vermont, eastern New York, and western Connecticut, aiming to prove the continuity of the rocks of the belt so as to use the Vermont fossils to prove their age, began in 1871, and were continued at intervals to 1887. The last four seasons were employed in obtaining data for a geological map of a large part of the region.

For papers by Dale, Dwight, Walcott, and the author, and an account of Wing's discoveries, see the American Jounal for the years mentioned; and for a brief history of Taconic ideas, vol. xxxvi., 1888. The more important of the species of fossils discovered by Wing and identified by Billings, and their varieties, are mentioned beyond, on page 517 .

The Upper Taconic of Emmons, as shown by the fossils at Reynold's Inn, north. east of Bald Mountain, Washington County, N.Y., is Lower Cambrian; and that of Georgia, Vt., another locality, is the same.

Quebec group in Canada. - The Quebec group of Logan (1861-63), established on rocks occurring near Quebec, at Point Levis, and to the south, included (1868): (1) the Levis beds, which were fossiliferous; (2) the Lauzon beds, green and purple shales, affording Lingula and Obolella; and (3) the Sillery sandstone, consisting of sandstones and shales. They were regarded by Logan and Billings as mostly of the age of the Calciferous and Chazy groups. The recent investigations of Selwyn (1877, 1882, and later), and the confirmatory studies of R. W. Ells (1889), have proved that the fossiliferous beds include rocks from the Hudson epoch to the Cambrian; that the Levis is Calciferous in its lower parts; that the Sillery is probably all Cambrian. (Selwyn, Rep. G. Can. for 1880, 1881, 1882 ; Ells, ib. for 1889; also Walcott, Am. Jour. Sc., Feb., 1890; also on the Graptolites, Lapworth, Trans. R. Soc. Can., 1886.) The Quebec group is for the most part a northern portion of the Taconic series.

In Newfoundland the Quebec series, consisting of limestones and sandstones, is described by Logan and Murray as occurring on the northwest and west coast of Newfoundland, along the Straits of Belle Isle, and to the south. It includes the Calciferous, Cambrian, and other beds overlying the Archæan. The thickness given for the Newfoundland-Quebec group is 4600 '. For the original account of the Quebec group, see Logan's Report on the Geology of Canada, 1863, pages 225 and 844.

\section{LIFE.}

Of the terrestrial animal life of the Lower Silurian era nothing is yet known from American rocks; but Insects are already reported from those of Europe. The aquatic animals comprised, besides many new species of the several grand divisions represented in the Cambrian, other kinds showing progress; and among these, the earliest of Vertebrates-Fishes, as recently announced by C. D. Walcott; the first known of Barnacles, a group still common along all seashores, and the first of the Eurypterids, a tribe somewhat resembling Crustaceans, but having their only modern representatives in four species of Limulus.

\section{Canadian Period.}

\section{Calciferous Epoch.}

In the rocks of the Calciferous epoch fossils are usually few, although the limestones have great thickness. Since such limestones are made mainly out of calcareous animal relics, the absence of fossils means that the triturating waters obliterated them by reducing them to the calcareous mud which became the limestone. At some localities fossils are abundant, and there is 
no doubt that the seas were everywhere well populated. Among the occurring fossils in the shales, Graptolites (Figs. 604-609) are often very numerous. The American rocks have afforded a number of Sponges, a few Crinoids and Corals, some Bryozoans, many Brachiopods, few Lamellibranchs, some Pteropods and Gastropods, and a number of Orthocerata and Trilobites.

Plants. - But little is known of the Seaweeds, as only easts of rounded stems, sometimes simple, often more or less entangled, and consisting of the material of the rock, have been found - and the vegetable nature of these forms is doubted. The coal nodules (page 493) are supposed to have been once in the state of mineral oil, and may have been derived from the decomposition of organic matter of any kind. The hot moisture which consolidated the rock and made the siliceous solution for the associated quartz crystals (in which the coal is sometimes enveloped) probably drove the oil from the beds and led to its collection in the cavities or geodes.

Aximals. - Some of the Sponges were of large size. Fig. 596 represents a specimen (the lower part restored) of a species of Archoeoscyphia described by Billings, which attained a length of two or three feet and a diameter of four inches. These Sponges are Hexactinellid in type; that is, have sixrayed siliceous spicules (the rays at right angles with one another). These

596.

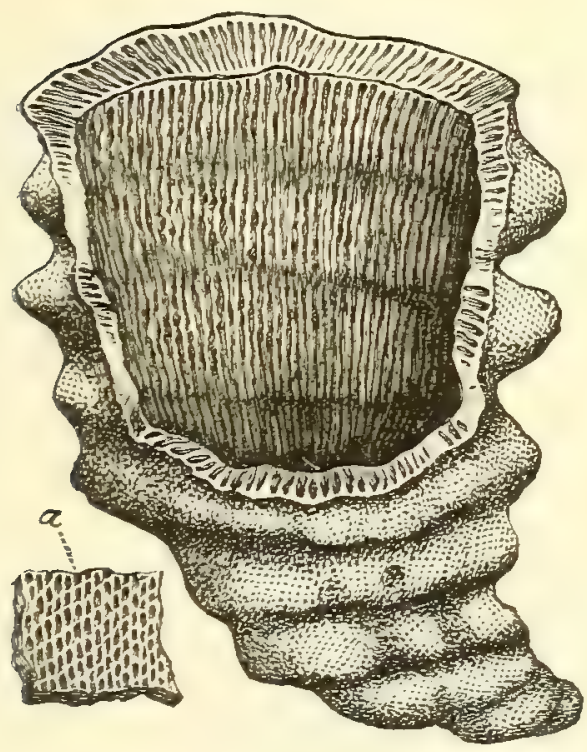

$596-598$.
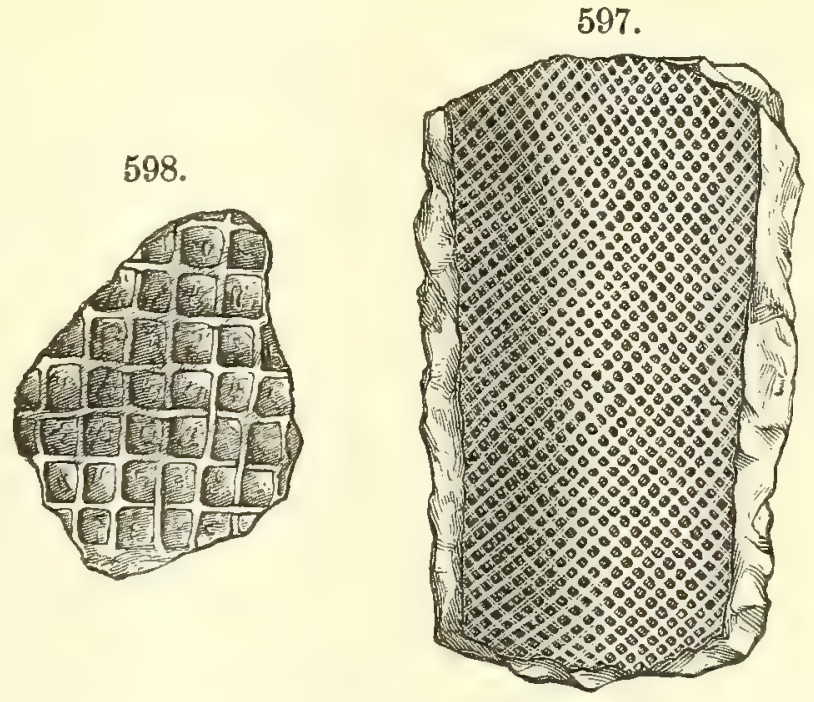

Spongtozonss. - Figs. 596, a, Archæoseyphia Minganensis; 597, Receptaculites elegantulus, drawn from a gutta-percha cast; 598, R. Calciferus, fragment showing inner surface. Billings.

species are from the Mingan Islands. Other Hexactinellid Sponges, from Little Metis, Canada, of the genus Protospongia of Salter, are represented in Figs. 599 to 603, natural size. Another species of sac-like form - and rhombic meshes half an inch wide, Paloesaccus Dawsoni of Hinde-had a diameter of 14 inches. They are from the base of the Levis beds, Quebec group, and, according to Dawson, are not newer than the Calciferous. The Receptaculites (Figs. 597, 598) are supposed to be Sponges.

DANA'S MANUAL - 32 
Some of the Graptolites - Hydrozoans - are represented in Firs. 604-609. The texture of the fossil Graptolite was usually thinner than the most delicate
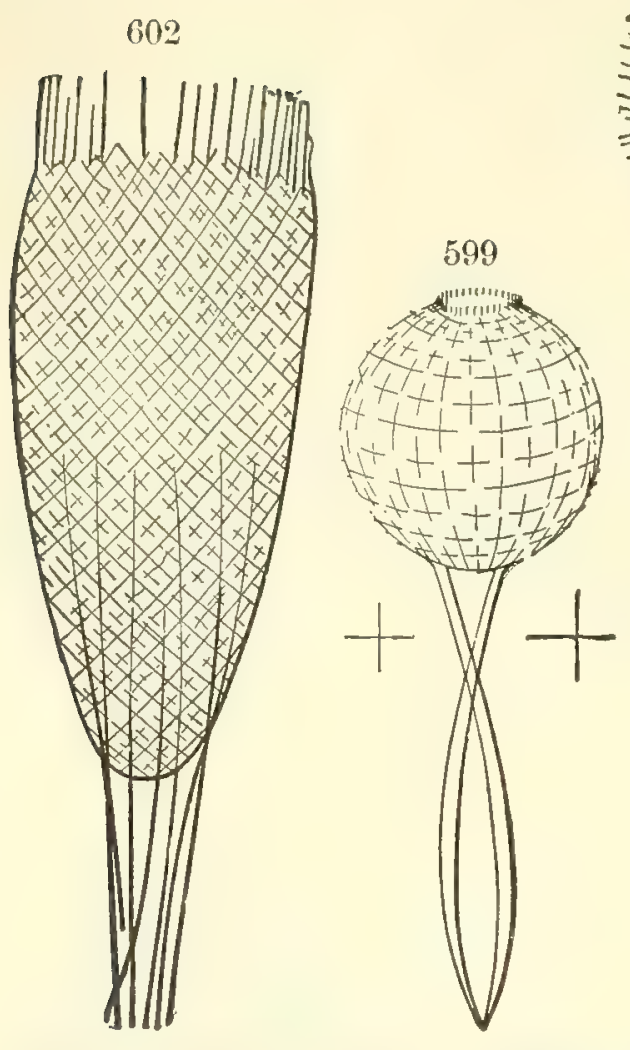

$$
599-603 .
$$

600
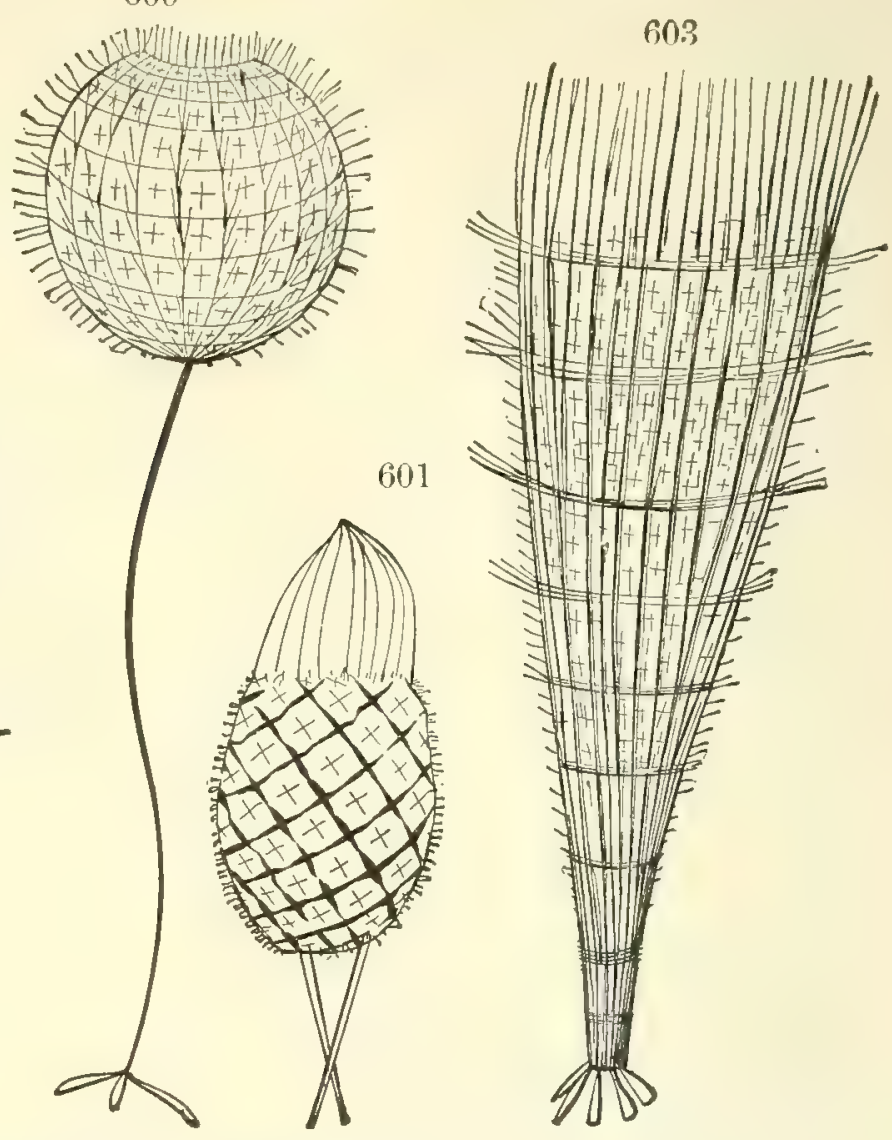

Spovges. - Fig. 599, Protospongia tetranema (1); 600, P. mononema ; 601, P. cyathiformis ; 602, P. coronata : 603, P. Quebecensis. All from Dawson.

membrane. Only the finest of sediments were therefore adapted to their preservation. The forms with one row of cells, or one-edged (Monoprionidæ), are represented by the Loganograptus (Figs. 604-606) and species of

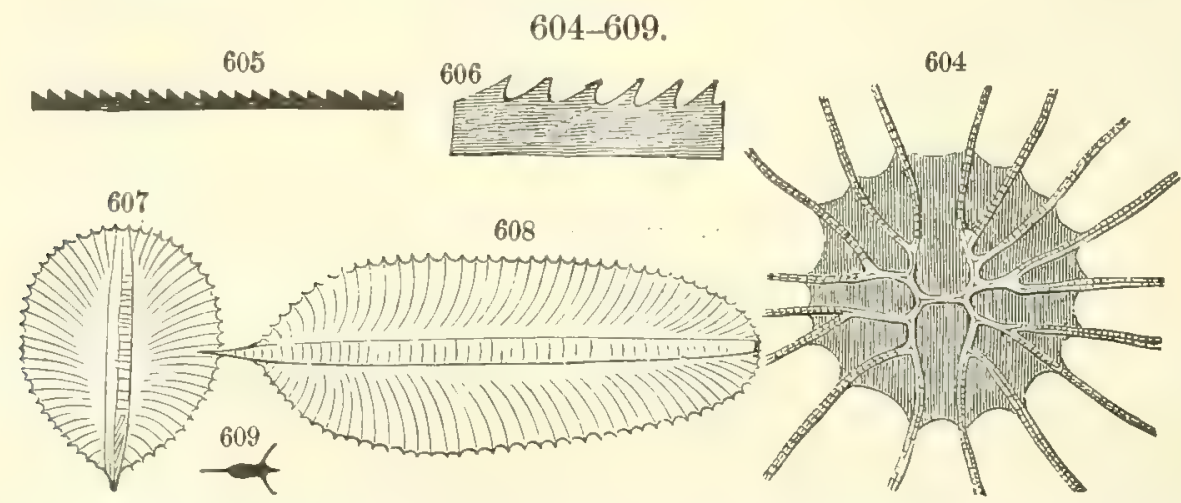

Graptolites. - Fig. 604, Loganorraytus Logani, branches broken off; 605, portion of a stem; 606, same, more enlarged; 607, 608, Phyllograptus typus; 609, the supposed young of a Graptolite. Hall.

other genera. They occur either in long, flat, notched threads spreading from a center (Fig. 604), or in simple forms; but most specimens are only frag- 
ments of branches of the slender polypary. The diameter of the form Fig. 604, when living, and having its arms of full length, may have been 15 to 20 inches. Figs. 607, 608 represent a species of the two-edged forms (Diprionidæ), that is, those having cells along both margins.

Besides Graptolites, there were massive Hydrozoan corals, of the Stromatopora type, related, it is supposed, to the modern Millepora.

Under Echinoderms, there were Crinoids and Cystoids, and also the 610. earliest known of American Starfishes (Fig. 610). Among the Brachiopods, a common species is the Orthis (Billingsella) grandaeva (Fig. 611).

Gastropods, of flat or short spiral forms, like Figs. 612-614, of species of the genus Ophileta and Maclurea, were common, and some were of large size. The genus Platyceras continued on from the Cambrian. There were also spiral forms of the genera Pleu-

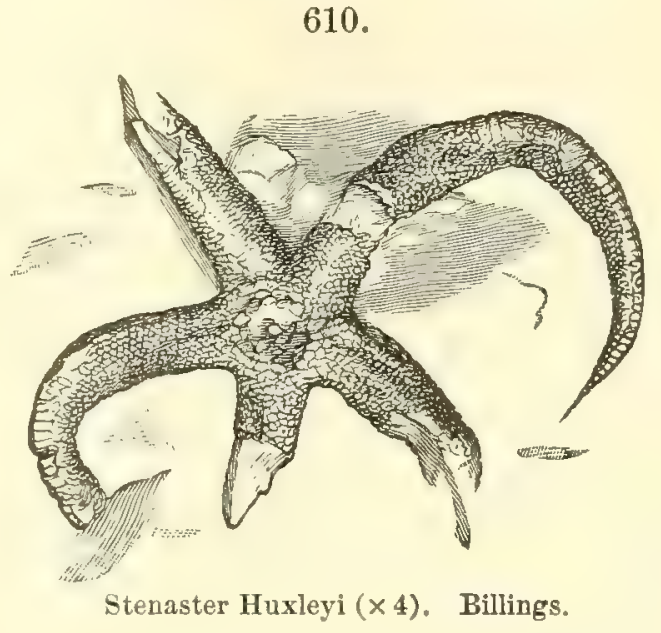

611.

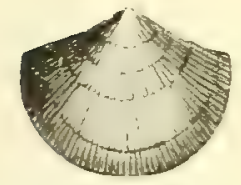

rotomaria, Murchisonia, Holopea (Fig. 615), and others of the Bellerophon family. The shells of Cephalopods in the Calciferous beds occur of many and varied forms, and some are over a foot in length. Those of the genus Orthoceras are straight or slightly curved. In O.primigenium of Vanuxem, Orthis (Billings. ella) grandæva. first described from the Mohawk Valley, N.Y., the septa, as shown in Fig. 618, are closely crowded. A curved species is represented in Fig. 620, Cyrtoceras (?) Vassarinum from Dutchess County, N.Y.
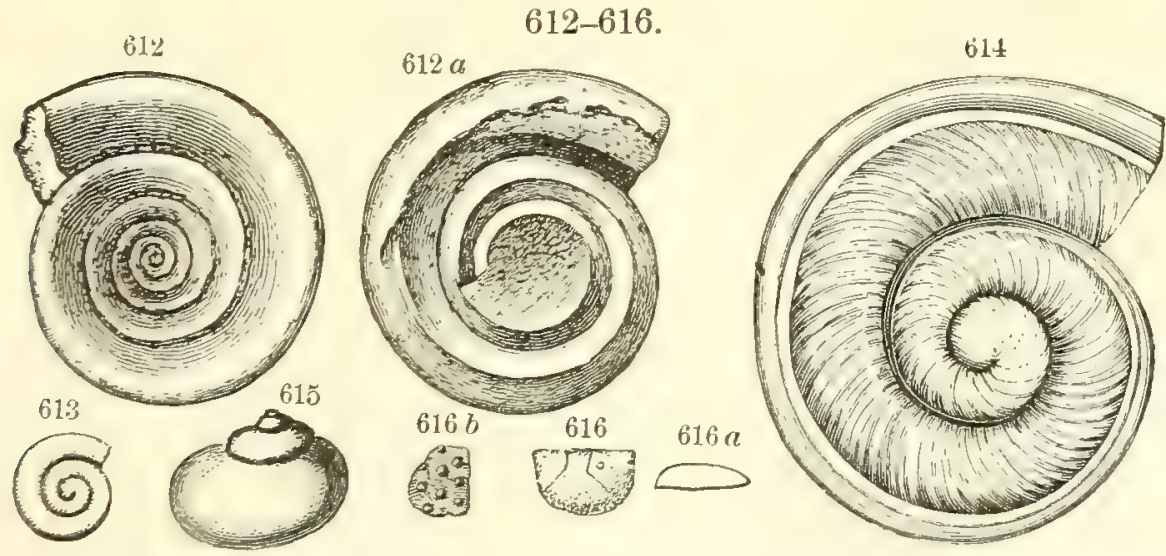

GASTROPODS:-Fig. 612, $612 \boldsymbol{a}$, Ophileta complanata (1), opposite sides; 613 , O. levata (1); 614, O. uniangulata (1); 615, Holopea dilucula - Ostracom Crustacean: 616, Leperditia anna enlarged, side view ; $616 \boldsymbol{a}$, same, upper view; $616 b$, several of the shells, natural size. Figs. $612,612 a$, Whitfield ; $613,614,615$, Hall; $616,616 a, b, \mathrm{~T}$. R. Jones.

There were also coiled species, both the open-coiled of the genus Lituites, and others that were close-coiled, Nautilus-like. Lituites (?) imperator B., Philipsburg, Canada, had a diameter of $10 \frac{1}{2}$ inches. 
Trilobites existed of the Cambrian genera Agnostus, Dicellocephalus, Ptychoparia, Bathyurus (seven species or more), and Bathyurellus (Figs. 621-624), and also of the genera Illoenus, Asaphus, Ceraurus (Cheirurus), Amphion, Ampyx, which have here their first American species.

$617-620$.

617.

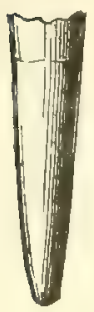

618.

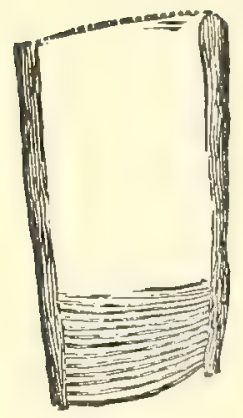

619.

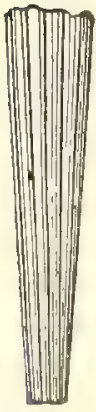

Cephatopods. - Figs. 617, 618, Orthoceras primigenium: 619, Kionoceras (Orth.) laqueatum ; 620 . Cyrtoceras (?) Tassarinum. Figs. 617, 618, 619 . Hall; 620 , W. B. Dwight.

An Ostracoid, or bivalve Crustacean, is represented much enlarged in Fig. 616 (a profile view in 616 a), and several of natural size in the rock in Fig. $616 b$.

\section{Characteristic Species.}

1. Spongiozoans. - Receptaculites elegantulus B.(Fig. 597) was a hollow sponge, with the thickness to the inner tube about half an inch; tubes passed from the outer to the inner surface, which opened inward. The species from Little Metis (Figs. 599603 ) occur in beds that contain also the Brachiopod Linnarssonia pretiosa B. (Dawson, Trans. Roy. Soc. Canada, 1889). The stem of Protospongia mononema (Fig. 600) is of doubtful reality, according to Hinde.

2. Hydrozoans. - The characteristic Calciferous forms, besides those figured, are Phyllograptus Anna H., Tetragraptus bryonoides H., T. fruticosus H., Didymograptus exten-

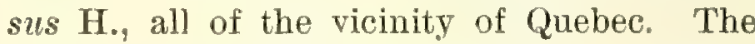
Cryptozoon protiferum H. (1884), from Greenfield, Saratoga County, N.Y., and C. Steeli, Seely and Br, another species from Vermont, if really organic, perhaps belong here.

3. Echinoderms. - Stenaster Huxleyi B. (Fig. 610), having a breadth of 5 lines, is from Point Rich, Newfoundland.

4. Molluscoids. - Fig. 611, Orthis (Bitlingsella) grandoeva B.; Lingula acuminata, Camarella calcifera B.; C. varians B. (also from Newfoundland); Clitambonites.

5. Mollusks. - a. Lamellibranchs. Euchasma Blumenbachii B., Newfoundland; Tellinomya Angela B.

b. Gastropods. - Ophileta compacta S., a fine species from Canada, is $1 \frac{1}{2}$ inches across ; Pleurotomaria Calcifera B., from near Beauharnois, Canada; $P$. gregaria B., St. Ann's, island of Montreal, Canada, extremely abundant; Maclurea matutina H., from New York and Canada; Murchisonia Anna B. (a long turreted shell, approaching the M. bellicincta, Fig. 675), St. Ann's, the Mingan Islands; Eccyliomphalus priscus Whitf., a large opencoiled shell from Fort Cassin, Vt.

c. Cephalopods. - Orthoceras Orarkense Shum. is from the Magnesian limestone, Ozark County, Mo.; Lituites (?) Farnsworthi B., a species partly coiled, and nearly 5 inches in its longer diameter, and L. imperator B., are from the upper part of the Calciferous sand- 
rock of Philipsburg, Canada East; Piloceras Canadense B., from the Mingan Islands, north of Anticosti Island; $P$. Wortheni B., from western Newfoundland. Nautilus pomponius B. is from Philipsburg; $N$. ferox B., Mingan Islands, is referred by Hyatt to the genera Plectoceras and Litoceras, there being no true species of Nautilus in Paleozoic rocks. At Philipsburg, Fort Cassin, and in Newfoundland, the fauna included also, according to Hyatt, species of the genera Sannionites (Fischer, Hyatt), Endoceras Hall, and Actinoceras Bronn (= Ormoceras Hall). On Hyatt's review of the genera of Fossil Cephalopods, see Proc. Boston Soc. Nat. Hist., xxii., 253, 1883.

$621-624$.

621.

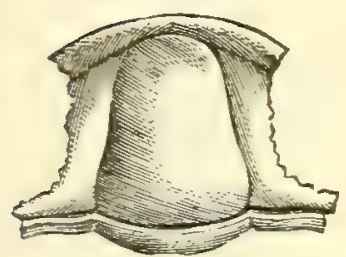

622.

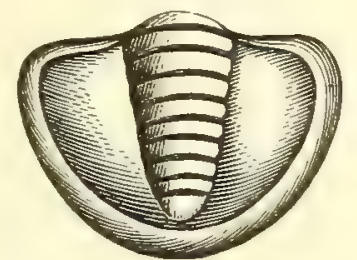

623.

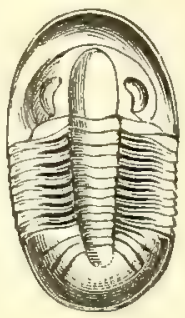

624 .

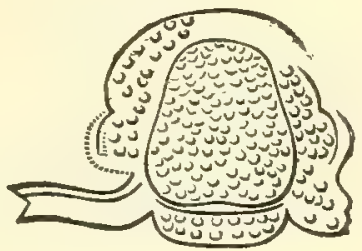

Figs. 621, 622, Bathyurus Saffordi ; 623, Bathyurellus nitidus; 624, Bathyurus (?) crotalifrons. Figrs. 621-623, Billings ; 624, Dwight.

6. Crustaceans. - Among Trilobites, Bathyurus Saffordi B. (Figs. 621, 622) is common in Canada, and occurs also in Newfoundland and Idaho; B. crotalifrons at Rochdale, N.Y.; B. armatus, Quebec and Saratoga County, N.Y.; Ptychaspis speciosa, Ptychoparia Calcifera, P. Hartti, are other Saratoga County species. Bathyurellus nitidus B. (Fig. 623 ) is from Cow Head, Newfoundland. None of these species occur in the Trenton.

The Calciferous fossils reported by S. Calvin from the Lower Magnesian limestone of Iowa are Metoptoma alta Whitfield, Straparollus Claytonensis Calvin, S. pristiniformis Calvin, Raphistoma Pepinense Meek, R. multivolvatum Calvin, Holopea turgida Hall, Orthoceras primigenium V., O. Luthei Calvin.

\section{Chazy Epoch.}

In the Chazy limestone occur small concretion-like forms (Fig. 625) having the structure represented in Fig. 626, which are supposed by some to be of vegetable origin, and by others, a Sponge or the secretions of Hydrozoans.

The Corals of the period include Cyathophylloids, a tribe that dates from the early Cambrian; massive columnar Corals of the genus Columnaria; and species with quadrangular cells, of the genus Tetradium - this name, from the Greek for four, referring to the form of the cells (see Fig. 707, page 511, for a Trenton species).

625.

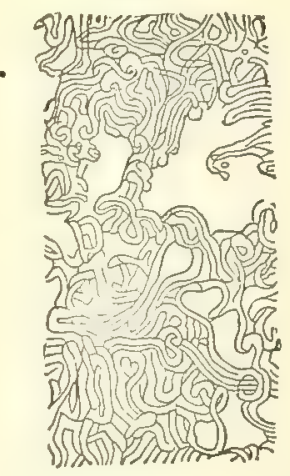

Fig. 625, Girvanella ocellata; 626, interior enlarged. Seely.

One of the Cystoids is represented in Fig. 628, and the body of a Crinoid in Fig. 627. The stem is wanting in each. 
1. Molluscoids. - Fig. 630 shows a branching coral-like species of Bryozoan, Sulcopora fenestrata H., and Fig. 629 one of the reticulate kinds, Subretepora

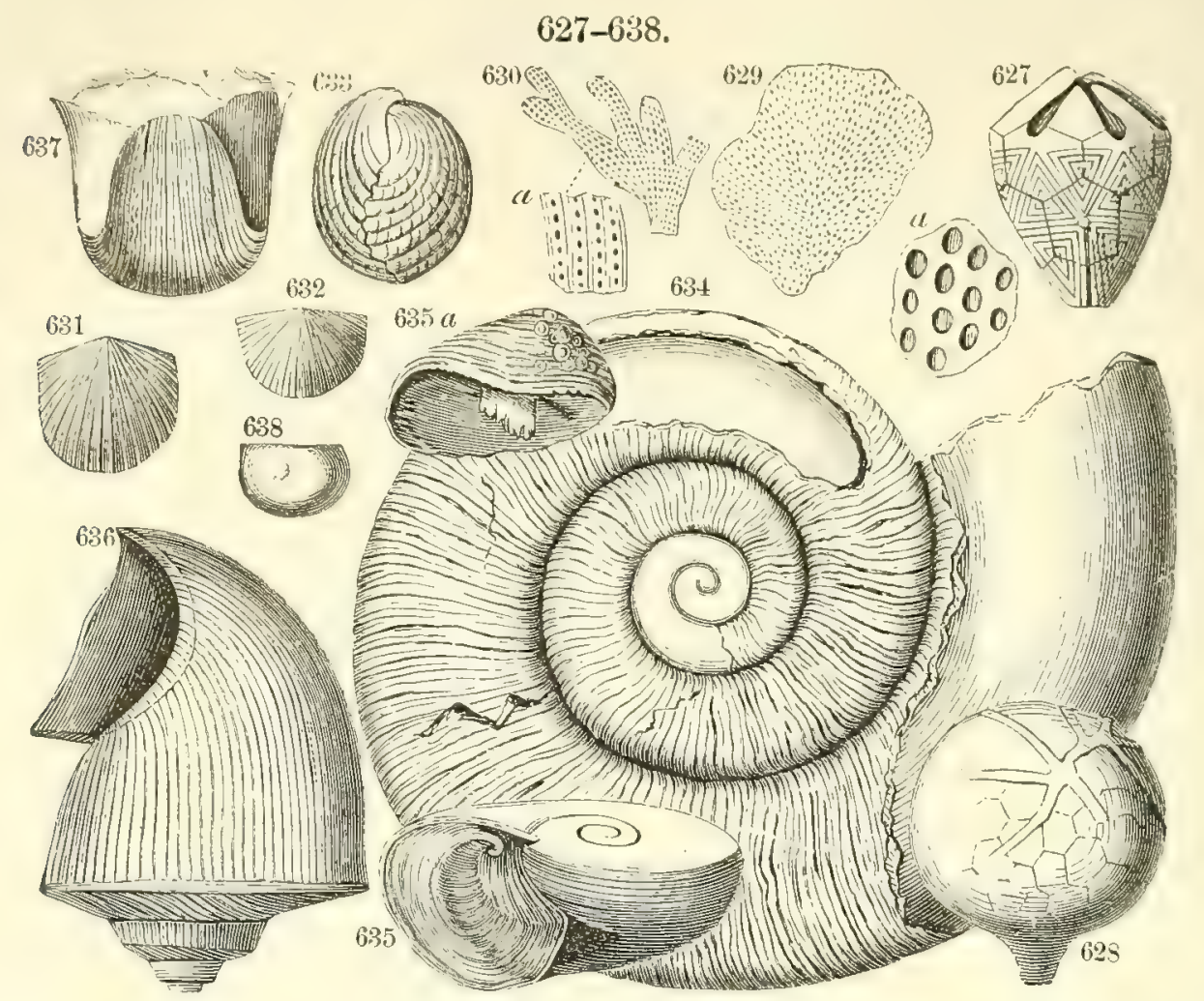

CRINoIDs. - Fig. 627, Palæocrinus striatus; 628, Malocystites Murchisoni. MolluscoIds. - 629, Subretepora incepta; 630, Sulcopora fenestrata; 631, Orthis costalis; 632, Strophomena plicifera; 633, Rhynchonella plena. Moluusos. - 634, Maclurea naagna; 635, M. Logani $\left(\times \frac{1}{3}\right)$; $635 \alpha$, operculum of same; 636 , Scalites angulatus; 637, Bucania rotundata. Crustacesns.-638, Leperditia Canadensis, var. nana. Figs. 627, 628 , Billings; $629-634$, and 636,637 , Hall; 635 , $635 \boldsymbol{a}$, Salter ; 638 , T. R. Jones.

incepta $\mathrm{H}_{\text {. }}$; and Fig. $\alpha$ for each is an enlarged view of the surface. Some of the common Brachiopods are Orthis costalis H. (Fig. 631), Strophomena (?)

639.

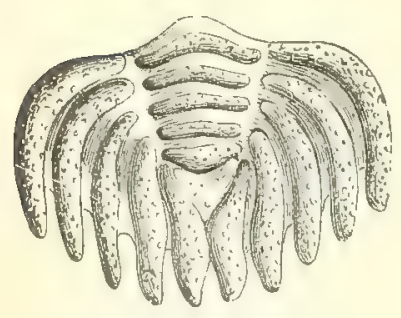

Amphion Canadensis. Billings. plicifera, H. (Fig. 632), and Rhynchonella plena H.

2. Mollusks. - Figs. 634 to 637 show the forms of various Gastropods; 634 is the very abundant Maclurea magna; it is often eight inches in diameter. Fig. 635 is a view of another species which shows also the operculum closing the aperture; and $635 \alpha$ is the separated operenlum. Fig. 637, Bucania rotundata, is related to Bellerophon.

3. Crustaceans. - Ostracoid Crustaceans of the species Leperditia Canadensis (Fig. 638) are common.

Several Cambrian genera of Trilobites, Dicellocephalus and others, had disappeared, Bathyurus had lost the prominence it had in the Calciferous era, and the genera Illcenus, Asaphus, Cercumus, Amphion, were continued on with new species. Fig. 639 represents the pygidium of an Amphion.

1. Rhizopods. - Girvanella of Nicholson and Etheridge (1878), made by them doubtingly Foraminiferous, includes, according to its describers, Strephochetus (Figs. 625, 626) 
of Seely (1885), who referred it to the Sponges, and Siphonema of Bornemann (1886), who placed it among the Algre. It is made a calcareous Alga by Rothpletz (1891).

2. Spongiozoans. - Eospongia (Astylospongia) Romeri B. and E. varians B. occur at the Mingan Islands.

3. Actinozoans. - Columnaria incerta B. and C. parva B.; the Cyathophylloid, Streptelasma expansum H.; Monticulipora patula B., M. adhcerens B., from Canada.

4. Echinoderms. - (1) Crinoids. - Palococrinus striatus (Fig. 627), the body, showing the five radiating ambulacral grooves at top; Blastoidocrinus carcharidens $\mathrm{B}$. (2) Cystoids. - Malocystites Murchisoni B. (Fig. 628) has the body nearly spherical (whence the name, from the Latin malum, an apple), the ambulacral grooves irregularly radiating; $M$. Barrandi B., Paloevystites temiradiatus B., which is common, and has been identified but doubtfully, from crinoid stems from crystalline limestone of West Rutland (Am. Jour. Sc., III. iv. 133) ; also P. Dowsoni B., P. pulcher B., P. Chapmani B., from Canada.

5. Molluscoids. - Other species are Rafinesquina incrassata H., which continues into the Trenton Strophomena (?) plicifera H., Rhynchonella acutirostris H., R. altitis H., Rafinesquina fasciata $\mathrm{H}$., in the Upper Chazy; Lingula Lyelli B., L. Huronensis B., etc.; Orthis imperator B., a species nearly $1 \frac{1}{2}$ inches across.

Note. - Hall proposes (1892) the generic name Rafinesquina for the species of Strophomena of the type of $S$. alternata, restricting the name Strophomena to resupinate species like S.planumbona. He applies the name Leptona to forms like S. rhomboidalis, and restores Pander's generic name Plectambonites to species commonly known as Leptcena, as L. sericea and L. transiersatis (Hall, Pal. N. I., vol. viii., Genera of Paleozoic Brachiopoda, 1892).

6. Mollusks. - (a) Lamellibranchs. - Cypricardites (Vanuxemia) Montrealensis B. -a species nearly $1 \frac{1}{2}$ inches long.

(b) Gastropods. - Besides the species figured, other common kinds are Raphistoma planistrium H., Pleurotomaria biangulata H., P. antiquata H., Bucania sulcata (Bucania differs from Bellerophon only in having the outlines of the spire show externally on either side). Metoptoma dubia H., Platyceras auriformis $\mathrm{H}$.

(c) Cephalopods. - Orthoceras rectiannulatum $\mathrm{H}$., also found in the Birdseye limestone; O. tenuiseptum $\mathrm{H}$, septa very thin and rather crowded; O. velox B., Montreal, Mingan Islands; O. diffidens B., Mingan Islands; $O$. Allumettense B. (which is also a Black River limestone species).

7. Crustaceans. - The Trilobites, Illcmus Arcturus H.; Asaphus obtusus H., A. (Isotelus) canalis Conr., New York and Canada, A. marginalis H., and also Quebec group of Newfoundland. Bathyurus Angelini B.; Ceraurus Satyrus B., at Montreal. The earlier genera, Dicellocephatus, Crepicephalus, Menocephalus, Bathyurellus, Loganellus, Nileus, are not represented, so far as known, in the Chazy or later periods.

The Ostracoids, Leperditia Canadensis Jones, Fig. 698, from Grenville, Huntley, and elsewhere in Canada; L. amygdalina Jones, from near L'Original, Canada.

In the gorge of the Kentucky River, near the mouth of Cooper's branch, Ulrich reports a limestone stratum ( $150^{\prime}$ thick) as affording the Chazy species Maclurea magna, Raphistoma planistrium, Rhynchonella dubia H., Sulcopora fenestrata, Leperditia Canadensis, with Orthis sutrocquata Conr. a Trenton species, Orthocerus explorator B. a Quebec species and O. furtivum B. a Calciferous species; with also species of Bathyurus, Dalmanites, Pterotheca, and the Trenton Bryozoan Mitoclema cinctosum Ulr.

Other species described by Billings, in Can. G. Rep. of 1863, are Monticulipora (Stenopora) fibrosa; Rhynchonella orientalis, Camurella varians, C. longirostris, Orthis platys, O. borealis, O. Porcia, O. acuminata, O. disparilis Con. (from the Chazy and Trenton); Pleurotomaria calys, $P$. docens; Illonns globosus, I. Bayfieldi, Spharexochus parvus (from the Chazy and Black River), Hrrises antiquatus. 


\section{Trenton Period.}

\section{Trenton Epoch.}

Plants. - Two of the forms referred to Algæ or Seaweeds are here represented. They are much like the so-called Fucoids of earlier and later time; but whether of vegetable origin is questioned.

640.

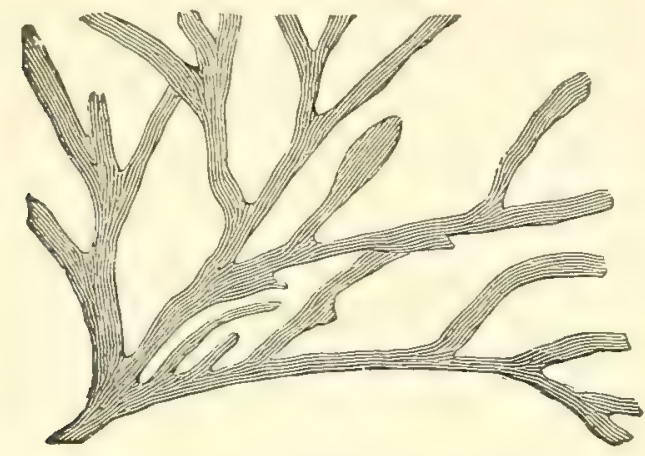

641.

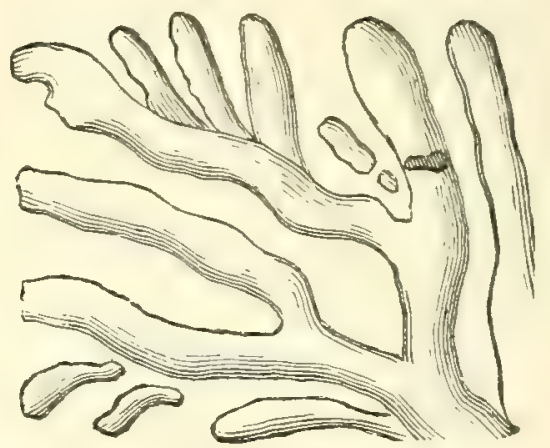

ALGs.-Fig. 640, Buthotrephis gracilis ; 641, B. succulens. Hall.

Specimens of supposed terrestrial plants have been reported from the Cincinnati beds of Ohio and Kentucky; but no certain evidence from fossils of vegetation over the land had been found up to the year 1894 .

642.

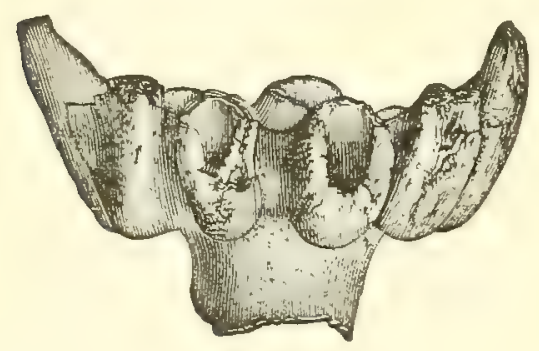

643.

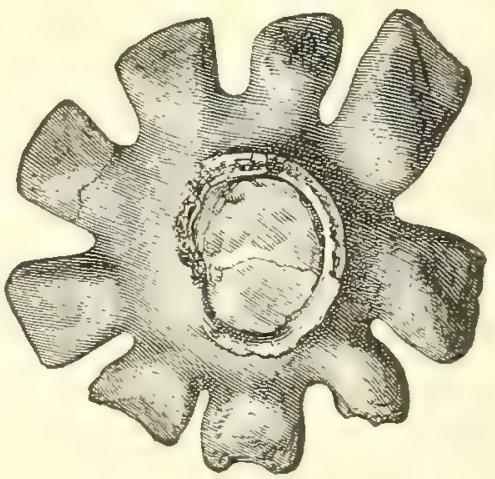

SPonge.-Brachiospongia digitata. Beecher.

Animals. 1. Spongiozoans. - A large branching Hexactinellid Sponge, Brachiospongia digitata, from the Trenton of Kentucky and Tennessee, is represented in different positions in Figs. 642, 643. The number of short branchings varies from 8 to 12 , and specimens having 12 are sometimes $10 \frac{1}{2}$ inches in diameter.

2. Hydrozoans are represented by Graptolites $(647, a)$ and Stromatoporids.

3. Actinozoans comprise Cyathophylloid Corals like Fig. 644, Streptelasma. corriculum H.; and tabulate Corals as Columnaria alveolata H., - the term tabulate referring to the horizontal partitions seen in vertical sections of the columnar cells (Fig. 645). 
There were also many of the minutely columnar Corals, of the Monticulipora family, differing from Choetetes, to which genus they were formerly referred in having the columns separable. Prasopora lycoperdon, Fig. 646, is a hemispherical species, having the structure shown in Fig. $646 a$; others are branching and foliaceous forms. The branching Corals which form the crystalline points called "birdseyes" in the Birdseye limestone are

$644-651$.

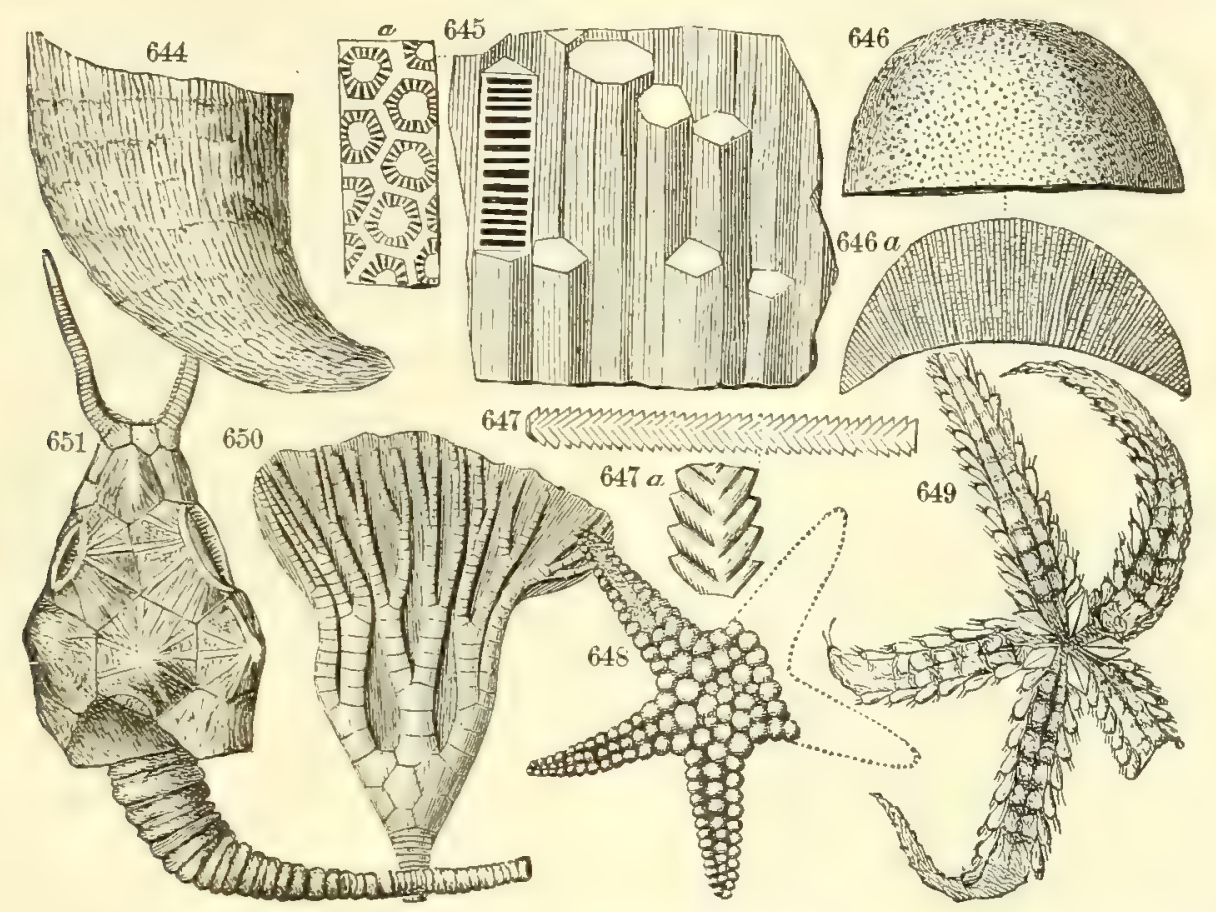

RADidtes. - Fig. 644, Streptelasma corniculum; 645, Columnaria alveolata; $645 a$, surface showing cells; 646 , Prasopora lycoperdon; $646 a$, transverse section of same; 647 , portion of Diplograptus amplexicaulis ; $647 a$, same enlarged; 648, Palæaster matutinus; 649, Tæniaster spinosus; 650, Taxocrinus elegans; 651, Pleurocystites filitextus. Figs. 644, 645, Hall ; 646, 647, Meek ; 648-651, Billings.

referred to the genus Tetradium, distinguished by its four-sided cell with four points within it, as in Fig. 707, page 511. These peculiar fossils were first called Fucoids by Conrad, and later named Phytopsis cellulosa by Hall, the generic name referring to the resemblance to plants.

4. Echinoderms include true Crinoids (Fig. 650), Cystoids (Fig. 651), Asterioids, under which are true Starfishes (Fig. 648), and the Ophiuroids or Serpent-star (Fig. 649).

5. Molluscoids. - Three species of the Trenton Bryozoans are represented on the next page from a memoir by Ulrich (1893); Fig. 652, of a Stictoporella, represents the retiform frond of natural size, and 653 , a portion between two of the spaces much enlarged, showing the cells. Fig. 654 is a jointed branching form from Ottawa, Canada, natural size, and 655 represents three joints much enlarged.

On page 507 are figures of common Trenton Brachiopods of the genera and species named underneath. The figures are mostly from specimens 
obtained in the beds of Cincinnati of the Hudson period, and in part differ somewhat in habit from those of the Trenton limestone.

652.

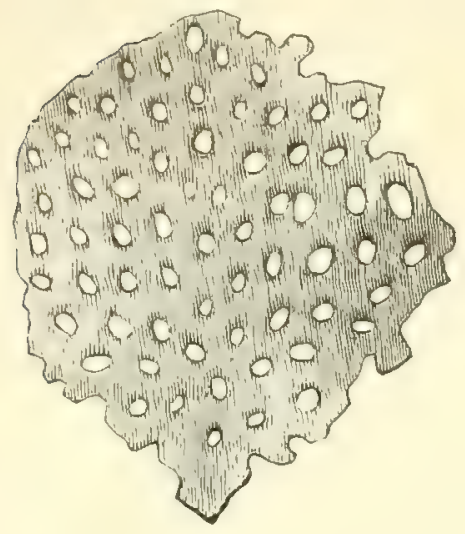

654 .

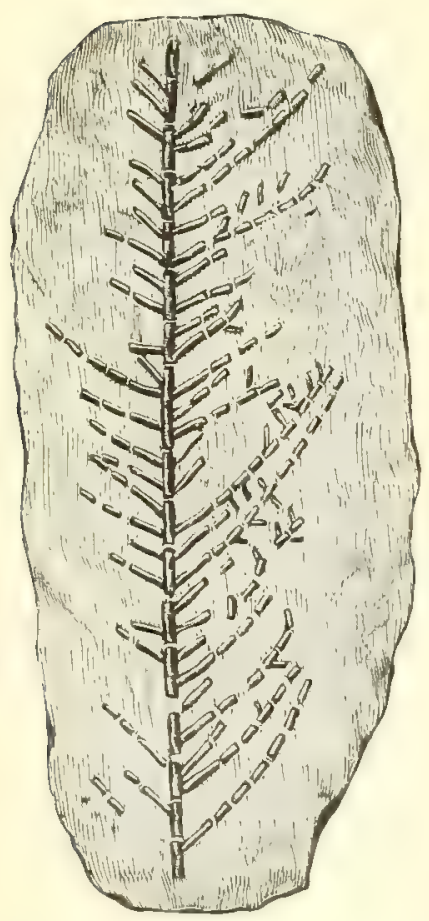

$652-655$.

653.

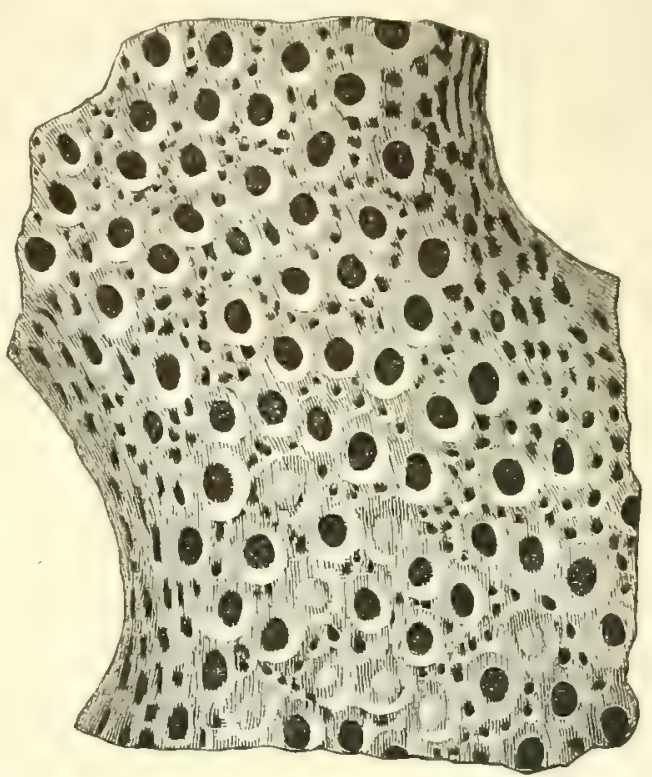

BryozoArs. - Fig. 652, Stictoporella cribrosa (1) ; 653, same ( $\times 18) ; 654$, Arthroclema Billingsi $(1) ; 655$, A. cornutum $(\times 7)$. Ulrich.

6. Mollusks. - Some of the Lamellibranchs are figured in Nos. 670-672, and also 709-712 (page 511); and Gastropods in Figs. 673-681. Fig. 673 represents a $R a-$ phistoma; 674, 675, species of the genus Murchisonia; 677, 678, a Bellerophon in different views; and 679-681, species of the related genus Cyrtolites, symmetrical shells of swimming Mollusks, related to the modern Atlantis (Heteropods).

Pteropods were represented by species of Pterotheca, and of Conularia; in the latter, the shell admits of some movement along vertical sutures (Fig. 682).

A few of the shells of Cephalopods are represented on page 508: Fig. 683, Orthoceres junceum $H_{\text {. }}$; the cross-lines representing the partitions or septa, and Fig. a, a transverse section, showing the position and size of the siphuncle. Fig. 685, part of the shell of Actinoceras Bigsbyi of Bronn (1837); the whole length of the shell when entire was over a foot; the view is of a section showing the large beaded siphuncle within; 686, Cyrtocercs subannulatum D'Orb.; and 687, 688, species of Trocholites, T. undatus and T. Ammonius of Conrad. In another genus, Endoceras, from the Black River limestone, some specimens have a diameter exceeding a foot, and a 
length of 10 or 12 feet. They were the largest and most powerful animals of the seas; but they must have been much encumbered in locomotion by the long bulky shell.

$656-669$.

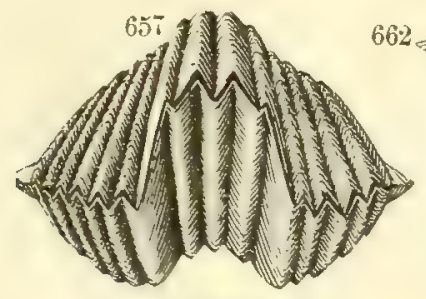

65

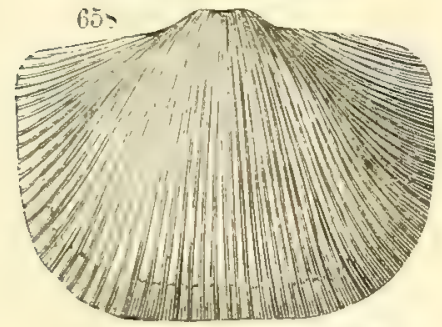

669
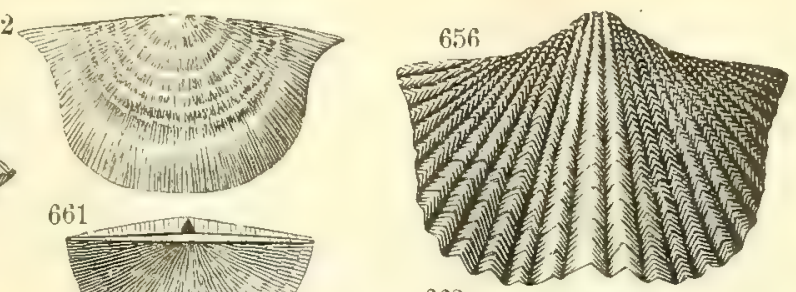

663
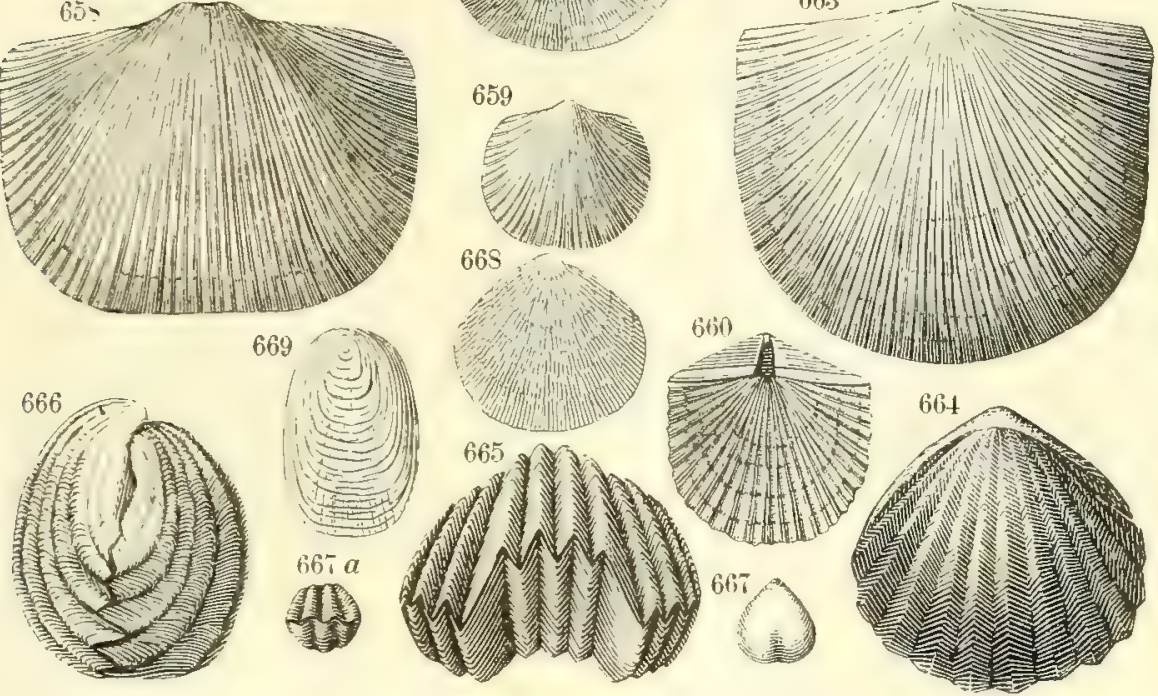

BRAchiopoDs. - Figs. 656, 657, Orthis (Platystrophia) biforata; 658, 0. occidentalis ; 659, O. testudinaria; 660, 0. tricenaria; 661, Leptrena (Plectambonites) sexicea; 662, Leptæena rhomboidalis ; 663, Strophomena (Rafinesquina) alternata; 664-666, Rhynchonella capax; 667, $667 a$, Cyclospira bisulcata ; 668, Schizocrania filosa ; 669, Lingula quadrata. Figs. 656-666 from Meek; 667-669, from Hall.

$670-682$.
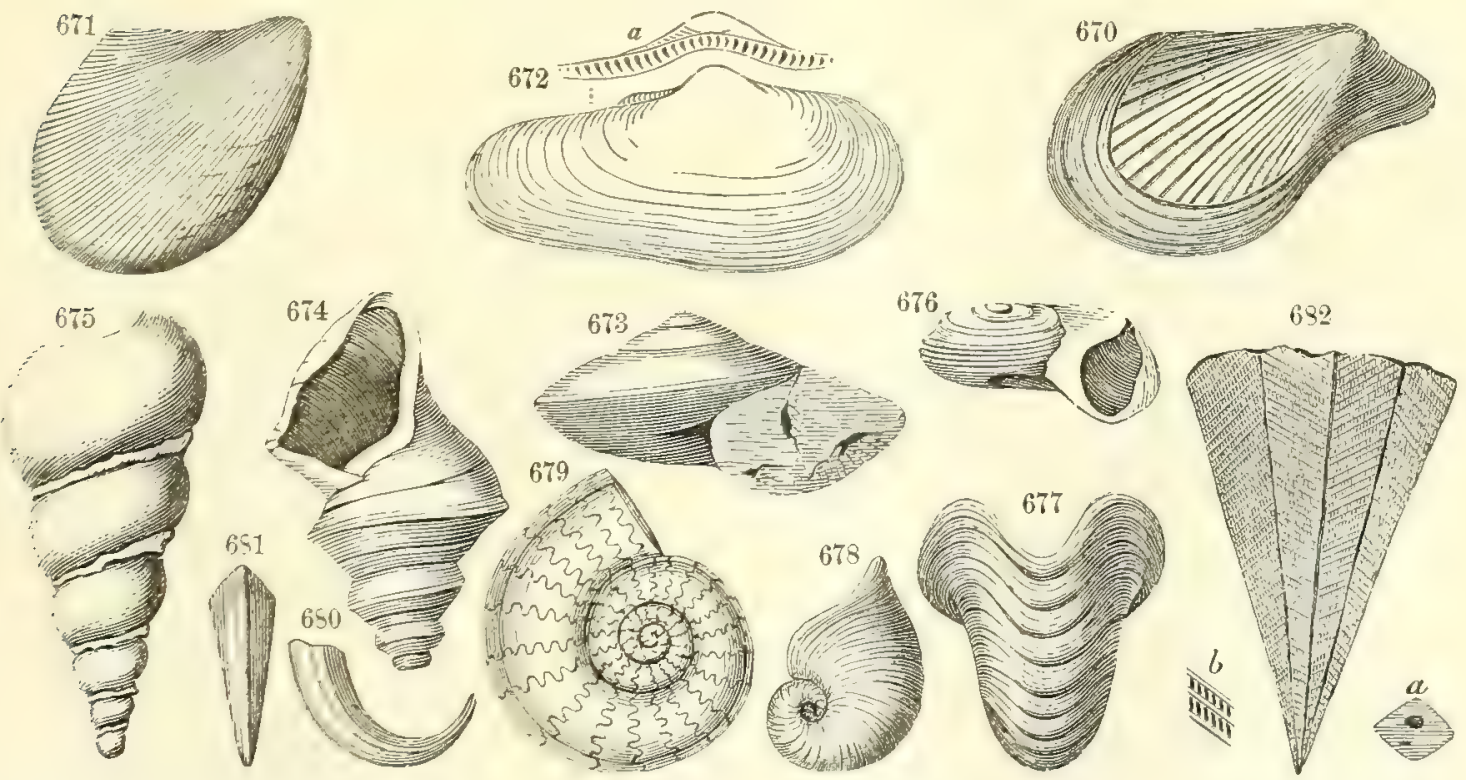

Lameltnifavchs. - Fig. 670, Pterinea Trentonensis; 671, Ambonychia bellistriata; 672, Tellinomya nasuta. Gastropods. - Fig. 673, Raphistona lenticulare; 674, Murchisonia Milleri ; 675, M. bellicincta ; 676, Helicotorna planulata: 677,678 , Bellerophon bilobetus: 679 , Cyrtolites compressus; 680,681 , C. (?) Trentonensis ; 632, $a, b$, Conularia Trentonensis. Figs. 670, 671, 677-682, Hall ; e72, Billings ; 673, 675, Meek ; 674, 676, Salter. 
The genus Orthoceras had many later species. But Endoceras, of which there are over twenty described American species, began in the Canadian and ended in the Trenton period.

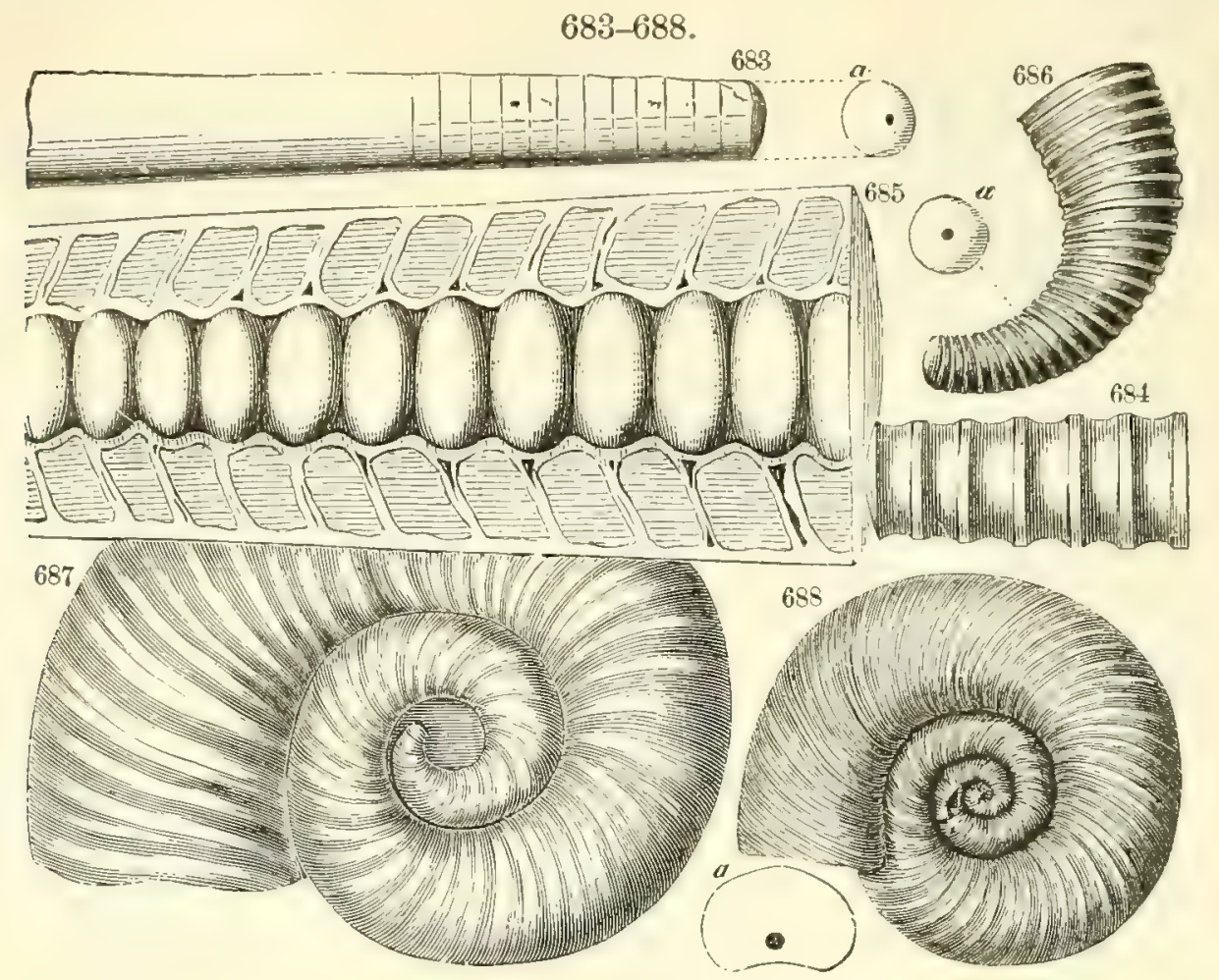

CePHalopons. - Fig. 683, $a$, Orthoceras junceum; 684, O. olorus $(\times 1 / 3) ; 685$, Actinoceras Bigsbyi ; 686, $a$, Cyrtoceras subannulatum D'Orb. ; 687, Trocholites undatus; 688, T. Ammonius. Figs. 683-687, Hall; 688, D.

7. Crustaceans. - Trilobites were of varied forms and many new genera; Asaphus, a Calciferous genus, holds on; and so also Illcenus, Ceraurus, and Bathyurus; the latter two have their last species in the Trenton. Fig. 689 represents Asaphus platycephalus, from Trenton Falls, N.Y., which is often

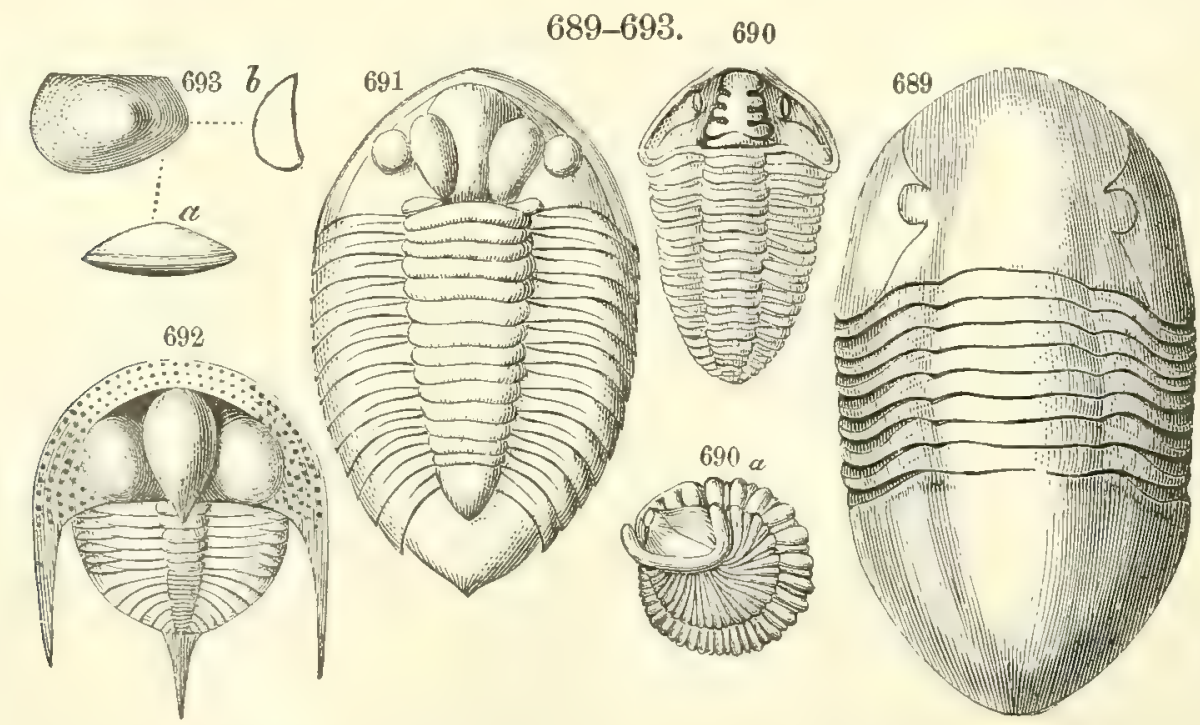

Crustaceans. - Fig. 659, Asaphus (Isotelus) platycephalus $(\times 1 / 3) ; 690, \boldsymbol{a}$, Calymene callicephala; 691, Lichas Trentonensis; 692, Trinucleus concentricus; 693, $a, b$, Leperditia fabulites (natural size). 689, 691, Hall; 690, 692, Meek; 693, T. R. Jones, 
eight inches long; Calymene (Figs. 690, a) is still more common, -690a showing it rolled up, as is often the case (like a modern Oniscus among Crustaceans); 691, a Lichos; 692, Trinucleus concentricus (the name referring to the three prominences on the head, and its fillet-like border); all are found at Trenton Falls. Another common Trenton species is the Ceraurus pleurexanthemus Green. Fig. 694 represents an under view of the shell - the exuvia of the Trilobite. Walcott states that out of 1160 specimens found by him, only 50 lay with the back upward, - a natural consequence of their being mere empty exuviæ, as they would be likely to float like a boat, with the concavity upward.

Crustaceans of the Ostracoid tribe are not rare. A Leperditia is represented in Fig. 693.

8. Fishes.-Remains of Fishes, the earliest knownVertebrates, occur in rocks of the Trenton period. The discovery was announced by Walcott in 1891. The fossils are

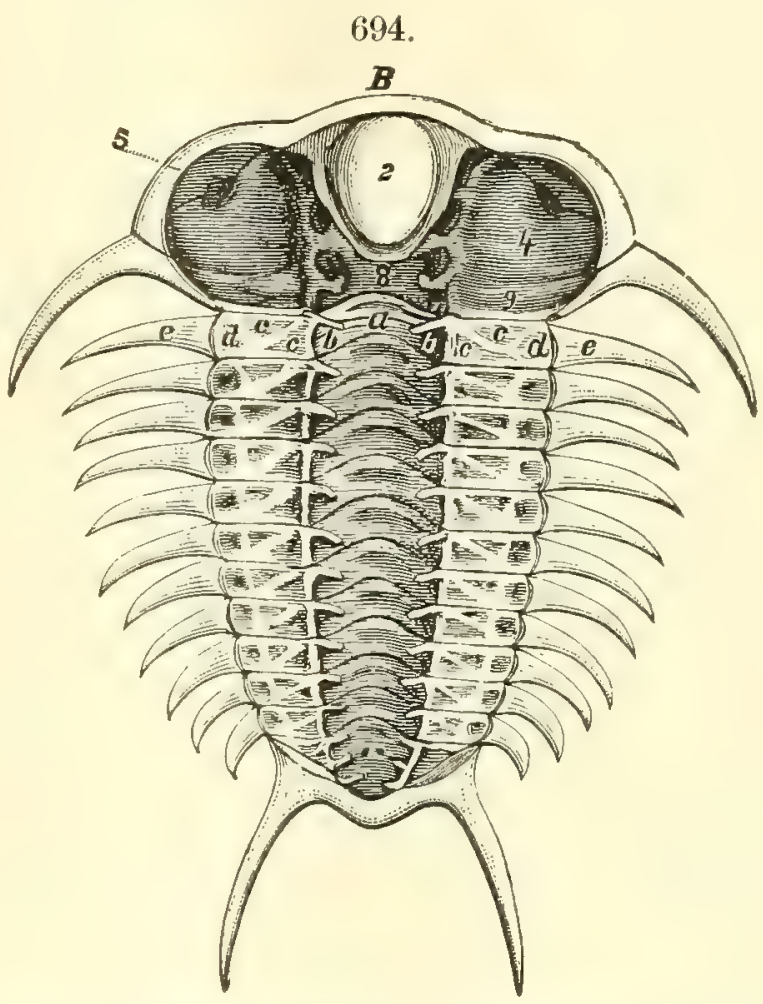

Trilob ITE. - Fig. 694, Ceraurus pleurexanthemus, under surface, natural size : 2 , the hypostome; 4,5 , occipital depression and cavity; $a, b, c, d$, depressions in the shell of the thorax; $e$, free pleuræ. Walcott, '75. abundant in sandstone near Cañon City, Col. Most of them are the plates and scales of Ganoids, the largest about half an inch across. Of

695.

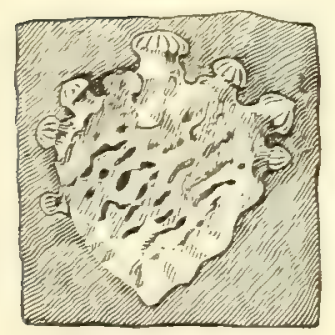

$697 a$

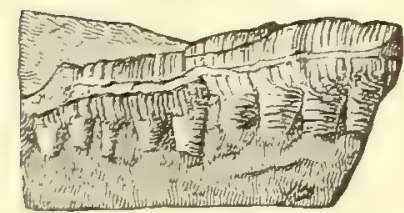

$695-697$.

$695 \alpha$
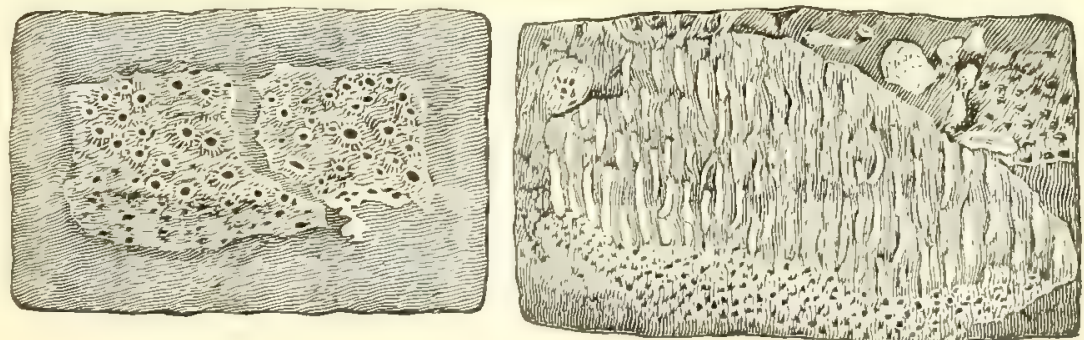

697.

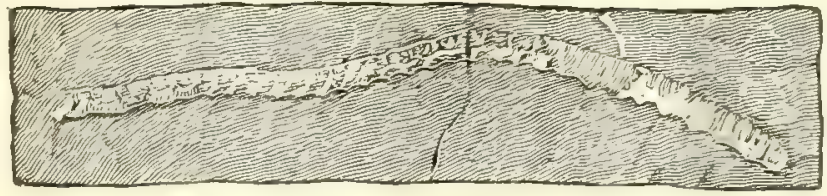

Rumatrs of Fishes. - Fig. 695, Astraspis desiderata, dermal plate; $695 \boldsymbol{a}$, id. (× 3); 696, Eriptychius Americanus $(\times 4) ; 697,697 a$, Dictyorhabdus priscus, supposed notochord. Walcott. 
these plates, two, represented enlarged in Figs. 695, 695 a, are referred to Placoderms (see page 417), the group which comprises the oldest Fishes previously known, those of the Upper Silurian and early Devonian. The scales, Fig. 696, have the markings of a typical Ganoid, much like those of the genus Holoptychius, a form not found hitherto in beds earlier than the Middle Devonian. Besides these, there are remains (Figs. 697, 697 a) of what are supposed to be the ossified sheaths of the notochord of a species of the Shark tribe related to the Chimæra (page 416). The beds affording these remains of Fishes contain many other fossils that are referred to the Lower Trenton, and are overlaid by others carrying Upper Trenton fossils.

\section{Utica and Hudson Epochs.}

Graptolites abound in the shales of the Utica and Hudson groups, especially the former. Thirty species or more have been described from the Utica slate, and some of these are represented in Figs. 698-702.

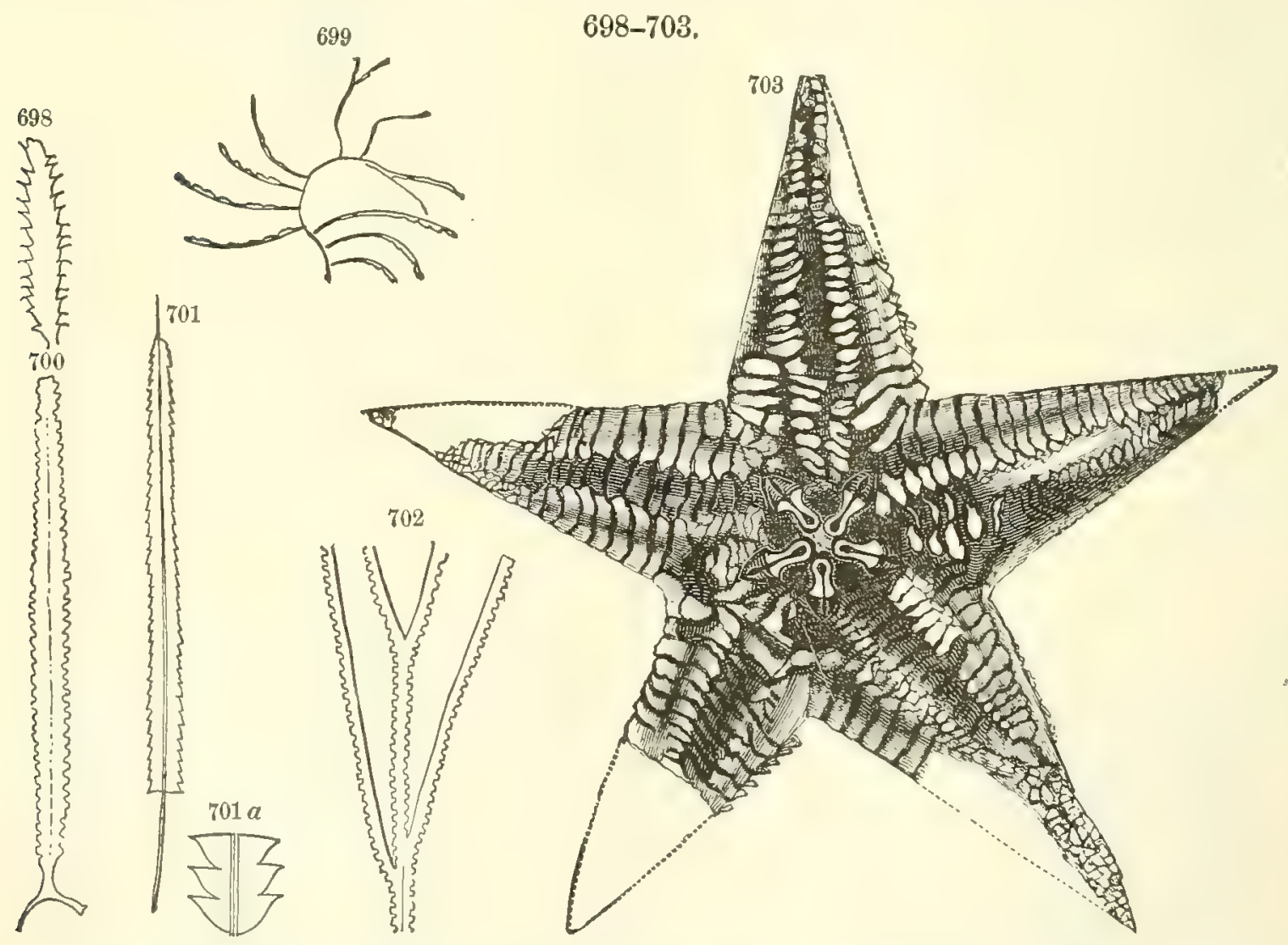

Graptolites. - Fig. 698, Lasiograptus (Diplograptus) mueronatus; 699, Cønograptus gracilis; 700, Climacograptus bicornis; 701, $701 a$, Diplograptus pristis; 702, Dicranograptus ramosus. AsteriolD, - Fig. 703, Palaaster Jamesi. Figs. 698-702 from Hall; 703, J. G. Anthony.

Corals occur of several genera. Favistella, Fig. 704, is a massive Coral, with crowded stellate cells. Halysites, Fig. 705, grew in vertical plates, intersecting one another; in a transverse section the cells look like the loops of a chain, whence the common name chain coral. Another Coral grew in 
clustered stems, Fig. 706, with the cells above stellate. A species of Tetradium, T. fibratum of Tennessee, is represented in Fig. 707.

Minutely columnar Bryozoan corals of the Monticulipora tribe were rery numerous, 70 or 75 species having been described from the Cincinnati beds.

$704-708$.
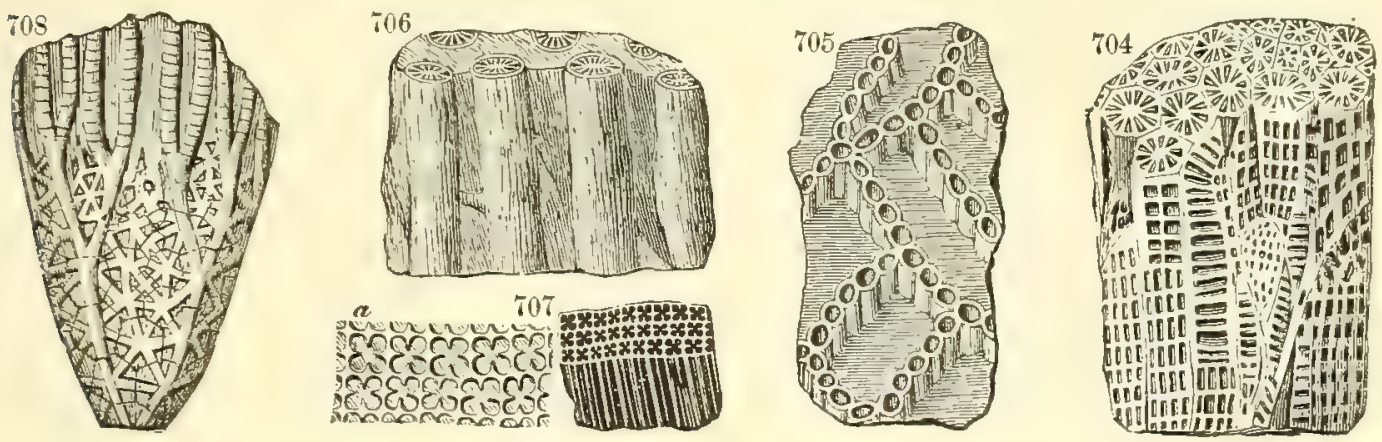

Fig. 704, Favistella stellata; 705, Halysites gracilis; 706, Sarcinula (?) obsoleta; 707, $\boldsymbol{a}$, Tetradium fibratum; 708, Glyptocrinus decadactylus. Hall.

The Echinoderms included Crinoids and Cystoids of several kinds. Fig. 708 represents a fine Glyptocrinus, one of the most common; and Fig. 703, a remarkable Star-fish from the Cincinnati beds, Palceaster Jamesi D. Two other fine Star-fishes from the same locality ( $P$. Dyeri Meek and $P$. magnificus

$709-712$.

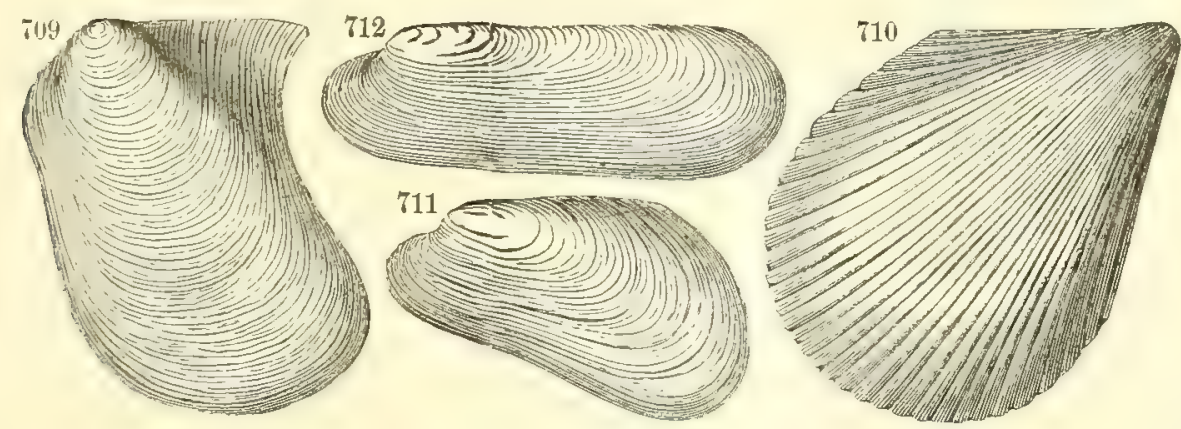

LAMellibravchs.-Fig. 709, Avicula demissa ; 710, Ambonychia radiata ; 711, Modiolopsis modiolaris (x $\frac{2}{3}$; 712, Orthodesma parallelum. Hall.

Miller) have a diameter of about six inches. Bryozoan corals also are common in the Cincinnati beds.

The Brachiopods are nearly the same as in the Trenton.

Lamellibranchs are rather common, they being usually more abundant in shales and shaly sandstones than in limestones. Some of the kinds are shown in Figs. 709-712.

Of the Gastropods represented on page 507, Figs. 673-675 are also Hudson group species; and the same is true of the

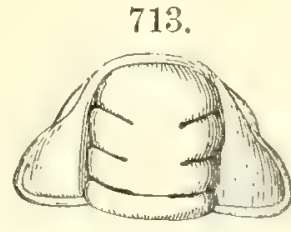

Head-shield of Triarthrus Beckii. Lituites (Trocholites) Ammonius, Fig. 688. Of Cephalopods, the Cincinnati beds have afforded 13 species of Orthoceras, 5 of Endoceras, 4 of Lituites, and 10 of other genera. 
The Trilobites include Asaphus platycephalus, Fig. 689; a still larger species, A. megistos Locke, over a foot long, the Calymene of Fig. 690, Lichas of Fig. 691, and Trinucleus of Fig. 692.

The most common species is the Triarthrus Beckii, and the remains usually found are simply the head-shield, represented in Fig. 713. The
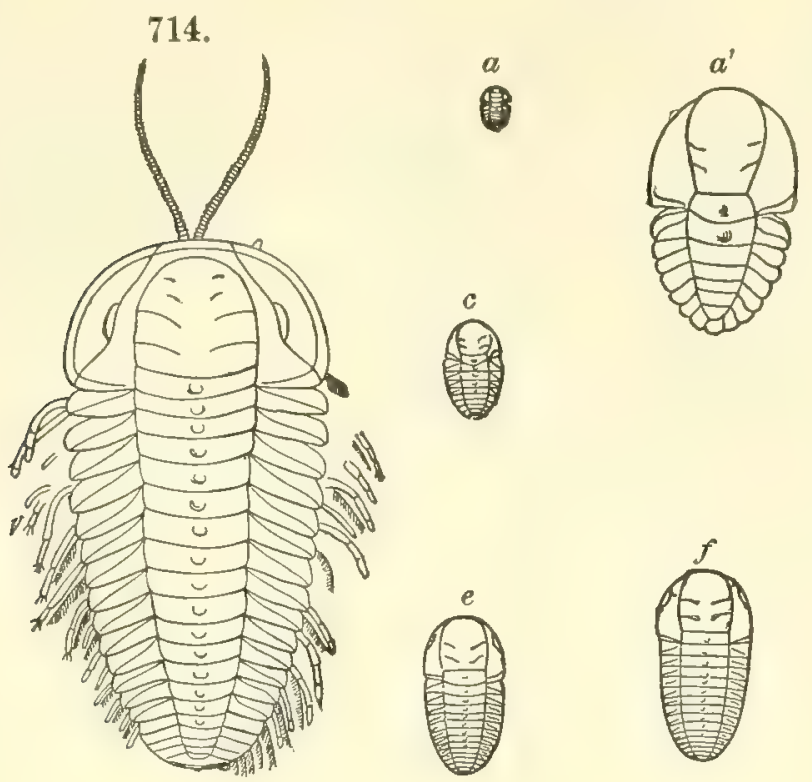

715.
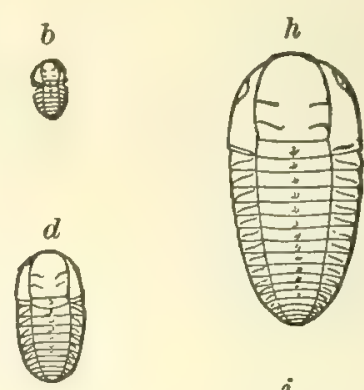

Trilobires. - Fig. 714, Triarthrus Beckii, nat. size; 715 , $a$ to $i(\times 3)$, young of same, at different stages of growth; $a$, the youngest stage $(\times 15)$. Fig. 714 , Beecher; $715, a$ to $i$, Walcott.

nearly entire Trilobite, having its tentacles and many of its legs protruded, found as yet at but one locality on the continent, - near Rome, N.Y., is shown in Fig. 714, from a sketch by C. E. Beecher. Less perfect speci-

716.

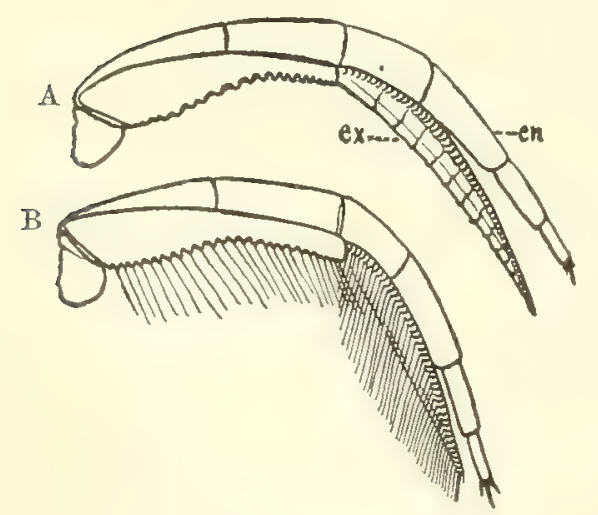

Fig. 116. A, B, leg of Triarthrus Beckii $(\times 12)$; A, leg with the setre remored to show the articulations, en, the main stem of the leg (endopodite); $e x$, the natatory branch (exopodite). Beecher. mens, from the same place, as figured by Matthew, are represented on page 422 . The legs of the left and right sides of Fig. 714 are from two different specimens, but are not in any respect "restored." Each has, as made known by Beecher, two branches, and one of them is fringed, and thereby natatory in function. The natatory branch is strietly an appendage to the basal joint of the other branch, which is the true leg. In Fig. $716 \mathrm{~A}$ the fringe is removed to show the articulations; in $716 \mathrm{~B}$ the limb is in its entire state. Beecher's observations make

717.

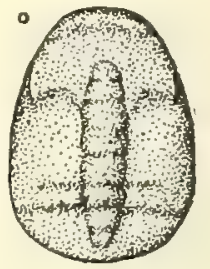

Embryonic form of Triarthrus Beckii ( $\times 30)$. Beecher.

certain the close relations of Trilobites to Isopod Crustaceans, as stated on pages 421,422 . 
Under Fig. 715 are figures of the young Trilobite at different stages of growth, as made out by Walcott - all magnified three times excepting $a^{\prime}$, which is the stage a magnified 15 times. In this young stage the thorax has but one thoracic segment, and this has a short spine on the back; the following five segments are abdominal. The other figures ( $b$ to $i$ ) have an increasing number of thoracic segments. Walcott figures 12 of these stages of growth below the adult, and nine are here reproduced. Beecher has observed a still younger stage having no thoracic segment, represented, magnified 30 times, in Fig. 717.

Other genera of Trilobites of this epoch are Ceraurus, Acidaspis, Proetus, Dalmanites, and Cyphaspis.

718.

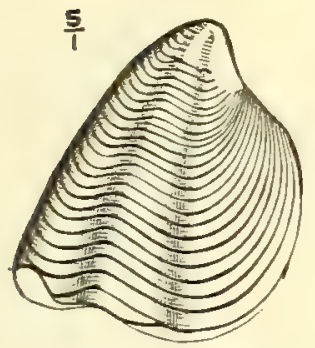

Crrripeds. - Fig. 718, Turrilepas Canadensis, a single plate $(\times 5)$.

Besides Ostracoids of several genera, there were also the first known species of the Barnacle or Cirriped tribe - the Turrilepas Canadensis Woodward. The specimen figured (Fig. 718), representing one of the pieces of the shell, was from near Ottawa, Canada.

The Utica slate has afforded the first specimens of the Eurypterids - species remotely related to Crustaceans, and peculiar in having five pairs of large legs projecting either side of the head whose basal joints serve as jaws (page 556). Fig. 719 rep-

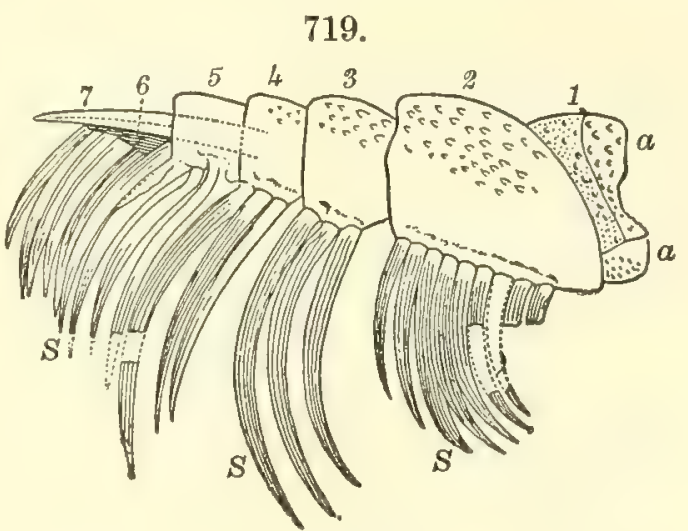

Fig. 719, Leg of Echinognathus Clevelandi. Walcott. resents a leg of one of the pairs; and as it is half the natural size, the whole animal was probably more than a foot long. Its fringe of spines aided it in swimming, and perhaps also in securing its food. Entire specimens of other species of the tribe are shown on pages 556,564 .

\section{Characteristic S Species.}

\section{Trenton Epoch.}

1. Spongiozoans. - Receptaculites Oweni H., characteristic of the Galena limestone, with $R$. glohularis H., R. Iowensis Owen. Astylospongia parvula Bill., near Ottawa City, Canada; Brachiospongia digitata (Fig. 642) is from a paper by C. E. Beecher, which is illustrated by 6 plates, published by the Peabody Museum of Yale College. The species was first described and figured by Troost in 1839 ; named Scyphia digitata by D. D. Owen in 1858, and Brachiospongia Roemerana by Marsh in 1867. Beecher also describes in the same paper two other species of Sponge under the generic name Strobilospongia; they occur with the preceding. The most recent observations of Rauff make the supposed relations of the Receptaculites to the Sponges very doubtful.

2. Actinozoans. - Fig. 644, Streptelasma corniculum H., S. profundum Con., Trenton limestone; S. apertum B., Black River limestone. Hig. 645, Columnaria alveolata Goldf., Black River limestone, and Trenton; C. Halli Nicholson, Kentucky ; C. calicina Nicholson, 
from Kentucky ; Figs. 646, 646 a, Prasopora 7ycuperdon; Halysites catenulatus or related, Galena limestone, and in Canada; Tetradium columnare H., Tennessee.

3. Hydrozoans. - Fig. 647, Diplugraptus amplexicanlis H., New York and Tennessee; 647 a, enlarged; Climacograptus; Stromatocerium pustulosum Saff., Tennessee. Solenopora compacta B., Canada, eastern New York, Kentucky, looks like a pebble, and a limestone made largely of them resembles a conglomerate. It occurs abundantly at Pleasant Valley, in Dutchess County, N.Y. (Dwight).

4. Echinoderms. - Fig. 648, Palceaster matutinus H., of the Trenton; 649, Taniaster spinosus B.; the Crinoids, Taxocrinus elegans B. (Fig. 650), Agelacrinus Billingsi Chapman, Glyptocrinus decadactylus H., Kentucky, Schizocrinus nodosus H., Heterocrinus Canadensis B.; also species of genera Hybocrinus, Porocrinus, Palacocinus; and the Cystoids, Comarocystites Shumardi M. \& W., Missouri, C. punctatus B., Canada; Dendrocrinus retractilis Walc., Trenton Falls, Calceocrinus Barrandei Walc, ibid.; Merocrinus typus Walc., ibid., Iocrinus crassus H., ibid.; Fig. 651, Pleurocystites filitextus B., Amygdalocystites, Kentucky.

5. Molluscoids. - (a) Bryozoans. - Species of Stictopora and Ptilodictya (related to Figs. 629,630 ) are common; Clathropora flabellata H. ; Stomatopora arachnoidea H.

(b) Brachiopods. - Figs. 656, 657, Orthis biforata Schl.; 658, O. occidentalis H.; 659 , O. testudinaria Dalm.; 660, O. tricenaria Con., O. disparitis H., O. subquadrata $\mathrm{H}$. , and others; 661, Leptona (Plectambonites) sericea Sow.; 662, Leptana rhomboidalis Wilc.; 663, Strophomena (Rafinesquina) alternata Con., S. incrassata H. ; 664-666, Rhynchonella capax Con.; 667, 667 a, Cyclospira bisulcata Emm.; Zygospira modesta Say; 668, Schizocrania filosa H.; Crania scabiosa H., Galena limestone; 669, Lingula quadrata Eichw., and other species; also species of Orbiculoidea, Trematis, etc.

6. Mollusks. - (a) Lamellibranchs. - Tellinomya alta H., Wisconsin, etc. ;'Ambonychia attenuata H., Wisconsin, and others; Conocardium immaturum B., Black River limestone, Ottawa; Modiolopsis faba H., M. superba Bill., Wisconsin, etc.; Cypricardites Niota $\mathrm{H}_{\text {. }}$, Wisconsin, C. rectirostris.

(b) Gastropods. - Fig. 673, Raphistoma lenticulare Emm., very common; Pleurotomaria subconica $\mathrm{H}$., and other species; 674, Murchisonia Milleri; 675, M. bellicincta H., often 4 inches long, M. gracilis H., M. tricarinata H.; 676, Helicotoma planulata Salter, Canada, Cyclonema bilix Con., Ophileta Owenana M. \& W., Galena limestone; 67\}, Bellerophon bilobatus Sow., common; 678, same, side view; 679, Cyrtolites compressus Con.; 680,681, Cyrtolites (?) Trentonensis Con. ; species of Metoptoma, a genus which began in the Cambrian, Holopea, Trochonema, Eunema, Subulites, etc. Maclurea magna (Fig. 634), Trenton of middle Tennessee (Safford); Chiton Canadensis B. is a Metoptoma, Black River limestone, Canada.

(c) Pteropods. - Pteropods were represented by the earliest known of the straight, slender shells called Tentaculites; $T$. incurvus of Shumard is from Trenton beds in Missouri and T. Sterlingensis and Oswegoensis of M. \& Worthen and T. Richmondensis of Miller, from the Cincinnati group. There were also Conularix, and species of the Theca family. Fig. 682, Conularia Trentonensis H.; Pterotheca attenuata H. ; Theca pariuscula H., Wisconsin; Hyolithes, frequently having septa within in the smaller extremity.

(d) Cephalopods. - Fig. 683, Orthoceras junceum H.; O. anellum Conr., (Cycloceras nnellum of Hyatt); 684, O. olorus H.; 685, Actinoceras Bigsbyi of Bronn is Ormoceras tenuifilum of Hall, from the Black River limestone; good specimens show a transverse row of foramina in each of the subdivisions of the beaded siphuncle, common in the Black River limestone; Endoceras proteiforme H., Gonioceras anceps H. Endoceras (кépas, horn, and $\epsilon^{\prime} \nu \delta o \nu$, within) has a concentric structure of cone within cone in the siphuncle. Fig. 686, Cyrtoceras subannulatum D'Orb. ; $a$, a transverse section; Fig. 687, Trocholites undatus Hyatt $=$ Lituites undatus Hall, from the Black River limestone, referred to 
Trochoceras of Barrande by Foord, and named T. Halli Emm.; Fig. 688, Trocholites Ammonius Hall, from the Trenton, at Middleville, N.Y. Whiteaves has described and figured several species of the Orthoceras family from Manitoba, from the vicinity of Winnipeg Lake and elsewhere (1891).

7. Worms. - Serpulites dissolutus B., Trenton, Canada; Salterella Billingsi Saff., Tennessee.

8. Crustaceans. - Fig.689, Asaphus platycephalus DeKay ; Fig. 690, Calymene callicephala Green; Dalmanites (Phacops) callicephalus H.; Fig. 691, Lichas Trentonensis Con.; L. cucullus M. \& W., Illinois; Fig. 692, Trinucleus concentricus Eaton; Ceraurus pleurexanthemus Green; Illanus crassicauda Wahl., New York and Illinois ; I. Taurus H. Other genera are Bathyurus, Triarthrus, Acidaspis, Encrinurus, Harpes, Proetus.

Fig. 698, Leperditia fabulites Con., New York, Canada, and Tennessee; L. armata Walc. ; L. Canadensis Jones ; Beyrichia bella Walc., Trenton Falls.

9. Vertebrates. - For Walcott's account of the discovery of the remains of Fishes in the Trenton of Colorado see Bull. Geol. Soc., iii., 153, March 15, 1892. It was announced to the Biological Society of Washington, at a meeting, February 7, 1891. The remains were first found in the Harding sandstone, near Harding quarry, within a mile of Cañon City. They also occur in Helena Cañon, 18 miles to the north-northeast. The section at the latter place, above the Archæan gneiss, consists of $22 \frac{1}{2}^{\prime}$ of arenaceous limestone with thin layers of chert, containing Upper Cambrian fossils; 51' of a similar rock, with Calciferous species, of the genera Ophileta, Straparollus, etc.; 101' of sandstone - the Harding sandstone - containing the plates of Placoderms and Lower Trenton fossils ; $110^{\prime}$ of massive arenaceous limestone; a thin band of Carboniferous limestone. The section is repeated many times in the cañons, removing all doubt, says Walcott, as to the stratigraphic position of the Harding sandstone. There are no strata of the Upper Silurian or Devonian series at either of the localities.

The characteristic species of the Galena limestone include Receptaculites Oweni H., Halysites catenulatus, Lingulela Iowensis Owen, Clitambonites Americanus Whitf., Murchisonia major H., Fusispira ventricosa H., F. elongata H., Maclurea cuneata Whitf., $M$. subrotunda Whitf.

\section{Utica and Hudson Epochs.}

Figures representing the supposed terrestrial plants described by Lesquereux from the rocks of the Cincinnati group near Cincinnati, O., and Covington, Ky., are contained on page 198 of the last edition of this work. Dr. Newberry, after an examination of the specimens, published the same year his opinion against them.

1. Spongiozoans. - Cyathophycus reticulatus Walc. and C. subsphericus Walc. from the Utica slate, Oneida County, N.Y. Trans. Albany Inst., x., 18, 1879. Species of Pasceolus, Astylospongia, Microspongia, Receptaculites, Brachiospongia.

2. Actinozoans. - In the Hudson beds, Favistella stellata H., Fig. 704 ; several species of Cotumnaria; Cyathophylloids of the genus Petraia, as in the Trenton; also of the genus Zaphrentis, Z. Canadensis B.; Halysites gracilis H., Fig. 705, from Green Bay, Wis.; Sarcinula? obsoleta H., Fig. 706 ; Tetradium fibratum Saff., from Tennessee, etc., Figs. $707,707 a ; T$. cellulosum, the Birdseye species from Kentucky.

3. Hydrozoans. - The species of Graptolites figured on page 510 are a few from the large numbers afforded by the Utica and Hudson shales. The specimens for figures 699 , Conograptus gracilis, and 702, Dicranograptus ramosus, besides others, were from the Normanskill shales near Albany. The age of these shales has been questioned by Lapworth on paleontological grounds (Trans. Roy. Soc. Canada, iv., pages 167-172). The New York State gerlogists have considered the beds to be equivalent to the IIudsun River. or the Utica shales, or to both. Lapworth refers the Graptolites to his "Conograptus zone" of Llandeilo age, equivalent to the Black River and Trenton limestones. The same beds 
at Cincinnati, holding Conograptus gracilis and three other species of Normanskill Grap. tolites, also contain Triarthrus Beckii and other characteristic Utica species (Ulrich, Am. Geol., i.).

4. Echinoderms. - Among Crinoids, Fig. 708, Glyptocrinus decadactylus H., not uncommon in New York, Ohio, Kentucky, and other states; also Dendrocrinus Cincinnatiensis Meek, and species of the genera Heterocrinus, Porocrinus, Carabocrinus, Reteocrinus, Canistrocrinus, Stenocrinus, Ohiocrinus, Iocrinus, Anomalocrinus, Merocrimus. Fig. 703 represents a large Star-fish from the blue limestone of Cincinnati, as figured by J. G. Anthony, the original of which was 4 inches across.

There are also Cystoids of the genera Agelacrinites, Lichenocrinus, Hemicystites, all sessile species, and in this respect Actinia-like; also Star-fishes of the genus Palacaster, etc.

5. Brachiopods. - The figures of Brachiopods on page 507 are from specimens obtained in the Cincinnati beds. Other characteristic species are Lingula quadrata, Crania scabiosa, Zygospira modesta.

6. Mollusks. - (a) Lamellibranchs. - Cypricardites Sterlingensis M. \& W.

(b) Gastropods. - Murchisonia Milleri H.; Cyrtolites ornatus Con., near Fig. 679 ; C. imbricatus M.\& W., Illinois; C. carinatus Miller and others; Cyclonema bilix Con.; $C$. Cincinnatiense Ulr., etc.; Pleurotomaria Ohioensis H., etc.; Cyclora parvula H.; also species of the genera Trochonema, Helicotoma, Metoptoma, etc.

(c) Pteropods. - Species of Tentaculites, T. tenuistriatus M.\& W., and T. Oswegoensis M. \& W., from Illinois, in the Cincinnati group; Theca parviuscula, H.; Conularia for mosa M. \& D. ; C. Trentonensis $\mathrm{H}$.

(d) Cephatopods. - Some of the species, besides those figured, are Orthoceras amplicameratum H.; O. coralliferum (4 inches hroad); O. transversum Miller; Gomphoceras eos H. \& Whitf., from Cincinnati; Actinoceras (Ormoceras) crebriseptum Hall; Endoceras proteiforme H.; Trocholites Ammonius.

\section{Crustaceans. - Asaphus platycephalus; A. Canadensis Chapm.}

Ostracoids occur of the genera Leperditia, Cytheropsis, Beyrichia, Primitia.

Some of the genera and species from the Cincinnati beds are the following: Coenograptus gracilis H., Fig. 699 ; Dendrograptus gracillimus Lesq.; D. tenuiramosus Walc. ; Dicranograptus ramosus H., Fig. 702 ; Diplograptus Whitfieldi H.; D. spinulosus H.; Climacograptus typicalis $\mathrm{H}$. ; species of Zaphrentis ; Inocaulis arbuscula $\mathrm{U7v}$.; the Trenton species, Glyptocrinus decadactylus; Heterocrinus Canadensis; H. geniculatus; species of Palcaster, Protaster, Codaster; of Lingula, Strophomena, Orthis, Rhyncho. nella, Crania; Tellinomya alta; Fig 709, Avicula demissa; Ambonychia radiata; species of Lyrodesma, Modiolopsis, Orthodesma; Conularia Trentonensis, C. formosa M. \& D., Fusispira terebriformis, Endoceras proteiforme, Cyrtoceras ornatum; Trinucleus concentricus, Calymene Christyi H., Dalmanites breviceps H., Proetus parviusculus H.; species of Primitia, Beyrichia, Leperditia, Cytheropsis.

In the Eureka district, Nevada, according to Walcott, the Pogonip limestone, which rests on the Cambrian and is $2700^{\prime}$ thick, contains in the lower part a mixture of Potsdam and Silurian species; the genera Dicellocephalus, Agnostus, Ptychoparia being largely developed, and some species identical with Wisconsin Potsdam species; and with these are Acrotreta gemma and some other Calciferous species; but above the middle of the Pogonip beds the characteristic Cambrian features are absent, and there occur the genera Receptaculites, Monticulipora, Pleurotomaria, Maclurea, Cyphaspis, Bathyurus and Asaphus; and still higher the genera Orthis, Strophomena, Cyrtolites, Orthoceras, Endoceras, Tellinomya, Amphion, Ceraurus, Asaphus, Leperdetia, Beyrichia, which appear to indicate the horizon of the Lower Trenton, or the Chazy. Between the Pogonip limestone and the Devonian there are $500^{\prime}$ of Eureka quartzyte and $1800^{\prime}$ of Lone Mountain limestone, and only Halysites catenulatus has been found here. See Walcott, U.S. G.S. Rep., 4to, 1884. 
The fossils discovered by $\mathbf{A}$. Wing in the Taconic formation in the limestone of central Vermont were from many localities, and were more or less perfectly determined by Billings of Canada (Am. Jour. Sc., xiii., 1877). Some of them are Pleurotomaria staminea, Pleurocystites tenuiradiatus, Crinoidal disks, and large specimens of Maclurea from West Rutland; Trinucleus concentricus from Hubbardton; from East Cornwall, Stenopora fibrosa, S. Petropolitana, with species of Orthis, Strophomena, Rhynchonella, and Orthoceras, pronounced Trenton by Billings; north and south of East Cornwall, Rhynchonella beds containing pygidia of Trilobites, a large Maclurea, Bathyurus Saffordi; at Bascom's Ledge, 3 miles west of south of West Cornwall, Asaphus canalis, Bathyurus conicus, Maclurea matutina, made Calciferous by Billings; east of Shoreham, Bathyurus extans, Columnaria alveolata, Trinucleus concentricus; in southern Bridport, Asaphus canalis, Bathyuri, Maclurea matutina; in Orwell, Petraia profunda (?), Stenopora fibrosa, and S. Petropolitana, Receptaculites Neptuni; at Ellsworth Ledge, 2 to 3 miles west of Middlebury, a large Orthoceras, Bathyurus Saffordi, and from higher beds B. Angelini, Asaphus canalis, Maclurea, Orthis, Leperditia, Crinoidal stems; 2 miles north of Middlebury, the slightly curved Orthoceras, here figured, natural size, having 40 to 52 septa to an inch (1877); and half a mile to the northwest a large Maclurea. For an account of the discoveries of Dwight and others, see the references already given, page 495 . The discoveries of Walcott were among the latest, and as they were made in the typical quartzyte of Vermont almost down to the Massachusetts line, also in the Eolian limestone just west, in Bennington, Vt., Williamstown, Mass., and

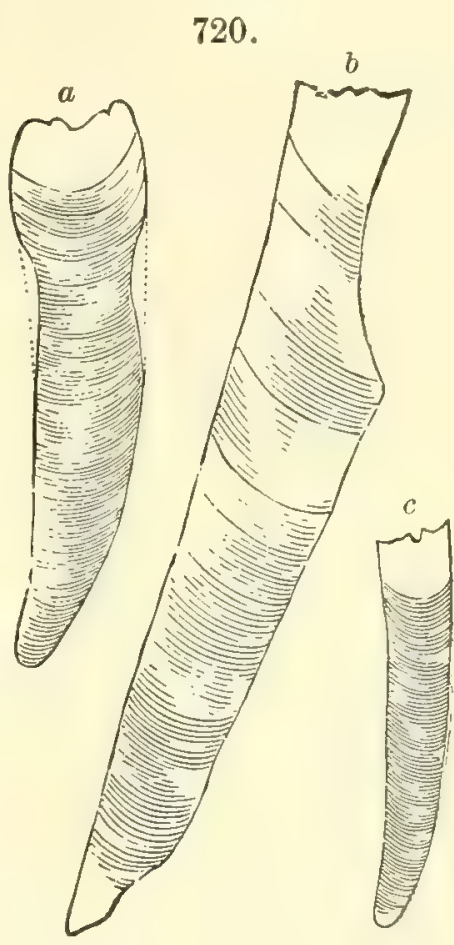

Orthoceras primigenium? in eastern New York, and in other localities in western Vermont and eastern New York, and thus covered all the Taconic formations, the demonstration became complete that the Taconic series is simply a combination of the Cambrian and Lower Silurian.

\section{EUROPEAN.}

The Lower Silurian series of Great Britain comprises, commencing below, the following groups :-

1. The Arenig group (Sedgwick, 1852): slates and flaggy sandstones which rest comformably on the Tremadoc slates of the Upper Cambrian. The beds occur in North and South Wales, and have a thickness of 2500 feet in the latter. The stiper stone beds of Shropshire are here included, and the upper part of the Skiddaw slates. In Merionethshire, North Wales, the volcanic rocks of this period include a lower series of ashes and conglomerates, in some places 3300 feet thick; a middle group of felstones and porphyries 1500 feet thick; and an upper series of fragmental deposits 800 feet.

2. The Llandeilo flags: sandstones and shales of Llandeilo in Caermarthenshire, Wales, where first described by Murchison (1834). - In Westmoreland and Cumberland, or the Lake District, the volcanic deposits of this period, but beginning in the Arenig and continuing through the Baln, 
cover an area of not less than 550 miles and have a thickness of about 8000 feet; the rocks are felsytes, andesytic and other lavas, and volcanic tufa.

3. The Bala (Sedgwick, 1838), or Caradoc group (Murchison, 1839) : consisting of shales, flags, and sandstones, with some limestone. - The Caradoc rocks in Shropshire are about 4000 feet thick, while the Bala, in the Bala district, Merionethshire, have a thickness of only 1100 to 1200 feet, and the chief limestone stratum is only 20 or 30 feet thick near the middle. The Coniston limestone, the equivalent of the Bala, has a thickness of 200 feet. The Upper Coniston beds are Upper Silurian.

In Caernarronshire, northwestern Wales, great eruptions took place in this period, making eruptive accumulations 6000 to 8000 feet thick. The rocks are porphyries, felsytes, andesytes, besides diabases. Ireland, also, had its eruptions.

4. The Lower Llandovery group. The beds have a thickness in South Wales of 600 to 1000 feet, but they are absent from North Wales. They consist of shales, flags, sandstones, and conglomerates. The Upper Llandovery is closely related to the Lower in rocks and fossils. The two were separated, and the former made the base of the Upper Silurian, by Sedgwick in 1853, who called them the May Hill sandstones. This arrangement is adopted by Geikie.

The thickness of the Lower Silurian rocks of Wales has been estimater at 25,000 feet. But over a fourth of this is owing to volcanic contributions, which, as they are of an extraordinary source, should be set aside in comparing the thickness of the sedimentary beds of different regions with reference to elapsed time. In the south of Scotland the thickness is over 16,000 feet.

It is not possible to make out a precise parallelism between the British and American strata. Approximately the Arenig group represents the Calciferous; the Llandeilo flags, the Chazy; the Bala and Caradoc, the Trenton; and the Lower Llandovery, the Utica and Hudson beds.

The Lower Silurian and Cambrian formations of Norway, Sweden, Russia, and Bohemia, which rest upon Archæan rocks, have but little thickness 1000 to 2000 feet; and, adding what denudation may have carried away, 4000 or 5000 feet would be a large estimate for the original amount.

In northern and northwestern France, or Normandy and Brittany, Lower Silurian rocks occur in a much upturned condition. The gres Armoricain is a sandstone, according to Barrois, of the age of the Chazy and Trenton limestones. Below it, and also above it, are shales or slates, and those above may represent the remainder of the Lower Silurian. They are found, also, of similar character in the Asturias, northern Spain, and in the Pyrenees.

In Bohemia, the Lower Silurian of the basin of the Prague is the Stage D, or $2 d$ Fauna, of Barrande. It consists of shales, with some quartzyte and conglomerate below, and has a thickness of about 3000 feet.

In southern Sweden (Scania), the beds are mostly shales, many of the beds Graptolitic, with some limestone; and are divided into a Lower, Middle, 
and Upper Group; and the Christiania district, a Lower Group of Graptolitic shales with sandstone, and an Upper, consisting largely of limestone with some shales.

\section{LIFE.}

Plants. - The figure here given has great interest on account of its representing a specimen of a Lower Silurian plant above the level of a seaweed. It is from the Skiddaw slates. A. Nicholson, the discoverer, described it as a seaweed (Buthotrephis Harknessi), and this it may still be. But Dawson refers it, with reason apparently, to the Marsileaceæ, - at present fresh-water plants of the higher Cryptogams. As the group of leaves resembles the whorl on the stem of an Equisetum, he named the genus Protannularia, the name implying a relation to the genus Annularia of this tribe.

Animals. - The following are figures of a few other fossils. Orthis flabellulum (Fig. 722) oceurs in the Bala limestone. Orthis elegantula (Fig. 723) ranges from the middle of the Lower Silurian (Coniston limestone) to the Wenlock of the Upper Silurian. The Crania (Fig. 724) is from the Bala. Asaphus Powisi (Fig. 726) and Ampyx nudus (Fig. 728) are Llandeilo Trilobites, and Illoenus Davisi (Fig. 727) occurs in the Bala limestone.

721.

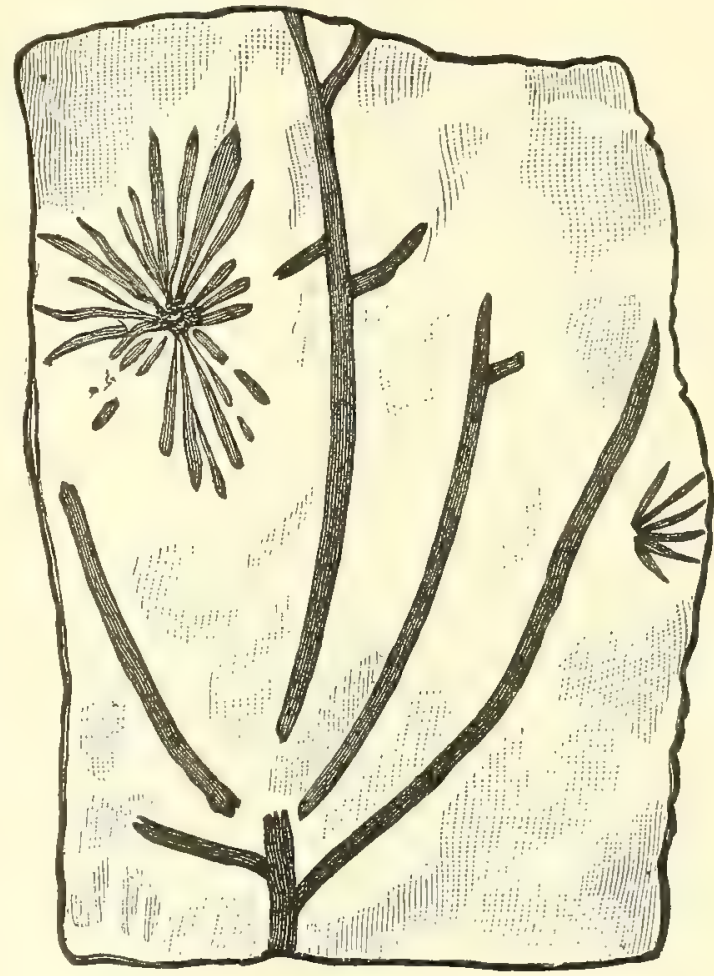

Protannularia Harknessi.

Fig. 729 represents the telson or eaudal segment and appendage of a large Ceratiocaris, C. Angelini, from the upper member of the Lower Silurian in
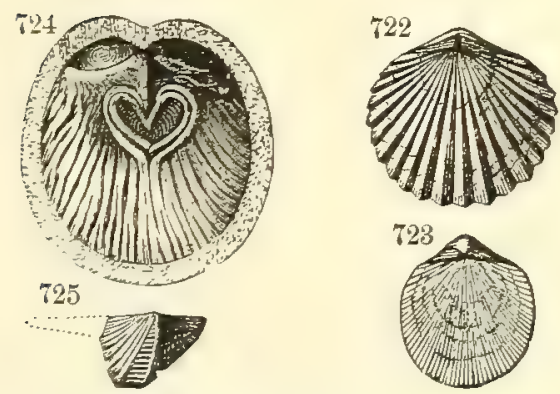
$722-728$.

Brachropods. - Fig. 722, Orthis flabellulum; 723, O. elegantula; 724, Crania divaricata. LAMELlibranch. 725, Conocardium dipterum. Trilobites. - 726, Asaphus Powisi ; 727, Illenus Davisi ; 728, Ampyx nudus.

Sweden. The length of this Crustacean in its entire state must have been fully one foot. 
The earliest of known fossil insects is from Graptolitic slates in the upper part of the Lower Silurian of southern Sweden. It is a Hemipter, and is named by Moberg Protocimex Siluricus (1892).

729.

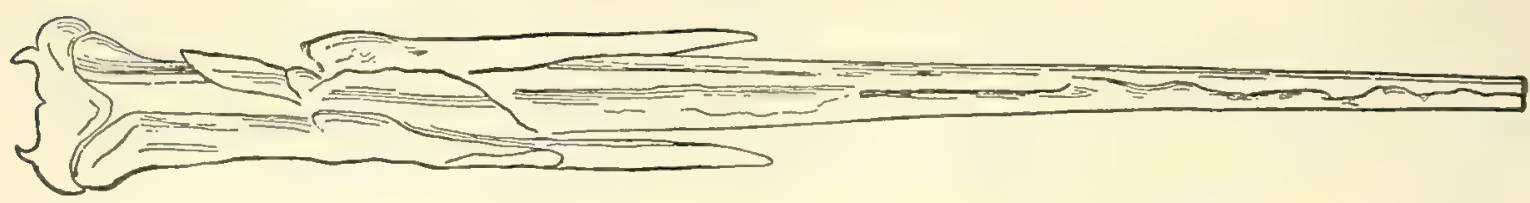

Telson of Ceratiocaris Angelini, nat. size. Jones and Woodward, '88.

\section{Characteristic Species.}

Great Britain. - Arenig group. - The Skiddaw slates of the Arenig group abound in Graptolites of the genera Diplograptus, Climacograptus, Didymograptus, Phyllograptus, Dendrograptus, etc. Other prominent genera and species of the group are: Orthis calligramma, Obolella plicata, Lingulella Davisi; Pleurotomavia, Ophileta, Raphistoma; Bellerophon, Conularia Homfrayi, Orthoceras; Agnostus, Eglina grandis, Ogygia, Asaphus Homfrayi, Ampyx Salteri; also the new genera Tinucleus, Illanus, Barrandia, Calymene, Phacops, Placoparia, Homolonotus.

Llandeilo flays and Lower Bala. - Graptolites of the same genera as in the Arenig; also Halysites catenulatus, Monticulipora favulosa, Favosites fibrosus; Actinocrinus, Echinospharites, Glyptocrinus, Palcaster; Acrotreta, Crania, Leptana, Strophomena, Rhynchonella; Modiolopsis, Ctenodonta, Paladarca, Pleurorhynchus (Conocardium), Ophileta compacta, Murchisonia bellicincta, Euomphalus, Loxonema, Pleurotomaria; Orthoceras, Endoceras, Piloceras; Ogygia Buchii, Asaphus tyrannus, A. Powisi, Ampyx nudus, Barrandia, Trinucleus, Acidaspis Jomesii, Lichas, Illonus, Homalonotus, Cheirurus, Phacops, Calymene Blumenbachii, Alglina mirabilis.

Bala beds, Caradoc sandstone, and Coniston limestone.- Monticulipora frondosa M., Favosites fibrosus, Heliolites interstinctus, Halysites catenulatus, Cyathophyllum, Petraia; Leptona rhomboidalis, Orthis biforata, O. calligramma, O. flabellulum, O. porcata, O. elegantula, Atrypa imbricata, Leptona (Plectambonites) sericea, Crania divaricata; Murchisonia, Holopella, Trochonema, Raphistoma, Cyclonema, Belleropkon bilobatus, $B$. nodosus, B. carinatus (which three species occur also in the Lower and Upper Llandovery); Orthoceras vagans, O. annulatum, O. Barrandii (the three continuing into the Lower Llandovery); Endoceras, Lituites, Cyrtoceras, Trocholites, Piloceras; Illcnus, Phacops, Cheirurus, Lichas, Acidaspis, Ampyx, Agnostus, Harpes, Remopleurides, Calymene Blumenbachii, C. Allportiana, Sphorexochus mirus.

Lower Llandovery group. - Favosites fibrosus, Halysites catenulatus, Heliolites interstinctus, Petraia bina, Orthis Bouchardi, Atrypa, Meristella subundata, Stricklandinia lens, Rhynchonella tripartita, Spirifer plicatellus, S. exporrectus, Strophomena arenacea, Pentamerus oblongus, $P$. undatus, $P$. globosus (the three occurring in the Lower and Upper Llandovery); Illcenus Bowmani, Cheirurus bimucronatus, Trinucleus concentricus, Proetus Girvanensis. Lower Silurian beds occur in the south of Scotland, and also in the northwest Highlands. But in the latter region there is a striking resemblance in fossils, as pointed out by Salter, to forms in Canada and New York - the species including Orthoceras arcuoliratum, Orthis striatula, Ophileta compacta, Murchisonia gracitis, M. bellicincta, and also species of Maclurea, Raphistoma, and others of American type. Moreover, at the same time, the species of northwestern Scotland differed from those of England and Wales. From these facts it is evident that troughs with Archæan confines had the same importance on the British or European border of the Atlantic as on the North American side. We may conclude also that the barrier between northwestern Scot- 
land and the areas to the south and southeast, which could have made its fauna more American than British, must have had great length. According to Etheridge, the Lower Silurian of Great Britain, up to 1885, had afforded 161 species of Hydrozoans, 47 of Actinozoans, 5 of Crinoids, 23 of Cystoids, 6 of Asterioids, 174 of Brachiopods, 18 of Bryozoans, 80 of Lamellibranchs, 19 of Pteropods, 67 of Gastropods, 21 of Heteropods, 66 of Cephalopods, 188 of Trilobites, 31 of Entomostracan and Phyllopod Crustaceans; no Eurypterids, no Insects, no Fishes.

Scandinavia and Russia adjoining. - The area of metamorphic-mostly Archæan - rocks covers, besides the Scandinavian peninsula, the country to and including the White Sea and thence southwest to the Gulf of Finland, thus inclosing entirely the Gulf of Bothnia. The Cambro-Silurian borders this region at the North Cape; also north of St. Petersburg and south of this place westward along the south side of the Gulf of Finland to the Swedish islands of Gotland and Öland in the Baltic, and the adjoining east coast of Sweden. Then, over the interior of Scandinavia, there is a large area on the west side of the mountains from above Trondhjem to the shores south of Bergen; and east of the mountains about Östersund and Christiania, and also at some other points. The beds have in general a thickness of from $1000^{\prime}$ to $2000^{\prime}$. There are in Finland, Stage $\mathbf{B}$ (the first), Graptolitic beds containing Lingula, Siphonotreta, Obolus, the limestones containing Megalaspis, Orthis (O. parva), Orthoceras, Porambonites, Asaphus, Ceraurus, Ampyx, Phacops; in Stage C, Echinospharites, Orthoceras; and above, Orthis (O. lynx), Porambonites, Pleurotomaria, Ceraurus, Phacops; Stage D, with Strophomena, Lichas, Ceraurus, Phacops (Chasmops); Stage E, with Leptcena (L. sericea), Strophomena (S. deltoidea), Orthis (O. testudinaria), Phacops, Encrinurus, Cybele; Stage F, with Orthis, Strophomena (S. expansa), Bellerophon (B. bilobatus), Phacops, Ceraurus, Encrinurus.

France. - The Armorican sandstone of Brittany afforded Lebesconte and Barrois: 3 Trilobites; only 4 Brachiopods, and those of the Lingula family ; over 30 Lamellibranchs, a Bucania, and 3 Ceratiocarids, - but a poor representation of the fauna of the period, because of the impurity in the waters which a sandstone formation indicates. Barrois refers the beds to the age of the Chazy and Trenton limestones of the United States. The Ceratiocarids include: Ceratiocaris, Myocaris lutsaria Salter and Trigonocaris Lebescontei Barrois. The Lower Silurian rocks of Portugal have afforded a very large Trilobite of the genus Lichas. It is named Lichas (Uralichas) Ribeiroi. The total length is estimated to be $560 \mathrm{~mm}$., and $385 \mathrm{~mm}$. without the caudal spine, which is $175 \mathrm{~mm}$. long. (Comm. des Trav. Géol. du Portugal, Fauna Silurica, Lisbon, 1892.) This is the longest Trilobite described; it exceeds 2 feet in length. Paradoxides regina, described by Matthew from the Cambrian of New Brunswick, was estimated to have a total length of $450 \mathrm{~mm}$.

Bohemia. - The Lower Silurian of Bohemia is divided by Barrande into 5 sections. They afford Trilobites of the following genera. (The numbers in parentheses show in which of the 5 sections they occur; and the - and + , that the genus had species also in preceding or later time.) Agnostus $(+1,5)$, Acidaspis ( 1 to $5+)$, Aglina (1 to 5), Amphion (1), Ampyx (5 + ), Areia (2,5), Arethusina (4 + ), Asaphus (1 to 5), Barrandia (1), Bohemilla (1), Calymene (1 to 5 +), Carmon (1,5), Ceraurus (1 to 5 +), Cyphaspis $(5+)$, Dalmanites (1 to 5), Dindymine (1 to 5), Dionide $(1,3,5)$, Harpes $(1+)$; Harpides (1), Homalonotus (2 to 5), Illonus ( 1 to $5+$ ), Lichas $(1,5+)$, Ogygia $(1,5)$, Phacops (4, 5+), Phillipsia (5), Placoparia (1, 2), Proetus (1,5+), Remopleurides (5), Sphorexcochus $(5+)$, Telephus $(4,5)$, Trinucleus (1 to 5), Triopus (2).

In Asia, Silurian beds of the Tibetan Himalayas, described by Salter and Blanford, have a thickness of $6000^{\prime}$, and afford species of Heliolites, Ptilodictya; Leptona. Strophomena, Orthis, Ctenodonta; Holopea, Cyclonema, Trochonema, Raphistoma, Pleurotomaria, Murchisonia, Bellerophon, Theca; Orthoceras, Cyrtoceras, Lituites; Calymene, Sphcerexochus, Lichas, Ceraurus, Illonus, Asaphus, but no American or European species. 
From western China, Richthofen has reported Orthis calligramma, Leptana (Plectamhonites) sericea, Spirifer radiatus, Atrypa reticularis, Favosites fibrosus, Heliolites interstinctus, Halysites catenulatus, etc. In southern Australia, in Victoria, Lower Silurian beds, made $: 35,000^{\prime}$ thick by Mr. Selwyn, have afforded various Graptolites of the common Lower Silurian genera.

\section{ECONOMICAL PRODUCTS OF THE LOWER SILURIAN FORMATIONS.}

Lead Ore, Galena. - The Galena limestone of Wisconsin and the adjoining states on the south and west derires its name from the valuable lead deposits which it contains. Similar deposits occur in the Lower Silurian limestones of Missouri (though not at present profitable like those of the Cambrian and Subearboniferous limestones of that state) and also in Arkansas. The large Joplin mines of Missouri are in the Subcarboniferous. On these deposits see under "Veins," page 342. None of them, as there stated, are of Lower Silurian origin, but of some later, unascertained date.

Mineral Oil and Gas. - Mineral oil and gas come from the decomposition of animal or vegetable materials, when buried and under close confinement from the atmosphere. The Trenton limestone and the Utica and Hudson shales have long been known to afford mineral oil, especially since the early reports on the subject by T. S. Hunt, who rightly referred these substances to organic materials buried in the limestone or shale at the time of their formation $(1861,1866)$. The black color of the Utica shale is due to carbonaceous substances, and oil is easily obtained by heating; and in Collingwood, Canada, there were formerly works for the purpose, 30 to 36 tons of shale yielding 250 gallons of crude oil (at a cost of about 14 cents per gallon) - an amount corresponding to about 3 per cent of the rock (Hunt). At Manitoulin Islands, also, petroleum was early procured by boring. Whitney obtained 21 per cent from the shale of Savannah, Ill.; 11 to 16 per cent from that of Dubuque; and 12 to 14 per cent from that of Herkimer County, N.Y. The oil has been found in Orthocerata at Pakenham, Canada, and in fossil Corals at Watertown, N.Y.

The distillation process was long since thrown aside in consequence of the free supplies of the liquid oil through Artesian borings; and among the productive rocks are some of the Lower Silurian. The idea, now fully substantiated, that the oil and gas are usually to be obtained along anticlinals, was announced in 1861 by T. S. Hunt, and independently by E. B. Andrews.

In Ohio and eastern Indiana the Trenton limestone affords both oil and gas abundantly, but chiefly the latter. The region is within the underground range of the Cincinnati anticline, and the principal Ohio localities are at and near Findlay, 150 miles north of Cincinnati, on the axial part of a portion of the anticline, where it has a local upward bulge or bend; and to this upward bulge in the axis the Findlay region appears to owe its gas-confining power. The borings descend 1100 to 1200 feet to the Trenton limestone, and ouly 15 to 25 feet, or, in some parts, 50 feet, into the rock, a greater depth usually being only sparingly productive. The Findlay wells yielded, in 1886, 
at the rate of 20 to 25 millions of eubic feet of gas per day, and half the whole amount came from a single well, the Karg well. One boring in the vicinity, at Bairdstown, yielded 4,000,000 cubic feet per day when 9 feet down in the limestone, and 12,400,000 when 17 feet down; and the tools "refused to descend deeper, dancing in the well like rubber balls." (Orton, Rep. Econ. G. Ohio, 1888.)

The rock pressure in some parts has been found to equal 650 pounds to the square inch; in the Findlay field it is about 450 pounds; in the Indiana field about 320 pounds. Owing to the pressure, the gas, as it is confined in the Trenton limestone, is greatly condensed, - its volume, if the pressure equals 320 pounds to the square inch, being about $\frac{1}{15}$ th of that after escape.

The productive limestone, as stated by Orton, is in all cases dolomyte. In the Findlay region the composition was found to vary from a ratio, for the calcium and magnesium, of $1: 1$ to that of $2: 1$. The marsh conditions under which dolomyte is formed are favorable for the gentle trituration or maceration of organic materials, and their inclusion in the deposits so made. It is found, also, by Professor Orton, that the limestone is porous, and is thus enabled to contain the oil or gas. Since the conversion of calcyte to dolomyte causes a diminution in bulk of $\frac{1}{10}$ to $\frac{1}{8}$ (page 134), the pores, which are a result of the change, should give the rock great containing capacity - equal, says Orton, to the actual amount afforded.

The amount of marsh gas (ordinary illuminating gas) in the mineral gas of Findlay is about 92.5 per cent; and with this are 2 per cent of hydrogen, 0.3 of olefiant gas, 3.5 of nitrogen, and about 0.5 per cent each, of oxygen, carbonic acid, and carbonic oxide, and $0 \cdot 2$ of hydrogen sulphide. In the region of Lima, Ohio, the limestone yields oil. Salt water, also, comes up in some borings. In the borings water is excluded by tubing. The production of the wells is often greatly increased by lowering torpedoes containing from 20 to 160 quarts of nitro-glycerine to the bottom of the well and exploding them by means of a piece of iron called a "go-devil," which is dropped down the hole and strikes a fulminating eap on the torpedo. The whole process is termed "shooting" a well. The explosion shatters the rock and opens fissures. Thus the area of supply is extended and the yield of oil or gas increased.

In Indiana the natural gas territory adjoins the eastern, or Ohio, boundary for about 65 miles, and has an average width of 50 miles. The porous layer, according to A. J. Phinney, is 1 to 20 feet thick, and lies beneath a non-porous outer layer of the limestone, 1 to 15 feet thick; and the rock is sometimes so open-textured that air may be freely blown through it, and it will absorb $\frac{1}{10}$ or even $\frac{1}{8}$ of its weight of water. In 1890 , the aggregate daily flow of the Indiana gas wells was 779,525,000 cubic feet. (Phinney, U.S.G.S.Rep.) The Trenton limestone has afforded no gas or oil in Kentucky or Pennsylvania.

Marbles. - The Chazy affords black marble in the vicinity of Lake Champlain. The Taconic crystalline limestone yields white and clouded statuary 
and ornamental marble in West Rutland, Dorset, Pittsford, etc., Vt.; architectural marble in Lee, Mass., Canaan, Conn., Westchester County, N.Y., and in Pennsylvania; the Trenton, a beautiful mottled brown and reddish brown marble in east Tennessee in Hawkins County and Knox County ; the lighter spots in it are delicate Corals (Monticulipora, Stenopora, etc.).

Iron ore. - The valuable iron ore, limonite, occurs in great beds along the junction of the Lower Silurian limestone and the overlying Hudson shales in all the states on the line from Vermont to Alabama, and in many places it is worked for the iron. But the ore is a result of the decomposition of the rocks long subsequent to the Lower Silurian era (page 126).

\section{GENERAL OBSERVATIONS ON THE LOWER SILURIAN.}

\section{ROCKS.}

It is a point to be noted that, during the Lower Silurian, the rocks of the Continental Interior over the Mississippi Basin were chiefly limestones; and that in the Trenton period the limestones extended in great force to and beyond the Appalachian protaxis. There is no evidence of their origin at abyssal depths. The beds were mostly made in clear waters near the surface, as in modern coral seas, and at moderate depths, probably not exceeding a few hundred feet. Magnesian limestones prevail below the Trenton, and occur to some extent within this formation; and such limestones (dolomytes) are strong evidence of a sea-marsh condition during their origin, or of shallow sea-border flats, as explained on page 133. Such an origin also explains that fine trituration of all the calcareous relics, which made the magnesian limestone so generally unfossiliferous.

\section{CLIMATE.}

No proof that a marked diversity of zones of climate prevailed over the globe is observable in the fossils of the Cambrian period, or of any part of the Lower Silurian era, so far as yet studied. The difference between the polar regions and the parallel of $40^{\circ}$ was probably not greater than between cold temperate and warm temperate. It has been inferred that some difference in zonal temperature exists from the closer resemblance of fossils of northwestern Scotland to those of Canada (page 572) than to those of England, and the existence of the Gulf Stream of the Cambrian Atlantic is suggested by G. F. Matthew. The following species, common in the United States, and occurring at least as far south as Tennessee, have been found in the strata near Lake Winnipeg: Strophomena (Rafinesquina) alternata, Leptoena (Plectambonites) sericea (?), Maclurea magna, Raphistoma lenticulare, Calymene callicephala, Monticulipora lycoperdon, Receptaculites Neptuni.

The mild temperature of the Aretic waters is evident from the occurrence of the following species on King William's Island, North Devon, and at Depot Bay, in Bellot's Strait (lat. $72^{\circ}$, long. 94 ): Monticulipora lycoperdon, Orthoceras moniliforme H., Receptaculites Neptuni De France, Actino- 
ceras crebriseptum H., besides Maclurea arctica Haugliton, a species near $M$. magna of the Chazy. Moreover, the formation of thick strata of limestone shows that life like that of the lower latitudes not only existed there, but flourished in profusion.

\section{BIOLOGICAL PROGRESS.}

1. General Progress. - During the Lower Silurian era progress in animal life was marvelously great. Before it closed, nearly all the grander divisions of marine invertebrates were represented. And these grand divisions were displayed under nearly all their subdivisions. The Actinozoans were represented by Aleyonoids and Madreporids, as well as by Cyathophylloids; Lamellibranchs, by Monomyaries, related to the modern Avicula and Pecten; Heteromyaries, related to Modiola and Mytilus; Dimyaries, both of the Integripallial section related to Arca and Nucula, and of the Sinupallial section related to Cypricardia and Tellina; Pteropods, by more types and much larger species than now exist; Gastropods, by the species of the Trochus and Pleurotomaria types; Trilobites, by many new genera; and in addition there were Eurypterids of large size. Besides all these, there were Fishes, the first of Vertebrates.

The chief divisions of marine Invertebrates supposed to be absent are: Crustaceans above Entomostracans, that is, the typical Tetradecapods and Decapods; the Dibranchs, or Squids and Cuttles, among Cephalopods; the Echinoids among Echinoderms, and the Actinoids, or modern type of Corals, among the Actinozoans. The exhibition of marine Invertebrates was, therefore, very wide in range and far advanced in grade. There was diversity enough to have afforded material for quite a full work on Invertebrate zoölogy.

But, in addition to life in the waters, there was already life over the land, and life, also, that could fly, and so bring the air above the land into new service. The water-margins and moist places of the growing continents were green with acrogenous plants that gave promise of future forests. Insects, as the one specimen reported proves, were common almost everywhere. Hemipters are the so-called "Bugs" and Aphides. They are incomplete in metamorphosis, like other low-grade Insects, and, therefore, are a kind that might be among the earliest in geological time; but until the discovery in 1892, no fossil Paleozoic species had been reported. It has already been remarked that terrestrial animal species rarely become fossilized; among the rarer of these are Insects, and of the rarest are Myriapods and Spiders, and those Insects that do not frequent water-margins. Myriapods were probably part of the terrestrial population, and perhaps, but less probably, Spiders.

2. Culmination of the types of Graptolites, Cystoids, Pteropods, Trilobites, and Ostracoids. - The Graptolite, Cystoid, Pteropod, Trilobite, and Ostracoid types appear to have reached, in the Lower Silurian era, and passed, their time of highest display. 
Barrande, in his review of the Trilobite Fauna of the Paleozoic, which he published in 1871, made the total number of Cambrian and Silurian species then known 1500; and those subsequently introduced, in the Devonian and Carboniferous eras, about 200. He states that in the Cambrian period the number of species known was 252 in 28 genera; in the Lower Silurian, 886 species in 52 genera, eight of these genera being of Cambrian origin; then in the Upper Silurian - his third Fauna - there were 482 species in 20 genera, but only three of these 20 genera were of Upper Silurian origin, the rest already existing in the Lower Silurian.

The number of known Cambrian species of Trilobites has been inereased since 1871 by more than 200 ; and besides, a larger number of the genera are now known to date from the Cambrian. But still Barrande's conclusion remains right - that the Lower Silurian was the era of maximum development of Trilobites. In North America, the Lower Silurian beds add 215 species and 30 genera of Trilobites; the Upper Silurian only 81 species and three genera; and of these three, two occur in Europe. The type for awhile was the highest of the seas; but that of Cephalopods, of later introduction, had passed it in size, grade, and power before the Lower Silurian era closed. Such facts give strong characteristics to the Lower Silurian, and exhibit its contrast to the Upper.

The Hydrozoans, Actinozoans, and Bryozoans, which usually produce, by multiplication, compound groups of branching and other forms, and show thereby their low grade among species, are rare fossils in the Cambrian as simple individuals, and are wholly unknown in compound groups, although such groups are indicative of low grade, and the Bryozoans are the lowest of the Molluscoids. But in the Lower Silurian era the compound forms after the commencement of the Chazy period were common, and were eminently so during the Trenton period. Ulrich states, after an investigation of the Bryozoans of Minnesota (a few of his figures are reproduced on page 506), that the contributions from them of calcareous material for the Lower Silurian limestones of that state were twice as great as those from the Brachiopods (Rep. L. Sil. Bry. Minnesota, 1893).

\section{UPTURNINGS AT THE CLOSE OF THE LOWER SILURIAN.}

\section{AMERICAN.}

General quiet of the Lower Silurian era. - The strata of the Lower Silurian in eastern North America appear to have been laid down, one over the other, without intervening dislocations. Through the era there were extensive oscillations in the water level, for this is indicated by the varying limits of the formations, as well as by changes in the kinds of rocks; and the exposed beds of one period probably suffered much by denudation before the next were deposited. But these oscillations resulted in no great upturnings of the rocks. The era was one of quiet progress in sedimentary 
deposition from the beginning of the Cambrian to the close of the Lower Silurian; and it was a very long era, possibly as long as all time that has since elapsed. Mountain-making finally ensued, producing, among its effects, the Taconic Mountain Range along western and northwestern New England, and also the Cincinnati geanticline, besides uplifts in Nova Scotia and New Brunswick. Moreover, there is probable evidence that the Taconic Range at the north was but one of a series along the Atlantic border.

The Taconic Range and system. - Some account of the Taconic Range has been given on pages 386, 387. There were great flexures, great faults, and general metamorphism. Fig. 730 represents a section, by Selwyn, extending, near Quebec, from Montmorenci Falls on the northwest and crossing the north channel of the St. Lawrence to Orleans Island.

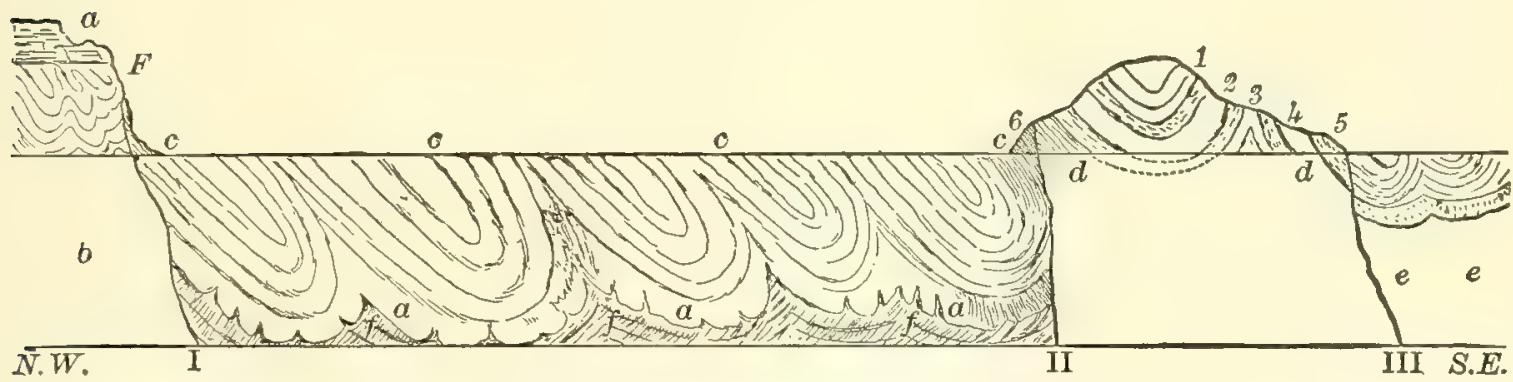

Faulted and plicated rocks from Montmorenci Falls to the island of Orleans and beyond. Vertical scale, 500 feet $=1$ inch ; horizontal scale, $1 \frac{1}{2}$ miles $=1$ inch. Selwyn.

The falls are to the left at F, and I marks the line of one fault. To the left of this fault-line are Archæan rocks overlaid horizontally by 50 feet of Trenton limestone. To the right of it there are Lower Silurian rocks, in a plicated condition, from the Calciferous and Chazy (Quebec group, $f, f, f$ ) at the bottom, through the Trenton limestone $(a, a, a)$ to the Utica and Hudson shales $(c, c, c)$, the upper of these rocks making the bottom of the north channel of the river. To the right, at II, there is a second fault, the main fracture; and at III, a third fault. Between the two is Orleans Island, the beds numbered 6 containing Utica Graptolites; and 1 to 5 , those of the socalled Levis formations of the Quebec group of the age of the Calciferous and Chazy.

From this region faults continue in a south-by-west direction, through Vermont and eastern -New York. They are conspicuous in Vermont, at Snake Mountain, in Addison County, and also south of Shoreham, where the red sandrock rests on Hudson shales (Wing); and in New York at Bald Mountain, and elsewhere in Washington County, near Rhinebeck on the Hudson, and in Dutchess County; and also in New Jersey, a mile west of Otisville, and at the Lehigh Water Gap (G. H. Cook).

Fig. 731 represents the fault at Snake Mountain, as given by A. Wing (1877). To the right of $\mathrm{F}$ is the south end of the ridge of Cambrian red sandrock, called Snake Mountain; to the left are Lower Silurian formations 
in an overthrust flexure, with the Hudson slates $(d)$ lying in the syncline. The fault extends for many miles to the north and south.

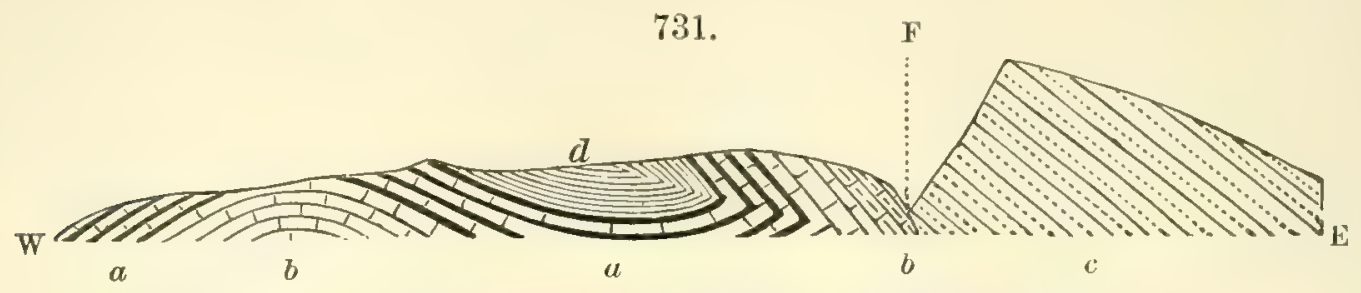

Fault at Snake Mountain, Vt. - F, fault; $a$, Trenton limestone; $b$, Chazy limestone $; c$, Cambrian; $d$, Hudson shales, A, Wing.

The great western fault of eastern New York, as described by Walcott, enters New York from Vermont in Hampton, Washington County, and extends south-southwest to the Rensselaer County boundary line, passing through Argyle to Bald Mountain in Greenwich and beyond. In the fault, as in those of Vermont, the Lower Cambrian strata are upthrust westward over the Silurian. Fig. 732 represents a section of Bald Mountain, as viewed from the south. According to it the plane of the fault dips at the low angle

732.

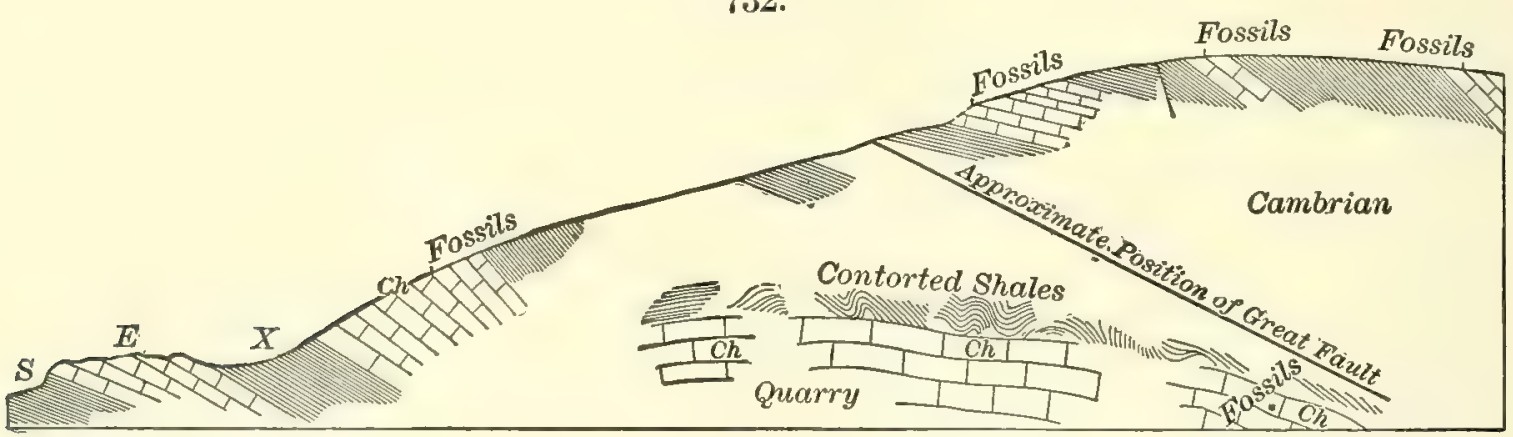

Section of Bald Mountain, the profile as seen from the south. Ch, Chazy limestone; E, Calciferous; X, S, shales. Walcott.

of $25^{\circ}$. To the right are the Cambrian beds, and to the left, the underlying Chazy and Calciferous, and in other localities the Trenton and Hudson formations. Another similar fault, of like westward thrust, and on a nearly parallel line, lies three to four miles farther eastward; and a third, still more to the eastward. The amount of displacement at Bald Mountain is stated to be between two and three miles.

For a map of the Taconic limestone belts, as now existing in part of eastern New York and the associated schists and quartzytes of western Massachusetts and Connecticut, reference may be made to a description of the region in the author's papers of 1880,1881 , and 1885, 1887. The chief belts lie to the west of the Green Mountain Archæan protaxis, and continue west of it into eastern New York, and also, after an interruption, in belts that cross Hudson River into New Jersey and beyond. The largest belt is that of Eolian limestone (or marble) of Vermont, and the Stockbridge limestone of Berkshire, Mass. (so named by E. Hitcheock), lying to the eastward of the main Taconic Ridge. It passes by the east side of Mount Washing- 


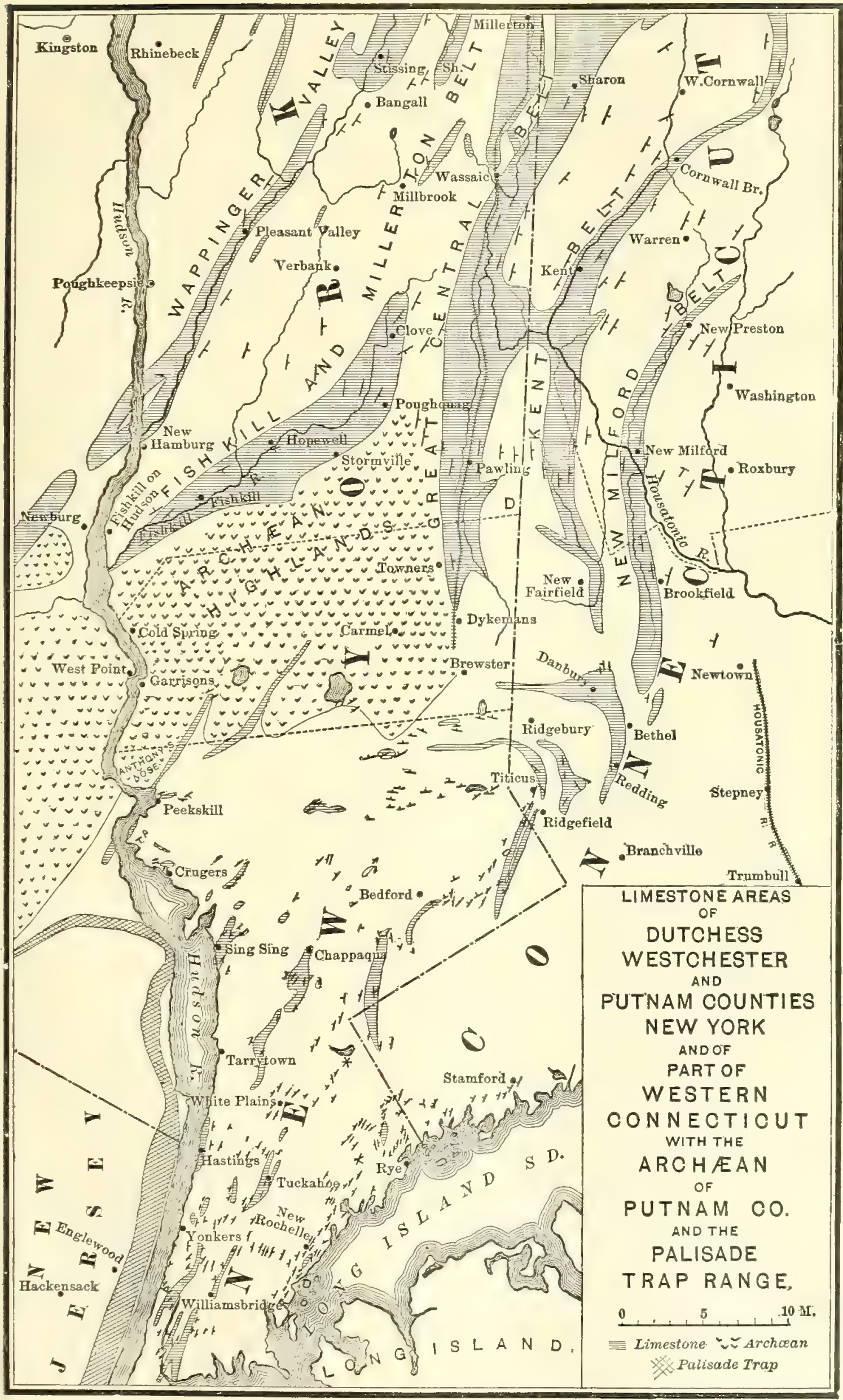


ton, in southwestern Massachusetts, into Canaan and Salisbury in northwestern Connecticut.

The accompanying map (Fig. 733) illustrates the character and positions of the belts of limestone (horizontally lined areas), which extend southward in eastern New York and from Canaan and Salisbury in Comecticut. The area corered with $\mathbf{V}$ symbols is mainly Archæan. It is a continuation of the New Jersey Highlands (a part of the protaxis); it crosses the Hudson, between Peekskill and Fishkill, N.Y. West of the Kent Belt of limestone there is an area of gneiss and other schists and some limestone of Archæan age, between borders of Taconic schists and quartzyte. The crosslined area, west of the Hudson, is the Palisade belt of trap.

At the northeast corner of the map, in Canaan (a town lying mostly to the north of the northern limit of the map), the southern part of the great Stockbridge belt divides. The chief branch extends southwestward into eastern New York, and then southward to Dykemans, where it ends against the Archæan, after an interval of mica schist. Just west of the Taconic Ridge are other belts of limestone. The first of these is a western portion of the limestone belt of Stockbridge and West Stockbridge; for the limestone east of the Taconic Ridge dips under the schist of the mountain, and comes again to the surface, through a synclinal flexure; the character of the syncline is illustrated for the Mount Washington region, in Fig. 103, page 105.

In further illustration of the synclines of the Taconic Range, Figs. 734, 735 are here introduced. Fig. 734 represents the general structure of Grey-

734.
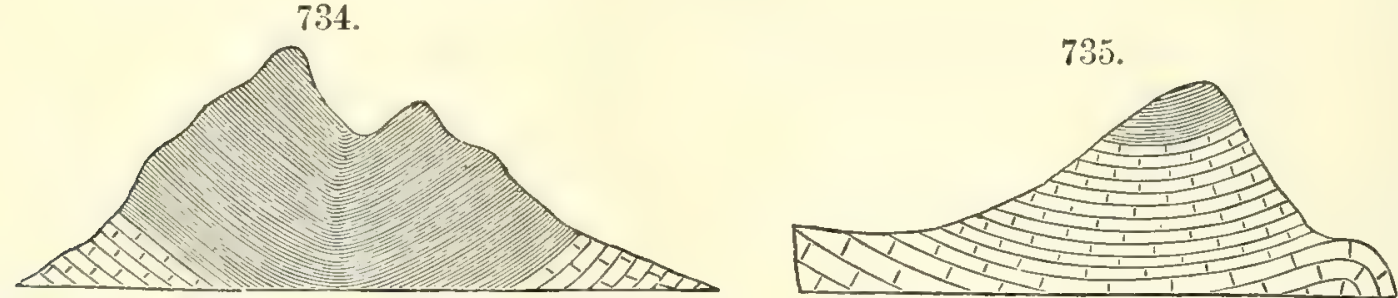

Taconic synclinal mountains of erystalline limestone overlaid by mica or hydromica schist. Fig. 734, Greylock, Emmons. 735, Mount Eolus in Dorset, Vt. Hitcheock.

lock, the Taconic Mountain of northwestern Massachusetts (the blocked areas are limestone); and Fig. 735, Mount Eolus, Vt., a different phase of the syncline, in which the mountain consists mainly of limestone. All the western belts of limestone have similar relations to the schists. On the map they are shown to extend southwestward, with one or two interruptions, into and through Dutchess County, N.Y., and to and beyond the Hudson River, as above stated.

The other narrower branch, which begins in southern Canaan (just beyond the north border of the map), as shown by Percival, extends southward, and passes Kent. Farther eastward, there is still another outerop of this same limestone, owing to a syncline, in a belt that passes by New Milford. Southward from the extremities of these two belts (see the map) a series of smaller limestone belts is continued through Westchester County, N.Y., 
into New York (or Manhattan) Island. The limestone, which is everywhere crystalline, or is a marble, contains abundantly the same accessory minerals in southern Massachusetts and Connecticut, as in Westchester County and New York Island; namely, tremolite and white pyroxene. In this respect the Taconic limestone is widely different from the Archæan limestones of the protaxis in Massachusetts, and of outcrops in the Kent-Cornwall Ridge, west of Kent, these being chondroditic (p. 67).

Two of the Westchester belts, near Peekskill, extend northward up the Archæan Highlands of Putnam County. They lie in what were originally valley-depressions in the Archæan, although not valleys now. Their beds are much upturned, although confined so closely by the Archæan; and they are metamorphic, but of the lighter kind characterizing the corresponding beds on the north border of Peekskill. To produce the upturning, the inclosing Archæan rocks must have been thrust forward either along fractures, or molecularly. The metamorphism apparently indicates that the beds once had great thickness over this part of the Highlands.

The Taconic series of rocks, and series of upturnings, appear therefore to extend all the way from the St. Lawrence valley to New York City. They are situated mostly to the west of the Archæan protaxis ; but, in Canaan, the more eastern branch, described above, passes to the eastward of it, leaving part of the Archæan area on the west; and it is this eastern branch that continues on through Westchester County. The east and west positions of part of the limestone belts of Westchester County, just south of the Arehæan of Putnam County, indicate that, in the upturning, the schists and other Taconic rocks were forced up against the essentially stable Archæan area. The T-shaped symbols on the map indicate the strike and dip of the rocks, and show that the limestone and schists, referred to the Taconic series, are conformable in strike.

The Taconic upturning is known to have occurred not later than the close of the Lower Silurian era from the fact that Upper Silurian rocks are not present in the series, but actually overlie the Lower unconformably in some localities; as at Becrafts Mountain, near Hudson, N.Y.; on St. Helens Island and Beloeil Mountain, near Montreal, where the Lower Helderberg beds cover unconformably Lower Silurian slates; and near Lake Memphremagog, where the Niagara limestone occurs with its characteristic fossils, and also beds of Devonian Corals. Again, on the eastern side of the Green Mountains, in the Connecticut valley, there are unconformable Devonian beds at Bernardston, Mass, and Upper Silurian at Littleton, N.H. The earlier of the formations of the Upper Silurian are very thin in the eastern part of the state of New York, and this is apparently owing to the previous emergence of the Green Mountain area, shallowing the waters to the eastward. The schists, which are argillyte and hydromica schist in Vermont, are mica schist, chlorite schist, and gneiss in Massachusetts, and coarser mica schist and gneiss in Westchester County.

The probability that the upturning was continued southward through 
Virginia has been sustained by the discovery, in 1892, of Crinoids, by $\mathrm{N}$. H. Darton, in the slate quarries of Arvon, Buckingham County, Va. A figure of one of the species is here given from Darton's paper. Walcott states

736.

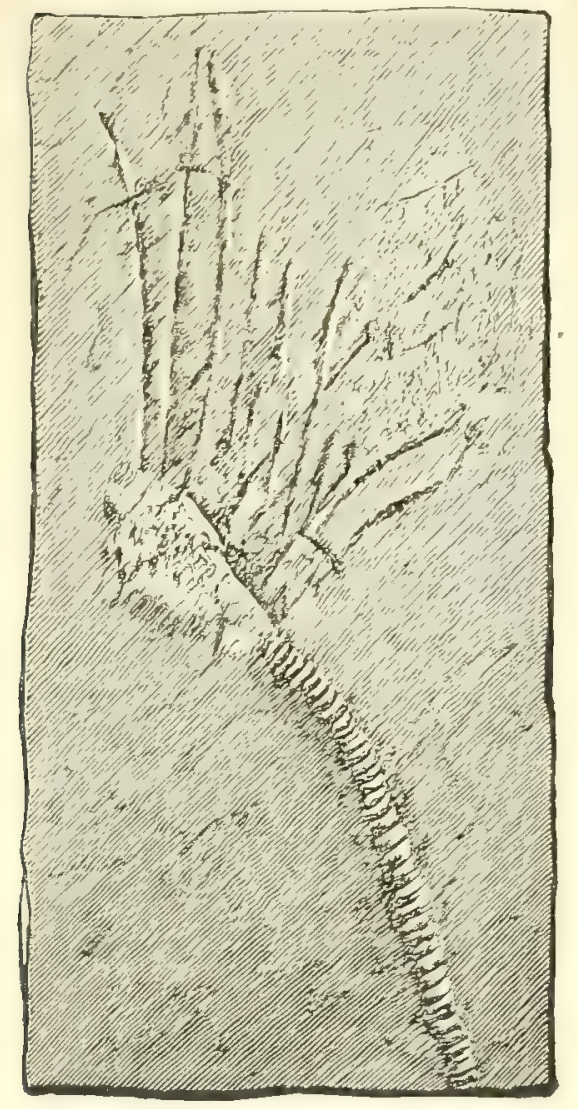

Crinoid from the crystalline slates of Buckingham County, $\mathrm{Va}$. Darton, '92. that the species are allied to those of the genera Schizocrinus, Heterocrinus, and Poteriocrinus, and are of either Trenton or Hudson age. It will be seen on a map that the Westchester belt and the Buckingham County locality are so related in position that the latter may have been a part of a long Westchester Taconic Range, which passed just west of Philadelphia and Baltimore, and may have included South Mountain, Pa., and other ridges beyond, to the east of the protaxis, - the Appalachian Range being to the west of the same. This would make the Taconic Range of western New England one in a great Taconic system of mountain ranges.

Eruptive rocks. - Rocks that came up melted, probably at the time of the Taconic disturbance, exist south of Peekskill, N.Y., spread widely over much of Cortland County, and also oceur on Stony Point on the opposite (west) side of the Hudson River. The rocks cut through Lower Silurian limestones, and hence are not of earlier ejection; but they may be of much later origin. They are rocks of unusual kinds, being noryte, chrysolitic hornblendyte and pyroxenyte, coarse dioryte, and a granite-like rock in which the feldspar is oligoclase. The rocks were described by the author in 1880, 1881, and by G. H. Williams in 1886. The long strips of schist and limestone in the igneous rocks appear to prove, as the author stated in his paper, that these eruptive rocks are partly or wholly metamorphic-igneous, produced by the fusion of Cambrian or Lower Silurian rocks during the period of upturning and metamorphism. A dike cutting through the Hudson beds of the Blue Mountains, of west New Jersey, near Beemerville, is probably of the same age. The Beemerville rock also is a rare kind - an Elæolite-syenyte (B. K. Emerson, 1882). Many "trap dikes" cut through the Taconic formation in the vicinity of Lake Champlain which may be of cotemporaneous origin (Kemp and Masters, 1893).

The Cincinnati geanticline. - Cotemporaneously with the disturbances above described the low geanticline was formed, called the Cincinnati uplift (page 537). making trro islands, one over part of Ohio, eastern Indiana and Kentucky, and the other over Tennessee, as reported by Safford, Newberry, and Orton. The general course of the upward bend of the crust was north- 
easterly, nearly parallel with the Appalachians. But at the north, in Ohio, it extends northwesterly, and has also a northeastern branch in the direction of Findlay, Ohio, toward Lake Erie. That this was the time of the uplift is proved by the absence of Upper Silurian and Lower Devonian beds over the region, these formations thinning out toward the axis, where the Cincinnati limestone is the surface rock; and, in Tennessee, as Safford states, by the Devonian black slate resting directly on the Lower Silurian beds. The line of the axis presents now no conspicuous topographical feature; but the direction of the draining streams, which follow the strike of the strata on either side, indicates that it once formed a watershed that gave the initial bearing to their flow. The part of the arch about Cincinnati has been more deeply and extensively removed than farther north, though higher now than elsewhere, and, therefore, "this probably was originally the highest part of the arch within the limits of the state of Ohio."

According to R. Bell, of the Canada survey, the geanticline is continued northward across the west end of Lake Ontario to Lambton, in Ontario, Canada, and perhaps beneath Lake Huron, but its emergence to this distance is not proved. This range of broad islands and shallows had great influence on the rock-making of later Paleozoic time - a view first recognized by James Hall in 1859 ( $P$ al. N. Y. Y., iii.).

Upturnings in Nova Scotia and New Brunswick. - Unconformability between the Upper Silurian and Lower Silurian rocks has been observed in Carleton County, N.B., just north of the boundary near Metapedia Lake, and also on Lake Temiscoutata, and elsewhere (L. W. Bailey); and in Nova Scotia at Cape St. George, Arisaig, Lochaber, and from Kerrowgane down the East River of Pictou, and north of Sunderland Lake.

But through this epoch there was comparative quiet north of Gaspé in the northern part of the St. Lawrence Gulf; for the great limestone formation of Anticosti, which was begun in the Lower Silurian era, continued its unbroken progress through the whole prolonged era of revolution, and afterwards far into the Upper Silurian era.

\section{EUROPEAN.}

In America the disturbances closing the Lower Silurian were confined to regions of very thick depositions, and mountain-making was the final result of the upturning. Over central New York and farther west in the Continental Interior, the beds of the Lower and Upper Silurian eras follow one another without any marked unconformability. Cases of intervening erosion may be found; for every period loses by erosion a large part of its depositions in the supply of material for the beds of the following period; but no case occurs of horizontal deposition on upturned Lower Silurian strata.

In Europe the facts are similar. Over the Continental Interior of Europe, which includes all European Russia up to the Archæan mountains on either sirle. and the surface south to the foot hills of the Alps, the Upper Silurian beds lie conformably on the Lower Silurian. The cases of unconformability 
are foum in westem England and Wales, where the strata claim a thickness exceeding 20,000 feet independently of ash-ejections. The Upper Llandovery and other Upuer Silurian beds rest upon the upturned edges of the Lower Llandovery, Caradoc, or other inferior strata. "In one district, between the Longmynd and Wenlock Edge, the base of the Upper Silurian rocks is found within a few miles to pass from the Caradoe group across to the Lower Cambrian rocks." (Geikie, p. 672.)

Another remarkable region of disturbance is that of the northwest Highlands of Scotland, along the chain of mountains between Eriboll and Ullapool. For some distance east of this region, according to the investigations of Hicks, Lapworth, Peach, Horne, and others, the Silurian and Cambrian rocks, which overlie the Archran, are much plicated, and the plications, on nearing it, become overthrust flexures, often flexure-faulted, with the thrust westward. Then commences over the wide region a series of nearly horizontal thrust-planes of great extent, along which the Archæan and overlying formations are thrust westward, in some places for ten miles.

Besides minor shovings, there are three maximum thrust-planes which overlap so as to carry the formations over one another, pile them to a great thickness, and produce a series of extensive unconformabilities between Archæan, Cambrian, and Lower Silurian terranes; and undisturbed Lower Silurian limestone is often the base of the pile, with Archæan rocks above. The thrust-planes look like planes of bedding, and were long so considered. Under the enormous amount of friction along the lower thrust-plane, the materials at the bottom of the moving mass were sometimes folded over and curved under it as well as abraded or crushed; and, in addition, through the aid of the heat generated, sheets of sericite schist were made along the plane out of the abraded feldspar, and layers of other foliated metamorphic rock out of other material, - the strike of the foliation being more or less parallel with that of the thrust-plane.

In some cases the softer pebbles of a Cambrian conglomerate (made of pebbles of quartz, gneiss, dioryte, granite) are drawn out so as to form "thin lenticular bands of mica or hornblende schist flowing round the harder pebbles of quartz-rock"; and at one place Cambrian sandstones have been converted into schists containing mica, and quartzytes merge into quartzose sericite schists. The fossiliferous silurian limestones below the thrust-plane are not generally altered, but in some places have been rendered crystalline. (Q.J.G. Soc., 1884, 1888, the latter giving full references to earlier writers on the subject.)

In northern Ireland, where the Lower Silurian and Cambrian beds have a thickness of more than 7000 feet, there are evidences of metamorphism in portions of the beds, while others still retain their fossils, and mark their Siluro-Cambrian age. The Upper Silurian beds above are undisturbed and unaltered. Geikie states that the crystalline schists of the Scottish Highlands are prolonged over northern Ireland to Galway Bay, which makes the disturbed region 400 miles long. 
The Ural Mountains include long ranges of upturned and more or less crystalline Lower Silurian rocks, but it remains undetermined whether or not there is unconformability with the Upper Silurian beds.

Of the 204 species of fossils in 68 genera, found in the Lower Llandovery beds, 104 species in 45 genera still exist in the Upper Llandovery. (Etheridge.)

\section{NEOPALEOZOIC SECTION.}

In contrast with the EOPALEOzoIc part of geological history, when vast continental seas prevailed, - a condition well styled thalassic, ${ }^{1}$ both as regards geography and life, - the Neopaleozorc was the time of the increasing emergence of the land over large areas, and the emergence also of life in various forms, until in eastem North America a great semi-continent existed, over 1000 miles wide, which was covered with grand forests and other vegetation, and populated by Amphibians and Reptiles of ancient kinds, and by the largest of Insects, besides other inferior terrestrial Invertebrates.

\section{UPPER SILURIAN ERA.}

Srnony мy. - Upper Silurian, Murchison, Phit. Mag., vii., July, 1835; Rep. Brit. Assoc., Aug., 1835; Silur. System, 1838. Upper part of Silurian, Sedgwick, Rep. Brit. Assoc., 1835; Proc. G. Soc., 1838; Q. J. G. Soc., Jan., 1846. Silurian, Sedgwick, Q. J. G. Soc., 147, 1852 (the Lower Silurian being made Upper Cambrian); Lapworth, G. Mag., 1879, p. 13 ; H. B. Woodward, Geol. Eng. and Wales, 1887. Murchisonian, D'Orbigny, Pal. et Géol., ii., 301, 1851. Bohémien, A. de Lapparent, Tr. de Géol., 1883.

\section{NORTH AMERICAN.}

\section{SUBDIVISIONS.}

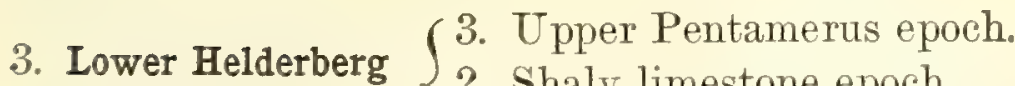 Period. \\ $\{$ 2. Shaly limestone epoch. \\ (1. Lower Pentamerus epoch.}

2. Onondaga Period. - Salina beds, Water-lime, Tentaculite limestone.
1. Niagara Period.
(3. Niagara epoch. Shale and limestone.
2. Clinton epoch. Clinton group.
(1. Medina epoch. Oneida and Medina beds.

The map on page 536 (Fig. 737) presents a general idea of the dry land of North America at the opening of the Upper Silurian. The shore line of the time was not far outside of the Archæan limits (indicated by the dotted line), showing that the growth of the continent had been mainly along its Archæan borders. There was an extension of the land over the

1 With Homer, the $\Theta a ́ \lambda a \sigma \sigma \alpha$ was the great Interior Continental Sea, the Mediterranean, while

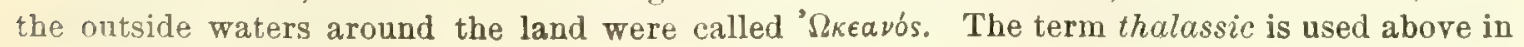
the Homeric sense. 
region of Wisconsin, on the borders of New York and Canada, and about the Adirondacks. The Taconic Range had just been made, and probably a Taconic system, consisting of ranges from Canada to Georgia; and as a part of the uplifting, the eastern portion of New York became emerged, and also a large area along the Atlantic, south of New York. (The Archæan limits in the latter area are not marked, because not yet defined.) Western North America was not notably changed.

The upward movements, moreover, closed against the sea the broad St. Lawrence channel. This channel had been in earlier time a great highway

737.

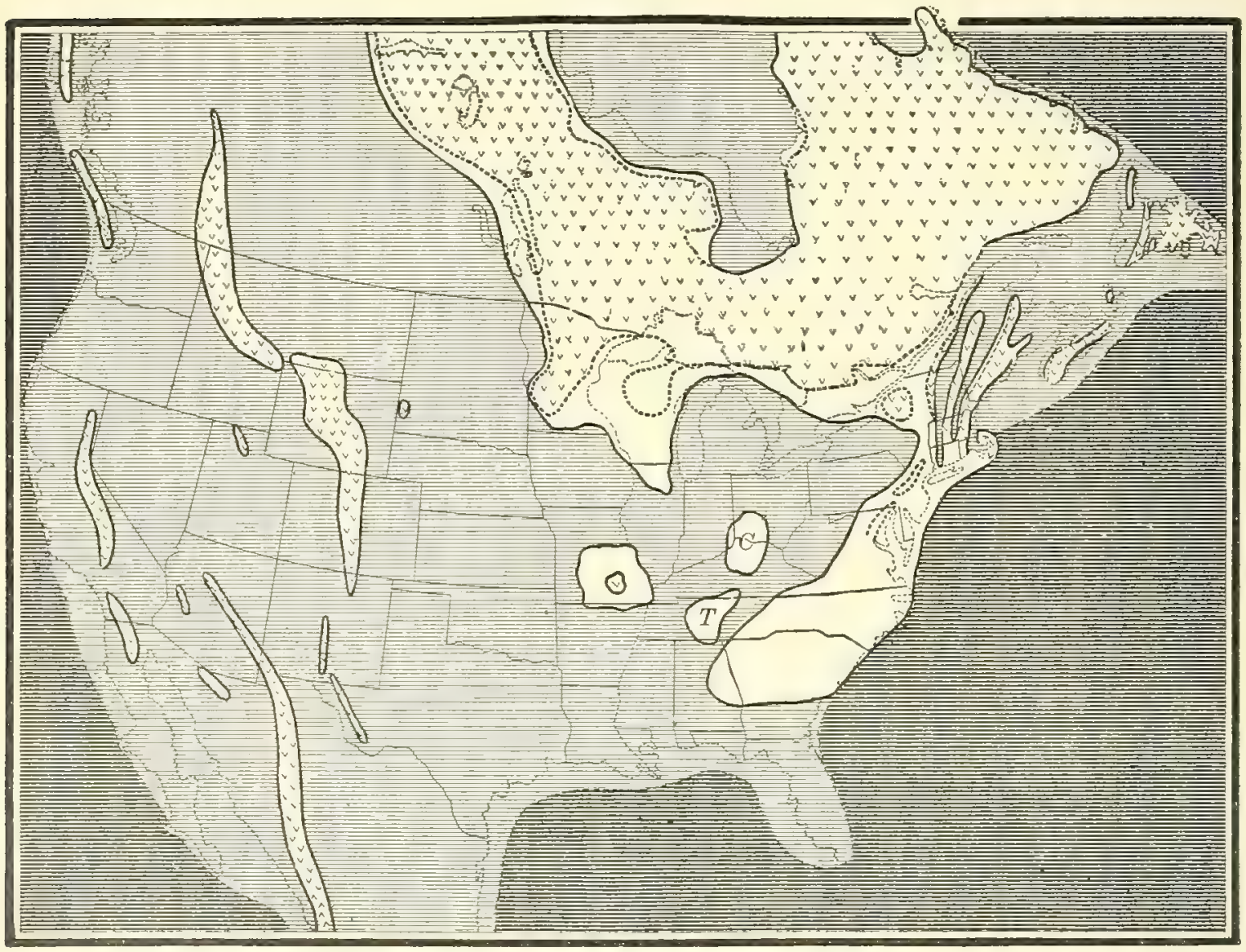

North Americe at the opening of the Upper Silurian.

for tides and currents, and what they could transport between the Atlantic and the Continental Interior. But now the Interior Sea had to depend for rock-making material on what could be gathered from its borders and the stony secretions of aquatic life. But it left open the northeastern troughs, east of the Green Mountains and St. Lawrence - the Connecticut valley trough, the Gaspé-Worcester, and the Acadian, or that from western Newfoundland to Narragansett Bay, over the Bay of Fundy and Massachusetts Bay; for these have severally their Upper Silurian and later rock formations. It is even probable that the Gaspé-Worcester trough had its eastern Archæan confine, which separated it from the Acadian trough, extended 
northeastward across the present Gulf of St. Lawrence to Newfoundland; for it has been shown by Canadian geologists that the Upper Silurian fossils within the Acadian trough in Nova Scotia are not all of American type, but have many relations to those of Great Britain, much closer relations than the fossils of the island of Anticosti. The fact would put Anticosti within the Gaspé-Worcester trough. But such a confine could not have been an uninterrupted barrier, since the troughs of the Connecticut valley and GaspéWorcester belt must have had tidal connection with the Atlantic.

The two large islands of the Cincinnati uplift are those marked $\mathrm{C}$ and $\mathrm{T}$. They partially divide off from the great Continental Interior a portion called the Eastern Interior Sea, which from this time onward was like a great bay, having a narrow southwest opening over Alabama, a length of about 700 miles, and its northern limits near the sites of Albany and Troy. Its waters communicated, in the Upper Silurian era, with those of the Central Interior Sea, over Michigan and northern Ohio. But this connection was diminished during the progress of Paleozoic time. It had probably, also, a shallow connection with the Atlantic over Pennsylvania and Maryland, where the land is now low, permitting of an interchange of water and life.

The conditions of this Eastern Interior Sea influenced not only its tides and currents, but also the temperature and purity of the waters, the supply of sediments, the kinds of life, and hence in various ways modified rockmaking and biological distribution. And this influence was all the more profound that the eastern part of the great bay was within the limits of the slowly deepening Appalachian trough, or geosyncline, in which thick deposits were in progress for the future Appalachian Range.

West of the Mississippi there was another island, that of Missouri. Probably Upper Silurian beds exist to the south of it, according to recent observations by H. S. Williams. But farther southwestward, over much of Arkansas and over Texas, to the Pecos (R. 'T. Hill), Upper Silurian and Devonian beds are absent; and it is probable that a large area of dry land here existed. Its limits, however, are so uncertain that it is not indicated on the map. Moreover, Silurian and Devonian beds have not yet been reported from Mexico, and the Carboniferous are the only Paleozoic beds.

The dry land of the continent was small, and hence there were only small streams for the supply of sediments. Among them an embryo Hudsou River brought down Adirondack waters and detritus to the head of the Eastern Interior Sea, near Albany, and an embryo Mississippi and a St. Lawrence drained other Archæan areas.

The rock-making of the period was confined, so far as has been ascertained, to the Interior Continental Sea and the troughs or channels of New England and eastern Canada. These troughs are those of Archæan origin, already reported: commencing to the eastward, the Acadian, the GaspéWorcester, the Connecticut valley, and, during the later part of the period only, the Hudson-Champlain trough. No Upper Silurian beds are known along the Atlantic border south of New York. 
The conditions described and illustrated on the map make it apparent that the Interior Continental Sea opened westwarl towarl the Pacific, but not eastward over temperate latitules toward the Atlantic; and hence that migrations to those seas from Eurasia should have been chiefly from the west rather than from the east. On the contrary, New England and eastern Canada remained still open toward the Atlantic and. Europe, and hence differences in the cotemporaneous faunas of this eastern part of North America and of the Continental Interior should be expected.

\section{Niagara Period. ROCKS-KINDS AND DISTRIBUTION.}

The beds over New York referred to the Merlina epoch - the earlier part of the Niagara period - include, to the eastward, a seashore formation, called the Oneida conglomerate from Oneida in central New York, and an offshore sand-flat formation, called the Medina sandstone from Medina in the western part of the state.

The Oneida conglomerate is a hard light-gray rock made of quartz pebbles and sand. It covers large areas in Oneida and Herkimer counties, N.Y., but thins out eastward to 15 to 20 feet at Rondout on the Hudson. It comes up again in Ulster County (southeastern New York), owing to an uplift along the Shawangunk (pronounced Shong-gum) Mountains, and is there called the Shawangunk grit. This range commences near the Hudson, southwest of Kingston, and to the southwest, between New Jersey and Pennsylvania, becomes the Kittatimny Mountains. The grit makes the crest and southwest front of these mountains, and the beds dip westward $30^{\circ}-40^{\circ}$. Thence the conglomerate, or grit, stretches on southwestward through Pennsylvania into Tirginia, where "it makes the bony axis of the principal Appalachian ridges" (Rogers), and beyond into east Tennessee, where it is the Clinch Mountain sandstone of Safford. In Ulster County, N.Y., near Redbridge, the Shawangunk grit has afforded galena and copper pyrites in large masses, and fine crystals; but the mine is not now worked. The Medina sandstone is ordinarily a gray to red mottled sandstone, fine-grained, thinbedded, somewhat argillaceous, especially so to the westward, and bears evidence of having originated as a great sand-flat formation in shallow waters, as first described by Hall; for its layers are often covered with ripplemarks, wave-marks, and rill-marks, evidences of exposure above the waters, perhaps with the retreat of the tide, and in many places of gentle wave action on a slightly inclined beach. In making the rill-marks (page 95), the retreating undertow swept past worn shells of Lingula cuneata or small pebbles in the surface sands of the beach.

The beds are not found in eastern New York near the Hudson, but mainly to the west of Oneida County. They border Lake Ontario to its western extremity, and constitute the lower half of the Niagara bluffs at Lew- 
iston. Thence they continue westward through Ontario with a thickness of 300 to 400 feet, and in eastern Ohio thin out to 10 to 150 feet of reddish shale (as found in deep borings) resting on Hudson or Utica shales. They are not found in Michigan. To the southward, in New York, the formation disappears beneath the later beds; but it reappears on the west slope of the Kittatinny Mountains, and outcrops to the southwest in east central Pennsylvania, Virginia, and eastern Tennessee.

The thickness of the Shawangunk grit is 500 feet in New York, and 700 to 800 feet in Pennsylvania; and that of the Medina beds, in the latter state, 1800 feet.

The beds thus give an idea of the seashore work of the period. They also indicate the generally shallow depths of the Eastern Interior Sea, but nothing as to the condition of the seas over the rest of the continent.

The Clinton group has a wide distribution. Its beds oceur in central and western New York (the group taking its name from Clinton in Oneida County), in Penusylvania, Ohio, Indiana, Wisconsin, eastern Tennessee, Kentucky, Alabama, and Georgia. The Cincinnati geanticline, which put above the surface the Lower Silurian rocks, accounts for the absence of the Clinton not only from part of Ohio, but also from western Kentucky and Tennessee. In New York and Pennsylvania the rock is mainly a shaly sandstone and shale of rough, irregular aspect, with some intercalated limestone; on the Niagara River it is about half limestone; and in Ohio and farther west almost wholly limestone.

A peculiar feature of the formation is the occurrence in many regions of one to three beds, 1 to 10 feet thick, of argillaceous red iron ore (hematite), usually oölytic, with the grains round or flattened. The grains are often concentric in structure, proving them to be true concretions, like those of an ordinary oölyte, and of sea-margin origin. (C. H. Smyth, from observations near Clinton, N.Y., and elsewhere in 1892.)

These ore-beds accompany the Clinton formation from New York to Alabama, through Pennsylvania, Virginia, eastern Kentucky, and Tennessee, and also occur in Wisconsin. They are usually fossiliferous, and the ore is sometimes called the "red fossil ore." The fossils are broken, and include stems of Crinoids, Bryozoans in small fragments, and other species. The beds were evidently made over tide-washed, salt-water flats, where trituration was gentle. They indicate a wonderful degree of uniformity in continental level over a wide area.

Clinton fossils nccur with those of the Niagara at some points along the Atlantic border of Maine, from the boundary of New Brunswick to Penobscot Bay. They are found also in Nova Scotia, and on Anticosti several hundred feet of limestone are referred to the Clinton.

The Niagara formation is still more widely spread than the Clinton, though far from continental in its distribution. In most regions it is a thick limestone, but in New York and other parts of the Eastern Interior Sea, the lower portion is shale, indicating a gradual transition in rock-making condi- 
tions from those of the Clinton epoch. The limestone is largely a coral-made rock, and thereby indicates clear seas during the time of its formation. In Iowa and some other parts of the West, it abounds in chert or hornstone, which is usually in layers coincident with the bedding, like flint in chalk; and the fossils are all siliceous. At Lockport, N.Y., cavities in the limestone afford fine crystallizations of dog-tooth spar (calcite) and pearl-spar (dolomite), with gypsum, and occasionally celestite, and still more rarely a crystal of fluor.

In New York, the beds reach quite to the Hudson River, and are there distinguished as the Coralline limestone; they are, however, but a few yards in thickness. They spread westward through New York, making 250 feet of the height of the Niagara bluffs; continue beyond through Ontario, in Canada, with a thickness of 250 to 300 feet, to Lake Huron, west of Georgian Bay, and to the Manitoulin Islands; extend around the north side of Lake Michigan to Illinois, Wisconsin, northeastern Iowa, and the adjoining part of Minnesota - making in all a distance from east to west of 1000 miles.

The Niagara is stated to be absent south of New York, from the eastern half of Pennsylvania (where Lower Helderberg beds rest on (linton), and from the larger part of West Virginia. It is absent also from eastern Tennessee and part of southern Ohio, owing to the Cincinnati geanticline; but occurs in western Tennessee, along Tennessee River, and in northern Kentucky; and also in Missouri, and in northern Arkansas, as a continuation probably of the area of central and southwestern Illinois.

In western New York, the lower third of the rock is usually shale, the other two thirds limestone. It is prominent on the Genesee River at Rochester, N.Y., and also at Lockport, where its geodes gave it early the name of the "Geodiferous" limestone. At Niagara Falls, directly at the fall, the limestone makes the upper 85 feet, and the shale the lower 80 feet, as illustrated in the following section, Fig. 738, from Hall. In the section, Nos.

738.

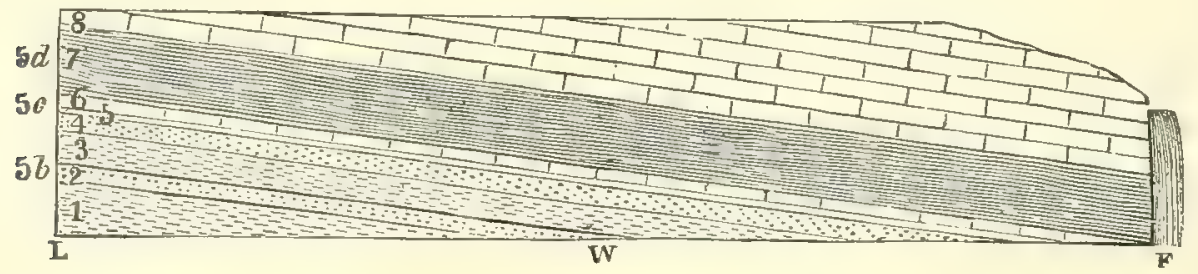

Section along the Niagara, from the Falls at $F$ (south) to Lewiston Heights at $\mathrm{L}$ (north); W, the whirlpool; Nos. $1,3,5,7$, are shales, and 6,8 , limestones. Hall.

7,8 , are the Niagara, the greatest thickness of which is 165 feet; below it, as is seen in the bluff, at Lewiston Heights (L), lie the Medina beds, 1, 2, and the Clinton, 3 to 6 . The recession of the fall is slowly going on, because of the undermining of the limestone by the wearing out of the shale.

In Ohio, the limestone, 300 feet thick with 10 to 100 feet of shale below, outcrops as a belt around the area of the Cincinnati geanticline. 
In Illinois, the limestone underlies the city of Chicago and constitutes the gray "Athens Marble" and the gray and buff "Joliet" building-stone. In the Mississippi valley it often contains flint or chert in nodules and is dolomyte. In Wisconsin, it has distinctly the features, in some places, of an old coral-reef. Forty species of Corals have been described from it. Some large coral masses "stand erect in the rock, precisely as they grew," making up, along with fragments and sand derived from broken corals, shells, and Crinoids, the coral reef-like limestone bed. Between and about what look like true barrier reefs, there are accumulations of coral fragments, becoming finer and finer on receding from the reef, and thus the rock graduates into ordinary limestone. (Chamberlin.)

In New England, the St. Lawrence Bay of the Niagara period extended far south along the Connecticut valley; for Niagara beds, with their fossils, occur at Littleton, N.H., resting unconformably on older beds. They occur also in northern Maine and New Brunswick; and on the coast of Maine in Penobscot Bay, near Machiasport, in Cobscook Bay; along the Acadian trough; they exist also in Nova Scotia. In Anticosti, a thick limestone ranges continuously from the Hudson to the Clinton groups.

The Rocky Mountain region has few outcrops of Upper Silurian rocks. The Niagara beds have been observed in the Black Hills of South Dakota, near Deadwood, but not in the Wasatch Mountains; and they have not been identified in Arizona at the Colorado Cañon, nor over the Great Basin. They are doubtfully identified in the Eureka district, Nevada, in the upper part of a limestone stratum which is Trenton at base - a Halysites occurring in the beds. The formation has a wide range in Aretic seas, and occurs on some islands in Hudson Bay.

Mineral oil exists in large quantities in the Niagara limestone at Chicago, though not capable of being collected to advantage. Worthen says that a portion of the limestone is "completely saturated with oil."

The distribution of the rocks of the Niagara period sustains the conclusions presented on a preceding page with regard to American geography at the opening of the Upper Silurian. They show that the waters over the state of New York shallowed toward the Hudson River, and thickened westward, thus according with other evidence as to the emergence of the Green Mountain region in connection with the making of the Taconic Mountains. The shallowing was toward the emerged mountain belt. They prove also, through the abundant arenaceous deposits, that while in the earlier part of the period the region of the Eastern Interior Sea was shallow, at a later date deeper and clearer seas prevailed, even from Hudson River to and beyond the Mississippi, in which Corals and Crinoids were growing abundantly; yet they were not necessarily deep seas, since 150 feet of depth is enough for all the work of the modern reef-making Polyps.

1. Medina Group. - The Oneida conglomerate is a thick-bedded formation, and the rock so hard as to stand out boldly in rocky ledges and ridges. The Shawangunk grit was 
the "millstone grit" of Eaton. It was formerly much used for making the "Esopus millstones," so named from Esopus, an early name of Kingston; and at Ellenville, for glass-making. It is intersected by quartz veins; and mines of lead and zinc have been worked in it at Ellenville, Wurtsborough, and elsewhere, which have yielded remarkable geodes of quartz crystals, with crystals of lead ore (galena), sphalerite, chalcopyrite, and other minerals.

The Medina sandstone, where fullest developed in New York, includes, according to Hall, four divisions, as follows:-

(4) Red marl or shale and shaly sandstone, resembling No. 2, below; banded and spotted with red and green.

(3) Flagstone, - a gray, laminated quartzose sandstone, called "gray band."

(2) Argillaceous sandstone and shale, red, or mottled with red and gray.

(1) Greenish gray sandstone, graduating below into the Oneida conglomerate, the "gray band" of Eaton.

In the Genesee section (page 91), the strata 1 and 2 correspond to the Medina; 3, 4, 5,6 , to the Clinton group ; and 7,8 , to the Niagara shales and limestone.

In Canada the Medina beds, besides existing in Ontario, occur south of the St. Lawrence, over a few areas east and northeast of Lake St. Peter.

The Oneida conglomerate disappears before reaching the southern border of Pennsylvania, and the passage from Hudson into the red Medina is imperceptible. Hudson fossils continue far up into the Medina in Bedford County. (Rep.T 2, Penn. Surv., pp. 91 and 92, J. J. Stevenson.) This condition becomes more striking in southwest Virginia beyond the New River, where Hudson forms occur up to within $100^{\prime}$ of the white Medina. (J. J. Stevenson, Proc. Amer. Phil. Soc., xxiv., 85, 87, 94; and xxii., 142, 150.) A peculiarity of the Upper or white Medina in Pennsylvania and southward is, that exposure to atmosphere polishes it; all other sandstones there are roughened by exposure. (J. J.S.)

2. Chinton Grodp. - This is the "Protean group" of the N. Y. Annual Geological Reports of 1836-1840. The sandstone of the Clinton epoch in New York is often quite hard; and much of it has the surface uneven from knobby and vermiform prominences, some of which are attributed to Fucoids.

(a) Interior Continental basin. - On the Genesee River, at the falls near Rochester, the Clinton group consists of: (1) $24^{\prime}$ of green shale, of which the lower part is shaly sandstone and the upper part an iron-ore bed; (2) 14' of limestone, called Pentamerus limestone, from a characteristic fossil; (3) $24^{\prime}$ of green shale; (4) $18 \frac{1}{2}$ ' of limestone, called the Upper limestone.

On the Niagara (see section, Fig. 738, page 540) there is shale $4^{\prime}$, without the iron ore, overlaid by limestone $25^{\prime}$, the limestone corresponding to the three upper divisions, and its upper $20^{\prime}$ to the upper limestone. To the eastward, in Oneida, Herkimer, and Montgomery counties, the rock is $100^{\prime}-200^{\prime}$ thick, and includes no limestone, though partly calcareous. The group consists of shale and hard grit or sandstone, in two or more alternations, along with two beds of the iron ore. Near Canajoharie - which is not far from its eastern limit - the formation has a thickness of 50\%. In Starkville, Herkimer County, the rock contains a bed of gypsum.

North of Lake Huron, the Clinton beds occur along the Manitoulin Islands, Drummond Island, and 20 miles to the westward.

(b) Appalachian region. - The relations of the Clinton of Pennsylvania and the country southward to that of central New York are not determined in detail. The rocks in Pennsylvania are shales, olive to almost black, with some sandstones and beds of calcareous iron ore. The series is persistent, northwestwardly, to the last exposures, almost at the easterly foot of the Alleghany Mountains. Its subdivisions are: (1) Reddish to olive shales, $100^{\prime}$ to $700^{\prime}$; (2) iron sandstone, $5^{\prime}$ to $50^{\prime}$; (3) shales, $200^{\prime}$ to $675^{\prime}$; (4) iron sandstone, $10^{\prime}$ to $20^{\prime}$; (5) shales with calcareous layers, $100^{\prime}$. The whole thickness is from $900^{\prime}$ to $1000^{\prime}$. A commingling of Clinton and Niagara forms occurs in the upper 
portion of the column. In Virginia the Clinton consists of sandstones and shales, mostly sandy, having an estimated thickness of not far from $850^{\prime}$. Beds of fossil or calcareous ore are present from central Pennsylvania to Alabama. (J. J. S.)

In east Tennessee the rocks are $200^{\prime}$ to $300^{\prime}$ thick, and include one or two beds of the oölitic iron ore.

In western Kentucky the oölitic red ore beds occur in Montgomery, Bath, and Fleming counties and along Pine Mountain.

(c) Eastern Border region. - In Nova Scotia, at Arisaig, which is within the Acadian trough, the rocks are shales and limestone, and have a thickness of about $500^{\prime}$. At the East River of Pictou, there are also slates and calcareous bands, probably of the same age. They include a deposit of oolitic iron ore, like that of the Clinton rocks of central New York, which in some places has a thickness of $40^{\prime}$. In southern New Brunswick the beds are like the Arisaig.

The fossiliferous Upper Silurian rocks of the coast of Maine, on the borders of the same Acadian trough, are described in Hitchcock's Report on Maine, 1861, and in papers by W. O. Crosby, Am. Jour. Sc., xxiii., 1862 ; N. S. Shaler, $i b$., xxxii., 1886 ; Dodge and Beecher, $i b ., x l i i i ., 1892$. See also Foerste, on the iron ore, $i b .$, xli., 1891 ; and Smyth, on the same, $i b$., xliii., 1892.

3. Niagara Grotr. - (a) Interior Continental basin. - At Rochester, N.Y., there are about $80^{\prime}$ of limestone, overlying $80^{\prime}$ of shale; and the limestone makes nearly the whole height of the upper fall. At Lockport there is a fine exhibition of the rock, and it includes an "encrinital" layer, which is mottled with red, and over it a bed full of delicate Corals. The limestone in some places breaks vertically into small columns, and such specimens have been called Stylolites. The structure is due, as explained by Marsh, to a slipping, through vertical pressure, of a part capped by a fossil shell against an adjoining part not so capped. Such Stylolites occur in limestones of other periods from the Cambrian to the Carboniferous.

The "Coralline limestone" is only $4^{\prime}$ thick at the base of the Helderberg Mountains; but at Nearpass's quarry, south of Port Jervis, it is $50^{\prime}$ thick, and contains numerous Niagara fossils.

The Guelph limestone (a dolomyte), well seen at Galt and Guelph, in Ontario, western Canada, and farther west (formerly supposed to be of the age of the Salina beds), is the upper part of the Niagara limestone. The thickness in Ontario is about $160^{\prime}$.

The Niagara limestone and shale extend through Ohio and Indiana to Wisconsin and Iowa. But it is wanting in southern Illinois. The "Clear Creek limestone" of Union, Jackson, and Alexander counties is probably Lower Helderberg (Worthen). The rock has a wide distribution in Iowa (where it is in part the Leclaire limestone). Much of it is cherty, and has the fossils silicified. An analysis, by J. D. Whitney, of a specimen from Makoqueta County, Iowa, obtained calcium carbonate $52 \cdot 18$, magnesium carbonate $42 \cdot 64$, with 0.35 of sodium carbonate, traces of potash, iron carbonate, and sulphuric acid, 0.63 of alumina and iron sesquioxide, and 4.00 insoluble in acid. The beds form the summits of some of the mounds, as Table Mound, near Dubuque.

In west Tennessee the Meniscus limestone, $150^{\prime}$ to $200^{\prime}$ thick, noted for its fossil sponges, of which one is meniscus-shaped, is probably the equivalent of the Niagara limestone.

The Niagara beds of the Black Hills, near Deadwood, were identified through their fossils, by C. E. Beecher. In the Deadwood section there are Cambrian beds below, resting on Archæan; above, there is the Carboniferous limestone, with probably Devonian strata between.

(b) Appalachian region. - The Niagara has not been recognized distinctly in Pennsylvania; though in the central and southern portion of the state there occurs, at varying distances above the uppermost bed of iron ore, a succession of very thin limestones, which, in many localities, contain Niagara forms. This has been placed by Lesley in the lower 
division of the Salina. The thickness of the shale and limestone varies from $150^{\prime}$ to $235^{\prime}$. (J. J. S.)

(c) Eastern Border region. - The Niagara limestone occurs in eastern Canada, some distance south of the St. Lawrence, being part, according to Logan, of an extensive formation, which stretches from northern Vermont, eastward over a part of northern New Hampshire and northern Maine, to Cape Gaspé on St. Lawrence Bay, as limestone with some massive and shaly sandstone. The formation embraces also the strata of the Lower Helderberg, and possibly part of those of the Lower Devonian. Niagara fossils occur ia the lower part of the Gaspé limestone, as well as at some intermediate points. They have been found also near Penobscot Bay.

At Arisaig, in Nova Scotia, there are shales of the Niagara epoch, $1300^{\prime}$ thick; and they occur also in New Canaan and Pictou.

(d) Arctic regions. - In the Arctic, the Niagara limestone has been observed between the parallels of $72^{\circ}$ and $76^{\circ}$, on the shores of Wellington and Barrow straits, and on King William's Island. The common chain coral Halysites catenulatus has been found at several localities, along with various Upper Silurian species, and also at other places between $79^{\circ}$ and $82^{\circ} \mathrm{N}$.

\section{LIFE.}

\section{Plants.}

Supposed Algæ or Fucoids, of branching form, of the genus Buthotrephis, occur in the Clinton group. They are various rounded casts looking like those of stems, or groups of stems, some of which are probably tracks of marine animals, as already explained.

\section{Animals.}

In the Niagara series no evidence of fresh-water or terrestrial species of plants or animals has yet been observed. Aquatic Vertebrates or Fishes

$739-743$.

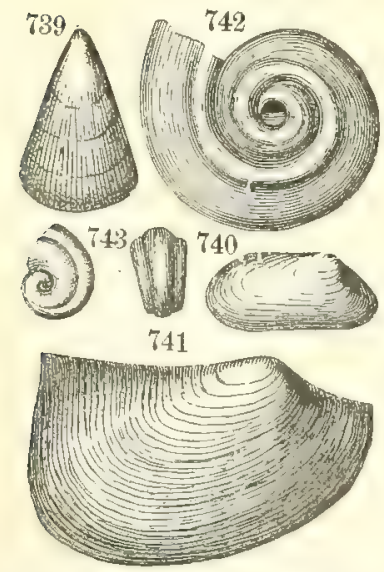

Medina. - Fig. 739, Lingula cuneata; 740, Modiolopsis orthonota ; 741, M. primigenia; 742, Pleurotomaria litorea; 743 , Bucania trilobata. Hall. have been reported from the Clinton beds.

The Medina beds contain few fossils. These are chiefly Brachiopods and Lamellibranchs, with rarely Gastropods and Cephalopods among Mollusks. Tracks of Sea-worms are common, because the beds are of mudflat and sand-flat origin. The Clinton group has more numerous fossils, of the same general character, and partly the same species; but as it includes limestone beds, there are also Polyp-corals, Bryozoans, and Trilobites. The Niagara beds, which were largely formed in clear, open seas, contain a profusion of fossils of marine types: Bryozoans, Polyp-corals, Crinoids of various forms, Brachiopods in great numbers, and various kinds of Mollusks, with many small and large Trilobites.

The most common of Medina Brachiopods is the Lingula cuneata, Fig. 739, a wedge-shaped species. Figs. 740 and 741 represent Lamellibranchs; and 742, 743, Gastropods, the last a Bucania. 
Tracks, probably of a Sea-worm, are represented by Fig. 744. These tracks cover large surfaces of the Medina sandstone, and are occasionally found in the Oneida conglomerate. They are simply impressions, the material being

744.

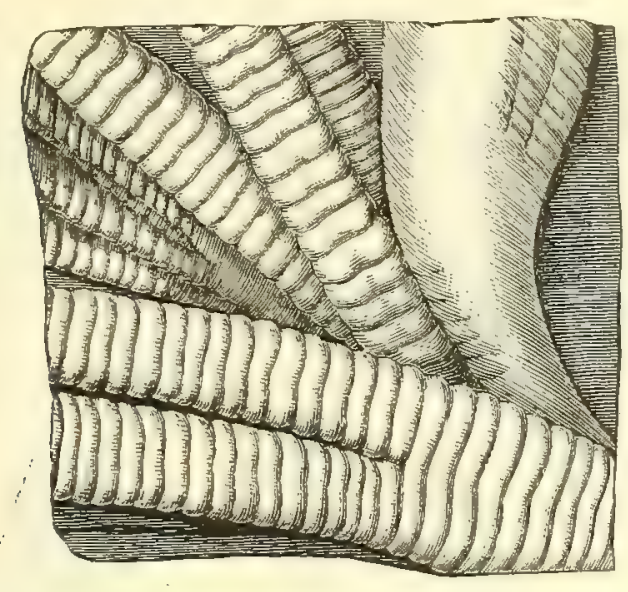

745.

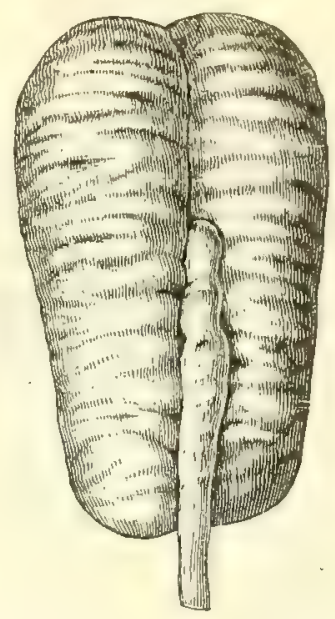

Fig. 744, Harlania Falli ; 745, Cruziana (Rusophycus) bilobata ( $\times 2$ ). Hall.

sandstone, and without structure internally, except the occasional occurrence of parallel or concentric layers, due to deposition in the depressions. Fig. 745 represents another form of track supposed to be of Molluscan origin.

The following figures represent Corals, a Bryozoan, and a Graptolite of the Clinton group:-Figs. 746, 747, one of the common Cyathophylloid Corals

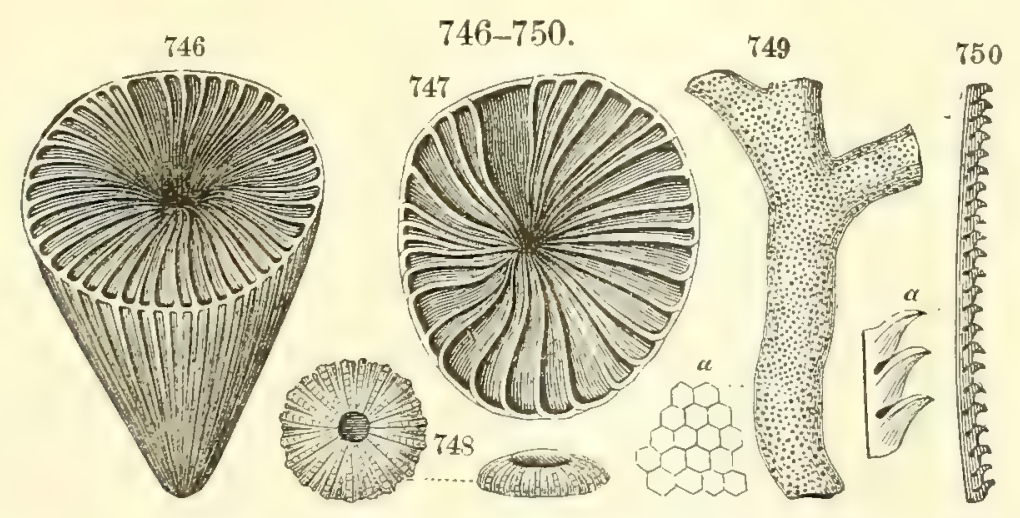

Corals, Graptoltie, Berozoax. - Figs. 746,747 , Zaphrentis bilateralis; $748, a$, Palæocyclus rotuloides; $749, a$, Monticulipora; 750, a, Graptolithus Clintonensis. Hall.

of the genus Zaphrentis, the latter a view from above; 748, a small diskshaped Coral; 749, a minutely columnar coral-shaped Bryozoan of the genus Monticulipora; 750, a Graptolite; $750 \mathrm{a}$, an enlarged view of the same.

Other Clinton fossils are shown in Figs. 751-760. A finely reticulate Bryozoan of the genus Fenestella (Fig. 751) is represented enlarged in 751 a. Fig. 752 is that of the characteristic Brachiopod, Pentamerus oblongus, and opposite views of the hinge end of the cast of the interior are given in Figs. 753, 753 $\alpha$. Figs. 754, a represent the Brachiopod, DANA'S MANUAL - 35 
Atrypa reticularis, which continues on through the Devonian; Fig. 756, a Chonetes - a genus of the Productus family. There were also species of Orthoceras.

Besides these, Figs. 759, 760 represent tracks probably of Mollusks. The Cruziana (Rusophychus), called also Bilobites (Fig. 745), is a large

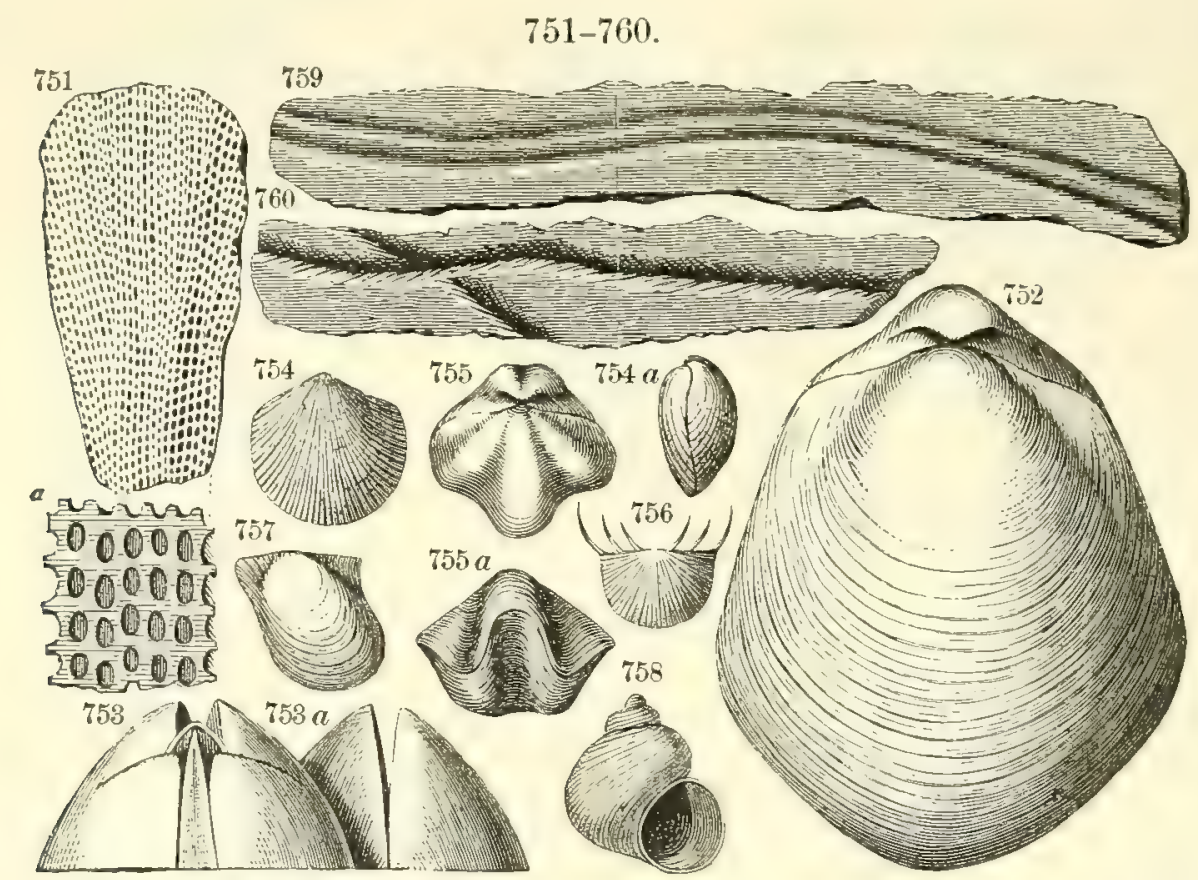

Molidsks. - Figs. 751, a, Fenestella prisca; 752, Pentamerus oblongus; 753, $a$, part of casts of the interior; $754, a$, Atrypa reticularis ; $755, a$, Hyattella congesta; 756, Chonetes cornutus; 757 , Avicula rhomboidea; 758 , Cyclonema cancellatum; 759 , track of a Lamellibranch $\left(\times \frac{\frac{1}{2}}{2}\right) ; 760$, track of an Annelid ? $\left(\times \frac{1}{2}\right)$. Hall.

species, the figure being reduced one half; other related kinds from the Clinton are narrower, and six to eight inches long.

The Cephalopods include Orthoceras desideratum; also species of the genus Discosorus of Hall, near Actinoceras in its broad beaded siphuncle, but having a shorter shell, more rapidly tapering and slightly curved; the species $D$. conoideus extends into the Niagara epoch.

Trilobites occur of the genera Calymene, Dalmanites, Ceraurus, Illoenus, Homalonotus and others, and some kinds are identical with Niagara species.

The remains of Fishes, reported from the Clinton beds of Pennsylvania, are a small portion of a spine referred to a Shark, named by Claypole Onchus Clintoni, together with fragments of what appear to be fish scales and plates. The spines from British Upper Silurian berls, on which the genus Onchus was established, are now regarded as portions of the telsons of species of Cerativaris; and the American may be of similar relations, but this is not deemed probable. See under the Onondaga period, page 556.

Remains of a Fish, Diplaspis Acadica Latthew (1888), are found at Westfield, in southern New Brunswick, in Silurian shales that underlie Niagara beds, and are supposed to be of the Clinton group. The same beds contain "myriads" of the Ceratiocaris pusilla of Matthew. 
A few of the many Corals in the Niagara group are represented in the following figures, 761-766. Fig. 761 is one of the Cyathophylloids or cup Corals; 762, a Favosites, a columnar, tabulate Coral, so named from favus, a honeycomb, in allusion to its columnar structure; 763, a chain Coral, or

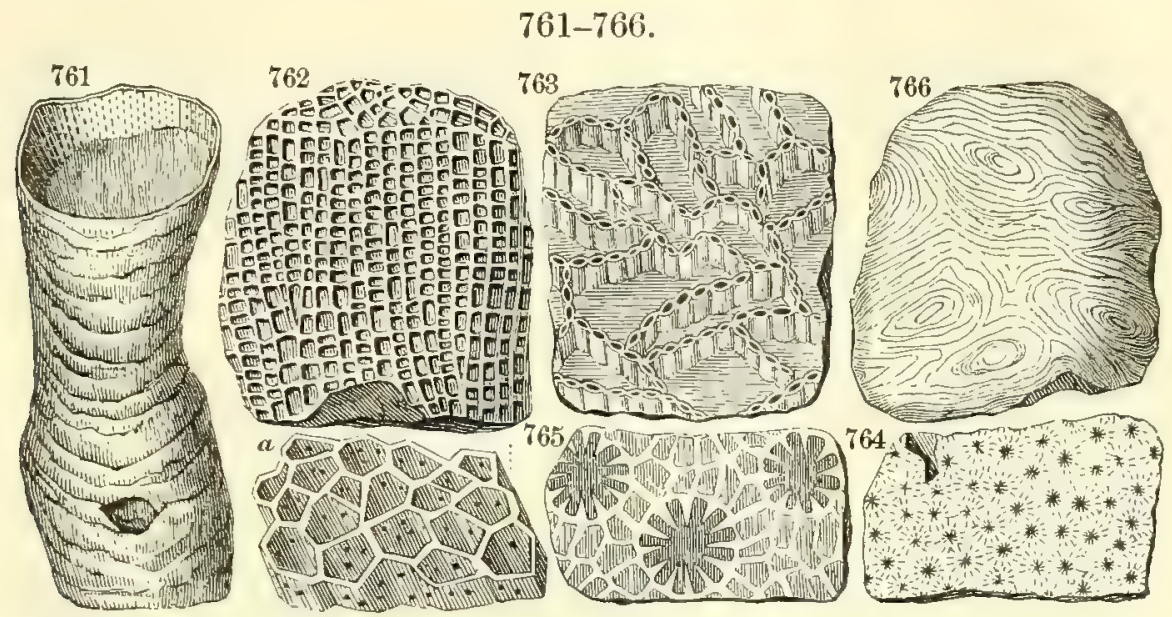

Corals. - Fig. 761, Chonophyllum Niagarense; 762, $a$, Favosites Niagarensis; 763, Halysites catenulatus ; 764 , 765 , Heliolites spiniporus ; 766 , Stromatopora concentrica. Hall.

species of Halysites, mostly imbedded in the limestones; 766, a Stromatopora, a calcareous Hydroid, the lines showing the edges of the very thin, barely distinguishable layers.

Figs. 767-770 are the forms of some of the common Crinoids and Cystoids. In Fig. 767 the arms clustered about the mouth of the Crinoid are perfect. Fig. 768 has the box-like body of a Cystoid, to which group it is related. It
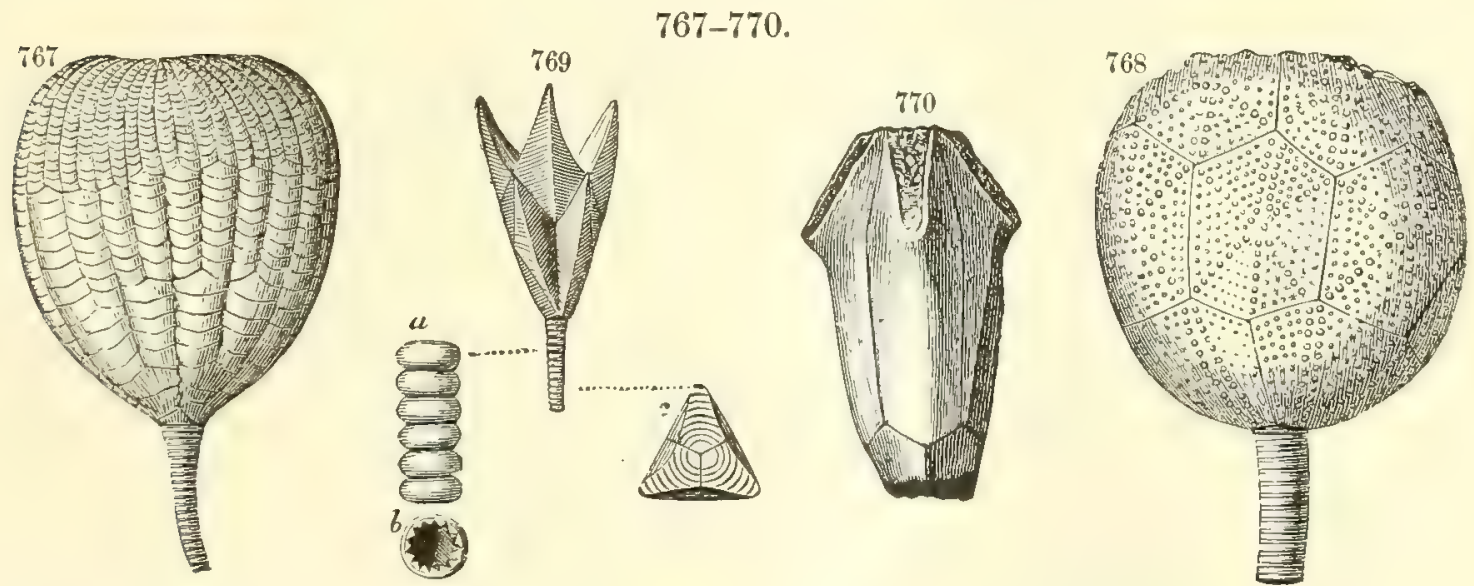

Cerroms. - Fig. 767 , Ichthyocrinus lævis; 768, Caryocrinus ornatus; $769, \boldsymbol{a}, \boldsymbol{b}, \boldsymbol{c}$, Stephanocrinus angulatus ; 770, Troostocrinus subeylindricus. Hall.

had slender arms, three to four inches long, fixed to the top of the box, which were very fragile and are seldom preserved. The stem is sometimes found six to eight inches long. The genus Stephanocrinus, Fig. 769, includes Crinoids with short delicate arms. Among Cystoids, Callocystites Jewetti, Fig. 444, page 429 , is very common.

Besides the above forms, the Niagara group has afforded the first of the 
Blastoids, or Bud-crinoids, which, like the typical Cystoids, have no free arms, and usually are pentagonal in form. A species from the Niagara limestone of Ohio is represented, without its stem, in Fig. 770.

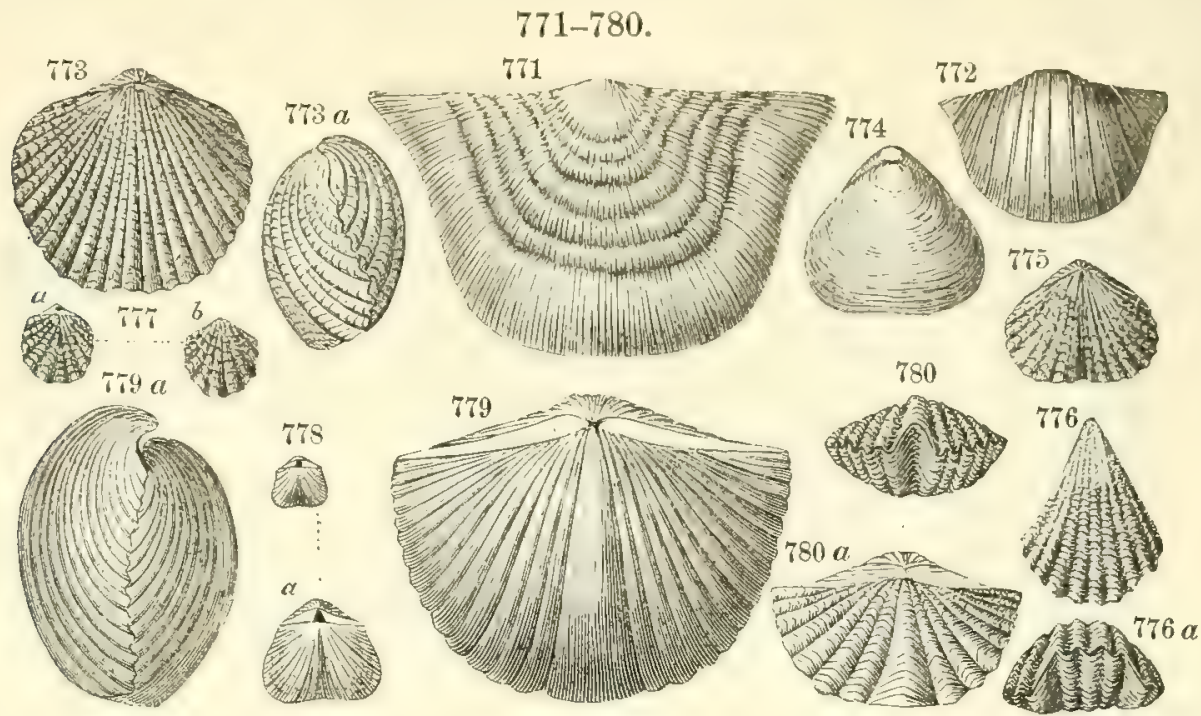

Brachopods. - Fig. 771, Leptrena rhomboidalis; 772, Plectambonites transversalis; 773, a, Atrypa nodostriata; 774, Meristina (Whitfieldella) nitida; 775, Anastrophia interplicata; 776, $a$, Rhynchotreta cuneata; $777, a, b$, Atrypina disparilis; $778, a$, Orthis biloba ; 779, $a$, Spirifer Niagarensis ; 780, $a$, Sp. sulcatus. Hall ; except 778, Meek.

Some of the characteristic Brachiopods of the Niagara group are represented, natural in size, in Figs. 771 to 780 - all very abundant species.

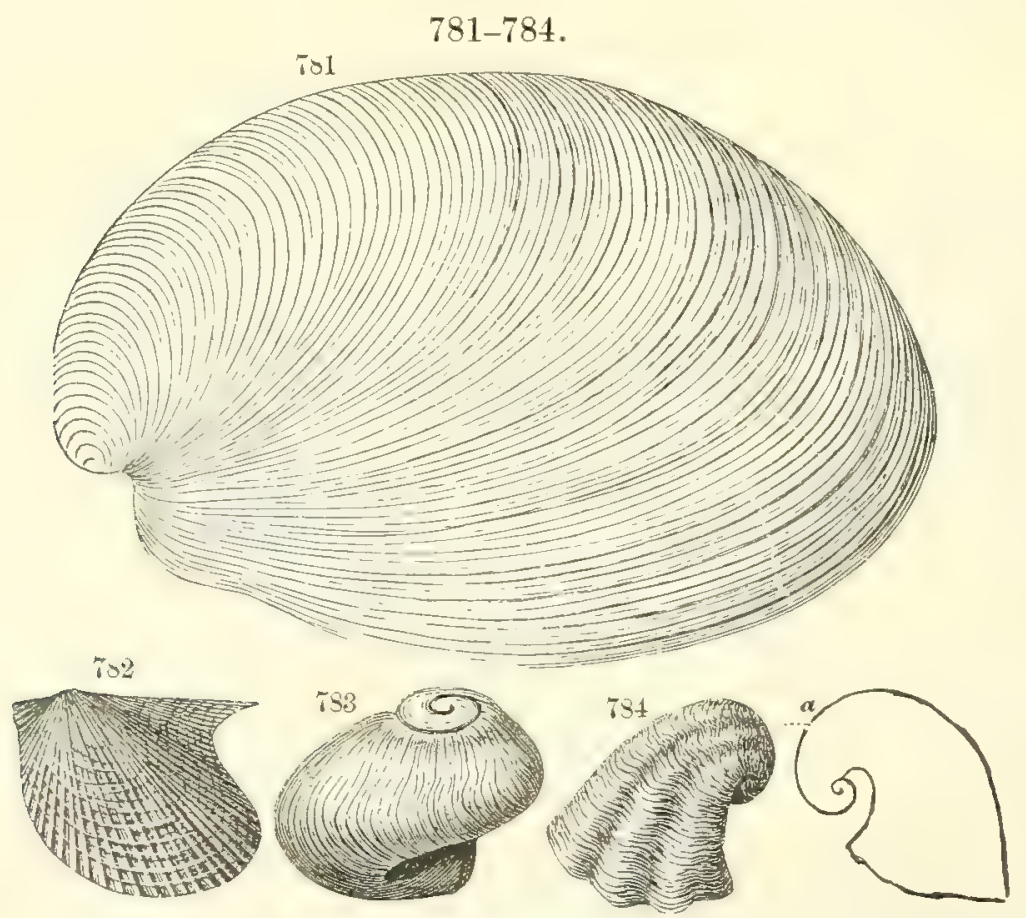

Lamellibranchs and Gastropods. - Fig. 781, Megalomus Canadensis; 782, Avicula emacerata; 783, Platystoma Niagarense; 784, $\boldsymbol{a}$, Platyceras angulatum.

Leptoena rhomboidalis, Fig. 771, is one of the long-lived species - as it began in the Trenton period and continued on, with little change, through the Devonian. 
Lamellibranchs are not numerous, - a common fact with limestones. One of them from the Coralline limestone, and also from Guelph in Ontario, is shown in Fig. 781; another more common form, an Avicula, in Fig. 782. Figs. 783, 784 are of two Gastropods, the latter also a Clinton group species. A Pleurotomaria ( $P$. solarioides), from the Guelph limestone, has a diameter of four inches. There were also Conularice of unusual size. Cephalopods include species of Orthoceras, Actinoceras, Discosorus, Huronia, Gomphoceras, Trochoceras.

The following figures, 785-789, are the forms of some of the Niagara Trilobites, all reduced one half or more. The Lichas Boltoni (Fig. 786) has sometimes a length of seven inches, and the Homalonotus (Fig. 787), remarkable for its small eyes, even a greater length. The Calymene Niagarensis is very similar to the C. callicephala of the Trenton period (Fig. 690).

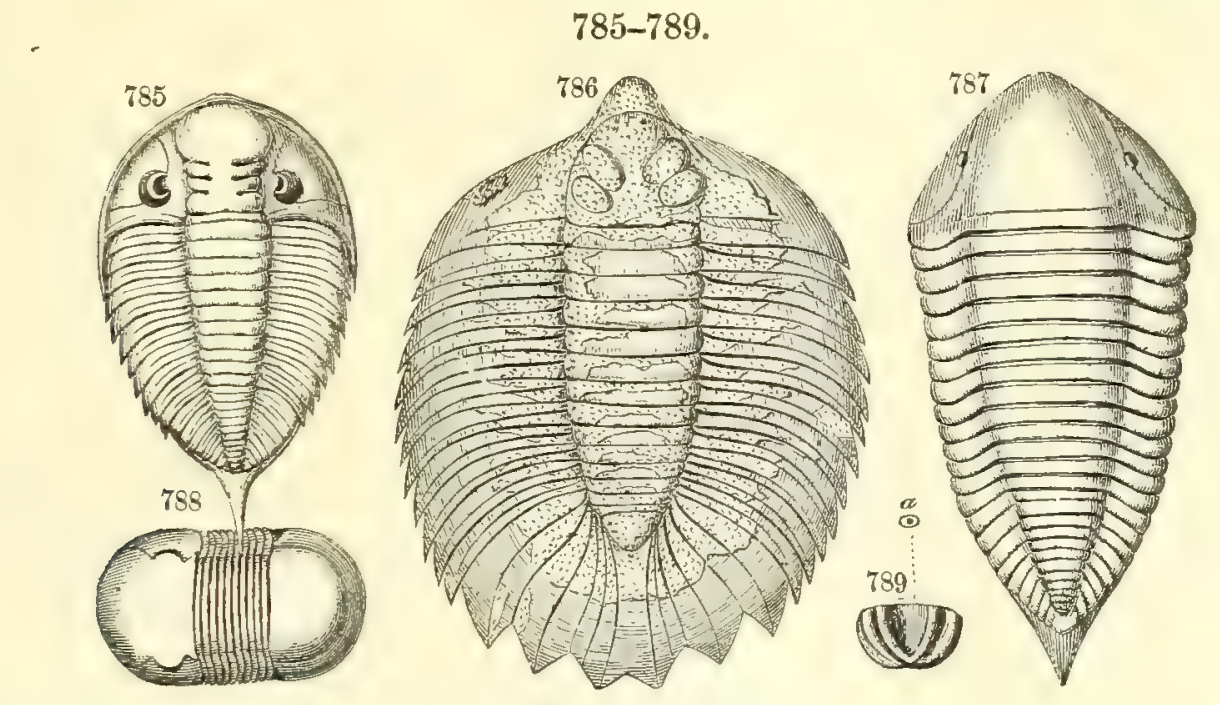

Terrobites. - Fig. 785, Dalmanites limulurus $\left(\times \frac{1}{2}\right) ; 786$, Lichas Boltoni $\left(\times \frac{1}{4}\right) ; 787$, Homalonotus delphinocephalus $\left(\times \frac{2}{4}\right) ; 788$, Illænus Ioxus $\left(\times \frac{1}{4}\right)$. Crustacean. - 789, Beyrichia symmetrica; $789 a$, same, patural size. Hall.

Ceratiocarids, among Crustaceans, occur of large size. The telson, or tail-spine, of one from western New York, Ceratiocaris Deweyi, is over six inches long, indicating a length for the Ceratiacaris of nearly two feet, or as great as that of C. Angelini (Fig. 729).

\section{Characteristic Species.}

\section{Medina Epoch.}

Fig. 744, Arthrophycus Harlani H. (1853) = Harlania Halli Gopp. (1852) = Fucoides Harlani Con. (1838). Fig. 739, Lingula cuneata Con.; Atrypa (Whitfieldella) oblata H.; 740, Modialopsis arthonota Con.; 741, M. primigenia Con. ; 742, Pleurotomeria litorea H.; $P$. pervetusta Con.; 748, Bucania trilobata Con., different views; Oncoceras gibbosum H.; Orthoceras multiseptum $\mathbf{H}$.

\section{Clinton Epoch.}

Plants. - Buthotrephis gracitis H., B. ramosa H. A Lycopod (or Fern) has been reported from Ohio by E. W. Claypole (1878). It is of doubtful nature. 
Animazs. 1. Hydrozoans. - Fig. 750, Graptolithus Clintonensis H.

2. Actinozoans. - Figs. 746, 747, Zaphrentis bilateralis H.; Favosites frvosus, Favistella favosidea H., Palceoyclus rotuloides H., Cannapora junciformis H., Halysites escharoides Lamk., H. catenulatus, species of Cyathophyllum, Streptelasma, Aulopora, Diphyphyllum.

3. Echinoderms. - Caryocrinus, but rare.

4. Molluscoids. - (a) Bryozoans. - Fig. 751, Fenestella prisca Lonsdale ; Ptilodictya, Stictopora, many species.

(b) Brachiopods. - Species of Lingula, Orthis, Plectambonites, Rhynchonella, Spirifer, Chonetes, and Pentamerus; Fig. 752, Pentamerus oblongus Sow.; some specimens are twice the size of the figure; the interior of the shell is shown in Figs. 753, 753 $\alpha$; Figs. 754, a, Atrypa reticularis Linu. ; Figs. 755, a, Hyattella congesta Con. ( = Camarella congesta); Fig. 756, Chonetes cornutus.

5. Mollusks. - (a) Lamellibranchs. - Fig. 757, Avicula rhomboidea H.; A. emacerata Con., Tellinomya machoriformis H., abundant.

(b) Gastropods. - Fig. 758, Cyclonema cancellatum H.; Bucania trilobata of the Medina also occurs here, besides other Gastropods.

6. Crustaceans. - Homalonotus delphinocephalus, Calymene Clintoni Van., C. Niagarensis, Ceraurus Niagarensis $\mathrm{H}$., Phacops trisulcata $\mathrm{H}$.

(a) Ostracoids, or Bivalve Crustaceans. - Fig. 789, Beyrichia symmetrica H., showing one of the valves; $789 a$, same, natural size; B. spinosa H., Lockport. (b) Ceratiocarids. - Ceratiocaris Deweyi H., specimens of the caudal spine, formerly supposed to belong to a Fish, and named Onchus Deveyi. Onchus Clintoni of Claypole is from the Iron Sandstone stratum of Perry County, Pa. $(1884,1885)$; that it belonged to a Fish is not certain.

7. Eurypterids (Limuloids). - Eurypterus prominens $\mathbf{H}$.

Among the Clinton species are the following from the Lower Silurian: Orthis (Platystrophia) biforata, Leptcena (Plectambonites) sericea, Bellerophon bilobatus, Calymene callicephala. The following are known in Europe: Orthis biforata, Atrypa reticularis, Coelospira (Atrypa) hemisphorica Murch., Spirifer radiatus Sow., Pentamerus oblongus.

\section{Niagara Epoch.}

1. Spongiozoans. - Astraespongia, Astylospongia, Palceomanon of Rœmer in Tennessee, in the upper part of the Niagara (or Meniscus) limestone; Astroeospongia meniscus is the most abundant. (Sit. Faun. W. Tenn., 1870.)

2. Hydrozoans. - Dictyonema, common; Fig. 766, Stromatopora concentrica Goldf.

3. Actinozoans. - Fig. 761, Chonophyllum Niagarense H. ; Streptelasma calyculus H., Astrocerium venustum H., masses often 2 or 3 feet in diameter ; Strombodes gracilis Bill. ; 762, Favosites Niagarensis H.; F. Gothlandicus Lamk., F. venustus H.; 763, Halysites catenulatus Linn., H. escharoides Lamk., H. agglomeratus $\mathrm{H}_{.} ; 764$, Heliolites spiniporus H. ; 765, an enlarged view, showing the 12-rayed cells, and the interval of a cellular character separating them, both of which are distinguishing characteristics of the genus Heliolites; $H$. interstinctus Linn., H. pyriformis Guettard, Syringopora retiformis Bill., S. multicaulis H., Aulopora precia H., A. repens.

4. Echinoderms. - Fig. 767, Ichthyocrinus laevis Con., Lockport, sometimes twice as large as the figure; 768, Caryocrinus ornatus Say, New York, Wisconsin, and Tennessee, named from Carya, the hickory-nut; 769, Stephanocrinus angulatus Con., Lockport ; $a$, part of the stem, enlarged; $b$, joint; $c$, base of the body, showing the 3 pieces of which it consists; species of Melocrinus, Eucalyptocrinus decorus Phillips, New York, Kentucky, Tennessee; Camarocrinus Saffordi H., Tennessee; Lecanocrinus, etc. Also Fig. 444 (page 429), the Cystoid, Callocystites Jewetti H. ; Apiocystites elegans H., A. Canadensis, and A. Huronensis of Billings, from Anticosti. Troostocrinus subcylindricus H. and 
Wh., from the Niagara beds of Ohio, Fig. 770. The Star-fishes, Paloeaster Niagarensis $\mathrm{H}$., Glyptaster occidentalis $\mathrm{H}$.

5. Molluscoids. - (a) Bryozoans. - Many species of delicate Corals of the genus Fenestella, resembling Fig. 751 ; Trematopora, and other genera. (b) Brachiopods. Fig. 771, Leptcena rhomboidalis Wilck.; 772, Plectambonites transversalis Dalman; Strophomena depressa Sow.; 773, Atrypa nodostriata H., the Niagara form of this species; $773 \alpha$, same, side view ; A. reticularis Linn.; A. rugosa H. ; 774, Meristina (Whitfieldella) nitida H. ; 775, Anastrophia interplicata H. ; 776, a, Rhynchotreta cuneata Dalm.; 777, a, b, Atrypina disparilis H.; 778, Orthis (Bilobites) biloba Linn., 778 a, same, enlarged; O. elegantula Dalm., O. hybrida Sow., Nucleospira pisiformis H.; 779, Spirifer Niagarensis Con., 779 a, same, side view ; 780, $a$, Sp. sulcatus His. ; Pentamerus oblongus (Fig. 752), a Clinton group species, abundant in the Niagara limestone of the Mississippi basin; Pentamerus occidentalis H., from the Guelph.

6. Mollusks. - (a) Lamellibranchs. - Fig. 781, Megalomus Canadensis H., from the Guelph, Canada; 782, Avicula emacerata Con.; Orthonota curta H.

(b) Gastropods.-Fig. 783, Platystoma Niagarense H.; 784, Platyceras angulatum H. ; Murchisonia bivittata H., M. macrospira H., Subulites ventricosus H., Pleurotomaria solarioides $\mathrm{H}$.

(c) Pteropods. - Conularia Niagarensis H., C. longa H., Lockport.

(d) Cephalopods. - Orthoceras annulatum Sow., O. rectum Worthen, Orthoceras (Fionoceras Hyatt) strix Worthen; Phragmoceras parvum H. and Whitf., Huronia Bigsbyi Stokes, $H$. vertebralis Stokes, Gomphoceras Wabashense and $G$. angustum Newell, Pentameroceras mirum Barrande, Ascoceras Newberryi B., Hexameroceras delphicolum Newell, etc., Lituites Marshi Hall, Trochoceras costatum H., T. notum H., T. Desplain. ense McChesney.

7. Crustaceans. - Fig. 785, Dalmanites limulurus Green; 786, Lichas Boltoni Bigsby ; 787, Homalonotus delphinocephalus Green, one specimen 7 inches long and 5 broad; 788, Illanus Ioxus H.; Calymene Niagarensis H., near Fig. 690 ; Ceraurus Niagarensis H.; Proetus Stokesi Murch., at Lockport.

The following genera and species of fossils have been identified in the Niagara beds of Littleton, N.H.: Favosites basalticus, F. Gothlandicus, Syringopora, Stromatopora, Halysites near catenulatus, Zaphrentis, Leptona rhomboidalis, Stropheodonta, Pentamerus Knightii, Trematospira multistriata H., Pleurotomaria, Dalmanites limulurus abundant.

In the Anticosti beds there are Cephalopods of the genera Orthoceras, Cyrtoceras, Oncoceras, Ascoceras, and Glossoceras; and Trilobites of the genera Asaphus, Calymene, Illsenus, Phacops, Dalmanites, Encrinurus, Harpes, Lichas, etc., and among these Asaphus megistos and Calymene Blumenbachii.

A section of the Anticosti group, or that of Anticosti Island, on the north side of the St. Lawrence Bay, opposite Gaspé, is particularly described by Logan in the volume of the Canadian Survey for 1863 (pages 298-310), and the fossils in its successive parts are enumerated from determinations by Billings, and also, where new, described by the latter.

The following are some of the species common to the Niagara and Clinton groups:-

Halysites catenulatus (Fig. 763).

Caryocrinus ornatus (Fig. 768).

Eucalyptocrinus decorus.

Lingula lamellata.

Orthis elegantula (Fig. 723).

Leptæna rhomboidalis (Fig. 771).

Pentamerus oblongus (Fig. 752).

Rhynchonella neglecta.

A trypa reticularis (Fig. 754).

Spirifer radiatus.
A vicula emacerata (Fig. 782).

Orthonota curta.

Modiolopsis subalata.

Ceraurus Niagarensis.

Homalonotus delphinocephalus (Fig. 787).

Calymene tubereulosa.

Calymene Niagarensis.

Dalmanites limulurus (Fig. 785).

Illænus Ioxus (Fig. 788). 
Foerste reports the absence of several Clinton fossils from the Clinton beds along the borders of the Cincinnati geanticline in Ohio and Indiana that occur in New York $(B . S$. N. $H ., 1889$ ).

According to Salter, a number of species of the Upper Silurian, and probably of this part of it, have been observed in Arctic rocks on the shores of Wellington and Barrow Straits and on King William's Island, lat. $72^{\circ}$ to $76^{\circ}$; Halysites catenulatus, Orthis elegantula, Favosites Gothlandicus, Leperditia Baltica Hisinger, species of Calophyllum, Heliolites, Cystiphyllum, Cyathophyllum, Syringopora, with Pentamerus conchidium Dalm., Atrypa reticularis, etc.; and, at the southern extremity of Hudson Bay, Pentamerus oblongus, Atrypa reticularis, ete. Trochoceras boreale Foord is from Wellington Channel. Between $79^{\circ}$ and $82^{\circ} 5^{\prime}$, the expedition of Captain Nares obtained, according to Etheridge, Corals of the genera Halysites, Favosites, Heliolites, Favistella, Zaphrentis, Amplexus, Cyathophyllum, and Arachnophyllum, and Trilobites of the genera Bronteus, Calymene, Encrinurus, and Proetus, with Brachiopods of Pentamerus, Rhynchonella, Chonetes, Atrypa, Strophomena. About Lake Winnipeg, also, Upper Silurian fossils have been found. See An. Jour. Sc., II., xxi. 313, xxvi. 119 ; III., xvi., 1878.

The beds of northern Maine, about Square Lake, described by C. H. Hitchcock, have afforded both Niagara and Lower Helderberg fossils, and many of them are made new species by Billings.

The Niagara beds of the vicinity of Cobscook and Penobscot bays, Maine, contain, besides Niagara fossils, some of the Clinton group; the latter, in Penobscot Bay, are mostly confined to the lower half, but many Niagara species occur with them. (Shaler, 1886 ; Dodge and Beecher, 1892.)

\section{The Onondaga Period.}

\section{ROCKS-KINDS AND DISTRIBUTION.}

The Onondaga period embraces two somewhat unlike formations; one, the Salina beds of shales and marlytes, or the Salt group, the source of the brines of central New York and of rock salt in the western half of the state, as well as in Ontario and Ohio; the other, the Water-lime group, in general an impure limestone, along with the overlying Tentaculite limestone. Each was of shallow water origin, and partly marsh-made; but the former was. produced under conditions suited for the deposition and storing of salt from the sea water. This classification was first proposed by D. Sharpe, in 1847.

The following sections (Figs. 790, 791, from Hall), taken on a north-andsouth line south of Lake Ontario, show the relations of the Onondaga beds $(6, a, b)$ to those above and below, - they being underlaid in one section (Fig. 790 ) by the Niagara beds $(5 c)$, Clinton $(5 b)$, and Medina $(5 a)$, and overlaid in the other (Fig. 791) by rocks of the Upper Helderberg (9), Hamilton $(10 a, 10 b, 10 c)$ and Portage group (11), the Lower Helderberg being there absent.

The rocks spread eastward to the Hudson River valley, the Water-lime occurring as a thin stratum even east of the river in the base of Becrafts Mountain, near Hudson, N.Y., and also in Mount Bob, a few miles farther north, in each case resting on the upturned Hudson formation. They increase in thickness westward. They extend beyond New York over much of Ohio, cross Ontario to Lake Huron and northwestward to Mackinac in 
Michigan, and thin out in Wisconsin. They also cross Pennsylvania southwestward. They have not been observed in Missouri, Iowa, or elsewhere in the Mississippi valley. They are absent from the Black Hills of Dakota,

790.

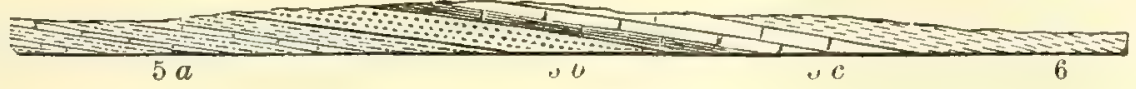

791.

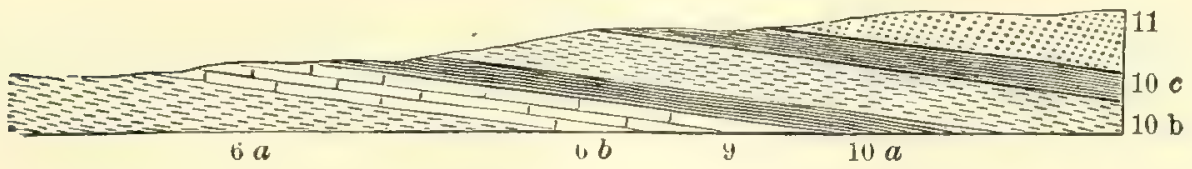

Sections illustrating the relations of the Onondaga beds. Hall.

and nothing definite is known of their occurrence over the Rocky Mountain region, or the Great Basin, or in California, or any part of the Pacific Coast region.

The group is 100 to 200 feet thick south of Albany in the Helderberg Mountains, 800 in Onondaga County, central New York, 1500 at Ithaca, 1600 in central Pennsylvania, 600 in northern Ohio, and only 100 in southern Ohio.

The two formations, the Salina and Water-lime, are not consecutive strata, but more or less cotemporaneous, the Water-lime being thin where the Salina beds are thickest.

\section{Salina Group.}

The rocks of the Salina group are mostly reddish shales or marlytes, with little limestone, which is usually dolomyte; or alternations of shales with thick beds of limestone. In either case, gypsum and rock salt are often present.

The outerop of the formation extends as a narrow belt across New York State, extending from the Helderberg Mountains south of Albany, westward, passing just north of Sharon Springs, Syracuse, and Batavia to the Niagara River above the Falls, where the thickness is but 300 feet. From this belt it dips southward beneath the higher beds of the Upper Silurian and Devonian, becoming 1000 feet below the surface in 25 miles nearly south of Batavia, and 1500 feet in 33 miles. At Syracuse the thickness of the formation is about 600 feet; at Ithaca, 30 miles south of the belt, it is 1230 feet. In western Ontario, Canada, on Lake Huron, about Goderich, the thickness is over 1400 feet, the lower 600 feet consisting of limestone, shale, and salt, and the rest of dolomyte; and to the south, near Cleveland, Ohio, there are 750 feet of shale, limestone, and rock salt beneath 800 feet of dolomyte.

Salt springs occur in many parts of New York, west of Syracuse and Tully. Those around Onondaga Lake led, first in 1825, to the sinking of wells 70 feet to 75 feet deep at Salina, for the manufacture of salt by evaporation. Rock salt appears to have been first discovered in New York, in Bristol, Ontario County, at a depth of 1200 to 1300 feet; but the discovery 
that attracted attention was made when boring for gas or oil, in 1878, in Wyoming County, a dozen years after the discovery at Goderich, and ten years before that near Cleveland, Ohio.

By evidence from borings, rock salt is now known to occur in New York at depths of 800 to 3000 feet or more, over an area measuring 150 miles from east to west, and 60 to 65 miles in width if extending only to the Pennsylvania boundary. The northern limit of the area is near Morrisville, where 12 feet of salt were found, and near Leroy, 100 miles west of syracuse, where a bed 40 feet thick exists. To the south, in Livingston and Wyoming counties, beds of salt occur at depths of 1000 to 2500 feet, and they have an aggregate thickness of 50 to 100 feet, some beds of pure salt being 40 to 80 feet thick. At Ithaca, the several beds of salt have together a thickness of 250 feet; they alternate with shale between depths of 1900 feet and 3130 feet. At Goderich, six beds 6 to 35 feet thick were passed in a boring 1617 feet deep; and other localities occur within 40 miles to the north, east, and south. Near Cleveland (at Newburg) there are four beds 5 to 50 feet thick in a range of beds 500 feet thick, between 2000 and 2500 feet below the surface. The evidence shows that the Goderich basin is independent of the New York, as pointed out in 1876 by T. S. Hunt. How it is related to the Cleveland basin is not positively known.

The strata are non-fossiliferous; but as they include beds of limestone, this is probably owing to loss of shells and other relies by trituration through the gentle movements of the water. The beds abound in mud-cracks, and other evidences that they were made as mud-flats or bottoms in shallow water. The facts are believed to prove that the region through which the salt beds extend was an area of great salt marshes or flats, or in other words "salt-pans," over which sea water, admitted at intervals from the interior continental sea, evaporated and deposited salt. The fineness of the material of the shales is such as would be produced by the gentle ripplings of such waters.

The gypsum in the beds sometimes constitutes layers, but oftener parts of layers, or imbedded masses, as illustrated in the following figures (from Hall); but the most of the gypsum is connected with the overlying Waterlime beds. The lines of stratification in the beds sometimes run through the gypsum, as in Fig. 792; and in other cases the layers of the shale are bulged up around the nodular masses (Fig. 793). In all such cases, the gypsum was formed after the beds were deposited, by the action of sulphuric acid on an imbedded mass or bed of limestone, converting $\mathrm{CaO}_{3} \mathrm{C}$ into gypsum (hydrous lime sulphate $=\mathrm{CaO}_{4} \mathrm{~S}+2 \mathrm{H}_{2} \mathrm{O}$ ). It may be now forming. Sulphur springs, emitting sulphuretted hydrogen, are common in New York, and especially about Salina and Syracuse. Dr. Beck describes several, and mentions one, near Manlius, which is "a natural sulphur bath, a mile and a half long, half a mile wide, and 168 feet deep, - a fact exhibiting in a striking manner the extent and power of the agency concerned in the evolution of the gas," and showing, it may be added, that the effects on the rocks 
below must be on as large a scale. These sulphur springs often produce sulphuric acid, by the oxidation of the sulphuretted hydrogen. There is a noted acid spring in Byron, Genesee County, N.Y., first noticed by Amos Eaton (Am. Jour. Sc., xv., 1829), whose waters Beck showed to have a specific gravity of 1.113. The laminæ which pass through the gypsum unaltered, as in Fig. 792, are those which consist of clay, instead of limestone.

792.

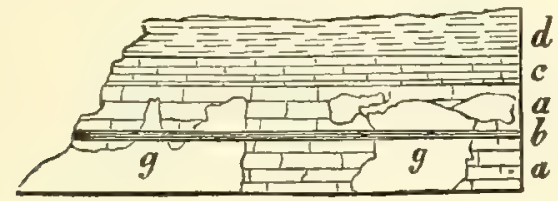

793.

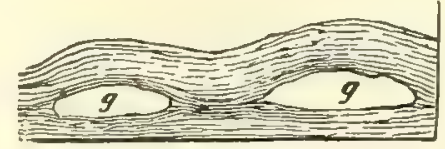

Beds of gypsum $(g)$ in limestone and calcareous shales. Hall.

The gypsum is usually of an earthy variety, of dull gray, reddish and brownish, sometimes black, colors. That all the gypsum of the formation had this source is reasonably questioned. It may have been in part a deposit from the same sea waters that supplied the salt.

\section{Water-lime Group.}

The Water-lime rock, so-called because it is a hydraulic limestone, is an impure, thin-bedded magnesian limestone of usually a drab color. It sometimes contains a little petroleum. It owes its hydraulic character to its impurities, as explained on page 79 (under Rocks). The group has, in general, the distribution above given for the Onondaga series. In the Helderberg Mountains it is about 150 feet thick, and nearly the same in the central part; but farther north, near Oriskany Falls in Oneida County, it runs out. It contains much gypsum, and quarries of it are worked near Syracuse, and also in Cayuga and Genesee counties. In Northern Ohio, where the Onondaga series has a thickness of 600 feet, it contains layers of shale; and gypsum is abundant at Gypsum, 10 miles west of Sandusky. Hydraulic cement is made extensively from it in Ulster County, N.Y., at Rosendale near Rondout, whence the oft-used name "Rosendale cement," but not in Ohio, where the limestone is not suited for it. The presence of chert is one cause of the unfitness of the beds for the purpose.

In the New York report by Vanuxem, the salt group between Oneida Creek and Cayuga Lake is stated to consist of (1) red shales with green spots, $1^{\prime}$ to $500^{\prime}$ thick; (2) the Lower Gypseous shales, light green and drab, alternating with No. 1 near the plane of junction; (3) beds containing two ranges of gypsum in masses, and often containing hopper-shaped cavities due to crystallized salt, the Vermicular limerock of Eaton; and (4) impure limestone containing "Epsomites," or vertically grooved surfaces formerly supposec' to have been made by the crystallizing of Epsom salts (the Stylolites, mentioned above).

In middle Pennsylvania there are $700^{\prime}$ of red shales, overlaid by $700^{\prime}$ of variegated shale and $200^{\prime}$ of gray shale (Claypole). The thickness of the formations overlying the Salina near the New York and Pennsylvania boundary is so great that no borings have yet penetrated to them. On the salt and gypsum industries of New York, see the Report of F. J. H. Merrill, Bull. N. Y. State Mus., iii., 1893, which contains maps showing the distribution. 
A dike of a chrysolitic eruptive rock, altered to serpentine, intersects the Salina group at Syracuse (though now concealed from view), which was first described by Vanuxem in 1839, and by Beck in 1842, and has recently been studied and explained by G. H. Williams (Am. Jour. Sc., 1887).

LIFE.

The fossils that have been supposed to occur in the lower beds of the Salina group in New York are referred to the Niagara group, and those at the top are Water-lime species. Regarding the Water-lime beds of Ohio as synchronous with the Salina and Water-lime of New York, the fossils of the Water-lime stand for those of the Onondaga period. But they are few in number, the limestone having originated, as its fine texture and impurity

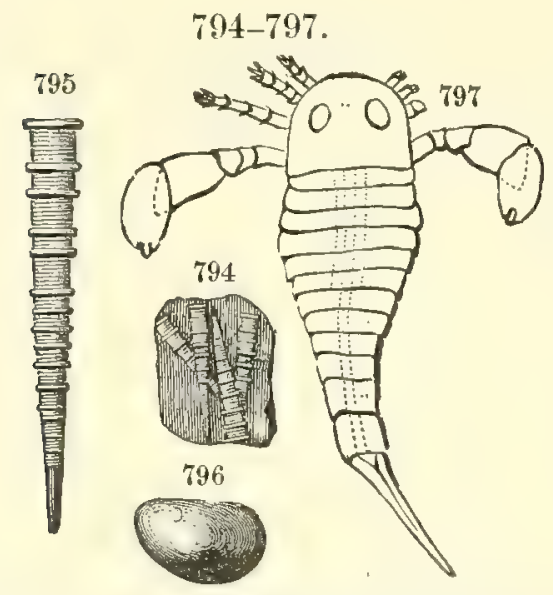

Figs. 794, 795, Tentaculites gyracanthus; 796, Leperditia alta; 797, Eurypterus remipes, the three anterior legs of the right side mutilated, a young individual. Meek. show, in shallow waters, under their gentle triturating action, and differing in origin from the Salina beds in having had more open connection with the Interior Continental Sea. Unquestioned remains of Fishes are among the fossils, and also the first of American terrestrial species, a Scorpion.

Some of the characteristic fossils of the Water-lime are represented in the annexed figures. Fig. 794 is the more common species of Tentaculites of the Tentaculite limestone, and 795 is the same enlarged. It is regarded as the shell of a small Pteropod. Fig. 796 is an Ostracoid Crustacean (Leperditia alta); it is very common in the Tentaculite limestone and Water-lime. Fig. 797 represents a young Eurypterid (Eurypterus remipes), a common species in the Waterlime, related to the species of the Trenton period, mentioned on page 513, but of different genus. Some specimens are a foot in length. E. giganteus, a species from near Buffalo, described by J. Pohlman, was nearly six inches broad and probably 20 inches long. The under surface of $E$. remipes restored is shown in Fig. 798 ; and on it the segments of the thorax and abdomen are numbered. Anteriorly, the members of the cephalic portion are five in number of pairs, and they serve both as feet and jaws, as in the modern Limulus. There are no antennæ corresponding to the chelate or pincer-like antennæ of Limulus. Behind the legs, an apron-like pair of limbs, with a narrow prolongation at the center, per-

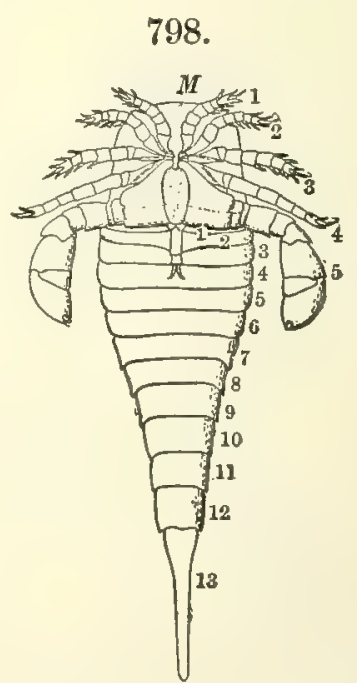

Restoration of Eurypterus remipes, ventral view. $M$, mouth. Hall. tains to the first thoracic segment, which has the position of a similar pair in Limulus. 
Other genera of Eurypterids have their species in the Water-lime. One from Kokomo, Indiana, Carcinosoma ingens of Claypole (1894), had a length of 24 inches. In Pterygotus, which is one of them, there are chelate antennæ at the front margin, and the eaudal segment is broad. In $P$. acuticaudatus of Pohlman, from near Buffalo, the telson alone is $6 \frac{1}{4}$ inches long.

Crustaceans of the genus Ceratiocaris occur in the same beds.

Arachnids represented by Scorpions. - The American Scorpion of the Water-lime is from beds at Waterville, N.Y. It is represented in Fig. 799, from a paper by R. P. Whitfield (1885).

Vertebrates. - Remains of Placoderm Fishes, related to the Pteraspids (page 566), oceur in the upper portion of the Onondaga beds of middle Pennsylvania, and have been deseribed by E. W. Claypole (1884, 1892). Fig. 800 represents two imperfect plates, which are supposed to be parts of dorsal and ventral shields; Figs. 801, 802, side views of a dorsal plate, showing also the lateral plate; Fig. 803, a pectoral fin; and 804, a restoration, giving the supposed form of the Fish.

The few fossils of the Onondaga beds, which occur in the non-saliferous portion, exclusive of the Tentaculite limestone, include the following:-

799.

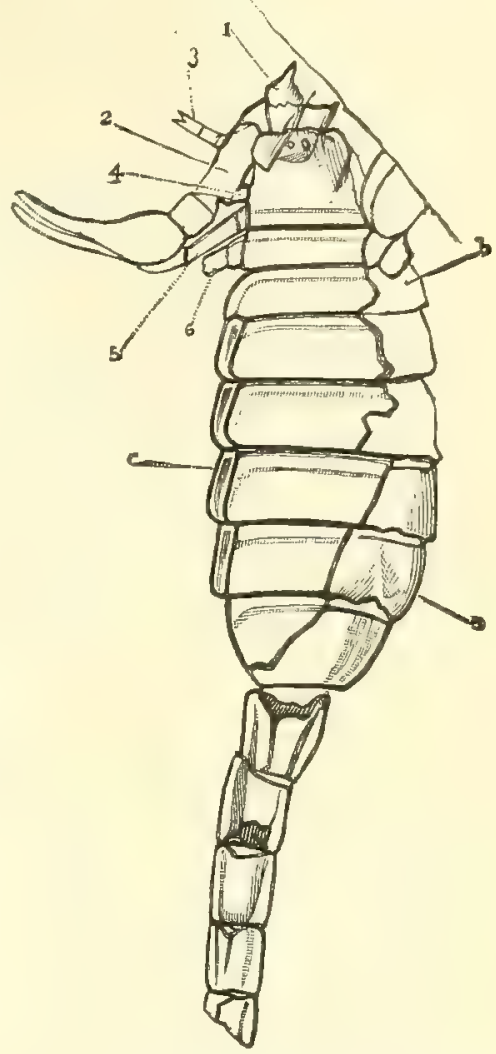

Proscorpius Osborni $(\times 2)$.

Whitfield.

Orbiculoidea Vanuxemi H., Meristella sulcata Van., Leperditia alta Con., species of
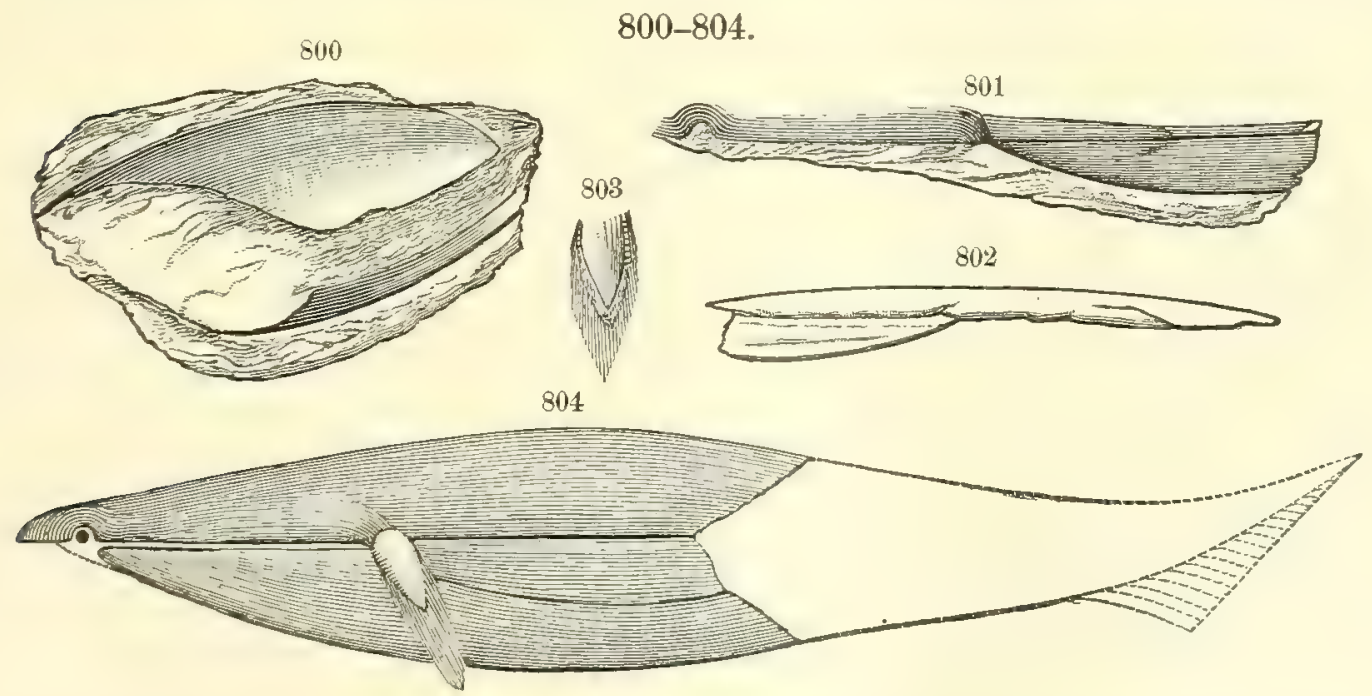

Placodery. - Palæaspis Americana: Fig. 800, two plates, supposed to be part of ventral and dorsal, in position; 801,802 , side view of dorsal plate, with the lateral plate; 803 , pectoral fin; 804, restoration, giving probable forma $\left(\right.$ all $\left.\times \frac{2}{3}\right)$. Claypole.

Eurypterus, Pterygotus, Eusarcus, Dolichopterus, Ceratiocaris (4 sp.), Tentaculites gyra- 
canthus (Claypole). The telson in Fig. 797 is half too short; it was partly buried in the rock when drawn, and has been recently uncovered by C. E. Beecher.

The Tentaculite limestone has afforded Camarocrinus stellatus H. (a form found also in Bohemia), Stropheodonta varistriata Con., Spirifer Vanuxemi, Tellinomya nucleiformis H., Modiolopsis (?) dubia H., Avicula obscura H., Holopea subconica H., H. antiqua H., H. elongata H., Murchisonia extenuata H., M. minuta H., Oncoceras ovoides H., Cyrtoceras subrectum H., Spirorbis laxus H., Beyrichia trisulcata H.

\section{The Lower Helderberg Period.}

ROCKS-KINDS AND DISTRIBUTION.

The preceding Onondaga formation has been described as extending far eastward, as well as westward, but as having its greatest thickness in central New York, central Pennsylvania, and Ohio. The Helderberg beds not only extend far eastward, but, in contrast with the preceding, have their greatest thickness to the eastward, and thin out in western New York. They are doubtfully recognized in Ohio, 20 feet being the greatest thickness reported. The representative rocks over the Central Interior Sea have not been made out.

East of Hudson River the beds constitute the low, isolated elevation called Becrafts Mountain, near Hudson, excepting its basal layer (the Water-lime) and the upper stratum, which is of the Oriskany sandstone with the Cauda-galli grit; also the smaller and similar Mount Bob, not far distant to the north. Each of these hills is all that is left of a great formation after ages of denudation. Logan was probably right in his conclusion that it once extended northward, along the Hudson River and Lake Champlain valleys, to Montreal; for similar beds occur on the island of St. Helens in the St. Lawrence, opposite Montreal, resting on Utica shale of the Lower Silurian. Hence the waters of the Eastern Interior Sea during this Lower Helderberg era had resumed their deep connection with the waters of the St. Lawrence region about Montreal.

The beds are 300 to 400 feet thick in eastern New York, 350 feet in central Pennsylvania (Perry County), and 600 in eastern (in Monroe County), and in New Jersey. They occur also in the Appalachians in Virginia, but not in eastern Tennessee. They are 20 to 100 feet thick in western Tennessee, and 175 feet thick in Missouri, but are not distinct in Illinois or Wisconsin. In other words, the beds are either thin or wanting over the Central Interior region.

The St. Lawrence tidal waters of this period must have extended westward to the borders of Vermont and Montreal and southward along the Connecticut valley. In Canada, in the line of the Connecticut valley, Lower Helderberg fossils occur in Dudswell and near Lakes Massawipi and Aylmer. They are also found in northern New Brunswick, northern Maine, near Square Lake, and along the Gaspé-Worcester trough. They also occur in southern New Brunswick and near the coast in Pembroke, Me., with many fossils, and in northern Nova Scotia, within the limits of the Acadian trough. 
The Lower Pentamerus limestone, Delthyris Shaly limestone, Encrinal limestone, and Upper Pentamerus occur in eastern New York. The upper two of these subdivisions are quite distinct in eastern New York, though not separable in the center of the State. They thin out in Cayuga County.

In the Arctic regions, Kennedy Channel, latitude $79^{\circ}-80^{\circ}$, fossils were obtained by Dr. Hayes, which, according to Meek (J. Sc., 1865), closely resemble those of the Shaly limestone of the Lower Helderberg of New York.

Lower Helderberg. - The Lower Pentamerus limestone, overlying the Water-lime, to the eastward, is compact, and mostly in thick layers and about $50^{\prime}$ thick. The Catskill or Delthyris Shaly limestone (No.3) consists of shale and impure thin-bedded limestone. An upper part of the formation was called the Scutella limestone by Vanuxem in his Annual New York Report, the Scutella referred to being the discoidal basal plate of an Encrinite. A bed of limestone corresponding to these two divisions, but without the subdivision, has a thickness of $65^{\prime}$ on Cayuga Lake.

Part of the so-called Upper Pentamerus of eastern New York, in the Hudson valley, according to recent observations of $\mathrm{C}$. E. Beecher, fails of the characteristic fossils of the group, and is referred by him to the lower Oriskany; it includes the impure limestones above the Encrinal limestone at Becrafts Mountain, near Catskill, and southward. The Upper Pentamerus is distinct at Schoharie and westward nearly to the center of the state, where all the subdivisions of the period merge together.

Becrafts Mountain, two miles east of the Hudson, near Hudson, consists below (1) of a thin bed of the Tentaculite limestone of the Water-lime; (2) Lower Pentamerus, 40' to $50^{\prime}$; (3) Shaly limestone, $50^{\prime}$ to $60^{\prime}$; (4) Encrinal limestone, $40^{\prime}$ to 50 . Over these occur the Oriskany sandstone and the Caudagalli grit.

In west Tennessee, light-blue limestones of this period, abounding in fossils, occur in Hardin, Henry, Denton, Decatur, and Stewart counties. The maximum thickness is about $100^{\circ}$. In southern Illinois there are beds of siliceous limestone underlying the Clear Creek limestone, the lower part of which Worthen refers to this period. They rest directly upon limestones of the Cincinnati or Hudson age (the Cape Girardeau limestone of the Missouri Report), no Niagara limestone intervening (Worthen).

In the Appalachian region in Pennsylvania, the Lower Helderberg, consisting also of impure limestones, has a thickness of $100^{\prime}$ or more in the middle belt, and $200^{\prime}$ to $250^{\prime}$ in the southeastern, which thickness is maintained along the Appalachian chain (Rogers).

In the Eastern Border region, at Pembroke, Me., slates and hard sandstones occur with many fossils. In northern Maine the rock is limestone; and to the north they have great thickness, about Lake Temiscouata, and include both Niagara and Lower Helderberg (L. W. Bailey). The formation extends northeastward to Cape Gaspé, where there are $2000^{\prime}$ of limestones, the larger part referred to the Lower Helderberg by Logan, with the upper beds probably Oriskany. They also stretch southwestward toward New Hampshire, in the line of the Gaspé-Worcester trough.

At Arisaig, in northern Nova Scotia, the Lower Helderberg

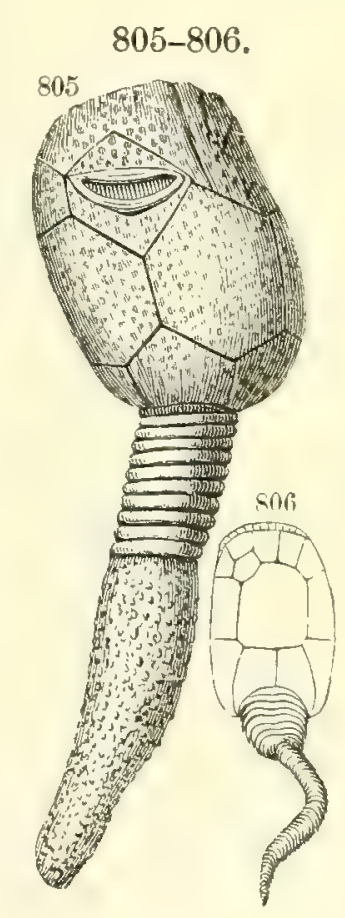

Crstideans. - Fig. 805, A piocystites Gebhardi, from Hall; s06, Anomalocystites cornutus, from Meek. beds have a thickness of $1040^{\prime}$, and overlie nearly $1293^{\prime}$ of Niagara, $500^{\prime}$ of Clinton, and $180^{\prime}$ of Medina beds (H. Fletcher, in an extended report on Nova Scotia, in Rep. Can., 1886). 
LIFE.

Plants supposed to be related to the Equiseta occur in the Lower Helderberg sandstone of Michigan; the species is Annularia Romingeri of Lesquereux. Another species from the same region is the Psilophyton cornutum Lesq.

The beds abound in animal fossils, the number of species even exceeding those of the Niagara group. Species of the Receptaculites group occur of large size. Crinoids were rather numerous, and some of them, like Melocrinus nobilissimus, were remarkable for their size and beauty. Two Cystoids of the period are shown in Figs. 805, 806; the stems of each were fitted for

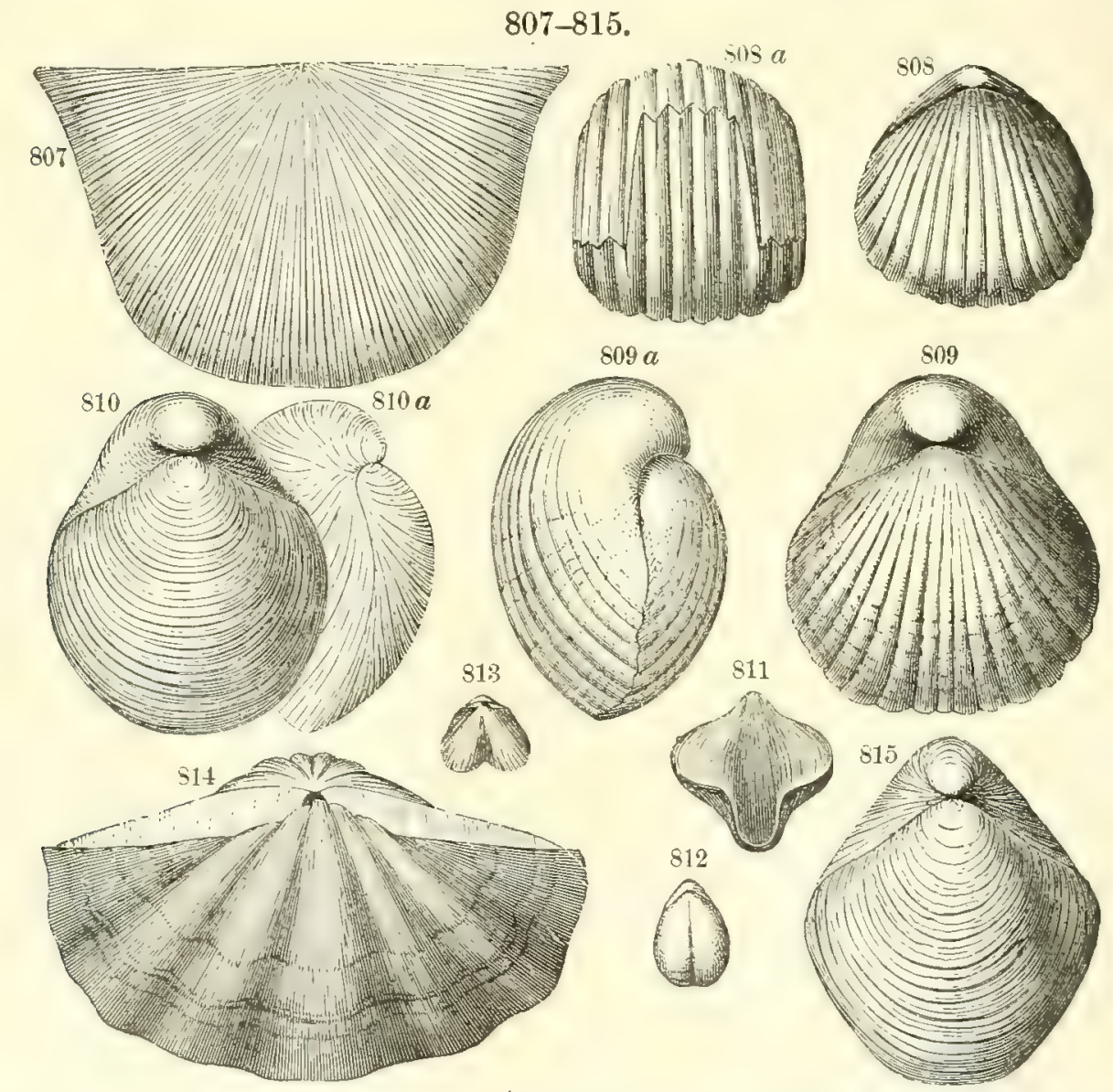

BrAoHIOPODs. - Fig. S0\%, Strophonella radiata; s08, $\boldsymbol{a}$, Rhrnchonella ventricosa; 809, $\boldsymbol{a}$, Pentamerus galeatus; 810, $a$, P. pseudo-galeatus ; 811, Eatonia singularis; 812 , Meristella sulcata ; 813, Orthis varica; 814, Spirifer macropleurus ; 815, Meristella lævis. 807, 808, Hall; the others, Meek.

anchoring in the mud of the sea bottom. The last of reported Graptolites occurs in the rocks. Polyp-corals were not largely represented; Favosites Helderbergice appears to have been the most common kind. Hydroid Corals and Bryozoans were numerous. Tentaculites were common, and one kind, T. elongatus, from the Shaly limestone, was three inches in length.

Some of the common Brachiopods are represented in Figs. 807 to 815. Among them Figs. 809, $809 a$, are of Pentamerus galeatus, of the Lower 
Pentamerus limestone, and $810,810 a, P$. pseudo-galeatus, of the Upper Pentamerus; Fig. 814 is of Spirifer macropleurus, characteristic of the Shaly limestone. Species of Spirifer and Orthis, and Gastropods of the genus Platyceras were numerous.

The Pentamerus (Anastrophia) Verneuili, Fig. 816, is a common species in the Shaly limestone; it occurs abundantly in the Helderberg Mountains, and also in Schoharie, Carlisle, and other places.

Orthocerata were few in species, of the genera Orthoceras, Gomphoceras, Cyrtoceras, Oncoceras, and others. A Gomphoceras, G. parvulum, of Whiteaves, Fig. 817, occurs in beds of probably the lower part of the series in Manitoba. Fig. 817 a shows the form of the aperture.

Among Trilobites occur species of Dalmanites,

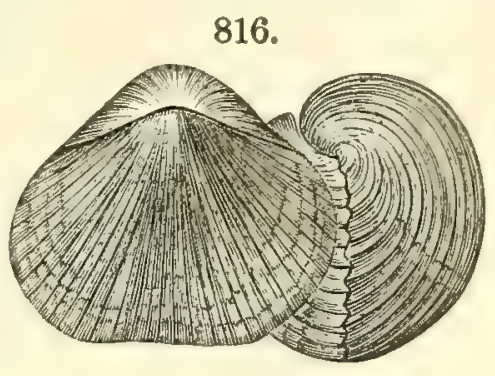

Pentamerus (Anastrophia) Verneuili. Hall. Lichas, Acidaspis, Phacops (Fig. 818), Bronteus (Fig. 819). Dalmanites pleuropteryx Green, $D$. nasutus Conrad, $D$. tridens Hall, having the front of the head-shield at the center prolonged into a beak, and three-pointed; Lichas Bigsbyi Hall, L. pustulosus Hall, ornate with tubercles and having the margin of the pygidium deeply dentate, are among the species.

\section{$817-819$}

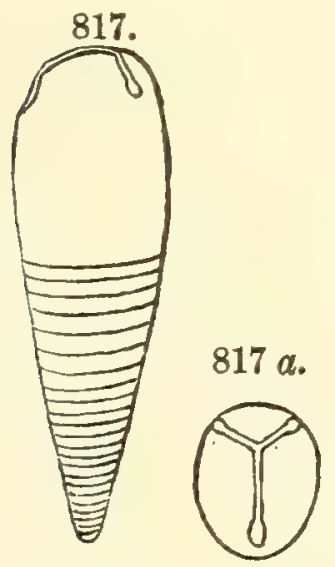

818.

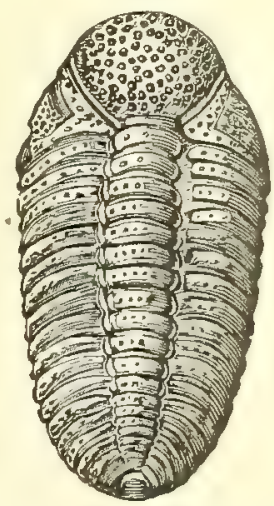

819.

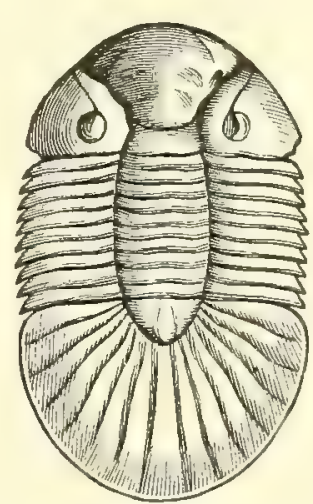

CephaLOPod. - Fig. 817, Gomphoceras parvulum; $817 a$, upper view showing aperture. Trilobites. - Fig. 818, Phacops Logani ; 819, Bronteus pompilins. 817, $817 a$, Whiteaves ; 818, Hall ; 819, Billings.

An upper view of the head of Acidaspis tuberculata is shown in Fig. 820, a section of a segment of the thorax in 821 , and the pygidium or caudal extremity in 822 . Fig. 824 is a dorsal view of the young of the same Trilobite, when but a twenty-fifth of an inch long, as described by C. E. Beecher. As the figure represents, the larve is nearly all head; only a small lower part of the figure corresponds to the posterior portion of the body. Fig. 825 shows the larval Acidaspis in profile.

The genus Monticutipora and many others and a few Polyp-corals are described by Hall in Pal. N. Y., vol. vi. ; Crinoids and Cystoids in Part vi., vol. iii.; also Brachiopods, Gastropods, Cephalopods, and Trilobites in the same; Pteropods in vol. vii. 


\section{Characteristic Species.}

Some of the species of the subdivisions from eastern New York are :-

1. Lower Pentamerus. - Lepadocrinus Gebhardi, Rhynchonella semiplicata, Pentamerus galeatus, Meristella lavis (also in the Shaly), Favosites Helderbergice.

2. Shaly Limestone. - Hemipronites radiatus, $H$. punctuliferus, Orthis oblata, O. planoconvexa, O. varica, Eatonia singularis, Spirifer macropleurus, Sp. perlanellosus, Sp. cyclopterus, Platyceras ventricosum, Dalmanites pleuropteryx.

3. Upper Pentanerus. - Pentamerus pseudogaleatus, Rhynchonella ventricosa, R. nobilis $\mathrm{H}$.

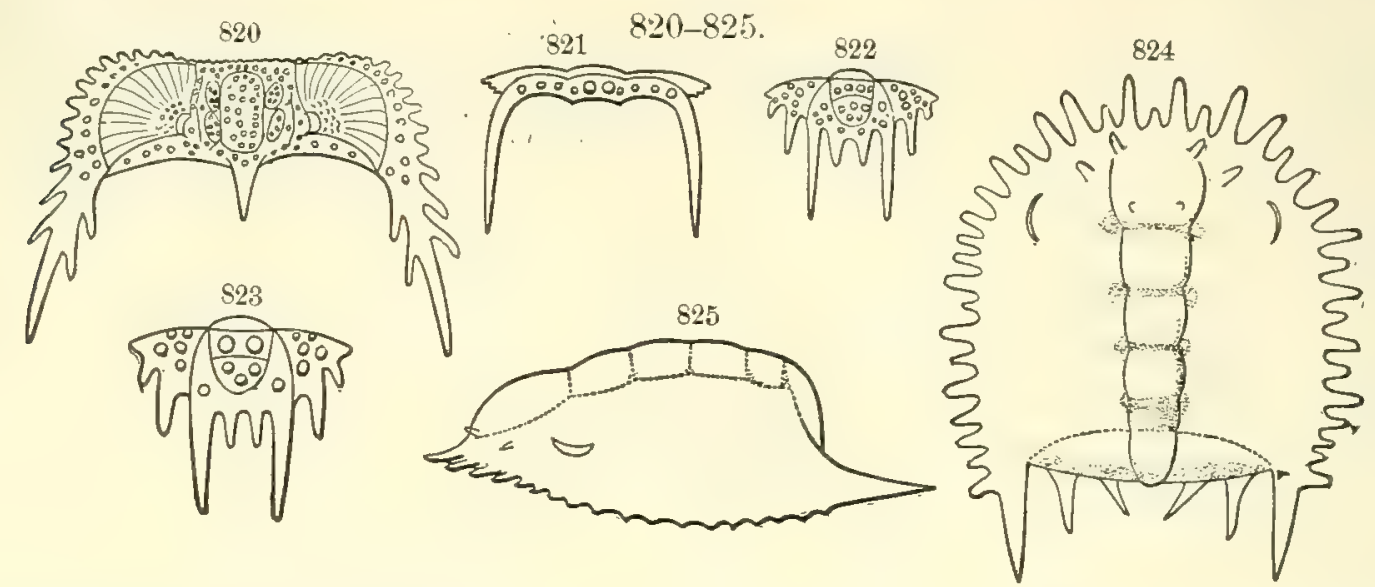

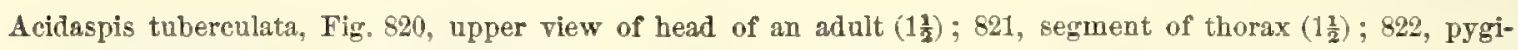
dium of adult $\left(\times \frac{3}{2}\right) ; 823$, pygidium of young $\left(\times 3 \frac{3}{4}\right) ; 824$, dorsal view of larva $(\times 30) ; 825$, profile view of same $(\times 30)$. Beecher.

Atrypa recticularis and Leptcena rhomboidalis of the Niagara are supposed to be the only species that are continued into the Lower Helderberg.

Some of the genera are as follows:-

1. Spongiozoans. - Stromatopora, very common in the Lower Pentamerus, constituting in some places a bed 3 or 4 feet thick. Also Ischadites, Hindia, Receptaculites infundibuliformis.

2. Actinozoans. - Streptelasma, Zaphrentis, Michelinia (begins), Favosites (of which F. Helderbergice is often a foot across), Aulopor $\alpha$.

3. Echinoderms. - Lepadocrinus, Anomalocystites, Sphorocystites, Melocrinus, Cordylocrinus, Edriocrinus, Homocrinus, Coronocrinus, Protaster ( $P$. Forbesii H.).

4. Brachiopods. - Orthis (many species), Strophomena (Leptana of Hall, 1892), Stropheodonta, Chonetes (2), Rhynchonella (numerous species), Pentamerus, Eatonia, Anastrophia, Spirifer (very many, some with dichotomizing ribs, a feature especially of later time), Cyrtina, Trematospira (several species), Meristella, Atrypa, Rensselceria.

5. Mollusks. - Lamellibranchs. - Aviculopecten, Mytilarca, Megambonia, Cypricardinia, Conocardium.

Gastropods. - Platyceras, Platystoma, Holopea, Loxonema, Murchisonia, Pleurotomaria, Strophostylus, Euomphalus, Bucania.

Cephalopods. - Orthoceras of several species, Oncoceras ovoides H., Cyrtoceras.

Pteropods. - Conularia, Tentaculites, and Hyolithes.

6. Crustaceans. - Besides those mentioned, Bronteus, Homalonotus, Cyphaspis, Proetus. The Ostracoid genera, Leperditia, Beyrichia, ELchmina.

The Lower Helderberg beds, near Fastport, southeastern Maine, include Favosites cervicomis, Leptona rhomboidalis, Chonetes Novascoticus, Rhynchonella Witsmi, Atrypa reticularis, Orticluoidea tenuitamellata, Spirifer sulcatus, Orthis elegantula, Avirula naviformis, Calymene Blumenbachii, Homalonotus Dawsoni, Conulites Alexuosus, Tentaculites distans, Beyrichia lata, and others (W. A. Rogers). 
For a list of 163 Upper Silurian species found at Arisaig, Nova Scotia, see H. M. Ami, Nova Scotia Inst. Sc., 1892. In this paper Ami remarks on the relations of the fossils that "they are much closer to the Ludlow rocks of Kendal, in Westmoreland, England, than to either the Upper Silurian species of Anticosti, of Ontario, or those of the state of New York." The species range from the Medina to the Lower Helderberg.

Hall remarks that many Niagara species have their nearly related or representative species in the Lower Helderberg: thus, Orthis elegantula is represented by 0 . subcarinate and $O$. perelegans; $O$. hybrida by $O$. oblata and $O$. discus; $O$. punctostriata by 0 . tubulostriata; Spirifer Niagarensis by S. macropleume; S. sulcatus by S. perlamellosus; S. crispus by S. cyclopterus; Strophomena (Orthothetes) subplana by S. (O.) Woolworthana. So also Pentamerus fornicatus of the Clinton is represented by $P$. galeatus.

\section{FOREIGN.}

The rocks of the Upper Silurian are widely distributed over the globe, though less universal than those of the Lower Silurian. They occur in Great Britain, Scandinavia, Russia, Germany, Bohemia, and Sardinia, and in Asia, Africa, and Australia. They seem on a geological map to cover but small areas, but only because they are concealed by later formations.

The rocks in Great Britain where best displayed are subdivided as follows : -

1. May Hill (Gloucestershire) Sandstone, or Upper Llandovery group. Sandstones, with some arenaceous limestone ("Pentamerus limestone"), which terminate above in the Tarannon shales. - American Equivalent, the Medina and Clinton groups.

2. Wenlock Group. - Consists of (1) the Woolhope beds, limestone and shale; (2) Wenlock shale; (3) Wenlock or Dudley limestone. - Amer. Equiv., the Niagara shale and limestone.

3. Ludlow Group. - Consists of (1) the Lower Ludlow rock; (2) the Aymestry limestone; (3) the Upper Ludlow; (4) Tilestones. - Amer. Equiv., the Onondaga and Lower Helderberg groups.

These subdivisions are well exhibited in Shropshire or western England and in eastern and southern Wales. Between the Tilestones and the Ludlow are one or two thin bone-beds consisting of remains of Fishes and Crustaceans. In North Wales, and in Westmoreland, Cumberland, southern Scotland, and southwestern Ireland, the beds are mostly grits and shales, and are much upturned, with the subdivisions not distinct. The Wenlock group is represented by the Denbighshire grit in North Wales, and the Coniston grits in Cumberland. The thickness is stated to be from 3000 to 5000 feet.

Upper Silurian beds outcrop: in Russia over a large area south of the Gulf of Finland; in southern Sweden; about Christiania and some points to the north in Norway; in the Bohemian basin near Prague, where Barrande's formation $\mathrm{E}$ corresponds to the Niagara and Onondaga periods. and his F, G. H, approximately to the Lower Hellerberg and Oriskany; in the Fichtelgebirge; and the upper section only in the eastern Hartz, where the 
beds are the Hercynian of Beyrich; and under this name are placed, by Barrois, beds occurring at Erbray in the Lower Loire. They have been identified also in Sardinia, India, China, Australia, New Zealand, and the Argentine Republic.

\section{LIFE.}

The Wenlock and Ludlow beds abound in fossils, especially the former, which represent nearly the American Niagara group. Evidence of British land plants occurs in the Ludlow beds; the earliest of British Fishes species of Pteraspis and Cephalaspis - in the Lower Ludlow; the earliest of Scorpions, in the Upper Ludlow and the Upper Silurian of Gothland, Sweden.

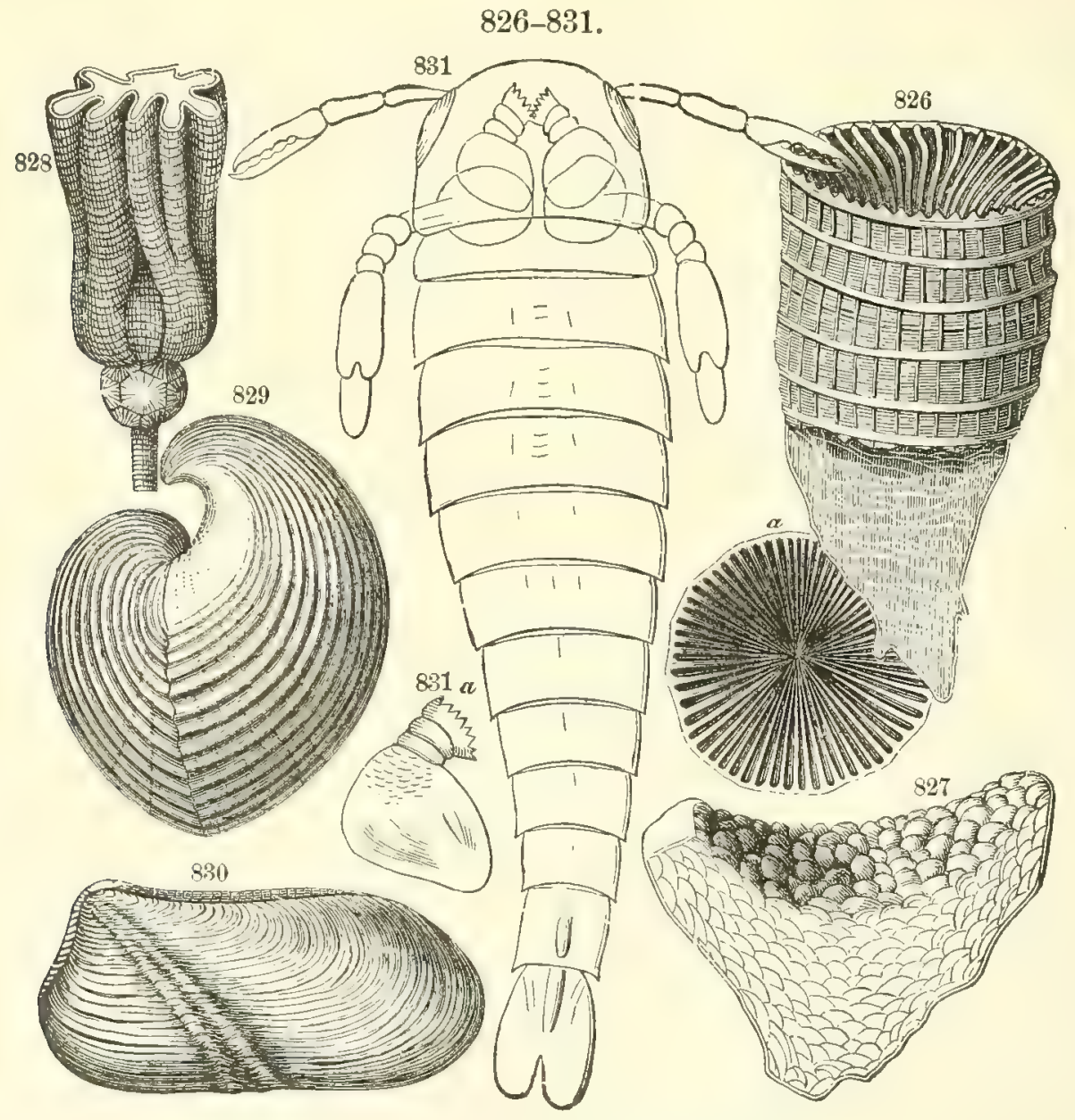

Fig. 826, Omphyma turbinata; 827, Cystiphyllum Siluriense; 828, Crotalncrinus rugosus; 829, Pentamerus Knightii ; 880, Grammysia cingulata; 831, $\boldsymbol{a}$, Pterygotus bilobus. 826, 827, from Edwards and Haime; 828, Murchison ; 829, Brown; 830, Naumann; 831, Salter.

Land Plants. - The Pachytheca of Hooker is supposed to be the spores or sporangia of a terrestrial plant (Q. J. G. Soc., xxxviii., 107, 1882). The Denbighshire grits of the Wenlock of North Wales have afforded the Nematophyton of Dawson, having loose tubular cells within, supposed to be from a tree of large size, but now admitted to be a Seaweed. The earliest of welldefined ferns has been described by Saporta for the schists of Angers, which 
are referred to the Middle Silurian. It is a portion of the frond of a Neuropteris.

Avimals. - The genera of Corals, Crinoids, Brachiopods, Trilobites, and of other classes are to a large extent the same as in America. A Crinoid of an unusual form is represented in Fig. 828, a Crotalocrinus; Corals, in Figs. 826, 827; a common Pentamerus, in Fig. 829.

'Trilobites are common, as in the American rocks. Some of the species are represented in Figs. 832-841. Figs. 832, 835, and 838 are of species from the Wenlock; Figs. 833, 834, 836, 837, 839, and 840 range below, and all but 840 above, the Wenlock.

Fig. 831, from Salter, is that of a large Limuloid, of the genus Pterygotus, from the Wenlock beds. It shows well the chelate termination of the antennæ, but it is imperfect in wanting the four pairs of slender legs which
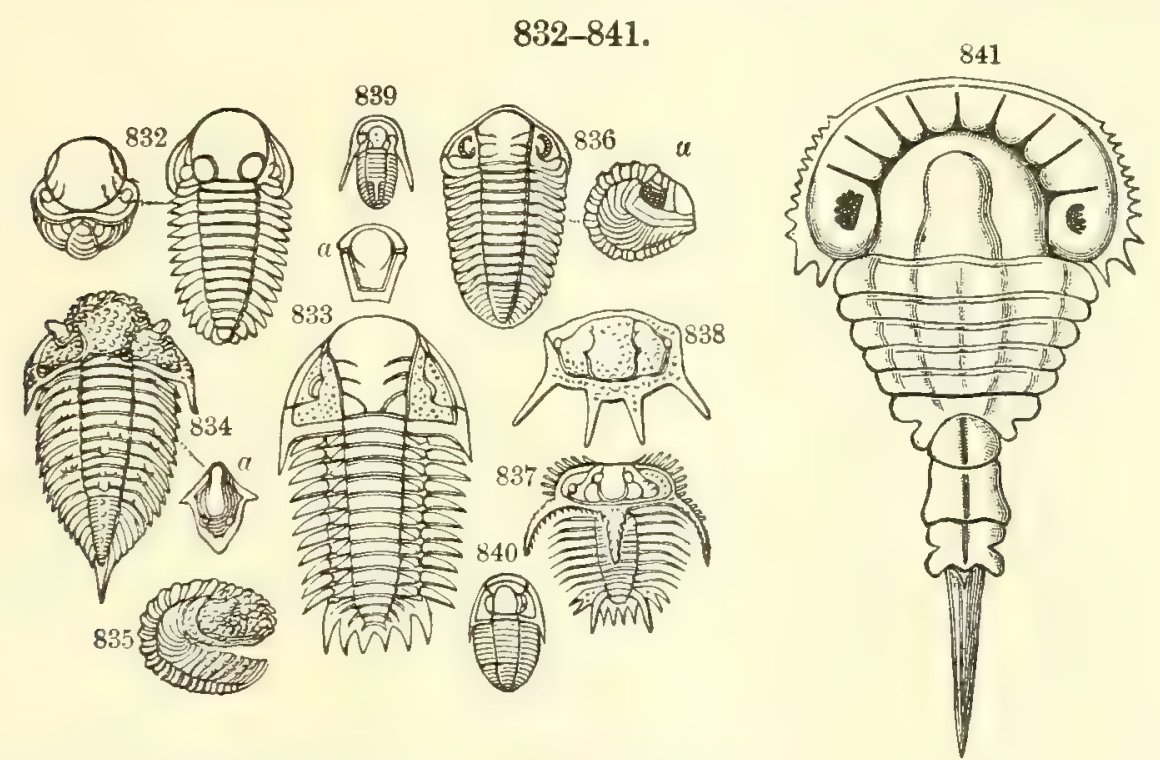

Fig. 832, Sphærexochus mirus ; 833, $a$, Cheirurus bimucronatus ; $834, a$, Encrinurus punctatus ; 835, E. variolaris ; 836, $\boldsymbol{a}$, Phacops Downingii ; 837, Acidaspis Brightii ; 838, A. Barrandii ; 839, Cyphaspis megalops ; 840, Proetus latifrons; 841, Hemiaspis limuloides. Figs. 832 to 840, after Murchison; 841, after Woodward.

are situated between it and the large posterior paîn (see page 623). The jaws in the figure, one of which is separately shown in Fig. $831 \alpha$, are the basal portions of the posterior legs.

Fig. 841 represents the Hemiaspis limuloides of Woodward, a form intermediate between a modern Limulus and the Eurypterids; the genus has species in both the Wenlock and Ludlow beds.

A Ceratiocaris of the Ludlow group is shown in Fig. 842. Fig. 845, a spine (referred to a genus of Sharks, Onchus), is supposed to be from a Ceratiocaris.

The first of Amphipod Crustaceans, Necrogammarus Salweyi, is reported from the Ludlow.

A Scorpion has been found in the Upper Ludlow beds of Lesmahago in Lanarkshire, Scotland, and in beds of nearly the same age in Gothland, Sweden; the latter is named the Palocophonus nuncius by Torell and Lind- 
ström, the generic name meaning the ancient murderer. Both specimens have traces of spiracles, showing them to have been terrestrial species.

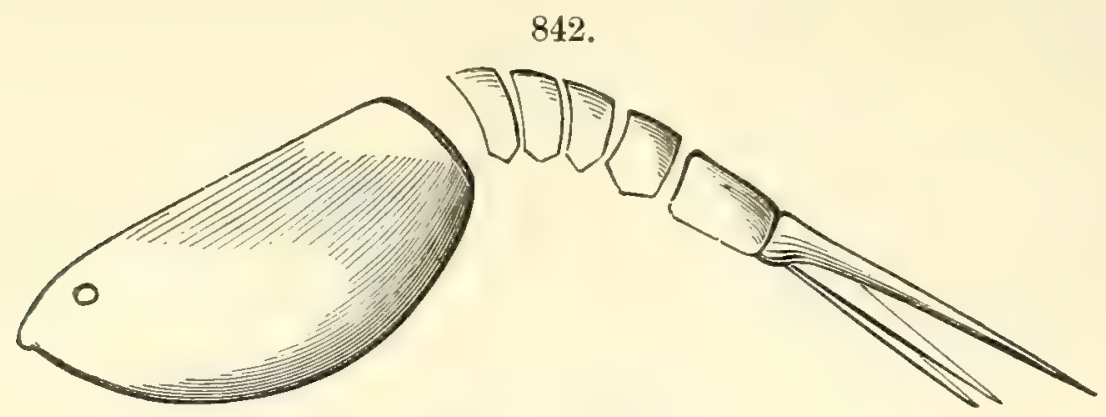

Ceratiocaris papilio. Salter.

The wing of an insect, Puloeoblattina Douvillei of Brongniart, has been found in the sandstone of Jurques in northwestern France, and for the present it is the oldest known insect. Its relation to the Cockroaches, which is thought probable by Brongniart, is questioned by Scudder, a Neuropteroid character being thought more probable. The sandstone is of the age of the May Hill sandstone of England, at the bottom of the Upper Silurian. Jaws of Annelids of several species have been described by Hinde from the Wenlock and Ludlow groups.

Fish-remains occur especially in the bone-bed below the Tilestones, and also in the Tilestones. Fig. 843 represents a head-shield of Pteraspis Banksii Huxl. \& S. Fig. 844 is the head-shield of a Cephalaspis - so named from the Greek for a shield-like head. A complete animal, but different in species, and from the Devonian, is shown in Fig. 980 ; and Fig. 846 represents probably part of the jaw-bone of a Cephalaspis.

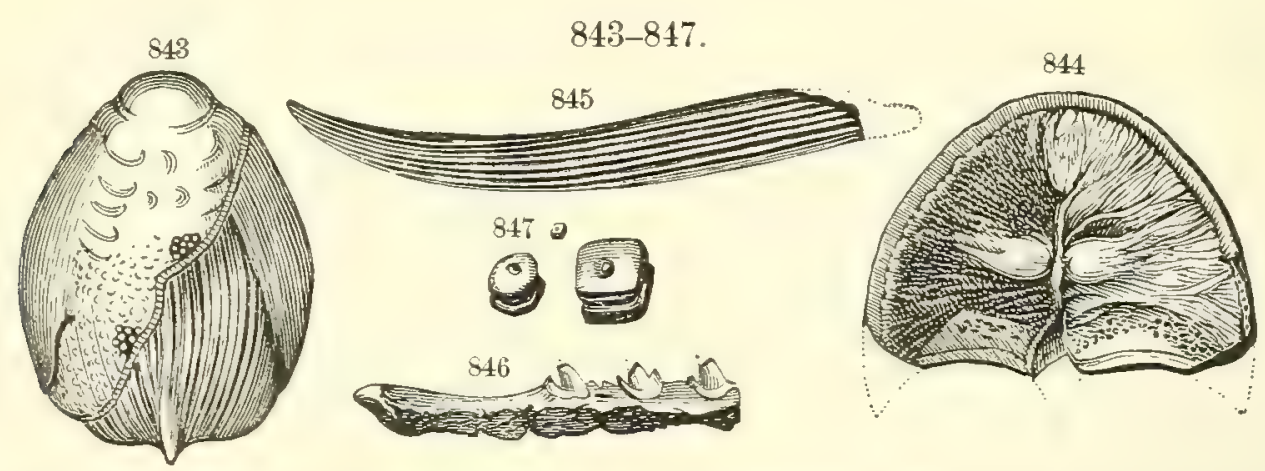

Fi8HEs, - Fig. 843, Pteraspis Banksii, head-shield; 844, Cephalaspis Murchisoni, inside of head-shield ; 845, spine of Onchus tenuistriatus = Ceratiocaris tenuistriata ; 846 , part of jawbone of Cephalaspis(?); 847, shagreen pieces (?), Thelodus parvidens. Murchison.

Fishes of the Shark tribe are supposed to be indicated by spines, teeth, and portions of the shagreen, or skin; but all are doubtful. A number of Upper Silurian Fishes have been deseribed from the rocks of Russia and Bohemia, including species of Coccosteus and Pterichthys, and the fin-spines of Sharks. 


\section{Characteristic Species.}

1. Upper Llandovery. - Petraia, species of Favosites, Heliolites, Syringopora, Halysites, Omphyma, Palceocyclus, Actinocrinus, Palacechinus, Tentaculites ornatus, Cornulites serpularius, Colospira Scotica, Rhynchonella neglecta, Meristella angustifrons, Strophomena arenacea, S. compressa, Pentamerus oblongus, P. caudatus, Stricklandinia lens, S. lyrata, Oithis lata, O. calligramma, O. elegantula, Lyrodesma cuneatum, Pterinea sublaevis, Murchisonia angulata, $M$. articulata, Cyclonema quadristriatum, Euomphalus ala. tus, Raphistoma lenticulare, Holopella obsoleta, Conularia, Calymene Blumenbachii, Encrinurus punctatus, Illanus Thomsoni, Proetus Stokesi, Phacops Stokesi; also Trinucleus concentricus, Lichas laxatus, Acidaspis, etc.

2. Wenlock Group. - Petraia bina, Cyathophyllum truncatum Linn., Favosites Gothlandicus, F. fibrosus, Halysites catenulutus, H. interstinctus, Syringopora bifurcata, C'ystıphyllum Siluriense (Fig. 827), Stenopora fibrosa, Ptilodictya scalpellum, and many other Bryozoans; Eucalyptocrinus decorus, Actinocrinus simplex, Crotalocrinus rugosus (Fig. 828), Marsupiocrinus calatus, Atrypa reticularis, Orthis elegantula, Rhynchonella Wilsoni, R. nucula, Pentamerus galeatus, Leptana rhomboidalis, Spirifer elevatus, S. sulcatus, Nucleospira pisum, Obolus Davidsoni, Turrilepas, Modiolopsis complanata, Conocardium aquicostatum, Pterinea retroflexa, Grammysia cingulata (Fig. 830), Orthoceras, Lituites, Actinoceras, Tentacuites ornatus, Acidaspis coronata, A. hamata, Calymene tuberculosa, Homalonotus delphinocephalus, Lichas Anglicus, Phacops caudata, Encrinurus variolaris.

3. Lower Ludlow. - Palcasterina primava, Protaster Sedgwickii, P. hirudo, Omphyma turbinat, Rhynchonella Wilsoni, R. navicula, Cyntia exporrecta, Spirifer crispus, Strophonella euglypha, Atrypa reticularis, Lingula lata, Pentamerus galeatus, Orthonota affinis, Loxonema sinuosum, Orthoceras Ludense, O. annulatum, Phragmoceras, Lituites giganteus, Calymene Blumenbachii, Phacops caudata, P. longicaudata, Proetus latifrons, Acidaspis Brightii, Lichas Anglicus, Homalonotus delphinocephalus, Cyphaspis megalops, Hemiaspis sperata.

4. Aymestry Limestone. - Tentaculites ornatus, Cyathophyllum truncatum, Pentamerus Knightii (Fig. 829), Atrypa reticularis, Rhynchonella Wilsoni, $R$. navicula, $R$. Stricklandi, Lingula Lewisii, L. lata, Strophonella euglypha, Meristella (Whitfieldella) didyma, Chonetes striatellus, Bellerophon dilatatus, B. trilobatus, Lituites giganteus, Orthoceras tenuiannulatum, Pterinea Sowerbyi, P. hians, Calymene Blumenbachii, Homalonotus delphinocephalus, Phacops caudata.

5. Upper Ludlow. - Lingula minima, L. lata, Orliculoidea rugata, Atrypa reticularis, Rhynchonella Wilsoni, Orthis elegantula var. orbicularis, O. Lunata, Stropheodonta filosa, Strophonella euglypha, Chonetes striatellus, C. Tatus, Orthonota angulifera, Platyschisma helicites, Holopella obsoleta, H. gregaria, H. conica, Cyclonema coralli, Murchisonia corallii, Bellerophon carinatus, Orthoceras bullatum, Homalonotus Knightii, Encrinurus punctatus, Phacops Downingii, Calymene Blumenbachi, Ceratiocaris, Dictyocaris, Entomis, Beyrichia, Leperditia, Eurypterus, Pterygotus bitobus (Fig. 8.31), Slimonia, Stylonurus.

Fishes from the Lower Ludlow include only Scaphaspis (Pteraspis) Ludensis; from the Upper, mostly from the bone-bed, Cephalaspis ornata, C. Murchisoni, Plectrodus mirabilis, P. pleiopristis, Pteraspis Banksii, P. truncata, Scaphodus Ludensis, Thelodus parvidens, Thysetes vervucosus, and others. There are, also, in the same rocks Coprolites from some of these Fishes, containing fragments of the shells of the Mollusks and Crinoids on which they fed. Remains of Fishes have also been found in the upper part of the Upper Silurian of Russia and Bohemia. C'tenacanthus Bohemicus Barr, abundant in Stage G.

The Hercynian fossils of the Hartz and Erbray have closer analogy with those of the Lower Helderberg than with those of the Upper Helderberg, but they also have close 
analogy with the Oriskany in the large number of species of Platyceras, Spirifer, and Strophomenids. (J. M. Clarke, on the Hercynian Question, 42d Rep., Rep. N.Y. State Mus., 1889.)

All writers have made the Limuloids of the Middle and Upper part of the era good evidence of equivalency. But there are large species in the Lower Silurian; and, moreover, they may have lived in brackish or fresh waters, as some facts render probable, so that they really have very little chronological value.

According to Barrande, the following are characteristic species of his subdivisions, E, F, G, H, of the Upper Silurian of the Bohemian basin :-

E. Graptolitic slates, passing above into limestone, corresponding to the Niagara period. Many Graptolites: Halysites catenulatus, Leptana rhomboidalis, Atrypa (Dayia) navicula, Pentamerus Knightii, Rhynchonella, Spirifer, Orthis. Many species of Orthoceras, and others of Cyrtoceras, Gomphoceras, Trochoceras, etc.; Calymene, Phacops, Lichas, Cyphaspis, Illonus, Cheirurus, Acidaspis, Proetus.

F. A dark limestone, cherty above: Favosites Gothlandicus, F. fibrosus; Orthis palliata, Atrypa reticularis, A. comata, Pentamerus galeatus, Rhynchonella, Spirifer, Leptana Verneuili; Phacops, Lichas, Bronteus; Tentaculites, Goniatites.

G. A cherty or impure limestone, with an intermediate shaly layer: Atrypa reticularis, Pentamerus ; Tentaculites ornatus; Lituites, Goniatites, Orthoceras Midas ; Phacops fecunda, Dalmanites Hausmanni, Bronteus, Cheirurus Sternbergi, Proetus, Harpes.

H. Shale and sandstone: Leptcena, Orthoceras, Lituites, Goniatites, Phacops fecunda, Proetus, Tentaculites.

In Russia, on the Baltic, south of the Gulf of Finland, the four subdivisions, G, H, I, $\mathbf{K}$, have afforded the following species: G. Rhynchonella affinis, Strophomena pecten, Orthis Davidsoni, Pentamerus boreatis, Leperditia Keyserlingi, Phacops elegans. H. Dolomytes and Coral limestone: Syringopora bifurcata, Favosites Gothlandicus, Halysites, Pentamerus oblongus. I. The Lower Oesel Zone, dolomytes = Wenlock: Euomphatus funatus, Orthoceras annulatum, Spirifer crispus, Orthis elegantula, Leptona transversalis. K. The Upper Oesel Zone, limestones: Pterinea retroflexa, Chonetes striatellus, Spirifer elevatus, Beyrichia tuberculata.

In New South Wales occur Favosites Gothlandicus, Heliolites interstinctus, Calymene Blumenbachii, Encrinurus punctatus, Phacops caudata, Atrypa reticularis, Strophomena pecten, Pentamerus Knightii, P.oblongus, Meristella tumida, Orthoceras ibex.

\section{American Upper Silurian Species Occurring Elsewhere.}

Halysites catenulatus, Niagara, Great Britain (Llandeilo, Wenlock, Aymestry), Norway, Sweden, Russia, Eifel.

Heliolites pyriformis, Niagara, Great Britain (Wenlock, Ludlow), France, Sweden, Russia, Eifel.

Favosites Gothlandicus, Bohemia.

Eucalyptocrinus decorus, Niagara, Great Britain (Wenlock), Scandinavia.

Orthis elegantula, Clinton, Niagara, Great Britain (Wenlock, Ludlow), Gothland.

Orthis hybrida, Niagara, Great Britain, Gothland.

Orthis biloba, Niagara, Great Britain (Wenlock), Gothland.

Plectambonites transversalis, Anticosti, Great Britain (Wenlock), Gothland.

Leptona rhomboidalis, Trenton, through Upper Silurian, into Devonian, Great Britain

(Wenlock, Ludlow), Sweden, Russia, Belgium, Eifel, France, Spain.

Strophomena rugosa, Niagara, Helderberg, Great Britain (Wenlock, Ludlow), Gothland, Russia, Eifel.

Spirifer crispus, Niagara, Great Britain (Llandeilo, Wenlock), Gothland.

Atrypa reticularis, Clinton, Niagara, Helderberg, Great Britain (Wenlock, Ludlow), Gothland, Bohemia, Russia (Urals, Altai). 
Coelospira Scotica, Clinton, Great Britain (May Hill).

Rhynchonella bidentata, Niagara, Great Britain (Wenlock).

Rhynchotreta cuneata, Niagara, Great Britain (Wenlock), Gothland.

Rhynchonella Wilsoni, Niagara, Great Britain (Wenlock).

Rhynchonella Stricklandi.

Pentamerus galeatus, Helderberg, Great Britain (Wenlock, Ludlow), Eifel.

Pentamerus brevirostris, Niagara, Great Britain (Devonian).

Pentamerus oblongus, Clinton, Niagara, Great Britain (Wenlock).

Pentamerus lacvis, Great Britain (Wenlock). - P. Knightii, Great Britain (Ludlow). Anastrophia interplicata, Great Britain.

Bellerophon bilobatus, Trenton to Clinton, Great Britain (Wenlock).

Orthoceras annulatum, Clinton, Niagara, Great Britain (Wenlock, Ludlow).

Orthoceras virgatum, Niagara, Great Britain.

Calymene tuberculosa, Niagara, Great Britain (Bala, Wenlock, Ludlow), Sweden, Norway,

Bohemia, France.

Homalonotus delphinocephalus, Clinton, Niagara, Great Britain (May Hill, Wenlock).

Proetus Stokesi, Niagara, Great Britain (Wenlock).

Trinucleus concentricus, Trenton, Hudson, Great Britain (May Hill).

Tentaculites ornatus, Water-lime, Great Britain (May Hill, Ludlow).

\section{Arctic American Upper Silurian Species Occurring Elsewhere.}

Stromatopora concentrica, Great Britain, Eifel.

Halysites catenulatus, Great Britain, Norway, Sweden, Russia, United States.

Favosites Gothlandicus, Great Britain, Sweden, United States.

Favosites polymorphus, Great Britain, France, Belgium, Eifel.

Receptaculites Neptuni, Great Britain, Belgium, Eifel, United States.

Orthis elegantula, Great Britain, Gothland, Russia, United States.

Atrypa reticularis, Great Britain, Gothland, Urals, Altai, United States.

Pentamerus conchidium, Gothland.

Encrinurus lowis (?), Gothland.

Leperditia Baltica, Gothland.

The number of Lower Llandovery (top of Lower Silurian) species that are known to pass into the Upper Silurian in Great Britain is 104 in 45 genera, out of a fauna of 204 species in 68 genera (Etheridge).

\section{Devonian Relations of the Lower Helderberg Fauna.}

This subject has been ably discussed by J. M. Clarke, in the 42d Annual Report of the New York State Museum, 1889, under the title "The Hercynian Question." The terms Hercynian shates and Hercynian fauna were first given by E. Kayser, in a paper on the oldest Devonian formations of the Hartz Mountains, to the second of four formations in the region - the "Unterer Wieder Schiefer" of A. Koemer. It contains the oldest fauna of the Hartz, and was pronounced by him the oldest or lowest Devonian, and also the equivalent of Barrande's Upper Silurian divisions, F, G, H.

Clarke gives the following summary of the history of Hereynian ideas: "A. RoEMER, in 1843, regarded the fauna in the Hartz, in its typical development, as Upper Silurian; but subsequently made the Cephalopod facies and Brachiopod facies thereof represent distinct faunas, the former Devonian, the latter Silurian. Beyrich, in 1867, believed the two faunas of Roemer one, and suggested their equivalence to the Bohemian F, G, H, and their relation to the Devonian. KAYSER, in 1878, demonstrated their unity and Devonian character and regarded them as the lowest Devonian, and as representing a calcareous 
facies of the Coblenzian fauna of the Rhine, and paralleled them with the Bohemian faunas of F, G, H, taken in their entirety ; in 1880 he regarded them as a lower (not lowest) Devonian fauna and still as a calcareous facies of the Coblenzian; but in 1884 he appears to have resumed his original position as to the age of the Hercynian, and modified his conception of the parallelism with the Bohemian fauna by removing from his equivalent the lower portion of F. ... BARRoIs, in 1889, made the Hercynian lowest Devonian, but differed from Kayser $(1878,1880)$, in regarding it, not as a calcareous facies of the Spirifersandstein or Coblenzian, but as such a facies of the older Gedinnian, considering the Bohemian G as its equivalent."

Kayser concluded further that the Lower Helderberg formation of America was Hercynian, that is, lowest Devonian, contrary to the views of Barrande, who had made it Upper Silurian, and the equivalent of the three divisions in his Bohemian system just mentioned. In his recent Lehrbuch (1891), Kayser leaves the Water-lime in the Upper Silurian.

Some of the alleged Devonian characteristics of the Lower Helderberg are: its many species of Dalmanites of the D. Hausmanni type; its species of Phacops, of the type of $P$. fecunda, and of Homalonotus, of the type of $H$. Vanuxemi; the occurrence of many species of Platyceras; the special Devonian features among several genera of Brachiopods and Lamellibranchs. On the contrary the formation is unlike the Hercynian in containing no Goniatites, and like the Silurian in including several species of Cystideans. Mr. Clarke presents in his paper a full account of the discussion; and while he unhesitatingly refers the Oriskany formation to the Devonian, on the ground of its fauna, he leaves the question as to the Lower Helderberg without a decision. No attempt is made to compare the American fauna with that of the Ludlow beds of England, which is really the typical fauna of the later part of the Upper Silurian - the limits of the Devonian and Silurian having been first laid down by Murchison and Sedgwick.

\section{GENERAL OBSERVATIONS ON THE UPPER SILURIAN.}

\section{GEOLOGICAL AND GEOGRAPHICAL CHANGES DURING THE UPPER SILURIAN.}

\section{NORTH AMERICAN.}

In the region of the Appalachian geosyncline. - As in the Lower Silurian, the successive formations have their greatest thickness along the Appalachian geosyncline, and at the same time limestones were the prevailing rocks of the continental interior.

The thickness of the argillaceous beds and sandstones of the East indicate that during the Niagara period the deepening of the geosyncline amounted, in Penmsylvania, to at least 1500 feet in the Medina epoch, over 2000 in the Clinton, 1500 in the Niagara and Onondaga, and 500 in the Lower Helderberg, - in all 5500 feet. In the Onondaga period, the subsiding area extended. up into New York, west of its center; for it was there that the Onondaga heds were formed to a thickness of 1000 feet, with evidence in many parts of shallow-water origin. In the Lower Helderberg, and in the following ()riskany periods, the greatest thickness of the beds was in the eastern half of the state.

No sediments for rock-making over the continent from the Atlantic Ocean.Although the Champlain channel between the St. Lawrence seas and those of New York was again opened wide during the Lower Helderberg period, it 
still gave no passage to coarse sediments; for the rocks formed over the channel were mainly limestone.

So again, over the continental border from New York to Georgia, since Upper Silurian rocks are unknown along the border region, no sediments were supplied to the interior sea across this border from the Atlantic. Upper Silurian beds may exist there beneath the Cretaceous or Tertiary formations, or in the sea bottom outside; but if so, the broad region of Archæan making the protaxis, without Upper Silurian beds, lies between. The Continental Interior received no Atlantic sediments.

It has further been shown that the Upper Silurian formations of New England and eastern Canada and Newfoundland were in general made, not on the borders of the open ocean, if so at all, but within the limits of channels or bays bounded by Archæan ridges, or ridges of Archæan and Lower Silurian rocks. Of Pacific sea-border beds belonging to the Upper Silurian nothing has come to light. In the Aretic regions the rocks occupy a large basin or area, quite distinct from that of the Continental Interior. Its limits are unknown.

Influence of the Cincinnati geanticline. - The influence on the eastern interior sea of this barrier of emerged land and shallow seas was strongly marked. Owing to changes in level that were in progress, shifting the areas of deepest water, large changes were made from time to time in the courses of the tidal movements, in the character of the depositions, the clearness or foulness of the water, and accordingly in the character of the life. With clear, deep waters, life of great variety abounded and limestones were formed; but with sediment-laden waters, or waters half freshened by contributions from the land, the living species were only those that could survive under such adverse circumstances.

Abrupt variations in the rocks and the life become thus intelligible. It is hence easy to understand that a Niagara epoch might be followed, through a wide shallowing of the seas, by a region of immense salt-pans (evaporating sea-border flats) over a large part of New York, making the Salina group of rocks, while to the eastward, southward, and westward a tide-washed region existed, - that of the Water-lime group, - free from saline deposits because the tides had access; and that fresh-water and brackish-water flats, containing species of Eurypterids, might well have been a feature, at the same time, of the sea borders. Then the occurrence of a slight subsidence would account for clearer seas again, for a restored fauna, and the making of Lower Helderberg limestones, and also for the extension of the limestones over eastern New York to Montreal in the St. Lawrence Channel, and southward over western New Jersey and part of Pennsylvania. Such salt-evaporating basins are due to local conditions and cannot be a universal feature of a period.

Larye shallow-water and emerged areas over the continent characteristic of the Upper Silurian era. - The absence of Upper Silurian formations from much of the region west of the Mississippi, and their thinness where present, 
is a remarkable feature of the era. Even in the Laramide Range of southern British America, McConnell found the Upper Silurian series only 1500 feet thick; and in the Wasatch Range, according to King, the thickness of the whole Silurian is but 1000 feet. The era began, as the Medina rocks show, with shallow waters over central New York, and probably large, emerged areas east of the Mississippi as well as west. In its progress through the Clinton epoch there were still shallow waters and emerging lands; for the extensive beds of iron ore, ranging far south and west to Wisconsin, are evidence of great seashore flats through long intervals over much of the eastern half of the continent. In the Niagara epoch there were somewhat deeper and purer waters over the Interior Continental Seas, but the areas were not of very wide extent, and the epoch closed through the coming on of another period, the Onondaga, in which again great seashore flats prevailed, with feeble submergences or emergences where any occurred.

The length of this period of great briny flats and salt deposits - which were 100 miles or more long in the state of New York, and twice this to Goderich, on Lake Huron - cannot be estimated; for thinness of rocks means nothing as regards elapsed time where a region is undergoing no oscillations of level, or only those of extreme slowness.

The prevailing characteristic of the continent during the early and middle Upper Silurian, that of shallow seas and emerging seashore flats, continued on, with little change, through the closing Lower Helderberg period; for the formations are unknown over the Mississippi basin and farther west, and have their greatest extent along the region of the progressing Appalachian geosyncline, and its temporary prolongation northward through the Hudson and Champlain depressions to Montreal.

The period of briny flats unfavorable to aquatic life. - Only two species of the Niagara fauna, the widely ranging Leptcena rhomboidalis and Atrypa reticularis, are known to occur in the Lower Helderberg beds, although the epoch which intervened was only one of muddy, briny flats. But the remark applies only to eastern North America, for nothing has been ascertained with regard to the Onondaga and Lower Helderberg faunas for the larger part of the continent.

No upturnings at the close of the Upper Silurian. - The era appears to have passed and ended quietly. It had slow and gentle oscillations in level, like other geological eras, but it was marked with no great upturning in its progress, and with none at its close. The Lower Helderberg formation graduates into that of the opening Devonian, and if transferred to the Devonian, the statement would still hold true.

The eastern continental border related in life to the European. - In Canada and New England the formations of the Upper Silurian have not yet been so fully distinguished and described that the succession of events for this part of the continental border can be deduced. But the fact that the region was distinct from the Interior Continental region has been well made out from the Upper Silurian fossils, by Salter and Billings, who state the following facts :- 
In the beds of this region of the Cambrian and Canadian periods there are Salterella rugosa Billings, closely like the Scottish; S. Maccullochi Salter; Kutorgina cingulata B., said by Davidson and Hall to occur in the Lingula flags; Acrotreta gemma B., very near A. subconica Kutorga; four species of Piloceras, a genus described from Scotland, but not known in the United States; Holometopus Angelini B., very near H. limbatus Angelin, of Sweden; Nileus macrops B., N. scrutatus B., N. affinis B., all closely allied to $N$. armadillo Dalman; Harpides Atlanticus, very near Angelin's H. rugosus of Sweden. In beds of Hudson age there are Ascoceras Canadense B., A. Newberryi B., and Glossoceras desideratum B., not found in the United States. In the Upper Silurian there are, as shown by Salter, the British species, Rhynchonella Wilsoni Sow., Grammysia triangulata Salter, G. cingulata His., Platyschisma helicoides Sow., Platyceras Haliotis Sow., Bellerophon expansus Sow., B. carinatus Sow., Orthoceras bullatum Sow. (?), O. ibex Sow., Homalonotus Knightii König, Phacops Downingii Salt.; to which Billings adds Rhynchonella Stricklandi Sow., and Lituites Americanus B., very near, if not quite identical with $L$. giganteus Sow. Billings, who furnished the above list of species, adds that, through the Cambrian and Canadian periods, there is a decided European tinge in the life, but in the Trenton period its character was peculiarly American. Then in the Hudson epoch there was again a European tinge, which increased in strength through the Upper Silurian.

H. M. Ami has given (1892) a list of 163 fossils from the Upper Silurian beds of Arisaig, Nova Scotia, and states that a closer relation exists between the fauna and that of the Ludlow rocks of Kendal in Westmoreland, England, than with either the Silurian rocks of Anticosti, Ontario, or New York.

\section{EUROPEAN.}

The endogenous growth of the European continent during the Upper Silurian era is manifest, though of less regular progress than that of North America. The Upper Silurian formations over the British Isles were not on the outer Atlantic border, but on the opposite side of a border region of Archæan and Lower Silurian rocks, and this inner side continued to be the region of growth to the end. Moreover, there appear to have been two or three confined and parallel troughs. In Scandinavia and Russia, part of France and the Spanish peninsula, the same is true. All the Upper Silurian rocks of Russia are the work of an Interior Continental Sea, wihout oceanic aid; and this great Interior Sea extended south and west over Hungary and Austria to Bohemia and the Alps. The Mediterranean Sea is related to the continent like the West Indies and Mexican Gulf to America.

The progress through the era was in general quiet; for the Upper Silurian rocks are conformable in superposition. They are horizontal, or very nearly so, over the great interior region in Russia and elsewhere. Nearer the ocean, in England, the rocks to a considerable extent pass regularly upward 
into the Devonian. But in the western part in Wales, - and in the Lake region to the north, - they lie unconformably beneath the Old Rell Sandstone (Devonian), proving thereby that an epoch of local mountain-making in that region closed the period. Similar evidence of disturbance exists in Ireland.

\section{BIOLOGICAL PROGRESS.}

The records of the Upper Silurian era add to the terrestrial fauna the earliest of Arachnids, or Spiders, in the form of Scorpions, and additional species of Insects. The former are in the successional line of the Eurypterids, whose earliest species is Lower Silurian; the Insects are structurally in the line of the Myriapods, although no antecedent species of Myriapod is yet known. The Cockroaches are Orthopters, and species of imperfect metamorphosis, like the Hemipters. The relations of the above-mentioned groups are illustrated in the course of the General Observations on the Paleozoic, on pages 721, 722 .

Among marine Invertebrates, the era is marked by a large diminution in the number of species and genera of Graptolites and Trilobites - Lower Silurian characteristics; by an abundance of Cystoids and Orthids - also Lower Silurian in aspect; by an increase in the number and size of the Brachiopods of the families of Spiriferids, Pentamerids, and Productids - Devonian characteristics; by an increase in the Pteropods of the Conularia type; by an increase in the number of Gastropods of the Platyceras (Capulus) type, and in the number of species and genera of Polyp-corals, Crinoids, and Asterioids — which also look toward the Devonian; by an increase in the number and variety of Eurypterids and Ceratiocarids - facts having the same bearing.

Still more marked is the advance from Entomostracans to Tetradecapod Crustaceans; and far beyond this is the appearance of Insects. It is remarkable that the first remains of Scorpions should have been found in Europe and America in rocks of very nearly the same age. But it may be that earlier specimens are yet to be found.

Fishes, the only Vertebrates of the Upper Silurian, were represented by Placoderms, the mail-clad type that first appeared in the Trenton Period of the Lower Silurian, and possibly also by Selachians. But no remains of other Ganoids have yet been found in the beds, although reported from the Trenton. Rarity in fossils of lime-secreting aquatic species is not common. Remains of Chimæroids, mostly cartilaginous species, also are absent.

\section{CLIMATE.}

There is no evidence that the climate of America was roughened by frigid winds, or that the ocean was much modified in temperature by polar currents. The species living in the waters between the parallels of $30^{\circ}$ and $45^{\circ}$ were in part the same with, or closely related to, those that flourished between the parallels of $65^{\circ}$ and $80^{\circ}$. (See prge 544.) From this life thermometer we learn only of warm or temperate seas. 


\section{DEVONIAN ERA.}

Synonymy. - Old Red Sandstone Series (from the rocks in Scotland), British Geologists before 1839. Devonian system, Sedgwick and Murchison, in a paper on the Classification of the older rocks of Devonshire and Cornwall, Ann. Phil., April, 1839. Old Red Sandstone, or Devonian system, Lyell, Elements of Geol., 1841. Devonian, of later geologists, système Devonien, or Période Devonienne, Beudant, D'Orbigny, Lapparent. Devonische Formation, of the Germans. Devonic, International Congress of Geologists.

As the era of the Upper Silurian passed quietly into that of the Devonian, no mountain range marks the interval between them, and no abrupt transition is apparent in the rocks or in the world's fauna. The Devonian was eminently a transition era as regards land vegetation, but the culminant time of aquatic Vertebrates - Fishes. The land population was low grade, it comprising only Myriapods, Spiders with the related Scorpions, and Insects; and not the higher Insects, since there were no conspicuous flowers over the land. Terrestrial Mollusks also may have been in existence, but evidence of this has not yet been reported. The Devonian seas contained, in general, similar Invertebrate forms to those of the Silurian, but with proportionally fewer Trilobites, a profusion of Corals and Brachiopods, along with new forms of Cephalopods in the Goniatites and related species.

\section{NORTH AMERICAN.}

\section{GENERAL FEATURES OF THE CONTINENT.}

The map of North America, representing its condition at the commencement of the Upper Silurian, gives a good general idea, so far as has been learned, of the continental seas and land at the opening of the Devonian era. 'There is the same uncertainty, or error, it may be called, with regard to the emerging lands over the Western Interior and Rocky Mountain region; the map fails to indicate them, because the limits of such areas have not been fully ascertained. These limits will in part always remain in doubt, unless determined by deep borings; because absence of formations from the region of outcrops about Archæan mountains is far from being proof of absence beneath the plains between the mountains, or 50 miles or so distant from the mountains. It is, however, almost certain that in the Devonian era the Silurian island, covering much of Missouri, extended southward and westward over a large part of Arkansas and Texas, and beyond, as referred to on page 537. The Silurian islands of Tennessee and the Cincinnati region ( $\mathrm{C}$ and $\mathrm{T}$ on the map, page 536) were still islands. A marked feature of the Continental seas is the half-confined Northeast Bay, of the Eastern Interior; and it has special importance in this era, since a large part of the described Devonian beds were deposited within it and owe to its varying conditions their characteristics. 


\section{Subdivisions.}

\begin{tabular}{|c|c|c|}
\hline $\begin{array}{l}\text { UPPER, } \\
\text { OR LATER } \\
\text { DEVONIAN. }\end{array}$ & $\begin{array}{l}\text { 4. Chemung } \\
\text { Period. }\end{array}$ & $\begin{array}{l}\text { 2. Chemung Epoch: that of the Chemung } \\
\text { group, N. Y. Geol. Reports, } 1842,1843 \text {. } \\
\text { 1. Portage Epoch: that of the Portage group, } \\
\text { N. Y. Geol. Reports, } 1842,1843 \text {. }\end{array}$ \\
\hline MIDDLE & 3. Hamilton & $\begin{array}{l}\text { 2. Hamilton Еросн: that of the Hamilton } \\
\text { beds with the Tully limestone in places at top, } \\
\text { N. Y. Geol. Reports, } 1842,1843 \text {. }\end{array}$ \\
\hline DEVONIAN. & Period. & $\begin{array}{l}\text { 1. Marcellus EpocH: that of the Marcellus } \\
\text { shales (with the Goniatite limestone near the } \\
\text { bottom), } N . Y \text {. Geol. Reports, 1842, } 1843 \text {. }\end{array}$ \\
\hline $\begin{array}{l}\text { LOWER, } \\
\text { OR EARLY } \\
\text { DEVONIAN. }\end{array}$ & $\begin{array}{l}\text { 2. Cornife- } \\
\text { rous Period. }\end{array}$ & $\begin{array}{l}\text { 2. CorvifErous Epoch : that of the Cornif- } \\
\text { erous and Onondaga limestones, } N . Y \text {. Geol. Re- } \\
\text { ports, } 1842,1843 \text {. } \\
\text { 1. SchoHARIE EpocH: that of the Schoharie } \\
\text { grit and Cauda-galli grit, } N . Y \text {. Geol. Reports, } \\
\text { 1842, } 1843 \text {. }\end{array}$ \\
\hline & $\begin{array}{l}\text { 1. Oriskany } \\
\text { Period : }\end{array}$ & $\begin{array}{l}\text { That of the Oriskany sandstone, } N . Y \text {. Geol. } \\
\text { Reports, } 1842,1843 .\end{array}$ \\
\hline
\end{tabular}

The Devonian formations commence in eastern North America with sandstones. Then follows a great continental limestone, the Corniferous. 'This limestone has in the Devonian era, therefore, a position corresponding with that of the Niagara limestone in the Later Silurian. Above the limestone there is a great thickness of shales and sandstones with but little limestone. To the eastward, in New York and Pennsylvania especially, the sea border deposits of coarse sands, gravel, and pebble beds, of great thickness, which were in progress during the Upper and partly the Middle Devonian, make now red sandstone and conglomerate, and constitute what is called the Catskill formation. These beds have been heretofore regarded as mainly of subsequent origin to the Chemung, and have been referred to a period following it, called the Catskill period; but, as explained beyond, they are now believed to be a cotemporaneous formation parallel in its deposition with that of the off-shore and deeper waters of the Chemung period, or Chemung and Hamilton periods, to the westward.

Over the Eastern Interior region limestones constitute the chief part of the beds of the earlier half of the era, and black shale, of moderate thickness, those of the later beds.

The three divisions of the Devonian, the Early, Middle, and Later, have been named by H. S. Williams (1894), respectively, the Eodevonian, Mesodevonian, and Neodevonian. The term Erian is applied to the Devonian of North America by Dawson. 


\section{Oriskany Period. \\ ROCKS - KINDS AND DISTRIBUTION.}

The Oriskany sandstone in eastern North America has nearly the limits and distribution of the Lower Helderberg formation. It occurs over the eastern half of New York, between Cayuga Lake and Albany, and reaches northward to Oriskany Falls, northeast of Utica, having a thickness seldom exceeding 20 or 25 feet. It overlies the Lower Helderberg in Becrafts Mountain, and abounds in fossils. It extends southward along the Appalachian region, with increasing thickness, being 200 feet or more at Port Jervis, 150 to 200 feet along the western border of New Jersey, and eastern of Pennsylvania, and of still greater thickness in western Maryland (at Cumberland), West Virginia, and Virginia. It occurs also in eastern Canada, at Gaspé, and in Maine along the Gaspé-Worcester trough, over Parlin Pond and the northern part of Moosehead Lake, where it is reported to be several thousand feet thick (C. H. Hitcheock). It is found also in Ontario, west of Niagara, and in southern Illinois, where, in Union and adjoining counties, its maximum thickness is 250 feet.

The rock is usually a rough calcareous sandstone, or arenaceous limestone, becoming, where weathered, porous and full of holes, from the dissolving away of its many fossils by percolating waters. It is sometimes cherty limestone, a pebbly sandstone, and in part a shale. In its distribution, its great abundance of fossils, and its usually calcareous or semi-calcareous character, it is widely different from the grits which follow it, and bears a close relation to the Lower Helderberg series of impure limestones. At Becrafts Mountain the beds represent the Lower Oriskany, and the rock is a hard, cherty, arenaceous limestone. A similar rock exists at Port Jervis.

A sandstone containing what appear to be Oriskany fossils has been observed by C. W. Hayes in the highly disturbed region of northern Alabama, in Frog Mountain, between Weisner and Indian mountains. It rests on Lower Silurian and Cambrian unconformably; but the uneonformability, though extensive, is described as due to overlap. No intervening Upper Silurian beds occur in the region. The Clinton group (Rockwood beds) exists to the south, but not at that locality (1891, '94).

The geological connections of the Oriskany are with the Lower Helderberg formation, its beds thickening to the eastward as in the Lower Helderberg. It is, however, pronounced Devonian in its fauna and flora, and hence belongs in the Devonian era.

\section{LIFE.}

The Oriskany fauna, although the rocks are rarely pure limestones, included a few Crinoids, of the genera Melocrinus, Mariacrinus, Technocrinus, Edriocrinus, etc., common fossils in western Maryland, but not in New York; some Cystoids; numerous Brachiopods, of which the two represented DANA'S MANUAL - 37 
on this page are characteristic; among Gastropods, a dozen or more species of Platyceras; Conularice, one, C. lata, over five inches long; a few Ortho-
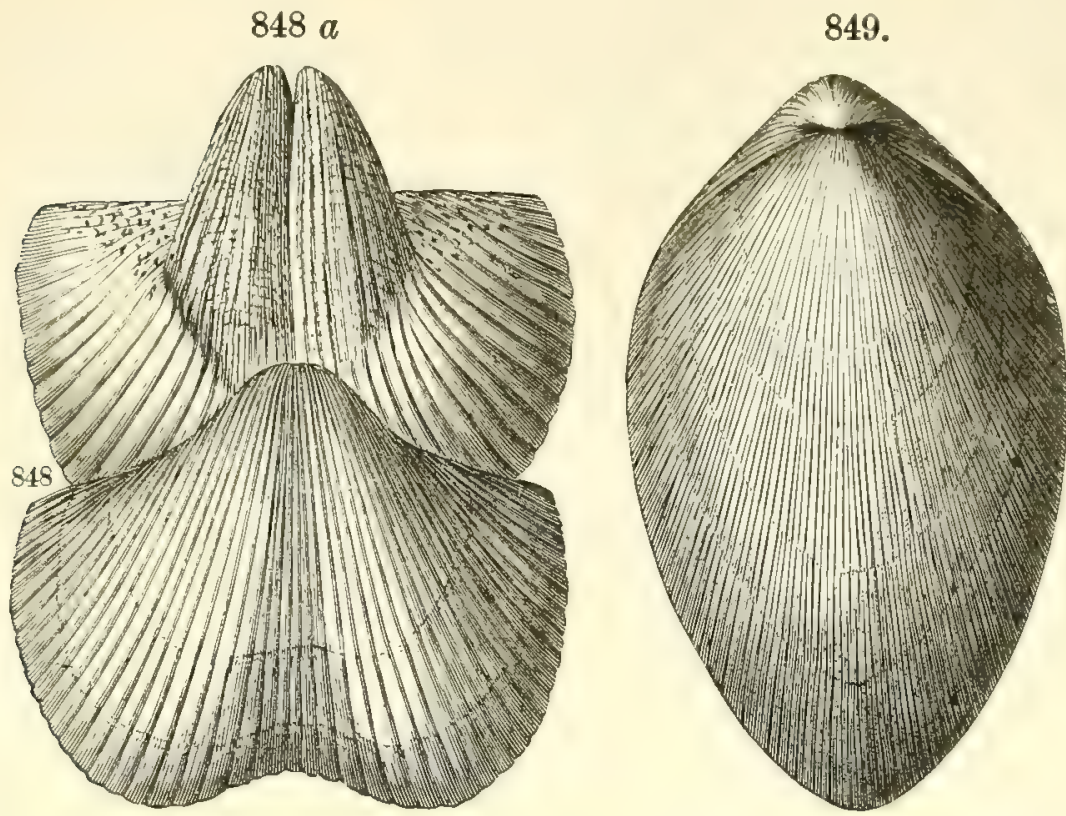

BRACHIopoDs. - Figs. 848, a, Spirifer arenosus ; 849, Rensselæria ovoides. cerata; Trilobites of the genera Homalonotus, Dalmanites, and others. The Homalonotus major, of Whitfield, had a length exceeding 15 inches, and a breadth of 5 inches. Dalmanites dentatus, of Barrett, has the front ornamented with a range of large triangular teeth, and is the earliest species of this type of $\mathrm{Dal}$. manites. Acidaspis tuberculata occurs

here and also in the Shaly limestone of the Lower Helderberg.

With the close of the Oriskany period, the Lower Helderberg conditions of the Eastern Interior ended. The deposits no longer thickened to the eastward.

Hall remarks on the close relation of the Oriskany fauna in central New York to that of the Lower Helderberg, but in other regions, especially in Ontario and Maryland, to that of the overlying Upper Helderberg. The true Oriskany sandstone or Hipparionyx fauna of New York comprises 45 species (Schuchert), which are chiefly large Brachiopods, Lamellibranchs, and Gastropods, with an almost total absence of Corals and Crustacea. In contrast with this, Beecher and Clarke have shown that the Lower Oriskany fauna of Becrafts Mountain and to the southward contains more than 120 species, of which 15 are Trilobites and about 10 are Corals, and the whole fauna is transitional, showing the passage of the Lower Helderberg fauna into typical Lower Devonian.

I. C. White concluded, from his observations in eastern Pennsylvania (1882), that the beds were accumulated on the borders of the seas in which the Lower Helderberg limestones were at the same time forming in clearer waters, thus making it one with them in period of origin. The beds of the latter often pass directly into the Oriskany, as if they constituted it. In Virginia there is the same close relation to the Lower Helderberg. It is to be observed, on the other hand, that the beds of Becrafts Mountain overlie those of the Lower Helderberg. At the Delaware Water Gap the rock is largely a shale ; in Maryland, a crumbling sandstone, from loss of its calcareous part ; at Gaspé, a limestone, with probably a part of the underlying sandstone beds, a Rensseloria having been found $1100^{\prime}$ above the base of the sandstones. Oriskany fossils are reported also from the head of Tobique River in New Brunswick. The Nova Scotia strata of this epoch occur at Nictaux and on Moose and Bear rivers. They include a thick band of fossiliferous iron ore, which is an argillaceous deposit at Nictaux, but, owing to partial metamorphism, is magnetic iron ore, and partly specular, on Moose River. The Oriskany beds of New York are described in the $N$. Y, Geol. Rep. of Vanuxem and Hall, in Hall's Pal. Rep., vols. iii. and iv.; by 
Beecher and Clarke in the Am. Jour. Sc., 1892 ; of eastern Pennsylvania, by I. C. White in Penn. Geol. Rep., G 6, 1882 ; of Illinois, in the Geol. Rep., Ill., by Worthen, vol. iii.; of Canada, in Can. Geol. Rep., 1863, and also in later Annual Reports. Among the Brachiopods of the Oriskany occur the genera Orthis, Stropheodonta, Leptrena, Rafinesquina, Chonetes, Leptostrophia, Meristella, Cyrtina, Spirifer, Rhynchonella, Centronella, Cryptonella; also the genera Rensselceria, Eatonia, Leptocolia, which are more largely developed in the Oriskany than in any other period. Orthis hipparionyx $=$ Hipparionyx proximus, Spirifer arenosus, S. arrectus, Leptocolia flabellites, Cyrtina rostrata, Rensselcria ovoides are characteristic species.

The Illinois beds, of cherty limestone, have afforded Anoplia nucleata, Rhynchonella speciosa, Eatonia peculiaris, Leptocolia flabellites, Newberria Condoni, Amphigenia elongata, Strophostylus? cancellatus, Platyceras spirale, and other species. At Becrafts Mountain, the species include, according to C. E. Beecher and J. M. Clarke, six species of Dalmanites, two of Phacops, a Homalonotus, Cyphasphis, Proetus, Acidaspis; a Cirriped of the genus Turrilepas; corals of the genera Zaphrentis, Romingeria, the Crinoid Edriocrinus sacculus. The unusual number of Trilobites for the Oriskany indicates apparently clearer waters along the Hudson River valley than to the westward along central New York. The Lower Helderberg species obtained are Acidaspis tuberculata of the Shaly limestone, a Cyphaspis, two Dalmanites, and a Phacops of L. H. type ; Tentaculites elongatus; Orthis perelegans, and O. oblata? of the Shaly limestone; Leptostrophia Becki, Trematospira multistriata, of the Shaly; a Colospira, Anastrophia; Eatonia medialis, of the Shaly; a Zaphrentis, Shaly in type. The Devonian forms are Dalmanites phacoptyx (known previously only from the Upper Helderberg of Ontario), a Phacops, Leptostrophia perplana, a Chonetes?, Hemitrypa?, Fenestella celsipora of the Corniferous. At Parlin Pond, in western Maine, there occur Rensselaeria ovoides, Leptocolia flabellites, Spirifer arrectus H., S. pyxidatus H., Stropheodonta magnifica H., Rhynchonella oblata H., Orthis musculosa H., Dalmanites pleuropteryx, etc. (Billings).

See, further, on the relations of the Lower Helderberg, Oriskany, and Devonian faunas, the remarks on page 569 .

\section{Corniferous Period.}

The Corniferous period includes two epochs, the Schoнarie and the Corniferous. To the former belong the Cauda-galli grit and the Schoharie grit, now considered cotemporaneous formations; to the latter, the Corniferous limestone.

\section{ROCKS - KINDS AND DISTRIBUTION.}

The rocks of the Corniferous period in New York have their greatest thickness in the region of the Eastern Interior Sea, along the Appalachian belt. The Cauda-galli grit, a dark gritty slate, thickens toward the Hudson, being 50 or 60 feet thick in the Helderberg mountains, and 100 to 150 feet east of the Hudson River in Becrafts Mountain, near Hudson; and the Schoharie grit is best displayed in the eastern counties of New York, Albany, Greene, and Schoharie. Neither formation is found to extend far west over the Oriskany beds of western New York and Ontario. The Cauda-galli, like many seashore deposits, is almost destitute of fossils; but the Schoharie beds abound in them, and they are closely related to those of the following Corniferous epoch.

The Corniferous limestone - so called by Eaton, with reference to the hornstone or flint often imbedded in it (from the Latin cornu, hor $n$ ) - extends 
from near the Hudson in eastern New York, westward through the state, and at the Niagara River forms the rapids at Black Rock. Thence, it is continued westward through Ontario to Ohio, across northern Ohio, and to Mackinac in northern Michigan. It thus passes beyond the limits of the Eastern Interior Sea into the Central Interior, where it is widely distributed, occurring in Indiana; in great force at the Falls of the Ohio, just east of New Albany and Louisville; also in Illinois and Kentucky; in eastern Iowa, near Davenport, as a bed of gray to buff limestone 150 feet thick, resting on Niagara and Trenton; and in Missouri.

The limestone is commonly light gray to bluish or buff (lightest, which means purest, to the west); occasionally it is blackish and rough from the abundance of hornstone masses, which are left projecting by surface wear.

Much of the rock abounds in corals, like many reef-rocks of modern coral seas. It exhibits its coral-reef character grandly at the Falls of the Ohio, where the corals are crowded together in great numbers, some standing as they grew, others lying in fragments, as they were broken and heaped up by the waves, branching forms of large and small size mingled with massive kinds of hemispherical and other shapes. Some of the cup corals (Cyathophylloids) are six or seven inches across at top, indicating a coral animal seven or eight inches in diameter. Hemispherical compound corals occur five or six feet in diameter. The various coral-polyps of the era had, beyond doubt, bright and varied coloring, like those of the existing tropics; and the reefs were therefore an almost interminable flower-garden.

In the Canada-New-England region a limestone made up of corals occurs on Lake Memphremagog, between Vermont and Canada, showing that coral reefs flourished there also; and other localities exist to the eastward. At Gaspé, a thick limestone formation underlies 7036 feet of Devonian sandstone; and about 800 feet of the limestone with 1000 feet or so of the overlying sandstones are referred to the Corniferous period.

Over the western part of the Continental Interior, beyond the Mississippi, at Paleozoic outcrops, the Carboniferous beds often rest directly on the Lower Silurian, or the Cambrian, with nothing of the Devonian between. This is so at the Black Hills, in Dakota, and in central Texas, and east of the Front Range, in Colorado. Farther west, in the Eureka district, there are 6000 feet of Devonian limestone (Hague).

In the Wasatch Mountains the Devonian is made by King 2400 feet thick, the lower 1000 feet consisting of the "Ogden quartzyte," and the part above this being the lower portion of the "Wasatch limestone," whose total thickness is 7000 feet. Just north of Montana, in British America, there are 1500 feet of Devonian limestone.

In California, Devonian limestone and shales occur east of the Sacramento in Siskiyou and Shasta Counties (Diller and Schuchert).

In the northern part of British America Devonian rocks occur along the Mackenzie River (F. B. Meek, from the collection of R. Kennicutt); but the fossils yet observed are those only of the Hnmilton and later Devonian, 
so that the presence of Corniferous rocks is doubtful. The recent map of the Canadian survey makes a Devonian belt (with Carboniferous beds) to come down from the far north, along by the summit of the Rocky Mountains, into the United States.

The Corniferous limestone in some places abounds in mineral oil. The oil wells of Enniskillen, western Canada, are from this rock, according to T. S. Hunt (1863); large areas are covered with the inspissated bitumen. At Rainham, Canada, on Lake Erie, shells of Pentamerella arata are sometimes filled with the oil; and in other localities Corals of the genera Heliophyllum and Favosites have their cells full, in some layers of the limestone, while empty in other layers.

The facts, with regard to the distribution of the Devonian formations in North America, the history of geological discovery in connection with them, their geological relations and distinctive features, are clearly and fully presented by H. S. Williams, in Bulletin No. 80 of the U. S. Geol. Survey, and partly from personal observation.

Interior Continental and Appalachian region. - The Cauda-galli grit in New York is a drab or brownish argillaceous sandstone, often shaly and crumbling. From eastern New York it continues along the northwestern boundary of New Jersey, and the eastern of Pennsylvania, where it is a gritty slate, and is in some places $400^{\prime}$ to $500^{\prime}$ thick.

The Corniferous limestone in New York consists of two members, - the gray Onondaga limestone, or lower part, and the darker Corniferous, or upper. But the two alternate with one another, and no distinction is now recognized. The limestone is sometimes oölytic. Its thickness, as found where boring for oil and salt, is commonly $100^{\prime}$ to $160^{\prime}$; at Ithaca only $78^{\prime}$. Along the Delaware, south of Port Jervis, N.Y., to the New Jersey boundary, the thickness is about $250^{\prime}$; the flint nodules are from an inch to a foot in diameter, and often contain shells and remains of Crinoids.

In Ohio it occurs on both sides of the Cincinnati geanticline, and also along the shores of Lake Erie. On Kelleys and Middle islands, in this lake, the beds have the characters of old coral reefs, like those at the Falls of the Ohio. It corresponds, it is supposed, to the whole Upper Helderberg period; two divisions are made out, - the lower, named the Columbus, or Sandusky, and the upper, the Delaware limestone.

In Missouri, siliceous and sandstone layers alternate with the limestone.

Rocky Mountain and Pacific border regions. - In the Eureka district, the thickness, according to A. Hague, is $8000^{\prime}$; the lower, $6000^{\prime}$, limestone (see page 592); and the rest, shales. Lower Devonian fossils exist in the lower part for at least $500^{\prime}$, and Upper, in the upper portion; but no subdivisions could be marked off. The Eureka district appears, therefore, to be the center of one of the extra thick Devonian basins, like those of the Appalachian region, and Gaspé of eastern Canada, on the St. Lawrence Gulf. How far south or north the thick beds continue is not known. To the north, in the Tucubit Mountains, Devonian occurs.

In Arizona, in the Kanab Cañon ( $112 \frac{1}{2}^{\circ}$ W.), the whole Devonian is only $100^{\prime}$ thick (Walcott).

In the Wasatch region, the "Ogden quartzyte" is referred to the Devonian, by King, who found it at Ogden Cañon $1200^{\prime}$ to $1400^{\prime}$ thick, at Cottonwood Cañon $1000^{\prime}$, and at some points in Middle Nevada $800^{\prime}$ to $900^{\prime}$. In the Wasatch Mountains, the lower $1400^{\prime}$ or more of the overlying Wasatch limestone ( $7000^{\prime}$ thick) is Devonian, it affording fossils of the Upper Helderberg, Genesee, and Chemung. See King, Geol. 10th Par., page 236 .

In the Laramide range of the southern part of British America occur $1500^{\prime}$ of Devonian limestone (McConnell). 


\section{LIFE.}

Pitants. - Among Algæ, or Seaweeds, the most remarkable is the Spirophyton Caudagalli. Fig. 850 represents a fragment of the plant. The broad blade of the seaweed grows spirally about the central axis, much like that of the erect Alaska seaweed, Thalassophyllum clathrus. The Nematophyton (Dawson), Fig. 851, is a tree-like Fucoid. The specimen was found in the lower part of the Devonian of Gaspé, Canada, where the stems are

$850-852$.

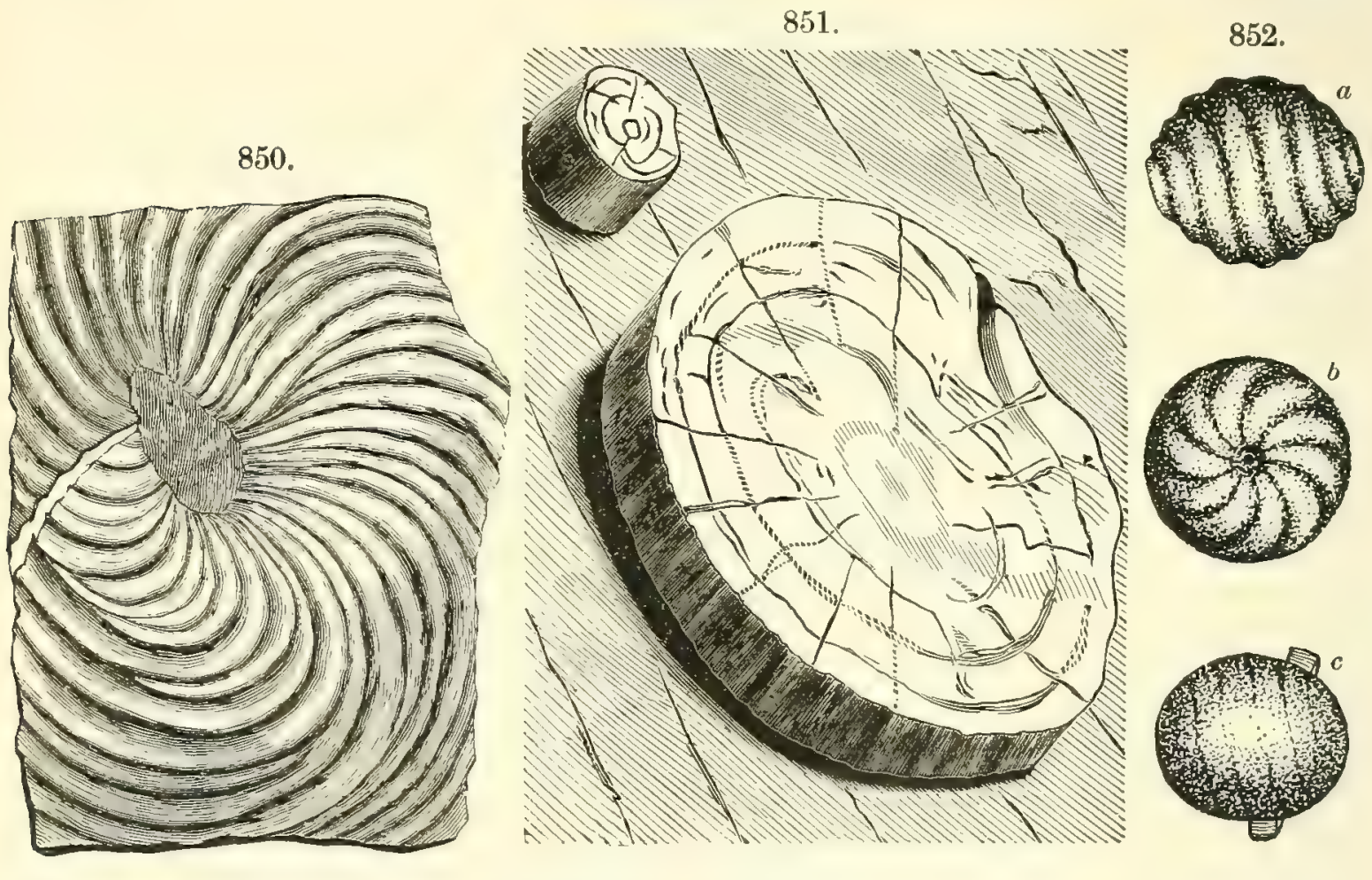

Fig. 850, Spirophyton Caudagalli ; 851, Nematophyton Logani $\left(\times \frac{1}{8}\right) ; 852 a, b, c$, fruit of Charæ? Figs. from Hall, Dawson, and Knowlton.

sometimes three feet in diameter. The presence of Charoe, water-plants of simple cellular structure (inferior to Mosses, but Equiseta-like in habit, and now common in marshy places), has been rendered probable by the discovery (first made by F. B. Meek) of minute calcareous fossils resembling their fruit (spore-cases) (Figs. $852 a, b, c$ ), in the Corniferous limestone of Ohio, and in the cellular chert at the Falls of the Ohio, near Louisville.

The hornstone, or chert, in the Corniferous limestone, as shown by M. C. White, is full of microseopic plants from $\frac{1}{5000}$ to $\frac{1}{500}$ of an inch in diameter; and with them occur sponge-spicules and teeth of Annelids. Fig. 853: $a$ to $e$ are Xanthidia, spore-cases of Desmids (page 437); $f, g$, conferva-like filaments, made of a series of cells; $i$, a Diatom. Besides these there are siliceous spicules of sponges, Figs. $j, k, l, m, n$; and $o, p$ represent portions of jaws of Annelids. The mass of the hornstone was probably made out of siliceous sponge-spicules and Diatoms. 
The higher Cryptogams, or Acrogens, are represented by Lycopods, or Ground Pines, Ferns, and Equiseta.

To the Lycopod tribe are referred species of Psilophyton, similar to those of the Oriskany period; portions of the plant are shown in Figs. $854 a, b$, and

853.

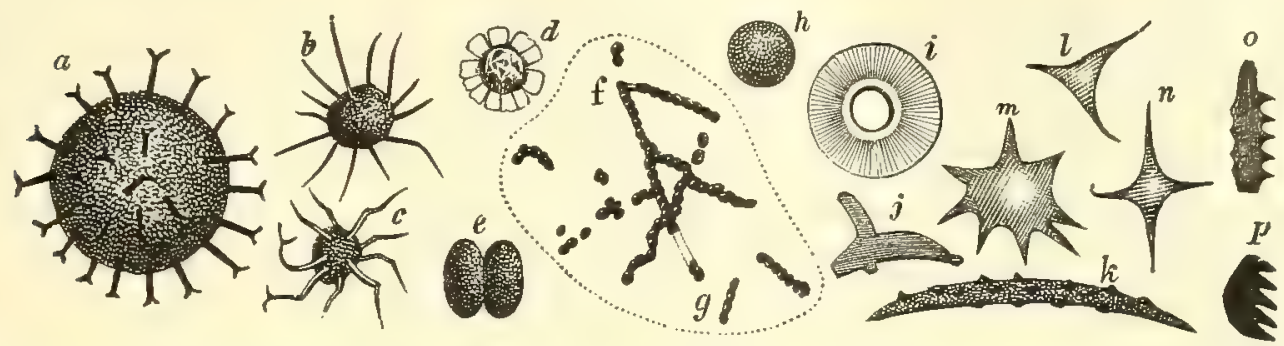

Mrcroscopic Organisms in Hornstone. - Figs. $\boldsymbol{a}$ - $\boldsymbol{i}$, Protophytes; $j-n$, spicules of Sponges; $o, \boldsymbol{p}$, Annelid jaws.

its fructification in $c, d$. They were one to three feet high. The species differ from the common Ground Pine in having the leaves on the stems nearly wanting, and also in having the axis made up of scalariform vessels, and the spore-cases (fruit, $c, d$ ) usually in pairs on short pedicels.

$854-857$.

855
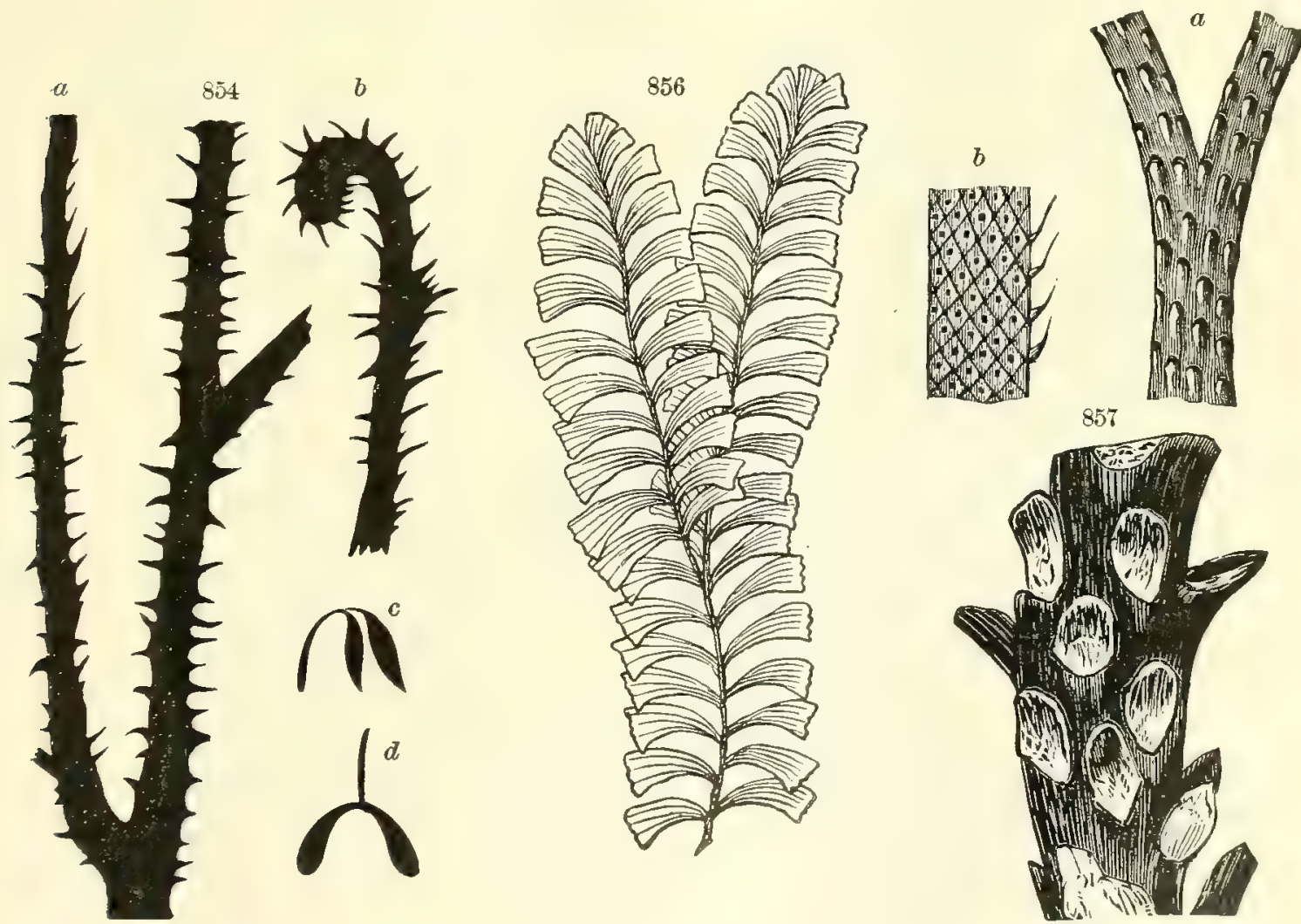

Lrcopons. - Figs. $854 \boldsymbol{a}, \boldsymbol{b}$, Psilophyton princeps ; $\boldsymbol{c}, \boldsymbol{d}$, same, fruit; $855 \boldsymbol{a}$, Lepidodendron Gaspianum (1); $\boldsymbol{b}$ same, showing surface scars of lower part of stem. FerNs. - Fig. 856, Sphenophyllum vetustum (1); 85T, stem of tree fern, Caulopteris antiqua $\left(\times \frac{1}{7}\right)$. Figs. 854, 855, Dawson; 856, 857, Newberry.

The Corniferous limestone of Ohio has afforded the Ferns, Figs. 856 and 857, described by Newberry. The latter is part of the trunk of a tree fern 
of the genus Caulopteris; and C. advena Newb. is the name of another species. The trunks of both are three to four inches in diameter. Newberry states that these tree ferns probably grew over the region of the Cincinnati uplift - then an island (C, map, page 412 or 536).

Spores and spore-cases (sporangites) have been reported from the limestone of Ontario County, N.Y. As described by J. M. Clarke they are $\frac{1}{500}$ and $\frac{1}{50}$ of an inch in diameter; he suggests that they may be from Rhizocarps (the lowest of Acrogens) of the genus Salvinia (p. 436), and they are referred to the species Protosalvinia Huronensis of Dawson.

Avimals. - The Upper Helderberg period was eminently, as has been stated, a corcl-reef period, but besides corals, it abounded also in species of other tribes of invertebrate life characteristic of Paleozoic time.

1. Sponges. - The existence of Sponges is indicated by the presence of their siliceous spicules in the hornstone, two slender forms of which are shown in Figs. $853 j, k$, and others in $l, m, n$. Besides, there are species of Astraeospongia and Hindia. There are also several species of Stromatopora, and the last known in America of Receptaculites.

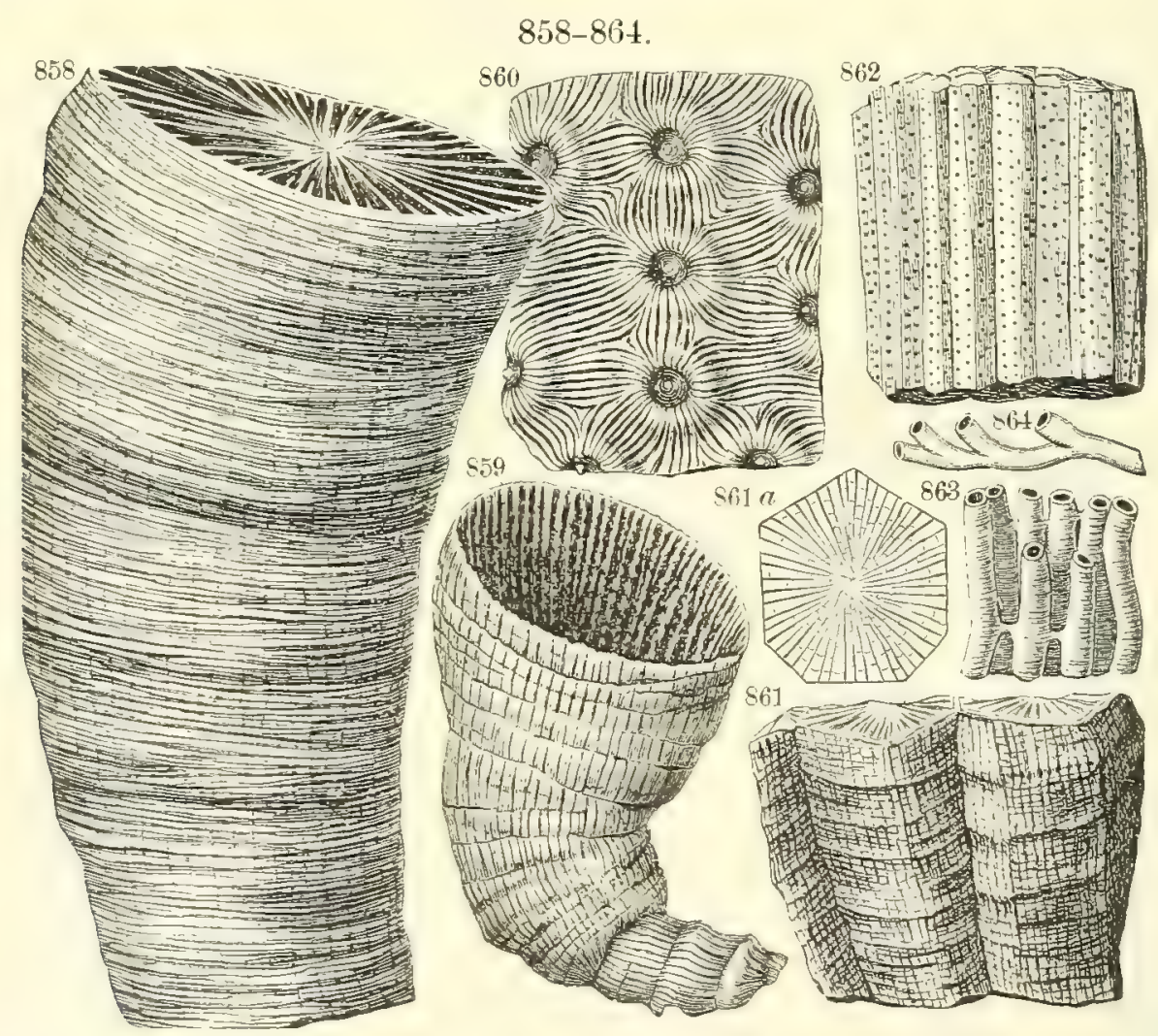

Polyps.-Fig. 858, Zaphrentis gigantea; 859, Z. Rafinesquii ; 860, Phillipsastrea Vernenili ; 861, 861 , Cyathophyllum rugosum; 862, Farosites Goldfussi ; 863, Syringopora Maclurii ; 864, Romingeria cornuta. Figs. 858, 860, 862, Edwards and Haime; 859, 861, Meek; 863, Yandell and Shumard; 864, Billings.

2. Polyp-corals. - Figs. 858 to 864 represent a few of the many Corals: 859 shows the radiated cup-shaped termination to which the name Cyatho-

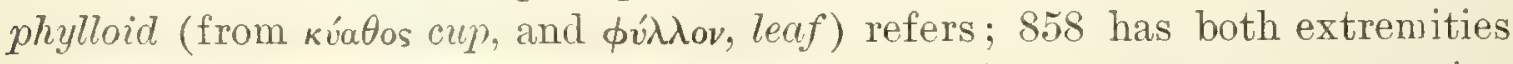
broken off, but exhibits the interior radiation. Fig. 862 represents a portion 
of a common species of Favosites (honey-comb Coral, named from favus, honey-comb), which is sometimes in hemispheres five feet across; 860, part of the surface of a Phillipsastrea, a common massive Coral, and 861, a fragment of a species of Cyathophyllum; 863, a group of clustered tubes scarcely radiated within, of the genus Syringopora, broken from what was once a convex hemispherical mass of branching tubes; 864, a ereeping tube, having cells at intervals.

3. Echinoderms. - Besides true Crinoids of several species, some of them of very large size, there were the Blastoids one of which is represented in Fig. 865. Though ovoidal in form, it is related to the pentagonal Pentremites of the Lower Carboniferous.

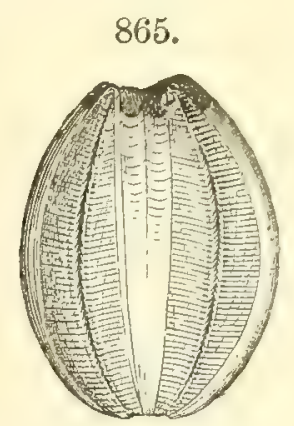

Nucleocrinus Verneuili. Meek.

4. Molluscoids. - Brachiopods were very numerous; and Figs. 866 to 870 represent common species. The Terebratula family, the most abundant in species in existing seas, has its species; Fig. 870 is one of them: it shows the opening at the beak.

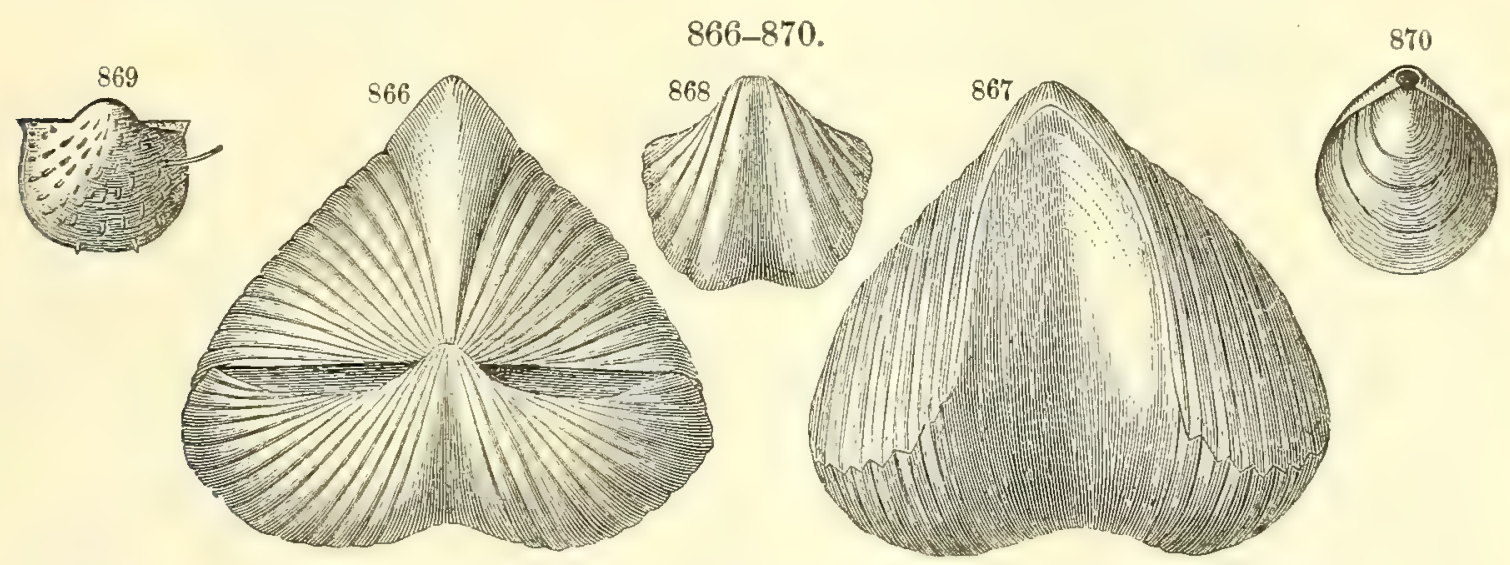

Brachorods. - Figs. 866, 867, Spirifer acuminatus;-868, S. gregarius; 869, Productelia subaculeata ; 870 , Cryptonella lens. Figs. 866 to 868 by Meek; 869,870 , Hall.

5. Mollusks. - The few Lamellitranchs described include the following kinds, with species of the Avicula family and others.

871.

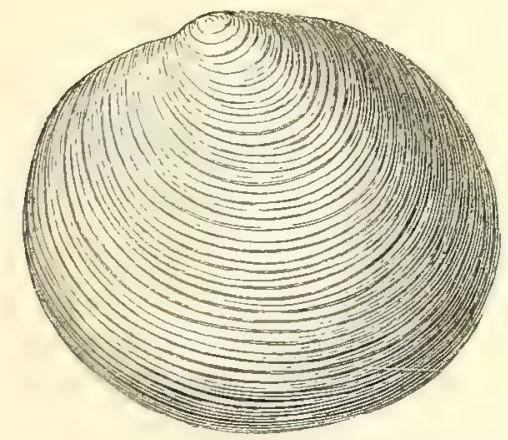

Lamelutbranchs. - Fig. 871, Paracyclas proavia; 872, Conocardium cuneus, Meek.

872.

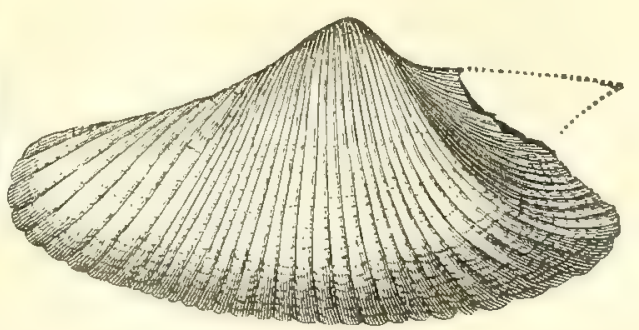

Among Gastropods occur many species of the genus Platyceras, one of 
which, covered with spines, is represented in Fig. 873; also species of Bellerophon, Euomphalus, Pleurotomaria, Murehisonia, Lower Silurian genera that continue through the Devonian, into, and part of them beyond, the Carboniferous. Among Cephalopods there are species of Orthoceras, Gomphoceras, Cyrtoceras, and the last known of Trochoceras, a Silurian type; also the first known of American Goniatites - G. mithrax H. (Fig. 874), and a variety

874.
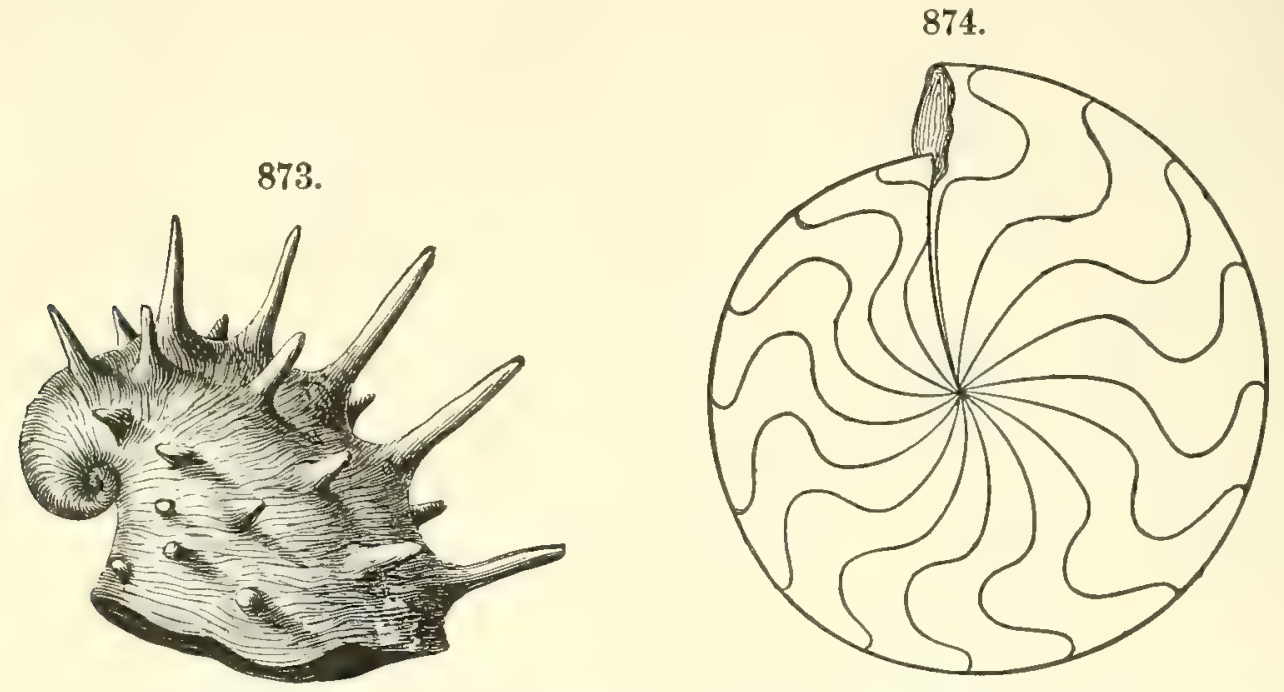

Fig. 873, Platyceras dumosum; Meek. Fig. 874, Goniatites mithrax; Hall.

of $G$. discoideus $\mathrm{H}$. being reported from Ohio. The Goniatites differ from species of the Nautilus family in having the siphuncle ventral, and the margin of the septa deeply flexed. Tentaculites of large size also occur, and the related genus Styliolina (Fig. 916).

6. Crustaceans. - Trilobites of the Lower Silurian genera, Calymene and Dalmanites, and of the Upper Silurian, Homalonotus, Lichas, Phacops, Proetus, Cyphaspis, are most common. Under some genera there is a large diversification of form in ornamented heads and pygidia. The following figures from Hall and Clarke illustrate some of the forms from the beds of the Early and Middle Devonian. Figs. 875, 876 are heads of species of Dalmanites; 877,878 , pygidia of species of the same genus; 879 , the head of an Acidaspis; 880, part of a pygidium of another Acidaspis; 881, 882, heads of species of Lichas; 883, part of a pygidium of a Lichas; 884, pygidium of a Proetus.

The most extravagant of all is Lichas grandis H., which had a pygidium four inches broad armed with seven thorny spines $1 \frac{1}{2}$ to $2 \frac{1}{2}$ inches long, and a grossly protuberant warty head, with a stout spine by the side of each eye. The extremity of the pygidium, restored from an imperfect specimen, is represented in Fig. 883. In contrast with these, other species of Dalmanites and Lichas are very plain. Those of Proetus (Fig. 884) are all primlooking species, with evenly curving outline before and behind.

Crustaceans of the Phyllopod and Ostracoid types are rare. But Barnacles of a peculiar kind occur, imbedded to their upper surfaces in the Corals of 
the old coral reefs, precisely like related kinds in corals of the present day. The related species now living are free-swimming animals in their young state; the free stage is ended by the animal's coming to rest on the surface

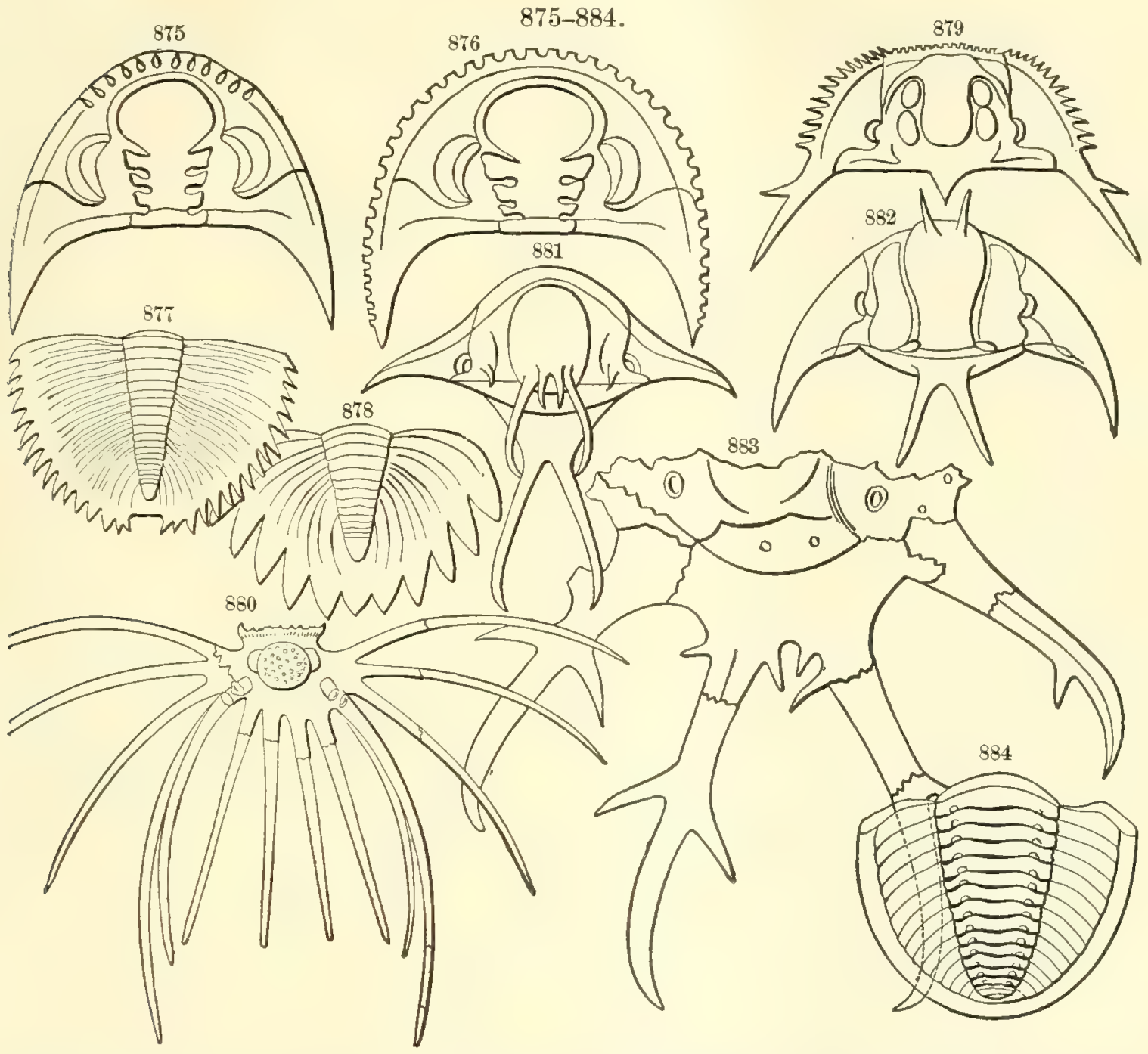

Fig. 875 , Head of Dalmanites selenurus ; 876, id. D. regalis ; 877 , pygidium of D. aspectans ; 878 , id. D. Boothi of the Hamilton beds; 879 , head of Acidaspis callicera ; 880 , portion of the pygidium of Acidaspis Romingeri restored $\left(\times \frac{1}{2}\right)$; 881, "head" of Lichas gryps ; 882, id. Lichas hylæus ; 883, posterior extremity of pygidium, restored, of Lichas grandis, from the Schoharie grit; 884, pygidium of Proetus crassimarginatus, from the Corniferous limestone. Hall and Clarke.

of a living Coral; and once there, it stays and forms a dwelling cavity lined with shell within the growing Coral, - a case of commensalism, not parasit. ism, it receiving lodging, not board. Similar Barnacles - Paloeocreusia Devonica of Hall - were commensals of Devonian Corals, showing that the practice is an ancient one.

7. Fishes. - Fishes are the only Vertebrates known. The species discovered in the Corniferous limestone are: (1) Placoderms ; (2) Dipnoans, or Lung-fishes; (3) Ganoids; (4) Chimæroids; (5) Selachians, or Elasmobranchs (Sharks). The Placoderms include two species of Cephalaspis, - one from Gaspé (Fig. 885), and the other from Campbellton, New Brunswick (Fig. 886, 
its head-shield). The surface of the former is (as usual with the species) covered with small tubercles (Fig. 885 a), while the latter has a minutely pitted surface. A restored figure of a foreign species is shown on page 557.
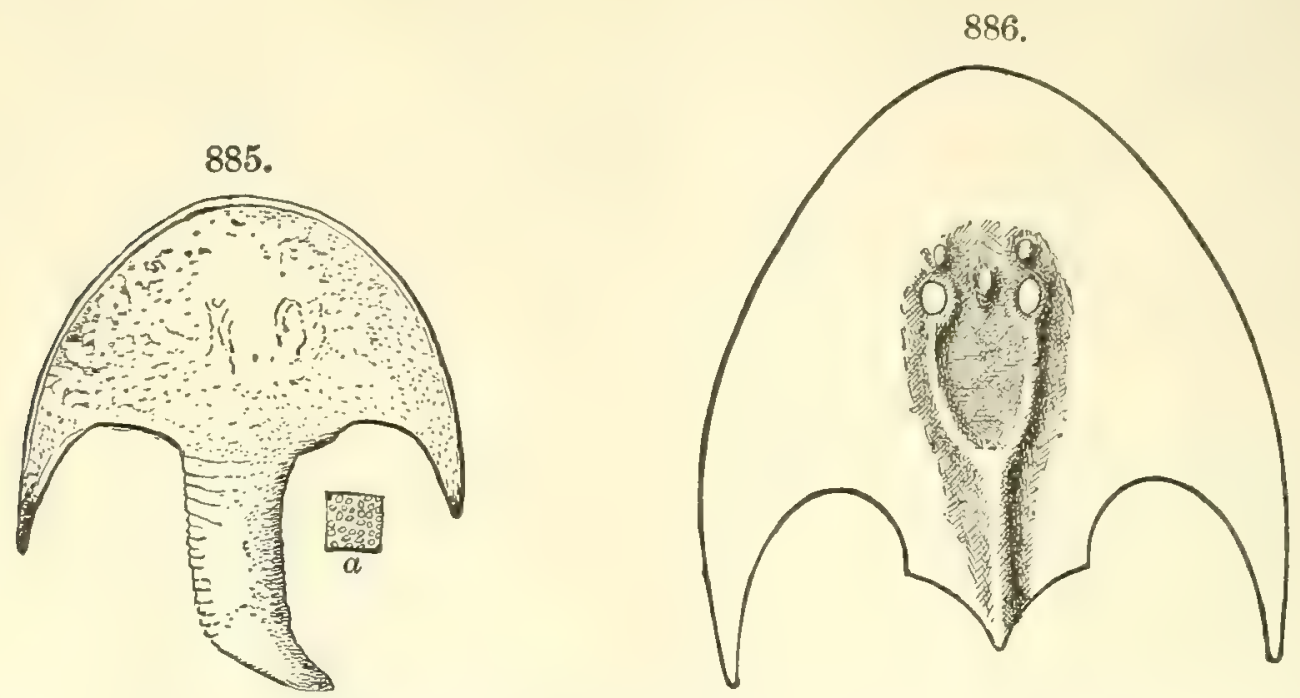

Placoderms, - Fig. 885, Cephalaspis Dawsoni $\left(\times \frac{3}{4}\right)$, Lankester; $\boldsymbol{a}$, tubercles of surface; 886, C. Campbelltonensis $\left(\times \frac{1}{4}\right)$, Whiteaves.

The posterior, or caudal extremity, of the C. Dawsoni is so very short, relatively to the breadth of head, that the fish must have been poor at sculling - its chief means of locomotion. Any relation to the Trilobites is set aside by the tubercular surface. Lankester states that it belongs to the subdivision of the genus which he calls Encephalaspis.

$887-889$.

889.
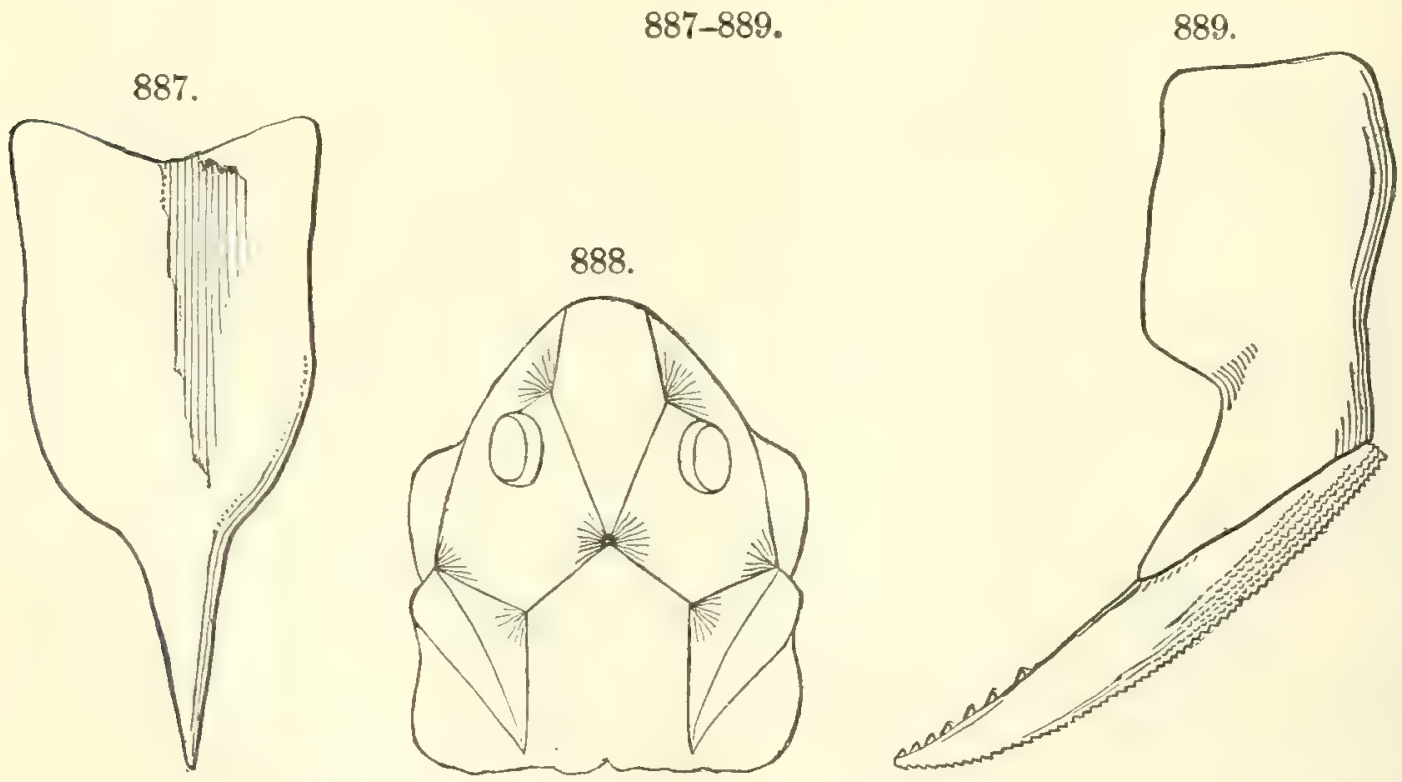

Diprosrs. - Fig. 887 , Coccosteus occidentalis $\left(\times \frac{1}{2}\right) ; 888$, Macropetalichthys Sullivanti $\left(\times \frac{1}{4}-\frac{1}{10}\right) ; 889$, Acanthaspis armata $\left(\times \frac{2}{2}\right)$. From Newberry.

Among the Dipnoans of the period there was a species of Coccosteus, C. occidentalis of Newberry; only the posterior dorsal plate (Fig. 887) is known; its surface is in part fine-tuberculate. Fig. 888 represents the 
head-shield of another large Dipnoan; its length in some specimens is 16 inches, indicating a fish of large size. The peculiar spine-bearing plate shown in Fig. 889 is of uncertain relations.

Ganoids existed of formidable size and dental armature. In one of them, Onychodus sigmoides, the mandible, or jaw (Fig. 890), was 14 inches long, and the head 18 inches. At the extremity of the lower jaw there were very
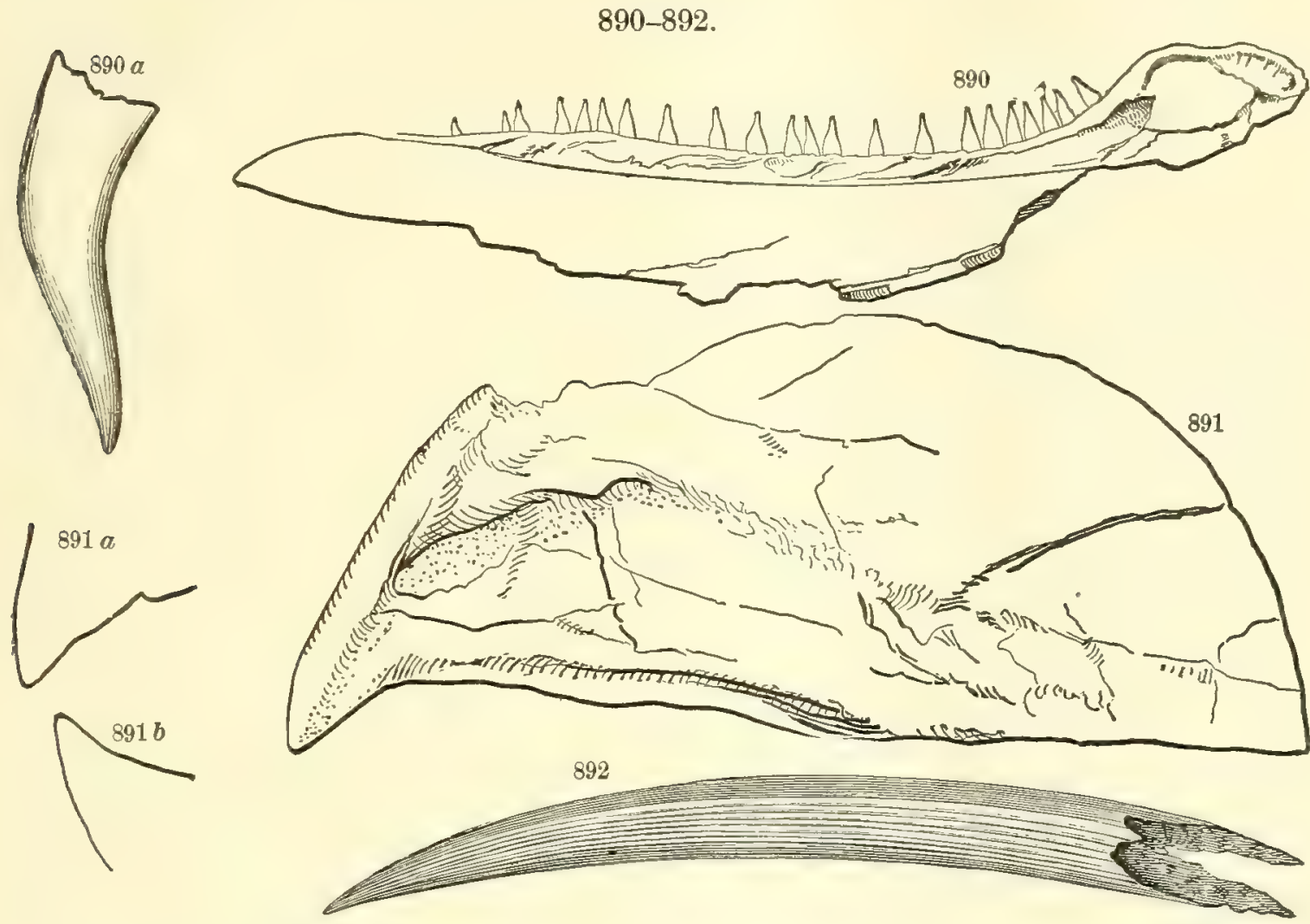

Garoms. - Fig. 890, mandible of Onychodus sigmoides $\left(\times \frac{1}{4}\right) ; 890 \boldsymbol{a}$, one of the large teeth at the extremity of the mandible $\left(\times \frac{3}{7}\right)$. Chmerom Selachian. - Fig. 891, Rhynchodus secans, upper tooth; $891 \boldsymbol{a}, \boldsymbol{b}$ extremities of upper and lower mandibles in natural position. FIN-SPINE OF A SELAchian. - Fig. 892, Machæracanthus sulcatus $\left(\times \frac{2}{3}\right)$. Figs. 890, 891, Newberry ; 892, Hall.

few very large teeth; and one of them, nearly half the natural size, is represented in Fig. 890 a.

To the Chimæroids are referred the species of Rhynchodus, having 4 large, beak-like teeth, two in each jaw. One of these teeth is shown, natural size, in Fig. 891. The relative positions of the upper and lower jaws at the extremity is shown in Figs. $891 a, b$.

The Selachians or Sharks of Cestraciont type were represented by species of Psammodus. One of the spines of a Shark, probably from the dorsal fin, is represented in Fig. 892; the length of this spine is 4 to 6 inches; but that of another Ohio species is 20 inches.

The Nevada Devonian. - In the Devonian of Nevada, where a limestone 6000 feet thick represents nearly the whole era, the Lower, Middle, and Upper Devonian, out of the 144 species described by Walcott, more than half occur also in the New York Devonian, a number in the Iowa that are 
not known in New York, besides two at Mackenzie River. But in Nevada, 10 per cent occur in both the Lower and Upper 500 feet of the limestone; and 11 per cent of the Lower Devonian are known only in the Middle or Upper of New York. Many species, therefore, were in existence over the central and west-central portion of the continent before they reached, by migration, the shallower waters of New York and Pennsylvania on the eastern border of the Continental Interior. The species include about 25 of Corals, numerous Brachiopods, Lamellibranchs and Gastropods, very few Cephalopods, Trilobites and Crustaceans, and no Eurypterids or Fishes.

\section{Characteristic Species.}

Plasts. - On Nematophyton and other Devonian plants see Dawson's G. Hist. Plants, 1888; Trans. Roy. Soc. Can., 1889; also on other Devonian (Erian) Flora, the Report in the Geol. Survey of Canada, 1871; also earlier, Q. J. Geol. Soc., vols. xv. xviii., xix., xxvii. Dawson also reports a species of Leptophloum from the Lower Gaspe beds or Upper Helderberg. Drepanophycus of Göppert (1852), described as a seaweed, has been shown to be the same as Psilophyton. The supposed fruit of Chara is still of doubtful nature. See Knowlton, Am. Jour. Sc., xxxvii., 1889.

Animals. 1. Spongiozoans.-Species of Astrceospongia, and Hindia; Ischadites bursiformis H., Schoharie grit; Stromatopora ponderosa Nich., Ohio ; Syringostroma densum and $S$. columnare Nich., Ohio.

2. Actinozoans. - Fig. 858, Zaphrentis gigantea Raf., and 859, Zaph. Rafinesquii E. \& H., from the Falls of the Ohio, Z. Edwardsi Nich., Ohio, Z. prolifica B., Ohio; another Coral, of the genus Chonophyllum (C. magnificum B.), has a diameter at top of 6 or 7 inches; it is from Walpole, Canada West. Fig. 860, Phillipsastrea Verneuili E. \& H., P. gigas Owen, Iowa, Ohio; Cystiphyllum Americanum E.\& H., Heliophyllum Halli, E. \& H. ; Fig. 861, Cyathopyllum rugosum H., fragment from a large mass, Falls of the Ohio; Fig. 862, Favosites Goldfussi D'Orb., Falls of the Ohio, a fragment; F. turbinatus B., Canada, Ohio ; Fig. 863, Syringopora Maclurii B., Canada, Ohio; Fig. 864, Romingeria cornuta B., from Canada.

3. Hydrozoans. - Of the genus Dictyonema.

4. Echinoderms.- Species of Dolatocrinus, Megistocrinus. Of Blastoids (Pentremites), Fig. 865, Nucleocrinus Verneuili L. \& C.

5. Molluscoids. - (a) Bryozoans are represented by many species of Fenestella and other genera.

(b) Brachiopods. - Figs. 866, 867, Spirifer acuminatus, Con., N.Y., Ohio, Ind.; Fig. 868, Spirifer gregarius Clapp, N.Y., Ind., Ky., Falls of the Ohio; Leptona rhomboidalis, Wilckens, Canada. Also, Pentamerella arata Con., N.Y. and the West, Atrypa reticularis Linn., A. impressa H., A. aspera H. var. occidentalis, Amphigenia elongata Van., Chonetes hemisphericus H., C. lineatus Van., Productella navicella H. Meristella nasuta Con., N.Y. and the West.

6. Mollusks. (a) Lamellibranchs.-Fig. 871, Paracyclas proavia Goldf. (elliptica H.), N.Y., Ohio, Ind. Fig. 872, Conocardium cuneus Con., Ohio, Ind.; Solenomya vetusta Meek, the first known species of the genus, Ohio.

(b) Pteropods. - Tentaculites scalariformis H., N.Y., Ohio, Ind., Hyolithes ligea H.; Conularia elegantula Meek.

(c) Gastropods and Cephalopods. - Fig. 873, Platyceras dumosum Con., from New York and Columbus, Ohio. A dozen species of Platyceras have been described, and 5 or 6 or more of each Platystoma, Euomphalus, Loxonema, Pleurotomaria, Murchisonia, 
Bellerophon. Turbo Shumardi Vern. is a fine large shell, $3 \frac{1}{2}$ inches in diameter, from the Falls of the Ohio. It was named after B. F. Shumard of St. Louis. It is well figared by Hall. Among Cephalopods, 30 species of Orthoceras are reported by Hall; besides these there are 12 of Gomphoceras ( 4 in the Schoharie grit), as many of Cyrtoceras and Gyroceras (4 Schoharie grit), 9 of Trochoceras, all from the Schoharie grit; 1 Goniatites (Fig. 874), G. mithrax H. (T'ornoceras mithrax Hyatt, and referred to the Corniferous with some doubt), 2 Discites. Hyatt states that most of the species of Gomphoceras have a triangular aperture instead of lobed like that on page 561, and that they accordingly belong to his genus Acleistoceras. The species of Gastropods, etc., are described and figured in Hall's N. Y. Pal., vol. v. Gyroceras undulatum H. is a type of Halloceras of Hyatt; G. Jason H. is Rutoceras Hyatt; Trochoceras pandum H. is Endoceras Hyatt; T. clio H. is Sphyradoceras Hyatt; T. eugenium H. is Noedoceras Hyatt.

7. Crustaceans. - The most common Trilobites are: Fig. 875, Dalmanites selenurus, having a two-pointed tail; and Fig. 884, Proetus crassimarginatus H. There are also: Calymene platys, the latest American species of the genus, and one of the largest perfect specimens being 4 inches long, and an imperfect one indicating a length of 8 inches; over 20 species of Dalmanites (one over 16 inches long), besides the Lower Helderberg species D. pleuropteryx; also, of Homalonotus 1 species, of Phacops 3, Lichas 7, Acidaspis 2 (Fig. 879, A. callicera), Proetus over 15, Cyphaspis 4, and the new genus Phathonides, 3 species.

The figures of Trilobites on page 587 represent the following sub-genera, as recognized by Hall: Under Dalmanites: Odontocephalus (D. selenurus Eaton); Corycephalus (D. regalis H.); Coronura (D. aspectans Con.); Cryphaus (D. Boothi Green). Under Lichas: Hoplolichas; Ceratolichas. For figure of Palcocreusia, see Hall's N. Y. Pal., vii. pl. 36.

8. Vertebrates. - For descriptions and figures of the Fishes mentioned and others, see Newberry, in Ohio Pal. Rep., i. and ii., where the figures of the large species are of natural size, and also his 4 to Rep.U.S.G.S., 1889; also papers by Cope, Claypole, Whiteaves, and others. From the Lower Devonian of Campbelltown, Canada, Whiteaves has described fin-spines of Ctenacanthus latispinosus and Homacanthus gracilis. The Cephalaspis Danosoni is from below the middle of the Gaspe sandstones, from the beds affording Prototaxites Logani and other plants. That the beds are Lower Devonian is doubtful.

At Owl's Head, on Lake Memphremagog, near the northern borders of Vermont, the coral-reef rock is overlaid by mica schist; and, although it is partially metamorphic, many of the specimens of fossils are tolerably perfect. Among the species, Billings has recognized Syringopora Hisingeri B., Favosites basalticus Goldf., Diphyphyllum stramineum B., and Zaphrentis gigantea Lesueur. Besides these, according to Hitchcock, Atrypa reticularis has been identified by Hall.

Between northern Vermont and Cape Gaspé there are many localities of Devonian fossils. One locality, given by Logan, is on the Chaudière River, where occur, besides Favosites Gothlandicus and F. basalticus, the species Syringopora Hisingeri, Diphyphyllum arundinaceum B., a small Productus resembling a Corniferous species, a Zaphrentis, Spirifer duodenarius H., S. gregarius Clapp, S. acuminatus H., a Cyrtina like C. rostrata H., etc. Other localities occur at Dudswell and on Famine River.

Species of Brachiopods range as follows: From the Oriskany to the Hamilton, Spirifer fimbriatus Con. (= S. Conradanus S. A. Miller); from the base of the Lower Helderberg or beyond to the Chemung, Atrypa reticularis and Stropheodonta perplana, but with some slight characteristic features in the successive periods ; from the Oriskany to the Chemung, Stropheodonta demissa; from the Upper Helderberg to the Chemung, Atrypa aspera; from the Schoharie grit to the Hamilton or Chemung, Orthis Vanuxemi, Orthothetes Chemungensis; common in the Upper Helderberg and Hamilton, Spirifer acuminatus, Meristella nasuta. 
The Devonian of California, mentioned on page 580, contains, according to Schuchert, Favosites Canadensis, Cyathophyllum robustum, Cladopora labiosa, Syringopora Maclurii, and is referred by him with a query to the Corniferous ; at Gazelle, in Siskiyou County, occur Diphyphyllum fasciculum and Acervularia pentagona; and he suggests that the beds may be of later date (1894).

In the lower part of the Eureka Devonian limestone (p. 589) occur, according to C. D. Walcott, the following Corniferous or Lower Devonian species of New York, etc.: Favosites hemisphericus Y. \& S., Cyathophyllum rugosum Edw. \& H., Orthis impressa, Stropheodonta perplana, S. punctulifera, Chonetes hemisphericus, C. mucronatus, Spirifer raricosta, S. varicosus, Atrypa reticularis, Nucleospira concinna, Meristella nasuta, Platyceras carinatum, P. conicum, $P$. dentalium, $P$. nodosum, Phacops rana, and many others. But with these are very many that are Middle and Upper Devonian in New York and elsewhere, and among these are the three Hamilton Tentaculites, T. attenuatus, T. bellulus, T. gracilistriatus. Besides, some New York Upper Helderberg species are found in the upper part of the 6000 feet of Devonian limestone. Again, many of the species of the lower part occur also in the upper part, showing long survival of individual forms; this is true of Orthothetes Chemungensis, of 4 species of Productus, Chonetes deflectus, Stropheodonta perplana, 2 of Spirifer, Rhynchonella castanea of Meek (a Mackenzie River species), a Paracyclas, Styliolina fissurella. Orthis McFarlani Meek is a second Mackenzie River species; and as the two are Lower Devonian in Nevada, they may be so at the arctic localities. Many of the species are represented in the Devonian of Iowa, or the Continental Interior, where the waters were purer and probably deeper than in the New York Bay, and therefore more like those of the Eureka district.

Of the Eureka Devonian species that are found only in the upper division, the following are confined to the Lower Devonian in New York: Syringopora Hisingeri, Cyathophyllum corniculum, and Chonetes mucronatus; and the following are among those that are Middle or Upper Devonian in New York or Iowa: Orbiculoidea minuta (Hamilton), Orthis Tulliensis (Ham.), Productus lacrymosus (Chemung), P. speciosus (Ch.), Spirifer disjunctus (Ch.), Athyris angelica (Ch.), Rhynchonella duplicata (Ch.), R. Laura (Ham.), R. sinuata (Ch.), Bellerophon mcera (Ch.). The preceding conclusions appear to be well sustained, unless it may be that there are unseen faults in the limestone. See, further, Walcott, Pal. Eureka, U.S.G.S., 4to, vol. viii., 1884, where 144 Devonian species are described; and also Arnold Hague, Rep., vol. xx., U. S. G.S.

\section{Hamilton Period, or Middle Devonian.}

\section{ROCKS - KINDS, SUBDIVISIONS, AND DISTRIBUTION.}

The Hamilton group was so named from Hamilton, in Madison County, N.Y. The beds have a wide range, like the Corniferous limestone. They extend from eastern New York (Schoharie County) westward to Iowa; but in New York and Penneylvania they are mainly shales and sandstones, of shallow water origin, and wholly calcareous only in the Central Interior region. Moreover, they have great thickness to the eastward, 1500 feet, but thin down rapidly to the westward, being only 300 to 1100 feet thick near Lake Erie, thinning down to 20 to 50 feet. They border Lake Erie in Ontario; pass by the south end of Lake Huron into Michigan, where they are limestone, and 10 to 120 feet thick. They appear also in Ohio, as 25 feet of impure bluish limestone; in Indiana, where at the Falls of the Ohio, above Louisville, they are 20 feet thick, and include the hydraulic and overlying beds of the limestone formation of the place. They occur also in Kentucky; Illinois, 
at Rock Island, etc.; Wisconsin, north of Milwaukee; in Iowa, near Independence; on the Mississippi, shale (Marcellus) overlaid by limestone; and in Missouri. The greatest thickness is along the Appalachian region, where the beds are almost wholly fragmental; and within these limits in Monroe County, eastern Pennsylvania, the group is 2000 to 5000 feet thick.

The Hamilton group of New York has as its lower member, the Marcellus shate, a formation of soft, black shale, except near the bottom, where occurs a thin limestone stratum called the Goniatite limestone. The shale is bituminous, and much unavailing search for coal has hence been made in it. Hall states that in many places it contains so much bitumen as to give out flame when thrown into a fire of hot coals. Its fossils are few in species, and mostly small, excepting the Goniatites.

Above the Marcellus come the true Hamilton beds - chiefly shaly sandstones with some fine shales and thin limestone layers; and at top, in many places, the Tully limestone, 10 to 20 feet thick, which is, by some, made the base of the Upper Devonian. This limestone is sometimes referred to as the Cuboides zone, in reference to a common fossil, Rhynchonella cuboides.

In eastern New York, in Ulster, Green and Albany counties, the Hamilton affords "the North River flagstone," affording excellent flags and pavements, used much in New York and the adjoining states. The thicker layers are called bluestone, from the bluish gray color. The bluestone is easily worked by machine-planing for use in the trimmings of buildings, and is convenient for the purpose if the stone can be selected that will not drip iron stains down the front below a course of it. The flagstone contains an occasional, slender worm-boring, and coaly fragments, and is often ripple-marked, like other layers of the Hamilton. Moreover, the strata are frequently intersected by joints of great extent and regularity. The scene in Fig. 121, page 112, is from the Hamilton near Cayuga Lake.

In eastern Canada, at Gaspé and Baie des Chaleurs, a middle portion of the 7036 feet of Devonian sandstones is referred to the Hamilton or Middle Devonian; and the next above to the Upper Devonian. The Little River group of Nova Scotia, and Cordaites shales and flags of St. John County, New Brunswick, are referred to the Hamilton by Dawson.

West of the Mississippi, in the Eureka district, Nevada, the 8000 feet of Devonian limestone and shale include the Hamilton group; but it has not been found possible to separate the Hamilton portion. Hamilton beds are also found in the valley of the Mackenzie River, between Clear Water River and the Arctic Ocean, some of the species of fossils being identical with those of the United States and Canada (Meek).

Interior Continental Region. - The Hamilton beds of New York are separated into two parts by a thin layer of Encrinal limestone. The annexed section (by Hall) is from the borders of Lake Erie. The Hamilton beds, 10 b, include (1) blue shale, (2) Encrinal limestone, (3) Upper or Moscow shale; the Tully limestone is wanting. Above lie (10 c) the Genesee slate, and (11) a following part of the Portage group, both of the Upper Devonian. A section near Canandaigua Lake, in Ontario County, N.Y., includes, accord- 
ing to J. Mr. Clarke, (1) Marcellus shale, $100^{\prime} ;$ (2) a thin stratum of limestone of coral-reef character, at the base of the Hamilton beds ; (3) the lower shales of the Hamilton, $140^{\prime}$; (4) the Encrinal Band; (5) the Upper shales, 250'. In Chautauqua County, a boring gave

893.

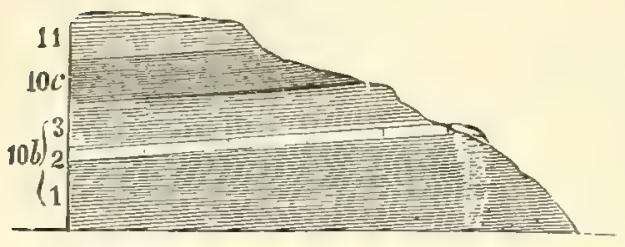

Section of Hamilton beds, Lake Erie. Hall. $50^{\prime}$ Marcellus shale and $395^{\prime}$ Hamilton (G. D. Harris, 1891). To the eastward, the beds are coarser and more arenaceous. The Tully limestone thins out in the eastern part of Ontario County, and is the most southern limestone in New York State. It is quarried and burnt for lime in the village of Tully, Onondaga County, where it is $12^{\prime}$ thick. The flagging-stone of the Hamilton is quarried near Kingston, Saugerties, Coxsackie, and elsewhere on the Hudson. In Perry County, central Pennsylvania, the Marcellus is 200' thick, and the Hamilton, $900^{\prime}$ or more ; they consist of shales and sandstones, and include the Montebello sandstone. At the Falls of the Ohio, the Hamilton is represented by a magnesian limestone, more or less shaly. On the west side of the Mississippi River, in Iowa, outcrops south of Davenport consist of about $50^{\prime}$ of shale with some crinoidal limestone. In Missouri, Swallow reported the occurrence of Hamilton shales, $45^{\prime}$ thick, near Ashley, in Pike County.

In eastern Pennsylvania, Monroe County, where the thickness of the beds of the Hamton period is $1750^{\prime}$ to $5000^{\prime}$, that of the Marcellus shale is $200^{\prime}$ to $800^{\prime}$ or more. The shale is black to gray in color, and the darker kinds are very carbonaceous, or even coaly at times. Tully limestone is absent. The high cliffs on the Delaware, in Pike County, from Port Jervis southward, are Hamilton. North-northwest of Monroe County, in Columbia County, Penn., the whole thickness is $2200^{\prime}$ to $2500^{\prime}$; but farther south, near the south border of Northumberland County, Penn., a highly disturbed region, the total thickness, for some reason, is stated to be only $600^{\prime}$. Prosser made a section across Monroe County, along the D., L. and Western R.R., and found the Marcellus shale $800^{\prime}$ thick, and the Hamilton overlying it, $1400^{\prime}$, the latter being proved by the fossils to include the Hamilton, Tully, and Genesee beds of I. C. White's Report.

In the Eastern-border region, at Gaspé, the $6000^{\prime}$ of sandstones, above the $1100^{\prime}$ referred to the Corniferous period, are believed to be for the most part of Hamilton age. St. John, in New Brunswick, is a noted locality of fossil plants of this era. In that region there are (1) below, of the Middle Devonian series, the Dadoxylon sandstone resting on the Bloomsbury conglomerate, and overlaid by the Cordaites shales; (2) above the Mispec conglomerate and slate; and (3), of the Upper Devonian, the Perry sandstones, with remains of plants. (Dawson.)

The Devonian is well developed in the Mackenzie River district, British America, and southward in the vicinity of lakes Manitoba and Winnipegosis. In the Mackenzie River district the section shows (1) at the base $200^{\prime}$ of grayish limestone, interstratified with dolomytes, the lower part of which may be olker than the Devonian; above this, (2) about $500^{\prime}$ of greenish and bluish shales alternating with limestones, followed by (3) about $300^{\prime}$ of limestones. (McConnell.)

Whiteaves has described a rich fauna, mainly from the upper part of the second division. Among the species, 22 are also found in the Hamilton formation of Ontario and New York; 10 are also found in Iowa, there referred to Chemung; and 7 are regarded as characteristic Chemung fossils in New York and Pennsylvania; 29 of the species are either identical (19), or closely allied with European Devonian species. Mr. Whiteaves considers the fauna to belong to the "Cuboides zone" of Europe, of which the Tully limestone of New York is by Williams regarded as an equivalent.

The Manitoba section consists of (1) a few feet of red shales resting upon Silurian rocks, followed by (2) $200^{\prime}$ of dolomytes, and then by (3) $50^{\prime}-75^{\prime}$ of calcareous shales, above which are $(1)$ the fossiliferous limestones containing the "Cuboides fauna." The 
dolomytes are referred to the Middle Devonian, the Stringocephalus zone of Europe, containing characteristic specimens of $S$. Burtini, one specimen measuring 7 by 5 inches in diameter.

LIFE.

Plants. - In the beds of the Hamilton period, the evidences of verdure over the land are abundant. The remains show that there were trees, as well as smaller plants; that there were forests of moderate growth, and great jungles over wide-spread marshes. The plants included Lycopods, Ferns, and Equiseta, the three orders of Acrogens, or higher Crytogams; and also Gymnosperms, among Phænogams.

1. Lycopods. - The Lycopods generally have scars over the exterior, much like those of a branch of spruce after the leaves have been removed. A Hamilton specimen of the Lepidodendron primcevum is represented in Fig. 894, and of another species in Fig. 895. L. Gaspianum (see Fig. 855) has been found in the Genesee slate of New York and Pennsylvania.

2. Ferns. - Many species of ferns have been described from beds of the Hamilton period, the most of them from those of St. John, New Brunswick. One species, a Neuropteris, is represented in Fig. 897; part of a frond of another, an Archoopteris, in Fig. 898, and a single leaflet, illustrating the divergent nervures of this genus, in Fig. 899. Large trunks of tree-ferns have been found in the Hamilton beds of New York and Ohio, showing that 894-899.
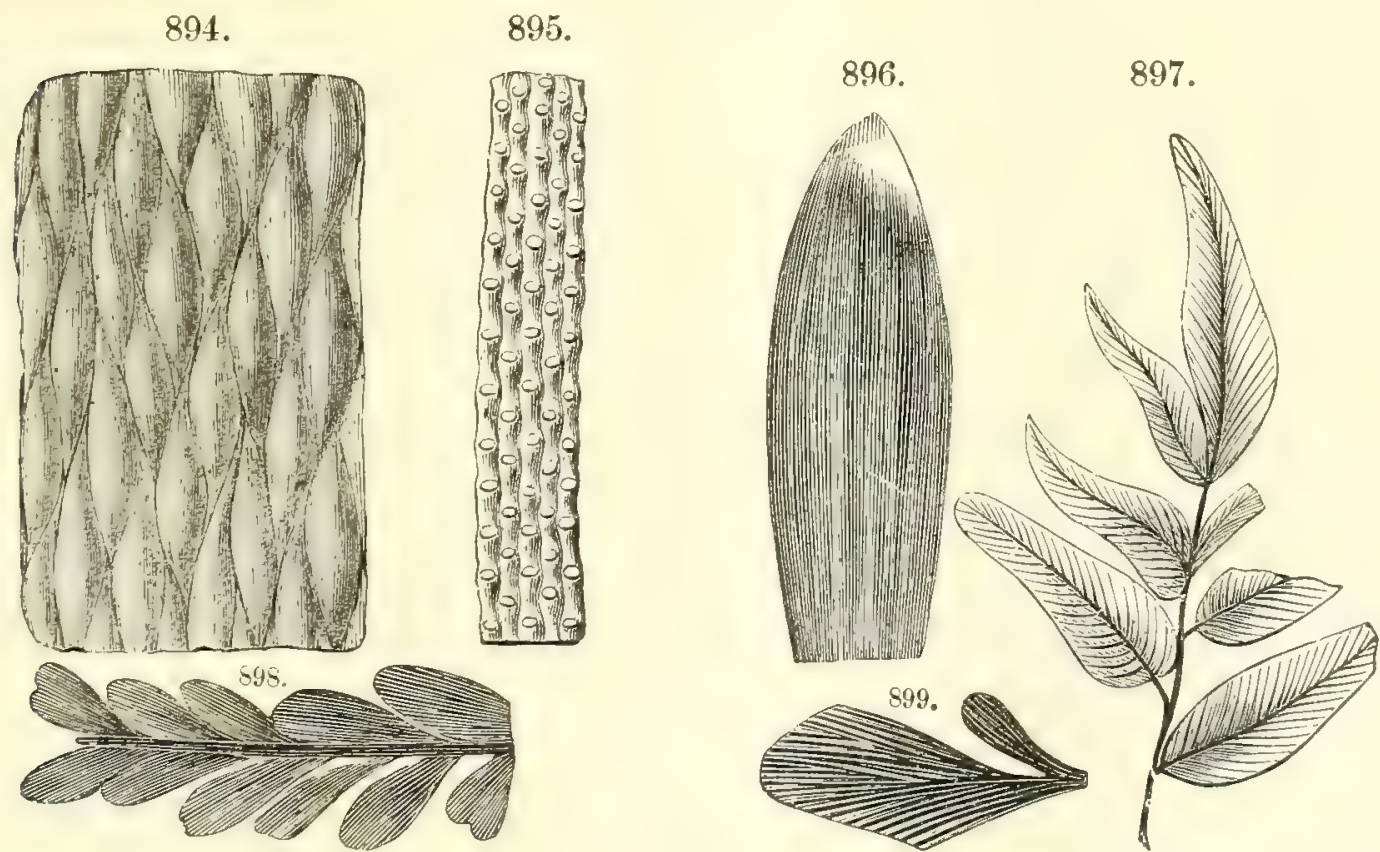

Acrogens. - Fig. 894, Lepidodendron primævum; 895, Sigillaria Halli ; 896, Cordaites Robbii ; 897, Neuropteris polymorpha ; 898, 899, Arehæopteris Jacksoni. Fig. 894, Lesquereux; 895, Meek; 896-899, Dawson.

there was beauty of foliage in the forests, if not of flowers. One of them, Psaronius Erianus Dawson $(1870,1871)$ had a trunk three to four feet in diameter, and was therefore a tree of large size. 
3. Equiseta or Horse-tails. - Calamites (named from calamus, a reed, in allusion to their reed-like or rush-like aspect) are ancient Equiseta. Fig. 900 represents a portion of a stem (in horizontal position) flattened out by

900.
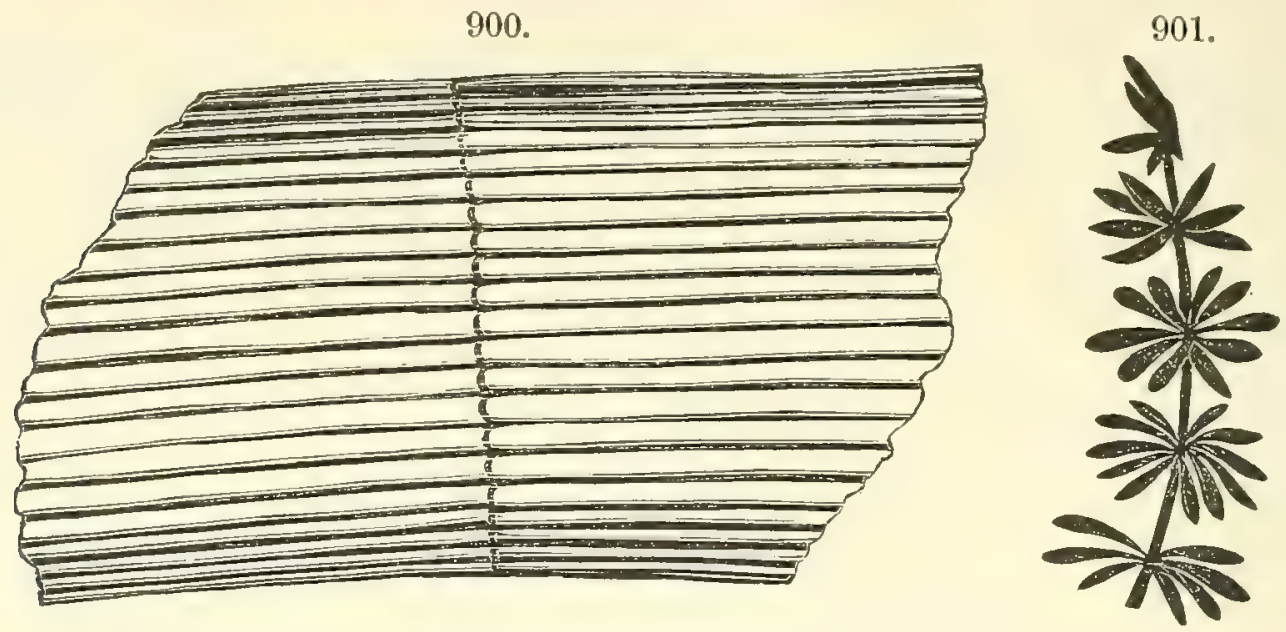

Fig. 900, Archæocalamites radiatus; 901, Asterophyllites latifolius. Dawson.

pressure. It shows that the Devonian species of the tribe exceeded much in size the modern species; as in recent kinds, the stems were jointed $(a b)$. A plant of the same tribe, called Asterophyllites (because of the arrangement of the leaves in stars), is represented in Fig. 901.

4. Gymnosperms. - Gymnosperms were represented by species of the Yew family (Taxineæ), and by leaves of plants of the tribe of Cycads. Trunks a foot in diameter, of the former, occur in the black shale of the Hamilton, and others as large, or larger, in the New Brunswick beds. Most of the latter are referred by Dawson to the genus Dadoxylon. To the Cycad family belongs the Cordaites Robbii, a leaf of which, from a cluster figured by Dawson, is represented in Fig. 896. It is questioned whether leaves like those of Archoopteris may not be from a related Cycadean, as one genus of modern Cycads, Strangeria, has fern-like leaves (Williamson). Fossil nuts were found with the specimen of $C$. Robbii, which "may have belonged to it" (Dawson).

5. Sporangites. - Spore-cases and spores are abundant in the black Marcellus shale of New York and Pennsylvania, and are a prominent source of its bituminous character. They are usually minute black shining spots in the shale.

Animals. - The animal remains of the Marcellus are comparatively few, and, excepting the Cephalopods, generally small. Their small number corresponds with the fact that the rock is a fine shale. In the Hamilton beds, which are coarser, and often resemble a consolidated mud-bed, fossils are much more numerous; but Lamellibranchs and Brachiopods are most abundant, as is usual in impure waters.

1. Spongiozoans. - A Middle Devonian species of Sphoerospongia, first described by Phillips from British specimens, is represented in Figs. $902 a, b$, 
from Manitoba specimens described by Whiteaves; the latter figure shows the natural outer surface, consisting of hexagonal plates, and the former, the interior; Fig. 902 c, is from a portion of the exterior enlarged, and $902 d$

$$
902-902 c \text {. }
$$

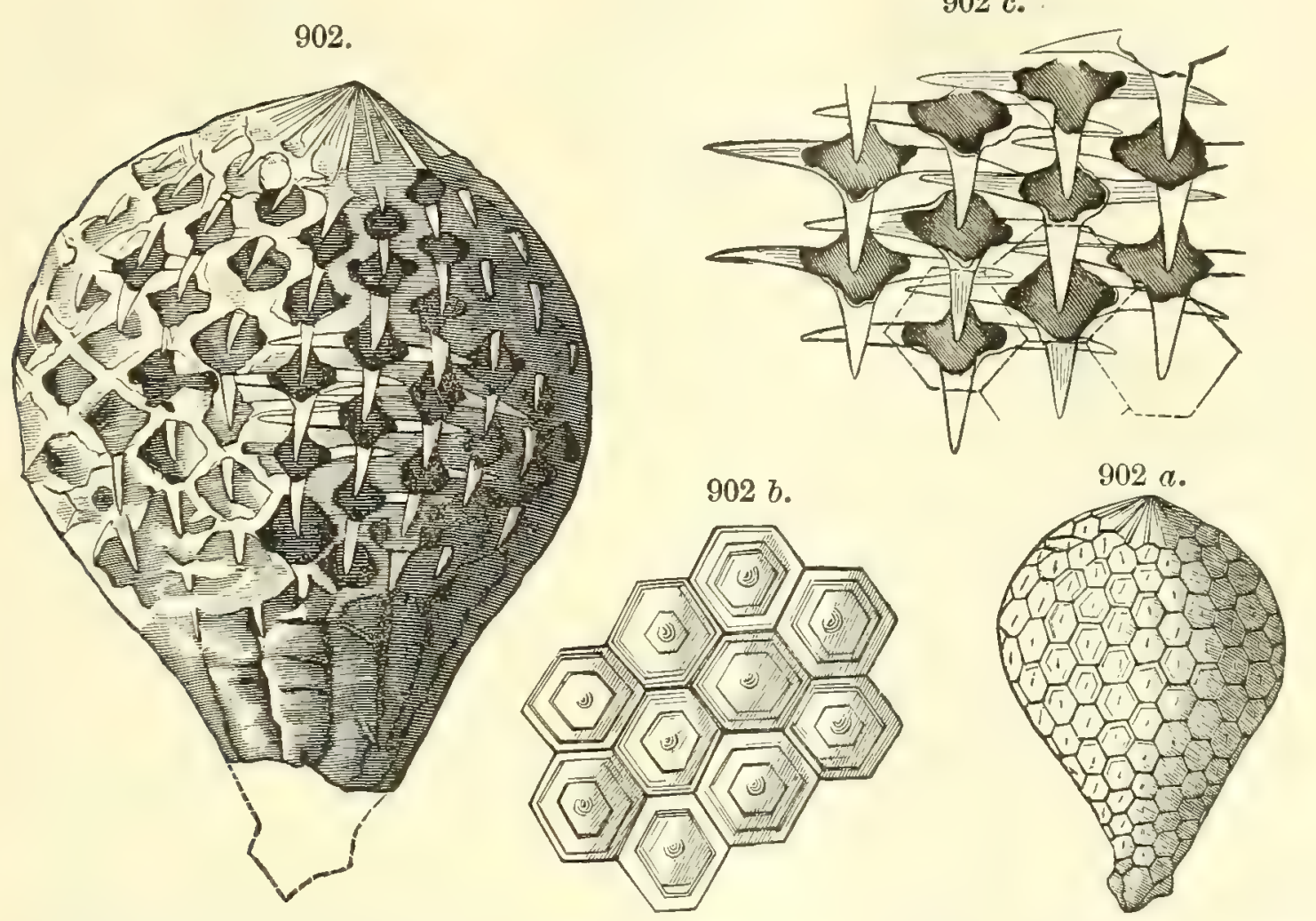

Spongrozodx. - Fig. 902, $a$, Sphærospongia tesselata ; $b$, enlarged view of exterior hexagonal plates; $c$, enlarged view of spicules. Whiteaves, '92.

represents the cruciform spicules. The genus is put in the same group with Receptaculites, by Rauff, who doubts, as in the case of that genus, the supposed relation to Sponges, and states that the spicules were originally calcareous. The rock is dolomyte.

2. Polyp-corals. - Corals are found chiefly in connection with the few beds of limestone; and near Canandaigua, N.Y., and to the westward, the Hamilton contains large numbers in coral-reef style. Fig. 903 represents a common species of Heliophyllum; and among the other genera there are Cyathophyllum, Cystiphyllum, Zaphrentis, Favosites, and Michelinia.

3. Crinoids. - Crinoids occur sparingly, in New York, but more abundantly at the Falls of the Ohio. They include species of Platycrinus, Actin908.

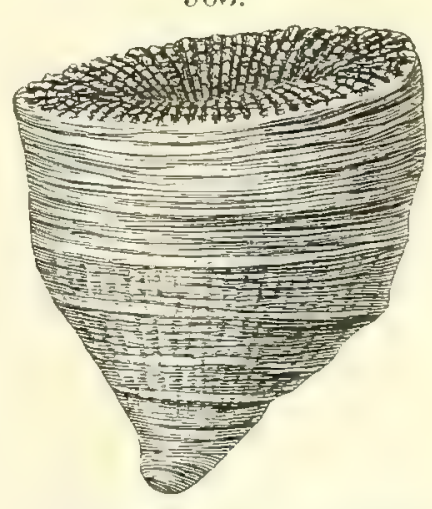

Heliophyllum Halli. Edw. and Haime. ocrinus, Cyathocrinus, Rhodocrinus; also Nucleocrinus, Pentremites, etc.

4. Molluscoids. - Brachiopods continue to be common fossils. Figs. 
904 to 911 represent the most common kinds. The broad-winged species, Fig. 907, Spirifer pennatus, was one of the most abundant.

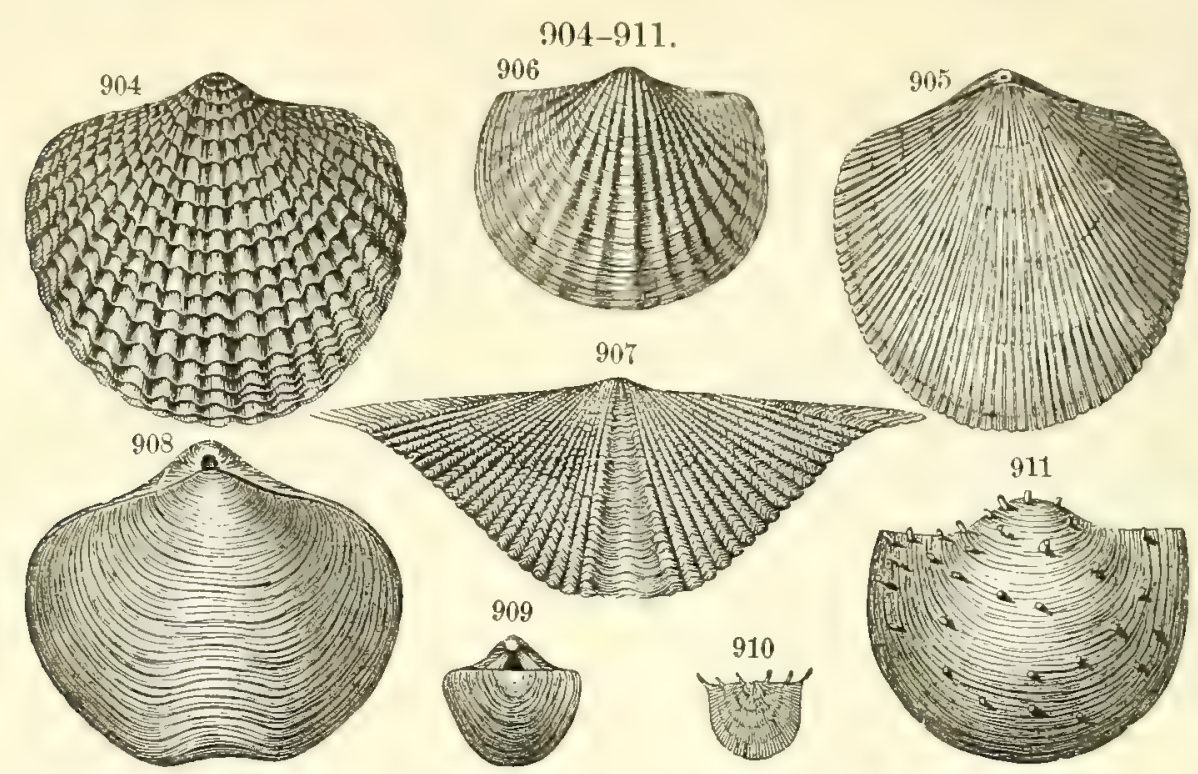

Brachopods. - Fig. 904, Atrypa aspera; 905, A. reticularis; 906, Tropidoleptus carinatus; 907, Spirifer pennatus; 908, Athyris spiriferoides; 909, Ambocelia umbonata ; 910, Chonetes setigerus ; 911, Productella subalata. Figs. 904, 906-908, Meek; 905, 909-911, Hall.

5. Mollusks. - In the shaly sandstones of this period Lamellibranchs abound. 21 species have been described by Hall from the Marcellus beds, and 174 from the Hamilton, only one being common to the two. But in Ohio and farther west, where the beds are calcareous, they are few in number. Only 10 New York species occur at the Falls of the Ohio. The following figures, 912-916, show some of the characteristic species. The Gastro-

\section{$912-916$}
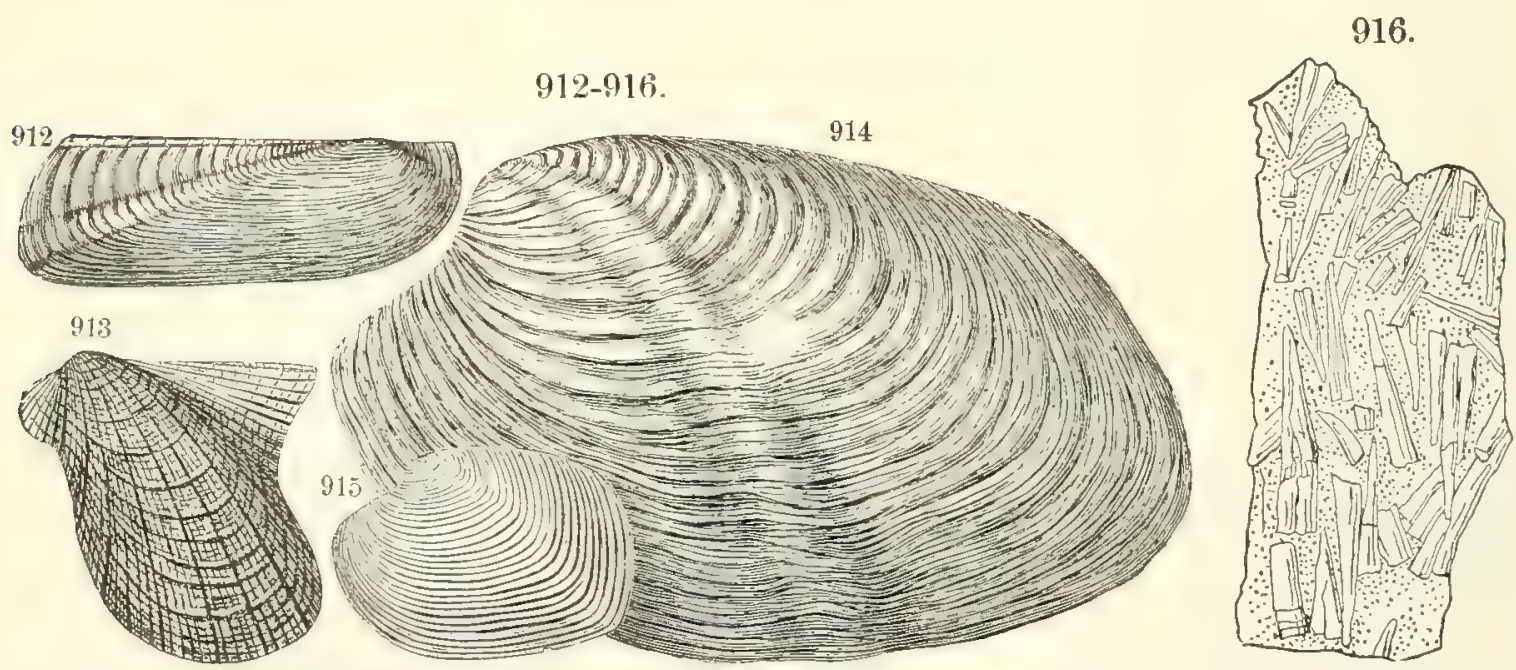

Conchirers. - Fig. 912, Orthonota undulata $\left(\times \frac{2}{3}\right) ; 913$, Pterinea flabella $\left(\times \frac{1}{2}\right) ; 914$, Grammysia bisulcata ; 915 , Microdon (Cypricardella) bellistriatus ; 916, Styliolina fissurella. Fig. 912, 916, Hall; 913, 915, Conrad; 914, deVerneuil.

pods were mostly of the same genera as in the earlier Devonian: Platyceras (many species), Platystoma, Trochonema, Pleurotomaria (many), Euom- 
phahus, Bellerophon (many species), Murchisonia (but one), Loxonema (many), with also the Devonian and Carboniferous genus Macrocheilus. Pteropods were still represented by Tentaculites, Hyolithes, and Conularia, and also by species of Styliolina (Fig. 916), Coleolus, etc. Styliolina is like Tentaculites, but has a smooth shell.

Under Cephalopods, the old genus, Orthoceras, had 29 described species in 1880 (to 30 in the Corniferous); with these were species of Gomphoceras, Cyrtoceras, and Gyroceras. The Nautiloid, Nephriticeras maximum oceurs over a foot in diameter. The genus Goniatites, first known from the Corniferous group, has a number of species; G. Vanuxemi (Fig. 917) is one of the earliest, being from the Marcellus shale; it has only one flexure in the septa, as shown in Fig. $917 \alpha$, a mark of its antiquity; and it has been made, on this account, by Hyatt, the type of the new genus Agoniatites. The largest specimens are a foot or more in diameter. A straight form of Goniatites, Bactrites clavus $\mathrm{H}$., has been found in the New York Marcellus shale.

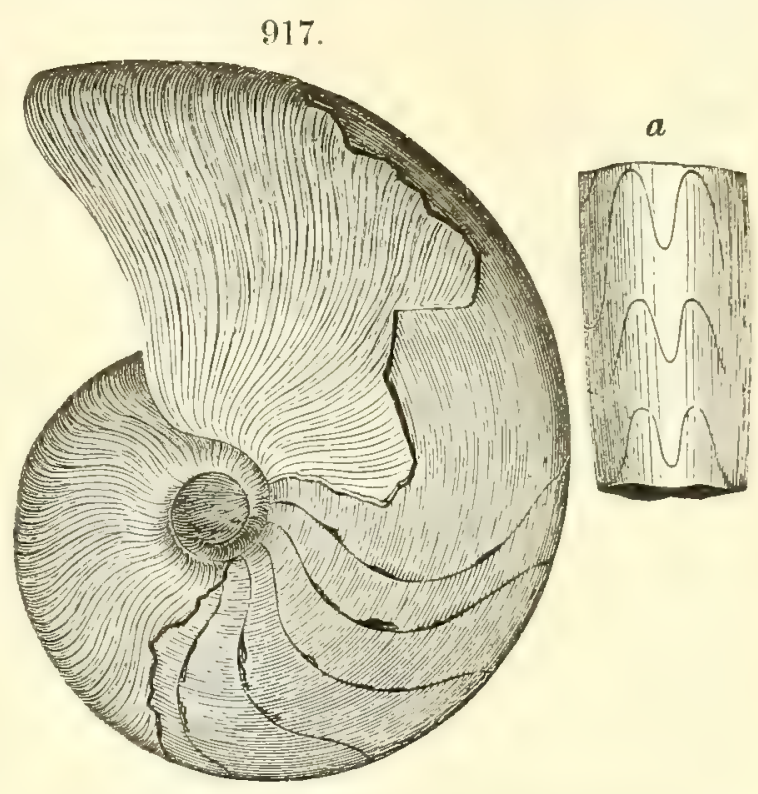

Cephalopod. - Figs. 917, $\boldsymbol{a}$, Goniatites Vanuxemi. Meek.

6. Crustaceans. - The most characteristic species of Trilobite, Phacops rana of Green ( $=P$. bufo), is represented in Fig. 918 ; its maximum length is eight inches. The genus Dalmanites, which had nearly 25 Corniferous species, has five described from the Hamilton; the pygidium of $D$. Boothi Green is represented on page 587, and that of the variety calliteles, in Fig. 919. Other genera are Homalonotus (which has a species 15 inches long), Proetus, and Acidaspis. Fig. 880 (page 587) is the pygidium of $A$. Romingeri. There is also a species of the European genus Bronteus, B. Tullius H., found in the Tully limestone. Out of all the genera of Trilobites existing during the Hamilton and earlier geological time, only Phacops and Cyphaspis have species reported from the later Devonian. Others no doubt existed; but still the decline of what was once the leading life of the seas is strongly manifested. The dash for ornamentation in the early and middle Devonian was a mark of luxuriant, rather than natural progress, and the same appears in the size of many of the species.

$918-919$.

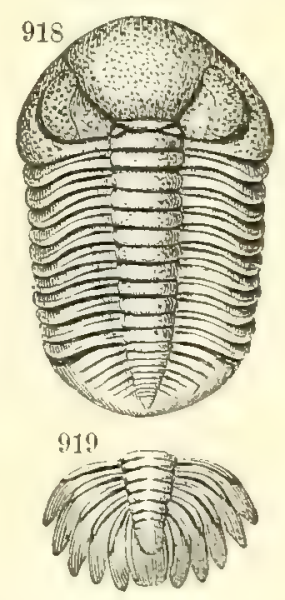

Fig. 918, Phacops rana: 919, pygidium of Dalmanites calliteles $\left(\times \frac{1}{2}\right)$. Meek.

Phyllopods, of the Ceratiocarid type, are of several kinds. Fig. 920 represents an Echinocaris, one specimen of which, figured by Hall, from 
near Canandaigua Lake, is eight inches long. Another kind, Mesothyra Neptuni H., differed little from the Portage species, M. Oceani, figured

920.

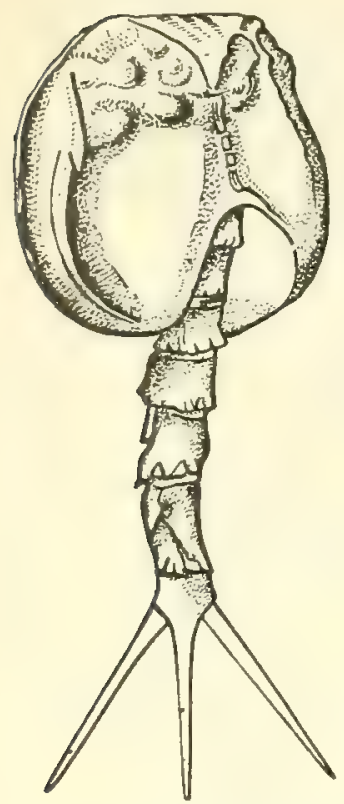

Fig. 920, Echinocaris punctata; 921, $921 a$, Turrilepas Devonicus. Fig. 920, Beecher; 921, Clarke.
921.

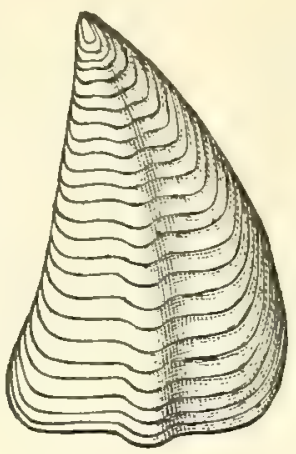

$921 a$.

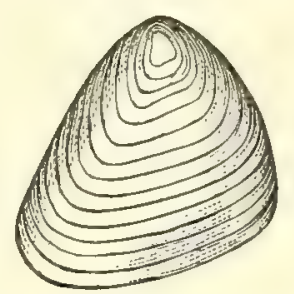
on page 615, and was probably nearly a foot long, independent of the tail spines, which add five and a half inches.

There were also Ostracoid Crustaceans of several genera, and among them the oldest known of Estheriæ -E. pulex of Clarke. The Barnacle tribe of Crustaceans also had its species. Fig. 922 represents a true sessile barnacle of the Hamilton, Protobalanus Hamiltonensis Whitfield, and Fig. 921 two plates of the pedunculate Barnacles of the Lepas family, named Turrilepas Devonicus by Clarke.

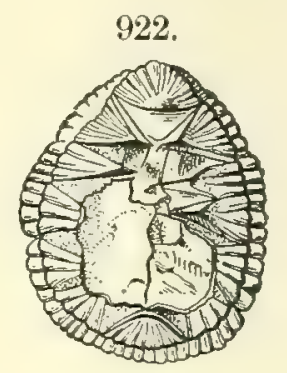

Fig. 922, Protobalanus Hamiltonensis. Whitfield.

7. Insects. - Remains of Insects have been found at St. John, New Brunswick. They are related to the Ephemerce or Mayflies; and one of these is represented in Fig. 923-the Platephemera antiqua of Scudder-species whose larves live in the water, and which frequent moist places, and therefore stood a good chance of becoming preserved as fossils. It was a gigantic species, measuring five inches in spread of wings.

929.

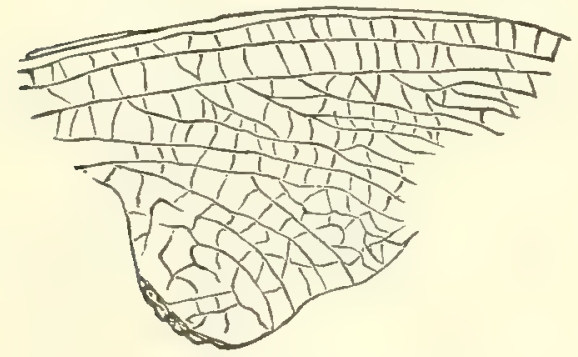

924

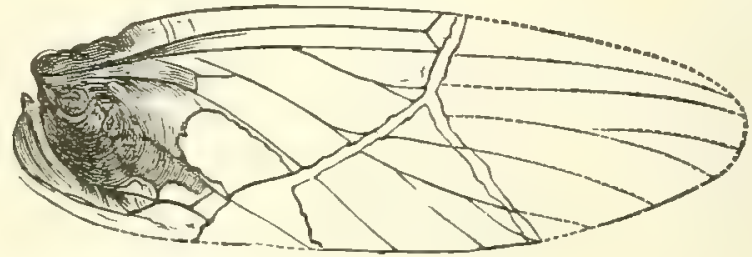

Fig. 928, Platephemera antiqua; 924, Xenoneura antiquorum. Scudder.

Several other species of Insects have been described from the same locality. One of them, the Xenoneura antiquorum of Scudder (Fig. 924), while related to the Ephemerids, under the Neuropters, has some characters of the Orthopters, one of which is the possession, according to Scudder, of what appears to be a stridulating organ on the surface of the wing near its base (see the figure), an organ for making their shrill sounds by friction. 
Dawson thereupon observes that " the trill and hum of insect life must have enlivened the solitudes of the strange old Devonian forests." Insects appear to have been the only winged life of the Devonian and Carboniferous ages.

8. Vertebrates. - Remains of Fishes occur sparingly in the Hamilton beds, while abundant in the overlying Genesee and Portage beds. Those observed are the plates or fragments of jaws of Placoderms, or teeth or fin-spines of Selachians. One of the large fin-spines, from the Hamilton beds of Yates County, N.Y., called Ctenacanthus Wrighti by Newberry, is nine inches long and an inch and a half in diameter at base.

\section{Characteristic Species.}

Plants. - The seaweed, Spirophyton, occurs in the Hamilton and through the later Deronian. Fig. 894, of Lepidodendron primcevum Rogers, shows only the inner surface of the bark, and not the true surface scars. Fig. 896 is one of a group of leaves of Cordaites Robbii, figured by Dawson; and Figs. 897, 898, from Dawson, are portions only of his figures. For J. M. Clarke's papers on Sporangites, see Am. Jour. Sc., xxix., 1885.

Anmals. 1. Spongiozoans. - Sphorospongia tesselata (Fig. 902) is associated with Terebratula (Eunella) Sullivanti Hall, of the Corniferous, Spivifer fimbriatus Con., Pentanerus comis, Atrypa reticularis, Nucula lirata Hall, of the Hamilton shales, Paracyclas elliptica Hall, of the Corniferous and Hamilton, Goniophora perangulata Hall, of the Schoharie grit, etc.; also, the following European species, not known from the United States, Murchisonia turbinata, Euomphalus annulatus, Stringocephalus Burtini, Loxonema priscum, Macrochilina subcostata, etc. The Stringocephalus is characteristic of the "Stringocephalus zone" of the Middle Devonian of Europe. The Devonian fossils of Manitoba, according to Whiteaves, have close relation to those of Europe, while many differ in species from those of the United States.

2. Actinozoans. - Fig. 903, Heliophyllum Halli E.\& H., N.Y., H. obconicum H., H. confluens H., Cyathophyllum robustum H., C. nanum H., C. conatum H.; Zaphrentis Halli E. \& H., Z. simplex H., Cystiphyllum varians H., C. Americanum E.\& H., C. conifollis H., Amplexus Hamiltonice H.; Michelinia stylopora Eaton, Favosites placenta Rominger, $F$. arbuscula H., $F$. Hamiltonice, $F$. Argus, all from a "coral-reef" area of the N.Y. Lower Hamilton, near Canandaigua, N.Y. (Clarke), and nearly equally abundant to the westward in New York and Ontario.

3. Echinoderms. - The forms, described under the generic name, Heteroschisma, by Wachsmuth, from Iowa, show a relation between Codaster and Pentremites ( $I l l$. G. Rep., vii., 1883).

4. Molluscoids. - Large numbers of Bryozoans are described in Hall's vol. vi., of the N. Y. Geological Survey.

Brachiopods.-Fig. 904, Atrypa aspera Schloth, also European; 905, A. reticularis, larger than the same in the Corniferous, and fuller, sometimes nearly 2 inches broad; 906, Tropidoleptus carinatus H., New York, Mllinois, Iowa, Europe; 907, Spirifer mucronatus Con., very common; 908, Athyris spiriferoides Eaton; 909, Ambocolia umbonata, N.Y. and the West ; 910, Chonetes setigerus H., in the Marcellus and Genesee shales, and also the Chemung; 911, Productella subalata H., Rock Island, Hl. ; Spirifer granuliferus $\mathrm{H}$., a large species, having a granulated surface.

The Rhynchonella cuboides is characteristic of the Tully limestone; and as beds containing this species and others associated with it in England and Europe are referred to the base of the Upper Devonian, the "Frasnian stage," the limestone, according to H. S. Williams, ought to be arranged with the Upper Devonian in New York, etc. He 
observes that the facts from the Devonian of Manitoba and Mackenzie rivers described by Whiteaves confirm this view.

5. Mollusks.- (a) Lamellibranchs. - Fig. 912, Orthonota undulata Con.; 913, Pterinea Aabella Con.; 914, Grammysia bisulcata Con. (Hamiltonensis of Verneuil), also European, in the Eifel; 915, Microdon bellistriatus Con. Of the genera of Lamellibranchs represented, Grammysia has 15 species (all in the Hamilton), Modiomorpha 9 (all Ham., 1 also Mare.), Aviculopecten 15, one, A. princeps, occurring in New York, Ontario, Kentucky, and Indiana. Nucula 9 (all Ham.), Leda 4 (all Ham.), Paracyclas (Lucina) 4, Schizodus 3, Solemya 1, Orthonota 4 (all Ham.), Lunulicardium 5 (all Marc., and 2 continuing into the Hamilton).

(b) Gastropods. - Of the 10 species of Platyceras, $P$. conicum, $P$. erectum, $P$. carinatum, $P$. thetis, $P$. symmetricum and $P$. rectum come up from the Corniferous. There are a dozen species of Bellerophon, several of them like B. patulus, large and beautiful, much exceeding, in both respects, any of the Silurian species.

(c) Pteropods and Cephalopods. - For figures and descriptions of many species, see Hall, vol. v. ; also publications of Meek and Worthen, Whitfield, Beecher, Billings, and others. Among the species are Orthoceras crotalum H. (Spyroceras of Hyatt); Gomphoceras oviforme H. (Acleistoceras Hyatt); Gyroceras transversum H. (Rutoceras Hyatt); Nautilus buccinum H. (Nephriticeras Hyatt, a type having many Hamilton species); Goniatites (Discites) Marcellensis Van. (Centroceras Hyatt); Goniatites discoideus H. (Parodiceras Hyatt).

6. Crustaceans. - For figures of the Hamilton (and other Devonian) species of these tribes, see Hall, N.Y. Pal., vol. vii. ; Beecher, Rep. Geol. Pa., vol. PPP, 1884 ; Packard, Monogruph on N. A. Phyllop., 1883; Whitfield, Am. Jour. Sc., xix., 1880; and J. M. Clarke, Am. Jour. Sc., xxiii., 1882 ; and $i b .$, xxiv., 1882 (on Turrilepas). Dithyrocaris Belli Woodw. (Geol. Mag., 1871) is from Gaspé.

Some of the characteristic Marcellus fossils are: Productella truncata H., Orbiculoidea minuta H., Leiorhynchus limitare H., Chonetes mucronatus H., Leiopteria lovis H., Pleurotomaria virgulata $\mathrm{H}$., Styliolina fissurella $\mathrm{H}$. , Orthoceras subulatum $\mathrm{H}$.

The Iowa Hamilton has afforded species of Megistocrinus, Taxocrinus, Synbathocrinus, Pentremites; Orthis suborbicularis H., O. Vanuxemi H., O. Iowensis, O. incequalis, O. prava, Stropheodonta arcuata H., S. nacrea H., S. reversa H., S. demissa, S. perplana, Productus dissimilis H., Productella pyxidata H., P. subalata H., Productus Shumardianus H., Spirifer Hungerfordi, S. Whitneyi H., S. fimbriatus Con., S. bimesiaTis H., S. asper H., S. Parryanus H., S. pennatus Owen, S. Marionensis Shumard, Cyrtina umbonata H., C. triquetra H., Gypidula occidentalis H., Atrypa aspera, A. reticularis, Euomphalus cyclostomus $\mathrm{H}$.

\section{Chemung Period, or Later Devonian. ROCKS-KINDS AND DISTRIBUTION.}

The Chemung Period includes (1) the Portage epoch, represented by the Genesee shale below, and the true Portage group above; and (2) the Chemung epoch. The Catskill group, which has usually been made to represent a third epoch, is mainly, as stated on page 576, the sea-border part of the Upper Devonian.

The Genesee shale, at the base of the Portage, is black and bituminous, like the Marcellus shale, and rather sparingly fossiliferous. It is 100 to 150 feet thick in central New York, along Cayuga Lake, where it overlies 
the Tully limestone, and 25 feet on Lake Erie, and 200 to 300 in west central Pennsylvania. Along one or two levels there are great numbers of large and small calcareous concretions which are often septate (page 97), so as to make the concretions look a little like the backs of turtles. In western New York a layer of bituminous limestone, six inches to two feet thick, occurs near the middle, which is mostly made up of shells of a Pteropod, the Styliolina fissurella Hall (Fig. 916), and is called the Styliolina limestone. With it occur remains of fossil fishes, Dinichthys, Palconiscus, and other species.

The Portage group, of New York (so named from the village of Portage, Livingston County, N.Y.), outcrops along a wide belt extending eastward from the south shore of Lake Erie. It is well displayed about the south end of Cayuga and Seneca lakes. Its beds are shales and flags, or shaly sandstones, - the Naples group, - and, above these, the Portage sandstone, which has relations to the Chemung. The rocks have a thickness of 1000 feet on the Genesee River, and 1300 to 1400 near Lake Erie. The rocks are in general very sparingly fossiliferous. They abound in ripple-marks and mud-cracks, and the sandstones are often cross-bedded. But a portion in central New York, called the Ithaca group, - prominently displayed on the Cascadilla and Fall creeks, near Ithaca, - abounds in fossils. According to H. S. Williams, the fossils, which are largely Brachiopods, have near relations to those of the Chemung group, and also about as close to Hamilton species; and as they are overlaid by 500 or 600 feet of sandstones, mostly barren, but containing some Portage species, they are referred to the Portage group. They are the only part of the beds that give much knowledge of the life of the period; and this is imperfect, as Trilobites, Corals, Crinoids, and other species of purer waters, are absent.

In eastern central New York, in Delaware, Otsego, and Chemung counties, there is a sandstone formation, the Oneonta sandstone of Vanuxem, which resembles the Catskill beds; but it is overlaid by beds containing Portage fossils; and in some places, Chemung species. It indicates the existence, at these localities, of Catskill conditions during the Portage and Chemung epochs, if not also during part of the Hamilton period. (H. S. Williams.) On the distribution of the Oneonta beds, see Darton, Am. Jour. Sc., 1893.

In central and western Pennsylvania the limit between the Portage and Chemung is not clearly ascertained. The thickness of the two in Monroe County, eastern Pennsylvania, is about 2500 feet; Fulton County, south central Pennsylvania, about 3600 feet, of which 400 are referred to the Portage. Along the south shore of Lake Erie, the lower part of the "Ohio shales" is referred to the Portage, and the rest to the Chemung. Near Cleveland, O., the thickness of the "Ohio shales" is about 1350 feet, and farther west, at Elyria, 950; but at Wellsville on the Ohio, 2600 feet.

The Chemung beds in New York are a continuation of the Portage, with little change in the rocks, except that they are slightly more arenaceous, and of a lighter color, but with a great change in the abundance of fossils and 
in their kinds. They cover a large part of southern and western New York. The layers bear the same evidences of shallow waters as the Portage, and are often cross-bedded from the sweep of the currents of probably the tidal ebb and flow. The thickness south of Cayuga Lake is stated at 1500 feet, and in Chautauqua County, bordering Lake Erie, 950 feet. At Panama, in this county, about a dozen miles from the western border of New York, the Chemung rock is a hard, quartzose "flat-pebble" conglomerate, its pebbles, which are mostly of quartz, being commonly flat. The rock near Panama stands up in bold bluffs and walls, with intersecting passages and isolated towers, making the place one of the so-called "Rock-cities" of western New York. The conglomerate is 200 to 300 feet below the top of the fossiliferous Chemung of that region. The rocks dip southward gently, and in the northwestern counties of Pennsylvania are succeeded by the shales and sandstones of the Waverly group containing a different fauna.

The thickness of the group is greater over northern and central Pennsylvania, along the Appalachian area, becoming 2000 to 8000 feet; but, like the Portage, it diminishes rapidly westward, where it passes outside of this area.

The Upper Devonian is represented over the larger part of the Central Continental Interior by a "Black shale," a stratum 10 to 200 feet thick, carbonaceous, but not always black. At Burlington, Iowa, it includes some limestone. It indicates nearly uniform conditions of level over a great extent of surface, but with variations only between salt or brackish and fresh waters. Its fossils are mainly small Brachiopods, Ceratiocarids, and Fishes.

The Catskill group - so named from the Catskill Mountains of eastern New York - consists of sandstones, often passing into conglomerates, with some shale. The beds are usually red, but occur also of greenish and other shades. They are rarely fossiliferous; and the few animal fossils found are those of Fishes, Eurypterids, and some fresh-water Lamellibranchs. A prevailing red color, and no marine fossils, are its accepted characteristics; but these are poor criteria for separation chronologically from the Chemung. Hall was the first to show that they were in part Chemung. H. S. Williams has recently referred the whole to the Upper and Middle Devonian, and speaks thus of its relation in position over the state of New York to the rocks of these periods: "In the Genesee section in western New York, the whole of Devonian time is recorded without any trace of the Catskill formation; it is neither above, below, nor within the Chemung. One hundred miles eastward, the section running through Cayuga Lake shows at the close of the Devonian, after the cessation of the Chemung fauna, a Catskill formation several hundred feet thick. Another hundred miles eastward, across Otsego County, the section contains (1) rocks of the Catskill formation for the upper third of the Upper Devonian; below these (2) a sparsely fossiliferous zone of Chemung - probably its lower part, and (3) a modified Ithaca fauna; then (4) the Oneonta formation, which is but a detached zone of the Catskill; next (5) a fauna intermediate between that of the Ithaca and the typical Hamilton, underlaid by (6) the Hamilton formation of the 
Middle Devonian. Still farther east, along the Hudson River valley, the Catskill formation occupies the whole of the Upper Devonian interval." The beds show that the region of their depositions was invaded here and there at times by fresh waters from the bordering hills.

In the Catskill Mountain region the Catskill rocks are to a large extent the summit rocks and have a thickness there of 3000 feet. Marking them, as is usual, by their coarse sandstone character and red color, they extend southwestward into Pennsylvania, along the course of the Appalachian trough, from Port Jervis, N.Y., to Fulton County, and have a reported thickness, in this part of the state, of 4500 to 7000 feet; 3430 at Port Jervis, 4000 to 5300 in Monroe County, Pa., 7544 near Mauch Chunk, 6000 in Perry County, and 3900 in Fulton County. In Fulton County, Chemung fossils have been observed in the so-called Catskill beds by J. J. Stevenson, through the lower 900 feet, reducing the thickness of the so-called Catskills at that point to 3000 feet. West of the above-mentioned line, the reported thickness diminishes; in southwestern Bedford County, it being but 2000 feet, and only a few feet in western Somerset County.

Eastern New York and Pennsylvania continued to be for a long time a seaborder region, undergoing the subsidence required for thousands of feet of seashore deposits, because here lay the border of the Appalachian geosyncline.

The Portage group was early called the Nunda group, from this early name of the village of Portage, situated on the banks of the Genesee River, where the beds occur. The Genesee shale is finely displayed at the opening of the gorge of the Genesee at Mount Morris; and it also forms high cliffs above the Tully limestone along the borders of Cayuga and Seneca lakes. The concretions occurring in the rocks sometimes contain mineral oil, and a soft substance looking like spermaceti. The region of the Portage beds in New York is famous for its waterfalls.

On the Genesee River, the group includes, above the Genesee shale, (1) the Cashaqua shale, and the Gardeau shale and sandstones, the Naples beds of J. M. Clarke; and (2) the Portage sandstones. The Portage beds of western Pennsylvania are so deeply buried that their thickness is unknown; the drillings for oil do not reach down to them.

The Ithaca group abounds in ripple-marks, mud-cracks, calcareous concretions, and cone-in-cone forms. It is referred by Hall to the Chemung series.

Prosser has deduced from the many drillings in western New York, and the observations of Hall, H. S. Williams, and others, the following section for the region not far west of the Genesee River, near Rochester:-

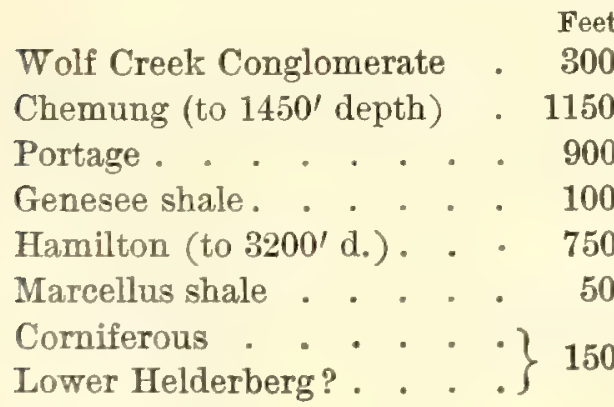

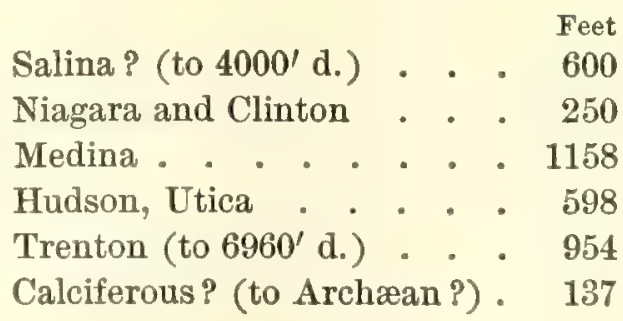

In Pennsylvania, in Perry County, the Chemung is $3300^{\prime}$ thick, and the Catskill $6000^{\prime}$ (Claypole); but the latter contains in its lower third some Chemung fossils. In Columbia 
County, where the Catskill is made $4500^{\prime}$ thick, $2300^{\prime}$ to $2443^{\prime}$ are referred to the Chemung and Portage (I. C. White). Above lies a transition Catskill-Chemung group of 1000', regarded as transitional because they are so in color, and contain some Chemung fossils; and to the west, the true Catskill group wholly disappears; that is, the rocks have nothing of the Catskill characteristics.

In Prosser's section in Monroe County, Pa., referred to on page 594, he found the beds to correspond to the Portage, Oneonta, and Chemung, through a thickness of $3050^{\prime}$, and to include the Chemung beds of White, and the overlying Starucca sandstone, $600^{\prime}$, New Milford shales, $100^{\prime}$, and the Delaware flags, 1200'. Above come the Montrose shales and the so-called Catskill beds, the last consisting of the Honesdale sandstone, the Cherry Ridge group, 325', the Elk Mountain sandstone and shale, 200', and the Mount Pleasant, $1150^{\prime}$, Red shale, $300^{\prime}$; about $2000^{\prime}$ in all.

The "Black shale" of the Central Interior occurs in Indiana, at the Falls of the Ohio, with Genesee shale fossils at its base; in Kentucky, $200^{\prime}$ thick in the northeast part, and diminishing southwestward. In Illinois it is $40^{\prime}$ to $60^{\prime}$ thick, the thickest along the Ohio; it contains a Genesee Lingula. In Tennessee, through much of the state, it is $100^{\prime}$ thick and less. Owing to denudation, it is not found in central Tennessee. In Arkansas and Missouri, its equivalent, the Eureka shale, is $0^{\prime}$ to $50^{\prime}$ thick.

In Ohio, the Ohio shales include the Cleveland shale, Erie shale, and Huron shale of Newberry; a belt of it, 10 to 20 miles wide, and several hundred feet thick, stretches across Ohio from Lake Erie to the Ohio Valley, and is noted for its calcareous and ferruginous concretions; the lower part corresponds to the Huron shale, and the upper beds to the Cleveland shale. At its base, or directly below. it, Hamilton fossils have been found; but above, a few Portage and Chemung species. The Cleveland shale has afforded many remains of Fishes. The Perry sandstones of southern New Brunswick are mentioned on page 594 .

The yellow sandstone at Pine Cove, Muscatine County, Iowa, and the Rockford shale belong near the base of the Chemung.

In a paper by Darton (1893) it is proposed to adopt the name Catskill for the period including the Chemung and Portage. But, as has been shown, it has not the fossils that would entitle it to such a position. In fact, the name Catskill has no right to a place in the time series. Its introduction was from the first an error.

In the Arctic regions, on the eastern part of the north coast of Grinnell Land, at Dana Bay, occurs an area of rocks containing Productus mesolobus or costatus, a Spirifer, etc., which are referred by the authors to Devonian (Feilden \& De Rance, Q. J. G. S., Exxiv.; 1878); but these fossils are Carboniferous.

An interesting excursion in eastern New York, for the study of the Devonian series, may be had by going to Catskill Village, and passing westward over the hills at the base of the Catskill Mountains. Over the Hudson River slates lies the water-lime of the Middle Upper Silurian; then the successive subdivisions of the Lower Helderberg. Beyond lies the Corniferous limestone of the Lower Devonian; then the Marcellus shale and Hamilton sandstones. Moreover, the flexures of the rocks are instructive. See W. M. Davis on the Little Mountains, Appalachic, 1882, page 20.

Rondout, N.Y., on the Hudson River, affords a section from the Hudson beds to the Corniferous inclusive, part quite fossiliferous, and the line of a great fault above the Hudson beds, and is another good place for the geological student. See W. M. Davis, Am. Jour. Sc., 1883, vol. xxvi.

The Devonian series of the Pahranagat Range, central Nevada, is $3000^{\prime}$ thick, and is fossiliferous. It rests on the Silurian. For notes on the Upper Devonian of the Eureka district, see pages 589,592 .

Mineral oil and gas. - The upper part of the Upper Devonian is the chief source of the mineral oil and gas of Pennsylvania. The drillings 
descend to a coarse oil-yielding porous sandstone called an oil-sand; and on reaching it, the oil, if the well is successful, usually rises to, or above, the surface; or if a gas well, the gas comes ont with great force. The number of different oil-sands in a region is one to three; they are confined to about 300 feet in thickness of the beds, and each is 20 to 60 feet, or more, thick. The productive counties lie in a belt, nearly northeastward in course, from Greene County, in the southwest part of the state, to McKean County, on the northern border; and they pass this border into Alleghany County, N.Y., and also on the south, into Monongalia County, W.Va. See map, page 731. In the counties from Warren to Washington the oil-sands are within 400 feet of the summit of the Devonian; in the part of the belt more to the northeast, in McKean County, and in New York, they are in its lower part, or between 1200 and 1800 feet of the summit. The latter is a high region, the surface 1800 to 2600 feet above the sea level. The wells often let up much salt water from different levels. Frequently water rises with the oil or gas, making the well valueless unless tubing to the bottom will exclude the water.

The oil-sands are coarse, open-textured sandstones - so open in texture that they are able to hold a vast amount of oil in the spaces between the grains. All the oil-bearing regions are also gas-producing; but the well is available for gas only when the latter comes to the surface free from oil as well as water. Moreover, the gas is abundant, according to I. C. White, only where the rocks passed through in the drilling lie in a low anticline. The open-textured sandstones are possibly sandstones that have lost the finer material between the grains by percolating waters. As some of the Chemung beds are more or less calcareous, they may originally have been calcareous sand-beds, and have become porous by the removal of the calcareous part; but this is only conjecture.

The oil is usually projected in jets, and the power has been shown to be Artesian, or hydrostatic, by I. C. White, in agreement with Orton's view for the Trenton limestone gas of Ohio and Indiana. A well near Kane, in McKean County, Pa., drilled to a depth of 2000 feet, in 1878, but abandoned because of the small yield of oil, became afterward a water-and-gas geyser, gas and not steam being the moving agent. Fig. 925 is from a photograph received in 1879 by the author from C. A. Ashburner, accompanying a description by him of the geyser. The well at that time threw up a column of water and gas, at intervals of 10 to 15 minutes, to heights varying from 100 to 150 feet. On August $2 d$ four successive jets had heights of 108, 132,120 , and 138 feet. When the gas of the columns was lighted at night, "the antagonistic elements of fire and water were promiscuously blended, at one moment the flame being almost extinguished, but only to burst forth the next instant with increased energy and greater brilliancy." Mr. Ashburner explains the action thus: "The water flows into the well on top of the gas until the pressure of the confined gas becomes greater than the weight of the superincumbent water, when an explosion takes place, and a column of water and gas is thrown to a great height." The gas comes 
from the deep-seated rock that has yielded also the oil, and some higher temperature than that of the surface was needed for its production. At a depth

925

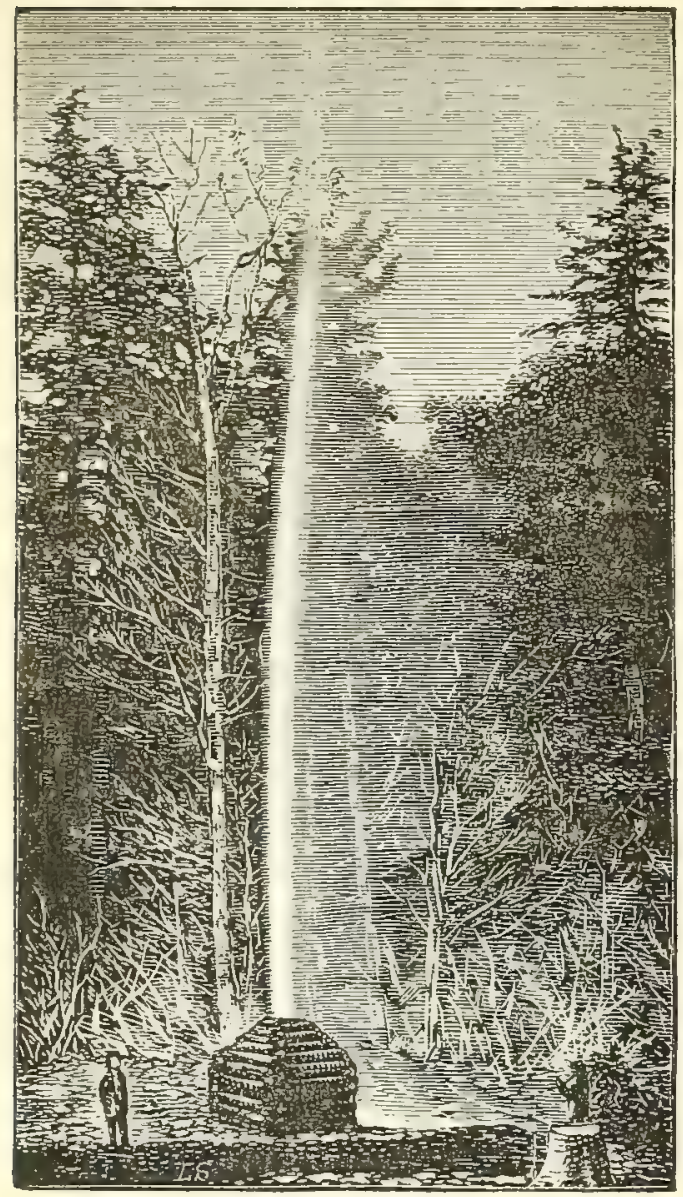

Water-and-gas geyser.

of 1415 feet in the drilling a very heavy "gas vein" was struck, and this was the chief source of the gas. Ashburner remarks further that several other wells in the oil-regions have had similar geysers ; and as early as 1833, in the valley of the Ohio, a salt well threw jets of water and gas, at intervals of 10 to 12 hours, to heights of 50 to 100 feet.

The original source of the oil is supposed, by most writers on the subject, to have been a Devonian shale, like the Genesee or Marcellus, below the level of the Chemung beds, from which it was evolved by a slow process of distillation. The conditions necessary for oil, on this view, are (1) a primary source of the oil; (2) strata to receive and hold it; and (3) overlying deposits to prevent its escape to the surface and consequent dissipation. These three conditions are fulfilled by (1) a deepseated carbonaceous rock containing abundant organic remains; (2) an overlying porous stratum; and (3) superincumbent shales, slates, etc. These statements also apply to gas production. Slight subterranean movements attending the making of the Appalachian Mountains to the east and southeast would have produced some heat, and so have caused oil to escape from the shales; and the vaporized oils would have risen until they were somewhere condensed - either in confined places in or among the rocks, or still higher in the open air (Peckham, 1884). I. C. White regards the source as organic materials within the sand-beds.

The oil wells of western Pennsylvania yielded, in 1891, 31,793,477 barrels of the crude oil, or petroleum. Of this, 5,452,418 barrels were from the Bradford district, McKean County, and 10,317,258 from Alleghany County, the county of which Pittsburg is the capital. In the same year, the yield of Alleghany County, N.Y., adjoining the northern end of the Pennsylvania belt, was 1,121,574 barrels; and that of West Virginia, adjoining the southern end, 2,406,218 barrels. The total yield of the United States in 1891 was $54,291,980$ barrels. Ohio produced 17,740,307 barrels, making the yield for Pennsylvania and Ohio together $49,533,784$ barrels. But the oil of Ohio was nearly all from the Lower Silurian Trenton limestone - this formation affording $17,316,000$ barrels; the Berea grit, which is referred to the Subcarboniferous, supplied only a few hundred thousand barrels. 
A barrel equals 42 gallons. The yield of Pennsylvania in 1859 was 2000 barrels; in 1860 , 500,000 barrels; in $1870,5,260,234$ barrels; in 1880 , over $26,000,000$ barrels. In 1892 , the yield was over $4,000,000$ barrels less than in 1891.

For a report on the oil and gas regions of Pennsylvania, with maps, see Rep. I 5, of the Penn. Geol. Surv., by John F. Carll, 1890 ; and for Ohio, Rep. vol, vi., on Economic Geology, by E. Orton, 1888 ; and for Kentucky, Rep. by E. Orton, 1891 ; and for Statistics, Mineral Resources of the U. S., by D. T. Day, 8vo.; U.S.G.S., volumes for 1891 and 1892, issued in1893.

926-930.

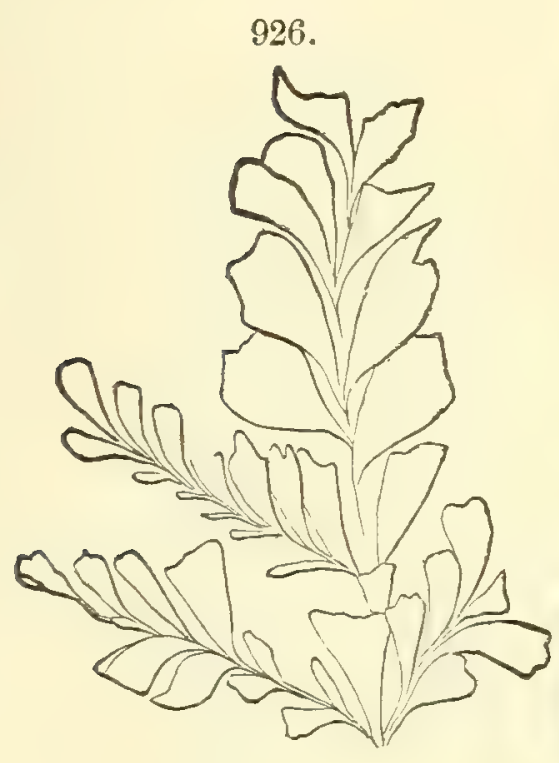

929.

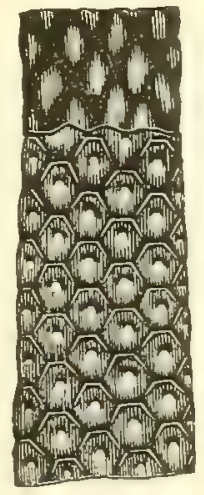

930.

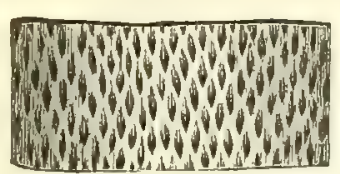

928.
927.

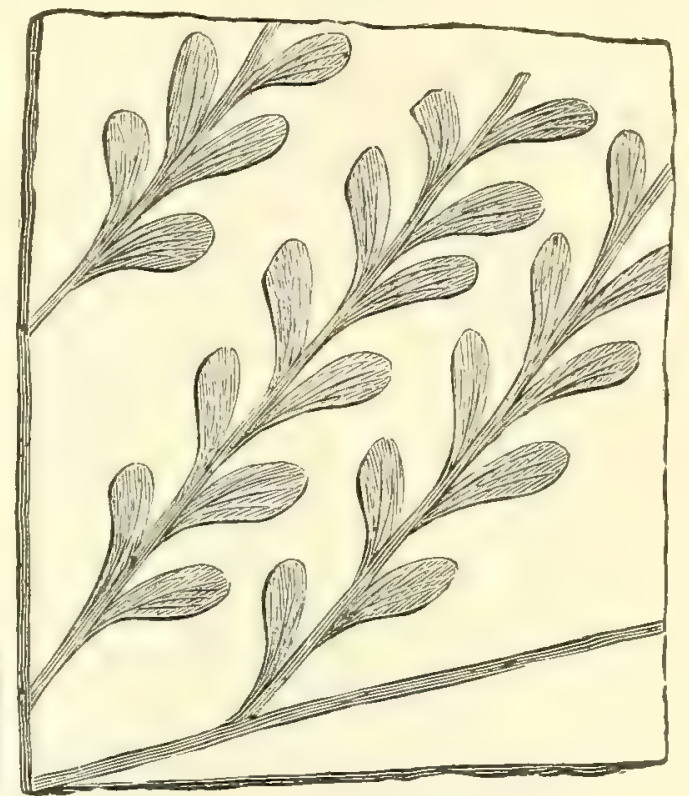

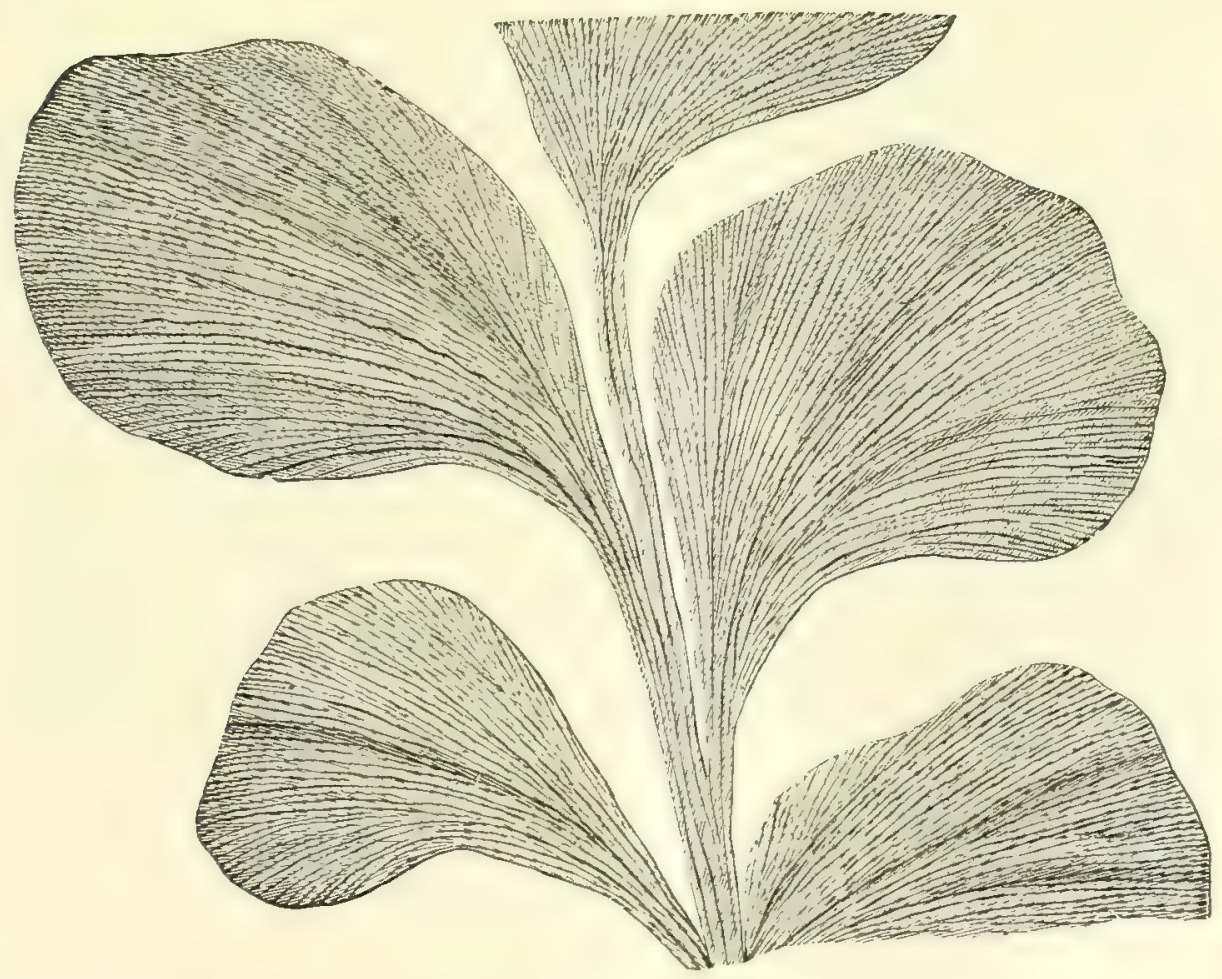

Fig. 926, Archæopteris Halliana ; 927, A. minor ; 928, Aneimites obtusus; 929, Sigillaria Vanuxemi ; 930, Lepidodendron Chemungense. Figs. 926, 930, Hall; 927, 928, Lesquereux; 929, Vanuxem.

DANA'S MANUAL - 39 
LIFE.

Plants. - In the Portage the remains of land plants are rare. There are stems of species of Lepidodendron-L. Chemungense and L.primcevum; of Lycopodites and Knorvia; of Cyclostigma-C. affine Dn.; of Calamites Bornia inornata Dn.; of Tree-ferns, Asterochlona (Asteropteris) Noveboracensis Dn., from Milo, N.Y.; and woods of Gymnosperms, as Cordaites (formerly Dadoxylon) Clarki Dn. Sporangites (S. Huronensis) occur in the more bituminous portions of the Genesee shale.

931.

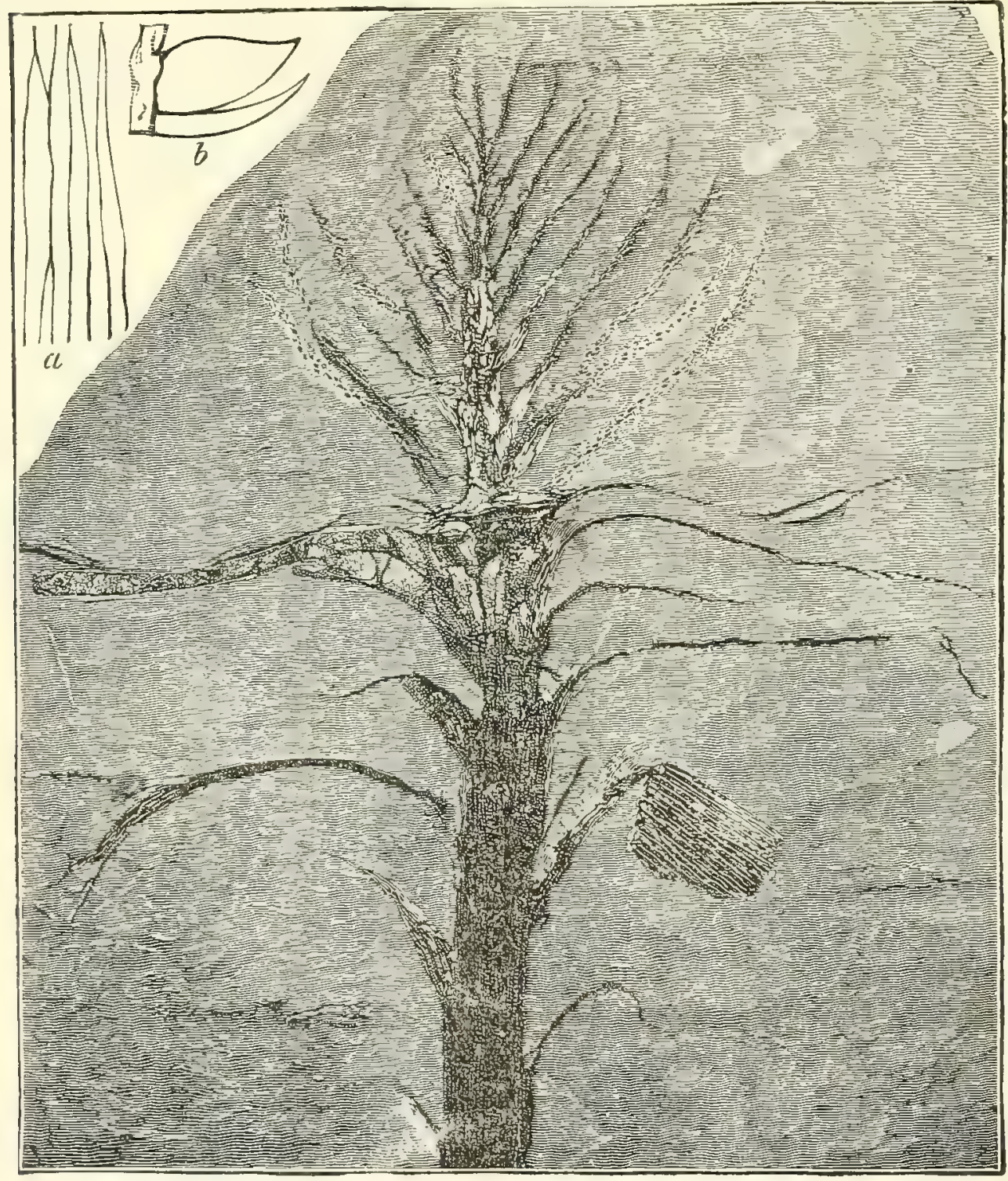

Dictyo-cordaites Lacoei, Dawson (1): $a$, venation of leaf; $b$, fruit enlarged. Dawson, '89.

The Chemung land plants discovered melude those of the Portage and others. Some of them are represented on page 609. Figs. 926, 927, 928 show portions of plants from the Chemung of Gilboa, N.Y.; 928, from the Catskill beds of Montrose, Pa.; 929, from Pottsville, Pa., and Franklin, N.Y. The 
Pottsville specimen of Aneimites obtusus Lx. (Fig. 928) was over a foot across. A Tree-fern also, Caulopteris Lockwoodi Dn., has been obtained at Gilboa. Fig. 929 represents a Sigillaria from the Chemung of Owego, N.Y., and 930, a Lepidodendron from Elmira, N.Y., the latter with very small leaf-scars. In the specimen of Fig. 929, the upper part shows the scars as they appear on the inner surface of the bark. Specimens of L. Gaspianum, of the Lower Devonian, and some other species, have also been found in the Chemung beds of New York; and L. corrugatum of Dawson in the Chemung of Ohio, and also at the base of the Carboniferous near Pottsville, Pa., and in Virginia. The Gaspé species accompanying the Pterichthys Canadensis, and indicating thereby that the beds are Upper Devonian (Dawson), are Archcoopteris Gaspiensis Dn., Aneimites obtusus Lesq., and Rhacophyllum Brownii Dn.

Fig. 931 represents a remarkable plant from beds in Wyoming County, $\mathrm{Pa}$, referred to the lower part of the Catskill series. Dawson regards it as belonging to the Cordaites group, under Gymnosperms. The fruit enlarged is shown at $b$.

The black shales of the Upper Devonian in New York, Canada, Ohio, and elsewhere, like those of the Lower Devonian, abound in Sporangites (page 596). The facts show that the simple plants - the Rhizocarps - were, as Dawson states, very abundant in the waters. Dawson speaks of the spores as "dispersed in countless millions of tons through the Devonian shales of Canada and the United States," and as being the source of their black color and their oil-yielding character.

Axinals. 1. Spongiozoans. - The network hexactinellid Sponge, Dictyopteyton tuberosum of Conrad, occurs in the Chemung, where there are also other species of the genus. Uphantoenia Chemungensis of Vanuxem is another peculiar glass Sponge of the Chemung, found near Owego, N.Y., first referred to the Sponges by Thitfield.

2. Corals and Crinoids. - These are not common in the Portage or Chemung group. Some calcareous beds of the Chemung have afforded Corals of the genera Zaphrentis and Heliophyllum (near H. Halli of the Hamilton); also remains of Crinoids, showing that these animals were absent from the Upper Devonian only because the conditions of the New York and the bordering seas were unfavorable; they were back when the seas were again of sufficient purity.

3. Molluscoids. - Some of the few Genesee and Portage Brachiopods are represented in Figs. 933 to 936. In the lettering underneath the cut the letters G. and P. are initials of Genesee and Portage. Besides 932. the genera represented in the figures, Chonetes and Productella are also prominent. 
Brachiopods were far more numerous in the Chemung beds than in the Portage. The figures 939 to 942 represent common species; 941, an Atrypa of ornate type, like the young of A. reticnluris; 940 , a species of Productella.

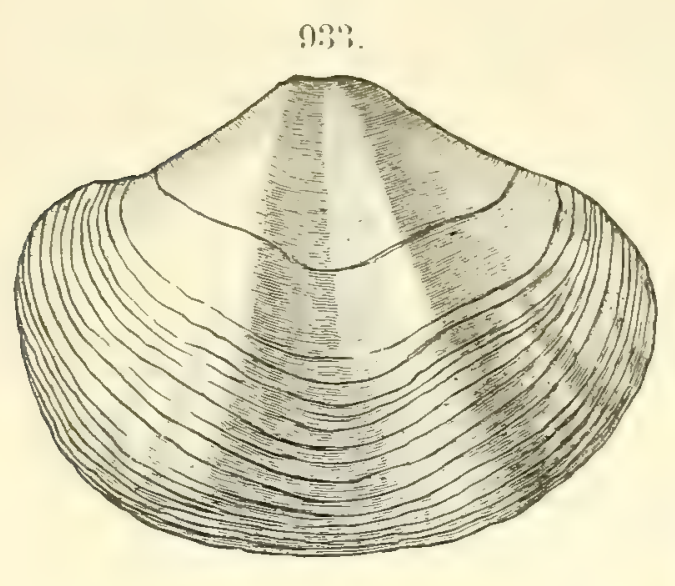

$933-938$,
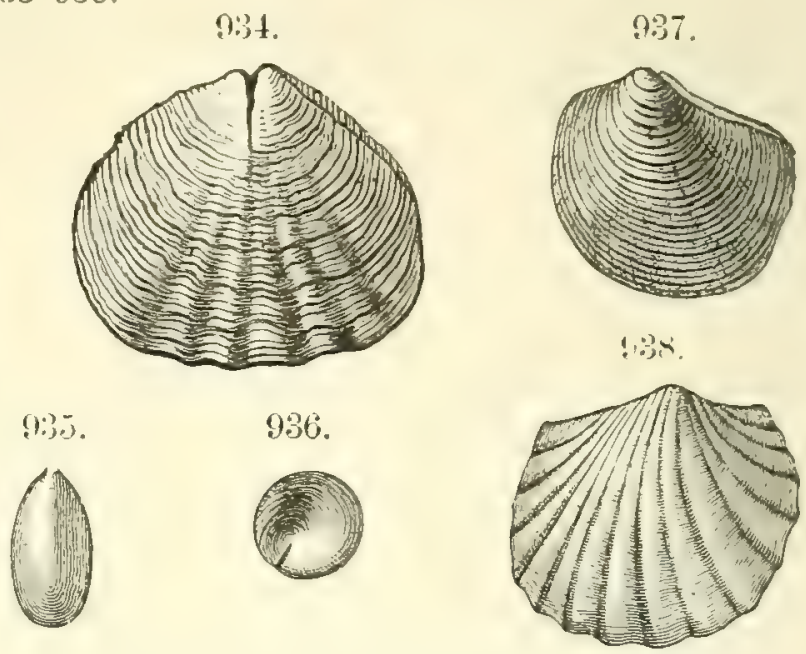

Brachopods. - Fig. 933, Spirifer lævis (P.) ; 934, Leiorhyncus quadricostatum (G.); 935, Lingula spatulata, $(\times 3)$ (G.); 936, Orbiculoidea Lodensis, $(\times 2)\left(G_{0}\right)$. Lamellibravchs. - Fig. 937, Lunulicardium fragile (G. and $P_{\circ}$ ); 938, Glyptocardia speciosa (G. and P.). Hall, except Fig. 934, King.

4. Mollusks. - Lamellibranchs were few in the Portage, but very numerous in the New York and Pennsylvania Chemung beds, outnumbering all other Mollusks. Hall describes 252 Chemung species, and only 11 from the Portage and Genesee beds, with 174 from the Hamilton. Figs. 939, 940, $943,944,945$, represent some common forms. A compressed specimen of a New York Catskill species is representel in Fig. 948. It has the form of a freshwater Unio, and the name Amnigenia, of Hall, alludes to its suspected freshwater habitat. It is from the "Oneonta sandstone" of Chenango and Otsego counties, N.I., and has been found also in the Catskill beds of Bedford County, Pa.

The "Black shale" of Ohio and the states west and south, which represents the Genesee with more or less of the Portage and Chemung beds, is remarkable for the great rarity of fossils. In Ohio the lower beds have afforded the Portage species: Chonetes scitulus, Goniatites complanatus, Coleolus acicula, Styliolina fissurella; and the upper and middle portion, the Chemung species: Leiorhynchus mesacostale, Spivifer disjunctus, S. altus; also species of Lingula and Orbiculoidea. Southern Indiana has afforded Lingula spatulata, Discina (Schizobolus) truncata, Chonetes lepidus, Leiorhynchus quadricostatum (Genesee species), L. limitare (a Marcellus sp.), Styliolina fissurella. Fossil plants also are rare; but wood of Gymnosperms, referred to Dadoxylon and Cordaites, is found in it. In most parts of the shale, Sporangites are in great abundance, $S$. Huronensis of Dawson, $\frac{1}{400}$ to $\frac{1}{100}$ inch in diameter.

Gastropods are few in both the Portage and Chemung beds. The prolific genera of the earlier Devonian, Platyceras and Platystoma, have a number 
of species. The genera having the most of the species are Loxonema, Cyclonema, and Bellerophon. Conularioe are not uneommon.

939.

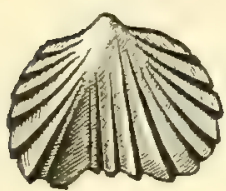

$989 a$ a.

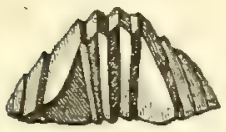

940 .

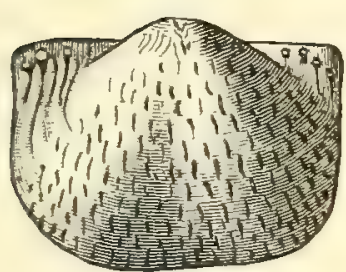

946.

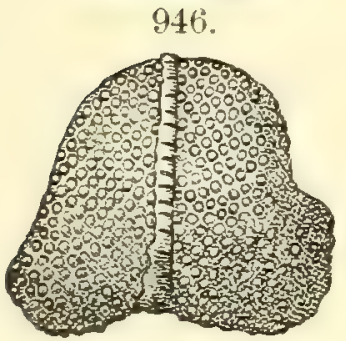

$942 a$

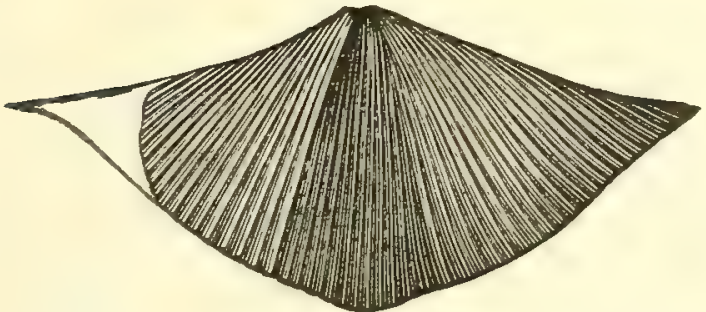

943.

$940 a$.
$939-947$
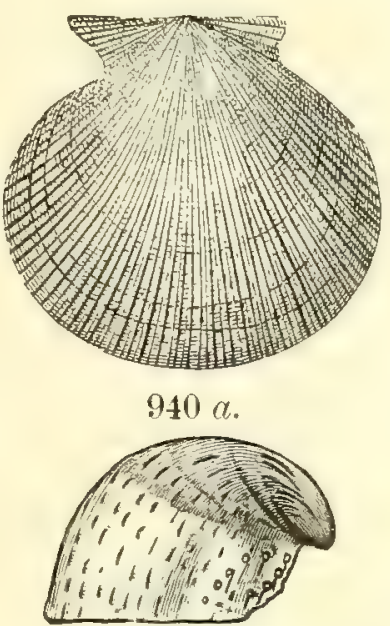

941 .

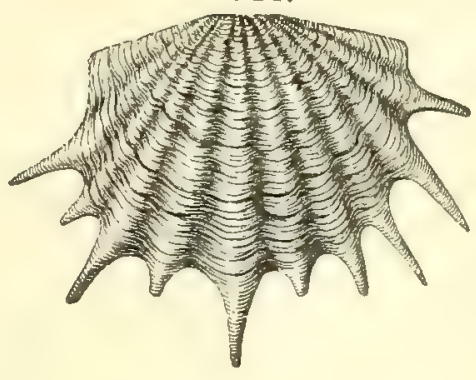

945.

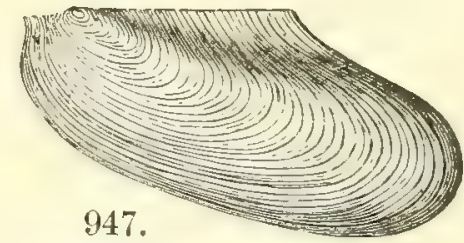

942 b.

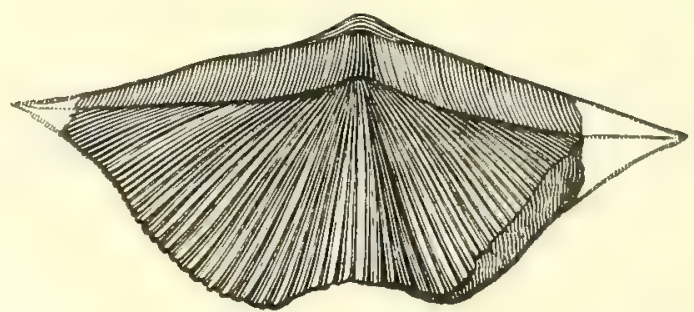

Brachlopods, Chemung. - Figs. 939, $939 a$, Rhynchonella contracta; 940, $940 a$, Productella lacrymosa ; 941, Atrypa hystrix; $942 a, b$, Spirifer disjunctus. LameLlibranchs. - Fig. 943, Aviculopecten duplicatus; 944, Pterinea Chemungensis; 945, Leptodesma lichas, Gastropod。- Fig. 946, Bellerophon mæra; 947, Bactrites acicula. From Hall.

ก12

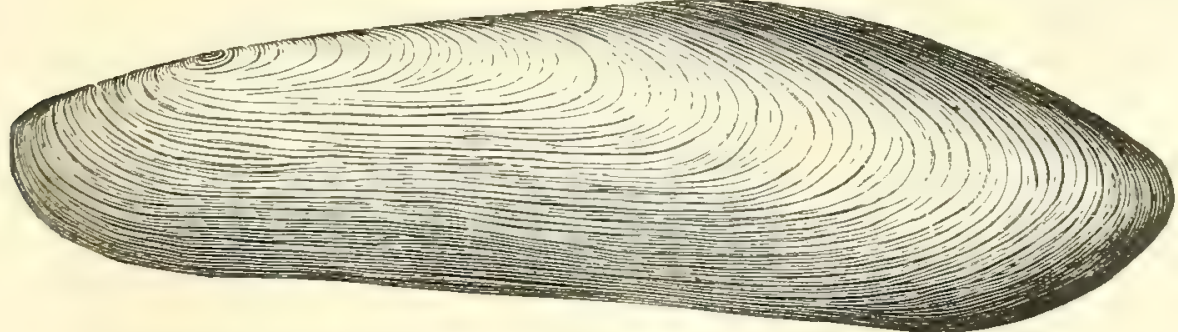

Lamelibranch, Catskill. - Amnigenia Catskillensis, Vanuxem.

Cephalopods are few, except under the genera Goniatites and Orthoceras. The thin Styliolina limestone bed in the Genesee shale contains several 
species of Goniatites and Orthoceras, and a few other species. The Naples beds, in the Lower Portage, have afforded the first of American species of

$$
949-953 .
$$

949.
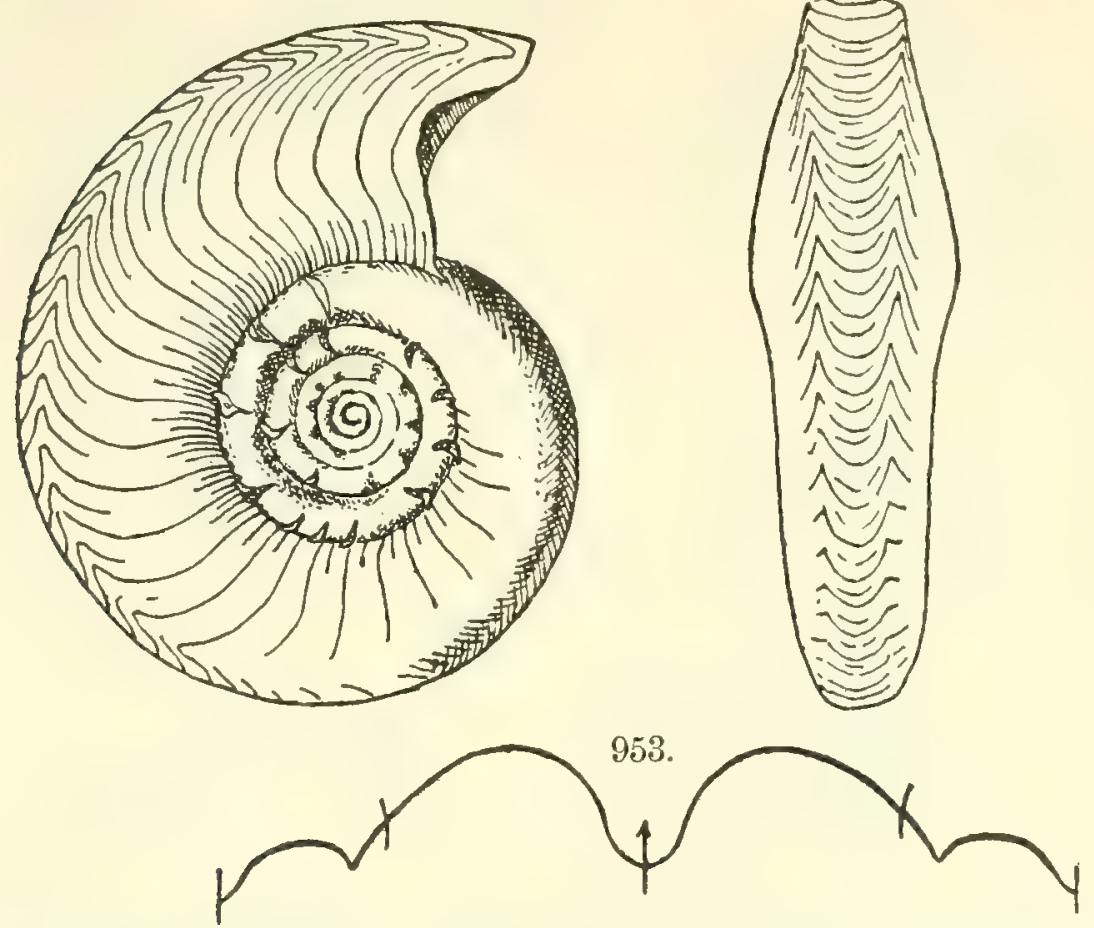

950.

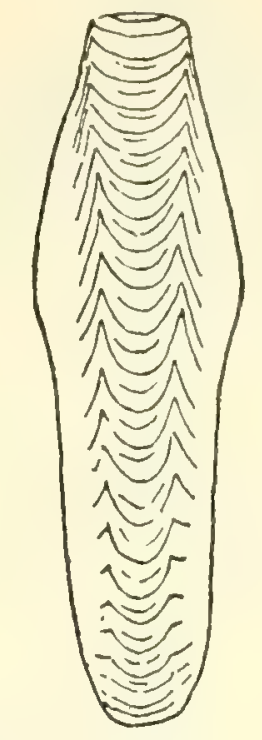

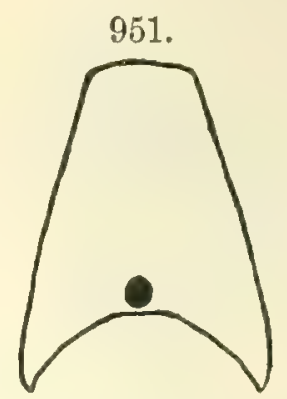

952.

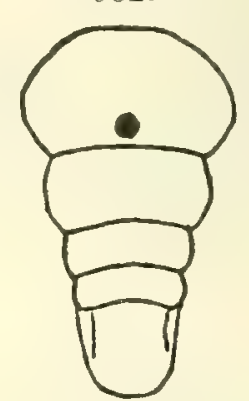

Fig. 949, Clymenia Neapolitana, of New York $(\times 4)$; 950, profile of same ; 951, transverse section near beginning of 5 th whorl; 952 , same at end of 1 st, $2 \mathrm{~d}$, $3 \mathrm{~d}$, and 4 th whorls; 953 , form of the suture at $2 \frac{1}{4}$ revolutions. J. M. Clarke.

Clymenia (Fig. 949), a genus related to Nautilus, but having the siphuncle dorsal (Fig. 951). Fig. 954 represents Goniatites intumescens (G. Patersoni Hall) of the same beds; it occurs also in the Ithaca group.

The so-called Catskill beds contain no

9044.

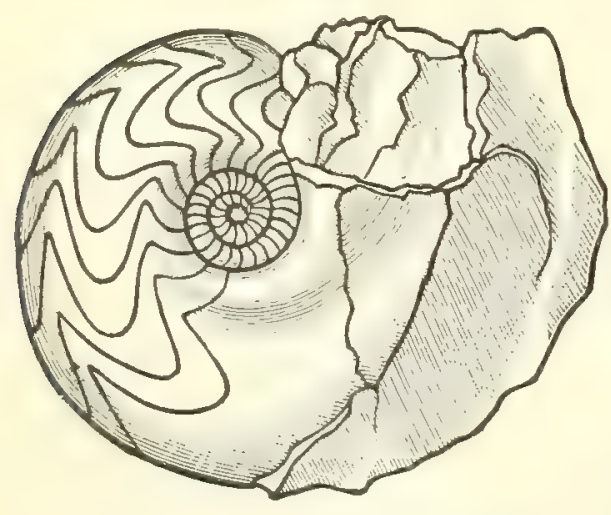

Goniatites Patersoni Hall. remains of marine Mollusks of any kind, except occasionally such as are regarded as Chemung, and as indications that the beds are Chemung.

5. Crustaceans. - Trilobites have not a recorded species from the New York Portage; and in the Chemung occur only Phacops nupera $\mathrm{H}$., doubtfully, and Cyphasphis lovis H., Phacops rana and Dalmanites (Cryphoeus) Boothi. But conditions were more favorable in Ohio, and a Chemung fauna, according to Herrick, has afforded the following species: Proetus minutus Hk., $P$. proceursor, $P$. doris Winchell, $P$. auriculatus H., Phothonides occidentalis Hk., P. spinosus Hk., and others.

Phyllopod Crustaceans were of various forms and species in the Portage, 
and besides these, there are the first of true Shrimps, or Macrural Decapod

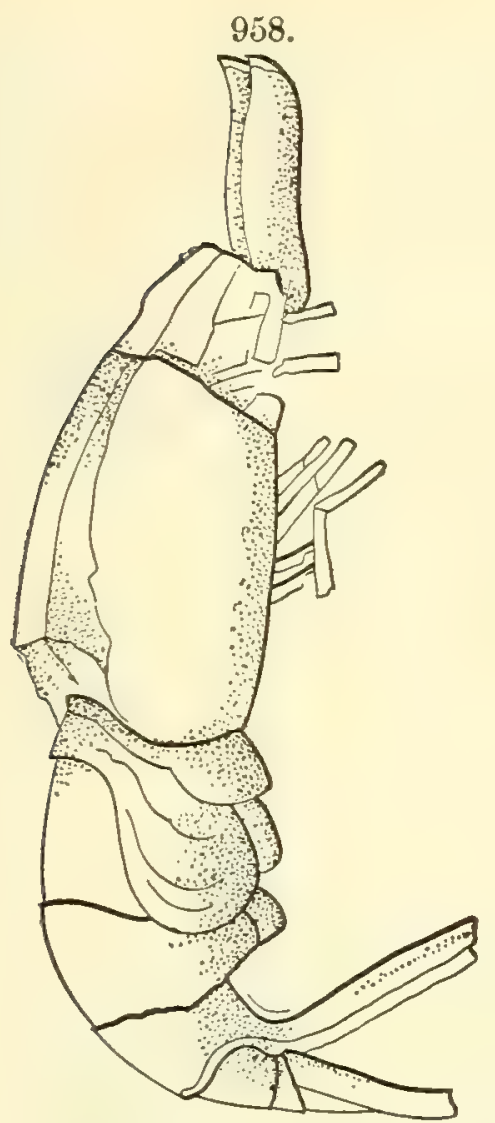

$955-958$

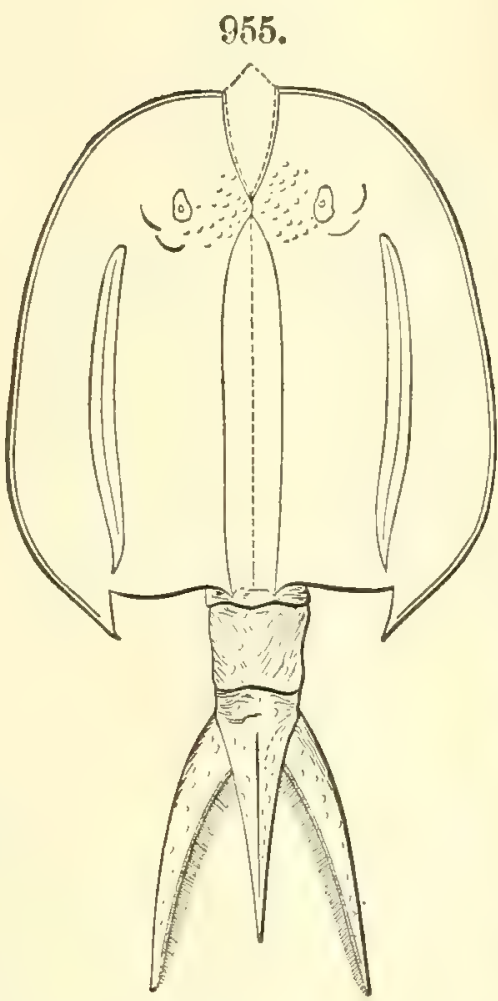

957.

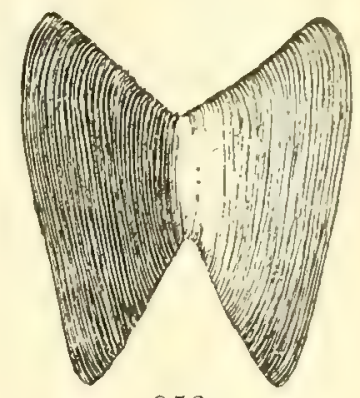

956.

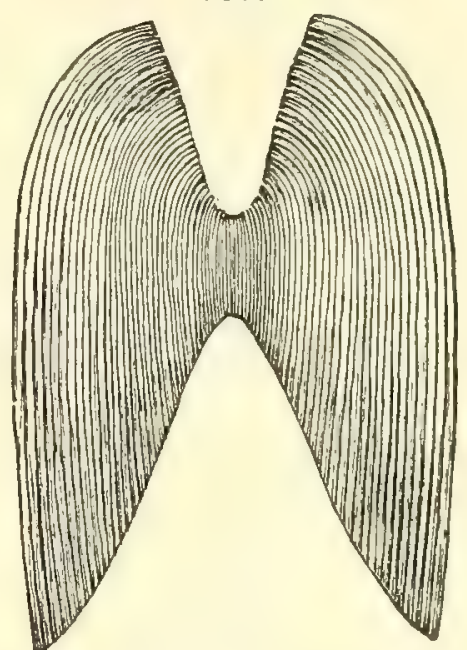

PoBtage. - Fig. 955, Mesothyra Oceani ; 956, Dipterocaris penna Dædali ; 957, D. Procne; 958, Palæopalæmon Newberryi. Fig. 955, Hall; 956, 957, J. M. Clarke; 958, Whitfield.

Crustaceans, Palceopalcemon Newberryi of Whitfield (Fig. 958). Under the Phyllopod genus Echinocaris of the same author there are a number of species; and the related $\mathrm{Me}$ sothyra Oceani of Hall (Fig. 955) had a length and breadth of more than 10 and 5 inches. Figs. 956 and 957 represent carapaces of two other Phyllopods. The specimen of Paloopaloemon was found in Ohio, in the lower part of the Ohio shale.

6. Limuloids. - The lower beds of the Portage and Upper Chemung have afforded species of Eurypterus. Also a few abdominal segments of great size, which have been made the basis of the species Stylonurus Wrightianus, supposed to have been two feet long.

Of Catskill Eurypterids, one gigantic species, Stylonurus excelsior $\mathrm{H}$., has been described from imperfect specimens found in the Catskill beds of Delaware County, N.Y., and Wyoming County, Pa. The cara-

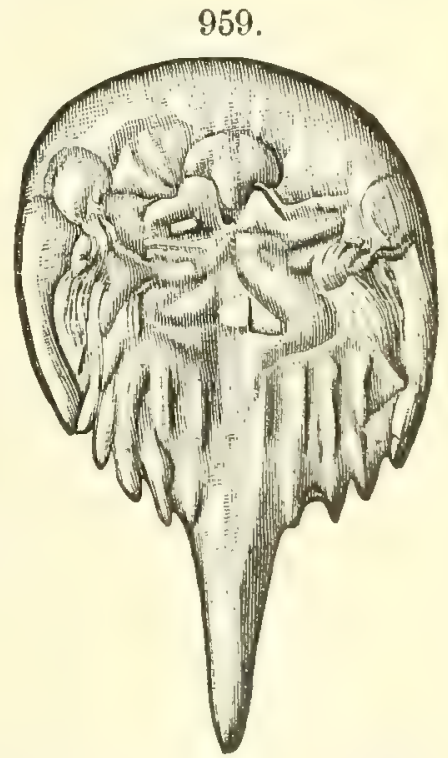

Chemtrg. - Fig. 959, Protolimulus Eriensis, ventral side. H. S. Williams. 
pace is nearly 10 inches square, the toothed-edge of the mandible $1 \frac{1}{4}$ inches long, and the whole length probably over 4 feet (Hall). In addition, a

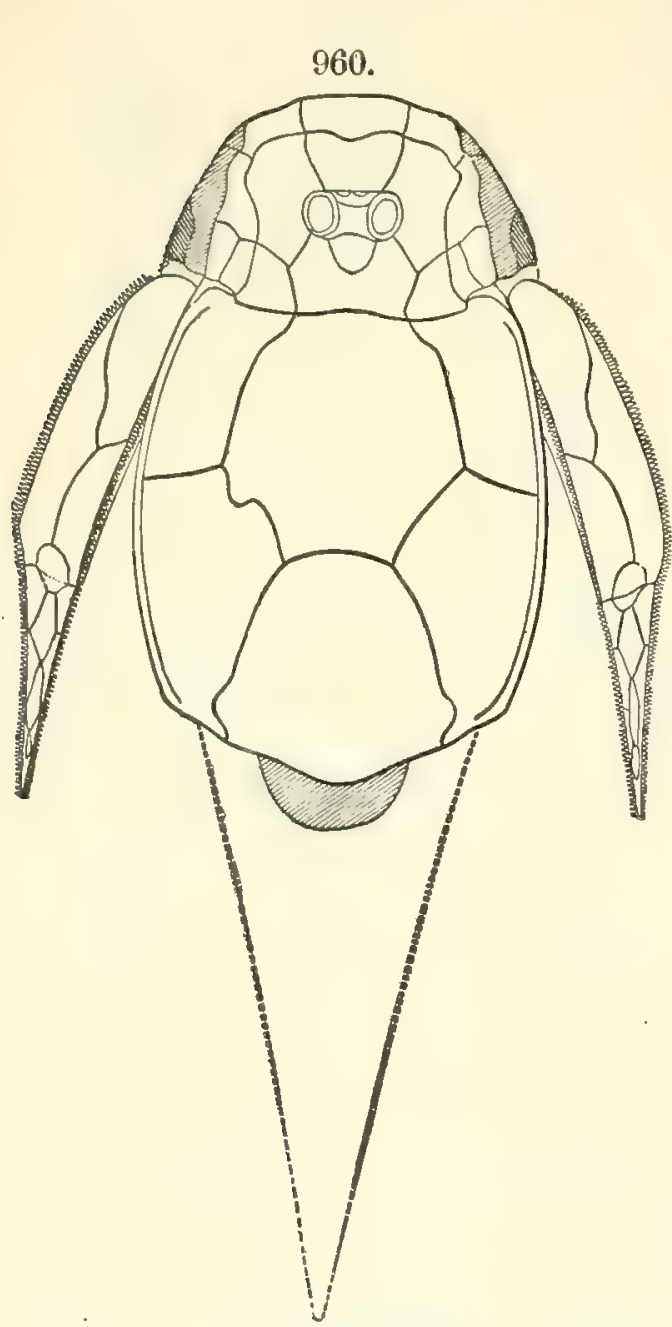

$960-962$. 960 a.
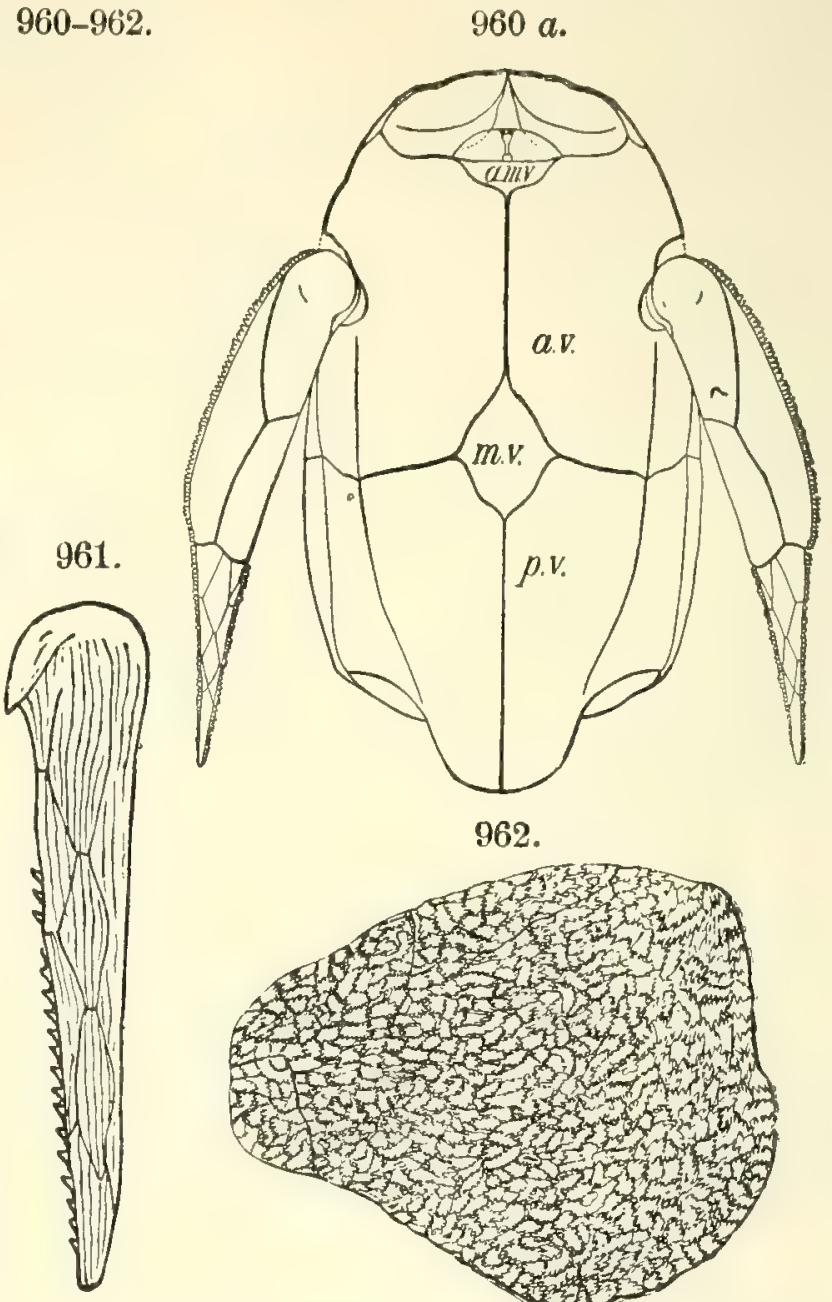

962.

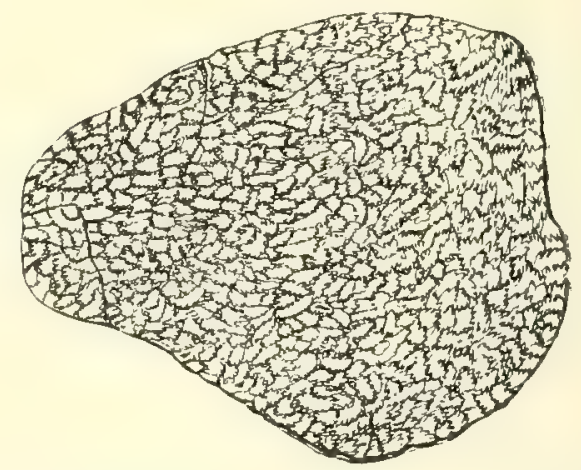

Placoderms. - Fig. 960, Bothriolepis Canadensis $\left(\times \frac{1}{8}\right)$, dorsal view; $960 a$, id. ventral view ; from Whiteaves ; $m$. $v$., middle ventral plate; $\boldsymbol{a} . \boldsymbol{m} . \boldsymbol{v}$, anterior middle ventral; $\boldsymbol{a} . \boldsymbol{v}$, anterior ventral; $\boldsymbol{p}$. $\boldsymbol{v}$, posterior ventral; 961, terminal part of pectoral limb of a Bothriolepis (Cope); 962, plate of a Bothriolepis (Leidy).
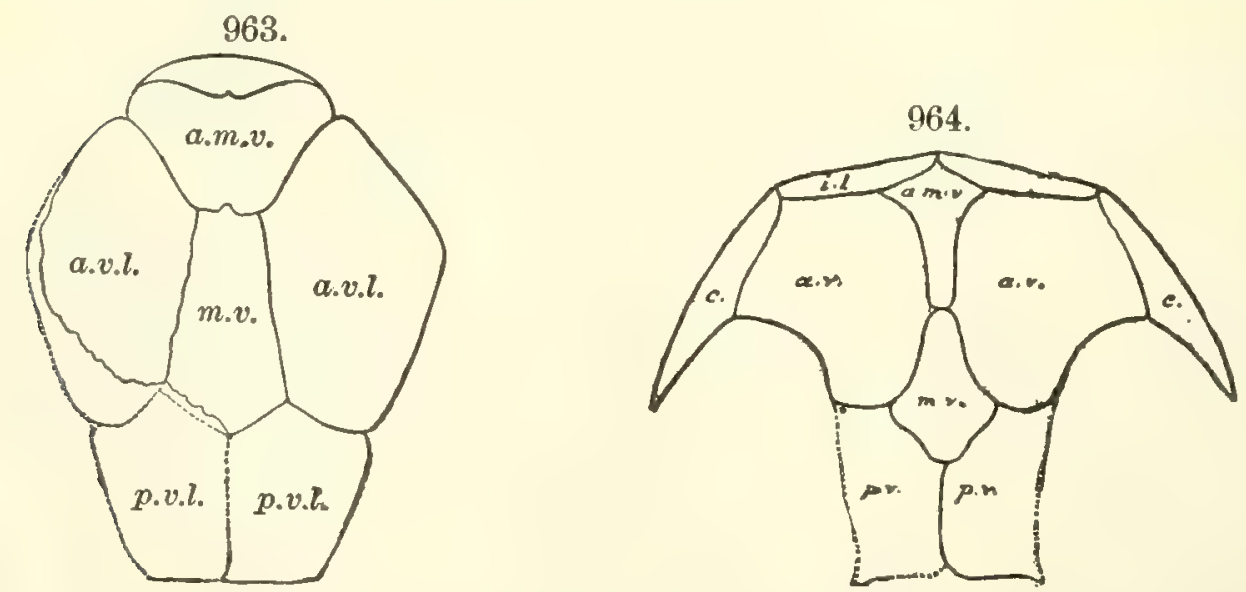

Cocoosteid Frshes.-- Fig. 963 restored ventral plates of Holonema rugosum $\left(\times \frac{2}{8}\right)$, from H. $\mathbf{S}$. Williams; 964, restored ventral plates of Phlyctænaspis Acadica of Whiteaves $\left(\times \frac{1}{2}\right)$, from Traquair.

species, related apparently to Limulus (Fig. 959), has been found in the 
Chemung of Erie County, Pa. It is the Protolimulus Eriensis of H. S. Williams.

7. Vertebrates. - Remains of Placoderms, of the brachiate type, or related to Pterichthys, have been found in Ohio and in the Catskill sandstone of New York and Pennsylvania, and nearly perfect specimens (Figs. 960, 960 a) of one species, Bothriolepis Canadensis of Whiteaves, at Scaumenac Bay (in Baie de Chaleurs), New Brunswick. Fig. 960 is a view of the dorsal shield, and $960 a$, the ventral, both reduced to a third of the natural size; and 960 shows also the probable outline of the posterior extremity, which has been added to Whiteaves's figures from the form in Pterichthys. Fig. 961 represents, natural size, the finger-like termination of a fore limb of possibly the same species, described by Cope, which was found at Mansfield,
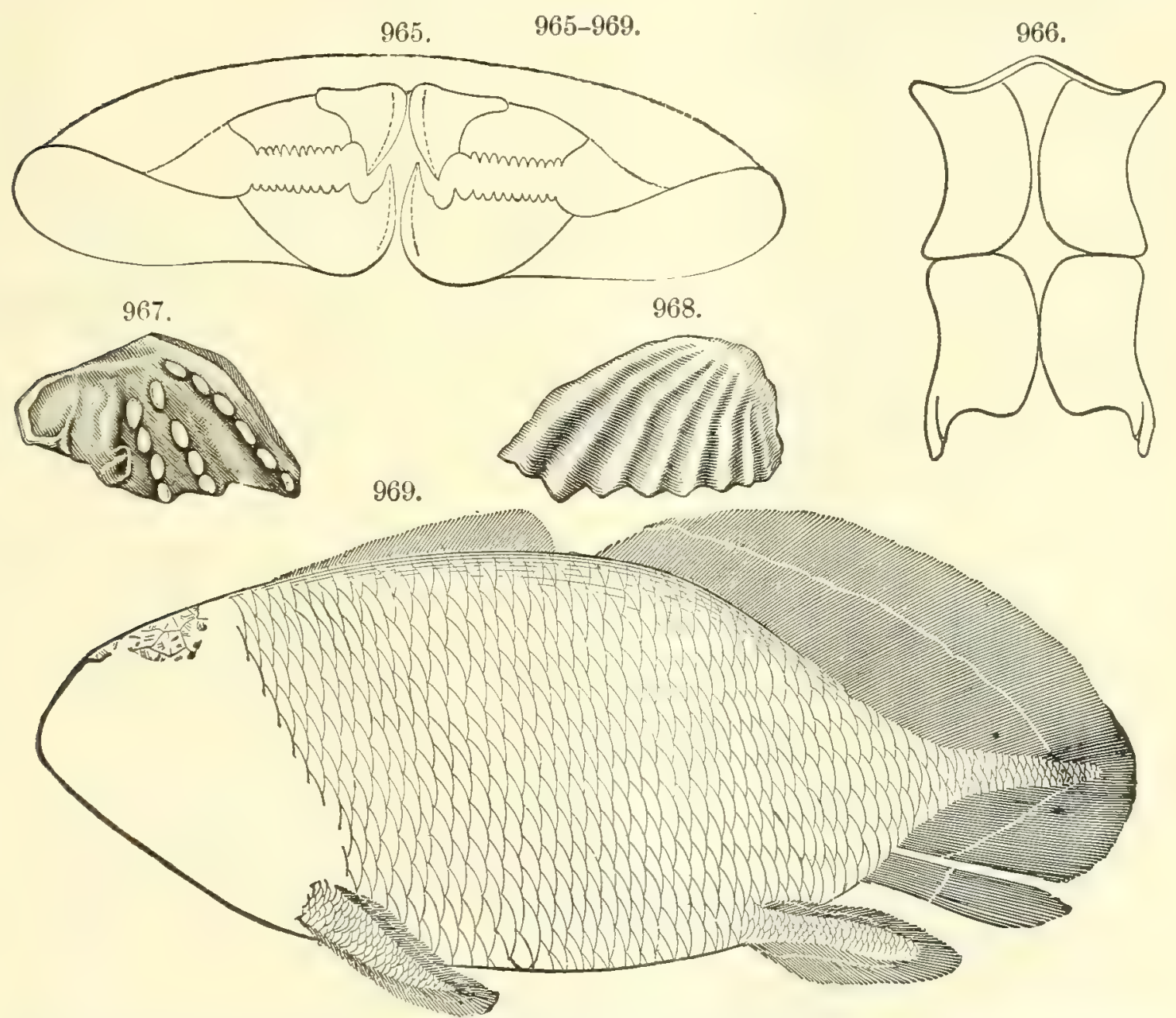

DrPNoan Frshes, - Fig. 965, Dinichthys Hertzeri, front view of jaws $\left(x_{\frac{1}{15}}\right)$; 966 , ventral plates $\left(x_{\frac{1}{2}}\right)$; 967 , palato tooth of Dipterus Sherwoodi; 968 , id. of Ctenodus Nelsoni : all from Newberry. Fig. 969, Phaneropleuron curtum $\left(x \frac{2}{3}\right)$, from Whiteaves.

Tioga County, Pa., with remains of Holonema. Fig. 962 represents a plate of Bothriolepis from the Catskill beds.

No remains of the posterior scaly part of the body have been observed in connection with specimens of the American species of Bothriolepis, though occurring in Scotland with those of Pterichthys. 
The Coccosteus family was represented by species of large size. The ventral plates of two are represented on page 616. Fig. 963 is Holonema rugosum of Claypole; as determined by H. S. Williams, the central plate in the ventral shield $\left(m . v\right.$.) has a length of $8 \frac{1}{2}$ inches. The specimen figured is from the Oneonta sandstone, near Oxford, N.I. In the related species, Fig. 964, from Campbelltown, New Brunswick, the central plate is but one inch long.

$970-974$.

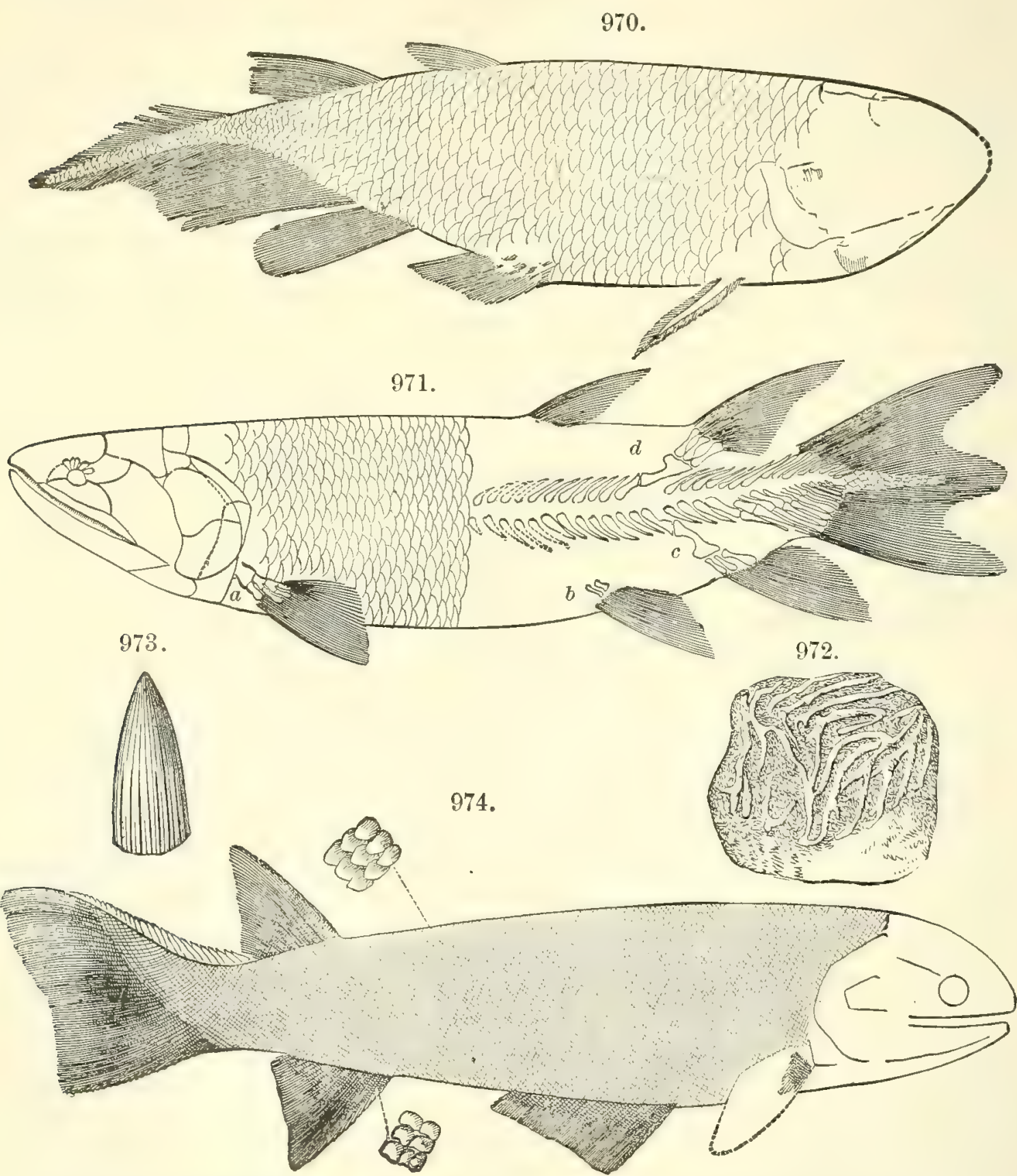

GaxoIDs. - Fig. 970, Glyptolepis Quebecensis ( $\left.\times \frac{2}{9}\right)$; 971, Eusthenopteron Foordi $\left(\times \frac{2}{4}\right)$; 972 , scale from a species of Holoptychius ; 973, tooth, id. ; 974, Chirolepis Canadensis. Figs. 970, 971, 974, Whiteaves ; 972, 973, Leidy.

The Dipnoans, or "Lung-fishes," were represented by gigantic species called by Newberry Dinichthys and Titanichthys, from their size and formidable dental armature. The species of Dinichthys, to which Figs. 965, 966 
pertain, were described from specimens found in the Cleveland shale of Ohio. Fig. 965 shows the form of the upper and lower jaws in natural position of Dinichthys Hertzeri. To represent the natural size, the figure should have a breadth of 45 inches. Fig. 966 is the ventral shield. It resembles that of Coccosteus, and also that of Bothriolepis. A still larger species is the Titanichthys Clarki of Newberry, in which the head was four feet or more broad, the lower jaw a yard long. This jaw was shaped posteriorly like an oar blade, and anteriorly was turned upward like a sled-runner. Dinichthys Gouldi of Newberry had enormous eyes surrounded by sclerotic plates. The Phaneropleuron of Whiteaves (Fig. 969) is a smaller Dipnoan from the Upper Devonian at Scaumenac Bay, New Brunswick. Figs. 967, 968 represent the palate teeth of two Dipnoans; such teeth, and the brachiate pectoral and ventral fins are special Dipnoan characteristics.

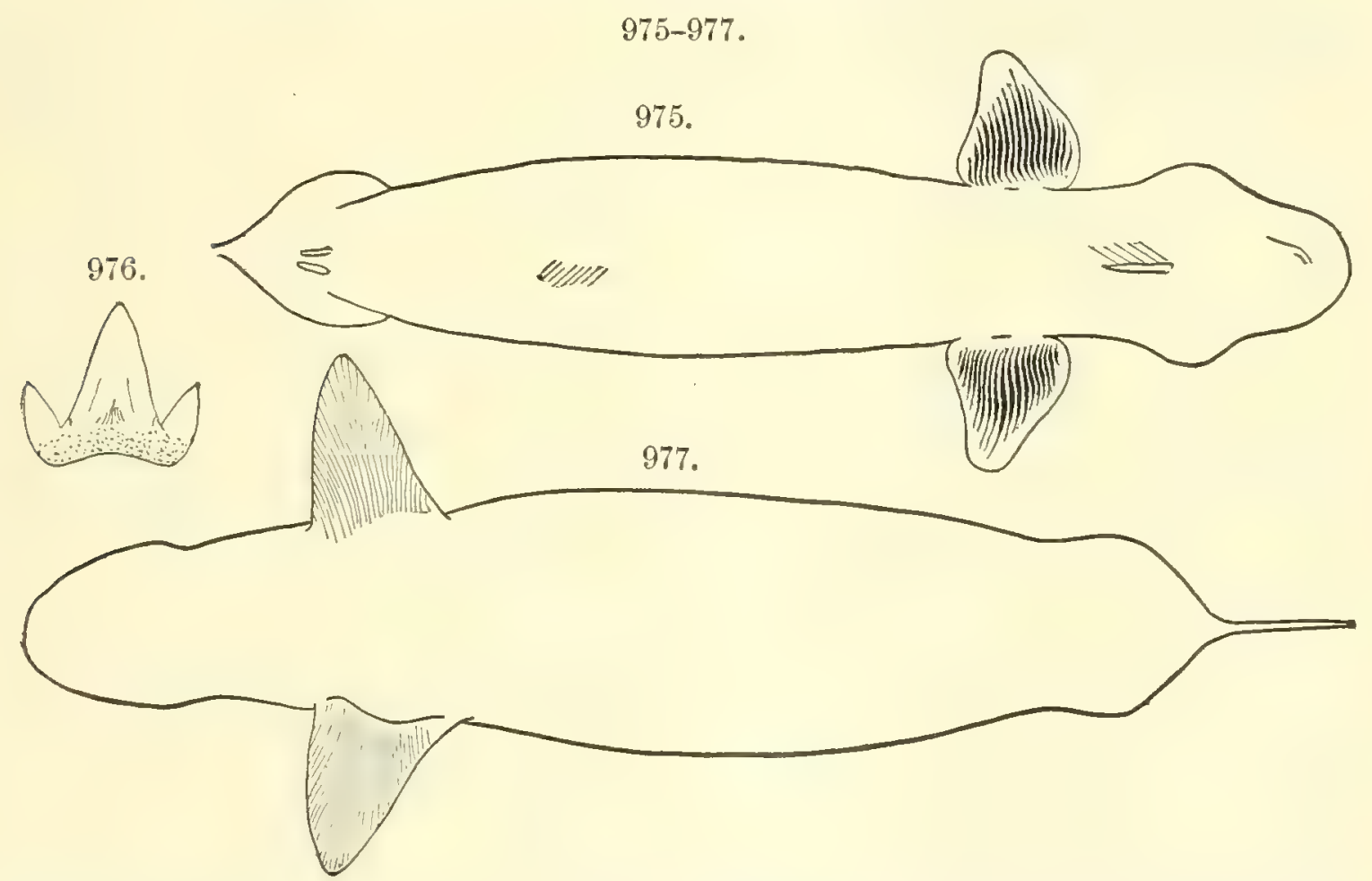

SElachians. - 975, Cladodus sinuatus $\left(\times \frac{1}{6}\right) ; 976$, tooth of C. Clarki; 977, C. Fyleri $\left(\times \frac{2}{5}\right)$. Figs. 975, 976, Claypole; 977 , Newberry.

Fig. 970 represents a Ganoid of Crossopterygian type - as indicated in this tigure by the thickened finger-like medial portion of the pectoral fin - a structure better exemplified in Fig. 969. A scale of a related genus, Holoptychius, is represented, of natural size, in Fig. 972, and a tooth, referred to the same genus by Leidy, in Fig. 973. (See also page 625 for a figure of a nearly complete specimen of another species.) The genus Eusthenopteron of Whiteaves (Fig. 971) has special interest on account (as the name implies) of the supports with which the fins are provided, answering to the pectoral and pelvic arches of higher Vertebrates - $a$, the pectoral, and $b$, the pelvic (only two bones of which are preserved); and also the similar and even larger supports for the anal fin at $c$ and for the posterior dorsal at $d$, with a 
like arrangement, but less perfectly, for the lower part of the caudal fin. They gave the posterior part of the body great strength for sculling. It is further to be observed that the open space along the c 'nicr of the rertebral column indicates a persistent notochord (cartilaginous), the spinous processes being the only calcareous portions of the column. Fig. 974 represents a Canada species of Chirolepis, a genus of the family Palæoniscidr. Palconiscus Devonicus of Clarke is another Devonian Ganoid, from the Portage of New York. The species, Figs. 970, 971, 974, are from Scaumenac Bay.

Selachians, or Sharks, were represented not only by fin-spines and teeth, but also, in the Cleveland shale of Ohio, by impressions or remains of the

978.

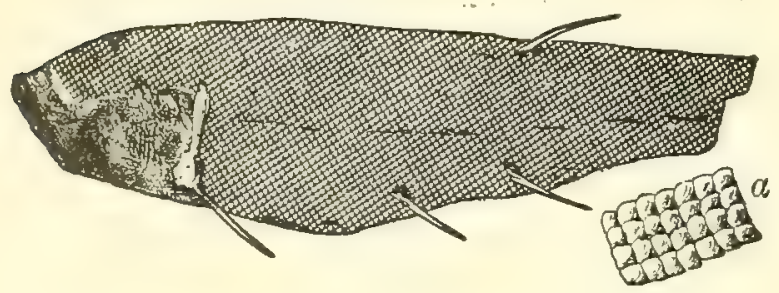

Szischiar. - Fig. 978, Acanthodes affinis; $\boldsymbol{a}$, scales, natural size. Whiteaves. nearly entire body. Two siecimens of the latter are shown, much reduced, in Figs. 975, 977. The largest yet found, Cladodus Kepleri, had a length of six feet. Newberry's figure of C. Fyleri, in his Paleozoic Fishes of North America, gives it a length of 22 inches. It is referred to a new genus, Cladoselacha, by B.

Dean. The tooth, Fig. 976, is of the species Cladodus Clarki of Claypole.

Remains of a species of another genus, Acanthodes, related to the Sharks, but having minute square or rhombic scales, has been found at Scaumenac Bay. A small specimen is represented in Fig. 978. Other species of the genus have been reported from New York and Pennsylvania.

\section{Characteristic Species.}

Genesee shales. - Orbiculoidea Lodensis, Discina truncata, Lingula spatulata (also Portage), Chonetes lepidus (also Hamilton), Ambocolia umbonata (also Ham. \& Mar.), Leiorhynchus quadricostatum, Strophalosia truncata (also Marcelius), Lunulicardium fragile (Marcellus to Portage), Cardiola (Glyptocardia) speciosa (Ham. to Chemung), Styliolina fissurella, Tentaculites gracilistriatus (also in the Harcellus), Orthoceras subulatum (also Marcellus), Goniatites complanatus (also Lpper Ham. and Portage), G. discoideus (Marc., Ham. also), G. intumescens $(=G$. Patersoni) (also Portage and Chemung).

Portage group. - Ambocolia umbonata, Grammysia subarcuata, Lunulicardium fragile, L. acutirostrum, L. ornatum, Cardiola speciosa, Styliolina fissurella, Bellerophon natator, Coleolus acicula, Tentaculites gracilistriatus, Orthoceras pacator, Goniatites complanatus, G. intumescens, G. bicostatus, G. sinuosus.

Ithaca beds (noted for the number of Brachiopods). - Lingula spatulata, Atrypa reticularis, Spirifer mesacostalis and S. mesastrialis, Cryptonella eudora, Stropheodonta mucronata, Rhynchonella pugnus, R. eximia, Productella speciosa, Leiorhynchus mesacostale, Orthis impressa, Chonetes setigerus, C. scitulus, Crania; Lunulicardium fragile, Schizodus quadrangularis, Palconeilo filosa, species of Leptodesma and Aviculopecten, Grammysia subarcuata, Tentaculites spiculus, Orthoceras bebryx, O. fulgidum. Spathiocaris Emersoni Clarke, of the Portage, is described and figured in Am. Jour. Sc., xxiii., 1882. The Paloopalcemon was first described by Whitfield, in Am. Jour. Sc., xix., 1880.

The Naples beds, in the Portage, containing the Clynenia (Fig. 949), have afforded also, according to J. M. Clarke (1891, '92), Palconiscus Devonicus Clarke, Acrnthodes 
priscus Cl., Conodonts, Echinocaris Whitfieldi Cl., E.? Beecheri Cl., Spathiocaris Emersoni $\mathrm{Cl}$, species of Entomis, Goniatites intumescens Beyrich, and many other species of the genus, Orthoceras pacator Hall, and other species of 0 , species of Bactrites, Bactrites? acicula, Hyolithes, Tentaculites gracilistriatus, Styliolina fissurella Hall, species of Wacrocheilus, Platystoma, Pleurotomaria, Loxonema, Bellerophon, Leptodesma, Leiopteria, Grammysia, IIacrodon, Nucula, Ungulina, Lunulicardium, Cardiola (Cardiola retrostriata abundant), Pholadella, Lingula, Chonetes, Aulopora, Melocrinus Clarki Williams, also species of fossil wood. The Styliolina limestone, in the Genesee shale below, contains the first representatives of the Naples, or $G$. intumescens, fauna ; in it, Dawson has identified Dadoxylon (Cordaites) Clarki, Cladoxylon mirabile Unger. The fauna and flora are related to that associated with Goniatites intumescens in Europe. (J. M. Clarke.)

Chemung beds of New York and Pennsylvania. - Dictyophyton tuberosum; Orthis Tioga, O. impressa, Stropheodonta Cayuta, Productella lachrymosa, P. hirsuta, Phynchonella contracta, Leiorhynchus sinuatum, L. mesacostale, Spivifer disjunctus, Ambocatia umbonata var. gregaria, Athyris Angelica; Aviculopecten duplicatus, Pterinea Chemungensis, Ptychopteria Sao, P. falcata, Leptodesma spinigerum, Goniophora Chemungensis, Schizodus Chemungensis, Grammysia subarcuata, G. communis, Sphenotus contractus, Prorhynchus nasutum; Tropidocaris bicarinata, Echinocaris socialis. For descriptions of Chemung fossils see Pal. N. Y., vols. iv., v., vii., viii. (C. E. Beecher.)

Lamellibranchs of the Middle and Upper Devonian. - The total number of species of Lamellibranchs described and figured by Hall in vol. v. of the Palcoontology of New York is 458 ; and of these 195 occur in the Hamilton beds, and 263 in the Chemung. The principal genera to which they are referred, and the number of species in each, are as follows - H. signifying Hamilton, and C., Chemung :-

Actinopteria (H. 7, C. 10), Aviculopecten (H. 13, C. 16), Conocardium (H. 4, C. 2), Cypricardinia (H. 2, C. 1), Edmondia (H. 0, C. 7), Glossites (H. 1, C. 7), Goniophora (H. 7, C. 4), Grammysia (H. 15, C. 9), Leda (H. 4, C. 0), Leiopteria (H. 12, C. 3), Leptodesma (H. 2, C. 55), Lunuticardium (H. 7, C. 6), Microdon (H. 4, C. 2), Modiomorpha (H. 10, C. 7), Mytilarca (H. 2, C. 8), Nucula (H. 9, C. 5), Nuculites (H. 5, C. 0), Orthonata (H. 4, C. 1), Palceanatina (H. 0, C. 4), Palceoneilo (H. 10, C. 10), Panenka (H. 12, C. 3), Paracyclas (H. 4, C. 5), Prorhynchus (H. 0, C. 3), Pterinea (H. 1, C. 10), Ptychopteria (H. 0, C. 22), Schizodus (H. 3, C. 8), Sphenotus (H. 5, C. 5).

E. D. Cope has announced (1892), from the bed containing Fish remains, of Chemung age, in Nansfield, Tioga County, Pa., besides Holoptychius Americanus, the species Bothriolepis nitida Leidy, Holonema rugosum Clay p., Ganorhynchus oblongum Cope, Holoptychius giganteus $\mathrm{Ag}$.; in Leroy, Bradford County, Pa., the bed probably Chemung, H. rugosus, H. horridus Cope, H. filosus Cope; at a neighboring locality, Bothriolepis minor Newb., Coccosteus macromus Cope, and fragments of Osteolepis or Megalichthys. Phaneropleuron curtum of Whiteares (Fig. 969) has been made by Traquair into a new genus, named Scaumenacia, on the basis of a slight difference, in the dorsal or dorso-caudal fin, between it and the original Phaneropleuron of Huxley. Plates of the large pterichthyoid fish, Holonema rugosum, have been found in the red sandstones of the Oneonta group, near Oxford, N.Y. (See Proc. A. A. A. S., vol. 39, 1890, page 337. Also, Am. Geol., vol. vi., page 226.)

The minute teeth, long of doubtful ownership, called Conodonts, now regarded as the teeth of Annelids, occur of several species in the Genesee shales of Erie County, N.Y., at North Evans, including the following described by Hinde (Q.J. G. Soc., 1877): Prioniodus angulatus, $P$. acicularis, $P$. armatus, $P$. spicatus, $P$. erraticus, Polygnathus dutius, $P$. nasutus, $P$. princeps, $P$. palmatus, $P$. punctatus. A plate is devoted to figures of Conodonts (Pl. 57), in Ohio Pal., ii., 1875.

Additional Devonian plants. - The following are some of the species of St. John, New Brunswick; those that occur also at Gaspé are marked with an asterisk, and those also in New York or farther West, with a dagger. 
Psilophyton princeps Dn. ${ }^{*}+$ (Fig. 854, page 58:3), Lepidadendron Gaspianum Dn., (Fig. 855), Sigillaria palpebra Dn., Stigmaria perlata Dn., Cordaites Robbii † (Fig. 896), Archaopteris Jacksoni (Figs. 898, 899), Neuropteris polymorpha Dn. (Fig. 897), N. Dawsoni Hartt (leaflet over six inches long), Sphenopteris Hitchcockiana Dn., S. Hœninghausi Brngt., S. Hartti Dn., Callipteris pilosa Dn., Hymenophyllites Gersdorti Göpp., $H$. obtusilobus Göpp., Alethopteris discrepans Dn., Pecopteris preciosa Hartt, species of Trichomanites, Calamites radiatus Göpp. (Fig. 900), C. cannaformis Schlotheim, Asterophyllites acicularis Dn., A. latifolius Dn. (Fig. 901), Sphenophyllum antiquum Dn.; Dadoxylon Ouangondianum Dn., besides fruits of Gymnosperms, of the genera Cardiocarpus and Trigonocarpus.

A Gymnosperm fossil wood, from Schoharie County, N.Y., has been named Ormoxylon Erianum by Dawson. At Perry, Me., occur Lepidodendron Gaspianum Dn., Leptophroum rhombicum Dn., Archcopteris Jacksoni Dn., A. Halliana, A. Rogersi Dn., A. (Cyclopteris) Browni Dn., Caulopteris Lockwoodi Dn., Anarthrocanna Perryana Dn., Stigmaria pusilla Dn., and others, there being very few of the St. John species. Some species are the same that occur in Subcarboniferous beds. See, for descriptions of plants, in addition to Dawson's publications, also C. F. Hartt in Bailey's New Brunswick Geol. Rep., 1865; Lesquereux, Report on Coal Flora of Pennsylvania, and another on Indiana; Newberry's Ohio Reports, and other publications, etc.

\section{FOREIGN.}

The Devonian beds in the British Isles comprise the Old Red sandstone of Scotland; the same in southeastern Wales and the adjoining region of Herefordshire in England, and of some parts of Ireland; and areas of slates and limestone in Devon and Cornwall, or southeastern England. The fossiliferous Devon areas suggested the name for the beds.

The more northern of the Scottish areas $(a)$ stretches in a southsouthwest direction, from the Shetland and Orkney Islands, along the west coast of Scotland into Loch Ness; it has for part of its western boundary the northern Highland Archæan region of Scotland-along which must have run a western shore-line in the Devonian sea. (b) Nearly parallel with this northern area, another crosses central Scotland from Stoneham to the Firth of Clyde; and farther south, beyond a Carboniferous belt, is still another intermpted line; and this central trough of chiefly Devonian and Carboniferous rocks, about 50 miles wide, is in the line of the area of Carboniferous beds (mostly Subcarboniferous), and outcrops of Devonian, which oceur over western Ireland. (c) A third area is that of eastern Wales and the country adjoining; it has the Siluro-Cambrian region of Wales as its. western border; and its continuation sonthwestward embraces the Carboniferous area of South Wales; thence, the combined Devonian and Carboniferous area extends over Devon and Cornwall. The northeastward and eastward continuation of this third area to the North Sea is under the cover of Triassic and later rocks, except where Carboniferous beds outcrop. Borings have been supposed to prove the presence of Devonian shales and sandstone to the eastward, under London, at a depth of about 1000 feet, Etheridge identifying the fossils Spirifer disjunctus, Rhynchonella cuboides with species. of Orthis, Chonetes, and Edmondia. 
The Old Red sandstone is the rock of all the areas excepting that of Devon and Cornwall. It consists of red, purplish, and brown sandstones, coarse and fine, passing to a conglomerate and also to bituminous flags. It shows by its coarse and varying features, by the absence of fossiliferous beds bearing shells, corals, and other invertebrate remains, and by the presence here and there of relics of Fishes and Eurypterids, that its origin was much like that of the Catskill Red sandstone of eastern America - a roughly made sea-border formation, in waters that suffered in purity from the contributions of streams from the bordering hills. The American Devonian has abundant life beyond the Catskill sandstone area; and in the British seas the beds of Devon are as prolific as the Chemung, Hamilton, and Corniferous of eastern America.

The Old Red sandstone of Scotland (called old Red in contrast with the New Red or Triassic) is reported to have the extraordinary thickness of 10,000 to 16,000 feet. It is divided into an Upper and Lower division, by a plane of unconformability above the level of the Caithness flags (A. Geikie). Besides sandstones the central basin of Scotland includes a great thickness (6000 feet) of igneous rocks - felsyte and felsyte porphyry, doleryte and other kinds; now forming, as Geikie states, chains of hills, as in the Pentland, Orchir and Sidlaw ranges. They occur interstratified with the ordinary beds, several thousand feet above the base of the Devonian, and indicate a long period of ejections. The basins of the Cheviot Hills and of Lorne also had their volcanic ejections.

The old Red sandstone is remarkable for its Eurypterids. A Pterygotus is represented in

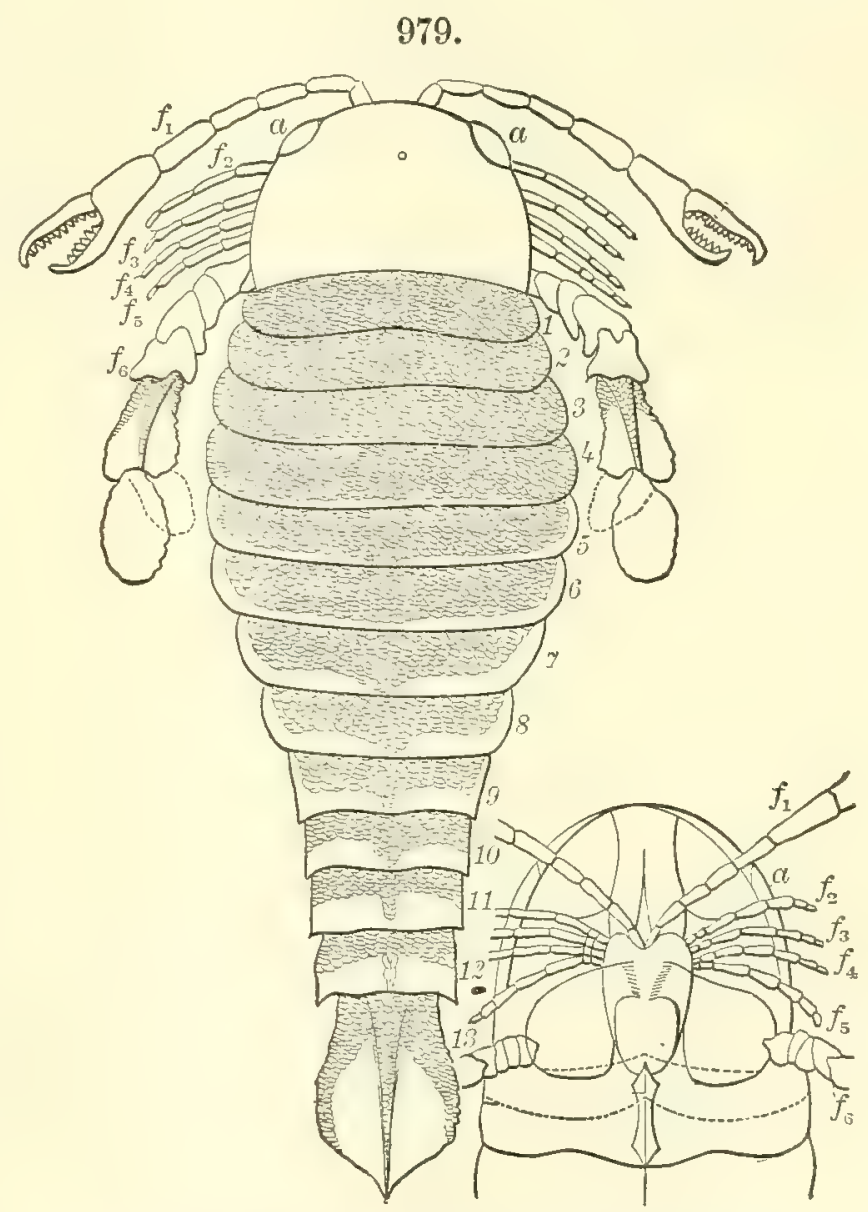

EURYPterid。-Fig. 979, Pterygotus Anglieus; $a$, eye; $f$, appendages; 1 to 13 , numbering of segments.

Fig. 979, P. Anglicus, which has a length of six feet-more than three times that of any Crustacean now living. Other common genera are Eurypterus and Stylonurus. An Ostracoid, Estheria, is abundant in some places. A gigantic Isopod Crustacean, the Prcearcturus, has been described by Woodward (1870) from the Old Red sandstone of Herefordshire. 
Modern Isopods are seldom over two inches long. The basal joint of a leg of the Præarcturus was three inches long, and three quarters of au inch

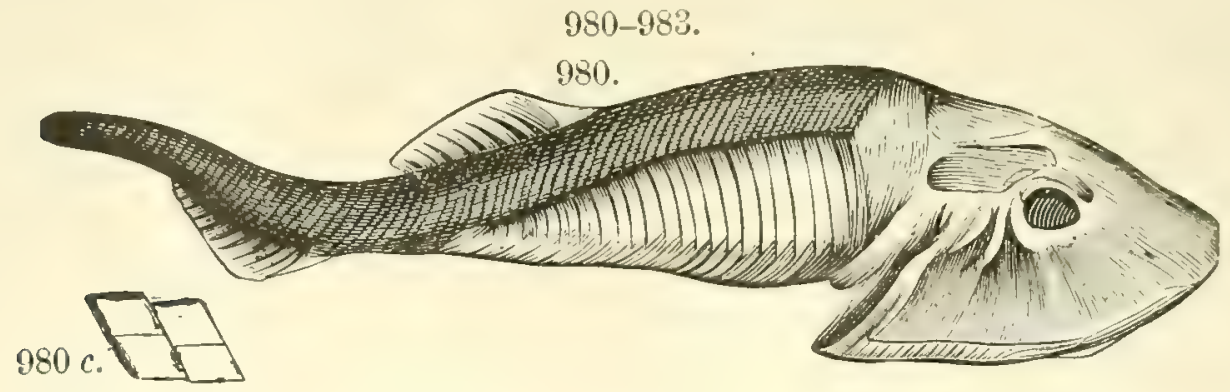

$980 a$

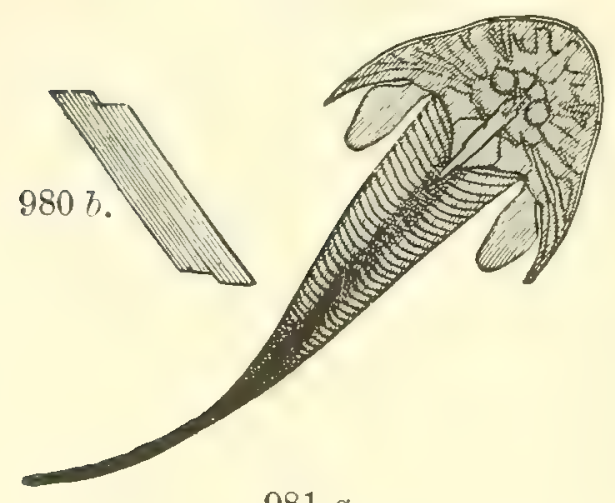

$981 a$.

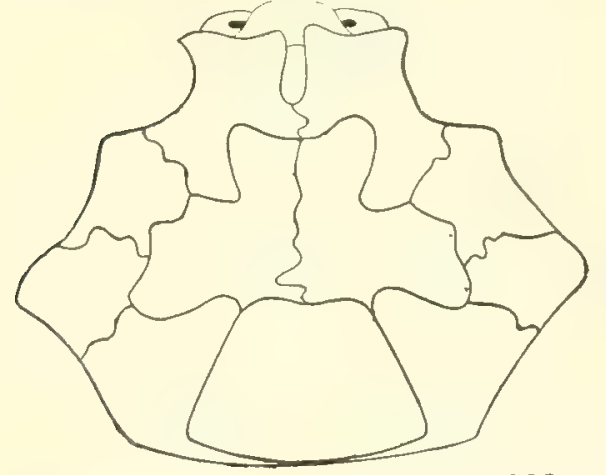

983.

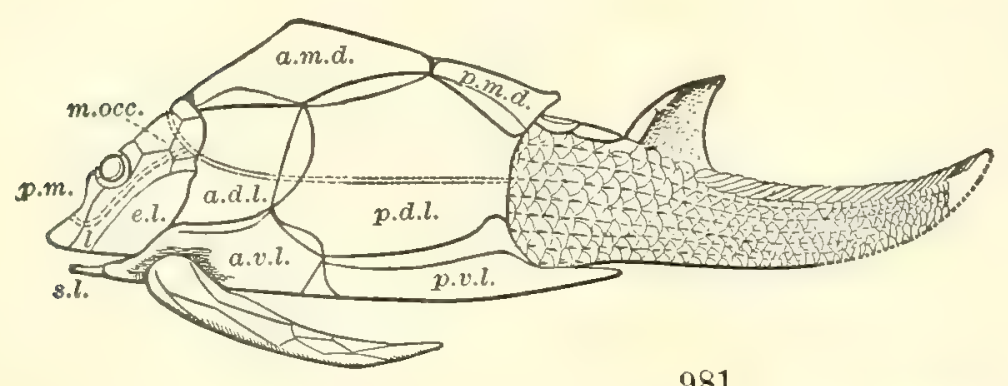

982.

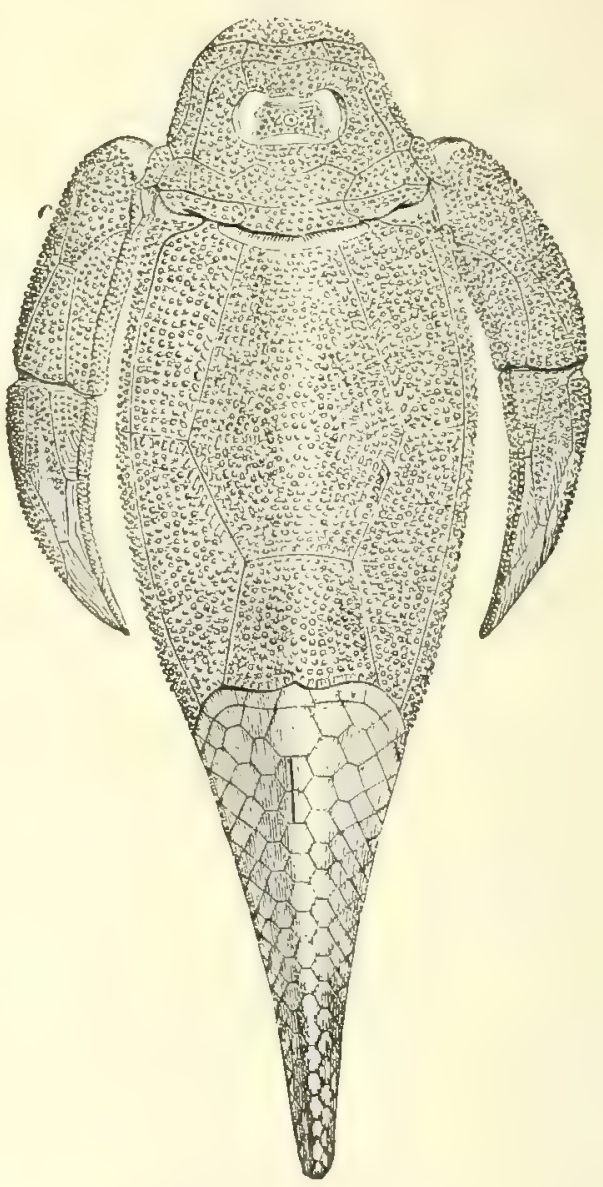

981.

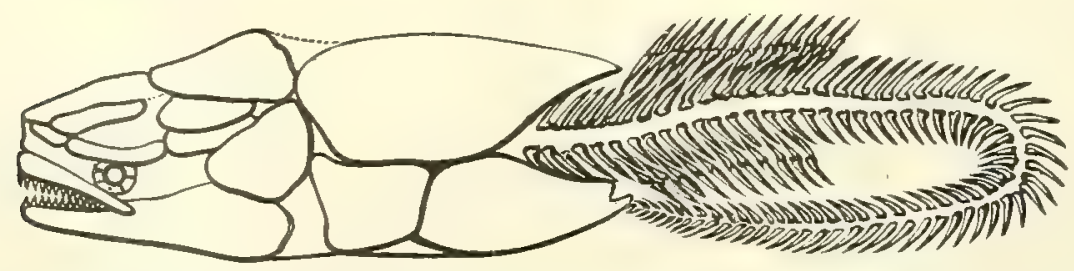

Pucoderms. - Fig. 980, Cephalaspis Lyelli $\left(\times \frac{2}{3}\right) ; 980 a$, same, with pectoral fins in place; $980 \boldsymbol{b}, \boldsymbol{c}$, scales ; 981, Coccosteus decipiens, side view; 981 a, dorsal plates; 982, Pterichthys Milleri $\left(\times \frac{2}{3}\right) ; 983$, Pterichthys cornutus. Figs. 980, 981, Agassiz; 981 a, 983, Traquair ; 982, Pander. 
through. Two species of Myriapods have been described from the lower Old Red sandstone of Forfarshire, Scotland, Kampecaris Forfarensis Page, and Archidesmus MacNicoli Peach.

The Fishes of the Old Red sandstone have come mostly from bituminous flags in northern Scotland and North Wales, and include species of the Placoderm genera Cephalaspis (Fig. 980), Pteraspis, Cyathaspis, Auchenaspis, Holaspis; Asterolepis, Pterichthys (Figs. 982, 983), Bothriolepis, Coccosteus (Fig. 981); also the Dipnoan genera, Dipterus, Phaneropleuron; and the true Ganoids, Holoptychius, Glyptolepis, Dendrodus, Cheiracanthus. The Cephalaspids are absent from the Upper Devonian of Scotland.

$984-985$.

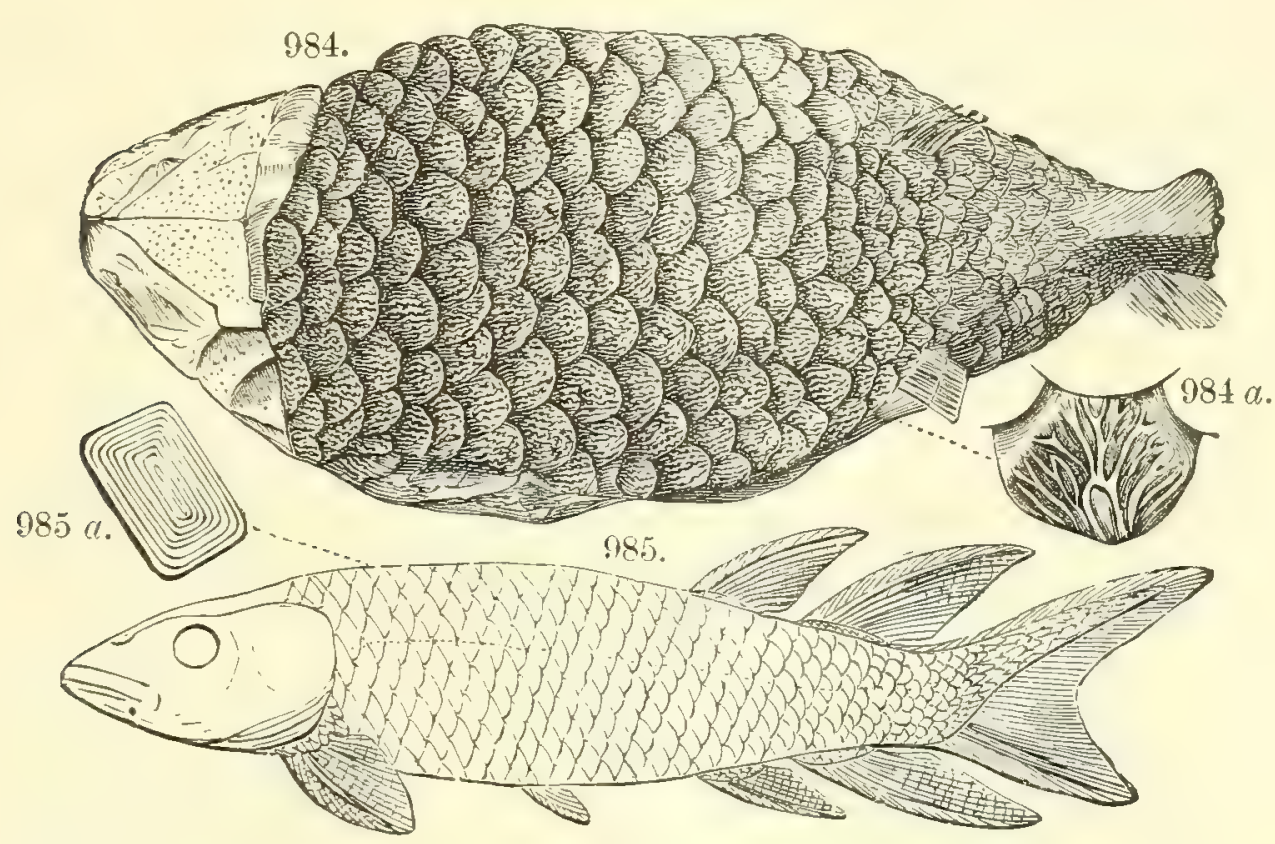

Garom. - Fig. 984, Holoptychins $\left(\times \frac{1}{7}\right) ; 984 a$, a scale. Dipnoan. - 985, Dipterus macrolepidotus $\left(\times \frac{1}{2}\right) ; 985 a$, a scale.

The Devon beds have an estimated thickness of $10,000^{\prime}$ to $12,000^{\prime}$. They afford a large variety of Corais, Brachiopods, and other species, a number of them related to those of the American Devonian.1 The Lower, Middle, and Upper divisions are: (1) the Lower or Lrxтox group of sandy slates and grits, affording Actinocrinus tenuistriatus, Favosites cervicornis, Orthis arcuato, O. granulosu, Spirifer canaliferus, S. hystericus, S. Icevicostatus, Streptorhynchus umbraculum, Chonetes Hardrensis; (2) the Midde or Ilfracombe group of slate and grits, with beds of limestone, containing several species of Crinoids; many Corals, including Heliophyllum Halli, Cyathophyllum caspitosum, species of Favosites, Acevvularia, etc.; Stromatopora of several species; Atrypa reticularis, A.laevis, A.aspera, Rhynchonella cubrides, Merista pleheia, Orthis striatula, Spirifer curvatus, S. disjunctus, Stringocephalus Burtini, Streptorhynchus crenistria, Strophomena vhomboidalis, Platyceras vetustum, species of Euomphalus, Loxonema, Murchisonia; Goniatites, Orthoceras, Cyrtoceras; Tentaculites scalaris; Phocops latifrons, P. granulata, and also species of Bronteus, Harpes and Ceraurus; (3) Upper, including Pickwell Down and Pilton beds,

1 In the following lists of foreign species, the new generic names of Brachiopods, recently introduced by Hall and Clarke in their revision of the subject, are not inserted, as they are not yet in use in any foreign work on geology or paleontology.

DANA'S MANUAL - 40 
containing many Crinoids and Brachiopods: Pextremites ovalis, Athyris concentrica, Spirifer decussatus, S. Urii, Orthis plicata, O. parallela, O. interlineata, Productus prcelongus, Streptorhynchus crenistria; with several species of Clymenia, Goniatites, Orthoceras; also Phacops latifrons, etc.

Among the Devonian plants of Ireland, in beds that contain also remains of Coccosteus and Glyptolepis, there are Cyclopteris Hibernica Forbes, Sphenopteris Hookeri Baily, S. Humphriesiana, Calamites radiatus Br., Lepidadendron Veltheimanum Sternb., Lnorria acicularis Göpp., Cyclostigma minutum Haughton, C. Kiltorkense Haughton, and other species. The whole number known of species of Fishes from the Lower Devonian of Great Britain, as stated by Etheridge in 1885, is 88, 4 species of Onchus being excluded; in the riddle Devonian, 2; in the Upper, 28. The only genera common to the Lower and Upper are Pterichthys, Asterolepis, Holoptychius and Platygnathus. Of the 577 species in the fauna, 50 pass up into the Carboniferous.

In the Ardennes, on the borders of France and Belgium, there is the west border of a broad Devonian area which crosses the Rhine north of Mayence with bold features along the river, and extends to Nassau and Westrhalia. The Lower, Middle, and Lpper divisions are named(1) the Rhenan, (2) the Eifelian, and (3) the Famennian. In the region of the Ardennes the Lower consists, according to Gosselet, of (1) the Gedinnian, about 2500' thick, containing Homalonotus, Tentaculites, Spirifer Dumonti; (2) the Taunusian, about 1800' thick, with Pleurodictyon, Leptcena Murchisoni, L. laticosta; (3) the Coblenzian, about $8000^{\prime}$ thick, with Strophomena depressa, Grammysia Hamiltonensis (=bisulcata); and at top, Spirifer cultringatus, Calcenta sandalina (the latter, perhaps, Eifelian). The Middle or Eifetian, over $3000^{\prime}$ thick, includes the Calceola slates, and above these the Givet lime$986-987$.

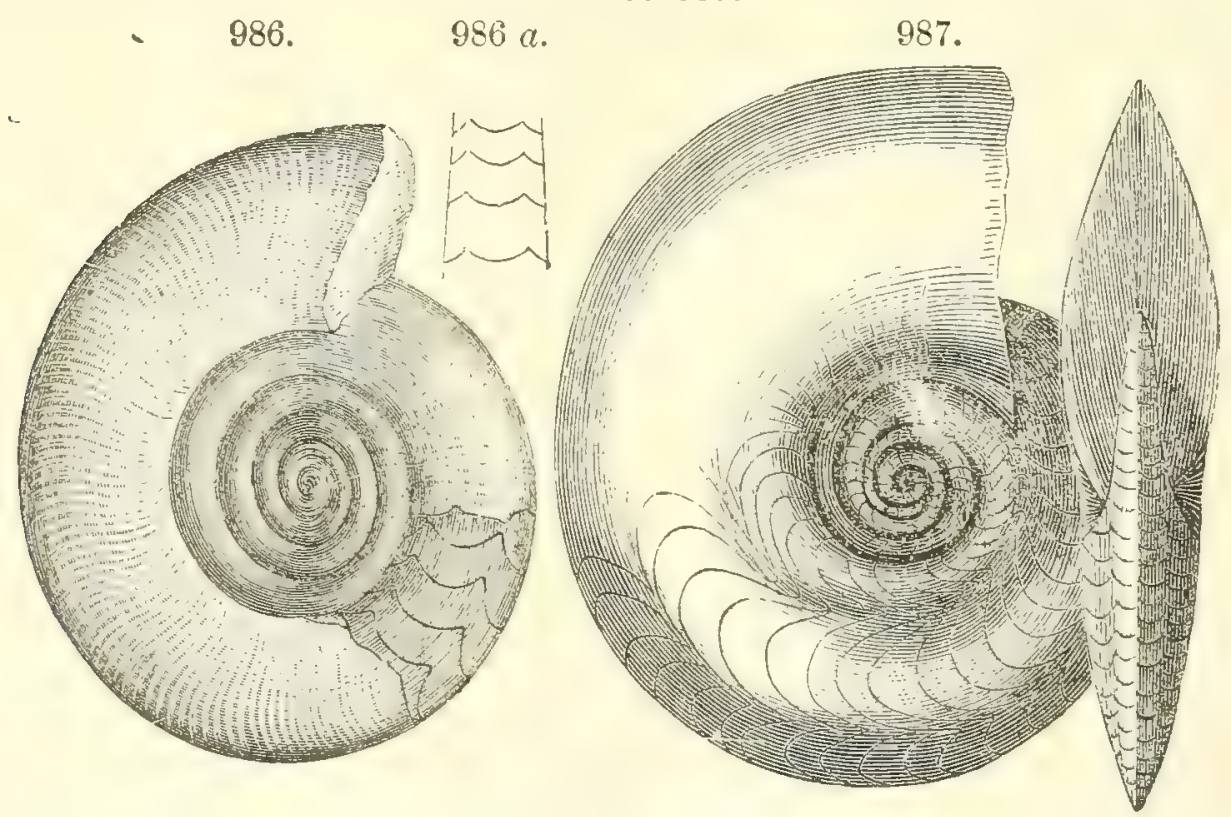

Cephalopods. - Fig. 986, Clymenia Sedgwicki ; 996 , dorsal view of septa; 987 , Goniatites retrorsus. Fig. 9\$6, D'Orbigny ; 987, Vogt.

stone (Giretian) or Stringocephalus beds ; the former containing Phacops, Bronteus, Orthis striatula, Productus subaculeatus, Pentamerus galeatus; the latter, Stringocephalus Burtini, Heliolites porosus, etc. The Upper or Famennian, over 2500', consisting of the Frasnian shales and limestone below, and the Famennian shales and Sandstones of Condros above, with Atrypa reticularis, Orthis striatuta, Spirifer Verneuiti (S. disjunctus), Clymenia, Archaopteris Hilienica, Sphenopteris flaccidu. The Devonian outcrops also to the northwest in the Bonlonnais, in Brittany and the Vosges, and to the eastward, in the Harz and Thuringia. 
In the Eifel, the three divisions, the Rhenan, Eifelian and Famennian are well developed. The Rhénan contains Dalmanites, Placops latifrons, Spirifer cultrijugatus, etc. The Eifelian consists below of the Calceola bers, with C. sandalina and Spirifer cultrijugatus, and above, of the Stringocephalus beds.

The Famennian, or Upper Devonian, consists of (1, or below) the Cuboides shale with dolomytic beds, containing Rhynchonella cuboides, Spirifer glaber, S. Verneuili, S. Urii, Atrypa reticularis, Athyris concentrica, Productus subaculeatus, Camarophoria formosa; (2) Goniatite bed, with Goniatites retrorsus (Fig. 987), G. primardialis, Orthoceras subflexuosum, Bactrites gracilis, Pleurotomaria turbinea, Cardiola retrostriata, Cypridina serrato-striata; (3) the Cypridina shale, with C. serrato-striata (Fig. 989) and Posidonomya venusta.

Similar subdivisions occur in Westphalia and Nassau, the Fichtelgebirge, and other areas of Germany. In the Thuringian Forest and the Fichtelgebirge, the Upper Devonian contains in the Clymenia and Orthoceratite limestones, Clymenia lovigata, C. undulata,

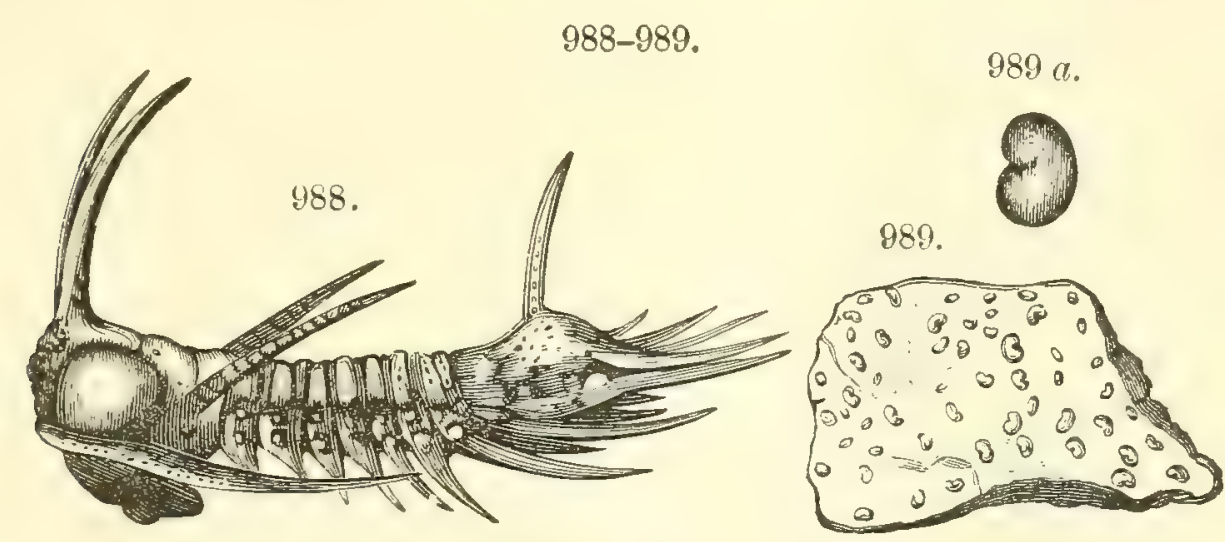

Crustaceans. - Fig. 958, Arges armatus of the Eifel; 989, slate, from Weilburg, containing Cypridina serratostriata, natural size; $989 a$, same enlarged. Vogt.

Goniatites retrorsus, G. intumescens, Orthoceras interruptum, Gomphoceras, Cyrtoceras, Athyris concentrica, Rhynchonella cuboides, Bronteus arandis, and other species, besides remains of Catamites, Lepidodendron, Stigmaria, Aporoxylon.

In Russia (the Continental Interior of Europe) the Devonian beds cover a large area, and are nearly horizontal. The western areas include only Middle and Upper Devonian. Below are limestone and red marls; and above, limestone and shales with some sandstones, having partly the character of the Old Red sandstone of Scotland, and like that containing, says Murchison, remains of Fishes as almost the only fossils. Pander has described species of Coccosteus, Osterlepis, Dipterus, and Diplopterus from the Middle, and Holoptychius nobilissimus, Pterichthys major, and Asterolepis from the Upper. The Lower, Middle, and Lpper Devonian occur in the Urals, through nearly the whole length of the range.

In South America, Devonian beds occur over the Highlands of eastern Bolivia, — Lower and Middle Devonian (D'Orbigny, M. D. Forbes, Steinmann); in the region of Lake Titicaca, Lower Devonian (Agassiz and Garman); in Brazil, in the province of Para, north and south of the Amazon, 200 to 400 miles from the coast, Lower, Middle, and Upper Devonian (O. A. Derby, and others); in the Falkland Islands(Darwin). In the vicinity of the Amazon, on its north rise, Hamilton beds include species of the genera Fituline, Tropidoleptus, Retzia, and others, described by Rathbun, and one variety of Discina Lodensis Hall. Ulrich reports, from eastern Bolivia, species of the genera Leptocoetic, Vitulina, and Tropidoleptus, besides others, and states that the first of these three genera occuirs also in the Devonian of the Falkland Islands and of South Africa, and that the second is also South African. (For remarks on the distribution of these and other genera, see 
Address of H. S. Williams, Am. Assoc., 1892.) The Icla shales of Bolivia are Corniferous, and the Huamampampa sandstone is Hamilton.

In southwestern China Richthofen obtained from the Devonian beds the wide-range fossils Pentamerus galeatus, Atrypa reticularis var. desquamata, Merista plebeia, Spirijer Tremenili (=disjunctus), Orthis striatula, Productus subaculeatus, Strophalosia productoides, Rhynchonella cuboides, $R$. pugnus, Autopora tubiformis (China, iv., 75).

Australian Devonian beds of the Rydal District, and to the north and south of it, have afforded the species Cyathophyllum Damnoniense, Favosites reticulatus, F. fibrosus, Heliolites porosus, Chonetes Hardrensis, Orthis striatula, Rhynchonella pleurudon, $R$. pugnus, R. cuboides, Atrypa reticularis, Spirifer Verneuiti, and also the plant Lepidodendron (W. B. Clarke, On. Sedim. Form. N.S.W., 4th edit., 1882). The Devonian occurs also in Queensland, and near Bathurst in Tasmania.

\section{GEOLOGICAL AND GEOGRAPHICAL PROGRESS DURING THE DEVONIAN.}

\section{AMERICAN.}

In the Devonian era, as in the Upper Silurian, the great rock formations that are open to investigation were the work of the Interior Continental waters. Progress was still, in the main, endogenous, or within the Interior Sea. No Paleozoic rocks, later than the Lower Silurian, have yet been reported from the Atlantic border, along the coast region of New Jersey and the states southward.

The confined condition of the Eastern Interior Sea, or Bay, had, with the progress of the era, an increasingly profound influence on the nature of the successive formations. The bay had its northwest passage over Michigan open, but not the northeast passage to Canada. The Devonian, as has been shown, began, like the Silurian, with beach and sea-border deposition, sparingly fossiliferous, marking off the coast-line on the north and northeast, and an off-shore bay-like formation - the Schoharie - bearing evidence of abundant life. But these rocks had acquired little thickness before the commencement of the Corniferous limestone formation, or rock coral-reef, when clearer waters, with growing Corals, Crinoids, Trilobites, and other species of the purer seas, were in great profusion, and spread from near the Hudson to Missouri and Iowa. The waters reached north to Mackinac, the head of a great Michigan bay of the era, but appear not to have covered northern Illinois or Tisconsin. Moreover, the Canada and New England seas also had their coral reefs.

It is remarkable that this coral-reef rock is not recognized over Pennsylvania and to the southwest. The Eastern Interior Sea had open connection with the Central Interior by the northwest. As to the southern entrance, nothing is known.

At the close of the Early Devonian the evidences of clear seas - the Corals and Crinoids, with most of the attendant life — disappear, migrating no one knows whither. Depositions of silt, mud, and sand prevail to the eastward with various alternations and but thin interealations of limestone; and so it was also over the Central Interior, except sparingly in the Hamilton 
period. With the variations in the fineness, or other characteristics of the beds, as H. S. Williams has illustrated, the species vary. The fine shales of the Marcellus and Genesee shales have few and small species, owing to some unfavorable conditions; and, in part, the species are repeated in each later return of the beds to fine shales. With the coarser sand-beds of the Hamilton and Chemung, life abounds; but Brachiopods and Lamellibranchs predominate, especially in the latter, where Trilobites fail completely. With beds of intermediate character, as those of the Portage, life is much less abundant than in the Chemung - except at one time of change to beds allied to those of the Hamilton and Chemung (the Ithaca beds), when the life takes a character resembling that of the latter period. A thin limestone stratum in some cases indicates by the species an approximation again to the clearer waters of the Corniferous. There are thus alternations in living species correlatively with alternations in kinds of deposits. The species evidently migrated in the direction in which the conditions were favorable to them. The faunas of each stratum are not strictly faunas of epochs or periods of time, but local topographical faunas. After the Corniferous period, Corals, Crinoids, and Trilobites still flourished somewhere, as before; but they are absent from the Central Interior until the Carboniferous age opens.

The condition producing the Genesee shale in New York appears to have spread westward over Ohio, and to have invaded the Central Interior through Michigan, Indiana, the southern half of Illinois, and southward to Tennessee; and to have continued to prevail over this great region through the remainder of the Devonian era with but little change. The area was mud-making, with more evidence of fresh-water or brackish-water life than of marine conditions, and it probably had its extensive shallow lagoons and bayous in which lived the great Ganoids and Eurypterids. During the Later Devonian, in the Eastern Interior Sea, the Catskill sandstone to the northeast - a shore and off-shore formation of the Interior Continental Sea - reached a thickness of 3000 to 7545 feet (I. C. White), because it lay within the range of the Appalachian geosyncline.

If the condition of the Atlantic border, its sounds and bays, with their varying depths and fortunes, and of off-shore deeper waters and depositions and fresh-water inlets, be taken as a type of the conditions and depositions that existed in several successions within the Eastern Interior Sea, no difficulty will be found in finding a reason for all the variations in wave action, in tidal and current action, in depth, in purity of waters - ranging off to over-fresh or over-salt conditions, which may be needed to explain the geological and biological facts of the Middle and Later Devonian.

The effects of tidal currents appear to be marked in the Chemung beds of western New York and Pennšlvania, and eastern Ohio. The strata of coarse conglomerates occurring among the sand-beds appear to be due to their action. The tidal waters, which, in their rounds, converged from the south and west toward the head of the Eastern Interior Bay, with increasing height 
as they advanced, may have made their ebb or their flow over this more western part of the bay-like channel; and, by their rapid movement, have produced the assorting of the gravel and the accumulations of large stones or pebbles; and they may also, by some variation in their route, as time passed, have made pebble deposits locally at different levels. Such rapid tidal flows, causing the stones in shallow waters to slip over one another with each return of the current, would tend to make them flat, as in the Panama conglomerate, and not round as in ordinary round-pebble conglomerates, the latter being work of plunging waves along a beach and of strong currents.

\section{BIOLOGICAL PROGRESS.}

The progress of the systems of life through the Devonian era was continued into and through the following era without any abrupt transition, and the review of the subject is given for both eras after the account of the Carbonic era.

\section{UPTLRNING OR MOUNTAIN-MAKING AT THE CLOSE OF THE DEVONIAN.}

Through nearly all of North America, where Devonian and Carboniferous rocks occur together, the two formations pass into one another continuously, as if one in series. But in eastern Canada at Gaspé, in Maine, and in Nova Scotia, and at Perry in southern New Brunswick, as reported by Dawson and Logan, there was an upturning of the Devonian and inferior beds, so that the overlying Carboniferous rests upon them unconformably. Dawson makes the unconformability general for the Acadian Provinces.

The upturning and crystallization of the Devonian and Upper Silurian beds of the Connecticut valley, as well as of those of Lake Memphremagog and the St. Lawrence valley, may have been a part of the events of this epoch. But it is equally possible and probable that the upturning took place at the close of Paleozoic time.

In Great Britain, Russia, and Bohemia, some evidences of upturning between the Devonian and Carboniferous have been observed, and not in central and southern France. But all these cases are small exceptions to the general fact that the Lower Carboniferous and the underlying rocks are conformable almost the whole world over. The epoch of transition was not an epoch of general disturbance. There were extensive oscillations of level; but for the most part they involved no violent upturnings. The following era opens with a period of marine formations; and the beds accumulated, in most regions where they occur, are a direct continuation of the deposits of the Devonian. 


\section{CARBONIC ERA.}

Srnonymr. - Carboniferous and Permian periods, Lyell (Elements of Geol., 1839), and other British geologists, German geologists, and D'Orbigny, 1851, in France. Carboniferous age (Permian included), Dana, Man. Geol., 1st edit., 1863, $2 d$ edit., 1874, 3 d edit., 1880; Le Conte, Elements of Geol., 1877, and later; A. Winchell, Geol. Studies, 1886. Permo-Carboniferous, Dawson, Suppl. Acad. Geol., 1878. Carboniferous, Permo-Carboniferous, W. M. Fontaine and I. C. White, on Permian Plants of W. Va. and Penn., 1880. Permo-Carbonifère, Lapparent, Tr. de Géol., 1883. Permo-Carbonic, Portuguese Committee Internat. Congr. Geol., 1886. Carbonic (Permic or Permian included), E. Renevier, Tableau des Terrains Sedimentaires, 1874, Int. Congr. Geol., 1880.

This first great coal-making era in the world's history commenced, both in Europe and America, with an extensive submergence of the land and a consequent formation of marine terranes of great thickness over parts of the continental areas. It passed its culmination during a long period of gentle oscillations in the surface, causing successive, more or less wide, emergencies and submergencies, the former favoring the growth of boundless forests and jungles, the latter burying the vegetable debris and other terrestrial accumulations beneath marine or fresh-water deposits. It declined through a period in which the Carboniferous marshes gradually disappeared, as the sea regained its place over the land; but again to retreat, as Paleozoic time ended, and the making of the Appalachian Mountains - the next great event in North American history — was commenced.

The occurrence in Europe of alternating conditions like those of eastern North America is part of the evidence that the coal formations of the two continents were essentially cotemporaneous in origin. Facts from the fossils sustain this conclusion. They lead to the following subdivisions of the era :-

\section{Sobdivisions of the Carbonic Era.}

3. Permian Period. - Part of New Red Sandstone or Poikilitic group of J. Phillips (the rest Trias).

Lower New Red Sandstone or Magnesian limestone group, Lyell, El. Geol., 2 d edit., 1841.

Permian, Murchison, Leonh. u. Bronn's Jahrb., 1841, Phil. Mag., xix. 417; Murchison, de Verneuil, and Keyserling, Geol. Russ., 1845; Lyell, El. Geol., 3d edit., 1851. Permisches System, Geinitz, 1848, 1858.

Part of Mercian (the rest Triassic and Jurassic), T. McK. Hughes, Proc. Cambr. Phil. Soc., iii. 24.

Dyas, J. Marcou, Dyas et Trias, Genève, 1859, H. B. Geinitz, 1861, 1862 (Murchison's Permian having been made by him to include a small part of the Trias in Germany, though not of that in England).

2. Carboniferous Period. - The Coal-measures, with the underlying Millstone Grit.

Carboniferous period of Lyell, Murchison, and other English geologists (the Mountain limestone commonly included). 
Carboniférien, Calcaire Carbonifère et Terrain Houiller, E. de Beaumont, D'Orbigny.

Carboniferous Period, Dana, Man. Geol., 1st. edit., 1863 and later.

Pennsylvanian, H. S. Williams, U. S. Geol. Surv., Bull. 80, 1891.

1. Subcarboniferous Period. - Mountain, or Carboniferous, limestone, the lower division of the Carboniferous system, Murchison, Lyell, ete.

Lower Carboniferous. Lower part of the Système Carboniférien, Calcaire Carbonifère, D'Orbigny, Lapparent. Pergkalk, Untercarbon.

Subcarboniferous, D. D. Owen, Rep. Geol. Wisconsin, Iowa, and Minnesota, 1852 ; Dana, Man. Geol., 1863 and in subsequent editions.

Subcarbon, Steinmann and Döderlein, Elem.d. Pal., 1888.

Mississippian, H. S. Williams, U. S. Geol. Surv., Bull. 80, Correlation of the Devonian and Carboniferous, 1891.

Eocarboniferous, H. S. Williams, Journ. Geol., Chicago, 1894.

The comprising of the Permian period and the Carboniferous in a common era is questioned by some geologists. In North America the Permian beds are a direct continuation of the Carboniferous, and from the general absence of vertebrate and invertebrate fossils they are scarcely separable in most regions except through a careful study of the fossil plants. Such a study, made for Pennsylvania and Virginia in part by Lesquereux, but with completeness by Fontaine and I. C. White, has afforded satisfactory proof, as they state, that the Permian is fully represented in eastern America, and that the period is here only a continuation of, or a closing addition to, the Carboniferous period. There is the same evidence from the plants and also from the nearly universal conformity in the stratification of the two formations as to the close relations of the two periods in Europe, and this is sustained paleontologically, as these authors remark, "by the investigations of Weiss, Grand' Eury, and others."

The other continents were not so well supplied with coal-making areas as North America and Europe. South America has the rocks over part of its great interior, with little of the coal, and is in this respect like the western half of North America.

Asia has much coal of the Carboniferous period in northern China. But in India, or southern Asia, the chief coal era began in the Permian and continued into the Triassic; and the same was true for southwestern Africa, and the southern continent, Australia. The fact that one of the world's hemispheres was not concurrent in its geological movements with the other, mentioned on page 406, is here exemplified. It has afforded some strength to the argument that the Permian period should not be united to the Carboniferous. But the distinctions that exist can be recognized and appreciated for lands about the Indian Ocean, without interfering with the chronological subdivisions which best accord with the facts in the others where these subdivisions were first laid down. 


\section{NORTH AMERICA.}

\section{TOPOGRAPHY.}

The topography of the continent at the commencement of this era is approximately represented on the accompanying map, Fig. 990, on which the dotted lines over the surface, marking river courses, outlines of lakes, etc., are to be taken only as indicating positions. The chief change since the commencement of the Upper Silurian (page 536) is in the eastern portion or that of the Eastern Interior or Great Northeast Bay, which, at the opening of the coal era, was a complete bay in outline, reaching northeastward to the

990.

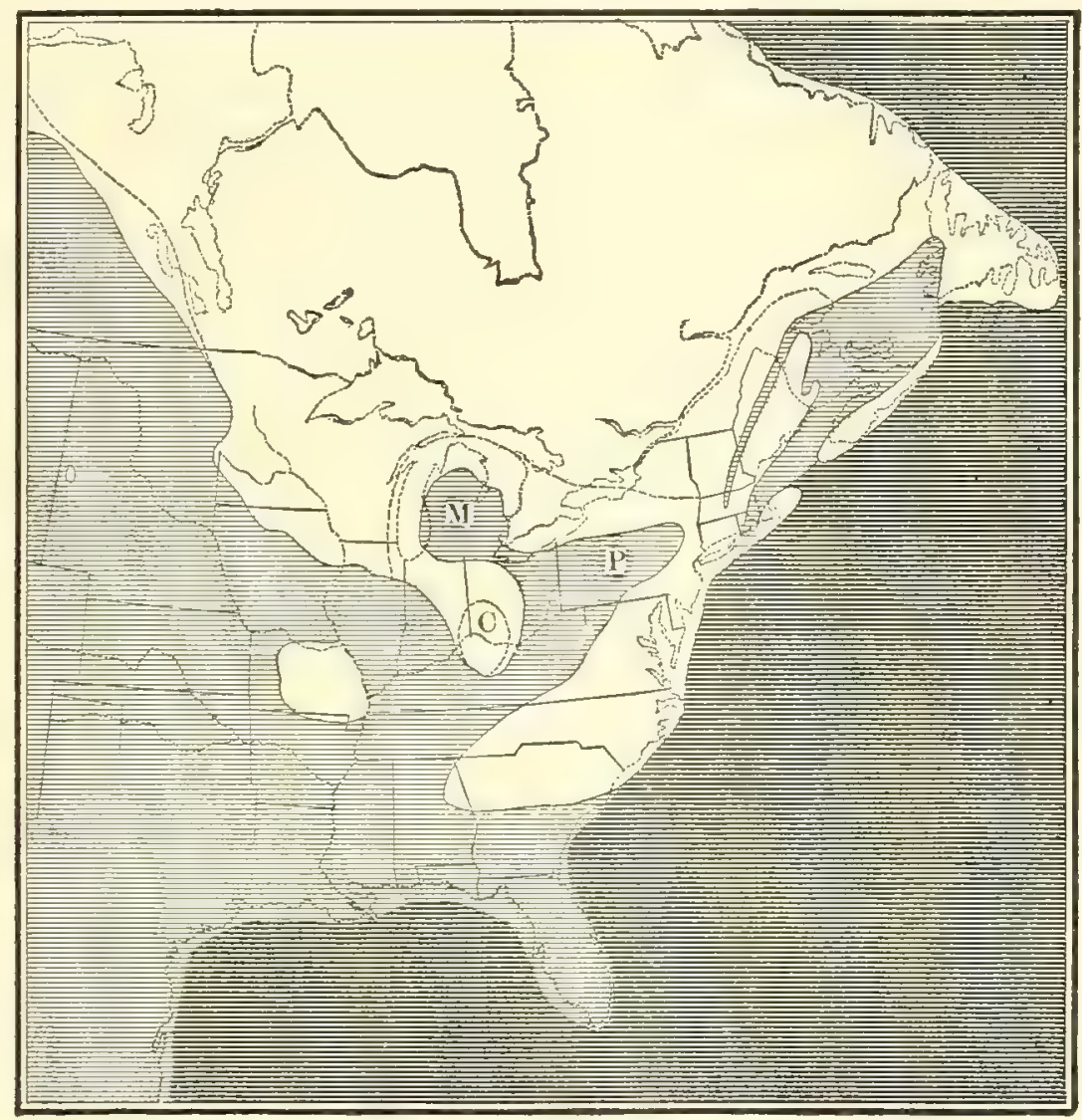

Map of part of North America at the commencement of the Carbonic era.

boundary of northeast Pennsylvania. It was in fact a double-headed bay, a branch passing northwestward from the Pennsylvania portion or bay $(P)$, over Michigan, and making thereby a Michigan Bay $(\boldsymbol{M})$. The Cincinnati Island $(C)$ became part of the mainland, while the Tennessee was submerged. In addition, the Connecticnt valley trough and the St. Lawrence valley trough were probably above the reach of salt water, or, at least, were not subsiding troughs, for no Carboniferous rocks occur within them; they were probably the courses of fresh-water streams. But the Gaspé-Worcester trough must have been an open channel, southward to Worcester at least, and the Acadian trough, from western Newfoundland to Narragansett Bay, was a still larger 
channel, in coal-making times, as is proved by the coal-beds in Newfoundland, Nova Scotia, and New Brunswick on the north, and in Rhode Island and a part of eastern Massachusetts on the south.

The Western Interior, Rocky Mountain, and Pacific Border regions of the continent were largely covered by the Mediterranean Continental Sea, so that the western part of the map for the Upper Silurian era, on page 536, answers sufficiently well for this portion of the continent in the Carbonic era.

\section{SUbdivisions.}
PENNSYLVANiA,
3. Permian Period. $\left\{\begin{array}{c}\text { The Upper Barren } \\ \text { Measures }\end{array}\right.$ \{ Measures.
MISSISSIPPI BASIN.
Permian beds.

\section{Carboniferous}

Period.

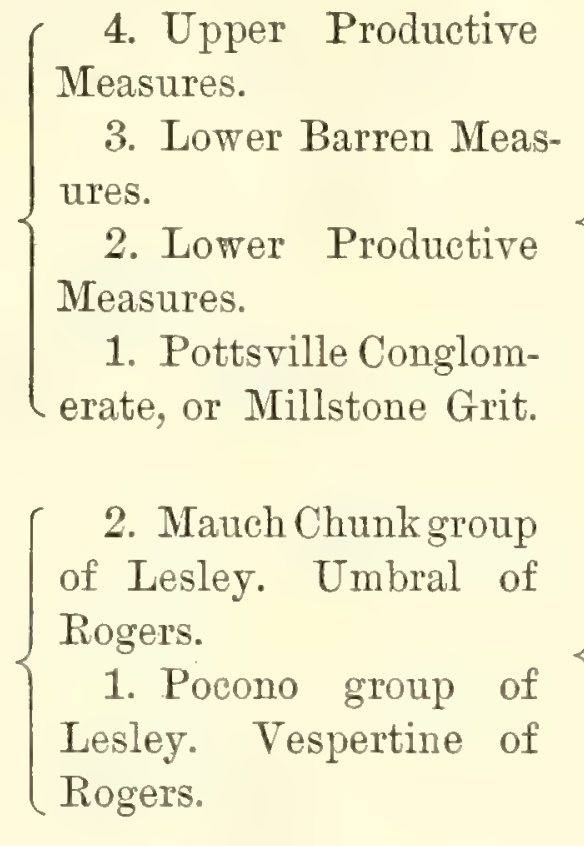

2. Coal-measures.

1. Millstone Grit.

4. Chester, or Kaskaskia group.

3. St. Louis group.

2. Osage $\left\{\begin{array}{l}\text { Warsaw. } \\ \text { Keokuk. }\end{array}\right.$ group. $\quad\left\{\begin{array}{l}\text { Keoluk. } \\ \text { Burlington. }\end{array}\right.$

1. Kinderhook group.

The Subcarboniferous rocks of the Mississippi basin are mainly great limestone formations. The term Subcarboniferous was first applied to them by D. D. Owen in his Quarto Report, of 1852, on the Geology of Wisconsin, Iowa, and Minnesota. In this report (page 90) he divides the Carboniferous rocks of Iowa into "(1) the great calcareous formation at the base, (2) the coal-bearing strata in the middle, and (3) heavy beds of sandstone at the top," and gives (on page 92) a section of the "Subcarboniferous limestones." On the following page he presents a "table exhibiting the analogy between the Carboniferous limestones of Yorkshire, England, and those of Iowa," thus applying the term, in effect, to the corresponding rocks of Great Britain and Europe. The preposition sub is here used in the same sense as in substructure; and the great limestone formations of the Mississippi basin make a grand substructure for the coal-measures or the beds of the Carboniferous period. The term Mountain limestone, used for the British rocks, and for awhile employed in the United States, is not applicable to limestones of the plains. 


\section{GENERAL DISTRIBUTION OF THE ROCKS OF THE ERA.}

The geological map on page 412, though small, is sufficiently detailed to give a general idea of the distribution of the Carboniferous and Subcarboniferous areas of the eastern part of the continent. The former are distinguished by doubly cross-barred marking; the latter, which border these, by singly cross-barred, with a cross in the small squares. The several areas of the two combined formations are as follows:-

I. The Acadian : covering part of western Newfoundland, of Nova Scotia, and of New Brunswick.

II. The Rhode Island: covering part of Rhode Island, and extending northward and eastward into Massachusetts.

III. The Worcester area: about Worcester, Massachusetts.

IV. The Michigan area: occupying the larger part of Michigan between the southern half of Lake Huron and Lake Michigan, having the coalmeasures over its central portion.

T. The Pennsylvania-Arkansas area: stretching in a zigzag way over 25 degrees of longitude and 12 of latitude; first, from the southern border of western New York, and a line just south of Lake Erie, to Alabama and Mississippi; then, northward and westward to Illinois and Iowa; thence southward and westward again to Arkansas and Texas. At the western limit commences the "Western Interior Sea," where the Carboniferous strata pass out of sight beneath those of the Cretaceous. The coal-measures of this area are mostly in three parts, underlaid and connected by the Subcarboniferous. These parts are thus separate, either because never united, or more probably because of the removal of the coal-measures that once covered the intermediate Subcarboniferous beds.

VI. Over the Western Interior and along the summit region of the Rocky Mountains, but without coal, and mostly as a limestone wherever there are outerops.

TII. Along parts of the Great Basin, being a constituent of many of the mountain ridges; also in the Sierra Nevada, and in other portions of the Western border region.

TIII. In the Arctic regions, along a wide belt between the parallels of $72^{\circ}$ and $82 \frac{1}{2}^{\circ}$, northeast in course, from Banks Land on the west to Grinnell Land on the east, and reaching beyond the latter to $83^{\circ}$, nearly the most northern point of Arctic exploration. Also on Spitzbergen and Bear Island.

The Coal-measures, or the areas of the Carboniferous period, have a smaller range, and the productive Coal-measures, a still smaller. Of the above eight regions, only numbers I., II., IV., and V., to the east of the meridian of $100^{\circ} \mathrm{W}$., are coal-producing; but the Arctic beds of Grinnell Land afford coal, which may be available whenever the seas shall become navigable.

The term Permo-Carboniferous is sometimes used for the beds of the Carboniferous and Permian periods of central and eastern North America, because they make an essentially undivided series. 


\section{Subcarboniferous Period.}

\section{ROCKS-KINDS AND DISTRIBUTION.}

The Subcarboniferous period, like several other periods of the Paleozoic, is noted for extensive limestone formations with thin shales and sandstone over the Central Continental Interior, or the area of the Mississippi basin; for sandstones and shales, with little limestone, along the Eastern Interior region, especially its northern bay-like portion; and, like all the preceding periods after the close of the Lower Silurian, for no deposits yet known over the Atlantic continental border south of the latitude of New York. The peculiarities of the Eastern Interior are attended by another distinctive feature: The limestones of the Mississippi basin abound in fossils, especially Crinoids, Brachiopods, and Corals; and, owing to the Crinoids, they are often called Crinoidal limestones; while the fragmental rocks to the eastward contain fewer fossils, and almost all of these are of different species from the western, except where limestone occurs in the series. Owing to the wide differences in the rocks and fossils, there is much difficulty in bringing the beds of the two distant regions into parallelism.

The rocks of the lower of the two groups in Pennsylvania, the Pocono, are mainly beds of hard gray sandstone and conglomerate; and those of the upper, the Mauch Chunk, reddish shales and shaly sandstones. In southwestern Pennsylvania a thin bed of siliceous limestone makes the top of the Pocono, and a similar layer occurs also in the upper shales.

The enduring Pocono sandstone is 800 feet thick near Pottsville, Pa. It extends northeastward, capping at many points the high northern plateau of the state; and it also stretches southwestward, making the summit, in Bedford County, of the Alleghanies, where it is 1400 feet thick - holding its place against denuding agencies. It is supposed, by Lesley, to constitute some hundreds of feet of the higher peaks of the Catskills. The overlying Mauch Chunk shale is a fragile rock and was easily swept off by denuding waters from the Pocono floor. Its thickness is stated to be 3000 feet at Pottsville. The two formations thin down to 600 feet, in southwestern, and 300 feet in northwestern, Pennsylvania.

The thickness of the limestone layers of the Eastern Interior increases in West Virginia; and in the southwest counties of Virginia becomes rather abruptly over 2000 feet thick. Farther south, in Tennessee and Alabama, siliceous beds and cherty limestones make the chief parts of the formation, and they once covered the Silurian limestone basin of central Tennessee. Some thin beds of coal occur in the upper formation, and one in southwest Virginia, near New River, is worked.

In Ohio, about 600 feet of shale and sandstone are overlaid in some parts by 15 to 20 feet of limestone. In Michigan, the beds are chiefly shales and limestones, with less than 70 feet of limestone in the upper part.

The limestones of the Mississippi basin, with the included shales and sand- 
stone, - constituting the Mississippian group of Williams, - have an aggregate thickness in southwestern Illinois of 1200 to 1500 feet. They thin out northward in this state before reaching Rock Island County; and beyond, the coal-measures rest on the Devonian. These limestones extend in part into Iowa, Indiana, Kentucky, Missouri, and southward into Texas. The Kinderhook group extends far into Iowa; but after its deposition a long retreat of the shore line took place before the Burlington beds, the first part of the Osage group, were deposited; and this retreat was continued after the deposit of the Burlington group. But before the St. Louis epoch began there was a subsidence, allowing of an advance again northward, as the northward extension of the beds shows. There is thus unconformability by overlap of the St. Louis limestone over the underlying beds, as stated by C. A. White (1870, Rep. Iowa).

The subdivisions of the Mississippian group in Illinois and the adjoining parts of the Central Interior area are arranged as follows by C. R. Keyes (G. S. A., 1892): -

1. The Kinderhook Group. - This group was so named by Meek and Worthen (1861). The "Lithographic limestone," "Vermicular sandstone and shales," and "Chouteau limestone " of Missouri, are three rather persistent divisions. The term Louisiana, from a place in Pike County, Mo., is used by Keyes in place of Lithographic, and Hannibal shales for Vermicular sandstone and shales. The "Louisiana" limestone is 60 ' thick in Missouri. The Hannibal shales are reported from Iowa, as well as Missouri, with a thickness of $70^{\prime}$ to $150^{\prime}$ or more. The Chouteau is a fine buff-colored limestone, $10^{\prime}$ to $15^{\prime}$ thick at Hannibal and Louisiana, $100^{\prime}$ or more at Sedalia, in Missouri, and perhaps 50' at Burlington, Iowa. The Goniatite limestone of Rockford, Ind., was referred to the horizon of the Chouteau by Meek. The larger part of the "Knobstone group" of sandstones and shales (partly calcareous), which makes the eastern border of the Carboniferous area of Indiana, is referred to the Kinderhook.

2. The Osage Group. - The subdivisions of the Osage group - so named by H. S. Williams - are: (1) Lower Burlington, (2) Upper Burlington, (3) Keokuk, with the "geode-bed" and the Warsaw shales and limestone. The Lower Burlington is described as having Crinoids of delicate forms; the Upper, of stouter forms; the Keokuk, of still coarser and larger kinds, massive in construction. The geode-bed is a bed of blue shale, $30^{\prime}$ to $: 85^{\prime}$ thick, containing thin layers of limestone. The geodes are sometimes $2^{\prime}$ in diameter; they contain within: quartz crystals, agate, crystals of calcite, dolomite, and often pyrite, sphalerite, millerite (in hair-like needles, or tufts of needles), besides other minerals. An extermination of a large part of the Feokuk species occurred at the close of the epoch.

3. The St. Louis Group. - The St. Louis limestones were so named by Shumard from the evenly bedded limestone of St. Louis, Mo. They are oölitic 3 miles above Alton. The northern limit in north-central Iowa, near Fort Dodge, is the evidence of the northward return of the shore line for several hundred miles beyond the limit of the Keokuk, and here the beds are fossiliferous marls. In St. Genevieve County, Mo., the thickness of the beds is over $300^{\prime}$, and it is still greater to the southeastward. The rock at Spergen Hill, Ind., is of this division.

4. The Chester or Kaskaskia Group. - This group includes limestone, in three or four beds, with intercalated shale and sandstone, and sandstone below; it is occasionally 600 ' thick. It comprises the "Pentremital" limestone, and the "Upper Archimedes" limestones, called also the "Kaskaskia" limestone. The stratum of sandstone at the 
bottom is the fermginous sandstone of Shumard. The sandstone is regarded by C. R. Keyes as having been made while a final retreat of the shore line was in progress. $\mathrm{He}$ names it the "Aux Vases" sandstone.

The section of the Subcarboniferous at Burlington, Iowa, includes: (1) of the Kinderhook, $50^{\prime}+$ of clay shale; (2) $20^{\prime}-30^{\prime}$, soft shaly sandstone; (3) gray impure limestone, often oölitic below, $9^{\prime}-13^{\prime} ;(4)$ fine sandstone, $6^{\prime} ;(5)$ gray oölyte, $4^{\prime} ;(6)$ buff limestone, $5^{\prime}$, of the Lower Burlington; (7) brown and gray encrinal limestone, $2 \bar{\tau}^{\prime}$; (8) buff calcareous and siliceous shales, with thin limestone layers and chert, $2 \cdot 3$ ', of the Cpper Burlington; (9) gray encrinal limestone, somewhat cherty, $30^{\prime} ;(10)$ impure limestone with chert nodules and seams, $20^{\prime}$ (Keyes). The Keokuk exposures include about $100^{\prime}$ of Keokuk below and above Warsaw and St. Louis beds.

Keyes has further reported (Dec, 1892) the discovery, in northeastern Missouri, of a bed of the Kinderhook limestone, containing its typical fossils, and these chiefly Mollusks, intercalated in the overlying Burlington group, where typical in its fauna, and this chiefly crinoidal, and without a change in lithological characters or the purity of the limestone beds. It shows, as Keyes observes, that the Kinderhook and Burlington stages were not wholly successive as regards time; that after the Burlington group had made progress, the Kinderhook species still existed, for a while at least, outside of their former limits, but ready to return when the conditions favored. In Missouri, the whole thickness of the Subcarboniferous limestone is $1150^{\prime}$.

In Indiana, the "Knobstone," below the Keokuk, has a thickness in some places of $500^{\prime}$, the Keokuk of $100^{\prime}$, the St. Louis of $330^{\prime}$, and the Chester of $75^{\prime}$; the latter consists of sandstones alternating with limestones. In Lawrence County, an irregular bed, or series of pockets, of porcelain clay, ranging to $6^{\prime}$ in thickness, lies at the top of the Chester limestone, over a bed of iron ore. About a third is of pure white color. It has been called indianaite; with it occurs the mineral allophane.

In Michigan, the Subcarboniferous consists of four groups of strata, according to A. Winchell: (1) or lowest, 173' of grit and sandstone, called the Marshall Group; (2) $123^{\prime}$ of shale and sandstone, the Napoleon Group; (3) $184^{\prime}$ of shale and marlyte, with some limestone and gypsum, the Nichigan Salt-group; (4) the Carboniferous limestone, $66^{\prime}$ thick. This limestone is well exposed at Grand Rapids. The Marshall group is made the equivalent, in part, of the Kinderhook; and the limestone, at the top, the equivalent of the Chester and St. Louis groups.

In Ohio, the Subcarboniferous beds comprise the Waverly group.

In northwestern Penusylvania, the Subcarboniferous is in the main equivalent to the Waverly. I. C. White has recognized three divisions: (1) the Oil-creek group, the equivalent, it is believed, of the Pocono; (2) Meadville group; and (3) Shenango group. In Warren County, the Panama conglomerate is more than $20 \theta^{\prime}$ below the top of the Chemung, and may be recognized by abundant remains of Ptychopteria. The Waverly consists of shaly sandstones in its lower third, followed by a conglomerate (= Sub-Olean ?) above which are thin-bedded buff sandstones.

In West Virginia, the Lower Subcarboniferous occurs along the middle portion of the main Alleghany Mountains, from the Potomac southward. In Greenbrier County, near the White Sulphur Springs, it includes a stratum of limestone $822^{\prime}$ thick, with $1260^{\prime}$ of shales and sandstone. The limestone to the north, in Monongalia County, was found by Meek, through its fossils, to be the probable equivalent of the Chester group.

In middle Tennessee, according to Safford, the Siticeous group consists, commencing below, of (1) the Protean beds, cherty and argillaceous, with some limestone, $250^{\prime}$ to $300^{\prime}$, and (2) the Lithostrotion or Coral beds, an impure cherty limestone, the equivalent of the St. Louis limestone, about $250^{\prime}$ thick. The Upper member is limestone, $400^{\prime}$ thick on the northern borders of the state, and $720^{\prime}$ on the southern. These two divisions occur also in eastern Kentucky. The Upper member also extends into the northeast corner of Mississippi, where it is overlaid by Cretaceous beds (Hilgard). At Huntsville, Ala., 
Worthen found it to consist principally of gray limestone, partly oölitic, partly eherty, with some shaly beds, in all about $900 \%$. The larger portion of the series yields Chester fossils; but characteristic forms of the St. Louis group mark the age of the lowest $250^{\prime}$ to $300^{\prime}$.

In Nova Scotia and New Brunswick, the Subcarboniferous rocks are: (1) the Horton series, consisting of red sandstones, conglomerates, red and green marlytes; and, above these, (2) the Windsor series, consisting of thick beds of limestone, full of fossils, with some red marlytes, and beds of gypsum, affording the gypsum exported from Nova Scotia and New Brunswick. Thus the upper part is calcareous, as in Ohio, Tennessee, and West Virginia. The estimated thickness is 6000'. To the north, toward the Archæan, the limestones fail ; and, instead, the rocks are to a greater extent a coarse conglomerate. To the south, limestones prevail. The best exposures of the lower or Horton series are at Horton Bluff, Hillsborough, and other places in southern New Brunswick.

In the lower part of these Subcarboniferous beds, as in those of Virginia, there are, on a small scale, "false" Coal-measures, and, in one instance, a bed of erect trees, underclays, and thin coal seams; and the same beds contain numerous remains of fishes. The fish-bearing shales of Albert Mine, New Brunswick, are of this period (Dawson).

Rocky-Mountain and Pacific-border regions. - Over large portions of these regions, the limestones of the Subcarboniferous have not been distinguished from those of the following period. In most cases their recognition only waits for the more careful study of the fossils; but, at many points, these appear to be wanting. They have been identified. in the Elk Mountains, and other ranges of the crest chain of the mountains in western Colorado; on the eastern slopes of the Wind River Mountains, in Wyoming. In Montana, at "Old Baldy," near Virginia City, there are fossils of the Chester group, and probably the Lower Subcarboniferous beds are also present (Meek). In Idaho, near Fort Hall, Bradley found masses of limestone filled with minute shells, many species of which Metk has identified with forms characteristic of the oölitic beds of the St. Louis group, at Spergen Hill, Ind.

\section{LIFE.}

Plaxts. - The vegetation of the period included species of Lycopods of the genera Lepidodendron, Sigitlaria, Fnomia; Ferns of the Deronian genera, Archcoopteris, Neuropteris, Sphenopteris, Odontopteris, with species also of the new genera Alethopteris, Lesleya; Equiseta of the genera Calamites, Sphenophyllum, and Asterophyllites; and Cycads, under Gymnosperms, of the genus Cordaites; and among the fossil fruits, those cf Cordaites, and probably some of Conifers of the Yew family.

Axtmals. 1. Spongiozoans. Several sponges have been described of the genera Palcacis (which has deep cup-like cavities), Physospongia, etc. Hexactinellid sponges are common in the beds at Crawfordsville, Ind. The chert, which occurs in many beds, abounds in sponge spicules.
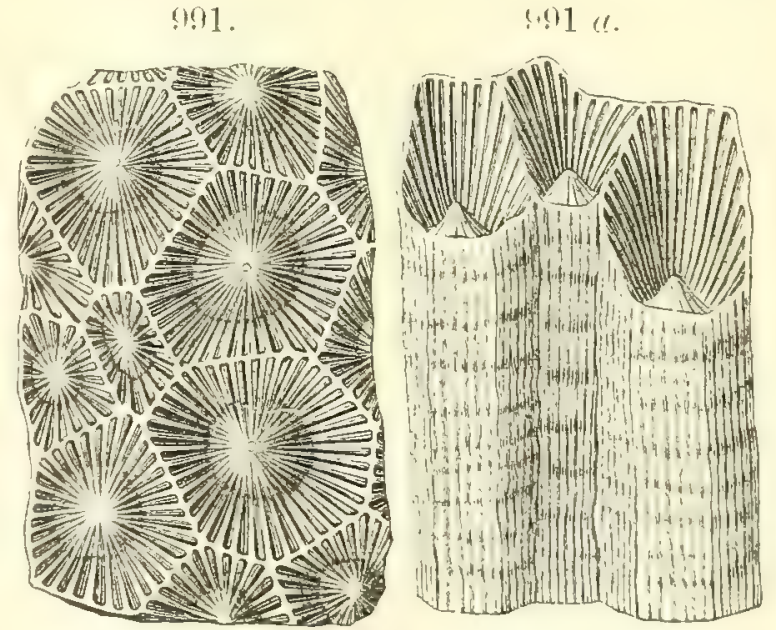

Polyp-Copal. - Fig. 991, portion of the Coral, Lithostrotion Canadense; $991 a$, vertical riew of the same. Meek and Worthen. 
2. Actinozoans, Echinoderms. - The animal life was remarkable for the abundance of a species of Lithostiotion, represented in Fig. 991, and for a great profusion and diversity of Crinoids. This Lithostrotion is often columnar in the external form of parts of masses (as shown in Fig. 991 a), although essentially a massive coral. Among other Corals the old genera $Z\left(w_{1}\right)$ hrentis and Cyathophyllum have their species, but not Favosites, Michelinia, Cystiphyllum, Diphyphyllum, Sarcinula, and others that were common in the Devonian. Species of Lithostrotion have been found in the Aretic lands between Point Barrow and Kotzebue Sound.

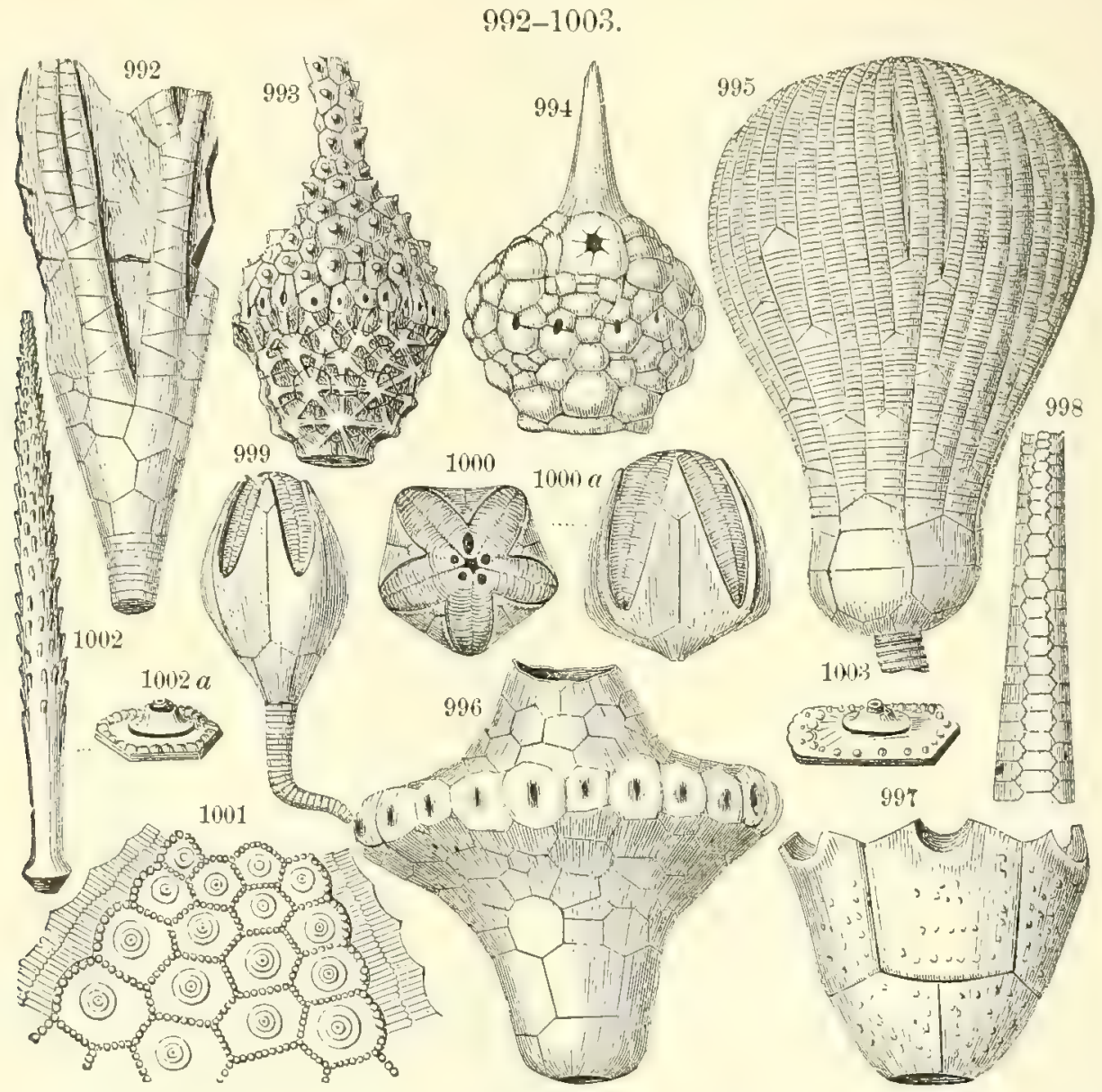

Eohivoperms. - Fig. 992, Scaphiocrinus Missouriensis; 993, Actinocrinus proboscidialis; 994, Dorycrinus unicornis; 995, Woodocrinus elegans ; 996, Batocrinus Christyi ; 997, Platycrinus Saffordi; 998, the proboscis of Batocrinus longirostris; 999 , Pentremites pyriformis; $1000,1000 a$, P. Godoni; $1000 a$, top view ; 1001 , portion of the shell of Archrocidaris Wortheni; 1002, spine of A. Shumardiana $(\times 2)$; $1002 a$, base of spine; 1003, id. of A. Norwoodi. Figs. 992-995, 997-1008, Hall; 996, Swallow.

The number of species of Crinoids described from the American Subcarboniferous limestone exceeds 650 . Some of the forms are represented in Figs. 992 to 1000, but mostly wanting the arms and stem, as is common with these fragile species. Fig. 995 represents the perfect body of Woodocrinus elegans, with the arms closed together, and, below, a few segments of the pedicel, which, entire, may have been a foot long; 992 is a Scaphiocrinus, with the arms broken. In Poteriocrimus Coxanus Worthen, the arms are six inches long, and the brealth of the expanded Crinoid must have been nearly 
a foot. Figs. 993, 994, 996, 997 are the bodies of different species of Crinoids without the radiating arms. The Crinoids often have a long or short proboscis-like projection, at the center above, which is made of stout calcareous pieces like the body, but is tubular; it is seen broken off in Figs. 993 and 996; and Fig. 998 represents one separate from the body of a Batocrinus (near that of Fig. 996), showing the calcareous pieces constituting it. Fine figures of the Subcarboniferous Crinoids, illustrating the wonderful diversity of forms among them, are contained in the Illinois, Iowa, and Ohio geological reports. In some species the length and form of the proboseis (which contains the anal or excretory tube, not that to the mouth) are very remarkable.

Two species of Pentremites, armless bud-shaped, five-sided species, of the tribe of Blastoids, eminently characteristic of the Subcarboniferous, are represented in Figs. 999, 1000.

1004.

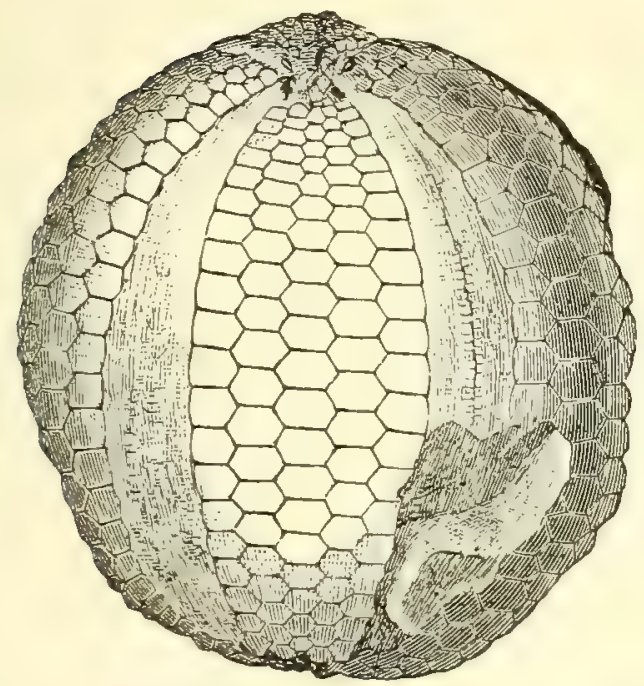

1005 .

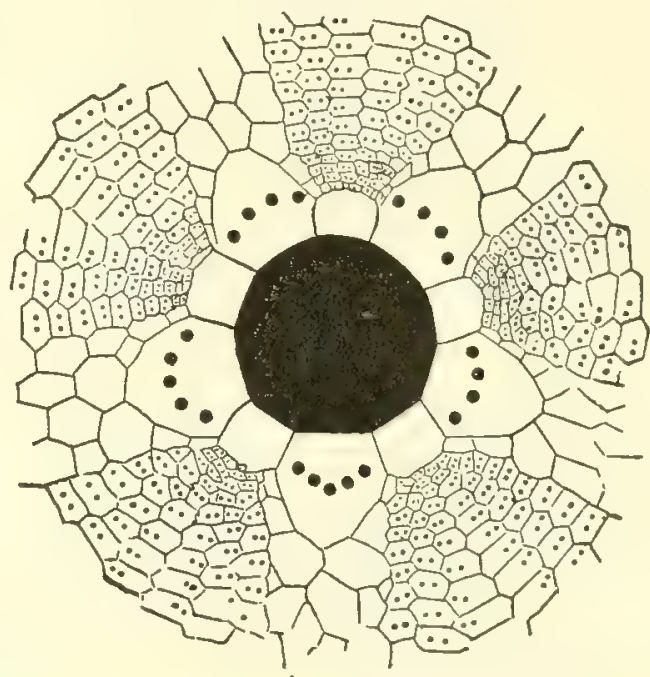

Echroms. - Fig. 1004, Oligoporus nobilis $\left(\times \frac{1}{2}\right) ; 1005$, Melonites multiporus, view of top $(\times 2)$. Meek snd Worthen.

Echinoids were of large size, and were unlike modern species in the excessive number of vertical series of plates between the ambulacral areas. One species (Fig. 1004) has 5 series of these plates, instead of the normal or modern number, two. In Archoeocidaris (a portion of a shell of one species of which is shown in Fig. 1001), the spines with which the shell was bristled were (as in modern species of Cidaris) of large size and few (like Fig. 1002 in form), as the large prominences over the shell (Fig. $1002 a$ ) indicate; but in Fig. 1004 they were very small. Fig. 1005 is a top view, enlarged, of Melonites multiporus. One very large slab in the Yale Museum, from St. Louis, MIo, contains 11 Melonites to a square foot. The generic name alludes to the resemblance in form to a melon.

3. Molluscoids. - Of Molluscoids, the screw-shaped Bryozoans, species of Archimedes, Fig. 1006, are characteristic. The screw has lost the larger DANA'S MANUAL - 41 
part of the blade, the part that carries, on its under surface, the cells occupied by the animals, as illustrated in Figs. $1007 a$ and $100 \pi b$.

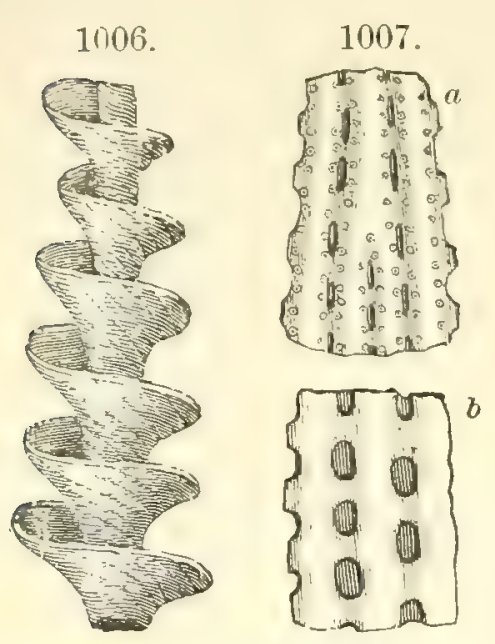

BryozoANs. - Figs, $1006,1007 a, b$, Archimedes Wortheni (1007 $a$ and $\left.100 \tau b, \times \frac{6}{1}\right)$. Hall.

Brachiopods were numerous, especially of the genera Productus (Fig. 1013), Chonetes (Figs. 1012, 1015), Spirifer (1010, 1014), Athyris, Dielasma and Rhynchonella. There were also species of the Luwer Silurian genus Orthis (Fig. 1008), but none of Stropheodonta, Merista, Meristella, so well represented in the Devonian.

4. Mollusks. - Among Mollusks, Lamellibranchs were common. Under Gastropods, the genus Bellerophon, which first appears in the Cambrian; the Lower Silurian genera, Euomphalus, Murchisonia, Pleurotomaria, and the Upper Silurian Platyceras, Loxonema, and Macrocheilus, which had many Devonian species, were still well represented. The shells of Platyceras are often attached to a Crinoid, like those of a modern Crepidula to an oyster.

Cephatopods were of many kinds under the old genus Orthoceras; and Discites, Goniatites, Gyroceras, had their species. Nautilus (Endolobus of Hyatt) spectabilis M. and W., from the Chester limestone, was two feet in

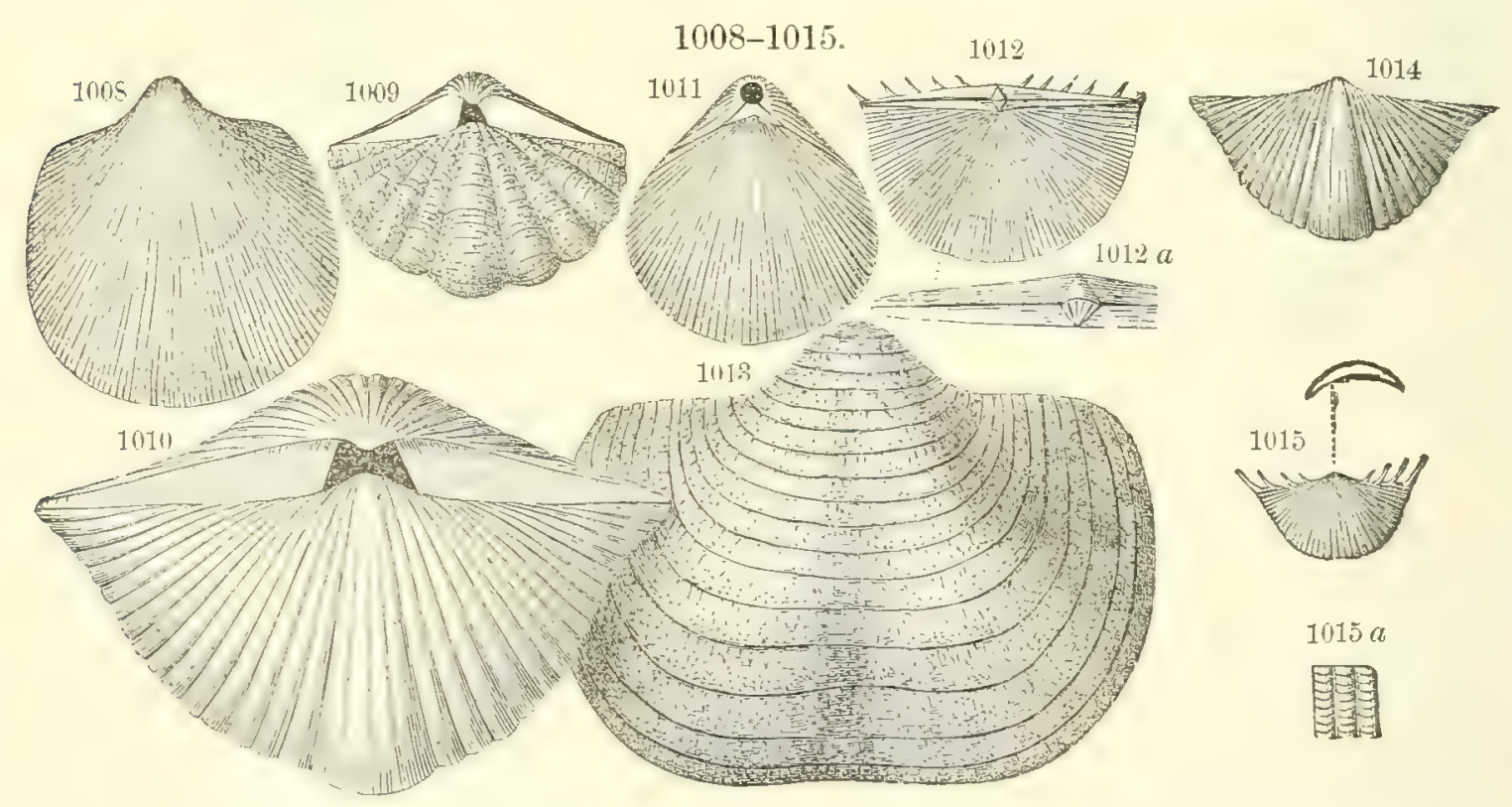

Brachiopons. - 1008, Orthis Michelini var. Burlingtonensis; 1009, Spiriferina spinosa; 1010, Spirifer increbescens ; 1011, Eumetria Verneuliana; 1012, Chonetes Illinoisensis ; 1013, Productus punctatus ; 1014, \$pirifer biplicatus; 1015, $1015 \mathrm{a}$, Chonetes ornatus. Figs. 1008-1011, Hall ; 1012, Koninck ; 1013, Meek; 1014, 1015, Swallow.

diameter; Orthocerus nobile MI. and W., of Illinois, was five to six feet long, and a foot in diameter; and Gyrocercs Burlingtonense Owen, five inches in diameter. The species represented in Figs. 1016,1017 are from the Goniatite bed of Rockford, Ind. 
5. Crustaceans. - Trilobites were of twenty or more species, all small primlooking forms, of the Devonian genera Proetus, Phothonides, and the related, but low-featured, Carboniferous genera Griffithides and Phillipsia. Half of the twenty species are of the genus Phillipsia.

The other Crustaceans known from the beds are Phyllopods and Ostracoids; and the shells of a Beyrichia make the chief part of the material of a layer four feet thick, north of Pella, Iowa.

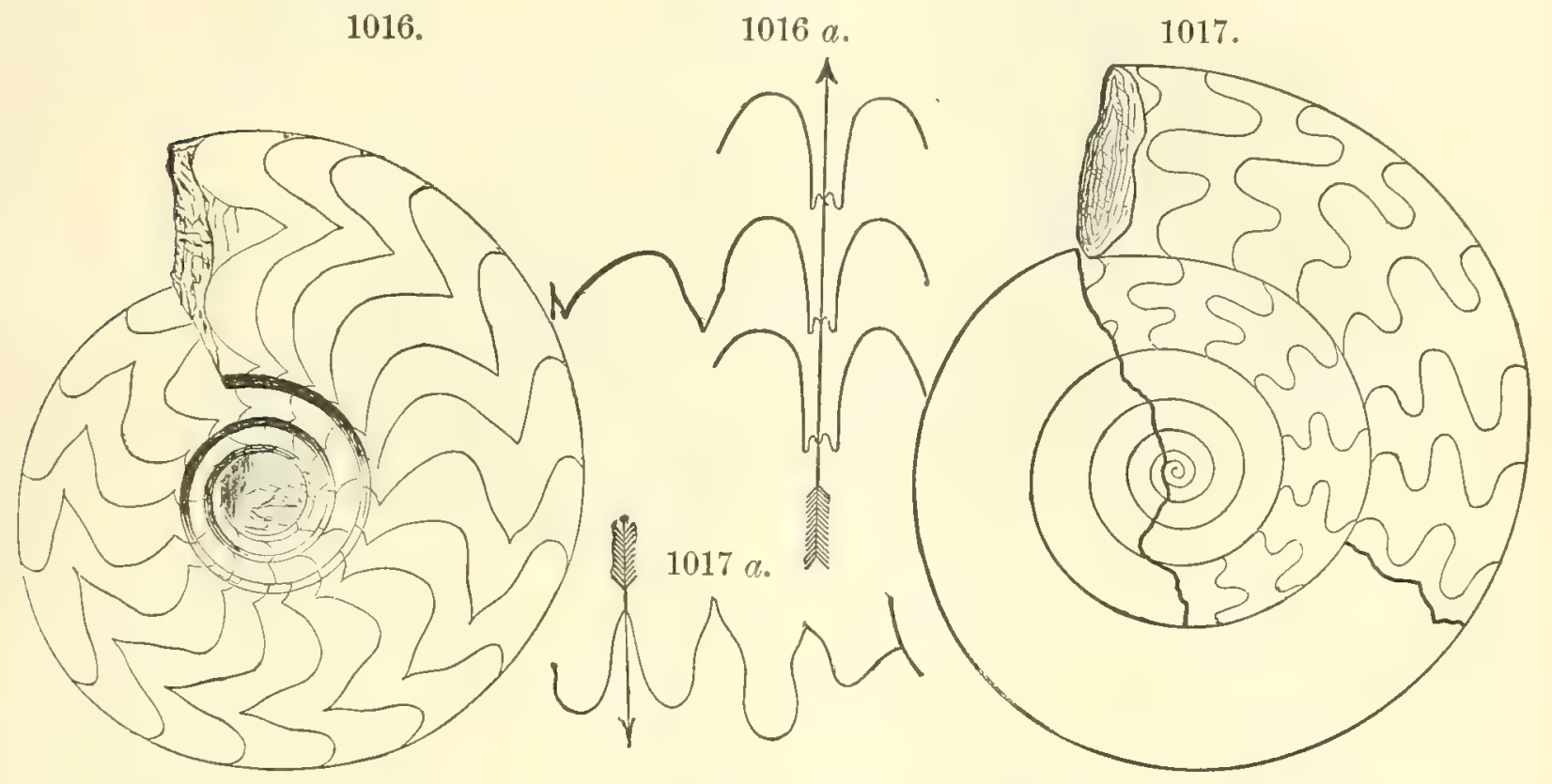

Cermalopods. - Fig. 1016, Goniatites Oweni; 1016 a, id., outline, showing direction of septa ; 1017, G. (Prolecanites) Lyoni ; $1017 a$, id., direction of septa. Hall.

6. Insects. - Remains of Insects, and other terrestrial species, are necessarily rare in marine deposits, and no species have yet been reported.

7. Vertebrates. - Vertebrates were represented by Ganoids and Selachians, as in the Devonian, but with apparently no Placoderms. There-were also the first yet known of Amphibians.

The remains of Selachians are teeth and fin-spines. The teeth are either of the pavement kind, allied to those of the living Cestracion (or Port Jackson Shark), and to Myliobatis (or Eagle Ray), or of pointed and triangular form, more or less resembling some of the modern type referred to the Hybodont and Petalodont families.

Of the parement-mouthed forms, the Cochliodonts, which have a large massive plate on either ramus of the jaw, were numerous in the Subcarboniferous. One of these plates is represented, natural size, in Fig. 1018, from Worthen's Illinois Report; and the form for the whole jaw in a foreign species is shown one third the natural size in Fig. 1019. Over 50 species are described from the Illinois limestone. The Psammodonts, haviug the inner surface of the jaw covered by flat rectangular plates, nearly as in Myliobatis, have over a dozen Subcarboniferous species of the genera Pscmmodus and Copodus. A Petalodont tooth, Petalodus curtus, has been reported from the 
Keokuk limestone. The Cestracionts (see page 416), with a rough, uneven pavement, were represented by species of Helodus and Orodus. Some of the sharp-pointed teeth of Hybodonts are shown in Figs. 1020-1022 (Newberry and Worthen).

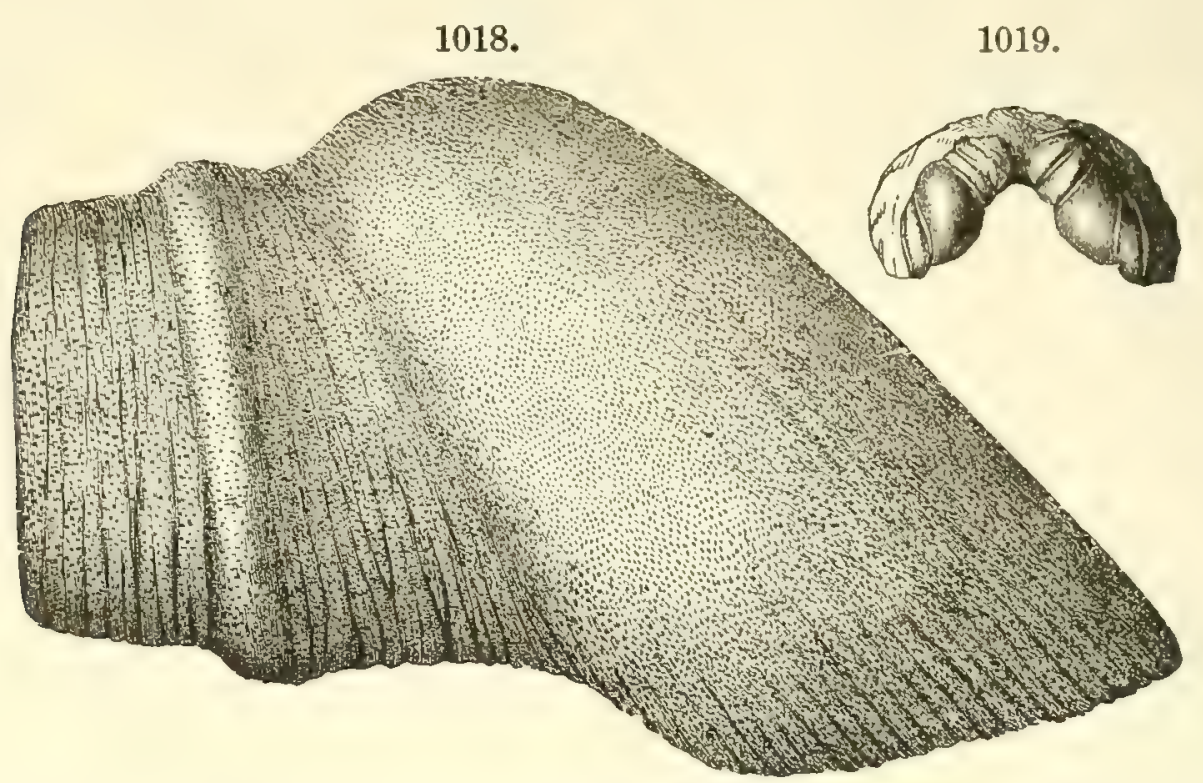

Tekth of Cestraciont Sharks. - Fig. 1018, Cochliodus nobilis ; 1019, C. contortus (× $\left.\frac{1}{3}\right)$. Fig. 1018, Meek ; 1019, Agassiz.

Fin-spines of Sharks are various in size and form. One, of Ctenacanthus, has a length of a foot; and others, now broken, were probably 6 inches longer; they indicate fins of large size, and therefore the existence of great Sharks.

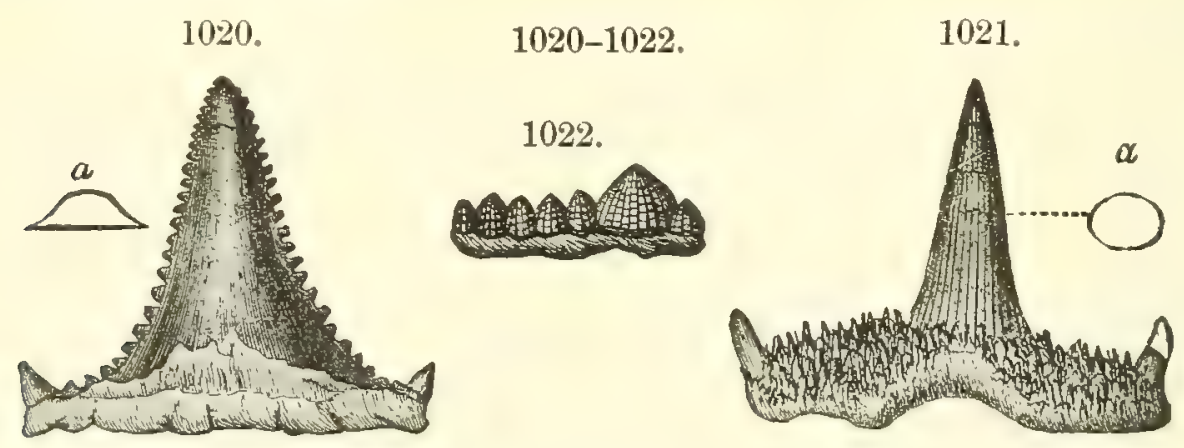

Theth of Sharks. - Fig. 1020, Carcharopsis Wortheni ; 1021, Cladodus spinosus; 1022, Orodus mammillaris. Newberry.

Amphibians are known from their footprints on a layer of the Mauch Chunk shale near Pottsville, in Pennsylvania, as described by Isaac Lea. A reduced view of the slab is shown in Fig. 1023. There is a succession of six steps, along a surface little over five feet long; each step is a double one, as the hind-feet trod nearly in the impressions of the fore-feet. The prints were hand-like; that of the fore-foot five-fingered and four inches broad; that of the hind-foot somewhat smaller, and four-fingered. That the Amphibian was therefore large, is also evident from the length of the stride, which was thirteen inches, and the breadth between the outer edges of the footprints, 
eight inches. There is also a distinct impression of a tail, an inch or more wide. The slab is crossed by a few distinct ripple-marks (eight or nine inches apart), which are partially obliterated by the tread. The whole surface, including the footprints, is covered throughout with rain-drop impressions.

1023 .

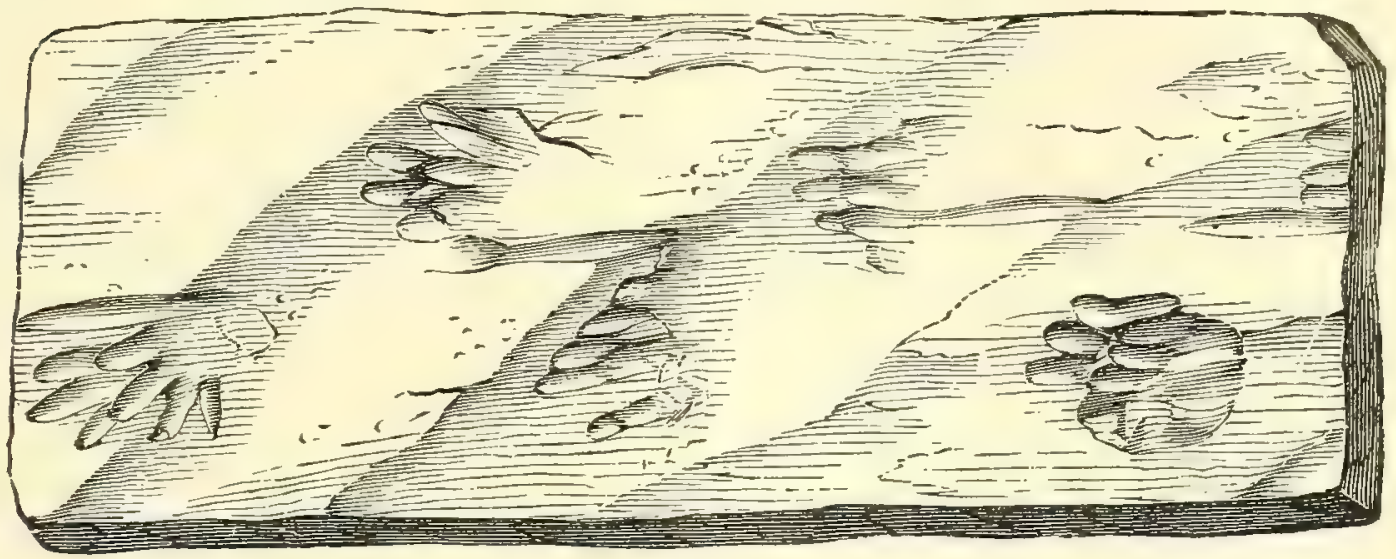

Tracks of Sauropus primævus $\left(\times \frac{1}{8}\right)$. I. Lea.

We thus learn that in the region about Pottsville a mud-flat was left by the retreating waters, perhaps those of an ebbing tide, covered with ripplemarks; that the ripples were still fresh when a large Amphibian crossed the flat; that a brief shower of rain followed, dotting with its drops the half-dried mud; that the waters again flowed over the flat, making new deposits of detritus, and so buried the records. The records were opened and deciphered in 1849 by Dr. Lea.

\section{Characteristic Species.}

Plants. - In the Subcarboniferous of Pennsylvania occur, according to Lesquereux, Archaopteris obtusa Lx., and A. minor Lx. (both found in the Chemung of the Devonian), A. Bockschiana Göpp.; remains of Lepidodendron, as L. corrugatum Dn., and Stigmaria minuta Lx.; in Illinois, in the Chester group, the Ferns Megaphyton protuberans Lx., Caulopteris Wortheni Lx., Alethopteris Helence Lx., Neuropteris capitata Lx., Pseudopecopteris anceps Lx., Rhacophyllum flabellatum St., Sphenopteris cristata St., Megalopteris fasciculata Lx. ; also Lepidodendron costatum Lx., L. turbinatum Lx., L. obscurum Lx., L. Veltheimanum St., L. Wortheni Lx., Stigmaria anabathra Corda, S. minor Göpp., S. umbonata Lx., Knorria imbricata St., Calamites Suckovi Bngt., Asterophyllites equisetiformis Schl., and others.

In the Chester group of Indiana, according to Collett, occur Stigmaria, Lepidodendron aculeatum St., L. diplostegioides Lx., L. forulatum Lx., Lepidostrobus, Knorria, Neuropteris biformis, Alethopteris, etc. One specimien of Lepidodendron had portions of the leaves attached to the stem, which were 12 to 14 inches long, though only from one eighth to one fourth of an inch in width.

In the Subcarboniferous of Nova Scotia and New Brunswick, Dawson has made out the following species: FErss - Cyclopteris Acadica Dn., Cardiopteris, Hymenophyllites; Lrcopons - Ptilophyton plumula Dn., the last of the genus, Lepidodendron corrugatum Dn. (near L. Veltheimanum of Europe), L. tetragonum St., L. obovatum St., L. dichoto- 
mum st., L. aruleatum St., also Stigmariu ficoicles Brugt., Cordailes borassifolius St., Darloxylon antiquum Dn.

The metamorphic Carboniferous region of Worcester, Mass., where the slates are mica schist, have afforded I. H. Perry specimens of Lepidodendron (Sagenaria) acuminatum Göpp., as identified by Lesquereux (Am. Jour. Sc., xix., 1885). It is doubtful whether the plant is Subcarboniferous or Carboniferous.

See, further, Pa. Geol. Rep., No. P.; Ill. Geol. Rep., vols. ii. and iv.; Ind. Geol. Rep. for 1883 ; Davoson's Hist. Plants, 1888, etc.

Animals. - 1. Rhizopods. - Endothyra Baileyi H. occurs in the St. Louis limestone of Indiana.

2. Spongiozoans. - The hornstones of the limestones in Illinois and Indiana abound in microscopic spicules of sponges, with a few Desmid-like forms similar in general to those of the Corniferous limestone (page 583) (M. C. White). Palacacis (Sphonopterium) obtusus M. \& W., Keokuk limestone, P. cuneiformis M. Edw., St. Louis limestone. In the Keokuk occur many Hexactinellid sponges of the genera Hydnoceras, Physospongia, Phragmodictya.

3. Actinozoans. - Fig. 991, Lithostrotion Canadense Castelnau, St. Louis 1.; L. proliferum H., St. Louis group; Zaphrentis spinulosa E. \& H.; Z. minas Dn., West River, Pictou; Cyathophyllum Billingsi Dn., Nova Scotia.

4. Echinoderms. - ( ( ) Blastoids: Fig. 999, Pentrenites pyriformis Say, Kaskaskia 1. ; 1000, P. Godoni Defr., ibid., and 50 other species of this and the related genera Granatocrinus and Troostocrinus.

(b) Crinoids. - Fig. 992, Scaphiocrinus Missouriensis Shum., St. Louis 1. ; 993, Actinocrinus proboscidialis H., Burlington 1. ; 994, Dorycrinus unicornis Owen \& Shum., ibid.; 995, Woodocrinus elegans H., ibid.; 996, Batocrinus Christyi Shum., arms broken off, ibid. ; 998, proboscis of Batocrinus longirostris H., ibid.; 997, Platycrinus Saffordi'Troost, side-view, Keokuk 1. The most prolific locality of Crinoids, as yet known, is Burlington, Iowa, where over 350 species, representing over 50 genera, were collected by Mr. C. Wachsmuth, besides 6 Echinoids, 4 Asterioids, and 1 Ophiuroid. Many of them are described by Hall in his Iowa report of 1858. The Keokuk beds of Crawfordsville, Ind., liave yielded 50 species. The genera most numerously represented are Actinocrinus, Cyathocrinus, Dichocrinus, Batocrinus, Platycrinus, Poteriocrinus, Scaphiocrinus, and Zeacrinus.

(c) Echinoids. - Fig. 1001, Archoocidaris Wortheni H., St. Louis 1. ; 1002, A. Shumardana H., St. Lonis 1.; 1003, plate of A. Norwoodi H., Chester 1. ; 1005, Melonites multiporus 0. \& N., St. Louis 1. ; 1004, Otigoporus'nobilis M. \& W., Burlington 1. Figs. 1004, 1005 are from Worthen's Report on the Geology and Paleontology of Illinois.

(d) Asterioids and Ophiuroids. - Worthen and S. A. Miller have described (in Ill. Rep., vii., 1883), from Illinois, Compsaster formosus, Chester limestone; Cholaster peculiaris, ibid., and the Ophiuroid Tremataster disparitis, ibid.

5. Molluscoids. - (a) Bryozoans. - Fig. 1006, Archimedes Wortheni H., being a portion of the spiral axis, with the reticulated expansion of the spiral worn off. Fig. $1007 a$, a portion of the reticulated expansion, magnified and showing the upper surface. Fig. $1007 b$, the under or cell-bearing side of the same.

(b) Brachiopods. - Kinderhook : Spirifer Cooperensis Swallow; S. Marionensis, Chonetes ornatus Shum. (Fig. 1015), 1015 , surface enlarged, Lithographic and Chouteau limestone, Mo.; 1014, Spirifer biplicatus H. Burlington 1.: 1008, Orthis Michelini L'Eveille (var. Burlingtonensis H.), Spirifer Meeki, S. Logani, Productus Flemingi Sow. Keokuk 1.: Actinoconchus planosulcatus Phill., Ill., Chonetes planumbonus M. \& W., Iowa, Camarophoria subtrigona M. \& W., Ill., etc., Spirifer Keokuk H. St. Louis 1. : Productus scitulus .1. \& W., 1011, Eumetria Verneuilana H., Warsaw, Spiriferina spinosa N. \& P., Warsaw, Lower Archimedes, Mo. Chester 1.: 1010, Spirifer increbescens H., Kaskaskia 
limestone, Spirifer glaber var. contractus M. \& W., 1009, Spiriferina spinosa; 1012, Chonetes Illinoisensis W., Productus parvus M. \& W.

(c) Lamellibranchs.-Kinderhook 1.: Cardiopsis radiata M. \& W. Burlington 1.: Aviculopecten Burtingtonensis M.\& W., Iowa. Keokuk 1.: Aviculopecten Oweni, A. oblongus, A. amplus, of M. \& W., Ill. St. Louis 1.: Myalina concentrica M. \&. W., Nucuta Shumardana H., Warsaw, Idaho, $N$. nasuta H., ibid., Conocardium Meekanum H., ibid. Chester 1.: Pinna Missouriensis Swallow, Ill., Myalina angulata M. \& W., Ill., Schizodus Chesterensis M. \& W., Ill.

(d) Gastropods. - Kinderhook 1. : Straparollus lens H., Goniatite bed, Ind., Bellerophon cyrtolites H., ibid. Burlington 1.: Platyceras reversum H., Iowa. Keokuk 1.: Pleuratomaria Shumardi M. \& W., Ill., Platyceras equilaterale H., Iowa. St. Louis 1. : Dentalium remustum M. \& W., Ill., Straparollus simitis M. \& W., Spergen Hill, Ind., S. Spergensis H., ibid.

6. Vertebrates. - Fishes. - The species of American Subcarboniferous Fishes have been described mainly by Newberry, Newberry and Worthen, and St. John and Worthen in the Ohio and Illinois Geol. Reports. The species described by Newberry and Worthen, from Illinois specimens, include 16 of Hybodonts, 26 of Petalodonts, 52 of Cestracionts, with 9 of fin-spines and Psammodonts. St. John and Worthen have added over 50 species of Cochliodonts, a dozen of Psammodonts, and over 20 kinds of fin-spines (I Il. Geol. Rep., vol. vii., 1883). Fig. 1018, tooth of Cochliodus nobilis N. \& W., Ill.; 1021, Cladodus spinosus N. \& W., St. Louis 1., Mo.; a, section of the same; 1020, Carcharopsis Wortheni Newb., Huntsville, Ala.; 1022, Orodus mammillaris N. \& W., Warsaw, Ill. The Subcarboniferous at Ogden has afforded a tooth of a species of Dendrodus.

\section{Carboniferous Period.}

Since the Carboniferous period, or that of the Coal-measures, was a period largely of marshes, as it opened the land gradually became emerged; and the first rocks that were laid down bear evidence, in many regions, of the change of condition by their beach-like character. Other evidence of the transition epoch exists in erosions over the Subcarboniferous rocks, making a surface of hills and depressions for the reception of the later depositions. Part of this irregularity may be the work of denudation before the Subcarboniferous period had closed; but other parts are referred to the time of emergence.

\section{ROCKS - SUBDIVISIONS, KINDS, AND DISTRIBUTION.}

The most prominent subdivisions of the Carboniferous formations are those of (1) the Millstone grit, or the Great conglomerate, named, in Pennsylvania, the Pottsvilue Conglomerate; and (2) the Coal-measures.

\section{THE POTTSVILLE CONGLOMERATE.}

The conglomerate beneath the coal-measures is generally a hard gritty siliceous rock, made of quartzose gravel or sand - a rock that was literally a millstone grit early in the century. It has a thickness of 800 to 1700 feet in the center of the Anthracite region of Pennsylvania, but thins northward in this state to less than 300 feet in the Wilkesbarre region, and westward to 200-300 feet. Its lower part spreads northward into western New York and constitutes there the "Olean conglomerate" of Alleghany and Cattaraugus counties, the rock of "Rock City," 25 to 60 feet thick. It extends westward 
through Ohio, Kentucky, Indiana, and beyond; but is mostly a sandstone, where present, in the Mississippi basin. But even there, beach-like features are often observed. Like the coal-beds of the Coal-measures the formation was only approximately at a common level.

In part of western Pennsylvania the Pottsville conglomerate contains one or more coal-beds. Just above the Sharon conglomerate, the base of the Pottsville series in Mercer County, Pa., one coal-bed is two to four feet thick, and has long been worked. The same bed is mined also in Ohio. A bed of similar character occurs in the conglomerate of Kentucky, Tennessee, and Alabama, and that of Alabama affords excellent coal. These coal-beds, with their alternating beds of shale, prove that slow and varying changes of level were in progress, but that for prolonged intervals portions of the surface lay quiet until deep accumulations of vegetable debris had been made in the marshes. The fact of a general parallelism in the movements over Europe and America favors the view that the changes in level and in deposits were a consequence, in a general way, of oscillations in the sea level, that is, in the crust of the sea bottom; but at the same time there were other variations in level which were dependent on local conditions and movements over the continents.

\section{THE COAL-MEASURES.}

The Coal-measures in Pennsylvania are divided into (1) the Lower Productive Measures, (2) the Lower Barren Measures, (3) the Upper Productive Measures. Above the last there are the Upper Barren Measures, corresponding to the Permian.

Over the great Appalachian-Arkansas area, the three great Carboniferous or Coal-measure regions are, as shown on the map, page 412, (1) the Appalachian, extending from northern Pennsylvania to Alabama, and having the Anthracite region as a detached portion in eastern Pennsylvania; (2) the Illinois-Indiana, east of the Mississippi, extending south into Kentucky; and (3) the Iowa-Texas, west of the Mississippi.

The Appalachian area spreads west into Ohio, eastern Kentucky, eastern Tennessee, and northern Alabama. In Tennessee, the Cumberland Tableland has the Coal-measures for the top, and a substructure of Subcarboniferous rocks, 1000 feet or more thick, for the rest of its height. In Alabama, the western portion, constituting the large Winrior coal-fields, is a continuation of the Cumberland Measures, with an extension far westward nearly to the Mississippi line - Mississippi having only a small patch of Subcarboniferous beds.

It is probable that the Coal-measures of Tennessee, and those of Alabama, originally spread across what is now the Mississippi valley and joined the area of southern Missouri.

The Carboniferous areas are generally much broken, especially so in Peunsylvania and along the Appalachians to the southwest of this state. The following map, by Iesley, illustrates in a general way the condition in Pennsylvania. The Anthracite coal is in narrow isolated strips to the east- 
ward, among upturned rocks; and the Pittsburg coal at the west end of the state, although among nearly horizontal rocks, also has its outlying patches. Geological investigation has proved that the two distant areas were once

1024.

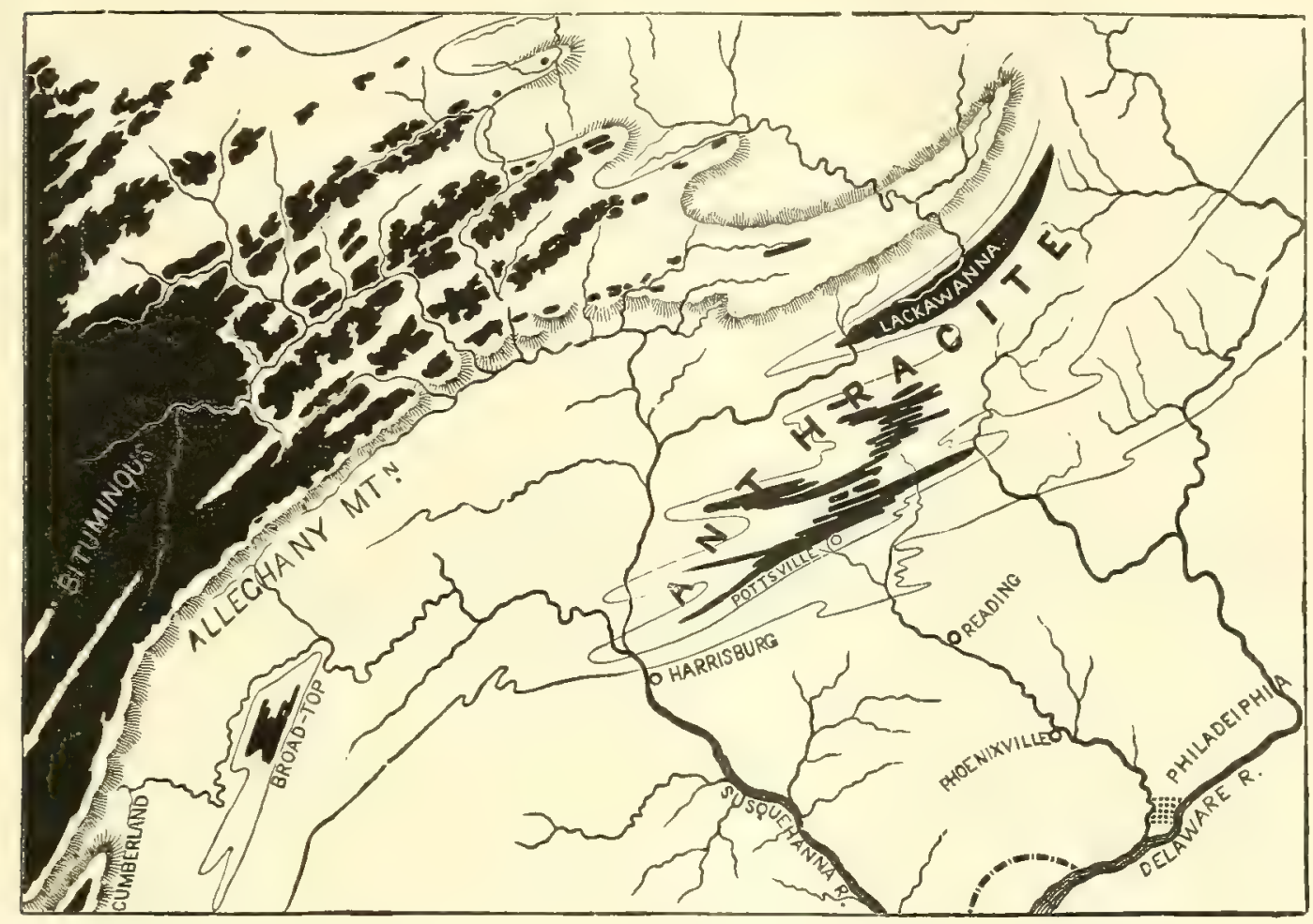

Map of part of Pennsylvania, showing the coal areas of the state, in black; the Anthracite beds east of the Susquehanna, and the Bituminous beds to the westward.

united and that the coal once covered 10 times its present area. "Broad Top" in southwestern Pennsylvania is shown by Lesley to be a fragment of the Pittsburg coal-bed, about 80 square miles in area, left in the general denudation of the Appalachian region.

1025.

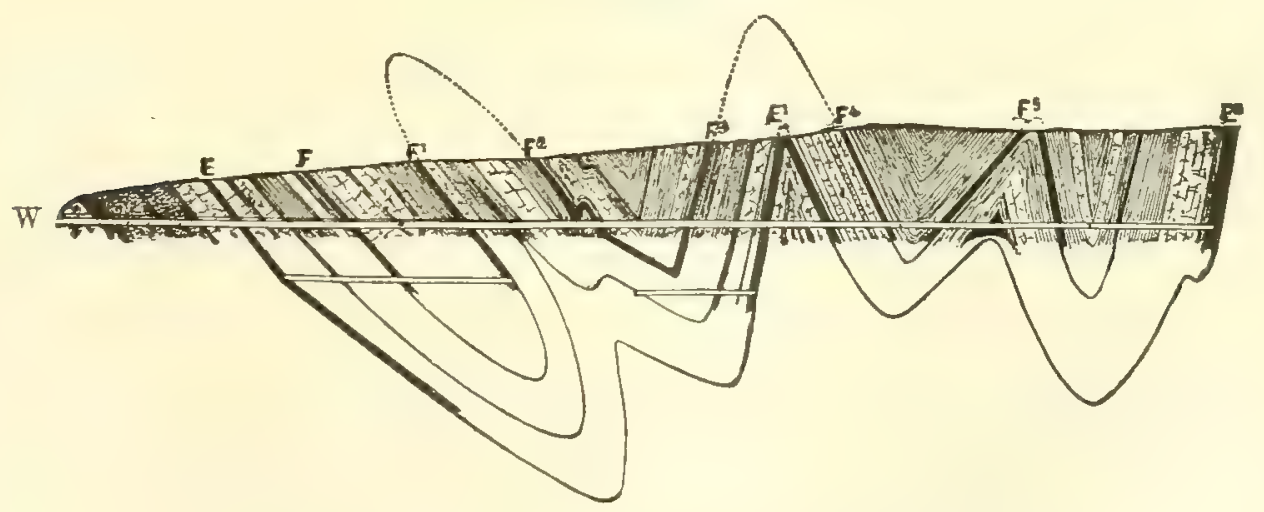

Section of the Panther Creek Anthracite basin at Nesquehoning tunnel.

Figs. 1025 to 1027 represent sections of portions of the Anthracite region, showing the character of the flexures that led, through denudation, to the breaking of the coal-beds into nearly parallel belts. Fig. 1025 is a vertical 
section from the heart of the Anthracite region, between Nesquehoning Talley on the west (left in section), and Mauch Chunk. It is from the Report of C. A. Ashburner, of the Geologieal Survey of Pennsylvania. The length is about 1200 yards (the scale of the figure being 1000 feet to the inch). The flexures to the west have their summits pushed westward $40^{\circ}$ beyond the vertical. The folded rocks consist of beds of Anthracite, and intervening strata of shale and sandstone; and the Anthracite beds include the great "Mammoth bed" (lettered at its outcrop $\mathrm{E}, \mathrm{E},{ }^{1} \mathrm{E}{ }^{2}$ ), which is 13 to 27 feet thick, and the bed $\mathrm{F}$ (outeropping at $\mathrm{F},{ }^{1} \mathrm{~F},{ }^{2} \mathrm{~F},{ }^{3} \mathrm{~F},{ }^{4} \mathrm{~F}^{5}$ ), 11 to 20 feet thick, besides one of eight to nine feet. The "Mammoth bed" is doubled on itself at $\mathrm{E}^{\mathrm{I}}$. Fig. 1026, from Lesley, is from the Anthracite

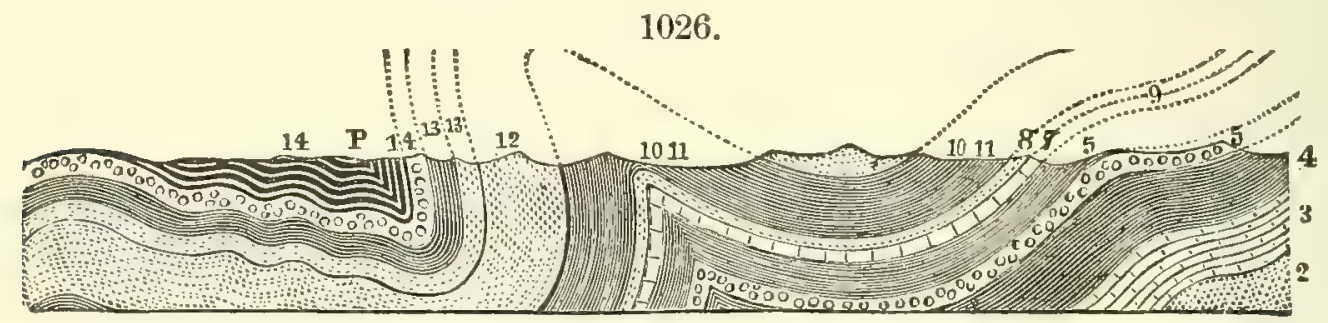

Section on the Schuylkill, Pa.; P, Pottsville, on the Coal-measures (14), Lesley.

region of Pottsville, about 30 miles south of west of Mauch Chunk. All the Paleozoic formations from the bottom of the Paleozoic (2) to the last, the Carboniferous (14), are here flexed together: No. 2 being Cambrian; 3, Canadian; 4, Trenton; 5, Niagara; 7, Lower Helderberg; 8, Oriskany; 9, Corniferous; 10, Hamilton; 11, 12, Upper Devonian; 13, Subcarboniferous; 14, Carboniferous. Fig. 1027, from H. D. Rogers, in which the flexures

1027.

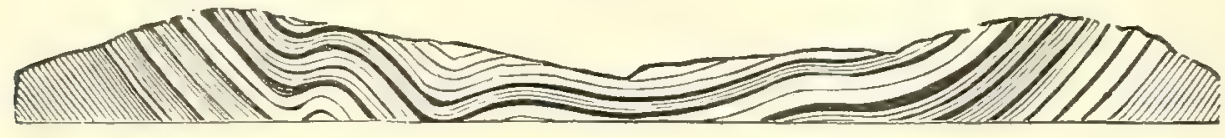

Section of the Coal-measures, half a mile west of Trevorton Gap, Pa. H. D. Rogers.

are more gentle, is from Trevorton Gap, 45 miles west of Mauch Chunk. The whole Anthracite region has been thus upturned.

Constitution of the Coal-measures. - Beds of sandstone, shale, clay, and limestone, with occasional beds of coal, and a bed of fire clay commonly beneath the coal-bed, make up the Coal-measures. About one foot in 40 of the total thickness is usually good coal; but in the Upper and Lower Productive Measures, the proportion is larger, rising to one foot in 20.

The following tables, $1 \mathrm{~A}, 1 \mathrm{~B}, 2,3$, 4 , derived from the reports of the recent Pennsylvania Survey (1, 2, and 3, by J. J. Stevenson, and 4, by H. M. Chance) will give a general idea of the many coal-beds in the series in western Pennsylvania, from the Upper Barren series to the Lower Productive Measures, and of their alternating beds of sandstone, shale, limestone, fire clay, and iron ore: 
1. Upper Barren Series, or Permian Beds.

A. Dunkard Creek Measures, Greene County (Southwestern County of Pa.), ABOUT 700 FEET.

Beneath $80^{\prime}$ of concealed beds including some limestone:

Limestone $10^{\prime}$, sandstone $50^{\prime}$, limestone $4^{\prime}$, shale $80^{\prime} \ldots \ldots \ldots \ldots$.

Sandstone $30^{\prime}$, shale $12^{\prime}$, limestone $2 \frac{1}{2}^{\prime}$, sandstone and shale $80^{\prime} \ldots$

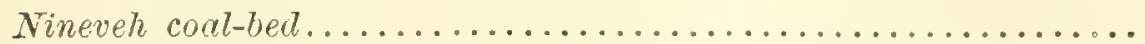

Sandstone $100^{\prime}$, limestone $2 \frac{1}{2}$, bitum. shale $1^{\prime}$, sandstone $36^{\prime} \ldots \ldots$

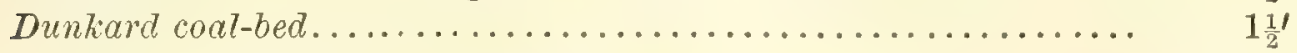

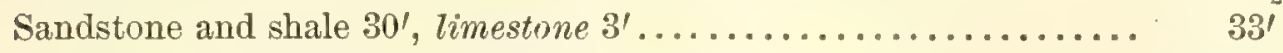

Limestone $2^{\prime}-5^{\prime}$, sandy shale $70^{\prime}$, limestone $66^{\prime}-155^{\prime} \ldots \ldots \ldots \ldots \ldots .78^{\prime}-90^{\prime}$

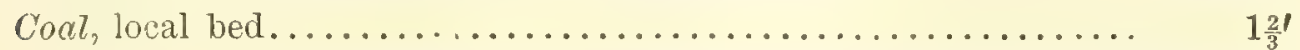

Shale and iron ore $10^{\prime}$, sandstone $31^{\prime}$, limestone $2 \frac{1}{2}^{\prime}$, sandstone $19^{\prime}-30^{\prime} 62 \frac{1}{2}^{\prime}-73 \frac{1^{\prime}}{2}$

\section{B. Washington Group, Maximum Thickness 400 feet.}

Sandstone $40^{\prime}$, Upper Washington limestone $30^{\prime} \ldots \ldots \ldots \ldots \ldots . . \ldots 70^{\prime}$

Jolleytown coal-bed............................ 1

Middle Washington limestone $15^{\prime}$, sandstone $40^{\prime} \ldots \ldots \ldots \ldots \ldots \ldots .55^{\prime}$

Sandstone and shale $20^{\prime}$, limestone $8^{\prime}$, sandstone and shale $60^{\prime} \ldots . .8 \quad 88^{\prime}$

Bituminous shate or coal-bed........................... $\mathbf{1}^{\prime}$

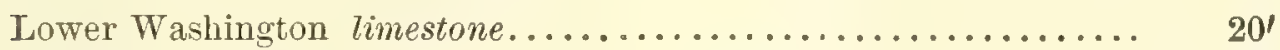

Washington coal-bed............................ $10^{\prime}$

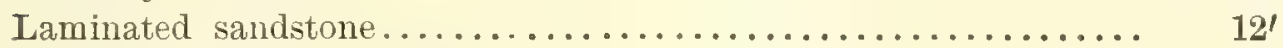

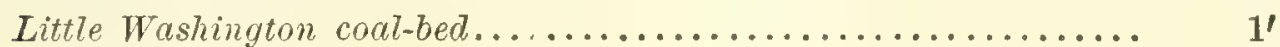

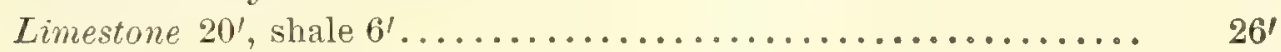

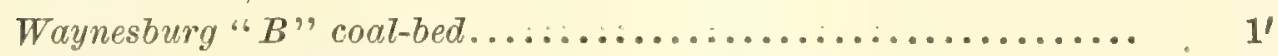

Limestone $8^{\prime}$, sandstone $30^{\prime} \ldots \ldots \ldots \ldots \ldots \ldots \ldots \ldots \ldots \ldots \ldots \ldots . \ldots \ldots \ldots$

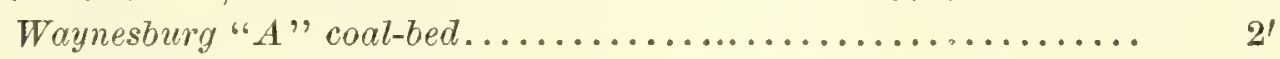

2. Upper Productive Coal Series or Monongahela River Series, Maximum 494 feet.

Shale $0^{\prime}-12^{\prime}$, Waynesburg sandstone $70^{\prime} \ldots \ldots \ldots \ldots \ldots \ldots \ldots . \ldots 70^{\prime}-82^{\prime}$

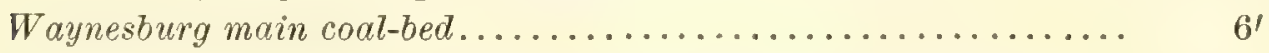

Sandstone and shale $60^{\prime}$, timestone $5^{\prime}$, sandstone $20^{\prime}$, fire clay $3^{\prime} \ldots . \quad 88^{\prime}$

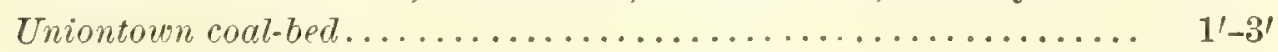

Sandstone and shale $60^{\prime}$, limestone and shale $18^{\prime}$, sandy shale $40^{\prime}$,

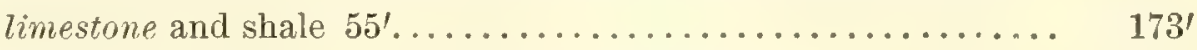

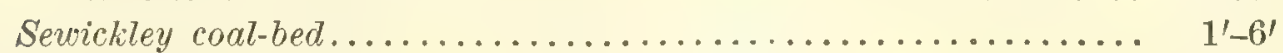

Sandstone and shale $25^{\prime}$, limestone $18^{\prime}$, sandstone $10^{\prime} \ldots . . \ldots \ldots .53^{\prime}$

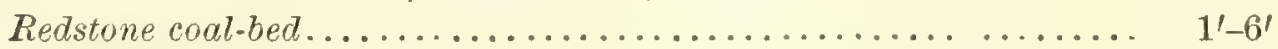

Shale $0^{\prime}-12^{\prime}$, Pittsburg Upper sandstone $40^{\prime}$, limestone $10^{\prime} \ldots . . .550^{\prime}-62^{\prime}$

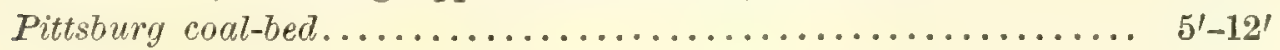

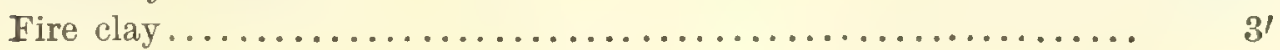

3. Lower Barren Coal-measures (in Westmoreland County, Pa.), 654 feet.

Limestone $6^{\prime}$, shale $10^{\prime}$ (underneath $3^{\prime}$ fire clay and Pittsburg coal) 16'

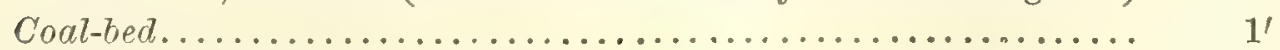

Shale $10^{\prime}$, limestone $3^{\prime}$, shale $25^{\prime} \ldots \ldots \ldots \ldots \ldots \ldots \ldots \ldots \ldots \ldots . \ldots \ldots 8^{\prime}$

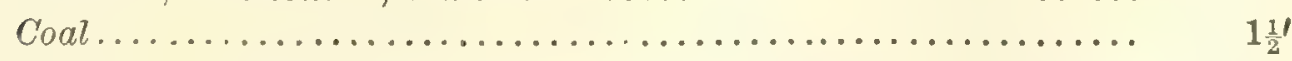

Shale $355^{\prime}$, Connellsville sandstone $60^{\prime}$ (not persistent), limestone $5^{\prime} \quad 100^{\prime}$

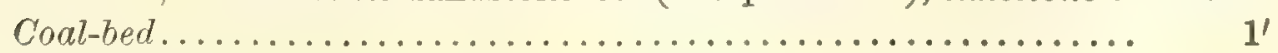

Clay $9^{\prime}$, Morgantown sandstone $50^{\prime}$, limestone $4^{\prime} \ldots \ldots \ldots . \ldots . . .63^{\prime}$ 


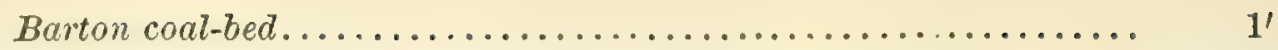

Shale $100^{\prime}$, Crinoidal limestone $4^{\prime}$, shale $30^{\prime} \ldots \ldots \ldots \ldots \ldots \ldots \ldots \ldots 1^{\prime}$

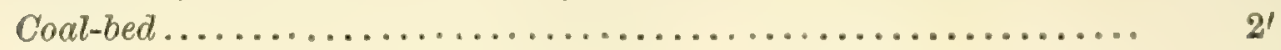

Shale and sandstone $35^{\prime}$, black limestone $4^{\prime}$, shale $60^{\prime} \ldots \ldots \ldots \ldots . . . . .69^{\prime}$

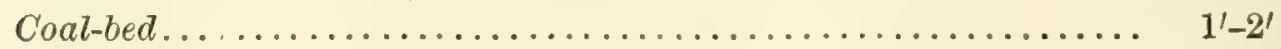

Shale $30^{\prime}-50^{\prime}$, with Mahoning sandstone (divided sometimes into

Upper, Middle, and Lower), with thin layers of shale and limestone, and sometimes a thin coal-bed, in all $195 \frac{11}{2}$ in Ligonier

Valley, varying to $75^{\prime}$ and less elsewhere............... $75^{\prime}-195 \frac{1}{2}^{\prime}$

\section{Lower Productive Coal-measures, or Alleghany River Series, W. Pa.}

Freeport Upper coal, E.................................... $2^{\prime}$

Fire clay $2^{\prime}-6{ }^{\prime}$, shale with ore, Freeport Upper limestone, shales,

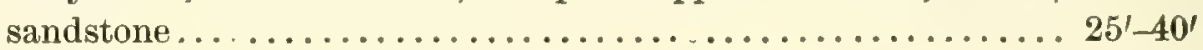

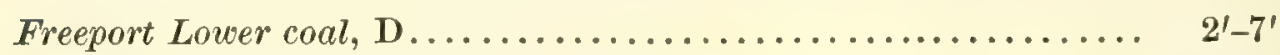

Fire clay $11_{2}^{\prime}-4^{\prime}$, Freeport Lower limestone..............4 42'-50'

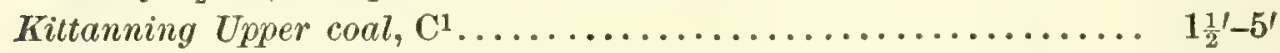

Fire clay $2^{\prime}-4^{\prime}$, Johnstown cement-bed, shales............. $2^{\prime}-8^{\prime}$

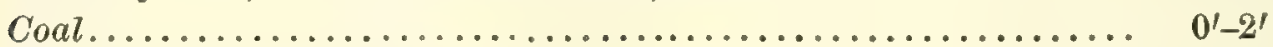

Fire clay $0^{\prime}-22^{\prime}$, shales and slate..................... 30.40.

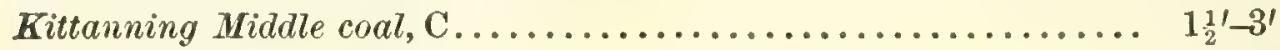

Fire clay, shales, sandstone.............................

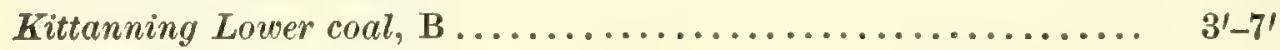

Fire clay $4^{\prime}-88^{\prime}$, sandy shales............ sometimes $\left\{50^{\prime}-60^{\prime}\right.$

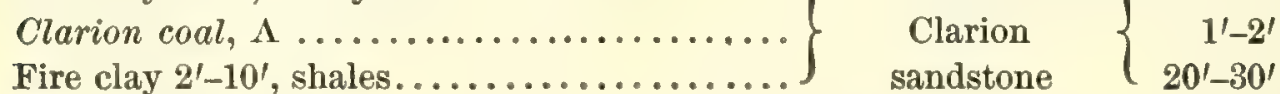

Brookville coal, A.............................. $0^{\prime}-4^{\prime}$

Fire clay, brick clay............................ $0^{\prime}-10^{\prime}$

Pottsuille conglomerate.

These sections show many alternations of sandstone, limestone, and shale, with the several coal-beds, but without giving the many minor changes.

Sections from the Anthracite region afford the same alternation of coalbeds with beds of sandstone (or conglomerate) and shale, but without even thin layers of limestone. But the coal-beds and the various rocks reach a much greater thickness, all being on a grander scale in this central part of the Appalachian area. The "Mammoth" coal-bed (numbered E by the Geological Survey) attains a maximum thickness of 50 feet; and then, above 200 to 300 feet of sandstone (or conglomerate) and shale containing two or three thin coal seams, comes the Red Ash Bed (F), 16 to 24 feet; and above another such interval, a third great bed (G), 15 to 16 feet; and so on. But these thicknesses are not constant, the minimum in each of these beds in other localities (mining shafts) being half the above or less.

The thickness diminishes not only westward, but rapidiy also northward. At Carbondale, it is, for the whole Coal-measures, only 300 feet, and for the included coal-beds less than 20 feet. Near Wilkesbarre, the thickness is about 867 feet, with 85 feet of coal-beds, or about one foot of coal to 10 of rock. In the western Middle Anthracite field, the total at Hammond is 1512 feet, with 83 of coal-beds. Near Pottsville, in the southern field, the total 
thickness is 3251 feet, and that of the 27 coal-beds, 154 feet, a ratio of $1: 21$. Of the 27 coal-beds, numbers 19 and 20 (counting from below), together 23 feet thick, but separated by 15 feet of shales - in all 47 feet-correspond in position to the "Mammoth" bed. The facts relating to the Anthracite region are given in detail, with magnificent naps in folio, by Ashburner, in his Report of the Pennsylvania Geological Survey.

The Coal-measures of western Pennsylvania continue to decrease in thickness as they spread northward.

Beyond Ohio, in Illinois and Indiana, a region wholly independent in its coal areas, as shown by the Ohio and Pennsylvania geologists, the Coalmeasures are less than 1200 feet in thickness; and a considerable portion of the intervening beds consists of limestone.

The accompanying rocks may be of marine origin, brackish water or fresh; and limestones with their many fossils are usually marks of marine origin.

The coal-beds are not all coal. They have commonly layers of shale or shaly coal at intervals; and sometimes so many that the bed is worthless. A bed may change in the course of a few miles to a dirt-bed, or the carbonaceous material may wholly fail.

The Pittsburg, at Pittsburg, Pa., is 10 feet thick; but it is made up of one foot, at bottom, of coal with pyritiferous shale; 5 to 6 feet of good coal; and, above this, shale and coal, left as the roof for working, though sometimes including one or two feet of pure coal. It borders the Monongahela for a long distance, the black horizontal band being a conspicuous object in the high shores, and in some places contains seven or eight feet of good coal. It extends into West Virginia and Ohio, over an area at least 225 miles by 100 . It varies in thickness, being 12 to 16 feet in the Cumberland basin; 6 feet at Wheeling; 5 to 8 feet in Morgan, Athens, and Meigs counties, Ohio; 5 to 6 feet at Pomeroy, where it is the "Pomeroy" bed; $6 \frac{1}{2}$ to $9 \frac{1}{2}$ feet in West Virginia, at Morgantown. But, according to I. C. White (1891), it fails nearly or wholly to the southwest of Pennsylvania, over part of West Virginia and Ohio, along a belt north-and-south in course, and 30 to 50 miles wide.

Layers of clay-ironstone are often in the series, as the sections show, making parts of beds of limestone, shale, or coal, or intervening between them; and a bed of fire clay generally underlies a coal-bed.

The coal chiefly of vegetable origin. - The clay-bed beneath the coal, often called the underclay, generally contains fossil plants, and especially the roots or under-water stems of Lepidodendrids and Sigillarids, called Stigmarice; it is often the old dirt-bed, or the bed of earth over which the plants grew that commenced to form the coal-bed. It was either this, or the elayey bottom of the plant-bearing marshes or lakes. In some eases, trunks of trees rise from it, penetrating the coal layer and rock above it. The Nova Scotia coal region abounds in erect trunks, standing on the old "dirt-beds," as illustrated in Fig. 1028.

The rock capping a coal-bed may be of any kind, for the rocks are the 
result of whatever circumstances succeeded; but it is common to find great numbers of fragments or trunks of trees and ferns in the first stratum. The shaly beds often contain the ancient ferns, spread out between the layers with all the perfection they have in an herbarium, and so abundant that,

1028.

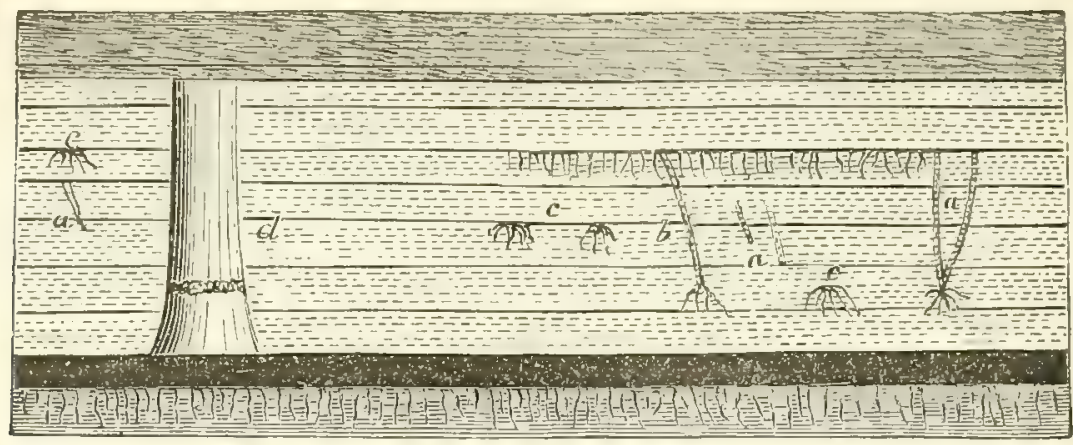

Section of Coal-measures at the Joggins, Nova Scotia (with erect stumps and stems, a, b, c, d, in the sandstone, and rootlets in the underclays). Dawson.

however thin the shale be split, it opens to view new impressions of plants. In the sandstone layers, broken trunks of trees sometimes lie scattered through the beds. Some of the logs in the Olio Coal-measures, described by Dr. Hildreth, are 50 to 60 feet long, and three in diameter. At Carbondale, in Pennsylvania, a forest of Calamites, or tree-rushes, was cut through in opening an inclined tunnel through sandstone to the underlying coal-bed, and the trunks, or rather their fragments, were so numerous that they were used as a foundation for a tramway for transporting the coal out of the mine. In the walls crowds of other stems of the old jungle were left. Lesquereux refers the species of Calamites to C. Suckovi and C. approximatus. He also states that in the roof-shale of the coal-bed at Carbondale, Pa., there was found an impression of the bark of a Lepidodendron, two feet wide and seventy-five feet long. Andrews mentions that thousands of the trunks of the Fern, Pecopteris arborescens Schloth., are found in the shale over the Pomeroy coal-bed; and at one place the trunk of a Sigillaria was traced by him for more than 40 feet. In Kentucky, at Paintsville, the stony bottom of the river is an irregular mosaic work made of cross-sections of trunks of Sigillaria which stand crowded together in the position of growth (Lesquereux). One trunk is 22 inches across, showing that the region was the site of a forest.

Such facts are common. These facts are enough to prove the vegetable origin of coal. But Ferns, Lepidodendra, and other plant-remains are often spread out in perfection within the coal-beds, and sometimes in the solid masses of anthracite. They occur also in the textureless cannel coal, as at Breckenridge, Ky., where the coal "is marked through its whole mass by stems and leaves of Stigmaria and Lepidodendron rendered distinct by infiltration of sulphuret of iron" (Lesquereux). Further, the coal is often penetrated with the tissues and spores of the plants. Even the solid anthra- 
cite has been found to contain vegetable tissues. On examining a piece partly burnt, J. W. Bailey found that it was made up of carbonized vegetable fibers. Figs. 1029, $\alpha, b$ are from his paper on this subject. He selected specimens which were imperfectly burnt (like Fig. 1029), and examined the surface just on the borders of the black portion. Fig. 1029 a represents a number of ducts, thus brought to light, as they appeared when moderately magnified; and Fig 1029 b, two of the ducts, more enlarged; the

$1029 b$

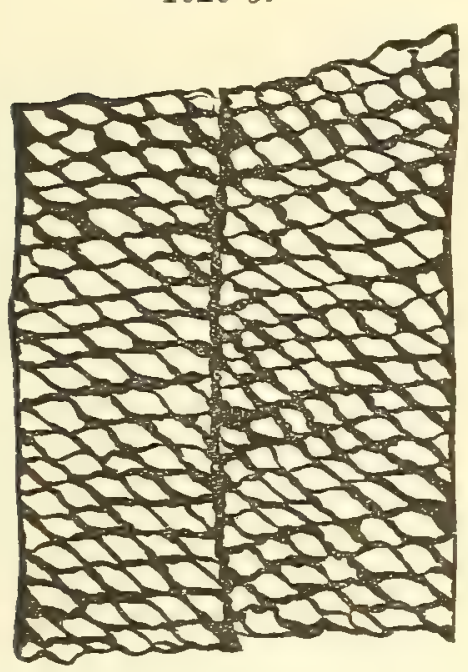

1029.

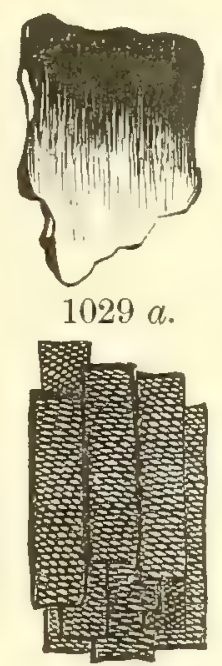

1030.

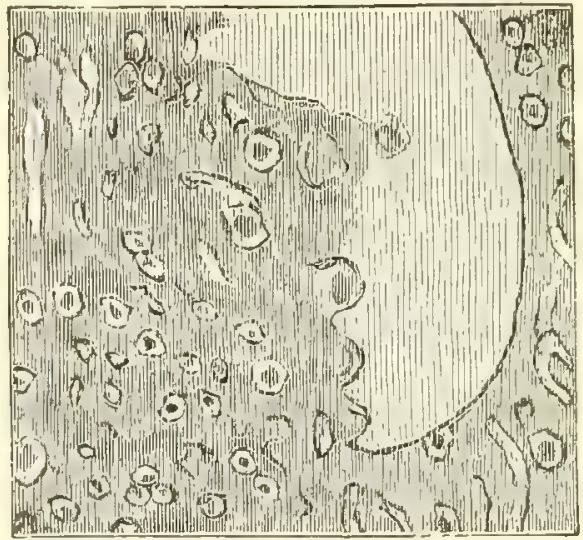

Figs. 1029, $a, b$, Vegetable tissues in anthracite; 1030, Spores and part of a Sporangium, in bituminous coal of Ohio ( $\times$ 70). Figs. 1029, Bailey; 1030, Dawson.

black lines being the coal that remained after the partial burning, and the light spaces silica. The ducts were one tenth of a millimeter (about four thousandths of an inch) broad. Dawson reports like results from bituminous coal.

The spores and sporangites, or spore-cases, of the Lycopods (Lepidoden(lrids) and other Acrogens, abound in the coal to such an extent in some places, that it has been suggested that mineral coal was made mainly out of them. While, as Dawson has shown, this inference is not sustained by facts, such spore-cases are very common in most coal. Fig. 1030 represents, much magnified, the surface of a piece of Ohio bituminous coal, showing a fragment of a spore-case and many of the spores. The spore-cases vary in size, from a tenth to a hundredth of an inch, and in the coal they often have an amberyellow color. Dr. Dawson states that he has a specimen of Pennsylvania anthracite full of spore-cases, but that the Pictou coal is remarkably free from them.

Animal materials have also contributed to the coal, though sparingly. For animal decomposition also yields carbonaceous material; and animal life was so abundant in the waters that the contributions in some places may have been important. The great number of fossil fishes in some very carbonaceous or bituminous shales has led to the suggestion that fish-oil may have been the sole source of the oil or gas yielded by the shales. It is not 
improbable that it was a prominent source, since the same process which will convert vegetable tissues into coal or mineral oil (page 124), will produce a like result from animal oils.

Equivalent coal-beds in the series. - Since the coal marsh area of Pennsylvania, eastern Ohio, Kentucky, and West Virginia was in all probability essentially continuous, it is reasonable to look for the beds over the areas that are of equivalent age. It has been found difficult, however, to make out even the relations between those of eastern and western Pennsylvania; that is, of the Anthracite and Pittsburg regions. The related West Pennsylvania and Ohio beds are more easily correlated. But any parallelism between the beds of Pennsylvania and those of Illinois and other states of the Mississippi valley, unless in the Lower Coal-measures, is improbable.

Coal-measures. - Full details with regard to the Bituminous Coal-measures of western Pennsylvania, West Virginia, and partly of Ohio, will be found in a Report by I. C. White, constituting Bulletin 65 of the U. S. Geological Survey. The following are facts from eastern Pennsylvania:-

In the Panther Creek basin at Tamaqua, where the total thickness is 2168', the lowest coal-bed is the Lykens Valley coal, $6^{\prime}$ thick, within the Pottsville conglomerate. $240^{\prime}$ above is the $A$ coal-bed, $16^{\prime} ; 115^{\prime}$ higher, the $B$ coal-bed, $9^{\prime} ; 235^{\prime}$ higher the $C$ coal-bed, $8^{\prime}$ (with a thin bed between); and then, $122^{\prime}$ above the last, the Mammoth bed, including beds $D$, $12^{\prime}$, and $E, 24^{\prime}$, and another between of $5^{\prime}$, together with $45^{\prime}$ and $48^{\prime}$ of intervening rock. $211^{\prime}$ higher comes the $F$, or Lower Red Ash coal-bed, 10'; 55' higher, the Bony coal-bed, $44^{\prime} ; 46^{\prime}$ higher, the 6 , or Upper Red Ash coal-bed, 6'; 84' higher, the Washington coal-bed, 3'; $92^{\prime}$ higher, the Jock coal-bed, 7'; and then 4 coal-beds of $2^{\prime}$ each in the next $150^{\prime} ; 158^{\prime}$ higher, the First Upper Red Ash coal-bed, 4'; 106' higher, the Second Upper Red Ash coal-bed, 3'; 63' higher, the Third Upper Red Ash coal-bed, 1'. From the Mammoth to the Lykens valley coal-bed the coals are of the White Ash group; the remainder are divided into the Upper and Lower Red Ash groups, along a plane below the third coal-bed from the top.

In the Pottsville basin, between the Mammoth and Lykens Valley coal-beds, there are 7 coal-beds; and one, $66^{\prime} 0^{\prime}$ above the Lykens, called the Buck Mountain coal-bed, is 8' thick. The Wilkesbarre section gives widely different results. In western Pennsylvania the Coal-measures have their greatest thickness at the West Virginia line, midway in Greene County, $\mathrm{Pa}$. ; and from this point there is a thinning westward to about one third. Passing into Ohio, the interval between the Pittsburg and Uniontown coal decreases northward from $200^{\prime}$ to $60^{\prime}$ or less (Stevenson).

The Pottsville conglomerate in Mercer County, Pa., afforded I. C. White (Pa. Rep. $Q, 3,1880$ ) the following section :-

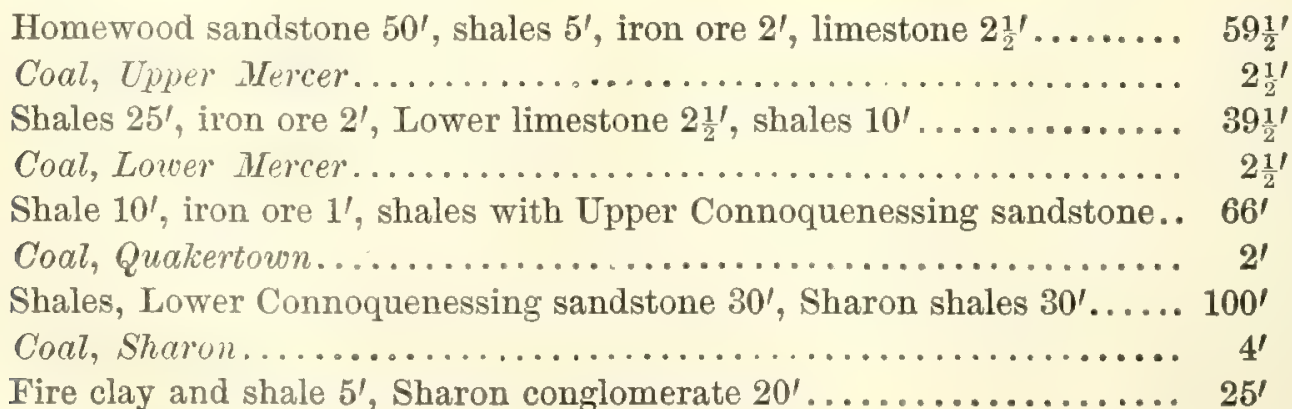

The thickness of the Coal-measures in Ohio is about 1250': the Lower Productive 250', with 7 coal-beds; the Lower Barren, having the Mahoning sandstone at its base, $500^{\prime}$; 
Upper Productive, 200'; Upper Barren, 500', but much reduced from the original thickness by denudation; the total number of coal-beds is 13 ; the mean thickness of the lower 7 is

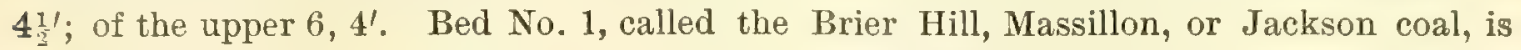
$3^{\prime}$ to $6^{\prime}$ thick, and is supposed to be No. $\mathbf{A}$ of the Pittsburg section; No. 6, the Upper Freeport, $3^{\prime}$ to $12^{\prime}$ thick; No. $8,4^{\prime}$ to $8^{\prime}$ thick, the Pittsburg coal-bed, at the top of the Lower Barren Measures ; and No. 11, $1_{2}^{1 \prime}$ to $4^{\prime}$ thick, the Waynesburg coal-bed (Newberry).

In Indiana, the Coal-measures cover an area of about 7000 square miles over the western part of the state, are $800^{\prime}$ to $1000^{\prime}$ thick, and include 10 coal-beds varying from $1^{\prime}$ to $11^{\prime}$ in thickness (Collett).

In Illinois, the total thickness is $600^{\prime}$ to $1000^{\prime}$, and the number of workable coal-beds 6 , and of other thin seams, 6 . The thickness of the former is nearly $20^{\prime}$ (Worthen). Near Morris, and elsewhere, in northeastern Illinois, there is a single bed of coal with clay above and below. Four miles to the southeast of Morris, sandy shales of the Coal-measures contain concretions which have made the place famous because of the many kinds of Ferns, Insects, Spiders, Myriapods, rare Crustaceans, and even Amphibians, which have been found in the concretions - the specimens having been in many cases the nuclei. No marine fauna has been found in them.

In southwestern Kentucky, the Coal-measures north of Pine Mountain are $1650^{\prime}$ thick, and contain 9 workable beds of coal; and farther east they are still thicker.

The Coal-measures spread northwestward over southwestern Iowa, where they have a maximum thickness of $600^{\prime}$, and a thickness of coal-beds of about $8^{\prime}$, as in Illinois. The Coal-measures extend northward beyond the limits of the upper beds of the Subcarboniferous limestone. At Davenport, on the Mississippi, a boring found a thickness of $30^{\prime}$, and the beds resting on the Devonian Corniferous limestone.

In Arkansas, the area of the Coal-measures is about 1000 square miles, and the mean thickness of the coal-beds is estimated at $3 \prime$.

The isolated coal area of Michigan covers about 6700 square miles, and the beds have a thickness of $300^{\prime}$ or less. At East Saginaw, this $300^{\prime}$ includes the underlying Parma white sandstone 105', and the overlying Woodville brown sandstone 79 feet; and in the intermediate shales and sandstone there is one bed of coal $3^{\prime}$ to $4^{\prime}$ thick (Winchell).

In Alabama, the Coal-measures cover 5500 square miles. There are 3 areas, - the Warrior, the Cahaba, and the Coosa. The first contains nine tenths of the whole area. The thickness near Tuscaloosa, where the beds disappear beneath more recent formations, is about $3000^{\prime}$. The number of coal seams is about 35 , of which 15 are over $2 \frac{1}{2}$ thick, and 6 , of $4^{\prime}$ and over. The beds become thinner to the northwest. The lowest of the coal-beds are those in the Pottsville conglomerate.

The Rhode Island Carboniferous covers the most of the southern part of the state, and extends northward, through Providence, to the northern border; there it passes into Norfolk County, Mass., and thence eastward, through Bristol County, to Plymouth County. The exact limits, east, west, and north, have not been made out, the stratification of the rocks being much obscured by displacements or flexures and metamorphism. There are conglomerates and slates which are supposed by Hitchcock and Jackson to be a part of the formation. The quartzose conglomerate outcrops at Newport and elsewhere, and forms a bold feature in the landscape at "Purgatory," $2 \frac{1}{2}$ miles east of Newport, and at the "Hanging Rocks." The stones vary in size from an inch to a foot or more. Associated with the slate there are beds of limestone.

The principal points where coal outcrops are near Providence, Cranston, Bristol, Portsmouth, Valley Falls, Cumberland, and Newport (a thin bed outcropping on the coast), in Rhode Island; and in Raynham, Wrentham, Foxboro, and Mansfield, in Massachusetts. The beds are much broken and very irregular in thickness, owing to the upturning and flezures the formation has experienced, and the coal is an exceedingly hard anthracite, because of the metamorphism, and to some extent is graphitic. Still, the slates often contain fossil plants, part of which are identical in species with those of Pennsylvania. DANA'S MANUAL - 42 
Near Portsmouth, at Aquidneck, three beds are reported to exist, $2^{\prime}$ to $20^{\prime}$ thick, and at Case's, one of the three is $13^{\prime}$ thick; at Providence, one, of $10^{\prime}$; at Valley Falls, tive, $6^{\prime}$ to 9'; at Cumberland, two, $15^{\prime}$ to $23^{\prime}$; near Mansfield, several, with the maximum thickness 10'. The earliest opening was made at Case's, near Portsmouth, in 1808.

At Worcester, Mass, an independent coal area, there are mica schists and graphitic slate, with remains of a species of Lepidodendron.

Cape Breton, Nova Scotia, New Brunswicl. - A large part of Cape Breton and the northern half of Nova Scotia, and more than two thirds of New Brunswick, are covered by the coal formation. The chief of the coal mines are in Nova Scotia, in the Pictou, Colchester, and Cumberland districts. In New Brunswick, the formation is thin and yields little coal. At the Joggins, in the Cumberland district, the beds, according to Dawson, rest on $3000^{\prime}$ of Subearboniferous beds, have a thickness of $1: 3,000^{\prime}$, and are made up of sandstone, conglomerates, shales, and impure limestone. Of the whole, $5000^{\prime}$ to $6000^{\prime}$ pertain to the conglomerate or Millstone grit, $4000^{\prime}$ to the Lower Coal-measures, and $30010^{\prime}$ to the Upper, a large portion of which is regarded by Dawson, on account of the fossils, as Permian. In the series, there are 76 dirt-beds and coal-seams, indicating as many levels of verdant fields or marshes. Each dirt-bed is a clayey layer with stumps of Stigmariæ and other plant remains; but only 15 contain any coal. The main coal-bed at the Joggins is only $5^{\prime}$ thick, with a foot or so of clay along the middle. The Permian at Pictou has a thickness, according to Fletcher, of $1146^{\prime}$, but on John River, near the boundary of the Colchester district, 8107'. For a detailed report on the Pictou and Colchester districts, by Fletcher, see Can. Geol. Rep. for 1890-91.

The Millstone-grit portion includes thick beds of coarse gray sandstones, containing prostrate trunks of Coniferous trees in its upper and middle parts, with red and comparatively soft beds in its lower; many layers of coaly shale occur throughout, but no coal-beds. At Pictou, where the beds dip $20^{\circ}$ or more, the mean thickness of the main coal-bed is 38'; of another, $159^{\prime}$ below, $15 \frac{1}{2}^{\prime}$; and $280^{\prime}$ below this occurs the McGregor seam $12^{\prime}$ thick. The total thickness of the Carbonifererous is about the same as at the Joggins (Dawson).

A Carboniferous formation without coal is the great fact for the western half of the continent. Beyond the Mississippi, near the meridians of $97^{\circ}$ to $101^{\circ} \mathrm{W}$., the formation, as it extends westward, becomes increasingly thinner in its coal-beds and passes beneath the Triassic, Cretaceous, and Tertiary beds of the eastern Rocky Mountain slope. The formation makes its first reappearance at the surface at about $104^{\circ} \mathrm{W}$., in the Black Hills of Dakota; but it comes up destitute of coal, and is a limestone formation $400^{\prime}$ thick, including a middle portion of sandstone, $75^{\prime}$ thick. Moreover, through the region of the Rocky Mountains farther west, and also northward through British America, wherever the Carboniferous is to be seen, the rock is a barren limestone, or limestone and sandstone. It is widely distributed as a surface rock at the base of Archæan ridges and elsewhere, has its largest continuous area in Arizona, is widely distributed over the Great Basin in Nevada, occurs also in Utah and Montana, whence it extends northward beyond the United States boundary along the summit region of the mountains. The deposition of Mesozoic, Cenozoic, and lacustrine beds, and the extensive ejection of igneous rocks over the vast region of the United States, between the meridian of $105^{\circ} \mathrm{W}$. and the Pacific, have left little of the Paleozoic formations in sight. Along the summit region the beds rest on Silurian or Cambrian beds.

The Carboniferous is the surface rock at the Grand Cañon of the Colorado. It there comprises the Aubrey limestone, as the summit portion of the lofty walls, $835^{\prime}$ thick; below this, the Aubrey sandstone, often having cross-bedded layers for 1455'; and then the "Red-wall" limestone, having a thickness of $970^{\prime}$ (Walcott), in all $3260^{\prime}$. The limestones are more or less cherty and in part shaly or arenaceous, and the upper contains some gypsum. A portion of the lower limestone, of undetermined thickness, contains Subcarboniferous fossils. 
In the Wasatch, the Carboniferous beds are about $13,000^{\prime}$ thick, the Upper Coalmeasure limestone $2000^{\prime}$ thick; below this is the Weber quartzyte, $6000^{\prime}$; and then $5000^{\prime}$ of the Wasatch limestone, the lower part of which contains Subcarboniferous fossils. The Carboniferous formation in the Eureka basin, Nevada, has a total thickness not far from $10,000^{\prime}$, of which the Weber conglomerate comprises $2000^{\prime}$, and a quartzyte at the base, $3000^{\prime}$. The upper member is only $500^{\prime}$ thick, but has a thickness of $2000^{\prime}$ to the northwest. (Hague.)

In California, Carboniferous beds, consisting partly of limestone, occur in the Sierra Nevada along a broad belt west of, and nearly parallel to, its axis. They extend interruptedly, says Whitney (1866), from Shasta County, near Pitt River (40 $45^{\prime} \mathrm{N}$. where limestone of the period was first identified by Trask in 1855) through Plumas County, southwestward, to the Tahichipi valley, more than 500 miles, The limestone occurs at intervals interstratified with the argillyte, mica schist, and siliceous slates of the auriferous series, and disappears at times, as Whitney states, by graduating into calcareous sandstones and the siliceous slate. The fossils obtained by Trask near Bass Ranch, comprising species of Fusulina (Fig. 1069), a Lithostrotion hardly distinguishable from L. mammitlare, and other kinds, were referred by Meek, with much expressed doubt, to the Subcarboniferous; and Gabb suggested the same conclusion for the fossils of the limestone at Pence's Ranch, 80 miles to the southeastward. H. W. Turner reports Fusulina from Hite's Cove, Mariposa County, and, from other parts of the same interrupted limestone belt, in Calaveras and Amador counties, and at different points in Plumas County. It is probabke that the rocks are partly at least of the Carboniferous period.

Carboniferous rocks occur also in the Klamath Mountains and Coast Range, according to Fairbanks and Diller. But they have not yet been identified in Oregon and Washington. They exist in British Columbia, in some parts of the Coast region, and are extensively distributed over the interior plateau, extending northward as far at least as the Peace River region, in latitude $55^{\circ}-56^{\circ} \mathrm{N}$.

In the Arctic regions, Carboniferous beds are reported from Melville Island, at Cape Dundas, Bridgeport Inlet and Skene Bay ; Baring Island at Cape Hamilton; Byam Martin Island; and on Bathurst at Schomberg Point and Graham Moore Bay. The line of outcrops of the beds runs E.N.E. They are accompanied by clay ironstone in nodules, as is usual in coal regions (Haughton). For notes on the Carboniferous areas of the Arctic regions, see, further, G. M. Dawson, Rep. Geol. Canada, for 1886.

In Mexico, Carboniferous limestone, representing the Carboniferous period, or the Carboniferous and Permian periods, has been observed in some of the ridges and mountains of Coahuila and Nuevo Leon (Frazer and Hall), and also on the borders of Mexico and Guatemala; also, in Nicaragua, with overlying Permian and underlying Silurian and Devonian (Crawford, 1890).

In South America, the Carboniferous beds have great extent in Brazil, in the Amazon valley, - as great as the North American Carboniferous, - but they afford no coal (Derby, Am. Jour. Sc., xvii., 1879).

The following probable correlations are based by Lesquereux on the distribution of the species of coal-plants :-

Coal A, which exists within the Pottsville conglomerate, or Millstone grit, at the basis of the Coal-measures, or its equivalent plant-bearing beds: at Shamokin, Lehigh Summit, lower bed at Trevorton, Broad Top, in Pennsylvania; at Massillon, Ohio ; at C'nion Mines, in Crittenden County, Kentucky.

Coal B, Archbald, Pa.; Spring Creek, Ind.; Union, Greenup, and Carter counties, Ky.; Murphysboro, Mazon Creek, Morris, Ml., in shale over coal.

Coal B or C, Carbondale, Pa.; Cannelton, Pa.; Clinton, Mo.

Coal C, Archbald, Shamokin, Pittston, at Boston mine, etc.; Eugene, Vermilion County, Ind. 
Coal D, Carbon Hill, Pittston, Pa. ; Vermilion County, Ind. ; Duquoin and St. John, Ill.

Coal D or E, Sullivan County, Ind. ; Hopkins and Christian counties, Ky.

Coal E, Mammoth bed at Pottsville, Pittston, Yatesville, Pa.; Nelsonville and Coshocton, Ohio ; Stark and Peoria counties, Ill.

Coal E and F, Wilkesbarre, Pa. ; Nelsonville and Coshocton, Ohio.

Coal F, Plymouth, Pittston, and Maltby, Pa.

Coal G, Olyphant, Plainsville, Gate and Salem veins, Pottsville, Pa.; Pomeroy, Ohio.

At Cannelton, $\mathrm{Pa}$, the number of species of plants obtained from the coal-bed of the $\mathrm{B}$ or C horizon, according to Lesquereux, is 140; at Mazon Creek, Ill., from the bottom of the coal-bed B, 150 species, and adding those from the overlying clay-bed, 200 species; and if the species from the same bed at Murphysboro be added, with others the bed affords in Missouri, the number mounts up to 250 species, which is a very large flora for one coal-bed level. The whole number of plants thus far described from the American Coal-measures, the Permian portion included, is 900 .

\section{Permian Period.}

\section{ROCKS-KINDS AND DISTRIBUTION.}

It has been stated that the Upper Barren Measures of Pennsylvania and West Virginia, having a thickness in Monongalia County of 1044 feet, were of the age of the Permian period, though continuous in bedding with the strata below. Similarly, the upper beds - clayey beds, sandstones, with some impure limestones - in the Coal-measures of Kansas, Missouri, Illinois, Nebraska, and Texas, are referred to the Permian. The same is true for an upper part of the Coal-measures of Nova Scotia, New Brunswick, and Prince Edward Island. The evidence of Permian age consists in the presence of remains of plants, Mollusks and Vertebrates, like those of the foreign Permian. Permian beds have also been identified in the region of the Colorado Cañon in Arizona and Utah, where 845 feet of limestone and shales containing gypsum, overlying Carboniferous limestone, are referred to this period. In the Wasatch, the beds have a thickness of 600 feet.

Permian beds were identified in the San Francisco Mountains by Marcou in 1853 ; and in the Guadalupe Mountains, New Mexico (a white limestone), by B. F. Shumard in 1858. About the Colorado Cañon they have been studied by Walcott (in 1880) and others. The rock in the Wasatch is the "Bellerophon limestone" described by King (1878). Permian was identified in Nova Scotia by Dawson in 1845; in Kansas, by Meek, Swallow and Hawn, in 1858; in Hlinois, by Worthen, in 1858; and soon after in Missouri and Nebraska by Meek; in Pennsylvania and West Virginia, by Fontaine and I. C. White, in 1880. Cope's observations in Illinois and Texas were made in 1875, and later; C. A. White's, in Texas, in 1889. On the Kansas Permian, see, further, Prosser's paper of 1894.

The Texas Permian occupies the western portion of the Carboniferous area. North of the Brazos River the lower beds, in the Wichita of Cummins, are red clays and sandstones, with some impure limestone at top. The fossils described by C. A. White are from this part of the series, and so also the Vertebrates described by Cope. Above are the so-called Clear-Fork and Double Mountain division, and then come the Dockum beds, different in rocks and fossils, which are referred to the Triassic. 
ECONOMICAL PRODUCTS.

Coals, Iron Ores, Clays, and Salt of the Carboniferous and Subcarboniferous Formations.

1. Coal. - Coal occurs of three kinds: (1) Anthracite, or stone coal; (2) ordinary Bituminous, sometimes distinguished as "cubical coal," in view of its natural fracture; and (3) Cannel coal, the dull textureless bituminous coal, breaking irregularly, with a conchoidal fracture, and only occasionally constituting parts of coal-beds. Excepting the cannel, the coals have distinctly, on a cross-fracture, a faint banding, due to a straticulate structure or bedding, and are rarely laminated unless very impure. The blocks into which bituminous coals break have probably been made by the strains to which the coalbed had been subjected; they are not those of crystallization.

The bituminous coals which soften in the fire and cake over are called caking or cementing coal; and those which burn without caking, the openburning coals. The "Block coal" of Ohio, Indiana, and the neighboring states, is of the non-caking kind, that most convenient for furnaces and open fires. The caking coals are prepared for metallurgical purposes by conversion into coke by partial combustion under cover (in ovens), which drives off the volatile matter. In the best process there is a loss usually of 20 to 35 per cent of weight, and an increase in bulk and hardness. At the same time the coal loses about half its sulphur.

The first of the following tables gives the results of analyses of coals, and also of peat, showing the amount of the several constituents; and the second, the amount of fixed carbon, and of volatile hydrocarbons (gas, oil) afforded, and besides, the water and ash, or impurities.

The flame given out in a fire is that of the burning gas as it escapes. This gas is almost wholly a compound of carbon and hydrogen, or a hydrocarbon; but it includes a little carbonic oxide (carbon monoxide), which has a bluish flame; and in the case of anthracites, which have very little volatile matter apart from the moisture, this gas is the chief one. But anthracites shade down into the semi-bituminous, and the flame varies consequently from bluish to yellow.

Cannel coal (called in Scotland Parrot coal) affords usually the most volatile hydrocarbons, and is valuable for gas making; and it will be much used for its yield of mineral oil or petroleum whenever the oil-wells give out. It occurs in Ohio and Indiana, and still more abundantly in eastern Kentucky, where Breckenridge is a noted locality. The amount of impurity in them is often large, and the beds frequently contain remains of Fishes, Crustaceans, and some other fossils, which is not true of the ordinary bituminous coal. The fossils appear to be almost solely those of fresh waters. Linton, Ohio, is a locality famous for its Fishes and Amphibians, its cannel coal affording 50 species or more.

The Subcarboniferous beds of New Brunswick, in some parts of King's, Albert, and Westmoreland counties, afford a semi-asphaltic material called 
albertite, looking like bitumen or asphalt. but not readily fusing like it in a candle. It occupies rents in the rock, instead of constituting layers. A similar substance, called grahamite, occurs under similar comlitions in the Cual-measures of West Tirginia, 20 miles south of l'arkersburg. It is partly columnar in fracture at right angles to the walls of the vein. Both are supposed to have been made from the oxidation of mineral oil.

\begin{tabular}{|c|c|c|c|c|c|c|c|}
\hline & Carbon & Hydr. & $0 x$ & Nitr. & Sulph. & Ash & Analysts \\
\hline 1. Anthracite, Pennsylvania...... & $90 \cdot 45$ & $2 \cdot 43$ & $2 \cdot 45$ & - & - & $4 \cdot 67$, & Regnault. \\
\hline 2. Anthracite, Pennsylvania...... & $92 \cdot 59$ & $2 \cdot 63$ & $1 \cdot 61$ & $0 \cdot 92$ & - & $2 \cdot 25$ & Percy. \\
\hline 3. Anthracite, South Wales....... & $92 \cdot 56$ & $3 \cdot 33$ & $2 \cdot 53$ & - & - & 1.58, & Regnault. \\
\hline 4. Caking Coal, Kentucky....... & $74: 45$ & $4 \cdot 93$ & $13 \cdot 08$ & $1 \cdot 03$ & $0 \cdot 91$ & $5 \cdot 00$ & Peters. \\
\hline 5. Caking Coal, Nelsonville, Ohio.. & $73 \cdot 80$ & $5 \cdot 79$ & $16 \cdot 58$ & $1 \cdot 52$ & $0 \cdot 41$ & $1 \cdot 90$ & Wormley. \\
\hline 6. Caking Coal, South Wales...... & $82 \cdot 56$ & $5 \cdot 36$ & $8 \cdot 22$ & $1 \cdot 65$ & $0 \cdot 75$ & $1 \cdot 46$ & Noad. \\
\hline 7. Caking Coal, Northumberland.. & $78 \cdot 69$ & $6 \cdot 00$ & $10 \cdot 07$ & $2 \cdot 37$ & $1 \cdot 51$ & $1 \cdot 36$ & Tookey. \\
\hline 8. Non-caking, Kentucky......... & $77 \cdot 89$ & $5 \cdot 42$ & $12 \cdot 57$ & $1 \cdot 82$ & $3 \cdot 00$ & $2 \cdot 00$ & Peters. \\
\hline 9. Non-caking, "Block Coal," Ind. & $82 \cdot 70$ & $4 \cdot 77$ & $9 \cdot 39$ & $1 \cdot 62$ & $0 \cdot 45$ & 1.07, & Cox. \\
\hline 10. Non-caking, Brier Hill, Ohio... & $78 \cdot 94$ & $5 \cdot 92$ & $11 \cdot 50$ & $1 \cdot 58$ & 0.56 & $1 \cdot 45$ & Wormley. \\
\hline 11. Non-caking, S. Staffordshire.... & $76 \cdot 40$ & $4 \cdot 62$ & $17 \cdot 43$ & - & 0.55 & $1 \cdot 55$ & Dick. \\
\hline 12. Non-caking, Scotland......... & $76 \cdot 08$ & $5 \cdot 31$ & $13 \cdot 33$ & $2 \cdot 09$ & $1 \cdot 23$ & $1 \cdot 96$ & Rowney. \\
\hline 13. Cannel Coal, Breckenridge..... & $68 \cdot 13$ & $6 \cdot 49$ & $5 \cdot 83$ & $2 \cdot 27$ & $2 \cdot 48$ & $12 \cdot 30$ & Peters. \\
\hline 14. Cannel Coal, Wigan........... & $80 \cdot 07$ & $5 \cdot 53$ & $8 \cdot 10$ & $2 \cdot 12$ & $1 \cdot 50$ & $2 \cdot 70$ & Vaux. \\
\hline 15. Cannel Coal, "Torbanite".... & $64 \cdot 02$ & $8 \cdot 90$ & $5 \cdot 66$ & $0 \cdot 55$ & $0 \cdot 50$ & $20 \cdot 32$ & Anderson. \\
\hline 16. Bituminous Coal, Wyoming.... & $73 \cdot 55$ & $4 \cdot 17$ & $17 \cdot 20$ & $1 \cdot 93$ & $1 \cdot 18$ & $1 \cdot 86$ & $\ldots \ldots \ldots$ \\
\hline 17. Bituminous Coal, Wyoming.... & $75 \cdot 20$ & $4 \cdot 74$ & $10 \cdot 37$ & $1 \cdot 37$ & $1 \cdot 11$ & $7 \cdot 20$ & $\ldots \ldots \ldots$ \\
\hline 18. Albertite, Nova Scotia.......... & $86 \cdot 04$ & $8 \cdot 96$ & $1 \cdot 97$ & $2 \cdot 93$ & trace & $0 \cdot 10$ & Wetherell. \\
\hline 19. Brown Coal, Bovey .......... & $66 \cdot 31$ & $5 \cdot 63$ & $22 \cdot 86$ & 0.57 & $2 \cdot 36$ & $2 \cdot 27$ & Vaux. \\
\hline 20. Brown Coal, Wittenberg....... & $64 \cdot 07$ & $5 \cdot 03$ & $27 \cdot 55$ & - & - & $3 \cdot 35$, & Baer. \\
\hline 21. Peat, light brown (imperfect)... & $50 \cdot 86$ & $5 \cdot 80$ & $42 \cdot 57$ & 0.77 & - & - & Websky. \\
\hline 22. Peat, dark brown............. & $59 \cdot 47$ & $6 \cdot 52$ & $31 \cdot 51$ & $2 \cdot 51$ & - & - & Websky. \\
\hline 23. Peat, black................ & $59 \cdot 70$ & $5 \cdot 70$ & 3304 & $1 \cdot 56$ & - & - & Websky. \\
\hline 24. Peat, black............... & $59 \cdot 71$ & $5 \cdot 27$ & $32 \cdot 07$ & $2 \cdot 59$ & - & - & Websky. \\
\hline
\end{tabular}

No. 13, the Breckenridge cannel, of Hancock County, Ky., consists, when the ash is excluded, of carbon $82 \cdot 36$, hydrogen $7 \cdot 84$, oxygen $7 \cdot 05$, nitrogen $2 \cdot 75$; and the Bog-head cannel of Scotland, called also torbanite, contains carbon $80 \cdot 39$, hydrogen $11 \cdot 19$, oxygen $7 \cdot 11$, nitrogen and sulphur 1·31.

The "Mineral charcoal" differs little in composition from ordinary bituminous coal ; there is less hydrogen and oxygen. Rowney obtained, for that of Glasgow and Fifeshire, carbon $82 \cdot 97,74 \cdot 71$, hydrogen $3 \cdot 34,2 \cdot 74$, oxygen $7 \cdot 59,7 \cdot 67$, ash $6 \cdot 08,14 \cdot 86$. The nitrogen is included with the oxygen; it amounted to 0.75 per cent in the Glasgow charcoal. Exclusive of the ash, the composition is, carbon $88 \cdot 36,87 \cdot 78$, hydrogen $3 \cdot 56,3 \cdot 21$, oxygen and nitrogen $7 \cdot 28,9 \cdot 01$.

The oxygen in a coal, which, as the table shows, varies from about 10 pounds to 15 in a hundred in the ordinary bituminous coals, is so much waste material as far as the heating purposes of the coal are concerned, because the atmosphere is at hand to supply all that combustion requires. The moisture also causes loss of heat, because of the amount required to evaporate and expel it.

The following are other analyses of anthracite and bituminous coal; they are a few from the many by McCreath, of the Pennsylvania Geological Survey. The amount of volatile hydrocarbons is given in the second column. 


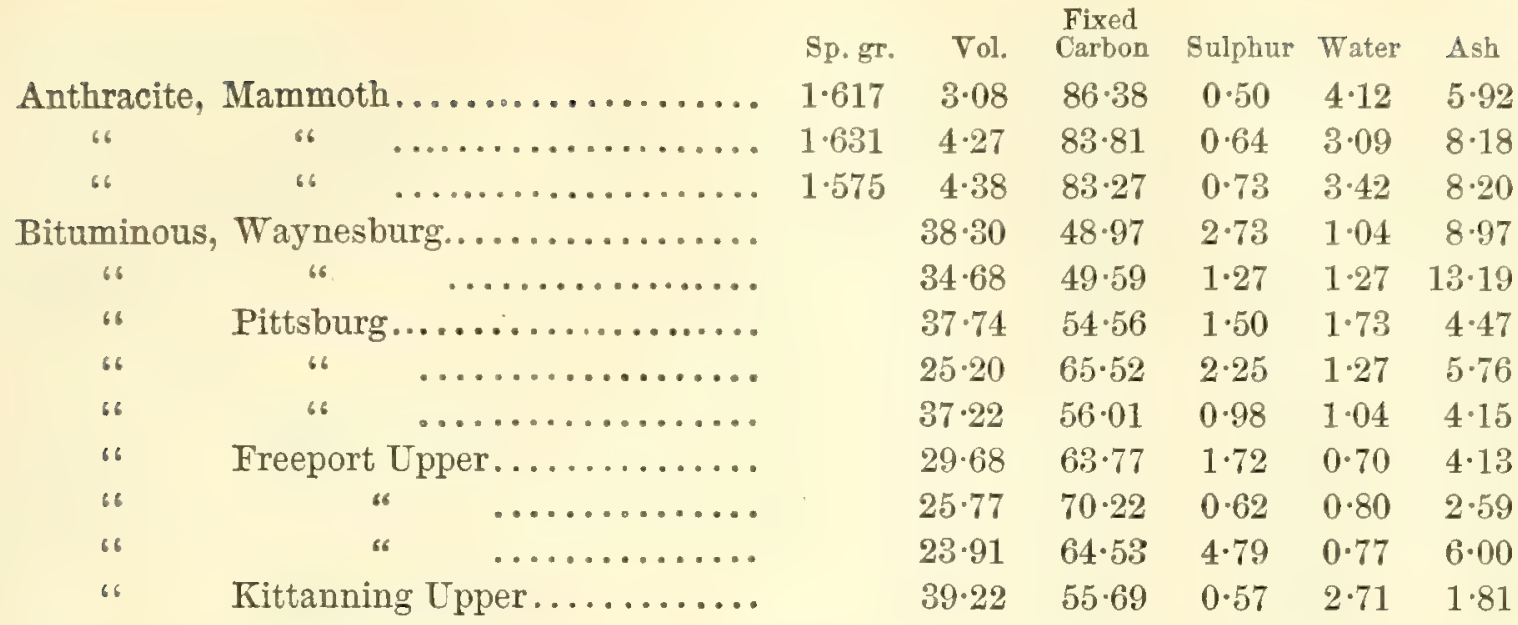

It is found that the Pittsburg coal affords $0 \cdot 0011$ to $0 \cdot 1248$ per cent of phosphorus, which becomes 0.0018 to 0.2003 in the coke. Other analyses are given in the Geological Reports of Ohio, Kentucky, Indiana, Illinois, etc. It is useless to cite further from them, since the variation is very large in a single bed as it is traced over the country, and the state reports should be referred to for details.

The Arctic coal, of Grinnell Land $\left(81^{\circ} 43^{\prime} \mathrm{N}\right.$. and $64^{\circ} 4^{\prime} \mathrm{W}$.), is good caking bituminous coal ; it afforded R. J. Moss, on analysis, carbon $75 \cdot 49$, hydrogen $5 \cdot 60$, oxygen and nitrogen 9.89, sulphur 0.52, ash 6.49, water $2 \cdot 01=100$ (Proc. R. Dublin Soc., 1878).

The ordinary impurities of coal, making up its ash, are silica, a little potash and soda, and sometimes alumina, with often oxide of iron, derived usually from sulphide of iron (pyrite or marcasite), besides, in the less pure kinds, more or less clay or shale. The amount of ash in the selected coal does not ordinarily exceed 10 per cent, but it is sometimes 30 per cent; and rarely it is less than 2 per cent. Thin layers of pyrite are rather common, and occasionally a bed of other ores of iron is intercalated.

Wormley gives the following analyses (besides others) of the ash of two coals, one from the Youghiogheny, in western Pennsylvania, and the second from Pigeon Creek, Jackson County, Ohio: Silica $49 \cdot 10,37 \cdot 40$, alumina $38 \cdot 60,40 \cdot 77$, sesquioxide of iron $3 \cdot 68$, $9 \cdot 73$, magnesia $0 \cdot 16,1 \cdot 60$, lime $4 \cdot 53,6 \cdot 27$, potash and soda $1 \cdot 10,1 \cdot 29$, phosphoric acid $2 \cdot 23$, $0 \cdot 51$, sulphuric acid $0 \cdot 07,1 \cdot 99$, sulphur (combined) $0 \cdot 14,0 \cdot 08$, chlorine trace $=99 \cdot 61,99 \cdot 64$. The fact that there is too much sulphur in the Ohio coals for combination with the iron present is shown in the following table, containing some of his results :-

$\begin{array}{llllll}\text { Sulphur in the coals . . . . . } & 0.57 & 1.18 & 2.00 & 0.91 & 0.86 \\ \text { Iron in the coals........... } & 0.075 & 0.742 & 0.425 & 0.122 & 0.052 \\ \text { Sulphur required by the iron... } & 0.086 & 0.848 & 0.486 & 0.139 & 0.06\end{array}$

The source of the impurities is in part the vegetation of which the coal was made, which is shown on page 74 to be sometimes large, even as regards silica and alumina, the constituents of a clay, and large also for calcium carbonate and potash.

According to the average composition of Lycopods, the dried plant affords 5 pounds of ash to 100 of the plant, and 40 per cent of this is alumina and silica (27 alumina and 13 silica), and hence these two ingredients make up 2 per cent of the plants. Ferns, with the same amount of ash, afford, as the average, 27 per cent of silica, with no alumina. Equiseta afford, on an average, 20 per cent of ash, and 50 per cent of this may be silica. 
Supposing, now, that Lycopods (Lepidodendrids, etc.) afforded one half the material of the coal-beds, and the other plants the rest, and that the silica and alumina of the former averaged 40 per cent, and of the latter only 27 per cent, this being all silica, then the amount of these ingredients afforded by the vegetation would be 1.66 per cent of the whole weight when dried. This would make the amount of silica and alumina, in the bituminous coal made from such plants (supposing three fifths of the material of the wood lost in making the coal, as estimated on page 713$), 4$ per cent; and the whole amount of ash about 4.75 per cent. At the same time, the ratio of silica to alumina would be nearly 3 to 2.

Now many analyses of bituminous coal have obtained not over 3 per cent of ash, or impurity, although the general average, excluding obviously impure kinds, reaches 4.5 to 6 per cent; being, for the coals of the northern half of Ohio, $5 \cdot 12$, and for the southern half, $4 \cdot 72$.

It hence follows that (1) the whole of the impurity in the best coals may have been derived from the plants; (2) the amount of ash in the plants was less than the average in modern species of the same tribes; (3) the winds and waters for long periods contributed almost no dust or detritus to the marshes; and (4) the ash, or else the detritus, was. greatest in amount toward the borders of each marsh-region. In that era of moist climate and universal forests, there was almost no chance for the winds to gather dust or sand for transportation.

In rare cases, an occasional bowlder or rounded stone has been found in: a coal-bed, as well as in other layers of the Coal-measures. E. B. Andrews. describes one of quartzyte, lying half buried in the top of the Nelsonville coal-bed, at Zaleski, Ohio, which was 12 and 17 inches in its two diameters. F. H. Bradley reports one, also of quartzyte, about four by six inches, found in the middle of the coal-bed mined at Coal Creek, East Tennessee. These may have been dropped from the roots of floating trees, as has happened to. masses of basaltic rocks occasionally found upon the coral atolls of the Pacific.

Sulphur also occurs, in some coal-beds, as a constituent of a resinous substance; and Wormley suggested that part of the sulphur in the Ohio coals. is in some analogous state.

The mineral oil and gas of western Pennsylvania come wholly, or nearly so, from Chemung beds of the Devonian - not from the Carboniferous (page $606)$.

2. Iron Ores. - The ore-bearing layers of the Subcarboniferous and Carboniferous series occur in connection usually with the beds either of limestone or of shale, but sometimes with the sandstone and coal-beds. As these ores are more or less impure from mixture with clay, they are called clay-ironstone. The limestones often contain iron carbonate (siderite) - a gray ore, stone-like in aspect, of specific gravity $3 \cdot 7$ to $3 \cdot 8$. It occurs either in solid beds, from a few inches to two or three feet in thickness, or in nodules, or "ball ore," more or less united into a layer. The same limestone often contains also nodules of another valuable ore, limonite (page 71), the ore which affords a brownish yellow powder, though often brownish black to black in outside color. This limonite has frequently been made by the oxidation of the siderite. The Ferriferous limestone, just below the Kittanning coal-bed, contains both of the ores mentioned. The limonite in nodules, or as a "ball 
ore," is common also in beds of shale, in layers of a few inches to a foot or more in thickness, and sometimes forms beds beneath the fire clay that underlies a coal-bed. Another kind of clay-ironstone is hematite or ironsesquioxide, looking usually as stone-like as the preceding, but distinguished by its affording a red powder. These ore-masses are often siliceous, from disseminated silica, and therefore very hard.

These ores, but especially the first two, are a very important source of iron in coal regions. The nodules are of concretionary origin; that is, were made by the concreting together of iron oxide from iron-bearing salts carried down into marshes, and are not transported stones rounded by friction.

3. Clay-beds. - A bed of fire clay has been mentioned as usually underlying a coal-bed. The clay varies in purity on one side down to sandy clay, or to carbonaceous shales, and on the other to the purest of white clays, valuable for making pottery, fire-brick, and tile (see page 81). The thickness of the beds varies from a few inches to sometimes half a dozen feet. They are apt to be more or less discolored by iron-oxide, so as to make cream-colored instead of white pottery; and sometimes the bed overlies a bed of iron ore, and is pure white only at top.

The very common presence of pure white clays in the Coal-measures is a consequence of the production of carbonic acid, and also of organic acids, by the vegetable decomposition that goes on indefinitely in the plant beds. The sediments, whether of sand or mud, contain more or less feldspar; and the action of these acids on the feldspar removes the alkali and produces the clay (page 129). The clay so made will be at first colored by iron oxide, if any iron-bearing mineral is present (the common fact); but the vegetable decomposition going forward results in partly deoxidizing the iron oxide (reducing it to $\mathrm{FeO}$ ); and then the iron in this state is taken up by the acids and carried off in solution (page 124) until the blanching in many cases is complete through part or all of a thick bed. 'The abundance of carbonic acid, set free under the conditions described, accounts also for the very frequent occurrence of iron-carbonate (or siderite) mentioned above.

The presence of potash or soda in the clay is probable evidence of the presence of undecomposed feldspar, and of over 7 per cent of it to 1 per cent of the alkali - a point of geological as well as economical interest; for such clays are fusible and not properly fire clays, and therefore are not suitable for fire brick. The presence also of lime and iron gives the clays fusibility. On Ohio clays, see Ohio G. Rep., v., 656.

4. Salt. - Saline waters have been obtained in many regions from borings down to the Carboniferous strata, but usually they are only saline enough to be spoilt water. In Michigan, strong brines are supplied from the Subcarboniferous beds, and they are used for the manufacture of salt in the Saginaw valley. The same beds contain extensive deposits of gypsum. In Ohio, productive brines come partly from the same horizon. Those of Kanawha in West Virginia are from the lower part of the Coal-measures; and Kansas beds of the same period have been found to afford brines. 


\section{LIFE OF THE CARBONIFEROUS PERIOD.}

PuAnts. - Forests and jungles male of cryptogans of the tribes of Ferns, Equiseta, and Lycopods, along with Gymmosperms related to the Cycads and Yews, and covering interminable marshy plains and fields, were the striking

1031.

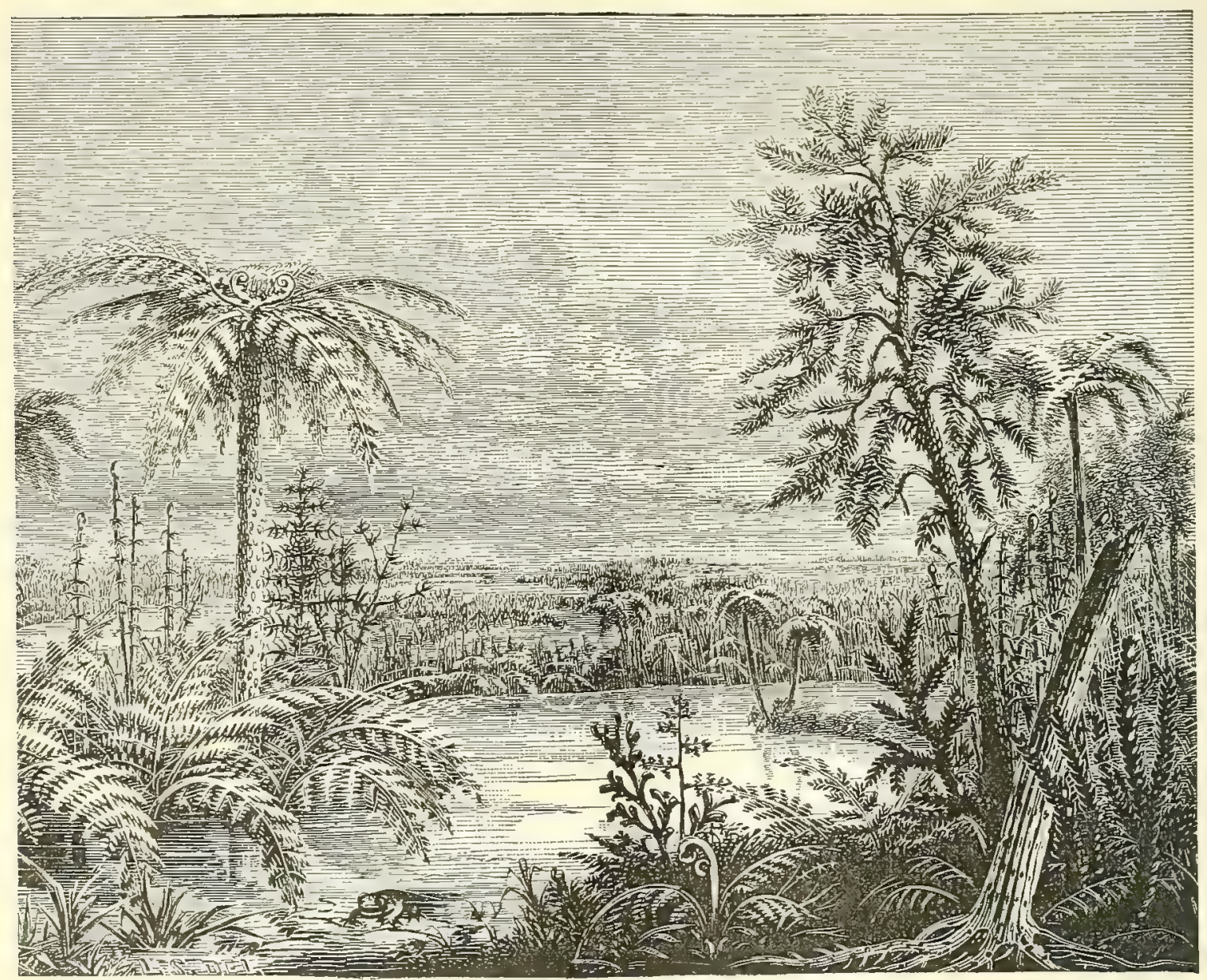

Carboniferous vegetation. Russell Smith.

feature of the coal era. Though desolated again and again, either universally or partially, by the returning waters, and over the large submerged areas kept desolate for many centuries or series of centuries again and again, the verdure in all its luxuriance spread over the emerging land, with little change in the foliage, for other times of luxuriant growth and of peat-making. Only toward the close of the era, when the Permian period was commencing, had the forests lost the larger part of their great trees of the tribe of Lycopods.

Unlike the present world, there were no Angiosperms and no Palms. It is not positively known that there were Endogens of any kind. There was certainly no grass over the fields, the most common of Endogens. With Angiosperms and Endogens absent, there were no conspicuous flowers, no beautiful foliage except that of the Ferns and fern-like trees, and no fruit 
and no fragrance but that of Conifers and Cycals. Even Mosses, so common in modern swamps, and the chief source of modern peat, have left no evidence of their presence.

A general idea of the vegetation and scenery of the era during its periods of rerdure may be gathered from the accompanying ideal sketch (Fig. 1031), from a painting by Russell Smith. The tree to the left of the center, and others with similar palm-like tops, are the Tree-ferns; and smaller Ferns make up much of the foreground. The other trees are Lycopods, the Lepidodendrids; and one bare trunk to the right is that of a Sigillaria. Other straight stems with leaves (or branchlets) at regular intervals are the Equiseta or Calamites. The Cycad-like Cordaites, with their long strap-like leaves, with probably others having almost the foliage of a Fern-tree, should have been in the view; for they added largely, as Lesquereux and others have stated, to the forest trees. But of other Gymnosperms, the so-called Conifers, there are few indications in the beds. They may have been common over the drier fields and hills.

Forests made of the Equiseta and Lycopods of to-day would hardly overtop a man's head. They would be simply shrubbery of "Horse-tails" and "Ground Pines." The

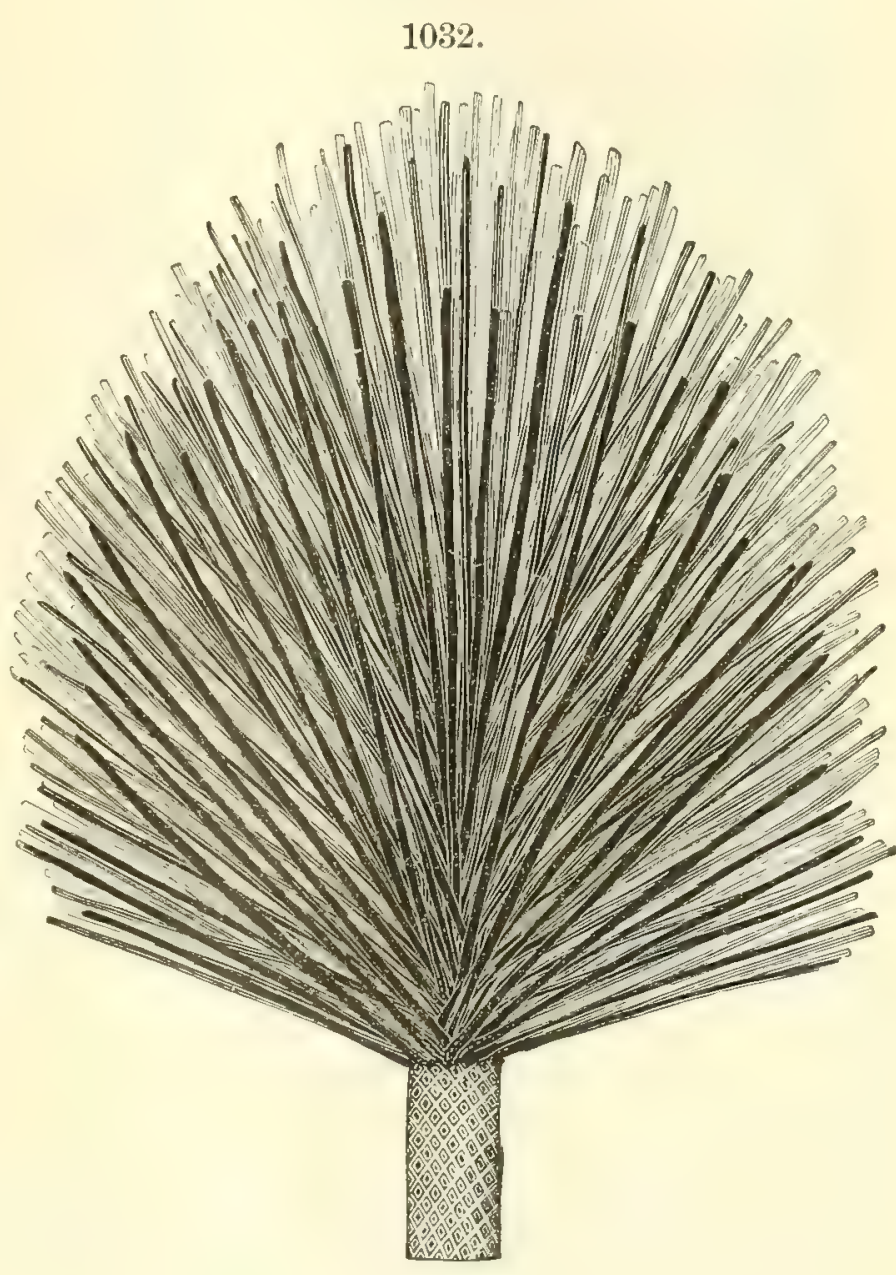

Extremity of a branch of Lepidodendron, with the leaves attached. height of the largest modern Lycopod is five to six feet; that of the ancient, 60 to 90 feet. In habit and in foliage they were much like the Spruces and Pines of the present day, the length of the leaves varying greatly, as illustrated in Fig. 1032. The Equiseta of the present time are slender, herbaceous plants, with hollow stems; while the Calamites of the Carboniferous marshes included species having partly woody trunks, a diameter of 3 to 10 inches, and a height of 30 or 40 feet. Ferns now grow into trees in tropical and warm temperate climates, hut only small trees, and poor in wood compared with some in the coal era.

While the terrestrial vegetation was thus abundant, seaweeds after the old style were still in the waters. The Spirophyton caudagalli of the Lower 
Devonian, or a related species, is common in some portions of the Pottsville conglomerate in Kentucky and elsewhere.

1. Vascular Cryptogams. - Lycopods. The Lepidodendron trees had the exterior embossed with oblong sears, as in Figs. 1033, 1034, and 1036.

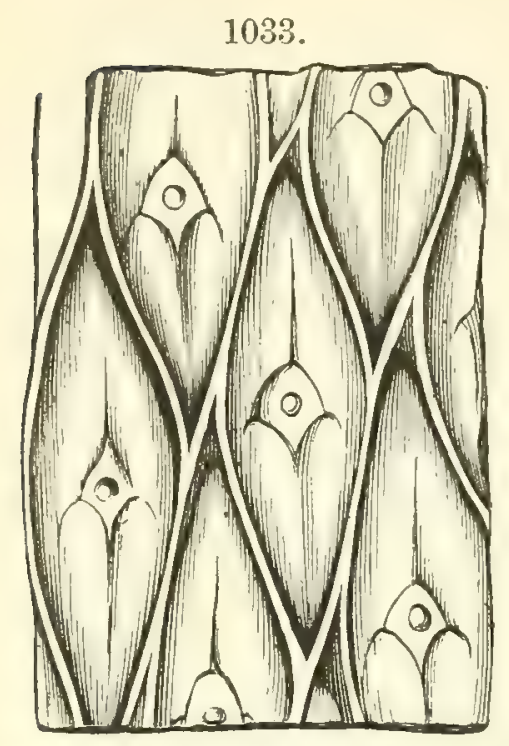

\section{3-1035.}

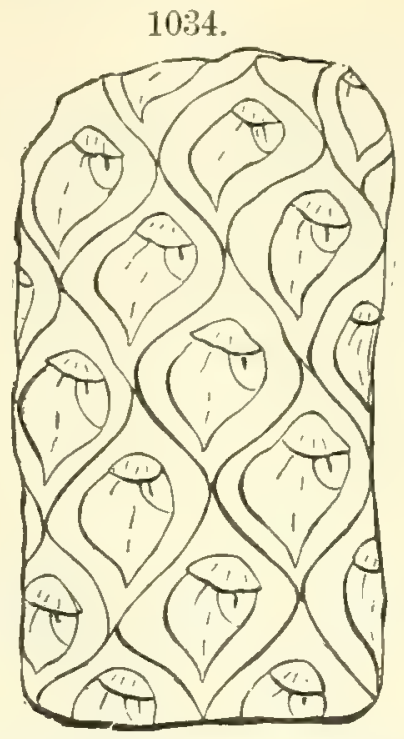

1035.

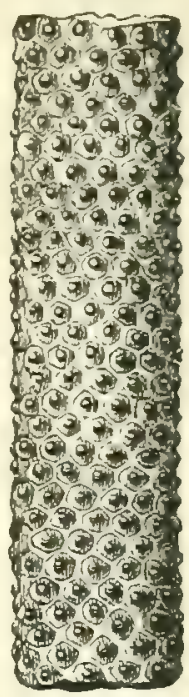

Fig. 1033, Lepidodendron aculeatum ; 1034, Lepidodendron ely peatum; 1035, Halonia pulchella. Fig. 1033, Fairchild; 1084, 1035, Lesquereux.

Leaves like those of the Spruce or Pine occasionally occur on the fossil stems (Fig. 1040); and in some foreign specimens of L. Sternbergii Brgt., from Austrian coal-beds, they are over a foot long, and as closely crowded on the branches as in any modern pine. The Lycopodium dendroideum of modern forests, if magnified largely, would give a good idea of the aspect of the

1036.

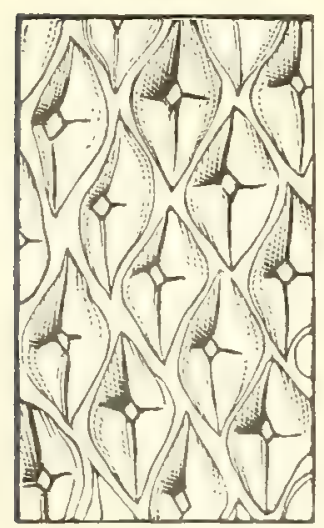

$1036-1038$.

1037.

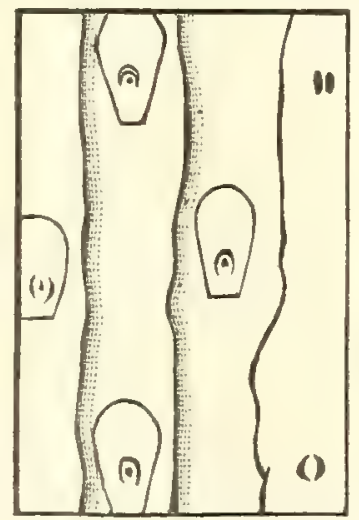

1038.

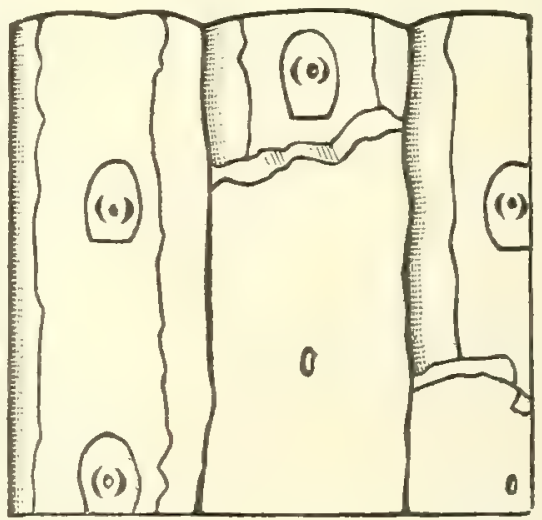

Fig. 1036, Lepidodendron Veltheimanum; 1037, Sigillaria Sillimani; 1038, S. Pittstonana. Lesquereux.

trees. The cones of Lepidodendrids were long, and much like those of a living Lycopod, and are referred to under the name Lepidostrobus, and the leaves of the cone under that of Lepidophyllum. The stems, called Lycopo- 
dites, are slender, small-leaved, and much like those of Lycopodium dendroideum, though often large. The Halonia, Fig. 1035, is a decorticated stem or rootlet of uncertain relations. Two species of Sigillaria are represented in Figs. 1037, 1038. The figures show that the scars are peculiar in having at the center a dot, and a short convex line either side; the exterior of the stem is generally vertically banded or costate, as in the figures.

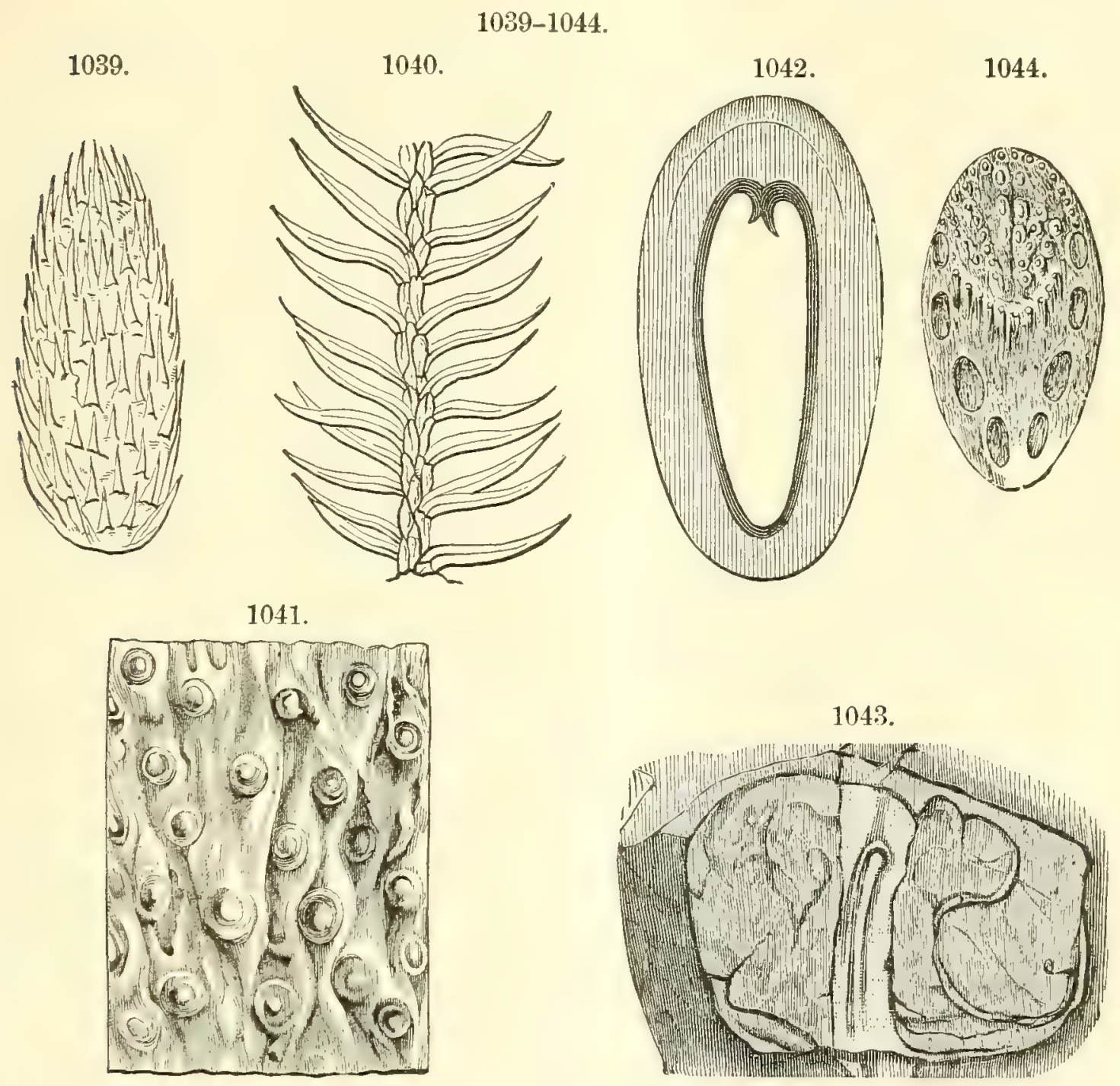

LrCopoDs. - Fig. 1039, Lepidostrobus hastatus (or cone of a Lepidodendron); 1040, Lepidodendron lanceolatum, Lx. ; 1041, Stigmaria. Scars of TreE-Ferns. - Fig. 1042, Stemmatopteris punctata $\left(\times \frac{1}{2}\right)$; 1043, Megaphyton McLayi ; 1044, Cyathea compta. Figs. 103:-1043, Lesquereux; except 1041, Dawson.

In both Sigillarids and Lepidodendrids, the appearance of the scars of the same species varied much with age; moreover, the same scar is wholly different in form at the surface from what it is below, as Figs. 1037, 1038 illustrate. The trunk, while woody and firm outside, consisted inside mostly of cellular tissue, with usually a very large pith along the center; and hence the stumps easily became hollow by decay. Such hollow stumps, filled with sand or clay, are common in the Coal-measures; and sometimes there remain only easts of them in sand having a scarred exterior. 
One of the cones of a Lepidodendrid from Pittsburg, Pa., is represented in Fig. 1039.

The Stigmarice, which were either roots or under-water-stems of Sigillarids or Lepidodendrids, were often large, many of the fossil stems being four to six inches in diameter. Fig. 1041 represents a portion of a stem, with its rounded impressions or scars. When perfect, each scar was the base of a long and slender leaf-like appendage.

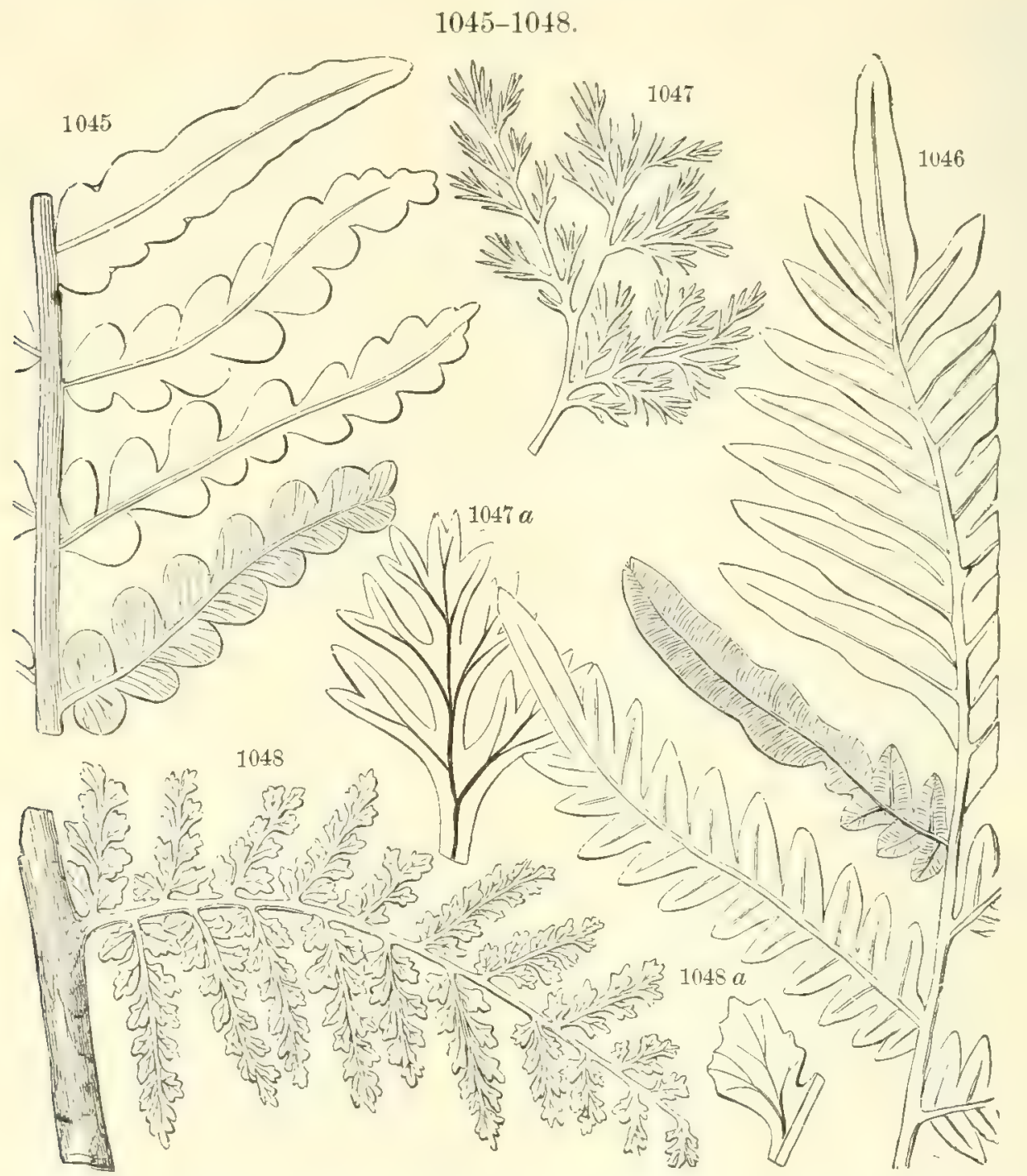

FERrs, - Fig. 1040̃, Odontopteris Schlotheimi ; 1046, Alethopteris lonchitica; 1047, Sphenopteris (Hymenophyllites) Hildrethi ; $1047 a$, portion of the same, enlarged; 1048, Sphenopteris Gravenhorstii ; $1048 a$, portion of the same, enlarged. Figs. 1045-1047, Lesquereux; 1048, Brongniart.

Ferns. - Two of the large scars of stems of Tree-ferns are shown in Figs. 1042,1043; and, for comparison, one from a modern Tree-fern (resembling the tree to the left in the sketch, page 666) is represented half-size in Fig. 1044. The trunks of Tree-ferns consist within of vertically plicated woody plates, with more or less cellular tissue between, and not of concentric rings. The twisted plates are sometimes well shown in a transverse section of a fossil trunk from the Coal-measures.

The variety of Ferns was very large. Some of the more common forms 
are represented in Figs. 1045 to 1052 . The genus Neuropteris (Figs. 1049, 1050 ) is one of the most abundant in species. The basal leaves (Figs. 1050, 1052 ) vary widely in form in the same species, and are sometimes delicately fimbriated. Odontopteris (Fig. 1045) has many species; and so also Alethopteris (Fig. 1046), Sphenopteris (Figs. 1047, 1048), and Pecopteris (Fig. 1051).

$1049-1056$.

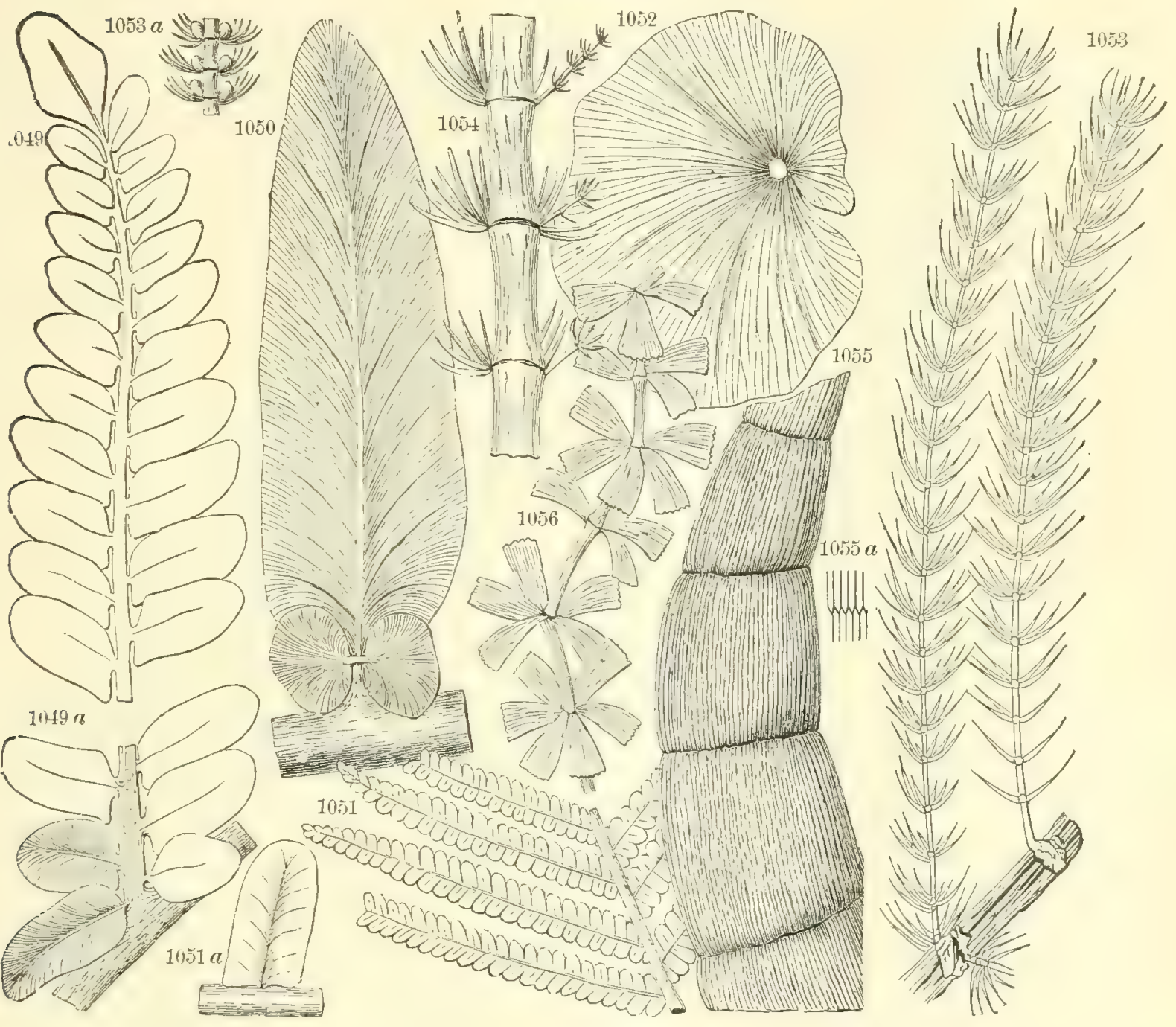

FERrs. - Figs. 1049, $1049 a$, Neuropteris Loschii, parts of the same leaflet; 1050, Neuropteris hirsuta; 1051, Pecopteris arborescens; $1051 \boldsymbol{a}$, a portion of the same, enlarged; 1052 , basal leaf of Neuropteris tenuifolia. EQU18ETA, - 1053, Asterophyllites equisetiformis; $1053 a$, the same (?) with sporangia at the axils of the leaves; 1054 , A. sublævis; 1055 , Calanites cannæformis; $1055 \alpha$, surface-markings of same, enlarged. - Fig. 1056, Sphenophyllum Schlotheimi. Figs. 1049-1054, 1056, Lesquereux ; 1055, Brongniart.

Equiseta. - The more common Equiseta of the Coal-measures are species of Calamites, as in the Devonian. One of the jointed, delicately fluted stems is represented in Fig. 1055; and the junction of the flutings of the surface at a joint, in Fig. 1055 a. The Asterophyllites (Fig. 1053) and Annularice are sometimes branches of the same plant, the former occurring toward its base. Fig. $1053 a$ shows the sporangia at the base of the leaves.

Fig. 1056 represents a common species of Sphenophyllum; the name alludes to the wedge-shaped leares; W. C. Williamson states (1894) that the 
species are not related in fructification to the Lycopods or Equiseta, or to any known group of Cryptogams.

2. Gymnosperms of the Order of Cycads. - The character and fruit of Cordaites has been well illustrated by Lesquereux from specimens obtained at Cannelton, Pa. Fig. 1057 shows the Cycad-like foliage; and Fig. 1057 a

1057.

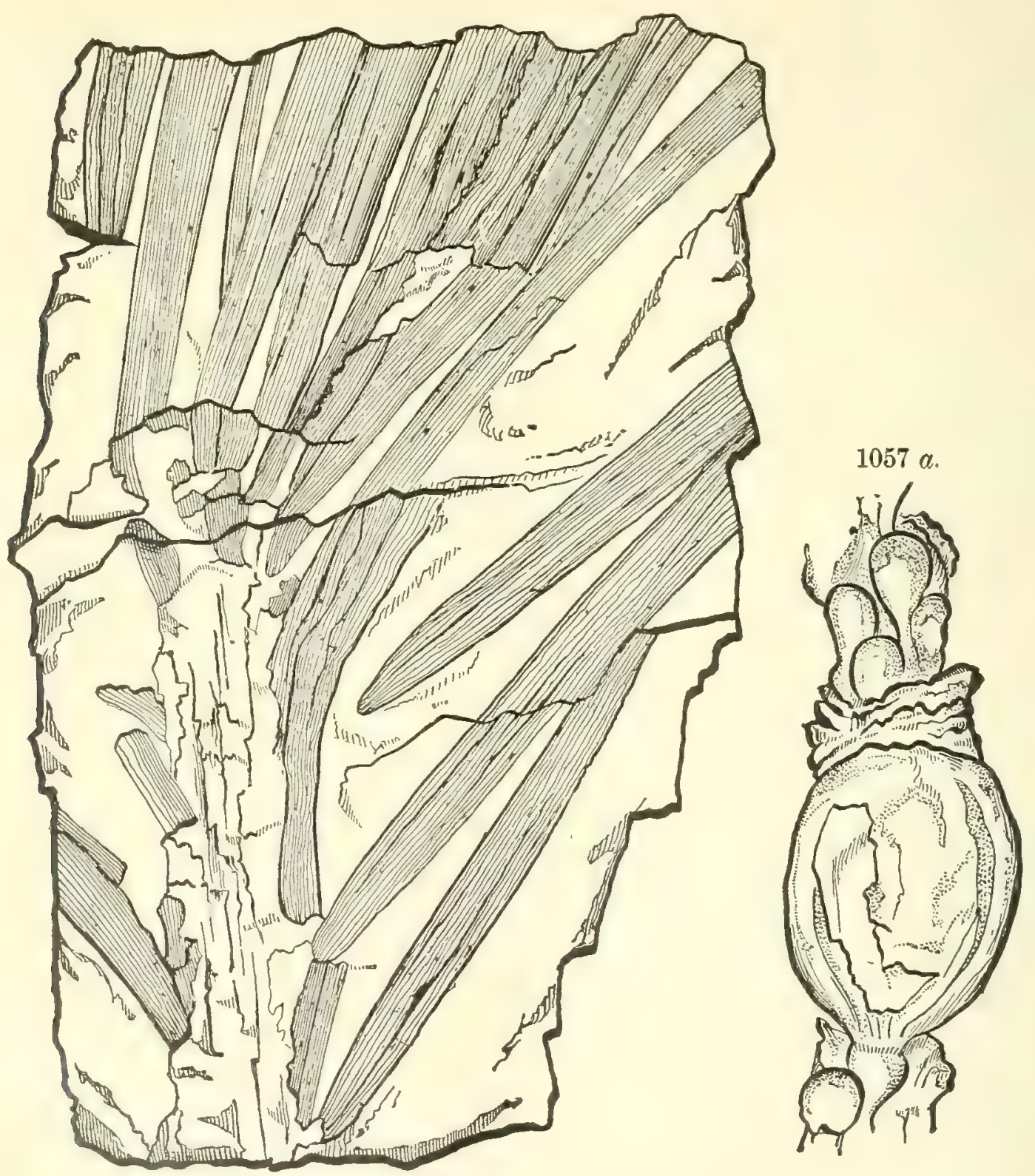

Fig. 1057, Cordaites costatus; $1057 a$, fruit, with a portion of the attached stem. Lesquereux.

represents fruit which occurs at the same locality, and is found there so closely associated with the leaves as to be probably of the same species. Lesquerenx figures the leaves and fruit also of C. Mansfieldi from this Iocality, a species with much broader leaves, and nuts of a smooth obovate form, $2 \frac{1}{2}$ inches long.

The Sigillarids are referred to this division of the Gymnosperms by Renalt and Dawson, but to the Lycopod tribe by Williamson and most authors. 
The fruit of Cordaites (Cordaicarpus) Gutbieri is represented in Fig. 1062.
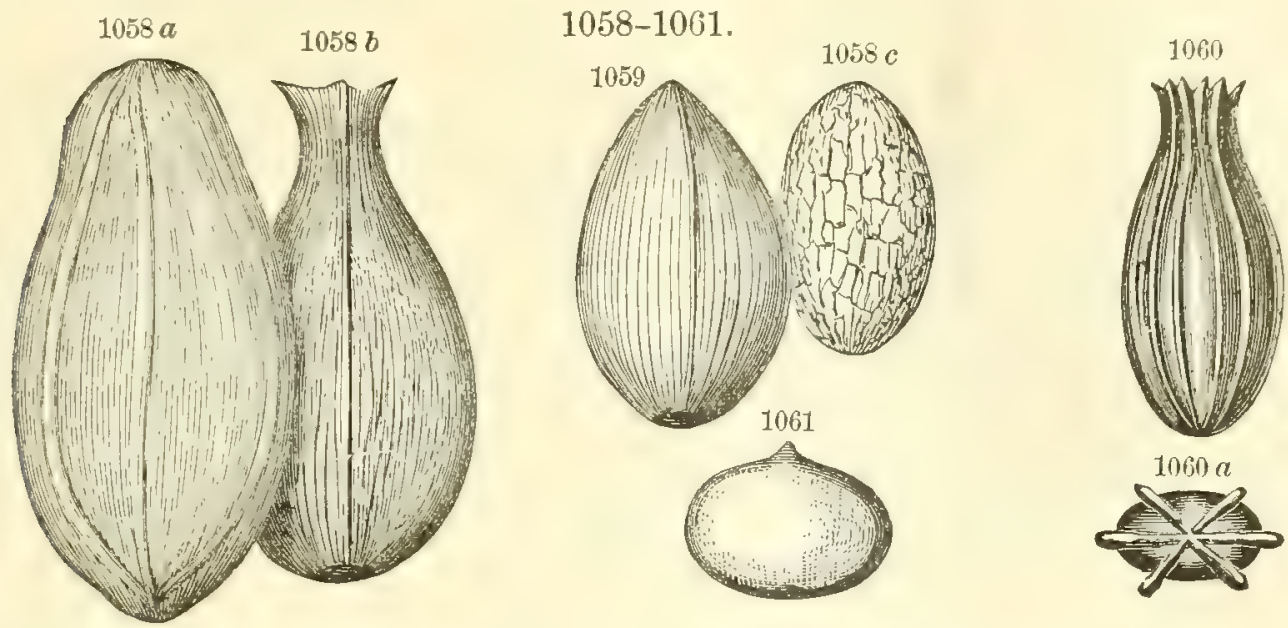

FrUTts. - Figs. $1058 a, b, c$, Trigonocarpus tricuspidatus ; $a$, the exterior husk or rind; $b$, the nut separate from the rind; $c$, kernel; 1059 , nut of Trigonocarpus _ $; 1060$, T. ornatus ; $1060 a$, vertical view of summit, showing the ribs of the surface; 1061, Cardiocarpus bicuspidatus. Newberry.

The Cordaites had a large pith, like that named Artisia and Sternbergia, as figured by Lesquereux on plate lxxxi. of his Pennsylvania Report. The genera Lepidoxylon, Dieranophyllum, Toeniophyllum are related to Cordaites, and probably others in which the pith is large.

3. Gymnosperms re1ated to the Yews. - The other Gymnosperms of the era, usually called Conifers, were probably related to the Taxineæ or Yews, which have single fruit instead of cones, and vary widely in foliage, the leaves sometimes broad, and occasionally Fern-like. From such trees came probably the fossil nuts, as suggested by Hooker. The above figures are from Newberry's Ohio Report. Fig. 1058 represents one of the threesided or six-sided fruits,

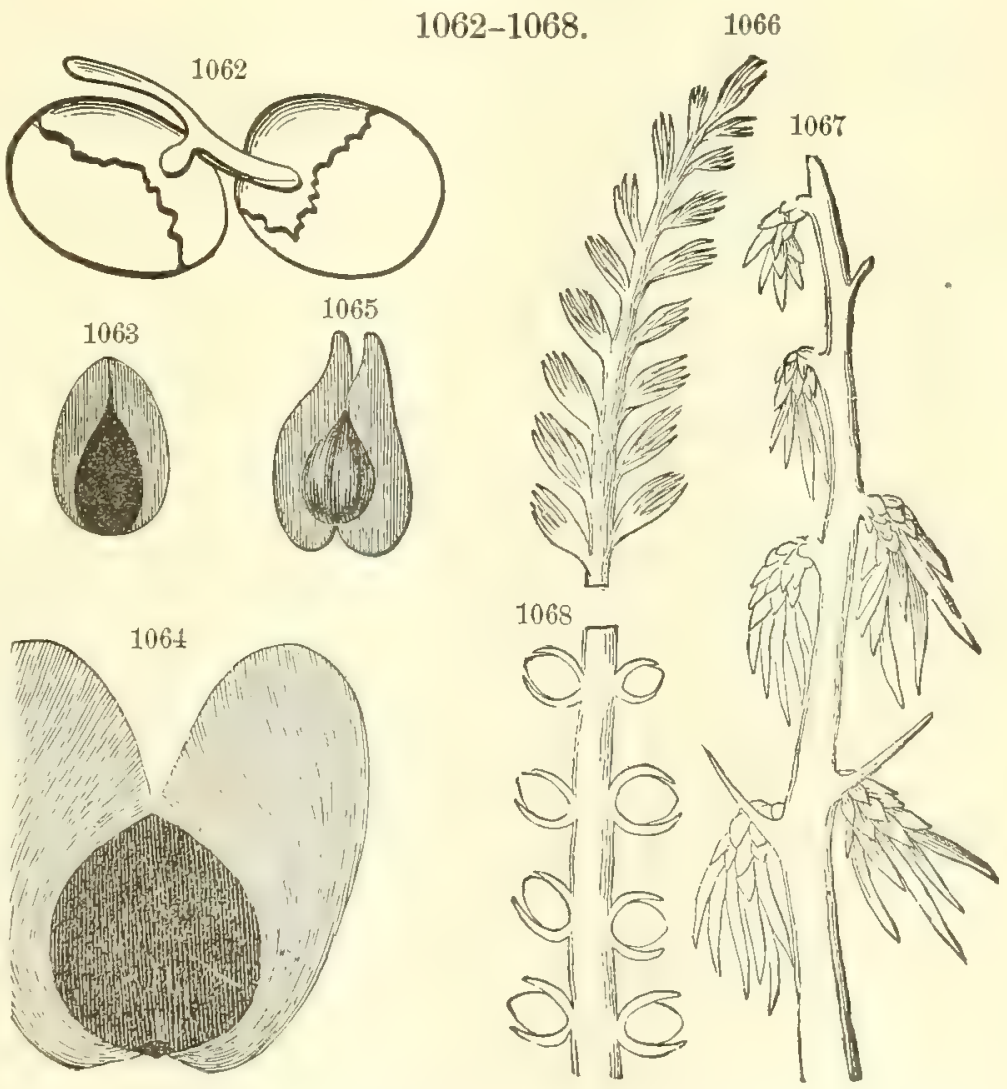

Frouts, - Fig. 1062, Cordaicarpus Gutbieri ; 1068, Cardiocarpus elongatus; 1064, C. samarieformis; 1065, C. bisectus; 1066, Botryoconus (Antholithes) Pitcairnix ?; 1067, B. priscus ; 1068, Cordaianthus, flower (fruit?) of a Cordaites. Fig. 1062, Lesquereux; 1063, 1064, 10661068, Newberry; 1065 , Dawson.

called Trigonocarpus: 1058 a, the husk; $b$, the nut; c, the kernel. Fig. 1059 DANA'S MANUAL -43 
is the nut of another species. Figs. 1063 to 1065 represent species of $\mathrm{Car}$ diocarpus; they resemble the fruit of the anomalous Gymnosperms of Africa, Welwitschia (page 435). The peculiar but beautiful fan-shaped leaves, named Whittleseya elegans by Newberry, are of unascertained relations. Figs. 1066, 1067 are supposed to be fruit of Gymnosperms, in different stages of development; and Fig. 1068, fruit of doubtful species.

Figs. 1066, 1067 have the forms of half developed flowers or leaf-buds, and were called Antholithes by Newberry. They are referred to the Conifers by Grand' Eury. Lesquereux regards Botryoconus priscus (Fig. 1067) as a more advanced stage of B. Pitcairnice. Fig. 1068, Antholithes of Newberry, is the fruit or flower of a Cordaites, according to Lesquereux.

Animals. - The animal life of the Carboniferous period included, besides marine Invertebrates, terrestrial Mollusks, and a large variety of terrestrial Articulates, as Insects, Spiders, Myriapods; and, among Vertebrates, besides Fishes and Amphibians, a higher range of life, in true Reptiles. No evidence has been obtained of the existence then of Birds or Mammals.

1. Rhizopods. - Shells of Rhizopods, of the shape and size of a kernel of wheat, belonging to the genus Fusulina, Figs. 1069, a, are common in some

1069.

a.

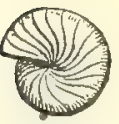

Fusulina cylindrica; $a$, end view. of the shales and limestones of the Mississippi valley and beyond, in Illinois, Kansas, Utah, New Mexico, California, and elsewhere. In British Columbia, on Fraser's River, at Marble Cañon, the Fusulino, of a thick limestone, are associated with a very abundant arenaceous Rhizopod, $\frac{3}{10}$ of an inch long, shaped like an elongated shot, which has been referred to the genus Loftusia, and named L.Columbiana. In Europe the Fusulinæ are found in Subcarboniferous beds as well as in the Carboniferous and Lower Permian.

2. Actinozoans and Echinoderms. - Corals, seldom abundant, are of the genera Lophophyllum, Zaphrentis, Lithostrotion, and others. Lophophyllum protiferum McChesney occurs in roof shales over coal at Springfield, Ill. Crinoids are few compared with those of the Subcarboniferous; Illinois has afforder about a dozen species; and Missouri others. In Nevada, Arizona, New Mexico, Nebraska, etc., have been found a few Echinoids of the genus Archoeocidaris.

3. Molluscoids and Mollusks. - The Brachiopods are similar in genera to those of the Subcarboniferous, though partly of new species; and the same is true in the main of the marine Gastropods, Lamellibranchs, and Cephalopods. Some of the characteristic species are here figured: a characteristic Productus in Fig. 1070, a Chonetes in 1071, and Gastropods in 1076 to 1080.

But besides marine Gastropods, the Coal-measures have afforded the first known of terrestrial shells. One of the small land-snails, or Pulmonates, is represented, a little enlarged, in Fig. 1081, - a species found in the Nova Scotia Coal-measures, and described by Dawson; and Figs. 1082, 1083, from F. H. Bradley, show the forms of two others from Illinois. 
Among the Cephalopods, the Nautiloids, as Hyatt observes, reach their greatest expansion in the Carboniferous period. They include species of

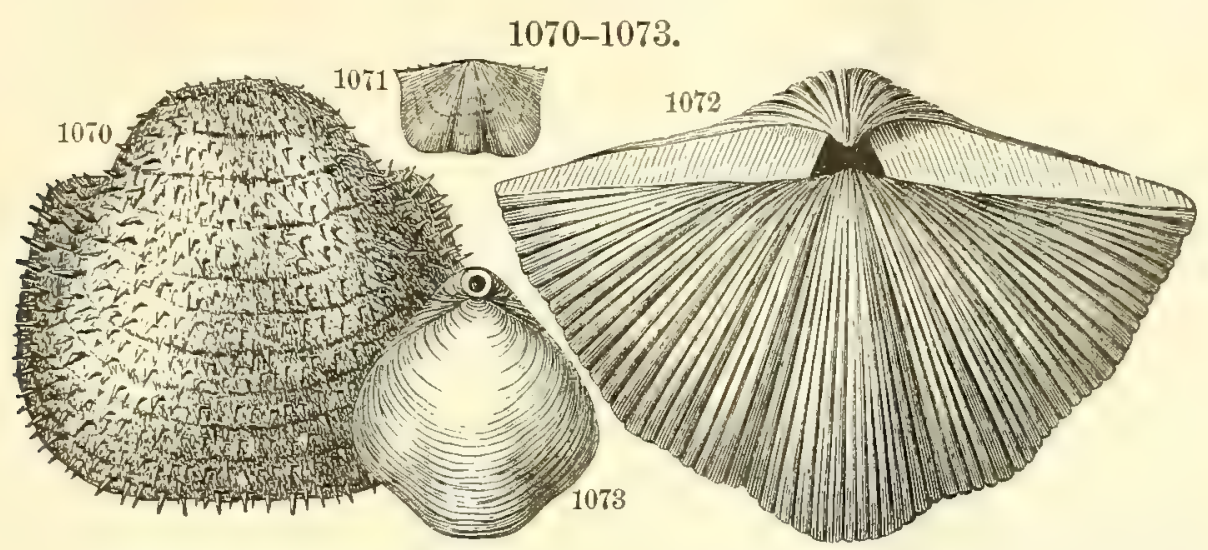

Brachopods. - Fig. 1070, Productus Nebrascensis; 1071, Chonetes mesolobus ; 1072, Spirifer cameratus ; 1073 , Seminula (Athyris) subtilita. Fig. 1070, Hall; 1071-1073, Meek.

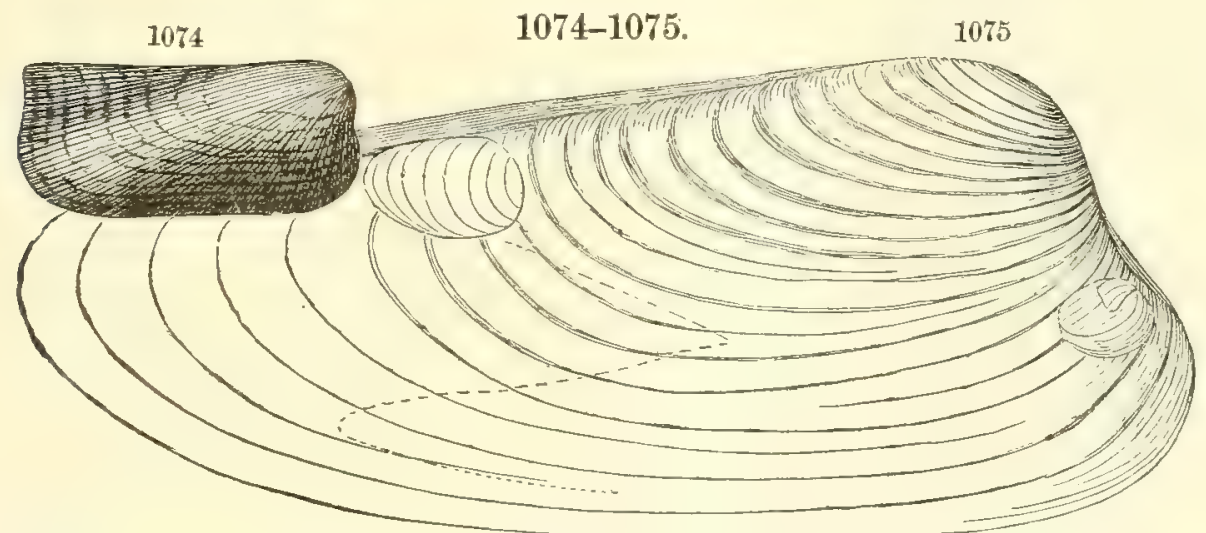

La3ellibeanchs. - Fig. 1074, Macrodon carbonarius; 1075, Allorisma subcuneata. Fig. 1074, Cox; 1075, Meek.

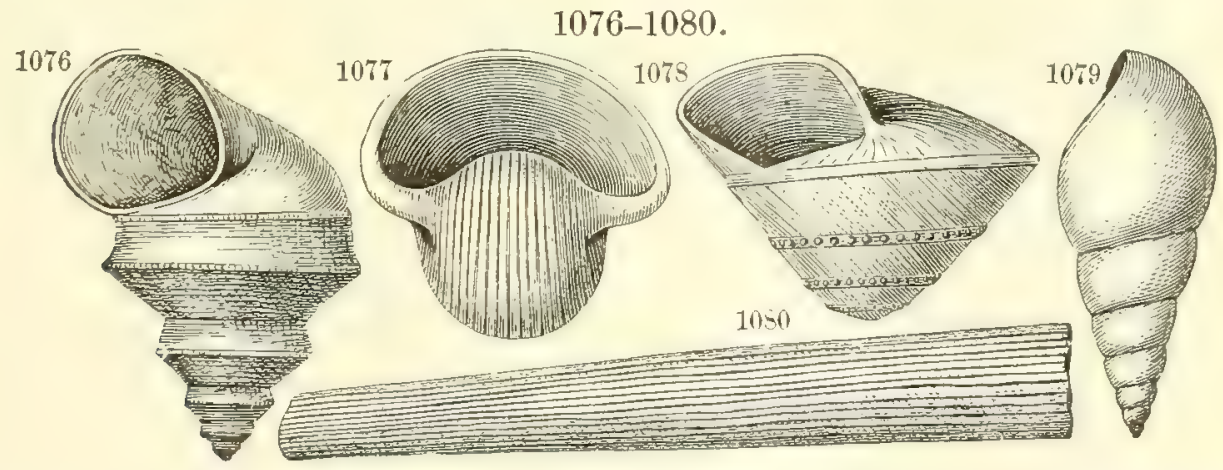

GAstropods.-Fig. 1076, Pleurotomaria tabulata; 1077, Bellerophon carbonarius ; 1078, Pleurotomaria sphærulata; 1079, Macrocheilus (?) fusiformis; 1080, Dentalium sublæve. Figs. 1076, 1077, de Koninck ; 1078-1080, Hall.

Orthoceras, Cycloceras, Phacocercus (P. Dumb7i Hyatt - Figs. 1084, a. reduced one half), Temnochilus ( $T$. crassum Hyatt, Fig. 1085), and a number of genera with longitudinal ridges and keels, as in the Trigonoceratidæ. There are also species of the Goniatites group.

4. Worms. - Sea-worms or Annelids have been supposed to be represented by a small coiled shell, referred to the genus Spirorbis, found attached to 
the leaves and stems of submerged plants. The specimen figured is from Nova Scotia (Dawson). They are reported also from the Peunsylvania Coal-measures.

1081-1085.

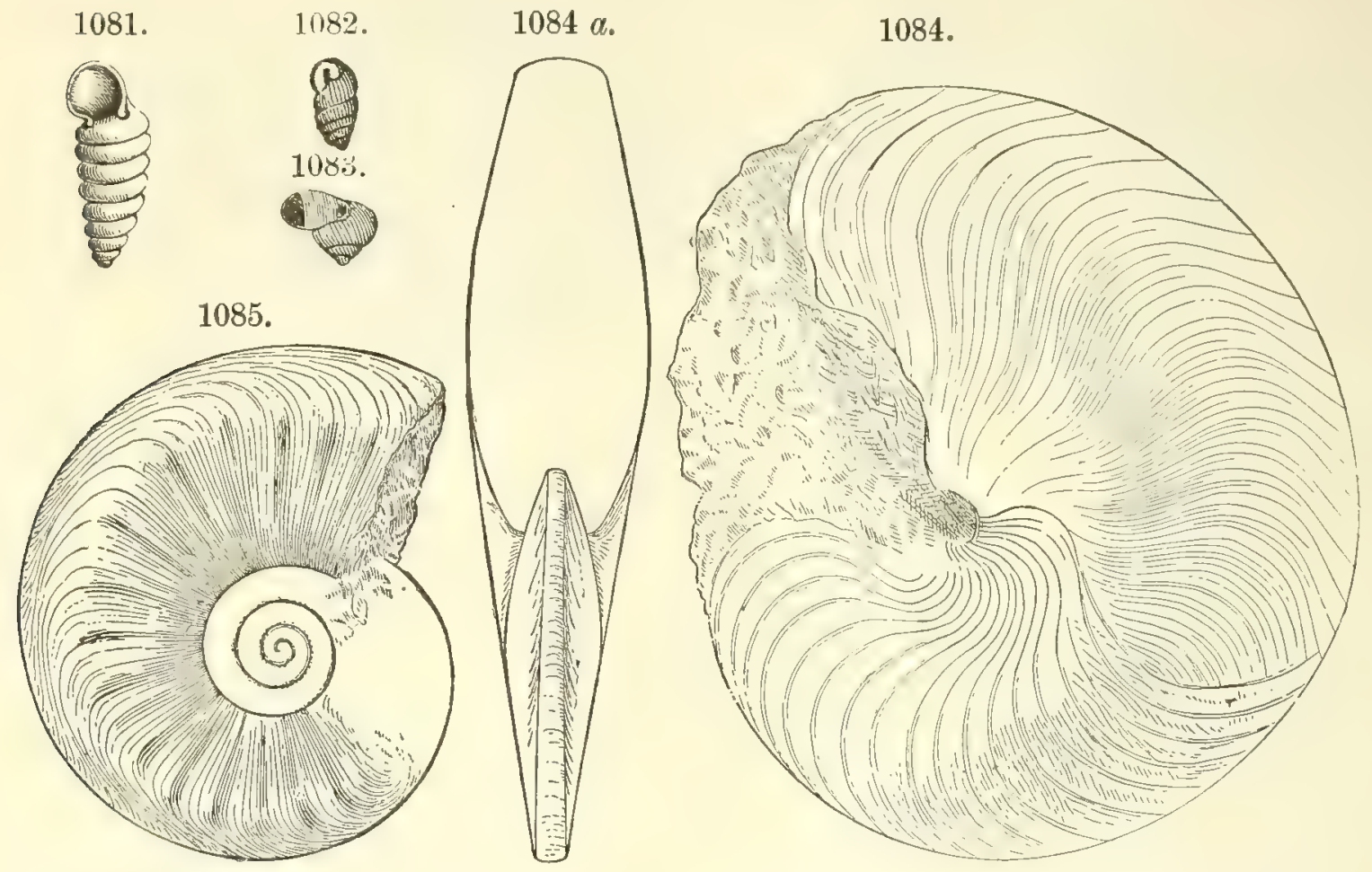

Pulmonate Gastropods. - Fig. 1081, Pupa vetusta $\left(\times \frac{2}{3}\right)$; 1082, P. Vermilionensis; 1083, Dawsonella Meeki. Nadtrlom Cephalopod8, - Figs. 1084, $a$, Phacoceras Dumbli $\left(\times \frac{1}{2}\right) ; 1085$, Temnochilus crassum. Fig. 1081, Dawson; 1082, 1083, F. H. Bradley ; 1084, 1085, Hyatt, '90.

5. Limuloids. - Species of the group of Eurypterids were common. Specimens of one of them, four to ten inches long, the Eurypterus Mansfieldi of C. E. Hall, are found in the shale below the Darlington cannel 1086. coal, near Cannelton, Pa., laid out among Ferns and Calamites,

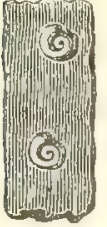

Spirorbis carbonarius. as represented in Fig. 1087. The species probably lived in freshwater marshes and ponds. In addition, the modern tribe of Limulids had its species: one from Morris, Ill., is represented in Fig. 1088. Another species, Cyclus Americanus of Packard, had an even, nearly circular outline, without a telson, and closely resembled an embryonic Limulus.

6. Crustaceans. - Trilobites were rare, and of the genera Phillipsia, Griffithides and Brachymetopus.

Under Crustaceans there were also various species of modern aspect, represented in Figs. 1089 to 1091, the latter two, if not all three, true Decapods. The Myriapods were mostly related to the inferior Iulus tribe - nearly cylindrical species (as Figs. 1092, 1093) having often two pairs of legs to a body segment. But in one species, the Palcoocampa anthrax of Meek and Worthen, from Illinois, the body had but 10 segments; and on its 
back were tufts of minute spines, so that it looked much like some caterpillars.

7. Arachnids. - Among Arachnids, there were Spiders (Fig. 1095) as well as Scorpions (Fig. 1094).

1087.

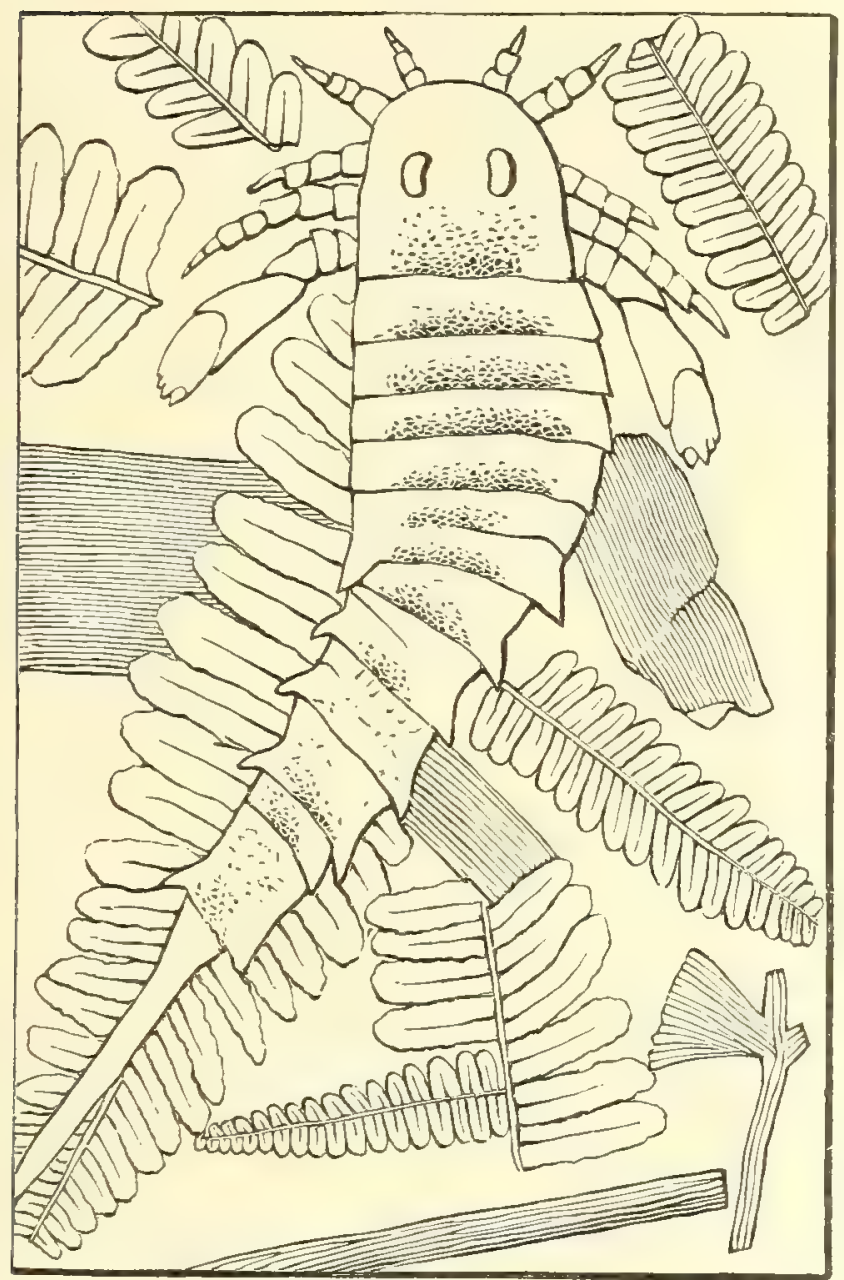

Fig. 1087, Eurypterus Mansfieldi. C. E. Hall, '77.

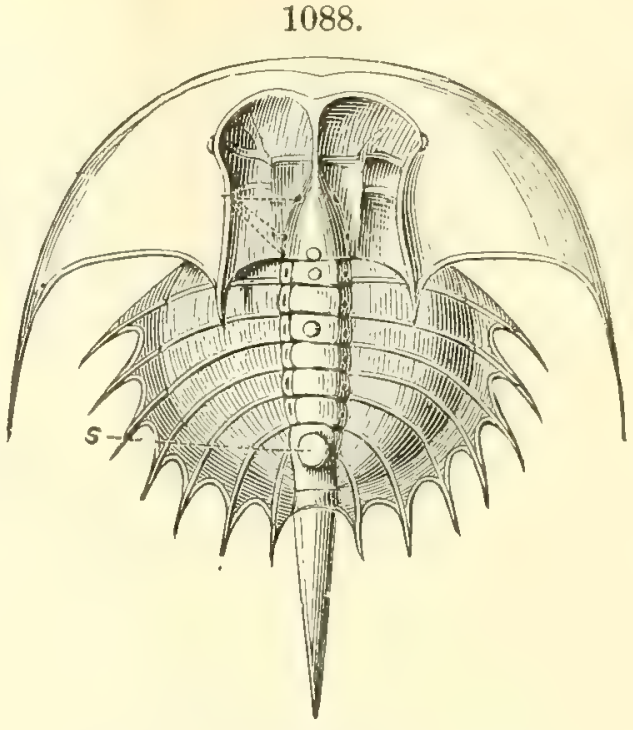

Fig. 1088, Prestwichia Danæ. Meek and Worthen.

All the species represented in Figs. 1089-1093 are from the Coal-measures at Mazon Creek, in Morris, Ill., where they occur in the centers of concretions, and were the nuclei about which the concretions were formed. Thus entombed, they were safe against removal by infiltrating waters. The locality has afforded 16 species of Myriapods and nearly

a dozen kinds of Spiders, besides Scorpions.

8. Insects. - Insects are found at Morris, under the same conditions (besides Ferns and other plants), and in the shales of the Coal-measures elsewhere. The Neuropter-like, or Neuropteroid, species are common (Figs. 1096, 1097), and still more so the Orthopteroid, and especially those of Orthopteroids related to the Cockroach, a wing of one of which is shown in Fig. 1098; and less abundantly the species related to the modem Phasma and Locust, the Protophasmids (Fig. 1099). Scudder enumerates in a recent paper 133 American species of Coal-measure Cockroaches from the Coalmeasures of the Continent, pertaining to 14 different genera, and nearly all are of his own describing. Of these, 56 species are from the IVaynesburg coal-bed at Cassville, W.Va., where the beds are Permian, according to I. C. White; 12 from Providence, R.I.; 22 from the Lower Barren Coal- 
measures at Richmond, 0.; 7 from Pittston, Pa., and as many from Cannelton; 17 from Illinois, 5 from Missouri, 1 from Arkansas, 1 from Kansas, 1 from Nova Scotia, and 3 from Cape Breton; and only in one case has a species

1089-1093.

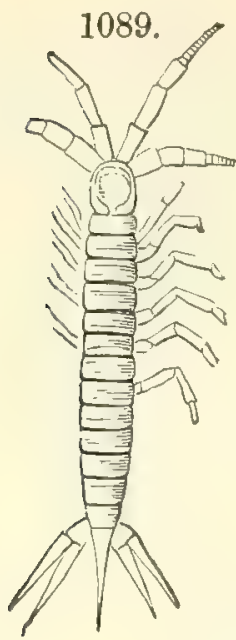

1093.

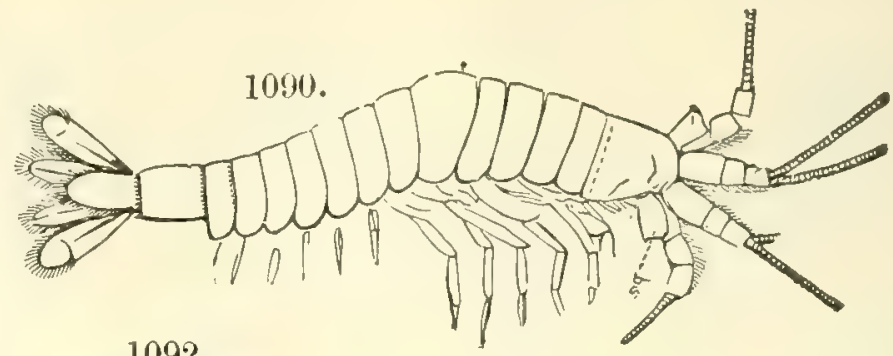

1092.
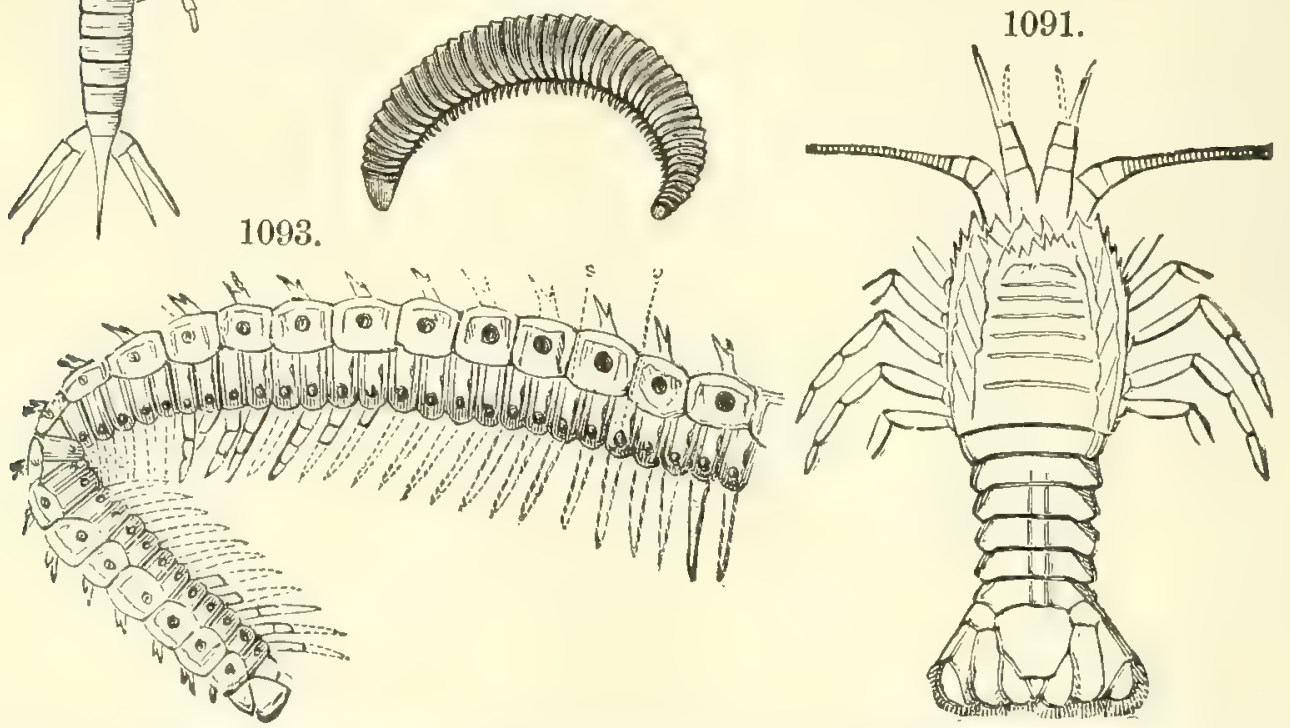

Crustaoeass. - Fig. 1089, Acanthotelson Stimpsoni; 1090, Palæocaris typus $(\times 3)$; 1091, Anthracopalæmon gracilis. Mrriapods.-1092, Xylobius sigillariæ; 1093, Euphoberia armigera. Figs. 1089-1091, 1093, Meek and Worthen; 1092, Dawson.

$1095 \alpha$.

1094-1095.
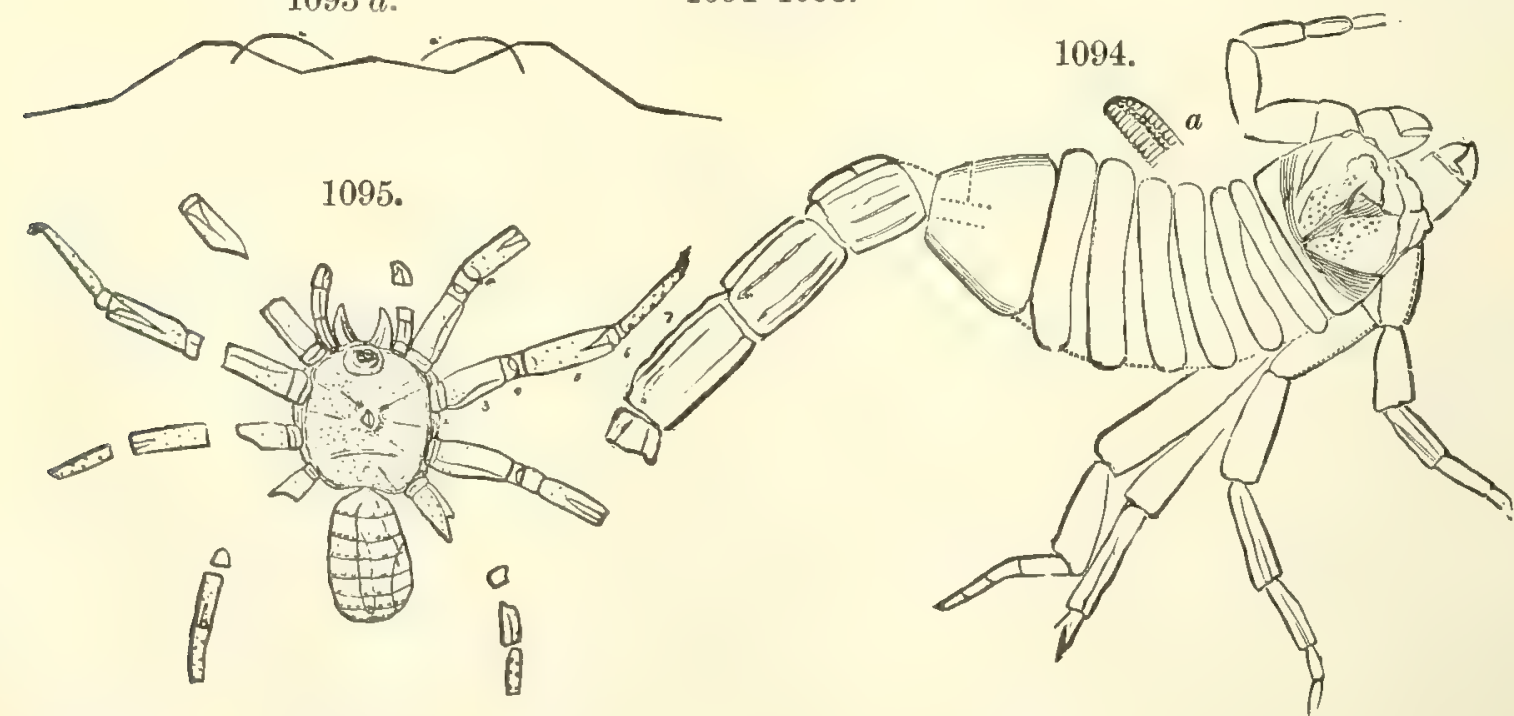

Araohrids. - Fig. 1094, Eoscorpius carbonarius ; $\boldsymbol{a}$, one of the combs; 1095 , Arthrolycosa antiqua; $\boldsymbol{a}$, profile, showing the elevation of the cephalothorax and the position of the legs. Fig. 1094, Meek and Worthen, '68; 1095, Beecher. 
been found at two localities. All of the great marshes of the Continent appear to have been infested by Cockroaches. Probably the Neuropteroids were equally numerous, although less common as fossils. The Insect fauna

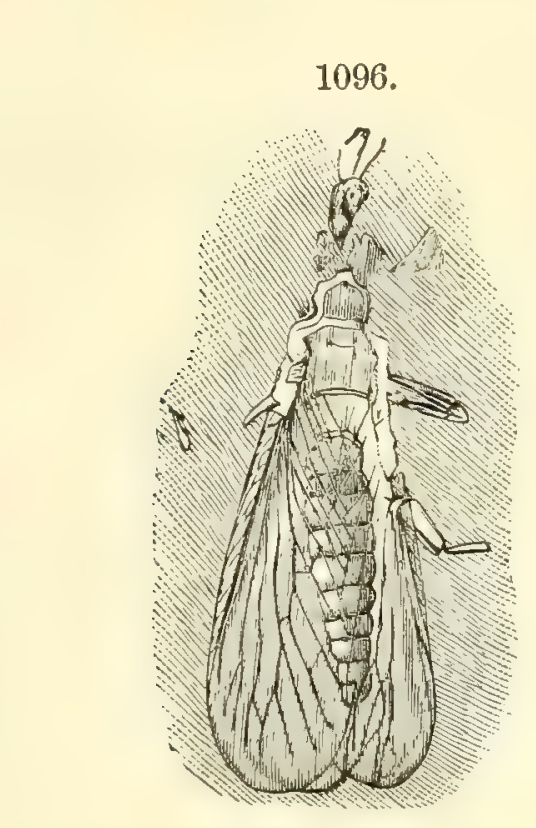

1096-1099.
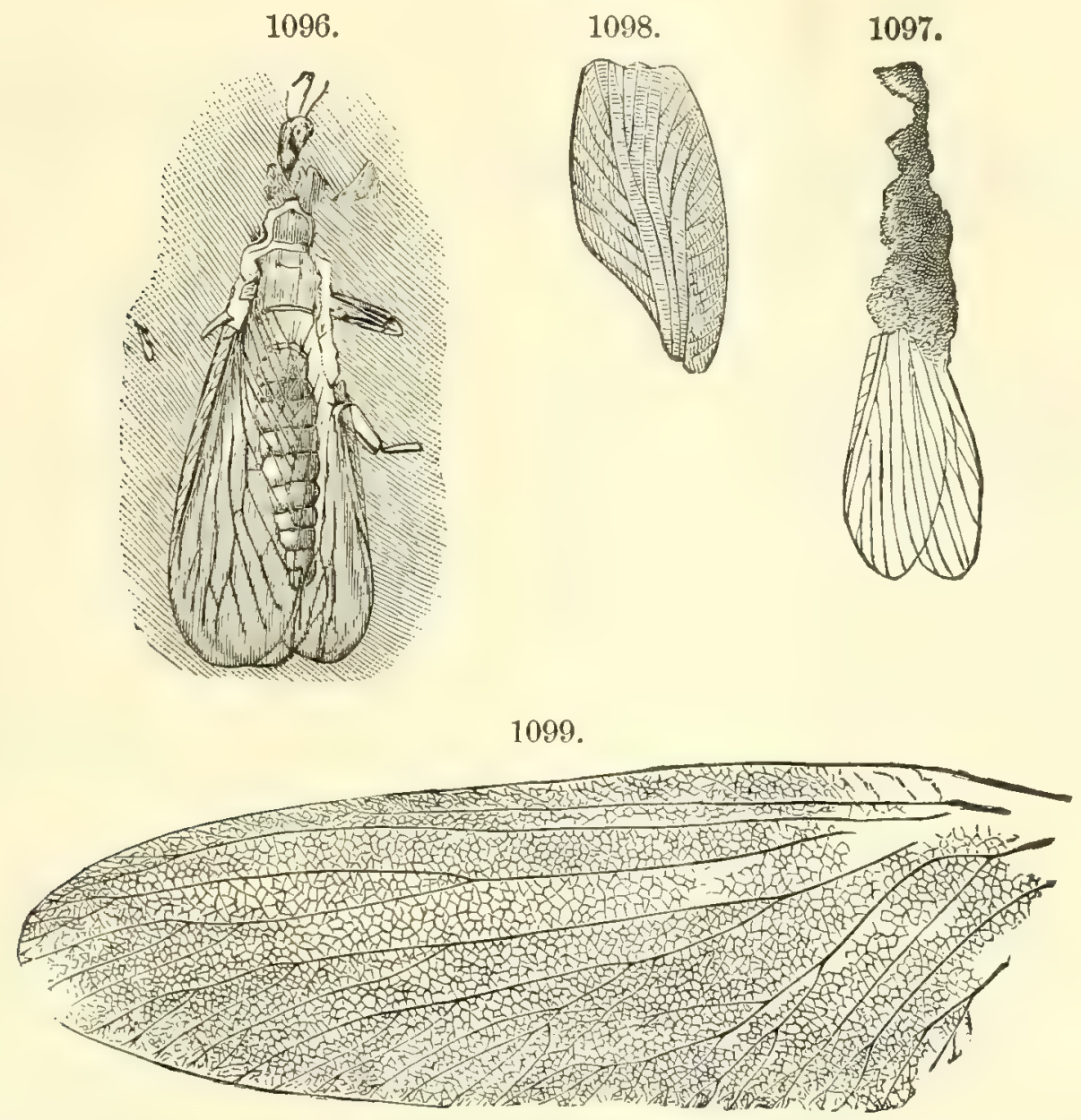

Netropteroto Irsects. - Fig. 1096, Miamia Bronsoni; 1097, Gerarus Danæ. Orthópteroids. - Fig. 1098,

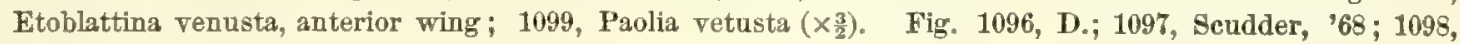
Lesquereux; 1099, S. I. Smith.

was also remarkable for the large size of many species. A Protophasmid of the genus Haplophlebium of Scudder, from Cape Breton, related to the Locust, had an expanse of wing of seven inches. In a Neuropteroid of the genus Megathentomum, from Illinois, the breadth of a wing was two inches, and the length over three. No Beetles (Coleopters) had been found in the American Coal-measures up to 1894. The absence of Butterflies and all Lepidopters, and of Hymenopters and Dipters, is considered certain.

9. Vertebrates. - Fishes. The class of Fishes in the Carboniferous included only Selachians and Ganoids; and the Ganoids had still the ancient feature of vertebrated tails. Two of these Ganoids, one of them, a Coelacanthus, having the vertebral column extending along the middle of the tail, the other, a Eurylepis, are illustrated in Figs. 1100, 1101; they are from a black, very carbonaceous shale, at Linton, Ohio, which abounds in Fishes, and has 
afforded Newberry nine species of Eurylepis, three of Colacanthus, and a Paloeoniscus, besides some Selachian remains.

A Selachian tooth from Illinois, related to the Petalodus from the Subcarboniferous, is represented of reduced size in Fig. 110\%. Part of the

$1100-1104$.

1100.

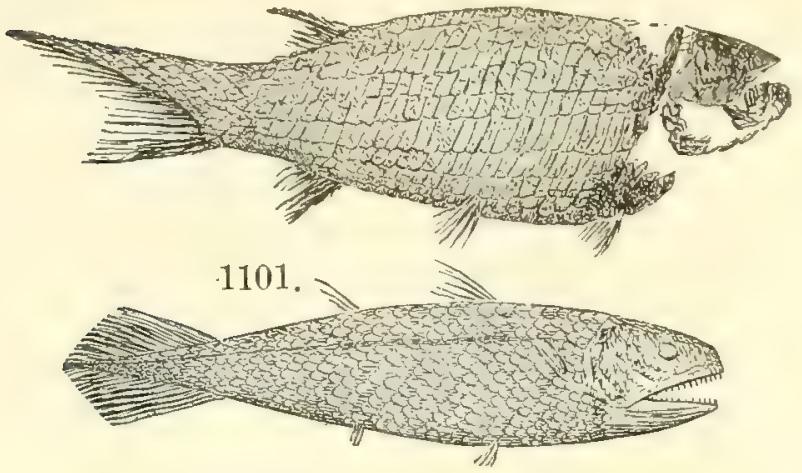

1108.

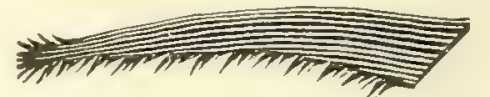

$110 \%$.

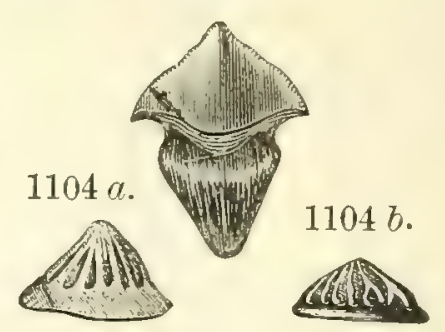

Gavords. - Fig. 1100, Eurylepis tuberculata; 1101, Coelacanthus elegans. Sxuachians. - Fig. 1102, Petalodus destructor; 1103, fin-spine ; $1104 a, b$, dermal tubercles of Petrodus occidentalis. Figs. 1100-1102, Newberry; 1103, F. H. Bradley.

lower jaw of a Cestraciont Shark, named by Newberry and Worthen after Agassiz, is represented of reduced size in Fig. 1105; the actual length of the specimen was nearly 24 inches, and the estimated length of the Shark

1105.

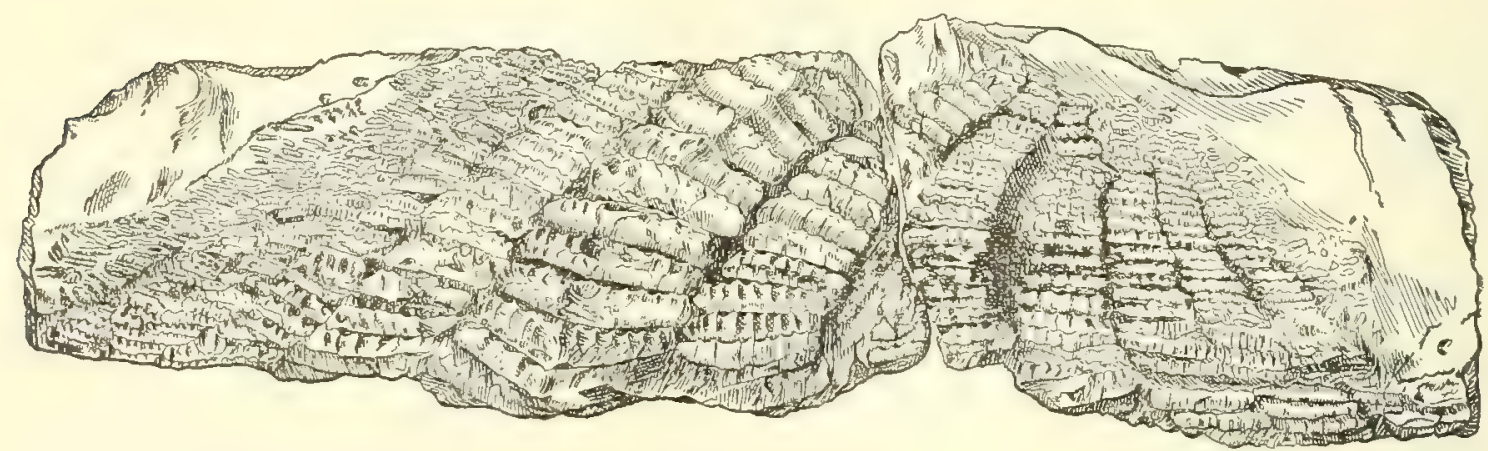

Cestraciont Shark. - Agassizodus variabilis $\left(\times \frac{2}{9}\right)$. Newberry and Worthen.

15 to 20 feet. The teeth of the species have been found in the Upper Coalmeasures of Kansas, Illinois, and Iowa. A mouth so paved was a most effective crushing organ.

Fin-spines of Sharks oceur of many kinds and sizes. A portion of a small one is represented in Fig. 1103. The bony tubercles, Figs. $1104 a, b$, were found with the spine, and are supposed to be from the surface of the body of the same Fish.

Large spines of species of Edestus, having one edge armed with great teeth, as in Figs. 1106, 1107, have been found in the Coal-measures of Indiana, Illinois, and Arkansas. In E. minor of Newberry, Fig. 1107, the teeth are nearly two inches long, and in E. giganteus Newberry, Fig. 1106, 
nearly three long and two broad. The figure of the latter represents, reduced, only a small portion of the specimen; as figured by Newberry the spine has tive teeth; when entire it was probably 18 inches in length, and occupied, along the body of the Shark, according to Newberry, the place of the posterior dorsal fin. It could thus rip open its prey when swimming underneath it, and slash effectually in defense.

Amphibians. - Besides footprints, which thus far are the only evidence of Amphibians in the Subcarboniferous, the Coal-measures have afforded

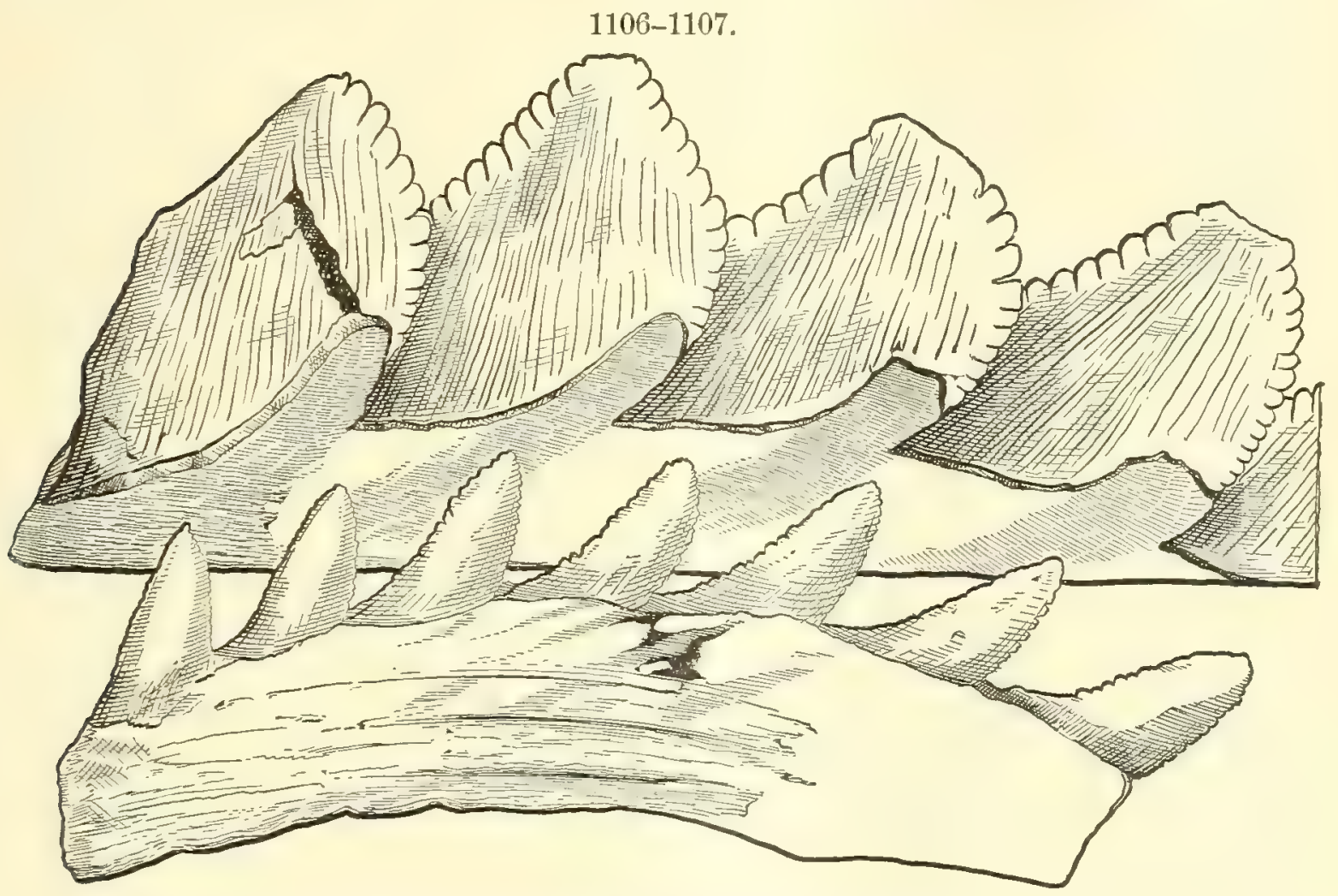

FiN-SPINES OF SHAREs. - Fig. 1106, Edestus giganteus; 1107, E. minor (each $\times \frac{1}{2}$ )。 Newberry.

remains of skeletons. They show that many of the earlier kinds were much like their predecessors, the higher Ganoid and Dipnoan Fishes, in having a bony cranium instead of one with large open spaces and little bone, like the modern Frog; and in allusion to the well-ronferl head, they are called Stegocephs by Cope. Among morlern Amphibians only some snake-like kinds have a similar cranium. They are also like the Fishes in their teeth, the most of them having the enamel inflexed along the surface grooves, producing the Labvrinthine texture which suggested for the species the name of Labyrinthodonts. Further, they generally have biconcave vertebræ, like Fishes. Moreover. the Amphibians occur of all grades from (1) Snake-like forms without limbs, to (2) those with feeble swimming organs; and thence to (3) the four-limbed species of various sizes, up to kinds as large and formidable as Alligators. It is interesting to note also that the feet have five toes (or less), and the fingers the modern number of bones.

The Coal-measures of Ohio, at Linton, afforded Newberry numerous 
specimens, and other regions have added to the number. Of the snake-like species, part without limbs, and others with feeble limbs, Cope has made out over a dozen species from Linton. Phlegethontia linearis of Cope had no limbs, and the proportion of a Whip-snake; and Molgophis macrurus was nearly of the size of the common Rattlesnake. One of these nearly snake-like species, Ptyonius sermla of Cope, is represented in Fig. 1112; it had hindlimbs, but no fore-limbs. A four-limbed, Salamander-like species, Petion Lyelli, from Linton, described in 1857 by Wyman, is shown in Fig. 1109; and in Fig. 1108, another species, the Amphibamus grandiceps of Cope, from Illinois. Leptophractus obsoletus Cope, from Linton, of Alligator size, had stout teeth three fourths of an inch long.

Nova Scotia has afforded species of Dendrerpeton and Hylerpeton of Owen, and of Hylonomus of Dawson, the last peculiar in having a slender head. The Nova Scotia species come mostly from the South Joggins, where they were first discovered by Lyell and Dawson in 1851. They were found in the sandstone filling the once hollow trunks of large Sigillariæ, along with land-shells (Pupa vetusta, Fig. 1081) and Myriapods (Xylobius sigillarice, Fig. 1092); and leaves of Ferns and Cycads, and this mode of occurrence suggested the name Dendrerpeton (or tree-reptile). The conditions appear to show that the hollow stumps, the poor pithy wood of which had decayed as they stood in the marshes, were the resort of the Amphibians, and a catch-place for other species of the wet region; or, that the shells were the food of the Amphibians, as Dawson suggests, who states that he has found, in the stomach of a recent Menobranchus (M. lateralis Harlan), as many as 11 unbroken shells of the fresh-water snail, Physa heterostropha. In 1876, Dawson obtained at the Joggins, from a stump 18 inches in diameter, remains of 13 Amphibian skeletons, pertaining probably to six species. The Baphetes planiceps Owen, of Nova Scotia, had a head $3 \frac{1}{2}$ inches broad.

The South Joggins has also afforded, about 5000 feet below the top of the Coal-measures, two biconcave vertebræ (Fig. 1111, with the cross-section, 1111 a), which are the basis of the species Eosaurus Acadianus Marsh. The vertebræ resemble those of an Enaliosaur (Sea-Saurian, page 785), but, as observed by Huxley, from his observations on the Anthracosaurus Russelli of the British Coal-measures, and, as recognized by Marsh, they probably belonged to a large Amphibian.

Footprints of Amphibians occur in the Coal-measures of Pennsylvania, Indiana, Illinois, Kansas, and Nova Scotia. Figs. 1113 to 1116 represent tracks of four out of five species described by Marsh from the middle of the Coal-measures in Osage, Kan. All are from one surface about 12 feet square. Between the right and left tracks in Fig. 1.113, there is the impression of the tail. In the tracks of Dromopus, having long slender toes, the phalanges or joints are very distinct, and on account of the form, Marsh questions whether the species may not have been Reptilian; but he regards the sweep of the foot in walking, indicated by the lines between the two tracks to the right, as favoring Amphibian relations. So many kinds of 
1108.

$1108-1112$.

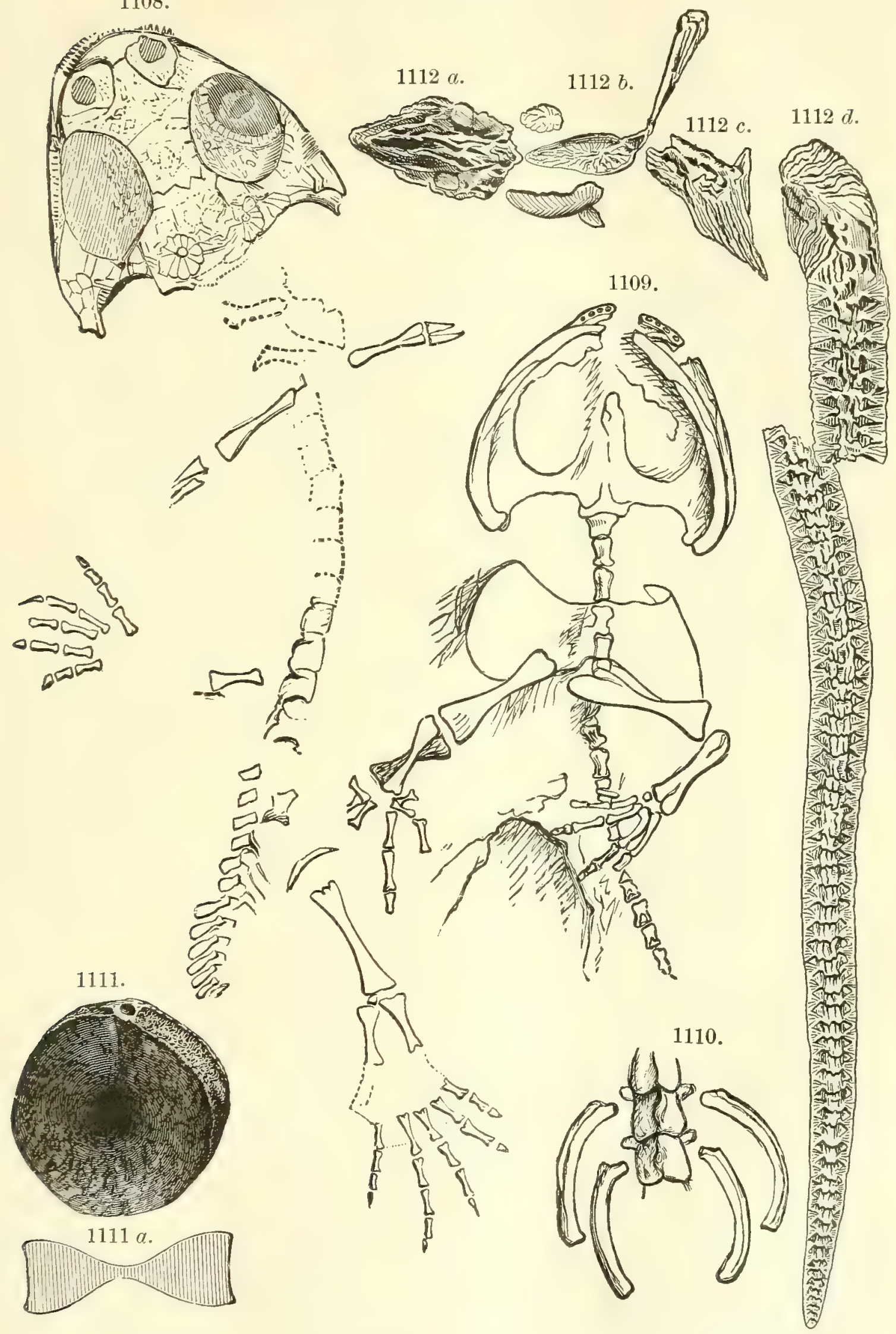

Amphibians. - Fig. 1108, Amphibamus grandiceps $(\times 2) ; 1109$, Pelion Lyelli ; 1110, Molgophis macrurus?; 1111, $1111 a$, Eosaurus Acadianus, vertebra $\left(\times \frac{1}{2}\right) ; 1112 a, b, c, d$, Ptyonius serrula. Figs. 1108, 1109, 1110, J. Wyman; 1111, Marsh; 1112, Cope. 
tracks on so small an area show that the Amphibians of the period were in great numbers.

1113.

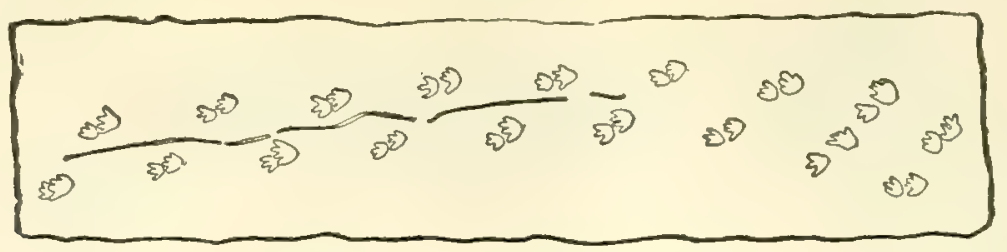

1114 .

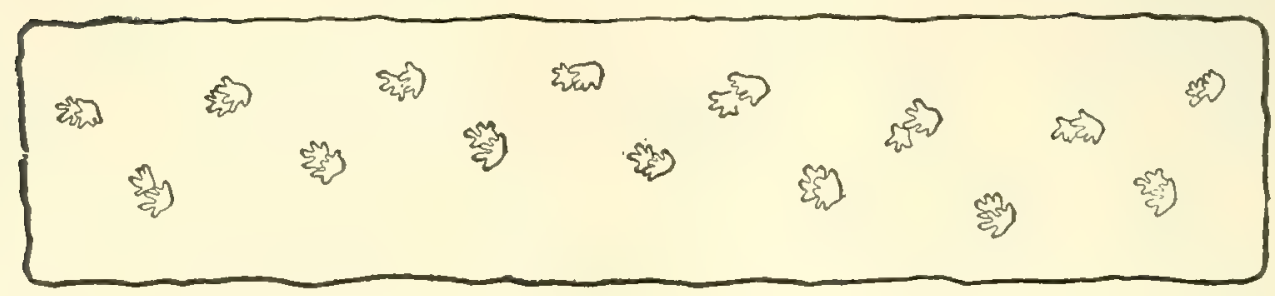

1115.

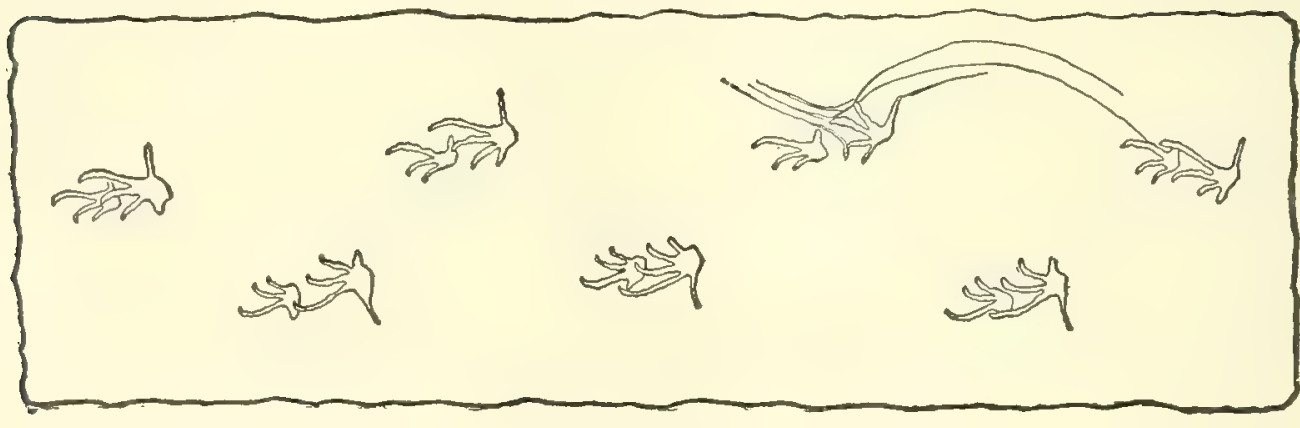

g

1116.

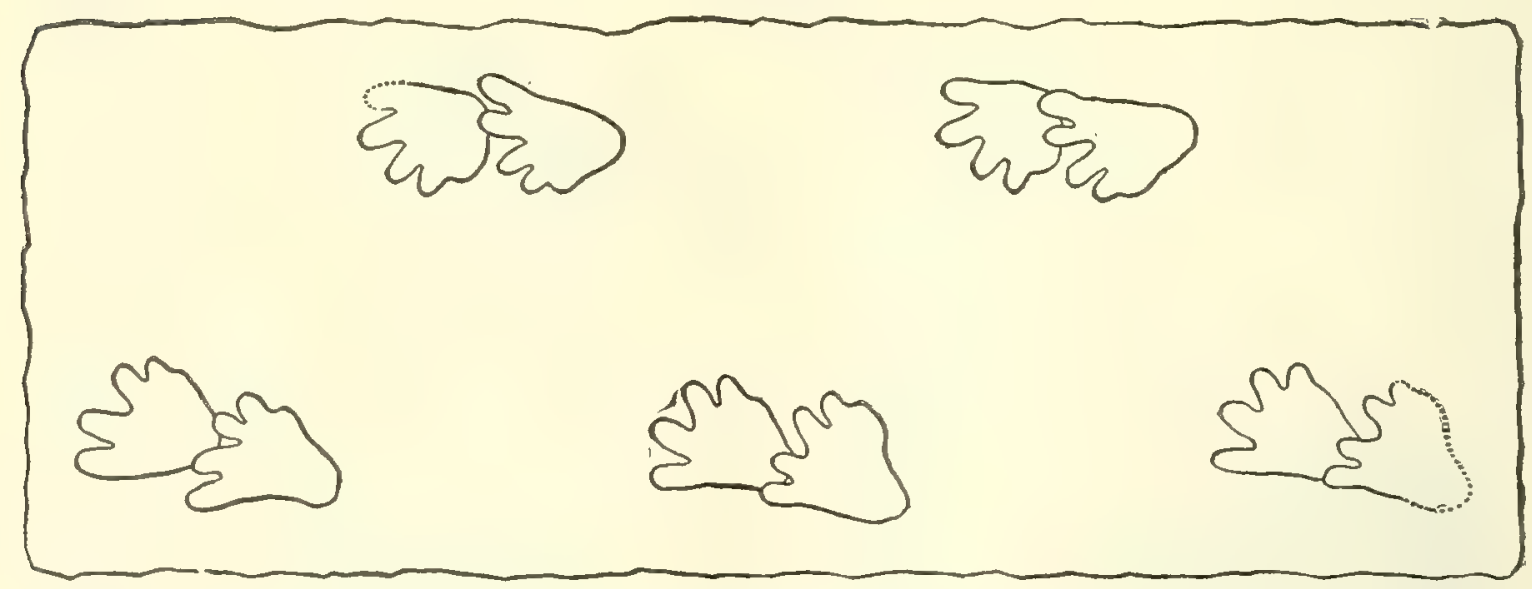

Footprints of Amphibians, - Fig. 1113, Nasopus caudatus; 1114, Limnopus vagus; 1115, Dromopus agilis; 1116, Baropus lentus $\left(\times \frac{1}{12}\right)$. Marsh, '94.

\section{LIFE OF THE PERMIAN PERIOD.}

Plants. - The vegetation of the Upper Barren Coal-measures or Permian strata of Pennsylvania and West Virginia (page 651), is characterized, as shown by Fontaine and White, by the absence of Lepidodendrids; by the rarity of Sigillario, only two being known; by the large number of species of Ferns (over 30) of the genus Pecopteris, some arborescent, and, only a third 
of them known to occur in the Coal-measures, with other species of the related genera Cymoglossa, Goniopteris, Callipteridium, Callipteris, and also of Neuropteris, Sphenopteris, Alethopteris, Odontopteris; many species of the Equisetum tribe, of the genera Sphenophyllum, Annularia and Equisetites, and the continuation of the Calamites, C. Suckovi; also, the occurrence of Cycads of the Permian genus Baiera, and of the remarkable Conifer of the Yew family, of the new genus Saportoe, whose leaves were nearly four inches

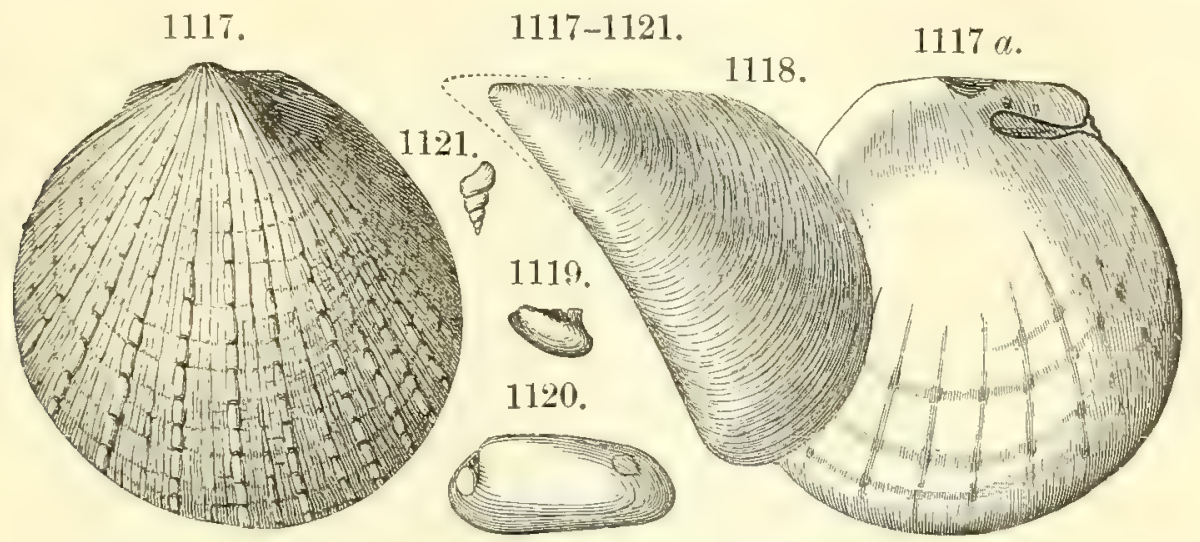

Molıd8кs. - Fig. 1117, 1117 a, Pseudomonotis Hawni ; 1118, Myalina perattenuata; 1119, Bakewellia parva; 1120, Pleurophorus subeuneatus ; 1121, an undetermined Gastropod. Meek.

wide. Only 20 per cent of the species have been found in the Coal-measures, and over 25 per cent occur in the Permian of Europe, and the genus Cymoglossa is confined abroad to the Permian.

Animals. - 1. Brachiopods, Mollusks. - Many of the common Coal-measure species continue on into the Permian. Some of these are: Productus semireticulatus, $P$. Rogersi, Chonetes Flemingi, Spirifer cameratus, Seminula (Athyris) subtilita; and with these are others confined to the Permian, as Meekella (Orthisina) Shumardana, Productus Norwoodi, Monotis Halli, M. speluncaria, M. variabilis, Pseudomonotis Hawni var. ovata (Fig. 1117), Myalina perattenuata (Fig. 1118), M. Permiana, M. Halli, M. recta, Bakewellia parva

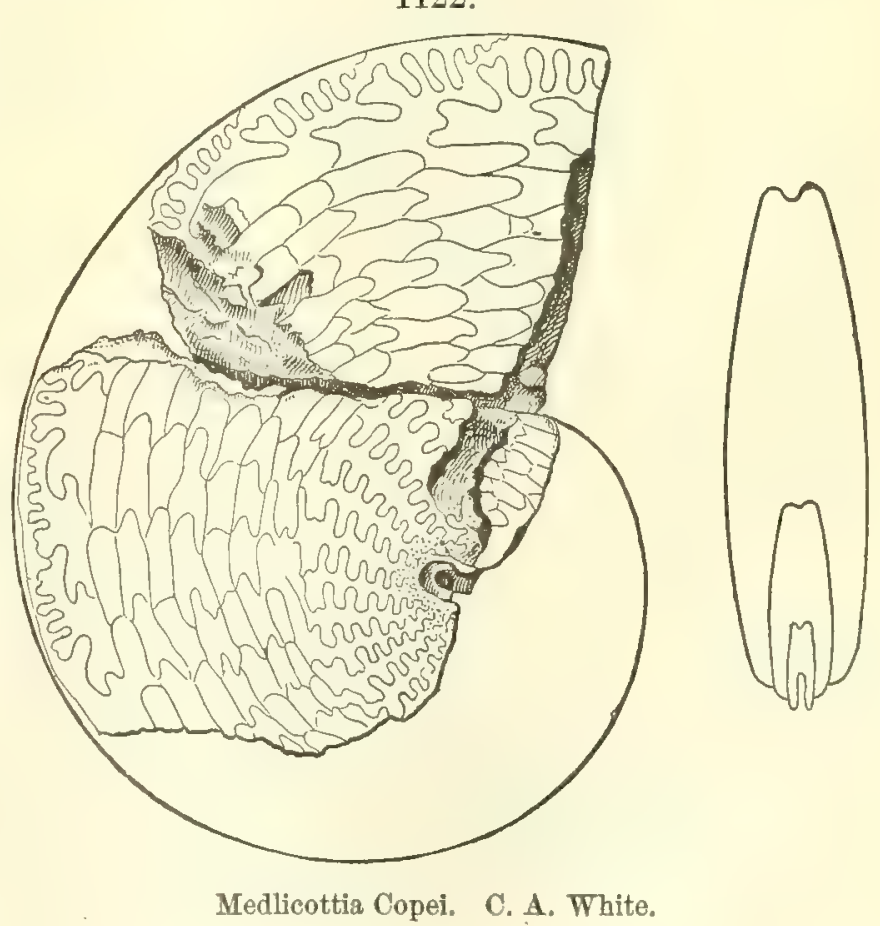
(Fig. 1119), Pleurophorus subcuneatus (Fig. 1120), Schizodus Rossicus, Nautilus eccentricus, N. Permianus, Cyrtoceras dorsatum; and Texas has afforded C. A. White five species of 
Nautilus, a Goniatites, a species of Medlicottia (Fig. 1122), and other Ammonites of the genera Ptychites, Popanoceras, and Waagenoceras, which are Permian in Russia and India.

2. Crustaceans, Insects. - A Trilobite, of the genus Phillipsia, has been observed in the Permian of Missouri (Swallow); and a Cockroach, Gerablattina balteata Scudd., in West Virginia and Ohio beds.

1123.

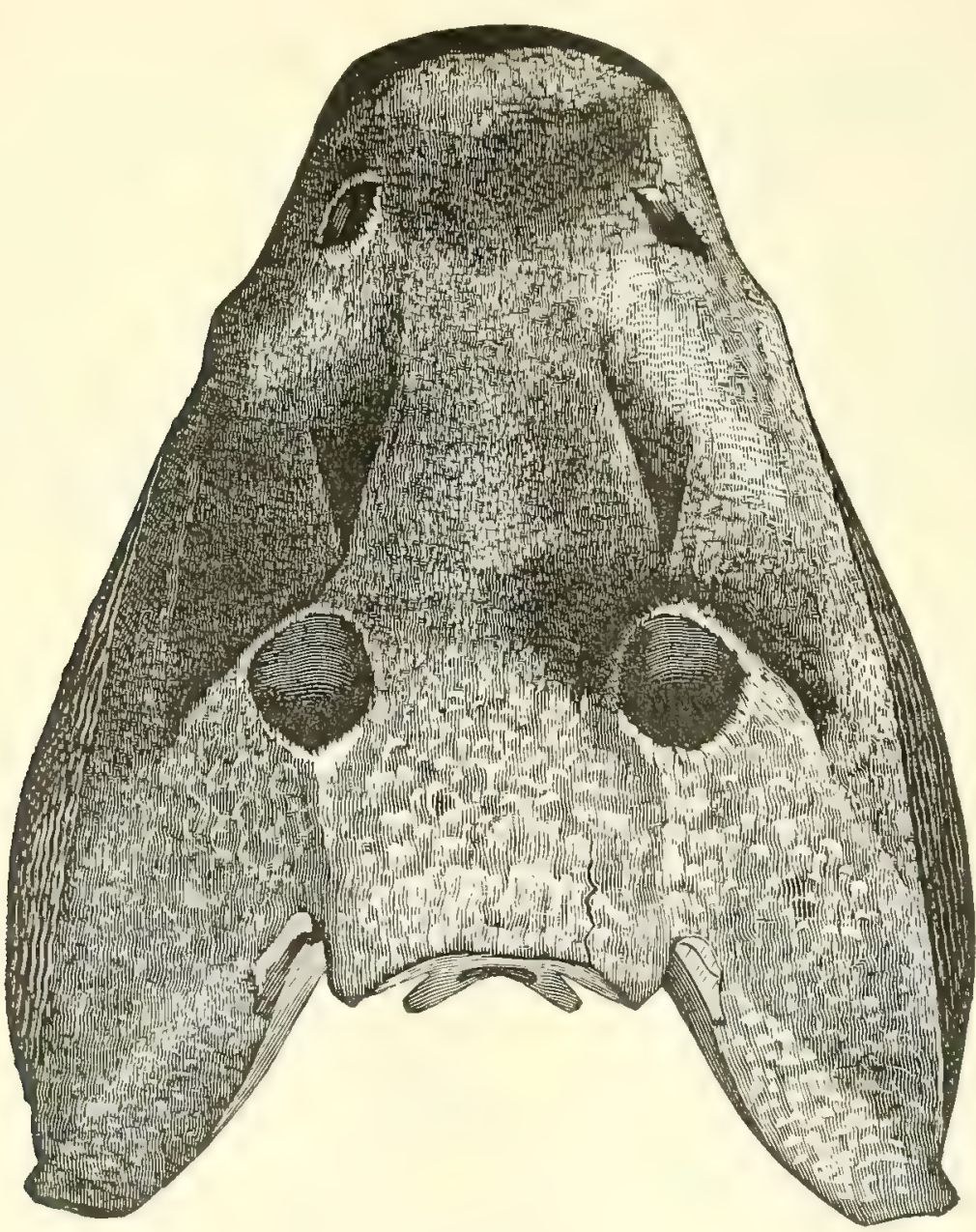

$1123 a$.

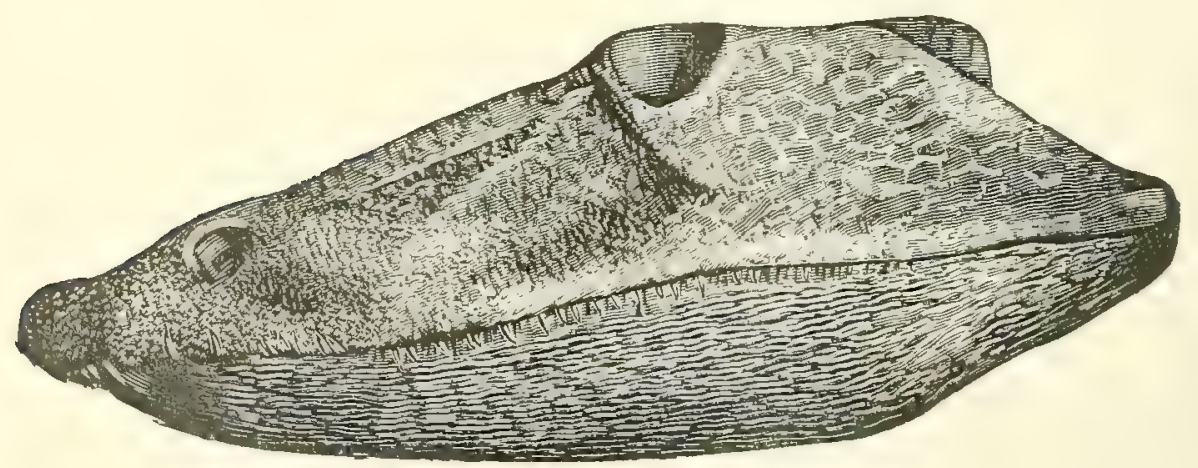

A Mphimian. - Eryops megacephalus $\left(\times \frac{1}{6}\right)$. Cope, "81.

3. Vertebrates. - To Fishes and Amphibians the Permian beds of America, like those of Europe, added Reptiles. 
The Fishes were of Coal-measure types of Ganoids and Selachians. The genera of the former included Ctenodus, Ptyonodus, and others; also Ceratodus, a Dipnoan genus, which here has its first known species, while its last is still living in Australia; the Permian, C. fuvosus of Cope, is from Texas. Sharks occurred of the genus Diplodus, and along with them spines of Orthacanthus, which have been shown to have belonged to Diplodus, as suggested by Dawson in 1869 from the association of specimens in the Pictou coalfield, Nova Scotia.

The Amphibians were, like the earlier, mostly Stegocephs. Fig. 1123 of the cranium of Eryops megacephalus of Cope, from Texas, shows that the head had the well-roofed character to which the name Stegoceph alludes; and the length of the cranium, over 22 inches, indicates a large species. Two long, narrow-headed species, Cricotus heteroclitus (Fig. 1124) and $C$.

1124.

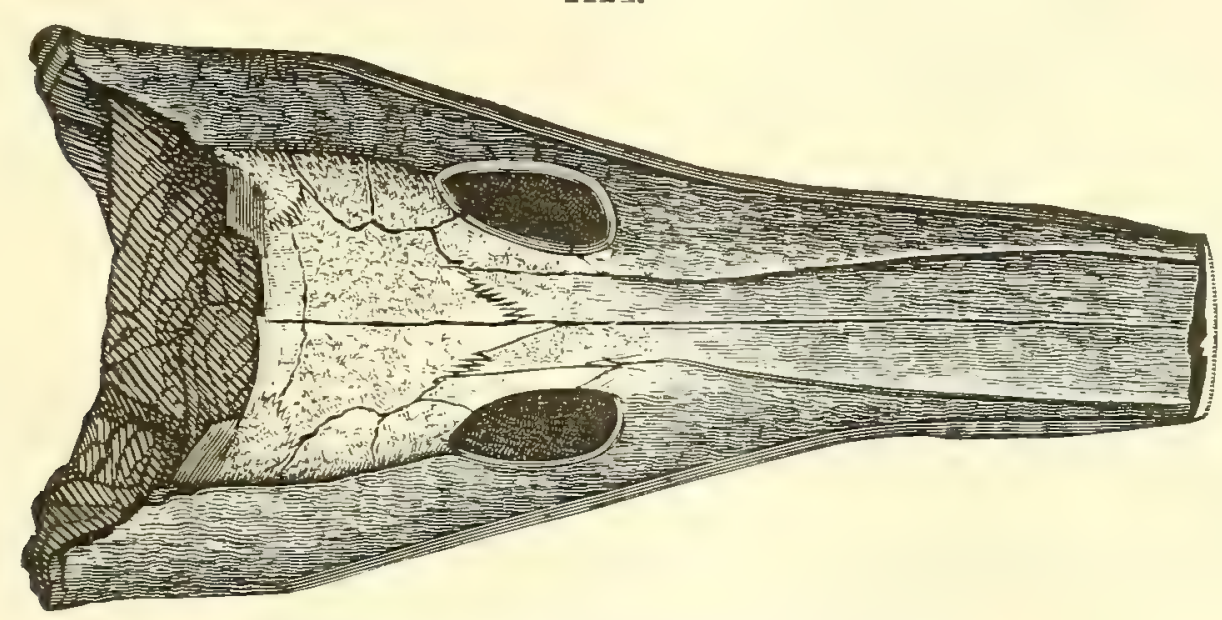

AMphibian. - Cricotus heteroclitus $\left(\times \frac{1}{2}\right)$. Cope.

Gibsoni Cope, have been found in the Permian of Danville, eastern Illinois, and the former also in northern Texas.

The Permian Reptiles, the earliest of the class, belong to the tribe Rhynchocephalia, which, like the genus Ceratodus among Fishes, is nearly extinct. Only two species, of the genus Sphenodon (or Hatteria), now exist, and these are confined to New Zealand - a piece, like New Guinea, of a now half-extinct continent, Australia. One of the earliest of the species is probably the Mesoscums (Stereosternum) tumidus of Cope (Fig. 1125), from beds containing shells of Schizodus in the Permo-Carboniferous of São Paolo, Brazil. It may be, however, from a bed below the Permian. Cope mentions its relations to the Amphibians and closer to the Rhynchocephalian Reptiles, and the interesting fact, of primitive aspect, that the foot, as the figure shows, has a tarsal bone ( 1 to 5 in figure) to each of the five metatarsals ( $\mathrm{I}$ to $\mathrm{V}$ ), five in all, or the normal number, instead of four, which is the largest number in later Reptiles.

Other Permian reptiles, but probably later stratigraphically, are those of Clepsydrops of Cope, three from Texas and as many from Illinois; of 
Dimetrodon of Cope, which has several Texas species, remarkable for the great length of the neural spines of the lumbar vertebre which supported the broad dorsal fin characteristic of the genus; and other related genera, for which Cope instituted the family of Theromora - made by some a part of

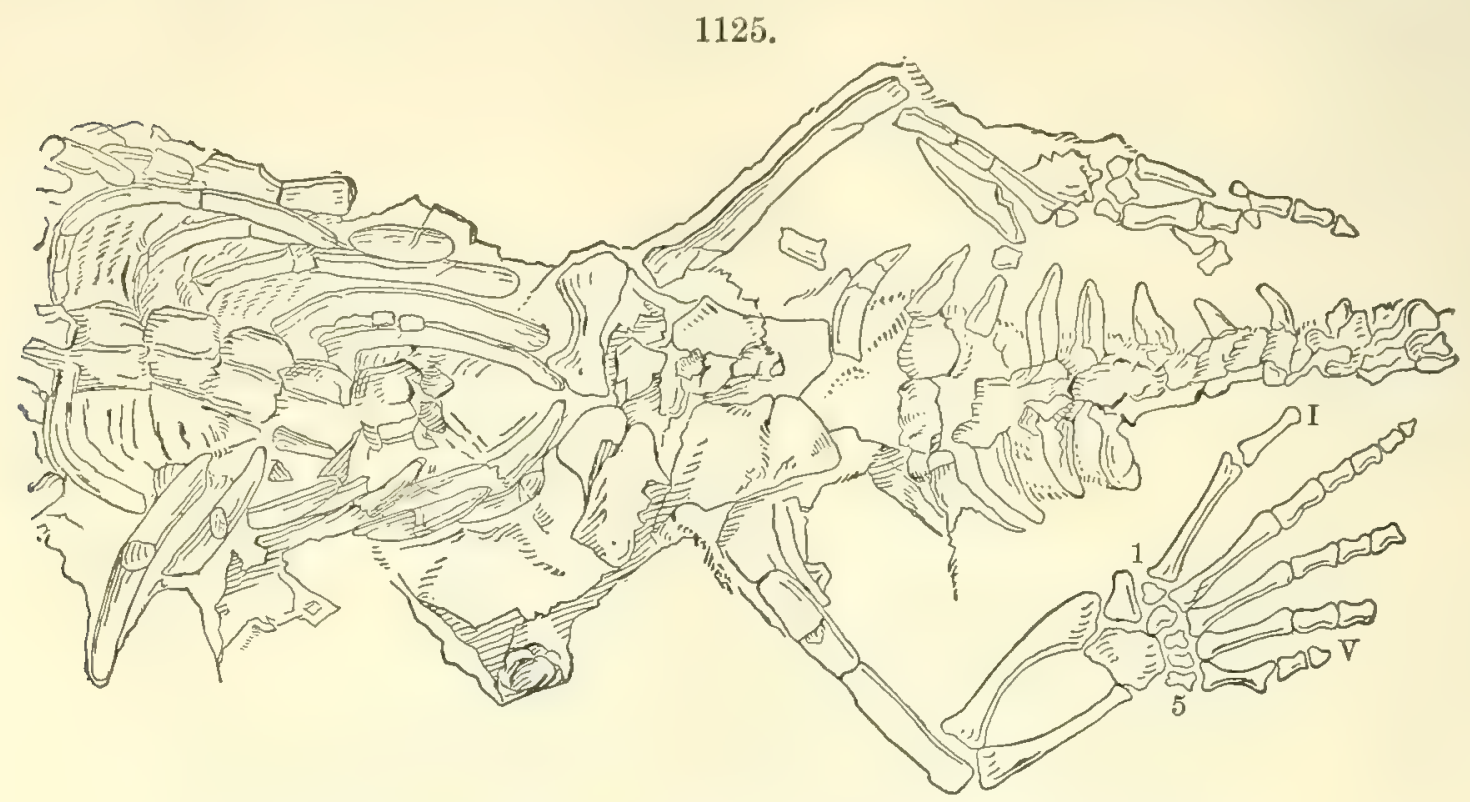

Mesosauras tumidus (natural size); 1-5, tarsals ; I-V, metatarsals. Cope.

the group Anomodontia. Other related species, from New Mexico, are the Ophiacodon grandis Marsh, about 10 feet long; also species of Sphenacodon and Nothodon of Marsh. These early Rhynchocephalians and Anomodonts combine Amphibian and Mammalian characteristics along with the Reptilian.

\section{Characteristic Species.}

\section{Carboniferous Period.}

Puants. - 1. Seaweeds are rare in the Coal-measures. A Spirophyton, like S. caudagalli (page 582), has been reported by Lesquereux as occurring in sandstone, probably of this era, or of the Subcarboniferous, in Crawford County; Ark. Species of the genus Caulerpites have been observed in Pennsylvania, Illinois, Indiana, Missouri, in both the Lower and Upper Coal-measures. Chondrites Colletti Lsqx. was obtained near Lodi, Ind., overlying a thin coal-bed at the base of the Coal-measures. Lesquereux remarks that, although the iron-stone concretions have preserved the most delicate parts of Ferns and Insects, no trace of a Fungus or Lichen has been found in them. He observed elsewhere, however, evidences of parasitic Fungi. A large Fungus, having some resemblance to an Agaricus, has been reported, with iliustrations, by H. Herzer, from the Lower Kittanning coal-bed of Tuscarawas County, Ohio, and named Dactyloporus archceus.

2. Lepidodendrids. - Fig. 1033, part of the surface of the Lepidodendron aculeatum Sternb., a common species both in the United States and in Europe; 1034, L. clypeatum Lx.; 1036, L. Veltheimanum St., which is also Subcarboniferous and European; 1035, Halonia pulchella Lx., Arkansas. Other common species, and of wide range, are Lepidodendron Stembergii (also Subcarboniferous), L. dichotomum Brgt., L. modulatum Lx.

3. Sigillarids. - Fig. 1037, Sigillaria Sillimani Brgt., Pa., Ind. ; 1038, S. Pittstonana Lx., Pittston, Pa., Ky. 
4. Ferns. - Fig. 1042, scar of the Tree-fern, Stemmatopteris punctata Lx., Gate vein, Pa.; 1043, same of Megaphyton McLayi Lx., Ill. ; 1044, scar of Cyathea compta, a species now growing in the islands of the Pacific; 1045, Odontopteris Schlotheimi Brgt., Pa., Ohio, III., Europe ; 1046, Alethopteris lonchitica Brgt., most common in the Lower Coal-measures, Pa., etc. ; 1047, Sphenopteris (Hymenophyllites) Hildrethi Lx., Kanawha Salines ; 1047 a, same, enlarged ; 1048, S. Gravenhorstii Brgt., R. I., Mo. ; 1048 a, same, enlarged ; 1049, $a$, Neuropteris Loschii Brgt., and 1050, Neuropteris hirsuta Lx., from figures by Lesquereux, common in the Upper Coal-measures, in Ohio and Kentucky, and the former particularly abundant in the Pomeroy bed; 1051, Pecopteris arborescens Brgt., Pa., Ohio ; P. cyathea Brgt. and P. unita Brgt., common; 1052, Neuropteris tenuifolia Lx., Shamokin, Pa. In Arctic America, on Melville Island, impressions of a Sphenopteris have been observed in connection with the coal.

5. Calamitids. - Fig. 1056, Calamites cannceformis Schloth., Pottsville conglomerate and Lower Coal-measures; 1054, Asterophyllites sublcevis Lx.; 1053, A. equisetiformis Lx., Pa., R. I. ; 1055, Sphenophyllum Schlotheimi Brgt., through all the Coal-measures.

6. Gymnosperms. - Cordaites borassifolius Ung., a common Coal-measure species; Fig. 1057, Cordaites costatus, Lx., Cannelton, Pa. ; 1057 a, fruit of same ; 1062, Cordaicarpus Gutbieri d'Eury, Cannelton; 1063, Cardiocarpus elongatus Newb., Ohio; 1065, C. bisectus Dn., Nova Scotia; 1064, C. samaraformis Newb., Ohio; 1058 a, b, c, Trigonocarpus tricuspidatus Newb., Ohio, representing the rind, the nut, and the kernel; 1059, nut of another Ohio species, figured by Newberry, but not described ; 1060, a, T. ornatus Newb., Ohio; 1061, Cardiocarpus bicuspidatus Newb., Ohio. Figs. 1066 and 1067 are made the type of the genus of Conifers, Botryoconus of Grand'Eury, being immature fruits. The specimens, and that of the fruit, Fig. 1068, are from the Lower Coal-measures of Youngstown, Ohio.

The Rhode Island coal region, according to Lesquereux, belongs to the Upper Productive Measures. See Am. Jour. Sc., xxxvii., 229, 1889.

For lists of species of plants characteristic of the several subdivisions of the Carboniferous period, and their geographical distribution in America, see Lesquereux's Pennsylvania Report, No. P, page 855 and beyond, and also page 636. According to Lesquereux the following species commence in the Pottsville conglomerate, or the beds next above, and continue through the Coal-measures:-

The names of species not in the Conglomerate have a dash before them; those which have a dagger after them continue into the Permian; and those starred are also European.

Calamites Suckovi †*, C. ramosus*, C.cannofformis*, C.approximatus $*$, C. Cistii*; Asterophyllites equisetiformis*, A. foliosus*, Annularia longifolia $\dagger^{*},-$ A. sphenophylloides †*, Sphenophyllum Schlotheimi*, S.longifolium $\uparrow,-S$. emarginatum $*$, Neuropteris hirsuta $\dagger$ *,$N$. fimbriata $\dagger, N$. inflata, $-N$. angustifolia $*, N$. Loschii $*, N$. tenuifolia $*, N$. capitata, N. Germari*, -N. cordata $\dagger^{*}$, Odontopteris Schlotheimi*, O. sphenopteroides; Alethopteris Serlii*, A. lonchitica*; Pseudopecopteris nervosa, P. muricata*, P. anceps, $P$. irregularis $*$, P.nummularia $*$, $P$.decipiens, P.latifolia*; Pecopteris acuta*, P. serrulata, -P.arborescens $\uparrow^{\dagger},-P . n o t a t a \dagger, P . p t e r o i d e s \dagger *$, P.erosa*; Sphenopteris (Hymenophyllites) spinosa*, S. furcata*, S. tridactylites $*$; Rhacophyllum lactuca ${ }^{*}$, R. filiciforme*;-Lepidodendron Sternbergii *, L. aculeatum, L. Veltheimanum*, L. vestitum, L. clypeatum, L. dichotomum *, L. obovatum*, L. modulatum, L. rimosum*; Ulodendron majus $*$, $-U$. punctatum; Knorria imbricata*; Lepidophtoins laricinus*; Sigillaria monostigma, S. Brardii †米, -S. Menardi*, S. tesselata*, S. mammillaris $\dagger$, S. Lescurii, -Cordaites diversifolius, C. borassifolius.*

The genera especially characterizing the Lower Coal-measures are: Megalopteris, Toniopteris, Veriopteris, Hymenophyllites section of Sphenopteris, Eremopteris, Knorria, Lepidophloios, Lepidodendron, Sigillaria, Cordaites, Whittleseya.

DANA's MANUAL - 44 
For Reports on American coal plants with figures, see Indiana Gen7. Rep. for 1883, by Lesquereux; Illinois Geol. Rep., vols. ii. and iv., by Lesquereux; Ohio Pul., vols. i. and ii., by Newberry; Pennsylvania Geol. Rep., No. 1, by Lesquereux, 1st vol. text, 2 d vol. plates, 3d vol. text and plates, 1880-84.

On the Permian flora, see Fontaine and White, Pa. Geol. Rep., No. PP, 1880.

Animals. - 1. Rhizopods. - Fig. 1069, Fusulina cylindrica of Fisher, is a Russian species, to which the American specimens in part are referred. F. elongata Shumard, Fr robusta, $F$.ventricosa, and F. gracitis of Meek, are supposed to be probably varieties of it. Loftusia Columbiana G. M. Dawson, Q.J.G.S., xxxv., 74. Dentalina priscilla Dn., from Nova Scotia, consists of a single series of cells.

2. Actinozoans. - Syringopora multattenuata McCh., Campophyllum torquium Ow., etc.

3. Echinoderms. - Crinoids, of the genera Poteriocrinus, Actinocrinus, Cyathocrinus, Zeacrinus, Delocrinus, Scaphiocrinus, Eupachycrinus, Agassizocrinus, Acrocrinus, etc.

4. Molluscoids. - Fig. 1072, Spirifer cameratus Mort., Lower and Upper Coal-measures, in Ohio, Ky., Ind., Ill., Mo., Utah, etc. ; 1070, Productus Nelrascensis Ow., Ill., Kan., N. Mex. ; 1071, Chonetes mesolobus N. \& P., a common species; 1073, Seminula subtilita Hall, common in the Coal-measures; Spiriferina Kentuckensis Lpper Coal-measures, Ill., Ky., Mo., and near Pecos village, N. Mex.; Spirifer lineatus Phill., Meekella striatocostata Cox, Ill., Mo., Iowa; Orthis Pecosi Marcou; Dielasma (Terrebratula) bovidens Mort.; Derbya (Streptorhynchus) crassa M. \& H. ; Waldheimia? (Cryptacanthia) compacta W. \& St. John. The following first appeared in the Subcarboniferous, and are continued into the Carboniferous: Productus punctatus (Fig. 1013, page 642), P. cor $\alpha, P$. muricatus, P. semireticulatus (Fig. 423, page 427), Spirifer lineatus.

5. Mollusks. - Lamellibranchs. - Fig. 1074, Macrodon carbonarius M., Upper Coalmeasures, Ky.; 1075, Allorisma subcuneata M. \& H., Kan. ; Aviculopecten rectilaterarius Cox, Upper and Lower, Avicula (Gervillia) longa M., Nuculana bellistriata M., Cardiomorpha Missouriensis Shum., Solenomya radiata M.\& W., Myalina perattenuata M. \& H., M. recurvirostris M. \& W., Schizodus amplus M. \& W., all from Ill. Entolium avicula Swallow, Kan. ; Pinna peracuta Shum., Mo., Kan.; Lima retifera Shum., Kan.; Mytitus [Modiola (?)] Shawneensis Shum., Kan.; Monodon, species of Monopteria, Pseudomonotis, Placunopsis, etc.; Modiola Wyomingensis Lea, Wyoming, Pa.; Anthracomya (Naiadites) carbonaria Dn., N. Scotia; A. elongata Dn., N. Scotia; A. lovis Dn., N. Scotia.

6. Gastropods. - Fig. 1077, Bellerophon carbonarius Cox (often referred to B. Urii Fleming), Upper Coal, Ky. ; 1076, Pleurotomaria tabulata Con.; 1078, P. sphcerulata Con.; P. carbonaria N.\& P., P. Grayvillensis N. \& P. ; 1079 , Macrocheilus (?) fusiformis H., M. Newberryi Stevens, M. ventricosus H., Iowa, Murchisonia minima Swallow, Mo. ; 1080, Dentalium sublceve H., D. Meekanum Gein., Neb. and Ill.; Straparollus pernodosus M. \& W., Ill.; Chiton carbonarius Stevens, Straparollus subrugosus M. \& W., Ill., Loxonema semicostatum M., Aclis robusta Stevens, Streptaxis Whitfieldi M., all from Illinois; Naticopsis. Also the Land-snails (Helix family), Fig. 1081, Pupa vetusta Dn., half an inch long, Coal-measures, Joggins, N. Scotia; 1082, Pupa Vermilionensis Bradley, Vermilion County, Ill., in a concretionary limestone; 1083, Dawsonella Meeki Bradley, same locality.

For Cephalopods of the Carboniferous, see papers by Shumard, McChesney, Swallow, Hall, Hall and Whitfield, and the Geological Reports of Illinois (Meek and Worthen), Missouri (Swallow), Texas (Hyatt).

Some of the Nautiloids of the Carboniferous, part of them new species, as named and figured by Hyatt in the second Annual Texas Geological Report are: Temnochilus conchiferum, Tex.; T. Forbesanum, Tex. (Nautilus F. of McChesney); T. latum, Meek and Worthen, Kan. ; T. depressum, Kan. ; T. crassum, Kan. ; Metacoceras cavatiforme, Kansas 
City, Mo. ; M. dubium, Kan.; M. Walcotti, Tex.; M. Hayi, Kan.; M. inconspicuum, Kan.; Tainoceras cavatum, Tex.; Domatoceras umbilicatum, Kan.; Asymptoceras Newtoni, Kan. ; A. capax (Cryptoceras capax, Meek and Worthen), Mo.; Phacoceras Dumbli, Tex.; Ephippioceras divisum (Nautilus divisus of White and St. John); Endolobus gibbosus, Tex. They are mostly large species, 4 to 6 inches in diameter.

7. Worms. - Fig. 1086, Spirorbis carbonarius Dn.; also, S. arietinus Dn.

8. Limuloids. - Fig. 1088, Prestwichia Dana = Euproops Dana of M. \& W., Morris, Ill.; P. longispina Packard, Pittston, Pa.; Dipeltis diplodiscus Packard, Mazon Creek, Ill.; Cyclus Americanus Packard, Mazon Creek, Ill. (Mem. Nat. Acad. Sc., iii., 14, 1888).

9. Crustaceans. - (a) Trilobites. - Phillipsia Missouriensis, P. major, P. Cliftonensis of Shumard, from the Upper Coal of Missouri ; $P$. (Grifithides) scitula M. \& W., Ill., Ind., and Neb.; P. (Griff.) Sangamonensis M. \& W., Upper Coal, Ill.

(b) Entomostracans. - Cythere Americana Shum., Upper C., Mo.; Leaia tricarinata M. \& W., Upper Coal-measures, Ill.; Dithyrocaris carbonaria M. \& W., Ill.; Ceratiocaris sinuata M. \& W., Ill.

(c) Decapods. - Fig. 1089, Acanthotelson Stimpsoni M. \& W., Morris, Ill.; A. Eveni M. \& W., Morris, Ill.; 1090, Pataocaris typus M. \& W., Morris, Ill.; 1091, Anthracopalamon gracilis M. \& W., Morris, Ill.; A. Hillanus Dn., N. Scotia.

10. Myriapods. - Mazon Creek, Ill., has afforded species of a dozen genera, including Palcocampa anthrax M. \& W., Acantherpestes major M. \& W., Euphoberia armigera M. \& W., and 10 other species of the genus; Anthracerpes typus M. \& W., Eileticus anthracinus Scudder, Xylobius Mazonus Sc., Trichiulus villosus Sc., and others of Archiulus, Ilyodes, etc. In Nova Scotia have been found Xylobius sigillarice Dn. (Fig. 1092), $X$. fractus Sc., $X$. similis Sc., Archiulus Dawsoni Sc., A. Lyelli Sc., A. euphoberioides, and others.

11. Arachnids. - Besides the Scorpion of Fig. 1094, Mazon Creek has afforded Mazonia (Eoscorpius) Woodiana M. \& W., Architarbus rotundatus Sc., allied to the Phalangidæ, Arthrolycosa antiqua Harger (Fig. 1095), Geraphrynus carbonarius Sc., the long-tailed Geralinura carbonaria Sc. From Arkansas has come Anthracomartus tritobitus Sc.; from Rhode Island, another species of Anthracomartus; from Nova Scotia, Mazonia Acadica Sc.

12. Insects. - (a) Neuropteroids. - From Morris, Ill., Miamia Bronsoni D., Hemeristia occidentalis D., Chrestotes Dana Brot., C. lapidea Sc., Megathentomum pustulatum Sc., Genentomum validum Sc., Anthracothremma robusta Sc., and others. From Pittston, Pa., species of Dieconeura and Polyernus.

(b) Orthopteroids. - Of the Cockroach group there have been found : at Mazon Creek, 4 species of Mylacris, 2 of Promylacris, 2 of Paromylacvis, 1 of Archimylacris, 2 of Etoblattina, 1 of Progonoblattina, and 1 of Oryctollattina; in Pennsylvania, 6 of Mylacris, 2 of Neomylacris, 1 of Archimylacris, 3 of Lithomylacris, 1 of Promylacris, 1 of Etoblattina, 1 of Gerablattina; at Cassville, W. Va., 6 of Etoblattina, 15 of Gerablattina, 1 of Anthracoblattina, 3 of Poroblattina, and 1 of Petrablattina; at Richmond, Ohio, 17 of Etoblattina, 3 of Gerablattina, and 2 of Poroblattina; near Providence, R. I., 8 of Etoblattina, 2 of Gerablattina, and 1 of each Mylacris and Microblattina; and a few others in Missouri, Kansas, Arkansas, Nova Scotia, and Cape Breton. Orthopters of the Protophasmid type occur at several of the above localities.

Of Carboniferous Hemipteroid Insects, which are not uncommon in Europe, a species, Phthanocoris occidentalis, occurs near Kansas City, Mo. Of Coleopteroid Insects, no American species have yet been reported.

The above lists of fossil Myriapods, Arachnids, and Insects are from Mr. Scudder's publications and correspondence. See his Bulletin No. 31, U. S. G.S., for a review of the subject up to 1886 ; also, Bulletin No. 71,1891 , for a full index by him to the known fossil 
Myriapods, Arachnids, and Insects of the world, with references to all published papers and works on the subject, covering 744 octavo pages.

13. Vertebrates._(a)Fishes. - Ganoids. Fig. 1100, Eurylepis tuberculata Newb.; 1101, Colacanthus elegans Newb., Linton, Ohio, remarkable for not having the tail heterocercal, although strictly vertebrated; 8 other species of Eurylepis, 2 of Colacanthus, and 3 of Rhizodus, have been described by Newberry from Linton, also Palconiscus scutigerus and P. peltigerus Newb., Ohio; P. Leidyanus Lea, Pa.; P.gracilis N. \& W., Ill.; P. Browni of Albert Coal Mine, N. B.; P. Jacksoni Dn. Other Ganoids occur, of the genera Megalichthys, Ambtypterus, Pygopterus, and Rhadinichthys, in the Coal-measures of the United States and Nova Scotia.

Among Selachians, the following European genera have been recognized in the Coalmeasure limestones of Pennsylvania, Ohio, Indiana, Illinois, etc., - the species being generally distinct from those of the Old World: Diplodus, Cladodus, Orodus; Diplodus compressus Newb., Linton, Ohio ; D. latus Newb., ibid.; D. gracilis Newb., ibid.; Petalodus, Ctenoptychius, Chomatodus; Fig. 1102, Petalodus destructor N. \& W., from Illinois ; $1104 a$, $1104 b$, Petrodus occidentalis N. \& W., from Illinois, Indiana, etc.; 1103, fin-spine found associated with the scales of Petrodus occidentalis, and referred by F. H. Bradley to the same species. Cholodus, Peltodus, Calopodus, Ctenoptychius are other genera. Of finspines, there are Orthacanthus arcuatus Newb., Linton; Compsacanthus lavis Newb., Linton; Drepanacanthus anceps N. \& W., from Springfield, Ill., and others.

The genera of the Subcarboniferous are in part represented among the Carboniferous species, as Diplodus, Orodus, Cladodus; Petalodus (Fig. 1102, P. destructor N. \& W., Ill.), Petrodus (Fig. $1104 a, b, P$. occidentalis, N. \& W., Ill., Ind., etc.), Ctenoptychius, Chomatodus, Deltodus, Pocilodus, Xystrodus. Besides, there are 4 species of Agassizodus, all from the Coal-measures. Also fin-spines of the genera Compsacanthus, Drepanacanthus, etc. For figures and descriptions of fossil species the most important volumes are those of the Ohio Geological Report by Newberry, and those of the Illinois Report by Newberry and Worthen and St. John and Worthen.

(b) Amphibians. - Fig. 1109, Pelion Lyelli Wyman, Linton, Ohio ; Fig. 1108, Amphibamus grandiceps Cope, Morris, Ill.; Fig. 1110, vertebræ and ribs from Linton, figured by Wyman, but not named, referred by Cope doubtingly to the snake-like Molgophis macrurus Cope. Baphetes planiceps Owen, from Pictou, N.S.; the specimen is a portion of the skull 7 inches broad. The genera Phlegethontia and Molgophis of Cope are referred to Dolichosoma of Huxley by Fritsch. For descriptions and figures of the species of Ohio, see Geol. Rep., Pal. ii.; of Nova Scotia, Dawson's Acad. Geol., and its supplement of 1878, the latter containing also figures of Insects, Crustaceans, and Myriapods ; also Supplement of 1891, and later in the Trans. Roy. Soc. The Linton layer in Ohio is a local formation of cannel coal at the bottom of the Pittsburg coal-bed, indicating, as Newberry states, lakelike conditions cluring the progress of the layer. Twenty-three consecutive footprints of an Amphibian, Thenaropus heterodactylus, were found by A. T. King, near Westmoreland, Pa., in a layer about $100^{\prime}$ below the horizon of the Pittsburg coal; the tracks of the hind-feet 5-toed, and of the fore-feet 4-toed, - the former $5 \frac{1}{3}$ inches long, and the latter $4 \frac{1}{2}$ inches; and the distance between the successive tracks 6 to 8 inches, and between the 2 lines about the same. Another species from the same region is the Chirotherium Reiteri of Moore.

\section{Permian Period.}

On the Permian Flora of West Virginia, etc., see Fontaine and White, l.c.; contains 38 plates. The following are the Coal-measure species which continue, according to these authors, into the Permian or Upper Barren Measures of West Virginia and Pennsylvania: Calamites Suctovi, Sphenophyllum filiculme, Annularia longifolia, A. sphenophylloides, Neuropteris hirsuta, $\boldsymbol{N}$. flexuosa, $N$. auriculata, $N$. cordata, Pecopteris arborescens, $\boldsymbol{P}$. 
Candolleana, $P$. pteroides, $P$. dentata, $P$. notata, $P$. oreopteridea, $P$. Miltoni, $P$. Pluckeneti, Goniopteris emarginata, G. elegans (?), G. arguta (?), Rhacophyllum lactuca, Sigillaria Biardii. Of these species, all but Sphenophyllum filiculme, Neuropteris hirsuta and Pecopteris notata are also European Permian species. The genera Baiera and Callipteridium commence in the Permian. Out of 107 species of plants in the Upper Barren Measures of West Virginia, 28 are European Permian species.

The Red-beds of South Park, near Fairplay, Col., have afforded Permian species of Walchia, Callipteris, Odontopteris, Sphenopteris, Ullmannia, etc. (Lesquereux, Bull. Mus. Comp. Zoöl., vii., No. 8).

On Amphibians and Reptiles of Texas and Illinois, Cope, Amer. Phil. Soc. for 1877 and several later years, and also Proc. Acad. N. S., Philadelphia, Amer. Naturalist Bull., vi., Hayden Surv., 1881, and publications of Texas Geological Survey.

\section{FOREIGN.}

\section{Subcarboniferous and Carboniferods Periods.}

\section{ROCKS - KINDS AND DISTRIBUTION.}

The rocks of the Subcarboniferous and Carboniferous periods cover a very large area in the western half of Russia, or the Continental Interior of Europe, much of the area of Great Britain and Ireland, a moderately large area on the borders of Belgium, France, and Prussia, and small areas in Spain, Italy, Austria, and some other parts of Europe. The beds of the Carboniferous period - the period of the Coal-measures - have their greatest thickness and largest amount of coal in the British Isles, and but little thickness and little coal in Russia. There are workable coal-beds of this era, if the Permian be included, also in China, India, and Australia, but none, so so far as known, in South America, Africa, or Asiatic Russia.

The proportion of coal-beds to area in different parts of Europe has been stated as follows: in France, $\frac{1}{100}$ of the surface; in Spain, $\frac{1}{50}$; in Belgium, $\frac{1}{20}$; in Great Britain, $\frac{1}{10}$. But, while the area of the Coal-measures in Great Britain is about 12,000 square miles, it is in Spain, 4000; in France, about 2000 ; in Belgium, 518.

The distribution of the areas in England is shown on the accompanying map. The cross-lined black areas are Subcarboniferous, and the black those of the Coal-measures. The principal regions of the latter are (1) the South Wales, 1000 square miles in area; and, in nearly the same latitude, the Forest of Dean, west of the Severn, and the region about Bristol, east of the Severn, together 184 square miles; (2) the small patches in central England, in Shropshire (Coalbrook Dale), Warwickshire, Leicestershire, and Staffordshire, 240 square miles; (3) north of these, on the west, the great South Lancashire region, just east of Liverpool, with the basin of Flintshire on the Dee, the whole together, 220 square miles; (4), to the eastward of the last, the large Derbyshire coal region, between Nottingham and Leeds, and adjoining Sheffield, 800 square miles; (5) farther north on the west coast, in Cumberlanf, about Whitehaven, 25 square miles; (6) on the east coast, the great 
coal-field of Northumberland and Durham, about Newcastle, 796 square miles.

In Scotland, the beds cover an area 100 miles long by 25 broad, lying in the depression between the Grampian range on the north and the Lammer-

1126.

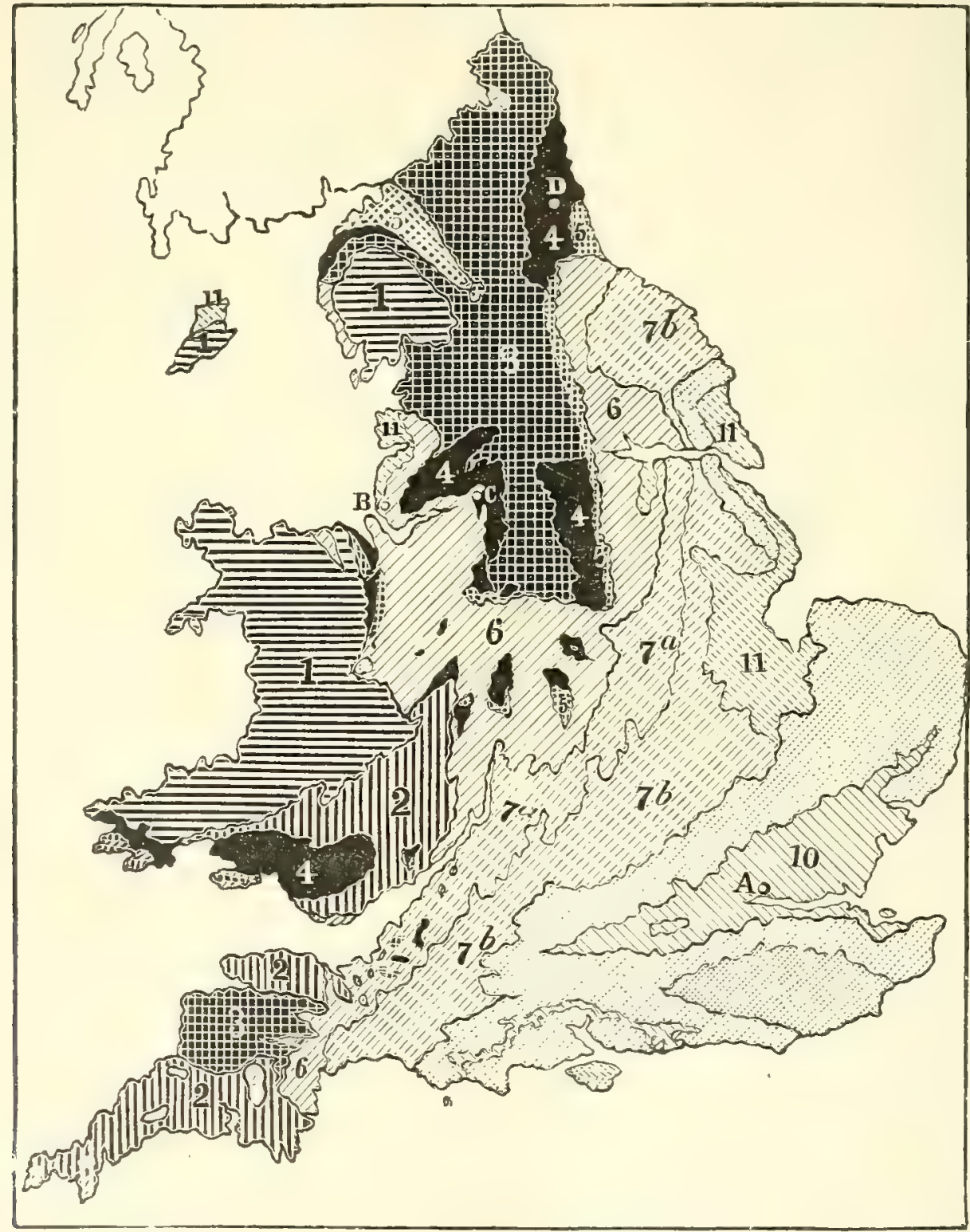

Fig. 1126, Geological map of England. The areas lined horizontally and numbered 1 are Silurio-Cambrian; those lined vertically (2) Devonian; those cross-lined (3) Subcarboniferous; the black areas (4) Carboniferous ; the dotted areas (5) Permian; those lined obliquely from right to left (6) Triassic, ( $7 a$ ) Lias, $(7 b)$ Oölyte, (8) Wealden, (9) Cretaceous; those lined obliquely from left to right $(10,11)$ Tertiary. A is London; B, Liverpool; C, Manchester; D, Newcastle. Ramsay.

muirs on the south. The most of the workable coal-beds occur in the Subcarboniferous.

In Ireland, over its center and to the southwest, a large part of the surface rock is Subcarboniferous limestone. It is believed that the Coalmeasures once covered this limestone. 
The Subcarboniferous rocks of Great Britain include a limestone formation called often the "Mountain limestone," and also shales and sandstone. The limestone is the chief rock in southern England, where, near Bristol, it is $2000^{\prime}$ thick and has shaly beds at base, the "Lower limestone shale." In Derbyshire, the limestone, 4000' in maximum thickness, is succeeded by a series of shales and sandstones with beds of limestone, called the Yoredale group. This Yoredale group is $2300^{\prime}$ thick in North Staffordshire, making a total thickness of $6300^{\prime}$; it is $4500^{\prime}$ thick in Lancashire. In Wales the thickness of the limestone is but $500^{\prime}$, and in Anglesey, $200^{\prime}$ to $500^{\prime}$.

In Scotland, the Subcarboniferous rocks are mainly fragmental, and are called the Calciferous limestone group.

In southwestern Ireland, the limestone has a thickness, in Limerick, of 3600 。 But in northern Ireland, the fragmental beds increase in amount and thereby become similar to those of Scotland, as if they were their continuation.

In Northumberland, in northern England, fragmental beds greatly predominate; the total maximum thickness is $8000^{\prime}$, and of this, only $20^{\prime}$ to $50^{\prime}$ is limestone; they have received a distinct name, - that of the Bernician group, - because they are so unlike the rest and without any natural subdivision; and those of the valley of the Tweed and the vicinity have been termed the Tuedian group.

The Carboniferous limestone of the Lake District and Yorkshire was called the "Scar limestone" by Sedgwick, from the topographic features, or "scars" produced by the rock. It makes a strong impression on the scenery of many parts of England. "Massive beds of it," says Prestwich, "rising from beneath the Mesozoic strata in the neighborhood of Frome and Wells, constitute the main range of the Mendips. At Clifton it is traversed by the gorge of the Avon. A few miles to the north the limestone passes under the great plains of central England to reappear in the picturesque hills of Derbyshire, the bluffs of Matlock, the scarps of Dovedale, and the high ridges of Buxton. In Yorkshire the limestone hills, which rise to heights of $2000^{\prime}$ to $2500^{\prime}$ in the Pennine chain, are intersected by the many beautiful dales so characteristic of that district. The prevailing cold gray color of the limestone, the frequency of bared surfaces, and the innumerable caves - famous for their magnitude and their stalactites, or as the dens of Pleistocene Mammals - render the rocks easily recognizable, and contribute greatly to their scenic effects." The limestone contains much chert. Hinde has shown that the chert abounds in sponge-spicules; and Carter has observed facts illustrating the passage by solution of the spicules into chert.

The beds of the Coal-measures in England have generally at bottom the Millstone grit, answering to the Pottsville conglomerate of Pennsylvania. The thickness is 400 to 1000 feet in South Wales, about 1200 feet in the Bristol coal-field, 3000 to 5000 feet in the Lancashire region; but in the north of England only 500 feet, and in Scotland it is barely recognizable.

The Coal-measures in South Wales have a thickness of 7000 to 12,000 feet, and include more than 100 coal-beds, 120 feet in total thickness, 70 of which are worked. While the coal is bituminous near Swansea, it becomes anthracite to the west and north.

In the Forest of Dean, the thickness of the beds is 2400 feet, and they comprise at least 23 coal-beds; while in the Bristol coal-field, on the other side of the Severn, there are 5090 feet of Coal-measures, with 87 coal-beds.

In the south Lancashire coal region, which reaches nearly to Liverpool, the Coal-measures are stated to have a thickness of 7200 to 8000 feet, and to include more than 40 beds of coal over one foot in thickness, and in north 
Staffordshire the thickness is 8000 feet. But to the northward, in Derbyshire, the thickness is about 2500 feet, and in Northumberland and Durham, and in Scotland 2000 feet. The coal-berls, as elsewhere, usually rest on a bed of fire clay containing rootlets. In the Newcastle region, the Coal-measures are about 2000 feet thick, and include about 60 feet of coal: the beds afford about a fourth of the coal of England.

The Lancashire area and the Cumberland farther north lie on the west side of an anticlinal ridge, mostly of Subcarboniferous and Lower Carboniferous rocks, called the Pennine chain, in some points 2000 feet high, which extends north to the Cheviot Hills, between England and Scotland. The Derbyshire and Newcastle areas are to the east of this anticlinal.

Prestwich observes, with regard to a parallelism in the several coal-beds, between the different British coal-fields, and between these and European coal-fields, that, while this is not to be looked for, some general relations may be made out. The great dividing mass of rock, 2000 to 3000 feet thick, called Pennant, exists in both the Welsh and Bristol coal-fields; and the total thickness is not very different in the two - about 10,500 feet in one and 8500 in the other, with 76 coal-beds in Wales, and 55 in Somerset. In the Hainault (or Mons and Charleroi) basin, the measures are 9400 feet thick, with 100 beds of coal; in the Liège basin, 7600 feet, with 85 beds; in Westphalia, 7200 feet, with 117 beds.

In Belgium, in the region of the Meuse, the Carboniferous limestone has a thickness. of nearly $2500^{\prime}$, and includes at top the "Limestone of Visé"; $800^{\prime}$ below the top, the "Dolomite of Namur" ; and 2000 ' below the top, the "Limestone of Dinant."

The wide-spread Subcarboniferous formation in Russia is chiefly limestone. To the eastward, at the west base of the Urals, there is one wide north-and-south belt, and another to the westward extending from the Arctic Sea, in $66_{2}^{1 \circ} \mathrm{N}$, to $54^{\circ} \mathrm{N}$. Near Moscow the formation was reached by boring through the Jurassic and underlying beds.

The Carboniferous limestone has been found by Richthofen to underlie a large coal region in China, and to be marked by Fusulina and other fossils of the European Subcarboniferous beds.

The Belgian Coal-measures of Liège and Mons extend 80 miles along the northern flanks of the Ardennes, and have numerous coal-beds, the thickest $3 \%$ The principal coal basin of Germany is that of Saarbriick in the Rhenish provinces, 900 square miles in area. In a thickness of Coal-measures of nearly $20,000^{\prime}$, it contains 82 workable beds, included mainly in the lower $9000 \%$. Another area is that of Westphalia. Silesia, in a coal region 16 miles square, has one coal-bed $50^{\prime}$ thick. Some anthracite-bearing beds occur in the western Alps among schistose crystalline rocks, but none of economical value. The chief Austrian basin is in Bohemia at Pilsen. Russia has valuable coal-beds at Donetz on the north shore of the Azof. In China, plants of Carboniferous age have been obtained, to the north in the peninsula of Manchuria, where coal-beds are worked, and also in the provinces of Shansi, Hunan, Pe-chi-li, and others (Richthofen's China, vols. ii. and iv.). Carboniferous Coal-measures occur also in Japan and Borneo.

In the Arctic seas, Spitzbergen has a coal formation well developed, but no beds of coal. The Coal-measures are $1000^{\prime}$ to $2000^{\prime}$ thick in Robert's valley, with many coal plants in the shales; and the Subcarboniferous limestone and other rocks (which probably pass down into Devonian), and afford fossil Corals, Crinoids, and Brachiopods related to European and American species, besides plants; and the chert has been reported by Hinde to be full of Sponge-spicules. 


\section{Permian Period.}

On the map of England (Fig. 1126) a border of Permian is represented along the east side of the Newcastle Carboniferous area, and also adjoining other coal areas excepting that of South Wales. (The areas are marked with dots on a white ground, and numbered 5.) A small area occurs in Ireland, about the Lough of Belfast. The rocks are red sandstone and marlytes, along with Magnesian limestone. Before their relations were correctly made out, they were included, along with part of the Triassic, under the name "New Red Sandstone."

In Durham, northeastern England, there is (1) a Lower Red sandstone, 200 feet thick; then (2) $a, 60$ feet of marl-slate; $b$, two strata of Magnesian limestone, the lower 500, and the upper 100 feet thick, separated by 200 feet of gypseous marlyte, and overlaid by 100 feet of the same. The Magnesian and other limestones disappear to the south, near Nottingham. In northwestern England, the Lower Permian includes 3000 feet of marlytes and sandstones; the Middle, only 10 to 30 feet of Magnesian limestone; the Upper, 600 feet, similar to the Lower. There are detached Permian areas in Dumfriesshire, Ayrshire, etc., in Scotland.

In European Russia, Permian strata cover a region more than twice as large as all France; it includes the greater part of the governments of Perm, Orenburg, Kazan, Nizhni Novgorod, Yaroslavl, Kostroma, Viatka, and Vologda. The beds are sandstones, shales, marlytes, and dolomitic limestone, and contain an occasional thin seam of coal. The deposits are flanked and underlaid on nearly all sides by different members of the Carboniferous formation containing comparatively little coal.

In central Germany small areas occur, from southern Saxony along the Erzgebirge, over the adjoining small German states, west to Hesse Cassel, and north to the Harz Mountains and Hanover. Within this area, Mansfeld is one noted locality, situated in Prussian Saxony, not far from Eisleben; another is on the southwest borders of the Thuringian forest (Thüringerwald) in Saxe-Gotha, a line which is continued to the northwest, by Eisenach, toward Münden in southern Germany. In Thuringia and Saxony, the subdivisions of the rocks, beginning below, are (1) the Rothliegende, or Red beds, consisting of red sandstone, and barren of copper ores; near the town of Eisenach, about 4000 feet thick; (2) The Zechstein formation, or Magnesian limestone, consisting of (a) the Lower Zechstein, a gray, earthy limestone, overlying the Kupferschiefer, or copper-bearing shales, and the still lower Weissliegende or Grauliegende, or white or gray beds; (b) the Middle Zechstein, Magnesian limestone, called the Rauchwacke and Rauhkalk; (c) the Upper Zechstein, or the Plattendolomit, and including the impure fetid limestone called Stinkstein.

The lower part of the Lower Permian of England includes, in some places, beds of coarse conglomerate, containing angular masses of rock of great size. 
Ramsay attributes the transportation of the blocks to floating ice. Bowlders in beds of great thickness and coarseness, glacial-like, with many of the bowlders scratched, occur toward the bottom of the Tálchir group of India, regarded as Lower Permian; in equivalent beds of the Salt Range of northern India; in the related Ecca beds of South Africa, below the Karoo beds; in beds beneath the Glossopteris Coal-measures of eastern Australia, and also other beds overlying the same, called the Hawkesbury sandstone; and also in Victoria and Queensland. In New Zealand similar bowlder beds are referred by Dr. Hector to the Trias.

The above facts have led some geologists to the conclusion that over India, Australia, and South Africa, there were glacial conditions in the course of the Permian era - a time when Europe and America were under luxuriant vegetation.

The Permian has much extent also in Bohemia and Moravia. On both sides of the Alps are red sandstones underneath Triassic beds, which are referred to the Permian. In France, its beds lie at the base of the Vosges, whence they extend into the Black Forest; at Autun, the thickness is $3000^{\prime}$; the rocks are, as usual elsewhere, sandstone, marlytes, and conglomerates.

In the Indian peninsula, according to the report of W. T. Blanford, Director of the Geological Survey, the Damúda series in western Bengal, with its valuable coal-beds, and also the underlying Tálchir beds, - called together the Lower Gondwána series, - correspond to the upper part of the Carboniferous and the Permian, excepting the Panchet group at the top, which is Triassic. The beds have a thickness of $6000^{\prime}$ to $11,000^{\prime}$, and the coal-beds an aggregate thickness of $175^{\prime}$ or more. A 6-inch bed of coal occurs in the Tálchir group. The Coal-measures of Karharbári overlie the Tálchir beds. The Damúda beds contain species of Glossopteris (Glossopteris Browniana most abundant), Alethopteris, Toniopteris, Sphenopteris, Sphenophyllum, Gangamopteris, Sagenopteris, besides Pterophyllum and other Cycads, Voltzia heterophylla, Vertebraria, etc. The Rájmahál group, of the Upper Gondwána series, is supposed from its fossil plants to be Lower Jurassic, Cycads being the prevailing species, as much so as Glossopteris and Vertebraria are in the Damúdas.

In Australia, the coal formation, with excellent coal, occurs in Ilawarra, also on Hunter's River, and elsewhere; and, from the fossil plants, the absence of Lepidodendrids and Sigillarids, and the abundance of Glossopteris, with species of Sphenopteris, Vertebraria, etc. (the range of species much resembling that of the Damúda beds), together with the occurrence, immediately below, of shales containing Carboniferous Brachiopods, Conulariæ, etc., and a heterocercal Ganoid, Urosthenes australis D., the series was referred by the author (in his Wilkes Exped. Geol. Rep., 1849) to the "Upper Carboniferous or partly Lower Permian." It is made the equivalent of the Damúda series by Blanford. W. B. Clarke mentions the occurrence of leaves of Glossopteris in the Coal-measures, having a length of about 2', and of the frond of a Sphenopteris, which when entire must have measured $5^{\prime}$ in length. The Coal-measures are about $480^{\prime}$ thick, and contain 11 seams of coal. D. Stur has shown that in Germany and Austria the Permian is characterized by related species of Tceniopteris, Pterophyllum and Sagenopteris, closely representing those of India and Australia.

The Lower coal-beds occur in Australia also, below the above-mentioned beds, in the Hunter's River region, and westward through Durham, Brisbane, etc., which contain species of Lepidodendron, Sigillaria, Knorria, Cyclopteris, etc. Above the Upper Coal-measures in Australia comes the wide-spread Hawkesbury sandstone and the 
Wianamatta shale, with Palconiscus antipodens Eg., but without Glossopteris and other lower species; the beds are probably 'Triassic and Jurassic. Jurassic Ganoids of the genera Coccolepis, Leptolepis, and others, have been reported by A. Smith Woodward (1890), from specimens discovered by C. S. Wilkinson and R. Etheridge, Jr. Both the Glossopteris and Lepidodendron floras occur in Victoria, and the former in Queensland.

South Africa has a coast border of gneiss and other schists, and inside of it a belt of Paleozoic rocks with Carboniferous at top (in Table Mountain, etc.). The great interior region thus bordered is occupied by the "Karoo formation" from Table Mountain northward over Orange Free State and Basutoland, reaching the coast only to the southeast in Caffraria. It includes (1) the Ecca beds (with the Dwyka bowlder bed [glacial?] in the lower part), which contain Glossopteris, etc., and are regarded as Permian, or of the age of the Tálchir and Damúda beds of India; (2) the Middle Karoo, or Beaufort beds, Permian or Triassic; and (3) the Upper Karoo or Stormberg beds, supposed to be Triassic. For a colored geological map by A. Schenk, see Peterm. Mittheil., 1888.

\section{LIFE OF THE SUBCARBONIFEROUS AND CARBONIFEROES PERIODS.}

Plants. - The same genera of plants, with few exceptions, are represented among the European coal-beds as occur in America; and about a third of the American species are found also in Europe. In this respect the vegetable and animal kingdoms are in strong contrast; for the species of animals common to the two continents have always been few.

The number of species in the European flora of the Carboniferous (the British included) is stated to be nearly 1400, while North America, so far as described, including the Carboniferous and Subcarboniferous periods, has afforded, as enumerated by Lesquereux in the concluding part of his Pennsylvania Report of 1884, excluding fruits, about 625 species, and including fruits, nearly 800 . Over 200 species of the 625 exist also in Europe. The number of species of the several genera common to the two continents is given by Lesquereux as follows:-

Calamites, 11 ; Asterophyllites, 6 ; Annularia, 6 ; Sphenophyllum, 8; Macrostachya, 1 ; Neuropteris, 17 ; Odontopteris, 5; Dictyopteris, 3; Callipteridium, 3 ; Alethopteris, 6 ; Pseudopecopteris, 16; Pecopteris, 29; Otigocarpia, 1 (O. Gutbieri) ; Sphenopteris, 20 ; Eremopteris, 2; Rhacophyllum, 7 ; Stemmatopteris, 1 ; Caulopteris, 1 ; Megaphyton, 1 ; Lepidodendron, 14; Ulodendron, 4; Knorria, 3; Halonia, 3; Cyclostigma, 1 ; Lepidophloios, 3 ; Lepidophyllum, 1; Sigillaria, 25; Syringodendron, 3 ; Stigmaria, 1 ; Cordaites, 1.

The flora of the Subcarboniferous of Europe includes species of Archoopteris, Sphenopteris, Lepidodendron (as L. Veltheimanum, L. squamosum); Knorria (K. imbricata, $K$. aciculanis); Bornia transitionis, Asterophyllites elegans, Stigmaria ficoides. The flora of the Middle and Lower coal is much like the American. The Upper coal contains Sigillariæ, but rarely a Lepidodendron; species of Calamites, Calamodendron, and Annularia are common, the Annularia becoming rare above; species also of Pecopteris, Callipteris, Neuropteris, and Odontopteris, are common, but not of Sphenopteris. Cordaites also is common. With these occur species of true Cycads, and of Walchia (W. piniformis), a Conifer.

Among the Diatoms observed by Castracani in the coal of England, the following 8 species are now living: Fragillaria Harrisoni Sm., Epithemia gibba Ehr., Sphenella glacialis Ktz., Gomphonema capitatum Ehr., Nitschea curvula Ktz., Cymbella Scotica Tm., Synedra vitrea Ktz., Diatoma vulgare Bory. 
Avimals. - Rhizopods are of many kinds. Fusulina cylindrica (Fig. 1069) occurs in the beds from the Subcarboniferous to the Permian in Europe and Asia; and $F$. Japonica is a species from Japan described by Gümbel. The Subcarboniferous limestone in northern England contains abundantly the arenaceous form, Saccammina Carteri Brady, occurring as groups of single isolated spheroids, or occasionally of strings of them, averag-

\section{$1127-1132$.}
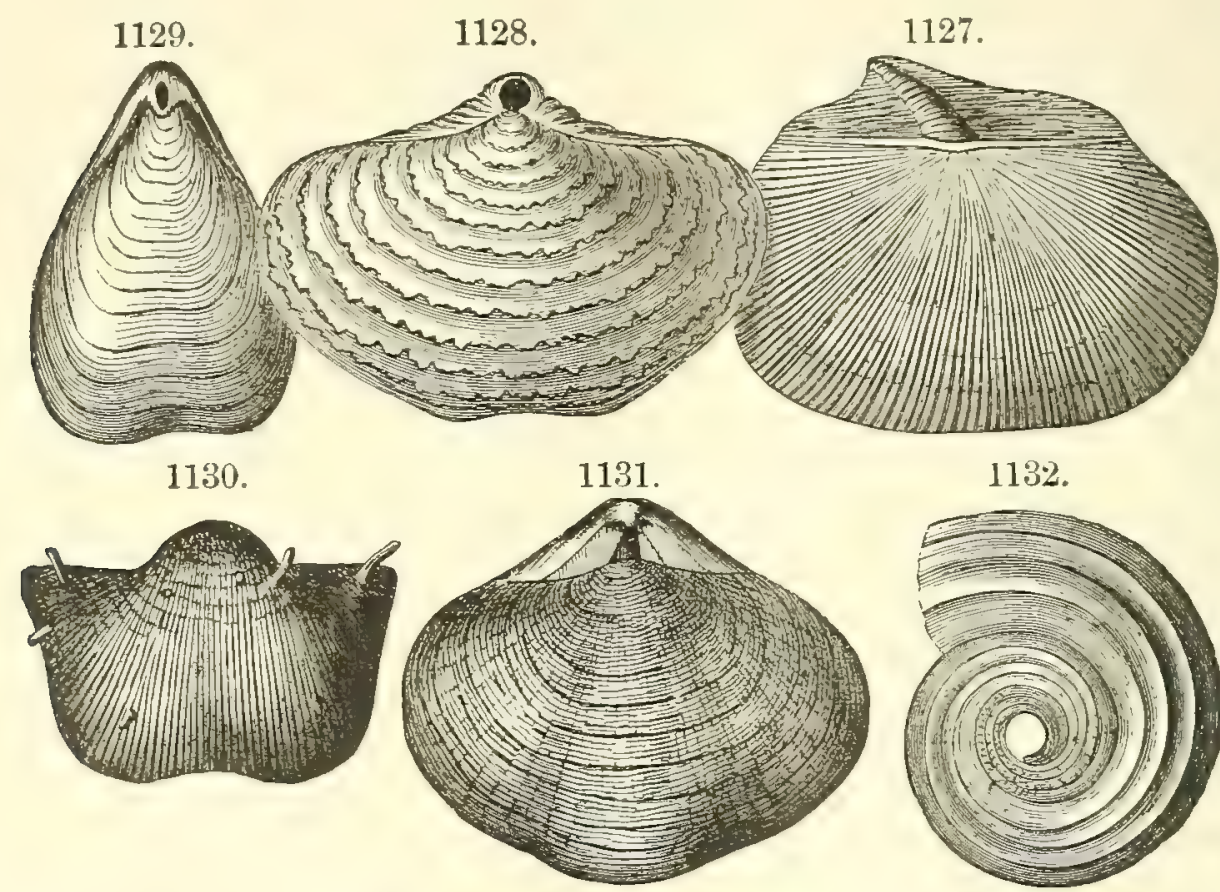

1132.

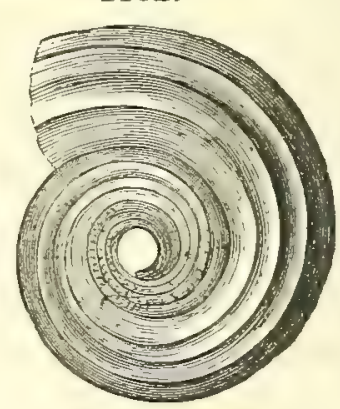

Braoniopods. - Fig. 1127, Orthothetes (Streptorhynchus) crenistria; 1128, Athyris lamellosa; 1129, Terebratula (Dielasma) hastata; 1130, Productus longispinus; 1131, Spirifer glaber; 1132, Nautilus (Trematodiscus) Konincki. Figs. 1127-1130, de Koninck; 1131, Davidson; 1132, D'Orbigny.

ing one eighth of an inch, though rarely one fifth of an inch, and making the rock to look as if oölitic. It is very abundant in the "four-fathom" lime-

1133.

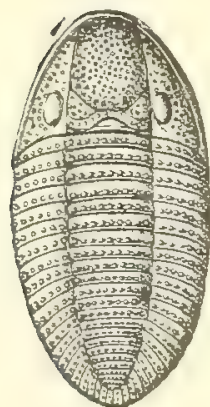

Phillipsia seminifera. De Koninck. stone of the English Subcarboniferous.

The Subcarboniferous limestone, like the American, is noted for its Crinoids; its many Brachiopods of the genera Productus, Chonetes, and Rhynchonella; its Corals of the genus Lithostrotion, Cyathophyllum, Zaphrentis, of which only the first is found in the Coal-measures; its many Gastropods of the genera Loxonema, Pleurotomaria, Euomphalus, Murchisonia, Bellerophon, Macrocheilus, etc.; its many Goniatites, Nautili, Orthocerata, and Discites; the limited variety of Trilobites; for Ganoids, Selachians, and Amphibians among Vertebrates.

Trilobites occur only of the three Carboniferous genera, Phillipsia, Griffthides, and Brachymetopus. A species of Phillipsia is represented in Fig. 1133, P. seminifera Morr. 
The Subcarboniferous beds of Great Britain have yielded 16 species, but the Coal-measures none.

The foreign Coal-measures have afforded also Eurypterids; Limulids, as species of Prestwichia, Fig. 1136, and Belinurus; Crustaceans, of the higher

1134.

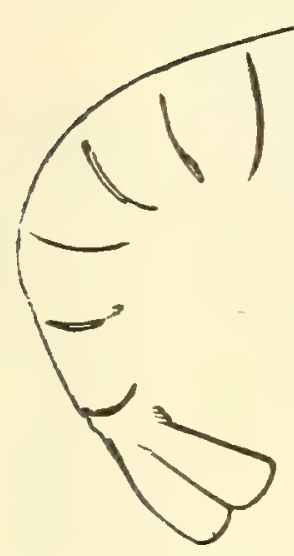

Anthracopalæmon Salteri. Salter. tribe of Macrurans, as Fig. 1134, Anthracopaloemon, Fig. 1135, Gampsonyx, from Saarbrück; Scorpions, one of which, from Bohemia, Cyclophthalmus senior of Corda, is shown in Fig. 1137 ; also Spiders of the genera Architarbus, Anthracomartus, Geralinura, etc.; Myriapods of the genera Euphoberia, Xylobius, Acantherpestes, Archiulus.

There were also Insects of many kinds. The Orthopteroids included Cockroaches, of the genera Etoblattina, Fig. 1139, Anthracoblattina, Gerablattina, and others; but few kinds compared with North

1135 .

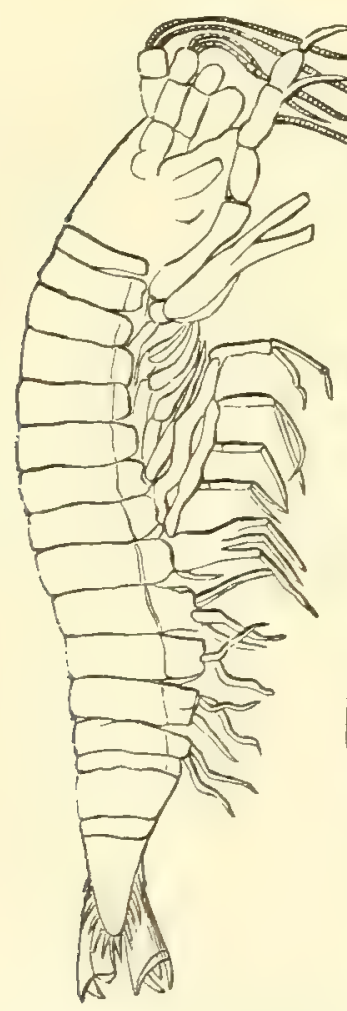

$1135-1139$.

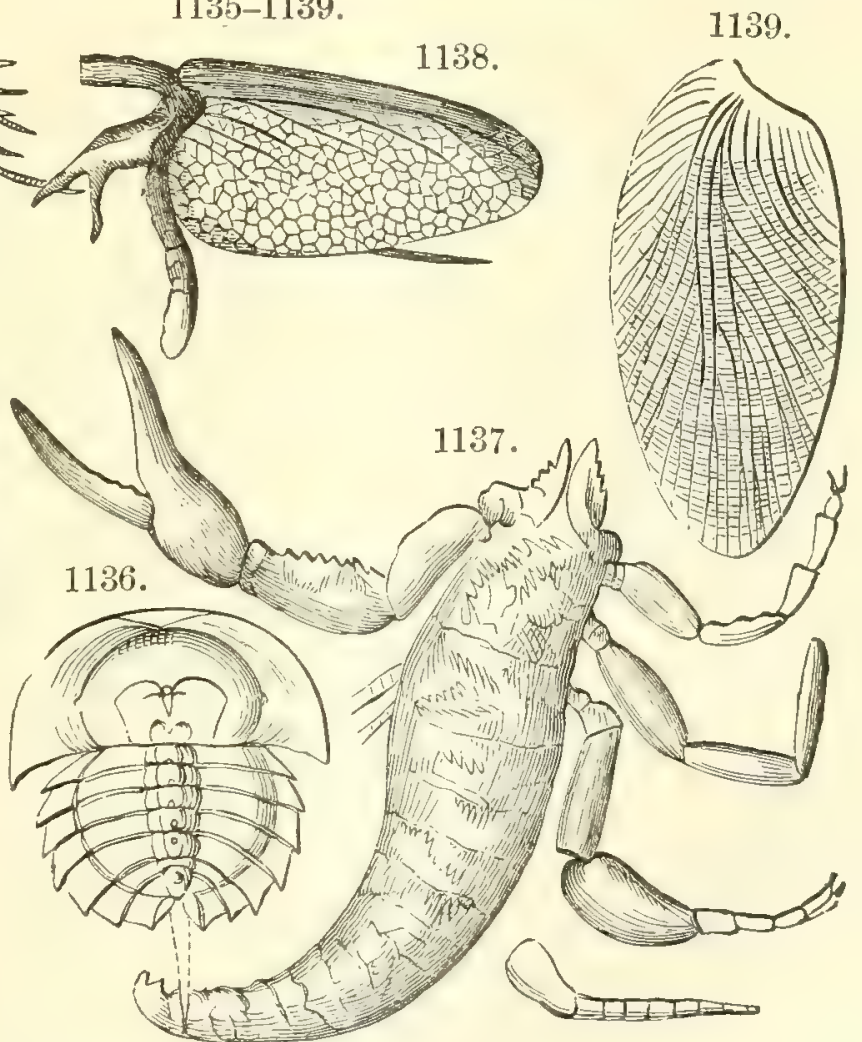

Crostacean. - Fig. 1135, Gampsonyx fimbriatus. Limulid, - Fig. 1136, Prestwichia rotundata $\left(\times \frac{1}{2}\right)$, ScorPION. - Fig. 1137, Cyclophthalmus senior. InsECTs. - Fig. 1138, Dictyoneura anthracophila ; 1139, Etoblattina primæva. Figs. 1135, 1137, 1138, Brown; 1136, Murchison; 1139, Vogt.

America; Protophasmids (or species related to the modern "Leaf-insects" and "Walking-sticks") of several genera, as Titanophasma Fayoli of Brong- 
niart, represented in Fig. 1140, only $\frac{1}{4}$ the natural size, (which has, as Brongniart states, the wings of a Neuropter with many characteristics of an Orthopter,) Dictyoneura anthracophila, Fig. 1138; D. Monyi, having wings a foot long, Archceoptilus ingens Scudder, of the British Coal-measures, having a spread of wing of about 14 inches ; also forerunners of the "Dragon-flies," one of them having a spread of wing much exceeding two feet. Among the

1140.

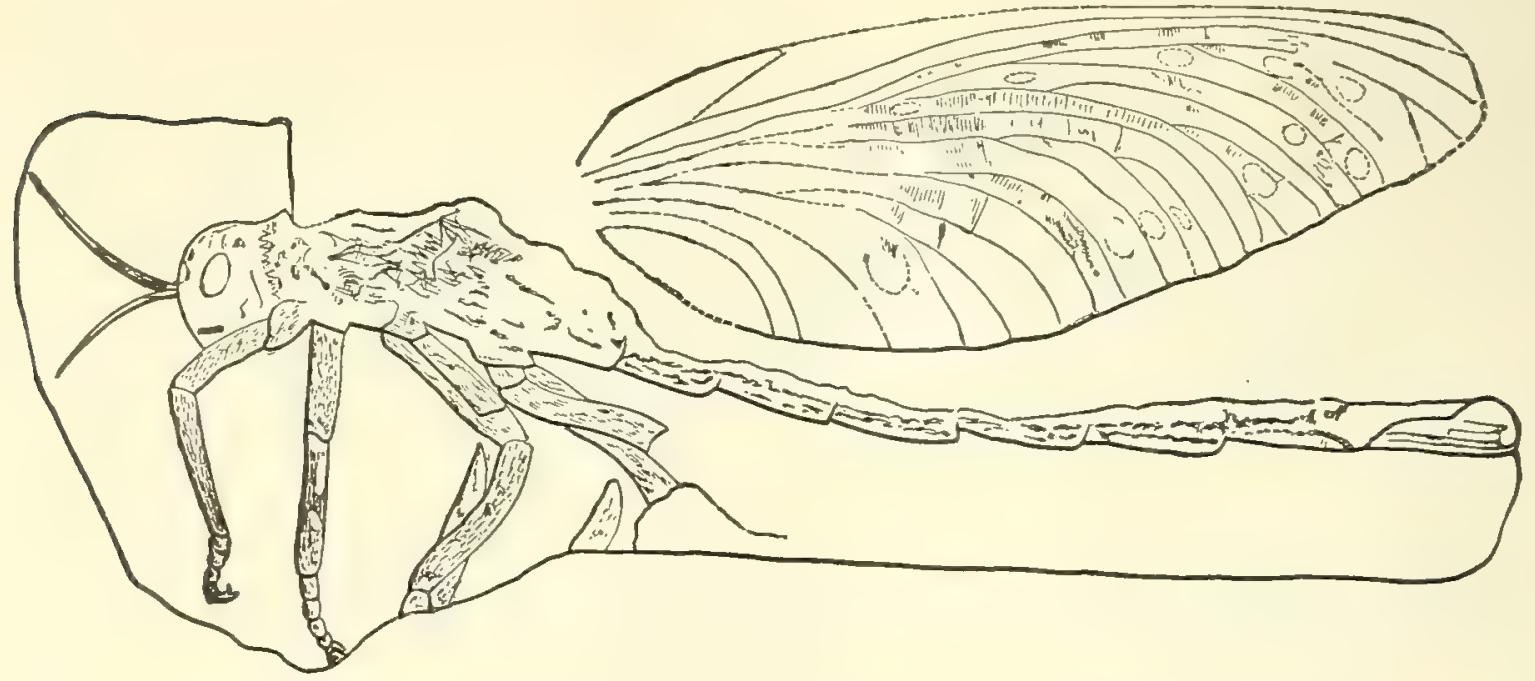

Orthopter. - Titanophasma Fayoli $\left(\times \frac{1}{4}\right)$, with the outline in part of the rock. Brongniart.

Neurnpteroids, the Lithomantis carbonaria of Scotland was probably nearly six inches in spread of wing. Moreover, Beetles, or Coleopteroids, have been reported from the Coal-measures of Silesia, and Hemipters from several localities. There were also the inferior wingless species, the Thysanura (common existing genera of which are Lepisma or Silver-moth, and Podura).

The gigantic Titanophasma Fayoli, Dictyoneura Monyi, and the forerunner of the Dragon-flies, as well as the small Thysanurce, were from the Coal-measures of Commentry, in central France, a locality that has afforded C. Brongniart for deseription a wonderful variety and number of species.

Remains of Subcarboniferous Fishes are common in Europe and Britain; the British Islands alone have afforded 150 species. Among them are Coch-

1141.

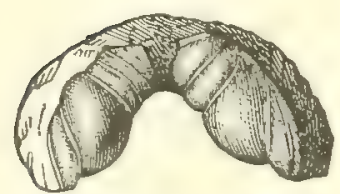

Cochliodus contortus $\left(\times \frac{1}{3}\right)$.

liodus contortus Ag., Fig. 1141; Cladodus marginatus Ag.; Ctenacanthus major, Fig. 1142, one broken specimen of which is $14 \frac{1}{2}$ inches long. Another broken spine, described by Agassiz, Oracanthus Milleri, is $9 \frac{1}{2}$ inches long and 3 inches wide at base.

Fig. 1143 represents a restoration of the Pleuracanthus (=Diplodus Ag.) Gaudryi of Brongniart, from the Carboniferous rocks of France - a Shark having a terminal mouth.

The Fishes of the Coal-measures include Selachians also of the genera Ctenodus, Ctenoptychius, Helodus, Cladodus, Orodus, etc., which are also mostly Subcarboniferous. The most common Coal-measure genera of Ganoids are Pulceoniscus, Amblypterus, Holoptychius, and Megalichthys. 
The Amphibians have nearly the same range of characters as the American. There are Loxomma Allmanni Hux., from Edinburgh, the skull 10 inches wide and 14 inches long, and the teeth with cutting edges; Anthracosaurus

1142.

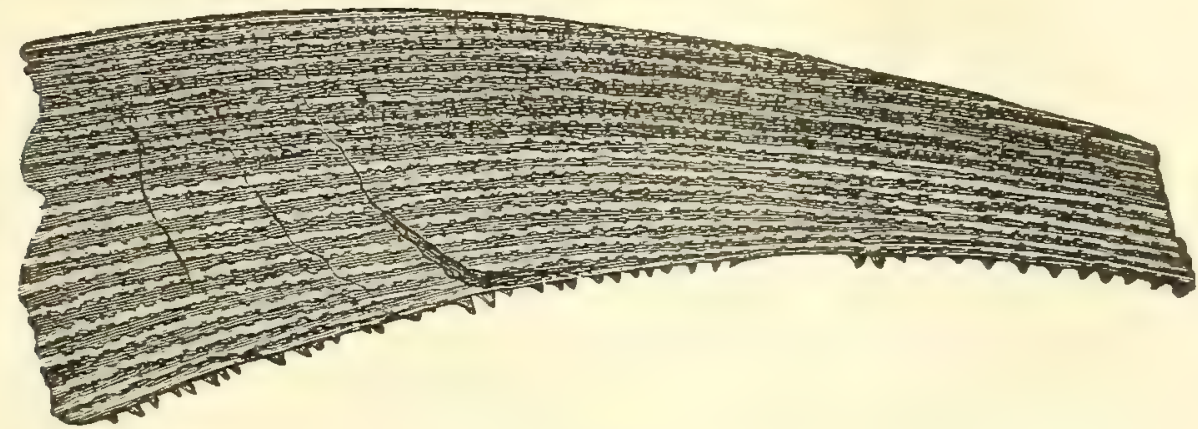

1143.

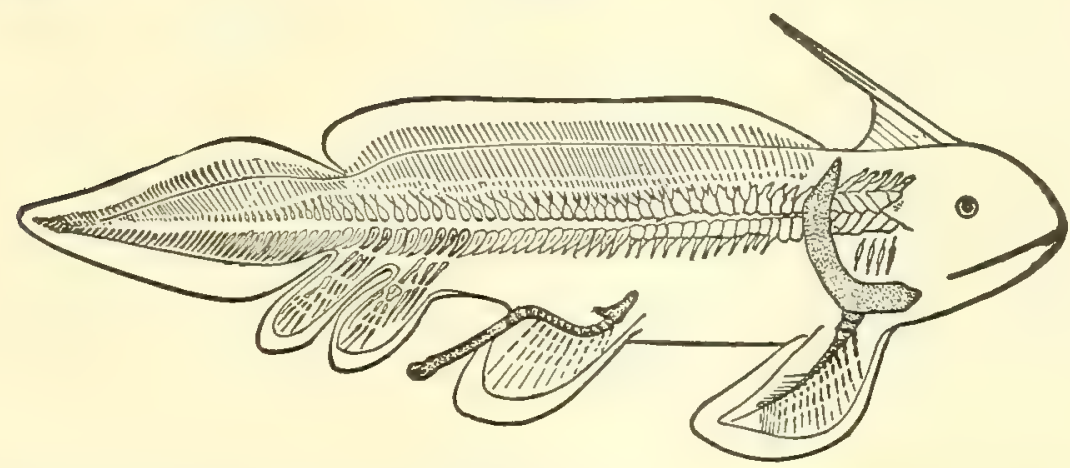

Fig. 1142, part of a spine of Ctenacanthus major Ag.; 1143, restoration of Pleuracanthus Gaudryi ( $\left.\times \frac{1}{12}\right)$, Brongniart.

Russelli Hux., Lanarkshire; Parabatrachus Colei Owen, British Coal-measures; Anthracerpeton crassosteum Owen, Glamorganshire; Archegosaurus

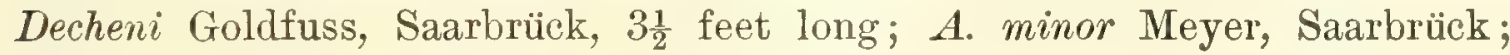
besides various snake-like and other species.

1. Brachiopods. - Some of the characteristic species, besides those figured, are: Productus scabriculus Sow.; Spirifer speciosus Br., S. cuspidatus Sow., S. disjunctus Sow.; Chonetes Dalmanianus Kon. ; Orthis Michelini Morr.

2. Limulids. - Fig. 1136, Prestwichia rotundata Woodw., Coalbrook Dale; P. anthrax Woodw., Coalbrook Dale; Belinurus trilobitoides Woodw., Ireland, Coalbrook Dale; $B$. Regince Baily, Ireland; B. arcuatus Baily, Ireland.

3. Crustaceans. - Fig. 1135, Gampsonyx fimbriatus Jordan, a Schizopod; 1134, Anthracopalcemon Salteri, Lanarkshire, A. dubius S., Coalbrook Dale, A. Grossarti S. Lanarkshire; the broad flattened thorax indicates a nearer relation to Eglea and Galathea than to Palomon. Pygocephalus Couperi Hux., a Schizopod, Manchester, England.

4. Myriapods. - Euphoberia Brownii Woodw., Glasgow, E. anthrax Woodw., Coalbrook Dale, Xylobius sigillarice Dn., Glasgow and Huddersfield.

5. Arachnids. - Fig. 1137, Cyclophthalmus senior Corda, Chomle, Bohemia; Eophrynus Prestwichii Buckl., Dudley; Geralinura Bohemica Kusta; Architarbus subovalis Woodw., Lancashire, very near the Illinois species (page 691); Protolycosa anthracophila R., Silesia; Anthracomartus Völkelianus Kranch, Silesia. 
6. Insects. - Dictyoneura anthracophila Goldb., from Saarbrück; D. Humboldtiana Goldb., ib. ; Polioptenus elegans Goldb., ib. ; Etoblattina primceva Goldb., ib. ; Gryllacris lithanthraca Goldb. (Locust), ib.; Corydalis Brongniarti Mant., Coalbrook Dale.

7. Amphibians. - The Amphibians included Apateon pedestris H. v. Meyer, Münsterappel ; Urocordylus Wandesfordii Hux., Kilkenny, the tail with 75 vertebræ; Ophiderpeton Brownriggii Hux., Kilkenny, limbless, snake-like and $3^{\prime}$ long; Dolichosoma longissimum Fritsch, from Ireland, probably about $3^{\prime}$ long and much like the whip-snake; species of Dendrophis, and of other genera.

The following foreign Coal-measure Brachiopods occur also in the American beds: Athyris subtilita, Spirifer lineatus Martin, Productus longispinus Sow., P. latissimus Sow., $P$. punctatus Martin, $P$. scabriculus Martin, $P$. costatus Sow., Orthothetes (Streptorhynchus) umbraculus v. Buch, Devonian to Permian.

The Arctic Spitzbergen Coal-measure plants include species of Lepidodendron, Stigmaria, Sphenophyllum, Asterophyllites, Sphenopteris, Cordaites; and the Subcarboniferous of Bear Island ( $30 \mathrm{~m}$. south), the Europcan species Calamites radiatus, Lepidodendron Veltheimanum, Knorria imbricata, $\boldsymbol{K}$. acicularis, Cyclostigma Kiltorkense, Paloopteris (Archaopteris) Ræmeriana, Sphenopteris Schimperi, Cardiopteris frondosa, C. polymorpha, etc., made a basis by Heer for his Ursa stage, but supposed by Dawson to include some Devonian species. The beds of Spitzbergen contain the Permian species, Productus horridus, specimens twice the size of those of the European Permian, P. Cancrini Vern., P. Leplayi Vern., Camarophoria Humbletonensis Howse, Strophalosia lamellosa Gein.; Carboniferous species of Euomphalus, Cyathophyllum, Syringopora, Chetetes; and the Subcarboniferous includes a Cyathophyllum limestone in which there are 4 species of Corals, 2 of Crinoids, and Spirifer incrassatus, Terebratula fusiformis, and other Russian Brachiopods.

\section{LIFE OF THE PERMIAN PERIOD.}

Plants. - The Permian plants include no Lepidodendrids, a few Sigillarids; Ferns of the genera Neuropteris, Sphenopteris, Pecopteris, Alethopteris, Toniopteris, Sagenopteris, Glossopteris, and others ; also Calamites, Annularia, Asterophyllites; Cycads and Conifers. The Conifers included species of Dadoxylon, Pinites, Ullmannia, etc. The genus Walchia, Fig. 1147, Walchia piniformis Sternberg, characterized by lax and short spreading leaves, began near the close of the Carboniferous period, but is most numerous in species during the Permian. Tree-ferns of the genus Psaronius were common, as in the Upper Coal-measures.

Fig. 1144 is the pinnule or branchlet of a frond of Neuropteris Loschii, a species common to the Permian and Coal-measures; 1145, showing the venation. Fig. 1146, Annularia carinata Sternberg; in 1146, only the first joint and its whorl are shown, of natural size; in $1146 a$, a branch is shown (of reduced size), consisting of its several joints and whorls, but the natural termination is wanting. The figures are from the work of Geinitz and Gutbier on the "Dyas" of Saxony.

The American Permian species that are common to the Permian formation of Europe, according to Fontaine and White, Pennsylvania Report (1880), are, for the several genera, as follows: Equisetites rugosus, Calamites Suckovi, Sphenophyllum longifolium, Annularia carinata, A. longifolia, A. sphenophylloides, A. radiata, A. minuta, Neuropteris flexuosa, $N$. auriculata, $N$. cordata, Odontopteris obtusiloba, Callipteris conferta; Pecopteris ar- 
borescens, $P$. Candolleana, $P$. oreopteridia, $P$. pennoformis, $P$. latifolia, $P$. Miltoni, $P$. dentata, P. pteroides, P. Pluckeneti, P. Germari, Goniopteris emarginata, G. elegans, Alethopteris gigas; Rhacophyllum filiciforme, R. lactuca, Sigillaria Brardii. In addition, Taniopteris Lescuriana is near $T$. multinervis, $T$. Newberryiana near T. vittata; Caulopteris elliptica is allied to $C$. peltigera, $C$. gigantea to $C$. microdiscus, and Baiera Tirginiana to $B$. digitata.

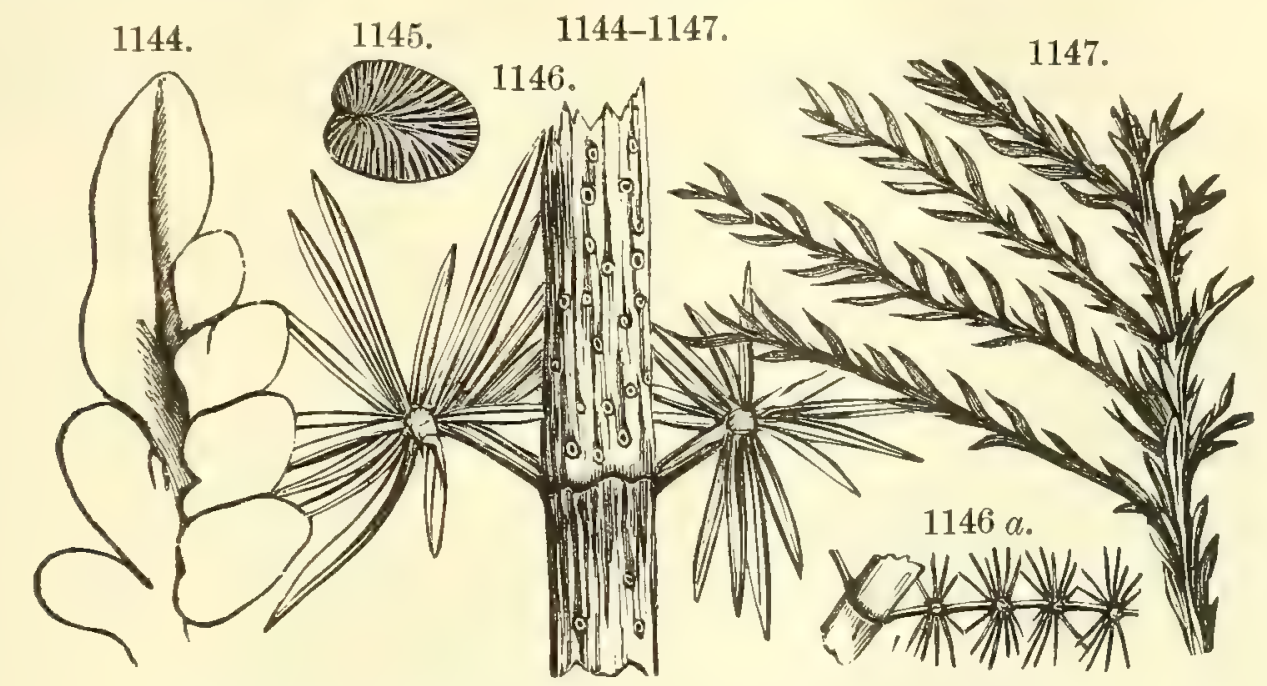

Figs. 1144, 1145, Neuropteris Loschii ; 1146, $1146 a$, Annularia carinata ; 1147, Walchia piniformis. All Geinitz.

Avimals. - Corals of the Cyathophyllum family, Brachiopods of the genera Productus, Spirifer, and Orthis, Pteropods of the genus Conularia, Cephalopods of the genus Orthoceras, and Ganoid fishes with vertebrated tails, give a Paleozoic character to the Fauna. But there are many new tribes: among these, the most prominent is that of Reptiles.

This transition character is apparent also in the number of old animal types as well as vegetable that here nearly or quite fade out, - for it is the period of the last of the species of Productus, Orthis, Murchisonia; nearly the last of the extensive tribe of Cyathophylloid Corals, which made coral reefs of far greater extent than those of modern seas; nearly the last of the extreme vertebrate-tailed (heterocercal) Ganoids.

1148.

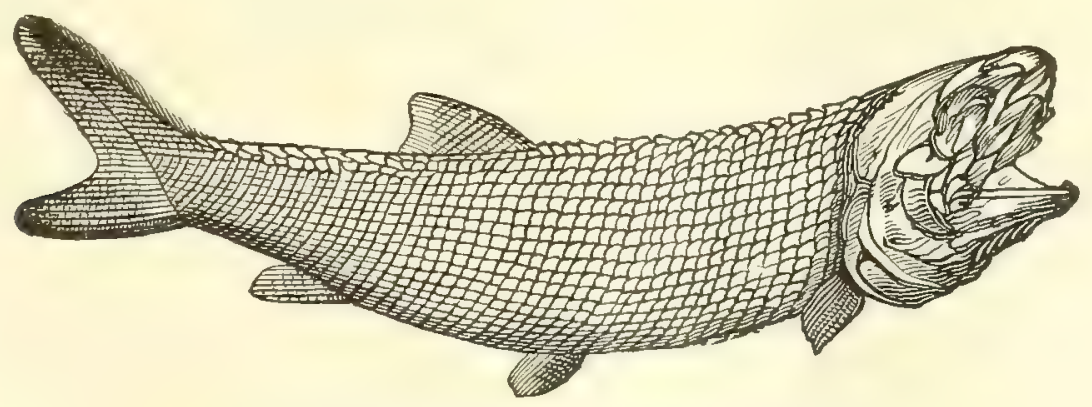

Palæoniscus Freieslebeni $\left(\times \frac{1}{3}\right)$. Murchison.

1. Fishes. - Ganoids occur of the genera Puloeoniscus, Fig. 1148; Platysomus, Acrolepis, Pygopterus, Colacanthus; genera that are also Carboniferous. The figure illustrates the heterocercal feature of the species. There were also Cochliodont and Petalodont Sharks. 
2. Amphibians. - A species of Dasyceps, D. Bucklandi, occurs at Durham, England, and others of Branchiosaurus, Hylonomus, Ophiderpeton, etc., in European beds.

3. Reptiles. - The Reptiles of the foreign Permian, like those of America, are in part Rhynchocephalians. The earliest genus, Palcohatteria of Credner (1888) is from the Middle Permian (Rothliegende) of Saxony. A skull from one of Credner's figures is shown in Fig. 1150. The palatine bone has

1149.

1149-1152.

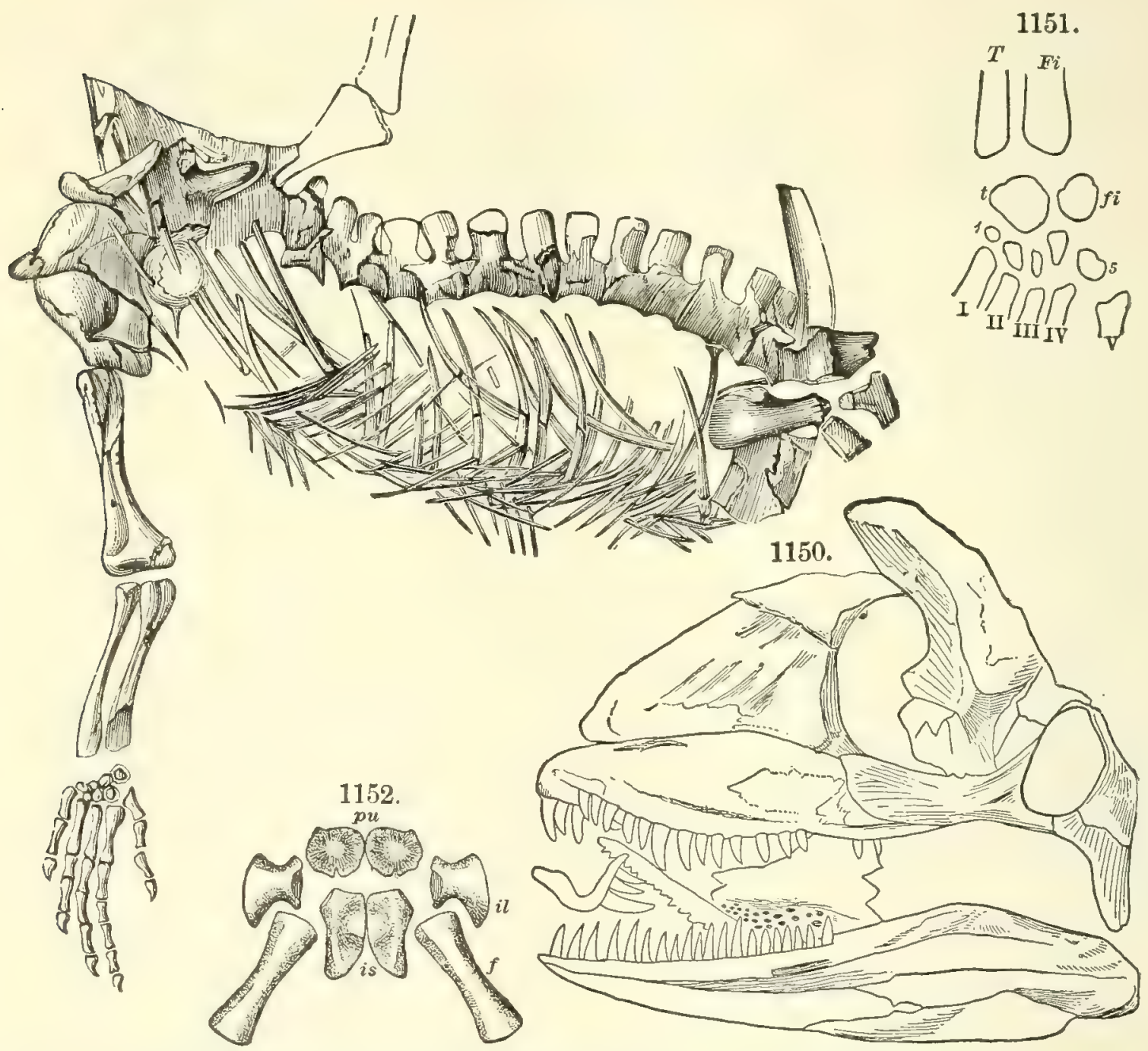

RePtiles. - Fig. 1149, Proterosaurus Speneri; 1150, Palæohatteria longicaudata; 1151, ankle bones ( $t$, astragalus, $f$, calcaneum, I to $\mathrm{V}$, metatarsals, with $\mathrm{T}$, tibia, and $\mathrm{Fi}$, fibula); 1152 , pelvic bones ( $p u$, pubis ; $i l$, ilium ; is, ischium; with $f$, femur). Fig. 1149, von Meyer; 1150-1152, Credner, '88.

teeth, and also the vomer, as common in Amphibians. The close relations to the New Zealand Hatteria are pointod out by Credner. The beak-like form of the anterior part of the head, to which the name Rhynchocephalian refers, is absent in this early species of the group. Proterosaurus (Fig. 1149) is a related but more lizard-like form from the Upper Permian of Thuringia. With the Palæohatteria occurs also (Credner, 1889) a related Reptile, the Cadatiosaurus. Like Mesosaurus (Stereosternum), these Permian Reptiles 
represent the most generalized type of Reptiles, the five tarsal bones of the Palæohatteria ( 1 to 5 ) with which the five metatarsals (I, II, III, IV, V) Tere articulated are shown in Fig. 1151, in which T, Fi are parts of the tibia and fibula.

Other Reptiles are the Anomodonts and Theromores. The former have large tusks in the jaws, and no other teeth; they include the genus Dicynodon of Owen, which has species in the Permian Beaufort beds of South Africa, and also in the overlying Triassic beds.

1. Echinoderms.-Crinoids near Cyathocrinus; Echinoderms of the genus Archaocidaris.

2. Molluscoids. Brachiopods. - Spirifer alatus Schloth., England, Lower Zechstein in Saxony - some specimens $2 \frac{1}{2}$ inches broad ; Spiriferina cristata Dav., Zechstein, Germany; Productus horridus Sow., England, Germany, characteristic particularly of the Lower Zechstein, and occuring also in the Kupferschiefer ; Strophalosia excavata Gein., England, Germany, S. Goldfussi, ibid.; the species of the genera Productus and Strophalosia are exceedingly abundant in individuals; Camarophoria Schlotheimi von Buch, Russia, Germany, England; C. superstes, Russia.

3. Mollusks. (a) Lamellibranchs. - Pseudomonotis speluncaria Beyr., England, Russia, Germany, in the Lower Zechstein; Clidophorus Pullasi Gein., Russia, Germany ; Myalina squamosa Sedg., Russia, England ; Avicula Kazanensis Vern., Russia; Bakewellia antiqua King, England, Russia, Germany; Schizodus dubius M., common in England, Germany, Russia; S. Schlotheimi Gein., S. obscurus Sow., and S. truncatus King. The genus Schizodus is of the same family with Trigonia, a characteristic genus in the Reptilian age; it commenced in the Devonian and ends with the Permian.

(b) Gastropods are rare fossils in the Permian. There are a few species of Murchisonia, Pleurotomaria, and Straparollus, Paleozoic genera, and of Dentalium, Natica, Turbo, etc.

(c) Pteropods occur of the genera Theca and Conularia.

(d) Cephalopods existed, and among them two or three species of Orthoceras and Nautilus.

4. Crustaceans. - No Trilobites are known. Ostracoids are common. Under Tetradecapods, the Amphipod, Prosoponiscus problematicus Schloth., Durham, England. Under Decapods, besides Macrurans, there is reported a Crab or Brachyuran, from the Permian, by von Schauroth, who named it Hemitrochiscus paradoxus. It is $\frac{1}{8}$ of an inch long. Whether a true Crab or not is doubtful.

5. Vertebrates. Fishes. - Palceoniscus Freieslebeni Agassiz is common in the Kupferschiefer, and is found also in the Coal-measures in England, at Ardwick. Other species are: Palconiscus elegans Sedgw., P. comptus Ag., Platysomus macrurus Ag., Pl. gibbosus Bl., Acrolepis Sedyuickii Ag., Pygopterus mandibularis Ag., Coelacanthus granulatus Ag., etc. Janassa bituminosa Münst. and Wodnika striatula Münst. are species of Cestraciont sharks from the Kupferschiefer.

The Paleozoic character of the life of the Permian, as already shown, is strongly marked. Geinitz observes, further, that the Terebratula (Dielasma) elongata Schloth. of the Zechstein approaches a Devonian form; Camarophoria Schlotheimi Kg. (Zechstein) is near the Carboniferous C. crumena Mart.; Spirifer Clannyanus Dav. (Zechstein), near the Carboniferous S. Urii; Spiriferina cristata, near the Carboniferous S. octoplicata. The genus Schizodus ends with the Permian, as well as Orthis, Camarophoria, Productus, and Strophalosia. 


\section{GEOLOGICAL AND GEOGRAPHICAL CHANGES DURING THE PROGRESS OF THE COAL-MEASURES.}

The beds of the Coal-measures vary in kind of rock between shales, sandstones, conglomerates, and limestones, clay beds, iron ore beds, and coal-beds; and differ in conditions of origin, between those of salt water, brackish water, and fresh water. Moreover, the beds bear evidence of the changes in water level that took place during the progress of the long series. In the various regions, the clayey beds beneath the coal evince that they were usually of marsh or fresh-water origin, like the coal-beds, by the absence of marine relics, and the presence of roots and sometimes of stumps of the trees that grew in the clay as their soil.

In Nova Scotia, where deposits were made during the era to a thickness of 13,000 feet, the beds of the Subcarboniferous are partly marine, kut the Coal-measures and Permian are mainly of brackish or fresh-water origin; for only one bed has been found to contain marine fossils. This region was a wide basin in the Acadian trough, at the mouth of the St. Lawrence River. Specimens of the Pupa or land-snail, described by Dawson (page 676), occur in an under-clay more than 1200 feet below the level of the stump in which the species was first discovered; and in this interval there are 21 coal-seams, showing, as Dawson observes, that the species existed during the growth and burial of at least 21 forests.

The oscillations in water level, indicated by the alternations in the deposits, were slow in progress; movement by the few inches a century accords best with the facts. When under verdure, the surface must have lain for a long period almost without motion; for only a very small change of level would have let in salt water to extinguish the life of the forests and jungles, or have so raised the land as to dry up its lakes and marshes. Hence the grand feature of the period was its prolonged eras of quiet, with the land little above the sea limit. Again, for the making of shales or sandstones, the continent may have rested long near the water's surface, just swept by the wares and currents, subsiding with extreme slowness, so as to make thick deposits without letting in the sea. It may have been long a region of barren marshes, and, in this condition, have received its iron-ore deposits, as now marshes become occupied by bog-ores. It must have been long in somewhat deeper waters, and covered with a luxuriance of marine life, in order to have received its beds of limestone holding marine fossils. Again the land slowly emerged from the waters, and the old vegetation spread rapidly across the great plains, commencing a new era of coal-making vegetable debris; or the escape was only partial, and coal-plants took possession of one part, and made limited coal-deposits, while the sea still held the rest beneath it. Uniformity in oscillations of level, through so great an area, is not probable; and therefore the former continuity of a single coal-bed through the East and West requires strong proof to be admitted.

Such alternations of verdure and rock depositions occurred also during 
the Subcarboniferous and the epoch of the Millstone grit; and they were continued even after the Carboniferous, during the Permian.

These submergences, although quietly carried forward, played havoc with the leaves, trunks, and stumps, floating them away for burial by the in-washed sediments. Some of the transported stumps may occasionally have had aboard large stones which they finally dropped, thus putting an occasional "bowlder" into the forming beds. The encroaching waters at times flowed with great force and plunging waves, as is shown not only by the formation of coarse gravel beds (now conglomerates), but also by the erosion of the rock deposits, and in some cases of the beds of vegetable debris. In Vermilion County, Ill., as observed by F. H. Bradley, a portion of the Upper Coal-measures, including shales, argillaceous limestones, and two coal-beds, were carried away to a depth of 60 feet; and, in the depression thus made, a sandstone, which belongs at the top of the series, was laid down so as to fill and overlie it. Also, on the same authority, in Vermilion County, Ind. (adjoining the county just mentioned), the Millstone grit (here a pebbly sandstone), under the (oal-measures, is cut off short and followed horizontally by shale and limestone; as if the grit stood as a bluff in the waters, in which the latter rocks were deposited. Other evidences of erosion have been described from these states, and also from Ohio, Kentucky, and Missouri. The change of level over Iowa, Illinois, and Missouri, which permitted the Coal-measures to spread northward beyond the limits of the Chester limestone, the last of the Subcarboniferous beds, and even beyond the Kinderhook beds, was of the same nature with the oscillations above referred to. No unconformity with the Subcarboniferous was produced except that of overlap. The little value, as regards time divisions in geological history, of unconformity by overlap or erosion is well illustrated by the facts here stated.

The coal-beds are thin compared with the associated rocks. But the time of their accumulation, or the length of all the periods of verdure together, may have far exceeded the time occupied in the accumulation of sands and limestones. If there were but 100 feet of coal in all, it would correspond to more than 500 feet in depth of vegetable debris. The sands and clays which came in after each time of verdure put under heavy cover the thick bed of vegetable debris which had accumulated, and thus the decomposition of the plants and the change to coal took place, under the best of conditions for coal-making. In some regions the coal-plants may have been drifted to their places of deposit; but this was not the usual way in North America.

The great marsh from which proceeded the Pittsburg coal-bed of the Upper Productive Measures, according to J. J. Stevenson, was the "parent marsh" also of the coal-beds above it in the series, times of temporary burial being indicated by the intervening beds of shale and sandstone during the progress of a very slow and intermittent subsidence.

A coal-bed itself bears evidence of alternations of condition in its own lamination, and even in the alternations in its shades of color. A layer one 
eighth of an inch thick corresponds to an inch, at least, of the accumulating vegetable remains; and hence the regularity and delicacy of the structure are not surprising. Alternations are a consequence of (1) the periodicity in the growth of plants and the shedding of leaves; (2) the periodicity of the seasons, the alternations of the season of floods with the season of low waters or comparative dryness; (3) the occurrence, at intervals of several years, of excessive floods. Floods may bring in more or less detritus, besides influencing the fall and distribution of the regetation. There may have been great variations in the length of time before the peat-like vegetation after its formation was put under the pressure of beds of clay or sand; and the precise quality of the coal would be varied thereby, the decomposition of the vegetation depending on the amount of water, the composition of that water, and the length of time exposed.

In some parts of the marshes there were pools or lakes where the vegetation was long steeping and so becoming reduced to a pulp, to the obliteration of all bedding; and in such places, according to Newberry, cannel coal was often formed; for it usually constitutes locally the lower parts of a coalbed, though sometimes making the whole thickness. And, as such ponds or lakes were likely to have their living species, so a bed of cannel coal often contains remains of fossil Fishes, Eurypterids, Crustaceans, and other species. The Eurypterus in its bed of Ferns figured on page 677 was obtained from a locality of cannel coal.

In conclusion, the Coal period was a time of unceasing change, - eras of verdure alternating with others of wide-spread waters, destructive of all the vegetation and of other terrestrial life except that which covered regions beyond the Coal-measure limits. Yet it was an era in which the changes went forward for the most part with such extreme slowness, and with such prevailing quiet, that, if man had been living then, he would not have suspected their progress.

In Europe the conditions were similar, in the main, to those of America. The succession of Carboniferous rocks and coal in the British Isles exceeds much in thickness that in any part of Europe, very much as that of Nova Scotia exceeds that of Pennsylvania and the states west. The greater thickness of the formations (if not of the coal-beds), supposing the peat-making conditions to exist, has probably depended in each region on the extent of the slowly progressing subsidence or geosyncline. The longer continued and deeper subsidence in Nova Scotia favored greater thickness than in Pennsylvania; and the amount of subsidence in Pennsylvania determined greater thickness in that state than in Illinois. So it was also in the British Isles as compared with Europe. Far west of the Mississippi in North America the general submergence of the surface put a Carboniferous limestone over the region instead of profitable Coal-measures; and far east in Europe, Russia has her barren coal-strata of vast extent, on both sides of the Urals.

For the making of extensive Coal-measures a nice balancing of the land surface between submergences and emergences was a requisite. With a very 
little too much emergence, even if only a few hundred feet, there would have been no marshes in North America; for the land would have been drained. And with a little too much submergence, limestones or barren sediments of sand or gravel would have covered the region. North America was admirably arranged and poised for the grand result. South America probably lay a little too low, and vast plains, although situated just like those of North America, were left barren. Europe was not so well off as North America, because of the less extent of the level land surface, and the consequently less equable system of oscillations. Moreover, the lands of North America were on the wet border of the Atlantic, the western; and those of Europe, as at the present time, on the dry border, the two differing now a fourth in amount of precipitation.

\section{METEOROLOGICAL CONDITIONS OF THE CARBONIC ERA.}

1. Temperature of the air and waters.-- Using the facts from the rela. tions of existing plants to climate, - that Ferns and Lycopods thrive best in tropical and temperate latitudes, and Equiseta in temperate, - it is inferred from the occurrence of coal-plants of each of these groups in all latitudes to the Arctic regions that the climate of the globe in the Carbonic era was nowhere colder than the modern temperate zone, or below a mean temperature of $60^{\circ} \mathrm{F}$. Similarly, the occurrence in Spitzbergen of Corals of the genera Lithostrotion, Cyathophyllum, and Syringopora, and of some species of Brachiopods of twice the size they have in Europe, seems to show that the waters of the ocean were equally temperate throughout. As to excessive heat in the tropics, we have no evidence, since the common Carboniferous Brachiopods, Productus semireticulatus, P. Iongispinus, Athyris subtilita, and a Bellerophon near $B$. Urii are found in the Bolivian Andes.

2. Hygrometric conditions. - With the atmosphere so genial and the ocean so warm, evaporation would have been excessive, rains abundant, and mists almost perpetual. Over the land on the favored side of the ocean, from the tropics to the higher temperate latitudes, atmospheric moisture would have reached its maximum. The great tropical Atlantic current - a part of the world's machinery from the beginning of oceans and continents - would have given moisture freely to the British Isles, more so than to Europe, and more to Spitzbergen than to Greeniand and the western Arctic lands. Moreover, Lycopods, Equiseta and most Ferns like shady as well as moist places.

3. Influence of the carbonic acid and moisture of the atmosphere. - If the amount of carbonic acid used up in the making of Subcarboniferous and later limestones, and of coal and other carbonaceous products stored in the rocks of the Carbonic era, could be ascertained, the amount of carbonic acid abstracted from the atmosphere by the rock-making and coal-making of the era would be known. In view of the facts it is safe to say that the amount of carbonic acid in the atmosphere at the beginning of the era was at the least 3 in 1000 parts instead of 3 in 10,000, as it is now.

(See page 485.) 
The presence of this large percentage of carbonic acid and moisture would have given the atmosphere a correspondingly greater power of absorbing non-luminous heat, or that radiated by the warmed earth, and it therefore accounts for the uniformity in the earth's climate.

With conditions in the climate and atmosphere so favorable, the plants would have been rapid in growth, in covering emerged lands with jungles and forests, and in supplying vegetable debris for the thickening peat-beds. Although the era was one of more clouds than sunshine, growth must have been, if possible, more exuberant than it is now in tropical America.

The conditions were also favorable for decay. Old stumps of Lepidodendrids and Sigillarids, poor in wood, decayed within as they stood in the swamps, while the debris of the growing vegetation, or, in some cases, the detritus borne by the waters, accumulated around them; so that their hollow interiors received sands, or leaves, or bones, or became the haunts of reptiles, as was their chance.

\section{FORMATION OF COAL FROM THE BEDS OF VEGETABLE DEBRIS.}

The formation of coal out of the beds of vegetable debris probably only made a beginning while these beds lay as open beds of peat. The process is carried forward imperfectly in the modern peat-bed, and the best result is a poor coal, as it contains 25 per cent or more of oxygen. The deposits of clay or sand over the peat accumulations of the Carbonic era prevented the atmospheric oxygen from participating in the change, and to this is due the better product. The making of coal from wood has been explained on page 124, under Chemical Geology. The resulting mineral coal consists (1) chiefly of carbon; but (2) anthracite contains usually 2 to 5 per cent of oxygen and hydrogen, and the bituminous coals often 12 per cent in weight of oxygen and 4 to 6 of hydrogen; while brown coal, the bituminous coal of later formations (which ordinarily gives a brownish-black powder), contains 20 per cent or more of oxygen with 5 or 6 of hydrogen.

Mineral coal, therefore, is not carbon, but a compound, or a mixture of two or more compounds, of carbon, hydrogen and oxygen, associated probably with some free carbon in anthracite, and possibly in some or all bituminous coal. In this view, coals are mainly oxidized hydrocarbons, or mixtures of them. They are feebly acted on by ether or benzine, if at all, and hence contain little or no mineral oil, or only a trace of any soluble hydrocarbon; but, at a high temperature, hydrocarbons (compounds of hydrogen and carbon) are given out, and often very abundantly, in the form of either mineral oil, tar, or gas.

The process of the conversion of woody material into coal is briefly described on the page referred to. The vegetable material from which coal is made may be $(a)$ woody fiber; (b) cellular tissue; $(c)$ bark; $(d)$ spores of Lycopods (Lepidodendrids, etc.); (e) resins and associated substances. The following is the composition of (1) dried wood in the mass; (2) cork (the 
bark of Quercus suber); (3) the spores of Lycopods; $(4,5,6)$ the common kinds of mineral coal; and (7) peat or vegetable material, partly altered to the coal-like condition.

I. Woody ingredients Carbon

1. Wood........................ $49 \cdot 66$

2. Cork........................65. 65 73

3. Lycopod spores................. 64:80

II. Coal products
4. Anthracite.................... 95:0
5. Bituminous coal................. $81 \cdot 2$
6. Brown coal....................68.7
7. Peat .......................... 59.5

$\begin{array}{rrr}2 \cdot 5 & 2 \cdot 5 & \\ 5 \cdot 5 & 12 \cdot 5 & 0.8 \\ 5 \cdot 5 & 25 \cdot 0 & 0.8 \\ 5.5 & 33 \cdot 0 & 2 \cdot 0\end{array}$

$\begin{array}{ccl}\text { Hydrogen } & \text { Oxygen } & \text { Nitrogen } \\ 6 \cdot 21 & 43 \cdot 03 & 1 \cdot 10 \\ 8 \cdot 33 & 24 \cdot 44 & 1 \cdot 50=100 \\ 8 \cdot 73 & 20 \cdot 29 & 6 \cdot 18=100\end{array}$

The relations of these woody materials and coals are still better exhibited in the following table, giving the atomic proportions of the constituents, carbon being made 100 ; the atomic equivalents of carbon, hydrogen, and oxygen being respectively $12,1,16$.

\begin{tabular}{|c|c|c|}
\hline Carbon & Hydrogen & Oxygen \\
\hline 1. Wood ... & 150 & \\
\hline 2. Cork ................................... 100 & 150 & 30 \\
\hline 3. Lycopod spores ............................ 100 & 166 & 24 \\
\hline 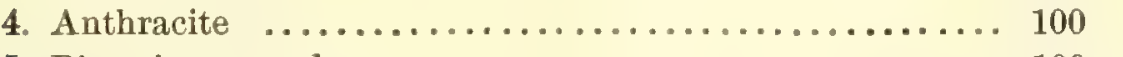 & 33 & 2 \\
\hline 5. Bituminous coal ........................... 100 & 83 & 12 \\
\hline 6. Brown coal .............................. 100 & 96 & 27 \\
\hline 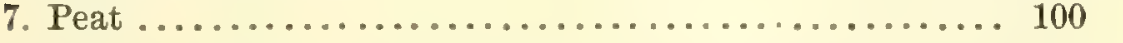 & $112 \cdot 5$ & 40 \\
\hline
\end{tabular}

There was little ordinary bark in the beds of vegetable debris, since the cortical part of Lycopods, Ferns, and Calamites is not of this nature; although nearer coal in constitution than true wood, bark resists alteration longer, and is less easily converted into coal. The spores of Lycopods often retain their amber-yellow color in the coal, although undoubtedly changed in constitution. Resins, which are still nearer coal in the amount of carbon, but hold less oxygen, are found mostly as resins in coal, especially when they are in lumps or grains, but of somewhat altered composition. It is probable that, in the making of bituminous coal, at least three fifths of the material of the wood were lost; and in the making of anthracite, about three fourths. Besides this reduction to two fifths and one fourth by decomposition, there is a reduction in bulk by compression; which, if only to one half, would make the whole reduction of bulk to one fifth and one eighth. On this estimate, it would take five feet in depth of compact vegetable debris to make one foot of bituminous coal, and eight feet to make one of anthracite. For a bed of pure anthracite 30 feet thick (like that at Wilkesbarre), the bed of vegetation should have been at least 240 feet thick.

Anthracite coal is a result, according to most writers on the subject, of the action of heat on bituminous coal, under pressure, attending an upturning of the rocks, the heat driving off nearly all volatile matters it could develop, and so leaving a coke (the anthracite) behind. Made in this way, 
the reduction, in the case of authracite, would be to about one eighth, as above estimated. The average amount of ash in anthracite ought, consequently, to be nearly half greater than in bituminous coal.

The production of the anthracite of eastern Pennsylvania was referred to the action of heat on ordinary bituminous coal first by H. D. Rogers, on the ground of the upturned and flexed condition of the rocks in that part of the state. The upturning fades out to the northwestward, and the Wilkesbarre anthracite region is on its outskirts. The heat produced in the rocks by the upturning need not, for the result, have been either great or much prolonged; moreover, it would have spread laterally from the area of greatest disturbance, more or less far into the outskirts, as is well exemplified in various metamorphic regions. The following are other facts favoring this origin of the anthracite: (1) The coal of the upturned and more or less metamorphic Coal-measures of Rhode Island is the hardest of anthracite. (2) The coal of the Carboniferous Coal-measures of western Pennsylvania, and that of the states farther west, where the beds are nearly horizontal, is, throughout, bituminous coal and not anthracite. (3) Variations in the conditions of the coal-making areas over the globe have led to various kinds of coal without making anthracite. Brown coal, or that containing a large percentage of oxygen, is known to form where there is much access of air; and cannel coal, a kind rich in oil-producing hydrocarbons, and little oxygen, under conditions of prolonged steeping beneath a deep covering of sediments; for all the characters of the beds associated with cannel coal indicate, as Newberry held, the fact of such a steeping of the bed of vegetable debris. These are the extreme results, except that more remarkable extreme, the loss of all the oxygen through union with carbon, and thereby the making of hydrocarbon oil or gas as the substitute for coal. Anthracite is not known among the products so made, except in regions of upturned rocks, or in the vicinity of igneous rocks. Graphite, a grade beyond anthracite, is formed from the excessive heating of mineral coal, as is proved in the metamorphic coal regions of Rhode Island, Worcester, and elsewhere.

\section{GENERAL OBSERVATIONS ON THE PALEOZOIC ERAS.}

\section{GROWTH OF THE AMERICAN CONTINENT.}

1. Focts connected with its growth. - The facts which have been presented sustain the view that the American continent throughout Paleozoic time was gradually growing in its rock formations and dry land, and thereby extending from the Archæan nucleus southeastward and southward, but not much in a sonthwestward direction. It is manifest, also, that after the Lower Silurian era had passed, the growth took place mainly through processes at work over the great Continental Interior, - a vast American Mediterranean Sea, bounded on the north, northeast, and east, by Archæan confines. Moreover, the eastern areas of progress in New England and beyond had like- 
wise Archæan confines, even during Cambro-Silurian time, each having been an independent trough or basin. In the Acadian trough the subsidence carried down the bottom of the trough as deposition went forward, but not the Archæan ridges along the confines; for if these Archæan ridges had subsided also, they should have had, at the beginning, the extremely improbable height of 30,000 or 40,000 feet. The Acadian and the Gaspé-Worcester troughs were sinking, and receiving, in some parts, if not generally, formation after formation, to the close of the Carboniferous period; and the Connecticutvalley trough, to the middle or later part of the Devonian era; and this was not the last, as will be shown, of the rock-making carried on in the Acadian and Connecticut-valley troughs. 'The western part of the Continental Sea had also its areas of subsidence and deposition. Only subsiding troughs received thick deposits for the various formations.

2. Diversities in kinds and in thickness of rocks. - The vast Continental Interior, shut away from the more destructive forces of the ocean, afforded the most favorable conditions possible for the growth of aquatic life, and therefore for the making of limestones; and the life had no doubt the luxuriance prevailing in the existing coral reef seas of the tropics. What this degree of luxuriance is at the present time may be well learned from the admirable photographs of a volume by W. Saville Kent on The Great Barrier Reef of Australia. To see the reefs themselves is better; but this not being readily attainable, the geological student, who would appreciate the profusion of life, and something of the beauty of Paleozoic reefgrounds, should see the photographs. The colors are absent, but there is everything else in the pictures. The species represented are modern Corals of various kinds and forms; but it will be easy, afterward, to think of vast areas of Crinoids, ancient Corals, and other Paleozoic productions; for the result is the same in kind, if shell-making Mollusks were the ehief kind of life. He would learn also the pertinent fact that limestone-making is not necessarily, or ordinarily, deep-water work.

The effects of the tidal and wind-made currents in forming fragmental accumulations within the Interior Sea, especially along its borders, have been variously illustrated in the preceding pages, with special reference to those of the northeast and east; and there has been brought out to view, also, the contrast with those of the limestone formations over its interior. This contrast was augmented through each of the successive periods by the contrast in the amount of subsidence in progress:- over the Interior Sea, but little, the formations only 3000 to 6000 feet thick; over the eastern portion, a great subsidence, 30,000 to 40,000 feet, because included within the area of the subsiding Appalachian trough. In the Continental Interior, the Paleozoic rocks are full two thirds limestones. The coal formation there has many limestone strata; the Subcarboniferous consists mostly of limestone; the Devonian and Upper Silurian strata are chiefly limestone; the Lower Silurian, even through the Hudson period, mostly limestone; and the Cambrian chiefly limestone. The intercalations of strata of sandstone and shale indicate 
the varying locations and effects of the marine currents, owing to varying depths and changing outlines of the land. The rocks of the northern border of the Interior area include much less limestone than those of the more central portion.

3. Maximum thickness of the rocks in North America. - The maximum thickness of the rocks of North America is not known. The methods of measurement of upturned rocks give so very doubtful results and lead generally to so large overstatements, that a trustworthy estimate cannot be made. It is, however, probable that the maximum thickness of the Cambrian is at least 20,000 feet, though only so where the rocks are mostly fragmental; of the Lower Silurian, 18,000 feet; of the Upper Silurian, 7000; of the Devonian, 14,000; of the Carbonic, 16,000; making a total of 75,000 feet.

The relative maximum thicknesses of the rocks have been used, first by S. Haughton, as a means of deducing the relative duration of geological eras and periods. There is great doubt over conclusions based on this criterion, because thickness is dependent so generally on a progressing subsidence no subsidence giving little thickness, however many the millions of years that may pass. But as it is the only available method, it is still used.

Limestones increase with extreme slowness, five to ten feet of fragmental deposits accumulating in the time required for one foot of limestone. This general fact at least is plain, that Eopaleozoic time, or that of the Cambrian and Lower Silurian eras, was much longer than all the rest, for, as shown on pages 509, 520, it continued on after the first appearance of Fishes and Insects, types that were formerly supposed to date from the Devonian. The ratio for the Eopaleozoic, Upper Silurian, Devonian, and Carbonie is perhaps $7: 1: 2: 2$ or $8: 1: 2: 2$.

\section{BIOLOGICAL CHANGES AND PROGRESS.}

To appreciate the general system of biological progress, it is necessary to have some knowledge of the general principles under which successions of forms and structures were produced. The following is a brief review of some of the principles.

1. From the simple, regular, or primitive in structure to the specialized. Some of the changes included, in cases generally of rising grade, are the following: (1) From a structure in which there are two or more functions to an organ, to one in which each function has its special organ (an organ being any part of a structure that is more or less independent in action, as even a digit or a tooth). (2) From a structure in which the organ corresponding to a special function has several uses, to one in which special forms exist in the same structure for each kind of use. (3) From simpler forms of specialization to more complex forms, better adapted to the required use. (4) From any specialized form to others adapted to newly acquired uses, with either accompanying rise or decline in general grade of structure. (5) From structures in which the head has large sense-organs and mouthorgans, to those having all the organs small, and the parts well compacted. 
(6) From large aquatic structures to smaller and more concentrated terrestrial structures.

2. Approximate parallelism, in many cases under any tribe, between the geological succession of structures and embryological succession in the development of living organisms. - On this subject see the remarks on page 401.

3. Degeneration. - (1) In eases where progress is upward, or where there is no manifest decline in grade: $(a)$ Degeneration of an organ to a more primitive form; $(b)$ diminished size and often complete disappearance of an organ (either from disuse, or in consequence of accelerated enlargement in associated organs). (2) In cases of decline in grade: Degeneration widely in a structure through changes that have the reverse order of those enumerated in the preceding paragraphs, leading often through youth-like to embryonic forms; producing low-grade structures that are nearly normal in form and activity; also lower down, variously defective structures, sluggish in movement; and at the extreme limit of degradation in Invertebrates, structures that are incapable of locomotion after leaving the young stage; also, where an animal becomes aquatic among Vertebrates, producing structures which retain activity, become urosthenic and multiplicate, and often have great length of body and large size.

Degeneration has its limits. Degenerate Mammals are mammalian in their more fundamental characteristics. Degenerate Crustaceans are Crustaceans still, as they show in their embryonic development.

4. From diffuse structures to concentrated. - Since the brain or cephalic ganglion, besides being the source of physical energy, and the chief seat of sensorial energy, is the center of control of all the forces of the structures except the involuntary, concentration consists in a shortening of the radius of control, or the distance through which it has to act. Compare a Lobster with the highest of Crustaceans, a Crab; or a Crab with its superior, an Ant. Some of the cases included are the following: (1) From a much elongate structure - the elongation chiefly posterior - to an abbreviated structure. (2) From a multiplicate structure, or one having an excessive or indefinite number of body segments, pairs of limbs, articulations of limbs, etc. - a prevailing feature of Articulates of the early Paleozoic - to one consisting of a normally limited number of such parts and usually also an arrangement of these parts in two or three groups. (3) From a structure having the posterior part of the body the chief locomotive organ to one having regular pairs of limbs as the organs of locomotion, and having these pairs of limbs situated anteriorly in the structure; in which case the structure is styled podosthenic (from the Greek for foot and strong). (4) From a structure in which the posterior pair of limbs in Vertebrates is the strongest, and which is therefore merosthenic (so-named from the Greek for thigh and strong), to one in which the anterior feet are the strongest, - a structure styled prosthenic. 


\section{Plants.}

The line of succession for Paleozoic terrestrial plants has been made apparently clear by the observation that the Rhizocarps, the simple and small, mud-growing Acrogens, few in existing species, of which Salvinia and Marsilea are two of the four modern genera, were the probable source of the spores that so greatly abound in Devonian shales (Dawson). Through the Protosalvinia, according to this author, the line leads up to the Equiseta, that is, to the Calamites and Annularice of the earliest terrestrial flora. Another simple type of Cryptogam, related to the former in fructification, that of Selaginella, which is represented now by only one single genus and thus shows that it is a type of the past now dwindled, is regarded as the probable source of the Lepidodendrids, and through them of the Sigillarids, or semi-exogenous Acrogens, and of the Yews and other true Gymnosperms.

The special type among these simpler Cryptogams that was precursor to the Ferns has not been ascertained. Since circinate vernation characterizes both Cycads and Ferns, and since a genus of Cycads, Stangeria, now exists in which the foliage is Fern-like, it is probable that the line to the Ferns led beyond to the Cycads, the other grand division of the Gymnosperms, and, therefore, that the Gymnosperms had a double source.

In the Lepidodendrids, Sigillarids, and related species, Cryptogams reached their culmination, or their greatest expansion in number of species, and their highest perfection in type of structure. The Lepidodendrids have no species in the Permian period, and the Sigillarids none after it. Further, the Equiseta passed, throngh the Calamodendra, their time of maximum development during the Carboniferous period. The genus Calamites had later species, but they were smaller, and the associated Equiseta were of the inferior modern type.

The Cycads culminated in later time; and the same is true also of the more typical Gymnosperms - the Conifers.

\section{INVERTEBRATES.}

1. Hydrozoans; Actinozoans. - The Graptolites, Cambrian in their beginning and Lower Silurian in culmination, disappear with the Lower Devonian. The Cyathophylloid Corals, or Tetracoralla, also dating from the Cambrian, increase in number of genera and species in the Silurian; with other Corals make coral reefs in the Upper Silurian; are in much greater numbers, and of larger size, and make still more extensive reefs, but undergo little increase in genera, in the Lower Devonian; then in the Lower Carboniferous they almost disappear. Three of the species observed pertain to the three older genera, Cyathophyllum, Zaphrentis, and Phillipsastrea, and three are new genera, Lithostrotion, Cyathaxonia, and Lonsdalia. The recent discoveries of the "Challenger" Expedition report a living species of a Cyathophylloid Coral from the bottom of the ocean. 
The Favosites ended in the Devonian, but related tabulate Corals still exist.

2. Echinoderms. - Cystoids, one of the early Cambrian types, the simplest of the Crinoid tribe, embryo-like in their want of symmetry, are unknown after the Devonian. Crinoids, also Cambrian, multiply in genera and species through the Silurian and Devonian, appear under a marvelous diversity of forms in the Subcarboniferous period, and then rapidly decline, few appearing in the Permian, and none of the same paleozoic type in after time. The next period, or that commencing the Mesozoic, has more modern forms under the genus Encrinus, closely related to the living Pentacrinus.

Starfishes commence in the Cambrian, and Echinoids, the higher Echinoderms, in the Silurian. The latter are abundant in the early Carboniferous era, but they do not lose in Paleozoic time their low-grade multiplicate characteristic; that is, the excessive number of vertical series of plates in the shell.

3. Molluscoids. - The Brachiopods, earliest Cambrian in origin, the most abundant of all Paleozoic animal life in species, and in individuals under species, had the larger part of the groups, to which they are referred, introduced in the Cambrian and Lower Silurian, but were most numerous in genera and species in the Upper Silurian and Devonian. And although of many species and few genera in the Carboniferous and Permian, the type appears to have lost, at the close of the Permian, all the genera then existing excepting four. These are: Lingula, Crania, Spirifer, and Rhynchonella; all of these continue into the Mesozoic, showing remarkable adaptability to varying conditions. Further study may subdivide the genera; but the general fact remains as regards the groups. The early Cambrian Orthis group continued through Paleozoic time, but appears to have ended at its close.

4. Mollusks. - The tribe of Pteropods - if the species, so referred, rightly belong here - had predominance over other Mollusks in the Early and Middle Cambrian, the species being many and large. They were numerous also in the Lower Silurian; but they diminish in numbers afterward. Conulariæ of much more uncertain relations - existed in the Upper Cambrian, but had their largest species in the Silurian, Devonian, and Carboniferous. They are rare fossils afterward; the last known is from the Lias.

Lamellibranchs and Gastropods, commencing in very small forms during the Early Cambrian, increased slowly in number of genera through the Paleozoic, without reaching a culminant condition in either of their higher divisions. The Cephalopods also culminate after Paleozoic time. One of the early genera, Orthoceras, had species of large size through the whole Paleozoic, and survived until the middle of the Mesozoic.

5. Limuloids. - Limuloids of Eurypterid type commenced in the Lower Silurian, have species of great size in the Upper Silurian and Devonian, in which era they passed their culmination, and ended with small species in the Carboniferous era. The family of Limulids, a branch from the earlier 
Limuloids, appeared in the Silurian. They existed through the Carboniferous era, and under more compacted forms have been continued to the present time, four species now representing the genus Limulus, one North American, and three East Asiatic and East Indian. The Carboniferous genera Belinurus and Prestwichia represent, under an adult form, rather closely, the young of the modern Limulus; and Cyclus Packard considers as representing a still younger embryonic stage of Limulus.

6. Crustaceans. - It is stated on page 526, that Trilobites had their culmination in number of genera, and in number, size, and grade of species, in the Lower Silurian. They continued, with few new genera, but under many new species, in the Upper Silurian, and appeared under some extravagant spiny forms during the Devonian; but afterward, in the Carboniferous era, the species were few and simple, only a score being known. The number of new Carboniferous genera yet found is only two, and these are closely related to the Devonian Proetus. Here the type ends.

No other subdivision of Crustaceans appears to have passed its culmination in Paleozoic time excepting that of the Ostracoids, or the bivalved Crustaceans (page 525).

The Cirriped or Barnacle tribe, a degenerate group, derived from some family of Ostracoids, as remarked on page 421, and one of the lowest stages of Crustacean life, appeared as early at least as the Lower Silurian.

Other tribes of Crustaceans continue to expand. True Isopods make their appearance as early as the Devonian, and probably in the successional line of the Trilobites. The Decapods are represented by Macrurans (or Shrimps) in the Devonian, and by Brachyurans (Crabs) in the Carboniferous.

Trilobites and many of the so-called Phyllopod Crustaceans are examples, as has already been stated, of multiplicate forms, or those having an excessive number of segments and members. The Early Cambrian Protocaris of Walcott (page 474) is a good example of a multiplicate, Apus-like Phyllopod, precursor of the true Decapod type. But normal numbers in segments exist in some of the "Phyllopods," even those of the Cambrian, the abdominal segments being reduced in number to six, the normal number in the Crustacean type, and in the same Phyllopods the thorax also has apparently its normal number of body segments; in which case they are not multiplicate, unless in legs, and these are not in sight in the fossil specimens. With the appearance of 'Tetradecapods and Decapods in the Devonian, typical numbers, as to body segments and limbs - that is, for all parts of the structure -have full expression; for the Isopods appear to be (in view of the researches of Walcott, Matthew and Beecher) essentially non-multiplicate Trilobites.

7. Derivation of Limuloids and Crustaceans. - As has been suggested by Lankester (and is recognized on page 423), it is probable that all the Articulates are successional to the Rotifers. There is reason for believing, further, that the type of Annelids, that of Crustaceans, and probably that of Limuloids, had their independent Rotifer origin. 
The Nauplius, or larval form, of a Crustacean shows, by its having but three pairs of limbs (two besides an antennary pair), that the type is not successional to a many-jointed Annelid, but rather to some type of Rotifer.

The Eurypterids, the early form of the Limuloids, are related to Crustaceans in the number of body segments, it being 19, as in the Tetradecapods; and in the fact that 13 of these 19 segments pertain to the thorax and abdomen. But the wide distinction exists that the Eurypterids have no thoracic or abdominal limbs, and the only true feet which they have are also at base mouth organs; that is, organs that pertain to the head. Moreover, as has been shown to be true in Limulus by Packard and others, they do not pass through the Nauplius stage in their development. These diversities and agreements appear to indicate a derivation for the Limuloids nearly like that of the Crustacean type, but probably not from Crustaceans. But since Limuloids cannot yet be proved to have existed before the Trenton period in the Lower Silurian, a derivation from some species related to the Ceratiocarids is possible.

Since many of the Eurypterids were fresh-water or brackish-water species, the transfer to fresh water may have been an incident attending the divergence; and also an explanation of their attaining so great dimensions, fresh waters having been their protection. The large Eurypterids, several feet in length, would have been helpless among Sharks and Ganoids.

8. Myriapods, Arachnids, Insects. - Arachnids and Insects have their Upper Silurian species, but the first of Myriapods yet found are from the Lower Devonian.

The remains of Insects in the Lower and Upper Silurian, together with those of the Devonian and Carboniferous, indicate, according to Scudder and Brongniart, that Hemipteroid, Neuropteroid, and Orthopteroid species, and more or less intermediate forms, were then the common kinds. Nothing about the earlier forms of Insects is known. The existence of six pairs of wings instead of four, that is, one for each segment of the thorax, may have been a primitive feature; but this is not considered probable. The great size of some of the Devonian and Carboniferous species is a remarkable feature of the age. A spread of wing exceeding two feet is a size now existing only in large Bats and Birds.

The Neuropteroids and Orthopteroids were the predominant types; and among them were intermediate species, as has been already illustrated. The latter type as regards the family of Cockroaches, as explained by Scudder, culminated before the close of the Paleozoic. Previous to its close, the wings of the two pairs in these species were alike in diaphaneity, very nearly alike in size, and hence equally efficient as flying organs. But in the following period (as illustrated by specimens from Colorado), the anterior pair begin to show some thickening and obscuration; and in the present era nearly all the species have the anterior wings coriaceous, and fitted to serve, as in Beetles, almost solely or solely as wing covers. The posterior wings, on 
the contrary, have retained their transparency, neuration, and use. Scudder remarks, further, that a similar change took place after the Paleozoic, in the Orthopteroids generally, though to a less extreme degree; and it appears therefore that the Carbonic era was the time of culmination not only for the Cockroach family, but for the tribe as a whole. The change was a loss of locomotive function by the anterior pair of wings, and an example therefore of degeneration; and it was attended, as Scudder states, by a great loss in the size of the species, and especially of the wings; the mean length of the anterior wings in the Paleozoic species of Cockroaches being a little over an inch (26 mm.), and 40 per cent less in later kinds. Among Hemipteroid species, the Permian Eugereon Böckingi, of Germany, had the wings of both pairs similarly diaphanous, while in the Phthanocoris of the Permian of Missouri, described by Scudder, the anterior pair were much thickened; the result, probably, as in the Orthopteroids, of degeneration. It is probable that Carboniferous Beetles had a like method of origin from Insects having four diaphanous wings; but the line of descent remains unknown.

The Scorpions of the Upper Silurian are much like those of modern time. The type is the lowest among the tribes of Arachnids, notwithstanding their size. As in a Crustacean or Eury pterus, the body (Fig. 799) obviously consists of a cephalothorax and a long abdomen.

True Spiders have not yet been found in rocks earlier than the Carboniferous; and this is probably because Spiders are so little likely to be fossilized; for they are not only smaller animals than the Scorpion, but also they are unlike them in not having a durable exterior.

9. Derivation of Arachnids. - The line to the lower and earlier Arachnids - that is, to the Scorpions - leads up, according to Van Beneden, Packard, and others, from the early Pterygotus-like Limuloids. The early Scorpions, as well as the modern kinds, have the same number of body segments as a Eurypterus or Pterygotus: namely, seven thoracic and six abdominal (precisely the normal number in Crustaceans); the same cephalic relations of the legs; the same absence of abdominal appendages; a like absence of thoracic appendages from all the segments excepting the first two; and similar functions in the members pertaining to these two segments. Further, according to B. Peach, these early Limuloids sometimes have, like the Scorpions, pairs of "combs" or pectinated organs on the underside of some of the thoracic segments.

But in this change from an aquatic to a terrestrial species the upward progress in structure was great. The four posterior pairs of feet in the terrestrial Scorpion have no longer the low-grade feature of serving for jaws as well as feet, but are simply feet; they are the chief organs of locomotion, and only those of the anterior pair are appendages to the mouth. The antennæe are shortened to pincers (falces) that also serve the mouth. 'The four pairs of feet are thus cephalic organs, if comparison be made with the Limuloids and Crustaceans; though in Arachnology, they are called 
thoracic. Air-breathing was another new feature; and for this purpose parts of the body had air-vessels or trachere which opened by breathing holes, or spiracles, on the under side of four of these "thoracic" segments. In the later true Spiders the body had lost its Eurypteroid abdomen, but had still, in Paleozoic species, its distinctly segmented thorax; and this thorax is the abdomen of Arachnology. (It is segmented in some modern species, while in others the subdivisions have become obsolete or are but faintly indicated.) The abdomen of the Eurypterid, however, exists as a slender jointed thread in Geralinura of Scudder, of the Carboniferous, which has its Illinois and also Bohemian species, and has survived till now in the modern Thelyphonus.

10. Derivation of Myriapods and Insects. - Myriapods, although inferior to Insects, are as yet known only from the early Devonian. The Devonian species, and also those of the Carboniferous, are of the Milleped, or lower, doubly-multiplicate section of Myriapods, with one exception, that of the remarkable few-jointed, caterpillar-like Palcocampa of Meek and Worthen.

The fact of a line of succession from Worms to Myriapods and from Myriapods to Insects has not been proved by geological discovery. The derivation of Myriapods from some ty pe of Annelids is zoölogically suggested, as long since recognized, by the apparently transitional form of Peripatus, a low-grade Myriapod resembling much the larve of some Insects, and by the like multiplicate structure of Anuelids and Myriapods. It might be inferred also from the resemblance of the Palæocampa of the Illinois Carboniferous to the caterpillar of an Insect of the genus Aretia, as remarked by Scudder.

Myriapods are regarded as the precursors of Insects, on account of their approximate resemblance to the latter in antennæ and the appendages of the mouth, and because also of the worm-like form of most Insect larves, these larves appearing to be survivals of the Myriapod stage. In the change from an Annelid and Myriapod to an Insect, the multiplicate feature disappeared, and the number of parts became essentially the fixed normal number of the type, both as regards the body segments and their jointed appendages.

The rise of grade from the Myriapod to the Insect involved the appropriation of the three body segments of the Myriapod bearing the three anterior pairs of feet (which correspond normally to half the body segments of the head of an Isopod Crustacean) for forming the isolated middle section of the body called the thorax, and the suppression of all the other pairs of feet. In both Spiders and Insects, the change involved also a general concentration of the structure toward the cephalic nervous center; that is, a shortening of the range of cephalic control, and especially the distance to the posterior limits of locomotive action.

While in the Cockroach, and related low-grade species, there is no proper metamorphosis, in higher Insects, as they rise in grade, the larval stage is lower and lower in embryonic level, becoming, in the highest, destitute of locomotive organs; and this fact suggests that the larval stage results from an attendant retrograde embryonic change toward, and to, a line parallel with 
the Myriapod type, and beyond this, to the memberless condition of the Worm. This accords with a common fact that the higher the species, the longer the stage of youth.

The relations in body segments and limbs between the classes of Crustaceans, Limuloids, Arachnids, Myriapods, and Insects, are shown in the following table. The segments of the parts of the body are numbered along the left margin; the zero opposite signifies that the segment, though present, has no appendage.

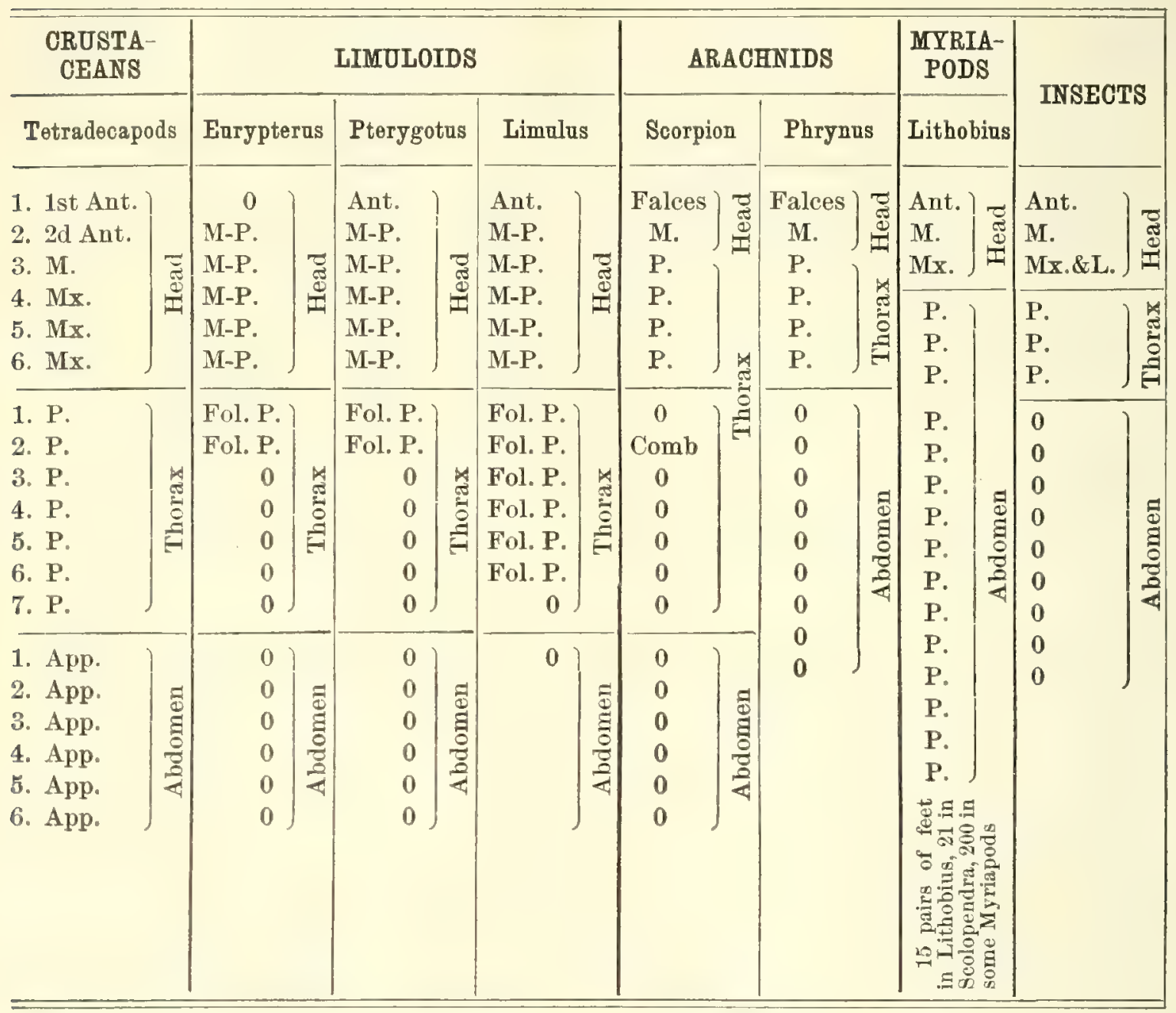

In this table, the following abbreviations are used: $\Lambda$ nt, antenna; App., pairs of jointed appendages, either pediform or branchial ; M., mandible ; Mx., maxilla; P., feet ; M-P., feet that serve also as jaws; Mx. \& L. (under Insects), maxillæ and labium; Fol. $\mathrm{P}$., foliaceous or lamellar feet or appendages.

Under the Limuloids, the genus Eurypterus fails of antennæ; but they are present in Pterygotus, and are chelate; and this chelate (or thumb-andfinger) form characterizes also the modern Limulus, the Scorpions, and the common Spiders. In the table, the two pairs of maxillæ of Insects are assumed to belong to a single body segment, as held by many zoölogists, including (as he himself informs the author) S. I. Smith; the table shows 
that, with this admission, the thorax and head of an Insect are essentially homologous with the head of a Tetradecapod Crustacean.

\section{VERTEBRATES.}

1. Fishes. - The Pteraspid section of the Placoderms, having long vertebrated tails fitting them to be fleet scullers, commenced (according to the present state of the facts) in the Lower Silurian (page 509). Cotemporaneously (the same locality attesting) there were normal Ganoids, the Crossopterygian, which till recently were supposed to have made their first appearance in the Devonian. Along with these there probably existed also the Chimæroids, precursors of the Selachians, - a type of primitive features now almost extinct.

The Devonian adds to these paleozoic tribes the Brachiate Placoderms, admirably armor-clad fishes. But they were short in body, and hence poor at sculling, but were furnished with pectoral limbs in the shape of arms that were seemingly fitted for crawling and grubbing over muddy or sandy bottoms rather than for swimming. Although the appendages are called "arms," and the Fishes were in appearance "brachiate" (Fig. 982, page 624 ), the pectoral fins (to which they correspond) are homologous with the hands in Vertebrates and not with the arms. They were a poor equipment for either aquatic or terrestrial service, and the species end with the Devonian.

At the same time the Devonian waters were full, as has been shown, of Selachians, Dipnoans, and typical Ganoids, of great diversity in characters, and many of them unsurpassed at any later time in magnitude.

Fishes appear to have reached their highest grade of vertebrate structure, and thus to have culminated in the Dipnoans, - species that have not only lungs for breathing, as well as gills, but also, in the Ceratodus, a genus dating from the Carboniferous, a finger-like jointed midrib to the pectoral fin (Archypterygian), with jointed branches diverging from either side of it.

No records of the precursors of Placoderms, Ganoids and Sharks have yet been found in the rocks. The little Amphioxus, of existing seas (page 418), is supposed to represent one of the early forms, because, while having the general characteristics of the class, it is strikingly like an Invertebrate in part of its embryological development. The Ascidians are probably degenerate forms, as held by Lankester, derived from some species of still lower grade.

All Fishes are in several ways eminently multiplicate species. This is seen in the number of vertebræ; of articulations in the limbs when articulations exist; of teeth, and of tooth-bearing parts in the mouth.

2. Amphibians and Reptiles. - The line from the Fishes to the Amphibians is supposed to have been from the Dipnoan section. The resemblance in Amphibians to the Ganoids generally is in many respects close, it extending even to the form and structure of their labyrinthine teeth; and the Dipnoans 
already had the lung for respiration, which is the characteristic feature of all terrestrial Vertebrates.

In rising from the multiplicate structure of the Fish to the grade of Amphibian, the Vertebrate type reached a fixed or normal limit in the number of limbs, in the number of the bones of the fore and hind limbs, including even the number of digits, but not in the number of articulations of the digits. In the typical species of the old Carboniferous Amphibians the fore limbs have the scapula, humerus, radius and ulna, wrist bones, and the five fingers characteristic of the higher Vertebrates.

Further, in rising to Amphibians, the method of progression, which is urosthenic in Fishes, became podosthenic in the adult Amphibian. The young Amphibian, or Tadpole, retains the urosthenic feature and the gills of the Fish; but in passing to the adult stage, when feet are developed, the higher Amphibians lose both the tail and gills and have only feet for locomotion. The tailed Amphibians are intermediate forms representing the stages of progress. The absence of limbs in the Amphibian Snakes of the Carboniferous is probably a case of degeneration.

True Reptiles occur in the Permian. In this higher grade of Vertebrates the fish-like features of gills, and of tails for locomotion, are absent in the young state, and feet are throughout the locomotive organs. Besides, the number of joints in the digits of the fore and hind feet of these terrestrial Vertebrates has essentially the normal limit. But the teeth in the earlier spccies are still multiplicate in number and in series.

One prominent difference between the Reptilian and Amphibian skeletons is the existence in Amphibians of two occipital condyles for the articulation of the skull with the first cervical vertebra, while in Reptiles there is but one. In this feature Mammals, as early stated by Huxley, are more nearly related to Amphibians than to Reptiles or Birds.

\section{REALITY OF THE PALEOZOIC WORLD.}

The term Paleozoic is not simply a name for a division of geological time. It expresses a profound historical truth. It signifies the reality of a Paleozoic character in the world's early life which was exhibited not only in the very earliest of plants and animals, but also throughout the succession of species, and so decidedly that the Paleozoic world stands out in bold contrast with the Mesozoic. This truth has the greater importance inasmuch as Paleozoic species were the earth's population for more than half of all postArchæan time.

The truth of this statement is obvious after the review of Paleozoic life on the preceding pages. Corals, Crinoids, Trilobites, Brachiopods and Mollusks, even of their highest group, that of Cephalopods, commence in the Cambrian and are prominent through the Paleozoic. Trilobites end near the close of Paleozoic time. The prolific Brachiopods at its close lose nearly all their Paleozoic genera; Crinoids drop their Paleozoic characteristics, and 
Corals also with few exceptions; Nautiloids lose nearly all their Orthoceraslike forms; while the coiled Nautilus-like species culminate in the Carboniferous, and have few species and genera afterward. So the Insects had Paleozoic features which were dropped at the same time, and one division passed its time of culmination. The Placoderm, Dipnoan, and Ganoid Fishes, which were eminently Paleozoic types, culminated in the Devonian and Carbonic eras, and only inferior Dipnoans and Ganoids existed later. Cryptogamous Plants culminated in the Carboniferous era, and only the Calamites and some related genera, and a few genera of Ferns survived into the Mesozoic.

Should discovery open to view earlier species than those now known in the Cambrian, they would be only earlier representatives of Paleozoic types, or their precursor embryonic kinds. And if some of these latter existed in preceding Archæan time, this fact would be parallel with the appearance of many Mesozoic types in the course of Paleozoie time.

The disappearance of species at the close of Paleozoic time was not due chiefly to physical catastrophe, for the Trilobites had dwindled greatly by the close of the Devonian; and similar expansions to culmination in many other tribes, with subsequently a commencing decline, have been mentioned in the preceding pages, both among plants and animals.

How far such culminations were a consequence primarily of laws of growth it is not possible to say. There is no doubt as to their connection with physical changes in progress. One of these physical changes was the slow removal of carbonic acid from the atmosphere. The making of shells, corals, and Crinoid skeletons, and thereby the making of limestones, was, through Paleozoic time, dependent mainly on carbon abstracted from the carbonic acid of the air and waters; and vegetation, so far as its products became stored in the rocks, in the form of coal, oil, gas, and other carbonaceous products, involved a further abstraction, as explained on page 485 . The purification of the air which was thus carried on was the means of fitting it for Spiders, Insects, and other terrestrial life, and afterwards for Amphibians, and finally for Reptiles. Change in animal as well as vegetable types must have been involved in this using up of the deleterious carbonic acid. But the extent of its influence can only be conjectured. An examination into the amount of carbonic acid which air can contain without being injurious to different kinds of Insects, and to Amphibians, Reptiles, and other species, would have much geological interest. Decline in the temperature of the sea and air through Paleozoic time also had its influerce. But it is not safe at present to attribute special facts to this cause.

\section{SECTION OF THE PALEOZOIC ROCKS OF PENNSYLVANIA.}

The following section of the Paleozoic rocks of Pennsylvania, published by H. D. Rogers, after the first survey of the state, is here added because of its geological and historical value. 


\section{Lower Silurian.}

I. Potsdam. - "Primal Series" of Rogers: sandstones and slates, 3000 '-4000".

II. Calciferous. - "Auroral" calcareous sandstone, 250'.

Chazy. - "Auroral" magnesian limestone, with some cherty beds, 5400 '.

Trenton. - "Matinal" limestone, with blue shale, 550 '.

III. Utica. - "Matinal" bituminous shale, 400 '

Hudson. - "Matinal" blue shale and slate, with some thin gray calcareous sandstones, $1200^{\prime}$.

\section{Upper Silurian.}

IV. Oneida. - "Levant Gray" sandstone and conglomerate, 700".

Medina. - "Levant Red" sandstone and shale, 1050'; and "Levant White" sandstone, with olive and green shales, $760^{\prime}$ : total, $1810^{\prime}$.

V. Clinton.- "Surgent Series," shales of various colors, both argillaceous and calcareous, with some limestones, ferruginous sandstones, and iron-ore beds, 2600 '.

Niagara. - Not well defined; possibly corresponds with part of the "Surgent Series."

Salina._" "Scalent" variegated marls and shales, some layers of argillaceous limestone, $1650^{\prime}$.

VI. Lower Helderberg. - "Scalent" limestone, thin-bedded, with much chert, 350 ; "Pre-meridian" encrinal and coralline limestone, 250 ': total, 600 '.

VII. Oriskany. - "Meridian" calcareous shales, and calcareous and argillaceous sandstone, 520 '。

\section{Devonian.}

VIII. Upper Helderberg, Cauda-galli. - "Post-meridian" silico-calcareous shales, 200 ' to $300^{\prime}$.

Corniferous. - "Post-meridian" massive blue limestone, 80'.

Marcellus. - "Cadent" Lower black and ash-colored slate, with some argillaceous limestone, $800^{\prime}$.

Hamilton. - "Cadent" argillaceous and calcareous shales and sandstone, 1100'。

Genesee. - "Cadent" Upper black calcareous slate, 700'.

Portage. - "Vergent" dark-gray, flaggy sandstones, with some blue shale, $1700 \%$.

Chemung. - "Vergent" gray, red, and olive shales, with gray and red sandstones, $3200^{\prime}$.

IX. Catskill. - "Ponent" red sandstone and shale, with some conglomerate, $6000^{\prime}$.

\section{Carboniferous.}

X. Pocono. - "Vespertine" coarse, gray sandstones and siliceous conglomerate at the eastward, becoming fine sandstones and shales at the westward, 2660 '.

XI. Mauch Chunk. - "Umbral" fine red sandstones and shales, with some limestone, $3000^{\prime}$.

XII. Millstone-grit, or Pottsville conglomerate. - "Seral" siliceous conglomerate, coarse sandstone and shale, including coal-beds, 1100 '

Coal-measures. $-2000^{\prime}-3000^{\prime}$.

\section{POST-PALEOZOIC OR APPALACHIAN REVOLUTION.}

Paleozoic time closed with the making of one of the great mountain systems of North America - the Appalachian, besides ranges in other lands, and in producing one of the most universal and abrupt disappearances of life in geological history. So great an event is properly styled a revolution. 


\section{MOUNTAIN-MAKING IN NORTH AMERICA.}

The various steps in the making of the Appalachian Mountain Range, or Synclinorium, and the events of the prolonged catastrophe, have been reviewed at length on pages $353-357$. It is there stated that general quiet prevailed over the continent throughout the Paleozoic eras, with the exception of the interval of Taconic upturning, and those gentle oscillations of level in the earth's crust that seem to have been always in progress. The extent and steps of progress in the geanticline of deposition, which began in the early Cambrian, has also been explained, and particulars mentioned as to its variations in eastern and western limits, as shown by the limits of the several formations; and its inequalities in rate of subsidence over its different parts and in successive periods, as indicated (1) by the varying thickness of the formations from nothing to thousands of feet, and also (2) in the varying kinds of rocks from shales to conglomerates and limestones.

The review of the facts relating to the history of the successive formations from the Cambrian onward has given greater definiteness and reality to the events. Moreover, it has derived new illustrations of the changes from the remains which the rocks contain of the life of the world. The varying conditions of the preparatory geosyncline during its progress have thus become strongly apparent; and they will be much more so when the limits of the successive formations, now so well understood over New York, shall have been as thoroughly investigated by the paleontologist and geologist over Pennsylvania, the Virginias, and beyond.

The general facts connected with the upturning of strata, 30,000 to 40,000 feet thick, which the geosyncline at the end contained, have also been reviewed; and an account given of the flexures of the beds in many long lines, and the general parallelism of the flexures, but with interruptions and overlappings, and of upthrust faults of 10,000 feet and more. Mention has also been made of curves in the course of the finished mountain range; one bending from north-by-east in the northern or Catskill portion to east-northeast in Pennsylvania, the whole nearly parallel with the eastern and southern outline of the nucleal Archæan mass; the other, from Pennsylvania to Alabama and Mississippi, and becoming at the south nearly parallel with the Mexican Gulf.

The courses and character of the flexures in the nearly east-and-west portion of the range in Pennsylvania are well shown on Lesley's topographic map of the state, although greatly disguised in consequence of the denudation that has taken place since the time of mountain-making. A copy of the map (Fig. 1153) is here introduced, exhibiting the courses of the multitudes of ridges, and their bends and terminations either side of the channel of the Susquehanna River. The map is here reduced to too small a scale to show all the minor flexures, and a diagram is added (Fig. 1154) giving in simple lines the courses, positions, and bends of the various ridges over the center of the state. 


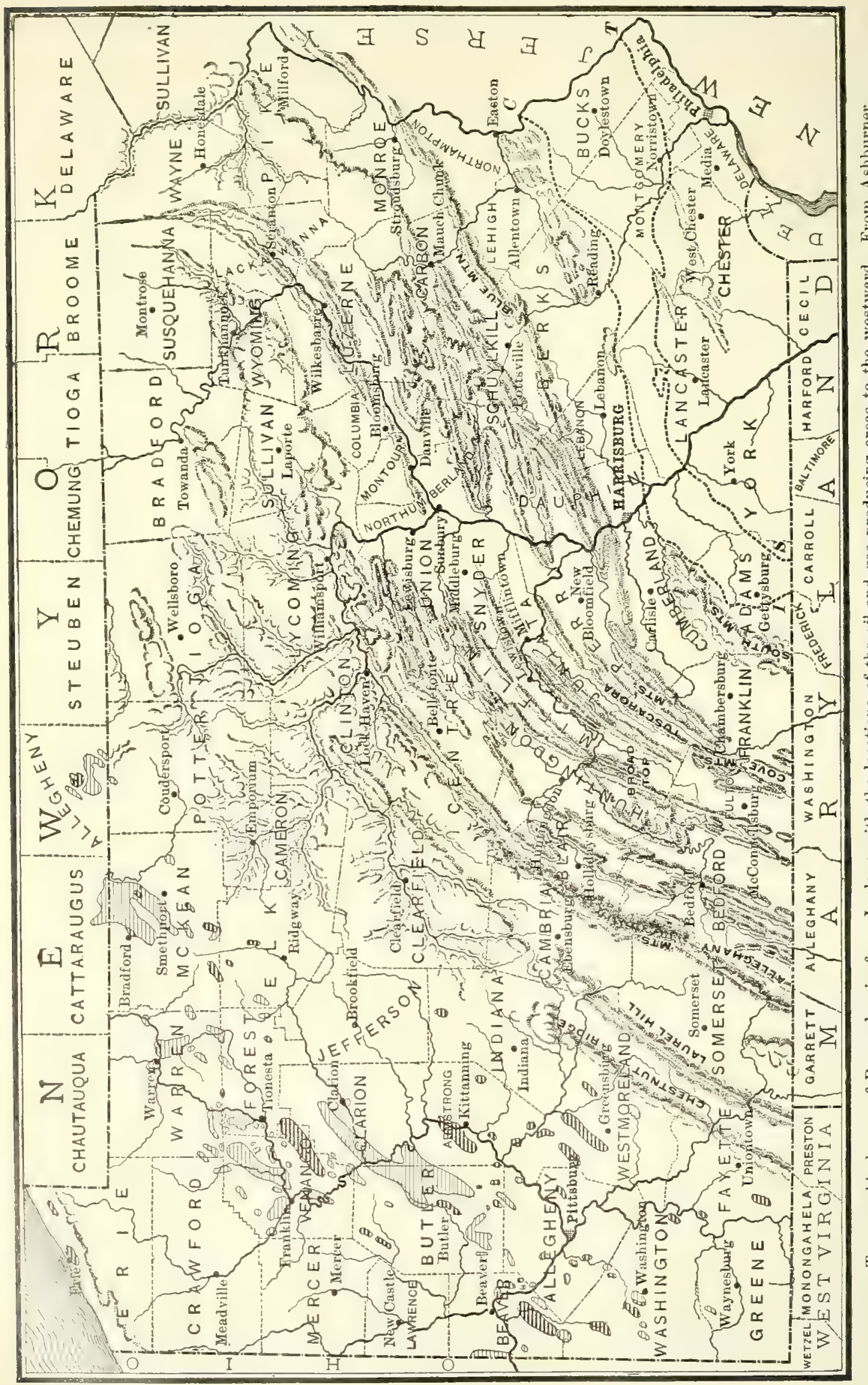


On the map on page 730 the lines TS, IC are the outline of the Triassic area of Pennsylvania. The transversely lined areas on its western part are the oil-producing and gas-producing areas of the state; the former light-lined, the latter dark-lined.

The character of the ridges in this east-northeast portion of the ranges, as they approach the Susquehanna on either side, their many small zigzag flexures (well exhibited in the diagram), and at the same time the wider spacing of the ridges there than to the westward, where the Appalachian Range takes its more normal northeasterly course, are points to be noted. These differences appear to have resulted in some way from the inequality of the action of the orogenic lateral pressure in the two directions; that is, at right angles to the normal northwesterly course, and to the less normal northnorthwesterly. The course of the Susquehanna River appears to have been determined by the warpings then occasioned.

1154.

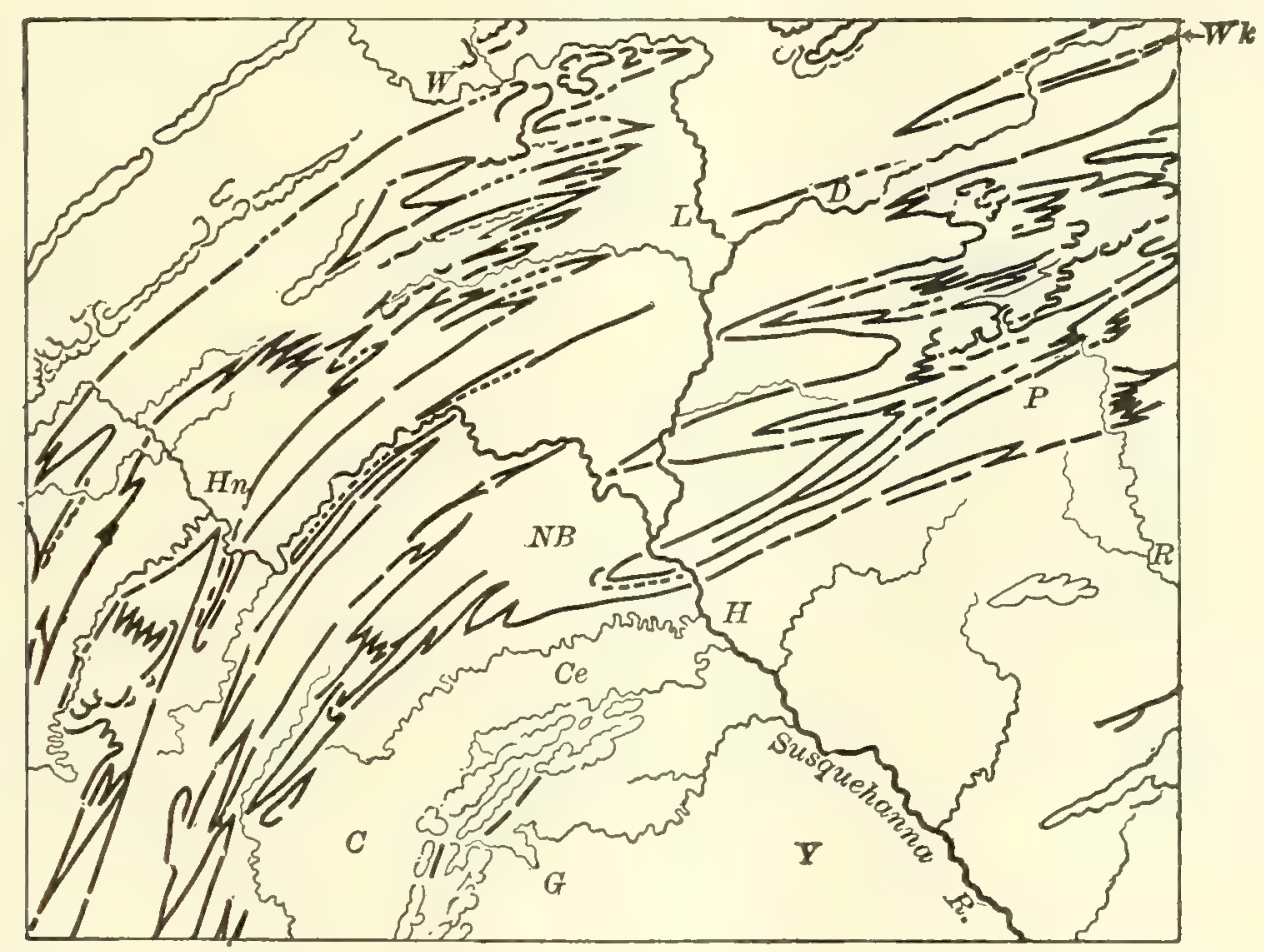

Diagram, showing the courses and flexures of the ridges in central Pennsylvania. From map by Lesley. Abbreviations: C, Chambersburg; Ce, Carlisle; D, Danville; G, Gettysburg; H, Harrisburg; Hn, Huntington; L, Lewisburg; NB, New Bloomfield; P, Pottsville; R, Reading; W, Williamsport; Wk, Wilkesbarre; $\bar{X}$, York.

The map also shows the parallelism between the positions of the oil-well and gas-well areas in western Pennsylvania and the trend of the mountains, and indicates a relation in their positions to the mountain structure, as already pointed out. The region of the anthracite is to the eastward, as will be seen on comparison with the map on page 730 ; while to the west and southwest there are the great areas of bituminous coal.

The Appalachian Range is a single mountain individual, or synclinorium, nearly 1000 miles long. But it is only one of the ranges made at this time 
in eastern North America. There was another to the eastward, the Acadian Range, extending from Newfoundland probably to Narraganset Bay in Rhode Island, - a distance exceeding 800 miles, and still another, that of the Ouachita Range in Arkansas (pages 380, 389).

In the Acadian trough the beds of Cape Breton and Nova Scotia are variously flexed, and at the southern end of the trough, in Rhode Island and part of Massachusetts adjoining, there are like evidences of disturbance; and, moreover, the coal is changed to anthracite, and in some places to graphite.

Since the close of the Lower Silurian was an epoch of upturning for the beds then in the northern part of the Acadian trough, it is probable that it was so for the whole trough, including the coast of Maine and the Cambrian beds of the Boston basin. But there is no direct evidence as to this or to later times of disturbance along the belt except in the Nova Scotia, New Brunswick, and Maine regions. Slates, grits, conglomerates, and eruptive rocks occur in the Boston basin above the Cambrian, without fossils or any other evidence of age; and, as described by Crosby and Bouvé, they may be of any period from Cambrian to Carboniferous.

The three ranges, the Appalachian, Acadian, and Ouachita, constitute together the Appalachian Mountain System. The length of the whole region of orogenic disturbance is over 2000 miles.

The Gaspé-Worcester trough, which contains some carbonaceous beds, with graphite, at Worcester, underwent post-Carboniferous upturnings. But details are wanting.

It is probable that various dislocations and anticlines over the states north along the Mississippi valley date from this epoch ; and in Illinois, several lines of dislocation, between northwest and west-northwest in trend, have been described by Worthen (Geol. Rep., i., 1866). (1) One crosses the Mississippi in Alexander County at the "Grand Chain," where the Trenton forms a ledge across the river; (2) another at Salt Creek Point in Monroe County ; (3) another below St. Louis, near the south line of St. Clair County ; (4) another at "Cap au Grès," in Calhoun County, "where there is a downthrow of the beds on the south side of at least a thousand feet," and the St. Peters sandstone constitutes the "Cap au Grès" ; (5) another, north-northwest in trend, farther north, intersecting Rock River, Grand Detour, and the Illinois River in La Salle County, between La Salle and Utica, bringing the Lower Magnesian limestone to the surface; (6) another, traceable from Bailey's Landing on the west side of the Mississippi to Shawneetown on the Ohio. Of the fifth, he states that "it elevates the Coal-measures 300 ' to 400 ', showing that the disturbance took place at a period subsequent to the deposition of the Coal formation" ; and afterward adds, with reference to the whole series of upturnings, "It is impossible, with the evidence before us at this time, to fix with certainty the relative dates of these disturbances; but it seems quite probable that none of them date back to a period anterior to the Carboniferous epoch; for we find, in general, no want of conformity between the uplifted strata and any of the superincumbent Paleozoic beds."

There are other lines of uplift or undulations farther north across Iowa, as described by McGee (11th U. S. Geol. Surv., Annual Report, 338, 1891), which have a trend of N. $30^{\circ}-40^{\circ} \mathrm{W}$. The time of origin is stated to be doubtful, except for one anticline, that of the Cedar Valley, near Davenport, Iowa, which "does not appear to affect the Coalmeasures at Davenport and Rock Island."

So far as yet ascertained no great mountain-making events occurred at this time over the Summit Region of the Rocky Mountains. The Carbonif- 
erous rocks appear to have been followed by the Mesozoic without extensive intervening upturnings in the region of the Wasatch and through the whole length of the mountains, from western Texas and Mexico to the Aretic Seas.

But west of the Wasatch belt, in the mountain ridges of the Great Basin to the meridian of $117 \frac{1}{2}^{\circ} \mathrm{W}$., according to King, Carboniferous limestone is to a considerable extent the surface rock, there being no overlying Mesozoic strata; and this limestone and the older Paleozoic formations are flexed and faulted in mountain-making style. The time of the upturning is uncertain because of the absence of later beds except over the region beyond the meridian of $117 \frac{1}{2}^{\circ}$. But, as King implies, it took place probably at the close of the Paleozoic.

The Eureka Mountains in the Great Basin (near $116^{\circ} \mathrm{W}$. and $39 \frac{1}{2}^{\circ} \mathrm{N}$.), described by Arnold Hague (Geol. of the Eureka District, U. S. G. S. Memoirs, 4to, vol. xx., 1892), are one of the mountain groups of eastern Nevada, which probably was upturned at this time. The prominent ridges, which were produced largely by faults and uplifts (their maximum displacement $13,000^{\prime}$ ), are: the Prospect Ridges, consisting of Cambrian and Silurian rocks; the Fish Creek Mountains, Silurian; the Silverado and Country Peak, Silurian and Devonian ; Diamond Mountain, Devonian and Carboniferous ; Carbon Ridge and Spring Hill, Carboniferous. The thickness of the formations, as deduced from several sections, according to Hague and Walcott, is as follows: Cambrian, 7700'; Silurian, 5000'; Devonian, $8000^{\prime}$; Carboniferous, $9300^{\prime}$, - in all $30,000^{\prime}$. This great thickness indicates, as Hague suggests, that a profound geosyncline north and south in trend was here made. The Eureka, Carboniferous, Devonian, and Silurian beds have been traced from the Eureka district westward to that of the Piñon Range, which is an indication that the latter range participated in the geosyncline. How far north the belt extends remains to be ascertained. The Archæan ridge of the East Humboldt Mountains stands to the east and north of the Eureka Range.

The Eureka geosyncline was wholly independent of that of the Wasatch, as shown by the thicknesses of the several Paleozoic formations occurring in the two; for the thickness of the Silurian of the Wasatch is only $1000^{\prime}$, of the Devonian, $2400^{\prime}$, while that of the Carboniferous is $14,000^{\prime}$. Whether the Silurian unconformability in the Eureka region between the Lone Mountain limestone and the underlying quartzyte is a result of an upturning at the close of the Lower Silurian, or of later faulting, does not appear to be determined by the observed facts.

\section{UPTURNINGS IN FOREIGN COUNTRIES.}

Regions of upturned rocks are the only kind in which there is good reason to look for unconformabilities. Through the course of Paleozoic time in Europe, disturbances appear to have been more frequent than in America. But they were inferior in extent to those at its close. Murehison remarks that the close of the Carboniferous period was specially marked by disturbances and upliftings. He states that it was then "that the coal strata and their antecedent formations were very generally broken up, and thrown, by grand upheavals, into separate basins, which were fractured by numberless powerful dislocations." In the north of England, as first shown by Sedgwick, and also near Bristol, and in the southeastern part of the Coalmeasures of South Wales, there is distinct unconformability between the 
Carboniferous and lowest Permian, and this is true also in Lancashire and Yorkshire. The "Hereynian system" of Bertrand includes a long range of dislocated Devonian and Carboniferous rocks extending from Brittany to the Vosges and Ardennes, and beyond along the Black Forest, the Harz to Bohemia. The line corresponds nearly with the "System of the Rhine" of de Beaumont, which was upturned, as he showed, before the Triassic period.

The "great fault" in the Alps raising the crystalline schists in the zone of Mont Blane, between the Bernese Alps on the east and the maritime Alps on the sonthwest, was made between the Carboniferous and Triassic (or the Lias, where the Trias is absent). The coal-formation, which is extensively distributed in the Swiss Alps, is in part semi-crystalline.

In Russia, strata are generally horizontal or nearly so, and lie above the Carboniferous without unconformability. In the closing part of Paleozoic time, either after the Carboniferous or after the Permian, a belt of rocks along the Urals was folded and erystallized; for Carboniferous rocks are flexed and altered in the same manner as in the Alleghany region. But the backbone of the Urals is Archæan.

\section{NORTH AMERICAN GEOGRAPHY AFTER THE REVOLUTION.}

The various movements over North America closing Paleozoic time ended, as announced on page 714, in making dry land of the eastern half of the continent. The western coast within the United States extended along a north-and-south line near the meridian of $95^{\circ} \mathrm{W}$.. and farther north trended northwestward through British America, as delineated on the accompanying map (Fig. 1155). The dry land had its Appalachian Mountain chain, and was for the most part finished in its rock foundation, its mountains, and its store of coal-beds.

The positions of the rivers and lakes are doubtful. There were, beyond question, a St. Lawrence River and other streams flowing off from Archæan lands. The Hudson River had been a small stream from the Adirondacks, merely the head of the present Hudson River, emptying into the waters of the eastern Continental Interior below Albany. But what course it took after the making of the Appalachians, remains to be learned from later records. The eastern coast-line of the continent, south of New York, which was still outside of the existing position of the sea border, is placed on the map near that of the 100-fathom line - the true margin of the Atlantic basin. For not only are all Paleozoic formations later than the Lower Silurian unknown on this part of the border, but also all marine formations of the Early and Middle Mesozoic. This was probably true, likewise, of the Gulf border. Whatever marine beds were formed are now deeply suomerged. The burial of the shore region by Cretacenus and Tertiary strata prevents direct observation except through borings, and these have not yet been carried to a sufficient depth to decide the question. 
Nearly all the western half of the continent was still a sea of varying depth, with perhaps its widespread sand flats. Only one large dry-land addition to the western part of the continental area is known to have taken place; it occupied, as shown by King, a portion of the Great Basin, over what is now eastern and central Nevada, having the meridian of $117 \frac{1}{2}^{\circ} \mathrm{W}$. near its western limit. The western semi-continent was yet to be supplied with thick rock-formations and with its grander mountains; and veins of gold, silver, and other metals were to be formed, and coal-beds to be accumulated, before finally the emergence of "the Great West" from the waters was completed.

1155.

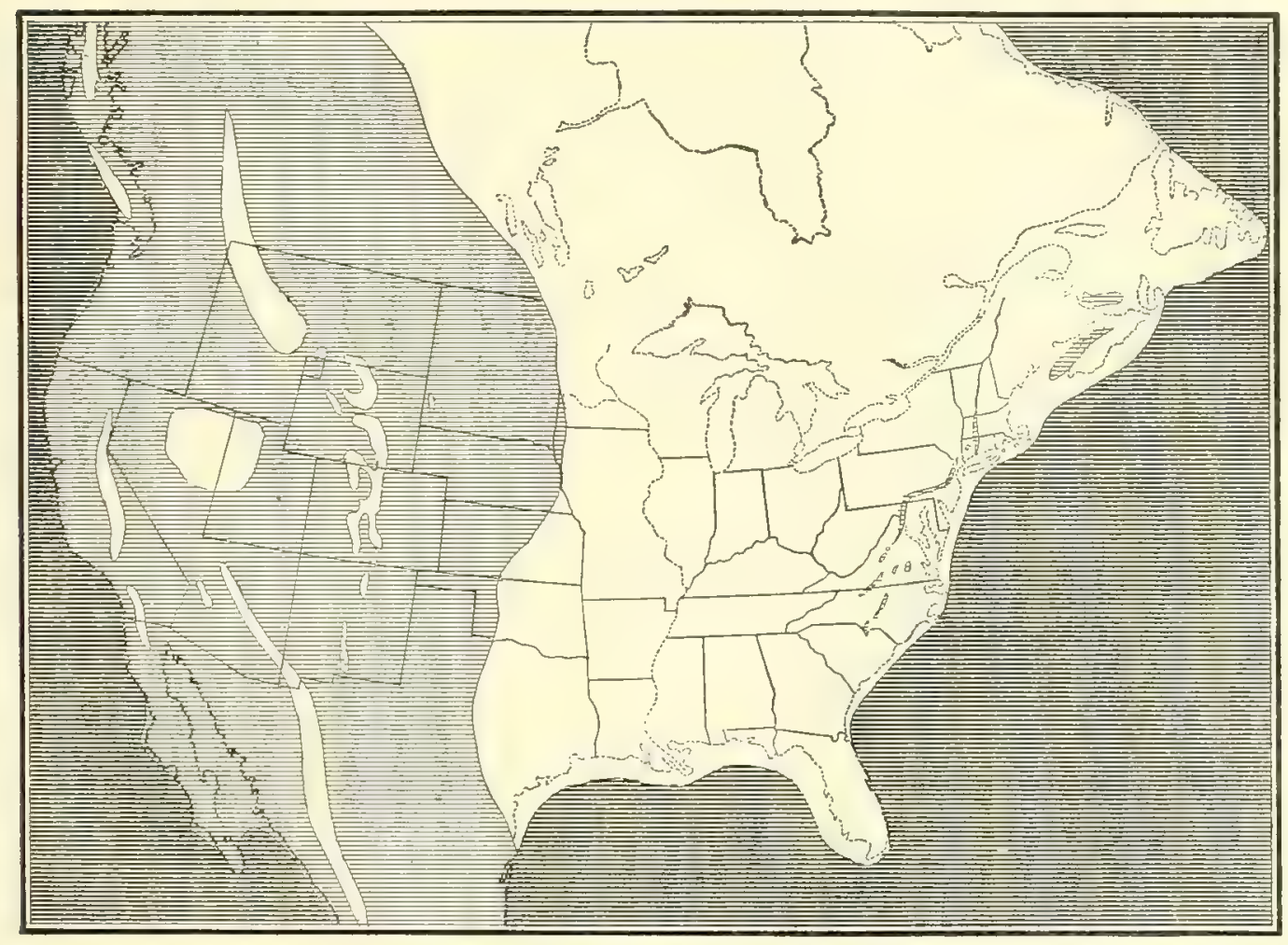

Map of North America after the Appalachian Revolution.

Disappearance of life. - The disappearance of life at the close of Paleozoic time was so general and extensive that no Carboniferous species is known to occur among the fossils of succeeding beds, not only in America and Europe, but also over the rest of the world. The fact is learned better from Europe than from America; for in Europe remains of marine life occur in beds representing the early part of the following period, while in America, the first marine fossil known from the Atlantic border is of the Cretaceous period. A large part of the old tribes of the sea and land continues on, species having survived through the time of catastrophe; and yet their species did not find burial among later fossils. Many underwent modifications and appear later under new forms, and thereby as new species. The Cycads and Yews were among the tribes of plants which were continued and increased to a later culmination. Some of the Corals of the Paleozoic belong to the 
group that is represented among, and make, modern coral reefs. Even the old straight Nautiloid, the Orthoceras, had its later species.

The Insects lost, as has been said, a Paleozoic feature at this time; but the tribes are still the same as before in their more fundamental characters. Fishes, although their period of culmination had passed, still continued under the tribes of Ganoids and Dipnoans. Amphibians and Reptiles held on, and the latter became the ruling life of Mesozoic time. So it was with the greater part of the tribes of the Paleozoic. There was no break in the stream of life, but for the most part only seeming interruptions; and many of these owe their prominence in geological history to the culminations and declines of types that were in progress.

But it was an epoch of relatively abrupt change; and if chiefly due to the progressive evolution of new species, as has been urged by some geologists, there must have been for the result a great acceleration in such changes in consequence of the physical conditions produced by the orogenic disturbance. But the orogenic movements were local, and the biologically transforming effects from such a cause should have been confined to the countries where these movements were in progress. The universality and abruptness of the disappearances cannot therefore be so explained. Very much is left for the destructive effects, direct and indirect, that is, the exterminations attending the mountain-making.

The causes of the exterminations suggested by the changes are two. (1) A colder climate over the land, and colder waters in the extra-tropical oceans; for the emergence of the eastern semi-continent of North America and of large lands in the other continents could not fail to lower somewhat the temperature of the whole globe. With a lower temperature, the currents from the north sweeping along the coasts would have been destructive to the marine species living in the waters. (2) Earthquake waves produced by orogenic movements. If North America from the west of the Carolinas to the Mississippi valley can be shaken in consequence of a little slip along a fracture in times of perfect quiet, and ruin mark its movements, incalculable violence and great surgings of the ocean should have occurred and been often repeated during the progress of flexures, miles in height and space, and slips along newly opened fractures that kept up their interrupted progress through thousands of feet of displacement. The Acadian upturning took place on the ocean's border'; and the Appalachian was not far distant from it. Arkansas, moreover, added to the extent of the belt of disturbance. Under such circumstances the devastation of the sea border and the low-lying land of the period, the destruction of their animals and plants, would have been a sure result. The survivors within a long distance of the coast-line would have been few. The same waves would have swept over European land and seas, and there found coadjutors for new strife in earthquake waves of European origin. These times of catastrophe may have continued in America through half of the following Triassic period; for fully two thirds of the Triassic period are unrepresented by rocks and fossils on the Atlantic border. 


\section{TOPOGRAPHIC CHANGES IN THE INDIAN OCEAN; GONDWÁNA IAND.}

The close relations in species of India and South Africa during the Permian and Triassic periods has led to the belief that the two were then connected by a belt of land, and Suess has named the emerged area "Gondwána Land," from the name of the series, including the Permian and Triassic beds, in India. R. D. Oldham remarks (1894) that "the plants of the India and Africa Coal-measures are absolutely identical; and among the fer animals which have been found in the India deposits, one is indistinguishable from South African species, and another is closely allied; and both faunas are characterized by the remarkable group of Reptiles comprising the Dicynodon and other allied forms." In a map by Neumayr (1885), and its reproduction with some modifications by Oldham, the connecting belt of land extends from India south-southwestward over the Indian Ocean along the range of islands to Madagascar and southern Africa. Among the groups of islands there is the line of the Maldives and the Chagos group; then, farther west, the Seychelles group heading a line reaching to Newfoundland, and also, to the eastward, a line extending to the Mascarene Islands east of Madagascar. The emerged land makes an off-shore belt for eastern Africa, somewhat like the island range off the shores of eastern Asia, but more continuous. But great depths now exist between the groups.

The identity in Permicn coal-plant vegetation is as great with Australia as with South Africa. The emerged land, on this evidence, has been supposed by some writers to have covered much of the Indian Ocean. But it is most probable that whatever connection existed for the migration of the plants, it was produced by the spreading of the Antarctic continent northward to a line between the parallels of $35^{\circ}$ and $45^{\circ} \mathrm{S}$. The absence of the Karoo Reptiles from Australia appears to indicate that the connection with South Africa was not complete; but it may be that the climate of the northerm part of Antarctica was not warm enough to favor their migration, while sufficient for that of the plants. Australia also was enlarged; for Triassic fossil plants from Tew Zealand and New Caledonia show that these islands, as well as New Guinea, were then included within its limits.

The idea that Antarctic land of so great extent became emerged in the Permian era, or about that time, suggests a reason for the existence of evidences of glacial phenomena in the Permian of South Africa, India, and Australia. For such a geographical change would certainly have caused a general refrigeration of southern climates; and if sufficient to produce icy winters and glaciers about high summits, all the observed facts would have their explanation.

$$
\text { DANA'S MAYUAL }-47
$$




\section{MESOZOIC TIME.}

Mesozoic or mediæval time in the earth's history comprises a single era only. It is the era of the Secondary formations of early geological science, and that of the Reign of Reptiles of Agassiz.

It is remarkable as the era of the culmination and incipient decline of three great types in the Animal Kingdom, the Amphibian, Reptilian, and Molluscan, and of one in the Vegetable Kingdom, the Cycadean. It is also remarkable as the era of the first Mammals, of the first Birds, of the first of the Common or Osseous Fishes, and of the first Palms and first Angiosperms.

\section{SubDivisions.}

3. Cretaceous Period, W. H. Fitton, Ann. Phil., 2d. Ser., viii., 382, 1824. The Chalk Period, or the period of the Chalk formation.

2. Jurassic Period, A. Brongniart, Tabl. des Terrains, 221, 1829, the name referring to the Jura limestone and other related beds of the Jura Mountains between France and Switzerland.

1. Triassic Period, F. v. Alberti, Beitrag Mon. d. bunten Sandsteins, Muschelkalks u. Keupers, Stuttgart, 1834, - the name, from the Latin, referring to a threefold division of the formation in Swabia, Franconia, and Lorraine. Variegated sandstone. Buntersandstein, this German name used for part of the strata by Werner. Poikilitic group (Pocilitic),

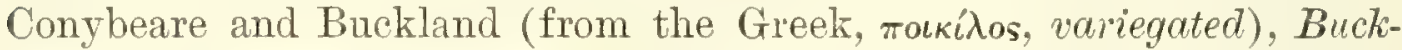
land's Bridgewater Treatise, ii., 38, 1836. New Red Sandstone group or formation, Lyell, El. of Geol., 1833, 1842 - Mercian of T. MeK. Hughes $=$ Triassic + Jurassic.

The Triassic and Jurassic rocks in some regions make together a continuous series, not easily separated, and the formation is then often called the Jura-Trias.

The generally accepted subdivisions of the three periods are the following:-

3. Cremaceous: (1) Lower; (2) Upper.

2. Jurassic: (1) Lower, or Liassic (from the Lias, of England); (2) Middle, or Oölytic (from the oölitic character of some of the limestones in England); (3) Upper, or Portlandian (from the Portland beds in England).

1. Triassic: (1) Lower Trias, or Vosgian (from the Vosges Mountains); (2) Middle Trias, or Franconian (from Franconia in Germany) ; (3) Upper Trias, or Keuperian (from the name Keuper in Germany); (4) Rhoetic (from the Rhætian or Tyrolese Alps). 


\section{Triassic and Jurassic Periods.}

\section{AMERICAN.}

The orographic events in North America closing Paleozoic time changed greatly the areas of future rock-making. The map on page 735 shows that no marine deposits were possible on the Atlantic border except far outside of the present coast-line. Moreover, as announced on page 734, all of the eastern half of the continent had become dry land, leaving only the western half covered with the Interior Continental Sea, and therefore as the great arena of progress. The mostly emerged condition of the Atlantic border, indicated on the map, continued through the Triassic and Jurassic periods and after the Cretaceous period had opened; for the beds of the Upper Cretaceous are the earliest Mesozoic marine deposits on the border. Before this, however, in the Triassic period, there were large estuary and fresh-water deposits in progress, and these constitute the Triassic formation of the Atlantic border.

In this condition of the continent, the regions of Mesozoic rock-making were the following: (1) the Atlantic border area; (2) the Gulf border area; (3) the area of the Western Continental Interior; (4) the Pacific border; (5) the Arctic area, Arctic rock-making continuing to be independent of that over the North American continent in changes of level and in the formations produced.

The Pacific border comprises four belts, ranging from northwest to southeast, which were more or less independent in their geological history :-

I. The Rocky Mountain belt, which includes in British America the Archæan protaxis and the adjoining upturned or mountain region situated mainly to the east of the protaxis, comprises over the United States the mide summit region between the Great Basin and the eastern foothills of the Front or Colorado Range.

II. The Plateau belt, or that of the Great Basin, with its continuation northward in British Columbia over the interior platean west of the Gold Range or Protaxis; and southward into Mexico, along the corresponding plateau region.

III. The Sierra belt, or that of the Sierra chain, including the Sierra Nevada, the Cascade Range, and the high ridges in the same line through British Columbia.

IV. The Coast belt, or that of the Coast Range of California and Oregon, and the Island Range of British Columbia.

The interval between the Sierra and Coast ranges, also, is in some respects entitled to be considered a separate belt; but it is narrow, and its history is mostly involved in that of these ranges.

Only in western North America have the Triassic and Jurassic formations been separately distinguished, and there at but few outcrops. Deposits of the 
Lower and Middle Triassic have rarely been positively identified; only those of the later part have been found on the Atlantic border; and none of either of the periods are yet known to exist on the Gulf border beneath its Cretaceous and Tertiary formations.

\section{ROCKS - EQUIVALENCE, DISTRIBUTION, AND KINDS.}

\section{Triassic of the Atlantic Border, or the Newark Group.}

1. Equivalence. - The Triassic beds of the Atlantic border, according to the most recent authorities, correspond with the upper part of the Trias, or the Keuper and Rhætic of Europe. The evidence is based on the characters of the fossil Plants and Vertebrates, marine Invertebrates being absent.

In 1819, A. Brongniart, on the basis of specimens of fossil fishes of the Connecticut valley (received from E. Hitchcock), which he referred to Palconiscus (Paloothrissum) Freieslebeni of De Blainville (Am. Jour. Sc., iii., 1821, and vi., 1823, with figures on a plate), made the age of the beds Middle Permian. In 1835 , E. Hitchcock added to the evidence from the fossil fishes additional facts from the bones of a Saurian discovered at East Windsor, Conn., in 1820, and pronounced the age that of the New Red Sandstone, - a term that then covered both the Permian and Trias. In 1842, William B. Rogers, after a study of the coal-plants from Virginia beds, referred the fossils to the bottom of the Oölyte, and in 1854 to the base of the Jurassic. In 1855, E. Hitchcock, Jr., concluded, from the presence, in the beds in Massachusetts, of a Fern of the genus Clathropteris, that the age of the Connecticut River New Red Sandstone was that of the Upper Trias and Lower Iias. In 1856, William C. Redfield advocated the equivalency of the beds with the Lias and Oölyte on the basis of the fossil fishes; and at the same time he proposed the name Newark Group (from Newark, N.J.) for all the Triassic deposits of the Atlantic border. More recently the evidence from the fossil plants has been discussed, and the reference of the beds to the Upper Triassic sustained by Newberry, Fontaine, and Ward in this country, and by Stur and others abroad. The Vertebrate fossils lead to the same conclusion.

2. Distribution. - The Triassic beds of the Atlantic border occur in long, narrow independent areas, which are east of and closely parallel to the Appalachian protaxis, as shown on the map, page 412. They lie in troughs or basins over this border region of upturned Archæan, Cambrian, and some later Paleozoic rocks. Over the region sontheast of New England these later rocks comprise only the Lower Silurian. But in Nora Scotia, the beds rest on the upturned Carboniferous, Subcarboniferous, and Devonian; and in New England, probably on Devonian or Upper Silurian. The areas are nearly parallel in direction to the mountain ranges to the west of them.

The most important of these areas are: the Acadian, of Nova Scotia, 120 miles long; that of the Connecticut valley, extending north and south along the Connecticut valley through Massachusetts and Connecticut, 110 miles long and mostly about 20 wide; the Palisade belt, extending from the Palisales on the west side of the Hudson through New Jersey, Maryland, and Pennsylvania to Orange County, Va., parallel with the Appalachians, 350 miles long and mostly 10 to 30 miles wide; the Richmond belt, west of Richmond, 
Ta., 35 miles long; the Pittsylvania area, farther west in Virginia, 100 miles long, and 40 of the 100 in North Carolina, where it is called the Dan River area; the Deep River, in North Carolina, east of the Dan River, 145 miles long, the last 30 of them separated by five or six miles from the rest, and distinguished as the Wadesboro area.

Leaving out of consideration the Nova Scotia belt, the areas may be viewed as lying in two ranges, an eastern and a western, - the Eastern including the Connecticut valley, Richmond, and Deep River areas; the Western, the Palisade, and the Pittsylvania (and Dan River) areas, with the small intervening Buckingham area.

The following is a list of the areas :-

(1) The Acadian area, along the west margin of Nova Scotia (or the northeast border of the Bay of Fundy), having a course nearly northeast to the south, but with much easting to the north; and bending to east and west along the Minas Basin (its north side).

(2) The Connecticut valley belt, from northern Massachusetts to New Haven Bay, this bay being the southern termination of the valley.

(3) The Southbury belt, 15 miles west of the Connecticut valley in Connecticut, only 8 miles long and $2 \frac{1}{4}$ wide.

(4) The Palisade area, commencing near Haverstraw on the Hudson, 30 miles wide in New Jersey, 12 on the Susquehanna, and 6 to 8 on the Potomac ; and including a small area in Orange, Va., which was probably separated by erosion.

(5) The Buckingham area, farther south, on James River, 18 miles long and 2 wide.

(6) The Richmond area.

(7) A small Hanover area, a few miles north of the Richmond, but probably a former part of the Richmond.

(8) The Cumberland area, 30 miles west of the Richmond and mainly in Cumberland County, 22 miles long.

(9) The Pittsylvania area, including the Dan River of North Carolina.

(10) The Deep River area of North Carolina, commencing at Oxford in Granville County, passing west of Raleigh, and having a width of 18 miles.

A Triassic area has been supposed to exist on Prince Edward Island, in the Bay of St. Lawrence, and is so described by Dawson in his Acadian Geology. According to R. W. Ells, the beds are part of the Permian of the island, with which they are conformable (1883-84). Bain has since claimed as Triassic the upper 50 feet, horizontal in position, occurring on the north shores of the island, near New London (1885); and Dawson states in an appendix to his work (dated 1891), that the strongest evidence of Triassic age for this part of the sandstone is the presence in it of Bathygnathus borealis of Leidy. Marsh, in a private note to the author, confirms this view of Dawson, stating that Bathygnathus, a carnivorous Dinosaur, is very much like the Triassic forms of England, Germany, Asia, and Africa.

3. Rocks. - The rocks are mostly: granitic sandstones (a much better name for them than the meaningless term arkose); conglomerates, varying from fine pebble beds to those consisting chiefly of cobble stones and larger rounded masses; sandy shales; less commonly fine black carbonaceous shales; occasionally thin beds of impure limestone; anc, in some localities, bituminous coal in thick beds along with carbonaceous shales.

In general, the formation is well stratified; but the strata, when followed laterally, vary much in thickness and coarseness. In some places borings 
have gone down 3000 feet through sandstone alone; and seldom are the intercalated beds of limestone and shale of sufficient extent to mark a horizon and serve as the means of measuring the thickness. At New Haven, Conn., an artesian boring was carried down 4000 feet through porous sandstone without finding variation enough in texture to get a supply of water.

The layers often have a cross-bedded structure and other evidences of strong currents. In many regions they are here and there covered with ripple-marks, mud-cracks, raindrop impressions, footprints of Reptiles and Amphibians; the fine shales with tracks of Insects and Crustaceans - facts which indicate temporary exposures above the water level of great sand-flats and mud-llats. A slab from Greenfield, Mass., a dozen feet long, now in the Yale Nuseum, is covered throughout with deep impressions of raindrops the work of a short large-drop shower. The impressions are a little elliptical so as to register the direction of the accompanying wind. Besides this, two lines of large three-toed tracks cross the slab, and those of the longer line are dotted by the raindrops, showing that a biped reptile had passed that way before the shower began.

The material of the sandstones and conglomerates, exclusive of the calcareous, is almost solely such as would be afforded by the wear of granite, gneiss, mica schist, syenyte, and other crystalline rocks of the neighboring hills or mountains; and the amount of mica and other ingredients and kinds of rock material vary with the kind of rock in the adjacent hills. Several examples of this are mentioned by Emerson, Fontaine, and others. The feldspar is usually fresh and undecomposed, and well mixed with the quartz, showing no evidence of any assortment of the ingredients by beach action. The ingredients are often in proportions fitted to make granite again by subjection to metamorphic action. Mica is sparingly present except where mica schists exist on the border of the areas. There are also limestone conglomerates in regions where Cambrian or Lower Silurian rocks exist along the border; and occasionally stones of a quartzose conglomerate derived from a Cambrian sandstone or quartzyte.

The coarsest conglomerates consist of stones of all sizes up to five feet across, and usually occur along the eastern or western border of an area. In Montague, Mass., east of the Connecticut, on the eastern border of the area, and in Branford, Conn., some of the bowlders are three feet across. Similar cases exist on the west border of the western area in New Jersey, Virginia, and North Carolina. In the Pittsylvania belt, the larger stones are four to five feet in diameter. Near Point of Rocks, Md., the stones are of Paleozoic limestone, and some are two feet through; the finer variety of this limestone conglomerate is the "Potomac pudding-stone marble."

The Coal-measures in the Richmond basin and Virginia, and in North Carolina, consist of beds of shale and sandstone with thick beds of good coal. In the Richmond area there are two to eight coal-beds, and the main bed is 10 to 40 feet thick; but they include some thin dividing layers of sandstone and shale. The Coal-measures are situated within 250 to 500 feet of the bottom 
of the formation; and the same is true of those of the Deep River and Dan River areas in North Carolina. The Connecticut valley area has some carbonaceous shale, but no coal.

On the Virginia belts and the Richmond coal areas, see Fontaine in Am. Jour. Sc., 1879 , and U.S.G.S., Memoir, 4to, 1883; on those of North Carolina, Emmons's Geol. Rep. of North Carolina, 18äb, and Kerr's Rep., 1875. Also, for a general review of the Triassic, the Correlation report of I. C. Russell, Bull. U. S. G. S., No. 85, 1892, which contains colored maps of the areas.

Besides the sandstones and other rocks of aqueous origin, there are in the several areas rocks of igneous origin. These are described beyond (page $800)$.

The thickness of the Triassic formation in the several areas is determined with difficulty, not only on account of the want of continuous easily recognized strata to mark horizons, but also because of the many concealed faults and the upturned condition of the beds, as explained beyond. The maximum may be, in some of the areas, 8000 to 10,000 feet. In the Richmond area, Virginia, the thickness has been made 2000 to 2500 feet. In North Carolina, in the Deep River area, according to Emmons, it is 3000 feet. Much larger estimates have been made.

On the southern border of New York, in Rockland County, at Ramapo, near the northwestern limit of the Triassic beds, the thickness, down to the underlying gneiss, was found in a boring to be $120^{\prime}$ (J. C. Smock).

The large estimates are obtained by calculation from the dip, and the width at right angles to the dip. By this very unsatisfactory method a thickness of $12,000^{\prime}$ to $25,000^{\prime}$ has been obtained. Kerr thus arrived at a thickness of $10,000^{\prime}$ for the beds of the Dan River area, North Carolina, and 25,000' for those of the Deep River area. In New Jersey and Pennsylvania, according to B. S. Lyman, there is a long longitudinal fault of $14,000^{\prime}$.

4. Sources of the material and conditions of accumulation. - So large a number of independent belts of sandstone ranging along for 1000 miles is an unusual feature for a Continental border. It is not possible that the sandstone formation was made during a general submergence, and in a great common body of water; for there is nothing marine about it in fossils or in structure; and fresh waters for the work could not have spread over the region of hills, ridges, and valleys, under any probable circumstances. Moreover, the Nova Scotia belt occupies the same Acadian trough which received deposits through Paleozoic time, even to the Carboniferous and Permian; and the Connecticut valley belt is in the same trough which had Silurian and Devonian beds laid down in its northern half, and possibly also in its southern half, for in this part the Triassic formation conceals what is below. Further, the parallelism of the belts to the mountain ranges of the Continental border is close, the Palisade trough taking faithfully their bends, from south by west on the Hudson River, to west-southwest in Pennsylvania (see map, page 731), and southwest in Virginia, as if occupying orographic valleys of the Appalachian Mountain chain. The facts show that the courses of the 
areas were determined not mainly by fluvial action, nor by a great sulmergence, but by the topography of the Continental border as it existed immediately after the Appalachian upturning.

It is plain that some of the areas were marsh regions along the courses of streams and lakes; and two or more may have been estuaries, like the Chesapeake or Delaware Bay, receiving the tides during part or all of their history. But it is also proved by the deposits that the broad streams sometimes were great streams, making conglomerates where the water had great velocity, sandstones in gentler currents, shales in the sluggish waters, and beds of vegetable debris, for a coal-bed, where the conditions were those of a great marsh. As in other fluvial regions, conglomerate-beds, sand-beds, and mud-beds may have been forming simultaneously at the same horizon in different portions of an area. Moreover, under fluvial action, different kinds of deposits in flowing waters would be lengthened out in the direction of the flow, making unlike formations, longitudinal with the stream, of parallel position and history, looking, to one traversing the surface, or studying the exposed beds, like consecutive formations. If a region were slowly subsiding so that the beds could thicken, there would probably be, in a portion having like velocity throughout, four or five rather prominent kinds of deposits, - one made along the bed of the stream; two others along the banks; two others beyond the banks on either side; and each of these would have their local belts. These and other sources of diversity existed in the Triassic areas.

Where were the sources, and what the directions, of the rivers over the higher lands from New York to North Carolina, which supplied so generally granitic sediments instead of quartzose sands and fine clays, are questions not easily answered.

The recently made Appalachian Mountains stood along the western side of the Archran protaxis, and these Triassic formations on the east side. It would seem to be a necessary consequence that the Appalachians should have sent off streams eastward to the Atlantic and loaded the waters with Appalachian sands and other detritus. But it is proved, by the prevailing granitic character of the material of the sandstones, that little if any of these sediments reached the Triassic troughs, either from the Appalachian Mountains of Virginia and Pennsylvania, or from the plateau region of Pennsylvania and the Catskills - the present sources of the murl, sand, and water of the Delaware, Chesapeake, and other streams; that the Archrean protaxis was so high and continuous as to wholly prerent drainage from the west and northwest; that this range of crystalline rocks and the ridges of more or less crystalline Cambro-Silurian, of the region in the ricinity, supplied the streams with sediments for transportation to the Triassic areas. The drainage from the Appalachian Mountains must have flowed westrard or southwestward.

The river or waters of the time flowing southward just west of the site of New Iork City - where now flow's the Hudson - were 25 miles wide, as the breadth of the Triassic of the region shows; and they had sources evidently 
in the nearer mountains to the north, west, and south. These sources were probably in the Highlands and other ridges of crystalline rocks; the waters and sediment certainly did not come from the Catskill Mountains to the north, nor from the Alleghanies to the west. The outlet of the Hudson River of the period to the Atlantic is indicated, apparently, by the submerged Hudson River channel on the map on page 18.

The barrier along the sea margin that kept out salt water and its living species was evidently the remains of the old geanticline referred to on page 387.

The coarse conglomerate at or near the top of the sandstone series, observed at many points on the east margin of the Connecticut valley area, and on the west or inmer margin of that of Maryland, Virginia, and North Carolina, in which many of the rounded stones are one to three feet in diameter, and also the similar large stones, or groups of stones, occurring isolated in some of the finer sandstones, are remarkable features of the formation. Rivers cannot transport so large bowlders, unless down rapid slopes. The tide in an estuary opening seaward only moves quietly, and usually makes muddy or sandy shores. Igneous eruptions are never attended by ejections of rounded stones or bowlders. The stones, excepting those of Triassic sandstone and trap, show by their kinds that they were from the adjoining ridges or hills. Moving ice would carry them; but the Blue Ridge and other adjoining ridges at the present time are far from high enough to have glaciers about their summits. The question arises: Were they high enough then? Was there, at or near the close of the period, an epoch of unusual cold having icy winters and covering the adjoining ridges with glaciers that carried bowlders, and made streams that bore floating ice laden with stones out over the river or estuary waters?

5. Subsidence in progress during the deposition. - Since a thickness of some thousands of feet was acquired in the several areas by the strata, and the beds often bear evidence in their ripple-marks, mud-cracks, and footprints of shallow-water origin, each of the troughs of valleys must have been undergoing, during the slow accumulation, a concurrent subsidence of as many thousands of feet. On the upturning of the beds and other orographic phenomena see page 798 .

Economical products. - The coal-beds, already described, are a prominent part of these products. Veins containing copper ores occur in Connecticut, New Jersey, Pennsylvania, which have been worked; but none are now producing ore. The copper ores are chiefly chalcocite and bornite, with occasionally native copper. One mass of native copper found in the drift north of New Haven, Conn., weighs nearly 200 pounds. A copper mine at Bristol, Conn., which was for a while productive, is situated on the western border of the Triassic, in the crystalline rocks outside of the sandstune area, but belongs to a fissure of the Triassic series. Barite often accompanies the ore, and sometimes is the chief mineral of the vein, and occasionally occurs in crystals weighing over 100 pounds. A vein in Cheshire, Conn., now exhausted, yielded a large amount of the mineral for the adulteration of white lead, and for calsomining and other purposes.

The beds of sandstone afford much rock for building purposes. The rock so used is 
often called brownstone. The material of many of the "brownstone fronts" of New York and other eastern cities is mostly from this formation. The Potomac conglomerate marble is used as an ornamental stone, and columns of it stand in the Capitol at Washington.

\section{The Triassic and Jurassic of the Western Interior and Pacific Border Regions.}

The Triassic and Jurassic formations of the Western Interior and of the Pacific border have a wide distribution, and, to some extent, distinguishable limits. The former consist almost everywhere, in the Interior, of reddish sandstones and marlytes, and are often ealled "Red Beds." They frequently contain gypsum and sometimes salt. Upon the Pacific border the rocks of this period are chiefly slates, with occasional sandstones, and much limestone.

The Jurassic beds are usually of lighter shades of color, and are in most regions partly or chiefly calcareous, and the limestone is often cherty. A large part of the Triassic formation is without fossils, excepting occasional traces of plants; but the Jurassic is often fossiliferous, though seldom prolific in species.

\section{Triassic.}

Over the Continental Interior, the Triassic formation is exposed to view in northern Texas, adjoining Indian Territory and western Kansas. The beds probably underlie the Cretaceous beds farther northward, but no outcrops occur in that direction except in mountainous regions to the west and northwest. They exist about the Black Hills of Dakota, and cover large areas along the Summit Region of the Rocky Mountains in New Mexico, Colorado, and $\mathrm{C}$ tah, east of the western limit of the Wasatch Range, and also in Wyoming, Montana, and Idaho. In British America, east of the Archæan protaxis, they have been observed on Peace and Pine rivers, beyond $55^{\circ} \mathrm{N}$. and between $122^{\circ}$ and $125 \frac{1}{2}^{\circ} \mathrm{W}$; and also on Liard River, near $59^{\circ} \mathrm{N}$. Beds in southeastern Idaho, near Soda Springs, have been referred to the Lower Trias (Mojsisovics, Hyatt); but the absence or nondiscovery of fossils leaves the age of the beds of the Rocky Mountains and Interior Continental regions generally undetermined.

West of the meridian of the Wasatch Mountains, and of the Rocky Mountain protaxis in British America, over the Great Basin plateau, and its continuation in the plateau region of British Columbia, the Trias appears to have a wide range. In the United States it is confined to the west side of the plateau or Great Basin beyond $117 \frac{1}{2}^{\circ} \mathrm{W}$., on the 40 th parallel. In the west Humboldt region, according to King, 15,000 feet of beds, partly Middle Trias, underlie 4,000 feet or more of Jurassic beds. In the plateau region of British Columbia, Triassic areas occur on Nicola Lake ( $50^{\circ} \mathrm{N}, 120 \frac{1}{2}^{\circ} \mathrm{W}$.) and Stikine River ( $57^{\circ} \mathrm{N} ., 137 \frac{1}{2}^{\circ} \mathrm{W}$.).

Farther west, in the Sierra belt, beds of the Upper Triassic occur near the summit of the Sierra Nevada in Plumas County, Cal., as first identified 
by Gabb from fossils discovered during the Whitney Geological Survey (1864), and later studied over the Taylorville region by Diller and Hyatt (1892). The thickness of the Triassic in this region is about 4800 feet, and of the overlying Jurassic sandstones, limestones, and tufa about 2000 feet. The formation is continued northwestward into the Klamath Mountains. Whether it exists in the Cascade Range still farther north is unknown, as these mountains are mostly under recent volcanic rocks.

The Island belt in British Columbia contains areas of Upper Triassic on Vancouver Island, Queen Charlotte Islands, in the Straits of Georgia; and beyond they occur at Wrangel Bay, Alaska.

Upper Triassic beds occur also in Mexico, in the states of Sonora (Newberry, 1876), Puebla and Oasaca (Aguilera and Ordonez, 1893). They are found also in Honduras (Newberry, 1888).

In the Black Hills, the Triassic beds, or the "Red Beds" supposed to be Triassic, come to the surface, along with the Jurassic, from beneath the Cretacenus beds of the Continental Interior, as first shown by Meek $(1858,1860)$. They are mainly arenaceous clays, unfossiliferous, $300^{\prime}$ to $400^{\prime}$ thick, with $15^{\prime}$ to $30^{\prime}$ of impure limestone below the middle, and with gypsum in the upper half. In the foot hills east of the Front Range in Colorado, the Triassic and Jurassic often appear overlying the Archæan, or the Paleozoic, $600^{\prime}$ to $1000^{\prime}$ of the former, to $200^{\prime}$ or $300^{\prime}$ of the latter. In these foot hills, to the westward, within 30 miles of the line of New Mexico, and for 50 miles beyond, as stated by Stevenson, the Cretaceous rests on the Carboniferous over Archæan, the Triassic not extending so far west.

Bordering the Laramie Plains, in Wyoming, these formations may be seen over Archæan; the gypsum beds of the Triassic are sometimes over $20^{\prime}$ thick.

In Idaho, north of the Wasatch, between the Wyoming and Portneuf ranges (110 ${ }_{2}^{\circ}$ $112^{\circ}$ W.), upturned Triassic and Jurassic beds, according to A.C. Peale (1879), enter largely into the structure of the ridges; and these formations in the Blackfoot Basin, where the Triassic is about $4000^{\prime}$ thick and the Jurassic $1500^{\prime}$ (more than half limestones), afforded the fossils described by C. A. White in 1879 (page 758). In the Wasatch there are $1000^{\prime}$ to $1200^{\prime}$ of Trias overlaid by $1600^{\prime}$ to $1800^{\prime}$ of Jurassic beds (King). In the High Plateaus to the south, north of the Colorado Cañon, the "Vermilion Cliffs" of Powell, $1000^{\prime}$ to $1500^{\prime}$ high, which extend for 100 miles from Hurricane fault to Paria, and the "Shinarump Cliffs" below, are Triassic, while the overlying "White Cliff group," 2000 ' or more thick, consisting of white sandstone and calcareous beds, and the "Flaming Gorge group " in Utah, are referred with some doubt to the Jurassic. The beds are continued southward in plateaus of Arizona and New Mexico.

The Trias of western Nevada consists, according to King, of a lower Koipato group of siliceous and argillaceous beds, 5000', and above this, great limestone strata and alternating quartzyte of the Star Peak groups, 10,000\%. The Trias of this region may have once been connected with that of the Sierra Nevada just west.

Upon the northern end of the Sierra Nevada, near Taylorville, Diller measured nearly $5000^{\prime}$ of Upper Trias. It lies apparently unconformably upon both sides between the Jurassic and Carboniferous. It consists below of $200^{\prime}$ of slates overlaid by $140^{\prime}$ of limestone, and above of over $4000^{\prime}$ of sandstones and slates. In the two lower members fossils are often abundant, but in the upper slates they are rare and chiefly land plants. The limestone is most persistent, and has been recognized by its fossils near Pit River and elsewhere in the Klamath Mountains, and even as far north as Siskiyou County, near the Oregon line. The presence in that region of large masses of eruptive material, often fossiliferous, shors 
that volcanic forces were vigorously active, not only cluring a portion of the later Trias, but also in the earlier Carboniferous and later Jurassic.

The Trias was first recognized as existing probably in Sonora, Mexico, by A. Rémond (J. D. Whitney, Am. Jour. Sc., 1866). He speaks of it as consisting of sandstones and conglomerates with coal-bearing clay shales. He adds that the metamorphic slates of the Altar and Magdalena districts, which include the richest gold placers of Sonora, may possibly be of Triassic age, but that it is also possible that they are Jurassic, as they "resemble rather the Jurassic gold-bearing slates of the Sierra Nevada."

\section{Jurassic.}

Jurassic beds are found at the west base of the Black Hills in Dakota, where the rock is limestone with intercalated marls. The thickness, 200 feet, increases to 600 feet 40 miles from the Hills (Newton), indicating, as W. O. Crosby implies, less subsidence in the sea-bottom about the Archæan center than at a distance from it. They also come out to view at points along the base of the Laramie Mountains, the Big Horn Mountains, the Wind River, and other mountains in the Rocky chain. They overlie Triassic through much of the Summit Region within the United States, both east of the Great Basin or Plateau belt, and, as has been mentioned, along its western border beyond $117 \frac{1}{2}^{\circ}$. Farther north in the same belt, they have been observed by Diller on the Blue Mountains of Oregon.

The Upper Jurassic in Colorado, Wyoming, and Montana includes the freshwater Atlantosaurus beds of Marsh, from 100 to 300 feet thick, which have afforded, near Morrison and Cañon City in Colorado and elsewhere, the remains of many large Reptiles, teeth and jaws of Marsupial and Oviparous Mammals. The Baptanodon beds of Marsh, when present, are next below. They contain remains of large aquatic Reptiles, besides some marine invertebrate fossils.

The Jurassic beds are found along a large part of the western slope of the Sierra Nevada. The first discoveries were made in Plumas County, on the north slope of Genesee valley, by Clarence King, of the Whitney Survey, in 1863. They were afterward discovered in the auriferous slates of the Mariposa region and identified by fossils (Gabb, 1864; Mreek, 1865).

In the Taylorville region in Plumas County, the Jurassic beds, according to Diller and Hyatt, are found to consist of nearly $1500^{\prime}$ of sandstones, $10^{\prime}$ to $30^{\prime}$ of limestones, and $500^{\prime}$ of tufa. The series represents, as Hyatt has found from the fossils, the Lias and the Lower and Upper Oölyte. The Upper oölyte has also been identified by fossils over a wide range of the western slopes of the Sierra, where the rocks are upturned metamorphic slates, hydromica, mica, and siliceous schist, with sandstone, and in some parts, serpentine, and thin beds of crystalline limestone, besides more coarsely crystalline rocks. The belt of slates - which is in general 20 to 25 miles wide - contains the chief part of the goldbearing veins of quartz, some of which are of great width. Turner describes the Mariposa slates as including much diabase tufa, besides some conglomerates made of siliceous pebbles from the associated rocks (1894).

The most abundant fossil in the Mariposa beds is a species of Aucella (see beyond, page $7(60)$, and hence related beds have been called Aucella beds. The Mariposa rocks were promounced Jurassic by Gabb (1864) and Meek (1865), and recently also by Hyatt. 
The Lias and earlier Oölyte appear to be unrepresented along the Coast region and Plateau belt of British America (G. M. Dawson).

Jurassic beds, related in fossils to those of Taylorville, occur also in the Pit River region on the western and northern borders of the Sacramento valley, with Triassic and Carboniferous below, and are covered unconformably by the Cretaceous; also on the upper waters of Crooked River, in the Blue Mountains of Oregon; and, according to Hyatt, these areas were connected, during the Lias, with that of western Nevada.

Small Jurassic areas are laid down on Castillo's geological map of Mexico, in the states of Sonora, Coahuila, San Luis Potosi, Queretaro, Hidalgo, Puebla, and others near the eastern border of the great central plateau, and also in Colima near the coast. The beds, according to Aguilera and Ordonez (1893), contain Aucellæ, and Ammonites of the genus Perisphinctes, and pass conformably into the overlying Cretaceous.

In the Arctic Regions, the Jurassic (Lias?) has been identified far north on Prince Patrick Island and near the northwest extremity of Bathurst Island, and on Exmouth Island and other places in the vicinity. At the locality on Bathurst Island, a vertebra of a Saurian, Arctosaumes Osborni, has been found ; and on Exmouth Island, remains of an Ichthyosaurus.

The Jura-Trias regions of part of Utah and Nevada are mapped (in colors) in King's 40th Parallel Report (1878); and of Idaho and part of Utah, by Peale, Endlich, and St. John, in the Hayden Expedition Report for 1878; and of part of California by Diller (1893) in the Atlas of the U.S. Geological Surrey, on the sheets of the Lassen Peak district.

$1156-1160$.

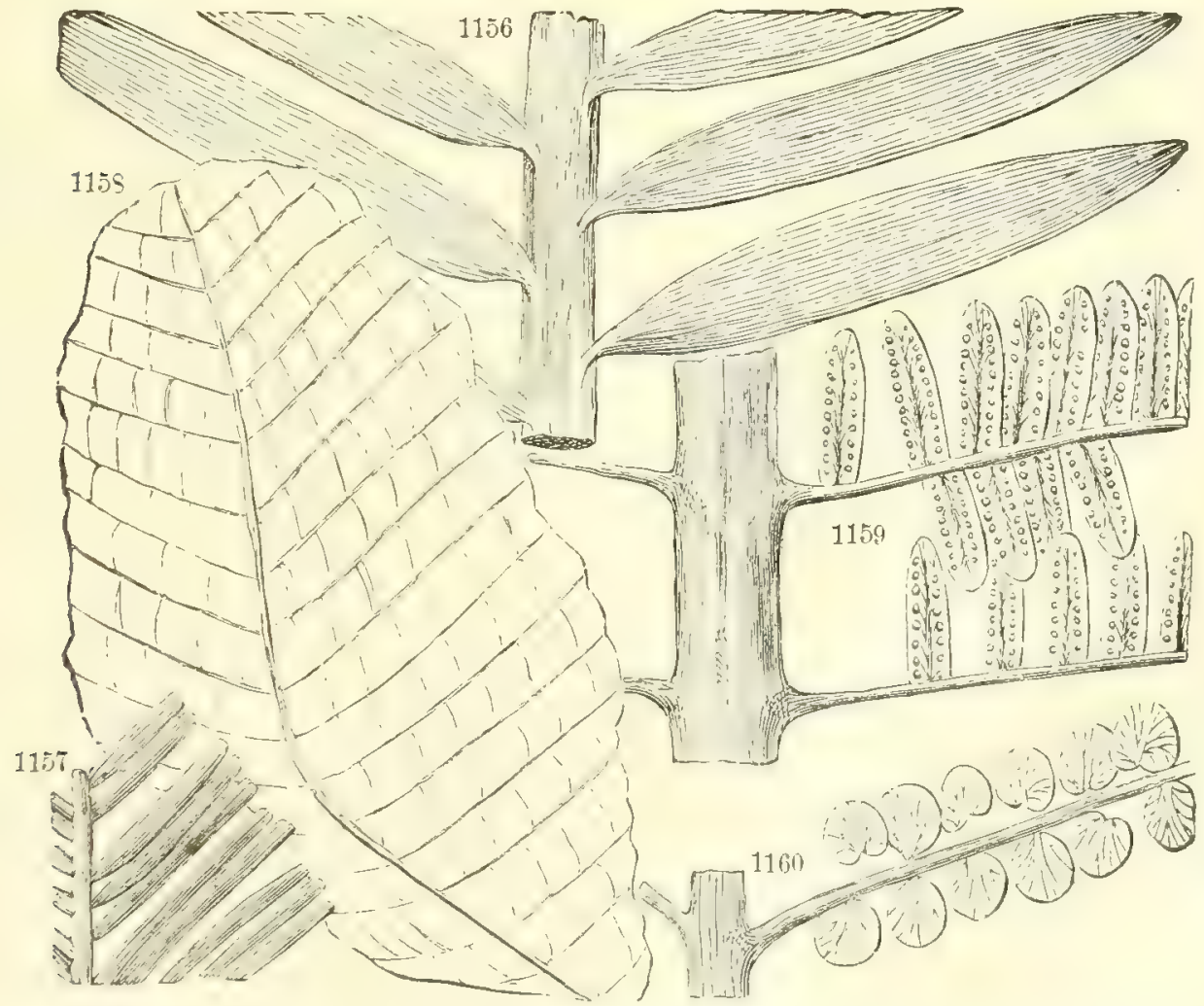

Fig. 1156. Podnzamites Emmonsi; 1157, Pterophyllum Riegeri; 1158, Clathropteris rectiuscula; 1159, Oligocarpia (Pecopteris) robustior, part of a frond in fructification; 1160, Tæniopteris linnæifolia. Figs. 11561159, E. Emmons; 1160, E. Hitchcock, Jr. 
LIFE.

\section{Triassic of the Atlantic Border.}

Plants. - The vegetation of the Triassic was characterized not by Sigillarids and Lepidodendrids, like that of the Carbonic era, but by Cycads, Conifers, Ferns, and Equiseta.

As the Cycads were a prominent feature of the forests in both the Triassic and Jurassic periods, a figure of a common East India species, Cycas circinalis $\left(\times \frac{1}{12} \overline{0}\right)$ is given on page 434. Its relation to Conifers, both groups being Gymnosperms, notwithstanding its palm-like foliage, has already been explained. Portions of leaves of two species related somewhat to the modern Zamia are represented in Figs. 1156 and 1157.

Conifers existed of the genera Voltzia (differing little from Walchia of the Permian, page 705), Baiera, and Arancarites. Stems, leaves, cones, and trunks of such trees are not uncommon. Ferns were numerous, of the genera Pecopteris (Fig. 1159), Tceniopteris (Fig. 1160), Clathropteris (Fig. 1158), and others related. Some of the Equiseta (Calamites) had a breadth of stem of four inches or more.

Axmids. - The Triassic beds of the Atlantic border have afforded no

\section{$1161-1163$}
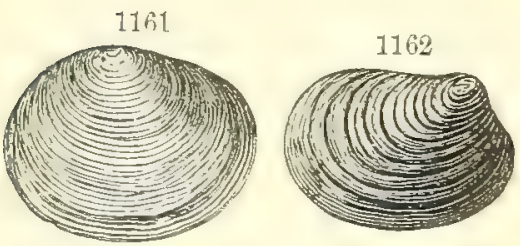

1163

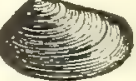

Figs. 1161-1168, Estheria ovata. Fig. 1161, Lyell; 1162, E. Emmons: 1168, L. Sanford. marine species of any kind; all are either of fresh or brackish waters, or else terrestrial.

1. Crustaceans and Insects. - The Crustaceans observed are mostly Ostracoids. The little shells (Figs. 1161-1163) are abundant in some beds of shale.

The presence of Insects is known from their tracks and from the discovery of the larves of one species. These larves (Fig. 1164) were found by E. Hitchcock rather abundantly in shales at Turner's Falls, and have since

$1164-1169$.
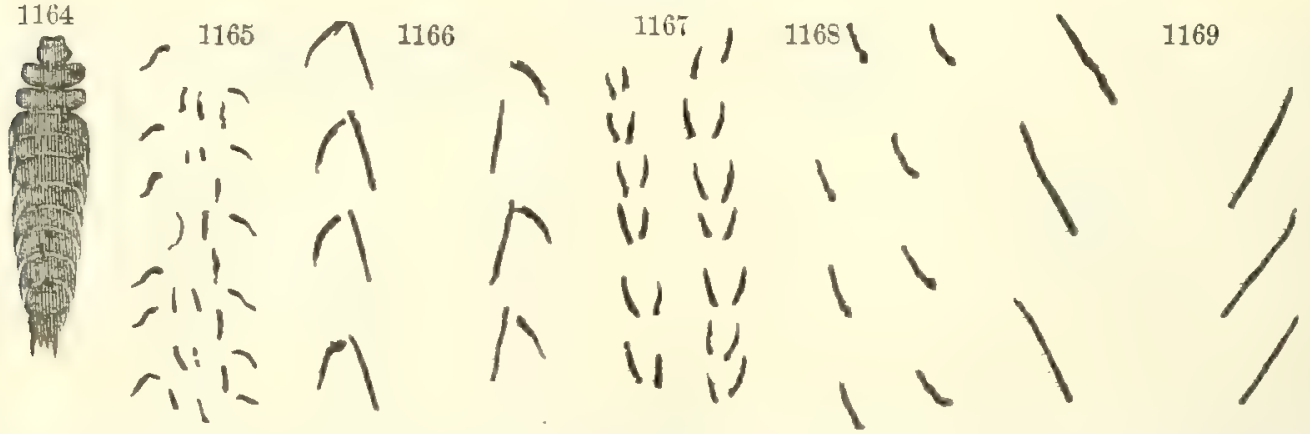

INsECTs, - Fig. 1164, Insect larve, Mormolucoides articulatus; 1165-1167, tracks of Insects; 1168, 1169, tracks of Crustaceans (?). Fig. 1164, from Scudder; 1165-1169, E. Hitchcock.

been obtained at Montague, and at Horse Race in Gill, Mass. The Insect was a Neuropter. Figs 1165 to 1167 are of tracks from the Connecticut 
valley beds, referred by $\mathrm{E}$. Hitcheock to Insects, and the others $(1168,1169)$ are regarded by him as made by Crustaceans. Nearly 30 species of these delicate tracks are described by Hitcheock.

2. Fishes. - The Fishes of the era were Ganoids and Sharks, but only remains of Ganoids have been found in the American rocks; one of them, from black shales at Durham, Conn., is represented, reduced, in figure 1170. The largest species found is Diplurus longicaudatus Newb., about three feet long. Unlike Paleozoic Ganoids, the Triassic species are not all heterocercal; many have the tails partly, or not at all, vertebrated; and this is the last period in which the old Paleozoic characteristic appeared. Thus, as Agassiz first observed, the progress of the ages was marked in the tails of the fishes.

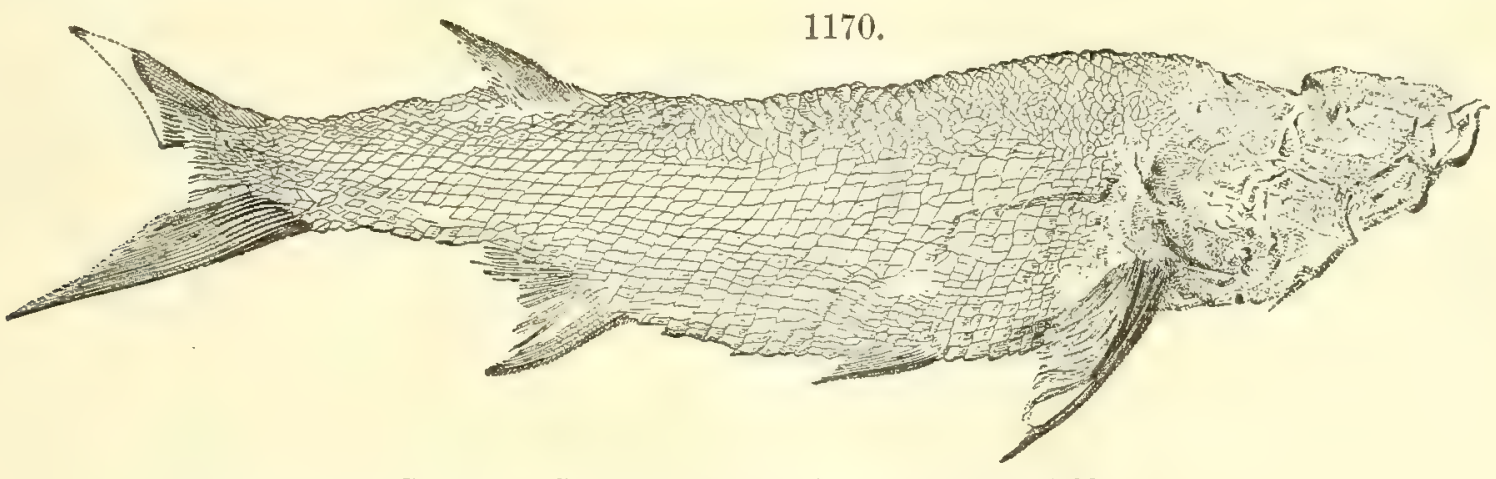

GANoI, - Catopterus gracilis $\left(\times \frac{1}{2}\right)$. J. H. Redfield.

3. Amphibians. - Portions of large crania have been found in black shale in Chatham County, N.C., and in a literal "bone-bed" at Phonixville, Pa. With the latter were teeth two inches long, of a species named Eupelor durus by Cope. The figures of footprints annexed, 1171, $1171 \alpha$, and 1172, $1172 \alpha$ (half to two thirds the natural size), are the fore and hind feet of probably two Amphibians (Hitcheock). The tracks were from the Connecticut valley beds.

4. Reptiles. - The Reptiles pertain to the two grand divisions of Dinosaurs and Crocodilians.

Dinosaurs. - The Dinosaurs are mostly of large size, and were so named by Owen, from $\delta \epsilon \iota v$ s, terrible, and ravpos, lizard. They are more or less bird-like in some characteristics ; these all having (1) the posterior limbs the stouter, as in Fig. 1179, page 753, and sometimes these are the only locomotive limbs, the Reptiles in that case being bipeds in walking, like birds; (2) the bones of the limbs, especially the anterior, often hollow; and in some, the vertebræ of the neck very cellular and light; (3) of the pelvic bones the ischium (is, Fig. 1179) is a long and often slender bone 1171-1172.

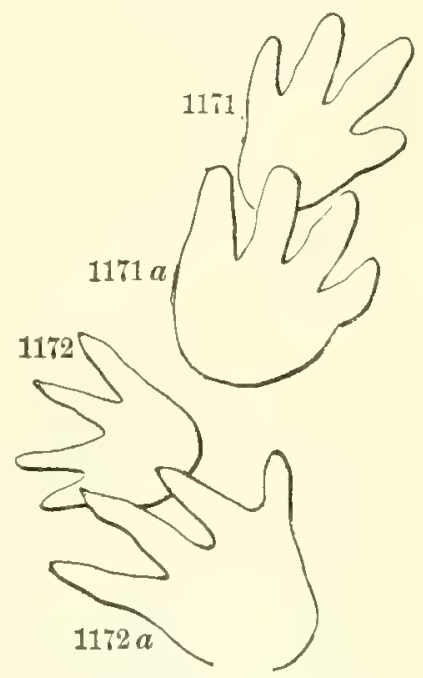

Amphibians.-Fig. 1171, $1171 a$ $\left(\times \frac{1}{2}\right)$, Amsopus Deweyanus ; $1172,1172 a, \mathbf{A}$. gracilis ( $\times$ ? $)$. E. Hitcheock. projecting backward, and the pubes also are long. Many herbivorous Dinosaurs that were not biped in locomotion used their strong hind limbs for 
holding their bodies raised against trees or other objects; and hence there was great convenience in having the bones of the anterior part of the body cellular and thereby light.

$1173-1177$.

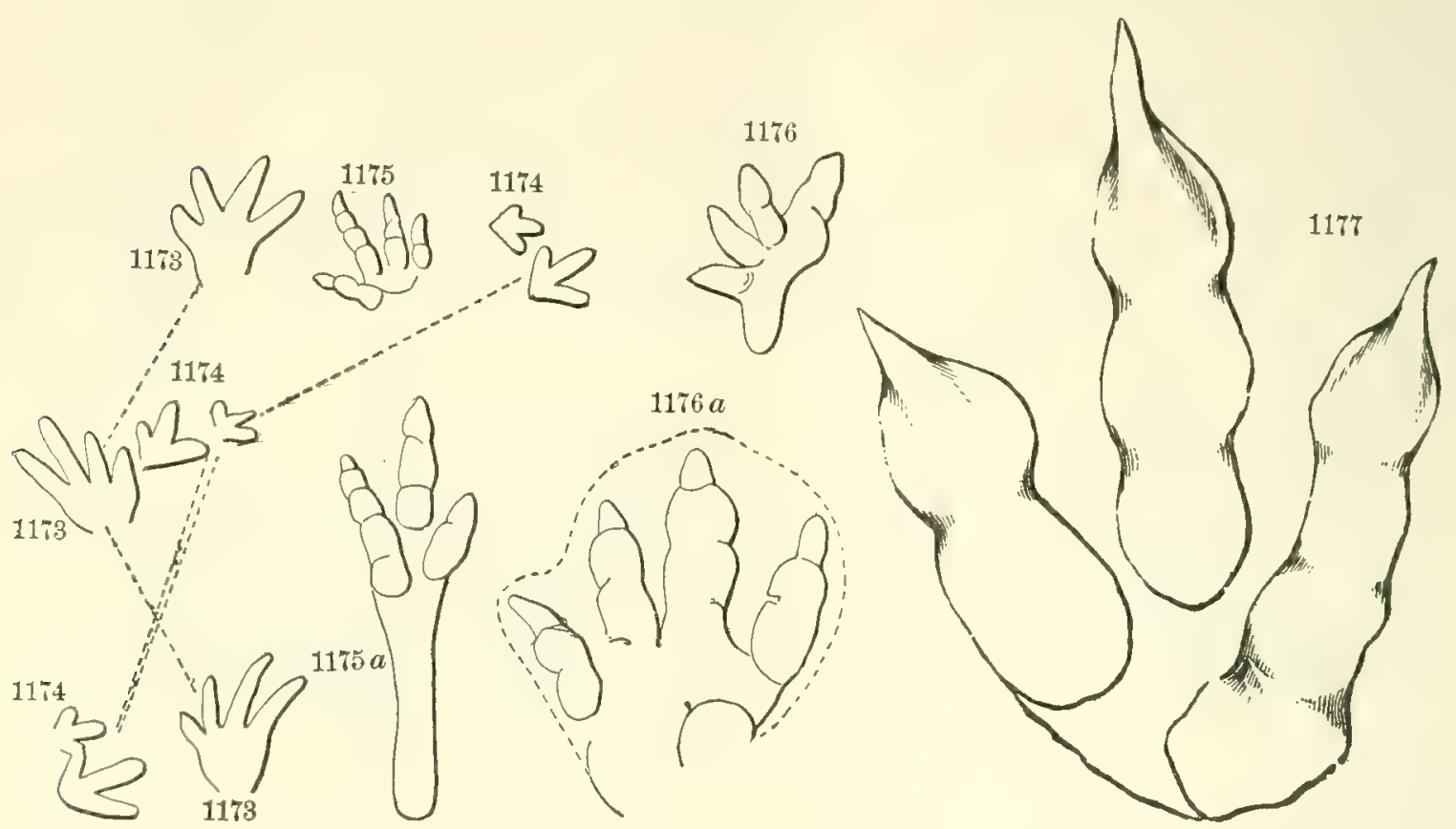

Dinosadrians. -Fig. 1173, Macropterna divaricans $\left(\times \frac{1}{6}\right) ; 1174$, Apatichnus bellus $\left(\times \frac{1}{2}\right)$; 1175, Anomopus scambus, fore foot $\left(\times \frac{1}{6}\right) ; 1175 a$, hind foot of same; 1176, Otozoum Moodii, fore foot; $1176 a$, hind foot of same (both $\left.\times \frac{1}{18}\right)$; 1177 , Brontozoum giganteum $\left(\times \frac{1}{6}\right)$. All from Hitchcock.

The track represented in Fig. 1177 occurs from 14 to 18 inches in length, and was made by one of the biped Dinosaurs; it is the Brontozoum giganteum

1178.

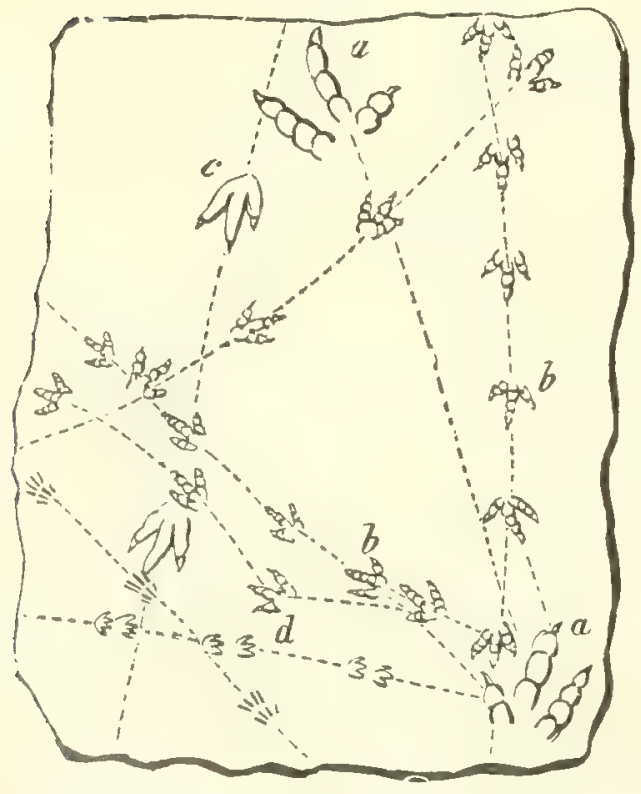

Slab of sandstone, with footprints. Hitcheock. of Hitcheock. The tracks 1175, $1175 a$, also much reduced, are of another bird-like Dinosaur, but one that had three-toed feet behind $(1175 a)$, and a small four-fingered hand in front that was only occasionally brought to the ground. The track $1176 a$, 20 inches long natural size, is of the hind foot of an Otozoum, a gigantic Dinosaur that usually walked erect, biped-like; its much smaller fore feet (1176) served as hands, for they were seldom brought to the ground. The stride of the Otozoum was a yard in length. The other lines of tracks, 1173 and 1174 , are of species that walked on all fours.

These tracks indicate three kinds of Dinosaurs: (1) bipeds with the hind feet 3-toed; (2) bipeds with the hind feet fourtoed; (3) quadrupeds walking on all fours.

A slab of sandstone, with its footprints in several series, is represented in 
Fig. 1178; it is reduced to $\frac{1}{30}$ the natural size, excepting the two tracks lettered $a$, which are enlarged views of the tracks of the line $b$. No tracks of fore feet have been found with them, and hence it is thought possible that some are tracks of Birds. But no positive evidence of Birds has been found.

The collection of Amherst College, and that of Yale at New Haven, contain each several thousands of tracks from the Connecticut valley; a fact that gives some idea of the abundance of life on the continent in Triassic time. Other estuaries and valleys besides those now occupied by Triassic beds were probably equally populous. Twenty-one consecutive tracks of the Otozoum were exposed to view in 1874, at one of the quarries at Portland, Conn.

Bones of the Dinosaurian Reptiles were first found in 1818, in the sandstone of East Windsor, Conn., and near Springfield, Mass.; and the foot of one 1179. from the latter locality was figured in 1865 by Hitcheock, who (in allusion to the length of the bones) named the species Megadactylus polyzelus; and in 1870 the Reptile was described and pronounced a Dinosaur by Cope. Remains have since been discovered in North Carolina, Pennsylvania, and Prince Edward Island, and again in Connecticut. Near Manchester, Conn., large portions of four skeletons of the same genus, and of another, Ammosaurus, have been obtained by Marsh. Fig. 1179 represents a restoration published by him in 1893 . The name Megadactylus being preoccupied, it is changed by him to Anchisaurus. It was one of the carnivorous Dinosaurs that left tracks on the sandflats and mudflats of the Connecticut valley estuary.

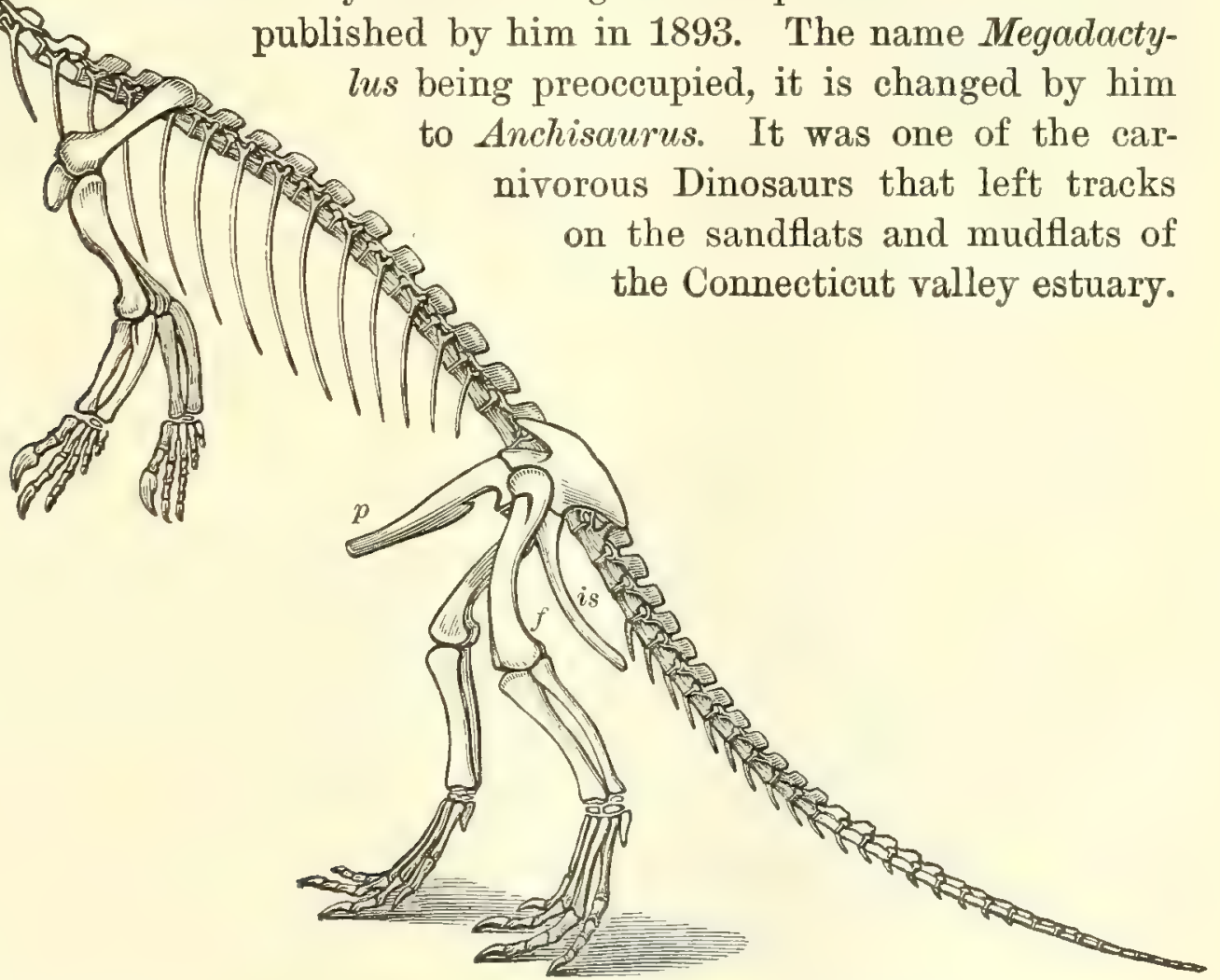

Fig. 1179, restoration of Anchisaurus colurus Marsh ( $\left.\times \frac{1}{12}\right) . \quad p$, pubis ; is, ischium ; $f$, femur.

Other Dinosaurs are: Clepsysaurus Pennsylvanicus of Lea, from Phœnixville, Pa., Fig. 1181; Buthygnathus borealis of Leidy, from Prince Edward Island, DANA'S MANUAL - 48 
a tooth of which, from a skull described and figured by him, is represented

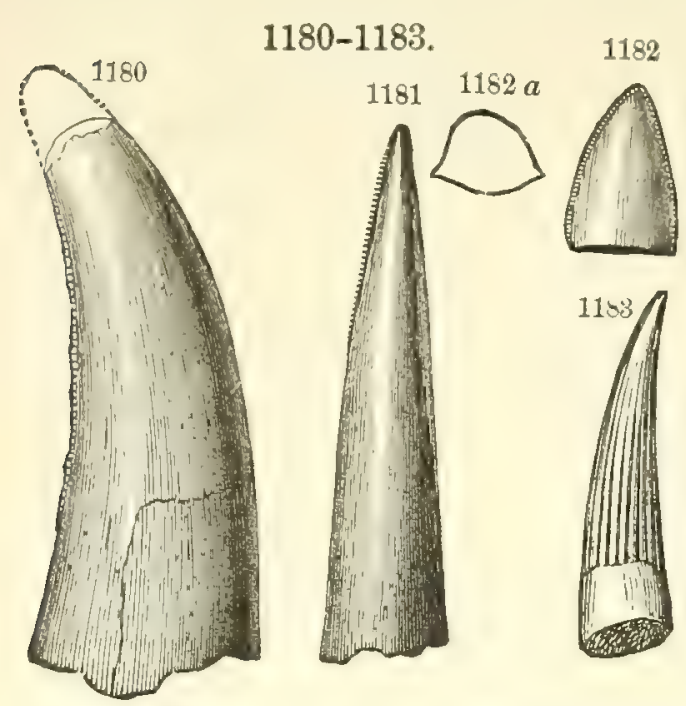

Dinosauns. - Fig. 1180, Bathygnathus borealis; 1181, Clepsysaurus Pennsylvanicus.

Crocodiluans. - Fig. 1182, tooth of Belodon priscus; $1182 a$, section of same; 1183, B. Carolinensis. Fig. 1180, Leidy; 1181-1183, E. Emmons. half the natural size in Fig. 1180; the teeth were four inches long; also, Palcooctonus Appalachianus Cope, from Phœuixville; an anterior tooth having a length of $3 \frac{1}{4}$ inches; also Thecodontosaurus gibbidens Cope, Palcosaurus Fraserianus Cope, Suchoprion aulacodus Cope, from Phœnixville.

Crocodilians. - The Crocodilians are Thecodont species (that is, have the teeth in sockets). They pertain to the genus Belodon, and are characterized by the Palæic features of biconcave vertebræ; the jaws were long and slender, like those of the Gavials. Teeth of two species are represented in Figs. 1182, 1182 a, Belodon priscus of Leidy, and Fig. 1183, B. Carolinensis of Cope, from Pennsylvania and North Carolina. Bones of one species have been found by Marsh in the Connecticut sandstone. Coprolites are common in the shales at Phøixiville, $\mathrm{Pa}$.

5. Mammals. - The only Mammalian remains of the Atlantic border are two jaw-bones, found in Chatham County, N. C., by E. Emmons. They belong to

1184-1185.
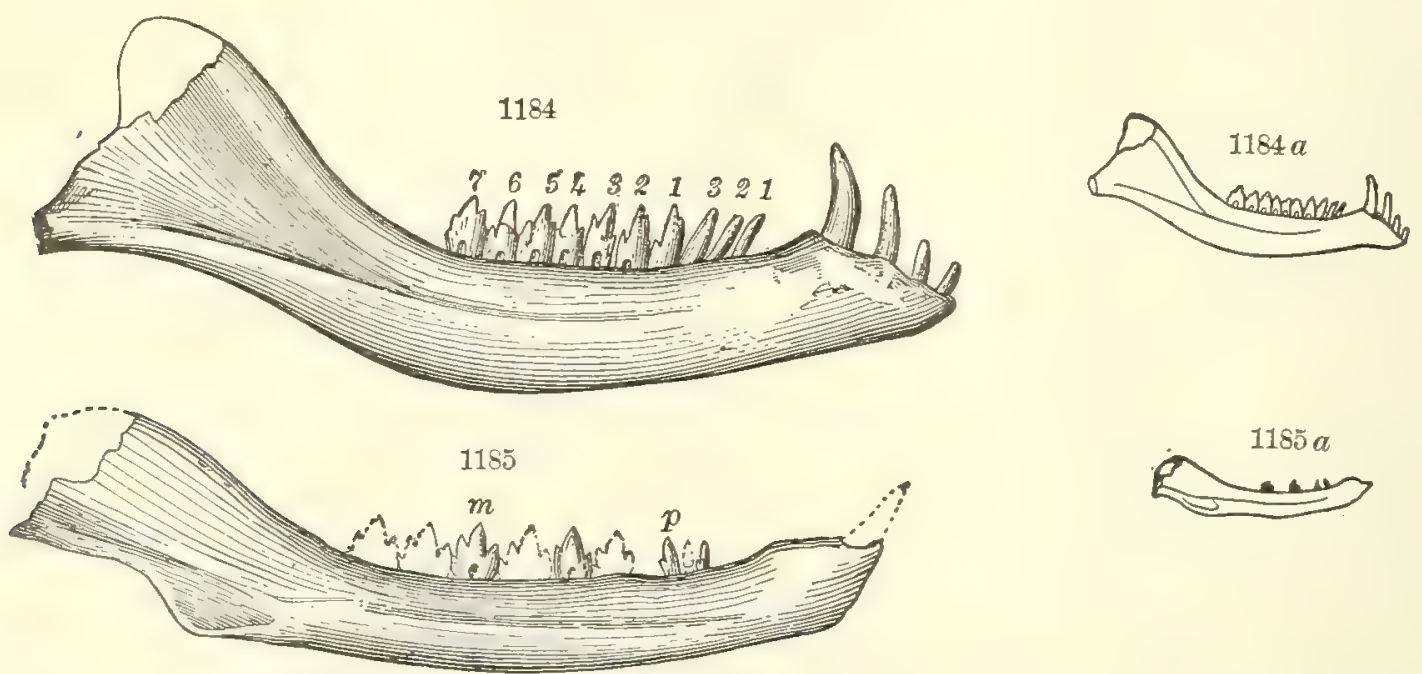

$1185 a$

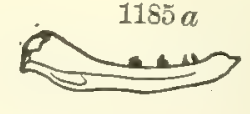

Marsupial Mammals. - Fig. 1184, Dromatherium sylvestre $(\times 3) ; 1184 \boldsymbol{a}$, id. $(\times 1)$; 1185, Microconodon tenuirostris $(\times 4)$; $1185 a$, id. (x 1), Osborn.

Insectivorous Marsupials, Dromatherium sylvestre of Emmons, and Microconocton temirostris of Osborn.* Mammals of similar character probably spread over the continent, and may have been of many species.

\footnotetext{
* Owen says of the Dromatherium that "this Triassic or Liassic Mammal would appear to
} 


\section{Characteristic Species.}

Plants of the Eastern Border Triassic.-For figures and descriptions of Virginia and North Carolina plants, see Fontaine's Report, containing 53 plates, which contains also the figures in Emmons's $N$. Car. Rep. of 1853, and in his American Geology; also, for those of other localities, Newberry, U. S. G. S., 4to, 1888. The plants are referred to the Upper Triassic by Fontaine, Newberry, and L. F. Ward. D. Stur, of Vienna, after a study of the figures and specimens, concludes (Verh. G. Reichsanst., 1888, and $A m$. Jour. Sc., xxxvii., 1889) that over a dozen of the Virginia species are identical with Austrian plants from the Lettenkohle or Lower Keuper of Lunz and other European localities. Fontaine states that the plants collected in Virginia are mostly from the Richmond Coal-measures, and therefore from the lower part of the Triassic formation, while those of North Carolina are from a higher horizon; and that a number of species from the latter region are related to the Rhætic of Europe, and 2 are probably identical with species of the Lias. According to Newberry only 6 to 8 of the few species of New Jersey and the Connecticut River valley are identical with those of Virginia. The black shale of Durham, Conn., has afforded 5 of these species. He also states that several North Carolina species are found at Abiquiu in New Mexico, and Los Bronces in Sonora, Mexico, rendering it probable that the beds are alike Upper Triassic.

Dawson has described Dadoxylon Edwardianum and Cycadeoidea Abequidensis, from Prince Edward Island.

Arima Ls. - Footprints appear to have been first critically observed in the Connecticut valley by J. Deane of Greenfield, Mass, in 1835, and made known by him to E. Hitchcock. The latter in 1836 began his extended collection and study of the footprints, and his publications thereon; first in 1836, of 7 species ( $A m$. Jour. Sc.), and later in his Rep. Geol. Mass., 1841, and his Reports on Ichnology in 4to, of 1848 and 1858 and 1865. He first made all 3-toed tracks ornithic; but later proved this erroneous by finding impressions of the fore feet. In 1837, discoveries were made in Connecticut by William A. Redfield, and later others in New Jersey and Pennsylvania. Deane published papers in 1844, 1845, and later; and a posthumous volume on Ichnographs, from his notes, by T. T. Bouvé, appeared, in 4 to, in 1861. See also publications of Boston Soc. N. Hist. for many papers by different authors.

For descriptions of the Reptiles see Hitchcock, loc. cit.; Emmons, loc. cit.; Wyman, Am. Jour. Sc., 1855; Leidy's papers in the publications of Acad. Nat. Sc. Philad., 1854

1186.

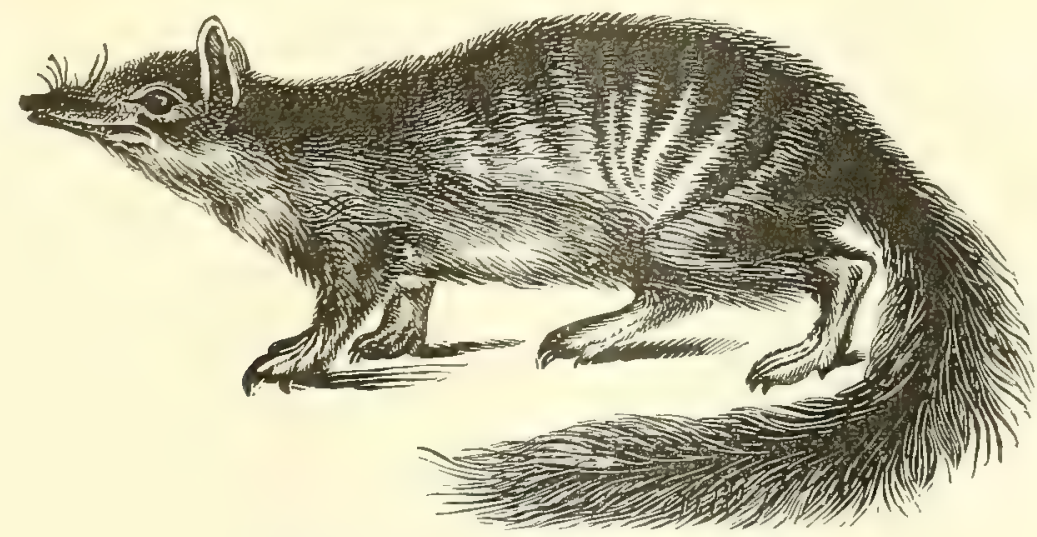

Fig. 1186, Myrmecobius fasciatus $\left(\times \frac{1}{4}\right)$.

find its nearest living analogue in Myrmecobius, for each ramus of the lower jaw contained ten molars (premolars included) in a continuous series, one canine and three conical incisors, - the latter being divided by short intervals." 
and later; Marsh, in Am. Jour. Sc., since 1875; Cope in publications of Acad. Nat. Sc. Philad., Amer. Phil. Soc. and Amer. Naturalist, since 1864.

On Fossil Fishes, John H. Redfield, Ann. N. Y. Lyc. N. Hist., 18:36 ; William C. Redfield, Am. Jour. Sc., 1838 to 1843; Newberry, U. S. G. S., 4to, 1888, with figures of the species.

On the Hammals, E. Emmons, loc. cit.; H. F. Osborn, Acad. Nat. Sc. Philad., 4to, 1888, and also in later papers; R. Owen, Pal. Soc. London, 1871.

\section{Triassic and Jurassic of the Western Interior and Pacific Border Regions.}

\section{Triassic Formation.}

The Trias of the Western Interior and Pacific border regions, although of great thickness, has afforded few organic relics of any kind.

Plants. - The following are figures of three species of Cycads from the Upper Triassic (Rhætic) of Honduras, described by Newberry (1888). At the Abiquiu Copper Mines, New Mexico, Newberry obtained (San Juan Rep.) the new species Otozamites Macombii (also from Sonora), and Zamites

1187

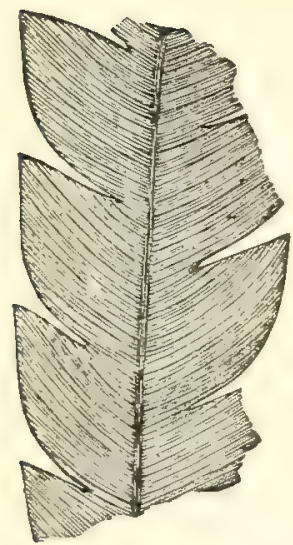

1187-1189.

1188

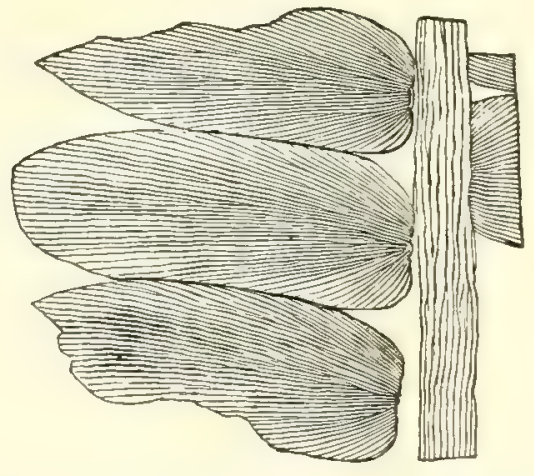

1189

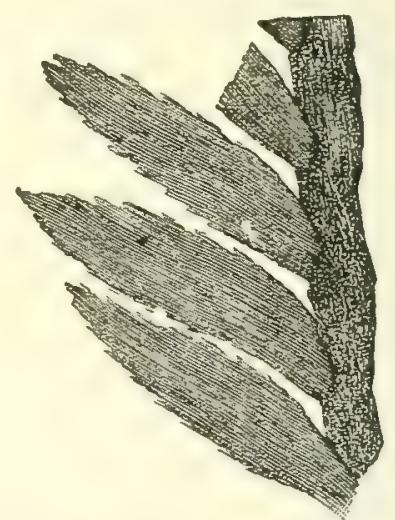

Crosds. - Fig. 11si, Anomozamites elegans; 1188, Otozamites linguiformis; 1189, Encephalartos (?) denticulatus. Newberry.

occidentalis. Sonora, Mexico, has afforded Newberry species of Pecopteris (Oligocarpia), Alethopteris, Camptopteris, Toeniopteris, including the Virginia species Tamiopteris magnifolia (T. latior. Stur), and also a Jeanpaullia, J. radiata, Nby., near J. Miinsteriana of the Richmond basin.

Anmals. - The marine species of Invertebrates include Brachiopods of the genera Rhynchonella, Spiriferina, and Terebratula; Lamellibranch Mollusks of the genera Pecten, Lima, Avicula, Monotis, Halobia, Daonella, Posidonomya, Corbula, Myophoria, and others; and Cephalopods of the old genus Orthoceras, and under the Ammonite group, of the genera Sageceras (Figs. 1190, a), Trachyceras (Figs. 1191, a), Arcestes, Tropites, which are characteristic, and also many others.

A few Insects have been described by Scudder from Fairplay, Col., which are supposed to be Triassic. All but one, a Hemipter, are of the 
Cockroach group (Blattariæ); and out of the 17 species, 11 have the wings like those of the Paleozoic species as to transparency and nervures, and belong partly to described genera, while six are Mesozoic in the character of

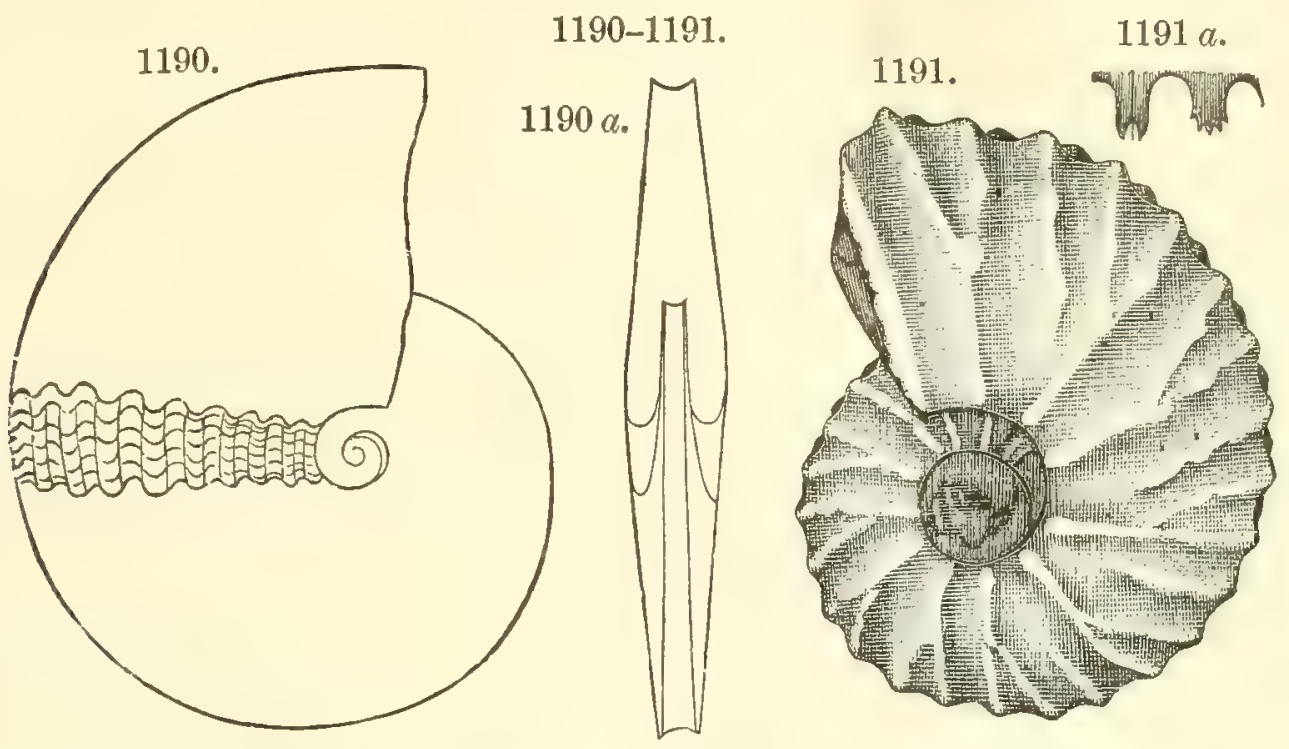

AmonITE FAMILT. - Fig. 1190, Sageceras Haidingeri; $1190 a$, same in profile; 1191, Trachyceras Whitneyi ; $1191 a$, same, showing form of pockets. Gabb.

the nervures, and in having the fore wings more or less opaque, approaching thus the modern kinds. This commingling of Paleozoic and Mesozoic types leads Scudder to the conclusion that the beds are Triassic, although referred by Lesquereux, on the ground of some imperfectly preserved fossil leaves, to the Permian.

The Trias of Idaho, which Hyatt considers the lowest yet found in this country, contains, according to White (1879), Terebratula augusta, T. semisimplex, Aviculopecten Idahoensis Meek, A. Pealsi, A. altus, Eumicrotis curta Mk. \& H., Arcestes cirratus (?), Meekoceras aplanatum, and others.

In western Nevada, West Humboldt region (King), Orthoceras Blakei, Sageceras Haidingeri, Trachyceras Whitneyi, Arcestes Nevadensis Mk., A. Gabbi, Myophoria alta, Monotis subcircularis, Halobia dubia, Avicula Homfrayi, Hulohia (Damella) Lommeli, Pecten deformis, Pentacrinus asteriscus (?), etc. Hyatt reports from Desatoya Mountains, New Pass, and Walker's Lake of Nevada, besides some of the above forms, Gymnotoceras rotelliforme, Trachyceras Whitneyi.

In the Taylorville region, Plumas County, Cal., occur, as identified by Hyatt (1829) from the successive beds: ( $a$, or lowest) slates, the Monotis bed, Monotis subcircularis Gabb (which he says may be $M$. salinaria Schloth.), Pecten deformis Gabb, and at the top, Daonella tenuistriata Hyatt; $(b)$ a limestone, the Rhabdoceras bed, with, besides the preceding, species of Nucula, Lima, Modiola, Myacites, Rhynchonella, and Ammonites of the genera Ammonites and Arcestes, Rhabcloceras Russelli (a strait Ceratite), with Belemnites of the genus Atractites; (c) the Halobia bed, with species of Halobia, Arcestes, Tropites; $(d)$ the Hosselkus limestone, with the same Ammonites, and others of the genera Ceratites, Badiotites, and Juvavites. The upper subdivision is referred by Hyat to the Lower Carnic of the Alpine (Upper) Trias, and the others to the Upper Noric.

From British Columbia have been reported by Whiteaves, who has described several of the species as new from Queen Charlotte Islands, the Ammonites Arcestes Gabbi, 
Badiotites Carlottensis, Aulacoceras Corlottensis; from northern Vancouver, Arcestes Gabbi and Arniotites (Balatonites) T'ancmeverensis; from Liard River, about $59^{\circ} 16^{\prime} \mathrm{N}$. and $125^{\circ} 35^{\prime}$ W., Spirifer horealis, Terebratula Liardensis, Halobia (Daonella) Lommeli, H. occidentalis, Monotis subcircularis Gabb (probably = Pseudomonotis Ochotica of lieyserling), Nautitus Liardensis (near $N$. Sibylla of Spitzbergen), and Trachyceras Canadense (1889). All are of the Upper Trias.

Of Fishes, few species are known.

Several Saurian vertebræ are mentioned by King as having been observed in the Trias of western Nevada, and Hyatt speaks of fragments of Vertebrates in the Sierra Nevada Triassic. A large Crocodilian of the genus Belodon has been described by Cope, from the Gallinas valley in the Sierra Madre Mountains, New Mexico, under the name Typothorax coccinamu. Dystrophous viamalce Cope (1877), found by Newberry in Painted Cañon, southeastern Utah, is supposed to be a Dinosaur.

Although Amphibians are many and of great size in Europe at this era, no remains are yet known from the western half of North America.

\section{Jurassic Formation.}

The Jurassic beds are much less barren in fossils than the Triassic, and yet are seldom prolific in species. Gastropods are rare, and Cephalopods not numerous. Invertebrate species were first discovered in them by Meek, at the Black Hills, where the species here figured occur along with many others. The Crinoid disk, Fig. 1192, is of the genus Pentacrinus. A species

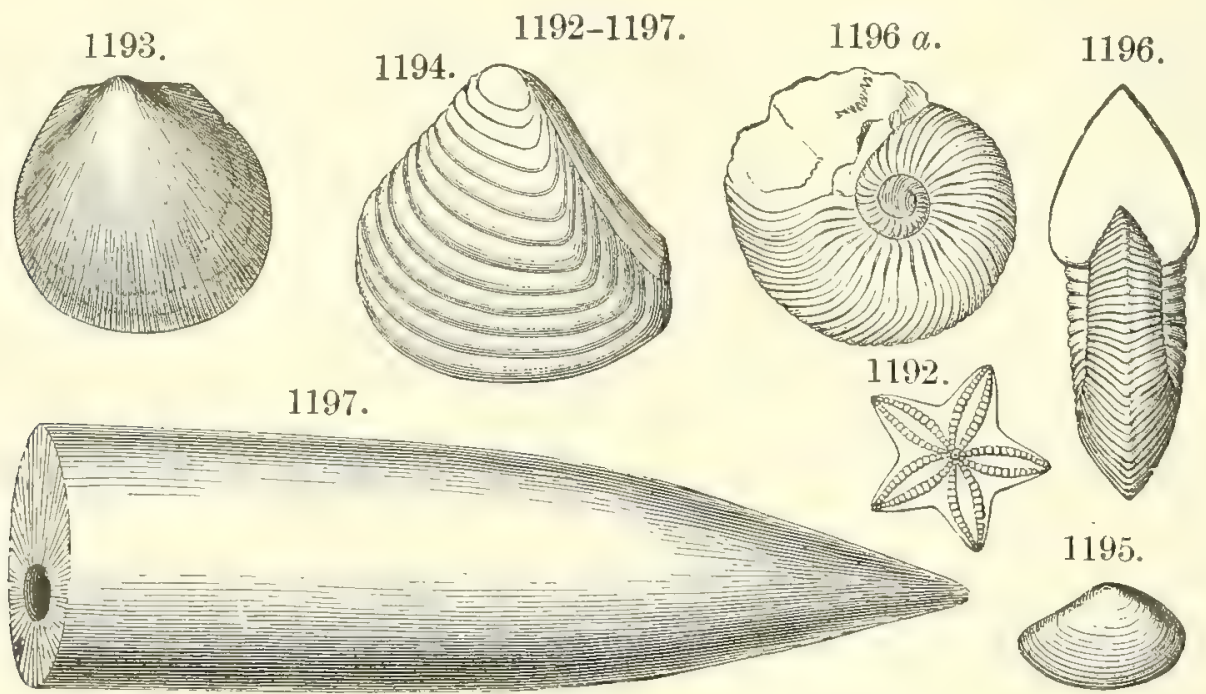

Fig. 1192, a segment of the column of Pentacrinus asteriseus; 1193, Monotis curta; 1194, Trigonia Conradi; 1195, Tancredia Warreniana; 1196, Quenstedioceras cordiforme; $1196 a$, side view of same, a little reduced ; 1197, Belemnites densus. Meek.

of the Ammonite group is represented in Figs. 1196, $1196 \alpha$. The Belemnite, Belemnites densus Meek, Fig. 1197, is from these beds, which have been named by Marsh the Baptanodon beds. (These Baptanodon beds, near Como, Colorado, are marine, and overlie Red beds which are referred to the Triassic; above them are the freshwater Atlantosaurus beds of Marsh, and overlying these comes the Dakota group.) The fossil here represented is the lower end of the internal bone answering to the bone of the Squid, but differing from those of modern species in the texture and weight of the 
posterior portion or "guard." (A perfect bone of similar nature is shown in Fig. 1300, page 782.)

The Jurassic of Taylorville, Plumas County, Cal., has afforded Hyatt many species, and among them, from the Upper Lias, Pinna expansa, Fig. 1201; from the Oölyte, Lima Taylorensis, 1199, and Entolium gibbosum, 1200; and from the Coral bed, Stylina tubulifera, 1202. The Ammonite, Amioceras Neraduum (Fig. 1198) is from the Jurassic at Volcano, Nev. (Am. Jour. Conch., vol. v., pl. 3).
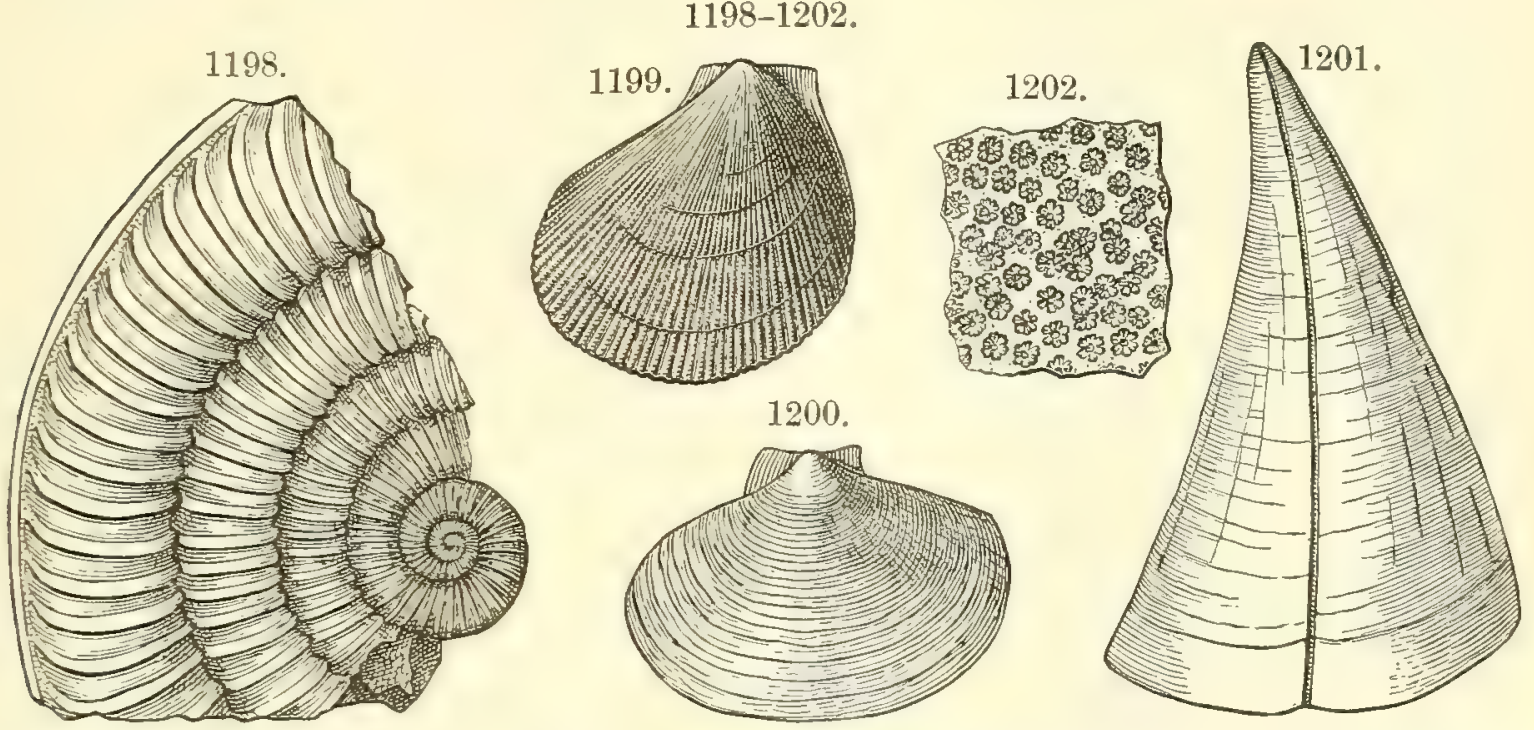

Fig. 1198, Arnioceras Nevađuum; 1199, Lima Taylorensis; 1200, Entolium gibbosum; 1201, Pinna expansa; 1202, Stylina tubulifera. Original.

Shells of the species of Aucella from the Auriferous slates are represented in Figs. 1203-1205. Aucella Eringtoni (so named in commemoration of the first discoverer of fossils on the Mariposa estate, Miss Errington) occurs in the partially metamorphic upturned slates; Fig. 1203 represents the cornmon form; and 1204, a narrower variety occurring in the sandstone. The Triassic genus Monotis is continued, one species of which is shown in

$1203-1205$.

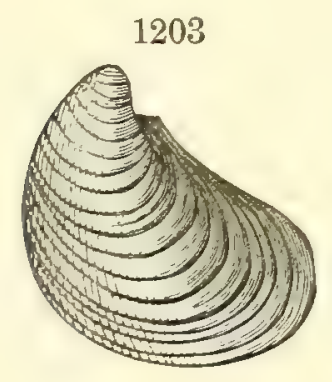

1204

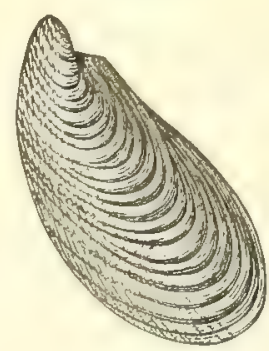

1205

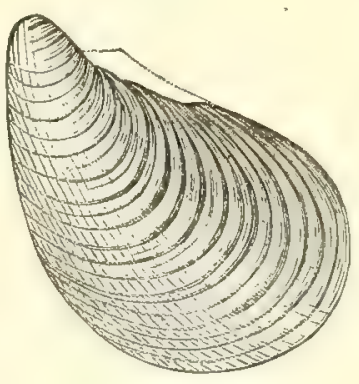

MoluUsז. - Aucella Erringtoni. Meek.

Fig. 1193. Trigonia, related to Myophoria, has its first American species. Other characteristic genera of Lamellibranchs are Tancredia, Lima, Gervillia, Gryphoea, Inoceramus, and Pholadomya. 
The Jurassic of Dakota, Wyoming, and Utah have afforded Ostrec stringilecula, Tancredia extensa, Camptonectes bellistriatus, and the Ammonite Quenstedioceras curdiforme. That of Idaho afforded White: Pentacrinus asteriscus, Ostrea stringilecula, species of Tancredia, Trigonia, Myacites, etc. In the Uintah Mountains, where the rocks are shales and sandstones with limestone, occur Pentacrinus asteriscus, Belemnites densus, Trigonia, Gryphcea calceola, Myophoria lineala, Camptonectes bellistriatus, Eumicrotis curta, etc.; and in the Wasatch have been found Cucullcea Haguei, Myophoria lineata, Myacites subcompressa, Volsella scalpra (King's Report on the 40th Parallel).

In the West Humboldt region, west Nevada, occur Belemnites Nevadensis, species of Mantlivaltia, etc.; and probably from this region came the Ammonite, Arnioceras Humboldti; in Esmeralda County, Nev., Vermiceras Crossmani, Arnioceras Nevadense; in Inyo County, Cal., Arnioceras Woodhulli.

Jurassic beds at Taylorville, Cal., on the Sierra Nevada, afforded Hyatt, in the lower beds referred to the Lias, besides the most of the above genera, species of Pinna, Entolium, Goniomya, Pleuromya; also an Echinoderm of the genus Cidaris and a Crustacean of the genus Glyphoc. The Middle Oölytic beds contain, among the species, Ammonites of the genera Grammoceras and Spharoceras; and the Upper Oölyte, species of the genus Rhacophyllites, with 3 species of Trigonia in the lower bed referred to the Callovian division of the Oölyte, and several species of Coral of the genus Stylina referred to the Corallian, besides the Camptonectes bellistriatus Mk, and the Rhacophyllites of the Upper Oölyte. Hyatt speaks of the contrast of the species with those of the summit region of the Black Hills, southeastern Wyoming, whose Ammonites are of the Cardioceras family and whose beds are Callovian or Oxfordian.

The Mariposa beds extending to near Colfax, Placer County, Cal., contain, according to Hyatt, Cardioceras dubium of Oxfordian age, and striated Aucellce (Figs. 1203-1205) in great numbers, Perisphinctes of the same types as those found in the Upper Jura, Upper Oxfordian, and Volgian of Russia, namely, Perisphinctes virgulatiformis, P. Colfaxi, P. Mühlbachi, and Belemnites Pacificus. None of these species pass into the Knoxville beds.

The Queen Charlotte beds have afforded Whiteaves (Mesozoic Foss., Can. Survey, 1884) species of the Ammonite group of the genera Lytoceras, Haploceras, Ancyloceras (A. Remondi of Gabb), Hamites, and also species of Trigonia, Inoceramus, Aucella, Amusium, Yoldia, etc.; also Belemnites densus.

Among the Arctic fossils of this period, there are, at Prince Patrick Island, Ammonites M'Clintocki, a species near $A$. concavus Sow., of the Lower Oölyte; and at Cook's Inlet, Ammonites Wosnessenski, A. biplex Sow. (?), Belemnites paxillosus (B. niger List ?), and Pleuromya unioiles Br. (Unio liassinus Schubler). A. biplex also is reported to occur in the Chilean Andes, in latitude $34^{\circ} \mathrm{S}$., as well as in Britain and Europe.

1. Fishes. - Fishes are rare fossils. The teeth of Ceratodus Güntheri of Marsh have been described from the Upper Jurassic (Atlantosaurus beds) of Colorado.

2. Reptiles. - The Upper Jurassic formation of Colorado and Wyoming has. afforded remains of a few Amphibians, many great and small Reptiles, and of some Mammals. The specimens are thus far from the "Baptanodon and Atlantosaurus beds" of Colorado and Wyoming. They include Sea-Saurians related to the Ichthyosaurs (page 784), and also Dinosaurs, Crocodilians, Turtles, and Pterosaurs or Flying Reptiles.

Fnaliosaurians (Ichthyopterygians). - These Sea-Saurians are the most. fish-like of Reptiles. This appears (1) in their biconcave vertebræ (Fig. 
131ว $a$, page 784 ); (2) in their locomotive organs or paddles (Fig. 1206) which are fin-like in having no defined limb-bones beyond the upper, the rest of the limb being represented by several series of bones, and the number of series exceeding the normal number of fingers, five; and (3) in the absence of a breast bone, and the presence of dorsal fins. The specimens from Wyoming of Baptanodon discus of Marsh indicate a species eight or

1206.

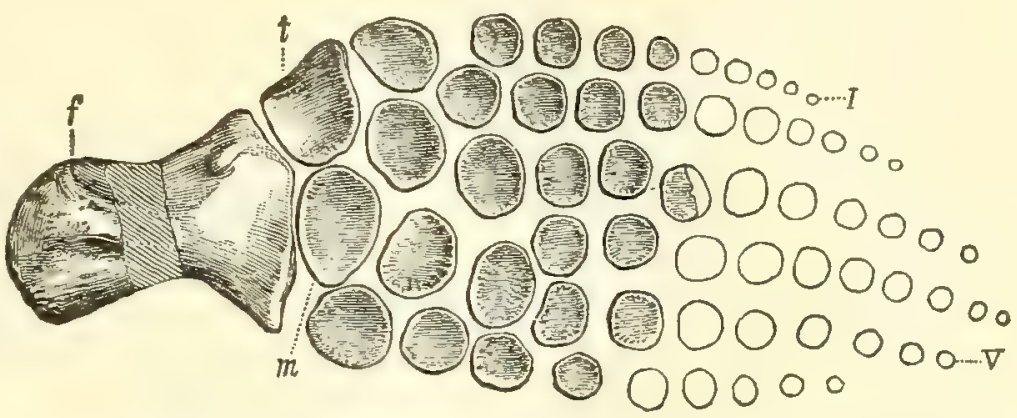

Fig. 1206, Baptanodon discus, left hind paddle $\left(\times \frac{1}{8}\right) ; f$, femur ; $t$ and $m$, bones answering to tibia and fibula; $I$, first digit; $V$, fifth digit. Marsh.

nine feet in length, with a toothless head and the orbit of great size (as in Ichthyosaurs, page 784), with a sclerotic ring of 8 plates, which is conical as in some birds.

Dinosaurs. - Localities in Colorado and Wyoming are the most important source of what is known about Jurassic Dinosaurs. They were the most gigantic of terrestrial animals, in some cases reaching a length of 70 or 80 feet, while at the same time they had a height of body and massiveness of limb that, without evidence from the bones, would have been thought too great for muscle to move. Besides this, some of the huge beasts had the most diminutive of brains; but, as a compensation, a nervous mass in the sacrum 20 to 30 times as large as the brain for use in connection with the hinder limbs and tail. There were both Carnivorous and Herbivorous kinds, the latter the inferior.

The American Herbivorous species are of three groups: (a) The Scuropods or Saurian-footed; kinds having the fore and hind limbs nearly equal, crocodile-like, with all the feet five-toed (that is, with five usable toes); the limb bones solid, but the vertebræ, especially the anterior, cavernous, and thereby light. (b) The Stegosaurians, having very short fore limbs; the fore feet five-toed and hinder three-toed; the limb bones and vertebræ solid; and the body covered with bony pieces or plates; the vertebræ all biconcave. (c) The Ornithopoda or bird-footed, having very short fore limbs with the long hind limbs three-toed, bird-like, rarely fourtoed; the bones of the hind limbs hollow, but the vertebræ solid. (Marsh.)

The Carnivorous species have in all cases the fore limbs short compared with the hind limbs, and the latter usually three-toed, bird-like. The limb bones are hollow, and the vertebræ are more or less cavernous, in order, as in birds, to have less to lift, especially in the anterior part of the body.

The following are some examples of Jurassic species under the several subdivisions. The specimens are all from the Atlantosaurus beds of Colorado and Wyoming. 
(1) Herbivorous Dinosaurs. - (a) Sauropods. An idea of the skull in this group is afforded by the following figures of Diplodocus longus Marsh, found near Cañon City. The length of skull in this species was about 21 inches; of

1207.

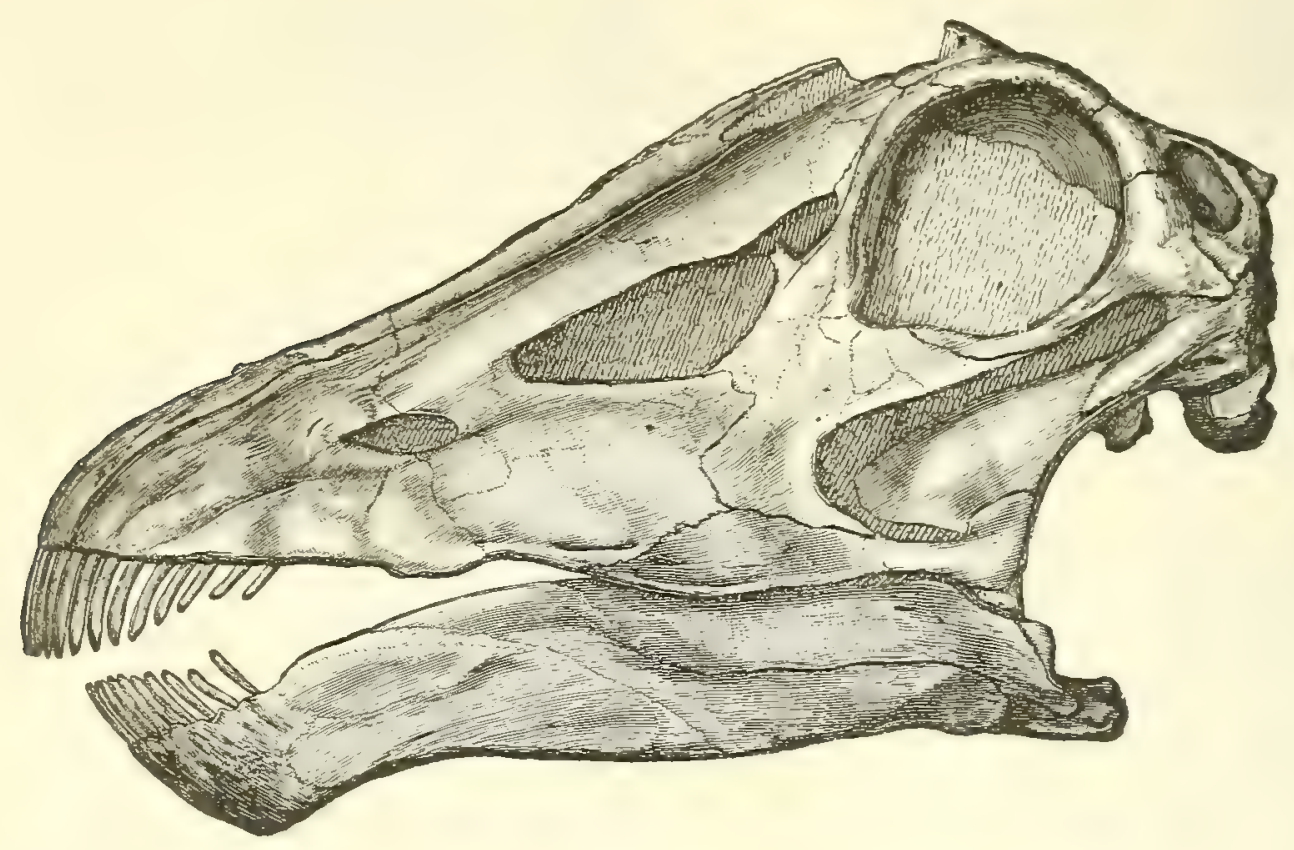

1208.

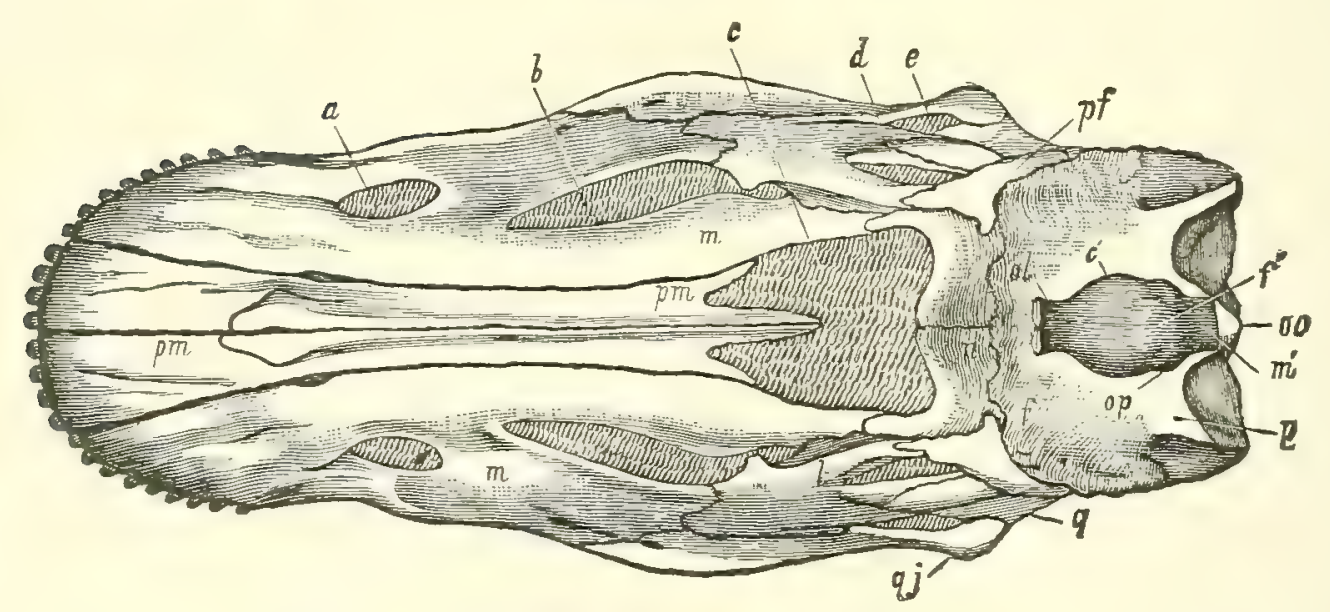

Fig. 1207, Diplodocus longus, skull, side view ( $\left.\times \frac{1}{6}\right)$; 1208, id. upper view ( $\left.\times \frac{1}{6}\right) ; a$, aperture in maxillary ; $b$, antorbital opening; $c$, nasal opening; $c^{\prime}$, cerebral hemispheres ; $d$, orbit; $e$, lower temporal fossa ; $f$, frontal bone; $f^{\prime}$, fontanelle; $m$, maxillary bone; $m^{\prime}$, medulla; $n$, nasal bone; oc, occipital condyle ; ol, olfactory lobes; op, optic lobe; $p$, parietal bone; $p f$, pre-frontal bone; $p m$, pre-maxillary bone; $q$, quadrate bone; $q j$, quadrato-jugal bone. Marsh.

brain, about three inches; of body, 50 feet. The position and relative size of the brain is shown in Fig. 1208 at $c^{\prime}$. The teeth were peculiar, being very slender and long, and confined to the terminal part of the jaws. The animal is supposed to have been a hippopotamus-like wader, and to have lived on vegetation in the waters. 
The general character of the limbs, their height and massiveness, and the form of the pelvic bones, are exhibited in Figs. 1209-1211 of Morosaurus grandis Marsh, a species about 40 feet long. The femur $(f)$ is about four feet in length. The teeth (Fig. 1211, half the natural size) are shorter than in the preceding species, and more numerous. Nearly complete skeletons of this Morosaurus have been obtained by Marsh in Wyoming.

Fig. 1212 represents a restoration of an allied species, the Brontosaurus excelsus Marsh, of which also a skeleton nearly complete has been obtained. The total length is about 60 feet, and the height of the skeleton at the middle of the body about

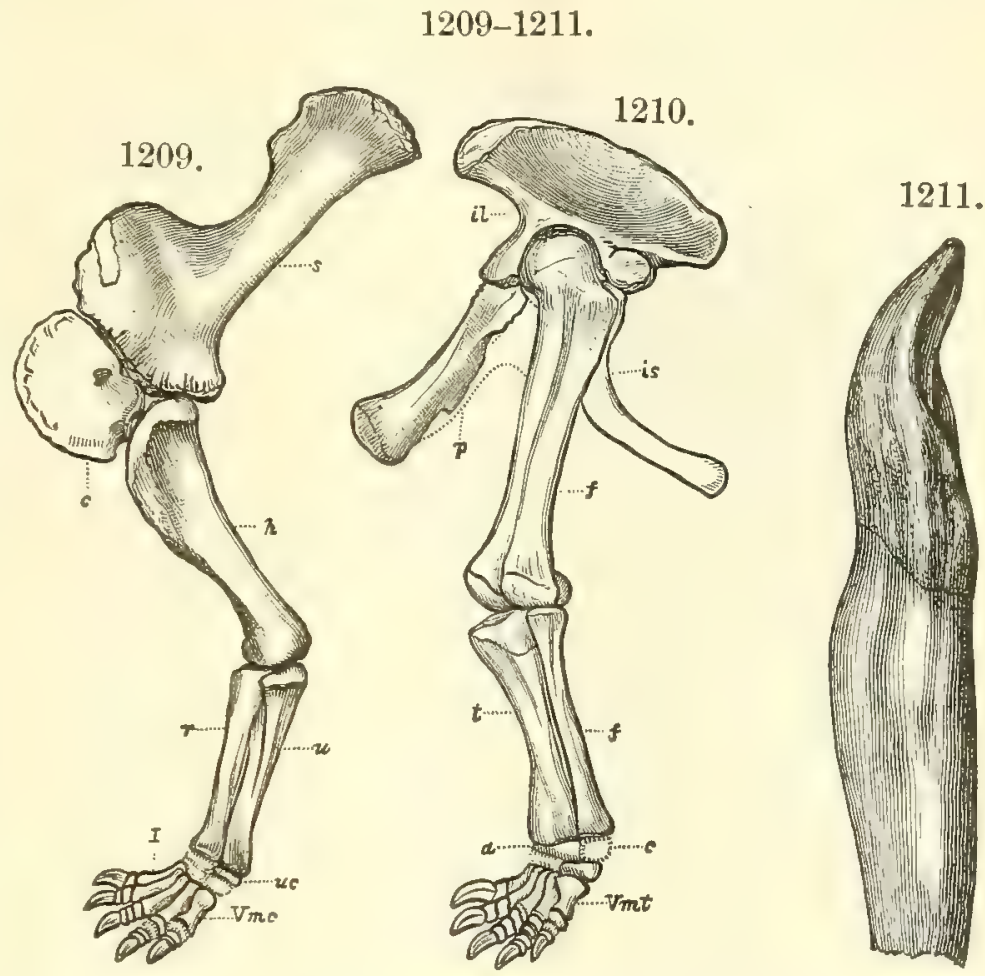

Drrosatr. - Morosaurus grandis $\left(\times \frac{1}{40}\right)$. Fig. 1209, fore leg; $s$, scapula ; $c$, coracoid ; $h$, humerus ; $r$, radius ; $u$, ulna ; $u c$, ulnar carpal; $I$, first metacarpal; $\nabla m c$, fifth metacarpal. Fig. 1210, hind leg; $i$, illiac ; is, ischium; $p$, pubis; $f$, femur; $t$, tibia ; $f^{\prime}$, fibula; $a$, astragalus; $c$, calcaneum; $\nabla m t$, fifth metatarsal. Fig. 1211, tooth $\left(\times \frac{1}{2}\right)$. From Marsh.

15 feet, showing great magnitude; and yet it had, relatively to size of body, one of the smallest of heads known among vertebrates. Like Morosaurus,

1212.

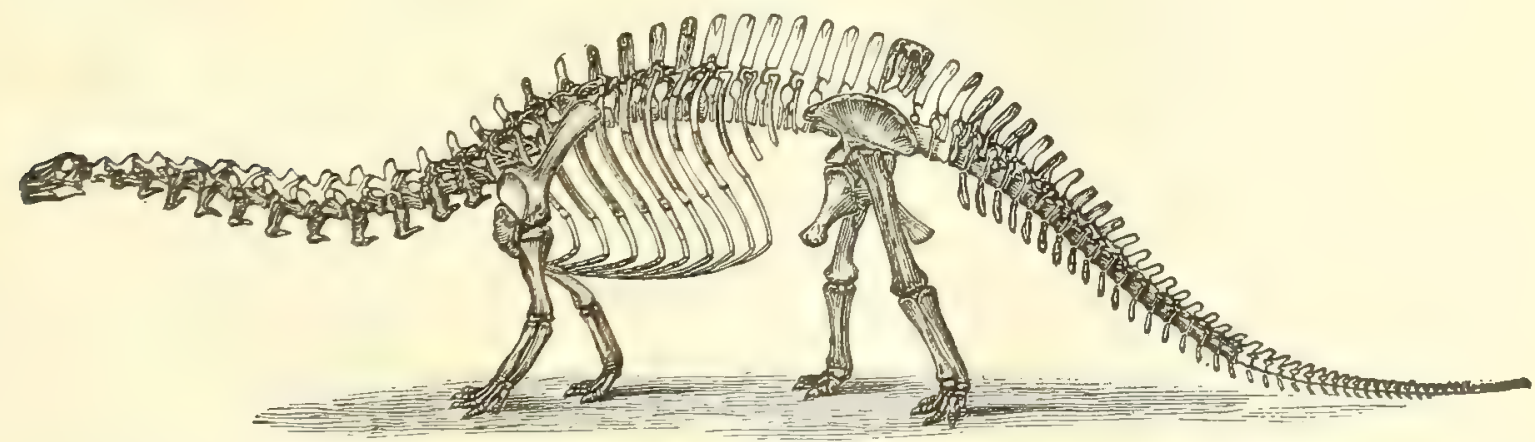

Fig. 1212, Brontosaurus excelsus, restoration $\left(x_{\frac{1}{130}}\right)$. Marsh.

its vertebræ were very light and cavernous, with thin walls, even in the axis of the sacrum. The feet were large enough to make tracks a square yard in area. The sixth cervical vertebra was over 25 inches high and 21 broad. The size of neck was still greater in another species, Apatosaurus laticollis 
Marsh, the corresponding dimensions of a cervical vertebra (Fig. 1213) being 4 feet and $2 \frac{1}{2}$ feet. In Atlantosaurus immanis Narsh, a species probably 70 or 80 feet long, the femur was over six feet in length.

(b) Stegosaurians. The Stegosaurs of Marsh were other huge species, but

1213.

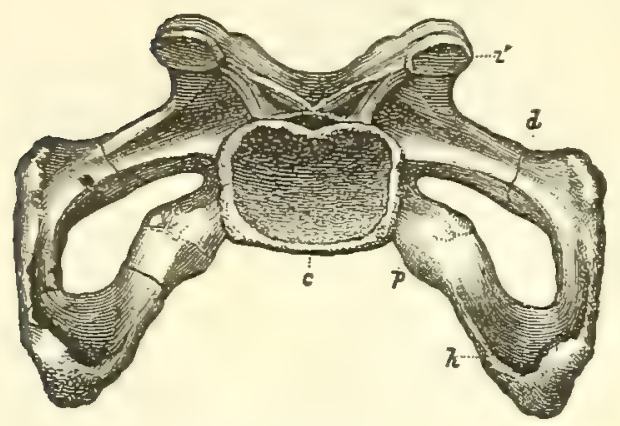

Fig. 1213, Apatosaurus laticollis, cervical vertebra $\left(\times \frac{1}{16}\right) ; c$, concave posterior articular surface; $d$, diapophysis; $p$, para popysis; $h$, hatchet bone, or anchylosed rib; $z^{\prime}$, postzygapophysis. Marsh. with the fore limbs much the shorter, and all the bones solid. They were remarkable for the crest of great bony plates along the back, the diminutive size of the brain, and the enormous supplementary nervous mass in the sacrum. The figure is the restoration of Stegosaurus ungulatus Marsh, by the describer, $\frac{1}{50}$ the natural size. The head had a horny beak. The throat was covered with small ossicles. The larger of the plates along the back were $1 \frac{1}{2}$ feet broad; and the spines along the caudal portion, nearly 2 feet long. All the plates and spines had originally a thick horny covering. The relative size of the brain and the nervous mass in the sacrum is shown in the figures, of $\frac{1}{4}$ natural size: Fig. 1215, the brain; 1216, the mass in the sacrum.

1214.

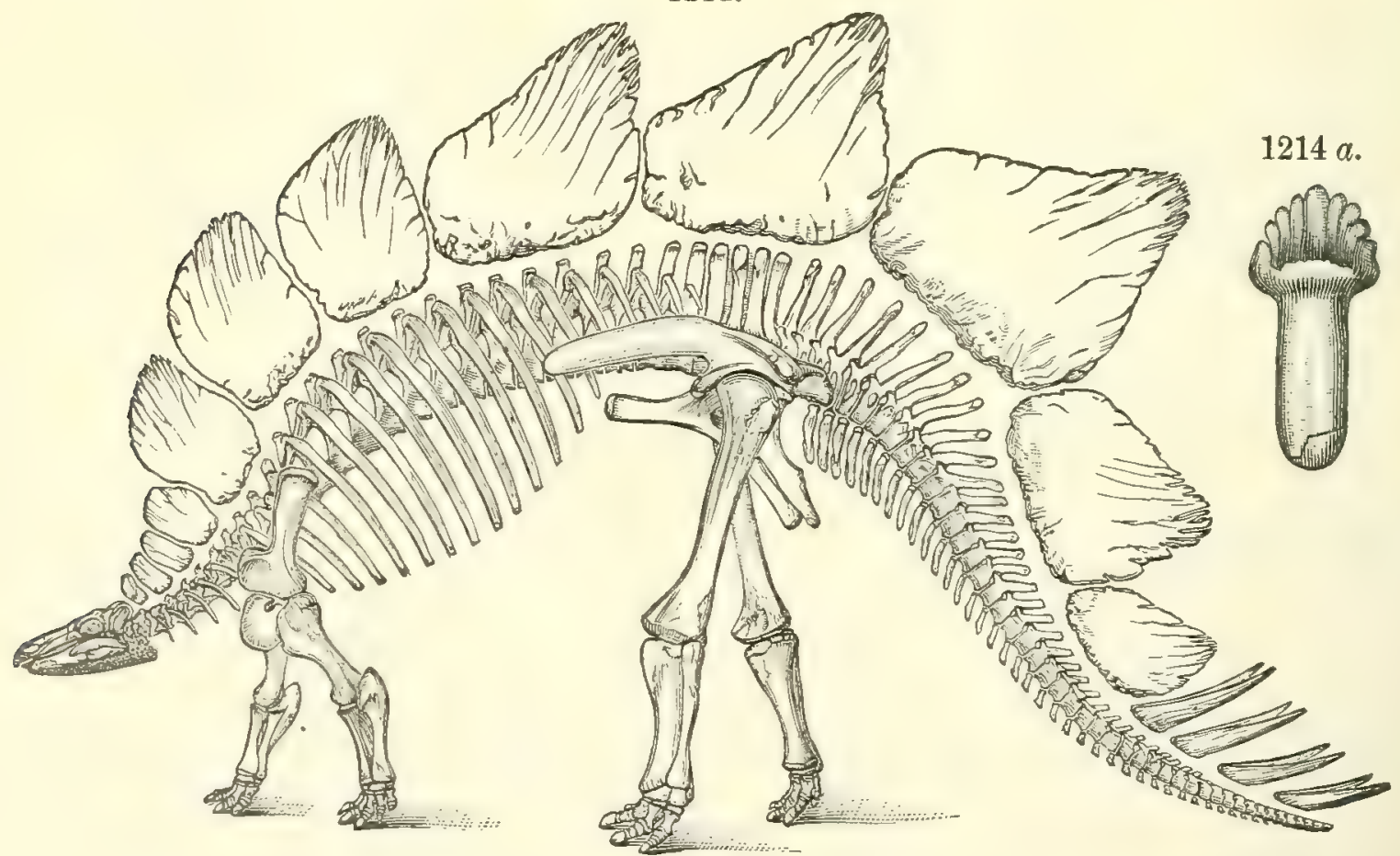

Fig. 1214, restoration of Stegosaurus ungulatus $\left(\times \frac{1}{50}\right) ; 1214 a_{3}$ tooth of same $(\times 2)$. Marsh.

(c) Ornithopoda. - The animals of this group of Herbivorous Dinosaurs were bird-like in feet, and strikingly so in the pelvic bones. Both of these characters are shown in the restoration of Camptosunrus dispar of Marsh 
(Fig. 1217), in which the skeleton is reduced to $\frac{1}{40}$ the natural size. (Compare with Fig. 1423, page 850.)

Fig. 1219 represents the hind leg of an allied species, Laosaurus consors of Marsh, and $1219 \alpha$, a tooth. Nanosaurus agilis Marsh (Fig. 1220), from Colorado, is the smallest of known Dinosaurs, being about as large as a partridge. Another species, Nanosaunus Rex Marsh, also from Colorado, was not larger than a Fox.

(2) Carnivorous Dinosaurs. - Fig. 1221 represents a restoration of Ceratosaurus nasicornis Marsh, a moderately large species related in general characters to the Megalosaurus of Europe. The name nasicornis alludes to their having a horncore ( $h$ in Fig. 1222) on the nose. Owing to the form of the pelvis, the body was keeled beneath; and the existence of such a keel in some Triassic species is supposed to account for an impression sometimes found in the sandstone between pairs of footprints.

1217

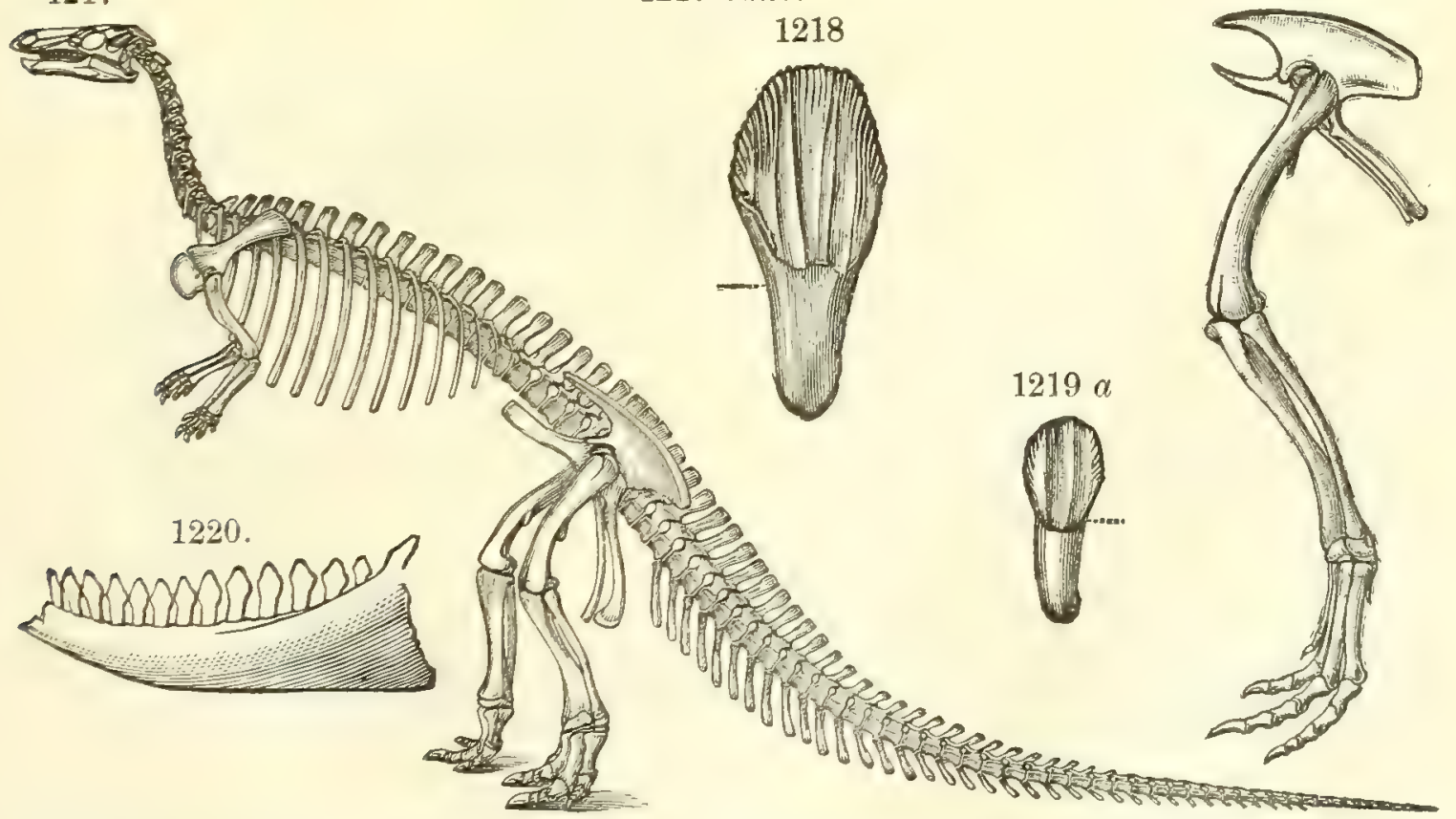

$1215-1216$.

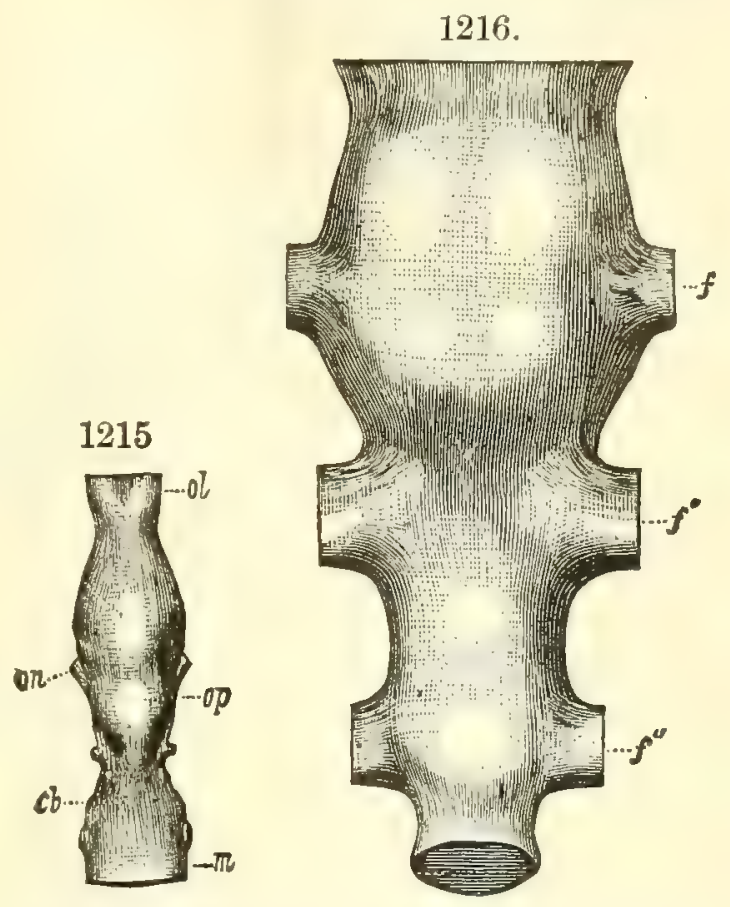

Fig. 1215, cast of brain of Stegosaurus $\left(\times \frac{1}{4}\right)$; ol, olfactory nerves; op, optic lobes; on, optic nerve; $c b$, cerebellum; $m$, medulla oblongata. Fig. 1216, cast of eavity of nerrous mass in the sacrum, seen from above $\left(\times \frac{1}{4}\right) ; f, f^{\prime}, f^{\prime \prime}$, each foramen between two sacral vertebræ. Marsh.

Heratrorots DrNosatrs. - Fig. 1217, restoration of Camptosaurus dispar $\left(\times \frac{1}{40}\right)$; 1218, tooth of C. medius; 1219 , Laosauras consors, hind leg $\left(\times \frac{1}{12}\right) ; 1219 a$, tooth of same; 1220, Nanosaurus agilis, dentary bone, as seen from the left, natural size. All from Marsh. 
1221.

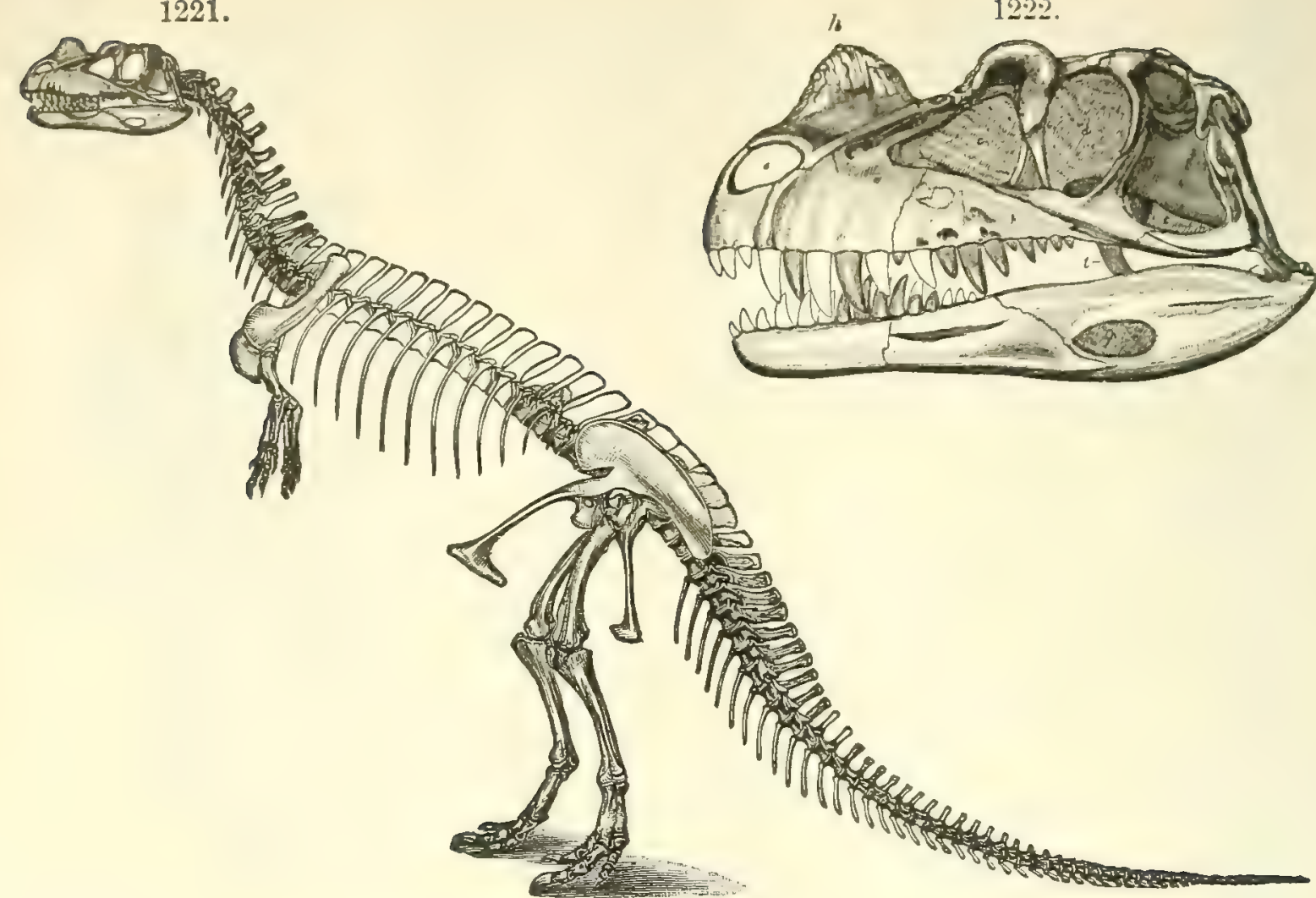

Disosatr. - Fig. 1221, Restoration of Ceratosaurus nasicornis $\left(\times \frac{x}{40}\right) ; 1222$, skull of same $\left(\times \frac{1}{12}\right) ; h$, horneore. Marsh.

Allosaurus Marsh is another genus of Carnivorous Dinosaurs from the Atlantosaurus beds, near Megalosaurus in its characters. Labrosaurus of Marsh is another.
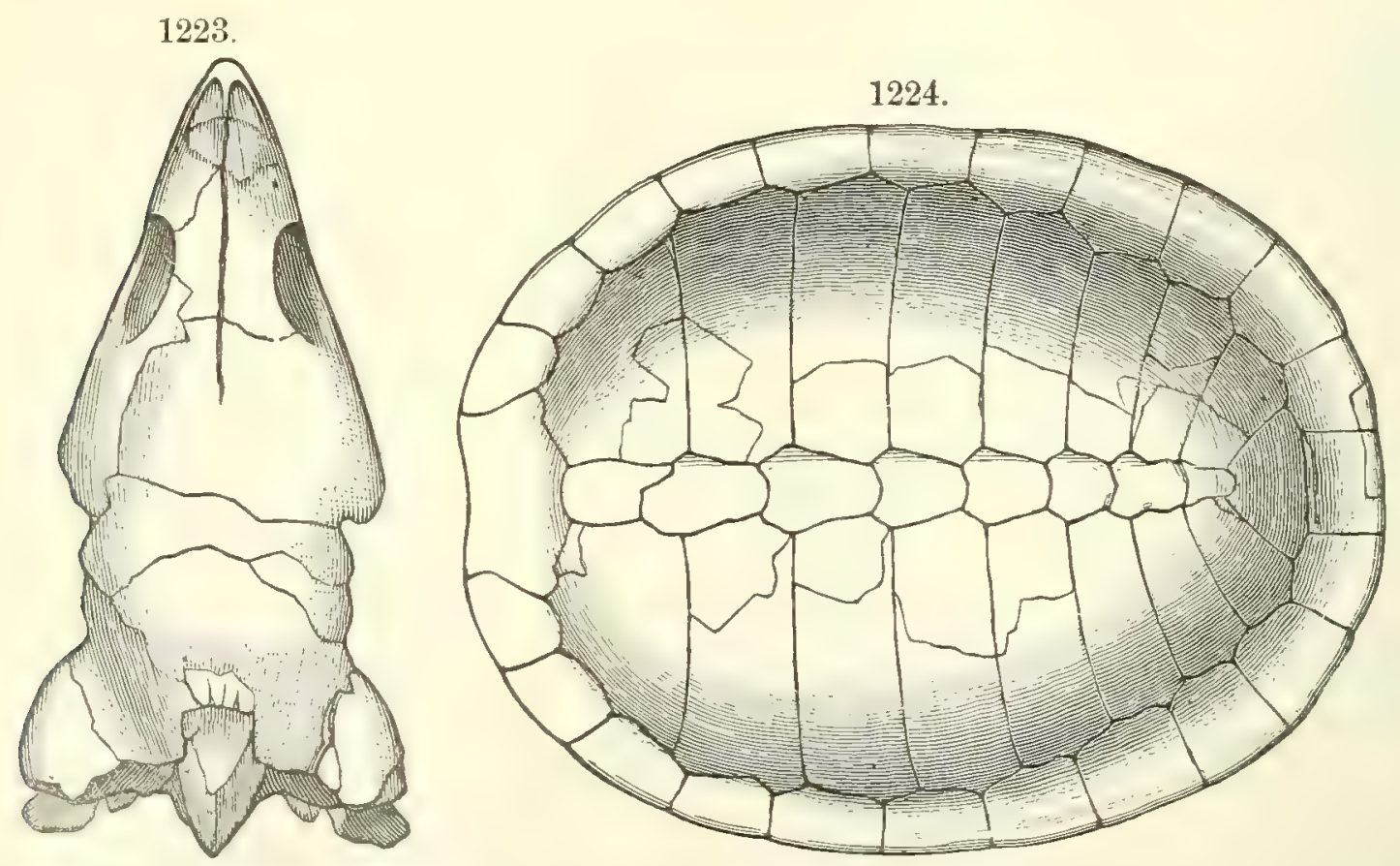

Trrtues. - Fig. 1223, Glyptops, a Turtle skull, natural size; 1224, carapace of probably the same species ( $\left.\times \frac{1}{4}\right)$. Marsh. 
Testudinates. - Glyptops ornatus Marsh (1890) was a Turtle with an elaborately sculptured skull, from the freshwater Atlantosaurus beds of Wyoming. The form of the skull is shown in Fig. 1223. The carapace represented in Fig. 1224 was found in the same beds, and is probably of the same, or an allied, species.

A tortoise over a foot in diameter has been described by Cope (1878), under the name Compsemys plicatulus, from the Upper Jurassic beds of Como, Wyoming. The bony case or carapace is as complete, according to Cope, as in a modern tortoise, being without any embryonic or transitional characters.

Pterosaurs, or Alying Reptiles (Figs. 1321 to 1325, pages 786, 787), are known from a few bones from Wyoming. The character of the wing in the Pterosaurs is shown in Fig. 1321. The type specimen of Pterodactylus montanus Marsh is the distal portion of the metacarpal bone. The size indicates a spread of wing of four or five feet.

3. Birds. - A portion of a skull of a bird rather larger than a Blue Heron (Ardea herodias), from the Atlantosaurus beds of Wyoming, is the

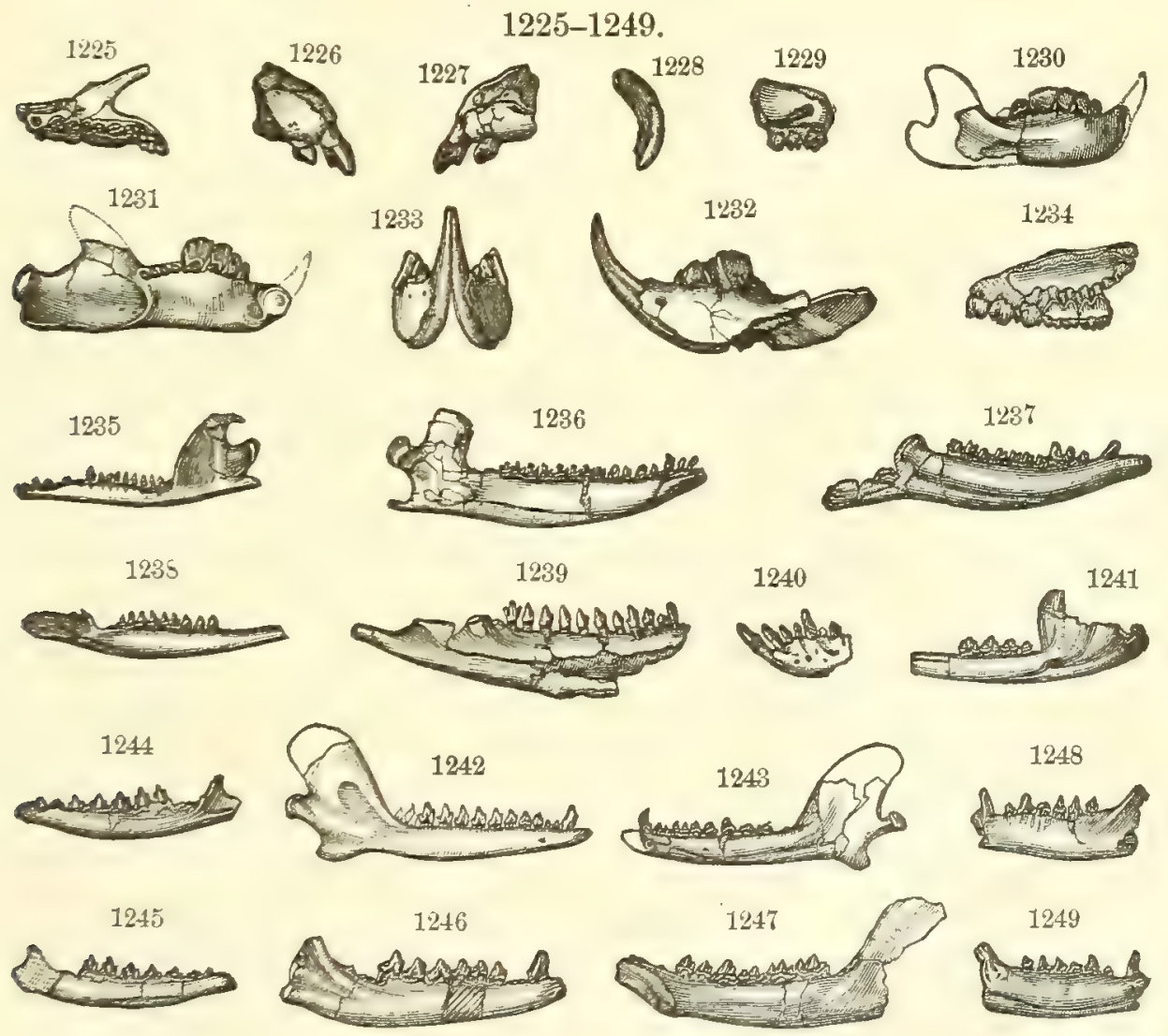

Mamars. - Fig. 1225, Allodon laticeps, upper jaw, view from below; 1226, A. fortis, right premaxillary, outer view; 1227, id., inner view; 1228, id., lower incisor; 1229, id., left upper jaw ; 1230, Ctenacodon serratus, right lower jaw; 1231, id., left lower jaw; 1232, C. potens, left lower jaw; 1233, front view, showing the two long incisors together; 1234, id., right upper jaw; 1235, Stylacodon gracilis, left lower jaw; 1236, Dryolestes priscus, left lower jaw; 1237, D. varax, left lower jaw; 1238, Laodon venustus, left, inner view; 1239, Asthenodon segais, right, outer view; 1240, id., anterior part left lower jaw ; 1241, Tinodon bellus, right, inner view ; 1242, Diplocynodon victor, outer view; 1243, Docodon striatus, inner; 1244, Menacodon rarus, outer View; 1245, id., inner ; 1246, Enneodon crassus, outer view ; 1247, Priacodon ferox, inner view ; 1248, 1249, Paurodon valens, left lower jaw. All natural size except 1225, 1230, 1238, which are $\frac{4}{3}$; and $1242,1243, \frac{2}{3}$. From Marsh. 
basis of the species Laopteryx priscus of Marsh. It probably had teeth and biconcave vertebræ.

4. Mammals. - Remains of Jurassic Mammals have been described by Marsh from the Atlantosaurus series, and mostly from Wyoming, where portions of lower jaws of some hundreds of individuals have been found in thin dirt-beds. (The same beds have afforded, besides Dinosaurian bones, remaius of Crocodiles, Turtles, small Lizards, and Fishes, besides the Laopteryx.) The Mammals were like mice and rats in size, the length of the lower jaw varying from half an inch to one and one half inches. Specimens, more or less perfect, of the jaws of species are shown in Figs. 1225-1249, from Marsh. Ctenacodon has a large cutting incisor, as Figs. 1230-1233 show, and is referred, along with the genus Allodon, to the same family with the genus Plagiaulax of Owen. The characters of the others are mostly those of Marsupial Insectivores. The number of teeth in some modern Marsupials is 2 to 4 above the normal number 44 ; but in the Triassic and Jurassic species, where determinable, as tabulated by Osborn, it is beyond the normal number by 4 to 24 teeth; the earliest Dromatherium is stated to have had 56 teeth; the Jurassic Stylacodon, 68.

\section{FOREIGN TRIASSIC AND JURASSIC.}

\section{Triassic.}

At the commencement of the Triassic period, Scotland and western England were mostly dry land. Triassic beds show that the only underwater or rock-making region of western England (Wales included) was that of a broad channel, passing westward over Cheshire to the coast of the Irish Sea by Liverpool, and northward of that city. Eastward, the channel opened into the North Sea of the era, or into its great sea-border flats; and the shore line stretched northward nearly to Newcastle, thence along by eastern Scotland, and southwestward to Torquay on the British Channel. But the seashore flats appear to have been emerged land over southeastern England, the Triassic being absent according to evidence from borings. In Europe, southeast of England, beyond a broad border region of the continent (now under Tertiary or Cretaceous rocks), Triassic beds again appear over both eastern France and the Netherlands; and the two areas, united (beneath a strip of Tertiary) behind the Carboniferous area of the Belgian border, continue from the Vosges Mountains to Saxony, Bohemia, and the Juras on the borders of Switzerland, and also along the western and eastern Alps into Italy and Austria. Further, they appear again over a large surface in Russia, west of the Urals, reaching from the Caspian to the coast east of the White Sea, and again farther north, in Spitzbergen, as already stated. And since the interval between the Triassic outcrops of Austria and Russia, and that between the Alpine and the Franco-Prussian areas are largely under later rocks, it is probable that at this period nearly all outside of Scandinavia and the Baltic provinces in Russia was a shallow 
continental sea. In the earlier and later part of the Triassic, it was very shallow, the conditions those of sea margins and seashore basins, and brackish-water flats; in its middle portion of somewhat deeper waters; but about the region of the eastern Alps, and along the side of the Alps toward the Mediterranean, as well as in southern France and Austria, the waters, judging from the prevalence of limestones, their thickness and the fossils, were those of a clear, open sea. This region has been designated the Mediterronean region.

\section{ROCKS-SUBDIVISIONS, KINDS AND DISTRIBUTION.}

1. Lower Trias or Vosgian. - Represented generally by red or variegated sandstones passing to whitish marlytes and pebbly beds; salt beds are sometimes present, and also gypsum. In England it includes the Lower Red Sandstone of the Trias, 1000 feet to 2000 feet thick; in Germany, the Buntersandstein; in France, the Grès des Vosges and Grès bigarré (bunter and bigarré meaning variegated); but in the eastern Alps, in Lombardy, and the Tyrol, a limestone, the Gutenstein, underlying the Werfen sandstone with rock salt and gypsum.

2. Middee Trias or Franconian. - The rock is limestone in Germany, France, and the Alps; it is not recognized in England. It is represented by the Muschelkalk of Germany, with the Wellenkalk below, and affords rock salt in Würtemberg; and by the Calcaire Conchylien in France.

3. Upper Trias. - (1) Keuperian. In England mostly like the Lower Trias in its rocks; it affords rock salt at Cheshire. In Germany there are, below, red shales and marlytes with thin coal seams - the Kohlenkeuper or Lettenkohle; and above, the Keupermergel, marlytes containing gypsum. Gypsiferous beds and rock salt occur in Lorraine, and at Salzkammergut, near Salzburg, Austria. In the eastern Alps, there are the St. Cassian beds; in Sweden, gray and red marlytes, with some good coal.

(2) The Rhcetic, so-named from the Rhætic Alps. The beds are limestone or shales. They include the Kössen beds of Germany, the Avicula contorta beds; the larger part of the Dachstein limestone of the eastern Alps; and in England the Penarth beds of shales overlying the Trias from Yorkshire to Lyme-Regis, 50 to 150 feet thick. One to three bone-beds occur in the lower part in England, and also in Bourgogne, Hanover, Brunswick, and Franconia. The Rhætic is sometimes placed at the base of the Lias.

The Trias has great thickness in the Alps, especially the Italian, it being nearly 13,000 feet along a belt from Bardonnèche (Savoy), by the Mont Cenis tunnel, to. Modena. This great thickness is owing to the fact that preparations were in progress, through a geosyncline of accumulation, for the Tertiary mountain making, which took place along the range at the close of the Miocene.

In peninsular India, the upper part of the Gondwána series, the Panchet group, is Triassic; it is without marine fossils. Outside of the peninsula, Triassic beds occur in DANA'S MANUAL - 49 
the Salt Range of the Punjab; in northern Kashmir, and along the mountain region as far as Spiti in western Tibet, resting on Carboniferous rocks, where the succession of beds from the Lower to the Upper is closely like that of the Alps. They are concealed by Cretaceous if they exist in Sind. In South Africa, the Karoo beds include, above the Ecca beds (which are referred to the Permian, and are equivalents of the Lower Gondwána of India): (1) the Kimberley shale; (2) the Beaufort beds; and (3) the Stormberg beds or Upper Karoo; and the last have afforded Ialceoniscus Bainei, P. sculptus, Ceratodus Capensis, etc. None of the fossils are marine.

In Australia, in New South Wales, the widespread Hawkesbury sandstone, mostly unfossiliferous, is probably Jurassic or Jura-Trias. In New Zealand, Dr. Hector has described as Triassic an Oreti series, including great bowlder deposits, in northern and southern New Zealand, containing stones up to $5^{\prime}$ in diameter; and the overlying Wairoa series, in which are some Upper Triassic fossils.

For further details as to subdivisions, see page 773.

\section{LIFE OF THE FOREIGN TRIASSIC.}

Plants. - The range of Triassic plants corresponds with that of North America. Among Conifers occur the Cypress, Figs. 1250, 1251, Voltzia heterophylla, from the Lower Trias, and Spruces of the genus Albertia. Of Cycads,

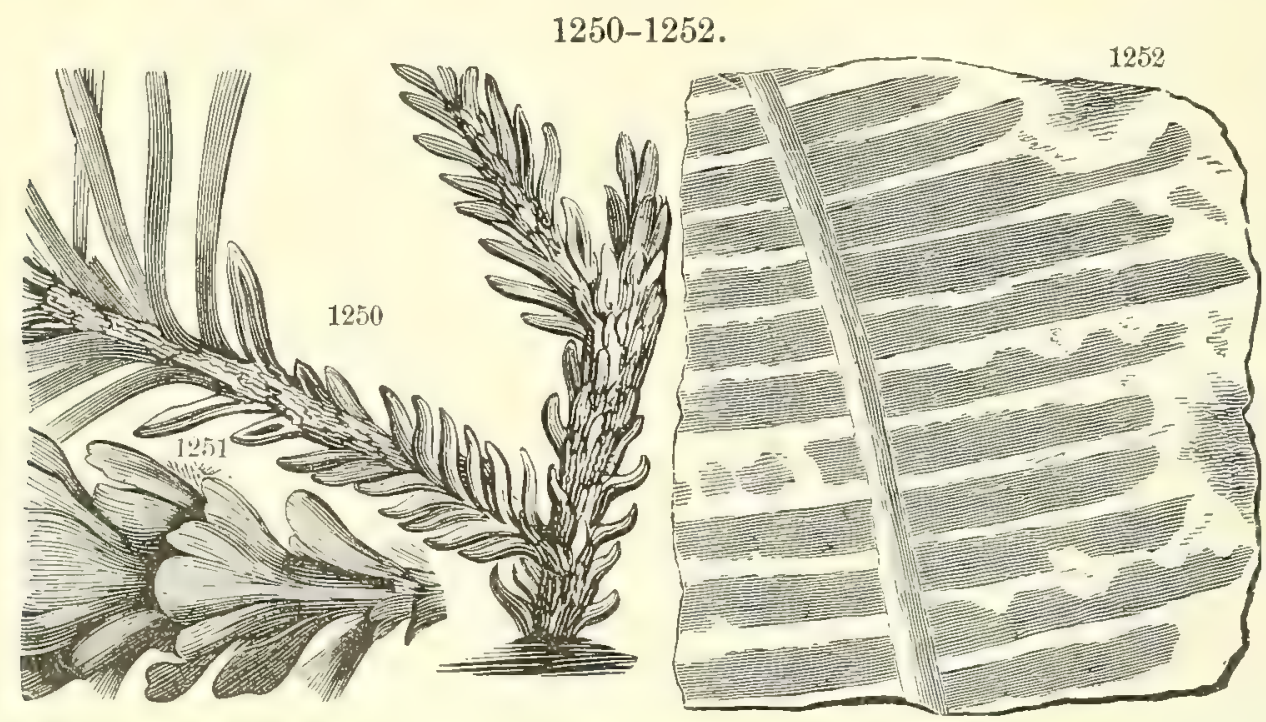

Fig. 1250, Voltzia heterophylla; 1251, one of its fruit-bearing branches; 1252, Pterophyllum Jægeri. Figs. 1250, 1251, from Vogt; 1252, Bromn.

Pterophyllum Joegeri, Fig. 1252, is a species from the Upper Trias. Ferns and Equiseta were common.

Animals. - 1. Radiates, though not abundant, are represented by Crinoids, Starfishes, and a few Corals. Among Crinoids, the Middle Trias (Muschelkalk) affords abundantly the Lily Encrinite, Encrinus liliiformis, Fig. 1253. The Lamellibranch, Gervillia socialis, Fig. 1254, is from the same limestone; the Myophoria, Fig. 1255, of the Trigonia family, is from the Upper Trias. The Avicula contonta Portl., characteristic of the Rhætic beds, is represented in Fig. 1256. The Cephalopods were represented by Ceratites, one of which, from the Muschelkalk, C. nodosus Schloth., is shown in Figs. 
1258, 1259; an Ammonite, from the Keuper, is the Cladiscites tornatus Braun. The genus Choristoceras, of the Ammonite family, contains Triassic species

1253.
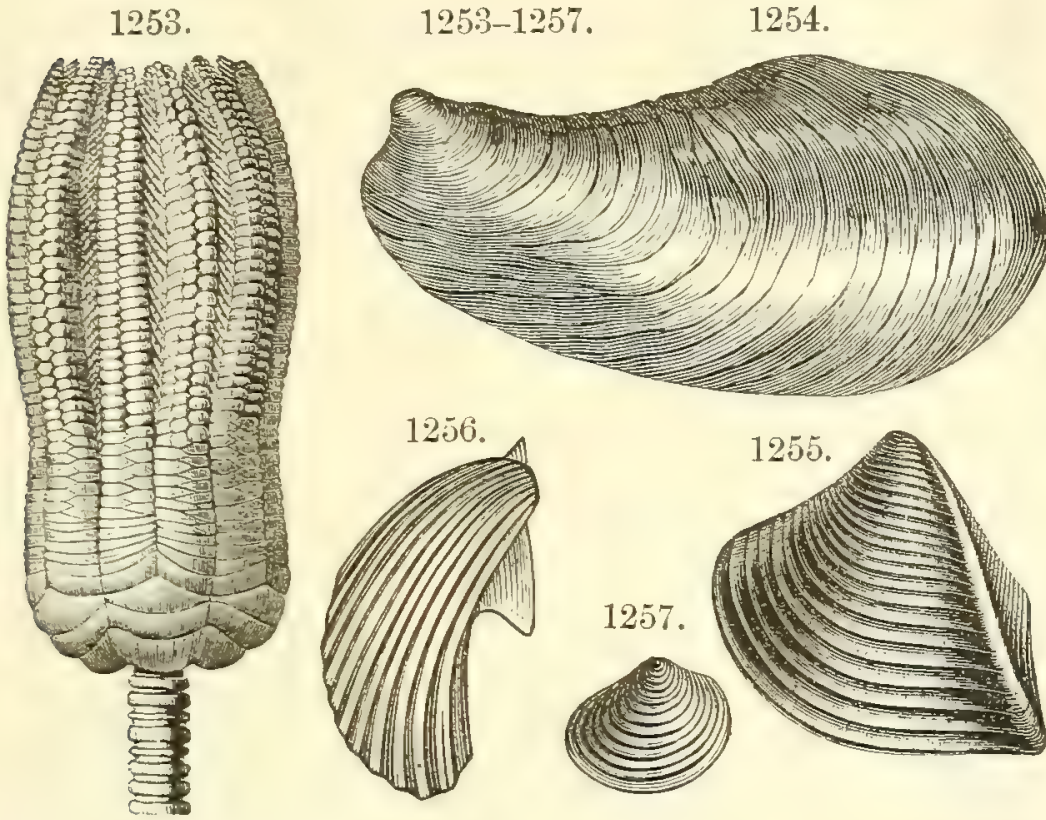

Crivom. - Fig. 1253, Encrinus liliformis. Lamellibranchs. - Fig. 1254, Gervillia socialis; 1255 , Myophoria lineata; 1256, A vicula contorta. Ostracow. - Fig. 1257, Estheria minuta. Figs. 1253, 1257, D'Orbigny ; 1254, Vogt; 1255, Lyell; 1256, Portlock. that are like Ceratites in the partitions, but the whorls of the shell are not contiguous, - a feature here first presented under the type; and Cochloceras of the Trias has a turreted shell like Turrilites of the Cretaceous.

\section{Crustaceans,}

Insects. - Ostracoids are common. Estheria minuta Goldf. (Fig. 1257) abounds in a stratum of the Lower Trias, and has given rise to the name $E s$ theria shales. Macrurans, allied to the Crawfish or Lobsters, oceur, one of which is Pemphix Sueurii Desm., of the Muschelkalk (Fig. 1262).

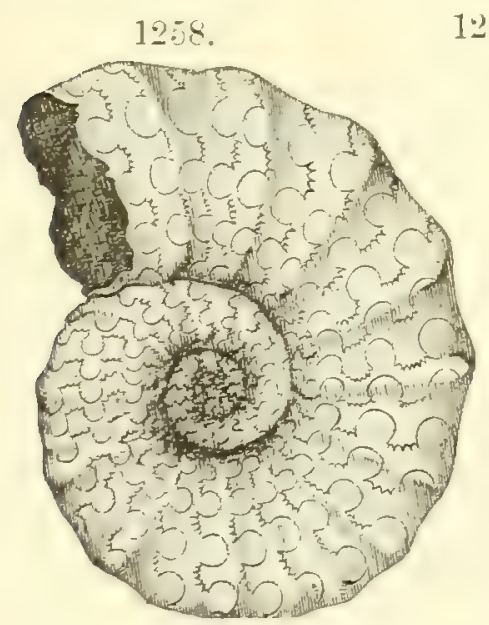

$1258-1 \div 61$.
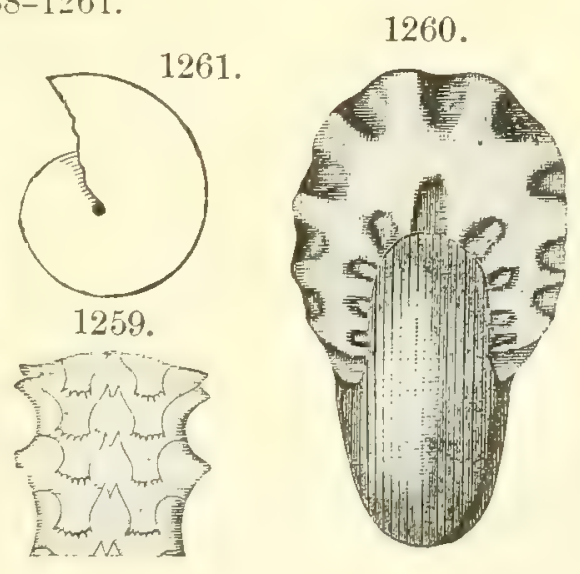

Cephalopons. - Fig. 1258, Ceratites nodosus; 1259, dorsal view of portion of same, showing the dorsal lobes of the septa; 1260, Cladiscites tornatus; 1261 , side view of same $\left(\times \frac{1}{2}\right)$. Figs. 1258 , 1259, D'Orbigny ; 1260, 1261, from Vogt.

Insects of the Trias are Cockroaches (Orthopters) of

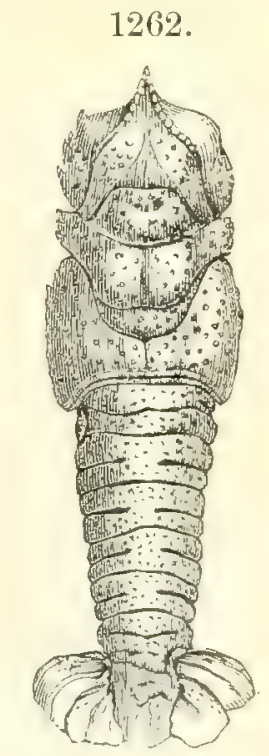

Pemphix Sueurii, from Naumann.

both palæic and modern type; several true Neuropters; and Beetles or Coleopters of the Curculio (Weevil) family, as Curculionites prodiomus Heer, and of Chrysomelids and Buprestids, from the Lower Keuper. 
3. Fishes. - Hybodont and Cestraciont sharks of the genera Hybodus, Acrodus, and Strophodus here first appear: Fig. 361, a tooth of Hybodus minor Ag., from the Keuper, and Fig. 362, of II. plicatilis Ag. There were also Ganoids of the genera Saurichthys, Gyrolepis, Amblypterus, Palcooniscus, Pycnodus, etc.; and Ceratodus of the Dipnoans.

4. Amphibians. - The Labyrinthodont, Mastodonsaurus giganteus, was a scale-covered species; Fig. 1263 represents its cranium, which was two feet long, and Fig. 1263 a, a tooth three inches long. Several other species of Laby rinthodonts are known from British and European beds. The tracks, Fig. 1264, named (hirotherium (from xєip, hand, and Appiov), are supposed to be those of a Labyrinthodont.

$1263 a$.

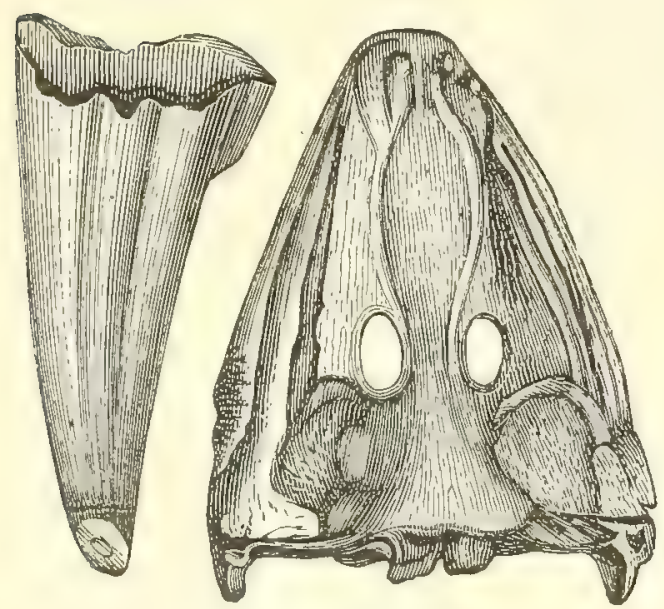

$1263-1265$.

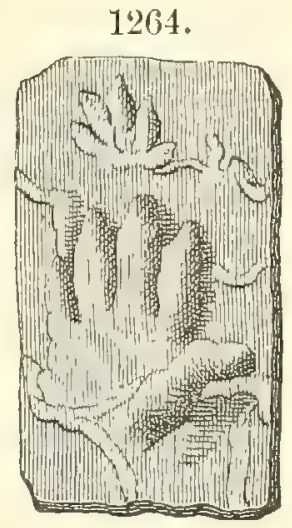

Amphibians. - Fig. 1263, Mastodonsaurus giganteus $\left(x_{\frac{1}{12}}\right) ; 1263 a$, tooth of same; 1264, Chirotherium $\left(\times \frac{1}{12}\right)$; 1265, track of a Turtle? Figs. 1263, 1263 a, Braun; 1264, 1265, D'Orbigny.

5. Reptiles. - The British and other foreign Triassic Reptiles comprise species of Rhynchocephs, Anomodonts, Belodont Crocodilians, Dinosaurs,

1266 .

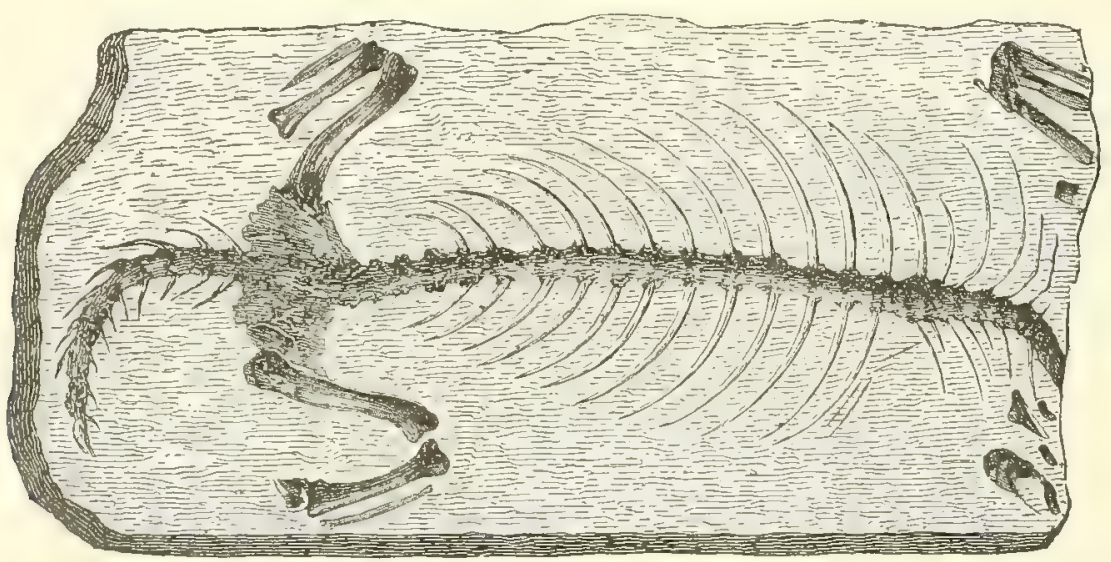

RнчмоносеPH. - Fig. 1266, Telerpeton Elginense. From Mantell.

Chelonians, and Sea-Saurians. Under the Rhynchocephs, there are the genera: Hyperodapedon of Huxley, species of which occur in the Triassic 
beds of India, as well as Great Britain; and Rhynchoscurus, from the Upper Trias of England, both having the jaws beaked at the extremity, but supplied with short palatal teeth. Telerpeton Elginense (Fig. 1266), from the Elgin sandstones of Scotland (at first supposed to be Devonian in age), is referred to the Rhynchocephs. The Anomodonts include Dicynodon of Owen, and other genera from the Karoo beds of South Africa, and from India; also horned Reptiles from Elgin, one of which, the Elginia mirabilis, had, besides a pair of long horns in the position of those in cattle, other smaller horn-like projections over the front and sides of the cranium. The Elgin fauna was closely like that of the African Karoo beds, and the Indian Panchet and Maléri beds.

Crocodilians of the genus Stagonolepis occur in the Upper Trias of England and Scotland, and a Belodont in the Rhætic beds of Germany. The carnivorous Dinosaurians included Thecodontosaurus and Palceosaurus of the Keuper.

The earliest Sect-Saurians are from the Middle Trias, and are of Plesiosaurian type. The paddles have the limb bone distinct and the normal number of fingers; the teeth are in sockets; the vertebræ feebly biconcave; the neck very long; the orbits very large, without a sclerotic ring. The Triassic genera Simosaurus, Nothosaurus, and others, are characterized by very large orbital openings. Both of the genera Plesiosaurus and Ichthyosaurus have Rhætic species.

Turtles are represented in the Keuper by the Proganochelys Quenstedtii of Baur. The tracks, Fig. 1265, are supposed to be those of a Turtle, as the rights and lefts, in the series observed, are far apart.

6. Mammals. - The earliest remains of Mammals are found in the Rhrtic beds; one species at Würtemberg (Figs. 1267, $1267 a$ ), Microlestes antiquus Plieninger, and another, M. Moorei Owen, 1267.

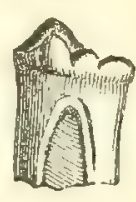

$1267 a$. from Somerset, England. The teeth resemble those of Dromatherium. The species were Marsupial. Tritylodon is a related genus from the Triassic of South Africa.

\section{Characteristic Species.}

1. Vosgian, or Lower Trias (in the Alps, the Werfenian). - In Germany, the upper part contains, with sandstone, some limestone or dolomyte and gypsum, with IFyophoria costata, II. vulgaris, Naticella costata, Estheria minuta, Voltzia heterophylla, Equisetum arenaceum, Chirotherium (tracks), Placodus, Nothosaurus, Trematosaurus. Other Lower Triassic species are Ceratites Middendorfi, Triolites Cassianus, Kenodiscus Schmidti, and Dinarites Liccanus.

In the Alps and Mediterranean province: the Werfen shales; stage of Tirolanus Cassianus and Naticella costata.

2. Franconian, or Middle Trias. - In Germany: (a) The Wellen Kalk in Franconia (Würzburg, etc.) and elsewhere, with Beneckia Buchii (Nautilus bidorsatus), Spirifer fragilis, Gervillia costata, G. socialis, Myophoria orbicularis; (b) limestones, partiy 
oölytic, with Ceratites nodosus, Encrinus litiformis, Nyophoria vulgaris, Honotis Alberti, Lima striata, Pecten discites, Spirifer fragilis.

In the Alps, the Virgloria or Gutenstein limestone (the Virglorian): (a) stage of Trachyceras balatmicum and T. binodosum; (b) stage of Trachyceras trinodosum. In Lombardy the same stages: Varenna marble, Salvator dolomyte, Besano dolomy te. Other Middle Triassic species are Ptychites gibbosus, Gymnites incultus, Foosdiceras bidorsatum, Atractites secundus.

3. Upper Trias. - (1) Keuperian. In Germany: (a) Lettenkohle group with the Grenzdolomit; Anoplophora lettica, Myophoria Goldfussi, Estheria minuta, Ceratodus, Equiseta, Calamites, Voltzia; (b) Keupermergel, with Anoplophora Münsteri, Estheria, Mastodonsaurus Jageri, Equiseta, Pterophyllum .Jegeri, Calamites arenaceus, Dancopsis.

In the Alps: (a) Wengen shales overlaid by (b) the St. Cassian beds and (c) the Hallstadt limestone of the Salzburg region; $(d)$ Wetterstein limestone and $(e)$ Schlern dolomyte; with the stages (a) Arcestes giganto-galeatus and Pinacoceras Metternichi (overlying beds of the Middle Trias containing Choristoceras H(ueri); (b) Pinacoceras parma, and Didymites globus; (c) Arcestes ruber; (d) Didymites tectus; (e) Tropites subbullatus. In Lombardy: the zones of (a) Trachyceras Reitzi and T. Curionii; (b) $T$. Archelaus and Daonella Lommeli.

(2) Rhatic beds. - In England: Avicula contorta, Pecten Valoniensis (these two species characteristic and abundant), Pleurophorus elongatus, Pullastra arenicola, Monotis decussata, Modiola minima, Ostrea liassica; Spirifer Münsteri, Estheria minuta; Acrodus minimus, Hybodus plicatilis, Saurichthys apicalis, Gyrolepis tenuistriata, vertebræ of Ichthyosaurs and Plesiosaurs, tracks of Chirotherium; Microlestes in Bone-bed. Many of the species occur also in the Lias.

In the Alps: (a) Raibl shales; (b) Hauptdolomit (Dachstein limestone); (c) Köossen beds: stages (a) Trachyceras aonoides, Cardites crenatus, Gervillia bipartita; (b) Turbo solitarius, Avicula exilis, Megalodon triqueter; (c) Avicula contorta.

The "White Lias" of England, at the top of the Rhætic, also called the Infra-Lias, is the Hettangian of Renevier.

The Triassic rocks of Spitzbergen, partly bituminous shales, have afforded species of Nautilus, Ammonites, Ceratites, Halobia, etc., closely like, if not identical with, species of the St. Cassian beds (Laube).

\section{JURASSIC.}

The belt of Trias in England (see map, page 694) is succeeded on the eastward by approximately parallel and interlocking belts of Lias and Oölyte, and then follows the Cretaceous. This position of the Jurassic areas between the Triassic and Cretaceous is common over Europe. In France and Germany, south of the broad coast region of Tertiary and Cretaceous, comes first the Jurassic next to the Cretaceous, and then the Triassic. The British Jurassic belt, which reaches the Channel at Lyme-Regis, reappears in France, and is continued along by the inner side of the Cretaceous, about the so-called Paris Basin, and also in Hanover, in northwestern Germany. Further, Jurassic areas border the inner side of the Triassic. From west-central France they extend southeast to the Mediterranean, and from east-central southeast to the Juras; and a long Jura-mountain belt, of northeastward course, reaches far into northern Bavaria and Germany. Jurassic rocks occur also along both sides of the Alps, and extend on through the Austrian Alps; and after an interruption about Vienna, appear again in the Carpathians. 
They outcrop along the Apennines, the Pyrenees, and east-central Spain. They cover large areas in central and northern Russia. The beds have a small development along the Alps compared with the Triassic; but the fossils and rocks show, by their kinds, that the great continental sea was here of unusual depth and purity.

In England the subdivisions of the Jurassic series are as follows:-

\section{Liassic Group.}

(1) The Lower Lias, consisting of clays, shales, and gray limestone, and about 900 feet thick.

(2) The Midde Lias, or Marlstone, a coarse shaly argillaceous and ferruginous limestone with sand-beds and clays; 200 to 350 feet thick.

(3) 'The UPPER Lias, consisting of clays and shales, and containing limestone concretions; 200 to 300 feet thick; with the Midford sands in southern England about 200 feet. The jet of the Yorkshire coast is a compact variety of coal from the Upper Lias.

These subdivisions were named in France by D'Orbigny: (1) the Sinemurian, from the Latin word for the town of Semur; (2) the Liassian; and (3) the Toarcian, from Thouars, in western France.

\section{(1) The Lower OöLxte.}

\section{Oölytic Group.}

Divided into (1) the Inferior Oölyte, which includes the sandstones or Dogger of Yorkshire and the Cheltenham beds - the Bajocian; and (2) the Great or Bath Oölyte - the Bathonian, including (a) the Fuller's earth, or clay-beds of varying thickness up to $400^{\prime}$ in Dorsetshire; $(b)$ the Stonesfield slate, a thin-bedded limestone in Oxfordshire, and above it; (c) the Forest Marble, consisting of sandy and clayey layers with Oölyte; and $(d)$ the Cornbrash, a coarse shelly limestone. At Brora, on the east coast of northern Scotland, there is a coal-bed $2 \frac{1}{2}^{\prime}$ thick, overlaid by beds containing Middle Oölyte fossils. In Yorkshire, the Inferior Oölyte contains estuarine beds with thin seams of coal and many remains of plants.

\section{(2) The Middee, or Oxford Oölxte.}

Divided into (1) the Callovian, consisting of the Kellaways rock; (2) the Oxfordian, calcareous sandstune and the Oxford clay; and (3) the Corallian, made up of the Coral rag or Coralline Oölyte, $10^{\prime}$ to $120^{\prime}$, with more or less of calcareous grit, $5^{\prime}$ to $80^{\prime}$.

(3) The Upper, or Portland Oöryte.

Divided into (1) the Kimmeridgian, or Kimmeridge clay, having ferruginous con. cretions in the lower division, called "doggers"; (2) the Portlandian, or the Portland stone, including marlytes and limestone, in part oölytic, with fresh-water beds ; and (3) the Purbeckian, or Purbeck beds, well displayed in Dorsetshire, mostly shales with some limestone at middle which is partly of marine origin, $100^{\prime}$ to $400^{\prime}$ thick, and affording remains of numerous Insects and Mammals. The "Portland dirt-bed" is at its base.

In Europe other subdivisions have been introduced, for which see page 790 . 
The "Black Jura" of Germany corresponds to the Lias; the "Brown Jura" or "Dogger" to the Lower ()ölyte and Callovian; and the Lpper or White Jura, or Malm, to the rest of the Middle and the Upper ()ölytes, from the Callovian to the Portland beds inclusive. To the Kimmeridgian group belongs the fine-grained lithographic limestone of Solenhofen at Papenheim, in Bavaria, near Munich, about $80^{\prime}$ thick, noted for its wonderfully perfect preservation of fossil Crustaceans, Squids, Insects, impressions of birds' feathers and of wings of Pterodactyls.

In Peninsular India, in the district of Cutch, the beds referred to the Jurassic have a thickness of $6000^{\prime}$, the lower chiefly marine, and the upper as prominently fresh-water. Outside of the peninsula the Jurassic occurs in the Salt Range and northwest Himalaya, with characteristic fossils.

In Australia, Jurassic rocks with many fossils have been observed in Western Australia, of the periods of the Middle and Upper Lias and Lower Oölyte; and in Queensland, of the Upper Oölyte (C. Moore, Q. J. G. Soc., 1870).

Aucella-bearing beds have been observed, as C. A. White states in Becker's Report (see page 835), near Moscow, in Petschora-land, near the Caspian, in northern Siberia, in Nova Zembla, Spitzbergen, in the Kuhn Islands near the east coast of Greenland, in southern India, in New Zealand, and in Brazil; and they have been referred by most authors to the Jurassic; but Professor Eichwald makes them Neocomian, and Zittel refers those of New Zealand to the Jura or Lower Cretaceous.

\section{LIFE OF THE FOREIGN JURASSIC.}

The Lias and Oölyte of Britain and Europe afforded the first full display of the marine fauna of the world since the era of the Subcarboniferous. Very partial exhibits were made by the few marine beds among the Coalmeasures; still less by the beds of the Permian, and far less by the Triassic. The seas had not been depopulated. The occurrence of over 4000 invertebrate species in Britain in the single Jurassic period is evidence, not of deficient life for the eras preceding, but of extremely deficient records. Further, this meagerness in American records continued until the Cretaceous period. Moreover, in order to put together rightly the American and European records, it is necessary to note that the events of the epochs of the Lias and Lower Oölyte, with their vertebrate life, have their place, according to
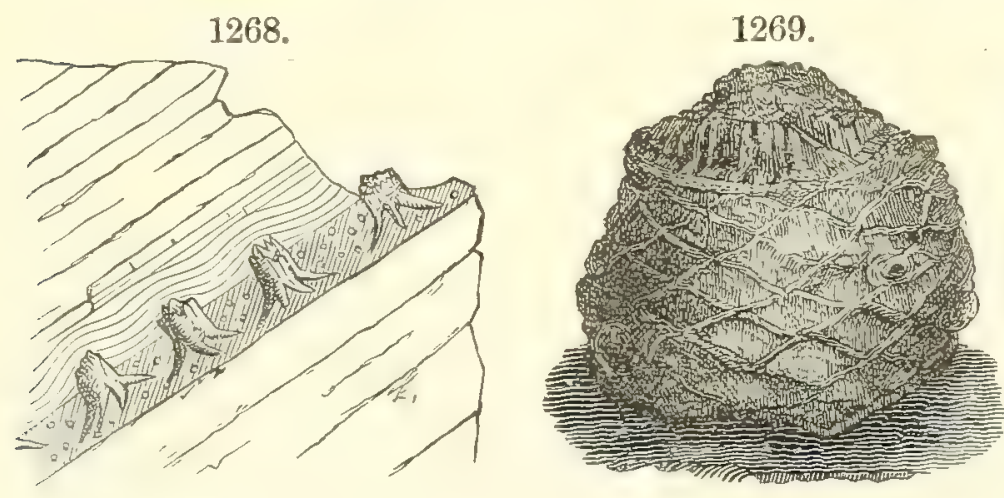

present knowledge, before those of the American Atlantosaurus beds; that is, between those of the Middle Oölyte and of the Triassic.

Plants. - The land plants of the Jurassic period were mainly Cycads, Conifers, Ferns,

Fig. 1268, Section from near Lullworth Cove, showing stumps of trees and Equiseto, as in the in the Portland "dirt-bed"; 1269 , stump of the Cycad, Mantellia mega- Triassic. Leaves and
lophylla $\left(\times_{\frac{1}{2}}^{\frac{1}{2}}\right)$. Buckland.

stems occur in many strata, and especially in the Lower Oölyte in the Yorkshire beds and in the 
Stonesfield slate, chiefly near Woodstock, where have been found over 80 species of Ferns, nearly 20 of Conifers, and 40 of Cycads. The Middle and Upper Oölyte have afforded about 16 other species. The Conifers are of the genera Taxites, Thryites, Cupressites, Araucarites, - names which express their modern relations. There were also Endogens of the Arum and Pandanus families; but no Angiosperms or Palms. The "dirt-bed" at the base of the Purbeck has afforded stumps of Cycads (Fig. 1268), including three species of Mantellia, one of which is shown in Fig. 1269. There is also a species of Pine (Pinites), besides a few other plants.

Invertebrates. - Siliceous Sponges, both the Hexactinellid (Fig. 1270) and Lithistid kinds, were very common in the Middle and Upper Oölyte, and so-called sponge-beds occur in the European Oölyte at different levels.

Polyp-corals were of many kinds, of the modern Hexacoralla type (having the rays a multiple of 6 ). The Corals flourished like the species of

1270.

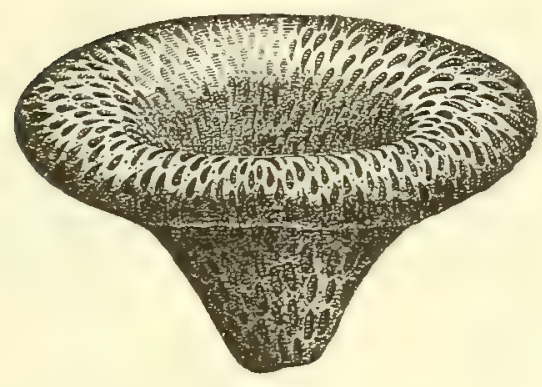

1271

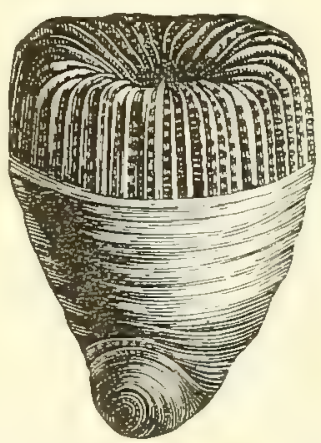

1272.

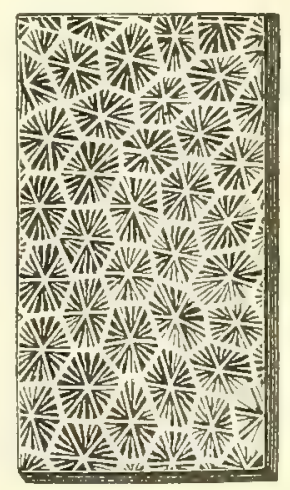

SPONGE, of the Oölyte. - Fig. 1270, Tremadictyon reticulatum. PolyP-Corals, of the Oölyte. - Fig. 1271, Montlivaltia caryophyllata; 1272, Isastræa oblonga. D'Orbigny.

modern coral reefs (1) in the pure ocean waters, and (2) many too in the shallow waters of the ocean's borders, as about modern coral reefs. For (1) the limestones make several alternations with the sediments, clays, and sand-beds of the sea margins; and (2) only the purer limestones contain the corals. They abound in England in some beds of the Lias, in both sections of the Lower Oölyte, the Inferior and the Great Oölyte, in the Corallian of the Middle Oölyte, but are absent from the Kellaway beds or Oxford clay of the Middle, and from all of the Upper Oölyte beds in England, excepting a single species, Isastruca oblonga (Fig. 1272), in the Portland limestone. The reef species of the Oölyte may have flourished at greater depths than those of existing reefs, but appear not to have been, in general, abyssal species.

The most of the species of the Lias are of the genera Montlivaltic (II. caryophyllata, Fig. 1271, from the Bath Oölyte), Thecosmilia, Astrocenia, Isastrce, and excepting Astrocrenia these, with Thamnastrac, are the most prominent genera in the Lower Oölyte. 
The Isastroea, Thecosmilia, and Thamnastraea corals are massive kinds. Etheridge's tables for British fossils in 1885 give the number of Jurassic species, in all, 236, and of these the genera mentioned contain :-

\begin{tabular}{|c|c|c|c|c|c|}
\hline & Total & Lias & Lower Oölyte & Middle Oölyte & Upper Oölyt \\
\hline Astrocœenia............ & 14 & 14 & 0 & 0 & 0 \\
\hline Isastræa. . . . . . . . . . . . & 24 & 10 & 18 & 4 & 1 \\
\hline Montlivaltia............ & 44 & 25 & 18 & 1 & 0 \\
\hline Thecosmilia ........... & 21 & 14 & 6 & 1 & 0 \\
\hline Thamnastræa........... & 27 & 21 & 23 & 3 & 0 \\
\hline
\end{tabular}

Echinoderms were in profusion, as in existing coral seas. Crinoids were numerous of the genera Pentacrinus, Apiocrinus, and others. Pentacrinus (Extracrinus) Briareus (Fig. 1278) is one of the common and most remarkable of the species in the Lias; a bed in the Lower Lias is largely

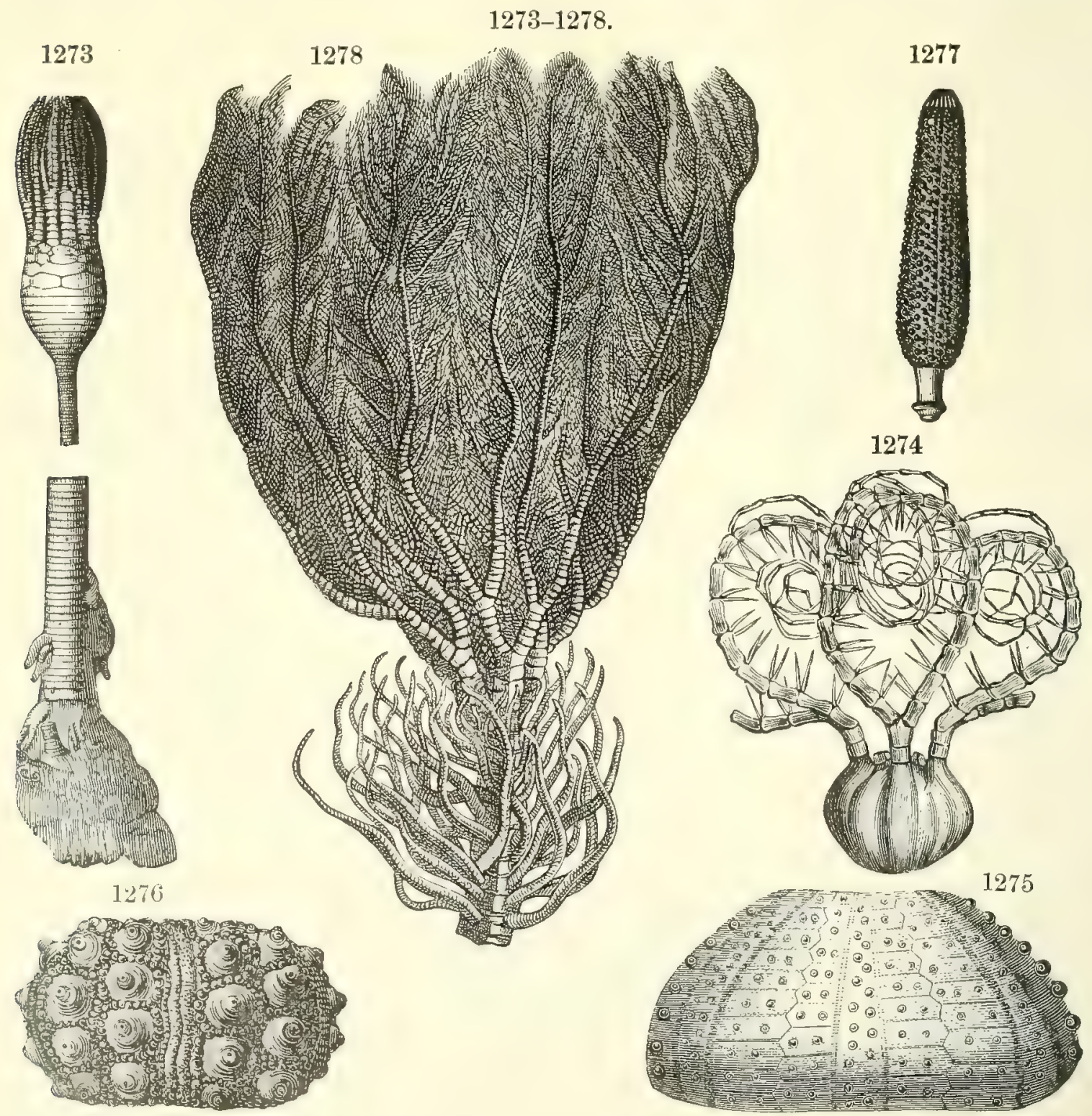

Eohmodrrms, - Fig. 1273, Apiocrinus Roissyanus $\left(\times \frac{1}{4}\right)$, Oölyte, the middle part of the stem omitted; 1274, Saccosoma pectinata, Oxfordian; 1275, Pseudodiadema seriale ; 1276, Cidaris Blumenbachii ; 1277, spine of the last; 1278, Pentacrinus (Extracrinus) Briareus. 
made of it and shells of Gryphoca arcuata (Etheridge). Apiocrinus Roissyanus D'Orb. (Fig. 1273) is from the Middle Oölyte of Europe. Saccosoma pectinata Ag. is a Comatulid, or free Crinoid, from the Oxfordian group. Of Echinoids, the genera Cidaris (Fig. 1276), Hemicidaris, Pseudodiadema, and Hemapedina include the larger part of the species. Pseudodiadema seriale (Fig. 1275) is from the Lower Lias.

Brachiopods of the spire-bearing genera had their last species in the Jurassic period. These excepted, the Jurassic Brachiopods were mostly of

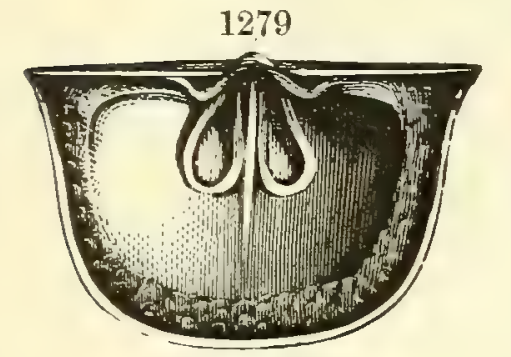

1283

1279-1285.
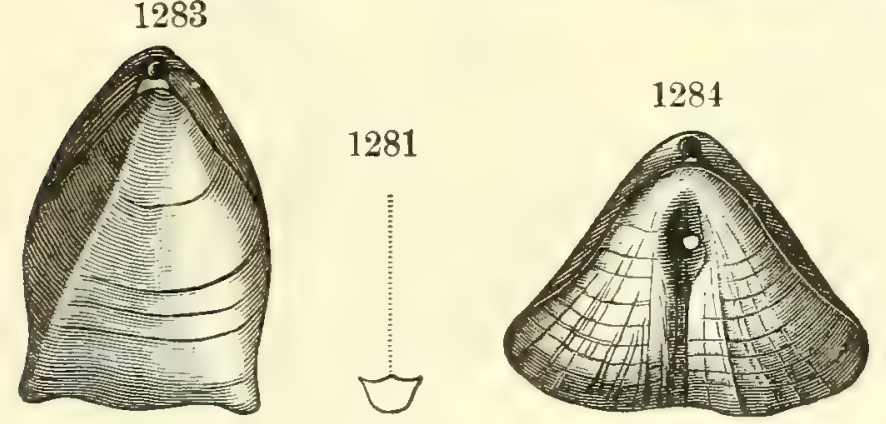

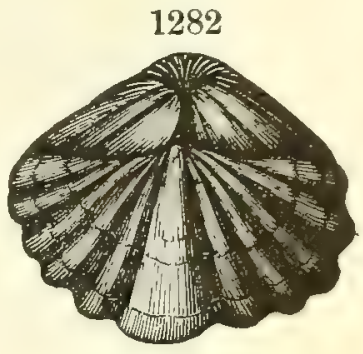

1285

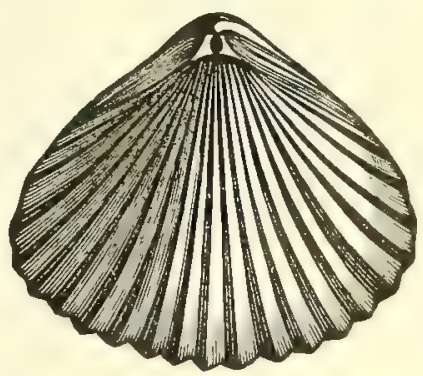

Brachiopods. - Figs. 1279, 1280, Cadomella Moorei ( $\left.\times \frac{7}{1}\right)$; 1281, same, nat. size ; 1282, Spiriferina Walcotti, Lias; 1283, Terebratula digona, Great Oölyte; 1284, T. diphya, Tithonian; 1285, Rhynchonella inconstans, Kimmeridge.

the Terebratula, Rhynchonella, Thecidium, Lingula, and Discina families, which have also living species.

Lamellibranchs were of several new genera. Gryphaca (Figs. 1287, 1290), of the Oyster family, having an incurved beak, commenced in the Lias and

1286.

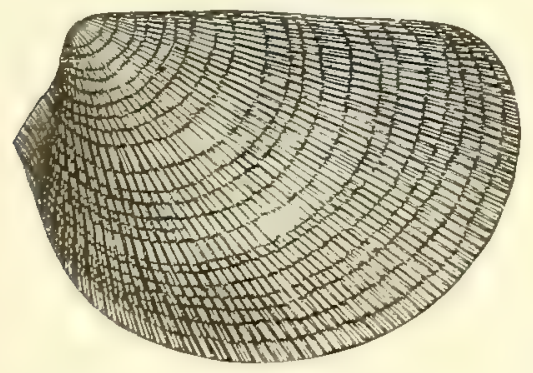

1287.

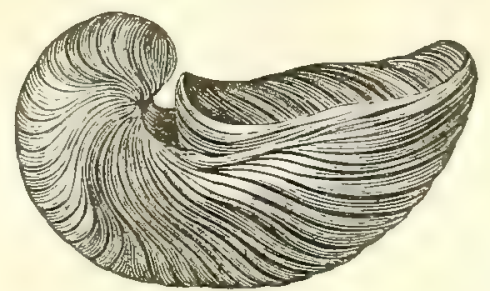

Lamellibranchs. - Fig. 1286, Lima gigantea $\left(\times \frac{1}{2}\right)$, Lias; 1287, Gryphæa incurva $\left(\times \frac{2}{3}\right)$, Lias.

continued into the Cretaceous. Fig. 1287, G. incurva, is from the Lias, and 1290, G. ditatata, is from the Oxfordian beds. Exogyra (Fig. 1289), also of the Oyster family, is another characteristic genus, but more so of the Cre- 
taceous; the beak is twisted to one side, as is implied in the name. Trigonia (Fig. 1291), the name alluding to the somewhat triangular form, has over 100 Jurassic species. Another peculiar type common in the Middle Oölyte

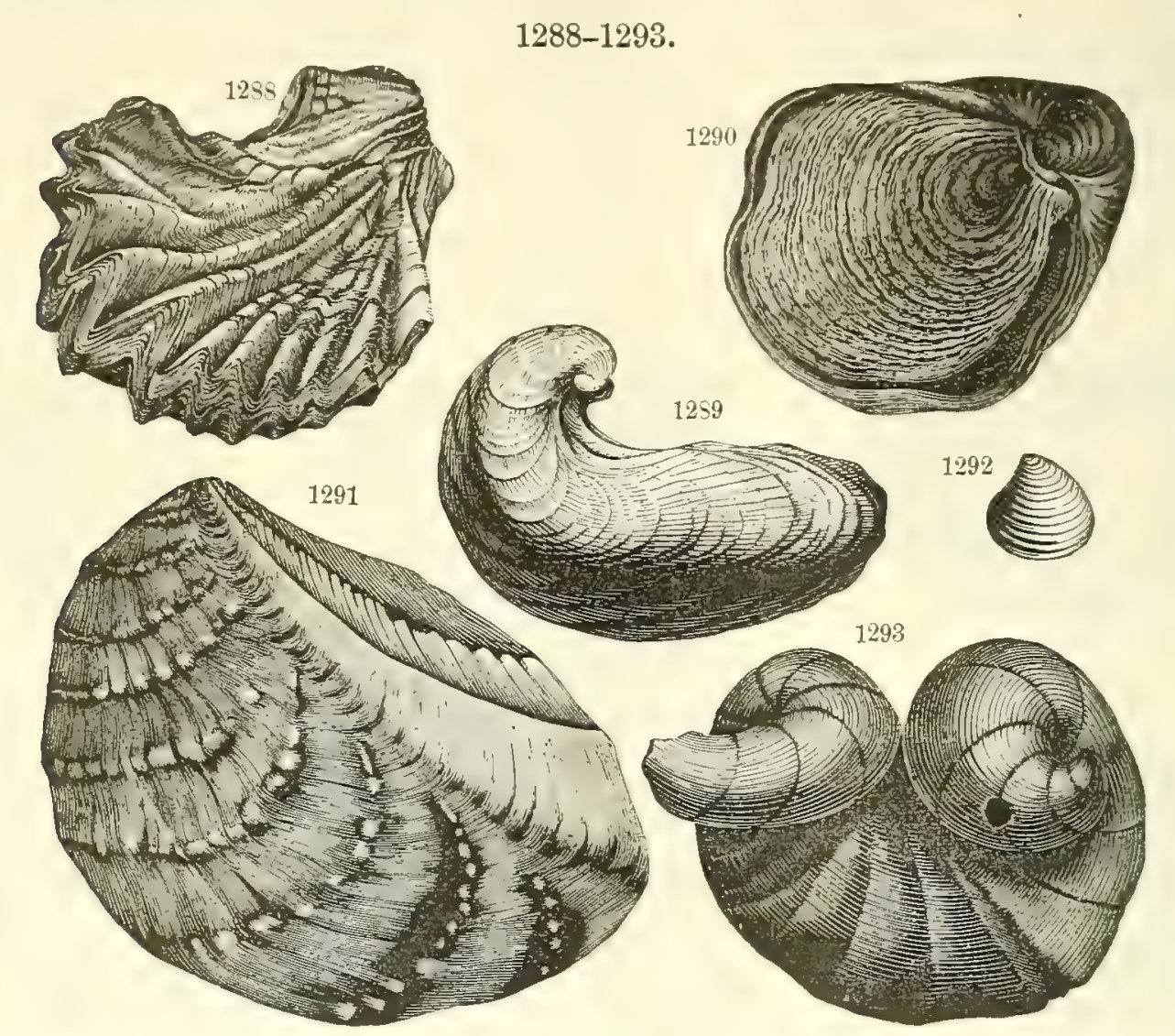

LAMellibanchs. - Fig. 1288, Ostrea Marshii, Lower Oölyte; 1289, Exogyra virgula, Kimmeridgian; 1290, Gryphæa dilatata, Callovian; 1291, Trigonia clavellata, Corallian; 1292, Astarte minima, Corallian; 1293, Diceras arietinum, Diceratian.

in the northern Alps is that of Diceras (Fig. 1293), a species in which the beak of each valve is curved spirally; it is related to the modern Chama. Of

1294

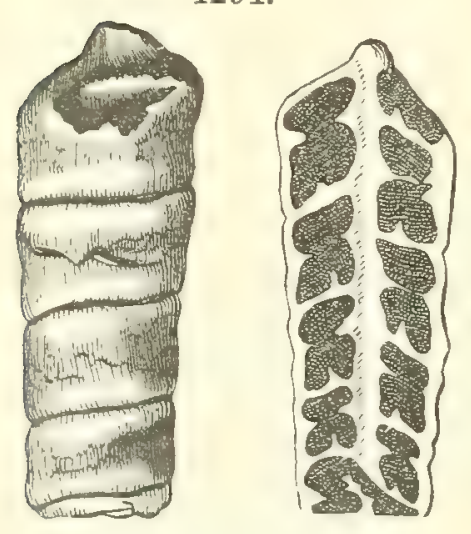

GAstropod. - Fig. 1294, Nerinea Goodhalli, Corallian. existing genera having many Jurassic species there are Ostrea, Pecten, Lima (Fig. 1286), Astarte (Fig. 1292), Lucina, Corbula, Nucula, Pholadomya, and many others.

Gastropods were very numerous. The number of species found in British Jurassic rocks alone is nearly 1000; and of these over 10 per cent were of the old genus Pleurotomaria, the number being larger than for all preceding time. It was the culminating time for the type; only two living species are known. Other genera of many species dating from the Paleozoic, and also modern, are Trochus, Turbo, Patella, Natica, which comprise 25 per cent of the British Jurassic Gastropods; and among the many of Mesozoic origin, Cerithium has 10 per cent of all the 
species, and Chemnitzia 20 per cent (Etheridge). The genus Nerinea, having one or more ridges in the spiral cavity (Fig. 1294) is confined to the Oölyte, and the Cretaceous period.

Cephalopods of the Ammonite type have an enormous expansion in the period; 250, or three-fifths of the British species, occur in the Lias. Figs. 1296, $a$ are from the Lower Lias; 1295 and 1297 from the Middle Lias;

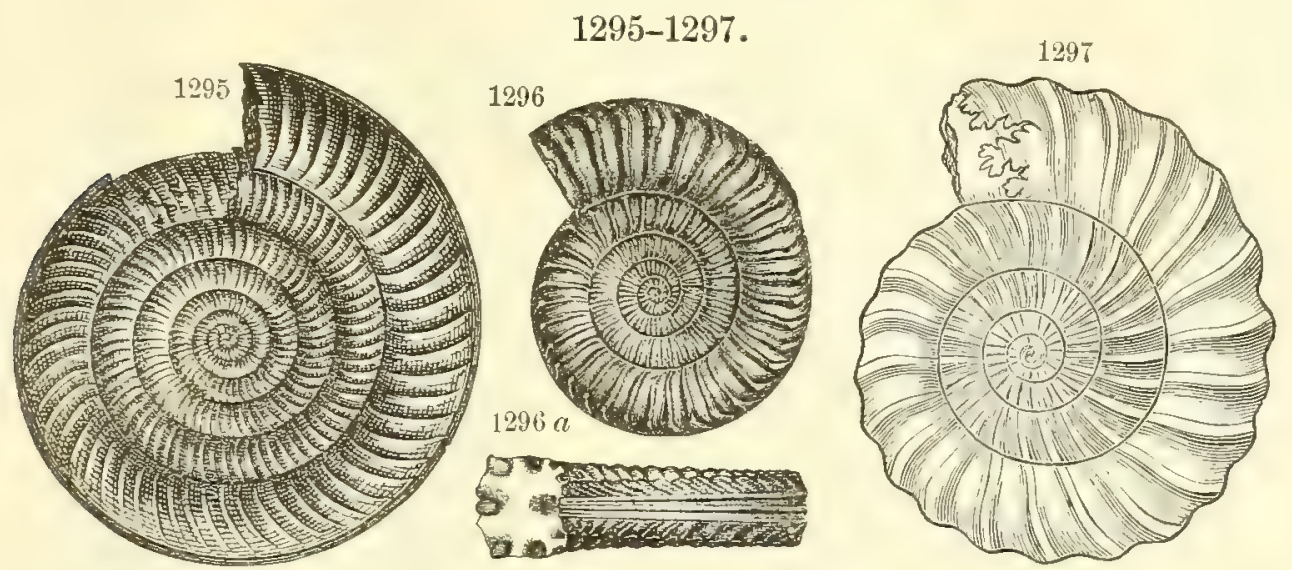

Cephazopods (Ammonites) of the Lias. - Fig. 1295, Pleuroceras spinatum ; 1296, a, Coroniceras Bucklandi ; 1297 , Egoceras capricornus.

1298, from the Inferior Oölyte ; 1299, from the Middle Oölyte. The last two figures have the aperture unbroken; and in 1299 it is much prolonged on either side.

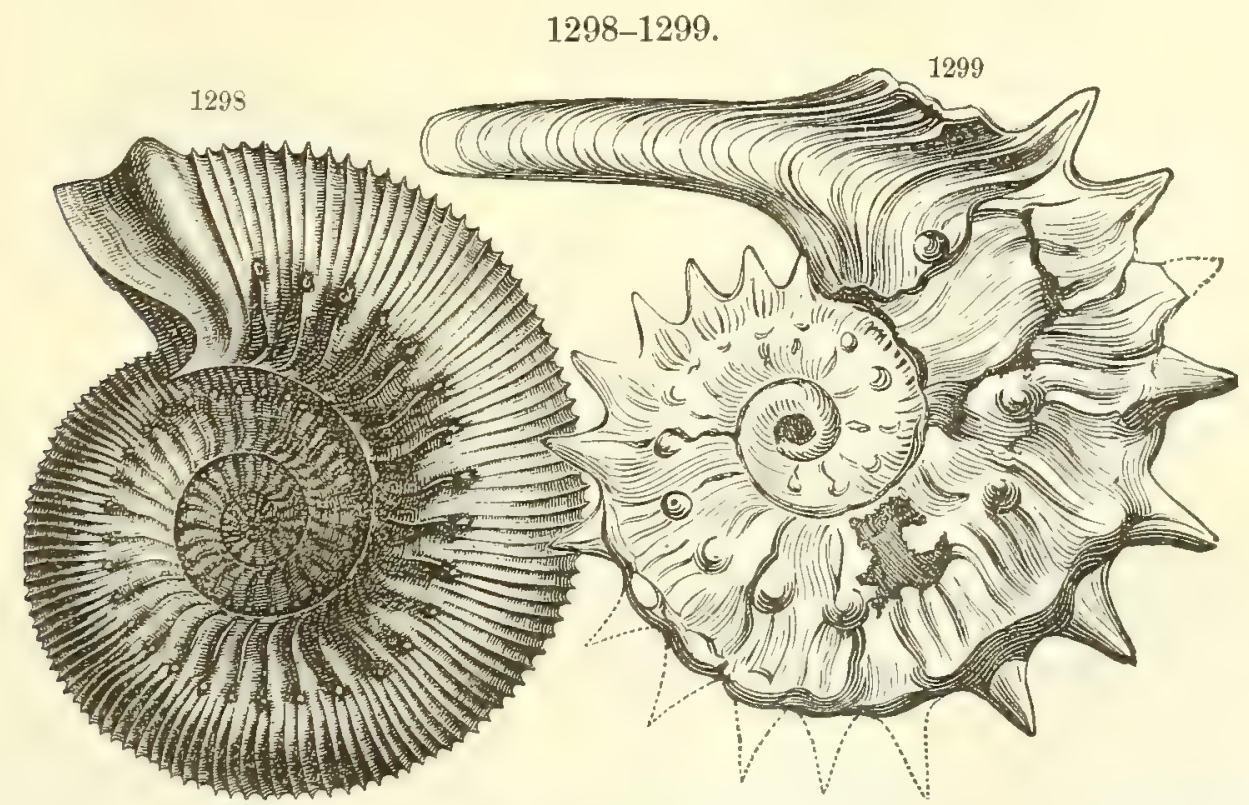

Cephalopods of the Oölyte. - Fig. 1298, Stephanoceras Humphriesianum ; 1299, Cosmoceras Jason.

Besides the Cephalopods with external chambered shells (Tetrabranchs), the Belemnites (Dibranchs) (page 424) were of many species. Figs. 1302, 1303 , represent the bones or osselets of two species, in their ordinary broken state; and Figs. 1300, 1301, an unbroken one, in two different positions. 
Fig. 1305 represents the animal of an allied genus, called Belemnoteuthis. The ink-bags of Belemnites are sometimes found fossil (Fig. 1304), and
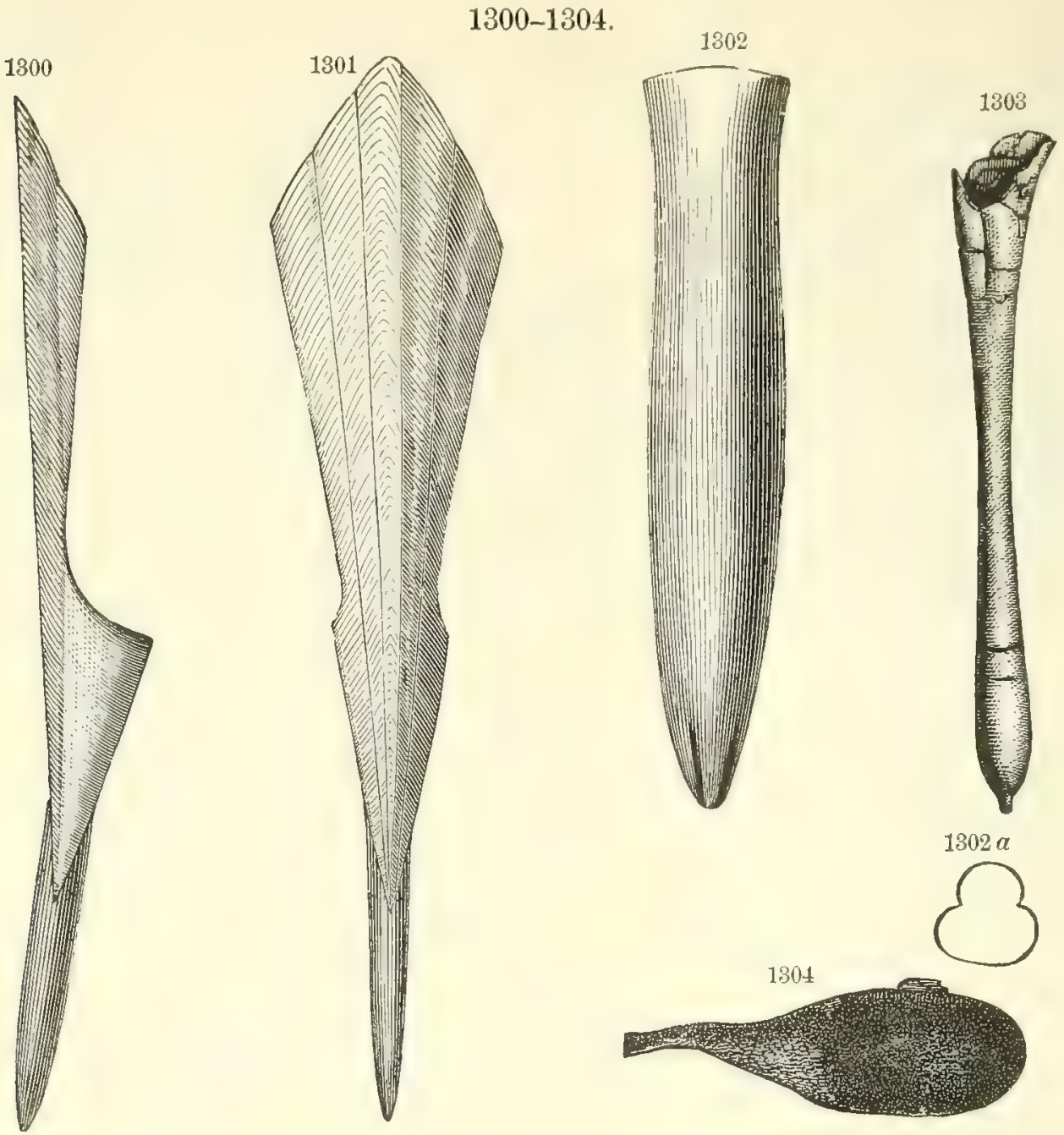

Cephalopods. - Fig. 1300, Complete osselet of a Belemnite, side view, reduced; 1301, dorsal view; 1302, $\boldsymbol{a}$, Belemnites paxillosus, Middle Lias; 1308 , B. clavatus; 1304, ink-bag.

Buckland states that he had drawings of the remains of extinct species made with their own ink.

1305.

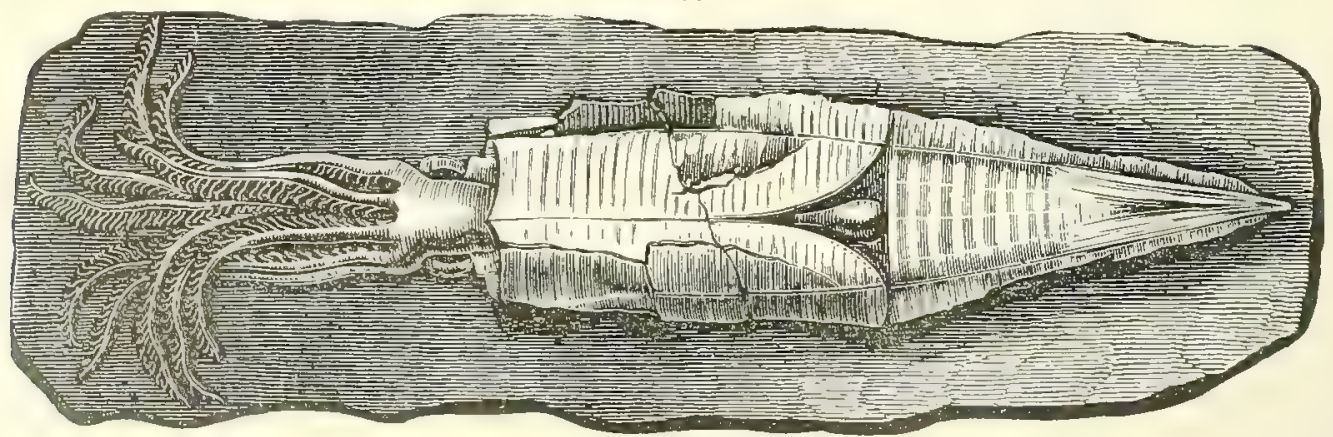

Fig. 1305, Belemnoteuthis antiqua $\left(\times \frac{1}{3}\right)$, of the Oxford clay. From Mantell.

Crustaceans included forms of modern aspect, and among them species of the highest of the divisions of Crabs, the Triangular Crabs - Palæinachus 
of Woodward. Fig. 1307 is one of the Macrurans from Solenhofen, and 1308, an Isopod related to the modern Oniscus, from the Purbeck beds of England. A species of Astacus, or Lobster, is reported from the Lias. Fig. 1310, though Spider-like, is a Stomapod Crustacean.

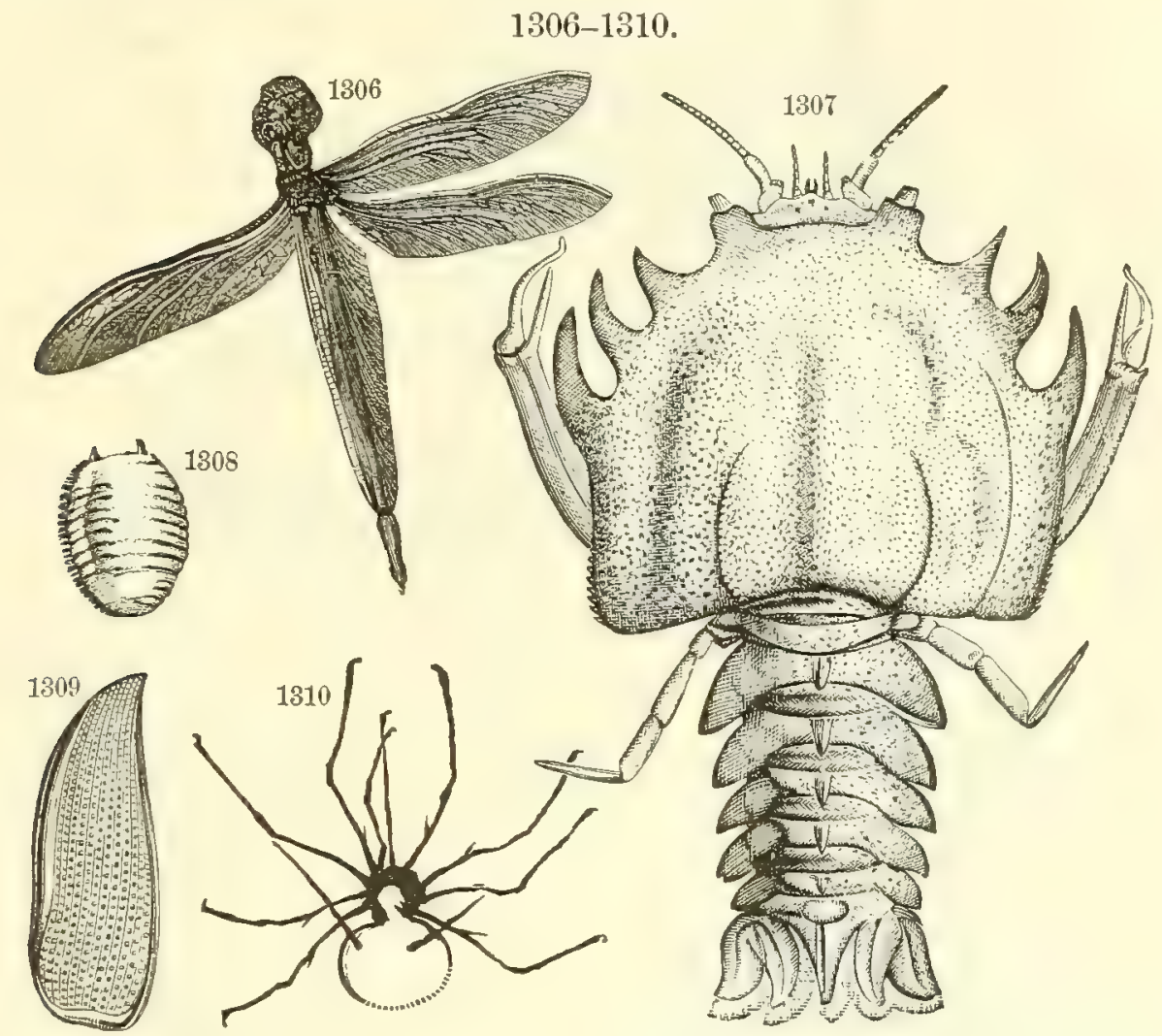

Articulates. - Fig. 1306, Libellula ; 1307, Eryon arctiformis ; 1308, Archæoniscus Brodiei ; 1309, elytron or wing-case of Buprestis ; 1310 , Palpipes priseus.

Insects of all the prominent tribes, even those of Dipters and Hymenopters, occur as early as the Lias; and the Hymenopters belong to one of the higher divisions, that of the Ants. A Lias species of Ant is the Palcoomyrmex prodromus of Heer, from Switzerland. Two other related species were described by Woodward from the Purbeck of England. Fig. 1306 represents a Dragon-fly, and 1319 a Beetle's wing-case (a Buprestis), both from Solenhofen; and another Dragon-fly, Libellula Brodiei, is from the Upper Lias of England.

Vertebrates. - The Jurassic Vertebrates included Birds, as well as Fishes, Reptiles, and Mammals.

1. Fishes. - The Fishes were Ganoids and Selachians. Two genera are illustrated in Figs. 1311, 1312. Pycnodus had many species, and also, among Selachians, Hybodus, Acrodus, Strophodus; and among Ganoids, Lepidotus, and others. The Ganoids most nearly related to the Teleosts are those of the Amia family, of Pike-like form, species of which oceur at Solenhofen. The Amioids have been referred to the Teleosts, but are now regarded as true Ganoids. 
2. Reptiles. - Sea-Saurians. - The skeleton, in restored form, of Ichthyosaurus communis is represented, $\frac{1}{100}$ the natural size, in Fig. 1313; the head,

$$
1311-1312 .
$$

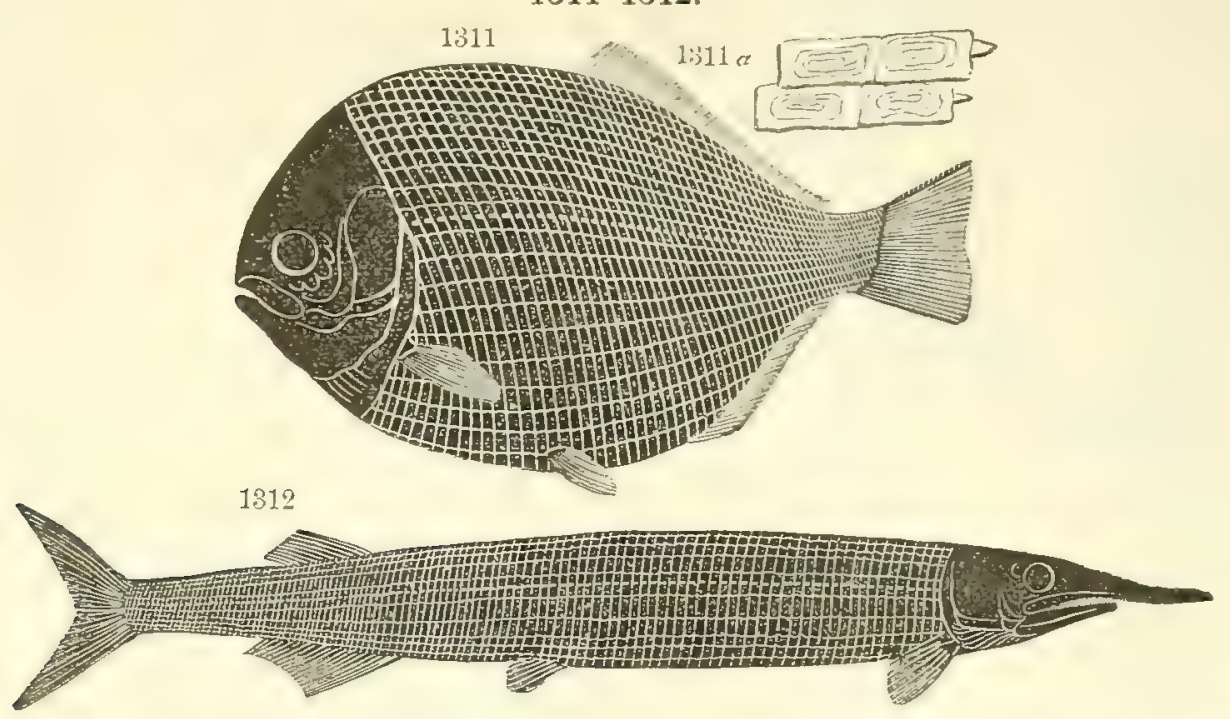

GAxoms. - Fig. 1311, Dapedius, restored $\left(\times \frac{1}{6}\right)$, Lias; $1311 \boldsymbol{a}$, scales of same; 1312, A spidorhyncus $\left(\times \frac{1}{8}\right)$, Solenhofen.

reduced to $\frac{1}{30}$, in 1314; one of the teeth, natural size, in 1316; and a vertebra in 1315. The Fish-like biconcave vertebræ suggested the name of the group,

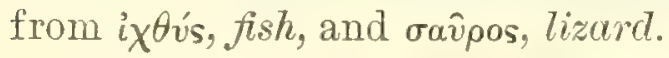

\section{$1313-1318$.}

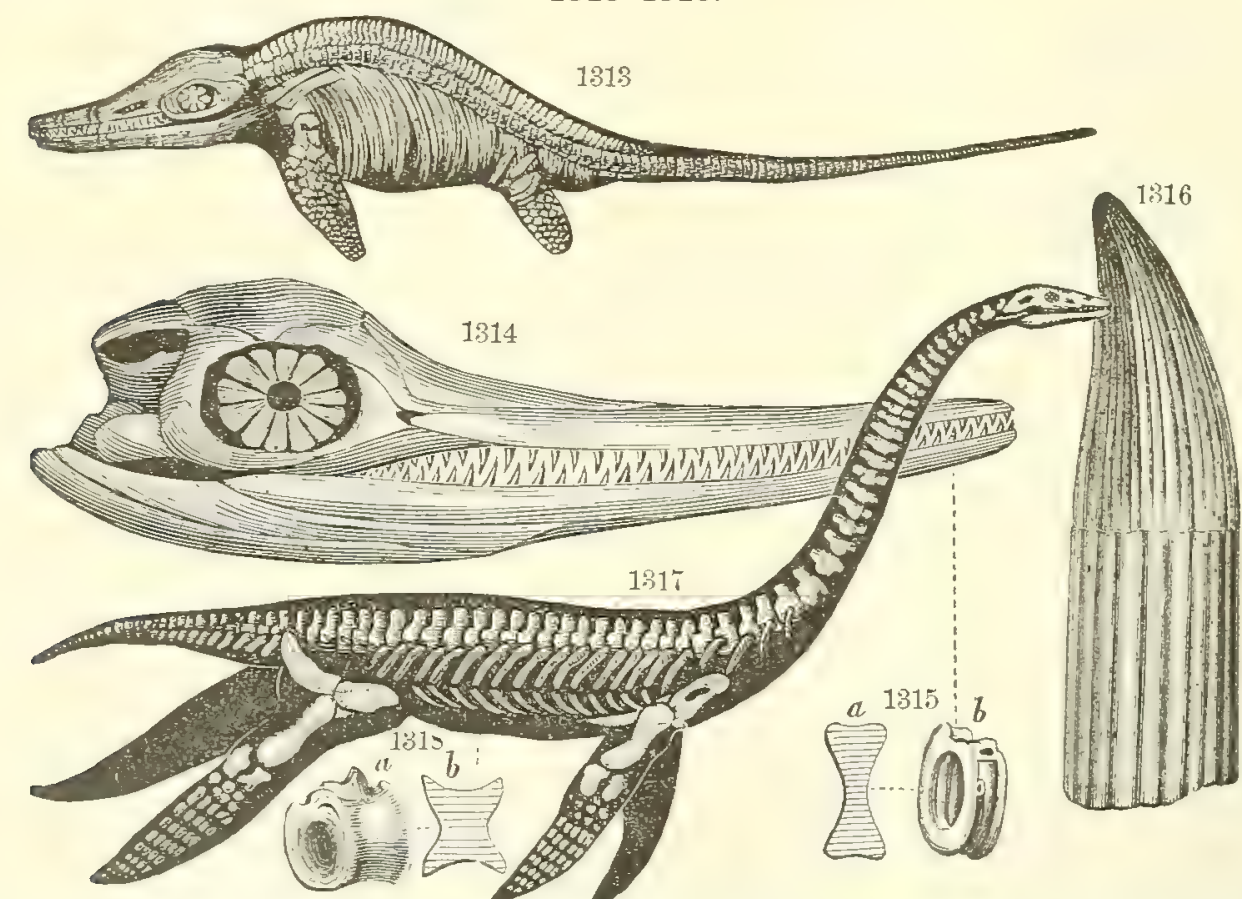

RePtrues. - Fig. 1318, Ichthyosaurus communis $\left(\times \frac{1}{100}\right) ; 1314$, head, id. $\left(\times \frac{1}{30}\right) ; 1315 a, b$, view and section of vertebra, id. $\left(\times \frac{1}{3}\right) ; 1316$, tooth. id. $\left(\times \frac{1}{3}\right) ; 1317$, Plesiosaurus dolichodeirus $\left(\times \frac{1}{80}\right) ; 1318 a, b$, view and section of vertebra of same.

Of Ichthyosaurians, 25 species have been described from the British rocks; and of these, 15 were found in the Lias, and 7 in the Upper Jurassic (Etheridge). 
A restoration of a Plesiosaur, - a long-necked, somewhat Turtle-like, SeaSaurian, - reduced to $\frac{1}{80}$ the natural size, is given in Fig. 1317; and figures of the vertebræ - here also biconcave - in $1318 a, b$. Fig. 1319 represents another species, Plesiosaurus macrocephalus Owen, as it lay in the rocks. The figures illustrate the long Snake-like neck of the species, the short body, and

1319.

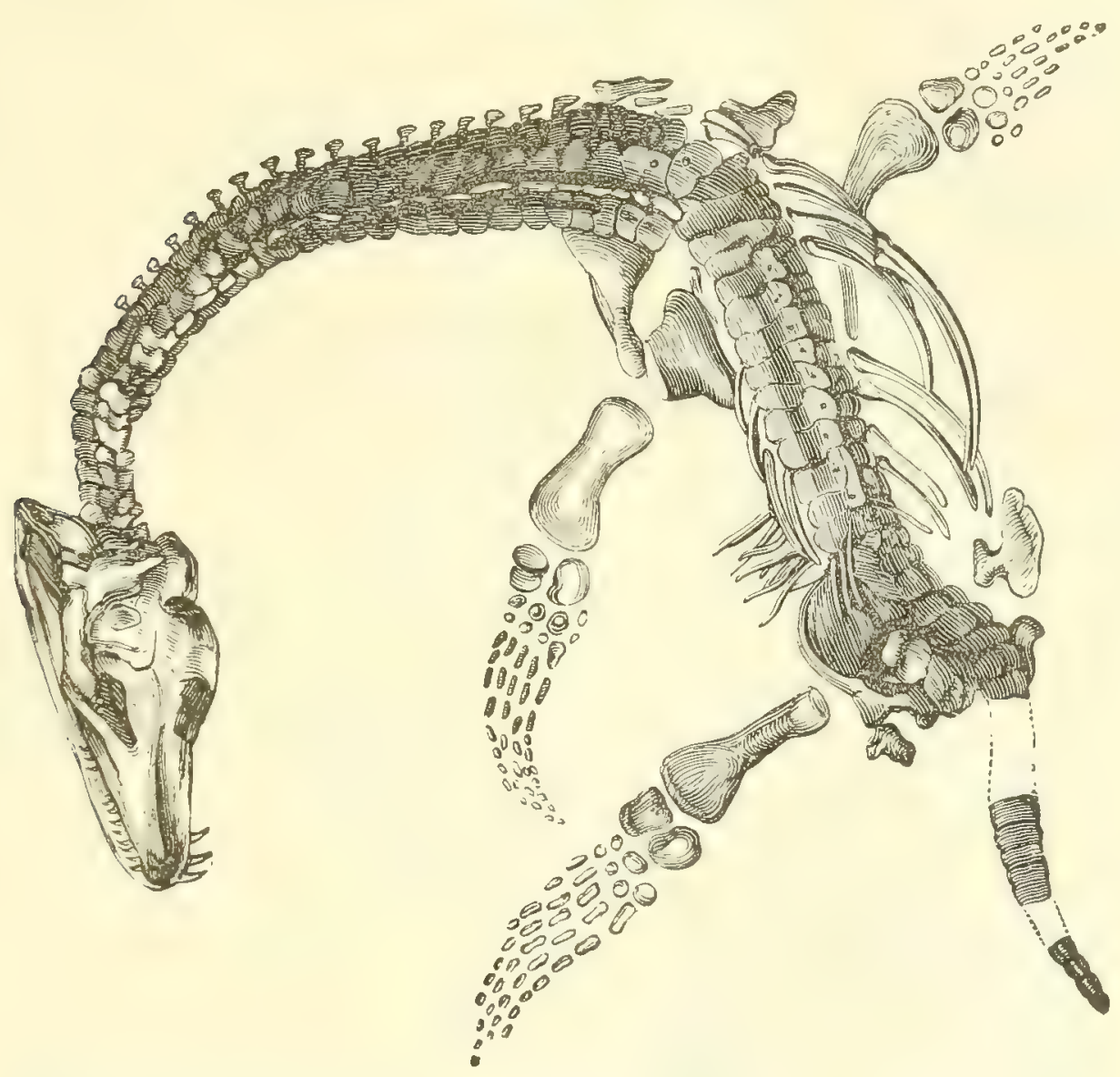

Reptile. - Fig. 1319, Plesiosaurus macrocephalus $\left(\times \frac{1}{40}\right)$. Buckland.

the character of the paddles. Pliosaurus is another genus, Out of 47 British species of Plesiosaurids, 22 occur in the Lias, all but one pertaining to the genus Plesioscurus. The group continues into the Upper Jurassic, which has afforded, in Great Britain, 12 species of Plesiosaurus, six of Pliosaurus, and one of Dinotosaurus (Etheridge).

The Coprolites (fossil excrements) of the Saurians are not uncommon; one is represented in Fig. 1322. They are sometimes silicified, and, notwithstanding their origin, are beautiful objects when sliced and polished.

Dinosaurs. - The earliest discovered of the Carnivorous Dinosaurs was the Megalosaurus Bucklandi (1824). The length of the skull was perhaps two feet, and that of the body probably 30 or 40 feet. It appeared in the Lower Lias and continued through to the Upper - a length of survival for such a species that is most extraordinary, and indicates high supremacy among its cotemporaries - if the apparent short life limit of other species is DANa's MaNUAL -50 
not merely poor luck as to becoming fossilized. The fore limbs were much the shorter pair, as in other species of the group.

In contrast with the Megalosaurs there was the strongly Bird-like Compsognathus, from Solenhofen, C. longipes of Wagner, one of the smaller Dinosaurs, the length not over two feet. The feet were all three-toed; the fore limbs very short, the hinder long, with the femur shorter than the tibia; the neck long and slender; the head small, but well armed with teeth, characters indicating, as Huxley states, a strong resemblance to the Bird not only in general form, but probably also in an erect or nearly erect posture in walking. It is perhaps related to Hallopus Marsh, of the North American Jurassic.

1320.

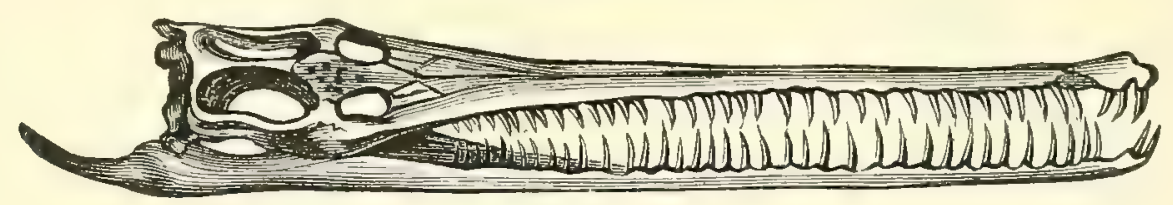

Mystriosaurus Tiedemanni.

Among Herbivorous Dinosaurs, of the Sauropod division, the largest European species known was the Cetiosaurus of Owen (1841), related to the American Morosaurus. C. Oxoniensis was 40 or 50 feet long, "not less than 10 feet in height when standing, and of a bulk in proportion." The fernur is 64 inches long. Cetiosaurian remains occur in the Lower and Upper Oölyte, and five species have been described.
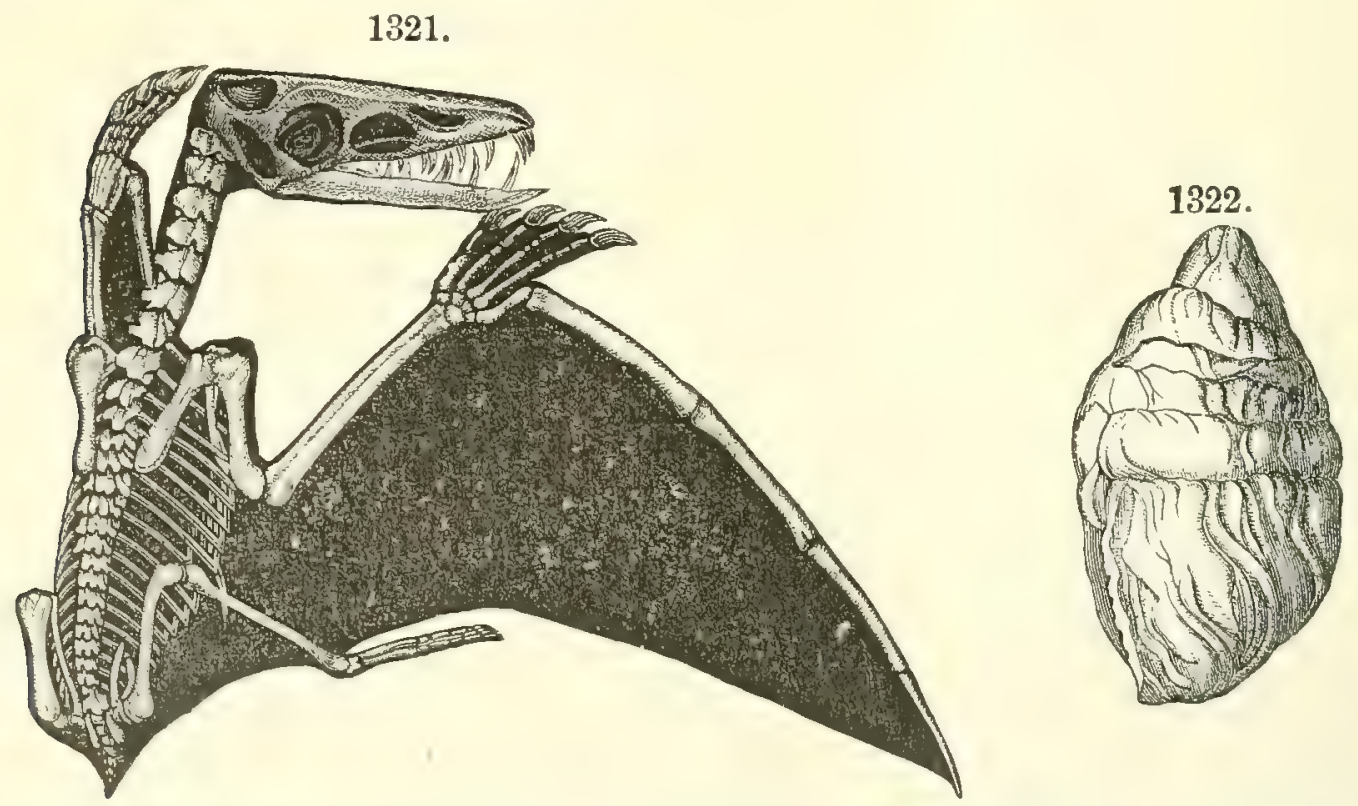

Pterosadr. - Fig. 1321, Pterodactylus crassirostris $\left(\times \frac{1}{4}\right) ; 1322$, Coprolite. Fig. 1321, from D'Orbigny ; 1322, Buckland.

Another genus of gigantic Herbivorous Dinosaurs is the Iguanodon of Iíantell, which first appears in the Middle Oölyte; it was of the Ornithopod groip. 
The Omosaurus armatus of Owen (1875) was Stegosaurian, and perhaps, as Marsh suggests, a species of the genus Stegosaurus; and he observes that the Scelidosaurus of Owen is an allied form.

Crocodilians, Lacertians, Chelonians. - The Crocodilians were represented by Teleosaurs, species having the size and slender head of the Gavial of the Ganges, but with biconcave vertebræ. Two species occur in the Upper

$1323-1325$.

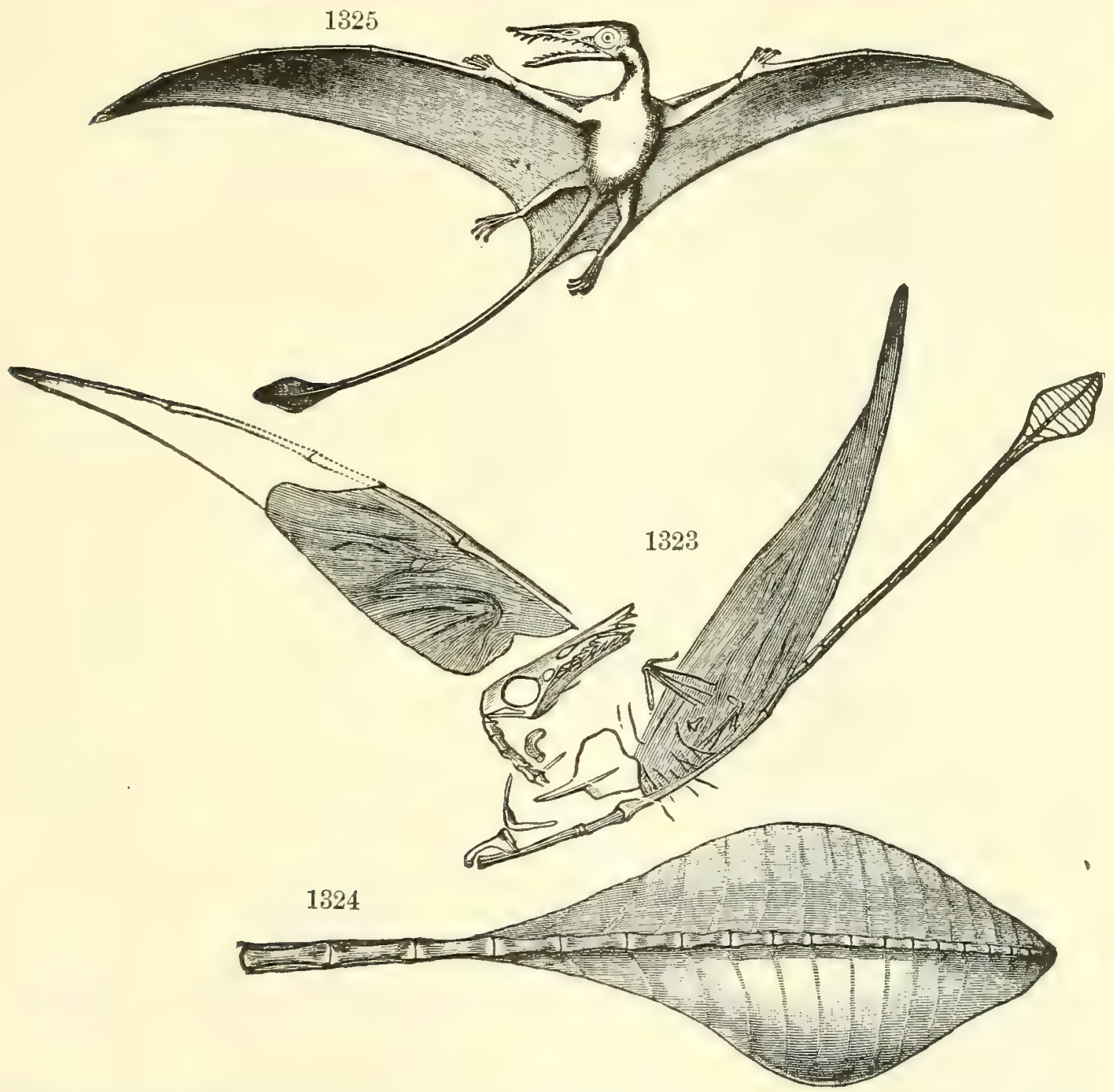

PTERosatr. - Fig. 1323, Rhamphorhynchus phyllurus $\left(\times \frac{1}{4}\right) ; 1324$, caudal oar $\left(\times \frac{1}{2}\right) ; 1325$, restoration $\left(\times \frac{1}{4}\right)$. All from Marsh.

Lias of England, and five others in the Lower and Upper Oölyte. Fossil eggs from Cirencester are suspected to be Teleosaurian (Buckman). The Mystriosaur (Fig. 1320) is a related species from the Lias of Europe.

A species of Lizard, referred to the genus Lacerta, occurs in the Lower (Oölyte of England. Tortoises (Chelonians) are found in the Oölyte; and a terrestrial species, Testudo Stricklandi Phillips, in the Stonesfield slate. 
Pterosaurs. - The Pterosaurs, or flying Lizards, have hollow bones like Birds. The genera Dimorphodon, chararterizen by a long tail, and Pterodactylus, by a very short one (Fig. 1321), oceur in the Lias, and Rhamphorhynchus (Figs. 1323-1325) in the Stonesfield slate and at Solenhofen.

Fig. 1321 represents the skeleton ( $\frac{1}{4}$ natural size) of Pterodactylus crassirostris; it wias a foot long. and the spread of the wings ahout three fret. Fig. 1323 is the Rhamphorynchus phyllurus of MLarsh, from Solenhofen, Eich-

1326.

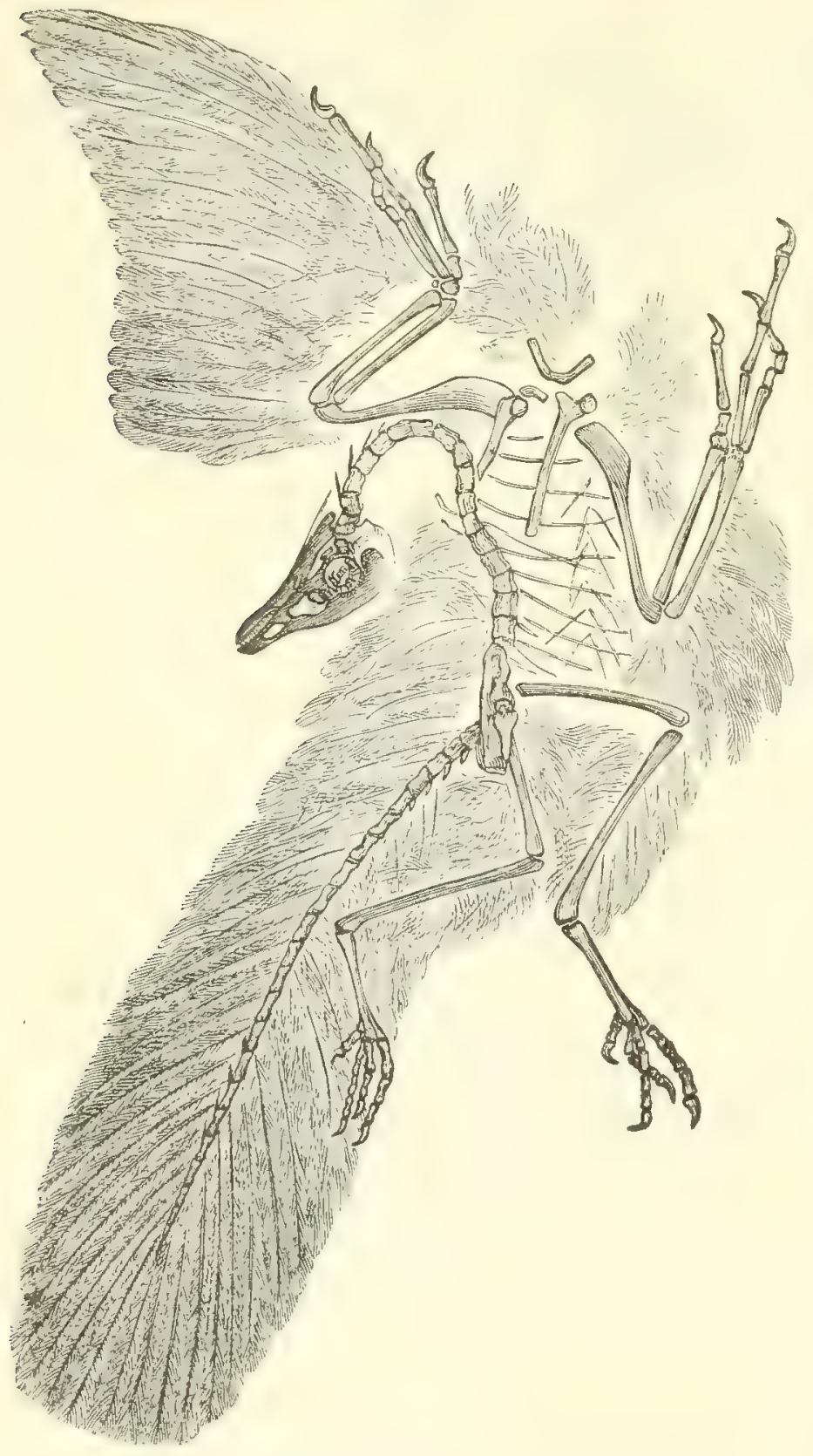

BiR.D. - Archæopteryx macrura $\left(\times \frac{1}{4}\right)$. W. Dames. stadt, Bavaria, and 1325 a restoration; its long slender tail ends in a broad oar (Fig. 1324). The fine specimen in the Yale $\mathrm{Mu}$ seum, New Haven, Conn., has an impression of the wing membrane, showing it to be without feathers.

3. Birds. - Specimens of birds have been found in the lithographic limestone of Solenhofen, with nearly complete impressions of the feathers and also well-preserved bones of the limbs, heads, and most other parts of the skeleton. They pertain to a single species, the Archoopteryx macrura of Owen. A single feather was first found in 1860 . This was followed, two years later, by the discovery of a nearly entire skeleton, but wanting the head; it was described by Owen. The specimen is now in the British Museum. Later, a third and still more complete skeleton was obtained, and this is in the Museum at Berlin. It has (1) in the jaws on either side, in sockets, 13 Reptile-like teeth; (2) a long vertebrated tail, having 20 vertebræ, each carrying a pair of long feathers; (3) wing bones like those of the fore leg of a normal three-toed Reptile, having claws at the extremity; (4) four-toed hind limbs, Bird-like in adaptation to biped loco- 
motion; (5) the vertebræ biconcave, as in Fishes and many Mesozoic Reptiles; (6) a small pelvis with the bones separate, ancl no elongation of the pubes. As at the present time the breed of fowls having feathered legs is produced by breeding from fowls having the legs scale-covered, thus substituting feathers for scales, the succession of Birds to Reptiles as regards this particular point is not so strange as, at first thought, it might seem to be.

4. Mammals. - Jurassic Mammals have been found in the Stonesfield slate, Lower Oölyte, and in the Middle Purbeck beds. As in America, the species are probably Marsupials, and Monotremes. Among the species at the former locality are Amphilestes Broderipi (Fig. 1327) and Phascolotherium

$$
1327-1328 \text {. }
$$

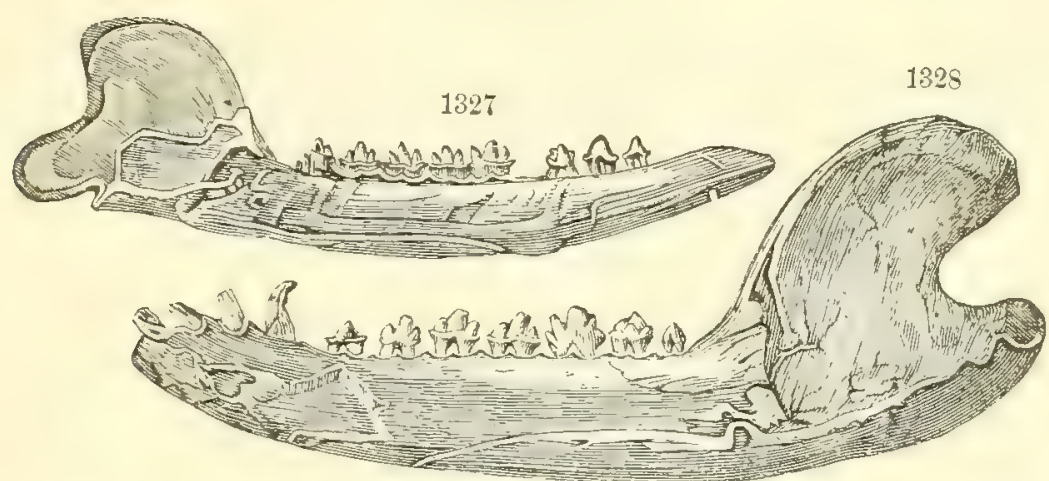

Mamras. - Fig, 1327, Amphilestes Broderipi $(\times 2)$; 132s, Phascolotherium Bucklandi $(\times 2)$. Pictet.

Bucklandi (Fig. 1328). The genera Plagiaulax, Microlestes, and Tritylodon are supposed to be Monotreme.

The following figures of jaw bones of the British species, of natural size, showing the dentition, derived chiefly from Owen's papers, are copied from Osborn's review of the Mesozoic Mammalia.

$1329-1345$.

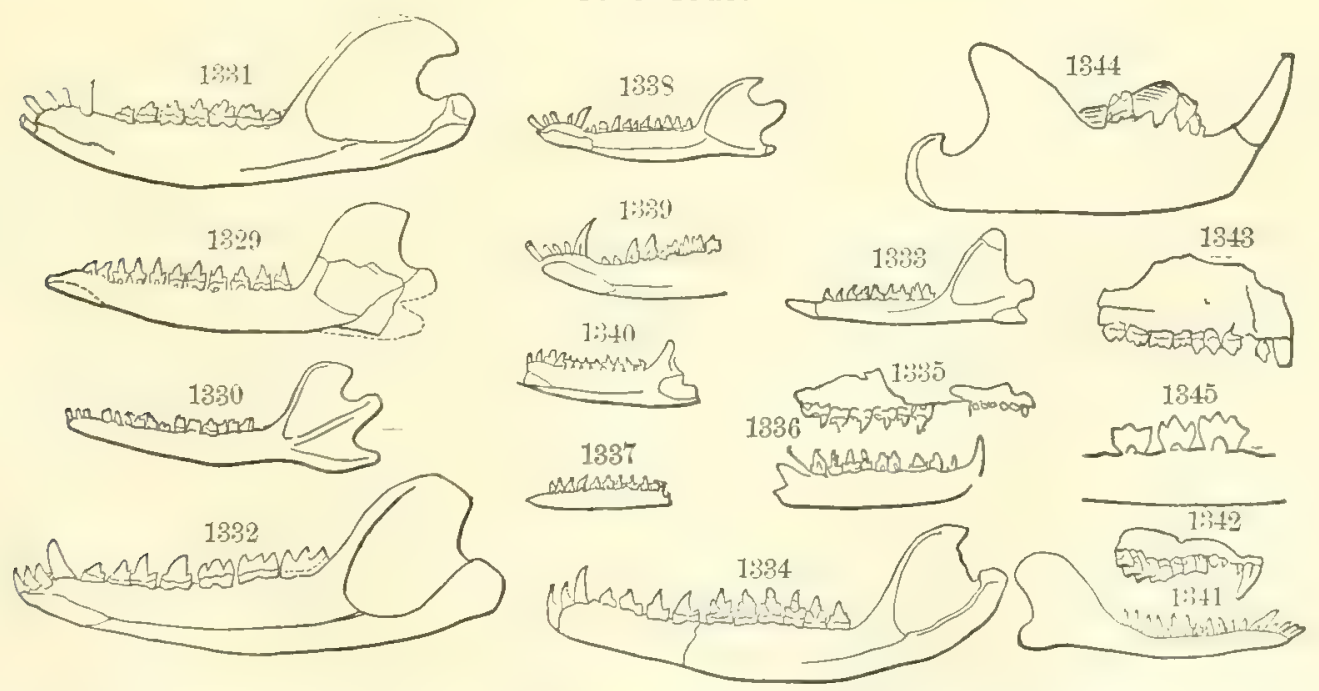

Fig. 1329, Amphilestes: 1330. Amphitylus; 1331, Phascolotheriuna; 1332, Triconodon mordax; 1833, Peramus; 1334, Spalacotherium; 1335, Peralestes; 1336, Peraspalax; 1337, Leptocladus; 1338, Amblotherium; 1339, Phascolestes; 1340, Achyrodon; 1341, Stylodon; 1342, Athrodon; 1343, Bolodon; 1344, Plagisulax minor; 1345, Stereognathus. All natural size. 


\section{Characteristic Species.}

\section{Lias.}

1. Lower Sinemurian. - Ammonites (Agoceras) planorbis, A. (Coroniceras) BuckIandi, Ostrea Liassica, Gryphoea arcuata, Lima gigantea, Hippopodium ponderosum, Spiriferina Walcotti, Isastraea Murchisoni, Pentacrinus (Extracrinus) Briareus, Ichthyosaurus, Plesiosaurus. The "White Lias" or Hettangian, beneath the Sinemurian, or at the top of the Rhætic, contains Ammonites planorbis, A. Burgundia, Cardinia Listeri, C. concinna, Pecten Valoniensis.

2. Middle Liassian. -Ammonites (Amaltheus) spinatus, A. (A.) ibex, A. (Agoceras) Jamesoni, Belemnites paxillosus, B. clavatus, Gryphcea obliqua, Avicula inæquivalvis, Inoceramus substriatus, Plicatula spinosa, Pentacrinus subangularis.

3. Upper Toarcian. - Ammonites (Harpoceras) serpentimus, A. (Harpoceras) bifrons, A. (Lytoceras) Jurensis, A. (Harpoceras) radians, Nautilus Jurensis, Belemnites vulgaris, Leda ovum, Posidonomya Bronni, Rhynchonella pigmoe, Cadomella, Spiriferina, Pseudodiadema Moorei, Extracrinus Briareus, Ichthyosaurs, Plesiosaurs, Teleosaurus Chapmanni (at Whitby).

\section{Oölyte.}

1. Lower Oölyte. - (1) Bajocian. The subdivisions recognized in England are those of Ammonites (Harpoceras) Murchisona, Lower; of Stephanoceras Humphriesianum, and Cosmoceras Parkinsoni, Upper. In Europe: (a) Aalenian, with Amm. (Harpoceras) Murchisona, Rhynchonella subangulata, Terebratula perovalis, T. fimbria, Pecten lens, Pholadomya fidicula. (b) Bajocian, with Amm. (Stephanoceras) Humphriesianus, A. (Cosmoceras) Parkinsoni, Astarte obliqua, Trigonia costata, Grypha a sublobata (Gryphoca beds), Ostrea Marshii, Rhynchonella spinosa, Terebratula perovalis.

(2) Bathonian. (a) Vesulian or Fuller's Earth, with Amm. discus (and up to Cornbrash), A. Herveyi (and up to Forest Marble), A. ferrugineus, Anabacia hemisphcerica, Pecten vagans, Ostrea acuminata, Rhynchonella varians. (b) Bradfordian, or Great (or Bath) Oölyte, with Amm. macrocephalus, A. aspidioides, Ostrea Marshii, Pecten lens, Rhynchonella decorata, $R$. concinna, Megalosaurus, Cetiosaurus, Pterodactylus, Waldheimia digona, Steneosaums; and in the Stonesfield slate, at the base, with many plants, Ostrea Sowerbyi, Rhynchonella obsoleta, Gervillia acuta, Ichthyosaurus, Plesiosaurus, Teliosaurus, Rhamphorhynchus, Testudo Stricklandi, Chelys Blakei, Mammals. In Russia the Oxford Oölyte is overlaid by beds called the Volgian.

2. Middle Oölxte. - (1) Oxfordian. (a) Callovian or Kellaways Rock, with Amm. Gowerianus, A. macrocephalus, Belemnites Oweni, B. hastatus, Gryphoa bilobata, G. dilatata, Trigonia paucicosta, Terebratula digona. (b) Oxfordian or Oxford Clay, with Amm. Lamberti (up to Kimmeridgian), A. Mario, Trigonia clavellata, Pecten vagans, Avicula incequivalvis, Rhynchonella socialis.

(2) Corallian. (a) Argoviun, Sponge-bearing beds, Scyphian-Kalk, and those of Amm. canaliculatus. (b) Corallian, divided into Rauracian or Glyptician, with Glypticus hieroglyphicus, Amm. bimammatus, Thecosmitia annulata. (c) Isastrcea explanata and Diceratian, with Diceras arietinum, Nerinea Defrancii. The Coral Rag and Corallian Oölyte of the Corallian contain Amm. plicatilis, Thamnastraca gregaria, $T$. concinna, Cidaris forigemma, Hemicidaris intermodia, Psendodiadema hemispharicum, Avicula ovalis, Lima rudis, Perna mylitoides; and the underlying Lower limestones, Amm. cordatus, Avicula ovalis, A. expansa, Pecten fibrosus.

3. UPPER OöLyte. - (1) Kimmeridgian. (a) Sequanian or Astartian, with Astarte minima, A. supracorallina, A. gregaria, Ostrea deltoidea, Rhynchonella corallina, Amm. mutabilis, A. decipiens, A. tenuilobatus, Pseudodiadema hemisphoricum, Cidaris 
florigemma, C. Blumenl,achii, Apiocrinus Meriani. (b) Pterocerian, with Amm. acanthicus, Pterocera oceani, P. ponti, Nerinea depressa, Waldheimia humeralis. (c) Virgulian, with Grypha a virgula, Trigonia gibbosa, Terebratula diphya, Pholadomya multicostata, Thracia depressa. (d) Bolonian, with Amm. gigas, A. suprajurensis, A. biplex, Trigonia incurva, Cyprina Brongniarti.

(2) Portlandian or Tithonian. (a) Portlandian or Nerinean, Amm. gigas, Trigonia gibbosa, Gryphcea virgula, Ostrea solitaria, Lucina Portlandica, Nerinea trinodosa, Pterocera aceani. (b) Purbeckian, with Corbula inflexa, C. Forbesiana, Cardium Purbeckense, Terebratula diphyoides, Hemicidaris Purbeckensis, Astraca distorta, Inserts, Iammals.

The Tithonian group in the eastern Alps includes a coral limestone near Salzkammergut, and the Diphya limestone abounding in Terebratula diphya; also Aptychus beds; and some of the limestones contain many Ammonites, Phylloceras ptychoicum, and others.

The Jurassic beds of Cutch, in India, contain, in the Lower Oölyte, Astarte compressa, Corbula pectinata, Rhynchonella concinna; in the Middle Oölyte, Amm. (Stephanoceras) macrocephalus, $A$. (Peltoceras) athleta, Terebratula biplicata, $T$. sella, and many other Ammonites, many Belemnites, etc. ; in the Upper Oölyte, Amm. (Phylloceras) ptychoicus, and many other species. Also many species of plants, as Sphenopteris arguta, Alethopteris Thitbyensis, Otozamites contiguus. The Portlandian beds afford Trigonia Smeei and T. ventricosa, the latter also a South African species; also jaw of a Plesiosaur.

The Upper Jurassic of the Zanskar area in the central Himalayas has afforded Belemnites clavatus, Ammonites macrocephalus, A. Parkinsoni, A. biplex, Trigonia costata, and other species. The Hundes area in the Tibetan Himalayas also has many Jurassic species. (Cf. Medlicott and Blandford, Geology of India, vols. i. and ii., 1879, and second edition by Oldham, 1894.)

In western Australia, 20 species of Liassic and Oölytic fossils are identical with British species: 3 of the Ammonite group, Nautilus semistriatus and Gresslya donaciformis of the Upper Lias; Myacites Liassinus of the Middle Lias; and 2 of the Ammonite group, with Belemnites canaliculatus, Cuculloxa oblonga, Pholadomya ovulum, Avicula Münsteri, A. echinata, Pecten cinctus, P. calvus, Lima proboscidea, L. punctata, Ostrea Marshii, Rhynchonella variabitis, Cristellaria cultrata, of the Oölyte (C. Moore).

\section{CONTINENTAL RESEMBLANCES AND CONTRASTS IN THE TRIASSIC AND JURAS- SIC PERIODS; CLIMATE.}

The Triassic formation is alike over a large part of Europe and America in kinds of rocks, in paucity of fossils, and in evidences of shallow-water origin, and of largely brackish water, if not fresh. The continental surface in each case was very near or above the water level over large areas; and it oscillated between brackish or fresh-water flats and barren or half-barren salt-water flats or sea-border salt-pans. The European exception is in the Mediterranean region. Not only is this general fact true for the two continents mentioned, but also for India, South Africa, and Australia, or the continental regions in the opposite hemisphere. This so general prevalence over large parts of the continents of slight submergence, too slight for abundant remains of marine life, - although this life must undoubtedly have been as profuse in kinds as in any earlier or later era, -indicates general and synchronous movements in the earth's surface, and correlate progress in continental growth. The Jurassic period was, in contrast, a period of somewhat deeper and clearer seas, sustaining at many levels abundant life, 
but still with wide differences between the continents as to the extent of such seas.

It is an interesting fact, bearing on the conditions under which the Liassic beds were made, and the facility with which the clear open waters of a fossiliferous limestone horizon may change to the confined waters of a sea border, that a bed of limonite or fermginous limestone occurs in the Lower Lias northwest of Lincolnshire, England, which is 27 feet thick, and in the Upper Lias, near Bath, two feet thick; on the continent, in Lorraine, in the Upper Lias, 10 to 50 feet thick, containing Ammonites, a Gryphaea, Trigonia navis, etc.; in Auxois, France, near the base of the Lower Lias overlying a bed of "lumachelle" limestone; and, as stated by C. Moore, in western Australia, in the Middle Lias, a very ferruginous limestone, which on analysis gave 49 to 56 per cent of metallic iron. Moore goes so far as to regard the ferruginous bed of Australia as proof of Liassic age; the associated fossils are much better evidence.

But with all the resemblance in physical conditions between Europe and America, there was a remarkable contrast in the abundance of marine life in the continental seas. This contrast was especially great in the Jurassic period. The number of species of Jurassic Invertebrates thus far described from the American rocks is less than 250; very few of these are Corals, 17 are Cephalopods, 5 Echinoderms, 17 Gastropods, 113 Lamellibranchs (Whitfield). In the Jurassic of Great Britain alone the number of known marine species, as stated by Etheridge (Geol., 1885), is over 3900; those of Corals 236, Echinoderms 208, Ammonites 417, Belemnites 112, Gastropods 988, and Lamellibranchs 1319. More study may quadruple the number of American species; but this will little diminish the contrast.

As indications of the climate of the Triassic and Jurassic periods, there are these pertinent facts from the Arctic regions: that the species Ceratites Malmgreni, Ammonites Gaytani, Nautilus Nordenskiüldi, Halobia Lommeli, H. Zitteli were living in the Spitzbergen seas during the Triassic period; and Ammonites (Harpoceras) M'Clintocki, Monotis septentrionulis, and species of Pleurotomaria and Nucula, about Bathurst Island, Exmouth Island, and Prince Patrick Island, probably during the Jurassic period, - species that have closer relations to European than to American species (Haughton, Waagen); that Ichthyosaurs were living in Triassic or Jurassic time about Exmouth Island $\left(77^{\circ} 16^{\prime} \mathrm{N} ., 96^{\circ} \mathrm{W}\right.$.), their remains having been found on this island by the Belcher Expedition; and that other Ichthyosaurs existed in the Spitzbergen seas, probably during the Triassic period, remains of two having been found by Nordenskiöld, which have been named, by Hulke, Ichthyosaurus Nordenskiöldi and I. Polaris; that another Saurian - "probably a Dinosaur, allied to the Anchisauridæ," inhabited the region about Bathurst Island, Captain Sherard Osborn having brought home a vertebra, which has been made a basis of a species named by A. L. Adams Arctosaurus Osborni.

The continent of North America, as already explained (page 47), is peculiar in climatal situation. It has the Gulf Stream warm with tropical 
heat, flowing northward and eastward near its eastern border, but not much for the warming of North American waters north of Cape Hatteras; its heat is carried on for distribution over northern and western Europe and the Arctic seas. Heading off the Gulf Stream from the American coast north of Hatteras, there flows from the north a current of Arctic waters, that makes its escape from the polar basin by the only large passage way out - the way leading into the Atlantic; and these cold waters are like a cold wall along the eastern side of the continent. The American coast has a means of protection against the polar current, through an elevation of the border sufficient to make Newfoundland a peninsula by closing the Strait of Belle Isle. Moreover, if the elevation were only 500 feet, the eastern cape, around which the cold current would be forced to flow, would be set 250 miles east of its present position.

On the Pacific side a cold northwestern current follows the coast of North America from Alaska southward, as part of the normal oceanic circulation.

Thus at the present time North America has relatively cold waters along both its eastern and western shores. Hence there is reason enough for the paucity of its existing marine faunas. In Paleozoic time this contrast with Europe did not exist, or only to a small degree; for the Paleozoic species eren exceed in numbers those of Europe. The Aretic basin was probably op $\geq n$ widely in all directions. But in the early Mesozoic it must have becone the closed basin which it now is, with its only free outlet into the Atlantic; and in this way the continent of North America was thus early put between northern cold Atlantic and cold Pacific currents.

The actual difference of temperature between the waters of the North American and European sides of the Atlantic in the Triassic and Jurassic periods is uncertain, because no marine fossils of these periods have been found on the American side. On the European side the presence of warm seas is proved by the profusion of marine species and by their kinds. The coral reefs of the Oölyte in England consist of corals of the same group with the reef-making species of the existing tropics. This favors the conclusion that the British waters, and nearly all the European, were within the coralreef temperature limit; that is, the line along which $68^{\circ} \mathrm{F}$. is the mean temperature of the year. The Oölytic isocryme of $68^{\circ} \mathrm{F}$. (see map, page $4 i$ ), accordingly, would have had nearly the position of the line of $44^{\circ} \mathrm{F}$. in existing seas, but with a little less northing and more leaning to the eastward. The Gulf Stream was the probable cause of this long northward extension of warm waters in Jurassic time.

Further, in Europe, according to Neumayr, differences in the climate of the later Jurassic are indicated by the distribution of fossil Invertebrates. The Mediterranean Province, or that of southern Europe, including the regions of the Alps and Carpathians, Italy, Spain, and the Balkan peninsula, is characterized by Ammonites of the genera Phylloceras, Lytoceras, and Simoceras, with the Brachiopod Terebratula diphya. The Middle European Province, comprising the region of the Juras, France, Germany, England, 
and the vicinity of the Baltic, has few species of Phylloceras and Lytoceras, and very many of Harpoceras, Oppelia, Peltoceras, and Aspidoceras, and coral reefs have great extent. The north Russian or Boreal province has in its Jurassic rocks no species of Lytoceras, Phylloceras, and Haploceras, and no coral reefs, while those of Cardioceras and Aucella are widely distributed. On the other hand, the flora of the earliest part of the following Cretaceous period in Greenland included an abundance of Cycads.

Although the cold of the Atlantic and Pacific barriers of North America was manifestly of little severity, it was enough for wide results in the geographical distribution of species.

The Mexican Gulf was a source of warm waters for southern and interior North America, while at the same time the Aretic seas may have sent down polar currents over its northwestern interior during the Triassie period. The effects of the cold northwesterly currents of the Pacific border are plainly seen in the many species peculiar to that coast, and prominently in the Aucellæ, which are related to the Siberian species.

\section{BIOLOGICAL CHANGES AND PROGRESS.}

\section{Some of the Successional Lines.}

It is noteworthy that the new types of the Jura-Trias did not appear at equable intervals successively along the era. They were rather evolvings in its commencing part, the Triassic, the opening period of Mesozoic time. The Triassic period is thus, after the Cambrian, which opened the Paleozoic, the most eventful in the earth's biological history; that is, the most productive of great branchings in the higher departments of the Animal Kingdom - the type of Mammals, that probably of Birds, and those of each of the grand divisions of Reptiles excepting such as had already appeared in the Permian. This is true also of the modern, or nearly modern, style of Orthopters, Neuropters, and Coleopters among Insects, as illustrated by Scudder; and the Lias completed the display of the system of Insects by the introduction of the Dipters or Flies, and of Hymenopters as represented by Ants and other families. It is to be admitted, however, that part of the developments indicated by the relics in Triassic beds may date from the Permian. The physical change of a purified atmosphere prepared the way for terrestrial life; and the preparation was essentially complete before the close of the Permian.

This crowding together of the origins of so many types in connection with the barrenness of most Triassic regions makes it doubtful whether facts illustrating the precursor lines will ever be fully made out.

As regards the precursors of Mammals, their closer relation to Amphibians than to Reptiles is proved, as Huxley first pointed out, by the fact that Amphibians and Mammals have two occipital condyles, and Reptiles and Birds but one; and hence their derivation was almost certainly from some Amphibian type, and not from a Reptilian. The Monotremes (of which but 
three species exist, one of Ornithorhynchus and two of Echidna) are the lowest of Mammals, and have many Amphibian and Reptilian characters in their skeleton, besides that striking one of bearing eggs, like Reptiles and Birds. They are called Prototheria in some zoölogical systems; and this they undoubtedly are in type, though the Duck-like bill and webbed foot of the Ornithorkynchus are unquestionably degenerate characteristics; for the earliest species had almost certainly a full set of teeth. That they were first in origin, however, is far from proved.

Among Reptiles, the Permian type represented by the genus Palcohatteria, with the associated Rhynchocephalia, as explained on page 707, is the most generalized or comprehensive of the class. Besides its Amphibian relations on one side and its Reptilian on the other, it has, as Baur explains, characteristics also of Birds and Mammals. This author regards the type as the precursor type of the class of Reptiles and also of the class of Birds. It is like Mammals, he states, and unlike all other Reptiles, except the Rhynchocephs, in having the foramen of the distal end of the humerus on the inner side of the epicondyle; in other Reptiles it is on the outer side or is absent; and it is absent from all Amphibians and Birds. It is probable, therefore, that, nearly as Baur concludes, the line from the Amphibians which gave off a Rhynchocephalian branch, later gave off a Mammalian.

The relation of Birds to the Dinosaurs in pelvis and hind limbs, especially to the Carnivorous kinds, was pointed out by Huxley; and it is supposed that the two types may have originated from a common type in either the Triassic or Permian period. The Jurassic bird, Archæopteryx, which is so remarkably Reptilian, has the long limbs, and but little else, of a Dinosaur; and this feature in the hind limbs of both is partly a consequence of an elongation of the metatarsals. The cranium and the sternum are Bird-like, but not so the fore limbs, pelvis, and some other parts. The Berlin specimen was first described as a Reptile by Carl Vogt. The relations of Birds to Dinosaurs in the structure of the skeleton are largely a consequence of the demands made by the animal on its hind limbs; and the unlike demands on the fore limbs are the source of divergences.

\section{General Changes Attending Biological Progress.}

1. Reduction in multiplicate numbers. - The reduction in number of posterior vertebræ when the Fish type passed to that of the Amphibian has been noticed on page 726. Their absence from the upper lobe of the tail in most Triassic Ganoids, rendering the Fish homocercal in place of heterocercal, is a change in the same direction, like that which takes place when the Tadpole becomes a Frog, or the young of a Ganoid or other Fish loses a caudal lobe, or some caudal vertebræ, when becoming adult. The long vertebrated tail of the Jurassic Bird was a related multiplicate feature, which disappeared early in Cretaceous time, if not before it.

The reduction of the number of parts in the limbs of Fishes before the close of the Paleozoic to the typical number of five for the digits in 
Amphibians, and to typical numbers and arrangement in the bones of the leg, has been stated on page 726 . Once reached, these numbers remain the normal or typical numbers for Reptiles, Birds, and Nammals. The typical number of cervical vertebræ, seven, sometimes occurs in Reptiles; but variation from this number is not in them a character of generic importance.

Under Mammals, the differentiation of the teeth in all typical species, into incisors, canines, and molars, exists, commencing with Triassic Marsupials; but the number of teeth continues to be multiplicate through the Jurassic, the typical Mammalian number, 44, being usually exceeded, and sometimes by 24 . The number seven became the fixed or normal number of cervical vertebræ, first, among Vertebrates, in Mammals. It is a character of all existing Marsupials, and probably was of those of the early Mesozoic, - a doubt remaining because no skeleton of an ancient species has yet been found.

Exceptions to normal numbers, after they were once attained, have proceeded from specializations in the course of upward as well as downward progress; but the larger part occur among degenerate forms, and in these, as the examples mentioned show, the divergence is often very great.

2. Location of the function of locomotion. - As remarked on page 726, the typical Amphibian, on becoming adult, passes from the stage of caudal or urosthenic locomotion, to locomotion by limbs, or podosthenic. The latter is the typical condition in Reptiles, Birds, and Mammals. But groups under each differ as to the pair of limbs which bears the chief part of the work.

The Triassic and Jurassic periods were distinguished eminently by hind-limb location of force and locomotion. It was the era of very small brains, and of great development of the posterior extremities - the era of Merosthenic Vertebrates, as the Devonian and Carboniferous eras were of Urosthenic Tertebrates. The prominent feature of all Dinosaurs is their enormous hinder parts. Moreover, as has been mentioned, many of the species, the gigantic Stegosaurs preëminently, have a provision for this arrangement of the forces of the Reptile, as Marsh first brought out, in the great nervous mass of the sacrum.

The Amphibians also were strongest in the hind limbs, as is indicated by the remains of the Labyrinthodonts. The wings of the Jurassic Bird of Solenhofen prove that they were poor flyers, and consequently that their legs or hind limbs were their chief locomotive organs. MLreover, in this merosthenic era, the Mammals probably had the hind limbs much the stronger of the two pairs, as is true of modern Marsupials.

The species of Reptiles that were distinctively strong in the fore limbs, or prosthenic, are the Pterosaurs; and among these, the Pterodactyls, having the head large, the posterior feet small, and the tail short, with the brain and sternum Bird-like, appear to have taken the lead. Seeley has placed them in in independent group separate from Reptiles. The absence of scales from the body, and the light bones, with air cavities and pneumatic foramina, still further ally them to Birds, and separate them from other Reptiles. It 
is probable, therefore, that this highly specialized type ranked above all other Reptilian types of the Jurassic.

3. Degeneration. - Progress in a type from toothed jaws to toothless must be viewed as a decline, although there may be true progress in other respects. Among the Rhynchocephalians - which, in the Permian genus Palceoluatteria, hare numerous formidable teeth - occur later species having a horn-covered extremity of the jaws like the beak of a turtle. Again, the Dinosaurians vary from many-toothed, tiger-mouthed species, to those with few teeth.

The Plesiosaurians are supposed to be degenerate land Reptiles, whose limbs, even in the Triassic, had become paddles, with fingers multiplicate in number of phalanges; and the Ichthyosaurs, species of some other Reptilian type, carried downward to a still lower urosthenic stage, in which the pelvic girdle had become nearly obsolete, and the fingers sometimes excessive in number, as well as multiplicate in segments. Turtles are other degenerate forms of the Triassic as well as of the Jurassic period.

Such facts make it manifest that through geological time progress in the Tertebrate type, as in the Invertebrate, was downward as well as upward; that degeneration, while it may make obsolete, may also return a species to a low multiplicate condition, in which the multiplicate characteristic extends to the number of vertebræ, to the teeth, to the fingers, to the number of finger bones, and to other parts of the structure. It is atavism under some physiological law deeper than atavism, bringing back characters, not of the earlier Reptiles, but of the earliest Vertebrates, the Fishes, yet not without any loss of the fundamental characteristics of Reptiles.

Considering the very long time that Fishes were in the seas before the rise in grade to the terrestrial type of the Amphibian, and the relatively short time for the much greater rise from the Amphibian to the Reptile, Bird, and Iammal, there is no reason to believe that any of the upward successional lines passed through the water. Through the water, for terrestrial Vertebrates, as many examples show, was a quick way down in grade, not a possible way up.

4. A fragment of the Triassic world. - Australia is often spoken of as a Triassic continent. As the world in Triassic time had only Marsupials and Monotremes for its Mammals, so Australia has now, man's encroachments excluded, Marsupials and Monotremes for its only Mammals. The existence there of a species of Bat, and of some Mice and Rats, is hardly an exception to be considered. But although thus restricted in its modern fauna, its Mammals are not of few kinds; for, as Wallace states, "some are carnivorous, some herbivorous; some arboreal, others terrestrial; there are insect eaters, fruit eaters, honey eaters, leaf or grass feeders; some resemble wolves, others marmots, weasels, squirrels, flying squirrels, dormice, or jerboas." Moreover, one of the last four species of Cestraciont Sharks, a tribe of Mesozoic and Paleozoic affinities, the Cestrocion Philippi, or Port Jackson Shark, lives in Australian seas; and one of the last three species of the Dipnoans, the Ceratodus, Carboniferous and Triassic in type, inhabits its 
interior waters. Besides, the surface rocks of the continent are to a large extent Permian, Triassic, or Jurassic. Marsupials and Monotremes formerly had a wide range over the globe. A large Echidna, or Monotreme Poreupine, was among the species of England in the Middle Quaternary; and Marsupials, among the Mammals of Europe and America in the Tertiary; but at the present time the few of South and North America are all that exist out of Australia. It cannot be affirmed that Triassic Australia was the source of all the Marsupials of the world; but there is little doubt that its only Triassic Mammals were Marsupials and Monotremes.

It has already been explained that New Guinea and New Zealand show by their faunas that they were once parts of a great Australasian continent, New Guinea having its Marsupials, and New Zealand the only surviving species of the Permian and Triassic tribe of Rhynchocephalians, in a species of the genus Hatteria. The possible extension of the continent southward, and its union for a time with an Antarctic continent, are considered on page 737 .

\section{DISTURBANCES AND UPTURNINGS DURING, OR AT THE CLOSE OF, THE TRIASSIC AND JURASSIC PERIODS.}

\section{Triassic of the Attantic border.}

The Triassic areas of the Atlantic border bear evidence of a general upturning, in which the beds were, with small exceptions, raised not into flexures, but into monoclines. The effects of the movements have been briefly stated on page 357, under the subject of mountain-making. Additional facts and illustrations, respecting the disturbed areas, and the orographic results and methods, are here presented.

The close parallelism between the Triassic areas and the Appalachian chain is one of the great facts to be here noted. It is well seen on the map, page 412, and for Pennsylvania on that of page 730. The general parallelism between the strike of the upturned beds and the same course - that is, the trend of the areas - is another important fact. The two are satisfactory evidence that the agency concerned over the Atlantic border was the same for Jurassic time, as for the epoch when the Appalachians were made; and, it may be added, for all epochs of Eastern Border mountain-making.

In the Connecticut valley area there was an eastward dip also in the fracture planes, and a westward upthrust along these planes; and this also was a feature of the Appalachian upturning. These facts imply the action of lateral pressure from the eastward, or the direction of the ocean.

In the Palisade area passing from New York through New Jersey and Pennsylvania into Virginia, and in the western areas, of Virginia and North Carolina, the results of the upturning are in general the reverse of those in the Connecticut valley and in eastern North Carolina. The beds of sandstone and the great fracture-planes, for the most part, dip westward or northwestward, and the upthrust along the fracture-planes was southeastward. 
In Connecticut, the sandstone beds almost invariably dip eastward. In Virginia, in the Richmond area, which is one of the easterrmost, the beds have a synclinal structure, the rocks on the east side dipping northwestward, and those on the west side, southeastward (Fontaine). In the eastern Deep River area of North Carolina the dip averages $20^{\circ}$ southeastward, but varies from $10^{\circ}$ to $35^{\circ}$ (Fontaine).

Notwithstanding the diversity between the orographic features of the more western and the eastern belts, the intimate relation to the Appalachian system as regards method of upturning of the former as well as of the latter cannot be questioned. The opposition of direction in dip is connected with opposition in all other structural features in the two ranges of belts, and eminently so in the topography.

The opposition in dip between the Connecticut valley and the Palisade area has been explained by supposing that the sandstone was made in waters that spread over the intervening region, and that an actual anticline was produced by an uplift. But only marine waters could have covered the wide region after great subsidences; and to this idea, all the facts as to the freshwater origin of the beds by fluvial, lacustrine, or estuary agency are opposed. Moreover, the Connecticut valley area is wholly in latitudes more northern than the Palisade.

This reversed condition, so marked in the results over the two areas, simply implies reverse action in the forces concerned. In the Palisade region, accordingly, the lateral pressure was from the westward; thus came the reversed dip and reversed fault-planes and faulting. On this view of the action along the two belts,- that is, the lateral thrust from the eastward for the eastern, and from the westward for the western, - - the pressure was such as would tend to make, or actually did make, a geanticline between two extended lines, an eastern and a western. But upturnings of beds took place only where there had been geosynclines of deposition, that is, in the Triassic areas.

The effective upturning force acted alike from opposite directions, the eastern, or oceanward, and the western, or landward; while in the Appalachians its action was from the eastward chiefly; but, still, like the Appalachian Range as a whole, each of the several areas is inequilateral in orogenic structure. The Connecticut valley area tapers out, both as to width and depth of deposits, at New Haven Bay on the Sound. There is no trace of the trough over Long Island. It is possible that in the direction of this eastern Triassie line a sandstone area existed over the shallow-water border of the Atlantic, south of Long Island and east of New Jersey; but no proof of this has been observed. In the Richmond area of eastern Virginia, however, and in the Deep River area of North Carolina, as the dip of the beds of each proves, the true continuation is found, for these areas have the same position relatively to the western areas of those states, as the Connecticut valley area has to the Palisade area. The map on page 412 illustrates the fact, not only that these areas mark out the position of the eastern side of the series of Triassic belts, but also that it is parallel to its axial line. 
In the progress of the upturning the sandstone was rariously fractured and faulted; and the masses into which it was thus divided were in part forced over one another, and up whatever surfaces lay beyond, and thus the monoclinal structure was produced. The abraded surfaces of the beds, extensirely exhibited in some regions, indicate that there was a vast amount of intestinal movement as well as ordinary faulting. The sandstone should therefore have acquired its greatest thickness, from piling on itself, on the side of the area in the direction of the movement; that is, on the west sicle in the Connecticut valley, and on the east, in the Palisade belt. Noreover, the confining slope of the trough on this side would have been an obstruction that would have there increased the fracturing and the amount of piling.

The lateral thrust would have narrowed the belt of deposits of each geosyncline. The amount of narrowing, taking the mean dip of the beds at $15^{\circ}$, and supposing no modifying conditions, would have been about 100 feet for every 3000 feet of width. But the piling of the beds referreci to above, and the shoving of the beds beyond the limit of the original area or trough, are modifying conditions that cannot be estimated.

The shallow mass of deposits in each geosyncline had a temperature at bottom possibly of $200^{\circ} \mathrm{F}$. or $300^{\circ} \mathrm{F}$; for, if 10,000 feet thick, the present rate of increase in temperature downward would make the maximum only $200^{\circ} \mathrm{F}$. This temperature was sufficient only for a partial consolidation of the beds through any siliceous waters that might have been made, and for the reddening of them by the oxidation of any iron present. The movements from lateral pressure against the trough in the earth's crust, in which the beds lay, might have produced their results by molecular transfer in the mass of the crust. But the facts point unquestionably to great and deep fractures. The directions of such fracture-planes would have been deter. mined partly by the positions of the weaker planes in the rocks beneath. Such weak planes may be due to kinds of rocks; to the foliation or bedding of the rocks; to earlier fault-planes; or to preëxisting mountain features of the Atlantic border. But their actual positions are not often determinable except so far as they may be inferred from the lines of eruptive rocks.

Igneous eruptions over the Triassic areas. - The general features of the outcrops of trap orer the areas are well displayed in the Connecticut valley, an excellent map of which for the state of Connecticut is contained in J. G. Percival's Geological Report (1842); and for the Massachusetts portion, by B. K. Emerson, in the Bulletin of the Geological Society of America for 1891. The accompanying map, Fig. 1346, which is part of Percival's, embraces the southern three fifths of the whole area in Connecticut, or the part from the Sound to the latitude of Hartford. Its length is 37 miles, or about one third of that of the whole valley.

On the map the dotted lines $n n, m m$ mark the outlines of the Triassic area; outside, both to the east and west, the rocks are crystalline rocks. The heavy black lines represent the outcrops of trap. Commencing at the south, the abbreviations used on it are as follows: N H, New Haven; $p p, b b$, dikes of trap outside of the area, on the west; and 
1346.

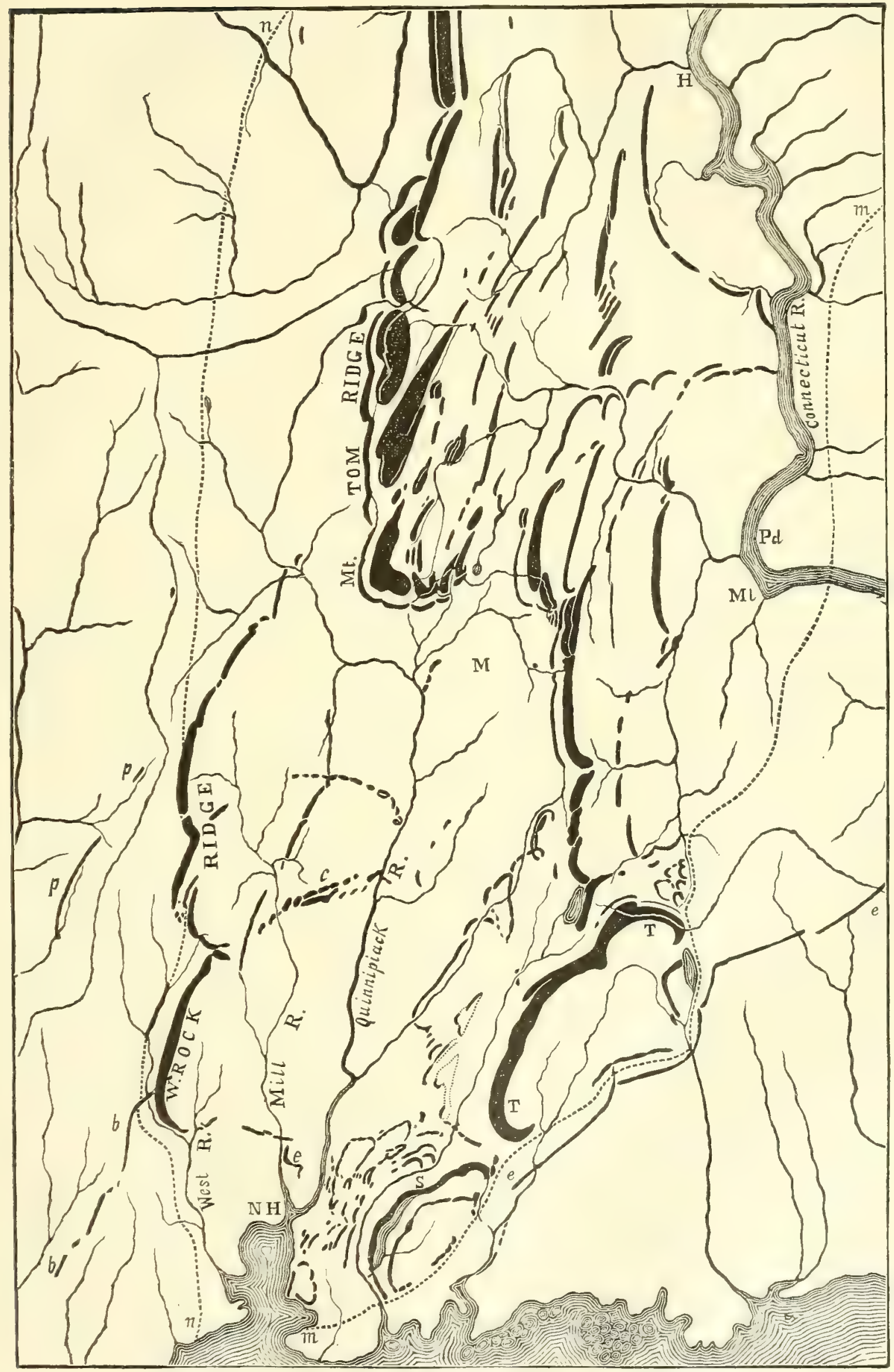

Map of part of the Triassic area of central Connecticut. J. G. Percival. 
ee, another on the east; S, Saltonstall Ridge, called Pond Ridge by Percival; T T, Totoket Ridge; C, Mount Carmel; M, Meriden; Mt, Middletown; Pd, Portland and Portland sandstone quarries; H, Hartford. The scale of the map is $\frac{9}{10}$ of an inch to 5 miles. The many interruptions in the lines of trap on Percival's map are generally due to intervals of sandstone, and the smaller of them may often have resulted from falls of the sandstone walls of oblique fissures, as explained on page 298. But in some cases they are breaks in the outcrop of trap in which no sandstone was in view, and where further investigation may prove the line to be continuous. One such case exists in the termination of West Rock, and another in the south side of the summit of Mount Carmel; and changes have been made correspondingly in Percival's map. One other change made, in order to represent the results of later observation, is the continuation of the dike $b b$ to and across West Rock.

Some of the general facts of importance illustrated on the map are the following:-

1. The outcrops are most numerous in this southern portion of the area. To the north of the region here mapped, there are only continuations of the three western lines to Mount Tom and Mount Holyoke in Massachusetts, and an isolated line farther north which passes near Greenfield.

2. The outcrops of trap are not wholly confined to the Triassic area. Two lines of dikes exist on the west side ( $p p, b b$, on the map); they continue southwestward to the Sound. In one of them, the trap is sparsely porphyritic with crystals of anorthite. There are also two long dikes on the east: one, commencing in ee, to the eastward of New Haven, not a mile distant from the area, has a course nearly parallel to its eastern outline for 10 miles, but afterward diverges from it; the other commencing nearly east of Hartford, just outside of the area, is parallel to the area for the same distance. Both were traced by Percival to the Massachusetts line.

The convergence of the dike ee, southwestward toward New Haven Bay, and that of the other lines of trap in the Triassic area, are part of the evidence that the estuary or trough terminated at this place.

3. The trap (doleryte or diabase) is essentially the same rock in all the belts, and through all the Triassic areas. It is sparingly chrysolitic, according to Iddings, in Orange, N. J., and rarely so in other places. The chief variation is a result of alteration by means of water imbibed as vapor, when, it is believed, the rock was on its way through the sandstone to the surface. The rocks are sometimes unaltered on one side of a belt, and much altered along its middle or on the other side. Dikes intersecting the outside crystalline rocks are wholly free from the alteration, showing that the moisture was not from the same source as the trap, but more superficial. The altered hydrated trap has little luster; is often amygdaloidal within 50 feet or so of the surface; and decomposes rapidly, and often to a depth of several yards, so that a small dike between layers of sandstone is sometimes found wholly changed to a brownish yellow earth, and looks like a bed of tufa. For remarks on amygdaloids, see pages 78, 336. Along some of the fissures there were carried up with the trap ores of copper, and thus copper veins were made in the trap and in the sandstone of the vicinity (page 338). 
4. The lines of trap on the map are usually curved, with the convexities to the west; or they consist of a series of similar curves. Some are bowshaped with hooked ends. Saltonstall Ridge at S, on the east side of Saltonstall Lake, near the Sound, is a marked example of the bow-shaperl outcrop. So also is the narrow line just east of it, and another broader and larger line to the northeast, the Totoket Ridge, T T. The Mount Tom Ridge has an eastward bend, hook-like, at its southern end, in the Meriden region, and another long one at its northern end, constituting Mount Holyoke. The distance between the two hooked ends is over 50 miles, so that it is a very long bow. West Rock Ridge has a hook at its southern extremity, and a series of curves in its course to the north; but it terminates northward near where the Mount Tom Ridge ends, as if a sequel to the latter in formation.

These features are so general that they seem to indicate some comprehensive method of origin.

5. The belts are for the most part approximately parallel to the axial line of the area, or nearly north-by-east in course. But there are many exceptions, especially in the southern part of the area.

The large north-and-south outeropping belts of trap usually have bold features over the landscapes. This prominence is owing to denudation since the time of the eruption of the trap, for originally the trap was probably all under the cover of the sandstone. The hard igneous rock generally makes the summits of ridges. The slope of the ridge in the direction of the dip of the sandstone (eastward in the Connecticut valley) is usually gradual, and along it the trap disappears beneath overlying sandstone; but in the opposite direction, the ridge has a bold front of columnar trap resting on the sandstone. At the contact with the trap, in a north-and-south ridge, the sandstone appears to be horizontal, because its dip is not northward or southward, but eastward. Only in a transverse section of such a ridge should the underlying sandstone show its true inclined position. These facts are illustrated in the figures on page 302. The general features of the bold trap front are better shown in the following view of West Rock; but the part exposed to view is an east-and-west section, so that here the dip of the sandstone is exhibited. Below the bold columnar front of such ridges there is usually a talus of broken blocks of trap; the removal of this talus (for road making) has exposed the sandstone to view. (The nearly horizontal line below the outcropping sandstone is the course of a road.)

The Palisades along the Hudson are another good example of a trap ridge. The bold front of the Palisades faces eastward, the dip of the sandstone being to the westward; and as the ridge has a northward course, the underlying sandstone, which makes about half the height above the river's level, presents a nearly horizontal line beneath the trap.

The east-and-west outcrops of trap are generally lines of simple trap dikes; that is, of trap within the fissure up which it flowed. On the contrary, each north-and-south outcrop in almost all cases is that of an outflow of trap from a supply fissure, which is situated somewhere to the eastward. Examples 
of large dikes, 180 to 300 feet wide, are shown in Pine Rock and Mill Rock, on the map on page 299. Smaller dikes are very common in many localities.

The West Rock Ridge, Mount Tom Ridge, and Saltonstall Ridge afford examples of outllow masses or sheets. With regard to the West Rock trapmass it is proved, on page 302, that it is a laceolith; that the eruptive rock, coming up from below, was forced into a space opened by itself between layers of the sandstone, and there it accumulated under the weight of the superincumbent sandstone, - probably one or more thousands of feet thick. It is also shown that the upturned sandstone underneath the outflow, Fig. 1347, was profoundly abraded by the forced movement, over it, of the melted

1347.

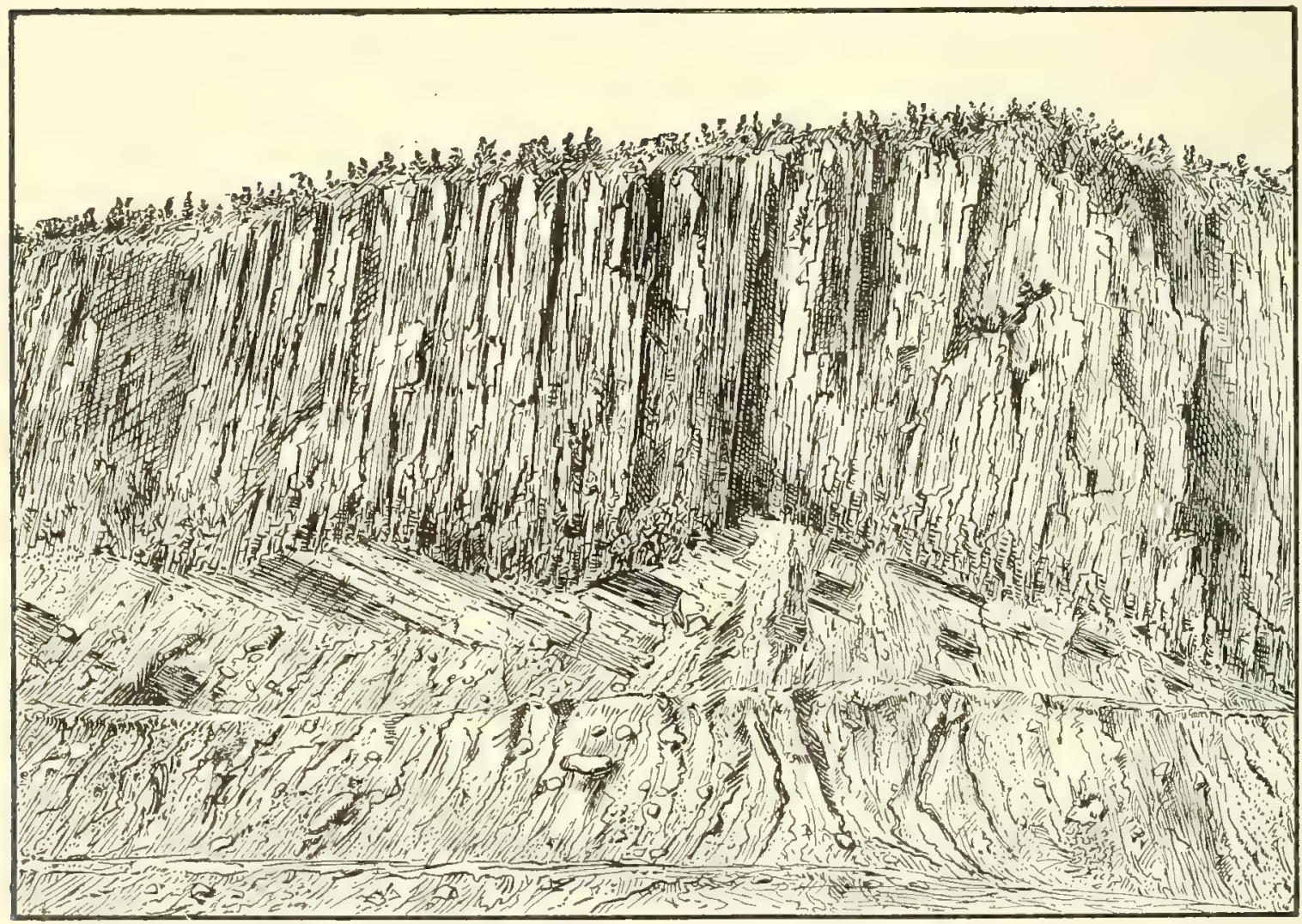

View of the south front of West Rock, near New Haven, Conn., showing the columnar trap and the sandstone underneath it.

rock, and thereby reduced to a nearly horizontal surface. No earth or stones intervene between the trap and sandstone in the section exhibited, showing that the material removed by abrasion was pushed on and lodged elsewhere; and also proving that the flow was not surficial, inasmuch as all surface earth or debris is absent. It has been shown, besides, that East Rock, near New Haven, is laccolithic; and so also the trap belt next west of the Saltonstall Ridge, and the second trap belt east of the same, as described by E. O. Hovey. In addition, the trap rests, in each case, on upturned sandstone, proving that the upturning was a previous event for the region. It follows, therefore, that the trap of the intervening Saltonstall Ridge must be similar in mode of origin and time of eruption. 
While the West Rock section, Fig. 1347, indicates, not only a great amount of abrasion, but also a shoving forward of the abraded material beyond or west of the place in view, that of the second trap belt east of the Saltonstall Ridge has the abraded material resting on the underlying sandstone in the form of rounded and angular stones of the trap and sandstone; the accumulation was evidently made, as Hovey states, by the friction between the liquid and solid rock.

B. K. Emerson reports that the trap sheet of northern Greenfield, Mass., where the bluff or trap faces westward (the dip being eastward), as shown in Fig. 1348, rests on a bed of coarse sandstone breccia, 12 to 16 feet thick, the upper part of which $(T t)$ is cemented by trap, which extends from above between the blocks, and the lower part, 6 or 8 feet thick ( $T s$ ), by red sand, which is continuous with the underlying sandstone. Moreover, the bed of trap breccia rests on unbaked sandstone. At a locality in the Mount Tom Ridge, in the town of Holyoke, the base of the trap, according to Emerson, is "kneaded full of

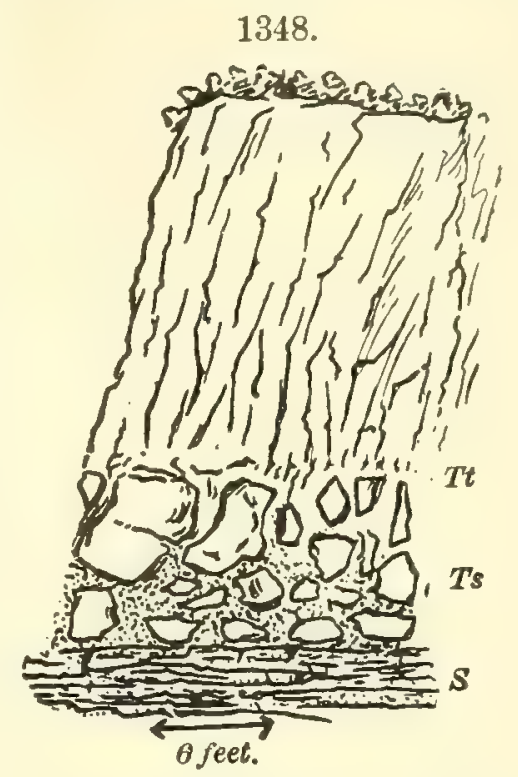

Trap bluff at Greenfield, Mass., with breccia of sandstone blocks (the part $T t$ cemented by trap, and $T s$ by sandstone) lying between it and the sandstone $S$. B. K. Emerson, '92. dove-colored limestone," looking "as if the limestone and trap had been plastic at the same time"; and at one place, where the trap is about 300 feet thick, its "upper surface is filled in the same way with the same limestone to a depth of 8 or 10 feet." The limestone had been torn off from a layer not visible in the section; for, as he says, only sandstone is there in view, or was found in a boring carried down 3500 feet.

The large north-and-south belts of trap often have an attendant belt on the east or west side, or on both, which is generally made of hydrous and amygdaloidal trap, even when the trap of the large belt is of the normal anhydrous kind. Percival draws special attention to this feature. The Mount Tom Ridge is thus attended, as the map on page 801 shows, from the Meriden region northward; the line, which is low from denudation, is on the western side through the southern part of the Mount Tom Ridge, and on the eastern side for the more northern part. Saltonstall Ridge has a similar parallel belt to the east, and another to the west of it, only a few hundred yards distant, and each is perhaps of like relations to the "attendant" dike of the Mount Tom Ridge.

The time of the eruptions and their relation to the upturning of the sandstone. - The evidence is complete that eruptions of trap preceded, as held by Emerson and Davis, the deposition of part of the sandstone. The sandstone of East Haven, east of Saltonstall Ridge, contains stones of trap at many places, as described by E. O. Hovey, while none are known to occur 
over the region west of the ridge. It follows therefore that the eruptive work began before the close of the period of the sandstone formation.

But it appears to be also true that it characterized the closing part of the period. The facts from West Rock, and others of similar import from East Haven, where the trap rests on upturned sandstone, are evidence that so far as these regions are concerned, the upturning preceded the eruptions. This conclusion involves the Saltonstall region; and if this, so also the Totoket Ridge and others to the north, since all are closely alike, and in close conjunction. Moreover, a laccolithic origin may be inferred not only for East and West Rock, but for all such cases.

With regard to the Mount Tom Ridge, direct evidence of age of eruption is wanting; for no east-and-west sections have been reported. But a laccolithic origin and the abrasion of the underlying sandstone are indicated by the occurrence of breccia beneath the trap, and especially by the limestone chips in the lower part of the mass of the trap, and also over its upper surface, as described by Emerson. A bed of limestone was evidently divided by the advancing tongue of melted trap, part being left below, and the rest above. As Emerson observes, the facts prove that the heavy trap flowed over the sandstone, abrading and tearing it. But they prove also that the flow was not surficial, but laccolithic; for in the case of an advaneing surficial stream the lava, being retarded by friction at bottom, has a downward flow at the front, and hence could not bear to its upper surface material met with along its track.

A laccolithic origin for the Mount Tom Ridge explains also the existence of the attendant dike parallel with its southern, western, or eastern side, and for similar cases elsewhere. For whenever, in the forced flow of lava from the supply fissure to make the laccolith, the force could not so easily contribute to the laccolithic mass (owing to the weight it had acquired by accumulation and that of the overlying sandstone, and to resistance froin other sources) as make a fracture either side for a new place of escape, the latter event would take place. A dike of five inches, which is visible under the trap mass in the south front of West Rock, and which is both amygdaloidal and chrysolitic, is probably an example of this mode of origin.

This evidence of a laceolithic origin brings the north-and-sonth trap belts into the same category, as to method and time of origin, with West Rock and East Rock. After or during the upturning of the sandstone appears, therefore, to be the time of origin of the larger part of the eruptions.

The hypothesis has been brought forward by W. M. Davis (U. S. G. S. Rep., vol. vii., and elsewhere), that the larger part of the trap was erupted in the early part of the Triassic period long before the upturning; that in the case of the Connecticut valley area, the trap was poured out surficially from fissures along the eastern margin of the area, and thence flowed westward across it over the underlying sandstone; that after more sandstone had been deposited a second and larger surficial flow took place; then after more deposition of sand-beds a third smaller flow; and that this interstratified sandstone and trap were covered by other horizontal deposits of sandstone of great thickness; that, 
finally, at the time of upturning, the trap and sandstone, thus interstratified, were forced up into monoclines, which by denudation became the existing trap ridges.

According to the views already presented, (1) the trap mass in the trap ridges may be conformable, or not, to the associated sandstone; and (2) the supply fissure was near the eastern base of the ridges, or not far distant. These conditions are illustrated in Figs. 275,276 , on page 302. In the views of W. M. Davis, on the contrary, (1) the trap mass of the ridges is conformable with the sandstome and with its other trap sheets; and (2) it extends to the east and west of the ridges as a conformable sheet in the sandstone formation, and should be found there by boring if not exposed at surface.

It is favorable to this hypothesis that the sandstone is admitted to be in monoclines; that the trap ridges look like monoclines, the trap and sandstone so far as exposed to view being eastward in dip ; that the greater trap belt and the smaller attendant belt on the east and west have the positions in the external view that correspond to layers in a monocline; that in some regions the beds of the sandstone formation underneath the columnar trap in the front of trap ridges have a like order of succession.

But it is unfavorable to it that the hooked or bow-like shapes among the ridges are not such as are characteristic of monoclinal regions; that the varying dip of the sandstone within the bow - it being nearly at right angles to the direction of its sides and ends is an exceptional feature for monoclines, and an actual feature of those trap ridges which are admitted by all to be eruptive. It is also unfavorable that no outcrops of either of the three conformable sheets of trap have been observed along the eastern margin of the area; that no sections of the sandstone formation occur anywhere in the part of the area east of the Connecticut River, which exhibit the conformability of the trap sheets with one another or with the sandstone, or that show any trap at all; that no sections exhibiting conformability have been observed in any of the trap ridges themselves, and none over the part of the Triassic area west of these ridges. Thus positive evidence in favor of the hypothesis fails; and there is the evidence against it that the Saltonstall region, instead of exemplifying it, as claimed by its author, is a region of eruptions after the upturning of the sandstone, and that the Mount Tom Ridge bears the strongest evidence of a laccolithic origin.

The existence of buried volcanoes at Mount Carmel ( $740^{\prime}$ high), 9 miles north of New Haven, has been announced. But there is no evidence of the "buried volcanoes" in sight: neither in lava streams, volcanic ashes, nor anything else. The rocks in view are the ordinary compact trap of the trap dikes of the region and the intersected granitic sandstone.

Origin of the eruptions. - Although the geosynclines or troughs in the earth's supercrust occupied by the deposits were comparatively shallow, none probably exceeding in depth 10,000 feet, the lateral thrust from the opposing directions produced, at intervals, fractures and movements, if not also crushings, at considerable depths for the whole length of the Eastern Continental border, from Nova Scotia to southern North Carolina. For, according to existing theory, the region of fusion was where the earth's interior temperature was so near the fusing point of the rock, that the heat from dynamical sources, added to the statical heat of the region, would produce fusion. The near uniformity in the kind of ejected rock, through all the Triassic areas, has been already mentioned as other evidence that the fissures descended below the supercrust to regions where basic Archæan-like rocks prevail. The ejection of rocks of the basaltic type alone may, however, be a consequence of the temperature not being high enough to melt the less fusible rocks containing oligoclase or orthoclase. 
It is a fact deserving especial note that although the subterranean fusion occurred at intervals for 1000 miles, the fissures by which ejections took place were almost wholly confined to the narrow areas of the Triassic geosynclines. The isolated Southbury area of Connecticut, a dozen miles west of that of the Connecticut valley, and only seven by two and one half miles in area, has its many trap dikes; and none exist over the intervening region or to the north, west, or south of it. The isolation of the eruptions corresponds with that of the upturning. The areas of the geosynclines - that is, of subsidence and deposition - in some way localized the areas of fractures and fusion. There seems to be good reason, in the facts, for locating the chief of the fractures underneath the center or central line of each area and under that half of it which is nearest to the general axial line of the chain of areas, rather than underneath the outer margin of the other half, or in any part of this half; that is, in the Connecticut.valley area, as Percival's map illustrates, for locating it underneath its central line and the half to the westward, rather than underneath the eastern part.

There are, however, two long dikes just east of this Triassic area, besides two others to the west of it. One of the southwestern of these outside dikes, $b b$ on the map, is proved, by its cutting through the West Rock trap, to have been of subsequent origin; and this is probably true of all four. The four are alike, moreover, in having a mean course of N. $25^{\circ}-30^{\circ} \mathrm{E}$., thus differing about $15^{\circ}$ in easting from the average course of the trap belts in the Connecticut valley. Similar facts are afforded by the region of the Palisade Range. They accord with the idea that these outside dikes were erupted when the orogenic catastrophe was near its close, and the localizing geosynclinal conditions had lost part of their influence. Perhaps tension from a decline in the lateral thrust, or from a dissipation of the subterranean heat generated by the movement, led to these divergent lines of fracture and eruption.

According to J.J. Stevenson, great displacements have been produced in the faulted Appalachian region of northwest Virginia at some time subsequent to the origin of the range; and it is probable that the epoch was coincident with that of the Triassic upturning. (Am. Jour. Sc., xxxiii., 262, 1887.)

\section{Movements over the Rocky Mountain Region and the Pacific Border. Making of the Sierra Nevada.}

Along from Mexico northward, in the Rocky Mountain region, thick Triassic and Jurassic deposits were in progress, preparatory for future mountain-making; but, in general, only oscillations, and some emergences in the general course of geosynclinal subsidence, have been reported. Over the summit region of the Rocky Mountains deposition was continued quietly, as a general thing, through another period, the Cretaceous, before any great disturbance took place. On the ground of the absence of Liassic beds over the region south of Wyoming, $\mathrm{R}$. C. Hills has inferred that an emergence 
there took place after the Triassic. In the Sierra Nevada an unconformity occurs, according to Diller, between the Lias and Upper Trias of the Taylorville region, but the succession of deposits shows that no emergence in that portion of the Sierra Nevada accompanied the disturbance. In the Island belt of British Columbia, along Vancouver and the Queen Charlotte Islands, an emergence occurred after the Triassic period; for no Jurassic beds exist between the Triassic formation of the region and the Cretaceous; moreover, at some time between the Triassic period and the Cretaceous, according to G. M. Dawson, an extensive upturning of the Triassic beds took place; but whether at the close of the Triassic or of the Jurassic is left uncertain $(1886,1887)$.

The close of the Jurassic period was the time of the making of the Sierra Nevada Range, as announced by J. D. Whitney in 1864 (Am. Jour. Sc., xxxviii., 1864; Rep. Geol., 1865), after the discovery of Triassic and Jurassic fossils in Plumas County, and of Jurassic in the Auriferous slates of Mariposa County and other regions. This conclusion has been questioned and the event referred to the Middle Cretaceous, on the ground chiefly of resemblance between the Aucellæ of the Jurassic Sierra slates and those of the Lower Cretaceous; but it has been fully confirmed by the study of the Mariposa and other fossils by Hyatt and others, and by the fact of the unconformability of the Lower Cretaceous with the rocks of the Sierra in many places west of the Sacramento River.

It is also sustained by the fact of the conformability of the Lower and Upper Cretaceous, or the Shasta and Chico series, as observed by Diller; who has, moreover, traced the unconformability, not only along the west side of the Sacramento, from Pit River southward by Redding, Horsetown, and Ono, into Tehama County, but also northward by Yreka and Ashland, far into Oregon. Moreover, other ranges to the west and north participated in the upturning; for the Coast Range and the Klamath Mountains were parts of the result, according to Diller and Fairbanks; and it may be that still others in the Sierra line, to the north or south, were then formed.

The black slates and siliceous rocks of the auriferous belt of the Sierra are associated with hydromica schist, hornblende schist, serpentine, crystalline limestone, along with some sandstone, and with limestone which is semi-crystalline. From the Mariposa region northward they commonly have a dip eastward of $60^{\circ}$ to $80^{\circ}$ or $90^{\circ}$. The relative positions of the rocks of the belt are finely exhibited on the colored geological maps of parts of the Sierra region published by the United States Geological Survey, prepared chiefly by Lindgren and Turner. They show by colors the positions of the areas of outcrop of the granite or dioryte, which makes the core of the Sierra, and also of the various eruptive rocks of the region as well as the belts which make up the Auriferous series.

In the Taylorville region, Plumas County, the beds, ranging from Upper Jurassic to the Silurian, are partly in overthrust flexures, the thrust being to the eastward (landward) as described and figured by Diller (G. Soc. Am., 
1892). It is probable that there were ranges of flexures and monoclinal shoves along the rest of the Sierra to the southward and great upthrust faults also in the Taylorville region.

The maximum thickness of the rock in the Taylorville region is 24,500 feet, of which 17,500 feet are Paleozoic and 7000 feet Mesozoic (Diller). The Sierra Nevada geosyncline of deposition, which began during or before Upper Silurian time, hence reached in this part a depth nearly of 25,000 feet; this was the thickness of the pile of deposits that was upturned and flexed in the crisis of mountain-making at the close of the Jurassic. The heat generated by the movements was sufficient for the rather feeble metamorphism which characterizes the rocks. Facts also appear to prove that the core of diorytic granite, which is the chief rock of the ridge to the south, was an Archæan ridge over and against which the thrust took place; for the stratified rocks, where in contact with it, show in some places in their erystallization or metamorphism the effects of the friction. For an example of such effects, see page 534. This view of the Archæan age of the Sierra core of granite is presented by King in his 40th Parallel Report, 1878.

The Sierra Nevada, when first formed, probably had not half its present height. It has a later history of great geological interest.

The formation of the gold-bearing veins of quartz in the Sierra rocks was a consequence of the upturning. The wrenching of the strata opened the leaves of the slates, and also made great intersecting fissures. The opened spaces and fissures became filled with silica (quartz) which the heated moisture took into solution, and also with suck ores as the vapors found in the beds. Some of the auriferous quartz veins have a width of 10 to 40 feet. As the modern Sierra gravels contain gold from the rocks which make the modern Sierra, so the more ancient rocks, of Jurassic and earlier origin, must have held gold from the earlier crystalline rocks of the Sierra; and this gold, with ores of lead, copper, and other metals, the hot vapors gathered into the fissures. It was not the work of superficial waters ; for the veins now visible on the Mariposa estate and elsewhere are, owing to denudation, thousands of feet below the original surface; but there is no doubt that superficial waters took part in the work. The metamorphic effects include many rocks in the Coast Range, besides prevailing kinds above mentioned, as stated on page 318; and through Becker's studies the region has become an especially instructive one on the general subject of metamorphism.

The "granite core" of the Sierra constitutes the culminating points in the southern portion of the range - among them Mount Whitney, which has a height of 14,898 feet above sea level; and it is the rock of the famous Yosemite Valley. Whitney states that the slates near the granite are harder than at a distance from it, and contain hornblende; that veins of granite extend into the altered schists. And Diller describes contact phenomena observed by him in the Taylorville region. Moreover, some of the auriferous quartz veins extend into the granite. Evidence of this kind led Whitney, in his California Report, to present the view of the post-Jurassic age of the granite; and several recent investigators of the region hold the same opinion. But intrusions of 
dioryte in dikes would be a natural result of friction along fault-planes cutting through such an underlying crystalline mass. The extrusion of igneous rocks accompanying mountain-making has been a common fact over the summit region of the Rocky Mountains ; an example occurs in the Wasatch, which has, like the Sierra, a "granite" core.

Had the granitoid mass been a result of deep-seated eruption at the time of the upturning, or at any later date, or earlier, it would have come to the surface in great fissures ; for fissures, as the result of fractures, give exit to the confined liquid rock of the earth's depths. Moreover, liquid dioryte is identical with andesyte lava, and liquid granite with rhyolyte; and if ejected at the time supposed, it should show evidence of the chilling effect of the relatively cold Sierra rocks along their contacts with them. Instead of this, the rock of the core is well crystallized to its surface, and has a coarseness of crystalline texture which indicates extremely slow cooling. Neither is the existence of auriferous quartz veins in the granite positive evidence of its recent origin; for the granite of Pike's Peak, according to W. Cross, contains sandstone dikes (Feb., 1894). Further, if the ridges of crystalline rock in California and to the north are all eruptive and of late Mesozoic age, as is urged, and the emergence at the close of the Triassic is the earliest of much importance, there is no sufficient source for the sediments of which the successive sedimentary rocks were made. They could not have come from the eastward; for the oceanic currents of the Pacific border are now, and must have been in early time, from the northwest; and besides, the ridges of the Pacific border are north or northwest in course. Moreover, oceanic currents are relatively feeble transporters, and find their material for rock making near at hand.

Such a mass of crystalline rock having irregular or indefinite outline has received the name of bathylite. (Bathylith would be a better name, as it is here used for a mass, not a kind, of rock.) It has one mode of origin that is consistent with indefiniteness of outline. When a pile of deposits, 30,000 feet or more in depth, has beds in its lower portion that admit of fusion under the action of the heat producing metamorphism, the melted material would make a mass of indefinite outline. The fusion, under the same circumstances, of the rocks immediately below the pile, might add to the melted mass or be its chief source. Here is fusion unbounded by the walls of a fissure. This was common, as has been elsewhere remarked, in Archæan time. There is no sufficient evidence that it occurred during the Sierra upturning at the close of the Jurassic, or in any other part of Mesozoic time.

The pre-Cretaceous age of the metamorphic rocks of the Coast Range has been urged by Fairbanks (1892). This view is held also to some extent by Turner and Diller; and the latter states that the Coast Range was upheaved with the Sierra Nevada at the close of the Jurassic. This conclusion is drawn from the fact that the Cretaceous thins out, both to the eastward and westward of the Sacramento valley, and that the later beds have their greatest extension in these directions.

The Cascade Range appears, from its position, to be part of the Sierra system. Becker reports that the same class of metamorphic rocks characterizes the portion of it in Oregon where not buried beneath later volcanic ejections. The Blue Mountains of Oregon also have their Jurassic rocks, and were probably among the results of the post-Jurassic upturning.

In the Platean Belt, or that of the Great Basin, near Carson Lake, the West-Humboldt range, according to King, was made at this time. It includes several ridges between $117 \frac{1}{2}^{\circ} \mathrm{W}$. and $119^{\circ} \mathrm{W}$; and the thickness of the 
Triassic and Jurassic rocks in the West-Humboldt and Pah-Ute ridges is stated to be 20,000 feet or more.

The Sierra and Wasatch ranges have reverse positions with reference to the Great Basin. Each stands with its steepest side and its high shoulders toward the basin; and in each, if the views above stated with reference to the Sierra Nevada are correct, this bold side is made up in part of an Archæan range, which was really the protaxis and backbone of the mountains.

In the Vancouver and "Coast Ranges" of British Columbia the underlying rocks are gray granitoid kinds, containing much hornblende. The granite of the latter is associated with mica schist and hornblende schist. In the former, according to Dawson, the granite underneath the stratified beds of the Vancouver Island series is charged with innumerable darker fragments from these overlying rocks for a distance inward from the surface of the granite in some places of a few hundred feet to half a mile. How such a penetration of fragments from the non-metamorphic beds could have been produced, whether the granite were of later eruptive origin, or of earlier production, is unexplained. If the granite were metamorphic eruptive, and thereby simultaneous with the upturning in its eruption, the Vancouver strata would have been distinctly metamorphic.

In Europe, through the Triassic and Jurassic periods, great preparations in rock deposition were in progress over deepening troughs, for the making of the Alps, Pyrenees, Carpathians, Apennines; but the crisis in all these cases was delayed until the Tertiary.

\section{Cretaceous Period.}

The Cretaceous period, the closing part of the "Age of Reptiles," is remarkable, like the earlier Mesozoic, for the number of Ammonites and Belemnites among its marine species; for the diversity and size of the Reptiles populating the seas, land, and air; for Birds that had teeth like the Reptiles; and for Marsupial and Oviparous Mammals. Unlike the earlier Mesozoic, it is not less remarkable for the existence in the seas, along with Ganoids and Cestraciont and other Sharks, of Teleost Fishes, related to the Perch, Mackerel, and Salmon, and for the addition to the forest trees of Angiosperms of kinds related to the Sassafras, Magnolia, Tulip Tree, Plantain, Fig, Beech, and the like, together with Endogens of the tribe of Palms.

\section{General Subdivisions.}

Only the grander subdivisions of the Cretaceous series, the Lower Cretaceous and the UPPER, or the EARLIER and LATER, are adopted alike in Europe and America. But it is not yet established that the limits between these two divisions as recognized on the two continents are the same.

\section{NORTH AMERICAN.}

\section{General Geographical Features of North America.}

The map here introduced presents a general idea of the distribution of land and salt water over the continent of North America during the period 
of greatest submergence in the course of the Cretaceous period. 'The vertical lining indicates the parts that were submerged during the Lower Cretaceous; the horizontal lining, those that were submerged during the Upper Cretaceous; and the cross-lining, the areas under water through the whole period. The map is too small for an infication separately of the fresh-water Cretaceous areas.

1349.

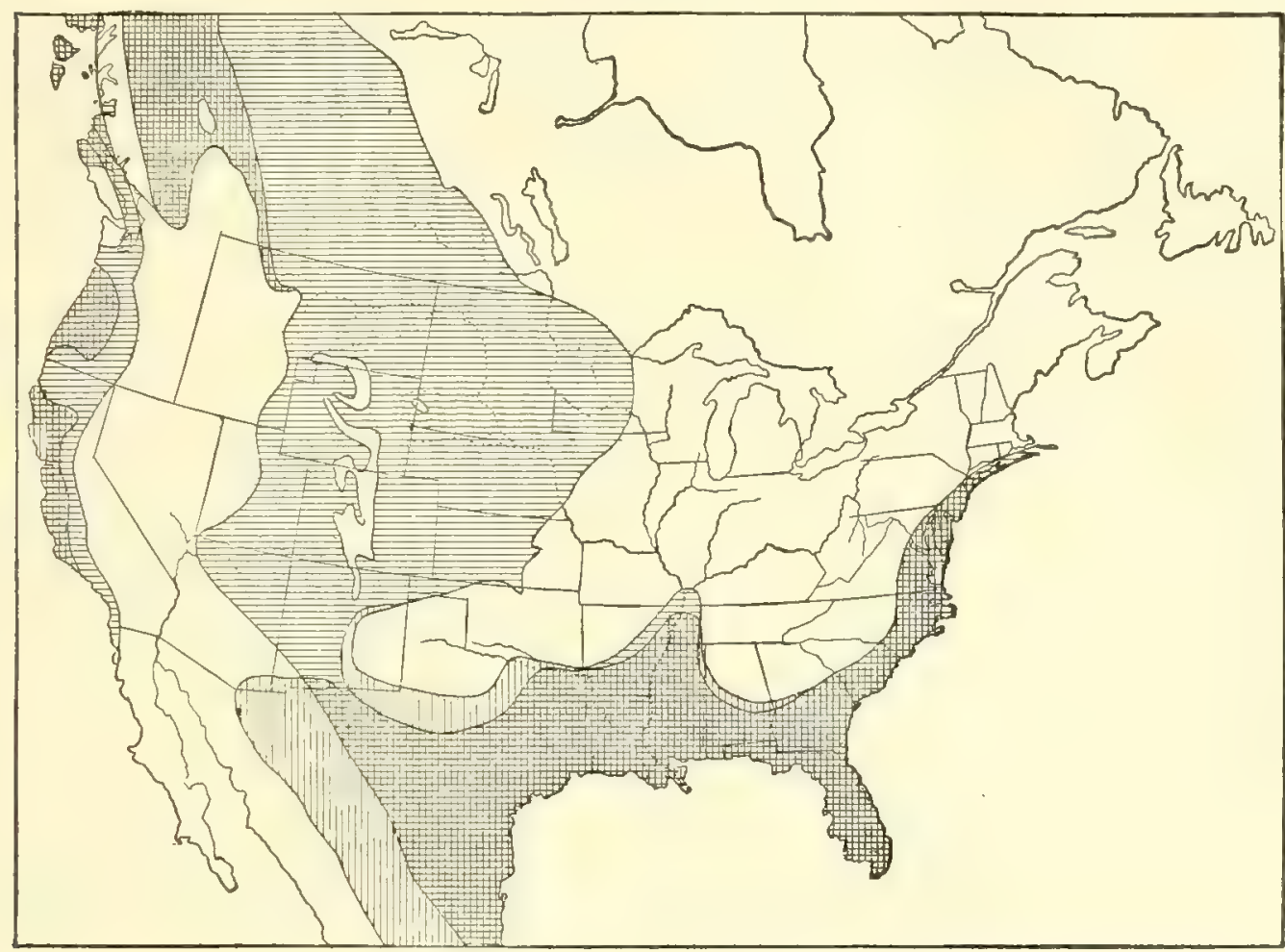

North America in the Cretaceous period.

The positions of the areas of Cretaceous rock-making, as illustrated for the most part on the map, are the following:-

1. The Atlantic border.

2. The Gulf border to the Mississippi River.

3. The Western Gulf border, or the area of Texas and Mexico.

4. The Western Interior Continental Sea, including the summit region of the Rocky Mountains, and extending south through New Mexico and western Texas into Mexico.

5. The Pacific border.

Besides these there are the independent areas of Arctic lands.

The submergence reached its maximum during the earlier half of the Upper Cretaceous. During the progress of Lower Cretaceous time, the great Western Interior region was, for the most part, at or near the water level; for the outcropping beds are fresh-water or marsh-made formations. Only in its southern part from Kansas over Texas, part of New Mexico and Mexico, are they marine. At the same time the Atlantic border and the northern Gulf border had their fresh-water formations. But after the Upper Creta- 
ceous period had made some progress, the waters of the Mexican Gulf began to spread northward over the subsiding Continental Interior; and before its earlier half had passed, the submergence had reached its maximum. A vast Mediterranean Sea extended from the inner portion of the Mexican Gulf, probably to the Arctic Ocean. The Atlantic border, south of New York, as the map shows, was also submerged, and a wider portion of the Gulf border; and along the valley of the Mississippi the waters stretched northward beyond the present mouth of the Ohio, making a great Mississippi Bay, which was 100 miles wide in the latitude of Memphis. But in Mexico, at this time, the large Lower Cretaceous area over which the Atlantic and Pacific had been exchanging waters, was, to a great extent, emerged. Over the Pacific coast region there was a narrow strip of water-narrower than in Jurassic time because of the making, at its close, of the Sierra Nevada and other mountain ranges to the north.

At the time of maximum submergence during the Upper Cretaceous, the American Mediterranean Sea of the period had a length, if extending to the Arctic Ocean, of about 3000 miles. The decline in depth and size began perhaps by the middle of this later half of the Cretaceous period. As explained in detail beyond, there were successively: a shallowing of the sea and an emergence of dry land far north in British America, cutting off connection with the Arctic Ocean, and thus converting the waters on the south into a Mexican Gulf, 2000 miles or more in length; a contraction of the great gulf commencing along the eastern border; the conversion of the gulf, while still 1500 miles in length, into a region of alternating brackish waters and fresh waters and low marsh-covered lands, situated along and just east of what is now the Rocky Mountain section of the Western Continental Interior; the disappearance of the salt waters, leaving only fresh waters; and, finally, the disappearance of these waters over the mountain region, and the end of Cretaceous deposition, with a change in the events to mountain-making.

The preceding map, illustrating North America in the Cretaceous period, was prepared for this work chiefly by J. S. Diller and T. W. Stanton, of the U. S. Geological Survey, from the map by C. A. White in his paper On the Correlation of the Cretaceous $(U . S$. G. S. Bulletin, No. 82, 1891), and from those for British America by G. M. Dawson in the Transactions of the Royal Society of Canada for 1890, and largely from later papers since published, and more recent results in possession of the U. S. Geological Survey. White's Bulletin, which contains a review of the literature, facts, and theories pertaining to the North American Cretaceous formation, has been of much service in the preparation of the following pages.

\section{Subdivisions.}

No general subdivisions of either the Lower or Upper Cretaceous for all the regions in North America have been adopted, on account of the wide diversity of the regions as to conditions. Part of the deposits being fresh water, and the marine fossils of the Atlantic and Pacific borders and of the 
Atlantic and Continental Interior being almost completely unlike, it has proved very difficult to determine equivalency.

The Lower Cretaceous series is less well displayed on the Atlantic and Pacific borders than in Texas, and hence the division into epochs has been based on the subdivisions recognized in the latter region. For a like reason the epochs of the Upper Cretaceous are based on the subdivisions over the Continental Interior.

The principal subdivisions in each of the geographical belts are given in the following tables. The equivalency indicated is, for the reasons stated, largely doubtful. For comparison, the corresponding subdivisions in European geology are presented in the last column.

\section{Lower Cretaceous Division.}

\begin{tabular}{|c|c|c|c|c|}
\hline $\begin{array}{l}\text { Atlantic and } \\
\text { Northern Gulf } \\
\text { Borders }\end{array}$ & $\begin{array}{c}\text { Western Gulf Bor- } \\
\text { der, Texas }\end{array}$ & $\begin{array}{c}\text { Rocky Mountain } \\
\text { Region }\end{array}$ & Pacific Border & Europe \\
\hline $\begin{array}{l}\text { 1, 2, 3, Potomac } \\
\text { group, Atlantic } \\
\text { border; Tusca- } \\
\text { loosa group, Ala.; } \\
\text { Eutaw in Miss. }\end{array}$ & 尊 $\left\{\begin{array}{c}\text { 3. WASHITA } \\
\text { EPOCH } \\
\text { 2. FREDERICKS- } \\
\text { BURG EPOCH } \\
\text { 1. TRINITY } \\
\text { EPOCH }\end{array}\right.$ & 1. Kootanie Group & $\begin{array}{l}\text { Horsetown } \\
\text { Knoxville }\end{array}$ & $\begin{array}{l}\text { 3. Gault or Albian } \\
\text { 2. Aptian or Lower } \\
\text { Greensand } \\
\text { 1. Neocomian }\end{array}$ \\
\hline
\end{tabular}

2. Upper Cretaceous Division.

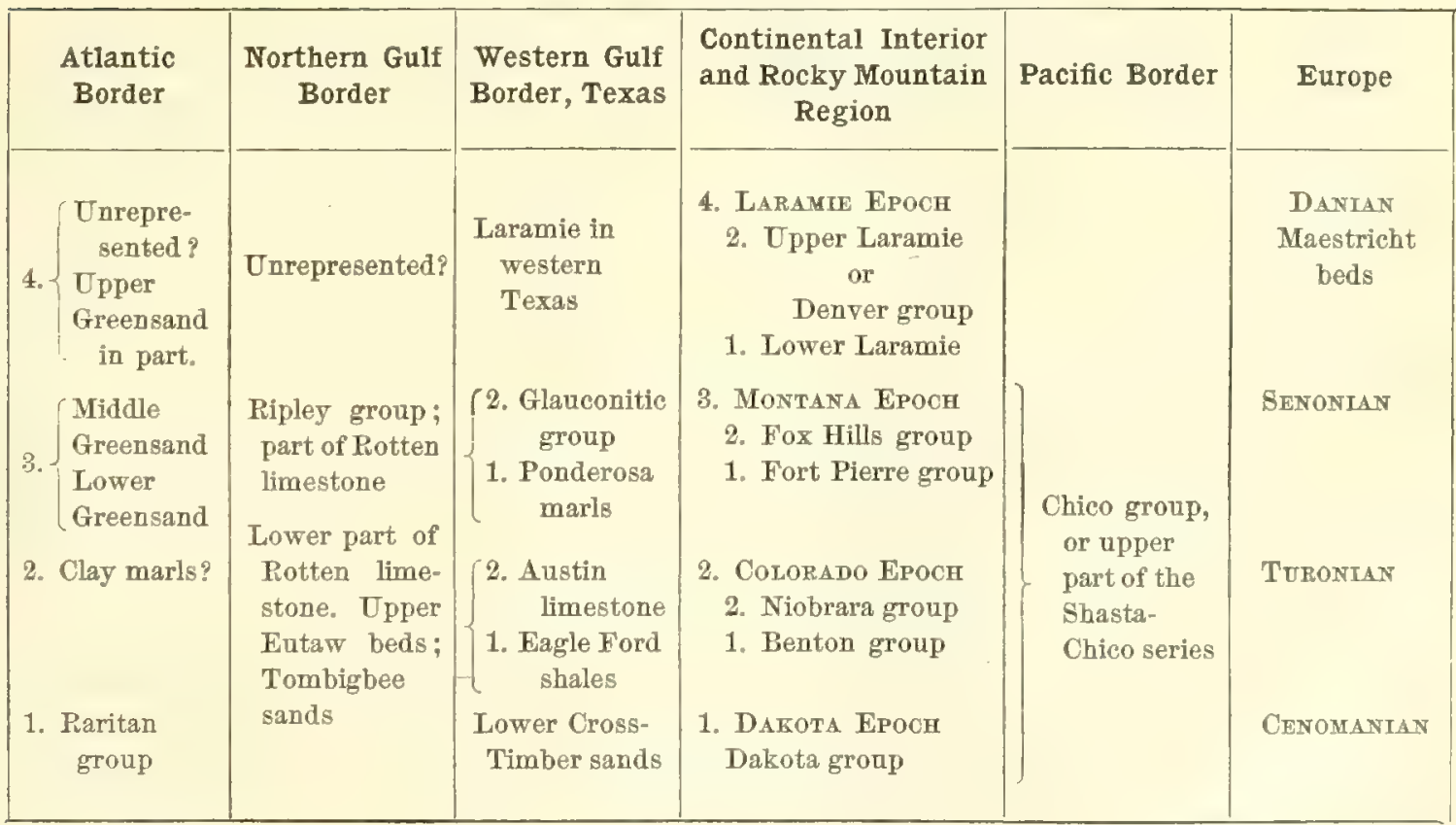

The lower limit of the Cretaceous series in North America has been made out by a comparison of fossils with those of the Neocomian of Europe. It is especially marked, in most localities where the remains of plants occur, by the presence of the leaves of the earliest species of Angiosperms, along with those of the still abundant Cycads. As at present understood, the 
series extends as far upward in the geological formations as the remains of Mammals are of the oviparous kinds, with none of the ordinary or placental Mammils, and as far as the remains of Reptiles include the Mesozoic types of Dinosaurs and Mosasaurs; and, moreover, until the epoch of mountainmaking, which closed Mesozoic time, had reached its climax. No marine fossils of the Cretaceous beds, or remains of Cretaceous Vertebrates, are positively known to be continued from the Cretaceous into the Tertiary formation.

\section{ROCKS-KINDS AND DISTRIBUTION.}

\section{Lower Cretaceous.}

Attantic border. - The Potomac formation. - The Lower Cretaceous beds of the Atlantic border are those of the fresh-water Potomac formation, so named by W. J. MeGee in 1888. It consists mostly of granitic sandstones and conglomerates, loosely aggregated and irregularly bedded, with clay-beds chiefly in the upper portion. It occurs on the Atlantic border near the inner limit of the Cretaceous, in an interrupted belt, passing through Delaware, Maryland, the District of Columbia, Virginia, and beyond to Weldon in North Carolina. The thickness is 600 feet and less. The width of the belt where continuous is seldom over 10 miles; but outliers make its probable original width in some parts perhaps 40 or 50 miles. The coarser conglomerates occur in the vicinity of the larger rivers, the Delaware, Schuylkill, Susquehanna, Potomac, and James River, showing that the rivers had then their place over the Atlantic border, and also that their floods were concerned in the coarser deposition, while the finer materials and clays mark off the relatively quiet areas and intervals. The presence of a rare marine shell shows that the sea was not far away. The granitic material is that of the rocks over much of the region adjoining, and of the Triassic, which in some cases they overlie. But the other sands are probable evidence that the drainage over the Atlantic border had now its head in the Appalachian Mountains.

According to Fontaine, its plants, which include Cycad stumps and leaves, Conifers, and Angiosperms, range in types through the whole of the Lower Cretaceous of Europe, and include some species that are related to those of the first division of the Upper Cretaceous.

Accorling to L. F. Ward, the Cycad stumps occur in the lower part of the Potomac group, the same that includes the Rappahannock freestones. He states, also, that on James River, Virginia, the beds contain Cycads and Sequoian trunks without Angiosperms, suggesting the idea that they are perhaps lower in the series.

Northern Gulf border. - The Tuscaloosa group in Alabama - so named by E. A. Smith and L. C. Johnson - consists of clay-beds and sand-beds, containing impressions of leaves. The Eutaw group, in Mississippi, 300 to 400 feet thick, has similar characters, and contains some lignite (Hilgard, $1860)$. 
Western Gulf border. - In Texas, and to the north and northeast in Indian Territory and Kansas, west and northwest in New Mexico, and west and southwest in Mexico, the Lower Cretaceous beds are mainly marine. They are the Comanche series of R. T. Hill. They have fresh-water beds at bottom, but consist above largely of thick limestones, which are partly chalk. They abound in fossils, and indicate, for the most part, the presence of pure subtropical oceanic waters. The thickness is 1000 to 2000 feet in central Texas, and 5000 feet on the Rio Grande.

The subdivisions adopted by Hill (on which the division of the Lower Cretaceous into epochs is based) are as follows:-

3. Washiта Eросн. - Washita group.

4. Shoal Creek limestone.

3. Denison beds, sands, clays, limestones; Exogyra arietina clays.

2. Fort Worth, or Washita, limestone.

1. Preston beds, Duck Creek chalk, Kiamitia clays.

2. Fredericksburg Epoch. - Fredericksburg group.

3. Caprina limestone, Austin marble.

2. Comanche Peak chalk.

1. Walnut clays, with Exogyra Texana and Gryphra Pitcheri of Romer (G. mucronata of Gabb).

1. Trinrtx Epoch. - Trinity group.

3. Paluxy sands.

2. Glen Rose beds, sandy below, calcareous above, containing marine fossils and some vegetable and Reptilian remains.

1. Trinity sands, with fossil leaves and lignite.

As above indicated, the Cretaceous limestones of Texas are partly chalk, like the Cretaceous of southern England; and the chalk contains flint. Chalk, as already explained, is made from sea-bottom accumulations consisting largely of the minute shells of Rhizopods, corresponding to the Globigerina ooze of modern seas; and flint, from the siliceous spicules of sponges and siliceous shells of Diatoms or Radiolarians that may exist in the same calcareous deposits. Chalk is supposed to show therefore that the seas in which it was formed had a depth of at least some hundreds of feet. The various fossils in the beds are also evidence of deep water. The beds continue to be thick orer the Indian Territory, but thin out in Kansas. The Ouachita Mountain range was emerged land, and the Cretaceous sea, as Hill observes, had a shore line at its base.

In Mexico, the Lower Cretaceous, on the map of Castillo (1891), extends nearly to the city of Mexico; and it is continued beyond to the southward and westward, in isolated patches. According to Hill (1893), all, except a small portion to the northeast, is a continuation of the Comanche group of Texas, but with less distinct subdivisions; and he concludes further that DANA'S MANUAL - 52 
over Mexico during this time the Atlantic and Pacific oceans were united. He makes the thickness 20,000 feet.

Rocky Mountain region and Central Interior. - The Lower Cretaceous of the Rocky Mountain region includes, at some localities at base, the fresh-water Kootanie beds of Dawson (1885), so named from the Kootanie Pass, in the Rocky Mountains, about 30 miles north of the 49 th parallel, where they were first found and characterized by their fossil plants. The beds are sandstones and shales, and contain some coal. Other localities occur at intervals to the northward for 150 miles, and to the southward in western Montana. The beds also outcrop, according to recent determinations by L. F. Ward, about the Black Hills, in western Dakota, where they have a thickness of 200 to 300 feet, contain trunks of Cycads and other plants, and underlie plant beds of the Dakota group (Upper Cretaceous) to which they had been referred. How far they extend eastward and southward is not yet ascertained. In New Mexico they are mainly marine beds, and resemble those of Texas, with which they are continuous.

Pacific border. - The Lower Cretaceous beds of the Pacific border in the United States are marine, but in British Columbia they are partly of freshwater or marsh origin. They occur (1) in the Plateau or interior region of British America, and (2) along the Coast belt.

Over the Plateau region they are described as extending over Washington to the Yukon district and northward to the Arctic Ocean (G. M. Dawson). The Plateau region within the United States, that is, the Great Basin, was apparently emerged; but south in Mexico, as already described, long submergence is proved by the existence of many thousand feet in thickness of Lower Cretaceous beds.

The coast region has a border of Lower Cretaceous beds along the greater part of California and Oregon, and also on Queen Charlotte Islands and Vancouver Island; and again far north along both the northern and southern shores of the Alaskan peninsula.

The beds in California constitute the Shasta group of J. D. Whitney (1869). They are well exposed along the western border of the Sacramento valley, where they are divided into the Knoxville and Horsetown bedsso named from localities in the region by C.A. White. These two groups were made by White to represent only part of the Shasta group; but later observations by Diller and Stanton (1893) show that they correspond to the whole. In Tehama County the total thickness is about 26,000 feet; in Shasta County, where the Horsetown beds alone occur, 5200 feet (Diller, Stanley-Brown). The Knoxville or lower group has among its fossils various forms of Aucelloe (Figs. 1203-1205, page 759), and the Horsetown includes in its abundant fauna many Ammonites; the species of the two have close relations to the Neocomian, Gault, and intermediate beds of Europe. The two groups in Califormia thus cover the whole of the Lower Cretaceous; and these are continued in the Chico series of the Upper Cretaceous (Diller).

In British America, the lower part only of the coast Cretaceous on Van- 
couver and Queen Charlotte Islands is referred to the Lower Cretaceous. On Queen Charlotte Islands, fossil plants of Lower Cretaceous species occur in the beds, as first discovered in 1872, and reported in the following year by Dawson. G. M. Dawson makes five subdivisions of the beds; and the three lower, C, D, E, 9500 feet thick, are now regarded as identical with the Shasta group, on the basis of several common fossils (Whiteaves, C. A. White, T. W. Stanton).

Arctic Ocean. - On western Greenland, in the vicinity of Disco Island, there are deposits containing Cretaceous and Tertiary plants, and the lower part are the Komé group, of Heer (1882), referred by him to the Neocomian of Europe, and by Newberry and Fontaine to the age of the Kootanie and Potomac.

A portion of the Potomac formation in Maryland was referred, on account of its stumps of Cycads, in 1860, by P. T. Tyson to the "Wealden"; and in 1875 to the same by W. B. Rogers. A careful study of the many fossil plants led Fontaine (1889) to essentially the same conclusion. The remains of Reptiles which it has afforded (see beyond). are pronounced Jurassic by Marsh.

The Potomac formation in the region of the Chesapeake Bay, in Maryland, is described by N. H. Darton (1893) as overlaid by beds of white sand, gravels, and brownish sandstones, which he calls the Magothy formation. It contains lignite and plant remains ; but no fossils are mentioned for identifying or distinguishing it; and its separation from the Potomac by a plane of erosion is of uncertain importance. The Albirupean group of Uhler (1888) consists chiefly of white sand-beds occurring along the Chesapeake Bay, and is largely exposed near the head of Magothy River; and it is supposed to belong in part with the Potomac formation. But such evidence is very doubtful; for the deposits of sand, mud, and gravel now forming about Chesapeake and Delaware bays, and elsewhere along the Atlantic border, show that kinds of material, color, coarseness, texture, structure, are nearly valueless characters for determining the equivalency of Cretaceous and later-time beds as well as those of earlier time. All sorts are formed cotemporaneously, and the same sorts at successive epochs.

On the Gulf border, the Tuscaloosa group in Alabama, as described by Smith and Johnson, consists of clayey layers with intercalated beds of sand; it outcrops beneath and either side of Tuscaloosa, along the northern limit of the Cretaceous belt. The thickness is about $1000^{\prime}$. The Eutaw beds of Mississippi, first described by E. W. Hilgard, are referred to the group, as far as non-marine, by C. A. White. The Tuscaloosa group is described in detail by E. A. Smith and L. C. Johnson, in Bulletin 43, U. S. Geul. Surv., 1887, and some observations are added on the Eutaw group in Mississippi.

In Texas, the Lower Cretaceous has a thickness to the northeastward, at Red River, of $1000^{\prime}$; to the southwestward, on the Rio Grande, of $5000^{\prime}$; and northwestward it extends into New Mexico. At Kent, 163 miles east of El Paso, the westernmost station in Texas, the thickness is made about $600^{\prime}$ by Dumble and Cummins; $550^{\prime}$ of it belong to the Washita division, and are characterized by the Gryphoea dilatata var. Tucumcari of Marcou, a fossil well known from the Cretaceous of New Mexico. In Kansas, the whole thickness is but $150^{\prime}$, half of it Trinity sands, and the rest, the Fredericksburg beds (Cragin).

The more important older investigations in Texan geology are those of Ferdinand Romer (1852), B. F. Shumard (1856-1860), Marcou (1854-1859). Shumard made the Washita and Comanche Peak groups Upper Cretaceous; and Marcou placed the upper line of the Lower Cretaceous between these two groups, with the Comanche Peak limestone above. 
The Lower Cretaceous of northern Mexico, in Chihuahua and Coahuila, was described by C. A. White in 1889 , who speaks of the strata of bluish limestones as strongly upturned and flexed, and having a thickness in the Sierra San Carlos of $4000^{\prime}$. Felix and Lenk, in their memoir of 1890,1891 , separate from the Cretaceous of Texas a lower part, consisting of gray to black limestones having intercalated clays as the Lower Cretaceous, and refer the rest, which consists chiefly of whitish, somewhat cherty limestones, to the Upper. He reports the former as having nearly three fourths of its 46 species of described fossils identical with the Neocomian of Europe; and the latter as containing Radiolite-like forms, with species of Caprina and Nerinea.

The Kootanie beds of Montana, which in some places contain beds of coal $12^{\prime}$ thick, were described by Newberry in 1887, and by $\mathrm{H}$. Weed in 1872 .

The Knoxville and Horsetown beds, i.e. the Shasta portion of the Shasta-Chico series, have a wide distribution along the Pacific coast, extending with interruptions from southern California probably to Alaska. Their greatest development, according to Diller, is upon the western border of the Sacramento valley of California, where they are composed chiefly of shales with only occasional sandstones above and many thin beds below. The beds are rarely calcareous, and where the successively newer overlapping series come in, lying unconformably on the pre-Cretaceous metamorphic rocks, local conglomerates are common. The greatest thickness of the Knoxville beds measured is nearly $20,000^{\prime}$. The absence of faults is not assured. The Horsetown beds have a thickness of over $6000^{\prime}$, and overlap the Knoxville beds in all directions toward the Cretaceous shore. The conformability of the Knoxville and Horsetown beds and their detrital and faunal continuity in both California and Oregon indicate uninterrupted sedimentation; and the shoreward overlapping of the newer beds, with marked unconformity upon the pre-Cretaceous rocks, shows that upon the Pacific border the land was subsiding and the sea encroaching.

\section{Upper Cretaceous.}

\section{Atlantic Border.}

On the Atlantic border the Upper Cretaceous formation outcrops from Martha's Vineyard, along the islands south of New England to New Jersey; thence it continues southward, in a narrow belt by the west side of the Tertiary to southern Virginia. It occurs in North and South Carolina only in small patches. Near Macon, Ga., a belt commences north of the Tertiary area, which widens westward, and, on approaching the Mississippi valley, spreads northward up its east side to the Ohio near Paducah; where it crosses the river and narrows out in an area of sandy clays and "micaceous sands" like those of the Kentucky Cretaceous beds. The rest of the Mississippi Bay of the Cretaceous Period became covered later by Tertiary beds and fluvial deposits.

The formation along the New Jersey coast includes at bottom a freshwater group, called the Raritan, and, above this, beds of greensand or marl interstratified with beds of common sand, clay, and occasionally of marine shells. Remains of Reptiles are sometimes found in the upper beds, and occasionally a complete skeleton.

The subdivisions as laid down by G. H. Cook are given in the following table; and the epochs to which they probably belong are also stated. 
4. Laramie Epoch. -

Unrepresented? Possibly here the Upper Greensand, Manasquan group of W. B. Clark: 15 to 20 feet thick of greensand, with above, sandy clays and blue marl; fossiliferous.

3. Montana or Riplex Epoch. -

2. Middle Greensand, Rancocas group of Clark: about 45 feet of marl, with as much of yellow sand above; fossiliferous.

1. Lower Greensand, Navesink group of Clark: 30 to 45 feet of greensand, and above this a red-sand stratum, 100 feet thick; with below Clay marls, 250 to 300 feet.

2. Colorado Epoch. -

Unrepresented? or perhaps the Clay marls.

1. Dakota Epoch. -

Raritan group or Plastic clays: thick beds of plastic clay with some interstratified sand-beds; more sandy above; 350 feet; fossil leaves and lignite, especially toward the base (one third of the thickness from its base in New Jersey); shells rare, and these freshwater of the genus Unio, or brackish-water Gastropods.

The Raritan group is proved by its remains of plants to be the probable equivalent of the Dakota of the Continental Interior; and the Lower Greensand group, by its fossils, as well brought out by Whitfield, to be the equivalent of the Ripley group of the Gulf border. Whitfield refers to the same group, but doubtingly, the nearly unfossiliferous Clay marls which lie below it. The Upper Greensand group graduates, without a break in the stratification, into the overlying Eocene Tertiary, as if its formation were, like the Upper Laramie, the closing work of the Cretaceous period. If not so, the Laramie epoch is not represented on the Atlantic border.

The Lower Greensand is the most fossiliferous of the series. Whitfield has described from it 19 species of Cephalopods, 127 of Gastropods, 155 of Lamellibranchs, and 2 of Brachiopods, or a total of 303 species, against 47 , under the same tribes, from the Middle and Upper Greensand groups. Notwithstanding the unbroken passage of the Upper Greensand group into the Eocene Tertiary, out of the 79 Eocene species of Mollusks described by Whitfield, none occurs in the underlying Cretaceous.

The clay of the Raritan group is partly pure white clay, but it varies to gray, yellow, and red in color, owing to traces of iron oxide, and in some places to black in consequence of disseminated fragments of lignite which had been gathered from some lignitic bed. In general, it is not laminated clay, like that of nearly all river valleys, but a massive clay free from lamination and of remarkable purity. The best of it has great value for the manufacture of fine pottery and other purposes.

The Raritan formation, with its massive clays of various colors, occurs 
also on Staten Island. It includes the clay-beds of northern Long Island, which are well displayed at Glen Cove, and at various points between this place and Huntington and farther to the eastward; and also part of the clays of Fisher Island, Block Island, and Martha's Vineyard. Gay Head, the west cape of Martha's Vineyard, owes its name to the variously colored clay-beds.

The several beds of greensand, or marl, consist of common sand and blackish to olive-green grains of glauconite - a silicate of iron and potash made chemically within the cavities of the shells of Rhizopods, Corals, and other marine organic materials. The bluffs after a rain often look black or greenish black. They are called marl-beds because the material is useful as a fertilizer. The fertilizing properties of the marl, according to G. H. Cook, are not due to the potash of the glauconite, but to the presence of some lime phosphate.

The fresh-water origin of the New Jersey clay-beds is generally recognized. The absence of lamination and the thickness indicate, not river action, but the existence of quiet fresh-water areas parallel with the New Jersey seacoast and that of southern New England from New Jersey eastward as far as Cape Cod, or about 300 miles. The coast-line may have been some miles distant to seaward. Rivers were not the transporters, for they do only coarser work. No river in New England, where feldspathic rocks abound, is now making such non-laminated clay-beds. Only small streamlets and rills could have been concerned; and the feldspathic rocks must have been near by. For New Jersey the Triassic granitic sandstones may have been the feldspathic rocks at hand; and for Long Island and the islands to the eastward crystalline rocks were not far away to the northward. The bleaching of the deposits in the case of the white clay-beds required the action of carbonic acid or organic acids proceeding from the decomposition of beds of peat or leaves underlying the Raritan or intercalated with its layers; for the clays from granitic rocks always derive a tinge of iron oxide from the black mica and other iron-bearing minerals among their constituents. The origin of the clay-beds in all these particulars was very much like that of those of the coal-formation (page 665).

After the making of the Raritan beds, the sea regained access, as the marine shells evince, to the shore region of the Atlantic border; and this was the first submergence of the border since the close of the Lower Silurian. The geanticline, which was probably increasing through the Paleozoic, at last had disappeared.

The beds of greensand are supposed to have been formed in moderately deep waters off the coast. The least depth required for the production of greensand is not known.

Ehrenberg, who first discovered that the grains of glauconite often have the shape of casts of Rhizopod shells, also detected them in the bones of the Zeuglodon of the Alabama Tertiary, which were probably in shallow water when the formation took place. J. W. Bailey reported in 1856 their occurrence in the cells of recent Corals and Rhizopods, 
over the sea bottom near Cape Hatteras, at depths of 40 or 50 fathoms. Similar facts were obtained abundantly by the "Challenger" Expedition, as mentioned by Murray. But glauconite grains have been observed also as a covering of stones and in their clefts, and sometimes as the coloring material of concretions of silica in the form of opal (Cayeux). The ingredients for making glauconite must be derived from the sea water or sea bottom, or partly from organic matters at hand. It has been suggested that the silica may, in some cases, have come from minute sponges that had previously grown in the cells which it occupies.

The equivalency of the Raritan clay-beds of New Jersey and those of Staten Island and Long Island was announced in 1843 by W. W. Mather, on the ground of their resemblances. It was proved for Staten Island and Long Island from the fossil leaves, by Newberry in 1874, and for Martha's Vineyard by C. D. White in 1890. Since the latter date the number of known Cretaceous plants has been increased by the discoveries of A. Hollick. Newberry pointed out the identity of some of the Raritan plants with those of the Dakota group.

\section{Northern Gulf Border.}

The Upper Cretaceous beds of Alabama and Mississippi, in the northern Gulf border west of the Florida peninsula, comprise the following groups :-

\section{Laramie Epoch. -}

Not represented.

3. Montana or Ripleey Epoch. -

Ripley group: hard white limestone 200 to 300 feet thick, often sandy, with but little greensand or glauconite in the beds.

Also the upper part of the Rotten limestone.

\section{Colorado Epoch? -}

Lower part of Rotten limestone: hard or soft chalky limestone; total thickness of Rotten limestone 500 to 1200 feet.

1. Daкота Eросн?; possibly Lower Colorado. -

Upper Eutaw beds of Alabarna; Tombigbee sands of Mississippi.

The limestones on the Gulf border diminish in thickness to the eastward and fail wholly in Georgia, where, according to J. W. Spencer, the Florida axis probably determined the eastern limit of the Cretaceous belt. The beds in that state consist of mixed clays and sands, and are about 1385 feet thick, with few fossils. They look, according to Spencer, as if made from sediments of fluvial origin.

The Ripley group, as brought out in Whitfield's paleontological report, is the equivalent of the Lower Greensand group of the New Jersey Cretaceous, and of its continuation through Delaware, Maryland, and North Carolina. In view of the much better preservation of the fossils on the Gulf border, Stanton speaks of the Ripley fauna as having this wide range. The number of identical species along the Atlantic and Gulf borders is large, as shown in the lists of species given beyond. 
In Tennessee and Kentucky, the Ripley group is represented chiefly by micaceous clays and sand-beds; and, while the thickness is $401^{\prime}$ to $500^{\prime}$ in Tennessee, it becomes a few scores of feet in Kentucky.

Below it, in southern Tennessee, lie $200^{\prime}$ to $300^{\prime}$ of beds, sparingly calcareous, representing the Rotten limestone, and at bottom, the "Coffee sands of Safford, 200' thick" ; which are Lower Cretaceous. The age of the beds below the Ripley group on the Gulf border, as Stanton remarks, is not clearly defined by the fossils, and the Colorado epoch is therefore not known positively to be represented. The Rotten limestone contains many Ripley fossils. During the Laramie epoch, according to White and Stanton, the Atlantic and Gulf borders were probably somewhat emerged, the Ripley beds being covered directly by beds with Eocene fossils.

\section{Western Gulf Border.}

In Texas, the Upper Cretaceous beds are 2000 feet thick (R. T. Hill). There are sand-beds and clays at base which are non-marine; and above these thick beds of limestone with much chalk, followed by marls and greensand. They extend northeastward into Arkansas, and westward through the TransPecos region and its mountains, to northeastern Mexico, where they occur in the states of Chihuahua, Coahuila, and Tamaulipas, chiefly along the mountain region between Presidio del Norte and Tampico, resting on the Lower Cretaceous conformably, although upturned.

The subdivisions, as determined by Hill, are as follows :-

\section{Laramie Epoch. -}

\section{Laramie series in western Texas.}

3. Montana Epoch. -

Exogyra ponderosc marls, with glauconitic (or greensand) beds (Navarro beds, Eagle Pass beds) above: chalk, overlaid by marls and greensand.

\section{Colorado Epoch. -}

2. Austin limestone, or Austin-Dallas chalk; 300 to 500 feet thick.

1. Eagle Ford shales; 500 feet thick.

1. Dakota Epoch. -

Lower Cross Timber sands; 300 feet thick.

The beds are marine, excepting the sand and clays of the Lower Cross Timber sands, and some beds of the Eagle Ford shales. The fossils are all different from those of the Lower Cretaceous beds. The Glauconite group contains over 40 species of fossils, identical, according to Stanton, with those of the Ripley fauna, and many also of the species of the Montana group in the Continental Interior.

\section{Continental Interior.}

The Cretaceous beds of the Interior Continental Sea were early studied by Meek and Hayden, and their subdivisions in the main are those still in use. 
4. Laramie Epoch. -

2. Upper Laramie or Denver group: fresh-water beds of sandstone, conglomerates; and partly of eruptive material (andesytic, etc.); with or without coal-beds.

1. Lower Laramie: fresh-water beds of coarse, friable sandstones, often cross-bedded, with clay-beds; occasional fossiliferous brackishwater beds; with beds of bituminous coal, in some places " 15 to 20 coal-beds in 1000 feet;" thickness 1000-5000 feet.

3. Montana Epoch. -

2. Fox Hills group: sandstones and shales with many marine fossils; maximum thickness, 1000 feet.

1. Fort Pierre group: plastic clays, sand-beds often with limestone concretions; marine fossils ; maximum thickness 7700 feet.

2. Colorado Epoch. -

2. Niobrarc group: calcareous marls, chalk, shales, sandstones, with limestones; marine fossils; maximum thickness 2000 feet.

1. Fort Benton group (near Fort Benton): laminated clays, limestone, with marine fossils; maximum thickness, 1000 feet.

Probably includes the Coalville coal-bed, with 1500 feet of the lower part of the Coalville group.

1. Dakota Eросн. -

Dakota group: sandstones, clays, some lignitic layers, with conglomerates sometimes at base; fossil leaves abundant, and other evidences of fresh-water origin, and little of brackish or marine waters. Probably includes the Bear River coal-beds.

The grouping of the subdivisions adopted above (which accords with the results of Meek's paleontological work) and the terms used are those of G. H. Eldridge. The name, Lignitic, used by Meek and Hayden for the Upper division (which they made Lower Tertiary), was changed by King in 1878 to Laramie. Subdivisions of the Laramie into Lower and Upper is based chiefly on the work of Cross (1888 and later).

The Cretaceous was the coal period of western America. As Paleozoic time, the era of extended continental submergence, elosed with the slow emergence of the eastern half of the continent, so Mesozoic time, the era of extensive submergence of the western half of the continent, elosed with the slow emergence of this western half. And the later coal-beds, like the earlier. mark long periods of small emergence and persistent marshes in the alternating conditions of level. The Upper Cretaceous affords coal at different levels : at Bear River, western Wyoming, and at Mill Creek, British America, in the Dakota group; at Coalville, Utah, in the Colorado group (Stanton); and at Dunvegan, Peace River region $\left(1171^{\circ} \mathrm{W} .56^{\circ} \mathrm{N}\right.$.) (Dawson); in the Belly River region, north of Montana, on Vancouver Island, at Nanaimo and 
Comox, and in the Bow River region, north of Montana, probably in beds of Montana age (Dawson).

But the coal-beds are mostly in the Laramie formation. They are worked for coal in Colorado, Utah, Wyoming, Montana, and New Mexico. In Colorado alone the coal-fields have an aggregate area of about 18,000 square miles (R. C. Hills, 1892). The beds are often five to six feet in thickness, and one at Evanston, in western Wyoming, has been deseribed as 26 feet thick. In British America, at Edmonton ( $113 \frac{1}{2}^{\circ} \mathrm{W} .53 \frac{1}{2}^{\circ} \mathrm{N}$.), and in the Souris district, there are Laramie coal-beds.

In Gunnison County, Col., at Crested Butte, a bed of anthracite five feet thick is worked; and in New Mexico, at the Old Placer Mountain, eight miles east of San Antonio, is another locality of anthracite. The anthracite is a result of alteration by the heat of eruptive rocks.

To appreciate the position and width of the Cretaceous seas over the western Continental Interior during the Colorado and Montana epochs, and especially the Niobrara portion of the former, the reader should refer again to the map on page 813; and, still better, to some colored geological map of North America.

Their eastern border extended, from what is now western Texas, eastward and northward over central Kansas, and thence along eastern Nebraska and Dakota into British America. In the western portion of these interior waters there were the large Archæan islands of the protaxis, high lands and low lands varying in limits with oscillations in level, which were mostly forest-clad, and well populated, as evidence shows, by Mammals, Amphibians, and Reptiles, the Reptiles taking the lead in size and power. Beyond these islands the seas spread still westward over nearly all of Wyoming and Utah to a line passing southward through Great Salt Lake, where the western shores lay along the lands of the Great Basin.

In the progress of the Upper Cretaceous, the non-marine Dakota epoch was followed by a second, the CoLORADo, in which the Interior sea gradually attained ocean-like conditions, and was inhabited by great Mosasaurids or Pythonomorphs, and Sea-Saurians related to the Plesiosaurs, as well as Sharks and Saurodont Fishes. Even before the Niobrara beds had all been deposited, a shallowing had begun in Kansas. S. W. Williston states that in the beds of Kansas Invertebrates abound; that Reptilian remains are unknown in the lower part of the Niobrara beds within 100 feet of the base, but higher up are common fossils. "Species of two or three genera of Mosasaurs occur at different levels, but those of Clidastes [Edestosaurus of Marsh] only in the upper part. Turtles are rare in the lower portion, while very common in the uppermost beds."

This shallowing was general over the Continental Interior as the Colorado epoch closed. Moreover, the Colorado fauna, in some unexplained way, disappeared. During the Montana epoch the waters, however, were still salt, and marine life was abundant, and included Plesiosaurids. But the shallowing was continued; and in the following Laramie epoch the waters 
were, to a large extent, fresh, and only occasionally, or else locally, brackish. Moreover, at many intervals, great areas emerged which were speedily covered with marshes and forests in the warm and moist climate, and thus peat-beds were made, which later became coal-beds.

The length of the Laramie Interior Sea in this condition was nearly 2000 miles, it reaching to the parallel of $57^{\circ} \mathrm{N}$.; and another, the Mackenzie valley area, opening on the Arctic Ocean, was 500 miles long. The southern of these Laramie areas was probably tidal as well as the northern. For the width south of $49^{\circ} \mathrm{N}$. was 600 to 800 miles, - which is too great for fluvial waters. Besides, the strata are generally cross-bedded in stratification, and they include occasionally conglomerates, proving seemingly strong inovements in opposite directions, and at times in some parts violent currents. Moreover, although the waters were generally fresh, still Sea-Saurians, Sharks, and other marine species occasionally ascended to Dakota and beyond. The bay received the drainage from all the bordering lands for the 2000 miles from the Mexican Gulf to the limit of the Laramie beds in British America; and hence a great amount of fresh water flowed southward toward the outlet.

Hence the tides from the western part of the gulf generally carried in salt waters for a short distance only, and thence the tidal movement was propagated northward by the fresh waters. But occasionally the Gulf waters were able, through a subsiding in the land, to flow far northward, and let in the Sea-Saurians, and Sharks, the Oysters, and other SeaMollusks, so as to make the brackish-water fossiliferous beds of the Laramie formation. The spawn of Oysters and other Mollusks would have been rapidly transported.

If the above explanation of the conditions in the Laramie epoch is correct, the distance to which the salt waters of the Gulf were carried in westward and northward, whether one mile or many, is a subject for investigation. The Laramie beds derived their material from the land on the borders of the Interior Sea. The existence of Paleozoic and Mesozoic rocks of various ages about the base of the Black Hills, where there is also the Cretaceous formation, indicate how the other adjoining Archæan lands may have been skirted, where now covered by Tertiary beds and those of the later Cretaceous.

The Upper Laramie or Denver group was first defined by Cross and Eldridge in 1888. It derives the latter name from its distribution about the city of Denver, east of the Front Range (Archæan) of the Rocky Mountains, where it overlies the Lower Laramie. It is described as resting on the latter unconformably, - the unconformity being, however, not that of bedding in a marked degree, but the unconformity consequent on the previous erosion of the beds on which the formation was deposited. The upper portion in that region, 1400 feet thick, consists largely of the debris of eruptive rocks, mostly different kinds of andesytes; while the lower part, 800 feet thick, distinguished as the Arapahoe beds, is mostly made up of conglom- 
erates formed out of various older stratified rocks, some identified as Carboniferous by their fossils. The oceurrence of eruptive debris in the Laramie beds of other regions has been regarded as a probable sign of Denver age. The plants include species not found for the most part in the Lower Laramie. The Denver group has afforded Homed Dinosaurs (Ceratopsids) and other kinds, showing their Mesozoic relations. Ordinary Mammals are absent, and all other evidence of a Tertiary fauna.

To the Upper Laramie are referred, by Cross, - on the ground of the plants (studied by Knowlton) as well as the eruptive conglomerates and unconformity at base chiefly by erosion, - beds in the Middle Park, and at other localities, from Greeley, Col., to the Raton Mountains in New Mexico; and beds about Livingston, in Central Montana, called by W. H. Weed the Livingston beds (U.S.G.S. Bulletin, No. 105, 1893). The latter, as described, have a thickness of 7000 feet, and rest over 1000 feet of Laramie beds, but were deposited, like the Denver, after a time of extensive erosion, and therefore the conformability is not perfect. The group, however, according to Weed, has a brackish-water, oyster-bearing layer, which is well packed with oyster shells, Laramie-like, at a height of 200 feet above its base, that is, above the plane of extensive erosion.

In southern Wyoming, along Bitter Creek, in the vicinity of the Union Pacific Railway, near Hallville, Black Butte, Point of Rocks, Rock Spring, and elsewhere, the Laramie contains a number of coal-beds. South of Black Butte there are nine or more distinct coal-beds; and between two of them were obtained remains of a Horned Dinosaur (Agathaumas of Cope).

Beds in eastern Wyoming, called by Marsh the "Ceratops beds," are referred, with a query, by Cross to the Upper Laramie, because of the presence of Ceratopsids in both; but to the Lower, by Marsh. They rest on 400 feet of sandstone conformably, and the sandstone directly on Fox Hills beds, and contain no eruptive debris. Besides Horned Dinosaurs of several species, the beds have afforded remains of other Dinosaurs related to the Iguanodon and Megalosaurs, and of Marsupial and Oviparous Mammals. Above the stratum containing the fossils there is a bed of coal, the Shawnee coal-bed, 10 inches thick.

"Judith River" beds in northern Montana, first described by Hayden and Meek, afford Dinosaurs of the same genera, according to Marsh, as the Ceratops beds, besides many others, including Plesiosaurids; and also remains of Sharks, Chimæroids, Ganoids, and, as other evidence of brackishwater conditions, shells of Ostrea, Anomia, Corbicula, Corbula, and Goniobasis.

The Fort Union beds, near the border of North Dakota and Montana, have been referred to the Upper Laramie and also to the Tertiary. They are of doubtful relations.

The most eastern "Lignitic" beds referred to the Laramie are those of South Dakota, near Morean River, west of the Missouri, in $101^{\circ} \mathrm{W}$, where remains of two Plesiosaurids have been found, Plesiosaurus occiduus, and 
Ischyrosaums antiquus, both described by Leidy in 1873. Nothing of the Laramie is recognized in Kansas.

The Reptiles and other fossils in the beds referred to as Upper Laramie indicate not only their Cretaceous age, but also their close relations to the Lower Laramie. At present the line between the two divisions cannot be definitely drawn.

The subdivisions of the Rocky Mountain Cretaceous, including the Laramie, were first described by Hayden and Meek. Their papers commenced in 1856, and appeared at intervals for 20 years. Meek's Report on the fossils, in which the stratification is reviewed, constitutes vol. ix. of the Reports of the Hayden Expedition (1876). Their subdivisions were the Dakota, Fort Benton, Niobrara, Fort Pierre, and Fox Hills. The Tertiary section in the "Upper Missouri region," described by Meek and Hayden, contained: (1) Dakota group, $400^{\prime}$; (2) Fort Benton, $800^{\prime}$; (3) Niobrara, 200'; (4) Fort Pierre, $700^{\prime}$; and (5) Fox Hills, 500\% G. H. Eldridge in 1889 grouped the divisions into the three: (1) Dakota; (2) Colorado, and (3) Montana. C. A. White had earlier recognized (1876) the same grouping under the names Dakota, Colorado, and Fox Hills.

The Colorado formation and its relations to the other divisions of the Cretaceous have been reviewed in detail by T. W. Stanton; and from his report of 1893 many of the following facts are taken. The thickness of the Upper Cretaceous series at the Black Hills is less than $1000^{\prime}$ : (1) the Dakota, $250^{\prime}-100^{\prime}$; (2) the Colorado, $300^{\prime}-500^{\prime}$; (3) the Montana, $150^{\prime}-350^{\prime}$ (H. Newton). In Cinnabar Mountain, Montana, the total thickness, according to Weed, is about $4300^{\prime}$ : (1) the Dakota, $526^{\prime} ;(2,3)$ the Colorado and Montana, 2850'; (4) the Laramie, 935'. East of the Front Range, in Colorado, the Dakota outcrops at the base of the range, and, outside of this, the other later groups in succession, as first shown by Marvine. In the Denver region there are: (1) Dakota, 300'; (2) Colorado, $1100^{\prime}$, of which 400 is Fort Benton and 700 Niobrara; (3) Montana, $8700^{\prime}$, of which the Fort Pierre, $7700^{\prime}$, and Fox Hills, $800^{\prime}-1000^{\prime}$; (4) the Laramie with the Denver group, 2000'. The thickness diminishes southward, and between Cañon City and Pueblo, on the Arkansas River, the Montana group is but $3000^{\prime}$ thick. The section at Coalville, in Utah, according to Stanton, which is peculiar in containing a great coal-bed in the Colorado portion, consists as follows: (1) Dakota, 5000'? ; (2) Colorado, $1560^{\prime}-1660^{\prime}$, mostly sandstone and fossiliferous, but with a heavy bed of coal at the top of the lower stratum of $500^{\prime}$ to $600^{\prime}$; (3) Montana, about $2900^{\prime}$, of sandstone and shales, with probably $1500^{\prime}$ of beds above; and in the part referred to the Montana group on account of the marine fossils, there are some thin plant beds, the fossil plants of which are in part Laramie.

The Kansas Cretaceous consists, according to S. W. Williston, of $350^{\prime}$ to $400^{\prime}$ of Dakota beds, $300^{\prime}$ to $400^{\prime}$ of overlying shales and limestone of the Benton group, and $400^{\prime}$ to $450^{\prime}$ of chalk and other beds of the Niobrara, making the Colorado series $700^{\prime}$ to $850^{\prime}$ in thickness; and above these, $50^{\prime}$ to $100^{\prime}$ of beds of the Montana group. The Laramie is absent, the next beds above being those of the Loup Fork Miocene Tertiary.

Newberry divided the Cretaceous of New Mexico into: (1) Dakota, 250' to $400^{\prime}$; (2) Colorado, $1200^{\prime}$ to $1500^{\prime}$; and (3) Montana, $1500^{\prime}$, part of the Laramie being here probably included. (Macomb's Expl. Exp., with a review by Newberry of the conclusions he presented in Lieutenant Ives's Rep. on the Colorado River of the West.)

The age of the Laramie beds (or the Lignitic, as they were called), whether Tertiary or Cretaceous, was left undecided by Meek in his report of 1870. To the Lignitic horizon he referred the Judith River group, occurring at the mouth of Judith River in Montana, having there a thickness of about $415^{\prime}$ and consisting, beginning below, of sands and clays with Unio, 100'; impure lignite, 25'; sand and clay-beds with shells and Dinosaurian remains, $100^{\prime}$; sand and clay, $100^{\prime}$; impure lignite with Ostrea, $10^{\prime}$; sandy marl with some lignite and species of Ostrea, Corbicula (3 species), Goniobasis, salt-water species, 80'. 
The Fort Union group (first examined by Hayden in 1860) also was placed in this connection by Meek, on the ground of its fresh-water shells and lignite. The group was estimated by Hayden to have a thickness of 2000 . He reported it (1871) as extending southward from Fort Union, across the Yellowstone between the Black Hills and Big Horn Mountains, and northward into British America; but the conclusions were not based on a full study of the region. The 150 feet of deposits exposed near Fort Union include three beds of impure "lignite," $1^{\prime}, 1 \cdot 5^{\prime}$, and 4 inches thick, alternating with beds of indurated clay and clayey sands, $20^{\prime}$ to $70^{\prime}$ thick containing occasionally land shells and some leaves. The age of the Fort Union beds has remained doubtful. Newberry (1890) separated it from the Laramie on the ground of differences in the plants; L. F. Ward refers it on the same ground to the Upper Laramie.

The beds in Middle Park, Col., referred to the Denver horizon by Cross, consist largely of andesytic breccia, sand-beds and conglomerates, and are $800^{\prime}-900^{\prime}$ in thickness (Marvine). They rest on upturned Cretaceous strata.

Underneath the Fort Pierre group in the Belly River district, Canada, fresh-water beds occur containing fossil leaves, which have been called the Belly River group. The plants are in part identical with the Laramie (Dawson, 1886). The Dunvegan beds, on Peace River, are supposed to be of the same age. A large area has been referred to the Laramie in British America extending from the United States boundary to the 55th parallel, and eastward to $111^{\circ} \mathrm{W}$.; in it have been recognized a Lower Laramie or St. Mary River series; a Middle, the Willow Creek beds ; an Upper, or Porcupine Hills beds, which correspond in fossils to the Souris River beds, just north of the United States boundary. A more eastern area extends from $49^{\circ} \mathrm{N}$. to $51^{\circ} \mathrm{N}$, , between $102^{\circ}$ and $109^{\circ} \mathrm{W}$.

In Manitoba, Central North America, the Cretaceous formation is nearly $2000^{\prime}$ thick; and the Montana group contains in its lower part many Rhizopod shells with some Radiolarians. The thickness of the Dakota beds in this region is $13^{\prime}$ to $200^{\prime}$; of the Colorado beds, $200^{\prime}$ to $700^{\prime}$; and of the Montana, over $1000^{\prime}$. The Cretaceous rests unconformably on the Devonian (J. B. Tyrrell, 1892). Fossil plants from Laramie beds in the Mackenzie River have been described by Dawson (1882 to 1889) and identified with others from Alaska.

\section{Pacific Border.}

On the Pacific Border, the Upper Cretaceous, or the Chico beds, occupies a broad belt extending originally from Lower California northward beyond the Queen Charlotte Islands. It formerly covered the region of the Coast and Cascade ranges, reaching the western base of the Sierra Nevada in California, and of the Blue Mountains in Oregon. Its eastern limit is indicated upon the map on page 813 .

The Upper Cretaceous of California includes only the Chico beds of the Shasta-Chico series. The Tejon, which Gabb considered Cretaceous, has been shown by Conrad, Heilprin, and White to be Eocene. The Wallala beds of White and Becker (1885), according to Dall and Fairbanks (1893), are only a phase of the Chico. The Chico beds are exposed upon both sides of the Sacramento valley. Thence they extend southward near the coast to Lower California, according to Lindgren and Fairbanks, and northward, with local interruptions, to Jacksonville, and Riddles, Oregon; and beneath the covering of later lavas they are supposed to connect with the Chico of eastern Oregon (Diller). The lower portion of the Chico beds consists chiefly of sandstone and conglomerate, and ranges from $900^{\prime}$ to $1400^{\prime}$ in thickness. 'In the upper portion shale predominates, excepting near the shore line where the sediments are generally coarse. The greatest thickness of the Chico, according to Diller, is nearly $4000^{\prime}$ in Tehama County, Cal.; it thins out northward and 
eastward, overlapping toward the Cretaceous shore, beyond the Knoxville and Horsetown beds, which form the lower part of the Shasta-Chico series. The Chico thus comes in unconformable contact with the Jura-Trias and Carboniferous and extends inland from the Lower Cretaceous, as indicated upon the map, to the dotted line. The subsidence and consequent transgression of the sea that gave rise to the landward overlapping of the later beds of the Shasta-Chico series began soon after the great upheaval at the close of the Jurassic, and continued to at least the middle of the Upper Cretaceous (Diller).

In the Tertiary the Tejon beds of California are conformable with the Chico, and they were regarded by Gabb, and also by White, as faunally continuous. The Tejon is absent in northern California, and in Oregon it rests unconformably upon the Shasta-Chico series. (Diller, 1893.)

In Washington, the Puget group of White, underlying the Tejon, is a non-marine formation containing beds of coal. It extends from near the Columbia to the Puget Sound region, and is several thousand feet in thickness. From its Molluscan and Plant remains it has been supposed by Newberry and White to represent a part of the Laramie or 'Tejon group. Baculites Chicoensis shows the presence of Chico beds on the Snoqualmie and other rivers at the western foot of the Cascade Range. The same beds are found at Lucia Island, just north of Puget Sound, and connect with the coal-bearing Nanaimo beds of Dawson upon the eastern side of Vancouver Island. Their correlation with the Chico of California is well established by fossils. (Diller.)

In Vancouver and Queen Charlotte Islands, over the Lower Cretaceous, there are (1) the Middle Cretaceous, consisting of sandstones, shales, and conglomerates (which are $9700^{\prime}$ thick in the latter), and (2) Upper, consisting of shales and sandstones ( $1500^{\prime}$ thick in the latter). G. M. Dawson (1886).

In Greenland, the plant beds of the vicinity of Disco Island, described by Heer, above the Fromé group, or Lower Cretaceous, consist of (1) the Atané group of the Middle Cretaceous, corresponding nearly to the Colorado group, and (2) the Patoot group of the Upper, corresponding nearly to the Montana group.

\section{LIFE.}

\section{Lower Cretaceods.}

Plavis. - The beds have afforded the earliest remains of the modern group of Angiosperms. They are associated with many species of Cycads, and the flora has therefore a transitional character between that of the Jurassic and the Upper Cretaceous. Remains of more than 300 species have been described by Fontaine from the Potomac formation (U. S. G. S., 4to, 1889). Among them are 75 Angiosperms, 22 Cycads, over 90 Conifers, and 140 Ferns. In 1894, 30 Cyead trunks were found in Maryland.

Some of them occur in the Wealden (or Neocomian) of England, as Pecopteris Browniana, Aspidium Dunkeri, Sphenopteris Mantelli (Fig. 1353), and two Conifers of the genus Sphenolepidium. Four of the nine species of Sequoia or Redwood (the genus to which the giant trees of California belong) agree with species described by Heer from the older Greenland Cretaceous. The Cycad trunks of Maryland are of the species Cycadeoidea Marylandica (Tysomir $M$. of Fontaine). No species is identical with any of those from Triassic beds. The Angiosperms include species of Ficus (Fig. 1351) or Ficophyllum, Sassafras, Aralia, Myrica, Platanus (or Plane tree), ete.; and several of the genera, as those of Ficophyllum, Protceiphyllum, have compre- 
hensive features, indicative of early forms. The Cyead genus, Dioönites (Fig. 1350), occurs in the Neocomian of Europe (at Wernsdorf), and is very common in the Potomae beds. Fontaine says, in his conclusion, that the flora ranges from the Wealden through the Neocomian, and includes some later (Cenomanian) forms. All, or nearly all, the species are absent from the later Cretaceous beds of New Jersey.

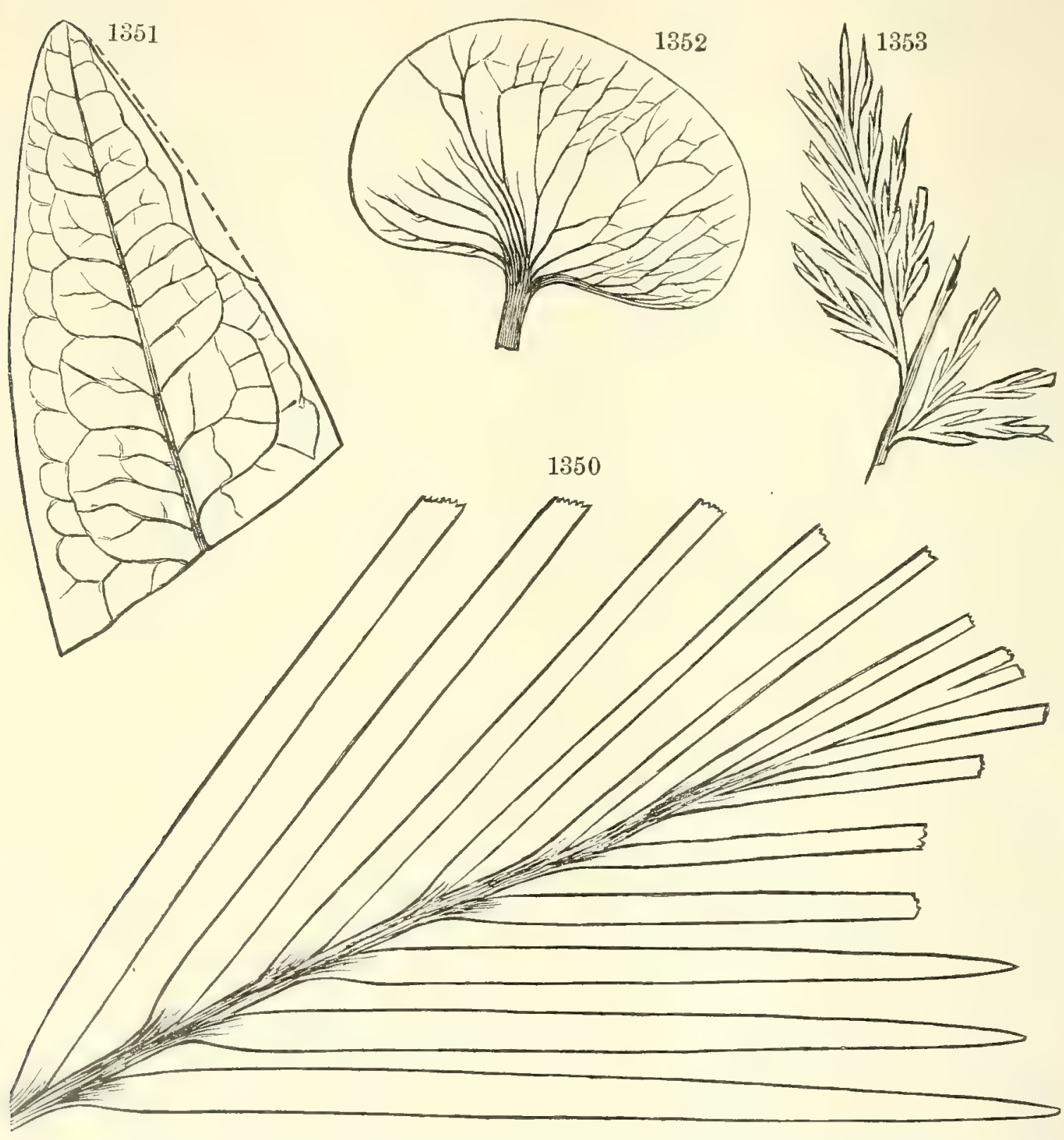

$1350-1353$.

Plants of the Potoma Group. - Croad. - Fig. 1350, portion of a frond of Dioönites Buchianus. AvgroSPæRMs. - Fig. 1351, Ficus Virginiensis; 1352, Protxiphyllum reniforme. Fens. - Fig. 1353, Sphenopteris Mantelli. All from Fontaine.

The plants of the Trinity beds of Texas are to a large extent identical, according to Fontaine, with those of the lower Potomac beds (1893). They include Cycad stumps named Cycadeoidea munita by Cragin. Cycadeoidea Jenneyana of L. F. Ward occurs in the form of stumps at the Black Hills, on 
the western border of South Dakota, in beds that are shown by Ward to be Lower Cretaceous, though formerly referred to the Dakota group.

The flora of the Kootanie beds, in British America, deseribed by Dawson, includes no Angiosperms; but the identity of other species with some of those of the Potomac group is regarded as sufficient evidence of equivalency. Some of the kinds are here represented. Fig. 1354, Sequoia Smittiana of Heer, common in the Greenland beds; 1355, Salisburia Sibirica, a species described by Heer from the Lower Cretaceous of Greenland; and 1356, the Cycad, Podozamites lanceolatus Lindley, a species that is found also in Siberia, Sweden, India, and China, and appeared first in the Jurassic. The same species occur in the Kootanie beds of Montana, as first observed by Newberry. Cretaceous plants from Cape Lisburne, Alaska, were referred by Lesquereux, in 1888, to the Neocomian. The number of species thus far described from the region is 60 (Knowlton). The Komé beds of Greenland afforded Heer species of Ferns, Cyeads, Conifers, a few Endogens, and but one Angiosperm, Populus primove.

The plants of the Kootanie beds include, according to Dawson, besides those of Figs. 1354-1356, Dioönites borealis Dawson, Zamites Montana Daws., Z. acutipennis

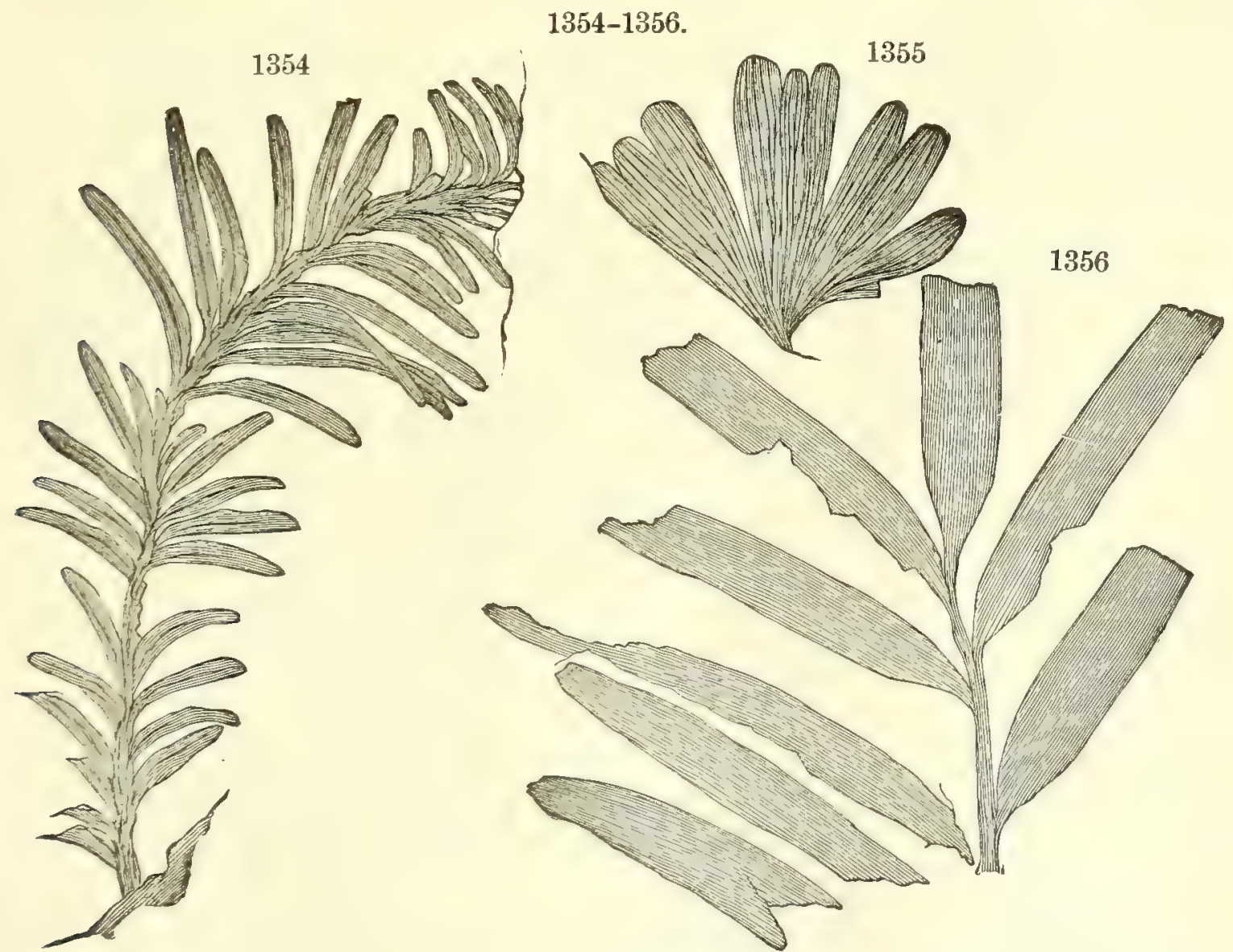

Kontante Plant8. - ContFers. - Fig. 1354, Sequoia Smittiana; 1355, Salisburia Sibirica. Cyoad.-Fig. 1350, Podozamites lanceolatus. J. W. Dawson.

Heer, Salisburia nana Daws., Baiera longifulia Heer, Glyptostrobus Gronlandicus Heer, Tasodium cuneatum Newberry. (Heer's species are all Greenland species.) From DANA'S MANUAL - 53 
Queen Charlotte Islands he has announced Diö̈nites Columbianus Dawson. From the Kootanie beds of Montana at Great Falls, Newberry has described (1891) 25 species of plants, and among them, Zamites ILntana, Z. acutipmuis, Z. boreulis ILeer, Z. apertus Newberry, Polozamites nervosus Newb., Seruoia Sinittiana Heer, S'. gracilis Heer, $S$. Reichenbachi Heer, and Sphenolepidium Virginicum Fontaine. The last two are also found in the Potomac group. From the Trinity group of 'Texas, Fontaine has identified some Neocomian species: as Diö̈nites Buchianus, D. Dunterianus, Abietites Linkii, and a species very near Sphenopteris Valdensis, besides several other species that occur in the Potomac group.

Animals. - Marine fossils are confined almost solely to the beds of Texas and Mexico, and the Pacific Coast region; and these two regions widely differ in

1357.

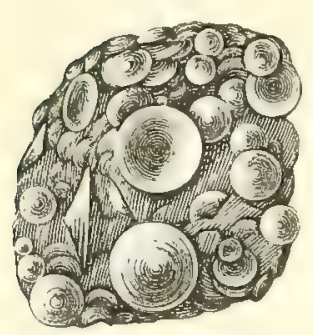

Ririzopon, - Patellina Texana. Remer. fauna. The former was apparently tropical, while the latter bears evidence of cooler waters, just as the Mexican Gulf and California seas now differ. At present this difference (as shown on the isocrymal chart, page 47 ) is about $16^{\circ} \mathrm{F}$., owing to the cold currents that descend the Pacific coast from the north; and it was probably $10^{\circ}$ or $12^{\circ}$ in Cretaceous times, when like species occurred on that coast from Califormia to Alaska.

Texas. - The Comanche beds are largely made of the minute shells of Rhizopods, and also contain the larger Nummulite-like fossil, the Patellina (Orbitulites) Texana (Fig. 1357). Echinoderms are represented by species of Enallaster (Fig. 1358), Pseudodiadema, Hemiaster, Cidaris, etc.; Brachiopods, by species of Terebratula.

Lamellibranchs occur of the genera Gryphoce (Fig. 1359), Exogyra (Fig. 1360), Lima, Inoceramus, which are very common. Some specimens of Exogyra ponderosa in Texas are nine inches long,

1358.
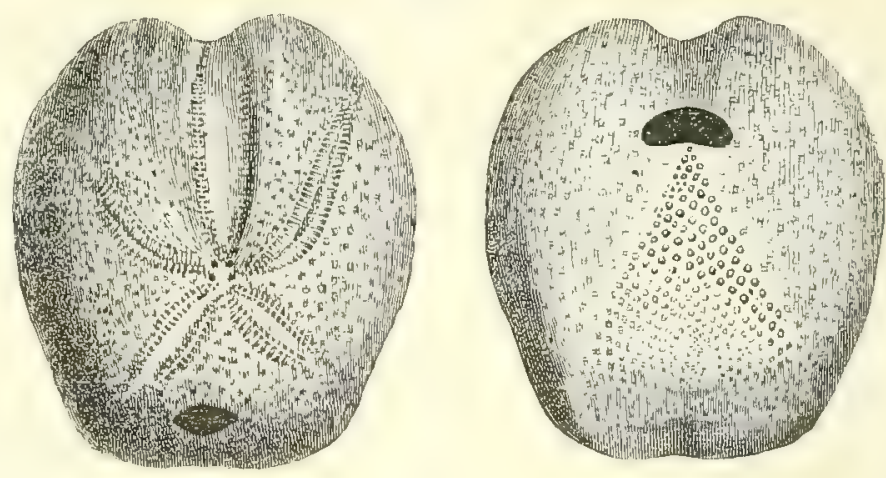

EChixoderk. - Enallaster Texanus, upper and under surface. Rœmer.

and the shell four inches thick at middle. Two species of genera related to the modern Chama, peculiar to the Cretaceous, are Radiolites Texanus (Fig. 1361, 1361 a), reduced from a length of $4 \frac{1}{2}$ inches, and Requienia (Caprina) Texana (Fig. 1362). The genus Nerinea (Fig. 1363) is also characteristic of the Cretaceous.

Of the fossils of the Shasta group, California, the Aucelloe are especially characteristic. The forms vary much, but all are referred to one species named by Gabb, A. Piochii. Fig. 1364 represents a common form of the shell, and Fig. 1365, the smaller valve of a specimen. Another specimen figured has a height of more than two inches, while but little wider than 
Fig. 1365. The shells are in great profusion in many localities, and are often associated with Belemnites appressus. Fig. 1366 is from a small shell from
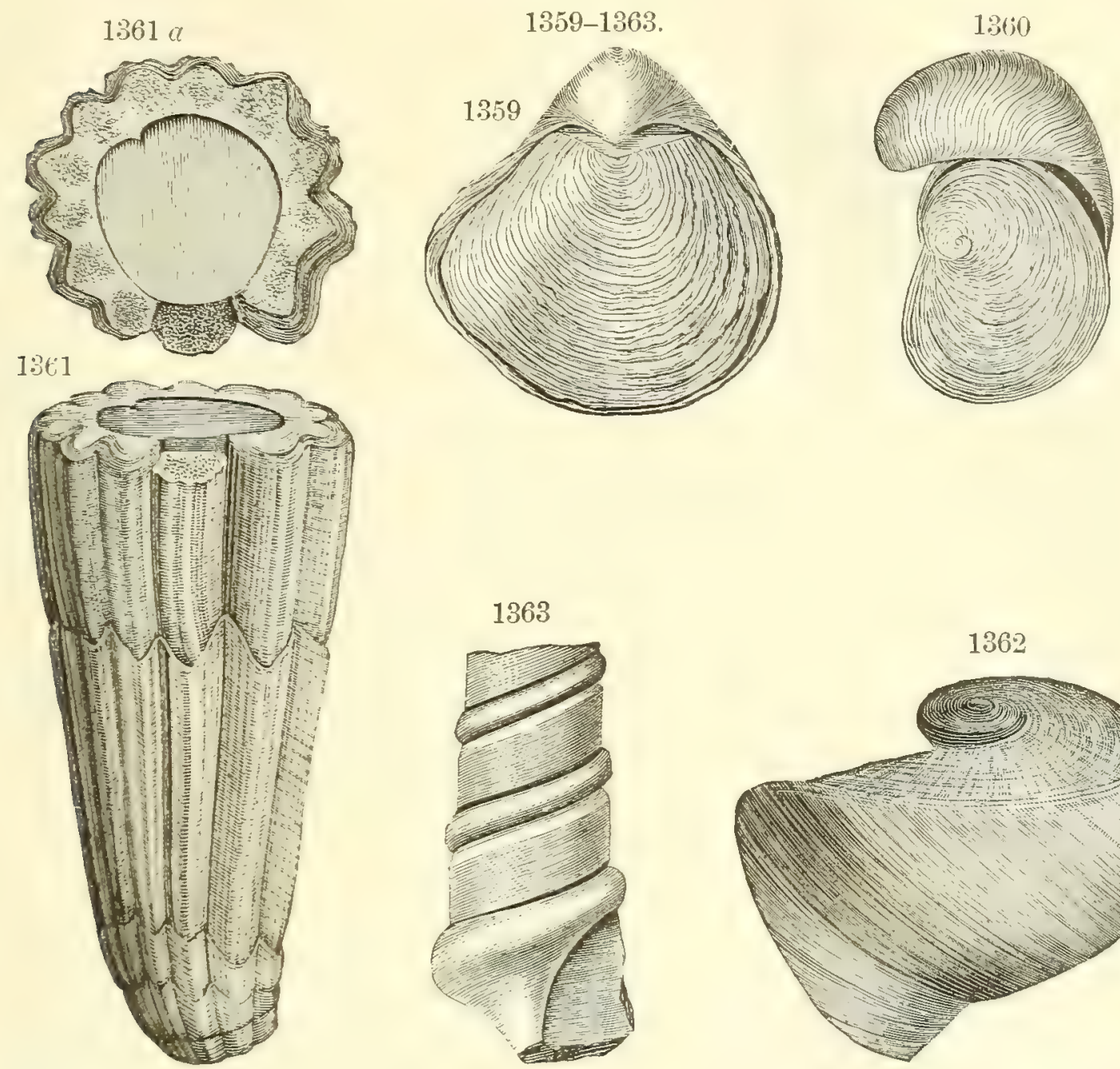

LAirelibranchs. - Fig. 1359, Gryphæa Pitcheri of Morton; 1360, Exogyra arietina; 1361, Radiolites Texanus, without upper valre $\left(\times \frac{1}{2}\right) ; 1361 \boldsymbol{a}$, the lid-like upper valve; 1362, Requienia Texana. GAstropod. - Fig. 1363, Nerinea Texana. All from Romer.

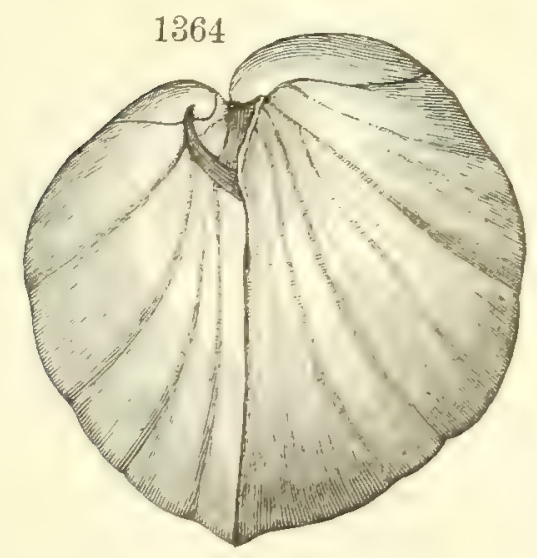

$1364-1366$.
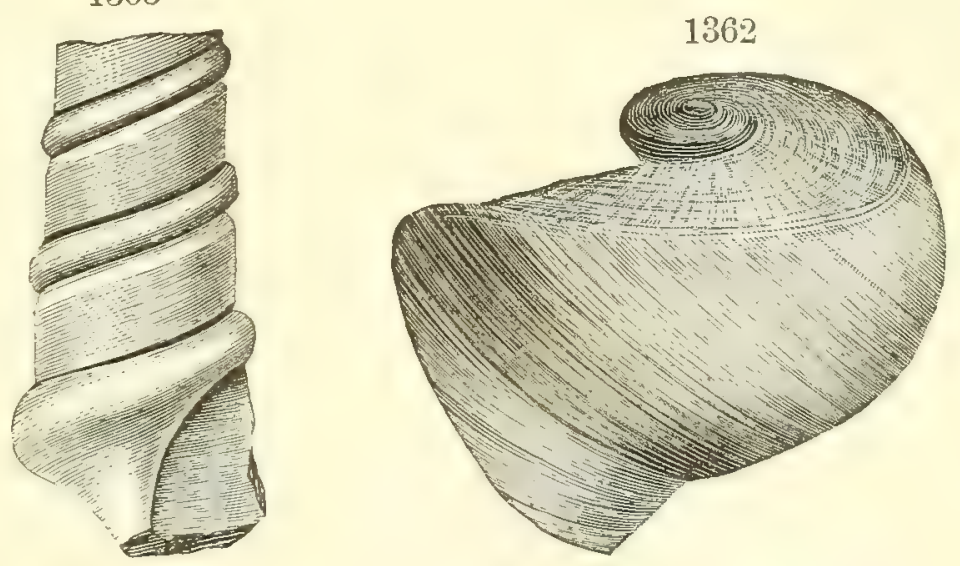

Mollusk. - Figs. 1364-1366, Aucella Piochii. Gabb.

Mit. Diablo, where they are rare. The shells fail entirely, or very nearly so, of the rarliating striæ which characterize the Jurassic Aucella of Mariposa (page 759 ). 
Vertebrates. - Some scales of Ctenoid fishes have been found in the Potomac beds. But the Vertebrates of special interest are the large Reptiles:

$1367-1368$
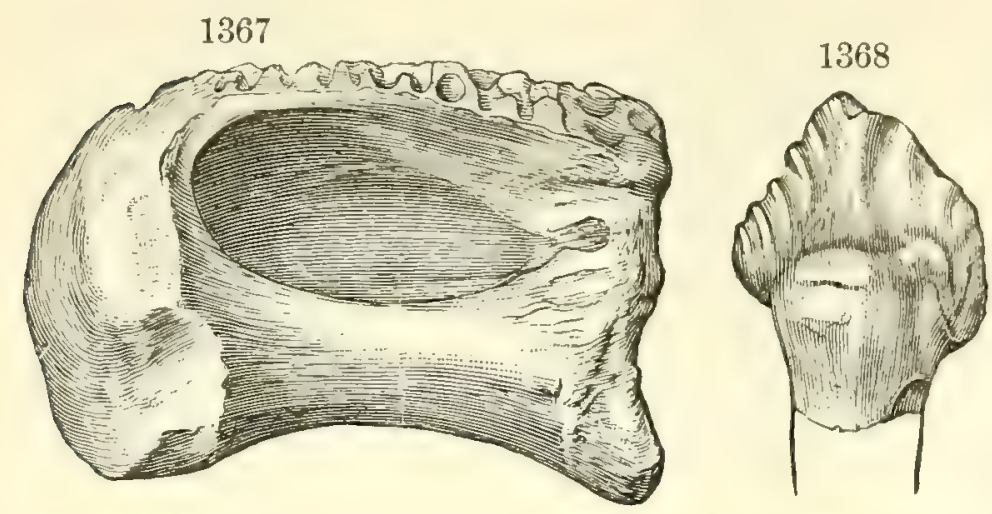

Divosaurs. - Fig. 1367, Vertebra of Pleurocelus nanus; 1368 , tooth of Priconodon crassus. From Marsh. a species related to the Morosaurus, the Astrodon Johnstonii of Leidy (1865); and the other Dinosaurs Pleurocolus nanus, P. altus, Priconodon crassus, Allosaurus (?) medius, and Coelurus gracilis, described by Marsh (1888). Fig. 1367 represents a side view of one of the dorsal vertebræ of Pleurocolus nanus, and 1368, an inside view of a tooth of Priconodon crassus. On account of the Jurassic features of the Reptiles, the Potomac group has been referred by Marsh to the Upper Jurassic.

From the Lower Cretaceous of Texas and its continuation into Oklahoma (formerly Indian Territory) five species of Pycnodont Fishes have been described by Cope: Mesodon diastematicus, M. Dumblei, and two species of Uranoplosus and one of Coelodus.

\section{Characteristic Species.}

The fauna of Texas (and the country beyond to Mexico) has special interest, because the region is the only one of the Lower Cretaceous in North America abounding in marine fossils. The characteristic species are as follows, according to Hill:

1. Trinity group. - The Glen Rose beds have afforded: Ostrea Franklini Coquand, Modiola Branneri Hill, Pecten Stantoni Hill, Requienia Texana, Barbatia parva Missouriensis, Isocardia medialis Conrad, Natica pedernatis Romer, Nerinea Austinensis Romer; also, Crocodiles, Dinosaurs, Chelonians, and Fishes not yet studied. A bed of chalk is composed of the Rhizopod Patellina (Orbitulites) Texana R. (Fig. 1357).

2. Fredericksburg group. - The prominent fossils of its several subdivisions are the following: (1) The Gryphaea rock and Walnut sands: Exogyra Texana R. (=E. flabellata Goldfuss); and, higher up, a bed made up of Gryphoa Pitcheri (the small form figured by Conrad). (2) The Comanche Peak chalk: Pseudodiadema Texanum R:, Enallaster Texanus R., Exogyra Texana, Gryphaca Pitcheri Conrad (not Marcou), Janira occidentalis Con., Protocardium Hillanum Sowerby, Nerinea acus R., Ammonites (Buchiceras) pedernalis R. (3) The Caprina limestone, also called the "Hippurite" limestone: Nerinea Austinensis R., $N$. cultrispira R., $N$. subula R., Cerithium Austinense R., Trochus Texanus R., Solartum planorbis R., Monopleura marcida White, II. pinguiscula White, Requienia patagiata White, Ichthyosarcolithes (Caprina) anguis R., I. (?) crassifibra R., I. (\&) planatus Con., Radiolites (Sphorulites) Texanus R.

3. Washita group. - (1) The Preston beds, Schloenbachia clays, including limestone flags, Gryphea forniculata White ( $=G$. Pitcheri Marcou), and the Ammonite Schlonhachia Peruviana v. Buch.; the limestone is the building material of old Fort Washita. (2) The Duck Creek chalk, many Ammonoids, among them Pachydiscus Brazoensis Shum., Schloenbachia Belknapi Marcou, and Hamites Fremonti Marcou; with 
Isocardia Washita Marcou, Inoceramus, Terebratula Choctawensis Shum. (3) The Fort Worth or Washita limestone: with Terebratula Wacoënsis R., Cidaris Texana R., Leiocidaris hemigranosa Shum., Holectypus planatus R., Epiaster elegans Shum., Holaster simplex Shum., Ostrea carinata Lam., Exogyra sinuata Marcou, Gryphcea Pitcheri Morton, Janira Wrightii Shum., Plicatula placunea d'Orb., Pleurotomaria Austinensis Shum., Lima Kimballi Gabb, Nautilus elegans Shum., Ammonites (Mortoniceras) Leonensis Con., Turrilites Brazoensis R. (4) The Denison Beds of clays and limestone: having at base Exogyra arietina R., Ostrea quadruplicata Shum., Grypleca Pitcheri R. (not Morton, which is G. mucronata Gabb), the Ammonites Buchiceras inaruiplicatum Shum., Hoplites Deshayesi Leym., and many other species. Turbinotia Texana is abundant in the western exposures of the Denison beds, and the Rhizopod, Nodosaria Texana Con., occurs throughout them.

Hill concludes from the fossils that the Trinity group is closely related in age to the Wealden of Europe, and the Washita to the Lower Greensand or Gault.

The Horsetoon beds of California have afforded many species, described chiefly by Gabb and Trask. Among them are: Pecten operculiformis, Pleuromya lavigata, Nemodon Vancouverensis, Nerita deformis, Nerinea dispar, Neithea grandicostata, Lima Shastaensis, and the Ammonites Desmoceras Breweri, Lytoceras Batesii, Pachycliscus Whitneyi, Olcostephanus Traskii, Ancyloceras Remondi, etc. The first three Ammonites occur in the Quten Charlotte group, according to Whiteaves.

The Knoxville beds are characterized, according to the latest researches of Hyatt, Stanton, and Diller, by its Aucella, Ammonites, and a few other fossils, which show close relations to the Horsetown beds and a wide divergence from the Mariposa beds.

The Potomac beds have afforded a few rare marine shells. Whitfield mentions Astarte veta, Ambonicardia Cookii, Corbicula emacerata, C. annosa (Astarte annosa Conrad), and Gnathodon tenuides, besides 6 species of Unio and Anodonta.

\section{Upper Cretaceous.}

Plants. - In the Upper Cretaceous, leaves of Cycads are comparatively rare, while those of Angiosperms are of great variety; and to these are added the leaves or fronds of Palms.

Some of the prominent kinds in the new flora were species of Sassafras, Laurus, Liriodendron (Tulip Tree), Magnolia, Aralia, Cinnamomum, Sequoia, the Poplar, Willow, Maple, Birch, Chestnut, Alder, Beech, Elm, ete. A leaf of a PaIm (Sabal) from Vancouver Island is described by Newberry as 8 to 10 feet in diameter. Dawson gives an interesting review of the Sequoias in his Geological History of Plants - a genus of many species then, but now of only 2, and these exclusively North American.

The leaves of Angiosperms, here figured, are all from the Dakota beds, or their probable equivalent, on the Atlantic border, the Raritan clays of New Jersey, Martha's Vineyard, and Long Island. Fig. 1369 represents a leaf of Sassafras Cretaceum Newb., of the Dakota group; 1370, the leaf of a T'ulip Tree, Liriodendron Meekii Heer, from Greenland (Atané group) and the Dakota; 1371, L. simplex Newb., from the Amboy clays of New Jersey, Long Island, and Gay Head, Martha's Vineyard, - the figure from a leaf of the latter locality; 1372, an Andromeda, from Gay Head, a kind found also in Greenland and the Dakota group; 1373, a Myrsine of Gay Head, and likewise a Greenland species; 1374, a Willow, Salix Meekii Newb., of the Dakota; 
and 1375, Eucalyptus Geinitzi Heer, from Gay Head, also occurring in Greenland, Bohemid, and Moravia, - a genus now mostly confined to Australia. Fig. 1376 represents in nut of the Eucalyptus. D. White, the describer of the Gay Head plants (1890), states that these nuts contain in their furrows an amber-like resin, and suggests that the Eucalyptus Tree may have been the source of the "amber" of the Gay Head and New Jersey regions.

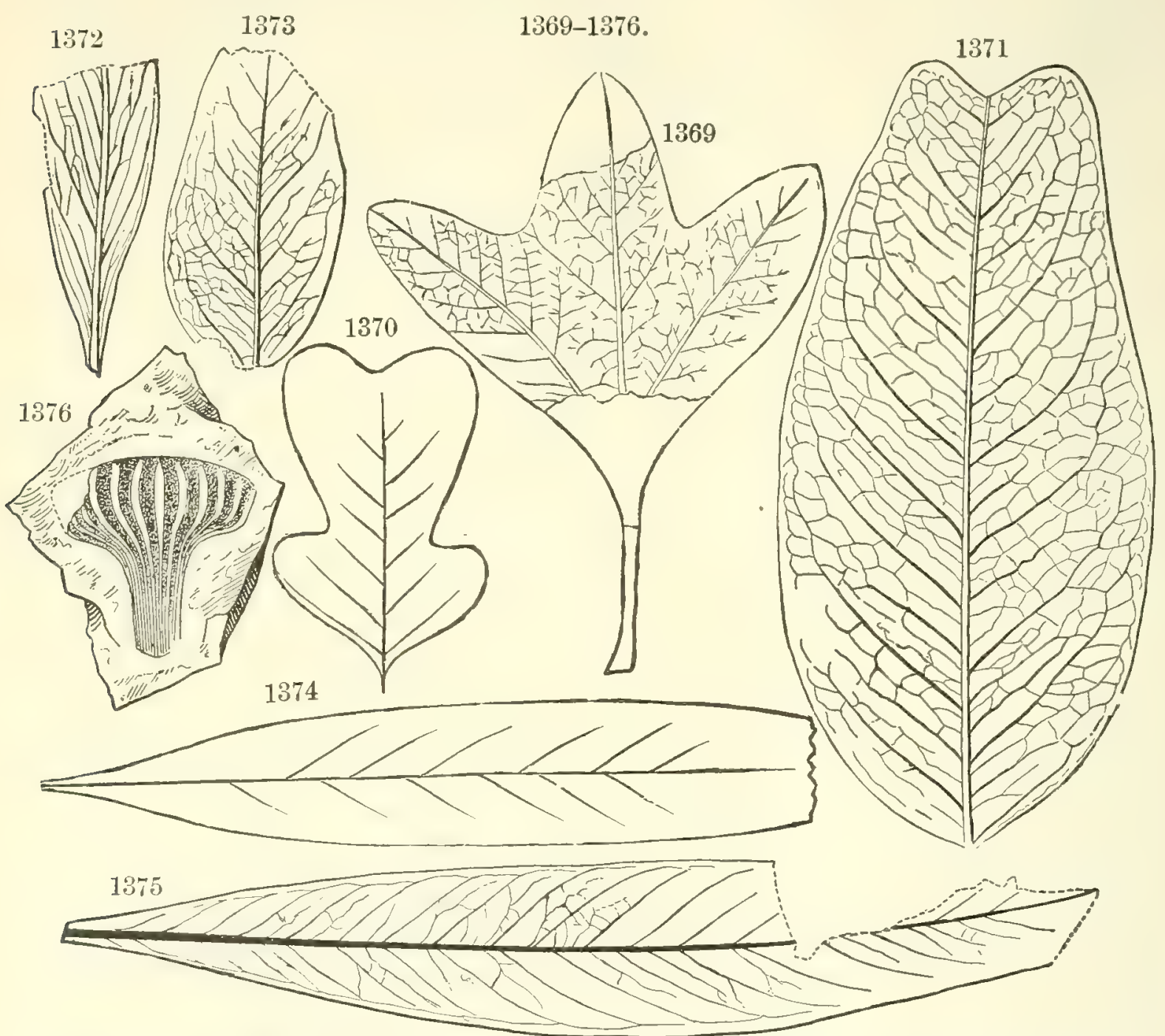

Avgrosperms. - Fig. 1369, Sassafras Cretaceum; 1370, Liriodendron Meekii ; 1371, L. simplex ; 1372, Andromeda Parlatorii; 1373, Myrsine borealis ; 1374, Salix Meekii ; 1375, Eucalyptus Geinitzi; 1376, nut of Eucalyptus. Figs. 1369, 1370, 1374, Newberry; others, D. White.

Coccoliths, calcareous disks less than a hundredth of an inch in diameter (page 437), which are now common over the bottom of the deep oceans, contributed to the Cretaceous limestones, and are abundant in the Cretaceous of the east slope of the Rocky Mountains.

In the clays of Gay Head, on Martha's Vineyard, the most eastern Cretaceous region of the continent, D. White identified Sphenopteris Grevillioides Heer, of the Komé beds, Greenland; Sequoia ambigua Heer, Komé and the Lower Atané (or Middle Cretaceous); Andromerla Parlatorii, Lower Atané; and also a Sapindus, near S. Morrisoni of Lesquereux, a Dakota and Greenland species. 
A report by J. S. Newberry, on the plants of the Raritan group of the Atlantic border, nearly ready for publication at the time of his death in 1892, has not yet appeared (1894). A few Long Island species have been described and figured by A. Hollick (1892-93). They were from the clays on the north side of the island between Eaton's Neck and Glen Core,

An account of the plants of the Dakota group is contained in Lesquereux's quarto reports - one volume published in connection with the reports of the Hayden Expedition, and another posthumous volume, edited by F. H. Knowlton, published as vol. xvii. of the Memoirs of the U. S. Geological Survey (1893). The flora, so far as now known, includes 429 Angiosperms, 8 Endogens, 15 Conifers, 12 Cycads, and 6 Ferns; in all 470 species. As Knowlton states, the proportion of Cycads is nearly the same as in the Atane group of Greenland described by Heer, while the Angiosperms make 91 per cent of the whole and in the Atané group 72 per cent; and a fourteenth of the whole are identical with Greenland species. The spirally marked fruit of a Chara, C. Stantoni, has been found by Knowlton in the Bear River beds.

The Laramie plants also were described by Lesquereux in one of the quarto volumes of the Hayden Expedition reports. But it is found that there is some uncertainty with regard to localities, and the subject is undergoing revision. They include no Cycads.

The following lists of characteristic species of the Laramie and Denver groups are from F. H. Knowlton:-

Fossil plants characteristic of the Lower Laramie: Musophyllum complicatum, Flabellaria eocenica, Ficus lanceolata, Ficus latifolia, Quercus angustiloba, Sterculia modesta, Anona robusta, Dombeyopsis squarrosa, Nelumbium tenuifolium, Rhamnus salicifolius, Cornus suborbifera.

Fossil plants characteristic of the Denver group: Osmunda affinis, Asplenium erosum (Pteris erosa Lx.), Aspidium Lakesii, Woodwardia latiloba, Oreodoxites plicatus, Ficus ocridentalis, F. spectabitis, Populus Nebrascensis (varieties), Fraxinus eocenica, Zizyphus fibrillosus, Rhamnus Goldianus, Platanus Raynoldsii, Viburnum Goldianum.

Fossil plants common to both the Lower Laramie and Denver groups: Ficus planicostata, Dombeyopsis obtusa, Paliurus zizyphoides, Artocarpus Lessigiana.

The plants of the Livingston beds, referred by Weed and Knowlton to the Denver horizon, are the following (U.S.G.S. Bulletin, No. 105, 1893). They are stated to be, by Weed, from the lower $300^{\prime}$ of the beds. Those species that occur also in the Lower Laramie beds are designated by Lar.; those in the Denver group of the Denver region, by the letter D; and those that are known from the Miocene Tertiary, by the letter M : -

Abietites dubius Lesquereux.........Lar. Sequoia Reichenbachi Geinitz........Lar. Taxodium distichum Miocenum Heer.

Ginkgo adiantoides Ung.

Phragmites Alaskanus Heer.

Caulinites sparganioides Lx..........Lar. Populus mutabilis ovalis Heer.........Lar.

" lævigata Lx.............. D.

Salix angusta A1. Br.............Lar., M. Quercus castanopsis Newb.

"6 Godeti ? Heer.

" Ellisiana Lx..............Lar.

Juglans rugosa Lx........... Lar., D., M.

"6 denticulata Lx........... D., M.

" rhamnoides Lx.......... Lar, D.
Platanus Guillelmæ Göppert...Lar., D. M. ? " aceroides Göppert........D., M. Ficus auriculata Lx............... D. ? "6 tiliæfolia (AI. Br.) Heer... Lar., D. "planicostata Lx.............Lar., D.

Cinnamomum Scheuchzeri? Heer. "6 ellipticum Knowlton.

Litsæa Weediana Knowlton.

Laurus socialis Lx .......type from Lar. Fraxinus denticulata Heer.........Lar.? Andromeda affinis Lx.

? Nyssa lanceolata Lx.............. D. Rhamnus rectinervis ............Lar., D. "salicifolius ? Lx............ Lar. Celastrinites lævigatus Lx. 
The fossil plants of the Dunvegan group of northern Canada (north of $55^{\circ} \mathrm{N}$.) contain, according to Dawson, species of Magnolia, Lemens, Ficus, Querus, Fugus, Betula, Sequoia, and cyrads, and are referred to the age of the Niobrara. The plant-bearing Mill Creek beds overlying the Lower Cretaceous of the Queen Charlotte Islands are made Dakota in age; and the Coal-measures of Vancouver Island are, on the same authority, of the age of the Montana group. Dawson refers to this time Heer's Patoot flora of Greenland. He compares this flora with that of Georgia, and from the general resemblance in genera infers that the temperature of the region may have been, like that of Georgia, about $65^{\circ} \mathrm{F}$. The Laramie flora, he observes, is most remarkable for its Crnifers, Taxites, Sequoia, Thuia, etc., and for the great development of the genus Platanus; also for containing some modern species of Ferns, as Onoclea sensibilis, Davallia tenuifolia.

References to all papers and reports on fossil plants published before 1884 will be found in Ward's Sketch of Palæobotany, U. S. G. S. Ann. Rep., vol. v.

Animals. - Invertebrates. - The shells of Rhizopods, or Foraminifers, are abundant in many of the beds in New Jersey, and still more so in those of Texas. Sponges are thus far rare fossils in the beds. Corals are not numerous.

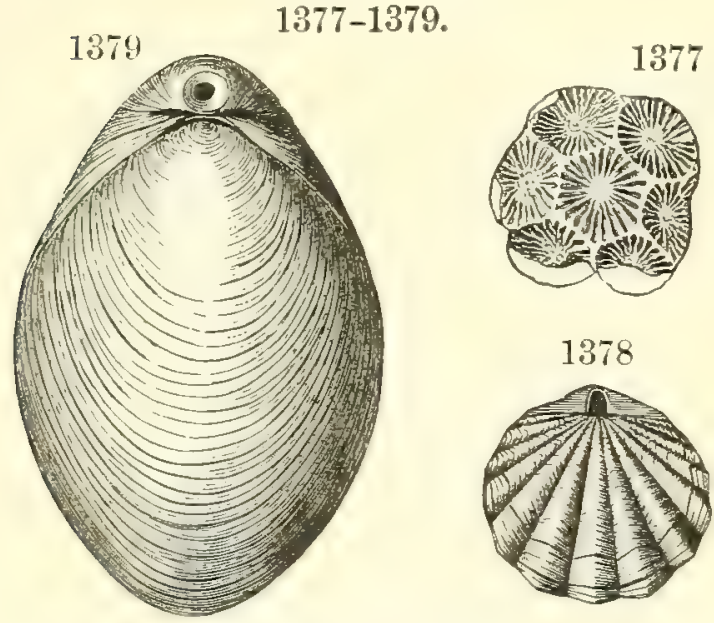

Corat. - Fig. 1377, Hindeastraz discoidea. BrachIoPoDs. - Fig. 1378, Terebratella plicata ; 1379, Terebratula Harlani. Fig. 1377, C. A. White; 1378 , 1379, Morton.
One from the Ripley beds of Texas, described and figured by C. A. White, is represented in Fig. 1377. No coral reefs have been reported; but they may possibly exist underneath the Tertiary of some part of the Gulf or Atlantic border. Echinoids occur of the genera Cidaris, Salenia, Cassidulus, Holaster, Hemiaster, and others. Less than 35 Upper Cretaceous species are known from all North America, while Great Britain has afforded nearly 150 .

Brachiopods are few in species. The two here figured, Terebratella plicata (Fig. 1378), and Terebratula Harlani (Fig. 1379) of Morton, are quite common in New Jersey. Meek described only one Lingula, $L$. nitida, from the Upper Cretaceous of the Continental Interior, and this was from the Fox Hills group. The contrast in species between the closing period of the Mesozoie and that of the Paleozoic is in no tribe more marked.

Of the characteristic Lamellibranchs there are, in the Oyster family, the genera Ostrea (Figs. 1380, 1381), Giyphoca (Figs. 1384, 1385), and Exogyra (Fig. 1383); and in the Avicula family, Inoceramus, I. labiatus (Fig. 1386) being very common.

The Rudistes, one Neocomian species of which is figured on page 835 (Fig. 1361), are very rare fossils in America in the Upper Cretaceous. Fig. 1387 represents one species described by C. A. White from the Wallala section of the Chico beds of California. Other Gastropods of modern forms are represented in Figs. 1388-1392. 
Cephalopods of the tribes of Belemnites and Ammonoids are of many species. One of the most common of the Belemnites, common to New Jersey,

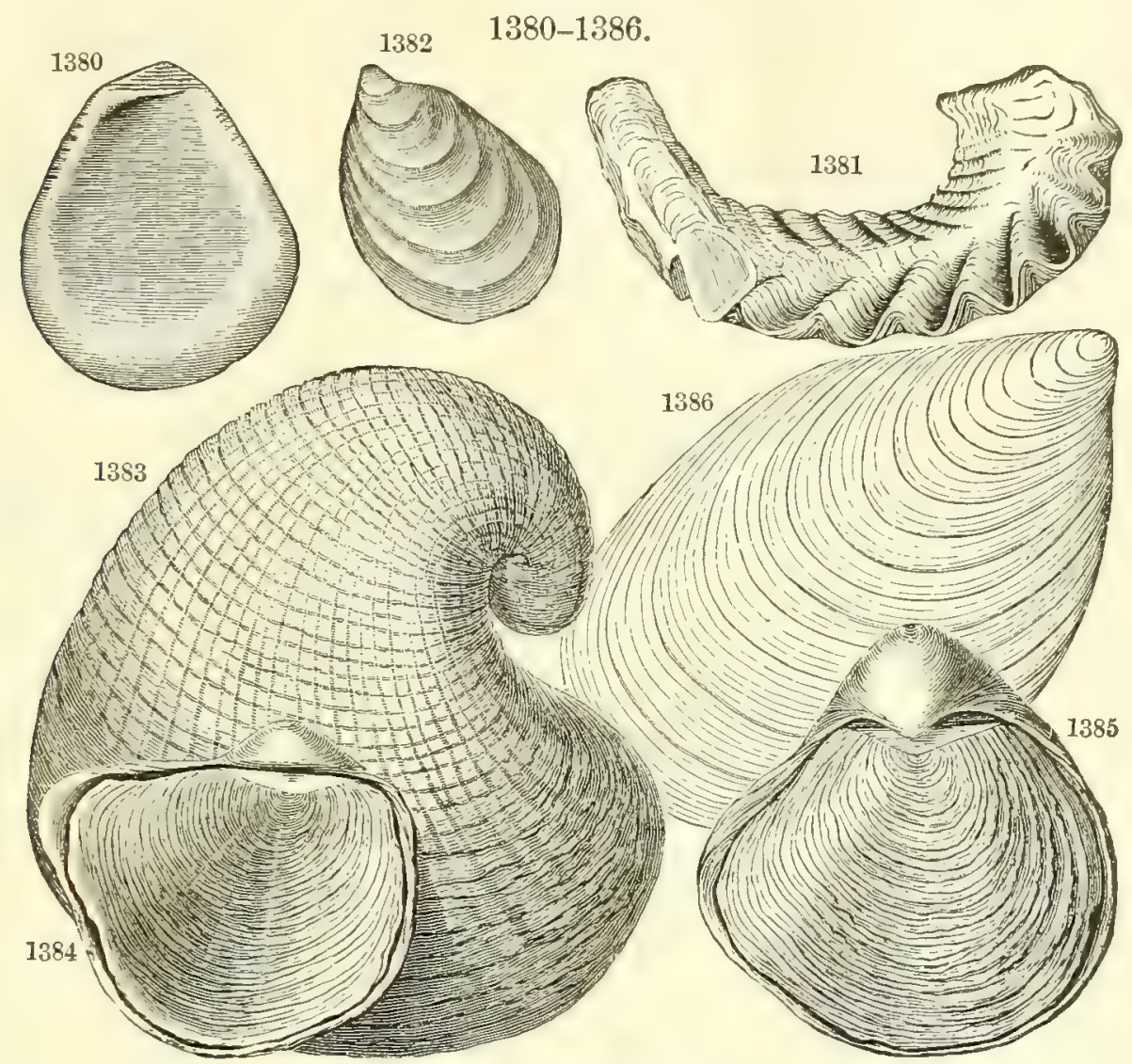

LAMELlibanchs. - Fig. 1380, Ostrea congesta ; 1381, Ostrea larva ; 1382, Inoceramus dimidius; 1383, Exogyra costata ; 1384, Gryphæa vesicularis ; 1385, G. Pitcheri ; 1386, Inoceramus labiatus (formerly problematicus). Fig. 1380, 1382, Stanton; 1381, D'Orbigny ; 1383-1385, Meek; 1386, Romer.

$1387-1392$.
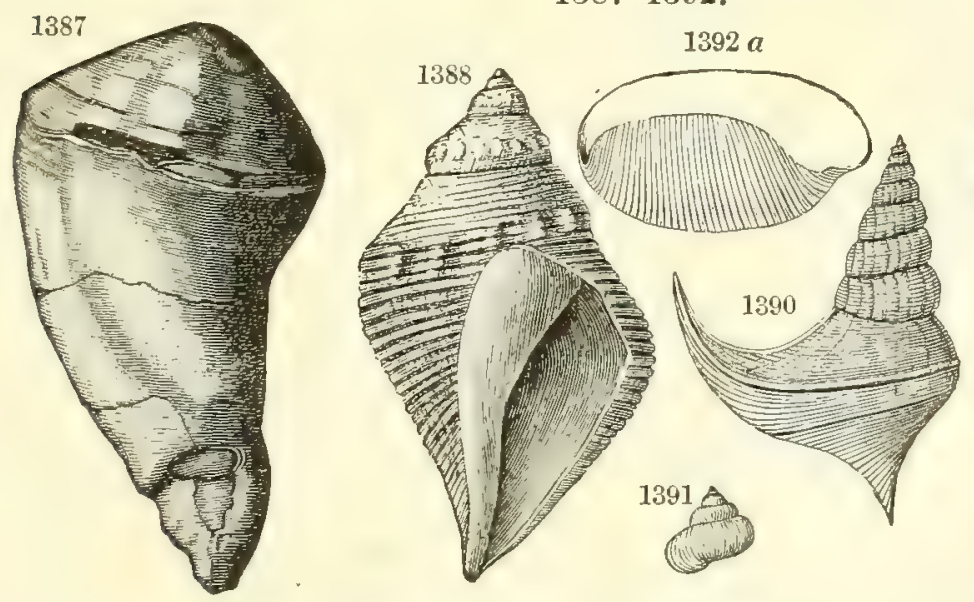

$1392 b$
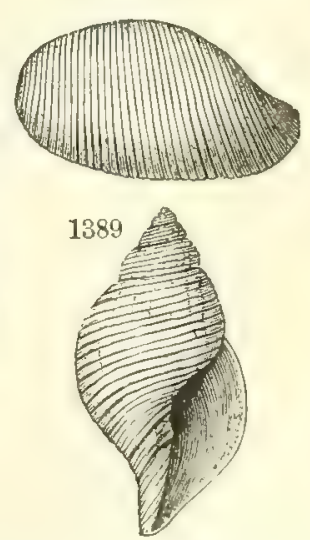

Lamelltbranch. - Fig. 1387, Coralliochama Orcutti $\left(\times \frac{1}{2}\right)$. Gastropods. - Fig. 1388, Pyrifusus Newberryi ; 1389, Fasciolaria buccinoides; 1390, Anchura (Drepanocheilus) Americana; 1391, Margarita Nebrascensis; $1392 a, b$, Bulla speciosa. Fig. 1387, C. A. White; 1388-1392, Meek.

Texas, and the Upper Missouri, is represented in Fig. 1393. Fig. 1394 represents the Ammonite, Placenticeras placenta of Dekay; 1394 a, the same in side view; and $1394 b$ shows the flexures in the partition at the sutures; 
specimens of this species have been found measuring more than two feet in diameter.

Among the more or less uncoiled Ammonoids there are: Fig. 1395, the Seaphites, S. Conradi, from the Fox Hills group, which is sometimes six feet

$1393-1400$

1393

DA
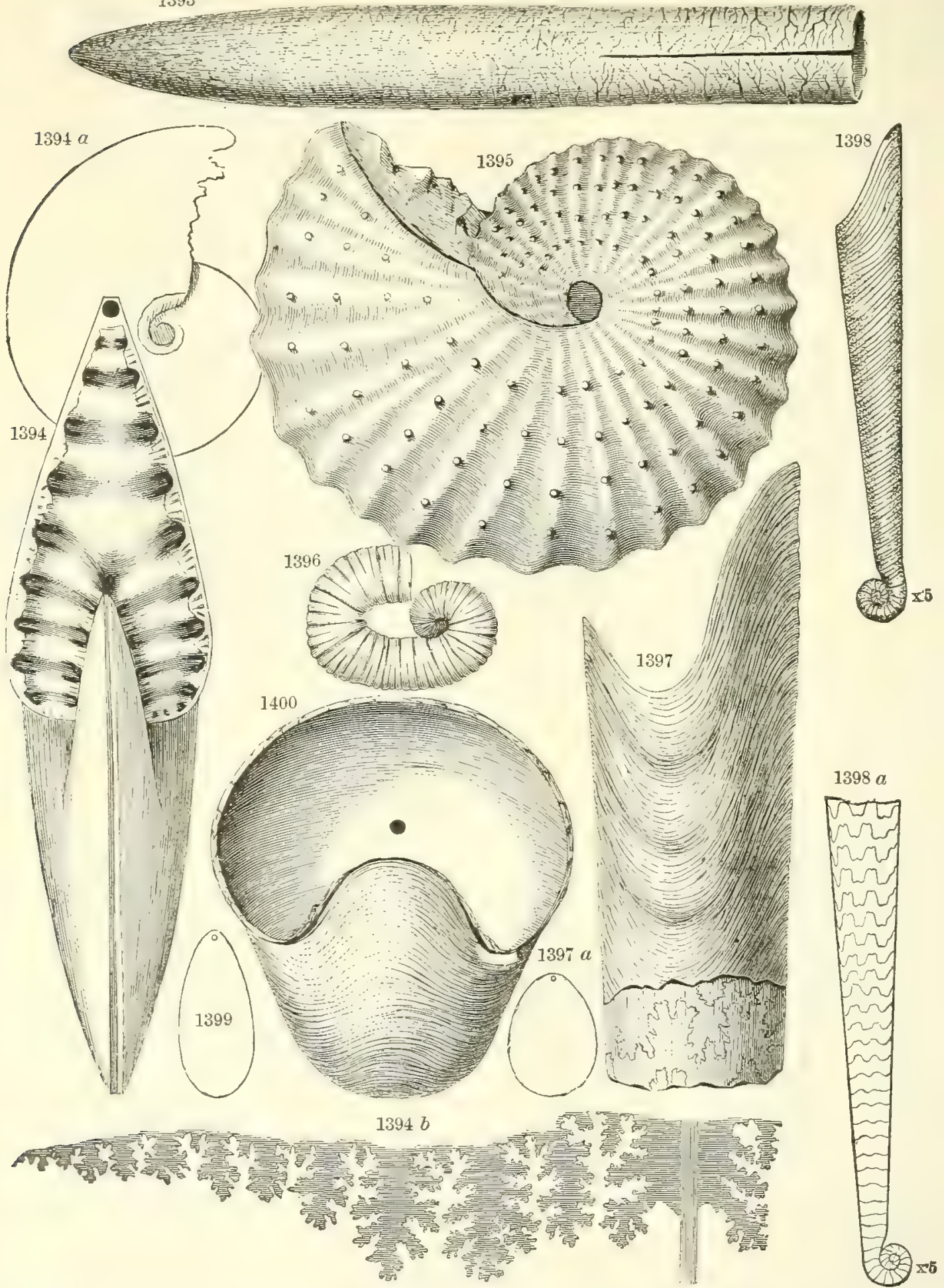

Cerpalopods, - Fig. 1393, Belemnitella Americana; 1394, a, b, Placenticeras (Ammonites) placenta; 1395, Scaphites Conradi; 1396, $\mathbf{S}$. Iarvaformis; 1397, 1397 a, Baculites ovatus; 1398, young stage of B. compressus; $1398 a$, same, with outer lajer of shell removed, showing sutures; 1399 , section of B. compressus, reduced; 1400, Nautilus Dekayi. Figs. 1393-1397, 1399, 1400, Meek; 1398, 1398 a, A. P. Brown 
long; and 1396, S. larveformis, another, showing more decidedly the imperfectly coiled condition, from the Fort Benton group. Fig. 1397 is an Ammonoid in which the form is straight, and hence the name Baculites, from the Latin baculum, a walking-stick. The length of this Baculite is over a foot, and the diameter $2 \frac{1}{2}$ inches; other associated species are more than a yard long. Another species, common in New Jersey, is the B. compressus Say, and Fig. 1399 is a section of it. A young stage of it is represented, enlarged, in Figs. 1398, a, by A. P. Brown (1891); the specimens were from the Black Hills, S. D.; they show that the animal in the young stage has a perfectly coiled shell. Others of these partly uncoiled kinds are represented on page 862. Fig. 1400 is a Nautilus from the Lower Greensand, New Jersey.

Vertebrates. - 1. Fishes. - In addition to Selachians and Ganoids there were Teleosts, or Osseous Fishes, the tribe which includes the larger part of modern fishes, and nearly all edible species. The Cestraciont Sharks still continue; and the bony pavement pieces of the mouth are not rare fossils. Two views of one from New Jersey are given in Figs. 1406, $1406 \alpha$.
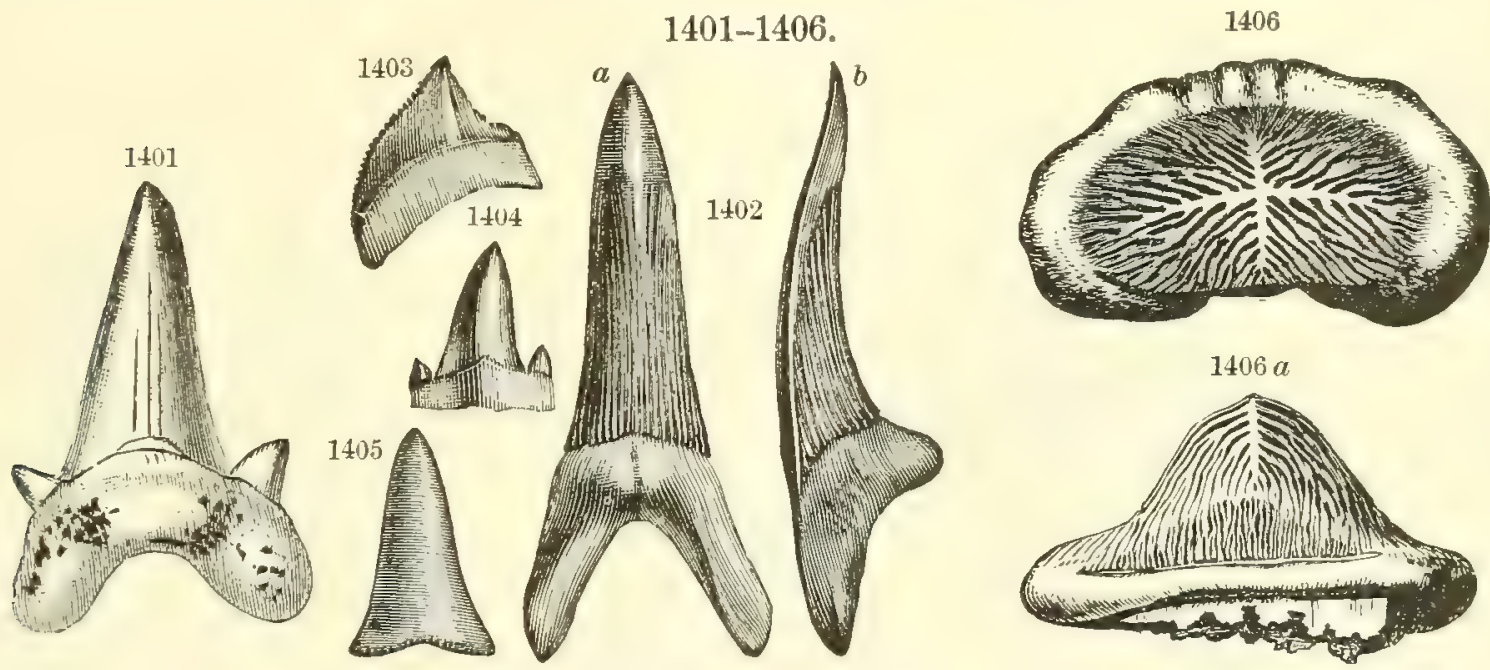

Squalodont Selachians. - Fig. 1401, Otodus appendiculatus ; $1402 a, b$, Lamna Texana ; 1403, Corax heterodon; 1404, Otodus appendiculatus; 1405, Oxyrhina Nantelli. Cestraciont Selachian. - Figs. 1406, 1406 a, Ptychodus Mortoni. Fig. 1401, Gibbes; 1402-1405, Rœmer ; 1406, Morton.

Many of the Sharks were of the modern tribe of Squalodonts - distinguished by the sharp cutting edges of the teeth, and other peculiarities. One kind is represented in Figs. 1401 and 1404 of the genus Otodus, the latter from Texas; 1403, tooth of a Corax; 1405, of an Oxyrhina; $1402 a$, b, of Lamna Texana.

The Teleosts of the Middle and Upper Cretaceous of North America include species of the Mullet family, represented by Beryx insculptus Cope, from New Jersey; the Sphyrenids of several large species described by Cope, of the genera Pachyrhizodus, Empo, and others, from Kansas; the Siluroids, powerful carnivorous fishes, ealled Saurodonts by Cope, one of which, Portheus molossus Cope, from Kansas, had the vertical diameter of the head 
nearly two feet. They appear to have been among the most formidable of all Teleosts. Saurocephalus lanciformis Harlan (Saurodon lanciformis Hays, 1830), from the "Upper Missouri region," is one of the group.

1407.

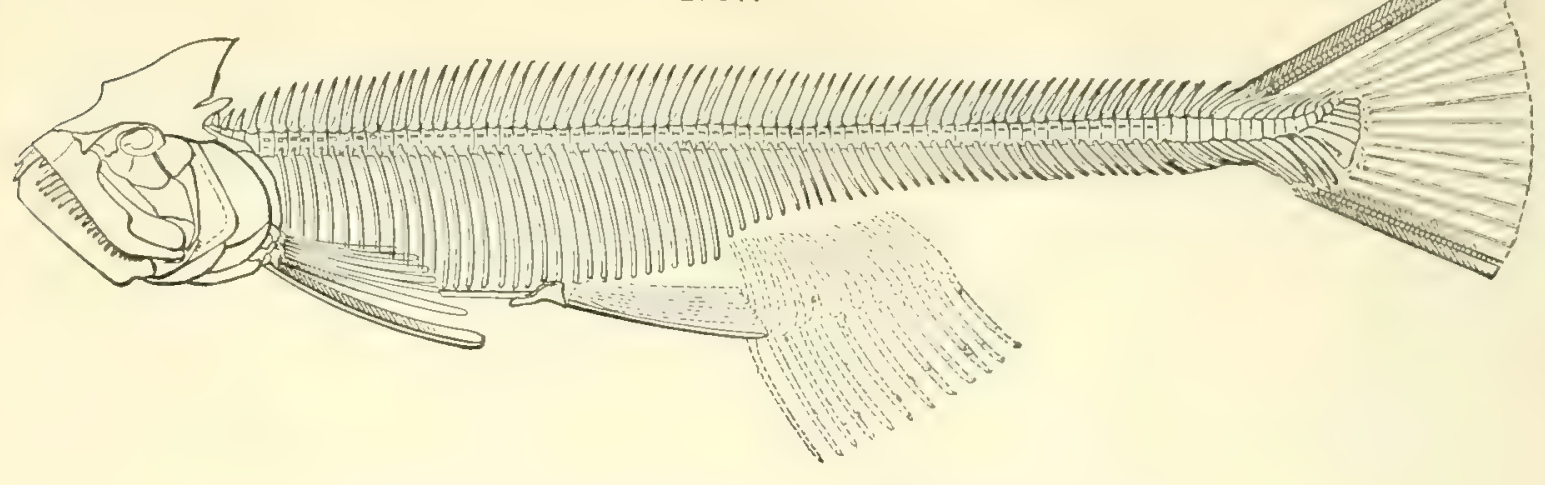

Restoration, showing the probable form of Portheus, Cope.

2. Reptiles. - The Reptiles included species of enormous size, yielding to few if any of the Jurassic period. Besides long-necked Sea-Saurians, related to

1408 .

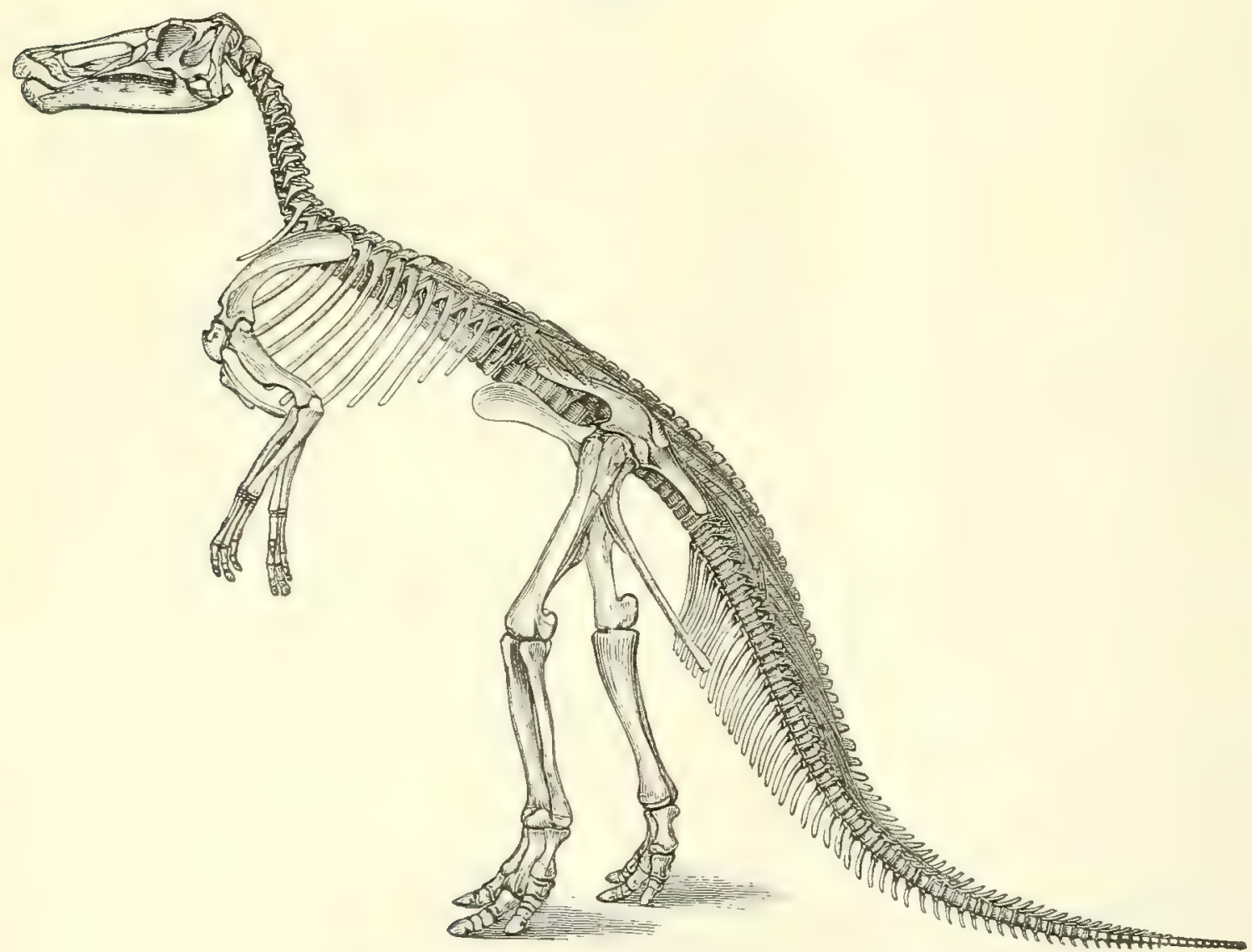

Restoration of Claosaurus annectens $\left(\times \frac{x}{50}\right)$. Marsh.

the Plesiosaurs, and huge carnivorous and herbivorous Dinosaurs, related to the older kinds, there were other Dinosaurs equally huge, having horns with horn-cores, like cattle, but with a third horn on the nose; Pterosaurs, 20 feet 
and upward in span of wings; and, as a new feature, great Sea-serpents, the Mosasaurids, having a length of 10 to 80 feet.

Plesiosaurids of the genus Cimoliosaurus of Leidy (1865) have been found in New Jersey, Alabama, and Mississippi, and others, of the genus Elasmosaurus of Cope, in the Continental Interior. The E. platyurus, a carnivorous species, 45 to 50 feet in length, had a neck 22 feet long, containing over 60 vertebræ.

The Herbivorous Dinosaurs include species of widely diverse forms and great magnitude. The first discorered is the Hadrosaurus Foulkii of Leidy (1858), a species about 28 feet long, having many of the characters of the Iguanodon of Great Britain.

A related species, equally large, is the Claosaurus annectens of Marsh (1890), from the Ceratops beds of eastern Wyoming, of which a restoration by the describer is here given (Fig. 1408).

It is an excellent example of these three-toed Ornithopod Reptiles, with their short fore feet, and very massive tail, - the latter, one of the three supports of the heavy body when erecting itself for brousing. A side view of the skull is shown in Fig. 1409. The teeth are confined to the maxillary

1409-1411.
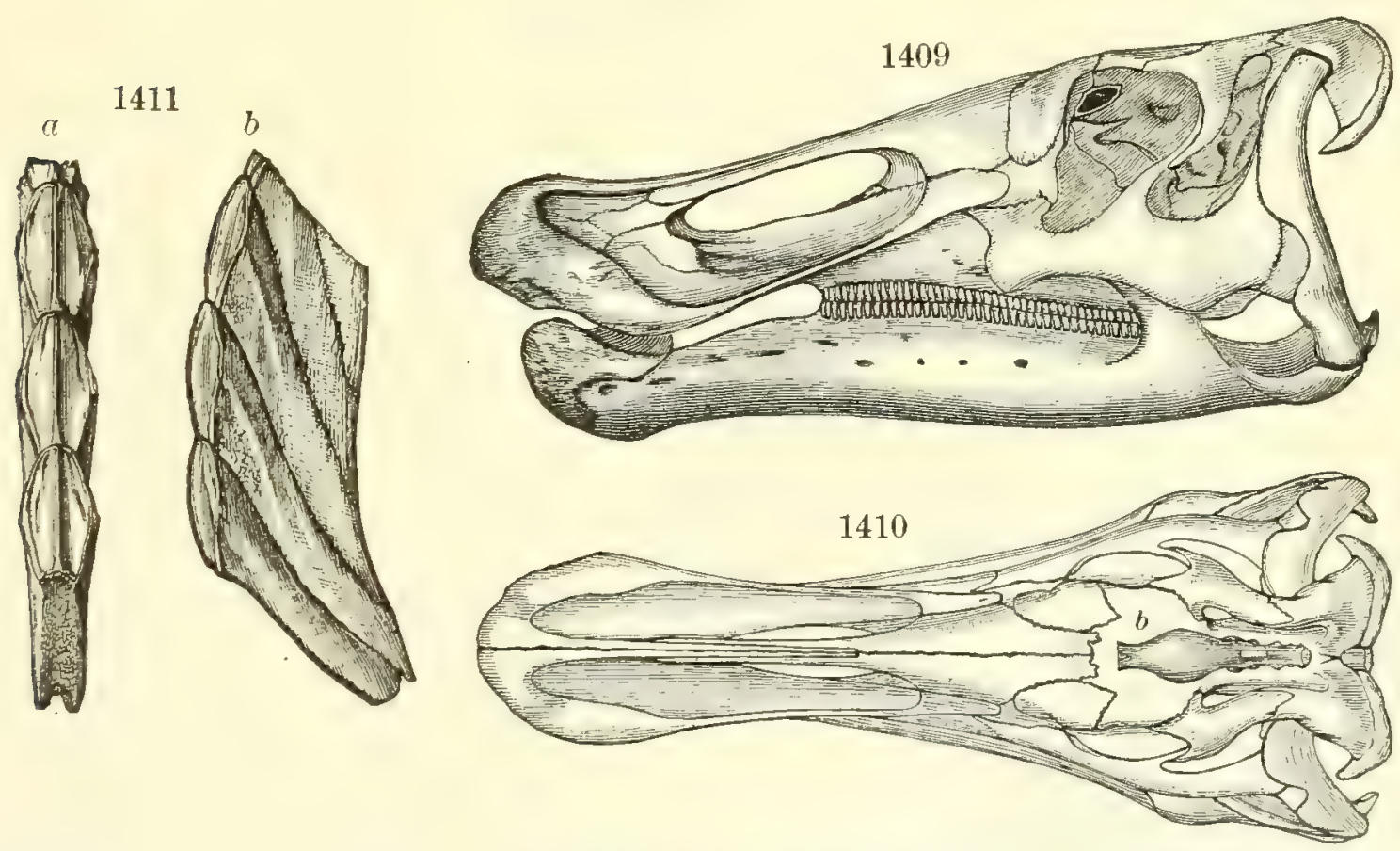

Claosaurus annectens. - Fig. 1409, the skull, side view $\left(\times \frac{1}{15}\right) ; 1410$, top view $\left(\times \frac{1}{15}\right) ; 1411 a, b$, series of teeth: $a$, front view; $b$, side view $\left(\times \frac{1}{2}\right)$. From Marsh.

and dentary bones, and are in great numbers; they are arranged in rertical series, and Fig. 1411 is an outer view of one of the series, in which the number of teeth is five. The number of teeth in the series is largest over the middle of the jaw, and is sometimes six or more. Fig. 1410 is an upper view of the skull. At $b$ is the brain cavity, which, as Marsh states, is very small in proportion to the head. 
Another species, more closely like Hadrosaurus, is the Diclonius mirabilis of Cope (1883; Trachodon mirabilis of Leidy, 1868), from the Laramie beds of Dakota. The length stated is 38 feet, and that of the head, $3 \frac{1}{6}$ feet.

1412.

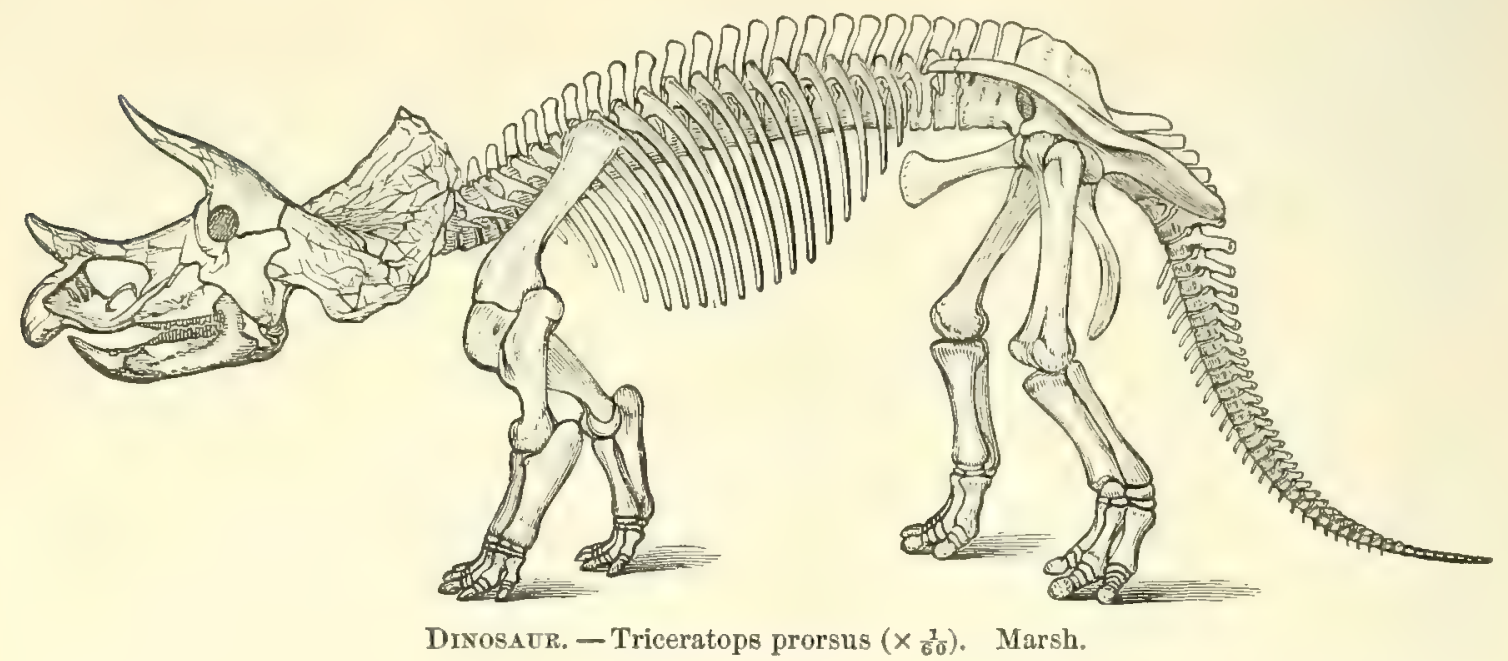

Widely different were the Herbivorous Dinosaurs of the family Ceratopsidæ of Marsh, - species of great magnitude, having the horns of cattle with

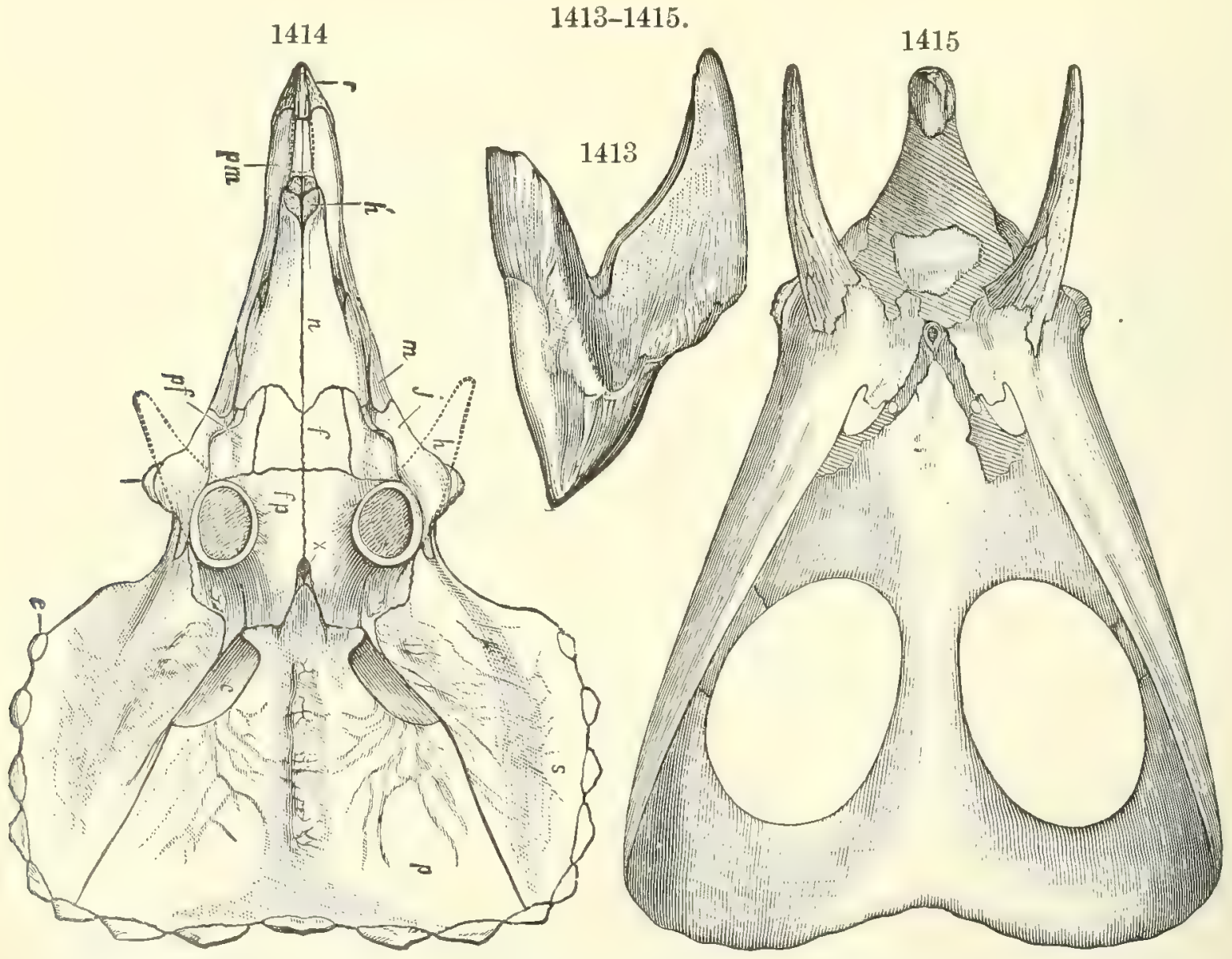

Dirosadrs. - Fig. 1413, Tooth of Triceratops prorsus, showing the two prongs (natural size); 1414, skull of T. serratus $\left(x \frac{1}{20}\right.$ ?) ; 1415, skull of Torosaurus gladius ( $\left.\frac{1}{25}\right)$. Marsh. 
the beaked mouth of a Turtle, or rather of the Rhynchocephs of the Trias. They are from the same Laramie beds in Wyoming that afforded the Claosaunu, and oceur also in the Denver beds, near Denver, Col. (where the first specimen was found), at Black Butte, Wyoming, and in the Judith River beds, Montana. The restoration by Marsh (Fig. 1412), one sixtieth the natural size, shows the general character of the skeleton of these strange but stupid inhabitants of the waning Mesozoic. The broad cranium (over eight feet long in one species) projects far over the neck, like the posterior flap of some forms of helmet, and sometimes has a degree of decoration in its pointed posterior margin.

The teeth had two prongs (Fig. 1413), a Mammalian feature not known in other Reptiles. The skull of another species of the genus is shown in Fig. 1414; and of a third, but of a distinct genus, Torosaurus, in Fig. 1415. J. B. Hatcher, who procured many of the bones described by Marsh, gives evidence (1893) that the great Dinosaurs lived in the region where they died; and he speaks of one skeleton of Claosaumus annectens Marsh (Fig. 1408), as found in a partially erect condition, the limbs extended, the ribs in natural position about the abdominal and thoracic cavities, and every bone in its natural place, showing that the animal had been mired in the quicksands. Some of the Ceratopsid skulls, although seven to eight feet long, make the centers of sandstone concretions, weighing many tons.

Other genera of Ceratopsids described by Cope are Agathaumas, Monoclonius, and Polyonax, severally from Wyoming, Montana, and Colorado. Agathaumas sylvestris is from the Laramie of Black Butte station in southern Wyoming.

Carnivorous Dinosaurs were represented by a number of species. Laelaps aquilunguis of Cope (1869), from the Upper Greensand, New Jersey, is about 24 feet long; it probably could stand nearly erect. L. incrassatus is reported by him from Montana, and also from the Laramie beds of Red Deer River in British America. The Ornithomimus of Marsh is a small species from the Laramie Ceratops beds of Wyoming, remarkably bird-like in its skeleton, as illustrated in the figure (Fig. 1416). It probably could stand erect like a bird.

The Mosasaurids, or Sea-serpents, of the era, Pythonomorphs of Cope (after the genus Pytho),

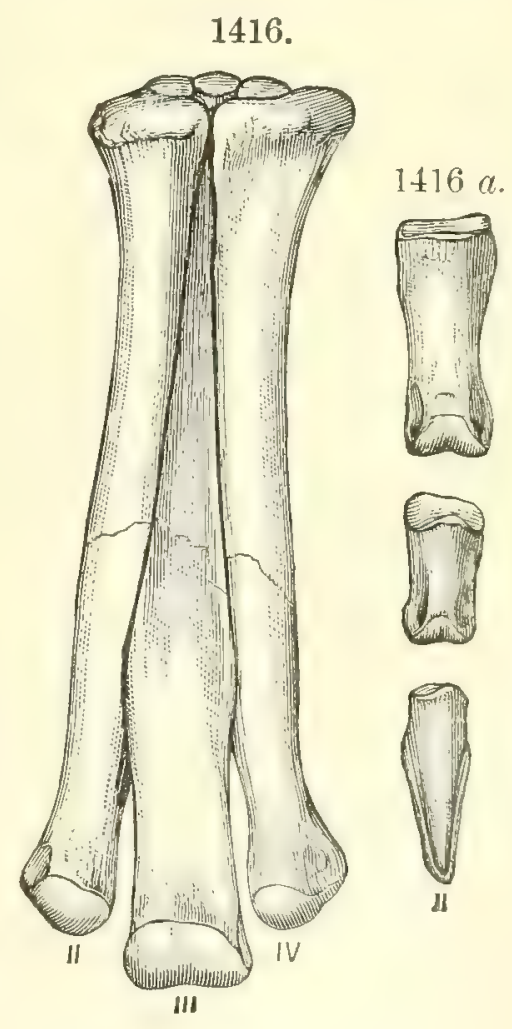

DinosAUR. Fig. 1416, Ornithomimus velox, 2d, 3d, and 4th metatarsals, natural size; $1416 a_{\text {, }}$ phalanges of $2 d$ digit. Marsh.

were eminently characteristic of the Upper Cretaceous. Previous to the American discoveries of their remains, knowledge of them was confined 
almost solely to a skull found in the uppermost Cretaceous beds of Belgium, on the river Meuse, 1785, whence was derived the name Mosasaurus. The first American species was a tooth in a fragment of a jaw, found at Monmouth, N.J., and figured in S. L. Mitchill's Geology of North America, 1818, described by Dekay in 1830, and named Mosasaurus major by him in 1841. Previously it had been named $M$. Dekayi by Bronn (1838). The tooth, according to Dekay, was 1.06 inches long and 1.02 and 1.33 broad at base. Through the discoveries since made, the number of American species described is near 50; and their remains have come from the borders of the Atlantic and the Mexican Gulf, and from the Interior Continental seas in Kansas, Dakota, Colorado, and beyond. Kansas is credited with 25 or more Mosasaurids from the Niobrara beds.

The species are related, like true Snakes, to the Lacertians; but they had paddles, and a skulling tail which was nearly half the length of the body, as shown in the restoration of Edestosaurus (Clidastes) velox of Marsh, by S. W. Williston, in the following figure. The Clidastes iguanavus of Cope is from

1417.

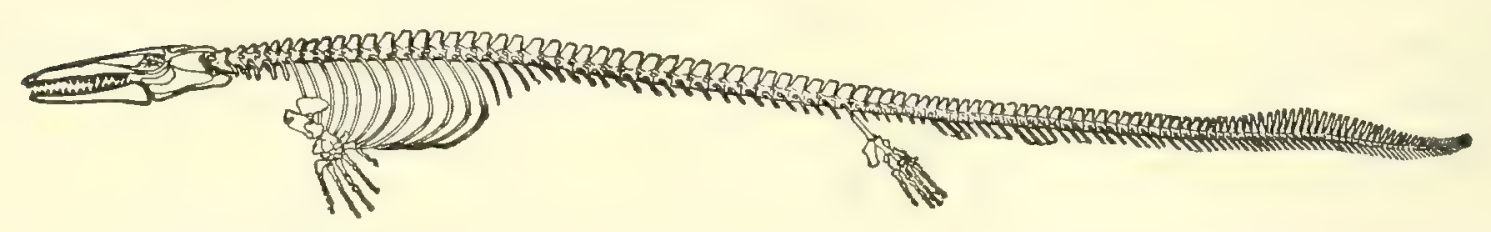

Restoration of Edestosaurus (Clidastes) velox $\left(x_{7}^{\prime}\right)$. Williston.

the Lower Greensand, New Jersey, and C. propython of Cope, from the Rotten Limestone in Alabama. Baptosaurus platyspondylus and B. fraternus, both of Marsh, are from the Upper Greensand of New Jersey.

One of the fore paddles of Lestosaurus of Marsh is represented, much reduced, in Fig. 1420. Fig. 1418 represents the tooth of Mosasaurus princeps of Marsh, from New Jersey, and 1419, the head extremity of one of the Mosasaurids, showing the bases of four teeth. An anomaly in Mosasaurus is the existence of an articulation for lateral motion in either ramus of the lower jaw (at $a$ in Fig. 1421), where there is in all other Reptiles a suture only; a fact first recognized by Cope. Besides, the extremities of the two rami were free, so that they could serve like a pair of arms in the process of swallowing whole a large animal.

True Snakes are rare species in the Mesozoic. The Coniophis precedens of Marsh, the only one known in this country, oceurs in the same beds with the remains of the Ceratopsidæ in eastern Wyoming.

Crocodilians were represented by the Thoracosaurus of Leidy (the New Jersey Gavial, or Gavialis Neocesariensis of De Kay, 1833), Holops pneumuticus and Gavialis fraterculus, of Cope, from New Jersey, and other species having the vertebræ concavo-convex, as in true Crocodiles. The older type, with biconcave vertebræ, also was represented; and Hyposaurus Rogersi Owen (1849) from New Jersey, and H. Webbii Cope from Kansas are exam- 
ples. Two Lizards, Chamops segnis Marsh, and Iguanavus teres Marsh (1892), occur in Wyoming in the beds affording the Ceratops remains.

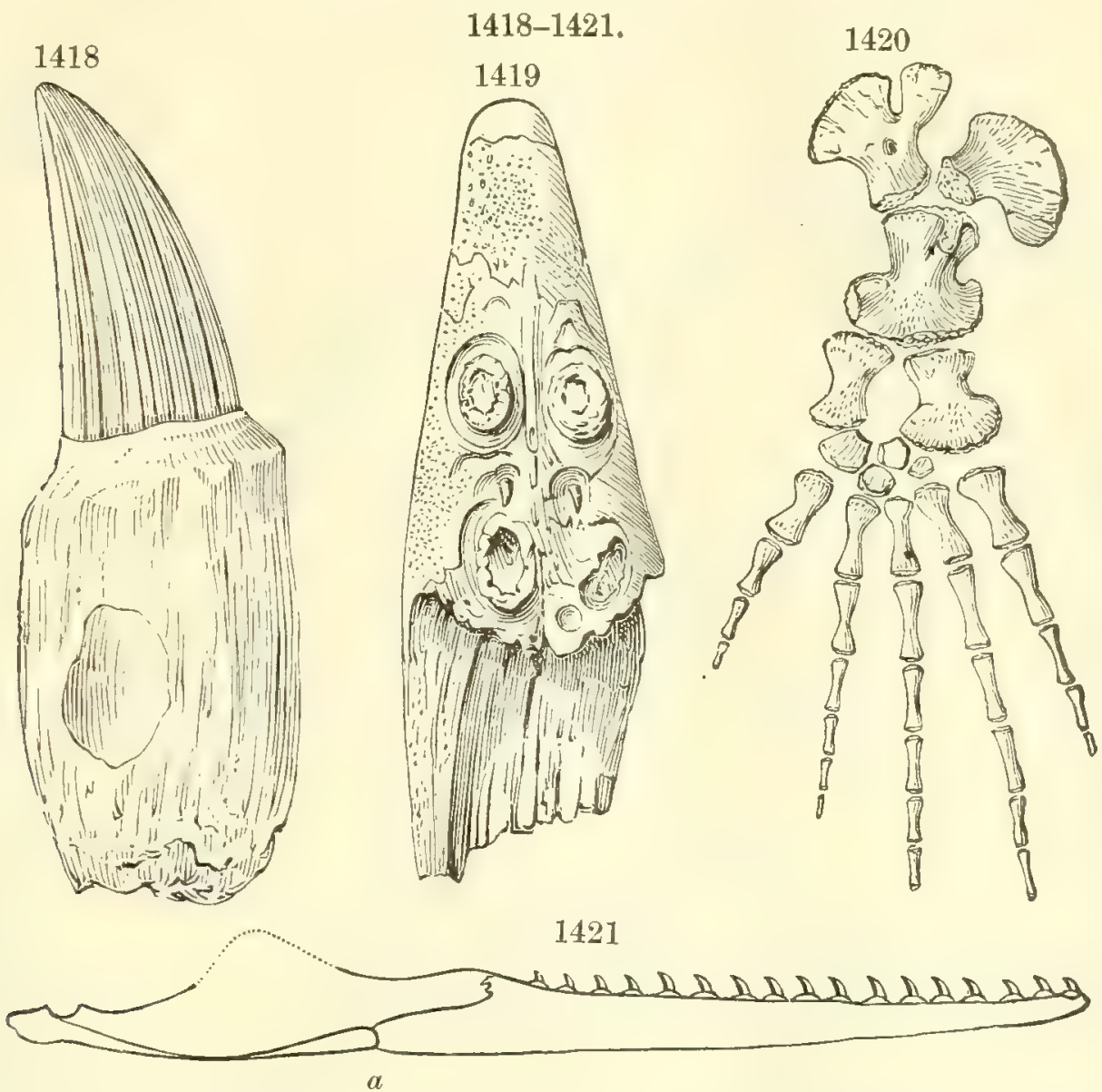

Mosagaurids. - Fig. 1418, tooth of Mosasaurus princeps $\left(\times \frac{1}{2}\right) ; 1419$, snout of Tylosaurus micromus, showing bases of four teeth $\left(\times \frac{1}{2}\right) ; 1420$, right paddle of Lestosaurus simus $\left(\times \frac{1}{12}\right) ; 1421$, restored jaw of Edestosaurus dispar $\left(\times \frac{1}{6}\right)$. All from Marsh.

The Turtles (or Chelonians of the American Cretaceous) were of 50 or more species; and one, Protostega gigas of Cope (?Atlantochelys Mortoni Agas-

1422.

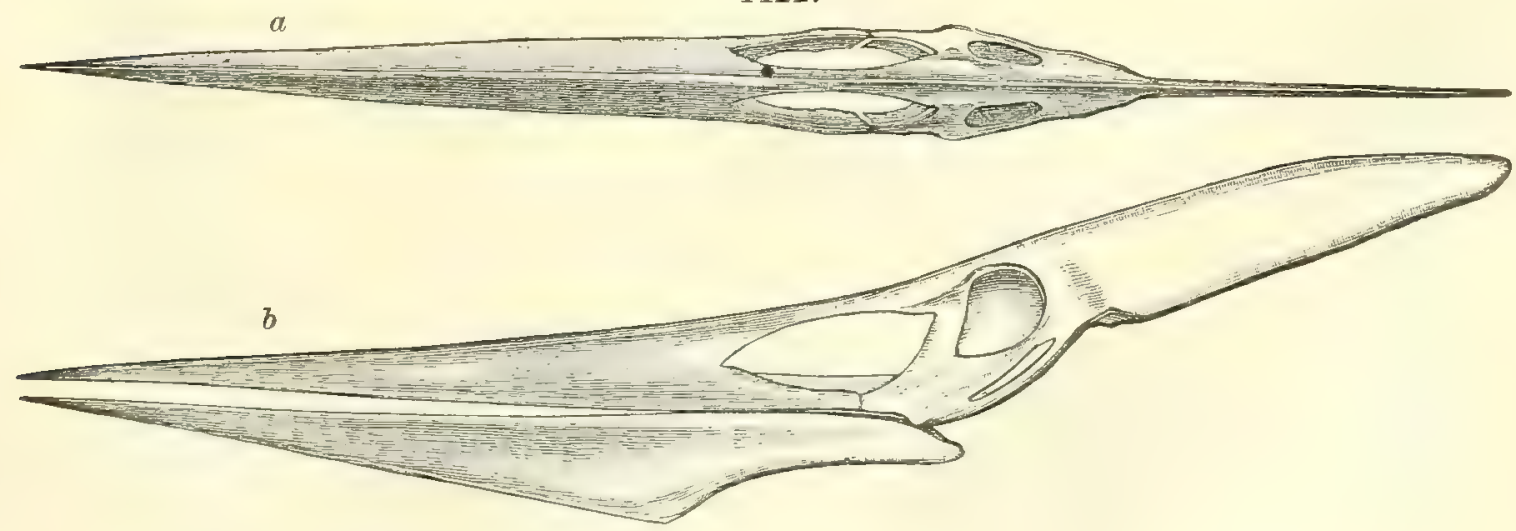

Fig. 1422, Pteranodon longiceps, head $\left(\times \frac{1}{3}\right): a$, upper view ; $\boldsymbol{b}$, side view. Marsh.

siz), from the Niobrara beds of western Kansas, had a head two feet long, and a total length of nearly 13 feet. Desmatochelys Lowii of Williston is DANA'S MANUAL - 54 
from the Benton group in Kansas. Species of Compsemys occur in the Laramie beds at Judith River and elsewhere, and also of Triony $x$ and Plastomenus. Adocus beatus Leidy, A. punctatus Marsh, A. agitis Cope, are New Jersey species.

$1428-1429$.
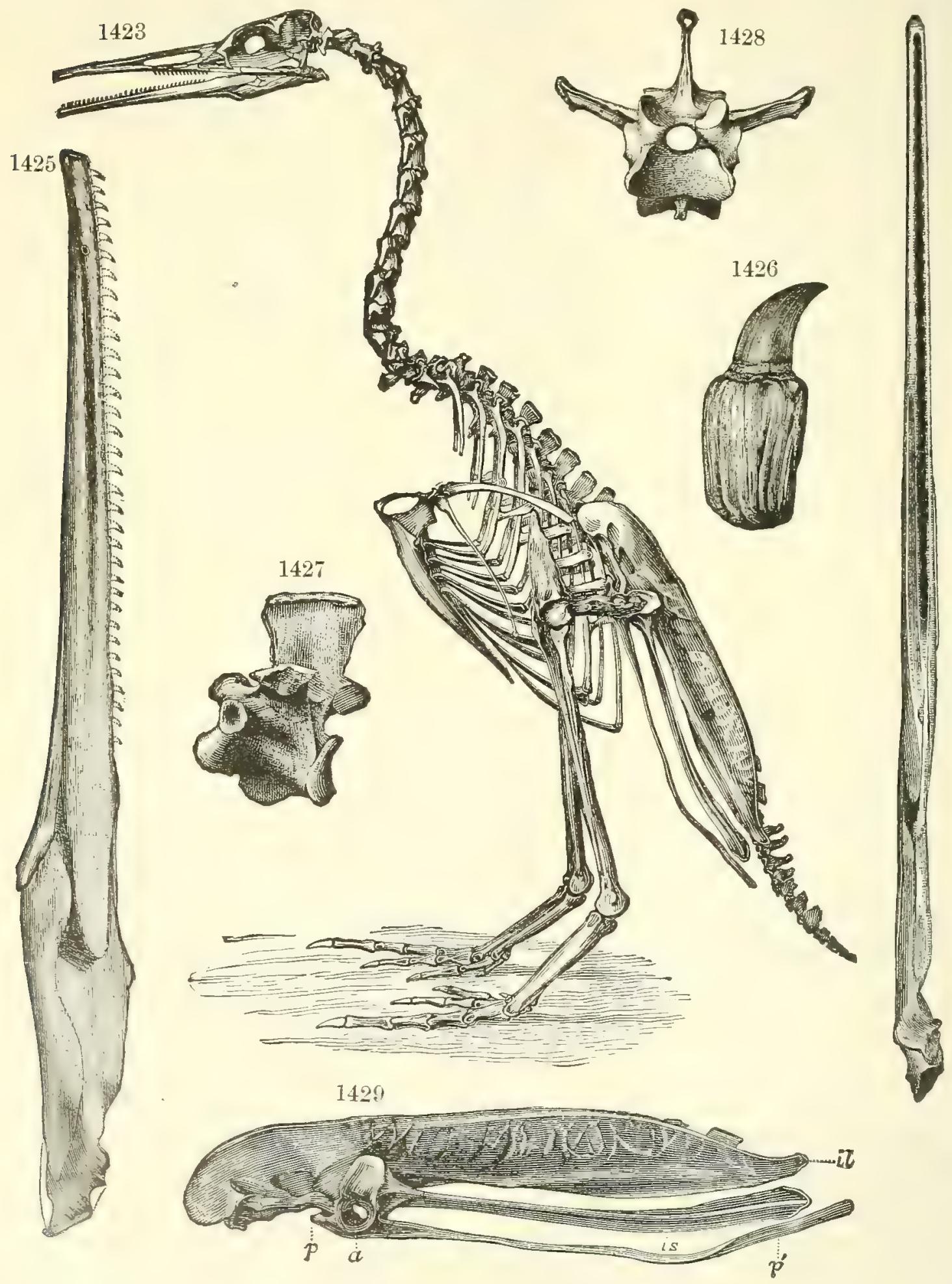

BIRD. - Fig. 1423, Hesperornis regalis, skeleton $\left(\times \frac{1}{8}\right) ; 1424$, left lower jaw, top view $\left(\times \frac{1}{2}\right) ; 1425$, same, side view ; 1426 , tooth $\left(\times \frac{4}{1}\right) ; 1427,20$ th dorsal vertebra, side view $\left(\times \frac{1}{2}\right) ; 1428$, same, front view; 1429, pelvis $\left(\times \frac{1}{8}\right) ; \boldsymbol{a}$, acetabulum; $i l$, ilium; is, ischium ; $p$, pubis ; $p^{\prime}$, post-pubis. Marsh. 
Pterosaurs of several species have been discovered in western Kansas, in the "Middle" Cretaceous, the first by Marsh in 1870; two had an expanse of wings of 20 to 25 feet, and another of 18 feet. They are toothless, unlike the foreign species, and are named by Marsh Pteranodonts; anodont from the

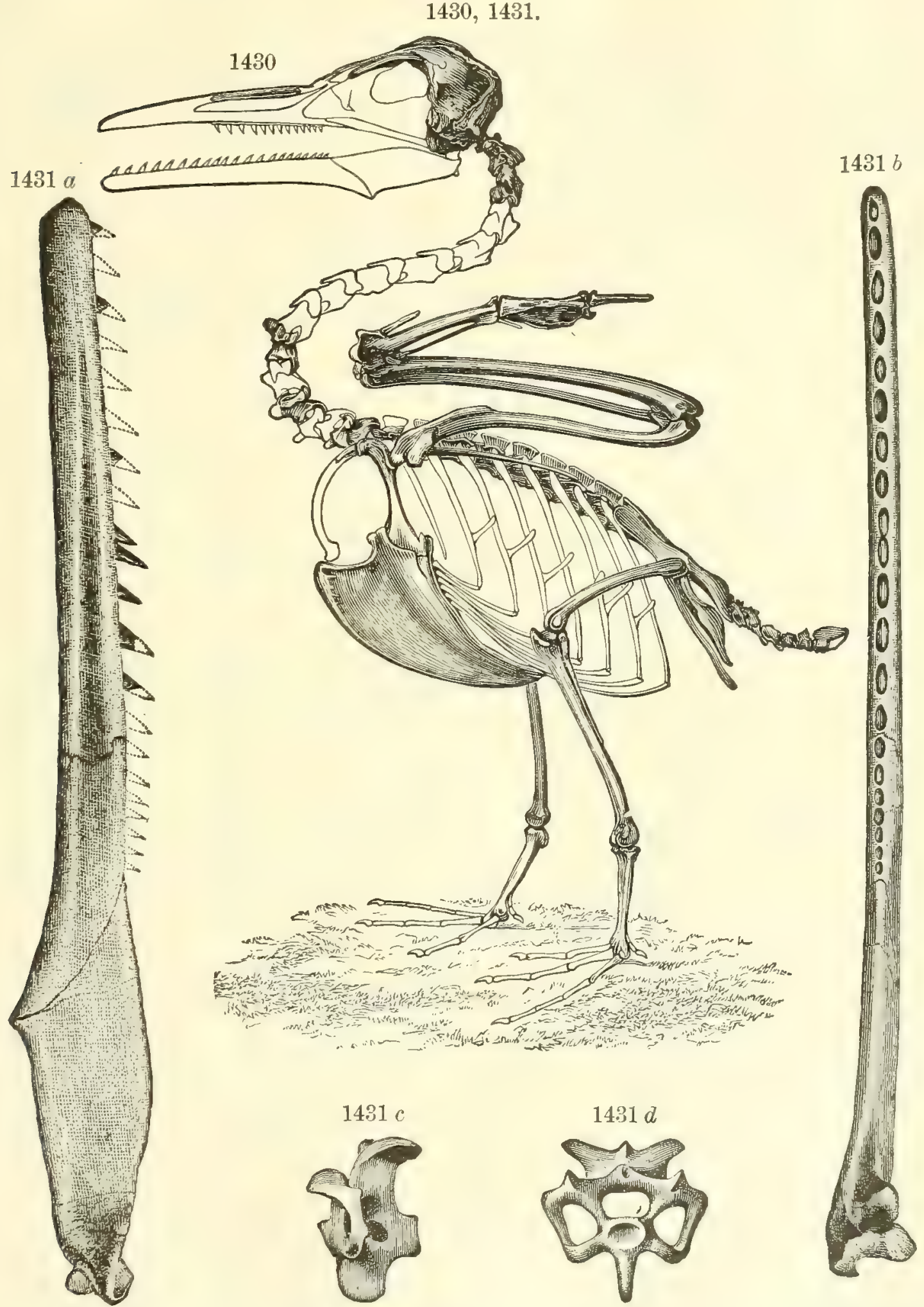

$\mathrm{BTRD}$ :-Fig. 1430, Ichthyornis victor, skeleton, restored $\left(\times \frac{1}{2}\right) ; 1431 a, b, c, d, \mathrm{I}$. dispar: $a$, left lower jaw; side view $\left(\times_{\frac{2}{1}}^{2}\right) ; b$, same, top view; $c$, cervical vertebra, side view $\left(x_{\frac{2}{1}}^{2}\right) ; d$, same, front view. Marsh. 
Greek, signifying without teeth. The skull and slevder bird-like jaws of Pteranodon longiceps Marsh are shown in Fig. 142' $b$, and an upper view in Fig. 1422 a. The fore limbs (wings) are enormous, the hind limbs very small. These animals, as Marsh observes, have several vertebræe anchylosed to act as a sacrum to the pectoral arch (like the sacrum in the pelvic arch), for the support of the powerful wings. 'The skull alone of $P$. ingens of Marsh is about four feet long, and that of $P$. longiceps over three feet. The abundance of their remains in the Kansas beds appears to show that these great bird-billed Pterosaurs frequented the borders of the Cretaceous sea as its Kingfishers.

3. Birds. - The Cretaceous Birds, in part, had teeth (like the Jurassic of Solenhofen), as first reported by Marsh from Kansas specimens. One of the species, the Hesperomis regalis of Marsh, tive to six feet in height, is represented in Fig. 1423 (reduced to $\frac{1}{8}$ ) from an essentially complete skeleton. The figures also illustrate, besides the skeleton, one of the teeth, the jaw in two positions, a dorsal vertebra, and the pelvis. The teeth are fixed in a groove, as in many Reptiles. 'This large bird had short wings, ostrich-like, with many of the characteristics of a Loon, one of the Divers. Another Kansas bird of different type is the Ichthyomis victor of Marsh, a small bird, with good wings. The fish-like feature to which the name alludes is the biconcave form of the vertebræ. But, with this low-grade feature, it has the teeth in sockets. In the restored skeleton (half the natural size), Fig. 1430, the bones actually found are those of the shaded part. Apatomis of Marsh is a related bird. Marsh has described, also, species of two other genera related to Hesperornis; namely, Baptornis and Coniomis, the latter from the Fox Hills group, Montana. All the Cretaceous birds have the fore limb greatly modified for wing purposes, bird-like; but in the Hesperornis it has passed beyond this and become rudimentary, as in the Ostrich. This is in striking contrast with the earlier Jurassic birds, in which the fore limb is more completely and normally a leg than a wing. The toothless birds (or those not yet proved to be toothed) of the Cretaceous beds of New Jersey were related to the Cormorants and Waders.

4. Mammals. - The Mammals of the Cretaceous thus far discovered are probably all Marsupial or Monotreme, like those of the Jurassic period. The remains are mainly teeth, with a few broken jaws and limbs. The earliest described is the Meniscoëssus conquistus of Cope, discovered by $\mathbf{J}$. L. Wortman in the Laramie of Dakota $(1882,1884)$. Many kinds have been described by Marsh (1889-1892). The following figures are from his plates of 1892 .

The figures 1432-1438 are supposed by Marsh to represent teeth and portions of jaws of Marsupials, and the remainder probably of Monotremes. The teeth of the genus Tripriodon have some resemblance to the tooth of the Meniscoëssus figured by Cope, and have been referred by Osborn to that species. 
1432-1443.

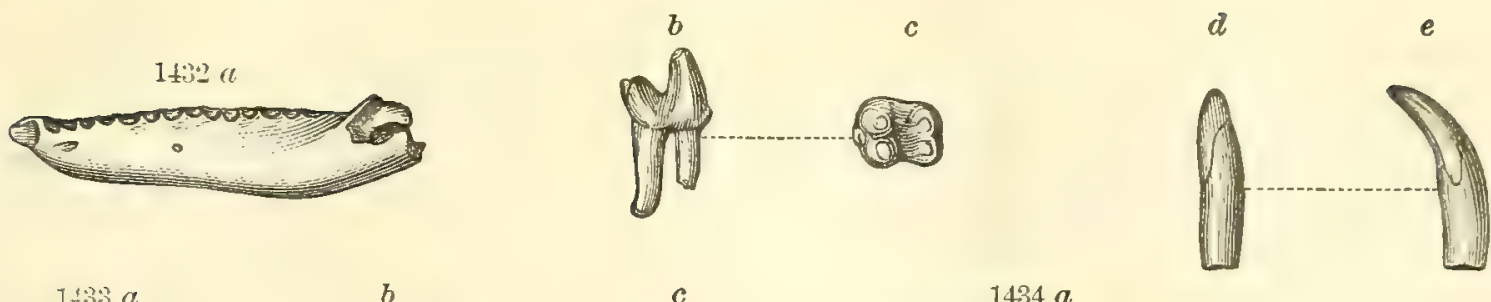

$14303 \alpha$

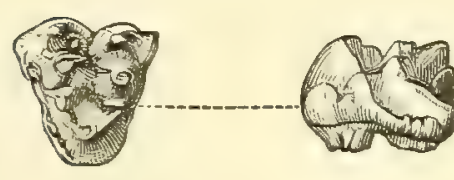

c

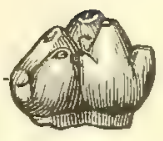

$1434 a$

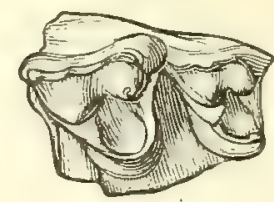

$1434 b$
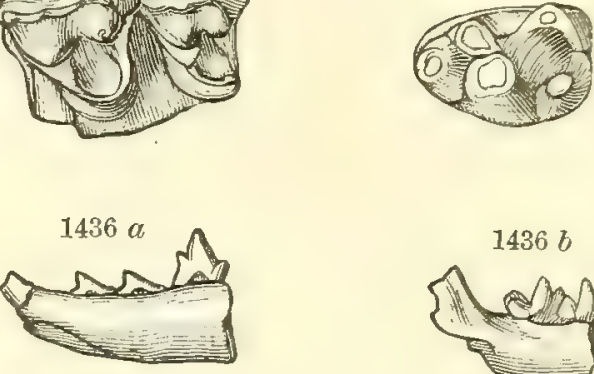

$1436 b$
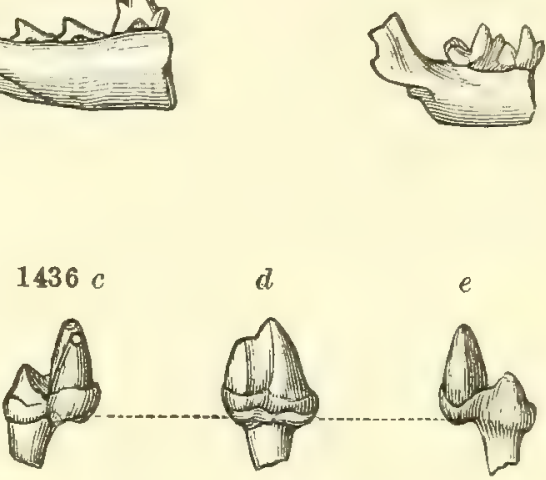

$1437 d$

$1437 e$
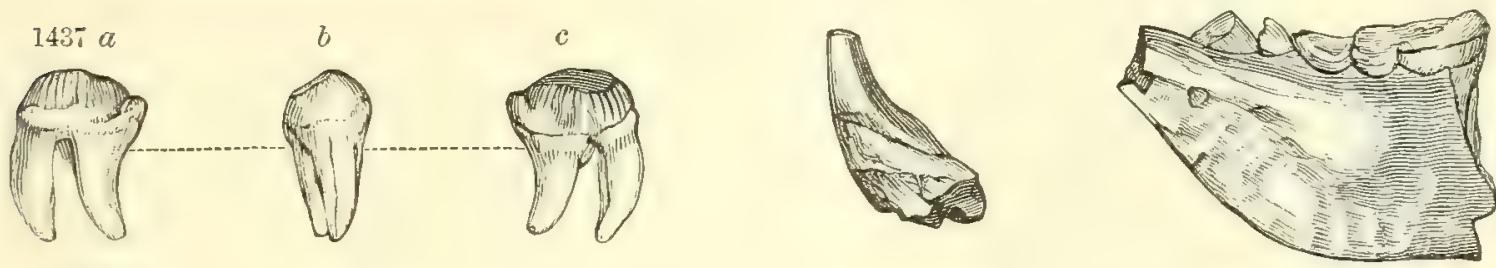

1440

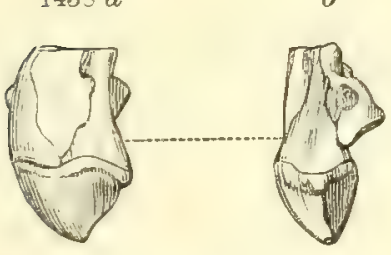

$1439 a$

b

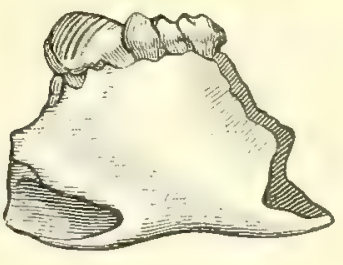

1443
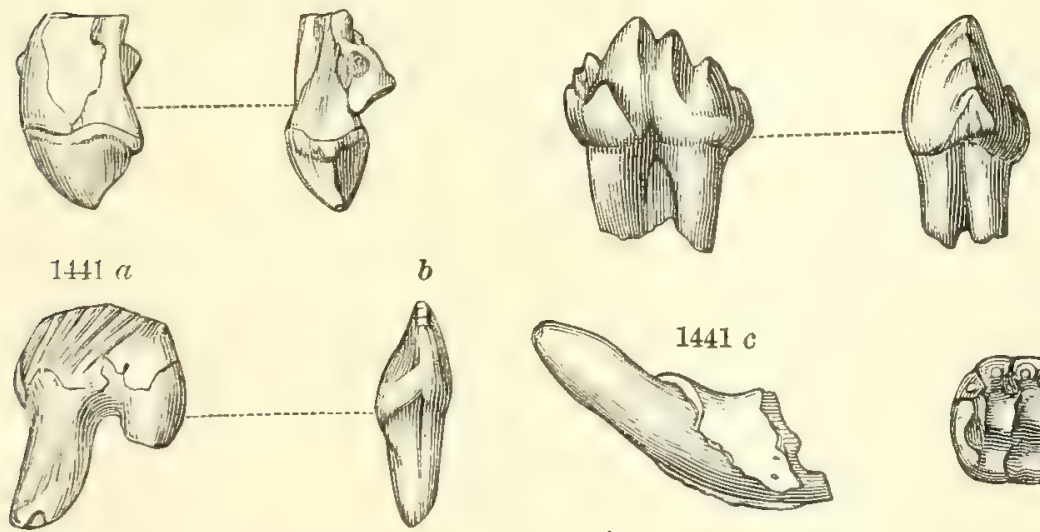

1442
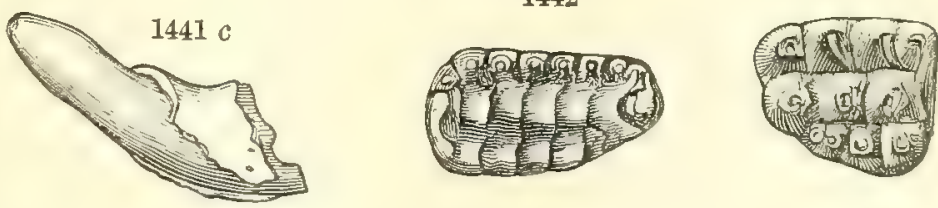

Mofotpeme and Marsupial Mammats. - Fig. $1432 \boldsymbol{a}$, Cimolestes incisus, left lower jaw ( $\times 2$ ); $1432 b, c$, lower naolar $(\times 3)$; $1432 d$, e, id., canine, natural size; $1433 a, b, c$, Didelphops comptus, upper molar ( $x 3$ ); $1434 a$, D. vorax, two upper molars $(\times 2)$; $1434 b$, Didelphops, milk tooth $(\times 3)$; $1435 a, b$, D. ferox, views of right lower jaw; $1436 a$, Batodon tenuis, lower jaw (x 3); $1436 b$, id, with last two molars ( $\times 2$ ); 1436

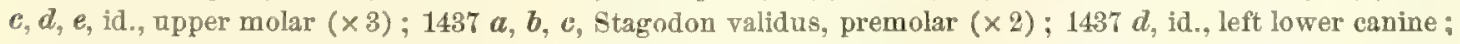
$1437 \mathrm{e}$, id., part of lower jaw, showing canine and two molars, natural size; $1438 a$, $b$, Stagodon tumidus, upper premolar $(\times 2) ; 1439 a, b$, Oracodon conulus, upper premolar $(\times 3)$; 1440, Dipriodon lunatus, natural size; $1441 a, b$, Halodon sculptus, right lower, fourth premolar $(\times 2)$; $1441 \mathrm{c}$, id., left lower incisor; 1442 , Tripriodon colatus, right upper molar $(\times 2)$; 1443, T. caperatus, right upper molar $(\times 2)$. Marsh, 1892 . 


\section{Characteristic Species.}

NEW JERSEY. - The following lists of New Jersey species are from the reports of R. P. Whitfield, from whom have been taken also the chief part of the references to occurreuce in the Ripley group of Alabama (indicated by R.), and in the Upper Cretaceous beds of Texas (indicated by T.); the other references being from T. W. Stanton:-

Lower Greensand. - Catopygus pusillus, Cassidulus florealis, Terebratula Harlani, Terebratella plicata, Ostrea larva (R., T.), Exogyra costata (R., T.), Gryphaca vesicularis (R., T.), Pecten venustus, Amusium simplicum (R.), Neithea quinquecostata (R.), Radula acutilineata (R.), Spondylus gregalis, Gervilliopsis ensiformis (R., T.), Inoceramus Crispii var. Barabini (R., T.), Idonearca vulgaris (R., T.), Trigonia Mortoni, T. Eufaulensis (R.), Cardium (Criocardium) dumosum (R., T.), C. Eufaulense (R., T.), Crassatella vadosa (R.), Veniella Conradi (R., T.), V. trapezoidea (R.), Anchura abrupta (R., T.), Cyprimeria depressa (R., T.), Gyrodes crenatus (R., T.), G. petrosus (R., T.), Veleda lintea (R., T.), Leptosolen biplicata (R., T.), Scalaria Sillimani, S. Hercules, Turritella com. pacta, T. vertebroides (R., T.), Ligumen planulatum (R., T.), Nautilus Dekayi (R., T.), Placenticeras placenta (R., T.), Scaphites hippocrepis, S. Conradi (R.), Baculites ovatus (R., T.), B. compressus, Turrilites pauper, Solenoceras annulifer, Belemnitella Americana; and in the Clay Marls, below the Lower Greensand, A mmonites (Mortoniceras) Delawarensis.

Middle Greensand. - Montlivattia Atlantica, Cidaris splendens, Pseudodiadema diatretum, Ananchytes ovalis, Hemiaster parastatus, Terebratula Harlani, Gryphaa vesicularis, Gryphaostrea vomer, Natica abyssina, Isocardia Conradi, Nautilus Dekayi, Baculites ovatus, Sphenodiscus lenticularis.

Base of Upper Marl bed. - Terebratulina Atlantica, Ostrea glandiformis, Gryphaca Bryani, Crassatella curta, C. littoralis, Turritella pumila, Rostellaria nobilis, Pleurotomaria Brittoni.

The latest and fullest work on New Jersey Brachiopods, Lamellibranchs, Gastropods, and Cephalopods, with illustrations of all the species, is Whitfield's Report, in 4 to, $U$. S. G. S., vol. ix., 1885, and vol. xviii., 1892. It contains full references to the works of Morton, Lea, Conrad, and all other authors on New Jersey Cretaceous paleontology.

Mississippi and Alabama. - Eutaw group, - chiefly Oysters in the marine part. Rotten Limestone: Placuna scabra, Neithea quinquecostata, Gryphra convexa, G. vesicularis, G. Pitcheri, Ostrea falcatn, Rudistes, Mosasaurus; and in the Tombigbee sand, many Selachian remains, and the gigantic Ammonites Mississippiensis Spillm.

Ripley group. - Besides the species indicated, in the list for the Lower Greensand group, by the letter R., the following are common kinds; the references to Texas are from Whitfield and Stanton: Ostrea subspatulata (T.), Gryphcea mutabilis, Anomia argentina, Inoceramus proximus, Gervilliopsis ensiformis, Cucullac capax, Pecten quinquecostatus, Nucula percrassa (T.), Aphrodina Tippana (T.), Veleda lintea (T.), Lunatia obiquata (T.), Pugnellus densatus (T.), Pyrifusus subduratus (T.), Volutomorpha Eufaulensis (T.), Morea naticella (T.), M. cancellaria (T.), Cinulia pulchella ( $\left.\mathrm{T}_{0}\right)$, Baculites anceps (T.).

Texas. - (The species of the Upper Cretaceous are wholly different from those of the Lower.)

(1) Lower Cross Timbers: Leaves of Salix, Ilex, Laurus, etc. (Shumard); Otodus appendimutatus, and other Fish remains; Anguillaria Cumminsi White, species of Ostrea, Cerithium, Turitella, Neritina, Scaphites, with Ammonites Swallovi Shumard.

(2) Eagle Ford shales: Isastraea discoidea White, Ostrea congesta Con., O. belliplicata, Exofyra columbella. Meek, Lima crenulicosta Romer, Inoceramus labiatus, I. latus Sow., I. confertim-anmulatus Romer; the Ammonoids, Buchiceras Swallovi, Hoplites Deshayesi, 
Acanthoceras mammillare, Scaphites Texanus R.; Ptychodus mammillaris, Lamna compressa, L. Texana, Galeocerdo, Carcharodon.

(3) The Austin limestone (chalk): Rhizopods of the genera Textulariu and Globigerina; also Hemiaster Texanus R., Cassidulus aquoreus Morton, Terelwatulina Guadalupo R., Ostrea congesta, Gryphoa vesicularis Lamk., Exogyra ponderosa (young form), E. costata Say, E. columbella, Ostrea larva, Pecten Villsoni, Inoceramus biformis, I. umbonatus, $I$. subquadratus, I. exogyroides, I. labiatus, Rauliolites (?) Austinensis R., Eulima Texana R., Chemnitzia gloriosa R., Nautilus Dekayi, Baculites anceps, B. asper, Ammonites (Placenticeras) Guadalupce R., A. (Mortoniceras) Texanus R., Mortoniceras Shoshonense, Schloenbachia dentato-carinata R.

(4) The Taylor or Exogyra ponderosa marls: E. ponderosa (very abundant), Gryphaea vesicularis, Ostrea larva, Amusium simplicum Con., Pyrifusus granosus Con. The species have greater resemblance to those of the Atlantic and Gulf borders than to those of the Continental Interior; and this is true also of the following.

(5) Glauconitic beds of northeast Texas: the species of (4), and also Pecten Burlingtonensis, Inoceramus Crispii, Crassatella lineata Shum., Pachycardium Spillmani, Pholadomya Lincenumi, Chemnitzia gloriosa, Purpura cancellata, Pleurotoma Texana, P. Tippana, Anisomyon Haydeni, Nautilus Dekayi, Ptychoceras Texanum, Turritites helicinus, Helicoceras Navarroense, Baculites annulatus, B. Spillmani, B. Tippoënsis, Placenticeras placenta, Belemnitella mucronata. Further, the Eagle Pass beds on the Rio Grande, referred to the age of the Fox Hills and Laramie, contain Ostrea glabra Meek, Anomia micronema, and species of Arca, Cyrena, Amm. (Sphenodiscus) pleurasepta Con., and other species. The above names are from lists by Hill. See further, for species of the Glauconitic group and Ponderosa marls that are identical with those of the Ripley and Lower Greensand groups, tables on page 854 .

On the Invertebrate Paleontology of 'Texas, see especially F. Rœmer, Kreid. Texas, 1852 ; also, Pal. Abhandl., Berlin, 1888 ; Shumard, Acad. Sc., St. Louis, i., 1860, and Boston Soc. N. H., viii., 1861-62; R. T. Hill, Am. .Jour. Sc., 1887 ; Rep. Geol., Texas, vol. i., annotated check-list, Bull. No.4, Geol. Texas, 1889 ; Proceedings of the Biological Society of Washington, D.C., vol. viii., 1893; Bull. Geol. Soc. of Am., vol. v., 1894 ; C. A. White, on fossils from Texas, Proc. U. S. Nat. Mus., ii., and his Correlation of the Cretaceous, Bull. U. S. G. S., No. 82 ; F. W. Cragin, Texas Geol. Survey, 1893.

Continental Irterior (Upper Missouri region), according to Meek :-

1. Dakota Series. - Besides species of fossil plants, Pharella (?) Dakotensis, Trigonarca Siouxensis, Cyrena arenarea, Margaritana, Nebrascensis, etc.

2. Colorado Series. - (a) Fort Benton: Inoceramus labiatus, I. fragilis, I. tenuicostatus, Ostrea cangesta, Pholadomya (Anatimya) papyracea, Scaphites larvaformis, S. vermiformis, S. ventricosus, Nautilus elegans; the Ammonites, A. Mullananus, Mortoniceras Shoshonense, Prionocyclus Woolgari, etc. (b) Niobrara: Inoceramus (aviculoides) labiatus, I. deformis, Ostrea congesta, etc.

3. Montana Series.- (a) Fort Pierre: Inoceramus sublovis, I. Crispii, I.tenuilineatus, Busycon Bairdii, Neithea quinquecostata, Anisomyon borealis, Lucina occidentalis, Avicula linguiformis; the Ammonoids, Ammonites complexus and Placenticeras placenta, with Baculites ovatus, B. compressus, Helicoceras Mortoni, Scaphites Conradi, S. nodosus; Nautilus Dekayi. (b) Fox Hills: Anchura Americana, Pyrifusus Newberryi, Cardium speciosum, Mactra alta, Tancredia Americana, Belemnitella bulbosa, Nautilus Dekayi, Placenticeras placenta, Scaphites Conradi, Baculites ovatus, B. grandis.

No species of the genera of keeled Ammonites, Prionocyclus, Prionotropis, Mortoniceras, states Stanton, have been found in America above the limits of the Colorado formation; and further, no species of Heteroceras, Ptychoceras, and Anisomyon occurs below the Montana, no large Baculites, such as B. ovatus, B. grandis, and B. compressus, nor the species Scaphites Conradi, S. nodosus. 
4. Laranie Beds at Judith River (Rej. H(tyden Survey, vol. ix., 4to), according to Meek, in the lower part: Unio Dance and U. Deweyi, Viviparus, Goniobasis, Sphorium, Planorbis, Ostrea subtrigonalis; in the upper part: Ostrea subtrigonalis (?), Corbicula occidentalis, C. cytheriformis, Goniobasis convexa, etc.

Among Vertebrates of the Laramie beds are the following: At Moreau River, South Dakota (west of the Missouri), the Plesiosaurids, Plesioscurus occiduus and Ischyrosaurus antiquus, both described by Leidy. At the Judith River Basin, remains of species related to the Iguanodon of the genera Palcoscincus, Trö̈dr,n and Aublysodon of Leidy; according to Marsh, of Claosaurus, of Ceratopsids and Ornithomimus; of Plesiosaurus and Ischyrosaurus; also of the Rhynchoceph, Chumpsosaurus profundus Cope; and Turtles of the genus Compsemys. At Black Butte, the Ceratopsid, Agathaumas sylvestris Cope. At Castle Gate in southwestern Utah, an important coal-mining village, a species of Claosaurus; in the Denver group, or Upper Laramie, near Denver, species of Ceratops and Ornithomimus. Some of the Mammals of the Laramie are mentioned on pages 852 , 853.

Aublysodon mirandus of Leidy $(1859,1868)$, referred by him to the tribe of Dinosaurs, was based on a number of teeth. Marsh has suggested (1892) that some of the incisors figured may be Mammalian, stating that only the discovery of a tooth of the kind in a jaw will remove doubt.

Fossils from the Cretaceous formation of New Jersey were first described by the excellent naturalist of Philadelphia, Thomas Say, in 1820 (Am. Jour. Sc., ii., 34), who then named species of Baculites, Exogyra (instituting this genus), and Terebratula. 'The beds were called by him "the New Jersey Alluvium." The first reference of the beds to the Cretaceous formation, and first account of their geographical distribution along the Atlantic and Gulf borders, was made by Lardner Vanuxem in January, 1828 (Acad. N. S. Phitad., vi.); and the first systematic description of the fossils, with figures, by S. G. Morton, in a paper of the same date, which follows Vanuxem's. Vanuxem, in a note to his paper (page 63), alludes to Morton's extensive collections of fossils of New Jersey and Delaware, which he had examined in addition to his own. Morton's paper was soon followed by others in continuation.

The Radiolarians found by Tyrrell in the Montana group, Manitoba, have been described and figured by D. Rüst (Canada Survey, 1892).

On the Invertebrate paleontology of the Continental Interior, see especially the publications of Meek in connection with the Hayden Survey and also elsewhere; also papers by C. A. White, and his Correlation of the Cretaceous; also T. W. Stanton's Colorado Formation (1893).

\section{FOREIGN.}

\section{ROCKS - GENERAL DISTRIBUTION.}

The Cretaceous formation covers a large part of southeastern England, east of the Jurassic boundary, from Dorset on the British Channel to Norfolk on the German Ocear; and also a narrow coast region, about and south of Flamborough Head, as shown on the map, page 694, and small areas in northern Ireland and on the islands of Mull and Morven, off Scotland, where it is covered by Tertiary basaltic lavas.

Like the Jurassic, it reappears across the British Channel in France and Demmark, and to the east and south over much of Europe. It usually outcrops along the borders of the great Tertiary areas or within them, indicating that the seas of the early Tertiary, which cover so large a part of the conti- 
nent, were also, for the most part, Cretaceous seas with still wider limits and larger intercommunications. The London-Paris basin, spreading eastward to Denmark, was one of these partly isolated areas; it was 800 miles wide from north to south in the Cretaceous period, 400 in the Jurassic, and about 250 in the Tertiary. Southwestern France and the northeastern half of Spain, making the Pyrenean basin, was another, 450 miles broad; Switzerland and a broad area across Bavaria was another. Italy and the eastern coast region of the Adriatic, with a very broad region in northern Africa, in Egypt and Syria to the eastward, made another, the Mediterranean basin. A great Austro-Russian basin spread beyond the Azof and Black seas to the Caspian, the Caucasus, and farther east over large areas in Persia; and in the Neocomian, it is supposed to have extended by the west side of the Urals to the borders of the Arctic Sea. Only parts of the borders of these great areas are at surface Cretaceous, the Tertiary being the overlying formation.

It is necessary thus to view the Tertiary with the Cretaceous in order to appreciate the fact that Cretaceous Europe, across from the Bay of Biscay and Spain to its eastern border, was mostly a submerged region. The Mediterranean basin, like that of the West India and Gulf basin in America, was the deeper part of the subinerged area. The dry land included the regions of Scandinavia with the Baltic provinces in Russia, a western and northern part of Great Britain, and some isolated areas along the western border and over the central portions of the continent. The resemblance to North American distribution consists in the fact that the dry land was most extensive to the north, and that the deepest waters were about the Mediterranean Sea on the south. The contrast consists in the widespread submergence of the continental surface across from east to west, and the absence of any distinctively Atlantic border region.

In India, there is no evidence of marine Cretaceous beds in the great valley of the Ganges, and only small areas near Pondicherry in the southeastern part of the Peninsula. They cover a large area in Queensland, northeastern Australia, and occur in some other parts of that continent. They are found also in New Zealand, where they contain valuable coal-beds:

In South America, narrow belts of Cretaceous rocks extend, in Venezuela, from Cumana to Pamplona, and from there northward and southward along the Andes, being at an elevation of 9000 to 14,000 feet at the passes of the Portillo and Rio Volcan, and having a height of 20,000 feet. The Upper Cretaceous forms most of the peaks of the eastern Andes, some of the ridges having a height of nearly 19,700 feet. In Peru, latitude $11 \frac{1}{2}^{\circ} \mathrm{S}$, near the pass of Antaranga, its height is about 15,750 feet, and in the Province of Huamachuco, the Gault reaches a height of 16,405 feet. In Chile, in the Cordillera of Chillan $\left(36^{\circ} 18^{\prime}\right)$, the Cenomanian has a height of nearly 15,000 feet. The Cretaceous are the oldest of the beds exposed over the most of northern South America, the crystalline rocks (Archain) excepted (H. Karsten). There is a large area also in the eastern part of Brazil. 
C. A. White has described Cretaceous fossils, from the provinces of Sergipe, Pernambuco, Para, Bahia, and elsewhere, in vol. vii. of the Archives of the National Museum of Rio de Janeiro (1888). Darwin found Cretaceous fossils in Fuegia, on the summit of Mount 'Tarn and near Port Famine, in the Straits of Magellan; and the author, in 1838, obtained Belemnites, probably Cretaceous, on the shores of Orange Bay, near Cape Horn. ${ }^{1}$

\section{Subdivisions.}

In view of the very wide and various distribution of these continental Cretaceous beds, and the diversity of conditions as to water, depth, and temperature under which they have originated, it is not to be expected that there should be uniformity in the succession of rocks, either as to kinds or as to fossils, since life varies in distribution with variations in the above conditions. As a consequence, the Cretaceous formation is, even in Europe, a formation with or without chalk, with or without limestone, with or without sandstones, or chiefly made up of sandstones, and with wide variations in the fauna.

The principal British subdivisions are the following :-

I. Lower Cretaceous. - The Neocomian of Thurman (1832), so named from the Latin name of Neufchâtel, Neocomium; including (1) the Wealden, and (2) the Lower Greensand, but restricted by some to the Wealden.

II. Upper Cretaceous. - (1) The Gault or Albian, consisting of clay with some greensand (it is made Lower Cretaceous by most European geologists); (2) the Cenomanian, consisting of ( $\alpha$ ) the Upper Greensand, marl beds, and the Gray Chalk of Folkestone; (3) the Turonian, the Lower White Chalk without flints; (4) the Senonian, or the Upper Chalk with flints. Above comes, in Denmark, (5) the Danian, or the Maestricht beds.

The Wealden, including the Hastings sands below and the Weald clay above, is about 1500 feet thick in southern England, where it was deposited in the fresh waters of a delta over 20,000 miles in area. The Gault is 100 feet to 200 feet thick. The chalk without flints is a prominent formation across from Flamborough Head, on the east coast of England, to the southern coast, in Dorset.

The "greensand" is like that of America (page 68). The chalk consists chietly of Foraminifers, or the shells of Rhizopods, but contains also remains of Sponges and other forms of life, which together appear to indicate that the beds were formed at depths of a few hundred feet - by some made 300 fathoms or more; they are similar in general character to those now accumulating over the sea-bottom. The flint nodules occur in layers in the chalk. The facts seem to show that the sea-bottom, on account of depth or for some other reason, was in a more favorable condition for growing siliceous Sponges in some places than at others. The material of a flint nodule, while

1 For a note on the discovery, see Am. Jour. Sc., xxxv., 83, 1888. 
ordinarily black or grayish-black flint, is sometimes chalcedony or agate, and on the other hand, it is often white exteriorly from admixture with chalk. The fantastic shapes of some flints are often due in part to the fossils they include.

The rocks in northern France or Belgium much resemble those of England. In Germany, above the Lower Cretaceous, there is a large predominance of sandstones and marls. In Switzerland, the Lower Cretaceous of the Jura, about Neufchâtel, is mostly limestone; and of the same nature is the chief part of the Upper in other parts of Switzerland and the Austrian Alps. The same is true for most of the Cretaceous of Italy, northern Africa, Syria, the Mediterranean region being marked in places by coral reefs, Hippurite limestone, and other evidences of pure ocean waters.

The following are the subdivisions adopted in France and Belgium and Switzerland. (See further on their distinctions, page 864.)

\section{Upper Cretaceous.}

4. Danian. - 1. Maestrichtian or Dordonian ; 2. Garumnian (Pisolitic limestone).

3. Senonian. - 1. Santonian; 2. Campanian.

2. Turonia N. - 1. Ligerian; 2. Angoumian.

1. Cenomanian. - 1. Rhotomagian; 2. Carentonian.

\section{Lower Cretaceous.}

4. Albian (= Gault). - Vraconnian = Upper Albian, at Cheville in the Valais.

3. Aptian ( = rest of Lower Greensand).

2. URGONIAN (= lower part of Lower Greensand). - 1. Urgonian ; 2. Rhodanian.

1. Neосомгал (=Wealden). - 1. Valenginian (= Hastings sand); 2. Hauterivian (Weald clay).

\section{LIFE.}

Plants. - The plants of the Wealden, and the rest of the Neocomian in England and Europe, are Cycads, Ferns, and Conifers, as in the Jurassic, with a show of progress in the first appearance of species of the genera Pinus and Abies, the true Pines and Spruces, but with no Angiosperms. But in the Gault and the Upper Cretaceous occur leaves of Angiosperms of many common kinds, though all of extinct species; as the Magnolia, Myrtle, Willow, Walnut, Maple, Fig, Holly, besides a Redwood (Sequoia); and there were also Palms, of the genus Palmacites. No remains of Lower Cretaceous Angiosperms and Palms have been reported from England. Vegetable remains are rare fossils because the beds are mostly marine.

The microscopic Protophytes, called Diatoms and Desmids, are found in some of the beds, especially in the flint. The Desmids are far the more common because not siliceous, and therefore not dissolved; the kinds called Xanthidia are especially abundant, and are similar to those from Devonian hornstone (page 583). Coccoliths are common in the Chalk. 
Animals. - 1. Rhizopods. - Foraminifers are commonly the principal 1444-1447.
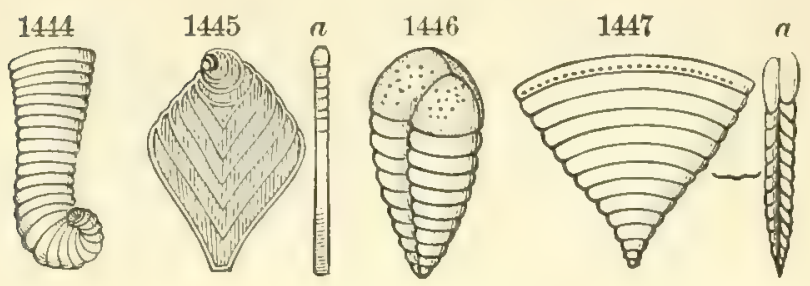

RHIzopoDs. - Fig. 1444, Lituola nautiloidea ; 1445, $a$, Flabellina rugosa; 1446, Chrysalidina gradata; $1447, a$, Cuneolina pavonia. material of the Chalk. According to Ehrenberg, a cubic inch of chalk often contains more than a million of microscopic organisms, which are chiefly the shells of Rhizopods. Some of the species are represented much enlarged in Figs. 1444-1447.

2. Sponges. - Sponges were of like importance in the history of the Cretaceous rocks on account of their siliceous spicules and framework, which were the chief source of the flint. The recent discovery over the ocean's bottom of Sponges whose fibers are wholly siliceous was a revelation as to their importance in flint-making. The species are mostly of the Hexactinellid and Lithistid

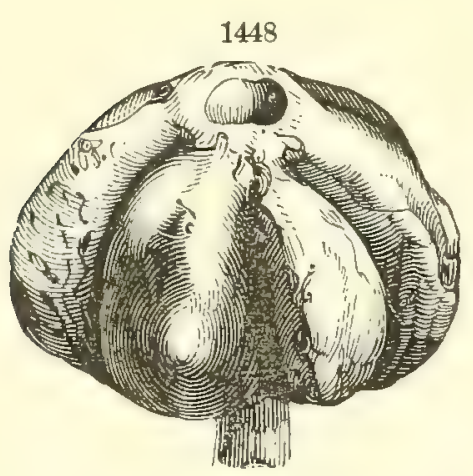

$1448,1449$.

Sponge. - Fig. 1448, Siphonia lobata. Echinoderm. - Figs. $1449 a, b$, Ananchytes ovatus.

kinds. One of the Lithistid kind is represented in Fig. 1448, and spicules from various sponges in Figs. 446-460, on page 432, obtained by G. J. Hinde, from a cavity in a mass of flint, which afforded also a multitude of other forms. The Cretaceous Hexactinellids comprised the goblet-shaped Ventriculites, and many other kinds.

3. Corals, Echinoids. - Corals and Echinoids were common in some of the limestones, especially those of southern Europe. The Corals were of modern type in being Hexacoralla; and one Cretaceous genus, Caryophyllia, has still its many species.

Echinoderms were of many genera and species, especially in the Upper Greensand (Cenomanian) and chalk. The Ananchytes ovatus, Fig. 1449, is of the Upper Chalk (Senonian) of England. With it, and also in the Cenomanian, occur species of Holaster, Micraster, Salenia, Galerites, and others.

4. Mollusks. - Lamellibranchs included many species of the genera Grypheca, Exogyra, Inoceramus, Trigonia, which are rare after the Cretaceous, or end with it, and also of Pecten, Lima, etc. They comprise also the pecul- 
iar Rudistes, of which there are over a hundred species in the Cretaceous, and none later; they are especially common in the Mediterranean region.
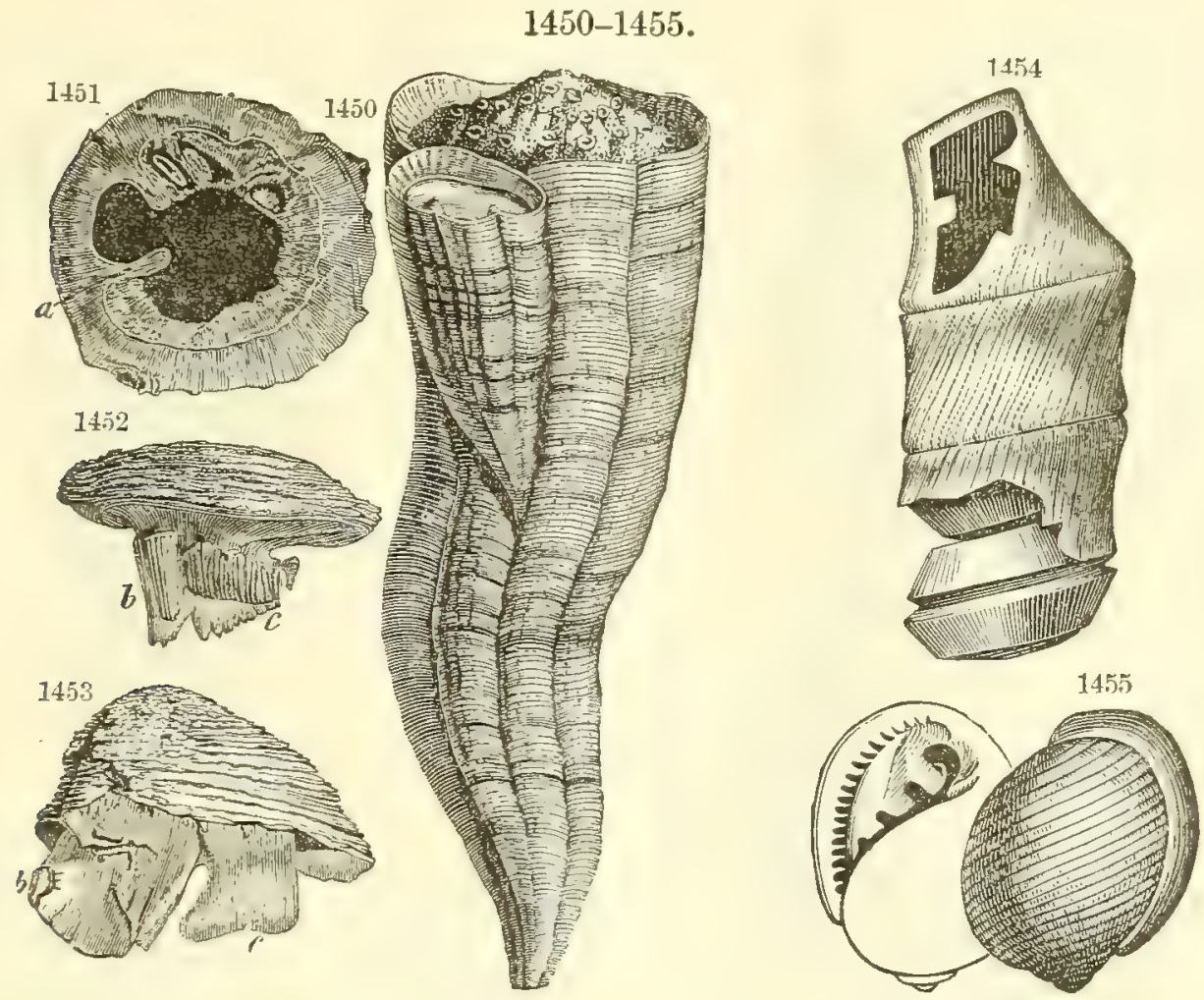

Lamelltbrarchs, Rudistes Family. - Fig. 1450, Hippurites Toucasianus; 1451, H. dilatatus ; 1452, Radiolites Bournoni; 1453, Sphærulites Hœninghausì. GAstropods. - 1454, Nerinea bisulcata ; 1455, Cinulia avellana.

Fig. 1450 represents Hippurites Toucasianus d'Orb. (with a small one attached), and 1451 , the interior of the shell of $H$. dilatatus. Figs. 1452, 1453 show the forms of the upper valves, in profile, of species of Radiolites and Sphoerulites, of the same family. The prominences $b, c$ are for the attachments of muscles. A single species, Radiolites Mortoni Woodw., has been found in England. Figs. 1454, 1455 , are Gastropods of the peculiar genera Nerinea and Cinulia, both now extinet.

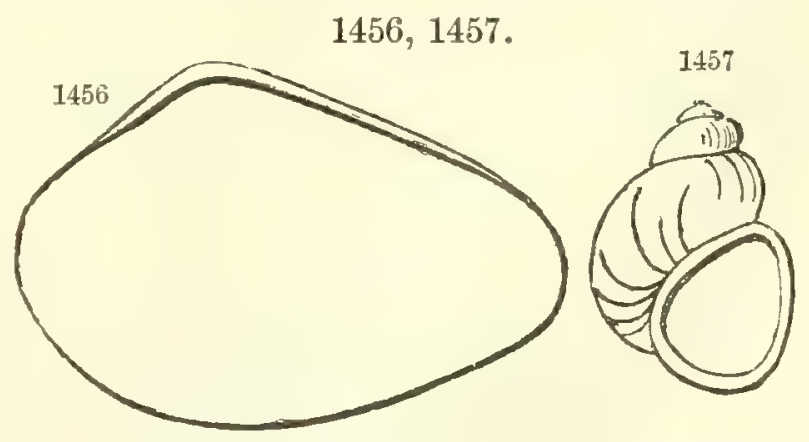

Fig. 1456, Unio Valdensis; 1457, Viviparus (Paludina) fluviorum.

Two of the fresh-water shells from the Wealden are represented in Figs. 1456,1457 , one a Unio, and the other the common Viviparus.

Ammonites were in great numbers; and, as in America, the open-coiled forms are far more abundant than in the Jurassic. Several of the latter are shown in Figs. 1458-1461, and a spiral form, Turrilites, in 1462. Another related form is that of the open-coiled Turrilite, Helicoceras, which has several species in Europe, as well as in America. Nautilus also has many 
species. The Ammonites Lewesiensis Mant., from the Lower Chalk of England, has a diameter of a yard.

1458
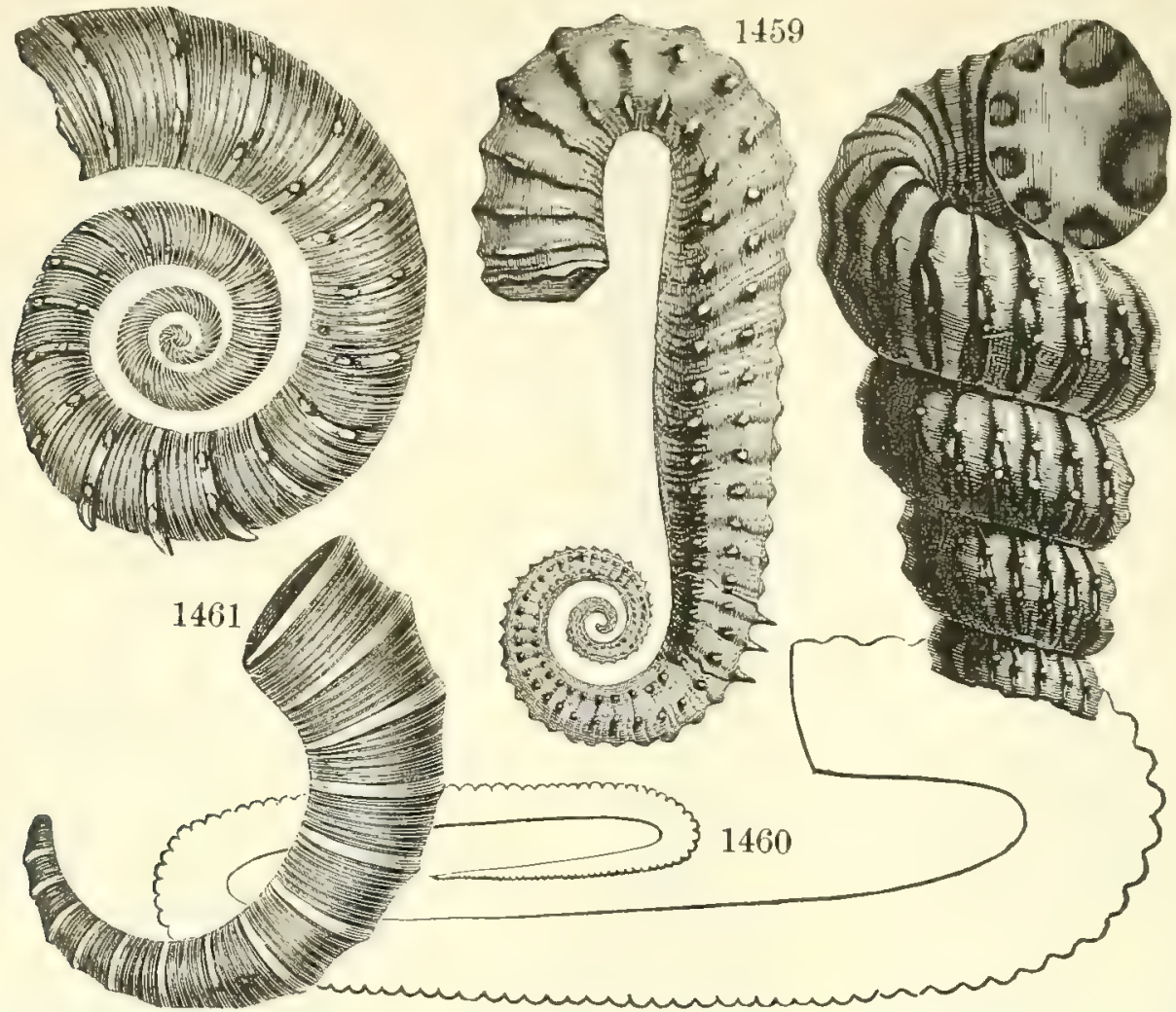

Cephalopons, Ammonite Family. - Fig. 1458, Crioceras Duvalii ; 1459, Ancyloceras Matheronianum, 1460, Hamites attenuatus; 1461, Toxoceras bituberculatum; 1462, Turrilites catenatus.

Vertebrates. - 1. Fishes. - The earliest of the Teleost Fishes are first known from remains in the Middle Cretaceous, and with them were Sharks of modern as well as ancient type, with numerous Ganoids. Among Teleosts, the Salmon family was represented by species of Osmeroides (Fig. 1463),

1463.

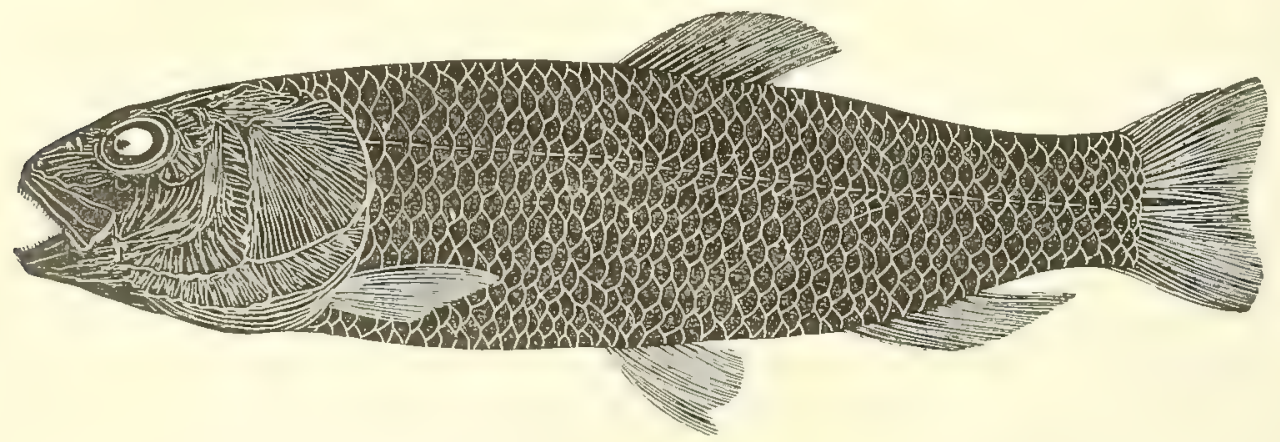

TELeost. - Osmeroides Lewesiensis $\left(\times \frac{1}{4}\right)$.

8 to 14 inches long; the Perch family, by species of Beryx; the Herrings, by species of Clupea; Mackerels, by several species; the rapacious Saurodonts, by species of the American genera Saurocephahus, Ichthyodectes, Portheus, 
Daptinus, etc. Ganoids were numerous, both of Cestraciont Sharks and of Squalodonts, the latter being represented by species of the genera Carcharias, Lamna, Oxyrhina, Odontaspis, Otodus, ete.

2. Reptiles. - The Wealden of England, a region of great marshes and lakes, and the beginning of the Cretaceous, has afforded remains of 30 or more species of Dinosaurians, Crocodilians, and Plesiosaurians. The number is very large even for an area of 20,000 square miles (100 miles by 200). But these Reptiles may not all have been cotemporaries; yet the period was not so long but that one of the Iguanodons that existed in the Lower Wealden continued on into the Lower Greensand. Moreover, the species known may not be a fourth of those that existed in the region during the Wealden epoch. They included Dinosaurs of nearly all the subdivisions: the Herbivorous Morosaurids, as Morosaurus (Pelorosaurus) Becklesii, Cetiosaurus brevis; Stegosaurids, as Hylcosaurus Oweni and Polacanthus Foxi; Ornithopoda, as Iguanodon Bernissartensis, 33 feet long, I. Mantelli, 20 feet long,
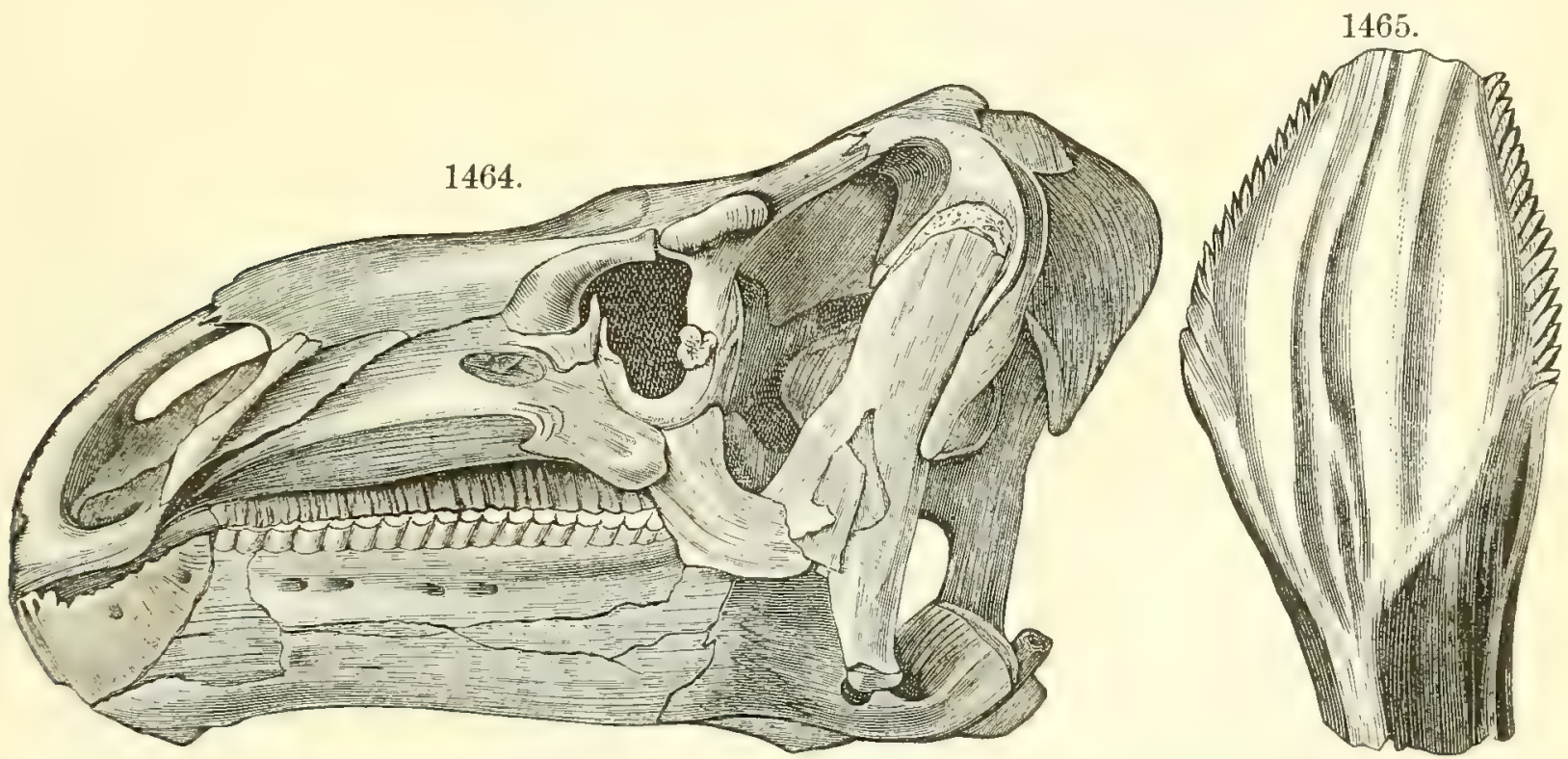

Dikosatr. - Fig. 1464, Iguanodon Bernissartensis $\left(\times \frac{2}{2}\right)$. Dollo. 1465, I. Mantelli, tooth, natural size. Mantei.

Hypsilophodon Foxi; Carnivorous Dinosaurs, as Megalosaurus Dunkeri. And with these and other Dinosaurs, there were some Crocodilians, a Plesiosaurus, Chelonians, and several species of Pterosaurs.

The skull of an Iguanodon, from the Wealden of Belgium, is represented in Fig. 1464, and a tooth, full size, of I. Mantelli, from the Wealden, in Fig. 1465. The foot, which is over $4 \frac{1}{2}$ feet long, has the three-toed characteristic of the Ornithopods. The genus was named from a resemblance in the teeth to those of the Iguana. Among the Pterosaurs, the genus Ornithostoma of Seeley includes a toothless species from the Cambridge Greensand, related to Pteranodon of America.

After the Wealden, Reptiles were less numerous. But both Herbivorous and Carnivorous Dinosaurs continued. The carnivorous Acanthopholis 
horridus of Huxley occurs in the Upper Cretaceous, and Megalosanrus Bredai of Seeley at the top of the Cretaceous in the Mastricht beds. Mosasaurids make their first appearance after the Neocomian, as in America; a Liodon occurring in the Upper Chalk, and Mosasaurus Camperi Meyer (Fig. 1466), in the Maestricht beds, and also at Lewes, England.

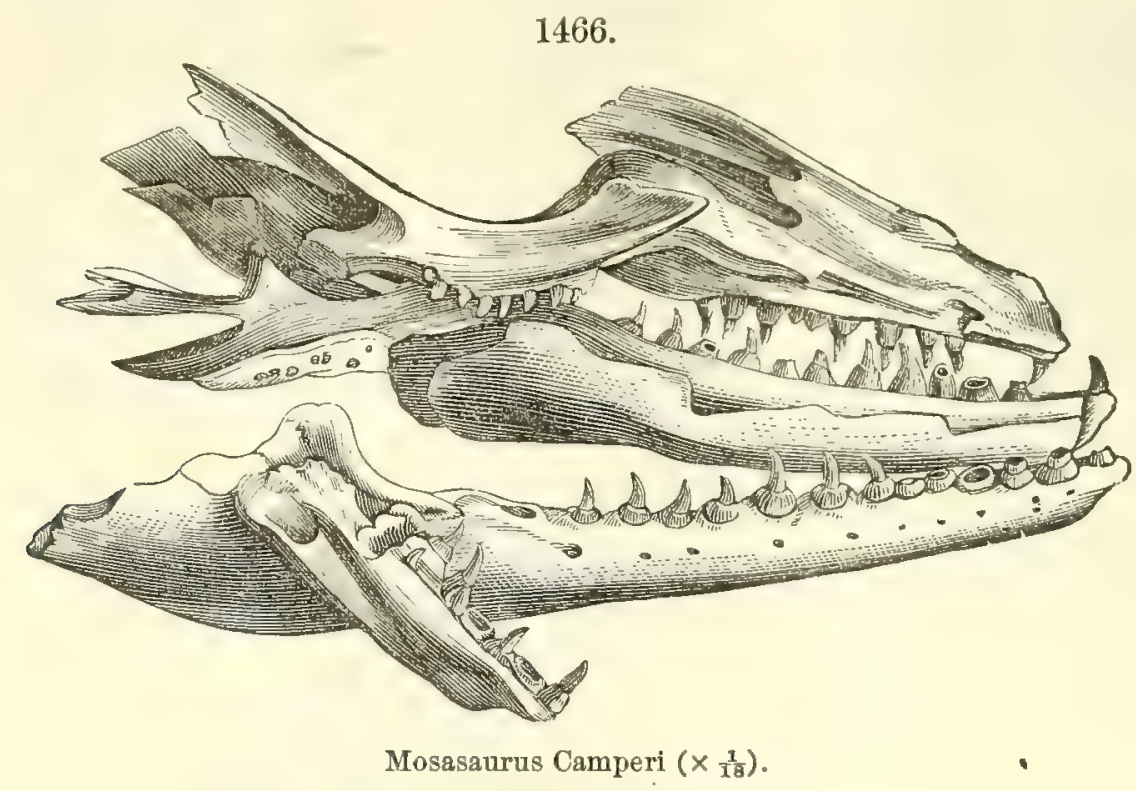

At Gosau in the northeastern Alps, Austria, remains of the horn-cores of Ceratopsids have been found in beds of the Upper Greensand, and described under the name Struthiosaurus.

3. Birds. - Imperfect remains of two species of Enaliornis Seeley have been obtained from the Cambridge Greensand; and Professor Seeley observes that they may be related to the Hesperornis of Kansas. A species of Paloeornis occurs in the Wealden.

4. Mammals. - Only one species had been reported up to 1894 . It is referred to the Jurassic Marsupial genus Plagiaulax. The only specimen is a molar tooth from the Wealden of Hastings (S. Woodward, 1891).

\section{Local Subdivisions and their Characteristic Fossils.}

\section{Lower Cretaceous.}

A. Great Britain. - 1. The Wealden. (a) The Hastings sand and clays, or Lower Neocomian, which have afforded, besides plant remains and fresh-water shells, the bones of many Saurians.

(b) The Weald clay or Midale Neocomian $\left(400^{\prime}-1000^{\prime}\right)$, containing, at a level about $100^{\prime}$ from its top, the Paludina limestone, sometimes called Sussex marble, consisting chiefly of fresh-water shells of Paludina fuviorum - a marble "renowned in the annals of church architecture." In addition to fresh-water shells, and fish remains, there are remains also of Reptiles; and on the Isle of Wight occur Exogyra sinuata and an Ostrea.

The Lcwer Greensand, $250^{\prime}-450^{\prime}$, overlies the Wealden in southern England, but overlaps northward the Cpper Oölytic beds. Contains Ammonites (Hoplites) Deshayesi, 
A. (Hoplites) Noricus, Ancyloceras gigas, Diceras Lonsdalei, Exogyra sinuata, Gervillia anceps, Pinna Mulleti.

The clays of Speeton cliffs of the Neocomian have afforded marine fossils ; the Lower, the 3 zones of Ammonites (Olcostephanus) Astierianus (lowest), with Toxaster complanatus, Olcostephanus Speetonensis, Hoplites Noricus; and the Middle, Pecten cinctus, Exogyra sinuata, Belemnites jaculum, etc.

B. France. - The term Neocomian, as first used (by D'Orbigny) was restricted to beds of the age of the Wealden; his Urgonian (named from Orgon, Bouches-du-Rhône), as used by Lapparent corresponds to the lower part of the Lower Greensand (Atherton clay); Aptian, to the rest of the Lower Greensand, except the upper part (Folkestone beds); and Albian, to the latter with the Gault. Lapparent includes all to the top of the Gault in his "Infra-Crétacé."

The Neocomian is divided into (1) the Valenginuan (so named from the Château de Valengin, near Neufchâtel), and (2) the Hauterivian (so named from Hauterive). The Valenginian contains Toxaster Canpicheii, Strombus Sautievi, Pygurus rostratus, Nerinea Favrei, N. Meriani; and the Hauterivian, Dysaster ovulum, Toxaster complanatus, Ostrea CouToni, O. macroptera, Pinna Mulleti, Trigonia carinata, Ammonites (Hoplites) radiatus, A. (Engonoceras) Gervillianus, A. (Olcostephanus) Astierianus.

The Urgonian contains Heteraster oblongus, Requienia ammonia, R. Lonsdalei, Radiolites Neocomiensis. The upper part of the Urgonian, containing Heteraster oblongus and Requienia oblonga, is the Rhodanian of Renevier. In southern France, toward the Pyrenees, the Urgonian contains Requienia Lonsdalei with Orbitulina conoidea, O. discoidea, Nerinea gigantea, Heteraster oblongus.

The Aptian (from Apt, in Vaucluse) contains, at the Perte-du-Rhône, Epiaster polygonus, Plicatula placunea, Ostrea aquila, Trigonia caudata.

In Germany, the Lower Cretaceous to the base of the Gault is the Hils formation or Neocomian. In northwestern Germany, in Hanover, on the borders of Holland, the Hastings sand is represented by the Deistersandstein, containing some coal, remains of Reptiles including the Iguanodon, and many plants; and above this is the Weald clay (Wälderthon) $70^{\prime}-100^{\prime}$. The marine beds in north Germany contain Toxaster complanatus, Ammonites (Olcostephanus) Astierianus, Hoplites radiatus, Hoplites Noricus, Exogyra Couloni. Next is the Gault, the lower part of which is made the equivalent of the Lower Greensand of England, or the Aptian, with Ammonites Martini, A. Deshayesi, Exogyra Couloni, and the rest the English Gault, with Ammonites (Schlönbachia) inflatus, $A$. (Hoplites) auritus, A. (Hoplites) lautus, A. (Hoplites) interruptus.

\section{Upper Cretaceous.}

1. Albian or Gault. - In England contains Ammonites (Hoplites) auritus, A. (Schlönbachia) varicosus, A. (Schlönbachia) cristatus, A. (Acanthoceras) mammillaris, Inocer $\alpha$ mus sulcatus, Pterocera hicarinata, Hamites attenuatus (Fig. 1460), Toxoceras bituberculatum (Fig. 1461), Turritites catenatus. Includes 3 zones according to Barrois, those of (1) Schlönbachia inflata; (2) Hoplites interruptus; (3) Acanthoceras mammillare. In France, near Montiérender, there are the Ammonites: (1) Schlönbachia inflata ; (2) Hoplites splendens. Hoplites auritus, Acanthoceras mammillare, Hoplites Deluci, Acanthoceras Lyelli; (3) Turvilites catenatus. The Gault is the Flammenmergel of Germany with Schlönbachia inflata, Hoplites lautus, Hoplites auritus, Aucella gryphooides.

2. Cenomanian. - In England consists of (1) the Upper Greensand, (2) Chloritic or Glauconitic Marl, (3) Chalk Marl, (4) Gray Chalk. The Upper Greensand contains below, Exomyra conica, Pecten quadricostatus, Inoceramus concentricus, Cardium Hillanum, Trigonia scabricula, Hamites alternatus, and above, Holaster nodulosus, Pecten asper, Terebratula biplicata, Rhynchonella compressa. The Chloritic Marl contains Terebratula DANA's MANUAL $-\mathbf{5 5}$ 
biplicata, Solarium ornatum, Plicatula inflata, Schlönbachia rarians. The Chalk Marl contains Holaster lavis, Rhymchonella Martini, Turritites costatus, Inoceramus striatus, Schönbachia ravians. The Crray Chalk, which is the upper part of the Cenomanian, called also the Lower Chalk, includes in England the zones: (1) of Scaphites crqualis and Plocoscyphia maendrina; (2) of Rhynchonella Martini; (3) of Holaster subglobosus; (4) of Belemnitella plena.

In France, the beds in the valley of the Seine, called the "Craie glauconieuse" or Rhotomagian of M. Coquand, contain Holaster suborbicularis, Cidaris vesiculosa, Ammonites (Acanthoceras) Rhotomagensis, Acanthoceras.Mantelli, Turrilites costatus, Pecten asper, Inoceramus striatus. The overlying Carentonian of Renevier is the zone of Ostrea biauriculata, Belemnitella plena, Caprina adversa.

In Germany, the Cenomanian is the Lower Pläner, affording Pecten asper, Ostrea diluviana, Catopygus carinatus, Schlönbachia varians, Acanthoceras Rhotomagense, Acanthoceras Iantelli, Turilites costatus, $T$. tuberculatus. Three zones are recognized: (1) zone of Pecten asper and Catopygus carinatus; (2) of Schlönbachia varians; and (3) of Acanthoceras Rhotomagense and Holaster subglobosus.

3. Turonian, or the Lower White Chalk without flints, with the nodular chalk of Dover at the top, contains Holaster planus, Ananchytes ovatus, Rhynchonella Cuvieri, R. plicatilis, Ostrea vesicularis, Spondylus spinosus, Ammonites (Pachydiscus) peramplus, Hemiaster Verneuili, Scaphites Geinitzi.

In England the zones recognized are: (1) of Rhynchonella Cuvieri; (2) of Terebratulina gracitis; (3) of Holaster planus.

In France, (1) the Ligerian (named from the basin of the Loire) (the Middle Pläner of Germany) is the zone of Exogyra columba, Inoceramus labiatus, Pinna decussata ; and (2) the Angoumian, the zone of Terebratula gracilis, Holaster planus, and of Radiolite and Hippurite limestone in the eastern Alps.

4. Senonian, or the Chalk with flints (named from a locality of chalk at Sens). Contains Ananchytes ovatus, Micraster cor-bovis, M. cor-anguinum, M. glyphus, Inoceramus labiatus, Spondylus spinosus, Ostrea vesicularis, Belemnitella quadrata, B. mucronata, Scaphites pulcherrimus. (1) The Santonian is the zone of Micraster brevis, $M$. coranguinum, and Inoceramus digitatus; (2) the overlying Campanian is the zone of Ostrea vesicularis, Belemnitella mucronata, B. quadrata, and includes the Upper Quadersandstein, the Lemberg chalk, and chalk of Meudon and of Reims.

5. Danian. - The Lower Danian or Maestrichtian or Dordonian is the zone of Nautilus Danicus, Ostrea decussata, Belemnitella mucronata, Baculites Faujasi; the Upper or Garumnian (named from Garonne), that of Micraster tercensis, and includes the chalk of Faxe, fresh-water beds in Provence, and marine and brackish-water beds in the Pyrenees, $100^{\prime}$ to $1000^{\prime}$ thick. From the Danian comes the Mosasaurus Camperi (page 864).

In Provence, southeast France, the Sexosian, overlying the Angoumian, or limestones containing Hippurites Petrocorriensis, etc., includes, according to M. 'Toucas (1891):-

1. The Santonian (a) with Hippurites giganteus, Rhynchonella Petrocorriensis, Trigonia limbata; (b) with Amm. tricarinatus, Hippurites brevis, Micraster brevis; (c) Ammonites Texanus, Inoceramus digitatus, Cidaris clavigera; (d) Ammonites Texanus, Actinoceras verum, Hippurites Corbaricus, Cidaris clavigera.

2. Campantan, (a) Hippurites dilatatus, H. Toucasi, H. socialis, Ostrea vesicularis; (7) Hippurites Iilatatus, H. floridus, Ostrea Merceyi, Schizaster atavus; Upper, (c) CiTaris cretosa, Ostrea Matheroni, Lima decussata; (d) Ammonites Gallici, Nerinea bisulcata, Hippurites, Hemiaster Regulusanus.

The following species are reported from different continents :-

Ostrea larva, North America; Europe; India. Gryphoea vesicularis, North America; 
Europe; southwest Asia. Exogyra lavigata Sow., Europe; Colombia, South America. Exogyra Buussingaultii D'Orb., Europe; Colombia, South America. Inoceramus Crispii Iant., North America; Europe. Inoceramus latus Mant., North America; Europe. Inoceramus mytiloides Mant, North America; Europe. Neithea Mortoni, North America; Europe; India; Peru, South America. Pecten circularis Goldf., North America; Europe; India; Peru; South America. Trigonia limbata D'Orb., North America; Europe; India. Trigonia aliformis Sow., North America; Europe; southwest Asia; Colombia, South America. Trigonia longa Ag., Europe; Colombia, South America. Hippurites organisans, Europe; southwest Asia; Peru and Chile, South America. Nerinea bisulcata D'Arch., North America (T'exas); Europe. Baculites anceps, North America; Europe; Chile, South America. Ammonites vespertinus Mort., North America ; Europe.

In South America, in the Argentine Cordillera, Behrendien found the following European Cretaceous species: Hoplites dispar D'Orb., H. Desori Pictet, Lithodomus prolongus D'Orb., Corbula Neocomiensis D'Orb., Mytilus simplex and M. Carteroni D'Orb., Exogyra subplicata Rœm., Astarte obovata, and others (1892). Two Cretaceous fossils from St. Paul's and St. Peter's, islands in the straits of Magellan, have been described by C. A. White (Proc.U. S. Nat. Mus., xiii., 13, 1890), namely a large Hrmites, probably H. elatior of Forbes, a species collected by Darwin, and a large Lucina.

In La Plata, in South America, the Cretaceous (probably Lower Cretaceous) has afforded, according to Lydekker (1893), Dinosaurs, of new genera, two of the Sauropod. type, Titanosaurus and Argyrosaurus, and one Microcoelus, of undetermined relations.

The Cretaceous of Brazil along the coast region between $3^{\circ}$ and $13^{\circ} \mathrm{S}$. probably constitutes the Abrolhos Islands, and is found also in the interior along the Purús. The Bahian group of Hartt, supposed to be Neocomian, has afforded Saurians; the Sergipian, Lpper or Middle Cretaceous, contains Ceratites and Ammonites, some identical with species of the Texas Cretaceous. The Continguiban group, probably Senonian, as in the Province of Sergipe, contains Ammonites and Inocerami. The Amazonian group of Purús - Upper Chalk or Maestrichtian - has afforded remains of Mosasaurs and Turtles.

\section{GENERAL OBSERVATIONS ON THE CRETACEOUS PERIOD.}

\section{GEOLOGICAL AND GEOGRAPHICAL PROGRESS.}

1. General progress. - Continental progress in North America previous to the Cretaceous period was chiefly interior work; the work of the great Interior Continental seas, - endogenous, as it has been styled. During the Cretaceous period, this endogenous work was continued over the Western Continental Interior; but, in addition, progress went forward largely through sea-border work, on both the Atlantic and the Pacific sides. On the Atlantic, after marine formations began, no outside ridges or elevated land are supposed to have existed; and this appears to have been the fact also on parts of the Pacific border.

In Europe, the rock-making continued to be essentially Interior Continental throughout the period. The beds of Mull, Morven, and Antrim were deposited within one of the continental troughs; for the Archæan Hebrides existed outside, and probably were a longer range than now. It was the same sinking trough, moreover, in which beds had been deposited during earlier Miesozoic times. 
2. Changes at the close of the Lower Cretaceous. - After the earlier Cretaceous, the emergence of the Mexican plateau took place, shutting off the Atlantic waters from the Pacific; and at the same time, movement change occurred in Texas. According to Hill, faults and flexures were produced, especially in the vicinity of Austin. The general direction of the faults in the region is $\mathrm{N} .20^{\circ} \mathrm{E}$. The amount of displacement is generally less than 100 feet; but in the chief fault it is 500 to 750 feet, and the course is marked by an escarpment 100 to 250 feet high. Along the faults the beds are in some places flexed, and the limestone is rendered crystalline. Moreover, there is an abrupt transition in species in passing from the Lower to the Upper Cretaceous. The Potomac beds, of the Atlantic border, underwent some change in level and some surface erosion; but no upturning.

On the California coast the continuity of the Shasta-Chico series indicates that the general subsidence mentioned by Diller as in progress during the Cretaceous period was not interrupted at the close of the Lower Cretaceous. But in Western British America, the increased subsidence which introduced the Upper Cretaceous, and spread the sea over the Continental Interior, is supposed by G. M. Dawson (1890) to be marked in a deposit of marine conglomerates, occurring in many places in the southern part of British Columbia, in the Queen Charlotte Islands, northward about the Upper Yukon, and eastward along the line of the Rocky Mountains. Dawson reports also that at this stage of the Cretaceous, or near it, there was renewed volcanic activity in the Queen Charlotte Islands and in the Rocky Mountain Range.

\section{BIOLOGICAL CHANGES AND PROGRESS.}

Part of the biological history of Mesozoic time has already been reviewed. Still greater changes took place in this later portion, and these now come under consideration.

Plants: Cycads, Angiosperms, Palms. - The Cycads, the most characteristic feature of the Triassic and Jurassic, had their maximum development during the latter period. They were still prominent, however, in the forests of the Early Cretaceous, and flourished even in the Aretic regions on Greenland, Spitzbergen, and Alaska; but they were subordinate to the Conifers, and, in the Upper Cretaceous, to the Angiosperms. At present there are only about 50 species of Cycads.

The line leading up to Angiosperms is uncertain. It is a notable fact that remains of plants of this class are wholly absent from the Wealden of England and from the Kootanie of America, and that only one species of doubted locality has been reported from the Neocomian of Europe. The 75 species identified by Fontaine from the fossil leaves of the Potomac formation of eastern America show that the trees were then well established in the American forests, although Conifers were by far the more numerous. But still, as Fontaine shows, they leave their origin unexplained. 
The Palms came in during the Middle Cretaceous as the decline of the Cycads made progress. It is supposed probable that they were in the successional line of some type of Cycads, since they approach them in their foliage, in their usually simple stems, and in having the pithy interior traversed by bundles of woody fibers.

Progress in Mollusks: Culminations under the type. - The Tetrabranch Nollusks, which include the Nautilus and Ammonite tribes, pass their climax and decline in the Cretaceous period. The Nautiloid, which commenced with a straight body and a shell no longer than the little finger, and was continued in curved and coiled forms, and reached its maximum in the Carboniferous, is continued to the present time, but only in two or three species of Nautilus; and these are the last of the Tetrabranchiates. The Ammonite section, which commenced with the closely coiled Goniatite in the Early Devonian, became increasingly complex in the flexures of the septa, and finally two to three feet in diameter in the Jurassic and Cretaceous seas, where it numbered thousands of species. It disappeared entirely, or nearly so, at the close of the Cretaceous.

The Dibranchiate Mollusks, or the Cuttle-fishes, whose shells are internal when any exist, are known first from the later Triassic beds. Under the Belemnite family they become very numerous in the Cretaceous, and apparently end at its close. But other Cuttle-fishes were continued; and probably the giant species of modern Newfoundland and other seas, having bodies 12 to 15 feet long, arms of 25 feet, and eyes of 8 inches diameter, the largest in the animal kingdom, are evidence that the type, and the type of Mollusks, has now its time of culmination as to grade of species, though not as to numbers and predominance in the marine fauna of the world.

Fishes: their culmination in Mesozoic time. - The type of Fishes is supposed to have culminated as early as the Triassic in the Ceratodus and related Dipnoans, which have rudimentary arms in the fins, essentially lungs as well as gills, and other Amphibian-like characteristics. The line to the Teleosts, through the Amioids, was a declining line. In some respects the Teleosts are more highly specialized, but not in a way toward superiority; they are purer representatives of the Fish-type, and better illustrate the fact that the Fish-type is a low style of Vertebrate. The Selachians hold to their early characteristics of a cartilaginous or semiosseous skeleton, of gills without gill-covers, and of a heterocercal or vertebrated tail. The Cestraciont Sharks, which were common in the Cretaceous, became fewer afterward, and now only four species exist - and these live in Australian and Japan seas. The Squalodonts, or Sharks of modern type, reached later their time of maximum display.

Decline in Amphibians. - Amphibians, so far as registry gives evidence, were few in species after the Triassic period. In the scale-covered and largetoothed Labyrinthodonts of the Permian or Triassic periods they passed their maximum as to size, grade, and numbers. No American, British, or Euro- 
pean species of Cretaceous Labyrinthodonts are yet reported. The species were too few and too largely terrestrial to have secured frequent fossilization.

Reptiles. - The Reptiles of the Cretaceous are for the most part a continuation of Jurassic types, without marked evidence of upward progress. The Horned Dinosaurs, or Ceratopsids of Marsh, probably the latest of the larger species, while showing striking advances toward Mammalian forms in the bovine or rhinoceros-like horns and the two-pronged teeth, are a degenerate group, specialized downward, not upward. As Marsh states, they have the largest heads and smallest brains of any of the Reptile race.

The Mosasaurids also, exclusively Cretaceous species, illustrate profound degeneration. For, in these Snake-like species, the Lacertian type becomes enormously multiplicate posteriorly in the vertebral column; the legs are reduced to fins, as in Plesiosaurians, the posterior part of the body is turned into a fish-like skulling organ, and made the chief means of locomotion; and the pelvic girdle has lost connection with the vertebræ, there being no sacrum. Here degeneration has developed, not imperfect limbs and a defective skeleton, not something between a Fish or Amphibian and a Reptile, but a profoundly decephalized Reptile, adapted to aquatic life as if its outcome. The last of the Mosasaurs in America occur in the Montana Cretaceous; in Europe, in the beds of Maestricht.

Snakes are known from the American Laramie, and also from the Cretaceous of France. They were no doubt successors to an aquatic type, and related, it is supposed, either to the Mosasaurs, or to the Dolichosaurs of the English Chalk.

The true Crocodilians have a heart of four cavities, and traces of a diaphragm; and the teeth are implanted in sockets. But these high characteristics lose part of their apparent significance in view of the fact (1) that the four-cavity heart, after all, does not prevent the commingling of the venous and arterial blood before it enters the system; (2) that the character of teeth in sockets began in the Permian; and (3) that the animal has limbs so short that it "drags its body somewhat along the ground," in true Reptilian style.

The Dinosaurs, on the contrary, stood on long limbs like a Mammal, and had nearly the same freedom of locomotion. They were, however, as has been explained, merosthenic Reptiles, that is Reptiles having great and powerful hind limbs as the chief organs of locomotion, with usually small fore limbs and small brains. If they were the highest of Reptiles, then the Reptilian type reached its perfection under a merosthenic structure.

But the distinction of highest, as remarked on page 797, probably belongs to the Pterosaurs, which are eminently prosthenic. The largest species of the group existed in the Cretaceous period. It is not improbable that they had a double heart, like the Crocodiles, and one as good as that of the Birds. 
There are grounds enough, therefore, for the conclusion that the class of Reptiles culminated in the latter half of the Reptilian age. The reality of the Reptilian feature of the era comes out strongly on comparing the great Reptiles in the Wealden as to size and numbers with those of the present time.

Now, in India, or the continent of Asia, there are but two species of Reptiles over 15 feet long; in Africa, but one; in all America, but three; and not more than six in the whole world; and the length of the largest does not exceed 25 feet. During the Wealden there lived in England alone 16 large Dinosaurs and 12 Crocodiles, besides a Plesiosaur and three Pterosaurs. The Reign of Reptiles becomes more strongly pronounced when the little Marsupial Mammals of the era are brought into view by way of contrast.

Birds. - Since Birds are so poorly represented among fossils, little can be said as to progress in the Cretaceous period beyond the fact that part of the Cretaceous Birds, as known first from Marsh's discoveries, retained the teeth of the Jurassic Birds; and some, even the low character of biconcave vertebræ. They had lost the Reptile-like bones and fingers of the fore limb, and the long tail existing in the Jurassic species, and had, in general, the style of vertebræ characterizing modern Birds, besides modern features in most other respects.

It is also a fact of interest that already degenerate forms were in existence under the Bird-type; for such is the Hesperornis, as shown in its obsolescent wing-bones and wings, a feature that reduced it to the merosthenic condition of an Ostrich and a Dinosaur. Thus, between the Middle Jurassic and Middle Cretaceous the Bird-type reached essential perfection, though not advanced to its highest stage; and also it passed along at least one line downward to Ostrich-like imperfection. The presence of teeth is not a structural imperfection. Their absence looks much more so; but it is not inconsistent with a high and advaneing grade of structure in all other respects.

Progress in Mammals. - The Monotremes and Marsupials from the Cretaceous formation show little progress in Mammals beyond the condition in the Jurassic period - nothing, up to the present time, that bears the decided character of a placental Mammal. As the known fossils are mainly teeth and jaws, full comparisons are not yet possible, and certainty of conclusion as to the question, Marsupial or not, is not yet, in all cases, possible.

Contrast of the European and North American marine faunas. - The contrast between the marine species of Europe and North America, which characterizes the Early and Middle Mesozoic (page 792), continues, but in diminished degree, into the Cretaceous period. The following table gives the number of species that have been described from the Cretaceous beds of Great Britain and North America, under the tribes mentioned in the first column; the former from Etheridge, as enumerated by him in 1885; the latter, by Whitfield, in 1894 . 


\begin{tabular}{|c|c|c|}
\hline & $\begin{array}{l}\text { Great Britain, } 1885 \text {, } \\
\text { Etheridge }\end{array}$ & $\begin{array}{l}\text { American, } 1894 \text {, } \\
\text { R. P. Whitfield }\end{array}$ \\
\hline 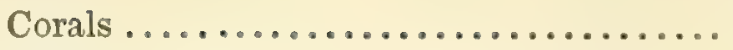 & 76 & 27 \\
\hline 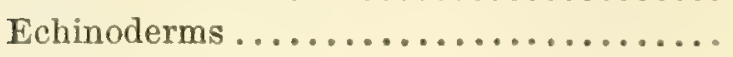 & 201 & 65 \\
\hline 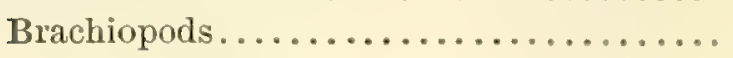 & 106 & 28 \\
\hline 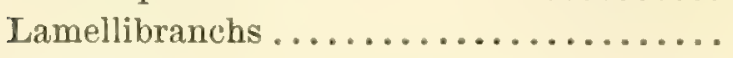 & 476 & 1329 \\
\hline 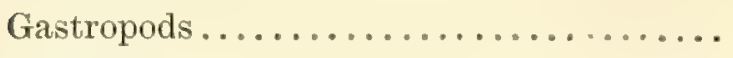 & 298 & 839 \\
\hline 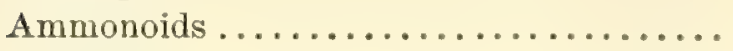 & 206 & 224 \\
\hline 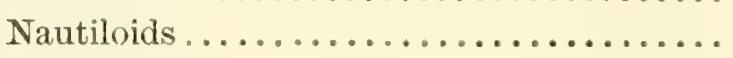 & 20 & 12 \\
\hline Belemnites....................... & 14 & 19 \\
\hline 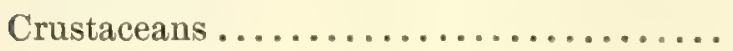 & 110 & 17 \\
\hline
\end{tabular}

The contrast is equally great with the marine fauna of the Parisian and Mediterranean basins in Europe. It will be noted that the American species are from all North America. The species are, it is true, but imperfectly studied; yet the contrast, if all were known, would be strong. Great Britain leads in species of clear seas, and those of moderately deep water Corals, Echinoderms, and Brachiopods; and if the comparison were confined to the Atlantic border of North America, immensely so in Ammonoids and Nautiloids. The number of both groups from this border is only 24, and that of Echinoderms less than 15.

But in number of species of Reptiles America is far ahead of Britain and Europe; and probably because its broad Western Interior had a vast extent of shallow sea-borders and emerging lands, and thus afforded them especially favorable conditions for existence.

\section{CLIMATE.}

During the Cretaceous period, a warm climate still prevailed over the earth even to the poles, but with some cooling during the closing part of the period; and in North America with a great Central Interior Sea, to the end of the period, the climate was moist. The Cycads and associated species of plants in the lower Cretaceous beds of Greenland indicate, according to Heer, a mean temperate of $21^{\circ} \mathrm{C}$. to $22^{\circ} \mathrm{C}$, , or about $70^{\circ} \mathrm{F}$. to $72^{\circ} \mathrm{F}$. This temperature is that of Cuba. The facts prove that a somewhat similar temperature prevailed at the same time over Spitzbergen and in Alaska, where the same flora existed; even along the Atlantic border at least as far north as Long Island; in the region of the Kootinie beds in Montana and the neighboring part of British America; and over more western North America to Alaska. The Gulf Stream of the Atlantic may account in part for the extension of so high a temperature to Greenland; and a like stream over the Pacific, for that to Alaska.

The plants of the Vancouver coal-beds, and those of the Patoot beds in Greenland, which Dawson refers to the age of the Montana series, he compares with those of Georgia at the present time, where the mean temperature, he states, is about $65^{\circ} \mathrm{F}$. The Dakota plants of Kansas and elsewhere, with those of the Mill Creek group, Canada, and the Atané of Greenland, 
are intermediate in kinds, some Cycads being present in Greenland as well as Kansas, and evidently indicate an intermediate temperature. The flora of the Laramie, without Cycads, is, according to the same authority, "not a tropical, but a temperate flora."

The testimony as to temperature from the animal life of the Cretaceous seas bears in the same direction with that from plants. There appear to have been no true coral reefs in the British seas; but they were present beyond doubt in the Mediterranean basin. The facts lead to the inference that the temperature of the waters about the British Islands was below a mean of $68^{\circ}$ during the coldest winter month, but not much below, while a large part of southern Europe was within the Coral-sea limit. Texas was in all probability included by the same temperature boundary, although no true coral reefs and not many species of Corals have yet been reported from the region.

The distribution of a like fauna, for the most part, in the Lower Greensand group of New Jersey, the Ripley group of the Gulf border, and the Montana division of the Cretaceous of Texas and the Western Continental Interior testifies to a nearly common temperature in the waters through this long geographical range. But it cannot be inferred that in the earlier Colorado epoch, or the later Laramie, the temperature was alike in the waters on the Atlantic border and in those of Texas or of the Interior Continental sea; for the influencing conditions were widely different; and hence, even if there were a full series of fossils, there would be marked differences in the cotemporaneous beds of the Interior and the Atlantic border. The Texas waters were within the subtorrid influences of the Mexican Gulf, with no probable source of cold in Arctic currents. But on the Atlantic border the Labrador current may have much modified the temperature of the waters, even if partly shut off by the closing of the Straits of Belle Isle. The coast had, apparently, no Cape Hatteras, and the waters of the Gulf, therefore, had free sweep from the tropics to Cape Cod; and this would have reduced the effect of any Aretic flow to a minimum.

\section{GONDWÁNA LAND.}

The belt of emerged land between India and South Africa, mentioned on page 737, is supposed to have continued to exist through the Jurassic and Cretaceous periods. R. D. Oldham remarks, in his paper of 1894, speaking of the contrasts of the fauna of eastern and western India, that in western India the Jurassic fossils belong to a fauna that is represented in the north of Madagascar, in northern and eastern Africa, and also in Europe, differing so completely from the fauna of eastern India, that "only a few species of world-wide range are found in both." Further, the remains of plants in the Jurassic Rájmahál series of the east coast of India are mostly identical with, or closely allied to, the species of the Uitenhage series occurring near the coast of South Africa, and now regarded as 
Neocomian or Lower Cretaceous; besides, at least one species of shell occurs in both regions. It is thus shown that the belt still existed during the early Cretaceous, and that, at the same time, as he observes, some barrier along the region separated in India an eastern zoölogical province from a western. With reference to the connection of South Africa with Australia, all known facts would be explained if it were confined to the Permian and early Triassic periods.

\section{POST-MESOZOIC REVOLUTION : MOUNTAIN-MAKING AND ITS RESULTS.}

The upturning. - The close of Mesozoic time was marked by the making of the greatest of North American mountain systems. The upturnings took place along the summit region of the Rocky Mountains, where over a broad belt, as long probably as the western side of the continent, a series of geosynclines had been accumulating deposits ever since Archæan time. This mountain system of North America, which stands as the Mesozoie time boundary, is the Laramide system already described, explained, and illustrated on pages 359-364. The system includes the Wasatch range, and others to the north and south. Another figure (Fig. 1467), representing a section of the Lower Cretaceous in the eastern mountain range of Mexico, northwest of Monterey, is here added from a paper by R. T. Hill. The beds stand in a series of nearly vertical anticlines and synclines, from

1467.

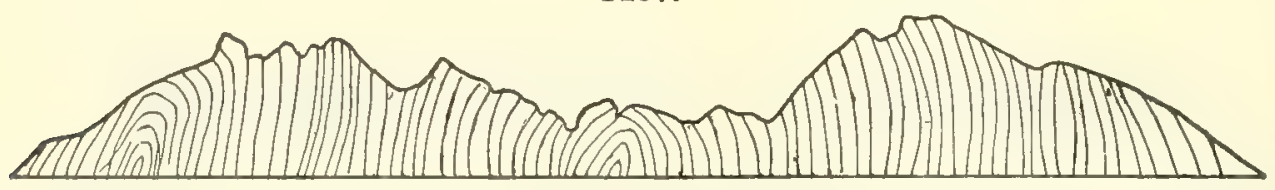

Section showing the folding of the Comanche limestone in the eastern mountain range northwest of Monterey. R. T. Hill.

participation in the system of Laramide upturnings. A section showing vertical beds of limestone and a flexure in the Chinate Mountains, 25 miles north of Presidio, not far from the boundary of Texas, is published by C. A. White in his Correlation Report on the Cretaceous of North America. Further, Streeruwitz has given sections illustrating the upturned condition of the Cretaceous formation of the Sierra Blanca and other mountains in Trans-Pecos, or western, Texas.

The great belt of orogenic work extending from the Arctic regions through North America, was probably paralleled by like work, of equal extent, in South America, but on a more eastern line. A long lesson with regard to the comprehensiveness of mountain-making forces and work is afforded by the single case of North America; and it comes with tenfold emphasis if the western borders of the two Americas, through $120^{\circ}$ of 
latitude, or a third of the circumference of the globe, were undergoing simultaneous orogenic movements, with like grand results.

The deposit-making, preparatory to the Laramide system of ranges, began, as has been stated, in the Cambrian, and went forward, with some large interruptions, until the subsidence in the geosynclines of deposition amounted to 25,000 feet. While the Laramie epoch was passing, there was a deepening of 10,000 feet in some places during the Cretaceous period alone, and in Montana over 7000 feet if the estimates of thickness are right.

As once before stated, it is not supposable that the Archæan ridges bounding such troughs participated in the great subsidence. Assuming the load of sediments to have caused the sinking, in accordance with the isostatic theory, the trough would have been made in the waters off the shores, and would have been greatest a little distance out from the shores; and the same might be a consequence if lateral pressure were the cause of the subsidence. The denudation of the ridges would have caused them to rise rather than sink.

The earlier movements connected with the upturning appear to have begun before the Laramie depositions were completed, producing, according to Cross, a small unconformity in bedding between the Lower Laramie and the Denver beds, besides unconformity by erosion. The latter is deseribed by Weed as marking the junction of the Lower Laramie and the Livingston beds. But the erosion-plane occurs at a level 200 feet below that of a brackish-water bed, abounding in Oyster shells, like those of the Lower Laramie, showing that true Laramie conditions still prevailed, and that the erosion was an event of minor importance. If the orogenic work had actually begun, violent currents in the water may have been produced where quiet deposition had before been in progress; and then great excavations of the earlier-made beds may have been occasioned, followed by depositions of conglomerates and other coarse beds. Moreover, earthquakes and earthquake waves from the adjoining sea may have been an agent in producing erosions of the unconsolidated strata.

The erosion at the base of the Upper Laramie has been supposed to amount to several thousands of feet and to have taken place as a result of an elevation of the region to this height; and this elevation has been thought necessary for the supply of the Paleozoic material of the conglomerates. But such a lift of the region would have changed the climate, and through consequent river-erosion would have cut down the Laramie formation into mountain valleys and ridges; and it would also have exterminated the fauna and flora; when, in fact, horned Dinosaurs existed after it, while the Denver beds were in course of deposition, and their bones are associated with those of various other Dinosaurs in regions not far distant.

Igneous eruptions were also a feature of the early stages of the orogenic movements, and also of its latest. The Wasatch, as described by King (see map, page 360 ), had its outflows of trachyte chiefly from the region of greatest wrenching between the main range and the Uinta plateau. 
The laccoliths of the Henry Mountains in southern Utah (page 301), according to Gilbert's deseriptions, are other products of this time of disturbance; and so also, as remarked by Hills, those of the Spanish Peaks in southern Colorado.

Other eruptions of the epoch contributed to the making of some of the remarkable silver and lead mines of the Rocky Mountain region. S. F. Emmons, in his excellent Report on the famous Leadville region (page 340 ), briefly considers the question of the age of the veins. He points out the fact that some of the largest eruptions preceded the Laramie upturning, while others attended the upturning; but he leaves the question as to the precise time of vein-making undecided. Emmons also considers it probable that a large part of the eruptive rocks of Colorado are of the same Laramide epoch.

According to Iddings, the igneous eruptions in Wyoming and Montana and the adjoining Yellowstone Park went on near, and at, the close of the Cretaceous. The rocks are largely andesytes of various kinds, much like those of Colorado. They occur as dikes, intrusive sheets, and laccoliths; and later in the epoch of eruption, probably in the early Tertiary, volcanic cones were thrown up. In Montana similar eruptive conditions, of the same epoch, have been observed by J. E. Wolff (1892) in the Crazy Mountains, producing intrusive sheets; and among the rocks occur elæolite syenyte, and varieties containing nephelite and sodalite. Similar rocks occur, according to Lindgren (1890, 1893), in the Highwood Mountains, farther north.

The occurrence of dikes of sandstone, as described by Cross (1894), in the granite of the region of Pike's Peak, evidently filling fissures in the granite, may be mentioned here, although their time of origin is uncertain. They occur on the west side of the Manitou Park. They are narrower below, and sometimes branch downward. The width varies from 300 yards to a few inches and even a thin film. The rock is an even-grained quartzose sandstone, usually as hard as quartzyte, with some limonite among the grains as cement.

In India the eruption of the "Deccan traps," the most enormous on record, took place probably, according to Blanford, at or near the close of the Cretaceous. The facts are mentioned on page 299, under the subject of non-volcanic igneous eruptions. The eruptions at the close of Mesozoic time mark the commencement of an eruptive period in the earth's history, which had its maximum effects during the following Tertiary period.

Disappearance of species. - The disappearance of species at the close of Mesozoic time was one of the two most noted in all geological history. Probably not a tenth part of the animal species of the world disappeared at the time, and far less of the vegetable life and terrestrial Invertebrates; yet the change was so comprehensive that no Cretaceous species of Vertebrate is yet known to occur in the rocks of the American Tertiary, and not even a marine Invertebrate. The only species in North America known to have continued on into the Tertiary are plants, some of which existed still in the Miocene, and a few differ little from existing species. Here ended not only the living species of Dinosaurs, of Mosasaurs, and Pterosaurs, but these tribes of Reptiles. This was true also of the Belemnites, so far as 
fossils give information, and, with a single doubtful exception, of the Ammonites; and, among other Mollusks, of the genera Exogyra, Diceras, Requienia, Hippurites, Radiolites, Pterinea, Inoceramus, and others. Part of the change had been accomplished before the time of the catastrophe, for decline had made much progress in the Cycads, Ammonites, Belemnites, and in the Reptilian tribes. But still the destruction was great, world-wide, one of the most-marvelous events in geological history. Among the larger land animals the species most likely to have escaped extermination are the Mammals; for many of them had no doubt already accustomed themselves to the higher lands or ridges of the continents, and their covering of fur would have made adaptation to a colder climate easy. The Birds also would have been to a large extent tenants of the interior and denser forests of the continent of the time. The Pterosaurs might have had, perhaps, an equal chance with the Birds, but for the absence of a coat of feathers.

As to the cause of the epochal disappearance of species, the remarks on the like event after the Appalachian revolution, on page 735, apply also here.

The Laramide orogenic disturbance in America passed with no marked contemporary movements in Europe, none sufficient to account for the thoroughness of the disappearance of species. Change by modification had its marked effects, for it has always been in progress; but extermination must have been the more prominent method of bringing about the great result.

Causes of extermination. - Since the destructions were to a very large extent marine, the oceanic circulation was probably one means of destruction. The world, by the end of the Cretaceous period, had become more diversified than ever before in its zones of temperature. The emergence from the ocean of a third of North America had taken place, and probably of as much of South America, and of large portions also of the other continents, and this would have determined some lowering of the earth's mean temperature, cooling both the air and oceanic waters. The cooling, during the Cretaceous period, it is certain, was great enough to drive Cycads from the Arctic regions to latitudes that are now at the middle of the Temperate Zone. If the change had made the Arctic waters only $15^{\circ} \mathrm{F}$. colder than they were during the Cretaceous period, the polar waters, as they flowed southward, would probably have been exterminating to the greater part of the life of coast regions along the shallower waters, and down to such depths as the cold current reached. Such a eause might make a complete break in the succession of species in a region, without any break in the succession of beds, as happened in New Jersey (page 821). Its action would have been least on the western coast of North America, because of the shallowness of Bering Strait. Moreover, under these circumstances temperature would have worked similarly over the land, forcing Cycads southward, and putting unfavorable conditions into the old haunts of Reptile life.

The other most probable cause of destruction to life is that from earthquake waves. The making of a mountain system along the whole length of 
a continent, causing displacements of the rock formations along lines measuring hundreds of miles in extent, must have been attended by a succession of earthquakes of unwonted violence, which would have caused destruction by the vibrations in the rocks beneath, and also indirectly through the deluging waves sent careering over the land from any seas in the range of the vibrations. Whenever the shakings of the continent extended beneath the ocean, these deluges from earthquakes of Laramide origin would have been destructive over all the coasts of a hemisphere. As land was mostly low at the time, the earthquake waves may have made their marches inland for hundreds of miles, and have left alive only the smaller animal species and the vegetation.

This sweeping from the world of so large a part of its life, and especially that of Mesozoic characteristics, was a much-needed preparation for the era of the "Reign of Mammals." It was an opportunity for the "survival of the fittest" on a grand scale; that is, the survival of those species that could withstand the special causes of destruction, and of the many that were out of harm's way. The exterminations were the removals of hindrances to progress. The survival of the fittest and of the lucky ones, while not directly species-making, was the origin of new associations in continental and oceanic life; that is, of new faunas and new floras over the world, in which, under the modified geographical and physical conditions, the elements existed for further change and progress. 


\section{CENOZOIC TIME.}

It has been observed that, before the close of Mesozoic time, the medieval features of the era were already passing away. The Cycads had mostly given place to the Sassafras, Tulip tree, Willow, Maple, Oak, and Palm; the ancient type of Ganoids, to Salmon, Perch, and Herring; and the Corals, Echini, and Mollusks had close relations to those of existing seas, though of extinct species. But, notwithstanding these changes, the Mesozoic aspect continued to the end. Even the little Mammals, which appeared among the Reptiles, bore the mark of the age, for they approximated to the oviparous Reptiles and Birds, in being themselves either semioviparous or oviparous; that is, either Marsupials or Monotremes.

But with the opening of the new era, the Mammals in their turn became the dominant race. Types much like those of the age of Man were multiplied among them, in all departments of nature. As the era advanced, the first of the species now living appeared, - a few among multitudes that became extinct; and afterward a larger proportion; and, before it closed, nearly all kinds of life, excepting Mammals, were identical with those of the present era. As the Paleozoic or ancient life was followed by the Mesozoic or Medieval, so now there was as marked a change to the Cenozoic or recent life and world.

Cenozoic time embraces two eras:-

I. The Tertiary, or era of Mammals.

II. The Quaternary, or era of Man.

These eras, like consecutive eras in preceding time, were continuous in life through both the vegetable and animal kingdoms, and it is not proved that Man, the most characteristic feature of the Quaternary, was not in existence before the close of the Tertiary. But one of the grandest and most sweeping catastrophic epochs intervened between the two, the Glacial, and so separated them, although the destructive influence of this epoch did not extend over tropical regions, except in the vicinity of lofty mountains.

\section{TERTIARY ERA.}

The Mammals of the Tertiary era are all extinct; and the proportion of living Invertebrates, the Protozoans excluded, varies from none in the earlier part of the era to 95 per cent in the later part. The Early and Middle Quaternary Mammals are largely extinct, but the Invertebrates and Plants are existing species. The Later Quaternary or Recent animals and plants are of existing species, except those that have become extinct through the agency of man. 


\section{General Subdivisions.}

The subdivisions of the Tertiary in general use were introduced by Lyell in the first edition of his Geology. They were based by him primarily on his own geological-investigations in England and Europe, and on those of the French conchologist, Deshayes, who was already familiar with the fossil species of the Paris Basin. The proportion of living to extinct species was accepted as the distinctive character of the subdivisions. These subdivisions, and the proportions now adopted for the approximate limits, are as follows :-

1. Eocene period (from ’̉ws, dawn, and kaıvós, recent) : no species, or less than 5 per cent living.

2. Mrocene period (from $\mu \epsilon_{i} \omega v$, less, and kaıvós): 20 to 40 per cent living.

3. Pliocene period (from $\pi \lambda \epsilon i \omega v$, more, and kalvós): more than half the species living.

The Miocene and Pliocene are sometimes united under the name Neocene (from véos, new, and кatvós), especially when the divisions are not well differentiated. The term Oligocene (from ódíyos, few, and kaıvós) is sometimes used for a fourth division, consisting of the upper part of the Eocene and the lower part of what had been referred to the Miocene.

The term Oligocene was proposed by Beyrich, of Berlin, in 1855. In 1864, Hörues, of Vienna, proposed the term Paloeogene for the combined Eocene and Oligocene, and Neogene for the Miocene and Pliocene; Eogene has also been used in place of Paloogene. Further, the Lower Eocene has also received the separate name of Paleocene. J. W. Dawson adopted, in 1889, the term Orthrocene for the Lower Eocene, Nummulitic for the Middle, and Proicene for the Upper or (as he says) that of the Vicksburg Epoch.

On the geological map published in 1884 by the U. S. Geological Survey, Eocene includes the Eocene and Oligocene, and Neocene the Miocene and Pliocene. In 1887, Heilprin proposed the substitution of Eogene, Metagene, and Neogene, severally, for Eocene + Oligocene, Miocene, and Pliocene + Quaternary.

The name Tertiary is a relic of early geological science. When introduced, it was preceded in the system by Primary and Secondary. The first of these terms was thrown out when the crystalline rocks so called were proved to belong to no particular age, though not without an ineffectual attempt to substitute for it Paleozoic; and the second, after use for a while under a restricted signification, has given way to Mesozoic. Tertiary holds its place, simply because of the convenience of continuing an accepted name. Neozoic is sometimes used in place of Tertiary, while it is also occasionally made a substitute for the whole Cenozoic. It was originally proposed by Edward Forbes to comprise both the Mesozoic and Cenozoic.

\section{NORTH AMERICA.}

\section{GENERAL GEOGRAPHICAL FEATURES OF THE TERTIARY ERA.}

It has been shown that the deposition of the Laramie beds and the upturning which followed left the great interior of North America emerged. The Cretaceous sea, which had covered the Western Continental Interior and the Rocky Summit region from Mexico to the Arctic coast, was gone, excepting 
a large bay on the Aretic shores, and an extended "Gulf of Mexico" at its southern limit. Isolated salt lakes probably remained for a while over the Interior, of which Great Salt Lake of Utah is the last survivor; but no marine Tertiary strata found in and about them are known to exist.

The submerged portions of the continent, or the areas of marine rock making, were therefore confined to the borders of the continent, - the Atlantic border, the Gulf border, and the Pacific border. This general condition of the continent during the early Tertiary is represented on the accompanying map, Fig. 1468.

1468.

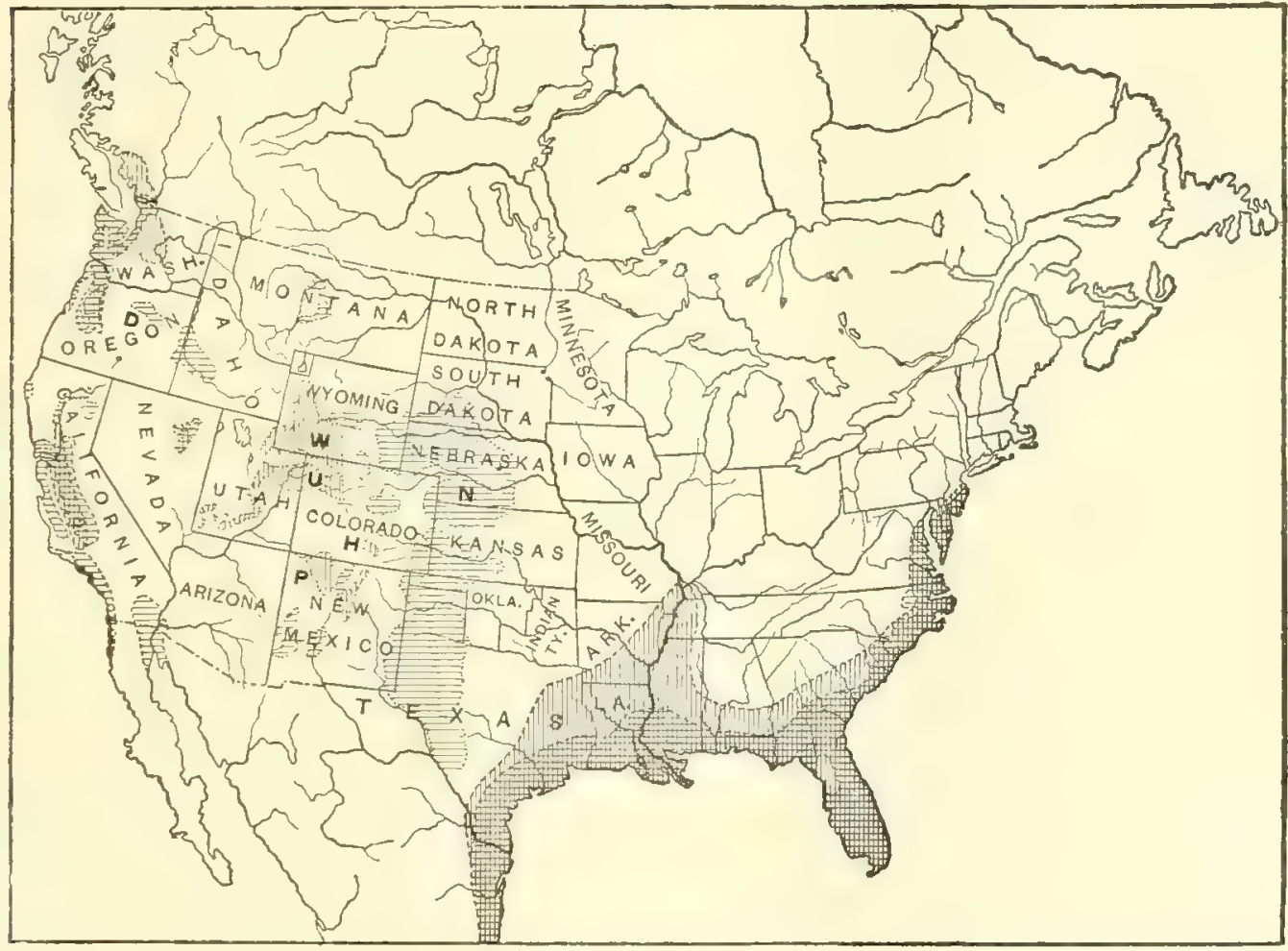

Map of North America showing the parts under water in the Tertiary Era; the vertically-lined is the Eocene; the horizontally-lined, the Miocene or Miocene and Pliocene; the cross-lined, the Eocene and later Tertiary.

It is observed on the map that the condition of the Atlantic border was much like that of the Cretaceous period; that Florida was under water, as then, and that the Mississippi bay was scarcely diminished in extent during the time of greatest submergence.

The portions of the Tertiary area which are lined vertically are those of the Eocene beds, and those lined horizontally, of the Miocene or Miocene and Pliocene. The map thus indicates the fact that along the Atlantic coast region the sea had nearly the same limit through both the Eocene and Miocene periods; but that on the Gulf border a great retreat of the waters took place before the beginning of the Miocene.

On the Atlantic border northeast of New Jersey, Tertiary beds have been identified by fossils only on Martha's Vineyard; and, doubtfully, through shells brought up by the dredge, on St. George's Shoal, east of Cape Cod,

DANA'S MANUAL - 56 
and at one place on the Banks of Newfoundland. Their absence from the coast region in the higher latitude may be owing, as generally believed, to the present submergence of the border on which such beds were deposited. But the existence, for the most part, of rapidly deepening waters north of Newfoundland, and the denuding power of the waves of the open ocean may have been the effective cause along much of the coast.

Although the ocean had been excluded from the Continental Interior at the close of the Cretaceous period, rock-making was still carried forward over much of its area by means of vast freshwater lakes. These lakes had their Fishes and other aquatic life, and their borders were frequented by various animals of the land, including Mammals of many species, with various small Reptiles, and the remains of these species abound in the lacustrine deposits. The freshwater Tertiary formations have consequently an importance not inferior to that of the marine beds.

The great lakes of the earlier Tertiary - the Eocene - were situated in the Rocky Summit region, within the United States, mostly over the area of the Laramide mountain system. One Eocene lake, the Wasatch ( $W$ on the map), covered a large region north of the Uinta Mountains, between the parallels of $40^{\circ}$ and $44^{\circ}$, including parts of Utah, Wyoming, and a portion of northwestern Colorado; and as the earlier Wasatch Lake narrowed its limits in the later Eocene, it became the Bridger Lake. The "Green River basin" was part of the Wasatch. Another, the Uinta Lake (U), lay south of the Uinta Mountains, chiefly within the boundaries of Utah. Another smaller lake, the Puerco (P), was situated in the northern part of New Mexico, and extended across the border into Colorado. Two others, of small size, were situated in the region of the Great Basin west of Great Salt Lake.

The lacustrine beds of Wasatch Lake occupy a plateau region about 6500 feet (6000 to 7000) above the sea level. The height of the village of Green River, within the former, above tide level, is 6140 feet; of Bridger, 6780 feet; of Wasatch, 6789 feet.

Nearly all the later Tertiary lake basins lie either to the east or west of the Summit region, over Nebraska and the adjoining states on the eastern slope of the Rocky Mountains, or between nearly the same parallels but farther west; part of them in the Oregon and Nevada portions of the Great Basin region. The extent of the Eocene lakes over the Summit region is regarded as evidence that the general mass of the mountains at the time stood but little above the sea level. The great thickness which the beds attained in the course of the Eocene is proof that the areas were undergoing a slow subsidence, keeping pace with the deposition, while their borders were essentially stable; and that the position of the area of maximum subsidence changed in the course of the Eocene period. Further, the position and great extent of the Miocene lakes, covering a large part of the eastern slope of the mountains, are evidence that the elevation which took place at the close of the Eocene, draining the lake basin, was small.

All the land of the Tertiary continent had its working streams and 
streamlets, denuding, transporting, making alluvial deposits, and carrying sediments to the seashores; and the whole surface was well populated, beyond doubt, by Mammals, Birds, and inferior terrestrial life. The mountains of the Appalachian System and its bordering regions on the east, west, and south contributed material for the marine Tertiary beds of the Atlantic and Gulf borders; the weakly consolidated beds of the recently made Laramide mountain ranges afforded the same more abundantly for the thick deposits of the vast freshwater lakes about the summit of the Rocky Mountains and over its eastern slopes; and the Sierra Nevada and other ranges of the western slopes were a source of supply for other lakes and for the marine Tertiary of the Pacifie border. But notwithstanding the work of rivers and other agencies, there have not been found, up to 1894, over the eastern half of the continent away from the sea border, any recognizable fossil-bearing, lacustrine Tertiary deposits, excepting over small spots near the center of the state of Vermont. In the western half of the continent, the only fluvial beds recognized as Tertiary, by means of fossils, are those of the auriferous gravels of the Sierra Nevada. Nothing of Tertiary origin has yet been identified in or about the basin of Hudson Bay, or those of the Great Lakes, or in limestone eaverns of the Mississippi valley and elsewhere, to prove that these basins and caverns were in existence during Tertiary time. They may have existed, but the proof is wanting.

This work is indebted for the preceding Tertiary map of North America to G. D. Harris, who has prepared it from earlier maps and publications, from unpublished records of the U.S. Geological Survey, and to a considerable extent also from his own personal study of the marine Tertiary along the Atlantic and Gulf borders. Further, the subdivisions of the eastern Tertiary adopted beyond, and the remarks on the distribution of the beds, are partly from his manuscript notes. In addition, he has revised the pages on the Invertebrate paleontology, of the same region; and part of its illustrations are from his work on the Tertiary Paleontology of Texas. A list of earlier publications and a review of the facts and of the question of equivalency may be found in the U.S.G.S. Bulletin, No. 83, by W. B. Clarke, on the Correlation of the Eocene Tertiary, 1891, and in the U. S. G.S. Bulletin, No. 84, on the Correlation of the Neocene, by William H. Dall and G. D. Harris, 1892.

\section{Subdivisions.}

The periods of the Tertiary era proposed by Lyell are the basis of the American subdivisions, namely: (1) Eocene, (2) Miocene, (3) Pliocene. To these are added by some, OLIGOCENE, corresponding in age to the European Oligocene. Neocene is also sometimes used for the Miocene and Pliocene.

The marine and lacustrine formations are independent in fossils, and besides are nowhere interstratified, and hence it is not possible to make out their precise equivalents. As regards the lacustrine beds, even the division into periods is based largely on facts from Europe. Moreover, the species of the marine Tertiary of the Atlantic and Pacific borders are almost wholly 
different; and besides, those of the latter thus far make but one group for the Eocene, and one for the Miocene. For these reasons, the three regions, the Atlantic and Gulf borders, the Pacific border, and the Lacustrine areas, are independent in their subdivisions and cannot be satisfactorily correlated. They are brought together, however, in the following table, to exhibit the general relations of the subdivisions, and nothing more. It is not yet known in all cases what subdivisions of the Eocene formations recognized on the coast are equivalents of the Lower, Middle, and Upper Tertiary in the Continental Interior.

Table of Approximate Equivalency of the Subdivisions.

\begin{tabular}{|c|c|c|c|c|}
\hline & Atlantic and Gulf borders & Lacustrine areas & Pacific border & Foreign \\
\hline Pliocene & Floridian & $\begin{array}{l}\text { Blanco } \\
\text { Palo Duro }\end{array}$ & Pliocene & Pliocene \\
\hline Miocene & $\begin{array}{l}\text { Yorktown } \\
\text { Chipola } \\
\text { Chattahoochee }\end{array}$ & $\begin{array}{l}\text { Loup Fork } \\
\text { John Day } \\
\text { White River }\end{array}$ & Miocene & $\begin{array}{l}\text { Tortonian } \\
\text { Aquitanian }\end{array}$ \\
\hline \multirow{3}{*}{ Eocene } & Upper; Vicksburg & Uinta & & $\begin{array}{l}\text { Tongrian } \\
\text { Ligurian }\end{array}$ \\
\hline & Middle $\left\{\begin{array}{l}\text { Jackson } \\
\text { Claiborne } \\
\text { Lower Claiborne }\end{array}\right.$ & $\begin{array}{l}\text { Bridger } \\
\text { Wind River }\end{array}$ & \multirow[t]{2}{*}{ Tejon } & $\begin{array}{l}\text { Parisian, or Calcaire } \\
\text { Grossier }\end{array}$ \\
\hline & Lower $\left\{\begin{array}{l}\text { Lignitic } \\
\text { Midway }\end{array}\right.$ & $\begin{array}{l}\text { Wasatch } \\
\text { Puerco }\end{array}$ & & $\begin{array}{l}\text { Suessonian } \\
\text { Cernaysian }\end{array}$ \\
\hline
\end{tabular}

a. MARINE TERTIARY OF THE ATLANTIC AND GULF BORDERS.

3. Pliocene period.

Floridian Epoch. Floridian of Heilprin, as modified by Dall. Merced group of the peninsula of San Francisco, of A. C. Lawson.

2. Miocene period.

3. Yorktown Eросн. So named from Yorktown, Va., Dana's Geol., 1863. Chesapeake of Darton and Dall, 1891.

2. Chipola Eросн. Represented by the Chipola group of Burns, occurring along the Chipola River, Florida.

1. Сhatтahoochee Epoch. Chattahoochee of Langdon, named from typical exposures on the Chattahoochee River in southwest Georgia and northwest Florida.

1. Eocene period.

6. Vicksburg Epoch. Vicksburg of Conrad; named from beds at Vicksburg, Miss.

5. JACKSON EPOCH. Jackson of Conrad, exposed near Jackson, Miss. 
4. Clatborne Epoch. Upper part of Claiborne of Conrad, occurring along the Alabama and Tombigbee rivers (Langdon), and in Arkansas.

3. Lower Claiborne Epoch. Part of the Claiborne of Conrad, separated here by Harris; occurs in Alabama, Georgia, and South Carolina, and includes the Buhrstone of. Tuomey and Lyell, and the Siliceous and Calcareous Claiborne of Mississippi.

2. Lignitxc Еросн. Represented by the Lignitic beds, in part, of Conrad and Hilgard, including the beds between the Buhrstone and the Matthews Landing clays, as restricted by Harris; La Grange group, in part, of Safford; Eolignitic, in part, of Heilprin.

1. Midwax Epocr. Part of the Lignitic of Conrad, and of Smith and Johnson; represented by the Calcareous beds near Midway, and the Matthews Landing clays, on the Alabama River.

\section{b. MARINE TERTIARY OF THE PACIFIC BORDER.}

\section{Pliocene period.}

Represented by local deposits in California, Oregon, and Washington.

\section{Miocene period.}

Represented by deposits in the coast region of California, which partly constitute the Coast Range at Astoria, Oregon, on the Columbia River, and also in Washington, to the north.

1. Eocene period.

Represented by the Tejon group of J. D. Whitney (1869), named from the locality near Fort Tejon, Kern County, Cal.; beds occur especially along the east side of the Coast Range, near Astoria, Oregon.

\section{c. LACUSTRINE TERTIARY.}

\section{Pliocene period.}

2. Blanco group of Cummins and Cope (1892), occurring at Blanco Cañon, Crosby County, Tex., and extending northward along the Staked Plains beyond Red River.

1. Palo Duro beds of Scott; Good-night beds of Cummins; observed near the Cañon of Palo Duro in Texas, and also in northern Kansas.

\section{Miocene period.}

3. Upper Miocene. Loup Fork group of Meek and Hayden.

2. Loup Fork beds: On Loup Fork of Platte River in central Nebraska, but extending southward interrupterlly to Mexico, and occurring in New Mexico on the Rio Grande, Gila, and San Francisco rivers. Pliocene and Pliohippus beds of Marsh. 
1. Deep River beds, the Cyclopidius beds of Scott, in the Deep River (оr Deep Creek) region, which are overlaid by beds with Loup Fork fossils. Ticholeptus beds of Cope, but not those so named of Wyoming and Oregon.

2. Midde Miocene. Miohippus beds and John Day beds of Marsh (1877), occurring on John Day River, Oregon.

1. Lower Miocene. White River beds of Hayden (1857); Oligocene of Scott.

3. Protoceras beds of Wortman, of the White River region.

2. Oreodon beds of Marsh (1877), in the White River basin.

1. Titanotherium beds of Hayden $(1857,1869)$, in the White River region on the Niobrara, and in Dakota and Colorado. Brontotherium beds of Marsh.

\section{Eocene period.}

3. UpPer Eocene.

4. Uinta group of Marsh (1871), and of King (1878), lying to the south of the Uinta Mountains in Utah ( $U$ on the map, page 881). Diplacodon beds of Marsh (1877); includes the Brown's Park group of Powell (1876). The Florissant group of South Park, Col. The Amyzon beds of Elko and Osino, Nev., are referred to the top of the Uinta or base of the Miocene.

2. Middle Eocene.

3. Bridger group of Hayden (1869), named from Fort Bridger, Wyoming, represented to the north of the Uinta Mountains overlying the Wasatch beds. Dinoceras beds of Marsh. Green River group of Hayden (1869) is included; probably also the Wushakie group of King (1878). The Wind River group of Hayden (1861) has been referred to the bottom of the Bridger by Scott and Osborn, and made the equivalent of the Green River group; but to the top of the Wasatch by Cope.

1. LOWER EOCENE.

2. Wasatch group of Hayden (1870), covering parts of Utah, Wyoming, and Colorado. Coryphodon beds of Marsh. Vermilion group of King. Bitter Creek group of Powell.

1. Puerco group of Cope (1875), named from Puerco River, New Mexico, occupying a basin extending from northern New Mexico into southern Colorado (P, map). Lower Wasatch of Marsh.

\section{ROCKS-RINDS AND DISTRIBUTION.}

The beds, especially the marine, commonly vary much in character from mile to mile. Instead of great strata of almost continental extent and uniformity, as in the Silurian, there is the diversity which exists among the modern formations of the seacoast. But yet such diversity is not 
universal, for in some regions the sands from shells and corals were made into hard limestones, as they are now, and over areas of great extent. Moreover, firm shales and sandstones occur that are like those of early time. Besides, there are thick beds of greensand, like those of the Cretaceous formation in constitution, and equally valuable as a fertilizer. There are also beds of coal or lignite associated with some of the deposits.

Beds of siliceous organisms, Diatoms, Radiolarians, and Sponge spicules, have sometimes much thickness, and are occasionally partly consolidated into opal.

The rocks of the lacustrine and terrestrial deposits are generally finegrained, and either feebly indurated sandstones, soft straticulate clays passing into shales, or soft fragile limestones of fine grain; but these soft kinds graduate into harder and sometimes into coarser varieties. They have derived their great thickness in the usual way; that is, through a gradual subsidence attending the deposition from waters of the region. On the coast of Florida, some beds have been converted partially into phosphates (or phosphatized), by water filtrating through overlying guano deposits. In the Rocky Mountain region and over the Pacific slope occur deposits, sometimes hundreds or thousands of feet thick, made of volcanic ashes. There are also coarse voleanic conglomerates or breccia. The volcanic beds sometimes cover the stumps of many successive growths of forests (page 135); and the finer kinds occasionally contain remains of the Beetles, Butterflies, and other Insects of the period.

Lignite beds also occur locally over the country. One of the most noted of them is that of Brandon, Vt., which is probably of Eocene origin. It is associated with a bed of limonite.

Denudation was universal over the exposed continental surface, as in all past time, dissecting and degrading mountains, and making fluvial deposits as well as lacustrine. The Auriferous gravels of the western slope of the Sierra Nevada are largely fluvial deposits of Tertiary origin, as shown by J. D. Whitney in his Geological Report on California (1865), and much more fully in his Auriferous Gravels of the Sierra Nevada (1880). The plants found in the gravel beds indicate, according to Lesquereux, a Miocene and Pliocene age; but Whitney regards the formation as representing the whole of the Tertiary. It probably began in the Cretaceous period. As Le Conte states, the detritus of the old gravels is in general exceptionally coarse, showing strong currents.

\section{Sea-border Areas.}

I. Eocene. - Along the Atlantic and Gulf borders (see map, page 881), the Tertiary belt is very narrow and interrupted through New Jersey; it is broader in Maryland and Virginia, and still broader in South Carolina. But the formation is best displayed on the Gulf border. The inner limit, or that against the Cretaceous in the Carolinas and the Gulf region, is over 100 miles 
from the seacoast; and in the Mississipui valley - then a great bay, as in the Cretaceous period - it extends northward over 500 miles, covering on the east a broal portion of the state of Temessee, and reaching into Illinois, and on the west, an eastern portion of Missouri and Arkansas. From Texas it extends southward into Mexico.

The formation exposed to view from New Jersey through Virginia consists of sand-beds of different colors, including greensand or glauconitic beds, often shell-bearing, and is referred to the Lignitic Eocene. In South Carolina the exposure reaches nearly to the coast, and is more varied in its constitution. Along the inner margin occurs a stratum of Buhrstone, about 200 feet thick, a cellular siliceous rock, from which the shells have been dissolved away by siliceous waters; and over this, to the eastward, occur calcareous beds with some greensand, the Santee beds of Tuomey, and the related Ashley and Cooper beds, or beds along the basins of the Ashley and Cooper rivers. On the Gulf border the belt averages 65 miles in width.

1. The Midway, the lowest member of the Eocene, was named thus after a landing on Alabama River, Wilcox County, Ala., by Smith and Johnson in 1887. It was regarded by them as a subdivision of the Lignitic; it is made by Harris to include the Black Bluff and Matthews' Landing beds, and given coördinate rank with the Lignitic; the Clayton or Monterey beds of Langdon.

It is distinguished from the Lignitic by (1) its fossil contents and (2) the off-shore character of its deposits. In the region of Red River and the Mississippi Embayment, marine fossils are often wanting, and the beds are more or less lignitic; open sea deposits are found in southeast central Texas, central Arkansas, eastern Alabama and Georgia. No outcrops of this group have been recorded to the northeast of the last mentioned state. Total thickness, about $250^{\prime}$.

2. The term Lignitic was used by E. W. Hilgard (1860) for the Lower Eocene of Mississippi, consisting partly of freshwater lignitic beds and partly of estuarine fossiliferous deposits. The name Lignitic formation had been still earlier used by Conrad; and EoIignitic was proposed by Heilprin in 1884; Lignitic is used by Smith and Johnson (1887), to designate all Eocene deposits lying beneath the Buhrstone. The name has recently been restricted by Harris to the beds lying between the Buhrstone and the Matthews Landing clays, and is so employed here. The formation includes shallow-water depositions. Lignitic clay beds alternate with sands; the latter are often cross-bedded; huge bowlders or septaria-like concretions are locally very abundant. Animal remains are scarce or wanting in the deposits west of the Mississippi ; but in Alabama and to the northeast, in Maryland and Virginia, they are abundant in certain layers. Where most typically developed (in Alabama) the various subdivisions have received the following names and estimates of thickness from Smith and Johnson: (1) Nanafalia, 200'; (2) Bell's Landing, 140'; (3) Wood's Bluff', 80'-85'; (4) Hatchetigbee, 175'; total, 600'.

The Pamunkey formation (Darton), i.e. the Eocene deposits of Maryland and Virginia, are referable to the Bell's Landing horizon.

3. The Lower Cleiborne was so designated by Harris to distinguish it from the Claiborne proper. It is represented in South Carolina, Georgia, and Alabama by the Buhrstone of Tuomey and Lyell; in Mississippi by the Siliceous and Calcareous Claiborne of Hilgard; in Loulisiana by the Lover Claiborne of Harris; in Texas by the Timber Belt beds and the Laftyette beds in part, of Penrose; in California by part of the Tejon group of Gabb and Whitney. Near the axis of the Mississippi Embayment this group is without marine fossils; elsewhere, especially in its upper portion, it is often highly fossiliferous. In Ala- 
bama Smith and Johnson have assigned the following thicknesses to its various subdivisions: Buhrstone, $300^{\prime}$; Lisbon beds, $50^{\prime}$; Ostrea selloeformis beds, about $65^{\prime}$; in all about $415^{\prime}$.

4. The Claiborne was named by Conrad from Claiborne, Ala. The typical development of this group is of very limited geographical extent, being confined to the drainage of the Alabama and Tombigbee rivers (Langdon); but in Arkansas at White Bluff on the Arkansas River and elsewhere, there are marly sands with a fauna showing Jackson affinities, though they are at present classed as uppermost Claiborne. The typical Claiborne bed is $16^{\prime}$ thick; the White Bluff bed over it, $20^{\prime}$.

5. The Jackson beds were so named by Conrad from typical exposures at Jackson, Miss. They are sometimes improperly classed with the Vicksburg, under the name of White Limestone. They occur on the Gulf slope east of the Sabine River. In Arkansas and probably in Mississippi they extend some distance up the Mississippi Embayment, orerlapping Claiborne and Lignitic beds. They are clayey and lignitiferous in this region; but to the east, in Alabama, become calcareous and constitute beds of impure limestone. Thickness over $50^{\prime}$.

6. The Vickshurg, named by Conrad from typical exposures at Vicksburg, Miss. This group is mainly composed of limestones, pure and impure, and like the Jackson is confined to the Gulf slope east of Sabine River; and unlike the preceding groups, it is little influenced by the Mississippi Embayment. According to Langdon's figures its thickness varies from $150^{\prime}$ to $210^{\prime}$. The Red Bluff group of Hilgard is scarcely separable faunally from this.

General Remarks. - Although it has been said that the Cretaceous (Chico) and the Eocene (Tejon) deposits west of the Rocky intergrade without a perceptible break, their respective faunas indicate that there is a break somewhere. On the Atlantic and Gulf slopes there is abundant proof of a marked discordance, both faunal and stratigraphic, between the Cretaceous and Eocene Tertiary series. In the Mississippi Embayment, at least in eastern Arkansas, the earliest known Eocene beds pass up and over the Cretaceous, while in southwest Arkansas, Texas, Alabama, and Georgia, broad areas of Cretaceous are exposed; in Maryland and Virginia, where lowest Eocene is wanting, Lignitic beds rest upon the Cretaceous.

II. Miocene and Pliocene, or Neocene of the Atlantic and Gulf Borders. - While dredgings from the Grand Bank of Newfoundland, as well as from St. George's Shoal, off the coast of Massachusetts, render it probable that later Tertiary deposits exist beneath these shallow seas, the first distinct exposures found on the Atlantic coast are those of Martha's Vineyard at Gay Head and Chilmark, as recently proved through a study of the fossils by Dall (1894). The next is near the village of Bridgeport in New Jersey. These exhibit Miocene marls of black, yellow, and gray hues, with a thickness of from 12 to 15 feet. The sands, clays, and marls from the Artesian well at Atlantic City indicate that the thickness of the Miocene strata there is not less than 700 feet. These deposits are mainly, if not exclusively, of Upper or Yorktown Miocene age.

In Maryland the escarpments along the western shore of Chesapeake Bay, and along the Patuxent and Potomac rivers, show Miocene beds of sand and clay, rarely indurated, and, at base, thick deposits of diatomaceous earth, amounting in all to a thickness of 400 feet. In Virginia a similar series is exhibited along the river courses; and in the region of Dismal Swamp younger beds of Pliocene age are reported. 
In North Carolina these deposits are much thinner than in Maryland and Virginia, and in South Carolina they usually occur in isolated basins or sinks in the subjacent Eocene or Cretaceous strata; they often show a reworking or rearrangement of material, so that Miocene, Pliocene, and even Cretaceous fossils occur in one and the same bed. The component materials are sand, clay, and comminuted shells.

There are deposits in Georgia of limestone, buhrstone, and conglomerates that belong to the older Miocene series, but their geographical extent is not well determined.

Florida presents the most complete section of American marine Miocene and Pliocene formations. Immediately above the Eocene along the Chattahoochee River occur beds of limestone, clay, and marl, - the Chattahoochee group of Langdon, - having a thickness of about 200 feet. Higher still are the fossiliferous Chipola sands, succeeded in turn by the Alum Bluff sands, 40 feet thick, containing few organic remains save lignite and plants. Above these occurs a gray marl having a Yorktown fauna 35 feet thick. These Miocene deposits oceupy much of the northern portion of the state. To the south the Peace Creek lacustrine deposits and Caloosahatchie beds of Pliocene or Pleistocene age are probably well developed, though their exact limits are not definitely determined.

The Neocene beds of Mississippi as well as Alabama and Louisiana Grand Gulf group of Hilgard - contain but few animal remains, and their horizon has been, and still is to some extent a matter of dispute; but the labors of L. C. Johnson and Langdon in southeastern Mississippi, southern Alabama, and northwestern Florida tend to show that they should be correlated with the lower Miocene of the Floridian section. They are well developed in Mississippi, and although concealed to the south, doubtless underlie the greater part of the state south of a line roughly drawn through Vicksburg, Raymond, Byram, Brandon, Raleigh, and Waynesboro, or, in other words, south of the Vicksburg formation. Below and to the east these beds are clayey, lignitie, and gypsiferous; above and to the west the aranaceous material predominates, and when indurated gives a rugged topography to the region in which it occurs. No traces of similar deposits have been found in Tennessee or Arkansas; but in Louisiana they occur resting upon the Vicksburg limestone and extending in a southwestern direction toward the Sabine River.

Certain deposits of clay, lignite, and sandstone in Texas - the Lafayette beds of Penrose - have been correlated with the Grand Gulf rocks of Mississippi; but the presence of Lower Claiborne species - although rarethroughout much of their vertical range, renders it quite probable that all should be referred to the Eocene period. To the seaward marine Neocene beds are unknown at the surface; yet borings from the Deep Well at Galveston show that at no great depth such deposits do occur with a thickness of 1500 feet or more. Many lacustrine deposits are found at the surface bearing Vertebrate remains of a late Tertiary age. 
The epochs of the marine Miocene, as defined from the formations of the Atlantic and Gulf borders, are as follows :-

1. Chattahoochee: so named by Langdon, from typical exposures on Chattahoochee River, southwest Georgia, and northwest Florida. Dall correlates with the Chattahoochee deposits the Hawthorn beds of central Florida, consisting of phosphatic oölyte, ferruginous gravel, and green clays, the Orthaulax bed and Tampa limestone at Tampa, the Altamaha grits of Georgia, and also the "typical Grand Gulf" of southern Alabama. The lastnamed deposits are placed at this horizon because they are "analogous to and probably synchronous" with the Altamaha grits of Georgia, and are overlaid at Roberts, Escambia County, Fla. (according to Smith), by a bed containing Chipola fossils, as identified by Dall. The Chattahoochee fauna is closely related to the Miocene of West Indies, Jamaica, Trinidad, Haiti, Curaçoa, Panama, and Costa Rica (Dall).

2. Chipola : distinguished by Burns, and first named by him in manuscript as the Chipola formation from typical exposures on a river by that name in northwestern Florida. The lower member of the group, the Chipola sands, is famous for its vast number of fossil shells, nearly 400 species having been found at the type locality. This remarkable faunal development is to the Miocene what the Claiborne fauna is to the Eocene; both occur in slightly ferruginous sands about $16^{\prime}$ thick, both appear to be very limited in areal extent, and both occur medially in their respective periods.

The fauna of the Alum Bluff sands (Dall) immediately overlying the fossiliferous Chipola bed has not been carefully studied.

All these older Miocene deposits are characterized by a warm-water or subtropical fauna (Dall).

3. Yorkтоwм : named from Yorktown, Va., by Dana (1863). It is the time-equivalent of the Chesapeake group of Darton and Dall (1891). It includes the Miocene of the Atlantic slope as known to geologists prior to 1887. The section at Alum Bluff shows that this group lies above the Chipola. It is well developed in Duplin County, N. C., at Yorktown, and elsewhere in Virginia, and along the river courses in Maryland. Calvert Cliffs on the west shore of Chesapeake Bay exhibit three well-defined fossiliferous zones, named, in descending order, the St. Mary's, Jones Wharf, and Plum Point. Beds lower still in the series are found on the eastern shore of Maryland, and with these in New Jersey Dall finds traces of older Miocene fossils. It has been identified by its fossils on Martha's Vineyard by Dall.

A modification of this fauna is found in the Galveston Deep Well, Tex., between depths of $2000^{\prime}$ and $3000^{\prime}$.

Since the publication of Gabb's work on the California Geological Survey the Miocene as well as Pliocene fossil remains of the Pacific slope have received little attention. As a rule the Miocene fossils are poorly preserved, and are often embedded in firm rock. Their general aspect indicates a horizon more nearly that of the Yorktown group than that of the older Miocene.

In Georgia and Florida, where newest Eocene and oldest Miocene occur, there is a marked faunal break between the two, yet there are several species in common. In Maryland and Virginia, where Yorktown Miocene rests upon Lignitic Eocene, the break is complete, not one species being found common to the two. The upper, or Yorktown, Miocene was characterized by a fauna indicative of a temperature similar to that of to-day.

The Ashley marl bed of South Carolina, containing phosphatic nodules with fossils in them, which was referred by Tuomey doubtingly to the Eocene, affords Miocene fossils (1894). Of marine Pliocene, there are the Floridian deposits of Heilprin as modified by Dall (1892); the Pliocene of Tuomey (1848), excluding some Miocene beds as determined by the investigations of C. W. Johnson and Dall. To this period have been referred the Orange sand group of Safford (1856), occurring in Tennessee, the Orange sand of Hilgard (1860), in Mississippi and Temnessee, the Orange sand, or Lagrange 
group, of Safford (1864), the Appomattox of McGee (1888), - all of one formation, and now named by agreement the Lafayette; made by Hilgard, and in this work, a formation of the Glacial period. Marine deposits of this period are well developed along the Caloosahatchie River, south Florida. To the north, considerable areas are supposed to have been occupied by lakes having but slight elevations, and subject to occasional intrusions of the sea with its salt-water fauna; hence the Peace Creek bone beds in Manatee County, and Alachua clays, in Alachua County, are found apparently interstratified with marine Pliocene deposits (Dall, $T$. S. G.S. Bulletin, No. 84). The Mammals include a considerable number of Eocene, Quaternary, and Pliocene species, and the beds are supposed to be Quaternary in accumulation.

Dall reports that the Miocene group of Gay Head, Martha's Vineyard, is overlaid by beds affording Pliocene fossils (1894).

Miocene and Pliocene of the Pacific Coast. - Along Carrizo Creek, east of the coastal range of mountains in southem California, there is a bank or terrace, sometimes composed of fossil shells in its upper part, that has been referred to the Miocene Tertiary by Conrad and to the Pliocene by Gabb. The sandstones and shales of the Santa Suzanna, Santa Monica, and Santa Inez ranges are mainly referable to the Miocene; the conglomerates and sandstones about the base of the San Gabriel range can only be classed as Neocene. Resting on the granitic axis of Santa Lucia Mountains are highly metamorphosed Neocene (Miocene?) sandstones; stratigraphically above are thick deposits of bituminous shales, which toward the southeast are overlaid by soft, sometimes calcareous, sandstone, having a thickness of over $1000^{\prime}$, and referable to the Miocene series on paleontological evidence. Sandstones and bituminous slates of this age have been described from the Sierra de Salina, Gavilian, Santa Cruz, and Mount Diablo ranges. In the region of Mount Diablo Turner finds the Miocene series made up of coarse gray sandstone containing the large Ostrea titan, and conglomerates with pebbles of rhyolyte, quartz, and metamorphic rock. The Pliocene beds contain marine fossils, silicified wood, hornblende-andesyte tufa, and pebbles. North of the Golden Gate several fossiliferous Miocene deposits have been recorded, but their characters and limits are unknown. Along the foothills of the Sierra Nevada, especially in the vicinity of Ocoya Creek, there are Miocene beds of fine sand, coarse sand, conglomerates, fragments of pumicestone, ferruginous fossiliferous gravel, and clay nodules, in all $160^{\prime}$ thick. Farther to the north, the Ione formation of Lindgren, best developed in Amador and Calaveras counties, is composed of (1) $100^{\prime}$ of clay rock, (2) $100^{\prime}$ of sandstone, (3) $860^{\prime}$ or more of white clay and sand beds containing coal seams.

In Oregon, Miocene sandstones and shales occur at Astoria, and others, presumably of the same age, at Port Orford, Cape Blanco, and near Yaquina Bay. They are perhaps a continuation of the bituminous shales and sandstones of California. From 1 to 3 miles east of Eugene City, Dall has noted a Miocene sandstone $37^{\prime}$ thick. Condon states that the backbone of the Coast Range consists of argillaceous Miocene shale similar to that at Astoria; stratigraphically above are the fossiliferous Solen beds of Condon, also of Mincene age; on the flanks of the highlands there are lacustrine deposits containing some Equus bed (Quaternary) fossils.

In Washington, the Astoria clay-shales are reported from near Bruceport, and at various points on Shoalwater Bay. Other outcrops of the same formation are known from Vancouver Islands and Alaska.

The Pliocene Herced group of Lawson (Bull. Geol. Univ. Cal., i., 142, 1893), on the coast of the San Francisco peninsula, south of the Golden Gate, is described as having a thickness of $5834^{\prime}$. A cliff consisting of the beds, $720^{\prime}$ high, extends from Lake Merced, near San Francisco, to Mussel Rock, about 8 miles south of Point Lobos. The basal bed contains some carbonized wood and leaves. Some of the fossils were described by J. G. Cooper in 1888, and a list of others, determined by Dall, is given in Lawson's paper. Delta material in the great valley of California at San Benito also is referred by him to the Pliocene. 
Miocene and Pliocene beds have been identified in Alaska, and descriptions and a map showing their distribution, by W. H. Dall, are contained in his Bulletin 84 of the $U$. S. G. S., 1892.

\section{Lacustrine Deposits of the Continental Interior and Pacific Slope.}

I. EOCENE. - The lacustrine Eocene areas are confined mostly to the summit region of the Rocky Mountains and its broad slopes, and are noted for the abundance of fossil vertebrates. The oldest, according to present knowledge, that of the Puerco basin, covers a large area in northwestern New Mexico, and extends northward into Colorado. The beds rest on the upturned Laramie, and are overlaid conformably by the Wasatch beds.

The Wasatch basin (W on the map, Fig. 1468), also Lower Eocene, lies to the north of the Uinta Mountains, and east of the Wasatch range. Its original breadth was probably nearly 300 miles, and the extreme length from north to south perhaps 500 miles. The thickness of the beds near the Wasatch range is about 4000 . The Wasatch also occupies a basin extending from New Mexico northward, to the Uinta Mountains and the Big Horn basin in Wyoming. The beds also of the Cuchara basin of R. C. Hills are referred to the Wasatch Eocene.

Two other basins, the Green River and Wind River, are situated to the north of the Uinta Mountains, and are intermediate in age between the Wasatch and Bridger. The Green River basin is situated mostly within Wyoming, and has an area of more than 5000 square miles. The beds consist of impure limestone below, and thin fissile calcareous shales above, in all $3000^{\prime}$ to $4000^{\prime}$, and are especially noted for their fossil Fishes and Insects. Fine views of the bluffs and of the "Bad Lands" of the Wasatch are given in King's 40th Parallel Report, on plates 13, 14, 15; and general views of the Green River basin, in Hayden's Report for 1872. The Manti beds of Cope (1880), occurring in Sevier and San Pete counties, Utah, are similar in character and fossils to those of the Green River basin.

The Bridger basin of the Middle Eocene is situated between the meridians of $109 \frac{1}{2}^{\circ}$ W. and $110 \frac{1}{2}^{\circ} \mathrm{W}$, and for the most part north of the parallel of $41^{\circ}$. Washakie basin of King (1878), which lies 60 miles farther east, and the Huerfano group of R. C. Hills (1888-1891), are of the same age. The latter lies to the east of the Front Range in Huerfano and Las Animas counties, southern Colorado.

The Uinta lake basin (U, Fig. 1468), of the Upper Eocene, lies wholly to the south of the Linta Mountains, and has now a level of about $10,000^{\prime}$ above the sea. Its width from east to west is over 140 miles.

The Amyzon beds, referred to the later part of the Eocene, occur in northeastern Nevada, in South Park, Col., and in central Oregon. They are probably intermediate between the Uinta and White River beds.

The small Florissant basin is situated $8000^{\prime}$ up in the mountains of southern Colorado. Its beds are largely made of volcanic earth, or tufa, and have become famous for their great numbers of fossil Insects and Spiders, and also for their Fishes, and for feathers and other remains of Birds, besides plant remains.

II. Mrocene. - In the Miocene period the Eocene lakes of the Rocky Mountain region bad mostly been drained through an increase in the elevation of the land or changes in its surface level; but the mountain area still remained so low that even greater lakes then existed over what are now the eastern slopes of the mountains. They were situated in the region of the upper Missouri, and covered most of the state of Nebraska and a portion of Wyoming and Colorado, and extended from Nebraska southward. The area is over 350 miles in its maximum breadth, and has a height at the present time, through subsequent elevation, of about $6000^{\prime}$ to the west and $3000^{\prime}$ to the east.

The Earlier Miocene is that of the White River group. Its oldest deposits, the Titanotherium beds of Hayden, consist mainly of variegated clays, together with sandstones and conglomerates, and have a thickness of $180^{\prime}$ (J. B. Hatcher); above are the 
Oreodon beds of sandstones and clays, often nodulous, about $150^{\prime}$, with $100^{\prime}$ of overlying clays (Wortman); and above these the Protoceres bed.s, sandy below, but clayey above, $150^{\prime}$, in all $480^{\prime}$ thick (Wortman).

In the region of these basins the strata, owing to erosion by rills and streams from occasional rains, stand in isolated earthworks or embankments, pyramids and spires, over the great plain, looking like a field of desolate ruins, parched and barren in the dry climate. To this region was first applied the term "Mauvaises Terres," or Bad Lands.

In Oregon, on John Day and Des Chutes rivers, near $120^{\circ} \mathrm{W}$., is another lake-basin, the John Day basin (D, Fig. 1468), hardly 500 square miles in area. The Miohippus beds of Marsh, the upper portion, have afforded remains of Miocene Mammals, apparently of a little later date than the White River beds. Marsh correlates with the Oregon Miohippus beds the Protoceras beds of Wortman, stating that the latter contain the Oregon species Miohippus annectens Marsh; and he further makes his Ammodon beds of the Miocene on the Atlantic border essentially of the same horizon.

The Loup Fork Group, of the Upper Miocene, was so named from a river in Central Nebraska. The beds cover for the most part the Nebraska lake region (marked $\mathbf{N}$ on the map), and its extension southward to Texas, New Mexico, and Mexico. King gives the thickness in Wyoming as 2000'. To the eastward, on the White River, it is $150^{\prime}$. The Deep Creek beds of Montana, first made known by S. B. Grinnell and E. S. Dana (1876), or the Ticholeptus beds of Cope, are referred by W. B. Scott to the earlier part of the Loup Fork epoch. The basin is situated near Camp Baker, 50 miles east of Helena, along

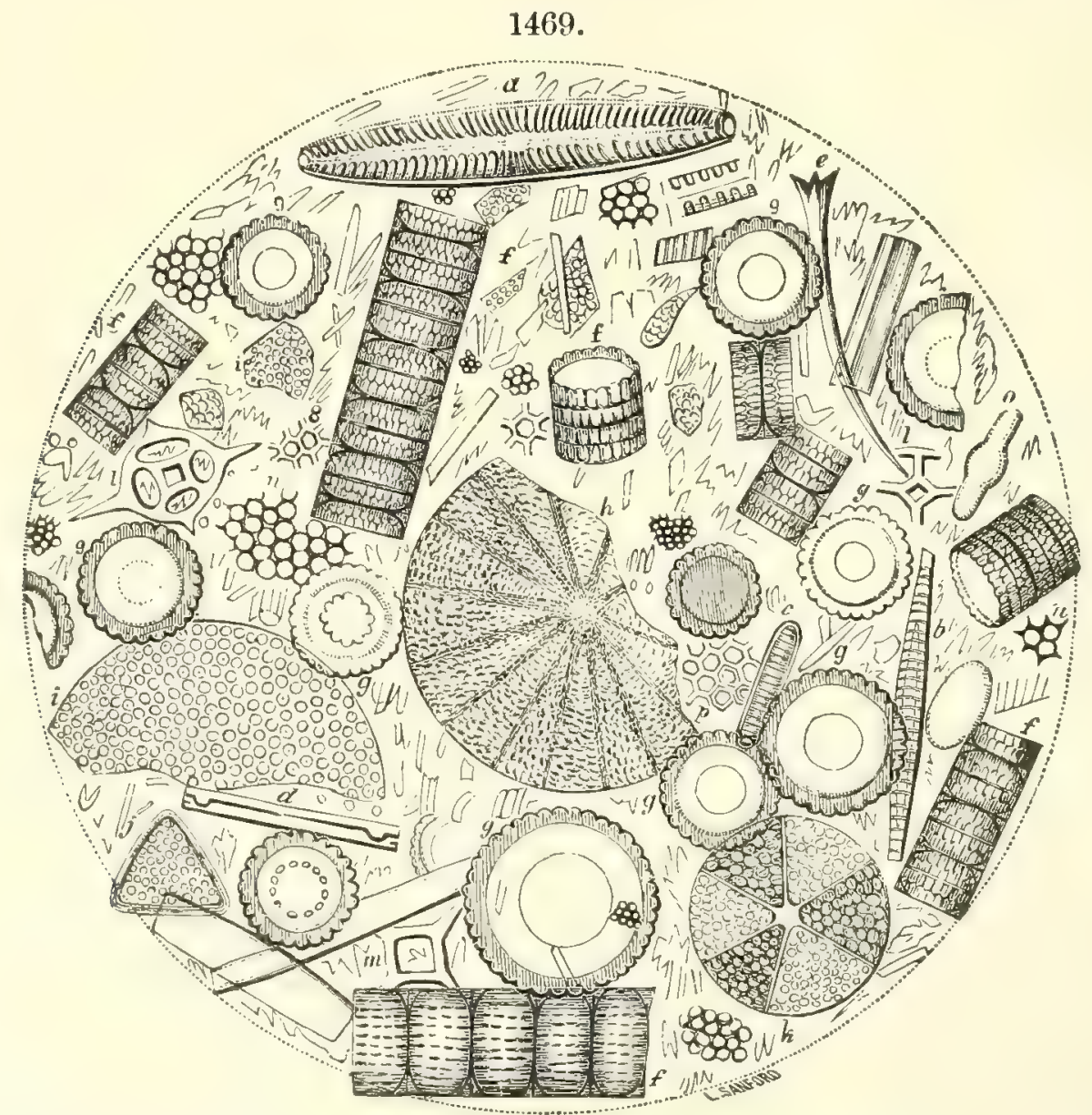

Richmond Infusoriat EARth. - $a$, Pinnularia peregrina; $b, c$, Odontidium pinnulatum; $d$, Grammatophora marina; $e$, Spongiolithis appendiculata ; $f$, Melosira sulcata ; $g$, transverse view, id.; $h$, Actinocyclus Ehrenbergii ; $i$, Coscinodiscus apiculatus; $j$, Triceratium obtusum; $k$, Actinoptychus undulatus ; $l$, Dictyocha crux; $m$, Dictyocha; $n$, fragment of a segment of Actinoptychus senarius; $o$, Navicula; $p$, fragment of Coscinodiscus gigas. 
Deep River Valley (or Deep Creek) and other valleys of the vicinity. The beds are hard cream-colored clays, overlaid by loose beds of coarse and fine material of the Loup Fork horizon. Cope's Ticholeptus beds of Cottonwood Creek, in Oregon, according to Scott, are probably of the Loup Fork horizon; but those of western Nebraska he refers to the White River group.

The Pah-Ute Lake of King, named from a mountain ridge in Nevada, was described by him as extending from the Columbia River, through Oregon and Nevada, into California - an improbable range for one lake. He named its beds the Truckee Miocene. They include, in Nevada, sands, grits, volcanic tufa, and infusorial deposits, the last $250^{\prime}$ to $300^{\prime}$ thick.

Diller reports the Upper Sacramento Valley as the area of a great Miocene lake, covering part of the northern end of the Sierra Nevada.

III. Pliocene. - The Blanco beds of Cummins and Cope, on the Staked Plains of western Texas, consist at Blanco Cañon of beds of clays and sands, in all $150^{\prime}$ to $200^{\prime}$ thick. The underlying beds are referred to the Triassic. The beds extend northward beyond Red River.

\section{LIFE.}

Plants. - 1. Protophytes. - About 100 species of Diatoms have been described by Ehrenberg and Bailey, from the Infusorial stratum of Richmond, besides a few Polycystines and many sponge-spicules. Fig. 1469 represents a portion of the Richmond earth, as it appeared in the field view of Ehrenberg's microscope. This is an example of one of the many Infusorial earths of the era.

2. Angiosperms, Conifers, Palms. - The lignitic beds in the lower part

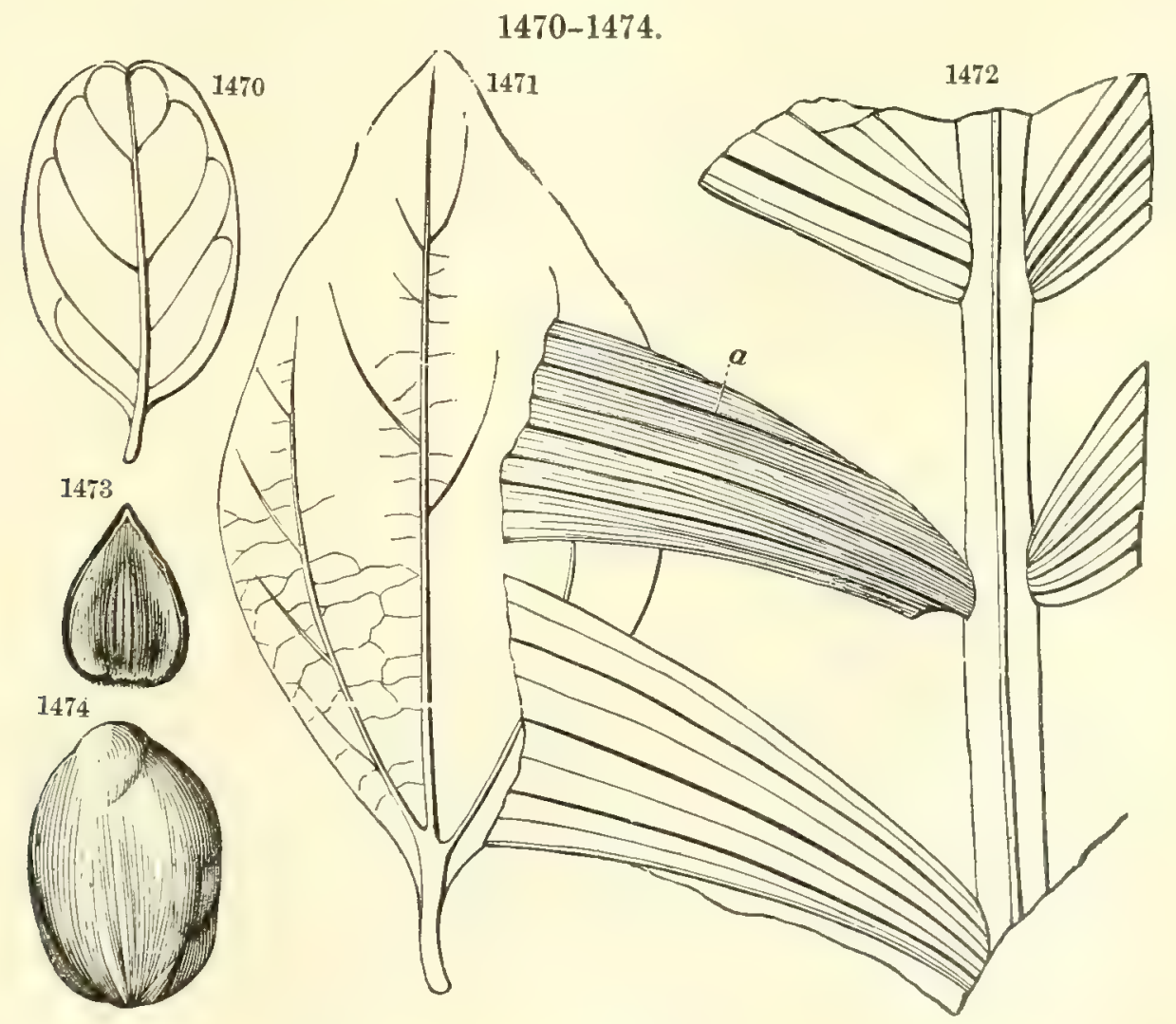

Fig. 1470, Quercus myrtifolia (?); 1471, Cinnamomum Mississippiense; 1472, Calamopsis Danæ; 1473, Fagus ferruginea (?); 1474, Carpolithes irregularis. 
of the Eocene of Mississippi, Arkansas, and elsewhere, have afforded large numbers of leaves of plants; others have been obtained, together with a variety of nuts, from the bed of lignite at Brandon, Vt.

The plants of these beds, some of which are here represented, are closely related to those of the present era.

Fig. 1470 represents an oak leaf (Quercus myrtifolia) from Somerville,

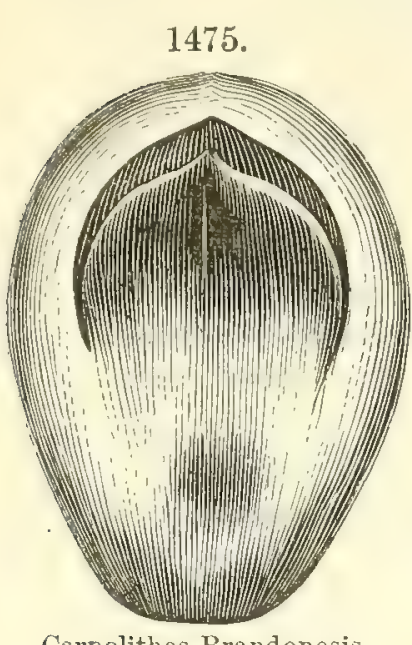

Carpolithes Brandonesis. Tenn., the Lagrange group of Safford; Fig. 1471, leaf of a cinnamon (Cinnamomum Mississippiense), from Mississippi, at Winston; Fig. 1472, a palm (Calamopsis Dance Lsqx.), from Mississippi, in Tippah, Lafayette, Calhoun; Fig. 1473, nut of a beach (Fagus ferruginea (?)), from the Lagrange group of Tennessee; Fig. 1474, fruit (Carpolithes irregularis Lsqx.), from the Brandon Lignite bed; Fig. 1475 (Carpolithes Brandonensis Lsqx.), the most abundant of the Brandon nuts, natural size. The kind of plant producing these two fruits is undetermined. Among the other Brandon fruits, Lesquereux recognized the genera Carya, Fagus, Aristolochia, Sapindus, Cinnamomum, Illicium, Carpinus, and Nyssa. (Am. Jour. Sc., xxxii., 355, 1861.)

Animals. - Invertebrates. - In the Eocene, among Protozoans, Rhizopods are very numerous in some of the beds. The coin-shaped fossils, Orbitoides, resembling Nummulites in form, abound in the Vicksburg beds, and the rock is often called the Orbitoides limestone; the common species, O. Mantelli, is represented in Fig. 1494.

Midway. - Characteristic species of the Midway group are represented in Figs. 1476-1478; of the Lignitic group, in Figs. 1479-1481; and Eocene of the Lower Claiborne, in Figs. 1482-1484, 1487, 1488; of the Upper Claiborne, in Figs. 1485, 1486, 1489; of the Vicksburg, in Figs. 1490-1496; of the Miocene, in Figs. 1497-1507; of the Pliocene, in Figs. 1508-1510.

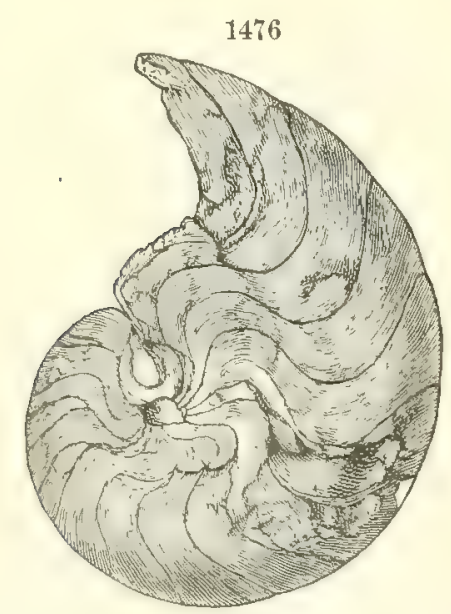

$1476-1478$.
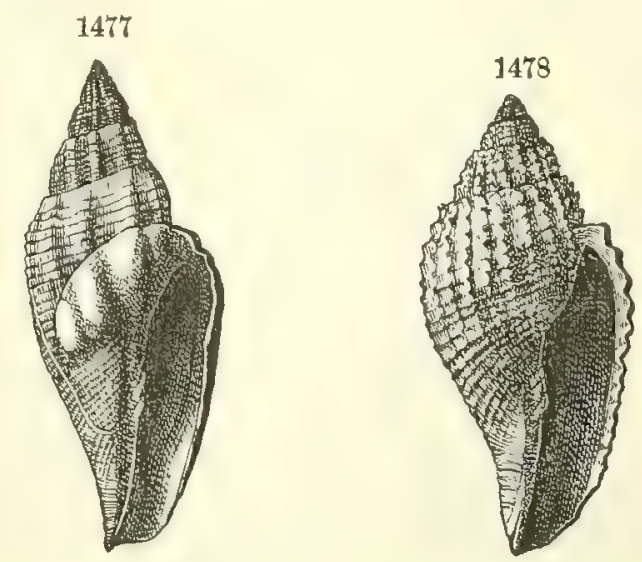

EOOHNE, Midway Group. - Fig. 1476, Enclimatoceras Ulrichi ; 1477, Volutilithes rugatus; 1478, V. limopsis. Fig. 1476, C. A. White; 1477,1478 , Harris. 
1479.

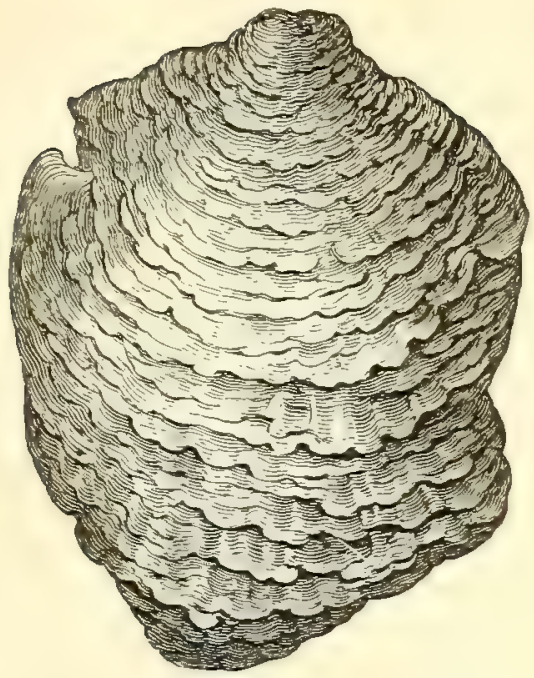

1480.

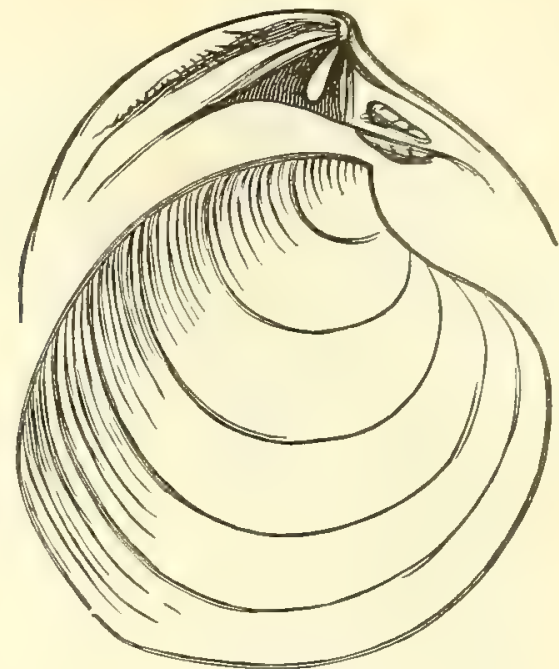

Lignitio Group. - Fig. 1479, Ostrea compressirostra $\left(x_{\frac{2}{7}}\right) ; 1480$, Dosiniopsis lenticularis, var. Meekii. Fig. 1479 , Say ; 1480 , Conrad.

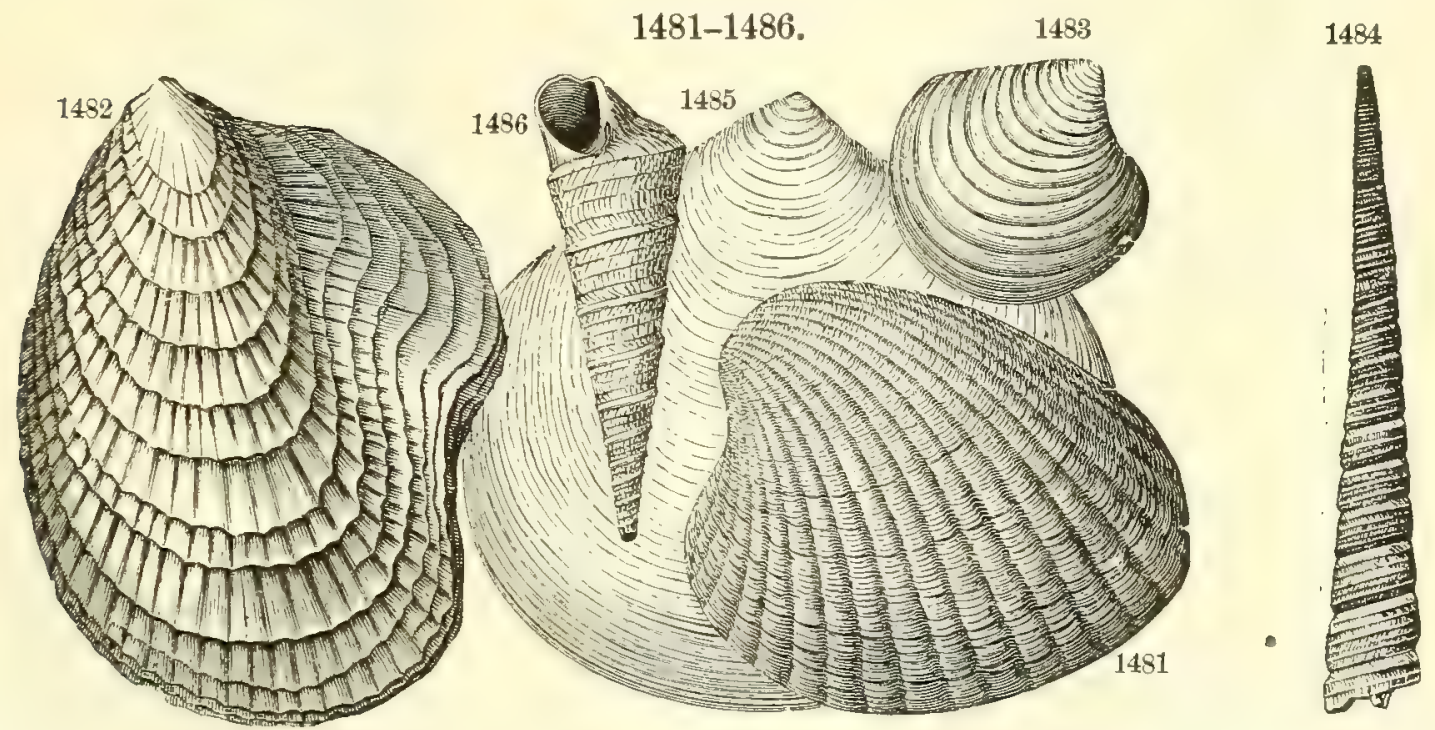

LigntTic. - Fig. 1481, Venericardia planicosta $\left(\times \frac{1}{3}\right)$. Lowkr Clargonne. - Fig. 1482, Ostrea sellæformis; 1483 , Pteropsis Conradi; 1484, Turritella nasuta. UpPre Claiborne. - Fig. 1485, Crassatella alta; 1486, Turritella carinata. Figs. 1481-1483, 1485, 1486, Meek; 1484, Harris.

\section{$1487-1489$.}
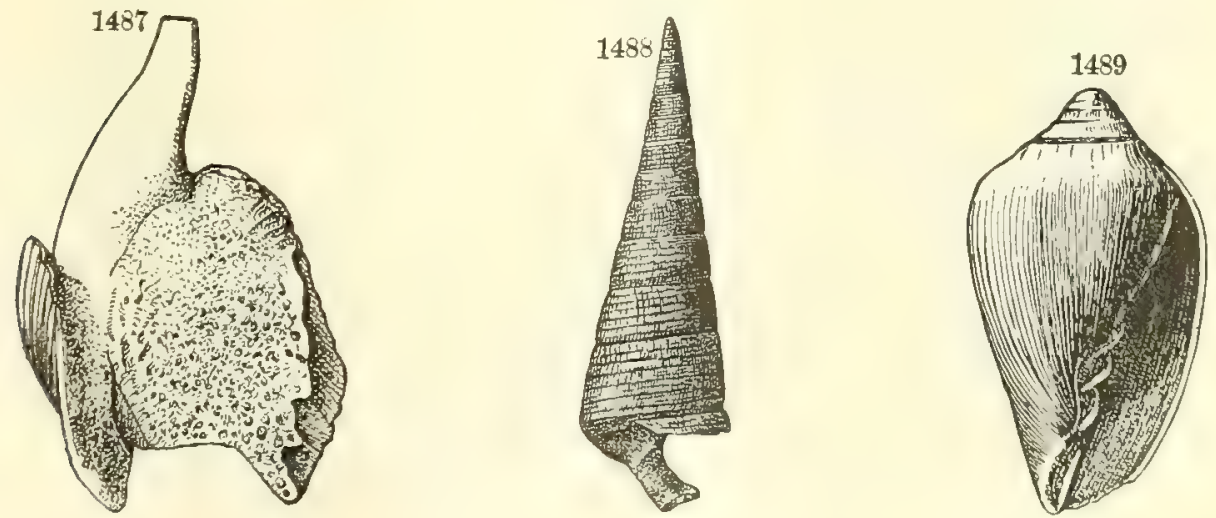

Lower Clamorne. - Fig. 1487, Belosepia ungula; 1488, Mesalia Claibornensis. Upper Claiborne. - Fig. 1489, Caricella Claibornensis. Harris. 
$1490-1496$.
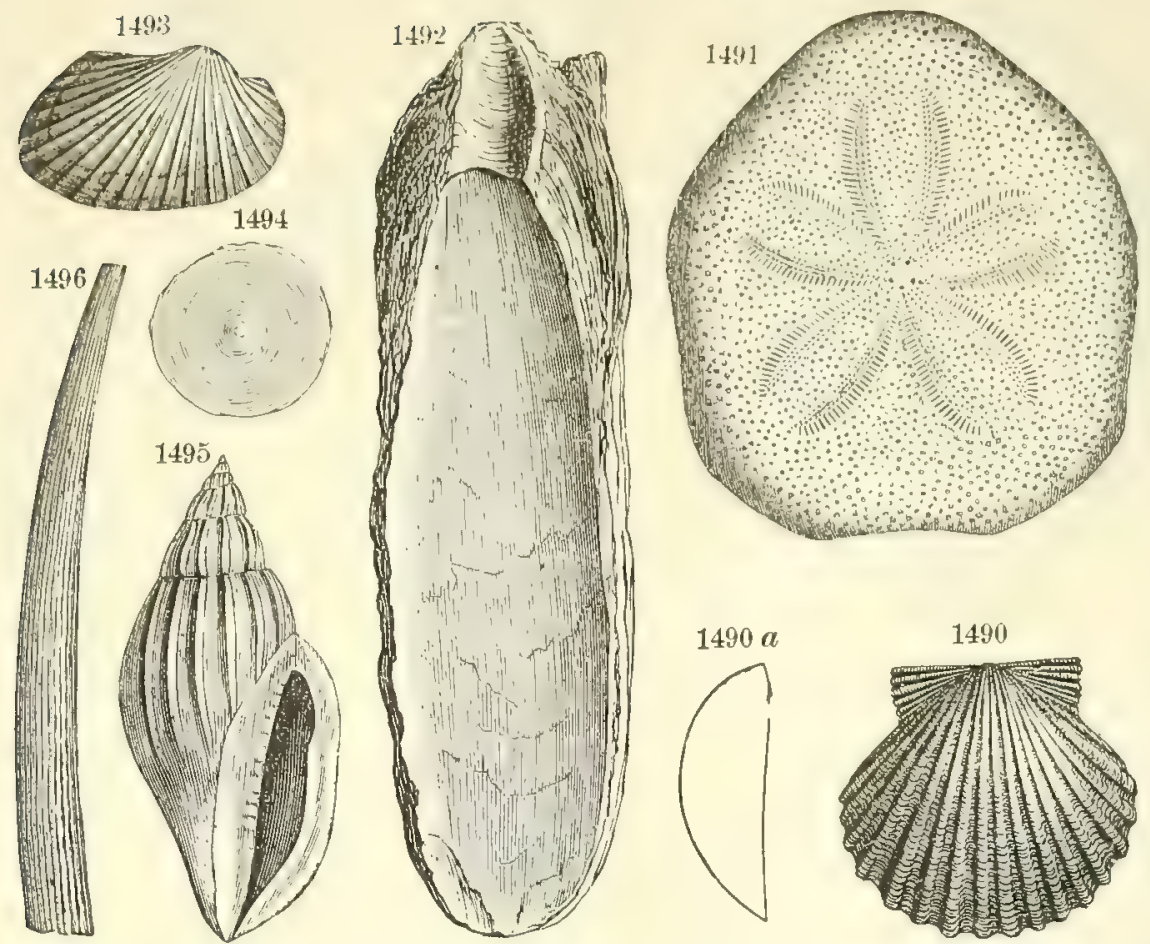

Eocene. - Vicksburg group. - Fig. 1490, Pecten Poulsoni; $\boldsymbol{a}$, section of same ; 1491, Mortonia Rogersi ; 1492 , Ostrea Georgiana $\left(\times \frac{1}{4}\right)$, Vicksburg (?); 1493, Arca Mississippiensis; 1494, Orbitoides Mantelli ; 1495, Lyria. costata; 1496, Dentalium Mississippiense. Figs. 1490-1492, 1494, Meek ; 1493, 1495, 1496, Conrad.

$1497-1499$.
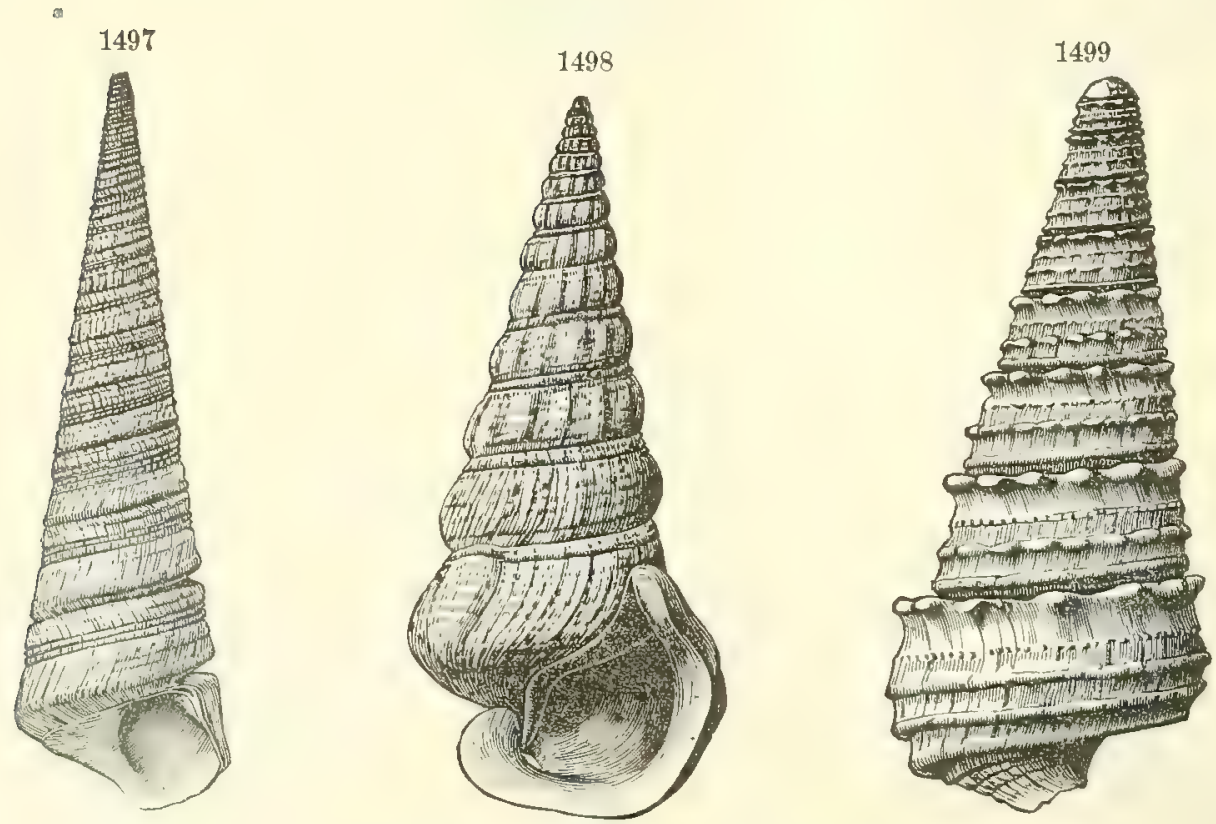

MIocens, - Chattahoochee group.-Fig. 1497, Turritella Tampr $\left(\times \frac{2}{3}\right) ; 1498$, Pyrazisinus campanulatus; 1499, Cerithium Hillsboroense. From Dall. 
1500-1502.
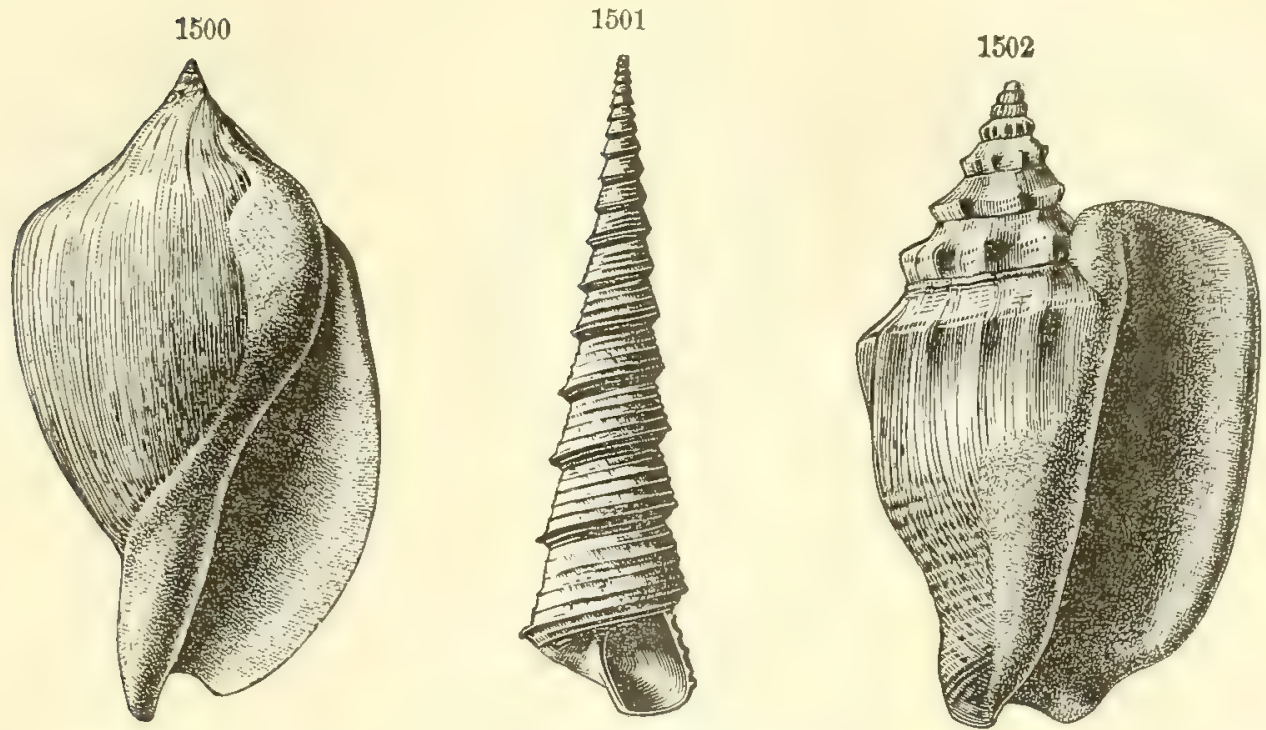

Mrocexe. - Chipola group. - Fig. 1500, Orthaulax Gabbi ; 1501, Turritella subgrundifera $\left(\times \frac{2}{3}\right)$; 1502, Stromabus Aldrichi. From Dall.

1503-1505.

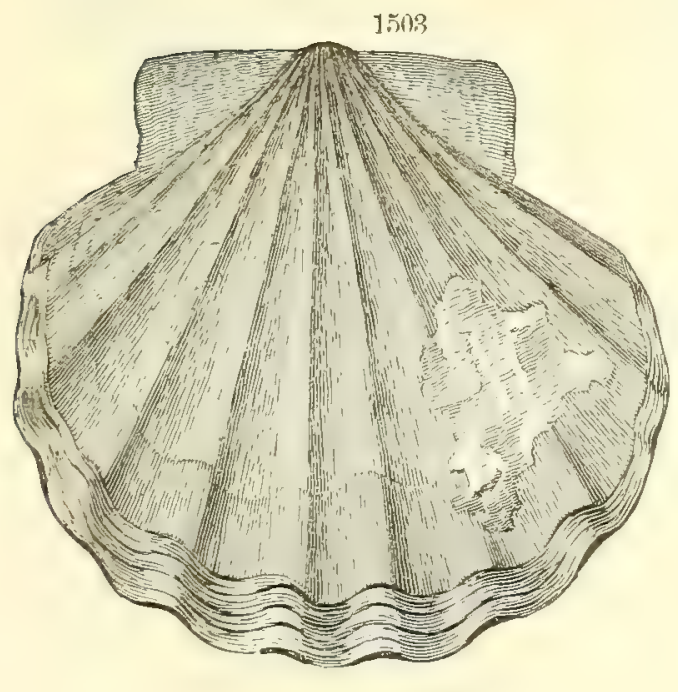

1515
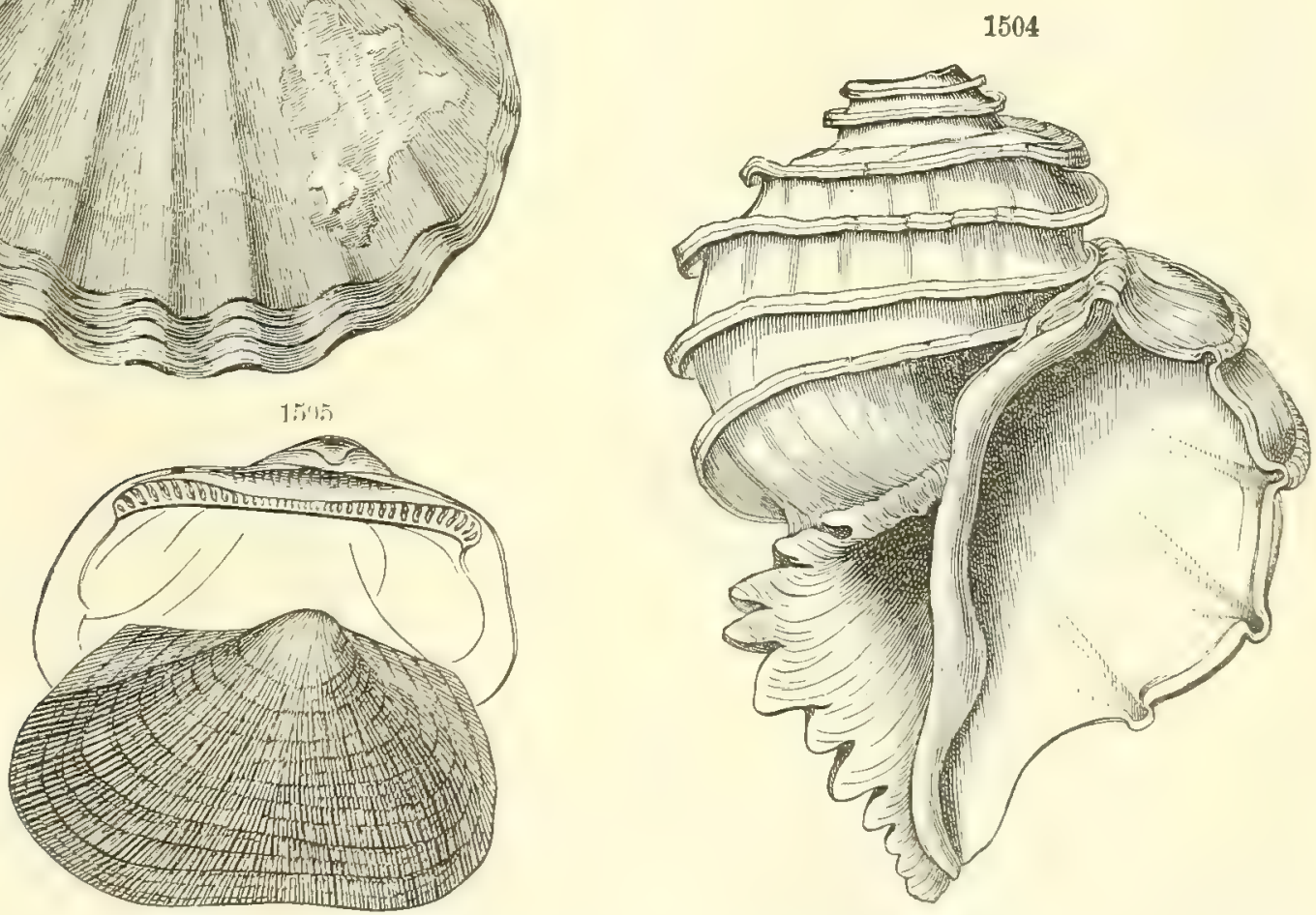

MrOCENE. - Yorktown group. - Fig. 1508, Pecten Jeffersonius $\left(\times \frac{2}{2}\right) ; 1504$, Ecphora quadricostata $\left(\times \frac{2}{3}\right) ; 1505$, Striarca centenaria. T. Say, 1824. 


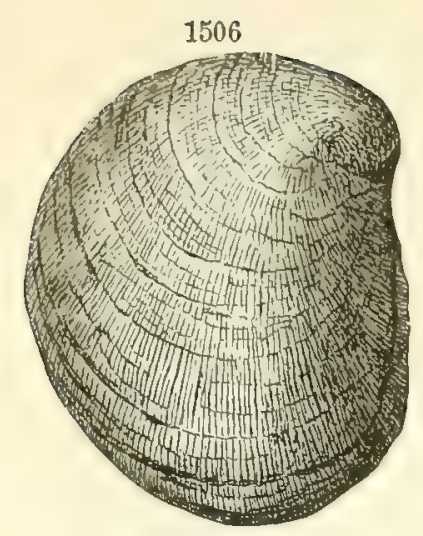

$1506,1507$.
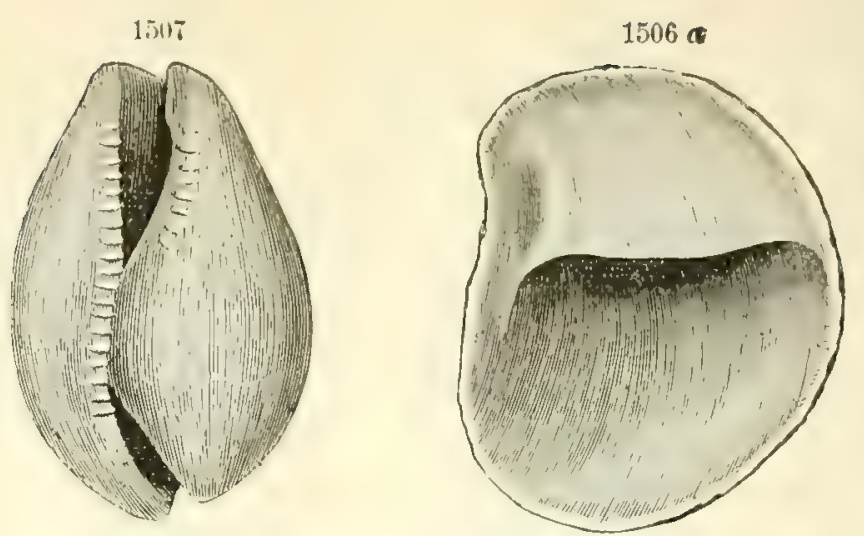

Mrocene. - Figs. 1506, a, Crepidula costata; 1507, Cypræa Carolinensis. Meek.

\section{8-1510.}
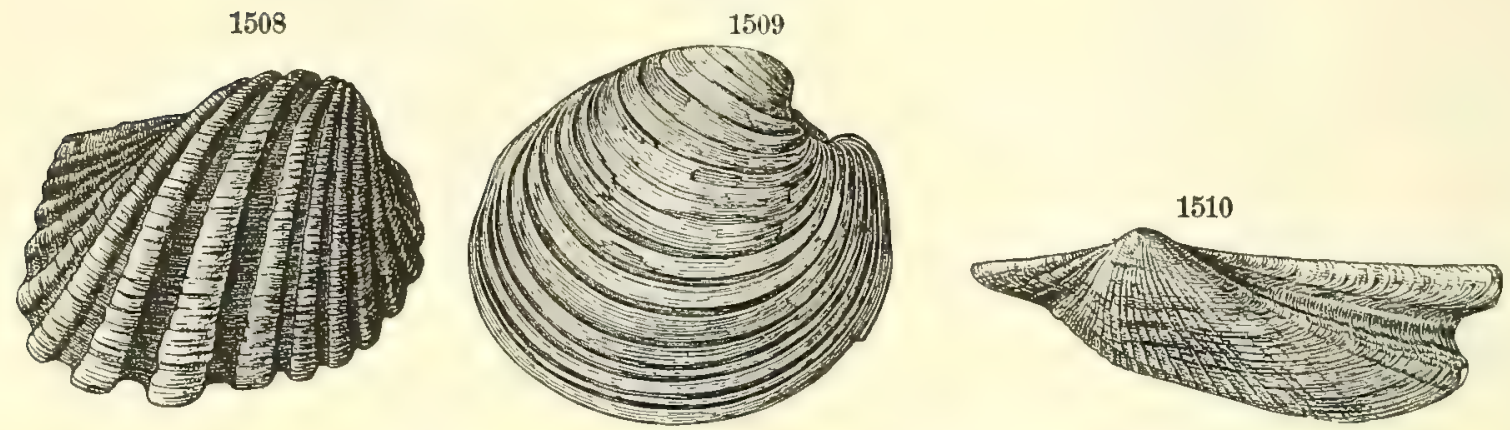

Pliocene, -- Floridian group. - Fig. 1508, Area crassicosta ; 1509, Venus rugatina $\left(\times \frac{1}{2}\right)$; 1510, Arcoptera avículieformis $\left(\times \frac{1}{2}\right)$. Original.

Insects. - The Insects of the Florissant basin, described by Scudder, include species of all the grand divisions; and hundreds of some of them. The number, thus far made out, according to this author, is of Orthopters, 24; Neuropters, 57 ; Hemipters, 220 ; Coleopters, over 400, of which 116 are
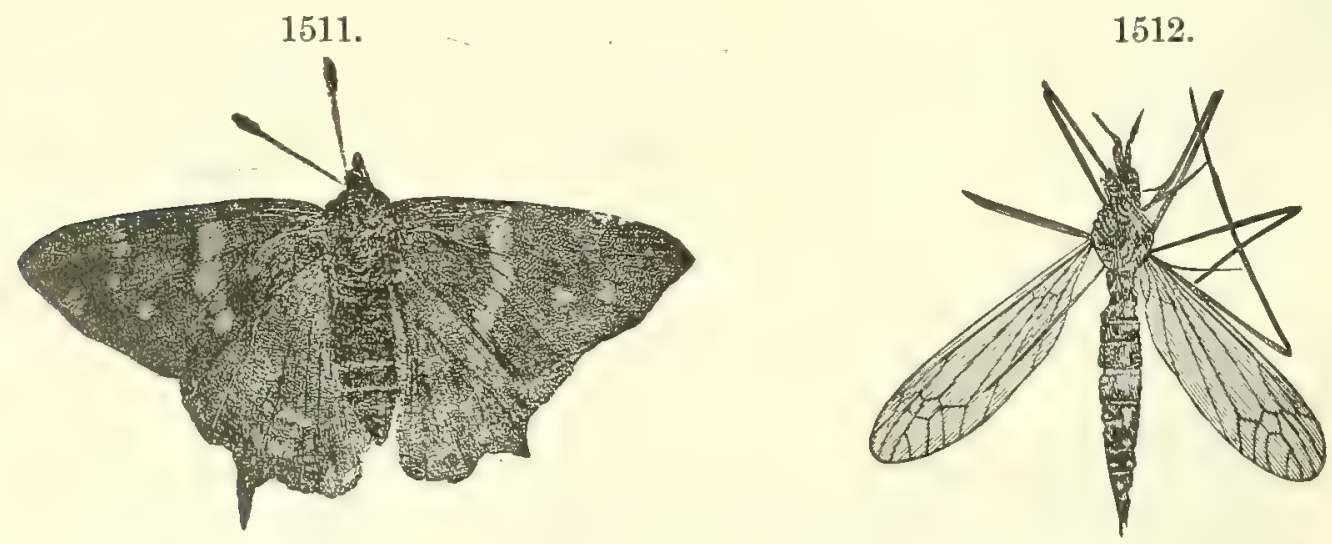

Insecrs. - Fig. 1511, Prodryas Persephone; 1512, Tipula Carolinæ. Scudder.

Rhynchophora; Dipters, 250; Lepidopters, 9; Hymenopters, about 235 species. Of the Dipters, 51 are Tipulidæ, and one of these, two thirds of an inch in length, is represented in Fig. 1512, and one of the Butterflies. in Fig. 
1511. Besides these, Scudder has made out 31 species of Arachnids or Spiders. He states that about a fourth of all the species at Florissant are Ants (Formicidæ), and that by 1885 more than 4000 specimens of Ants had been brought from the beds. Of Aphides, or Plant-lice, an eighth of an inch long, or less, he has collected over 100 specimens, representing 32 species, and all but one showing well the wings. Two other localities, affording similar species, one on the crest of the Roan Mountains in western Colorado, and the second on the lower part of White River, at the Utah line, are supposed to be at least as rich as Florissant.

Eocene Vertebrates. 1. Fishes. - The remains of Ganoid fishes (genera Lepidosteus, Amia), and Teleosts, of the Perch, Herring, and other families, are abundant in the Green River shales, along with remains of Plants and Insects. The marine Tertiary beds of the Gulf and Atlantic borders, and especially of the Eocene, contain, in many places, the teeth of Sharks in great numbers; three kinds are represented in the accompanying figures. Some of the triangular teeth of Carcharodon megalodon Ag. (resembling Fig. 1513), are six inches broad at base and six and a half long.

$1513-1516$.
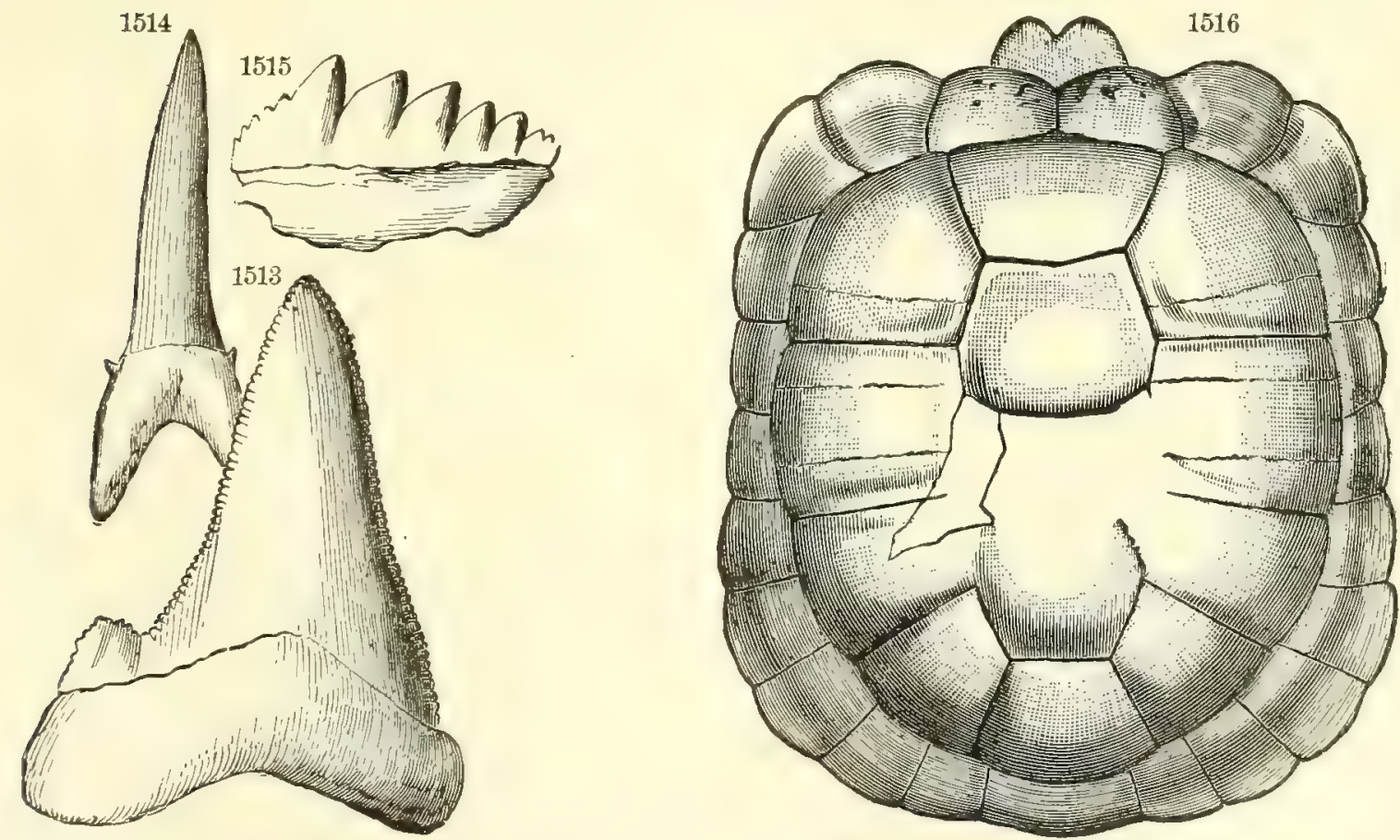

TeEth of Sharks,-Fig. 1513, Carcharodon angustidens; 1514, Lamna elegans; 1515, Notidanus primigenius. Testudivate. - Fig. 1516, Testudo brontops $\left(X_{\text {II }}\right)$. Figs. 1512-1515, Agassiz; 1516, Marsh.

2. Reptiles. - The Tertiary Reptiles include species of Crocodiles, among them, Crocadilus Elliotti Leidy, from South Carolina, and C. Squankensis of Marsh, from New Jersey; of Snakes, of the genus Dinophis Marsh, from New Jersey, and of Boavus and Lithophis, from Fort Bridger, about 20 feet long; of 'Turtles, of the genera Testudo, Emys, etc., from the Atlantic border and the Rocky Mountain region. Fig. 1516 represents one of the largest of 
American Turtles, from the Lower Hiocene, or I'hite River beds, of Dakota, Testudo brontops of Marsh, which had a length of about two and two thirds feet. The Puerco beds have afforded a species of Champsosaurus (C. Saponensis of Cope), a Laramie genus. A very small species of Crocodile has been reported from the White River beds.

3. Birds. - The Eocene and Miocene have afforded remains of species related to Waders, an Owl, Bubo leptosteus of Marsh, a bird near the Woodpeckers, some web-footed species allied to the Gannet; and the Miocene, remains of a large Eagle, a Cormorant, and other birds. 'The Diatryma gigantea of Cope, from the early Eocene of New Mrexico, was larger than the Ostrich. The Baromis regens of Marsh, from the Upper marl beds of Squankum, N.J., of the Eocene, had about the size and many of the characters of the Ostrich. From the Florissant beds have been obtained a Plover and other species.

4. Mammals. - The sea-border Tertiary of the continent has afforded remains of but few Mammals; for seashores are not their ordinary resort except for aquatic kinds. The regions of the great lakes over the Rocky Mountain area, on the contrary, have been found to be literally Tertiary burial-grounds. They bear evidence that Mammals in great numbers, and of several successions of faunas, lived and died about these lakes, and by lacustrine agencies were buried.

These ancient bone-beds remained almost unknown to science until the year 1847; and now, through the labors of explorers, and the works of Leidy, followed by the memoirs of Marsh, Cope, Scott, Osborn, and others, the number of known species far exceeds that of existing North American Mammals. These Mammals are, with rare exceptions, of the ordinary or placental type. The Marsupials, as in earlier time, were small species, related to the Opossums; and their remains are known from the Early Eocene onward.

Eocene. - The Eocene species comprise Herbivorous, or Ungulate, Carnivorous, Insectivorous, and Rodent species, and also Quadrumana; and before the close of the period, Cetaceans, or Whales. The remains of Ungulates are most abundant, because such species frequent lake borders. They are related to the modern Tapir, Wild Boar, and Rhinoceros, yet only in a very general way, as these special types belong to a later period. The earliest of the Eocene species are remarkable for their prototype or primitive characteristics: $(a)$ the legs being approximately equal; $(b)$ the feet five-toed and of typical form, the five toes similar, with the third or middle toe a little the longest; $(c)$ the carpal bones and the tarsal in vertical series with the following bones of the foot; $(d)$ the teeth of the typical number, 44, - that is, 11 in either ramus of each jaw, - the 11 including 3 incisors, 1 canine, \pm premolars, and 3 molars; (e) the molars of simple form, being usually tritubercular at summit, or trigonodont; $(f)$ the head without armature of horns or tusks. 
Moreover, the types are generally comprehensive or intermediate kinds. The flesh-eaters are intermediate in their teeth and other characters between Carnivores and Insectivores, and have been referred by Cope to a separate group named Creodonts, from the Greek for flesh and tooth. Another group has some of the features of the Tillodonts, Rodents, and Ungulates; and the Ungulates also have some of the characteristics of Carnivores or Quadrumana.

The prototypic features are presented by species of the genera Phenacodus, Coryphodon, and many others. They are well illustrated, as pointed out by Cope, in the Phenacodus primavus, described by him from a specimen found in the Wasatch beds (Fig. 1517). Besides the primitive features of 44 teeth, of five similar toes to both fore and hind feet, of the carpal in series with the digits (Figs. $1517 a, b$ ), the feet were probably plantigrade, the foot striking the ground with the whole sole, instead of being

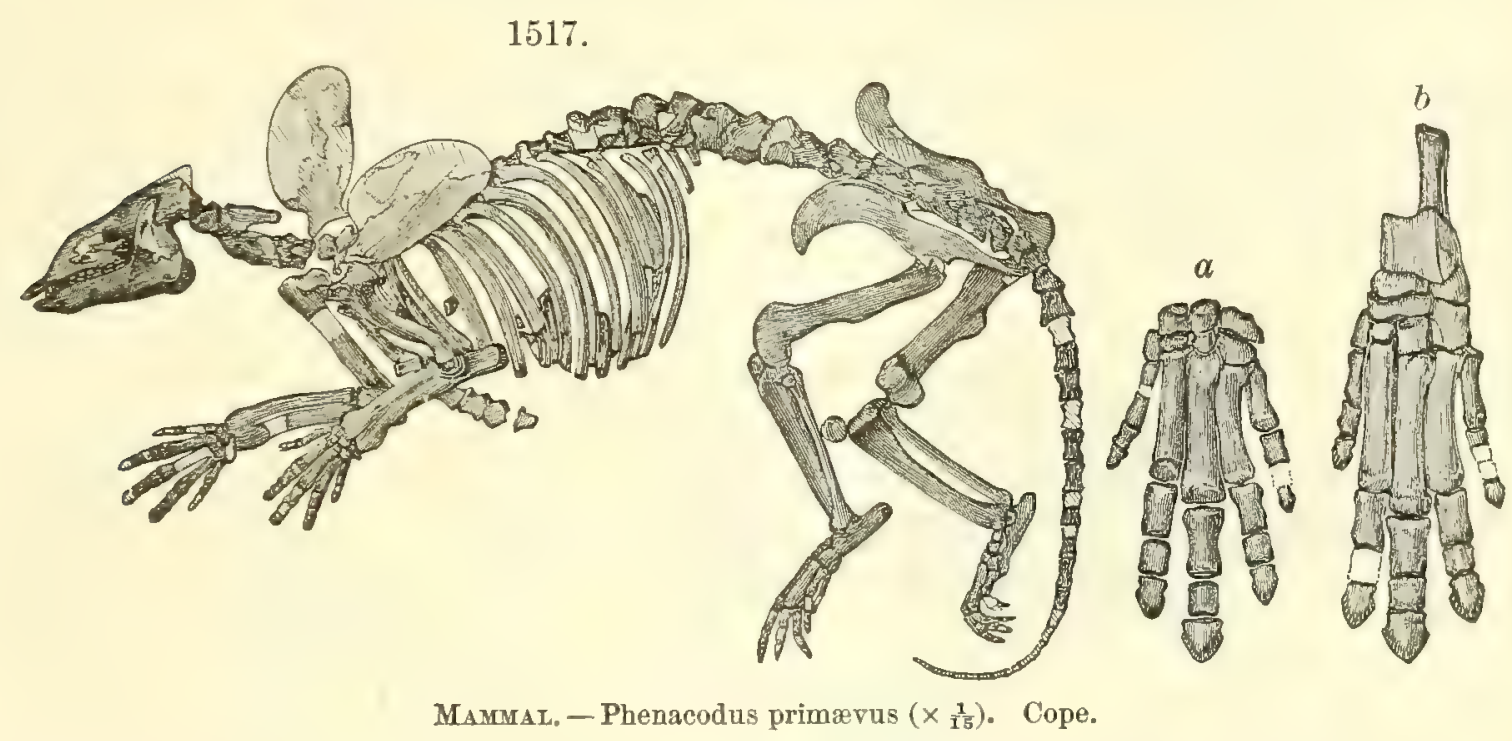

raised on the toes (digitigrade). The animal is supposed to have been omnivorous, from its teeth. The length of the body was about four feet. The Creodonts (prototypic Carnivores) of the Puerco beds also are described by Cope as plantigrade species.

These characters are also well exhibited, as shown by Marsh, in species of Coryphodon from the Wasatch group. A restoration of Coryphodon hamatus of Marsh is represented in Fig. 1518, and the fore feet and hind feet in Figs. $1518 a, b$. The length of the body was six feet. The special prototypic features of the feet and limbs are manifest, after the above statements, without special remarks. The animal was digitigrade, and had short, nearly equal toes, a type of foot which is represented also in the modern Elephant.

An early genus in the line of the Tapir is Systemodon of Cope, represented by S. tapirinus from the Wasatch. Besides other primitive features, it has the teeth in a continuous series, there being no interval (diastema) between the canines and the premolars. 
The Tillodonts of Marsh, which range from the Puerco through the Bridger Eocene, fail of prototypic characters in having less than the normal

1518

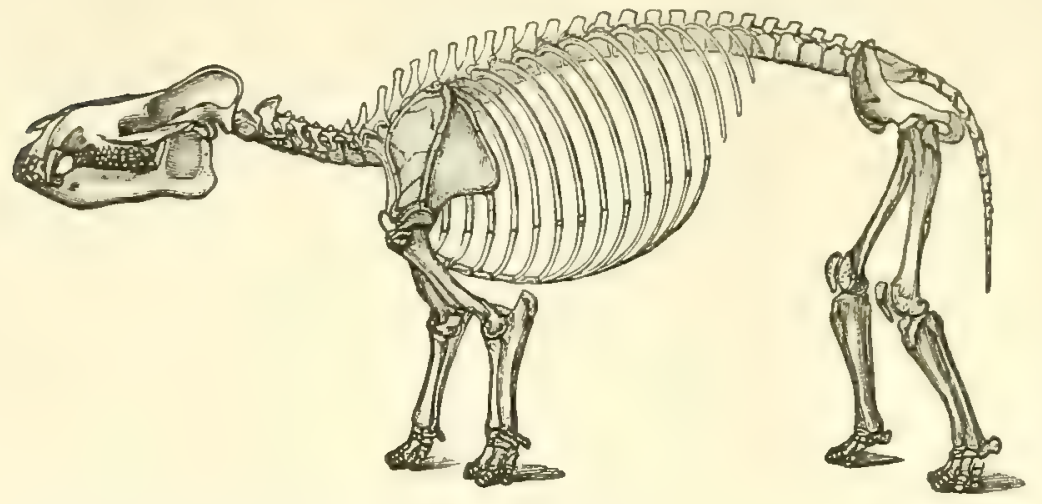

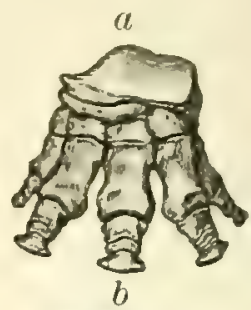

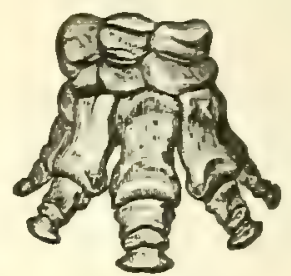

Fig. 1518, Restoration of Coryphodon hamatus $\left(\times \frac{1}{24}\right) ; a$, fore foot; $b$, hind foot $\left(\times \frac{1}{6}\right)$. Marsh.

number of incisors, with one of the pairs much elongated like those of a Beaver and other Rodents, as shown in the figures of Tillotherium fodiens of Marsh. The name, from $\tau \iota \lambda \lambda \omega$, bite, alludes to the long incisors. Psittc-

1519-1523.
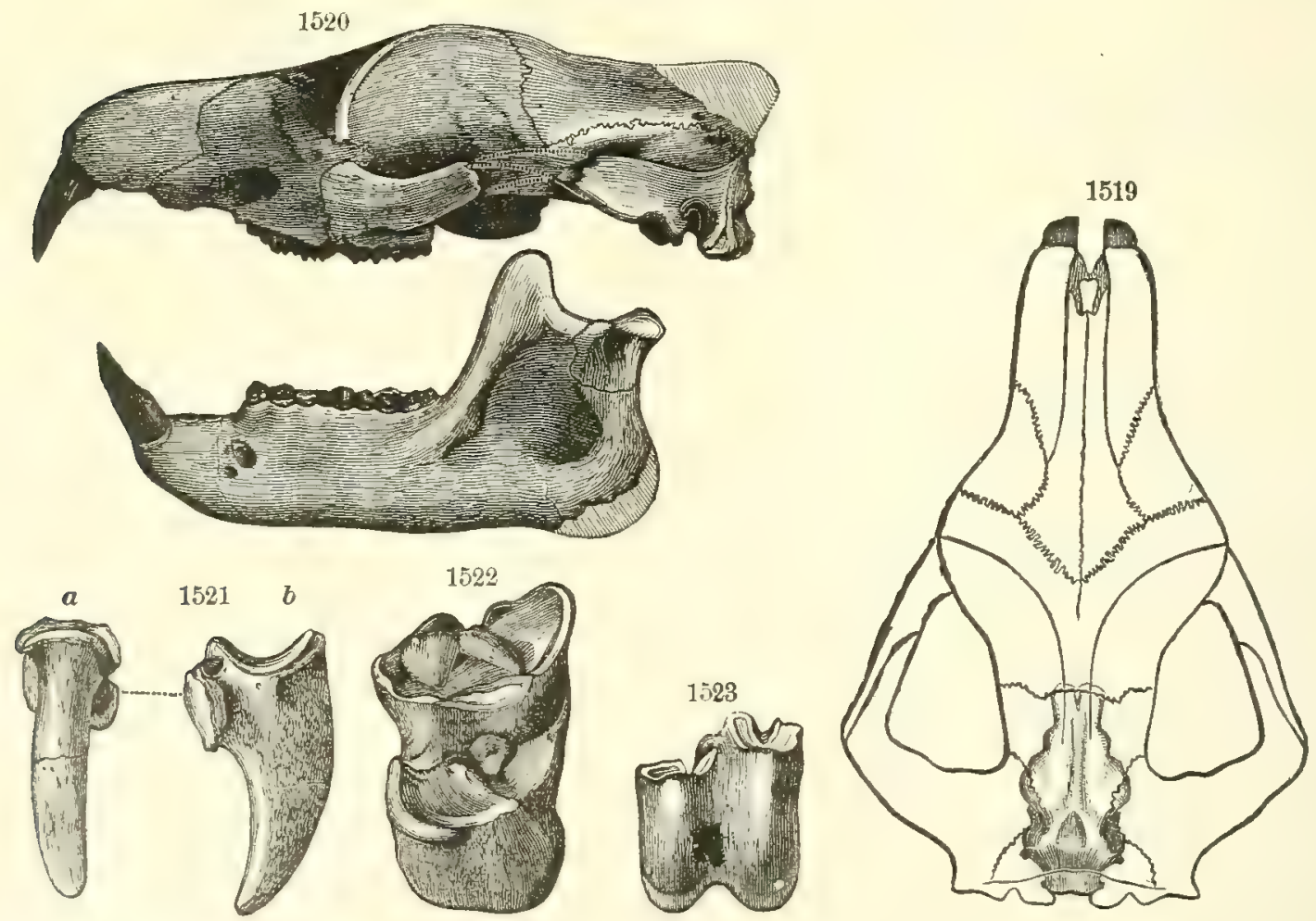

Figs. 1519, Tillotherium fodiens, top view, with form of brain cavity $\left(\times \frac{1}{6}\right) ; 1520$, same, skull and lower jaw ; 1521 $a, b$, same, ungual phalanx or claw, front and side view; 1522, T. latidens, last upper molar $\left(\times \frac{2}{3}\right) ; 1523$, Anchippodus minor, lower molar $\left(\times \frac{2}{3}\right)$. All from Marsh.

cotherium of Cope is a genus of the group from the Puerco beds; Anchippodus of Leidy, from the Bridger group and the New Jersey Eocene; and Tillo- 
therium and Stylinodon of Marsh, from the Bridger beds. Figs. 1519-1521 are of Tillotherium fodiens; 1522, of T. latidens; and 1523, of Anchippodus from Marsh.

Examples of later specializations are here illustrated (Figs. 1524-1527), in Tapir-like species ${ }^{1}$ of the genera Eohippus and Orohippus of Marsh, the former from the Wasatch beds, and the latter from the Bridger. In Eohippus the fore feet (Fig. 1524) have all the five toes represented, but the first toe is already reduced to a "splint-bone" in its metacarpal, while the hind feet (Fig. 1525) have lost wholly the first toe with the metatarsal above, and the fifth toe is reduced to a splintbone. In the later Orohippus the first toe of the fore foot with its metacarpal (Fig. 1526) is wholly wanting, and the first and fifth of the hind foot (Fig. $1527)$ are wanting. Fig. 1526 affords an illustration also of the change in the relative positions of the carpals of most Mammals

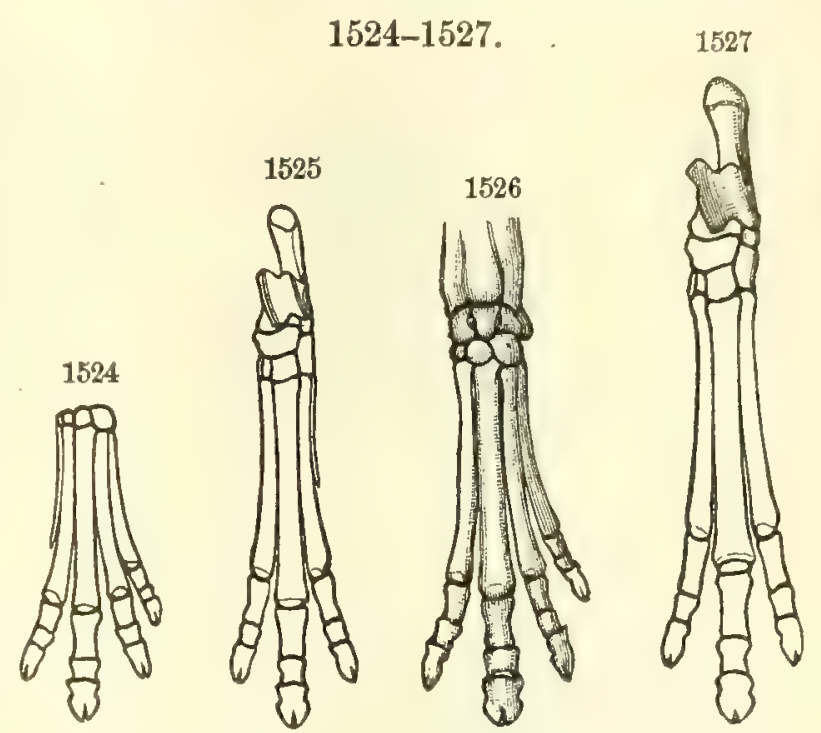

Fig. 1524, Eohippus pernix, left fore foot; 1525, id. left hind foot; 1526, Orohippus agilis, fore foot; 1527 , id. hind foot $\left(\right.$ all $\left.\times \frac{2}{3}\right)$. Marsh.

(and also usually of the tarsals) from that of vertical series (the prototypic position) to that in which the bones alternate with one another (Fig. 1526), so as to give the joint greater strength and safety. This change, with others of like import, began even in the Eocene. In addition, the metacarpals are much elongated.

1528.

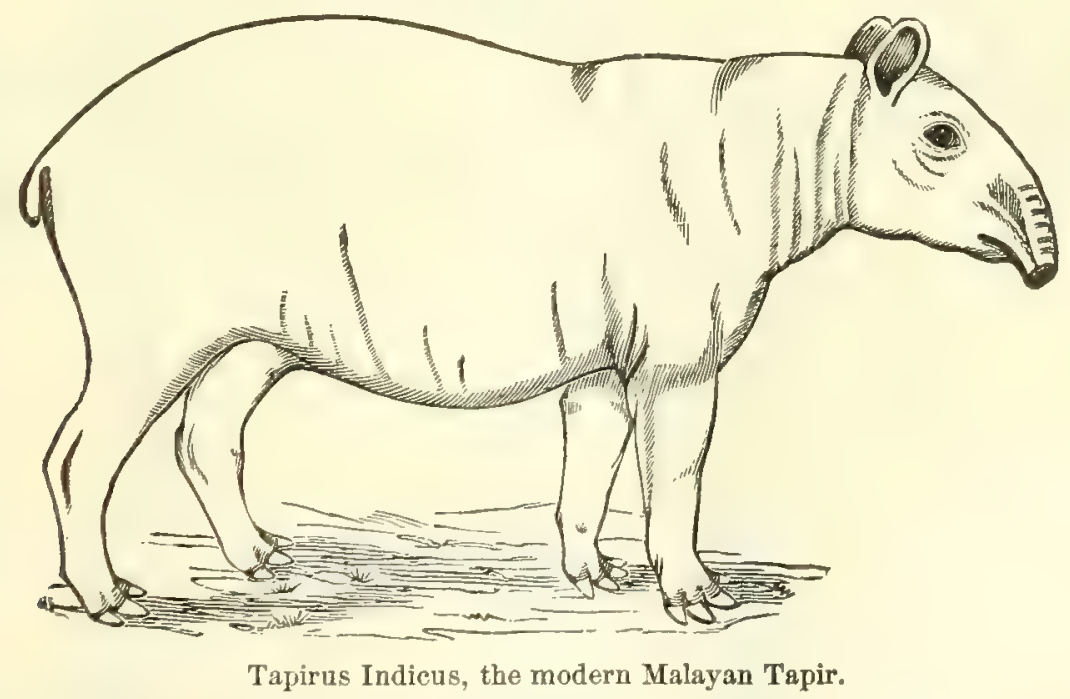

1 On account of the frequent references in the remarks on Tertiary Mammals to the Tapir, a figure of a modern species is here introduced. It shows its general form, short legs, and elongate nose. 
From the Puerco and Wasatch beds come the earliest of the Quadrumana. Fig. 1529 represents the skull of one of the species, Anaptomorphus homunculus Cope, from the Wasatch beds of the Big Horn Basin, of Wyoming.
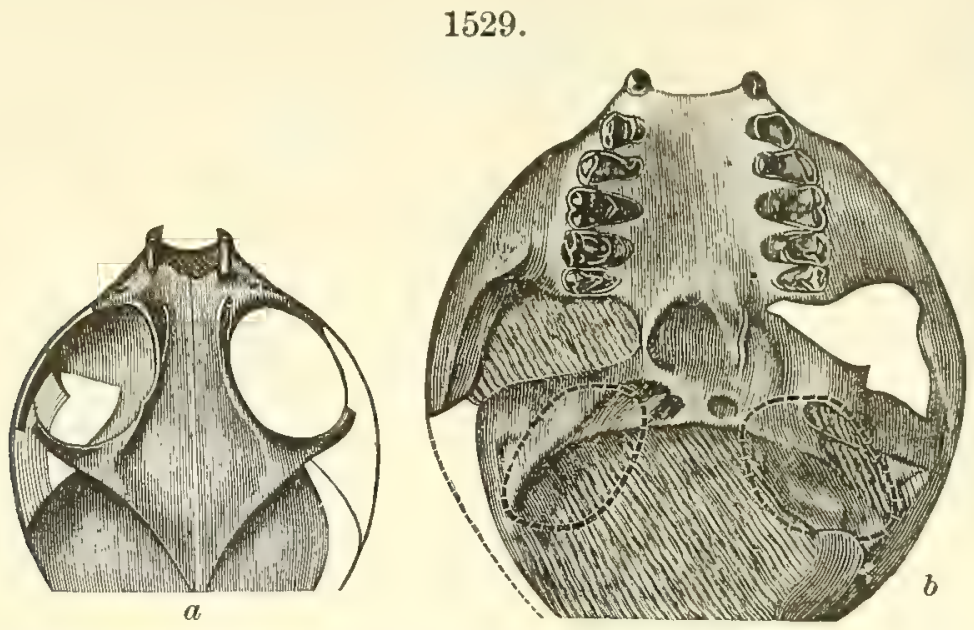

Anaptomorphus homunculus; $\boldsymbol{a}$, cranium, from above; $\boldsymbol{b}$, same, from below, enlarged. Cope.

Other Wasatch species include Creodonts of several genera, Insectivores, and the earliest of true Rodents. There were also in the Wasatch beds, and others equivalent, the first of Artiodactyl Ungulates, the 4-toed Pantolestes brachystomus of Cope, and Homacodon priscus of Marsh; named Artiodactyls (and also Paridigitates) because the four toes are in pairs, the third and fourth being equal, and also the second and fifth if present. Examples are shown in Fig. 1538. The two pairs are present in the Hog, Hippopotamus, ete.; the

1530.

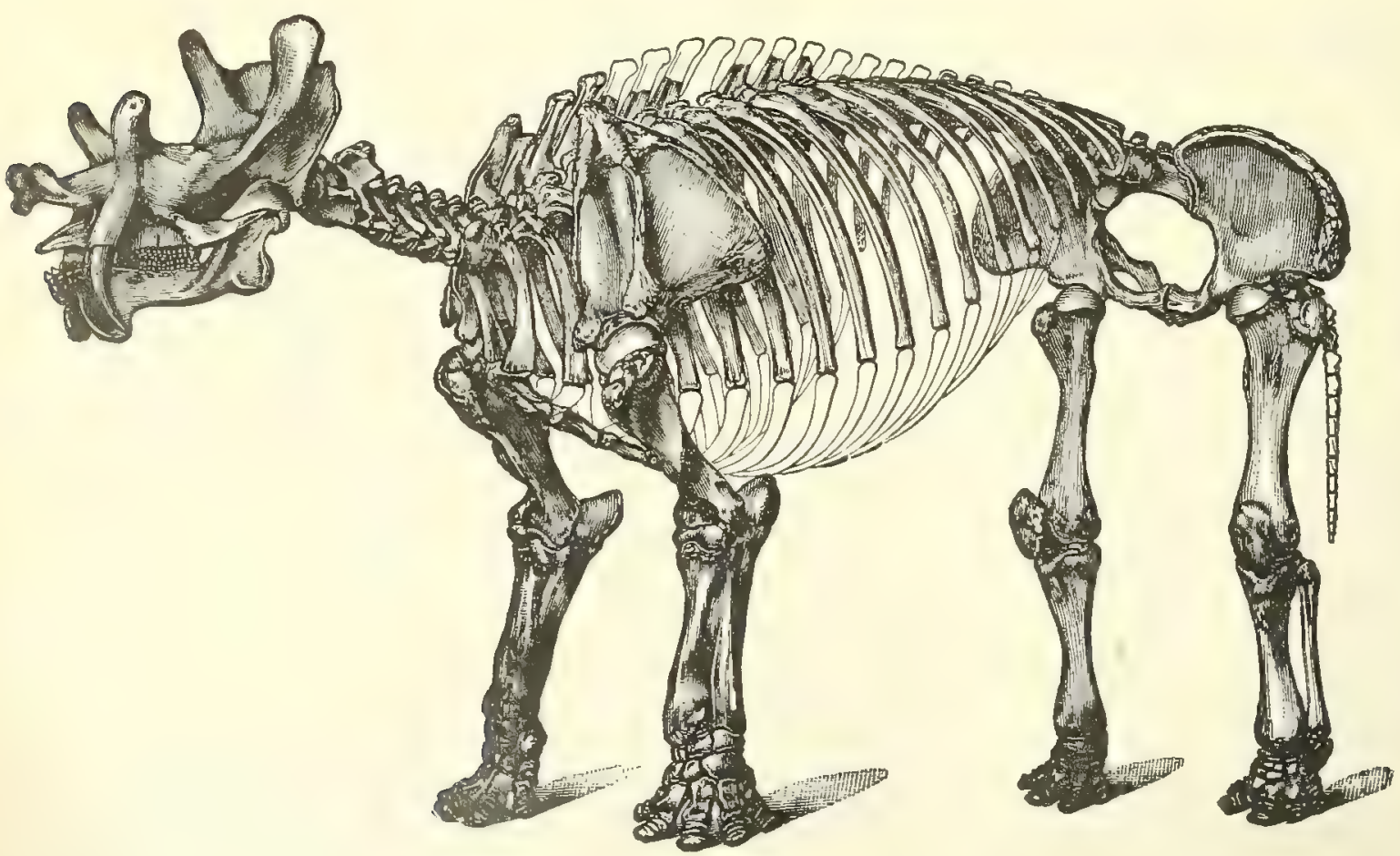

Restoration of Tinoceras ingens of $\operatorname{Marsh}\left(\times \frac{1}{30}\right)$. 
single pair (often with rudiments of the other), in the Camel, Stag, Ox, etc. Another Artiodactyl of the same horizon is the Eohyus distans of Marsh, having Suilline or hog-like characteristics.

The Bridger Eocene is remarkable for the remains of Dinocerata, animals of Elephantine dimensions, having elongate canines, and two or three pairs of bony prominences or horns on the head. Fig. 1530 represents the Tinoceras ingens of Marsh, an animal 12 feet in length. They were successors to the Coryphodons of the Wasatch. The prominences referred to are situated severally on the snout, the cheeks, and the forehead. Marsh observes that part, if not all of them, were horn-cores or bases of horns; and that those that were not so must have been covered with the hide, as in the Giraffe. While thus armed to excess, and probably of great strength, the very small brain shows that they were extremely low in intelligence. The earliest species are: Tinoceras anceps of Marsh, described in October, 1872 (his Titanotherium anceps of 1871, found in 1870); Uintatherium robustum of Leidy, August, 1872; and Tinoceras grandis and Dinoceras mirabilis of Marsh, October, 1872.

Uintatherium Leidyanum of Osborn $(1878,1881)$ has very prominent horn-cores and is from Dry Creek, Wyoming. Uintatherium has 36 teeth, Dinoceras and Tinoceras 34 .

The Bridger beds have afforded, among species related to the Tapir, the genus Helaletes of Marsh, having the teeth 44 in number and in contact, which are prototy pic ehar-

1531.

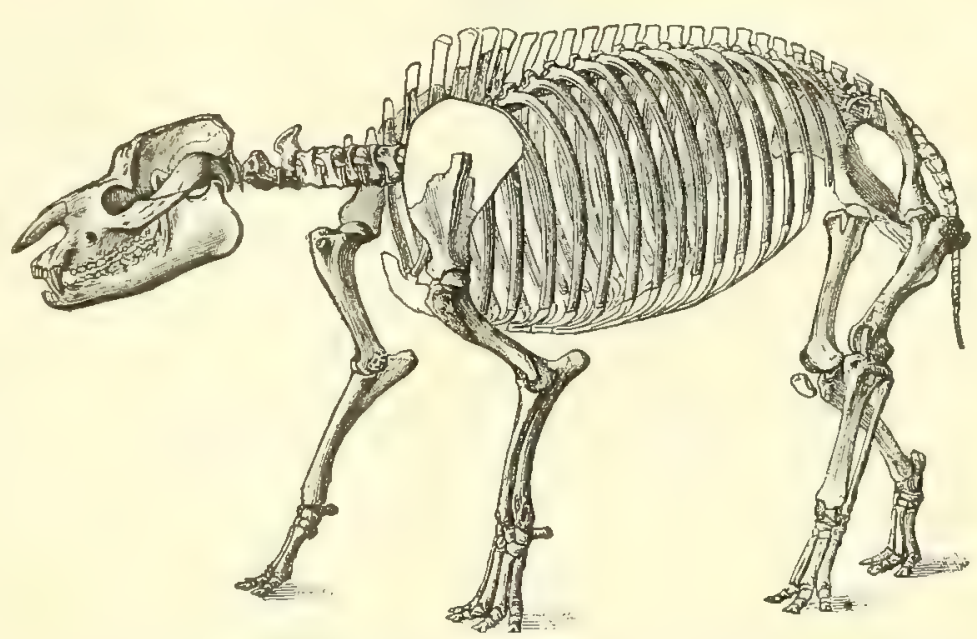

Restoration of Palrosyops paludosus $\left(x \frac{1}{2}\right)$ by C. Earle, 1892. acters; also species of Hyrachyus and Palcosyops of Leidy, which are especially common in the beds. Fig. 1531 is a restoration, by C. Earle, of Palceosyops paludosus of Leidy, an animal about six feet in length.

There are also in the Bridger beds remains of Quadrumana, Creodonts, and Bats, as well as Rodents and Insectivores.

The Uinta group, the last division of the Eocene, has afforded new Tapirlike species of the genus Diplacodon of Marsh, related to Palceosyops of the Bridger group and to the Titanotheres of the Miocene; species of Amynodon of Marsh, related to the Rhinoceros; the Epihippus gracilis of Marsh, an early form of the Horse; also the earliest of the Camel group, Leptotragulus of Scott and Osborn; and of the Oreodonts, Protoreodon; a single genus of Creodonts, besides many other kinds.

The sea-border Jackson beds of Mississippi, Alabama, Georgia, and South Carolina have afforded bones of two whale-like Mammals of the genus 
Zeuglodon, one of which, $Z$. cetoides, was nearly 70 feet long. One nearly perfect skeleton was found in place by S. B. Buckley in Clark County, Ala.,

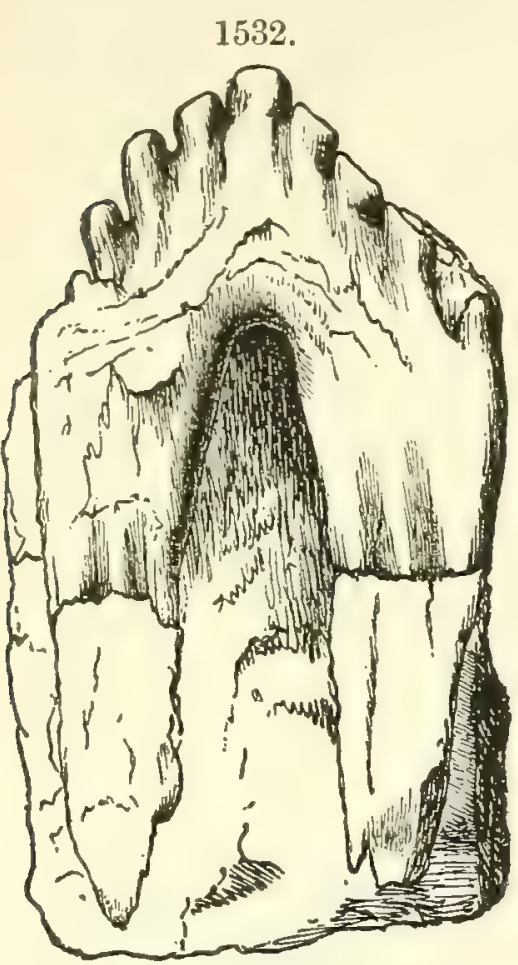

Tooth of Zeuglodon cetoides $\left(x \frac{2}{3}\right)$. D. about 100 miles north of Mobile, having the length here stated. Vertebræ were so abundant, on the first discovery, in some places that many of these Eocene whales must have been stranded together, in a common eatastrophe, on the northern borders of the Mexican Gulf, - possibly through a series of earthquake waves of great violence; or, by an elevation along the sea limit that made a confined basin of the border region, which the hot sun rendered destructive alike to Zeuglodons and their game; or, by an unusual retreat of the tide, which left them dry and floundering for many hours under a tropical sun. The Zeuglodon is the Basilosaurus of Harlan (1834), the Zeuglodon of Owen. Some of the dorsal vertebræ have a length of a foot and a half, and a diameter of a foot; and a rib, a length of nearly six feet. Fig. 1532 represents one of the molar teeth, the yoke-like form of which suggested the name Zeuglodon, from $\zeta \in v \gamma \lambda \eta$, yoke, and obovis, tooth. Some of these teeth had a longer diameter of four and a half inches.

Mrocene. - The Miocene Ungulates were of different species from those of the Eocene, and mostly of different genera.

1533.

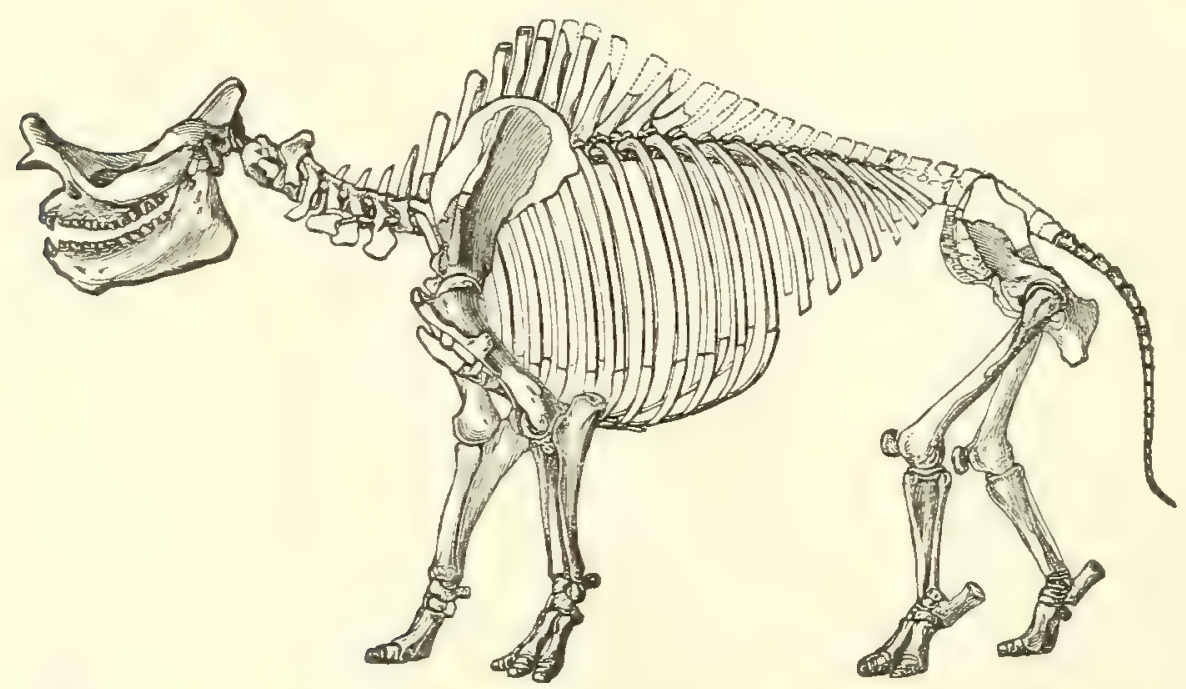

Titanotherium giganteum of Leidy $\left(x \frac{1}{65}\right)$. Restoration by Scott and Osborn.

In the earliest of the White River group, the Titanotherium beds, the species include the gigantic Titanotheres; new Horses of the genus Mesohip- 
pus; several new genera of the Hog family, among them species of Elotherium as large as a Rhinoceros.

The Titanotherium giganteum of Leidy (1852) is one of the earliest species discovered in the White River region. The restoration, Fig. $1533, \frac{1}{45}$ the natural size, is by Scott and Osborn. The length was over 13 feet.

1534.

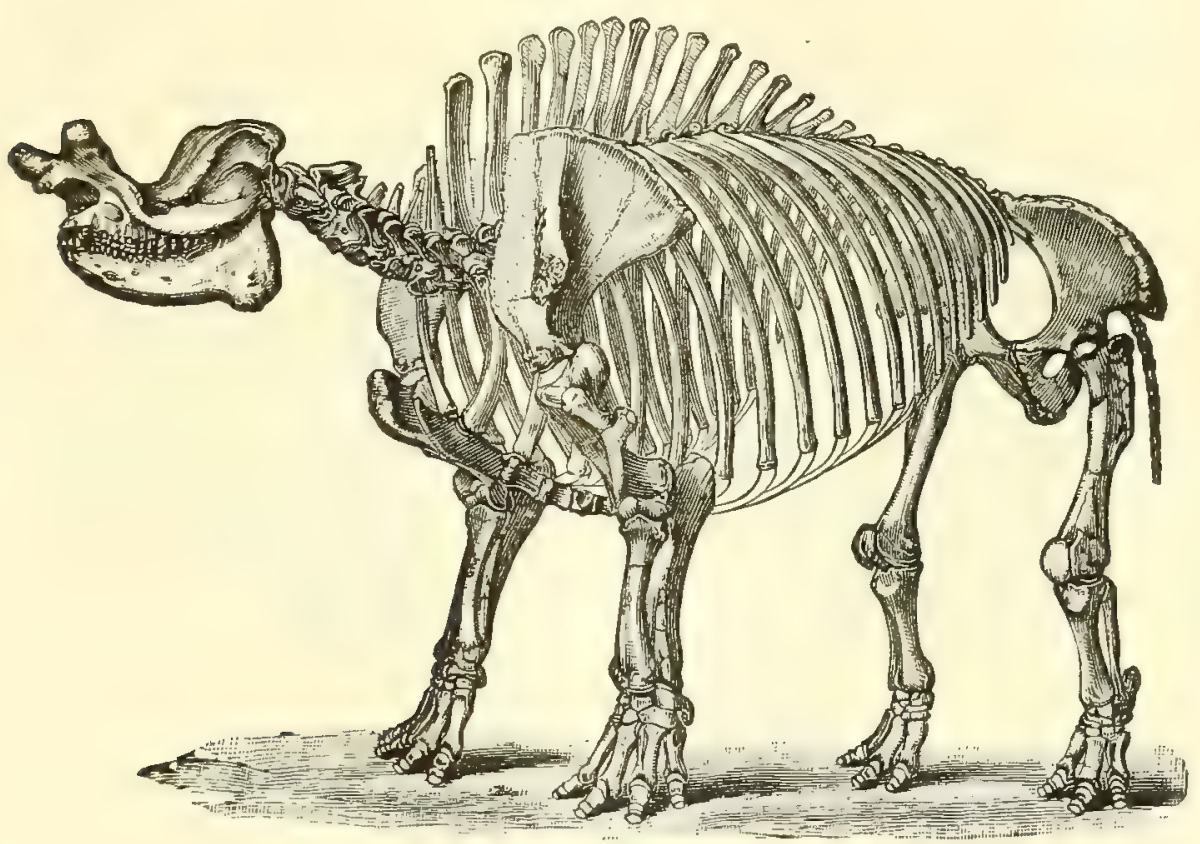

Restoration of Brontops robustus ( $\left.\times \frac{1}{40}\right)$. Marsh.

Fig. 1534 represents a restoration, $\frac{1}{40}$ natural size, of another of these Titanotheres, the Brontops robustus of Marsh. The length of body was nearly 12 feet.

1535.

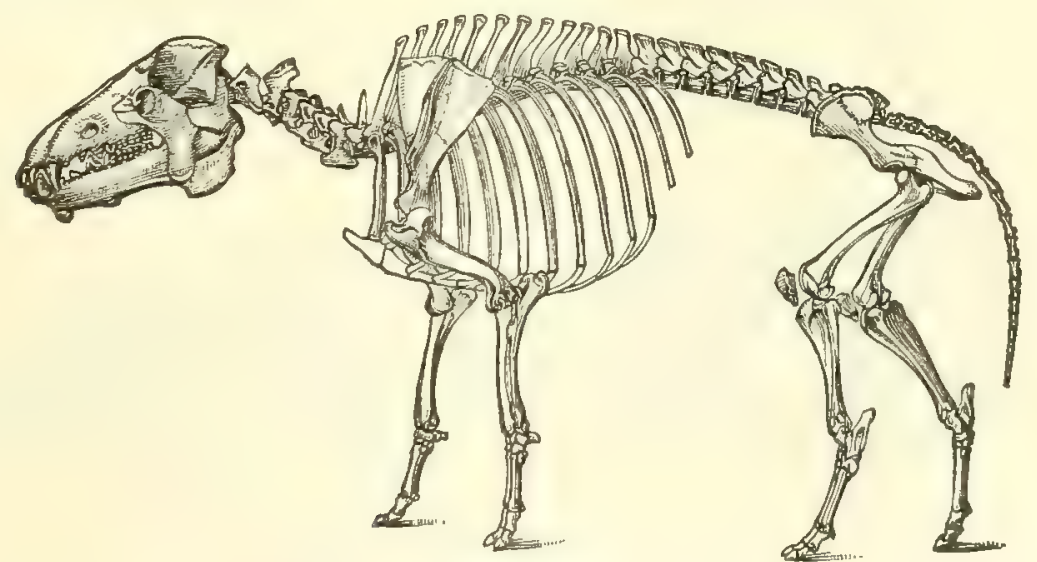

Elotherium crassum of Marsh $\left(\times \frac{1}{36}\right)$.

A restoration of one of the Artiodactyl Ungulates is shown in Fig. 1535, representing a large species of Elotherium, E. crassum of Marsh. Its length was about seven feet. Its remains occur in Colorado and South Dakota. 
Above the Titanotherium beds lie the Oreodon beds, so named from a characteristic Artiodactyl, between the Hog and Deer in structure. Fig. 1536 represents, natural size, the skull of the species, Oreodon gracilis of Łeidy.

The Oreodon beds have afforded, besides species of several genera occurring in the Titanotherium beds, remains of Tapir-like Ungulates of the genus

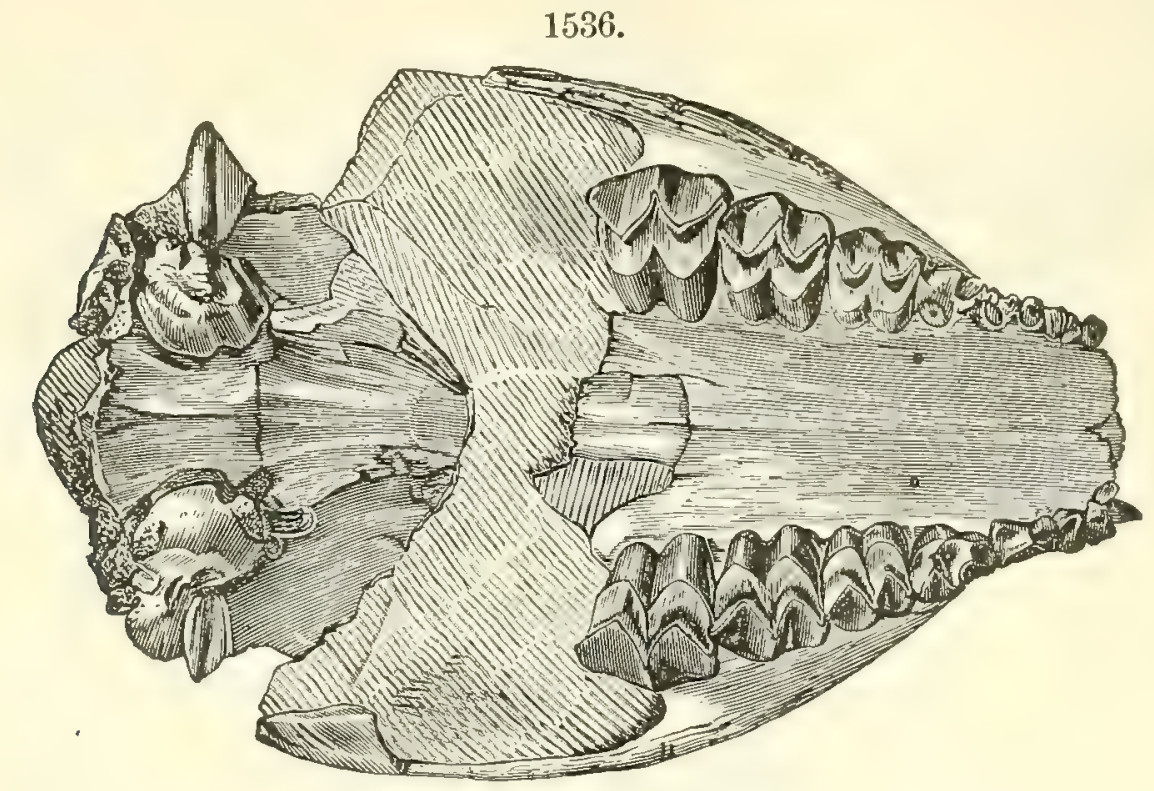

Oreodon gracilis. From Leidy.

Protapirus; also others related to the Rhinoceros, teeth from one of which, of the genus Hyracodon ( $H$. Nebrascensis of Leidy), are shown in Fig. 1537.

There were also species related to the Camel; the earliest of true Carnivores; the earliest known of Bats; of Squirrels of the modern genus Sciurus, with many other Rodents; and Marsupials of the modern genus Didelphys, or that to which the Opossum belongs.

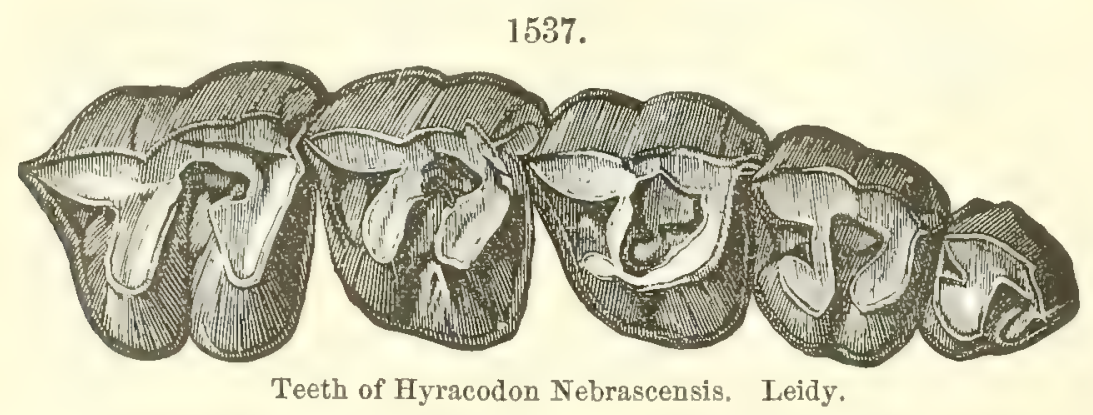

The following is a restoration, $\frac{1}{14}$ the natural size, of Poëbrotherium labiatum of Cope, by W. B. Scott, a species of the Camel family, near the Llama in its proportions. It is a fine example of a two-hoofed Artiodactyl. Its characteristics will be understood after a comparison of the feet with those of Phenacodus, Fig. 1517. The foot in Fig. 1538 includes the part 
of the leg from $f$ to $t$. Moreover, the upper ends of the tibia and fibula are soldered into one bone. In many species of Artiodactyls the soldering is so complete that no suture is left to indicate it. This addition to the length of the legs, by putting the foot vertical on its toes and elongating the foot

1538.

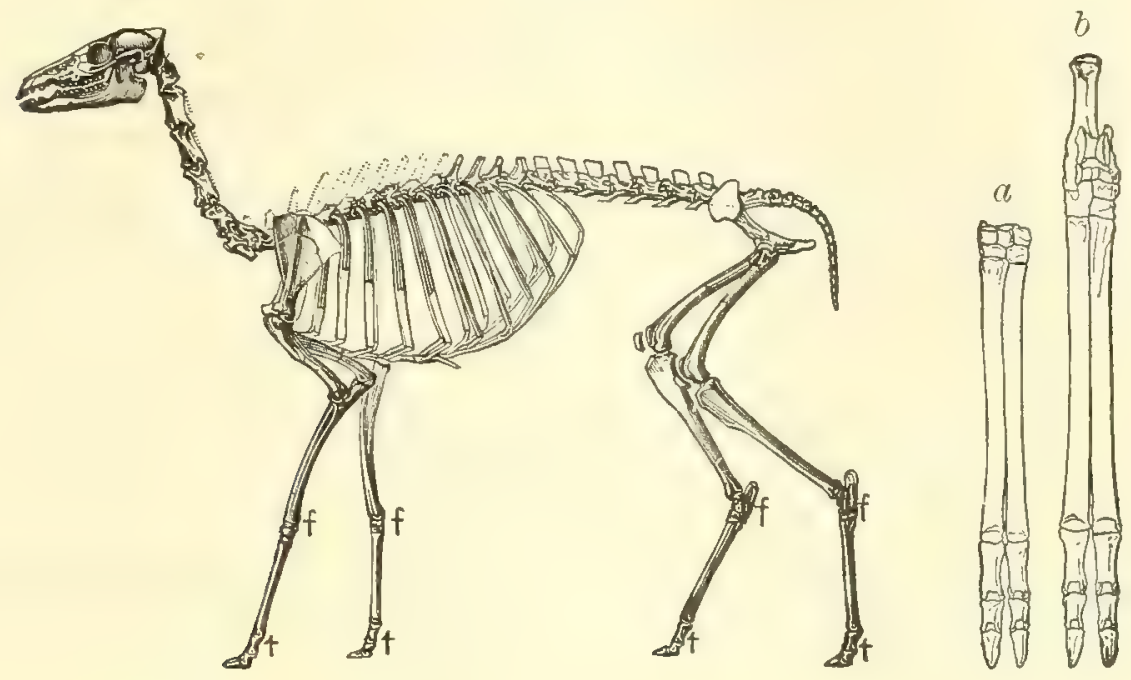

Artiodactrl UNgulate. - Fig. 1588, Poëbrotherium labiatum, restoration $\left(\times \frac{1}{14}\right) ; a, b$, same, feet, less reduced. Scott.

(especially the metatarsal and metacarpal bones), was of great advantage to the running animal; for it served, as also in the Horse, to give a proportional increase of speed, other things equal.

The Fauna comprised also several Insectivores; also Beavers, among Rodents, as the Palceocastor Nebrascensis Leidy, besides other species.

The Protoceras beds of Wortman, making the upper part of the White River group, are characterized by various Artiodactyls related to the Camel, Deer, and Hog, and the remarkable Protoceras of Marsh, which has long canines and horn-cores, the fore feet 4-toed, while the hind feet are 2-toed; also others related to the Tapir and Rhinoceros, and various Carnivores and other species.

The John Day beds of Oregon are characterized by the genera Miohippus. Diceratherium, Thinohyus, Poëbrotherium, Eporeodon, Elotherium, various Rodents and Carnivores of the genera Cynodon, Temnocyon, Dinictis, and others.

In the Deep River beds of the Upper Miocene occur the first known of Mastodons (M. proavus of Cope), Rhinoceroses of the genus Aphelops, several genera of the Horse type, Miokippus, Desmatippus, Anchitherium. Protohippus.

The Loup Fork beds are characterized by species of Procamelus, and the related Protolabis, Protohippus, Aphelops, Mastodon ( $M$. mivificus of Leidy), and by Deer of the genera Blustomeryx and Cosoryx, together with Carnivores of the genera Canis and Machoerodus. 
The Miocene of the Atlantic border has afforded remains of many Cetaceans. Among them are various Dolphins, several species of Whales of the genus Squalodon, related in teeth to the Zeuglodon, the largest about 30 feet long. Others having the teeth excessive in number, or inultiplicate, and provided with only one root; others having similar teeth, but only in the upper jaw, as in the genus Physeter, or that including the Sperm Whale; others with teeth in neither jaw, as the Baleen or Whale-bone Whales, but having several hundred plates of the so-called whale-bone, growing vertically downward from above, with edges of fine fibers, to serve, net-like, for gathering food of small Crustaceans and other species from the ocean's waters. Fig. 1539 represents a restoration of a species of

1539.

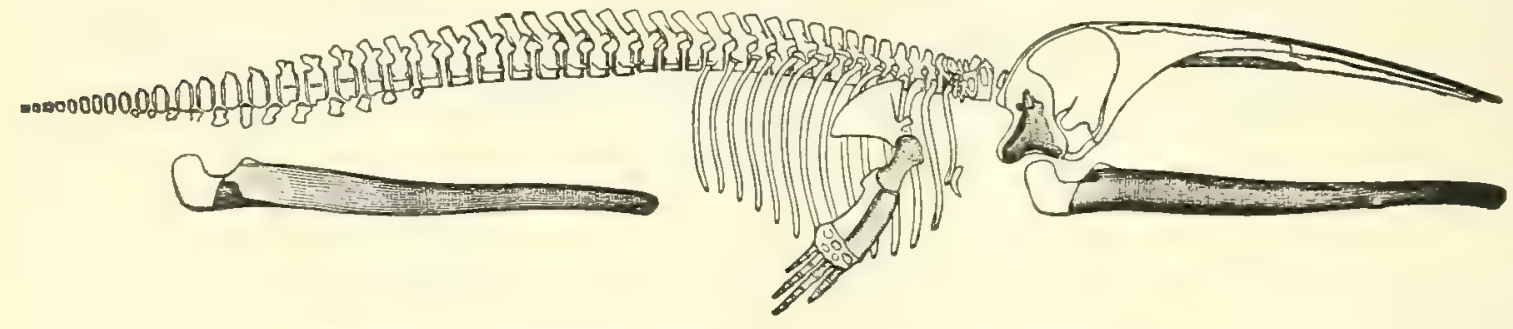

Cetacean. - Cetotherium cephalus $\left(x \frac{\frac{1}{5}^{-}}{\frac{5}{0}}\right)$. Restoration by Cope.

this kind, 30 feet long, from the Maryland Miocene, the Cetotherium cephalus of Cope (1890). The head of the Baleen Whales makes about a third of the length of the body.

Pliocene. - The Blanco beds of the Llano Estacado, western Texas, in the Pliocene, have afforded Cope remains of a Megalonyx, Mastodon mirificus, Equus simplicidens Cope, a Camel of the genus Pliauchenia, and some other species.

The succession of forms in the feet and teeth under the Horse type is illustrated by Marsh with the following diagram. The plate contains, in a series of seven columns, figures of the fore foot, hind foot, lower joint of the forearm (made up of the radius and ulna), the same of the leg (tibia and fibula); and $(5,6,7)$, others showing the length of the teeth and the convolutions within them. Columns 1 and 2 illustrate the fact of the diminishing number of toes with the progress of the Tertiary, until at last, in the modern kind, only the middle or third toe remains, with, either side, rudiments of the second and fourth in the form of the splint bones, while the third toe has become increasingly larger and longer. In the regular series, besides the genera there mentioned, Epihippus of Marsh is an intermediate genus between Orohippus and Mesohippus; and Desmatippus of Scott, one between Miohippus and Protohippus. In the derivation from the Tapir-like precursors, the type of the Horse became distinct when the middle toe was decidedly stouter than that either side of it; and it reached its maximum when this toe was the only one, and the other two were merely "splint" bones. 
1540.

IV. Recent.

EQUUS,

Fore foot. Hind foot. Forearm. Leg. Upper molar. Lower molar.

III. Pliocene.

(2) Prionippos.
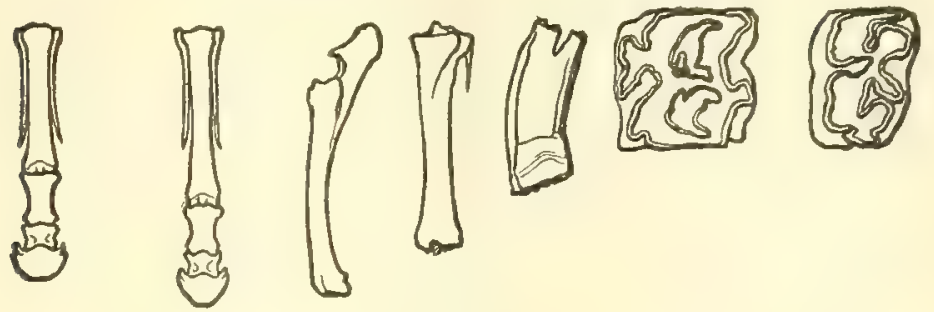

(1) Рвотонippts.
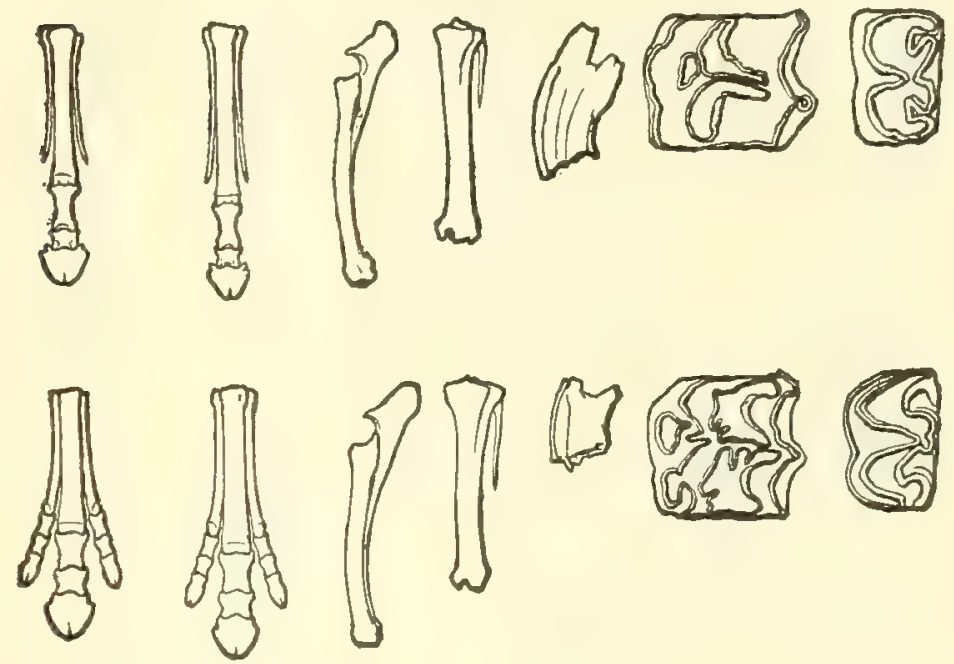

II. Miocene.

(2) Miонippus.
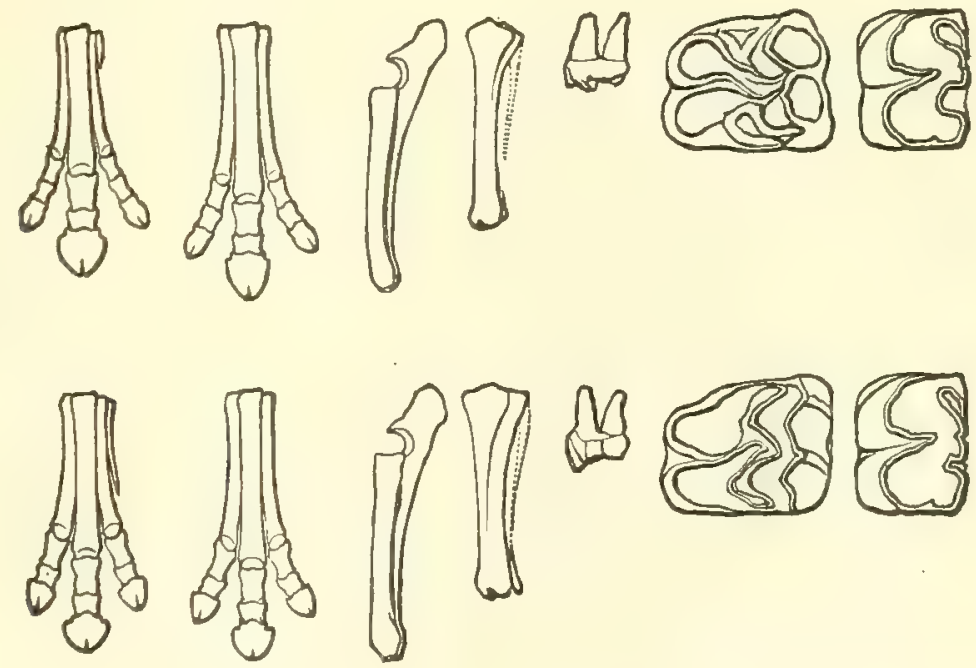

I. Eocene.
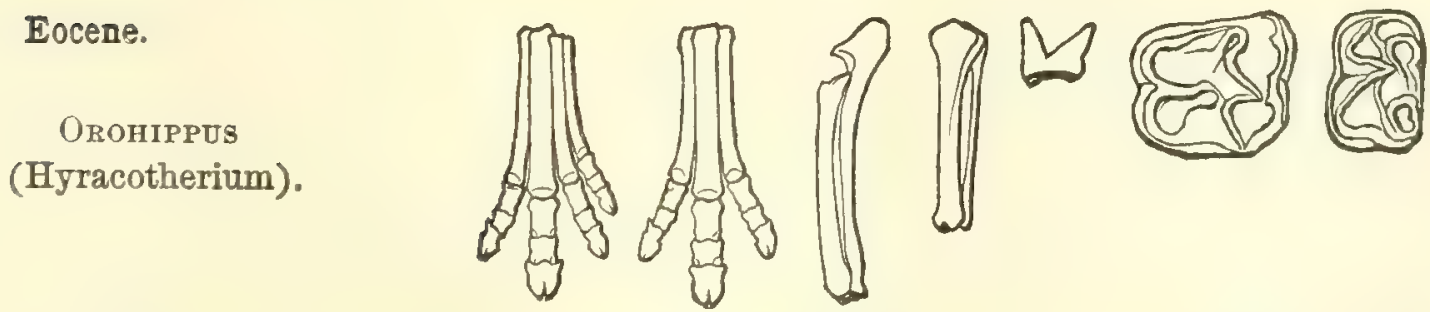

Illustrations of the characters of successive genera under the Horse type. From Marsh.

Another important fact in the history of life as suggested by Lartet from some early European Mammals, and demonstrated by Marsh from the DANA's MANUAL - 58 
American, is the increasing size of the brain with the progress of the Tertiary. In most of the earliest Eocene species the brain was extremely small, and especially the cerebral or anterior part; that of the Dinoceras might have been drawn entire through the cavity of the spinal corl. This point is illustrated in figures 1541-1543 (from Marsh), representing the skulls, reduced to a common length, with the brain cavity: of the Eocene Dinocerus
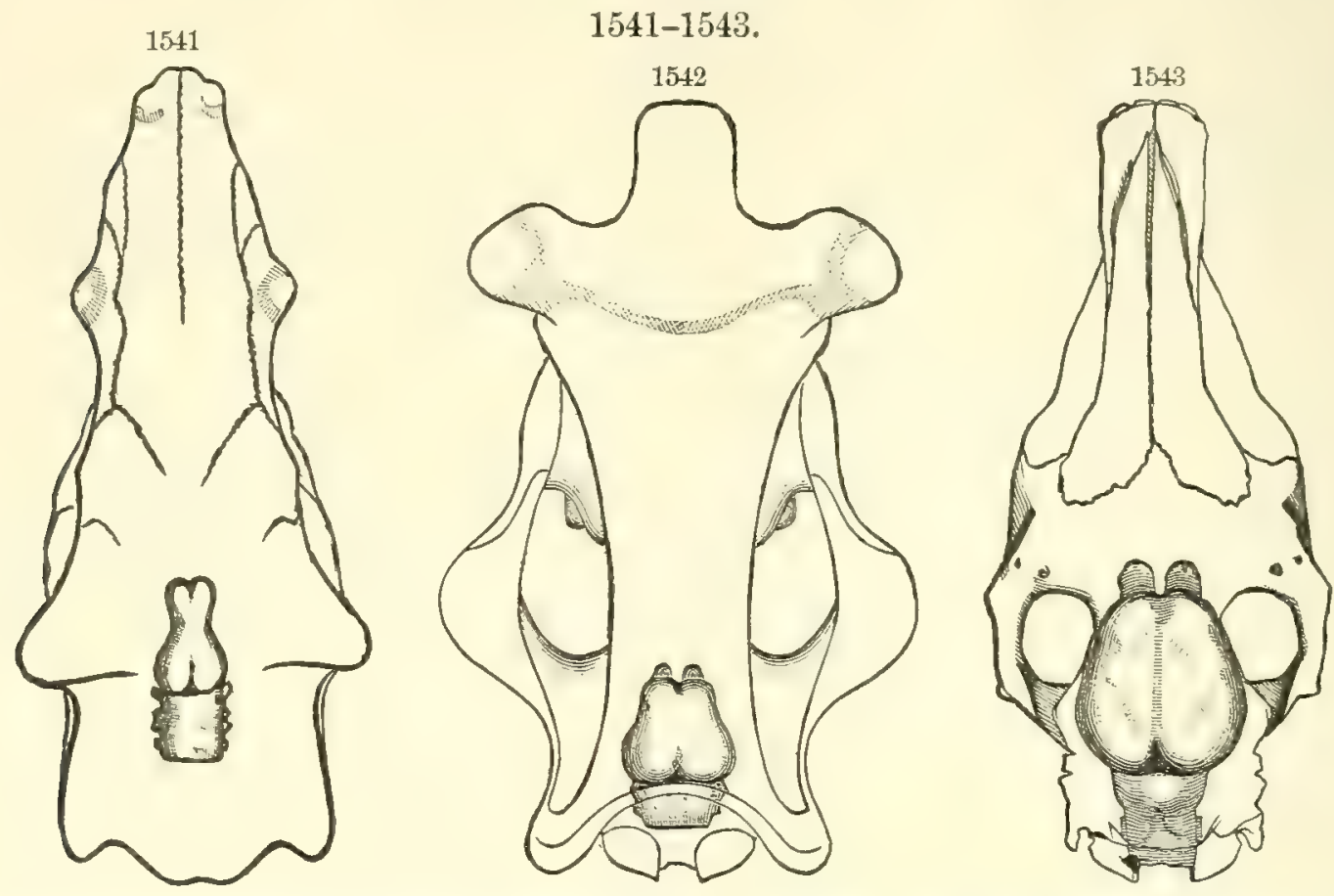

Illustrations of the sizes of brains in successive genera of Ungulates. Fig. 1541, Dinoceras (Eocene); 1542, Brontotherium (Miocene); 15t3, Modern Horse. From Marsh.

(Fig. 1541), the Miocene Brontotherium (Fig. 1542), and the modern Horse (Fig. 1543). The Horse has a brain more than eight times the bulk of that of the Dinoceras. It is seen in these figures that the posterior part of the brain, as Marsh observes, has undergone little change of size, the enlargement having been eminently in the cerebral portion. The principle has necessarily its exceptions, since size is not the element of most importance in a brain. Marsh has further shown that the principle is exemplified in fossil Birds, and also in the Dinosaurian group of Reptiles.

In addition to relies of Rodents in the form of bones and teeth, there are, in the Niobrara region, what have been supposed to be burrows of some species of Rodent. They were described as probably fossil Sponges by E. H. Barbour (Univ. Studies, Yebraska, 1892, where many excellent figures are given, some showing specimens in place). They stand vertically, in large numbers, in the Miocene of the region, some of them 8 or 9 feet in height. Each usually ends below in a long horizontal or oblique chamber. Dcemonetix is a Greek form (abbreviated) of the popular name "Devil's corkscrew." The figure includes two views of one of the specimens, the vertical spiral of which is 53 inches high, and the oblique basal portion 76 inches. 
Since Rodents have been described from the same beds, and a skeleton of one has been found at the base of one of the spirals, there has seemed to be strong reason for regarding them as the core of a fossil burrow; and this has appeared to be confirmed by the fact that the skeleton belonged to a Rodent that was of the right size to have made the spiral carity. But according to the latest investigations of $\mathrm{E} . \mathrm{H}$. Barbour (published in November, 1894), the spiral stems or fillings have a cellular structure, as if of vegetable origin. The oblong cells average one thirty-second of an inch in diameter, but vary from one sixty-fourth to one eighth, and even to one fourth. The exterior is made of these tubules variously intertwined. The whole of a spiral and its long transverse continuation at base 1544.

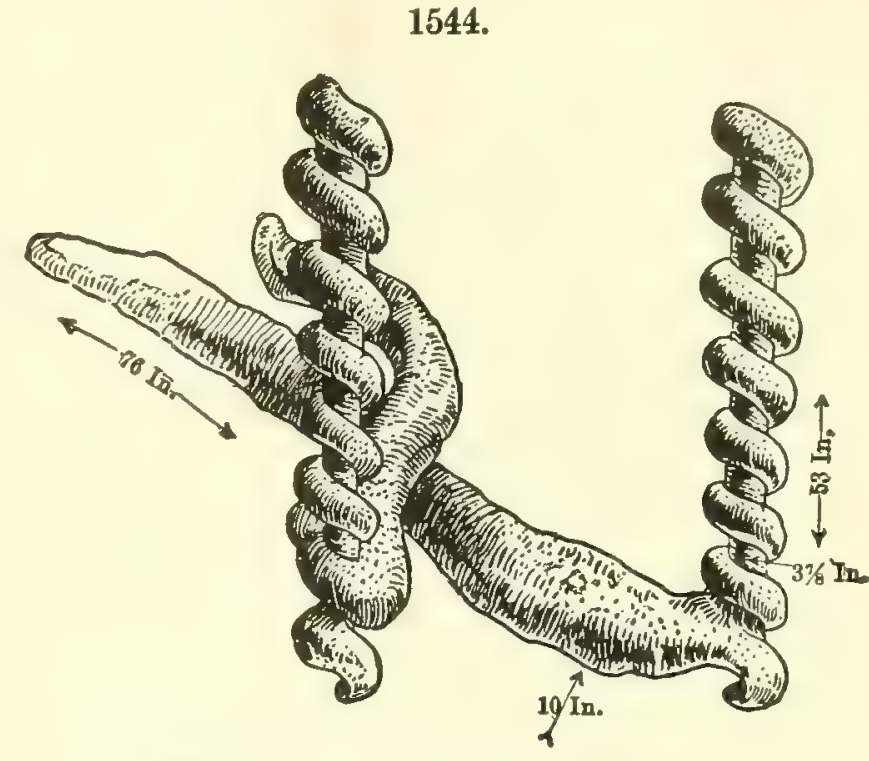

Two views of a specimen of Dæmonelix.

E. H. Barbour. have the cellular structure. "Each and every well-cut section shows parenchymatous tissue, no matter from what specimen, or from what portion of an individual specimen, the section is made; there has not been an exception to this." The final conclusion therefore is that the fossil having the spiral form, together with its basal portion, was probably some kind of plant, and that it grew around the inclosed skeleton.

\section{Characteristic Invertebrate Species.}

\section{EOCENE.}

1. Midwax. - Enclimatoceras Ulrichi White, Ostrea Pulaskensis Harris, Ostrea pra-compressirostra Har., Pecten Alabamiensis Aldrich, Yoldia eborea Conrad, Cucullaca macrodonta Whitfield, Cadulus turgidus Meyer, Caricella Leana Dall, Voluta Showalteri Aldrich, Volutilithes rugatus Conrad, Volutilithes limopsis Con., Leucozonia biplicata Aldrich, Neptunea constricta Aldrich, N. Matthevsensis Aldrich, Pseudoliva unicarinata Aldrich, Murex Alabamiensis Aldrich, Turritella Alabamiensis Whitfield.

2. Ligvitic. - Maryland and Virginia: Ostrea compressirostra Say, Cucullad gigantea Conrad, Crassatella alceformis Conrad, Dosiniopsis lenticularis, Cytherea ovata Rogers, Panopcea elongata Conrad, Pholadomya Marylandica Conrad, Turritella procincta Conrad. Alabama: Ostrea compressirostra, O.thirsa Gabb, Cuculloca gigantea Con., var., Crassatella tumidula Whitfield, Dosiniopsis lenticularis, Pholas alatoidea Aldrich, Voluta Newcombiana Whitfield, Pseudoliva tuberculifera Conrad. Upper beds, Alabama: Fusus interstriatus Heilprin, Pleurotoma monitiata Heilprin, Lavibuccinum lineatum Heilp., Pseudoliva scalina Heilp., Corbula Aldrichi Meyer, Cardium Hatchetigbeense Aldrich.

3. Lower Claiborne. - Ostrea Johnsoni Aldrich, Anomia ephippoides Gabb, Foldia Claibornensis Conrad, Trigonarca pulchra Gabb, Crassatella antestriata Gabb, C. 
texalta Harris, C. Texenu Heilp., C. Trapaquara Harris, Astarte protracta Meyer, Astarte Smithvillensis Harris, Lucina Claibornensis Conrad, Pteropsis lapidosa Conrad, Corbula oniscus var. fossata Ald., Tellina Mooreana Gabb, Solen Lisbonensis Aldrich, Pholadomya Claibornensis Aldrich, Terebra Houstonia Harris, Pleurotoma beadata Harris, Pleurotoma Huppertzi Harris, Nassa Dalli Aldrich, Nussa scalata Heilprin, Phos Texanus Gabb, Distortrix septemdentata Gabb, Odontopolys compsorhytis Gabb, Volutilithes Haleanus Whitfield, Mazzalina mymla Conrad (typical), Strepsidura ficus Gabb, Clavitithes Penrosei Heilprin, Neptunea enterogramma Gabb, Turricula polita Gabb, Borsonia biconica Whitfield, Mesalia Claibornensis Con., Turritella nasuta Gabb, Rimella Texana Harris, Ancilla ancillops Heilp., Cassidaria dubia, Natica recurva, Belosepia ungula Gabb.

4. Claiborne. - Crassatella alta Con., Panopaea porrectoides Ald., Lutraria papyria Con., Arca inornata Meyer, Cytherea Mortomi Con., Cytherea cequorea Con., Corbis distans Con., Ringicula biplicata Lea, Rimella laqueata Con., Caricella doliata Con., C. Claibornensis Har., Clavilithes pachyleurus Con., Cerithium Claibornense Con., Mesalia obruta Con., M. vetusta Con., Turritella carinata Lea.

5. Jackson. - Ostrea trigonalis Con., Pecten nuperus Con., Leda multilineata Con., Leda mater Meyer, Crassatella flexura Con., Tellina linifera Con., Bullinella Jacksonensis Meyer, Haminea grandis Aldrich, Pleurotoma Heilprini Aldrich, P. Americana Aldrich, $P$. perexilis Aldrich, Turricula Millingtoni Con. (typical), Conomitra Hammakeri Har., Clavilithes humerosus Con., Fusus pearlensis Aldrich, Conorbis alatoideus Aldrich, Cassidaria Petersoni Con., Turritella alveata Con., Turritella arenicala Con. (typical), Turritella perdita Con., Natica permunda Con.

6. Vicksburg. - Ostrea Vicksburgensis Con., Pecten anatipes Morton, Pecten Poulsoni Morton, Byssoarca protracta Con., Arca Mississippiensis Con., Pectunculus arctatus Con., Crassutella Mississippiensis Con., Cardium diversum Con., Cytherea sobrina Con., C. imitabilis Con., Dentatium Mississippiense Con., Pleurotoma congesta Con., P. tenella Con., $P$. cristata Con., $P$. rotodens Con., $P$. declivis Con., $P$. abundans Con., Mitra cellulifera Con., M. conquisita Con., Turbinella Wilsoni Con., Caricella demissa Con., Murex simplex Aldrich, Typhis curvirostratus Con., Oliva Mississippiensis Con., Fulgur spiniger Con., Chenopus liratus Con., Oniscia harpula Con., Lyria costata Sow., Melongena crassicornuta Con., Clavitithes Mississippiensis Con., Turritella calatura Con., T. Mississippiensis Con., Solarium tritiratum Con., Natica Mississippiensis Con.

Ostrea Georgiana, Fig. 896, was originally described from Shell Bluff, Ga., of Lower Claiborne horizon. It is doubted whether it is rightly made a Vicksburg species.

A specimen containing Eocene fossils has been reported by Upham and Crosby from the drift of Cape Cod.

In California, in the Tejon group, occur, according to Gabb, Ammonites (A. jugalis Gabb), Fusus, Surcula, Typhis, Tritonium, Nassa, Pseudoliva, Otivella, Fasciolaria, Mitra, Ficus, Natica, Lunatia, Neverita, Naticina, Scalaria, Terebro, Niso, Cerithiopsis, Architectonica, Conus, Rimella, Cyproe, Loxotrema, Turritella, Galerus, Nerita, Margaritella, (tadus, Bulla, Solen, Corbula, Nexra, Tellina, Donax, Venus, Meretrix, Dosinia, Tapes, Cardium, Cardita, Lucina, Crassatella (C. alta Con.), Mytilus, Modiola, Avicula, Arca, Axincea, Pecten, Ostrea, with the coral Trochosmilia striata Gabb.

\section{MIOCENE.}

1. Ciattahoochee. - Orthaulax pugnax Heilprin, Pyrazisinus campanulatus Heilp., $P$. acutus Heilp., Cerithium Hillsboroense Heilp., Potamides transsectus Dall, Vasum subcapitellum Heilp., Coralliophila magna Dall, Ampullina solidula Dall, Turritella Tampa Heilp. The famna of the Chattahoochee deposits where typically exposed has not been carefully studied; the above-mentioned species are mainly from near Tampa. 
2. Chipola. - Orthaulax Gabbi Dall, Strombus Aldrichi Dall, Turritella subgrundifera Dall, T. Chipolana Dall, Pollinices Burnsii Dall, Ampullina Fischeri Dall, Clave Chipolana Dall, Bittium Chipolanum Dall, Modulus compectus Dall, Turritella indenta var mixta Dall, Tuba acutissima Dall.

3. Yonktown. - Ostrea percrassa Con., O. disparilis Con., Pecten Jeffersonius Say, P. Madisonius Say, P. Clintonius Say, Mytiloconcha incurva Con., Arca idonea Con., A. subrostrata Con., A. incilis Say, Striarca centenaria Say, Pectunculus subovatus Say, P. quinquerugatus Con., Astarte undulata Say, Crassatella undulatu Say, C. melina Con., C. Marylandica Con., Lucina anodonta Say, L. cribraria Say, Diplodonta acclinis Con., Carditamera arata Con., Cardium laqueatum Con., Venus cortinarea Rogers, Cytherea Marylandica Con., C. staminea Con., Isocardia fraterna Say, Dosinia acetabula Con., Mactra delumbis Con., Petricola centenaria Con., Panopoea reflexa Say, P. Americana Con., Pholadomya abrupta Con., Corbula idonea Con., Tellina biplicata Con., Terebra simplex Con., Eephora quadricostata Say, Fasciolaria rhomboidea Rogers, Typhis acuticosta Con., Urosalpinx trossulus Con., Fusus parilis Con., F. exilis Con., F. strumosus Con.

The Miocene species of the Ashley Marl bed, South Carolina, determined by Dall $(1894$, include Astarte vicina Say, Ecphora quadricostata, an Amusium not distinguishable from A. Mortoni, Lucina contracta, Dentalium attenuatum, Pecten decennarius, with others of Corbula, Leda, Yoldia, Tellina, Marginella, Solen, Modiola. The species show closer relations to the Yorktown epoch than to the Chipola. Dall adds that the change in the rock to the phosphate condition probably took place in Pliocene time like that of the similar phosphatic pebbles of Peace River, Fla.

The Miocene of Gay Head, Martha's Vineyard, afforded Dall: Carcharodon angustidens, Hemipristis serra, Oxyrhina hastalis; the Crustacean Archooplax signifera Stimson; the Mollusks, Yoldia Timatula, Y. sapotilla, Cardium Virginianum, Nucula Shaleri Dall, Gemma purpurea var. Totteni, Mya arenaria, Mya truncata, Glycimeris reflexa, Chrysodomus Stonei Pilsbury. The overlying Pliocene contained, according to J. B. Woolworth, Corbicula densata, and Venericardia borealis of Pliocene type.

\section{PLIOCENE.}

Floridian, - Arca scalarina Heilp., Arcoptera aviculaformis Heilp., Arca crassicosta Heilp., Chama crassa Heilp., Cardium Dalli Heilp., Venus rugatina Heilp., Cythara terminula Dall, Strombus Leideyi Heilp., Siphocyproea problematica Heilp., Vasum horridum Heilp., Fasciolaria scalarina Heilp., Liochlamys bulbosa Heilp., Turbinella regina Heilp.

The above lists of Atlantic border and Gulf border species are from G. D. Harris. The species are "characteristic" in being found "either exclusively, typically, or most abundantly, in the group where mentioned."

\section{Characteristic Genera of Vertebrates.}

In this list of genera the names of those which occur in corresponding beds abroad are put in small capitals; those which are represented by existing species are followed by an interjection mark.

\section{EOCENE.}

Puerco Group. - Monotremes or Marsupials (Multituberculates): Ptitodus, Neoplagiaulax, Chirox, Polymastodon. Tillodonts: Psittacotherium. Ungulates: Hoploconus, Periptychus, Protogonia, Protogonodon; Pantolambda. Creodonts: Oxyclcenus, Pentacodon, Triisodon, Microclcenodon, Dissacus, Deltatherium, Didymictis. Quadrumana (Lemuroids): Mixodectes, Indrodon.

Wasatch Grodp.- Rodents : Paramys. Tillodonts : Dryptodon, Esthonxx, CalaMonos. Ungulates: Phenacodus, Trispomlylus, Meniscotherium, Hyracops; Coryphodon, 
Manteodon, Ectacodon, Metalophodon; Hyracotherium, Eohippus, Systemodon, HepTonon, Lambdotherium; Artiodactyl Ungulates, Pantolestes, Homacodon, Eohyus, ?Achanodon. Insectivores: Diacodon. Creodonts: Anacodon,? Dissacus, Pachyana, Sinopa, Didelphodus, Paleonictis, Oxycena, Miacis, Didymictis. Quadrumana: Anaptomorphus, Hyopsodus, Pelycodus, Cynodontomys, Microsyops.

Wind River, Green River Groups. - Rodents: Paramys. Tillodonts: Esthonyx, Calamodon. Ungulates: Phenacodus, Trispondylus; Coryphodon, Bathyopsis ; Hyracotherium, Pachynolophus, Lambdotherium, Palcosyops; Artiodactyl Ungulates, Pantolestes. Insectivores: Ictops. Chiropters: Vesperugo. Creodonts: Sinopa, Putriofelis, Miacis, Didymictis. Quadrumana: Microsyops, Pelycodus.

Bridger Group.-Rodents: Paramys, Mysops. Tillodonts: Anchippodus, Tillotherium. Ungulates: Uintatherium, Dinoceras, Tinoceras; Orohippus, Lambdotherium, Palcosyops, Limnosyops, Telmatherium, Hyrachyus, Helohyus, Colonoceras, Triplopus, Helaletes, Isectolophus, Amynodon; Artiodactyl Ungulates, Achonodon, Homacodon, Nanomeryx, Helohyus, Ithygrammodon. Insectivores: Ictops, Palceacodon, ? Passalacodon. Rodent: ? Apatemys. Chiropters: Nyctilestes, Vesperugo. Creodonts : Miacis, Didymictis, Mesonyx, Sinopa, Proviverra, ? Viverravus, Patriofelis. Quadrumana: Hropsodus, Notharctus, Microsyops, Tomitherium, ? Lemuravus.

Uinta Grodp. - Rodents: Paramys. Ungulates: Epihippus, Triplopus, Amynodon, Isectolophus, Diplacodon; Artiodactyl Ungulates, Protoreadon, Hyomeryx, Leptotragulus, Oromeryx. Creodonts: Mesonyx, \& Miacis. Quadrumana: Hyopsodus.

\section{MIOCENE.}

\section{Lower Miocene.}

A. White River Grodp. - (In part, Oligocene of W. B. Scott.)

(1) Titanotherium beds. - Ungulates: Titanotherium, Brontotherium, Brontops; Teleodus, Clenopus, Mesohippus, Colodon; Schizotherium (Canada); Artiodactyl Ungulates,? Oreodon, Elotherium, Ancodus (Hyopotamus), Anthracotherum, Poëbrotherium,? Leptomeryx, ? Hypertragulus. Creodonts: Hemipsalodon (near Pterodon, Canada).

(2) Oreodon beds. - Marsupials: Didelphys! Rodents: Ischyromys, Gymnoptychus, Heliscomys, Steneofiber, Sciurus, Eumys, Palocolagus. Ungulates: Mesohippus, C.enopus, Hyracodon, Metamynodon, Colodon, Protapirus ; Artiodactyl Ungulates, Oreodon, Agriochorus, Ancodus; Elotheridm, Anthracotherium, Percherus, Leptochœrus, Poёbrotherium ; Leptomeryx, Hypertragulus, Hypisodus, Stibarus. - Insectivores : Ictops, Leptictis, Mesodectes, Geolabis. Chiropters: \&omnina. Creodonts: Hr五nodon. Carnivores: Daphonus, Crnodon, Disictis, Hoplophoneus, Buncelurus. Quadrumana : ? Laopithecus.

(3) Protoceras beds. - (Rodents not studied.) Ungulates: Cenopus, Diceratherúr, Hyracodon; ? Miohippus; Protapreus; Artiodactyl Ungulates, Oreodon, ? Eporeodon, Agriochorus, Coloreodon; Leptauchenia, Ancodus; Anthracotherium, Perchorus; Lentomeryx; Protoceras. Creodonts: Hyonodon. Carnivores: Crnodon, Dinictis, Hoplophoneus, ? Pogonodon.

B. John Day Grodp. - Rodents: Allomys, Sciurus, Steneofiber, Sitomys, Paciculus, Pleurolichus, Eutoptychus, Palcolagus, Lepus! Ungulates: Macrotheridm; Cienopus, Diceratheriom; Miohippus; ? Protapirus; Artiodactyl Ungulates, Eporeodon, Mesorendon*, Merycochorus, Agriochcerus, Coloreodon (Agriomeryx), HypertraguTus; Pö̈brotherium, Gomphotherium; Elotherium, Chonohyus, Bothriolabis, Thinohyus. Carnivores: Daphoenus, Cryodos, Temnocyon, Cynodesmus*, Enhydrocyon, Hycenocyon, Oligobunis, Archochurus, Dinictis, Hoplophoneus, Nimravus, Pogonodon, Parictis.

(The gencra in small caps are found in the Lower Miocene of Europe. The genera, the names of which have an asterisk added, are known only from the John Day of Montana.) 


\section{Upper Miocene.}

Lodp Fork Group. - (1) Deep River beds. (Ticholeptus beds.) - Ungulates: Miohippus, Desmatippus*, Anchitherium, Protohippus, Aphelops, Mastodon.

(2) Nebraska beds or Loup Fork proper. - Rodents: Steneofiber, Sitomys (Hesperomys), Hystricops, Palcolagus, Panolax. Edentates: Caryoderma. Ungulates: Chalicotherium, Pliohippus, Protohippus, Hipparion, ? Tapiravus, Aphelops, Teleoceras; Artiodactyl Ungulates, Merychyus, Merycochorus, Protolabis, Procamelus, Platygonus, Pliauchenia, Blastomeryx, Cosoryx. Proboscideans: Mastodon. Carnivores:? Canis! Elurodon, Pseudelurus, Macharodus, Stenogale, Brachypsalis.

\section{PLIOCENE.}

1. Palo Duro beds. - Rodents:? Arctomys, ? Geomys. Ungulates: Protohippus, Equus!, Hippidium, Aphelops; Artiodactyl Ungulates, large Camel, probably Pliauchenia. Proboscidean: Mastodon.

2. Blanco beds. - Edentates: Megalonyx. Ungulates: EQuUs!; Artiodactyl Ungulates, Platygonus, Pliauchenia. Proboscidean: Masrodon. Carnivores: Canimartes, Borophagus, ? FELIS !

The preceding list of genera has been prepared for this place, for the most part, by W. B. Scott.

The more important publications on North American Tertiary Mammals and their historical relations, are those of Leidy on the Mammalian Fauna of Dakota and Nebraska (1869), and other memoirs; Marsh, on the Introduction and Succession of Vertebrate life in America (1877), and his many earlier and later papers; Cope, on horizons of Extinct Vertebrates (1878), on the Origin of the Fittest (1887), and his other various publications ; H. F. Osborn, on The Rise of the Mammalia of North America (1893), and other memoirs; and papers by W. B. Scott.

\section{FOREIGN.}

Notwithstanding the catastrophe that produced over the continental seas the wide exterminations of species which closed Mesozoic time, Europe in the earlier part of the Tertiary era was much like Europe of the Cretaceous period. In the interval there had been emergencies and a widening of the areas of dry land; yet nearly half the continent south of the parallel of $55^{\circ}$ remained under salt water, or was barely emerged. There were frequent oscillations during the progress of the Eocene; but in its later part the sea had great extent over southern Europe, covering, in part, the sites of the chief mountain ranges and spreading largely over Asia. Great Britain was still continuous with Europe, and the London-Paris basin was one of the large local seas; but that basin had narrowed limits in southeastern England and also in France. After the Eocene the conditions were changed by the making and partial elevation of the Pyrenees and large emergencies elsewhere, but part of the region of the Alps and Juras was still producing rocks for the finishing of the mountains.

The contrast with Tertiary North America was great. There was no localized sea-border belt of accumulating deposits; and what it had of interior lakes were estuarine or lacustrine in alternation with marine conditions. 
Consequently, Mammalian life is much less perfectly represented in the European Tertiary than in the North American.

\section{ROCKS-KINDS AND DISTRIBUTION.}

In England, beds of the Eocene occur in the London and Hampshire basins, resting on the Chalk. The Lower Eocene consists of beds of sand, with marine fossils called the Thanet sands, with some clay-beds above, and the London Clay, an estuariue deposit, 500 feet in maximum thickness, which has afforded many species of fossil leaves and Eocene Mammals, besides marine shells. The Middle and Upper Eocene consist of marine fossiliferous sands called the Bagshot beds, with some leaf-bearing clay-beds. Among the fossils occur some Nummulites, species that were abundant farther south over Europe.

In northern France and Belgium there is a general resemblance in the Eocene strata to those of the British part of the London-Paris basin. The Lower are clay-beds, marlytes, and sand-beds, partly marine, but containing in some parts Plants and Mammals. The Middle Eocene in France consists largely of a coarse limestone, the Calcaire grossier, partly glauconitic and Nummulitic; and the Upper is a series of sand-beds, sandstones, and marls, with some limestones, having at top a bed containing gypsum 100 to 160 feet thick, containing in some layers nodules of opal-silica (menilite).

In southern Europe the Eocene beds are largely Nummulitic limestones of great thickness; and they range widely from southern France, the Pyrenees, and Spain, over much of the region, eastward to Asia Minor and beyond, indicating a pure sea of great extent. The Nummulitic beds are 3000 feet thick in southern France. In the Alps they constitute the summits of the Dent du Midi, 10,531 feet, of Diablerets, 10,670 feet in elevation, and of other heights. They occur in the Apennines and the Carpathians. They extend into Egypt (where the Pyramids were in part made of Nummulitic limestone); also through Algeria and Morocco, parts of Asia Minor, Persia, Cancasus, India, the mountains of Afghanistan, the southern slopes of the Himalayas, and to a height of 20,000 feet in middle Tibet. They occur also in Japan, on Luzon in the Philippine Islands, and in Java.

Oligocene beds of alternate salt and fresh water origin are found in the Isle of Wight and the Hampshire basin. In the Paris basin, in France, they are largely of freshwater origin. They include the Grès de Fontainebleau in the Paris basin, and below, marlytes, with gypsum, affording remains of Mammals at the quarries of Montmartre. They have wide distribution in north Germany, and hold in the lower part beds of brown coal with remains of plants. In Switzerland they constitute the lower lacustrine part of the sanistone formation called Molasse, having a thickness of 7000 feet. The beds called. Flysch are at the base of the Oligocene.

Hiocene Tertiary beds are not recognized in England or in the Paris basin, and are mostly confined to scattered areas which are only in part 
marine. The upper part of the Molasse, mostly marine, is Miocene. The beds of Eningen, on Lake Constance, affording Insects in fine preservation, along with leaves and some Mammals, Birds, and other species, are of the Upper Miocene. Among the noted Eningen fossils is the Homo dituvii testis of Scheuchzer (1700), shown by Cuvier to be an aquatic Salamander.

The Miocene has a thickness of 10,000 feet in northem Italy and the Ligurian Alps, and extends southward. It occurs also in Sicily and Malta.

The Marine Pliocene of Europe is mostly found along the sea border. This is its position in eastern England, where it is called the Crag, in Belgium, and on the French Mediterranean coasts; but in Italy the beds spread more widely along both sides of the Apennines, and in Sicily they have an elevation in some places of 3000 feet.

\section{LIFE.}

Plants. - The higher plants were mainly Angiosperms, Conifers, and Palms.

The Isle of Sheppey is famous for its fossil fruits; and among them are those of several species of Palm, related to the Nipoe of the Moluccus and Philippine Islands, England in the Eocene having been a land of Palms. In the Middle Eocene, in England, there were species of Fig, Cinnamon, various Proteacece, ete, indicating a climate and flora much like that of India and Australia. In the Tyrol, Eocene beds contain Palms; nearly a third of the plants were Australian in character, and a fifth were allied to plants of tropical America. The Oligocene contains, in its lignitic beds, species of Taxites, Cupressinoxylon, Sequoia, and affords elsewhere leaves of Laurus, Cinnamomum, Magnolia, Sassafias, Quercus, with Palms of the genera Sabul, Flabellaria, Phonicites. In the Miocene, Palms were absent from England, and the forests of Europe had lost their tropical character. It is remarkable that a much larger proportion of species than now were of North American type, showing that, while the Eocene vegetation of Europe was largely Australian, the second or Miocene phase (including in part at least the Upper Eocene of Lyell) was more like that of North America than now. In the Pliocene, the Flora embraced the modern genera of Rose, Plum, Almond, Myrtle, Acacia, Whortleberry. There were also species of the genera (now unknown in Europe) of Taxodium, Comptonia, Liquidambar, Nyssa, Robinia, Gleditschia, Cassia, Rhus, Juglans, Ceunothus, Celastrus, Liriodendron, indicating that there was still a strong American character. Moreover, certain genera, as that of the Oak (Quercus), which have numerous species in America, had many in Pliocene Europe, but have few now.

In Greenland, according to Heer, Eocene beds, named by him the Unartok series, occur on the shores of Disco Island, containing species of Magnolia, Laurus, Juglans, Quercus, Sequoia (S. Langsdorffi); and Miocene beds of the Atanekerdluk series, that have afforded 187 species of plants, including the same Sequoia, Glyptostrolus Europreus, Taxodium distichum, Taxites 
Olriti, Onoclea sensibilis and species of Fagus, Platanus, Salix. Dawson refers the former to the Laramie, and the latter to the Eocene (1888). Spitzbergen, in lat. $78^{\circ} 56^{\prime}$, has yielded many species, including two species of Taxodium, and species of Hazel, Poplar, Alder, Beech, Plane Tree and Lime. But it is now questioned whether part of the Miocene of Greenland is not Eocene.

Out of 180 species from the Eocene beds of Haring, 55, according to Ettingshausen, are Australian in type, 28 East Indian, 23 tropical American, 14 South African, 8 Pacific, 7 North American and Mexican, 6 West Indian, 5 South European. The resemblance to Australia consists not merely in the number of related species, but in their character, the small, oblong, leathery-leaved Proteacere and Myrtacea, the delicately branching Casuarince, the Cypress-like species of Frenela and Callitris, etc. Only 11 species have their representatives in warm temperate climates.

In the Miocene of Vienna, nearly a third are North American in type ; but with these there are some South American, East Indian, Australian, central Asiatic, and not a sixth European. The species particularly related to those of North America (its warmer portion) belong to the genera Fagus, Quevcus, Liquidambar, Laurus, Bumelia, Diospyros, and Andromedites.

Animals. - No fossil Invertebrate or Vertebrate of the Cretaceous of Great Britain is known from the 'Tertiary; and this is true also for Europe.

Invertebrates. - The shells of Rhizopods, Foraminifers, were as important 1545 .

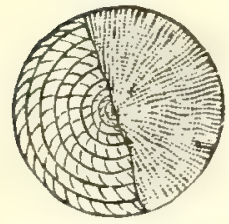
in rock-making during the Eocene Tertiary as during the Cretaceous. The species of greatest interest are the coin-shaped Nummulites which contributed largely to the constitution of Eocene strata, as already stated. A common species is here represented, with the exterior of half of it removed, so as to show the spiral ranges of cells that were formed by the Nummulites num- successive budding of Rhizopods. There are but few Brachiomularius. pods known, and these are mostly of the groups of Lingulids, Discinids, Terebratulids and Rhynchonellids.

The Mollusks were nearly all of modern genera. Some of the common Eocene Gastropods are species of Otiva, Fusus, Voluta, Fasciolaria, Conus, Mitra, Cerithium, Turritella, Rostellaria, Pleurotoma, Cyproea, Natica, Scalaria. England had six species of Eocene Nautilus.

Insects, and also Arachnids and Myriapods, have been obtained in great numbers from the amber in the Lignitic portions of the Lower Oligocene of northern Germany, near Königsberg. Over 2000 species have been collected from it. They were caught in the resin while it was in its original liquid state, and the most delicate parts are preserved in perfection. The lignite was made chiefly from Conifers, and the common species is a Pinus, $P$. succinifer. They show that forests of Conifers were a common feature of northern Europe. Insects occur also abundantly in the Middle Tertiary of CEningen, Radoboj, Parschlug, Auvergne, and in the Rhenish Brown coal.

Vertebrates. - Among Fishes, Teleosts, or common Fishes, which began in the Cretaceous, were profusely represented. Ganoids were relatively few; 
and among them in the Eocene occurred species of Acipenser or Sturgeon. Teeth of Sharks are also common, and are like those of America in genera and partly in species.

Among Reptiles, there were many true Crocodiles, -18 or 20 species having been described. Over 60 species of Tertiary Turtles are known; and the shell of one Indian species from the Pliocene of the Siwalik Hills, Testudo (Colossochelys) Atlas, had a length of six feet.

A species of Snake, 20 feet long, Pulocophis typhoeus Owen, was discovered in the Bracklesham beds of the Middle Eocene, and another species, 30 feet long, in the Lower Eocene of Sheppey. Several species related to the common Black Snake (Colubridoe) oceur in the Miocene.

Remains of a large number of Tertiary Birds have been found and described. According to A. Milne Edwards, the Miocene beds of the Department of Allier, in central France (between $46^{\circ}$ and $47^{\circ}$ in latitude), has alone afforded 70 species; and many of these Miocene birds are of tropical character. He thus speaks of them: Parrots and Trogons inhabited the woods. Swallows built, in the fissures of the rock, nests in all probability like those now found in certain parts of Asia and the Indian Archipelago. A Secretary Bird, nearly allie 1 to that of the Cape of Good Hope, sought in the plains the serpents and reptiles which at that time, as now, must have furnished its nourishment. Large Adjutants, Cranes, and Flamingoes, the Pulcelodi (birds of curious forms, partaking of the characters both of the Flamingoes and of ordinary Grallæ) with Ibises frequented the banks of the watercourses, where the larvæ of Insects and Mollusks abounded; Pelicans floated in the midst of the lakes; and, lastly, Sand-grouse and numerous gallinaceous birds assisted in giving to this ornithological population a strange physiognomy, which recalls to mind the descriptions that Livingstone has given us of certain lakes of southern Africa.

The London Clay (Eocene) afforded Owen a bird, named by him Odontopteryx, having tooth-like dentations of the bony edge of the bill.

The Mammals of Europe were much like those of America in the characteristics of the earliest known species and in the lines of succession. The beds of the Lower Eocene of Europe, the Cernaysian, near Reims, and elsewhere, in France, have afforded kinds of Ungulates, Creodonts, and Quadrumana, related to those of the Puerco group. Remains of species of Zeuglodon have been reported from England, France, Germany, Russia, and even from New Zealand. The London Clay of the London basin, representing the Middle Eocene, has, like the Wasatch, its species of Coryphodon and Hyracotherium, genera first established by Owen from British species, and also new Creodonts; and the Upper Eocene, including the Calcaire grossier of Paris, is like the Bridger group in its Ungulates, Creodonts, and Quadrumana, the genera Lophiodon, Hyrachyus, being characteristic. Further, the Uinta beds, or those of the closing Eocene, have equivalents in the Gypsum heds of Montmartre of the Paris basin, the beds that afforded Cuvier the earliest known of Tertiary Mammals. These Parisian strata, the 
Calcaire grossier, and the beds of the Montmartre Quarries are referred to the upper section of the Eocene in French geology; the latter is the Lower Oligocene of other parts of Europe.

The same general facts are true with regard to the Mammals of the Lower Miocene corresponding to the White River beds of America, designated Upper Oligocene in Germany, and to those of the later Miocene and Pliocene.

Among the species of the Upper Eocene, brought to new existence by Cuvier from the beds in the vicinity of Paris, one of the most characteristic is the Paleothere (named from $\pi \alpha \lambda a i o s$, ancient, and $\theta \dot{\eta} \rho$, wild beast), related

1546.

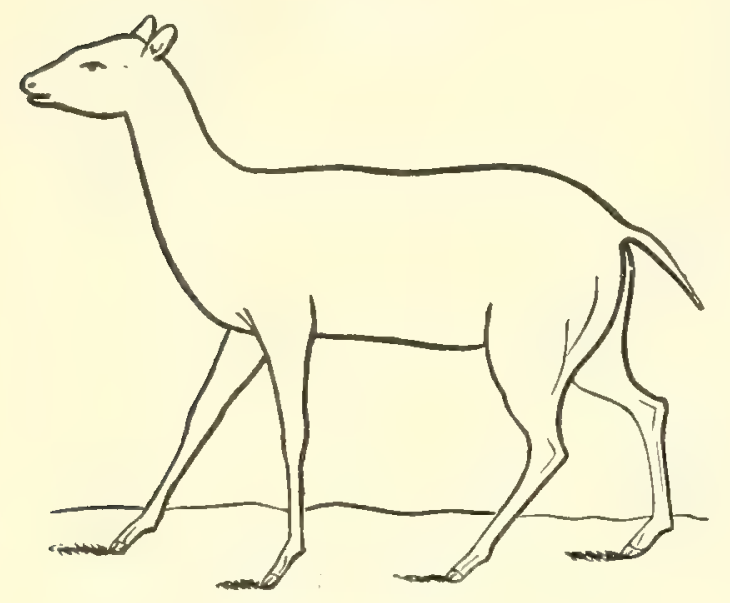

Xiphodon gracilis, as restored by Cuvier. to the Tapir in its elongated nose and other respects. The restoration by Cuvier has a close resemblance to the figure of the Tapir on page 905 . The largest species of the genus, Palcotherium magnum Cuv., was of the size of a horse, and a smaller, $P$. curtum Cuv., not larger than a sheep. The restoration by Cuvier has the stout form of the Tapir; but a skeleton, discovered in 1874, referred to this species, has the long neck and nearly the figure of a Llama. With the Paleothere were Tapir-like beasts of the genus Lophiodon, and others. Higher in the series were found the remains of Anoplotheres and Xiphodons, Artiodactyls related to the Ruminants in their feet, but at the same time having some characters of the Hogs. The Xiphodons were of slender form (Fig. 1546). The species were remarkable for having the full number of teeth, 44, and the set of teeth as even in outline as in Man, the eye-tooth having nothing of the elongation which is common in brutes and is so striking a part of the armature of Hogs and Carnivores;

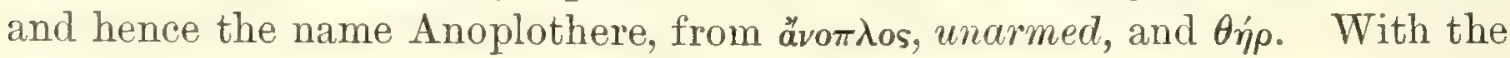
Anoplotheres, there were also Hog-like Artiodactyls, species of Choeropotamus and of other genera. The fauna included also various Carnivores, Rodents, Bats, and an Opossum. The Carnivores included a Wolf, Canis Parisiensis, the Weasel-like Cynodon Parisiensis; and the Creodonts, the Dog-like Hyoenodon dasyuroides, etc.

In the Miocene occur the earliest of Mastodons, Elephants, and the still stranger Elephant-like animal, the Dinothere, besides Paleotheres and other Tapir-like beasts, new Carnivores, Monkeys, Deer, Antelopes, and the first Edentates.

Fig, 1547 represents, much reduced, the skull of the Dinothere (Dinotherium giganteum Kaup). The head carried a trunk, and two tusks, like an Elephant; but the tusks were turned downward. There is a mixture 
of the characteristics of the Elephant, Hippopotamus, Tapir, and the marine Manatus (Dugong), in its skull; but its nearest relations are with the Elephant or Mastodon. One fine skull was dug up at Eppelsheim in Germany; and the remains have been found also in France, Switzerland, and other parts of Europe, and also in Sind, India.

In the Miocene, Europe had its species of Ant-eater, the Macrotherium, which was an Ungulate, related to the later Chalicotherium.

The Pliocene of Europe has afforded also species of the Baleen Cetaceans (Whale-bone Whales). Species of the genus Cetotherium oceur in the Pliocene of England and Belgium, and also, according to Lydekker, in the Miocene of Patagonia, along with Cetaceans of other genera.

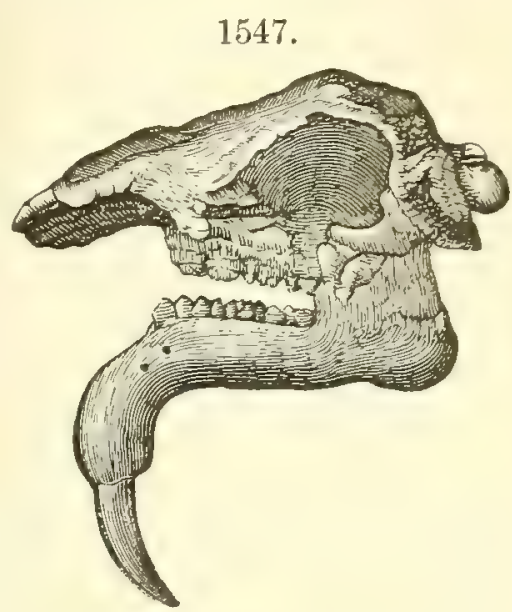

Dinotherium giganteum $\left(\times \frac{1}{40}\right)$.

All the Fishes, Reptiles, Birds, and Mammals of the Tertiary are extinct species.

\section{Subdivisions and Characteristic Species.}

Lower Eocene. - (1) Cernatsian (= Puerco). - Beds at Reims and La Fere in the adjoining departments of Marne and Aisne in northern France. At Cernay, near Reims, occur the following Mammals:-Marsupial: Neoplagiaulax. Creodont: Arctocyon, Hyodectes, Heteroborus. Insectirore: Adapisorex. Quadrumana : Plesiadapis, Protoadapis. There are also the BiRDs, Gastornis Edwardsi, Eupteromis.

In overlying beds occur Hyonodictis, Proviverra, Plesiadapis, with Teredina personata; and some sand-beds afford Cyrena cuneiformis, Melania inguinata, Cerithium variabile.

(2) Suessontan of d'Orbigny ( = Wasatch, the Landenian of Belgium). Includes the Thanet sands of the London basin (Thanetian, of Lapparent). Also, (a) the marls of Meudon, with (b) Lignitic clays, and (c) Plastic clay, but more marine in Belgium, to which correspond the stages (a) Maudunian, (b) Sparnacian, and (c) Ypresian. The Paniselian beds of Dumont are part of the Ypresian.

In England. - Thanet sands. - Pholadomya cuneata Sow., Cyprina Morrisii Sow., Corbula longirostris Desh., Scalaria Bowerbankii Morr.

Woolwich and Reading beds. - Cyrena cuneiformis Fer., C. tellinella Fer., Melania inguinata Dfr., Ostrea bellovacina Lam.

London Clay (Island of Sheppey, etc). - Nautilus centratis Sow., N. imperialis Sow., Aturia ziczac Bronn, Belosepia sepioidea Blv., Voluta Wetherellii Sow., V. nodosa Sow., Aporrhais Sowerbyi Mant., Cyrena cuneiformis, Cryptodon (Axinus) angulatus Sow., Leda amygdaloides Sow., Pinna affinis Sow.

Vertebrates of the London clay. - Fishes and Reptiles: Tetrapterus priscus Ag., Pristis bisulcatus Ag., Lamna elegans Ag., Paloeophis toliapicus Owen. Mammals. Marsupial: Didelphis. Uxgutates: Lopmiodon, Miolophus, Hyracotherium, Coryphodon.

In France, at Meudon, Coryphodon, Palconictis, Phenacodus, with Gastornis.

Middle and Upper Eocene.-PARIsian (= the Bridger beds). (1) The Calcaire grnssier of Paris (Lutetian of Lapparent); with above, (2) the sands of Beauchamp, France, etc.; Bagshot sands of the London Basin, and the Barton clay of the Hampshire Basin, England (Bartonian). 
In the Bagshot Sands, England. - Nummulites levigatus Lam., Cardita planicosta Lam., Pleurotoma attenuata Sow., Turritella multisulcata Lam., Conus deperditus Brngt., Lucina serrata Sow.; Myliobatis Edwardsi Dixon, Carcharodon angustidens Ag., Otodus obliquus Ag., Galeocerdo latidens Ag., Lamna elegans Ag. Reptiles, P'alcophis typhous Owen, Gavialis Dixoni Owen, Crocodilus Hastingsice Owen; Mammals, Dichodon cuspidatus Owen, Lophiodon minimus Cuv., Microchurus erinaceus Wood, Paloplotherium annectens Owen.

Barton Series. - Mitra scabra Sow., Voluta ambigua Lam., Typhis pungens Morr., Voluta athleta Sow., Terebellum fusiforme Lam., T. sopita Morr., Cardita sulcata Morr., Crassatella sulcata Sow., Nummulites variolarius Morr. (variety of N. radiatus Sow.), Chama squamosa Brand.

The Calcaire Grossier contains many species of Fishes, and also of other tribes identical with those of the Upper Eocene of England.

Oligocene. - Ludian (= Uinta beds). The Montmartre gypsiferous marls of Paris, Bembridge and Headon beds of the Isle of Wight. Tongrian (=White River beds; Upper Oligocene, of Europe). Includes the Hempstead beds of the Isle of Wight, the Fontainebleau sandstone, in France, clays with Cyrena convexa, near Tongern in Belgium, the Lower marine Molasse of Switzerland. 'The name Rupelian is given in Belgium to an upper portion of the beds; and Bolderian to still higher beds.

Headon Series. - Planorbis euomphalus Sow., Helix labyrinthica Say, Neritina concava Sow., Limnaca caudata Edw., Cerithium concavum Desh.; Lepidosteus; Reptiles, Enys, Trionyx; Mammals, Palootherium minus Cuv., Anoplotherium, Anthracotherium, Dichodon, Dichobune, Spalacodon, Hycenodon.

Bembridge Series (120 feet thick). - Cyrena semistriata Desh., Paludina lenta Desh., $P$. orbicularis Voltz., Melania turritissima Forbes, Cerithium mutabile Lam., Cyrena pulchra Morr., Bulimus ellipticus Sow., Helix occlusa Edw., Planorbis discus Edw.; Mammals: Palcotherium magnum Cuv., $P$. medium Cuv., $P$. minus Cuv., $P$. minimum Cuv., $P$. curtum Cuv., $P$. crassum Cuv., Anoplotherium commune Cuv., A. secundarium Cuv., Dichobune cervinum Owen, Chœropotamus Cuvieri Owen.

From the Montmartre gypsum beds of France, and equivalent beds, have been obtained

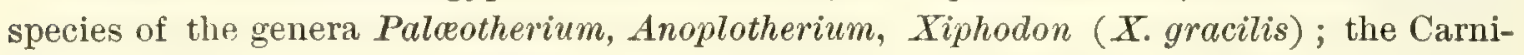
vores, Hycenodon (H. leptorhynchus Blv.), Cynodon Parisiensis Pomel, Bats, and Opossum.

The Phosphorite beds of Quercy, referred to the Oligocene, have afforded Palootherium, Anoplotherium, Xiphodon, Hycenodon, Cynodictis, Cebochorus, along with Amphitragulus, Aceratherium, Necrolemur, and others.

Lapparent divides the Oligocene into the Tongrian and Aquitanian stages; and the Tongrian into Sannoisian and Stampian substages.

The Hempstead beds of England have afforded Corbula pisum, Cyrena semistriata Desh., Cerithium plicatum, C. elegans, Rissoa Chastelii, Paludina lenta, Melania fasciata, M. costata Sow.; the Mammal, Hyopotamus bovinus Owen.

Lower Miocene ( $=\int$ ohn Day Beds, Lower Miocene, in Germany, etc.). - Lacustrine limestone of Beauce and Meulières de Montmorency, in France, and limestone of Agenais in Aquitania, southwest France; Red Molasse, Lignitic Molasse in Switzerland.

1. Maremeray (Langhian, Burdigalian). - Freshwater Molasse of Switzerland; beds at Mayence, Belgium.

2. Helvetian. - Marine Molasse of Switzerland, Faluns of Anjou with Ostrea crassissima, etc., of Touraine, in western France, Molasse of the Superga, Italy.

Upper Miocene. - Tortoxian. - Marls with Helix Turonensis in western France; CEningen beds, Leitha limestone near Vienna, Blue marls of Tortone in Italy. Above 
the Tortonian, the stages Sarmatian and Pontian are recognized in Dauphiné, Austria, and Italy.

Some of the Miocene genera are Pliopithecus, Dryopithecus, of Quadrumanes; Macharodus, Felis, Hyonarctos, Hyana, Canis, Viverra, Mustela, of Carnivores ; Mastodon (M. longirostris, M. tapiroides Cuv., etc.), Elephas, Dinotherium; Rhinoceros, Listriodon, Sus, Anchitherium, Hipparion, Equus, Hippopotamus ; Camelopardalis, Antelope, Cervus, of Ruminants; Evinaceus, Talpa, of Insectivores ; Halitherium, Squalodon, Physeter, Delphinus.

The Tertiary Mammals of the Siwalik Hills, India, from beds now referred to the Pliocene, include, besides Quadrumana, species of Hyanarctos, Hyana, Macharodus, Felis, Canis, Mustela, Viverra; Elephas, Mastodon, Rhinoceros, Hexaprotodon, Hippotherium, Equus, Hippopotamus, Sus, Anoplotherium, Chalicotherium, Merycopotamus, Camelus, Camelopardalis ; Sivatherium, Antilope, Moschus, Cervus, Ovis, Bos ; Dinotherium; Hystrix; Enhydriodon. The Sivatherium was an elephantine Stag, having four horns, allied to the Deer, but larger, being in some points between the Stags and Pachyderms. It is supposed to have had the bulk of an Elephant, and greater height. Bos and the related genera probably occur nowhere earlier than the Pliocene. There were also Crocodiles of large size, and the great turtle Colossochelys Atlas.

In southern South America, the Santa Cruz beds, which are referred to the Miocene, afford species of Edentates, Rodents, Marsupials, Nesodon, Toxodon, Prototherium, Prosqualodon, Argyrocetus, Odontoceti, or Toothed Whales, and other species.

The following new Miocene species from East Siberia have been described and figured by W. H. Dall : Semele Stimpsoni, Siphonaria Penjince, Conus Okhotensis, Cerithium cymatophorum, Diloma ruderata; and he has identified also Ostrea gigas Thunberg. They occur in a bed in the northeastern angle of the Okhotsk Sea, on a small bay in the Gulf of Penjinsk containing a layer of coal. They were brought from the region in 1855 by Wm. Stimpson, a member of the Ringgold and Rogers Exploring Expedition. The fauna is related to that of the China and South Japan seas, and indicates, states Dall, a change downward of water temperature since the Miocene of $30^{\circ}$ to $40^{\circ} \mathrm{F}$.

Lower Pliocene. - Messinian, the Zanclean beds in Italy of Seguenza, and over the Zanclean beds, along the Apennines, Plaisancian of Seguenza.

Upper Pliocene. - Astian. - Crag of Norwich, etc., Eastern England; Subapennine marls and sands of beds of Val d'Arno. In the Red Crag, Felis pardoides Owen, Mastodon Arvernensis Croizet \& Jobert (angustidens Owen), Rhinoceros Schleiermacheri Kaup (incisivus Cuv.), Tapirus priscus Kaup (Arvernensis Croizet \& Jobert), Cervus anoceros Kaup. In the Norwich Crag, Mastodon Arvernensis, $\boldsymbol{M}$. longirostris, $\boldsymbol{M}$. Borsoni, Elephas meridionalis, Cervus Falconeri, C. verticornis.

Forest bed of Cromer on the east coast of England, referred by many to the Lowest Quaternary, includes, besides the Cave Bear, the Irish Deer; and several modern species, as the Beaver, Wolf, Fox, Stag, Aurochs, Mole, Wild Boar, Horse; also the European Pliocene species, Ursus Arvernensis, Cervus Polignacus Robert, Hippopotamus major Cuv., Rhinoceros Etruscus, R. megarhinus, Elpphas meridionalis, E. antiquus, Equus Stenonis, and without any remains of man. The Forest bed is made Pliocene in the Manuals of Etheridge and H. B. Woodward, but lower Glacial by Geikie and others.

The Pikermi Middle Pliocene beds in Greece contain out of 29 genera of Mammals, 18 that are found also in the Middle Pliocene of the Siwaliks of India; there is the same remarkable abundance of true Ruminants, and among them, as in the Siwaliks, several species of Giraffice and Antelope; there are at Pikermi 15 Ruminants to $1 \mathrm{Pig}$ and 1 Chaticotherium, and in the Siwaliks 37 Ruminants to 12 other Artiodactyl Ungulates (Oldham, Geol. of India). 


\section{GENERAL OBSERVATIONS ON THE TERTIARY.}

BIOLOGICAL CHANGES AND PROGRESS.

The precursors of the Tertiary Mammuls. - No immediate precursors of the Tertiary non-marsupial or placental Mammals, linking them to the Marsupial, have yet been found in any part of the world, notwithstanding the occurrence in many regions over America as well as the other continents of a gradual passage from the Cretaceous formation into the Tertiary. They are naturally supposed to have existed in the later Cretaceous over the dry land of eastern and western America; but still it is strange that they did not find resorts somewhere on the border of the Cretaceous seas along with the Marsupials. The nearest approach in the Reptilian type to the Mammalian yet known was made by the stupidest of the Dinosaurs, which had a pair of Bovine horns and two-pronged teeth.

Early prototypic character. - Another strange fact is that although the Marsupials of earlier time had become variously specialized, their placental successors should have had unspecialized or prototype characteristics, such as have been described; that there should have been at this time so striking a starting from what appears to be a new beginning. The removal of the former mystery may also remove this. Moreover, it is to be considered that among the fossils of the Mesozoic Marsupials, remains of the limbs, or of any parts of the skeleton excepting the jaws and teeth, are of very rare occurrence.

Diversity of Eocene Mamuals. - Another remarkable fact is that so great a diversity of Mammals, diversity in structure as well as size, should have appeared before the Eocene period had passed. The prototypic planteaters and flesh-eaters of the earliest part, supposed to be plantigrade in feet, were followed, even in the Wasatch division of the Lower Eocene, by species of large, short-footed Ungulates, the Coryphodonts, and in the later Eocene huge Dinocerata, the latter supplied with horns for attack and defense. In the Eocene, also, the Tapir-like species advanced far toward the modern genera, Tapirus and Rhinoceros. There also appeared various species with paired toes, in the line of the Hogs, Hippopotamus, Camel, so that the type of Artiodactyls, and the types of several of its principal subdivisions, were established. There were also some prominent Eocene types of Rodents and Insectivores. Further, the Quadrumana of the Early Eocene, having the typical number of teeth, 44, were followed in the Later Eocene, by others, in which the number of teeth was reduced to 32 , the final limit in the Quadrumana, and that characterizing Man.

Moreover, there were several successions of Mammalian faunas in this first period of the North American Tertiary, and the species in each of them probably outnumbered those of Recent North America. The kinds found fossil may have been a fourth of all then existing in the region, and probably not more.

Loss of prototype characters. - Very early in the Eocene, prototype charac- 
ters began to disappear. The teeth had the typical number, 44 , reduced; their structure made more complex; and their characters varied otherwise through use and adaptations to different purposes.

The feet had the number of digits reduced in most Ungulates, but not in the Coryphodon line, or in the Carnivores, or the Quadrumana, or rarely in the Insectivores or Rodents. Moreover, the feet lost the plantigrade tread in the Herbirores, and Carnivores, but not in the Quadrumana, Insectivores, or Rodents.

In most of the larger species the regularity in the carpal and tarsal series of the feet gave way to the oblique or alternating position of the bones required for firmness in running.

Some of the canses favoring change. - The development of so great a diversity of Eocene Vertebrate structures is the more remarkable in view of the absence of all evidence as to any great physical or meteorological disturbance to require new adaptations. No change of climate is indicated beyond what might have occasioned a feeble amount of migration. No evidence of disquiet in the earth's crust has been noted, excepting that relating to the imperceptible geosynclinal movements over the areas of the Eocene lakes attending the slow deposition of sediments.

The only sources of disquiet that can be appealed to as causes of biological change, are biological sources proceeding from the appetites or needs or impulses of the animals. Of these appetites the dominant one. the most imperative, the only daily recurring one, was the demand for food. As nearly half of the Mammals lived on animal food, there was perpetual strife between the stronger flesh-eaters and the weaker, and between all flesh-eaters and other species. It would naturally have driven the weak kinds to holes, or somewhere out of reach of their enemies, where poor food, darkness, and other privations, would have been unfarorable to high progress. The strife, moreover, as writers on the derivation of species have illustrated, would have promoted fleetness, cumning, devices for protection, and have favored those changes in the Mammalian structures that would better fit or accommodate the species to the new demands.

The evolution of the Horse through the necessity of running to escape from enemies has often been set forth as an example of the effects. under certain conditions, of such a cause. An animal of primitive Ungulate type, having the third or middle toe the longest of the five, raising itself on its toes for greater speed in running, and forcing itself forward naturally by its longer toe, had this toe, as Eocene and Miocene time passed, with the bone of the foot above it (the metatarsal and the metacarpal) enlarged and elongated, while the less-used toes either side dwindled till too short to reach the ground; and finally, through these and other concurrent changes. there was evolved, a long-legged one-toed animal - the Horse. It became tall and long-legged, not only by elongating growth in certain bones, but also through the functional appropriation by the leg of all of the foot excepting the terminal hoofed joint.

DANA'S MANUAL -59 
For the Artiodactyl, the theoretical history is the same, excepting that two toes, the third and fourth, were concerner instead of one-the two acting together in dynamical unison. An early Ungulate rising on these two toes in running in order to make thus its greatest speed, the toes and also their metatarsals and metacarpals became equally enlarged and alike elongated, while the less-used toes either side, the second and fifth, became a shorter, weaker pair - as illustrated in the $\mathrm{Hog}$; or, after further change, the dominant pair became still longer, while the shorter was reduced to a rudimentary pair or to hoofs, or became wholly obsolete excepting metacarpal and metatarsal splint bones, as in the fleeter Artiodactyls.

Further: the stroke of the foot demanded, for high speed and safety, that there should be little or no rotation of the foot by a movement of the bones of the lower leg, - that is, of the radius and ulna of the front pair and the tibia and fibula of the hind pair, - and consequently the ulna and fibula became reduced sometimes to splint bones, or united by coössification severally to the radius and tibia; and likewise, in the two-toed Artiodactyl, the corresponding two metatarsals and metacarpals, having no movement between them, became coössified into a "cannon bone."

There is little that is hypothetical in the above statements, for the successional lines and the sutures of half-finished coössification are fully illustrated among the species. Modern surgery finds that bones at joints become coössified by too long confinement in splints without a chance for movement. The variety of four-toed Artiodactyls during the Tertiary was very large; but at present they are confined to the few of the Suillines, or the Hog family, and the Hippopotamus group. The two-toed species, on the contrary, or the Stags, Deer, Cattle, and the like, are most abundant in recent time.

The following considerations bear on the character of the changes that went forward among the Mammals. Of the three divisions (1) the Planteaters, (2) the Animal-eaters, (3) the Omnivores, the last-mentioned, - that is, the Quadrumana or Monkeys, - must have early taken to the trees, as their habits indicate. This was an easy method of escaping enemies. Being strong in their fore limbs, they had the trees and the ground, fruit and flesh, within their range. For defense or attack they needed no abnormal growths, such as horns; and they have been from the first without them.

The Animal-eaters, in their development, would have divided according to food and habits. Those forced to take the poorest and most abundant and easily got of animal food, the Insectivores, fossorial and skulking species, degenerated, becoming small species, mostly remaining plantigrades, the teeth in some losing their differentiation, in others disappearing altogether. The insects which they ate needed no chewing. Some of them found protection in the substitution of spines for fur (the Hedgehogs), and in the safe but cowardly method of rolling into a ball with spines out in all directions.

The higher section of the Animal-eaters, or the Carnivores, living on the best of animal food, and generally having to fight for it, and always on the alert, having the fore limbs the strnnger pair, and efficient as arms in secur- 
ing or holding food, and jaws armed with long canines, they, too, needed no abnormal growths for defense or attack.

The larger Plant-eaters, who dared to face the Carnivores, at least when escape was not easy, whose legs, while good for locomotion, were of no service for prehension or attack, ised themselves as battering-rams, with the head as the striking end and the means also of tossing away or rending the daring enemy. Under the peressities of their condition, the forehead and nose grew horns, and a pair of teeth became elongated into tusks. As the legs, besides, were of no service for gathering food, the nose, as well as the elongated canines, was sometimes made to serve for grubbing; and the nose thus used became elongated, until the Tapir's nose could pull over a tree, and the Elephant's serve as a long agile arm of great strength and wide diversity of work. Such abnormal growths are characteristics of Herbivores alone. The graceful Horse is one of the exceptions among Herbivorous locomotors, for it finds its chief means of attack in its hind legs, and of escape in its fleetness.

Great degeneration also took place among the Mammals; for before the close of the Eocene there were Whales in the seas - the Zeuglodons. The species is supposed, from its teeth and food, to be a degenerate flesh-eating species, which, for escape, took to the water, where support from limbs is not needed. In this supporting element the body became enormously enlarged and multiplicate in its vertebral column, like the Sea-Saurians, the length being increased from four or five feet to 70 feet, and the size of the dorsal vertebræ to a diameter of a foot and a length of a foot and a half. Its teeth remained few, 36 ; and the molars retained their two roots, but the distinction between molars and premolars was lost.

Further: in the Miocene, as stated on page 912, Whales appeared of greater degeneration along two or more lines: species appearing that were multiplicate in teeth, and in the phalanges of some of the digits of the fore limbs, as well as in vertebre; others that had teeth only in one jaw and all single-rooted; and still others that had no teeth, but only plates of whalebone with unravelled edges in a huge mouth to strain out small animals from the sea-water for food.

It may be supposed that these aquatic animals became urosthenic, like Fishes, because sculling with the whole posterior part of the body was their best mode of progression; that the body became long and almost indefinite in number of vertebræ, to secure greater force in the sculling organ; that the hind limbs disappeared because useless; and that, in one branch of the tribe, the teeth began to disappear altogether when the smaller swarming life of some parts of the ocean received into the mouth almost without effort, began to satisfy appetite. It may also be presumed that the whale-bone plates, over 350 in number, either side of the middle line, grew downward from the palate just as soon as they were needed; but the question, what made them grow, remains, as in many like cases, unanswered. In the young state these Whales have rudimentary teeth. The results were much like 
those that had before occurred in Reptiles. It was progress downward almost indefinitely, but without loss of the essential characteristics of a Mammal.

The above examples and explanations may serve to illustrate some of the methods by which the morifications of species are supposed to have taken place without the aid of physical catastrophe.

The great diversity in the characters of Eocene Mammals, wrought out, it is believed, in such quiet times, teach this plainly - that the first period of the Tertiary was exceedingly long, whatever may be gathered to the contrary from some persistent Cretaceous plants.

\section{OROGENIC AND EPEIROGENIC MOVEMENTS.}

In the opening of the Tertiary era geological history reaches the time when, as mentioned under Dynamical Geology, besides the making of great mountain ranges, nearly all the mountain chains of the world received additions of many thousands of feet to their heights and hundreds of thousands of square miles to their areas; and also when igneous eruptions took place of extraordinary extent.

1. Orogenic movements at the close of the Nummulitic epoch of the Eocene. In Europe, the elevation of the Pyrenees, and of some other heights in eastern Europe, occurred after the marine Nummulitic beds of the Eocene had been deposited. The mean direction of the Pyrenees is about N. $80^{\circ} \mathrm{W}$. There are large flexures and steep slopes on the side toward France, but less upturning and gentler slopes toward Spain.

2. Orogenic movements at the close of the Miocene. - In North America an upturning took place at this epoch along the coast region of California and Oregon, tilting and, in some cases, flexing the Miocene, Eocene, and Cretaceous formations, 5000 feet or more in thickness, as is proved by Miocene fossils in the upturned beds (J. D. Whitney). The earlier Jurassic strata are believed to have been earlier upturned and metamorphosed, being of cotemporaneous origin with the Sierra Nevada.

At this epoch also the great upturning of the Alps and Juras occurred briefly described on page 367 . It gave to the mountains the bold flexures of the Mesozoic formations with the overlying Eocene and Miocene, which are a remarkable feature of many of the lofty summits. The Apennines, according to Stefani, passed through a crisis of upturning and flexures at the close of the Nummulitic Eocene, like the Pyrenees, and also at the close of the Miocene, with the Alps.

The Himalayas were, to a large extent, beneath the sea during the Nummulitic epoch, and at least 20,000 feet lower than now (page 368). Either directly after this epoch, or before the close of the Miocene, there was an upturning and flexing of the Nummulitic and underlying Cretaceous beds (down to the top of the Carboniferous) and the commencement of the final elevation of the mountain chain. According to the Geological Survey 
of India, the beds above the Nummulitic formation at the top of the upturned series are probably Miocene, as indicated by the plant beds, one species, the Sabal major, ranging from Lower to Middle Miocene in Europe. The Siwalik Tertiary beds (of the Sub-Himalayas), many thousand feet thick, along the length of the Himalayas, which are Pliocene with probably Upper Miocene at top, rest on the inferior Mesozoic and Paleozoic rocks along what appears to be an enormous fault-plane. This steep "faultplane," as shown by Meulicott, is really an original limit of deposition, in part almost cliff-like, to the north of which the Siwalik beds never extended. These beds are, therefore, not included in the disturbed region. There appears to be doubt remaining whether the epoch of upturning followed the close of the Nummulitic Eocene or that of the Miocene.

The mountain chains to the north of the Himalayas for $22^{\circ}$ of latitude are nearly parallel to it, and this has led to the suggestion that all this great region in Asia was involved in one system of orogenic movements.

Epeirogenic movements during the Tertiary era. - Through the Tertiary, changes of level went slowly forward by geanticlinal bendings of the earth's crust and slippings along old or new fracture planes, giving great altitude to vast continental areas, and especially those within 800 miles of the seiborder, and affecting all the continents alike with the same stupendous results. The continuing of the movements through all Tertiary time, and also beyond it, during part of the Quaternary, teaches that they were extremely slow in general progress; yet sudden slips of scores and hundreds of feet were probably among the events.

In the Rocky Mountain region the change was slight during the Eocene, and yet it was sufficient to modify the outlines and positions of the Eocene lakes. With the close of this period, the land was so far raised that the Eocene lakes were drained; but the elevation attained was so small, as Hayden first remarked, that vast Miocene lakes covered a large part of what now constitutes the eastern slopes of the mountains, and continued into the Pliocene. The long continuance of the lakes indicates not only slowness of emergence, but also that the movements were interrupted through long intervals. The western margin of the Nebraska lacustrine beds is 3500 feet above the level of the eastern, the former having a height of about 6000 feet and the latter of 2000 feet. This is proof that the elevation of the mountains went on through the Pliocene, for the rise to the westward could not have made much progress in the Miocene without drying up the lake.

The height which the Rocky Mountains had reashed by this change of level is not ascertained. This much is known: (1) that the Cretaceous areas were originally at or near the sea level; and (2) that within the area of the United States the present height of the upper beds is now, in part, 13,000 feet. Moreover, the corresponding height in central Mexico is 10,000 feet, and in British America, toward the Arctic seas, 4000 feet.

During the progress of these changes over western North America there were also, according to Gilbert, Powell, L Conte, and others, faults along 
fracture-planes thousands of feet in displacement in the mountain ranges of the Great Basin, the High Plateaus of Utah, the Wasateh Mountains, and the Sierra Nevada.

Through a study of the river systems of the Sierra Nevada, it has been proved by LeConte (1886) that a great elevation of the Sierra took place at or near the close of the Pliocene. The drainage of the Sierra is chiefly to the westward, the eastern front being very steep. Whitney describes in his Report (1865) the facts respecting an early system of valleys having been covered up and obliterated by basaltic eruptions, and the new and much deeper system of subsequent time (page 300). He illustrates also, by a plate in his work on the Auriferous Gravels (1880), the difference in the depth of erosion of the two systems, the earlier that occupied all Cretaceous and Tertiary time, and the later, of subsequent time after the eruptions. In view of these and related facts, LeConte urges that the deeper erosion by the existing streams, although their time of work was short compared with that of the earlier system which existed through the Cretaceous and Tertiary, proves that a great elevation of the Sierra Nevada, increasing the fluvial denuding power, took place soon after the Pliocene; and that this was accomplished by a rise along a fault-plane having the course of the steep eastern front of the range. It is to be remarked that the Glacial period followed the Pliocene; and its glaciers and abundant precipitation would account for part of the profound denudation of the later rivers. But this fact does not invalidate seriously the conclusions. It is sustained through additional facts by other geologists, including Lindgren and Diller.

The eastern border of the continent underwent only small changes. At the close of the Eocene some modification of the surface oceurred within the Mexican Gulf which put an end to the deposition of true marine beds along its northern beds west of Florida. The only Miocene beds recognized are of fresh-water or brackish-water origin. With the close of the Tertiary, and probably before the Pliocene had fully passed, elevatory movements occurred which raised the Tertiary of the Atlantic border about 100 feet, and that of the Gulf border not much more, except along a region in Georgia, and the border of Alabama in a line with the Peninsula of Florida, where the height is 300 to 400 feet above sea level. A Florida axis of elevation is indicated by it. On Long Island, Martha's Vineyard, and other istands south of New England, occur upturned beds of the Cretaceous or Cretaceous and Tertiary, indicating orogenic movements before the Quatemary. Seefurther, page 1021.

The elevation of the Atlantic border may have been part of a greater change which affected also the whole of the Appalachian region; but no positive evidence of this is yet obtained.

What was the total gain in mass through the great Tertiary elevation of the North American continent? On this point little is known with regard to its eastern half, but the western affords available facts.

With the opening of the Tertiary the larger purt of the western half of the United States was at the water's level from the eastern foot of the Sierra Nevada 
near the meridian of $120^{\circ}$ to the meridian of $97^{\circ}$, or through a breadth of $23^{\circ}$, or nearly 1500 miles. The higher emerged peaks of the Rocky Mountain region were perhaps 4000 or 5000 feet out of water; the Sierra Nevada, 3000 to 4000 feet. Many peaks have Cretaceous rocks at a high level; one, slaty Peak, in Colorado, at 13,000 feet, and this is supposed to have lost 3000 feet of L pper Cretaceous by denudation. The floor of the Great Basin was probably at a height of 1000 feet and less, and its ridges 2000 to 4000 above sea level. Almost all the rest of the surface was near the sea level or below it. The geanticline added at least 13,000 to the height of the summit region; of central Nebraska, 3000 feet (taking only present altitudes), and of western, 5000 to 6000 feet; of Colorado, east of the Front Range, 6000 to 7000 feet; of central Mexico, at least 10,000 feet; of the Sierra Nevada, 10,000, a third of it probably through the general geosynclinal movement, and the rest through one or more faults; and so on. The average elevation of western North America was certainly tripled. This would make the increase of mass at least 10 times. But, as a large part was a total gain, since it rose from the sea level, the amount probably much exceeded this; 12 or 15 times may be nearer the fact. Supposing no addition in the eastern half except that of the Cretaceous and Tertiary sea border, the gain in mass for the whole continent would be over six times.

It is to be admitted that the present elevation cannot in any region be a correct measure of the actual height at the close of the Tertiary. It is safe to say only that it is the final elevation after denudation and such Quaternary oscillations as may have since occurred. The mean height may be much less now than it was at the close of the Tertiary.

In South America, the region of the Andes through the length of the continent underwent at the same time an elevation of many thousands of feet. In Ecuador, the Upper Cretaceous forms most of the peaks of the eastern Andes, and has a height in some of the ridges of 6000 meters (19,686 feet); in Peru, northenst of Lima in $11 \frac{1}{2}^{\circ} \mathrm{S}$., near the Pass of Antaranga, a height of 4803 meters (15,754 feet); in the Province of Huamachuco, 2000 to 5000 meters; in $12^{\circ} \mathrm{S}$., between Pachachaca and Jauja, the Gault, at 5000 meters $(16,405$ feet $)$.

In Haiti, according to Gabb, the Miocene has an elevation of 200 to 2000 feet; and a sea-border of limestone, a height of 170 feet and less. In Jamaica there are 2000 feet or more of white limestone, and the rock covers six sevenths of the area of the island. A yellow limestone below on Jamaica is Miocene; and the thick white limestones of Jamaica and Santo Domingo as well as of Cuba are probably of Tertiary origin, if not partly of Quaternary.

On the Barbados, there is an oceanic deposit consisting of a score or two of feet of calcareous earthy material, largely made of Globigerinæ, overlaid in some places by 100 to 130 feet of siliceous Radiolarian earth, and above this other calcareous and pumiceous beds, with red clays 100 feet or more; and these beds underlie the elevated coral-reef rock of the island from the seashore to a height of 800 to 900 feet. They are regarded by Jukes-Browne and Harrison $(1891,1892)$ as probably Pliocene, and as evidence of a Pliocene subsidence of 2000 to 3000 fathoms, or to such depths as now afford similar 
Radiolarian earths. The Barbados are outside of the outermost range of islands; and whatever changes of level they have experienced may not have affected the Caribbean Sea. At present the bottom of this sea is made of Globigerina and not of Radiolarian earth. Radiolarian deposits occur also on Haiti, Jamaica, and Cuba; but they have less extent and are less decisive as to change of level.

Whether the following changes of level were epeirogenic or not is undecided.

Over Europe and Asia the same elevation of the land over extensive areas was in progress, especially during the Pliocene. Europe was much changed in elevation cotemporaneously with the disturbance in the Alps; and "by the close of the Pliocene all its main features had come into existence." The Alps were carried up probably 12,000 feet or more, and the Pyrenees over 10,000 feet.

The Himalayan chain, a region of upturning at the close of the Miocene (if not before, at the close of the marine, Nummulitic epoch), when 20,000 feet lower than now, began afterward, or simultaneously, its slow emergence and attained its present level according to Blanford by the end of the Pliocene or in the early Quaternary. The Tertiary beds of the Sub-Himalayas, or the Siwalik Hills, which are chiefly freshwater Pliocene and contain the remains of the Fauna Antiqua Sivalensis, were laid down during the progress of the uplift. During all this Himalayan elevation, yeuinsular India underwent little change.

Blanford derives additional evidence as to the remoteness of the time of the uplift, from the existing Mammalian fauna of Tibet. Ont of 43 species of Mammals in Tibet. pertaining to 26 genera, 27 species and 4 genera are not known out of Tibet. Out of 16 species of Rodents, only one is not purely Tibetan. The various facts accord with the view that the elevation of the Himalaya Range commenced early in the Tertiary.

During the early Eocene, as well as the Cretaceous period, the British Channel was crossed by an Interior basin, perhaps having, as Jukes-Browne suggests (1892), a range of land over the western part, uniting Brittany to Cornwall. But in the Miocene, on the same authority, even the area of the Eocene Anglo-Parisian basin had become dry land; and in the Pliocene, ridges were formed crossing the Channel from northwest to southeast, as the Weald Axis, the Portsdown, the Purbeck corresponding to the axis of Artois, Bresle, and Bray to the south. Only in the Middle Quaternary, after a phase in which a passage extended across from below Dover and Brighton on the north to the Province of Calais in France, did the Channel secure its place through a general subsidence.

"Thus, throughout the Tertiary era, the continents of Europe and Asia, as well as America, were making progress in their bolder surface features, as well as in the extent of dry land. The evidence is sufficient to show that, wnen the period ended, the continents had in general their mountains raised to their full height." The evidence is stronger now than it was, more than 30 years since, when those words were written.

Geosynctinal movements over the oceanic basin - the "Coral Istand subsidence." - That there were profound geosynclines over the oceanic basins during the later Tertiary and early Quaternary is put beyond question by 
the fact of the great continental elevations of the same time. The Coral Island subsidence, announced by Darwin in 1839, recognized such geosynclines; and they were long since set forth by Dana as the counterpart of the continental movements. The subsidence is thus a real event in geological history ; and if marvelous, equally so is that of the world's so recent elevations.

"Gondwána-Land," connecting India with southern Africa (page 737), continued to exist, according to Oldham (1894), from the Carboniferous period throughout Mesozoic time, and "sank beneath the sea in the Tertiary era," leaving some volcanic and coral islands in its course, including to the northward the sunken atoll of the Chagos bank. The extension of "Gondwána-Land" over the Indian Ocean is not here in view, because it is not believed to have ever been a fact.

A paper by Haddon, Sollas, and Cole ( $R$. Irish Acad., 1894), after mentioning the observation of Jukes that the eastern mountain range of Australia, extending for $35^{\circ}$ of latitude from Tasmania to the northern cape, Cape York, is continued in islands across Torres Strait to New Guinea, and describing the straits and the lands beyond, concludes that this southern continent lost its border lands of New Zealand, New Caledonia, and New Guinea and the intermediate islands "possibly during the great Alpine and Himalayan revolutions" of the Tertiary period.

Igneous eruptions during the Tertiary. - An eruptive period in the earth's history commenced in the Later Cretaceous (page 875) and passed its maximum in the course of the Miocene. Eruptions through fissures covered vast areas of the Pacific slope with igneous rocks, and volcanic eruptions made great volcanic cones, which added largely to the outflows and ejections. The eruptions continued through the Pliocene, and some of the cones are not yet extinct. The loftiest of the volcanoes are situated along the Coast region, from Washington to northern California, the heights varying from 10,400 to 14,500 ; and those farther south along a belt through Mexico - the highest three, Orizaba 18,200 feet, Popocatapetl 17,500 feet, and Ixtaccituatl 16,770 - are probably of like Miocene origin.

Some of the regions of fissure eruptions have been already described. South of Lassen's Peak, in northern California, the southermmost of the cones of the Pacific border, the region of the Sierra Nevada had its outflows of broad streams of basalt from fissures which were later cut up into Table Mountains; and similar floods occurred over Nevada, New Mexico, and Arizona.

The higher western slopes and summit region of the Rocky Mountains also had their cones. The Yellowstone National Park and its vicinity was one of the volcanic centers. Electric Peak and Sepulchre Mountain are two denuded cones in the Park, as described by Iddings; Emigrant Peak, on the Yellowstone, 16 miles north of the boundary, is another, where dacyte and quartzose porphyry are the igneous rocks; Haystack Mountain, 12 miles north of the east corner of the Park, is another, its cone consisting of gabbro and dioryte; and another stands just east of the east corner of the Park, 
which is like the last in its rocks. Iddings refer's these cones to the early Tertiary. He states that after a long period of eruption of acidic andesytes, basic andesytes and basalts were ejected; and after these had been much denuded, the great outflow of rhyolyte took place, forming the Park plateau; and that finally the basalt was poured forth that extends widely orer the Snake River plains in Idaho.

Igneous eruptions occurred through all the successive geological ages. But at no time in American history since the Archæan, have they approached in extent those of the Later Cretaceous and Tertiary periods. It was a time of pouring from fissures and of the birth of volcanoes, as never before.

It is not yet certain that a volcano ever existed on the continent of North America before the Cretaceous period; for the published facts relating to supposed or alleged volcanic ertutions in the course of the Paleozoic ages are as well explained on the supposition of outflows from fissures and tufa ejections under submarine conditions; and none of the accounts present evidence of the former existence of a volcanic cone, that is, of an elevation pericentric in structure made by igneous ejections. Such cones in the tropical Pacific are now encircled by coral reefs as well as beds of detritus, and are thus in process of burial; and so they might have been buried by limestone and other strata, if an actual fact in Paleozoic North America.

During the Archæan, to its end, igneous ejections were on a vast scale. Even after the cooling had so far advanced that the sedimentary series in progress of deposition attained a thickness of many thousands of feet before a crisis of upturning and metamorphism occurred, the heat from below, which was added to the heat of a dynamical source to produce the metamorphism, was so far the greater of the two that fusion of the lower beds would have generally taken place; and, as a consequence, great effusions of the melted rock through the overlying and much broken metamorphic beds, should have occurred in true bathylithic style, as the facts attest. But there is no evidence that they ever made Archæan volcanic cones. Archæan conditions gradually declined as Paleozoic time was passing, and so also did the power of making bathyliths. Later came the power, not merely of eruption through fissures, which has always existed, but also that of producing lofty volcanic cones.

The volcanoes also of the Andes are supposed to be chiefly of Tertiary origin. In Europe "the grandest volcanic phenomena were those of Oligocene (Lower Miocene) times, to this date belonging the basalts of Antrim, Mull, Skye, the Faroe Islands, and the older series of voleanic rocks in Ireland"(Geikie). The volcanic eruptions of Auvergne, the Eifel, and of Italy, Bohemia, and Hungary are referred mostly to the Tertiary. Asia, if the ranges of islands off its eastern and southern coasts are excluded, is peculiarly free from volcanoes. But the outflow of the Decean trap in peninsular India, 200,000 square miles in area, was an event of the early Tertiary, and has been supposed to have occurred when the rising of the Himalayas began.

The concurrence during the era from the Later Cretaceous to the close of the Tertiary of the most extensive orogenic work in the world's history, of the chief part of its continental elevation, and unprecedented igneous eruptions, came when the earth's crust had reached a cooled condition that took all past time up to the present era for its production. The inquiry thence 
arises whether these events are not in somp way a consequence of the condition of the crust then for the first time reached. The conclusion has been before stated; it is here announced in its place in geological history.

\section{CLIMATE.}

The climate of the United States, even the northern, during the early Tertiary, was at least warm-temperate, as indicated by the fossil plants.

There is evidence, as Asa Gray has remarked $(1859,1872)$, from the distribution of Tertiary plants in the Aretic, made known by Heer and others, and their relation to similar kinds in the eastern United States and in Asia, that the northern parts of the continents of America, Asia, and Europe were, during that age, under a nearly common forest vegetation, with a comparatively moderate climate. The genus Sequoia, of California, has its species (as Heer has shown) in the Eocene of Greenland, Arctic America, Iceland, Spitzbergen, northern Europe; and one Greenland species is very near the great Californian S. gigantea; and these were successors to Arctic Cretaceous species. There were two species of Libocedrus in the Spitzbergen Miocene (Heer); and one ( $L$. decurrens Heer) now lives with the Redwoods of California, while the other occurs in the Andes of Chile. Gray adds that the common Taxodium, or Cypress, of the Southern States, occurs fossil in the Miocene of Spitzbergen, Greenland, and Alaska as well as Europe, and also, according to Lesquereux, in the Rocky Mountain Miocene. The Arctic Miocene-is now made by Dawson and others probably Eocene in age.

Europe evidently passed through a series of changes in its climate, from tropical to temperate. According to Von Ettingshausen, the Eocene flora of the Tyrol indicates a mean temperature between $74^{\circ}$ and $81^{\circ} \mathrm{F}$; and the species are largely Australian in character. The numerous Palms in England, at the same period, indicate a climate but little cooler.

The Miocene flora of the vicinity of Vienna the same author pronounces to be subtropical, or to correspond to a temperature between $68^{\circ}$ and $79^{\circ} \mathrm{F}$.; it most resembles that of subtropical America. Farther north in Europe, the flora indicates the warm-temperate climate characterizing the North American Tertiary; and it is also prominently North American in its types. In the Pliocene, the climate was cooler still, and approximated to that of the existing world.

The North American feature of the Miocene forests of Europe was probably owing to migration from America through the Arecic regions, and not from Europe; for a number of the European species, as shown by Lesquereux existed already in the American Laramie and Eocene. The Australian feature also may have been a result of migration, but from the opposite direction. The Indian Ocean currents favor migration northward, along the borders of Asia, and not that in the opposite direction.

What was the temperature of North America and the other continents at the close of the Tertiary, as a consequence of the addition of thousands of feet, and in some regions, of tens of thousands, to the height of the land, is to be learned from the events of the following era, the Quaternary. 


\section{QUATERNARY ERA, OR ERA OF MAN.}

Hitherto, along the ages, to the close of the Tertiary period, the continent of North America had been extending its foundations and dry land southward to the Gulf, southeastward to the Atlantic, and southwestward to the Pacific, chiefly through marine depositions. 'The scene of prominent action now changes. The Quaternary phenomena are mainly those that pertain to the continental surface; and this general fact is true for all the continents, north and south. Through the making of the great mountainranges in the era just passed, and the raising of them to icy altitudes, and by the growth of the continents to their full limits, the water-power of the world had been vastly increased, and this was the chief working agency.

Rivers had become of continental extent, and glaciers had gathered about the loftier mountains. These agencies, so eminently characteristic of the new era, were the means of finishing off the earth's physical arrangements.

The Quaternary era opens with a glacial period. "The existence at this time of an epoch of unusual cold was a natural sequence to the vast amount of elevation and mountain-making that had been going on in the Tertiary over all the continents; for this upward movement would necessarily have resulted in increasingly cold climates over the earth." (D., 1881.)

The following are the periods of the Quaternary:-

3. Recent Period. - A moderate elevation of the land where depressed in the preceding period. Mammals of existing species.

2. Champlais Period. - Depression of lands that were glaciated in the Glacial period; amelioration of climates; final disappearance of the ice; great river floods and lakes, and fluvial and lacustrine deposits. Mammals of the warm temperate zone over parts of the previously glaciated regions, their species largely extinct.

1. Glacial Period. - Increased elevation of the land over wide regions in higher latitudes; climate in these latitudes of low temperature and abundant precipitation, and consequently, the production of glaciers, and a wide-spread glaciation of the frigid lands, with the exclusion of all life except that of icy regions.

The Glacial and Champlain periods were united by Lyell, in his later works, under the general name of the Pleistocene; and thus the Quaternary era - or the Post-Tertiary, as he named it - was divided into the PleistoCENE and Recent periods. The term Pleistocene is used beyond in this sense.

Lyell used the term Post-Tertiary for the formations subsequent to the Tertiary, and through many editions of his works divided it into Post-Pliocene and Recent. In the first edition of his Princixles of Geology, published in 1830-3.3, the Tertiary was followed simply by the division Recent; and the subjects of the Drift and Cave animals were 
included under his second division of the Pliocene, called Newer Pliocene. In 1839, he proposed to substitute Pleistocene for Newer Pliocene, as a fourth division of the Tertiary, characterized by having about 95 per cent of the shells those of living species - a larger proportion, as the name implies, than in the earlier part of the Pliocene. But the new name, as he states, was used by $\mathbf{E}$. Forbes in 1846 and others for the Post-Pliocene instead of the Newer Pliocene, and he withdrew it. The perverted use of the term was partly owing to his retaining Glacial and related topics under the Newer Pliocene - an arrangement which was continued into the 5th edition of his Manual of Elementary Geology, published in 1855. This was later changed. But in the 4th edition of the Antiquity of Man (1873) Pleistocene was finally adopted as a substitute for Post-Pliocene.

The term Quaternary was used by Réboul, of France, in his work La Géologie de la Période Quaternaire, 8vo., 1833.

The division of the Post-Tertiary or Quaternary into the three periods mentioned above was presented by the Author in his address on "American Geological History" before the American Association, in August, 1855. (Amer. Jour. Sc., xxil., 305, 1856.) The names for these subdivisions then proposed were the Glucial, an epoch of elevation; the Laurentian, an epoch of depression; and the Terrace, an epoch of moderate elevation. In the first edition of this Geology (1863), the terms adopted were Glacial, Champlain, and Terrace.

The two earlier periods, the Glacial and Champlain, have their more prominent characteristics displayed almost solely over high-latitude regions. They are not represented in tropical latitudes, or in warm temperate latitudes south of the parallel of $35^{\circ}$, except locally about regions of lofty mountains. Moreover, deposits, like those of the Champlain period, were forming through the Glacial period along the southern border of the icesheet, owing to the melting that was going on, and the streams that were thereby made, especially in the summers, and still more largely during temporary relaxations of the extreme cold. Further, the Mammals of temperate climates that spread northward over the previously glaciated area when the Champlain period opened, probably were all in existence during the middle and later parts of the Glacial period, after the epoch of extremest cold and maximum extension of the ice had passed, if not earlier. Glacial and Champlain phenomena were thus cotemporaneous. Nevertheless the periods stand well apart in the great epeirogenic movement, or change of level, that separates them, and in the continuation of Champlain conditions long after the ice had disappeared.

Review of modern Glacial phenomena. - The general phenomena and laws of Glacial Geology have been stated on pages 232-250, and illustrated in part by facts from an existing continental glacier - that of Greenland. As there explained, the glacier moves over hills and ridges, up slopes as well as down, the pitch of its upper surface determining its direction and rate of movement. It is greatly aided in excavating work by subglacial streams, that are far more effectual workers than ice; which streams in Greenland, according to H. Rink, probably branch widely over the country, like a regular river-system, and have at times great volume. It gathers stones, gravel, and sand, for transportation, as well as large rock-masses. It abrades, through the stones at bottom, rocky surfaces passed over, and corrades the transported material, making rock-flour, sand, gravel, and smoothed or scratched stones out of the debris taken aboard; and it may convert the finer material into clay. It deposits rock-flour and other debris from subglacial streams 
before and after escape from the ice-sheet, and makes clay-beds, sand-beds, moraines, drumlins, eskers.

It makes glacier dams, producing thereby large lake-basins, by piling up the ice in narrow gorges, or by pressure against the sides of valleys, and thus crossing and so closing open valleys; and small lakes, liable to frequent discharges (page 238), by pressure of the ice against the side of the valley; and, in times of melting and dissolution, it may build ice-dams in narrows along river channels out of blocks of floating ice and accompanying glacier debris or drift, converting rivers into lakes. Further, the glacier, wherever it flows, usually leaves its tracks in scratched, grooved, or planed surfaces, upon the rocks passed over; in scratched stones distributed through the drift material; in large scattered bowlders that are traceable to a source in a direction opposite to that of the movement; and also in its moraines and other drift accumulations. In the use of glacial scratches to determine the direction of movement of the ice-mass, it is always to be noted that the direction is quite sure to be diverted from that of the general icemass by valleys, or valley-like depressions in the surface beneath the glacier when they are oblique to that course, even if the depression be snall; and that a knoll or low ledge of rock may have some divergent effect. Only scratches on high land, without such sources of error, are to be trusted. Moreover, with regard to traveled material or drift, the question is always to be asked whether water or floating ice may not have been the transporting agent.

A glacier period in geological history was first recognized in 1837 by Louis Agassiz, before the Helvetic Society of Natural History, and in 1840 announced at the meeting of the British Association. Agassiz visited Scotland to verify his theory. He says in a letter to Professor Jamieson (1840): "I had scarcely arrived in Glasgow when I found remote traces of glaciers; and the nearer I approached the high mountain chains, the more distinct these became, until, at the foot of Ben Nevis and in the principal valleys, I discovered the most distinct moraines and polished rocky surfaces, just as in the valleys of the Swiss Alps." On Nov. 4, 1840, he brought the subject before the Geological Society of London. His theory of the drift was for awhile opposed by advocates of the Iceberg theory, but it now has general acceptance.

The earlier systematic observations on the drift in North America were made between 1832 and 1842 by E. Hitcheock, W. W. Mather, C. Whittlesey, James Hall, and others. Mather devotes many pages to the subject in his New York quarto report (1842), and states that he had gathered facts personally from New England to the meridian of $97^{\circ} \mathrm{W}$., "traveling over 100,000 miles." His descriptions of Long Island drift, and that of the Coteau des Prairies and of many regions between, though he was not then a glacialist, are excellent; and they are supplemented with results from other sources, and a long table giving the courses of glacial scratches over different parts of the country.

Among the later investigators, over the Eastern and Central States, there are C. $\mathrm{H}$. Hitchcock, whose work has been mainly in New England, and has been published in the Geological Reports of Vermont and New Hampshire, and elsewhere; T. C. Chamberlin, whose papers have appeared in the Reports of the Wisconsin Geological Survey, those of the U. S. Geological Survey, and in other places; Warren Upham, who, after work "in New England, has served as one of the geologists in the survey of Minnesota, and temporarily also in the Canadian Survey, and in each has extended his studies to the Winnipeg region in British America; F. Leverett, R. D. Salisbury, J. S. Newberry, G. K. Gilbert, W. J. McGee, J. C. Branner, Carvill Lewis, G. F. Wright, and others. The author's publications on American Glacial history range from 1856 to 1893, and those giving the results of special investigations, from 1870 , onward.

For the Rocky Mountains and the Pacific Slope within the United States, the most important publications are those of J. D. Whitney, Clarence King, I. C. Russell, J. S. Newberry, and J.LeConte; and for British America, those of Dawson, G. M. Dawson, R. Bell, R. G. McConnell, J. B. Tyrrell, and R. Chalmers. 


\section{Glacial Period.}

\section{AMERICAN.}

Three subdivisions or epochs, of the Glacial period, are recognized: (1) the Early Glacial Epoch, or that of the Advance of the Ice and its maximum extension; (2) the Middle Glacial Epoch, or that of the First Retreat of the ice; (3) the Later Glacial Epoch, or that of the Final Retreat.

\section{Epoch of the Advance.}

\section{General Condition of the Continent during the Advance.}

Topographical and fluvial conditions. - The continent, when the Ice age began, had its high mountains and full-grown rivers. The elevating of the continental surface that was begun in the Tertiary had covered the land with running waters, and the new and vigorous streams made erosion their first work. The older streams, also, that had reached a level of no work, received new energy and were set to work deepening their channels, leaving the old flood grounds as terraces to mark progress. The time was especially favorable for pre-glacial erosion. In addition to this growth of rivers, forests took rapid possession of the continent, and faunas and floras greatly widened their range.

As the cold and precipitation increased, the time finally came when the heat of summer was not sufficient to melt all the snows of the colder season, and then began glacial accumulation. For a while glaciers were confined to the higher mountains; but gradually all glacier areas became united in one great continental ice-sheet, Greenland-like, with local glaciers only along some of the deeper terminal valleys.

While thus spreading over the land, there were oscillations in the progress of the ice-sheet, as in modern glacier regions, determined by meteorological cycles, - the 11-year cycle dependent on the cycle of the sun's spots, and a longer eycle of 35 to 50 years, as now in the Alps. And besides, there were other sources of meteorological change, causing longer halts and recessions in the ice-sheet, for which no explanation can yet be given.

A large ice-sheet gives a temperature of $32^{\circ} \mathrm{F}$. to the air above it, and this favors its perpetuity. But the southern margin, at the time of maximum advance, was in middle temperate latitudes with the tropics not far away; and warm or hot winds, therefore, were at hand to produce large fluctuations in the extension of the ice with the changing seasons.

Causes determining places of the first ice and of greatest accumulation. Since the ice would have accumulated most rapidly where abundant precipitation and low temperature were combined, the region of earliest commencement and maximum accumulation would have been over the eastern portion of the continent toward the Atlantic. Along the coast region of 
New England and Canada the annual rainfall is now 45 to 50 inches a year, and it was then probably still greater, perhaps 55 to 60 inches. Farther north, at the present time. the precipitation decreases while the cold increases. In northern Labrador the former is reduced to 20 inches. In Greenland, where ice is perpetual except within 30 to 60 miles of the coast, the mean annual precipitation is but 10 inches.

The mean annual precipitation west of New England orer three fourths of the state of New York is now 38 to 42 inches. But in the Mississippi valley, over Wisconsin, it varies from 32 to 38 inches; and over the larger part of Minnesota, from 20 to 32 inches, while farther north in Manitoba it is mostly between 20 and 10 inches. Moreover, in the Continental Interior the summer isotherms make a long sweep north, that of the July mean of $70^{\circ} \mathrm{F}$. extending beyond Lake Winnipeg, eren to $56^{\circ} \mathrm{N}$., which is $10^{\circ}$ of latitude, or 700 miles, farther north than the position of the same isotherm over New England. Consequently, New England would have made a large accumulation long before the Mississippi valley in the same latitudes had any permanent ice. And after the ice had become permanent, it might have disappeared orer the Interior while on the eastern border it was still accumulating. With the conditions in the Continental Interior so near the critical point, the ice-mass there would have responded readily to changes of temperature; a meteorological change might have carried off the ice for a breadth of scores or hundreds of miles, which would have made no impression in corresponding latitudes to the eastward.

At the same time, in latitudes beyond $60^{\circ} \mathrm{N}$., the precipitation might be too small for great accumulation and glacial morement. However great the cold became, the icy heights to windward were everywhere robbing the air of its moisture, and so leaving little for the règions to leeward.

Southem limit of the ice. - Under such various conditions the ice became distributed over the breadth of the continent from the Atlantic Ocean to the Pacific.

The map of North America, Fig. 1548, shows the southern limit of the ice-sheet, as ascertained from the traces it left over the surface. The limit is indicated by the heavy line crossing the map from southeastern Massachusetts over southern Illinois and northern Montana to the Pacific coast. Its most eastern observed point is Nantucket; thence, it extends along the islands south of New England, to Perth Amboy in New Jersey. Farther east and northeast its course was probably over George's Shoal, 150 miles east of Cape Cod, where the minimum depth is now but a few feet, and over the shoal region off Nova Scotia (by Sable Island) and Newfoundland. From Perth Amboy it crossed New Jersey and Pennsylvania obliquely, entered for a short distance western New York; then bent southwestward to southern Illinois. Beyond the Mississippi and the meridian of $97^{\circ} \mathrm{W}$. it made a bend northward to $47^{\circ} \mathrm{N}$., on account of the dry and warm summer climate of the Continental Interior, and near this parallel it reached the Pacific coast. But in the Rocky Mountain or Cordilleran region, it covered 



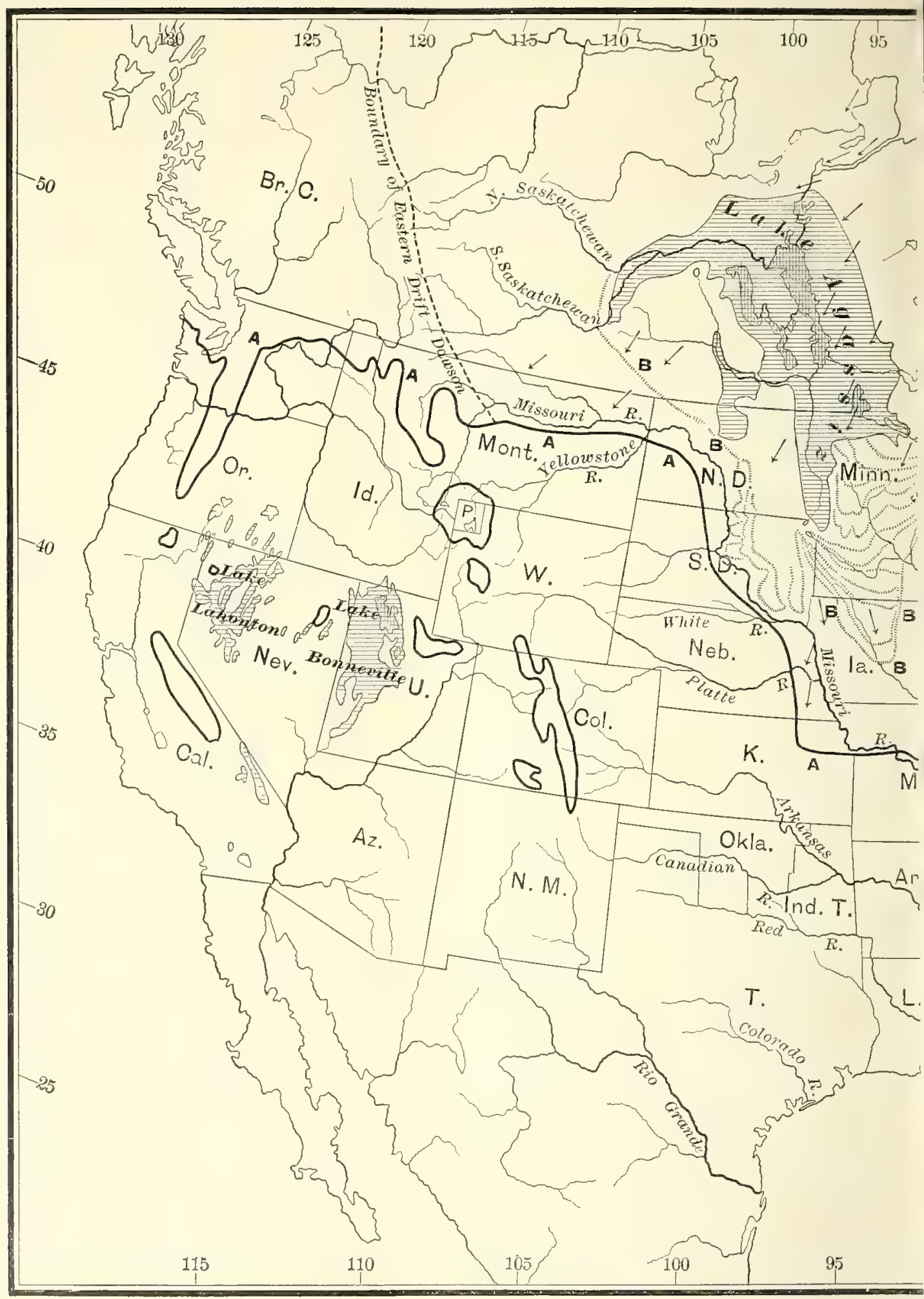



1its

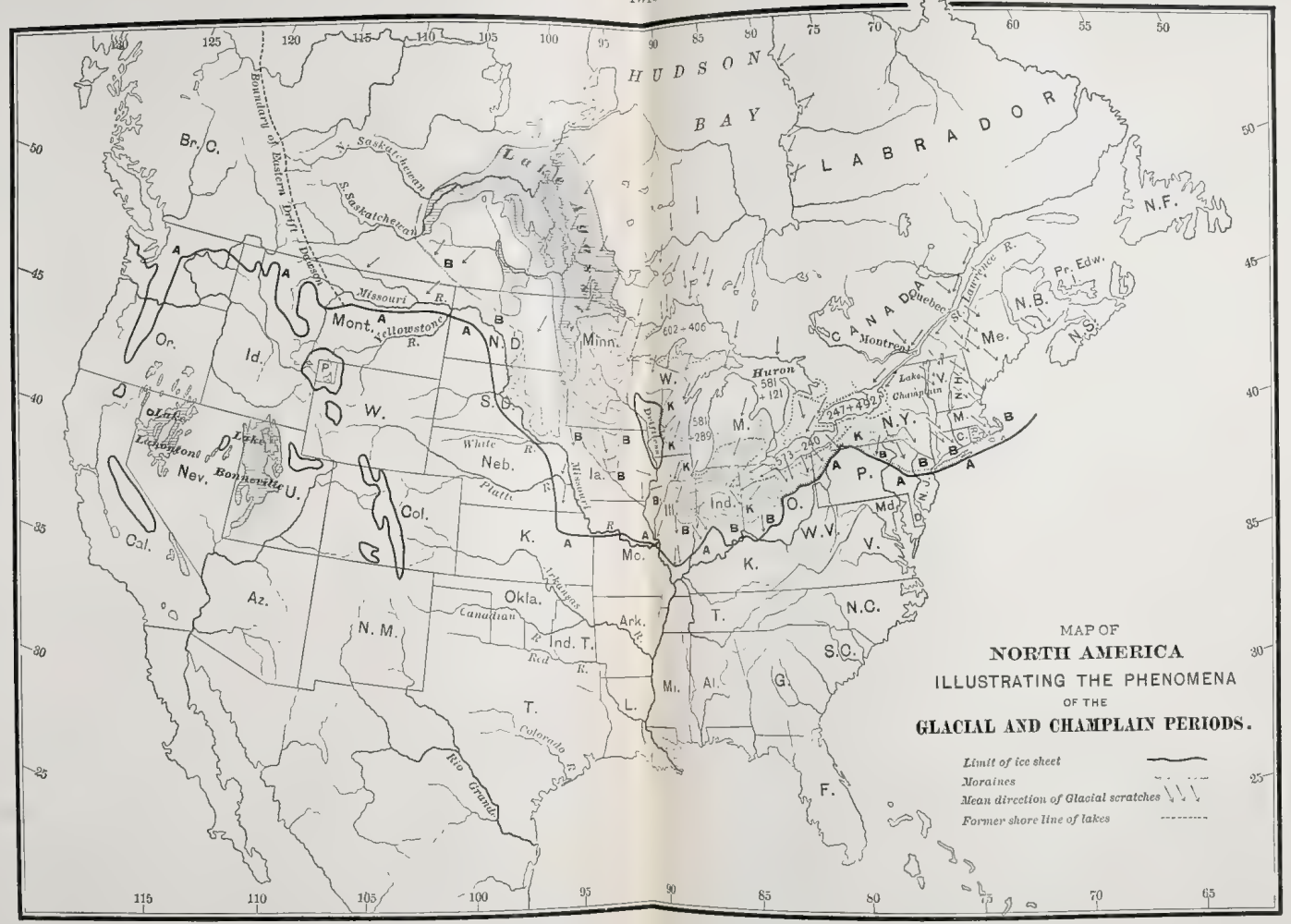



the higher summits at intervals, even as far south as New Mexico. Again, there were isolated glacier regions along the Cascade Range and the Sierra Nevada, about Rainier, St. Helens, Hood, Shasta, Lyell, and other summits; and in the Great Basin, on Jeff Davis Peak, the East Humboldt Range, Shoshone Range, and West Humboldt Range. Shrunken relics of the old glaciers still linger about the Wind River Mountains in Wyoming; on Mount Lyell and Mount Dana in the Sierra Nevada; and on Shasta, Rainier, and other summits of the Pacific coast region.

East of the summit range of the Rocky Mountains in British America, the limit between the eastern drift, or that from the region east of Lake Winnipeg, and the western, or that of the mountains beyond, has the position shown by the dotted line on the map, Fig. 1548, the height being 3000 to 3700 feet above sea level.

There was also a northern limit to glaciation in northwestern America, according to G. M. Dawson. The line crossed the plateau region of British Columbia, between $60^{\circ}$ and $64^{\circ} \mathrm{N}$., and consequently Alaska was uncovered - a fact confirmed by the more recent observations of Dall and Russell. Greenland had probably no more ice than now.

The details on the map (Fig. 1548) with reference to the moraines from the Mississippi to New Jersey have been obtained chiefly from published and unpublished notes of Chamberlin and Leverett; those over Iowa and Minnesota, from W. Upham; those about the Coteau des Prairies, from I. E. Todd; and those farther north, from G. M. Dawson; for the position of the southern ice-limit, or Moraine line A, from H. C. Lewis, Report Z; The Terminal Moraine in Pennsylvania, 1884, from G. F. Wright; for the line westward to the Mississippi, Lewis's Report Z, and also Wright's Ice Age, etc. ; for the positions of the glacial lakes of Manitoba, from W. Upham; those of the lakes of the Great Basin, from G. K. Gilbert and I. C. Russell; for the glacial striæ over New England, from C. H. Hitchcock mainly; and those of other regions from Chamberlin's map, 7th Ann. Rep. U.S.G.S., and other sources.

Condition outside of the Ice-limit. Forced migration. - South of the Icelimit, the preripitation was probably as heavy as to the north of it. But it made only deep snows about the Appalachians and other low mountains, and contributed water abundantly to rivers and lakes. Over a narrow belt near the front, there would have been marshes and ponds with Arctic vegetation, and cold-climate Mammals, which had been driven southward.

Several of the emigrant plants still remain and thrive on the summits of the mountains of both eastern and western North America. Thirty-seven species, according to Asa Gray, occur on the White Mountains of New Hampshire, and part of them also on the Adirondacks and Green Mountains. Out of 27 species observed by the Jensen expedition on a Greenland Nunatak in 1878, the White Mountain flora includes, according to Gray, the Grasses Luzula hyperborea and Trisetum subspicatum, the Sorrel, Oxyria digyna, the Moss-like Heath, Cassiope hypnoides, and the Moss-like Catchfly, Silene acautis. Sedum rhodiala, a subalpine species, occurs on cliffs of the Delaware, below Easton, Pa.; Saxifraga oppositifolia Linn., on Mount Willoughby, 
in Vermont; Arenaria Grönlandica, on the White Mountains, the Catskills, Shawangunk Mountain, and, in the form of A. glabra Michx., on the Alleghanies of Carolina; Scirpus ccespitosus in North Carolina, a patch remaining on Roan Mountain, and Nephroma arcticum, and other northern Lichens, with Lycopodium selago on the highest Alleghanies.

Even freshwater shells of the Unio family were among the immigrants, as C. T. Stimson has found by a study of fossil shells from near Toronto. Scudder has shown that in North America the fossil Coleopterous Insects of deposits laid down in the Glacial period are very nearly all of extinct species, while those from peat beds of later origin are, with a rare exception, existing species.

The bones of the Reindeer have occasionally been found in the valley drift. Two bones, referred by Marsh to the Arctic Reindeer, Rangifer tarandus, were found in the lower clay-beds of the Quinnipiac River, three miles north of New Haven, and others have been reported from near Vincentown, N.J. Other remains, but possibly of the $R$. caribou, have been found near Sing Sing, N.Y., in Kentucky at Big-bone Lick, and on Racket River in northern New York.

The region farther south abounded, no doubt, in the beasts, birds, and other species of a temperate climate. With so long a glacial front in latitudes of $40^{\circ}$ to $35^{\circ}$, at the time of greatest extension, the extreme cold would have swept at times over the south, and have probably excluded from the region north of Florida tropical and subtropical species, excepting migrating kinds.

\section{Elevation of the Continent.}

The evidence that the continent, especially orer its northern portions and along the mountain borders, continued its rise above the sea level after the Tertiary period is based largely on the facts relating to river channels, fiords, and Arctic migrations between Europe or Asia and America.

Evidence from river channels and fiords. - Near and beneath the southern margin of the ice, over the interior of the continent, many river channels, as proved by borings, have a depth of 100 to 400 feet below their present bed. These deep gorges are filled with drift, thus making it certain that the excavation was completed in the Glacial period. Newberry states that all the river valleys of Ohio are examples. The Cuyahoga, which is one of them, has, where it enters Lake Erie, its bottom 200 feet below the present bed, and this continues for 20 miles up the stream. The valleys of northern Yennsylvania are other examples, and according to Carll and White the depth of the drift-filling is, in some cases, 300 to 400 feet. At the west end of Lake Ontario, the Dundas gorge has been proved by borings to descend 227 feet below the sea level, or nearly half as far as the deepest part of Lake Ontario, the material penetrated by the boring being drift (J. W. Spencer). It is inferred that the lake was above the sea level in the period. and that a river flowed along its bottom, either eastward or westward, 
and produced the excavation. The depth of Lake Ontario is 738 feet, 492 of which are below tide level; and hence the minimum elevation that would give the same slope to the water as now was 738 feet. As shown on the map on page 201, this Ontario River (or the line of greatest depth) was near the south shore; and the depression had a high declivity on that side which was very steep for the first 500 feet. Similar conclusions may be drawn from all the Great Lakes; for they are generally believed to have been excavated by running waters during the Glacial period. The map on the page referred to has marked upon it the outlines of the drainage areas of the several lakes, the deep-water line, and the position of the point of maximum depth; and Schermerhorn remarks that the deep-water line of each is near the center of the area of drainage. The Lake Superior basin descends 407 feet below sea level; the Michigan, 289 feet; the Huron, 121 feet. For fluvial excavation, the elevation must have been not only that which would raise the basins above sea level, but to a height above the surrounding land that would enable even the bottom waters to flow out of the drainage basins; and to pass, not the existing drainage barriers, but the barriers of the Glacial period, when the land in the vicinity was far above its present level.

A change of level is also proved by the reversed flow of some streams. Carll and others have shown that the Pennsylvania rivers, the Alleghany and Beaver, then flowed northward into Lake Erie, proving that the land dipped toward the Erie basin. In the Beaver River channel in western Pennsylvania, now a tributary of the Ohio, the filling of drift, according to Foshay and Hice (1890), is only 60 feet deep at its mouth; but 20 miles above, it is 200 feet, according thus with the view that its drainage, as shown by Carll for the Alleghany, had been reversed. The Tionesta and Conewango basins, according to Carll, participated in reversed Erie-ward piteh. Facts on this subject of reversed drainage are presented by Chamberlin in a paper of 1894, along with illustrating maps. Moreover, Gilbert pointed out in 1871, that the Maumee River, now emptying into the west end of Lake Erie, then flowed westward, and joined the Wabash, and thus made the lake a tributary to the Ohio. He found the evidence both in westward glacial scratches and moraines, and in lake terraces. It is possible that a Huron River made another Ohio tributary.

Again, Lake Winnipeg, as pointed out by G. K. Warren (Rep. U. S. Engineer Dept., 1867, 1874, and Am. Jour. Sc., xvi., 417, 1878), which now discharges into Hudson Bay by the short Nelson River, formerly discharged into the Mississippi, and, with the Saskatchewan River, was its northern head waters. At the present time, the level of the lake is about 260 feet; too low for a southward flow. The divide is in Minnesota between Big Stone Lake, the head waters of Minnesota River, and Lake Traverse, the head waters of Red River of the North, a Winnipeg tributary. These two little lakes are but a few miles apart and differ but eight feet in level. The valley of Red River and that of the Minnesota were found by Warren to be continuous, and to be a great valley across the divides, 125 to 150 feet deep, and 
a mile and a half wide, enlarging southward to its junction with the Mississippi valley; and, in contrast, the valley of the Mississippi north of this junction is small. He thus obtained positive evidence that the valley and river from Winnipeg southward was not long since one, and that the continental level was then such as wonld give the southward flow to the waters. To reproduce now this slope would require a rise of the Winnipeg region (or a sinking of the divide) amounting to about 260 feet; and to give the waters also a pitch of half a foot a mile, an additional 165 feet. The former existence of this greater Mississippi is also shown by the fact that freshwater shells of the Winnipeg region also live in the Mississippi.

Warren also suggested that Lake Michigan at the same time, owing to the same northern uplift, discharged by the Illinois River into the Mississippi - its broad and deep valley widening in the vicinity of the lake in accordance with this direction of flow.

The changes about all the Great Lakes were such as tended to give them probably independent outlets. The channels that now unite them are all shallow, generally not exceeding 50 feet.

Further proof of high-latitude elevation in the Glacial period is afforded by the river-valleys of the coast region now filled with water, that is the fiords, and the multitudes of islands, and many channels among islands, along fiord coasts. The fiords of Maine, Labrador, Newfoundland, Greenland, British Columbia and Alaska, and those of Scandinavia, western South America south of $41^{\circ}$, of Tasmania and South Australia, are such valleys, and they all are confined to Glacial latitudes. None occur on southern Africa, which reaches only to $34^{\circ} 22^{\prime} \mathrm{S}$. They were made when the land stood high enough for the denudation of the rocky coast region; and in view of the great lift the continent and other continents were having in the Later Tertiary time and during the opening Quaternary, it is a reasonable supposition, as the author pointed out in 1856, that the work of excavation should have gone forward during the Glacial period. It cannot be affirmed that the work of denudation was not begun during emergencies long before; but if so, this period of so widely extended elevation, probably the greatest in the world's history, must have finished the work.

Some of the fiords of the Atlantic coast between southern Maine and Hudson Bay have been found by soundings, as stated by Spencer, to have depths of 2000 to 3670 feet below the sea level; and the St. Lawrence channel below the Saguenay has afforded soundings of 1104 and 1878 feet. The Saguenay gorge descends 300 to 840 feet below the sea level and rises 1500 feet above it. They compare well with the fiords of the Scandinavian coast, several of which are above 2000 feet in depth, and one, the Sogne Fiord, 4020 feet.

The fiords of a coast differ widely in breadth and depth; and the deepest and largest were probably those channels that had been excavated to the sea level, during the time of emergence, while others are the shallower gorges of the denuded region. They have generally at present a bottom of drift 
or other detritus, so that the actual depth of excavation may much exceed that obtained by soundings.

From such facts it is reasonable to estimate the elevation of portions of British North America along the Canadian watershed, or the great Iceplateau, to have been at least 3000 feet above the present level. This subject has been recently well discussed by Upham, with this estimate as his conclusion. 'The author, in 1871, suggested 5000 feet, and this may not be too high for some portions of the Canadian region of highest ice. With 3000 feet for the Canada watershed south of Hudson Bay, this bay must have been largely dry land. Along the coast of Maine the elevation indicated is less than a thousand feet.

South of Maine, on the New England coast, other fiord-like indentations of the coast exist in Narragansett Bay, R.I., and the gorge of the Thames, from New London to Norwich, Conn. Besides these, there are pot-holes in the gneiss of islands off the Connecticut coast; and those of the Thimble Islands, in the bay of Stony Creek, show that this bay was formerly crossed and probably excavated by a freshwater stream. The great depth of the bays on the north side of Long Island, 50 to 65 feet notwithstanding the later drift deposits over the region, is further proof of elevation. The amount for southern New England and Long Island could not have been less than 150 feet (D., 1870). With this elevation, Long Island Somnd in the Ice period would have been, instead of an arm of the sea, the channel of a river tributary to the larger Connecticut River; and Long: Island with New York on the west side and the south coast of New England on the east. would have been continuous dry land. (See map, page 18.) The soundings of the Sound and of the waters south of Long Island are shown on this map, and also more fully in $A \mathrm{~m}$. Jour. Se., xl., 1890, with explanations in the same volume.

If the fiords of the coast are proof of elevation, the absence of them farther south should be probable evidence of little elevation or none. The submarine Hudson River channel (map, page 18) indicates a former emerged condition of the sea bottom, requiring an elevation of the region and the adjoining coast of $2800^{\prime}$, judging from the deepest part; and it has been inferred by Lindenkohl and Upham that this elevation took place in the Glacial period. But the facts from the New England coast indicate only small elevations. Moreover, the origin of the submerged Hudson River channel appears to have been of much earlier date, as has been explained on page 744 .

J. W. Spencer has inferred from the Coast Survey maps that there are submarine river channels off the mouths of several of the rivers of the coast south of Cape Hatteras, and in the Gulf of Mexico, the Mississippi included. But no satisfactory evidence of such channels exists on these charts, in the opinion of officers of the Coast Survey.

G. M. Dawson states, with reference to the fiord region of western America, that the land in the Pliocene stood relatively to the Pacific about 900 feet higher than now ; and he concludes that the fiords were shaped and enlarged locally during the following Glacial period, when the amount of elevation was still further increased. The submerged river channels of the Pacific coast of North America, on the coast of California, as described by G. Davidson (1887), descending to depths of 2400, 3120, and 2700 feet, indicate a higher level of the region of 2500 to 3000 feet, and probably during the Glacial period. 
Evidence from Mammalian migration between North America and Europe or Asia. - Another argument for the elevation of the land of the higher latitudes, and particularly the polar, has been drawn from the fact that the migration of Plants and Mammals took place between the two continents in

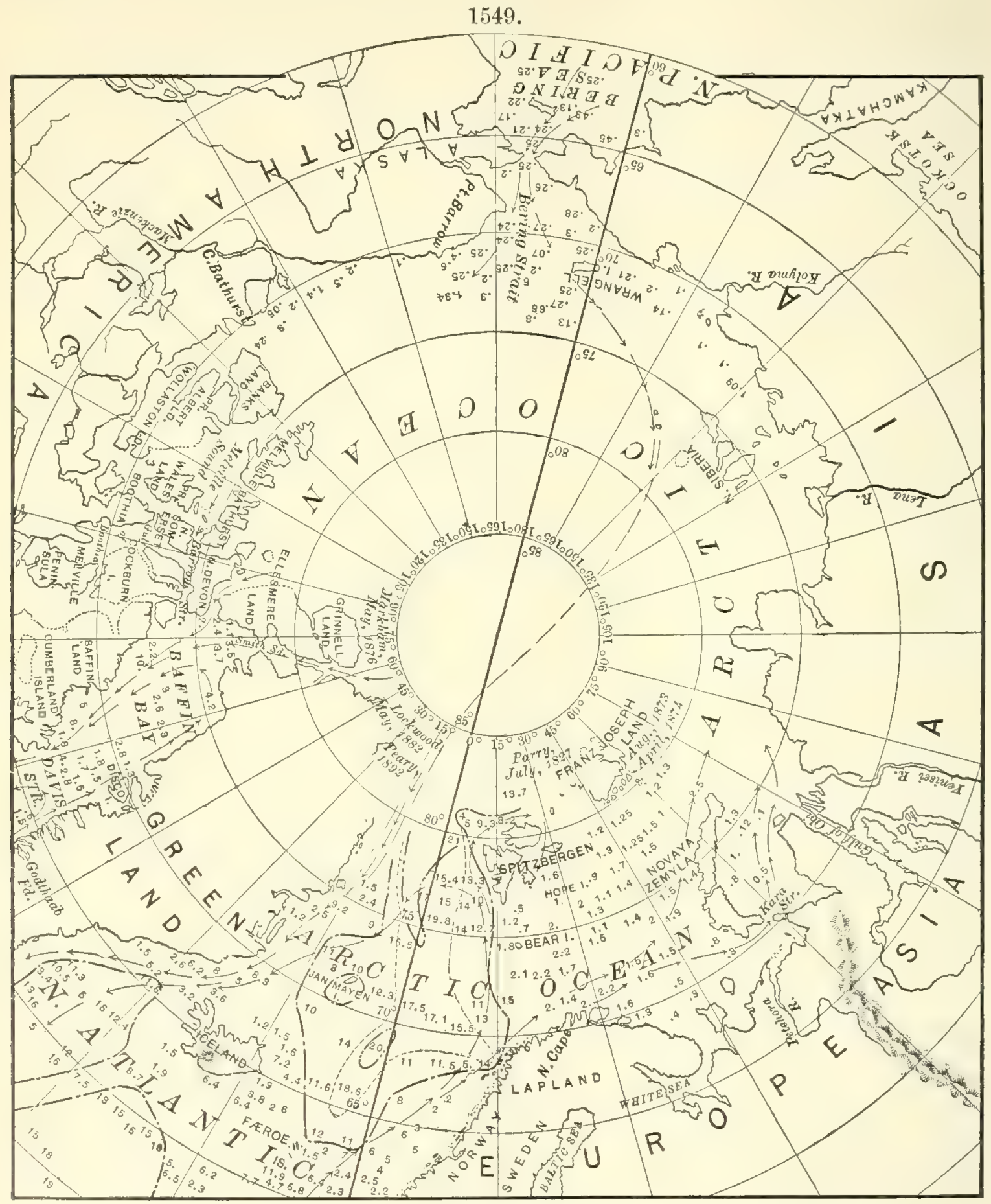

Bathymetric map of the Arctic seas, reduced from the chart of the U. S. Topographic Department.

the Quaternary. The migrating species include the Reindeer, Moose, Elk, Polar Bear, Grizzly Bear (the Brown Bear, Ursus Aretos of Europe, being regarded as identical with the Grizzly), Beaver, and probably other Mammals. There were also even migrating Unios, one species, Margaritana margaritifera, 
occurring in northern Europe and Asia, and also in North America from British Columbia to California, and on the east from eastern Canada to Pennsylvania. These facts prove land communication. Dry land at Bering Straits would have sufficed, and required an elevation of but 200 feet. But there was probably comnection also across from Europe to Arctic America. The connection was prolonged for the polar part into the Champlain period.

The accompanying bathymetric map will aid in appreciating the effects of a change of land in the Aretic regions. ${ }^{1}$ An elevation now of but 1000 feet would add certainly 700 to 1000 miles to the width in a northward direction of Europe ank Asia, putting Franz Joseph Land along the northern margin, and, perhaps, much of the unsounded region farther north. Only about 650 miles intervene between northern Spitsbergen and Greenland. The map shows further that an elevation of 3000 feet would make a dry land passage from Norway by Britain to Greenland, drying up the German Sea, and probably nearly the whole of the Arctic Ocean. The waters north of Melville and Bathurst lands may be as shallow as those north of Lapland.

Apparent upward change due to change in water level. - Part of the apparent upward change of level may have been only a downward change in the water level of the ocean. Agassiz, holding that ice covered nearly the whole continental area of the globe, argued that the abstracting of water from the ocean to make ice would have occasioned a large continental emergence. But the proportion that was actually covered was so small relatively to the whole surface of the globe that the consequent emergence could not have exceeded 60 feet. South America has but a narrow strip in glacial latitudes, and the ice areas of Australia and New Zealand were very small.

Another cause affecting the water level was the attraction of the mass of the high ice-plateau. It acted on the ocean's waters like that of any other elevated land-mass, by drawing the water up over the land, and thus occasional actual submergence. The effect was, therefore, opposite to that from the loss of water for making ice.

\section{Height, Thickness, and Flow of the Ice.}

Evidence from glacial scratches and transported bowlders. - On the map, Fig. 1548, the mean directions of glacial scratches are marked by arrows, and these directions are taken in all cases, as far as could be ascertained. from the results of observations over the higher land of a region, away from the influence of valleys or depressions.

Positive facts as to the height of the ice in particular localities are few. Scratches observed by E. Hitcheock on Mount Washington, in 1841, put the limit, in that part of New England, above 5500 feet; and the more recent discovery by C. H. Hitcheock (1875) of transported bowlders, some of them 90 pounds in weight, near the summit of the mountain (6293 feet above the sea level), proves that the mountain was completely covered, and that the

1 The depths, on the map, are given in 100 fathoms, 5 signifying 500 fathoms or 3000 feet, and $.5,50$ fathoms. The arrows show courses of marine currents. 
height of the ice was not less than 6500 feet. Mount Mansfield, the highest summit of the Green Mountains, Vt., 4389 feet high, was wholly under ice, as proved by transported bowlders. Mount Katahdin, in Maine, has bowlders to a height of 4700 feet. The Catskills have marks of glaciation to a height of 3200 feet (Smock, 1873), and Elk Mountain, in northeastern Pennsylvania, to a height of 2700 feet (Branner). It is probable that Mount Katahdin and some peaks in the Catskills were "Nunataks."

Evidence from the pitch required for movement. - From the probable pitch of the upper surface of the ice-sheet required for movement, estimates may be obtained of the height of the ice in other regions.

In Greenland, flow takes place when the slope of the surface of the ice is but $0^{\circ} 26^{\prime}$, or 40 feet to the mile $=1: 132$; and Helland obtained for the maximum rate of flow, where the slope of surface was less than half a degree, 20 meters per day. If the rate of slope between the summit over the White Mountains and the southeast side of Martha's Vineyard (which was the course of movement) was only 30 feet per mile, then the height of the ice-surface over these mountains was about $6500 \mathrm{feet}$; and it would have been a third larger, if 40 feet per mile. A like calculation for the Adirondacks gives a height of about 7000 feet. The height of the ice on the Catskill Mountains, mentioned above, 3200 feet, corresponds with the latter estimate; for the distance of these mountains from the southern limit of the ice, near Perth Amboy, N.J., is nearly one half as great as that of the Adirondack summits. Moreover, drifted stones of hypersthene rock from the Adirondacks occur upon them, as stated by Mather.

The ice of the Adirondack region flowed south-southeastward, over eastern Connecticut, into what might be called the realm of the White Mountains, and it did this notwithstanding the obstructing Green Mountain range on the route; and this is evidence that the Adirondack part of the iceplateau was the higher. By the same kind of evidence, the height of the watershed between the St. Lawrence and Hudson Bay, toward which the scratches over northern and northwestern New England point, is found to be 13,000 feet. But this part of the Laurentide ice-plateau may have been nearly level for a long distance south of its summit, so that the height may not have exceeded 10,000 feet. Again, Mount Katahdin is 60 miles from the summit of the mountain range that stands between Maine and the St. Lawrence River; and hence the height of the ice over this range was about 6500 feet, if 4700 feet at Katahdin.

Across Wisconsin the distance from the south shore of Lake Superior to the southern ice-limit is not less than 500 miles, and a slope of but 20 feet a mile would give a height at the lake of 10,000 feet. Part of the 10,000 feet was made by the greater height of the land in the Lake Superior region. The difference in elevation now is about 1000 feet. It was probably greater in the Glacial period, through the increased elevation of the Lake Superior region. As reported by C. A. White, a mass of native copper, of 30 pounds weight, was taken fron the drift of southern Iowa, Lucas County, 
and other smaller pieces from other parts of the state, and also from the southern part of Illinois. It came from the Keweenaw Copper region, in northern Michigan, south of Lake Superior, for this is the only possible. source. The distance is about 450 miles. A slope of 20 feet a mile, noting that the locality in Lucas County has a height of 1000 feet, would give, for the lheight of the ice-surface in the Keweenaw region, 10,000 feet. The present height of the land in this region is about 1500 feet; it was possibly then 3500 feet. It may be thought that detached ice, floating down the Mississippi, might have transported the copper. But the Lucas County locality is about 120 miles west of this river, and 500 feet higher than the land at Burlington, Iowa, a Mississippi town.

The distribution of copper in the drift has been attributed to the Indians. But in all probability they would have gathered it from the drift, and thus diminished the amount rather than increased it.

The distance of travel appears to have been still greater in British America. Along a line from the Laurentide ice-plateau in Canada, across the region of Lake Winnipeg, to the western limit of the drift, even a slope of 12 feet a mile would make the height of the Laurentide ice-surface over 8,000 feet. The drift at this limit contains Archæan bowlders of varying size up to a length of 40 feet, which proves its eastern origin. The rocks on the west side of Lake Winnipeg are Archæan.

With the slope at a minimum, the rate of transportation per century would be at a minimum, and the time for corrasion and decomposition, or the wearing out of stones, at a maximum; so that the material for the terminal moraine, under such circumstances, should be at a minimum.

The thickness of the ice in any place equaled the total height less the elevation of the land beneath; as the latter is an unknown quantity, the actual thickness is seldom obtainable. A thickness of ice of 4000 to 5000 feet probably existed along the Canada watershed, in northern New England and New York, and west of New York, in the region of the more northern of the Great Lakes; and a thickness of 1000 to 3000 feet was common over the region to the southward.

One large area of snows and thin ice - not thick enough to participate in the glacier movement - existed in the midst of the moving glaciers of Wisconsin, Iowa, and Minnesota. It is now driftless, and has an area of 12,000 square miles (map, Fig. 1548). J. G. Percival, in his survey of Wisconsin, first recognized its driftless character, and J. D. Whitney, in 1862, described and mapped it. It is now an area of minimum winter precipitation. The ice flowed either side of it, passing on the west side over the east border of Iowa.

Courses of glacial scratches in the White Mountain region, New Hampshire, according to C. H. Hitcheock: Near Lake of the Clouds, $5000^{\prime}$ to $5200^{\prime}$ above the sea, S. $34^{\circ}-54^{\circ} \mathrm{E}$.; on the $\mathrm{N}$. side, near top of Mount Clinton, $4430^{\prime}, 17 \mathrm{~m}$. W. of Mount Washington, S. $50^{\circ}$ $54^{\circ}$ E. ; and on S. peak of Mount Clinton, 4320' S. $54^{\circ}$ E. ; between Mount Pleasant and Mount Franklin, $4400^{\prime}$, S. $30^{\circ}$ E. ; between Mount Pleasant and Mount Clinton, 4050', 
S. $30^{\circ}$ E. ; S. end of Mount Webster, S. $37^{\circ}$ E. ; top of Mount Webster, $4000^{\prime}$, S. $30^{\circ}$ E.; top of Moosilauke, $4811^{\prime}$, S. $22^{\circ}$ E. Further, on Mount Abraham, in Maine, the direction found is $\mathrm{S} .59^{\circ} \mathrm{E}$.

From the White Mountains to the coast of Maine, along by Portland and the mouth of the Kennebec, the distance is but 70 miles; and hence, supposing the pitch of the surface the same as to Nantucket, the foot of the glacier in that direction, as remarked long since by Agassiz, was over the shoals off the coast of Maine, south of Nova Scotia, then probably an emerged area, and the depth of ice over this part of Maine was at the least $4000^{\prime}$.

The direction of the scratches (see map) over western New England is testimony as to the Adirondack source of the ice. The following are observed facts:-

Over high western Connecticut, $1000^{\prime}$ to $1200^{\prime}$ above the sea, in Warren and Litchfield, S. $29^{\circ}$ E. (D.); in Newtown, S. $32^{\circ}$ E. (D.); in Sharon, S. $333^{\circ}-36^{\circ}$ E. (D.); in Cornwall, S. $33^{\circ}-36^{\circ}$ E. (D.); near Norfolk, S. $20^{\circ}-25^{\circ}$ E. (Mather); on Mount Tom, near Litchfield, S. $17^{\circ}-22^{\circ}$ E. (Hitcheock) ; in Goshen, S. $23^{\circ}$ and S. $28^{\circ}$ E. (H. Norton); on Kent Mountain, S. $19^{\circ}$ E. ; and S. of Kent, S. $38^{\circ}$ E. (D.); bowlders, from Canaan, of limestone containing canaanite, found $5 \mathrm{~m}$. W. of New Haven, S. $16^{\circ}$ E. (D.).

In western Massachusetts, on Mount Washington, in its southwest corner, on the top of its summit peak Mount Everett, $2624^{\prime}$ high, S. $18^{\circ}$ E. (Hitchcock), S. $27^{\circ}$ E. (D.); on top of the ridge Tom Ball, nearly N. of Mount Washington, S. $43^{\circ}$ E. ; on the Taconic Range, W. of Richmond, S. 53०-S. $70^{\circ}$ E. ; on top of Lenox Mountain, between Stockbridge and Richmond, S. $41^{\circ}-45^{\circ}$ E. (Benton); E. slope of Taconic Range, near Pittsfield, S. $50^{\circ}$ E. (D.); on the mountain between Otis and Becket, about SE. (Hitchcock).

The bowlder train (page 959) over Richmond and Lenox has the course S. $45^{\circ}$ E. west of Richmond, and S. $35^{\circ}$ E. from Richmond through Lenox.

Over the higher part of Vermont (from E. and C. H. Hitcheock's Vermont Rep.), mostly S. $30^{\circ}$ E. S. $55^{\circ}$ E. the greatest to the northward; in the southern portion of Vermont, in Windham, S. $28^{\circ}$ E. ; in Wilmington, S. $29^{\circ}-39^{\circ}$ E. ; in central Vermont, West Hancock, S. $50^{\circ}$ E., Ripton, S. $60^{\circ}$ E. ; in northern Vermont, on Camel's Hump, 4077' above the sea, S. $55^{\circ}$ E., on Mount Mansfield, 4389', S. $55^{\circ}$ E. ; on Jay's Peak, north of the last, S. $50^{\circ} \mathrm{E}$.

In higher parts of eastern New York, in Dutchess County, mostly S. $15^{\circ}-30^{\circ} \mathrm{E}$. (Mather); near Arthursville, S. $24^{\circ}$ E. (D.); in Putnam County, near Patterson, S. $17^{\circ}$ $22^{\circ}$ E. (Mather) ; in Columbia County, north of Dutchess, S. $18^{\circ}-30^{\circ}$ E., and on mountain top east of Shaker village, S. $45^{\circ} \mathrm{E}$; ; beginning of Richmond bowlder train on the borders of Lebanon and Canaan, S. $55^{\circ}-45^{\circ} \mathrm{E}$. (Benton).

In northern Pennsylvania, J.C. Branner obtained for striæ on Pocono Mountain, west of Carbondale, a mean course of about S. $20^{\circ} \mathrm{W} .-\mathrm{S} .30^{\circ} \mathrm{W}$.; and on the summit of Bald Mountain west of Scranton, S. $10^{\circ}$ W.-S. $33^{\circ} \mathrm{W}$.

The facts prove that from all western New England the flow was from the northwestward, across the Taconic Range and the Green Mountains, and in a direction from the Adirondack region, or the more elevated Laurentide region beyond it.

The distance from the Adirondack part of the plateau to the southwest margin of the lobe in western New York is about 200 miles, or 150 if the Adirondack platean extends 50 miles west of Mount Marcy. It is about 250 miles to the ice-limit south of New York, and nearly the same to southern Long Island in the line over New Haven; and about 220 miles from the White Mountain center to the southeast side of Nantucket. It is to be noted, however, that the position of the margin in western New York was $1500^{\prime}$ above the sea level.

A bluff facing the water of Lake Cayuga, about a mile north of Ithaca, according to H.S.Williams, in a region where scratches, flutings, and planings of the rocks are exhibited on a grand scale, has its whole vertical face marked with scratches that have a descending 
course of about $25^{\circ}$ to $30^{\circ}$. The narrow lake trends about S. by W., not far from the direction of movement in the ice-sheet over the region.

Over Manitoba, the following courses of scratches are reported by S. B. Tyrrell : About Lake Manitoba, S. to S. $13^{\circ}$ E. ; about Lake Winnipegosis, S. $13^{\circ}$ E. to S. $58^{\circ}$ W. ; about Swan Lake, west of Winnipegosis, S. $48^{\circ}-53^{\circ}$ W. ; on Red Deer River, S. $68^{\circ}-$ $78^{\circ} \mathrm{W}$.; Grand Rapids on the Saskatchewan, S. $2^{\circ}-62^{\circ} \mathrm{W}$.; at Roche-rouge, S. $12^{\circ} \mathrm{W}$. ; Cedar Lake, S. $19^{\circ}-39^{\circ} \mathrm{W}$. The southward and southeasterly course is evidently due to a valley movement along the lakes. For others, over the interior of North America, see Upham's paper on Lake Agassiz, Can. Geol. Rep. for 1888-1889, and other Reports of the Canada Geological Survey.

In the use of scratches to determine direction of flow, the directions on page 942 should be observed. When scratches having different courses occur at the same locality, it is also to be remembered that direction of general movement in the ice-mass depends on the slope of the upper surface, as is true for any liquid; and therefore that the thinning of the ice from melting may change the direction of movement at bottom. But where thinning has diminished the slope of the ice-surface below the angle required for flow, the ice is that only of a dead glacier.

Bowlders were observed in Northampton and Monroe counties, Pa., by Lewis and Wright, which must have come from the Adirondacks. One of them of "labradorite syenyte," $2 \frac{1}{2}$ in diameter, was found in Upper Mount Bethel just south of Kittatinny Mountain; another, similar, measuring $4^{\prime} \times 3^{\prime} \times 3^{\prime}$, on the moraine near Taylorsburg, between Kittatinny Mountain and Pocono Mountain; and another, of gray Adirondack granite, containing magnetite, near Fork's Station, in Paradise, 5 miles north of Pocono summit, at a height of $1550^{\prime}$; and bowlders of gneiss are abundant over the Pocono plateau, 2000' above sea level. (Geol. Rep. Pa., vol. Z, On the Terminal Moraine in Pa. and N.Y., by H. C. Lewis, 1884, with an Appendix on the Terminal Moraine in Ohio and Kentucky, by G. F. Wright.)

General direction of flow. - From the Laurentide ice-plateau, or that which covered the Canada watershed and extended westward and northward, the flow was not only eastward and westward, but also northward, from its northern part toward the Arctic seas; and along the great eastward bend in the plateau over Canada south of Hudson Bay to Labrador, it was southwestward on the western part, and farther east, southward and southeastward. The observed courses of transported stones and lines of abrasion are the means of locating the summit region of the ice-plateau.

High mountains outside the plateau also influenced the flow, for they are regions of greatest precipitation. The White Mountains, Green Mountains, and Adirondacks, combined into a common platean by the ice, was one of these mountain regions, apparently determining southeastward directions of movement over New England and southwestward over Pennsylvania and much of New York. In western New York and over the higher parts of Ohio the flow was again east of south; but beyond Indiana to Dakota the direction was in general southward and southwestward, as if from an iceplateau in the Lake Superior region.

But above these plateaus, and farther north, dominated the higher Laurentide ice-plateau, which appears to have been the chief source of movement southward for the region during the time of maximum ice, although there were many subordinate sources. 
In the glaciated area along the Rocky Mountain Range of British America. called the "Cordillera area" by G. M. Dawson, and the region between this. range and the coast, the movement of the ice was for the larger part southeastward. But a northern part, north of $60^{\circ}-65^{\circ} \mathrm{N}$., moved northwestward, and central portions escaped westward through passes in the mountain ranges near the coast (G. M. Dawson).

About the Wisconsin driftless area the scratches over the surface east of it, according to Chamberlin and Leverett, mostly point westward or westsouthwestward, toward the area, in concordance with the fact that the area was that of a depression in the ice-sheet, so that the slope of the ice-surface was toward it. And to the south of it the same course is continued, showing that the depression in the ice-sheet was lengthened southward. But on the same authority, there was also an interval when the movement south of the area, as proved by the transported material, was reversed, or from Iowa into Illinois.

To the eastward, the ice-sheet, when at its maximum stage, extended southward in a broad convexity or lobe over New England and New York. (See map.) This was due in part to the general topographic form of the surface, but more directly to the position and height of the White Mountain and Adirondack ice-plateau, the head of the ice-movement. But besides this, Pennsylvania and southwestern New York were under the lee of the icecovered Adirondacks and Catskills, and it is for this reason, apparently, that over the former state the southern limit took its northwestward course into New York; a course which has no correspondence with the lines on a modern rain chart.

The flow was also guided in part by large lake depressions, and especially when these were near the border, as was the case during the progress of the Glacial period. Moreover, the flow of the lower ice was always influenced locally by the topographic form of the surface, and particularly by the courses of large river valleys as stated on page 247 . Such valleys have their valley drift and scratches, as proof of the valley movement. This movement, as in the case of that along the Connecticut River valley, has sometimes been attributed to a local glacier after the retreat of the ice-sheet. But the Connecticut, for the 200 miles from Haverhill, N.H., to the Sound, has a pitch of only two feet a mile. More than 50 feet a mile would be required for movement, and this would demand a height at Haverhill of 10,000 feet, which could not be unless the greatest of the earth's mountains existed there. A length of 200 miles in a local glacier along an open valley is more than three times greater than now exists.

The Connecticut River valley is a good example of the effect of large valleys, oblique in direction to the general movement of the ice, in carrying off the lower ice which lay in the depression, while the upper ice continued part way, or wholly, across it. Its direction along southern Vermont and over Massachusetts and Connecticut to New Haven is S. $8^{\circ}-15^{\circ} \mathrm{W}$., while that of the general glacier movement was S. $30^{\circ}-50^{\circ} \mathrm{E}$. The flowing bottom ice, within the confines of the valley, carried along for distribution almost solely 
stones from valley rocks - chiefly trap and red sandstone - and made scratches in the direction of the valley, while the upper ice left similar evidence of its direction of flow, S. $30^{\circ}-50^{\circ} \mathrm{E}$., in the distribution of bowlders from the region west of the valley. These bowlders, in general, were dropped in the valley, they sinking in the ice till within the valley flow; so that, in such a case, they prove only that the flow characterizing the upper ice continued part of the way across the Connecticut valley.

Other examples of valley ice-streams are those of the Merrimac, N.H., of the Winooski Valley in Vermont, and that of Lake Champlain, as proved by the glacial scratches observed by C. H. Hitchcock.

\section{Transportation and Deposition.}

1. Gathering of material, and its condition. - The ice-sheet received little material from avalanches, that is, through falls of ice or stones from precipitous declivities or overhanging cliffs, except toward its front margin; for, in the maximum stage of the ice, it covered all the mountains, except the highest. The moving mass carried debris for the most part, not from the slopes and summits of emerged ridges, but from those underneath it, against or upon which it rested, and chiefly from the slopes and summits of such ridges rather than from level surfaces. It obtained its load by abrading, plowing, crushing, and tearing from these underlying slopes and summits. It took up the loose earth and stones, abraded the hard rocks, plowed into the soft, and broke and tore off small and large bowlders from the fissured or jointed rocks.

The ice-mass was a coarse tool; but through the facility with which it broke and adapted itself to uneven surfaces, it was well fitted for all kinds of shoving, tearing, and abrading work. Moreover, it was a tool urged on by enormous pressure. A thickness of 1000 feet corresponds to at least 50,000 pounds to the square foot. The ice that was forced into the openings and crevices in the rocks had thereby enormous power in breaking down ledges, prying off bowlders, and in abrading and corrading. In contrast, the ice of an Alpine glacier has a thickness ordinarily of but 300 to 500 feet.

It gathered little from the lowest parts of the narrower valleys, because of the subglacial stream often present there, and the open space in the ice above it - the ice resting itself in such cases mostly against the sides of the valley.

There the fissured rocks were hard, large stones were taken up, some of them hundreds, and occasionally thousands, of tons in weight. But in regions of soft rocks, such as shale, slate, and fragile sandstone, and of rocks easily decomposed, the material obtained was merely sand, earth, or small stones that were readily reduced to earth. Over areas of great extent, therefore, the glacier moved on with little besides the finer debris to distribute. Such facts suggest a reason for the frequent absence of stones and large bowlders from large parts of a glaciated region.

In consequence of this subglacial method of gathering materials, nearly all transported debris of the glacier was confined at first to its lower part, 
within 500 to 1500 feet of the bottom. It was intraglacial, ${ }^{1}$ as now in Greenland; there was in general no superglacial drift over the ice-sheet. The local exceptions to this occur over the melting lower margin; for a short distance about some "Nunatak" (page 240), where local melting had favored the growth of alpine Algæ; and in regions reached by the dust of the drifting winds. Even the stones and gravel, taken up from the bottom over which the ice moved, might have been carried upward along oblique planes of bedding or lamination into the ice-mass.

A paragraph from the chapter on Glaciers (page 246) is here repeated because of its apparent importance in connection with the accumulation, transportation, and deposition of the drift.

The slipping of the ice along planes of bedding or straticulation like that of the blue bands has been shown by Forel to be a fact in several glaciers, among them the Bossons Glacier at Chamouni. In the lower part of a glacier these planes have a dip upstream; and as a consequence, the mass of the glacier, as it moves down the valley, rises by slipping along one or more of the planes of lamellar structure. Forel observes that the fact explains the difference of velocity between the upper and lower beds of the ice; the little movement at the extremity of a glacier; the reappearance, at the surface, of bodies buried in the interior of the glacier; and the preservation of the thickness of the ice at the lower extremity, notwithstanding the annual loss from melting. The cause must have great influence over the direction of crevasses, and in all adjustments to resistances. He states further that at the Glacier of Hochsbalm, a frontal moraine was formed in $\mathbf{1 8 8 4}$, by the slipping of a bed of clean ice over an old bed of debris-covered ice. (Arch. Phys. Nat. Genève, 1889, xxii., 276, and An. Jour. Sc., 1889, xxxviii., 412.)

Besides taking up material for transportation, the glacier pushed along bowlders and gravel wherever its mass rested, and especially where there was a rocky surface at shallow depth below for it to slip over; and the loose material gathered, besides serving for abrasion, made a prominent part of the ground-moraine here and there in progress of accumulation.

The uneasy glacier stream - uneasy because forced to make unceasingly new adjustments to the uneven surface underneath it - carried on the work of corrasion among the transported stones with vastly greater force than running water, because the ice had a firm hold on the stones and was plied by pressure of vast amount. It was a wonderfully efficient rock-mill. The stones, hard or soft, had their angles and surfaces rounded, and then were gradually reduced to sand, earth, and rock-flour. Owing to this wearing out of the stones, the drift in any region seldom contained stones gathered from points more remote than the last fifty miles of travel. Shaler states that the stones and bowlders on Nantucket were all gathered by the ice east of Narragansett Bay.

It is not surprising that, in Illinois, Indiana, and Iowa, where the distance of travel from any good gathering-place was great, stones in the drift should be few, and be almost confined to the hardest kinds, as those of chert; that the southern ice-limit should in some parts have no well-defined moraine;

1 The term englacial, used by some writers, is not here adopted because it is half Greek. Intraglacial accords with Latin usage. 
that clay makes a part of till, and sometimes interlaminating beds; and that half-decomposed rock-flour, fitted to make loess, should have been contributed so abundantly to the Mississippi and its tributaries.

The smaller traveled stones were sometimes ground smooth on several sides, and thus facetted, so as to resemble human flint implements. Shaler mentions the frequent occurrence of such facetted stones on Nantucket, and W. P. Blake has found many over Mill Rock, near New Haven, Conn.

The process of decomposition went forward rapidly because the stones were in a moist place, and the needed air penetrated all glaciers. Moreover, through the carbonic acid present in the ice, as it is present in all rain or snow, decomposition of other kinds went forward, and especially that of changing the finely powdered feldspar to clay (page 129). The microscopic vegetation not uncommon in glacier ice, including that of Greenland, may, through its decay, have afforded additional carbonic acid, and also organic acids for the work of decomposition.

There is little of this clay made in the region of the Alps, but it was almost universal when the continental ice flowed over regions where crystalline rocks were to be had; and the distribution of clay in great beds over glaciated areas, as well as in the bowlder clay, is thus accounted for.

The invading ice in its first novement trod down the forests and carried off the broken trunks; and some trunks and stumps and eddy-like gatherings of leaves in the till or bowlder clay of Ohio, Indiana, Illinois, and other states west may have thus been gathered. The accumulation of soil and the growth of forests over the debris that accumulates on the melting margin of a glacier, as on the St. Elias glacier (page 239), illustrates a common process of the Ice age.

2. Transportation. - In the work of transportation both ice and water were concerned. Melting, through the warmer season, and copious rains supplied the water. The glaciers of the Alps and Greenland teach that superglacial lakes and streams may thus have been made, which contributed water to sub-glacial rivers.

The distance of transportation by the glacier varied from 10 miles or less to 500 ; and more examples of distant travel would exist if stones did not wear out. Native copper has the advantage of stone, and some of its masses made a journey of at least 450 miles, as stated on page 952 .

The direction of travel is sometimes indicated by the occurrence of long trains of stones leading off from the ledge or peak which afforded them. A hill of hard quartzose chloritic rocks on the borders of Lebanon and Canaan, in Rensselaer County, N.Y., was the parent source of the "Richmond" train of large stones that crosses the Taconic Range into Massachusetts, and is continued on over Richmond and Lenox into 'Tyringham (S. Reid, 1842, E. Hitcheock, 1844, E. R. Benton, 1878).

Some of the transported bowlders exceed 1000 tons in weight. The "Churchill Rock" at Nottingham, N.H., deseribed by C. H. Hitcheock, is 62, 40, and 40 feet in its diameters, and is estimated to weigh about 6000 tons. 
The "Green Mountain Giant" at Whitingham, Vt., weighs about 3000 tous. W. O. Crosby has described a bowlder on the eastern border of New Hampshire having diameters of 30,40 , and 75 feet, and weighing 6000 tons. In Ohio there is one 16 feet thick, which covers three fourths of an acre.

From southwestern Vermont, the granite of a high hill, between Stamford and Pownal, which is almost as high as the Green and Hoosac Mountains lying to the east and southeast, was carried southeastwardly over the western sides of these mountains, nearly across the state of Massachusetts.

Iron Hill of Cumberland, R.I., furnished bowlders of iron ore for the country south of Providence, to the Newport region, thirty-five miles distant, and thence south of east, as shown by Shaler, to Gay Head on Martha's Vineyard.

Large bowlders are scattered widely over eastern Long Island, which are the crystalline rocks, trap, and sandstone of New England; and others, over western Long Island, which are from the Palisades and heights along the Hudson River. South of Lake Superior, there are bowlders which have come from the north shore of the lake.

In this movement of the glacier the transported stones and earth, at first intraglacial, have sometimes become superglacial, about any emerged or nearly emerged mountain peak, as in Greenland about the "Nunataks" (page 249). And after serving as a superglacial moraine for awhile, the whole may have sunk away through crevices or crevasses to intraglacial positions again. The ice, as it moves up a long slope of a hill or mountain-side, slips over the rising surface, and carries its load with it; and on many slopes such stones are found at a level 1000 to 3000 feet or more above their source. Mount Katahdin in Maine has many bowlders on its northern face derived from the Devonian rocks of the low country to the north, 3000 feet below it in level, which were thus carried up the mountain. Stones from a low level in the ice may thus, if not stranded on the slopes, use the high level for further travel or continue on at their original level.

3. Deposition. - The deposition of the transported material took place (1) through crevasses and crevices, aided by descending waters from the superficial lakes or streams; (2) from the melting bottom of the glacier; (3) from the melting always in progress along the front of the glacier, which was augmented during retreats. Moreover, the material pushed along by the glacier was an important addition to the moraine-making debris set free by the melting ice. Great bowlders would be the first landed from the decaying ice-mass; yet large and small stones, earth and clay, are so mingled in the till that the term bovlder-clay is well applied to the larger part. The stones of the till show their glacier origin usually by marks of abrasion. But flowing glacial waters carrying sand have often worn smooth the glacierdropped stones and bowlders. The subglacial waters, wherever in gentle flow along their valleys, may have made part of the local deposits of clay and sand, while others were made by the waters flowing away from the front.

4. The terminal moraine or southernmost Ice-limit. - The terminal moraine marks the limit of the ice-sheet when it was of maximum extension, and therefore when of maximum power for work, whether at abrasion, corrasion, 
or transportation. Along portions of the line in western Pennsylvania, Ohio, and Indiana, the amount of drift material is small, so that it is sometimes called the attenuated margin of the drift. But at some places in Ohio the terminal till is stated by Wright to be 100 feet thick or more. In southern Illinois, Williamson County, the thickness at the limit averages, according to Chamberlin and Leverett, 20 feet, and in some places is 50 feet thick; and striation is deep in the vicinity, proving the action of a land ice-mass. In Kansas and Missouri, the most southern portion of the drift, there are bowlders of considerable size. To the eastward, in eastern Pennsylvania, near South Bethlehem, the Durham and Reading Hills, 665 to 900 feet high, have bowlders and scratches at all altitudes.

Far eastward, south of New England, in the region of greatest precipitation, the terminal moraine extends along the islands from Nantucket, Martha's Vineyard, by Block Island, to the south part of Long Island. On this island, west of the Shinecock Hills, there is a long interval of stratified sands; and then at the western extremity of the island the drift is again at the surface, and continues to Staten Island and New Jersey. The deposits are coarse, 100 to 200 feet or more in thickness, partly stratified in places, and carry large bowlders.

Ten to twenty miles north of the line just described, from Cape Cod along the Elizabeth Islands and the shores of Rhode Island and Connecticut, between Narragansett Bay and Watch Hill, and then along Fishers Island and the north side of Long Island, there is a second range of terminal moraine, as first announced by Upham. The islands are not drift made; for they had an earlier existence, as subjacent Cretaceous and other terranes show; and they may, therefore, have determined the twofold subdivisions of the drift. Yet it is more probable that there are two lines of moraines, and that only the more southern is to be taken as the terminal moraine, or that at the limit of maximum extension. Nothing is known to exist over the sea bottom south of Long Island to indicate a still more southern line, although the surface for 25 miles or more seaward was part of the dry land.

This epoch of the advance in the Glacial period was probably of great length. The vastness of the area covered with ice, the thickness of the icemass, and its accumulation even over the dry Continental Interior, lead to this conclusion; and, as has been shown, the attenuation of the drift along much of the front is not evidence against it; for, notwithstanding this, there was slow transportation to the limit.

The terminal moraine, or southernmost limit of the ice, was located along the islands south of New England first by Upham and Clarence King; and along the coast east of Watch Hill (which is a continuation of Fishers Island) by C. King. Its location over New Jersey was made out by G. H. Cook and F. Smock.

\section{Epoch of the First Retreat.}

1. Distance of the Retreat. - The evidence of a retreat of the ice-front is afforded by the condition of the till and other glacial deposits over the region of the retreat, and by the record of a long halt at the close in the DANA'S MANUAT، - 61 
existence ordinarily, as the northern limit of the retreat, of a more or less prominent belt or line of moraine.

The course of this moraine-line, as mapped chiefly by Chamberlin and Leverett, is shown on the map (Fig. 1548). It is the line lettered B, B, B, and is designated the moraine $\mathrm{B}$, or moraine-line $\mathrm{B}$. The belt of land laid bare by the retreat extended westward to the Continental Interior; no such retreat has yet been recognized west of the Rocky Mountain region. In Illinois, the moraine B includes the Shelbyville moraine of Chamberlin and Leverett, which passes near Shelbyville in central Illinois, and probably the Altamont, of Upham, in central Iowa, the southernmost of the series in that state.

The width of this belt varies from 10 miles and less to more than 300 miles. It is least along the islands south of New England, and through New Jersey and Pennsylvania, where the precipitation was greatest - so great that the annual accumulation of ice fell but little behind the amount lost by melting. But farther west, from western Ohio to the Continental Interior, the width increases with the decrease in the amount of precipitation. In western Ohio and Indiana, the mean width is 40 miles; from Illinois to northwestern Kansas, it inereases from 150 to 275 miles; and the driftless area, lying chiefly in Wisconsin, is made part of a much larger iceless area.

From Kansas in a northwestward direction, the region of melting stretched northwestward over the district of Assiniboia to the Saskatchewan, or 1000 miles, if not beyond this; and as the dotted line (Fig. 1548) is the limit of transportation of drift from the eastward, and B B that of the morainic limit of the melting (along the Coteau du Missouris and the third Prairie level, in continuation of the Coteau des Prairies, as laid down by G. M. Dawson), the width of the area laid bare in British America is full 300 miles. The district of the Winnipeg region was still under ice.

Between Cape Cod and northeastern Kansas the retreat was from the south, northward, but in British America it was from the west, eastward, and east-northeastward; that is, it was from the borders of the great ice-sheet inward. Along the Coteau des Prairies, the retreat from west to east was small, because the region west of that part of the Missouri was bare through all the epoch of maximum ice owing to drought and heat.

South of New England the southernmost line, AA, from Nantucket to Perth Amboy is but a few miles from that of the moraine B situated along the inner range of islands, the cuast west of Narragansett Bay, Fishers Island, Peconic Bay, and the north half of Long Island westward. At the head of Peconic Bay the moraines of the north and south sides of the bay blend with one another. It is not certain that the moraine of the southern limit, or that of maximum ice, was not outside of these islands, as it was probably ontside the existing shore line to the east of New England, Georges Shoal being probably on or near the limit. The retreat from this eastern limit was probably to some line now under water; for the moraine on Cape Ann, north of the harbor of Boston, has been shown by Tarr to be part of the east-and-west moraine extending westward to the Connecticut. 
The nearness of the moraine-line A, or the southern ice-limit, to that of moraine-line $\mathrm{B}$ in Pennsylvania may be owing to the fact that the course of each was not dependent on the isotherms, but on the leeward position of the region with reference to the icy heights to the northeastward (page 956).

2. Deposition and distribution of drift. - With the melting and retreat of the ice-sheet, deposition of the transported material went forward making a covering of till of varying thickness, deposits in some parts of clay and rock-flour over and within the till, and intercalated deposits also of soil, sometimes with remains of forests, as has been already described. Besides, the escaping waters carried away material, fine and coarse, for stratified beds of clay, sand, and gravel. The older till over Illinois and Indiana has usually a depth of about 20 feet. In southeastern Indiana and southwestern Ohio, according to Leverett, it was followed by a covering of soil and then a deposit of clay to a depth of several feet; and as the clay contains, according to an analysis, $2 \cdot 32$ per cent of potash and soda, 16 per cent of it or more is feldspar in grains. The beds of soil and the forest-beds in glacial deposits are mostly contained in those that were made during this retreat.

1550.

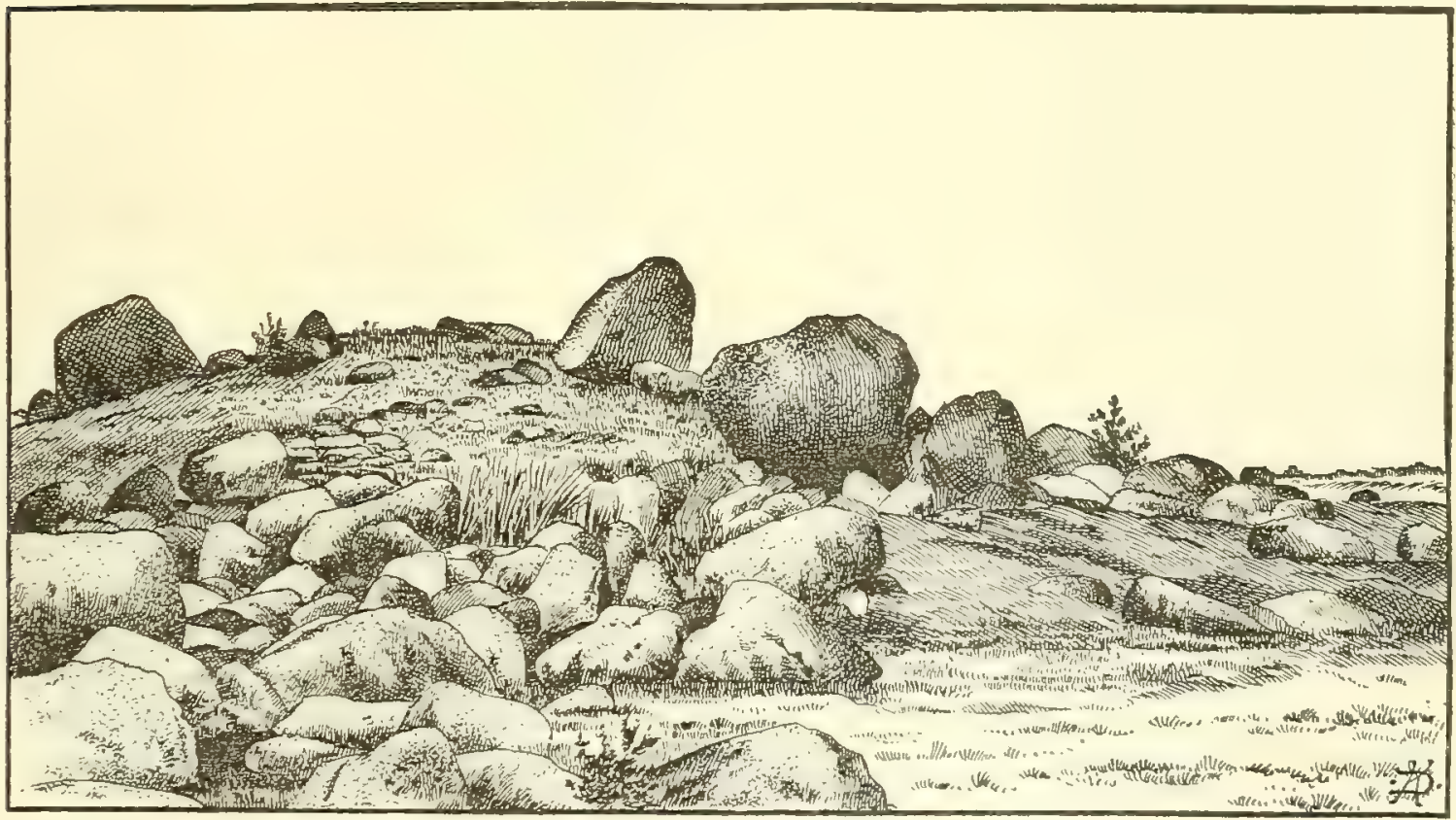

Cpper part of Moraine, Dogtown Commons, Cape Ann. Shaler, 1889.

The moraine ridge, which marks the limit of the retreat, consisting chiefly of gravel, stones, and bowlders, was made by the deposition, along the front, of material brought down by the ice-sheet during a long halt. It indicates the transporting power of the ice; and as the moraine in Illinois and Iowa is over 150 miles north of the sonthern ice-limit, the surface of the ice-sheet may have had a steeper pitch than during the period of maximum ice, so that transportation went on more rapidly, while corrasion and deposition were less effective agencies of rock-wear. The halt had, as usual, its advances and 
recessions; and this was one means by which the moraine ridge was widened and rendered irregular in height and surface.

The foregoing figure of part of a moraine on Cape Ann, Mass., from a paper by shaler, though belonging to a later part of the Glacial history, shows the common appearance of such moraines at the present time.

A great feature of the epoch was the amount of water discharged, making new channels by erosion and giving the streams in the region of melting great transporting and eroding powers. The Delaware, Susquehanna, Ohio, and other streams were flooded; and the Mississippi derived waters not only from the Ohio with its many tributaries and from the icy heights of the Rocky Mountains, but also through the Missouri from British America, far north of Montana, perhaps from the upper portion of the Saskatchewan. Distribution of the transported material supplied by the melting ice, and erosion by the loaded waters went forward, therefore, with unwonted energy.

With the continent at its high level, the flooded rivers over all the continent dug out their channels, during the time of maximum ice, often to great depths; then at the melting the channels were filled with till, and, over the till, with fluvial beds of sand or gravel. The Mississippi valley received then its earlier deposits of lœss, over lake-like regions along its course, while other portions of the valley had their coarser deposits.

South of New England, the retreat was short. On Long Island, then probably 500 feet high, the eroding waters carried off seaward the terminal moraine of the south shore for 70 miles of its length, and dropped till over the denuded surface; then later waters covered it with sand and fine gravel; for there are no bowlders or till to be seen over the even slopes, although abundant elsewhere on the island. So also the waters that descended the north slopes of the island from the moraine belt, cut out of the morainic accumulations and underlying Cretaceous formation a number of short, steep valleys, and left them similarly under fluvial sand-beds as the top-dressing, with no bowlders over their surface; and the valleys, after the Champlain subsidence - which restored the waters of the Sound to their place - became the deep and capacious harbors of the north coast.

During the epoch when the Mississippi was receiving waters, by the Missouri, from the melting in progress through a thousand miles from south to north, with other floods from the ice and snows to the east and the glacier regions in the Rocky Mountains, the deposition took place, of what has been named the Lafayette formation - the Orange sand formation of Hilgard. As shown by Hilgard, the Lafayette was a widespread floodmade formation, extending along the great valley of the continent, the Mississippi, south of its junction with the Missouri, from southern Illinois to the Gulf. Its eastern border passes near Cairo through western Kentucky and Tennessee, and the northeast corner of the Mississippi, and, according to L. Johnson, reaches the shore of Mobile Bay in Alabama. Its western border crosses Arkansas and Louisiana into Texas.

The formation is described as consisting mostly of rust-colored or reddish silicecus sand-beds. Near the great river channels, notably that of the 
Mississippi on either side, of the Tombigbee and Tennessee, as well as of the Sabine, there is a steady increase of gravel. It occasionally contains, even in Mississippi, stones of 10 to 100 pounds in weight, and rarely 150 pounds. There are also some local clayey beds. The stones show that the material came from the northward; many have in them Paleozoic fossils. The beds are irregularly stratified, sometimes structureless for 20 feet of thickness, but have generally the flow-and-plunge structure, illustrated in Fig. 63, page 93. The facts prove, as Hilgard states, that there was a vast and violent flow of waters down the broad Mississippi valley, bearing an immense amount of sand and coarser detritus, and also some floating ice for the transportation of the larger stones. Hilgard therefore concluded that it must have been made during the melting of the ice, while the continent had still the elevation characterizing the Glacial period. These conditions are those of the First Retreat.

There were cotemporaneous depositions from streams descending the Atlantic and southern slopes of the then snow-clad Appalachians; and large areas of the Lafayette formation in these regions and elsewhere have been defined and mapped by McGee.

The "Orange sand" is often 40 ' to 100 ' thick, and in some places over $200^{\prime}$ according to Hilgard, and toward the Gulf it has still greater thickness. In an Artesian well, near the Calcasieu River, 200 miles west of New Orleans, beds referred to the Lafayette are 450' thick, beneath $160^{\prime}$ of clay of the Port Hudson group; and at New Orleans $760^{\prime}$. This thickness along the Gulf is supposed to be evidence of a gradual subsidence of its border to the great depth stated, as deposition went forward.

The actual limit of the formation is in doubt because it contains no fossils, and the criterion usually appealed to in its correlation, - kinds and color of gravels, - is admitted to have, whatever the rock series, almost no value. In Texas, some beds referred to the Lafayette were found by G. D. Harris to contain Tertiary fossils.

In his early account of the formation, Hilgard stated, on the authority of Tuomey and LeConte, that the formation passed from Alabama eastward, around the higher Appalachian highlands into the Carolinas, and thence north to Virginia and Maryland. McGee described, in 1888, similar beds of orange-colored sands and clays along the Appomattox River and other points in Virginia, and also others, in North Carolina and beyond, to which he gave the name of the Appomattox formation, and he has since studied the beds in the Mississippi valley. He argues that part of the borders of the Atlantic and Mexican Gulf were $200^{\prime}$ to $800^{\prime}$ below their present level at the time, making the beds in part marine. No marine fossils or other marine relics have been described in evidence of the submergence. Moreover the formation is made preglacial by McGee, and others.

The term Lafayette was substituted in 1892, by agreement, for the older names of Orange sand and Appomattox.

Mr. Hilgard's last paper on the subject is in the Am. Jour. Sc., xliii., 1892; and Mr. McGee's first on the Appomattox in Am. Jour. Sc., xxxv., 1888, and his last on the Lafayette formation in vol. xii., Rep. U. S. Geol. Surv., 1892.

3. River channels filled by the drift. - The discharge of drift from the melting glacier sometimes filled up and blocked river channels at places, and compelled the river to make a new cut.

The Ohio River, according to Newberry, formerly had a more southern 
route around the Falls near Louisville, which it lost when the ice extended to its southernmost limit. 'The Falls are evidence of uncompleted work in subsequent erosion along the valley.

It is held by some investigators of the drift, and prominently by Chamberlin, that the retreat, instead of ending along the line of the moraine above described, continued until North $\Lambda$ merica had lost the chief part of its ice-sheet, and that this "First Glacial Epoch" was followed by a second advance, of which moraine B was the terminal moraine. This view is sustained on the ground that the erosion produced during the interval, the intercalation of forest-beds and stratified clays, and the weathering and oxidation of the lower tills would have required a very long period of time. It is, however, an important consideration in favor of the shorter retreat, that the beds eroded were, to a great extent, soft; that the amount of water discharged was very large; and that interstratified sandbeds and forest-beds are such as modern glaciers are now producing. The arguments and facts favoring the theory of two glacial epochs and an interglacial are presented by Chamberlin in his Report on the Geology of Wisconsin; also in the $3 \mathrm{~d}$ and 7 th Reports of the U. S. Geol. Surv., and in later publications, in part of which Leverett is joint author ; by G. M. Dawson in his Memoir on Rocky Mountain Geology in the Trans. Roy. Soc. Canada, vol. viii., 1890, etc. Upham, Hitcheock, Wright, and others favor the idea of a continuous succession of recessions and halts during the retreat.

In northeastern Iowa, according to McGee, the successive glacial deposits are : (1) the lower till, which is overlaid by stratified sands and clays (called locally gumbo); (2) a forest-bed, with unconformity beneath through erosion and decomposition; (3) an upper till of small extent, from ice that was of short duration; (4) the loess, which contains some bowlders, and graduates at base into the till. These are supposed to be anterior to what is called by Chamberlin the Second Glacial Epoch. The loess is stated to have been formed in an ice-bound lake, which he names Lake Hennepin, made by the meeting of two lobes of ice, advancing either side of the Driftless area. The lœss makes a fertile soil, which appears to be evidence that there was abundant vegetation in the waters in which it was deposited, and thus throws doubt over the presence of the ice. The depauperate condition of the shells shows only that the waters were cold; and their great numbers, that conditions of growth were still not very unfavorable.

The great distance of transportation of glacial drift over the Continental Interior in British America, and the remarkable uniformity in the drift deposits over the vast area" 250,000 square miles" — has led to the view that the region was submerged under fresh or salt waters, and that floating ice was the transporter. But the flow over such waters, whether tidal or not, would have been north and south, and not across the area; and there is no evidence of marine conditions. Moreover, if floating ice worked there, it was the agent to the south in the United States; and this is not in accordance with the facts there observed.

Land and freshwater shells and other fossils of the loess of the Mississippi valley.From Galena, Ill.: Succinea avara, S. obliqua, Patula striatella; Vallonia pulchella, Limnophysa humitis, L. desidiosa, Pupa contracta, P. muscorum (R. E. Call).--From Davenport, Ia.: Succinea avara, S. obliqua, Helicina occulta, Pupa fallax, Helix striatella. Also tusk and molars of Elephas primigenius (Pratt). - From Muscatine, Ia.: Helix striatella, H. fulva, H. pulchella, H. lineata, H. Cuperi, Pupa Blandi, P. quarticaria, P. muscorum, P. simplex, Succinea avara, S. obliqua, Helicina occulta, Limncea humilis, Unio ebenus, U. ligamentinus, U. rectus, Melantho subsolida, Margaritina confragosa. Also teeth, bones, and antlers of Cervus Muscatinensis (Witter, in McGee's Iowa).

From Hickman, in Kentucky: Conulus chersina, Hyalina arborea, Helicina orbicuLata, H. profunda, Limnce (Limnophysa) desidiosa, Mesodon profundus, M. albolabris, Macrocyctis concava, Patula alternata, P. perspectiva, P. solitaria, Stenotrema (Helix) 
monodon, S. hirsutum, Treodopsis appressa (Wetherby). The species are all of kinds now living in the vicinity of the several localities.

The shells of the Iowa lake are much below the natural size of the species, showing the depauperating effect of the cold water (McGee); but in Kentucky those obtained near the Mississippi are larger than those a few miles to the eastward (Loughridge).

\section{Epoch of the Final Retreat.}

At the commencement of the Final Retreat, as shown by the position of moraine B, ice still covered all New England, all New York, and very nearly all that part of Pennsylvania that was covered at the time of maximum ice. But in Illinois and farther west to Dakota, the First Retreat had left bare a broad belt, which extended northwestward into British America west of Manitoba.

In the Final Retreat the Mississippi valley was still, compared with the east, the region of most rapid melting, and for the same reason as before the warmer and drier climate. The series of loop-shaped moraines in Illinois and Wisconsin, and that in Iowa and Minnesota, mark the succession of halts and recessions in the course of the retreat northward from the moraine line B.

The Illinois series, as described by Chamberlin and Leverett, covers much of Illinois and passes thence into Wisconsin; and the Iowa-Minnesota series, as mapped by Upham, extends first northward and then over Minnesota northeastward, for more than 400 miles. In addition, the retreat was going on from the moraine line B in Assiniboia, north of Montana, laying bare much of Manitoba.

In the Illinois series of moraines, there is near Madison the noted Kettle moraine (KK on the map), more than 200 miles from the line $\mathrm{B}$, or that of the Shelbyville moraine. But in Indiana the distance of retreat between the moraine line $\mathrm{B}$ and the line $\mathrm{K}$, or that of the Kettle moraine, narrows rapidly; and in Ohio it is very small, the first moraine north of the moraine $\mathrm{B}$ being regarded by Chamberlin and Leverett as probably the moraine $\mathrm{K}$. Farther east, moraine $\mathrm{K}$ extends along with moraine $\mathrm{B}$ into western New York. It has been supposed by Chamberlin to pass probably south of Cayuga and the other Finger Lakes. In view of the nearness to the line B in Ohio, it may be questioned whether it does not take the same oblique course with it through Pennsylvania and become there indistinguishable from it; and the same also farther eastward across New Jersey and south of New England. If this is the right view, New England held to its ice during all the retreat in Illinois of 200 miles, precipitation to the eastward adding about as much ice as was lost by the melting.

Subsequently the final retreat involved the Eastern States as well as the Mississippi valley, and moraines over New England and New York mark its progress. One, as described by R. S. Tarr, crosses Massachusetts west of the Connecticut, passing south of Turner's Falls, Orange, Royalston, Winchendon, and terminates in the Cape Ann moraine described by Shaler. 
Three or four others, according to C. H. Hitchcock, exist in Vermont and New Hampshire.

The moraines made on this final retreat bring to light the fact, as observed by Chamberlin, that the movements of the ice-sheet in the region of the Great Lakes became largely resolved into movements along lakebasins. They thus bear testimony to the preglacial existence of the basins of the Great Lakes. The Kettle moraine $(\mathrm{KK})$ is concentric with the outline of the Green Bay trough, a western arm of Lake Michigan; a Michigan moraine borders the Lake Michigan basin; and a series of Erie moraines, as mapped by Leverett, are approximately parallel with the western part of the Lake Erie basin. Besides, there are indications of a Saginaw glacier movement, along the trough of Saginaw Bay on the west side of Lake Huron, as an outlet for the ice of the Lake Huron basin. There were thus brought to view more or less distinctly, as melting went forward, the outline of a Green Bay, Michigan, Saginaw or Huron and Erie glacier.

Lake Ontario and Lake Erie, during the time of maximum ice and long after retreat began, were crossed by the ice in a southward direction, the glacial scratches south of Ontario having the direction S. $8^{\circ}-20^{\circ} \mathrm{E}$., and those south of Erie mostly S. $20^{\circ}-30^{\circ} \mathrm{E}$. But the evidence of a lake-basin movement - really an Erie-Ontario movement - is sustained by scratches at the east end of Ontario, and over the region at the west end of Erie. In the latter region, the deep moldings in the limestone of Kelley Island have the courses S. $60^{\circ}-80^{\circ} \mathrm{W}$. (Newberry); and west of the lake the same directions prevail. This westward flow in the Erie basin, first pointed out by Gilbert, and later sustained by Chamberlin and Leverett, must have been dependent in part on a like movement in Lake Ontario, for the supply of ice required a general westward slope in the ice-surface to the eastward; and the Adirondack ice-region was its probable source. Chamberlin and Leverett also bring forward evidence from the moraines (see map, Fig. 1548) that Lake Erie was rid of its ice before the more northern Lake Ontario.

The movement along the troughs of Lake Michigan and Green Bay, suggested by the moraines, as Chamberlin points out, proves, if a fact, that the ice over the troughs had the slope at surface requisite for movement and transportation. The length of Lake Michigan is 335 miles; and hence, if the mean slope was but 30 feet per mile, the height of the ice-surface at the north end, above that at the south, woulil have been 10,000 feet; and two thirds of this if the rate were but 20 feet per mile. With such evidence of a southward movement there is no satisfactory proof that a subsidence was in progress to the north, although the retreat of the ice had even reached the Canadian borders.

The Iowa-Minnesota series of moraines appears to indicate a like movement, and a like northeastward rise in the slope of the ice-surface. With the retreat of the ice from Minnesota, the ice disappeared from much of the more northern Lake Winnipeg region; and Lake Winnipeg, receiving waters from melting ice on its eastern and northern borders, as well as from 
rivers to the west, then began, while the continent over this interior region was still at high elevation, its discharge by the Red River of the North into the Minnesota, and the Mississippi became emphatically the "Great Mississippi."

It was at this time of the departure of the ice from the lake region to the country north of Lake Superior, before a subsidence had made much if any progress, that the areas of the Great Lakes were fluvial areas, carrying on vigorously the work of excavation under the high southward slopes due to more northern elevation; that Michigan was discharging its abundant waters through the Illinois or the Kankakee channel to the Mississippi; Erie, with probably Huron, through the Wabash, to the Ohio; and Superior, through the Fox or Wisconsin, to the Mississippi. The waters of Ontario are supposed to have gone eastward to the valley of the Mohawk, but for want of satisfactory evidence as to any other course.

The following are the views of Chamberlin and Leverett, with regard to the stages in the interval between the time of maximum extension and that of the Kettle moraine: (1) Partial deglaciation, and the formation of a sheet of drift perhaps $20^{\prime}$ in thickness, with occasional layers of soil interbedded in the drift. (2) Interval of deglaciation of great length, the surface of old drift sheet deeply oxidized, leached, much eroded, with thick widespread soil above. (3) Deposition of main body of loess and associated silts along the Mississippi, Illinois, Wabash, and Ohio rivers, and between the Mlinois and Mississippi, and the material in southern Indiana and southwestern Ohio called "White Clay." (4) Long interval of deglaciation, and deep erosion, cutting large valleys in the lœss. (5) Formation of a thick sheet of drift terminated by the Shelbyville moraine, $75^{\prime}$ to $100^{\prime}$ deep, the maximum advance of the ice after the long deglaciation having terminated at or near the line of this moraine; and, following the deposition of the Shelbyville moraine, other moraines in succession at short intervals up to the Kettle moraine series. (6) An interval during which ice-lobes and ice-currents were shifted. (7) Moraines of the Kettle moraine series of Illinois and Wisconsin. In remarks on these stages, it is stated that as far as the correlation of the Kettle moraine has been made out, the Shelbyville series of moraines is represented in western Ohio by only a single moraine, and in eastern Ohio and northwestern Pennsylvania, it is nowhere in view, and is supposed to be concealed by the Kettle moraine series. The correlate line across western Indiana of the Kettle moraine is difficult to make out. In eastern Ohio the outer belt from the Scioto River to southwestern New York has knobs and basins like the Kettle moraine; and the moraine south of the Finger Lakes (Cayuga, Seneca, and others) is made the probable continuation of the Kettle moraine series. The overwash from the Lake Michigan and Erie moraines over Saginaw moraine in northern Indiana seems to show that the ice had withdrawn from the Saginaw moraine while it was forming the series west of Lake Erie. With regard to the conclusions of Chamberlin and also of Leverett here and elsewhere cited, they say that their observations are still in progress, and their statements are not to be taken as final.

Upham names as follows the Iowa-Minnesota moraines, commencing at the south: 1, the Altamont; 2, the Gary; 3, the Antelope ; 4, the Keister ; 5, the Elysian ; 6, the Waconia; 7, the Dorre ; 8, the Fergus Falls; 9 , the Leaf Hills; 10 , the Itasca; 11 , the Mesabi ; 12, the Vermilion (Final Rep. Geol. Minn., vols. i., ii., and 22d Ann. Rep.).

Lateral moraines are seldom well marked over any part of glaciated North America, because the mountains, with rare exceptions, were beneath the ice-sheet; and there were no true valley glaciers, except occasionally 
along the front. But in some large submerged valleys, like that of the Connecticut, in which the bottom ice had a morement of flow in the direction of the valley, there were sometimes obstructing conditions which produced a forced deposition of bowlders and till, and thus made an accumulation somewhat moraine-like, which might be called an obstruction moraine.

A good example exists along the west side of the south end of the Connecticut valley, in the vicinity of New Haven. This declivity is rather abrupt, and has a nearly northand-south direction, while the course of the valley ice-stream, as described on page 956 , was S. $15^{\circ} \mathrm{W}$. The ice-stream, in meeting the obstructing ridge or declivity, dropped along it a large amount of till and many great bowlders of trap and sandstone. The top of the ridge, five miles from the Sound, is about $300^{\prime}$ above the lower land to the east, and $400^{\prime}$ above the sea level. One great bowlder of 1200 tons, and several others of large size near by, were a little too low in the ice to pass the top of the ridge, and consequently became stranded against its slopes, or combed out by its summit ledges. Half a mile north is another trap bowlder of 500 tons, and several exceeding 100 tons lie to the south. A mile and a half to the east, but separated by an open valley $300^{\prime}$ deep, stands the West Rock trap ridge, of equal height; and on this ridge, and almost in an east and west line with the 1200-ton bowlder just mentioned, at a like height, there is a 1000-ton bowlder, which was similarly stranded. For a distance of 10 miles from Long Island Sound the great bowlders are common, and the till against the slopes has unusual thickness. The upper part of the glacier above the level of the ridges kept on its southeastward course (S. $30^{\circ}-40^{\circ}$ E.), carrying bowlders of gneiss from the northwest. But some, if not all, of these gneiss bowlders, while on their way over the valley, dropped down so as to come within the lower or valley ice-movement; and they are now, as a consequence, part of the obstruction moraine along the eastern base of the West Rock Ridge, and other northand-south trap ridges of the valley.

Among the formations produced by the melting, besides moraines and deposits of till, clay, and other ordinary materials, there were glacial accumulations of loose materials called drumlins, and eskers or kames, — formations that were much less common in connection with the early partial retreat than with the final. Kettle-holes, also, were a feature of many moraines, from the Coteau des Prairies to Cape Cod.

Kettle-holes are bowl-shaped depressions, usually 30 to 50 feet deep and 100 to 500 feet in larger diameter. Each depression, according to the accepted explanation, was the resting-place, and often the burial-place, of a huge mass of ice that became detached during the melting; and the final melting away of the ice left a hole where the ice lay. The great Wisconsin moraine about Green Bay is called by Chamberlin the "Kettle Range," from the great numbers of its kettle-holes. Near Wood's Hole, in southeastern Massachusetts, opposite Martha's Tineyard, 1000 kettle-holes occur, according to B. F. Koons, in a distance of about 12 miles. Kettle-holes occur sparingly over Long Island; but it is possible, since there is clay beneath the drift, that the weight of the overlying drift, with the addition of the resting glacier in some cases, forced aside the clay, flexing its layers in the process, and thus made the bowl-like depressions.

Dimulins are hills or ridges of till, 30 to 200 feet high, made ordinarily by deposition from the glacier. or in the course of its dissolution; and 
eskers or kames are rougher ridges and hills of rudely stratified coarse and fine gravel, produced by the discharged waters. Drumlins occur in great numbers over New England, especially in Massachusetts and its more northern states, and also in New York and the states west to Dakota. Eighteen hundred drumlins have been observed in Massachusetts alone, and thousands are reported from Wisconsin and the adjoining states.

Eskers are widely distributed over Maine, and are common in other parts of New England and in most regions of the melting ice.

Drumlins are commonly more or less oblong, smooth-featured hills, having the longer diameter in the direction of the movement of the glacier. In allusion to their form, they were called "lenticular hills" by E. Hitchcock, their first describer (1842). Such hills may be shaped by fluvial action from beds of till. But drumlins are generally results of local deposition. Their height indicates a source elevated above the general level. Such a source is afforded by the drift in the lower 200 feet or more of the ice. They were probably formed, therefore, under the ice-sheet, and not far from its melting margin. To gather and pile up the drift within the ice would require the descent of water along crevasses, the water acting by melting, eroding, and transporting. If the crevasse had a direction toward the front, the slow movement of the ice would bring forward new material for the enlargement and elongation of the hill. A large trench is sometimes made about a drumlin to carry off the copiously descending waters.

Crevasses are often due to obstructing rocky ledges or hills below, or to bends in a valley-like depression; and being thus local in origin, the same spot may be long accumulating deposits.

Drumlins sometimes have a nucleal mass of stratified gravel and sand containing occasionally intercalated till; and those of Madison, Wis., have the till confined to an outer shell, $20^{\prime}$ or $30^{\prime}$ thick. Upham, who has described such drumlins, attributes the nucleal stratified portion to moraine materials over the melting margin of the ice carried down by the superglacial waters; and the till to the final wasting of the glacier, or its removal by the descending waters. They sometimes show their subglacial origin by being crossed by small valleys or trenches of erosion (G. H. Barton).

A drumlin of nearly circular outline, on the west side of the valley at New Haven, Conn., height $115^{\prime}$, stands on the summit of a rocky ridge, its base being nearly $200^{\prime}$ above the sea level. The valley is the south end of the Connecticut valley near where it passes into the trough of Long Island Sound. The lower part of the ice lying in the valley was moving S. $15^{\circ} \mathrm{W}$. But, on reaching the trough of the Sound, it was forced to bend abruptly around to $\mathrm{S} .20^{\circ}-35^{\circ} \mathrm{E}$. in order to take the course of the general glacier movement along the Sound. This high isolated drumlin and lower accumulations along the coast westward are evidence of the wrenching and crevassing at the turning spot. This drumlin has, for half of its circuit, a deep valley, made by the deluge of waters that descended the crevasse.

Eskers or Kames, unlike the drumlins, are rudely stratified accumulations of gravel, sand, and waterworn stones. They are of rough fluvial or torrential origin, and occur in long tortuous ridges (serpent-kames), mounds, and hummocks. They have the general direction of the drainage, though sometimes not according with the present course of drainage. They occur usually over the lower lands, outside of the steep mountains where the slopes are not large; yet they are sometimes met with at high elevations. Indian Ridge, near Andover, Mass., was the first of them described (1842, by E. Hitchcock). Several modes of origin have been suggested. Their formation has generally taken place after melting had made great progress over regions favorable to torrential flows; where water, coarse gravel, and sand were freely discharged from the broken and 
melting ice-sheet and sometimes flowed along channels among the ice-masses or in its opened chasms. They were formed also by the gushing streams from the end of glaciers while the ice was rapidly disappearing, and sometimes beneath the ice. They often accompany moraines as an attendant effect. Stone refers those of Maine chiefly to superglacial streams; and J. B. Woodworth, those of southern New England mainly to subglacial waters, the ice giving them their limits. Deposition seems to have sometimes taken place in Maine over frozen soil and lakes, so that when the ice of the lake melted (as in the case of the Rangely Lakes) the kame over it dropped to the bottom. Some of the so-called kames are ordinary fluvial deposits. Kames were so named in Scotland. The Eskers of Ireland and Osars of Sweden are of like nature.

The till along seacoasts sometimes contains marine shells that had been gathered and transported by the glacier. Examples occur in the vicinity of Boston Harbor, especially to the southeast of it, and have been described by Upham (1888), and by W. O. Crosby and Miss Ballard, who enumerate 55 species collected chiefly from drumlins (1894). Similar localities, described by R. Chalmers (1893), exist on the coast of the Bay of Fundy.

The till over Ohio has a mean depth, according to measurements in borings made over 53 counties, collated by Orton, exceeding 93 feet, and four borings in Butler County, in the southeast corner of the state, gave 116 feet for the mean depth. The deeper places were along valleys. Excluding valley deposits, the depth is probably nearer 56 feet, as measured by Claypole. In Indiana and Illinois, the mean depth, according to Claypole, is 62 feet; for Central Minnesota, according to Upham, between 100 and 200 feet. Near Darrtown, Butler County, Ohio, there are cedar logs in the till, which, Wright says, point to short times of advance and recession of the ice-front.

The Erie clays, so named by Logan because forming extensive deposits along Lake Erie, are one of the results of deposition. According to an analysis by T. G. Wormley, the clay contains 3.40 per cent of alkalies, which indicates a mixture of clay with over 20 per cent of ground feldspar. They overlie the till, are unstratified for the most part, and often contain small seattered striated bowlders. The deposit was probably made by subglacial streams after their escape from the ice, and by discharged waters during the general melting. Over the Erie clays, near Cleveland, Ohio, there is a stratum of sand, gravel, and clay, and between the two occurs a bed of vegetable debris, one to two feet thick, which Newberry called a forestbed. It contains portions of tree trunks of Conifers and other vegetable materials. It may belong to the Champlain period.

In the Rocky Mountain region of British America and over the Interior Plateau to the west, as G. M. Dawson states, the later till is covered by a deposit called by him the "White silts," a well-stratified formation which is, at times, in terraces $100^{\prime}$ to $200^{\prime}$ high. Sometimes it passes gradually into sand-beds. It is supposed by him to have been formed in the valleys of those high regions before the ice had fully disappeared from them.

The obstruction of river valleys at points by the discharged till was of common occurrence during the Final Retreat. A noted case is that of Niagara River, where the river channel, then shallow, was thus filled and the stream forced to begin again the work of excavation. 
The accompanying birdseye view (Fig. 1551), from a paper by Gilbert, shows the river between Lake Erie to the south and the land below the Queenston Heights $(\mathrm{QH})$. To the right is seen the course of the old now drift-filled channel, first recognized by Lyell. The work of excavation is still going on, and chiefly at Niagara Falls.

The Mississippi River was similarly blocked near its junction with the Minnesota for a distance of about 10 miles, as described by N. H. Winchell. In the new valley, since made by the Mississippi, St. Anthony's Falls occur. The river is still working at the removal of the falls so as to make the cut complete.

1551.

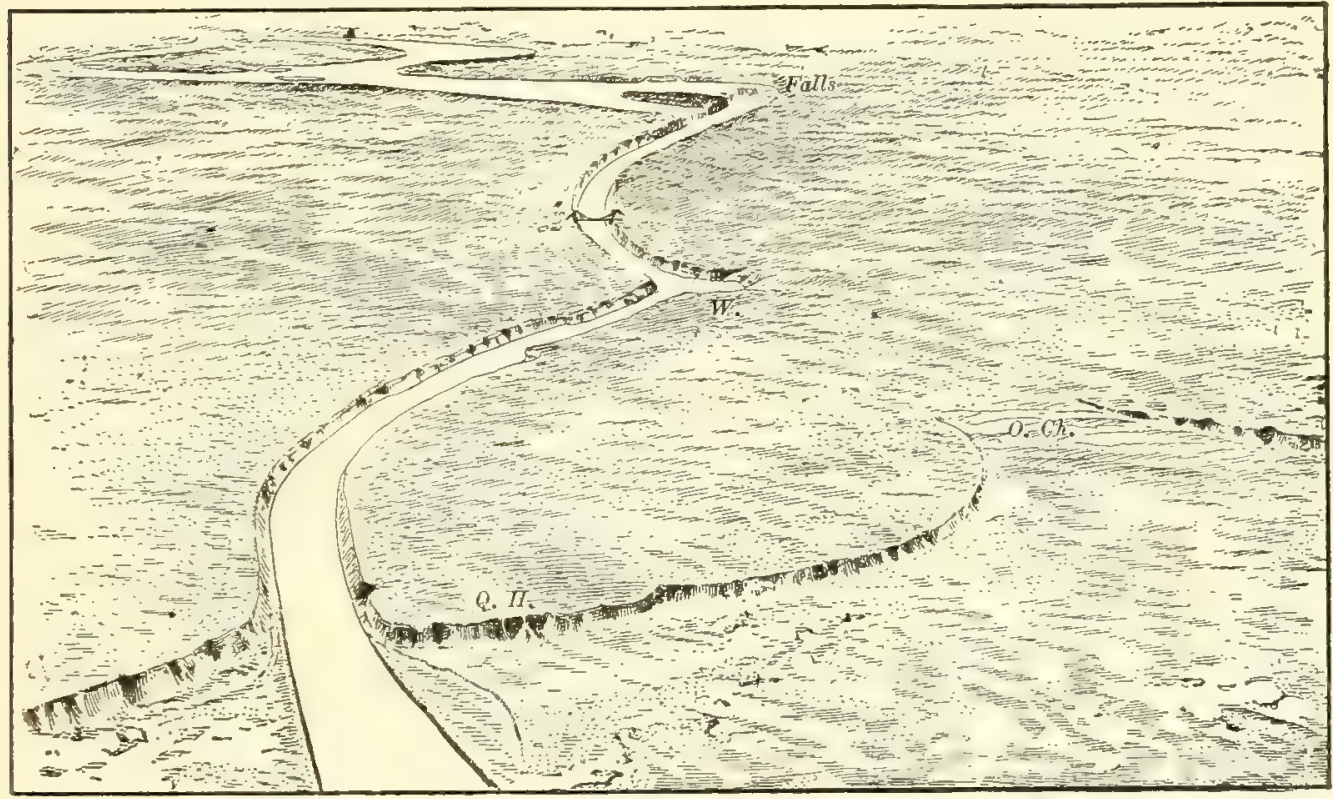

Birdseye view of the Niagara Gorge. W, Whirlpool; Q, Queenston; Q H, Queenston Heights; O Ch, old channel. From Gilbert.

Rock River, in northwestern Illinois, is stated by Chamberlin and Leverett to have been a tributary to the Illinois before the deposition of the Kettle moraine. But, through the drift-deposits then made, it was filled up for part of its course and thus was set to work making its present southwestward channel to the Mississippi.

During this time of melting, fluvial work was going on over all parts of the continent - quiet waters and those of prolonged floods alternating, where within the influence of the glaciers. The height of much of the land may still have favored the work of erosion along many valleys.

The Mississippi was the greater Mississippi through the larger part of the time; for there is yet no proof that before the ice left the United States it had lost its Winnipeg and Saskatchewan source. The valley received new deposits of loess and silt along some still-water portions, part of it over the earlier Lafayette formation, and silt and coarser beds elsewhere. The rivers of the Atlantic border south of New York were adding to the depositions in their valleys and along the seashore. But since snows were less 
common in the Appalachians than during the First Retreat, water was less abundant, and the deposits, therefore, were generally much like those of more recent time.

Deposits on the Atlantic border, partly marine and estuarine, and those of similar character elsewhere, have been named the Columbian formation. This formation is described by McGee (188s and later) as occurring over the coastal plain of the Atlantic slope, and ranging in height from over 100 feet in the south to 400 or more in the north. It consists of a series of subestuarine and submarine deltas and associated littoral deposits. The predominant and most significant phenomena are widespread stratified deposits and associated terraces, newer than the Lafayette formation of the same coastal region. Part of the deposits made during the earlier retreat also are described as Columbian. The formation, according to MeGee, is in part of submarine origin.

Another result of the melting and depositions during the long retreat was the making of innumerable lakes, especially over the more level portions of the glaciated region. There were probably thousands where there are now scores - like the Tundra regions of similar origin, in Russia. The gradual action of waters during their flood seasons have converted many lines into drainage channels, while numerous others have gradually become shallowed by depositions of earth and organic materials and passed to the conditions of swamps; and the swamps have ever since been drying up.

Topographical results of abrasion by the ice and ice-made streams. - The minor effects of abrasion by glaciers are scratches, groovings, polishing of surfaces over the harder rocks; making deep channels in the softer, such as limestone and many sandstones; producing forms over the surface like the moldings in architecture, but yards in depth and width, where the architect puts inches; carving out roches moutonnées, an example of which, from the region of the Holy Cross in Colorado, is represented on page 250; but not boring out pot-holes, which requires a stationary tool.

The larger effects of direct abrasion on the softer rocks are long and wide trenches, one or more hundreds of feet deep; shallow lake-basins, like that of Mono Lake in Nevada, which, according to Russell, was excavated out of limestone to a depth of 51 feet below the existing rim, its bottom and sides being limestone; river channels; ridges elongated in the direction of the movement of the ice; steep fronts on the struck or stoss side of hills - the side facing the ice-stream; and long-drawn-out ridges with gentle slopes on the opposite side. Another case is that of soft rocks saved from removal by being under the lee of a ridge of harder rocks, the harder ridge making a great cavity or notch in the ice, - as near New Haven, Conn., where a ridge of weak sandstone (Sachem Ridge, ou the map, page 993), a mile long and 100 to 165 feet high, was left under the lee of a trap ridge (Mill Rock), just as a tool with a notch in its cutting edge leaves a raised line on the surface of a board. The tearing and displacing work of frosts and freezing was also going on over all frosty regions, even those 
not glaciated. Deep lake basins in the harder rocks are not regarded as among the possible results of glacier excavation, their existence in glaciated regions being generally due to the damming of channels by the glacial deposits and sometimes to changes in level.

Thus a glaciated country bears everywhere the marks of the ice. The more delicate marks - the scratches or groovings - would be now universally visible over the exposed rocks, were it not for their removal by weathering. On the harder rocks they may generally be found by removing the soil.

The effects of abrasion and degradation are apparent also in the grander work of shaping mountains and excavating deep valleys; but in the production of these results, the ice was aided to a very large extent by the subglacial streams. Moreover, the degradation and excavation were carried on as effectually, or more so, by the later floods from the melting ice. The fiords are attributed to the ice; but the waters from the melted ice were the main eroding agent, while the ice worked chiefly by lateral abrasion.

\section{FOREIGN.}

In Europe the region of the Scandinavian Mountains was the great center of the accumulation and distribution of ice and bowlders. There were also some local centers : as in the Scotch Highlands ; in the Alps, Urals, Caucasus, and Pyrenees; in the mountains of Auvergne, Lyonnais, and Beaujolais, in France. At the time of maximum glaciation the ice was continuous from Scandinavia westward over the British Isles, eastward to the Urals, and southward almost to the parallel of $50^{\circ}$. The ice spread over nearly $55^{\circ}$ of longitude, which is $10^{\circ}$ more than was true in North America between the coast of Labrador and the Coteau des Prairies; but the degrees are much shorter, as the southern limit of the area lay $10^{\circ}$ to $13^{\circ}$ farther north than the North American. This difference in southern limits corresponds with the existing difference in the positions of isotherms on the two continents. The glacier did not cover England south of the Thames, nor any part of France. Brussels and Dresden were near its limit. The accompanying map (Fig. 1552), by J. Geikie (from his paper on The Glacial Succession in Europle. Roy. Soc. Edinb., 1892) shows, by the paler shading, the supposed limits of the ice during the time of maximum glaciation, and by the darker color. those during the epoch of the later Baltic glacier.

The glacial drift crossed the Baltic from Scandinavia eastward and southeastward over north Russia, the Baltic Provinces, and Noscow, reaching nearly as far south as Kieff; and southward over Denmark, part of Germany, and Poland. It spread southwestward over the Faroe and Shetland Islands and to the coast of Norfolk, in England. The distance of trarel varied from five miles, or less, to 500 or 600 . There is evidence also of transportation toward the Polar regions.

In Great Britain, the movements were mainly in the direction of the slopes of the mountains and their valleys, the drift radiating from different 
centers, as the Highlands and Southern Uplands of Scotland, the mountains of the Lake country in northern England, and the Snowdonian heights in North Wales; but only England received bowlders from Scandinavia.

1552.

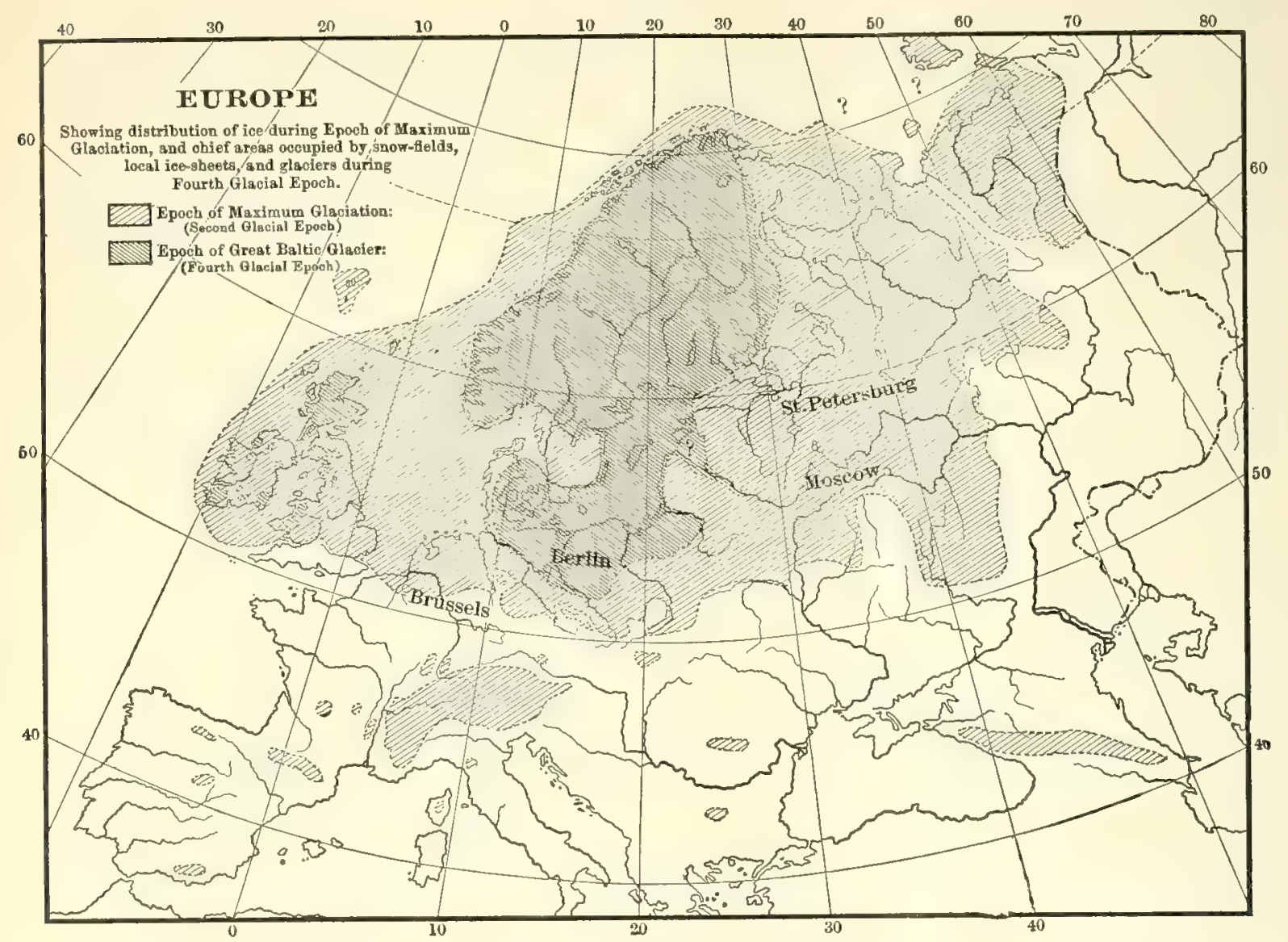

The height of northern Europe, if it was such as the fiords indicate, was sufficient to make dry land of the German Ocean (it being generally under 500 feet in depth, and 800-1200 feet along the Norway coast) and join Great Britain and Ireland to the continent, besides giving these islands widely extended borders on the Atlantic side. The depths of some Norwegian fiords vary from 2000 and less to 4020 feet.

The drift phenomena are exhibited on a grand scale about the Alps, especially along the valleys of the Rhone and Rhine. Lines of stones and gravel, and even great bowlders, have been traced (first by Professor Guyot) from the Alpine summits about Mount Blane, by the valleys of the Trient and Rhone, to the plains of Switzerland, and thence over the sites of Geneva and Neufchâtel to the Jura Mountains on the borders of France; and the declivity of this range, facing the Alps, is covered with the bowlders; one of them, the Pierre-a-bot, - a mass of granite (or more properly protogine), - is 62 feet long by 48 broad, and contains about 40,000 cubic feet, equivalent to a weight of 3000 tons.

Moreover, the valleys of the Alps have their sides nearly horizontally grooved or planed, to a height of 10,000 feet above the sea, or more than 
2000 feet above the present upper limit of the glaciers, or the level of any existing adequate abrading agency. The bowlders and scratches have been traced beyond Geneva, even to Lyons, and to Vienne, in Dauphiné.

A second epoch of glaciation is generally supposed in Europe to have followed a period of depression like that of the Champlain period, as mentioned beyond. J. Geikie makes the number of Glacial epochs in Europe five; but four counting from the epoch of maximum glaciation. In his Ice Age, of 1894, he recognizes in Great Britain six epochs, two of them after the Great Baltic glacier, or 4th. The first epoch in each case preceded the deposition of the Cromer Forest bed (page 927).

But the lofty mountains of Scandinavia - now in some peaks over $8000^{\prime}$ in height and glacier-covered, and then probably $11,000^{\prime}$ or $12,000^{\prime}$ - were not far distant, so that the glacial deposits of Great Britain might well bear evidence of the fluctuating conditions in the ice arising from modifications of climate and other causes. Oscillations in the deposits from till to stratified gravels and the reverse may have required no great length of time, and need no other cause. As Krapotkin, of Russia, says (1894), "The oscillations of the fringe of a vast ice-sheet may account for the formation of the layers which are described as interglacial. The considerable changes which must occur in the directions of flow of the ice-sheet may account for the crossing of striæ and erratics, as well as for the occurrence of interglacial beds." The deposits referred to as marking the intervals are not such as would necessarily have demanded, in each case, a long period of time.

It is a remarkable fact that no ice-mass covered the low lands of northern Siberia any more than those of Alaska. But recent accounts report that "the High Plateau of Asia, which stretches northeastward from the Himalayas as an immense triangle having its summit at Bering Strait, bear unmistakable traces, where studied in the region of the gold mines, of having been covered with thick sheets of ice. This is true of the border mountains of the High Plateau, the Himalayas, the Tian-Shan, the Altai, the Sayan, the Great Khingan, and others. With these few data, the only plausible hypothesis is that all of the High Plateau above 2000 feet to the north, above 3000 feet to the east of Lake Baikal, above 5000 feet in the middle portions, and still higher farther south, were covered with ice" (Krapotkin, 1894).

Over the southward slopes of the Himalayas, evidences of glacier action have been observed down to a level, 2000 feet above sea level in the Kangra Valley; to 4700 feet on the southern slopes of the Dháoladhár ; and to 5000 to 7000 feet in many valleys of Sikkim and eastern Nepaul. They occur also on Mount Antilibanus in Syria, in latitude $34^{\circ} \mathrm{N}$, on the Atlas Mountains in northern Africa, and on Mount Kenya, a peak about 18,500 feet high, not far from Kilima-Njaro, in British East Africa.

In South America, indications of a great ice-mass are met with, from Fuegia, as far toward the equator as the parallel of $37^{\circ} \mathrm{S}$., and especially, as Agassiz has shown, in the great valley between the main chain of the Andes and the Coast Mountains, to the latitude of Concepcion. Besides, glaciers had great extent about some of the higher summits along the Andes, and one near the equator. A. E. Douglass, of the Harvard College Observatory at Arequipa, has reported the existence of glacial phenomena of great extent, DANA'S MANUAL -62 
including vast moraines, on the slopes of Charchani in southern Peru. Glaciers existed in the Cordillera of Columbia about the peak of Cocui, 9,000 feet high, and in the Sierra Nevada de Santa Marta, 15,400 feet in height. In this region the decrease in temperature with altitude is now about $1^{\circ} \mathrm{F}$. in 330 feet.

In New Zealand, glaciers descended along the so-called Alps on the west side of the southern island, probably to the sea level. They were properly local glaciers. Captain Hutton states that in New Zealand the mountains were 3000 to 4000 feet higher than now. There were glaciers also in the Australian Alps about Mount Kosciusko in southeastern Australia, as reported by Von Lendenfeld in 1885, and in 1893 by R. Helms, and in western Tasmania.

\section{CAUSE OF THE Climate OF THE GLACIAL PERIOD.}

A. The cold climate. - 1. The elevation of the land over the globe, and especially in the higher latitudes, if a fact, as appears to be proved, is a sufficient reason for a large increase of cold, and thereby of frigid winds; and alone it goes far toward explaining the extension of a polar climate over the lower lands to latitudes where now the July temperature is $65^{\circ}$ to $70^{\circ} \mathrm{F}$.

2. This elevation would have made dry land, or a very shallow belt of water, across the North Atlantic from Scandinavia to Greenland and thus the Arctic regions would have been deprived of the large supply of heat they now derive from the Gulf Stream.

3. The confinement of the circnit of the Gulf Stream to the middle portions of the North Atlantic would concentrate thus its heat, make a much warmer ocean, and produce abundant precipitation.

4. With abundant vapors for precipitation thus produced, and the continents largely under a frigid climate, the snows which would have descended abundantly, would have been distributed over different regions with some reference proportionally to the ratio of precipitation; and this ratio would have been the modern ratio, modified by the topographic and oceanic conditions then existing.

The cold of the Glacial period has been attributed to the loss of the Gulf Stream by the Atlantic through the deep submergence of the Isthmus of Panama. But such a submergence is not sustained by evidence in the region. Moreover, there is proof that the Gulf Stream had the same effect on European climate in the Glacial period as now, in the fact that the relation of the isotherms of the two continents was unchanged.

Croll's theory, which makes the occurrence of a cold period dependent on the eccentricity of the earth's orbit, is explained on page 254. It is objected to by American geologists on the ground that the Glacial period closed, according to American geological facts, not more than 10,000 , or at the most 15,000 , years ago (page 255 ), instead of 150,000 , or at the least 80,000 , as the eccentricity hypothesis requires. According to this theory, the cold epochs of the northern and southern hemispheres occurred 11,500 years apart, or half the length of the precession cycle. J. Geikie, who recognizes six epochs of glaciation during the Quaternary, adopts the theory mentioned, and refers the times of the six 
epochs to as many precession cycles, during one period of maximum eccentricity, thus putting several thousand years between the till deposits of successive epochs in the northern and also in the southern hemisphere. There is no evidence yet reforted that the Glacial periods of the two hemispheres were not essentially simultaneous in their epochs. For a full appreciation of the views of Geikie, reference should be made to the recent edition of his Ice Age (1894), in which the arguments bearing on the question and on the views of others are fully presented. Moreover, he gives a later map of the Baltic glacier than that he published in 1892.

The merits of Croll's theory have been discussed mathematically and physically by G. F. Becker (Am. Jour. Sc., August, 1894), with adverse conclusions, as follows:-

"The summer of the eccentric period in the hemisphere of rigorous climate will be the hottest possible, nearly $20^{\circ} \mathrm{F}$. hotter, it would seem, than that of the present time in temperate latitudes. The evaporation would of course be immense. The heat gradient toward the pole is also considerably greater than it now is, or than it would be at the time of zero eccentricity. Hence the summer would be wet as well as hot. It seems to me, then, that the period of greatest eccentricity would be most unfavorable to glaciation, the snowfall being the smallest, and the summer rainfall the largest which can occur with the present obliquity. It seems much less favorable than the period of zero eccentricity when the winter cold is great enough to preclude much rain in the higher portion of the Temperate Zone, while the temperature in the tropics is great enough to produce active evaporation. It would be manifestly absurd to suppose equality of seasons sufficient to produce an ice age; but $I$ am forced to the conclusion that, so far as eccentricity is concerned in the matter at all, the smaller the eccentricity the more favorable are the conditions for glaciation." Considering the influence of the variation in the obliquity of the ecliptic, he states, as a further result of his investigation, "that the combination of low eccentricity and high obliquity will promote the accumulation of glacial ice in high latitudes more than any other set of circumstances pertaining to the earth's orbit. It seems to me that the Glacial period may be due to these conditions in combination with a favorable disposition of land and water. ... All the indications seem to point to the conclusion that within 30,000 or 40,000 years conditions have occurred, and have persisted for a considerable number of thousand years, which would have favored glaciation on the theory of this paper."

With reference to the return of the warmer climate which determined the departure of the ice, the theory suggests that when the period of combined low eccentricity and high obliquity of the apparent ecliptic was passed, the area of evaporation during the summer of the glaciated hemisphere must have increased, and, at the same time, the temperature gradient toward the pole must have become steeper. Both causes would have led to relatively heavy, warm summer rains in high temperate latitudes. Such rains would rapidly melt the ice-fields, making flooded streams.

The amount to which the mean temperature of the globe was lowered to bring on the conditions of the Glacial period was probably small. The existing mean temperature has been thought by some to be sufficiently low for the result, provided the summers were cool, and excessively wet through an increase of precipitation. This view is presented by J. D. Whitney, in his Climatic Changes of Later Geological Time (1882). But it appears to be more difficult to find a cause for such excessive precipitation than for greater cold. E. Brückner, in a recent discussion of the subject, concludes that a change in mean temperature of $8^{\circ} \mathrm{F}$. to $10^{\circ} \mathrm{F}$. would be sufficient. The lowering of the snow-line in Enrope required would be not over 3000 to 4000 feet. (Penck's Geogr. Abhandl., 1890.) 
B. The amelioration of the cold, and the retreat of the ice-sheet. - Setting asile Croll's theory, for the reasons already stated, the disappearance of the cold and wet climate that was the occasion of the ice period is naturally attributed to a reversal of the conditions that produced it - that is, to a subsidence of the land over the higher latitudes, and a deepening again of the sea over the submarine plateau between Scandinavia and Greenland, thereby restoring the Gulf Stream to its circuit in the Arctic regions.

But there appears to be good evidence that the melting had made great progress before there had been much subsidence of glacial regions. The facts stated on page 969 bear strongly in this direction; for they show that, however great the loss from melting and subsidence may have been, the southward slope of the ice-surface continued, and the Mississippi drained a large part of British America, even when the ice was making its last moraine on the northern borders of Minnesota.

These facts from the Continental Interior are sustained by others from the eastern border. It has been shown by N. L. Britton (1872), that the Pine Barren flora of the New Jersey coast region formerly occupied Staten Island and Long Island; and others have added to the range of its distribution the southern shores of Rhode Island and Massachusetts, with the adjoining islands. A. Hollick has reviewed the facts (1893) and referred the northward distribution of this southern flora to the period of Glacial emergence, which made New Jersey, Staten Island, Long Island, with the islands east of it and southern New England, continuous dry land.

The migration northward of the Pine Barren flora must have been during the later part of the time of high latitude elevation. The flora was first driven south by the ice, and long kept there. But finally, after the ice had retreated from New Jersey it was again restored; and when the retreat had made so great progress that the elimate of southern New England was right for the flora, it completed its northward migration. It is thus proved that southern New England had a climate warmer than now, long before the alleged subsidence had completed its work in southern New England.

These facts do not prove, however, that no subsidence had taken place in higher latitudes. That of the submarine plateau between Europe and Greenland may have been so far completed as to have caused a great modification in climate. Each stage in the retreat was a contraction of the area of perpetual frost, and a widening of the range of tropical winds, ensuring further encroachment. In view of all the facts, it is probable that before the subsidence had made large progress, the ice-sheet had retreated to Canadian territory, excepting the portions left about the higher mountains of eastern and western America.

It seems also to be true that the conclusion of Becker, deduced from his discussion of the question of Glacial climate, on page 979, suggests the right explanation of the initiation of the warmer climate and retreat. 


\section{Champlain Period.}

\section{AMERICAN.}

The Champlain period is so named from the occurrence of beds of the period on the borders of Lake Champlain.

The term Champlain was first used by C. H. Hitchcock, in the Report on the Geology of Termont (1861), for the marine beds of the period occurring along the lake, and for similar beds in the St. Lawrence valley, as a substitute for the term, "Laurentian deposits," applied to the latter by Desor. The author, in a paper, in 1856, adopted the latter name; but as Laurentian was earlier given by Logan to a subdivision of the Archæan, Champlain was substituted in the first edition of this work (1863).

The prominent events of the period are: (1) the completion of the subsidence begun in the closing part of the Glacial period; (2) the subsidence over large areas, greatest to the north; (3) the disappearance of the ice that remained on the mountains and elsewhere within the borders of the United States, and finally from the Canadian ice-plateau, completing the deglaciation of the continent; (4) a change of climate to one even warmer than that of Recent time; (5) the conversion of many of the southward flowing streams, that were eroding streams in the Glacial period, into feebly moving and feebly working streams, and the making of lakes; (6) the rapid growth of vegetation, covering hills, mountains, and prairie regions with the greatest of forests. A moister climate than the present is rendered probable by the greatly increased surface of fresh waters in lakes and rivers over the continent, as well as by the greater warmth of the climate.

The Champlain has been sometimes designated the Pluvial period, to mark its contrast with the Glacial period.

\section{THE SUBSIDENCE.}

1. Find of evidence. - Evidence of the subsidence is found on the borders of the continent in elevated shore-lines of the Champlain period, as beaches, shell-beds, seashore flats. rock planulations or terraces; and over the interior of the continent in the existence of lake-basins that were occupied by Champlain lakes, some of them exceeding in size any modern lake.

2. Amount aver the eastern Continental border. - The subsidence increased in amount over eastern America from the south, northward, and also from the seashore, landward. The difference between the level of the Champlain period and the present as indicated by shore-lines, terraces. shell-beds, and other eviclence is ahout as follows at the places mentioned: on the southern shores of New England, near New Haven, 20 feet; shell-beds in deposits at Sancati Head, on Nantucket, 80 feet; on the coast of Maine, as proved by fossils, 150 to 300 feet; the upper benches at Mount Desert, Me., 270 to 300 feet (Shaler).

Along the north and south valley of the Connecticut, terraces increase in 
height northward, to 260 feet at a distance of 200 miles from Long Island Sound.

Again, at the mouth of Hudson River, according to F. J. H. Merrill, there is evidence of a Champlain subsidence of 70 feet; 35 miles up the river, at Croton Landing, of 100 feet; 50 miles up, of 180 feet; 140 miles up, about Albany, of 335 feet. Farther north the divide between the Albany plain and that of the Champlain region, was evidently covered for awhile by fresh water as stated by S. P. Baldwin; and hence the rise in level along the Hudson may be regarded as continued along Lake Champlain. A reduced

\section{3.}

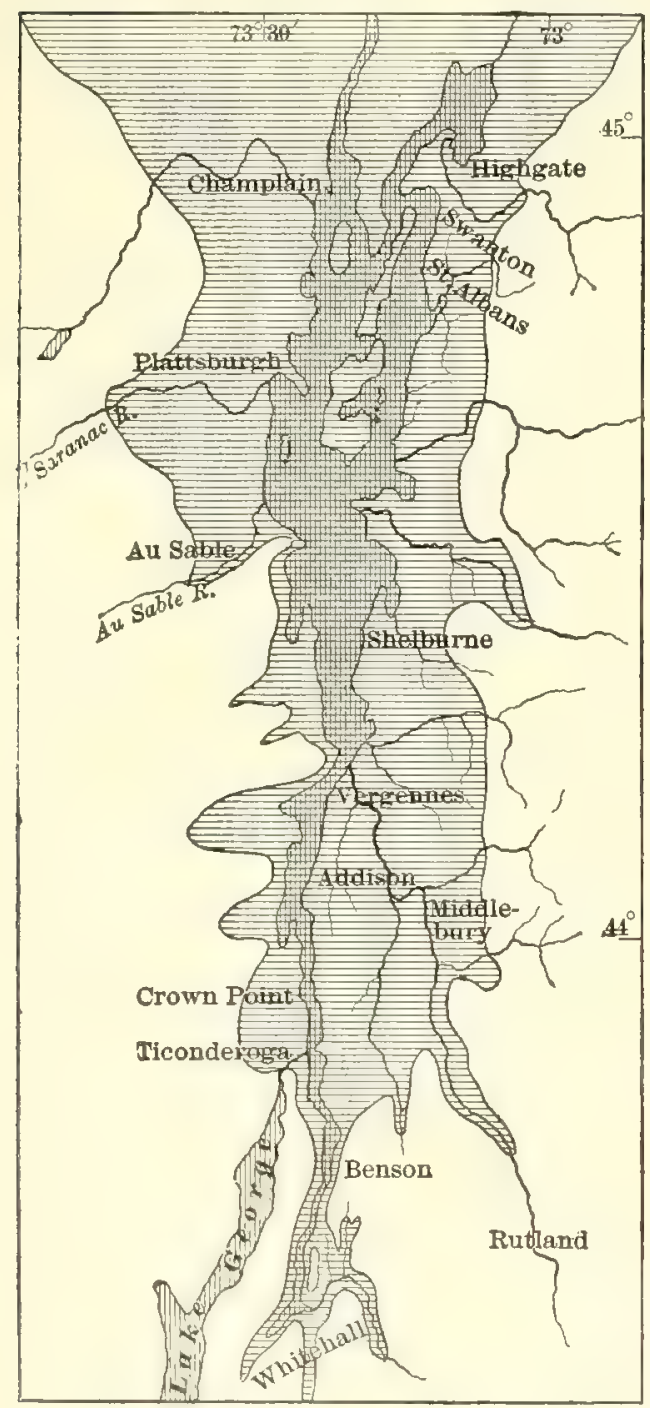

Map of Lake Champlain in the Champlain period (transversely lined), with the existing lake (cross-lined). copy of a map of Lake Champlain of the Champlain period is here inserted from a paper on the terraces of the lake by Baldwin (1894). On the southern part of the lake, at Benson Landing, terraces extend to 370 feet; at Orwell, 410 feet; at Charlotte, $\mathrm{Vt}$., near the middle of the lake, 415 and 450 feet, and they contain marine shells; at St. Albans, near its north end, 500 feet. Marine shells occur in the terraces of the Vermont side to Addison, or through the northern two thirds of the lake, and at Plattsburgh on the west side.

On the St. Lawrence, near Montreal, 30 miles distant in a nearly north direction from Lake Champlain, shell-beds occur at 520 feet; and up the St. Lawrence, according to Dawson, nearly to Lake Ontario, west of Lake Champlain, at 600 feet. The increase in the height of the terraces northward, as well as landward, is here apparent.

But these heights of beaches and terraces represent but a small part of the actual change of level. For the land in the preceding period stood higher than now. Adding to the above the minimum estimate of that elevation, the actual amount of subsidence for southern New England is 160 to 170 feet; for the coast of Maine, 1000 feet or more; at Montreal, 1500 feet at least, and 1200 feet or more for the Lake Champlain region. A similar addition is required also for the deductions from the heights of all terraces and beaches, including those of the region of the Great Lakes. The facts prove that ice barriers were not concerned in making limits for the lakes; for the ice had retreated 
to the north of them; that salt water reached up the St. Lawrence, then a great bay, nearly to Lake Ontario, and that this lake lay at sea level, receiving the tides, although freshened in its waters by the flow from the contributing streams, so that no marine remains have been found on its borders. It also appears that a great branch bay extended from the St. Lawrence northwestward up the Ottawa valley, to a point 75 miles beyond the city of Ottawa, and another southward over the region of Lake Champlain.

Morenver, this great arm of the sea, 500 to 600 feet in depth of water at Montreal, and 700 to 900 feet in Lake Champlain, besides nurturing Mollusks, was a sporting ground for Seals, Morses, and Whales. Bones of the Humpbacked Whale, Megaptera longimana, have been reported by Dawson as found 440 feet above the sea in the County of Lanark, 31 miles north of the outlet of Lake Ontario; and remains of the White Whale, or Beluga (a species related to the Porpoise), both along the St. Lawrence, and on the borders of Lake Champlain, in Vermont, where a skeleton was found. The latter is the Delphinapterus leucas (=catodon) or "White Whale," the Beluga Vermontana of Z. Thompson. These two Aretic species, the Humpbacked Whale and Beluga, are now occasionally met with in St. Lawrence River.

At New Haven, Conn., an even slope of the terrace surface is continued to the Sound, near Savin Rock, and appears to indicate no change of level since the Champlain period. But on the borders of the bay, both the eastern and western, there is a terrace of $20^{\prime}$, which is safer evidence on this point.

South of Cape Cod, at Sancati Head on Nantucket, the beds above sea level, as described and represented in a section by Desor (1849), consist, at base, of tilted beds of clay; horizontally above, of $33^{\prime}$ of beds of sand, gravel, and clay containing fossils ; $42^{\prime}$ of sand and gravel without fossils; and then, at top, of 1 of peat and $6^{t}$ of dune sand. The species of shells in the beds, according to Verrill (1875), are kinds now inhabiting the region, those of the lower beds indicating a summer temperature of $70^{\circ}-75^{\circ} \mathrm{F}$, and those above, of $55^{\circ}-60^{\circ} \mathrm{F}$. Shaler gives a full account of the geology, with Verrill's list of species, in Bull.53, U.S.G.S., 1889.

In Maine, shell-beds occur at many places near the coast - at Portland, Cumberland, Brunswick, Thomaston, Cherryfield, Lubec, Perry, etc., at different elevations up to $225^{\prime}$; also distant from the coast, at Gardiner, Hallowell, Lewiston, Skowhegan, Clinton Falls, and Bangor. At Lewiston, a starfish and various shells were found in a bed $200^{\prime}$ above the ocean and $100^{\prime}$ above the Androscoggin River; at Skowhegan, the beds are $150^{\circ}$ above the ocean, and $100^{\prime}$ at Bangor; near Mount Desert, a sea bottom deposit, on North Haven Island, is $217^{\prime}$ above sea level.

The beds of Maine have afforded (Packard): Pholas crispata, Saxicava aretica, Mya truncata, M. arenaria, Thracia Conradi, Mecoma fragitis, M. sabulosa, INactre ovalis, Astarte Banksii, A. elliptica, A. arctica, Cardium Islandicum, Serripes Gronlandicus, Leda pernula, L. minuta, Yoldia glacialis, Pecten Gronlandicus, P. Islandicus, Natica clausa, Lunatia heros, L. Groenlandica, etc.

Shell-beds occur at several levels and many localities, along the St. Lawrence, as observed by Logan and Dawson. Part of them, as Dawson has shown, are sea beaches, and others are offshore deposits - the Leda clays. Beds occur west of Montreal, near Kemptville, at a height of $250^{\prime}$; near Ogdensburg, $275^{\prime}$, and also near Brockville; near the city of Ottawa, $450^{\prime}$; in Winchester, $300^{\prime}$; in Kenyon, $20^{\prime}$; in Lochiel, $264^{\prime}$ and $290^{\prime}$; at Hobbes 
Falls in Fitzroy, 350' ; at Dulham Mills, 289'; in the counties of Renfrew, Lanark, Carlton, and Leeds, 425'; east of Montreal, near Upton Station, 257' f farther east, on the river Gouffre, near Murray Bay, $130^{\prime}$ and $360^{\prime}$; on Prince Edward Island, Tellina Groenlandica, at a height of 50 . At the Straits of Belle Isle, Labralor, the deposits, on either side, are about $400^{\prime}$ above the sea; at Chateau Bay, $500^{\prime}$, probably $800^{\prime}$ in some parts. (Packard); and at Nachvak, 1500' (R. Bell), where there are shell-beds. In Lake Champlain, the shell-beds extend to its southern extremity.

The Leda clays of Dawson afford species living now at depths less than $100^{\prime}$; the lower Leda clays containing Tellina Gronlandica and Leda arctica; and the upper, species that are now living in St. Lawrence Bay. Of the higher sand-beds, Saxicava rugosa is the common species.

The more common shells of the Montreal beds are the following (Dawson): Saxicava aretica, Mya truncata, M. arenaria, Macoma fragilis, M. sabulose, Astarte Laurentiana, Mytilus edulis, Natica clausa, Yoldia glacialis, Trophon clathratum, Buccinum Gronlandicum.

Among the species at Beauport, there are the following: Lunatia Groenlandica, L. heros, Turritella erosa, Scalaria Gronlandica, Litorina palliata, Serripes Groenlandicus, Cardium Istandicum, Pecten Islandicus, Rhynchonella psittacea, and many others. All are cold-water species, so that the fauna is more Aretic in character than that. of Montreal, corresponding with the fact that Montreal is 150 miles northwest of Beauport (Dawson).

The Capelin (Mallotus villosus Cuv., a common fish on the Labrador coast) has been found fossil on the Chaudière Lake in Canada, 183' above Lake St. Peter; on the Madawaska, 206'; at Fort Colonge Lake, 365'.

On the Bay of Fundy the shell-beds have a height of $200-225$, and on the Bay of Chaleurs, 200'. The beds descend below the sea level. The Leda clays of the latter region contain Leda minuta, L. pernula, Mya arenaria, M. truncata, Mytilus edulis, Nucula tenuis, Saxicava rugosa (most common), Macoma calcarea, Yoldia arctica (Leda truncata), Buccinum undatum, Margarita striata, Natica clausa, Serripes Grœnlandicus (abundant), and other species (Chalmers, 1885). The Saxicava sand in the Bay of Fundy contains Mya arenaria and Macoma fusca; but shells are rare.

On the coast of Labrador, the elevated Champlain beds contain mostly the same. species, both those of the Leda clays, and the overlying beds. Among the species lessabundant farther south, or not at all, are Cyclocardia borentis Con., Astarte Banksi, Margarita varicosa, Turitella reticulata, $T$. erosa, Aporrhais occidentalis, Admete viridula, Bela exarata, B. harpularia Adams, B. robusta Pack., B. turvicula, Fusus tornatus, F. Labradorensis Pack., Buccinum undatum. (Packard.)

On Grinnell Land, in the Arctic seas, shell-beds resting on Miocene have an elevation of 1000', and contain the usual cold-water species, Mya truncata, Saxicava rugosa, Cardium. Islandicum, Astarte borealis, Pecten Gronlandicus, etc. (Feilden, 1877.)

The paper on the Lake Champlain region, with a map by S. P. Baldwin, is contained: in the Amer. Geol., xiii., 1894. Baron de Geer (Proc. B. N. H. Soc., xxv., 1892, Amer. Geol., xi., 1893) gives 658' for the marine limit at St. Albans; but Baldwin concludes: that the terrace at this level was that of a glacial lake.

3. Amount of subsidence over the Western Continental border. - In the region of Mount St. Elias, according to Russell, deposits of moraine material 4000 to 5000 feet thick occur in the Chaix Hills; and the eliffs of Pinnacle Pass, at the sime height, contain shells of the Champlain species Mya arenaria, Mytilns erlulis, Leda minuta, Cardium Istandicum, Foldia limatula, Thracia curta, and others. B. Willis has reported that marine beds are found at a 
height of 1600 feet on the borders of Puget Sound, but nothing is further known with regard to the formation. G. M. Dawson states that beds, probably marine, occur at Queen Charlotte Islands and along the Straits of Georgia at a height of 100 to 200 feet.

Between San Francisco and San Diego, shore-lines and terraces have been observed by A. C. Lawson, at various levels up to $1500^{\prime}$; but no marine fossils are present, so that whether Quaternary or Pliocene is uncertain. The heights measured near San Diego are from $160^{\prime}$ to $700^{\prime}$; on San Pedro Hill, $120^{\prime}$ to $1240^{\prime}$; on San Clements Island, from $12^{\prime}$ to $1500^{\prime}$; the Bay of Monterey, near Santa Cruz, from $96^{\prime}$ to $120^{\prime}$, part of them showing grandly from the bay. Moreover, the Pliocene, near San Francisco (page 892), has now a height of $720^{\prime}$ above sea level.

About the mountains of the Interior Plateau of British Columbia, as stated by G. M. Dawson, there are extensive terraces $5000^{\prime}$ to $5500^{\prime}$ above sea level; and in the more southern part of the plateau, of $3900^{\prime}$ to $4900^{\prime}$. But they afford no marine fossils, and their origin remains unexplained. Dawson questions whether they may not have been made by superglacial lakes.

The depths of the submerged river channels of the California coast (page 949) indicate an equal subsidence of the region, if the channels were made, as is believed, during the Glacial period.

\section{The Winnipeg-Lake basin, in the Central Continental Interior, and Hudson} $B a y$. - The former discharge of a river from $55^{\circ} \mathrm{N}$. in the Winnipeg region, down the Minnesota into the Mississippi, as first made known by G. K. Warren, is mentioned on page 947. Later, as the same authority pointed out, the region then elevated had subsided and become the area of a vast lake. The outline of this lake, and the region of lakes it covers, are shown on the map, Fig. 1548, from the report by Upham, who named the lake, Lake Agassiz. Its waters extended, according to the map, from the Minnesota divide at Traverse Lake in $45^{\circ} 40^{\prime}$, over the Red River and Winnipeg region, to $55^{\circ} \mathrm{N}$. in Manitoba, nearly half of the whole length, 700 miles, being in Minnesota. The upper shore-line, called by Upham the Hermann Beach, was traced from Lake Traverse, where it is 85 feet above this lake, and 1055 feet above sea level, northward for more than 300 miles, where the height about the Brandon Hills is 1260 to 1269 above sea level, and about 560 feet above the present level of Lake Winnipeg. This shore-line indicates, therefore, a great Champlain depression for the region about Winnipeg. The Hermann Beach rises northward at a rate of six inches a mile near Iake Traverse, to 16 inches to the northward, bearing evidence, inasmuch as the lines were horizontal when made, of a subsequent elevation that increased northward, the time of which was probably at the opening of the Recent period.

Warren accounted for the non-discharge of the great lake by the present outlet, Nelson River, into Hudson Bay, on the ground of a land barrier; and his explanation appears to be sustained by the course of events of the period. For, if the region of the Laurentide ice-plateau about Hudson Bay was elevated 3000 feet or more in the Glacial period, the continuation into the early part of the Champlain period of only a small portion of this elevation 
would make all the barrier needed. The pitch of the land about Nelson River is now eastward, and the rate about two feet a mile.

Upham sets aside the idea of this change of level, and makes the lake and the southward discharge the result of a damming by the ice-sheet along the northeast border of the lake. For details of his observations and his view of the events of the period, the reader is referred to his elaborate report already mentioned. On the slopes leading down to James Bay, the southern extremity of Hudson Bay, marine deposits occur up to a height of 450 feet above the level of Hudson Bay, indicating that the Hudson Bay region finally lost all its elevation, and became, further, much depressed. This is part of the evidence presented by Upham to prove that the ice-dam was required. But there is doubt whether the retreating ice would have long remained a barrier under the warm climate of the Champlain period.

5. The region of the Great Lakes. - Lake Ontario, now 247 feet above the sea, was in Champlain time at sea level, at the head of the long St. Lawrence Bay, as already explained. But the northern and southern shore-lines are widely different in height, owing to the warping of the surface in the later reëlevation. North of the middle of the lake, the height above the water surface of the prominent shore-line or beach (called the Iroquois beach by Spencer, who mapped its position) is 355 feet, while south it is 189 feet, whence the increase in height northward is 166 feet in a distance of 60 miles. At the east end of the lake depression, the corresponding heights are 483 feet at Watertown and 194 near Rome, an increase northward of 289 feet in 60 miles. The depth of the lake at the time was nearly 1000 feet equal to the present depth, 740 feet, plus the mean height of the opposite shore-lines. (The positions of these upper shore-lines are given on the map.)

Westward along the lake, the height of the upper shore-line decreases, and at the west end, 200 miles distant from the east, it is only 116 feet - a diminution from Watertown of 367 feet in 200 miles.

Lake Erie is now 326 feet above Lake Ontario, or 573 feet above sea level. The height of its upper shore-line south of the lake, at Cleveland, is 213 feet; and that of the upper, north of it (the Ridgeway beach of Spencer), is 273 to 351 feet. The heights increase eastward. The upper at the west end, near Fort Wayne, is 207 feet, and toward the east end, 261 feet. The mean height of the upper line south of the lake is about 200 feet, and the same is true as regards the southern shore-line of Lake Ontario. The fact suggests the inference that the heights of the two lakes may have had the same difference then as now. Through the subsidence the lake lost its outlet to the Ohio - the Wabash River, which had served this purpose, becoming a tributary to the lake.

Lake Superior is now 602 feet above sea level, and Michigan and Huron, 582 feet. The latter lakes are but nine feet above Lake Erie.

On Lake Superior, the upper shore-line of the north side has a height above the lake at Josephine Mountain - 50 miles west of Thunder Bay according to A. C. Lawson, of 509 to 607 feet; at Duluth, the west end, of 534 
feet; and that of the south side, according to J. B. Taylor, at Marquette, a height of 588 feet; at Kimball, 90 miles east of Duluth, of 568 feet; and at Maple Ridge, 25 miles east of Duluth, of 532 feet. The observations, especially those on the north side, are not numerous enough to give the mean height, but it is not far from 550 feet. The outline of Lake Superior, which these shore-lines indicate, is shown on the map, as laid down by Taylor.

East of Georgian Bay, on the Nipissing Strait at North Bay, Ontario, Taylor obtained, on the south side, the terrace height, 618 feet above the level of Lake Superior, and on the north side, 538 feet.

At the south end of Lake Michigan, the height of the upper shore-line is only 45 feet; at Mackinac Island, in northern Michigan, 205 feet; southwest of Huron, 267 feet.

These heights of the upper shore-lines of the lakes - Superior, Huron, Michigan, and Erie - are widely different, yet they are supposed to have been the heights of the upper shore-line of one great lake, named by Spencer Lake Warren, after G. K. Warren.

The mean height of 550 feet above the lake, or 1152 feet above sea level for the shore-lines of Lake Superior is not the height to which, in the Champlain period, the copious waters of the period raised the surface of the lake; but that which was given the region at the epoch of elevation which closed the Champlain period. So great a height for Lake Superior without a barrier at the outlet to Huron and Michigan was an impossibility. Lower shore-lines exist which mark successive levels in the waters of the Lake Warren region during the progress of the elevation; and an upper series of these, about Huron and the more western lakes, is the Algonquin beach of Spencer.

There are various opinions as to the actual height of Lake Warren above sea level, and as to the discharge of its waters. Discharge by Lake Nipissing into the Ottawa and St. Lawrence has been suggested. The uncertainties involve the condition of Niagara Falls.

The present heights of these shore-lines above the sea for the four western lakes supposing the shore-lines assumed to be cotemporaneous to have been actually so - are $1100^{\prime}$ to $1200^{\prime}$ for Lake Superior; about $787^{\prime}$ for Mackinac Island, between Huron and Michigan; $850^{\prime}$ for southwest Huron; $630^{\prime}$ for the south end of Michigan, and $775^{\prime}$ for the south side of Erie. As to actual Champlain heights, that is, heights before the elevation at the close of the Champlain period, no good basis for a conclusion is known except for Lake Ontario, which was at tide level.

Supposing the height above sea level of the water plane of the combined four lakes to have been $600^{\prime}$, the Superior shore-lines would have had less height than now by $550^{\prime}$; the Mackinac and Huron by $187^{\prime}$ and $230^{\prime}$; the south Michigan by $30^{\prime}$, the south Erie by 175'. But with the water plane at this level, Niagara, if in the course of discharge, would have had a fall of $600^{\prime}-$ a condition not in accordance with any observed facts.

Again: if the water plane of these lakes were about $300^{\prime}$ above sea level (not far from the present height of Lake Erie above the level of Lake Ontario), Niagara Falls would have been like the modern Niagara in height, but possibly a third higher, and certainly of many times greater volume and power, owing to the northern drainage from the melting ice-plateau. 
Again, if the water plane were at or near the sea level, as is sometimes claimed, Cntario would have been in the combination, and there would have been no Niagara Falls until the elevation at the opening of the Recent period. The idea that it was low enough to receive salt water is set aside by the absence of remains of salt-water life.

As the above suppositions suggest, the subject has its many doubts; and they extend to Niagara Falls as well as to lake levels. Many, therefore, are the diverse geological explanations. The above are only suppositions. For other recent views, see C. K. Gilbert's History of the Niagara River, Smithsonian Report for 1890 ; J. W. Spencer, Amer. Jour. Sc. for 1891 and 1894; W. Upham, ibid., Jan., 1895 ; and F. B. Taylor, ibid., April, 1895.

Lake Ontario has been supposed to have had an outlet in Champlain time, from its southeastern extremity at Rome by the Mohawk River to the Hudson, on the ground that the St. Lawrence at the mouth and elsewhere was under the border of the ice-sheet; and it has been stated, in opposition, that the Mohawk flows over a rocky bottom at Little Falls, at a height of $370^{\prime}$ above the sea. The shell deposits on the St. Lawrence near its mouth at a height of 600 feet, are evidence that the ice had disappeared; so that its mouth must have been open for the discharge of the lake. But still, since the Champlain depression at Rome was 194', directly east at Albany near 350', and along the St. Lawrence $500^{\prime}$ to $600^{\prime}$, it is possible that all northern New York to and beyond the Mohawk was sufficiently depressed for the more southern discharge.

In reply to the suggestion that Lake Superior and others in the combination may have discharged through Huron and Lake Nipissing into Ottawa River and thence to the St. Lawrence, it has been stated that the channel beyond Lake Nipissing, along Mattawa River, has no appearance of having been the course of a stream larger than the present (A. Barlow, in letter from G. M. Dawson). The height of Lake Nipissing is only $40^{\prime}$ above that of Lake Superior, and the highest land farther east is but $25^{\prime}$ above this, while the height at the confluence of the Mattawa and Ottawa is $6^{\prime}$ below the level of Superior.

Lakes of the Great Basin. - Among the flooded lakes of the Glacial and Champlain periods none have greater interest than those of the Great Basin. The largest of them are: the expanded Great Salt Lake of Utah, or Lake Bonneville, as it was named by Gilbert in 1876 in honor of Captain Bonneville, who gave the first account of the existing lake after a visit in 1833; and Lake Lahontan, so named by C. King, in 1878, after the explorer La Hontan. The former lay against the eastern side of the Great Basin; and underneath it were Lakes Provo and Sevier, as well as the Great Salt Lake. Great Salt Lake was quadrupled in length and increased in its waters 400 fold. Lake Lahontan covered the localities of many small lakes along the western side of the Great Basin. Lake Bonneville is described at length by Gilbert (1890), and Lahontan by King, and also later by I. C. Russell (1885). The lakes, as defined by Gilbert and Russell, are shown on the map, Fig. 1548.

There are a number of terraces about both regions which mark the shore-lines of the former greater lakes. The highest terrace of Lake Bonneville shows that at maximum flood the water stood 1000 feet above the existing level of Great Salt Lake.

The occurrence of two sets of terraces, and of two sets of deposits in the lake area, one of clay and another of marl, indicate, according to Gilbert, the occurrence over the Great Basin, in the Quaternary era, of two epochs of floods, and of a dry interval between in which the level of the lake was reduced from $1000^{\prime}$ to $200^{\prime}$ above the present level. 
King and Russell deduced nearly corresponding conditions from the region of Lake Lahontan. They describe large depositions of tufa during a warm interval of evaporation; and a second deposition during the final desiccation. The latter produced, besides some tufa, a mineral which became changed to calcium carbonate (thinolite of King, page 133). Lake Mono and other lakes in the Basin experienced similar changes.

The Great Basin owes its existing dry condition to (1) the feeble amount of annual precipitation (less than 8 inches, according to Schott's chart) and (2) the great evaporation caused by the high temperature of the region. The precipitation would have been, even in the Glacial period, relatively small ; but the temperature then was cold, to freezing, and consequently evaporation became relatively small. It is thus argued that the lakes of the Great Basin were swollen during the times of Glacial cold, owing to the diminished evaporation and some melting; that floods from the melting at the time of the Glacial retreat would have added largely to the waters and carried them up to a state of maximum height; that the waters would have diminished during the following return of glaciers over the neighboring mouniains; and then would have reached a second maximum, when melting again made floods under the warm climate and abundant precipitation of the Champlain period. The floods having passed, a drier climate ensued; and that is still continued.

\section{EROSION, TRANSPORTATION, AND DEPOSITION.}

To Champlain history belong the events that occurred during the time of land depression and warm climate of the Middle Quaternary. The work of erosion, begun in the later Tertiary, and carried on over the continent and about the newly lifted mountains and elsewhere by the ice and waters of the Glacial period, was continued with great energy through the earlier part of Champlain time; and the results are to be seen in the bold and crested heights and deep cañons of the Rocky Mountain region, and in deeply cut gorges over a large part of the land. But later in the period, transportation and deposition were the chief work of the rivers. There were also shallow lakes about which Mammals congregated and left their bones in lacustrine deposits. Peat beds and marshes abounded, and these have special interest from the remains of Champlain life which they contain, especially the heavy Herbivores which became mired in them in their efforts to escape from pursuit. Cave deposits also have prominent importance, they having been the resorts of Carnivores, Rodents, and other species, and containing also bones of the various animals dragged in for food. And as the caverns commonly occur in limestone, the deposition of stalagmite over the floor of the cave has often enveloped in stone, skeletons and their fragments, with other relics of the occupants.

Champlain seashores also have their deposits; and by means of their numerous shells and other fossils of shallow-water and beach-made accumulations, they mark the limits, as already shown, of marine submergence in many regions from which the sea is now exeluded.

Fluvial and lacustrine deposits. - The Champlain subsidence diminished the pitch of southward-flowing rivers. It sometimes reduced it to zero, when lakes formed if there was room for them; and occasionally it reversed the direction of flow in a stream. Consequently it converted excavating 
rivers, which under the high slopes of the Glacial period had produced profound channels, into quiet streams that made fluvial deposits along the way, and often, when in gentlest flow, still-water deposits. It has been shown that when Champlain time began, the ice had already retreated to the mountains, and, with this exception, had left New England and the states to the westward. Enough ice still remained, however, to give waters freely, and some floating ice also, to the streams which had their sources near the borders.

The absence of the ice sheet from the St. Lawrence valley after the making of the lower fourth of the deposits, is proved by the presence in the beds of shells of Mollusks and relics of other species that lived in the waters when the 100-foot level, near Montreal, was in progress; and also in Lake Champlain, when but 50 feet of the beds had been laid down. Seals and Whales would not have gone beneath the ice hundreds of miles for a Champlain resort. Moreover, since the St. Lawrence River makes four degrees of northing on its way to the sea, the evidence proves that the clearing from ice extended as far north as the borders of Labrador.

But it is important to remember that the river valleys were to some extent the courses of streams in the Glacial period, and therefore that beds of the Champlain period may rest on others of clay or sand which are Glacial in period of formation. Sometimes these fluvial beds of the Glacial period may be distinguished by the presence of bowlders; but this criterion is not altogether safe, since floating ice of the Champlain period may have been the source of the bowlders. At the North Haven clay-pits, a few miles north of New Haven, the straticulate clays contain a few bowlders two or three feet in diameter; and it was in one of these clay-pits that the two bones of Arctic Reindeer were found, mentioned on page 946. The time of deposition was probably in the earliest part of the Champlain period or the later of the Glacial.

Deposits of clay appear to have been most abundant in the early part of the Champlain period, after the subsidence had reached its extreme limit, when the flow of the streams having a southward course was feeble. The later increase in the waters, raising the flood level, involved an increase in the pitch of the surface, and therefore a quicker flow; and then sands succeeded to the clays, and in many regions still coarser deposits, ending often with the coarsest cobblestone deposits when the flood was at its height.

The stratification of the deposits hence varies from the most regular, or that of gently-moving waters, to that which could form only under a vast simultaneous supply of gravel or sund, and water. The flow-and-plunge style of deposition (page 93) is common. Beds of this kind occur with others of horizontal bedding, or sometimes locally in the midst of coarse gravel deposits, such stony gravel not participating in it because of its coarseness. Very often, also, the beds indicate that after deposition large portions had been washed away by some local rush of the flooded stream, and that later the excavations thus made became filled. 
The tributaries of a river, when torrential, often carried into the valley great quantities of gravel and stones, and made river-border deltas on a continuous series of levels, as the deposits rose in height. The materials thus received were stratified in part by the waters of the river, the finer portions being taken up and drifted on to make the finer deposits down stream. The delta-like deposits give local coarseness and irregularity to the beds and somewhat greater firmness, so that, under erosion, they sometimes are made to stand out and look a little kame-like, although strictly of fluvial origin.

Under the abundant supply of water, the width of the flood grounds or river flats in many large valleys became increased to miles, and in some cases to scores of miles. Over such flood plains, through all the progressing deposition and varying velocities of flow in the river channel, there were, as in modern flood plains, areas of relatively quiet waters, where beds of clay or fine earth were formed, giving the valley-formations a great diversity of constitution. Further: rivers in some places became dammed by floating ice and whatever else the waters transported, as now in modern floods; and these dams were the cause of quiet deposits in the waters above them, that is, of extensive beds of clay and fine sands or earth. Through the two agencies, subsidence and dams, and perhaps in a few cases elevation of the land toward the mouth of the stream or elsewhere, nearly all the transitions in the nature of the fluvial deposits, from clays to the coarsest kinds, have their explanation. The height of the highest flood plain gives approximately the height of the maximum flood.

The Champlain deposits along valleys or about lakes are usually terraced. A view of the terraces on the Connecticut below Hanover is given on page 195.

The following figure is a generalized section of a terraced valley.

1554.

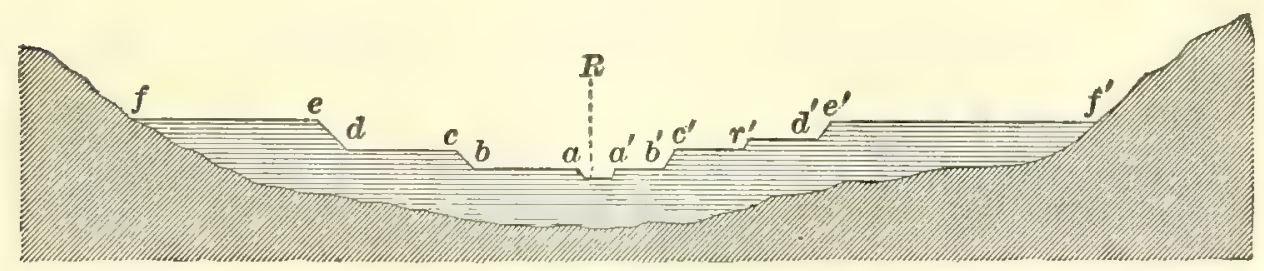

Section of a valley, with its terraces completed.

In this figure, the channel which the river occupies at low water is at $R$; $a b, a^{\prime} b^{\prime}$, are the flats either side which become flooded in modern high freshets, - in other words, the flood-grounds; ef, $e^{\prime} f^{\prime}$, are the flood-grounds of the river (or what is left of them) during the great Champlain floods. The intermediate terrace-plains are other levels, formed either during the rise of the flood, the water while on the increase flowing long, it may be, at certain levels; or during the decline, which also may have taken place by stages, and have been long in progress. Part may be under-water levels; for great streams and lakes, or lake-borders, often have shoals at two or 
three levels; and part may have been occasioned by the contributions of side valleys, and unequal resistance to wear. On account of this feature the formation is often called the Terrace formation.

On the Connecticut the upper flood plain or terrace is, for the most of the way, $150^{\prime}$ to $250^{\prime}$ above the river. Large deposits of clay occur in the lower part, and others of less extent at various levels to the top. The stream owes its abundant waters to the high mountains about its sources, of which the White Mountains were the highest. The depth of water may have been $50^{\prime}$ or $100^{\prime}$; there is no basis for a satisfactory estimate.

Along the Hudson River the height of the upper terrace is $100^{\prime}$ to $280^{\prime}$, and finally $340^{\prime}$ between Albany and Schenectady. As before stated, the heights increase to the northward, where the Champlain subsidence was greatest.

The Connecticut River had a dam at the narrows below Middletown, Conn., as the fall off in the terraces below it shows; another, as stated by B. K. Emerson, near Northampton, Mass, between the opposite trap ridges, Mount Tom and Mount Holyoke; and possibly others. Just above the Northampton dam, where the upper terrace-plain is about $200^{\prime}$ above the river, a portion of the flood-waters escaped over the west bank near Florence, passed to the west of Mount Tom, and took a southward course along the Farmington valley, as the levels of the terrace-plain show, to New Haven, Conn., where it was discharged by the bay into the Sound - resuming thus a route followed by the whole Connecticut stream or estuary in Triassic time. An ice-dam, or drift-dam, closed a narrow gorge through the trap ridge above Hartford, Conn., which was the channel of the Farmington River, and another deep gorge through sandstone above Cheshire, Conn., that of the Quinnipiac River, so that the new discharge-course of the Connecticut secured the upper parts or heads of both the Farmington and Quinnipiac rivers as its tributaries, and took possession of the valley of the small stream called Mill River to reach the Sound. On the terraces of the Connecticut valley, see the author's papers of 1870 to 1884 ; also E. Hitcheock, 1841, 1857 ; C. H. Hitchcock, Vermont Geol. Rep., 1861, and New Hampshire Geol. Rep., 1878; W. Upham, New Hampshire Geol. Rep., and later papers.

W. B. Dwight states that at the clay-beds, near Newburg, north of the Narrows, the clay fills large conoidal depressions in the sand-beds. One of the three there observed is elliptical in section, about $80^{\prime}$ by $50^{\prime}$ in diameter at bottom, $150^{\prime}$ in longer diameter at top, and $90^{\prime}-100^{\prime}$ in depth. The clay is straticulate, the layers concave, with the wall of the mass rather firm; and the sand and gravel beds outside bend downward at the wall. The clay contains a few bowlders.

In western Pennsylvania, plains of great extent have a height of $275^{\prime}$ to $300^{\prime}$ along the Monongahela, and of $300^{\prime}$ on the Ohio 5 miles below Pittsburg; their height above the sea level is about $1050^{\prime}$. Nothing of marine origin, however, has been found in the region to suggest the presence of the sea. On the lower Ohio occur terraces $160^{\prime}$ to $100^{\prime}$ in height above the river. They exist also along the Mississippi in Kentucky, and farther south.

Kettle-holes, although characteristic of many moraines, also occur at times over the stratified fluvial deposits of the Champlain period. An example occurs in the plain on which the city of New Haven, Conn., is built, one to four miles north of the center of the city. The terrace formation of the region consists chiefly of sand and fine gravel. The small depressions represented on the accompanying map. Fig. 1555, are the kettle-holes. They are often 100 to 150 feet in diameter, and 30 to 40 feet deep. The ice had left the region long before deposition of the beds had taken place. On the map, the depression in the plain lettered Beaver Pond Meadows has a depth of 25 
to 30 feet; and the kettle-holes are numerous along its borders. It was the course of a deep trewch made by the southward-moving glacier; and the depression over the site of the trench was left in the sand deposits made in

1555.

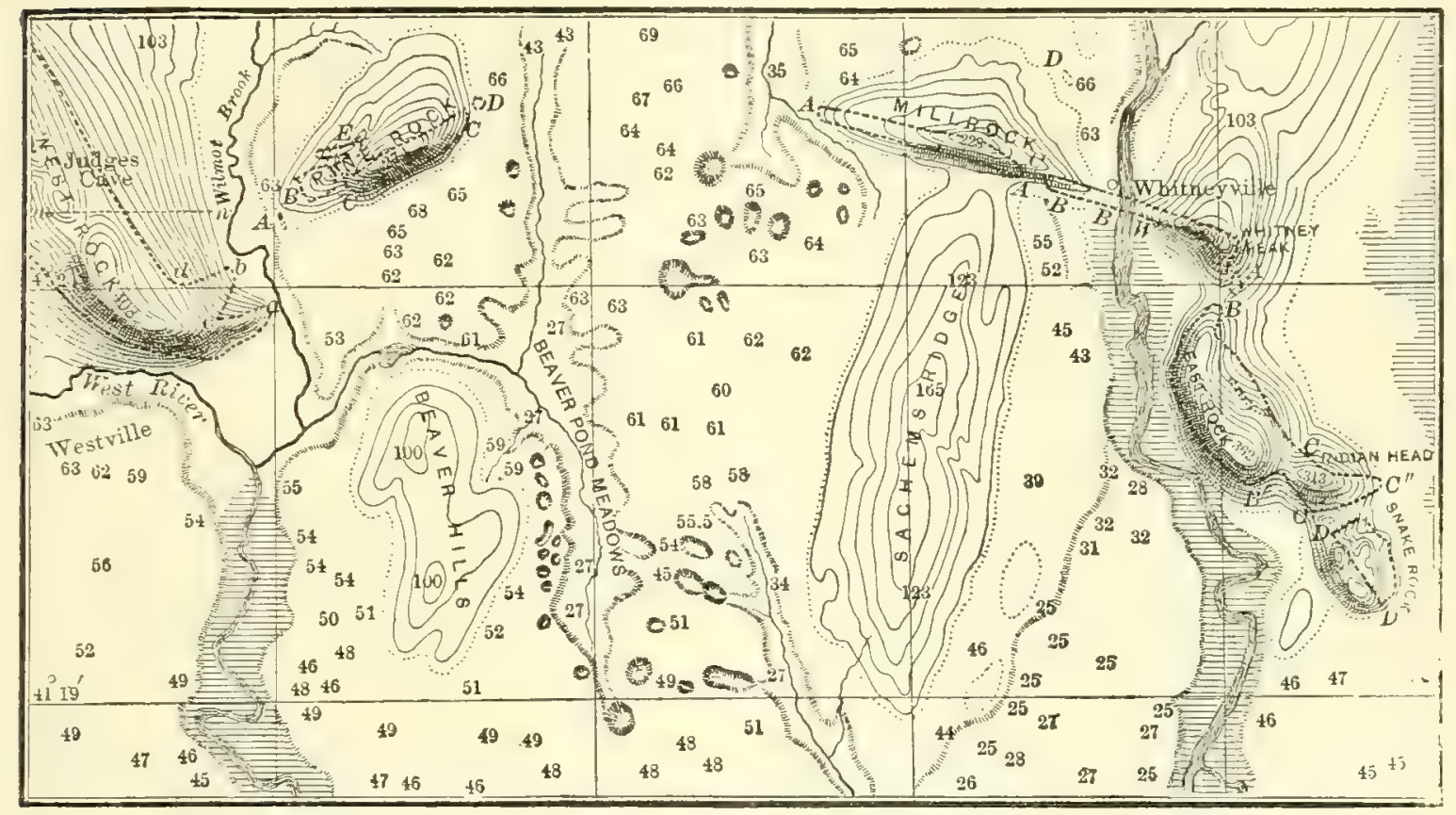

Kettle-holes in the New Haven Terrace formation. I Igures indicate the height above the sea level. 1 inch $=\frac{5}{6}$ mile.

the trench. The trench was too deep to be filled to the ordinary level of the plain by the deposition of the sand and gravel, and hence its present depth of 20 to 30 feet; and the kettle-holes, which border, blend with, and intervene between them were probably formed under the same conditions. (Pages 186, 193.)

\section{ELEVATION CLOSING THE CHAMPLAIN PERIOD.}

The elevation of the land which closed the Champlain period was of great extent over North America. The high level shore-lines already described are the evidence, they marking both the limit of the Champlain subsidence, and the fact, though not necessarily the limit, of the following elevation. Not the limit; for the present height of these elevated shore-lines is the final height after whatever oscillations of level may have in the mean time occurred. The movement may have earried the land up to a much higher level and returned it to its present position without leaving any distinct record.

The change in level was attended by a change also in climate, from a warm climate to the cooler of modern time; but to a climate even cooler than now if the level at the first was higher than now. It is certain that there was no return of the ice-sheet; but evidence of less extreme cold may yet be found about the local glacier areas of the Rocky Mountains, and possibly about the White Mountains of New Hampshire. 
The facts reviewed show that the amount of elevation east of the Rocky Mountains, over the northern half of the United States and the adjoining part of British America, increased to the northward. It is probable that there was a region of maximum height along the Canada watershed south of Hudson Bay; since the height of a shore-line on James Bay (Mo.) is only 450 feet. But this single observation leaves the question donbtful. The general rule of increase to the northward holds over the Winnipeg region, as is shown by the northward rise in the shore-lines of Lake Agassiz; the upper shore-line, or Herman beach, which at Lake Traverse is 85 feet above this lake, or 1055 feet above sea level, has a height at the national boundary, 224 miles from Lake Traverse, of 1230 feet, and 76 miles farther north, of 1315 feet (Upham).

The heights increased also from the Atlantic coast westward. But there appears to have been a maximum east of Lake Ontario, the heights, as has been stated, diminishing 120 feet along the line of the lake between Watertown at its eastern extremity and its western extremity. The region may have been within the range of the Appalachian uplift of the period as suggested by F. J. H. Merrill.

How far the change in level extended south of the Great Lakes is doubtful. The small elevation of the shore-line, 45 feet, at the south end of Lake Michigan, indicates nearness to the limit. But south of lakes Ontario and Erie, the distance to the limit may have been two or three hundred miles or more.

Through these changes, the Arctic, Labrador, Canadian, and New England coasts gained much in extent, and so also some parts of the Pacific border. Nova Scotia became again part of the mainland. The beds of rivers flowing south had their pitch increased to its present amount. 'The river channels within tidal limits were excavated to a deeper level, corresponding more or less closely with the amount of elevation in the region; and this excavation, as already explained, gave alditional height to the bordering terraces. Many lakes were drained that had been made by the northward depression of the land, thus carrying forward the drying of the continent that was commenced with the subsiding of the rivers.

On the coast of Maine, there are large Indian shell-heaps of the common Clam (Venus mercenaria, the Quahog of the Indians) and, in some places, of the Virginia Oyster, species which are now nearly extinct on that cold-water coast. As made known by Verrill, there is a colony of living southern species in Quahog Bay, near Bath (20 miles east of Portland), among which are Venus mercenaria Linn., Modiola plicatula Lam., Ilyanassa obsoleta Stimp., Urosalpynx cinerea Stimp., Crepidula fornicata Lam., Asterias arenicola Stimp., Enpagurus longicarpus Edw., and others, reminding one strongly, as Verrill says, of the coast fauna of New Haven, on Long Island Sound. Further, Venus, Ilymuss, Mrdiole, and other species occur, according to Dawson, also in Northumberland Straits, in the southern part of the Gulf of St. Lawrence. At the mouth of Damariscotta River, 30 miles east of Portland, there is the only locality of the living oyster north of Massachusetts Bay. Shells of Oysters, Clams, and Scallops (the southern Pecten irradians Lam.) are abundant in the deeper portions of the mud of the harbor of Portland. 
W. Upham mentions (1891) the occurrence of similar warm-water shells in the vicinity of Boston. W. F. Ganong reports (1890) that similar shells have been found in Halifax Harbor, Minas Basin, St. Mary's Bay, and on other parts of the Acadian coast.

These species are relics of a past southern population; none of the shells are found in elevated beaches; and hence the migration from south of Cape Cod took place in the Recent period. Such a migration, extending to the St. Lawrence Gulf, was not possible, unless the Labrador current had first been turned aside; and a closing of the Straits of Belle Isle would have brought this about. This implies an elevation of about 200 feet; and it may be that the rise which introduced the Recent period carried the continent, to the north, to this height above the present level. In the Champlain period of subsidence the Straits were open, this being proved by the cold-water shells of the now elevated beaches.

\section{FOREIGN.}

Whatever the facts relative to interglacial epochs in Europe, it appears to be certain that after a long period of glaciation there was a time of widely extended subsidence, initiating a period of ameliorated climate; and that this period was similar to that of the Champlain period, not only in this initiating subsidence, but also in marine deposits and other phenomena. This period of subsidence in Europe had, like that of America, its sea-border formations in Sweden and Norway closely like those of the coasts of Maine and the St. Lawrence, even to the "Leda clays" and "Saxicava sands," and its extensive fluvial formations along the river valleys. According to J. Geikie, the submergence of Great Britain after the epoch of maximum glaciation was probably 500 feet. This author inserts, as has been stated, a return of glacial conditions, and then another interglacial before the Glacial epoch generally recognized as the second; and estimates the subsidence of Scotland during this second interval as 100 feet. A 100 -foot terrace forms a wide plateau in the estuary of the Forth. The depression ten miles east of Glasgow was at least 524 feet, as indicated by the presence of marine shells in beds of clay, which are overlaid as well as underlaid by beds of till. The marine shells present are those mainly of Arctic seas, like the St. Lawrence species. Among them are Saxicava rugosa, Pecten Islandicus, Natica clausa, Trophon clathratum, Yoldia arctica, Macoma sabulosa.

Northern Germany was submerged during interglacial time. In Sweden the depression exceeded in some parts 600 feet. Near Uddevalla, in southern Sweden, at levels of 200 to 400 feet, shells of Mya truncata, Saxicava rugosa, Astarte borealis, Natica clausa, Buccinum Gronlandicum, etc., are in great abundance; and show thereby that the subsidence was of long continuance. Erdmann concludes that, at this time, the Baltic was connected with the North Sea, over the region of lakes from Stockholm westward, and with the Arctic Ocean by a great channel leading northeastward over Finland to the IThite Sea. The Caspian and Aral were united and connected with the Arctic Ocean, and so continued to the close of the Champlain period. As in America, the period was the time of flooded rivers and lakes, and of the most extensive freshwater formations in the world's history. Dupont states that with the 
close of the floods the flood-grounds of the river Meuse, near Dinant in Belgium, were diminished in breadth from seven and a half miles to a fourth of a mile; and this is an example of the general change over Europe. Europe also had rivers dammed up by gravel and sand from the unlading glacier. It has been shown that the Rhine owes its present channel at the Falls at Schaffhausen to its having been forced out of an older one; and it is probable that the Champlain period was the time of the change.

There is evidence in the remains of Mammals of Malta and Sicily that these islands, and probably Europe, were connected at this time with Africa; and Britain, as the ice departel, retained for awhile its connection with France, and gave passage across for the warm-climate IIammals. While the cold waters of the North Sea were thus shut off from the British Channel, warm water species, from the coast to the south, were living in the channel.

The valley of the Rhine and those of its tributaries contain extensive deposits of Pleistocene time. The material of the alluvium is mostly the loess, a fine yellowish-gray loam, much of it unstratified, - generally a little calcareous from pulverized shells; and in some parts it contains glacially marked stones. It rests in some places on stratified gravel or sand. Between Bâle and Bingen, this alluvium near Bâle has a height of 600 feet above the river; and through much of it there are land and freshwater shells. Similar facts are reported from most of the river valleys of Europe. The deposits on the Danube are as extensive as those of the Rhine; and Suess states that stones occur in it that were probably dropped by floating ice.

In Belgium, according to Dupont, along the valley of the Lesse, and others, the limestone caverns situated at the greatest elevations - 80 to 100 feet above the present river - are those which contain the older remains of MIammals; and those below are successively more recent as their height is less. Moreover, the river alluvium shows that, when the upper cares were inhabited, the valley was filled with water and river-border deposits, 11early to the level of the cave. Thus change is strikingly exhibited.

As Nikitin states, "the time corresponding to the 'interglacial epoch' and the second glaciation of the Swedes was probably, for the greater part of Russia, the epoch of the formation of the ancient lake deposits, the loss, ant the upper terraces of the rivers, which constitute the principal repository for the bones of the Mammoth and other extinct Mammals, which abounded here while Scandinavia and Finland were still covered by the glacier."

In Europe, a reeelevation of the land at the close of the Pleistocene was also a general fact; but the rise was great enough to make a partial return of glaciated conditions in northern Europe and about the Alps, before a settling down to modern levels and more genial climatal conditions.

The absence in North America of distinct evidence of unusual cold, as a consequence of the elevation closing the Champlain period, is not proof that some extension of glaciers did not mark the close of this period in Europe. For Europe has had glaciers ever since over the Scandinavian mountains and the Alps. While in the glaciated part of eastern America, Mount Washington 
is the only peak over 6000 feet, and but a very small part of it is as high as this. The Scandinavian areas are in much higher northern latitudes.

Geikie's map on page 976 presents the views of many European geologists with regard to the extension at this time of the Scandinavian ice. The only countries invaded beyond the Baltic are Holland and northern Germany. Russia was free. The evidence of the return consists chiefly in the occurrence of beds of peat or of stratified gravels, sometimes with animal remains, between deposits of till. In the Alps such intercalations are reported from Dürnten in the Canton of Zurich, in St. Gall, and elsewhere; and in some places they contain bones of the Elephant, Rhinoceros, Cave Bear, and other Mammals of the time.

Further evidence of a partial return of the cold consists in the occurrence in southern France of remains of arctic and subarctic Mammals, among which the Reindeer was prominent; whence the epoch is named, by Lartet, the Reindeer epoch. The reëlevation, before it was fully completed, cut off the Baltic again from the ocean on the north and west; for, as Erdmann states, while on the upper terraces the shells of the Baltic coasts include the outside kind, Yoldia arctica, the open-sea species are all excluded from the lower terraces, excepting a few Baltic kinds, of which the Mytilus is the most common.

\section{LIFE OF THE PLEISTOCENE, OR THAT OF THE EARLY AND MIDDLE QUATERNARY.}

It has been already stated that the Plants and Invertebrates (Mollusks, etc.) of the Quaternary are, with a rare exception, living species, while the Mammals are nearly all extinct. Another grand feature of the life is the great size of a large part of the Mammals, Elephants far exceeding modern Elephants, and the same with other Herbivores, and with many Carnivores, Edentates, Rodents, and Marsupials. The genial climate that followed the Glacial appears to have been marvelously genial to the species, and alike so for all the continents, Australia included. The kinds that continued into modern time became dwindled in the change wherever found over the globe, notwithstanding the fact that genial climates are still to be found over large regions. Moreover, it was during and after the final melting in the Champlain period, when the continents were everywhere dripping with water, that the greatest of forests covered the hills and prairies, - forests that in the present period could not be renewed without an impracticable amount of artificial irrigation, and which hence, through forest fires, have given way in America to prairies.

\section{BRUTE MAMMALS AND INFERIOR SPECIES.}

\section{North American.}

North America was prominently the continent of Herbivores; Carnivores were relatively few. The most widely distributed species and one of the largest was the Elephas primigenius. It ranged from Georgia, Florida, 
Texas, and Mexico on the south to Canada on the north, and Oregon and California on the west, and lived also in Alaska and over the interior plateau

1556.

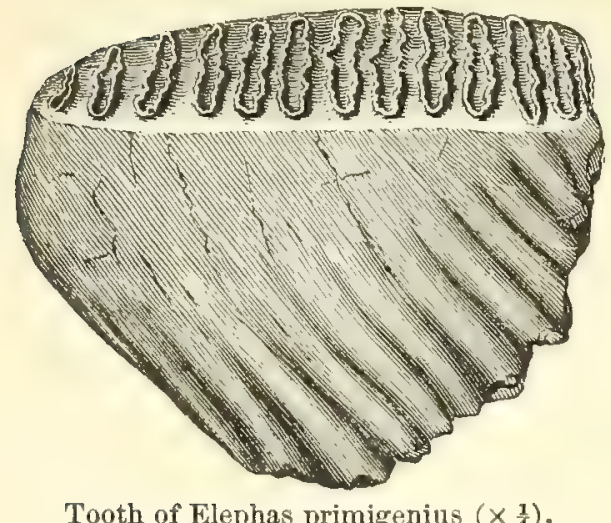

Tooth of Elephas primigenitus $\left(\times \frac{1}{4}\right)$. of British Columbia north of the glaciated area. Moreover, it was an inhabitant of Britain, of nearly all Europe, and of northern Asia. It was a hairy species, as some Russian specimens have shown, and was thereby fitted for life in cold-temperate latitudes. The species was over twice the weight of the largest modern Elephant and nearly a third taller. One of the teeth, from Ohio, a fourth the natural size, is shown in Fig. 1556. The American Elephant, excepting the variety in the remote northwest, has been regarded until recently as a distinct species and called Elephas Americanus. The chief difference is in the teeth, the plates of enamel being less closely crowded than in the European.

Another Elephant-like species, of still larger size, was the Mastodon Americanus, a restoration of which, $\frac{1}{48}$ the natural size, by Marsh, is given in Fig. 1557. Fig. 1558 represents one of the teeth, a fourth the natural size

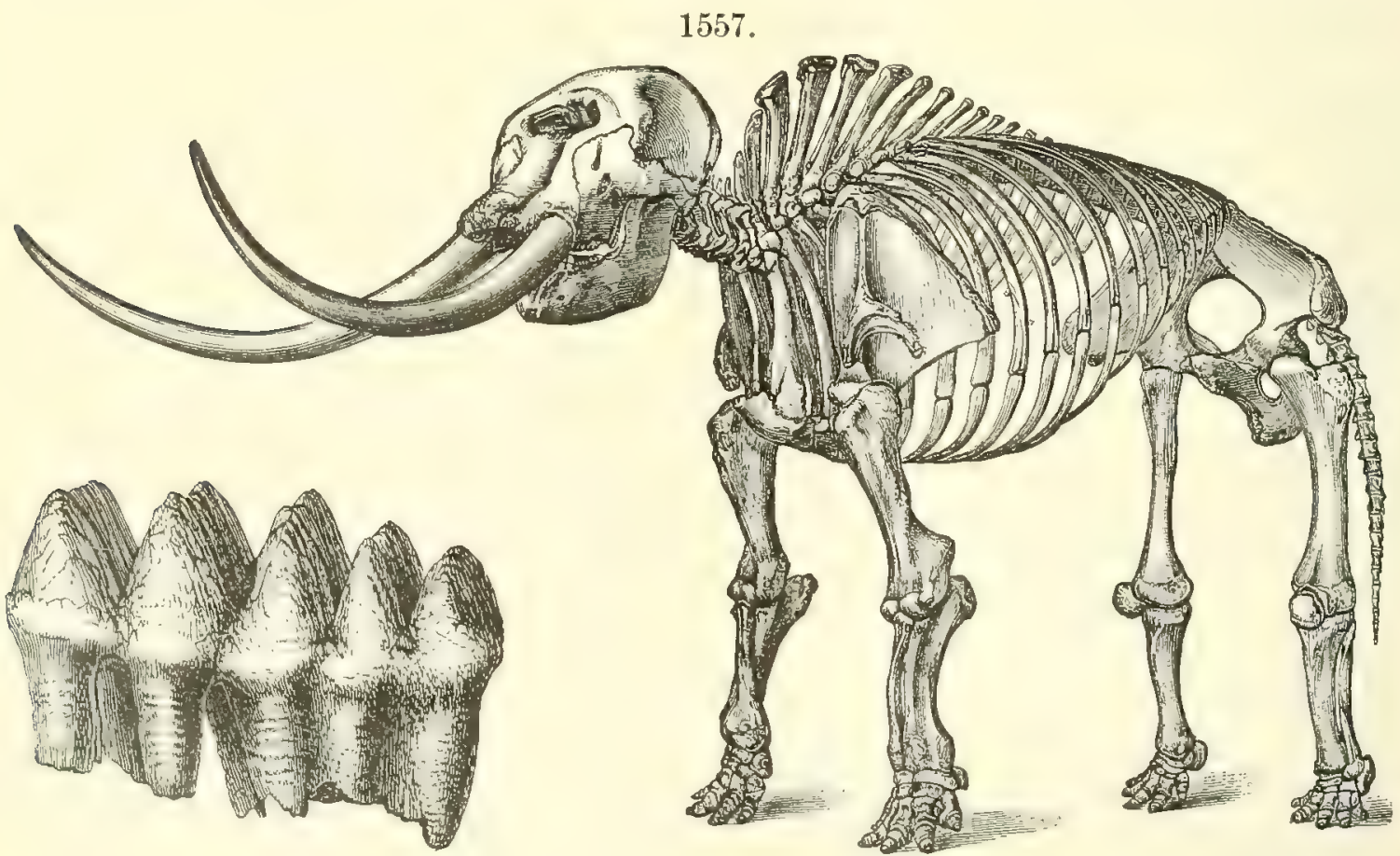

Fig. 1557, Restoration of Mastodon Americanus ( $\left.\times \frac{1}{48}\right)$, by Marsh; 1558, Tooth of same $\left(\times \frac{1}{4}\right)$.

lineally. The remains of the species are met with most abundantly over the northern half of the United States, though occurring also in the Carolinas, Mississippi, Arkansas, and Texas. They are found also in Canada and Nova Scotia. The best skeletons have been dug out of marshes, in which the animals had become mired. The skeleton here figured was from a marsh 
in Otisville, Orange County, N.Y., and is now in the Yale Museum. One bog in New Jersey near Hackettstown is reported to have afforded portions of six skeletons. When alive, the height must have been 12 or 13 feet, and the length, adding 7 feet for the tusks, 24 or 25 feet. Remains of the undigested food have been found with the skeletons, showing that it lived in part on spruce and fir trees. J. Collett states that a skeleton found in Indiana contained between the ribs "a crushed mass of herbs and grasses, similar to those which grow in the vicinity"; and the bed of clay contained also some modern freshwater and land shells; and he concludes that the extinction of the species must have been a comparatively recent event.

The Horse, Equus excelsus, was a fit cotemporary, as Leidy observes, of the Mastodon and Elephant. Several other species of Equus have been found in North America, showing that North America was abundantly provided with Horses in Champlain time, though not having among them the modern Horse, $E$. caballus.

The Cervalces Americanus of Harlan, a species related to the Elk and Stag, as the name implies, was of greater size than the famous Irish Deer, Cervus giganteus. It had much larger legs and a very large head. Harlan's

1559.

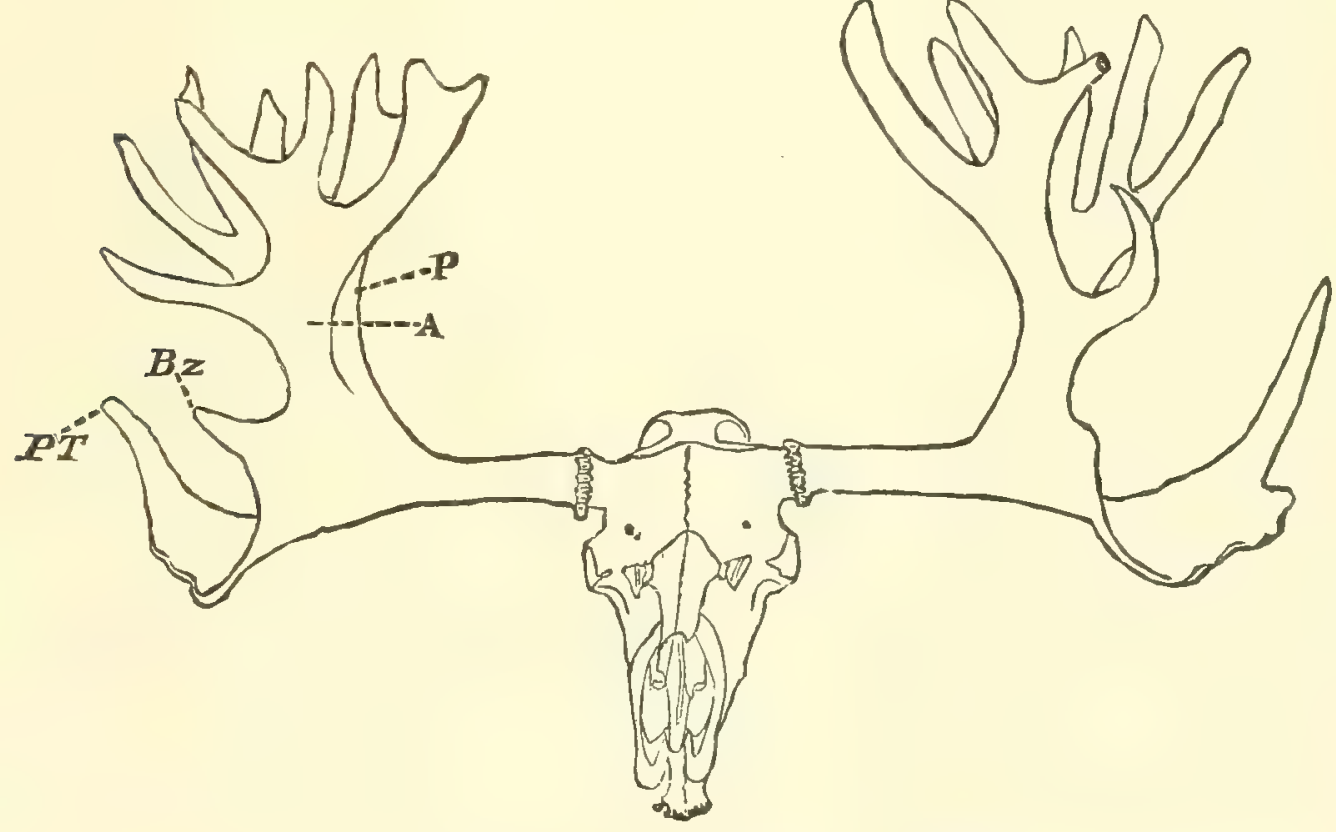

Antlers of Cervalces Americanus $\left(x \frac{1}{20}\right)$. Bcott, '85.

specimen was from Natchez, Miss. The head and antlers, by W. B. Scott, of a specimen from Warren County, New York, are represented of reduced size in Fig. 1559.

Bison latifrons L. was a Bison or Buffalo, much larger than the existing Buffalo, which lived in the Mississippi and Ohio valleys, and over the Southern States to Texas. There were also species related to the Musk Ox, Ovibos bombifrons and $O$. cavifrons. 
Gigantic Edentates, species related to the Sloth and Armadillo, of the genera Megatherium, Mylodon, Megalonyx, Glyptodon, and others were also in the North American fauna, although most characteristic of South Anerica. Their remains have been found at Natchez in Mississippi, in Florilla, and in Georgia, South Carolina, Texas, Kentucky, Uregon, and elsewhere.

Remains of the Megatherium mirabile of Leily were found in Georgia, at Skiddaway Island, and in South Carolina. Megalonyx is another genus of

1560.

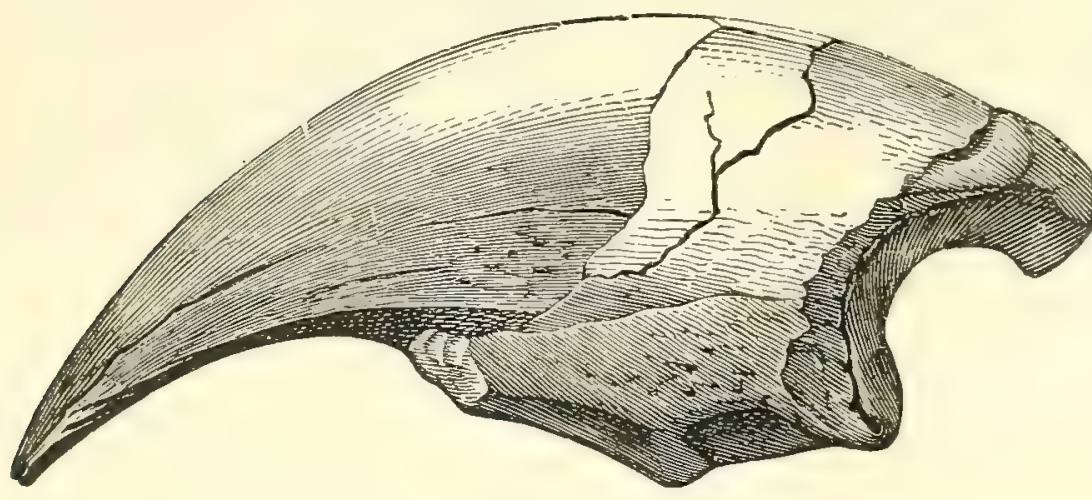

Claw of Megalonyx Jeffersonii $\left(\times \frac{1}{2}\right)$.

these large Slothlike animals. Its species occur over the Pampas of South America, to the Straits of Magellan; but the first known was found in Virginia, in Greenbrier County, and was named Megalonyx by Jefferson, in allusion to its large claws (Fig. 1560). Its bones have also been found at Big-Bone Lick, Ky., and elsewhere.

A North American Mylodon, M. Harlani, has been found both east and west of the Mississippi, and in Oregon.

Rodents were represented by the gigantic Castoroides Ohioensis, related to the Beaver (Castor Canadensis). The Beaver has a length, exclusive of the tail, of about three feet; the Castoroides was nearly or quite five feet long. Its remains have been found in New York, Ohio, and south to Mississippi (Natchez).

The Peccary, Dicotyles nasutus, has been found near Squankum, N. J., and in Virginia.

Among Carnivores, a Lion, Felis atrox, from Natchez, was about as large as that of Britain. There were also Bears, as the Ursus amplidens of Leidy, from the same locality, and the Arctotherium simum of Cope, from Shasta County, Cal.

The Equus beds of Marsh (1877) are deposits of Pleistocene Mammals, occurring over various parts of western North America, from Mexico and Texas to Oregon and western Nebraska. It has been questioned whether they were not of later Pliocene age. Many have afforded remains of four species of Equns, Elephas primigenius, Mastodon, Megatheridoe, Glyptodon, Machorrodus (Smilodon), and other kinds.

The marine species of the St. Lawrence and the borders of Canada and New England, in contrast with the terrestrial, were cold-water species, and show that the Straits of Belle Isle, between Newfoundland and Labrador, were very widely opened by the subsidence of the Champlain period. 
Fig. 1561 represents the bones of the head of the Vermont Cetacean, Delphinapterus leucas, mentioned on page 983 as frequenting the expanded Champlain Bay of the time. It was probably about 14 feet in length.

1561.

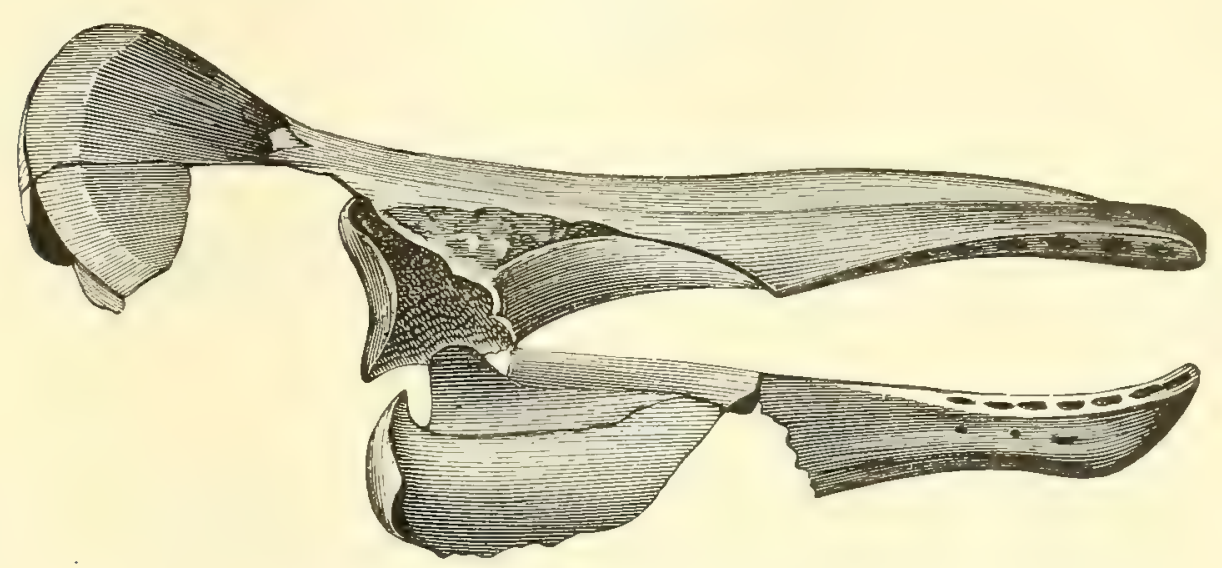

Delphinapterus leucas $\left(\times \frac{1}{6}\right)$. Z. Thompson, 1853 .

The Equus beds, in central Kansas, McPherson County, have afforded (1891) Equus major and a species of Megalonyx (M. Leidyi Lindahl). The beds consist of gravel, sand, and clay, with a layer of fine sand marl above, and indicate shallow water and marsh conditions. In the Smoky Hill Valley, the beds contain remains of Elephants, Horses, Dogs, Camels, and Platygonus; similar remains are found in the valley of the Salomon (Williston).

In a forest bed, overlying the Erie Clays (page 972), and covered by stratified sands and clays, Newberry found remains of the Champlain species of Mastodon, Elephant, and Castoroides.

Bones of Elephas or Mastodon, Equus, an Ox, Llama, occur in gravels of the Lahontan basin, Nevada.

Florida has afforded, according to Leidy, from the Alachua Clays of Archer and Ocala, remains of Elephas Columbi, Mastodon Floridanus, Rhinoceros proterus, Hippotherium ingenum, Auchenia major, A. minor, Machorodus Floridanus, etc.; and from the l'eace Creek beds, Manatee County, several of the above species, with Equus froternus, Bison Americanus, Megalonyx Jeffersonit, and a species of Glyptodon scarcely distinguishable from a South American form. Some mixture of Quaternary with earlier species at these localities is suspected. In Cuba, De Castro found the bones of a huge Sloth, later named Megalocnus rodens by Leidy; and from the caves of Anguilla, one of the Windward Islands, have come a gigantic Rodent related to the Chinchilla, as large as the Virginia Deer, Amblyrhiza inundata Cope, besides other species of the genus. The facts point to a Quaternary connection of Florida and the Western Islands with South America.

A vertical opening in the limestone strata at Port Kennedy, eastern Pennsylvania, described by C. M. Wheatley, has afforded remains of a large number of species of extinct Mammals, the animals having fallen into it as into a trap. As identified by Cope, the bones belong to 34 species and 72 individuals, and include 2 Tapirs ( $T$. Americanus I. and T. Haysii), a Bear (Ursus pristinus), a Felis, an Ox, a Horse, the American Mrstrodon. several species of Megalonyx, one of Mylodon, M. Harlani Owen, several Rodents, and a Bat; Cope observes that 11 were warm-climate species, and 3 North American Arctic. A cave in Wythe County, Va., and another near Galena, Ill., contain some extinct species along with others that are living. In another near Carlisle, Penn., Baird 
found bones of all the species of Mammals of the state, besides one or two other species not now Pennsylvanian, but known in regions not far remote; as a general rule, the bones of the cave appear to indicate that the size of the species exceeded that at the present time.

In western Canada, Chapman has found remains of the modern Beaver, Muskrat, Elk, and Moose, in stratified gravel which contained also bones of the Mammoth and Mastodon.

At Kotzebue Sound have been found Equus major, Alces Americanus, Rangifer caribou, Ovibos moschatus, O. maximus, O. cavifrons, Bison crassicomis $(=B$. antiquus Leidy), but no Mastodon remains.

The Quatemary deposits have afforded Marsh remains of the Birds, Meleagris altus Mh., and M. celer Mh. (Turkeys), from New Jersey; Grus proavus Mh., ibid.; and Catarractes affinis Mh., from Maine.

\section{South American.}

In South America, over 100 species of extinct Quaternary quadrupeds have been made out. The bones occur in great numbers, over the prairies or pampas of La Plata, in the "Pampean" formation, and in the eaverns of Brazil; and they include thirty or more species of Rodents (Squirrels, Beavers, etc.), species of Horse of the genera Hippidium and Equus, Tapir, Lama, Stag, Dicotyles; species of Macrauchenia; a Mastodon different from the North American; Hyena; Wolves; half a dozen Panther-like beasts, which occupied the caverns of Brazil; and, among Edentates, Ant-eaters, 12 or 14 species related in tribe to the Megatherium (Sloth tribe), and a dozen or more related to the Armadillo and Glyptodon. They number more species than now exist in that part of the continent, and were far larger animals.

1562.

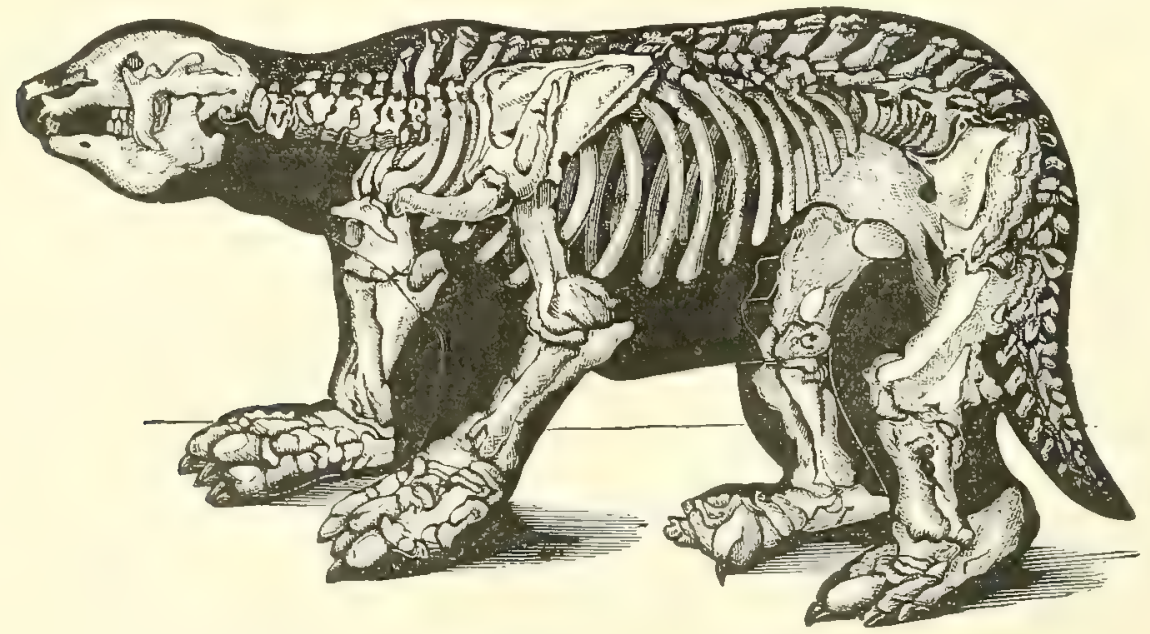

Edentate. - Megatherium Cuvieri $\left(x \frac{1}{76}\right)$.

The Edentates were the most remarkable. The animals of this order are stupid in aspect and lazy in movement and attitude.

The Megatherium (M. Curieri Desmarest, Fig. 1562) exceeded in size the largest Rhinoceros. The length of one of the skeletons is 18 feet. Its massy limbs were more like columns for support than like organs of motion. 
The femur was three times as thick as an elephant's; the clumsy tibia and fibula were soldered together; the huge tail was like another hind leg, making a tripod to support the heavy carcass when the animal raised itself against a tree and slowly wielded its great arms; and the hands terminating the arms were about a yard long, and ended in long claws. The teeth had a grinding surface of triangular ridges, well fitted for powerful mastication.

A fourth allied genus is Scelidotherium, of which seven South American species have been made out, - one as large as the Megalonyx, and one smaller than a Tapir.

Of the armor-clad kinds, the genus Glyptodon (Fig. 1563) contained several gigantic species. These animals had a shell something like that of a Turtle. In the $G$. clavipes Owen, the length of the shell, measuring along the curve, was five feet.

It has been found that in the restoration of this species (Fig. 1563) the tail is that of a species of the allied South American genus, Hoplophorus.

The following figure,

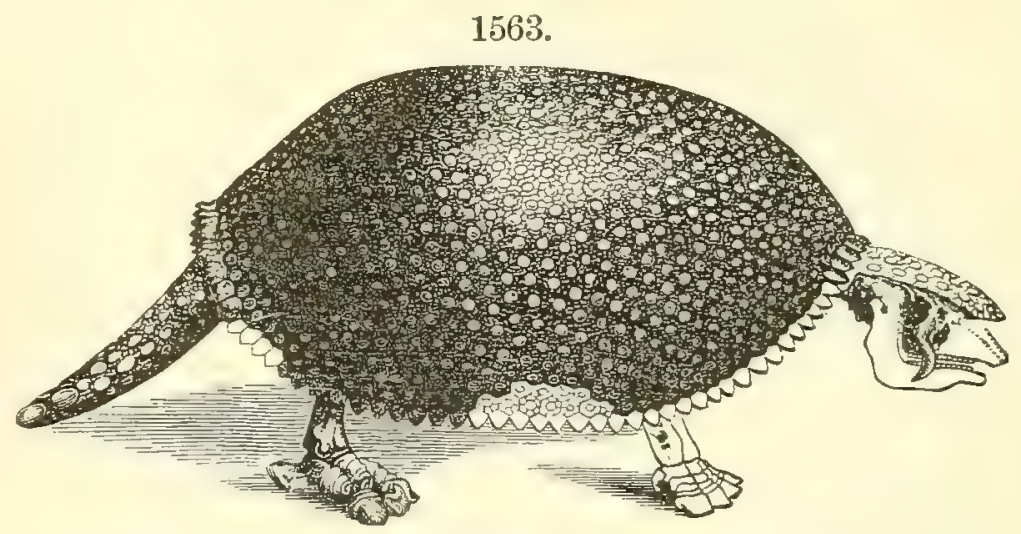

EDENTATE. - Glyptodon clavipes $\left(\times \frac{1}{30}\right)$; the tail, that of a Hoplophorus. from a photogravure of the specimen in the La Plata Museum at Buenos

1564.

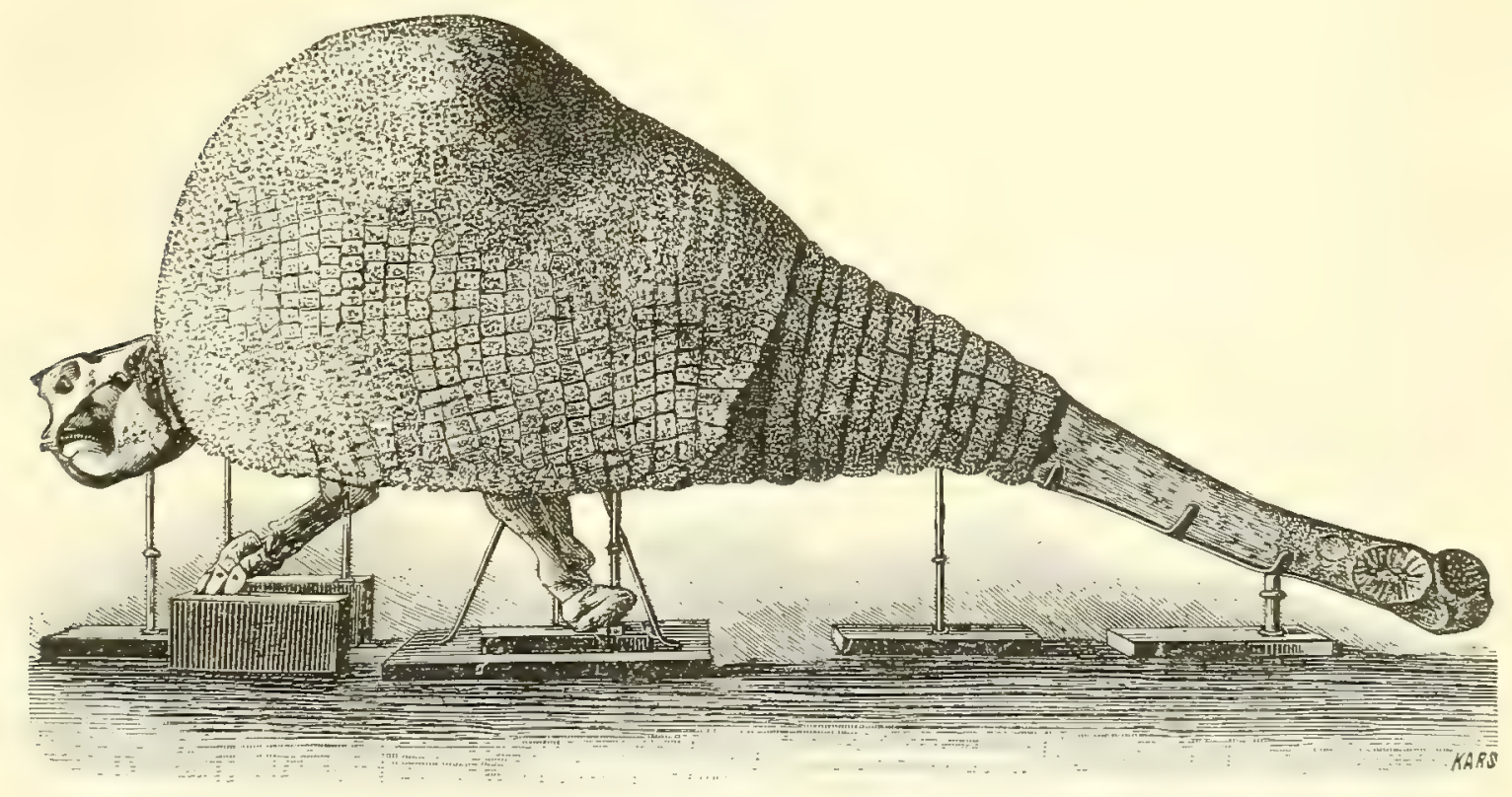

Edentate. - Dodicurus clavicaudatus. From a photogravure in a paper by Lydekker.

Ayres, published by Lydekker (1894), represents another Pampean species, the club-tailed Glyptodont, Doedicurus clavicaudatus.

Lydekker states (1894) that "marvelous as are all the Glyptodonts, this 
is the most astounding in the series. Its monstrous skeleton, as mounted in the museum, is over $11 \frac{2}{3}$ feet long; the caripax, across the back, $10 \frac{1}{3}$ feet wide; the massive club-like terminal tube of the caudal sheath, over 3 feet 11 inches long. The plates of the carapax are oblong plates of bone, smooth externally, but perforated by from one to five large circular holes through which quill-like bristles were doubtless protruded during life. The tremendous club bears, at its flattened and expanded extremity, a number of roughened, oval, depressed facets, which must have given support to huge horny spines not unlike the horns of a Rhinoceros. The whole animal must have bristled with horns and quills, a little like some giant Porcupine."

Another Glyptodont, the Panochthus, rivalled the Doedicurus in bulk.

The genus Chlamydotherium inchded other mailclad species in which the carapax consisted of movable bands; one, more Armadillo-like, was as large as a Rhinoceros.

Such were the characteristic animals of Quaternary South America. The largest Edentates of the existing period are but three or four feet in length. The Megatherium probably exceeded more than one hundred fold the bulk of any living Edentate.

\section{European and Asiatic.}

The Mammals of Quaternary Europe are equally remarkable for their great size. Caverns in Britain and Europe were the dens of gigantic Lions, Bears, and Hyenas, while Herbivores, equally gigantic, compared with modern species, roamed over the continent, from the Mediterranean and India to the Arctic seas. The remains are found in the earthy or stalagmitic floors of caverns; mired in ancient marshes; buried in river and lacustrine alluvium, or sea-border deposits; or frozen and cased in Arctic ice.

In Great Britain, the Mammals have been found in river border formations, in a large number of localities; and several of these have afforded also relics of man. The loess of the Rhine and the valley formations of other parts of Europe have afforded similar facts. The European caves were mostly caves of Bears (the great Ursus spelceus), while those of England were occupied by Hyenas (Hycena spelcea), with fewer Bears. The Cave Hyena, although of unusual size, is now regarded as of the same species with the Hycena crocute, of South Africa; and the Cave Lion, or Felis speloea, as a variety of Felis leo, or the Lion of Africa.

In a cavern at Kirkdale, one of the earliest explored, Hyena bones and teeth belonging to about 300 individuals were mingled with remains of the extinct species of Elephant or Mammoth (Elephas primigenius), Rhinoceros (R. tichorhinus), Hippopotamus (H. major), Ox. three kinds of Deer, along with the Cave Lion, Brown Bear (Ursus arctos), Wolf, Fox, Horse (Equus caballus), Hare, Rabbit, Water Rat, besides the Pigeon, Lark, Duck, etc. The Hyenas dragged into their caves the dead carcasses they found, and lived on the bones, and also on the bones of fellow Hyenas; and the bottom 
of the cave is often covered with the fragments. Calcareous excrements are also abundant, quite similar to the excrements of the modern Hyena.

The common species of Elephant in the county of Norfolk, on the North Sea, was the Elephas primigenius. It lived in herds over England, and extended its wanderings across the Siberian plains to the Arctic Ocean and Bering Straits, and beyond into North America; but it seems not to have gone far south of the parallel of $40^{\circ}$. It is stated by Woodward that over 2000 grinders were dredged up by the fishermen of the little village of Happisburgh, in the space of 13 years, and other localities in and about England are also noted.

This ancient Elephant, as Siberian specimens have indicated, had its body covered with a reddish wool and long black hair. One of the tusks measured $12 \frac{1}{2}$ feet in length. At the beginning of this century, one of these animals was found at the mouth of the Lena, frozen and encased in ice. It measured 16 feet 4 inches in length, to the extremity of the tail, exclusive of the tusks, and 9 feet 4 inches in height. It retained the wool on its hide, and was so perfectly preserved that the flesh was eaten by the dogs. The remains are exceedingly abundant at Eschscholtz Bay, near Bering Straits, where the ivory tusks of ancient generations of Elephants are gathered for exportation.

The Rhinoceros, $\boldsymbol{R}$. tichorhinus, spread from England to Siberia, and was a hairy species like the Elephant. A frozen specimen found near Wilui, in Siberia, in 1772, was $11 \frac{1}{2}$ feet long, and had a hairy skin. Another widespread species was the $\boldsymbol{k}$. hemitoechus.

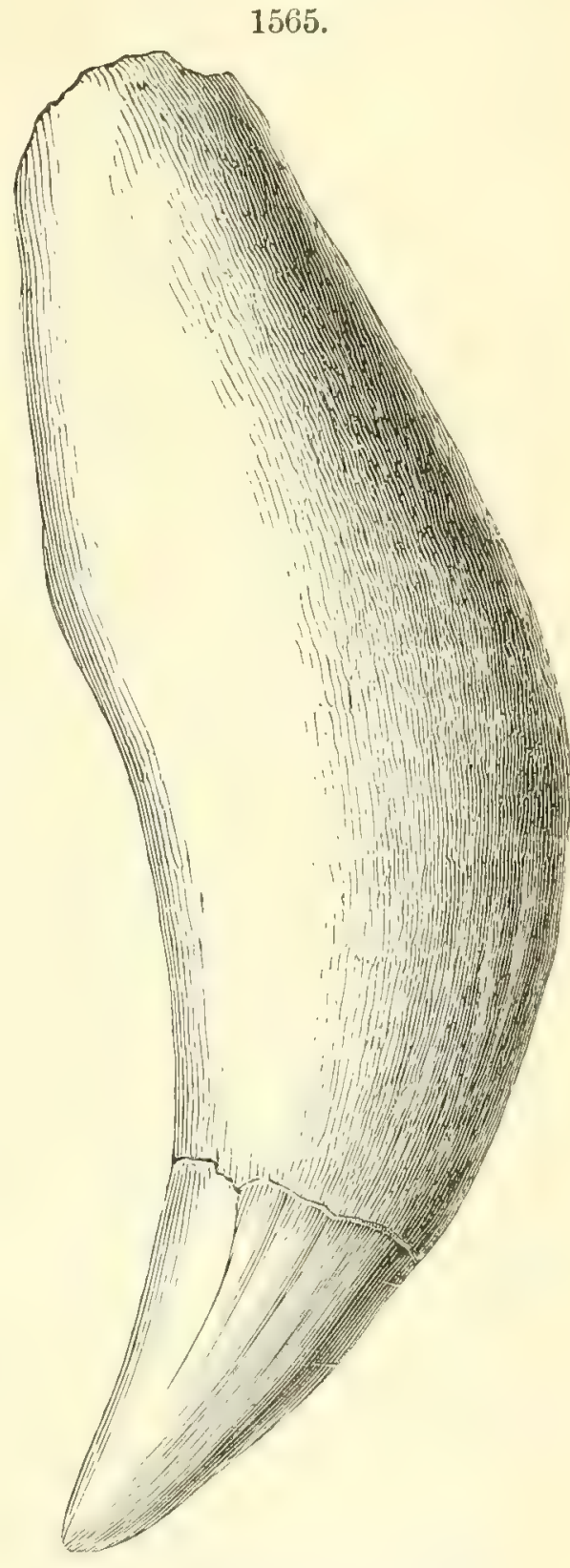

Canine tooth of the Cave Bear.

The Irish Deer, Cervus giganteus was another of the gigantic species. Skeletons have been found in marl, beneath the peat of swamps, in Ireland and England, and fragments in the bone caverns. The height, to the summit of the antlers, in the largest individuals, was 10 to 11 feet; and the span of the antlers was 10 feet, and in one specimen over 12 feet. It is supposed that it may have been extinct but a few centuries.

The modern Horse, Equus caballus. but of unusual size, has been found in the deposits of the period over all Europe, northern Asia, and northern 
Africa. An Ox of the period, the Aurochs, still lives under the protection of the Russian Czar; and another, Bison priscus, the Urus, was alive in the time of the Romans.

Kent's Hole, near Torquay, has afforded bones of the Mammoth, Rhinoceros ( $R$. tichorhinus), Cave Bear, Cave Lion, Cave Hyena, Wolf, Fox, Irish Deer, Reindeer, Nachcerodus latidens, Horse, besides relics of Man in the form of flint implements; and the Brixham Cave, in the same vicinity, in addition to flint implements, bones of the Cave Bear, Brown Bear, Grizzly Bear (U. ferox), Elephant, Cave Hyena, Cave Lion, Wolf, Fox, modern Horse, Reindeer, Goat, Irish Deer, Elk, modern Hare and Rabbit, Wild Boar, Lagomys spelceus, Aurochs (Bos primigenius), etc.

In France, in the older caves, according to Lartet, the bones of the Mammoth predominate along with $R$. tichorhinus, the Cave Hyena and Lion, etc., and in the later (the Reindeer epoch), those of the Reindeer. Remains of the Reindeer have been found on the southern slopes of the Pyrenees. Elephas antiquus and Rhinoceros hemitoechus with the Hyena, Horse, Elk, Wild Boar, Bos primigenins, occur as far south as Gibraltar in the "Ossiferous fissures" of the Gibraltar Rock; but E. primigenius and R. tichorhinus are unknown in Spain.

On Sicily have been found, besides the Gibraltar species, remains of Hippopotamus Pentlandi, H. major, and Elephas Africanus; and on Malta, besides several of the species of Sicily, a pigmy Elephant, $3^{\prime}$ to $5^{\prime}$ high, E. Melitensis Fale.; with also the Bear, Ursus arctos, a species of Wolf, a Stag, and other kinds. These species of Sicily and Malta are the evidence of a dry land connection with Africa, and probably across to Europe.

\section{Australian.}

In Australia, the living species are almost exclusively Marsupials; and they were Marsupials also in the Quaternary, but of different species. As on the other continents, the moderns are dwarfs by the side of the ancient species. The Quaternary Diprotodon (Fig. 1566) was as large as a Hippopotamus, and somewhat similar in habits, the skull alone being a yard long; and Nototherium Mitchelli Owen, an herbivorous species, was as large as a bullock; one of the Kangaroos, a species of Macropus, had the size of a Rhinoceros.

From this review of Quaternary Mammals, it is apparent that the characteristic species of each continent were mainly of the same type that now characterizes it. Both in the Quaternary and at the present time, the Orient is strikingly the continent of Carnivores; North America, of Herbivores; South America, of Edentates; Australia, of Marsupials.

The facts sustain, moreover, the view that the period in which these Mammals lived and thrived was one of warm climate. The species which have been mentioned, with a very few exceptions noted below, must have required a climate ranging between warm temperate on one side, and extreme cold temperate on the other; and this range belonged to the wide region from middle Europe and Britain to northern Siberia, where herds of Elephants, hairy Rhinoceroses, and other Mammals found abundant vegetation for food, and a good living place. If northern Siberia had then the mean temperature now forni in southern Scandinavia, or $40^{\circ} \mathrm{F}$., instead of its present $5^{\circ} \mathrm{F}$. to $10^{\circ} \mathrm{F}$., central Europe would necessarily have been within the warm temperate 
zone. One cause of such a climate may have been the extensive submergence of northern lands, giving an unusual sweep northward to the Gulf Stream and the corresponding warm current of the Pacific. Perhaps in the earlier part of the period, before the glacier had disappeared from northern Europe and America, Arctic Asia was still very cold; but, long before its close, the Elephants had taken full possession, as the vast abundance of their remains attests.

1566.

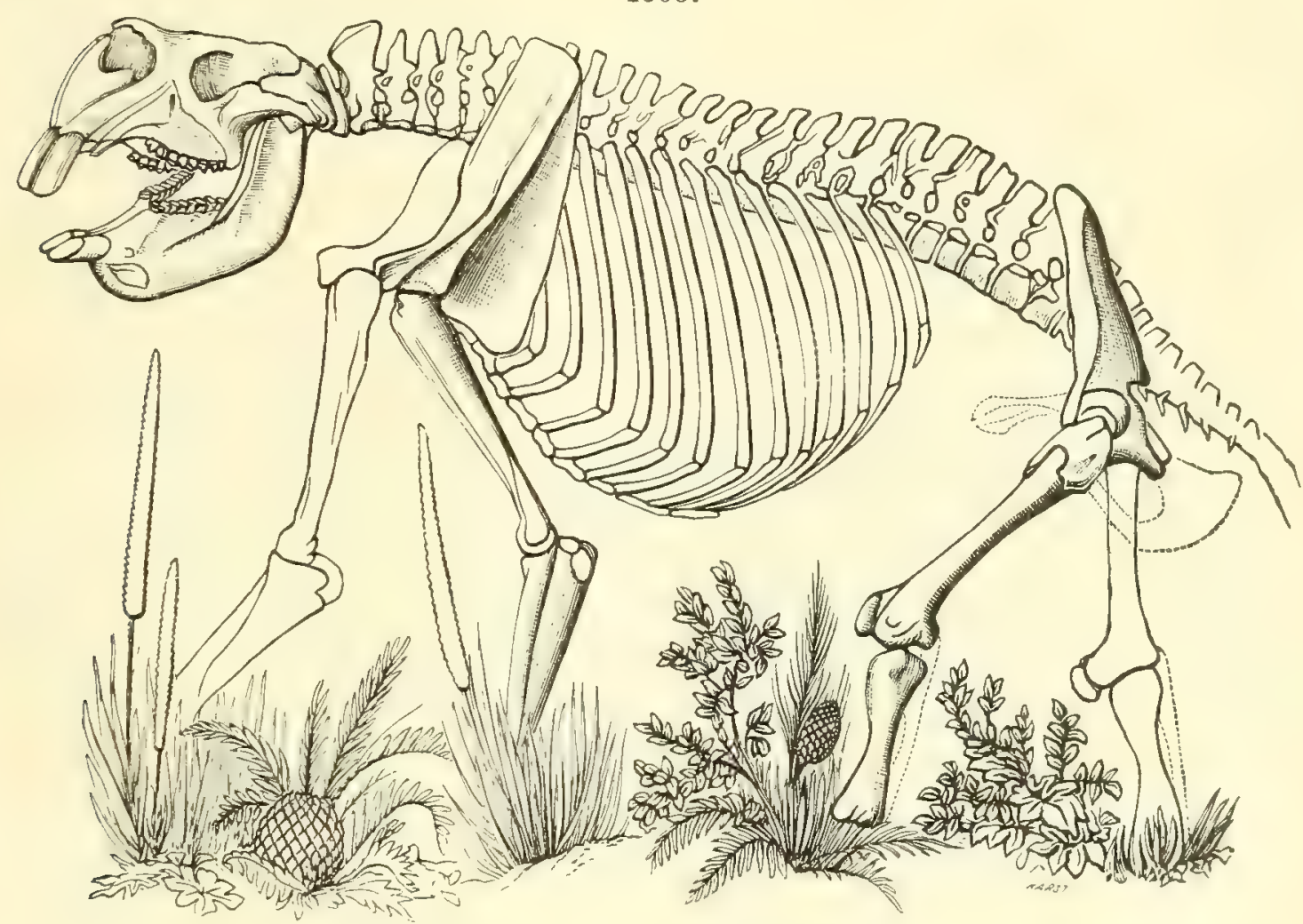

Restoration of Diprotodon Australis by Owen.

The migrations of the species from Europe to southern England took place as the Glacial era closed, but before the Champlain subsidence had taken place - this event, as in America, having been delayed until the retreat of the ice had made great progress.

The rarity of remains of Quaternary Mammals in Scotland and Ireland, in contrast with England and Wales, where they have been found in over 150 localities, has been attributed by Dawkins to the lingering of the ice about the Scotch and Irish mountains.

The cold that followed the Champlain period, or that of the Reindeer era of Lartet, appears to have brought destruction anong the northern tribes of Europe and Asia, and, at the same time, to have driven southward the more active survivors, or those which had the best chance for escape. The encasing in ice of huge Elephants, and the perfect preservation of the flesh, shows that the cold finally became suddenly extreme, as of a single winter's night, and knew no relenting afterward. The existence of remains of the Reindeer in southern France, of the Marmot, also a northern species, and of 
the Ibex and Chamois, now Alpine species, is attributed by Lartet to the forced migration thus occasioned. In the caves of Perigord (Dordogne, etc.), the bones of the Reindeer, far the most abundant kind, lie along with those of the Cave Hyena, Cave Bear, Cave Lion, Elephant, and Rhinoceros, as well as Horse and Aurochs.

Lartet says that, in the drift or valley gravels, the Elephant, Rhinoceros, Horse, and $O x$ are the predominant species, and the Reindeer appears sparingly; while, in the Dordogne caves, the Reindeer predominates, being associated in large numbers with the Horse and Aurochs, and exceptionally with remains of the Elephant, Hyena, etc. With the Mammals of the Reindeer era, in southern France, there are also great numbers of Grouse and the Snowy Owl, species which have since returned to northern Europe. The Reindeer was living in Scotland until near the end of the twelfth century. The absence of remains of the Reindeer and other subarctic species from Spain and Italy, and the southern character of the Champlain fauna, are evidence that the cold did not extend beyond the Alps and Pyrenees. At the same time, the presence of abundant remains of the Reindeer in Belgian deposits of this era, without bones of the extinct Mammals, may be evidence that the cold of Belgium was severe enough to drive off the old warm climate quadrupeds. An isothermal chart shows that England would have had a warmer climate than Belgium. The Quaternary fauna of Britain and Europe, and the caves are discussed at length by W. Boyd Dawkins in his works on Cave-Hunting, Early Man in Britain, and in later papers.

\section{MAN.}

The relics of Man, through which his geological history has been deciphered, are: (1) buried human bones; (2) stone arrow-heads, lanceheads, hatchets, pestles, etc.; (3) flint chips, made in the shaping of stone implements; (4) arrow-heads or harpoon-heads, and other implements, made of horns and bones of the Reindeer and other species; (5) bored or notched bones, teeth, or shells; (6) cut or carved wood; (7) bone, horn, ivory, or stone, graven with figures of existing animals, or cut into their shapes, one example of which, found by Lartet, in the bone cave of La Madelaine Perigorl, and representing the old Hairy Elephant, is here given; (8) marrow-bones broken longitudinally, in order to get out the marrow for food; (9) fragments of charcoal, and other marks of fire for warming or cooking; (10) fragments of pottery. Relies of the above kinds occur in the deposits of the "Stone Age."

In liater deposits, of Recent time, occur bronze implements, without iron - marking a "Bronze Age"; and, still later, iron implements, or those of the "Fion Are"; ant here occur, as fossils, coins, inscribed tablets of stone, buried cities, as Nineveh and Pompeii, etc.

The "Stone Age," here referred to, is properly the Stone Age of Euro- 
pean or Oriental history. The Stone Age in North America, or a large part of it, continued in full force till within two centuries since.

The principal facts with regard to human relics are these:-

1. Stone implements occur intimately associated with the remains of the Cave Bear, Cave Hyena, Cave Lion, the old Elephant and Rhinoceros and other extinct species, with some remains of the Reindeer and other living Mammals, in deposits of the Champlain period, if not earlier, - the Paleolithic epoch, proving the existence of Man at that time.

2. Similar implements, along with others of horn and bone, and drawings of animals, and other markings, occur in southern France, as well as more to the north, in caves and river-border deposits, along with great numbers of bones of the Reindeer, with other northern species now existing, and

1567.

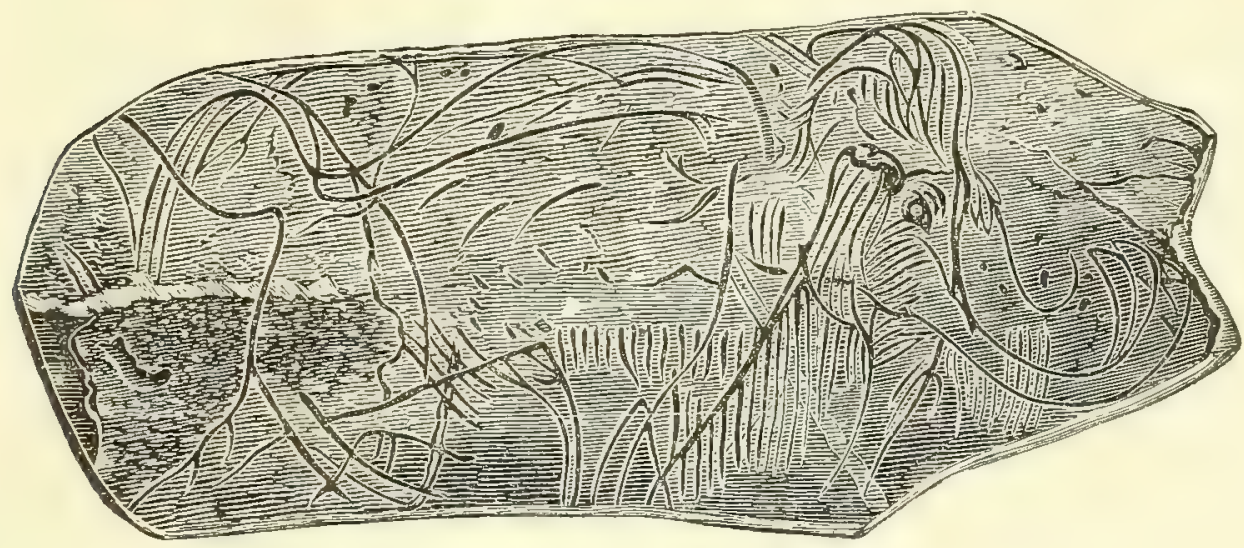

Elephas primigenius; engraved on ivory $\left(x \frac{3}{5}\right)$.

also with the remains of the extinct Urus, Elephant, Cave Bear, Cave Hyena, Cave Lion, etc., and also the now living Aurochs, Ibex, Elk, ete., pertaining to the Mesolithic or Reindeer epoch, or that of the "second Glacial epoch" of Europe. And, with these relics, human bones and even complete skeletons have been found; the marrow bones of the Reindeer and Aurochs so split as to show that they were broken by Man for the marrow; and charcoal and other relics of fires, probably used both for cooking and for warmth; for the weather must have been sometimes, if not generally, cold.

3. The skeletons of the Reindeer epoch of southern Europe are in part those of tall men. One of them, that of the cave of Mentone in the Mediterranean (just east of Nice), according to its describer, Mr. Rivière, was that of a man six feet high, with a rather long but large head, high and well-made forehearl, and very large facial angle $-85^{\circ}$. The woodeut on the next page, made from a photograph, published by Rivière, represents the skeleton as it lay, partly uncovered from the stalagmite, with Mediterranean shells and flint implements and chippings lying around, and a chaplet of stag's canines across the skull. The Mentone cave contained also bones of the Cave Lion, Bear, and Hyena, Rhinoceros tichorhinus, Wolf, and other species, but not the Reindeer. There are nine of these caves on this border DANA'S MANUAL -64 
1568.

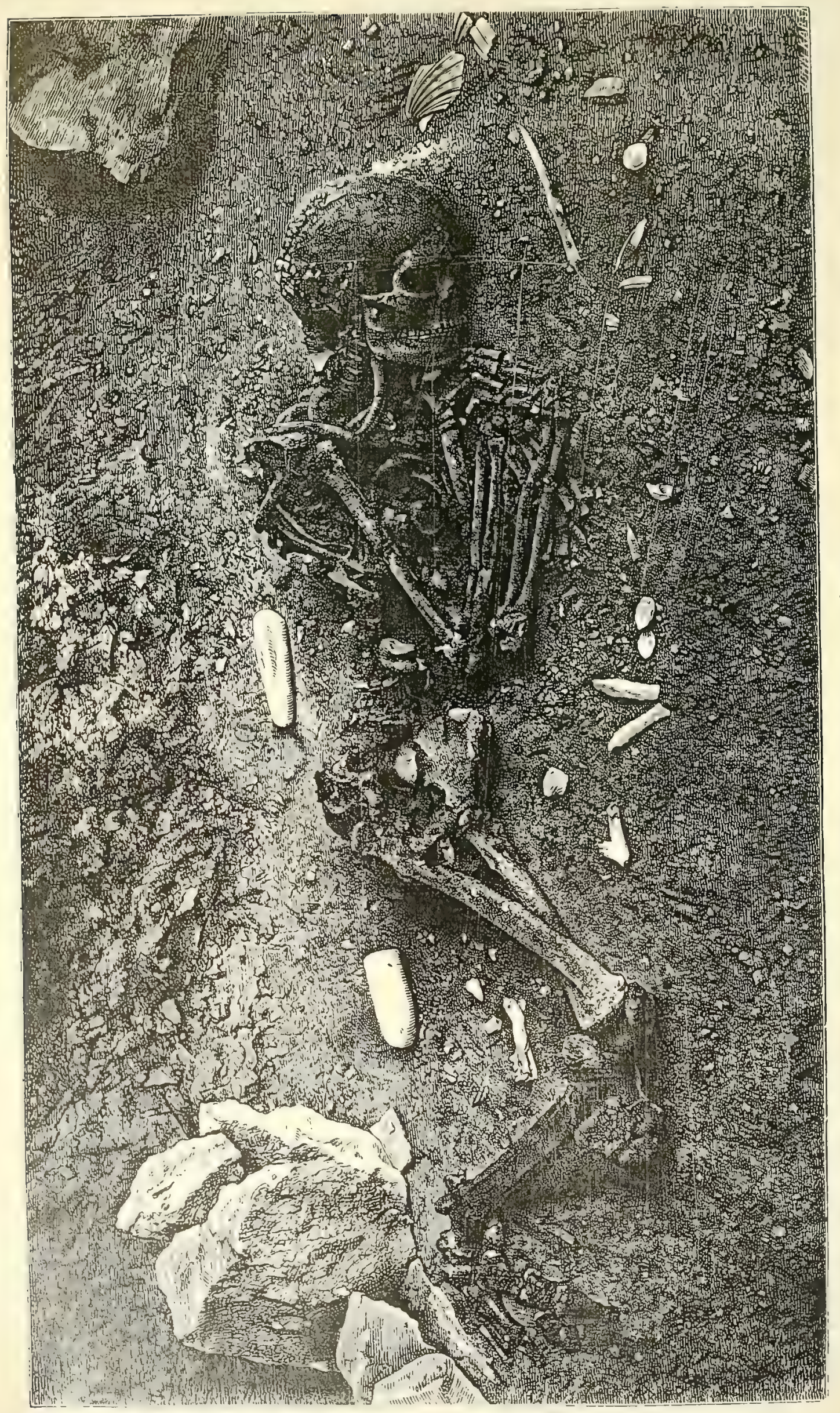


of the Mediterranean. A similar skeleton was obtained from the cave of Cro-Magnon, in Perigord, France, whose height was 5 feet 11 inches, and another at Grenelle, about 5 feet 10 inches. These are referred to the Reindeer epoch.

The human remains of caverns on the Lesse valley, in the vicinity of Liége, Belgium, first discovered by Schmerling in 1833-1834, are regarded as unquestionably Paleolithic. They belonged to less tall men; the cranium was high and short, and of good Caucasian type, though of medium capacity; "a fair average human skull," observes Huxley. But one Belgian jaw-bone, from the cave of the Naulette, has several marks of inferiority, for example, remarkable thickness and small height; the molar teeth increasing in size backward, the posterior or "wisdom-tooth" being the largest (besides having five roots), while the reverse is the case in civilized man; the prominence of the chim wanting. Fragments of crania and of some other bones were found with the jaw-bone.

The human crania of the caves of Furfooz in Belgium, of the Reindeer era, are described as intermediate between the broad and long types, and as "Mongoloid," approaching those of the Finns and Laplanders. The height of the men was not over four and a half feet, and thus they were like existing Man of Northern Europe; and it may be that Laplanders were driven south by the cold, as well as Reindeers. The habits of the people, according to Dupont, were like those of the Esquimaux.

Chipped flints have been reported by F. Noetling from the Upper Miocene or Lower Pliocene of Burma (1894); the bed affording them lies beneath 4620 feet of Pliocene and contained also remains of Rhinoceros Perimensis and Hipparion Antelopinum.

The remains of Paleolithic Man found in North America are sufficient to confirm the conclusions from those of Europe. But the evidence is not of the same satisfactory character, inasmuch as the precise age of the deposits is in dispute, and the localities have not, in general, been verified by a succession of discoveries.

Professor J. D. Whitney described many years since a skull, from Calaveras County, Cal., which was found, according to the owner of the mining claim, at a depth of 130 feet from the surface, underneath the lava-bed, in 1866. Doubts of its authenticity have been expressed by others who have examined the evidence; but Whitney, in his latest publication on the subject (On the Auriferous Gravels of the Sierra Nevada, 1879), refers to corroborating testimony, and gives it full credit. Whitney also mentions the discovery of flint implements in the Auriferous gravel in other parts of California. The fossil plants of the gravels are referred to the Pliocene (or partly Niocene) by Lesquerenx. The few Mammalian remains include the Champlain Mastodon and Elephant, but, in some places, Pliocene species. Some recent land shells were contained in the earth filling the cranium. The skull, according to Jeffries Wyman, resembles that of a modern Indian, especially the Esquimaux, but has a more prominent forehead and a larger 
chamber within. These high qualities of the "Calaveras" skull are part of the objection which has been brought forward to its being of Pliocene Tertiary age, and the Neolithic character of accompanying implements is another part.

Flint implements have been described by C. C. Abbott from stratified drift, along Delaware River, near Trenton, N.J. The deposits in which they occur are probably of Champlain age. At Loveland and Madisonville, Ohio, C. L. Metz found chipped implements in deposits of lœss and stratified gravel. N. H. Winchell has reported the discovery of implements of polished stone and copper, with human bones, in terraced and stratified deposits near Minneapolis. In the lœss of the Missouri valley, Neb., according to Aughey (1874), two chipped implements were found, associated with the vertebra of an Elephant. McGee reports his discovery of a chipped obsidian implement in the deposits about Lake Lahontan, Nev. Hartman's Cave, near Stroudsburg in Monroe County, Penn., has afforded T. D. Paret, and later H. C. Mercer, teeth of the Reindeer, a tooth of the American Bison, and remains of Dicotyles Pennsylvanicus, Castoroides Ohioensis, Horse, Lynx, Gray Fox, Wolf, Skunk, Beaver, Woodchuck, Muskrat, with a bone fish-hook, bone awls, harpoon, etc. There is apparently a mixture in the cave of Pleistocene and Recent. In Brazil, human remains were found many years since, by Lund, in caverns, along with extinct Quaternary Iammals; and Clausen has reported the occurrence of pottery in a bed of stalagmite containing these Mammals.

\section{Recent Period.}

After the great alternations in level and in climate of the Early and Middle Quaternary, the earth appears to have reached, as the Recent period opened, one of its stages of relative quiet. The excavation of valleys, the distribution of earth and gravel over the rugged surface, and the filling of valleys with drift and alluvium had prepared the way for Man, the dominant species of the period. At the final stage in the preparation, the Brute Mammals had become diminished in size, and greatly also in number of species.

But the geological agents of change are still at work — the air, rivers, ocean, heat, chemical forces and interior causes of earth movements; and thereby rock-deposits are still in progress: metamorphism and vein-making by quiet methods; volcanoes with somewhat lessened activity; and upward and downward changes of level. Absolute equilibrium and rest will not be attained until the earth no longer contracts from cooling and waters cease to move and transport.

In the organic kingdoms, interactions among species, and conflicts with natural conditions, are producing variation in Recent time as hitherto, but with this prominent difference: that Man, on leaving the wilderness, and taking full possession. became a powerful agent of modification and exter- 
mination. In conforming to the old organic law, kill and eat, he is like his predecessors. But his necessities lead him to drive wild nature from her grounds, in order to secure room for his farms and dwellings; and in the process, species of plants and animals are fast becoming extinct. Man's carelessness, moreover, has made destructive fires among forests common.

Neolithic Man. - The earlier deposits of the Recent period, made by human agency, are his shell-heaps found especially along coasts, those of the coasts of Danish Islands, in the Baltic - called Kjökken-mödding or Kitchenmiddens, and similar accumulations at other localities. They contain no remains of the Reindeer, showing that the glacial cold had receded toward its present limits, while those of the Urus, Stag, Roedeer, Witd Boar, Dog, Wolf, and other existing species are common.

In Denmark and elsewhere occur polished stone implements, with broken pottery, and bones of existing quadrupeds, and among them those of the domesticated Dog, but no remains of either the extinct Quaternary Mammals or the Reindeer. The Neolithic human remains of Denmark indicate the same small, round-headed race, Laplander-like, that were found in the Reindeer caves of Belgium.

In the same era, or perhaps a little later in the Neolithic era, existed the oldest of the lake-dwellings of Switzerland (dwellings in lakes, on piles, such as Herodotus described over 2000 years since). They have afforded

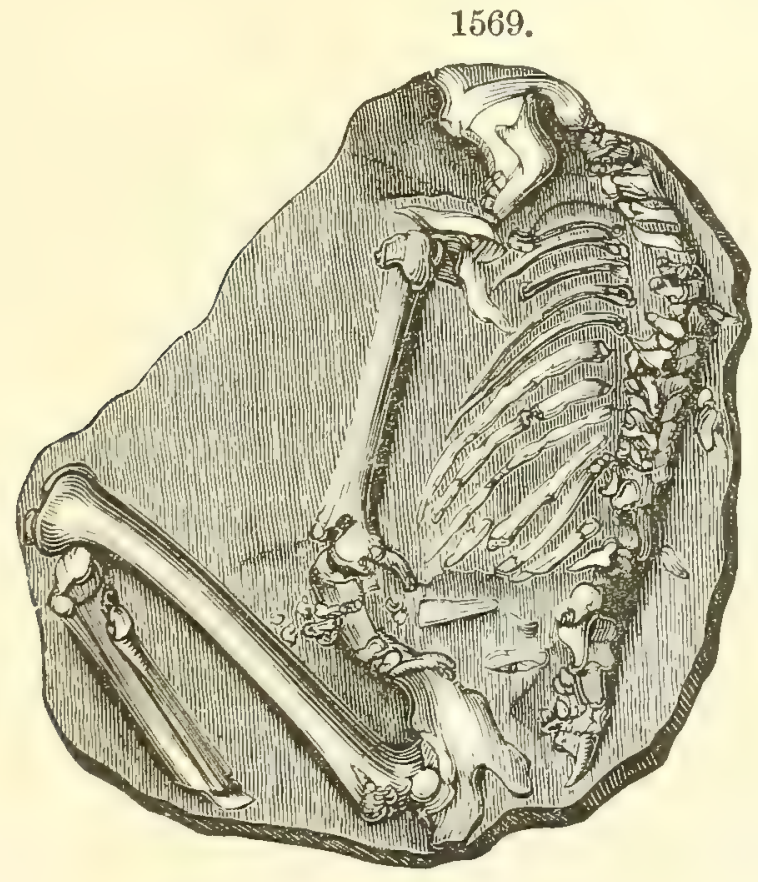

Human skeleton, from Guadaloupe.

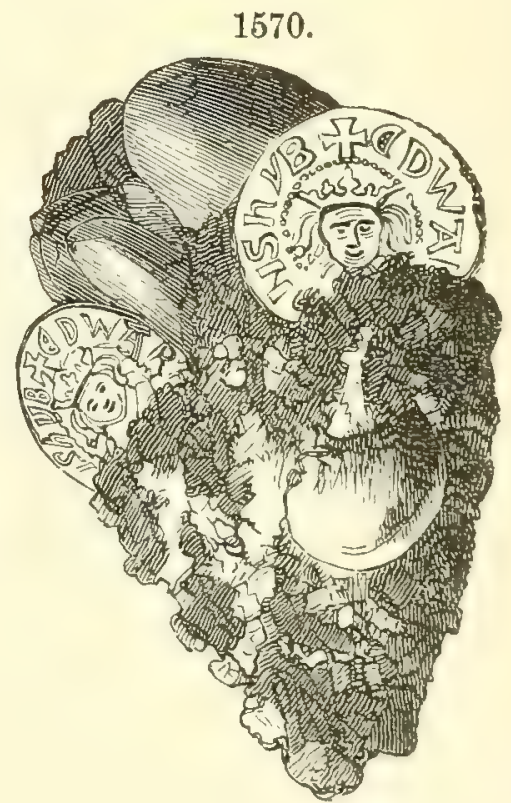

Conglomerate, containing coins

stone implements and pottery, with remains of Goats, Sheep, the Ox, as well as the Dog, but not the Reindeer or any extinct species; also, of Wheat and Barley; also a human skull, neither very long nor very short, but, according to Rutimeyer, much like those of the modern Swiss. These 
Neolithic structures occur mainly about the eastern lakes, Constance and Zurich, while those of the "Bronze Age" are found in the western lakes.

Lake-dwellings or "stockaded islands," called Crannoges, have been found in peat-bogs in the British Isles, and especially in Ireland. They belong to the Bronze and Stone Ages, affording remains of various living species of Mammals, with stone implements in some of them.

Examples of recent relics are presented in Figs. 1569, 1570. Fig. 1569 represents a human skeleton, from a shell limestone of modern formation now in progress, on the island of Guadaloupe. The specimen is in the Museum at Paris. The British Museum contains another from the same region, but wanting the head, which is in the collection of the Medical College at Charleston in South Carolina. They are the remains of Caribs, who were killed in a fight with a neighboring tribe, about two and a half centuries since. Fig. 1570 represents another fossil specimen, of the age of Man, - a ferruginous conglomerate, containing silver coins of the reign of Edward I. and some others, found at Tutbury, England. It was obtained at a depth of ten feet below the bed of the river Dove.

Among the species recently exterminated, there are the Moa (Dinornis) and other birds of New Zealand, the Dodo (Didus ineptus) and some of its associates on Mauritius and the adjoining islands in the Indian Ocean; the Apyornis of Madagascar. The species are of the half-fledged kind, like the Ostrich. Fig. 1571 (copied from Strickland's Dodo and its Kindred) is from a painting at Vienna, made by Roland Savery in 1628.

The Dodo was a large, clumsy bird, some 50 pounds in weight, with loose, downy plumage, and wings no more perfect than those of a young chicken. The Dutch navigators found it on Mauritius in great numbers, in the seventeenth century. But, after the possession of the island by the French, in 1712, nothing more is heard of the Dodo ; there are some pictures in the works of the Dutch voyagers, and a few imperfect remains.

The Solitaire (Pezophaps sulitaria) is another exterminated bird, of the same island, and the Heron (Nycticorax megacephalus) a third (Fig. 1571).

The Moa (Dinornis giganteus Owen), of New Zealand, exceeded the Ostrich in size, being $10^{\prime}$ to $12^{\prime}$ in height. 'The tibia (drumstick) of the bird was 30 to 32 inches in length; and the eggs so large that "a hat would make a good eggcup for them." The bones were found along with charred wood, showing that the birds had been killed

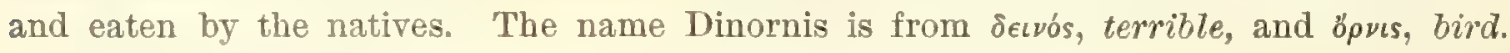
Eleven other species of Dinornis have been found on New Zealand.

Besides the Dinmmis giganteus, have been found also extinct species of Palapteryx and Notomis. Palaptery $x$ is related to Apteryx; and both Apteryx and Notomis have living species.

Besides these, there are other related extinct New Zealand Birds, pertaining to the genera Anomalniteryx. Pnesopteryx, Syomis, Euryapteryx, and others (Hector, 1891).

On Madagascar, other species of this family of gigantic birds formerly existed. Three species have been made out of the genus Epyornis. From the bones of the leg, one is supposed to have been at least $12^{\prime}$ in height. The egg was $13 \frac{1}{2}$ inches long.

The Drepanis Pecitica, or Sickle-bill of the Sandwich Islands, the bird used in making the royal robes, is now extinct.

The Great Auk of the North Sea (Alca impennis Linn.) is reported to be an extinct bird, by Professnr Steenstrup. The last known to have been seen were two taken near 
Iceland, in 1844. The bones occur in great numbers, on the shores of Iceland, Greenland, and Denmark, showing that it was once a common bird; and its remains have been found also on the coasts of Labrador, Maine, and eastern Massachusetts. They occur in the shell-heaps of Maine, Wyman having found seven specimens of the humerus, besides other bones. With these are bones of other species, but of none that are extinct, and also fragments of rude pottery, and some bone-implements.

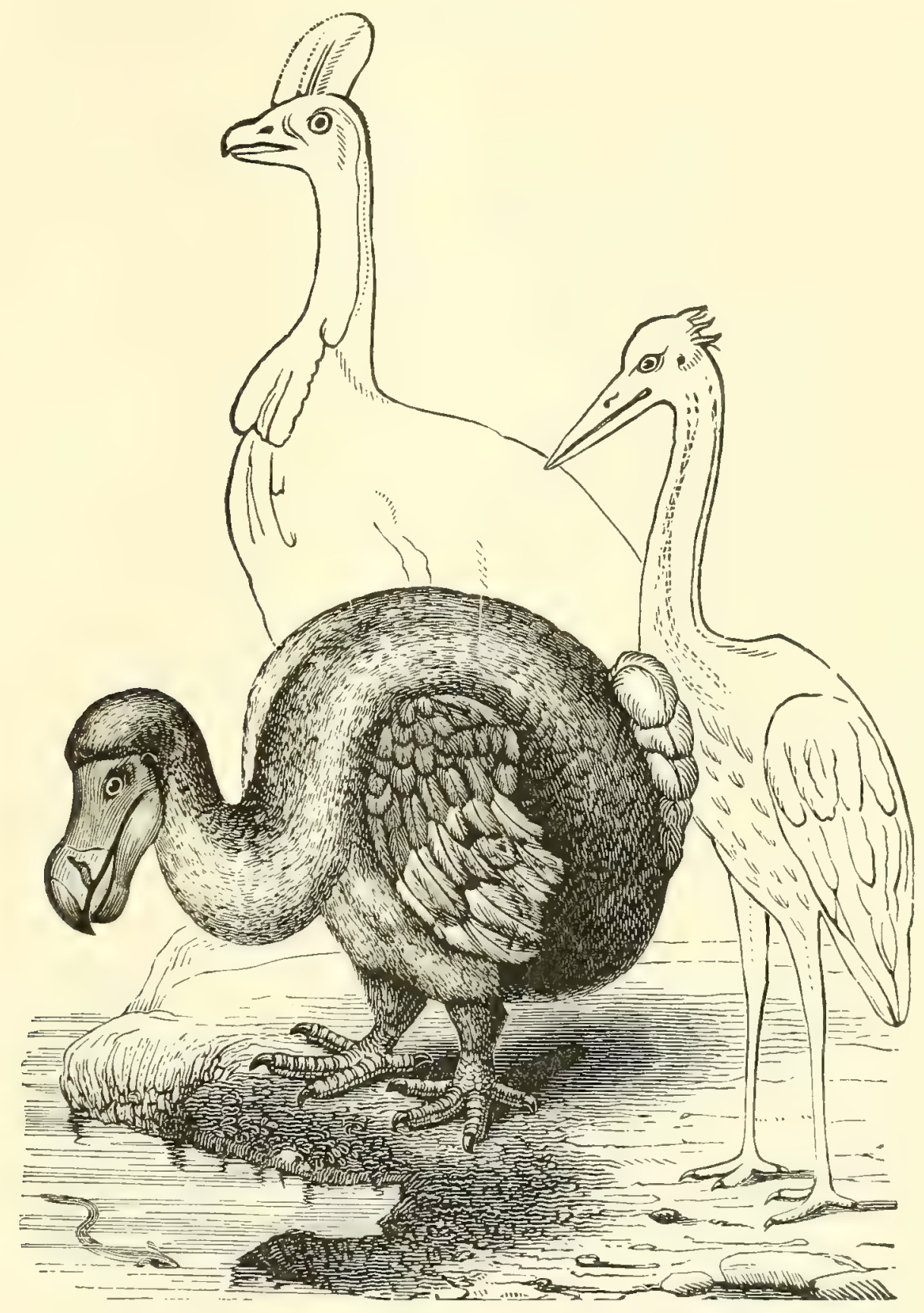

Dodo, with the Solitaire in the background and an extinct Night Heron to the right.

A species of Manatee, Rytina Stelleri Cuv., known in the last century on the Arctic shores of Siberia, is supposed to be now extinct.

The Aurochs (Bison priscus) of Europe, one of the cotemporaries of the old Elephant (Elephas primigenius), would have long since been exterminated from Europe, but for the protection of Man. Though once abundant, it is now confined on that continent 
to the imperial forests of the Russian Czar in Lithuania. It is said to exist also in the Caucasus. The now extinct Bos primigenius is supposed to be the same with the Urus (Ure-Ox, or Bos Urus, described by Cæsar in his Commentaries, and stated to abound in the Gallic forests), and is a distinct species from the Aurochs, with which it has been confounded. It is said to have continued in Switzerland into the sixteenth century.

The American Buffalo (Bos Americanus Gm.) formerly covered the eastern part of the continent, to the Atlantic, and extended south into Florida, Texas, and Mexico; but now it is practically an extinct species, except so far as it is under human protection.

The giant Sequoia or Redwood of California is sure to become extinct as a native: plant.

\section{GENERAL OBSERVATIONS ON THE QUATERNARY.}

\section{BIOLOGICAL PROGRESS.}

Culmination of the type of Brute Mammals. - The biological progress of the Quaternary as it appears in Brute Mammals was but a continuation of the types of the Tertiary onward to their culmination in the course of the Champlain period. The great average size of the species, in connection with the evidence of unimpaired powers, and also the large number of the species. as well as the dense population, are good evidence that Brute Mammals have passed their maximum development. More than half of the species that. then existed are probably yet unknown. But the facts are sufficient, nevertheless, to sustain the above statement. The area occupied by the great Mammals extends from Alaska to Patagonia, from Great Britain, and the Siberiun shores, to southern Australia. A species best thrives in the region of fittest climate. In the Pleistocene, the fittest climate was universal. Geologists have attributed the extinction of most of the species and the dwindling of others to the cold of the Reindeer epoch. It is the only explanation yet found, thongh seemingly insufficient for the Americas.

The era of Fishes, as has been stated, was the time of urosthenic Vertebrates, species in which the posterior extremity of the body serves as the locomotive organ; and the era of Amphibians and Reptiles, the time of merosthenic Vertebrates, the hind legs of the species being the stronger limbs in locomotion. Under, the era of Mammals the merosthenic species. comprise the Herbivores, and many of them are made to serve Man as draught-animals, because of their strong hind limbs; but the higher Mammals, the Carnivores and Quadrumana, are prosthenic, the anterior limbs. being not simply locomotive organs, but having some prehensile power, and in the most of the species eminently serviceable in this way. Only carnivorous and herbivorous species that have taken to a water life are urosthenic, and this they have become by returning to the element that is especially fitted for Fish-like locomotion.

Relation of the Quatemary to the Tertiary Mammals. - The Quaternary types of fiuna and flora on a continent were to a large extent closely related in kind to those of the Tertiary. South America in Pleistocene time was prominently the land of Erlentates; and so, during the Tertiary, Edentates. 
were common species. Australia is now and has been through the Quaternary the continent of Marsupials and Monotremes; and the same types were almost its only Mammalian population in the Tertiary. North Anerica, distinguished for its large number of Pleistocene Herbivores and relatively few Carnivores, was equally so distinguished during the Tertiary; while Eurasia, in both the Tertiary and Quaternary eras, was the chief region of Carnivores. The principle could be illustrated by examples from tribes and species throughout the kingdoms of life; but this would be out of place here. It is explained by Darwin on the ground that the Quaternary kinds have been derived from the Tertiary by descent; and this explanation is now generally accepted. The exceptions to the rule have come chiefly through migration.

Progress in degeneration. - The most prominent cases of degeneracy in terrestrial Quaternary Mammals occur in the Edentates. A great population of them lived in South America, pertaining to numerous genera against two in Europe, Asia, and Africa. The Glyptodonts (Figs. 1563, 1564) appear to have been the lowest. The thick bony covering is protective, and very completely so. It is Molluscan in idea. From what higher Mammals they descended is not known. The low-grade characteristics seem to be a consequence of inactive habits or sluggishness as a result of freedom from enemies and from all unsatisfied desires. Degeneracy from inactivity is well exemplified in parasitic Crustaceans, as the Lernæans, which live with the head-end inside of a fish, always content. As a consequence they have become worm-like in body, and almost limbless and senseless. There is here, emphatically, degeneracy through disuse, with adaptations to the conditions; their origin is thus explained by disuse and adaptation without reference to the "survival of the fittest," or "natural selection." The same is true of the Megatheria; their legs became reduced nearly to massive pedestals by inactivity, and the front teeth, as in other Edentates, were lost through disuse. The Glyptodonts degenerated on the same principle; but, through some organic tendency (like that less perfectly illustrated in the Turtles, the most sluggish of Reptiles), ossification gave them - and eminently so Doedicurus - a protective covering almost to their destruction. It was fitted to save from Carnivores, but not from the cooler climate that ensued, and so the later fauna of the region was rid of them, - exemplifying the fact that the principle of the "survival of the fittest" determines the species that survive to constitute new faunas, if not the existence of new species. The first of the Glyptodonts appeared in the Miocene.

Man. - Man stands in the successional line of the Quadrumana, at the head of the Animal Kingdom. But he is not a Primate among Primates. The Quadrumana are, as Cuvier called them, Quadrumana from the first to the last. 'They are Brute Mammals, as is manifested in their Carnivore-like canines and their powerful jaws; in their powerful muscular development; in their walking on all fours, and the adaptation thereto exhibited in the vertebræ, producing the convexity of the back; and also in other parts of the skeleton. 
Man, on the contrary, is not Quadrumanous. His limbs are of the primitive type so common in the Eocene. He is plantigrade, "has neither hoofs nor claws to his five toes and fingers, but something between the two." Moreover, in his teeth "Man is thoroughly primitive, he having in fact the original quadrituberculate form of molar, with but little modification," and also having "the teeth of the two jaws exactly alike, and making one continuous even series, with nothing of the diastema which prevailed among the higher Monkeys." The body of Man has retrograded also in being merosthenic in limbs, instead of prosthenic, the hinder limbs being the stronger as well as longer, and the fore limbs comparatively weak. All these low-grade characteristics and despecialized conditions of the structure evince that Man does not pertain zoölogically to the group called Primates, either to the higher or lower end of the series. Considering further the zoölogical fact that Man is an erect Mammal, and the only erect species in the whole series, the bones throughout the structure, with the double curvature of the back, being adapted to this characteristic; that his fore limbs are taken from the locomotive series and passed over to the cephalic, to subserve especially the purposes of the brain; that muscular power is not in him the foundation of grade and efficiency, but that he has a brain more than twice the size of the highest of the Quadrumana, and herein is prosthenic to a preëminent degree, as the labors of his hands and head declare, the divergence from the Quadrumana is manifestly great. Man's "low-grade" or "primitive" characteristics have special fitness for the exalted being; and this is sufficient reason for their existence.

Man, moreover, is the last species of the series. Agassiz observed that the Vertebrate type, which began during the Paleozoic in the prone or horizontal Fish, became erect in Man, and thus completed the possible changes in the series, to its last term. An erect body, with an erect forehead and a symmetry that is of ideal perfection, admits of no step beyond.

Man was the first being, in the geological succession, capable of an intelligent survey of nature and a comprehension of her laws; the first cupable of augmenting his strength by bending nature to his service, rendering thereby a weak body stronger than all possible animal force; the first capable of deriving happiness from truth and goodness; of apprehending eternal right; of reaching toward a knowledge of self and God; the first, therefore, capable of conscions obedience or disobedience of a moral law, and the first subject to debasement of his moral nature through his appetites.

There is in Man, therefore, a spiritual element in which the brute has no share. His power of indefinite progress, his thoughts and desires that look onward even beyond time, his recognition of spiritual existence and of a Divinity above, all evince a nature that partakes of the infinite and divine. Man is linked to the past through the system of life, of which he is the last, the completing, creation. But, unlike other species of that closing system of the past, he, through his spiritual nature, is more intimately connected with the opening future. 


\section{THE ANTARCTIC CONTINENT IN THE QUATERNARY.}

The Antaretic Continent appears to have been enlarged during the Pleistocene to the wide limits it had in Permian time, and to have thus renewed its connection with southern Africa, Madagascar, the Mauritius group or Mascarene Islands, and Australia, and probably also with South America. At the same time, Australia was enlarged eastward to New Zealand and beyond to the Chatham Islands, as well as northward along the islands in the New Zealand line; or else it derived a connection with these islands through extension of the Antarctic Continent. As shown on the Bathymetric chart, following page 20, the joining of Chatham Island to New Zealand would require an elevation of only 800 feet; and one of 1200 would unite northeastern Australia to New Caledonia; and one of 500, Australia to New Guinea.

The evidence of these connections is based chiefly on the near identity in some species of Birds and other animals of these widely distant lands. The genus Aphanapteryx (related to that of the Rails), known for some years from Mauritius (east of Madagascar), has been found by H. O. Forbes to have had a species on one of the Chatham Islands, - distant from Mauritius over $120^{\circ}$ in latitude; and the two species, A. Broecki of Mauritius, and A. Howkinsii of the Chatham Islands, are scarcely distinguishable. Several species of New Zealand Birds were found by Forbes on Chatham Island; among them the Kea, a Parrot "that changed its diet in recent years, forsaking fruits, and now kills sheep by eating through their backs to their vital organs"; the flightless Woodhen, Ocydromus Australis, the Owl, Glaucidium Novi-Zealondice, and also a Hawk and Swan.

Further, Australia had, in Quaternary time, a Dromornis, closely related to the gigantic Dinornis of New Zealand and the Apyornis of Madagascar. Moreover, Africa has the related Ostrich; and southern. South America has afforded remains of a great flightless bird of Ostrich affinities. The Penguins, also flightless birds, range from South America to South Africa, Australia, New Zealand, and the Antarctic Islands. Similar facts occur among Edentates, Amphibians, and Plants.

Forbes, in view of the facts, concludes that the land of the Antarctic circle had, in late geological time, a large extension, admitting of migration between the continents and with the adjoining or adjoined islands. $\mathrm{He}$ remarks, also, on the glaciated condition of such a continent in a Glacial period, and its effects in producing cold or glacial conditions in the southern hemisphere.

Forbes's paper is contained in the Proceedings of the Geographical Society of London, October, 1892, and in the Geological Magazine for Nay, 1893; and he has another paper on the subject of zoölogical character in the Magazine of Natural History, July, 1893. 


\section{EPEIROGENIC CHANGES DURING THE QUATERNARY.}

The upward continental movements of the early Quaternary and the late Tertiary, by which the greater mountain regions of the globe were elevated from 10,000 to more than 20,000 feet, and, following this, the wide-reaching but feeble downward movement of the Middle Quaternary, and then the more limited elevation closing the Champlain priod, and, last, the settling back of the land to the degree of equilibrium characterizing Recent time, brought gradually and grandly to an end the earth's mountain-making. The movements were epeirogenic, and involved the whole sphere. It has been thought incredible that the orographic climax should have come so near the end of geological time, instead of in an early age, when the crust had a plastic layer beneath, and was free to move; yet the fact is beyond question. The event is made, on page 392 , a legitimate effect of lateral pressure in the contracting crust; and the coral-island subsidence, or, in more general language, the deepening of great areas over the oceanic basin, is set forth on the same page as the counterpart.

Why, in the upward movement, the colder latitudes, or those outside of the parallel of $40^{\circ}$, should have been most affected, as the distribution of fiords and other facts make evident, is wholly unexplained. The interest of the problem is greatly enhanced by the new facts proving that the Antaretic Continent also was elevated and greatly enlarged, - probably to four times its present area; that not only the lands of the high northern latitudes were affected, but also their antipodes in the high southern latitudes. Under these conditions the earth's polar diameter would have received a considerable increase of length, and the waters would have been deepened over the lower latitudes.

The idea of Croll, that the Glacial periods of the northern and southern hemispheres followed one another, has no support from geological facts, and few supporters among geologists.

The Champlain subsidence following the elevation has been attributed, on the principle of isostasy, as stated on page 379, to the weight of the load of ice over the glaciated land. The cause is good in principle, but of doubtful sutficiency. The facts stated on page 980, with regard to the departure of the ice from the United States before the subsidence had made much progress, indicate a great lagging in the effect, far greater than is compatible with the results of a load. Moreover, the coast region of California subsicled deeply (page 985) although it had not been covered by ice; and the land which joined South America with Cuba and probably Florida, and that uniting Africa to Malta and Sicily disappeared, although far outside of the ice-limit. The dry land across the British Channel between England and France continued emerged long after the mild climate, which favored migration of warm climate Hammals, set in; and it became submerged although the land either side was never under the ice-sheet. France and 
other parts of Europe bear evidence of subsidence in the many terraced river valleys and sea borders, although never glaciated. Other facts bearing on the question will be found in a recent paper by Prestwich on the late Post-glacial submergence. The ice of the locally glaciated areas over Europe could have depressed isostatically only equal areas to a depth less than two fifths of the mean thickness of the ice.

The insufficiency of the ice-sheet to produce the widely extended Champlain submergence is evident. The only other agency to which appeal has been made is that of the earth's contraction; this makes the movements of the Quaternary one in cause and system.

The Recent period has its epeirogenic movements partly as a continuation of the earlier, and partly as a result, it is believed, of the deposition along coasts and elsewhere of river sediment. The principal facts have been reviewed on pages 341, 367. Another example, of a geanticlinal character, is afforded by the Scandinavian region. A recent report on the subject has been made by L. Holmström (1888). On the west coast, at two localities, in latitudes $57^{\circ} 53^{\prime} \mathrm{N}$. and $58^{\circ} 56^{\prime} \mathrm{N}$., the rate of rise of the land, during respectively 66 and 116 year's before 1886, was about two inches in ten years; and at another place, in $58^{\circ} 35^{\prime} \mathrm{N}$., about four inches in ten years. On the

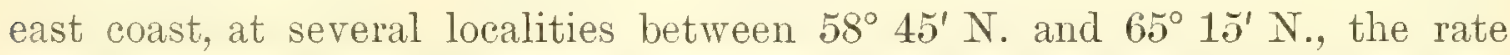
during various intervals from 45 to 139 years before 1867 to 1875 , was 1.8 to four inches in ten years; at Stockholm, 1.85 inches; and in Finland, in $63^{\circ} \mathrm{N}, 2.5$ to 3.75 inches. The rise is least to the south. The conclusions differ but little from those derived by Lyell from the facts he gathered, during his visit to the coast in 1834.

Moreover, the many fault planes in the earth's crust resulting from old orogenic movements are planes of weakness, and show it from time to time by slips and consequent earthquakes (prge 373). It is rendered probable that regions over the Rocky Mountains may still be in slow movement up or down.

Tpturned beds occur on all the islands south of New England from Long Island to Nantucket. But although the disturbance has been supposed to be of Quaternary origin, the chief part is of earlier date. The beds of Long Island were first described by W. W. Mather in his excellent account of Long Island geology contained in his New York Geological Report (in quarto) of 1843.

The deposits, as made by Mather and as has since been proved by fossils, are Cretaceous clays, sand and pebble beds with overlying Quaternary drift. The bluffs of 150 to 200 feet along the northern coast have the beds mostly concealed by the fallen debris from above. But part of Mather's investigations were made after a "storm of the 11th and 12th of October, 1836," when the cliffs were laid bare, giving him an unusual opportunity for the study of the stratification. He was led to the conclusion that the flexures are partly local displacements in the clay-beds, due to vertical pressure and slides, and partly a result of upturnings anterior to the drift deposits. This accords with the author's observations over the island. It sets aside the idea that the flexures were in any case an effect of pressure from the moving ice-sheet.

Figs. 1572 to 1575 are from Plate iv. in Mather's Report. The crumplings in Figs. 1572 and 1573 are like those that are made by local pressure or slides, or sinkings of the 
overlying beds, which shoved aside and forced out the wet and mobile clay. At many places along the coast the clay has been forced out in this way and now covers more or less of the slope below; and in the clay-pits, sinking and exclusions are not uncommon. At the Holmes clay-pit on Fresh Pond, near Northport, there were cracks in 1875 at the top of the bluff where the sinking was in progress, and where, as the proprietor stated, it had amounted to 16 inches in 20 months, and the movement, he added, was all the time going on. A clay-bed is made to vary greatly in thickmess in the face of a bluff because locally squeezed out.

$1572-1575$.
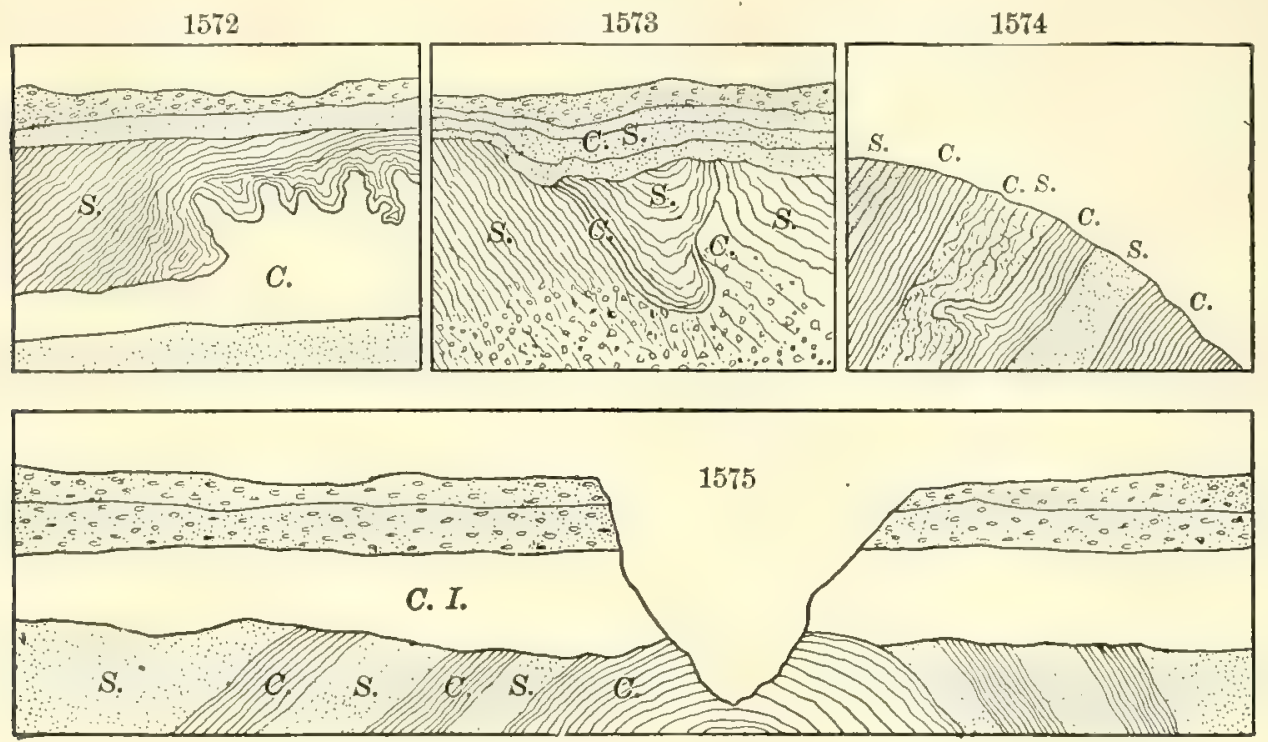

Sections of the Cretaceous and overlying beds on the north side of Long Island. Figs, 1572, 1573, Sections near

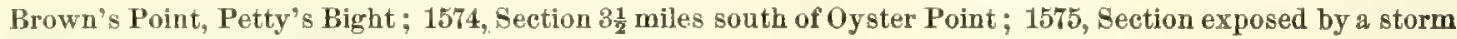
200 yards south of Brown's Point. W. W. Mather.

In the case represented by Fig. 1575, the position of the beds plainly proves, as Mather states (page 249), that an upturning and a subsequent denudation had taken place after the lower beds of alternating clay and sand had been formed, and before the deposition of the overlying clay-bed and the higher deposit of "coarse materials and bowlders" or drift. The tilting in Figs. 1572-1574 probably had the same origin. The age of the claybed C. I. in Fig. 1575 is left uncertain; but the upturned beds are Cretaceous. Mather states that in all sections the overlying drift deposits have the same horizontal position, and that some of the bowlders contained in them have great size. "Blocks of 50 to 500 tons are not uncommon on the island" (page 174); and he reports one having an estimated weight of 2000 tons.

The upturned beds in Desor's Nantucket section, referred to on page 983, are covered by others in horizontal position, and are probably of the same age and origin with those of Long Island.

On Martha's Vineyard, according to Shaler, the upturned beds, which include the Cretaceous and 'Tertiary, bear evidence in their erosion that the chief upturning preceded the Later Glacial epoch, if not partly at least the earlier. Lyell, in his Travels in North America (1845), describes the sections at Gay Head and Chilmark, figures the former (i, 204), and states that the upturning occurred between the Miocene Tertiary and the "Boulder" or Drift period.

There is grandeur in the simplicity as well as vastness of the movements by which the earth was made ready for its latest stage. Equally simple and 
comprehensive were the agencies set to work: glaciers that reached across from ocean to ocean; rivers deriving magnitude and energy from the loftiest of mountains, the greatest of ice-sheets and the most abundant of rains; and a genial climate that reached almost to polar latitudes, and produced luxuriant growth in all life, animal as well as vegetable. Thus were evolved, as never before, the sublimity of the mountain peaks, and the richness and varied beauty of the valleys and wide-reaching plains, and the many other surface details that were essential to the pastoral and agricultural pursuits with which man was to commence his own development.

\section{GENERAL OBSERVATIONS ON GEOLOGICAL HISTORY.}

\section{LENGTH OF GEOLOGICAL TIME.}

Time-ratios. - In the preceding edition of this work estimates are given of the relative lengths of the ages and periods, or their time-ratios, based on the maximum thicknesses of the rock formations of the several periods, allowing a ratio of 1 to 5 between the rate for limestone and that for ordinary fragmental rocks. These thicknesses have since been increased much for some parts of the geological column; but the increase is not far from proportional to the former numbers. The evidence at present obtained appears to favor the conclusion that the relative duration of the Cambrian and Silurian, the Devonian and the Carboniferous eras, corresponds to the ratio $4 \frac{1}{2}: 1: 1$, or perhaps $4: 1: 1$, the ratio hitherto adopted; and for the Paleozoic, Mesozoic, and Cenozoic, 12:3:1. The thickness of upturned rocks is so difficult to obtain with accuracy, and is so certainly exaggerated greatly when the absence of faults and flexures is not ascertained before drawing conclusions, especially in connection with the older tilted formations, that much careful geological work is yet to be done before reliable ratios can be deduced.

Length of time since the Glacial period. - The facts with regard to the present rate of recession of Niagara Falls have been used for calculating the length of time since the Glacial period. The argument has been presented thus. Niagara has made its present gorge by a slow process of excavation. and is still prolonging it toward Lake Erie. Near the fall, the gorge is 200 to 250 feet deep, and 160 feet at the fall, - the lower 80 feet shale, the upper 80 limestone. The waters wear out the shale, and thus undermine the limestone. The rocks dip 15 feet in a mile up stream, so that the limestone at the fall becomes thicker, as retrocession goes on. The distance from Niagara to the Queenston Heights, which face the plain bordering Lake Ontario, is seven miles. The general features of the region are shown in the bird's-eye view, page 973. The new excavation began again at the Queenston Heights, and gradually extended southward to its present limit at the Falls. The time of beginning was after the filling of the channel with drift, which occurred during the retreat of the glacier. The rate of progress in the exca- 
vation was estimated by R. Bakewell, Jr. (son of the English geologist), in 1829, on the basis of facts received from a 40-years' resident. His estimate was about three feet a year. Lyell, who was at the Falls in 1841 with James Hall, reduced the rate to one foot a year, making the elapsed time about 31,000 years.

The question has since been considered by other geologists. G. K. Gilbert, taking as data (1) a map made in 1842, after a careful survey by Blackwell in 1841, and published in the N. Y. Geological Report of J. Hall (1842), (2) another, made 33 years later, by the U. S. Army Engineers, and (3) a third, made in 1886 by R. S. Woodward, concluded that the rate of cutting, supposing the conditions to have been uniform, was about five feet a year, and the length of time about 7000 years; but he observes, that instead of uniform conditions, there have been great variations in the height of the fall, and in the amount of water, and that the deduced rate cannot be safely accepted (Ann. Rep. Smithsonian Inst. for 1890).

That the investigation is beset with doubt is evident from the remarks on page 987, and also by the various conclusions of recent writers on the subject. W. Upham, on the grounds stated in his various papers, makes the time 6000 to 10,000 years. J. W. Spencer, in his latest interpretation of the facts (1891), arrives at the conclusion that the excavation of the channel required 32,000 years. But, as already shown, the amount of water now discharged by the river is no measure of that during the Champlain period of moist climate and expanded but gradually diminishing lakes, and no other safe basis for an estimate is known. As the amount of water then was almost certainly much larger than now, the lower estimates are probably nearest the truth.

A similar estimate has been made by N. H. Winchell (Final Rep. Geol. Minnesota) for the rate of recession of the Falls of St. Anthony on the Mississippi at Minneapolis (page 973), with the result that the elapsed time was probably about 8000 years.

The rate of progress in a peat-bed, and that in a thickening deposit of stalagmite in limestone caverns, are other uncertain data that have been employed for deducing the length of time since the Glacial period. The amount of stalagmite is dependent on the amount of carbonic acid or organic acids in the filtrating waters, and partly on the texture of the limestone. The results of such calculations do not appear to have any geological or archæological value.

Length of geological time according to geological evidence.-The facts from geology used as a basis for calculating the length of geological time since the Archæan are: the rate of sedimentation or accumulation, and the rate of erosion or denudation, the former usually made dependent on the latter. The rate of denudation is generally based on the results obtained by Humphreys and Abbot from the Mississippi and its drainage area, and related results from the study of other rivers. The rate of sedimentation obtained from the Mississippi gives an average of one foot from the whole 
drainage area in about 6000 years. The rate usually taken is one foot in 3000 to 7000 years. The rate 1 to 3000 was deduced by S. Haughton (1880) from the rate of sedimentation of the following rivers: the Mississippi, 6000 years ; Ganges, 2358; Hoang Ho, 1464; Yang-tse-Kiang, 2700 ; Rhone, 1526; Danube, 6846; Po, 729 years; the mean of which is 3090 years. He adds that since the sea bottoms are to the land surfaces as 145 to 52 , the rate at which the sea bottoms are becoming silted up, that is to say the present rate of formation of strata, is one foot in 8616 years. Thence, supposing the rate the same as now for all past time from the Archæan onward, the whole duration of geological time is $200,000,000$ years. But Haughton incluced in the thickness of the terranes, 60,750 feet of Archæan, or over one third of his total (177,200 feet). Deducting for the Archæan, the length of the rest of geological time would be about $130,000,000$ years.

Mellard Reade makes the time since the Archæan, on the same kind of basis (taking the mean area of denudation as one third the entire land area, and the rate of denudation one foot in 3000 years), 95,000,000 years (1893).

C. D. Walcott deduces, for the elapsed time, 70,000,000 years (1893); H. H. Hutchinson, $600,000,000$ years (1892); M'Gee, including in his basis the rate of denudation at Niagara, and giving credit to the extreme estimates of thickness of the early Paleozoic formations, 6,000,000,000 years (1893).

All these estimates proceed on the solid basis of existing facts. Yet in deriving them the extreme difference between the existing earth and that of the geological past was not taken into account. Going back in geological time, the rock-making portion becomes more and more widely marine, and rivers have correspondingly diminished size and drainage areas. But, at the same time, climates become warmer and precipitation therefore increasingly abundant; and through Paleozoic to earlier time the eroding carbonic acid and oxygen of the atmosphere are increased in amount, and corrosion threby was proportionately greater. Even as late as the Middle Cretaceous, the western half of North America was an open sea with its large and small islands. In the Paleozoic, and still more in the Arehæan, the whole continent was in a like condition; and the Continental seas had only little streams and drainage areas to supply sediment for the thick formations, so that the sea did much more than half the work in its slow way. Further, changing climates have occasioned changing rates of erosion and sedimentary deposition; and have made, over large continental areas, times of great precipitation to alternate with times of prevailing drought, and times of full lakes and of large hard-working rivers, with times of dwindled or feeble waters. In addition, the deposits of one period have often been largely denuded to make those of the following; and the chief sources of all sediments are Archæan. Attempts therefore to find, in the results of aqueous action, a definite measure of any part of the geological past necessarily lead to very doubtful results.

Length of geological time on evidence from terrestrial physics. - Kelvin pointed out in 1862 that a limit to the earth's age is fixed by the known DANA'S MANUAI - 65 
facts as to the rate of downward increase of heat and the rate of loss of heat into space; that if the earth had cooled less than $20,000,000$ years since, the internal heat would have been greater than now; and if more than $400,000,000$ years, there would have been no sensible increase of heat downward; and he suggested a probable length of $100,000,000$ years. The bearing of the facts as to tidal retardation, and his hypothesis with reference to the origin and age of the sun's heat, gave him other arguments on the question; but the conclusions are less well based than that from rate of cooling.

Tait, arguing from the effect of tidal retardation on the figure of the earth and the rate of cooling, concluded, that the time which can be allowed to geologists is something less than 10,000,000 years; and, in view of the supposed origin of the sun's heat (by the falling together of masses of matter), that the time the sun has been illuminating the earth is not more than about $15,000,000$ or $20,000,000$ years; and, again, that the supposed concussion would have made heat enough to last the earth $100,000,000$ years. Croll has some speculations on this subject in Chapter xxi. of his Climate and Time.

Newcomb says: "If we reflect that a diminution of the solar heat by less than one fourth its amount would probably mean an earth so cold that all the water on its surface would freeze, while an increase of much more than one half would probably boil all the water away, it must be admitted that the balance of cause which would result in the sun radiating heat just fast enough to preserve the earth in its present state has probably not existed more than $10,000,000$ years."

The first of Kelvin's methods mentioned above has been adopted by C. King (Am. Jour. Sc., 1893), with new data, derived from experiments by C. Barus, with regard to the latent heat of fusion of the rock diabase, its specific heat when melted and when solid, and its volume expansion between the solid and melted state, besides other points bearing on the subject. The conclusion reached is that the earth's age is probably $24,000,000$ years.

The safe conclusion from all the Geological and Physical facts is that 'Time is long, very long; long enough for the development of all the earth's rocks, mountains, continents, and life. Geologists have no reason to feel hampered in their speculations, while the extreme results of calculation are $10,000,000$ and $6,000,000,000$ years.

\section{CLIMATAL DEVELOPMENT.}

A globe that has slowly cooled from fusion, and has had in the past, as now, a sun that is losing heat like itself, must have been a globe also of cooling climates. But its orbit has wide variations, and the sun, it is supposel, its varying phases. Moreover, the present era is a time of mild climate compared with that of the Glacial period which preceded it; and hence the cooling of the climates has not been continuous and regular, but one by oscillations, in which refrigeration was real, though often passing through extremes in both directions. 
Tet, notwithstanding these sources of change, no good evidence in all Paleozoic time, except near or at its end, has been found in the fossils or the rocks, of zones in the earth's climates or of variations in temperature. North America shows in its large coal formation, as compared with that of Europe, that it had then, as it has now, the moister climate; and therefore that the system of winds was the same as in Recent time, and hence that the system of oceanic currents was the same. Some difference must have existed, and more in the atmosphere than in the waters; but it was not enough to modify, as far as has been ascertained, the marine fauna of the globe. Uniformity in climate in the northern hemisphere is favored by unobstructed oceanic currents.

In the later part of the Permian, or at its close, a cold epoch occurred (page 737). At the same time happened one of the earth's most general exterminations of life. But large continental areas were then rising, and the Antaretic Continent was elevated and greatly extended; so that the elevations may have been the cause of the cold.

After the close of Paleozoic time, zones become apparent (page 791). But even in the earlier part of the Cretaceous period, Cycads abounded in the northern polar regions, showing only a small decline in mean temperature since the Cambrian. After the Middle Cretaceous, a more rapid decline began (page 872); but, concordantly, large continental elevations were in progress. The increasing elevations during the later Tertiary culminated in the Glacial period of the Quaternary.

Thus, throughout the earth's history since life began, the only cold epochs of which proof has been found occurred near or at the close of the Permian, at the close of the Triassic, and during the Glacial period. At the close of the Cretaceous, another epoch is suspected to have occurred, but without direct evidence.

The post-Permian and Glacial cold occurred at times when the Antarctic Continent had great extent, and therefore when the earth's polar diameter had unusual elongation. Since the Glacial period, the polar lands have again become submerged; but, inasmuch as Greenland affords evidence of continued subsidence, it may be questioned whether a time of minimum for the polar diameter is yet reached.

This review of the extremely slow decline of temperature it the earth's climates during its lifetime, - be it 10 millions of years or 600 times this, with traces of only three or four epochs of cold in the course of the millions, is calculated to give the impression that the eccentricity cycle in the earth's orbit is a very ineffectual epoch-making agency.

\section{THE EARTH'S DEVELOPMENT.}

The evolution of the earth's continents and their surface features is one of the two great subjects in the science of Geology. The idea-Continents always Continents - announced by the author first in 1846, has been affirmed 
by all that has since come to light, and Geology now has, as regards North America, a record of the chief consecutive events in a continuous process of development. It has become manifest also that the development has gone forward not simply by enlargement about a nucleus, but through successive stages of work in Interior seas, having, in general, Archæan confines; and that the great Interior Continental sea was not due to a return to oceanic conditions, but a phase in this endogenous feature in the method of progress. Europe also had its interior seas, and Asia, - the two almost one; and so also had Australia, for the later facts show that in Cretaceous, or Cretaceous and Tertiary time, the Australian continent was divided in two by such interior waters. An exception to the general principle has been made by putting a hypothetical continent in the Indian Ocean. But the facts suggesting the hypothesis have been shown to be explained otherwise.

A detailed review, in this place, of the steps in the process of development is not necessary. The closing pages of the Dynamical Geology, 391 to 396, are an appropriate continuation of these remarks on the earth's development. With regard to the hypothesis on page 396, respecting the alternate or zigzag arrangement of the continents, geological history affords no satisfactory testimony. There is only the interesting fact that the ore belt along the Andes of South America is continued through the nearly east and west bend of Central America to the Rocky Mountains and extends on northward to Wyoming, with remarkable similarity in its ores and the age of the veins. Whether the supposed continental displacement gave this displacement to the deep-seated ore region that in the earth's later eruptive periods supplied the ore; or whether the similar position of the ore veins was due simply to a like position of the two continents with reference to the Pacific oceanic basin, it is not safe to say.

Details with regard to continental development have been given in the chapters on Geographical and Geological progress, closing the accounts of the Lower Silurian (page 524), the Paleozoic (page 714), the Mesozoic (page 867 ), and the Tertiary (page 932 ).

\section{PROGRESS IN THE EARTH'S LIFE.}

General principles with regard to the progress in the earth's life. - The Animal and Vegetable Kingdoms studied by science comprised, not very long since, only living species. Through the revelations of geology they now include, in addition, the life of an indefinite succession of faunas through the past ages up to, if not over, the borders of Archæan time. As a consequence of these developments, the following principles were early announced with respect to the progress in the earth's life:-

I. Progress from aquatic life to terrestrial life, commencing in the waters in an era of nearly universal waters, and reaching its higher stages over the land. 
II. Progress from the simple to the complex or the more specialized; animal life, commencing with Protozoans, the simplest of species, without special organs of any kind-Radiolarians, the minute, silica-secreting, Rhizopod-like kinds, having been reported (1894) from rocks of Archæan time-and becoming displayed in a few comprehensive structural types, the simpler forms of which appeared in early time, and the more complex successively afterward; the new organs required in the highest manifestations of a type being only developments through modification of the older, or better appliances evolved from the structure for carrying forward old processes.

III. The succession under a type parallel to some extent with the embryonic stages in related living species, part of the early life of the globe representing in some points the embryonic or young life of to-day.

IV. Early types, often a combination of two or more types that were afterward differentiated, that is, became separate, independent branches in the system; synthetic types of Agassiz, comprehensive and generalized types of others.

V. The earlier species under a type often multiplicate in structure, and losing this feature with rise in grade (pages $421,437,486$ ).

VI. The culmination of types, followed by degeneration, and often extinction, at various times along the successive eras.

VII. In the degeneration of a type, often a partial return to some of its early characteristics.

VIII. The Animal kingdom, one in system from the beginning, - the grander divisions of modern time being, to a large extent, those of the earliest Paleozoic (page 486), and some Paleozoic genera still having their species. The facts prove unity in system of life as well as in organic and physical law.

IX. A headward concentration or cephalization of the structure attending generally a rise in grade, and the reverse, or decephalization, a decline.

$\mathrm{X}$. The localization of tribes in time, or chronographically, involved in the physical progress of the earth, that is, in its progressing climates, and its conditions as to water and land. As now there are different zones, and various localizations of species on going from the equator to the poles, so there were necessarily successive phases and increasing diversity in the life of the world on passing from the warm conditions and nearly universal seas of early time to the present age of frigid polar regions and greatly differentiated seas and lands.

Evidence with reference to evolution by variation. - The propositions above stated rearl like the heads in an argument for the evolution of the kingdoms of life. They were so recognized many years before Darwin's first publication on this subject. Most of them were used by Agassiz in his lectures on development, - by which he meant evolution; and evolution based on paleon- 
tological study, having therefore the successional lines which such study ascertains; but different in method, the change in species being dependent, in his view, on ereative acts, and not on natural variation. All students of nature, with a rare exception, then believed in permanence; for Lyell's chapter against the transmutation of species, in the successive editions of his Principles of Geology, had seemingly settled the question against Lamarck by scientific argument. It was not till 1859 that Darwin's work was published on the Origin of Species by means of Natural Selection, or the Preservation of Favored Races in the Struggle for Life.

The principles above stated are all in accord with a theory of evolution; and, through the added facts of later years, they favor the view of evolution by natural variation. Some of these added facts are the following: Botanists find numerous cases among existing species in which, owing to the many varieties, no line can be drawn between allied species; and other eases in which modern species of plants are but slight modifications of fossil Tertiary species, some too slight to be called distinct species, and others more divergent up to those of good distinctive characters. Similar facts occur as a consequence of migrations, among animals as well as plants. Aretic America contained, in Tertiary time, plants so much like species existing in the forests of both temperate North America and Japan (page 939), that the former have been pronounced the undoubted progenitors of the latter. Along the Pacific coast and Gulf coast of Central America there are so many identical and nearly related species of aquatic animals that migration during a time of submergence of the narrow strip of land, with subsequent variation, is regarded as the only reasonable explanation. These and other observations have proved sufficient to make all zoölogists of the present day, like the botanists, believers in a system of Evolution by variation.

It is admitted that in the geological record cases of unbroken gradation between species are of rare occurrence. But the geological record bears evidence, in all parts, of imperfections. It is imperfect, (1) because, under the most favorable circumstances, only a small part of the existing species could have been fossilized; (2) because in all lands there are great breaks in the series of rocks, as is known from comparing the rocks of different continents, and even different regions on the same continent; (3) because fossiliferous rocks are almost solely of aqueous origin, and consequently they contain exceedingly little of the terrestrial life of the ancient world - one species of Bird being all yet discovered in the world's rocks of the Jurassic period, and two species of Mammals all that are known from the American Triassic beds; (4) because marine strata that were formed around the land when it was at a higher level than the present are now buried in the ocean, and are therefore inaccessible, a condition that has affected half the borders of a continent for several successive periods; (5) because only a small part of the rocks of a continent are open to view. This subject has been abundantly illustrated in the preceding history of the formations and their life.

But transitions have been nearly filled in so many cases, and are indi- 
cated so plainly by the very gradual steps in the successional lines; the progress of rudimentary organs may so often be traced from an early condition of good size to that of rudiments, and variations in existing species are so often wide and perplexing to the systematist, that the evidence in favor of evolution by variation is now regarded as essentially complete.

The argument from the facts presented on page 929, respecting the descent of the Horse, is strengthened by the occurrence among modern horses occasionally of a small pair of hoofs growing from the extremity of the splint bones of each foot - the old toes lost by descent back again; and more rarely by the growth of a full-sized toe from one of these bones, on all the feet, approximating thus to horses of the later Tertiary (Marsh, Am. Jour. Se., xliii. 1892). Birds, now standing apart from other Vertebrates so stiffly, as animals with feathers, short tails, and bills without teeth, in former times had teeth in their jaws, and long tails, like Reptiles. Moreover, in the Reptilian age, there were biped Reptiles, with the hollow bones and some other characteristics of Birds; and also Mammals that laid eggs like Birds and Reptiles, - as they continue now to do in Australia.

There are, however, some large blanks in the series which are yet unexplained, although investigators have been at work over the subjects for scores of years. One of these is the apparently sudden appearance of plants of the tribe of Angiosperms, the most common kind of Recent time, in the Lower Cretaceous; another, the still more remarkably abrupt introduction of ordinary or placental Mammals as successors to the Marsupials at the commencement of the Tertiary; another, the introduction of well-characterized Fishes, without the discovery of their precursors. Such facts excite, at the present time, interest in further study, but not doubts as to the general system of progress. Already a small slender fossil, with a blade-like sculling tail and terminal mouth, - the Paloespondylus Gunni, from the Devonian of Caithness, Scotland, - has been described as probably a primeval Lamprey (an eel-like Cyclostome, page 403). But, if correctly referred, there is still a very wide interval between it and the early Placoderms.

Some other general facts respecting successional lines, are the following :

The lines of succession seldom connect the grander divisions of classes or tribes. None lead directly from Macrural to Brachyural Crustaceans, or from Amphipod to Isopod kinds. Instead, the group of Anomourans, intermediate between the two tribes first mentioned, was the course of successional lines in geological history, and of branches to both the Macrurans and Brachyurans. In a similar way the Anisopods, intermediate between the Isopods and Amphipods, or the typical Tetradecapods, were the source of branches to these tribes. The principle is in accordance with that respecting comprehensive or synthetic types, for the Anisopods and Anomourans are of this nature. A line leads direct from the higher Ganoids to the Amphibians; but, instead of lines from Amphibians to Reptiles, and thence to Birds or to Mammals, all three groups - Reptiles, Birds, and Mammals - were probably derived directly from the Amphibians. Instead of successional lines between Ungulates, Carnivores, and Quadrumana, these three groups were probably derived, as Cope has remarked, from some common tribe in the earliest Eocene. No successional lines among Insects appear to have passed between the higher tribes of 
Neuropters, Orthopters, Coleopters, Lepidopters, Hymenopters; but each was derived from some early comprehensive forms.

The results of degeneration afford other series of facts of the highest importance with reference to the origin of species. Some of them, and a few of the principles they illustrate, are mentioned on pages $717,931$.

Two systems of evolution. - LAvarck, in his system of Evolution (Phil. Zoöl., 1809), laid down as one chief cause of variation, the use and disuse of organs or parts, - use causing enlargement, and disuse a dwindling even to disappearance; and one of his illustrations was drawu from the difference in length of wing of the tame and wild Ducks. He put forth, as other sources of change, the surrounding physical conditions and their often abrupt changes, and referred also, in an imperfect way, to the effect of biological associations, or the influence of the living species of a region on one another. The importance of the principle of heredity was also recognized. He added to his system the principle - a tendency upward.

DARwIN, in his work of 1859 , recognized the obvious causes of variation, but claimed that these, and all means of change, derived their efficiency from action under the principle of "Natural Selection," as indicated in the title of his work. He elucidated the subject of evolution by many illustrations of the effects of breeding and culture under man's care and guidance; by his study of variation among living plants and animals, wild and domesticated, publishing a separate work of great value on Animals and Plants under Domestication; by full illustrations of the laws of heredity; and by new facts, almost a revelation to science, relating to the living environments of species, and the consequent interdependence and interaction of associated kinds in both kingdoms of life.

According to the principle of natural selection, "an animal or plant that varies in a manner profitable to itself will have, thereby, a better chance of surviving," and of contributing its qualities and progressive tendency to the race, while others not so favored, or varying disadvantageously, disappear. The favored ones, or the "naturally selected," are one or two, or a few, of a herd, or of a region; and the unfavored ones, fated to disappear because unadaptable, include, theoretically, all the rest. The principle of selective breeding is used in the development of the favored ones; for these have to be separated from the rest of the herd for success, as in man's selection. The adaptations are to any kind of conlition, whether favorable to the highest or to the lowest developments, so that progress under the principle may be upward or downward. The origin of variation is not considered. Everything in nature varies, and changing conditions are always adding to the variations. Howerer produced, the individual that is profited by a variation survives, propagates its characteristics, and becomes the type of a species, while "multitudes" are left behind in the struggle with adverse enviromments; and thus the new species, in the end, stands widely apart from other species.

In the expression, "preservation of favored races in the struggle for 
life," the direct effects of struggle or labor on the individual, that is, the beneficial and other effects of struggle itself, are not intended, though not excluded; only the effects of struggle or strife on disappearings and survivals, under the changing conditions, are referred to.

Augmentation of variations by interbreeding fundamental in evolution. IIan, by selective breeding carried on for successive generations, has obtained cattle with long horns, short horns, and no horns; fowls with large combs on the head, with no combs, or with a rosette of feathers in place of the crested comb, with bare legs and with feathered legs, with long spurs and long legs for fighting, and with no spurs and short legs, and with great diversity of color; Pigeons with long bills and with short bills, giving them characters belonging to different tribes of Birds, with long or short legs, with the fanlike tail of a Peacock and an attendant increase in the number of feathers. And, similarly, diversity has been obtained in the case of many other species. The varieties obtained range through a vastly wider diversity of characters than occurs under any species in nature.

It is perceived that the law of nature here exemplified is not "like produces like," but like with an increment or some addition to the variation. Consequently, the law of nature, as regards the kingdoms of life, is not permanence, but change, evolution.

Great plasticity in organic structures under variant agencies. - This is another principle taught by the above-mentioned facts. This plasticity under any type is usually most prominent in one or two of the kinds of organs, and consequently it leads to the evolution of species in lines, determining genera or natural groups.

"A tendency upward," determined, in the Animal Kingdom, by the existence of a cephalic nervous mass or brain. - This principle is explained on page 439 .

Articulates and Vertebrates first appear as multiplicate species: as exemplified in Worms, the earliest Crustaceans, and Fishes, and in the Myriapods, successors to the Worms. Through subsequent changes, types having a definite or normal number of parts are introduced, as Insects after Myriapods (page 721), Amphibians after Fishes (page 725), and so on.

In degeneration, Reptiles and Mammals, in some cases, have become multiplicate: as exhibited in the vertebræ and teeth, and sometimes in the phalanges and number of the digits. (Pages 797, 931.)

Natural selection not essential to evolution, variations being effectual without it. - The theory of natural selection is based on the assumption that variations come singly or nearly so, and that the selected are therefore few compared with the multitudes that disappear. The idea is derived from facts afforded by domesticated or cultivated races. But such races are in a large degree artificial products, selective methods carrying the individuals rapidly in the direction of the variation, and producing, in a few scores of generations, divergencies that in wild nature would require thousands of years. The structures are therefore in a strained or artificial state, and 
deteriorate when care ceases. But in wild nature variations are, in general, the slow and sure result of the conditions - the organic conditions on one side and the physical and biological on the other; they should occur, generally, in a large part of the associated individuals of a species; and being Nature-made, the results are permanent. When, therefore, a variation appears that admits of augmentation by continued interbreeding, progress should be general; and the unadaptable few should disappear, not the "multitudes."

Under such a system of evolution, - evolution by regional progress, the causes of variation mentioned by Darwin are all real causes. But they act directly, after the Lamarckian method, without dependence for success on the principle of natural selection. Use and disuse, labor, strife, physical changes or conditions, and organic influences act as such, and have their direct effects. The plants that migrated in the Tertiary from the Arctic regions southward over Japan and North America, and became new species on the way, simply changed. That is the sum of knowledge on the subject.

Man affords an example. The gradual gain of some races in lands and supremacy, and the disappearance of the inferior races, is an example of the Survival of the Fittest, or Natural Selection. But the superior races derived the power which led to their survival and preëminent position through favoring conditions in environments, that is, in geographical, geological, and biological conditions and resources; through the porrers of endurance, the courage, the mind power, the will power, which conflict with nature and with other races of men in the world is fitted to develop; and through the power and self-assurance which comes of a high moral sense. Hence victory, survival. The survival of the fittest is a fact; and the fact accounts in part for the geographical distribution of the races of men now existing and still in progress; but not for the existence of the fittest, or for the power that has determined survival.

Natural selection, a means of determining the successive floras and faunas of the world; a prominent cause of the geographical distribution of species. Natural selection is literally selection, survivals; the survivors are those that continue on to make faunas and floras.

Independent derivation of allied species. - The existence of related species under a genus or family on two or more continents, or in widely distant regions, has brought up the question whether such occurrences are not due in some cases to independent derivation. Migration accounts unquestionably for a large part of them; but it is doubtful whether it accounts for all. If not for all, if the evolution has gone forward parallelwise on different continents, then organic law is not only the source of change, the environments subordinate in influence, but the source of a system of changes in the progressing evolution. The subordination to the law of cephalization - that anterior concentration in the animal structure, involving posterior abbreviation, attends progress in grade-accords with this idea of organic eontrol. 
This view of the subordination of organic evolution to general laws is sustained by the paleontologist Professor A. Gaudry, of Paris, in his review of the parallelism between Europe and America in the succession of types from the Cambrian upward (Bull. Soc. Géol. de France, December, 1891). He compares the correlate tribes through the successive stages of progress, and the gradual changes by which old characteristics disappeared and new features were developed for the two distant regions, notwithstanding the differences that existed in climatal and other conditions; and he concludes that these and similar facts are not all explainable by migrations, but only by evolution under general laws of progress.

Origin of species. - The origin of the special causes for each line of change or variation, which Darwin did not undertake to study out, is yet very imperfectly understood. The paragraphs on the evolution of the Horse and the Artiodactyl, on page 929, and others bearing in the same direction, show some success. It is admitted that (1) bones will coössify if movement between them ceases; (2) that the progressive enlargement of one organ or part may cause the dwindling of others adjoining; (3) that running under an impulse would lead to a rising of the foot on the toes, to secure greater length of lever and greater speed; (4) that activity in the limbs may determine adjustments in the position of the ankle bones fitted for greatest strength and security; (5) that the use of the teeth may lead to increased complexity of structure.

But from the statements with regard to the Horse and Artiodactyl, it may be thought possible, also, that the great elongation of the foot, chiefly of the metacarpals and metatarsals, would be a natural consequence of the rhythmic stroke of the foot in running, this inducing a variation that was continued in growth by interbreeding. And this apparent success in explaining leads to the suggestion that the graceful form, so general in fleet animals, may be a result of the free movements of all parts of the structure in running; and that the horns in the Ruminants and other Ungulates may have come from a variation commenced by the strokes made by the foreliead or front of the head, in conflicts.

But another Artiodactyl, the "high-reaching" Giraffe, puts a check to speculation; for it has the anterior pair of legs much the longer, the foot portion alone three feet long; and the neck more than triple the ordinary length in Ruminants, owing to the great elongation of six of the seren vertebræ. The elongation of the legs has the same purpose as that of the neck - "high-reaching in quest of food." The question comes up - How should the Giraffe have had to run to make its fore legs grow faster than the hind legs, and what kind of antics would have started the change in the neck? It has to be supposed that the requisite augmentative variations were somehow begun, and that under interbreeding, accelerated growth went forward. But the origin of the variation is without explanation. Anr so it is for the most part throughout the Kingdoms of life. Enough is known to encourage study. 
It is of no avail to speak of chance variations. The use of the word chance indicates personal ignorance. Chance has no place in nature's laws, and can have none in nature-science.

Man's origin has thus far no sufficient explanation from science. His close relations in structure to the Man-A pes are unquestionable. They have the same number of bones with two exceptions, and the bones are the same in kind and structure. The muscles are mostly the same. Both carry their young in their arms. The affiliations strongly suggest community of descent. But the divergencies mentioned on page 1018, especially the cases of degeneracy in Man's structure, exhibited in his palmigrade feet and the primitive character of his teeth, allying him in these respects to the Lower Eocene forms, are admitted proof that he has not descended from any existing type of Ape. In addition, Man's erect posture makes the gap a very broad one. The brute, the Ape included, has powerful muscles in the back of the neck to carry the head in its horizontal position, while Man has no such muscles, as any one of the species can prove by crawling for a while on "all fours." Beyond this, the great size of the brain, his eminent intellectual and moral qualities, his voice and speech, give him sole title to the position at the head of the Kingdoms of Life. In this high position, he is able to use Nature as his work-mate, his companion, and his educator, and to find perpetual delight in her harmonies and her revelations.

The search for "missing links" has been carried forward with deep interest during recent years. But although fossil skeletons have been found among the remains of Pleistocene Mammals in Europe and America none show any indication of departure from the erect posture, or have smaller brain cavity than occurs among existing races of Men. The most probable regions for the discovery of precursor forms are those of Africa and the East Indies. Already, since these closing pages were first in type, the report has come of the discovery, in the Pleistocene deposits of Java, of an imperfect cranium, a femur bearing evidence of prolonged disease, and a molar tooth, which the describer, E. Dubois, has named Pithecanthropus erectus, placing it between the Man-Apes and Man. Others make the remains those of a low-grade Man, or of an idiot. Since Man's structural relations are, in several respects, closest with the precursors of the Quadrumana (p. 1017), his derivation from any known type of Man-Ape has been pronounced impossible.

Whatever the results of further search, we may feel assured, in accord with Wallace, who shares with Darwin in the authorship of the theory of Natural Selection, that the intervention of a Power above Nature was at the basis of Man's development. Believing that Nature exists through the will and ever-acting power of the Divine Being, and that all its great truths, its beauties, its harmonies, are manifestations of His wisdom and power, or, in the words nearly of Wallace, that the whole Universe is not merely dependent on, but actually is, the Will of one Supreme Intelligence, Nature, with Man as its culminant species, is no longer a mystery. 
INDEX. 



\section{INDEX.}

A star (*) after the number of a page indicates that there is a reference on the page to a figure of the species or object mentioned; and a section mark (\$) implies that the page contains a definition, explanation, or characteristic of the word or object mentioned.

Aa (lava-stream), 287§*, 288, 289

Aalenian, 790

Aar Glacier, 237, 248, 251; investigations by Hugi and Agassiz, 243 A bies, 859

A bietites dubius, 839 ; Linkii, 834

Abrasion, 131, 159, 168, 202, 804, $805,806,941$; assorts in proportion to hardness, 169 ; see also Glacial abrasion, Scratches

Abrolhos Islands, 867

Abyssal depths of the ocean, 229

Abyssinia. 26 (plateau), 33, 34, 177 Acacia, 921

Acadian area of Carboniferous and Subcarboniferous, 635

- period. See Cambrian, Middle

- protaxis, 444

- Range, 389, 391, 732

- Triassic area, $\mathbf{7 4 0}, \mathbf{7 4 1}$

- trough, 461, 467, 536, 537, 541, $543,558,633,708,715,732,743$

- upturning, 736

Acalephs, $430 \S$

Acanthaspis armata, 588*

Acantherpestes, 701; major, 691

A canthoceras Lyelli, 865 ; manmillare, 855, 865; Mantelli, 866; Photomagense, 866

Acanthodes, 620 ; affinis, $620 \%$; priscus, 620

Acanthodians, 416

Acanthopholis horridus, 863

Acanthotelson Eveni, 691; Stimpsoni, $678 *, 691$

Acephals, $424 \S$

Aceratherium, 926

Acervularia, 625 ; pentagona, 592

Achænodon, 918

Achyrodon, $789 *$

Acid. See Boracic acid; Carbonic;

Humus; Organic ; Sulphuric

Acidaspis, 513, 515, 520, 521, 561, $567,568,579,586$, 591, 599 ; Barrandii, 565*; Brightii, 565*, 567; callicera, 587*, 591 ; coronata, 567 ; hamata, 567 ; Jamesii, 520 ; Romingeri, 587*, 599 ; tuberculata, 561, $562 *, 578,579$

Acipenser, 923
Acleistoceras, 591, 602

Aclis robusta, 690

A concagua, 296

Acrocrinus, 690

Acrodus, 772 (first), 783 ; minimus, $416^{*}, 774$; nobilis, $416^{*}$

Acrogens, 435\$

Acrolepis, 705; Sedgwickii, 707

Acrothele, 481; Matthewi, 475*

Acrotreta, 520; gemma, 471*, 516, 573; subconica, 573

Actinia, $429 *, 431 \S, 516$

Actinoceras, 501, 546, 549, 567; Bigsbyi, 506, 508*, 514 ; erebriseptum, 516, 524; verum, 866

Actinoconchus planosulcatus, 646

Actinocrinus, 520, 567, 597, 646, 690 ; proboscidialis, 640*, 646; simplex, 567 ; tenuistriatus, 625

Aetinocyelus Ehrenbergii, 894*

Actinoids, 431§, 525

Actinolite, $67 * \S$

Actinolyte, $89 \S$

Actinopteria, 621

Actinoptychus senarius, 437*, 894*; undulatus, 894*

Adams, Mt., 296

Adapisorex, 925

Adelsberg cave, 207

Adipocere, 143, 154

Adirondack Mts, and region, 85, $204,384,442$; Arctic plants on summits of, 945

A djutants, 923

Admete viridula, 984

Admiralty Islands, 38, 39

Adobe, $195 \$$

Adocus agilis, 850 ; beatus, 850 ; punctatus, 850

Adriatic Sea, 41, 212

Echmina, 562

Aglea, 703

Eglina, 521; grandis, 520 ; mirabilis, 520

Agoceras capricornus, 781*; Jamesoni, 790 ; planorbis, 790

Egyrite, 85

Elurodon, 919

Æ̇on, 406§, 407

Epyornis, 54, 1014, 1019

1039
Afghanistan, 920

Africa, 17, 21, 22, 23, 26 (plateaus), $30,31,33 *, 51,165,297,394,395$, $406,435,674,737$; volcanoes in the Bight of Benin, 296; coral reefs of eastern coast, 145

-, Carbonic rocks in, 632, 693; Upper Silurian, 563; Triassic, 632, 741 ; Jurassic, 873 ; Cretaceous, $857,859,873$. See further South Africa

Agalmatolite, $68 \$$

Agalmatolyte, $84 \S$

Agaricus, 688

Agassizocrinus, 690

Agassizodus, 692; variabilis, 680*

Agathaumas, 828, 847; sylvestris, 847,856

Age of the Earth, 1023

Agelacrinites, 516

Agelacrinus Bîllingsi, 514

Agnostus, 473, 475, 481, 482, 486, $500,516,520,521$; Acadicus, 476* ; interstrictus, $476^{*}$; $\mathrm{Kje}$ rulfi, 482 ; nobilis, $473 *$; Rex, $481 *, 482$

Agnotozoic, 445, 447

Agoniatites, 599

Agriochœrus, 918

Agriomeryx, 918

Agui Range, 365

Alabaster, $69 \S$

Alachua clays, 891

A laska, 23, 284 (snow-line), 297, 582. 948 (fiords)

- Triassic in, 747; Cretaceous, $818,820,834,868,872$ (climate); Tertiary, 892, 893, 939 ; Glacial, 945,948

"Albatross," 60, 280

Albemarle Sound, 221*

Albert Mine, N.B., 639

Albertia, 770

Albertite, 662

Albian group, 815, 858, 859, 865

Albirupean group, 819

Albite, $64 \S, 82,83$

Alea impennis, 1014

Alces Americanus, 1002

Alcyonaria, 4318 
Alcyonium, $431 \S$

Alcyonoids, 431§, 525

Alder, 837, 922

Alethopteris, 639, 645, 671, 685, 698, $699,704,756$; discrepans, 622 ; gigas, 705; Helenæ, 645; lonchitica, 670*, 689 ; Serlii, 689 ; Whitbyensis, 791

Aleutian Islands, 40, 296

Algæ, $56,60,72,79,140,153,156$, 241 ; the earliest plants, $409 *, 441$, 454 ; in hot waters, $152,308,437$, 441,454

Algeria, 920

Algerite, 320

Algonkian formation, $445,447,469$

Alleghany Mts., 41, 106, 188, 636, 638,745 ; plants on summits, driven south by the ice, 946

Alligator, 54, 55, 681

Allodon, 768 ; fortis, 767*; laticeps, $767 *$

Allomys, 918

Allophane, 638

Allorchestes, 347

Allorisma subcuneata, 675*, 690

Allosaurus, 766 ; medius, 836

Alluvial cones, 99, 194§, 195*, 196

Alluvium, 81§, 98, 191, 198, 200, 228, 366

Almond, 921

Alps, 23, 32, 110, 233, 234 (snowline), $265,266,310,367^{*}, 368^{*}, 391$, $463,738,812,943$; coal-formation, 734; glaciers of, $235 *, 236 *, 237 *$, $239,243,244,248,251$; great fault in, 734 ; section, east of Lucerne, $102^{*}$

-, Archæan in, 368; Upper Silurian, 573: 'Triassic, 757, 768, 769 , 773, 774; Jurassic, 774, 780, 791, 793; Cretaceous, 859, 864; Тегtiary, $347,367,380,919,920$, 921, 932 (upturning), 936 (elevation)

Altai Mts., 32, 33, 200, 568, 569

Altamaha grits, 891

Alum Bluff sands, 890,891

Alum shale, $80 \S$

Alumina, $61 \S$

Aluminum sulphates, alums, 119, $126,138,294,335$

Amaltheus ibex, 790 ; spinatus, 790

A margura Island, 296

Amazon River, 24, 30 ; drainage area of 172 ; enger, 212, 215; floods of, $17 \%, 183$; slope of, 173

Amazonian group, 867

Amber, 143, 838, 922

Amblotherium, 789*

Amblygonite, 449

Amblypterus, $692,702,772$

Amblyrhiza inundata, 1001

Ambocolia gregaria, 621; umbonata, 598*, 601, 620, 621

Ambonicardia Cookii, 837

Ambonychia attenuata, 514 ; bellistriata, 507*; radiata, 511*, 516

Anboy clays, 837

Ambrym Island, 296

American continent, North, growth of, $714-716$
Amia, 418, 901 ; Amia family, 783, 869

Amianthus, $319 \S$

Ammodon beds, 894

Ammonia, 124, 137

Ammonites, or Ammonoids, 402, 424, 869; Devonian, 869 (first); Permian, 686 ; Triassic, 756, 757* 771 ; Jurassic, 749, 758*, 759*, $760,781^{*}$ (number of British), $791,792,793,861,869$; Cretaceous, $812,818,836,841,842 *, 855,861$, $862 *, 865,867,869,877$

Ammonites, 757, 774, 916 : acanthicus, 791 ; aspidioides, $790 ; A$ stierianus, 865 ; athleta, 791 ; auritus, 865 ; bifrons, 790 ; bimammatus, 790 ; biplex, 760, 791; Bucklandi, 790 ; Burgundiæ, 790 ; canaliculatus, 790 ; complexus, 855 ; concavus, 760 ; cordatus, 790 ; cristatus, 865 ; decipiens, 790 ; Delawarensis, 854; Deshayesi, 864; diseus, 790; ferrugineus, 790; Gallici, 866; Gaytani, 792; Gervillianus, 865 ; gigas, 791 ; Gowerianus, 790 ; Guadalupæ, 855; Herveyi, 790 ; Humphriesianus, 790 ; ibex, 790 ; intlatus, 865 ; interruptus, 865 ; Jamesoni, 790 ; jugalis, 916 ; Jurensis, 790 ; Lamberti, 790 ; lautus, 865 ; Leonensis, 837 ; Lewesiensis, 862; M'Clintocki, 760,792 ; macrocephalus, 790, 791; mammillaris, 865; Mariæ, 790 ; Mississippiensis, 854: Mullananus, 855; Murchisona, 790; mutabilis, 790 ; Noricus, 865: Parkinsoni, 790 , 791 ; pedernalis, 836 ; peramplus, 866 ; placenta, 842* ; planorbis, 790 ; pleurasepta, 855 ; plicatilis, 790 ; ptychoicus, 791; radians, 790 ; radiatus, 865 ; Rhotomagensis, 866 ; serpentinus, 790 ; spinatus, 790 ; suprajurensis, 791 ; Swallovi, 854; tenuilobatus, 790 ; Texanus, 855,866 ; tricarinatus, 866 ; variousus, 865 ; vespertinus, 867; Wosnessenski, 760

Ammonium chloride, 294 ; nitrates, 118

Ammosaurus, 753

Amnigenia, $612 \S$

Amœba, 433; Amoboids, 419

Ampelite, $81 \S$

Amphibamus grandiceps, 682, 683*, 692

Amphibians, 54, 409* (time range), $414,415,416,417,681,706,795,796$ - Reign of 460

— Relation to Mammals, 794

_- Paleozoic, 725-726, 727

-, Subcarboniferous, $643,644,645 *$, 700

-, Carboniferous, 657, 661, 674, 681, $682,683 *, 684,692,693,703,704,726$ - Permian, 686*, 687*, 706, 869

-, Triassic, 742, 751*, 758, 772*, 796,869

- Jurassic, 760,796

-, Cretaceous, 826, 869, 870

Amphibole, $67 \S$
Amphibolyte, 895

Amphigene, 85

Amphigenia elongata, 579, 590

A mphilestes, 789*; Broderipi, 789*

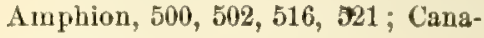
densis, 502*

Amphioxus, 418\$, 725

Amphipods, 420*, 421ई, 438, 439\$, 565,707

Amphitragulus, 926

A mphitylus, 789*

Amplexus, 552 ; Hamiltonire, 601

Ampullina, Fischeri, 917 ; solidula, 916

Ampyx, 481, 500, 520, 521 ; nudus, $519 *, 520$; Salteri, 520

Amsopus Deweyanus, 751*; gracilis, $751 *$

Amusium, 760, 917; Mortoni, 917; simplicum, 854, 855

Amygdalocystites, 514

Amygdaloidal cavities, $68,98,336$, 337,342

- rocks, $78 \$$

Amygdules, 339

Amynodon, 907, 918

Amyzon beds, 886, 893

A nabacia hemisphærica, 790

Anacodon, 918

Analcite, 68, 389

A nalyses of bones, 73 ; of coal (see Coal); coprolites, 73; corals, 72 ; granite, 82,83 ; limestones, 78 , 79 ; plants, 74,75 ; shells, 72 ; volcanic rocks, $82-89$

Ananchytes, 59 ; ovalis, 854 ; ovatus, $860^{*}, 866$

A naptomorphus, 918 ; homunculus, $906 *$

A narthrocanna Perryana, 622

Anastrophia, 562, 579; interplicata. 548*, 551, 569 : Verneuili, 561*

Anatifa, $420^{*}, 421 \S$

Anatimya papyracea, 855

Anchippodus, 904, 918 ; minor, 904*, 905

Anchisauridæ, 792

Anchisaurus, 753; colurus, 758*

Anchitherium, 911, 919, 927

Anchor-ice, 2328

Anchura sbrupta, 854; Americana, $841 *, 855$

Ancilla ancillops, 916

Ancodus, 918

Ancyloceras, 760 ; gigas, 865 ; Matheronianum, 862*; Remondi, 760 , 837

Andalusite, $65 * \S, 66,83,310,315$, $318,319,449$

Andalusitic rocks, 82, 83, 84

Andes, earthquake in, 349 ; glaciers in, 977 ; height of, 26,296 ; slopes of, 27,31 ; snow line of, 234 ; volcanoes, 296, 297

- Archæan in, 456; Carboniferous, 711: Jurassic, 760; Cretaceous, 857; Tertiary, 365, 392, 935; Quaternary, 392

Andesite, $64 \S, 273$

Andesyte, 86§, 87, 272, 273, 276, $301 *, 304,339,341,518,811$

- rocks, 273, 274, 296 
Andromeda, 837 ; affinis, 839 ; Parlatorii, $833^{*}$

Andromedites, 922

Aneimites obtusus, 609*, 611

Angau Island, 150

Angiosperms, 409, 434, 435\$; Cro taceous, 816, 831, 832*, 833, 837, 838*, 839, 859, 868; Tertiary, \$95, 921

Anglesea, 309, 440

Anglesite, 335

Angoumian, 859, 866

A nguillaria Cumminsi, 854

Anhydrite, $69 \S, 120,121,125,128$, 133

Animal kingdom, 9, 413, 414

Animals, geographical distribution, 52,53 ; materials they afford to rock-making, 140-141, 144-152

- and plants, distinctive characteristics, $413-414$

Animikie group, 446,469

Anisomyon, 85̃ ; borealis, 855 ; Haydeni, 855

Anjou, Faluns beds of, 926

Annabon Island, 297 (volcanoes)

Annelids, 55, 157, 428, 427, 438 $720,721,723$

Annularia, 519, 671, 685, 699, 704, 718; carinata, 704, 705*; longifolia, 689, 692, 704; minuta, 704; radiata, 704; Romingeri, 560; sphenophylloides, $689,692,704$

Anodonta, 837

A pomalocaris Canadensis, 476,477*

Anomaloerinus, 516

Anomalocystites, 562 ; cornutus, $559 *$

Anomalopteryx, 1014

Anomia, 828; argentina, 854 ; ephippoides, 915 ; micronema, 855

Anomocare, 482

Anomodontia, 688

Anomodonts, 688, 707, 772, 773

Anomcpus scambus, 752*

Anomozamaites elegans, 756 *

Anona robusta, 839

Anoplia nucleata, 579

A noplophora lettica, 774 ; Münsteri, Tit

Anoplotheres, $924 \S$

Anoplotherium, 926, 927; commune, 926 ; secundarium, 926

Anorthite, 64\$, 65, 82, 86, 87, $88,273,313,318,319,323,324$, 809

A northite rock, $87 \S$

Anorthityte, 875

Ant. See Ants

Ant-eater, 54, 925, 1002

Antarctic continent, 737, 798; in the Quaternary, 1019; see also Gondwána Land

- ice-barrier, 252

- islands, 17

- pole, 17

- regions, 737; glaciers, 233, 241;

volcanoes, $295,296,297$

Antedon, 429

Antelope Park, 178

Antelopes, 924, 927

Antholithes, 674 ; Pitcairnæ, 673*
Anthozoans, $431 \S$

Anthracerpes ty pus, 691

Anthracerpeton crassosteum, 703

Anthracite, 74, 315, 453, 648, 654 $655^{*}, 657,661,695,714,732,826$; composition, 662, 663, 712, 713 ; in geodes, 493, 497; of the Calciferous, 493

- origin of, 713-714

Anthracoblattina, 691, 701

Anthracomartus, 691, 701; trilobitus, 691 ; V ölkelianus, 703

Anthracomya carbonaria, 690 ; elongata, 690 ; lævis, 690

Anthracopalæemon gracilis, 678*, 691; Hillanus, 691

Anthracosaurus Russelli, 682, 708

Anthracotherium, 918, 926

Anthracothremma robusta, 691

Anthrapalæmon dubius, 703 ; Grossarti, 703; Salteri, 701*, 703

Anticlines, 102\$*, 103*, 109*, 186*, $368^{*}, 874^{*}$

Anticosti Island, shore-platform of, 221; Lower Silurian in, 493, 533 ; Upper Silurian, 493, 533, 537, $539,541,563,568,573$; species common to the Clinton and $\mathrm{Ni}$ agara, 551

Antilope, 927

Antimony, 381

Antipathes, 55

Antisana (Mt.) , 26, 296

Antrim, 867, 938

Ants, 158, 419, 717, 783, 794; number of Florissant, 901

A patemas, 915

Apateon pedestris, 704

Apatichnus bellus, 752*

Apatite, $63,69 \$, 79,86,143,313$, $447,450,453,455$

Apatornis, 852

Apatosaurus laticollis, 763, 764*

Apennines, 41, 319, 775, 812, 920, 921, 927, 932

Aphanapteryx, 1019 ; Broeki, 1019 ; Hawkinsii, 1019

Aphanitic texture, $76 \S$

A phelops, 911, 919

Aphis, Aphides, 419, 525, 901

A phrodina Tippana, 854

A pia Island, $145^{*}$

Apiocrinus, 778; Meriani, 791; Roissyanus, $778 *$, 779

Apiocystites Canadensis, 550 ; elegans, 550 ; Gebhardi, 559*; Huronensis, 550

Aporoxylon, 627

A porrhais occidentalis, 984; Sowerbyi, 925

A ppalachiar Chain, 24, 389, 559, 734, 743, 798, 799

- coal-field, 648

- flexures, 102*, 353, 354, 355*, $356^{*}$

- geosyncline, 357, 537, 570, 605, 629,715

- Mountain Range, 389 ; characteristics of, $353-357$

- Mountain System, 389, 732, 883

- Mountains, making of, 357,387 , $631,728,729,736$
Appalachian protaxis, 24, 443*, 444, $450,461,464,466,467,483,490$, 524,740

- revolution, 728, 735, 877

Appomattox formation, 965

- group, 892

Apteryx, 54, 1014

Aptian group, 859, 865

Aptychus beds, 791

Apuan Alps, fossils of, 310

Apus, 486

Aquamarine, $67 \S$

Aquitanian group, 884, 926

Arachnids, 418, 419, 420§, 721, 722 ; derivation, $722-723$; relations in body segments and limbs to Crustaceans, Limuloids, and Insects, 724

-, Upper Silurian, 557, 574, 721 . Carboniferous, 677, 678*, 691, 703; Paleozoic, 721; Tertiary, 901,922

Arachnophyllum, 552

Aragonite, 69§, 129, 130, 314, 317

Aral Sea, 22, 33

Aralia, 831, 837

Aralo-Caspian depression, 22, 23

Arapahoe beds, 827

Ararat (Mt.), 296 (height)

Araucarites, 750,777

Arbor vitæ, 435

Arca, 855, 916; crassicosta, 900*, 917; idonea, 917 ; incilis, 917 ; inornata, 916; Mississippiensis, 898*, 916 ; scalarina, 917 ; subrostrata, 917

Arcestes, 756, 757 ; cirratus, 757 ; Gabbi, 757, 758; giganto-galeatus, 774; Nevadensis, 757 ; ruber, 774

Archæan, 440; iron ores in, 376, 449

- Eozoon, 319

- maap of N. America, 442, 443*

- origin of later rocks, 458

- protaxes of $\mathrm{N}$. America, 359,393 , $457,581,744,746,812,826,875$

- ranges of the Atlantic border, 461

- system of mountains in eastern N. America, 389

- - of the Rocky Mountain Chain, and of the Front Range of Colorado, 389

Archæan time, 204, 311, 326, 368, $380,384,387,389,393,404,407$. $409 *, 410,440-459 ; N$. America, 442 ; foreign, 456 ; observations, 457; age of, in eastern America, 466

Archælurus, 918

A rehæocalamites radiatus, 596*

Archaocidaris, 641, 674, 707; Norwoodi, 640*, 646; Shumardans, 626; Wortheni, $640^{*}, 646$

A rchæocyathus profundus, $470^{*}$

Archæoniscus Brodiei, $793 *$

A rchæophyton Newberrianum, 454

Archroplax signifera, 917

Archæopteris, 596, 639, 699; Bockschiana, 645 ; Browni, 622 ; Gaspiensis, 611; Halliana, 609*, 622 ; Hibernica, 626; Jacksoni, 595*, 
622 ; minor, 609*, 645; obtusa, 645; Røemeriaua, 704; Rogersi, 622

Archropteryx, 795 ; macrura, 785*

Archroptilus ingens, 702

Archæoscyphia Minganensis, 497*

Arehreozoic æon, 407, 441, 442, 453

Archegosaurus Decheni, 703 ; minor, 703

A rehidesmus MacNicoli, 625

Archimedes, 641; Wortheni, 642*, 646

Archimedes limestones, 637,646

A rehimylacris, 691

Architarbus, 701; rotundatus, 691 ; subovalis, 708

Architectonica, 916

Archiulus, 691, 701 ; Dawsoni, 691 ; euphoberioides, 691 ; Lyelli, 691

Archypterygian, $725 \S$

A reoptera aviculæformis, 900*,917

Aretia, 723

Aretic bathymetric map, 950

Aretic border of N. Amer, 364, 739

- emigrant plants of the Glacial period still surviving, 945

- Ocean, 31, 43, 359, 814, 819, 82\%, 857

- pole, 17

- regions, climate of, $256,524,792$, 793,1026

- - Archæan in, 442; Carboniferous, $606,635,659,663,689,696$, 704,711 ; Cretaceous, 813, 818, $868,877,939$; Devonian, 606 ; Jurassic, $749,760,792,794$; Lower Helderberg, 559 ; Lower Silurian, 490, 495, 524; Mesozoic, 793 ; post-Mesozoic, 874 ; Niagara, 541, 544; Paleozoic, 793; Subcarboniferous, 640, 696; Tertiary, 880, 933, 939 (plants); Triassic, 792 ; Upper Silurian, 544, 552, 571

Arctocyon, 925

Aretomys, 919

Aretosaurus Osborni, 749, 792

Aretotherium simum, 1000

Ardea herodias, 767

Ardennes, 626, 696, 734

Areia, 521

Arenaceous rocks, 490,491, 495, 515 ; shale, 468

Arenaria glabra, 946 ; Grönlandica, 946

Arenicola, 423 ; marina, $420 *, 428$

Arenicolites, 446, 482

Arenig group, 517, 518, 520

Arequipa Mt., 274, 296

Arethusina, 521

Argentine Cordillera, Cretaceous in, 867

- Republic, Cambrian in, 483

Arges armatus, $627 *$

Argillaceous rocks, $78 \$$

Argillyte, $80 \S, 84,89,371,408,581$, 659

Argonaut, 424

A rovovian, 790

Argyrocetus, 927

Argyrosaurus, 867

Arica, earthquake at, 213

Arionellus, 48
Aristolochia, 896

Aristozoe rotundata, $474^{*}$

Arizona, 23 (height), 135 (agatized wood), $187,300,541$

-, Archæan in, 449; Cambrian, 466, 469, 477, 484; Upper Silurian, 541 ; Devonian, 581 ; Carboniferous, 469, 655, 674; Subcarboniferous, 469 ; Permian, 660 ; Jurassic, 747 ; Tertiary, 987 (eruptions

Arkansas Hot Springs, water of, analyzed, 121; lead mines, 342, 522 ; novaculite, 80

- Cañon, 495

Arkose, 82\&, 741

Armadillo, 54, 1002

Armorican sandstone, 521

Arnioceras Humboldti, 760 ; Nevadense, 760; Nevaduum, 759*; Woodhulli, 760

Arniotites Vancouverensis, 758

Arsenopyrite, $70 \S$

Artesian borings (wells), 120, 207* $\&$, $257,522,742,859,890$

Arthroclema Billingsi, 506*; cornutum, $506 \%$

Arthrolycosa antiqua, 678*, 691

Arthiophycus Harlani, 549

Arthropods, 141, 419, 423, 455, 469

Articulates, $141,409 *, 418,419,420 *$, $437,439,674,717,720,783^{*}$

Artiodactyls, $906 \S, 907,909,910$, 911*, 918, 919, 924, 927, 928, 930

Artisia, 673

Artocarpus Lessigiana, 839

Arum family, 777

Arvonian period, 446, 457

Asaphus, 422\$, 482, 488, 500, 502, 508, 516, 521, 551; Canadensis, 516, canalis, 503, 517; Homfrayi, 520 ; marginalis, 503; megistos, $422,512,551$; obtusus, 503 ; platycephalus, $422,508 *, 512,515,516$; Powisi, 519, 520*; tyrannus, 520

Asbestos, 67\&, 319

A scension Island, volcano of, 290, 297

A scidians, 55, 418, 725

A scoceras, 551; Canadense, 573 ; Newberryi, 551, 573

Ash beds, $80 \S$

- of coal, 661, 662, 663,664

- of plants, 73, 74, 75; see also Volcanic ashes

Ashley beds (marl), 888, 891, 917 Asia (see also Eurasia), 19, 22, 23 $24,31,32 *, 33,34,40,41,50,165$, $393,394,395,398,400,737,871,938$

- Carboniferous in, 632, 693, 700 ; Lower Silurian, 521; Upper Silurian, 563; Triassic, 632, 741 ; Cretaceous, 867; Tertiary, 365, 919, 933, 936, 939 ; Quaternary, 950

- eastern, island chains, 40

A sia Minor, 296 (voleanoes), 920 (Eocene)

A so-san (Mt.), 277

Asphalt, 74

Aspidella Terra-novica, 446

Aspidiun Dunkeri, 831 ; filix, 74 ; Lakesii. 839
Aspidoceras, 794

A spidorhynchus, 784*

Asplenium erosum, 899 ; filix, 74

A 88, 55

A ssat Lake, 200

Astacus, 783

Astarte, 780 ; annosa, 837 ; Banksii, 9S3, 9S4; borealis, 984, 995 ; com. pressa, 791; elliptica, 983 ; gregaria, 790; Laurentiana, 984; minima, $780 *$, 790 ; obliqua, 790 ; obovata, 867; protracta, 916; Smithvillensis, 916 ; supracorallina, 790; undulata, 917 ; veta, 837; vicina, 917

Astartian group, 790

Asterias arenicola, 994

Asterioids, 428§, 429*; Lower Silurian, number in Great Britain, 521 A sterochlena Noveboracensis, 610

Asterolepids, 417

A sterolepis, 625, 626, 627

Asterophyllites, 639, 671, 699, 704; acicularis, 622 ; elegans, 699 ; equisetiformis, $645,671 * 689$; foliosus, 689 ; latifolius, $596 \%$, 622 ; sublævis, $671 * 689$

Asteropteris Noveboracensis, 610

Asthenodon segnis, $767^{*}$

A stian group, 927

Astoria, Oregon, sandstone veins, 344*; sandstones and shales, 892

Astoria clay-shales in Washington, 892

Astræa distorta, 791

A stræospongia, 550, 584, 590 ; meniseus, 550

Astral æon, 440

A straspis desiderata, 509*

Astrocerium venustum, 550

Astrocenia, 777, 778 (number of British)

A strodon Johnstonii, 836

Astylospongia, 515, 550; parvula, 513 ; Romeri, 503

A symptoceras capax, 691; Newtoni, 691

Atacama desert, 51

A tacamite, 335

A tané group, 831, 837, 838, 839, 872

A tanekerdluk series, 921

A thabasca Lake, 29

A throdon, 789*

Athyris, 642 ; angelica, 592, 621 ; concentrica, $426^{*}, 626,627$; lamellosa, 700*; spiriferoides, $598 *$, 601 ; subtilita, $675^{*}, 685,704,711$

A tiu Island, elevation, 350

Atlantic City boring, 378

- coast of $\mathrm{N}$. $\Delta$ mer., 948 (fiords) subsidence in progress, 350

- division of Archran rocks, 446

- Ocean, 17, 19 (depth), 20, 21, 31 , $34,40,42,43,46$ (temperature), $47^{*}, 48,49,121$ (salinity), 230 (bottom), 252, 256, 354, 391, 394, $536,537,793$; volcanoes in, 297 - - curreuts, $43,44,45,46,47^{*}$ 48,256

- - and Pacific in Lower Cretaceous united over Mexico, 814, 818

Atlantis, 506 
Atlantis of fable, 20, 217

A tlantuchelys Mortoni, 849

Atlantosanrus immanis, 764

Atlantosaurus beds, $\mathbf{7 4 8}, \mathbf{7 5 8}, \mathbf{7 6 0}$, $761,766,767,768,776$

Atlas Mts., 33

Atmosphere, $63 \S$; currents of, 49 ; weight of, 158

- as a mechanical agent, 118, 158165

—, carbonic acid in, 128,727

-, estimated limit, 16, 158; variations in density, 256

— of the Carbonic era, 711; Paleozoic, 727

Atmospheric dust, 118

A tolls, 145*s, 146, 147, 148, 149*, $150,151,221,227,350,664$

Atractites, 757 ; secundus, 774

A tretia, 59

A trypa, 436*8, 520,552, 562, 612 ; aspera, 590, 591, 598*, 601, 602, 625: comata, 568; desquamata, 628; hemisphærica, 550; hystrix, 613*; imbricata, 520 ; impressa, 590 ; lævis, 625 ; navieula, 568 ; nodostriata, 548*, 551 ; oblata, 549 ; occidentalis, 590 ; reticularis, $426 \%$, $522,546 *, 550,551,552,562,567$, $566,569,572,590,591,592,598 *$ $601,602,612,620,625,626,627$, 628 ; rugosa, 551

A trypina disparilis, 548*, 551

Aturia ziczac, 925

A ublysodon, 856 ; mirandus, 856

Aubrey limestone, 658; sandstone, 658

Aucella, 748, 749, 760, 794, 809, 818, 834, 835, 837; Erringtoni, 759*; gryphæoides, 865 ; Piochii, 834, $835^{*}$

Aucella beds, 748,776

A uchenapsis, 625

Auchenia major, 1001 ; minor, 1001

A uckland Islands, 37

Augite, $67 * \S, 85,86,87,88,295,324$

- andesyte, $87 \S, 265,324$

- dioryte, $86 \S, 266$

- granite, $85 \S$

- quartz-syenyte, $\$ 5 \$$

- syenyte, $85 \$, 317$

Augitic rocks, 89, 309, 371, 449

Augitophyric, $77 \$$

A ulacoceras Carlottensis, 758

A ulopora, 550, 562, 621 ; precia, 550 ; repens, 550 ; tubiformis, 628

Auriferous belt of the Sierra, 809

Aurochs, 927, 1006

Aturoral group of Rogers, 490, 728

Austin limestone, 815, 817, 824, 855

A ustin-Dallas chalk, 824

Australasian chain of islands, 37 , $38,39 *, 40$

A ustralia, 17, 19, 21, 22, 34 (system of reliefs), 39, 51, 53 (animal characteristics), 148 \& 151 (reefs), 153, 346 (sea level at center), $394,395,398,406,415,418,687$, $715,797,798,838,869,874$ (connection with S. Africa), 921, 948 (fiords); related in species of birds to New Zealand, 1019
Australia, Cambrian in, 483 ; Lower Silurian, 522 ; Upper Silurian, 563 , 564; Devonian, 628; Carbonic 632, 693 ; Permian, 632, 698, 737 Triassic, 632, 699, 791, 797-79s* Jurassic, 699, 770, 776, 791, 792 Cretaceous, 887; Tertiary, 937; Glacial, 948

Australian Alps, 34, 380

- types in Europe, 922, 939

Austria, Upper Silurian in, 573 Subcarboniferous, 693 ; Carboniferous, 693, 696; Permian, 698; Triassic, 755, 768, 769 ; Jurassic, 774; Cretaceous, 857, 859, 864; Tertiary, 926, 927

Austro-Russian Cretaceous basin, 857

A uvergne, 26, 274, 297 (volcanoes), 922, 988 (eruptions)

Aux vases sandstone, 638

A valanche, $233 \S, 247$

Avalon, 446

Avicula, 525, 549, 585, 756, 916 contorta, $770,771 *, 774$; demissa, 511*, 516; echinata, 791; emacerata, 548*, 550, 551; exilis, 774 ; expansa, 790 ; Homfrayi, 757 inæquivalvis, 790 ; Kazanensis, 707 ; linguiformis, 855 ; longa 690 ; Münsteri, 791 ; naviformis, 562 ; obscura, 558; ovalis, 790 ; rhomboidea, $546^{*}, 550$

A vicula contorta beds, 769

A vicula family, 840

A viculoides labiatus, 855

A viculopecten, 562, 602, 620,621 altus, 757 ; amplus, 647 ; Burlingtonensis, 647 ; duplicatus, 613*, 621 ; Idahoensis, 757 ; oblongus, 647; Oweni, 647; Pealsi, 757; princeps, 602 ; rectilaterarius, 690 Axinæa, 916

Axinite, 310

Axinus angulatus, 925

Aymestry limestone, 563, 567, 568

Azof Sea, 857

Azoic, 440, 468

Azores, 41, 297 (rolcanoes), 308 (geysers)

Bacillaria paradoxa, 437*

Bacteria, 52, 136-137, 436, 441, 454

Bactrites, 621; acicula, 613*, 621; clavus, 599 ; gracilis, 627

Baculites, $843 \S, 856$; anceps, 854, 855,867 ; annulatus, 855 ; asper, 855; Chicoensis, 831 ; compressus, $842 *, 843,854,855 ;$ Faujasi, 866 grandis, 855 ; ovatus, $842 *$, 854 855; Spillmani, 855; Tippoënsis, $855 \%$

Bad Lands, 893, 894

Badiotites, 757 ; Carlottensis, 758

Baffin Bay, 40, 44, 252 (icebergs), 414

- Land, 44

Bagshot beds (sands), 920, 925, 926

Bahamas, 162, 163, 213

Bahian group, 867

Bahio Glacier, 240
Baiera, 685, 693, 750 : digitata, 705 longifolia, 833 ; Virginiana, 705

Baikal (Lake), 33, 200

Bajocian group, 775, 790

Baker (Mt.), 296 (height)

- Island, changes in position of beach, 225*

Bakewellia antiqua, 707; parra, 685*

Bala group, 517, 518, 520, 569 ; limestone, 519

Balæna, 144

Balænoptera, 144

Balatonites Vancouverensis, 758

Bald Mt., 467, 473, 495, 496, 527, 528*

Baleen Whales, 912, 925

Balkan peninsula, 793

Ball ore, 664

Ballston Springs, analysis, 121

Baltic provinces, 768,794

- Sea, 41, 121 (salinity)

Baluchistan earthquake, 375

Bandai-san eruption, 293

Banks Land, 635

Baphetes planiceps, 682, 692

Baptanodon beds, $748,75 \mathrm{~s}, 760$

Baptanodon discus, 761 *

Baptoruis, 852

Baptosaurus fraternus, 848 ; platysphondylus, 848

Baraboo quartzy te, 465

Barbados, 163, 433, 935, 936

Barbatia parva Missouriensis, 836

Baring Isl., 659

Barite, $69 \S, 143,331,333,342,493$, 745

Barium sulphate. See Barite

Bark, composition of 718

Barnacles, 157, 421\$, 513; Corniferous, 586, 587; Hamillton, 600*: Lower Silurian, 496, 720 ; Paleozoic, 720

Baropus lentus, 684*

Barornis regens, 902

Barrandia, 520, 521

Barren (Lower) Measures, 634, 64s, 651-652, 656, 657, 677

Barren (Upper) Measures, 634, 648, $651,657,660$

- See also Permian period

Barrier reefs, 146* $, 149 *, 150 *, 151$, $227,511,713$

Barriers, sand, of coasts, 223, 224*

Barrow (Point), 640

Barrow Strait, 544, 552

Barton clay (series), 925, 926

- coal-bed, 652

Bartonian group, 925

Baryerinus, 138

Baryta, Barytes, $69 \S$

Basalt, 16, 67, 87\$, 184, 259, 288*

Basaltic columns, 261*\$, 262*, 263, $27 \pm$

Basement Complex, 458

Basic igneous rocks, $64,65 \S, 86,273$, 938

Basilosaurus, 908

Bat. See Bats

Bat guano, 158

Bath Oölyte. See Oojlyte

Bathonian group, 775, 790 
Bathurst, N.B., 350

- Land, 659, 749, 792

Bathyactis syminetrica, 57

Bathycrinus, 59

Bathygnathus borealis, 741, 753, $754 *$

Bathylite, bathylith, $811 \S, 938$

Bathymetric map of the Pacific and Atlantic, following 20

- of the Arctic Ocean, 950

- of the Atlantic border of New Jersey, Long Island, etc., 18

Bathynomus giganteus, 59

Bathynotus holopyga, 478*

Bathyopsis, 918

Bathyurellus, 500, 503; nitidus, 501*

Bathyuriseus Howelli, 476*

Bathyurus, 500; Angelini, 503, 517 ; armatus, 501; conicus, 517; crotalifrons, 501*; extans, 517; Saffordi, $501 *, 517$

Batocrinus, 641, 646; Christyi, 640*, 646 ; longirostris, $428 *, 4308,640 \%$, 646

Batodon tenuis, 853*

Bats, 53, 54, 158, 415, 721, 797, 907, $910,924,926$

Batscham, tide at, 211

Bavaria, 26, 458

- Archæan in, 453, 454, 456; Cretaceous, 857 ; Jurassic, 774, 776

Bay of Biscay, 377

- of Fundy, 210 (tides), 350, 444, $461,536,741$

- of Plenty, 874

Beach formations, 94, 95, 151, 202, 222, 228 ; structure, 938, 99, 222

Bear Island, 635, 704

- River coal-beds, 825,839

Beauchamp sands, 925

Beaufort beds, 699, 707, 770

Beaver River, 947

Beavers, 55, 904, 911, 927, 950 (migration)

Becrafts Mt., 531, 552, 558, 559, 577, 578,579

Beds, $76 \S, 91 \S, 92$ (kinds)

- of ore. See Ore-beds

- of sand, mud, limestone, etc., simultaneously in progress, 399

Beech, 812, 837, 922

Beehive Geyser, 307*, 308*

Beemerville rock, 532

Beetles, 419, 679, 702, 721, 722, 771, 857

Beggiatoa, 137

Bela exarata, 984; harpularia, 984; robusta, 984 ; turricula, 984

Felcher Expedition, 792

Belemnitella A mericana, 842*, 854; bulbosa, 855: mueronata, 855, 866 ; plena, 866 ; quadrata, $\$ 66$

Belemnites appressus, 835; canaliculatus, 791 ; clavatus, 790,791 ; densus, 758*, 760; hastatus, 790 ; jaculuwo, 865; Nevadensis, 760 ; niger, 760; Oweni, 790 ; Pacificus, 760 ; paxillosus, 760, 782*, 790 vulgaris, 790

Belemnoteuthis, 782 ; antiqua, $782 *$ Belgium, Carboniferous in, 693,696 768; Cretaceous, 848, 859, 863;
Paleozoic, 463 ; 'Tertiary', 920, 921, 925, 926 ; Upper Silurian, 568, 569 Belinurus, 701, 720; arcuatus, 708 ; Reginæ, 703; trilobitoides, 708

Belle Isle, 467 ; Strait of, 793,573

Bellerophon antiquatus, 478* ; bilo. batus, $507 *, 514,520,521,550,569$; Cambrensis, 481; carbonarius, $675^{*}, 690$; carinatus, $520,567,573$; cyrtolites, 647; dilatatus, 567; expansus, 573 ; mæra, 592, 613*; natator, 620 ; nodosus, 520 ; patulus, 602 ; trilobatus, 567 ; Urii, 690,711

Bellerophon limestone, 660

Bell's Landing beds, 888

Belly River group, 830 ; region, 825 (coal), 830

Belodon, 754, 758; Carolinensis, 754*; priseus, 754*

Belodonts, 772, 773

Belœil Mt., 531

Belosepia sepioidea, 925; ungula, 897*, 916

Beluga Vermontana, 983

Bembridge beds, 926

Beneckia Buchii, 773

Bengal coal-beds, 698

Benton group, 815, 829, 850

Benzine, 74

Berea grit, 608

Bergkalk, 632

Bering Sea, 43; Strait, 43, 48, 257, $87 \%, 950$ (dry ?)

Bermuda Islands, 20, 46, 145, 162 , 213,224

Bernardston, Mass., 310, 325

Bernician group, 695

Beryl, 67\$, 69, 332, 336

Beryllia, 67

Beryx, 862; insculptus, 843

Besano dolomyte, 774

Betula, 810

Beverly Island, 39

Beyrichia, 516, 562, 567, 643; bella 515 ; lata, 562 ; spinosa, 550 ; symmetrica, 549*, 550; trisulcata, 558; tuberculata, 568

Big Cottonwood Cañon, 476, 495

- Horn basin, 893, 906

- Horn Mts, 266, 478, 748, 830

Billingsella festinata, 471* ; grandæra, 499*, 500; orientalis, 471*

Bilobites, 474, 546; bilobus, 551

Biotite, 65s, 83, 85, 86, 87, 318, 320

- gneiss, 83 ; granites, 82 ; mica 320

Birch, 837

Bird of paradise, 54

Birds, 141, 163, 414, 415, 721, 752 $786,789,794,795,796,877,879$, 914

-, Triassic, 794; Jurassic, 767, 776, 783, 788*, 795, 796, 852, 871; Cretaceous, $812,850 *, 851 *, 852,864$ 870,871 ; Tertiary, 883, 893, 902, $921,923,925$

Birdseye limestone, 489,492,493, $494,503,505,515$

Bismuth, 331

Bison Americanus, 1001 ; antiquus,
1002 ; crassicornis, 1002 ; latifrons, 999 ; priseus, 1015

Bitter Creek group, 886

Bittern, 1208

Bittium Chipolanum, 917

Bitumen, 387, 581, 593

Bituminous coal, $74,124,649,655 *$, $661,695,714,731,741,825$; analyses, $485,662,663,664,712,713$

Black Bluff beds, 888

Black Dome, 27

- Forest, 698, 734

- Hills, 830; Archæan in, 444 Cambrian, 469; Niagara, 541, 543 ; Carboniferous, 658 ; Trias sic, 746,747 ; Jurassic, 747,748 , 758,760 ; Cretaceous, 818,827 , $829,832,843$

Black lead, $62 \S$

Black River limestone, 489, 492 $494,503,506,513,514,515$

Black Sea, 22, 857

Blackfoot Basin, 747

Blake plateau, 230

Blanching of rocks, etc., 134, 822

Blanco group, 884, 885, 895, 912, 919

Blastoidocrinus carcharidens, 503

Blastoids, 430§, 547*, 548 (first), $585 *, 590,641,646$

Blastomeryx, 911, 919

Blattariæ, 757

Bleaching. See Blanching

Blende, 70§, 333,493

Block coal, 661, 662

Block Island, 852

Blood rains, 1635,165

Bloomsbury conglomerate, 594

Blowing-cone, 2798, 284

Blue limestone of Owen, 494, 516, 728

- or Maclurea limestone of Safford, 494

Blue Mts., Australia, 34

Blue Mts., N.J., 532

Blue Mts., Oregon, 748, 749, 811, 830

Blue Ridge, 468,745

Bluestone, 593

Boa constrictor, 156

Boavus, 901

Bob, Mt., 552, 558

Bodie Mt., anriferous veins of, 334

Bog-head cannel, 662

Bog ore, 128, 129, 708

Bohemia, upturnings in, 630,734

- Archæan in, 455, 456; Cambrian, 482, 518; Lower Silurian, 518, 521: Upper Silurian, 563; Carboniferous, 696, 703, 723; Triassic, 768 ; Cretaceous, 838; Tertiary, 938 (eruptions)

Bohemian formation, 535

Bohemilla, 521

Bolderian beds, 926

Bolivia, 26 (plateau), 41, 296 (volcanoes), 627, 628, 711

Bolodon, 789*

Bolonian, 791

Bombay, 299

Bombs, volcanic, $287 * \S, 289$

Bone-beds, Quaternary, 892 ; Ter- 
tiar'y, 902; Triassic, 769, 774 ; Upper Silurian, 563

Bones, 63§, 72, 73 (analyses), 141, $143,144,153,162,190$

Bonneville Lake, G. K. Gilbert on, 202, 382

Bony coal-bed, 656

Boothia Felix, 495

Boracic acid, 63, 66, 313

Boracite, 320

Borate springs, 313

Borates, 119, 187, 320

Borax, 638

- Lake, siliceous deposits, 323, 334, 335

Boring animals, 157,425

Borneo, 40, 297, 696

Bornia inornata, 610 ; transitionis, 699

Bornite, 335, 745

Boron, 63, 320, 335 ; salts, 320

Borophagus, 919

Borsonia biconica, 916

Bos, 927 ; Americanus, 1016 ; primigenius, 1006, 1016; Urus, 1016

Boston basin, 732

Bothriolabis, 918

Bothriolepis, $616 *, 617,619,625$; Canadensis, 616*, 617; minor, 621 ; nitida, 621

Botryoconus, 689 ; Pitcairnïæ, 673*, 674 ; priscus, $673^{*}, 674$

Bottom-lands, $181 \S$

Bourbon, Isle of, 296 (volcanoes)

Bourbonne-les-Bains, thermal waters at, 335

Bourgogne, 769

Bow River region, 826 (coal)

Bowlder elay, $81 \S, 251 \S$

Bowlders, 81, 127*, 664 (in coal); see Glacier Drift.

Brachiates (Brachiate Crinoids), 4295

Brachiopods, $59,60,425 * \S, 426 *$, $427 *$; articulate and inarticulate, 425 今, 471

Brachiospongia, 515 ; digitata, 504*, 513; Roemerana, 513

Brachymetopus, 676 , 700

Brachypsalis, 919

Brachyurans, $59,420 \S, 438 \S 439,707$, 720

Bracklesham beds, 923

Bradfordian, 790

Branchiates, $419 \S$

Branchiosaurus, 706

Branchiostoma, $418 \S$

Branchville granitic veins, 326

Brandon, Vt., lignite bed, 887, 895

Brandschiefer, $80 \&$

Brazil, 31 (mountains), 184; A rehæan in, 456; Carboniferous, 6อ9, 687; Devonian, 627; Jurassic, 776 ; Cretaceous, 857, 858,867

Breaks in the geological record, 406 , 458

Breccia, $\$ 0 \S$

Brecciated vein, 330 \$

Brick-clay, $81 \S$

Bricks from the depths of the Atlantic, 280

Bridgeman's Island, 296 (volcanoes)
Bridger group (beds), 884, 886, 893, $901,904,905,907,918,923,925$

- Lake (basin), 882, 893

Brier Hill coal, 657, 662

Brine springs, 120

Brines. See Salt

British Channel, 16, 210, 936

- Columbia, 25, 389, 390, 812, 948 (fiords); Cambrian, 476, 477 ; Carboniferous, 659, 674; Triassic, 746, 757; Triassic and Jurassic, 739, 809: Cretaceous, 818, 868 ; Glacial, 945, 948 ; Quaternary, 950 Brittany united with Cornwall, 936 Broad Top, 649, 659

Bromides, $68,335,341$

Bromine, 68, 120, 331

Bromo-chloride, 340

Bronteus, 552, 561, 562, 568, 599, 625,626 ; grandis, 627 ; pompilius, $561 *$; Tullius, 599

Brontops, 918 ; robustus, 909*

Brontosaurus excelsus, 763*

Brontotherium, 914*, 918

Brontotherium beds, 886

Brontozoum giganteum, $752 *$

Bronzite, $67 \S, 136$

Brooklyn, N.Y., water supply of, 206

Brookville coal, 652

Brown coal, 74, 662, 712, 713, 714, 920, 922

Brown's Park group, 886

Brownstone, 746

Brunswick, 769

Bryozoans, 141, 142, 147, 418, 419 , $425 *, 427 \& *$

Bubo leptosteus, 902

Bucania, 508, 521, 562 ; rotundata, 502*; sulcata, 503; trilobata, 544*, 549,550

Buccinum Grenlandieum, 984, 995 ; undatum, 984

Buchiceras inæquiplicatum, 837 ; pedernale, 836 ; Swallovi, 854

Buck Mountain coal-bed, 656

Buckingham ( $\mathrm{Va}$.) Triassic area, 741

Buckler, 421§

Buff limestone, 494

Bulurstone, $82 \S, 885,888 \S, 889,890$

Bulimus ellipticus, 926

Bulk, changes of, in mineral changes, 184, 138, 453, 523

Bulla, 916 ; speciosa, 841*

Bullinella Jacksonensis, 916

Bumelia, 922

Bunælurus, 918

Bunker Hill Monument, 260

Buntersandstein, 411, 738, 769

Buprestids, 771

Buprestis, $783 *$ (wing-case)

Burdigalian group, 926

Burlington group, 634, 637, 638

- limestone, 646 (Crinoids), 647

Burnetan, 446

Busycon Bairdii, 855

Buthotrephis, 544; gracilis, 504*, 549; Harknessi, 519*; ramosa, 549 ; succulens, $504 *$

Butterflies, 54, 419, 679; Tertiary, $202,887,900 *$

Byam Martin Is]. 659
Byssoarca protracta, 916

Byssus, 424

Cadaliosaurus, 706

Cadent series, 728

Cadomella, 790; Moorei, 779*

Cadulus turgidus, 915

Cænopus, 918

Caerfai group, 481

Crsium, 385, 449

Cahaba coal-fields, 657

Cainozoic. See Cenozoic

Caithness flags, 623

Caking coal, 661, 662 (analyses)

Calabria, earthquake in 1783, 375

Calais united with England, 936

Calamary, 424*

Calamine, 342

Calamites, 627, 629, 671, 699, 704, 718; approxinatus, 654, 689; arenaceus, 774; cannæformis, $622,671 * 689$; Cistii, 689 ; radiatus, 622, 626, 704; ramosus, 689 ; Suckovi, 615, 654, 685, 689, 692,704

Calamitids, 689

Calamodendron, 699, 718

Calamodon, 917, 918

Calamopora spongites, 310

Calamopsis Danæ, 895*, 896

Calamus, 435

Calaveras skull, 1012

Calcaire carbonifère, 632

- conchylien, 769

- grossier, 205, 884, 920, 923, 924, 925,926

Calcareous deposits, 181, 132*, 133 , 152-153 ; fossils, 129, 130, 314 . organic rock-material, $72 \S, 134$, $140,144,487,496$; rocks, $78 \S-80$; sponges, $431 \S$

- waters, 305 ; consolidation by, 138

Calceocrinus Barrandei, 514

Calceola sandalina, $427^{*}, 626,627$

Calceola slates, 626,627

Calciferous epoch, 490,491

- limestone group, 695

- sandrock, $45^{*}, 490,500$

Calcispongiæ, $431 \S$

Calcite, 15 (density), 68\$

Calcium, 61, 67; bicarbonate, 122 , 129 ; borate, 120 ; carbonate, $62 \$$; chloride, 119, 120; fluoride, 73, 121 (see also Fluorite); iodide, 120: calcium-magnesium carbonate (see Dolomite) ; nitrate, 187 ; phosphate, 63s (Apatite); sulphate, 72,73 ; sulphide, 125

Calcyte, $79 \S, 316,321,490$; converted to dolomyte with diminished bulk, 13t, 523

California, 18, 23 (height), 25, 29" silicified forests of, 135; Diatom bed, 152 ; Salton Lake, 200 ; volcanoes of, 296; Table Mtn., 300 . Borax Lake, 323

-, Arehæan in, 444: Silurian, 809 ; Devonian, 580, 592; Carboniferous, 659,674 ; Triassic 746,75 . 809,810 ; Jura-Trias, 749 ; Jurassic, $748, \quad 749, \quad 759, \quad 760,809$ : 
Cretaceous, 317, 318, 325, 811, $818,820,830,834,837,840,868$ (subsidence); Tertiary, 831, 8\$4, $885,888,891,892,895,916,932$, 937; Glacial, 949; Quaternary, 950

Caligus, 420

Callipteridium, 685, 693, 699

Callipteris, 685, 698, 699; conferta, 704 ; pilosa, 622

Callitris, 922

Callocystites Jewetti, 429*, 547, 550

Callovian group, $760,775,776,780$, 790

Caloosahatchie beds, 890

- River. 892

Calophyllum, 552

Calopodus, 692

Calumet mine, 339

Calvert Cliffs, 891

Calymene, $310,422,520,521,546$ 551 ; Allportiana, 520 ; Blumenbachii, $420^{*}, 421,520,551,552,562$, $567,568,586$; callicephala, 508*, $509, \quad 512, \quad 515, \quad 524,549,550$ Christyi, 516; Clintoni, 550 ; Niagarensis, 549, 550, 551; platys, 591 (last American species); tuberculosa, 551, 567, 569

Calyptræa, 475

Camaphoria subtrigona, 646

Camarella antiquata, 471* ; calcifera, 500 ; congesta, 550 ; longirostris, 503 ; primordialis, 478*; varians, 500,503

Camarocrinus Saffordi, 550; stellatus, 558

Camarophoria, 707 (ends in Permian); crumena, 707; formosa 627; Humbletonensis, 704; Schlotheimi, 707 ; superstes, 707

Cambrian and Silurian, history of the terms, $463,464 \S, 489$

Cambrian, 462; American, 464; foreign, 480

Cambric. See Cambrian

Cambridge Greensand, 863, 864

Camel, 54, 55, 907, 910, 911, 912 . 919,928

Camelopardalis, 54, 927

Camelus, 927

Cameroons Mts., 295, 297 (height)

Campanian, 859, 866

Campbell Island, 39

Campophyllum torquium, 690

Camptonectes bellistriatus, 760

Camptonyte, $87 \$$

Camptopteris, 756

Camptosaurus đispar, 764, $765^{*}$; medius, $765^{*}$

Campylodiseus ely peus, $163,164^{*}$

Canada, 24, 26, 78, 25s

- Archrean in, 443 ; Cambrian, $464,466,476,479,496$; Calciferous, 491,492,493,496,497,499, 500, 501; Chazy, 491, 493, 503 ; Trenton, 493; Clinton, 542; Medina, 589, 542; Niagara, 540, $543,544,549,551$; Deronian, $576,581,591,611,628,630$; Corniferous, 580, 581, 590, 591;
Carboniferous, 453, 581; Cretaceous, $825,880,840,872$; Tertiary, 918

Canada Bay, 467

Canadian Pacifie R.R., 26, 359

- period, 491

- River, 29

Canary Islands, 20, 41, 207

Cancer, $420^{*}$

Cancrinite, 85,449

Canimartes, 919

Canis, 911, 919, 927 ; Parisiensis, 924

Canistrocrinus, 516

Cannapora junciformis, 550

Cannel coal, 654, 661, 662 (analyses), 692,710 (formation), 714

Cap au Grès, 732

Cape Breton, Cambrian in, 476; Carboniferous, 691; Coal-measures, 658,678

Cape Cod, 160, 873, 881, 916

- Dundas, 659

- Girardeau limestone, 559

- Hatteras, 18, 43, 45, 48, 210, 224*, $793,823,873,949$

- Horn, 21, 23, 858

- of Good Hope, 21

- Verd Islands, 297

Capelin, 984

Caprina, 820 ; adversa, 866 ; anguis, 836 ; Texana, 834, 835*

Caprina limestone, 817,836

Capulus, 471, 482, 574

Carabocrinus, 516

Caradoc group, 463, 518, 534 ; sandstone, 520, 534

Carbon, 61, 62§; Archæan, 453, 454

- Ridge, 730

Carbonaceous clay, $81 \S$

- rock-material, $74 \$, 140,141,153-$ 155, 315 (metamorphic changes), 319,458

- shale, $80 \$$

Carbonate of lime. See Calcite

— of magnesia, 69

Carbonates, 68

Carbonic acid, 62, 128-135; in A rchæan, 440,441, 442, 450, 451, 454 ; in Cambrian atmosphere, 485 ; at beginning of Carbonic era, 711, 712; constructive effects, 131; destructive, 129 ; in geyser region, 309 ; from respiration, 186 ; from volcanoes, 128,278

Carbonic era, 631; American, 633 ; foreign, 693 ; formation of coal, 712 ; economical products, 661665

Carbonic oxide, 278 (from Kilauea), 523, 661

Carboniferous age, 631

Carboniferous period, 647

Carcharias, 863

Carcharodon, 144, 855 ; angustidens, $416 \%, 901 *, 917,926$; megalodon, 901

Carcharopsis Wortheni, 644*,647

Carcinosoma ingens, 557

Cardinia conciana, 790 ; Listeri, 790

Cardiocarpus, $435,622,674$; bicuspidatus, $673 *$, 689 ; bisectus, $673 *$,
689 ; elongatus, $673 *, 689$; samarxormis, $673 *, 689$

Cardioceras, 794 ; dubium, 760

Cardioceras family, 760

Cardiola, 621; retrostriata, 621, 627 ; speciosa, 620

Cardiomorpha Missouriensis, 690

Cardiopsis radiata, 647

Cardiopteris, 645; frondosa, 704; polymorpha, 704

Cardita, 916 ; planicosta, 926 ; sulcata, 926

Carditamera arata, 917

Cardites crenatus, 774

Cardium, 916 ; Dalli, 917 ; diversum, 916 ; dumosum, 854 ; Eufaulense, 854; Hatchetigbeense, 915; Hillanum, 865; Islandicum, 983, 984 ; laqueatum, 917; Purbeckense, 791; speciosum, 855; Virginianum, 917

Carentonian, 859, 866

Caribbean Sea, 20, 44, 45, 49, 936

Caricella Claibornensis, 897*, 916; demissa, 916 ; doliata, 916 ; Leana 915

Caridoids, $421 \S$

Carinaropsis, 482

Carmel (Mt.), Conn., 801*, 802, 807

Carmon, 521

Carnallite, 120

Carnic (Lower), 757

Carnivores, 902, 903, 910, 911, 918 $919,924,926,927,929,930,931$

Caroline Archipelago, 38, 39, 145, 350

Carp River, unconformability at, $465 *, 468$

Carpathian Mts., 32, 41, 365, 774, $793,812,920$

Carpinus, 896

Carpolithes Brandonensis, 896*; irregularis, 895*, 896

Carrara, 309

Carrizo Creek, Cal., 892

Carson Lake, 811

Carterella, 432*

Carya, 550, 896

Caryocrinus, 550 ; ornatus, 547*, 550,551

Caryoderma, 919

Caryophyllia, 860

Cascade Range, 25, 28, 29, 30, 40, 280,296 (volcanoes), 300, 389, 739, $747,811,830,831,945$

Cashaqua shale, 605

Caspian Sea, 22, 33, 49, 199, 200, $296,768,776,857$

Caspian steppes, 156

Cassia, 921

Cassidaria dubia, 916; Petersoni, 916

Cassidulus, 840 ; æquoreus, 855; florealis, 854

Cassiope hypnoides, 945

Cassowaries, 54

Castor Canadensis, 55, 1000 ; fiber, 55

Castoroides Ohioensis, 1000, 1012

Casuarinæ, 922

Casuarius, 54 
Catacecaumene region volcanoes, 296

Catarractes affinis, 1002

Catchfly, 945

Catlinite, 465

Catopterus gracilis, 751*

Catopygus carinatus, 866 ; pusillus, 854

Catskill beds (group), 576, 602

- Mts., 25, 188, 225, 357, 605, 636, $744,745,946$

- shaly limestone, 559

Caucasus, 41, 239, 265, 857, 920

Cauda-galli epoch, 410

- grit, 558, 559, 576, 579, 581, 728

Caulerpites, 688

Caulinites sparganioides, 839

Caulopteris, 5ัSt, 699 ; advena, 584; antiqua, 583*; elliptica, 705 ; gigantea, 705 ; Lockwoodi, 611, 622 ; microdiscus, 705 ; peltigera, 705: Wortheni, 645

Cave animals, 927,940

Cavern formations, 324

Caverns, 379, 399, 695, 883 ; making of $116,130 *, 324$ (Hawaiian): filled with vein-material, 328,334 , 342,343 ; nitrates in, 137 ; rivers in, 207

Cayambe Mt., 26

Cayuga Lake, 555, 559, 602, 603, 604, 605 ; jointed rocks, 112*

Ceanothus, 921

Cebochærus, 926

Celastrinites lævigatus, 839

Celastrus, 921

Celebes, 19, 40, 309

Celestite, 493,540

Cement, 79, 80, 555

Cementing coal, 661

Cenomanian group, 815, 832, 857, $858,859,860,865,866$

Cenozolc time, 879

Centipeds, 419

Central America, 40, 145, 296 (volcanoes), 297, 338

Central Continental Interior. See Interior Continental

Central Pacific R. R., 26

Centroceras, 602

Centronella, 579

Cephalaspids, 417, 625

Cephalaspis, 564, 566*, 587, 625; Campbelltonensis, 588* ; Dawsoni. 588*, 591; Lyelli, 624*; Murchisoni, 566, 567 ; ornata, 567

Cephalization, 414, 437-439

Cephalophora, 424

Cephalopods, 59, 130, 424§, 425* 501,569

Cerana Island, 38

Ceratiocarids, 550, 721; Cambrian (Upper), 488; Chemung, 604; Hamilton, 599, 600*; Lower Silurian, 521; Niagara epoch, 549; Upper Silurian, 574

Ceratiocaris, 482, 521, 546, 557, 565, 567 ; Angelini, 519, 520\%, 549; Deweyí, 549, 550 ; papilio, 566* ; pusilla, 546; sinuata, 691 ; tenuistrista, $566^{\text {* }}$
Ceratites, 757, 770, 771, 774; Malmgreni, 792; Middendorfi, 773; nodosus, $770,771 \%, 774$

Ceratodus, 59, 176, 417, 418, 687 $725,772,774,797$; culmination in Triassic, 869 ; Capensis, 770 ; favosus, 687 ; Güntheri, 760

Ceratolichas, 591

Ceratops, 856

Ceratops beds, 828, 845, 847, 849

Ceratopsidæ, 846,848

Ceratopsids, 828, 847, $856,864,870$

Ceratosaurus nasicornis, $765,766 \%$

Ceraurus (Cheirusus), 422, 482, 500 $502,508,513,516,520,521,546$. 568,625 ; bimueronatus, 520 , 565*; Niagarensis, 550,551 ; pleurexanthemus, 509*, 515: Satyrus, 503 ; Sternbergi, 568

Cerithiopsis, 916

Cerithium, 780, 854, 922 ; Austinense, 836; Claibornense, 916; concavum, 926 ; cymatophorum. 927 ; elegans, 926 ; Hillsboroense, $898^{*}, 916$; mutabile, 926 ; plicatum, 926 ; variabile, 925

Cernaysian group, 884, 923, 925

Cerussite, 335

C'ervalces Americanus, 999*

Cervus, 927 ; anoceros, 927 ; Falconeri, 927 ; giganteus, 999,1005 ; Muscatinensis, 966; Polignacus, 927 ; verticornis, 927

Cestracion, 60, 416*, 643; Philippi, $416^{*}, 797$

Cestracionts, 416*8, 797, 869 (four modern) ; Corniferous, 589 ; Subcarboniferous, 644, 647; Carboniferous, 680*; Permian, 707; Triassic, 772 ; Cretaceous, 812 , $843 *, 863,869$

Cetaceans, 902, 912*, 925

Cetiosaurus, 786, 790; brevis, 863 ; Oxoniensis, 786

Cetotherium, 925 ; cephalus, 912*

Chabazite, 68

Chænohyus, 918

Chæropotamus, 924 ; Cuvieri, 926

Chretetes, 505

Chagos Islauds, 737, 937

Chain coral. See Halysites

Chalcedony, 323, 340, 859

Chalcedony Park, 135

Chalcocite, 335,745

Chalcopyrite $70 \$, 331,334,335,339$, $340,538,542$

Chaleur Bay, 444

Chalieotherium, $919,925,927$

Chalk, 79§, 205 (absorptiveness), 817

- formation, 401, 407, 738

-, Gray, Lower, Upper, White, 858

- period, 738. See also Cretaceous

- marl, 865, 866

Challenger Expedition, 49, 59, 144, $230,241,718,823$

Chama, 780, 884; crassa, 917 ; squamosa, 926

Chamærops humilis, 58

Chamops segnis, 849
Chamouni, 233, 243, 246

Champlain (Lake), 200, 232, 467, 532, $558,982 \%$

Champlain period, American, 981 ; subsidence, 981 ; foreign, 995 ; elevation at close of, 993

- group of the Lower Silurian in New York, 489

Champsosaurus, 902; profundus, 856: Saponensis, 902

Chara, 72 (ash of), 582*, 590 ; fuetida, 72 : Stantoni, 839

Charcoal, 62\$, 124, 662; mineral, 712

Charleston earthquake of 1886,373 , 374,375

Chart. See Map

Chasroops, 521

Chatham Islands, 39, 154, 1019

Chattahoochee group, 884, 890, 891, $898 *, 916$

- River, 890, 891

Chaudière River, 591

Chazy epnch, 493

Cheiracanthus, 625

Cheirurus. See Ceraurus

Chelonians, $772,787,836,849,863$

Cheltenham beds, 775

Chelys Blakei, 790

Chemical attraction as a dynamical agency, 117

- changes producing heat, 258

- products, mechanical work of, 137, 138*

- work, 118-140 ; solution, 118 . 122 ; oxidation and deoxidation, 122-128; hydration, carbonic acid, humus acids, 128-135 ; silica, 135-136; living organisms, 136-137; chemical products, $137-$ 139 ; concretionary consolidation, 139-140

- - of metamorphism. See Metamorphism

Chemnitzia, 781; gloriosa, 855

Chemung period, 602

Chenopus liratus, 916

Cherry Ridge group, 606

Chert, $63 \S, 82 \S$

Chesapeake Bay, 744, 819, 859, 891

- epoch, 884, 891

Chester group, 634, 637, 638, 639 , $642,645,647,709$

Chestnut, 435, 837

Chetetes, 704

Cheyenne River, 266

Chiastolite, $65 * 66$

Chico group (beds), 815, 818, 830 $831,840,889$; see also ShastaChico series

Chile, 187; snow-line in, 234; rolcanoes of, 296 : earthquake in, 349 ; recent changes of level in, 349 : Cretaceous in, 857,867

Chilhowee sandstone, 468

Chillan Cordillera, 857

Chiloe, 23

Chilopoda, 419

Chimera, 510

Chimarids, 416\$, 574, 725

Chimæroids, Corniferous, 587, 589*; Cretaceous, 828 
Chimborazo (Mt.), 26, 274, 290, 296

China, 51, 84, 145; Cambrian in, 482 ; Lower Silurian, 522 ; Upper Silurian, 564; Devonian, 628; Carboniferous, 632, 693, 696 ; Cretaceous, 833

China Sea, 927

Chinate Mts., 874

Chipola epoch (group), 884, 891, 899*, 917

Chipola sands (fossiliferous), 890, 891

Chirolepis, 417, 620; Canadensis, 618*; Trallii, 41 \%*

Chiropters, 918

Chirotherium, 772*, 773, 774; Reiteri, 692

Chirox, 917

Chiton, $424 \S$; Canadensis, 514 ; carbonarius, 690

Chlamaydotherium, 1004

Chlorine, 63

Chlorite, $68 \S, 89$

- argillyte, 898

- rocks, $79 \S, 83,84,86,87,319,449$

- schist, $89 \S$

Chloritic maarl, 865

Chlorophyll, 136

Cholaster peculiaris, 646

Cholodus, 692

Chomatodus, 692

Chondrites Colletti, 688

Chondrodite, 63, 67§, 79, 319, 447, $449,450,531$

Chondroditic limestone, $79 \S, 449$, 450,531

Chonetes, 546*, 550, 552, 562, 579, $611,621,622,642,674,700$; cornutus, $546^{*}, 550 ;$ Dalmanianus, 703 ; deflectus, 592; Flemingi, 685 ; Hardrensis, 625, 628; hemisphæricus, 590, 592 ; Illinoisensis, $642 *$, 647 ; latus, 427*, 567; lepidus, 612,620 ; lineatus, 590; mesolobus, $675 *$, 690 ; mucronatus, 592, 602; Novascoticus, 562; ornatus, $642 *$, 646 ; planumbonus, 646 ; scitulus, 612,620 ; setigerus, $59 S^{*}, 601,620$; striatellus, 567 , 563

Chonophyllum Niagarense, 547*, 550

Choristoceras, 771 ; Haueri, 774

Chouteau limestone, 637, 646

Chrestutes Danæ, 691; lapidea, 691

Christinnia, 309

Christianite, 136

Christmas Island, 151 (height)

Chroune-spinel, 88

Chrysalidina gradata, 432*, 860*

Chrysoberyl, 449

Chrysocolla, 335

Chrysodomus Stonei, 917

Chrysolite, $67 \S$

Chrysolitic gabbro, 272; hornblendyte, 532; pyroxenyte, 582

- rocks, SS-S9

Chrysumelids, 7 \%

Cicada, 419

Cidaris, 59, 641, 760, 779, 834, 840 ; Blumenbachii, $778 \%$, 791; clavigera, 866; cretosa, 866; flori- gemma, 790, 791 ; splendens, 854 ; Texana, 837 ; vesiculosa, 866

Cimolestes incisus, $853 *$

Cimoliosaurus, 845

Cimolos Island, 296 (volcanoes)

Cincinnati, Ohio, 583

- anticline. See Cincinnati uplift

— beds, 492, 504, 506, 511, 514, 515.

516 ; characteristic species, 516

- epoch, 494, 559

- group, 489

- Island. See Cincinnati uplift

- uplift, 387§, 490, 494, 522, 527, $532-533,537,539,540,633$; intluence of, in the Upper Silurian, 571

Cinders, volcanic. See Volcanic

Cinnabar, 335

Cinuabar, Mt., 829

Cinnamomum, 887, 896, 921 ; ellipticum, 839 ; Mississippiense, 895*, 896 ; Scheuchzeri, 839

Cinnamon, 921

Cinulia, 861; avellana, 861*; pulchella, 854

Cirripeds, $420 *, 421 \S, 513$ (earliest), 579,720

Cladiscites tornatus, 771 \%

Cladodus, 692, 702; Clarki, 619*, 620; Fyleri, 619*, 620; Kepleri, 620 ; parginatus, 702 ; sinuatus, 619*; spinosus, 644*, 647

Cladonia, 75 ; rangiferina, 75

Cladopora labiosa, 592

Cladoxylon mirabile, 621

Claiborne epoch (group), 884, 885, $889,891,916$

-(Lower), 884, 885, 888, 890, 896, $897 *, 915,916$

- (Upper), 896, 897*

Clam, $423,424 \S$

Claosaurus, 847, 856; annectens, $844^{*}, 845^{*}, 847$

Clarion coal, 652 ; sandstone, 652

Clastic rocks, $75 \S$

Clathropora flabellata, 514

Clathropteris, 740,750 ; rectiuscula, $749 *$

Clava Chipolana, 917

Clavilithes humerosus, 916 ; Mississippiensis, 916 ; pachyleurus, 916 ; Penrosei, 916

Clay, 76§, $80 \S, 81$ (kinds), 134

Clay-ironstone, $70 \S, 82$

Clay marls, $815,821,854$

Clay shale, $638,748,892$; slate, $80 \S$, 84

Clayey layers, plication of, $208,209^{*}$ - rocks, 12,31

Clayton beds, 888

Clayton Peak, 360*, 361

Clear Creek limestone, 543, 559

Clear-Fork beds, 660

Clear Lake. See Borax Lake

Cleavage in rocks, $92,112 *, 113 *, 370$

Cleodora, 425*

Clepsydrops, 687

Clepsysaurus Pennsylvanicus, 758, $75 t^{*}$

Cleveland shale, $606,619,620$

Clidastes, 826 ; iguanavus, 848 ; propython, 848 ; velox, $846^{*}$
Clidophorus Pallasi, 707

Cliffs, wearing of, $220,221 *$

Climacograptus, 514, 520 ; bicornis, 510*; Emmonsi, 470* ; typicalis, 516

Climactichnites Fosteri, 479*; Wilsoni, 479*; Youngi, 479*

Climatal changes, causes of, 253-257

Climatal development, 1026

Climate, effects on the work of rivers, 189

- Cambrian, 484; Carbonic, 711712; Champlain, 940 ; Cretaceous, 872-873, 877; Eocene, 929; Glacial, 940, 943, 944; Lower Silurian 524; yost-Mesozoic, 875,877 ; Paleozoic, 727 ; post-Paleozoic, 736; Permian, 737 ; Quaternary 940; Tertiary, 921, 939 ; Triassic and Jurassic, 791, 792-793; Upper Silurian, 574

Clinch Mountain sandstone, 538

Clinkstone, $85 \S$

Clinometer, $100^{*}$ \& ; use of, for measuring distant slopes, 28

Clinton beds or epoch, $356,410,535$, $540,544,549-550,552,563,570$, $5 \% 2,577$

- - and Medina, British equivalent of, 563

Cliona sulphurea, 158

Clitambonites, 500 ; Americanus, 515

Clupea, 862

Clymenia, 614 (first American), 620 , 626; lævigata, 627; Neapolitana 614*; Sedgwicki, $620^{*}$; undulata, 627

Clymenia limestone, 627

Clypeus Hugi, 428*

Coahuila Valley, 200

Coal, $62 \S, 124,136,143,154,485$ 727,775 (jet); analyses, 661,662 , 663,713 ; formation of, from vegetable debris, 712-714; impurities, 663,664 ; kinds, 661 ; origin, 71 $155,653,654,655$; plant-remains in, $653-655,658,663,664$; struc ture, 709,710 ; regetable material of: kinds and composition, 712 , 713

- in Calciferous, 493; Carboniferous and Subcarboniferous, 684 , $636,639,648,661-664,674,693$, 694*, 695, 696; Permian, 660, 684, 685,698 ; Triassic, $742,744,745$, $748,755,769$; Jurassic, 775,776 ; Cretaceous, 818, 820, 822, 825, $826,827,828,829,831,857,865$ 872; Tertiary, 887, 892, 920, 922, 927

- areas of N. America, 635, 825

— fields of Europe, 693, 694, 696

Coal-beds, bowlders in, 664, 709 ; burning of $84,266,313$ (changed to coke); metamorphic changes in, 315, 453; thickness of, 651 , $652,653,656,657,658$

Coal-measures, dirt-beds of, 653 658 ; false, 639

- section of, near Nesquehoning, Pa., 649*; at Trevorton Gap, Pa. $650 *$ 
Coal period, 631, 647

Coalville (Utah) coal-bed, 825,829

- group, 825, 829

Coast barriers, 224*, 225*

- belt. See Coast Chain

- cordillera, 25

- Chain, 390, 739, 818, 987

- Range, Cal. and Oregon, 30, 659 $739,809,810,811,830,885,892$

- - of British Columbia, 389, 739, S12

Coastal plains, $24 \S$

Coasts, water-line of, 346

Cobalt, $70,342,344$; oxide, 344

Coblenzian beds, 626 ; fauna, 570

Cobscook Bay, 552

Coecolepis, 699

Coccoliths, 72, 140, 437§, $838 \$, 859$

Cocconeis atmospherica, 163,164 * lineata, 163, 164*

Cocconema cymbiforme, 163,164 *

Coccospheres, 72

Coccosteid, $616^{*}$

Coccosteus, 566, 619, 625, 626, 627 ; decipiens, 624* ; macromus, 621 ; occidentalis, 588*

Coccosteus family, 618

Cochliodonts, $643 \S, 647,705$

Cochliodus contortus, 644*, 702*; nobilis, $644 * 647$

Cochlocerus, 771

Cockroaches, 156, 419, 574, 677, 721, 723 ; Carboniferous, 677, 679, 691, 701, 722; Paleozoic, 721, 722 ; Permian, 686; Triassic, 757, 771

Codaster, 516, 601

Coelacanthus, $6799,680,692,705$; elegans, $680^{*}, 692$; granulatus, 707

Colenterates, $418 \S, 419,430 \S$

Coelodus, 836

Coelospira, 579; hemisphærica, 550 ; Scotica, 567, 569

Colurus gracilis, 836

Ccenenchyma, $431 \S$

Coenograptus graeilis, $510 *, 515,516$

Conograptus zone of Lapworth, 515

Coffee sands, 824

Coke, 313, 661, 663, 713

Coleolus, 599 ; acicula, 612,620

Coleopters, 54, 419, 794, 900 (number at Florissant); Coal-measure, 679, 691, 702; Triassic, 771; Glacial, 946

Colodon, 918

Colombia, Cretaceous in, 867

Colonoceras, 918

Color of rocks, 400

Colorado, 23 (height), 26, 85, 87, 109, $160,188,189,203,207,250,265$, $266,296,313,338,340,343,363$, 364,447 ; silver mines, 340 ; terraces, $363 *$; trachyte, $275 *$; see also Front Range of Colorado

-, Archran in, 444, 449 ; Cambrian, 464, 476; Trenton, 495, 509, 515; Devonian, 580 ; Subcarboniferous, 469, 639 ; Carboniferous, 469,475 , 658 ; Permian, 693 ; Triassic, 187, 208, 363, 721, 746, 747, 756 ; Jurassic, $187,368,747,748,758,760$, $761,762,765$; Cretaceous, 187, $274,363,826$ (coal), 828, 830,
847, 848; Tertiary, 185, 882, 886, $893,901,909,935$ (elevation); post-Mesozoic, 876

- Cañon (Grand Cañon), 107, 186, $187 *, 185 *, 189,362,381,447,464$, $469,484,541,658,660,747$

- Chain, 389

- desert, 160

- epoch, 815, 821, 823, 824, 825,826 , $829,830,831,855,873$

- plateaus, $109,110 \%, 362,368 *$

- Range. See Front Range

-River, 25, 26, 30, 200, 362

Coloreodon, 918

Colossochelys A tlas, 923, 927

Colubridæ, 923

Columbia River, 25, 30, 226, 831, 885, 695

Columbian formation, 974

Colúmbus limestone, 581

Columnar structure, $261 *, 262 *$

Columuaria, 501, 515; alveolata, 504, 505*, 513, 517 ; calicina, 513; Halli, 513 ; incerta, 503 ; parva, 503

Comanche group (beds), 815, 817, $834,874 *$

- Peak chalk, 817, 819, 836

Comarocystites punctatus, 514; Shumardi, 514

Comatulæ, 402, 429 §

Comatulids, 429, 779

Comb (mining term), 333§, 722

Comoro Islands, 296 (volcanoes)

Compact rocks, $80 \S$

Compass, clinometer, $100 * \S$

Compsacanthus, 692 ; lævis, 692

Compsaster formosus, 646

Compsemys, 850 , 856 ; plicatulus, 767

Compsognathus longipes, 786

Comptonia, 921

Comstock lode, 339

Concentrie discoloration, 139,140 *

- structure, $96 * \S, 97 *, 98,127,140 *$, 289,327

Concepcion, earthquake at, 213,349

Conchifer's. See Lamellibranchs

Concretionary consolidation, 139 $140 *$; rocks, $79,80,82,96,139$, 344,690 ; structure, 182, 289, 327

Concretions, 87, 96*, 97*, 139, 152, $195,230,274,307,327,493,608$, $605,606,657,665,677,688,775$, $822,825,847,888$

Condros, sandstones of, 826

Conduit of a volcano. See Volcano

Conewango basin, 945

Coney Island, 224

Confervæ, 60, 72, 133, 140, 157, 437, $582,583 *$

Conformability, 114§, $115^{*}$, 391, 400, $404,406,807,809$

Conglomerate, 80今, 292 (volcanic), 400 (coral)

-, limestone, $78 \S$

Congo River, 30

Congress Springs, analysis of - theory of mountain-making, 383waters, 121

Conifers, 53 ; ash of, 75 ; time range, $409 *$
Coniophis precedens, 848

Coniston grits, 563 ; limestone, 518 , 519,520

Connecticut, mean beight, 23 ; Branchville Mine, 321 ; Thimble Islands, 949 ; copper ores, 745 ; iron ore beds, 127; marble, 524, 530, 531; Triassic, 111, 740,741 , $742,751,753,754,755,799,800$, $801^{*}$ (map), 808

- River, 87, 172, 212 (tide); soundings at mouth of, 226 *

\section{- - Range, 358}

Connecticut River valley drift, 956 - valley, 194* (terraces), 195, 443 ; Devonian, 310, 531; Lower Helderberg, 555; Niagara, 541; Triassic, $264,316,740$

- - trough, 461, 536, 587, 541, 683, 715,743

Connellsville sandstone, 651

Connoquenessing sandstones, 656

Conocardium, 520, 562, 621; ær|⿲二丨costatum, 567; cuneus, 585*, 590 ; dipterum, 519*; immaturum, 514; Meekanum, 647

Conocephalites, 482,483

Conocoryphe, 481, 482 ; minuta, 479*

Conodonts, 621

Conomitra Hammakeri, 916

Conophyllum magnificum, 590

Conorbis alatoideus, 916

Consolidation (see also Solidification), 289 ; by calcareous waters, 133,139 ; by ferruginous waters, 134, 139; by iron oxide, 128; by metamorphism, 316, 322 ; by siliceous solutions, $135,139,313,323$, 800

-, concretionary, 139-140*

- of coral reefs, 151

Constance, Lake, 921

Contact-minerals and contact-phenomena, 312ミ, 318, 314, 333, 810 ; veins, 334

Continent, definition of, $34 \S, 35$

- making, $376 \S$

Continental border, 743,744

- Interior. See Interior Continental

- plateaus, 379

Continents, 383 ; arrangement of, 17,21 ; as individuals, 22 ; heights of, 23,380 ; mostly in the northern hemisphere, 394

-, mountain chains and volcanoes mostly on the borders of, 392

-, northern and southern, in a zigzag arrangement, 394

-, origin of, 383 ; submerged borders, 17 ; system in reliefs, 30-35

Continguiban group, 867

Contraction, effects of, $260 ; 32 \overline{\text {, }}$ 381 ; in glass and rock, 264, 265 ; in volcanic work, 283 ; on drying and on cooling makes fissures, 327

356

- and expansion, 259-265, 261* 382 
Conularia, 481, 488, 506, 514, 549, 562, $567,574,578,579,613,698,705$, 707,719 (time range); elegantula, 590 ; formosa, 516; Homfrayi, 520 ; lata, 578 ; longa, 551 ; Niagarensis, 551; Trentonensis, 507*, 514,516

Conulites flexuosus, 562

Conulus chersina, 966

Conus, 916, 922; deperditus, 926; Okhotensis, 927

Cook's Inlet, 760

Cooling, contraction from, in case of fusion, $261 *, 263,264,383$

- of the globe, 376 ; its consequences, 383,939

Cooper beds, 888

Coosa coal-fields, 657 ; series, 468

Copepods, $421 \S$

Copiapo earthquake, 349

Copodus, 643

Copper, 70, 333; chloride, 294; native, in drift, 953 ; oxide, 344 ; pyrites (see Chalcopyrite); see also Superior (Lake) region, copper

Copperas, 123, 125

Coprolites, 73§ (analyses); Upper Silurian, 567 ; Triassic, 754 ; Jurassic, $785,786^{*}$

Coral, precious, 72, 431; Coral atolls (see A tolls)

- bed, Taylorville, Cal., 759

- beds of the Siliceous group of Tennessee, 688

- formations, 144-152

- island, water supply of, 206

- - subsidence, 936-937

- islands, 20, 120, 131, 144§, 145$148,145 *, 146^{*}, 161,221,225,295$, $350,392,937$; most numerous in the tropical Pacific, 145; number in the several groups, 145 ; sections of, $149 *, 284 *, 285 *$

- oülyte, 147

- polyps. See Polyps

- rag, 411, 775, 790

- reef period, in the Devonian, 584

- reefs, 144§, 148-152

Corallian group, $760,775,777,780$, 790

Coralline limestone of the Niagara, $540,543,549$

Corallines, 56, 72, $437 \S$

Coralliochama Oreutti, 841 *

Coralliophila magna, 916

Corallium nobile, 72

Corals, 55, 140, 427*, 429*; limits of growth, 144, 145, 146, 149*

Corax, 843; heterodon, 843*

Corbicula, 828, 829; annosa, 837; ey theriformis, 856 ; densata, 917 ; emacerata, 837 ; occidentalis, 856 Corbis distans, 916

Corbula, 756, 780, 828, 916, 917 ; Aldrichi, 915; Forbesiana, 791; idonea, 917 ; inflexa, 791 ; longirostris, 925; Neucomiensis, 867 : oniscus var. fossata, 916; pectinata, 791 ; pisum, 926

Cordaianthus, $673 *$
Cordaicarpus Gutbieri, 678*, 689

Cordaites, 435, 611, 612, 639, 667, $672,673^{*}, 674,659,699,704$; borassifolius, 616, 659; Clarki, 610, 621 ; costatus, 672*, 689 ; diversifolius, 689 ; Gutbieri, 673*; Mans fieldi, 672 ; Robbii, 595*, 596, 601, 622

Cordaites shales, 593,594

Cordillera, $25 \S, 389,390 \S$

- of the Rocky Mts., 390

Cordillera glacial area, 956

Cordylocrinus, 562

Corea, 40

Cork, composition of, 713

Cormorant, 852, 902

Cornbrash, 775,790

Corneo-siliceous sponges, $431 \S$

Corneous sponges, $431 \S$

Corniferous limestone, 576,579

Corniferous period, 579

Corniornis, 852

Cornulites serpularius, 567

Cornus suborbifera, 839

Cornwall, 317, 936 (united with Brittany)

— veins, 329*, 332*, 338*

Cornwallis Isl., 495

Coroniceras Bucklandi, $781 *, 790$

Coronocrinus, 562

Coronura, 591

Corrasion, 168§, 941

Correlation of geological records, 398-404 (difficulties, 398 ; means, 399 ; precautions in the use of fossils, 402); difficult in crystal. line terranes, 458

- of A rehæan subdivisions, 457

Corrosion, 126, 136, 338-342

Corsica, 87

Corsyte, $87 \S$

Cortez Range, 366

Corundum, $64 \S, 79,320,455$

Corycephalus, 591

Corydalis Brongniarti, 704

Coryphodon, 908, 907, 917, 918, 928 , 925,929 ; hamatus, $903,904^{*}$

Coryphodon beds, 886

Coryphodonts, 928

Coscinodiscus, 163, 164*; apiculatus, $894 *$; atmosphericus, 163 , $164 *$; gigas, $894^{*}$

Coseguina volcano, 163

Cosmoceras Jason, 781*; Parkinsoni, 790

Cosoryx, 911, 919

Costa Rica, 891 (Miocene)

Coteau des Prairies, 942 (drift), 945

Cotopaxi (Mt.), 26, 274, 296

Cottonwood Cañon, 469, 476, 581

- Creek, 895

Country Peak, 733

- rock, $331 \S$

Coutchiching, 445

Crabs, $146,420 *$, 438, 707, 717, 720, 782

Crag, Pliocene of England, 921, 927

Craie glauconieuse, 866

Cranberry mine, 450

Cranes, 923
Crania, 59, 425§, 516, 520, 719; antiqua, $427 *$; divaricata, $519 *, 520$; seabiosa, 514, 516

Crassatella, 916 ; alnermis, 915 ; alta, $897 *, 916$; antestriata, 915 ; curta, 854; flexura, 916 ; lineata, 855 ; littoralis, 854 ; melina, 917 ; Marylandica, 917 ; Mississippiensis, 916 ; sulcata, 926 ; texalta, 916; Texana, 916; Trapaquara, 916 ; tumidula, 915 ; undulata, 917 ; vadosa, 854

Craters, $267 \S, 269 *, 270 *, 284 *, 286 *$; see also Volcanoes

Craw-fish, 158, 771

Crazy Mts., 876

Crenitic hypothesis of Hunt, 321

Creodonts, 908, 906, 907, 917, 918, $923,924,925$

Crepicephalus, 503

Crepidula, 642 ; costata, $900 *$; fornicata, 994

Cretaceous period, 812 ; N. American, 812 ; foreign, 556

-in N. A merica, map of, 812, 813*, 814

—, Lower, 816

-, Upper, 837

Cretacic period. See Cretaceous

Cricoceras Duvalii, 862*

Cricodus, $417^{*}$

Cricotus Gibsoni, 687 ; heteroclitus, $687 *$

Crillon (Mt.), 238

Crinidea (Crinideans), 429

Crinoidal limestones, 404, 594, 636, 652

Crinoids, 60, 72, 188, 140, 142, 310, $314,402,428 *, 429 * \S, 430 \S, 486$, $532 *, 541$

Criocardium dumosum, 854

Cristellaria cultrata, 791

Crocodiles, 54, 415; Jurassic, 768 ; Tertiary, 901, 902, 923, 927

Crocodilians, Cretaceous, 848,863 , 870,871 ; Jurassic, 760,787 ; Triassic, 751, 754*, 758, 772, 773

Crocodilus Elliotti, 901 ; Hastingsiæ, 926 ; Squankensis, 901

Cromer forest bed, 927

Crooked River, 749

Cross-bedded structure, 92§, 93*, $194,603,658,742,825,827,888$

Cross Sound, 238

Cross-Timber (Lower) sands, 815, 824,854

Crossopterygians, $417 \S, 619,725$

Crotalocrinus rugosus, 564*, 565, 567

Croton River water analyzed, 121

Crushing, 259, 322, 326, 338, 452

Crustaceans, $420^{*}, 421 \S, 422,423 \S$, 437,438 ; derivation, 720-721; tracks, 95,742

Crustal movements, 345,800

Cruziana, 474; bilobata, 545*, 546 ; similis, $477^{*}, 478$

Cryoconite, 241 §

Cryolite, 449

Cryphæus, 591; Boothi, 614

Cryptacanthia compacta, 690

Cryptoceras capax, 691 
Cryptodon angulatus, 925

Cryptogams, 53, 136, 140, 434, 435$437,519,595,668$ (vascular), 672, 718 ; Corniferous, 583*; Carboniferous, 666, 727 (culmination): Neopaleozoic, 460 (culmination) Cryptonella, 579; eudora, 620 ; lens, $595^{*}$

Cryptozoon proliferum, 500

Crystal kingdom, 98

Crystallization, 76§, 408; alongside of dikes, 312,313 ; see also Metamorphism

Crystallophyllian, 440 (Archæan synonymy)

Crystals, figures of, explained, 63

Ctenacanthus, 614; Bohemicus, 567 ; latispinosus, 591 ; major, $702,703 *$; Wrighti, 601

Ctenacodon, 768; potens, 767* ; serratus, $76 \pi^{*}$

Ctenodonta, 481, 520, 521

Ctenodus, 687, 702; Nelsoni, 617*

Ctenoids, $417 *, 836$

Ctenoptychius, 692, 702

Cuba, 19, 347, 872, 936

Cubical coal, 661

Cuboides shale, 627 ; zone, 593, 594

Cuchara basin, 893

Cucullæa capax, 85̃ ; gigantea, 915 ; Haguei, 760; macrodonta, 915: oblonga, 791

Cumberland Measures, 648

- Table-land, 25, 350*, 357, 362, 38C, 645

- (Va.) Triassic area, 741

- valley, 357

Cumbrian Mts., 463

Cuneolina pavonia, 432*, 860*

Cup-corals. See Cyathophylloids

Cupressinoxylon, 921

Cupressites, 777

Cuprite, 335

Curaçoa, 891 (Miocene)

Curculio family, 771

Curculionites prodromus, 771

Current-bedding, $93 \$$

Cutch, 299, 791

Cuttle-fishes, 424\$, 525, 869 (time range) ; bone, 424

Cuyahoga River, 942

Cyanite, 65ฐ, 66, 83, 318, 319, 449

Cyanitic rocks, 83

Cyathaspis, 625

Cyathaxonia, 718

Cyathea compta, $669 *, 689$

Cyathocrinus, 597, 646, 690, 707

Cyathophycus reticulatus, 515 ; subsphæricus, 515

Cyathophylloids, 431§, 718 (living)

Cyathophyllum limestone, 704

Cybele, 521

Cycadeoidea Abequidensis, 755 ; Jenneyana, 832 ; Marylandica. 831: munita, 832

Cycads, 53, 409*, 434*\&, 435, 718, 831, 868; Devonian, 409; Harnilton, 596; Carboniferous, 666 , 667, 672*, 682; Permian, 685, 698, 704; Triassic, 749*, 750, 756*, 770*, 868; Jurassic, 776, 777, 819, 868; Mesozoic, 738, 879; Crets- ceous, $794,815,818,868,869,873$ 877

Cycas circinalis, 434*, 750

Cyclocardia borealis, 984

Cycloceras, 675 ; anellum, 514

Cycloids, 417*

Oyclonema, 520, 521, 613 ; bilix 514, 516; cancellatum, 546*, 550 Cimeinnatiense, 516 ; corallii, 567 ; quadristriatum, 567

Cyclophthalmus senior, 701*, 708

Cyclopidius beds, 886

Cyclops, 421, 423\$

Cyclopteris, 698 ; Acadica, 645 ; Browni, 622 ; Hibernica, 626

Cyclora parvula, 516

Cyelospira bisuleata, 507*, 514

Cyclostigma, 699 ; affine, 610 ; minutum, 626; Kiltorkense, 626, 704

Cyclostomes, $418 \S$

Cyclothone, 60

Cyclus, 720 ; Americanus, 676, 691 Cymatolite, 321

Cymbella maculata, 163, 164* Scotica, 690

Cymoglossa, 685

Cynodesmus, 918

Cynodictis, 926

Cynodon, 911, 918; Parisiensis, 924, 926

Cynodontomys, 918

Cyphaspis, 513, 516, 521, 562, 568, $579,586,591,599$; lævis, 614. megalops, 565*, 567

Cyprea, 916,922 : Carolinensis, 900*

Cypress, $770^{*}, 939$

Cypricardella bellistriata, 595*

Cypricardia, 525, 621

Cypricardinia, 562

Cypricardites Montrealensis, 503; Niota, 514: rectirostris, 514 Sterlingensis, 516

Cypridina serrato-striata, 627*

Cypridina shale, 627*

Cyprimeria depressa, 854

Cyprina Brongniarti, 791 ; Morrisii, 925

Cypris, 420*, 481

Cyrena, 855; arenarea, 855: convexa, 926 ; cuneiformis, 925 ; pulchra, 926 ; semistriata, 926 ; tellinella, 925

Cyrtia exporrecta, 567

Cyrtina, 562, 579, 591; rostrata, 579,591 ; triquetra, 602 ; umbonata, 602

Cyrtoceras, 482, 488, 520, 521, 551, $561,562,568,586,591,599,625$, 627 ; dorsatum, 685 ; ornatum, 516 ; subannulatum, 506, 508*, 514; subrectum, 558; Vassarinum, 499, 500*

Cyrtolites, 506, 516 ; carinatus, 516 compressus, 507*, 514; imbricatus, 516; ornatus, 516; Trentonensis, $507^{*}, 514$

Cystideans. See Cystoids

Cystiphyllum, 552, 597, 640 ; Americanum, 590, 601 ; conifollis, 601 ; Siluriense, 564*, 567 ; varians, 601 Cystoids, 140, 429*, 430§, 570 ; Cambrian, 470, 474, 477, 452, 486, 719 (first) ; Calciferous, 499: Chazy, 501, 503; Trenton, 505*, 514; Utica and Hudson, 511, 516; Lower Helderberg, 559*, 560, 561 ; Devonian, 577, 719; Paleozoic, 719

Cythara terminula, 917

Cythere Americana, 420*, 691

Cytherea rquorea, 916 ; imitabilis, 916: Marylandica, 917 ; Mortoni, 916 ; ovata, 915; sobrina, 916 ; staminea, 917

Cytheropsis, 516

Dachstein beds, 769,774

Dactyloporus archæus, 688

Dacyte, 868, 272, 273, 296, 304. 987

Dadoxylon, 596, 612, 704: antiquum, 646 ; Clarki, 610, 621 ; Edwardianum, 755 ; Ouangondianum, 622

Dadoxylon sandstone, 594

Drmonelix, 914, 915*

Dakota, Arehrean in, 444; Cambrian, 466 ; Cretaceous, 818, 826 , $827,837,838,846,848,852$; Јurassic, 760 ; Niagara, 543 ; Tertiary, 886, 902, 919 ; Triassic, 746. See also North D. : South D.

Dakota epoch or group, 758, 818, $821,823,824,825,829,530,833$, $837,839,840,855,872$

Dalmanites, $310,422,503,513,521$, 546, 551, 561, 570, 578, 579, 586, $591,599,627$; aspectans, 587*, 591; Boothi, 587*, 591, 599, 614; breviceps, 516 ; callicephalus, 515 ; calliteles, 599*; dentatus, 578 ; Hausmanni, 421*, 422, 568, 570 ; limulurus, 549*, 551; nasutus, 561 ; phacoptyx, 579 ; pleuropteryx, 561, 562, 591; regalis, 587*, 591; selenurus, 587*, 591 ; tridens, 561

Dalradian group, 456

Damourite, $65 \S, 84$; slate, 84

Damúda series, 698, 699

Dan River Triassic, 741, 743

Dana Bay, 606

Dana Mt., glaciers on, 240, 945

Danæopsis, 774

Danburite, 63, 449

Danian epoch, 815, 858, 859, 866

Danube, 176 ; loess of, 195 ; sediment in, 190 ; denudation, 191

Daonella, 756; Lommeli, 757, 758, 774 ; tenuistriata, 757

Dapedius, 784*

Daphænus, 918

Daphnia, 421

Daptinus, 863

Darien, Isthmus of, $82,41,256$

Darlington cannel coal, 676

Dasyceps Bucklandi, 706

Datolite, 68

Dauphiné, 176, 927

Davallia tenuifolia, 840

Davidson Glacier, 240

Davis Strait. 40

Dawsonella Meeki, 676*, 690

Dayia navicula, 568

Dead Sea, 23, 49, 199, 256 
Death Gulch, 128

Death Valley, 23, 128, 200

Debris-cones, 269*, 2718,285

Decapods, 420§, 423§, 424, 438§, $439,525,615,676,691,707$, 720

Deccan, igneous outflows of, 299 , 876,938

Deception Island, 296

Decomposition, 258, 497, 522, 655, $665,710,822$

Deep River, or Deep Creek, Montana, 895

- beds, 886, 894, 911, 919

Deep River (N. C.) Triassic area, $741,743,799$

Deer, 54, 910, 911, 924, 927, 930

Deflation, $159 \S$

Deformation of fossils. See Fossils

Degeneration, 717 ; in Insects, 721 ; in Reptiles, 797, 870 ; in Amphibians, 869 ; in Birds, 871 ; in Mammals, 931, 1017

Deistersandstein, 865

Delaware, 23 (height), 87, 856; Cretaceous in, 816,823

- Bay, 230, 378, 744, 819

- Hags, 606 ; limestone, 581

- River, 594, 744, 816, 945

- Water Gap, 232, 578

Delocrinus, 690

Delphinapterus catodon, 983 ; leucas, 983, 1001*

Delphinus, 144, 927

Delta formations, $98,191,195,196-$ $198,197 *, 892$

Delta Survey, 190

Deltatherium, 917

Delthyris. See Spirifer

Delthyris shaly limestone, 559

Deltodus, 692

Demavend (Mt.), 296 (height)

Denbighshire grits, 563,564

Dendrerpeton, 682

Dendrocrinus Cambrensis, 481 ; Cincinnatiensis, 516 ; retractilis, 514

Dendrodus, 625, 647

Dendrograptus, 520; gracillimus, 516 ; Hallianus, 477*; tenuiramosus, 516

Dendrophis, 704

Dendrophylla, 429*

Denison beds, 817,837

Denmark, Cretaceous in, 856, 857, 858

Density of the earth, 15,376 ; of the moon, Mercury, Venus, Mars, Jupiter, 16; of mountains, 379

Dent de Moreles, profile of, $367^{*}$

Dent du Midi, 920

Dentalina priscilla, 690

Dentalium, 424, 707 ; attenuatum, 917 ; Meekianum, 690 ; Mississippiense, 898*, 916; sublæve, $675 * 690$; venustum, 647

Denudation by the atmosphere, $159,160 *$, $161 *$; by glaciers, $247-$ 251; by water, 167-169, 177-189, 186*, 451, 934; by waves, 217, 218, $219,221,882$
Denudation, relations of mountain ranges to, $387-388$

Denver, 364

- group, $815,825,827,828,829,830$, $839,847,856,875$

Deoxidation, 124\$, 127, 128; destructive effects of, 125, 126*, $127^{*}$; through the growth of plants, 136

Deposition, by glaciers, 247, 250; by water, 169-170, 189-202, 216, 628 ; by waves, 222 ; by winds, 161

Deposits, ore. See Ore. See also Sediment

Derbya crassa, 690

Derivation of Arachnids, 722-723; Limuloids and Crustaceans, 720 721; Myriapods and Insects, 723 724

Desatoya Mts., 757

Des Chutes River, 894

Deserts, distribution of, 50, 51; sands of, 160,161

Desmatippus, 911, 912, 919

Desmatochelys Lowii, 849

Desmids, $437 \S, 859$; in hornstone or flint, $582,583 *, 859$

Desmoceras Breweri, 837

Destruction of life. See Life

Detritus, $75 \S, 81 \S, 167 \S$

Devil-fishes, 424

Devonian (or Devonic) era, 575; North American, 575; Oriskany, 577; Corniferous, 579; Hamilton, 592; Chemung (with Catskill), 602 ; foreign, 622 ; geological and geographical progress, 628; biological, 630 ; upturning, 630

- relations of the Lower Helderberg fauna, the Hercynian question, 569-570

Diabase, $87 \S, 273,319,325,339,453$, $457,468,469,518,748,802$

Diabase-schist, $87 \S$

Diablerets, 920

Diablo, Mt., 835, 892

Diaclases, $113 \S$

Diacodon, 918

Diadema, 59

Diallage, 88 ; rock, 87 ; structure, 321

Diamond, 62, 64, 319, 455

Diamond Head, Oahu, 271*

Diamond Mt., 733

Diaspore, 320

Diatom ooze, 57, 143

Diatoma vulgare, 699

Diatomaceous earth, 889

Diatoms, 56, 57, 60, 64, 72, 81, 121 , $135,136,140,142,143,152,153$, $163,164 *, 229,319,433 *, 436,437 *$ $699,817,859,887,895$; in flint, $582,583^{*}$

Diatryma gigantea, 902

Dicellocephalus, 477, 478, 481, 483, $500,502,503,516$; Iowensis, $479 *$; Minnesotensis, 478, 479*

Diceras, 780, 877 (end); arietinum, $780 \%, 790$; Lonsdalei, 865

Diceratherium, 911, 918

Diceratian, 790
Dichobune, 926 ; cervinum, 926

Dichocrinus, 646

Dichodon, 926 ; cuspidatus, 926

Diclonius mirabilis, 846

Dicotyles, 54, 1002 ; nasutus, 1000 ; Pennsylvanicus, 1012

Diçanograptus ramosus, 510*, 515, 516

Dicranophyllum, 673

Dictyocaris, 567

Dictyocha, 894* ; crux, 894*

Dictyo-cordaites Lacoei, $610 *$

Dictyonema, 481, 550, 590

Dictyonema shales, 482

Dictyoneura anthracophila, 701*, 702, 704; Humboldtiana, 708; Monyi, 702

Dictyojhyton, 432; tuberosum, $611 *, 621$

Dictyopteris, 699

Dictyorhabdus priscus, 509*

Dicynodon, 707, 737, 773

Didelphis, 925

Didelphodus, 918

Didelphops, 853*; comptus, 853* ; ferox, 853*; vorax, 853*

Didelphys, 55, 910, 918

Didus ineptus, 54, 1014

Didymictis, 917,918

Didymites globus, 774; tectus, 774

Didymograptus, 520 ; extensus, 500

Dieconeura, 691

Dielasma, 642 ; bovidens, 690 ; elongata, 707 ; hastata, 700*

Dikes, $90,262 *, 264,298 \S, 299 *, 302$, $327 \S$

Diloma ruderata, 927

Dimetian period of Hicks, 457

Dimetrodon, 688

Dimorphodon, 788

Dinarites Liccanus, 773

Dindymine, 521

Dinichthys, 603, 618; Hertzeri, 617*, 619; Gouldi, 619

Dinictis, 911, 918

Dinoceras, $907 \S$; size of brain of, 914*; mirabilis, 907

Dinoceras beds, 886

Dinophis, 901

Dinornis, 54, 1014, 1019 ; giganteus, 54,1014

Dinosaurs, Triassic, 741, 751; Jurassic, 760, 768, 785, 796; Cretaceous, $816,828,836,844 * 856$, $863^{*}, 867,870$; relation to Birds, 796

Dinotherium, 927 ; giganteum, 924, $925 \%$

Dinotosaurus, 785

Dionide, 521

Dioönites, 832 ; borealis, 833 ; Buchianus, 832*, 884; Columbianus, 834; Dunkerianus, 834

Diopside, 318, 323

Dioryte, $86 \S, 97 *$; schist, $86 \S$

Diospyros, 922

Dip, 998*, 105, 114*

Dipeltis diplodiscus, 691

Diphya limestone, 791

Diphyphyllum, 550, 640; arundinaceum, 591; fasciculum, 592 ; stramineum, 591 
Diplacodon, 907, 918

Diplacodon beds, 886

Diplaspis Acadica, 546

Diplocynodon vietor, $767 *$

Diplodocus longus, 762*

Diplodonta acclinis, 917

Diplodus, 687, 692 ; compressus, 692 ; Gaudryi, 702 ; gracilis, 692 ; latus, 692

Diplograptus, 520; amplexicaulis, $505^{*}, 514$; mueronatus, 510*; pristis, 510*; spinulosus, 516 ; Whitfieldi, 516

Diploöpoda, 419

Diplopterus, 627

Diplurus longicaudatus, 751

Dipnoans, 417§; Paleozoic, 587, $588^{*}, 617 *, 613,619,625 *, 725$, 727; post-Paleozoli, 736; Permian, 687; Triassic, 772, 869

Dipnoi, 54, 59, 417

Dipriodon lunatus, 858*

Diprionidæ, 498*, $499 \S$

Diprotodon A ustralis, 1006*

Dipterocaris penna-Dadali, 615* Procne, $615^{*}$

Dipters, 419, 679, 783, 794, 900 (number of Florissant)

Dipterus, 625, 627 ; macrolepidotus, 625* ; Sherwoodi, $617 *$

Disappearance of life. See Life

Discina, 59, 72, 425§, 447, 475, 481, 482,487 ; Caerfaiensis, 481 ; lamellosa, 427*; Lodensis, 627 ; truncata, 612,620

Discinids, 779, 922

Discinisca lamellosa, 427*

Discites, 591, 602, 642, 700

Disco Bay, 244, 350

Disco Island, 272, 376, 819, 831, 921

Discosorus, 546, 549; conoideus, 546

Dismal Swamp, 154, 889

Displacements through frost, 230 , 231*. See also Faults; Flexures ; Fractures

Dissacus, 917, 918

Distortions of beds and fossils, 107, $369,370 *, 371$

Distortrix septemdentata, 916

Disturbances, $351 \S, 363,406$; of closing Archæan, 466

Dithyrocaris Belli, 602 ; carbonaria, 691

Ditroyte, 858

Dockum beds, 660

Docodon striatus, 767 *

Dodo, 54, 1014*

Dodicurus, 1017; clavicaudatus, 1003

Dog, 924

Doggers of the Ooilyte, 775,776

Dolatocrinus, 590

Doleryte, $78,85,87 \S$

Dolichopterus, 557

Dolichosaurs, 870

Dolichosoma, 692; longissimum, 704

Dolomite, $68 * \S$

Dolomization. See Dolomyte, making of

Dolomyte, $78 \S, 79 \S$; making of, 133 , $134,343,524$
Dolphin shoal, 19, 20, 217

Dolphins, 912

Domatoceras umbilicatum, 691

Dombeyopsis obtusa, 839 ; squarrosa, 839

Domnina, 918

Donax, 916

Dordonian, 859, 866

Doropyge, 482

Dorycrinus unicornis, $640 *, 646$

Dosinia, 916 ; acetabula, 917

Dosiniopsis lenticularis, 915 ; lenticularis var. Meekii, $897 *$

Double Mountain beds, 660

Drainage, antecedent, consequent, superimposed, $203 \S$; reversed. 947

- courses, direction of, 177,388

Drepanacanthus, 692 ; anceps, 692

Drepanis Pacifica, 1014

Drepanocheilus A mericanus, 841*

Drepanophycus, 590

Drift, 184, 916,942

Drift-sand hills, 94, 161, 162, 213

Dripstone, $79 \S, 131$

Dromæus, 54

Dromatherium, 754, 768, 773; sylvestre, 754*

Dromopus, 682 ; agilis, $684^{*}$

Dromornis, 1019

Drumlins, 942

Drummond Island, 542

Dry Creek, Wyoming, 907

Dryolestes priscus, 767*; vorax, $767 *$

Dryopithecus, 927

Dryptodon, 917

Duckbill, 53, 415

Dudley limestone, 563

Dugong, 925

Dundas gorge, 946

Dunes, $162 \S, 265$

Dunvegan beds (group), 830,840

Dunyte, $89 \S$

Dust, transportation of, 159,195 ; showers of, 168, 164*; on glaciers, 235,241

Dwyka bowlder bed, 699

Dyas. See Permian period

Dyke. See Dike

Dysaster ovulum, 865

Dysintrybyte, 84

Dystrophæus Viæmalæ, 758

Eager, 212§, 215

Eagle, 902

- Ford shales, 815, 824, 854

-- Pass beds, 824, 855

- ray, 643

Earth, 15 (density), 376 (specific gravity); general contour and surface subdivisions, 15-30

Earth as an individual, 9, 10, 393 ; relation of to the universe, 10 ; proportion of land and water, 16 ; system in the courses of feature lines, $35-42,393$

- changes in the ellipticity of its orbit, 254,255 ; in the position of its axis of rotation, 255,346 ; its circumference shortened in mountain-making, 391; heat reached the surface in three ways, 258
Earth, polar diameter maximum and minimum, 1027

-, development of, 391, 1027 thickness of the supercrust, 209 , 377

Earth-shaping, mountain-making, and attendant phenomena, 345 396 (changes of level, 345; disturbed regions, 351; typical mountain ranges, 353 ; subordinate effects of orographic movements, 369 ; origin of the earth's form and features, 376)

Earth (soil), 75, 76ฐ, 137 (nitrification)

Earth-worm, 156, 423

Earthquake waves (oceanic), 213, 221,875

Earthquakes, $222,229,265,286,287$, $344,349,372-375,386,875$; cause of exterminations, 877; geological effects, 375 ; not essential in volcanic eruptions, 286

East Indies, 17, 19, 21, 44, 145 (coral reefs) : trends of the islands, $38,39,40$; volcanoes, 295,296 , 297

East River, Pictou, 533, 543

East Rock dike, 299*, 302*, 303, $312,804,806$

Eastern-border life of $\mathbf{N}$. America related to European, 572-573

- Interior region of $\mathbf{N}$. America, $576,578,633,636$

- - Sea of N. America, 537, 539, $541,558,571,575,579,580,628$, $629,683,784$

Eatonia, 562, 579; medialis, 579; peculiaris, 579 ; singularis, 560*, 562

Ebb-and-flow structure, 938*

Ecea beds, 698, 699, 7\%0

Eccentricity cycle, influence of, on climate, 254, 978, 1027

Eccyliomphalus priseus, 500

Echidna, 53, 415§, 795, 798

Echinids, 59

Echinocaris, 599, 615; Beecheri, 621 ; punetata, $600 *$; socialis, 621 ; Whitfieldi, 621

Echinoderms, 59, 180, 140, 144, 158, $418,419,427 \S, 428 *, 429 *, 430$; Cambrian, 469, 480 ; Calciferous, 499, 500

Echinognathus Clevelandi, 513*

Echinoids, $428 * \S, 429 *$, 430§, 525, $6+1 \%$

Echinosphærites, 520, 521

Echinus, 157, 427, 428*\$, 429*, 879

Echo, 360*, 362

Echo Clifts, 363*

Eclogyte, $88 \S$

Ecphora quadricostata, 899*, 917

Ectacodon, 918

Ecuador, 935 (heights)

Eddies, $184 \mathrm{~s}$

Edentates, 54, 919, 924 (first), 927

Edestosaurus, 826 ; dispar, 849*; velox, $84 S^{*}$

Edestus, 680 ; giganteus, $680,681 *$; minor, $680,681 *$ 
Edmondia, 621, 622

Edriocrinus, 562,577 ; sacculus, 579

Egan Range, 365

Eggs, fossil, 787

Egypt, 160, 162 ; Cretaceous of, 857 ; Tertiary of, 920

Eifel, 289, 297, 568, 602, 627, 938

Eifelian beds, 626,627

Eiger, 236

Eileticus anthracinus, 691

Elæolite, $65 \S, 85,449$; syenyte, 532 , 876

Elasmobranchs, 587

Elasmosaurus, 845 ; platyurus, 845

Electric Peak, 937

Elephant, 54, 402, 903, 924, 925, 927 , 981

Elephas, 927 ; Africanus, 1016 ; Americanus, 998 ; antiquus, 927 , 1006 ; Columbi, 1001 ; Melitensis, 1006 ; meridionalis, 927 ; primigenius, $966^{*}, 997,1000,1004,1005$, $1006,1009,1015$

Elgin sandstones, 773

Elginia mirabilis, 773

Elizabeth Island, elevation, 350

Elk, 950 (migration)

Elk Mountain sandstone and shale, 606

Elk Mts., 106*, 363, 364*, 639

Ellipsocephalus, 482

Elm, 435,837

Elotherium, 909, 911, 918 ; crassum, 909*

Embryonoid, 423

Emerald Island, 39

Emery, 64§, 455

Emeu, 54

Emigrant Peak, 937

Empo, 843

Emys, 901, 926

Enaliornis, 864

Enaliosaurs, 682, 760

Enallaster, 834 ; Texanus, $834^{*}$, 836

Encephalartos denticulatus, $756^{*}$

Encephalaspis, 588

Enclimatoceras Ulrichi, 896*, 915

Encrinal limestone, 543, 559, 593, 638,728

Encrinites, 429\$, 430, 559

Encrinurus, 515, 521，551，552; lævis, 569 ; punctatus, 565*, 567, 568 ; variolaris, $565 *, 567$

Encrinus, 719 ; lillififormis, $429 *, 770$, $771 *, 774$

Endoceras, 501, 506, 508, 511, 514\$, $516,520,591$; proteiforme, 514, 516

Endogenous work, 867

Endogens, 434\$, 435

Endolobus gibbosus, 691 ; spectabilis, 642

Endothyra Baileyi, 646

England, 19, 32, 48, 162, 219, 234. 256, 297 (volcanoes), 374 (earthquakes), 431, 464, 760; disturbances and upturnings in, 534,630 , 733 ; geological map of, $693,694 *$

-, Archæan in, 456; Cambrian, 480,484

Engonoceras Gervillianum, 865

Enhydriodon, 927
Enhydrocyon, 918

Enneodon crassus, 767*

Enniskillen oil wells, 581

Enstatite, 67\$, 88

Entolium, 760 ; avicula, 690 ; gibbosum, 759 *

Entomis, 567, 621

Entomostracans, 420§, 421, 423, $439 \S, 525,574$

Eocarboniferous period, 632

Eocene lakes of N. America, 882, $893,894,929,933$

Eocene period. See Tertiary

Eocystites, 474 ; longidactylus, $474^{*}$

Eodevonian, $576 \S$

Eogene, 880 \$

Eohippus, 905, 918 ; pernix, 905*

Eohyus, 918 ; distans, 907

Eolian, $159 \S$

Eolian formations, characteristics of, 162

Eolian limestone, 491, 517, 528

Eolignitic, 885, 888

Eolus, Mt., 580*

Eopaleozoic time, 407, 4608, 462535,716

Eophrynus Prestwichii, 703

Eophyton, 482

Eophyton sandstone, 482

Eosaurus Acadianus, 682, 683*

Eoscorpius carbonarius, 678*; Woodianus, 691

Eospongia Romeri, 503; varians, 503

Eozoic, 442

Eozoon, 319, 454, 455 ; Bavaricum, 455; Canadense, 45.*

Eparchæan, 446

Epeirogenic movements, $376 \S$, 388, 392; of the Tertiary, 933-937; of the Quaternary, 1020

Ephedra, 435

Ephemera, 600

Ephemerids, 600

Ephippioceras divisum, 691

Epiaster elegans, 837; polygonus, 865

Epicentrum of an earthquake, $374 \S$, 375

Epidosyte, $88 \S$

Epidote, 668, 82, 85, 88, 312, 315, 318 , 881 ; gneiss, 83 ; rocks, 88 , 89

Epihippus, 912, 918; gracilis, 907

Epipodite, $422 \S$

Epithemia Argus, 163, 164*; gibba,

$168,164 * 699$; gibberula, 163,

$164^{*}$; longicornis, $163,164^{*}$

Epoch, $406 \S$

Eporeodon, 911, 918

Epsom saits, 555

Epsomites, 555

Equiseta, 434, 436ई, 560, 663, 667, 672,711

Equisetites, 685 ; rugosus, 704

Equisetum, 74 (ash), 519; arenaceum, 773 ; arvense, 74 ; hyemale, 75 ; telmateia, 74,75

Equivalence of strata, 398, 401, 815

Equus, 913*, 919, 927, 1002 ; caballus, 1004, 1005; excelsus, 999; fratelnus, 1001 ; major, 1001, 1002 ; simplieidens, 912 ; Stenonis, 927

Equus beds, 892,1000

Eras, 406§; reality and characteristics of geological, 897

Erebus, Mt., 296 (height)

Eremopteris, 689, 699

Erian, $576 \$, 590$

Erie clays, 972

Erie, Lake, 200, 947, 986

Erie shale, 606

Erinaceus, 927

Eriptychius Americanus, 509*

Erosion, 258, 300, 388, 390, 533, 647, $709,827,828,868,875,894,934$; by carbonated water with humus acids, 129 ; by drift sands, 160 ; by rivers, $167,178,181 *, 183 *, 195$, $196 *, 943$; by water containing carbonic acid, 130,131 ; in the Carboniferous, 709; causing unconformability, 115 , 116. See also Denudation

- Monument Park, 186*

Eruptions. See Igneous; Volcanic Eruptive rocks, $76 \S, 265 \S$

Eryon arctiformis, $783^{*}$

Eryops megacephalus, $686 *, 687$

Eschara, 425*, 427

Eskers, 942, 970

Esopus millstones, 542

Estheria, 600 (oldest known), 623, 774; minuta, 771*. 773, 774: ovata, $750 *$; pulex, 600

Estheria shales, 771

Esthonia, Cambrian in, 482, 484

Esthonyx, 917, 918

Estuary deposits, 191

Ethmophyllum, 483

Ethmosphæra, 319

Ethylene oils, 124

Etra (Mt.), 26, 279

Etoblattina, 691, 701; primæva, $701 *, 704$; venusta, $679 *$

Eua Island, elevation, 350

Encalyptocrinus decorus, 550, 551, 567,568

Eucalyptus, 838*; Geinitzi, 838*

Euchasma Blumenbachii, 500

Eucryptite, 321

Eucryte, $87 \S$

Eucyrtidium Mongolferi, 433*

Eudialyte, 85

Engereon Bïckingi, 722

Eulima Texana, 855

Eumetria Verneuiliana, 642*, 646

Eumierotis curta, 757, 760

Eumys, 918

Eunella Sullivanti, 601

Eunema, 514

Eunice, 428

Eunotia amphioxys, 163, 164* ; granulata, 168, 164*; lævis, 168, 164*; tridentula, $163,164^{*}$; zebrina, $163,164^{*}$; zygodon, $163,164^{*}$

Euomphalus, 520, 562, 586, 590, 598, $625,642,700$, 704; alatus, 567; annulatus, 601 ; cyclostomus, 602 ; funatus, 568

Eupachycrinus, 690

Eupagurus, 59 ; longicarpus, 994

Eupelor durus, 751 
Euphantrenia, 432

Euphoberia, 691, 701 ; anthrax, 703 ; armigera, 678*, 691; Brownii, 703

Euphotide, 85\$

Euplectella, 432 ; speciosa, 57*, 432

Euproōps Danæ, 691

Eupterornis, 925

Eurasia, 17, 21, 22, 32, 33, 51, 538 ; sea level at its center, 346

Eureka district, 447, 469, 478, 484 $495,516,541,580,581,592,593$ 659 , 738 ; mine, 340 ; quartzyte, 516 ; shale, 606

- Mts., 738

Europe (see also Eurasia), 22, 23 (mean height), 24, 26, 32, 34, 41 (trends), 51, 165, 234 (snow-line), 296 (volcanoes), 393, 395, 398, 402 , $408,405,406,407,411,760,793$ (warmed by the Gulf Stream), 913; American types in, 550, 573 Australian types in, 922

-, Archæan in, 442, 456 ; Cambrian 484 ; Carboniferous, 631, 674, 689 $691,692,699$; contrast of Juras sic with American, 792; Lower Silurian, upturnings at the close, $533-535$

Euryapteryx, 1014

Eurylepis, 679, 680, 692 ; tuberculata, $680^{*}, 692$

Eurynotus, 417

Eurypterids, 59, 420\$, 496, 565, 623, 719 , 721 ; Devonian, 604, 615, $623 *$, 629, 719 (culmination) ; Carboniferous, 676, 701, 710, 719 ; Lower Silurian, 496 (first), 521, 525, 719; Upper Silurian, 550 , 571, 574; Onondaga, 556*, 557 ; Paleozoic, 420, 719, 723

Eurypterus, 557, 567, 615, 623, 722, 724; giganteus, 556 : Mansfieldi, $676,677 *$, 710 ; prominens, 550 ; remipes, $556^{*}$

Euryte, $84 \$, 205$

Eusarcus, 557

Eusthenopteron, 619 ; Foordi, 618*

Eutaw beds (group), 815, 816, 819, 854; (Upper), 815, 823

Eutoptychus, 918

Everest (Mt.), 23

Evergreen-trees, 435

Evolution. See also Iife, progress of

Erolution by Natural Selection, 1030,1032

- and cephalization, 439

Excavation by water, $167 \S .178$

Excrements, fossil. See Coprolites

Exmouth Isl., 749, 792

Exogens, 434\$, 435

Exogyra, 160, 779, 834, 840, 856, 860, 877 (end); arietina, 835*, 837 ; Boussingaultii, 867 ; columba, 866 ; columbella, 854,855 ; conica, 865: costata, 841\%, 854, 855; Couloni, 865; flabellata, 836 ; lævigata, 867 ; ponderosa, 834, 855 ; sinuata, $837,864,865$; subplicata, 867; Texana, 817, 836 ; virgula, $780 \%$

Exogyra arietina clays, 817
Exogyre ponderosa marls, 815,824 , 855

Expansion and contraction, 259-265, 372,381

Exploits River channel, 461

Exploring Isles, 150

Extermination of species. See Life

Extracrinus Briareus, 778*, 790

Facial suture, 421 \$

Fagus, 896, 922 ; ferruginea, $895^{*}$, 896

Fairweather, Mt., 25, 238

Falkland Islands, $19,155,209,627$

Faluns beds of Anjou, 926

Famenaian beds, 626, 627

Fanning Islands, 38

Faroe Islands, 938

Fasciolaria, 916, 922 ; buccinoides, 841* ; rhomboidea, 917 ; scalarina, 917

Fats (animal), 123, 124, 655, 656

Faults, 107\$, 108*, 109*, 110*, 111 , $114 *, 115 *$, 353 ; in the Great Basin, 365, 366*; Taconic, 527*; Appalachian, 354

Fauna antiqua Sivalensis, 936

Faunas. See Life

Favistella, 552; favosidea, 550 ; stellata, 510, 511*, 515

Farosites, 310, 547*\$, 552, 562, 567, $581,585 \S, 597,625,640,719$; arbuscula, 601; Argus, 601 ; basalticus, 551, 591 ; Canadensis, 592 : cervicornis, 562, 625 ; favosus, 550 : fibrosus, 520, 522, 567, 568, 628; Goldfussi, 584*, 590 ; Gothlandieus, 550, 551, 552, 567, 568, 569, 591; Hamiltonire, 601 ; Helderbergix, 560, 562 ; hemisphæricus, 592 ; Niagarensis, $547 *$, 500 ; placenta, 601; polymorphus, 569 ; reticulatus, 628 ; turbinatus, 590 ; venustus, 550

Faxe ehalk, 866

Fayalite, 67\$, 84, 338

Feature-lines, system in courses of, 35

Feldspar, 64*\$, 129

Feldspathic rocks, $80,81,82$; veins, $331,332,336$

Felis, 919, 927, 1001; atrox, 1000 ; leo, 1004 ; pardoides, 927 ; spelsea, 1004, 1006, 1009

Felsitic, 88

Felstones, 517

Felsyte, 82, 84\$ ; porphyry, 468, 623

Fenestella, 545, 546*, 551, 590; celsipora, 579 ; prisca, $546 *, 550$

Fermentation, 137

Fernandian, 446

Fernando de Noronba, phonolyte peak, 263*

Fernando Po, 297

Ferns, 58, 434, 436; ash of, 74, 75, 663 ; Silurian, 564, 565 : Devonian, $583 \%$, 595\%; Subcarboniferous, 639 , 645 : Carboniferous. 654, 657, 666 , $667,670 *, 671 * 676,677,682,689$; Permian, 684, 655, 704; Triassic, $740,749 \%, 750,770$

Ferriferous limestone, 664, 792
Ferruginous clay, $81 \S$; rocks, $78 \$$; sandstone, 80

Fibrolite, $65 \$, 66,83$

Fibrolitic rock8, 83

Fichtelgebirge, 563, 627

Ficophyllum, 831

Ficus, $831,840,916$; auriculata, 889 ; lanceolata, 839 ; occidentalis, 839 ; planicostata, 839 ; spectabilis, 839 ; tiliwfolia, 839 ; Virginiensis, $832 *$

Fig, 812, 859, 921

Fiji Islands, 145, 148, 150\%, 297

Fin-spines, $416 * \S$,

Findlay, Ohio, 533; oil-region, 138 , $206,522-523$; yield of, 523

Finland, Archæan in, 455, 456 ; Lower Silurian, 521

Finsteraarhorn, 236

Fiords, 946-949 (Glacial)

Fioryte, $82 \$$

Fire clay, 650

Fire-Hole, 305,307

Firn, 2338

Fish, primitive, related to the Lamprey, 1081

Fish Creek Mts., 495, 738

Fish-oil in shales, 655,656

Fish-scales, composition of, 73

Fisher Island, 822

Fishes, 52, 55, 56, 59, 60, 141, 146 , $156,158,176,409 *, 414,415-418$, $564,681,789,797,931$; fossil, in oil-yielding coal-beds, 124 ; reign of, 411,460 ; earliest known, 509 ; culmination of, 869 ; first Teleosts, 738

Flabellaria, 921 ; eocenica, 839

Flabellina rugosa, $432 \%, 860 *$

Flagellates, 419, 431

Flagging-stone, $92 \S, 480$

Flaming Gorge group, 747

Flamingoes, 923

Flammenmergel, 865

Flat-jebble conglomerate, 604, 630

Flathead River, 240

Flexure-faults, 109*, 351

Flexures, 99, 101*, 102*, 103*, 104*, 105*, 106*; variations in, from pressure, 369; in the Alps and Juras, 367,368

-, Appalachian, 354, 355*, 356*, 649*, 650*; Taconic, 527*; Wasatch, 361, 369

Flies, 419, 794

Flint, 63\$, 97, $859 \S$; implements, 143,1008

Flocculation, 170

Flood-grounds of rivers, $181 \S, 182$, $133,191,193-194,943$. See also Shore-platforms ; Terraces

Flora. See Plants

Florida, 22, 23 (height), 40 (trend), $153,210,213,265,323,483,823$; coral reefs, $145,153,213$

- Tertiary in, 881*, 884, 887, 890 , $891,892,916,934$ (elevation)

- Banks, 163

- seas, Nullipores in, 147

- Strait, 44, 45, 229, 230, 256

Floridian epoch and beds, 884,891 , $900^{*}, 917$ 
Florissant group or basin, 886,893 , $900,901,902$

Flotation crust, $375 \S$

Flow-and-plunge structure, 93*\$, 194

Flow of solids, $351-352$

Flowerless plants. See Cryptogams Flucean, 453

Fluidal structure in rocks, $77 \S$

Fluor-apatite, 73

Fluor spar. See Fluorite

Fluorides, $69,73,143$

Fluorine, 61,63

Fluorite, fluor spar, 63, $69 \S$

Flustra, 427

Fluvial action, 744; formations, 191, 192, 820. See also Alluvial

Flysch, $367 *, 920$

Folds. See Flexures

Foliated rocks, $77 \S, 309,534$

- structure, foliation, $112,113 * \$$ $312,370-371$

Folkestone beds, 865

Fontainebleau sandstone, 318, 926

Foosdiceras bidorsatum, 774

Foot wall, 3288

Footprints (tracks, trails), 89, 95, 223: Cambrian, 446, 464, 469, $474,477 *, 479 *, 480,482$; Upper Silurian, 544, 545*, 546*; Carboniferous, $681,682,684^{*}, 692$; Subcarboniferous, 644, 645*; Triassic, $742,745,750 *, 751 *, 752 \%$, $753,755,772 \%$

Foraminifers, 57, 72, 432*, 454, 502, $840,858,860,922$

Fordilla Troyensis, 472*

Forest bed, 927

- Marble, 775, 790

Forests, 155; buried, 135, 887

Formation, 908

Formicidæ, 901

Formosa, 40

Fort Benton group, 825, 829, 843, 855

- Bridger, 886

- Pierre group, 815, 825, 829, 830 , 855

-Tejon, 885

- Union beds (group), 828, 830

-Worth limestone, 817,887

Fossil wood. See Wood, silicified

Fossiliferous rocks, 309, 400, 408

Fossilization, methods of, 142

Fossils, $12 \S, 71 \S, 141$; as means of correlation, 400-404 (precautions, 402-404), 405; distortion of, 107 $369,370 * 371$; obliterated by metamorphism, 314; silicified, $130,135,160,323$

Fox, 927

Fox Hills beds (group), 815, 825, $828,829,840,842,852,855$

Foyayte, 855

Fractures, 106, 107, 108*, 109*, 110*

- and displacements from pressure, $352 *, 353 * .371,507$; from freezing water, 230, 231; from variations in temperature, 260

Fragillaria Harrisoni, 699 ; pinnata, $164 *, 165$

Fraguental deposits, 76,89
France, 87, 167, 176, 297 (volcanoes), 734 (upturnings)

-, Archæan in, 456; Cambrian, 434; Lower Silurian, 518, 521 ; Upper Silurian, 564, 566, 568, 569, 573; Devonian, 626 ; Subcarboniferous, 698; Carboniferous, 698, 696, 702; Permian, 698; Triassic, 768, 769, 774; Jurassic, 774, 775, 792, 798; Cretaceous, 774, 856, 857 , $859,865,866,870$; Tertiary, 919, $920,921,923,924,925,926,932$

Franconia, 738, 769, 773

Franconian, 738, 769, 773

Franklinite, $70 \S, 449$

Frasnian shales and limestone, 626

Frasniarr stage, 601

Fraxinus denticulata, 839 ; eocenica, 839

Fredericksburg epoch (group), 815, $817,819,836$

Frederikshaab Glacier, 240, 241*

Freeport coal, 652, 657, 663 ; limestones, 652

Freezing, effects of, 230

Freiburg vein, 333

French chalk, 67

Frenela, 922

Friendly Islands, 19, 20, 296, 392

Frigid zone, 46\$

Fringing reefs, 148*, 149*, 150*, 151

Frisco, Utah, 340

Frobisher Bay, 495

Frog, 54, 415, 418, 681, 795

Frog Mt., Ala., 577

Frog-spittle, 437

Fromé group, 831

Frondicularia annularis, $432 *$

Front Range of Colorado, 24, 25, 29 , $208,359,363,389,580,739,747$, $827,829,893,935$

Frost causing displacement, 157, 231*

Fruits, Carboniferous, 668, 669*, $672 *, 673^{*}, 674$; Subcarboniferous, 639 ; Tertiary, $896 *, 921$

Fucoides Harlani, 549

Fucus, 75, 437

Fuegia, 154, 296; Cretaceous in, 858 ; snow line in, 234 ; glaciers on, 240

Fujiyama, volcano of, 290

Fulgur spiniger, 916

Fulgurite, 265\$, 266

Fuller's earth, 775, 790

Fumaroles, 82, 265, 293§, 294

Fundamental Gneiss, $408 \S, 440$

Funeral Mountains, 23

Fungi, 75, 136, 158, 434, 436\$, 441, 454,688

Fungoid plants, 63

Fusibility of igneons rocks, 273, 304 ; its degree determining the character of volcanic phenomena, 273,274

Fusion, cooling from, 261*, 264

Fusispira elongata, 515; terebriformis, 516 ; ventricosa, 515

Fusulina, 433, 659, 674, 696; cylindrica, 432*, 674*, 690, 700 ; elongata, 690 ; gracilis, 690 ; Japonica,
700 ; robusta, 690 ; ventricosa, 6910

Fusus, 180, 916, 922 ; exilis, 917 ; interstriatus, 915 ; Labradorensis, 954; parilis, 917; pearlensis, 916 ; strumosus, 917 ; tornatus, 951

Gabbro, $87 \$, 88$

Gadolinite, 449

Gadus, 916

Galathea, 703

Galdhöpig, 32

Galena, 70§, $125 \S$

- limestone, 342, 492, 494, 513, $514,515,522$

Galeocerdo, 855 ; latidens, 926

Galerites, 860

Galerus, 916

Galt limestone, 543

Galveston Deep Well, 890, 891

Gambier Islands, 150

Gampsonyx fimbriatus, 701*, 703

Gangamopteris, 698

Ganges, delta of, 378 ; discharge of, 173 ; silt of 190

Gangue, 69, 70, 331ฐ, 333

Gannet, 902

Ganoids, 55, 59, 401, 402, 416§, 417*, 418,510 ; structure of teeth, $417 *$, 725; Trenton, 509 (first), 574; Upper Silurian, 574; Devonian, $587,559 *, 618 *, 619,620,625 *$, 629 ; Subcarboniferous, 643, 700 ; Carboniferous, $679,680^{*}, 692,698$, 702; Permian, 687, 705; Paleozoic, 725, 727 ; post-Paleozoic, 736 ; Jurassic, 699, 783, 784* ; Mesozoic, 879 ; Cretaceous, 812, 828, 843, 862, 863; Tertiary, 922

Ganorhynchus oblongum, 621

Gardeau shale, 605

Gardiners River, 131, 132* (springs), $133,306,307$

Garnet, $66^{*} \S$; rocks, 82,88

Garnetyte, $88 \S$

Garonne, 191

Gars. See Ganoid

Garumnian, 859, 866

Gas, mineral. See Mineral oil and gas

Gaspé, 88, 466, 533, 544, 554, 581, $593,611,630$ (upturnings)

- limestone, 544, 580 ; sandstones, 591

Gaspé-Worcester trough, 536, 537, $558,559,577,6833,715,732$

Gastornis, 925 ; Edwardsi, 925

Gastrochæna, 157

Gastropods, 59, 130, 152, 157, 423§, $424 \S, 425 *$

Gault, 815, 818, 837, 857, 858, 859, 865,935

Gavialis Dixoni, 926; fraterculus, 848 ; Neocesariensis, 848

Gavials, 54, 754, 787, 848

Gavilian Range, 892

Gay Head. See Martha's Vineyard Géant, Glacier du, 235*, 236, 238, 242

Geanticline, Cincinnati. See Cincinnat1 uplift 
Geanticlines, 106§, 364, 381, 532 ; corresponding to geosynclines, 387,392

Gedinnian, 570, 626

Gehlenite, 313

Gemellaria loricata, 427*

Gemma purpurea var. Totteni, 917

Gems, 90, 327, 331

Genentomum validum, 691

Genesee beds, 594, 601

- epoch, 410

- Falls, section at, 91*, 542

- River, 540, 542, 605

- shale, 581, 601, 728 ; slate, 593, 595

Geneva, Lake, 199, 202

Geode bed, 637

Geodes, $97 \S, 98$

Geodia, 432*

Geodiferous limestone, 540

Geogenic work, $376 \$$

Geogly phies, $95 \S$

Geographical distribution of plants and animals, 52-60

Geolabis, 918

Geomys, 919

George's Shoal, 944

Georgia, 23 (height), 24, 184, 373 (earthquake), 872

Georgian Bay, 540

- period, 464

Geosynclinal movements over the oceanic basins, 936-987

Geosynclines, 106§, 199, 365 (Rocky Mits.), 380, 387

Geothermic, 257\$

Gerablattina, 691, 701; balteata, 686

Geralinura, 701, 723; Bohemica, 703; carbonaria, 691

Geraphryans carbonarius, 691

Gerarus Danæ, 679*

Germany, Paleozoic in, 463; Upper Silurian, 568, 567 ; Devonian, 626,627 ; Subcarboniferous, 693 ; Carboniferous, 693, 696, 703, 704; Permian, 697, 698, 707, 722 ; Triassic, 741, 769, 773, 774; Jurassic, 774, 776, 793; Cretaceous, $774,859,865,866$; Tertiary, 920 , $922,923,924,925$; volcanoes in Upper Silurian, 296

Gervillia, 759 ; acuta, 790 ; anceps, 865 ; bipartita, 774 ; costata, 773 ; longa, 690 : socialis, 770 , $771 *$, $77^{3}$

Gervilliopsis ensiformis, 854

Geyser, water-and-gas, 607, 608*

Geysers, 82, 265, 2\% , 291, 305*-309, $307 *$, 308*; basins of, in Yellowstone Park, 152, 305, 306*; siliceous deposits from: geyserite, $64 \S, 82 \S, 152,305,306,307$; terraces of New Zealand, 305*

Giant geyser, $307 *$

Giantess geyser, 307

Giants' Causeway, 261*

Gibraltar, 131, 214

-, Straits of, 20 ; currents at, 49 , 229

Gieseckite, $84 \S, 320,453$

Gila River, 885

Gilbert Islands, 36, 38, 39, 145
Ginkgo, 435; adiantoides, 839

Giordanella, 482

Giraffe, 907

Giraffidæe, 927

Girvanella, 470, 502 ; ocellata, 501*

Givet (Givetian) limestone, 626

Glabelia, 420*, 421§

Glacial period, 943 ; American, 943 ; migration of species caused by, 945 ; elevation of the land, 946 ; height of ice, 951 ; slope required for flow, 952 ; direction of flow, 952, 955; courses of scratches, 953; Driftless area, Wisconsin, 953; first Retreat, 961; final Retreat, 967 ; moraine, 900, 963*; Kettle moraine, 967

一, foreign, 975, 995; Asia, 977; Australia, 978; Europe, 975, 976*; New Zealand, South America, 978

- climate, cause of, 978 ; supposed in the Triassic, $\mathbf{7 4 5}$

- , map of N. America in, after page 944

- conditions, in the Permian, 698, 737

Glaciers, 195, 200, 233; flow, 242 ; of Zermatt, 237*; cascades connected with, 238 ; lakes, 238,240 , 251

Glanzschiefer, 84

Glass, $63 \S, 77,86,264,265$; relations of glassy rocks to stony, 276,289

Glass sponge, $57 *, 72$

Glauber salt, 137, 294

Glauconite, $68 \S, 136 \S, 468,822 \S, 823$, 824,920 ; see also Greensand

Glauconite group (beds), 815, 824, 855; marl, 865

Glaucophane, 89, 318 ; schist, 266

Glaucophanyte, $89 \S$

Gleditschia, 921

Glen Rose beds, 817, 836

Glimmerschiefer, 84

Globigerina, 57, 184, 144, 433*, 855, 935,936 ; rubra, $432 *$

Globigerina ooze, 144, 230, 438, 817

Globostellate spicule, $432 *$

Globuliferous rocks, 89

Glossites, 621

Glossoceras, 551; desideratum, 573

Glossopteris, 698, 699, 704 ; Browniana, 698

Glossopteris Coal-measures, 698

Glycimeris reflexa, 917

Gly phæa, 760

Glyptaster occidentalis, 551

Glyptician, 790

Glypticus hieroglyphicus, 790

Glyptocardia speciosa, $612 *, 620$

Glyptocrinus, 520 ; decadactylus, $511 *, 514,516$

Glyptodon, 1000, 1001, 1002 ; clavipes, $1003 *$

Glyptolepis, 417, 625, 626 ; Quebecensis, $618^{*}$

Glyptops ornatus, $766 * 767$

Glyptostrobus Europæus, 921; Gronlandicus, 833

Gnathodon tenuides, 837
Gneiss, 83\$, 122, 447

Gneissic quartzyte, 82

Gneissoid granite, $83 \$, 227,371$

Gnetaceæ, 435

Gnetum. 435

Gobi, Desert of, $32,33,51$

Gürner Glacier, 237*, 248

Görnerhorn, 248

Gold-bearing veins, 333 ; washings. 170,178

Gold Range, 739

Gomphoceras, 549, 561, 568, 586, $591,599,627$; angustuma, 551 eos, 516; oviforme, 602 ; parvulum, 561*: Wabashense, 551

Gomphonema capitatum, 699 ; gracile, $163,164 *$

Gomphotherium, 918

Gondwána Land, 737, 878-874, 937 (period of existence)

- (Lower) series, 698, 770

- (Upprer) series, 769

Goniatite limestone, 576, 593, 637 , 642,647

Goniatites, $570, \quad 575,586 *$ (first American), 593, 599, 700, 869

Goniatites, 568, 599, 613, 614, 625, $626,642,675,686$; bicostatus, 620 : complanatus, 612.620 ; discoideus, 586, 602, 620 ; intumescens, $614 * 620,621,627$; Lyoni, 643* ; Marcellensis, 602 ; mithrax, 586*, 591; Oweni, 643*; Patersoni, $614^{*}, 620$; primordialis, 626 ; retrorsus, 626*, 627; sinuosus, 620 ; Vanuxemi, 599*

Goniobasis, 828 , 829, 856 ; convex 856

Gonioceras anceps, 514

Goniomya, 760

Goniophora, 621; Chemungensis, 621 ; perangulata, 601

Goniopteris, 685; arguta, 693; elegans, 693, 705; emarginata, 693, 705

Good-night beds, 885

Gordon-Bennett, Mt., height of, 296

Gorgonia, 55, 429*, $431 \S$

Gorilla, 54

Goro Island, 150

Gosiute Range, 365

Gothic Mountain, 274, 275*

Gotland (Gothland), Lower Silurian in, 521 ; Upper Silurian, 564, 565, 568,569

Grahamite, 662

Grallæ, 92 ?

Grammatophora marina, $437 *$, $894 *$

Grammoceras, 760

Grammostomum phyllodes, 432*

Grammysia, 602, 621; bisuleata, 598*, 602, 626; cingulata, 564*, 567, 573; communis, 621 ; Hamiltonensis, 602, 626; subarcuata, 620,621 ; triangulata, 573

Grampian group, 456

Granatocrinus, 646

Grand Bank of Newfoundland, 859

- Cañon. See Colorado Cañon

- Chain, 732

- Gulf group, 890, 891 
Grand Manan Isl., subsidence of, 350

- Portage Bay, 469

Granite, $82 \S-83,122,205,259$

- and mica schist, $448 *$

Granitic rocks, $78 \S$; sediments, 744 ; veins, 314, 326, 329*, 331, $332 *, 335,336$

Granitoid rocks, $77 \S, 85,86,87$

Granular limestone, 79§; quartz, $82 \S$

Granulyte, $83 \S$ (kinds), 272, 316, 325,371

Graphic granulyte, $83 \S$

Graphite, 62\$, 79, 83, 313, 319, 485, 714, 732; in Archæan, 453, 454, 455,458

Graphitic coal, 657 ; rocks, $79 \S, 83$, $449,495,518,519,658$

Graptolites, 431§, 470§; Cambrian, $470,474,477^{*}, 481$; Calciferous, $497,498^{*}$; Lower Silurian, 495, $504,505 *, 510 *, 515,520,522,525$, 527, 718; Upper Silurian, 568, 574; Clinton, 545*; Lower Helderberg, 560, 718

Graptolithus Clintonensis, 545*, 550

Graptolitic shales and slates, 518, $519,520,521,568$

Grasses, 435,945 ; ash of, 73,75

Grasshoppers, 419

Grauliegende, 697

Gravel, 758, 76ฐ; auriferous, 344, $810,883,887,934$

Gravitation theory of mountainmaking, 381-383, 387

Gray band, 91, 542

- wacke, $80 \S, 408$

Great Basin, 25, 119, 132, 195, 199 $444,635,658,735,739,746,748$, $812,818,826,882,935$; faults in 365,366

- - ranges, 365, 366*, 733, 739, $811,934,985$

- - in the Quaternary, 988

- - System, 366

Great Bear Lake, 29, 200

Great Britain. See England

Great Lakes of North America, 29, $40,199,200,201 *, 442$; in Quaternary, $947,948,986$

Great Northeast Bay, 575, 638

Great Oölyte. See Oölyte

Great Salt Lake, 25, 51, 120, 153, $199,200,202,362,382,444,826$, $881,882,988$; valley, 361

Great Slave Lake, 29

Grecian Archipelago, 296

Greece, Pikermi beds of, 927

Green earth, $68 \S$

Green Mts., 24, 41, 326, 467, 490, 528, 531, 586, 541, 945 (Arctic plants)

Green River basin, 882, 893

- - epoch or group, $365,886,901$, 918

Green sand. See Greensand

- shale of the Clinton, 542

Greenland, 19, 40, 233, 234 (snowline), $236,239,240,249 * 251,252$, $256,272,320,337,347,376,395$ fiords, 240, 241, 948 ; glaciers, 240 , $241 *, 244,251,941$; map of western, 241* ; subsidence, 349, 350

Greenland, Arehrean in, 444; Carbonic, 711; Cretaceous, 794, 819 $831,838,837,838,839,840,868$, 872 (climate), 873 ; Tertiary, 819, 921, 939 ; Glacial, 945, 948

Greensand, $68 \S, 136 \S, 191,468,477$ $820,821,822 \S, 824,858,887,888$. See also Glauconite

Greenstone, 86, 449

Greisen, 82, 83§

Grenville limestone, 454, 493

Grenzdolomit, 774

Grès Armoricain, 518

- bigarré, 769

- de Fontainebleau, 205, 920

- des Vosges, 769

Gresslya donaciformis, 791

Grevlock (Mt.), 104, 495, 530*

Gries Glacier, 243

Griffith Isl., 495

Griffithides, 643, 676, 700 ; Sangamonensis, 691 ; scitulus, 691

Grindelwald Glacier, 233, 238

Grindstones, 80

Grinnell Land, 369, 606, 635, 663

Grit, $80 \S$

Grizzly Bear, 950 (migration)

Groovings. See Scratches

Ground-ice, $232 \S$

Ground-pines. See Lycopods

Groups, $406 \S$

Grus proavus, 1002

Gryllacris lithanthraca, 704

Gryphæa, 759, 779 (time range), 792, $834,840,860$; arcuata, 779, 790 ; bilobata, 790 ; Bryani, 854; calceola, 760 ; convexa, 854 ; dila tata, 779, 780*, 790, 819 (var. Tucumcari) ; forniculata, 886 ; incurva, 779*; mucronata, 817 , 837 ; mutabilis, 854; obliqua, 790 ; Pitcheri, $817,835 *$, 836, 837 , $841 *$, 854; sublobata, 790 ; vesicularis, $841 * 854,855,866$; virgula, 791

Gryphæa beds, $790 ;$ rock, 836

Gryphæostrea vomer, 854

Guadalupe Mts., 660

Guanaco, 54

Guano, 63§, 72§, 73, 153 (analysis), 887

Guatemala, 168

Guelph limestone, 543, 549, 551

Guiana, 31

Guinea, 33

Gulf of Bothnia, 521

— of California, $30,51,145,200$

- of Carpentaria, 39

- of Finland, 521

- of Guinea, 295

- of Mexico, 18, 20, 44, 45, 49, 190, $191,198,217,462,483,573,794$, $814,827,834,857,881,934$ (Tertiary), 940,949

— of Penjinsk, 927

- Stream, 44, 48, 49, 55, 56, 144, 166 , $229,230,256,524$ (Cambrian), 792, 793,872

Gutenstein, 769, 774

Guyot Glacier, 238
Gymnites incultus, 774

Gymnoptychus, 918

Gymnosperms, $434 \S, 674,718,750$ = Neopaleozoic. 460 ; Hamilton, 595 , 596 ; Chemung, 610, 612 ; Subcarboniferous, 639 ; Carboniferous, $666,667,672 *, 678,674,689$

Gymnotoceras rotelliforme, 757

Gypidula occidentalis, 602

Gypsum, 69*\$, 128, 138; how formed, 554; on coral islands, 120 ; in the Salina, $553,554,555^{*}$

- beds of Montmartre, 928

Gyroceras, 591, 599, 642 ; Burlingtoneuse, 642 ; Jason, 591 ; transversum, 602 ; undulatum, 591

Gyrodes crenatus, 854 ; petrosus, 854 Gyrodus, 417 ; umbilicus, $417^{*}$

Gyrolepis, 772 ; tenuistriata, 774

Haddock bones, analysis of, 78

Hade, $107 \S, 328 \S$

Hadrosaurus, 846 ; Foulkii, 845

Haiti, 347, 891 \& 935 (Miocene), 936

Haleakala, Mt., 270, 277, 290, 291, 346,379 (density)

Halemaumau, 269*, 271, 285, 291

Halicalyptra fimbriata, 433*

Halisarcoids, $481 \S$

Halitherium, 927

Halloceras, 591

Hallopus, 786

Hallstadt limestone, 774

Haloỉia, 756, 757, 774; dubia, 757 ; Lommeli, 757, 758, 792; occidentalis, 758; Zitteli, 792

Halobia bed, 757

Halodon sculptus, 853*

Halonia, 699; pulchella, 668*, 669, 688

Halysites, $310,541,547 *, 551,552$, 567, 568; agglomeratus, 550; catenulatus, $514,515,516,520,522$, $544,547 *, 550,551,552,567,568$, 569 ; escharoides, 550; gracilis, 510, 511*, 515: interstinctus, 567

Hamilton period, 592

Haminea grandis, 916

Hamites, 760,867 : alternatus, 865 ; attenuatus, 862*, 865; elatior, 867 : Fremonti, 836

Hanging wall, $328 \S$

Hannibal shales, 637

Haploceras, 760,794

Haploconus, 917

Haplophlebium, 679

Hard-pan, 128,2058

Harding sandstone, 495, 515

Harlania Halli, $545^{*}, 549$

Harpes, 515, 520, 521, 551, 568, 625; antiquatus, 503

Harpides, 521; Atlanticus, 573; rugosus, 573

Harpoceras, 794; bifrons, 790 ; M'Clintocki, 792; Murchisonæ, 790 ; radians, 790 ; serpentinum, 790

Harttia Matthewi, 475*

Harz Mts., 87, 563, 567, 569, 626, 697,734

Hastings sands (and clays), 858, $859,864,865$ 
Hatchetigbee beds, 888

Hatteras. See Cape

Hatteria, 54, 687, 706, 798

Haüynite, 88

Hauptdolomit, 774

Hauterivian, 859, 865

Hawaii, 213, 282, 269* ; map of, $268^{*}, 269,270$

—, volcanic action on, 268*, 269*, 372,379

Hawaiian Islands, $36^{*}$ (map), 51, $145,150,163,324,350,392$

Hawkesbury sandstone, 698,770

Hawthorn beds, 891

Haystack Mt., 937

Headon beds (series), 926

Heard Island, 241, 242

Heat, 253; earth's interior, 257; from chemical and physical changes and mechanical action, 258; from crushing, 322, 326 ; from interior sources, effects of, 260,381 ; in mines, 339

Heath, 945

Heavy spar, $69 \S$

Hebrides, 218; Archæan in, 456, 867

Hecla mine, 389

Hecla Mt., 241, 286, 305

Hedgehog, 54, 427, 930

Helaletes, 907, 918

Helderberg Mts., 543, 553, 555, 561, 579

Helderberg, Lower, 558

-, Upper, 579

Helena Cañon, 515

Helicina oceulta, 966; orbiculata, 966 ; profunda, 966

Helicoceras, 861; Mortoni, 855; Navarroense, 855

Helicopsyche, 60

Helicotoma, 516 ; planulata, 507*, 514

Heliolites, 521, 550, 552, 567; interstinctus, 520, 522, 550, 568; porosus, 626, 628; pyriformis, 550,568 ; spiniporus, $547 *$, 550

Heliophyllum, 581, 611; confluens, 601; Halli, 590, 597*, 601, 611, 625; obconicum, 601

Heliosphæra, 319

Heliscomys, 918

Helix, 425*; Cuperi, 966 ; fulva, 966 ; labyrinthica, 926 ; lineata. 966 ; occlusa, 926 ; pulchella, 966 striatella, 966 ; Turonensis, 926

Helix family, 690

Hell Gate, 211

Helminths, 428

Helodus, 644, 702

Helohyus, 918

Helvetian group, 926

Hemapedina, 779

Hematite, $70 \S, 71,83,123,126,127$, $449,450,453,539,665$

Hemeræ, $407 \S$

Hemeristia occidentalis, 691

Hemiaspis limuloides, 565*; sperata, 567

Hemiaster, 834, 840; parastatus, 854: Regulusanus, 866 ; Texanus, 855 ; Verneuili, 866
Hemicidaris, 779: intermedia, 790 ;

Purbeckensis, 791

Hemicystites, 516

Hemipristis serra, 917

Hemipronites punctuliferus, 562; radiatus, 562

Hemipsalodon, 918

Hemipteroids, Carboniferous, 691 , 702; Paleozoic, 721, 722

Hemipters, 419, 520, 525, 574, 756, 900

Hemitrochiscus paradoxus, 707

Hemitrypa, 579

Hempstead beds, 926

Henry Mts., 301, 876

Hepaticæ, 434, 436

Heptodon, 918

Herbivores, 902, 929, 930, 931

Herculaneum, 280

Hercynian beds, 564; fauna, Kayser's, 569; Question, Clarke's, $569-560$

Hercynian system, Bertrand's, 734

Herring, 862, 879, 901

Hervey Islands, 36, 37, 850

Hesperomys, 919

Hesperornis, 852, 864, 871 ; regalis, $850 *, 852$

Heteraster oblongus, 865

Heteroborus, 925

Heteroceras, 855

Heterocercal, 401, 402, $416 \S$

Heterocrinus, 516, 532; Canadensis, 514,516 ; geniculatus, 516

Heteromyaries, 525

Heteropods, 506

Heter'oschisma, 601

Hettangian, 774, 790

Hexacoralla, $777 \$, 860$

Hexactinellids, 57, 431§, 432*, 497, $498 * 504,611,639,646,777 * 860$

Hexameroceras delphicolum, 551

Hexaprotodon, 927

Highland Range, 448, 469

Highlands of N. J. and of Putnam Co., N.Y., 24, 443, 530, 531, 745

Highwood Mts., 876

Hilo, 295

Hils formation, 865

Himalayas, 26, 32, 41, 234, 365, 379, 392

- Archran in, 456; Silurian, 521 ; Jurassic, 776, 791; Tertiary, 347, $365,392,920$; changes of level in, 932, 938, 936, 938; Quaternary, 392,936 ; glaciers in, 239,240 ; upturning and elevation of, 368*, 936

Himantidium arcus, 163, 164*; Monodon, 163, 164*

Hindeastræa discoidea, $840^{*}$

Hindia, 562, 584, 590

Hindostan, 22

Hindu-Kush, 32, 41

Hipparion, 919, 927

Hipparionyx, 578; proximus, 579

Hippidium, 919, 1002

Hippopodium ponderosum, 790

Hippopotamus, 54, 906, 925, 927. 928, 930 ; major, 927, 1004, 1006 ; Pentlandi, 1006

Hippotherium, 927 ; ingenuum, 1001
Hippurite limestone, $836,859,866$

Hippurites, 866, 877 (end); brevis, 866: Corbaricus, 866; dilatatus, $861 *, 866$; floridus, 866 ; giganteus, 866 ; organisans, 867 ; Petrocorriensis, 866 ; socialis, 866 ; Toucasi, 866 ; Toucasianus, $861 *$

Hoang $\mathrm{Ho}, 30,195,196 *, 198$

Hoei Ho, 198

Hog, 906, 910, 911, 930 ; family, 909, $924,928,930$

Holaspis, 625

Holaster, 840,860 ; lævis, 866 ; nodulosus, 865 ; planus, 866 ; simaplex, 887 ; subglobosus, 866 ; suborbicularis, 866

Holectypus planatus, 837

Holometopus Angelini, 573; limbatus, 578

Holonema, 617 ; rugosum, $616^{*}, 618$, 621

Holopea, 499*, 514, 521, 562; antiqua, 558; dilucula, $499^{*}$; elongata, 558 ; subconica, 558 ; Sweeti, 478* ; turgida, 501

Holopella, 520; conica, 567; gregaria, 567; obsoleta, 567

Holops pneumaticus, 848

Holoptychius, 417, 510, 618*, 619, 625*, 626, 702; Americanus, 621; filosus, 621 ; giganteus, 621 ; horridus, 621 ; nobilissimus, 627 ; rugosus, 621

Holothurians, 423

Holothurioids, 427 \$

Holy Cross Mt., 250

Holy Island, 156

Holyoke Mt., 802, 803

Homacanthus gracilis, 591

Homacodon, 918 ; priseus, 906

Homalonotus, 4228, 520,521, 546 , $562,570,578,579,586,591,599$, 626 ; Dawsoni, 562 ; delphinocephalus, 549*, 550, 551, 567, 569; Knightii, 567, 573 ; major, 578; Vanuxemi, 570

Homewood sandstone, 656

Homo diluvii testis, 921

Homocercal tails of fishes, 417

Homocrinus, 562

Homotaxial, 398

Ho-Nan, 198

Honduras, 20, 747, 756

Honesdale sandstone, 606

Hood Mt., height of, 296 ; glaciers of, 240,945

Hoogly, mouth of the Ganges, 212

Hoplites auritus, 865; Deluci, 865 ; Deshayesi, 887, 854, 864; Desori, 867 ; dispar, 867 ; interruptus, 865 ; lautus, 865: Noricus, 865; radiatus, 865 ; splendens, 865

Hoplolichas, 591

Hoplophoneus, 918

Hoplophorus, 1008

Horizonality of strata, 98

Horn-silver, 340

Hornblende, 66, 67§*

- andesyte, 86§, 892; granite, 82, $83 \S, 85 \S$; picryte, $88 \S$

-, pyroxene, and chrysolite rocks, $82,88-89$ 
Hornblende schist, $85 \$$

Hornblendyte, $85 \S, 325,532$

Hornstone, 82, 540, 579§, 590, 584, 646, 859 ; in Corniferous, with Protophytes, 582, 583*

Horse, 54, 55, 907, 905, 911, 912, $914^{*}, 927$

-type, evolution of, $912,913^{*}, 929$, 981

Horse in a vein, $330 \S$

Horse-shoe crab, 420

Horse-tail. See Equiseta

Horsetown beds, 815, 818, 820, 831, 837

Horton series, 639

Husselkus limestone, 757

Hot springs, 121, 135, 137, 152, 265, $277,305,306,313,320,323,343$; analyses of waters, 121 ; life of, $60,152,308,454$; superficial veinmaking at, 334

Housatonic River, 227*, 325

House Range, Utah, 494

Hualalai Mt., 268*, 269

Huamampampa sandstone, 628

Hudson Bay, 29, 40, 442, 541, 552, $883,947,948,949$

Hudson-Champlain trough, 537, 572

Hudson epoch, 510

- River, 212, 216, 528, 529*, 530, $537,540,541,558,579,628,734$, $743,744,745$; submarine channel, 18*, 745, 949 ; valley, 357 , $552,558,559,579,605,982$

Huerfano group, 893

Ituman bones, analysis of, 73

Humboldt Glacier, 241; Ranges, $365,733,811,812,945$; region, $746,757,760$

Humite, $67 \S$

Humming birds, 54, 55

Humus acids, 119, 122, 124§, 125, $128,129,139$

Hunan, 696

Hungary, Archran in, 455; Upper Silurian, 573 ; Tertiary, 938

Hung-tse Lake, 198

Huron, Lake, 200, 201*, 445, 449, $452,493,533,540,542,552,558$, $572,592.635,947$

Huron Cupriferous Formation, 445

- Piver, 947

- shale, 606

Huronia, 549 ; Bigsbyi, 551 ; vertebralis, 551

Huronian, 407, 445, 446, 447, 448, $449,450,451,453,454,458,466$, 468,488

Hurricane fault, $363 *, 747$

Hyæna, 927 ; crocuta, 1004 ; spelæa, $1004,1006,1009$

Hyænaretos, 927

Hyænocyon, 918

Hyænodictis, 925

Hyænodon, 918, 926; drsyuroides, 924 ; leptorhynchus, 926

Hyalina arborea, 966

Hyalomicte, $88 \S$

Hyattella congesta, $546 *$, 550

Hybocrinus, 514
Hybodonts, 415§, 416*, 648, 644*, 647,772

Hybodus, 772 (first), 783; minor, $416 *, 772$; plicatilis, $416^{*}, 772,774$ Iydnoceras, 646

Hydra, 429*, 430

Hydration, 128

Hydraulic cement, $79 \S$, S0, 555 ; limestone, $79 \S, 555,592$

Hydrocarbon, 62, 74, 124

Hydrocephalus, 482

Hydrochloric acid, 68, 278; from rolcanoes, 278,294

Hydrogen, 61, 62 ; from volcanoes, $278,287,293,294$

- sulphide, 119, 124, 125, 523, 554

Hydroids, $140,419,430 \S, 547 *, 560$

Hydromica, 65§, 83, 318; granite, 82 ; quartzyte, 82 ; schist, 80,82 , $84 \S$

Hydrotalcite, 453

Hydrozoans, 140, 418, 419, 429*, $430 * \$, 431$

Hyena, 54

Hylæosaurus Oweni, 863

Hylerpeton, 682

Hylonomus, 682, 706

Hymenocarids, Upper Cambrian, 488

Hymenocaris vermicauda, 481*

Hymenophyllites, 645, 689 ; Gersdorff, 622; Hildrethi, 670*, 689 ; obtusilobus, 622 ; spinosus, 689

Hymenopters, 419, 679, 783, 794, 900 (number of Florissant)

Hyodectes, 925

Hyolithellus, 471, 472 ; micans, 472*

Hyolithes, 447, 471, 478, 481, 482, 514, 562, 599, 621 ; Acadicus, 475*; Americanus, 471, 472* ; Danianus, 475* ; gregarius, 478* ; impar, $472 *$; levigatus, 482 ; ligea, 590 ; princeps, $472 *$

Hyomeryx, 918

Hyopotamus, 918 ; borinus, 926

Hyopsodus, 918

Hyperodapedon, 772

Hypersthene, $67 \S, 86,87,88$

Hy pertragulus, 918

Hyperyte, $87 \S$

Hypisodus, 918

Hурnum, 154

Hypogeic work, 118§, 345-396

Hypogene rocks, $311 \S$

Hyposaurus Rogersi, 848; Webbii, 848

Hypostome, $421 \S$

Hypsilophodon Foxi, 863

Hyrachus, 907

Hyrachyus, 918, 928

Hyracodon, 910, 918 ; Nebrascensis, $910 \%$

Hyracops, 917

Hyracotherium, 913*, 918, 923, 925

Hyrax, 54, 55

Hystricops, 919

Hystrix, 927

Ibis, 923

Ice (see also Glaciers ; Water, freezing), 231, 232; glacier, 243, 846 ; plasticity, $243,244,245$
Ice, effects on lakes, rivers, and seacoasts, 23\%; fractures frum torsion, $371,372 *$

Iceberg theory of the drift, $9+2$

Icebergs, 241, 251-252; trausportation by, 217, 230, 252 ; transported by the Labrador current, 229, 289

Iceland, 19, 48, 256, 286, 297 ; geysers, 82, 305, 307; Sequoia of, 939 ; volcanoes of, 297

Ichthyocrinus lævis, $547 *$ *, 550

Ich thyodectes, 862

Ichthyopterygians, 760

Ichthyornis dispar, 851*; victor, $8551 *, 852$

Ichthyosarcolithus anguis, 836 ; crassifibra, 836 ; planatus, 836

Iehthyosaurs, 792, 797; Jurassic, $760,761,790$; number of British, 784; Triassie, 774

Ichthyosaurus, $749,773,790$; communis, 784*; Nordenskiöldi, 792 ; polaris, 792

Icla shales, 628

Ietops, 918

Idaho, 23 (height); Cambrian in, 477 ; Calciferous, 501 ; Subcarboniferous, 639, 647; Triassic, 746, 747, 757; Jurassic, 747, 760 ; Tertiary, 938

Idocrase, $66 \S, 313$

Idonearca vulgaris, 854

Igaliko, Firth of, 350

Igneous action and its results, 265 ; exterior agencies, 265 ; volcanoes, 267 ; non-volcanic eruptions, 297 ; thermal waters, geysers, 305

- ejections and intrusions, 89,258 , $364, " 382,383,658,811$; great in the later part of genlogical time, 392, 441 ; surficial, 299, $300 *$; veins made by, 338 - 343

- fusion, source of, 304

- phenomena due to exterior agencies, 265,266

- rocks, 67, 76§, 80. 272-274

- - and metamorphic, relations of, $326-327$

Iguana, 863

Iguanavus teres, 849

Iguanodon, $786,828,845,856,863$, 865 ; Bernissartensis, 863* ; Mantelli, $863^{*}$

Ilex, 854 ; cassine, 74, 75

Ilfracombe group, 625

Illænus, 500, 502, 508, 520, 521, 546, 551, 568 ; Areturus, 503 ; Bayfieldi, 503 ; Bowmani, 520 ; crassicauda, 515; Davisi, 519* ; globesus, 503; Ioxus, 549, 551; Taurus, 515; Thomsoni, 567

Illawarra, 261*

Illicium, 896

Illinois, mean height of, 23 ; uplifts in, 782; lead mines, 342, 522 Illinois River, 948

Ilmen Mts., 85

Ilmenite, $70 \S, 87$

Ilyanassa obsoleta, 994

Ilyodes, 691

India, $32,34,160,299,346,406$; united with S. Africa, $871,873,893$ 
India, Archæan in, 456; Cambrian, 483 ; Upper Silurian, 564 ; Carboniferous, 632, 693; Permian, $686,695,699,737,770$; Triassic, $602,698,737,769,770,773,791$; Jurassic, 698, 776, 791, 873 ; Cretaceous, 299, 833, 857, 866, 867, 873, 874, 876 ; Tertiary, 299, 920, $923,925,927,936,933$

Indian Ocean, 17, 19, 23, 31, 33, 43, $44,50,296,297,632,987,939$; topographic changes in, 737

Indian Territory, Cretaceous in, 817, $\$ 36$

Indiana, 23 (height), 207, 357 ; mineral gas and oil in, 206, 522, 523, 607 ; yield, 523

Indianaite, 6389

Individualities in nature, 9

Indrodon, 917

Indus Basin, alluvial cones of, 195*

- delta, earthquakes of 1819 and 1845,349

-, valley of Upper, $36 \mathrm{~S}$

Infra-Crétacé, $\$ 65$

Infra-Lias, 774

Infusorial earth, $81 \S, 895$; Tertiary, $894 *, 895$

Ink-bag of Belemnite, 782*

Inocaulis arbuscula, 516

Inoceramus, 759, 760, 884, 837, 840, $860,867,877$ (end); biformis, 855 ; concentricus, 865; confertim-annulatus, 854; Crispii, 855, 867 ; Crispii var. Barabini, 854; deformis, 855; digitatus, 866; dimidius, $841 \%$; exogyroides, 855 ; fragilis, 855; labiatus, 840, 841*, $854,855,866$; latus, 854, 867 ; mytiloides, 867; problematicus, (=I. labiatus), 841*; proximus, S5̃t; striatus, 866 ; sublævis, 855 ; subquadratus, 855; substriatus, 790 ; sulcatus, 865 ; tenuicostatus, 855 ; tenuilineatus, 855 ; umbonatus, 855

Inoperculates, 54

Inorganic distinguished from or ganic, 9, 413

Insectivores, 54,768,902,903,906, $907,911,918,925,927,928,929,930$

Insects, 54, $72,141,154,158,163$, $189,418,419 \S, 520$; derivation, 723-724; relations to other articulates, 724; tracks, 95, 742; Lower Silurian, 496, 521, 525: Upper SiIurian, 574, 721 (first); Devonian, $570,600 \%$ 601: Subcarboniferous (none), 643; Carboniferous, 657, $674,677,679 \%, 691,692,701 *, 704$ Permian, 686; Paleozoic, 525, 721, 727 ; post-Palenzoic, 736 ; Triassic, $742,750 *, 751,756,757,771,794$; Jurassic, 775, 776, 783*, 791, 794: Tertiary, 202, 887, 893, 900*, 901, 921, 922, 923; Glacial, 946

Integripallial, $425 \$$

Interior Continental region, 34, 199 - of N. Amer., 348, 387, 580, 581, $590,592,593-594,606,714,715$, $716,856,944$; of Europe, 533, 573 , $627,693,769,775,867$
Interior plains, $24 \S$

Intestinal worms, 428

Invertebrates, $404,414,418$; relation of, to Vertebrates, 418 ; reign of 460

Iocrinus, 516 ; crassus, 514

Iodine, 331,335

Iolitic granite, 83

Ione formation, 892

Iowa, height of, 23 ; uplifts in, 732 ; lead mines, 342, 522

Iowa-Texas Coal-measure region, 648

Iphidea bella, $471 *$

Ireland, 203; disturbances, 534; eruptions, 258, 518; peat-beds, 154

-, Archæan in, 456; Cambrian, 480, 481, 482, 534; Lower Silurian, 518, 534; Upper Silurian, 563, 574; Devonian, 622, 626 ; Subcarboniferous, 694, 695; Carboniferous, 698, 704; Permian, 697; Cretaceous, 856 ; Tertiary, 938

Irish Deer, 927

Iron, density of, 15; oxidation of, 123 ; carbonate, 81,125 ; oxides, 62,124 ; sulphate, 70 ; sulphides, $70,80,123$

- age, 445

- ore (and ore beds), 69,70,92,127, $315,326,327,344,391$; Archæan, $376,445,446,449 *, 450,451,453$, $454,455,456,458$; Cambrian, 446 ; Lower Silurian, 524: Clinton, 539 , $542,543,572,728$; Carboniferous, $650,651,652,656,663,664-665$, 708; Jurassic, 792

- sandstone, 542

Iron M ts, 444, 449

Ironstone, 344, 688

Irrawaddy, ratio of sediment to water, 190

Isastræa, 777,778 (number of British); discoidea, 854; explanata, 790 ; Murchisoni, 790 ; oblonga, $777 *$

Ischadites, 562; bursiformis, 590

Ischyromys, 918

Ischyrosaurus, 856 ; antiquus, 829 , 856

Isectolophus, 918

Isis nobilis, $72 \S$

Island Range of British Columbia. 739, 747,809

Islands, chains of, 20,374 ; curves in, $35 *, 36 *, 37 *, 39 *$

- as parts of continents, 22 ; of British Columbia, 390

Isle of Wight. See Wight

Isle Royale, 483

Isocardia Conradi, 854: fraterna, 917; medialis, 836 ; Washita, 837 Isocrymal chart, $46 \&, 47 *$

Isopods, $420^{*}, 421 \S, 422,438,439 \S$, $487,512,623,624,720,723,783$

Isoseismic curves, 375

Isostasy, $377 \S, 378,379,382,875$

Isotelus canalis, 503 ; platycephalus, 508*

Isothermal chart, $468,47 *$

Itabyryte, $83 \$$
Itacolumyte, 82

Italy, 296 (volcanoes); Subcarboniferous in, 693; Carboniferous, 693; Triassic, 768; Jurassic, 793; Oölyte, 309; Cretaceous, 857. 859; Tertiary, 921, 926, 927, 938 (eruptions)

Ithaca group, $603,604,605,614,620$, $6 * 29$

Ithygrammodon, 918

Iulids, 419

Iulus, 676

Ixtaccituatl, Mt., height of, 937

Jackson coal, 657

- epoch, 884, 859, 907,916

Jakobshavn Glacier, 244

Jamaica，29，163，347, 891，935, $936^{\circ}$

James River, 816

Jan Mayen, 19, 297

Janassa bituminosa, 707

Janira occidentalis, 836; Wrightii, 887

Japan, 19, 22, 32, 40, 183, 277, 280, $290,293,296,297$; earthquakes of, 373,374 ; Carboniferous, 696,700 ; Tertiary, 920

Japan Sea, 927

Jasper, 82\&, 84, 309, 450, 453, 454

Java, 38, 40, 277, 297 (volcanoes), 920

Jeanpaullia Münsteriana, 756 ; radiata, 756

Jeff Davis Peak, 945

Jefferson Mt., 240 (glacier), 296

Jelly-fish, $430 \S$

Jet, 7758

Joaquin River, 30

Jock coal-bed, 656

Joggins Coal-measures, 654* (section), 658, 682, 690

John Day beds, 884, 886, 894, 911, 918,926

John Day River, 886, 894

Johnstown cement-bed, 652

Joints, $111 \S, 112 *, 371-372,593$

$J$ ökuls Fiord, reconstructed glacier, 242

Joliet building-stone, 541

Jolleytown coal-bed, 651

Joplin lead mines, 522

Jordan valley, 28

Jorullo (Mt.), 27

Judith River beds, 828, 829, 847, 850,856

Juglans, 921 ; denticulata, 839 ; rhamnoides, 839 ; rugosa, 839

Jukes Butte, 301*

Juneus, 75

Jungfrau, 236, 237

Jupiter, density of, 16 ; oblique lines on, 395

Jupiter Serapis, 349

Jura limestone, 788

Jura Mts., 207, 382; Triassic in, 768 ; Jurassic, 738, 774, 793 ; Cretaceous, 859; Tertiary mountainmaking, 367, 365* (section), 919, 982

Jurn-Trias, 738, 749, 770,831; of Elk Mts., 364* 
Jurassic period, $738,739,758,774$, 857,873 ; foreign, 774

Justedal Glacier, 251

Juvavites, 757

Kaibab fault and fold, $362,363 *$

Kainozoic. See Cenozoic

Kalium, 61

Kamchatka, 40 ; volcanoes of, 296

Kames, 970

Kampecaris Forfarensis, 625

Kanab Cañon, 581

Kanawha Salines, 689

Kangaroo, 415

Kansas, 23 (height), 342 (lead mines) ; Paleozoic in, 342 ; Carboniferous, $130,665,674,678,690$, 691: Permian, 660 ; Cretaceous, $813,817,819,826,829,843,848$, $849,850,851,852,864,872,873$; Tertiary, 885

Kaolin (kaolinite), 68§, 81§, 134, 295

Karharbári Coal-measures, 695

Karoo beds, 698, 699, 737, 770, 773

Kashmir, 32, 770

Kaskaskia group, 634, 637, 646

Kanai, 36, 283, 290

Kea, Mt., 27, 179, 268*, 269, 270, $276,290,291$; density of, 379

Keeling atoll, 20

Keewatin, 466

Kellaway beds, 777

Kellaways rock, 775, 790

Kelp, 155

Kenia, or Kenya, Mt., 33, 977

Kennedy Channel, 495, 559

Kenodiscus Schmidti, 773

Kent Belt of limestone, 529*, 530

Kent-Cornwall ridge, Conn., 449, 531

Kentucky, 23 (height), 387; caverns, 130 (length), 137, 207 ; mineral oil, 609; Cincinnati beds, 504,692 ; Cincinnati uplift of, $387,490,532$

Kentucky River, 503

Keokuk group, 634, 637 ; limestone, $97,138,342,638,644,646,647$

Kerguelen Land, 296 (volcanoes)

Kermadec Islands, 37

Kersantyte, $86 \S$

Kettle holes, 970, 992, 993*

Keuper, Keuperian, 411, 738, 769, $771,772,773,774$

—, Lower, 755, 771

Keupermergel, 769,774

Keweenaw, Keweenawan, Keweenawian, Keweenian, 447, 464

- copper region, $341,342,466,468$, 483

- group, 445, 447, 465, 468, 469, 483, 484

- Point, 465

Key West, 168

Khingan Mts.. 32

Kiama, 281 ; basaltic columns, 261*, 262*; dike with outflow, 262*

Kiamitia clays, 817

Kieking Horse Pass, 26, 469, 495

Kilauea, 178, 268*, 269*, 270, 271, 272, 276, 277-283 (passim), 284*, 285* $286^{*}, 288,291,293,295,303$
Kilima-Njaro, Mt, 33 ; height of 296

Killinite, 321

Kimberley shale, 770

Kimmeridge clay, 411, 775

Kimmeridgian group, $775,776,779$, 780,790

Kinderhook group, 634, 637, 638, $646,647,709$

King William's Island, 495, 524, 544, 552

Kingdoms of nature, 9

Kingfisher, 54, 852

Kingsmill Islands. See Gilbert Islands

Kionoceras laqueatum, 500*; strix, 551

Kittanning coal-beds, 652, 663, 664, 688

- Mts., 588, 539 ; valley, 357

Kiusiu Island, 277

Klamath Mts., 659, 747, 809

Knobstone group, 637, 638

Knorria, 610, 639, 645, 689, 698, 699 ; acicularis, 626, 699, 704 ; imbricata, $645,639,699,704$

Knox dolomyte, 468, 493 ; sandstone, 468

Knoxville beds, $760,815,818,820$, 831,837

Kössen beds, 769,774

Kohala Range, Hawaii, 269

Koblenkeuper, 769

Koipato group, 747

Koko Head, Oahu, 271*

Komé group (beds), 819, 833 838

Kong Mts., 32

Kootanie beds (group), 815, 818, $819,820,838,834,868,872$

- Pass, 818

Kotzebue Sound, 240, 640, 1003

Krakatoa volcano, 163, 291

Kuen-Lun Mts., 26, 32

Kuhn Islands, 776

Kupferschiefer, 697,707

Kurile Islands, 19, 296 (volcanoes), 297

Kutorgina, $480,481,486$; cingulata, $471 *, 480$, 573; Labradorica var Swantonensis, 480

Kyanite. See Cyanite

Labradioryte, $86 \S, 325$

Labradophyric, 77 \$

Labrador, 350, 442, 944 (precipitiation), 948 (fiords); Cambrian in, 467

- current, 45, 48, 55, 166, 229, 230 793, 873

Labradorian, 446

Labradorite, $64 \S, 65,77,85,86,87$, $88,273,295,311,318,319,320,323$, $324,325,442$

Labrosaurus, 766

Labyrinthine structure of teeth, $417 *, 725$

Labyrinthodonts, $417 * \S$, 796 ; Coalmeasure, 772; Permian, 869; Triassic, 772*, 869; Cretaceous, 870

Laceadive Islands, 145

Laccolite, $301 \S$
Laceolitbs, 296, 301*, 302, 303, 345, $383,469,804,806,807,876$

Lacerta, 787

Lacertians, 787, 848

Lacustrine areas, Tertiary, 202, 365 882

- beds (deposits), 76, 191, 202; Quaternary, 985, 986, 988

- limestone of Beauce, 926

Ladrones, $19,20,37$; volcanoes of, 296

Lælaps aquilunguis, 847; incrassatus, 847

Lævibuccinum lineatum, 915

Lafayette beds (group), 888, 890, $\$ 92$

- formation, 964

Lagomys spelætus, 1006

Lagrange group, 885, 891, 896

Lahontan region, 119, 133

Lake $\mathbf{A}$ gassiz, 985

- Bonneville, 988

- Champlain, 982

- Lahontan, 988

- of the Woods, 200, 446

- Warren, 987

Lakes, Great, elevated shore lines of, 986. See Great Lakes

Lakes, 166, 198, 201*

Lambdotherium, 918

Lamellibranchs, $424 \$, 425 * \S$

Laminarians, 56

Laminated rocks, $80 \S, 309$; structure, $92 \$$

Lamna, 144, 863 ; compressa, 855 ; elegans, 416*, 901*, 925, 926 ; Texana, 843*, 855

Lampreys, $418 \S$

Land, arrangement of, 16, 21; below sea level, 22, 23 ; in one hemisphere, $16^{*}$; mean height of, 23 ; ratio of, to water, 16

Land-shells, 54

Landenian group, 925

Land's End, 317

Landslides, 208, 232

Langhian group, 926

Lanthanum, 449

Laodon venustus, $767^{*}$

Laopithecus, 918

Laopteryx, 768 ; priseus, 768

Laosaurus consors, 765*

Lapilli, 267

Lapland, 234 (snow-line); Archæan in, 456; Cambrian, 484

La Plata (Rio de la Plata), 24, 30, 171, 191 (ratio of sediment to water); Cretaceous of, 867

Laramide Range, 382, 383, 389, 391, $483,572,581$; Mountain System, $359 *-364,375,380,383,398,391$, $406,874^{*}-876,882,883$

Laramie beds, 824, 826, 827, 828, $846,847,850,852,856,870,873$, 880,893

-(Upper), 815, 821, 825, 827, 828, $829,830,856,873,875$

-Mts., 748

- Plains, 747

Lasiograptus mucronatus, 510*

Lassens Peak, 87, 296, 749,987

Laumontite, 68 
Lanrentian, 445

-, the Champlain period, 941

Laurentide Mts., 445

Laurus, 837, 840, 854, 921, 922 ; socialis, 839

Lauteraar Glacier, 237, 248

Lauzon group, 496

Lava, $76,85,267 \$, 272,275$

- conduit, 277\$; cones, conditions determining their forms, 274-276 ; stalactites and stalagmites, 294*, 295,324

- streams, 287*-291，293，294, 295

Layers, 76ฐ, 91, 92ฐ (structure)

Lead mines, Illinois and Wisconsin, 342, 522 ; Missouri, 342, 522 ; New York, 542; Rocky Mtn. region, 876

Leadville mines, $340,341 *, 343$; region, $304,342,876$

Leaia tricarinata, 691

Lecanocrinus, 550

Leclaire limestone, 543

Leda, 602, 621, 917 ; amygdaloides, 925 ; arctica, 984 ; mater, 916 ; minuta, 983, 984; multilineata, 916; ovum, 790; pernula, 983, 954; truncata, 984

Leech, 423

Leiocidaris hemigranosa, 837

Leiopteria, 621 ; lævis, 602

Leiorhynchus limitare, 602, 612 ; mesacostale, 612, 620,621; quadricostatum, 612*, 620 ; sinuatum, 621

Leitha limestone, 926

Lemberg chalk, 866

Lemuravus, 918

Lemuroids, 917

Lemurs, 54

Lena River, 30

Ienticular mass, $92 * \S$

Lepadocrinus, 562 ; Gebhardi, 562

Lepas family, 600

Leperditia, 481, 509, 516, 517, 562, 567 ; alta, 556*, 557 ; amygdalina, 503; Anna, 499*; Argenta, 476, 477*; armata, 515; Baltica, 552 , 569 ; Cambrensis, 481 ; Canadensis, 502*, 503, 515; dermatoides, 474*; fabulites, 508*, 515; Keyserlingi, 568 ; nana, 502*

Lepidodendrids, 664, 684, 698, 712, 718,750

Lepidodendron, 610, 611, 627, 628, $639,645,654,658,667 * 668 *, 689$, $698,699,704$; aculeatum, 645, 646, 668*, 688, 689 ; ac1m:natum, 646 Chemungense, $609 \%, 610$; cly peatum, 668*, 598 , 689 ; corrugatum, 611,645 ; costatum, 645 ; dichotomum, 645, 688, 689 ; diplostegioides, 645 ; forulatum, 645 ; Gaspianum, 583*, 595, 611, 622 lanceolatum, 669*; modulatum, 688, 689; obovatum, 645, 689 obscurum, 645 ; primævum, 595* 601,610 ; riwosum, 689 ; squamosum, 699; Sternbergii, 668, 688 689 ; tetragonum, 645; turbina tum, 645 ; Veltheimanum, 626,
$645,668^{*}, 688,689,699,704$; vestitum, 689 ; Wortheni, 645

Lepidomelane, $65 \S$

Lepidophloios, 689, 699 ; laricinus, 689

Lepidophyllum, 668, 699

Lepidopter8, 419, 679, 900

Lepidosiren, 54, 417, 418

Lepidosteus, 59, 73, 417*, 901, 926 ; osseus, 417 *

Lepidostrobus, 645, 668 ; hastatus, $669 *$

Lepidotus, 788

Lepidoxylon, 673

Lepisma, 419, 702

Leptæna, 508, 520, 521, 562, 568, 579 ; laticosta, 626; Murchisoni 626 ; rhomboidalis, $507 *$, 514, 520, $548 *, 551,562,567,568,572,590$ sericea, 508, 507*, 514, 520, 521, 522, 524, 550; transversalis, 503 , 568 ; Verneuili, 568

Leptauchenia, 918

Leptictis, 918

Leptocardians, 414, 418

Leptochœrus, 918

Leptocladus, 789

Leptocolia, 579, 627 ; flabellites, 579

Leptodesma, 620,621 ; lichas, $613 *$; spinigerum, 621

Leptolepis, 699

Leptomeryx, 918

Leptomitus Zittelli, 470*

Leptophloum, 590; rhombicum, 622

Leptophractus obsoletus, 682

Leptosolen biplicata, 854

Leptostrophia, 579; Becki, 579; perplana, 579

Leptotragulus, 907, 918

Leptynyte, $83 \S$

Lepus, 918

Lesleya, 639

Lessonia, 155

Lestosaurus, 848 ; simus, $849^{*}$

Lette Island, 296

Lettenkohle, 755, 769, 774

Leucite, $65 \S, 77,81,85,86,88,273$, 274 ; rocks, 81,85

Leucitophyre, $85 \S$

Leucitophyric, $77 \S$

Leucityte, $86 \S$

Leucotephryte, $85 \S$

Leucozonia biplieata, 915

Levant series, 728

Level, changes of, now in progress, $348,349 \%, 350$

Level of no strain. See Zero strain Levis formation, 490,496, 497, 527 *

Lewis Island, 456

Lewisian Gneiss, 440 (Archæan synonymy)

- group of Murchison, 456

Lherzolyte, 888

Liard River, 746, 753

Lias (Liassic), 775 ; in Western America, 808, 809

- White, 774, 790

Liassian of D'Orbigny, 775

Libellula, 783\% ; Brodiei, 783

Liberty Cap, geyser cone, $307 *$
Libocedrus, 939 ; decurrens, 939

Lichas, 520, 5ะ1, 551, 561, 568, 586, 591 ; Anglicus, 567 ; Bigsbyi, 561 ; Boltoni, 549*, 551 ; cucullus, 515 ; grandis, 586, 587*; gryps, 587*; hylæus, 587*; laxatus, 567; pustulosus, 561; Ribeiroi, 521; Trentonensis, 508*, 509, 512, 515

Lichenocrinus, 516

Lichens, 53, 75 (ash), 126, 136 (ash), $436 \S, 688,946$

Life, characteristics of, $9 \S, 413$; its chemical work, 136-137; contributions to rock-making, 71-75; destructive effects of, 157 ; protective effects, 155 ; transporting effects, 156

- , disappearance of, 403,404 ; at close of Mesozoic, 876-877; at close of Paleozoic, 727, 728, 735736 ; at close of Cretaceous, 576 -, evolution by variation, 1020

-, general laws as to progress in, 1028; geographical distribution of, $52-60$; injury to, from mineral and marine waters, 122 ; introduction of, 397,458

-, lowest species the best rockmakers, 142; mechanical work and rock contributions, 117,118 , 140-158

-, oceanic, distribution of, illustrated by the physiographic chart, $47 *$

- system of, animal kingdom, 413; vegetable, 434; cephalization, 437

Ligerian, 859, 866

Light affecting life, 52

Lighthouses and waves, 217, 218

Lightning, effects of, upon rocks and sand-heaps, 265, 266 ; heat of, 255

Lignite, $816,817,819,821,825,829$, $830,887,890,922$

Lignitic beds, 828, 829, 885, 887 (Brandon), 889, 895, 896, 921, 922

Ligumen planulatum, 854

Ligurian group, 884

Lily Encrinite, 770

Lima, 756, 757, 759, 780, 834, 860 ; crenulicosta, 854 ; decussata, 866 ; gigantea, $779 *, 790$; Kimballi, 837; proboscidea, 791 ; punctata; 791 ; retifera, 690 ; rudis, 790 ; Shastaensis, 837 ; striata, 774 ; Taylorensis, 759*

Limacina, 424

Limbs. See Merosthenic; Podosthenic; Prosthenic; Urosthenic

Limestone, 62§, 78-80; ferriferous, decaying to limonite, $126^{*}$; metamorphic, $309,310,315$; rate of formation, 716 ; teachings of coral reefs on, 151

- caverns, 883

Limnadia, 486

Limnæa, 152 ; caudata, 926 ; desidiosa, 966 ; humilis, 966

Limnophysa desidlosa, 966 ; humilis, 966 
Limnopus vagus, $684^{*}$

Limnoris, 158

Limnosyops, 918

Limonite, $71 \S$; from decaying ferriferous limestone, $126 *$

Limulids, Paleozoic, 676, 701*, 719

Limuloid $8,419,420 \S, 423,455$; derivation, 720-721

Limulus, 59, 420, 496, 556, 565, 616 , $676,720,721,724$; polyphemus, 420

Lingula, 59, 72, 73 (composition of shell), 425*\$, $468,481,487,493$, $496,516,521,550,606,612,621$, 719 ; acunainata, 500 ; cuneata, 538, 544*, 549 ; Huronensis, 503; lamellata, 551; lata, 567; Lewisii, 567; Lyelli, 503 ; ninima, 567 ; nitida, 840 ; ovalis, 73 ; quadrata, $507^{*}, 514,516$; spatulata, $612 *$, 620

- family, 779, 840 (Mesozoic and Paleozoic contrast)

- flags, 481, 489, 573

Lingulella. 425§, 481, 482 ; coelata, 471*; Davisi, 481*, 520 ; Dawsoni, 475*; ella, 471*; ferruginea, 481; Iowensis, 515; prima, 478*; primæva, 481

Lingulepis antiqua, $478 *$

Lingulocaris, 482

Linnarssonia pretiosa, 500 ; transversa, $475 *$

Linton, Ohio, fossils, $661,679,681$, 682,692

Liochlamys bulbosa, 917

Liodon, 864

Lion, 54

Lipari, 276

Liquidambar, 921, 922

Liriodendron, 837,921 ; Meekii, 837, 838* ; simplex, 837, 838*

Lisbon, earthquake, in 1755,373

Lisbon beds, 889

Listriodon. 927

Lithia, $61 \S, 321$

Lithia Well, Ballston, 121

Lithic era, 440

Lithistids, $777,860 *$

Lithium, 61, 335 ; salts, 119

Lithobius, 724

Lithodesare, 59; Agassizii, 59

Lithodomous shells, 348

Lithodomus, 157 ; prælongus, 867

Lithographic limestone, 637, 646, 776,788

Lithoidyte, $84 \S, 337$

Lithomantis carbonaria, 702

Lithomylacris, 691

Lithophis, 901

Lithophysæ (lithophyses), 289, $337 \$$, 338; of Obsidian Cliff, $337 * 338$

Lithosphere, $61 \S$

Lithostrotion, 640, 659, 674, 700, 711, 718; Canadense, 639*, 640, 646; manmillare, 659 ; proliferum, 646

Lithostrotion beds, 638

Litoceras, 501

Litsæa Weediana, 839

Little Ararat, 265, 296 (height)

- Elko Range, 366

- Metis, Can., 497, 500
Little Missouri River, 266

- River group, N. S., 593

Littoral and abyssal deposits compared, 151

- currents, 212 ; zone, 56

Littorina, 130 ; palliata, 984

Lituites, 499, 511, 520, 521, 567, 568; Americanus, 573; Ammonius, 511; Farnsworthi, 500; giganteus, $56 \pi$, 573 ; imperator, 499, 500; Marshi, 551; undatus, 514

Lituola nautiloidea, $432 *$, $860 *$

Liverworts, 436

Livingston beds, $828,839,875$

Lizards, 54, 415, 768, 787, 849

Llama, 54, 910, 924, 1002

Llandeilo group, 463, 515, 519, 568

Llandovery group, 518, 520, 534, 567,569

Llano Estacado, 912

Llano group, 447,469

Loa, Mt., $26,27,179,268^{*}, 269^{*}, 270$, $275,276,279,286^{*}, 288,304$

Loam, 76

Lob-worm, $156,420^{*}, 423$

Lobster, 73, 420, 421, 438, 717, 771, 783

Locusts, $419,677,679$

Lodes, $327,331 \S$

Loss, $81 \S, 152,195,196^{*}$

Loess, of the Mississippi, fossils in, $964,966,973$

Loftusia Columbiana, 674, 690

Loganellus, 503

Loganite, 454

Loganograptus Logani, 498*

Logs, 156, 189, 191 ; carbonized at one end and silicified at the other, 143 ; in the Coal-measures, 654 ; see also Wood

Loire River, peat marsh of, 154

Loligo vulgaris, $424 *$

Lombardy, 769, 774

London, 17

London basin, 920, 923, 925; clay, $920 \&, 923,925$

London-Paris basin, 857, 919, 920, 936

Lone Mountain, 495; limestone, 516, 733

Long Island, 18*, 41, 162, 167, 205, $206,211 * 223,224,225,350 ;$ origin of north bays of, 949 ; claybeds, $822,823,837,839$; drift, 942 - - Archæan of, 444; Cretaceous, $822,823,839,872$; beds upturned during the Tertiary, 934, 1022*; Glacial, 949, 960, 962, 964, 970

- - Sound, 18*, 211*, 226*, 227 , 444,461 ; a river channel in the Glacial period, 949 ; tides of, 211 , 214, 215, 216, 226

Longmynd rocks, 480, 534

Lonsdalia, 718

Loochoo Mts., 40

Loon, 852

Lophiodon, 923, 924, 925 ; minimus, 926

Lopholatilus, 56

Lophophyllum, 674; proliferum, 674
Lorraine, 788,792

Lorraine shales, 489, 494

Los Carlos Mts., 340

Louisiade Islands, 36,38

Louisiana, mean height of, 23

Louisiana limestone, Missouri, 687

Loup Fork beds, 829, 884, 885, 886 ; fossils of, $894,895,911,919$

Low-lands, $23 \S$

Lower California. See Californis

Lower Helderberg period, 558

- - Devonian relations of fauna, $569-570$

Lower Silurian era, 489

Lowlands, 23

Loxomma Allmanni, 703

Loxonema, 520, 562, 590, 599, 613, $621,625,642,700$; priscum, 601 ; semicostatum, 690 ; sinuosum, 567

Loxotrema, 916

Loyalty Islands, 36

Lucia Island, 831

Lucina, 602, $780,867,916$; anodonta, 917; Claibornensis, 916; contracta, 917; cribraria, 917; occidentalis, 855; Portlandica, 791 ; serrata, 926

Ludian beds, 926

Ludlow beds, $463,563,573$

Lumachelle limestone, 792

Lunatia, 916; Gronlandica, 983, 984 ; heros, 988,984 ; obliqua, 854

Lung fishes, $417 \S, 587,618$

Lunulicardium, 602, 621 ; acutirostrum, 620 ; fragile, $612 *$, 620 ; ornatum, 620

Lutetian group, 925

Lutraria papyria, 916

Luzon, 40,920

Luzula, 240; hyperborea, 945

Lychnocanium lucerna, 433*

Lycopodites, 610, 668

Lycopodium chamæeyparissus, 75 : clavatum, 74; complanatum, 75 ; dendroideum, $75,668,669$; selago, 946

Lycopods, 53, 74, 75, 434, 436§, 663, $667,668,672,711,712,718$; ash of 74,75 ; spores, composition of, 713 ; Clinton, 549 ; Corniferous, 583*; Hamilton, 595*; Subear boniferous, 639, 645; Carboniferous, $666,667,668^{*}$

Lyell (Mt.), glaciers of, 240, 945

Lykens Valley coal, 656

Lynton group, 625

Lyre bird, 54

Lyria costata, 898*, 916

Lyrodesma, 516 ; cuneatum, 567

Ly toceras, 760, 793, 794; Batesii, 837; Jurense, 790

Macacus, 55

MeGregor coal-bed, 658

Machæracanthus sulcatus, 589*

Machærodus, 911, 919, 927, 1000 : Floridanus, 1001 ; latidens, 1006

Mackenzie River, 40, 171, 359, 580, $590,592,593,594,602,830$

- Laramie area, 827

Mackerel, 812,862

Mackinac, 552, 580, 628 
Maclurea, 498, 499, 516, 517, 520 ; arctica, 525 ; euneata, 515 ; Logani, 502*; magna, 491, 502*, 503, 514, 524,525 ; matutina, 500, 517; subrotunda, 515

Maclurea limestone, 494

Macoma calcarea, 984 ; fragilis, 983 , 984 ; fusca, 984 ; sabulosa, 983,984 , 995

Macquarie Islands, 37, 39

Macrauchenia, 1002

Macrocheilus, 599, 621, 642, 700 ; fusiformis, $675 \%, 690$; Newberryi, 690 ; ventricosus, 690

Macrochilina subcostata, 601

Macrocyclis concava, 966

Macrocystis pyrifera, 156

Macrodon, 621 ; earbonarius, 675*, 690

Macropetalichthys Sullivanti, 588*

Macropterna divaricans, $752 *$

Macropus, 1006

Macroscopic texture, $76 \S$

Macrostachya, 699

Macrotherium, 918, 925

Macrurans, 52, 59, 421§, 438§, 439, $615,701 *, 707,720,771 *, 783 *$

Mactra alta, 85̃5; delumbis, 917 ; ovalis, 983

Madagascar, 296 (volcanoes), 737, 873

Madeira, 297

Madison River geysers, 305,307

Madrepora palmata, analysis of coral of, 72

Maestricht beds, Maestrichtian, 815 , $858,859,864,866,870$

Magellan, Straits of, 858,867

Magellania, 4268*; flavescens, 426\%

Maggiore, Lago, 199

Magnesia, $61 \S$

Magnesian limestone, 78§, 131; Cambrian, 468; Lower Silurian, $491,498,501,732$

- salts, of the ocean, 320

Magnetic iron (magnetite), $70 \$, 170$, 223,578

Magnetitic rocks, $83 \S, 84$

Magnolia, 812, 837, 840, 859, 921

Magothy formation, 819 ; River, 819

Mahoning sandstone, 652,656

Maine, 23, 85, 158, 160, 265, 461; fiords of, 444, 948 ; upturnings in, 630,732

-, Archrean in, 444; Paleozoic, 461 ; Cambrian, 466; Lower Silurian, 493; Niagara, 539, 541, 544, 552 ; Clinton, 539, 552 ; Lower Helderberg, 544, 552, 558, 559, 562; Oriskany, 577, 579; Devonian, 622, 630 ; Glacial, 948, 949

Maine-Worcester trough, 461

Malacca, 22, 38, 41

Malachite, 342

Malaspina Glacier, 238, 239*

Maldive Islands, 145, 150, 737

Maléri beds, 773

Mallotus villosus, 984

Malno, 776

Malocystites Barrandi, 508; Murchisoni, 502*, 503

Malta, 921
Mammals, geographical distribution, 54, 409*, 414; relation to A mophibians, 726, 794, 795, 796 ; increase in size of brain during the Tertiary, 913, 914; reign of, 878, 879 ; Triassie, $754^{*}, 773,797$; Jurassic, $767 *, 789 *$; Cretaceous, 852,871 ; Tertiary, 902, 920, 923, 927 ; evolution of Eocene, 928

-, Tertiary and Quaternary, relations of, 1017

-, Quaternary, 950, 997 ; culmination of, 1016; degeneration in some Quaternary species of, 1007

Mammoth coal-bed, 650, 652, 653, $656,660,663$

Man, 1008; relation to Quadrumana, 1017, 1036 ; Pleistocene, 1008 ; origin, 1036

Man-apes, 54, 1086

Manasquan group, 821

Manatus, 925

Manchuria, 32, 696

Mangaia Island, elevation, 350

Manganite, $71 \S$

Mangrove, 155

Manis, 54

Manitoba, rainfall in, 944; Trenton in, 515; Lower Helderberg, 561 ; Devonian, 594, 597, 601, 602 ; Cretaceous, 830,856 ; Glacial, 945

Manitoba (Lake), 594

Manitou Park, 876

Manitoulin Islands, 522, 540, 542

Mantellia, 777; megalophylla, 776** 777

Manteodon, 918

Manti beds, 593

Mautle, $425 \xi$

Map of Apia and Menchikoff, 145*

-, bathymetric, 17, 19, following $20^{*}$

- (bathymetric) of submerged Atlantic border, $18^{*}$

- of the Atlantic coast-region, 224*

- of Mont Blane glaciers, 235*, $236^{*}$

- of Triassic area of Connecticnt, $801 *$

- of harbor at mouth of Connecticut, $226 *$

-, geological, of England, 693, 694*

- of Fiji Islands, $150^{*}$

- of the Great Lakes, 201*

- of western Greenland, 240,241 * $249 *$

— of Hawaii, 268*

- of Hawaiian Islands, $36^{*}$

- of harbor at mouth of Housatonic River, $227 *$

- of land and water hemispheres, $16 \%$

- of Long Island Sound, Long Island, and the Atlantic Border, $17 \S, 18 *, 211 *$

- of Loyalty group, $35^{*}$

- of Marquesas Islands, 36*

— of Mars, 396*

— of Maui. 179 \%

- of delta of the Mississippi, 197*

- of New Caledonia, 35*

- of New Haven harbor, 226*
Map of trap dikes, near New Haven, $299 *$

一 of New Hebrides, 35*

- of part of eastern New York and western Connecticut, 529*, $530 \S$

-, geological, of North America, $412 \%, 635$

- of North America after the Appalachian revolution, $734,735^{*}$, 739

- of North America in the Archæan, $442,443 *$

- of North America at the commencement of the Carbonic era, 633*

- of North America in the Cretaceous, $812,813^{*}, 814$

- of North America, Glacial, illustrating the phenomena, after 944

- of North America, Tertiary, 881*, 883

- of North America, Upper Silurian, $535,536 *, 575,633,634$

— of Oahu, 292*

- of courses of Pacific island chains, $37 * 39 *$

- topographical, of Pennsylvania, $357,729,730 *, 731$

- of Pennsylvania coal-fields, 649*

- of courses and flexures of ridges in central Pennsylvania, 729, 731* - of Mt. St. Elias region, 239*

- of Tahitian Islands, 36 *

- of Tahiti, 180

- of United States, 412*, 799

- of Wasateh Mts. and Utah, $360 *$

- of tıe world, on Mercator's projection, $17 \S, 47 *$

-, physiographic, of the world, 46 , $47 *, 350$

- of Yellowstone Park, 306*

Maple, 837, 859, 879

Marble, 76, 79*, 131

Marble Cañon, 186, 187*, 362, $363 *$

Mareasite, $70 \S, 123,125,126, .258$, $331,342,663$

Marcellus epoch, 410, 576; shale, $576,593 \S$

Marcy, Mt., 452

Mareniscan, 446

Margaric acid, 124

Margarita Nebrascensis, 841*, 855; striata, 984 ; varicosa, 984

Margaritana margaritifera, 950

Margarite, 320

Margaritella, 916

Margaritina confragosa, 966

Marginella, 917

Mariacrinus, 577

Mariposa region, $748,760,837$

Marl, 68§, 79§; Tertiary, 820, 854

Marlstone, 411, 775

Marly clay, $81 \S$

Marlyte, 552, 553

Marmot, 156

Marquesas Islands, 297, 350 ; map of, $36^{*}, 38$

Marquette iron region, 445, 446, 450

Marquettian, 446 
Mars, density of, 16 ; oblique feature-lines on, $395,396 \%$

Marsh gas, 124, 523

Marsh ore, $71 \S, 344,455$. See also Bog ore

Marshall group (grit and sandstone), 638

Marshall Islands, 395

Marsilea, 718 ; quadrifolia, $436 *$

Marsileace 2,519

Marsipobranchs, $418 \S$

Marsupials, 53, 54, 55, 415§. See Mammals

Marsupiocrinus cælatus, 567

Martha's Vineyard, Cretaceous of, $822,837,838$; Tertiary of, 881 , 891: upturning of beds, 934,1022

Maryland, mean height of, 23 ; Cambrian in, 465, 466, 467

Mascarene Islands, 737

Kassachusetts, 23 (height), 85, 453, 496 ; coal-beds, 634, 646, 657; iron ore beds, 127 ; kaolin beds 134 ; marbles, 524, 530, 581 ; Cambrian in, $310,466,467,471,475$; Taconic, 491, 517, 524, 528, 530, 531 ; Treaton, 495 ; Triassic, 740 , $741,742,750,753,800,802$

- Bay, 444, 461, 536

Massawipi Lake, 558

Massillon coal, 657

Massive limestone, 76, 78§; quartz yte, $82 \S$; rocks, $76,78 \S$; structure, 928

Mastodon, 919, 927, 1000, 1011 Americanus, 998*; Arvernensis 927; angustidens, 927 ; Borsoni 927 ; Floridanus, 1001 ; longirostris, 927 ; mirificus, 911, 912 ; proavus, 911 ; tapiroides, 927

Mastodons, 141, 402, 911 (first), 924 925

Mastodonsaurus giganteus, 772* Jægeri, 774

Mastogloia, 164*, 165

Matheria variabilis, $478 *$

Matinal of Rogers, 490, 494, 728

Matterhorn, 189, 237

Matthows' Landing clays, 885,888

Mauch Chunk group, 410, 634, 636, 644,728

Maudunian group, 925

Maui, 150,$172 ; \operatorname{map}$ of, $179^{*}, 182$; cone of, 270

Maumee River, 947

Mauritius, volcanoes of, 277,296 , 1019

Mauvaises terres, 894

May-fly, 419, 600

May Hill sandstone, 518, 563, 566, 569

Mayencian group, 926

Mazonia Acadica, 691; Woodiana, 691

Mazzalina pyrula, 916

Meadville group, 638

Medina epoch, 535, 570

-. saradstone, 538,542

Mediterlanean Cretaceous basin $857,859,872,873$; earthquakes of, 374 ; region, $769,791,793,861$

- Sea, 20, 21, 22, 34, 45 ; tempera- ture of, 49 ; salinity of, 121 ; volcanoes of, 295

Medlicottia Copei, 685*, 686

Medusæ, 55, 418, 419, 429*, 430ई. $479,480,482$

Medusites, 482

Meekella Shumardana, 685 ; striatocostata, 690

Meekoceras aplanatum, 757

Megadactylus, 753 ; polyzelus, 753

Megalaspis, 521

Megalichthys, 621, 692, 702

Megalocnus rodens, 1001

Megalodon triqueter, 774

Megalomus Canadensis, 548*, 551

Megalonyx, 912, 919, 1000, 1001, 1003 ; Jeffersonit, $1000,1001 *$ : Leidyi, 1001

Megalopteris, 689 ; fasciculata, 645

Megalosaurs, 786, 828

Megalosaurus, 765, 766, 790 ; Bredai, 864 ; Bucklandi, 785 (time range); Dunkeri, 863

Megambonia, 562

Megaphyton, 699 ; McLayi, 669*, 689 ; protuberans, 645

Megaptera longimana, 983

Megathentomum, 679 ; pustulatum, 691

Megatheridæ, 1000

Megatherium, 1000, 1002, 1004; Cuvieri, 1002* ; mirabile, 1000

Megistocrinus, 590, 602

Meionite, 658

Meizoseismic curve, $375 \$$

Melania costata, 926 ; fasciata, 926 ; inguinata, 925 ; turritissima, 926

Melantho subsolida, 966

Melaphyre, $87 \S$

Meleagris altus, 1002 ; celer, 1002

Melocrinus, 550, 562, 577 ; Clarki, 621 ; nobilissimus, 560

Melongena crassicornuta, 916

Melonites multiporus, $641^{*}, 646$

Melosira distans, $168,164 *$; granulata, 163, 164*; decussata, 163, $164 \%$; Marchica, 163, 164*; sulcata, $437 *, 894^{*}$

Melville Island, 659, 689

Memphremagog (Lake), 531, 580, 591,630

Menaccanite, 708

Menacodon rarus, $767 \%$

Menchik off Island, 145*, 150

Mendip Hills, 695

Mendoza earthquake, 349

Menevian group, 481

Menilite, 920

Meniscoēssus conquistus, 852

Meniscotherium, 917

Meniscus limestone, 543,550

Menobranchus lateralis, 682

Menocephalus, 503

Menominee, 446

Menurids, 54

Merced group, 884, 892

Mercer coal-beds, 656

Mercian, 681, 738

Mercury, density of planet, 16

Mercury mines of California, 335

Meretrix, 916

Meridian series, 728
Merista, 642 ; plebeia, 625,628

Meristella, 562, 579, 642 ; angustifrons, 567; didyma, 567; lrevis, $560 *$, 562; nasuta, 590, 591, 592; subundata, 520; sulcata, 557 , $560 *$; tumida, 568

Meristina nitida, $548 *, 551$

Merjelen (Lake), 238

Merocrinus, 516 ; typus, 514

Merosthenic, $717 \S, 796,870,871$

Merychyus, 919

Merycochcerus, 918, 919

Merycopotamus, 927

Mesa, $185 \S, 186^{*}, 300$

Mesabi Range, 446

Mesalia Claibornensis, $897 *, 916$; obruta, 916 ; vetusta, 916

Mesnard, 446

Mesodectes, 918

Mesoderonian, $576 \S$

Mesodon albolabris, 966 ; diastematicus, 836 ; Dumblei, 836 ; profundus, 966

Mesohippus, 908, 912, 913*, 918

Mesonacis Vermontana, 473*

Mesonyx, 918

Mesoreodon, 918

Mesosaurus, 706 ; tumidus, 687 , 658 *

Mesothyra Neptuni, 600; Oceani, $600,615^{*}$

Mesozoic time, 738

Messinian group, 927

Metacoceras cavatiforme, 690 ; dubium, 691 ; Hayi, 691 ; inconspicuum, 691; Walcotti, 691

Metadiabase, $86 \S$

Metadoxides, 482

Metagene, $880 \$$

Metalophodon, 918

Metals heavier than iron not eruptive, 376 ; native, 331,332

Metamolphic rocks, $76 \S, 82$

- - and igneous, relations of, 326 , 327

Metamorphism, 309 ; dynamical, began in the Archæozoic era, 441 ; heat in, 311, 321-826; local, 311 , 312-314: metachemic, 314\$, 318321 ; moisture in, 311-312; paramorphic, 314\$, 317-318; regional, $311,313,314-315$; statical, began in the Lithic era, 440; without heat, 327

- in Archæan, 448, 450,451, 458

Metamynodon, 918

Metapedia Lake, 533

Metasomatic metamorphism, $314 \S$

Meteoric stones, 11, 376

Meteorites, 376, 486

Metia Island, 133, 151 (height), 350

Metoptoma, 482, 514, 516; alta, 501. dubia, 503

Meudon chalk, 866 ; marls, 925

Meuse, ratio of sediment to water, 190

Mexico, 25, 26; snow-line in, 234 ; volcanoes, 296, 937; mines of, 338,340 ; height of Cretaceous beds, 933 ; Archæan in, 444 ; Carboniferous, 537, 569; Permian, 659 ; Triassic, 739, 747, 755; 
Jurassic, 749 ; Cretaceous, 361 , $813 *, 814,817,818,820,824,834$, $836,874^{*}$; Tertiary, $880,885,888$, 894

Miacis, 918

Miamia Bronsoni, 679*, 691

Miarolyte, 83

Miascyte, $85 \S$

Mica, 655,81

- dioryte, $86 \S$

- schist, $83 \$$

- syenyte, $83 \$$; trachyte, $84 \$$

Michelinia, 562, 597, 640 ; stylopora, 601

Michigan, mean height of, 23 ; salt group, 638

-, Archæan in, 442, 445, 446, 449*, 450,454 ; Carabrian in, 464, 465*, $46 s$

Michigan Bay, 628, 633

Michigan, Lake, 200, 201*, 202, 540, 635 ; fiords of, 947,948 ; glacier of, 968

Michipicoten Island, 445, 488

Mieraster, 860 ; brevis, 866 ; coranguinum, $\mathrm{S} 66$; cor-bovis, 866 ; glyphus, 866 ; tercensis, 866

Microbes. See Bacteria

Microblattina, 691

Microchærus erinaceus, 926

Microclænodon, 917

Microcline, $64 \S, 83,85,129,321$

- granite, 83

Mierococcus nitrificans, 137

Microcœlus, 867

Microconodon tenuirostris, $754^{*}$

Mierodiscus, 473, 481; speciosus, $473 *$

Microdon, 621; bellistriatus, 598*, 602

Miero-granitic rocks, $77 \S$

Microlestes, 774 , 789; antiquus, 773*; Moorel, 773

Microlites, $77 \&, 266,273,288 *, 449$

Microscopic texture, $76 \S$

Microspongia, 515

Microsyops, 918

Midford sands, 775

Midway epoch, $884,885,888,896^{*}$, 915

Migrations forced by glacial conditions, 945 ; Arctic, between America and Europe or A sia, 946, 950 Mill Creek beds (group), 840, 872

Millepeds, 419, 723

Millepores, 72, 130, 142, $431 \S$

Millerite, 637

Mrllstone grit, 80, 410

Millstones, 82

Milo Island, volcanoes, 296

Minas Basin, N.S., 350, 741

Mineral charcoal. 662

- oil and gas, $62,74,80,124,138$; from the Trenton limestone, 522 523 ; from Salina group, 554 ; from the Devonian, 606 ; map of areas in Pennsylvania, 730*

- springs, 119, 128, 320 ; analyses, 121

Minerals, 63 ; making of, $317,318,323$

Mines, temperature in, 257,258

Minette, $83 \S$
Mingan Islands, 492, 498, 497, 500, 501,503

Minnesota, height of, 23 ; rainfall, 944; Archran in, 446, 448*; Cambrian, 468, 469, 478, 484; Cal ciferous, 491, 493; Trenton, 494; Niagara, 540; Subcarboniferous, 634 ; Glacial, 945, 968

Minnesota River, 947

Minyros Island, 296 (volcanoes)

Miocene lake basins, 882,933

- period, $880 \S, 881 *$, 883 ; lacustrine, 893-895

Miohippus, 911, 912, 913*, 918, 919 ; annectens, 894

Miohippus beds, 886,894

Miolophus, 925

Mispec conglomerate and slate, 594

Mississaga River, 445

Mississippi, mean height of the state, 23; Cambrian in, 466 ; Subcarboniferous, 638, 648; Carbonic, 635; Cretaceous, 638, 819 . $823,845,854,888$; Tertiary, 884 ; Glacial, 945

- River, 24, 29, 30, 31; piteh and amount of discharge, 173,190 delta of, 197; headwaters in the Glacial period, 947, 948, 964; Southwest Pass of 198

Mississippian period, 632

Missouri, mean height of, 23 ; iror mountains, 444, 449 ; lead mines, $134,342,522$

- River, 29 ; discharge and pitch, 173; headwaters in the Saskatchewan during the Glacial period, 964

—, region of Upper, 829, 841, 844, 855,893

Mitchell, Mt., 27

Mites, $420 \S$

Mitoclema cinetosum, 503

Mitra, 916, 922 ; cellulifera, 916 ; conquisita, 916 ; scabra, 926

Mixodectes, 917

Moa, 1014

Modiola, 525, 757, 916, 917 ; Branneri, 836 ; minima, 774 ; plicatula, 994; Shawneensis, 690 ; Wyom ingensis, 690

Modioloides priscus, 472*

Modiolopsis, 481, 516, 520; complanata, 567; dubia, 558; faba, 514; modiolaris, 511*; orthonota, $544 *, 549$; primigenia, $544 * 549$; subalata, 551 ; superba, 514

Modiomorpha, 602, 621

Modulus compactus, 917

Mohawk River, analysis of water of, 121

Moisture in rocks, 122, 205, 278, $311-312,315,324,325,334,354$, 802

Mokkatam, 160*

Molasse, 920, 921 ; Lignitic, 926 ; Lower, 926 ; Red, 926

Molds, $436 \S$

Mole, 158, 927

Molgophis, 692; macrurus, 682, 692

Molluscoids, 140, 419, 423, 425, 526

Mollusks, 55, 59, 72, 423
Molokai, 292

Moluccas, 921

Molybdate, 340

Mona Series, 440

Monads, 419

Monazite, 85, 455

Mongolia, 32, 38, 34

Monkeys, 54, 55, 402, 924, 930

Mono Lake, 26, 132*, 133*, 276, 296, 384

Monoclines, 102§*, 109, 110*

Monoclonius, 847

Monodon, 690

Monomyaries, 525

Monongahela River series, 651

Monopleura marcida, 836 ; pinguiscula, 836

Monoprionidæ, $498 * \S$

Monopteria, 690

Monotis, 756, 759; Alberti, 774; curta, $758 *$; decussata, 774 ; Halli, 685 ; salinaria, 757 ; septentrionalis, 792 ; speluncaria, 685 ; subcireularis, 757,758 ; variabilis, 685

Monotis bed, 757

Monotremes, 58, 54, 415, 789, 852, $853^{*}, 917$

Monroe County, Pa., Prosser's section of, 594, 606

Monson, Mass., quarry, 373

Mont Blanc. See Blane

Montalban, 446

Montana, mean height of, 23 ; Cambrian in, 476,477 ; Subcarboniferous, 639; Carboniferous, 658 ; Triassic, 746; Jurassic, 748: Cretaceous, Lower, 818,820 ; Upper, 825, 826, 828; Tertiary. 894, 918

Montauk Point, 224

Monte Rosa. See Rosa

Montebello sandstone, 594

Monterey beds, 888

Monticulipora, 505, 511, 516, 524, 545*, 561; adhærens, 503 ; favulosa, 520 ; fibrosa, 503 ; frondosa, 520 ; lycoperdon, 524 ; patula, 503

Montlivaltia, $760,777,778$ (number of British); Atlantica, 854; caryophyllata, $777 *$

Montmartre Gypsum beds (gypsiferous marls), 923, 924, 926

Montmorenci, fault at, $527^{*}$

Montrose shales, 606

Monument Park, 185, 186*

Monzonyte, $85 \$$

Moon, surface of, 11; density of, 16

Moosehead Lake, 577

Moravia, Cretaceous in, 838 ; Per. mian, 698

Morea cancellaria, 854 ; naticella, 854

Moreau River, \$56

Mormolucoides articulatus, 750 *

Morocco, 33, 920

Morosaurus, 768, 786, 836 ; Becklesii, 863; grandis, 763*

Morris (Mt.), 605

Mortar, 798

Mortonia Rogersi, 895*

Mortoniceras, 855; Delawarense, 854 ; Leonense, 837 ; Shoshonense, 855 ; Texanum, 855 
Morven, 867

Mosasaurids, Cretaceous, 870 ; Cretaceous (Lower), 864 (first) ; Cretaceous (Upper), 826. 845, 847, 848 (number in Kansas), 848*, $849 *$

Mosasaurs, Cretaceous, 816,826 , 867,870

Mosasaurus, 848 ; Camperi, 864*, 866; Dekayi, 848 ; major, 848 ; princeps, $848,849 *$

Moschus, 927

Moscow shale, 593

Moss-animals, $427 \S$

Mosses, 53, 153, 154, 434, 436§, 677 ; ash, 74, 75

Mother liquor, 1208

Moths, 419

Mount Desert, 218, 219*, 444

Mountain, $24 \S$; chain, $24 \S, 389 \S$, 390

Mountain chains, composite character of, 28*; mostly on the borders of continents, 392

- limestone, 681, 632, 634, 695

- mass, 26, 27

- range, $24 \$, 389 \$, 390$; relations of, to denudation, 387-388

- slopes, 26, 27; angle of, 27, 28

- system, 24§, $389 \S, 390$

Mountain-making, 345

- Archæan, 451-452; at close of Eopaleozoic, 526 ; post-Paleozoic, 358, 729 ; post-Triassic, 357, 798; post-Jurassic, 809 ; post-Mesozoic, 359, 874; Tertiary, 367, 369, 932,940

Mountains of circumdenudation, $345 \$$; of igneous accumulation, 3458; of subterranean igneous accumulation, $345 \$$

Mouse, 53, 797

Muck, 1548

Mud, 768 . See also Earth (soil)

Mud-cracks, 94*\&, 95, 140, 223, 260 $327,334,464,554,603,605,742$, 745

- lumps, 197 \%, 198

- volcanoes, 305

Muir Glacier, 238, 244, 251

- Inlet, 288

Mull, 867, 938

Mullet family, 843

Multiplicate species and structure, 421ई, 438, 489; in Cambrian 486 ; in Paleozoic, $720,723,725$; in Jura-Trias, 795-796; in Cretaceous, 870; in Tertiary, 912

Multituberculates, 917

Murchisonia anoulata, 567 ; Anna, 500 ; articulata. 567 ; bellicincta, $500,507 *, 514,520$; bivittata, 551 ; corallii, 567; extenuata, 558; gracilis, 514, 520; macrospira, 55 1; major, 515; Milleri, 507*, 514, 516; minima, 690; minuta, 558: tricarinata, 514; turbinata, 601

Murchisonian, 535 (Upper Silurian synonymy)

Murchisonite, 321
Murex Alabamiensis, 915 ; simplex, 916

Muriatic acid, 68

Muschelkalk, 411, 769, 770, 771

Muscovite, $65 \S, 88,318,321$; gneiss, 83 ; granite, 82

Muscovite-and-biotite granites, 82

Muscovite-biotite gneiss, 83

Muscovy glass, 65

Musophyllum complicatum, 889

Mussel, 428

Mustakh Range, 240

Mustela, 927

Mya, 425\$; arenaria, 917, 983, 984 ; truncata, $917,983,984,995$

Myacites, 757, 760 ; Liassinus, 791 ; subcompressa, 760

Myalina angulata, 647 ; concentrica, 647; Halli, 685; perattenuata 685*, 690; Permiana, 685 ; recta 685; recurvirostris, 690 ; squamosa, 707

Mylacris, 691

Myliobatis, 643 ; Edwardsi, 926

Mylodon, 1000, 1001; Harlani, 1000 , 1001

Myocaris lutsaria, 521

Myophoria, 756, 759; alta, 757; costata, 773; Goldfussi, 774 ; lineata, $760,770,771 *$; orbicularis, 773 ; vùlgaris, 773,774

Myriapods, 418,419\$; derivation of, 728-724; Upper Silurian, 574 Devonian, 575, 625, 721; Paleozoic, 721; Carboniferous, 657 , 674: Tertiary, 922

Myrica, 831

Myrmecobius, 755\$; fasciatus, 755*

Myrsine, 837 ; borealis, $838 *$

Myrtaceæ, 922

Myrtle, 859, 921

Mysops, 918

Mystriosaurs, 787

Mystriosaurus Tiedemanni, 786*

Mytilarca, 562, 621

Mytiloconcha incurva, 917

Mytílus, 129, 525, 916; Carteroni, 867 ; edulis, 984 ; Shawneensis, 690 ; simplex, 867

\section{Nædoceras, 59 91}

Naiadites carbonarius, 690

Naked Mollusks, 424

Namur dolomite, 696

Nanafalia beds, 888

Nanaimo beds, 831

Nanawale, 285

Nanomeryx, 918

Nanosaurus agilis, $765 *$; Rex, 765

Nantucket, 43, 210, 944 (Glacial), 983,1022

Naphtha. See Petroleum

Naples, earthquake of 1857,375

Naples group, 603, 605, 614, 620

Napoleon group, 638

Nalragansett Bay, 444, 536, 633, 949

Nashville group, 489,494

Nasopus caudatus, $684 *$

Nassa, 916; Dalli, 916; scalata, 916

Natica, 707, 780, 916, 922 ; abyssina,
854 ; clansa. 953, 984, 995; Mississippiensis, 916; pedernalis, 836; permunda, 916 ; recurva, 916

Naticella costata, 773

Naticina, 916

Naticopsis, 690

Natrolite, 68

Nauplius, 420\$, 721

Nautiloid8, 676*, 690, 727; culmina tion in Carboniferous, 675

Nautilus, 59, 424\&, 425*, 501, 614, $685,700,707,727,774,843,861$ 869,922 ; bidorsatus, 773 ; buccinum, 602 ; centralis, 925 ; Danicus, 866 ; Dekayi, $842 *, 854,855$; divisus, 691; eccentricus, 685 ; elegans, 837, 855; ferox, 501; Forbesanus, 690 ; imaperialis, 925 ; Jurensis, 790; Konincki, 700\%; Liardensis, 758; Nordenskiöldi, 792 ; Permianus, 685 ; pomponius, 501 ; semistriatus, 791 ; Sibyllæ, 758 ; spectabilis, 642

Navarro beds, 824

Navesink group, 821

Navicula, 894*; amphioxys, 163 164* : bacillum, $163,164 *$; serians, 164*, 165; semen, 164*, 165

Navigators Islands. See Samoan

Neæra, 916

Nebraska, 23 (height); Carboniferous in, 674, 690, 691; Permian, 660: Cretaceous, 826; Tertiary, $882,893,919,933,935$ (elevation)

Nebraska lacustrine beds, 919, 933

Necrogammarus Salweyi, 565

Necrolewur, 926

Negaunee, 446

Neithea grandicostata, 837; Mortoni, 867; quinquecostata, 854, 855

Nelumbium tenuifolium, 839

Nelson River, 947

Nematophyton, 564. 582, 590 ; Logani, 582*

Nemodon Vancouverensis, 837

Neobolus beds, 488

Neocene, $880 \$, 883$

Neocomian epoch, 815, 831, 857

Neodevonian, $576 \S$

Neogene, 8808

Neolithic period, 1013

Neomylacris, 691

Neopaleozoic time, 460,535

Neoplagianlax, 917, 925

Neozoic, $880 \$$

Nepheline-basalt, $88 \$$; dolery te, $87 \S$

Nephelinyte, $87 \$$

Nephelite, $65 \$$; rocks, $81,84,85$; artificial formation of, 274 ; changes of, 320 ; in Archæan rocks, 449 453

Nephriticeras, 602 ; maximum, 599

Nephroma arcticum, 946

Neptunea constricta, 915; enterogramma, 916 ; Matthewsensis, 915 Nerinea, 781, 820, 834, 861: acus, 836 ; Austinensis, 836; bisulcata, 861*, 866, 867 ; cultrispira, 836 ; Defrancii, 790 ; depressa, 791 ; dispar, 837; Favrei, 865; gigantea, 865 ; Gooduallii, 780*; Meri- 
ani, 865 ; subula, 836 ; Texana, 835*; trinodosa, 791

Nerinean beds, 791

Neriopteris, 689

Nerita, 916 ; deformis, 837

Neritina, 854; coneava, 926

Nesodon, 927

Nesquehoning, $\mathrm{Pa} ., 649,650$

Netherland coast, 378

Netherlands, Triassic in, 768

Neuropteris, 565, 639, 671, 685, 699, 704 ; angustifolia, 689 ; auriculata, 692,704 ; biformis, 645 ; capitata, 615, 689; cordata, 689, 692, 704; Dawsoni, 622 ; fimbriata, 689 ; flexuosa, 692, 704; Germari, 689 ; hirsuta, $671^{*}, 689,692,693$; inflata, 689 ; Loschii, 671*, 689, 704, $705^{*} ;$ polymorpha, 595*, 622; tenuifolia, 671*, 689

Neuropteroids, Paleozoic, 721 ; Carboniferous, $677,679 *, 691,702$

Neuropters, 141, 419, 600, 750, 771, 794, 900 (number of Florissant)

Nevada, mean height of, 23 ; siliceous deposits in, 152 ; minerals made at Steamboat Springs in, 323, 334; mines, 338, 339, 340, $341 *$

-, Archæan in, 447 ; Cambrian, 464, $469,470,478,474,477,478,484$; Lower Silurian, 495, 516; Niagara, 541; Deronian, 581, 589-590, 592, 606; Carboniferous, 658, 659, 674; Triassic, 747, 757, 758; Jurassic, 749, 759, 760; Tertiary, $882,886,893,895,937$ (eruptions); post-Paleozoic upturnings, 733

Nevadyte, $84 \S$

Névé, 2338

Neverita, 916

New Brunswick, upturnings in, $527,533,630,732$

-, Archæan in, 444; Cambrian, $446,466,467,474,475,476,521$; Lower Silurian, 493 ; Upper Silurian in, 541, 558; Devonian, 578, 593,621 ; insects of, 600 ; fishes of, 587,617 ; plants of St. John, 594; Subcarboniferous, 639; plants, 645 ; albertite of, 661 ; Carboniferous, 658, 692

New Caledonia, 23, 36*, 38, 145, 148, 737, 937

New England, marbles of, 524; Chazy in, 491; Corniferous, 580 ; Glacial, 949 ; Niagara, 541 ; Paleozoic, 714 ; 'Taconic, 490, 491, 495, 527; Triassic, 740; Upper Silurian, $538,571,572$

New Guinea, 19, 22, 38; volcanoes of, 296

New Hampshire, 23 (height), 87, 317, 332 ; Archæan in, 446 ; Cambrian, 466; Upper Silurian, 531; Niagara, 541, 544, 551; Lower Tielderberg, 544

New Haven, Conn., trap dikes of, $299,800 *$, $804 *$; kettle holes, 993 ; depth of harbor, $226 *$

New Hebrides, 35\%, 36, 38, 296 (volcanoes)
New Ireland, 36, 38, 39

New Jersey, mean height of, 23 ; coast of, 162, 224; Highlands of, 530 ; marl-beds, 822 ; clay-beds, 822 ; subsidence, 350,378

New Jersey Gavial, 848

New Mexico, 23 (height), 29, 340 (mines), 363, 364, 747; Archæan in, 444, 449; Lower Silurian, 495; Carboniferous, 674, 690 ; Permian, 660, 688; Triassic, $746,755,756$, 758 ; Jurassic, 747; Cretaceous, $813^{*}, 817,826,828,829$; 'Tertiary, $882,885,893,902$; igneous eruptions during, 937; Glacial, 945

New Red sandstone, 400, 623, 697, 740

\section{New River, 200}

New York, mean height of state, 23 ; iron ore beds, $127,326,449^{*}$, 450 ; lead mines, 542 ; marbles, 524 ; sulphur springs, 554

New York Bay, 211*, 224, 225, 230, 444, 592

New Zealand, 22, 36, 37, 221; volcanoes of, 296 ; connection with Australia, 737, 798, 1019 ; geysers of, 82,305 ; glaciers of, 242 ; U pper Silurian in, 564; Triassic, 698, 737, 770 ; Jurassic, 776 ; Cretaceous, 857 (coal); Tertiary, 923, 937; Quaternary, 1019

- chain of islands, $37,39,374$

Newark group, 740

Newberria Condoni, 579

Newburg, 357

Neweastle coal, 401

Newfoundland, 17, 41, 48, 232, 252 . $389,424,461,536,537,552,634$ (coal-beds), 737, 793, 944, 948 (fiords); Archæan in, 443, 444, 446, 447 ; Paleozoic, 461 ; Cambrian, 464, 465, 466, 467, 473,475 , 476, 496; Calciferous, 492, 496, 500, 501; Chazy, 503; Upper Silurian, 536, 571; Carbonic, 633, 635; Glacial, 944, 948

-Banks, 882

Niagara period, 538

Niagara River and Falls, 539, 540* (section), 542, 553, 580 ; obstructed by drift, $972 *$; age of, 1023

Nicaragua, Carboniferous in, 659

Nickel, 70,342

Nicola Lake, 746

Niger River, 30

Niihau. 37

Nile, 30, 172, 173 (slope), 177 (Hloods), 190 (silt), 417

Nileus, 508; affinis, 573 ; armadillo, 573 ; macrops, 573 ; scrutatus, 573

Nimravas, 918

Ninafou eruption, 374

Nineveh coal-bed, 651

Niobium, 449

Niobrara group, 815,825

- River, 886

Nipa, 921

Niso, 916

Nitrates, 63§, 137, 138, 191

Nitric acid, 63, 124

Nitrification, 137§
Nitrogen, 61, 118, 136, 153; from voleanoes, 293

Nitrous acid, 124, 137

Nitschea curvula, 699

Nobby Island, N. S. W., trap dike of, 313

Nodosaria Texana, 887; vulgaris, $432 \%$

Nodules, 73 (phosphatic), 97

Norfolk and Suffolk cliffs, 219

Norian, 446

Noric (Upper), 757

Normandy, 518

Normanskill Graptolites, 516 ; shales, 515

North Cape, 521

North Carolina, 85, 281, 358, 946 ; mean height of, 23 ; cuast, 224*; iron ores, 449

Norway, $19,33,41,85,87$; snowline in, 284; Archæan in, 453; Cambrian, 482, 518; Lower Silurian, 518; Upper Silurian, 563, 568,569

Norwich Crag, 927

Noryte, $86 \S, 87,532$

Nostoc calidarium, 60

Notharctus, 918

Nothodon, 688

Nothosaurus, $773 \S$

Notidanus primigenius, 416*, 901*

Notochord, $414 \S$

Notornis, 1014

Nototherium Mitchelli, 1006

Nova Scotia, 41 ; subsidence, 350 ; cral-beds, 634, 639 ; uplifts, 527, 533,630

- Archæan in, 444; Cambrian, 466; Lower Silurian (close of), 527, 533; Úpper Silurian, 537, 541, 558, 563, 573; Devonian, 578, 593 ; Subcarboniferous, 639 ; Carboniferous, 653, 654*; Permian, $658,660,708$; Triassic, 740 ; postPaleozoic upturnings in, 732

Nova Zembla, 48, 776

Novaculite, $80 \S$

Nueleocrinus, 597 ; Verneuili, 585*, 590

Nucleospira concinna, 592; pisiformis, 551 ; pisum, 567

Nucula, 525, 602, 621, 757, 780, 792 ; lirata, 601; nasuta, 647; percrassa, 854; Shaleri, 917; Shumådana, 647 ; tenuis, 984

Nuculana bellistriata, 690

Nuculites, 621

Nudibranchs, $424 \S$

Nullipores, 72, 140, 147, 156, 437

Nummulites, 438s, 896 ; Eocene, $347,920,922 *$

Numuulites levigatus, 926 ; nummularius, $432 *, 922 *$; radiatus, 926 ; variolarius, 926

Nummulitic epoch, $880 \$$; upturning at close of, 932,936

Numuku, 150

Nunataks, 240\$: 241*, 249*; plants of, 945

Nunda group, 605

Nyctilestes, 918

Nyssa, 896, 921 ; lanceolata, 839 
Oahu, 150, 163, 179, 271*, 282; map of, 292

Obi-Irtish River, 30

Obolella, 425§, 481, 486, 496 ; crassa, 471*; plicata, 520; polita, 478*

Obolus, 72, 78 (composition of shell), 425§, 482, 521; Apollinis, $427^{*}$; Davidsoni, 567 ; Labradoricus, 480

Obsidian, $64,84 \S$

-Cliff, 264*, 276, 337*

Occident, 21, 22

Ocean, abyssal depths of, 229 ; amount of salts in, 120,121 ; silicates made at the bottom, 136 ; the great mineral spring, 120, 320

- as a mechanical agent, 209 ; earthquake waves, 213 ; abyssal work, 229

Oceanic currents, $42,43,46 *$

- era, 440 ; islands, $20,22,23$; life not easily exterminated, 142

Oceans, arrangement of, 17 ; depth, $18,19 \S, 380$

Ocoee group, 468

Octopods, 424

Oculina arbuscula, analysis of, 72

Ocydromus Australis, 1019

Odontaspis, 863

Odontidium, 163, 164*, 165 ; pinnulatum, 89**

Odontocephalus, 591

Odontocetus, 927

Odontopolys compsorhytis, 916

Odontopteris, 637, 671, 685, 693, 699 ; obtusiloba, 704 ; Schlotheimi, $670 *$, 689 ; sphenopteroides, 689

Odontopteryx, $923 \S$

CEningen, fossils at, 921, 922, 926

Oesel zones, 568

Ogden, Utah, 360*, 361; Cañon, 581 ; quartzyte, 580, 581

Ogygia, 482, 520, 521; Buchii, 520

Ohio, mean height of, 23 ; mineral oil and gas, 522, 523, 554, 607, 608, 609

Ohio River, filled by drift, 965

Ohio shales, $603,606,615$

Ohiocrinus, 516

Oil. See Mineral eil

Oil-creek group, 638

Oil-sand, 607

Okhotsk Sea, 927

Oklahoma, 836 ; mean height of, 23

Üland, 521

Olcostephanus Astierianus, 865; Speetonensis, 865 ; Traskii, 837

Oldhamia, 482 ; antiqua, 481*; radiata, $481^{*}$

Olean conglomerate, 647

Olefiant gas, 523

Oleic acid, 124

Olenellus, 467, 473*, 479, 481, 482 ; asaphoides, 473; Callavei, 481; Gilberti, 473, 474*; Kjerulfi, 482; Thompsoni, 478*; Vermontanus, $473 \%$

Olenellus zone, 464, 482

Olenoides, 482; Fordi, 473*

Olenopsis, 482
Olenus, 481, 482, 483; micrurus, 481*

Olenus schists, 482

Oligobunis, 918

Oligocarpia, 699, 756; Gutbieri. 699 ; robustior, $749 *$

Oligocene, $880 \S, 886,918,920,921$, 926

Oligoclase, $64 * \S$; gneiss and granite, 83

Oligoporus nobilis, $641 *, 646$

Oliva, 922; Mississippiensis, 916

Olivella, 916

Olivine. See Chrysolite

Omnivores, 930

Omosaurus armatus, 787

Omphacyte, 88\$

Omphyma, 567; turbinata, 564*, 567

Onchidium, $424 \S$

Onchus, 546, 565, 626 ; Clintoni, 546, 550 : Deweyi, 550 ; tenuistriatus, $566 *$

Oncoceras, 551, 561; gibbosum, 549 ; ovoides, 558, 562

Oneida conglomerate, 588

Oneonta sandstone, $603,606,612$, 618,621

Oniscia harpuia, 916

Oniseus, 509, 783

Onoclea sensibilis, 840,922

Onondaga beds, sections of, 552 , $553 *$

- Lake, 553

- limestone, 576, 581

- period, 408, 410, 535, 552-558, 570, 572

- salt group, 552

Ontarian, 446

Ontario, salt group in, 552

Ontario (Lake), 200, 201*, 494, 533, 946, 947 (depth)

Onychodus, 417; sigmoides, 589*

Onyx, 133

Oölitic, 82 ; limestones, 79

Ooblyte, $79 \S, 96 \S$

-, Bath, 775, 777, 790; Corallian, 790 ; Great, $775,777,779,790$; Oxford, 775, 790

Oölytic epoch, 738, 775

Opal, 62§, 64§, 135

Operculates, 54

Ophiacodon grandis, 688

Ophiderpeton, 706; Brownriggii, 704

Ophileta, 495, 499*, 515, 520; compacta, 500,520 ; complanata, $499 *$; levata, 499*; Owenana, 514; primordialis, $478^{*}$; uniangulata, $499^{*}$

Ophiolyte, $79,89 \S$

Ophiurans, 55

Ophiuroids, $429 \S$, 505*, 646

Ophyte, $86 \S$

Opossum, 415, 902, 910, 924, 926

Oppelia, 794

Oquirrh Mts., 340, 469

Oracanthus Milleri, 702

Oracodon conulus, 853*

Orang-outang, 54

Orange, N.J., columnar basalt, $262 *$

- Bay, 858

- sand group, 891, 965

Orbieula, 482
Orbicular dioryte, $87 \$, 97 *$

Orbiculoidea, 514, 612 ; Lodensis, $612 *, 620$; minuta, 592, 602 ; rugata, 567; tenuilamellata, 562; Vanuxemi, 557

Orbitoides, 433§, 896; Mantelli, 896, 898*

Orbitoides limestone, 896

Orbitolites, $433 \S$

Orbitulina conoidea, 865 ; discoidea, $\varsigma 65$

Orbitulites Texanus, $834 *, 836$

Orbulina universa, $432 *$

Orca, 144

Orchestia, 420*

Orchids, 435

Ordovician, 489

Ore, ores, $327,345,810$; origin of, 342,343

Oregon, 23, 25; glaciers of, 240 ; igneous action in, $265,266,280$; volcanoes of, 296; Cretaceous in, 818,830 ; Tertiary, 882, 885, 892; John Day beds of, 911; sandstone veins, 34

Oreodon, 907, 918; gracilis, 910*

Oreodon beds, 886, 894, 910, 918

Oreodoxites plicatus, $8: 39$

Oreti series, 770

Organic acids, 665

- contributions to rock-making.

See Rocks, organic constituents of

- nature, essential elements of, 9 , 413

- remains, 71§

Orient, 21,22

Orinoco Piver, 30,456

Oriskany period, 577

- sandstone, 577,578

Orizaba (Mt.), height of, 937

Ormoceras, 501; crepriseptum, 516 ; teauifilum, 514

Ormoxylon Erianum, 622

Ornithomimus, 847, 856; velox, $847 *$

Ornithopoda, 761, 764, 786, 845, 863

Ornithorhynchus, 415, 795

Ornithostoma, 863

Orodus, 644, 692, 702 ; mammillaris, $644^{*}, 647$

Orogenie work, 345, 376§, 391

- movements, Tertiary, of Long Island and Martha's Vineyard, 1021*. See further, Mountainmaking

Orohippus, 905, 912, 913*, 918; agilis, 905*

Oromeryx, 918

Orthacanthus, 687 ; arcuatus, 692

Orthaulax Gabbi, 899*, 917 ; pugnax, 916

Orthaulax bed, 891

Orthids, 719 (time range); Upper Silurian, 574

Orthis, $310,425 \S, 426 \S, 481,482,516$, $517,521,550,561,562,568,579$, 622, 642, 705 (last in Permian), 707 ; acuminata, 503 ; arcuata, 625 ; biforata, 507*, 514, 520, 550; Billingsi, 475*; biloba, 548*, 551; borealis, 503; Bouchardi, 520; 
calligramma, 520, 522, 567; costalis, 502*; Davidsoni, 568; discus, 563; disparilis, 503,514 ; elegantula, 519*, 520, 551, 552, 562, $563,567,568,569$; flabellulum, 519*, 520; grandreva, 499*, 500; granulosa, 625; Highlandensis, 471*; hipparionyx, 579 ; hybrida, 551, 563; imperator, 503 ; im pressa, 592, 620, 621; inæqualis, 602 ; interlineata, 626 ; Iowensis, 602 ; lata, 567; lunata, 567 ; lynx, 521; McFarlani, 592; Michelini, 703; Michelini var. Burlingtonensis, $642^{*}$, 646; musculosa, 579 oblata, 562, 569, 579; occidentalis, $507 * 514 ;$ orbicularis, 567 ; palliata, 568; parallela, 626; parva, 521 ; Pecosi, 690 ; perelegans, 563, 579; planoconvexa, 562; platys, 503 ; plicata, 626 ; poreata, 520 ; Porcia, 503; prava, 602 ; punctostriata, 563; Salemensis, 471* striatula, $426^{*}, 520,625,626,628$; subrequata, 503 ; subcarinata, 563 ; suborbicularis, 602 ; subquadrata, 514; testudinaria, 507*, 514, 521 ; Tioga, 621; tricenaria, 507*, 514; tubulostriata, 563; Tulliensis, 592; Vanuxemi, 591, 602; varica, $560^{*}, 562$

Orthis family. See Orthids

Orthisina, 425\&, 481: festinata 471*; orientalis, 471*; Shumardana, 685

Orthoceras, 78, 481, 488, 499, 508, $511,515,516,517,520,521,546$ $549,551,561,562,567,568,586$, $591,599,613,614,625,626,642$, $675,705,707,719,727,736,756$; Allumettense, 508 ; amplicameratum, 516 ; anellum, 514 ; annulatum, $520,551,567,568,569$; areuo lirntum, 520: Barrandii, 520 bebryx, 620 ; Blakei, 757; bullatum, 567, 573; coralliferum, 516 ; crotalum, 602 ; desideratum, 546 ; diffidens, 503: explorator, 503; fulgidum, 620 ; furtivum, 503 ; ibex, 568,573 ; interruptum, 627 junceum, 506, 508*, 514; laqueatum, 500*; Ludense, 567 ; Luthei, 501; Midas, 568; moniliforme, 524; multiseptum, 549; nobile, 642 ; olorus, 508*, 514; Ozarkense, 500; pacator, 620, 621; primigenium, $499 *, 500,501,517 *$; rectiannulatum, 503; rectum, 551 ; strix, 551; subflexuosum, 627 ; subulatum, 602,620 ; tenuiannulatum, 567; tenuiseptum, 503 ; transversum, 516 ; vagans, 520 ; velox, 503 ; virgatum, 569

Orthocerata, $310,497,522,561,578$, 700

Orthoceratite limestone, 627

Orthoclase, $64 * \S$; angite, 84

Orthodesma, 516; parallelum, 511* Ortholy te, $83 \S$

Orthonota, 602, 621; affinis, 567 ; angulifera, 567; curta, 551; undulata, 598*, 602
Orthophyric rocks, $77 \S, 84$

Orthopteroids, 721, 722 ; Carbonic, 722 (culmination); Carboniferous, $677,679 *, 691$; Coal-measure, 701 $702 *$

Orthopters, $419, \quad 574, \quad 600, \quad 702$ 771,794 ; number of Florissant 900

Orthothetes Chemungensis, 591, 592 ; crenistria, $700 *$; subplanus, 563 ; umbraculus, 704; Wool worthanus, 563

Orthrocene, 8808

Orycteropus, 54

Oryctoblattina, 691

Osage group, 634, 637

Osars, 972

Oscillatoria, 60

Oshima (Mt.), 280

Osmeroides, 862 ; Lewesiensis, 862 Osmunda affinis, 839 ; spicant, 74 Osteolepis, 417, 621, 627

Ostracoids (Ostracodes). 421\$ ; Cambrian, 474*, 481, 486, 487

Ostrea, $780,828,829,840,854,864$, 916 ; acuminata, 790 ; aquila, 865 . belliplicata, 854; bellovacina, 925 biauriculata, 866; carinata, 837 compressirostra $897 *, 915$; con gesta, $841 *, 854,855$; Couloni, 865 crassissima, 926 ; decussata, 866 ; deltoidea, 790 ; diluviana 866 ; disparilis, 917 ; falcata, 854; Franklini, 836; Georgiana, 898*, 916 gigas, 927 ; glabra, 855 ; glandiformis, 854: Johnsoni, 915 ; larva, $841 *, 854,855,866$; Liassica, 774 790 ; macroptera, 865; Marshii. $780^{*}, 790,791$; Matheroni, 866; Merceyi, 866; percrassa, 917 ; præ-compressirostra, 915 ; Pulas kensis, 915; quadruplicata, 837 sellæformis, 889, 897*; solitaria, 791: Sowerbyi, 790 ; stringilecula, 760 ; subspatulata, 854 ; subtrigonalis, 856 ; thirsæ, 915 ; titan, 892 ; trigonalis, 916 ; vesicularis 866 ; Vicksburgensis, 916

Ostrea sellæformis beds, 889

Ostrich, 54, 852,871, 902

Otodus, 843,863 ; appendiculatus 843*, 854; obliquus, 926

Otozamites contiguus, 791 ; linguiformis, 756*; Macombii, 756

Otozoun, 753; Moodii, 752*

Ottawa, 490,491, 493, 494

Ottrelite, 315, 319

Ottrelitic rocks, 82, 83, 467

Ouachita Mts., 380, 389, 732, 817

Outerop, 99*8

Ovibos bombifrons, 999 ; cavifrons, 999, 1002 ; maxinnus, 1002 ; moschatus, 1002

Ovis, 927

Owl, 902

Ox, 54, 907

Oxfordian group, 775

Oxidation, 122, 123; constructive effects, 127 ; destructive effects, 125

Oxyæna, 918

Oxyclænus, 917
Oxygen, $61 \S, 122$; in atmosphere of the Lithic era, 440

Oxyrhina, 144, 843, 863; hastalis, 917: Mantelli, 843*

Oxyria, 240 ; digyna, 945

Oyster family, 840

Oysters, 56 ; analysis of shell, 72

Ozark series of Broadhead, 468

Pachyæna, 918

Pachycardium Spillmani, 855

Pachyderms, 927

Pachydiscus Brazoensis, 836; peramplus, 866 ; Whitneyi, 837

Pachynolophus, 918

Pachyrhizodus, 843

Pachytheca, 564

Pacieulus, 918

Pacific border of America, 18, 24 ; volcanoes of, $295,296,297,937$; glaciers of, 945 ; submerged river channels, 949: Triassic and Jurassic of, $746,756,808$; Cretaceous, S18; Tertiary, 885; lacustrine deposits of, 893

Prcific Ocean, 17, 19, 20, 31, 41, 42, 43 ; temperature of, 49 ; salinity of, 121

-, island-chains of, 35-39*, 40, 295, $296,398,395$

-, islands of, 17, 20, 23 (number), $38,39,151,161,182,227$; elevations in, 350

-, system of currents, 43,44

—, volcanoes in, 295, 296, 297, 938

Pah-Ute Lake, 895; Range, 366, 812

Pahoehoe, 287£, 288

Pahranagat Range, $366^{*}, 606$

Painted Cañon, 758

Palæacis, 639; cuneiformis, 646 ; obtusus, 646

Palæacodon, 918

Palæanatina, 621

Palæarca, 481, 520

Palæaspis Americana, 557*

Palæaster, 481, 516, 520; Dyeri, 511 ; Jamesi, 510*, 511; magnificus, 511 ; matutinus, $505 \%$, 514; Niagarensis, $429 *, 551$

Palæasterina primæva, 567

Palæechinus, 567

Palrichthyes, $415 \S$

Palæinachus, 782

Palælodi, 923

Palæmon, 703

Palæoblattina Donvillei, 566

Palæocampa, 723 ; anthrax, 6r6, 691

Palæocaris typus, 678*, 691

Palæocastor Nebrascensis, 911

Palæocreusia, 591; Devonica, 587

Palreocrinus, 514; striatus, 502*, 503

Palreoctonus Appalachianus, 754

Palæocyclus, 567; rotuloides, 545*, 550

Palæocystites Chapmani, 508; Dawsoni, 503 ; pulcher, 503 ; tenuiradiatus, 503

Palæogene, 8s0ई

Palæohatteria, 706, 707, 795, 797; longicaudata, $706 *$ 
Palrolagus, 918, 919

Paleolithic Man, 1011

Palæomanon, 550

Palæomyrmex prodromus, 783

Palroneilo, 621 ; filosa, 620

Palæonictis, 918, 925

Palæoniscidæ, 620

- Palæoniscoids, $417 \S$

Palæoniscus, 417, 603, 702, 705, 772 ; antipodeus, 699 ; Bainei, 770 ; Browni, 692; comptus, 707; Devonicus, 620 ; elegans, 707; Freieslebeni, 417*, 705*, 707, 740 ; gracilis, 692 ; Jacksoni, 692 ; Leidyanus, 692 ; lepidurus, 417 * ; peltigerus, 692; sculptus, 770 ; scutigerus, 692

Palæopalæmon, 620 ; Newberryi, 615*

Palæophis toliapicus, 925 ; typhæus 923, 926

Palæophonus nuncius, 565

Palæopteris Romeriana, 704

Palpornis, 864

Palæosaccus Dawsoni, 497

Palæosaurus, 773 ; Fraserianus, 754

Palæoscincus, 856

Palæospondylus Gunni, 1031

Palæosyops, 907, 918 ; paludosus, 907*

Palæotherium, 926 ; crassum, 926 ; curtum, 924, 926 ; magnum, 924 , 926 ; medium, 926 ; minimum, 926 ; minus, 926

Palæothrissum Freieslebeni, 740

Palapteryx, 54, 1014

Palawan, 40

Paleocene, $880 \S$

Paleothere, $924 \S$

Paleozoic, 407

- time, 460 ; growth of American continent during, 714 ; biological changes in, 716 ; mountain-making following, 729,733

Palinurus, 73

Palisade Range, 358, 808

- System of ranges, $357,380,389$

-Triassic area, $\mathbf{7 4 0}, \mathbf{7 4 1}, \mathbf{7 4 3}, \mathbf{7 9 8}$, 799,800

Paliuxus zizyphoides, 839

Pallium, 425\$

Palmacites, 859

Palms, 53, 409* (time range), 434, 435,879

Palo Duro beds, 884, 885, 919

Paloplotherium annectens, 926

Palpipes priseus, $783 *$

Paludina, 152; fluviorum, 861* 864 ; lenta, 926 ; orbicularis, 926

Paludina limestone, 864

Paluxy sands, 817

Pamlico Sound, 224*

Pampas, 24

Pamunkey formation, 888

Panama, 891 (Miocene); conglomerate, 630,638

Panamints, 23

Panchet group, 698, 769, 773

Pandanus family, 777

Panenka, 621

Paniselian beds, 925

Panochthus, 1004
Panolax, 919

Panopæa Americana, 917 ; elongata, 915; porrectoides, 916 ; reflexa, 917

Panther Creek anthracite basin, section of, $649 *$

Pantolambda, 917

Pantolestes, 918 ; brachystomus, 906

Paolia vetusta, 679*

Papandayang (Mt.), 277

Papaver, 240

Parabatrachus Colei, 703

Paraclases, $113 \S$

Paracyclas, 592, 602, 621 ; elliptica, 590,601 ; proavia, 585*, 590

Paradoxides, 474, 475, 477, 482; Bennetti, 475; Davidis, 481; Forchhammeri, 482; Harknessi, 481; Harlani, 475, 476* ; Regina, $475,476^{*}, 521$; Solvensis, 481; Tessini, 482

Paradoxides beds, 467, 481, 482; zone, 464

Paragonite, 84 ; schist, $84 \S$

Paraguay River, 183

Paramorphs, 62 $8,67,69,70$

Paramys, 917, 918

Paria, 747

Parictis, 918

Paridigitates, $906 \S$

Paris, 17, 347, 926

- basin, 774, 872, 880, 920, 923

Parisian group, 884, 925

Parma sandstone, 657

Parodiceras, 602

Paromylacris, 691

Parophite schist, 84

Parrots, 54, 928

Pasceolus, 515

Passalacodon, 918

Patagonia, 20, 209, 925

Patella, 130, 471, 487, 780

Patellina Texana, 834*, 836

Paterina, 480, 486

Patoot group (beds), 831, 840, 872

Patriofelis, 918

Patterson Glacier, 240

Patula alternata, 966 ; perspectiva, 966 ; solitaria, 966 ; striatella, 966 Patuxent River, 889

Paumotu Archipelago, 20, 36, 37, $145,222,350$

Paurodon valens, 767*

Peace Creek, Fla., deposits, 890, 892 (bone beds)

- River, Brit. Amer., 444, 659, 746, 830 ; coal of, 825

Pearl sinter, $82 \S ;$ spar, 540

Pearlyte, $84 \S$

Peat, $74,81,153 * \S, 666$; composition of, 661,713

Pebbles in Archæan rocks, 448, 449

Pebidian period, 457

Peccary, 54

Pe-chi-li, 198 (gulf), 696 (province)

Pecopteris, 671, 684, 699, 704, 750, 756 ; acuta, 689 ; arborescens, 654 , 671*, 689, 692, 704; Browniana, 831 ; Candolleana, 692-693, 705; cyathea, 689 ; dentata, 693,705 ; erosa, 689 ; Germari, 705; latifolia, 705 ; Miltoni, 693,704 ; notata, 689, 693; oreopteridea, 693,705 ; pennæformis, 705; Pluckeneti, 693, 705; preciosa, 622; pteroides, 689, 698, 705; robustior, $749^{*}$; serrulata, 689 ; unita, 689

Pecten, 525, 756, 780, 860, 916; Alabamiensis, 915 ; anatipes, 916 ; asper, 865,866 ; Burlingtonensis, 855 ; calvus, 791; cinctus, 791, 865 ; eircularis, 867 ; Clintonius, 917; decennarius, 917 ; deformis, 757 ; discites, 774 ; fibrosus, 790 ; Grœenlandicus, 983,984 ; irradians, 994; Islandicus, 983, 984, 995 ; Jeffersonius, 899*, 917 ; lens, 790 ; Madisonius, 917 ; Nillsoni, 855 ; nuperus, 916 ; operculiformis, 837 ; Poulsoni, 898*, 916 ; quadricostatus, 865 ; quinquecostatus, 854 ; Stantoni, 886 ; vagans, 790 ; Valoniensis, 774, 790 ; venustus, 854

Pectinated rhombs, $430 \S$

Pectolite, 68

Pectunculus aretatus, 916; quinquerugatus, 917 ; subovatus, 917 Pegmatyte, $83 \S$

Pei Ho, 198

Pelagic and abyssal life, deposits from, 143-144, 229

Pelagite, $71 \S$

Pele's hair, 279\$

Pelew Islands, 350

Pelicans, 928

Pelion Lyelli, 682, 683*, 692

Pelorosaurus Becklesii, 863

Peltoceras, 794 ; athleta, 791

Peltodus, 692

Pelycodus, 918

Pemphix Sueurii, 771*

Pen of the Cuttle-fish, $424 * \S$

Penarth beds, 769

Peneplane, $204 \S$

Pennant, 696

Pennine chain, 695, 696

Pennsylvania, 23 (beight), 24, 25, 41, $356,357,358,382,383,388,391$, 399,405 ; coal-field, map of, $649 \%$; copper ores, 745 ; iron ore beds, 127 ; marbles, 524

-, mineral gas and oil in, 606,607 , $609,664,730 *$, 731 ; yield of, 608 , 609

-, diagram showing the courses and flexures of the ridges, 729 , $731 *$

—, rocks, section of, 727, 728; Prosser's section of, 594,606 -, topographical maap of, 357,729 , 730*, 731, 798

Pennsylvania period, 632

Penobscot Bay, 544, 552

Penokee-Gogebic range, 446

Penokee-Marquette belt, 446, 449, 454

Pentacodon, 917

Pentacrinus, 59, 428*, 719, 758, 778; asteriscus, 757 , 758*, 760 ; Briareus, 778*, 790; caput-medusæ, 428*; decorus, 58*; subangularis, 79 
Pentamerella arata, 581, 590

Pentamerids, 574

Pentameroceras mirum, 551

Pentamerus, 425\$, 550, 552, 562, 568 ; bolealis, 568; brevirostris, 569 ; candatus, 567 ; comis, 601 ; conchidium, 552, 569 ; fornicatus, 563 ; galeatus, $560 *$, $562,563,567$, $568,569,626,628$; globosus, 520 ; Knightii, 551, 564*, 565, 567, 568, 569 ; lævis, 569 ; oblongus, 520, $545,546 *, 550,551,552,567,568$, 569 ; occidentalis, 551; pseudogaleatus, $560 *, 561,562$; undatus, 520; Verneuili, 561*

Pentamerus, Lower, 535; Upper, 535

Pentremites, 430§, 585, 590

Pentremites, 597, 601, 602, 641; Grodoni, $640^{*}, 646$; ovalis, 626 ; pyriformis, $640^{*}, 646$

Pentremital group, 637

Peoquop Range, 365

Peperino, 80\$

Peralestes, 789*

Peramus, 789*

Peraspalax, 789*

Perch, 812, 879 ; family, 862, 901

Perchoerus, 918

Pericentric stratification, 99

Peridot, $67 \S$

Peridotyte, 898

Perihelion and aphelion, changes of, 254

Period, $406 \S$

Peripatus, 723

Periptychus, 917

Perisphinctes, 749, 760 ; Colfaxi, 760 ; Mühlbachi, 760 ; virgulatiformis, 760

Perlyte, 122

Permian period, 660, 689, 690; foreign, 697, 704

- in India, etc., supposed to be glacial, 698; emergence of Antarctic land, 737

Permo-Carboniferous, 635£, 687

Perna maxillata, 378 ; mytiloides, 790

Perry sandstone, 594, 606

Persia, plateau of, 26 ; Cretaceous in, 857; Tertiary in, 920

Persian Gulf, 41

Perthite, 321

Peru, 41, 51, 218, 222 ; volcanoes of, 296 ; Cretaceous in, 857, 867; Tertiary, 935

Peruvian islands, 153

Petalite, 449

Petalodonts, 643, 647, 705

Petalodus, 680, 692; curtus, 643 ; destructor, 680*, 692

Petraia, 515, 520, 567 ; bina, 520, 567 ; profunda, 517

Petricola, 157 ; centenaria, 917

Petrifactions, 131, 135, 143

Petrified forests, 135

Petrodus, 692 ; occidentalis, $680 *, 692$

Petroleum, 522, 555, 661

Petrosilex, 84§

Petschora-land, 776

Phacoceras, 675; Dumbli, 675, 676* 691
Phacops, 422§, 520, 521, 551, 561, $568,570,579,586,591,599,626$; bufo, 599*; callicephala, 515; caudata, 567, 568; Downingii, 565*, 567, 573 ; elegans, 568; fecunda, 568,570 ; granulata, 625 ; latifrons, 625, 626, 627; Logani, 561*; longicaudata, 567; nupera, 614 ; rana, 592, 599*, 614 ; Stokesi, 567 ; trisulcata, 550

Phænogams, 434-435, 595; Neopaleozoic, 460

Phæthonides, 591, 643 ; occidentalis, 614 ; spinosus, 614

Phalangidæ, 691

Phaneropleuron, 418, 621, 625; curtum, $617 *, 619,621$

Pharella Dakotensis, 855

Phascolestes, 789

Phascolotherium, 789*; Bucklandi, 789*

Phasma, 677

Phenacodus, 908, 910, 917, 918, 925; primævus, 908*

Phenocryst, 775

Philippine Islands, 296 (volcanoes), 297, 920, 921

Phillipsastrea, 718; gigas, 590; Verneuili, 554*, 585, 590

Phillipsia, 521, 643, 676, 686, 700 ; Cliftonensis, 691; major, 691; Missourieusis, 691; scitula, 691; seminifera, $700^{*}$

Phillipsite, 136, 144

Phlegethontia, 692 ; linearis, 682

Phlegræan Fields, volcanic region of 293

Phlogopite, 65§

Phlyctænaspis Acadica, 616*, 618

Phoberus cæcus, 59

Phonicites, 921

Phonix Islands, 20

Pholadella, 621

Pholadomya, 759, 780 ; abrupta, 917; cuneata, 925 ; fiducula, 790 ; Lincenumi, 855; Marylandica, 915; multicostata, 791 ; ovulum, 791 ; papyracea, 855

Pholas, 157, 158; alatoidea, 915 ; crispata, 983

Phonolyte, 85§; columnar, 263*, 264* ; solubility, 122

Phos Texanus, 916

Phosgenite, 335

Phosphates, 63, 69

Phosphatic concretions, 73, 493, 891; deposits, 153; fossils, 314, 487

- rock-material, 72-74, 141

Phosphoric acid, 69, 72, 73, 74, 75, 153, 241, 663

Phosphorite beds of Querey, 926

Phosphorus, 62, 63\&, 123 ; in mineral coal, 663

Phragmites Alaskanus, 839

Phragmoceras, 567 ; parvum, 551

Phragmodictya, 646

Phrynus, 724

Phthanocoris, 722 ; occidentalis, 691

Phthanyte, 82§

Phylloceras, 793, 794; ptychoicum, 791
Phyllograptus, 470, 520 ; Anna, 500; typus, 498*

Phyllopods, 421§, 439§; Cambrian, Lower, 474*: Cambrian, Middle, 476, 477*; Chemung, 614, 615*; Corniferous, 586 ; Hamilton, 599 , 600*; Lower Silurian, 521 ; Paleozoic, 720 ; Subcarboniferous, 643

Phyllyte, $80 \S, 89 \S$

Physa, 152 ; heterostropha, 682

Physeter, 912, 927

Physiographic chart of the world, 46, 47*, 350

Physiographic geology, 14\$, 15

Physospongia, 639, 646

Phytolitharia, 163, 164*

Phytopsis cellulosa, 505

Pichincha (Mt.), 26, 296

Pickwell Down beds, 625

Picotite, 88

Picryte, $88 \S$

Pictured rocks, 94*, 464, 465*

Piedmont region, 24, 443

Pigeons, 54

Pikermi beds, 927

Pike's Peak, 811,876

Pileworm, 158

Piloceras, 520, 573 ; Canadense, 501 ;

Wortheni, 501

Pilton beds, 625

Pilularia globulifera, 436*

Pinacoceras Metternichi, 774; par$\mathrm{ma}, 774$

Pine, 435, 436, 667, 668, 777, 859

Pine Mountain, Ky., 543, 657

- River, 746

Pinite, 68§, 318, 320

Pinites, 704, 777

Pinna, 129, 760 ; affinis, 925 ; decussata, 866 ; expansa, 759*; Missouriensis, 647; Mulleti, 865 ; peracuta, 690

Pinnularia æqualis, 164*, 165 ; borealis, 164*, 165 ; peregrina, 437*, 894* ; viridis, 164*, 165; viridula, $164^{*}, 165$

Pinon Range, 365, 733

Pinus, 859, 922 ; abies, 74 ; succinifer, 922

Pinyte, $84 \S$

Pipestone quartzyte, 468

Pisolite, $96^{*} \S$

Pisolitic limestone, 859

Pit River, 747, 749, 809

Pitchstone, $84 \S$

Pithecanthropus erectus, 1036

Pitt, Mt., 296

Pittsburg coal-bed, 653

Placenticeras Guadalupæ, 855 ; placenta, $841,842 *, 854,855$

Placoderms, 417 ; Trenton, 509

Placodus, 773

Placoparia, 520, 521

Placuna scabra, 854

Placunopsis, 690

Pläner (Lower), 866 ; (Middle), 866

Plagiaulax, 768, 789, 864; minor, $759 *$

Plagioclase, $64 \S$

Plaisancian beds, 927

Planation, 167\$, 169, 219, 221*

Plane tree, 831, 922 
Planorbis, 152, 856 ; discus, 926 ; euomphalus, 926

Plant-beds, 933

Plantain, 812

Plants, 71, 72; geographical distribution of, 52-60; phosphoric acid in ash, 73; analyses of, 74, 75 ; chemical work by, 136 ; protective effects of, 155 ; materials for rock-making, 140, 143

Plaster of Paris, $69 \S$

Plastic clays, $821,525,925$

Plasticity of rocks from superheated steam, 324

Plastomenus, 850

Platanus, 831, 840, 922 ; aceroides, 839 ; Guillelmæ, 839 ; Reynoldsii, 839

Plateau, 25\$, 188

— belt, 739, 748, 749, 811; region, S1s

Plateaus carved into mountains, 180

Platephemera antiqua, $600 *$

Platinum, 331, 376, 455

Platte River, 29, 885

Plattendolomit, 697

Platyceras, 478, 487, 499, 561, 562, $568,570,574,578,585,590,598$, $602,612,642$; angulatum, 548*, 551 ; auriformis, 503 ; carinatum, 592, 602 ; conicum, 592, 602 ; dentalium, 592; dumosum, 586*, 590 ; equilaterale, 647 ; erectum, 602 ; Haliotis, 573 ; nodosum, 592 ; primævum, 471, 472* ; rectum, 602 ; reversum, 647 ; spirale, 579 ; symmetricum, 602 ; thetis, 602 ; ventricosum, 562 ; vetustum, 625

Platycrinus, 597, 646; Saffordi, $640 *, 646$

Platygnathus, 626

Platygonus, 919

Platyschisma belicites, 567; helicoides, 578

Platysomus, 705; gibbosus, 707 ; macrurus, 707

Platystoma, 562, 590, 612, 621; Niagarenese, 548*, 551

Platystrophia biforata, $507 *, 550$

Playa, $196 \S$

Pleasant (Mt.) beds, 606

Plectanabonites, 503 , 550 ; sericeus, $507 * 514,520,522,524,550$ transversalis, $426 *, 548 *, 551,568$

Plectoceras, 501

Plectrodus mairabilis, 567 ; pleiopristis, 567

Pleistocene life, North American, 997 ; South American, 1002 : Enropean, 1004; Australian, 1006: foreign, 1004 ; $\operatorname{man}, 1008$

Pleistocene period, 890, 940, 941

Plesiadapis, 925

Plesiosaurus, 773, 785, 790, 856, 863 ; dolichodeirus, 784*; macrocephalus, $785 *$; occiduus, 828,856

Pleuracanthus Gaudryi, 702, 703*

Pleuroceras spinatum, 781*

Pleurocolus altus, 836 ; nanus, $836^{*}$ Pleurocystites filitextus, 505*, 514 ; tenuiradiatus, 517
Pleurodictyon, 626

Pleurolichus, 918

Pleuromya, 760 ; lævigata, 887 ; unioides, 760

Pleurophorus elongatus, 774; subcuneatus, 685*

Pleurorhynchus, 520

Pleurosigma angulatum, 437*

Pleurotoma, 922; abundans, 916 ; Americana, 916; attenuata, 926; beadata, 916 ; congesta, 916 ; cristata, 916 ; declivis, 916 ; Heilprini, 916: Huppertzi, 916; moniliata, 915 ; perexilis, 916 ; rotædens, 916; tenella, 916 ; Texana, 855; Tippana, 855

Pleurotomaria, 59, 487, 493, 499, 516, $520,521,525,551,562,586,590$. $598,621,642,700,707,780$ (culmination), 792 ; Adansoniana, 59 ; antiquata, 503; Attleborensis, 471; Austinensis, 837 ; biangulata, 503 ; Brittoni, 854; calcifera, 500; calyx, 503 ; carbonaria, 690 ; docens, 503; Grayvillensis, 690 ; gregaria, 500 ; litorea, $544 *$, 549 ; Ohioensis, 516; pervetusta, 549; Shumardi, 647 ; solarioides, 549 , 551 ; sphærulata, 675*, 690; staminea, 517; subconica, 514; tabulata, $675 *, 690$; turbinea, 627 ; virgulata, 602

Pliauchenia, 912, 919

Plicated rocks, effects of erosion of, $186^{*}$

Plication of clayey layers, 208, 209* Plications and plicating, experiments by Daubrée on, 353; in mountains, 354

Plicatula inflata, 866 ; placunea, 837 . 865 ; spinosa, 790

Plinthosella squamosa, 432*

Pliocene period, $880 \S$

Pliohippus, 913*, 919

Pliohippus beds, 885

Pliopithecus, 927

Pliosaurus, 785

Plocoscyphia mæandrina, 866

Plombières, formation of zeolites at, 323

Plover, 902

Plum, 921

Plumbaginous rock. See Graphitic Plumbago, $62 \S$

Plutonic rocks, $298 \S$

Pluvial period, 981

Pnesopteryx, 1014

Po, ratio of sediment to water, 190

Pocono group, 410, 634, 636, 728

Podosthenic, 439, 717\$, 726, 796

Podozamites Emmonsi, $749 \%$; lanceolatus, $833^{*}$; nervosus, 834

Podura, 419, 702

Poëbrotherium, 911, 918; labiatum 910, 911*

Poecilodus, 692

Pogonip limestone, 495, 516

Pogonodon, 918

Poikilitic group, 631, 738

Polacanthus Foxi, 863

Polar Bear, 950

- ice-cap, 346
Polenos Island, 296 (rolcanoes)

Polioptenus elegans, 704

Polishing of rocks. See Scratches Pollinices Burnsii, 917

Polycystines, $433^{*}$

Polyernus, 691

Polygnathus dubius, 621 ; nasutus, 621; palmatus, 621; princeps, 621 ; punctatus, 621

Polymastodon, 917

Polynesian chain of islands, $37 *, 38$ 39

Polyonax, 847

Polyps, Polyp corals, 144, 419, 429* $431 \S$

Polypterus, 59, 417

Polyzoans, 427

Pomeroy coal-bed, 653, 654, 689

Pompeii, 280

Ponderosa marls. See Exogyra ponderosa marls

Ponent series, 728

Pontian stage, 927

Popanoceras, 686

Poplar, 837, 922

Popocatapetl (Mt.), height of, 937

Populus lævigata, 839 ; mutabilis ovalis, 839; Nebrascensis, 839 primæeva, 833

Porambonites, 521

Porcelain clay, 81, 134, 638; jasper, $84 \S$

Porcelanyte, $84 \S$

Porcellio, 420*

Porcupine, 798

Porcupine Hills beds, 830

Porifera, $431 \S$

Poroblattina, 691

Porocrinus, 514, 516

Pororoca, 212\$, 215

Porous rocks, 328

Porphyritic rocks, $77 * \S, 83 \S, 324$

Porphyry, 84§, 341*

Porphyryte, 86

Port Hudson clay, 198

Port Jackson, N. S, W., cliffs at, $201 *$

Port Jackson shark, 643, 797

Portage epoch and group, 576, 602 - sand stone, 608,605

Porte Blanche, 248

Portheus, 844*, 862 ; molossus, 843

Portland beds, England, 738, 777 ; dirt-bed, $775,776^{*}$

- cement, 798

Portland Oölyte, 411, 775 ; stone, 775

Portland, Victoria, 34

Portlandian group, 738, 775

Portsdown axis, 936

Portugal, 85: Cambrian in, 484; Lower Silurian, 521

Posidonomya, 756; Bronni, 790; venusta, 627

Post-Pliocene, $940 \S, 941$

Post-Tertiary, 940

Pot-holes, 184, 250, 949

Potamides transsectus, 916

Potash, 61\$, 81; salts, 320

Potassium, 61

Potentilla, 240

Poteriocrinus, 582, 646, 690 ; Coxanus, 640 
Potomac group, 816

Potosi, 26

Potsdam period, Potsdam Sandstone, 463,464

Potter's clay, $81 \S$

Pottsville coal-beds, 650, 656

- conglomerate, 647

Powder Piver, 266

Pozzuolana, 80 §

Præarcturus, 623, 624

Prasopora lycoperdon, 505*, 514

Prawn, 438

Precession of the equinoxes, 253

Prehnite, 68

Preston beds, 817, 836

Prestwichia, 701, 720 ; anthrax, 708 ;

Danæ, 977*, 691; longispina, 691; rotundata, $701 *, 703$

Priacodon ferox, 767*

Priconodon crassus, 836*

Primal of Rogers, 490, 728

- Sandstone, 463

Primary, 408§, 880

Primates. See Quadrumana

Primitia, 481, 516

Primitive system, $408 \S$

Primitivgebirge, 440

Primordial, 462, 464, 482

Prince Edward Island, 357, 741; Permian in, 660; Triassic, 753, 755

Prince Patrick Island, 749, 760, 792

Prince William Sound, 240

Prioniodus acicularis, 621 ; angulatus, 621 ; armatus, 621 ; erraticus, 621 ; spicatus, 621

Prionocyclus, 855 ; Woolgari, 855

Prionotropis, 855

Pristis bisulcatus, 925

Proboscideans, 919

Procamelus, 911, 919

Prodryas Persephone, 900*

Productella, 611, 612 ; hirsuta, 621; lacrymosa, 613*, 621; navicella, 590 ; pyxidata, 602; speciosa, 620 ; subaculeata, 585*; subulata, 598*, 601, 602 ; truncata, 602

Productus, 309, 427*, 591, 592, 642, $674,700,705,707$ : aculeatus, $427 *$; Cancrini, 704; cora, 690 ; costatus, 606,704 ; dissimilis, 602; Flemingi, 646; horridus, 704, 707 ; lacrymosus, 592 ; latissimus, 704 ; Leplayi, 704; longispinus, 700*, 704, 711; mesolobus, 606; muricatus, 690; Nebrascensis, 675* 690 ; Norwoodi, 685 ; parvus, 647 ; prælongus, 626 ; punctatus, $642 *$. 690, 704; Rogersi, 685; seabriculus, 703,704 ; scitulus, 646 ; semireticulatus, $427 *, 685,690$, 711; Shumardianus, 602; speciosus, 592; subaculeatus, 626 , 627, 628

Proetus, 513, 515, 521, 552, 562, 568, $579,586,591,643,720$; auriculatus, 614; crassimarginatus, 587*, 591, 599 ; doris, 614 ; Girvanensis, 520 ; latifrons, 565*, 567 ; minutus, 614 ; parviusculus, 516 ; præcursor, 614 ; Stokesi, 551, 567, 569
Proganochelys Quenstedtii, 773

Progonoblattina, 691

Progress in earth's development, 397

Proicene, $880 \S$

Prolecanites Lyoni, 643*

Promontory Range, 365

Promylacris, 691

Propylyte, 87\$, 304

Prorhynchus, 621 ; nasutum, 621

Proscorpius Osborni, 557*

Prosoponiscus problematicus, 707

Prospect Ridges, 495, 733

Prosqualodon, 927

Prosthenic, 717\$, 796, 870

Protæiphyllum, 881

Protannularia Harknessi, 519*

Protapirus, 910, 918

Protaster, 516, 562; Forbesii, 562 ; hirudo, 567 ; Sedgwickii, 567

Protaxis, 24§. See also Acadian protaxis ; Appalachian; Archæan ; Rocky Mountain; also Gold Range

Proteaceæ, 921, 922

Protean group, 542, 638

Proterosaurus Speneri, 706*

Protichnites septemnotatus, 478*

Protoadapis, 925

Protobalanus Hamiltonensis, 600*

Protocardium Hillannm, 836

Protocarids, 486

Protocaris, 720 ; Marshi, 474*

Protoceras, 911, 918

Protoceras beds, 886, 894, 911, 918

Protocimex Siluricus, 520

Protococcus, 235, 436; nivalis, 241, $436 \S$

Protogine, $88 \S$

Protogonia, 917

Protogonodon, 917

Protohippus, 911, 912, 913*, 919

Protolabis, 911, 919

Protolimulus Eriensis, 615*, 617

Protolycosa anthracophila, 703

Protophasmids, 677, 679, 691, 701

Protophytes, 407; Corniferous, 583*; Cretaceous, 859; Tertiary, 895

Protopterus, 60

Protoreodon, 907, 918

Protorthis Billingsi, 475*

Protosalvinia, 718; Huronensis, 584

Protospongia, 482, 497; coronata, 498\% ; cyathiformis, 498*; fenestrata, 474*, 481; mononema, 498*, 500; Quebecensis, 498*; tetranema, 498*

Protostega gigas, 849

Prototarites Logani, 591

Prototherium, 795, 927

Prototype characters, 928

Protozoans, 140, 141, 407, 409*, 418, $419,431,432 *$; Archæan, 455; Lower Cambrian, 470

Protozoic, 407

Provence, Cretaceous in, 866

Proviverra, 918, 925

Provo, 360*, 361

Psammodonts, 643\$, 647

Psammodus, 589, 643

Psaronius, 704; Erianus, 595
Pseudælurus, 919

Pseudodiadema, 779, 834; diatretun, 854; hemisphæricum, 790 ; Moorei, 790 ; seriale, $778^{*}, 779$; Texanum, 836

Pseudoliva, 916; sealina, 915; tuberculifera, 915 ; unicarinata, 915

Pseudomonotis, 690; Hawni, 685*; Ochotica, 758; speluncaria, 707

Pseudopecopteris, 699 ; anceps, 645, 689 ; decipiens, 689 ; irregularis, 689 ; latifolia, 689 ; muricata, 689 ; nervosa, 689 ; nummularia, 689

Psilomelane, $71 \S$

Psilophyton, 583, 590; cornutum, 560 ; princeps, 583*, 622

Psittacotherium, 904, 917

Pteranodon, 863 ; ingens, 852 ; longiceps, $849 *, 852$

Pteranodonts, 851

Pteraspids, 417, 557, 725

Pteraspis, 564, 625; Banksii, 566**

567 ; Ludensis, 567 ; truncata, 567

Pterichthys, 566, 617, 625, 627 ;

Canadensis, 611 ; cornutus, $624^{*}$; major, 627; Milleri, 624*

Pterinea, 621, 877 (end); Chemungensis, 613*, 621; flabella, 598*, 602 ; hians, 567 ; retroflexa, $56 \%$, 568; Sowerbyi, 567; sublævis, 567; Trentonensis, 507*

Pteris aquilina, 74 ; erosa, 839

Pterocera bicarinata, 865 ; oceani, 791 ; ponti, 791

Pterocerian beds, 791

Pterodactyls, 796; Jurassic, 776

Pterodactylus, 788, 790 ; crassirostris, $786^{*}, 788$; montanus, 767

Pterodon, 918

Pterophyllum, 698; Jægeri, 770*, 774; Riegeri, $749 *$

Pteropods, 59, 72, 141, 144, 428§, 4248, 425*; Cambrian, 469, 472*, $475^{*}, 478^{*}, 480,483$

Pteropsis Conradi, 897*; lapidosa, 916

Pteropus, 53

Pterosaurs, 796, 877; Jurassic, $760,767,787 *, 788$; Cretaceous, $844,851,852,863,870,871,876$ (end of tribe)

Pterotheca, 503, 506; attenuata, 514

Pterygotus, 557, 565, 722, 724; acuticaudatus, 557; Anglicus, 623*; bilobns, $564 *, 567$

Ptilodiotya, 514, 521, 550; scalpellum, $567^{\circ}$

Ptilodus, 917

Ptilophyton plumula, 645 (last of the genus)

Ptychaspis speciosa, 501

Ptychites, 686; gibbosus, 774

Ptychoceras, 855; Texanum, 855

Ptychodus mammillaris, 855; Mortoni, $843 *$

Ptychoparia, 500, 516; Adamsi, 473*; Calcifera, 501; formosa, 476*; Hartti, 501; Kingi, 476*; Matthewi, 476* ; minuta, 479*

Ptychopteria, 621, 688; falcata, 621 ; Sao, 621

Ptyonius serrula, 682, 683* 
Ptyonodus, 687

Pudding-granite, 97\$

Pudding-stone, $80 \S, 147$

Puerco Eocene lake or basin, 881*, 882,893

- group, 886

Puerto Rico, 19

Puget group, 831

- Sound, 831

Pugnellus densatus, 854

Pulaski shales, 494

Pullastra arenicola, 774

Pulmonates, 423, 674 (first), 676*

Pumice, 80, 84§, 136, 144, 266, 276, 892

Punjab, 770

Pupa, 152, 708; Blandi, 966 ; contracta, 966; fallax, 966; muscorum, 966 ; quarticaria, 966 ; simplex, 966; Vermilionensis, $676^{*}, 690$; vetusta, $676^{*}, 682,690$

Purbeck axis, 936

- beds, Purbeckian, 411, 775, 777, $783,789,791$

Purity of air and waters in the Cambrian, 484, 485

Purpura, 130 ; cancellata, 855

Purús, 867

Putnam County, N.

Pyenodonts, 417§, 836

Pycnodus, 417, 772, 783

Pyenogonids, 419

Pygidium, 421§

Pygocephalus Couperi, 703

Pygopterus, 692, 705 ; mandibularis, 707

Pygurus rostratus, 865

Pyramids of Egypt, made in part of Nummulitic limestone, 920

Pyrazisinus acutus, 916 ; campanulatus, 898*, 916

Pyrenean basin, 857

Pyrenees, 23, 239, 265, 812 ; Lower Silurian in, 518; Jurassic, 775; Cretaceous, 866; Tertiary, 347, $365,919,920$; elevation of, 932 , 936

Pyrifusus granosus, 855; Newberryi, 841*, 855; subduratus, 854

Pyrite, $70 * \S, 128$

Pyrites, 80

Pyritiferous rocks, 78\$, 84, 653

Pyromeride, 84

Pyrophyllite, 68\$, 89

Pyrophylly te schist, $89 \S$

Pyroxene, 67*8, 85, 86, 288*; rocks, 88-89

Pyroxenyte, 88\$, 532

Pyrrhotite, 70\$

Pytho, 847

Pythonomorphs, 826, 847

Quadersandstein, Upper, 866

Quadrumana, 54, 902, 903, 906, 907, 917 ; in Europe, 923, 925, 927

Quadrupeds. See Mammals

Quakertown coal-beds, 656

Quartz, 15, 62, 63§; work of solutions of, 135-136

Quartz-andesyte, $86 \S, \quad 273,296$; basalt, 296 ; dioryte, $86 \$, 272$; doleryte, 87 ; felsyte, 272,325 ; gabbro, 87\$; porphyry, $84 \$, 817$; syenyte, $85 \S$; trachyte, $84 \S, 86$, 273, 314 (see also Rhyolyte)

Quartz flour from glaciers, 169

Quartzophyric rocks, $77 \$, 83,84$

Quartzose rocks, $78 \S$

Quartzyte, $80 \S, 82 \S, 112 *$ (jointed) ; septaria, 138*

Quartzy tic rocks, 83,84

Quaternary era, 940 ; general observations on, 1016

Quebec, 466

- group, 482, 490, 496, 497, 503, $527^{*}$

Queen Charlotte Islands, 747, 757 , $760,809,818,830,868$

Queensland, 698, 699 ; Devonian in, 628 ; Jurassic, 776 ; Cretaceous, 857

Quenstedioceras cordiforme, 75s*, 760

Quercus, 840, 921, 922 ; angustiloba, 839 ; castanopsis, 839 ; Ellisiana, 839 ; Godeti, 839 ; myrtifolia, $895 *$, 896; suber, 713

Quercy phosphorite beds, 926

Quetta, earthquake in 1892, 375

Quicklime, 78§, 79

Quicksilver mines, 335

Quito, plateau, 26; rolcanoes of, 296

Racket River, 946

Pacodiscula, 432*

Radack Islands, 36, 38, 39, 145

Radiates, 419

Radiolarian earth, 935, 936; ooze, 144

Radiolarians, 57, 64, 72, 121, 136 , 141, 144, 433*; Archæan, 1029

Radiolite limestone, 866

Radiolites, 820, 861, 877; Austinensis, 855 ; Bournoni, 861* ; Mortoni, 861; Neocomiensis, 865; Texanus, 834, 835*, 836

Radula acutilieneata, 854

Rafinesquina, 503, 579 ; alternata, $507 * 514,524$; fasciata, 508 incrassata, 503

Raft of Red River, 191

Ragadinia annulata, $432 *$

Raibl shales, 774

Rain, causes influencing the amount of, 50,51

Rain-drop, work of, $177 \S, 178^{*}$ Rain-prints, 95§, 178, 223, 645, 742

Rainfall, 51, 944, 945

Rainier, Mt. See Tacoma

Rainy Lake, 446

Rájmahál group, 698, 873

Ralick Islands, 36, 38, 39, 145

Rancocas group, 821

Rangifer caribou, 946, 1002 ; tarandus, 946

Ranunculus, 240

Raphistoma, 506, 520, 521; lenticulare, $507 * 514,524,567$; multivolvatum, 501; Pepinense, 501; planistrium, 503

Rappahannock freestones, 816

Raritan beds (group), 815, 821

Rat, 53, 156,797
Raton coal-field, 364

Raton Mts., 828

Rattan, 435

Rattlesnake, 682

Rauchwacke, 697

Rauhkalk, 697

Rauracian group, 790

Rays, $415 \$, 418$

Razor stone, $88 \S$

Recent period, 1012

Receptaculites, $497 *, 513,515,516$ $560,584,597$; elegantulus, $497 *$ 500 ; globularis, 513 ; infundibuliformis, 562; Iowensis, 513; Neptuni, 517, 524, 569; Oweni, 513, 515

Red Bluff group, 889

Red Crag, 927

Red Deer River, 847

Red earth, 134

Red marl, 542, 627

Red ocher, 70§, 126, 331

Red porphyry, $86 \S$

Red River, 191 (raft), 819, 885, 888, 895

Red River of the North, 947

Red Sea, 21, 41, 200 ; volcanoes of, 295,296

Red Wall Group, 469, 658

Redwood, 831, 859, 939

Regelation, $245 \S$

Reindeer, 946, 950, 1013

Reindeer or Mesolithic epoch, 997, 1009

Remopleurides, 520, 521

Piensselæria, 562, 578, 579; ovoides, $578^{*}, 579$

Rensselaerite, $320,453 \S$

Reptiles, 54, 55, 414; reign, or era of, 737 ; Permian, 687, 706, 726 relation to Birds, 794, 795

Requienia, 87$\}$ (end of genus); ammonia, 865; Lonsdalei, 865; oblonga, 865 ; patagiata, 836 ; Texana $834,835 *, 836$

Resins, 74, 143, 712, 713

Respiration, $136 \S$

Reteocrinus, 516

Retepora, 427

Retzia, 627

Rhabdoceras Russelli, 757

Rhabdoceras bed, 757

Rhacophyllites, 760

Rhacophyllum, 699 ; Brownii, 611; filiciforme, 689,705 ; flabellatum, 645 ; lactuca, $689,693,705$

Rhadinichthys, 692

Rhrotic beds, 738, 769

Rhamnus Goldianus, 839 ; rectinervis, 839 ; salicifolius, 839

Rhamphorhynchus, 788, 790 ; phyllurus, $787 * 788$

Rhea, 54

Phénan beds, 626,627

Rhine, 169, 176, 191 (denudation), 195 (loess), 570

Rhinoceros, 54, 902, 907, 909, 910, 911, 927, 928 ; Etrusens, 927 ; hemitœehus, 1005,1006 ; incisivus, 927 ; megarhinus, 927 ; proterus, 1001 ; Schleiermacheri, 927 ; tichorhinus, 1004, 1005, 1006 
Rhizocarps, 435§, 436*, 584, 611, 718

Rhizocrinus, 59

Rlizodus, 417,692

Rhizopods, 56, 72, 140, 432*\&, 817 ; Arehæan, 454, 455

Rhodanian, 859, 865

Rhode Island, mean height of, 23 ; coal-beds of, 634

Rhodocrinus, 597

Rhone, slope of river, 173 ; discharge of detritus by, 190

— valley glaciers, 235*, 238, 242

Rhotomagian, 859,866

Rhus, 921

Rhynchocephalia, 54, 687, 706, 795, 856

Rhynchodus secans, $589 *$

Rhyncholites, $424 \S$

Rhynchonella, 425๊ , 426*, 516, 517, $520,550,552,562,568,579,642$, $700,719,756,757$; acutirostris, 503 ; affinis, 568 ; altilis, 503 ; bidentata, 569; capax, 507*, 514; castanea, 592 ; compressa, 865 ; concinna, 790, 791; contracta, $613^{*}, 621$; corallina, 790 ; cuboides, $593,601,622,625,627,628$; Cuvieri, 866 ; decorata, 790 ; dubia, 503 ; duplicata, 592 ; eximia, 620 ; inconstans, 779 ; Laura, 592 ; Martini, 866 ; navicula, 567 ; neglecta, 551, 567; nobilis, 562; nucula, 567 ; oblata, 579 ; obsoleta, 790 ; orientalis, 508; Petrocorriensis, 866 ; pigmæa, 790; plena, 502*; pleurodon, 628; plicatilis, 866 ; psittacea, 426*, 984; pugnus, 620 , 628 ; semiplicata, 562 ; sinuata, 592 ; socialis, 790 ; speciosa, 579 ; spinosa, 790 ; Stricklandi, 567, 569, 573 ; subangulata, 790 ; tripartita, 520 ; variabilis, 791 ; varians, 790 ; ventricosa, 560*, 562; Wilsoni, 562, 567, 569, 573

Rhynchonellids, 922

Phynchophora, number of Florissant, 900

Rhynchosaurus, 773

Rhynchotreta cuneata, 548*, 551, 569

Rhyolyte, $84 \S, 87,272,273,276$

Rhytina Stelleri, 1015

Richmond ( $\mathrm{Va}$. ) basin, 358, 742, 756 ; coal areas, 743,755 ; infusorial earth, 894*, 895; Triassic area, $740,741,743,799$

Ridges, 28*

Piffelhorn, 248

Rill-marks, 95*\$, 538

Pimella, 916 ; laqueata, 916 ; Texana, 916

Pinggold and Rogers Exploring Expedition, 927

Ringicula biplicata, 916

Río de la Plata. See La Plata

Rio Grande, $817,819,855,885$

Ripley epoch or group, 815, 821, $840,854,873$

Ripple-marks, 13, 89, 94§, 95*, 161, 223 ; Cambrian, 464, 484

Rissoa Chastelii, 926
River systems, 28, 29, 30

- valleys, excavation of, 178 ; buried, 204, 934

- waters, analy ses of, 121

Rivers: lengths and drainage areas, $30,172,173$; special points in fluvial history, 203-204; transportation and deposition by, 189202 ; distribution of transported material, 191; velocity of, 175 ; working-power of, 173-177

Roan Mts., 901, 946

Robinia, 921

Roche-Moutonnée Creek, 250*

Roches moutonnées, 250*ฐ

Rock-cities, 604, 647

liock-flour, 81§, 248, 251, 941

Rock-making, $140 \S$

Rock salt, $320,552,553,554,769$

Rockford shale, 606

Rocks : constituents, 61 ; kinds of, 75 ; organic constituents, 71-75, 140-141, 458; structure, 908 ; expansion, 259

-, volcanic. See Volcanic

Rockwood beds, 577

Rocky Mountain Chain, 389, 748; protaxis, 24, 444, 461, 464, 483, 490,746 ; silver and lead mines, 876

Rocky Mountain region, Archæan in, 444; Cambrian, 464; Lower Silurian, 494, 495; Upper Silurian, 541; Devonian, 575, 581; Glacial, 944; Subcarboniferous, 639; Carboniferous, 634, 635, 658; Triassic and Jurassic, 808812; Cretaceous, 814, 815, 818, $827,829,838,868,880$; Tertiary, 882, 887; elevation during, 983, 935

Rocky Mts., 24, 31*, 51; glaciers of, 240 ; changes of level in, 347 ; making of Laramide Mts., 874; volcanoes of, 296,937

Romingeria, 579; cornuta, 584*, 590

Roofing-slate, $80 \S, 92,112,113 *, 370$, 371

Rioots, acidity of, and the corroding effects, 136 ; destruction by, $157 *$

Rosa, Monte, glacier region of, 226 , 237,248

Rosendale cement. 555

Rossberg landslide, in 1806, 208

Rosso antico, 868

Rostellaria, 922 ; nobilis, 854

Rota Island, elevation of, 350

Rotalia Boucana, 432*; globulosa, $432 *$

Rothliegende, 697, 706

Rotifers, 423, 455 720, 721

Potomahana Lake, 305

Rotten limestone group, 815, 823, $824,848,854$

Rubidium, 335, 449

Ruby, 64§

Rudistes, $840,841 *$, 854, 861*

Rupelian beds, 926

Rurutu Islands, 37 ; elevation of, 350

Rusophycus bilobatus, 545*, 546
Russia, 34, 167 ; upturnings in, 630 , 734

-, Cambrian in, 482, 484, 518; Lower Silurian, 518, 521, 533 ; Upper Silurian, 533, 563, 566, 567, 568, 569, 573; Devonian, 627; Subcarboniferou.6, 693, 696, 704 ; Carboniferous, 690, 693, 697, 710 ; Permian, 686, 697, 707 ; Triassic, 768; Jurassic, 760 , 775, 776, 790, 794; Cretaceous, 857; Tertiary, 928

Rutoceras, 591, 602

Ruwenzori, Mt., 33, 296 (height)

Sabal, 837, 921 ; major, 933

Sabine River, 889,890

Sable Island, 444, 944

Saccamnaina Carteri, 700

Saccosoma pectinata, $778 *, 779$

Sacramento River, 30,809 ; valley, $749,811,818,820,830,895$

Saganaga Lake, 448

Sageceras, 756 ; Haidingeri, $757 *$

Sagenaria acuminata, 646

Sagenopteris, 698, 704

Saghalien, 40

Saguenay River, 948

Sahara, desert of, 51; plateau of, 26,34

St. Cassian beds, 769, 774

St. Elias, Mt., 25, 238, 239*, 240 (glaciers), 251, 390

St. George's Shoal, 881,889 '

St. Gothard tunnel, fossils, 310

St. Helena, volcano of, 290,297

St. Helens Island, 531, 558

St. Helens, Mt., 296, 945

St. John, N.B., elevation, 350

St. Lawrence Bay, 461, 541, 544

- channel, 536, 571

- Gulf, 444, 533, 537; coal making in, 708

- River, 40, 171, 536; depth of, 948

- valley in the Champlain period, 982

St. Louis limestone, 634, 637, 638, 646,647

St. Mary River series, 830

St. Paul's Island, 867

St. Peter, Lake, 542

St. Peter's Island, 867

- sandstone, $136,491,493,494,732$

St. Vincent Island, 163

Salamander, 415,920

Salenia, 840,860

Salina beds, 552

Saline deposits, 119 ; efflorescences, 138,160 ; springs, 200,553

Salinity of the ocean, 121, 214

Salisburia, 53, 435; nana, 833; Sibirica, 888*

Salix. 854, 922: angusta, 839 ; Meekii, 83\%, 538*

Salmon. 812 . 59 ; family, $\$ 62$

Salt, 68 (see also Rock salt); lakes, 119, SS1; making, 120 ; pans, 120 , 133, 184, 554, 791 ; water, subterranean, 320

Salt Lake City, $360 \%, 361$

Salt Range, India, 488, 698, 770, 776 
Salt-works of Salina, 553,554

Salterella, 471; Billingsi, 515; Maccullochi, 573 ; pulchella, 471, 472*; rugosa, 573

Salton Lake, 200

Saltonstall Ridge, 801*

Saltpeter, 63§, 137

Salvinia, 584,718 ; natans, $435,436 *$

Samoan Islands, 36, 38, 145, 283, 297

San Bernardino, Pass of, 160

San Francisco Mountains, 660 ; peninsula, 884, 892 ; River, 885

San Gabriel Range, 892

San Juan Mts., 363

Sand, 75§, 76§; barriers, 223, 224*; bars, 192, 193, 202, 212, 216, 225, $226^{*}, 227^{*}$; hills on sea shores, $94,155,161,162$; rock, 80 ; scratches, 160 ; spits, increase of, 228,224

Sand-blast, carving by, 161

Sand-flea, 420*, 421ई

sand-worm, 423

Sandstone, 80ई; dikes or veins, $344^{*}, 811,876$

Sandstones of Condros, 625

Sandusky limestone, 581

Sandy Hook, formation of, 224, 225

Sangay, 26

Sangre de Cristo Range, 266

Sanidin, $84 \S, 88$; trachyte, $84 \S$

Sannionites, 501

Sannoisian stage, 926

Santa Cruz beds, 927 ; Islands, volcanoes of, 296; Mts., 892

Santa Inez Range, 892

Santa Lucia Mts., 892

Santa Maria Island, elevation of, 349

Santa Monica Range, 892

Santa Suzanna Range, 892

Santee beds, 888

Santo Domingo, 19, 935

Santonian, 859, 866

Santorin Island, 296 (volcanoes)

San hirsuta, 481*, 482

Sã̃ Miguel, geysers of, 308

Sapindus, 838, 896; Morrisoni, 838

Saportæa, 685

Sapphire, $64 \S$

Sapphirina Iris, $420 *, 421$

Sarcinula, 640; obsoleta, 511*, 515

Sardinia, Cambrian in, 482 ; Upper Silurian, 563, 564

Sargasso Sea, 45, 121, 143, 156

Sargassum, 437

Sarmatian stage, 927

Sarotes venatorius, 163

Saskatchewan River, 29, 203, 947

Sassafras, $812,831,837,879,921$;

Cretaceum, 837, 838*

Sat valley, 240

Saurichthys, 772 ; apicalis, 774

Saurocephalus, 862 ; lanciformis, 844

Saurodon lanciformis, 844

Saurodonts, 826, 843, 862

Sauropods, $761,762-764,786,867$

Sauropus primævus, $645^{*}$

Saussurite, $65 \S, 88,318,319$; rocks, 82,88

Savage Island, elevation, 350
Savaii, 283

Saxicava, 157; aretica, 983, 984; rugosa, 984, 995

Saxifraga, 240 ; oppositifolia, 945

Saxony, Archean in, 455, 456; Permian, 706, 707; Triassie, 768

Scalaria, 916, 922; Bowerbankii, 925 ; Grœnlandica, 984; Hercules, 854 ; Sillimani, 854

Scalent series, 728

Scales, Fish, analysis of, 78

Scalites angulatus, $502 *$

Scandinavia, 32, 43, 256; fiords of, 948; Archæan in, 456; Cambrian, 482; Lower Silurian, 521; Upper Silurian, 563, 568, 569, 573; Cretaceous, 857; Glacial, 948. See also Norway; Sweden; etc.

Scandinavian plateau, 19

Scaphaspis Ludensis, 567

Scaphiocrinus, 646, 690 ; Missouriensis, $640 *, 646$

Scaphites, 854 ; æqualis, 866 ; Conradi, $842 *, 854,855$; Geinitzi, 866 ; hippocrepis, 854; larvæformis, 842*, 843, 855; nodosus, 855 ; pulcherrimus, 866; Texanus, 855 ; ventricosus, 855; vermiformis, 855

Scaphodus Ludensis, 567

Scaphopods, $424 \S$

Scapolite, 65\$, 79, 310, 318, 320

Scar limestone, 695

Scaumenacia, 621

Scelidosaurus, 787

Scelidotherium, 1008

Scenella, 482 ; reticulata, $472 *$; retusa, 472*

Schillerization, 321

Schist, $83 \S, 84 \S$

Schistose rocks, 82,83

Schistosity, 113\$, 371

Schizaster atavus, 866

Schizobolus truncatus, 612

Schizocrania filosa, $507 *, 514$

Schizocrinus, 532; nodosus, 514

Schizodus, $602,621,687,707$; amplus, 690 ; Chesterensis, 647 ; dubius, 707; obscurus, 707; quadrangularis, 620; Rossicus, 655; Schlotheimi, 707; truncatus, 707

Schizopods, $439 \S, 703$

Schizotherium, 918

Schlern dolomyte, 774

Schloenbachia Belknapi, 836 ; cristata, 865; dentato-carinata, 855 ; inflata, 865; Peruviana, 836; varians, 866 ; varicosa, 865

Schloenbachia elays, 836

Schoharie epoch, $410,576,579$; grit, $576,579,587,590,591,601,628$

Schorl rock, $88 \$$

Schuylkill River, 816

Scirpus, 75 ; cæspitosus, 946

Sciurus, 910, 918

Scolithus, 423,470 ; linearis, $477 *$

Scolopendra, 419, 724

Scoria, $266,267 \S, 281 *, 282$

Scoriaceous lavas, 280§, 281*, 298; rocks, $78 \S$
Scorpions, $420, \quad 564, \quad 722 \S, 724$ Upper Silurian, 556, 565, 574, 722 ; Devonian, 575; Carboniferous, $677,691,701^{*}$

Scotland, $155,218,229,258,288,453$, 534; Archæan in, 453, 456, 457; Cambrian, 457, 481; Lower Silurian, 518, 520, 524; Upper Silurian, 563, 565, 573; Devonian, 622, 623, 625 ; Subcarboniferous, 695: Carboniferous, 702, 703 ; Permian, 697 ; Triassic, 768,773 ; Jurassic, 775; great thrust movement in Highlands of, 534

Scratches, 95, $96 \S$

Scratching by drifting sand, 160 ; by icebergs, 252 ; by slides of rock, $249 *$

Scutella, 559

Scutella limestone, 559

Scyphia digitata, 513

Seyphian-Kalk, 790

Sea-anemone, $431 \S$

Sea bottom, changes in level of, $345,348,949$

Sea water, salts of, composition of 120 ; dolomization by means of, 134

Seals, 415

Seam, $92 \S$

Seaweeds, $56,75,143,155,436 \S$

Secondary formations, 738 ; minerals, $320 \S, 323,332,340,341$; rocks, $408 \S, 880$

Secretary Bird, 923

Section, general, of geological series, $410^{*}, 411 *$

- of Adirondacks, Can., 452*; A ppalachians, 102*, 109*, 355*, 356* ; Archrean, 451*; Bald Mt., N. Y., 528*

- of Coal-measures at Trevorton Gap, 650* ; Coal-measures near Nesquehoning, 649*

- of Colorado Plateau, $110 *, 363 *$; Cumberland Table-land, Tenn., $356 *$

- of Dent de Morcles, 367*; Mt. Eolus, Vt., 530*; at Genesee Falls, $91 *, 542$; of Greylock Mt. Mass., $530^{*}$

- of Hamilton beds, Lake Erie, 594*: Hawaii, 269*; Himalayas, 32*, 368* ; Jura Mts., 368*

- of Mt. Loa, 286*; of Portland dirt-bed, $776^{*}$; at Niagara River, 540*; of Paleozoic at Pottsville, 650*

- (Prosser's) of New York rocks near Rochester, 605; (Prosser's) of Pennsylvania rocks, Munroe Co., 594, 606

- on the Schuylkill, Pa., 650*; of Snake Mt., Vt., 528*; Taconic Range, near Montmorenci Falls, 527*; Tennessee Rocks, 356*; Timpahute Range, 366*; Utah ore-beds, 339 k

- showing cavern-making in lime stone, $130 *$; of decaying limestone, Amenia, N.Y., 126 
Section of Alps, 102*, 110*; Carbonate Hill, Leadville, $341^{*}$; Cosl-measures, 651-652, 656, 657 ; Kilauea, 284*, 285*

- of Laramide Mountain range, Brit. A., 359*

Sediment, $76 \S, 167 \S$; ratio of, to water, 190

Sedimentary rocks, 167 ; sedimentation more rapid in salt water than in fresh, 209, 210, 217

Sedum rhodiola, 945

Seeds, transportation of, 156,163

Seiches, $202 \S$

Seine, 191

Seismograph, seismometer, seismoscope, $375 \$$

Selachians, $415 \$, 416 *$

Selaginella, 718

Selenium, 331

Selkirk Mts., 240

Selvage, $332 \S$

Semele Stimpsoni, 927

Seminula subtilita, 675*, 685, 690

Semi-oviparous Mammals, 415

Seneca Lake, 608, 605

Senonian group, $815,858,859,860$, $\$ 66,867$

Sepia, 424

Septaria, 97*, 138* (quartzyte)

Sepulchre Mt., 937

Sequanian group, 790

Sequoia, $816,831,837,840,859,921$, 939 ; ambigua, 838 ; gigantea, 939 ; gracilis, 834; Langsdorffi, 921; Reichenbachi, 834, 839 ; Smittiana, $833 *, 834$

Seral series, 728

Sergestes mollis, 52

Sergipian group, 867

Serieite, $65 \S$; schist, $84,88,89$

Sericitschiefer, 84

Series, $406 \S$

Serolis, 420*

Serpentine, $68 \S, 319 \S$

Serpula, 423

Serpulidæ, 59

Serpulites dissolutus, 515

Serripes Gronlandicus, 983, 984

Sertularia, $430 * \S$; abietina, 430*; rosacea, $430 *$

Sevier Lake, 119

Sewickley coal-bed, 651

Seychelles Islands, 737

Shakopee linaestone, 493

Shale, shaly structure, $80 \S, 92 \S$

Shan-a-lin Mts., 32

Shansi, 696

Shan-Tung, 198

Sharks, $56,60,73$ (analy sis of bones), $415,416^{*}$; teeth of dredged, 144 . See Selachians

Sharon coal-beds, 656 ; conglomerate, 648,656

Shasta, Mt., 87, 267*; glaciers of, 240,945 ; height of, 296

- group, 818; Aucellæ of, 834

Shasta-Chico series, $809,815,820$, 830,868

Shawangunk grit, 538, 539, 541

- Mts., 538, 946

Shawnee coal-bed, 828
Shear-zones, 111ฐ, $322 \S$

Shearing, 168§, 216, 322

Sheep-backs, $250 * \S$

Shell-beds or heaps, 98, 158; of Maine, 983, 994

Shell Bluff, Ga., 916

Shell-limestone, $79 \S, 151$; marl, $79 \S$

Shenandoah valley, 357

Shenango group, 638

Sheppey, Isle of, 921, 923, 925

Sheridan, Mt., height of, 296

Shetlands, 87, 218

Shinarump Cliffs, 747

Shipworm, 158

Shoal Creek limestone, 817

Shore-lines, elevated, in region of Great Lakes, 906 ; about Lake Winnipeg, 985

Shore-platforms, 220, 221*, 222*

Shoshone Lake, 200, 305

- Range, 366, 945

Shot, angle of rest of, 165

Shrimps, 420, 438, 615*

Shrinkage cracks, $94 * \$, 464$

Siam, 22

Siberia, 32, 166, 195, 776, 794, 833, 927

Sicily, 296, 431, 921

Siderite, 69§, 126, 344, 449, 664, 665

Sierra Blanca, 874

Sierra Chain and System, 365, 389, 811

Sierra de Salina, 892

Sierra Madre, 444,758

Sierra Nevada, 25, 27; buried river valleys, 204; volcanoes of, 296 ; river systems of, 934; glaciers of, 240 ; upturnings at close of Jurassic, 809, 814; elevation in the Tertiary, 366,932

- Archæan in, 444: Upper Silu rian, 810 ; Carboniferous, 635 659: Triassic, 746, 747, 758, 809; Triassic and Jurassic, 739, 809; Jurassic, 358, 748, 760, 809 (close of), 810,932 ; Tertiary, 366 , $883,887,892,895,934$ (elevation), 935, 937 (eruptions); Glacial, 945 Sierra San Carlos, 820

Sigillaria, 611, 639, 654, 667, 668, 682, 689, 698, 699; Brardii, 689, 693, 705; Halli, 595*; Lescurii, 689 ; mammillaris, 689 ; Menardi, 689 ; monostigma, 689 ; palpebra, 622 : Pittstonana, 668*, 688; Sillimani, 668*, 688; tesselata, 689; Vanuxemi, $009 *$

Sigillarids, $698,712,718$, 750 ; Carboniferous, $669,670,672,688$; Coal-measure, 653 ; Permian, 684, 704,718 (last)

Silene, 240 ; acaulis, 945

Silesia, 88; Coal-measures in, 696, 702,703

Silica, $62 \S, 63,135-136$; as a solidifier, 323

Silicates, 62\$, 68, 64-68

Siliceous deposits, 82, 152, 305, 306, $308,309,335,441$

-Claiborne, 885, 888

- group. Tenn., 638
Siliceous organic rock-material, $72 \S$, 140,141

- rocks, $80,81,82$; slate, 828

- solutions, 82, 94, 97

- sponges, $431 \S$

Silicified wood, 125,135

Silicon, 62§, 68; fluoride, 66

Sillery sandstone, 467,496

Sillimanite, 319

Silt, $81 \S, 150,167 \S, 177,190,193$, 628 ; of rivers, amount of, 190

Silurian, 535 5

- and Cambrian, history of the terms, $463,464 \&, 489$

-, Lower, 489; European, 517; economical products, 522; general observations, 524; the Cincinnati uplift at close of, 387,582 , 537

- Upper, 535 ; foreign, 563 ; general observations, 570

Siluric era. See Silurian

Siluroids, 843

Silver Cañon, $366^{*}$

Silver Cliff, 340

Silver-moth, 702

Silver Peak, 469

Silverado, 733

Simeto, erosion of the, 184

Simoceras, 793

Simosaurus, 773

Sind, 299, 770, 925

Sindree, changes of level at, 349

Sinemurian group, 775; (Lower), 790

Singala Mt., 368*

Sinopa, 918

Sinter, $82 \$$

Sinupallial, $425 \S$

Sioux quartzyte, 468

Siphocy præa problematica, 917

Siphonaria Penjinæ, 927

Siphonema, 503

Siphonia lobata, $860 *$

Siphonotreta, 521; unguiculats, $427 *$

Sitomys, 918, 919

Sivatherium, 927

Siwalik Hills, 923, 927, 983 (Tertiary beds), 936

Skiddaw slates, $517,519,520$

Skye, 938

Slate, $83 \S, 92 \S$; siliceous, $82 \S$

Slates, auriferous, $748,759,809$

Slaty cleavage or structure, $\mathbf{7 7}, 92 \S$, $112 \S, 113^{*}, 370,371$

Slaty Peak, Col., height of Cretaceous rocks, 935

Slaty rocks, 66

Slickensides, 96 §, 108, 111

Slimonia, 567

Slope of loose materials, 165

- of mountains, $26,2 \tau * \S$; of Rocky Mts., 26*

Sloth, 54

Smaragdite, 88

Smilax, 435

Smilodon, 1000

Smith sonite, $34^{\circ}$

Snails, 424, 425*

Snake Mt., fault at, 527, 528*

Snake River, 300, 305; plains, 935 
Snakes, 415, 848; Carboniferous, 726 ; Cretaceous, 848, 870 ; Tertiary, 202, 901, 928

Snow-drifts, 162

Snow-line on heights, 233,234

- Soapstone, 67\$, 65, $89 \S$

Society Islands. See Tahitian

Soda, $61 \S$; in plants, 74,75

Soda-granite, $56 \S$

Soda Springs, Idaho, 746

Sodalite, $81,85,449,876$

Sodium, 61, 68, 120

Soil, $81 \S$; moved by frost, 231

Solarium ornatum, 866 ; planorbis, 836 ; triliratum, 916

Solemya, 602

Solen, 425\&, 916, 917

Solen beds, 892

Solenhofen, $776,783,784,786,788$, 796,852

Solenoceras annulifer, 854

Solenomya radiata, 690 ; vetusta, 590 (first known)

Solenopora compacta, 514

Solfataras, $128,265,278,283,293 \S$, 295,334

Solidification, $258,264,326$; of the earth, 376

Solids, flow of, 351-352

Solitaire, 1014

Soloman Islands, $36,38,156$

Solution, 118-122

Solva group, 481

Somma, Mt., 276, 291

Sonora, 747,748 (gold placers), 749 , 755,756

Sorata, Mt., 27

Sorrel, 945

Souris River beds, 830

South Africa, 406 ; united with India, 873, 937 ; and Australia, 874, 937; no fiords, 948; Paleozoic in, 699: Carboniferous, 699 : Permian, 698, 699, 707, 737; Triassic, $707,737,770,773$, 791; Jurassic, 791; Quaternary, 1019

South America, 16, 18; mean height of, 23 ; surface features of, 30 ; volcanic cones of, 274 ; elevations of, $347,874,877$ : eordilleras, 390 ; fiords of, 948 ; Archæan in, 442, 456: Cambrian, 483; Deronian, 627: Carboniferous, 632, 659, 693, 711; Cretaceous, 857, 867; Tertiary, 365, 456; elevation during, 927, 935; post-Mesozoic mountain-making, 874 ; Glacial, 948

South Carolina, mean height of, 23; phosphatic deposits of, 153 ; earthquakes of, 373

South Dakota, mean height of, 23 ; Cambrian in, 464, 468, 476 ; Niagara, 541; Cretaceous, 828, 833, 856; Tertiary, 909

South Mtn., Pa., 465, 532

South Park, 495, 886, 893

South Shetlands, 296 (rolcanoes)

Spain, plateau of, 26 ; volcanoes of, 296; Cambrian in, 484; Lower Silurian, 518; Upper Silurian, 568, 573 ; Subcarboniferous, 693 ; Car- boniferous, 693 ; Jurassic, 775 , 793; Cretaceous, 857 ; Tertiary, 920,982

Spalacodon, 926

Spalacotherium, 789*

Spanish Peaks, 296, 313, 876

Sparnacian group, 925

Spathiocaris Emersoni, 620, 621

Species, difference in, attending difference in environment, 402

Specific gravity in relation to fusibillity, 304

Specular iron, 70, 83, 578; rocks, 83

\section{Speeton Cliffs, $\$ 65$}

Sperm Whale, 912

Spermatophilus Eversmani, 156

Sphærexochus, 521; mirus, 520, 565*; parvus, 503

Sphærium, 152, 856

Sphæroceras, 760

Sphærocystites, 562

Sphærophthalmus, 481

Sphærospongia, 596 ; tesselata, 597*, 601

Sphærozoum orientale, $433 *$

Sphærulites, 861; Hoeninghausi, $861 *$; Texanus, 836

Sphagrum, 73 (ash), 153; commune, 74

Sphalerite, $70 \S, 125,333,340,542$, 637

Sphenacodon, 688

Sphene, 67

Sphenella glacialis, 699

Sphenodiscus lenticularis, 854 ; pleurasepta, 855

Sphenodon, 687 ; punctatum, 54

Sphenolepidium, 831; Virginicum, 834

Sphenophyllum, 639, 671, 685, 698, 699, 704; antiquum, 622 ; emarginatum, 689 ; filiculmie, 692, 693 ; longifolium, 689, 704; Schlotheimi, $671 * 689$; vetustum, 583* Sphenopteris, 639, 671, 685, 689, 693, 698, 699, 704; arguta, 791; cristata, 645 ; flaccida, 626 ; furcata, 689; Gravenhorstii, 670*, 689; Grevillioides, 838; Hartti, 622; Hildrethi, 670*, 689; Hitchcockiana, 622 ; Hœninghausi, 622 ; Hookeri, 626; Humphriesiana, 626 ; Mantelli, 831, 832*; Schimperi, 704 ; spinosa, 689 ; tridactylites, 689 ; Valdensis, 834

Sphenopterium obtusum, 646

Sphenotus, 621 ; contractus, 621

Spherophyric, $77 \S$; rocks, $83 \S, 84$

Spherulites, $84,96,97,289,338$

Sphyradoceras, 591

Sphyrenids, 843

Spicules of sponges. See Spongespicules

Spiders, 141, 163, 420, 525, 722, 723. 724; Upper Silurian, 574; Devonian, 575; Carboniferous, 657, 674, 677, 701, 722 (first); Paleozoic, 722, 723, 727 ; Tertiary, 893, 901

Spinax Blainvillii, 416*

Spinel, 313, 449, 453
Spirifer, $310,401,425 \$, 426 * \&, 550$ $561,562,568,579,592,606,642$, 705, 719; acuminatus, 585*, 590, 591 ; alatus, 707 ; altus, 612 ; arenosus, 578*, 579; arrectus, 579 ; asper, 602 ; bimesialis, 602 ; biplicatus, $642 *$, 646 ; borealis, 758 ; canaliferus, 625 ; cameratus, 675*, 685, 690 ; Clannyanus, 707 ; Conradanus, 591 ; Cooperensis, 646 ; crispus, $563,567,568$; cultrijugatus, 626,627 ; curvatus, 625 ; cuspidatus, 703 ; cyclopterus, 562, 563 ; decussatus, 626 ; disjunctus, $370^{*}, 592,612,613^{*}, 621,622,625$, $626,628,703$; Dumonti, 626; duodenarius, 591; elevatus, 567, 568 ; exporrectus, 520 ; fimbriatus, 591, 601, 602; fragilis, 773 , 774 ; giganteus, $370^{*}$; glaber, 627 ; $700 \%$; glaber (var. contractus), 647 ; granuliferus, 601 ; gregarius, $585^{*}, 590,591$; Hungerfordi, 602 ; hystericus, 625 ; incrassatus, 704 ; increbescens, 642*, 646; Keokuk, 646 ; lævicostatus, 625; lævis, 612*; lineatus, 690 , 704; Logani, 646 ; macropleurus, $560^{*}, 561$, 562, 563; Marionensis, 602, 646; Meeki, 646; mesacostalis, 620 ; mesastrialis, 620; mucronatus, 601 ; Münsteri, 774; Niagarensis, 548*, 551, 563; Parryanus, 602 ; pennatus, 508*, 602; perlamellosus, 562, 563; plicatellus, 520; pyxidatus, 579 ; radiatus, 522,550 , 551 ; raricosta, 592; speciosus, 703 ; striatus, $426 *$; sulcatus, $548^{*}, 551,562,563,567$; Urii, 626, 627, 707; Vanuxemi, 558; varicosus, 592; Verneuili, 626, 627, 628 ; Whitneyi, 602

\section{Spiriferids, 574}

Spiriferina, 756, 790 ; cristata, 707; Kentuckensis, 690; octoplicata, 707 ; spinosa, 642*, 646, 647; Walcotti, $779 *, 790$

Spirifersandstein, 570

Spirocyathus Atlanticus, $470^{*}$

Spirophyton, 601, 688; eaudagalli, $582 * 667,688$

Spirorbis, 675; arietinus, 691; carbonarius, $676^{*}, 691$; laxus, 558

Spitzbergen, $48,395,758$; Subcarboniferous in, 696, 704; Carboniferons, 635, 696, 704, 711; Permian, 704; Triassic, 768,774 , 792; Jurassic, 776 ; Cretaceous, 868, 872 (climate); Tertiary, 922, 939 (Sequoia)

Spodumene, 321, 332, 449

Spondylus, 130 ; gregalis, 854 ; spinosus, 866

Sponge-beds, 777,790

Sponges, sponge-spicules, 57, 64, $72,140,141,419,431 \S, 432 *, 474 *$, $513,515,583 *, 590,596,601,611$, $777,860^{*}$

Spongillæ, 432

Spongiolithis appendiculata, $894 *$

Sporangi in coal, $655^{*}$

Sporangites, 601 ; Coriviferous, 584 ; 
Hamilton, 596; Chemung, 610, 611, 612 ; Coal-measure, 65๊ Sporangites Huronensis, 610,612 Spores, 582*, 584, 611, 718; in coal, $654,655 *, 712$

Spring Hill, 733

Springs, 205. See also Hot springs ; Mineral; Sulphur; Thermal waters

Spruce, $435,436,667,668,770,859$

Spyroceras, 602

Squalodon, 912, 927

Squalodonts, $813 * 8,863,869$

Squalus cornubicus, 73

Square Lake, Me., 552, 558

Souash-bug, 419

Squid, $424 * \$, 525,758,776$

Squirrels, 910

Stages, $407 \S$

Stagodon tumidus, 853*; validus, S5马*

Stagonolepis, 778

Stags, 907, 927, 980, 1002, 1013

Staked Plains, 885, 895. See also

Llano Estacado

Btalactites, $79 \S, 181,294^{*}, 695$

- and stalagmites at Kilauea, 294*, 295,324

Stalagmites, 79§, 92, 131, 294*

Stampian stage, 926

Stangeria, 718

Star Peak groups, 747

Starfishes, 158, 428§, 429*

Starucca sandstone, 606

Staten Island clay-beds, 821,823

Statuary marble, $79 \S$

Staurolite, 65*, 668, 319, 449

Staurolitic rocks, 88,310

Steam, 300, 338 ; in metamorphism, $312,323,354$

5teamboat Springs, 323 ; superficial vein-making at, 334, 335; depositing gold, 335

Bteatite, $67 \S$

Steaty te, $89 \S, 450$

Steel ore, 69 \$

Stegocephs, $681 \S, 687$

Stegosaurids, 863

Stegosaurs, Stegosaurians, 761, 764, 787,796

Stegosaurus, 765*, 787 ; ungulatus, 764*

Stelletta, 432*

Stemmatopteris, 699 ; punctata, $669 *, 689$

Dtenaster Huxleyi, 499*, 500

Steneofiber, 918, 919

Steneosaurus, 790

Stenocriaus, 516

Stenogale, 919

Stenopora, 524; fibrosa, 503, 517, 567 ; Petropolitana, 517

Stenotheca, 481; Acadica, 475*; rugosa, $472 *$

Stenotrema hirsutum, 967; monodon, 966

Stephanoceras Humphriesianum, $781 *, 790$; macrocephalum, 791

Stephanocrinus, 547\% ; angulatus, $547 *, 550$

Sterculia modesta, 839

Stereocaulorr Vesuvianum, 136
Stereognathus, 789*

Stereosternum, 706; tumidum, 687 Sternbergia, 673

Sthenopterygians, 417

Stibarus, 918

Stictopora, 514, 550

Stictoporella, 505 ; cribrosa, 506*

Stigmaria, $627,645,653,658,669 \%$, $670,699,704$; anabathra, 645 ; ficoides, 646, 699; minor, 645; minuta, 645 ; perlata, 622 ; pusilla, 622 ; umbonata, 645

Stikine River, glaciers of, 240

Stilbite, 68

Stinkstein, 697

Stiper stones, 517

Stissing Mtn., 467

Stockbridge limestone, $467,491,528$ 530

Stomapod, 783

Stomatopora arachnoidea, 514

Stone age, 1009

Stone coal, 661 ; rivers, $209 \S$; state, 264

Stones on sea bottom, 144

Stonesfield slate, $411,775,777,787$, $788,789,790$

Stony Creek, Conn, 949

Stormberg beds, $699, \mathbf{7 7 0}$

Strain, level of no. See Zero-strain

Strangeria, 596

Straparollus, 495, 515, 707 ; Claytonensis, 501; lens, 647 ; pernodosus, 690 ; pristiniformis, 501 ; similis, 647 ; Spergensis, 647 ; subrugosus, 690

Strata, stratification, $91 * \S$

Straticulate, $92 \$$

Stratified formations, 90-116 (structure and characteristics, 90 ; cal culating thickness of, $113,114^{*}$; conformability, unconformability, 114), $398,441,450$

Stratigraphical, $91 \S$

Stratum, $91 \S$

Strephochetus, 502

Strepsidura ficus, 916

Streptaxis Whitfieldi, 690

Streptelasma, 550, 562; apertum, 513 ; calyculus, 550 ; corniculum, 504, 505*, 513; expansum, 503 ; profundum, 513

Streptorhyncus crassum, 690 crenistria, $625,626,700^{*}$; um braculum, 625, 704

Striæ. See Scratches

Striarca centenaria, 899*, 917

Stricklandia lens, 520, 567; lyrata, 567

Strike, $99 \%, 100 \S, 101,105 *$

Stringocephalus Burtini, 595, 601, 625,626

Stringocephalus beds, 626,627 ; zone, 595, 601

Strobilospongia .513

Stromatocerium pustulosum, 514

Stromatopora, 455, 499, 547, 551, $562,584,625$; concentrica, 547*, 550,$569 ;$ ponderosa, 590

Stromatoporids, 447, 504

Strombodes gracilis, 550

Stromboli, 276, 280
Strombus Aldrichi, 899*, 917; Leidyi, 917 ; Sautieri, 865

Strontium, 335

Strophalosia, 707 (ends with Permian); excavata, 707 ; Goldfussi, 707 ; lamellosa, 704 ; productoides, 628 ; truncata, 620

Stropheodonta, 551, 562, 579, 642 areuata, 602; Cayuta, 621; demissa, 591, 602 ; filosa, 567 ; magrnifica, 579 ; mucronata, 620 ; nacrea, 602 ; perplana, $591,592,602$; punctulifera, 592; reversa, 602; varistriata, 558

Strophodus, 772 (first), 783

Strophomena, $425 \S, 426 \S, 503,516$, 517, 520, 521, 552, 562; alternata, $503,507 *, 514,524$; arenacea, 520, 567 ; compressa, 567 ; deltoidea, 521 ; depressa, 551, 626 ; expansa, 521 ; incrassata, 514 ; pecten, 568 ; planumbona, $426 *$, 508 ; plicifera, 502*, 503; rhomboidalis, 503, 625 ; rugosa, 568 ; subplana, 563 ; Woolworthana, 563

Strophomenids, 568

Strophonella euglypha, 567; radiata, $560 *$

Strophostylus, 562 ; cancellatus, 579

Structural geology, 14§, 61-116 (rocks, 61 ; terranes, 89)

Struthio, 54

Struthiosaurus, 864

Sturgeon River, 445

Sturgeons, 59, 923

Stylacodon, 768 ; gracilis, 767*

Stylina, 760 ; tubulifera, $759 *$

Stylinodon, 905

Styliola, 59*

Styliolina, 586, 599 ; fissurella, 592, $598 * 602,603,612,620,621$

Styliolina limoestone, $603,613,621$

Stylodon, $789 *$

Stylolites, 543, 555

Stylonurus, 567, 623 ; excelsior, 615 ; Wrightianus, 615

Sub-, as a prefix, $407 \S, 684 \S$

Subapennine marls and sands, $92 \tau$

Subcarbon period, 632

Subcarboniferous period, $636^{\circ}$

Sub-Himalayas, 983, 936

Sub-Oleon conglomerate, 638

Subretopora incepta, 502*

Subsidence, 151, 345, 346, 347 ; Champlain, 981; modern, 34s, $349,350,378$, 392; through the Paleozuic, 380,385

-, coral island, the counterpart of continental elevation, 937 ; of the Pacific indicated by coral islands, $149,350,392$; rate of, in coral islands and in the history of coral reefs, $149 *, 150,151,202$

Subterranean waters. 204-209

Subulites, 514 ; ventricosus, 551

Succinea avara, 966 ; obliqua, 966

Suchoprion aulacodus, 754

Suessonian group, S84, 925

Suillines, 930

Sulcopora fenestrata, 502*, 503

Sulphates, $63 \S, 69$

Sulphides, 70 
Sulphur, $63 \S, 70$; in coals, 661,663 , 664

- springs, 125; in California, 335 ; in New York, 554, 555

Sulphuric acid, 63§; springs, 125, 555

Sulphurons acid, 63§, 124, 125, 324 ; from volcanoes, $278 \S, 293,294$

Sumatra, 22, 38,40 ; volcanoes of, 297

Sun, a chief source of geological energy, 117 ; causes of the varying degree and effects of its heat, 253-257; its heat as related to the ocean's work, $166,209,214$; as affecting the temperature and density of water, 214

- spots, 11-year cycle of, 177, 255

Sunderland Lake, 533

Superga, molasse of, 926

Superior, Lake, 29, 40, 85, 166, 200, $201 *, 206,483$; basin, 106,199 ; copper veins, 272, 323, 388, 339, 465,466

Superposition, order of, 399,400

Surcula, 916

Surficial, 198§, $272 \S$

Surgent series, 728

Surirella craticula, 164*, 165

Sus, 54, 927

Susquehanna River, 388, 465, 730*, 731, 816

Sussex marble, 864

Swabia, 738

Swallows, 923

Sweden, Arehæan in, 456; Cambrian, 482, 484, 518; Lower Silurian, 518, 519, 520, 521; Upper Silurian, 563, 564, 565, 568, 569, 573; Triassic, 769; Cretaceous, 833

Switzerland, Cretaceous in, 857, 859 Jurassic, 783 ; Tertiary, 920, 925, 926

Sydney sandstone, Australia, 221

Syenite, $85 \S$; granite, $85 \S$

Syenyte, $85 \S$

Syenytic gneiss, 858

Synbathocrinus, 602

Synclines, 102\$*, 108*, 104, 105*

Synclinorium, 380§, 729, 731

Syncoryne, 429*, 431

Synedra ulna, 164*, 165 ; vitrea, 699 Syornis, 1014

Syria, Cretaceous in, 857, 859

Syringodendron, 699

Syringopora, 551, 552, 567, 585, 704, 711 ; bifureata, 567, 568 ; Hisingeri, 591, 592; Maclurii, 584*, 590, 592 ; multattenuata, 690 ; multicaulis, 550 ; retiformis, 550

Syringostroma columnare, 590 ; densum, 590

System of formations, $406 \S$; of Mountain Ranges, 389; of the Rhine, De Beaumont's, 734

Systemodon, 903, 918; tapirinus, 903

Tabellaria, 168, 164*

Table mountain or mesa, 185, 186*, $300 *, 937$
Table Mountain, S. Africa, 699

Tachylyte, $87 \S$

Tacoma, Mt., 240 (glacier), 296 (height), 945

Taconian, 446

Taconic limestone belts, 528-531

- Range, 24 ; making of, 386, 527532; Cambrian of, 467,483 ; Lower Silurian of, $490,495,517$; metamorphism in, 309,325

Tænia solium, $437 \S$

Tæniaster spinosus, 505*, 514

Tæniophyllum, 633

Tæniopteris, 689, 698, 704, 750, 756; latior, 756 ; Lescuriana, 705 ; linnæifolia, $749^{*}$; magnifolia, 756 ; multinervis, 705; Newberryana, 705 ; vittata, 705

Tahiti, thickness of coral reef, 150 ; denudation of, $180^{*}$; waterfalls at, 185; tide at, 212 ; lava streams thicker toward the interior, 290

Tahitian Islands, map of, 36*

Tainoceras cavatum, 691

Tale, $65,67 \S, 68,79,89,318,320,453$

Talcahuano, elevation at, 349

Tálchir group, 698, 699

Talcose schist, $89 \S$; slate, $84,89 \S$

Talpa, 927

Tampa limestone, 891

Tancredia, 759, 760; Americana, 855 ; extensa, 760 ; Warreniana, $758 *$

Tanganyika (Lake), 33

Tanna Island, 296

Tantalum, 449

Tape-worm, $437 \S$

Tapes, 916

Tapir, 54, 902, 981, 1002

Tapiravus, 919

Tapirus, 928; Americanus, 1001 ; Arvernensis, 927; Haysii, 1001 ; Indicus, 905*; priscus, 927

Tar, mineral, 712

Tarannon shales, 563

Tarawan Islands. See Gilhert

Tarawera ertuption, 291, 305, 374

Tarn $(\mathbf{M t}$ ), 858

Tasmania, 21, 415, 628, 937, 948 (fiords)

Taunusian, 626

Taxineæ, 596, 673

Taxites, 777, 840, 921 ; Olriki, 921

Taxocrinus, 602; elegans, 505*, 514

Taxodium, 921, 922, 939 ; cuneatum, 883 ; distichum, 921 ; distichum Miocenum, 889

Taylor marls, 855

Tehad Lake, 34

Tecali, Mex., limestone, 133

Technocrinus, 577

Teeth, composition of, 72,73

Tejon beds or group, $830,831,884$, $885,888,889,916$

Teleoceras, 919

Teleodus, 918

Teleosaurs, 787

Teleosaurus, 790 ; Chapmanni, 790

Teleosts, 418§, 869; Cretaceous, 812,843

Telephus, 521

Telerpeton Elginense, 772*, 773
Tellina, 916, 917 ; biplicata, 917 ; Gronlandica, 984 ; linifera, 916

Tellinomya, 516; alta, 514, 516; Angela, 500 ; machæriformis, 550 ; nasuta, 507*; nucleiformis, 558

Tellurium, 331

Telmatherium, 918

Temaiscaming Lake, 445

Temiscouata Lake, 533, 559

Temnochilus, 675 ; conchiferum, 690 ; crassum, 675, 676*, 690; depressum, 690 ; Forbesanum, 690 ; latum, 690

Temnocyon, 911, 918

Temperature, 52, 727, 877 (change, exterminating life); in Archæan time, $440,441,442$; in mines, 257 ; of the ocean, $46 \S$. See also Climate

Temple of Jupiter Serapis, changes of level, $348,349 *$

Teneriffe, crater of, 277,291

Tennessee, mean height of, 23 ; marble, 494, 524

- River, 540

Tentaculite limestone, 535, 552, 556, $557,558,559$

Tentaculites, 556, 560

Tentaculites, 516, 562, 568, 586, 599, 626 ; attenuatus, 592 ; bellulus, 592 ; distans, 562 ; elongatus, 560 , 579; gracilistriatus, 592, 620, 621 ; gyracanthus, 556*, 557 ; incurvus, 514 ; ornatus, 567 , 568, 569 ; Oswegoensis, 514, 516 ; Richmondensis, 514; scalariformis, 590; scalaris, 625 ; spiculus, 620 ; Sterlingensis, 514; tenuistriatus, 516

Tephryte, $87 \S$

Terebellum fusiforme, 926 ; sopita, 926

Terebra, 916; Houstonia, 916 ; simplex, 917

Terebratula, 72 (analysis), 425§, $426 \%$ \% $756,834,856$; augusta, 757 ; biplicata, 791,865 ; bovidens, 690; Choctawensis, 837 ; digona, $779^{*}$; diphya, 779*, 791, 793 ; diphyoides, 791 ; elongata, 707 ; fimbria, 790 ; fusiformis, 704 ; gracilis, 866; Harlani, 378, $840^{*}, 854$; hastata, $700^{*}$; impressa, 425*; Liardensis, 758; perovalis, 790 ; plicata, $840^{*}$, 854 ; sella, 791 ; semisimplex, 757; Sullivanti, 601 ; vitrea, 426*; Wacoënsis, 837

Terebratula family, 585*, 779

Terebratulids, 922

Terebratulina A tlantica, 854 ; caputserpentis, 426*; gracilis, 866 ; Guadalupæ, 855

Teredina personata, 925

Teredo, 158, 425

Termites, 158

Terrace formation, 992

Terrace period, 941

Terraces of rivers, lakes, and seashores, 193, 194*, 228, 943, 947, 981-994; height due mostly to height of flood, 194. See also Flood-grounds; Shore platforms 
Terraces, of Champlain period, 981, $985,986,991 *$

Terrane, $90 \S$

Terranes, $61 \S, 89 \S-116$; stratified, 90 ; unstratified, 116

Terrestrial life rarely fossilized, 141, 525

Terrigenous, $144 \S$

Terror, Mt, height of, 296

Tertiary era, 188, 202, 339, 347, 350, $364-366,380,351,392,407,408$, $409 *, 411,822,828,829,831,857$, 879 ; subdivisions, 880 ; N. America, 880 ; foreign, 919 ; general observations, 928; Tertiary elevation continued into Glacial period, 946. See also Miocene; Pliocene

- eruptions, 876 ; in western America, 340; igneous outflows in the Decean, 299

- fresh-water lakes of $\mathrm{N}$. America, 202,882

- mountain-making, foreign examples of, $367-369,769,812$; orogenic and epeirogenic movements, 932-939 ; orographic movements along the Pacific mountain border, 364366

Teschenyte, $88 \$$

Testudinates, 767, 901*

Testudo, 901; Atlas, 923 ; brontops, 901*, 902 ; Stricklandi, 787 . 790

Tetrabranchs, 424§, 425*, 781, 869 (pass their climax)

Tetracoralla, 431§, 718

Tetractinellids, $431 \S$, 432*

Tetradecapods, $420 \$ *, 421,423 \S$, $438 \S, 439,525,574,707,720,721$ 724,725

Tetradium, 501, 505; cellulosum 515 ; columnare, 514; fibratum. $511 *, 515$

Tetragraptus bryonoides, 500 ; fruticosus, 500

Tetrahedrite, 335

Tetrapterus priscus, 925

Texas, mean height of, 23 ; Archæan in, 444, 446, 447; Cambrian, 464, $466,469,477,484$; Upper Silurian, 537; Devonian, 575, 580 ; Subcarboniferous, 637; Carboniferons, 648, 690, 693; Permian, $660,685,687,688$; Triassic, 660, 746: Cretaceous, 817, 824, 854; disturbances in, 868 ; Tertiary, 884, 885, 888; Quaternary, 378

Textularia, 855 ; globulosa, 432*

Thalassic, $535 \%$

Thalassophyllum clathrus, 582

Thames River, Conn., 461, 949

Thames River, Eng., 191

Thamnastræa, 777,778 (number of British); concinna, 790 ; gregaria, 790

Thanet sands, 920, 925

Thanetian group, 925

Theca, 481, 514, 521, 707 ; parviuscula, 514, 516

Thecidium family, 779
Thecodon tosaurus, 773 ; gibbidens, 754

Thecodonts, $754 \S$

Thecosmilia, 777, 778 (number of British); annulata, 790

Thelodus parvidens, 566*, 567

Thelyphonus, 723

Thenaropus heterodactylus, 692

Thermal waters, $258,305-309,384$, 335

Theromora, 688

Theromores, 707

Thian-Shan Mits., 32

Thick-bedded structure, $92 \S$

Thielson, Mt., 266

Thimble Islands, degradation at, 260 ; pot-holes of, 949

Thinohyus, 911, 918

Thinolite, $133^{*}$

Thoracosaurus, 848

Thorium, 449

Thracia Conradi, 983; curta, 984; depressa, 791

Thrissops, 417*

Thrust-planes, 584

Thuia, 840

Thuringia, Permian in, 706

Thuyites, 777

Thysanura, 419, 702

Thysetes verrucosus, 567

Tiaropsis, 429*

Tibet, 26,32 ; Silurian of, 368 ; Triassic in, 770; Jurassic, 791; folded Nummulitic beds of, 521, 920 ; Mammals of, 936

Tiburtine, 798

Ticholeptus beds, 886, 894, 895

Tick, 420

Tidal wave and currents, 43,210 ; on Lake Michigan, 202

Tide and currents in the Cambrian, 484; Devonian, 629, 630

Tierra del Fuego. See Fuegia

Tile clay, 665

Tile-fish, 56

Tilestones, 563, 566

Tilibiche, coral limestone at, 347

Till, $81 \S, 251 \S$

Tillodonts, 903, 904, 917, 918

Tillotherium, 904, 918; fodiens, $904 *, 905$; latidens, 904*, 905

Timber Belt beds, 888

Time, geological, subdivisions of, 404; ratios and length, 1028

Timpabute Range, $366 *, 469$

Tin, 83, 88, 336, 343

Tinacoro Island, 296

Tinoceras, 907 , 918: anceps, 907 ; grandis, 907 ; ingens, $906^{*}, 907$

Tinodon bellus, $767 *$

Tionesta basin, 947

Tipula Carolinæ, 900*

Tipulidæ, 900

Tirolanus Cassianus, 778

Tisiphonia, 432*

Titanic acid, 86 ; iron, 70 , 449, 450

Titanichthys, 618 ; Clarki, 619

Titanite, 67\$

Titanium, 70, 455

Titanophasma Fayoli, 701, 702*

Titanosaurus, 867

Titanotheres, 907, 908, 909, 918
Titanotherium anceps, 907 ; giganteuna, 908*, 909

Titanotherium beds, $886,893,908$, 910, 918

Tithonian group, 779, 791

Titicaca, Lake, $26,347,627$

Toarcian group, 775 ; (Upper), 790

T'redi-Windgrellen group of mooun. tains, 367

Tofua Island, 296

Toluca, Mex., 265

Tom, Mt., 802 ; Ridge, 801*, 803, $804,805,806,807$

Tombigbee River, 885, 889 ; sands, $815,823,854$

Tomitherium, 918

Tonga Islands, $37,350,374$

Tongrian group, 884, 926

Tongue River, 266

Ton to group of Gilbert, 447, 469

Topaz, 63, 66*\$, 338

Topazolites, 312

Torbanite, 662

Tornoceras mithrax, 591

Torosaurus, 847 ; gladius, $846^{*}$

Toroweap fault, $362,363 *$

Torre del Greco, 294

Torres Strait, 937

Torrid zone, $46 \S$

Torridonian group, 457

Torsion, 105, 106*, 107, 371 ; effects of, in ice, 371, 372*; in strata, $105,106 *, 371$

- as an explanation of the zigzag arrangement of continents, 394 , 395

Tortoises, 787

Tortone blue marls, 926

Tortonian group, 884, 926

Totoket Ridge, 801*, 802, 803, 806

Toucan, 54

Touraine, 926

Tourmaline, 63, 66*\$, 82, 88, 160 , 312,320 ; crystals displaced by quartz, 138*; rocks, 82, 83

Tourmalyte, $88 \S$

Toxaster Campicheii, 865 ; complanatus, 865

Toxoceras bituberculatum, $862 *, 865$

Toxodon, 927

Toyabe Range, 365

Tracheates, $419 \S$

Trachelomonas lævis, 163,164 *

Trachodon mirabilis, 846

Trachyceras, 756; aonoides, 774 ; Archelaus, 774 ; balatonicum, 774 ; binodosum, 774 ; Canadense, 758 ; Curionii, 774; Reitzi, 774 ; trinodosum, 774; Whitneyi, 757*

Trachyte, $80,84 \S, 86$; difference in density of glass and stone states of, 265 ; relation to granite, 314

Tracks. See Footprints

Trade winds, 50, 51, 159, 166

Trails. See Footprints

Transition rocks, $408 \S$

Translation-waves, 218

Trans-Pecos region, 824, 874

Transportation by currents of water, 169,189

- by glaciers, 247 ; by waves, 222

- of, and by, plants and animsls, 156 
Transylvania, 85

Trap, 86

-in Connecticut valley Triassic, 800

Trapa natans, ash of, 75

Traverse (Lake), 947

Travertine, 79§, 131, 132*, 133

Tree-ferns, 53, 669*

Trees, protection by, 155

Tremadictyon reticulatum, 777*

Tremadoc slates, 481,517

Tremataster disparilis, 646

Trematis, 514

Trematodiscus Konineki, 700 *

Trematopora, 551

Trematosaurus, 773

Trematospira, 562; multistriata, 551,579

Tremolite, 67\$, 79, 319, 531

Tremolitic limestone, $79 \$$

Trends, systems of, 35

Trenton, 490

Treodopsis appressa, 967

Triarthrus, 515; Beckii, 422*, 511*, $512 *, 516$

Triassic period, Trias, 738 ; American, 740,746 ; foreign, 768

Triceratium obtusum, 894 *

Triceratops prorsus, $846^{*}$; serratus, $846^{*}$

Trichiulus villosus, 691

Trichomanites, 622

Triconodon mordax, $789 *$

Tridymite, 64§, 84, 318, 323, 338

Trigonarca pulchra, 915; Siouxensis, 855

Trigonia, 59, 707, 759 (first American), 760,780 (number of Jurassic), 860 ; aliformis, 867 ; carinata, 865; caudata, 865; clavellata, $780 * 790$; Conradi, 758*; costata, 790, 791; Eufaulensis, 854 ; gibbosa, 791 ; incurva, 791 ; limbata, 866, 867; longa, 867; Mortoni, 854; navis, 792 ; pancicosta, 790 ; scabricula, 865 ; Smeei, 791; ventricosa, 791

Trigonia family, 770

Trigonocaris Lebescontei, 521

Trigonocarpus, 622, 673*, 689; ornatus, $673^{*}, 689$; tricuspidatus, $673 *, 689$

Trigonoceratidæ, 675

Triisodon, 917

Trilobites, 59, 420*, 421*; Cambrian, $469,480,482,483,488$; legs of, $422 *, 512 *$; young of, $512 *, 562 *$

Triloculina Josephina, 432*

Trinidad, Col., 313

Trinidad, W. I., 22, 891

Trinity epoch or group, 815, 817, $832,834,836,837$; sands, 817 , 819

Trinucleus, $422 \S, 520,521$; concentricus, 508*, 509, 512, 515, 516, $517,520,567,569$

Triolites Cassianus, 773

Trionyx, 850, 926

Triopus, 521

Triphylite, 321

Triplesia primordialis, 478*

Triplopus, 918
Tripolyte, $81 \S$

Triprlodon, 852 ; caperatus, 853*; coelatus, 858*

Trisetum, 240 ; subspicatum, 945

Trispondylus, 917,918

Tristan d'Acunha, 297

Tritonium, 916

Tritylodon, 773,789

Trochoceras, $515,549,568,586$ (last), 591 ; boreale, 552 ; clio, 591 ; costatum, 551; Desplainense, 551; eugenium, 591; Halli, 515; notum, 551; pandum, 591

Trocholites, 506, 520; Ammonius, $506,508^{*}, 511,515,516$; undatus, $506,508 *, 514$

Trochonema, 514, 516, 520, 521, 598

Trochosmilia striata, 916

Trochus, 525, 780 ; Texanus, 836

Trogons, 923

Troödon, 856

Troostocrinus, 646 ; subcylindricus, $547 * 550$

Trophon clathratum, 984, 995

Tropidocaris bicarinata, 621

Tropidoleptus, 627 ; carinatus, 598*, 601

Tropites, 756, 757 ; subbullatus, 774

Truckee Miocene, 895

Tsien-Tang, the eager of, 212,215

Tuba acutissima, 917

Tubicola, 423

Tueubit Mts., 581

Tuedian group, 695

Tufa, volcanic, $80 \S$; cones of, $270 \S$, $271^{*}, 276^{*}$

Tufa, calcareous, 131, 132*

Tulip Tree, 812, 837, 879

Tully limestone, 576, 593, 594, 599, $601,603,605$

Tunicates. See Ascidians

Tunneling by animals, 158

Turbinella regina, 917; Wilsoni, 916

Turbinolia Texana, 837

Turbo, 707, 780; Shumardi, 591 ; solitarius, 774

Turf, protection by, 155

Turkey, 34

Turonian group, $815,858,859,866$

Turricula Millingtoni, 916; polita, 916

Turrilepas, 567, 579, 602 ; Canadensis, 513*; Deronicus, $600 *$

Turrilite, 861

Turrilites, 771, 861; Brazoensis, 837 ; catenatus, $862 *, 865$; costatus, 866 ; helicinus, 855 ; pauper. 854 ; tuberculatus, 866

Turritella, 824, 916, 922 ; Alabamiensis, 915; alveata, 916; arenicola, 916 ; cælatura, 916 ; carinata, $897 *$, 916 ; Chipolana, 917 ; compacta, 854; erosa, 984; indenta var. mixta, 917; Mississippiensis, 916 ; multisulcata, 926 ; nasuta, 897*, 916; perdita, 916; plebia, 378 ; præcincta, 915 ; pumila, 854 ; reticulata, 984; subgrundifera, 899*, 917; Tampæ, 898*, 916; vertebroides, 854
Turtles, 415, 847; Triassic, 772*, 78,797 ; Jurassic, 760, 766*, 767, 768,797 ; Cretaceous, 826, 849, 856,867 ; Tertiary, 202, 901*, 902, 928,927

Tuscaloosa group, 815, 816, 819

Tylosaurus micromus, $849 *$

Typhis, 916 ; acuticosta, 917 ; curvirostratus, 916 ; pungens, 926

Typothorax coccinarum, 758

Tyrol, dolomyte of, 134

Tysonia Marylandica, 831

Uinta Eocene lake basin, 360*, 881*, $882,886,893$

- Mts., 109, 360*, 365

Uintatherium, $907 \S, 918$; Leidyanum, 907 ; robustum, 907 .

Uitenhage series, 873

Ullmannia, 693, 704

Ulodendron, 699 ; majus, 689 ; punctatum, 689

Umbone, 424

Umbral series, 634, 728

Unaka Mts., 85

Unakyte, $85 \S$

Unartok series, 921

Unconformability, 114, 115*§, 116

Unconformity, $115 * \S$

Under-clay, 639, 653, 708

Ungulates, 902, and beyond

Ungulina, 621

Unio, 612, 821, 829, 837; Danæ, 856 ; Deweyi, 856 ; ebenus, 966 ; Liassinus, 760 ; ligamentinus, 966 ; rectus, 966 ; Valdensis, 861 * Unio family, 946,950

Uniontown coal-bed, 651, 656

United States, mean height of, 23 ; geological map of, 412*; heights of the Cretaceous beds of the Rocky Mountains, 933

Untercarbon, 632

Unterer Wieder Schiefer, 569

Upernavik, 244

Uphantrenia Chemungensis, 611

Upper Pentanerus. See Pentamerus

- Silurian, 585

Uralichas Ribeiroi, 521

Uralite, 317

Uralitization, 317

Uraninite, 321

Uranium minerals, 321

Uranoplosus, 836

Urformation, 440 (Archæan synonymy)

Urgebirge, 440 (Archæan synonymy)

Urgineiss, $408 \S$

Urgneissformation, 440 (Archæan synonymy)

Urgonian, 367*, 859, 865

Urocordylus Wandesfordii, 704

Urosalpinx trossulus, 917

Urosalpynx cinerea, 994

Urosthenes australis, 698

Urosthenic, 439, 717, 726, 796, 931

Ursa stage of Heer, 704

Ursus amplidens, 1000 ; Aretos, 950, 1004, 1006 ; Arvernensis, 927 ; 
ferox, 1006 ; pristinus, 1001 ; spelæus, 1004*, 1009

Urus, 1013

Utah, mean height of, 23 ; high plateaus of, 187, 386 ; Henry Mts. in, 301 ; ore beds of, $338,339 *$, 310 ; map of, $360^{*}$

- Archæan in, 449 ; Cambrian, 469, 473, 476; Lower Silurian, 469,495 ; Trenton, 495 ; Carboniferous, $301,658,674,690$; Permian, 660; Triassic, 746; JuraTrias, 749 ; Jurassic, 747,760 ; Cretaceous, 302, 339*, 340, 825 (coal), 826, 829, 856 ; post-Mesozoic, 876 ; Tertiary, 302, 365, 366 , $852,886,893,901,934$

Ute limestone, 494

Utica and Hudson epochs, 489, 492

Val d'Arno, 927

Valdivia, 51

Valenginian, 859, 865

Valley drift, 946

Valleys, excavation of, 180,182 ; filled, not excarated by the ocean, 229

Vallonia pulchella, 966

Valparaiso, banded and other veins, $329 *$, 332*; earthquake in 1822, 349

Vanadate, 340

Vancouver Island, 23, 747; Cretaceous of, 818 ; coal of, 825 ; coalplants of, $837,840,872$

- Range, 25, 812, 892

Vanuxemia Montrealensis, 503

Varenna marble, 774

Vasum horridum, 917; subcapitellum, 916

Vavau Island, 39, 350 (elevation)

Vegetable kingdom, 9, 418, 414, 434-497

Vegetation, protection by, 155

Vein-structure of glaciers, 243

Veins, 327 ; of Archæan rocks, 449

Veinstone, $331 \S$

Veleda lintea, 854

Venericardia borealis, 917 ; planicosta, $897^{*}$

Venezuela, 31, 857 (Cretaceous)

Veniella Conradi, 854; trapezoidea, 854

Ventriculites, 482*, 860

Venus, density of, 16 ; oblique lines on surface of, 395

Venus, 425§, 916 ; cortinarea, 917 ; mercenaria, 994; rugatina, 900*, 917

Venus's Flower-basket, 432

Verd-antique marble, $68 \S, 77,79$, $89 \S$

Vergent series, 728

Vermes, 423

Vermiceras Crossmani, 760

Vermicular limerock, 555; sandstone and shales, 637

Vermilion Cliffs, 187, $\mathbf{7 4 7}$

- group, 886

- Pass, 469

- schists, 446
Vermont, 23 (height), 325, 496 ; eolian limestone, 517; faults, 527, $528 *$; fossils, $309,310,887,896$; marbles, 524, 523

Vertebraria, 698

Vertebrates, 141, 404, 414, 415-418, $424 \S$; relation of, to Invertebrates, 418; Merosthenic, era of, 796; Urosthenic, era of, 796

- Lower Silurian, 496, 509, 525; Paleozoic, 725-726

Vesicular rocks, $78 \S, 298$

Vespertine series, 634, 728

Vesperugo, 918

Vesulian group, 790

Vesuvius (Mt.), 85, 266*, 276, 280

Viburnum Goldianum, 839

Vicksburg epoch (beds), 880, 884, $889,890,896,898 *, 916$

Victoria, Lake, 200

Victoria (province), 698, 699

Vicuña, 54

Vienna, Miocene of, 922, 939

Viesch glacier, 237

View of the $a a$ lava-stream, 287*

View of alluvial cones, Indus Basin, $195 *$

View of an atoll, 145*

View of Beehive Geyser in action, 308*

View of blocks on the shore-platform of the Paumotus, 222*

$\nabla$ iew (ideal) of Carboniferous vegetation, 666*

View of cliffs, Port Jackson, N.S. W., 221*

View of Colorado Cañon, 188*

View of columnar basalt, Orange, N.J., 262*

View of drop-made and of rainmade columns, 178*

View in Elk Mts., showing upturned strata, $106 *, 364^{*}$

View of Geyserite Terraces, N. Zeal., 305*

View of the Görner Glacier, 237*

View of Gothic Mt., Col., 275*

View of a high island with barrier and fringing reefs, $148^{*}$

View of jointed rocks, Cayuga Lake, $112 *$

View of Juke's Butte, 301*

View of Kiama basaltic columns. $261 *, 262 *$

View of Kilauea, $270 *$

View of loss formation on the Hoang Ho, 196*

View of Mammoth Hot Springs, $132 *$

View of Marble Cañon, 187*

View of the southwest end of Mokkatam, 160*

View from Monument Park, illustrating erosion, 186*

View of Mount Shasta, 267*

View of Nanawale cinder-cones, 285*

View of Oahu tufa-cones, 271*

View of Obsidian Cliff, Yellowstone Park, 264*

View of "The Old Hat," New Zealand, 221*
View of Phonolyte Peak, Fernando de Noronha, 263*

View of plicated clayey layer, 209*

View on Roche-Moutonnée Creek, $250 *$

View of rocks detached by waveaction, Mount Desert, 219*, 220*

View of rocks disrupted by roots of trees, 157 *

View of sandstone veins, Oregon, $314^{*}$

View of Temple of Jupiter Serapis, 349*

View of terraces on the Connecticut River, 194*

View of trap bluff at Greenfield, 805*

View of tufa deposits, Lake Mono, $132 *$

View of upturned Cretaceous beds near Abu Roasch, 161*

View of Vesuvius, 266*

View of water-and-gas geyser, $\mathrm{Pa}$., 608*

View of West Rock, $804^{*}$

Virgen, Rio. See Virgin River

Virgin River, 339, 363

Virginia, 23 (height), 24, 125, 353 , $357,358,383,387,437,468$; iron ore beds, 127,449 ; section of rocks, 355 ; upturnings in, 532, 809

Virgloria, Virglorian, 774

Virgulian group, 791

Visé limestone, 696

Viso, Mt., 266

Vitrifiable clay, $81 \S$

Vitriol, 70

Vitulina, 627

Viverra, 927

Viviparous Mammals, 415

Viviparus, 856 ; fluviorum, 861 *

Volcanic action and its causes, 277 293: reached its maximum in later Cretaceous and Tertiary, 326

Volcanic ashes, eolian transportation of, 80 ; deposited over the sea bottom, 136

- belt separating northern and southern continents, 394

—bombs, 287*§, $289 \S$

- eruptions, earthquakes not essential in, 286

- glass, $848,86,87,263,264 * 272$ $258 \S$

- mud. See Tufa

- necks, 290 s

- rocks, 84, 272, 298

- vapors, 268\$, 269, 277-282, 283288 (passim); work of spent vapors, 298-295

Volcanoes, distribution of, $295-297$; number, 297 ; occurrence in lines, 282; of continents mostly on their borders, 295, 392; continental distinguished from oceanic, 379

- carbonic acid from, 128,279

-, extinction of, 290-291; interior of, before and after extinction, 290,291

Volga, 33 


\section{Volgian, 760,790}

Volsella scalpra, 760

Voltzia, 750,774; heterophylla, 698 , $770 *, 773$

Voluntomorpha Eufaulensis, 854

Voluta, 922 ; ambigua, 926 ; athleta, 926; Newcombiana, 915; nodosa, 925; Showalteri, 915; Wetherellii, 925

Volutilithes Haleanus, 916 ; limopsis, $896^{*}, 915$; rugatus, $896^{*}, 915$

Vosges, 310, 626, 734 (upturnings), 738 ; Archæan in, 456; Triassic, 768

Vosgian, 738, 769, 773

Vraconnian, 859

Vulcano, 276

Waagenoceras, 686

Wabash River, 947

Wachita Mts. See Ouachita

Wacke, 808,408

Waders, 141 (easily fossilized), 852, 902

Wadesboro Triassic area, 741

Wälderthon, 865

Wairoa series, 770

Wakes Island, 38

Walchia, 693, 699, 704, 750; piniformis, $699,704,705^{*}$

Waldheimia, 59; compacta, 690 ; digona, 790 ; humeralis, 791

Wales, $173,191,370,463,464$; eruptions in, 518; upturnings in, 534, 788 ; geological map of, $694^{*}$

- Archæan in, 456, 457; Cambrian, 457, 480, 481; Lower Silurian, 517, 518, 520; Upper Silurian, $563,564,568,574$; Devonian, 622 , 625 ; Subcarboniferous, 695 ; Carboniferous, $322,662,693,694 *$, $695,696,734$; Permian, 734; Triassic, 768

Walker's Lake, 757

Wallala beds, 830,840

Walnut clays, 817 ; sands, 836

Warrior coal-fields, 648,657

Warsaw group, 634, 637, 638

Wasatch Eocene basin or lake, $360 *$, $361,365,881 *, 882,893$

- limestone, 580, 581, 659

Wasatch Range, 24, 25, 340, 359, $360^{*}$ (map), 874

-, Archæan in, 444, 447; Cambrian, 469 ; Trenton, 494 ; Upper Silurian, 541; Devonian, 360*, 361, $362,580,581$; Carboniferous, 360*, 361, 362; Mesozolc, 380; Triassic, 747 ; Jurassic, 747,760 ; Cretaceous, $360 *$, 361 ; post-Mesozoic, 874, 875; Tertiary, 365, 366,934

Washakie group or basin, 886,893

Washburn, Mt., 276, 296 (height)

Washington, Mt., Mass., 104, 105*, 528,530

Washington, state, mean height of, 23 ; glaciers of, 240 ; volcanoes of, 296,937 ; conl of, 831 ; Tertiary in, 885,892

Washita epoch or group, 815,817 , 819,886 ; limestone, 817,887
Water, arrangement of seas, 16 ; composition of, $71 \S$; characteristics of, 170-171; amount absorbed within the earth, 209 ; freezing and frozen: glaciers and icebergs, 118, 171, 230-253

- as a chemical agent, 118; as a solvent, $118,119,121,122$; chemical absorption of, 128; earbonic acid in rain, river, and sea, 128

Water-lime group, $410,535,552,553$, $554,555,556,558,559,570,571$, 606 ; American species occurring elsewhere, 569

Water-line of coasts, 346

Water-sculpture of mountains, $185 \S$, $186 *$

Water-spout, 163

Waterfalls, 174, 184, 185; in glacier crevasses, 250

Waterglass, $135 \S$

Wave-marks, 94\$, 538

Waverly group, 604, 638

Waves, action and force of, 210,212 ; height of, 213,216 ; limit of denudation by, 219, 221. See also Tidal wave

Waynesburg coal-beds, 651, 657, 663, 677

Weald axis, 936

Wealden epoch, 858

Weasel, 924

Weathering, 128, 136

Weber, $360^{*}, 361,362$

- conglomerate, 659; quartzyte, 659

Weevils, 771

Weissliegende, 697

Wellenkalk, 769, 778

Wellington Strait, 544, 552

Wells. See Artesian; Mineral oil

Welwitsehia, 435, 674; mirabilis, $435 *$

Wengen shales, 774

Wenlock Edge, Scotland, 534

- group, 463, 519, 563, 564, 565, 566, 567,568

- limestone, 563 ; shale, 563

Werfen (Werfenian) beds, 769,773

Wernerite, $65 \S$

West Humboldt. See Humboldt

West India basin, 857

West Indies, 19, 21, 22, 40 (trends) 145 (coral reefs), 153, 296 (voleanoes), 428, 429, 431, 578, 891 (Miocene)

West Peak, Col., 266

West River, 227

West Rock dike and Ridge, 299*, $302 *, 303,801 *, 802,803,804 *$ (view), 805, 806, 808

West Virginia, height of, 23 ; mineral oil in, 607,608

Western border region. See Pacific border

Western Continental Interior (sea) of N. America, 575, 580, 635, 739, 872; Triassic and Jurassic in, $746-749, \quad 756-768$; Cretaceous, $813 *, 814,867,873,880$; Tertiary, 880

Western Isles of Scotland, 288
Westphalia, 627 ; coal-beds, 696

Wetterstein, 774

Whale-bone Whales, 912*§, 925

Whales, 56, 144, 415, 902, 908, 912, 927 (toothed), 931 ; ear-bones of, dredged, 144

Whetstone, 808

Whip-snake, 682

White ants, 159

White Bluff bed, 889

White Cliff group, 747

White Fish River, 445

White Island, eruption, 374

White Lias, 774, 790

White Mts., N. H., landslide in, 208 ; incipient glacier in, 234; Arctic plants of, 945,946

White Pine district, 495

White River, 894, 901

White River beds, 884, 886, 893

White Sea, 521, 768

Whitfieldella didyma, 567; nitida, 548*, 551; oblata, 549

Whitney, Mt., 810

Whittlesey, 689 ; elegans, 674

Whortleberry, 921

Wianamatta shale, 699

Wichita, 660

Wight, Isle of, 920,926

Wild Boar, 54, 902, 927

Willamette River, 30

Willoughby, Mt., 945

Willow, $837,859,879$

Willow Creek beds, 830

Willow River limestone, 493

Wind, 89 ; denudation by, 159

Wind-drift coral rocks, 151 ; structure, $93 * \S, 162$

Wind-made waves and currents, $166,212,216$

Wind River basio and group, 884, 886, 893, 918; Mts., 240 (glaciers), $639,748,945$

Windsor series, 639

Windward Islands, 44

Winnipeg Lake, 29, 199, 200, 515, 524,552 ; elimate of, 944 ; discharge into the Mississippi, 947; in the Champlain period, 985

Winnipegosis (Lake), 594

Winooski limestone, 467,472

Wisconsin, 23 (height), 536, 944 (rainfall); lead mines, 342,522

Wodnika striatula, 707

Wolf, 924, 927

Wolf Creek conglomerate, 605

Wood brought down by rivers, 191 ; carbonized, 892; composition of, $74,123,713$; decomposition of, $123,124,613$; silicified, 125,135 , $143,280,300,892$ (see also Petrifactions)

Woodehuck, 915

Woodocrinus elegans, $640^{*}, 646$

Woodpecker, 902

Wood's Bluff beds, 888

Woodville sandstone, 657

Woodwardia latiloba, 839

Woolhope beds, 563

Woolwich beds, 925

Worcester, Mass., 453, 461, 683, $635,646,658,714,732$ 
Worm-Lurrows, Archæan, 446; Yellow River, China. See Hoang

Cambrian, 464, 470, 477*, 480; Ho Hanailton, 593

Worms, Sea, 59 ; trails of, 95 ; work of common earth-, 156 ; characteristics of, $418,419,420 *, 4238$, 437; Cambrian, 469, 474, 477\%, 487

Wrangel Bay, 747

Wright, Mt., 238

Writing slate. See Roofing slate

Wyoming, height of, 23, 29, 85, $338,360,365,808$; Archæan, 449 ; Cambrian, 466,476 ; Subcarboniferous, 639 ; Coal-measures, 662 ; Triassic, 746, 747; Jurassic, 748 , $760,761,763,767,768$; Cretaceous, 825 (coal), 826, 828 (coal). $845,847,848,849,876$; Tertiary, $882,886,893,894,906,907$; Glacial, 945

Xanthidia, 582, 583*, 859

Xenoneura antiquorum, $600 *$

Xiphodon, 924, 926 ; gracilis, 924*, 926

Xylobius, 701; fractus, 691; Mazonus, 691 ; similis, 691 ; sigillarix, 678*, 682, 691, 703

Xystrodus, 692

Yablonoi Mts., 32

Yang-tse-Kiang, 30, 198

Yellow ocher, $71 \S, 126$
Yellow Sea, 198

Yellowstone Lake, 200, 306

Yellowstone National Park, 29, 30; geysirite, 82,152 ; Obsidian cliff, 84, 263; Death Gulch in, 128; calcareous deposits or travertine, $79,131,152$; volcanic peaks of, 296 ; lithophyses in, 337; time of eruptions, 876, 937; geyser region, hot springs, etc., 135,305 , 306*; siliceous A lgæ, 152

Yellowstone River, 29, 266, 830 , 937

Yenisei River, 30

Yews, 53, 435, 596, 639, 666, 673, $685,718,735$

Yoldia, 760, 917; aretica, 984, 995, 997; Claibornensis, 915 ; eborea, 917,984 ; sapotilla, 917

Yoredale group, 695

Yorktown epoch, 884, 891, 899*

Yosemite domes, origin of, 260

Yosemite valley, 810

Ypresian group, 925

Yttrium, 449

Yucatan, 40, 44

Yukon district, 818,868

Zambesi Piver, 30, 33

Zamia, 434, 750

Zamites acutipennis, 833,834 ; aper915 ; glacialis, 983, 984 ; limatula, tus, 834 ; borealis, 834; Montana, 833,834 ; occidentalis, 756

Zanclean beds, 927

Zanskar district, 456, 791

Zanzibar, 38

Zaphrentis, 515, 516, 551, 552, 562, $579,591,597,611,640,674,700$, 718 ; bilateralis, $545^{*}$, 550 ; Canadensis, 515; Edwardsi, 590; gigantea, 584*, 590, 591; Halli, 601 ; minas, 646 ; prolifica, 590 ; Rafinesquii, 584*, 590 ; simplex, 601 ; spinulosa, 646

Zeacrinus, 646,690

Zebra, 54

Zechstein, 697, 707

Zeolites, 68, 78, 312 ; at Plombières, 323 ; origin of, 336

Zermatt, glacier of, $237^{*}$

Zero-strain, depth of, $384,385,387$

Zeuglodon, 822, 908§, 912, 923, 931 ; cetoides, $908^{*}$

Zine ores, $70,340,342,449,542$

Ziphias, 144

Zircon, $67 \S, 85,455$; syenyte, 858 , 447

Zirconia, 67

Zirconitic granite, 83

Zirconium, 449

Zizyphus fibrillosus, 839

Zoantharia, $431 \S$

Zoisite, $66 \$, 88,318$

Zones, 407 ร

Zygospira modesta, 514, 516 


\section{CORRIGENDA AND ADDENDA.}

Page 93, Fig. 62 should be inverted.

“ 23\%, 3d line from foot, for "Lauterarr," read "Lauteraar."

" 525, 13th line, for "Area," read "Arca."

" 572, 25th line, for "geanticline," read "geosyncline."

"716, 25th line, after "was," read "much longer than Neopaleozoic;" 27 th line, for "6:1:2:2," read "7 (or 8):1:2:2;" also add to the paragraph: "The Eopaleozoic, as has been shown (pages 509 , 520), continued on after the first appearance of Fishes and Insects, types that were formerly supposed to date from the Devonian."

" 988, 9th line, after "1895," add " and F. B. Taylor, Am. Jour. Sc., 1895."

" 1036, add: "The Memoir by E. Dubois on Pithecanthropus erectus is noticed in the number of the Am. Jour. Sc. for February, 1895." 





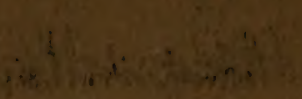
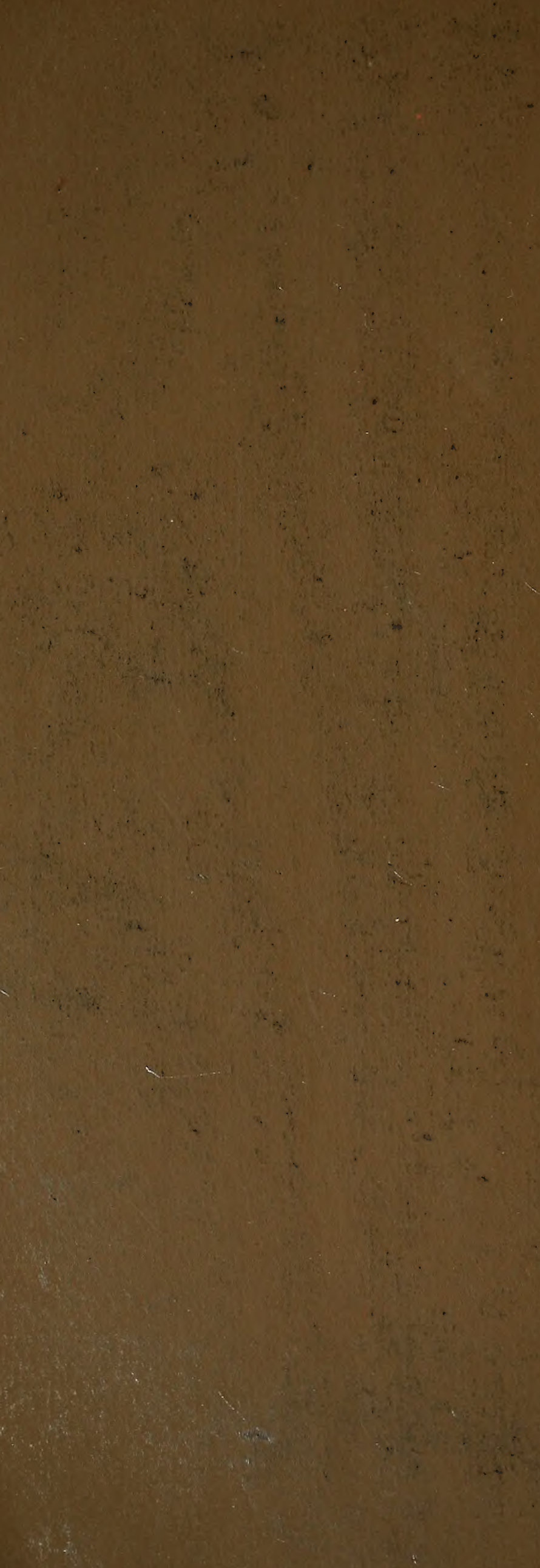
$(4,4), 7.45$
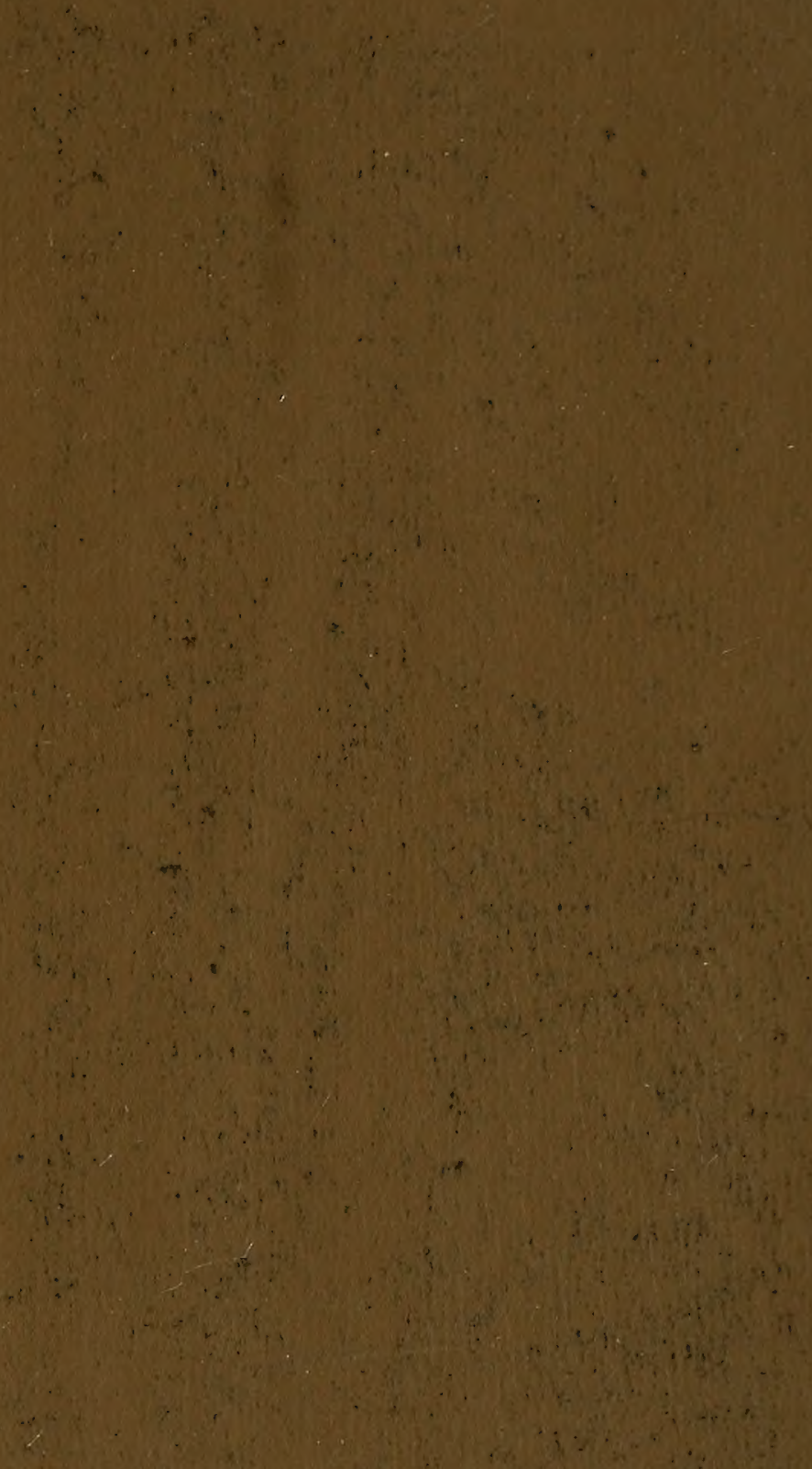
SMITHSONIAN INSTITUTION LIBRARIES

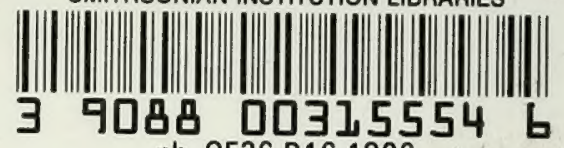
nh QE26.D16 1896 Manual of geology, 